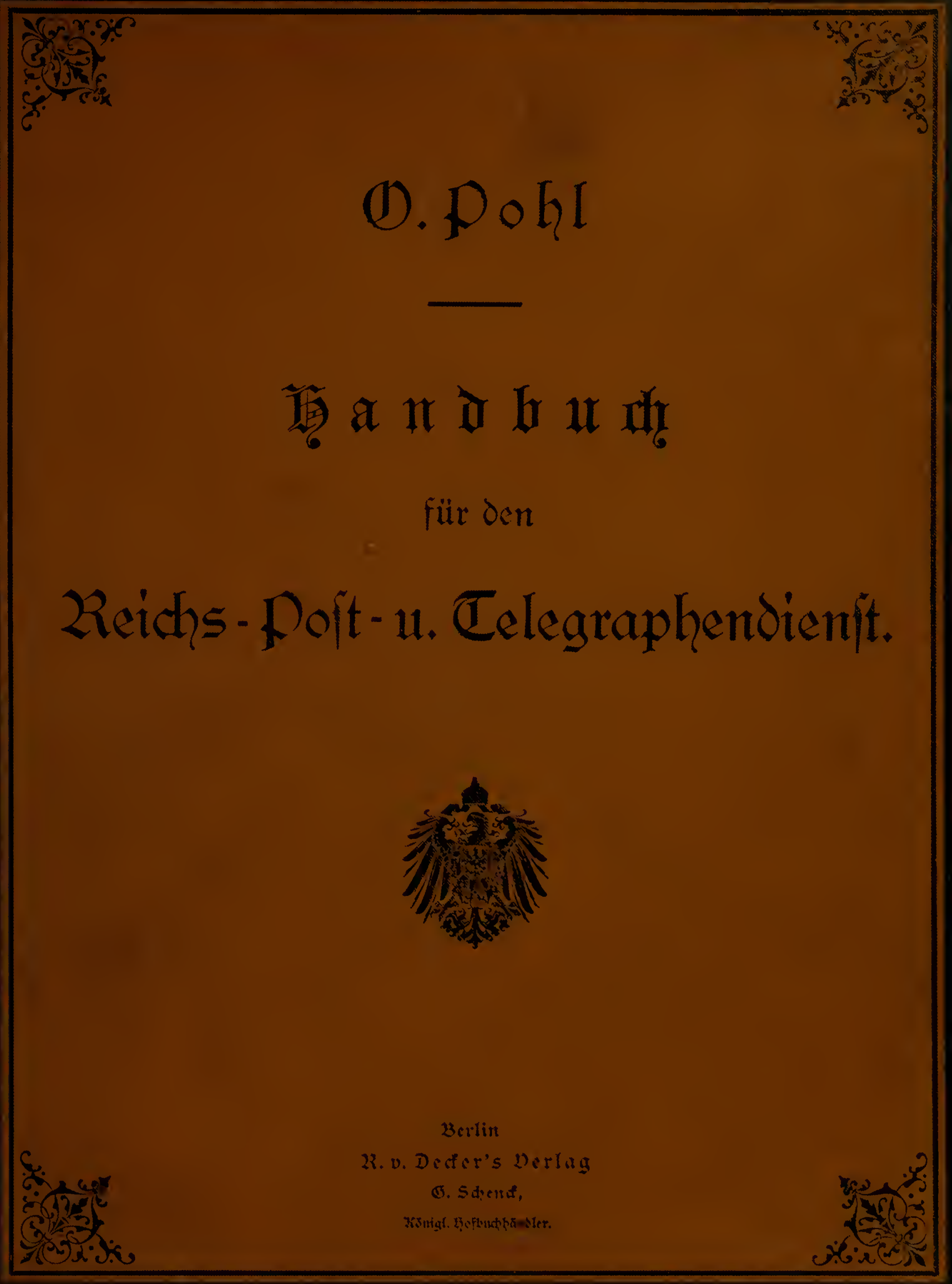



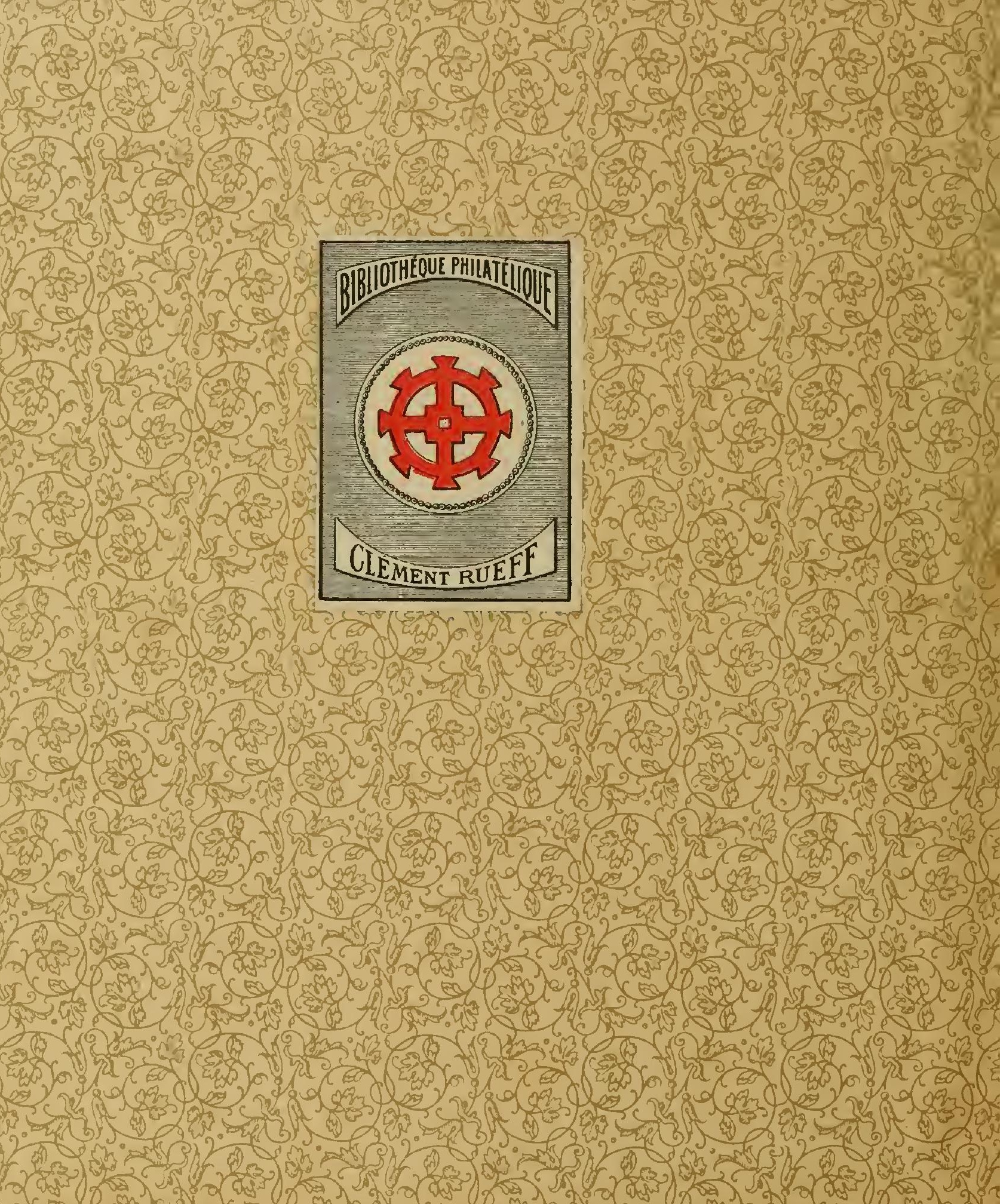

salle 


\section{Gandbud?}

fïr dell

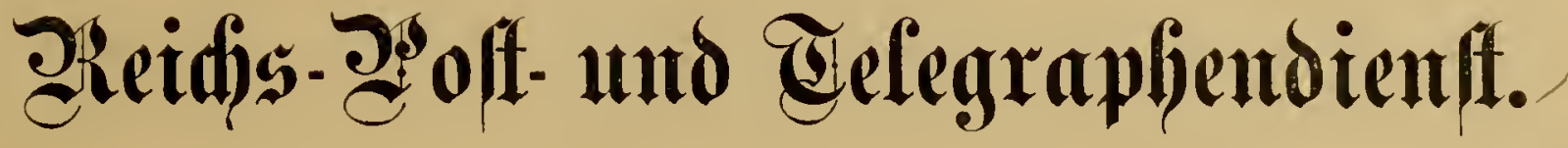

Eine

\section{E $\mathfrak{x} \mathfrak{m} \mathfrak{m} \mathfrak{l} \mathfrak{n} \mathfrak{n} \mathfrak{g}$}

von Gejetgen, Derordnumgen, Erlafien u. f. w.

jur

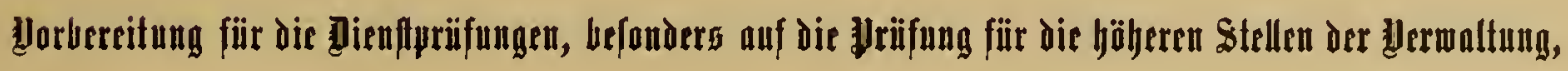
powie ein

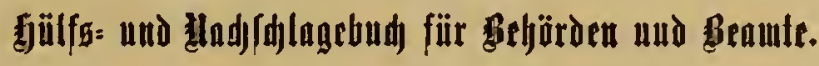

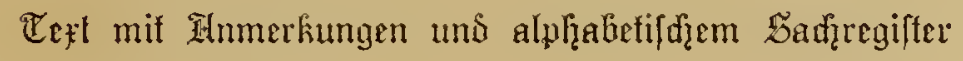

von

(iD. 19

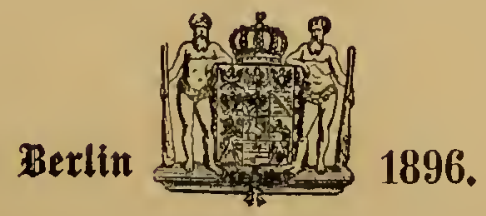

22. v. Deder's Derlag, G. Sdiend, 



\section{गृ $\circ \mathfrak{r} \mathfrak{w} \circ \mathfrak{x} \mathfrak{f}$}

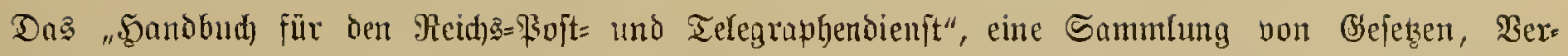

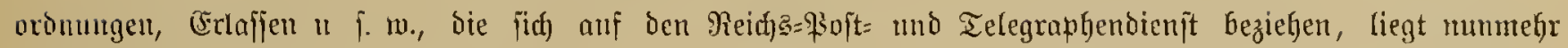

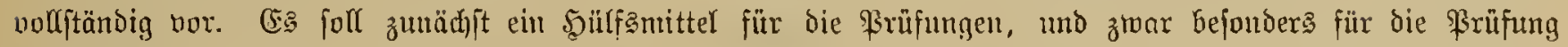

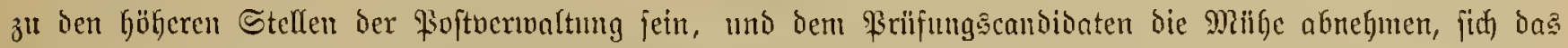

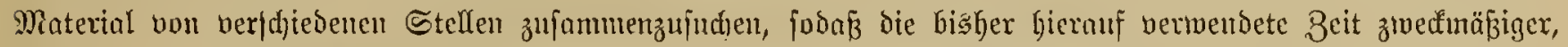
und zrwar gleidi zum Studium felbft, bemukgt werben Eann.

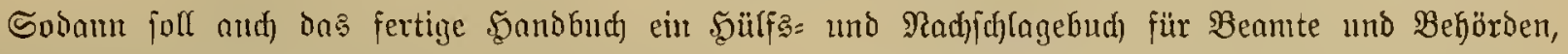
and) anberer \$Serwaltungen, filden.

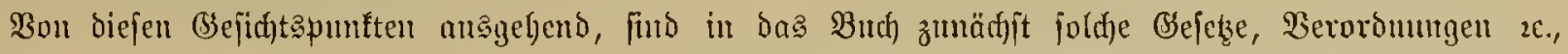
aufgenonmen worben, welche in bie für ben antlidhen (Bebrand) gelieferten Büd)erwerte $n$ i d) $t$ nufgenommen

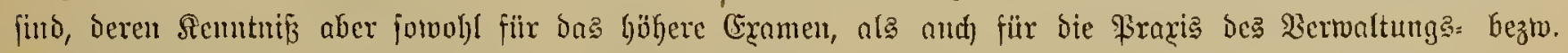
Bureaubeamten notfwendig ober bod) wenigitens münfdjenswertf ift.

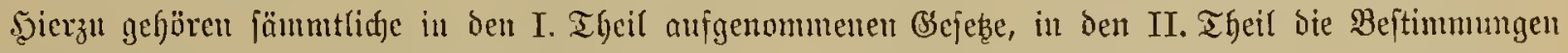

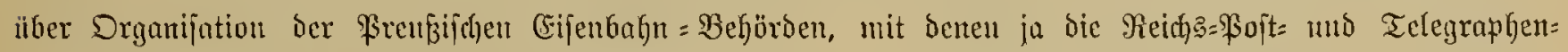
Bermaltung fo vielfache Beziefuntgen unterfält, mo in den III. Theil die nenen Stenergefesce.

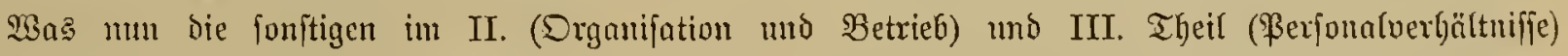

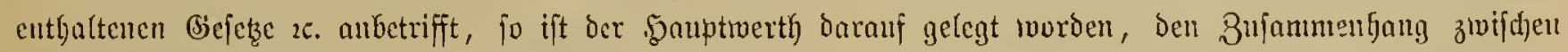

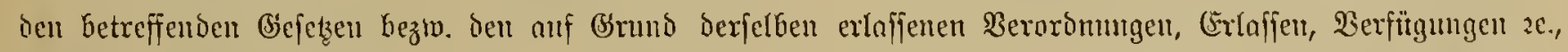

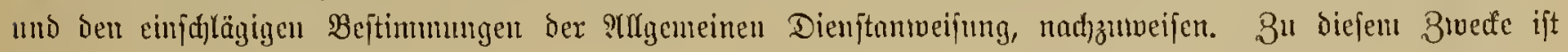

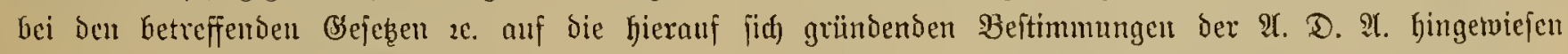

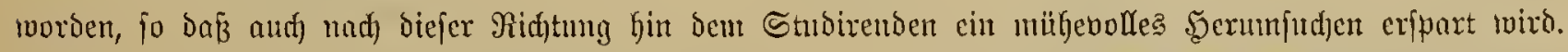

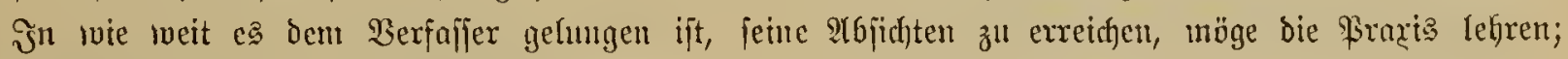

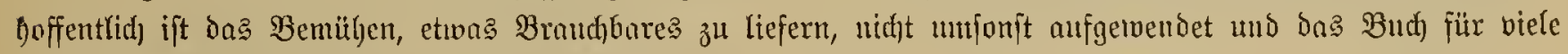
Johre den Studirenden cit werthuolles figndbud,

(9.) בֶּofl. 


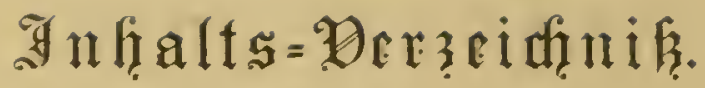

\section{Eheil. \\ 5ejege und Deroronungen allgemeinen Inḩalts.}

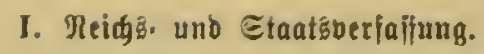

Beriailung des Dentiden Reides nebf Ciniührungs: Sejeb

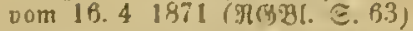

Deriaijung bes Preufifiden Etnates nebji (Einjührungs=(beję Dom 31. 1 18:, (B). ( 17 )

2Uerhödjitcr Erlás vom 4. 1. 1882

\section{3unere Berroaltung.}

(Y)icb über bie algemeine Landesocrmaltung Dom 30. 7. 1883 (195. (.. 195)*)

Bcjes, betr. Dle Berjafjung ber अermaltungsgeriate und bas

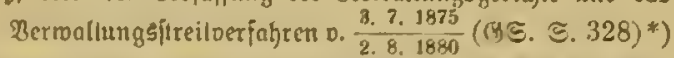

(s)ęç zur Ubänderung der $\$ \$ 26$ bis 30 ) bes sefebes, betr.

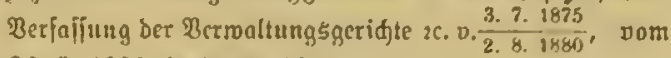
26. 3. 1893 (B). (. ค.) . . . . .

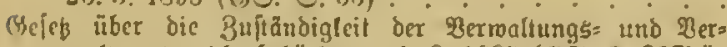

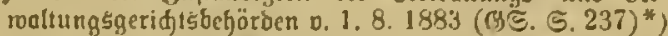

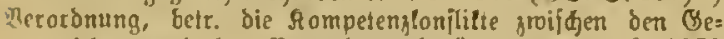

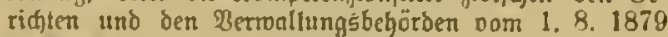
(Gङ. E. 573)

(Hejeb, betr. bic Sonjlitte bei geridtliden Beriolgungen

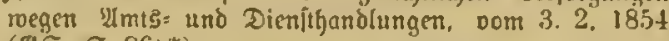
(अ5. 5. 86)*)

\section{Bolijei-:Berroaltung.}

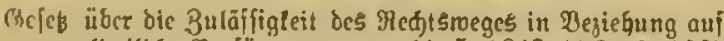

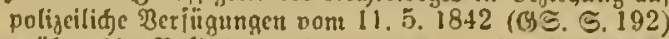

(Heję über bie \$olizcidermaltung nom 11. 3. 1850 (B) (5. 285).

\section{Redjung gabof bes Deutjden Reideg (Dber.Rechnungs? Stammer).}

(Scieb, beir. dic (Fintidlung und bie Bejugniffe der Sber=

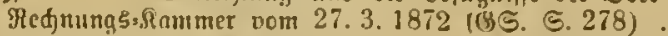

Tegulatio über ben (Heidäjisgang ber Dber. Rechnungs:

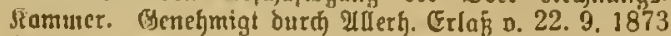
(अ.5. S. 458)

\section{Beriđt)}

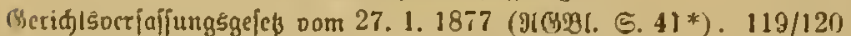

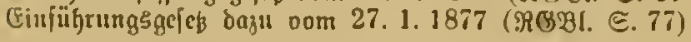

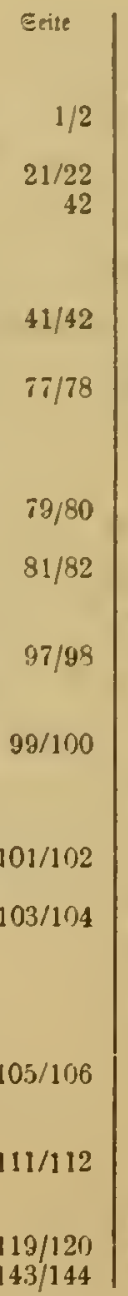

VI. (5ivilredgt.

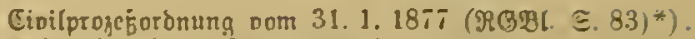
Bejes, betr. bic Bejolagnahme res આrbeits: ober Tientitohncs Dom 21 6. 1869 (ஐ)

VII. Etrairedgt.

Etraigelebbut für das ₹entide Reid oom $\frac{15.5 .1871}{26.2 .1976}$

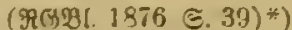

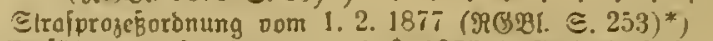

Beleb, betr. ben Erla $B$ polizeilicher Etrajoeriügunger megen llebertretungen onm 23.4. 1883 (Gङ. Є.65).

$289 / 290$

\section{Eigenthumserwerb von Grunoftüden, Brunbbudicht 26 .}

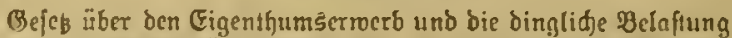

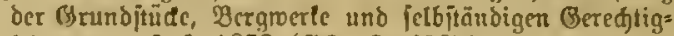
leiten vom 5.5.18\%2 (Bङ. Є. 433)*) (1)

\section{Bormunbidaft.}

Bormundjøafts=Eronung nom 5.7.1875 (ङS. S. 131)*) 313/314

\section{Beldoerlegr und Beldwertyjeiden.}

Bejeb, betr. dic Iuspprägung don Reifjsgolbmünjen vom

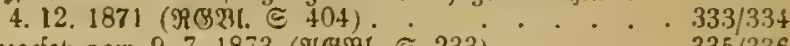

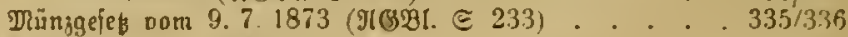
(Seleb. betr. dic Iusgabe Don Reidstajienjळeinen vom

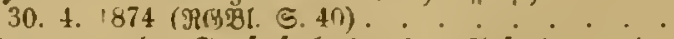

Befitimmungen oes Straige

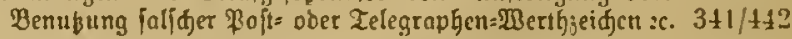

\section{Beridiedentez.}

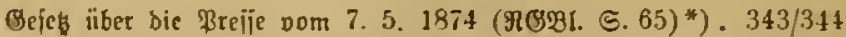
(Selé, belr. bie Cinführung cincr cinheitliden Beitbeltimmuna

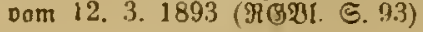

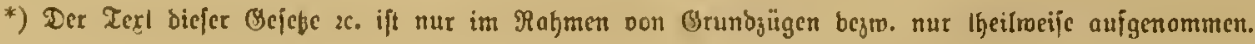




\section{Cyril.}

\section{Geiege und Derorinungen, welche jïh anf die Organijation wid den Betrieb der Reichs:poit= und Telegraphenverwaltung beziehen}

\section{Erganifation ber Rermaltung.}

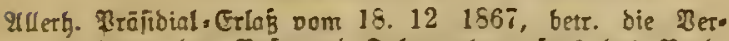

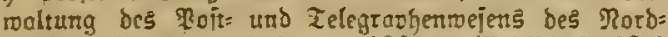

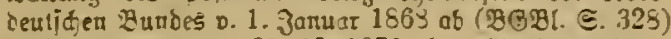

צ【eth. Berotonung vom 22.12.1575, betr. Die Detroltung bes \$ojt: und Telegraphenmejens nom 1. 3anuor 1876

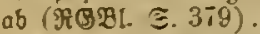

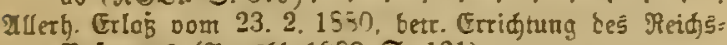

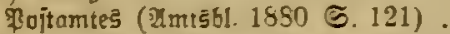

Lie gegenvartige Erganijation ber Reids= Poit= uno Zele= grophen=:ermoltung
A. Eentral=: Bermaltung.
B. Brirts=, Rojt: und Zelegraphen=3ehörden
C Berlehrsanitalten

\section{Figenthuméredte be Reides.}

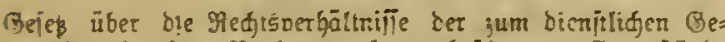

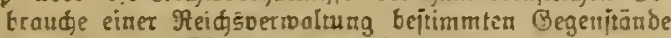

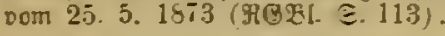

\section{Internationale :}

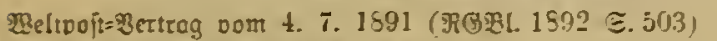

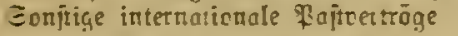

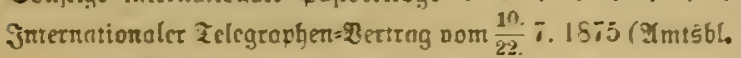
1875 ङ. 213).

\section{IT. Foptweien.}

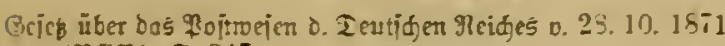
( $(301 \cong .34 \overline{1})$

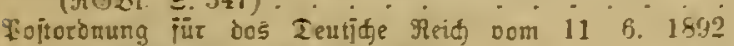
(3ngalisangate) (હß1. 3.428 ) . . .

Gejes über bos Pojtarnojen im Bebiete bes হeurjoen

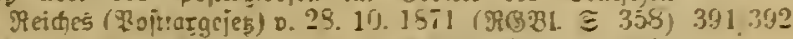

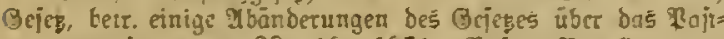
remejen rom 23 10. 15 il (q0jitar-Fovelle) nom 17. 3. $1 \geq 73$ ( $30 \mathrm{BPI} \Xi .107)$

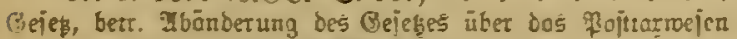
rom 3. 11. 1874 (अ(BRI. ङ.127).

\section{Fortobergünïtignngen, Fortojeigeiten, Uverīonirang von Forto.}

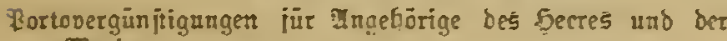
Marine.

Retonntmat,ung Dom 2S 1]. 18i1, bstr. bie Beireiung Der Dortopiliditigen Iienjtbrieje non bem jiur unirantirte

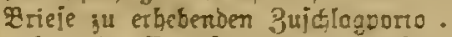

Bejes, betr. Die Portoireigeiten im Bebiete bes भordocutionen Runbes oom 5. 6. 1869 (BGB!. ミ. 141)

Bepimmungen Itter Partoireibeiten, relde aui bejonteren, mit cinjelnen Fegierungen ober Foptoermoltumgen $a b$ : geiळloffcren germägen aber Uetereinfommen beruher

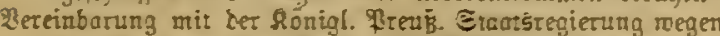

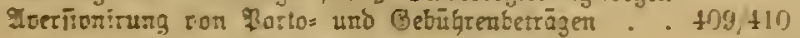

\section{IT. Ielegtaphenmejer.}

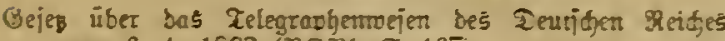
оом 6. 4. 1592 (भङझI. ङ. $45 \pi$ ).
$395 / 396$

$39-398$

399. 400

401 \& 22

Srite

349

350

3.52

$3.51 / 3.52$

351

35.3

356

$361 / 362$

$375 / 376$

$373 / 350$

$389^{\prime} 490$

$393 / 394$

$393 / 394$

$407 / 408$

$415: 416$

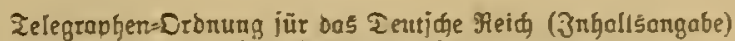
voin 15. 6. 1891 (CPI. ङ. 162)

₹eite

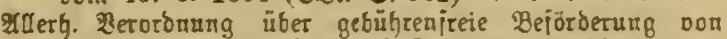

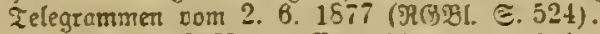

Requlatio über geiđä̈tliđe Behonolung der Telegramme

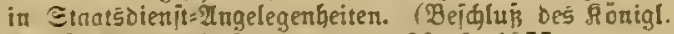

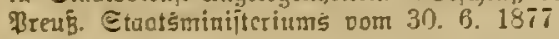

$+17 / 418$

$421 / 422$

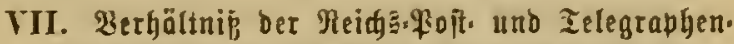 Retwaltung an ben (Eijenbahn.Bertoaltungen.}

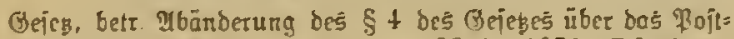

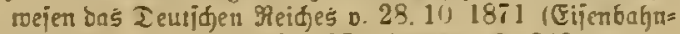

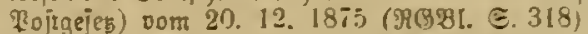

Bolfugsbejtimmungen gum Eijenbaha=? ojtgejeb o. 9 2. 18if

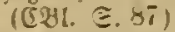

$423 ; 424$

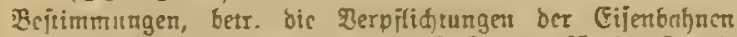
uarcgeotbneter Brbeutung su Q⿻ijtungen jür bie Zrocde bes Toitsienitcs dom 28 5. $18 \% 9$

Eiienbahnielegraphen=Heglemeat vam i. 3. 1876

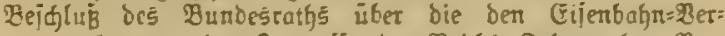

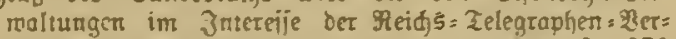
maltung abliegenben Derpilićtungen nom 21. 12. 1875

Eigraloronung ¡̈น bic Eijenbahnen হeutjdlands v. 5. T.1892 (

$427 / 425$

$13: / 433$

437,435

$413 \pm 11$

$4+3 / 44$

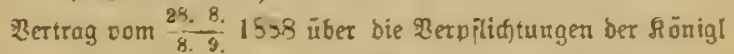

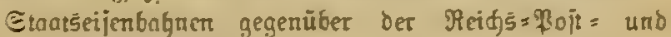
Zelegrargenvernolturg.

$401 / 452$

VII. Erganijation ber (Fijenbagn. Berwaltung.

(Gejes betr. Die Erridgtung cincs Reids: Eijenbahn= 20mtes vom 27.6. 1>7:3 (9i(3) E. 1fit).

Megulatio jur Eronung deś Geigöitsgatrges bei bem burd) Rictit veritärien Reids=teijenbahn= \$nt 0.13.3. 18it5 1 (52) $\approx 197)$

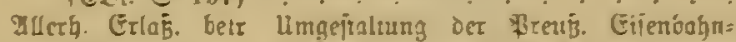
butöten oom 15. 12. 1894 (8)

ఇermaltungsoronung jür dic Stactseijembohnen

Bejes, betr. bic Eiriegung von Begirlseijenbohmätben und

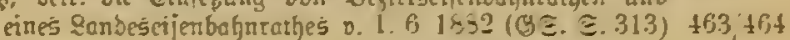

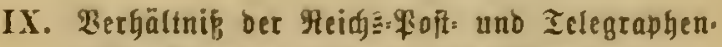 Bermaltung gu anderen Rerwaltungen.}

Doit=Pollregulatis (CBI $\Xi .605)$ $4.5 / 4: 50$

$457+5 \%$

$+57+53$

4594 fir

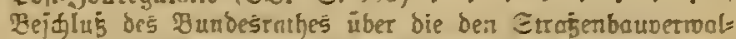

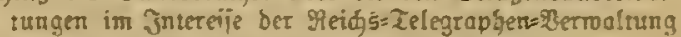
:uisehenden 2erpilitungen vam 25. F;. 1869

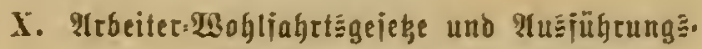 Beitimmnngen 20 .}

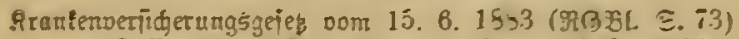

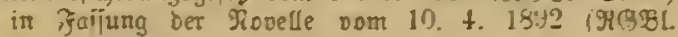
气. $117 \%$ ).

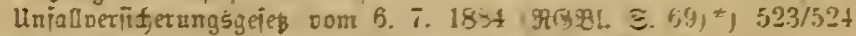

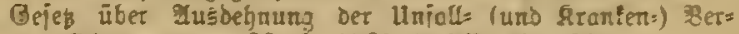

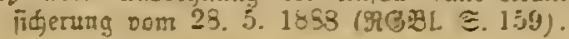

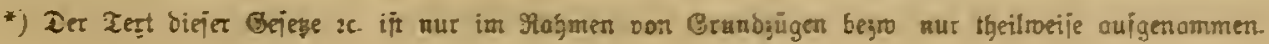


Regulatio, betr. bie unfalverffujeruntg für ben Betrleb ber Meid $s=\Re 0[t=$ und Telegraphen=\$erwaItung .

(3) 22. 6. 1889 (ঙHBL. S. 97)*)
XI. Poftorbung und Ielegraphenorbmang.

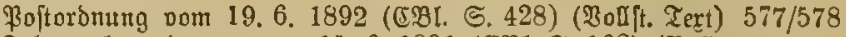

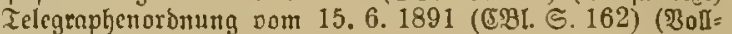
itünoiger Tert).

\section{III. $\mathbb{e} \mathfrak{l y} \mathfrak{i}$ il.}

\section{Gefeje und Deroronungen, welche fïh anf bie Beamtenverlä̈ltniffe bejiehen.}

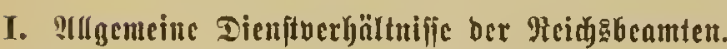

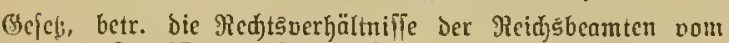

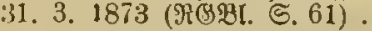

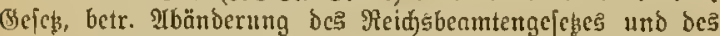

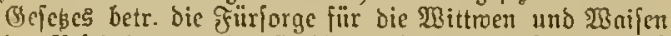
Der Ferchşbenten ber Civiloerwaltung vom 21. 4. 1886

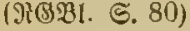

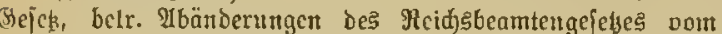

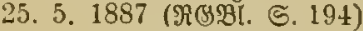

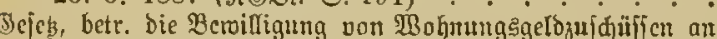

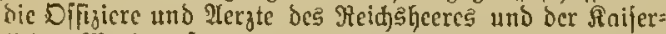
lidhen Marine, forwic an bie Reidjbeamten wom 30.6. 1873 (RSBI. S. 166).

IUerh. Beroromung, betr. Die flnfiffilation ber Ficidisbennten

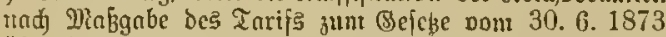

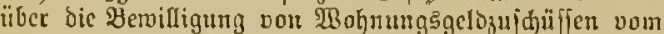

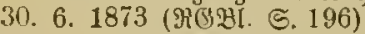

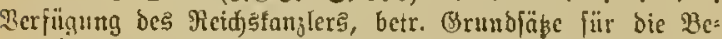
jestung ber Subalterns uno Utnterbcumtenitcllen bei ben

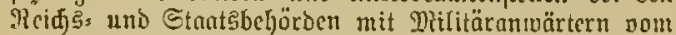
25. 3. 1882 (ङ21. 5. 123) * * . * . . . .

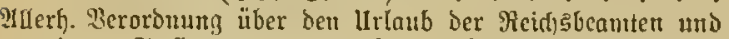
beren Stelloctretutg vom 2. 11. 187t (92021. S. 129)

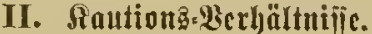

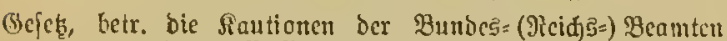
vom $\frac{2.6 .1869(98 B 81.5 .161)}{16.4 .1871(\Re(581.5 .63)}$

$705 / 706$

IIferh. Seroronung, betr. Die finutioner ber Beanten uno

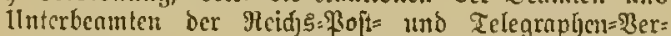
malung und Der Feidabruderei Dom 18.4. 1883 (9) (3). ङ. 35) . . . . . . . . . . . .

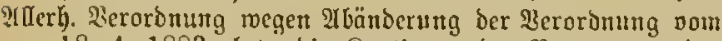
18. 4. 1883, betr. bie Fautionen ber Beamten 2c. Der Ricidte = Foft $=$ und Telegrapher = Bermaltung 2c., vou

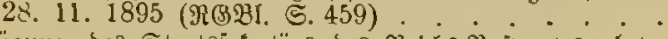

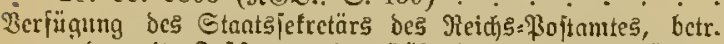
anticrmeite feitfebung ber 5öhe ber Fautionen für bie

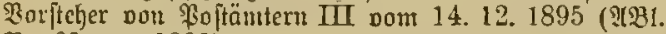
?R. 65 bon 1895)

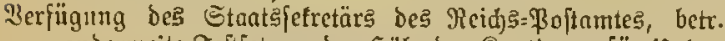

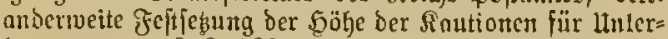
benmten pon 3. 3. 1895 (219I. Nr. 44 on 1895).

Tafel ïber Şähe ocr fautioneat tad) ben jest geltenton Beftimmungen .

Bejeb, megen Ergänzung bes (Bejeces oom 2. 6. 1869, betr.

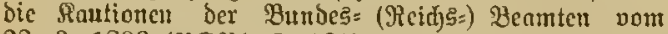

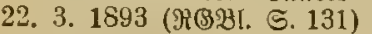

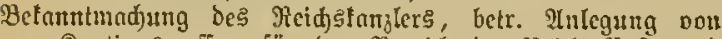

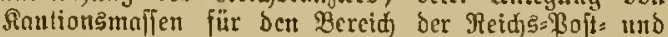

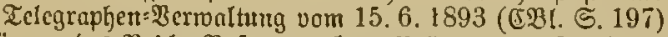

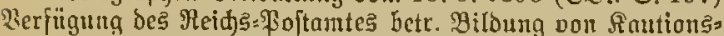

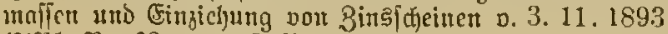
(भश). $\Re r .63$ von 1893) .

\section{Seite}

$653 / 654$

$685 / 686$

$687 / 688$

$687 / 688$

$689 / 690$

$693 / 694$

$703 / 704$

$709 / 7$ to

$711 / 712$

$711 / 712$

$7 \mathrm{t} 3 / 714$

$713 / 714$

$713 / 714$

$715 / 716$

$715 / 718$

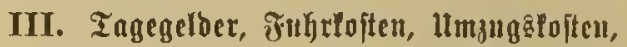
Fahts unb lleberlager = (5ebiïgren.

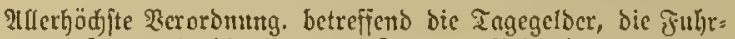

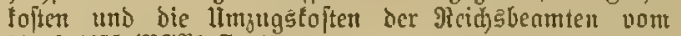

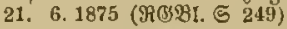

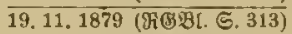

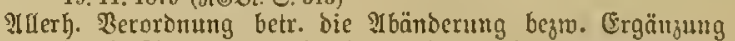
ber $\mathfrak{D e f t i m m u n g e n ~ u ̈ b e r ~ T n g e g e l d e r ~ z e . ~ b e r ~ \Re e i d j b e a m t e n ~}$

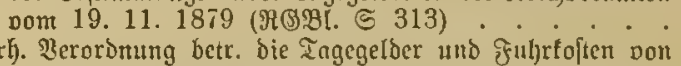
Beanten ber Reidss: \$oit= unt Telegraphen=:ermalumg vom 29.6. 1877 (अ(SBI. S. 545).

Rerfügunt Des Bencral = \$oftmeifters betr. 2usfühung ber

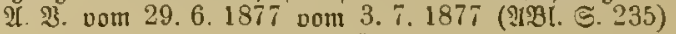

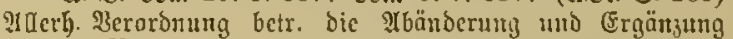
ber $\mathfrak{B c | t i m m u n g e n ~}$ von Beamten Der Reids=\$o[t= uno Telegraphen=93er= maltung vom 29.6. 1894 (R(52). S. 491).

Berfïgun Des Staats[efletär's des Reids=\$oftantes betr.

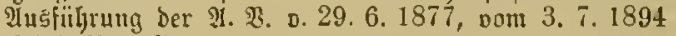
(अB!. $\Re r .36$ ).

2(Jerh. Beroromung betr. bie Tagegelder ic. vout Becunten

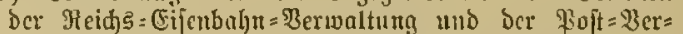

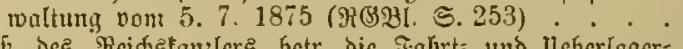

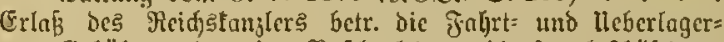
Bebuifret ber im Foitbegleitungsbienjte bejdäftigten Bcamten uns luterbeanten pom 20. 10. 1875 (श1: ธ. 393) .

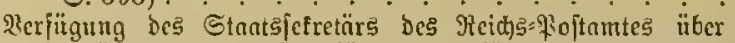
veräuberte Grumb|äbe für bic Musfïhrung von Dien[t=

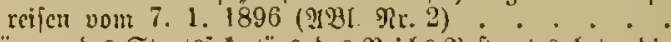

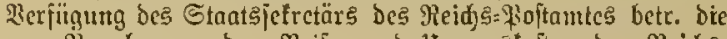

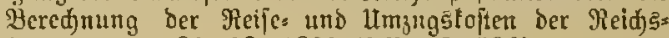
beamten vom 21. 12. 1881 (291. S. 390) •. •.

Tafer ̈̈ber \$öhe ber Tagegeloer, Juhrloften und Itmijugs: foiten ber Beamten uns Itnterbeanten ber Preidgs=\$opit= uns Ielegraphen= Berwaltung nad) ben 3 ut 3 cit be: ftehenoen Beftimnungen ......... . . 737/73s

\section{F̈̈rjorge für ginterblicbene.}

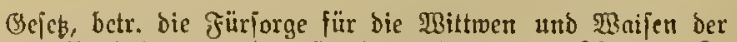
Reid) sbeanten ber (Eiviloermaltustg nom 20.4.1881 (HBR!. 5. 85)

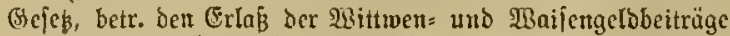

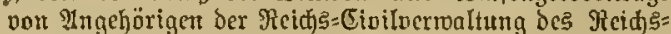
beeres und ber fariperlichen Marine vont 5.3. 1888

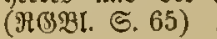

\section{T. Fïrīorge bei llufällett.}

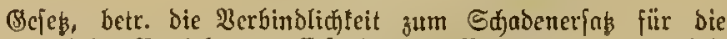
beim Betriebe non Eifenbahnen, Bergmerlen 2c. herbei=

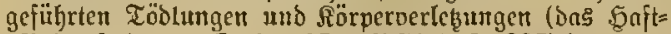

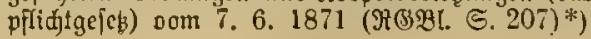

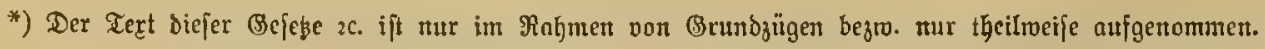


(Seles, betr. die Fürforge für Beamte und \$erfonen bes Solbatenitandes in Jolge von Betriebsunfällen oom

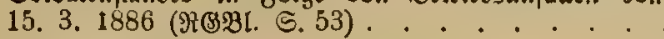
$747 / 748$

\section{Strafredytlidise $\mathfrak{B e f t i m m n n g e n .}$}

Beftimmungen bes Strafgefebudes von 15.5. 1876, welde fid) auf Beamte beziehen . . . . . . . . 751/752

\section{Mrilitärverhältmijīe.}

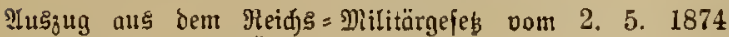

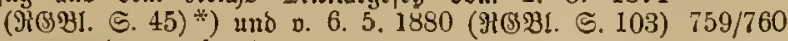

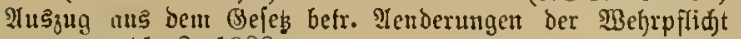
Dom 11. 2. 1888

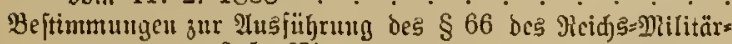
gefeses vom $\frac{2.5 .1874}{6.5 .1880}$ rïtfidiflid der Meidjobenten. (Benchmigt durd) Illerh. Beroronung vom 8 5. 1888 . $759 / 760$

\section{Stettern utb arbgaben.}

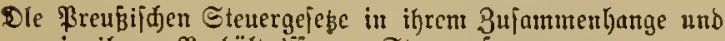
in ifrem Serbälnifife jur Etcuerreform .

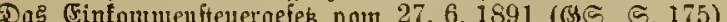

Das Ergäuzungsjtenergcjes o. 14 7.1893 (\$ङ. S. 134) $789 / 790$

Bejes regen Iufbebung biretter Staatsfteuern o. 14. 7. 1893 (BS. ङ. 119 ) *).

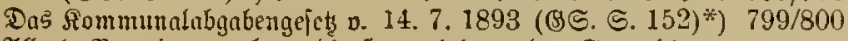

IIlerh. Berorbung, betr. bie Seraujiehung ber Etantzbiener zu ben Ronturnalauflagen in ben neu crworbonen

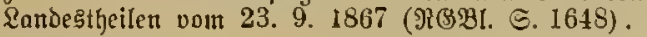

$811 / 812$

\section{Woblfahrtbanjtalten (Raijer Millyclm:-Stiftumg).}

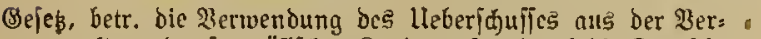

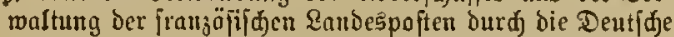

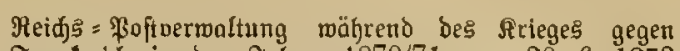
Franfreich in ben Эuhren $1870 / 71$ Dom 20.6. 1872

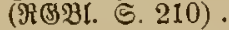

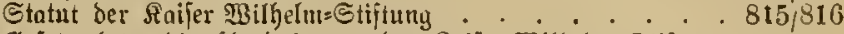

(Selet, betr. dic Sllusbehnumg ber Raijer \$3ilheln = Stiftung

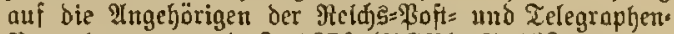

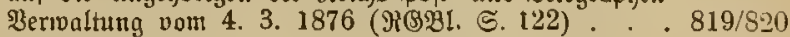

Illerh. Drore vom 4. 3. 1876 . . . . . . . . . 819/830

\section{Berbältnifie ber Zelegraphenarbeiter.}

Dronung für bie bei bem Reubau und ber Unterhaltung von Teleyraphen= und Fernipredanlagen, bei deu Stangen=

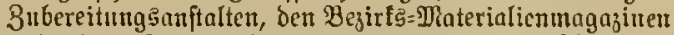
und der Telegraphen = 2lpparatwerlftatt bejdäftigten 2Trbeiter vom 13. 7. 1894 . . . , . . . .

linfallocrbütungsoorjdriften für die bei bem গeubau und ber llnterbaltung von Telegraphen = แno Fermpreds: anlagen, bei ben Stanyen=3ubereitungsanftalten, ben Bezirts = Diaterialienmagazinen ober ber Telegraphen: Ipparatwerfftatt bejäätigten $\mathfrak{A}$ rbeiter

\section{Madjträge uno Beridjtigungen.}

A. 3ur Eivilprozef̧oronung. . . . . . . . . . 837

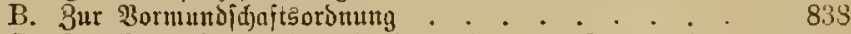

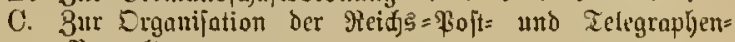
3ernaltung . . . . . . . . . . . 838

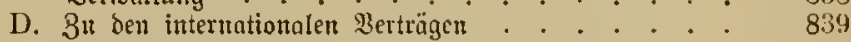

Is 3ur \$oftoronutug. . . . . . . . . . . . . $8: 39$

F. Rleinere Druffebler=Beridtigungen . . . . . . . $84 \mathbf{t}$

*) Der Tert biejer Gejebe ift nur im Mahmen von Brunozïgen beğo. mur theiltweife aufgenommen. 


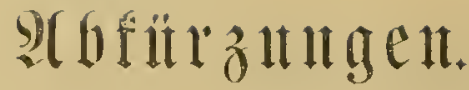

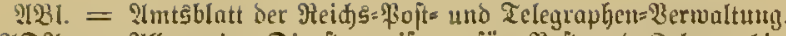
श्DP. = IIlaemeine Dicnitambeifung für \$oft und Telegrnphic.

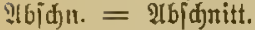

भibth. = Itbtheilung.

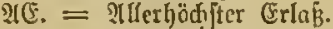

2RO. $=$ IILerbödjite Rabincts=Drore.

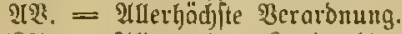

IRH. = MUgemeites Eandredt.

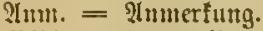

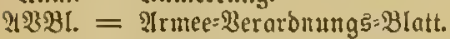

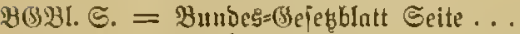

BR. $=$ Bundeร=fกngler.

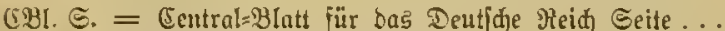

E\$0. = Civil= \$roze $=$ Drbunng vout 30. 1. 1877.

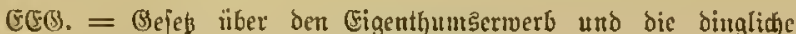
(5inj(s). = Eirtïürungs:Bejers.

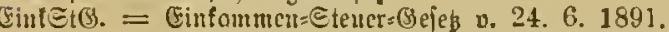

Entw. = Eutwuri eines (Befebes, betreffend 2lenderungen und

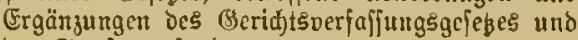
Der Strafprazeloromung.

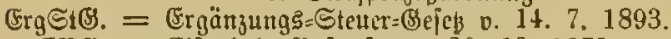

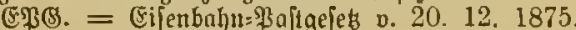

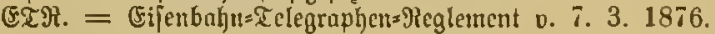

3. $=$ Gejeb.

(332. = (3rundbud)=Drbnnng vom 5. 5. 1872.

अฌ2. = Beneral:\$aftam!.

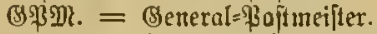

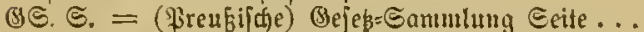

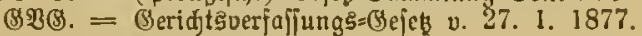

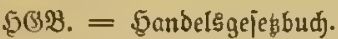

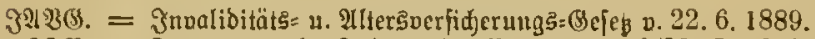

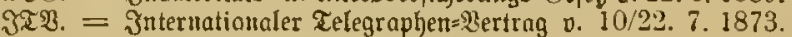

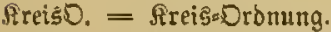

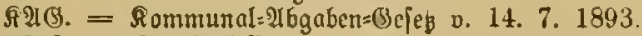

§rß. = §rantentajje.

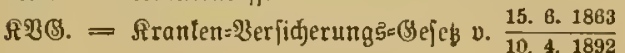

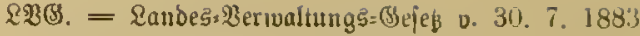

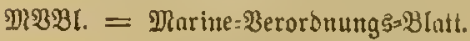

OßD. = Qber=\{oitdireftion.

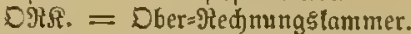

O2B(3. = Ober=:Bermaltungs:(3eridt.

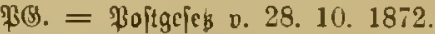

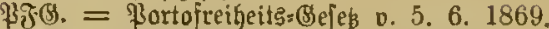

\$D. = \$optarbunng o. 11. 6. 1892.

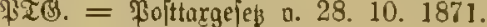

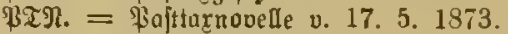

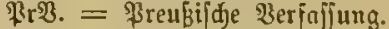

\$3Я. = \$̧oft:3allregulatio.

RP(3. = Reidsbeamten=(3ejeb v. 31. 3. 1873.

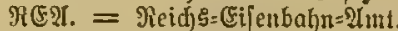

$\Re(3 .=$ Reid $=$ Beridt.

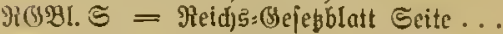

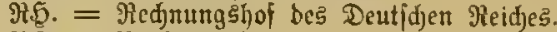

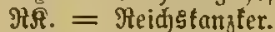

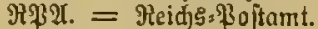

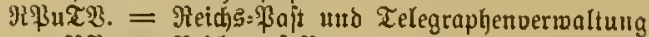

$\Re \mathfrak{R}=$ Reidjsoerfafjutg.

St(SB. = Straf=(Befebbud für bas Deutide Reid

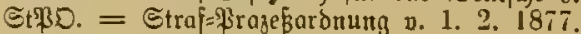

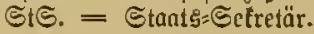

זB. = Telegrnphen=Bejeb v 6.4 .1892$.

TO. = Telegraphen:Dronung v. 15. 6. 1891.

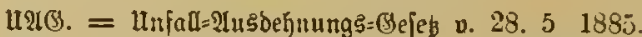

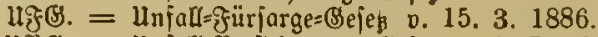

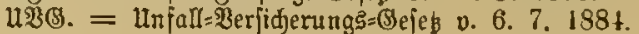

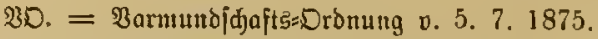

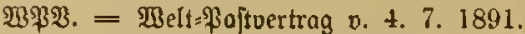

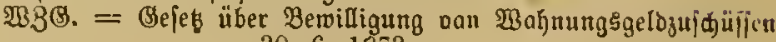
v. 30.6 .1873 .

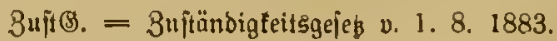


POSTAL History

REFERENCE LIBRARY

Smithsonian Institution

Gift of

Julius STOLOW

\section{I. $\mathfrak{d} \mathfrak{b} \mathfrak{e} \mathfrak{i l}$.}

\section{Gejefe und Deroronungen allgemeinen Inhalts.}

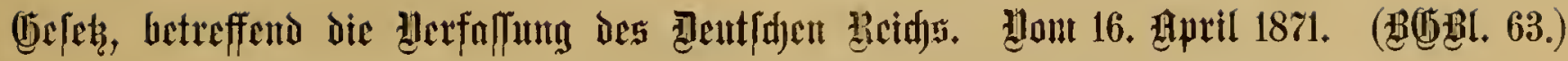

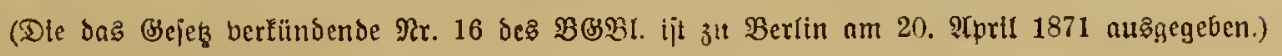

\section{1}

ir 2

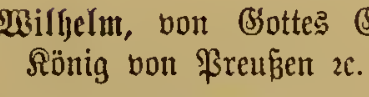

Deroronen ficrmit in Ramen bes Deutfden Reidjs, nađ erfolgter

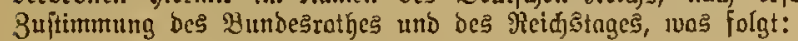

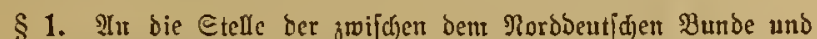

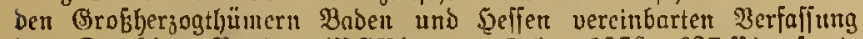

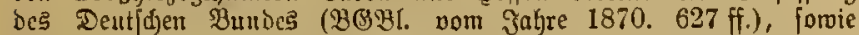

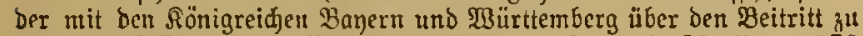

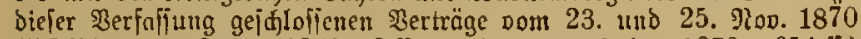

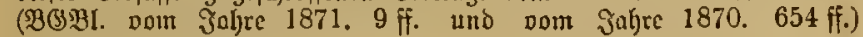
tritt bie beigefügte

\section{Berfaijungs:lufuแde für bas Deutidje Reid.}

\$ 2. Die B̧ejtimmungen in $\mathfrak{A}$ rt. 80 ber in $\$ 1$ gedadten Berfajiung bes Deutihen :Bundes (BOBgI. vont Jnhre 1870. 647), unter III. $\S 8$ bes Nertrages mił Bnyern Dom 23. Roo. 1870

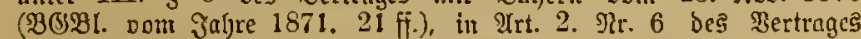

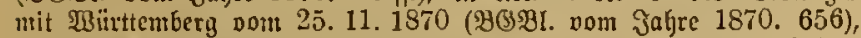
über bie Cinfübrung ber im Yorbbeutjhen Bunbe ergangenten Sefese in biejent Etaaten bleiben in \&raft.

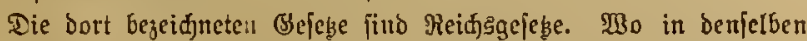

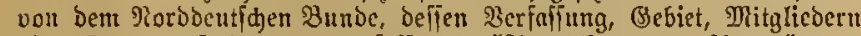
Dber Etanten, Indigenat, verfafiungsmïß̈igen Drganen, Ingehörigen, Beanten, Jlagge 2c. bie Pebe ift, find bas Deutide gicid unb beffen

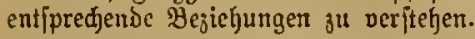

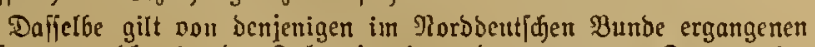
Befesen, neldje in ber Folge in einem ber genannten Etraten ein= gefüht werben.

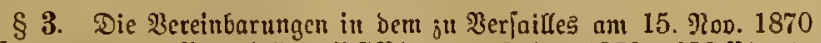

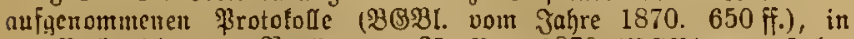

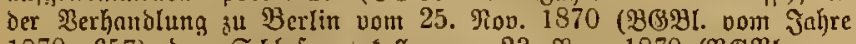

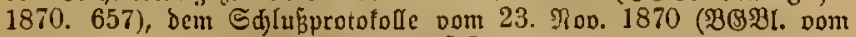
Jalye 1871. 23 ff.), powie unter IV. Des Bertrages mit Bonern

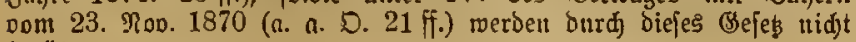
berïhrt.

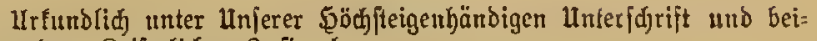
gebrudtem Saiferlichen כ̄nfiegel.

Gegeben Berlin, ben 16. Upril 1871.

$$
\text { (L. S.) }
$$

Milluelm.

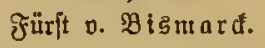

\section{delexfallium}

bes

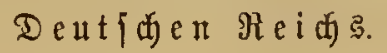

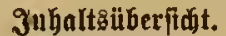

I. Bundesgebiet . . . . . . . . . . . . 9YUrt. 1

II. Reidsgejeßgebutrg . . . . . . . . . "2-5

III. Bundeşroth . . . . . . . . . . . . " 6-10

IV. \$räfitium . . . . . . . . . . . . "11-19

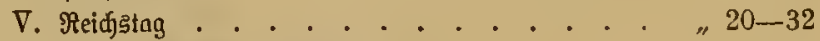

VI. 3olf = und 5andelsweien . . . . . . . . "33-40

VII. Cijenbahnwejen . . . . . . . . . . . " $41-47$

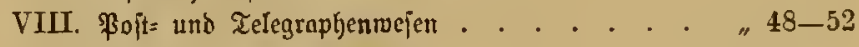

IX. Varine unঠ ভdiffahrt. . . . . . . . . " "53-55

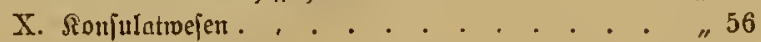

XI. Reidystriegswejen . . . . . . . . . "57-68

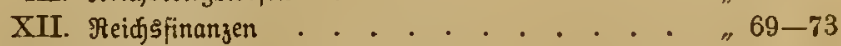

XIII. Sdjltutung von Streitigfeiten und Straf= beftimmungen. . . . . . . . . " $74-77$

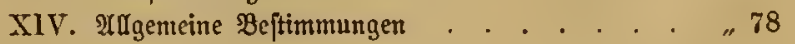




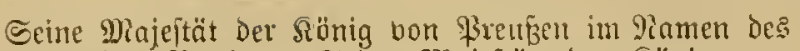

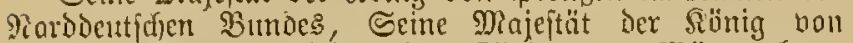
Babern, Scine Majeität dex Rönig bou Mürttemberg,

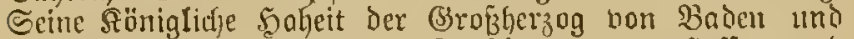

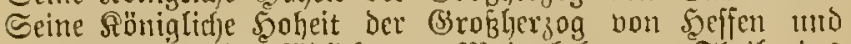
bei Mihein für oie fïblich boin Main belegenen Theile ies

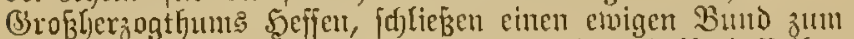
ธdjube des Bundesgebietes und des innerlyalb beffelben guiltigen Redjtes, fotwie jur Yiflege ber $230 h(f a l) r t$ bes Deutifien Solfes. Diejer Buno wird Den Ramen Deutides Reidf fülyen und twirb nadjpteljende

\section{$\mathfrak{l} \mathfrak{e r} \mathfrak{f} \mathfrak{\int} \mathfrak{f} \mathfrak{n} \mathfrak{a}$}

haben.

\section{2̧undesgefiet.}

Trt. 1. Das Bundesిgebiet bejteht ans Den Staaten Breufen mit Rauenburg, $\left.{ }^{1}\right)$ Babern, Sadjien, Wïtttemberg,

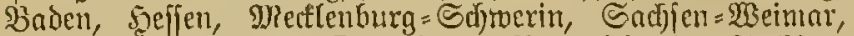
Medlenburg = Strelitz, Sldenburg, SBraunidjweig, Sadjen=

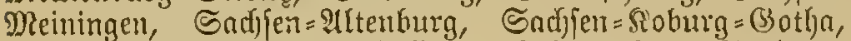

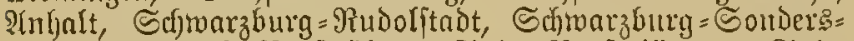

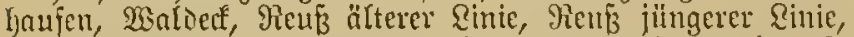

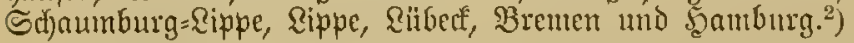

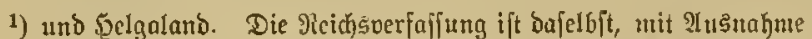
bes शุb/dnitts VI, am 1.4. 1891, al's bcm Tage Der Einverleibung mit ber \$rcubifden Mauardie, in Beltung getreten. (B. v. 15. 12. 1890. R(Bß1. 207.)

2) Durd) (9. v. 9.6.1871 (9r(5) 21. 212) ift ElfaE=2othringen nit bcm Deutfden Reid für imuncr percinigt. Dic Rcidsocrfoffung ift bart am 1.1. 1874 cingejührt. Sm Llebrigen ift die \$er=

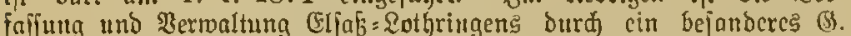

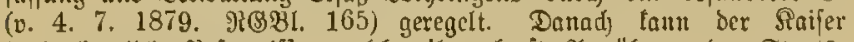
laubesherrlichc Befugniffe, melde ihm fraft S1 gewalt in (Eljak=2othritgen zultshen, einem Statthalter übertragen.

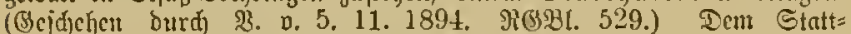

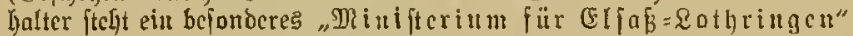
aur Scite, woldes in Strapburg feincu Sib hat und an beficn Spite ein Stantajefretär [icl)t. Reben bem Dinifterium bejtcht eit Stantsrath, in mejentiden zur Bcgutadtung von Bejebentwürfcr, 1mo ein $\Re a i f e r l i d e r ~ \Re a t h$, als oberftes Bermaltungsgerid)t. Ju

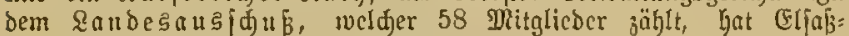
Sathringer fcine Boll'spertretunß.

\section{Defingsgelelggebung.}

Prt. 2. Jnnerhal6 diejes Bundesagebietes jibt Das Reid)

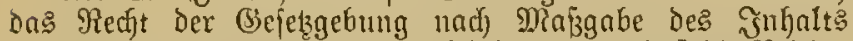

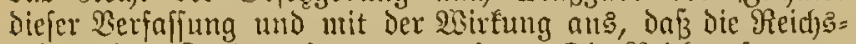
gefetze den Eandesgefezen vorgehen. Die Reidfsgejetze er=

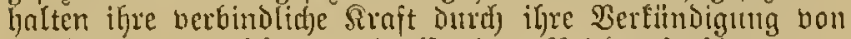

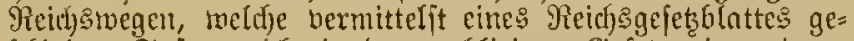
idjteljt. Eofern nidjt in Dem publizirten Befebe cin anderer Anjangstermin feiner berbinolidjen Siraft beftimmt ift, $b e=$ ginnt bie lekstere mit Dem 14. Tage nad) dent Itblauf bes= jenigen Tages, an weldjem bas betreffende Ctïd bes Reid)sgefetzlattes in 3erlin ausgegeben roorden ift.

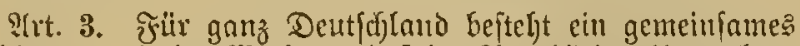

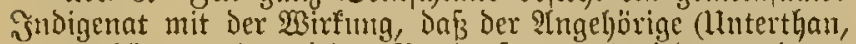
Stantshürger) eines jeden Bundesftates in jedem anderen

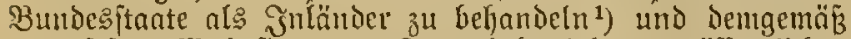

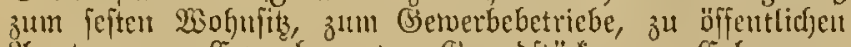

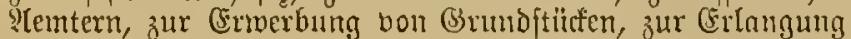

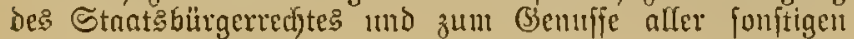

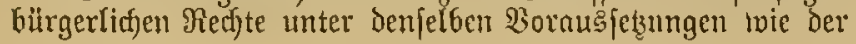

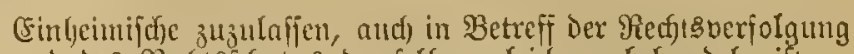
IIID De? Re(j)t3idjutzes Denifeloen gleid) zu behantoln ift.

Sein Deutfder Darf in Det 9lusitbung defer Befugnifs Duref) Die Dbrigfeit feiner Sgeimaty, oder Durdf Die Dbrigteit cine: anberen S3moesftantes befdinänlt merden.

Diejentgen Beftinmmungen, weldfe die Rrmenberjorgung unt bie ?tufnahme in ben Lofalen Bemeindeberband he= trefien, werden Durdf den im criten ?hfofts nusgefprodfenten (Britudjak nidjt beriifurt.

Ebenfo bleiben bis anf Weiteres bie $\mathfrak{B e r t r i ̈ g e ~ i n ~ S r a j t , ~}$ twelche ziwifgen Den einjelnen \$31utdesftanten in Bezieljung

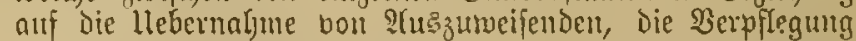

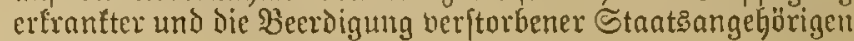
beftelen.

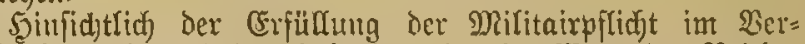

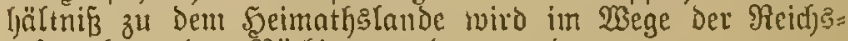
gefelsgebung das Töthige geordnet merden.

Dem Inslande gegenüber haben alle Deutfide gleirly=

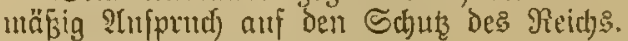

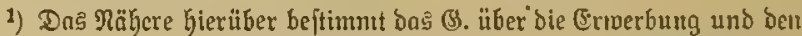

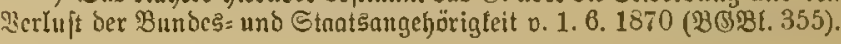

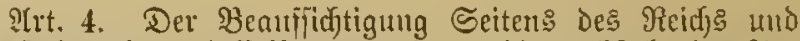
Der Gefetzgebung Deffelbeit unterliegen bie nad)fehenden ?t1= grlegenteiten:

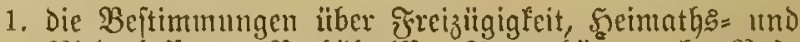

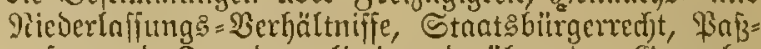
mejen und ofremdenpolizei und über den (Setwerbe=

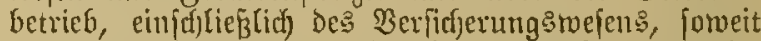
Diefe (segenjtände nicht jofjon durd den IYrt. 3. Diefer Berjafjumg ertedigt fiub, in Babern jedod) mit ?tus: id) Luß der Speintath Desigleicfen ïber bie Ralonifation und bie Rusmande= rung nady auferbeutidyen Ränbern;

2. Die Boll = und Sandelsgefergebung und die für die

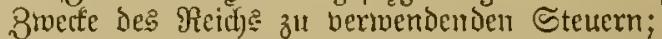

3. Die Dronung oes Maa $\bar{\beta}=$, Münz= und (Servichts:

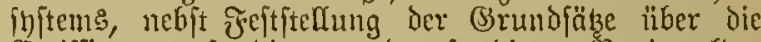

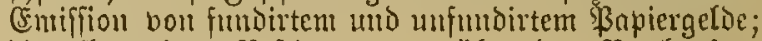

4. Die allgemeinen $\mathfrak{B} e$ timunungen

5. Dic Crfindung apatente;

6. der Schuts des geiftigen Cigenthums;

7. Drganifation cines gemeinfanen ङd)ubes Des Dentfdjen Sombels im $\mathfrak{A}$ ustande, Der Deutfhen Sdjiffahrt uno iljer Flagge zur See und Inorbnung gemeinfauter fonfularifdjer Bertretung, weldye bom ஒeidje alts:= gejtattet twird;

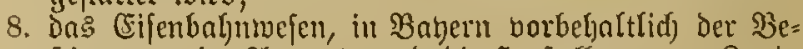
fitimmung im $\mathfrak{A}$ rt. 46 , und bie Serftelfung bon Ranb= und खajferftrafien im sntereffe der \&andesverthcidigung unto Des allgenteinen Berfer)rs;

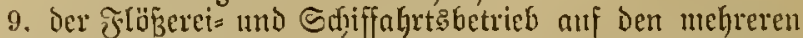
Stanten genteinfanen Wafferftrafen und der Buftand

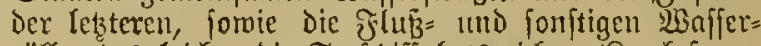
zöle; Desgleidfen Die Seejdiffahrt:seidfen (Reud)tfeuer, Tonnen, SBaten und fonitige Tagesmarten. ${ }^{2}$ )

10. Das Poît = und Ielegrapljentwefen, jebodj in Babern und 2 iturttemberg nur nach Maaß̧gabe Der Beftimmung im ?.rt. 52;

11. Beftimmungen ïber die wedjelfeitige Bollptredfung von (Erfeuntuiffen in Cibilfad)en und (Erledigung von Requifitiomen überhaupt;

12. forwic ïber die Beglaubigntug von offentlidfen $l \mathfrak{l} x=$ fumber; 
13. dic gemeinfame Bsefebgebung über bas gejammte

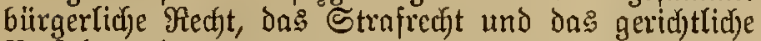
Berfahren ; ${ }^{1}$ )

14. Das Militaitmejen bes Reidjs und Die Siriegsmarine;

15. Majregeln Der Medijinnl= und Neterinailpolizei;

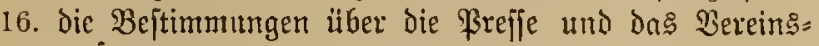
recien.

1) Dic Rru. 9 und 13 Galen bic Fafilung, wic fie burd) bic (3. v. 3. 3. 1873 แ⿰t) $20.12,1873$ besingt ift.

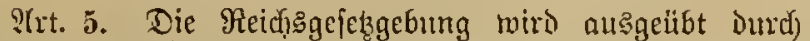

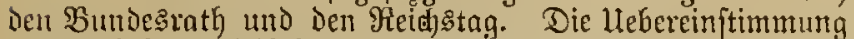

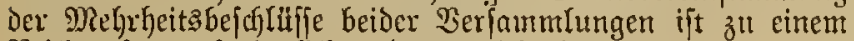

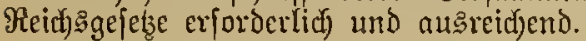

Bei (befebecsoorjhlägen ïber Das Militairmeicn, die Siriegsimarine und Die im 2Trt. 35 bezeidneten ?thgaben giebt, wenu im Bundešrathe eine Meinungsocridjiedenheit

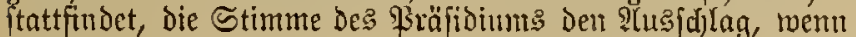
fie fidc) fitr bie Anfrechthaltung der beftebenden (Eimridjtungen attôpriç)t.

\section{III. ¿ֶandestatfj.}

2rt. 6. Der BunDeß̧rath beftelt nus Den Bertretern ber 9) litglieder de \$3undes, unter weldyen bie Stimmfiihrung

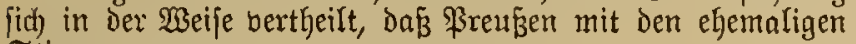
Stimmen bor

Şamover, Burheffen, Scolftein, Raffau und Jranffurt . . . . . 17 Stimmen

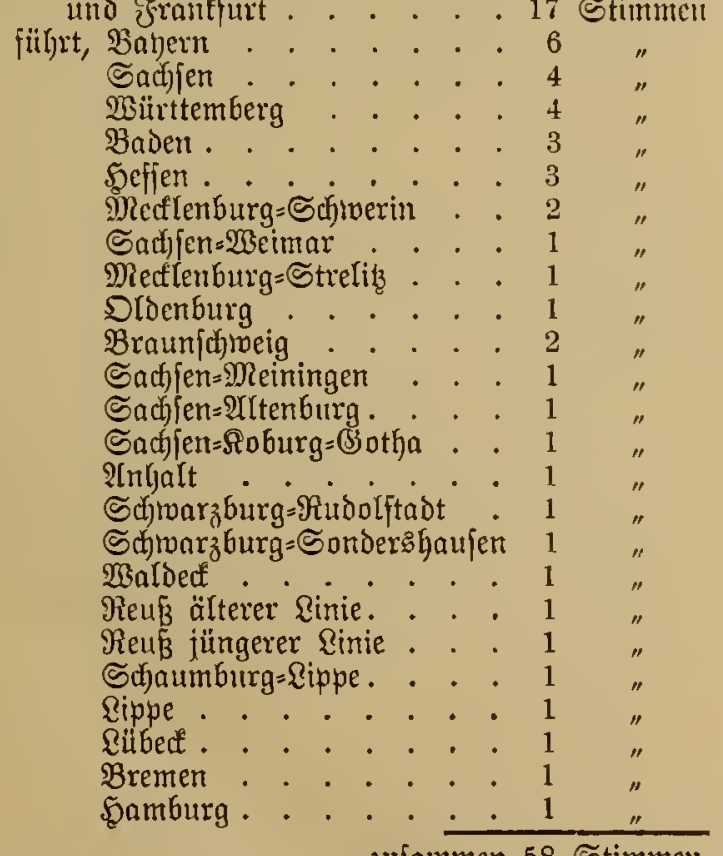

zujaumer 58 Stimmen.

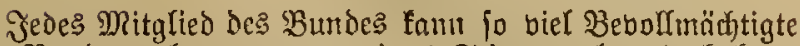
3um Bundesiathe ernennen, toie es Stumen hat, dod faun bie (Sejammtheit der zuftändigen Stimuten nutr einheitlict) abgegebell merdert.

21tt. 7. Der Bundešrath befchlief̧t:

1. itber die Dem ßeidistage zu madjenden Borlagen und bie bou demjelGen gefä̧ten Befd)lüfje;

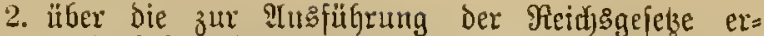
forderficjen allgemeinen Berwaltunggoorjatiften und

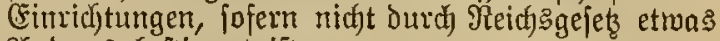
Ŷtueres beftimunt ift;

3. iiber Mängel, weldye bei ber श्Atsfüthrumg ber Reidjęgeferse oder der borjtehend erwähnten $\mathfrak{B o r}=$ idfriften oder (situridytungen hetbortreten.

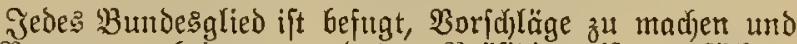
in Sartrag zu bringen, und Das Bräfidium ift berpflicidtet, Diefelben oer Berathung zu Hibergeben.

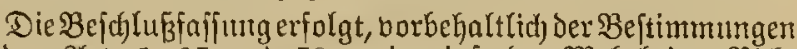
in Den 9rt. 5, 37 und 78, mit einfacher Mehrheit. Nidyt bertretene ober nicht inftruirte Stimmen werden nicht ge= zälylt. Bei Stimntengleidjheit giebt die \$rä́fibialfimme Den

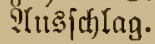

Bei Der Befdyluffaffung ïber eine INngelegenheit, weldje nach den Beftimmutgen biefer $\mathfrak{B e r f a f j u t g}$ nidht bem gausen Reiche gemeinj(d)aftlid ift, werden bie Stimmen mur ber= jenigen Bundesftaaten gezählt, welchen die Ingelegentheit gemeinidjaftlich) ift.

Mrt. 8. Der Buttdesrath bildet nus jeiner Mitte dauernde จุเisjujiitife

1. Fïr das Ranbheer und die Jeftungen;

2. für daร Sectrejent;

3. Fiir 8 all = und Stentervefen;

4. fiir Şandel und Bertehr;

5. für Eifenbahnen, Bopt und Telegraphen;

6. jür Эıtftiztocien;

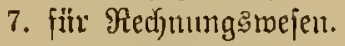

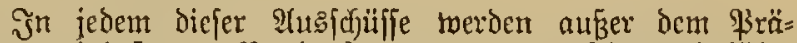
jioiuu mindeftens 4 Butrdesftanten vertreten fein, und filfrt immerhalb derfelben jeder Stat nut 1 Stimme. Sn

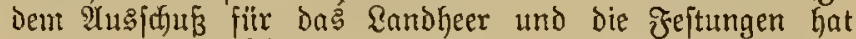
Babern einen Ftändigen Sik, Die übrigen Mitylieber

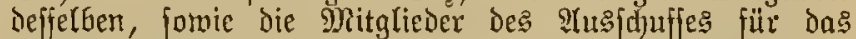
Seemejen werden bom Saijer ernannt; Die Mitglieder der

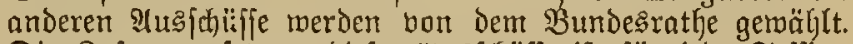

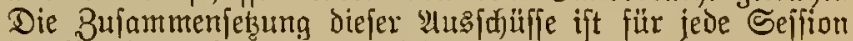
Des Bundeşrathes refp. mit jedem Эahre zu erneuern, wobei die auģ[d)eibenden Mlitglieder tvieder rählbar find.

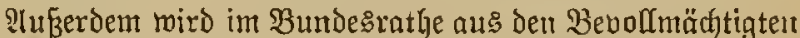
der Rönigreidhe Babern, Sachjent und Württemberg und 2 , boun Bundešratle alljährlich zu mählenden Beboll=

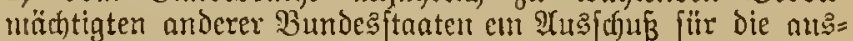
wärtigen 2 Angelegenteiten gebildet, in weldhem Babern ben Borjits füfrt.

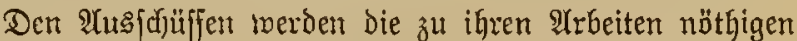
Benmten zur Berfïgung gejtellt.

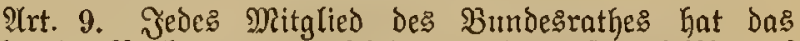

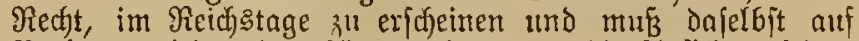
Zerlangen jederzeit gehört twerden, um die 2̂nfidten feimer Regierung zu vertreten, nudf bant, wenn diefelben von ber

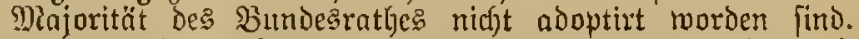
ఇiemand fam gleidjzeitig Mitglied des Bundesrathes und des Feicjestages lein.

Art. 10. Dem Saijer liegt es ob, Den Mitgliedern des Bundestathes den ilblidjen diplomatifden Sdut zu ge= währest. 


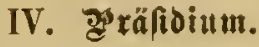

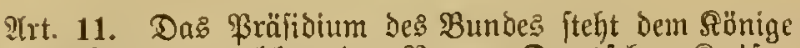

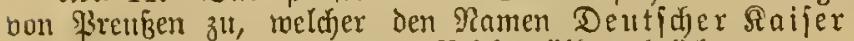

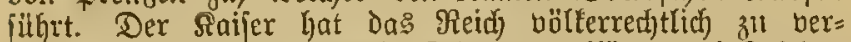

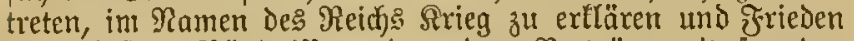

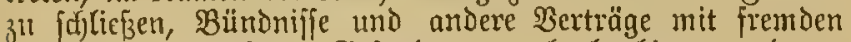
Staaten einzugehen, Befandte zu beglaubigen und zu emipfangen.

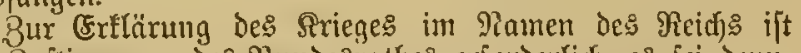

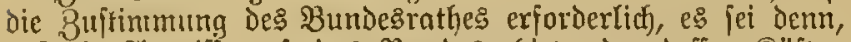

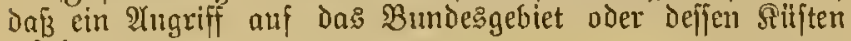
erfolgt.

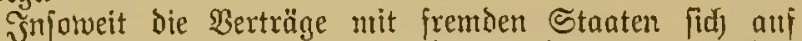
foldje (Segenjtände beziefen, tweldfe nad) 2 (rt. 4 in Den

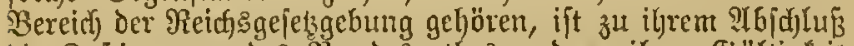
die Buftimmung des Bundestrathes uno zu ihrer Bsilttigleił

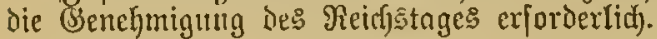

Irt. 12. Dem Raijer freht es zu, Den Bundesirath und

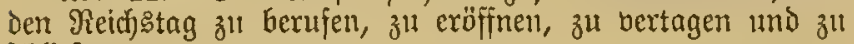
judlię̧en.

2(rt. 13. Die Bernlung desి Bundesrnthes und des Reichstages findet alljährlid itatt und fann Der $\mathfrak{B}$ undes: rath zur Borbereitung Der Ŝrbeiten ohne Den Reidsitng, lesterer aber nid)t ohne den Bundešrath Gernfen roerden.

2trt. 14. Die Bernfung DeE Bundesarathes muß $\mathrm{er}=$ folget, fobald fie bon einem Drittel der Stintmenzafjl berlargt twird.

Trt. 15. Der Borfits im Simndes rathe und dic Seitung

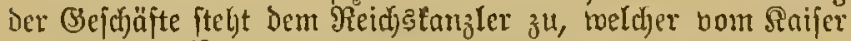
zu ernennen ift.

Der Reidjätanzler tann fid Durdj jedes andere Mitglied Des Sumdesrafhes vermöge fdriftlider Subftitution ver= treten lafjen.

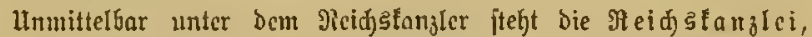

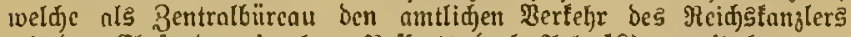

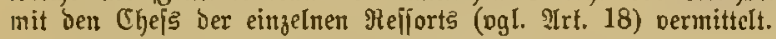

Irt. 16. Die erforderlicten $\mathfrak{B}$ orlagen twerden nad) MRaß $=$ gabe der Befrbliiffe bes SBundestrathes im Namen des Raifers an den Reid) Stag gebradt, too fie durch Mitglieder

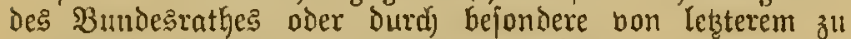
emennende Rommiffarien bertreten merden.

Irt. 17. Dem Raifer fteht Die Ausfertigung und Ber=

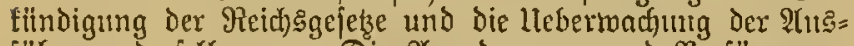
fiithrung Derjetben zu. Die Ânordnungen und $\mathfrak{B}$ erfügungen Des Saifers merden im Ramen des Reidjs erIaffen und be=

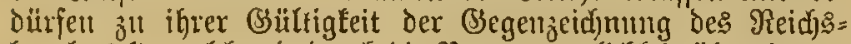
fanjlers, ${ }^{1}$ ) weldher dadurth die Berantworttichfeit übernimmt.

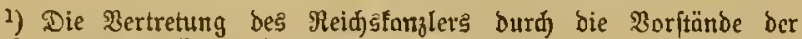

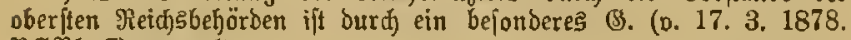
R(BßI. 7) geregelt.

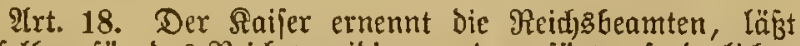
biefelben für Das Reiff vereibigen und verjügt exforderlichen Falles deren Entlaffung.

Den zu einemt $\Re$ eidjsamte bernjenen Beanten einez Bumdesftaates fteljen, fofern nicht bor ifrem Csintritt in

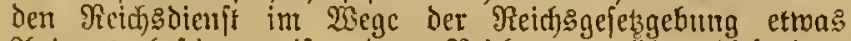
Arderes beftimmt if!, den Reifje gegenitber diejenigen
Redhte zu, weldhe ifnen in ifrem Seimathglande aus ifyer bienfttichen Stellung zutgeftandelt Gatten.

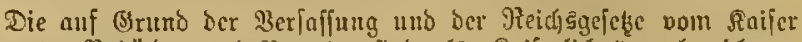

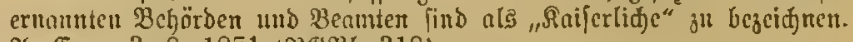

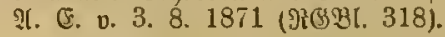

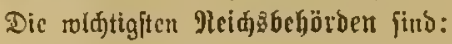

I. Das $\mathfrak{A}$ \& swärtige $\mathfrak{A} m \mathrm{t}$ mit einem Stautsjefretär an ber Spizc.

1. Ifbrheilung: a) politifde, bj \$erjonalien;

2. Asthcilung: handelspotitifde;

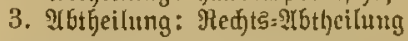

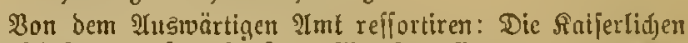
Botijaften, Sefanbtidaften, Mlinifterrefibenturen, bie Be=

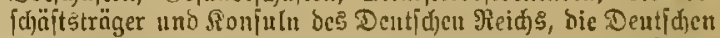

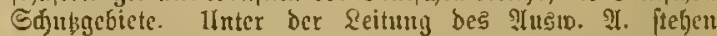

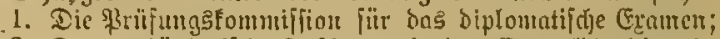
2. Das arduäologif(che Snititut mit ber Centralbireftion in Berfin und Den Selretariaten zu Fom und Nifer.

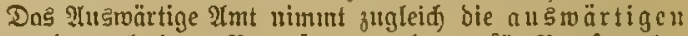
IIngelegengeiten \$ren Bens rohhr, rolür \$reuber elne

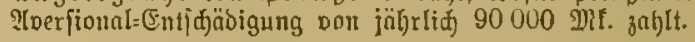

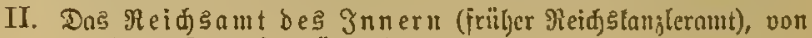
cinem Staatşeltretär geleltet.

1. Mbtheilung: Centraloervaltung;

2. Itbtheilung: Beauffidtigung und Benrbcitung pont

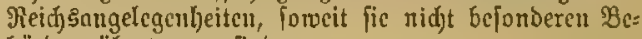
Görben iibertragen find;

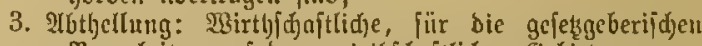
Borarbeiter auf bent virthjigajtliden (Sebiete.

Meffort: a) Reidstommiffare für bas Яtusmanberungs:

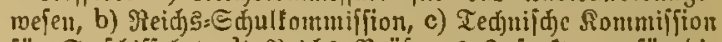

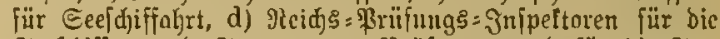
Seefáiffer= und Steue'manns=\$rüjungen und für bie See=

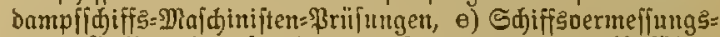

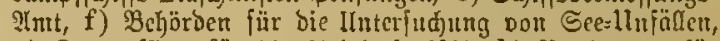

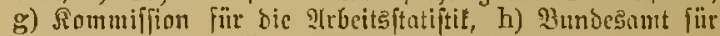
bas Seimathroejen, i) ber Dişiplinarhof in Reipjig uno bie Dissiplinarfaunuern an Den verjajedenen Drten, k) Das

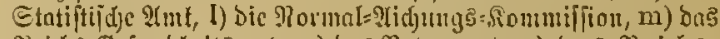

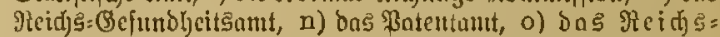

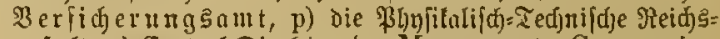
anftaIt, $q$ ) Central=Direftion der Monumenta Germaniae historica, weld)e bie Befonmutnuggabe bes Queflen= umb IIrfunbemuaterials zur (Befdinte bes bentfden Dittelnlters leitet.

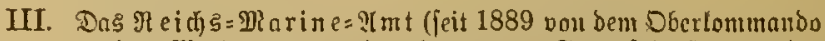
Der Marine getrennt) mit einem Etantsfetretär nut ber Spize. 3um 9teffort gefören: a) bie Merfiten jn Dantig,

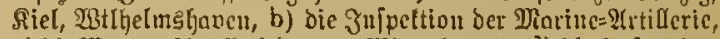

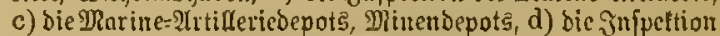

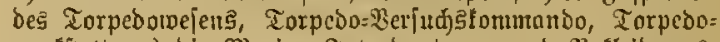
werfftntt, e) Dic Miarine= Sntenbunturen unto Befleibunge= ätnter 34 Riel unb Wilhelmshaven, f) Edjiffsprüfungs= tommiffiou, g) bie Deutlije Scenvarte zu f̧amburg.

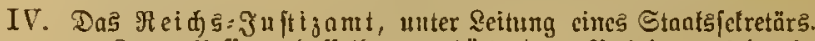
$3 \mathrm{um}$ Refiort Deffelben gehört Dos Reidisgeridt in Eeipsig uno bic Sommiffion gur IIusarbeiturg eines bürger=

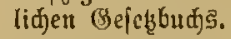

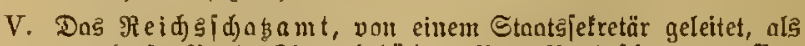

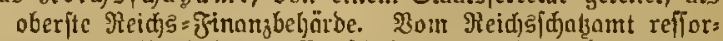

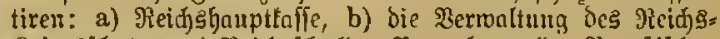

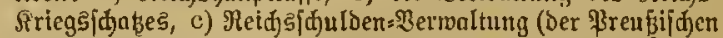
Gauptperroaltung ber Etantş\{dulden übertragen), d) bie

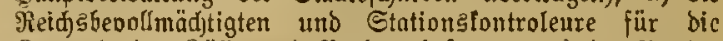

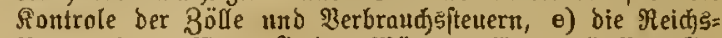

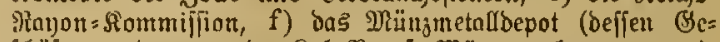

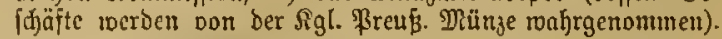

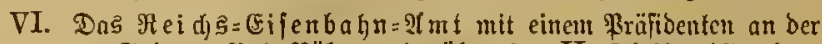
Spize. 3gl. Näheres barïber iur II. Theil. (B., bett.

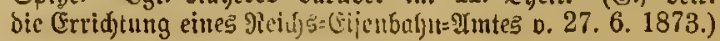


VII. Das Reidsamt für die ßerra!tung ber Reidseifeu= bahneu, befien Chef ber jobesmalige ßrenf. Minifter ber öfentliden IIrbeiten ift. Daffelbe ift burd भI. (E. v.

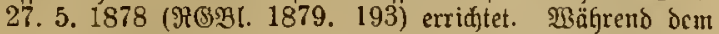

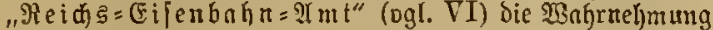

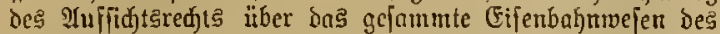

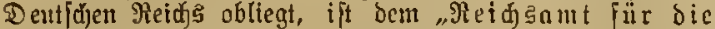
Derwalturg ber Reidseifenbahnen" bie obere Deituttg ocr Derwaltung utto bes Betricbes ber bem Dentidyen Reid) gebörigen (Eijenbahuten in Eljo $\bar{b}=$ 2othringen ïber= tragen. lluter bein . Reidfsamt für bie Berwaltung Der Reid)seifenbabnen" [teht bie "finiferlide Bentcralbirettion

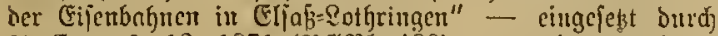

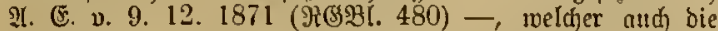

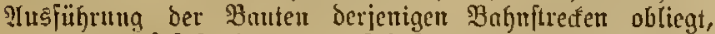

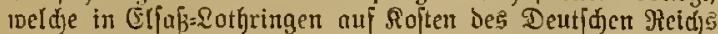
unghefülytt werben. Die Beneraldireftion Dermaltet auperdem

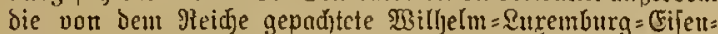
buhn. Dgl. (3., betr. Die Hebernalme ber Derwaltuty Jer

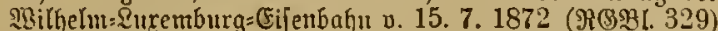
unb Hebereinfunjt mit Belgien, betr. ben $\mathfrak{B}$ ctricb Des anf Belgifhem Bebiete belegenen Theils bex 2lilhelm:\&urent=

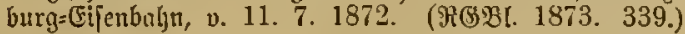

VIII. Der Redunngghof des Deatfden Reids unter einem Chejpräfibenten. Dic Rontrolc bes Reidşgusljolts unb

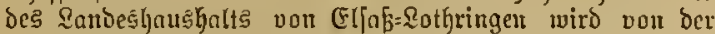

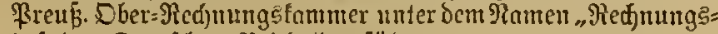

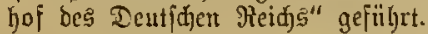

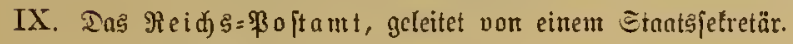

1. Ibtheilung: Roft;

2. Rbtheilung: Ielcgraphie;

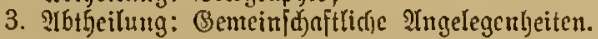

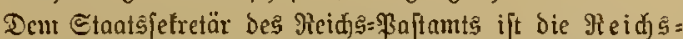
oruferei unteritell. Die Berwaltung ocs \$oft= uro

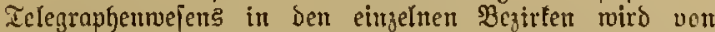

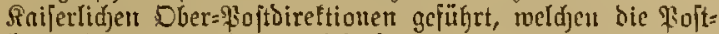
ämter, Ielegraphenoumter und Poftagentureu untergeorbnet find.

X. Dic Reidsbanf mird unter ber Reitung bes Reidjtanjlets von eittem Reid)

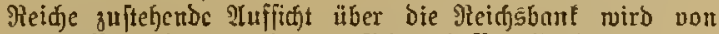
eitrem $\mathfrak{B}$ anlfuratorinm gefüht, befien $\mathfrak{B}$ orfibender ber

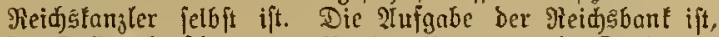

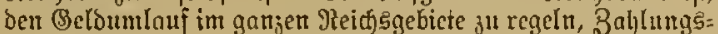
ausgleidungen zu erleidetern (Biroverfelyr) $2 c$. Sie hat ihren Sauptity in Berlin und 3meiquiederlafintgen (अeidjs=

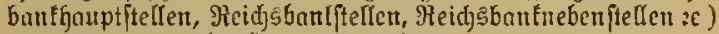
all vielen Sandelspläben bes Reidjs.

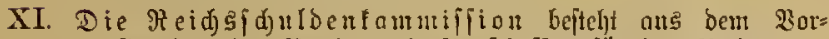

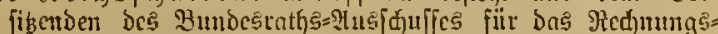

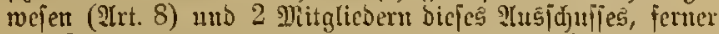

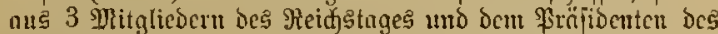
Rectumgshofes. Sht liegt u. o. Dic Routrole über bie

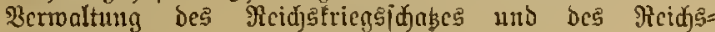

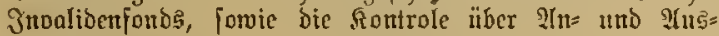

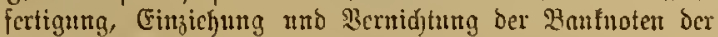
Jicidjsbonk ob.

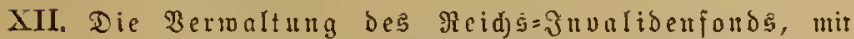

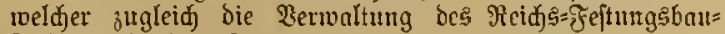
fonds ocrbunder ift.

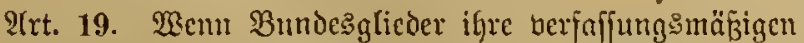
Bumbespflidyten nidht erjïllen, f̈̈nnen fie Der Erefintion angelalten werden. Dieje Erefution ift vom Bundesrathe ju bejhliegen no voin Saifer z" volffrecfen.

\section{Zeteifistag.}

Art. 20. Der Reidjstag gel)t aus allgemeinen umd bireften Wablen mit gefeimer äbftimmung hernor.

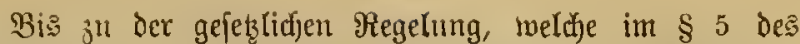
Maljlgefetze: vom 31. Mai 1869 (BSBBL. 145) vorbehalten

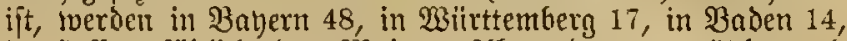

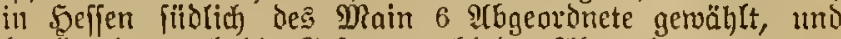
beträgt hemmad) dic (Bejammtzahl der 9Tbgeoroneten 382.

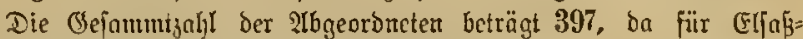

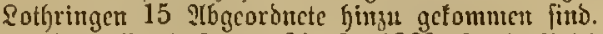

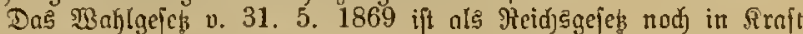
uto beftiunt in sBejenliden:

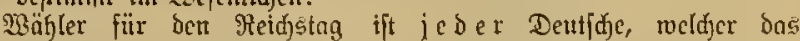

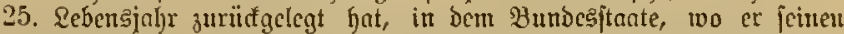

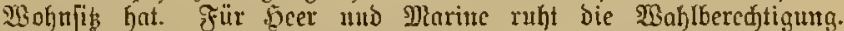

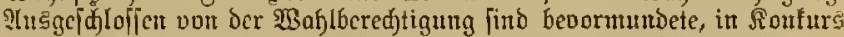

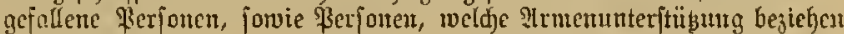

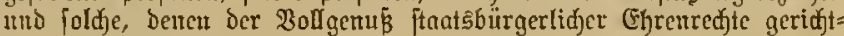
(id) aberfannt ift.

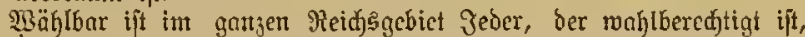

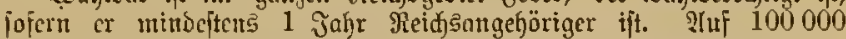

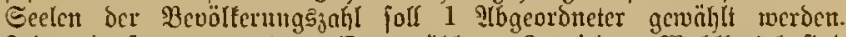

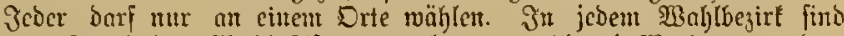

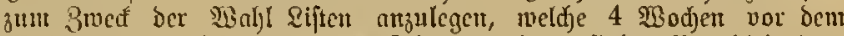

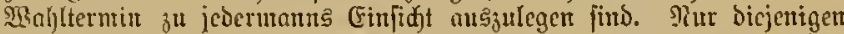

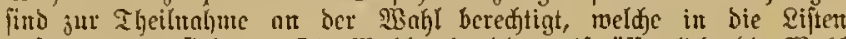

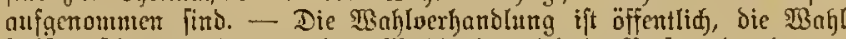

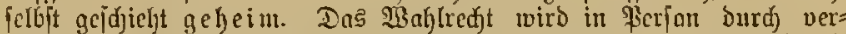

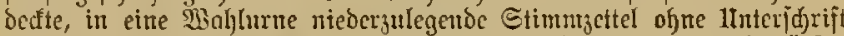
ausgeiibt. Die Gtinntzettel muiffen Don weiben \$apier und burfen

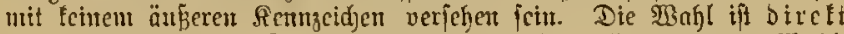
und erfolgt burd) ab olute Etinumenuchrheit nller in einent Mabl=

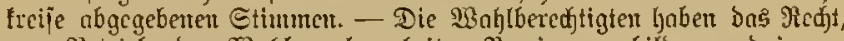

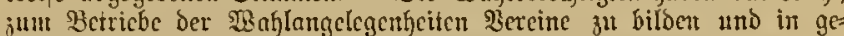

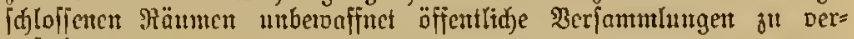
anitalten.

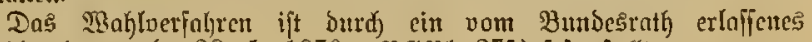

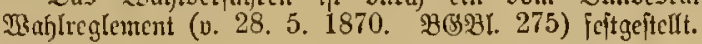

2trt. 21. Bentnte bediinfen feines llthaubs zum Fintritt it ben Ricidjestag.

23enn cin Mitglied des Reidistnges ein befoldetes Reidjs= ant oder in einem Bundesitant cin befoldetes Staatsamt

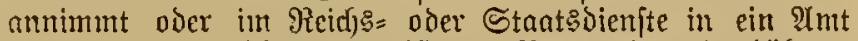
cintritt, mit weldhem ein höhcrer Fang oder eill göberes Gehalt verbunden i it, fo verliert es Silz und Stimme in Dem Feidjstag und fann jeine Stelle in bewrelken nur durd) netue $\mathfrak{K a h l}$ twieder crlangen.

Srt. 22. Dic Berbandlungen des Reidjtages find iffentlid).

Walyrheitggetrene Beridyte ïber Berhandlungen in Den öffentlicfen Silztungen des Reidjstages bleiben bon jeder Ternntwortlichfeit frei.

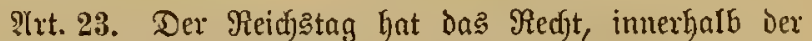
Sompetenz des Reidje (Bejebe borzujulagen und an ifn ge=

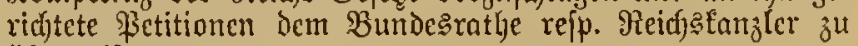
itbertweijen.

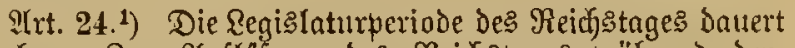

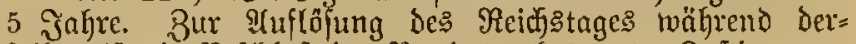

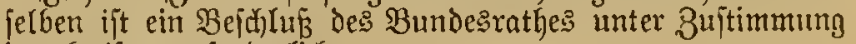
bes Siaijers exforderlidj.

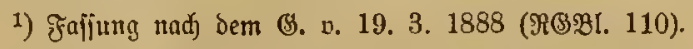

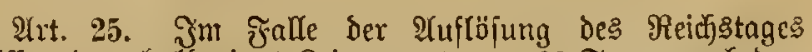
mülfen innerhalb eines Beitraumes bon 60 Tagen nach der= jelben die $\mathfrak{w a ̈ h l e r ~ u n o ~ i m e r h a l b ~ e i n e s ~ B e i t r a u m e s ~ b o n ~}$ 90 Tanen nadf der ?(uflöjung Der Reidstag verfammelt weroen. 


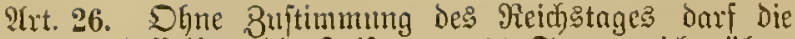
Vertagung Deffelken dic Jrift bon 30 Tagen nidut übers fteigen und während berfelben Eeffion nidgt wiedertholt joerden.

21rt. 27. Der Reidjstag prifft dic Regitimation jeiner Mitglieder uno enticheidet dorüber. Or regelt feinen Bse=

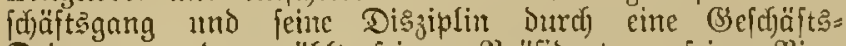
Dronm uno erwöhlt fcimen frräfidenten, jeine Bize= präfidenten und Sdyriftfïlgrer.

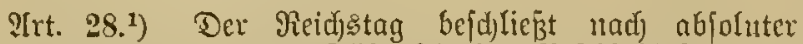

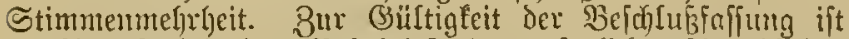

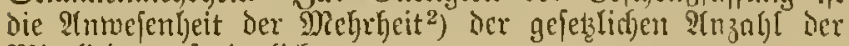
Mitglieder erforderficf.

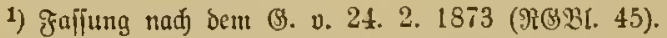

2) ช. . 199.

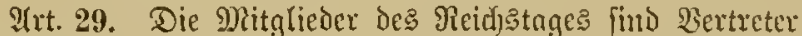

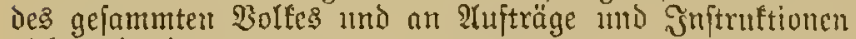
nicht gebunden.

Rtrt. 30. Rein Mitglied Des Reid)stnges durf ju irgend

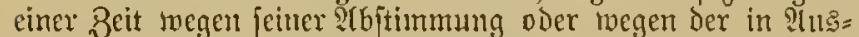
ïbung jeines Berufes gethanen Steuzerungen geridytlicf oder

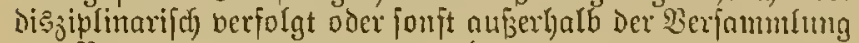
jut Berantwortung gezogen werdent.

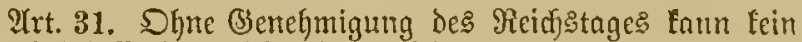
Mitglied Deffelben mähichd ber Sikzung gెperione wegen ciner

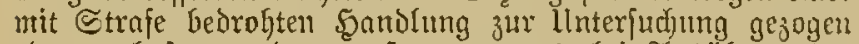

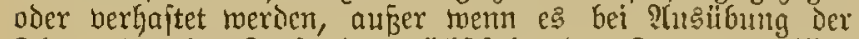
That oder in Eaufe des nübyffolgenden Iages ergriffen miro.

(B)leidye Beneburigung if bei ciner $\mathfrak{B e r b a f t m}$ twegen Sdiulden erjorberlidj.

Inf Berlangen des 9ieidftages twird jedes Strafberfafiren gegen cill Mitglied Deffetben umo jede llnterfud)ung Sivilhaft für bie Datter der Sitzungsperiobe aufgehobent.

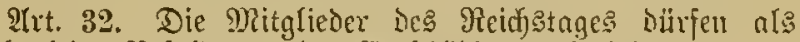
fordhe feiue Befordutg voer Contfoübigung bejichen.

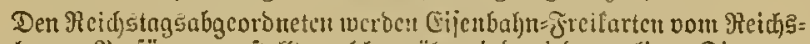

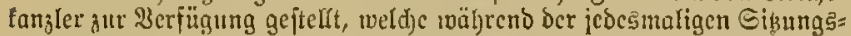
baucr, jomie 8 Tage vor= und nadher zur freien fahtrt in beliebiger 25agentlaffe auf ben in ben Rarten bezeiduneten Eijenbahnftreden berectitigen.

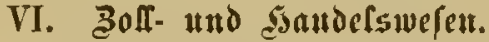

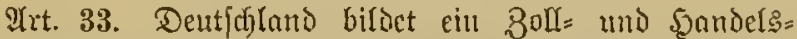
gebiet, umgeben bon gemeinfdiaftidjer Bollgrenze. QHes=

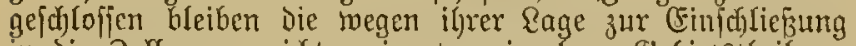
in dic 3ollgrenze nid)t gecigneten einzehnen (Bebietsthcile.

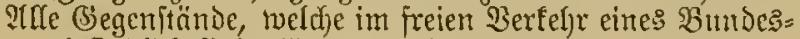
ftaates befindidf find, fönmen in jeden anderen Bumbesftaat cingefülyt und binrfen in letsterem einer 4 lbgabe nut in= foweit unterworfen reerden, als iajelbit gleidjartige in= ländifje Erzengniffe eincr imneren Stenter unterliegent.

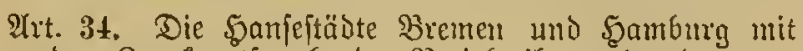
einem Dem Zrwed entfpredfenden $\mathfrak{B} e j$ irfe ifres oder Des um= liegenden Bebietes bleiben als đreibäfen auserhalb der ge=

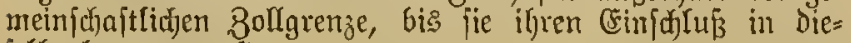
felbe beantragen. ${ }^{1}$ )

1) Bremen und Samburg find 1885 bç̧. 1882 bem beutichen 3ollgebiet angejwlofien.

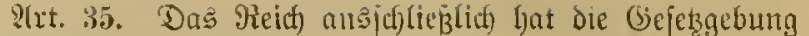
üher bas gefanmte Zolfmefen, ̈̈ber die Bejtenerung Des im Bundesgebicte gemomenen Galzę und Tabad?, bereiteten

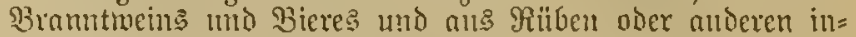

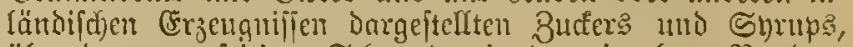
tiber Den gegenfeitigen Subut Der in Den einzelnen SBundes:

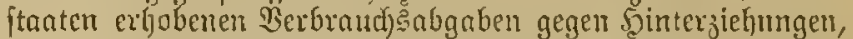

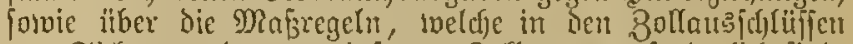
zur Sidjerung der genteinfamen Zollgrenze erforderlidf find.

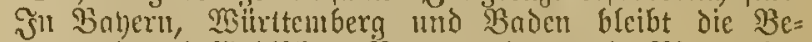
fteuerung be: inländifd)en SBranntweilis umb Bieres der Eanocsgefebgebumg vorbelgalten. Die Bundesftaten werden

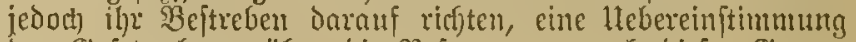
ber (Bejetzgebung über bic Beftenernng aud) biefer (Begen=

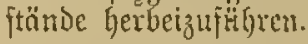

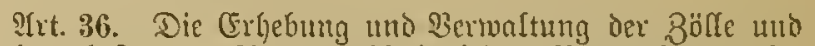
2erbraucfesftentern (IIt. 35) bleibt jedem Bundesftante, fo= tweit derjelbc fie bisher ausgeitht ljat, immerhalb feimes (B)e= bictes iibertaffer.

Der Raifer übermadyt die Cinfjaltumg des gefezzlichen

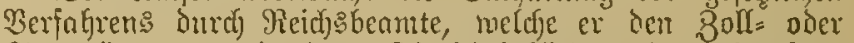
Stenerämtern und den Direftibheförden Der einzelnen

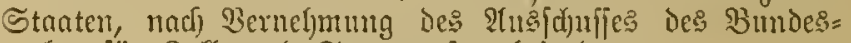
ratbes für 8 otl = uno Steuermejen, bciordnet.

Die von biefen Beanten

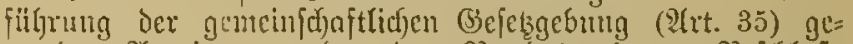

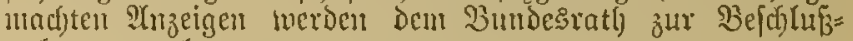
nabne vorgelegt.

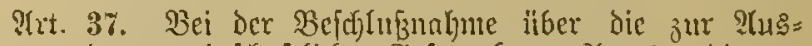

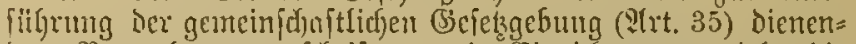
ben Sermaltungaboridhriften und (Eimrichtmigen giebt die

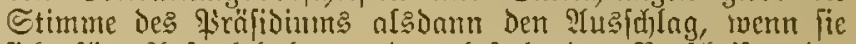
fidf jür Mufredjthaltung Der beftebenden Boridyrift oder Eimrichtung ausipridft.

1rt. 38. Der Ertrag Der 3ölle und Der anderen in

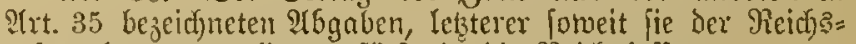
gefetgebung unterliegen, fließst in Dic Rcidjsfnfie.

Diefer (Ertrag bejtelyt aus Der gefanmten von den Böllen

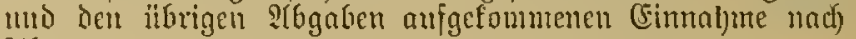
शto

1. der auf Befeken oder allgentinen Berwaltmas= vorfdriften berubenden Struerbergïtungen und हैmäţ่igumgen,

2. Der Riuiderftattungen für umid)tige Erthebungen,

3. Der Erthebungs: und Berwaltmigfoiten, und zwar: a) bei Den Bütlen Der Roften, toclche an Den gegert

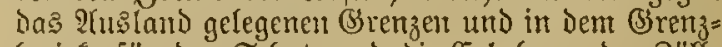
besirfe für Den Echuts mo bie Erbebung der Bölle erfordertidj find,

b) ba Der Salziteuer Der Soften, weldye zur $\mathfrak{B} e=$ foloumg Der mit Erfhebumg uns Sontrolinung dicfer Steuer auf den Salytwertell Geauftragten Beamten anigerwendet rerben,

c) bei Der Яiibenzuderfteuer uno Tabadefteuer Der Bergittung, weldje nad Den jemeifigen Bejefiltiffen

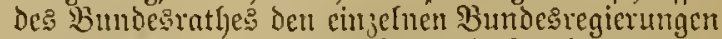
fiir die Sioften Der B̧ermaltung Diejer Stenert ju gewäfren ift,

d) bei den übrigen Steueru unit 15 Sirozent der (Bese fammtcimnaljme.

Die auberfalb Der gemeinjuaftlidjen 3olgrenze liegen= ocn (Seficte tragen ju Den Plusgaben bes Reidje Durth Bablumg eines 2lverjums bei. 
Raber", Württemberg und Baden haben an oem in Die Reid)gfaffe fliefenten (Ertrage der Steuern bon Branntmein und Bier und an Dem Diejem (Ertrage entiprectjenden Theite des vorjtel)eno ermähnten ?(berfunts feimen Theil.

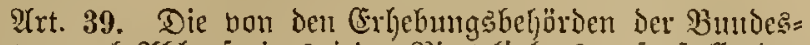

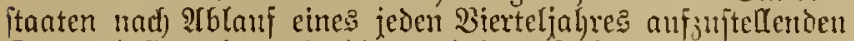

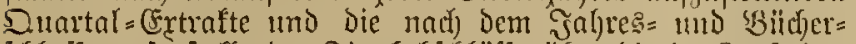

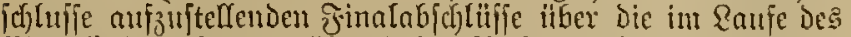
Bierteljabres bezw. wäljrend bes Rechmmggifahres fälling ge= morienen (Eimalimen an zöflen und nad) 2(rt. 38 zur

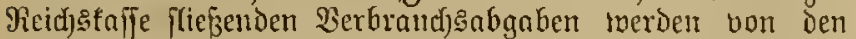
Direltivbefjörden bex Bundesftaaten, nad) borangegangener

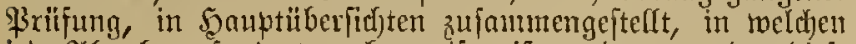
jede abgabe gefondert nadjutweifen ift, und es werìen diefe

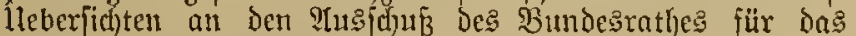
Recfnumgsidejen eingefandt.

Der lestere itellt auf Brumb biefer lleberideften bon 3 zu 3 Monaten ben bon der Raffe jebes Bundesftantes ter Reidjstnjfe fdulutben Betrag vorläufig fejt und jebt von biejer Fiejtitefung Den Bundesath und die Bundes=

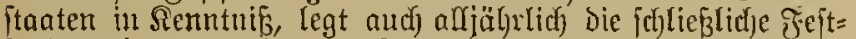
itellung jener Betráge mit jeinen Bemerfungen Dem Bumbe:

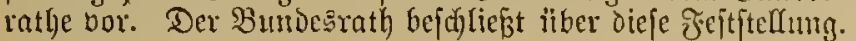

\{rt. 40. Die $\mathfrak{B e f t i m m u n g e n ~ i n ~ d e m ~ 3 o l l v e r e i n i g u n g s : ~}$ vertrage voun 8 . Suli 1867 bleiben in Siraft, foweit fie nicft

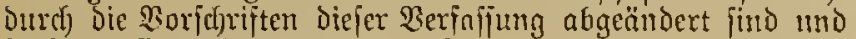
fo lange fie nicht nuf dem int 9trt. 7, bezm. 78 bezeididneten Wege abgeändert werden.

\section{Eifenbafumefen.}

21.t. 41. Eifenbahnen, weldje in Jntereffe ter $\mathfrak{B e r}=$

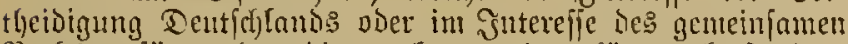
Sierfelurs für notlywendig eract)tet werden, fömen frait eines

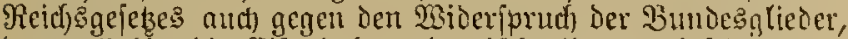

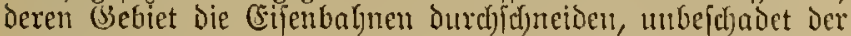

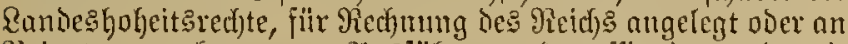

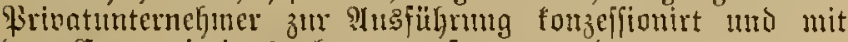
bent (Expropriationstechle ansigeinttet werient.

Jese bejteljende (Gifenbalynermaltung ift verpflichtet, fich

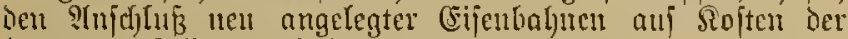
lebteren gefallen z" Iajjen.

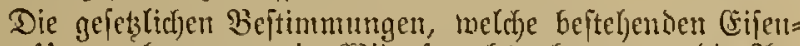
bahn=1lnternehmungen ein 2iberfprud)ered)t gegen bie ?(n=

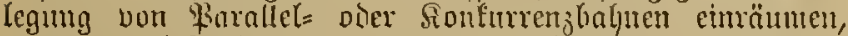
merden, untbefdjadet bereits erworbener Becf)te, für Das gुnuje

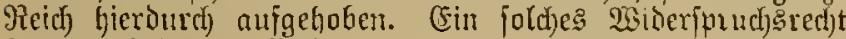
fam aud in ben füuftig zu ertheilenten sonzcfionen nicht meiter berlieljen werden.

Qrt. 42. Die Bmbesiegiemngen berpflidten fidt, bic Dentichon Eijenbahnen im Interejte des alfgemeinen $\mathfrak{B e r}=$

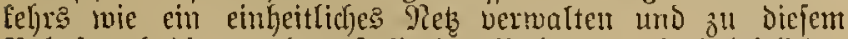
Bernu auch die neu herzujtellenden Baljnent mad) cintheitliden Rozmsen anlegen umo ausrifjten zu laffen.

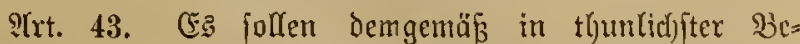
fd)leunigumg überemptimmende Betriebecinrifytungen $\mathrm{ge}=$ troffen, insbejondere gleid)e Balyupolizet=Fieglement: eint= gefiit)rt merben. Dns Reich lyat Dafitr Sorge zu tragen,

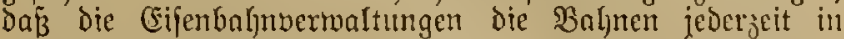
einem bie nöthige Sidjerfeit gewährenden baulichen Buitanic ergalten mo diejelben mit Betriefsmaterial fo nusüuften,

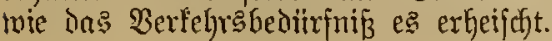

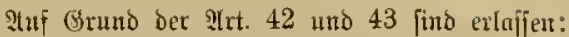

a) Die "Betriebsorbunng für bie Sraupteifenbahnen Dentifd)= Yantos" :

b) Ste \$sejtinnutugent ïber bie Befähtgung von Cifenbahn= betriebsbeanten;

c) bie "Eignalotbunty für die Gifenbahnen Deutfdlantos";

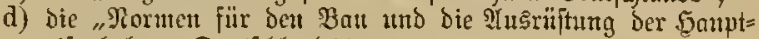
cijenbahten Dentífhlonds";

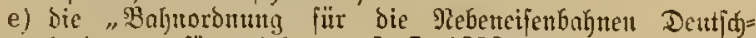
Iantós" - fämmtlidy vom 5. 7. 1892.

9rt. 44. Dic Gifenbahnwerwaltungen find nerpflictet, Die für den Durdjgehenten Berfegr uno zur Serftellung int= einander greifender faljrplätse nöthigen ßexjonenzüge mit

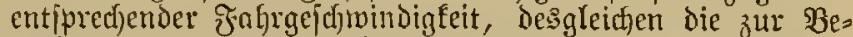

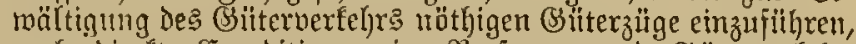
and) Direfte (Expeditionen im Ferionen= uno (Süterberfefr, unter Gicjtattung ties lteberganges ber Transportmittel bon einer Bahn auf bie andere, gegen bie iibliche Vergittung ciuzuridgten.

2(rt. 45. Dem Reidfe ftel)t die Rontrole über Das Tarif= wejen ju. Dafjelbe wiro namentlid) Dabin mirfen:

1. Daß baldigft auf nlfen Dentfden Eifenbaljnen überein= ftimmende Betrie63reglements eingeführt merden; ${ }^{1}$ )

2. Daf Dic möglidfite (Sleid)ntäBigfeit uno Serabjełsung Der Tarife erziett, insbefoudere, bas bei gröperen Entfermunger fiir den Transport von Rohlen, Roafe,

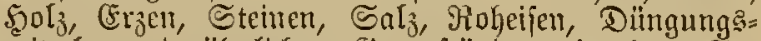

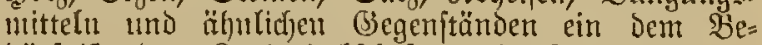

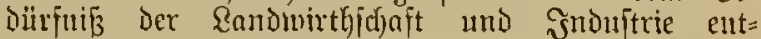
jpredjender ermäjigter Tarif, und zmar zunäcbjt thunlid jt ber Cimpfemig= Tarif, eingeführt merbe.

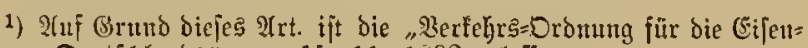
bahnen Deutfalonds" vout 15. 11. 1892 erlafien.

ITrt. 46. Bei eintretenden Pothftänden, insbefondere bei ungemöbnlidjer Thuerung Der Rebensmittel, find die Eifen= baljnterwaltumgen verpflidjtet, fitr ben Transport, namentlid)

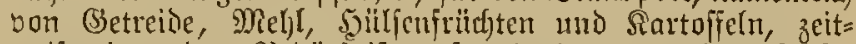
soeife einen bem Beoürinis entipredjenden, bon dem Siaijer

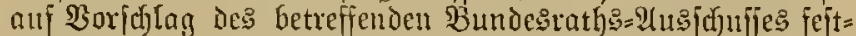
zuftelfenden, niedrigen Spezialtarif einzufiithren, weld)er jedod) nicht unter den nicorigiten auf der betreffenden $B \cap h n$ fïr Tohfprodufte geltenden Sazz herabgehen barf.

Die voriteljent, forwie bie in den 21rt. 42 bis $45 \mathrm{ge}=$ troffence Dejtimmungen find auf Sabern nidd anwendbar.

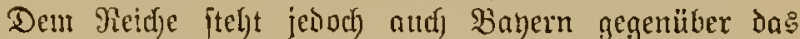
gied)t zu, im $23 e g e$ dex Befetzgebutg einheittiche Rornten fïr bie Sonftruftion und ?hisüjtung Der jür die Randes= vertheidigung trichtigen Eijenbahnen aufauftellen.

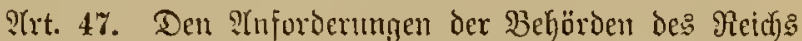
it Betreff Der 2ienutzung oer (Eifenbahnen zum Znecf Der Bertheidigung Dentichland haben fämmtliche (Eifentabu= verinaltungen unweigerlid) §olge zu Leijten. Jnsbejonoere ift Das Militair und alfes Sirtegsmaterinl zu gleidjen el= mäв̈igten ธäßzen zu hejördern.

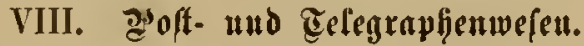

9lit. 48. Daڤ Fioftwejen und Das Telegraphenswejen werden für das gefammte (Bebiet Des Deutfhen ßeidjs als

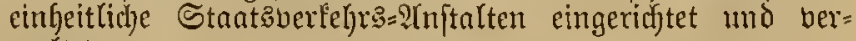
waltet. 


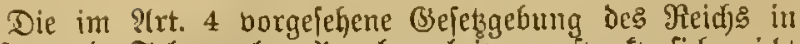
goft = und Iclegraplyen=:2ngelegenheiten exjtrectt fid nicht

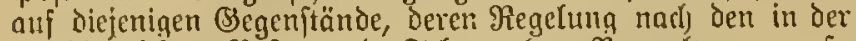
Rorbdeutiden Boft= und Telegraphen = Bermaltung unaf = gebeno getwejenen Srumbiätzen ber reglementarijajen jejt= festung oder abminiftratiben Anoronung üherlaffen ift.

अ.t. 49. Die Cinnahnen des Fojt= und Telegraphen= refens find jür das ganje Reid gemeinfdjaftlid). Die

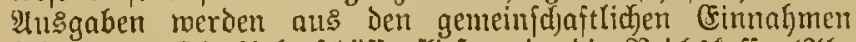

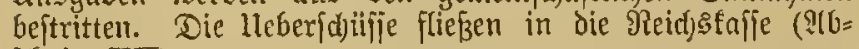
(if)nitt XII).

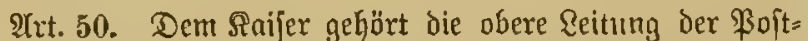
Ind Telegraphenvermaltung an. Die von Э̧hm beftellten Behörden haben die \$flidit und das Recht, bafïr zu forgen, d $a \bar{B}$ (Einlyeit in Der Drganifation Der Berwaltung und im Betriebe des Dienjtes, powie in Der Qualififation ber Beamten hergeftellt und erhalten wiro.

Dem Saifer fteht Der Erlaß̧ Der reglemeniarijden F̌ejt= fekzungen und allgemeinen abminiftratioen Inoronungen,

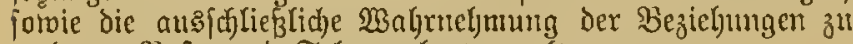
anderen Sioft = und Telegrapljenbertwaltungen zu.

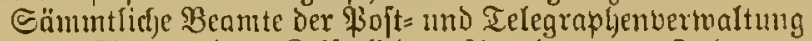
find berpflichtet, den Saiferlidjen Sturomungen Jolge zn leiften. Diefe 2 erpflidtung ift in den Dienfeio ani = 3unelymen.

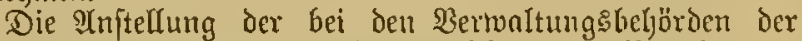
Fioft uni Telegrapljie in den veriffiedenen Bejirfen er= jordertichen oberen SBeamten (z. B. Der Direftoren, Räthe,

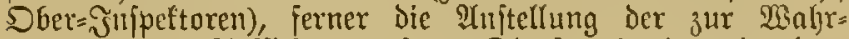

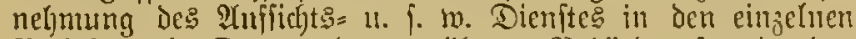
Bezirter als Drgane ber ersuähuten Behörden fungirenden Pioft = und Telegraplenbeanten (3. 3. Infpeftoren, Sontroleure)

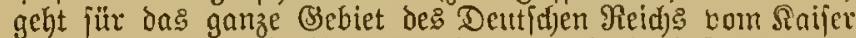
aus, velejen Dieje Beamten den Diempteid Leijten. Den

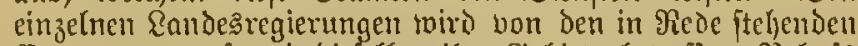
Ernemungen, fomeit dickelben ibre Bicbiete betreffen, Bebufs der landesherrlichen Beftätigung und Fublifation rechtzeitig Mittleilung gemadyt twerden.

Die anderen bei den Bermaltutgsbeljörden der Poit and Telegraphie erjorderlidjen Beamten, fomic alle fiir den lofalen und tedjuijden Betrieb beftimmten, mitljin bei beu

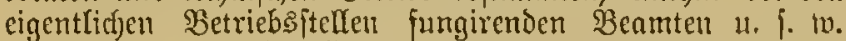
werden bon den betreffenden Randesiregierungen angeítellt.

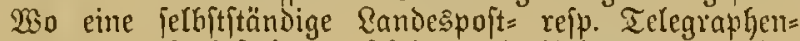
berwaltung nidjt bejteht, entfajeiden die Beftimmungen ber bejonderen $\mathfrak{B e r t r a ̈ g e . ~}$

21rt. 51. Bei llebertweifung des lleberidiuffes der Foft=

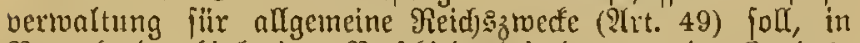
Betradjt ber bisherigen Beridjiedenheit ber von ben \&andeŝ floftuermaltungen der einzelnen Bebiete erzielten Rein= cimabmen, zum 3meffe ciner entiprechenden \&usgleifjung wälfend ber unten fefigejesten Hebergangszeit, folgendes Berfaljren beofoctjtet werben.

Ylug den \$ojtüberfdülffen, reldye in den einzelnen

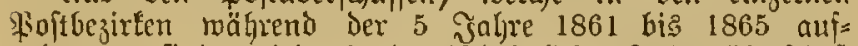

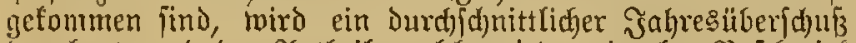
bered)net, und der $2(n t$ ljeil, meldjen jeder cinjelne \$ojtbezirf an dent für bos gejammte (Bebiet des शeids (id) Darnad)

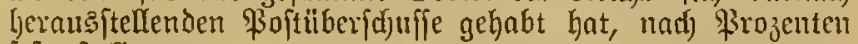
feitgeftellt.

Radi Manß̧gabe bes auf dieje weije feitgejtellten $\mathfrak{B e r}=$ bältniffes merden den einzelnen Staaten während der allf ifren (Eintritt in bie Reid) $=$ \$oftberwaltung folgenden

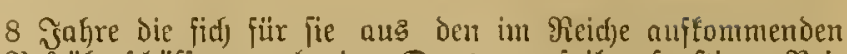
Gojtiberjdiffien ergebenden Dubten auf iljre fonftigen Bei=

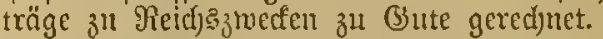

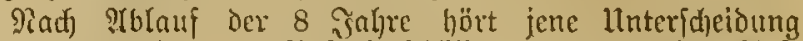

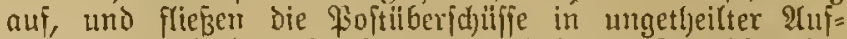
red)mung nad) bem im s(rt. 49 entljaltenen Srund $/ a$ ber Neid)

Don der wälyrend der borgedadjten 8 Эahre für die

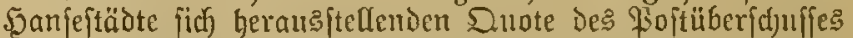
mird alljährlich borweg die Soäljte dem Sinifer zur Dis= pofition geftellt zu dem Brocfe, Daraus zunädjit die Rojten fiir bie Serfteflung normaler \$3ofteinridjtungen in ben \$anje= ftäbten z̧น bejtreiten.

Yrt. 52. Die Beftimmungen in Den boriteljenden $\{$ rt. 48 biş 51 finden anf Babern und $\mathfrak{B}$ ïrttemberg teine 2 tn= twendung. IIn iffrer Stelle gelten fiir beibe Bundesftaten folgende Beftimmungelt:

Dem Reiche ausjulieblid ftelyt die Befergebrung thber bie Borrechte Der Bojt und Telegraphie, über die redjtridjen

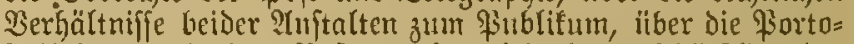

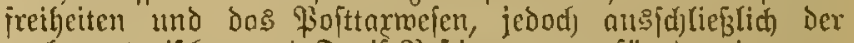
reglementarifdyen und Iarif=3citimumngen fiir den internen

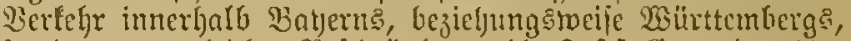
jowie, unter gleicher Befchränfung, die jeftftellung der (Se= biihren jür die telegraphijelse Rorrefpondertz zil.

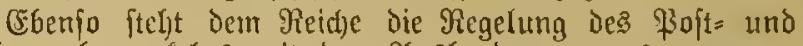

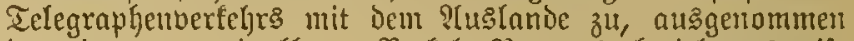
Den eigenen unmittelbaren Betfehr Baberns, beziehungsmeife 23inttembergs mit feinell dem Reidje nicjt augehörenden PiacljGarjtaatell, megen Defjen Regelung es bei ber $\mathfrak{B e}=$

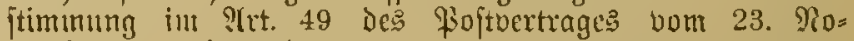
vember 1867 bemenict.

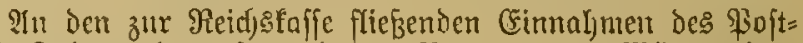
uno Telegraphenwejens haben Bayern uno 2 süttemberg Eeinen Tlyeil.

\section{IX. בְนariate แnd Sdiffafirt.}

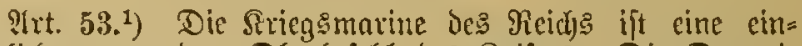
heitliche unter Dem Sberbefelyl des Saifers. Die Dignani= fation und Bufammenfetzumg derfelben liegt dem Raifer $\mathrm{ob}$, weld)er dic Difiziere und Beamten Der Piarine ermennt, und fiir twelifien diejelben nebft Den Manmfdaften eidfid) in Pfficjt zu nehmen find. lyäfen.

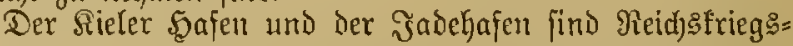

Sel zur Grïndung und Frthaltung Der Frtiegsflotte und

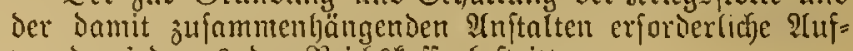
wano viro aut Der gieichstaffe beftritten.

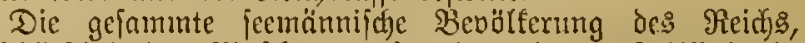
einfd)lieblid) Des Miajdjuenperjonals und der Edjiffshands twerfer, ift vom Dienjte im Enmohere befreit, bogegen zum Dienfte in Der Raijerlidjen Marime verpflidjtet.

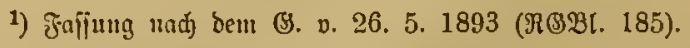

91t. 54. Die Rauffahrteifdiffe aller $\mathfrak{B}$ undesftaaten bilden eine cinbeit (idae Sandelsmarine.

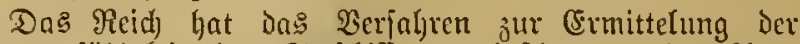

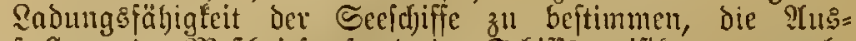
itellumg der y)ebloricle, fomvie Der Edjiffseertifitate zu regeln

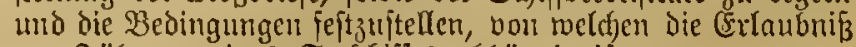
zux ơithrung eines Seejofiffes abluängig ift. 
Эn Den Seehäfen und nuf allen natiülichen und tünjt= lichen Wafjerftrafien Der eimzelnen Bundesftanten werden Die Sauffahrteifchiffe jämmtlicher Bundeşftaaten gleid)mäß̄ig jugelafjen und beliandelt. Die YYhgaben, weldhe in ben Seehäfen bon den Seejdjiffen oder Deren Eadungen fïr bie

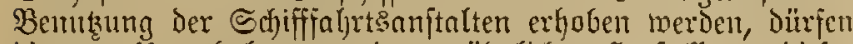
Die jur llnterhaltumg mo gewöhnlidjen Serftellung diejer 2irftalten erforberlichen Sioften nicht ïberfteigen.

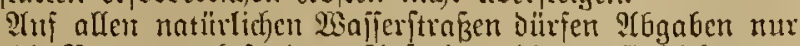
für die Benubzung befonderer An nitalten, Die zur (Erleichterung

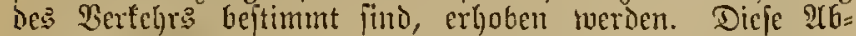
gaben, forvie die ?thgaben für die Befahrung foldher fünft= lidfen 23afferfiraben, weldche Staatseigentlyum find, Dürfen bie zur Unterhaltung und gewöljnlichen Seerjtellung der 2 finlten und IInlagen exforberlidjen Sipjen nidjt ïberjteigen.

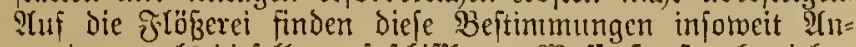
wendung, als dejelbe nuf faiffbaren Wajicrftrafen betrieben wirt.

Thuf frembe Srfijfe oder Deren Radungen andere oder

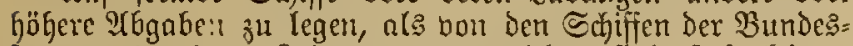
ftaaten oder deren Sadungen zu cntrichten find, fteht feinem Einzelftaate, fondern mur dem Reiche jut.

Prt. 55. Die Flagge Der Srieg ift jd)warz=mei $\bar{\beta}=$ roth.

\section{Soufulatweleu.}

9rt. 56. DaS geiammte Sionjulatmejen Des Deutidjen

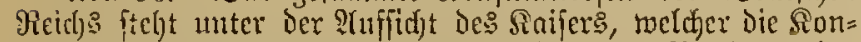

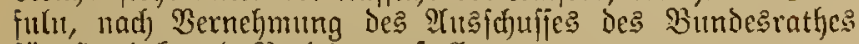
fiir Sandel und Bertehr, amitellt.

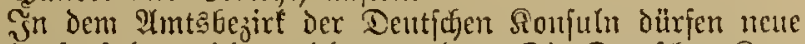
Sandesfomjulate nidjt errichtet merden. Die Deutjhen Sion= fuln üben fitr bie in ifrem Bejizf nidft vertretenen Bunic: itanten bie fountionen eines Randesfonfuls aus. Die jämuntlichen liẹtelyenden Eambestonjulate merten anfgeljobeu, jofald Die Drganijation Der Deutjdyen Sonjulate Dergejtalt

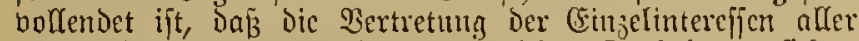
Bundesffanten n(S Durd) Dic Deutfd)en Foujulate gefirfjert von bem Bundestrathe auterfant wird.

\section{B̈eidjskriegswefeu.}

9rt. 5\%. F̌eber Deutfdje ift welhrpflidjtig mo fann fich

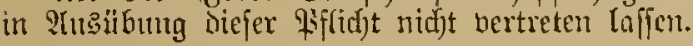

2(rt. 58. Dic Sojten und Saften des gefammen Sriegs: wejens des Reidje find von alfen Bumbesftanten und ifjen

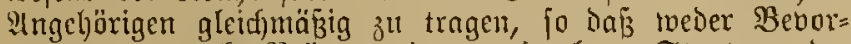
zugungen, nod Grägravationen einzelner Stanten oder

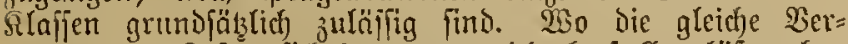
theilung der Raften fief in natura nidjt herjtellen läbst, ofne

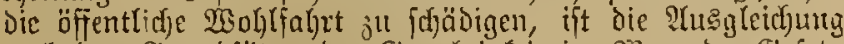

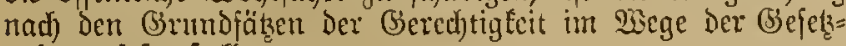
gebung feftzuitellen.

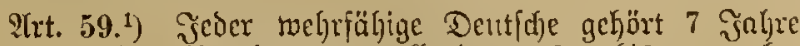

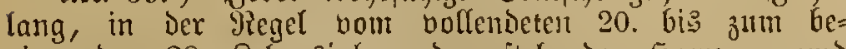
ginnenden 28. Rebengialjre, bem itehenden 5eere - tmo zwor bic eriten 3 Jahre bei den Jalynett, die letzten

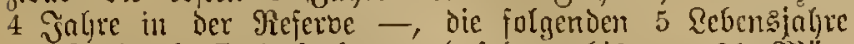

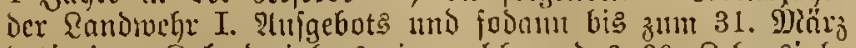
deşenigen Ralenderiahres, in melefent das 39. Eebensjaljr volleniet wird, ber Ranomely II. ?(ufgebots an. ${ }^{2}$ ) Jn

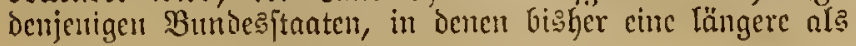

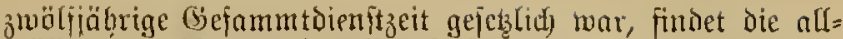
mälige Scrabjetzıng ber Berpflicftung nur in Den Maafe

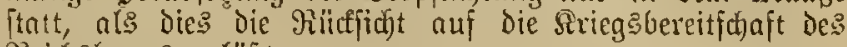
Ricidfosheerç juläßst.

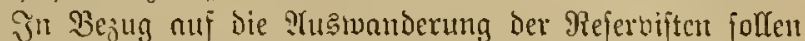

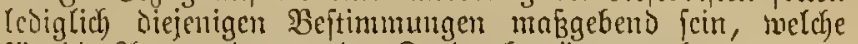
fiir bie ?tusmanderung ber Sandwefrmänner gelten.

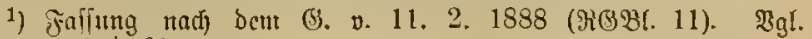

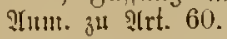

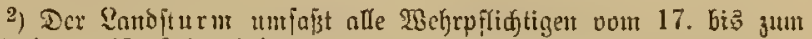
vollenocten 45 . \&cbensingre.

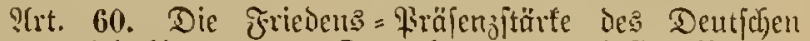
jeeres miro bis zum 31. Dezcmber 1871 all CEin Prozent ber Bebölferung bon 1867 normirt, und wiro pro rata cerictben von den einzelnen Bundesftanten geftelft. Fint

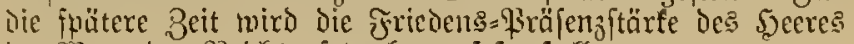

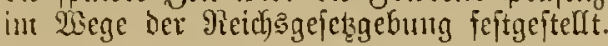

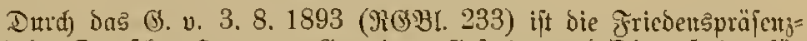
itärfe Des Dentiden Seercs an Genteinen, Befreiten uno Dbergefteiten für bic 3eit v. 1. 10. 1893 bis 31.3. 1899 anf 479229 Mian als

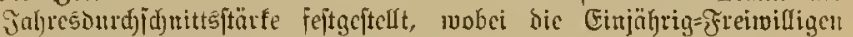
uid)t in Sluted)utug fommen.

Tie Etellen Der Ilnterofrigiete, Dfrijicre, Ifergte und Beanten

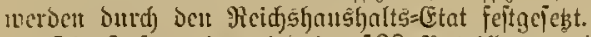

Die Jnfanterie wirs it 538 Batailfote utto 173 Salbbatuillonc, bic Ravalferic in 465 Esfadrons, Die Feldartilleric it 494 Batterien, dic Jubattilleric in 37 Bataillone, bie \$ionicre in 23 Bataillotte, bic Eifenthatutuppen in 7 Bataiflom, ber Tatu it 21 Bataiflone formirt.

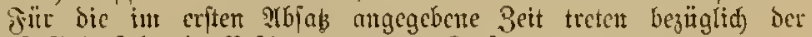
Dicuittpifidjt folgenos Beftintmungen in Rraft:

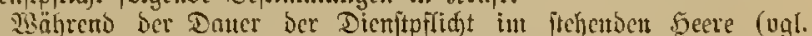

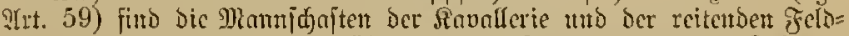
attillerie bie criten 3 , alle

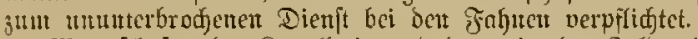

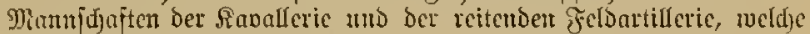
in Prehensen Seere 3 Jabre nftio gebient haben, bienten in Der Lans= meljr I. Sufgebots mur 3 Johre.

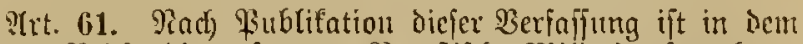

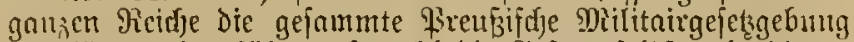

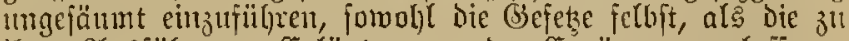

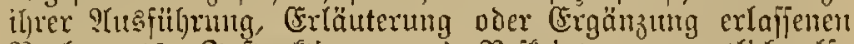

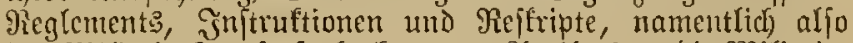

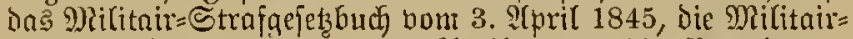
Strafgeridytsoromung vom 3. F(pril 1845, dic פeroromung iiber die (E)grentgerid)te bom 20. Sulf 1843, Die Beftimmungen iiber 2lushebung, Dienitzeit, Servis= und SBerpflegungstwejen, Einquartierung, Erifals bout fflutbeichäbigungen, Mobil= machung $2 \varepsilon$. fit Sirieg und Frieden. Die Mititair=Sirchen= orbutung ijt jedocf) ausge[chlofien.

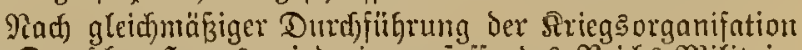

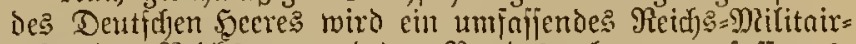
gejets Dem Reichstage und dem Bundestathe zut berfafiungs= mö́zigen Befd)lubifajiung borgelegt werben.

Irt. 62. Bur Seftreitung des 2tup̣andes für bas ge= fammte Deutjhe Seer und die zu Demjelben geljörigen Cin= ridjtutgen fino bis zam 31. Dezember 1871 Dem Raifer iälntliff fonielmal 225 Thaler, in $\mathfrak{B}$ orten stweifundert fïnf und zmauzig Thaler, als die Siopfahl Der Friebengitärle Des Seeres mad) Plrt. 60 beträgt, zur Berfügung zu ftellen. Vigl. शTGfhutt XII.

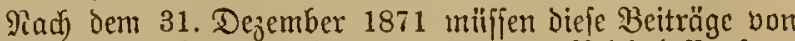
ben cinzelnen Staaten des Bundes znt Reichstaffe fort= gejahlt werden. Bur Bered)ntung berfelben wito bie int 


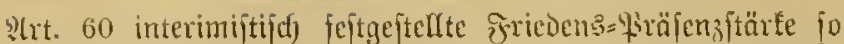
lange feftgebalten, bis fic butd) cin Reid)sgefets abgeänitert ift.

Die Bermsgabung bicjer Sumute für das gcjammte

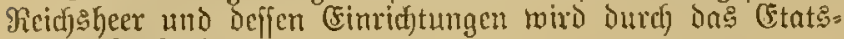
gejels feftgeftellt.

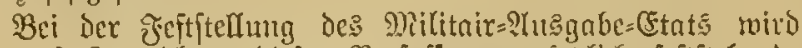

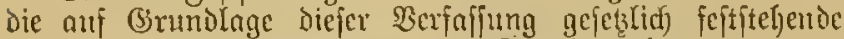
Drganifation des Reid)shectes ju (Sirunde gelegt.

21rt. 63. Dic gejammte Randmad)t des Reichs twird cin einlfeitlidjes 5eer bitden, todd)es in Sirieg und Jrieden unter bent Befelle des Saijer: fteht.

Die Regintenter 2c. fǘtren fortlanfende 9umment duth Das ganje Deutffe Scer. F̈̈r dic Befleibung find bic Grundarben und der Sdjnitt der Röniglid Gireuisifden Irmee inanżgebend. Dent betreffenden Sontingentaherm

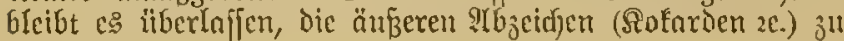
bcitimmen.

Der Raifer hat Die Pfficht mo Das Redıt, Dafür Sorge zn tragen, baf3 innerhal6 des Dentidjen 5eeres alle Iruppen=

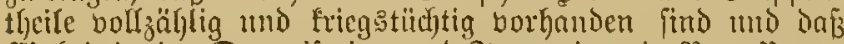
(Sinfeit in Der Drganifation und Formation, in Betwafimung

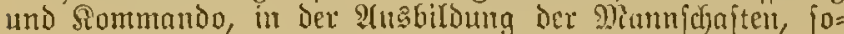
mie in Der Durfifitation ber Sifficere hergeftellt mo er: halten wiro. $3 \mathrm{u}$ biefem Behufe ift ber Staifer berefftigt, fid) jederzeit Durch Snippeftionen bon Det Serfajiung ber einzeluten Rontingente zu überzengen und die Ptbftellung der Dabei borgefundenet Mängel altzuoronen.

Der Saifer bejtimmt den Fräjeuzitand, die Brlicberung und (Fintheilung Der Rontingente Des Reidshlectes, fowie dic Srganifation ber Sandwelpr, unto lyat bas Piecht, inner= ljalb Des Bundesgebictes dic Binnifonen jll bejtmmen, jo= twie bie friegabereite ?tufftellung eines feden Iheilg bes Reictisheeres anjutromen.

Befufs (5rt)altung ber unentbefrelichen (Sintheit in Der

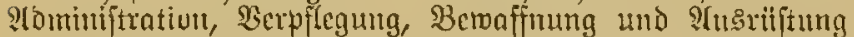
affer Iruppentheile des Deutichen Seeres find die bejighticfen

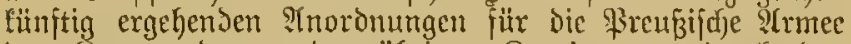
ben Sommandeuren der ïbrigen Sontingente, Durd) ben

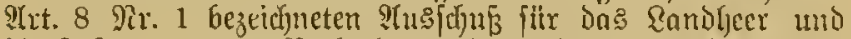

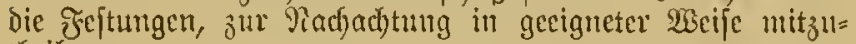
theilen.

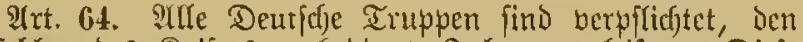
Befchlen Des Saijers mbehingte Jolge zu leiften. Dieje

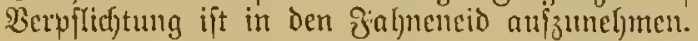

Der Scöchfftommanioirende eines Sentingent?, jorvie alle Difizicre, weldye Truppen melyt ale cines Sontingente be= fel)ligen, und alle iscittugsfummanianten werden bon Dem Saijer ernaunt. Dic non Demielben ernanten Difiziere

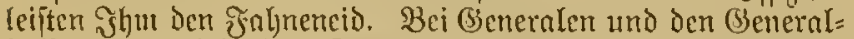

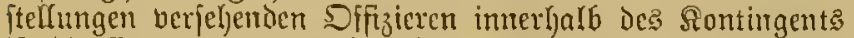
ift die Cenennung von Der jedesontaligen 3uftimmung bes Saijers abhängig su madjen.

Der Saifer ift beredjtigt, Beljufe 2erfebung mit oder ohne Seförderung, für die von Shm im Reichsoienjte, jei c: im tireusifaten Seere, oder in anderen Rontingenten 3 th be= fetzenden Stelfen aus den Difizieren aller Siontingente des

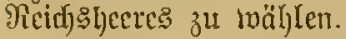

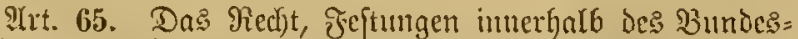
gebictes nuzulegen, fteht Dem Siaijer zu, weldyer die b̉e= milligung der Dazu erforderlidjen Mittel, jorweit bas Divi= narium fie nidgt gewährt, nack s(Gjefuitt XII beantragt.
Trt. 66. W20 nidjt bepondere Sonventionen cin \$nderes bejtimmen, ermentmen die B̈nndesfiliziten, bejieljentich die Senate bie Difiziere ifrer Sontmaente, mit der Em:

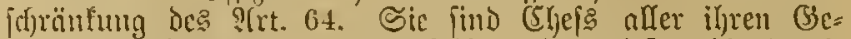
bieten nugeförenden Truppentfeile uno genieß̧en bie bamit

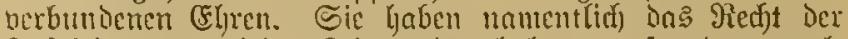

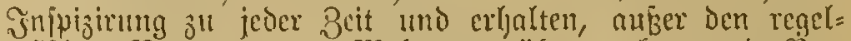

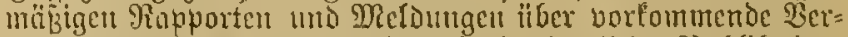

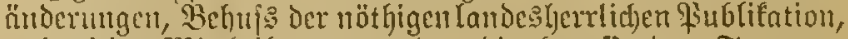
red)tzeitige MRittheifung bon Den bic betreffenten Truppen=

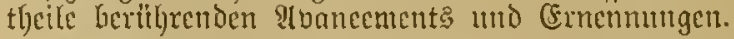

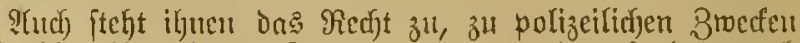

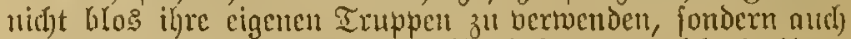

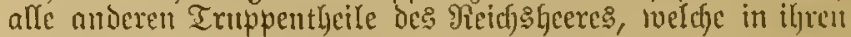
Rändergebirten dislocirt jino, z" requiriren.

Sirt. 6\%. Eriparnifie an Dem Militair=[5tat follen miter feinen Itmitänden cince einzelnen Regierutng, fonderu jeder= zeit Der Tieids?fnffe zh.

Sirt. 68. Der Saifer fann, wem die öffentlidje Sidyer= beit in Dem BBundeşgebicte bedroht ift, cinen jeden Iheil

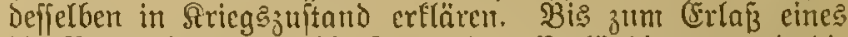

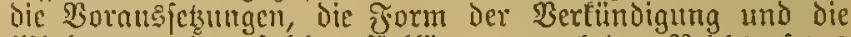

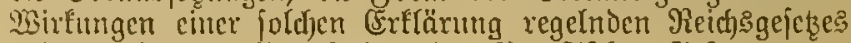

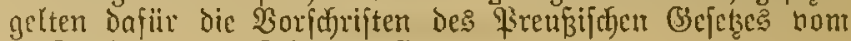
4. Эัmi 1851. (\$SS. 451 ff.).

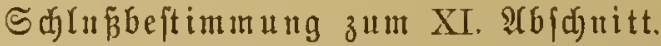

Die in Dicjen Abjanit enthaltenen Borjachiften fommen

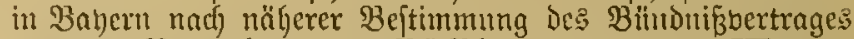

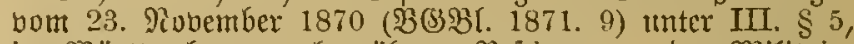
in Bürttemberg nach näherer Bejtimmung Der Dititair: fonbention bom 21./25. Nobember 1870 (BG3B1. 658) jutr STrtwendung.

\section{Zieidfstuaujen.}

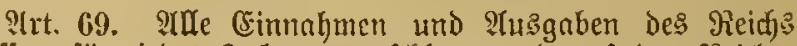

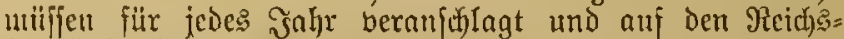
Gaushalts=(Etat gebradjt merden. Eebterer wird bor Beginu des Etatsjahres nad) folgenden (Srumbjäłzen duxd ein (B)ejets jeftgeitellt.

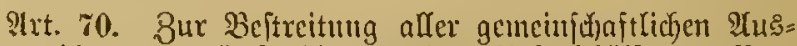
gaben dienen zunädjit die etwaigen lleberfchüfje oer $\mathfrak{B o r}=$

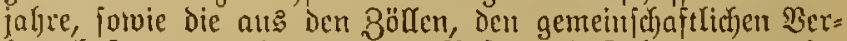

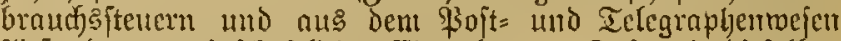

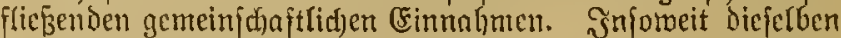
burd) diefe (simnahmen nidjt gededt werden, find fie, fo

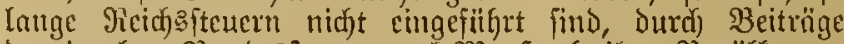

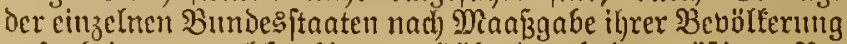

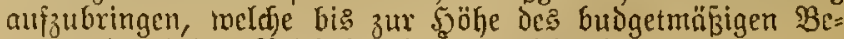
trages Durd) Den Reidfofanjler nusgejdrieben merden.

S(rt. 71. Dic gemeinjujajtidjen ?(usgaben werden in ber Regel fitr cin sahr bewilligt, fönnen jebor) in be= jonderen fä̈len and fïr cine längere Dauer betwilligt merden.

Während Der in 2 ret. 60 normirten Ulebergangşocit ift Der nach Titeln georoncte Ctat ïber die 2lusgaben für bas

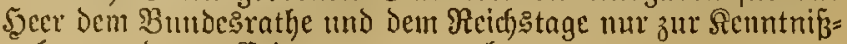
nalume mo zur Erinnertung vorzulegen. 
?lit. 72. Heber die Berwendung aller Einnahmen des Reichs ift Durdh den Reidjsfanjler Dem Bundesrathe und bem Reidjstage zur (Entfajtung jäbrlid) Redjnung zu legent.

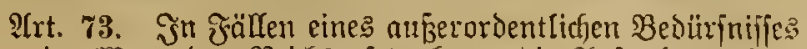
fonn in Wege ber Reidjsgeferzgebung Die PUfualjme einer Inteibe, jowie die Hebernahme einer Garantie zu \&aften Des Reidjs erfolgen.

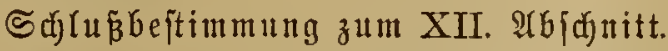

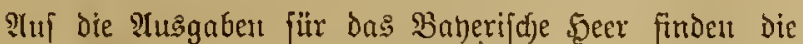

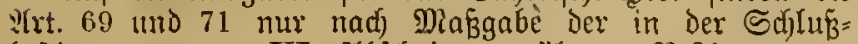
beftimmung zum XI. T(bjdjnitt ermähnten Bef́timmungen

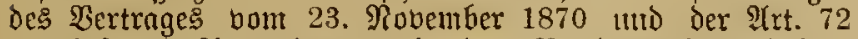
nur injoweit afnmendung, als Dem Bundesirathe und bent Reidjtage die Ulebertweifung der für Da: Baberifde Şeer erforderliden Summe an Babern nachaumeifen ift.

\section{Sdflidfung von Streitigkeitett und Strafbeftimututgen.}

2rt. 74. Sedes lluternelymen gegen die Erriftenz, die

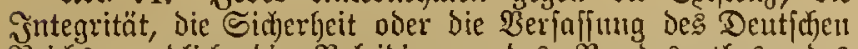
Reicts, endlich bie Belcioigutg bes Bumdestrathes, des Reichstanes, eines Mitgliedes Des Bundeక̉rathes oder des Reicjstages, einer Beförde oder eites öffentlicjen Beanten

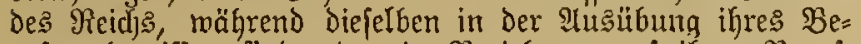
rufes begriffen find oder in Beziehung auf ibren Beruf, Durch 20 ort, Edgrift, Drudf, Beidjen, bilolidje oder antore Darftellung, werden in ben eimjelnen Bumbesftaten betrtheilt und beftraft nadj Manajgabe der in den letzteren beftehenden oder fitnftig in Wirfiamleit tretenden (befetze, nadj melcjen

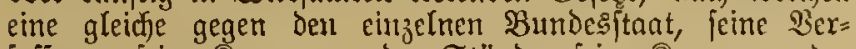
fafiung, jeine Sammern oder Stünde, feine Sammer= oder Ständemitglieder, feine Beförden uno Beanten begangene Şandlung 3u ricften träre.

Srt. 75. Für diejenigen in 2(rt. 74 bezeid)neten linter= nefynumgen gegen bas Deutidje Pieid), meldhe, menn gegen cinen Der einzeInen Bundesftaaten geridjtet, alE Sodjuerrath oder Randesverrath zu qualifiziren wären, ift Das gemein=

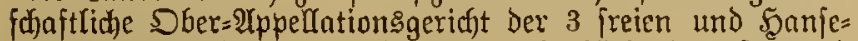
itäbte in \&übef bie juftänoige Sprntfbeförbe in erfter und

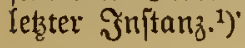

Die nägeren Bejtimntungen juber die Zujtändigfeit und

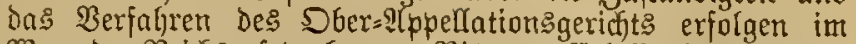

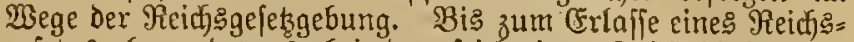
gejețes bemendet es bei der feitherigen Zujtändigfeit Der Seridgte in Den cinzelnen Bundesftaaten tmo ben auf bas Berfalyren diefer (Serichte fich bezichenden Beftimnungen.

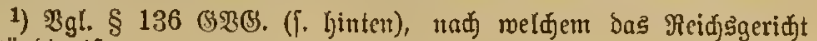
วuftäuذig ift.

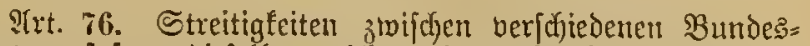

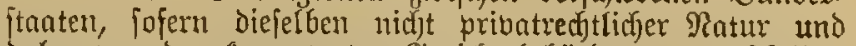
Dafer bon den fompetenten (Bierid)t [ino, twerden auf Thrufen des einen Theils bon Dem Bundesarathe erledigt.

Derfaffungsftreitigfeiten in foldyen Bumbeßftaateu, in Deren Verfaffung nidjt eime Beljarde jur (Entfdjeidung foldjer Streitigkeiten beftinment ift, hat auf STrufen emes Theiles ber Bundes?rath gütfid) auşzugleidfen oder, Ivenn Das nidft

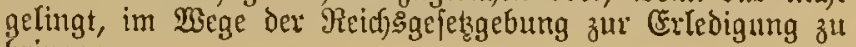
bringer.

YTrt. \%7. Wenn in einem Bundesftanate dex Falf einer Sujtizberweigerung eintritt, uno auf gejeţichen Wegen aus= reidende Sillfe nifjt erfangt toerden fann, fo liegt Dem Sumbesrathe of, erwiefene, nadj Der Berfaffung und Den bejtehenten Siefsien Des betreffenden Bundesftantes zu beurtheilende $\mathfrak{B} e j$ djwerden Redt) tspflege anzmeljnten, und darauf bie geridjtlidje Sülfe

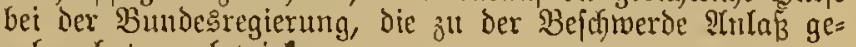
geben hat, zt betwirfen.

\section{AIfgemeine B̧eftimmungen.}

Tr.t. 78. Beränderungen Der Berfaffung exfolgen im Wege der B̧ejekgebung. Sie gelten als abgelehnt, wenn fie im Rumbesrathe 14 Stimmen gegen fid) hahen.1)

Diejenigen $\mathfrak{B}$ orfdriften Der: Reidfsuerfafiung, ourdy tweldye beitimute Redjte einzelter Bundesftanten in Deren $2 e r=$

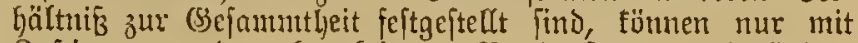
Buftimmung Des bereffigten Bundesftaates abgeändert werden.

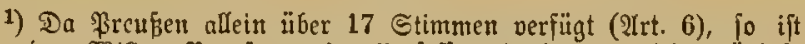

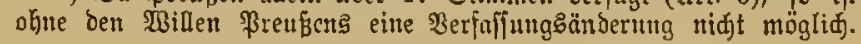

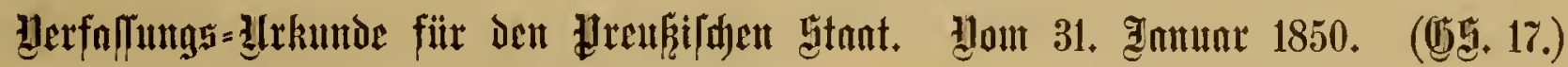

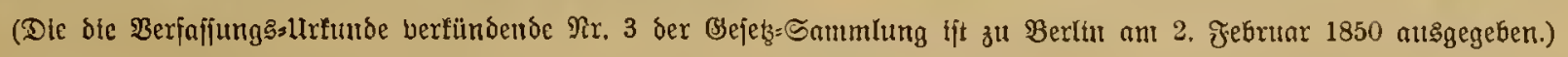

\section{Inhaltsiïberjint.}

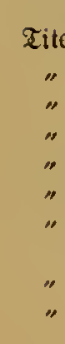

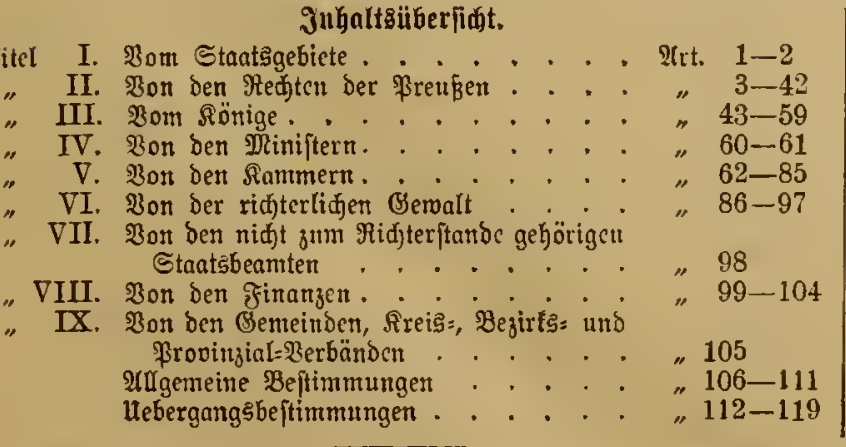

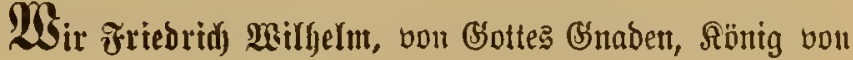 Prettíen 2e. 2e.}

thun fund und fügen zu triffen, dą̧ Wir, nadjdem die bon Unt unterut 5. Dejember 1848 vorbehaltlid der Revifion

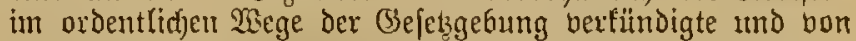
beiden Rammern llnjeres ßönigreid) Des preufijofen Staats der Darill angeoroneten Rebifion unterworfen ift, die Berfaffung in Uebereinftinmung mit beiben Rammern enogitltig iejtgejtelt ljabeu.

Wir verfünden demnach diejelbe als Staatsgrundgejets, wie folgt: 


\section{Titel I.}

\section{æom Staatsgefiete.}

Irt. 1. 2rfe Randestheile der Monartjie in ihrem gegenvërtigen llmpange bilden bns preubijache Staatsgebiet.

?trt. 2. Die Bränzen Dicjes Staatミgebiets tönnen nur Durtl) ein (Bejes verändert werden.

Grenzvetänderungen finb burd) Cinverleibungen neucr Landes= theile wicoerholt porgelonmen. Dic mid̆tigiten Einverleibungen find:

a) Des Rönigreidy Szannover, bes Surfüritenthunts Selfer, bes Serjogtljunts Raffau und der freiett Stabt Fronlfurt (B. D. 20.9. 1866. (5S. 555).

b) ber 5erogthümer 5oljtein uno Sdjlestoig (\$. n. 24. 12. 1866. (GS. 876 ).

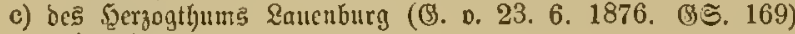
uno aulest

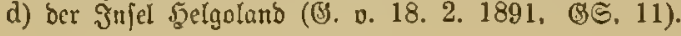

\section{Titel II.}

\section{ăon den Biediten der ḋrenken.}

Irt. 3. Dic গ̧erjaffung แmo das Bejeb bejtinmen, unter weldjen Beoingungen die Csigenifdajt sines Pireufent und die jtantEbitrgerlichen Rechte ${ }^{1}$ ) ermorben, ansgeitbt uno ber(ovell roerden. ${ }^{2}$ )

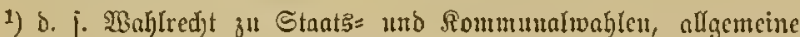

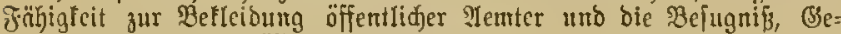

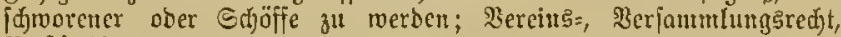
\$repireifeit 2e.

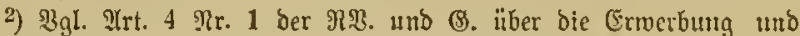
Den Berlujt ber Bunoç= แno Stantsangehörigfeit v. 1.6. 1870 (B3(381. 355).

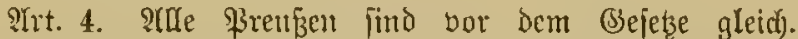
Standesvorred)te finden nifft ftatt. ${ }^{2}$ ) Die öffentlichen Ilemter Find, unter Einfjaltumg der bon Den Siefecsen feitgeftefleten \$edingungen, für alle dazu Befühigten gleid̄ zugänglicf.

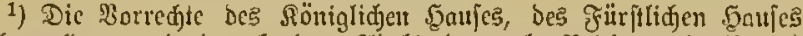

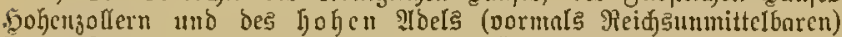
finto anfredst erfyalten bejo. soieber eingeführt morben.

21rt. 5. Die perjönlirge ơreiheit ift getwährleiftet. Die Bcoingungen uno Jormen, unter meldjen eine $B$ ejchränfung derfelben, insbejendere eine Berljaftung zuläfíig ift, toerden Durd) das (bejets bejtimmt.

2rt. 6. Die $\mathfrak{B o f n u n g}$ ift unverletzlid). Das (sin= Dringen it biefello und \$ansfurfungen, famie die Befchlag =

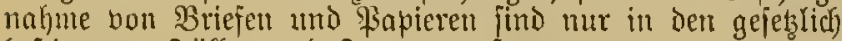
bejtimmten Fällen und Formes gejtattet.

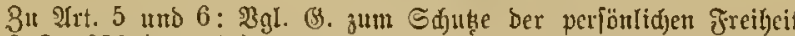

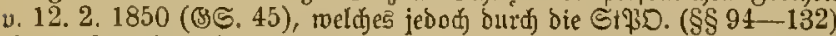
theilweije alfgehoben ift.

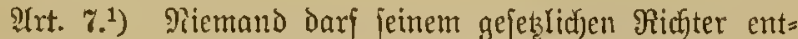
zogen werden. SAunahmegerid)te uno auţerordentlicfe Rom= miffitonen find unftatthaft.

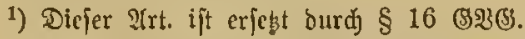

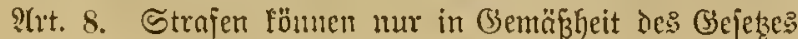
angecorolit oder nerfängt merden.

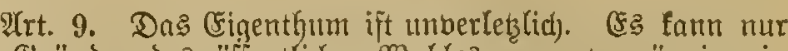

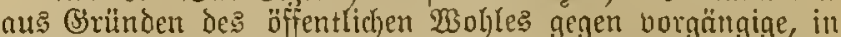

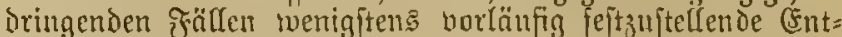

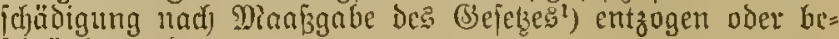
idjünfut werden.

1) 2kgl. (S. über bie Enteignustg von (Grunocigentlyun v. 11.6.1874 (im II. Th.). Neben biejem (5. Find u. a. bie 3orfdriften ïber bic

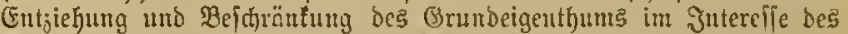

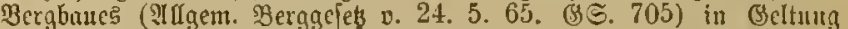

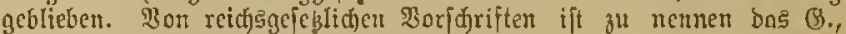

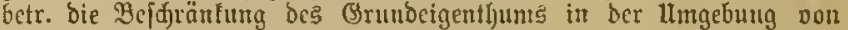
Jejtungelt v. 21. 12. 187 (

2rt. 10. Det bürger(idye Tob') unt die Strafe der Bermögenseinjielung finden nicht ftatt.

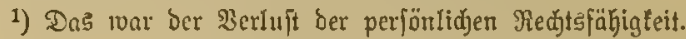

2rt. 11. Die Jreiheit der ?(thstwanderung fann bou

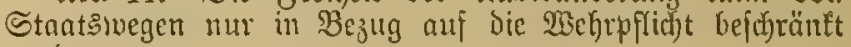
werden.

शtbzuggelder dïrfen nidft exhoben merden.

Art. 12. Die Freiłeit Des religiöfen Belenntnifjes, Der

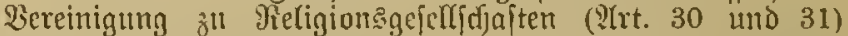

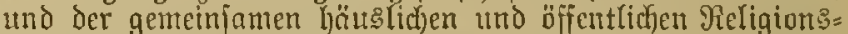

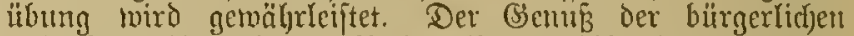
und ftant:̧birgerlichen Rechte ift unabhängig bon Dem religiöfen $\mathfrak{B e f e n n t n i f f e . ~ D e n ~ b u ̈ r g e r l i c h e n ~ u n o ~ t r a a t s b u ̈ r g e r s ~}$

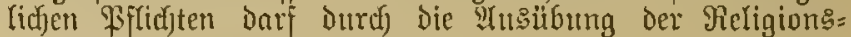

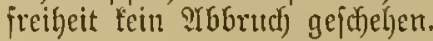

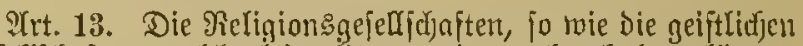
(Gejelfidjaften, meld)e leine Sorporationstedjte Gaben, Eönnen

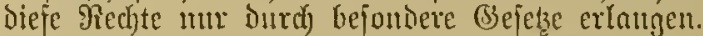

Strt. 14. Die d)riftlid) Religion wiro bei Denjenigen

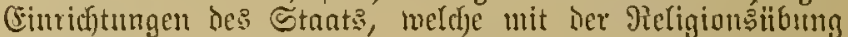
im Bufanmenfange jteljen, unbejuadet Der im ?(rt. 12 ge= wäbrleifteten Religionsfreifeit, zum Brunde gelegt.

Irt. 15, 16 u. 18 fint surd (3. v. 18. 6.1875 nufgehoben.

Dicielben Innteten:

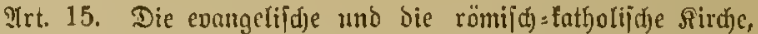
fo wic jede andere Religionsgefedidjaft, oronet unb verwaltet ifre II $n=$

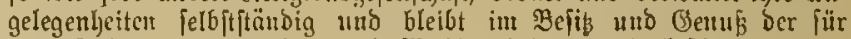

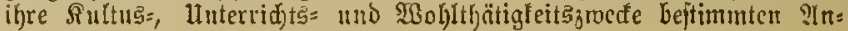
fitten, Stiftungen uno Fonds.

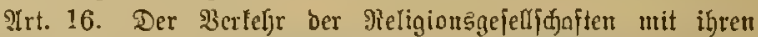

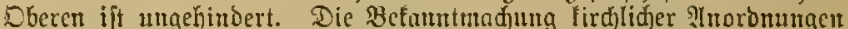

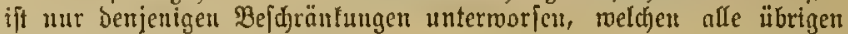
seröffentlidinungen unterliegen.

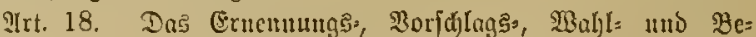

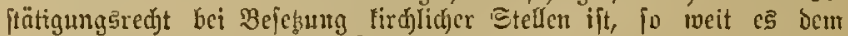

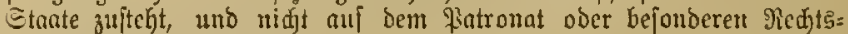
titeln beruht, aufgchoben.

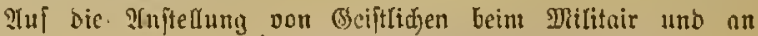

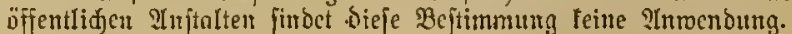

Irt. 1\%. Heber Das Sirchentpatronat und Die Bebingungen, unter welden baffelbe aufgefoben werien tann, loird eit bejonderes Giejetz ergeljen.

Sirt. 19. Die Cinitifrumg ber Civilehe eriolgt madh

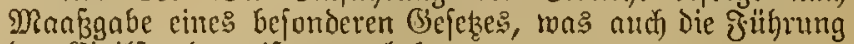
Der (Sivilitandsegijter regelt. ${ }^{1}$ )

1) Reidjggejeblich geregelt Durd (9. v. 6. 2. 1875 über bie

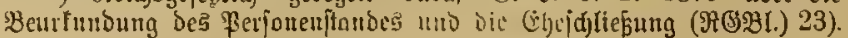


Trt. 20. Die Wiffenjujaft und ihre Refjre ift frei.

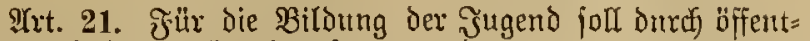
rid)e Sufulen genïgento geforgt werderr.

Eltern uno deren Stellwertreter dïrfen ihye Sinder oder Bflegebejoljlenen nidft ofine den lluterridjt laffen, weldher fïr bie öffentlidsen Doltefdulen borgefdrieben ift.

2(rt. 22. Ilnterridyt zu extheilen und Ilnterridytsanftalten zu grïnden und zul leiten, fteht Jedem frei, wem ex feine pittlidje, wiffenfacjajtlidje und terfjnijche Befäligung Den be= treffenden Staatabehörden nadjgetwiefen hat.

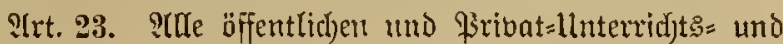
Erziehunggannitalten ftehen unter der Furffidyt bom Staate ernannter Behörden.

Die offentlidfen \&ehrer haben die Rechte und Pffichten der Stantsdienter.

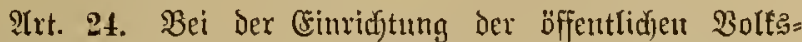
judulen find die fonjeffionellen $\mathfrak{B e r b a ̈ l t n i f f e ~ m o ̈ g l i c h j t ~} z^{u}$ be= rüuffitutigen.

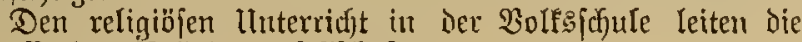

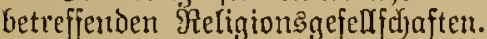

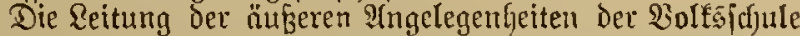
jteht Dex Benteinde ju. Der Etaat ftellt utnter gejetzlid) geordneter Betheiligung der Bemeinden, aus der Bahl Del Befähigten die Rehrer Der öffentticf,en $\mathfrak{V}$ olfşfudulen an.

Trt. 25. Die Mittel jur (Erridftung, Unterhaltung uno (Frmeiterung der offentlidjen Bolfs;idule rerden bon den (अemeindeu, und im Jalle des sach)geniejenen IInvermögens, ergänzungşweife vom Staate nufgebradjt. Die auf be= ionderen Redjtatiteln Gerulgenden Berpflichtungen Dritter bleiben beftefen.

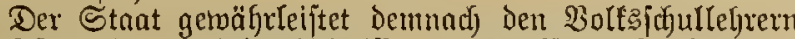
ein fejtes, den sotalberbältniffen angemefjenes Cinfommen.

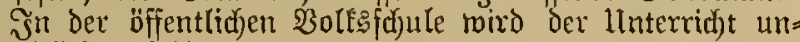
entgeltlidf ertheilt.

Art. 26. Ein bejonderes Gejelz regelt bas ganze lluter: ricjtsine (en. $\left.{ }^{1}\right)$

v) Die[es (3. ift nod nidte ergangen.

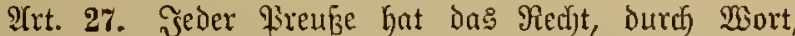
Solhrift, Druaf und bildlid)e Darịtellung feine Meinmg frei z" äuछern. $\left.{ }^{3}\right)$

Die (Senfur darf mifft eingefüf)xt rerden; jede andere Bejod)ränfung Der Freffireiheit nur im WBege Der (Sejebgebung.

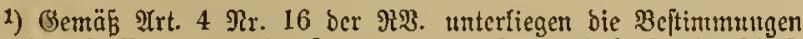

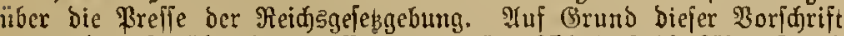

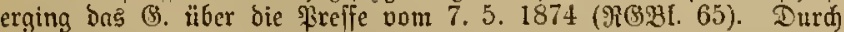
bieies "Bresgejets" ift aber bas alte Freubifde (5. vom 12. 5. 1851 (BS. 273) nidt ganj aufgeboben.

2(rt. 28. ${ }^{1}$ ) Bergeljen, meldfje Durd) Wort, Schrift, Drurf oder bildolidje Daritellung begangen merden, find nach ben allgemeinen Strafgejetzen ju bejtrafert.

1) In Stelfe des șrt. 28 gilt $\S 20$ bes Prefgeiebes v. 7. 5. 1874: „Die Berantroortitchfeit jür Sandlungen, Deren હtrajbarfeit

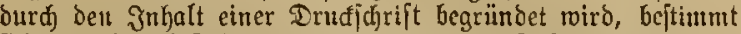
(iid) nad) ben beftehender affgenteinen Strafgejegen.

Sfit bie Drucfichrift eine periobifde, fo ift oer verantwortlide

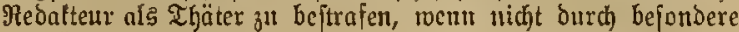

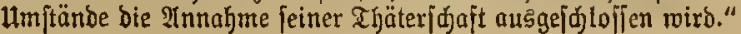

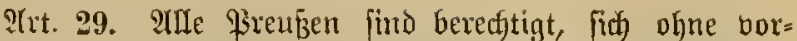

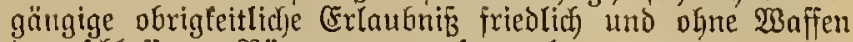
in geidjlofienen Räunten zut verjammeln.

Diefe Befitimmung Gezieht pich nicht nuf Dierfammlungen

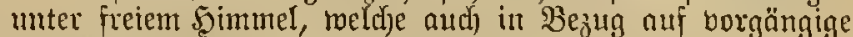
ofrigfeitliche Ertaubnif̧ Der Berfügung des Bejezes unter= worfen furd.

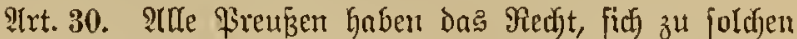
3roeden, weld)e ben Strafgeletzen nich)t jumberlanfer, is (jefellichnften zu vereinigen.

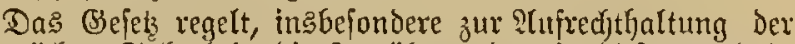
öffentlidjen Sicherbeit, bie \&ns̈übung des in biejent und in

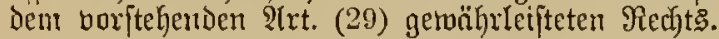

Fiolitifat)e Bereine fönnen Bejdränfungen und vorïber=

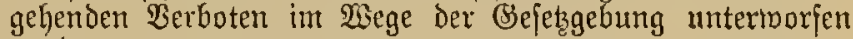
toerden.

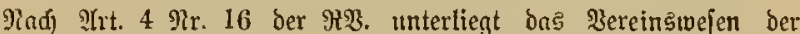

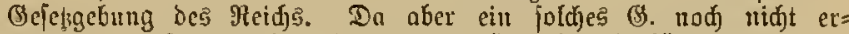
gangen ifit, fo gilt dic "3eroronung über bie Berfütung eines bic gefablidje Jreibeit uno Dronung gefährbenden Mifibraudjes bes $3 e r=$ fambtungs: แ⿰氵

2rt. 31. Die Bedingungen, unter melden Rurporntions= lect)te ertljetlt voor veriveigert merden, Geftimmt bas Gefeks.

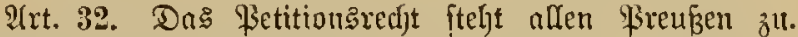
Sietitionen unter einem (B)ejammtnamen find nur Behöroen uno Sorporationen geftattet.

Irt. 33. Das Brriefgefeimnif ift umberleţlid). Die bei ftrajgeridytlicfen Ilnterfuchungen umo in Sriegsfällen noth= wentigen Befiduränfungen fino durth die Bejetgebung fejt= zuitellen. ${ }^{2}$ )

\section{1) 3gI. ๔125. §§ 99, 100, 110.}

2(rt. 34. צlle \$renfen find mehrpflidftig. Den llm= fang und die ?hat diejer Pfflicht beftimmt das (Sejets.")

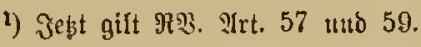

Shrt. 35. Das Seer begreift alle 2 ththeilungen des jtehen= Den Seeres uno ber Sandwefyr.

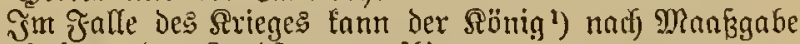
Des (Sefetzes den Entioftum aufbieten.

1) jeşt ber ßaijer.

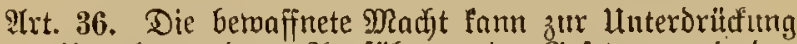

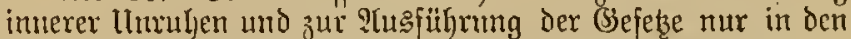
vom Gejebze beftimmten Fällen und Formen und auf $\Re e=$

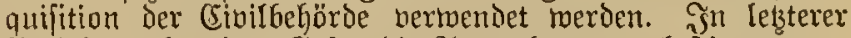
Beziehung hat bas Gejes die 2lusnahmen zu beftimmen.

भit. 37. Der Militairgeridt: jidf aut Straffadjen und wird burd) dos (Bejets geregelt. Die Beftimmungen über die Militairdizziplin im seere bleiben Begenjtand bejonderer Seroronungen.

Irt. 38. Die berwafinete Madjt barf meder in nod) auker

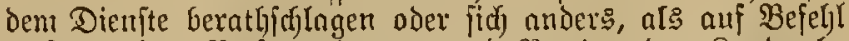

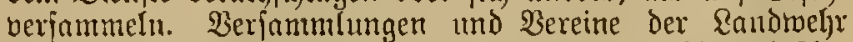
zur Berathutg militnirifher (Eintid)tungen, Befehle und $\mathscr{A} n=$ orounngen fino audf Dann, toenn Liefelbe nicht zufamuten= Gernfen ift, unterjagt. 


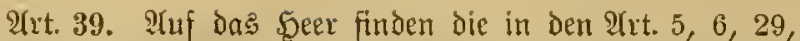
30 und 32 enthaltenen Bejtimmungen nut in folveit $2 \mathfrak{H}^{\prime}=$ wendung, als bie militairifchen Bejetze und Diszaplinarbor= jufriften nicht entgegenitelyen.

Y(xt. 40.1) Die (Errichtung bon Eeljen iit unterfagt.

Der in $\mathfrak{B} e z u g$ auf bic vorlandenen Rehen nod) beftebende

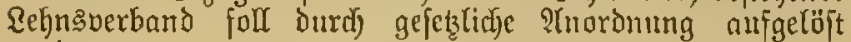
twerben.

1) Falfung nađ dem (5. v. 5. 6. 1852.

Y)(2t. 41.1) Die Bejtinmungen des 2(rt. 40 finden auf Thronleben und auj bie auferbalb des Staates liegenden Echen teine 2frwendung.

1) Fafjung nodj bem (3. v. 5. 6. 1852.

शr.t. 42.1) Shne (antjdjäbigung GTeiben aufgehoben, nadj Maaßjgabe der ergangenen bejonderen Bejetze:

1. Das mit bem Bcfitze gewiffer Brunoltidfe verbundene Recht ber \{tusilbung poer Mebertragung ber ridjter= lidjen (Semalt (Titel VI) und Die aus Diejem Red)te ffiebenden (5xemtionen und 2 Ggaben;

2. die aus den Beridgtg= แnd idjubherrlidjen 2 erbande, der frïberen (Erbuntertbänigfeit, ber früberen Steucr= und (Gemerbe $=$ Berfaffung berjtammenoen Berpflid)= tungen.

Mit den anfgefobenen Riedten jallen audj bie (segen= leifungen uno Eajten treg, tocldic ben bisher Beredfigten dafür oblagen.

1) รaffung แẳ రem (5. v. 14. 4. 1856.

\section{Titel III. \\ ģom ciönige.}

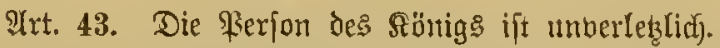

Irt. 44. Die Minifter Des R̈̈nigs find berantmortlidf.

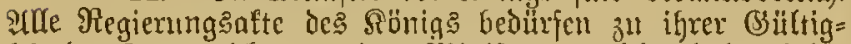

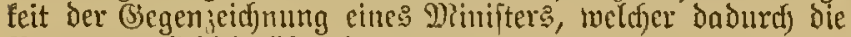
Berantwortlict)leit ïbernimmt.

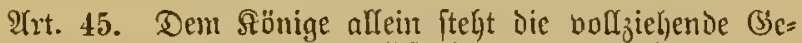
walt зน. Fre ernennt uno entläß̧t die Minipter. (5r befieglt

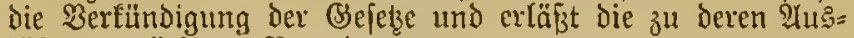
fübrung nötljigen $\mathfrak{B}$ eroronungen. Seer.

Art. 46. Der Siönig ${ }^{1}$ ) führt den Dberbefefl ïber Das

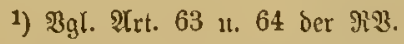

21rt. 4\%. Der Rönig beickt alle Stelfen im Scere, fowie in Den übrigen Bmeigen des Stantiobienites, pofern nicht bas (Sejets ein 2 nderes berordnet. ${ }^{1}$ )

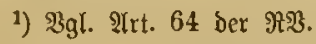

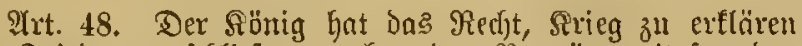

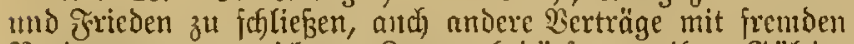
Regiermingen zu errictstl. Setztere bebürfen z" ifrer (Sültig=

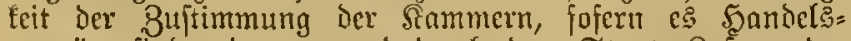
verträge fiud, oder rem dadurd) icin Staate Raften oder einzelnen Stantşbürgen Berpflicftungen nujerlegt merden.")

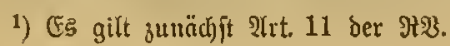

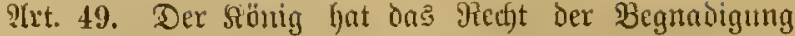
mo Strafmitberung.

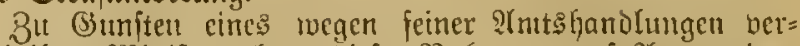

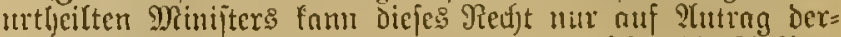
jenigen Sianmer alsisgeitbt merben, bon tweld)er die 2tnflage anteggegangen ift.

Der Siönig fant Gereits cingeleitete Unterjutfungen mu auf Brmub cines befonderen Beielzes niederjoflagen.

2rt. 50. Dent Sönige freht Die Berleifung von Drten und anberen mit 23orredjten nidjt verbundenen $9415=$ jeidjunngen ju.

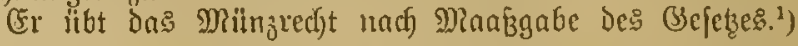

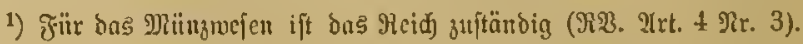

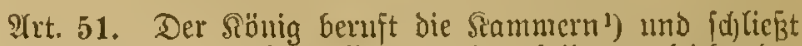
ifle Siłungen. Fr Enun fic entweder beide zugleirf oder aud m. eine auflöfen. ${ }^{2}$ ) (5) müffen aber in eirem foldjen Falfe inmerhalb cines Beitraums von 60 Tagen nad) ber

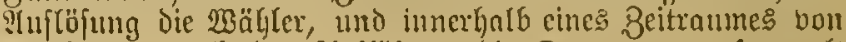
90 Sagen mad) ber ?luflöjung dic Santment berfammelt weriden.

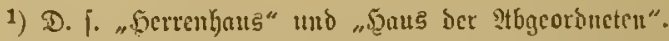

2) Das berrenhaus fanu mur "vertagt", nicjt aufgelöt verben,

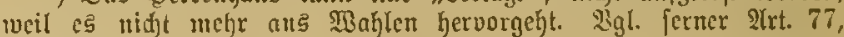
গtbj. 3 .

26.t. 52. Der Sïnig fam dic Sammern bertagen.1)

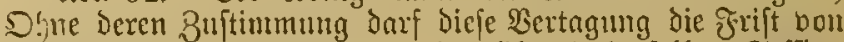
30 Tagen nidjt ibberfteigen und böhrend derjelbent Seffion nicfit micderljolt twerdest.

1) nur gleidgecitig. Ifrt. 77.

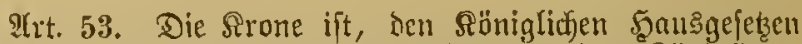

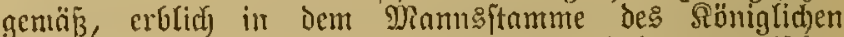
Jaufes nad) Dem Ped)te Der (Eritgeburt und der agmatifd)en ¿ittealfolge. $\left.{ }^{1}\right)$

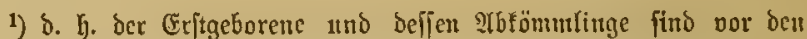

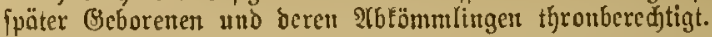

2(rt. 54. Der Rönig wiro mit Bolfendung des 18. Retents= jahres volljährig.

Ex Leiftet in Gegenwart der bereinigten Sammern das

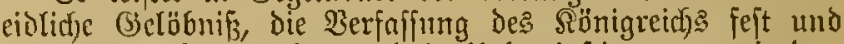
unberbrübjlidy za halten uno in Uebereinftintmung mit ber= fetben und Den (bejetzen zu regieren.

?(rt. 55. Dhne Cinmilligung beider Sammern fann ber Sönig nicht juglcid) Sgerr(d)er frember Ficidje fein.

212. 56. Wenn Der Rönig minderjälyrig ober jonjt

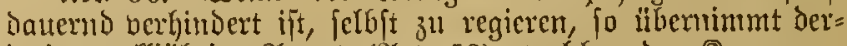

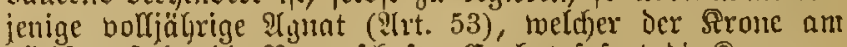
jüdjiten itelyt, bie giegentf(f)aft. (5r hat fofort die Sammern zu bernfen, bie in bercinigter Siknt itber bie Noth=

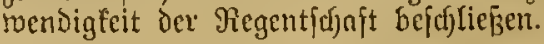

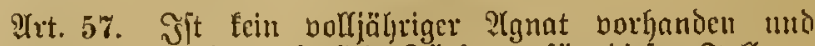
nicht bereits vorher gejekliche für forge fiit dicjen Jall ge= troffen, fo ljat bas Stantsminifterium die Samutern zu be= rufen, weldfe in bereinigter Sitzung einen Regenten cr= mil) Ien. Bis zum 2(utritt ber Regentfd)aft nou Geiten

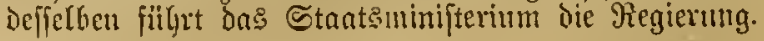


2rt. 58. Der Giegent übt die dem Sënige jujtetende (Semalt in Deffen Ramen au․ Derielbe idyobot nad) (Sin=

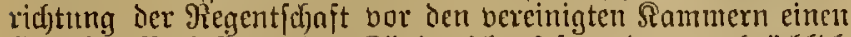

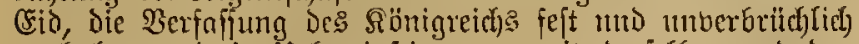
3 halten mo in ltebereinjtimmung mit Derjelben und ben Escietsen zu regieren.

Bis ju biefer cidesleiftung bleibt in jeden falle bas befichende gefommte Stantsminifterium für alle Regierung š Gandlungen verantwortlich.

Fit. 59. Dem Srou= Fideifommiņfonds verbleibt die Dutrd) Das (Siejets vom 17. Januar 1820 auf bie Einfinfte Der Domainen und ₹orften nugcwiejene Rente.

Dos waren 2,5 Mlin. Thaler Bold. Diefe Sronbotation (Einil=

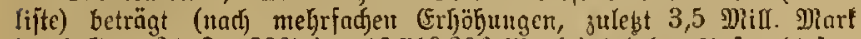

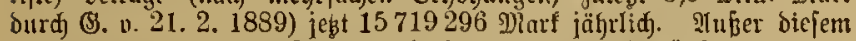
Betrage bejiellent der Röntg uno feitte fromilie (Eintünfte aus bent

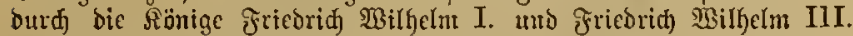
begrünbeten Fibeifomutiffen bezw. einem frrontrefor. III Deutfder Rnifer bezieht ber fiönig oon \$renfen fein bejonderes Einfoumen.

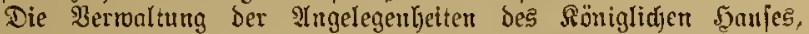

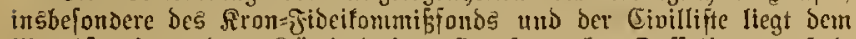
Dinifterium bes Rönigliden $5 a u f e 3$ ob. Daffelbe unterfegt

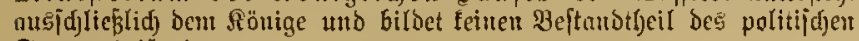
Stuatßminifteriums.

\section{Iiter IV. 马ुon den diriniffern.}

?(rt. 60. Die Miniftex, fowie dic zu ifrer Bertretung abgeoroneten Staatsbenmten baben Butritt ju jeder fanmer und milffen anf ihe Berlangen zu jeber Beit gehört merden.

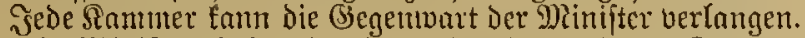

Die Minifter lyaben in ciner noer Der anderen Sammer unir banu Stimmreedt, menu fie Mitglieder Derfelfon find.

21rt. 61. Die Minifter fönnen Durch Befdulußs einer Bammer wegen Des Berbrechens Der Berfafjungsoerlełzang, der Beftectung und des Berrathes angethgt werden. IleGer

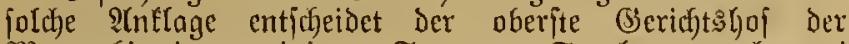
Monardie in bereinigten Senaten. So lange nod joei oberite (Geridgtahöfe befteken, treten hicjelben ju obigem Bruecfe 3ujammen.

Die wägeren Beptimmungen iiber die Fälle Der $\mathfrak{B e r}$ antwortlichfeit, ïber Das Berfnhren und itber Dic Etrajen merden einem bejonderen Bejetze vorbefintten.

Die cinzelnetr Mhinifter fitto:

I. Mittifter Der auswärtigen IIngelegenleiten. Dic

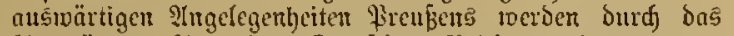

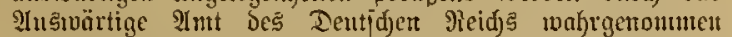

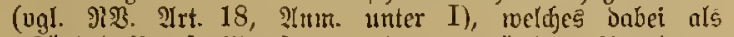

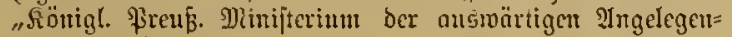
heiten" jeidjutet.

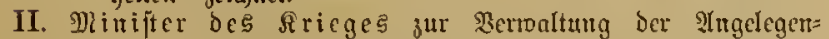

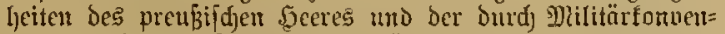

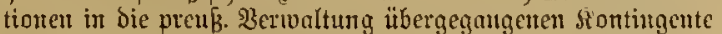

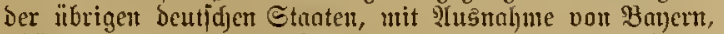
2Buirttemberg und Eadjen. Die finamieflen Pthgelegen=

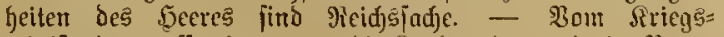
minifterium reffortiert u. a. Die \&anogenvarmerie in $\mathfrak{B} e \xi u g$ auf \$erjonalion.

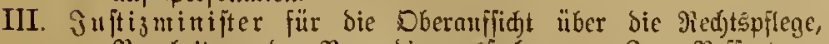
Bearbeitung ber Begnadigungsfadjen zc. Bunt Nefort ge=

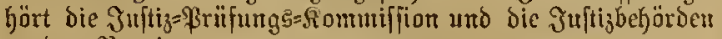
in ben \$rovinzert.

IV. Finanjuintiter, weldyent insbejondere bie Fefittellutg ber

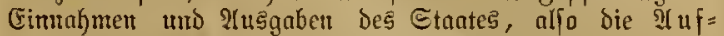
ftellung bes Stantshaushalts=(Etats und bie For= bereitung bejielben für ben Rantotag obliegt.
1. S1btheilung für Etats= mo fafjembejen;

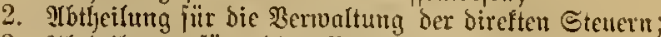

3. \$tbtheilung für bie Berroaltung ber indireften Etenem uno Der Bülle.

Iom Jinanaminijterium refiortieren: a) bie Benerol= Sotterie=Dircftion, b) dic Diüuzarjtalter, c) Sic Direftion fïr die Berwaltung ber bireften Stenem in Berlin, d) die Gesteral=Direftion ber Eechantlungs= Eozictüt, e) bie Saunt=

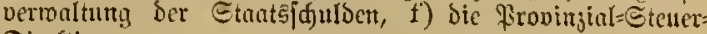
Direftiontell $2 \mathrm{c}$.

V. Minifter bes 马ntern für Beorbeitung ber Randes= unt Sofolpalizeifadjen, ber affgenteinen Ingeleaenheiten ber

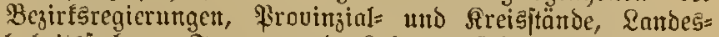
holjeitsjachen, frencr= und Qebensoerfidjerungs = Inftitute,

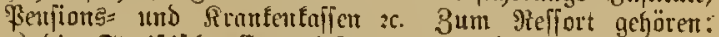

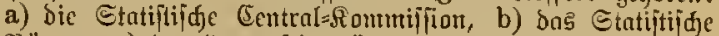
B̈̈reau, c) bas Yiterarifde Bïreau bes Etanatsuinifteriums, d) Die Ranogendamerie in Bezug auf igre Mirffamfeit und Dien[1]eiptung.

VI. Ninifter ber geiftiden, unterridjts= und Dedizi= nalangelegenbeiten (Nultusminifter). Demfetben unter=

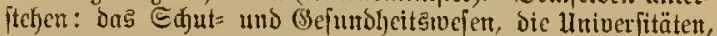
Runjtinjtitute, शffademie ber Biffenfdojten, Die Rönigl.

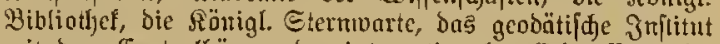
mit bent Centralbuirean ber intemationalent Eromelintug bei

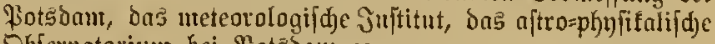
Dbfervatorium bei Potsbam zc.

rII. Si inifter für 5andel und Gewerbe, weldem das berg= Seütent= utto Solintembefar, bie Sandels= und Gerverbe

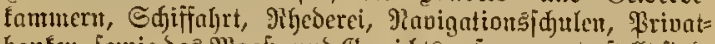

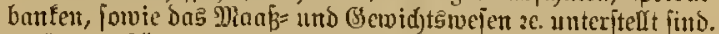

VIII. Minifter für Lanowirthfdyaft, Douänen un For jten fïr landwirthfdajtlidje und Beptïtangelegenbeiten, Jorit= uno 3agojoden. Bun Picijort Deffelben: a) Das ¿ambes=Defonomic=sollegium, b) Das Dberlandesfulturgeridt, c) bie Soneralfommiffionen, d) bie landowirthidgaftidgen Sdulten uno fircoitimititute $2 c$.

IX. Minifier ber öffentliden Il rbeiten. 3u beffen Refiort geförten efedent die Ingelegentheiten van 5 anbel, Ge= werbe utid offentlide Arbeiten einjolieflid bes 3erg=, Dütten= unb Salinemvejens. Dutd 1. (E. v. 7. 8. 1878

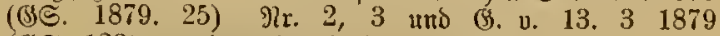
(\$s. 123) murben 5andel uts (serverbe eitem be jouberen "Pituiferiun fïr Sandel uno Bewerbe" über= tragen. Dic \$envalłung ber übrigen, bişfer im "Pinifterium fiir 5oubel, Gewerbe uno offentlidac Irbeiten" - Daffelbe war Durd) গ. (E. v. 17.4. 1848 (ङঙ. 109) cittgefest -

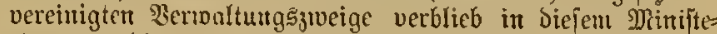
rimm, weld)es mumehr bie Bezeidnung "Dinifterium ber öffetitichen $\mathfrak{A}$ rbeiten “ erbiclt. Bufolge I.

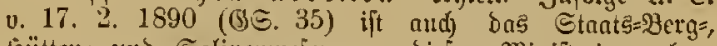
biitten= uno Salintemvejen von bicjen Minifterium abge= juetgt แnto bent Dinijterium für ఏandel und Gewerbe ïbervicien worben. Bum Reffort bes Mlä2. gehört bent= แad) nod) bas (Eifenbagnwejen unb bas Lano= uno Baffer $=\mathfrak{B}$ a uwe $\{$ en.

8ufolge II. E. v. 31. 12. 1894 (GS. 1895. 43) ijt bie Ber= maltung bes Berfeljrsabgabenoclens (einjd) I. Berwerthung bes fährregals, (Ertljeilung Don Fabrtonjcifionen, \$sermeffung ber

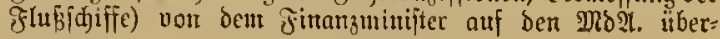
gegangen.

Jïir bas Eijerbafynwejen bejtchen feit bent 1. 4. 1895 jolgendo $\mathfrak{l}$ btheilungen:

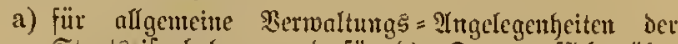
Etaatscifatbahuen uns für die Staatbanffidjt über bie Brivatcijertaftren (IV a);

b) für allgemeine finanzangelegenIjeiten ber Stants= eifenbafinen (IV b);

c) Fïr \$erfehrsangelegenteiten ber Stantsei|jenbahnten(II);

d) für tednifde Bauatgelegenheiten ber Stantseijen= balyten ( $\mathrm{I}$ a) uts

e) für Berwaltung Geiten ber Stantseijenbalyuen (I b). 
Die Ptbtheilungeu bearbeiten gleidjbered)tigt nebencinomoct ben ifurn angewicjencu Gejđäftsfreis unter je entem ver:

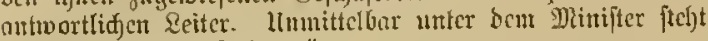
ein ll inter itade je f́retär.

Dic Berwaltum ocs Bamwejents ift cincr befonberen $2 t 6=$ thcilumg (III) iibertugen. \$on berfelbett rejortieren: a) bic

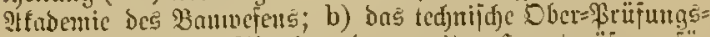

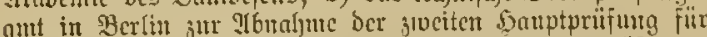

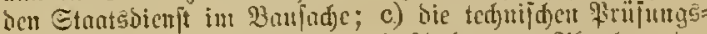

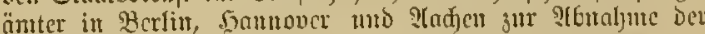

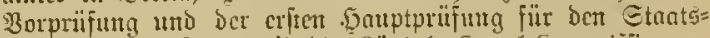

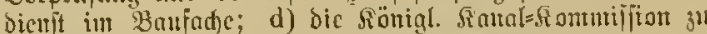

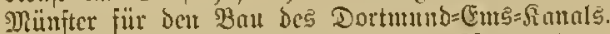

3un geme $u$ ud aftrid)en Rcfiort De* Minifter ber öffull. SIrbetten, fü bandel und Bewerbe umb fü: \&andwirthidaft 2c. gehöen ber \&andes=(Eijenbalunath und bie Besirl's=(Eijerba!)urn̈the.

Die unter I-IX nufgefïlyrten Dinifter, 3u wcldjen nod) ctwaige

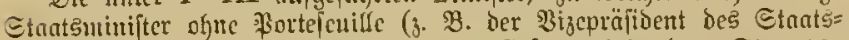
muifteriums) treten, bilsen in ihrer Bejammtheit bas stants=

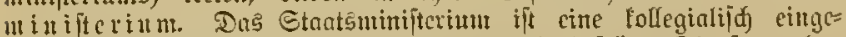

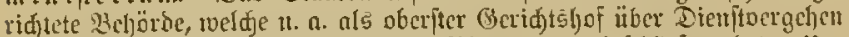

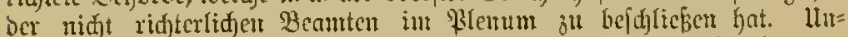
mittelbar unter bem Etontsminifterium ftel)en: a) bos (Eentrolbireftorimm

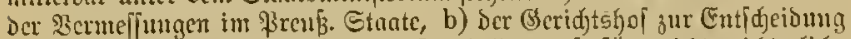
ber fompetenjfonffifte, c) ber Disgiplinorbof für nid)t ridjterlidje Bcantte, d) bas Dberverualtungsgeridt, e) bie firifungstommifion fïr höhere Scrnaltungsbente, f) bic Sinficbelungsfommiffion für

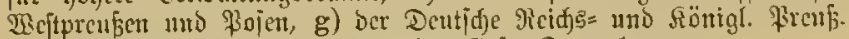

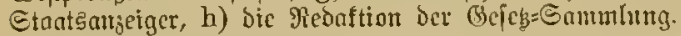

Eingche Refiorts ftchen unmittelbar unter ber Dberleitung bes Präjibenten bes Stratsminifteriumb, 3. B. Die Gereral= orbentstommifition, bic Stantsardive $2 c$.

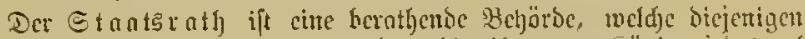
(Sejebentwörje 2c. 3u begutad)ten hat, bie ifr vom Sörige jobesuta!

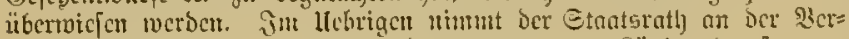
maltung nidgt theil. Die Mitglieder werben nom Sänige berujen.

\section{Titel $\mathrm{V}$.}

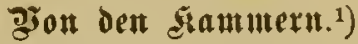

2trt. 62. Die gejekgebende Betwalt wird gemeinj(jajelich Dutrd) Den Sönig uno Durdf zmei Sammern ausgentht.

Die Ulebereinftinmung Des গünigs und beider fanmern ift zu jedem (Befetze erforderlich.

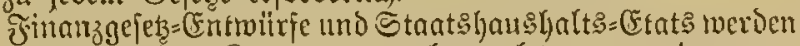
3terft Der zlveiten Sammer borgelegt; Ietztere merden von ber eriten Rammer im Banzen angenommen oder abgelehnt.

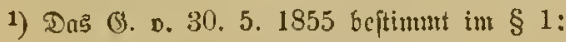

"Dic Erfte Samuner wirb fortan Das 5errenfants, Die Bucite bas Satts ber Itbgeoroncten gentumt."

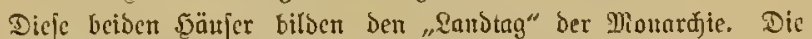
Bejeses=3erfïndungsformel Iautet feit 1855 jtets "unter 3uftinnung beiber Szäu[er bes Sambtagg".

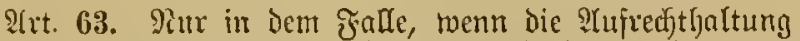
Der b̈fentlicfen Sidjerheit, oder bie Bejeitigung eines un= gewübnticfen Nothftandes es dringend erjordert, fömten, infojern die Rammern nidjt berfammelt find, unter 2 Ber $^{\circ}$ anfwortlid]feit des gefammen Stantsminifteriums, $\mathfrak{S e r}_{\mathrm{e}}=$ orônungen, Die Der Serfaffung nicjt zuwiderlaujel, mit (Se= jetzesfraft erlafien werden. Diejelben find aber den finutnern bei ifrem nächften Bufammtentritt zur Bentehmigung fojort vorzulegen.

2(rt. 64. Dem Ränige, fomic jeder Sammer, fteht bas Yedjt zu, (Bejetze vorzujd)lagen.
(Bejeksesvorjdtäge, roelcje Durd) eine der fiammern oder

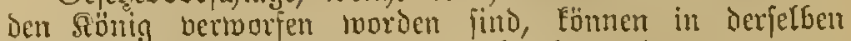
Silzungaperiode nicht wieder vorgebradjt werden.

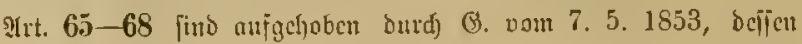
Irt. 2 lantet:

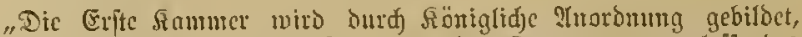

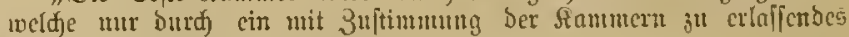

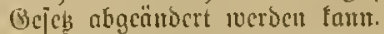

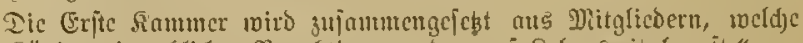

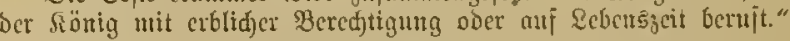

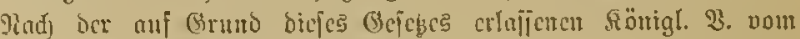
12. 10. 1854 bejteht bas 5errenlyans:

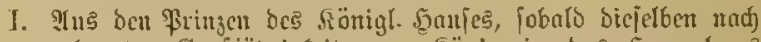

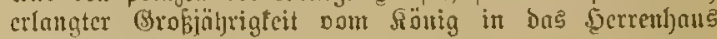
bernipen inerben.

II. $\mathfrak{I}$ ts Mitglicocrn mit ctblid)er Bercdjtigurg:

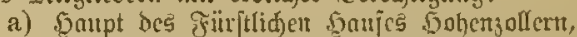

b) Säupter ber pormals reidjștäntoijden Säujer,

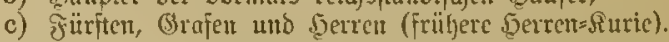

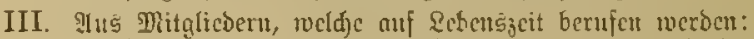

a) Die 3ngaber ber 4 groben Zambesänter (Oberburg=

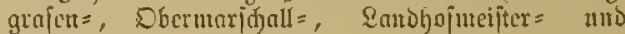

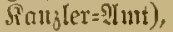

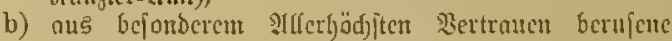
\$erjonen.

IV. Ŝ̉ Mitgliebcrn, welde injolge von Fräjentation ber mit

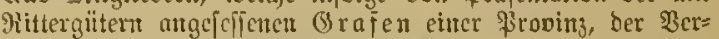
bünde des altent unb befejtigten Brutrobefiges, einer

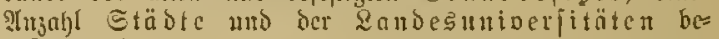
infen werben.

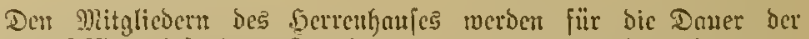

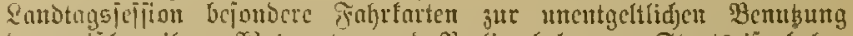
ber 3wijden iffren Sisobnorten uto Berlin belegenen Staatseifenbahn=

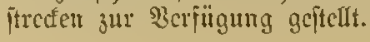

2Lrt. 69. Die Broeite Sammer befteht aus 433 Mit=

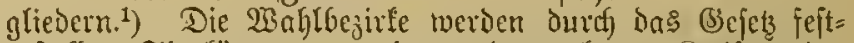
geitelft. Sie fönnen att: einem oder mehreren Sireifen oder aus ciner oder mefreten ber gröferen Stöbte bejteber.

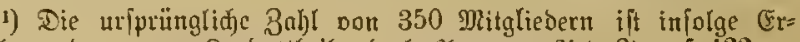

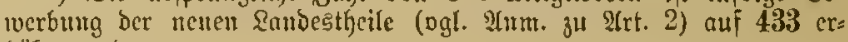
fögt roorden.

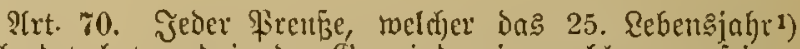
vollendet gat unt in der (Semeinbe, in reldjer ex jement Wohnliz lyat, die Bejähigung zu den Bemeintervahlen be= jitze ift fitmmberedytigter lltrwälyler.

Wer in mehreren Bemeinden an den Bemeinderwablen

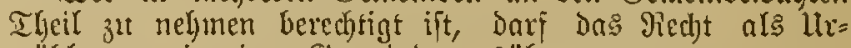
wäb!er nur in einer semeinde ansüben.

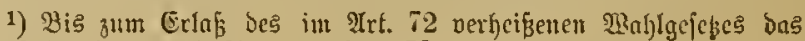

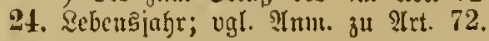

Itrt. 71.1) Thu jede $\mathfrak{B o l l} 3 a \mathfrak{l}$ von 250 Eeelen ber $\mathfrak{B} \in=$ völfermg ift cin Wablmann ju wählen. Die llrwähler werden nach Maabgahe der von ibnen zu entrichtenien Direften Stantsiteuern in 3 2tbtheílungen getbcilt, mto

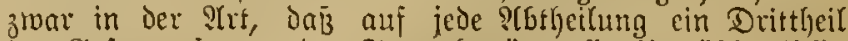
Der Bejanmtjumme der Steuerbeträge alfer uriwähler fällt.

Die Bejanmtfunme wito berectinet:

a) genteindomeije, falls die Sicmeinde einen Utrtwahl= bezirt für fith bildet;

b) bejirfismeife, falls ber Urwahlbezirk alts mehteren Biemeinden zufammengejekst ift. 
Die exite Atbtheilung befteht aus ienjenigen Urmählerm, auf welfice die böniten Steuerbeträge bis zum $\mathfrak{B e l a u j e}$ eines Drittheils Der Sciammtfteuer fallen.

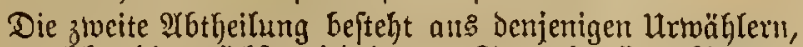
auf tweldye bie näufit nieorigeren Stenerbeträge bi६ zur Sränze Des zrveiten Drittheils fallen.

Die oritte Stbtheilung beiteht aus ben am nieorigiten befteuerten lltwäblern, auf weld́le bas dritte Drittheil fălt.

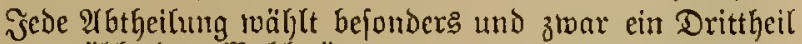
Der zu mähtenden $\mathfrak{B a h l m a ̈ n n e r . ~}$

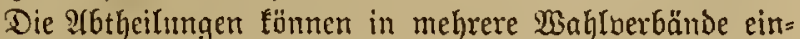
getheilt merden, deren feiner mehr als 500 Urmähler in (iid) id)lię̧en darf.

Die $\mathfrak{W n}$ hlmäuner werden in jeder 2aftheilung aus Der Zahl der ftimmberedjtigten Urtwähler Des Utrwahlbezirles, ohne Rürffidjt auf Die थbtheilungen, gewählt.

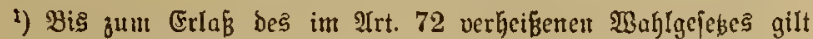

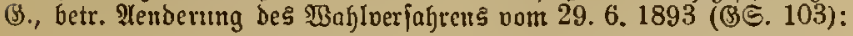

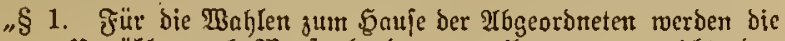

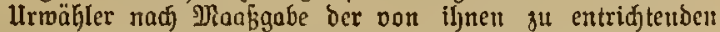
birelten Staats=, Bemteinde=, Rreis=, Besirfs= uno \$ro= vingialfteuern is 3 शुbtheilungen getheilt, und groar in oer IIt, Dấ auf jede Ibtheilung ein Dritttheil ber Gefammt= jumme ber Steucrbeträge oller lurmäbiler fäldt.

Für jebe nidjt zur Stantscinfommentfeuer veranlagte Berjon ift an Stelle diejer Steuer cis Betrag oon 3 Mait zuแ $\mathfrak{A}$ паß zu bringen.

§ ¿́. Itrmähler, welde zu einer Staatsfteuer nidjt veranlagt find, wöhlen in ber 3 . Abtheilung.

3erringert fin in Folge beifen bie auf bie 1. und 2. Ib= theilung entiallende (Sejammtiteueriumme, io firbet bie

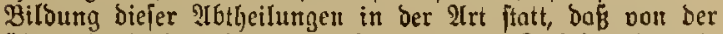
übrig bleibenden Summe auf bic 1. und 2. Abtheilung je bie Џälfte entiällt.

§ 4. Iuळ in Bencinden, welde in mehrere Hrwahlbezirle getheilt jüb, roird für jeben IIrunblbejilf eine bejonbere Ibtheilungstifte gebilbet."

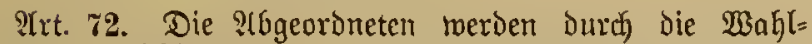
männer getwählt.

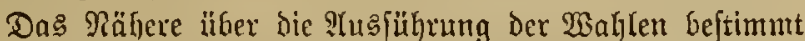

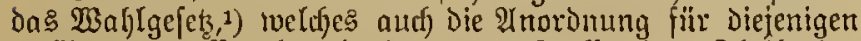
Städte zul treffen loat, in Denen an Stelle eines Theils der

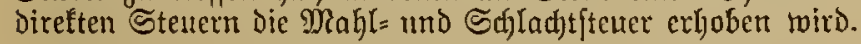

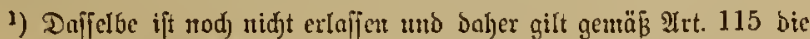
3. v. 30. 5. 1849 (ङS. 205). भUs berjelben jei herworgehoben:

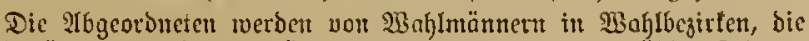

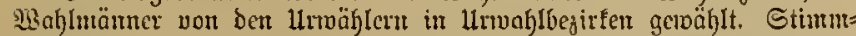
beredjtigter Hrwälyler ift jeber Freuß̉e, reldjer bas 24. Zebensjahr vollendet fot, in ber Gemeinde, in reldjer er jeit 6 Monaten feinten

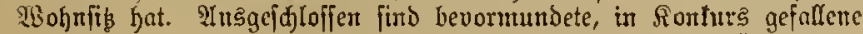

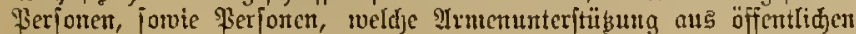
Mitteln bejichen uto joldje, benest ber Wollgentı ber bürgerlidgen Ehrentedite geridtlidj aberfonnt ipt.

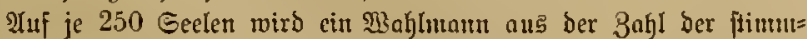
beredtigten llrwähler des Irrvahlbezirfes gewählt.

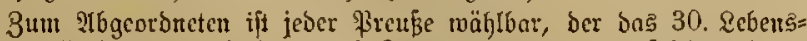
jafir vollentoct lyat und bereits 1 Jnhr long beur pretsifidjen bezrv.

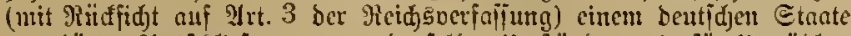

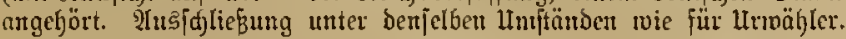

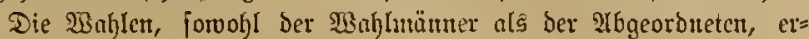
folgen burd Etimuabgabe zu prototoll bes \$Wahlvorjtegers bezm. WBahltommifín:s.

Das rocitere Berfahren ijt bur屯 ein befonberes Reglement georbnet. Eammfung yon Bejesen 2c. f. Pooft u. Telegr. 21rt. 73. Die Regislaturperiode des 5aufes Der $2(6=$ genroneten Dautert 5 Jaljre. 1 )

1) beruht auj bem (3. v. 27. 5. 1888.

STrt. 74. 8um 2Hbgeoroneten der 3rociten Sianmer ifft

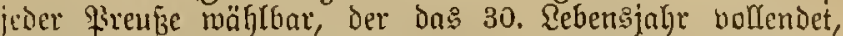
Den 20 olbefiz Der bürgertid)en Red)te in Folge rect)tsfräftigen ricjterlidgen (Erfenntniffes nicht berloren und bereits 3 Эahre ${ }^{1}$ )

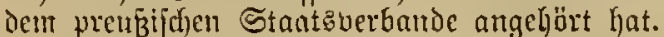

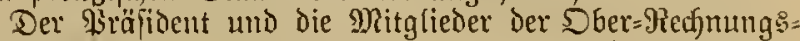

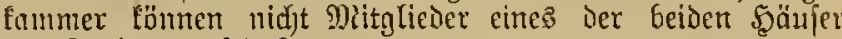
des Randtages [ein. ${ }^{2}$ )

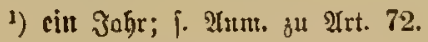

2) 26j. 2 beruht ouj bem G. o. 27, 3. 1872.

शrit. 75. Die Sammern merden nach PGlanf ibrer

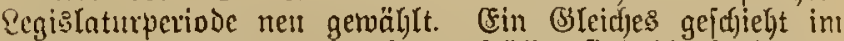

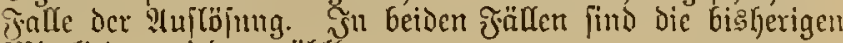
Mitglieذcr mieber wäl)tbar.

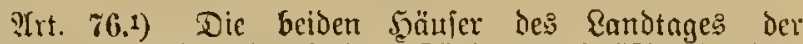
Mionardfie werden Dureff Den Rënig regelmǟsig in Dem Beitraum bon Dem 2Yujange des Mionats 2 avember jedeu

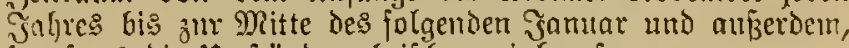
fo oft es die umitände erheifden, einberufen.

1) Jafiung nach dem (3. จ. 18. 5. 1857.

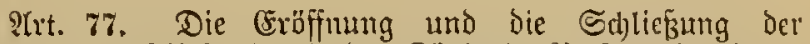
Sammern gejufieft Durch Den Rönig in Sierfon oder Durd) einen baju von ihm beauftragten MRinifter in einer Sitzung Der vereinigten Sammern.

Beide Sammern werden gleidfzeitig bernien, eröffnet, ver: tagt und geich) Loffer.

2Bird eine fianmer aufgelöpt, fo trird dic andere gleidf = jeitig bertagt.

Trt. 78. Эede Sammer prifft Die Regitimation ifrer Mritglieber uno entffyeibet bnüber. Sie regelt ifren (B)e=

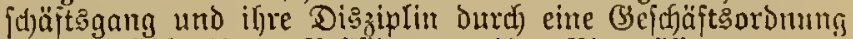
und ermählt ifjen \$räfioenten, ibre Bizepräfidenten uni (od)riftiillurer.

Beamte bedirrfen feines ltrlaubs zum csintritt in die Srammer.

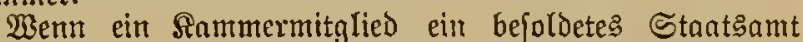
annimmt ober im Stantsobenfte in ein almt eintritt, mit

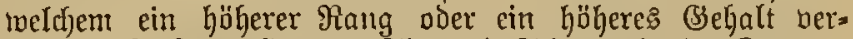
bumben ift, fo berliert 6 s Siz uno Stimme in ber Sammer und fann peine Stelfe in berfelben nur Durhy netre Wahl wicber erlangen.

Riemand fann Mritglied beider Rammern fein.

\{rt. 79. Die Sikzungen beiber Rammern find p̈ffentlidj. Sede Sammer tritt auf Den IIntrag ihres \$räfibenten oder von 10 Mitgliedern zu einer geheimen Sikzung znfammen,

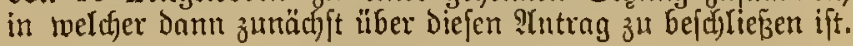

Irt. 80. Seine Der beiden Sammern fam eimen $\mathfrak{B} \mathfrak{c}=$

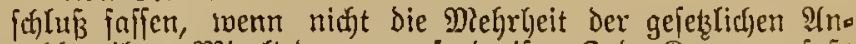
zahl') ifjer Mitglieder anmejend ift. Febe fammer fafat

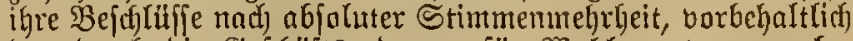

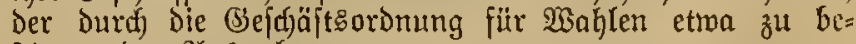
ftimmenden $\mathfrak{X}$ ushafimen.

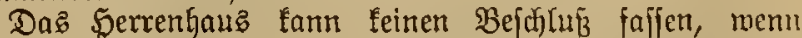
nidyt minbeften\& 60 ber nacf) Maajgabe ber Berordnum! 


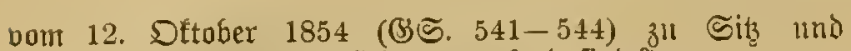
Stimme berufenen Mitglieder anwefent find. ${ }^{2}$ )

1) Das find beim গtbgeoronetenhaufe 217.

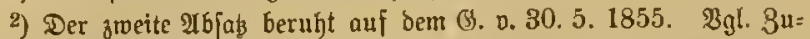
fäse zи 21rt. 65-68.

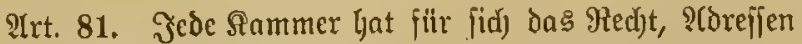
an Den S̈̈nig zu ridster.

Niemand Darf Den Sammern oder einer derfelten in Berfon eine Bittichrift oder idoeffe ïberreidjen.

Эede Rammer tann dic an fie gerid)teten Sujriften an

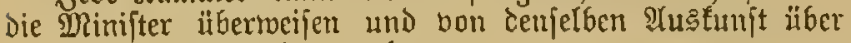
eingebende Befdjwerden berlangen.

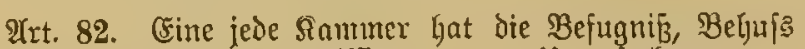
ifrer Snformation Sonmiffionen zur Unterjudbung bon Thatjacten zu ernennen.

21rt. 83. Die Mitglicder beider Sammern find Bertreter bes ganzen $\mathfrak{B o l f e s}$. Sie fimmen nadj ifrer freicn Heber=

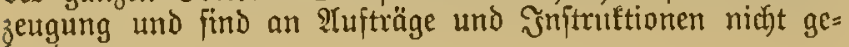
bunden.

2rt. 84. Sie tönnen fïr igre 2thftimmungen in der Sanmer niemals, für ifge barin nusge[prodjenen Mieinungen nur innerhalb der Siammer auf Bruno Der (Sejdjäftzoromung (2(rt. 78) zur Rerfenfdja\{t gejogen werden.

Siein Mitglied einer Siammer fann olgne deren (Bie= nehntigung toähreno ber Siłunggperiode toegen einer mit Strafe beorohten 5andolung zur llnterjudjung gezogen oder verbaftet iveroen, auber menn eริ bei ?tusitbung ber That oder im Saufe Dç räcjitfolgenden Tages nad) berfelfen ergriffen wird.

(S) Teiche Benehmigung ift bei ciner Berhajtung regen Sd)uldell nothwendig.

Jedes Strajberjahren gegen ein Mitglied der fiammer und eine jede Unterfudjungs= oder Civilbaft wirb fïr die Dauer Der Sitzungspertode aufgehoben, wein die betreffende Sammer es verlangt. ${ }^{1}$ )

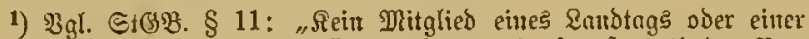

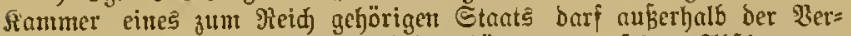
fontulung, au welder bas Ditalied geljört, wegen feiner Mbjtintunng

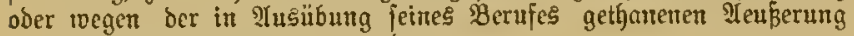
jur Berantwortung gesogen roerden.

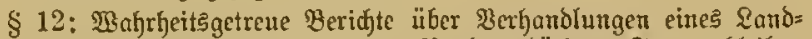

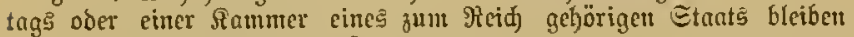
vor jeder Berantwortlidjeit frei."

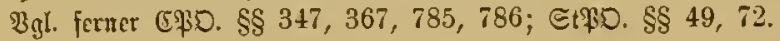

2rt. 85. Die Mitglieder Der Bmeiten Sammer exhalten aus Der Stant:̊fafje Reifefoften uno Diäten nach Maā̉gabe des (3ejebes. ${ }^{1}$ ) (Ein Berzicht hierauf ift unjtatthaft.

1) अ. ๒. 30. 3. 1873 (\$ङ. 175) und v. 24. 7. 1876 (ఆङ. 345). (Bei ßeifen auf Eifenbahnen oder Dampfidjiffen 13 ßfennig für $\mathrm{km}$ und 3 Dart $\beta_{\mu=}$ und Ilbgang; Eanoweg 60 Pfennig für $\mathrm{km}$. Diätent pro Tag 15 parf. Beredjnung wic für Stantsbeante).

\section{Titel VI.}

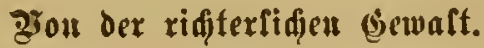

2irt. 86. Die rifferlifje Betwalt wird im Pamen bes Sënigs durd) unafhängige, feimer anderen Yutorität als ber des (Gejekses untermorfenc (Geridjte autigneỉbt.1)
Die Itrtgeile werden im Ramen des fönig ${ }^{2}$ ) aus: gejertigt und volljtrecft.

1) ஒgl. § 1 (ே)

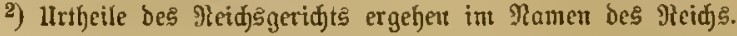

S(tr. 87. Die Ridjter merien bom Rönige oder in deffen Ramen allf iłre Qebenszzeit ernannt. ${ }^{\text {) }}$

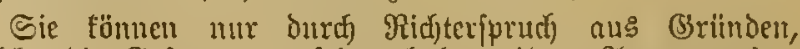

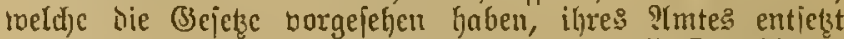
oder jeitiveife entljoben rocroen. Die borlänfige ?tmts

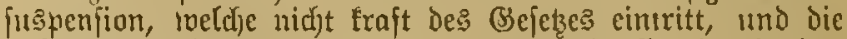
unfreimidlige Serjetzung an eine andere Stelle ader in beu

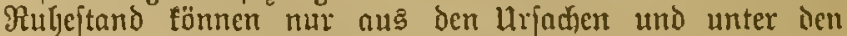
Farmen, meld)e im Bjefebe angegeben find, und mur auj

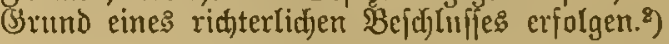

Iui die Berfetzungen, weldye durdy Beränderungen in Der Diganifation Der (Beriffte oder ihrer Bezirfe nötgig merden, finden biefe Bejtimmungen teille $\mathfrak{A n t w e n d u n g . ~}$

1) अखु. $\S \S 1-8$.

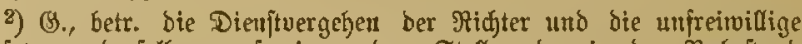
Berfekung berfelben auf cine andere Stelle ober in ben Ruheftand ৩. 7. 5. 1851 (\$S 218 ).

Irt. 87a.1) Bei Der Bildung gemeinjajaftlidjer (B)ridjte fiir \$reupiifbe (Bebictstbeile und (Sebiete anderer Bundes= ftnaten find abweichungen von ben Bejtimmungen bes Irt. 86 und bes erjten ?Lf. im $\mathfrak{A}$ t. 87 zuläffig.

1) Bgetuft auf bem (5, v. 19, 2. 1879.

It:t. 88 anfgehoben burd) ค. ‥ 30. 4. 1856.

S(rt. 89. Die Drganifation Der (serid)te riro Durd) Dag (Sejetz beftimmt.")

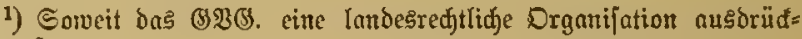
lid) ge|tattet.

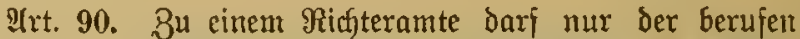

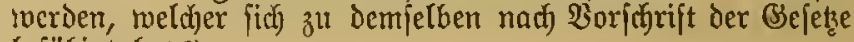
bejähigt hat. $\left.{ }^{1}\right)$

1) அஅ(3., bejonders § 2.

Art. 91. (Berid)te fïr bejondere Rlajfen von IIngelegeu= Geiten, insbejundere \$randel: = und Bctwerbegerid)te follen im Wege ber Beicksgebuing an den Drten errictet werden, wo

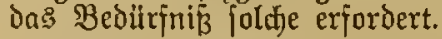

Die Drganijation mo Bu[tändigfeit foldyer Beridjte, bas Berjahren bei Denjelben, bie Crnennung ifrer Mrit= glieder, bie Gejonderen Berlö́ltnifje der lebteren und die Dauer ifres 2(mtes trerden burd) dą (Bejeb feftgeftellt.")

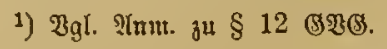

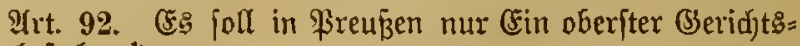
पof bejtęen. ${ }^{1}$ )

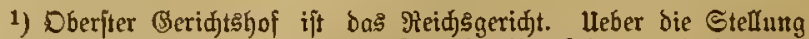

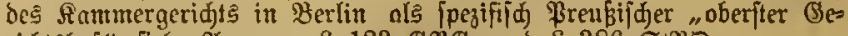

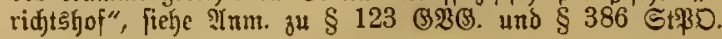

9rt. 93.1) Die Ber(jandlungen vor dem erfennenden (3)eridyte in (Sibil= und Strafjadjen follen öffentlid) jein. Die Deffentlicteit fann jedod) burdh einen öffentlid) zu ver. 


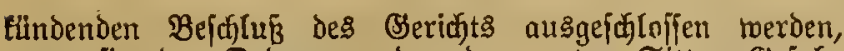
weln fie ber Dronung oder den gutell Sitten (Sejahi" orobt.

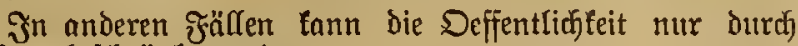
(Bejęse bejdräntt merden.

1) $\S \S 170-174$ अฌg.

2rrt. 9t. ${ }^{1}$ ) Bei Berbred)en erfolgt bic Entiळeidung über bie

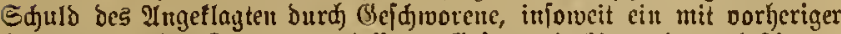

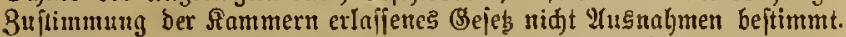
Die Billoung bes Befduorenengeridists regelt bas Gejeß.

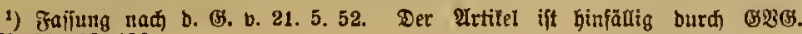
รง $73,81-98,136$.

Irt. 95.1) (Es tann burd ein mit vorheriger 8 uftimunumg ber

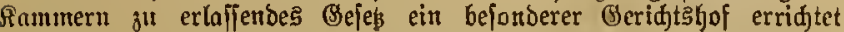

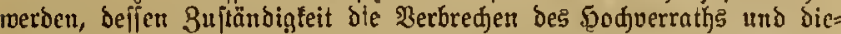

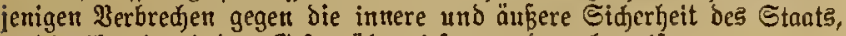

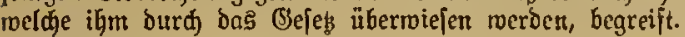

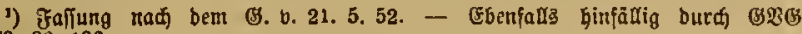
$\$ \S 73,80,136$.

Irt. 96. Die Sompetenz der (Berid)te und Bertoaltungs:= behörden wird durd) das (jejets bejtimmt. lleber fiompetenz= conflifte zroijchen ben Berwaltungs: = und (Berichtsbeljöroden

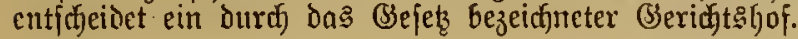

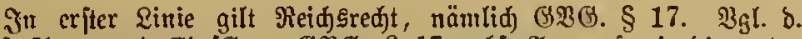

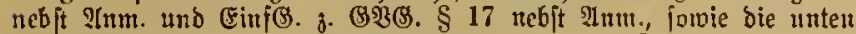

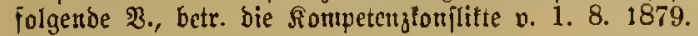

2rt. 97. Die Bedingungen, unter tveldhen öffentliche Sivil= und Dilitairbeamte megen durd lleberjefreitung ifrer

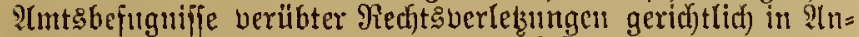
(prutd) genommen werden fönnen, bejtinmt ons (Se)[e(g. ${ }^{2}$ ) Cine vorgäugigc Benefmigung der vorgefesten Dienjtbeljöroe barf jedodi) nidft berlangt merden.

1) Bgl. bns unten folgende (3., betr. bie Sionfifte bei geridtlidjen

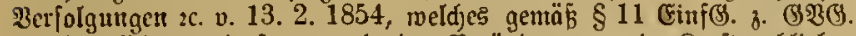
mit ben fid aus biejem ergebenden

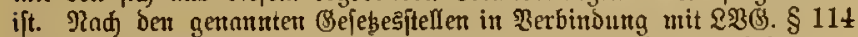
triffit bas DYG. Sie Borentideidung, „ob ber Beante fid einter lteberidreitung feiner IImt3befugnifie ober ber Unterlaifung einter ihm

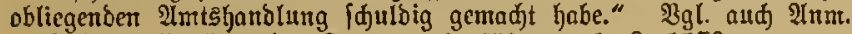
ju $\S 1$ ber $\mathfrak{3} .$, betr. bie Sompetengfonflifte, v. 1. 8. 1879.

\section{Titel VII.}

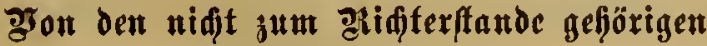 Sfaatsbeamten.}

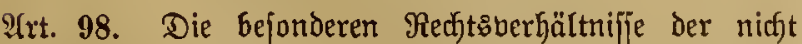

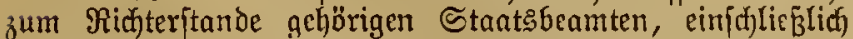
der Staatฐanwälte, folfen burch ein (Sejeb ${ }^{1}$ ) geregelt werden,

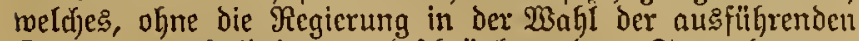
Srgane zmectwiorig zu bejfränfen, den Staatsbeamten gegen millfürtiche Entzichung bon Ümt und (sinfommen

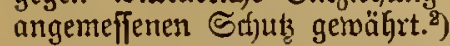

1) Ein allgemeines Etaatzbienergeię ift nodj nid)t ergangen.

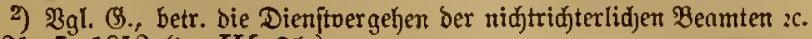
v. 21. 7. 1852 (im III. Th.)
Titel VIII.

\section{รुon den รituatyen.}

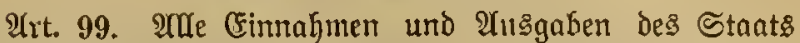

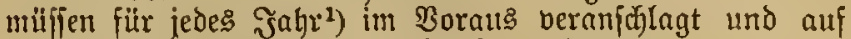
Den Staatzhaußghalts= (5tat gebracht werden.

Setzterer wiro jührlich Durch ein Bejeks jeitgeitellt.

1) ๖. G. Ctuts̄jahr, meldes mit bent 1. Tpril beginnt uno nit bem 31. शär; endet (G. v. 29. 6. 1876, (豸ङ. 177).

2rt. 100. Steuern und Mbanben für die Staaţfaffe

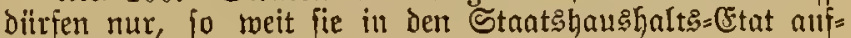
genommen ober iuret) bejondere (Sejebe angeorbnet find, er= hoben rerden.

2rt. 101. Эn Betreff der Steuern tönnen Beborzugungen nidjt eingeiübrt werdell.

Die beitehende Steuergefetgebung wird einer Revifion unterworfen und dabei jede Bevorzugung abgejdafft.

2rt. 102. Befüfren fönnen Staats= oder Sommunal= beamte nut auf Brund bes Bsejebes erheben.

2(rt. 103. Dic Ilufuahme bon IItuleiben für die Stants= fajle Findet nur allf (Sirund eines Bsefekes ftatt. Daffelbe gilt bon der llebernalyme bor (Sarantieen zu Eajten des Staats.

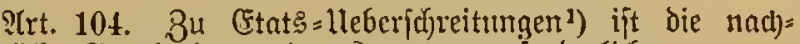
trägliche Sentehmigung Der Siammern erforderlich.

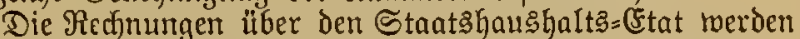

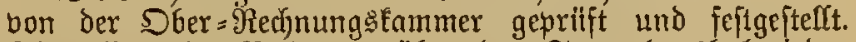
Die affgemeine Rect)unng itber Dell Staatshaushalt jeden

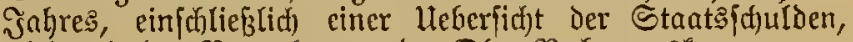

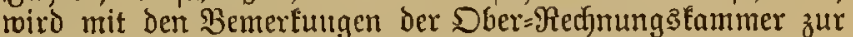
Entlaftung der Stantsiregicrung den Sammern borgelegt.

Fin bejonderes Bejets rird die (Einrichtung und bie $\mathfrak{B} e=$ fugniffe ber Dber=Redhungsfanmer beftimmen. ${ }^{2}$ )

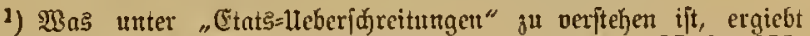

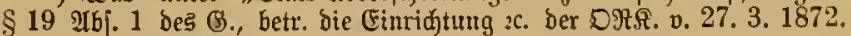
3gl. ferner §o. II $\S 1$.

2) ঠ. i. Das ebent genantte (3. o. 27. 3. 1872.

\section{Titel IX.}

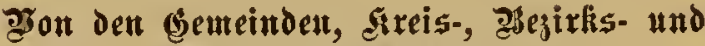 ¿̊rovinjial-כ̧erbänden.}

2(rt. 105.2) Die Vertretung und $\mathfrak{B}$ ermaltung Der (Se $=$ meinden, Sreile und Provinzen Deş \$reufijiden Etants wird burdf bejondere Beję̧e näher beftimmt.

1) Fa[jung mad) bem (अ. v. 24. 5. 1853. - E5 gelten ïberall

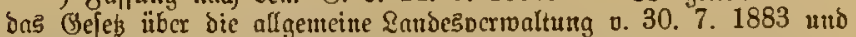

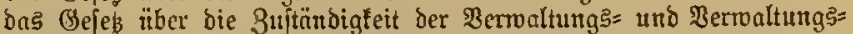
geriđtsbehörocn v. 1.8. 1883, beide unten folgent.

Bergleide icruer für

A. bie Gemeinden aufer צrag. Lanoredt Th. II. Tit. 8, 2b= (千)uitt 2:

a) ๔tD. für bie 6 (jebt 7) öjtlid)en ßrovingen v. 30.5, 1853 (\$S. 261);

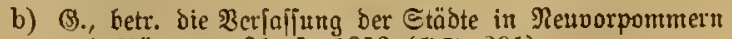

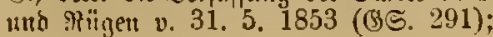


c) StD. für die \$rovim פgeffalen vom 19, 3. 1856 (BS. 237);

d) SOD. Fïr bie झroving Iieftfalen v. 19. 3. 1856 (अฐ. 265);

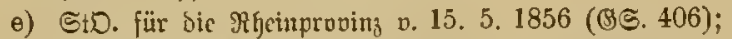

f) B., betr. Die Gemeindeverfaifung in ber Rheimprovim v. 15.5. 1856 (GS. 435 , als Ergänzutrg zur Gemeinie= Dronung v. $23,7.1815$, (Gङ. 523);

g) Grmeinbenerfaijungsgefes für die Ctobt franliurt a. \$D. v. 25. 3. 1867 (ङङऽ. 401);

h) GemD. Für die Stadt= und Sandgemeinom Rurheifens

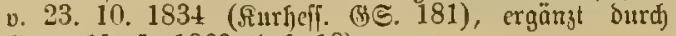
(3. จ. 15. 5. 1863 ( §af. 18);

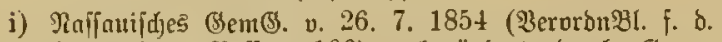

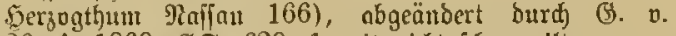
26. 4. 1869, GS. 629 , poneit utidt fajon gilt

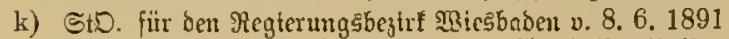

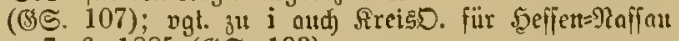
v. 7. 6. 1885 (హ) 193);

1) ๔เD. fiir bie \$rovint Sdylesิwig=5olftein v. 14. 4. 1869

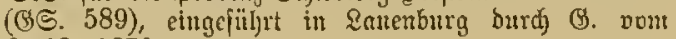
6. 12. 1870 ;

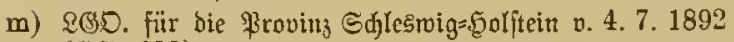
(अङ. 155);

n) revidirte StD. fïr die \$rovin Samnower v. 24,6. 1858 (5ann. (अङ. 141);

o) Бุatน. \&G8. v. 28. 4. 1859 (5aut. (5). 393 น. 409);

p) SGD. für die 7 öftliden ßroninzen vom 3. 7. 1891 (अङ. 233);

B. Die Rreife:

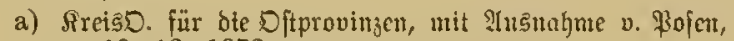
v. $\frac{13.12 .1872}{19.3 .1881}$ (BS. 1881. 181);

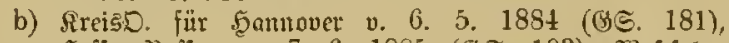
Selfen=?hafinan v. 7. 6. 1885 (GS. 193), Weftalen vom 31. 7. 1886 (SS. 217), Mhetuprovins pom

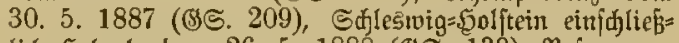
[idf) Selgoland v. 26. 5. 1888 (\$S. 139), ßojen vom 20. 12. 1828 (BS. 1829. 3.) แ⿰㇒⿻ (G. v. 19. 5. 1889 (बঙ. 108);

c) Sohenzollernfdje Intes= und Randesoronung voun 2.4. 1873 (अङ. 145).

C. bie \$ropinzen:

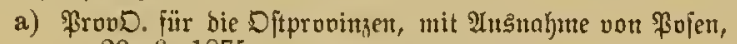
v. $\frac{29.6 .1875}{22.3 .1881}$ (ㄷ. 1881, 233);

b) ஒrovD. Für 5annoder vom 7. 5. 1884 (\$ङ 242), Sefien=Rafiau v. 8.6. 1885 (BS. 246), Weftfalen v. 1. 8. 1886 (Bङ. 255), Mheinprovin v. 8.6. 1887

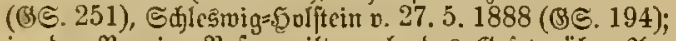

c) in ber \$roving \$ofer gilt nody bas beies ïber $\mathfrak{U}_{\mathfrak{n}}=$

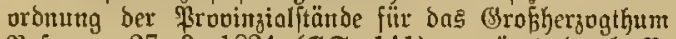
\$ojen v. 27. 3. 1824 (@S. 141), ergänt burd $\mathfrak{Z}$. v. 15. 12. 1830 (ఆङ. 1832. 9.), (5. v. 19. 5. 1889

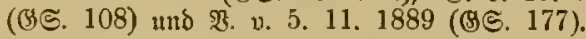

\section{Arrgemeine Beft immungen.}

Itrt. 106. Befeçe und Berordungen find berbindtid, ment fie in ber boun Bejetse borgejdriebenen Form befaunt gemactit worden find. ${ }^{\mathrm{I}}$ )

Die ßrüfung Der Rechtşgültigfeit geförig verfünoeter Nöniglidjer Berordnungen fteht niç)t den Beljödden, fondern mir den Somment zu.

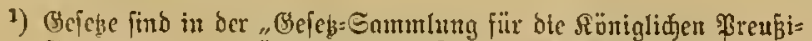

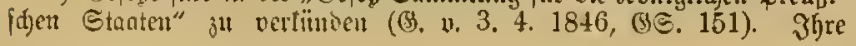

verbinoltdje Araft eriangen diefelben, menn bafür im (Befche ein anderer Beitpunft nidjt vorgefdrieben ift, mit bem 14. Tage nadj bem Tlblauf besjenigen Tages, an weldem bas betreffento etiid ber Wefes= Sammlung in Berlin ausgegeben morben ift (\$. v. 16. 2. $187 t$

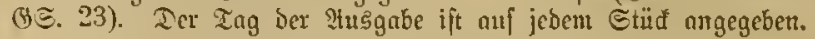

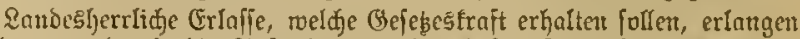

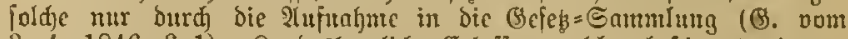
3. 4. 1846, § 1). Sanbesherrlidje Erlafie, meldje beftimmte intere

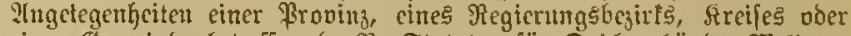
citter Bemeinde betreffen (o. B. Statuten für Deiductbände, Neliora=

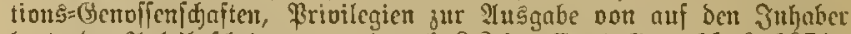
luutentor 2Inleilejdeine - vgl. aud $\$ 2$ bes (Enteig(S. v. 11.6. 187t),

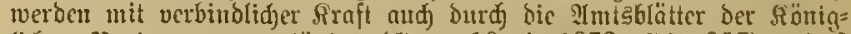
lidjen Regierunger verfiunbet (ఆ. v. 10. 4. 1872, BS. 357). Daß

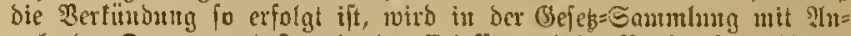

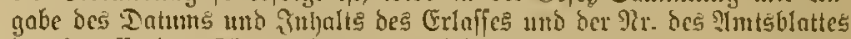
ber betreffenten §önigl. Regierung jedeŝmal mitgetheilt.

9rt. 107. Die Berfajiung fonn anf bem ordentlidjen Mrege der Bejetzgebung abgeändert merden, mobei in jeder Sinumer bie gemöhnlidye abjolute Stimmenmelyrheit bei zoei Ptbitimmungen, zwijhen tweid)en eir Beitranm bon ventgitens 21 Tagen liegen muś, genügt.

Art. 108. Die Mitglieder dex beiden Rnmmern und

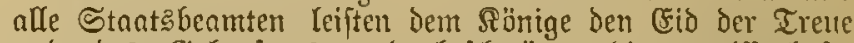
und bes Gehorjams tmo bejdjwören die gerviffenljafte Beobadytung der Berfaffung.

Cine Bereidigung des 5eere: nuf die Berfajjung findet midjt ftatt.

Trt. 109. Die beftehenden Steuem und ?tbgaben toerden forterljoben, und alle Bejtimunungen Der bejtehenden Bejeks= biid)er, einzelnen Bieletze und Berorommgen, weldye der gegenmärtigen Serfaffung nicht jumider[alfen, bleiben in Srajt, bis fie burth ein Gejets abgeänbert reerden.

?Yrt. 110. S(ne durch die beftehenden Befetze nugcordneten Beljörocn bleiben bis zur ?tusfilfrumg ber fie betreffenden

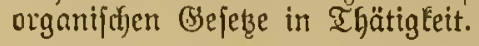

2ht. 111. Fitr den Fall cines Rrieges oder श्Ftruhrs Eönnen bei bringender Gefafr für bie öffentficje Sidjerheit bie भit. 5, 6, 7, 27, 28, 29, 30 uud 36 der ßexjafjungs. lirfunde zeit= und biftriftstveife nußzer sirajt gejekst roerden. Das ఇähere beftimmt das (Sejet..1)

1) (3. Z̈ber ben Belagcrungsuftano v. 4. 6. 1851 (ఆङ. 451 ),

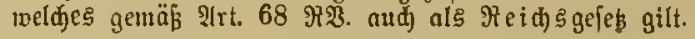

\section{Uebergangsbeft immungen.}

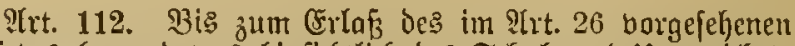

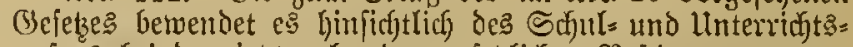
wejens bei ben jekzt geltenden gejekslichen Bejtimmungen.

2trt. 113. Bor Dex exfolgten Rebifion des Strafrectits

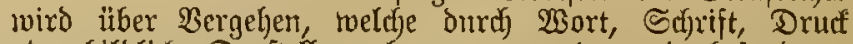
oder bildliche Darjtellung begnngen werden, ein befonderes (B) ejekz ergehen. ${ }^{1}$ )

\section{1) Inm. 3u Irt. 27.}

21rt. 114. Inigełoben ठurd) ஒ. v. 14. 4. 1856.

2(rt. 115. Bis jum Ertaffe bes im Art. 72 borgefebenen Wahlgcjetzes bfeibt die Beroromung bom 30. Mai 1849,

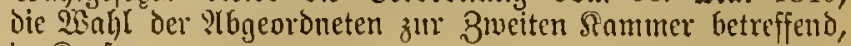
in Sraft. 
Irt. 116. Die now bejtehenden beiden oberjten (Geridfts: Göje follen z"l einem Einzigen bereinigt reerben. Die Drganifation expolgt bum ein bejonderes (Sefeb. ${ }^{1}$ )

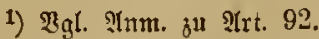

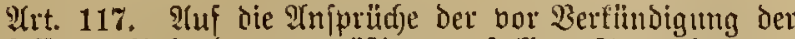

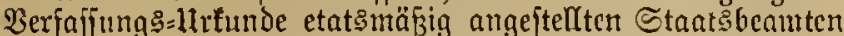
foll im Etantsdienergefets bcjondere Pitffidjt genommen werden.

Irt. 118. Sollten Durd) die fïr Den Dentfden $\mathfrak{B} u n d e s=$ itaat auf (Srund bes Gutmurfs vom 26. Mai 1849 feit =

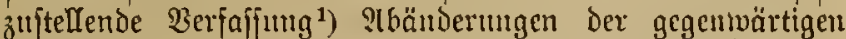
Berfajlung nötbig twerden, fo mird ber §önig diejclben an= ordnen und Dieje ?tnordulungen Den Sammern bei ifrer nädjiten פerjammlung mittheilen.

Die Rammetn werden Dann Bejdjluk Darüber fajien, ob bie borläufig augearbneten \&bänberungen mit ber $\mathfrak{B}$ erfaffung des Dcutidien Bundesffarts in llebcremitinmmug iteheu.

1) Diefe mit den fönigrełden Sannover und Sadjen vereitborte शerfafjung ift nidjt fu Etande gefoumen.

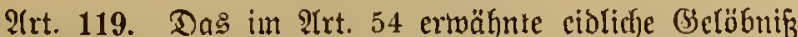
des Rönigs, fowie bie borgefdriebene Bereidigung ber beiden Ranmern und aller Staatşbeamten, exfolgen jogleid nad Der auf beur $\mathfrak{B e g e ~ D e r ~ B e j e t g g c b u n g ~ v o l l e n d e t e n ~ g e g e n w a ̈ r t i g e n ~}$ Revifition biefer Berfaffung. (Plrt. 62 und 108.)

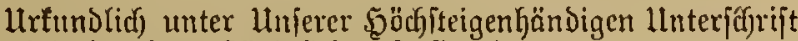
und beigedruftem $\Re$ önigliçen Infiegel.

Sbegeben Eljarlottenburg, den 31. Januar 1850.

\section{(L. S.) Friebrid Milfelw1.}

Braf v. Brandenburg. v. Rabenberg. v. Manteuffel.

b. Strotha. b. b. Sebdt. b. Rabe. Simons. b. Strleinib.

\section{Rlferfbödffer Grfaß vom 4. İamuar 1882.}

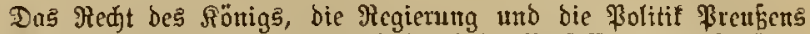
mnđ Eigenen Ermefien ju leiten, ift burd bie Berfaffung eingeldjränt, abcr nidjt aufgehoben. Die Regictungsalte bes Ronigs beourfen ber

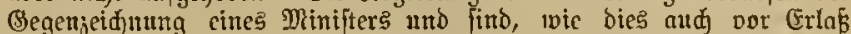
ber \$erfaffung geidjah, von ben Miniftern bes Rönigs ju vertreten,

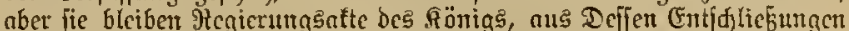
fie herporgehen und ber Seine rsiflensmeinturg burdy fie verfaifungs= mäBig ausbrüct. (Fs ift beshalb nidit suläfrig uno fïhrt sur ßer= bunfclung ber verfoffungsmäßigen fönigšed)te, wenn beren 2lusübung fo bargeftedt wirb, alg ob fic von bent bafür verantwortlidjen jedes= ualigen Miniftern, unb nidgt vou bent Rönige Eclbft ausgistge. Die

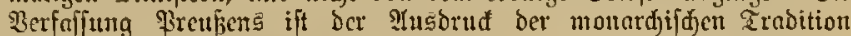
Dicjes Sandes, befien Entwidfelung auf ben lebendiget Bejichunget

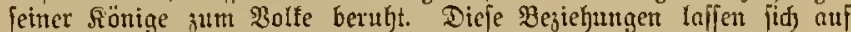

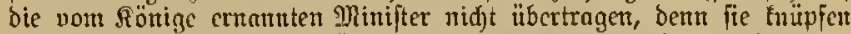

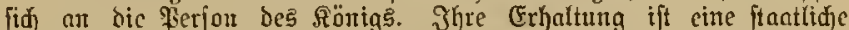

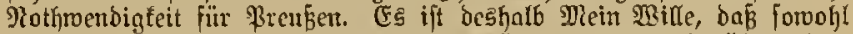

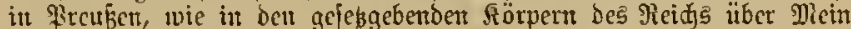

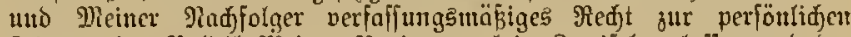
Reitutg ber \$olitif Peinet Pegicrung fein 3weifcl gelafien uno ber

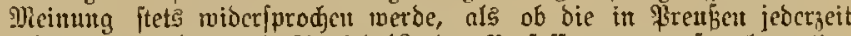

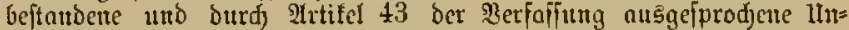
verlestidufeit ber ßerjon bes Rönigs ober bie Nothwendigfeit verant= twortlidjer Geacuseidjnung Meinen Reaicrungsnften bie SRatur felbft=

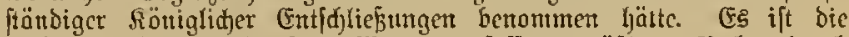
Stujgabe Meiner Niurifter, Mcinc veriajung

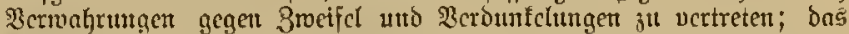

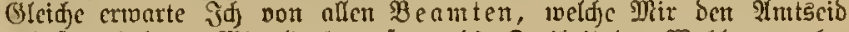
geteiftet haben. Mlir liegt es fern, die Freiheit ber WBahlen ou becinträdtigen, nber fïr biejenigen Beanten, wcldje mit ber 2fusführung Meiner Ricaierungsafte betraut find und beshalb ihres Dienjtes tad bem Disjiplinargejege enthobent werbct fönnen, erftredt fid bie burd) ben Dienjteib bcjdyoorene PFlidt auf Bertretung ber Politil Dieiner

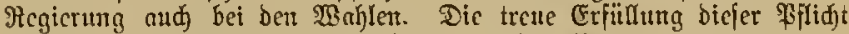
werbe id mit Danf crfenten und von allen Beamten criourten,

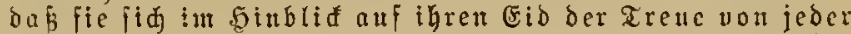
Ifgitation gegen Weine Regierung aud bei ben $\mathbb{B}$ ablen fermbalten. gę. Wilkelm.

ggç. Fïrft von $\mathfrak{Z} i \mathfrak{m a r d}$.
Un bas Stantsిmlnifterium

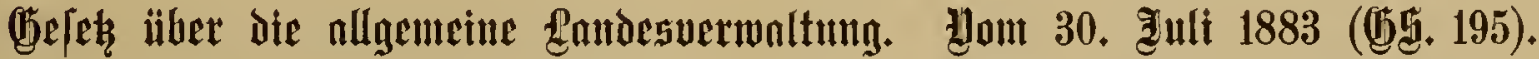

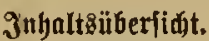
I. Titel. (Srundagen ber Drganifation. $\$ \S 1-7$
II. "Berronltungsbejörber.
Brovimalalberjöbert.
Bejirtsbejöroen. .
Sreisbehördet
Behörben fïr Den Stadtfrets Berlin
Steflumg ber Beförden
III. " פerfatren.
IIfgemeine \$orføriften
Bervaltungsftreitoerfahrent. $\cdot$.

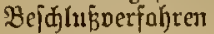
IV. "Redtsmittel gegen polizeilidic Berfügungen ......
V. "Brongsbefugniffe. . . .
VI. " Boltgetveroromugsted)t...
VII. " mungen

\section{Tittel. Grundagen der Qrganilation.}

\$1. Dic Berwaltungseintheilung des Stants̊gebiets

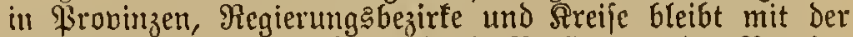
Manizgabe befteljen, daf3 die Stadt Berlin aus Der \$rovinz Branbenburg ausff(t)ciDet und einen Berroaltungąbezirf füt fich) bildet.

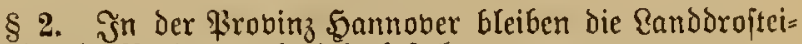
bezirfe als Regierungsbezirke beftehen.

Die ?tbänderung der Freis: und Imtseintheilung Der ßrovinz Sannober erfolgt mittelft bejonderen (Befekes. ${ }^{1}$ )

1) Bgl. Freis̄o. v. 6. 5.1884 (ఆS. 181).

§ 3. Die Befcjäite der allgemeinen Randesvermaltung werben, jotweit fic nidyt anderen $\mathfrak{B e f j o ̈ r d e n ~ H ̈ b e r w i e j e u ~ f i n d , ~}$ unter Sberleitung Der Minifter, in ben \$robinzen bon Den Dberpräfibenten, in Den Regierungşbejirfen bon ben Re= 


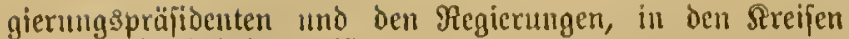
von den Sendräthen gefül)rt.

Dic Dherpräfibenten, Dic Regierungsprïfidenten und bic

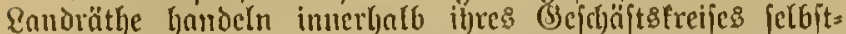
ftindig unter volfer perjünliclyer Berantwoutlichteit, bor=

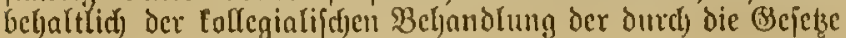
bezcidyneten slugelegent)eiten.

§4. Bur Mitwirtung bei den (Bejebäften ber afl= gemeinen Eandesnerwaltung nard) nälerer Boridjrift der

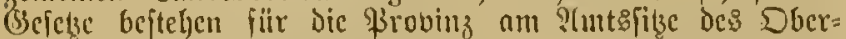
prïfidenten der Frovinzialtally, iitr ben Negierumgsbezirt

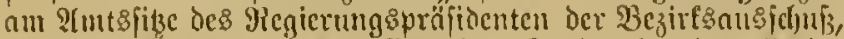
fiir den Streis an ?tmt!fike des Rnndratgs der streis=

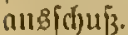

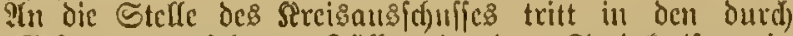
dic Befetze vorgefelienen Fälfen in den Stabtfreifen, in

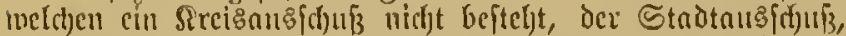
in ben cinem Enubfreife angeljürigen Stäbten mit utelye nls 10000 Cinwohnern Der Magijtrat (follegialifdye Bemeinbe= voritand).

Эn Stndtgemeinden, in weldyen ber Bifrgermeifter allein den Bemeindevorftand bildet, treten fïr die ili dem zmeiten शtbjake bezeichneten fönfle an bie Stefle des Magiftrats der Bitrgeruteifter mo bie Eeigeoroneten als Sollegimm.

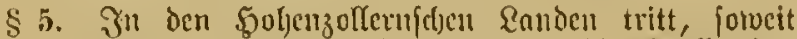
nidht dic (B)efese Anderes beftimmen, an dic Stelle des

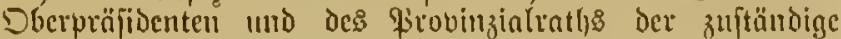

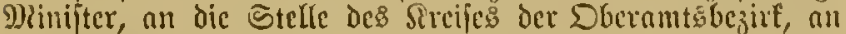
dic Stefle des Randrat)gి der Dbernmtmam, an die Etelle

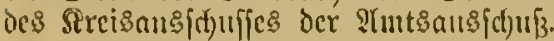

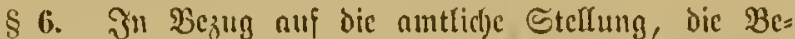

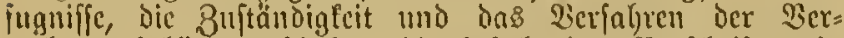
waltumgsbejorben bleiben dic befteljenden Gorforiften in

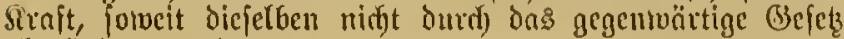
abgen̈udert tuerien.

§ 7. Die Berwaltungs gerichtsoarfeit ${ }^{1}$ ) (Entjd)cioung im

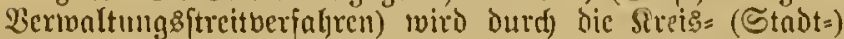

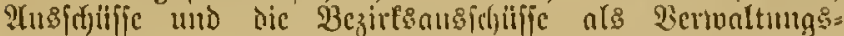
gerichte, fotvie durch dons in 2ictlin fïr ben ganzen llurfang ber Monardhic bejtehende Dberbermaltungsggeridjt ansgeübt. Dic Entfdreidungen ergehen unbejdyadet aller priuntredytlichen 2icrlıältnifje.

Dic fachliche Zujtändigteit dicjer Behürden zแr Ent=

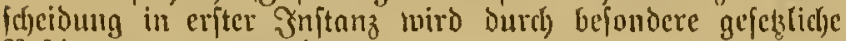
Beftuminungen geregelt.

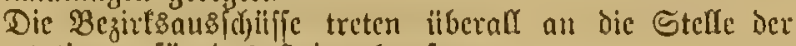
Deputationen fït das Seimatlymejen.

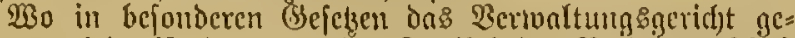

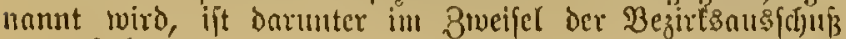
3" beriftelyen.

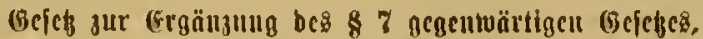 voul 2\%. 4. 1885 ((35. 127):}

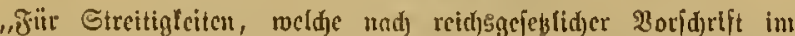

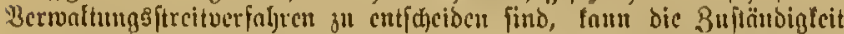

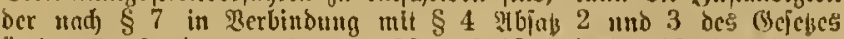
ii. b. nโfg. Snubespernoflung v. 30 . Juli 1883 (बS. 195) bezcidjueten Behörben, fowcit bleje(be nidft nubcrueit gefeblidi) feftfteht, fowic ber Эuftangenjug, Durd) Röntglid)e Berotbum!g beftimut verben."

1) 3nt Begenfap sur orbentlld)en fteitigert (Bertd)tsbarfeit in

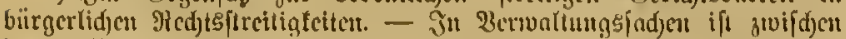

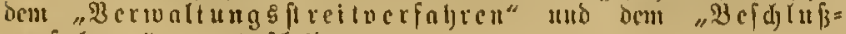
verfalyen" gu unterfociben.

\section{Citel. gormaltuugsbeförden.}

If rovingialbegäroen.

\section{Duerpräfìdent.}

§ ४. In der Spibe der Berwaltung Der \$3robiuz (teht ber Sberpräfident. Demfelben wiro cin Decrpräfioialratl)

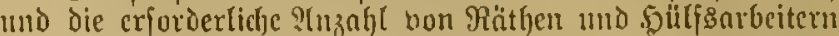
beigegeben, veld)e die (Bejeljäjte mad) feinen ?tumeifungen bearbeiten. S(uc) ift Der Dberpräijoent beiugt, die g)?it=

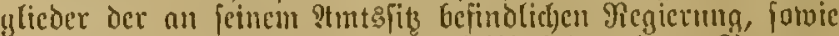
bic dem Regierumgspräfidenten dajelbft beigegebenen 2jenuten (\$ 19 ? Yb\{ak 1) zur Bearbeitung ber iljm iibertragenen (B)efdäfte heranzmgicl)en.

\$ 9. Dic Stellvertietung des. Sberpräfioenten in Fällen Der "Behinderung erfolgt, poweit fie nidf)t fïr einzelne (Se=

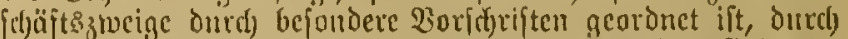
den Docipriffidinlrath. Dic zuftändigen 9)inifter find bes fugt, in bejonderen Fällen sinc andere Steffoettretning an= zuoronen.

\section{Frovillzialrath).}

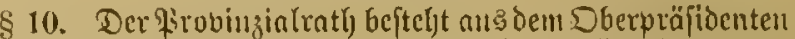

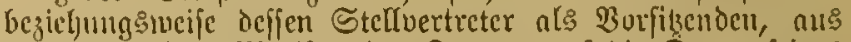
cinem von dem פiutifter bes Jumern auf die Dauer feines Sauptantes am Siłz Des Dberpräfidenten ernaunten ljöłcren Berwaltumģbenmten beziefungsiveife deffeu Stellvertreter

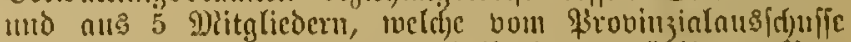

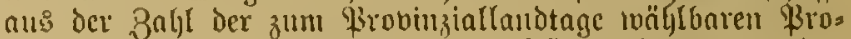
binzinlangelyürigen gemählt recoen. Fïr bie lezteten werben

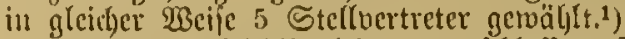

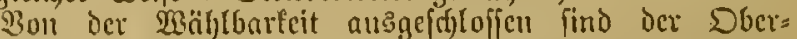

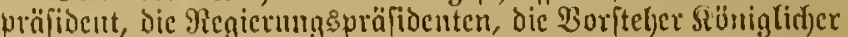
\$olizeibeljöròen, dic Eandräthe und die Beamten des 9ro= vinzialverbandes.

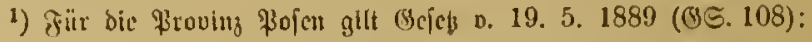

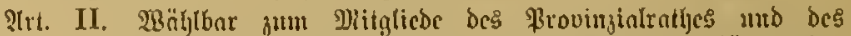

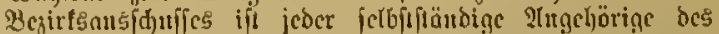

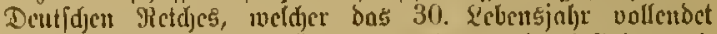

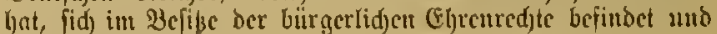

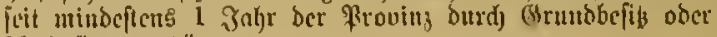
29 otjuilis angeljört.

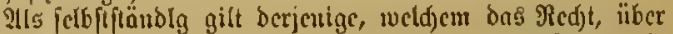

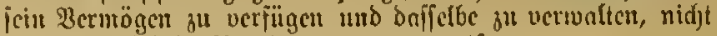

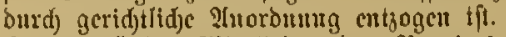

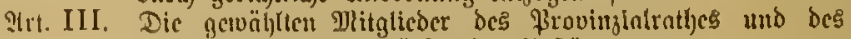

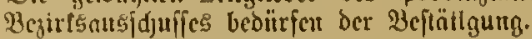

Dic Bcitütigung fleljt zu:

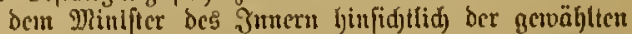
Ditglieder bes qprovinziatrntbes und beren Stell= verlteter:

beur Dberpräfibenten hlnfidfild ber gewählten Mlit=

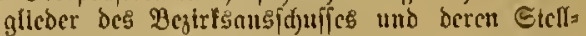
verticter.

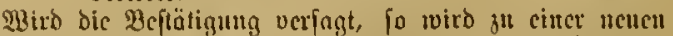

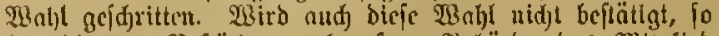

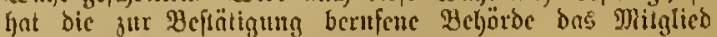
biziw. Den Eteflnertreter jut ernemien.

Doffetbe finbet fintt, went bic Bormalyme ber 28 aljt verwolgert merben jollte.

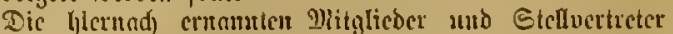

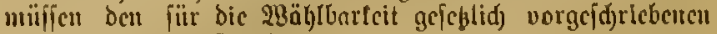
Erfordernifien entipredjen.

\$11. Die $\mathfrak{B a b l}$ der Mitglicoer des Firovinzialratlgs uni deten Stefluertreter crifulgt auf 6 Jabre. 
Yede wahl berliert ifre wirfung mit dem शujhören

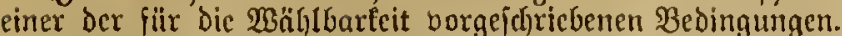

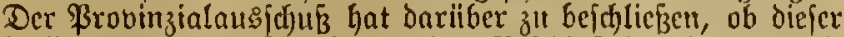
Fall cingetreten ift. Gegen den Befdlula des Frobingial=

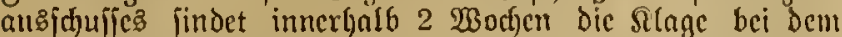
Dberbertwaltungsgeridjte itatt. Die Slage fteht auti) bem Borfikenden des \$rovinzialraths zu. Diejelbe hat Eeine auff(hicbende Wirfung; jedod) büricn bis jur (5ntfdeidung

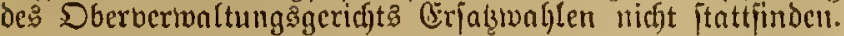

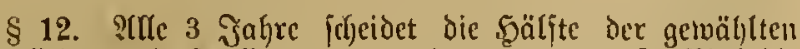
Mitglicber und Stellvertreter, und z war dns erfte Mal bic

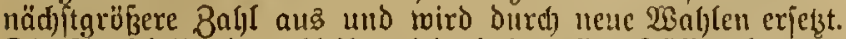

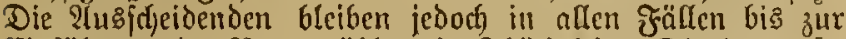

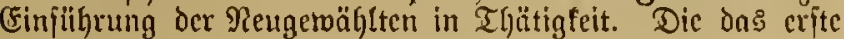

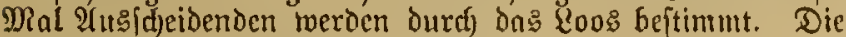
2uEsf(t)eidenden find inieder mäblbar.

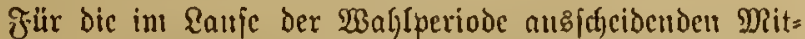
glieder und Stelfbertreter haben Erfaţwahlen ftattzufinden. Die Erjakmänner blciben mur bis zum Ende desjenigen

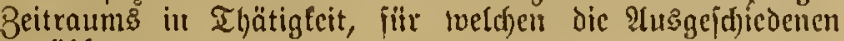
getwählt traren.

§ 13. Die Dauer Der Waljlpcriode faull durd) bas \$rovingial(ftatut audf) anderş bejtimmt tocrden.

§ 14. Die gewählten Mitglicder und ftellvertretenden MRitglieder des \$rovinzinlratlg merden bon bem Sber= präfìdenten bercioigt und in ifje Stellen cingefiilgrt.

Sie fönnen ats Brïnden, tweldye die Entiernung eines

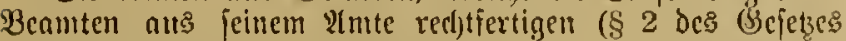

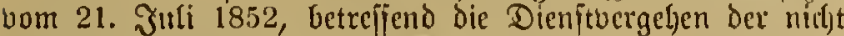
richterliçen Beamten, BS. 465), im $\mathfrak{B c g e}$ bes Dişziplinar= berjabrens iljrer Stellen enthoben werden.

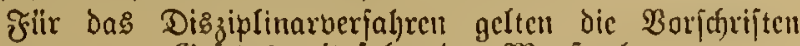
des genannten (Bejeses mit folgenden Manjzgaben:

Die Einleitung Des Berjabrens, jomic dic Erncnnung

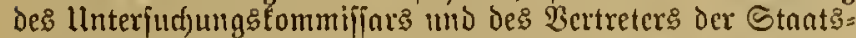
anwaltidnit exjolgt ourd bci: Minifter ocs Jnnern.

Disziplinargericht ift das \$lemmu des Dberberwaltungs: gerictits.

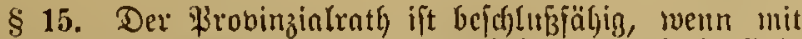

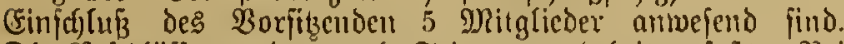

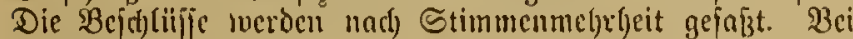
Stimmenglcid)heit giebt bic Stimme des $\mathfrak{B}$ orfikenden ben

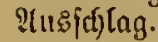

\section{Bencralfommiñonen.}

\$ 16. Dic Beneralfommifficn fïr die \$irovinzen ßommern und \$ojen zll Stargard in \$sommern bis d aufgeljoben.

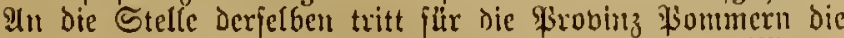
fïr dic \$robinz Brandenburg beftehende (Bencralfommiffion. ${ }^{1}$ )

Fiir die \$rovirjen Dits uno Beitprenfisen und \$ojen mirb eine gemeinjame (Schernlfommiffion gebildet. ${ }^{2}$ ) Die Seneralfommiffion für die \$rovinz Sonnover ${ }^{3}$ ) fungi, t

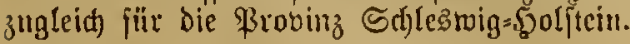

1) Sik in Frantīurt a. D.

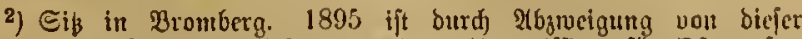
Beneralfommiffion cine bejondere Bencralfonmifition für Ditpreuken in Fiörigsberg $i$. Pr. erridtet.

3) Sib in .5annoder.
Bezirtabchörden.

\section{Regierungåpräftocut und Bejirfäregierımg.}

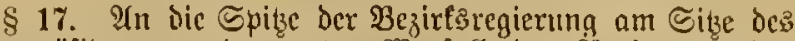

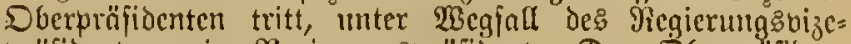
pröfidenten, ein Regierungspräfioent. Der Ḋberpräfident ijt fortan nicht melgr Sräfident diefer Regierung.

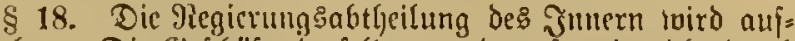
yehoben. Die Befejäfte derfelben merden, jomeit nicht burch dos gegentwärtige (Befeł abrweid)ende Bejtimmungen getroffen

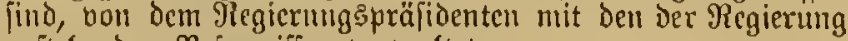
zufteljenden $\mathfrak{B}$ efugniffen berwaltet.

§ 19. Dem Regierıngspräfidenten wiro für dic ifmu periöntich iibertragenen 2(ngelegenlyeiten cil Dberregierumgs:

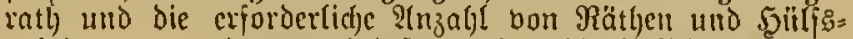
arbeitern, bon benen mindeftens einer bie Befälyigung zuแ

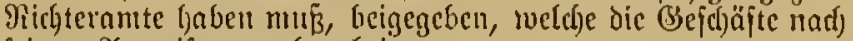
feinen Iltweifungen bearbeitell.

Diefe Beamten fömnen zuglcidh bei der Megierung bes fchäjtigt werden und nel)men an Den \$lenarberathungen

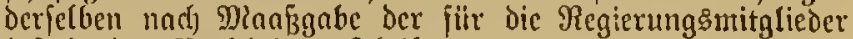
bejteljenden $\mathfrak{B}$ oridjrijten Theil.

Die Mitglieder Der Regierung tönnen bon bem $\Re=$

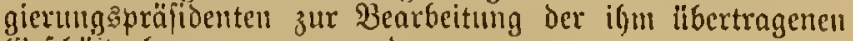
(Sej(t)äjte herangezogen merden.

§ 20. Dic Stcllocttetung oç Regierungapräfíbcuten in đällen ber Beffinderung erfolgt durd) Den ifm be gegebenen Dberregierungstath unt, tweml aud diejer be= hindert ift, durch cinen Dberregierunģrath oer $\mathfrak{B e z}$ irfe: regierung. Die zujtöndigen Mlinipter find bejugt, in be= jonderen fällen cinc andere Stelfuertretıng anzuoronen.

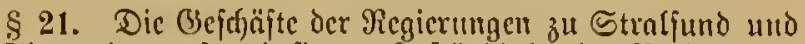
zu Eigmaringen, forweit fie zur Bujtändigfeit ber Regierungsి= abtheilutgen des Jnmern getören, werden nach 9lanß̧gabe beả \& 18 voil den Yiegierungspräfidenten vermaltet. Die Mitglieder Der Regierung bearbeiten dieje (Sejchn̈jte unach ben ŝntweijumgen ocs quäfidenten.

Die Stellvertretung des \$räfidenten in Fällen ber Behinderung erfolgt Duref ein bon ben zujtändigen Miniftern bealitragte Mitglicd ber Regierung.

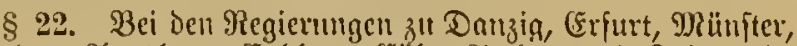

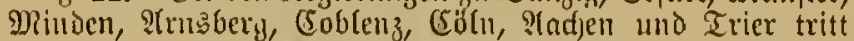

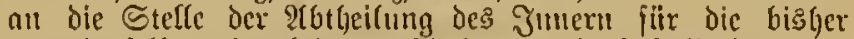
bou derjelben bearbeiteten Sirdjen= und Schulfachen cme 2tbtheilung für Sirtfen= mo ऽ(bulwejen.

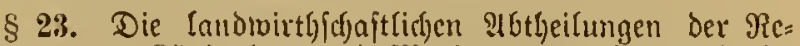
gierungen zal Rönigsberg und Marienmerder, fowie dic bei

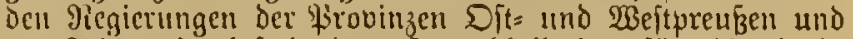
zll Srilesmig beftefenden Epruchfollegien fïr die land=

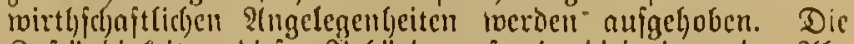
Buftänbigfeiten biejer 3efjörden, fomic dicjenigen der $2[\mathfrak{b}=$ theilungen des Ynneru der Regierungen zu Bumbinnen,

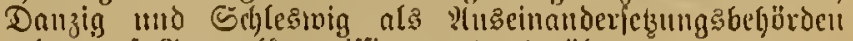
gelsell allf (Seneralfonmififionen $(\$ 16)$ itber.

Bei ber Regiermng z"Wiesbaden tritt an die Stelle

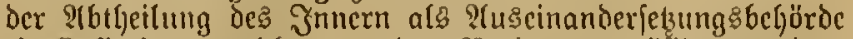
ein Rollegium, weldbes nus dcm Regierung $3 p$ räfidenten, dem fill inn hierz" beftimmten Stellvertreter und mindeftens 2 Mitgliebern bejteft, bon benen das einc bie Befäljigung zum 
Hidhteramte bejiken und der Innomirthjajajtiden (Bewerbs: lehre fundig fein, das andere die Befäljigung zum Defononic= fommiffarius baben atuß. Son diefen Sollegium find nut die Dbliegenfeiten Der Regierung Ginfidftlict) ber (Sïter= conjolidationen wafrzunebuen.

\$ 24. Der Regierungspräjident ift bejugt, Befdjliifie Der Regierung oder ciner 2lbtheilurg herfelben, mit meldsen er nidht cinverftanden ift, anger ßraft zu fetsen und, fofern ex ben $\mathfrak{A}$ ufenthalt in ber Sadje fïr nad)tbeilig ernditet, nuf peine Berantwortung nrzuoronen, baß̧ nadf feimer P(nficft verfabren werde. 2undernfalls ift löhere (Entfdjeiting cin= ätholet.

Xud if Der Regierungsిpräfident befugt, in Den jur Buftünoigleit ber Regierung geljörigen Rugelegenbeiten an Etelle bes Rollegiums nnter perfönlicher Serantmortlid)feit Berfügungen zu treffen, wenn er die Sadje fult eilbedintitig oder, in Jnfle jeiner Urnwefenheit an Drt und Stelle, cine fofortige Ânoronung fiir erforderlich eradjtet.

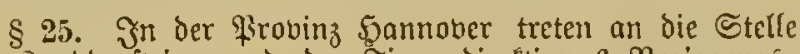
ber Ranborojteien und ber J̈innnzoireltion 6 Regierung $5=$ präfidenten uno Regierungen, weldje, gleich bem Dber= präfidenten, die Berjvaltung mit ien Befugnifjen und nach Den Borjdriften füluen, weldbe dofür in Den übrigen \$iro= binzen gelten, beziehungstweife in Dem gegentoürtigen Befeßs gegeben find.

Belde Der borbezeidjeten Regierungen nadj bem Sor= bild ber Regierung zu Stralfund zu organifiren find, bleibt Söniglider 'Q⿻roronung vorbefjalten.1)

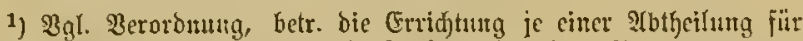
birefte Eteuerm, Doutänen uno Jorjtet bei ben Regierungen ju Stralfuno unb Osmabrüd, und einct Ibthcilung für birefte Stemern

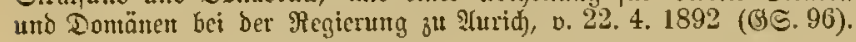

§ 26. Die Zuftändigfeiten Der Ronfiftorialbeljörden in ber Srovinz 5nmover in Betreff Des Sdjulmefens, jowie

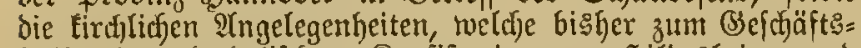
treife ber fatholijeden Ronfiftorien 3u Sildesheim mo

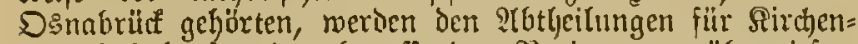
und Shulwejen der betreffenden liegierungen ïberwiejen. gehoben.

Die genannten fatgolifuen Sonfiftorien merden auf=

\$ 27. Den ebangelifden Sonfiftoriatbelörden in Der

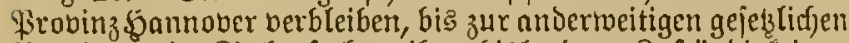

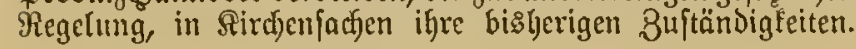

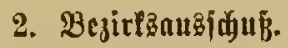

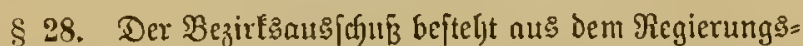
präjiocrten aโล $\mathfrak{B}$ orfitzenden แnd aแs 6 Mitgliedern.

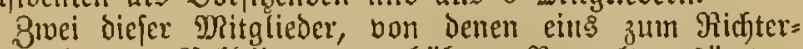

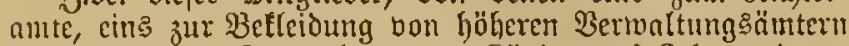

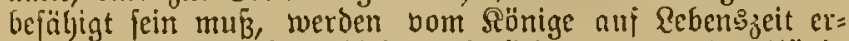
mannt. QfuE Der Bngl Diefer Mitglieder ermennt der sënig

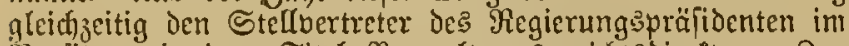

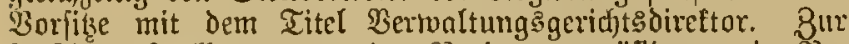
ponfigen Stelfvertretung des Fegierungspräfioenten im $2 B E=$ irksnusfduffe uno zur Stellvertretung jedes der beiden auf

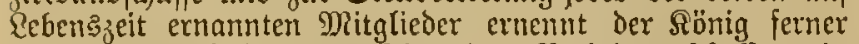

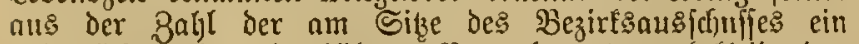
ridgterliches oder ein böheres Serwaltungsamt befleidenden Beamten einen Stellbertreter. Dic Ermennung Der Stell= bertreter exfolgt auf bie Dauer ifges Sauptamts am Size

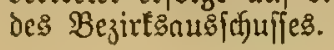

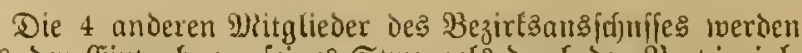
nus den (Einwohnern feines Sprenge[s burd) Den Provinzinl=

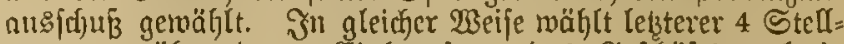

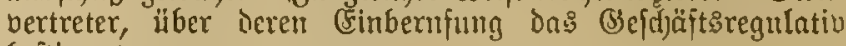
bejtinmt.

Wäblbar ift mit stusnalyme des Dherpräfidenten, Der

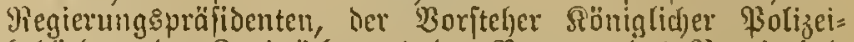

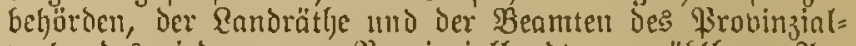

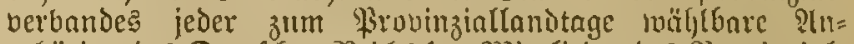

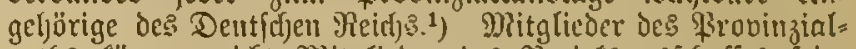

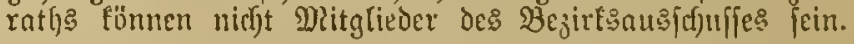

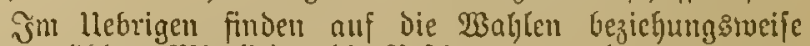
bis gerählten Mitglieder die 3 ejtimmungen der $\$ \S 11,12$ und 13 fimugemäße शnivendung.

1) Simjidtlid der Proninz Pojen vgl. Amm. 3u $\$ 10$.

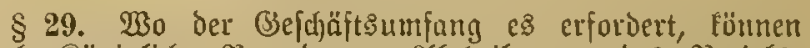

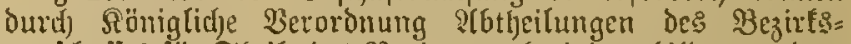
nusidjuffes fiir Theile des Regierungşbezirtes gebildet merdent.

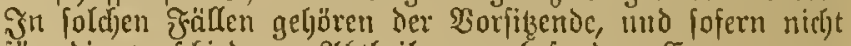
fiir die verfffiedenen :atheilungen befondere Emennungen erfolgen, die ermannten Mitglieder allen 2rbtheilungen all. Die gewählten Pitglieder und Deren Stelfuertreter miijfin fïr jede stbtheilung gefondert beftelt juerden. Jm llebrigen

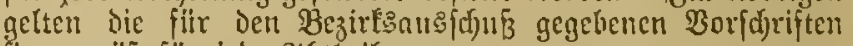
fimngemäß für jebe Abtheilung.

§30. Der Borjiz in $\mathfrak{B e z i r t : a u s f d u f f e ~ g e l j t ~ i n ~} \mathfrak{B} \varepsilon=$

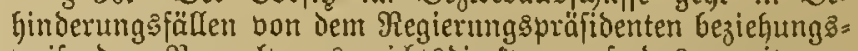
meife incm Perwaltunggigetichtsoireftor nuf bas zweite er: nannte Mitglied, joonn auf den Stefluertreter des $\mathfrak{B e r}=$ waltungsgerichtêoireftor: ïber. Der Regierungspräfitent gilt nls beljunort in allen fällen, in weldjen viber eine Bejchtwerde gegen bie Berfügung eines Regierungspräfidenten berfandelt wird.

§ 31. Den ermannten Mitgliedern darf eine Bertretung des Regierungşpräfidenten oder cine Juilfeleiftung in ben Diefem perföntich itberwiefenen (Sejejuäften nidjt aufgetragen merden. Beide nebmen an den \$lenarberathungen ber Regierung nad) Manß̧gabe Der für die Regierungsmitglieder beitefenden Borfariften Theil. Şn llebrigen ift ifnen die Jithrung eines anderen ?Tmte: nur geftattet, roem daffelbe ein richterlid)es ift oder ohne Bergittung gefiligrt wirb.

§ 32. Die getwöglten Mitglieder uno ftelfvertretenden Mitglieder rerden Durd) den Sorfitzenden vereidigt. গ[氏 Mitglieder und ftellvertretenden Mitglieder unterliegen in diefer i juer (Figenjafaft den Barfajriften des Befebes, be=

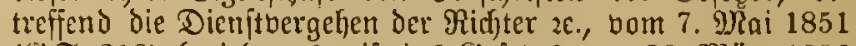

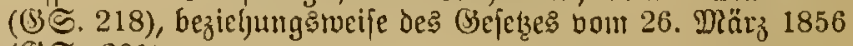
(अ5. 201).

Dişzip(inargerid)t ift Das \$(emun bes Dbervertvaltungs: geridits; der Sertreter der Stantsanwaltfdjaft wirb von dent

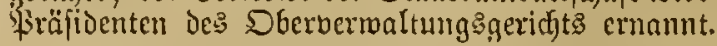

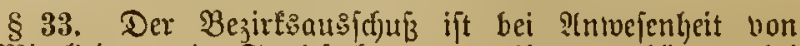
5 Plitgliedern, in Streitfadjen unter :Vrumenverbändeu bci

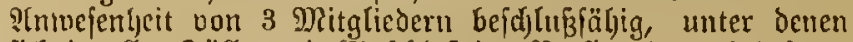

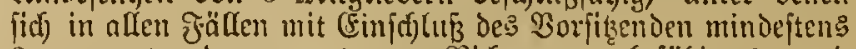
2 ermannte, Darumter 1 jum Richternmte befähigtes, mo 1 getuäbltes Mitglieo befinden mußs.

Die Bejd)liuffe werden nady Stimmenmehrbeit gefajt.

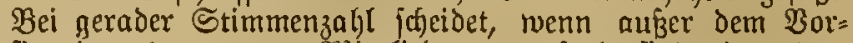
fikenden 2 ernannte Mitglieder anwejend find, daz dem 
Dienitalter nacf jüngite ermanute, ment aujer dem Bor= fibenden mur ein erranntes Mitglied antwejend ift, das Dem \&ebeng̊nlter nach jüngite gevählte Mitgliè mit Det Maaß̈gabe

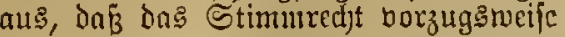

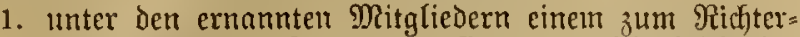
amte befägigten, fofern eร defjen zแr Şejd\}luffägigfeit bedari,

2. im llebrigen bem Beridjterftatter berbleibt.

§34. Die gerwäblten Mitglieder und beren Stell= bertreter erbalten Tagegelder uno Dicifefojten nach ien für

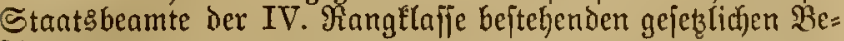
fimmungen.

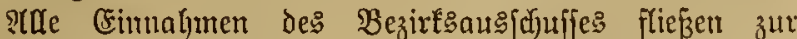
Stnatstaffe. Derfelben fallen aud alle $\mathfrak{A}$ usgaben zur \&ajt.

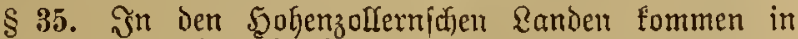

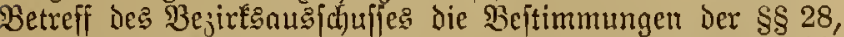
$30,32,33,3+$ mit Der Maangabe jur $\mathfrak{A n m e n d u n g , ~ D a ß ~ d i e ~}$

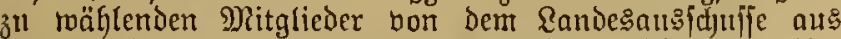
der Bahl Der zum Rommunallandtage twählbaren :In= gebörigen des Landesfommunalverbandes gemählt merien. Der Regierungspräfioent, Die Sberamtmänner und bie Beamten Des Randesfommunalverbandes find von der Wählbarfeit ausigeldjlofjen.

\section{Rreisbehörden.}

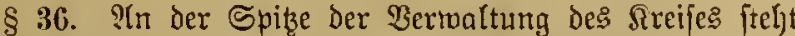

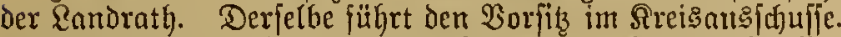

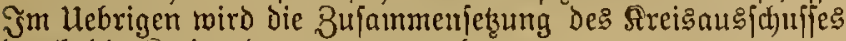
durd) bie Sreisorbmungen geregelt.

Für bie \$rodina \$ojen gillt (5. D. 19.5. 1889 (vgl. IInm. zu § 10):

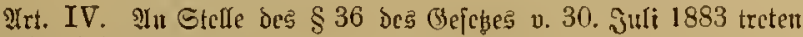
folgende Beftimmungen:

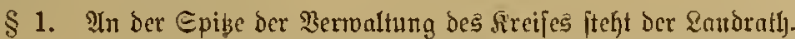

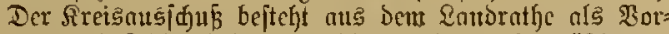

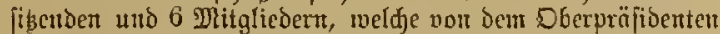
aus Der 3 afjl ber Rireisangelÿrigen entantt werben.

Die (5rinemunta eriolat ouf (3runt von \$orjalägen bes Rreistages, in welde aus ber Bahil ber fircisangehp̈rigen

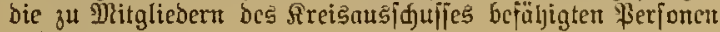
ăj

Qehnt ein $\Re$ reistag bie $\mathfrak{A}$ ufforderung Des Dberpräfidentent jur 3ervollftäntoigung biejer ßorjalage ab, jo hat ber

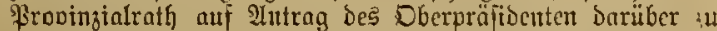

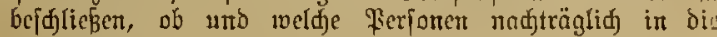
Borjdlagslifte nujzutcliment jino.

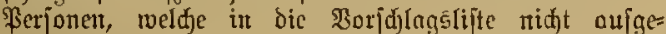
nommen fino, fönten voin Oberpräfidenten zu Mitglieberm

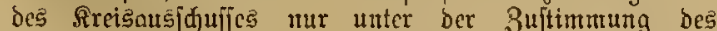
Frovingialrathes ernant werben. Regnt ber Provinzial= rath bie 3uftimusurg ab, fo foum bicjelbe auf 2lutrng bes Oberpräjibenten burd) ben Mhinifter des Jnter» ergänjt recroen.

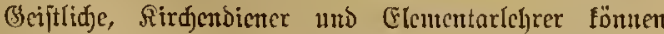

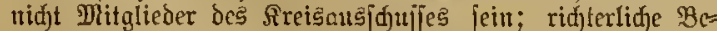
amte, зu benen jedod bie tednifden Mitglieber ber 5ande[s=,

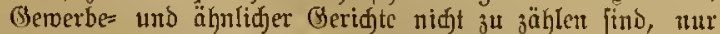
mit Brmehmigung bes vorgejçten Minijters.

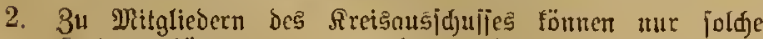
尺reisnngehörige ernannt merben, weldic

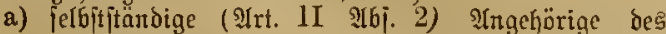
Deutiden Reides fino und bns 21. Eebentjatyr vollenoet haben,

b) fid in Befitge ber bürgerliden Ehrenzedte befinden.
Das Međt zur Mitgliebldaft gcht verlorent, fobalo cits

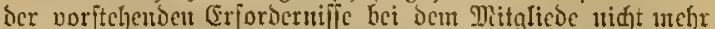
3utrifft. (E) ruljt wähtrento ber Dauter eines Sonfurfas,

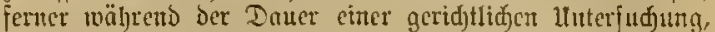

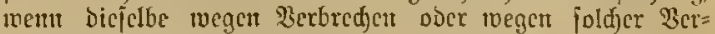

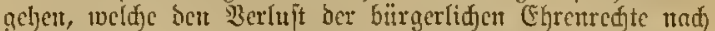

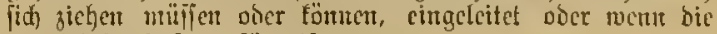
geridjtlidje Sant nerjïgt ift.

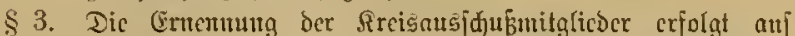

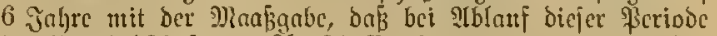

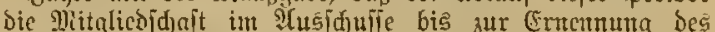

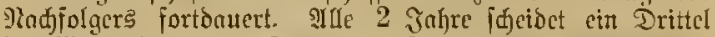
ber Mitglicoer aus. Dic Dus erite mo zrocite DRal গI

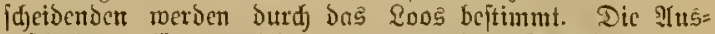

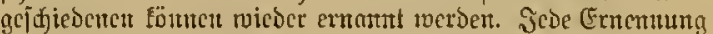

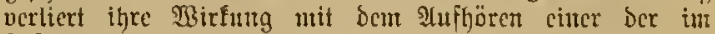

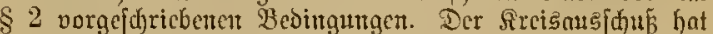

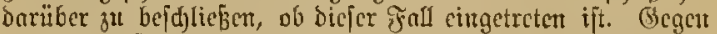

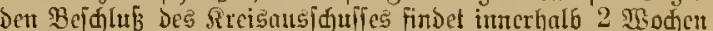

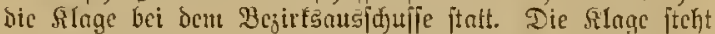

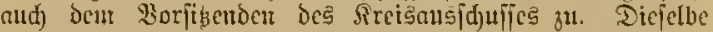

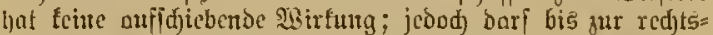

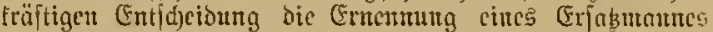

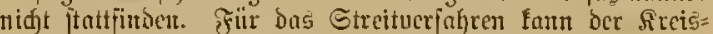

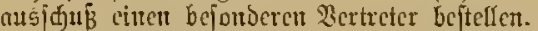

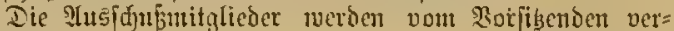
cioigt.

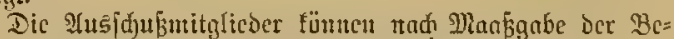

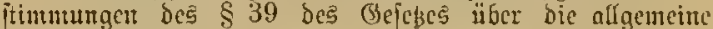

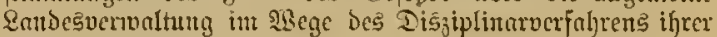
Etellen enthoben weroen.

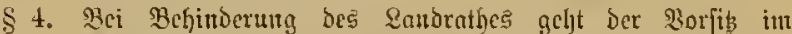
fireisausfulfe nuf feinen Stellvertreler über. Sit bics ber

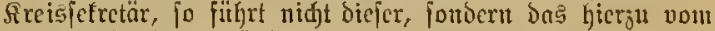

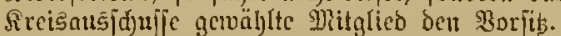

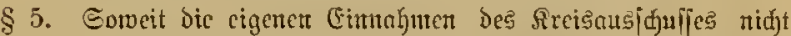

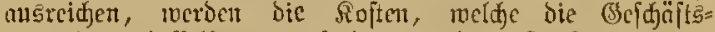
verivaltung befielben verurjadjt, von bem Sircife getragen.

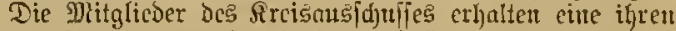
baaren গIsslngen entipred)ende Entidjäbigung. Heber bie

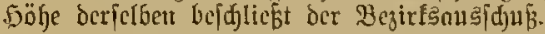

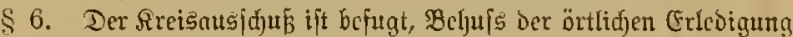

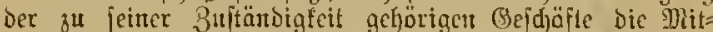
mirfung oce Polizeibiftriftstomni|jarien, jowic der Gemeinde=

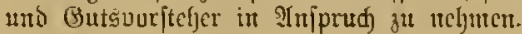

§37. Der Stnotausidjuf be[teht aus beur Bürger=

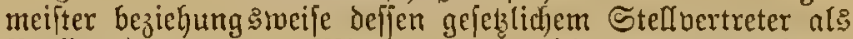
3orfitzenten umb 4 Mitgliedern, weldje bom Magiftrate (tolegialifden (Semeindevoritande) aนs feimer Mitte für die Dauer ifres Şauptamtes gewälyt werden.

Fïr Fälle der Behinderung fowoht des Bürgermeifters mie feines gejeblichen Stelfoertreters wähft der Stadtausid)uß Den Boriizenden al: 3 feiner Mitte. Derfelfe bedarf Der Bcitätigung des Regierungspräijidenten, in Dem Stadtfreife Berlin bes DGerpräfidenten der \$rovinz Brandenbutg.

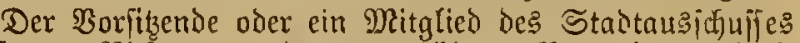
muf zum Ridfteramt oder zum löberen Verwaltungsoienft befähigt fein.

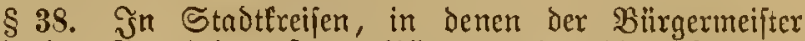
allein Den Semeinbeborjt ano bildet, inerden bie aufer Dem Zorfibenden zu beftelfenden Mitglieder von ber (jemeinde= bertretung aus ber 8 ahl Der (3emeinbebiirger gemäblt.

Die $\mathfrak{B a h l}$ erfolgt auf 6 Jalyre.

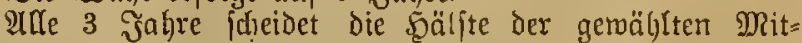

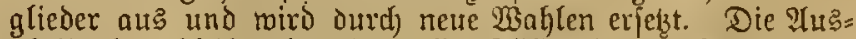

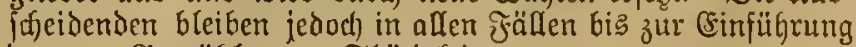
ber neu Berwählten $n$ Ijätigfeit. 


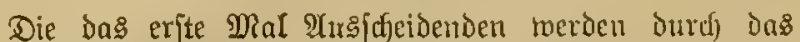

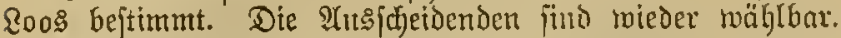

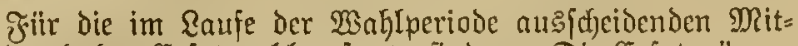
glicuer haben Eerjatzrahlen itattäfitten. Dic Erfałmänner bleiben nur biš zum Ende desjjenigen Beitraums in Thätigfeit, fïr tweldhen bie Aluggefdededenen getwählt worden.

Эnt Hebrigen gelten in Betreff ber Wählbarleit, ber Wahhl, Der Cinführung und der Bereidigung Der Mitglieder, forwie Des $\mathfrak{B e r l u f t e s}$ ifrer Stellen unter cinftmeiliger (Ent= hebung von denjelben, Die fïr unbefoldete Miagiftratsmitglieder beftehenden gefesticjen Borjarifer.

§ 39. Die gemählten Mitglieder Des Rreiș= (Stadt=)

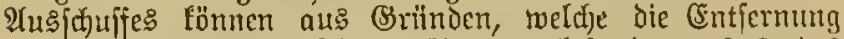
eines Beamten aus feinem 2 lmte rediffertigen (\$ 2 De: Bef. vom 21. Juli 1852, betreffend die Dienjtuergehen Der nidft ridjterlidjen Beamten), in wege des Disziplinar= berfabreng iffer Stellen enthoben werden.

₹̛ür das Disziplinarberfahren gelten bie Borfariften bes genaunten Bejekes mit folgenden Maaß̧gaben:

Die CEnleitung Desి Verfalgens, fomie die Ernemnung

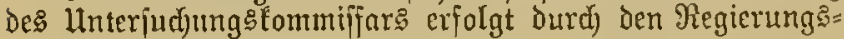
präfidenten.

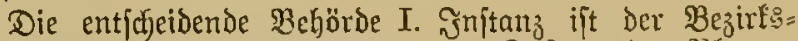

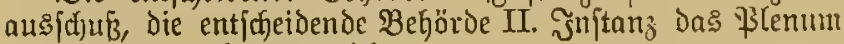
oes Dberbermaltungsgerichts.

Der Bertreter ber Stantsanmaltjdaft miro fiir die I. Initanz von dem Regierungspräjidenten, für Dic II. Jnjtanz bon dem Minifter bes Jnnern ernamnt.

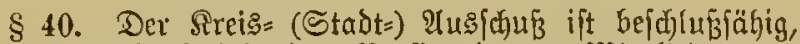
menn mit Cinfuluí des $\mathfrak{B}$ orjitzenden 3 Mitglieder an= mejend find. Die $\mathfrak{B} e\{d$ jlüffe werben nadj Stimmenmehrheit

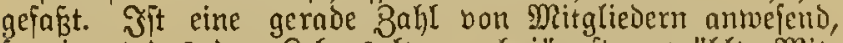
fo nimmt Das dem Rebenşalter nach jüngfte gemählte Mit= glied an der $\mathfrak{A}$ hfitimmung nicht Theil. Dem SBerichterftatter fteht jedoch in allen Fällen Stimmrecht zu.

\section{Behörden für Den Stadtreis Berlin.}

§ 41. Der Dberpräfident ber \$rovinz Brandenburg ift zuglcid) Dberpräfident von Berlin.

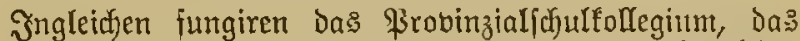
Medizinalfolfegium, die Beneralfommiffiton und Die Direftion

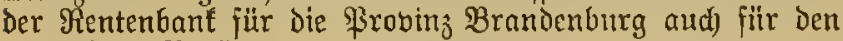
Stadtfreis Berlin.

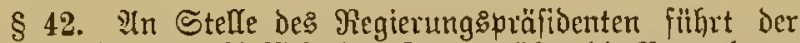

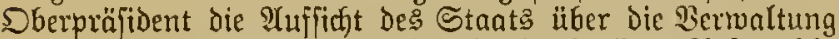
Der (Bemeindeangelegenbeiten Der Stadt Berlin. IIUf weldue Bejörden bie jonftigen Bujtändigfeiten ber Regierungs:

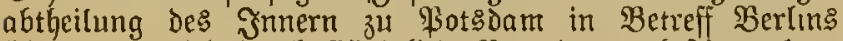
übergehen, wird butrch Siönigliche Berordnung beftimmt. ${ }^{1}$ )

Im Hebrigen, und jomeit nidft fonjt bie Bejetze Inderes bejtimmen, tritt für ben Stadtfreis Berlin an die Stelle

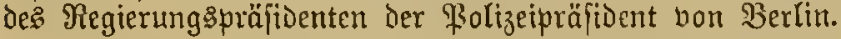

1) 2. จ. 26. 1. 1881 (GS. 14), melute in Rrajt geblicben ijt:

Irt. 1. "Mit Dem 1. Ifpril 1881 wirb bie Serwaltang ber Jnoulioen=,

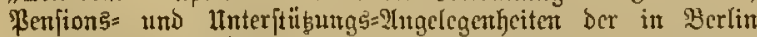
robnhaften Militär $=$ und Miarite-Jnvaliben aus bent Etande

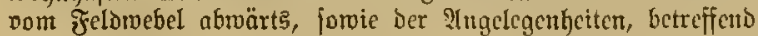
bie unterftïßnng ber hinterblicbenen Eltem, Rinoer tmo
Wittwen fold)er \$ecionen, fowcit Dieje Berwaltumg bisher vou

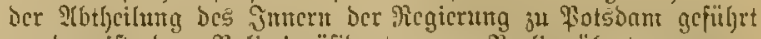
tworben ijt, bem Polizeipräfibenten von 2erlin ïbertragen.

Wit Dentjerben BeitputEte gehen alle fonjtiget Bujtäubią= feiter ber gedadten Regictungsabtheilung in Bctreff Burlins

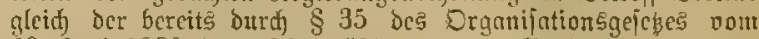
26. Jnli 1880 bem Oberpräfisenten Don 8 erlin iibertragentu Faffidgt bes Etnats über bic Bermalnung ber Gencino: ?tugelegentyeiten ber Etnot Berliu auf ben Dberpräfidentet not Berlitt ïfer.

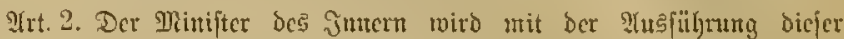
Beroromtutg beanftragt."

\$ 43. Th die Stefle Des \$̇robinzialrathg tritt in Den Fällen, in weld)en derjelbe in I. Jnftanz bejolię̧t, der

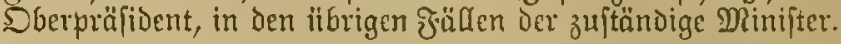

Fitr den Stadtfreis Berlin befteht ein befonderer $\mathfrak{B} \varepsilon=$

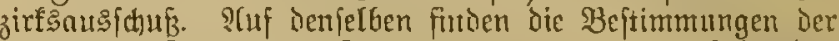
$\S \S 28,30$ Sałz 1, 31 Sats 3, 32, 33, 34 mit folgendell Maafigaben Mrmenoung:

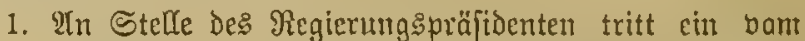

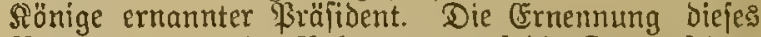
Beamten fann im Rebenamte auj bie Dauer jeines Sauptamtes in Berlin erfolgen. SBeamte Des $\mathfrak{B}$ olizci= präfioiumt find bon biejer (Ernennung ausgejchlojfen.

2. Die zu räglettben Mitglieber werden burd den Mingiftrat und Die Stadtueroronetenverfammlung unter bem 2orjił Des Bürgermeifters getoüljlt. Daffelbe Rollegium bejulięt an Stelle Des Provingialausiduffies

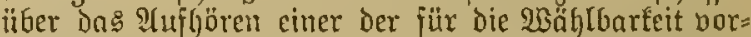

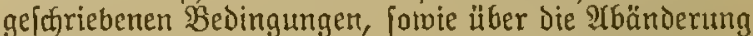
Der Dauer der Wahlperiode. Die Mitglieder des Magiftrats und der Stabtberoronetentocranmlung find bon der 23 äglbarfeit ausgefdilofien.

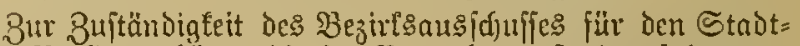
freis Berlin gehören Die im $\mathfrak{B e r w a l t u n g g | t r e i t b e r j a h r e n ~ z u ~}$ behandelnden ulngelegenbeiten und diejenigen im $\mathfrak{B e f d}$ lut $=$ verjahren ju behandelnden Ângelegenheiten, welche im (EinzeInen Durd) Dic Bejełze feiner Bujtändigleit überwiejen merben; in Betreff Der übrigen im Bejd)luzberfahren z"t behandelnden Plugelegenheiten tritt für den Stadtfreis Berlin

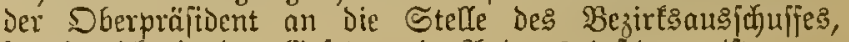
joweit nicht in ben (Sejetzen ein SItderes bejtimtmt ift.

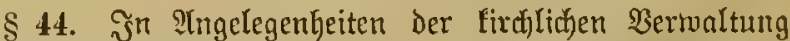

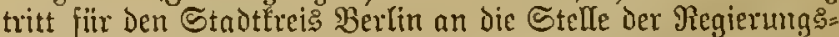

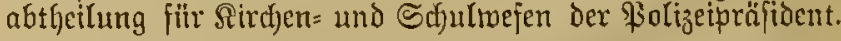

Bezüglidj Der Bermaltung des landesherrlichen Ratronats und des Schulwejens verbleift es bei den bejtehenden $\mathfrak{B} e=$ itimmungen.

\$ 45. Die Bejujäfte oer Direlten Stcuervermaltung merden an Stelle der Regierungsabtheilung für birefte Steuern, Donainen und Forjten, für Den Stadtfreis Berlin von Der "Direftion fït Die $\mathfrak{B e r t w a l t u n g ~ D e r ~ d i r e f t e n ~ S t e u e r n " ~}$ maljrgenomutr.

Dieje Beljörde wird in Betrejf ber 3uftändigfeit in Disiplinarfacten den im $\$ 24$ গir. 2 des (Bejezes vom 21. Jult 1852 , Getreffend bie Dienjtbergehen Der nidyt ridjter:= lichen Beamten ze., bezeidjneten \$rovinzialbehörden gleich)= gettellt.

$\S 46$ ift burd) bas (Sinfommeniteuergefels b. 24. 6.1891 (ङS. 175) gegenftandstos getworden. 
§ 47. Filu diejenigen Fategorien der in Berlin an= gejtellten Beamten, bezüglid) deren nicj)t die Zuitändigfeit einer amberen $B$ efjörde in Disziplinarjachen begrïndet ift, behält es bei ben Beftimmungen des $\S 25$ de

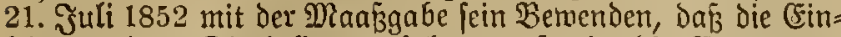
leitung Des Disziplinarberfahrens, powie Die Enmennung

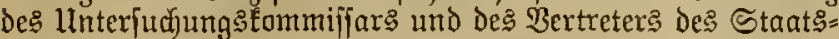
anroalts für die I. Injtanz dem Dberpräfidenten bon Berlin zujteht.

\section{Stellung Der Beদörden.}

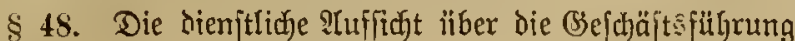

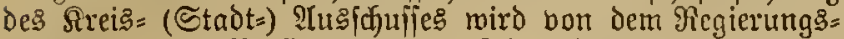
präfidenten, in Berlin bon Dem Dberpräfidenten, bie 2 (uj=

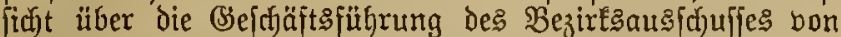

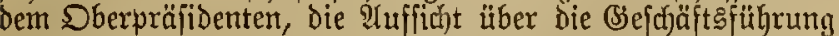
des \$rovinzialraths von bem Minifter des Jnnern gefïhrt.

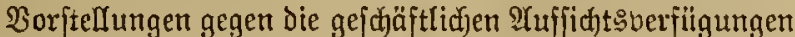
des Regierungspräfidenten unterliegen ber endgültigen $\mathfrak{B} e=$

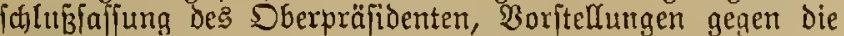

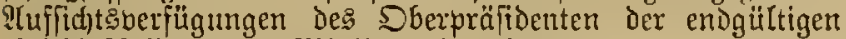
Bejujluffajfung des Minifters des Jnnern.

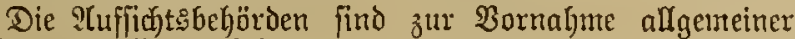
(Ge) djäft:irevifionen befugt.

$\S 49$. Die in $\S 48$ bezeidnneten Behörden haben fid

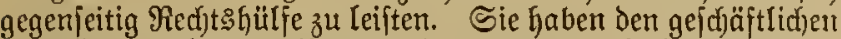

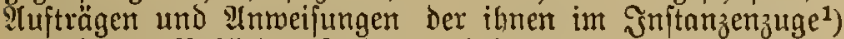
vorgejetzten Bebörden Folge zu leiften.

1) Snftangenzug im Bermaltungstreitucrfahren: Nreis=

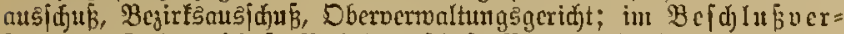

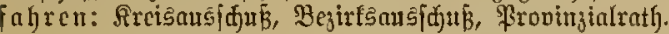

\section{Titel. כ̈erfafient.}

\section{Allgemeine Borfdriften.}

\$ 50. Dns Befeł bejtimmt, in trelcher weife Ber=

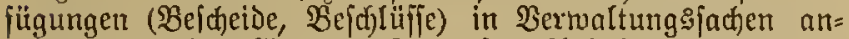
gefoditen werden fönnen. Bur eriten IInfechtung Dienen in

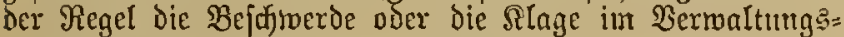
itreitberjahren.

Die Bejdmerde ift ausgeffilofien, fomeit bns $\mathfrak{B e r}=$

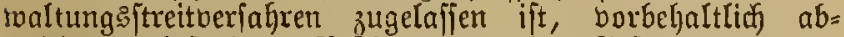
weichender bejonderer SBejtimmungen Des Bejezec.

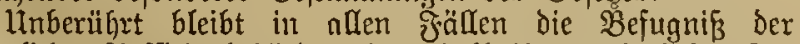
itaatlid)en ?luffid)tşbehörden, immethalb ihrer gejeblichen $8 \mathrm{n}=$ ftändigfeit $\mathfrak{B e r j u ̈ g u n g e n ~ u n d ~} \mathfrak{A}$ nordnungen der nadjgeordneten Bebörden nuper Serajt zu jetzen, ober diefe Behörden mit 2(ntweifungen zu verfeljen.

§ 51. Wo die (Sefetze für die Inbringung Der Befdrwerde

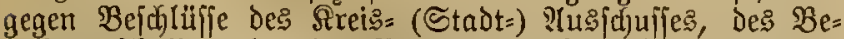

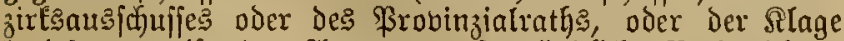

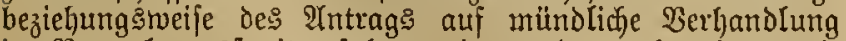
im Berwaltungş treitwerfabren eine andere als cine z'wei=

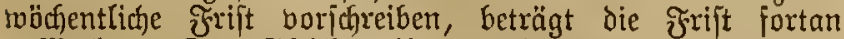
2 Wodjen. Das Bleidje gilt bon den int $\$ 11$ Des Bef. vom 14. Tuguft 1876 , betreffend die Termaltung Der Den (5) $=$

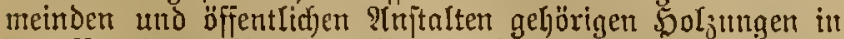
Den Frobinjen \$reufer, Brandenburg, Fammern, 3̧ofen, Sajlefien und Sadj) bom 1. 2(prif 1879, betreffend die Bildung bon $\mathfrak{B}$ afjergenofjen= jhaiten, (\$S. 297) borgeidriebenen Friften.
§ 52. Die ₹riften für die $\mathfrak{A n b r i n g u n g ~ d e r ~ B e f a d w e r d e ~}$

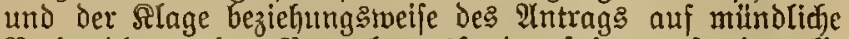
Berhandlung im Berwaltungs|treitberfahren, folwie alle

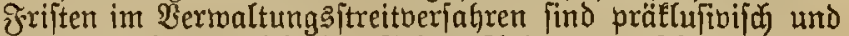
beginnen, jojern nicht die Sejeke Anderes boridjreiben, mit Der Bujtellung. Fitir die.Beredjung ber Friften find die

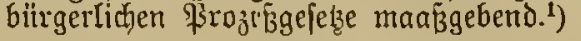

Bezüglid) Der Bej(fwerde fann die angerufene Befärde

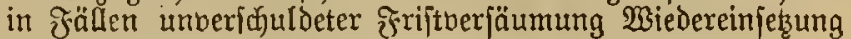
in ben borigen Stand getwähren.

Fit: eine in $\mathfrak{B e r w a l t u n g s f | t r e i t v e r f a h r e n ~ z น ~ g e t w a ̈ h r e n d e ~}$ Wiedereinfekung itt den vorigen Stand jind lediglidf die für Das Berwaltung: ftimnungen maafigebend ( $\$ 112)$ :

1) $\$ \S 198-200,226$ c98.

§53. Die Inbringung der Beidfverde, forvie Der Rlage beziefumgsmeije des Întrag auj mündlicfe Berhandlung

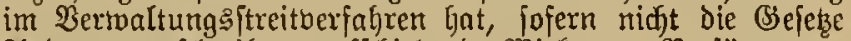
Anderes borfdjreibell, auficjiebende wirtung. Werfügungen,

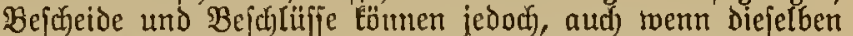

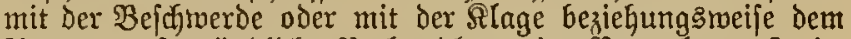
2Intrag auf milndliche Berbandlung im Berwaltung: Ftreit= verfafyrent angefochten jind, zur 2usführung gebracht merden, jojern letztere nad) Dem (Ermeffen ber Behörde ohne Radt: theil für Das (Bemeinwejen nidgt ausgefekzt bleiben fann,

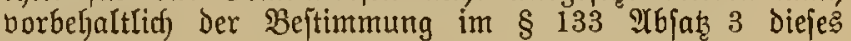
(Biejetes.

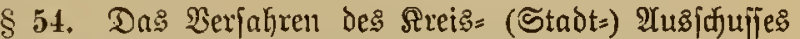

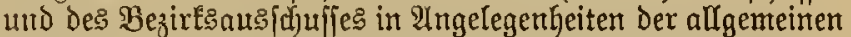

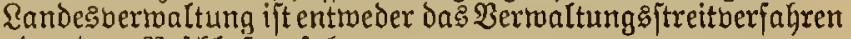
oder bas Sefidjlugberfahren.

Das $\mathfrak{B}$ ermaltungsftreitberfahren tritt in allen $\mathfrak{A}$ ngelegen= heiten ein, in rolchen Die Sejetze bon ber Entfofeibung in ftreitigen Verwaltungsachen ober bon ber Crlebigung ber âtngelegenteit im Streituerfahren oder burch Endurtheil

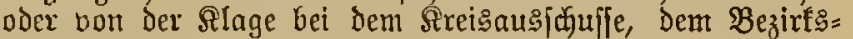
ausidfujfe oder einem Bertwaltungsggeridjte iprecten, uno mo jonjt biejes Berfahren gejestich borgefdrieben ift.

In allen anderen $\mathfrak{U}$ ngelegenheiten ift bas Berfahren bes

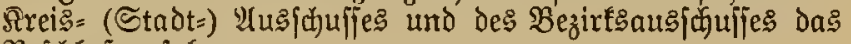
Beichlufuerfahren.

Das Sbervermaltungsgerid)t berfährt nur im $\mathfrak{B e r}=$

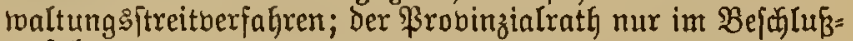
berfahren.

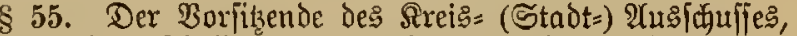

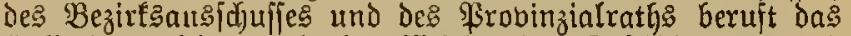
Siollegium, leitet und beauffichtigt Den Bejchäftsgang und jorgt für Die prompte (Erledigung Der Bejuäite. (Fr bereitet

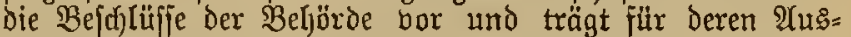
führung Sorge. (5r vertritt bie Befjürde nadf ausen, ver= handelt Ramens derfelben mit anderen Beförden und mit Srivatperfonen, fiifret Den Sdjriftwedffel und zeidjnet alle Sd)riftitüfe Ramens ber Bebörde.

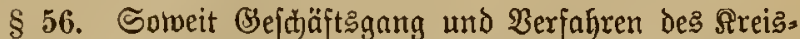

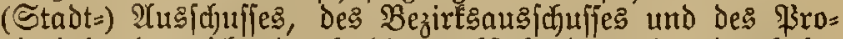
binzialraths nidft durch bie nadfitebenden oder burd be= fondere gejeblicje Beftimmungen geregelt find, werden bie=

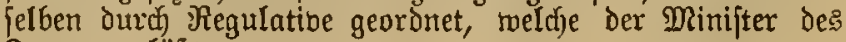
Эnnern erläßst. 


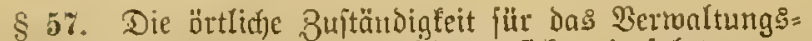
ftreits uno Befdjlufberfahren bejtimmt fich, wie folgt:

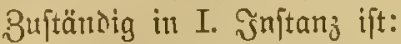

1. in Angelcgenlyciten, melche fich auf Grnmoftücfe be= zichen, Die Beljörde Der belegenen Satje;

2. in allen fonftigen fällen die şehörde desjenigen Bezirtes (Sreis, Regierungshejirf, \$robiuz), in weldem Die Perion wohut oder Dic Sorporation bezichungפmeife öffentlidje Behjörde ilyren Sitz hat,

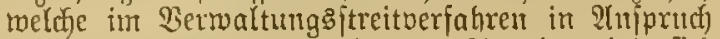
genommen twird oder auf Deren S(ngelegenheit fidf

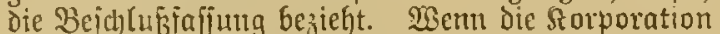

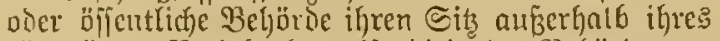
räumlichen Bezirf? hat, ift Diejenige Befjörde zu= ftänoig, welder biejer Bezinf angehört.

Bezïglidj bes Stommmalverbandes der \$rovinz

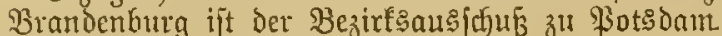
zultändig.

§58. Sind Die Grundftücfe in mefreren Bezirfen be= legen, oder ift es jweifelgaft, ju melchem Şezirfe fie gehören, fo wiro bie zultändige Bebörde

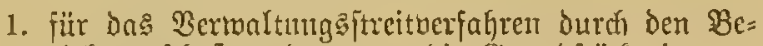

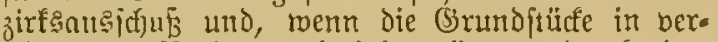

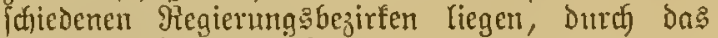
DGeivermaltung sergericht,

2. fitr Das Beichlufiberfahren Durch den Regierungs: präfitienten, Den Sberpräftónten oder den Minip̌ter des Эnnern, je nadjoent die betrefienden $\mathfrak{B} e z i r f e$ demielben Regierungsbezirte, Derjelben Frobinz, aber verfffiedenen Regierungsbejirfen, ober ber= fofiebenen Probinzen angeljören,

endgïltig bejtiunt.

Dafielbe findet ftatt, wenn Die \$erjonen oder Rorpo= rationen, Deren Ingelegenheit den Siegenjtano ber Cent= (d)eidung oder Befd)hitifafiung birdet, in mebreren Bezirfen woljnen oder ifgren Sik haben.

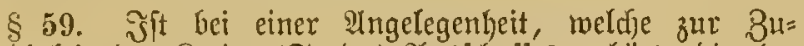

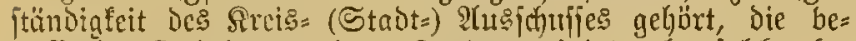
treffende ßreistorporation (Stadtgemeinde) als polche be= theiligt, fo wiro

1. für da: Bermaltungsftteitwerfahren bon dem $\mathfrak{B e}=$

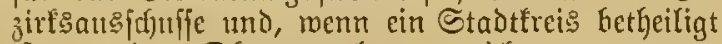
ift, bon dem Dherberwaltungsgeridite,

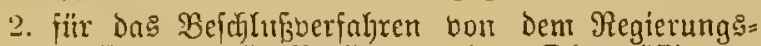
präfidenten, für Bertin von Dem DGerpräfidenten ciu andeter Siccišs oder Stadtauŝfdufs mit Der Centjdjeidung oder Bejeflubifaffung benuftragt.

$\$ 60$. Die 23olftrectumg im Zermaltungşftreitverfahren

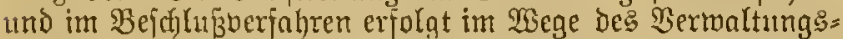
ztwangsberfaljrens. Die Solytrecfung twiro Ramens ter

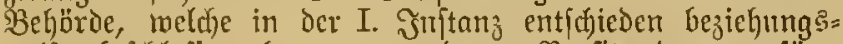
weife befchlofier hatte, bon deren Borfitzendem berfügt. Heber Bejdyerden gegen bie 2̇erfügungen Des Borfibenden

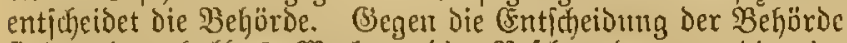

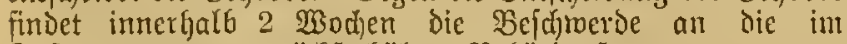

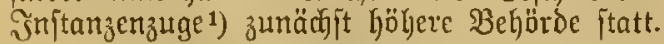

Dic (Entja)eidurng Der lebeteren ijt endgültig.

1) $\mathfrak{x g l . ~} \mathfrak{A} \mathfrak{n}$. зи $\S 49$.
Berma〔tu ug $\mathfrak{s}$ ftreitber $\{\mathfrak{a} \mathfrak{h} r \in \mathfrak{n}$.

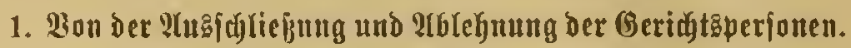

\$ 61. Die Beftimmungen der bürgerliden \$rozę̧geję̧е

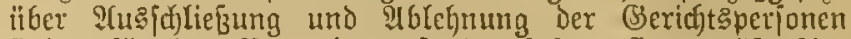

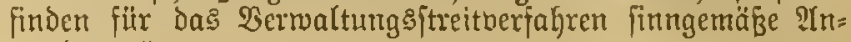
toendung. 1)

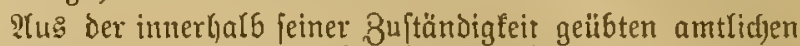
Thätigfeit Desీ Eandraths bejichungsmeife desి Regierungs: präfidenten dari fein Sirund zur" QTblehnung Deffelben megen Beforgníz Der Befangenbeit entnommen twerben.

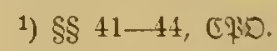

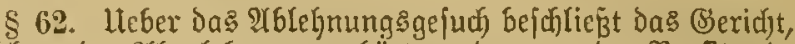
melchent Der YGgelegnte angefjort, und menn Der Borfitzende Des Sireis: (Stadt) oder Bezirf'sausfduljes abgelehnt merden joll, das näefjt höhere (Sericht.

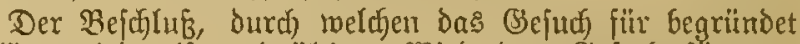
erflärt miro, ift endgültig. 2̧iro Das (iefud) für un= begrändet erf́ärt, fo fteht Der mit bemjelben zuridfgerwiejenen

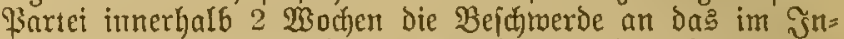
ftansenzuge1) zunächit böhere (5eridst zu. Das lektere ent=

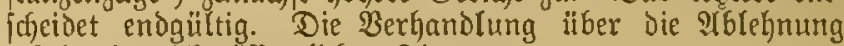
exfolgt in nich)t offentlicher Sizung.

Das im Inftanzenzuge zunädyft borgejetzte (seridjt ent= fhetbet Deşgleidjen endgültig uno bejtimmt bas zultändige (Serifft, wenn Das (Beridft, Dem bas ausgefdilofiene oder abgelehnte Mitglied angehört, bei bejfen Slugidetben $b_{e}=$ (d)lubunfägig wiro.

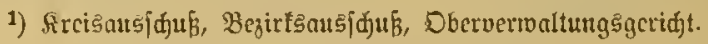

\section{Bon beut Berjalyren in I. Injtany.}

§ 63. Die Silage if̂t bei Dem zultändigen (S)eridyt

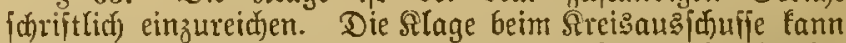
3tl \$rotofoll erflärt merben. Yit der Rlage ift ein be= fimmter $\mathfrak{A}$ ntrag zu ftellen, und find Die \$erfon Des $\mathfrak{B} e=$

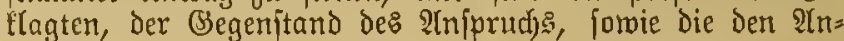
trag begründenden Thatjachen genau zu bezeicfnen.

§ 64. Stellt fid der exlobene 2uppruch fofort als rechitích) unzuläifitg oder unbegründet heraus, fo fann bic Slage ohne Weiteres Duref einen mit Girtïnden berjehenen Bejatheid zurüffgemiejen twerden.

Sodjeint der erhoberre Injprud bagegen redytlid bes gründet, jo fann beut Beflagten ohne Wisiteres durch einen nit (Sründen berfehenen Bejcheid Die אlaglosftellung Des siägcrs aufgegeben merden.

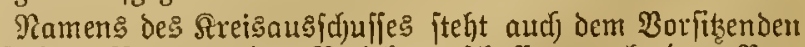

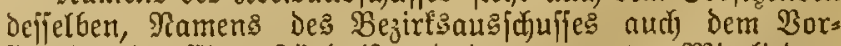
iitzenden im Cinveritänonif mit den ernannten Mitgliedern Der (Erlá̧ cines joldjen Bejdyeibes zu.

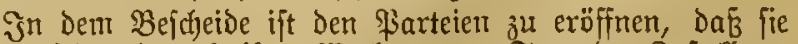
befugt jeien, innerhal5 2 æodjen, vom Iage ber Bujtellung ab, entweder bie 2Inberaumung der mündlict)en Berhandlung zu beantragen oder Dasjenige Rechtšmittel einzulegen, weldhe zuläifig märe, wenn der B̧ejheid als (Entfheidung des Rollegiums erạangen wäre.

Wirs mitndliche $\mathfrak{B e r l}$ andolung beantrant, fo mus diefelbe zunächjt jtattfinden. 
Sat einer dex Betheiligten mündliche Berhandlung beantragt, ein anderer das Rectitsmittel eingelcat, jo miro

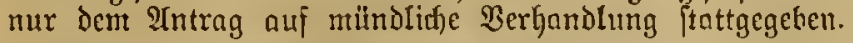

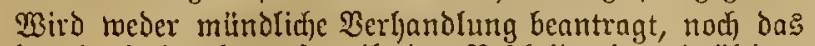
Rechtsmittel eingelegt, fo gilt der $\mathfrak{B}$ eidjeid als endogitltiges lltrtheil.

§ 65. Mird ein Beidjeid nad) den Beitimmungen des $\$ 64$ nidjt erInjien, jo ijt Dic Âlnge dem Beflagten mit Der Arufforderung zuzufertigen, jeine Begenerfflärmng innerlyalb

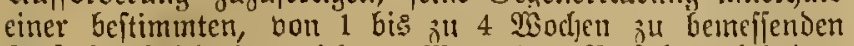

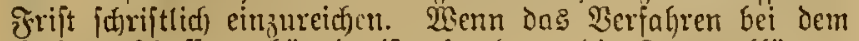

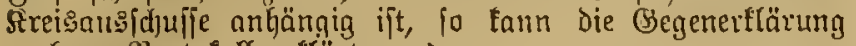
auch) zu Grotofoll eretärt werien.

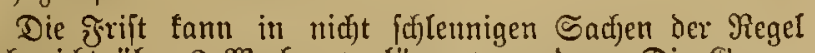
nach nicht iiber 2 wochen berlängert roerden. Die (Begen= erflärung des Bellagten wird dem Släger öugefertigt.

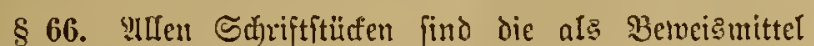
in $\mathfrak{B} \mathfrak{c}_{3} u g$ genommenen LIrfunden im Driginal ober in $\mathfrak{T}(6=$

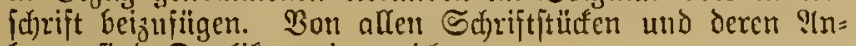
lagen find Duplifate einzureicjer.

Das (Berifht Eann geeigneten Falle gejtatten, daß̧ ftatt ber Cinreidfung bon Duplifaten dic Anlagen felbit zur Cin= fidft der Betheiligten in jeinem Bej(t)ĭfteilofale offen gelegt merden.

§ 67. S̄it neder bom STläger noch bom Betlagten die

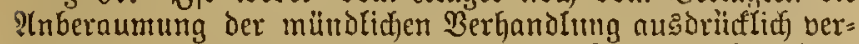
langt, io Eann das (Beridht aud) olhne foldje Berhandlunn idjon auf Brntno Der Erflärung ber Parteien leine CFnt= jđjeidung in Der Form eines mit Bründen nerfeljenen $2 B e=$ icheides f̧ăllen. Dabei gelten die Bepitimmungen Der 2 bjätse 4 bis 7 bcs $\S 64$.

\$ 68. Şat bagegen aud) nur eine Partei bie ?In= beraumung Der mïndidjen Verhandlung gejordert oder er= acfitet Das (bericft eine folche für erforderlicf), fo merden bie Parteien zur mündlidjen $\mathfrak{B e r b j a n d l u n g ~ u n t e r ~ d e r ~} \mathfrak{B}$ erwarnung

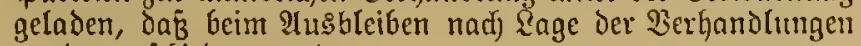
werde entichieden merden.

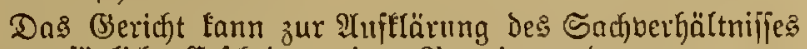
dos perjönlicfe Erfiffeinen einer \$artei nnordnen.

Den Parteien fteht es fiei, ifre (5rklärungen, aud ohne daju bejonders aufgejordert jul jein, bor dem Termine ichriftlid einzureichen mo ju ergänjen. Das Duplifat folcher Eretärungen ift der (siegenpartei zuzujertigen. Rann bies nicht mehr bor dem Termine zur mündidjen $\mathfrak{B e r}=$ handlung bemirft merden, jo ift ber wejentline Эngalt ber Ćrtlörungen in diejer Berhandlung mitzutbeilen.

$\$ 69$. Wo dic Brefełze zur Einleitung des Bertoaltung: itreitberfahrens fitt der filnge Den Intrag auf mündidje Berhandlung im Bertwaltungştreitberfaljen geben, erfolgt auf den Plntrag ohne Weiteres dic $\mathfrak{B}$ orladung Der Parteien zur mündliffen $\mathfrak{B e r h a n d l u n g . ~}$

Der Intrag muiz Alles entharten, loas nach $\S 63$ für ben Rlageantrag erfordert mirb, jomeit baffelbe nicjt aus

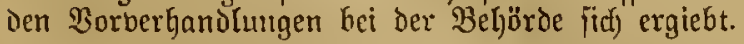

§ 70. Das (Berid)t fam alf $\mathcal{A}$ (ntrag oder von $2(m+s=$ megen die Beiladung Dritter, Deren Jnterefje Durd) bie zu erlafiende Entidjeidung beriifrt ivird, berfitgen. Die Ent= idjeibung ifft in biejem ₹alle aud den Beigeladenen gegen= über gültig.
§ 71. Э̌n Der mïndlidjen פerhandlung find die ßarteien oder ihte mit $\mathfrak{B}$ ollmad)t berfehenen $\mathfrak{B e r t r e t e r}$ zu hören.

Diejelben fömnen ifhre thatjädflidjen oder rect)tlichen $\mathfrak{2}(n=$ fülyrumgen ergänzen oder berichtigen umo bie Slage nbändern, injojern burd) Die 2(bänderung nad) dem (Frmefien bes

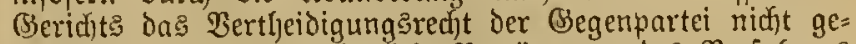

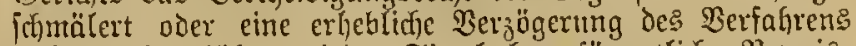
nifft berbeigefithrt wiro. Sie fyaben fämmtlirlye Bemeis= mittel anzugeben uns, fomeit bies micht bereits geiffelyen, die (d)riftlid)en ibnen zu (Siebote ftehenden Beneisuttel vor= julegen; aud) fönnen bon ifnen Beugen zur Vernelymung vorgefïht werden.

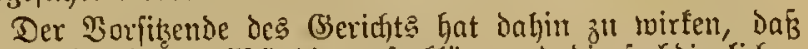
ber Sacfberhalt bollftändig aujgeflärt und bie jachbienfichen IInträge bou den Pinrteicn geftellt werben.

(Fx fanm einem Mitgliede des (Serichte geftatten, das Jragerecht ausjüuben.

(Eine Jrage ift zu itellen, menn das (Serich)t dieje fïr angemefien erardtet.

$\$$ \%2. Dic mimoliche 2 erhanolung erfolgt in offentlicfer Sitiut ies (Beridgts.

Die Deffentlicfleit Eann burd) einen öffentlicf zu ber= fündigenden BejchluF ausgejdloffen werDen, wenn Das

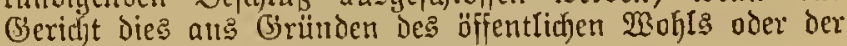
Gittliffeleit fïr angemelifen eradjtet.

Der Borfizende fann aus Der offientlichen Sitzung jeden Buhjörer entiernen Lajien, Der Beidjen bes Beifalls ober des Yisiallens giebt oder Störung irgent einer ?trt berurjadjt.

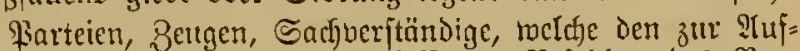

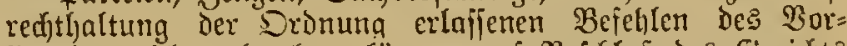

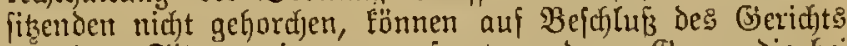
aus Dent Siturngsimmer entfernt werden. Giegen die bei Der Berfandlung betheiligten Perfonen wird jobann in gleidjer 23 eije berfahren, wie wenn fie jidj freinillig entfernt bättent.

$\$$ 73. Die Barteien find in Der Wabl der bon ifnet

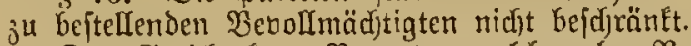

Das (Gerid)t fann Vertreter, weldje, ohne Recjtsanmalte

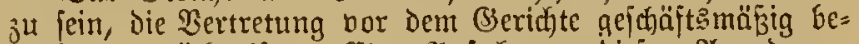
treiben, zuritufweifen. (Fine Injedjtung diejer Mnotonung findet niclit ftatt.

(Semeindcborjteher, weldje als joldje legitimirt jind, he= bürien zur Sertretumg ifrer Siemeinden einer befonderen Bollnad)t nicfit.

\$ \%t. Siegt einer öffentlidjen Behörde als Fartei dic Wahmehmung des öffentlid)en Эntereffes ob, jo fann nuf

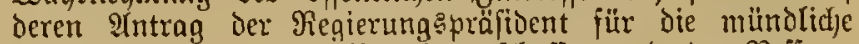

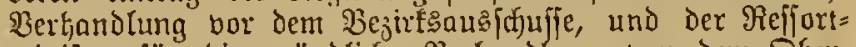
minifter fïr bie miindlide Berhandlung bor dem Sber" verwaltungsgeridjte einen Rommiffar zur Bertretung Der Behärbe beftelfer.

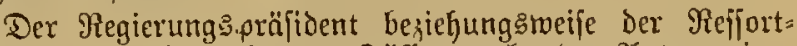

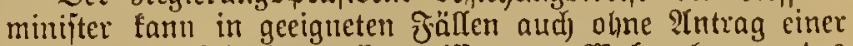
Bartei einen Gejonderen Siommijiar zur $\mathfrak{B a h r n e g m u n g}$ des offentlicfen Эntereffes für die mündlicke Berhandlung be=

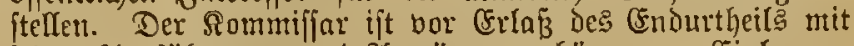

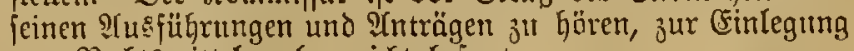
bon Reditsmitteln ober nidft befugt.

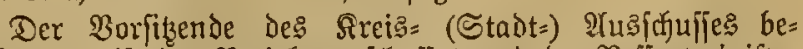

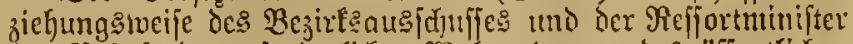
hat Behuf der erfordertidjen Wabnelnutug des offentficten 
Tnterefies einen Rommifjar zu beftellen, wenn das Bsefets

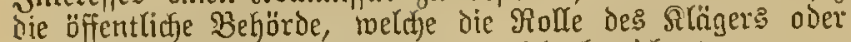
des Beflagten wahrzunehmen hat, ridyt bezeidjnet.

§ 75. Die miindlidje Berhandlung erfolgt unter $8 \mathrm{z}=$ jiefung eines vercidigten Protofolführers. Das Prototoll mus bie wcjentlidjen Sergänge ber :Bertjandlung enthalten. Daffelthe mird bon bem Sorfizenden und bem Brotofoll= füfyrer unterzeidinet.

§ 76. Da: (Gerid)t ift bejugt - geeigneten Fall fidfon bor STnberaumint der mündlidjen $\mathfrak{B e r b a n d l u n g}-$ Unter= fudfungen an Drt und Stelle zu veranlaijen, Zeugen umi Sadjberftänbige zu laden und eidlid) zu bermelymen, über= haupt Den angetretenen oder nady Dem (Ermejfen Des (seridyts erfordertictien Betweis in bollem llmfange z" erbeben.

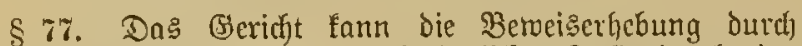
eines jeiner MRitglieder oner exporderlidjen Fralls Durch eine

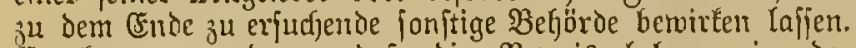
EF Enn beroronen, daB die Berveiserkebung in ber mündlidfen Berkandung ftattfinden jolf.

Die Berveisverbnolungen find unter 8 uziełung eines bereidigten oder bon der betreffenden Beljörde durd) Sand=

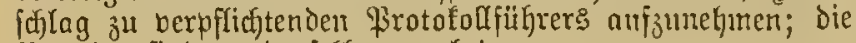
Garteien jimb zu denjelben zu laden.

§ 78. Şinjidytlicf) der Werpflidfung, fitch nIS Beuge oder Sadjperftänoiger bernebmen zu Lafien, fowie hinfichtlich ber im ₹ralle des lingehorfams zu berbäugenden Strnfen tommen Dic Beftimmungen ber Gürger(idjen Grozesgefeze1) mit ber

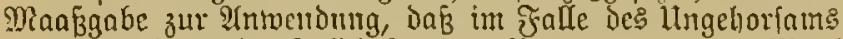
Die zu erfennende Gelobußse Den Betrag bon 150 Mark nid)t überjteigen darf.

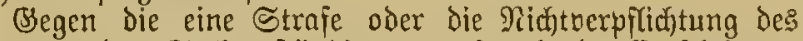
Beugen oder Sadfberftändigen ausfpredjende (Fntf(j)eidung

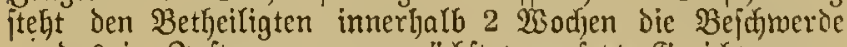

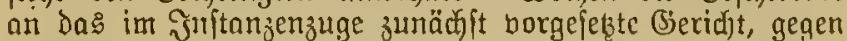

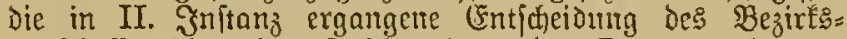

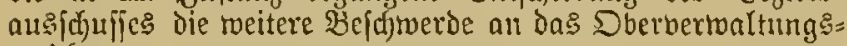
geridjt zut.

1) $\S \S 341,344-351,355$ ธฬ०.

§ 79. Das (Gerid)t hat madj jeiner freien, nus dem ganzen Эnbegriffe der 2erhandlungen und Bemeife ge= ifjoppiten Heberzeugung zu entideiden. Beim Plusbleiben Der betreffenden \$artei oder in Frmangelung einer $\mathbb{E} x=$ flärung Derjel6en fönnen die von Der (Segempartei bor= gebradjten Thatjadjen fïr zugeitnnden eradjtet werden. Tie Entjd)eidungen dürjen nur dic zum Streitberfabren vor= geladenen \$arteien und dic in Demfelben exfobenen $21 n=$ ipriiche betreffer.

$\S 80$. Die Enticheidung fann ofye borgängige 9 Tn= beraumung cimer mündlichen Berhandlumg erlajien werden,

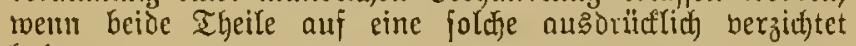
haber.

§ 81. Die Bertündigung Der Entfajeidung erfolgt Der Regel nad) in öffentlider Siknug bes (Beridhte. Cine mit

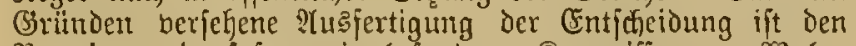
\$arteicn und, fofern ein bejonderer fommiffar jur $\mathfrak{E a h j}=$ nefymung bes offentlicten Эnterefjes beftellt war (§ 74 I(bfats 2), gleidjzeitig aud biefem zuzujtellen. Die $8 \mathrm{u}=$ ftellung genügt, wenn bie $\mathfrak{B}$ erfündigung in öffentlidjer Siłzung nicfit exfolgt ijt.

\section{23an bem Berfalyren in ben weiteren 3uftausen uno bou ber Wiederamjahme be̊ :ierjohren.}

§ 82. (3)gen bic in ftreitigen Bermaltungşad)en er= gangenen (Endurthcilc der Sreisausfajitije umo gegen dic Sefcheide in Den fällen der $\$ \S 64$ und 67 fteht, foreit ridjt gemäßz befonderer gejstzlider Borjd)rift diefe Utithcile end= gilltig oder bie geger diefelben ftattfuldender Rechtsmittel in abmeicfender 2 cife geregelt find, Den \$arteien und ants

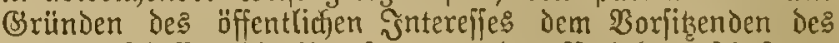

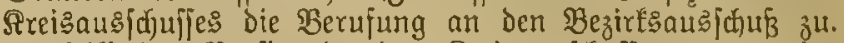

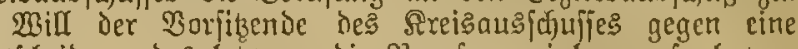
Entfcheidung Des lezteren Die Berufung einlegen, fo hat er

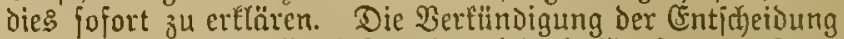
bleibt in diefent Falle einftreiler, jedoch längltens 3 Tage nusgejest. Sic exjolgt mit der Eröfinung, Daß̉ im öffentlichen

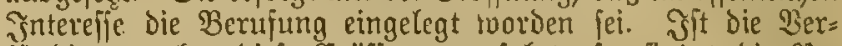
fündignng ohne biefe Erofofinumg erfolgt, fo findet bie 2 be: rufung im öffentlichen Sntereffe nidjt megr ftatt. Die Grinde der Berufung find den Farteien zur fúriftliden Erflärung inmerhalf der im $\S 86$ nedad)ten forift mit=

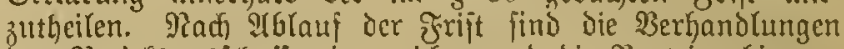

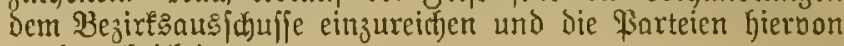
zul bemadtridfigen.

\$ 83. Begen die in ftreitigen Bermaltungsfacjen in

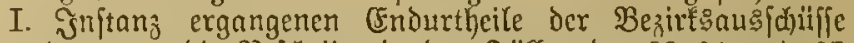
uno gegen die Bejdecide in Den Fälfen der $\$ \$ 64$ und 67

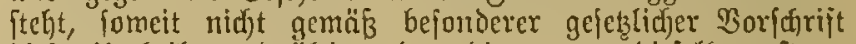
Dieje ltrtheile endgültig ober bie gegen biejelben ftatt= findenden Rechtomittel in abmeidjender Weife gerenelt find, den \$arteien und aus (Brïnden Deg offcittidjen jnterefies

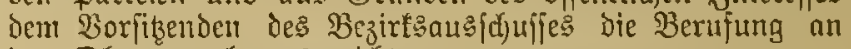
Da: Sberbermaltutmaggeridht zu.

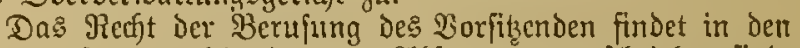
Formen ftatt, weld)e in $\$ 82$ TLfas 2 vorgejdurieben find.

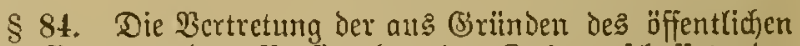

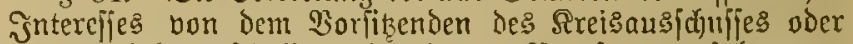
Des $\mathfrak{B}$ ejirfsangfdulfes cirgelegten Berufurg exfolgt bor Dem Bejirfsausjofulfe Durch Den bou Dem Regierung: präjitontert, bor dem DGerbervaltungsigeridjte ourd ben von Dem Refjortminifter au hejtellenden Sommiffar.

§ 85. Die ₹rift zur Finlegung ber Berufung beträgt

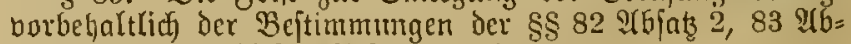
joks 2 und 157 dicfes Gefekses 2 Wodjen.

\$ 86. Эunterfalb der in $\$ 85$ gedadjten Frifit ift, hei

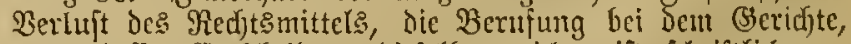
gegen Deffen (Entid)eioung diejelbe getid)tet ift, (d)riftlict) an= zumelden und ơ rechtjertigen.

Das (Serid)t prüft, ob bie :T(nmeloung red)tzeitig erfolgt

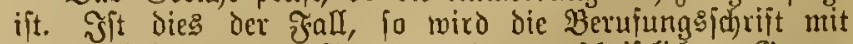
ifjen PInlagen der (S'egenpartei jux fubriftid)en (jegen= erflärung imiterfalb ciner beftimmten, von 1 bi: ju 4 23od)en ju bemelfenden ₹̛rift jugejertigt.

Bur Techtfertigung ber Bernfung, jowie jur Begen= erflärung fant in midjt fchleunigen sadjen eine angemejiene,

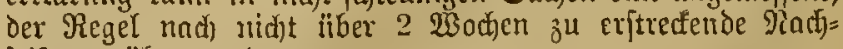
jrift gemährt toerden.

Şt die Frift berfäunt, jo ift die Berufung ofne $\mathfrak{W}$ eitere:

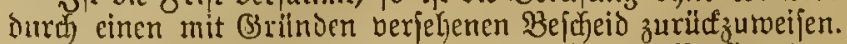

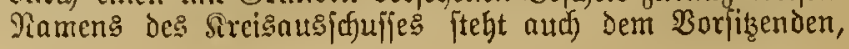




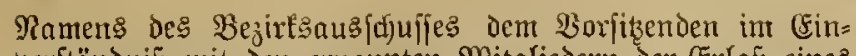
verftänontî́ mit Den ermannten Mitgliedern Der Erlás eines

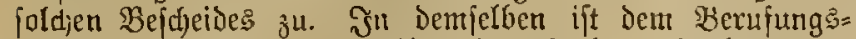

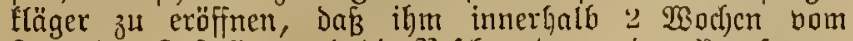
Tage der Zuftelung ab die Befdymerie an das Berufungs:

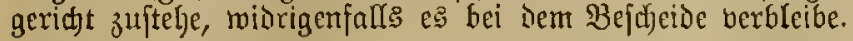

§ 87. Der Berujungsbeflagte famı fid) Der Berujung anjoblieben, jelbjt twenn bie Berujungsfrift verjtrichen ift.

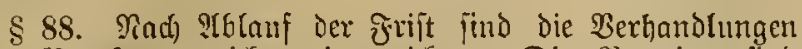
Dem Berufutgggeridate einzureidjen. Die Garteien find hicroon unter abfdrriftlicher Mittheilung der eingegnngenen (Gegenerflärungen ju Genachrid)tigen.

§ 89. Bezü̈glid Der bon einer \$artei eingelegten $\mathfrak{B e}=$ rufung findet Die $\mathfrak{B}$ eftimmung Deङ $\$ 67$ für Das Berufungs:

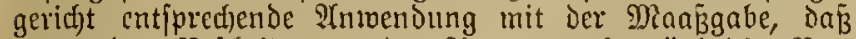
gegen den Bejdeid nut der 2Intrag auf milnblide $\mathfrak{B} e r=$ bandlung zuläffig ift.

Die ?tbünderung der Durd) Berufung angefodhtenen (Fnt= (d)eidung findet nur nach vorgängiger 2lnbcraumung der mündfidjen Berthandlung fratt.

\$ 90. Die \&aiung Der Barteien zแr mündlidjen $\mathfrak{B} e r=$

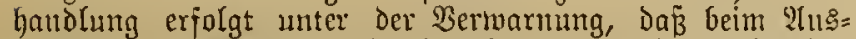
bleiben nad) Sage der Berbandlungen merde entjdjeden werden. Int gleidjer Weije erjolgt it den fällen der $\mathfrak{B}=$ rufung aus Bründen Des offentlichen Эntereffes die \&adung bes zur Bertretung deffelfon beftelften Fiommifjars.

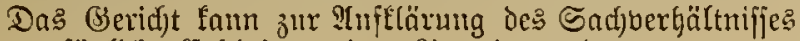
ons perfönlidje (Erfdeinet einer Fartei antoromen.

§ 91. Şit bie Berufung von dem Borïßzenden Des

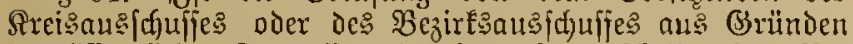
De: öffentlidjen Interejies eingelegt, fo enticteidet Das $\mathfrak{B} e=$

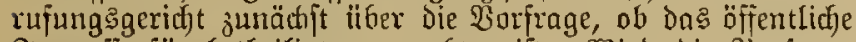
Snterefie für betheifigt zu eractent ift. Woird die vorfinge verneint, fo weift das Berufungsgericht, ohne in llebrigen in die Sadhe jelbit cinjutreten, bic Berufung als unfatthaft zurücte.

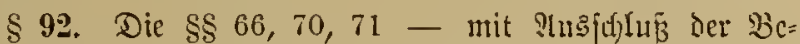

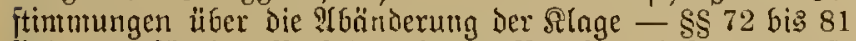
find aud für Das Berjabren in Der Berujungsinjtanz maa $\tilde{\beta}=$ gebend.

Die Bufertigntmg Der (Entidjeidung erfolgt Durcti Der: mittelung Desjenigen Berichts, gegen dejjen Entjpeidung die Berujung cingelegt worden war.

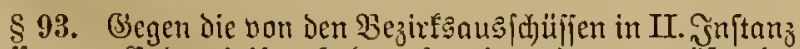
erlajienen Endurtheile fteht, foweit nidht geatä́b be=

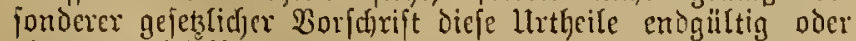
bie gegen biejelben ftattfintenden Rechtsmittel in abrveidfender Weije geregelt find, Den Partein Das Rechtsmittel Der

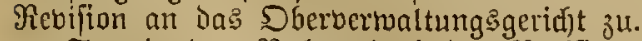

Sotweit Das Rechtsmittel Der gievifion überhaupt iu= gelaffen ift, fteljt Dafjelbe aus (Siründen Des offfentlicten

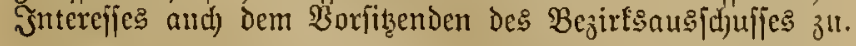

\$ 94. Die Revifion fann mur Darauf geititist rerden:

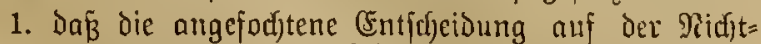
anmenoung oder auf ber unridfigen ITnwendung Des bejtehenden Recht: insbefondere audj Der bour den Behörden imerhalb iłrer 3uftändigfeit er= lajfenen Beroronungen berube;

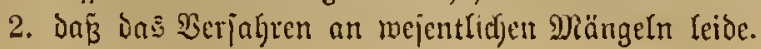

§ 95. Die Beftimmungen Des $\S 66$, De $\$ 71$ - mit

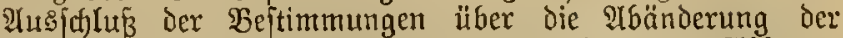

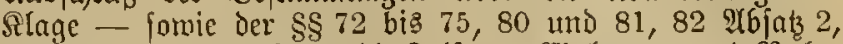

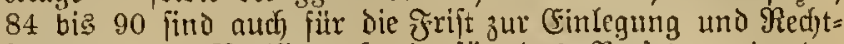
fertigung oer Rebifion, powie jür das $\mathfrak{B}$ erjahten in oer Rebifionsinftanz manß̧gefend.

Die P(nmeldung uno Rechtfertigung Der Revifion hat bei demjenigen (Sieridjte zu erfolgen, weld)es in I. Эuitanz entidjeden hat.

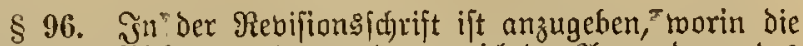

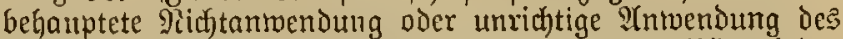
beftehenden Red)ts oder worin die behaupteten Mïngel bes Serfahrens gefunden verden.

\$ 9\%. Das Dberverwaltungsgerifft ift bei feiner Ent= jucioung an diejentigen (Bründe nicht gebunden, welche jur Red)tfertigung Der geitellten $\mathfrak{A}$ nträge geltend gemad)t worden find.

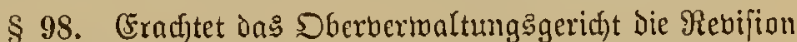
fïr begrïndet, fo hebt $\mathfrak{e s}^{\mathrm{s}}$ die angefodtene (Entidjeioung auf umb entf(c)eidet in Der Sache jelbit, menn dieje fprudjeif erfdeint. Die 3ufertigung Der (Entid)eidung erfolgt dured Sermittelung besjenigen (Serichts, meldjes in I. J̄nitans enticticden hat.

§ 99. Эit die Sache nicht iprudifreif, fo meift das Dober= berwalungsgeridtt biejelbe zur anderweitigen Entjd)eidung

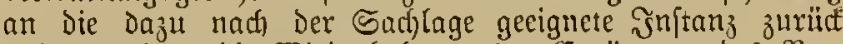
und verorduet Die Wicderfolung oder Crrgänzung Des $\mathfrak{B e r}=$ fahrens, fotweit es nad) jeinem (Ermejfen mit einem refentlidjen Mangel behajtet ift.

$\S 100$. Begen die im Vertoaltungsftreituerfahren er= gangenen, rectutsfräftig gewordenen (Endurtheile findet die SIage auf Wiederaufnabme bes $\mathfrak{B e r f a h r e n s ~ u n t e r ~ D e n f e l b e n ~}$ Vorausferzungen, in Demiflben llmfange und innerfjalb Der=

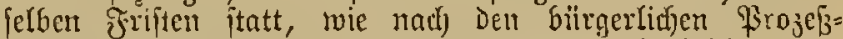

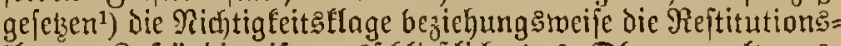

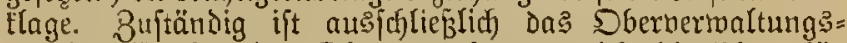

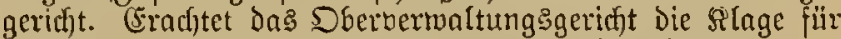
begründet, fo hebt ė Die angefodjtene Entjedjeioung auf, verweift die Sadje zur anderweitigen (Entfecheiong an die

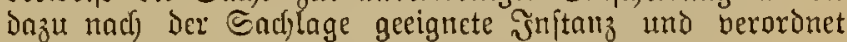

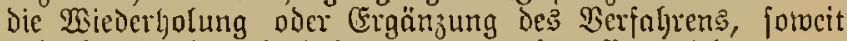
Oafjelbe bon Dent Infectutungsganue betroffell wiro.

1) $\S \S 541-544,549$ ฮ\$D.

\$101. Das (Seridyt, an treldjes die Sadje in Len Fällen ber $\$ \S 99,100$ getwiefen wiro, hat bei bem weiteren Werfahren und bei der von ihm anderweitig zt treffenden

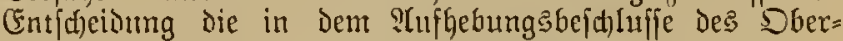
verwaltungsgerichts aufgeftellten Grundfätze, porvie in den

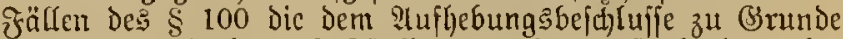
gelegten thatfät)lichen Jeftitellungen als maafigebend zu be= tradteten.

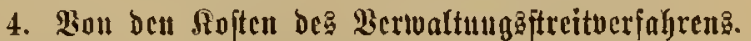

$\S 102$. Das Berwaltungsftteituerfahren ijt jtempelfrei.

\$ 103. Dem unterlisgenden Theile find die Soften uno

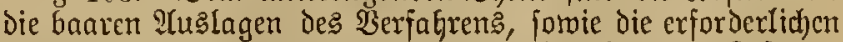
baaren Huslagen Des offiegenden Theils zur \&ajt ou

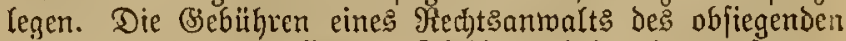
Theirs hat Der unterliegende Theil nutr infoweit zu erftatten, 


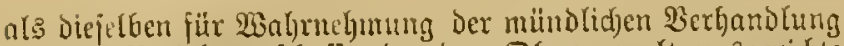

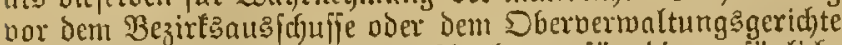

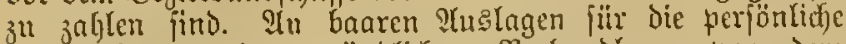

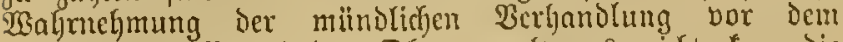
Bezinfsausfdhuje und dem Dferverroltungsgeridte fann bie

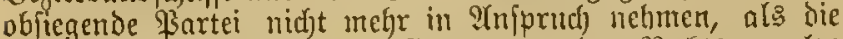
gejetzlicten (Bebübren cintes fie vertretenden Rechtsanmalt: betragen haben wilrden, es jei Denn, dấ ilje perfönlicjes (Frifheinen yon den (Berichte angeoronet war.

Int (Endurtheile ijt Der $\mathfrak{B e r t h}$ bes Streitobjeftes jejt= 3ujekien.

Dic (Gebülyren Der Rechtsanmalte beitimnten jid nady den fïr Diejelben bei den ordentlidjen Beridften geltenden Boridfriften.

\$ 10t. Die Soften und baaren ?Tulagen bleiben dent obfiegenden Theile zur Rajt, jormeit fie burd) fein eigenes Berichulden entitanden find.

§ 105. Die (Sntf(heidung über Den Roîtenpunft (\$\$ 103, 104) fam nur gleidjeitig mit Der (Entfheidung in Der Sauptjache burd) Serufung oder Rebifinn angefochten merden.

\$ 106. II Sioften tommt ein Paujdquantum zur

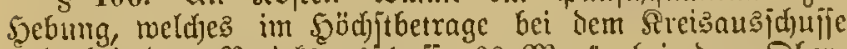
und be Dem Bezirtsausiltulje 60 Mart, bei bem Dher= vermaltungsgerichte 150 Diart nid)t iberiteigen Darf. Fïr bie (Gebiifren Der Beugen und Sadjeerjtändigen gelten die in (Evilprojeffen zur ?tnwendung fommenden Boridfiften, fiir Die Bered)nnng De? Banf(d)quantum? fann bon ben Miniftern Der Finanzen und De: Jnnem ein Tarif auf= gejtellt werden. $\left.{ }^{1}\right)$

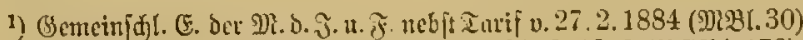

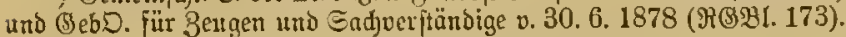

$\S 10 \%$ Die (srbebung des finafuquantums findet (1iid)t itatt:

1. wenn der unterliegende Theil eime öffentlidje $\mathfrak{B} e=$ jörde ift, injorweit bie angefodjtene Berfügung oder Entflheidung Derjelben nidjt lebiglid die Wafhrung ber Saughaltsinterefien eines von Der Behörbe vertretenen Stommmmalverbandes zum Geaenftande hatte; die baarell $\mathfrak{T}$ tulagen dez Derfaljens und des objiegenden I Ieils falen dem= jenigen zur Rajt, Der nach gejekzlidjer Beftimmung Die AmtEutoften Der Bethïroe su tragen hat;

2. wenn die Entidheidung oljne vorgängige mïno= liche Bertyandlung exjolgt ift;

3. bei Dem Sreisanझidulfie in ben Fïnllen der $\$ 60$ bis 62 des (Befeckes vom 8. M)är 1871 , betreffend die Tlusführung Des B̉ntesgefetzes ibber den llnter= itüßzungsmohniţ (\$S. 130);

4. bei Dem Bezirtsomsjelltife und bei dem Dher= vermaltungsgeridite, forbeit bie B̉erüung ober bie

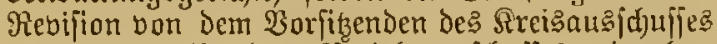
bezichungsmeije des Bెezirfsausjd)ujfę eingelegt morder mar;

5. von Denjenigen Ferjonen, mit Thonahme jedod Der (Semeinden in den Die Bermaltung Der ?trmen= pflege betreffenden Irgelegenheiten, benen nad) Den

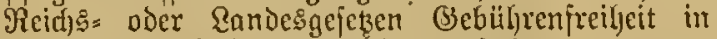
bürgerlichen Red)tsftreitigfeiter zultel)t.

§ 108. Sie Roften und baaren MUझโagen des Berfahren: werden jür jede รnjtanz bon Dem Bericjte jeftgejekt, bei Dem bie Sarbe felbit antängig gervejen ift.
Dic von Der obfiegenden Partei zแแ Erjtattung feitens Des unterliegenden Theils 〔iquibirten 2luslagen werden für

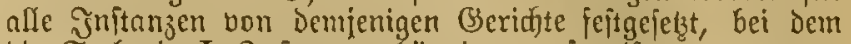
bie Sache in I. Jnjtanz nuthüngig gemejen ift.

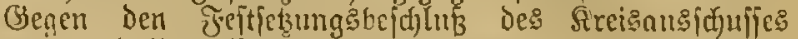

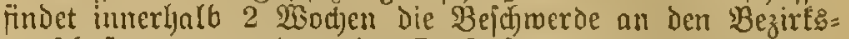

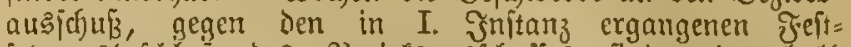

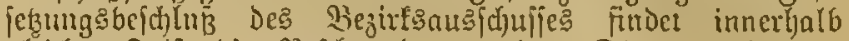
gleidjer Jrift die Befdurverde an Das Sberberwaltungs: gerid)t ftatt.

§ 109. Dem unterliegenien Theile fann im Falle Deß beid)einigten Unvermögens nach Maafigabe ocr Beftumnungen

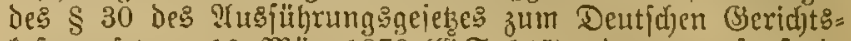

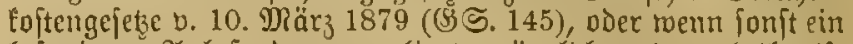
Gejonderer ? Inla Sioftenjreiheit bejieljungšmeife Stundung bemilligt merden.

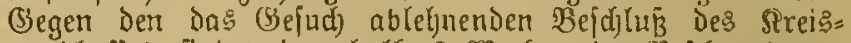

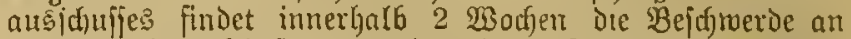

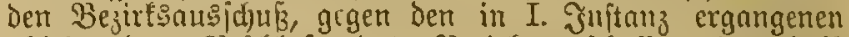

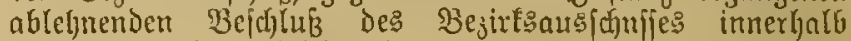

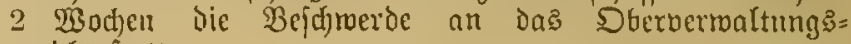
geridgt itatt.

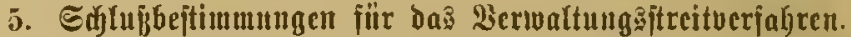

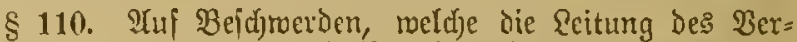
jahrens bei Den Sreis= und Sezirtsautsifjüljen zum Begen=

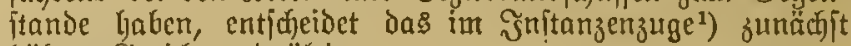
höhere (Seridjt enogilltig.

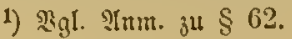

\$111. Stle Viefdrerden find innerhalb der für bie= jelben vorgejdricbesien Frijt bei Dem (Berid)te, gegen deffen Entjujeidung fie gerid)tet find, einzulegen.

Das (Seridit berfährt bei Verjäumung der borge=

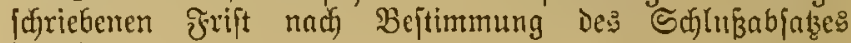
Deछ \$ 86.

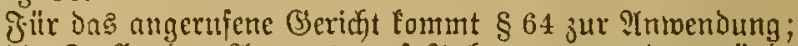
an bie Stelle bes ?tntrags auf Anberaumung ber mïno:

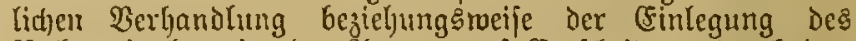

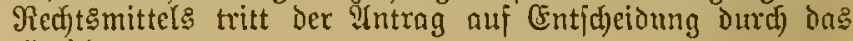
Sericht.

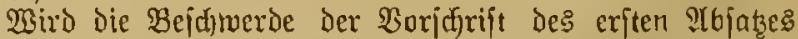
zumider innerhalb der gefetzlichen frift bei Demtenigen

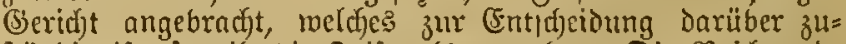
ftändig ift, po gilt die ơrift als gewahrt. Die Bejd)werde ift in polften Fülfen oon dem angeruienen (Berid)te zur weiteren Beranlajiung an dasejenige (Serid)t abzugetien, gegen deffen $\mathfrak{B e j d}$ lui fie gerichtet ift.

\$112. Die Wiedereinjeţung in Den borigen Stand fann beantragen, wer Durd Raturereignifie oder andere unabmeisbare Bufäle verhindert worden ift, die in dem gegenmärrigen (Sejekge doer Die in Den Bejez̧en für थnjtellumg ber Ŝlage bejiehunggsweife für den Întrag auf mitndlidje Berfanolung im Berivaltungs freitwerfahren voraejhriebenen

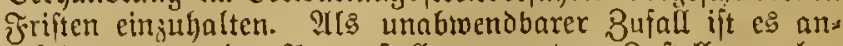
zujehen, menn Der Antragitefler von einer Buftellung ofjne

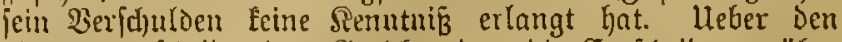
Antrag entldeidet Das Geridft, Dem Die Entfd)eidung über die verfäumle Streithandlung zufteht. Die verfäumte Streithanolung ift, unter Inführung der Thatjadjen, muttelit Deren der IYntrag anf Wiedereinjek̨ung begrïndet rerden foll, fowie Der Betweismittel, innerbalb 2 Wodjen nad)s 
zuholen; Der Rauf diejer frrift beginnt mit dem :Iblauf Des

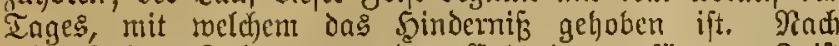
IL

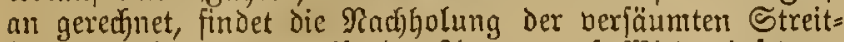
bandung beztehungsmeife ber 9htrag auf Wiedereinfebsung nidft mehr itatt. Die Durd) (Erörterung Des SIntrags auf

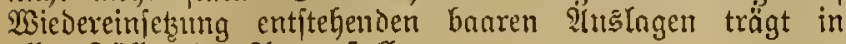
allen ङ̈ällen der গIttrngiteller.

\$113. Die Central= uno bie \$robinzialvermaltungs: behörden find auch fiir die im Bermaltungsftreitberfahren zu berljandelnden Stugelegenheiten zur Erhebung Des Sompeteriźtanflitte befugt. ${ }^{1}$ )

Die Erhebung Des Rompetenzfonflifts auf Esrumb Der Beljauptung, da: in cincr in Berroaltungşftreitverfahren antängig gemad)ten Sadje eine andere Bertoaltungsbehöroc ôuftöndig jei, findet nid)t itntt.

Die zur Entidcheidung im Bermaltunggifreitberfahren

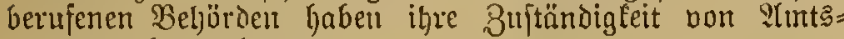
megen wahijuttelyetr.

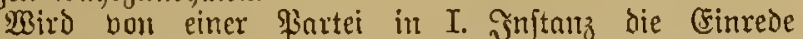
der Ilnjuftändigfeit ergoben, fo fam über diejelbe vornb entifjiedent roerdert.

Saben fidf in berfelben Sache bie zur (Entfiseidung im

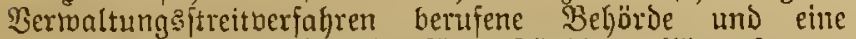
anvere Vermaltungşachörde fïr juftändig erflärt, fo ent=

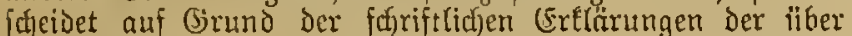

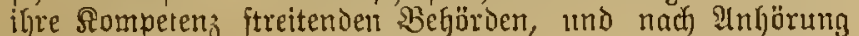
Der Farteien in mündlidber Berbandlung, dos Dót= verwaltungsagexidjt. Dos Bleidje gilt in Dem Falle, mentr beide Theile fiud in Der Sadje fïr unzultändig erflärt ljaben.

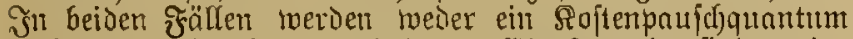
noch baare \$ltislagen erhabeli. Ébenjotwenig findet eine Erfitattung der Den \$arteien erroadjemoen ßojten ftatt.

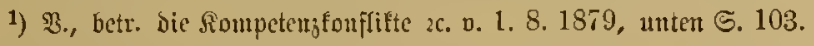

$\S 114$. Die gemäl § 11 Des (Finfülyrungsgeiekes jum

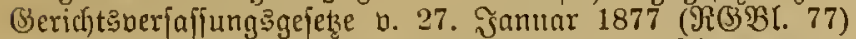
Dem Dberberwaltung geridjte zuftehenden Porenticheidungen $\left.{ }^{1}\right)$ erfalgen in Dent ourd) den lejten 216 ats bes $\$ 113$ diefe? (Sejebes vorgefditiebenen $B e r f a l y r e n$, für reldhes in llebrigen die Barjariften über das Berwaltunggftreitberfalyren ent= fprecfiende :mwendung finden.

1) bei geridtliden Berfolgungen ber Beamten wegen AImtahtamb= lutugen. Gejeb v. 13. 2, 1854, unten S. 107.

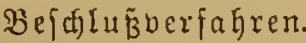

\$ 115. Betrifft Der (S)egenftand Der Bertjandtung einzelne Mitglieder der Begärde pder Deren Bermandte und Ser: id)rägerte in auf= und abjteigender (inie ober bie zum 3. Sirabe Dex Seitentinie, fo dürjen diefelber an der Berathung und ?lGitimmung nidjt theilnelgnen. (Ebenfo= twenig Darf ein Mitglied bei Der Bernthung und Beid)lußs= fajiung über joldje IIngelegenbeiten mitwirken, in weldhen es in andere? alş biffentlid)er (Sigenjujaft ein (Butachten $a b=$ gegeben hat, oder als Bejdjöftiłiiibrer, Beauftragter oder in anderer als offentlicher Stellung thätig gewejen ift.

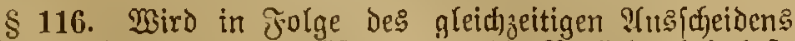

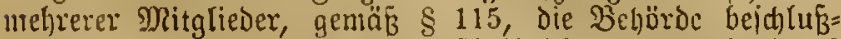

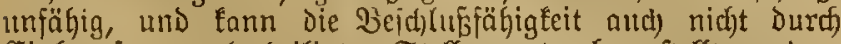
Cinberufung unbetheiligter Stelloertreter hergeftelft roerden,

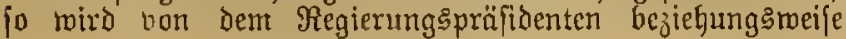

Dberpxöfidenten oder Minifter des Snnern, je nadjoent es

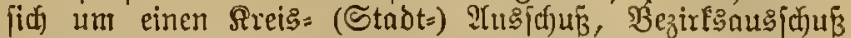
oder Frobinzialrath handelt, ein nnderer fretg= oder Stadt=

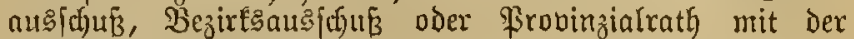
Bejd]lusffofiung benuftragt.

Für Den Stadtfreiß BerIin fteht die Bcauftragung an Stelle des Regierungşpräfidenten dem Dberpräfidenten zu.

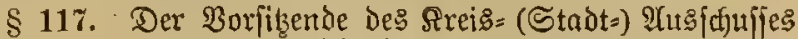
ift bejugt, in fällen, welche leinen Yuffdjub zula fien, ober

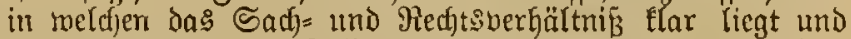

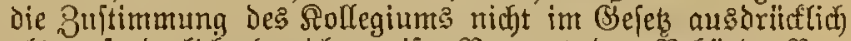
als erforderlich bezeidunet ift, Ramens Der Behörde Ber= fügungen zu extaffen und Befdetide ju ertheilen.

Die gleidje SBefugnif̈ fteht dem Borfizenien des $\mathfrak{B C}=$

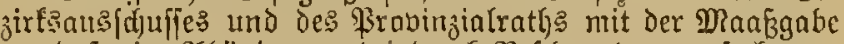

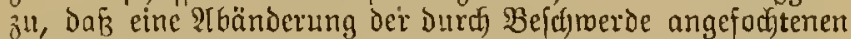

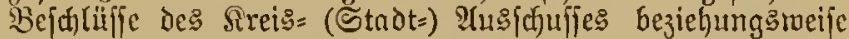

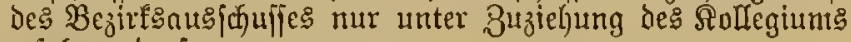
erfolgen darf.

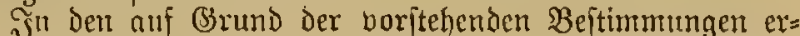
Iajfetien Berfügungen uno Bejoljeioen ift den Betheiligten, jofern Deren Antrügent nidft ftattgegeben wird, zu eröfinen,

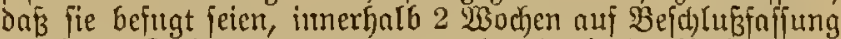

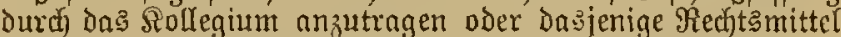
einzulegen, welches zulăffig wäre, wenn bie \$erfïgung be, jiehungsmeije Der Befdeio auf Bejdjlub des Rollegiums er= folgt toäre.

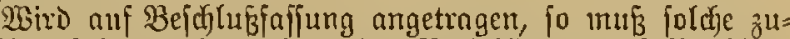
näd)ft erfolgen. Sent einer der $\mathfrak{B e t h e i l i g t e i t ~ n u f ~ B e i c h l u f ~}$ faffung angetragen, ein anderer Das Rechtsmittel cingelegt,

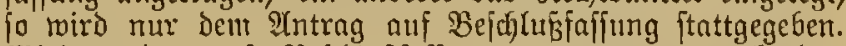
Wirs weder ouf Befdilubfafilung angetragen, nod Das Rechtomittel eingelegt, jo gilt bie Berfügung beziehung:

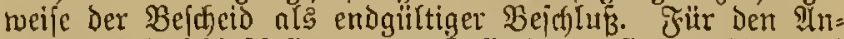
trag auf $\mathfrak{B e j d}$ lufffaffung beg Sollegiums fitben bie nadj den $\$ \$ 52$ und 53 für die Bejumerde geltenden $\mathfrak{B} e=$ ftimmungen 2 (n)mendung.

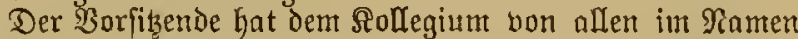
Dejielben ertaffenen Berfïgungen und ertheilten Bejohetben nadträglich Plittheilung zu mtncher.

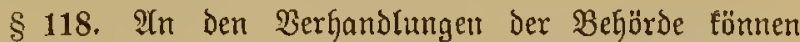
unter: Bufinimung Des Rollegiums tecfurijiche Stants= oder Sommunalbeamte nit berathender Stintme theilnehmen.

$\S 119$. Die Bebörden fafjen ihre Befchliffe auf Brund

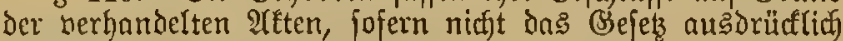
mündlid)e Serbandlung boridfreibt.

Die Beförden find befugt, auty in anderen, $n$ ts in ben im (Sejetze ausdriifflich) bezeid)neten 21 ingelegenheiten die $\mathfrak{B} e=$ theiligten beziefungsmeife deren mit Boulmadjt berfehene Vertreter $\mathfrak{B}$ hแt Berljandlung vorzula hent.

Эn Betreff ber mündlidjen Bertyandlung finden im llebrigen die Borfdriften der $\$ \S 68,71,72,73$ und 75 finngemtäß̈в $\mathfrak{A}$ htmenoung.

\$120. Fï bie Erffebung und $\mathfrak{B}$ ürbigung Des $\mathfrak{B}=$

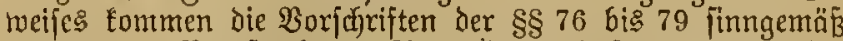
und mit der Maażgabe zแt Antweridung, Dấ gegen Den eine Strafe ober die Nichtberpflidftung eines Beugen oder Sadf=

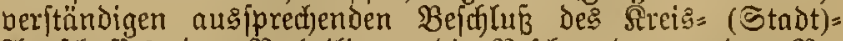

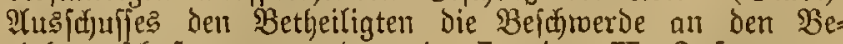
zirksaus/dfui, gegen den in I. oder II. Snjtanz er= gangenen Bejhluß Des lekteren oder bes \$3rovinzialrath: 
innerhalb gleicher frift bie Befdumerde an bas Sber= vermaltungsgericht zujtelgt.

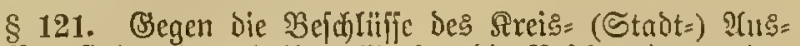
(c) ulfes findet immerlyalb 2 Wodfen bie Befunterbe an ben

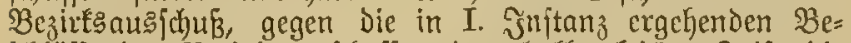

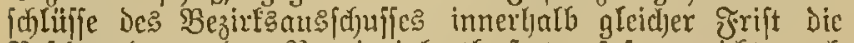
Befchmerde an Den Sirobinzialrath ftatt, fofern nidjt nach

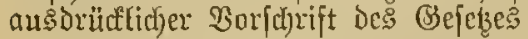

1. Die $\mathfrak{B}$ ejulitifie endgültig fino,

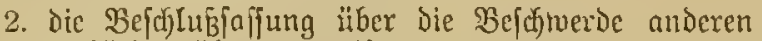
Beljörtoen ïbertragen ijt.

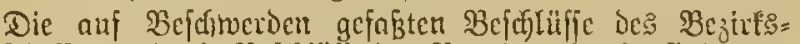

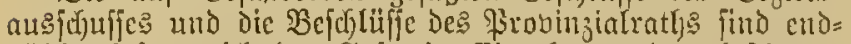
gitltig, fofern nidjt bas Befes im Einjelnen andors beftimnt.

Dic borftelienten Beftimmungen finden anf bic nad Maaßjgabe der Gefetze bon dem \&ambrathe unter 3 uptimmung Des Rreisauş Buftumung des Bezirfsans unter 8uitimmung Des Brobinjialratljs gejafiten Bejdyliffic entiprechende întoendung.

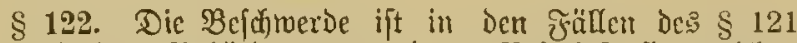
bei Derjenigen Beljäroc, gegen Deren Befdhlub fie geridjtet

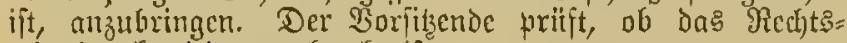
mittel rect)tzeitig angebradjt ift.

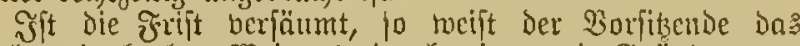
Rect)tsmittel olme Wciteres burd cinen mit (sründen ber=

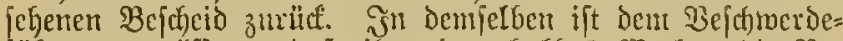

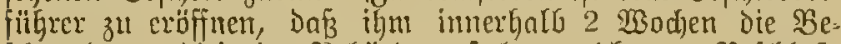

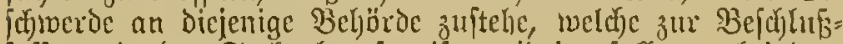
fafiung in ber Sache berufen ift, wiorigenfats es bei Dem Beicheide verbleibe.

Jit die đrift getwalyet, und ift cine (segenpartei vor=

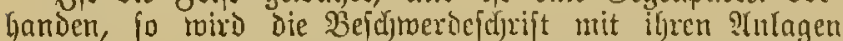

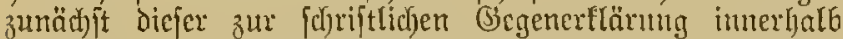
2 23odjen zugefertigt. Dic (segenpartei fann fid) Demt Red)timittel anf(hließen, felbft wenn die శrift berftriden ift.

?tbid)rift der cingegangenen (Begenerflärung crhält ber

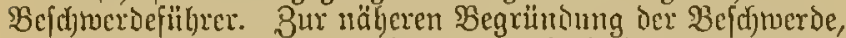
jowic zur Bsegenertlärnng fann in nicht fothlemigen Sachen

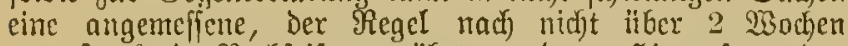
3u exftrecfende Rachfrift gervährt werden. Seieranf twerden Die Verljandlungen mittelft Beridjt: Derjenigen Behörbe cin=

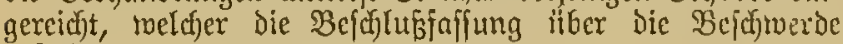
zu[telyt.

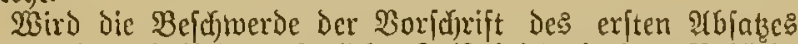

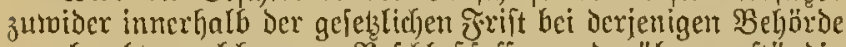

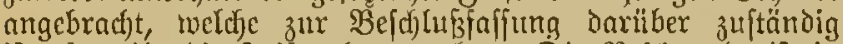
ift, fo gilt bie Jrift als gewalyrt. Dic Befchmerde ift in

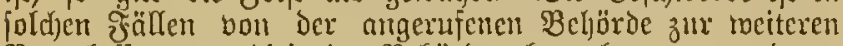

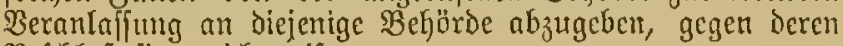
Befdiluß jie geridjtet ift.

\$ 123. Dic Einlegung Der Befdjmerde fteht in Den

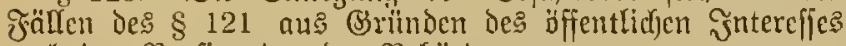
aud) Den פ̧orfizenden Der Beförden zu.

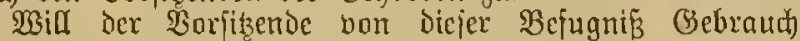
machen, fo hat er Dics Dem Stolleginm fofort mitzutheilen.

Die Buftellung des $\mathfrak{B}$ efduluffes bleibt in biefem Falle eimftubilen, jedod) längitens 3 Tage, autigefctzt. Sic ex=

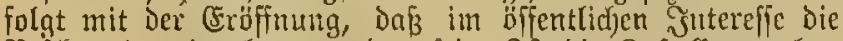
Beidjwerde cingelegt rourden jei. Jit Die Buftellung oljne bicfe cröffentug erfolgt, fo gift bie Beffiwerde als zuriffe genomment.
Die (Bründe dex Befuntwerde find den Betgeiligten zur jodriftlid)en (Erelärung innerbalb 2 Wodjen mitzutheilen.

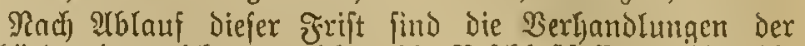
Befjörde einzureidjen, melctjer die Befdrlubfaffung über Dic Bejdytocrde jufteht.

Finc borläufige Boßftrectung Des mit Der Befdymerde

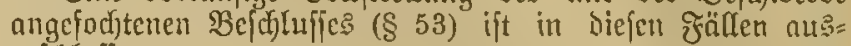
geficlofifen.

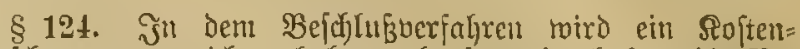
paujchquantum richt erhoben, ebenjowenig haben die $\mathbb{B} e=$

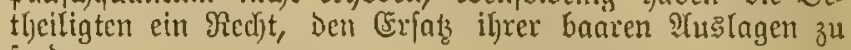
fordert.

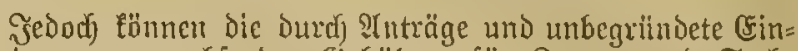
menbungen ctroadjpenoen (Bebillyren für Beugen und Sad)= berftänbige Demjenigen zur \&ajt gelegt merden, joelderer Den Shitrag geftellt bezichungsmeife Den (Finmand erljoben lyat.

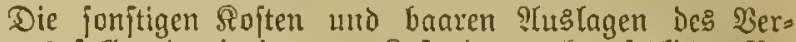
jaljrens faflen Demjenigen zur \&nit, der nad) gejetzlicher $\mathfrak{B} \subset=$ itmmung bie stmtsunfoften der Sefjöbe zu tragen hat.

Bei Den $\mathfrak{B a r f d j r i f t e n ~ D e s ~ ( S e t b e r b e o r o n u n g ~ b e h a ̈ l t ~ c ̧ ~ f e i n ~}$ Sectuenden.

§ 125. Heber B̊cfjmerDen, meldfe Die Reitung Des Ber: jahrens und bie Roîten betreffen, bejhließst endgifltig die in

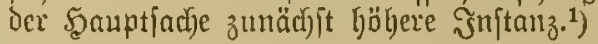

1) $\mathfrak{g l .} \S 121$.

§ 126. Der Sherpräfioent famt cudoültige Bejdjlüfie ถes Grovinzialratls, Der Regierungspräfioent endaültige Bejullitfie Des Bezirfiausichuffes und der Sandrath, be=

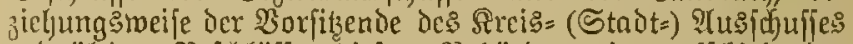

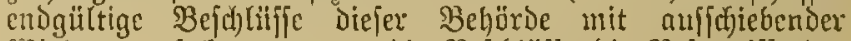
23irfung anfechten, wenn die Bejullifje die Befugniffe ber Beljöroc itberfahreiten ober ons beftehende Redht, insbefondere auch die bon den Bef̧örden innerhalb igrer Buftändigfeit erleffenen Beroronungen, berletzen. Die Stnfechtung exfolgt mittelft $\mathfrak{R}$ lage beim Dbervermaltungsgerid)t.

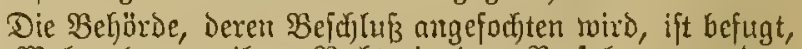

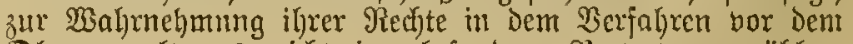
Dbernermaltungsgericht einen befonderen Dertreter zu wäblen.

\section{Citel. Z̈edftsutiftel gegen polizcilidfe כơrfügutugen. ${ }^{\text {) }}$}

§ 12\%. Begen polizeilicte Berfïgungen der Dorts= uni

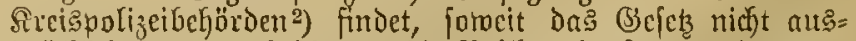

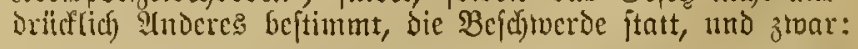

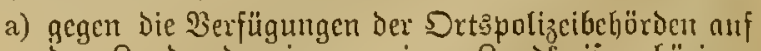
bem Rande oder einer zu einem Ranbfieije geförigen Stabt, deren Sintwohnerzahl bis zu 10000 Ëits= moljnern beträgt, an Den Randrath 1und gegen Deffen Beffeid an Den Regierungspräfidenten;

b) gegen bic Berfïgungen ber Drtspolizeibeförocn eines Stabtfreifes, mit Slusnahne bot Sertin, einer zu einem Samblieife geförigen Staot mit melyr als 10000 Einmolynern, oder des \&aniraths an Den Regierungıpräfibenten, und gegen Deffen Bejueid an Den Sberpräpidenten;

c) gegen ortspolizciliche Berïigungen in Berlin an Den Dberpräfibenten. 
(B)egen den in lekzter Snftanz ergangenen Bejucid des Regierungspräfỉenten Geziehungsmeife Des Sberpräfidenten findet bie §lage bei Dem Sbervermalturnggeridjte ftatt.

Die Silage fanm mur darauf geftïłst weroen,

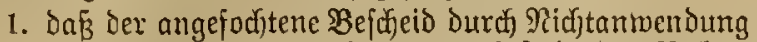
oder untiditige ITnmendung des beiteljenden Rechts, insbefondere aud) Der von den Behjörden immerhalb iGre: Bujtändigfeit exlafienen Berordnungen den

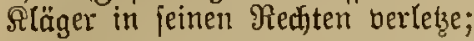

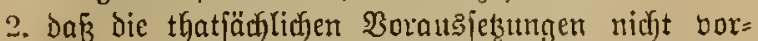
lamben feien, weldje die \$olizetbejärde zum crtaffe Der Serjügung beredtigt haben mürden.

Dic Prüfung Det Bjefekmäşigkeit Der angefocftenen

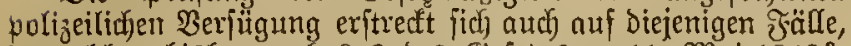
in meldten bisker naw $\$ 2$ Des (Beletzes b. 11 . Mai $1842^{3}$ )

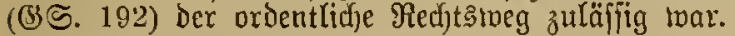

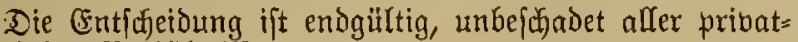

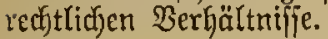

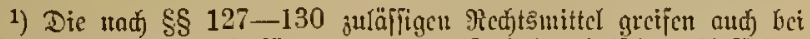

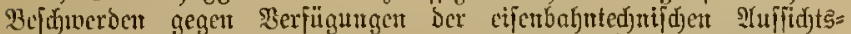

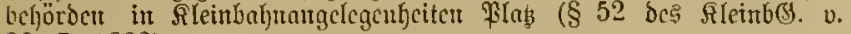
28. 7. 1892).

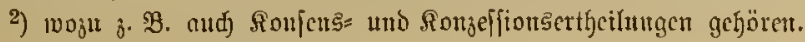

3) untert S. 109 abgedruteft.

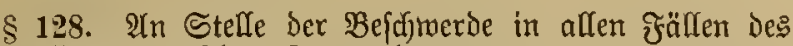
\$ 127 findet bie Rlage itatt und jwar:

a) gegen Die Berfügungen Der Drtipolizeibehörden auf bent Sande ober ciner ju cinem Ennotreife gehörigen Stadt, Deren Eimmohnerzahy bis zu 10000 Einmohnern beträgt, bei Dem ßreis:

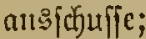

b) gegen bie Seriitgungen des Randrathes oder ber Srtspolizeibetiorden eintes Stadtfreifes oder ciner zu einem Randtreife gehörigen Stabt mit mehr aโร 10000 (sintwohnern bei Dem Bezirfsausfduffe.

Die Rlage fann nur auf bie gleidjen Befjauptungen ge= ftiltst rerden, wie die Rlage bei Dem Sberverwaltungs= geridfte (§ 127 शthi. 3 und 4).

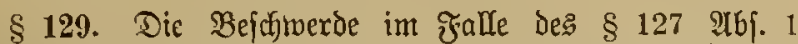
und bie Rlage im ₹alfe Desి $\$ 128$ fint bei derjeniget Beförbe anjubrittgen, gegen deren $\mathfrak{B e r f u ̈ g i t t g ~ f i e ~} \mathfrak{g} \mathfrak{c}=$ ridjtet find.

Die Beförde, bei welcher die Beffimerde oder Rlage angebractst ift, hat biejelbe an biejenige Behörde afuzugeben, meldje dariber zu befahliezen oder zu ent\{cheiven hat. Der 3efatwerdefiibrer beziehungsmeife släger ift fierbon in Senntnif́ z̆ fekert.

Die frift zur Einlegung der Befdiwerde und zur ?tubringung Der אlage gegen Die polizeilicke Berfügung, jowie gegen den auf Befdjwerde ergangenen Bejujeid beträgt 2 Wodjen.

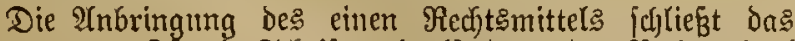
andere aus. Sit bie Sdyrift, mittelft Deren bas Redhtemittel

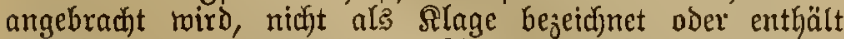
Diejelbe nidjt ausorücflidy Den YYntrag auf Entideidung im Bertwaltungsftreitberfabren, fo gilt biefelbe als \$Beidjwerde. Bei gleidhzeitiger S(nbringung beider Rechtsmittel ift nur ber Befdimerde Fortgang zu geben. Das hiernach unzuläffiger= weife angebradte Redhtsmittel ift Durch Berjügung ber im $\mathfrak{A b F} 1$ bezeidneten SBehörde zurüdfumeijen. Sbegen die

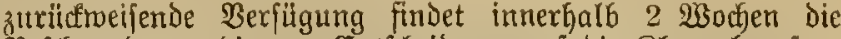
Befumerbe an bie zur Cruthetheing auf Die Slage betujene Beförde jtatt.

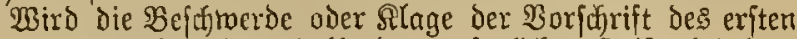

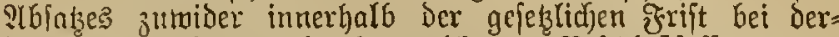
jenigen Sehörde angebradft, toeldje zur $\mathfrak{B}$ efdhlusfajiung oder (Entjueidung barüber zuftündig ift, fo gilt die Frift als ge=

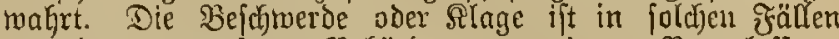
bon Dex angertifenen Bebärde zur treiteren Seranlafjung

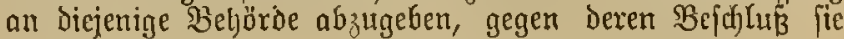
gerichtet ift.

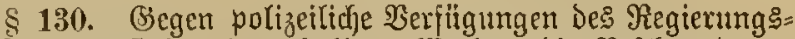
präfidenten findet innerbalb 2 Wodjen bie Bejujnerde an oen Dhcrpräfidenten und gegen ben vom Dberpräfibenten auf die Befdwerde erlaffenen Befdjeid innerfalb gleidjer

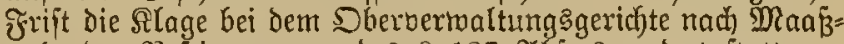

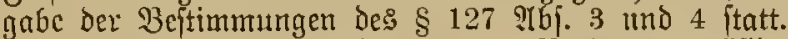

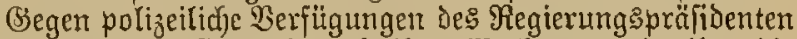
in Sigmaringen findet innerhalb 2 Wodjen ummittelbar Die Rlage bei Dent Dherbertwaltungsgerichte Ftatt.

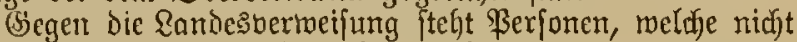

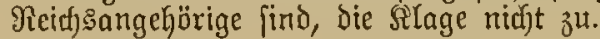

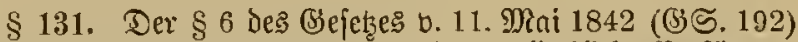

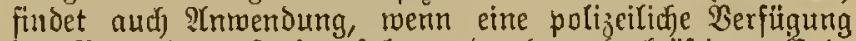
im Bertwaltumgsftreitverfabren burch red)tgfräftiges (End)= urtheil aufgehoben worden ift.

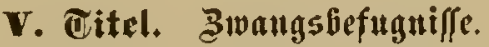

\$132. Der Regierungspräftdent, Der Landrath, Die Drtapolizeibehörde und Der Bsemeinde $=($ Suts $\Rightarrow$ Borjteher

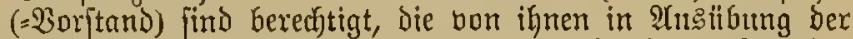
obrigfeitlicfen (bemalt getroffenen, Durd) ifyre gejetslidjen Befugniffe gereditfertigten Stnorsmungen ourch atmwenoumg folgender Brwangsimittel Durchjujeţen:

1. Die Beljöroc hat, fofern es thunlidy ift, die zu er= zrningende Sandlung burd) einen Dritten ausführen zu laffen und ben borläufig zu beftimmenden Softenbetrag im 3roangswege yon Den Berpflichteten cirzuzieken. ${ }^{1}$ )

2. Sann bic z山 crzloingende Sandlung nidyt Durdh einen Dritten geleiftet werben, - oder fteft e's feft, bas ber $\mathfrak{B}$ erpf(id)tete nicht in Stande ift, bie aus Der Stıtsführung Durd cinen Dritten entFte hen= Den Roften zut tragen, - ober foff eine Unter= laffung erztoungen werden, fo find bie Beljörben berechtigt, Geldiptrafen anjudroben und feitzufebsen, utro zroar:

a) Die Bemeinde= (Bistgs) Borftelyer bis jur Söhe von 5 Mart;

b) Die Drţpolizeibeföroen und Die ftädtifujen Gemtinde= Borjteher ( $=$ Borftände) in einem Sandfreife bis zur 5̧öhe bon 60 Marf;

c) Die Ranorätthe, fotvie die \$olizeibegärden und (Siemeinde $=\mathfrak{B}$ oriteher $(=$ Soritände) in einem Stadtfreife bis zur Şölje yon 150 Marf;

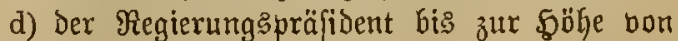
300 Mart.

(S)

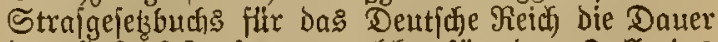
Der Sूaft leftzuleben, weldi)e für ben Fall beg 
Unvermönens an die Stelle der Bselditrafe treten foll. Der Gëchjthetrag Diejer Slajt ijt

$$
\begin{aligned}
& \text { in Den frällen zu } a=\text { (Sin Tag, } \\
& \mathrm{b}=\text { (Fine Wodhe, } \\
& c=8 \text { roei Wadjen, } \\
& \mathrm{d}=\text { Bier } \mathfrak{W} \text { odjen. }
\end{aligned}
$$

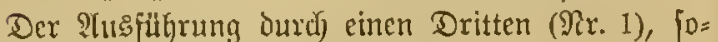
wie der Feftfetung einer Strafe (Nix. 2) muf immer cine fintiftlidise Indrofung borbergeben; in biejer ift, folern eine bandlung erzitwungen toerden fol, bie frzift zu beftimmen, interhalb weldyer bie 2usfithrung gefordert wird.

3. Inmittelbarer Bwang barf mit angetwendet werden, menn die $\mathfrak{A}$ norbmung ohtue einen folchen unausfüfr= bar ift.

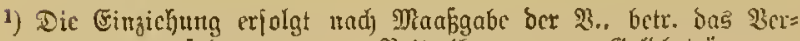
valtungşmantgsverfahren wegen Beitreibung von Belbbcträgen v. 7. 9.1879 (ङீऽ. 591 ).

§ 133. Begen bie 2 ndrohung cines Zmangsిmittels

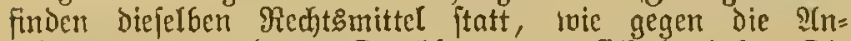
orbnungen, um Deren Durdfetzung eg fidf handelt. Die Rechtismittel exitrecten fich zugleidf auf bieje Anoronungen, fofern diefelben nidjt bereits Begenftand eines befonderen

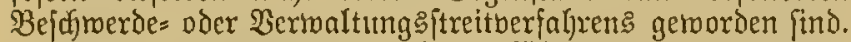

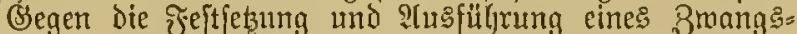

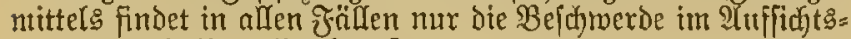
wege innergalb 2 23ochen jtatt.

Saftftrafen, weldje an Stelle einer (Beldjiftrafe nach $\$ 132$ Mr. 2 feftaefetzt find, Dïrfen vor exgangener endgitliger

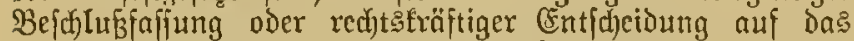
eingelegte Redjtsmittel beziehung:meife bor 2tblauf der jur Cinlegung beffelben bejtimnten ofrift nicht boljtreeft werden.

$\S 134$. Die Bejtimmungen des gegenmärtigen und des IV. Titels finoen finngentäb 2umenoung auf bie be= fonderen Beamten und Drgane, welche zur Beauffidtigung ber fiffjerei bom Stante bejtell find ( $\$ 46$ bes Fifdjerei= gefekes bom 30. Mari 1874, (s) S. 197).

Die Boridyriften der $\$ \S 127,128$ finden in den ₹̈äLen des \$ 2 Yhjat 2 des Bejeßzes, betreffend dic ?Tusführung Des

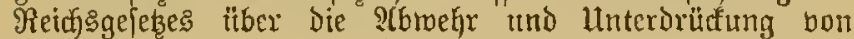

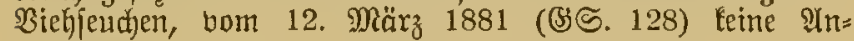
roendung.

§ 135. Ssegen Die Înorohung eines 3mangsmittels feitens der Sommiffarien für die bifdföflidje Bermögcn:s:

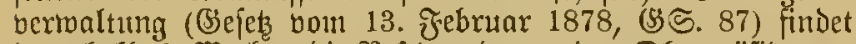

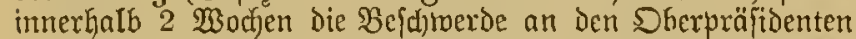
uni gegen den von dem Sberpräfidenten auf bie Bejumerde

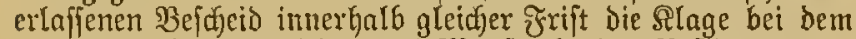
Sbervertmaltungsgerichte nact Maásgabe des: Bejtimmungen Des \& 127 शโbjat 3 umb 4 ftatt.

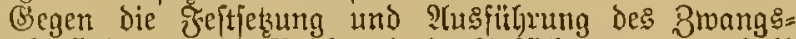

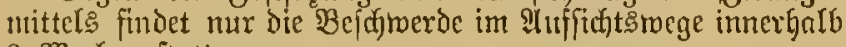
2 Wodjen jtatt.

\section{Titel. Zeofizeiveroromungsedft.}

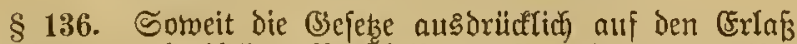
befonderer polizeilicher $\mathfrak{B}$ orfidjriften (Beroronungen, $\mathscr{U}(\mathrm{n}=$ oronutgen, Reglements ze.) Durd) die Eentralbefördent ber: weifen, find bie Minifter befugt, innerlalb igres Refforts

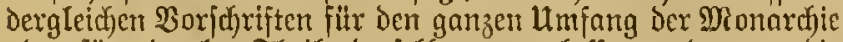
oder für einzelne Ilycile derjeltien zu erlaffen und gegen bie

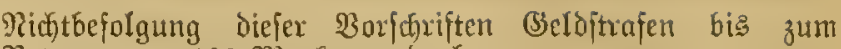
Betrage von 100 Niart anzubrohen.

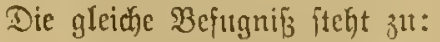

1. Dem Minifter Der D̈ffentlichen QItbeiten in Betreff der Hlebertretungen Der Borfdriften ber (Eijenbahn= Polizei= Reglements; ;

2. den Minifter für Şandel und Bemerbe in 23etreff Der zur Regelung Der Strom=, Schifffaljrts= mut Safenpolizei gu exlaffenden פ̧orfduriften, fojern biefelben fid) über das (sebtet einet cinzelnen Grobinz hinaus erftrecfen follett.

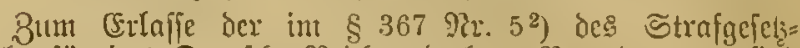

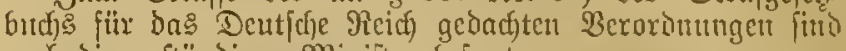
autch dic zuftändigen Dinifter bejugt.

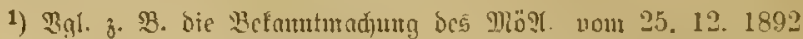

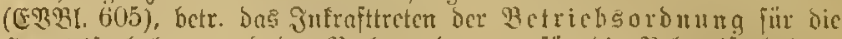

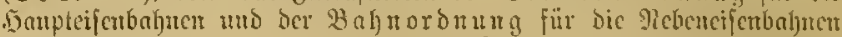

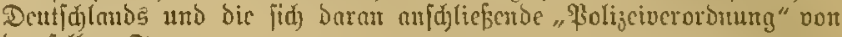
Dcuịclben Tage.

2) Betrifft bie ?tufhemalyrutg ober Beförberung bou (Giftuanent,

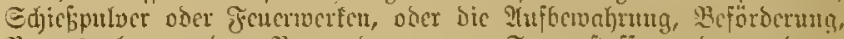

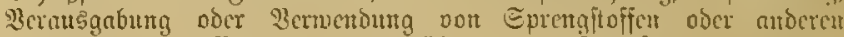

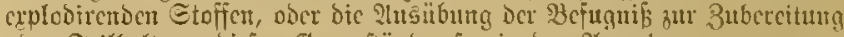

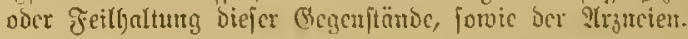

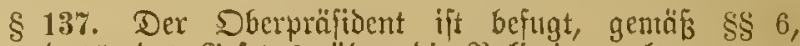
12 und 15 Des Befeckes itber die Bolizeinermaltung vom

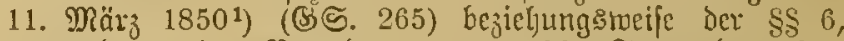
12 tmo 13 ber Veroronumg vont 20. September 1867

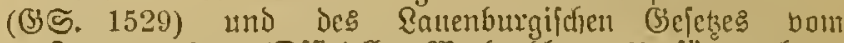
7. Samuar 1870 (Dffijielles Wochenblatt 13) fitr mehrete

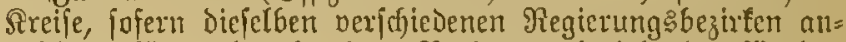

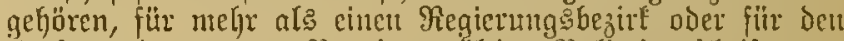
limfang ber ganjen \$robinz gültige Folizcivoridgriften z"l crlaffen und gegen Die Nicfthefolgung Derfelben Beloftrafen bis zum Betrage bon 60 Mart atthorohen.

Die gleiche Befugnif ftelyt dem Regierungepräfidenten

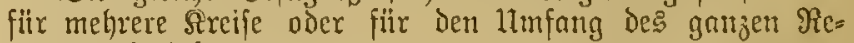
gierungsbezirts zll.

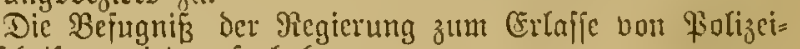
voridfriften wiro aufgehoben.

1) unten S. 109.

§ 138. Die Befugnif3, Bolizeivorfdyriften tiber Begen=

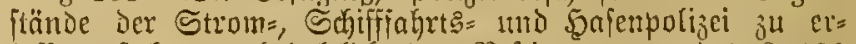
lajien, fteht, borbehaltficf) Der Beftimmungen ves \& 136

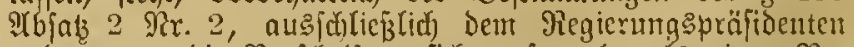
unto, menn dic Borfatriften fidf auf mehr als einen $\Re e=$ gierungsbezinf ober auf bic ganze Grovinz erftrectert follen, Dem Sberpräfitonten, foweit aber int Der Sermaltung diefer 3reige ber \$olizei bejondere, unmittelbar ban dent Minifter fü Sandel mo (Semerbe reffortierende Behörien Geruftragt

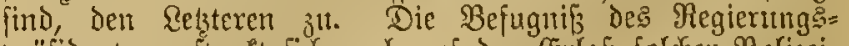

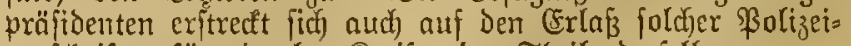
borjdyriften für einzelne 尺reije ober Theile Derfelben.

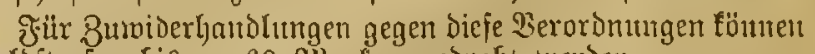
(Gelojtrafen bis ju 60 Diarf angedroljt tuerden.

Bei Den Barfdjriften Des Biefezes bont 9. Mai 1853, betreffend die (Erleidfterung des Rootfengrwanges in delt

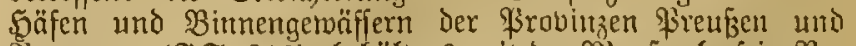

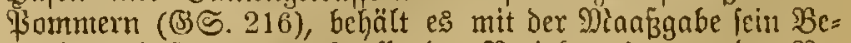
wenten, Daß an bic Stelle ber Bezirfsiegieruitg der Re= gierumgesprófitdent tritt. 
§ 139. Die gemäb $\S \S 137,138$ von Dem Dberpräjidenten

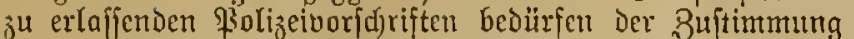

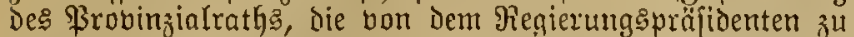
erlafjenden Folizcioorid)riften Der Buftimmung Des Bezirfs=

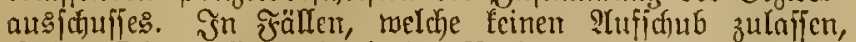
ift Der Dberpräfitient fowie Der Regiernngspräftoent befugt, die Bolizeivoridurift vor Cinfolung Der Bujtmunu des

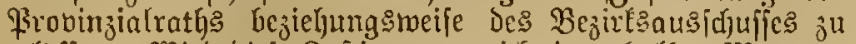
erlaffen. Wird biefe 8ujtimmung nidfyt intrethalb 3 Monaten nad) Dem Iage ber \$ublifation Der \$olizeinorjadyrift ertheilt,

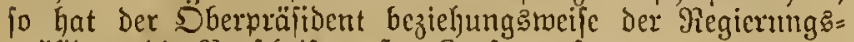
präfibent bie Borjdyrift außBer Sirajt ju feşent.

$\S 140$. Polizeiborfdyriften Der in Den $\S \S 136,137$ umb

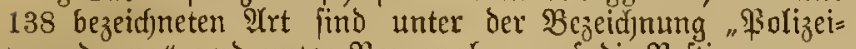
beroronung" und unter $\mathfrak{B}$ ezugnahme auf bie Bcjtimntungen bes \$ 136 bezichunggmeife der $\$ \$ 137$ nder 138, fotwie in den đ̈ällen Des $\$ 137$ auf Die in Demifelfen angezogenen aejeklididen Bejtimnnngen durd) Die Imtablätter Derjentgent Bezirfe befonnt zu madjen, in rocliben biefelben (seltung exlangen jollen.

§ 141. Şit in ciner gemäß $\$ 140$ verfündeten \$olizei= beroromung oer Beitpunkt beftimmt, mit relchem Diejelbe

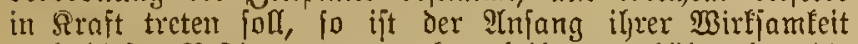
nad) diejer Bejtimmmng ju beurtheilen, entfält aber bie bertiindete Solizeiberoronnng eine folde Beitbejtimmung nidgt, fo beginnt bie Wirffamfeit berjelben mit bent 8. Tage nad) Dem Yibloule besienigen Tagrs, an melcfem das be=

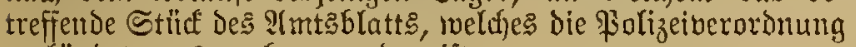
berfiilloct, ausgegeben worden ift.

\$ 142. Der Rmorath ift befugt, unter 3n「timmung Des

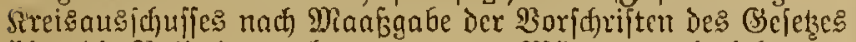

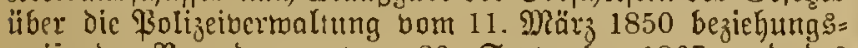
tweije Der Beroromung bom 20. September 1867 und bes Rauenburgifdjen (Beicbes vom 7. Januar 1870 für mehrere Drtspolizeibejirte oder für den ganjen llmijang des Sreifes gültrige Polizeioorjdyriften zlt erlafjen und gegen bie Ridjt= befolgung Derjelben Geloftafen bis zum Betrage voll 30 Miart anzubrohen.

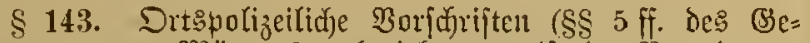

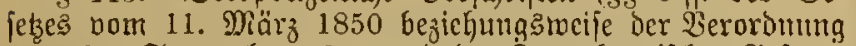
vom 20. September 1867 uno Des \&auenburgijden Sejetses bom 7. Yanuar 1870), forweit fie nidjt jum (Sebiete ber Sicherheitspolizei gehörett, bedirrfen in Stäbten der $B u=$ jitimmung bes SSemeindeborftandes. Berjagt Der Semcinde= borjtant die Zujtimmung, fo fonn diejel6e auf Intrag Der

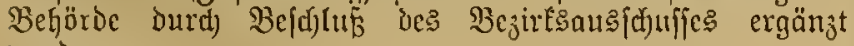
merden.

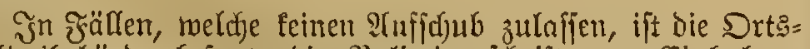
polizeibeljörde befugt, Dic \$olizeivoridjrift bor Einholung der 3uitimmung des Semeindcooritandes zu erlajien. 23iro biefe Buftimmung nidjt innerhalb 4 Wadhen nad Dem Iage Der \$ublifation Der Polizeivoridrift ertheilt, fo hat bie Behörde bie Borjfjrif̣t auf̧er Araft ju jełzen.

$\$ 144$. In Stadtfeeifen ift die Drtæpolizeibehörde bejugt, gegen bic Ridytbefolgung der bon ify exlaffenen polizeilichen Boridjriften Betoitrafen bis zum Betrage von 30 Marf anzudrohen. Sn llebrigen fteht bie Ertbeilung Der Gie=

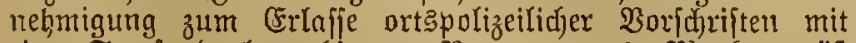
ciner Strafandroljumg bis zum Betrage von 30 Mlark, gemäß

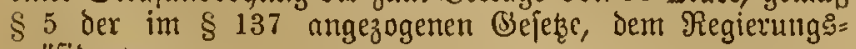
präfỉdenten zu.

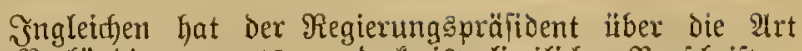

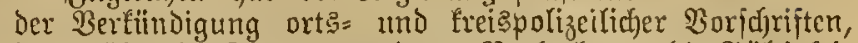

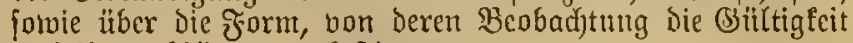
derjelben abjängt, zu beftimmen.

\$145. Die Befugutif, orts= ober freispolizciliche $\mathfrak{B o r}=$

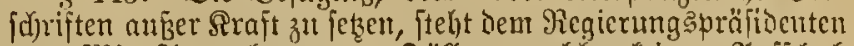

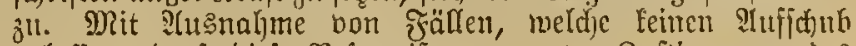
zulafien, Darf bieje Bejugnif mur unter Buftimmung des

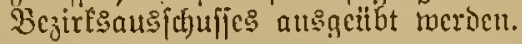

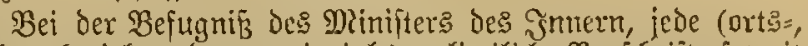

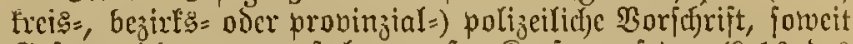

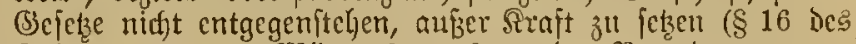
(3ejetzes bom 11. Miär 1850, \& 14 Der Werordunt vom 20. September 1867 bezichungsmeife des Sauenturgifłchen (Sejeckes bont 7. Samtuar 1870), befält es mit ber Maaß̉gabe

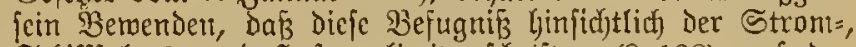
Sdjiffahrt: = แmo Safenpolizeivorid) riftent (\$ 138) auf Den Dimiter für Şandel und Betwerke übergeht.

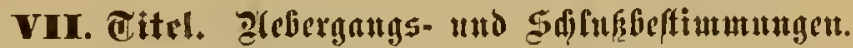

§ 146. Die Stellvertretung Des Regierungspräfidenten

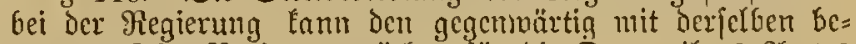

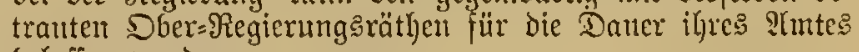
belaffen werden.

§ 14\%. Beamte, meldje bei Der auf (Brmb Des gegen=

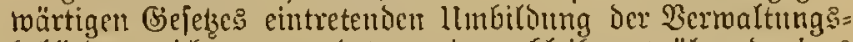
behörben nidjt vermentet merdon, GIciben mährend cines

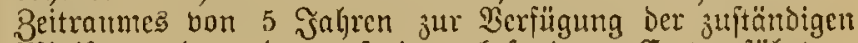
Minifter und werden auj cinem befomberen Etat gefübrt.

Diejenigen, weld̆e twäljrend des 5 jährigen Beitraumes

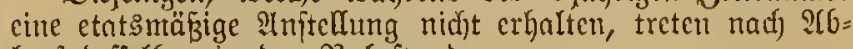
lauf beffelben in Den Muhcitand.

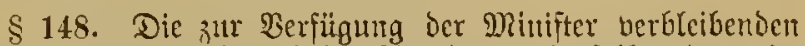

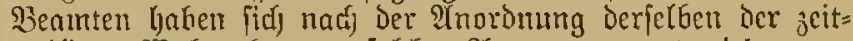

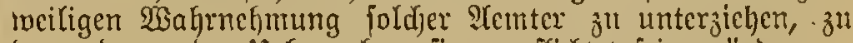
Deren Dauernder Ilebernahme fie verpffidjtet fein wiirocn.

Erfolgt die Bejuäf̣tigung auf̧erhalb des Drtes ifrer lebten Injtellung, io ertjalten biejelben bic gejeķmäßjigen Reifetojten und Ingegelder.

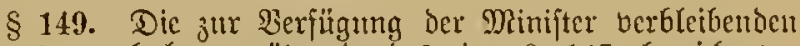
Bcanten erbalten wäl)rend bes im $\S 147$ bejeidjneten fiinfjägrigen 3citraumes, aud wenn fie mälyend deffelben bienjtunjähtg twerden, unverkürat ifje biajjeriges Dienjt=

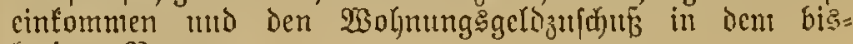
lerigen Betrage.

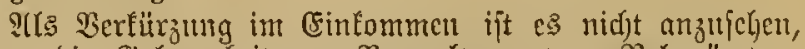

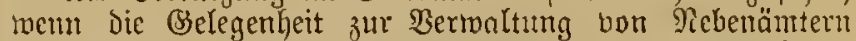
cutzogen miro oder dic Bezichung Der für Die Dienjtumfolten befondcrs ansgeferten (Eimnabmen mit biefen llntoften jelbjt megfällt.

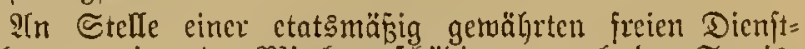
wohnung tritt eine Dliethşentjuäbigung nac) der Serbis=

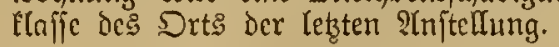

§ 150. Die nad) भhlauf des fünjjährigen Beitraumes,

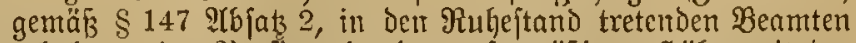

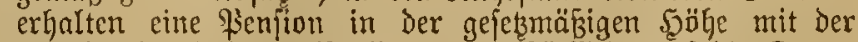

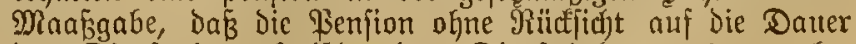
Der Dienftzeit auf $45 / 60$ Des Dieniteintommens zul be= meifen ift. 
§ 151. Den Bermaltungsbeamten, weldye zu ben im $\$ 2$ des Gejebes vom 27. März 1872 (अSS. 268) bezeidneten

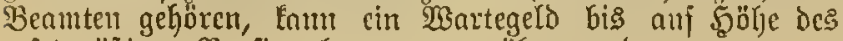

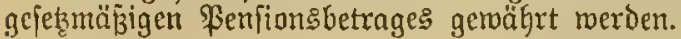

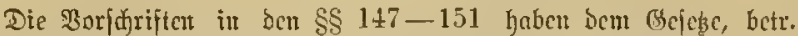

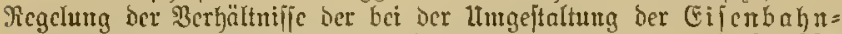
behörocr nidjt zur Bermenoung gelangenoci Beamtcu v. 4.6. 1894

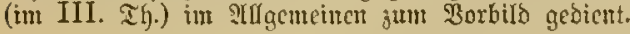

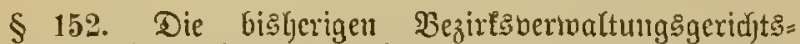
Direftoren inbernehmen mit bem Snfrafttreten bes gegen=

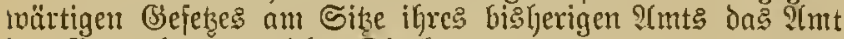
Des $\mathfrak{B e r t v a l t u n g}$ gegericht $t \mathfrak{s}=$ Direftorg $(\S 28)$.

Denjelben ift ge्tattet, bie bis bahin berwalteten nidjt

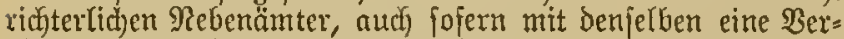
gitumg berbumben ift, beizubefalten.

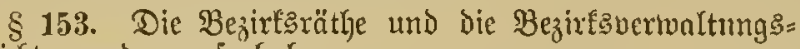
gerichte werden aufgchoben.

IYn beren Stelle treten die Bejirfiausjadjiifje.

\$ 154. Das gegenmärtige Bejes tritt mit bem 1. Sipril 1884, jedod) nur gleidyzeitig mit bem Bejeke ïber

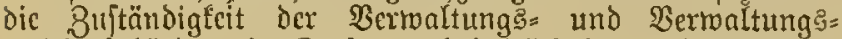
geridjtsbebörden, in Sraft, vorbeţaltlich Der Septimmungen Des \& 155.

(G)

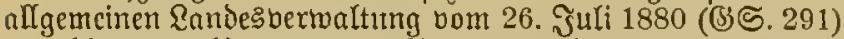

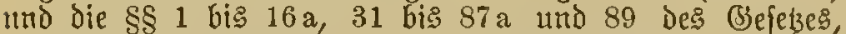
betreffend die Berfaffung Der Bermaltungsigerid)te und bas

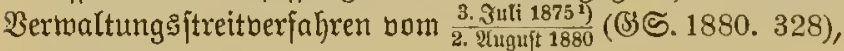
auber Srajt.

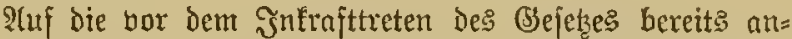
härgig gemadjten Sacjen finden in Bezichung auf bie Buftändigleit der Behörden, das :

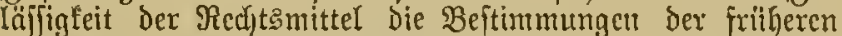
Bejeke, jedod) mit der Maajgabe N(nwendung, daf an Stelle

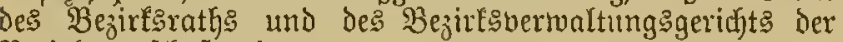

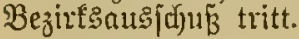

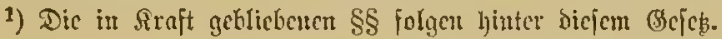

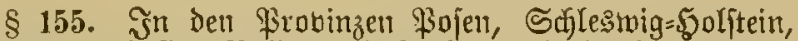

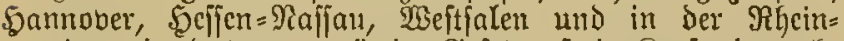

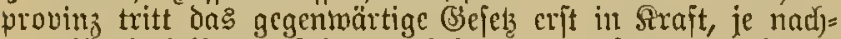
Dem für biejelben anif Grund bejonierer Sejeke neue Areis= und Frobinjialoromungel extaffen fein merden. ${ }^{1}$ Der betreffende Beitpunft wird für jede \$robiuz durdj Röniglidje Berordnung befonnt gemadyt.

Dic Beltung ber Bepitimmungen bes $\$ 16$ und Des $\$ 23$ श्रjak 1 mird jedod) ljierdurd nidjt berührt.

Jnnvicweit bie Beftimmungen Der $\$ \S 126$ und 128 all bie felbitftändigen Stäbte in der Provin Sannover $\mathfrak{A} n=$ twendung finden, GTeibt der Sireisordmung für biefe ßrobinz norbegalten.

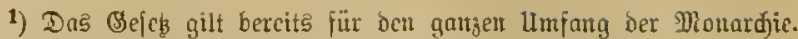

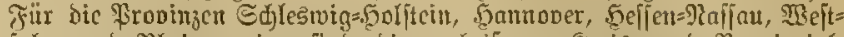

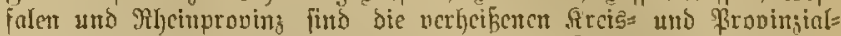

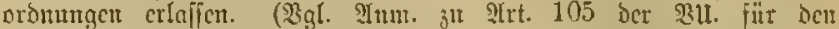

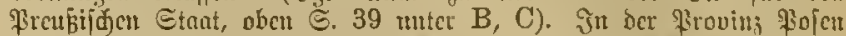

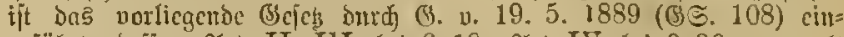

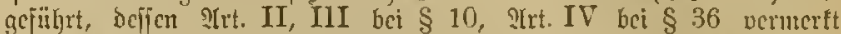

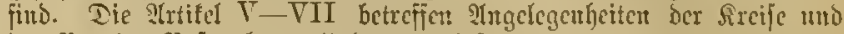

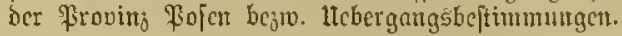

\$ 156. Э̌tt jever ßrobinz ift now bor bent Beitpunlte

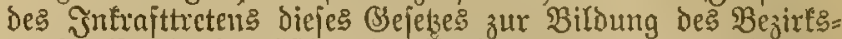

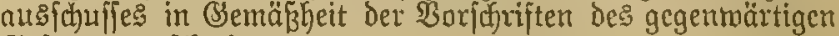
(3)efctzes zu [ăreiten.

$\S 15 \%$ Durch bas gegenwärtige (Sejetz merden nicht berifigrt:

1. Die Beftimmungen Der $\$ \S 20,21$ Der Bemerbe=

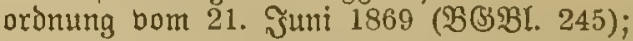

2. Dic Beftintmungen des Sefebç bou 21. Juli 1852, betreffend bie Dienjtbergehen der nidht ridjterlichen Beamten 2c. (BS S. 463); bicielben finden jeboch) jür bas Maafsgaben Nnwenoung: bie Entidfeioung erfolgt

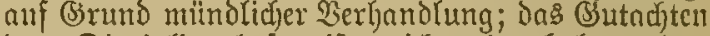
Des Disziplinarhofe ift nidht einzuholen; Das Disziplinarberfahren fan mit Siteffidjt auf ben

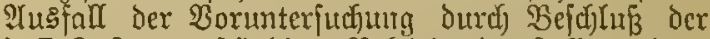

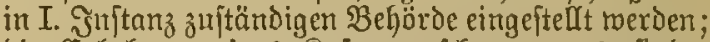
bie Erhebung eines Soitenpaufidquntums findet nicis)t ftntt;

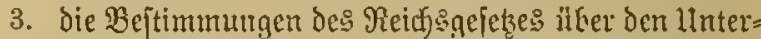

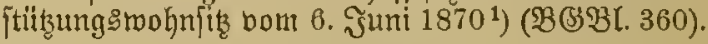

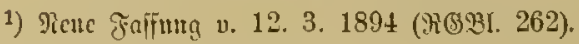

\$ 158. Yujgełaben find:

1. Dic $\$ \$ 40$ bis 48,50 bis 56 des Bejetzes bom

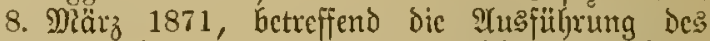
Bundesgejeţes über den llnteritübungstwohnjiţ (ङ5. 130);

2. Dic Ş 141 bis 163,165 Der §ิrcisoronung bom

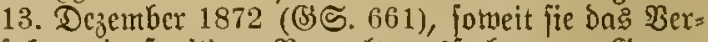
fahren in ftreitigen $\mathfrak{B}$ ermaltung gifachen sum (Begen= ftande haben, jotwie die $\$ \$ 187$ bis 198 Derfelben Freisoronung;

3. der 5. Qhjidmitt Des II. Titels, forwie Dic $\S \S 2$ IGfats 2 und 126 der Firobinzialoronung vom

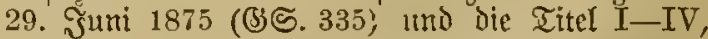
fowic bie $\S \S 168,169,170$ शir. 2,4 und 5 , und Der $\$ 174$ bes Ǵejetzes bom 26. ऊuli 1876, be= treffend bie Zujtändigteit der $\mathfrak{B e r}$ altungsbehörden

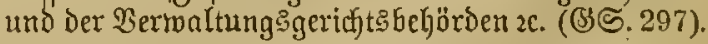

§ 159. Mit Dem Tage dcక Jnfrafttretens bes gegell.

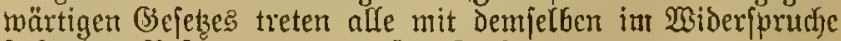
ftehenden Bejtimmungen anferer Siraft.

Itrf́nndlid $2 c$. 


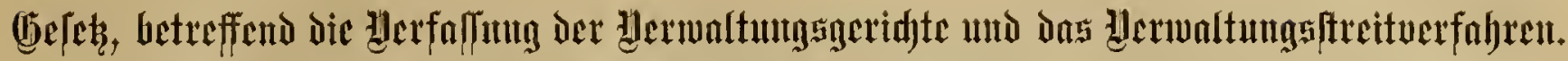

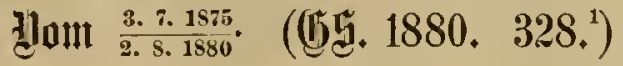

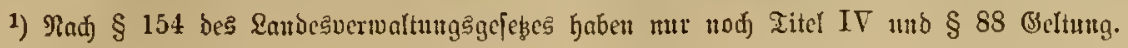

\section{Citel IV. Bơn dem Oberverwaltungsgeridife. $\left.{ }^{1}\right)$}

\$ 17. Das Dberbertwaltungşgeridjt beftelyt aus einem Bräfibenten, Den Seltatępräfibenten (\$26) und ber exjorder=

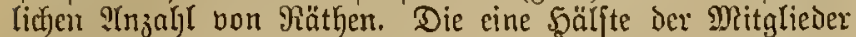
des Dberberwaltungggerichts muts zun Ridhteramte, Die

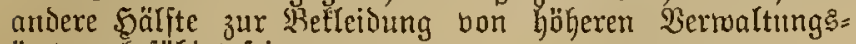
ämtern befähigt fein.

Zum Mitgliede Des Sherverwaltungsggeridyts faun nur emannt werden, wer bas 30. Rebensjaljr bollendet hat.

1) Das Sbcrucrualtungsgetiogt ift ber (3erid)tahof für bic $\mathfrak{B o r}=$

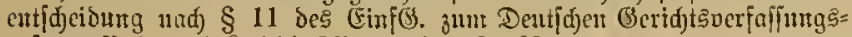

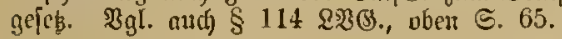

§ 18. Die Ditglicier Des Shervertwaltungggerichts werden auf Den Borfdhlag des Stantiminifteriums von Rönige exrannt. Die Errmennung exfolgt auf \&ebenşzeit.

$\S 19$. Die PRitglieder Des Sberberwaltungsgerid)t: fönnen ein befordetes Rebenamt nutr in den F̈älen befleiden, in Denen das Befes bie Hebertragung eines joldfen ?'mtes

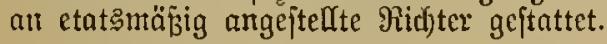

$\S 20$. Die Mitgliever des Sberbertwaltungsgeridht: unterliegen, borbehaltich Der Beftimmmugen ber s\$ 21 ff., feinem Dişziplinarberfahrer.

§ 21. Şit ein Mitglied zu cinter Straje toegen einet

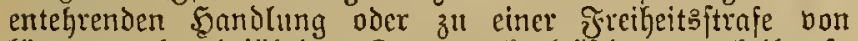
längerer als einjähriger Dauer red)t thäjtig berurtheilt, fo faun eE Durd) \$i(enarbejd) [uf des Sberbermaltungsgerichts

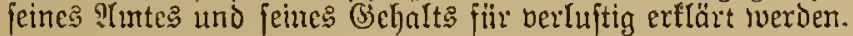

§ 22. Sิโt rocgen cines Sauptberfahren gegen ein Mitglied eröfnet, fo lann die

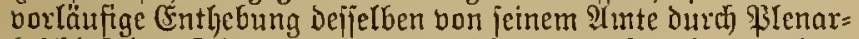

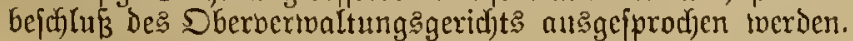

Wiro gegen ein Mitglico die llnterjuchungshlyaft berljängt, jo tritt fîr bie Daner Derfelben die norläufige Enthebung bon Red)tshegen ein.

Durd) Die vorläufige Entlyebung wird das Red)t auf

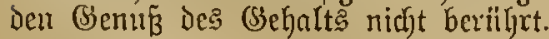

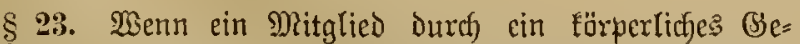
brecten oder Durch Sdjmädhe feirer förperlicher ober geiftigen

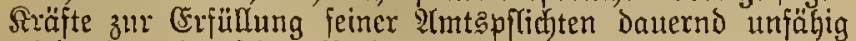
twird, fo tritt feine Serjęzung in Den Ruheftand gegen

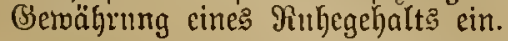

§ 24. Wird bie $\mathfrak{B e r f e z z u n g ~ e i n e s ~ M i t g l i e d e s ~ i n ~ b e n ~}$ Ruheitand nidgt Geantragt, obgleid dic Berausjebungen ber= jelben borliegen, fo hat ber \$räfident an bas 2 Ritglied die 2ufforberung zu erlafjen, binnen einer bejtimmten frift ben 2futrag zu ftellen. Wirb dicjer ?fufforderung nicht

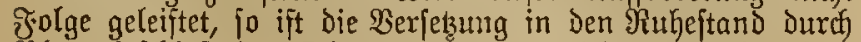
qilenarbefdhluß bes Sberbertwaltungsgerichts auszuppred)en.

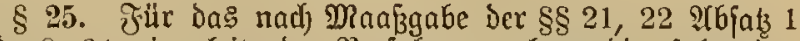
und $\& 24$ cirjuleitende Berjalyrew gelten bic folgenten Beptimmunget:

1. Der ßräfident exnennt aus ber 3 ahl ถer Mit= glieder Des DGerberwaltungs̈gerid)t einen Siom= mijiar.

Dex Rommiffar ljat die das Serfahren be=

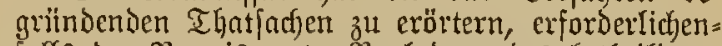
falls den Beweis unter Borlabung des betbeiligten Mritgliedes zu exlyeben und barther Beridtt z" erftatten.

Der Berifft ift Dem betlyeiligten Mitgliede zu= zufertigen.

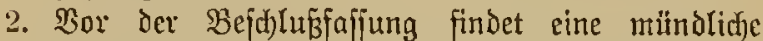
Berbandlung vor dem Sberbertwaltungsgeridte

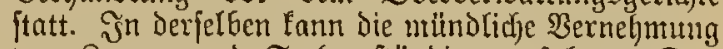
bon Beugen und Sacfberftändigen exfolgen. Das betherligte Mitglied Kezlw. fein Siurator ift zu fören.

3. Das betheiligte Mitglied fann fich des Beiftandes oDer Der Bertretung eineg Rechtsanwalts bebienen, jeodf ift bas Sberverwaltungsgeridjt befugt, bas perjönliche errjcheinen des PRitgliedes unter Der Wartung anzutoronen, då̃ bei feinem ?lusbleiben eirt Bertreter deffelfen nidyt werde zugelafien werden.

4. Die Binleitung des Berfabrens gegen den Siäfi= Denten erfolgt Durch den Stellbertreter Deffelben auf

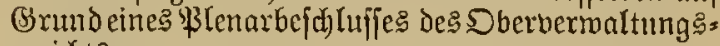
geridjta.

§ 26.*) Das Sherverwaltungggeridjt taun auf B̧ejchluß ies Staatsminifteriums in Senate cingetheilt werden.')

Das Präfidum bezeicfnet bei Beginn jedes Bejuäfts= jahres, ${ }^{2}$ ) mindeitens auf bie Datter Deffelben für jeden Eenat, Die jtändigen Mitglieder tmo für ben Fall ifrer Berhinde= rung bie erfordertichen $\mathfrak{B e r t r e t e r .}$

Эn gleidjer Weife exfolgt nach Maaßzgabe des fierfür erlafiener Riegulatios (\$ 30) Die Sertheilung Der Befchäfte unter die Senate.

Das ßräfisiun befteht aus dent ßröfibenten, Den Senatş= präfidenter und dem Den Dienftalter nad), bei gleid)en Dienjtalter Dem Der Gieburt nadj älteiten Mitgliedc. Das Iräjidium enticheidet nach Stimmenmelyrgeit; im Falle der Stimmengleid)geit giebt die Stimme Deß \$räfidenten Den 2łusfdulag.

1) Das Dbervenvaltungşgeridyt ift in 2 Ennate getheilt.

2) Das Gefjäftsjahr bes Dberverwaltungsgeridts beginnt mit bent 1. Dejentber mis ensigt mit Dem 30. Nopember.

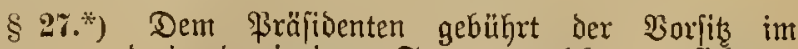
Blenum und in Demjenigen Senate, rolchem er fich an=

*) Dic $\S \S 26$ - 30 firto burd bas unten folgende (3. v. 26. 3. 1893 entipredjeno abgeänuert. 


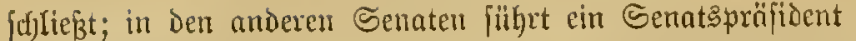
Den Vorjitz.

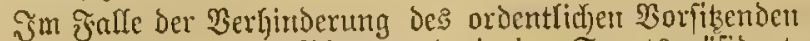

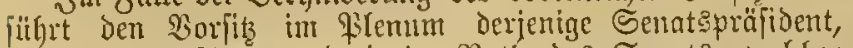

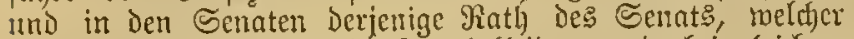

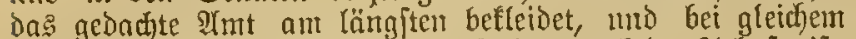
Dienjtalter Derjenige, welcher ier (S)burt nad) Der Shelteite ift.

§ 28.*) Bur Faffung gîltiger Bejulüfje Des Sber= bermaltungsgerichts ift bie Theilnahme bon wenigftens 5 Mitgliedern erforderlidf.

Die Zahl der Mitglieder, weldye bei Fofjung eines Befdyluffes eine entfdjetocnde Stimme fitleren, mus in allen Föllen eine ungerade jein. Sit die Zaht der ammejenden Mitglieder eine gerabe, fo hat ber zulekt ermannte Rath und bei gleichem Dienftalter ber Der (Seburt nach jüngere Fath fein Stimmrecht. Dem Beridfteritatter jteht jedod) in

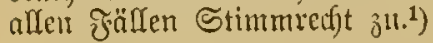

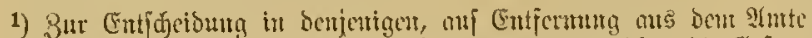

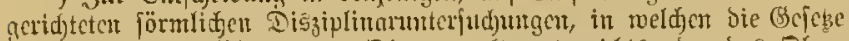

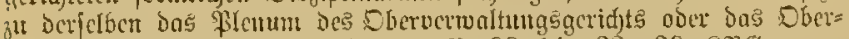

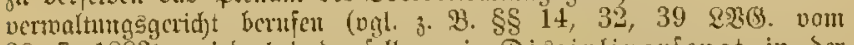
30. 7. 1883), wiro bei Demplben cin Disziplinarienat in ber

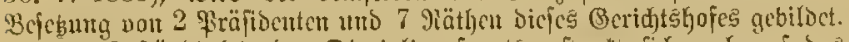

Dic 3uftänoigfeit bes Disjiplinarjenats erjtrectit fidy anth auf bas

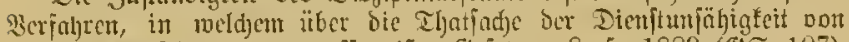

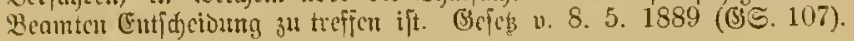

\$ 29.*) Wiff cin Senat DeS Sberbertwaltungsogerictes in ciner Rechtsfrage bou ciner fribleren (Entfocioung eines anderen ङenats oder bes fitenums abmeichen, jo ijt über

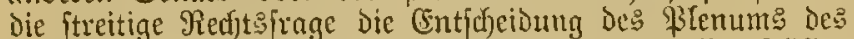
(3)eridtshofes cinjufjolet. Diejelbe erfolgt in affen Fällen olye borgängige münoliche Serbandrung. Bor Der Ent=

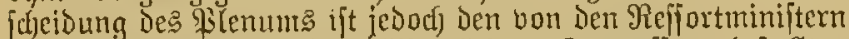
jur 2 abrnehmung Des offentidjen Jnterefies bejtellten fiommifjarien (belegentheit zit geben, fid) jedrifttlid) über bie

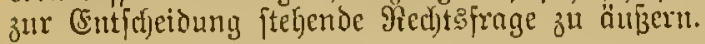

Die (Entid)eidung Der Rechtsfrage Duret) Das Pilerum ift in ber zu entideidenden Sache bindend.

*) Dic $\$ \$ 26-30$ fino surd bas unten folgentoe 6. v. 26. 3. 1893 entipred)end abgeändoct.
Someit bie Entfacibung ber Sache eine borgängige miindlict)e Serhandlung erforbert, erfolgt biefelbe burd den erfennenden Senat auf Sirutio einer ernetrten mündrichen Werhandlung, 3n meldfer Die giarteien unter Mittljeilung Der

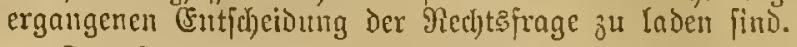

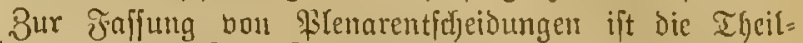
naljme bon merigitens $2 / 3$ Der Mitglieder erforderlid).

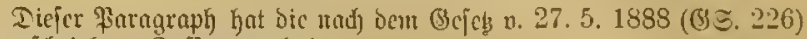

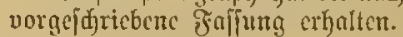

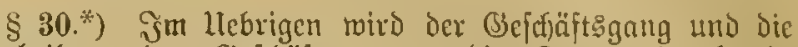
Bertheilung der (Bejdäjte unter die Senate Duref eir

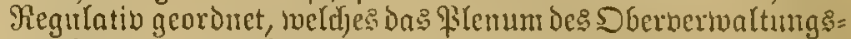
geridjts zu entwerfen und dem Staatonninifterim zur $\mathfrak{B} e=$ ftätigung eingurcichen hat. ${ }^{1}$ )

Die Ermennung Der erforderlicfen Subaltern. mo Unterbenmten bei dem Dherverwaltungsgerid)te erfolgt, injo=

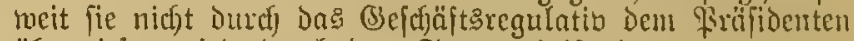
übertviejen wird, Durd) Das Etnatsminifterium.

3) Regulativ fïr bon (Sejdätsgang bei brm Dberverualtungs = geridite v. 2. 4. 1878 (ग9B!. 69), mebit Siad)tritg vout 22.9.1831 (ํㅏ. 1852. 42).

§30a. Die Disjiplin HtGer Die bei Dem Suerber= twaltungsgeridfte angeftelten Subaltern= mid IInterbeamten ïbt Der \$rräfident mit Denjenigen Befugniffen, meldje nach) Dem (Sejeze, betreffend die Dienftnergel)en der nicht rid)ter= fichen Benuten 2e., bom 21. Slult 1852 Den Miniftern in ?tujehutg Der ifueut untergeoroneten $B$ camten zujtefen. Die Cinleitung des Disziplinarverfahrens auf Entfermung aus

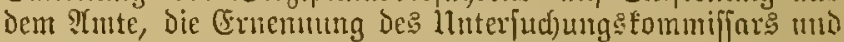

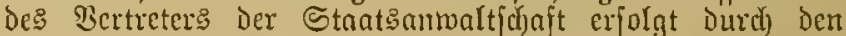

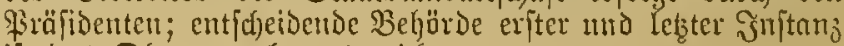
ift bas Dberverwaltungsgerint.

§ 88. Die Stplfe cines Mitgliedes des Sberver= waltungsgericjts barf als Rebenamt fortan nicht mebr: ber= liefjen werDen.

*) Die $\$ \S 26-30$ fino burd) bns unten folgende (\$. v. 26. 3. 1893 entipred)eno abgeämoert.

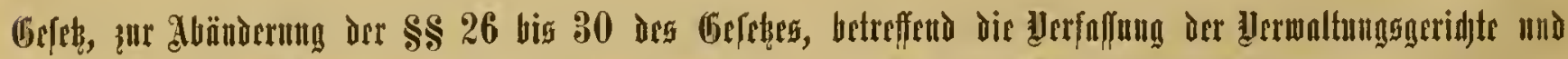

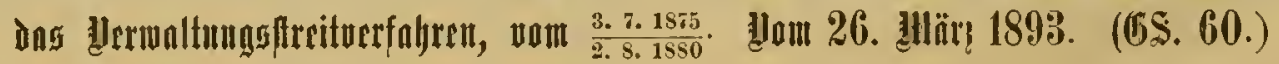

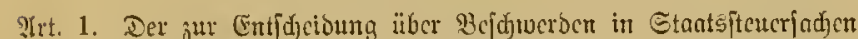
beraliche Senat des Dbcrverwaltungsgeridhts (Etcuerfouat) fam auf Bcjŏlús des Stantsminipterium in ßamutern einge theilt werben.

Die Bezeidumng Der Ditglieber Der Ranmern unt ihrer

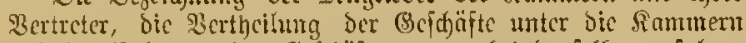
uno bic Dromung bes Bscjuäfsganges bei benfelten erfolgen

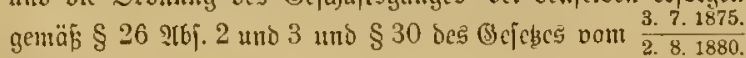

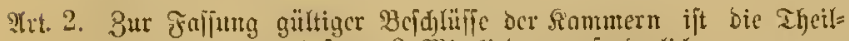
nabme von wenigiters 3 Mitglicbert crjorber!idj.

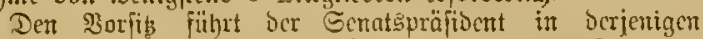

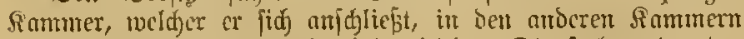
Der bem Dienitalter tad), bei glcidjem Dienjtalter Det ber (Geburt nad) ältcite Ratb.

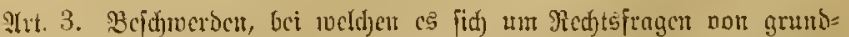

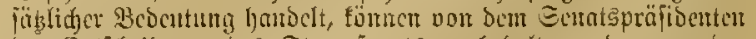
ber Entidjeioung des Eteuer|enats vorbehalten coer von ber

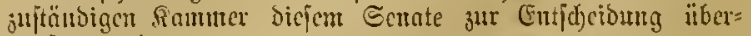
wicjer werbert.

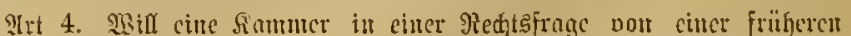

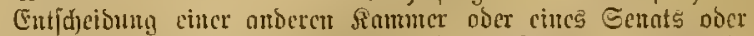
bcs FInmus abweidjen, io hat fic bic Entideioung Det Sade bcm Eteucrifnate zu viberncijen.

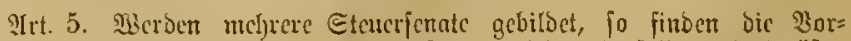

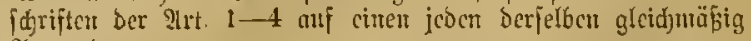
Mtrwentustrg.

Mill ein Eteuerjenat von ber Entidjeiduth cines anberen

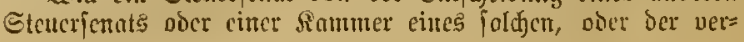


rinigten Etenterientu abucidjen, fo bebur cs ber Entidjeibung ber ucreinigten Stcuerienate.

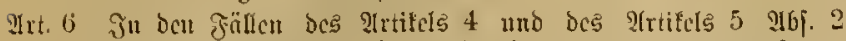

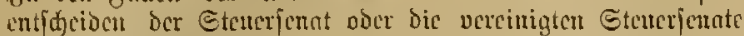
in ber Sadje iclbit.

Bur Fajifung biejer Entidjeibungen ift, wcmu der Steucr= feut nus meht als 7 Jitglieocrm befteht, obcr wenn dic

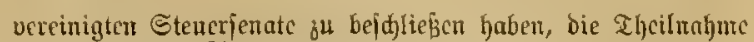
von wenigiterts $2 / 3$ aller Mitglieber erforberlid

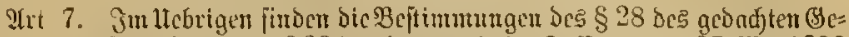

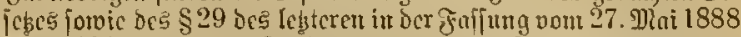

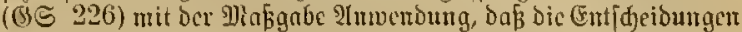
fomoh! Der תianumeru als aud) ber vereinigten Stmerjenate als Enatsentidjeibungen im Sinte biejes Bejeges gelten.

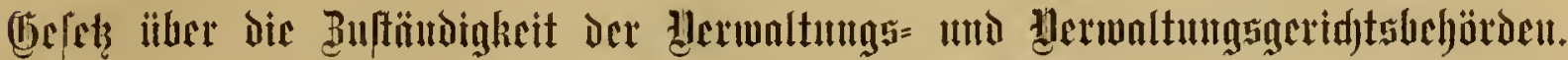

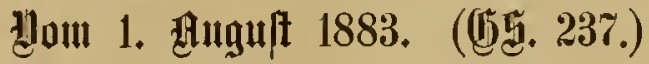

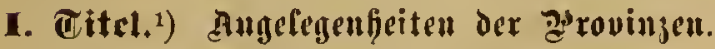

\section{Citcl.1) Autgefegenfjeiten det Sireile.}

\section{Citc! ${ }^{1}$ ) Rugefegenficiten der Auntsverbünde.}

I) Dieje Titcl bilben Ergämzungen ber Đroviugial= bezı. Rrcis= ordinumgert.

\section{EV. Qitel.1) Alugelegenljeiteu der Etadgemeinden.}

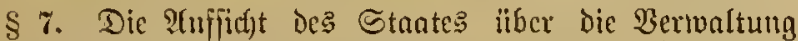
der fräbtifchen (Bicurembeangelegenleiten twird in I. S̈nftan?

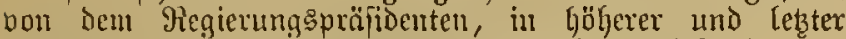
Juftanz bou dem Sberpräfioenten geübt, ubejuabet Dex

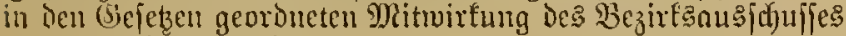
III1) Des Grovingialratha.

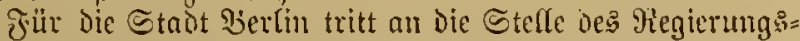
präfidenten Der Dberuräfident, an bie Stelle des Dber: präfidenten Der Minifter bes Şunern, jü Die 5ohenzolfernfduen Rambe tritt an die Stelle des Sberpräjidenten ber Minifter des รnutur.

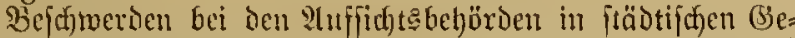

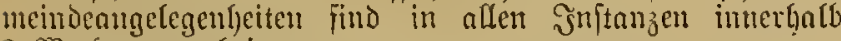
2 Bodfen anzubringen.

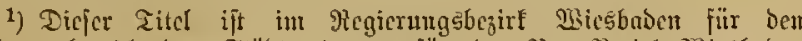

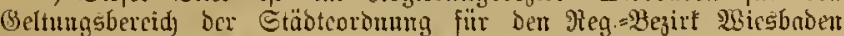
v. 8.6. 1891 (\$ङ. 107) nuber Rraft gefebt. Bgl anger ber ge=

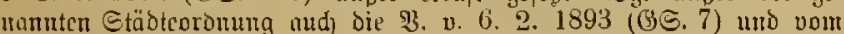
14. 1. 1895 (BS. 9).

\$ 8. Der Bezirfsanకf(d)

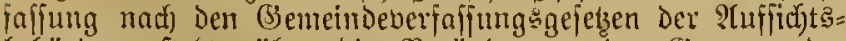
behörbe zujtelt, über die Beränderung Der Grenzen der Stabtbejirte.

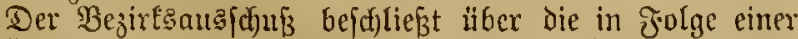
Deränderung der (Sirenzen Der Stadtbezilfe uotluvendig

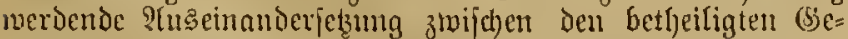
meinoen, borbehaltlict) Der den [eţteren gegen eimander zu= ftehenden Rlage im Derwaltungsftreitberfablen.

\$ 9. Streitigteiten itber dic beitehenden Brenzen der Etabtbegirfe unterliegen der Bntidjeidung im Dermaltungs: ftreituerfalyren.

lleber Die feitfetzung freitiger (Srenjen befdiefist oor:

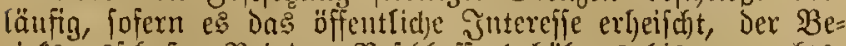

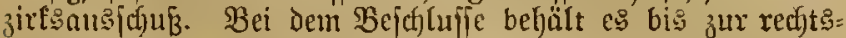

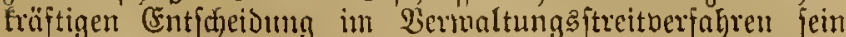
Benendoen.
$\$$ 10. Die Bemeinbebertietung bejaliē̄t:

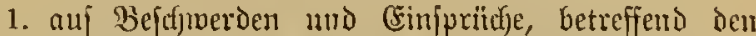
Befib oder ben Derluit des Sitrgerredjts, ins= befondele Des Rects zur Theilnalme an ben

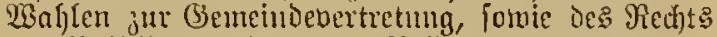

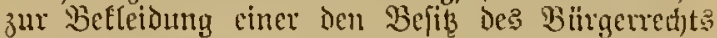
vorumsiezenden Stelle in ber Semeindeverivaltung oder Semeinbevertretumg, Die Berpflict)tung jun (5rwerbe oder jux Berleihung Des Bürgerred)ts, bejichungstocije zur Zahlumg von Bürgergenimn= geloern (24tsfertigungşgebühren) und zur Reiptung des Bürgereioes, Die Bugchörigleit zu einer be= jtimmten Bürgertafje, die Richtigfeit der (Semeinde= voählerlijte;

2. ïber bie (Silltigfeit ier $\mathfrak{W a l}$ len zแr (Benteinde= vertretung;

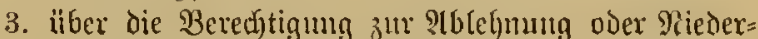
legung bou Iemtern und Stcllen in Der Gemeinde= bermaltumg oder Bertretung, über dic Sachtheile, suelcte gegen Mitglieder Der Stabtgeneinde wegen Ridjtexfillung Der ifynen nad) den (Gemeinde= verfajfungsgejetzen obliegenden Siflidten, forwe ïber die Strafen, welefe gegen Dritglicher Der Gemeinte= vertretung twegen Buviberhandungen gegen die

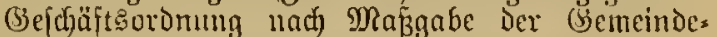
verfaffung geiebe zu verbängen fins.

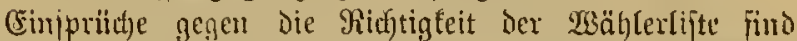

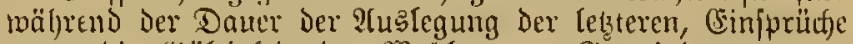
gegen Die Gibltigleit Der $\mathfrak{W a h l e n ~ z u r ~ B e m e i n d e v e r t r e t u n g ~}$ imerbalb 2 wadjen nad) Befammimadjung Des Wabl= ergebrifjes und in allen Jällen bei Dem Gemeindevoritande ju erljeben.

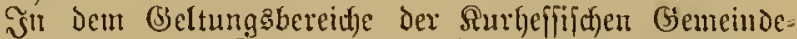
prounng vort 23. Sttober 1834 ift die Senteintemäbler: lifte nad) borgängiger öffentlicfer Betauntmachung 2 230 d)en

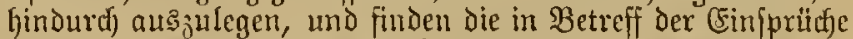
gegen dic Semeindetvählexlifte getroffenen Beitimmungen uud) auf (Finjprïh) gegen Das Berzeidnif ber hochbejteuerten Drtşürger $\mathcal{U}$ mwendung.

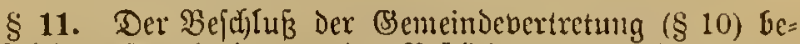
Darif feitter Senehmigung odcr Beftätigung bon Seiten Des Semeindeborftandes oder der 24uffichtsbehörbe. (Segen Den

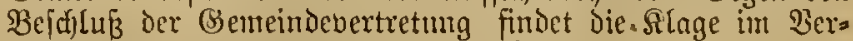

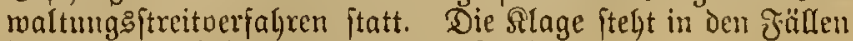
des $\$ 10$ aud dem (Senteindeborjtande zu.

Dic Strage hat in den Fällen des \& 10 unter 1 und 2

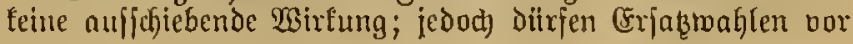


ergangener recftsfräftiger (5ntfocioung nidft borgenommen metden.

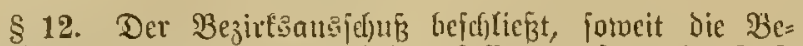

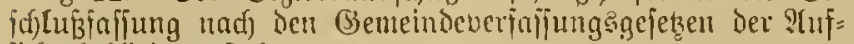
fichtsbebüroe zultegt,

1. Ḧber bic Bahl icr aus jeder cinzelnen Ditfdyalt cinet Stadtgemeinde ju wählenden Mitglicoer Det (S) emeindebertretung,

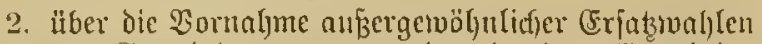
zut Bencindebertretung ober in ben (S)emeinde= poritand.

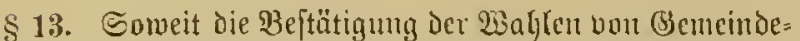

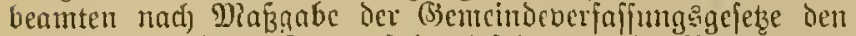

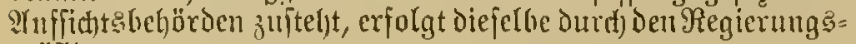
präpioentest.

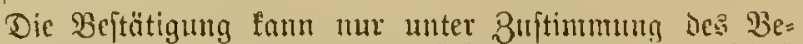

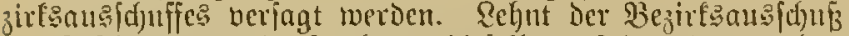

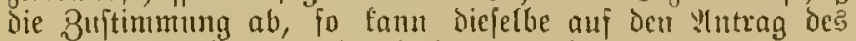

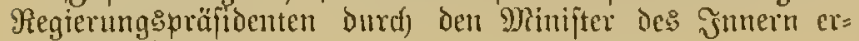
gänzt inerden.

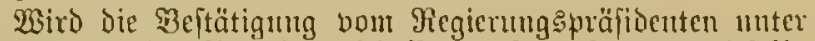

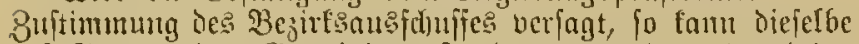
anf Stntrag des Gemeindeboritandes oder ber (Senteinde= vertretung won bem Minifter bes Sntmern ertfeilt werden

\$14. Ileber Die Gibltigfeit von Wablen foldjer (Semeinde: beamten, weldje der Befižtigung nidft bebürien, Gef(f)liçst,

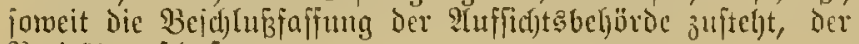

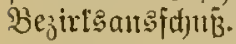

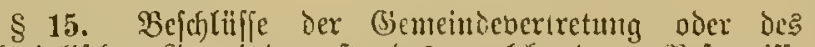
tollegialijden Bentemoeborftandes, weldie inen Befugniffe

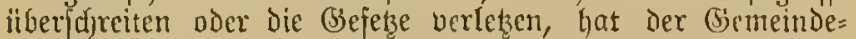
voritand, beziclyungsmeife Der Bürgermeifter, entitcljenden

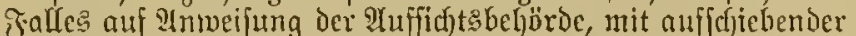
Wirtung, unter :Ingabe der (Srïnde, ju beanftanden. (Begen bic $\mathfrak{B e r f u ̈ g u n g ~ h e s ~ ( s e m e i n d e b o r i t a n d e s ~ ( B ̈ ̈ n g e r m e i f t e r s ) ~ j t e l j t ~}$ Der (Gemeindebertretung, bezichnngsweije ben follegialifben

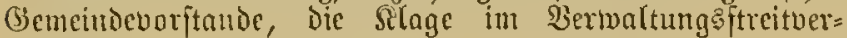
faljren 3 u.

Die in Den Genteindeberfaffmgsgefełen begrünbete $\mathfrak{B} \varepsilon=$

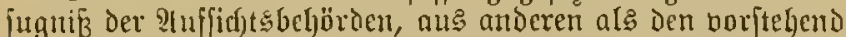

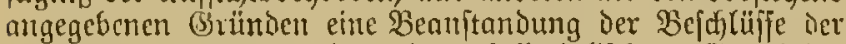
(5ienteindebertretung oder des follegialiferen (Semeinde= borftandes Gerbeizufïhren, wird aufgeloben.

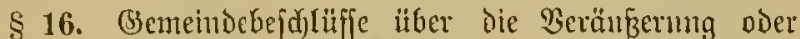

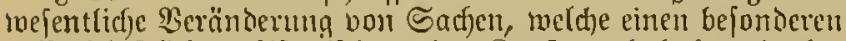
rifienfffaftrid)en, hiftorifden oder finnftruertb baben, insbe= fondere von Ardfiben ober Sheilen Derfelben, unterliegen Der (Scnehmigung des regierungspräfidenten.

Sinfidftid) der Derroaltung der (Semeindemaldungen berwendet es bei den beftebenion Beftimmungen.

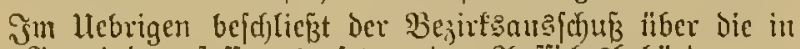

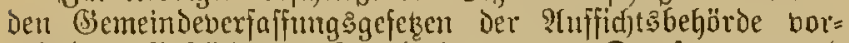
bebaltene Beftätigung ((Bench)nigung) von Srtsftatuten uno fonftigen die ftäbtifden (Sineindeangelegenlyeiten betreffenden (3) meindebefdulitifen.

Solveit $\mathrm{c}$ fid abgaben und Dienjte handelt, fteljt ans Gründen des öfient= [id]en! Juterefies gegen ien anf Beffjwerde ergehentien

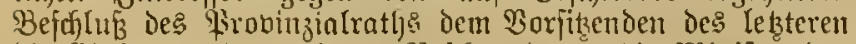
Dic Finlegung ber veiteren Befdineride an die Minifter bes

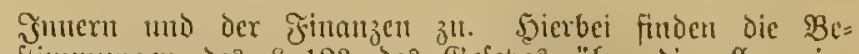
ftimmungen des $\$ 123$ des Gefeles ïber die aflgenteine Randesvermaltung bon 30. Suli 1883 ?tmmendung.

Die Beftätigung (Benchmigung) bon (Bencindebejd)liiffen,

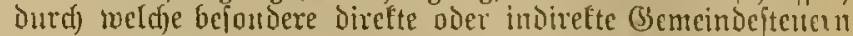

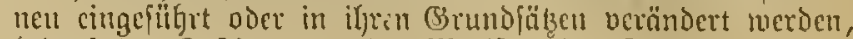

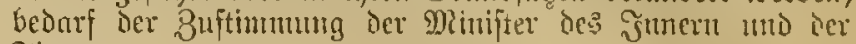
Jinanzen.

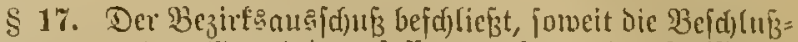
faffung nad) ben (Sicncinteverfaffungsgefetzen ber ?tufficht behörde zuftelit,

1. abgefehen von den gällen des \$ 15 ïbur die zroifden Dem Semeindeboritande mb iet Senteinde= vertretung, bezieljungşweife Dem B̈̈rgermeifter uno Dem folfegialifáen (Semeindevoritatoe cut= ftehenden Mreinungsonerjoficbentjeiten, menn non cinem Theile auf Entfdeioung angetragen miro

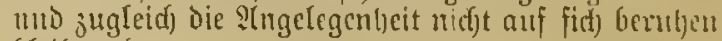
Gleiben farn,

2. an Gtelle der Bemeindebcböriten, in Salle ibrer Durdy rviberfpredjenbe Jutereffen herbeigefüluten Befăluß̉̆nfähiglécit,

3. an Stelle Der nad) Mafzgabe der Gemeindever: faffungsgefełs aufgelöjten (Sicmeindibertretung.

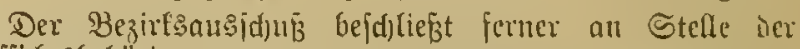
Nuffid)tşbebörbe:

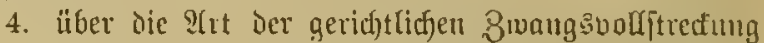
regen Beloforocinugen gegen Staitgemeinden (\$ 15 zu 4 des (5infitbrumgigeferzes zur Deutfden Sibilprozę̧orbung vom 30 . Januar 1877, R(SBL. 244),

5. über die Feftftellung unb Den Erjatz der Defefte der (Simeindebcamten nad) Maßzgabe der $\mathfrak{B e r}=$

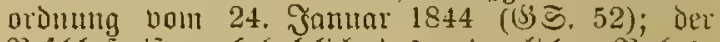

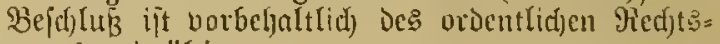
veges endgürtig.

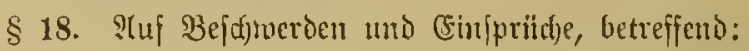

1. Das Red)t jut Mitbenutzung Der öffentlicfen (Se= meindeanftalten, fotvie zur Iljeilualjme an ien Rutzuyen uno Erträgen des (Semeindeverub̈gens,

2. Die Seranjielung oder dic Serantagung ju ben (Siemeitidelaiten,

Gefinliefit der Benteindevoritand.

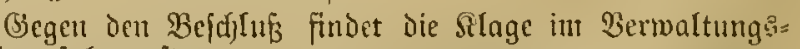
ftreituerialyed ftatt.

Dex Enticheioung in Verwaltungoftreitverfabren unter:

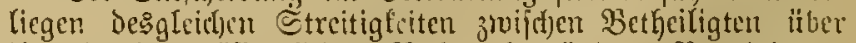
iGre in bem Bffentlidjen Red)te Gegründete Bered)tiguny

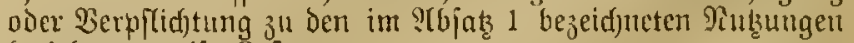
bejiclungsweife Raften.

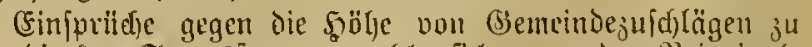
den direften Stantsfencm, weldse fid) gegen den \$rinzipal=

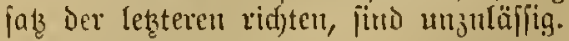

Die Refutwerben mb die (Finfpritude, fumie bic Sulnge baben teine anffítiebende Wirtung.

\$ 19. IIntertäßjt ober vermeigert cine Stadtgemeinde, bie ibr gefetzlict) obliegenden, bon Der Beljörde intmerball ber Brenzen iljrer Buptändigleit fritgeftelten Reiftungen anf den इaushaltsetat ju bringen ober auferorbentlid) zu ge=

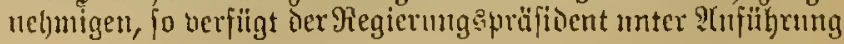




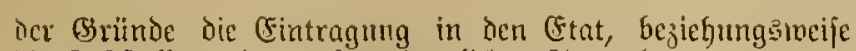
Dic Jefiftellumg der auliscrorbentlidjen ?usgabe.

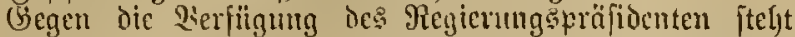

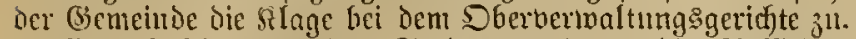
(Sine focititellung des Stadtetats Durd) hic ?uffidits= lébörde findet fortam nidjt ftatt; and) in ben Etäoten bon

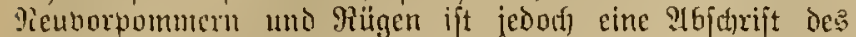

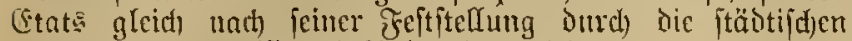

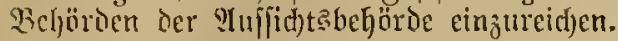

§ 20. B̧ęüglidf Der Dienftuergeljen Der Bürgermeijter, Reigeoroneten, y) iagiftratsmitglieder uno fonftigen Gemeinte= bcauten fommen die Beftimmungen des (5cjelses nom

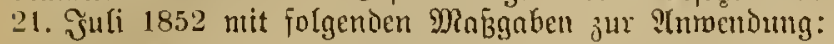

1. Begen Die Bürgermeijter, Rieigeordneten แ⿰ Magijtratannitglieber, folvie acgen die fonftigen Gencindebeamten tanm an Stelle der Bezirts= regierung tmo innerball des berfelben bisher zu= fteljenden Drommug präfident Dronungeftrajeu ieftjeken. Siegen die Etrafverjügungen bes Viegierung spräfioenten findot

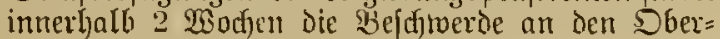
pröfidenten, gegen Den ani die Befduverde ergeljen= den Scidjlub des DGerpräfidenten findet intierhalb 2 Wofjen dic Silage bei Den Dherbermaltung = gericfte jtatt. Sn Berlin findet gegen dic Straf= beriitgungen bes Dberpräfioenten, in Den boben= zollernficen Sanden furdet gegen die ङtraf= berfügungen De: Regiermugspräfidenten innerbalb 2 Wodjen unmittelbar die Silage bei dem Dbet= vertwaltungsgeridhte jtatt.

2. (3) enen dic Etrajberfïgungen bes Bürgermeifters findet innerlyalb 2 Wodjen die $\mathfrak{B c}$ (d) werde an ben Regiezungspräjidenten, und gegen ien nuf die $\mathfrak{B} \varepsilon=$

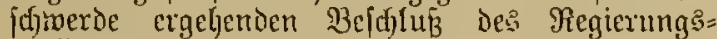
präfidenten innerhalg 2 Wod)en die Silage bei bem Dbervermaltungsgericf)te itatt.

3. Sn Den Verfaliren nuf Cntfermung ans bem SInte toird die finleitung ocs Qerfahrens bon iem

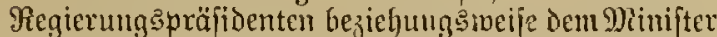
des Funern verïgt uno bon bemielben der llnter= (ud) unyşfommifiar ermannt; an die Stelle der Bejitforegierung bezielung smcije des Disziplinar= holes tritt als cntfdeinenbe Disziplinatbeljörde I. Snftanj der Besirfsansid)uß; an die Stelle les Stant:minifteriums tritt Do 5 bervermaltungs: gerid)t; Den Bertreter ber Stantammaltidnoft er=

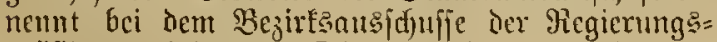
präfident, bei Dem Dberverwaltungsgeridite ber Minifiter bes Jnnern.

Эn dem norftehend bezüglid) Der Entfermung aus dem Imte borgeichenen Derfohren ift entitebenden J゙alles nud) \#̈ber die Ihatjadje Der Dienjtunjähigfeit der Bürgermeifter, Beigeoroneten, 9Ragifratsmitglieder und jonftigen Gemeinde= beanten (Entjcheibung öu treffer.

(3egen Mitglicher ber Gemeindevertretumg findet ein Disjiplinarberfahren nidjt ftntt.

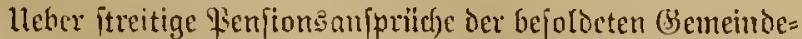

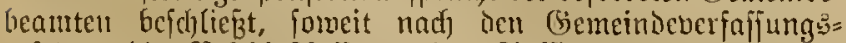

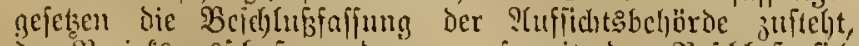

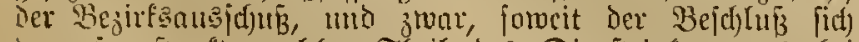
barauj exptreft, welder Theil des Dienfteinfonmens bei Feititelung Der Benfionganjprïlue als (Gehalt anzujehen ift, norbelyaltida ber oen Betheifigten gegen cinamber zuytelyenden
Rlage im Bermaltumgäftreitberfahten, im Lébrigen nor:

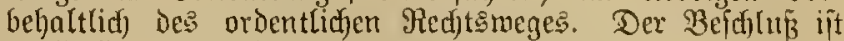
vorlänfig bollitredtbar.

\$ 21. Buftändig in I. Snftanj iit in Vorwaltungs: ftreituerjabren fïr bic in Dicjen Iitel borgejeljenen Jälle,

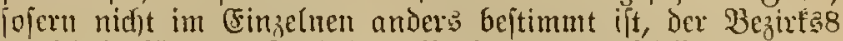

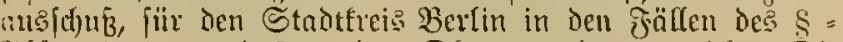

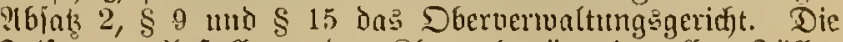

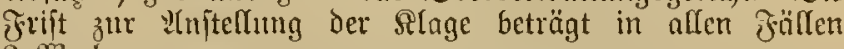
2 QBodjetr.

Die Gemeindenertretung, bejielyungsineife ber follegialifde

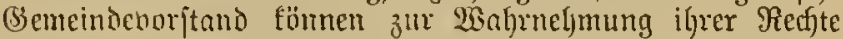
im Berwaltungsiftreituerfalyren cinen befonderen Bertreter beitellet.

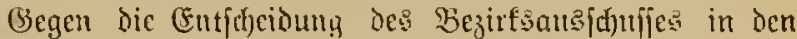
Föllen des \& 18 unter 2 ijt mux das Reditentittel der Kevifion juln̈ffig.

§ 22. Die Beftimmungen Dicjes ?(bjofuitts fommen jur

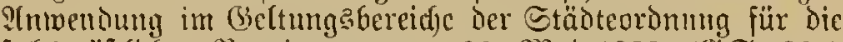
jed) öftlidjen Provinjen bom 30. Mai 1853 (\$S. 261) and auf die $\$ 1$ Zlbjab 2 injelbjt crwäljnten Drtj(f)ajten (Electen),

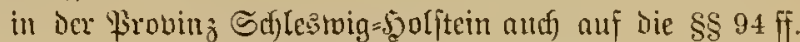
Des Sicjebes nou 14. 2(pril 1869 (Gङ. 589) ermähnten steden,

im Giegicrungsbezirte (Sajjel aud) auf die Stabt Drh,

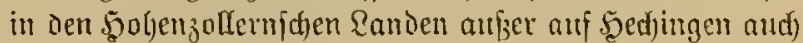
auf Die Gemeinte Sigmaringetr.

Welche Bemeinden im Regierungsbezirte Wiesbaten auber der Gtadt Franffurt als Stadtgemeinden im Sinnc

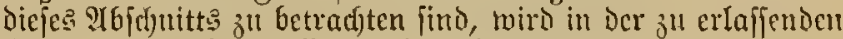
Rreisordung für Seffen=? Raffan beftinunt.

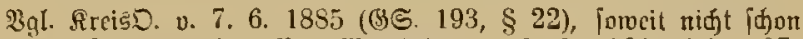

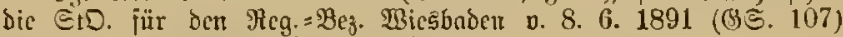
cingejithrt ijt (j. 2Imm. 1) binter $\$ 7$ )

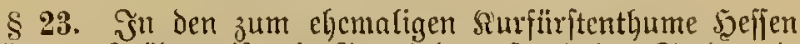
geโjörigen StäDten ift als (Semeindevoritano der Staotratl), als (S)emcindevertretung Der Bemeindenusjd)uB,

in ben Stadtgemeinden bes bormaligen \$erjogtljums Yaifau (\$ 2:2) ift als Genteindenorịtand ber (Semeindetath, als Gemeindebertretung Der Bürgerausf(f)uß́,

in Der Genteinde Somburg b. D. \$. ift als Gemeinde= voritand ber Bürgermeifter, als Bemcindebertretung ber Genteindevoritand,

in Der Semeinde Sedjingen ift als (Semeinieborftand

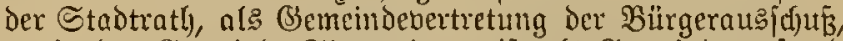

in ber Gemeinde Sigmaringen ift als Sicmeindeboritand ber Bemeindernth, als Bemeindebertretung ber Bürger=

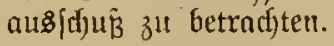

\section{Citel. ${ }^{1}$ ) Angelegenfeiten der sandgemeinden und der fefbfffäntoigen Gutsbejitke.}

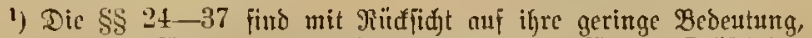
dic fie nad) Ginfïhrumg ber Eandgemeindeoromung für bic 7 öjtlidjen Frovinzen v. 3. 7. 1891 (\$S. 233) uno ber Landgentibeoromung

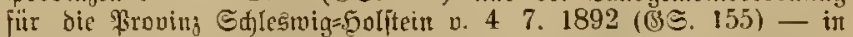

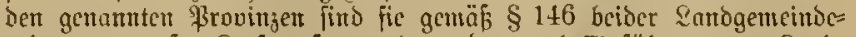
oromungen aufer Sraft gejebt uno merden mach Einfübrung von Rand= gemeinocoronungen in ben übrigen Prooingen anber firajt gejest rerben - rod) baben, hier fortgelajīen. 


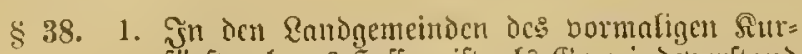
firitentlums Şeffen ift alB Gemeinocborftand ber Gemeinderatl), als (Gsincindevertretung ier (BemeintenแI:

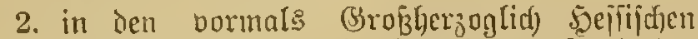
Enidesatheiten ift als Bemeindeborftano ber Bïrgermeifter, als Bencindebertietung ber (Beutcindocratly,

3. in ถen Randgemeimben ter bormnts fï̈niglich) Babcriffyen Rantestycile ift als (Semcinte: borftand der (Semeindeborfeher, als (Bemeinie=

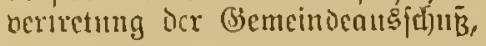

4. in Den Bemeinden des vormaligen Şerjog= thums Raffau ift als Geneindetoritand der (senteinderatb), nfs (Bemeindebertretung der

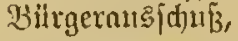

5. in Den (S) meinden des bormals Ranogräflict)

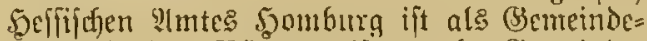
vorftard der Burgermeifter, als (Benteinde= vertretung der Bentcindocorjtand,

6. in den Randgemcinden des Stadtfrifes frant= furt a. $\mathfrak{M}$. ift als (Semeindeborftand Der

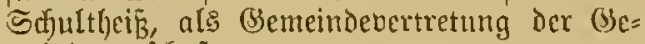

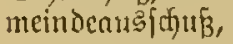

7. in Den Eandgemeinden des ehemaligen そ̋̈rften= thums sobenjollem = Soechingen ift als (Sic= meindeboritand bas Drtsgericts, als (Se=

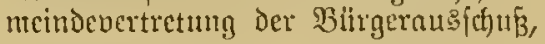

8. in den Gemeinton bes chemaligen Jüriten= thum soljenzollern= Signturingen ift als (B)e= meindeborftond der Giemcinderath, als (Ge= meindebertretung ber B̈̈rgerausfd)แई

3u betradjten.

\section{Citel. Antmenangelegenfieiten.}

VII. Cittel. Sdjufaugelegentieiten.

\section{Citel. Einquartierungsnugefegenfieiten.}

\section{Citel. Sparkinfentangefegenficiten.}

\section{Titel. Syntagogengenteindeangefegenfieiten.}

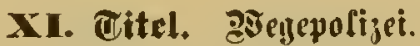

\section{Ergä̈zungen bicjes Titels biloen:}

(Sejeg, betr. megepolizeilidje \$orjdriften jür bie \$roving Shles̀nig=

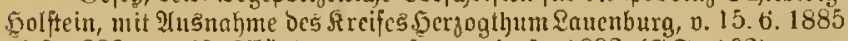
(ఆङ. 289); nebjt YIGänderungsgeiç v. 4.5 1892 (\$S. 102).

Gefes, betr. Die 2lbänderung eintger Bcftimmungen ber $\mathfrak{B}$ ege=

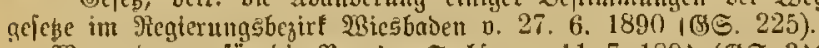

Begeoronung fur bie \$roding Sadjen v. 11.7.1891 (\$S.316).

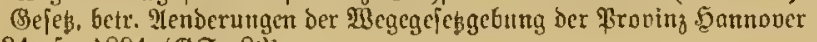
p. 24. 5. 1894 (85. 82).

§55. Die 2ufficht übcr dic öffentliden Wegc uno deren Zubehörungen, fotwic dic Sorge dafür, daf́ den $\mathfrak{B c}=$

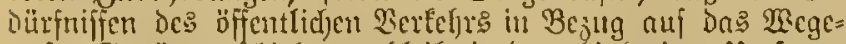
twejen Genüge geidjelgt, berbleibt in bem bišberigen llmfange Den fïr dic $\mathfrak{R a h r n e l j m u n g ~ D e r ~ W e g e p o l i z ̌ c i ~ j u f t u ̈ n d i g e n ~} \mathfrak{B} e=$

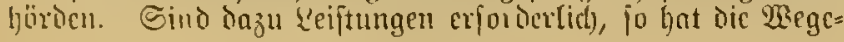

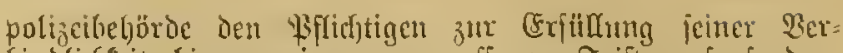
bindichfeit binten einer angeneffenen frift auf

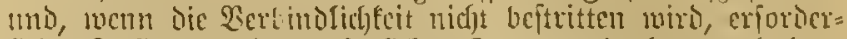

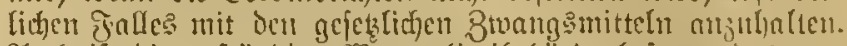

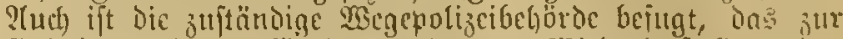

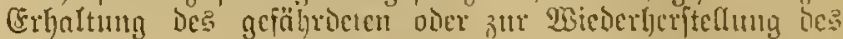

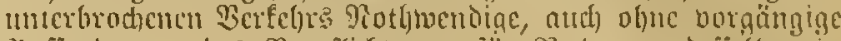

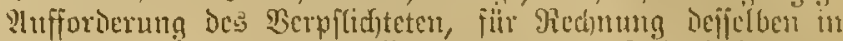

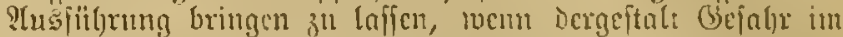
Berzuge ift, onf die Q Durch den Berpflid)teten nicht abgetuartit werden tonn.

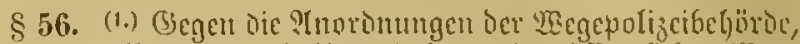
melde ien Ban uno bie lluterbaltung ier offentlichen $2 R e g e$

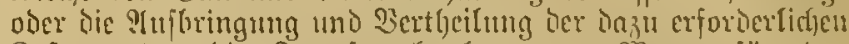

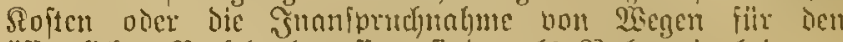

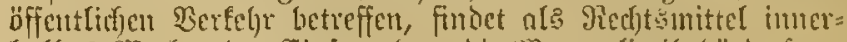

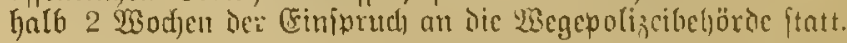

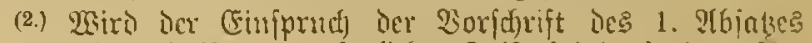

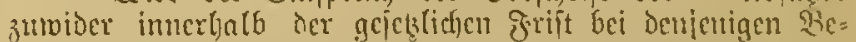

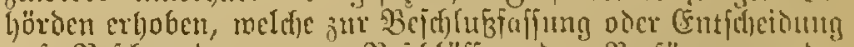
atl Befdinerden gegen Bejchlitiffe oder Berfígungen der 2Segcpolizeibchörde juftändig find, fo gilt bie Frift als geroabrt.

(3.) Der (Einjprud, ift in fold)en fä̈lfen bou den angerufenen

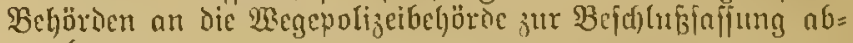
zugeben.

(4.) Heber ten (Einjprud) hat die Taegepolijeibeljörde ju be=

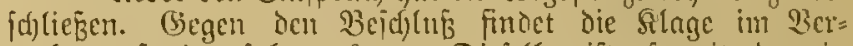
maltungeffreitberfahren ftatt. Diefelbe ift, forbeit Der in

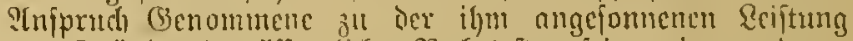

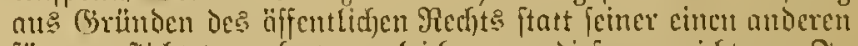
fïr berpflicftet eradflet, zugleid) gegen dicfen ju ridften. Fu

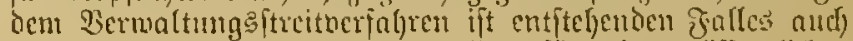
Darüber all entfdyciden, ob Der weg firr cinen bffentlidjen ju cractiten ift.

(5.) Itud in Mebrigen unterliegen Streitigfeiten ber $\mathfrak{B} e=$ theiligten Darïber, wem bon ibnen bic öffentliúl)=icd)tliclle Berpflidutung our ?tulegung oder IInterbnltung cines bffent=

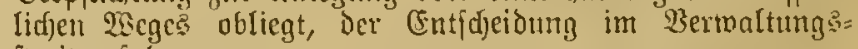
ftreitucrfabren.

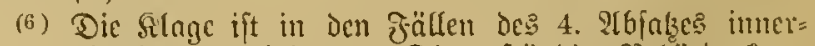
halb 2 Wodjen anjubringen. Die zuftündige Behörde fonm

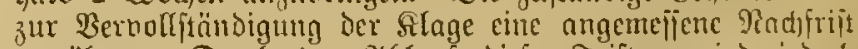
gewälien. Durd) ien 2tblauf diejer ofriften miro jedod)

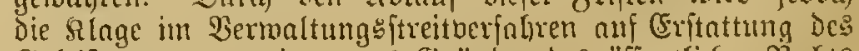

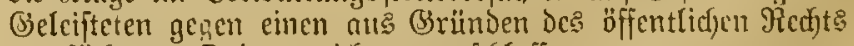
verpflidjteten Dritten uidyt ausgefdloffen.

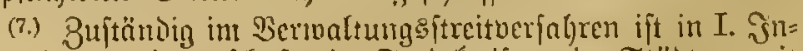
ftans Dor Sicisausf(f)uB, in Etantfreifen, in Städten mit mefro als 10000 Eimnolunern, und, fojern $\mathrm{e} 3$ fich $1 \mathrm{~m}$

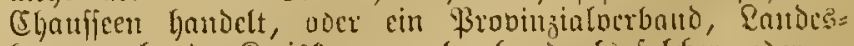
fommanat = Doer fireistonmunntberband nis foldfer, oder in der Froving 5ammober - cin Megeverband betheifigt

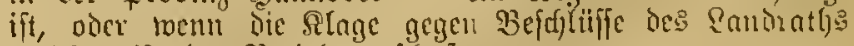

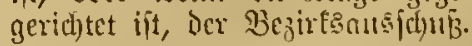

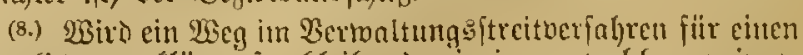
öfifentlidsen erflärt, jo bleibt iemjentgest, meld)er pritut=

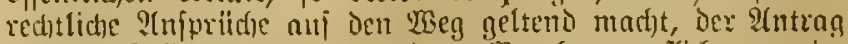
aui Enticjäbigung gegen den isegebauberpflidyteten in

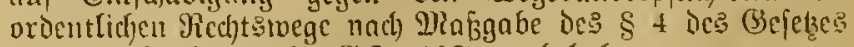
bom 11. Miai $1842^{1}$ ) ((55. 192) vorbelalten.

1) unten abgeoruadt. 
§57. Heber Ëmjichung oder Berlegung öffentlicher

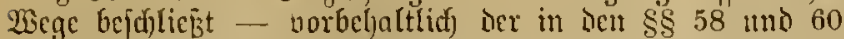

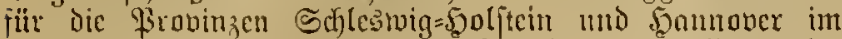

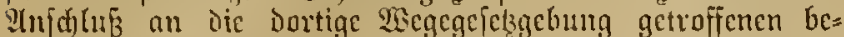

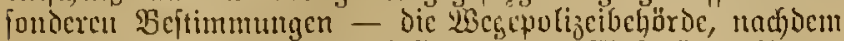

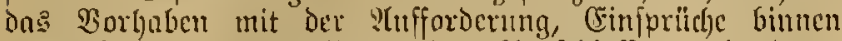

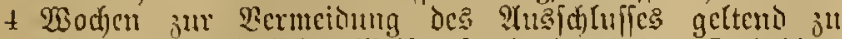
mad)en, in ortsüblicfer weife, forvic burch das Sreisblatt unt toa ?Imtsblatt neröffentlicht morden ift. Begen den

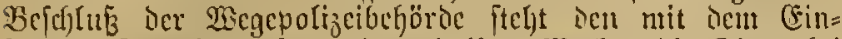

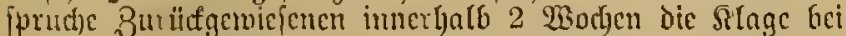

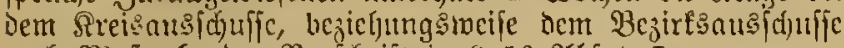

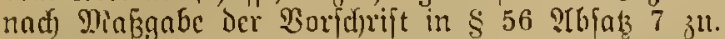

26irt dic beantragte 2 erlegung oder Einjichung ciute öffentlid)en Weges bon Der Wregepoliseiberjörbe bon varn= locrcin over nad) icm (sinjprud)

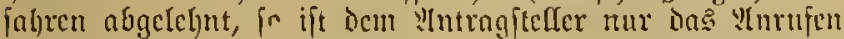

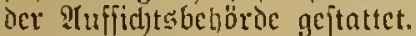

Der 2tr. IV Dcs Gefelics, betreffend dic Stbändertung bon 2 seftinmungen der Sicisorotung fïr die \$Srovinzen Firubert, Brandenburg, Bomment, Sofen, Sthleften tub Sach)fen bom 13. Dezcmber 1872 mind Dic (Ergänzung der= fclben vom 19, Mär 1881 ((5)ङ. 155) wird aufgehober.

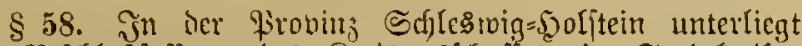

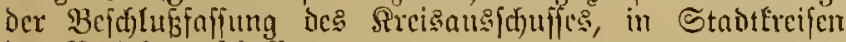

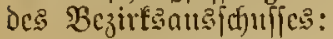

1. dic Beftätigung non Beftinunungen ber (b)emeinoen in Betreff Der TInlegum, Berlegung oder Cin= jichutg bon Rebenwegen, öffentlitsen Jufitcigen odcr Sandmegen mact) $\$ \$ 226,234$ Ibjak 1, 235 icr Wegcucrordtung fiir dic 5̧crogthottmer Schlesmig

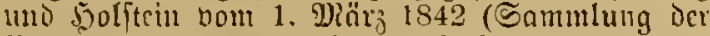

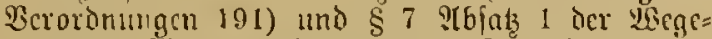
oronung für Das \$orrogthum Enuenburg vom 7. Fefruar 1876 (Difiziclles Woct)enblatt 27);

2. dic STnordunng Der Berlequng bon Rebentwegen narf) \& 226 Sak l Der שsegeverorbnung nom 1. Miär 1842, fornic bic Ilnordnung der Strlegumg netter Eandwege obcr ber $\mathfrak{B}$ erlegung obcr befferen (Finrid)tung bejtebender \&andocge int sereife 5erjog= thum Qauenburg nad) $\$ 7$ 2(biats 2 Der $\mathfrak{B e g e}=$ ordmuny bom 7. Februar 1876;

3. dic (Bencl)migung des $B$ uammentretens von (Bc= meinden uno (s)utepgirfen ju cinem berbande Behuf? gemeinfamer Şerftellung und lintergaltung von Fiebeumegen nad) \& 13 des Brietzes vom 26. Jebruar 1879, betreffend die 2tbändcrung dex 2uegegejeksgefung für dic \$rovinz Shlestwig= Solitein 2c. (GS. 94);

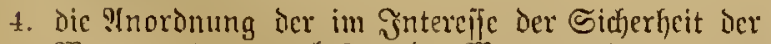

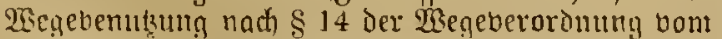

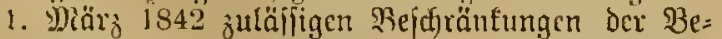

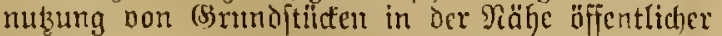
Wege.

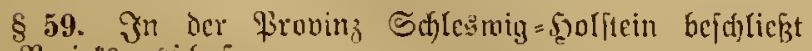

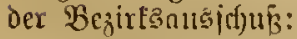

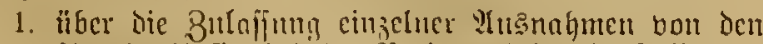

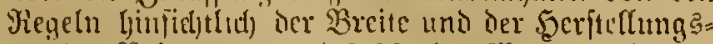

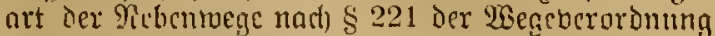
vom 1. शึärz 1842;

2. über die 5geritellungsart derjenigen neu aus=

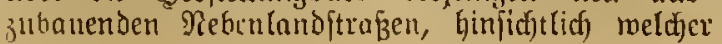

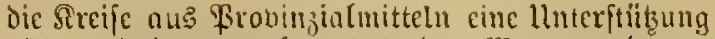
nid) crhalten, nad \& $\$ 1 t 6$ ber VEegiverorimung

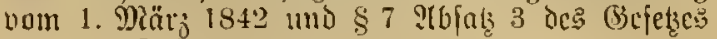
vom 26. ङchrma: 1879.

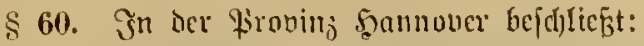

1. in Randection der Strisnusfdu joure in den bejüglich der Bermaltung ber

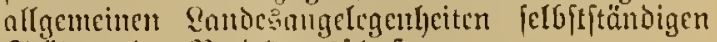
Stätten der Bejittsangidur

a) iiber Befdwerden Betheiligter gegen $\mathfrak{B} e=$ ftimtutungen ier (3)emcinien Darifber, voelche Wege als Bemeindosuege nujulegen, aujzugeben

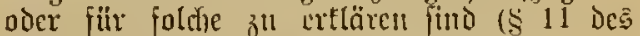
Sonmunerid)en (Geiteses vom 28. Sulti 1851 über Genteindewege und Eanditrafen Sammoverifhe (3) S. 141);

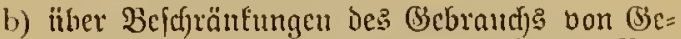
meindeswegen auf beftimmte Bruecfe de $\mathfrak{S} \mathfrak{B e r}=$

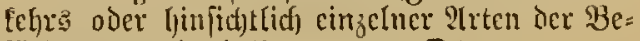
föriecungsunttel (\$ 17 a. a. D.);

c) Hitrer Beidymerden Betheiligter gegen bic : $: 1 n=$

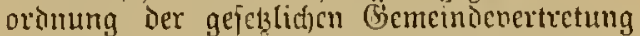
in Betreff ocr Theilung cincs Bemcindebezirf's in Unterbejirle zur abgcjonderten :Tnlegung oder linterbaltung von (s)emeiniervegen (\$ 24

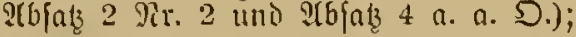

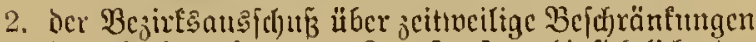
des (Sebraudfs van Randjtrajen binfichtlich der

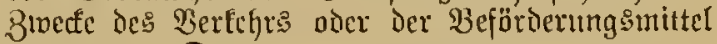
(\$ 18 a. a. D.).

3. Heber bic $\mathfrak{B}_{\mathrm{c}}$ bintung melnerer benachbarter Drt: gemeinden jur gemeinf(f)aftidjen Nolegung mo llnterbnltuta der für fie alle vithtigen Ssemeinde= socge innertjalb ocs cincn oder anteren Bejirt's (\$ 24 Mbjats 2 9ir. 1 und शbjatz 3 a. a. D.) befd)lief̧t

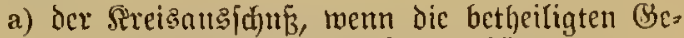
meinien demielben Sereife angetären;

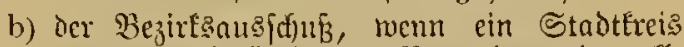
odcr eine bejüglich ber Bermaltung der all= gemeinen Randesangelegenheiten fclbjtitändige Stadt hetheiligt iit, nder dic Gemeinden ver= (d)iedenen ßreifen, aber nemfdben Regierungs: bezinfe angeljören;

c) Dex Frovinzialrath, twen die Bemeinden ver=

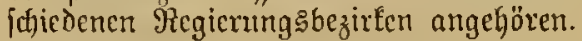

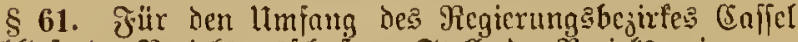

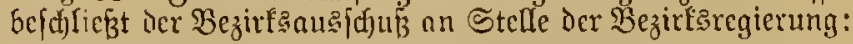
iiber Dic Socranzichung der Bemeinien und Gutsbezitte jum 2Begebau nuğerhalb ifjer Gemartungen, fowic

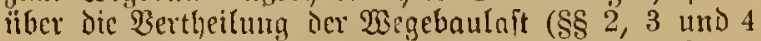

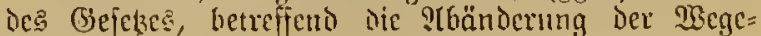

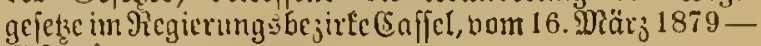
(5)

\$62. Fiir ien umfang ies normaligen berjogthume

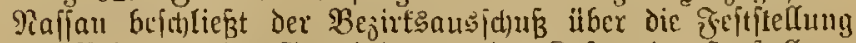
oc: BReitrage: Der (Semeinden zu Den Sioften Der Jecrfteflung

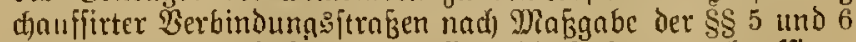

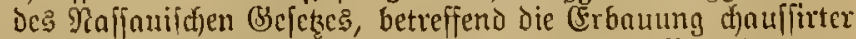
Berbindungsftrafen, vom 2. Dftoher 1862 (Secoromumg: blatt 176). 


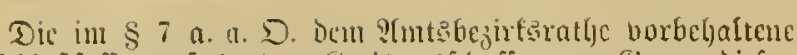

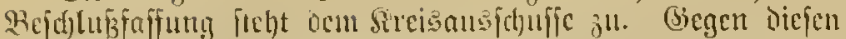

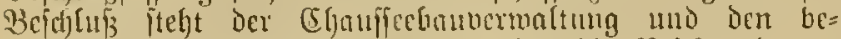

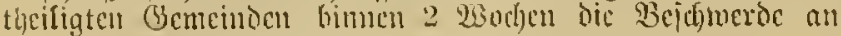

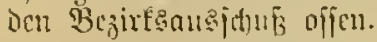

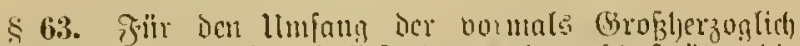

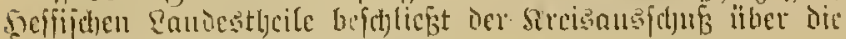
(5xtbeilung ber Genclutigung:

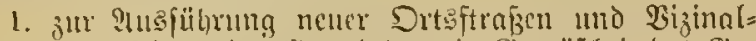
wege feitens ber (Somenom, in (S)emäfljeit des (B)e= fetzes vom 4. Šuli 1812, เą Ted)nungsmcjen der (S)meinten $2 \mathrm{e}$. betreffort;

2. ju Bilom von 23izinalucgcucrbämben, in Bic=

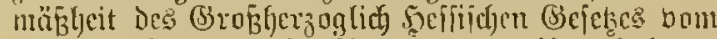

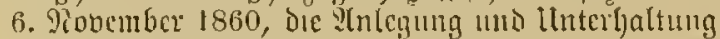

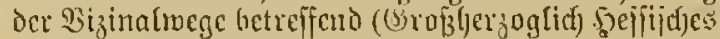
Regierung:6l. 333).

\$64. Uleber Dent bejonderen Beitrag, welden die Ilnter: neljmer vou frabifen 2c., Duref Deven Wetricb Wege in et=

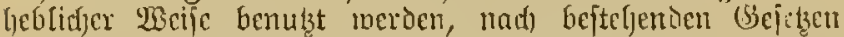
(Gejeks bom 26. Эsebruar 1877, Getreffend cinc \&bänberutu

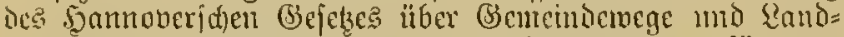

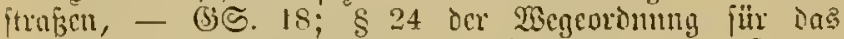
5 rrouthum Rauchburg boun 7. Fobruar 1876 - Raucu= burnifdes Dffiziclles 23odjentor. 27: § 7 bcs Gcjetses nom

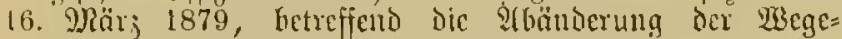

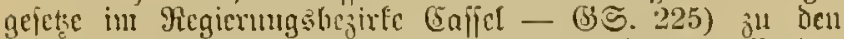
Soften bex Interlyalumg Dore bes ?eubaues bes betreffenden Wegcs zu leiften haben, cnlfticitet auf Slage des Wege= ufliditigen in I. Situptanz:

bei Senteinthemegen in Sendefeijen ber Streisattsid)uß,

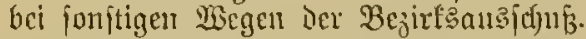

Sill der Grobinz Scannover itel]t bei Den Giememberucgen in allen bejüglid) der allgemeinen Ranicsuertbaltung jelbit=

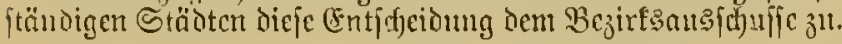

\section{Tittrl. 3ૈrafferpolizei.}

\section{Citcl. Deidiangelegenfeiten.}

\section{Citsl. Tildiereipolijei.}

XV. Titel. 3agopolizei.

\section{Titel. Geverbepolizei.}

\section{B. Semerblide Ronzeffionen.}

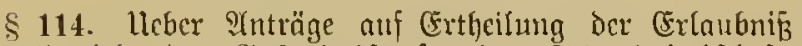

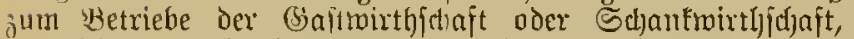
3um Sleimljandel mit Bramtrocin oocr Spiritus, forvie 3m Betriebe des \&jandeihgemerbes 1110 jum Sandel mit (Sijten (\$§ 33, 34 der Reid)

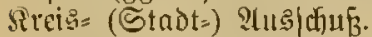

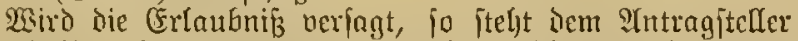
innerhalb 2 Wodjen der 2 (ntrag anf nilmblide $\mathfrak{B}$ crljandlung

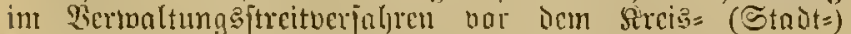
?(11:j(d)ujןe zu.

llcber ?huträge auf Ertheilung ber Frlaubuib zum פ̧c=

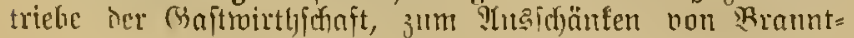
mein noter bon Rein, SBier nocr anderen geiptigen Setränfen, jotoic 3um Slcinhandel mit Branntwein oder Spiritus, ift

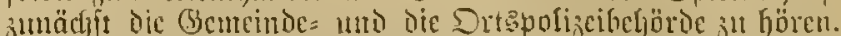
Wirb bon ciner dicjer 2ichörocn Witcrfprud erfjoben, fo

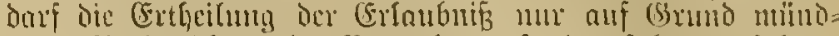
Cidjer Berljandlung in Berwaltungsitreitucrfabren elfolgen.

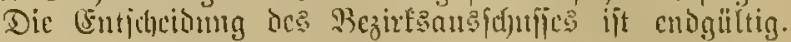

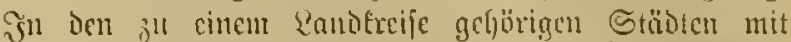

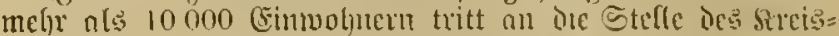

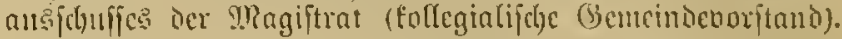

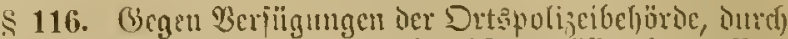

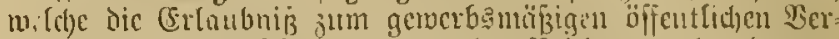

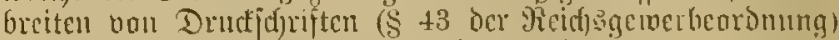

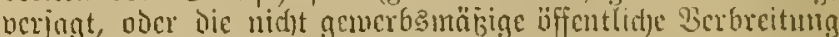

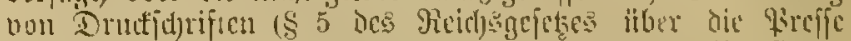

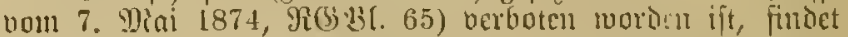

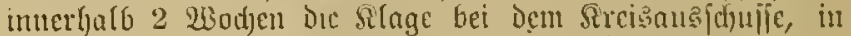
Stantkeijen uno in ien ju cincm Zandeteife geljörigen

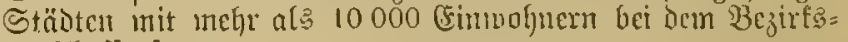
aแsichulufic itatt.

\section{Drtsftatuten.}

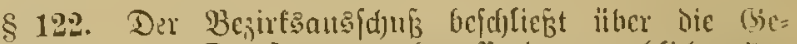

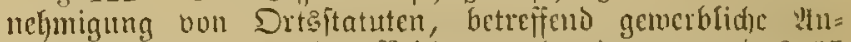

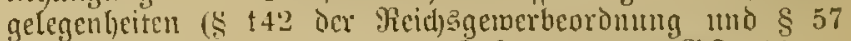

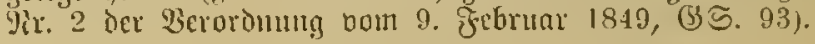

\section{D. ริunungen.}

E. Märte.

F. Deffertlidge Sdyladithäufer.

G. Siegrbezirte.

II. Thböfutg gelverblider Beredtigutgen

\section{Citel. Sandelskaumeru, lianfmänuildpe dorporationet, ¿ör ren.}

\section{Citrl. 尹etuerlöldiuefen.}

\section{Cittel. Sillfsiliafen.}

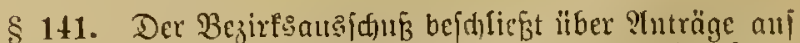

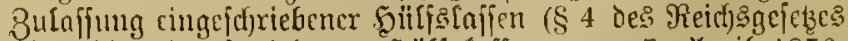

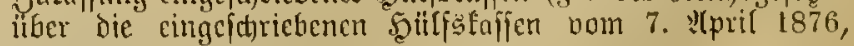
R(3)1. 125.1)

(Segen don die BnInijung beriagenden Beichlub fintet

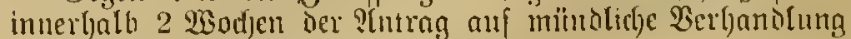
im Sierwaltmigs frecituelfahren ftatt.

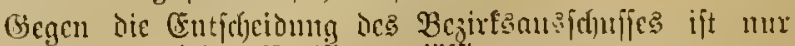

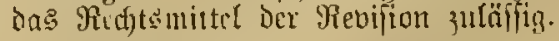

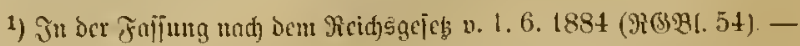

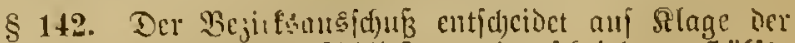

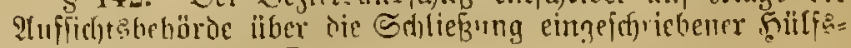
taffen (\$ 29 a. a. D.). 


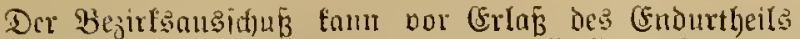

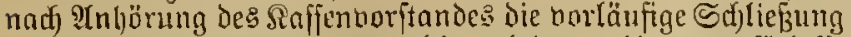

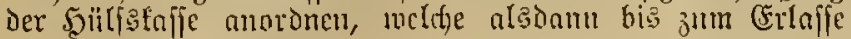
des Endurtheils fortoauert.

\section{Citrl. Záupolijei.}

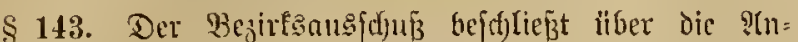
woendung Der in Den Stäbten geltenden feuer= Imo bau= polijeilidyen Siorfduriften bei (sicbänden anf fold)en zum

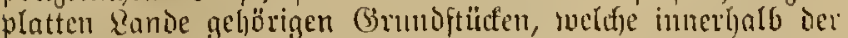

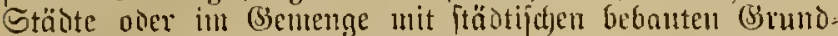

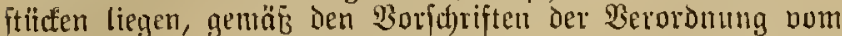
17. Эuli 1846 (G5. 399).

$\$$ 144. Leber Die Nanvonoung Der Bejtimmungen ier

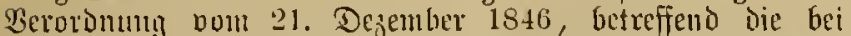

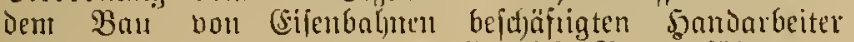

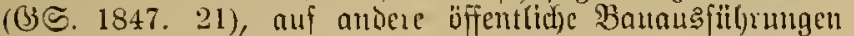

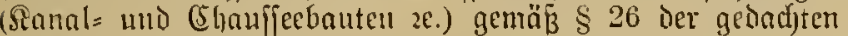
Berordmung bejudię̧t:

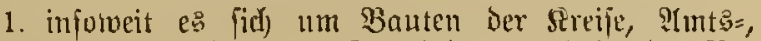
Wegeverbände oder Bemeinden handelt, Der $\Re e=$

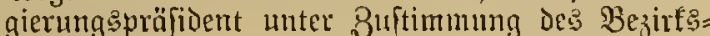
auย์(c)uाfes;

2. inforveit es fid um Santen des Brovinialoel bandes handelt, Der' Sberpräjident unter Buftimnung Des Wironinjialraths;

3. fï̀ Deu Stadtfecis Şerlin Der Sberpräfitient.

\$ 145. Heber Dispenje bon Beftimmungen Der Ban= polizeioronungen bejdlief̧t nad) Dafägabe diejer Sordmungen Der Sircisausf(huf, in Stadffreifen und in den ju einen Eandfreije gehörigen Stübten von meljt als 10000 Ein=

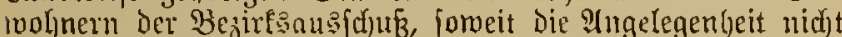
mach bicfeu Dronungen zur Zuftändigteit anderer Drgane

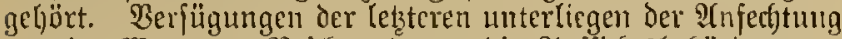

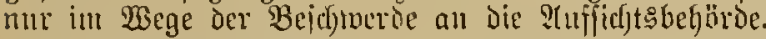

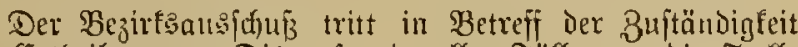
зur Crtheilnng von Dišpenjen in alfen J̈̈lfen an bie Stelfe der Bejirfizregiernng.

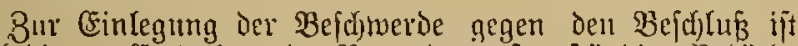
and Die zur Ertheilung der Bauerlaubnif 3ntändige 2Behörbe befugt, weld)er ber B̧ejchluß zujufteflen ift.

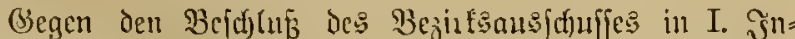

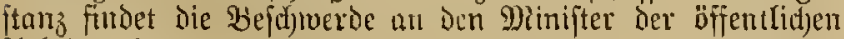
Arbeiten ftatt.

\$146. Die \$\& 17 und 18 des Gejetzes, hetreffend die Sulegung und Berönocrumg von Strafien und silätsen in Stäoten nnd länd cicfen Sttf(t)aften, vom 2. Sulli 1875 (\$S). 561) werden allgehoben.

Die $\mathfrak{W a h r n e l y m u n g}$ Der in Den $\$ \S 5,8,9$ a. a. 0 . dem Sircisausfidufie beigelegten Funftionen liegt für Den Stadt= Lreis Bertin dem 9hinifter Der öffentlidgen ?trbeiten, für Die ïbrigen Stantfreije, fornic fïr bie $3^{41}$ eimem Ranofreife $g \varepsilon=$ börigen Slädte mit mel)r als 10000 (Sinwolynern dem be= jirfకă $\$ \$ 12$ und 15 a. a. S. erfolgt jüt den Stadtfreis Berlin ourd) ben Minifter ide Şmern.

\section{Citel. Disuembrations- mo Aufiedelutgs[adjen.}

\section{Citcl. Ëntcignungsfaden.}

\$150. Die Befugniffe und Sbliegenfyeiten, meldye in Dem Erefetse nom 11. Suni 1874 itber die Enteignung bou (3rundeigenthum ((3) Drofteien) beigetegt worden find, merien in ben Fitflen ber

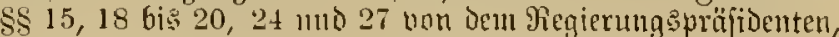
in den Jällen ber $\$ \S 3,4,5,14,21,29,32$ bis 35 und

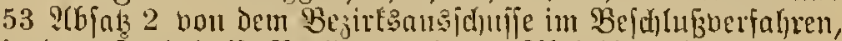

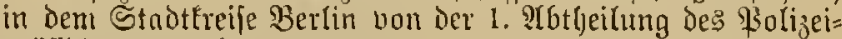
präpidiums, walnigenommen.

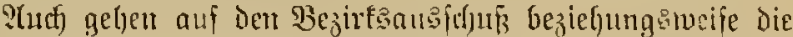
1. Plbtheilung des Folizeipräftoints in Berlin bie nad)

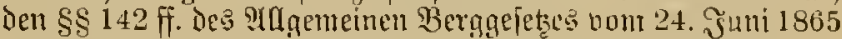

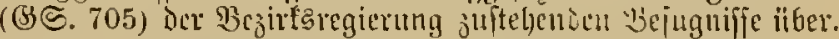

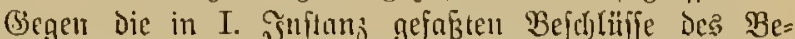

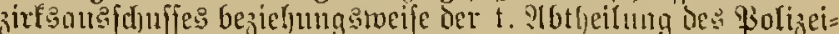
präfidiums findet, fomeit nicht oer ordentliche Mech)tsmeg zuläfïig ift, innerhalb 2 wodfen bie Befffmerìe an den g)tinifter ber öffentlidfen ?trbeiten ftntt.

Bei ber fïr die (Erljebumg Der Ŗef(f)werde in $\$ 34$ Des

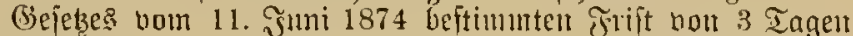
beljält es fein Betuenden.

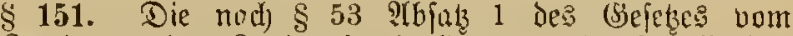
11. Эumi 1874 Dem Randrathe (in Szannover der betreffenden

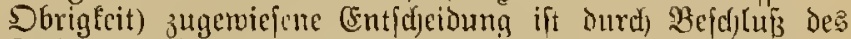

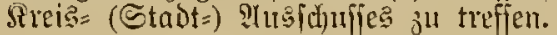

Der $\$ 56$ des gedachten Gejelzes tritt auber Sirnit.

\$ 152. Someit nach Den für Enteignungen im Эntereffe

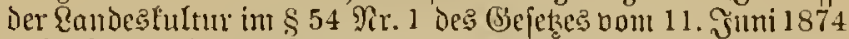
aufredjt erbaltenen (Gcietzen, in Berbinoung mit dem Gejetze

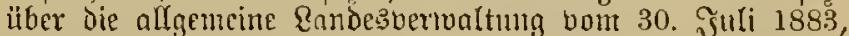
Der Regierungspräfiocnt über dic Enteignung Entfcheidung

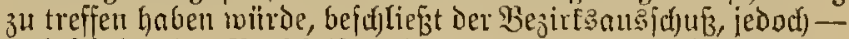

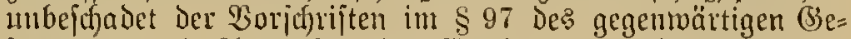
jetzes - mit ?tusnuhnte der Enteignungen fïr bie Btoecfe bon Deidjen, meld)e einem Seichuerbande angehören, uno für bie Zworte der Sielamitalten in Den Berbandsbezirten.

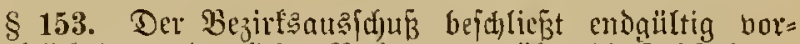

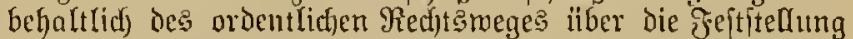

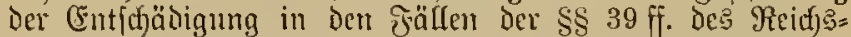
gejetzes bont 21. Dejember 1871, hetreffeno die Befchrünfurgen des Sirundeigentlgums in ber llutgebung bon Jeftungen

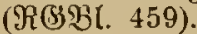

\section{Citel. Ḋerfouenftatio uto Stantsangefjörigheit.}

\$154. Die ftuntlict) ?(uffidft itber die ?intsfithrung

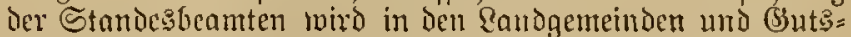
bejirfen bon Dent Eandrath als Borjikenden des fireis=

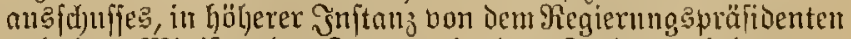
und Dem Minif́ter des Snnern, in den Stadtgemeinden bon

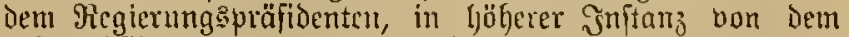
Sherpräfinenten und henı Minifter des Fnnem, im Stndt= 


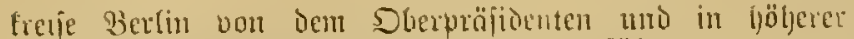
Snftanj bon ben yimiiter bes Gnmern gefülyrt.

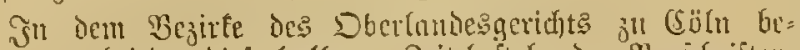

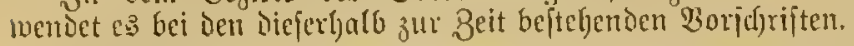

Die Fefifetzung Der (Entjổöigung fïr bie Waljuef)mung

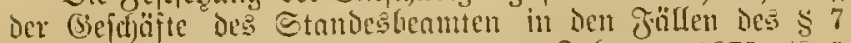
Ibjat 2 bes Reichegeictzes bom 6. Jebrun 1875 (\$ 5

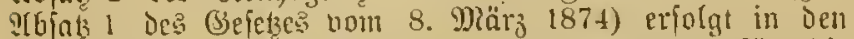
Etadgemeinden Durdi dic Gemeindenertretung, fiir bic

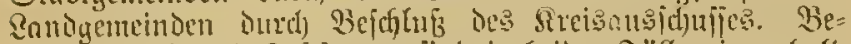

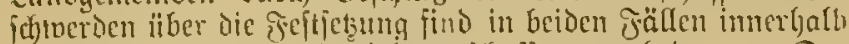

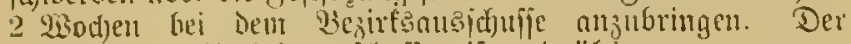

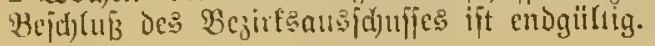

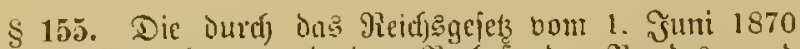
iiber die Cruverbung unt ben Berluft Der Bumbes= unb

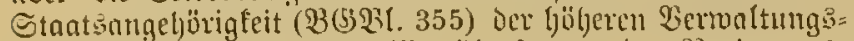

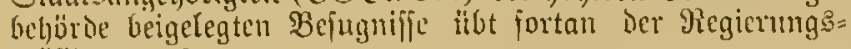
präfioent aus.

(i)egen Den Befdjeio Des Regierungspräpiomten, durd) weld)en ?tngeljörigen eines anderen Dentfden Kiundesftants

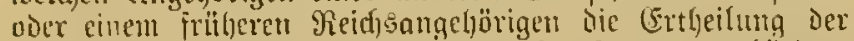

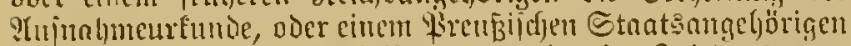
die Ertleilung ber (5ntlajiungsutunde in jorienensjerten nerfagt morden ift (\$\$ 7, 15, 17 und 21 leistex ?lbjats a. a. D.), findet imerbalb 2 Wodjen bie Slage bei Dem Dberner= maltungsgerichte ftatt.

\section{Citcl. Stenerangelegenfieiten. ${ }^{1}$ )}

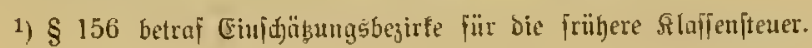

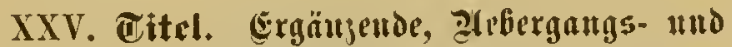 Sdifukbeftimunugen.}

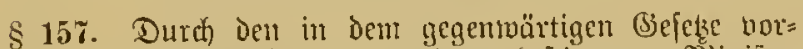

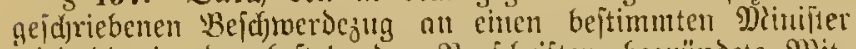

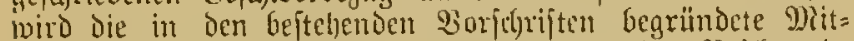

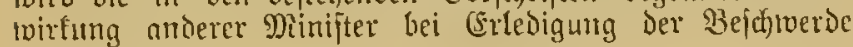
nidi)t berühtht.

\$ 158. Durd) Die Den Beljörden in bicjem Geję̧e bei= acleaten Befugniffe zur Entidjeidung hejieljungsincife $\mathfrak{B}_{\mathrm{e}}=$

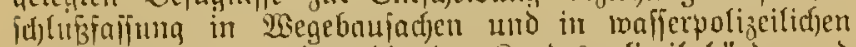

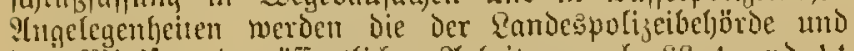
den Drinifter Dex ëffentlid)en Yrbeiten nad) \$s 4 umb 14

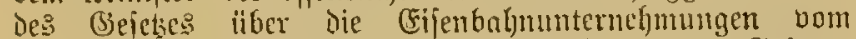
3. 9robember 1838 (\$) 5.505 ) แmo tract) $\$ 7$ des Gejetzes uom 1. Mai 1865') (S) S. 317) zuftebenden Refugnifje in (sijenbahnangelegenfyeiten nidft berithrt.

1) Betrifft Inlage non Eifutbahum in ben Gohenjollemigen Eanden. Der $\$ 7$ Defielben beft fid mit $\$ 14$ bes Gejeges vom 3. 11. 1838, im I1. Theil.
\$159. Die in Den $\$ \$ 7$ und 22 Des Gefetses tiluer die (Fifenbahnunternelymungen nom 3. Tobember 1838 und nad)

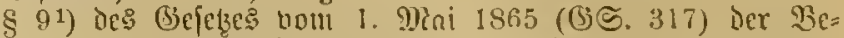
jirfsregierung beigelegten Befugutije geten auf ben Minifter ber öffentlidjen Sfrbeiten l̈ber.

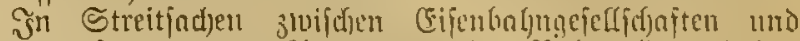

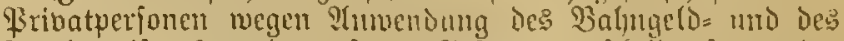
Fradittarijs (\$ 35 Des erjteren (Sejelses) entfofjeidet fortan ber ordentliche Ridfter.

1) Derpelbe bedt fid) mit $\$ 22$ Des Bejetses v. 3, 11. 1838.

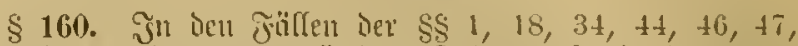
54 und 140 Des gegenmärtiaen (Seletzes, fowie des \$ 53 Des (Beiebes, betreffent die Bildung von baffergenofjen= (d)aften, bon 1. Uptil 1879 (GS. 297) ift die Bujtåndigfeit

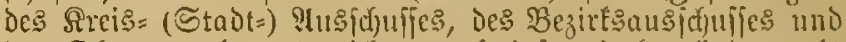

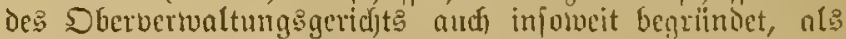

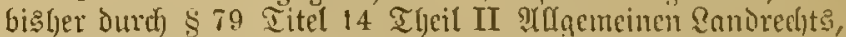
beziel)ungsweije s\$ 9, 10 des Befetzes itber bie frtweiterung Des Reditsweges bon 24. Mai 1861 (GiS. 241) vocr

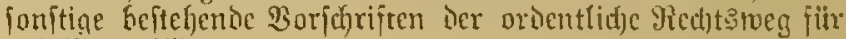
zuläfiig erflürt mar.

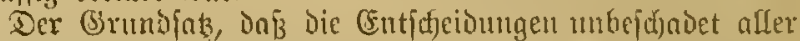

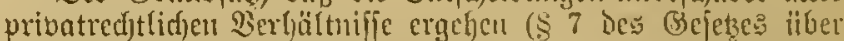
Die alfgemeine \&andestuertualtung bom 30. Sult 1883), bleibt ljierbei unberiigrt.

\$ 161. Jür Den Stabtfueis Berlin ift der Bejutf:

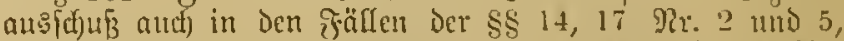
$41,110,111,112,123,128,130,132,145$ m1 $154 ?$ ?b $=$ fats 3 bicics Gejetzes juitüubig.

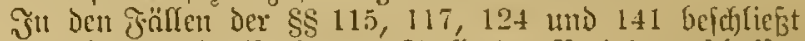

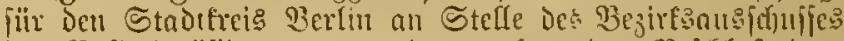
der Bolizeipräfident; gegen Den berfagenden Bejulfub Des=

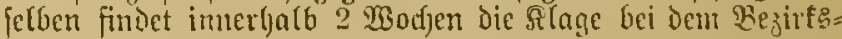
ausichulfe jtatt.

\$ 162. Maßjgebend fïr bie Betect)nung Der Ginwolyner= zohl einer Stabt ift in Betreff Der B3citimmungen bicies

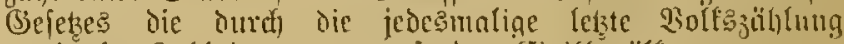
ermittelte Bubl der artsamucjenden (Sivilbebilfermig.

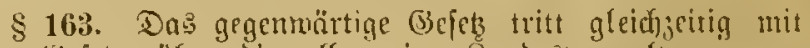
Demt Sejetse itber bie alfgenteine Eandesbermaltumg nom 30. Surti 1883 in strait.

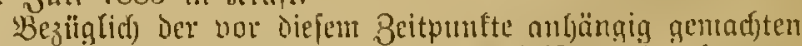

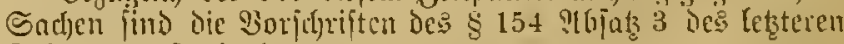
(s) efetzes mañgebend.

\$ 164. Dit iem Tage ies Jutraftretens bes gequ = märtigen Bejetzes foum das Gejets, betrefient dic $34=$

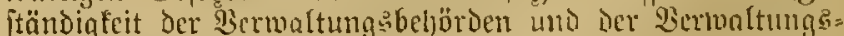
gerid)tsbefjörden zc., von 26. Şuni 1876 (S;S. 297) in allen jeinen Theilen in Wegjall.

Fngleiden treten mit dem gedaditen Beitpunfte alle mit ien Borfdriften Des gegentü̈rtigen (Sejetzes in Wiberfprud) ftebenien Beftimmungen aujer Srajt.

litfunolid) $2 c$. 


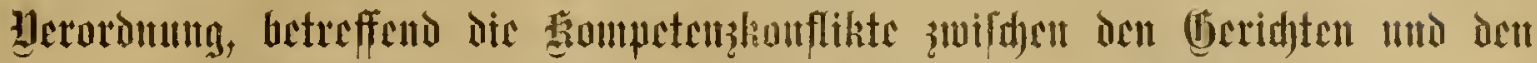

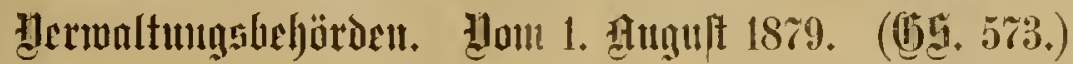

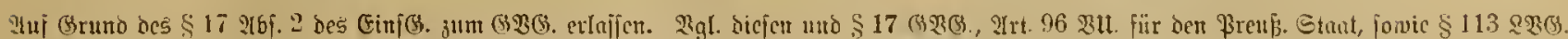
Durd) diefe $\mathfrak{B}$. ift bas (\$. v. S. 4. 1847 (\$) 170 ) crict.t.

$\$ 1$. Die Entfdyeidung von Streitigfeiten ilfer Die Blt=

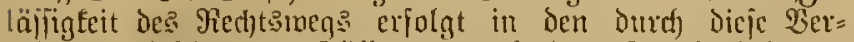

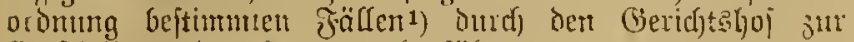
Entiffecioung ier Siampetenzfonflifte.

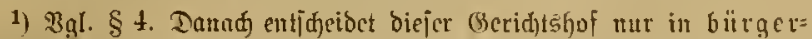

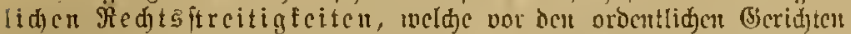
anbängig fitto. Sn Straffällen (ngl. bas folgende Gcjeb v. 13.2. 1854), jorvic bei Rompetenjtortififen zoilden Bermaltunasbehörocr uno

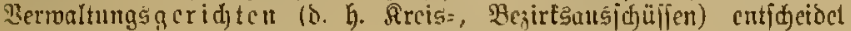
nidjt ber im $\S$ ! bejeiducte Geridishof, fondern Dos Dberver= waltungsgeridt. Bgl. \$11 des CinfG. Jum (9BG. in \$erbindung mit $\S 1$ t4 bes \&B(3. v. 30 . 7. 1883

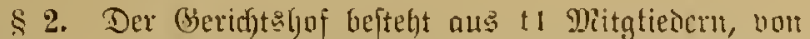
Denen 6 dem Dberlandesgeridyt zu Berfin ${ }^{1)}$ angehberen mäffen. Die anderen 5 Pritalicher uliffjen fïr Den böberen

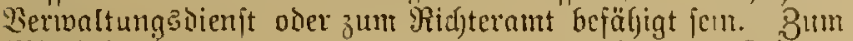
Mitgliede fami mur ernanut werden, mer bas 35. Refons: jaljr bollendet lyat.

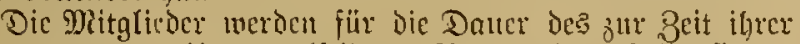
Enennung bon ihnen befleitoten ?Imtes ober, falls fie ill diejer Beit cin ?tmt nicht betleison, auf Sebon?zeit emannt. (Finc Enthebung bom :Intc fam mur unter demfelben Borausfekm itattifinden.

Det $\mathfrak{B a r j i b e n d e ~ u n d ~ d i c ~ t i b r i g e n ~ M i t g l i e h e r ~ m e r d e n ~ w o m ~}$

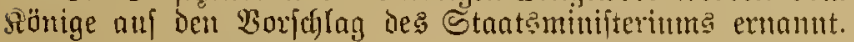

1) D. i. Sammergerifft.

\$3. Der (3eridjtêlyof entidjeidet in ber Bejeksung bon 7 Mitgliedern.

Die (bijd)äftsoronung, inabejunowc hie Beiugnific bes

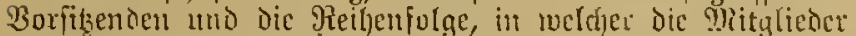
an ben einielnen Sisungen Theil ju neljmen haben, werden

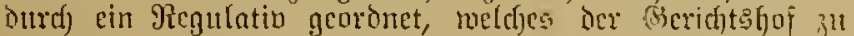
intwerjen uno bem Stnatsminifterium jur Bejtätigung ein= jureidjen bat.

§ 4. Det Beridftahof entiffeidet, Menn bie Berwaltungs: beljöroen dert Rechtsmeg in einemt bei ben (Beridjten an=

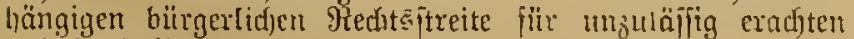
und deshalb der Rompetentonflift crlyohen miro.

Der Sompetenzfonffift fant nicht erlyoben merien, wemu

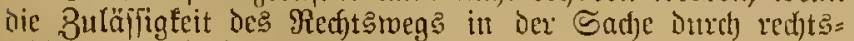
Fräftiges llrtbeil des (Serichtes fejtitel)t.

\$5. Zur Erhebung des Siompetenjonflifts ift mut die

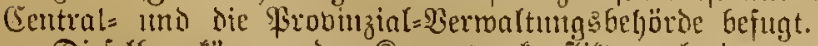

Dicjelben tömuen den Sompetenjentilift aud bam er= hehen, went die Buftäubigfeit zur Enticheidung Der Sudje fitr bie Berwaltungegeridhte in S(njprud) genommen wiro.

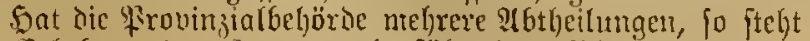

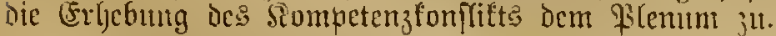

$\$$ 6. Die Erbebung Des Sompetenffouflifts eljolgt bei dem (Siericjte, bei meldhent die Sache nuljängig ift, burd)

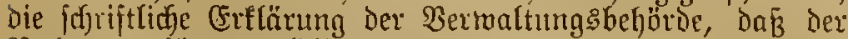

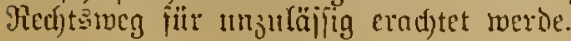

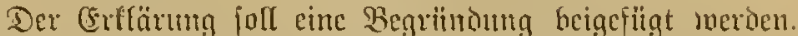

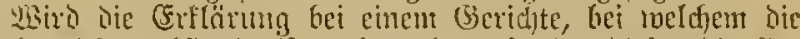

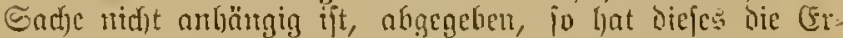
frärung ant das juftändige Gieridjt jul itberjenden.

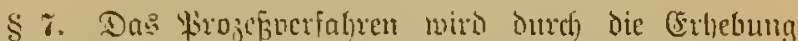

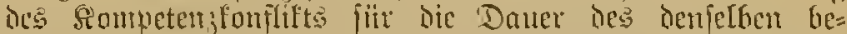

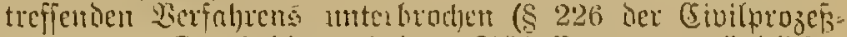
oromung). Durff Die nach bent Grhluffe eincr münblidgen

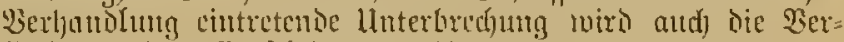
fïnDuna eincr Entidicioung geljindort.

Das Geridft lat bic 2iermaftungsheljübe nou dem Cin= gange dor Crflänurg unb die Gartcien bou bor Erhebung

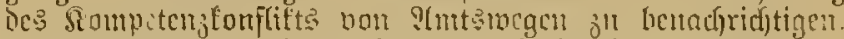

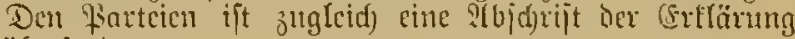
in ïberjenden.

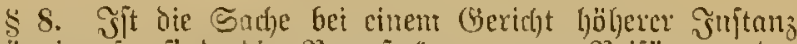

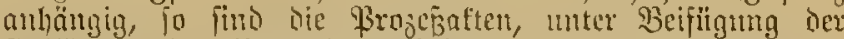

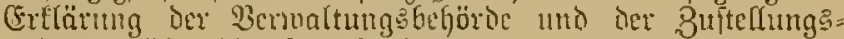
urfunden

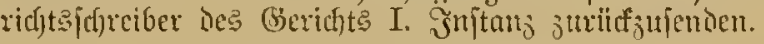

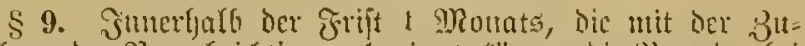

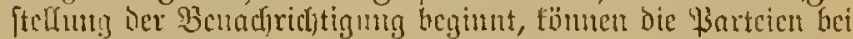

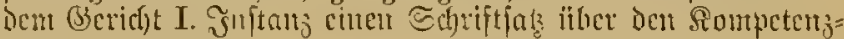
tonflift cimetdien.

Der Sdyrifial mús von cinem Rechtsanmalt inter:

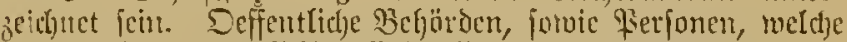

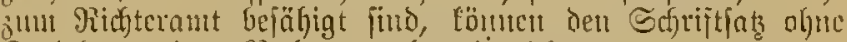
Bujichny eince gied)tsanmalts eiitreidjen.

Das Geridft hat der Bermaltungǎbelyörite und Der Gegen= partei ben Echriftiats in Ilbichtift miszutheilen. Die er. forbertiche Bahl bon ?(bjchriften ift bon ber fiartei einitreidfen.

Sind immerljalb ber ơtijt Sdyriftäks nidjt eingegangen,

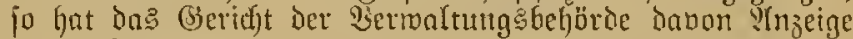
jt mact)en.

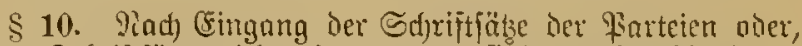

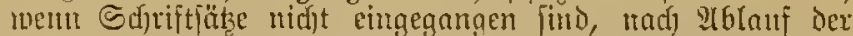
im \& 9 beftimnten jrift iendet Das Beridft dic âften mittelit gutadjtlicjen Beridjts an bas Sberlandesgeridft,

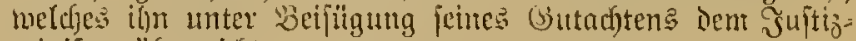
minifter

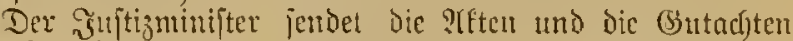

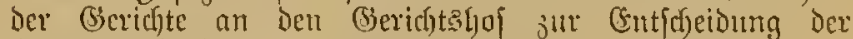

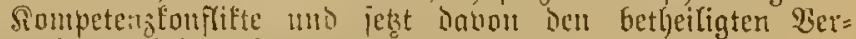

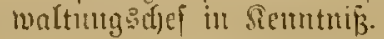

\$11. Die firovinzialberbaltungstefjörden gaben an ben betheiligten Wermalturysthel PInjeige van ioc (Erbebung des

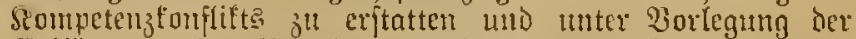
Creflïrumgen Der Farteien gittadftlid) ju bericften.

Der Sermaltungsdyef fan Dem (Serid)tรhof eine jd)riftliche

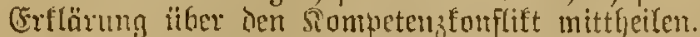

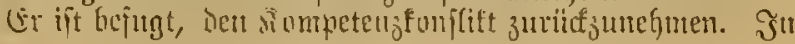


diejem falfe rerden die ?fften bon bem Gerid)tahof an den

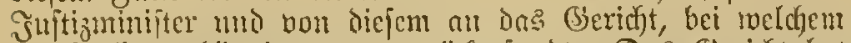

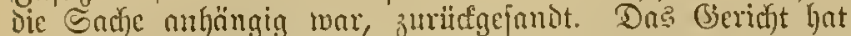

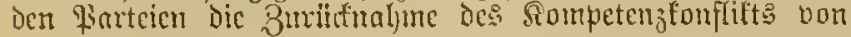
2tmtsmegen anzuzeigen.

\$12. Dic Entf(heidung des Berichtshofes über Den Simpetenz fonflift erfolgt auj (Grmo münolidjer Berljandlung in p̈ffentlicher Situng. Die Borfeljriften der $\$ \$ 170$ bis 185

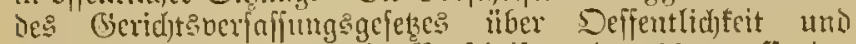
Sizumgepolizei, pomie bic Worjd)riften der §§ $145 \mathrm{ff}$. Der Civifprojefordonng itber die ?hifrahme eines Protofolls finden entfpredjende 2nmendung.

§13. Der Termin zur mündlichen $\mathfrak{B}$ erljandlung wiro von Dem Borfizenden bon :(metsmegen heitimnt.

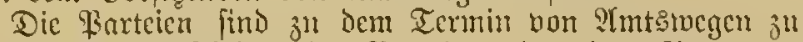
laben. Das Eriffeinen Der Parteien ober eines Bertreter's iit nidjt eriorder(id).

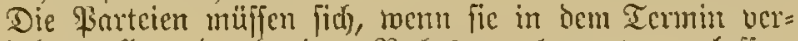
[nndocln mollen, Duxd) einen Rechtsantwalt bertreten lafien. Dieje Borjadrift findet anf öffentlidje Bebörocn mo nuf

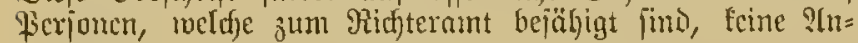
vocroung.

Dic Beitimmung bcs Termins ift dem betheiligten $23 \mathrm{cr}=$ woltumgshef mzแjeigen. Derielbe fann einen Benmten mit jeiner $\mathfrak{B}$ ctrtetung beanftragen.

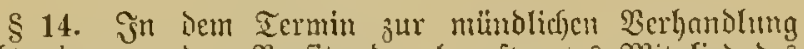
gicbt ein bon Dcm $\mathfrak{B}$ orfitzenden beanftragtes Ditglico des

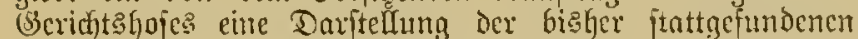
Berlyandumgen. Sodam werden die 2ertreter der Parteicu

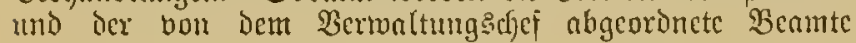
geljört.

\$15. Das Urtheil farm mux bon Denjenigen Mitgliciern

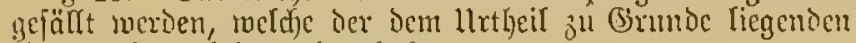
werhandlung beigewohnt haben.

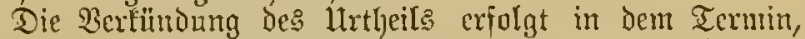
in meldjem bic münolidge Berhandlung gejulofien miro, oder in cimen fofort anzubernmenden Termin, melcher nidjt 1 Wodje hinats angeietzet merden foll.

Fn Dem llatheil find Die Namen Der MRitglieder, welde bei der Entfoheibung mitgetwirkt haben, nnzugeten.

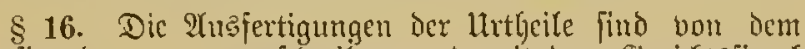
Borfizenden ju unteridgreiben und mit bem Beridjtsjicgel 3t verjeljer.

$\S 17$. Sine $\mathscr{A} u$ sfertigung des Urtheits ift Dem $\mathfrak{B e r}=$ waltungsefhef, eine nnderc mit Den geriffitlicjen Aften Dem Эuptizminifter miţutbeilen.

Der Эuftizminifter ilberifendet bie Tusfertigung des

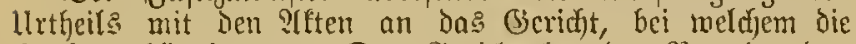
Sacje anljängig torr. Das (Gerid)t hat Den Fartcien bns llitlyeil von simtsmegen juftellen ju laffen.
\$ 18. 3it Der Reçftemeg für unzuläifig ertamnt, fo

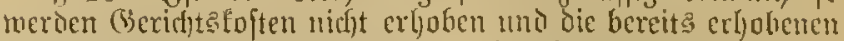

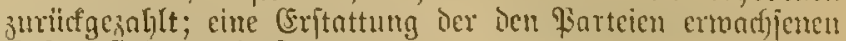
Soften findet nidjt ftatt.

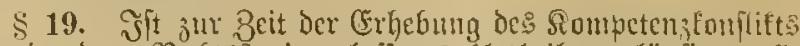
cin in bem Rechtêftreit erlafienes llrtheil borläufig noll= itreffbar, fo Gat ias Berid)t, bei welebem bic Sadje an=

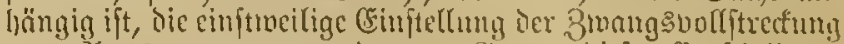

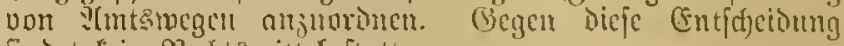
findet fein Red)tsmittel jtatt.

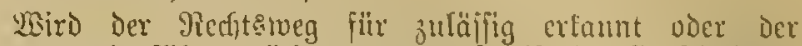
Sompetenzlouflift zurïfgenommen, fo ift bie Cntjosibumg von ?(mtstuegen wiener anfarbeben.

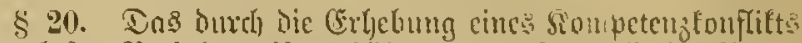

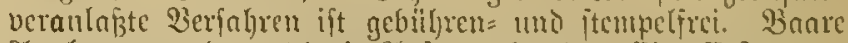
?luslager rocrien mid)t in ?(ufals gebracl)t. Eime Erftattung

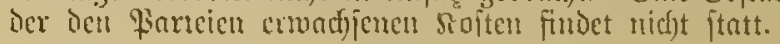

\$21. Saben in einer Sadfe cinerjeits Die (Sicridfte mo andererjects die 2icrwaltumgebljorben ober Werwaltung: gcrid)tc ifre llnzuftändigfent cuogulltig ausigejprod)en, weil

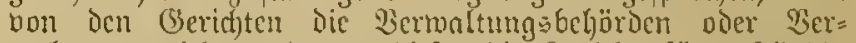
maltung sigerichte und bon dicjen die (jicrichte für zuftündig

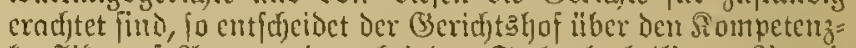
fonflift anf Intrag einer bei ier Eache betheiligten fintei.

Der Qntrag ift bei tem (Beritht anjubringen, bei melchem

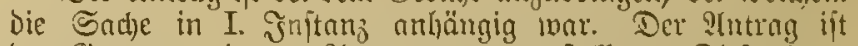

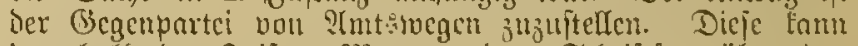

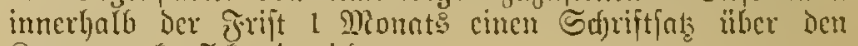
Sompeters fouflift eimeidien.

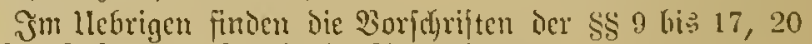
bicies (Sejetses entipredjende ?trmendurig.

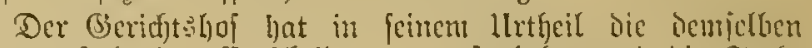
entgegenjteljenden Enticheidungen aufätheben mo dic Sache

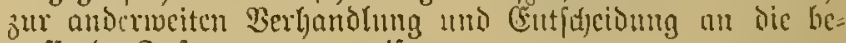
treffende Э̄nftam ju bermeifen.

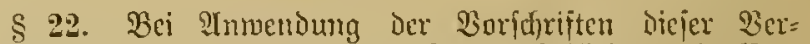

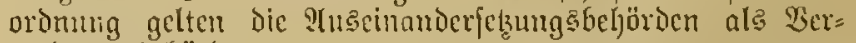
waltungs beföricn.

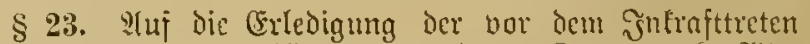
bicjer Reroriommg anljängig getoorbenen Ronipetenjtonflitte finden dic bisherigen Bejtunmungen über bas $\mathfrak{B}$ erfabren Slntwendung.

\$ 24. Dicje Beroronnng tritt glcictseitig mit Dem (Be= richtaverfajiungegcjetse in Srajt. ${ }^{1}$ )

1) Das war am 1. 10, 1879.

llrkunolidy $2 c$.

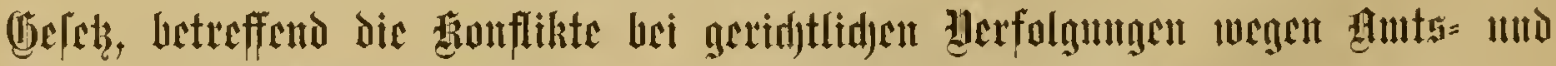

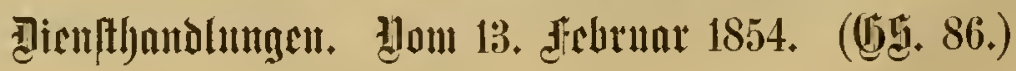

§1. W3enn gegen einen (Sivil= ober Militärbcamten ${ }^{1}$ ) megen einet in शlusübung oder in Beranlaffung ber P(us: übung feire: 2 mte: borgenommenen Şandlung oler megen ltnterlnffurg einer :(m) im $20 \mathrm{cgc}$ des Civil= oder Strafprojeffes cingeleitet moriten ift, fo ftegt der borgejekten frovinjial= oder Ecutralbeförde de Beamten, falls fie glaubt, Doß Demfelben cine zur

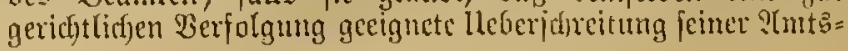




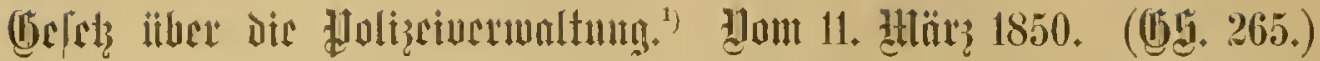

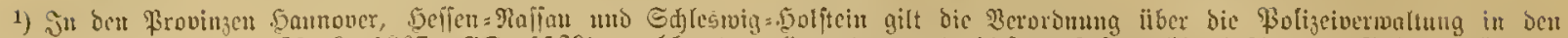

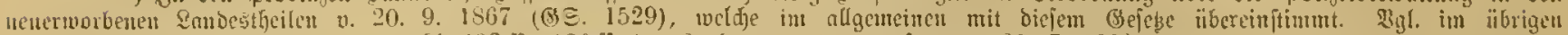

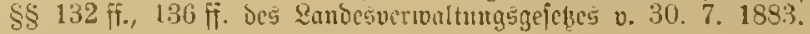

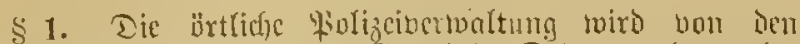

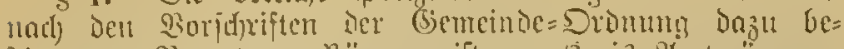

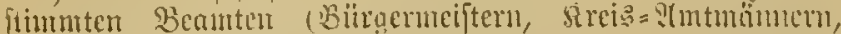

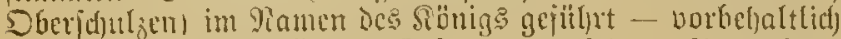
Der in \$2 Des genemmärtigen (bifetses vorgeicl)enen ?(usnal)me.

Tie Drtspoliseifenuten find nerpflieltet, Die ifhen von

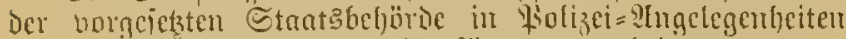

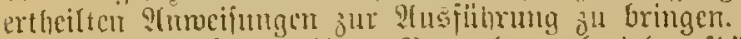

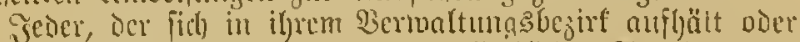
dafelbft nufüfing ift, mus iljen polijeilicjen ?tnorbum!̣en jolge leiftert.

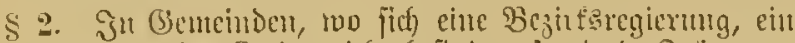

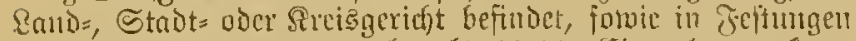

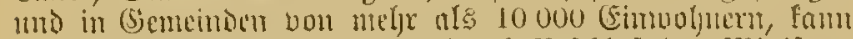

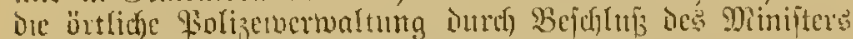

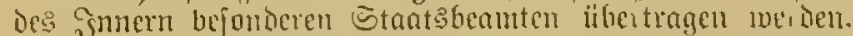

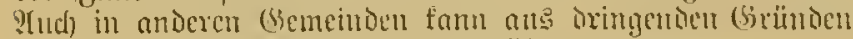

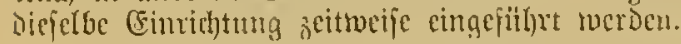

\$ 3. Die Roften oer örtlidjen fiolizcivermaltung find,

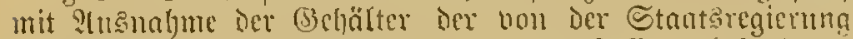
im gafle ber ?turbentum des $\$ 2$ autgefteften befonderes Beamten, bum ien Gencindeu jut beftriten.

Эn Etäbten mit Siöniglidger \$oliz̧civerwaltung bejteitet Der Etant

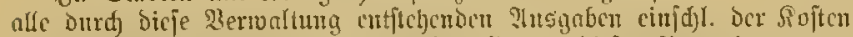

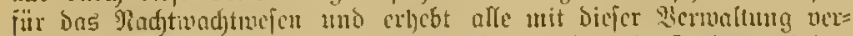

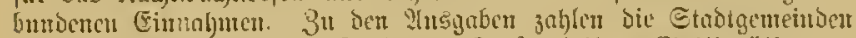

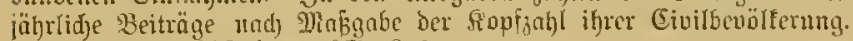
(3). v. 20. 4. 1892 (ङङ. \$7), §1.

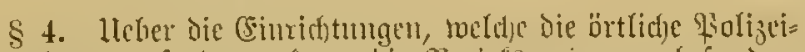

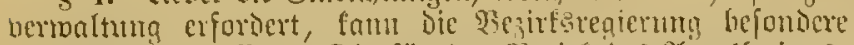

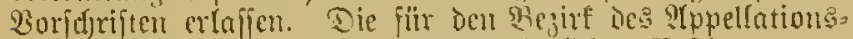

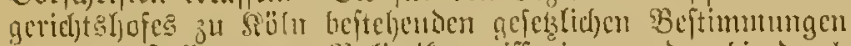

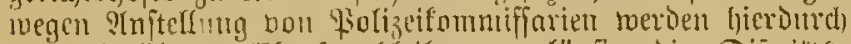

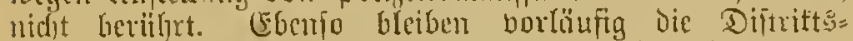
fomntifiarien in ber frovinz 7 sojen in witfianteit.

Die Ememung allet Polizeibeamten, Deren ?hiftelurg

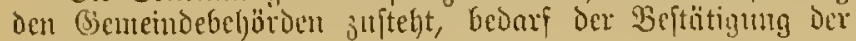
Stantiseaierming.

\$5.1) Die mit ber örtlithen łsoliseivermaltumg beaul=

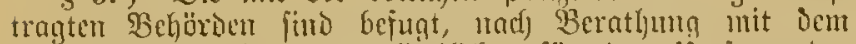
(Sememincoorftamde, ortepolizeifiche, fïr den lintjang Der (Semeinde gïltige Sorfdriftcu 3n erlajjen und gegen bic Wiid)thefolgung berfelfen Belojtrafen bis zum Betrage bou 3 Rthlr. altzuorolyet.

Die Strafanitohung farm bis zum Betrnge von $10 \Re$ thytr.

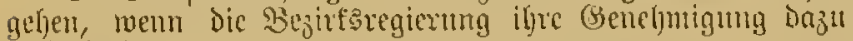
ertheilt loat.

Die Bejirfsegierungen haben Here die ?trt und die

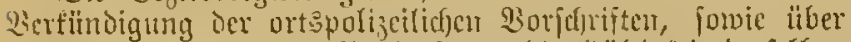
Sic Formen, bon beren Beobachtung Dic Ssiiltigfeit Derjelben abbüngt, Dic erforberlidjen Beffimnumgen j" r'Lafjen.

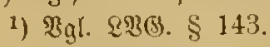

\$ 6. 3n Den Gegenftänien ber ortspolizeilidjen Bjor= (f)riften gehöret:

a) Der Soljut ier fierjonen und Des (Gigentlyums; b) Dronung, Sicherljeit uno Scid)tigfeit Des Butreltes auा Bffentliclyen Straßsen, weģen mun Filäzen,

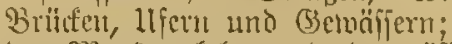

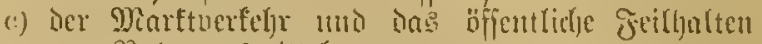
bon Raljrugsutteln;

d) Drontung unt Sejetslidffeit beti Dem offientidfent

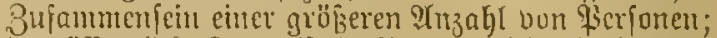

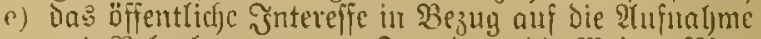

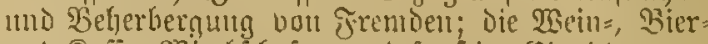

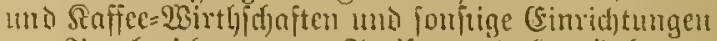
3แr Sicrabreidjuttg non Speifen tuto (bsetränfen;

f) Sorge fïr Reben tmit (Befumblytit;

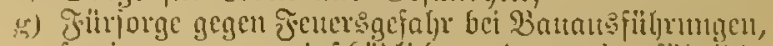

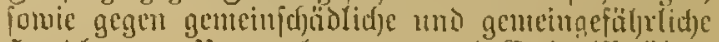

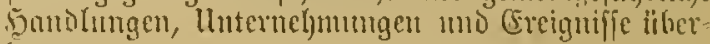
houpt;

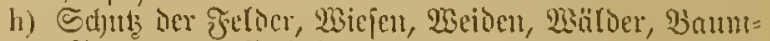
pflanzungen, 23 einberge $2 c$.;

i) alles andere, twas int hejonderen Juterefie ber Be= meinden und iljrer ?(1ngebörigen polizeilid) georinut merten muाp.

§ \%. 3u Berordmungen über (Segenitände der Iandroirtf)=

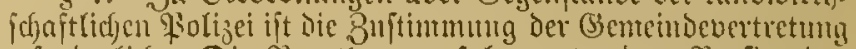
erforberTidy. Die Beratyung erfolgt unter Dem Borfite Des mit ocr betticfen \$olizeiberualtung beaujtragten Beamten.

8. Son jeder ortspolizeilidjen Beroromung ift fofort cine

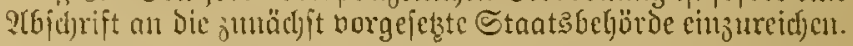

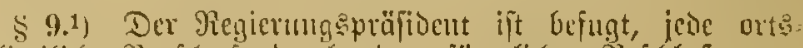

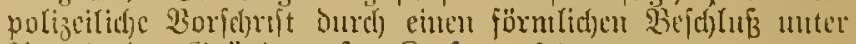
Stugabe ber Gitïnde anBer Serait zu jekel.

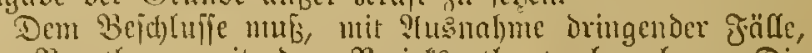
cine Berathung mit bem Bejinferathe borbergelyer. Die Crefärumg bes Qebteren ift entidjeiderio:

1. werm cine ortspolizeiliflye Sloridfrift anţer firaft ge= fekt merden foll, weil fie das (semeindemolgl berletis;

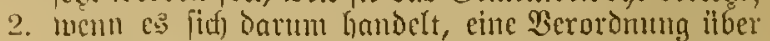

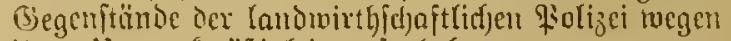
iljrer llnzruedmäjigfeit aujzubeben.

1) $2980 . \$ 145$.

\$10. Die Beftimunumgen ber $\$ \S 8$ unb 9 fmben and

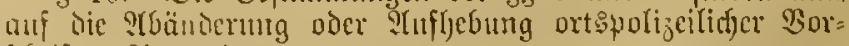
icf)riften inmendoung.

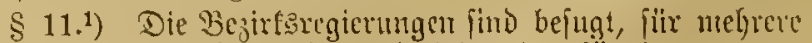

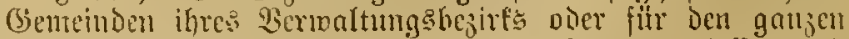
Ilufang ieffelben gulltige Polizeivorid)riften ju erlaffen mo aegen Die Piid)tbeforyung Derfelhen Beloptrafen bis ju Dera

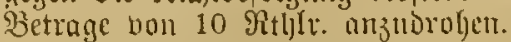

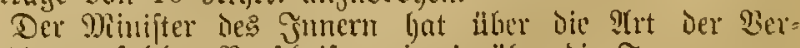

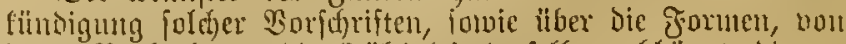

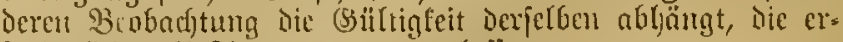
forticrtiden Beftimmungen ju erlaffen.

1) $8936 . \$ \$ 137,142$.

12. Die Borfdriften Der bezirtêregicumgen (\$ 11)

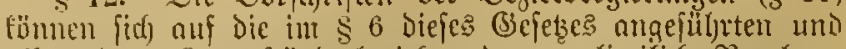

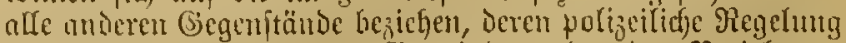

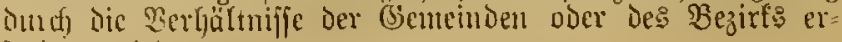
porbert wirt. 
ร 13. Bum Erlaffe joldfer Borid)riften ter Bejirfs:

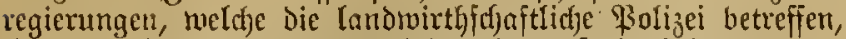

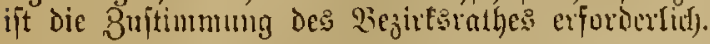

§ 14. Die Befugutí der Bezirtiregierungen, jonitige allgemeine Berbote und Strafbejtmmungen in Ermangelmng eines bereits beftehendan gejeķlicfen 2 erbotes mit höherer (S)eneljmigutg ju erlajien, ift aufgel)oben.

$\$ 15$. ES Dïrfen it bie polizeilidfen Borjufriften (\$\$ 5

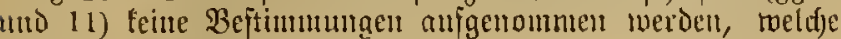
mit ben Gefersen oder ben Beroronumgen einer bäl)eten

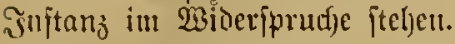

§ 16.1) Der Minifter des Эnnern ift befugt, jorveit Gejeßse nid)t entgegenftehen, jede poli, eilidje Borjd)rift durdf einen

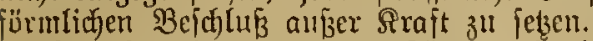

Die Genehmigung des Sënigg ift Gierzu erforderlid, sem die polizeiliche Borfdgrift bou ben Sibnige oder uit defien Bonelymigung erlaffen wat.

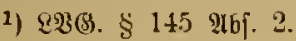

\$1\%. Die \$olizeirid)ter haben über alle Bunvioer= handlungen gegen polijeilid)e Borfd)riften (\$§ 5 mo 11)

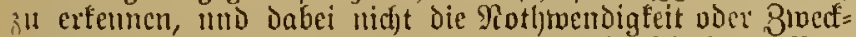

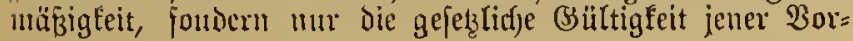

(d)riften nad den Beftimmungen der $\$ \$ 5,11$ uno 15 diefes Gefetzes in Ermägung zu ziehen.

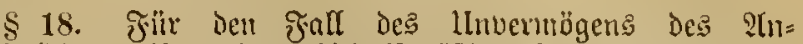

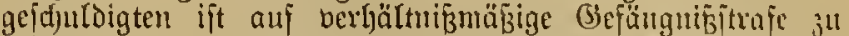

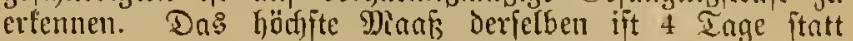

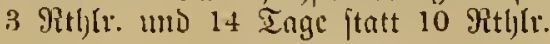

\$ 19. Die bisher erfafferen pulizeiliden Burjujriften bleiben fo lange in Rrajt, bis fie in Gentäßlyeit diejes Gejeties nufgetoben merben.

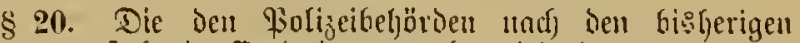
(sejesen juiteljende crefutionsigenalt wiro durd) bie vor: jteljenden Beitimmunaen nicft berïlyrt.

Эede Folijeibefärde ift beredtigt, ifye polizeilid)en Ber=

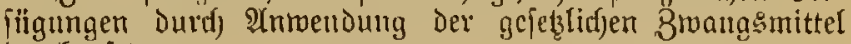
Durchizujetzin.

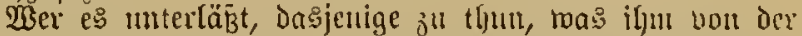

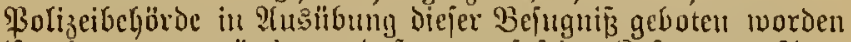

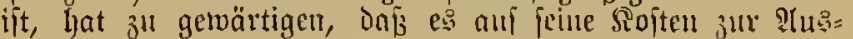
fiilhrung gebrad)t werde - vorbuhnitlid) bet elwa berwirften Strafe und ber berpftid)tumg zum Súnabenerjatze.

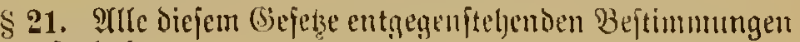
finn aujgeljoben.

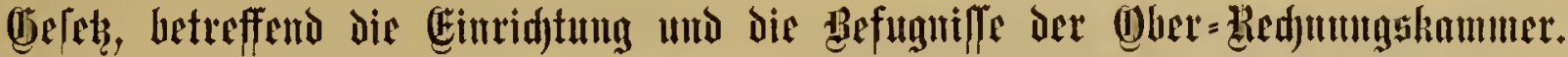

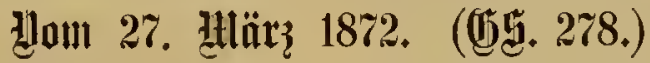

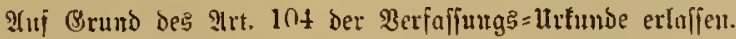

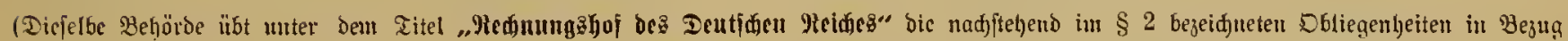
auf Den Soushalt dę Deutijhen Reides aus.)

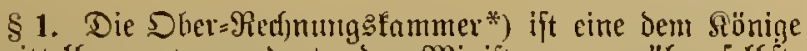
unnittelbar untergeorducte, Den MRiniftern gegenitber felbit= fiändiae Beljörde, melef)e die Rontrole ocs gejammten Staat:

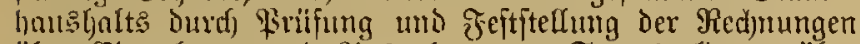
iiber (Fimalimen uno ?hisgaben bou Stantsgeloern, ïber 8ugang und Ilbgastg bon Staatseigentfum und tuber bic Berwaltung der Staatsjaulden zu jühren hat.

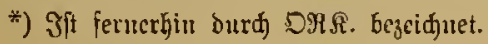

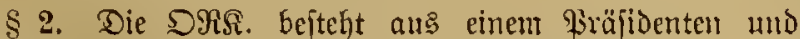
Der erforderlidjen Zahl bon Direftoren mo Räthen. ${ }^{1}$ )

Diejełben veroen bon Dem Sönige ernaunt, Der Präfi= Dent nuf Den Borffilag Des Staatsminijteriums, Die Diret=

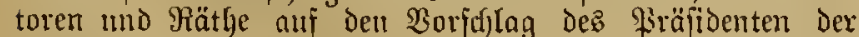

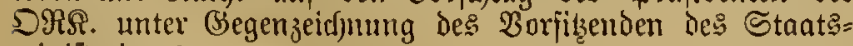
minifteriums.

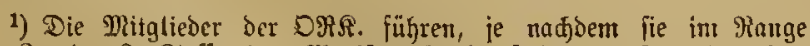
Det 2. oder 3. Rlaffe ber Minifteriufräthe Ptehen, anftatt ber bis:

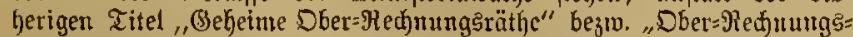

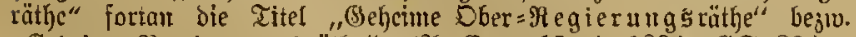
"Beheime Pegierungsräthe". (श. (E. v. 15. 4. 1894. Bङ. 33.)

\$ 3. Bater mo Sofn, Sdywiegerbater und Sdimieger= (ol)n, Brtioer und Sd)twäger diirfen nicht zugleid) Mitglieder

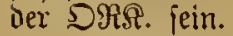

§ 4. Rebenämter oder mit Renumeration verbundene Rebenbejdäjtigungen bïrjen Dem Rräfibenten uno den Mit=

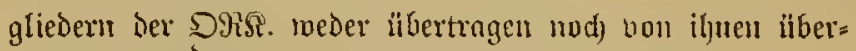
nommen werden.

(56enfomenig fünuen die gednd)ten Beamten Miitglieder cines der Şänfer Des \&anotages feil.

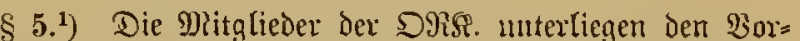

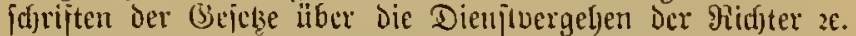
vom 7. Mai 1851 (\$S. 218) und bom 26. Märs 1856 (ङ5. 201) unter folgenden näheren Beftimmungen.

Das Sbertribuna ${ }^{2}$ ) ift bas juftändige Dişziplinargerifjt für den firäfibenten, die Direftoren und die iibrigen Mitglieder Der DRs. Die im $\$ 13$ Des Bejetzes bom 7. Miai 1851 borgejfriebene Mahnung an Direftoren und

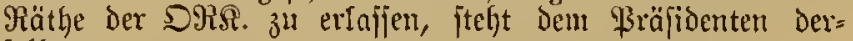
felben jul.

Die in \& 58 ebenoajclbit porgejdriebene Berrid)tung roiro in Injefung Des Gräfidenten Der DRЯ. von Dem 1. Bräfidenten des Sbertribunal( ${ }^{2}$ ) auf (Gruns eines

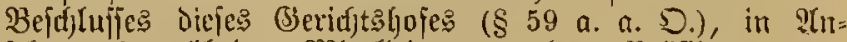
fefjung Der übrigen Mitglieher bon dem Bräficienten der S9iR. wakrgenoumten.

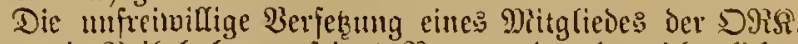
fam mit Beibelaltung jeines $\Re$ anges in ein ridjterlidfes

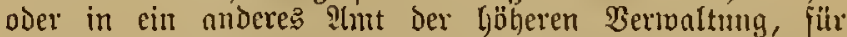
meldhes daffelbe die gejetzlid)e Sualififation bejitzt, erfolgen.

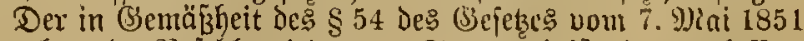

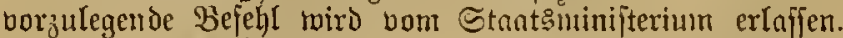

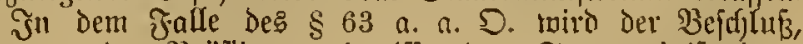
menn er den Firäpijdenten betrifft, dem Stantsminifterimm, 


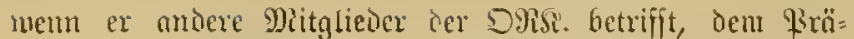
fidesten derfelhen iiberjeniet.

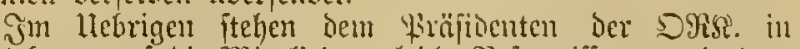

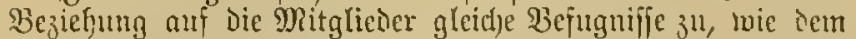

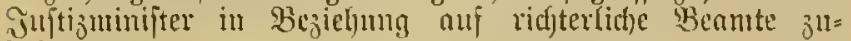
(tebell.

1) Diejer $\S$ ijt abgeänbert Durd bas Bejes, betreffeno bic ?(b= änderung von Beftimnunger der Dişiplinargejese v. 9. 4. 1879

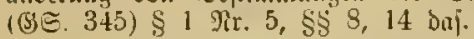

2) \$ 8 bes Bejeses v. 9.4. 1879 Inutet: ,Nu bie Stelle bes Dber= tribunts tritt ber bei Dem Oberlanbesgeridjt zu Perlin (b i. Finmer= aeriøt) зu bildende grobe Disjiplinarjenat.

Ter grobe Pisjiptinarient cut|djcibet in ber Befebung von 15 Mit=

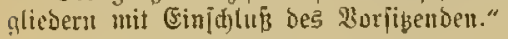

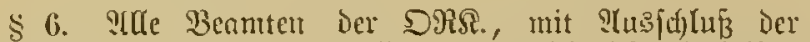

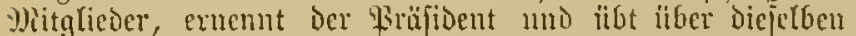

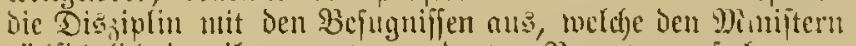
rïiffidstid Der ilyen untergcorbneten Beanten juftehen.

Die intfdeidende Disjiplinarbeljörde jür biejelben ift die Drisi., turluse in \$ilcmum unter Theilnalyme bon min= Deftens 7 Mitglicoen, cinjchlieflid) Des Purfikenden, mo im llehrigen Mar) Dem fïr Dns Dbertribmal giiltigen Disjo wharberfaben, in ber Eaffe aber nad) den Borf(t)riften Des Bejebes ïber die Dienftbergelju der nidutridjterlidjen

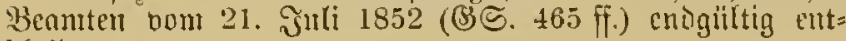
f(f)eisat.

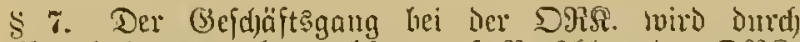
cin Regulatib geregelt, meldes auf Borfd)lag ier DRR. und Des Stantsminifteriums ourd) Sänigtide Scroronumg erlajien und Dem Randage jur Senntnifuahme mitgetheilt

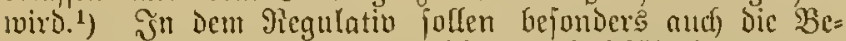

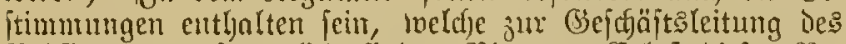

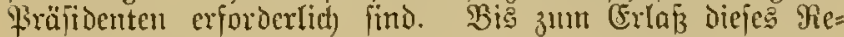
gulatins bleiben die bisher ergangenen Эnjtruttionen

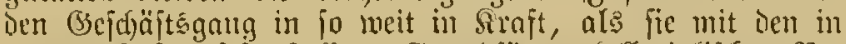

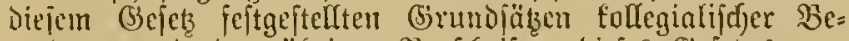
rathung mo den ilbrigen Borfdriften Diejes Gejełes ver= cinbar find.

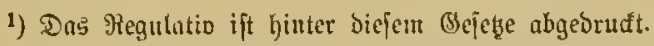

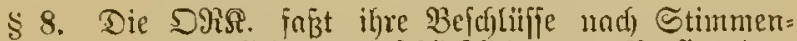
melyrheit Der Mitglieoer, eimjoließ̧lic) des Borfitzenden, weldfer bei gleidjer Theilung Der Stimumen Den $\mathfrak{A}$ th: fid)lag giebt.

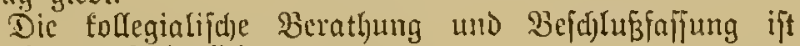
jedenfally erforberlid), wenn

1. nn Den S̈buig Berid)t erftattet,

2. Die jür bie Seäujer Dcs Randtages bejtimmten $18:=$ unerfungen ( $\$ 18)$ feftgejtellt,

3. alfgemeine Brumbjäţe aufgeitellt oder beftehende ah= geüniert,

4. alfgeneine Snftrultionen erlaffen ober abgeändert,

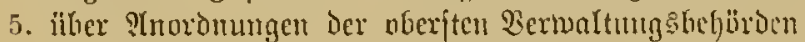
(5iutad)ten abgegeben werden follen.

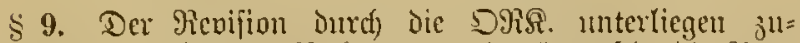
börterif alfe biejenigen Redfnungen, Durd) metd)e bie ?lus=

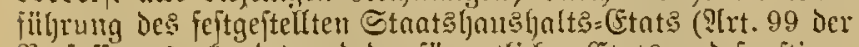
Berfafiugsurtunde) und ber fänmtliden (Etats und jonfitigen llnterlagen, auf weldyen berfelbe berulgt, Dargethan miro, insefondere aljo:

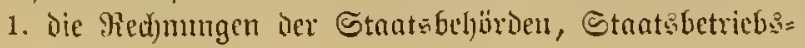

anftalten und ftantictjen Snititute ïber Gimabmen und Stusgaben uon Stantägeldoen;

2. Folveit nidft in einjeliren Fö̈lfen ftatutarif(t)e oder

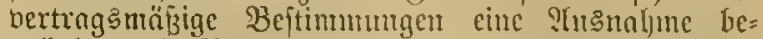

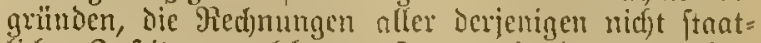

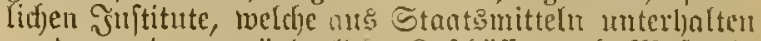
meroen, ober beränderlicle Bufdüiffe nad Miajgntue des Bedinfmiffes ans der Stantefnffe crljalten, oder mit Semährleifung Des Staates werwaltet merdu, jobalo umo fo lange diefe (Sarantic bermirflict)t werden joll.

Der DRR. wiro nament(ich) unter STufljebung Der ent= gegenitehenden ?noromungen die Renifion Der bon ber See=

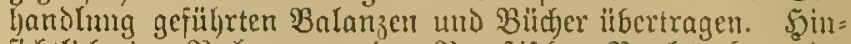

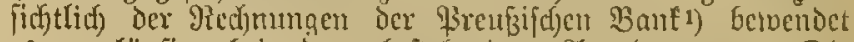

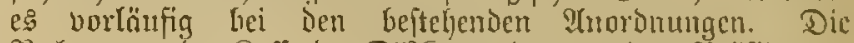

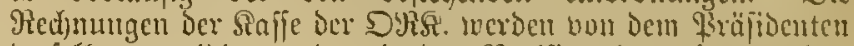
berfelben renibirt mo mit Den Rebifinonbenerfungen ben beiden Seäufern des Enndtages jul Frifinng uno Dedjarge vorgelegt.

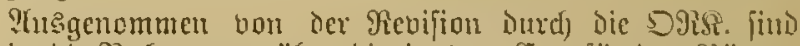
allein Die Red)mungen über Die in Bem Etat fïr Das Biirean

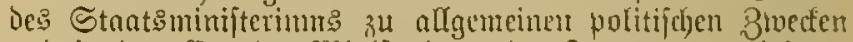
umb in Dem Citat des Minifteriunts Des Snnern 3 u geheimen

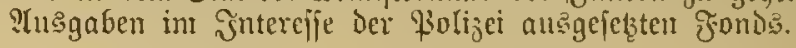

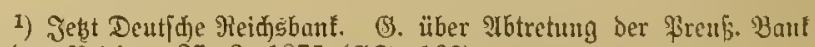

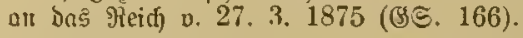

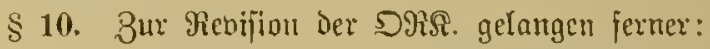

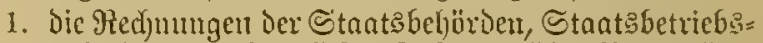
anjtalten und ftatfichen Snititute ïber giatmalien, Borräthe, Diaterialien umo fiberthaupt do gefammte nicht in (Geloc beitelyenie (Figenthum Des Stantes;

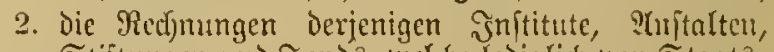
Stiftungen unt ơnos, weld)e leoiglid) von Stunts: behöroen oder buref) bon Stnatsivegen angeitelfte Beamte, ohne Ronturreuj Der Intereffenten bei der Ficd)unugsabualume uno Sunttinumg, verwaltet

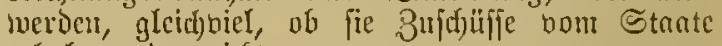
erlyaltem oder nicfst.

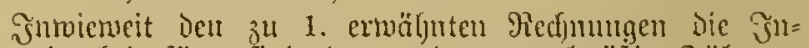

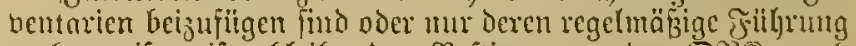
nact)jumeifen ift, bleibt der beftimmung ier Sors. nach Berjffiedentgeit Der Sajjen und Snjtitute ib berlajien.

§11. গুon Den in Den $\$ \S 9$ unI 10 bezeicyneten Redjungen ift bie $D \Re \Omega$. bered)tigt, diejenigen, belthe won untergeorbneter Bedentung fino, inmerljalb ber bisljer be= ftandenen (5retrjen bon iffer regelntäbigen Brifing alt: zufchliefen, unD Die Rebifion forwie Die Derfargirung Der= felben ben Bermaltungsbehörden z"t iiberlaffen, bis Daruber bei cintretendem Beoürfin

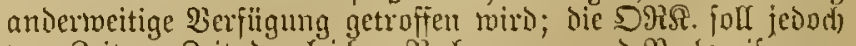

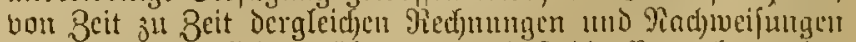
eimfordern, um fid) ju iiberjengen, Daf bie Bumalturg ber

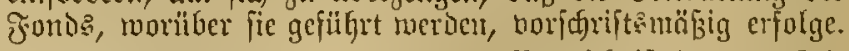

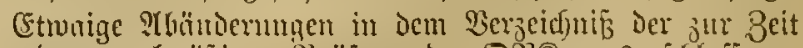

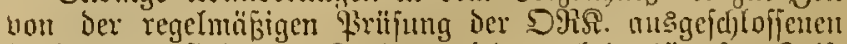

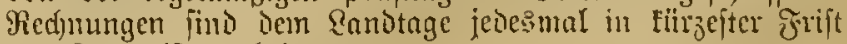
jur Sientuis jul luingen.

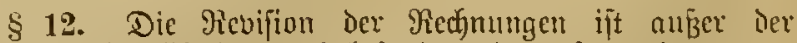

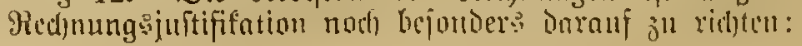


a) ob bei Dex Ermerbrung, dex Benutsung und dex Beröunerung bon Stnatseigentlyum und bei ber Erlyefumg und Bermendumg oer Stnatseinfünft, 2(bgabeu und Steucrm, nad) Den beftebenden Ge=

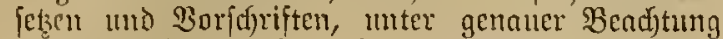

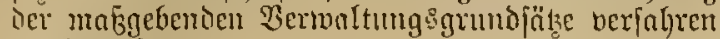
morien ift;

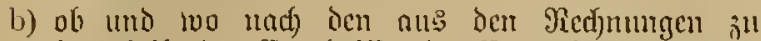
beurtheilenien Crgebniffen Der Bertualtung zur $\mathfrak{B} e=$ fürberung tes Stant: ober ratbjam firs.

\$ 13. Die DrR. ijt Gereutigt, vou Den Beförden jebe,

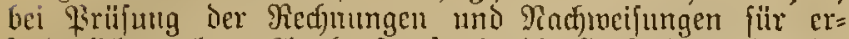
fordertict erad)tete Mustunit, jomic dic Sinfendung ber be=

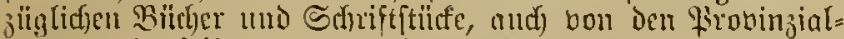
แnd ben benfelber mergeorbneten sebörben die Einfentung non affen ju verlangen.

Der Fräfident der DRR. ijt Gefugt, Bebenfen mi (5i= innerumgen gegen bic Red-mungen an Drt uno Stelle Durd) Sommiffarien erörtern ô [affen, oud) zur Jnformations: cinjiehung ẗber bie Cinjelheiten der Bermaltumg Simmiffarien abjuoroureur.

(Fbenfo iteht ilum das Redyt zu, anjerordentlide Raffen= uni Miagazimevifionen zu veranlaffen. Jin tiefem falle, jorvic in alleu Jällen ber 2 bfendung cines Soumiffarits

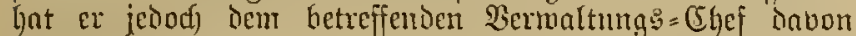
norberine Mittheilumg zu madjen, Damit biejer fidf an ben

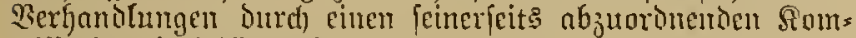
miffarius betbeiligen fam.

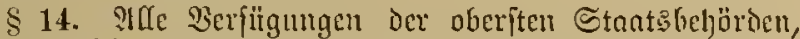

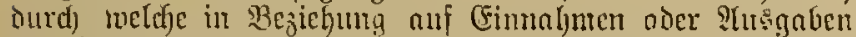

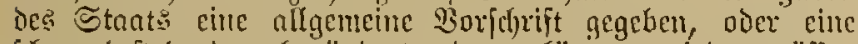
(d)on beftebenoe abgen̈mbert ober erläutert sviro, milifen

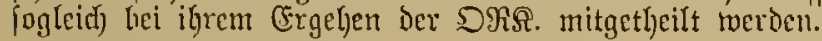

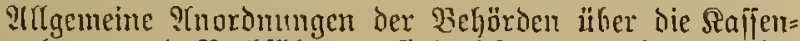

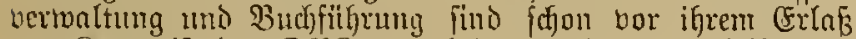

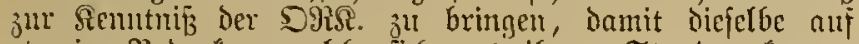
etwuaige Beberfen, Iocldje fïf) nus ifrem Standpunfte $\mathfrak{x}=$ getien, aujmertiom madjen farn.

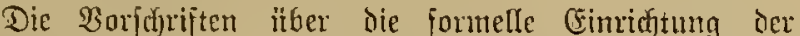

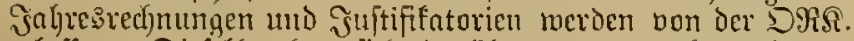
erlaffen. Diefelte loat fidj barïber imar vorfer unit den betheiligteu Debartements= 5 hefs in $\mathfrak{B}$ erbindung $3 n$ fetsen,

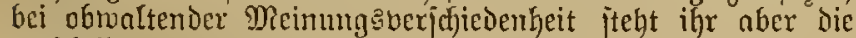
entfdjeidende étimme zu.

Bon allen auj dic Redjnungstegung bezïgliónen $\mathfrak{B}=$ idflïffer cines Der beiden Jäufer bes Qnubtages ift der

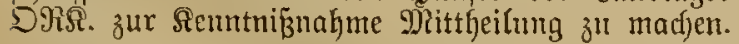

\$ 15. Die Termine zux Cinfendung Der Red)rungen und dic Friften zur Crledigung der bagegen aufgeltellen Frinnerungen werden bon ber $5 \Re \Re$. jeftgeitell.

$\S$ 16. Die Srovinginl= mo die ihnen gleidjitclenton

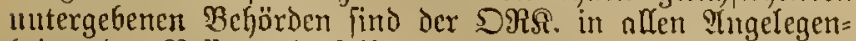
Geiten des Refjorts berjelben nntergeoronet. Dic DRR. ift befugt, ifren werfïlnumgen nötligenfalls ourd) Strnfbefehle,

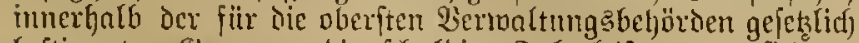
beftimmten Brenjen, bie foduldige Jolgelcifturg ju fidjern, aud) etmo vortommende Unangemeffenbeiten in (Frledigung iljer Erlaffe ju rïgen.

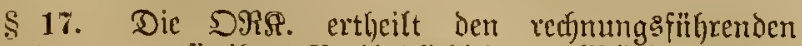
Bcamten, went fie ifren Berbindlidfeiten bolf tändig genügt und Die aufgeftellten Erimemngen exledigt haben, eine Dednarge mit oen in den $\$ s 146$ bit 153, Theil I, Titel 14 bes Pllgemeinen ?anoretits ciner Dutitumg beigeleaten

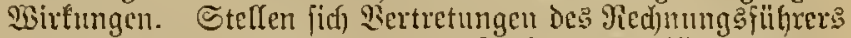
ober anberer Beantet bei ber Yecllungstevifion heraus,

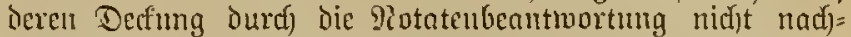
gemiejen tuino, fo hat dic DMS. Dic meitere Berfolgung, melche

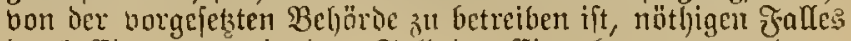
burd) Eintragumg in ons Soll ber Cimnbunen arjuoronen.

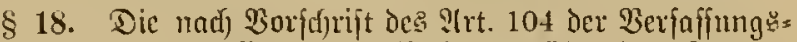
mfunde mit ber alfgemeinen Fed)mung liber den Etaats: haushalt jeden Jahres von der Staatsregierung dem Rant= tage vorjulegemben, bon Der DRR. nnter jelbftftändiger,

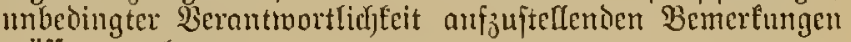
mitffen ergeben:

1. $\mathrm{ob}$ dic in bex Reclunumg nufgefiilyrten Beträge in

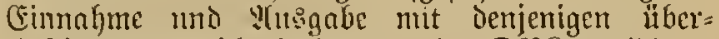

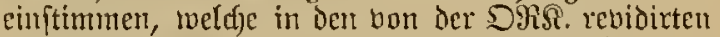
Saljencefum gerwicjen find,

2. ob und intwiencit bei ber Bercinnahumung แnd $6 \mathrm{x}=$ Gebuth, bei ber Derausgabung obcr Berucubung bon Stantigelderl ober bei ber: Srmerbung, $\mathfrak{B e}=$ nuţung ober Veräuß̧erung bon Stantseigenthum ?(Gweichungen vou den Beftimmungen bes gejelslid) jeftgeftellten Staatshanalyalts = Stats oder ber bou oer Pandesbertretung genelymigten Titel ber Spezinl= etats (\$ 19), oder vou den mit einjeluen \$ofitionen des Citats verbundenen Bemertungen, oder von den Beitimmungen der auf Die Stantseimmalymen und Etantiausgaben oder auf die Ermerbung, $\mathfrak{B e}=$ nutzung ober 2eräuberutu bon Gtantseigentlyu bejiiglidben Gejetze jtattgefunden haber, insbefordere

3. jll velchen (Etatsïberffreitungen im Simnc des strt. 104 ber Berfajfungsutunde $(\$ 19)$, fowie

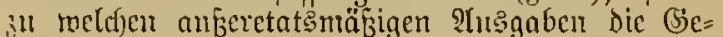
nebmigung Des Ranotages nod) nid)t beigefrad)t ift.

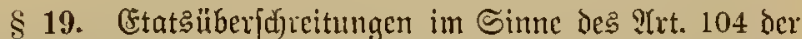
Berfaffungsurfunde find alle Mel)rausgnben, weldye gegen die eirjelncu Sapitel und Titel des nad) Qlit. 99 n. a. S. feitgeftellten Staatshaushalts=(Etats oder gegen die von Der Eandeşbertietung genelgmigten Iitel Der Spezialetatg itatt= gefunden haben, fomeit nid)t cinzelne Titel in den (Etats

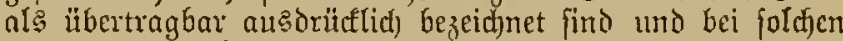
die Mehrausgaben bei einem Iitel durd) Minderausgaben bei anteren ausgeglichen merden. llnter dem Iitel eines Spezialetats ift im Sinne diejes (Bejetzes zu beritehen jede Gofition, weldfe ciner felbftitändigen Befdhluşaffing der Eandesbertretung unterlegen lat und als (Begenftand einer foldjen im Etat erfentbar gentacht morden ift. ${ }^{1}$ )

Ŝt die jur $\mathfrak{B}$ orlegumg an den Randtag gelongenden Spejialetats find portan, juerft in bie Ctate für das Эahr 1873, bei Den Befoldungsofonds dic Stellenzalyl und

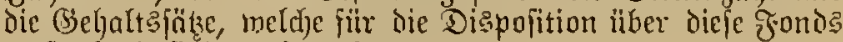
má̆gebend find, aufanehmen.

Eine Racjweifung der (Etatöiberid)reitungen und ber

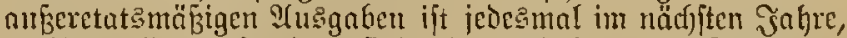
nachdem fie entftanden find, den 5ृäujern des Randages jux unct)trägtidjen Benefjmigung borjulegen. Die Erimne=

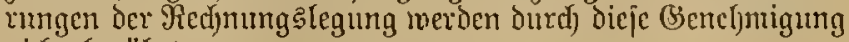
nicht berïlfet.

1) Räheres ïber ben Begriff ber Etats̈̈berijdreitungen ugl. in §D. $11, \S 1$ ? 
\$ 20. Tady :Iblauj eimes jeden Gejdjäftsijahres eritattet

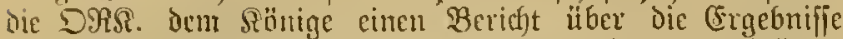

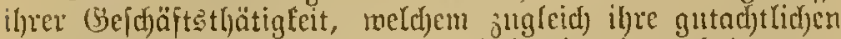

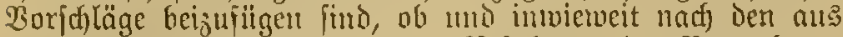
ien Redinungen fich ergebenden Fiejultaten ter Berwaltung

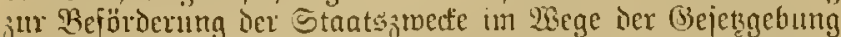
ober ber Perorinung ill treffende Beftimunumgen notljmendig ober ralbjam erfdjenen.
§ 21. T(Ale durd) frithere (Bejeţe und Werordmungen er= Lafjenen Bejtimnungen, pomeit fie Den gegembärtigen (sejelse jubider'Tau[en, treten auger Stra[t. $\left.{ }^{1}\right]$

1) Ridt aufer Rraft getreten i ît bie gutifruftion für bic Eber= Redun

llrfunolid) $2 e$.

\section{Reg $\Perp \mathfrak{a}$ tiu}

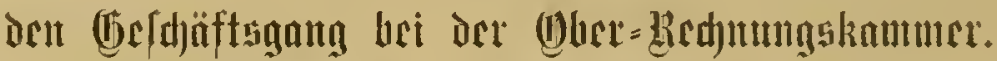

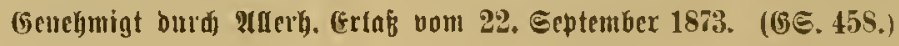

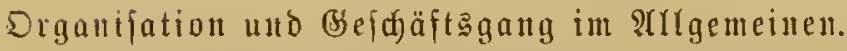

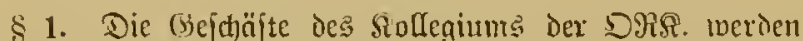

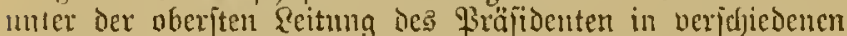

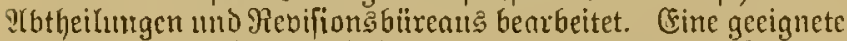
SInjahl biejer \$Bitreaus bildet eine ?(hth)eilung, meldjer cin Direftar borftelyt. Sn jebem Bürenn wirt unter \&eitung einces Ratlje des Rollegiums (des Departementeraths) Die erfutderlid) 3 ahl won Bicuifionseamen beidjäftigt.

\$ 2. Jïr dic anj ben perjönlicten wisfungstreis des

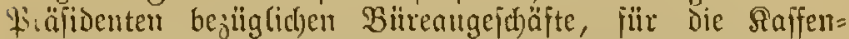
bermaltung, die Regittatur, Bibliothef, ̧ournalfübrung und Sianlei find bejondere Bürcaus und Sanjleibeante, des: gleidjen fïr den auf bie Sautaorbunng bezügliden Dienjt die erforderlidjen Ilnterbeamten bejtellt.

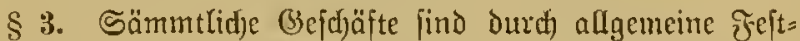
itellungen auf die Beamten möglideft gleid)mäßig und ber= geftalt zu bertheilen, bof jeicm dauernd ein befitimnter (jcichäjtâtrcis̆ übernicjen miro.

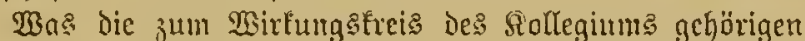
(sejejäfte betrifft, fo ift, pomeit es die obmaltenden $\mathfrak{B e r}=$ bältniffe geitatten, Darauf $\mathfrak{B e d a d} t$ zu nehmen, dẩ die (Se= id)äftstreife der cinzelmen Devartementsiäthe nad) Den ber=

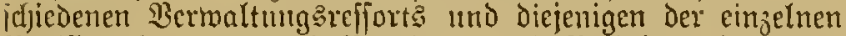
Kebifiongbcamten nad) qrovinjen und Besirfen oder nact)

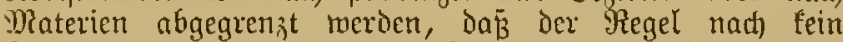
Departementšrath in smei berjdjiedenen ?(btheilungen und

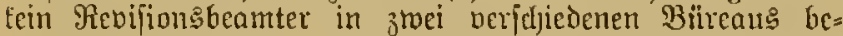

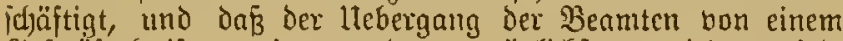
(sejchäftefreije zu einem anderen möglidfjt vermieden wiro.

\$ 4. Fï jeden Ricbifionß̧beanten ift aljährlid) ein

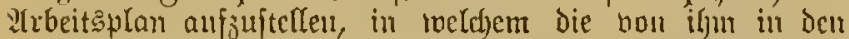
einjelnen Manaten des Bejcfäftsjahres zu revidirenden Rerfinungen und ju bearbeitenocn Totatenbeantwortungen wentgitens nad) der ?Inzahl uno (Sattung in Botaus feit= gejetzt merden. Dabei ift jedod) für dic Monate Şuli und 2uguft jujammen mur cin Monatspenjum in ?njaty ju bringen.

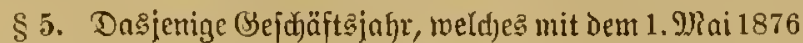

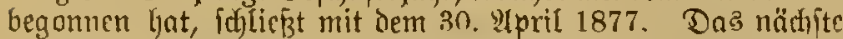
(sejoüftsjabr beginnt mit iem 1. Mai 1877 und endet nuit
Dem 30. September 1878. Von da ab begmm jede? meitere Bcichäftsjahr mit iem 1. Detoher des cinen mind [d) lief̧t mit dem 30. September des folgenden Faljes.'1)

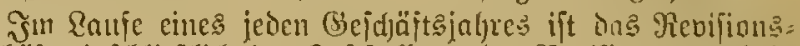

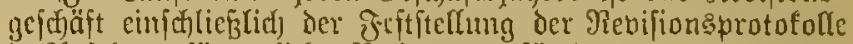
in $\mathfrak{T}$ (nj (Etatejahr ju becndigen. ${ }^{1}$ )

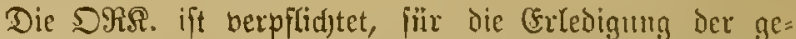
jogenen (Exinnerungen und dic $\mathfrak{B}$ erichtigung Der $\Re$ ied)numgen Dergeitalt ju jorgen, ia

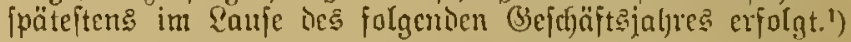

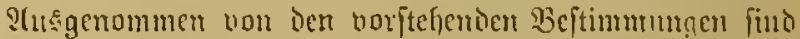

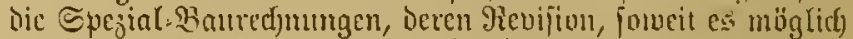
ift, immerhalb besjenigen Gejdäßtsjahre: erfolgen muß̧, in meldyem fie eingehen. Die DMS. hat onljin ju wirfen,

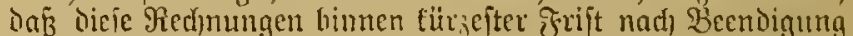
ies Baue: jur Rebifion eingereidyt werien mo, falls bie Bauten ju ifrer 30 dfendung melgrere Jalne in ?miprud nehnen, in den doju gecignteten föllen bic segung tun Stïftreffmungen anjuorduen.

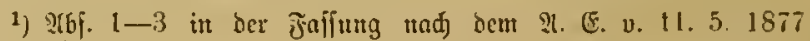
(अङ. 130).

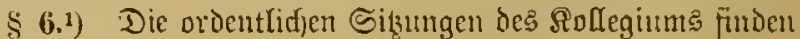
an fejtheftinmmen Tagen itatt. Qufuerordentlid)e Sikzungen

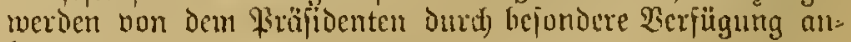
Gcraumt.

Wird ein Mitglied behindert, ciner Sikgurg beizumohnen,

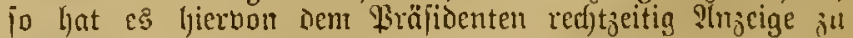
madjen.

Die $\mathfrak{A} b$ ftimumngen erfolgen in der Durd) dos Dicnjtaltex

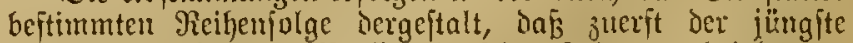
Ratl) mD julekst der Borfitzende peinc Stimme abgiebt.

Heber die Stellung der frrngen, intwic ïber das $\mathrm{Er}_{2}$ :

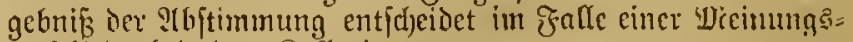
verichiedentheit das Sollegium.

Ŗei getheilten Stimmen bleibt $\mathrm{c}$ s Der Minderheit oder Den einjelnen Dritglitdern Derjelben überlaffen, iffr a bmeidjentes Botum idfriftfid) zu begrïnocn uno ben betreffenton s(ften beizurïgen.

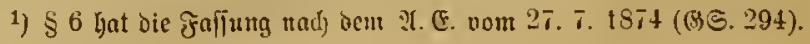




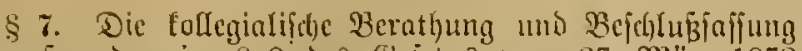
ift auber den im \& 8 bes Gicjetzes vom 27. Mär 1872 aufgefïgrter gä̈len erjorterlid):

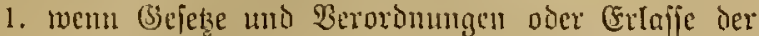
vberften Berwaltunaghehörden ergehen, sucldhe auf

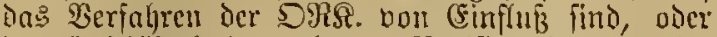
ben (Sejdiäftoftreis mehrerer Rebifionsbüreaus he= riibren;

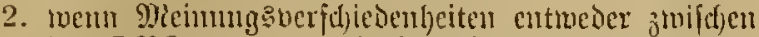

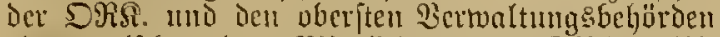

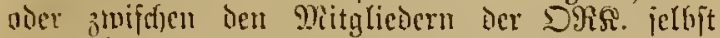
jur (Erö:terung foumen, nanentlid) aud), wenn in den (3rundiäten ober beu $\mathfrak{B}$ erfalyzen cinzelner Revifionsbiireans abuveid)ungen ou Tnge treten;

3. vecun Bmeifel itber Thmentung und ?tuslegung vou Gefrtzen, Beroronungen 2c. Der Erlebigung bedilrjen;

4. เvem andertweitige (Segenjtände von dem Fräpioenten

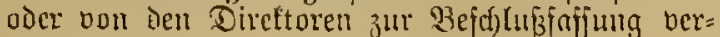
miejen werden;

5. mem bon Dem betreffenten Departementsrath Der

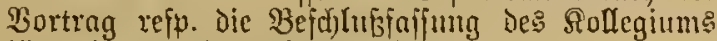
fiir erforberlich erad)tet twiro.

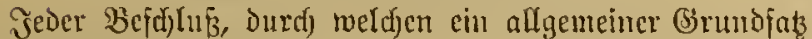
iejtgeitellt miro, ijt iddriftlich zu formuliren und alleu be= theiligten Revifionsbuireaus in șbfdrift mitjutheilen.

\$ 8. Die auf (Brumo Des Bortrages und Det Bejuluf = fajiung im Sollegium crgehenden 2Angaben find auf Den be:

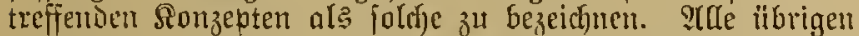
(Giegenitünde des getoöljnlidjen (jejduäftslaufes, weldje un= bedenflid) find und nad) (eftitehenden Beftimmungen und

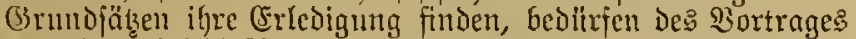
mo Det 3 eqhlufjaijung in Den Eibutgen nicht, ergehen jedod) unter Derjelben Form und Firma, wie dic Erjteren.

\$ 9. Sämuntiche deu Wirtungafteis des Solfegiums

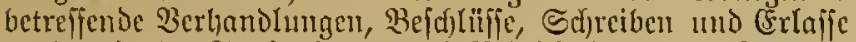
weroen in oer Atusfertigung mo Reinjdyrift mie im Ronzept,

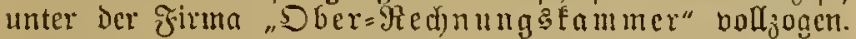

Die Bolfzichung Dexfelben in ber $\mathfrak{A}$ isfertigung oder in der Reinjdrift gejdjicht bon Dem Fräfidenten oder von Dem betreffenoen Direftor, je machbem dic Iebzte Zcidfmung ber

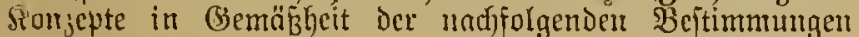
vou dem Grfteren oder bon Dem Eekzteren eljolgt ijt.

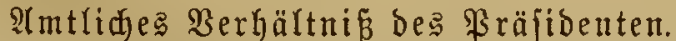

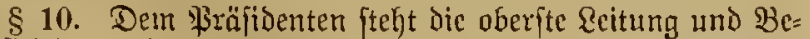

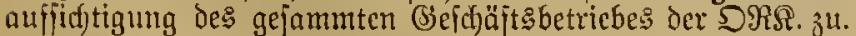

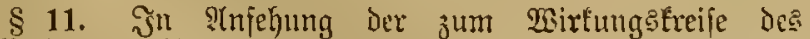
Sollegiums gehörigen Gejuäjte hat er in materieller $\mathfrak{B} e=$ jiebung Dahin ju mirfen, Daß̧ überall dic bejtehendon (sicjebc,

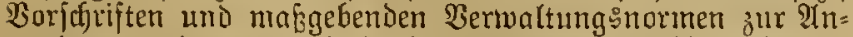
wendung gelangen und in ben verfdhiebencu ?tbtheilungen แnd Büreaus nad) gleidjen (Grundjäken berfahren mird, j"l

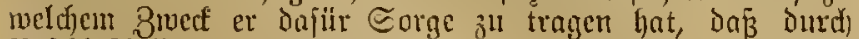
Befdjlufiafiung de? Frolleniums Da: in Diefer Beziebung (Exporderlidi)e fejtgejtelft roiro.

\$ 12. Die Regelung Des formellen Geftyäjtsbetriebes gehört ju feinem perfönlidfen sirfungşfreife. (5r hat alle Diejenigen Dienjteintichtungen uno S(noromugen zu treffen, welche zu dieicm Zmeafe erfordertids find und die materielle

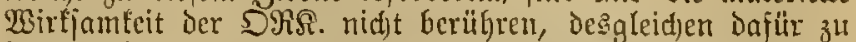

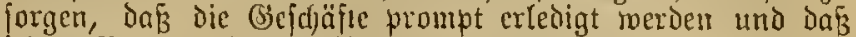
jeder Beamte innerfalb jeines Wirtungetreifes dic il)m obliegenton 2 erpflichtungen red)tzeitig und ordmungsmäbig exfitlle.

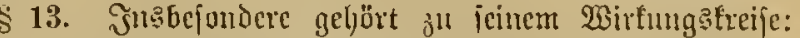

1. Der Ertä Der erforderlicfen alfgemeinen, mie be= fonteren Dienftammeifungen über ben formeffen (3e)duäft3betrieb in Den Revifionsbittenus, foner für Das Siüreall des grü̈jionten, die Rafien= verwaltung, die Regiftraturen, die Bibliothef, Die Journaliiilyang, die Stanzlei= uno Unterbcamten

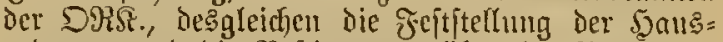
orommg und bie Beftumung über ถie Bemutung

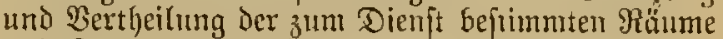

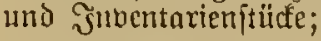

2. Dic Jeftftellung Der Geforjäftsvertheilung, die An= orbum!ng Danernder oder vorübergehender Mtbände= rungen derfelben, formie Det erforderticjen Stell= bertretungen und bie Beauftragung von Reamten

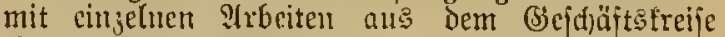
cines anderen Benmten;

3. dic fefftellung der ?rbeitspläne für Die Revifion: beanten und die Genebmigutig det 2 (bmeidumg uon denjelben (\$ 4);

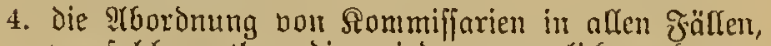
ivo foldje nothmendig wirb, namentlidf aud jum 3 wed Der cerörterung vou Bedenfen uno $6 r=$

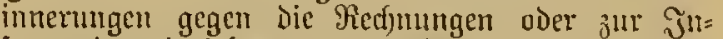
formationseinjiefung ( $\$ 13$ Itbi. 2 des (5), vom 27. Miärz 1872) oder z" aujetordentlidgen fiaffen= uno Diagazin = Revifionen (\$ 13 atb). 3 eben= Dafelbjt);

5. Die Gröffmung Det ueu eingehenden Sadjen, weld)e

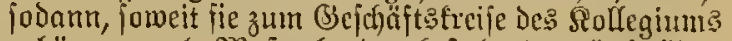

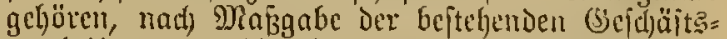
vertheilumg an Die Direftoren, Räthe und Re= vifionsbeamten gelangen -- vorbehalt(idi) ber $\mathfrak{B e}$ jugnis de Fräjidenten, Sorrcjerenten zैu beftellen;

6. die Serjügung auj alle foldje Sdjreiben, Beridjte,

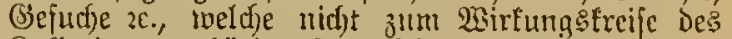
Sollegiums gegärige Begenjtände betreffen;

7. Die Beitinumung Der Beit für Die Siłungen Des Rollegiums nach Tag und Stunde, Die Crobffmung und Erfliebung Derjelben, Die Reitung ber Debatten und If

8. Die Superrevifion und Bollziehung aller derjenigen Sonzepte uno Berfügungen, deren \$rüfung und Mitzeidnung ex (id) Durd) alfgemeine ?(ubronumn oder Durdf die befondere Beżeidnung der eimzelnen Sadjen bei ihrem (Fingange vorbehalten lyat.

\$ 14. Bei Der Supertebifion (\$ 13, 9R. 8) Dürfen materielle ?lenderungen ohne Finberjtänonis mit den be= treffenden Direftoren uno Departementsräthen nidjt bor= genommen merben.

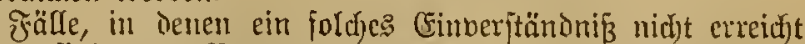
twiro, find zum Bortrag zu berweifen und nad) dem $\mathcal{B} c=$ idf)lufic des Sollegiums zu exledigen.

Formelle :ienderungen Dagegen, weldye fich lediglith anf

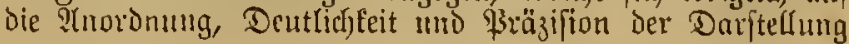


oder die Ingemeffentheit des Tusdrutes bejiehen, ift der

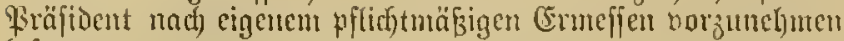
Eefugt.

$\S$ 15. Der qurn̈fident ift ferner beredytigt, Die Tht: $=$ fiil)rung eines Befd)luffes Des Sollegiums einftmeilen 311

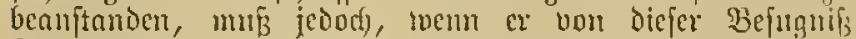

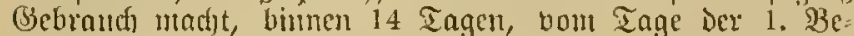

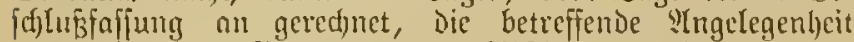

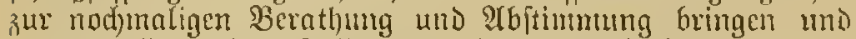
die Mitglicier bes Sollegium liervon fpäteitens 3 Tage vor der diesfälfigen Sikzung in Siemtnif fetzen. Bei demt

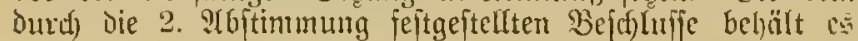
fein Berwenden.

§ 16. Bu den (Sefdjäften Des \&räfṫenten gehären ferner Die Berjonalien fämmtliffer Beanten, ingbejonderc dic \$ुor= fd)ln̈ge zu: Bejetzung von Stellen der Direftoren uno Miäthe Des Sollegimm (\$ 2 bes (5) bom 27. Närz 1872), Dic ( $\mathrm{r}=$ nennung der übrigen Beomten ( $\$ 6$ ebendafelbit), die \$and= habung der Dişziptin über fämntlicf)e iscante (\$S 5 uno 6

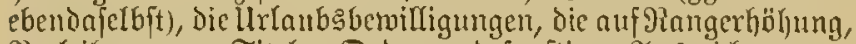

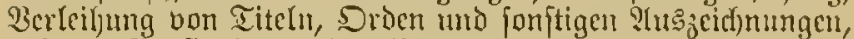
auj bie gienfiontirung der Beamten und auf dic Fïriorge fïr die Szinterbliebenen ierielben bejüglidgen ?tugelegenbeiten.

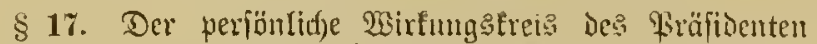
umfät ferner die Berwaltung ber Gelder, Simmbittiofe,

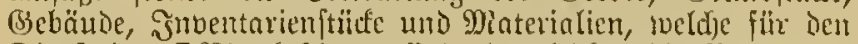

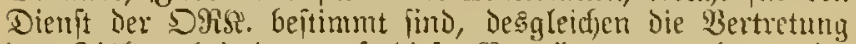

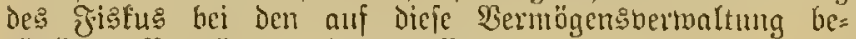
züglidben Dertrögen uno brozeffen.

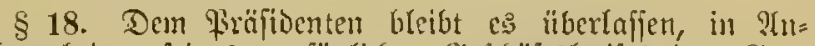

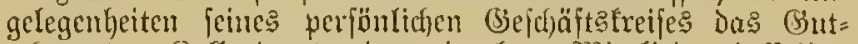
acten Des Sollegiums oder einzelner MRitglicier Defielben einzulyolen.

\$19. Dic Raffenbermaltung miro unu 2 Scitens des Fräfidenten dazu bejtimuten Revifionsheamten nla ఇeben= amt gefülyrt.

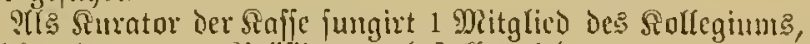
tweldjes dazu vou fiäfitienten beftellt wird.

§ 20. Эu Bezug auf Beulaubung Des Präfidenten ift nad) Den für Die 9) verfahren. Sn 2(njelunn des vom Bräfioenten ben Mit=

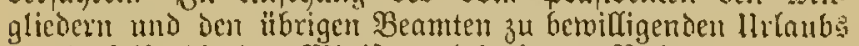
bat derfelbe dic den MRiniftern beigelegten Red te.

§ 21. Bei 9lbwefenlyeit oder Arantheit des Bräfìenten vertritt ilgn der ältefte mo, wemn aud diefer berfindert fein follte, der mäcjitfolgente Direftor:

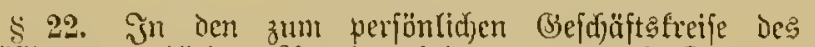

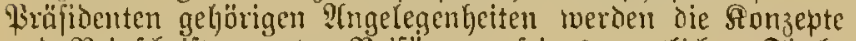
und Reinjodriften unter Beifügung peines nutlidjen Titels und Eharafters boll ongen.

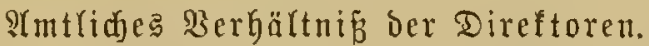

\$ 23. Die Direftoren leiten uno beanffichtigen fänmutlicfe

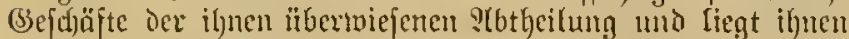
ob, fiir die grimoliche und prompte (5rledigung biefer (s)ef(d)äfle in तen daj" gebörigen Rebifionsbitreats z" jorgen.

§ 24. Bu den Bejugniffen und Dbliegenlyciten ber Direftorer gehört utsbejondere:
1. Die Senttniğnalyme bou alfen nen eingehenden auf

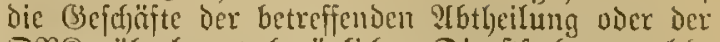

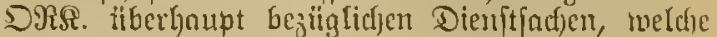
nach gefdechener Eröfijunng und firäfentation Seiten:

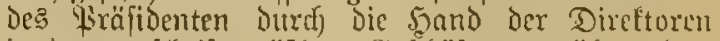

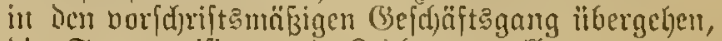

2. die Superrevifion und Beidynumg aller bon Den Deprartementseräthen ber S(btheilumg an fie ge= laugenden Fevifionsprotofolle, Berbandlungen, De=

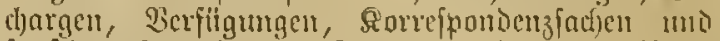
fonftigen ?!nguben in Sonzept umb in Der Rein=

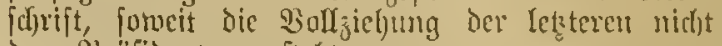
Dent Gräfilionten zuftel)t;

3. Die Begutndhtung Der von Den Departementerüthen ju eritattenden periodifden ober fonftigen Beridjte, jomie ber zu folder Begutad)tung geeigneten Dienit= licjen ?Inträge, Eingaben mid Promemurien der Mitglieder und Bcauten ilfrer abtheilung;

4. bit Benuffid)tigung Der regelntäbigen I Jätigleit umi (3ejd)äftsförderung in Den Revifionsbitrcaus iljer ?lbtheilumg;

5. Die $\mathfrak{B e r e c h t i g u n g , ~ i n ~} \mathfrak{B} \mathfrak{c}$ jug anf die Revifions= beanten boribucrgebende ?!bmeidumgen yon ber

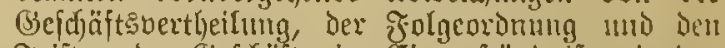

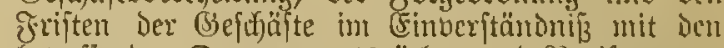
betreffenden Departemtentarzät)en und gieviforen zu geneljmigen, injojern weber eine Vermehrung Der Shrbeitsfrn̈pte badurd) Gedingt, nocf) Die (Entitel)umg von ITrbeitsrüdftänden bnvon 3u bejorgen ift;

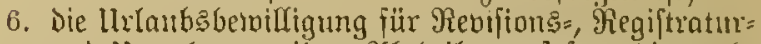
nino Unterbeamte ihrer I(btheilung, jofern die nack = gefuchte Entfermung aus Den. Dienft Die Beit von 3 Ingen nidft Hberfideretet แmo cine Bertretumg nicft erforderlich ift.

\$ 25. Dic Direttoren baben bei Siriffung Der ibnen

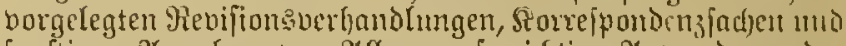

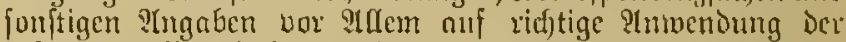

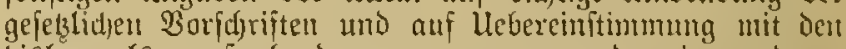
bis̆her als maß̈gcbend angenammenen oder in andercu

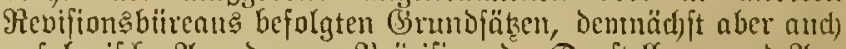
auf logifd)e ?turoronung, Siräjifion ber Dorftellumg und $24=$

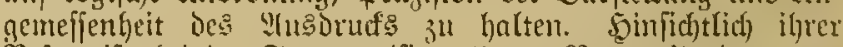

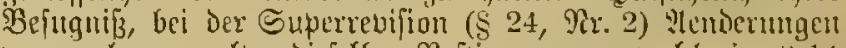
bor junelynes, getten diejelben Beptimumungen, fwelde im s 14 in ?tufehut des Präfidenten getroffen find.

\$ 26. Die Dircftoren haben fich in P(brefentheits= mo Sirantheitsfällen, fomeit es Der Umiang iljrer Gejchäfte ju=

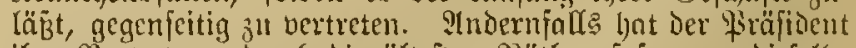

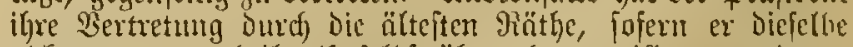

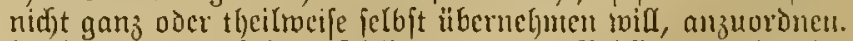

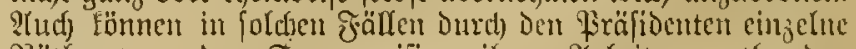
Päthe bou der Superrevifion ihrer ?lrbeiten entbumben swerden.

\section{Amtlides Berhältnif́ der Departementsäthe.}

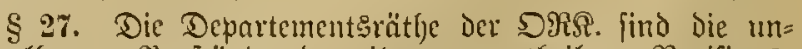
mittelbaren Borjtände Der ihnen Jugetheilten Revifions:

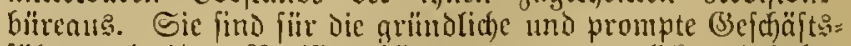
iïhrung in ibren gicuifionsbürents verantroostlidy mo haben

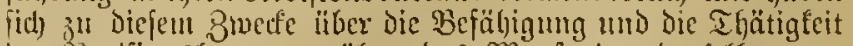
ber Yevifionsbeamten, ilber bas Maaß3 Der Denjelben ju= getheilten ?frbeiten und ïber bie (Grindolid)feit umb ben iBertl) il)rer Ecijtungest in fortbanernder Renutnifi ju er= l)alten. 
§ 28. Bu hen Dhliegenheiten ter Departementsräthe

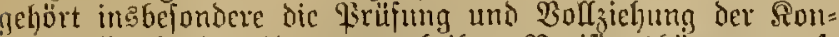
septe afler in ben iljnen zugetheiften Revifionsbiitreus auf= geftellten Rebiftonaprotofolle, Berbandfungen, Dedjargen, Serid)tigungs = Erttärungen und fonftigen Erapeditionen oder จeriügungen.

Durd) Die Bolljiehung der Dicsfälligen Sinujepte ilther=

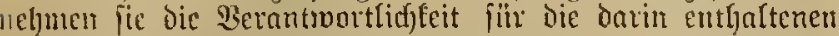

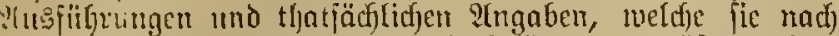
Ben betreffetuen Rechnungen un Belägen ju priffen haben.

(E) liegt ihnen vb, fith burd) jelbftitündiges (Eindringen

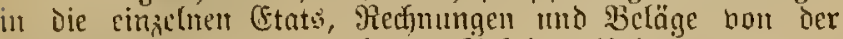

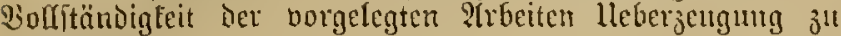
werifgaffen.

\$29. Die Departententsiäthe Gaben zuforge ber ifnen

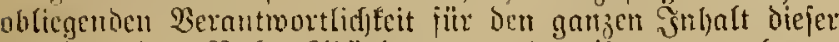

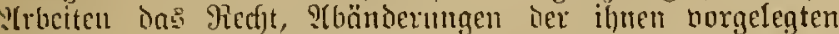
Sonjepte der Revifionsonerhandungen, Edfreiben, Ber= fügungen 2 . in materieller wie in formelfer $3 e^{2}$ jief)ung nad) felbftitändigem Emefien vorălnthmen, mridjtige oder un=

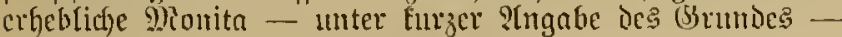
3ul ftreidjeu, und neue (Erinnerungen, wo fie foldfes fïr nöthig erad)ten, himzujuitgen.

DG und intwiefern fie babei cin borgängiges (5invernel)men

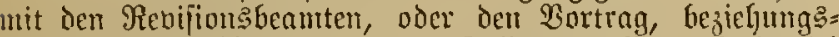

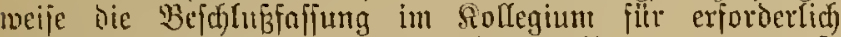
halten, Gleibt, fojern leţtere nicht ohnehin cintreten mus, ihtent pflicftmäß̈igen Ermeffen vorbehatten.

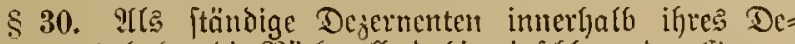

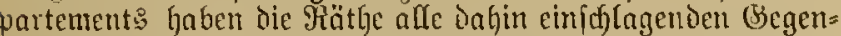
fiände, mantentlid) die Sorreipondenz mit den betreffenden Stnatsbeförien ju bearbeiten, dic daju bejtimmten ober noth ifren cigenen (5rmeifen bazu geeigneten Sadjen zum Bortrag ju brittgen und biejelben den gefaften $B$ ejd)tiffent gemtä ẩ àl ertringen.

\$31. 811 ien Dofiegenfeiten ier Dipartementsirütle

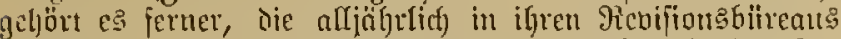

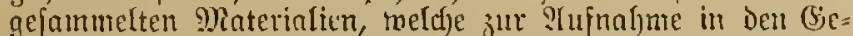
ichäftşberid)t, Gejun. in Die "Semertungen fïr den Panotag" bejtimmt find - nad) erijolgter Fejtitelung im Roffeginm ju resigiten uno fïr ibren (Sejedäjts bereid) jujammenzuftellen.

\$32. Die Departementsräthe haben fidf enofict) der (Erftattung fold)er (Sutachten und Berid)te zu unteriehen, meld)e vou iljen als forreferenten in eiriselnen Sadhen

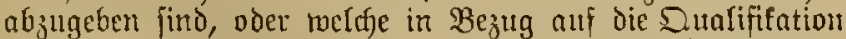
ber im Girobedienjt ober als Şilfsanbeiter bejuäjtigten Rebijoren oder aus anderen dienftlidjen Verantaffungen bou ihnelt verlangt merden.

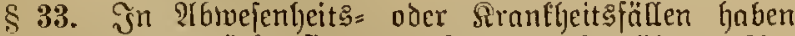
Die Separtementeräthe fich gegenjeitig nad) näherer: $:[n=$ vromung des Pröfidenten für bic cinjelnen fälle ju ver=

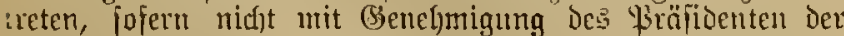
hetreffende Direttor bie Bertretung ganj oder theifmeife zu iibernelymen Eereit ift.

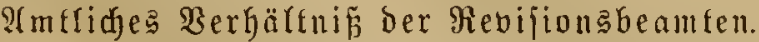

\$34. Die Rebifionzbeamten find ber Regel nad) als ben für bicien Beruj fid) borzugsmeife eignenden Beamten

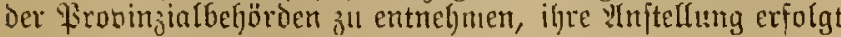

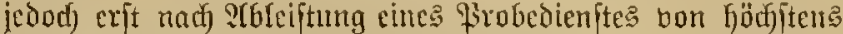
6 Minatert.

\& 35. Die Revifiongbamten liahen boraggrocife den

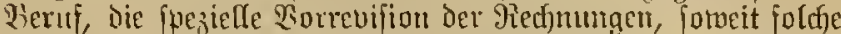

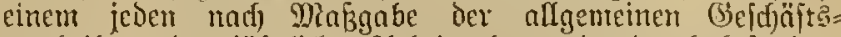
bertheilumg des jüfrtidjen ?(ubeitsplans oder duref bejondere

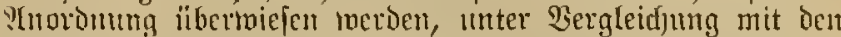

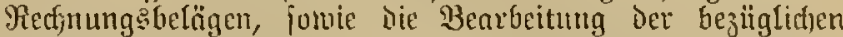

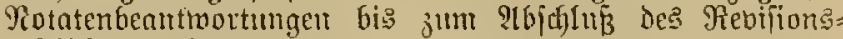
gefduäits ju berwirten.

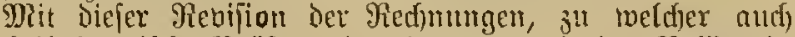
die folfutatorifd)e Firrifung ber Leţteren, wie der Beläge in Den vorgejhriebenen Grenjen gefört, if̣t die jorgfältige Briffung der neu aufigeitellten finffenetats unter iteter $\mathfrak{B} \mathcal{E}=$

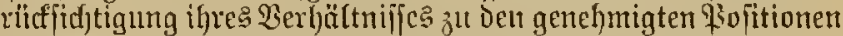
Des Stauteghashalts = Etate und feiner lluterlagen ju ver=

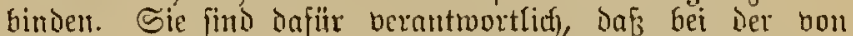
ifmen zu betwirfenden Rechnunģrebifiun und Bearbeitung der Rotatembeantwortungen nichts (Erbebridfes meder in der Paterie, noci in der Form umerinnert bleibe.

§36. Dic 9iebifion

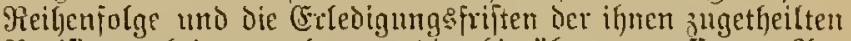
gebifionsarbeiten anlangt, die hieriiber getroffenen ?tn= ordmungen forgfältig jll bead)ten uno find verpffictet, jeden

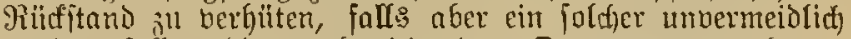
meroen jollte, bies redfaseitig Dem Departementsrath an= 3uzeigen. Das (j) feicfe gilt, wenn butod) verfpäteten (Fin=

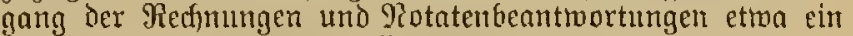
Trbeitsnangel eintreten follte.

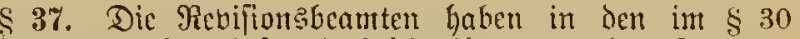
etroühnten Sachen, inforweit jolche ifnen bon den Departe= mentern̈then jugef(f)rieben werten, die Qberfitgung und Ron= zepte ju entswerfen, fermer auf (5)rumd ber bon ifnen 3 ll fïhrenten Tiotizen bie jäfrlichen 3ujammenjtellungen fomohl

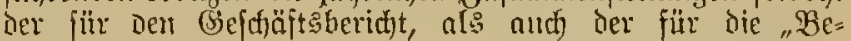
metfungen" beftinmten (Segenjtände ans ifrent (Sejduäfts= freife, fowie bic borgefdriebenen periodifden lleberfiditen

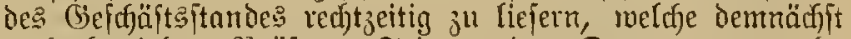
nad) bervirfter Brifung Seitens des Departementirnths

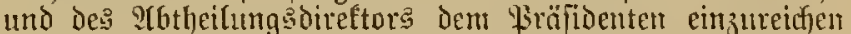

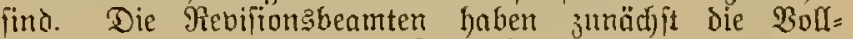

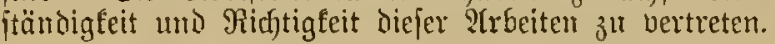

$\S 38$. Dic Revifionşbeamten find in Jalle bes $\mathfrak{B} e=$ Dinrfuifes zur Bertretung anderer Rebijoren oder jur hor=

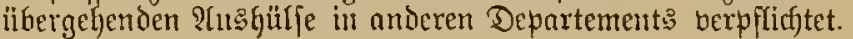

\section{Sonftigè (Befdüftsgang.}

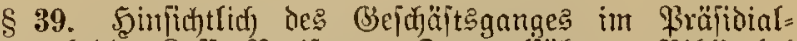

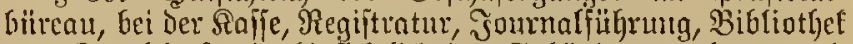
und Ranjlei, fowie hinfid̆tlid) der Sebäudeberwaltung und ber Dbliegenfeiten ber Interbeamten bementet es bei ben

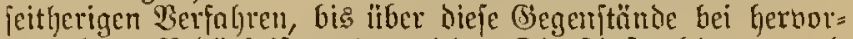
tretendem Bedürinif anderweitige Dienftinftruftionen uno Inordmungen bon bem Siräfidenten getroffen werden.

\section{Sd) lúbeftimmung.}

\$4. Die Snftruftion für den Egcfprëfidenten der DRR. bom 16. März 1831 und alfe Dem boritehenden Regulativ aumiderlaufenden Borjdriften werden hiermit nuf = gefohen. 


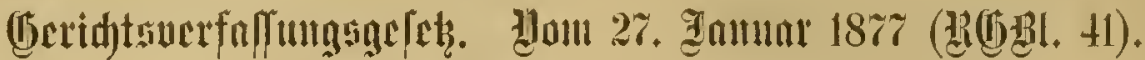

In Sraft getreten ou 1. Dltober 1879.

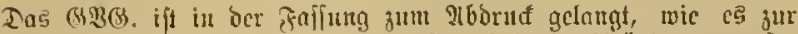

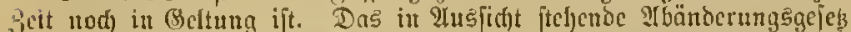

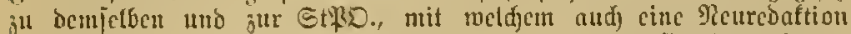
ber actunten Gejesc benbiintigt ift, mirb vorausfichtlich erit im näd)ften Tabre $(1896)$ erfdriteu. Dic midtiglicn Mbänderungen be= treffen:

1. Einführung ber B̧erufung gegen llrtheile Der Etraffantmern iit I. Jnitang;

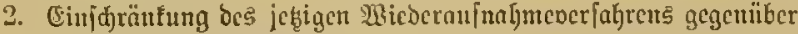
red)ţ̧fräftig Werurtheiltcı;

3. Entfdäbigung jolđer ßer[onen, bic in biejem Micoctanfnahmte= verfahren freigefprodjen fino, natjoem fic sorber redtsträftig verurtheilt woroen waren;

4. bie Bejeitigntng gemifier prozeffunlifder Formen, dic zun Erfase für bic mangelnoc Berufung cingcfülyrt waren (jog. Prozebuarantien);

5. Beptimmungen ïber veränderte Ilbual)ne ber Eibe;

6. Beränberungen in bet fodlidjen 3u[tändigfeit ber (Seriøte;

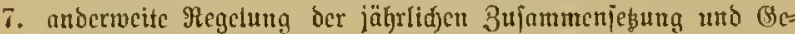
idgäftavertheilusg ber Rammern uno ber Senate bei ber $\mathrm{Be}^{-}$ ridtshöfen.

Mäheres ift bei ben betreffenden ßaragraphen auf Grund bes

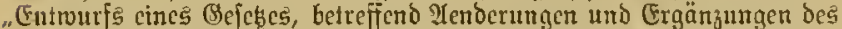

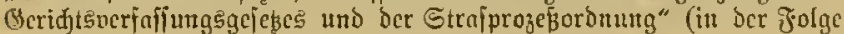
mit "Entw." bezeiduct) vermerft.

Dicjc Borbenterfug gill aud 3 แt StPo.

Jnhaltöiberfidt.

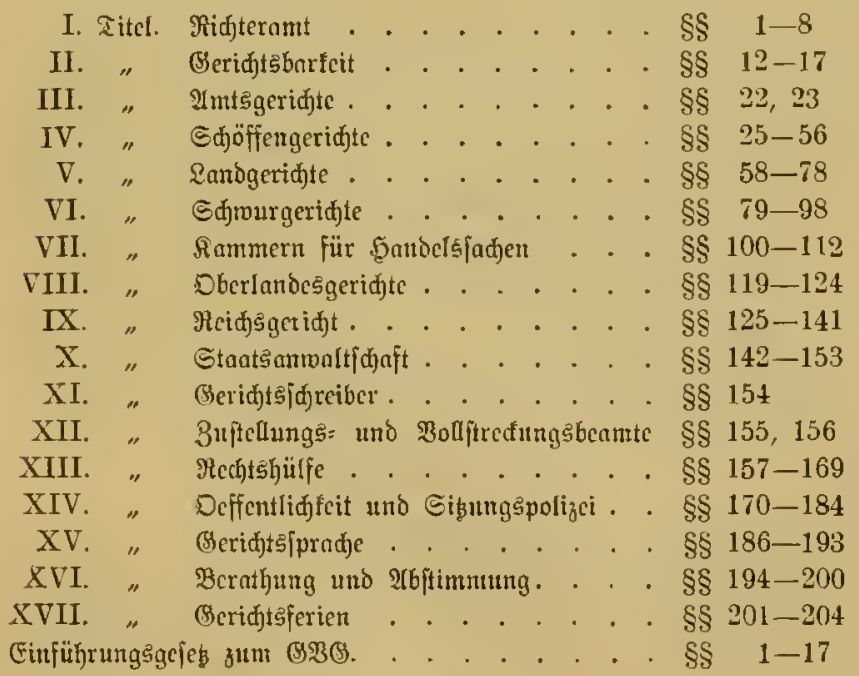

\section{Titcl. ąidiferamt.}

§ 1. Die ridjterlidje (Bicroalt tvird dumf unabljängige, mur Dem Befetze untermorfene (berid)te anşgeübt.

§ 2. (1) Die Fräbigfeit zum Ric)teramte miro burch dic

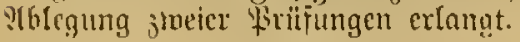

(2) Der 1. Hitifung muß cin 3 zälniges Stmium icr

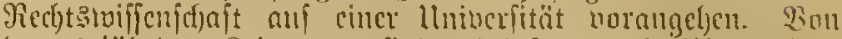

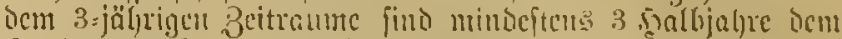

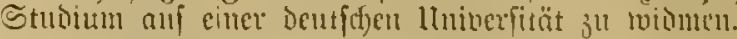

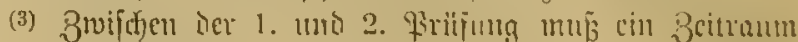
bon 3 Şalyren liegen, inclffer int Dienfte bei ben Useridften

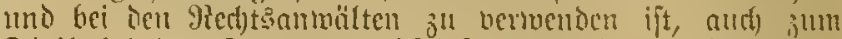
Theil bei ider Stantsanmaltidaft nermentet werden fam.

(4) ......

\$4. Bum Ridterante befühigt ift ferner jeder ardentlidfe

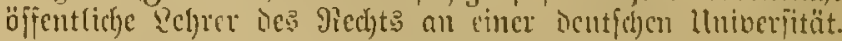

\&5. W3er in cincm Buntegftate bic Fäbinfeit zum

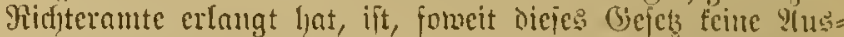

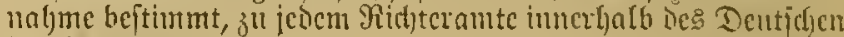
Reidys befähight.

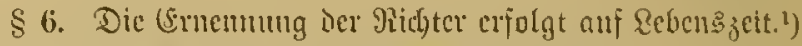

1) burct) bas Dberfaupt jeobs cinjelucu Buntes ptants.

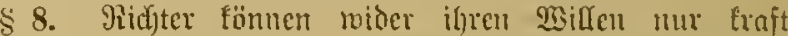

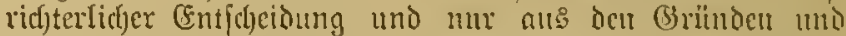

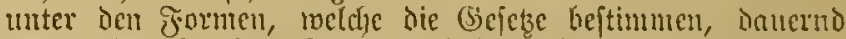
oder zeitrueife ifres ?tmts entfoben oder alt cine andere Stelle oder in Rulgeitand berifat recroen.

Die vorläufige ? (mtsenthefung, weld)c fraft (Sefetzes cin= tritt, wiro hierdurd nidyt berüfrit.

B̉ci ciner Beränderung in der Srganifation ber Beridle

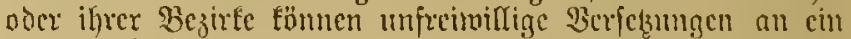
anderes (Seridit oice Entfermungen bou :Cunte unter $23 \mathrm{e}=$

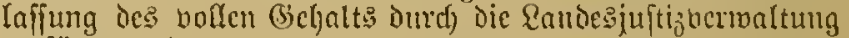
berfigit werten.

\section{I. Citel. Geridjtsoarlicit.}

\$ 12. Die orocnttide ftreitige (Serichtäbarfeit miro burt) ?(mtsgerichte und Ranbgeridite, ourd) Dberlandesinerid)te uni Dutrd) Das Reidfsggerid)t ausgelubt.

शIs befondere Beridete find a. a. bic Bewerbegeridate ante

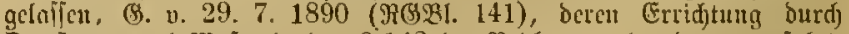

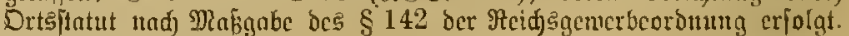
खg!. $\mathfrak{I}$ m. zи § 23.

$\S 15$. (1) Dic Berichte find Stantggericfte.

(2) Die Privatgerieftsbarfeit ift aufgeroben;

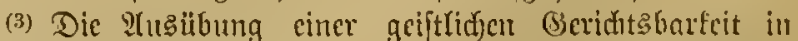
meltlichen S(ngelegertheiten ift olyne bütgerlide rBitung.

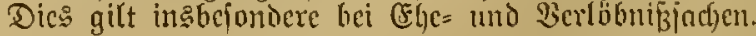

§ 16. PHônalyntegeridyte find unftatthaft. Riemand darf

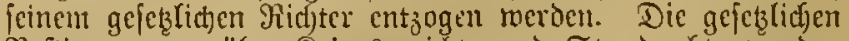
Beftimmungen über friegsgeridite und Standrectite werden hicroon nidjt beritlyrt.

§ 17. Die Beridyte entfheiden ilher die Buläffigleit des

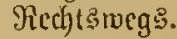


Dic Randesgejetzgebung famn jedod) die Entfheidung

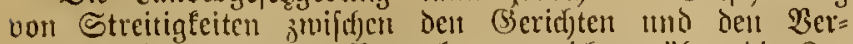
waltumgsbeljörden oder Serwaltungsgeridjten itber die $8 \mathrm{u}=$ Läifigfeit ies 9ecf) gabe Der folgenocu Beftinumutugen ïbcrtragen.

1. Die Mlitglicoer werden für dic Dauer des jut

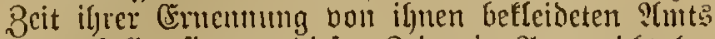
odcr, falla fic zu Dicicr Bcit ein Ment nicht bc: fletion, auf Rebensizeit exmannt. Eine Enthefung vom ?tmtc funn nur unter ienfelben Boraus:

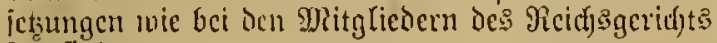
italtfindert.

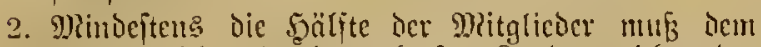
giridlsęgeridfte noer dom oheriten Eandesgerid)te oder cintem Dberlantesigeridjte angehören. Bei Ento

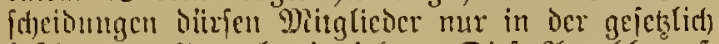

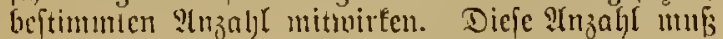
eine ungecade jein und mindeften: 5 betragent.

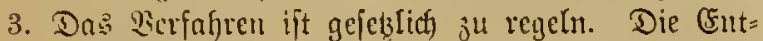
id)cioung erfolgt in offentlidjer Siksumg nad Eabuth icr Lartcien.

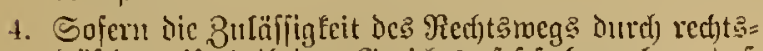

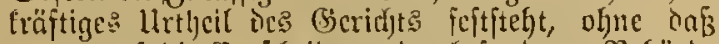

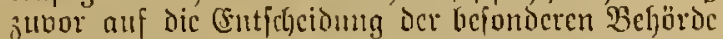
angetragen mai, bleibt bic Entfdecidung des Giericht: mangebent.

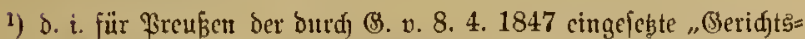

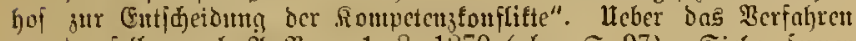

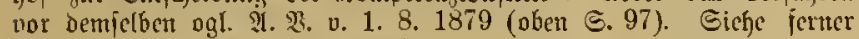
3. v. 13. 2. 1854 (oben ธ. 99).

\section{Titel. Antsgeridjte.}

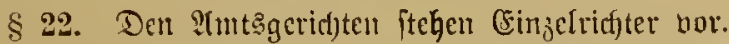

Sft cin P(mts̊geriff)t mit mehreren Rid)tern befeşt, fo wiro einem Derielben won Der S'nndesijutizbermaltung die

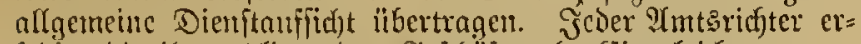

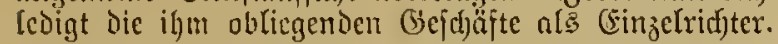

§ 23. Dic Buftändigfeit Der IInteggeridgte Immfafst in biirgetfid)cn Red)tsftreitigfeiten, forweit biejelben nidjt ofjne

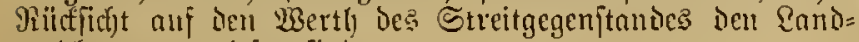
gerid)ten jugewicien fint:

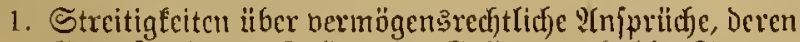
(Siegenitnnd nll Gicld oder (Bjeldesmerth die Summe bon 300 Mnet nicf) übcrjteigt;

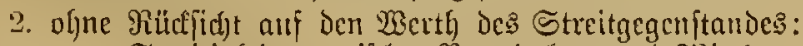
Streitigfeitell zmijhen $\mathfrak{B} e$ miethern uno 2kietleen

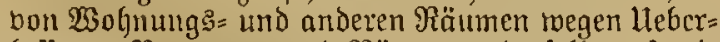
laffung, Benułung und Räuntung derjelbetl, fowie wegen Zurücfbaltung der bon Miether in die Micthsrảume cingebrad)en Snchen;

Streitigfeiten ztwifdent Dienftherridjaft uno (be=

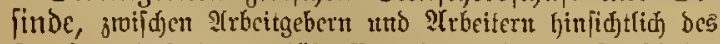
Dicn|t= utno ?trbcitsucrä̆ltnififeș, forvic bic im \& 108 ber (Scuverbentbunng bezeiduteten Strcitigfeiten, injofern bicfelber währens ber Dauter bes Dienft=, शrbeits= oder \&ehr= verhältuifies cutitehen; ${ }^{1}$ )

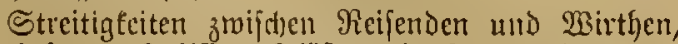

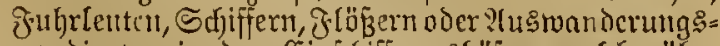
erpedienten in den Ginfofiffurgęhäfon, weldje itber

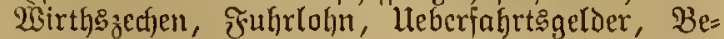

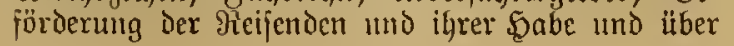

Berluft umo Bejdjädiqung bor leţteren, fowie

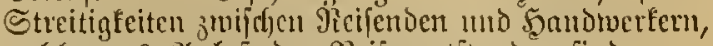

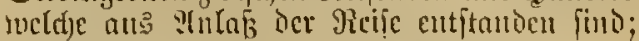

Streitigfeitcn megen Biel)mängel;

Streitigfeiten megen Wirofdonden:

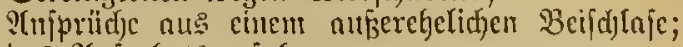
das ?hrgebotsuerfahren.

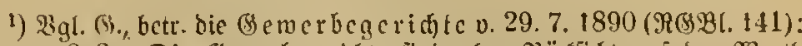

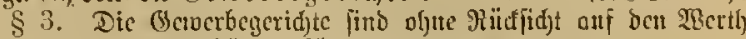
ठcs Etrcitgegentlanocs zultändig für Etreitigfeiten:

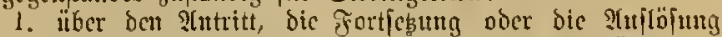

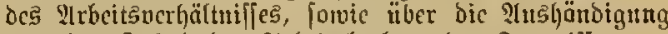
ober beit jnlorlt bes Itrbcitsbudfes poer 3ergniffes,

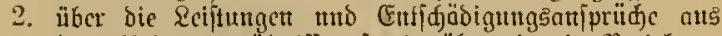
Dem शrbcitsuer!öltuific, porvie anf baffelbe beomacte Sinventionalitrafe,

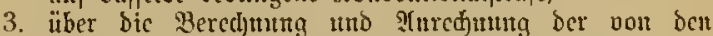

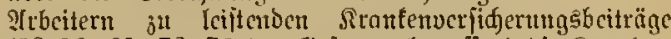
( $\S 53,65,72,73$ bes Bejcbes, betreffend dic firanfen=

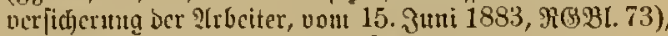

4. iiber bie SIn[prüdhe, veldje auf Sruno ber llebernahute citter gencinfamen शrbeit von Irbeitern beflelben Arbeit= gebers gegen eitrander erfoben merben.

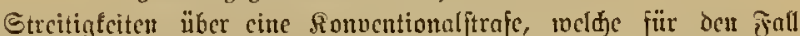

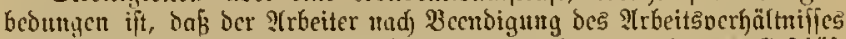
cin poldes bei anderen शrbcitgebern cingeht ober cin eigenes Befdäft crridjtet, gehörcu nidjt gur 3utöndigleit dcr Gctucrbcaeridjte.

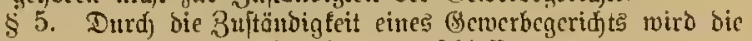
3ujtänbigfeit ber orbentlid̄en (Seridite ausgeidloffen.

\section{Citel. Sdjöffengeridjte.}

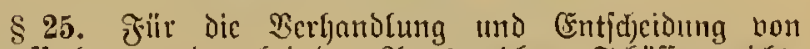
Straffad)en merden bei den 2(mtsgerid)ten Schöffengerid)te gebildet.

\$26. Die Srjöffengeridfte beitchen aus bem $9(m+s=$ rishter nle Borfitzendes und 2 Gdjöffen.

3nittünoigfeit.

§ 27. Dic Schoffengerichte find juftündig:

1. für alfe llchertictungen;

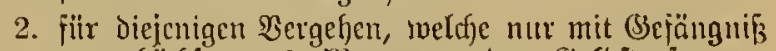
von Göeffiten 3 y)onaten oier GeLDjtrafe bon ljüchjtens 600 Mart, allein oder neben \$ajt oder in Berbindung mit einander oder in Verbindung

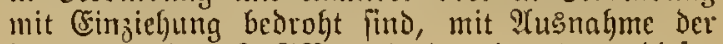
im $\S 320$ des ธt(33) uno der im $\$ 74$ diejes Brejckes bezcicfneten Bergelen;

3. Fïr Die nแ auf 2 (ntrag ju verjolgenden Beleibigungen uni Rörperberleb̧ungen, wenn dic Berfolgung im Mege Der PrivatElage gefdiegt;

4. fïr Das Bergelien Des Diebitahls im Jalle Des $\S 242$ des St(3)B., wenn oer Werth des Ge= itoffenen 25 Mart nicht iiberiteigt;

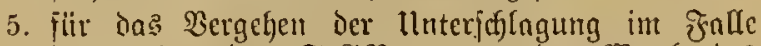
Des \& 246 des St(jiß., wenn ter Werth des Unterjfylagenen 25 Marf́ nitfyt überifeigt;

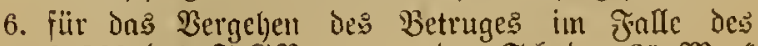
$\S 263$ des St@ig., menn der Sthaden 25 Rart nicfft überfteigt;

7. Für das Bergehen Det Sadjbejhädigung im Falle Des $\$ 303$ des St(\$B., wenn Der Sd)aden 25 Mart nid)t überfteigt; 
8. fiit Daร Rergelen ber Begünjtigung แnd fiit das

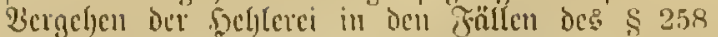

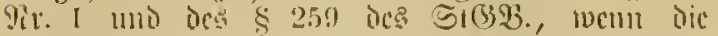

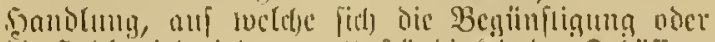

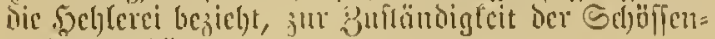
gerichtc gchört.

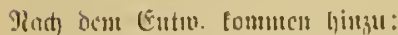

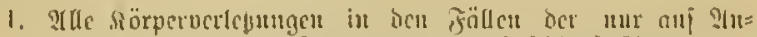

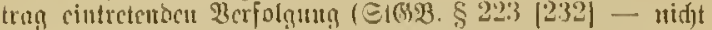

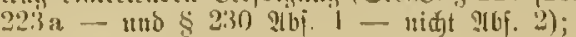

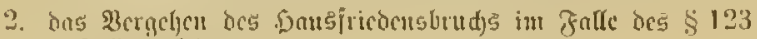
शी. 3 Et(52);

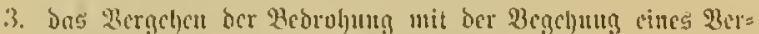

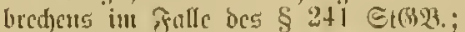

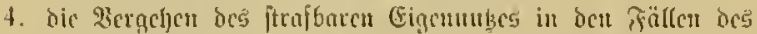

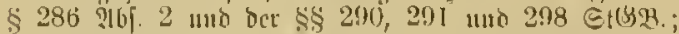

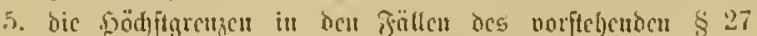
9irn. 4 (Dicbitabl), 5 (IInterfdolugutg), 6 (2)ctrug) und

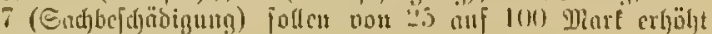
uncroent

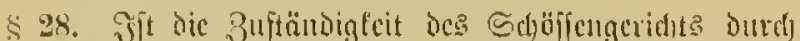

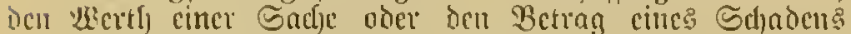
bedingt und ficlt fich in bet samtutucthandung beraus,

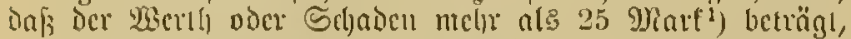

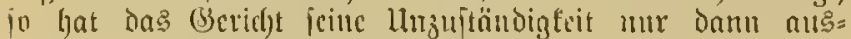

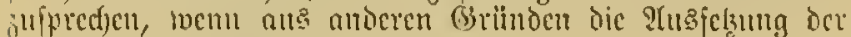

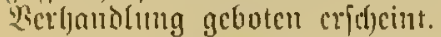

1) แach bcu Entw. 100) Miart.

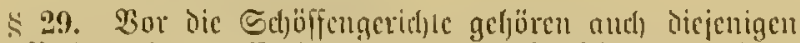

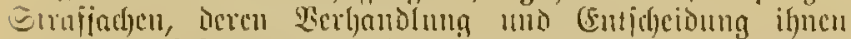

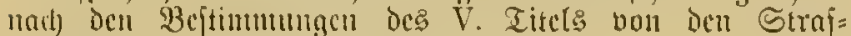
lammetu ber Sanogerid)te ïbervoicfen wito.

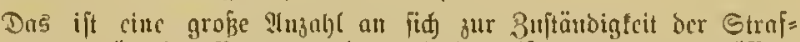

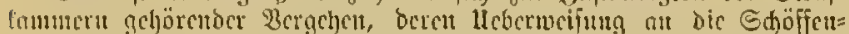

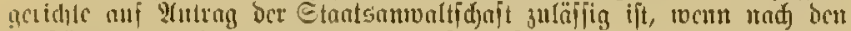

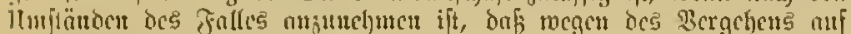

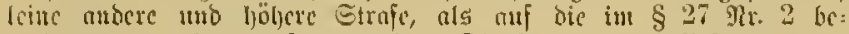

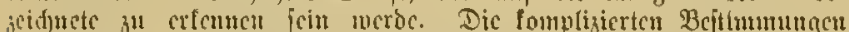
hicrïber bes \$ 75 find utd)t nufgenommen. \&s geföredt baju o.

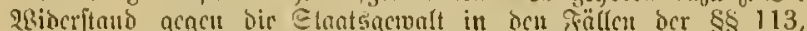

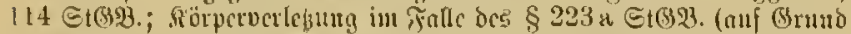

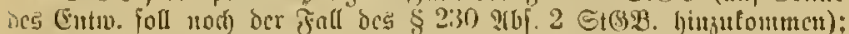
ictucr blcjenigen (i Mion. odcr (Mclojiraje non hödjtens 1500 Mart bedrots find, jebod

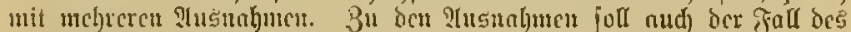

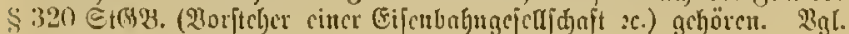
viren $\$ 27 \mathrm{Mr}$. ?.

\section{vint ber Edjöfien.}

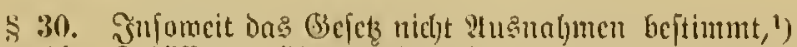

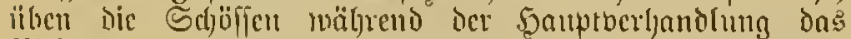
Ridfteramt im vollen llurfange und mit aleidjem Stimmedhte

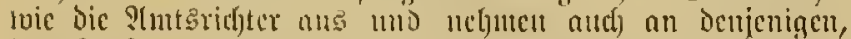

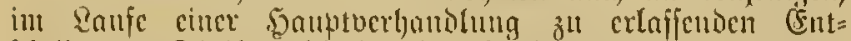

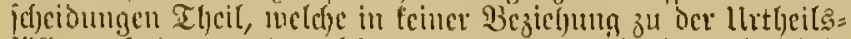
fällung fteljcu, แmb veld)c aud) vlyue norgängige müubliche Berljamblung erlafien tucroen fönnen.

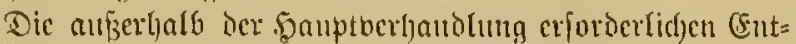
(d)eidungen werden boul den ?futertidfter crlnffen.

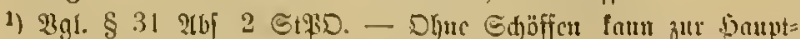

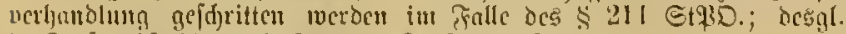

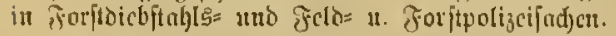

31. Das ?tut cines Soljoffen ift cin Ehrenant.

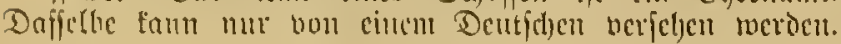

Befäbigung.

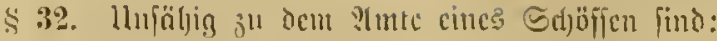

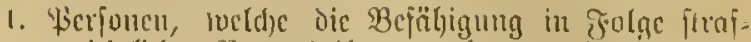

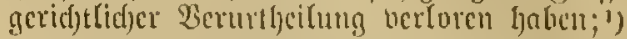

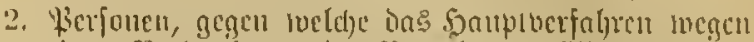

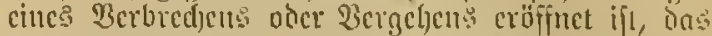

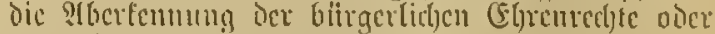

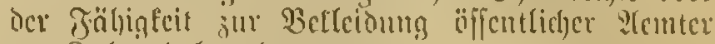
dur Jolge luabin fomm;

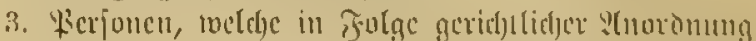

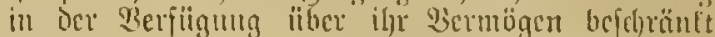
filio. ${ }^{2}$ )

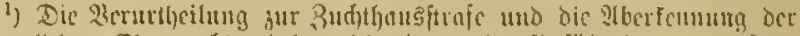

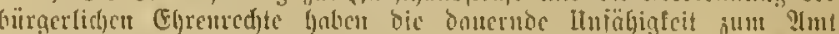

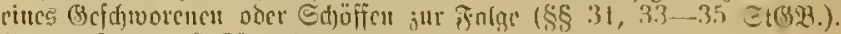

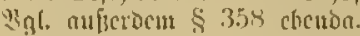

2) 2eriduncuber uno in Routurs (Befallenc.

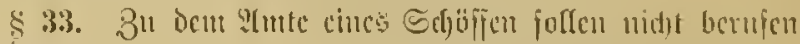
beltien:

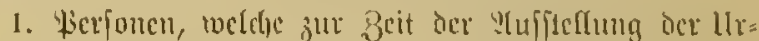

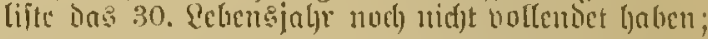

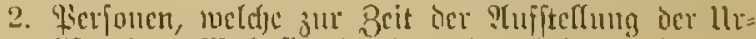

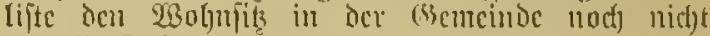
2 nolle כ̧nljec ljalicu;

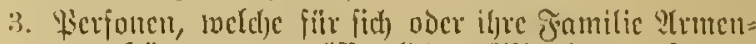

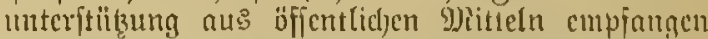

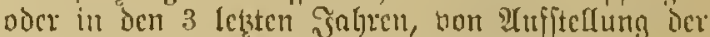

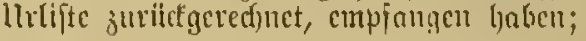

4. Berfonen, weldic megen geiftiger voet lörpertidfer (Gebred)en ju Deut ?tunte nidjt gerignet fiut;

5. Dienjthoten.

\$34. 3u Dem :) :ute cines Soljöffen follen ferner nid)t berufeu weroen:

1. 2)inifiter;

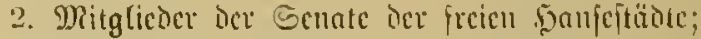

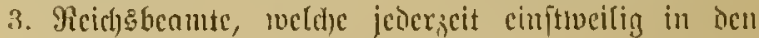

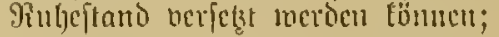

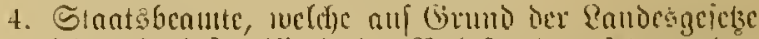

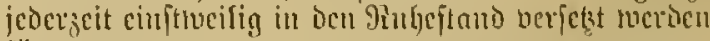
โölutıcı;

5. vidutertidse Beamte uno Beamte icr Stantsanmalt= idfait:

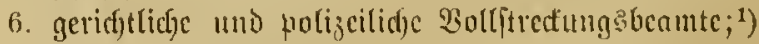

7. Rcligionsbicuer;

8. 23olfsidunlteluer;

9. Den aftiben Secte ober ber afliben Diatinc an, geljörende Wiilitärpcíponcu.

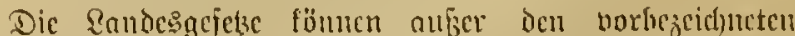

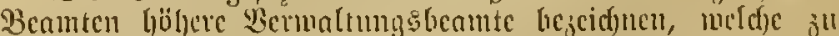

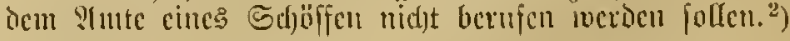

1) Dazu gelören aud bic Walupolizeibcauten. St the im $\frac{\$ 66}{\$ 47}$

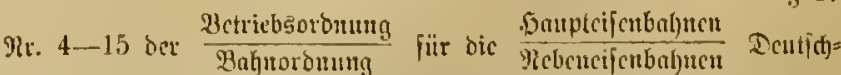

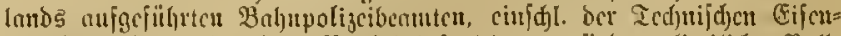

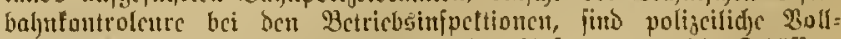

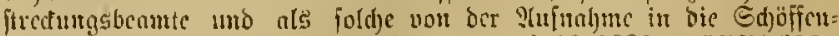

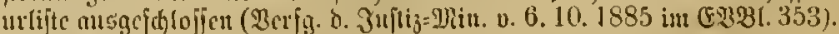

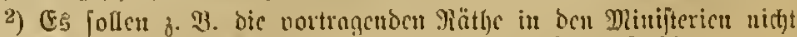
berufu merben. ?tus(3. ข. 24. 4. 1878 (Bङ. 230 ), § 33. 


\section{श(blehnumgăred)t.}

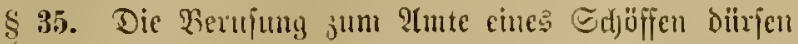
ablelınen:

1. Mitnficder ciner deutjefen gejetsgebenden Derjamm= lung;

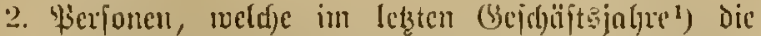
Berpflicltung cines (Bejd)worenen, oder an wenigftens

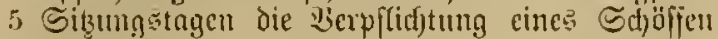
erfiilut baben;

3. Iergte;

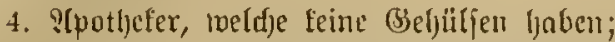

5. Berfonen, weldje das 65 . Eebensjabj zur Beit der Tuifteflung der urlifte vollendet haben oder das: felbe bis zum 2lblanfe des (bejdäftsjaljres boll= enten mitroen;

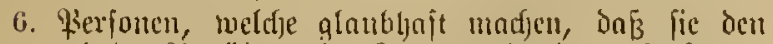

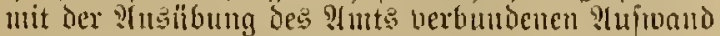
ju tragen nicht verunögent.

1) D. i. in \$renßen bas Statenderingr.

Ilrlijte.

$\$ 36$. Der Borjteljer einer jeden Gemeinde oder eines landesacietzlid) der Gemeinde gleidjfelyenden Derliandes lyat

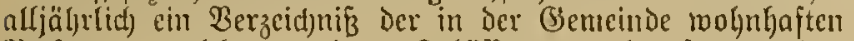

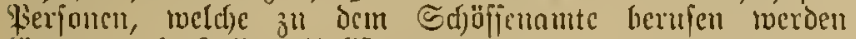

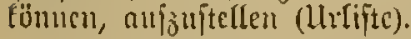

Die Mrlijte ijt in der Bemeinde 1 Wodse Inng zu Jedermants (Einficht auszulegen. Der Beitpunft der ?tus= legung ift vor(jer offentlid) befaunt $3^{11}$ madjelr.

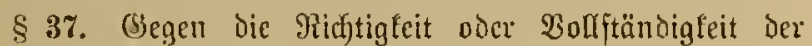

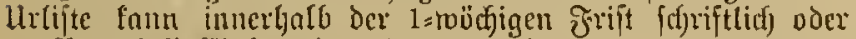
3h Sirotofoll Cimpradje erhoben merden.

\$35. Der Bemeindevorfteher jendet dic Urlifte nebjt ben erlyobenen Einfpradjen und den iljm erjurderlidj er:

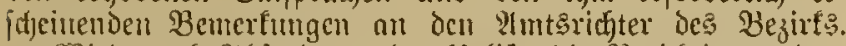

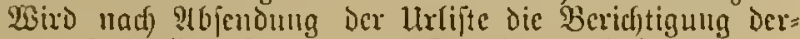
felben erjorderlid), jo ljat Der Bentendevorfteher ljervon

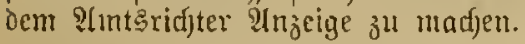

\$39. Der Tuntŝridjter ftellt dic lluliften des Bezirts

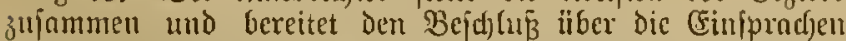

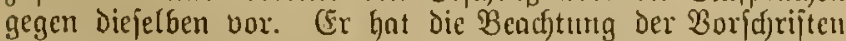
Des \$ 36 शु. 2 zu priffen mid bic ?tbftellumg chuaiger Mängel zu beranlaifen.

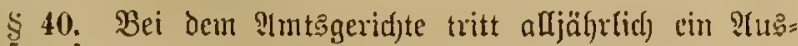

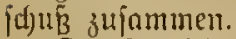

Der 2usfd)uB beftelit aus Dem 21mtsrid)ter a[s Vor= fizzenden und 1 bon Der Eandeşregierung 3 "bejtimmenden Staatsberwaltungşbeamten, foroie 7 Sertrauensmännem als Beifizern.

Die Bertrnucnsmänner werden aus den (Finvohnern des

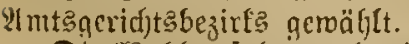

Die Wahl crjolgt nad näberer Beftimmung der Randes:

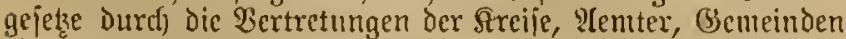
ober dergleidicn $\mathfrak{B e r b a ̈ n d e ; ~ w e u u ~ f o l d j e ~}$ Bertretungen nidjt vorfjandon find, burd) den ?tmteridjter. Eebterer hat bie B̉ertrantensmänner vornehmlid) auş den Buritehern der borbezeidjneten Berbände zu mälylen.

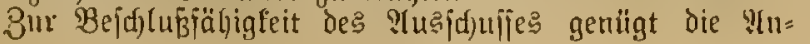

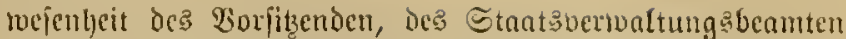

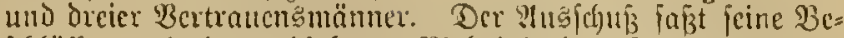
jujlüiffe nad) ber abjoluten Meljrbeit der Etimmen. Bei Stimunengleidybeit entidjeidet die Stinme des Borjizenden.

$\$ 41$. Der ? fijte erbobenen Eimprad)en. Die (Entid)eidungen fint in

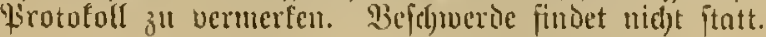

Jahreălifte.

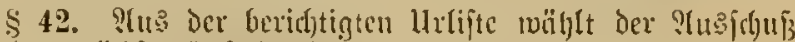

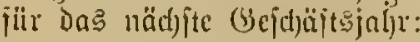

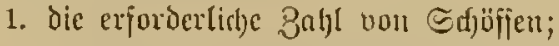

2. die erforderlidje Baljl derimigen Perjonen, weldje

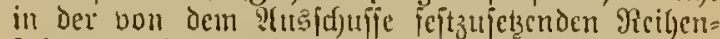
jolace at dic Etclle wegfallender Edfüffen treten

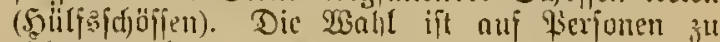
richtell, weld)e am Sitze des olmtageridjts ober in Deff́cn näcljfter llungebung woburm.

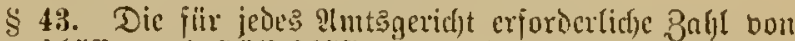

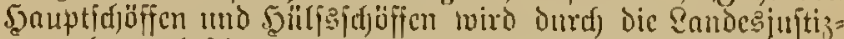
bermaltung beftimut.

Die Beftimmmug Der Balgl Der Santijdjöfien erjolat in

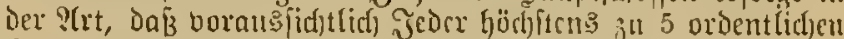
Sitzm,

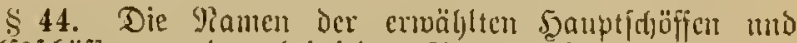
Soutisjübffen merden bei jedem ?tmtsgeridjte in gejonderte Werzeichnific aufgenummen (J゙al)res̆liften).

\$ 45. Die Tage Der ordentlidjen Sitzungen des Sdjöffen=

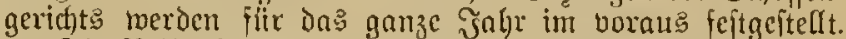

Die Reihenjolge, in weldter die Şauptichöffen an ben einzelnen ordontlidjen Sikungen des J̃hbres Theil nehmen,

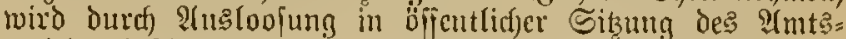

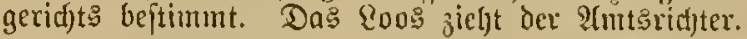

Lleber die ?tusloofung wirt bon dent (Serid)tsjad)reiber ein Frototoll nufgenommen.

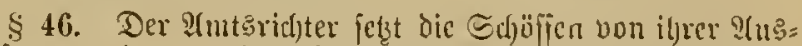
loviung und bon Den Eizungitagen, an welrlen fie in

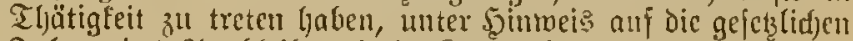
Jolgen des ?tusbreibens ${ }^{1}$ ) in Remntnif.

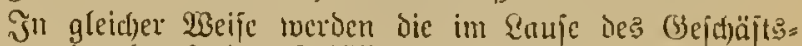
jalpres cinjubertijenion Sdjöfen benahyidhtigt.

\section{1) $3 g$ I. $§ 56$.}

\$ 47. Fine Penderung in der bejtimnten Reiljenfolge fann auj übereinfitimmenden Antrag der betheirigten Erljoffen bon ben $\mathscr{U}$ intäridfter belvilligt werden, fofern bic in den betreffenden Sizzumgen zlt berbandelnien Sadjen nod) nicht beftimmt find. Der 9lutrag und die Remilligung find atten= fundig z" madjen.

\$ 48. Wenn dic Bejffäfte dic Tnbernumung auß̉et= ordentlic)er Sitzungen erforderlict) macten, fo werden bic

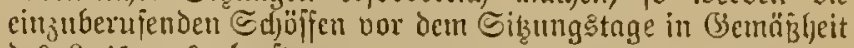
De $\& 45$ ausgelooit.

(Erjd)eint dies wegen Dringlidffeit untfumlitf), fo erjolgt

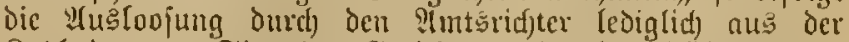

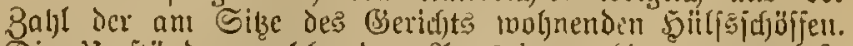
Die llmftände, meld)e den Ifmtsrid)ter Giergu veraulaßjt lpaben, fino aftenfundig zu madjen. 
§50. Erftredt fid) Dic Dauer ciner Sikung über dic 3eit hinaus, ffir rudche der Edjöfe ;unäd)ft cinberufen ift, fo hat ex bis jur Beendigung der Silzung feine ?tutt: thätigfeit jortjufeczen.

\section{Becibigung.}

\$51. Die Becioigntua Der Sdhöffen erfolgt bei iljrer erften Dienftleiftung in offentlid)er Eitzung. Eic nitt fïr die Daucr bes Gejuäftajnlures.

Der $\mathfrak{B}$ oritzende ridjtet an dic zu Becisigenten bie worte:

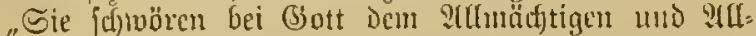

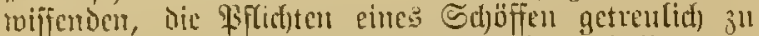

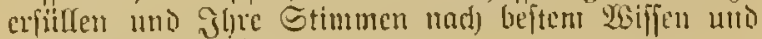
(Seiviffen nbjugeber."

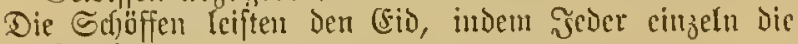
Worte jpridut:

"id) fdumöre es, fo waljr mir (Sott belje."

Der" Sdhtobrende foll bei ber Eidesteiftung die rethte sand erleberl.

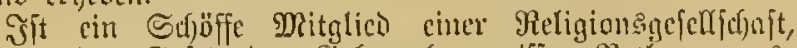
meldjer bas (jefets Den Gebraud getwiffer Bethenerung: formeln an Etefle Des Eites geitattet, io wirb bie ?thgabe ciner Erflärung unter Der Betl)euerung: jormel bicjer Religionts= gefclfflloft ber (sidesleiftung gleid) gead)tet.

lleber die Beeidigung turo von Dem Geridhtgfd)reiber ein Sirototoll aufgenommen.

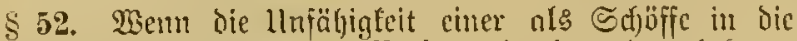
Jalje blifte anfigchommenen Berion eintritt oder befannt ruird, fo ift der Tiame Derfelben wou der Sifte ju itreichen.

(Ein Edjöffe, finfidftlidf) ieffen nadf fciner ?tupnaljme in die Sabreslifte andere lluitänse cintreten ober befonnt werDen, bei Deren Borhantenfein eine Berufurg jum Schöffen= amte nidjt erjolgen foll, ift jutr Dientleiftung ferner nicht l)erinzuzielyen.

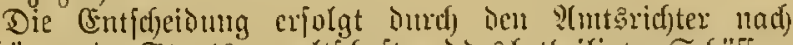

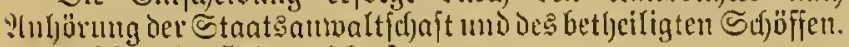

Bef(d)werde findet nicht jtatt.

§ 53. Thlel)nungggrïnie find mir ju herüaffictitigen,

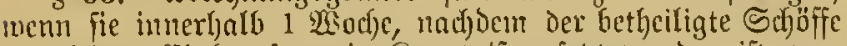
nout feiner Finferufung in Semntnifs geiest morben it, bon

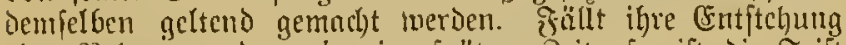
oder Betamtrocroung in eine fpätere Beit, fo iff Dic Jrijt crit bun biefem Beitpuntete ju beredpnen.

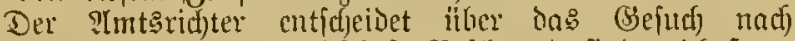

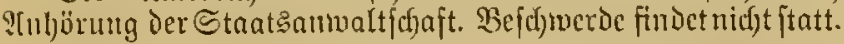

\$5. Der Imtŝrid)ter kam cincu Sdhöffen nuf deffen Vlitiag wegen eingetretener Sinderungsgrinde von der Dienfileiftung an beftimmten Silzungstagen entbinden.

Dic Entbindung Des Sdjöffen non Der Dienftleiftung taun Davon abhänaig gemad)t werden, Daßs cin anderer füx Da: Dienftjahr bejtimmter Sdjoffe fïr ifn cintritt.

Der? Intrag und Die Bemilligung find a ftenfundig zumarjen.

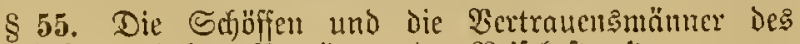

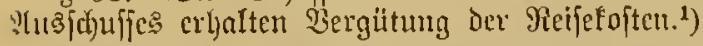

1) fofern fie anberhalb ifjres 2 nfenthaltsortcs meljr als $2 \mathrm{~km}$

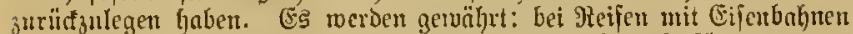

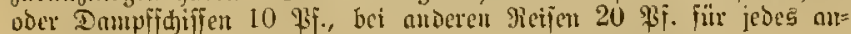

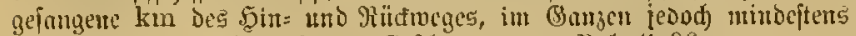

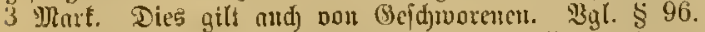

Mubte ber Bertrauensmaut ober Sdjöffe (utid)! aud) ber Be=

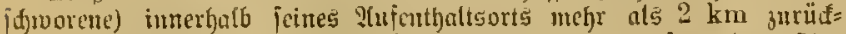
legen, io find ifm 20 g. fir jebes angefangene $\mathrm{km}$ bes Sill

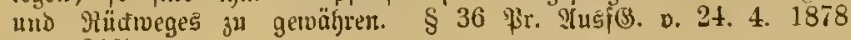
(अ) 230).

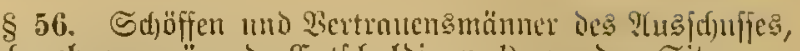
welche oljne gentigente (Entfd)uldigung") zu Den Sibungen nidft recflzeitig fich cinfinden nocr ihren Sbriegentheiten in anderer 2 eife fid) entziehen, fint ju cince Dronungsftraje ${ }^{2}$ ) bon 5 bis zu 1000 Minrt, fowic in bic verurfacten Sipten 3 berurtheilen.

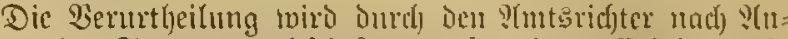

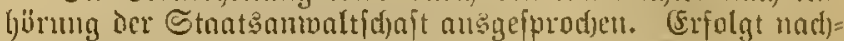
träglid) genitgende (Entf(f)uldinung, fo Eamu dic Serurtheiluna gan oder theilmeife juriidgenommen uerden. Gegen die

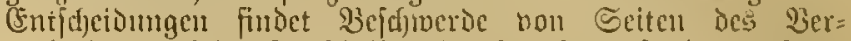
urtheilten nad) den Borfd)riften Der Strajprozefzordmung ftatt.

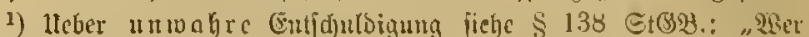
als 3euge, Bejdyorener ober Sdjoffe berufen, etue umbahre That=

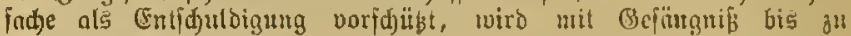
2 Miouaten bcitrajt.

Daffelbe gilt von cinem Eacljuerftänoigen, weldjer zun Eridgeinen gelestidi verpilidstet ift. ${ }^{3}$ )

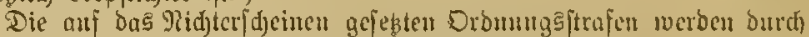

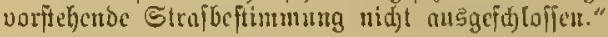

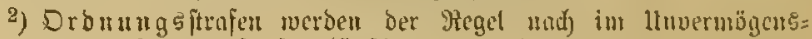

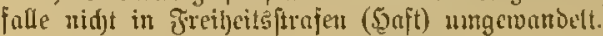

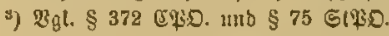

\section{Citel. Laudgeridite.}

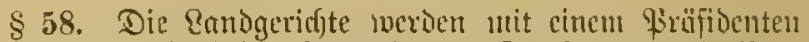

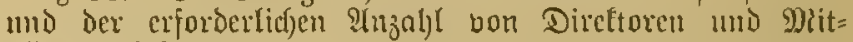
glicioern bejest.

§59. Bei Den Ranogeridften werDen Cibil= แmi Straf= fammern gebilidet.

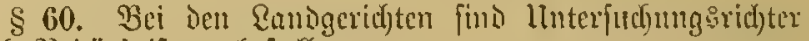
Itacl) Bebitrinifis ju beftellen.

Die Beftellung erfolgt Durd) Die Ennoesjuftizuermaltung anf die Daner eines Gej (t)äftsjabres.

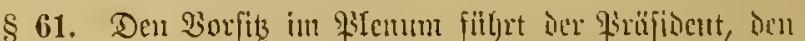

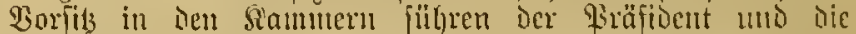

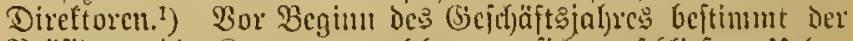
Bräfident Die Sammer, meldfer er jich anjedrejt. Ileber

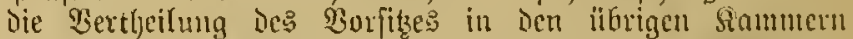
entf(heiden ber Hitiffident und bic Direftoren nad) Stimme'll=

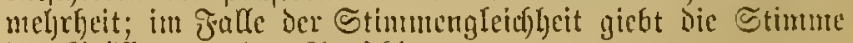
iles Präfioenten Den ?(usjur)lag.

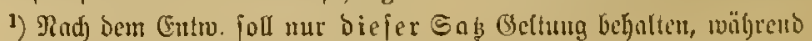
Der Mejt biefes Faragrapljen fortfällt.

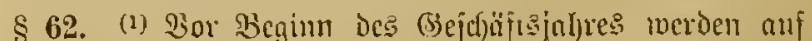

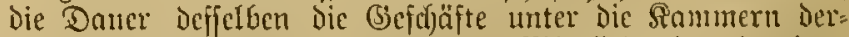
felben ?irt bertheilt und Dic ftändigen Diitglieier Der einzelnen

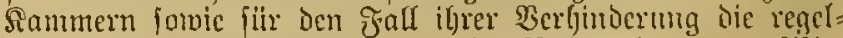

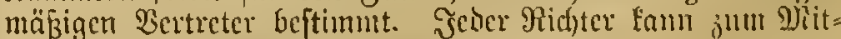
gliede melfrerer Sanmern bejtimmt werden.

(2) ......

\$ 63. Die in norftchenden Baragraphen bezeidfncten Inoronungen erfolgen Durdf Das \$rtäfioimut. ${ }^{1}$ )

Das Gräfidium miro Durd) Den Isräfidoenten als wor= fizenten, Die Direftorell und bas Dem Dienftalter nad), bei gleidicnt Dienftalter Das Der (Geburt mad) ältefte gritglici)

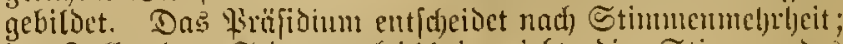
im Falle der Stimtmengleidbleit gieft die Stimme des giräpidenten ien ?lusjdylag. ${ }^{2}$ )

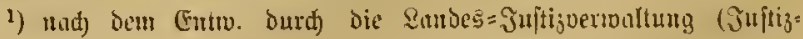
utinifter).

2) Der 2. I6f. foll aufget)oben weroen (Entw.). 3gl. and Tum. жи § 121 . 


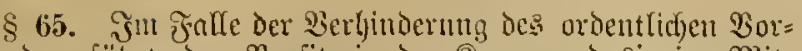
fikenden fülyrt ben $\mathfrak{B}$ orfits in Der Rammer basjenige Diit= glicd Der Siammer, tweldyes dem Dienftalter nady umb hei gleidfeur Dienjtalter ber Geburt nad) Das ältefte ift.

Der Bräpioent wirt in jeinen ïbrigen Duref diefes (hefels bejtimmten (3ejicjäften durch) benjenigen Direftor vertreten, meldjer dom Dienjtalter mach und bei gleidjem Dienitalter: ber (B)eburt madf) Der ältefte ift.

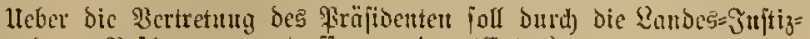
verwaltung Septimunurg getroffeu uerten (Entw.).

\section{3uftältoigfeit ber civilfammern.}

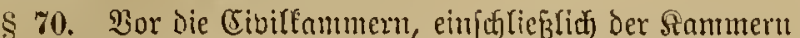
fiir Şandelşachen, geförzen alle bürgerlichen Redjtsftreitig= feit'n, weld)e nidgt den ?(mt:agerichten zugetviefen find.

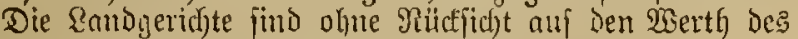

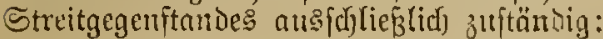

1. für die SInjprithe, tweldic auf (Srund des Befeties bom 1. Juni 1870 Hiber die ?tbgaben von Der

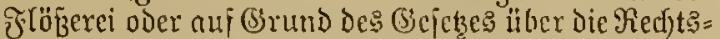

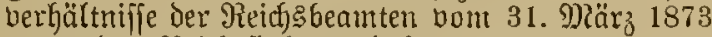
gegen den Reidsfistus erloben werden;

2. Für die 2Irfprït)e gegen Reidfsbeante wegen Heber= idjrcitung ifgrer amtlichen Befugnifîe ober toegen

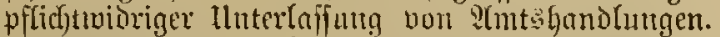

Der Sandesgefetsgefung Gleibt ibberlaffen, IInjprïiche der Staatsheauten gegen den Etaat aus iljzent Dienftuerlyältniffe, Injurïilje gegen den Etant megen Berfügungen der $\mathfrak{B e r}=$ walturgabebörden, wegen Berichuldumg von Stantabeamten und we zen Slufjebung bou Grivilegien, 2njprid de gegen Beamte wegen lleberforreitung ihrer antlidjen Befugniffe oder megen pflidftroioriger llnterlajlung bon ?tutshandlungen,

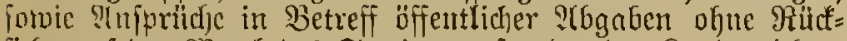
ficht auf Den 2iertly des Streitgegenitandes Den Ranogeridjten

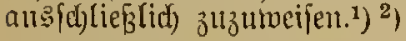
\$ 39.

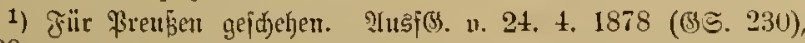

2) Die Civitfonmbern Der Eanbaerionte werden ferner im Folle bes

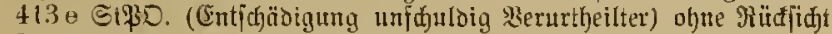

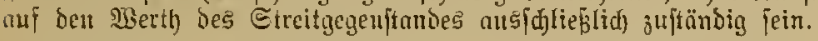

\$71. Die Sibilfammern find bie Berujungs= und

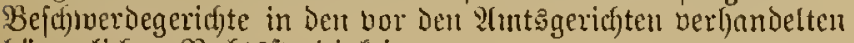
frürgerlicben Redftsjtreitigleiten.

\section{3uptändigfeit ber Etraflammern.}

$\$$ 72. Dic Strafenmmen find zuítöndig für Diejenigen die Vorunterfudung und Deren Ergebuiffe betreffenden Ent=

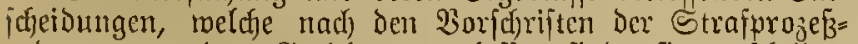
wronung bon Dem (Berichte zu erlaffen find; fie entidfeiden

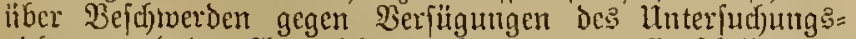

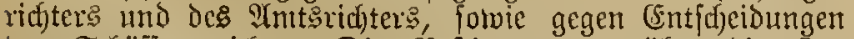
Der Sdjöffenneridyte. Die Beitimmungen über bie $3 \mathrm{nt}=$

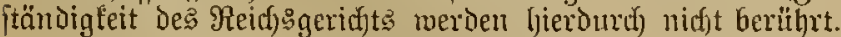

Die Straftammern erledigen außjerdem die in her Straf = prozefzordmung Den Sandgeridften jugeniefmen Bsefchäfte.

\$ 73. Die Strajfonmern find als erfentende (Sericfte วuftünıig:

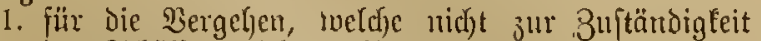
Der Sajöffengeridjte gelörum;

2. Für Diejenigen $\mathfrak{B e r}$ bredjen, tweld)e mit Zutfthaus

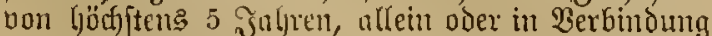
mit anderen Strafen Gedrolyt fint. Dieje $\mathfrak{B e}=$

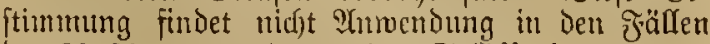
Der SS 86, 100 mo 106 Des St(3)

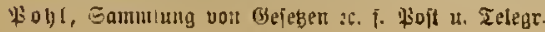

3. Fïr die Berbrecten Der ßerjonen, welche jur Zeit Der That bas 18. Rebensjalyr nody nicht bollendet lyatten;

4. fiir Das Berbredjen der Unjud)t im salle des \$ 176 গix. 3 Des ธt(3).; $\left.{ }^{2}\right)$

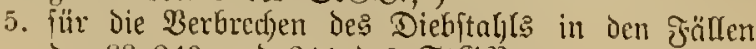
der $\$ S 243$ und 244 des St(j)B.;

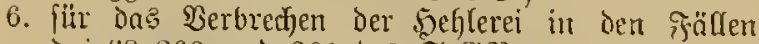
Der ss 260 und 261 des St@B.;

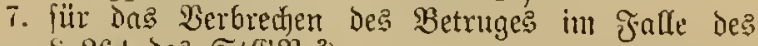
\$ 264 des St(S23. $\left.{ }^{3}\right)$

1) Die Iusnahmen betreffen:

5andlungen, meldje hodjuerräthcrijđe lluternetmungen vor: berciten,

Thätlidfeiten gegen Bundesfürften,

Bergeroaltigutig Don Mitgliebert eiucr gelebgebenden $\mathfrak{B e r}=$ fammlung bes Reidjs oder eines Bundesftants.

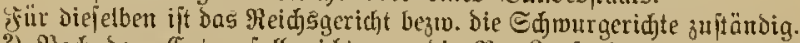

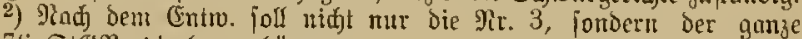
$\S 176^{\circ}$ ఏtङB. bierber gehörett.

3) Siă Dem Gntw. pollen hinjutreten:

Das Verfrechen des Wideritantos gegen die Stantsgenalt in

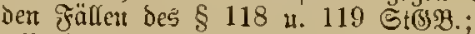

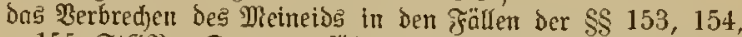

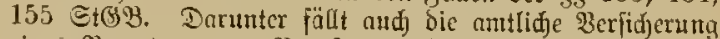
eines Beauten unter Bुerufung auf feinen Dienjteis;

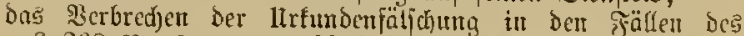
$\S 268$ भir. 2 unb ber $\$ \$ 272,273$ ङt(3:.;

bie 3 erbreden im $2 \mathrm{mt}$ in ben Fällen der $\$ \$ 349$ unt 351 ভt(BR. (ogl. bieje in III. Thcil);

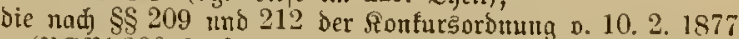

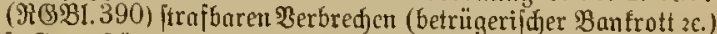

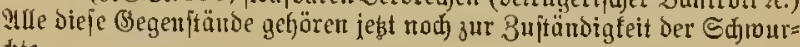
geridite.

\$ 74. Die Straftamtrem fint als erfernende Geriffte auşfchlief̧lich zuftändig:

1. fïr Bubiderhandlungen gegen das Befets bom 25. Detober 1867, Getreffend Die Rationalität Der Siauffaljteiffjiffe $2 c$. ;

2. fïr bie nad) Irt. 206, 249 und $249 a$ bes Beiebes vont 11. Эuni 1870 , betreffend bie Sommonditgejellifaften auf

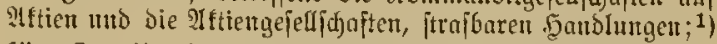

3. [ür Buniberhandungen gegen die Bejtimmungen ber ş 1, 2 und 3 de (Sejetes vom 8. जuni 1871, Getreffend die Эnljaberpapiere mit \$rämien;

4. für Die nach) \& 87 und \& 69 Des (3eferses vom 6. Februar 1875, Getreffend die Beurfunoumg Des \$erjonenjtandes 2e., itrafbaren Şandungen;

5. fitr bie nad) $\$ 59$ beş Banfgejęses vom 14 . Mär 1875 jtrajbaren 5andlungen.

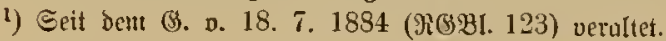

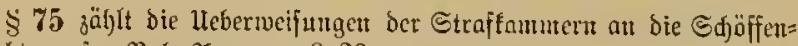

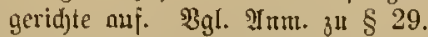

$\$$ 76. Die Straffammern fino als erfemende (Serid)te fermer zuftändig fïr bie Berhandlung und (Enticheidung fiber Das Recht mittel Der Berufung gegen bie urtheile Der Scjöffengeridfte.

\$77. Die Rammern entfdeiden in Der Befelzung bon

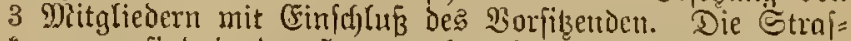
fammern find in Der 5ुanptberl)onolung mit 5 Mitgliedern, in Der Berufungsinftums bei llebertretungen umb in Den

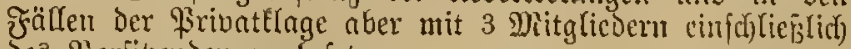
Des Sorjizenden zu bejezen.

Mađ ben Entro. Dollen bie Rnnment in allen Fällen in ber

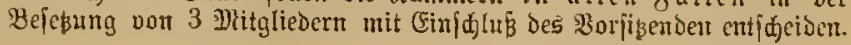


\$ 78. (r) Durd) 2Tnoronung Der Randesjuftiznermaltung fann wegen grober (Entfermung bes Eantogeridytsfitze: hei einem 2rintsgerichte fiir Den Bejirf eitcs ober melfreter

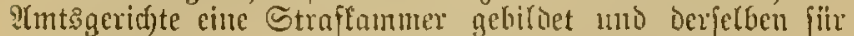

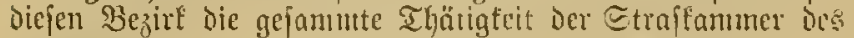
Eanogeridhts oder ein Igeil biefer Thätiglcit jugewicjen morden.

(2)

\section{Citcl. Sdimurgeridjte.}

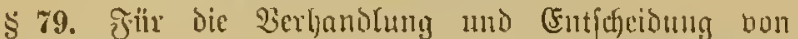

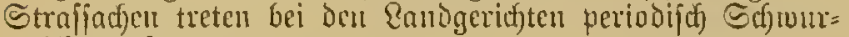
gerichte julammen.

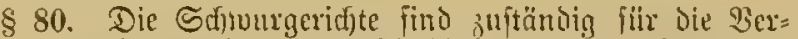
bredien, weldhe nicht jur Buftänoigteit Der Straftanmern oder des Reich) isgeriufte gehörent.

§ 81. Dic Scfmurgeribte beftehen aน: 3 richterlidfen Mitgliedern mit Eimfchlus bes Worfitzenden und ans 12 jur (Enticheidung Der Sefuldofrage berufenen (Sefichmorenen.

\$ 82. Dic (Entjdjeidungen, wetde nad) dett Borfdriften dicfes Gejezes odcr der Strafmrozefzordunng von dem el= fennenden (Serid)te ju erlaffen fino, erfolgen in beu bei ben Schmurgerieften anljängigen Sacten burch bie richter'fidien Mitglieber bes Sd)murgerichts. Waerden Dicje (Enticftidungen auBerhalb Der Dauer Der Sitzugsperiode erforderlict), fo erfolgen fie durd) bie Straftammern ber Ranigeridfte.

$\$ 83$. Der Burfizende Des Schumberichts miro jür

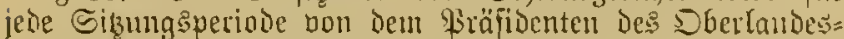
gerid)ts ernannt. Die Ernemung erjolgt ans Der Bahl Der

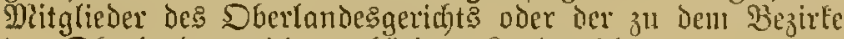
Des Sberlanicengericht ş geförigen Ranigerichte.

Der Stellbertreter De: 3̈orfitzenden unt Die ïbrigen ridhterlicfen Miitglieder werden non den \$rräfidenten bes Sandgeridfts ans Der Zahl ber Mitglieber Des Eanogerid)ts beftimmt.

So lange die Ermenung des Borfikenden nicht exfolgt

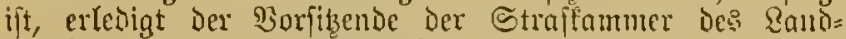
gerid)ts die in ber Strajprozésordmung dem Borfiţenden Des (Serichts zugewiejenen (Scichäfte.

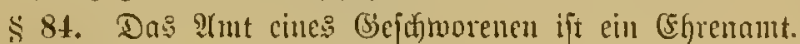
Daffetbe fann mur wan cinem Deutfitien berjeljen werben.

\section{Urrifite. Befähigung.}

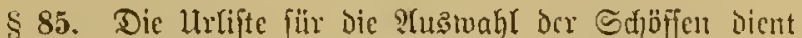

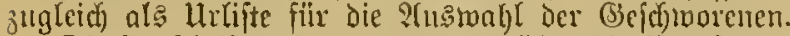

Die Borfdriften Der \$\$ 32-35 ïber bie Berufung juu

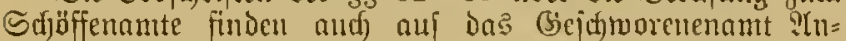
mentung.

\section{Barfdilagąlifte.}

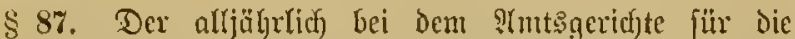

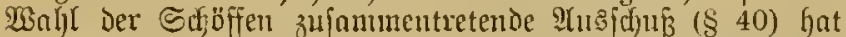
gleidjzeitig Diejenigen Perfonen nus Der Urlifte nuszunähten,

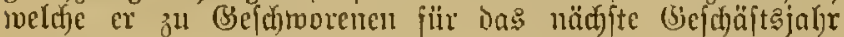
vorf(u)litgt. Die $\mathfrak{B}$ oufduläge find nath dem $3=$ fact)en Betrage

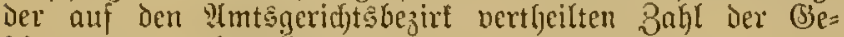
idjworenen on bemeffert.

\$ 88. Die Ramen Der zu (Sejdtworenen vorgejd)lagenen

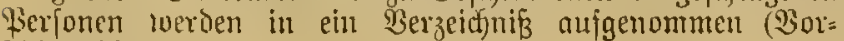
johlogstifte).

Jualjreąlifte.

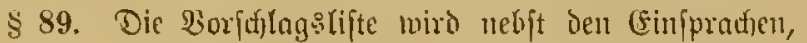

welche fidf auf bie in biejelbe aufgenommenen Berjonen be= jieljen, bem gräfidenten bes Sandqerichts jiberjentet.

Der Präfibent beftimmt ciue Simung ${ }^{1}$ des Sandgeridyts,

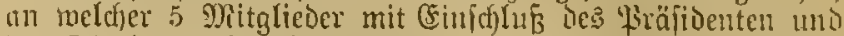

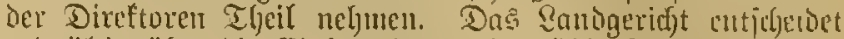

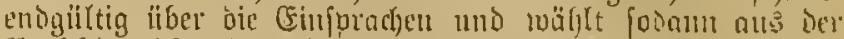

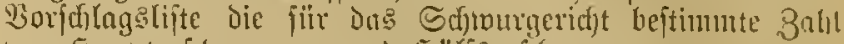

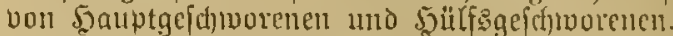

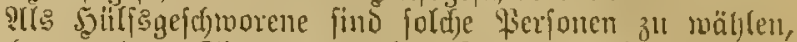

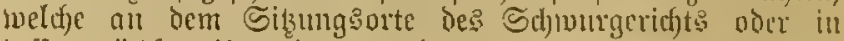

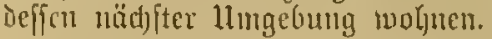

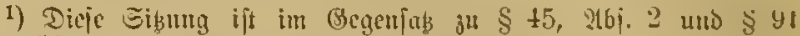

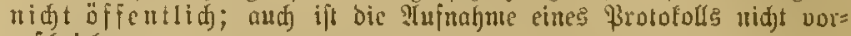
geid)riebert.

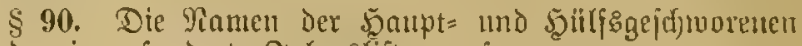
wertien in gefonderte Jatheshiften allpenommen.

Epruddifite.

8. 91. Späteften 2 woưfen nor Begiun ber Siłmugen

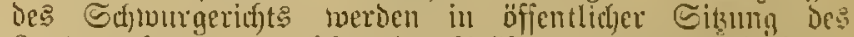

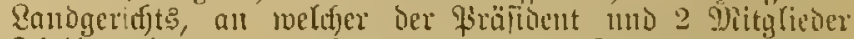
Theil nelumen, in (s)egentwart Der Staatsonmaltf(t)aft 30 5auptgeidjworene ausgeloojt. Das Roos wirb voll bent qiräpitienten gezogen.

Puf (sejumorene, weldye in einer frülieren Sibung:

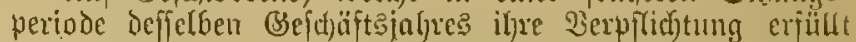

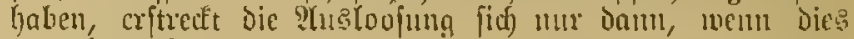
non ifjuen beantragt wiro.

lleber Die PHsloofung mird bou bem Berichtefdyreiber cin Frotofoll aufgenommen.

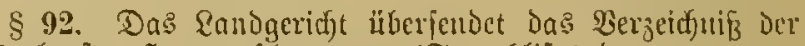
altsgeloojten 5Jauptgefdumorencn (Spritulifte) dem ernaunten Bolfizenden des Siffwurgeridfts.

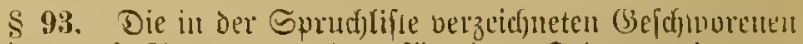

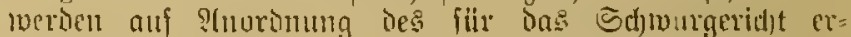

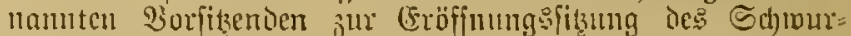

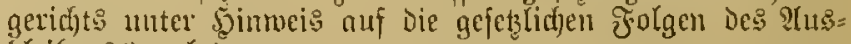
bleibens 1) gelaoch.

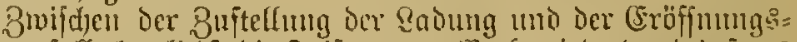

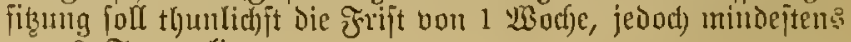
non 3 Tagen licgen.

1) $2 \mathrm{gl} . \S 96$.

\$ 94. Leber dic bon (Bejdjworenen geltenio geutect)ten

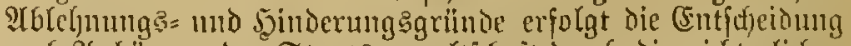

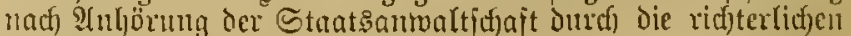

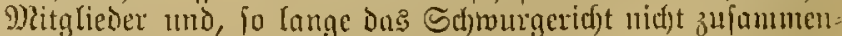
getreten ift, burdh Den ernannten Borjikenden oes Sdfrour geridfts. Beid)werde finset nicfit itatt.

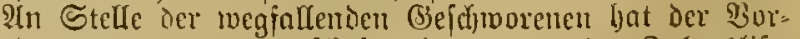

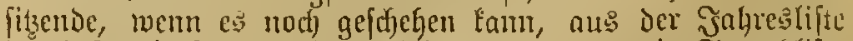
Durch ?(uslovfung andere (seff)morene auf die Eprud)lifte ôt fringen und Deren Radung anzuoronen. Heber Die Sha

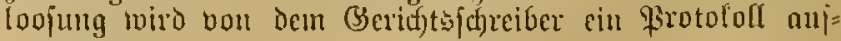
genommen.

\$ 95. (Er.tredt fid) eine Sitzungaperioie Des ๔utrur=

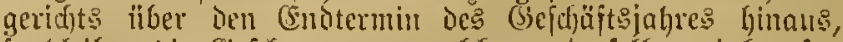
jo blcihen bie Gefdjworenen, meld)e z" Derjelben cinberufen

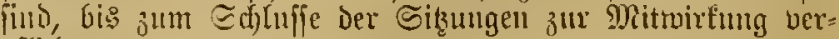
pflichtet.

\$ 96. Die 3ejtimmungen Der \$\$ 55, 56 fincen and) auf (Sejuftworeme צ्(ntwendung.

Die im \$ 56 bescidnuten (5ntjd)eidungen rocrden in Besug 
auf Bcidstworene bon den richterficyen Mitgfiedern des S(d) tourgcridfts crla[jen.

\$ 97. Nicntand jofl fiir bajiclbe (bejdjätsjalyt als (bie

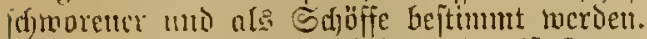

Sit dies demods geiffeljen, oder ift Semant fiir doffelbe (Bcidäjtsjahr in methreren Besirfen zil biejen ?lemtern be= ftimmt morden, fo hat de: Einberufenc basjenige :Imt ju

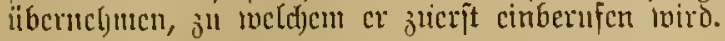

$\$$ 98. Dic Straffammer des Sandgeridjts fann be=

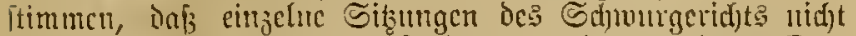
nm Sitsc des ?nndgerid)ts, fondern an eincm aniercu Drte

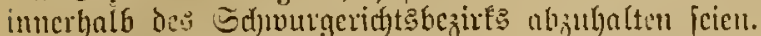

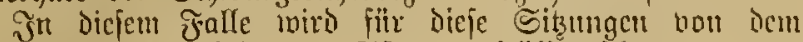

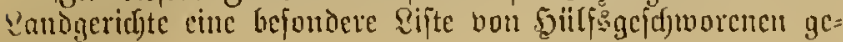
biliet.

\section{Titsl. Siaumertt fïr syandefsfadien.}

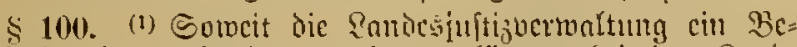

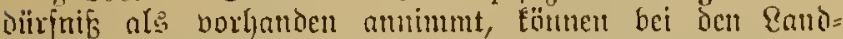
geridften fïr beren Bezirfe ober fiir bittid) abgegrenjte Theile

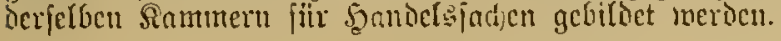

(2) . . . .

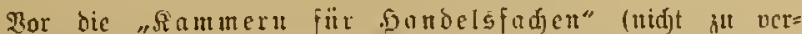

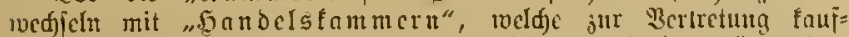

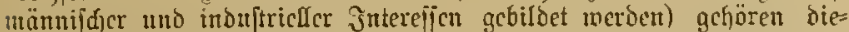

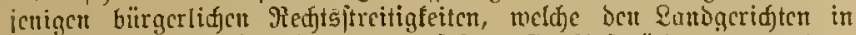

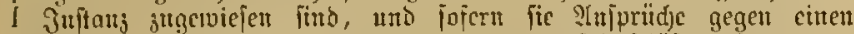

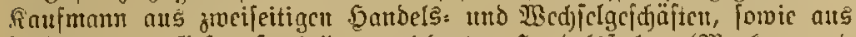

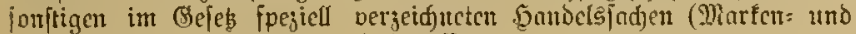
Mufter[dus, Somoclsfirma zc.) betreffen.

\$ 102. (1) Dic Bertyandum des Rectetejtreits erfolgt

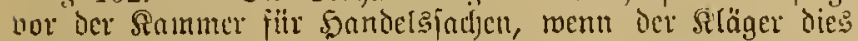
in der Rlagcingrift benntragt loat. . . . . .

(2) ......

§ 109. (1) Dic Sammern für Sandelsiad)en entfueiden

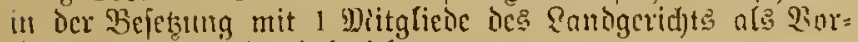
fitkendon und 2 sandelericitern.

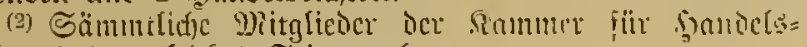
jadjen haben gleidjes Stimnnedft.

(3)......

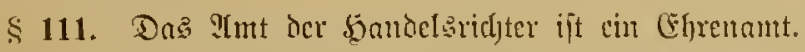

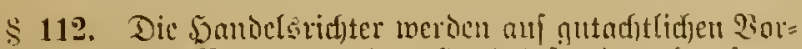

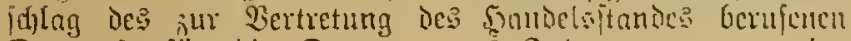
Drgans') fïr dic Dauce bon 3 Jaluren ermount; einc wicierhofte (Ernemnumg ift nidyt ausgejd)lofien.

1) D. i. Sarbelstammer.

\section{Titel. Qberlandesgeridjte.}

$\$ 119$. Dic Dberlanidesgeridjte werden mit cinem Prö= fidenten und ocr exjorderficjen ?hjahl von Senatspräfidenten und Räthen bejełt.

§ 120. Bei den DGerlandesgerifften merden Cinil= und Straffenate gebildet.

\$121. Dic Bejtimumungen ocr $\S \S 61-68$ finden mit

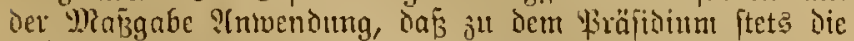
heiden ältejten Mitglieder de

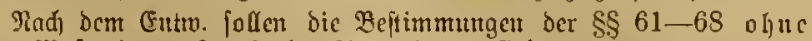

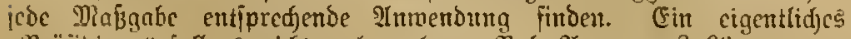

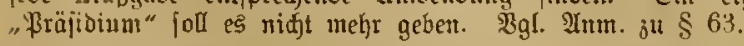

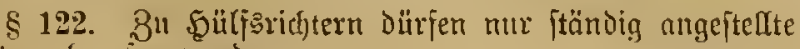
Ridjter berufen merden. 3utitäntoigfcit.

§ 123. Die Docrlandesgerid)te find zuftändig fïr dic

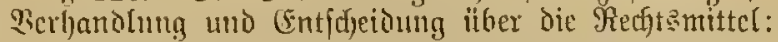

1. Ber Bcminn gegen die Endurtheile der Sant=

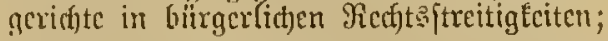

2. Der Renifion gegen llutbcile der Straffammern in Det Berufungsinjtanj; $\left.{ }^{1}\right)^{2}$ )

3. Der Revifion gegen llttheile der Straffantmern in

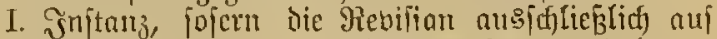

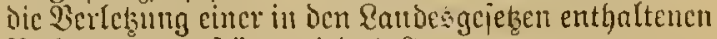

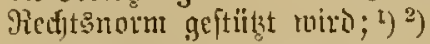

4. \er Bcidjmerde gegen Gutidfeioungen der \&and=

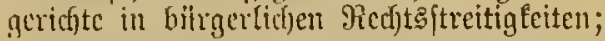

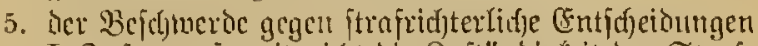

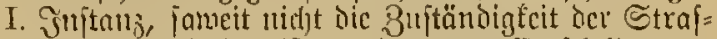
fanmer begributet ift, utno gegen (Entjdjeidungen

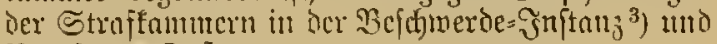
Bcrupung:-Yuitang.

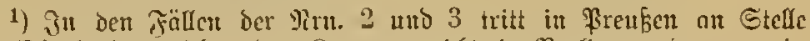

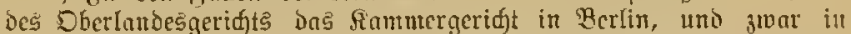

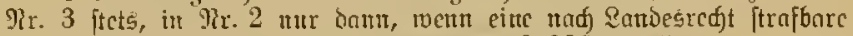

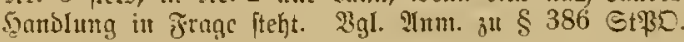

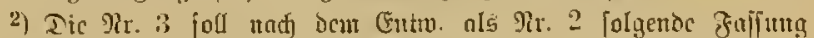
etfalten:

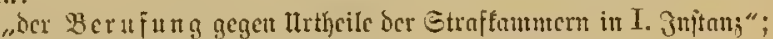
bie jesige 9 ir. "2 foll $9 \mathrm{r} .3$ crhalter.

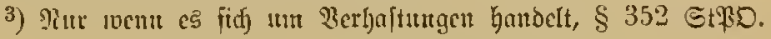

\$ 124. Die Senate der Sberlandesigcridjte entfaciden

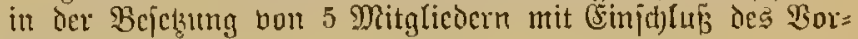
Filizenden.

Diejer Patagraph foll mach ocm Entw. folgende 8ufäbe crbalten:

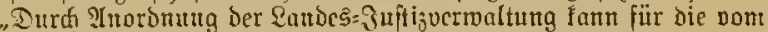
Sib des Sberlnmesgeridts cutfernteren 2 andgeridjte bei cimem voce mehreren bericlben cin Etraffent gebilbet mo bempelben fü:

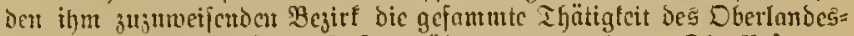
acridyts in ber Bernfungs= Jnftam ciucs poldjen Strafienats erfolat atts Ditglicient bes Dberlandes: gerifts oder Mitglicoern chres oder mehrerer Enogerifjte bes BezirEs, fï weldyen ber Ectat gebilbet mird. Der Borfibenbe mird ftändig

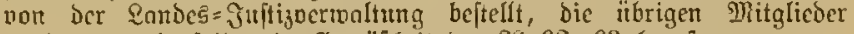
merden vou berfelbu in Gomäbreit ber $\$ \$ 62,63$ berufert.

Durd) dic Befergebung cincs Bundesfftants fonu beftimmt werden. Dof bic Bejcifuutug Der Sige ber bei Zardgeridten ju

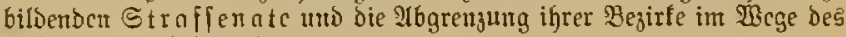
Gejebes jut crfolgen hat."

\section{Titcl. ąteidisgeridit.}

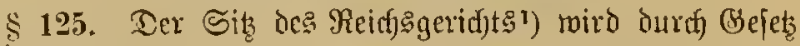
beftimmt.

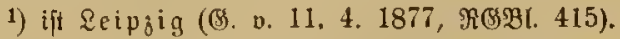

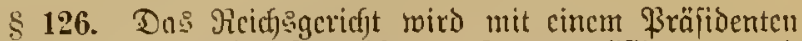

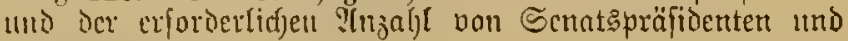
Rätben loçę̧t.

§ 12\%. Der Fräfident, dic Senntßpräfidenten und Räthe merden alf Borjdjlag des Bumiestaths von dem Raifer crnannt.

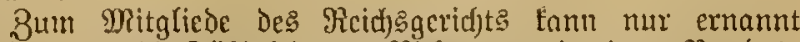

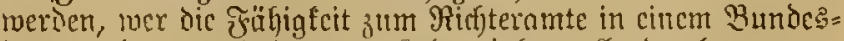
itate crlangt uno das 35 . Sebensijat vollendet lyat. 


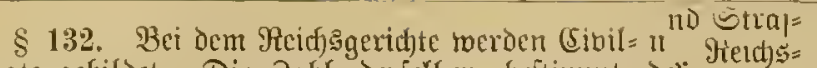
ienate gebiloct. Die Babl berfelben bejtimnt det Tetds= fanklcr.

\$ 133. Dic Dejtmmumugen oct $\$ \$ 61-68$ finocm urit

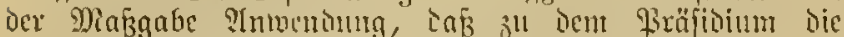

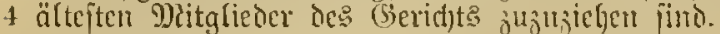

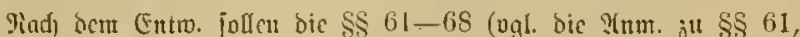

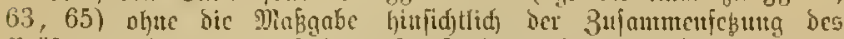

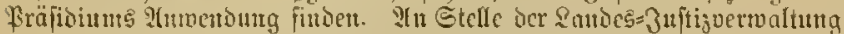
tritt hier jedod) ber Präjibent bes Reidjêgeridts.

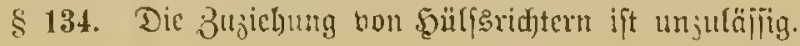

\section{Bujtänoigfeit: a) in bürgerlichen Med tâftreitigfeiten.}

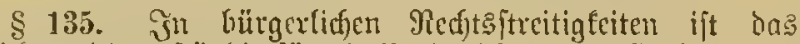

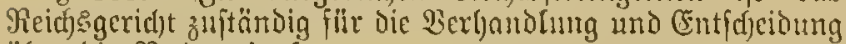

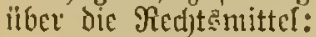

1. Der Revifion gegen bic Entintheile der Dherlnubes= geridte;

2. Der Bejdimerde gegen Entfideidungen der Dbet= landesgerid)te.

\section{b) in Strafiadjen.}

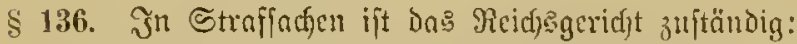

t. für bic Luteriudjung uno (Entid)cidung in I. uno

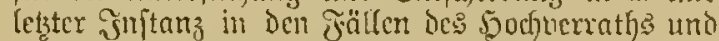

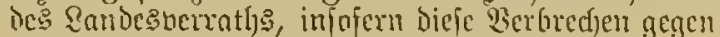
den Raifer oder Das Reich gerict)tet find; ${ }^{1}$ )

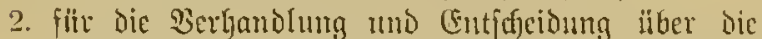
Refotsmmittel Der Rebifion gegen Urtbeile ber Straf= [ammern in I. Injtonj, infotweit nisf)t dic $3 u=$ ftändigfeit der Sbertandesgeridste begründet ifit, und gegen llatgcile der Er(jwurgerichte. ${ }^{2}$ )

Sิn Etrafiachen twegen Buwiderfjanblungen gegen bic 23orjhriften über die (Exhebung öffentlid)er in bie Feichestaffe fliegenter Thgaben uno (Befälle ift bas Reid) sgerid)t aud

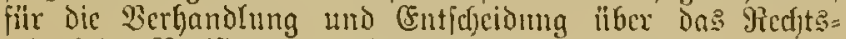
mittel ber Rebifion gegen Hrtheile Der Straftammern in Der

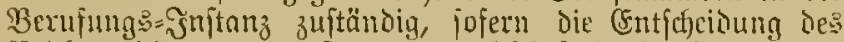

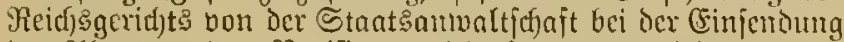

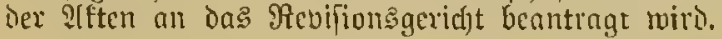

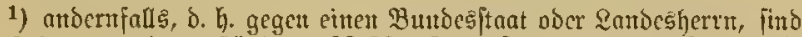

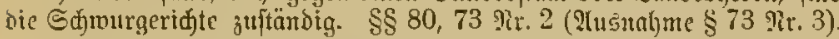

2) Dic গr. 2 joll folgertoc folfung crhaltert :

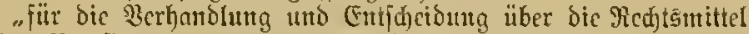
ber Revifion gegen Itrtheile ber Dberlanocsgertdyte in ber Be= rufurgs=3njtanj uno gegen lirtlycile ber Sdjunrgeridgte, fouve

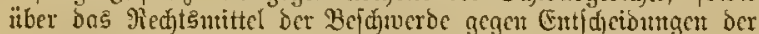
Dberlondesgeridjte in ber Berufungs=3nitan" (Entro.).

\$ $13 \%^{1}$ ) 23iff in cincr Red)tefrage cin (Sinilfenat non ber Enticheidung cines anderen Cibilimat: Doer Der ber= cinigten Civilienate, oder cin Strafienat bon ber Ent= id)eibung cines anoeren Strafienate odex ber bereinigten Etraffenate abtweidjen, jo ijt ibber dic ftreitige Redjtsfrage im crfteren galle eine (Entid)eioung Der bereinigten Civil= fennte, im letsteren Fralle cinc foldje ber bercinigten Strni= fenate einjubolen.

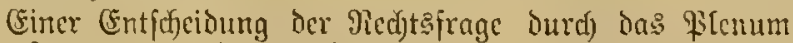
bedarf es, wenn ein CSivillenat von ber Entidheidung eines Enafichots ober ber bercinigten Etrafienate, voer ein Straf=

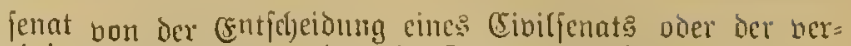
ciristen Civilfenate, oder cin Senat vou der frilfer cin=

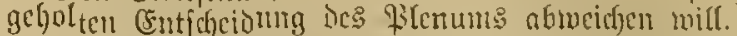

Dic Enticheioung der Fedtsfrage durdj bie vereinigten Senate ober bas gilenum ift in ber ju enticheidenden Sadhe bindent. Sic erfolgt in atlen fölten olnne vonnängige mïnolidge Berhondtung.

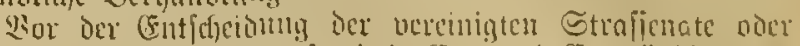

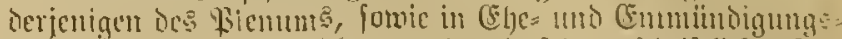

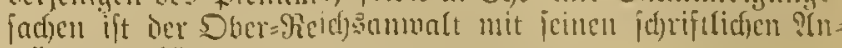
trägen jul hören.

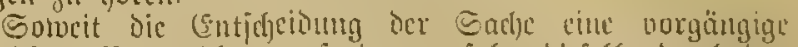

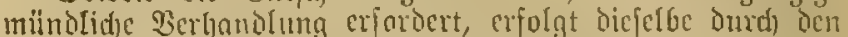
erfentuben Senat alf (Sruno ciner crneuten münotidhen

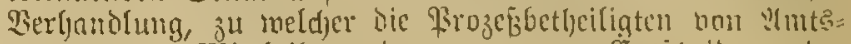

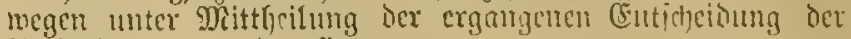
Ned)tsftage ju labeu fint.

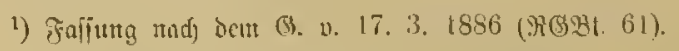

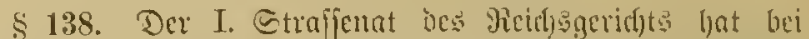

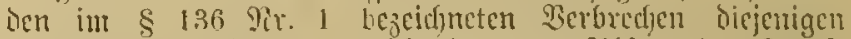

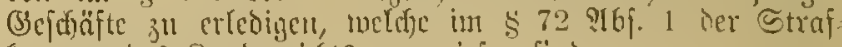
fammer bes Enogerichles jugewiefen fint.

Das Somptberfaljrell findot bor beur bereinigtem II. unt IIJ. Straffernate ftatt.

\$ 139. Zur Æaffung von \&i(enarenticfeioungen uno von (Entid)eioungen ber vereinigten Cinil= ober Strafjennte,

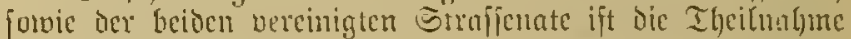

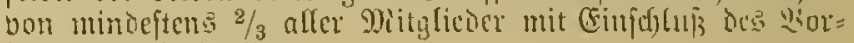
fitzenten erfariertict).

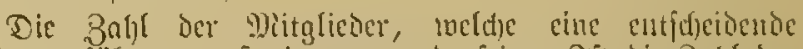

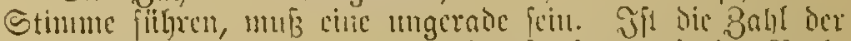
ammejenden Mitglicter cine gerade, fo hat Derjenige rath,

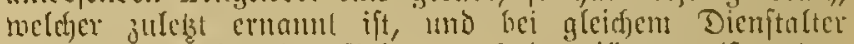

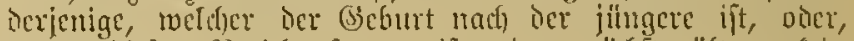

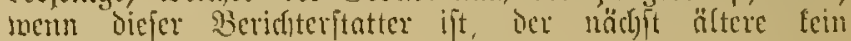
Stimmred)t.

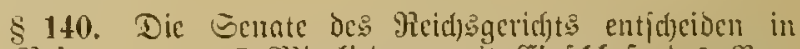

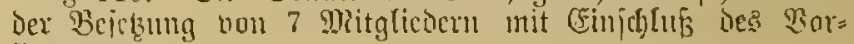
jitzenden.

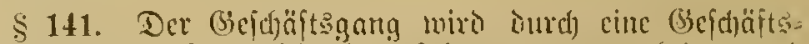
oronung geregelt, meld)e bas \$itenum allöjurbeiten mol Deut Bumbcerath jur Beftätigung vorjulegen Gat.

\section{Titcl. stantsamuaflidiaft.}

\$ 142. Bei jeden Bieridyte foll cine Stantsommaltichait bejtelch.

\$ 143. Das ?(ntt ber Stantenmualtfdjajt miro ansgeübt:

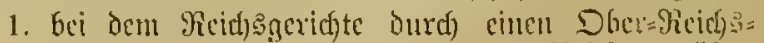
autwalt und Durch cinen ober meljere Reidfsaumälte;

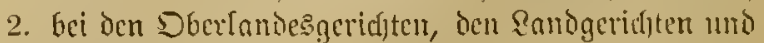
den Sdymurgeridfen Durdf einen vocr melfere Stantsammälte;

3. bei Dan Intsgerid)ten und ien Ghöffengerichten Durel) cinen ober mefjeere P(mtsanträlte.

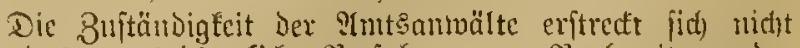
auf Das amtsiridjterlidje Berfafren zur Barbereitung Der

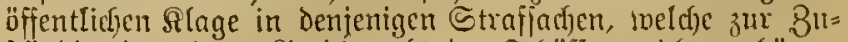

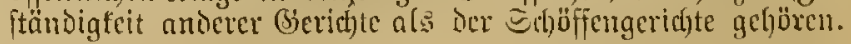


$\S$ 144. Die örtlidje Bujtändigfeit ier $\mathfrak{B e a m t e n ~ o e r ~}$ Stmatsanmaltichaft miro durch die örtlid)e Bujtändigfeit des Gerifite beftimmt, fïr inelefes fie beftellt find.

(Eil unzuftändiger Beanter ber Staatsanmaltfdajt ljat (iid) denjenigen inuterlialb jeiues Bezirfs vorzunefmenden

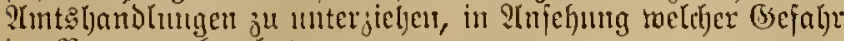
in Berjuge obranltet.

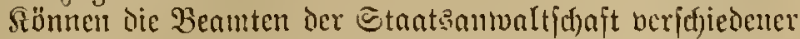
Bundesftaaten jiff nidyt onriiber einigen, mer von ifnen bie Serfolgung ju iibermefmen ljat, jo entfdjeidet der ifnen gemeinjam vorgejetzte Beante oer Stantsammaltjcjajt mo

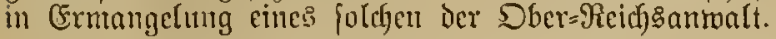

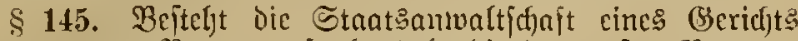
aus mehreren Beamten, jo handelu bie dent erften 23 amten beigeuroneten Sierjonen als beffen Bertueter; fie find, twent fie fïr ifn auftreten, zu allen 2 entsonerridjtungen deffelben ofue ten Tadjweis eines hefonderen Wuftragg beredftigt.

\$ 146. Dic erften Beanten Der Staatsanmaltidjait bei den Dberlanbesgeridjten mo Den Ranigeridyten find bejugt,

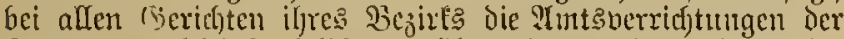

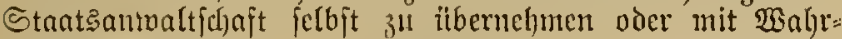
nefmung Derfelben cinen anderen alร ben junäefjpt ju= ftüudigen $\mathfrak{B e a m t e n ~ j u ~ b e a t l t r a g e n . ~}$

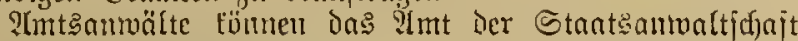

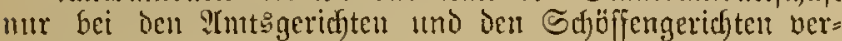
ieforit.

\$ 147. Die Benul'n iोer Staatsanmattellajt haben den

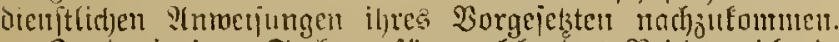

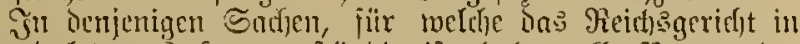

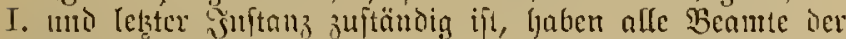

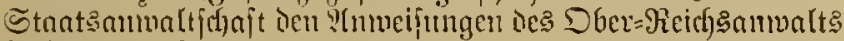

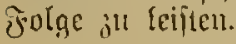

\$ 148. Das Fetht der Pluffint und seitung ftelt ju:

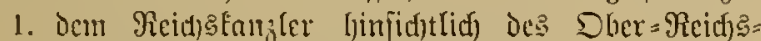
nmwalts und Der Reichsamwälte;

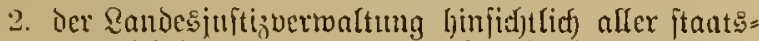
nunolttidyen Beanter dees betreffenden Bumbes: itrates;

3. Den eriten Beamten der Stantşaumaltidjaft bei den Dberlandesggerid)ten und den Randgeridften Gin=

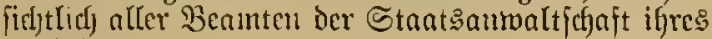
Bezirts.

\$149. Det Dber=9ieid) find nisljt ridfterlide Beamte. ${ }^{1}$ )

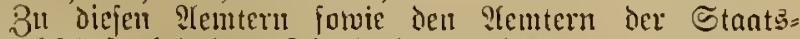
antwaltjuajt bei ben Dberlandesgeriçten uno Den Rand= geriçten fönnen 14 jum Fichterante Gejähigte Beamte ernamit merder.

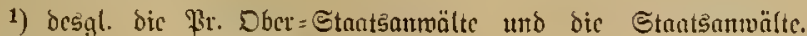

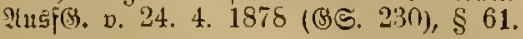

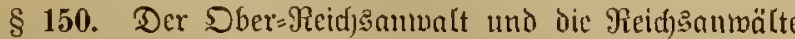

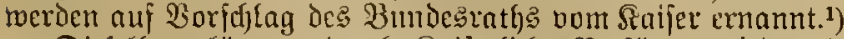

Diefelben tünnen ourd) SRaijerlicfje Berijitgung jederzeit

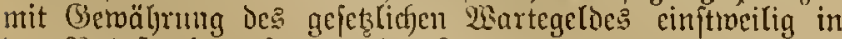
den Plubejtand verjekt werten. ${ }^{2}$,

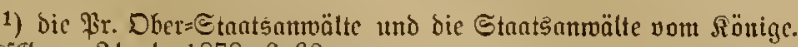

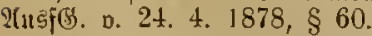

2) Desgl. Die Br. Dber:Staaţămmälte und die Staatsanmaälte. Diş̧וpt\$. v. 21. 7. 1852, §87.
\$ 151. Dic Stantäanmaltifiaft ift in ifren :Imts: berridftungen von ben Gierichten mab̧ängig.

§ 152. Die Stantsanmuälte dïrfen riçterliçe (sejd)äfte nicht roahrnelpmen. 91 ud bar iljnen eime Dienjtanfficft itber die Pidfter niçt ïbertragen rerden.

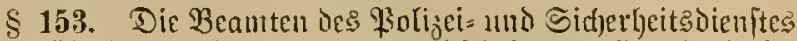

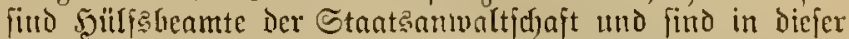
(Eigenjid)aft verpflifjtet, inen ?(nurdiungen der Stantsantoälte bei tem Randyerifjte ifres Bejirts und der diefen vorgefetzen Beamten folge zu leiften.

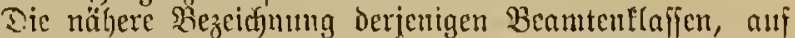
meldje diefe Beitimmung ?(mmenbung fintiet, erjolgt burch) die Sandestegierungen.

\section{Titel. (Geridjtsldireiber.}

§154. Bei jedem (Gerid)te mird eine (Geridytejafreiberei

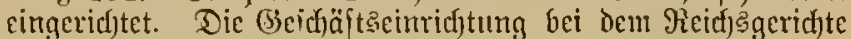

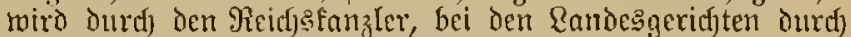
die Sandesjuftizuerwaltming beftimmt.

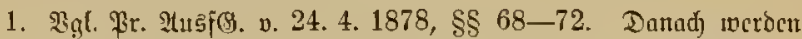

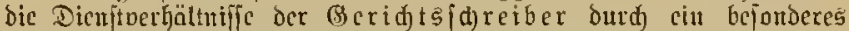
(3) (v. 3. 3. 1879, अS. 99) nto dic Gejdäftsocrbätmific derfelben

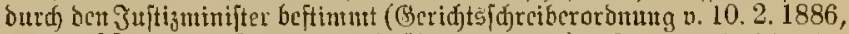

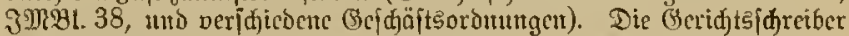
bes IImtsgeridts fint $u$. ?t. befugt, die 3 un Eintragung in dos

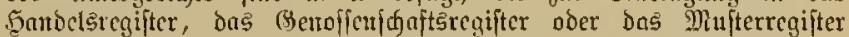

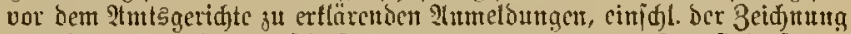
vou Firmen und Interfकुriften, entacoenzunchnen. Sic find fermer

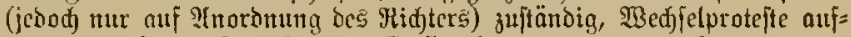
zunebmen, foute Sicgelungen, Entfiegefungen 2c. vorłunehmen.

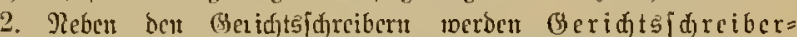

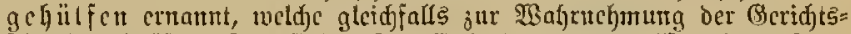

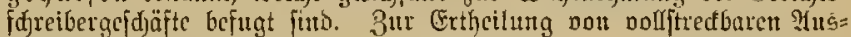

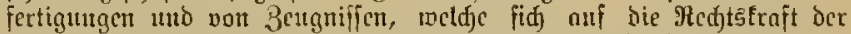

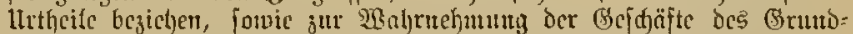

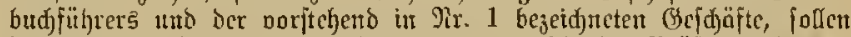
icbod) nur bicienigen verwenoet meroen, welde bic Brifiung als Ge= ridjtsidyreiber bejtanden haber.

\section{Titel. Zuftefungs- แnd వ̈offtredungsbeaute.}

§ 155. Dic Dienjt= แnD (Gejdjäitsecrbältnifje der mit Den Zuiteflungen, Eadungen und 2ollftredungen zu be= trauenden Beamten (Geridjtanollzieher) nerden bei dem

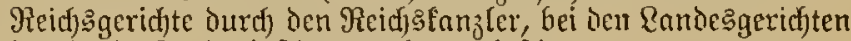

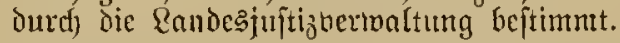

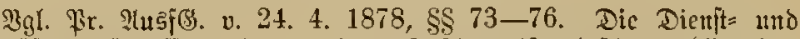

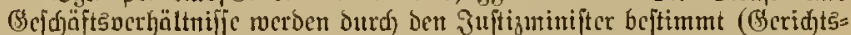

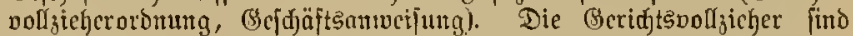

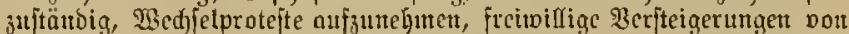

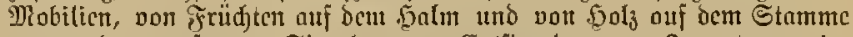
vorzunchntr ; ferter Siegelungen, Centfiegelungen, Inventuren im

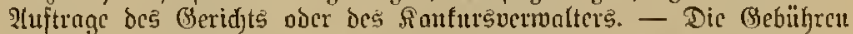

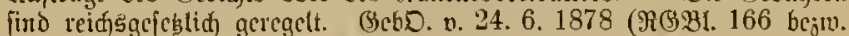

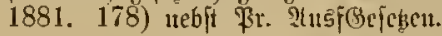

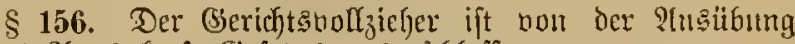

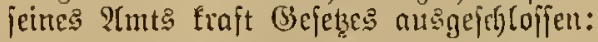

I. in büzgerlichen $\Re$ Rechtęftreitigleiten:

1. wem er jelbit Partci oder gejebzlicfer Bertreter einer \$artei ift, oder zu einer Partei in dem $\mathfrak{B e r}=$ ЦjäItuiffe eines Mitbered)tigten, Mituerpflid)teten oder Erfatenserjakpflidjtigen fteft; 
2. Imenn feine (E)ferau Fartei ift, ald wenn dic (E)he nicht melye beiteht;

3. rucm cine Fierion Gartei ift, mit welderer er in

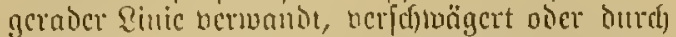
Slloption betbundon, in ber Seitentinic bi: jmm 3. Grade bermante viter his jum 2. (jirnote ner=

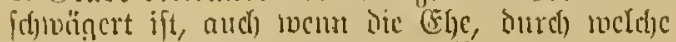

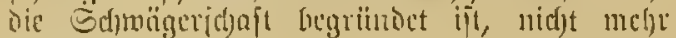
bciteht: 1 )

II. in Straffad)en:

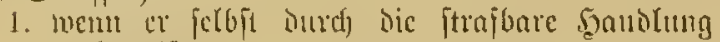
berlebt ift:

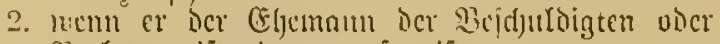
bertekten ijt oder gerucjun ift;

3. wemn er mit dem Beffjuldinten ober Berlekten

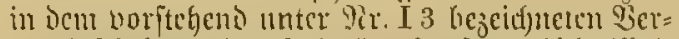

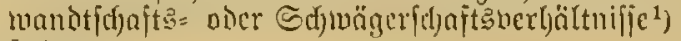
[tel)t.

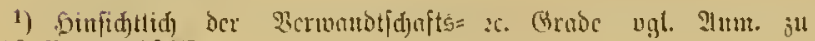
19 พืormuแojdo.

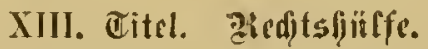

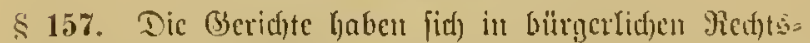

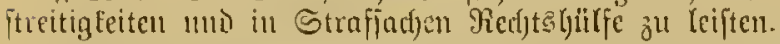

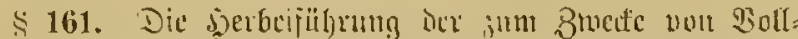

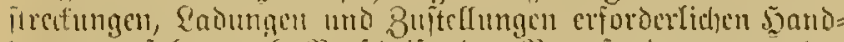

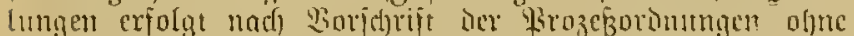

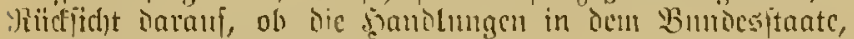

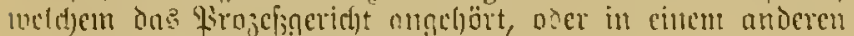
Bumbesptante borzunchuen (indo. ${ }^{2}$ )

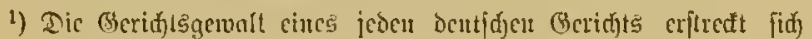
unj dic (Embohner aller deutjd)en Straten.

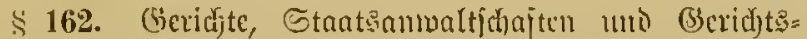

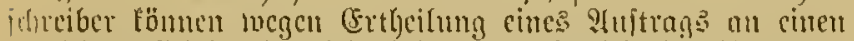

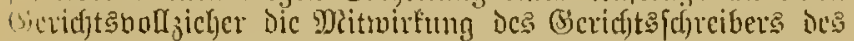

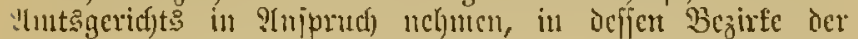
Whiftrag autsacfith:t ineroen folf. Der bon iem (Gerid)tes= id)reiber benuftragte (jerid)tsooll icher gilt als unmittelbar beauftragt.

\$163. Sinc frrcheitsftraje, weldye die Donter von (1) Wadjen nicjt ilberiteigt, if in Dcmjenigen Bundesftante in bollftresfer, in welchem ber Bernutljeilte fid befindet.

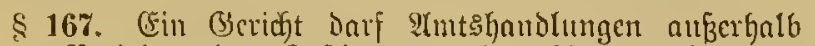

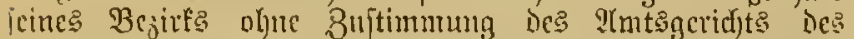
Drts nur vorneljmen, tocnn Bsefahr in Tier juge obmaltet.

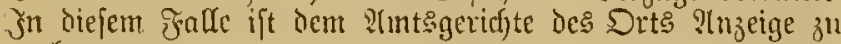
inacten.

§ 168. Dic ฐicherhcitsbcanten cines Bundesfitantes find crmächtigt, dic Vicrfolgung cinc: folïdjtigen auf ba:

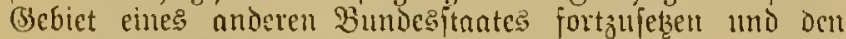
Flüchtiger Dafelbjt jull ergreiferr.

Scr (Ergriffene ift unberzïglid) an bos nädjfte (Serid)t

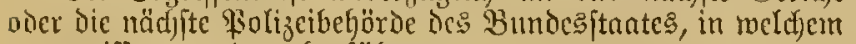
er ergriffen murde, abzufithren.

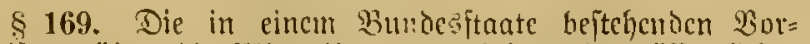

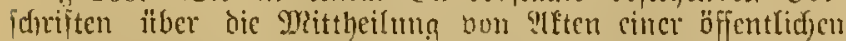
Befjörie an ein (Sericht bicies Bundesftantes tommen autd)

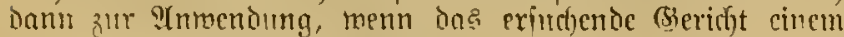
anderell Bundesftante angeljör.

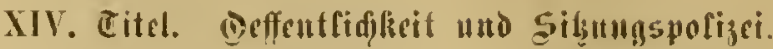

Deffentlidfeit.

$\$ 170$. Dic 23er(j)

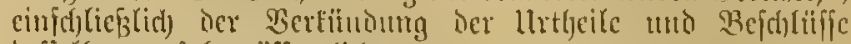
Deffelben, erịolgt ajfentlid).

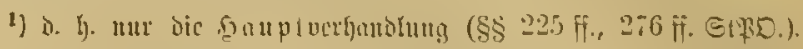

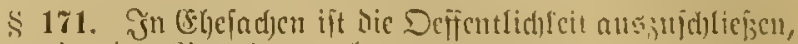
Iucull cinc ber Wirteich es beantrunt.

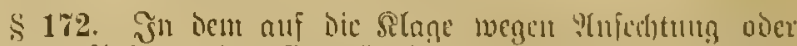

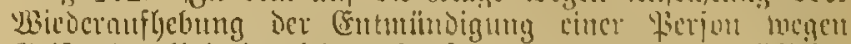
(Sciftestranflyeit ciugeleiteten Berfahtur (\$\$ 605, f:20 der (595D.) ift Dic Deffentlid)feit toübrent Der Bernelpunty oc: Ent=

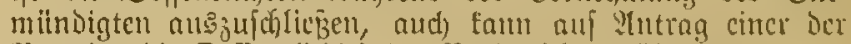
Barteien die Deffentlicffeit iscr Berlyandlung iiberljaupt ants= gc\{d्diloffar merben.

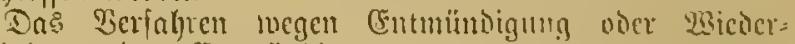
aufhcbung der CEntminnigung (\$§ 593-604, 616-61? bar (59D.) ift niclyt öffentlids.

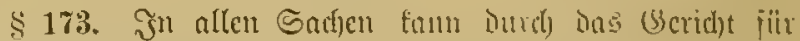

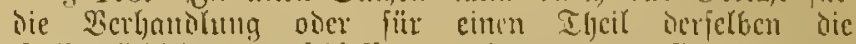

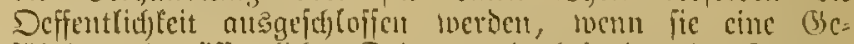

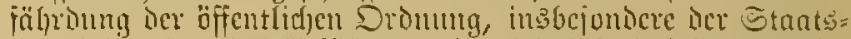

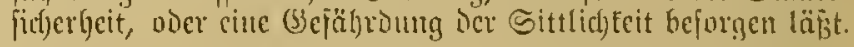

\$ 174. Dic Berfüntonng des ltrt)eifg crjolgt in jedem Falle öffentlid).

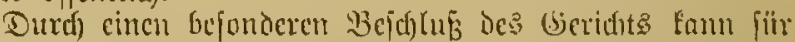

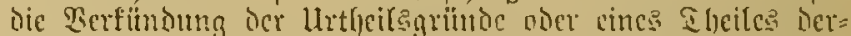

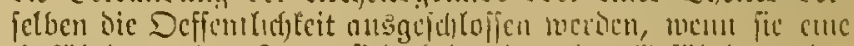

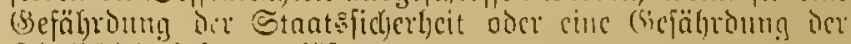
Sittlichfeit bcjorgen läpt.

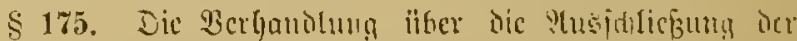

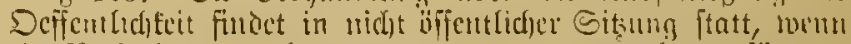
cill 2etheilinter es beantragt oder hos (sicridit cs firt an=

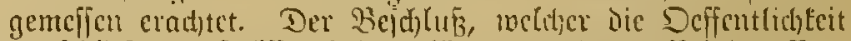

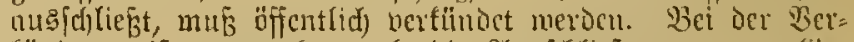

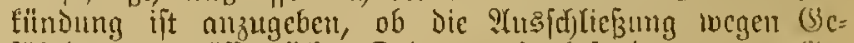

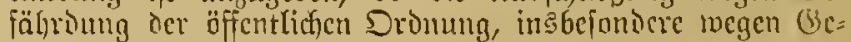

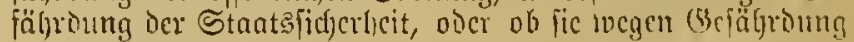
der Gittlidffeit erfolgt.

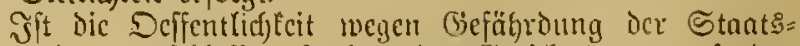

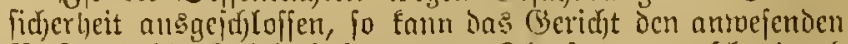
Tierfonen die (ischeimbaltung non Thatjadien, meldye durd)

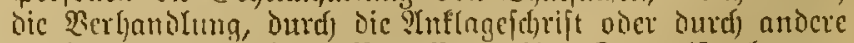

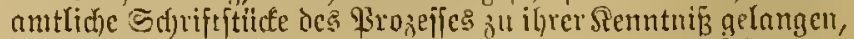

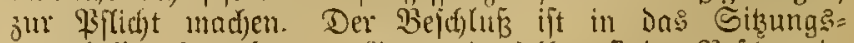
protofolf auisunchmen. (jegen denielben fundet Befditacrie

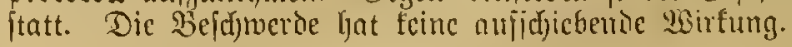

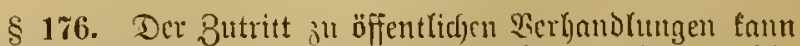

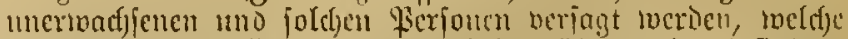
(iid) nicht im Bejize der büracelicfon (Eghrenredfte befindon,

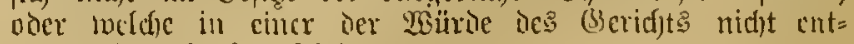
fprechenden 2̧Beije erjadjeinen.

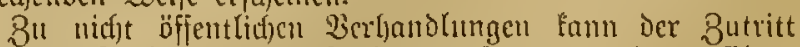

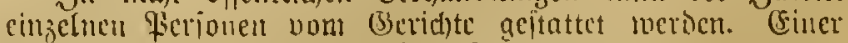

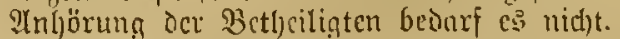

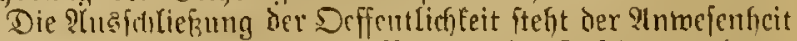

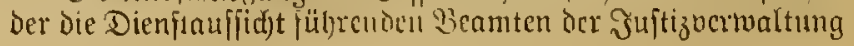


bei den Berbandrungen bor dem ertennenien Gerichte nidft entgegen.

3u $\$ \$ 173-176:$ 1. Die Jujijutg Derfelbeut beruht unf Dem

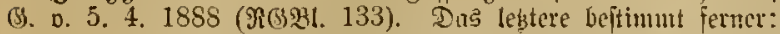

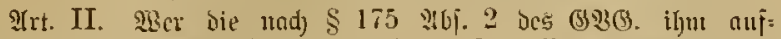

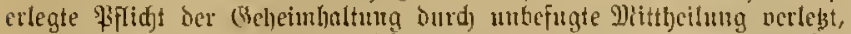

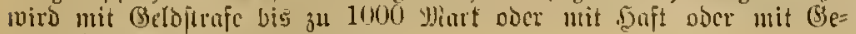
füng̣uís bis zu 6 sion. bejtraft.

2trt. III. Colveif bci ciner Beridtsverhmoluma bic Deffentlidfeit

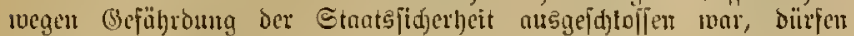

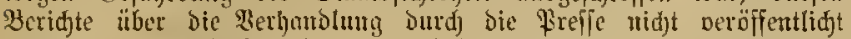

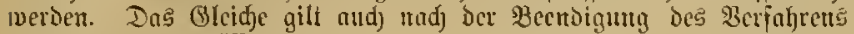
in Betreff Der Sdriftitüle bes Prozelies. Strafe.

Bumiberlfandlungen unterlicgen der in Irt. II beftumuten

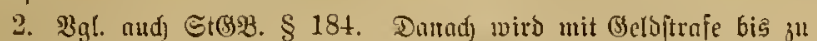

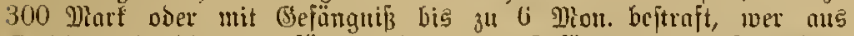

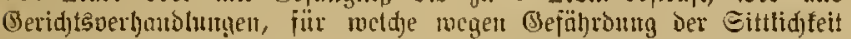

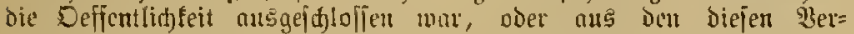

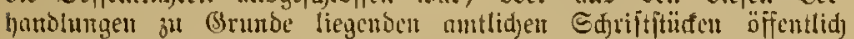

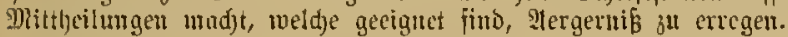

\section{Eiłung מิpolizei.}

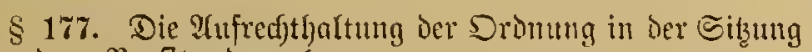
liegt bent Borfïzenden ob.

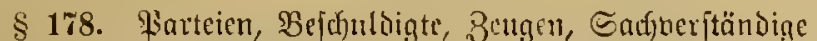

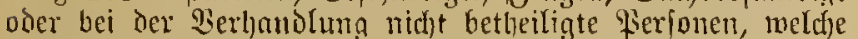

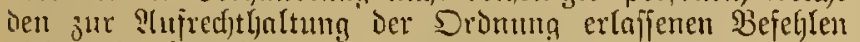

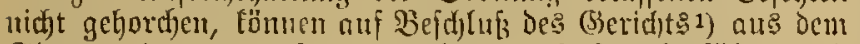
Sizung:zimmer entfert, and zur 5oaft abgefiilgrt und wäljrend einer in dem becidhluje ju bejtintmenten Beit, relche 24 Stmoen nidjt überjteigen Darf, fejtgehalten werben.

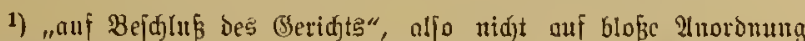

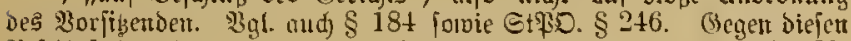

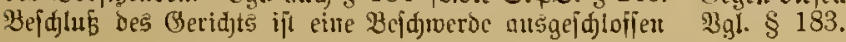

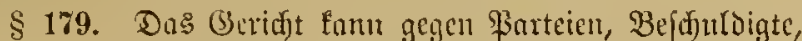

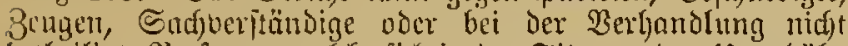
betheiligte \$er foneu, meldye fidy in der Sizzung ciner Ungebülyr id) loig machen, vorbelyaltlid) Der ftrafgeridhttichen Serfolgung, eine Srumngaftraje bis ju 100 Mint oder bis zu 3 sagen Jaft feftiezein und fofort bolffirection Iafjer.

$\$$ 180. Das (Scridft fam geoen einen bei der Ber=

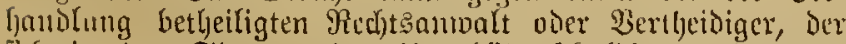
ficf) in Der Sikung einer llngebüln fduldoig madbt, bor=

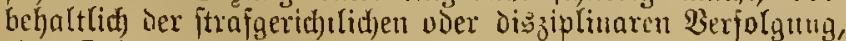
eine Dronungsftraje bis ju 100 y)

\$181. Die Bollftrectung Der vorftelfeno bezeicfureten Dronungšftrajen ljat ber 3orfitzende unmittelbar jul ber= aulafjen.

$\S 182$. Die in Den $\$ \$ 177-181$ bejeicfotneten Bejuguiffe fitelyen audh einem einjelnen Bicfter bei Der Bornalyme tou

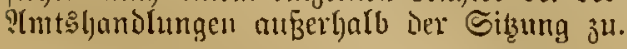

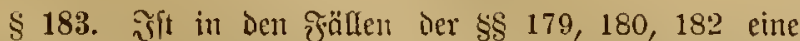
Dronumgsitrafe feitgefetzt, jo findet bimten Der frift von 1 Borfe nad) Der Befanntutadyung der (5ntid)eidung Beid)merde fitat, fofern Die (Entf(j)eibung nicf)t non Den Reidjsgericfte oder cinem She:Lannesgerichte getroffen ift.
Fic Befchuntoe hat in thent Falle des \& 179 feine au

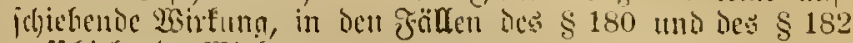
auffichiekende wirfung.

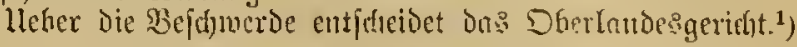

5) abrueidend vou $\$ 72$, แad weldeut bic Straffammeru iiber Hejduberben gegen \$serfïgungen Des Interfubungstidters uno

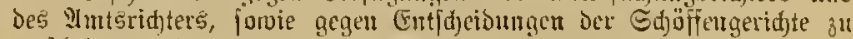
cutfdeider babeu.

\$ 18t. Sit eine Dromungsftrafe megen llugebii[j" feft:

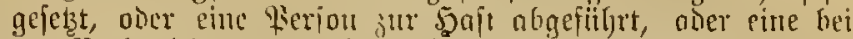
der Berlyandlung berheitigte fiserion enfernt worden, fo ift

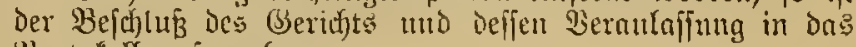
Srotofoll aufauthmen.

\section{Citel. Geridits/pradie.}

\$ 186. Die (jeridfotsprathe ift Dite beutiche.

Dies bezicht fidj nud nuf idriftldje (Einganbett. Eingaben in frember Epradje fint nidjt redjtsmirffaur.

§ 18\%. Wird unter Betheilignang bon Berfanen ber: Lumbelt, weld)e ber Deutjchen Epracle nicht mäd)tig find, fo

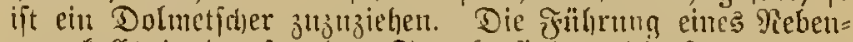

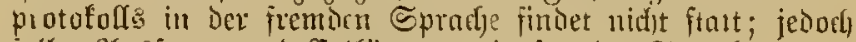

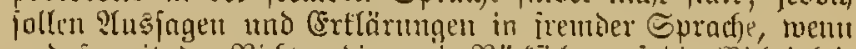

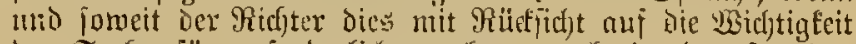
Der Sacfe fitr crfarderfid) erndjtet, alld in Der fremben Spratje it das firotofoll oder in eine ?hlaqu nieder"

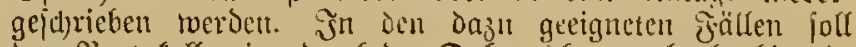

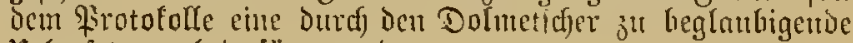
lleberfetzung beigejïgt merdin.

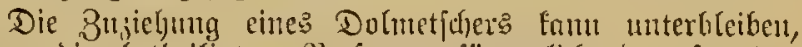
werun dic betbeifigten fierfonen fäntmtlid) Eer fremden Spradje mähtig finto.

\$ 188. Bur Sorkandung mit tauben ober ftummen

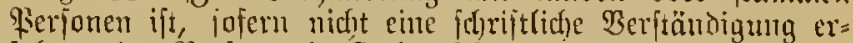
folgt, eine Sistion als Dolmetjefer :mijielorn, mit beren

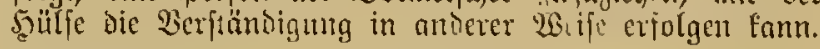

§ 189. Dh cincr Pintei, medje taub ift, bei ber müno= fichen Berbandlung der Bortrag ju geftatten fei, bleibt Deut (ermefien bes (Serid)ts überlaffen.

Dafielbe gilt in Imwaltsprojeffen won einet Wartci, Die ber Dentidjen Spratje nifjot mädtig ift.

$\$ 190$. Wierfonen, weldje Der beutjuen Spradje nidft mädltig find, reiften (Eide in ber ignen gelüufigen Sprache.

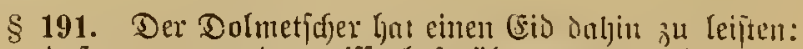
Dá̧ ex treu mo getwiffenlyajt übertingen werde.

Şit Der Dolmetjucter für llebertragnngen Ber betreffenticu Hrt im allgemcinen bceidigt, fo genügt bie Berufung auf den geleifteten (Eio.

\$ 192. Der Dienjt des Dolmetifjers fann bon dem (Serif)tsjaf)reiber jonlygenonmen merden. Einer bejonderen Beeisigung bedarf es nidjt.

§ 193. ILuf Den Dolntetf(t)er funten bie Beftimmungen

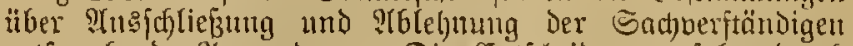

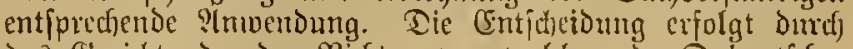

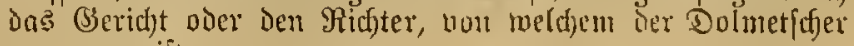
zugezogen $i j$ t. 


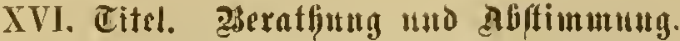

\$ 194. Bei (Entfdjeionngen dinfen Ridjter nur in Der gefezslid) Geftimmten ?(njahl mitruirfen. ${ }^{1}$ )

S3ei Berbandlungen von längerer Daner faum ber Bas: fizende dic Buziehuna non Grgänzunastidtem anoronen, weld)e der Serhandlung beizurvoljten und im jalle ber Berhinoerung eines Richters für Denfelben einjutreten faben.

Bie vorfteljenden Beftimumungen findem and aul Sifjöffen uni Befrtyotere Stmoendung.

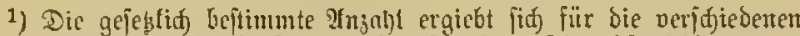
Geridite aus ben $\$ \S 22,26,77,81,89,91,124,139,140$.

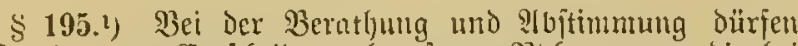
außer den zur Entfdjeidung berufenen Ridftern nut bie bei

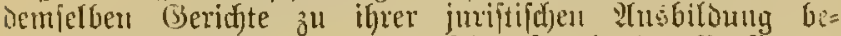

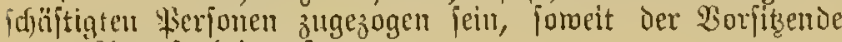
Deren ?Inwejenljeit gejtattet.

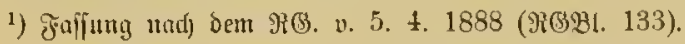

$\$$ 196. Der Borfizende leitet die Berathumg, fteflt die Jragen und faumelt Die Stinmen.

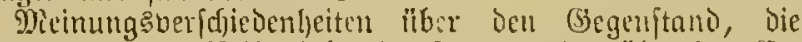
Foffung uno bie Reihenfolge Der Fragen oder üher Das Cr:

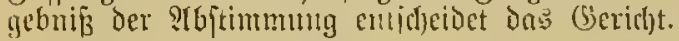

\$ 197. Rein Richter, Shjöffe oder Bejdfwotener Darf

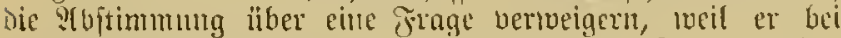

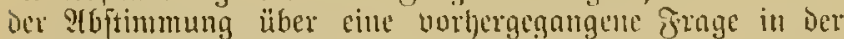
9yinderkeit geblichen ift.

\$ 198. Die Entidjeidungen eriolgen, foweit dos Befet nidit ein Snderes beítimmt, nad) Der abfoluten Mefprteit ber Stimuten. ${ }^{1}$ )

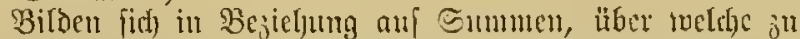
cutfdeiden ift, melyr als 2 gecinungen, deren leine bie 9)ebrljeit für fid hat, fo joeroen bie für bie größste Summe abnegebenen Stimmen den fïr die zแmädbit geringere $a b=$ yegebenen fo lange hinjugured)net, bis fidj eine Miel)rljeit ergi-fit.

Bifoen jiff in eimer Etrafjadje, bon ber Edjuldirnge ab= geirben, metn ols 2 Meinungen, deren linte die Mehrljeit iiir ficl) hat, fo rwerden Die bem Bejdjuldigten nadytheiligften Etimmen ben zunädyjt minder nadjtheiligen fo lange hinju= geredunet, bis fid cine Miebrheit ergiebt.

1) o. h. cine ङtimme über die Sälfte fänuntlidger Stimmen. -

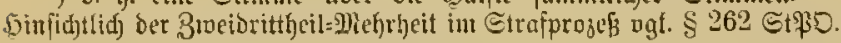

$\$ 199$. Die Reihenfolge bei Der 9lbftimmung ridtet fidf unat) den Dienitalter, bei Den Sefjöffengeridjten und ben

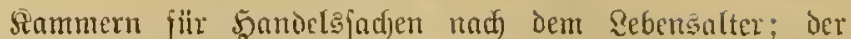

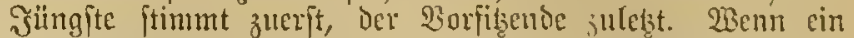
Qerid)terftatte: ermant ift, jo giebt biefer jeine Stimnte juerit ab.

Bei Der 2aftimmung der (Siefdyorenen rid)tet fidf die Reifenfolge mad) Der Thtsloofung. Der Dlmam ftimmt zuletzit.

\$ 200. Sdyöffen und (sefdymortuc find berpflictet, ïher den Sergang bei Der Beratbung uno ?tbftummug Still idjmeigen 3u beubarfiten. ${ }^{1}$ )

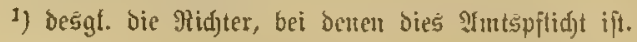

\section{Citel. Geridftsferiet.}

\$ 201. Die Beridjtefferien beginnen ant 15. Suli uno fubigell an 15. September.

§ 202. Währeno der Ferien werden nur in Ferienjadjen Termine abgeljalten uno entfdyeidumgen retaffen.

Ferienfadjen find:

1. Straffardert; 1 )

2. Trreitiacten und die ein: cinftreilige Berfügung betreffenden Sachen;

3. MeÉ = und Marftiadjen;

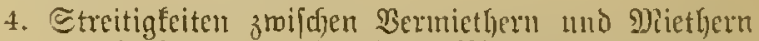

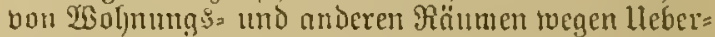

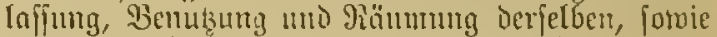
toegen 8urïcthaltung Der vont Dicther in dic Mietlys̆rüune eingebrad)ten Sadien;

5. Bedfelfadjen;

6. Baufacten, wenn ïber Jortfetung eincs an= gefangenen Batles geitritten wird.

Das (Beritht famm auf Trutrag and andere Sathen, jomeir jie bejonberer Bejthleunigung bedinrien, ale Ferien=

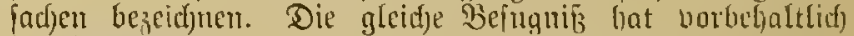
ter Entfdecidung des (Seridyts Der Borfitiente.

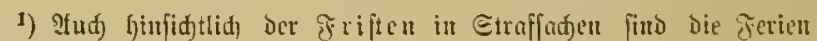
ofne Einflü.

\$ 203. Bur Ertedigung der Ferienfachen Ednuen hei Den Sentogeridhten Gerienfommern, bei den Sberlnnbesgeridten

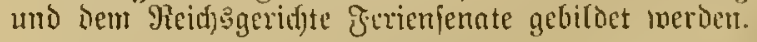

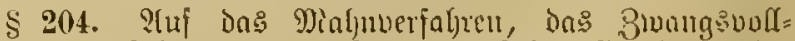

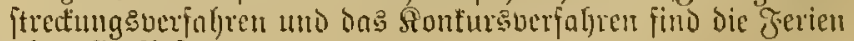
ohne Einflup.

Urfumolidg 2e.

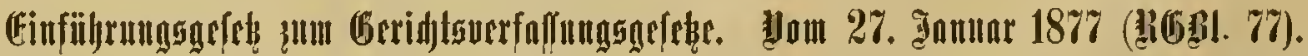

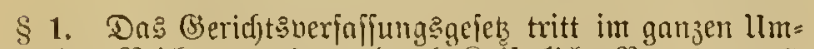

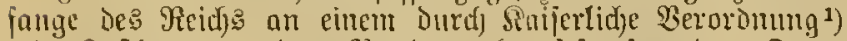
mit Buftimmung des Bundestathes ieitzupetzenden Tage, ipätejtens ant 1. Dftober 1879 , gleidj jeitig nit der im $\$ 2$

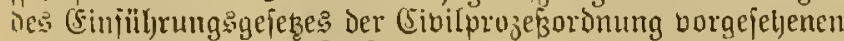
(3) bilibrenordiung in Siraft.

1) 9idift ergaugen, baher Snfrafttreten 1. 10. 1879.

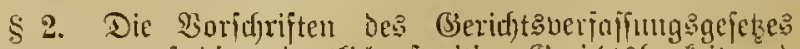
finden mur auf bie ordentlid)e jtreitige (Berid)tsbarfeit uno

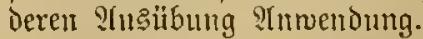

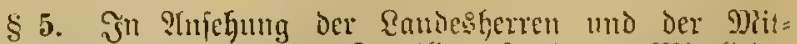
glieder Der: Landestyerticfen Fantilien, foure ber Mitglieiter

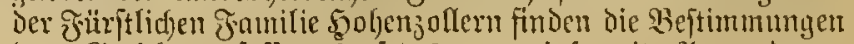

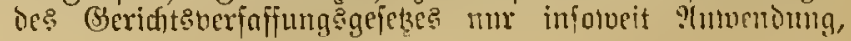




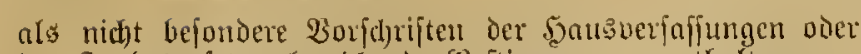
Det Enndesgefeke abrocidende SBejtimnungen enthalten.

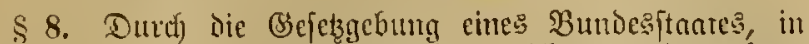
tweldhem ntehrere Sherlandesgeridhte erridytet werden, fann

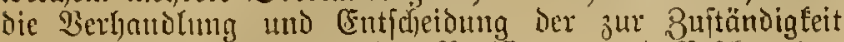

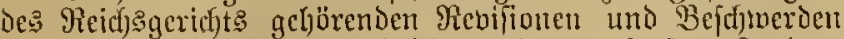

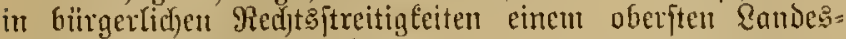
gerichte ${ }^{1}$ jugetwiejen merden.

Dieje Borjdrift findet ferodj nuf bitrgerlidfe giedtis:

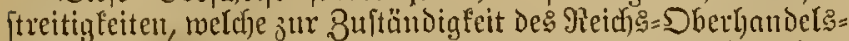

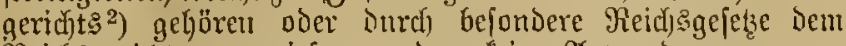

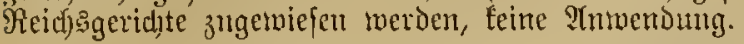

1) Das $\mathfrak{B r}$. Sammergeridyt in Berlin ift nur für $\Re$ coifionen in Straffadjen genäß $\$ 123$ গir. 2 und 3 unb iu Xugelegentheiten ber

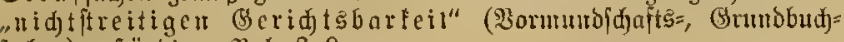
(åc)etr) juftändig. \$gl. §9.

2) $刃 g l . \$ 14$.

\$ 9. Dutd) dic (Siefergebung eines Bumbesftates, in meldjem meljrere Dberlanivesgeridyte errichtet merden, faum Die Berhanolung und Entjcljeidung der zแน Zuftändigfeit ber Sberlandesgeridgte geförenden revifionen mo $B \mathfrak{E}=$ (d) Dberlandesgeridjte jugewiefen merden. ${ }^{1}$ )

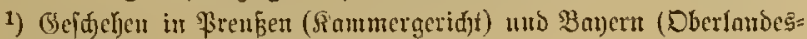

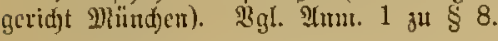

$\$ 10$. Die allgemeinent, ponvie bie in Den \$\$ 126, 132, $133,134,137,139,140,183$ शt6f. 1 enthaltenen bejonderen Borfariften des (seridhtsberfaffungsgejeses finden auf die oberiten Sandesgeridfte als Beljöruen der orientlidjen ftreitigen (Sericftäbarteit entiprecfende $\mathfrak{A}$ ntwendung.

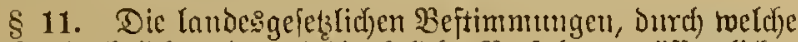
bie ftrafrect)tlicje oder civilrechtlidje Berfolgumg öffentlicjer Beamten wegen Der in 2Us̈übung oder in Beranlaffung

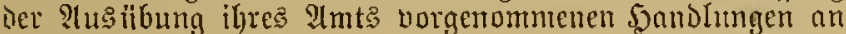
bejondece Boransfetzungen gebunden ift, treten anfer Sraft.

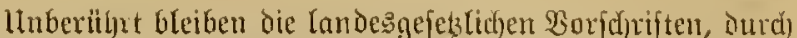
melfie die Rerfolgung der Beamten entweder im falfe des Berlangens einer borgeietenten Beböroc ober unbedingt an bie Borenticheionng einer befonoeren Befhörde gebunien ift, mit Der Miangathe:

1. Dof3 bic Borentidetoung auj die Fettftelfung be= ichränIt ift, ob Der Beamte fich ciner lleberifjreitutg feiner SInts bejugniffe oder der linterlafjug emer igu

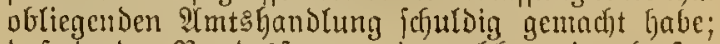

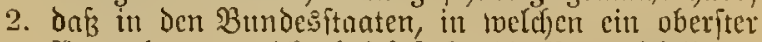

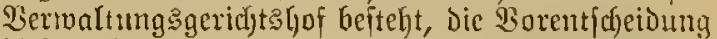
diefem, in den anderen Bundesftaten den Reid): gericjte zujtelyt.

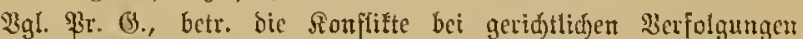

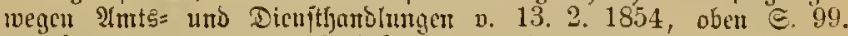

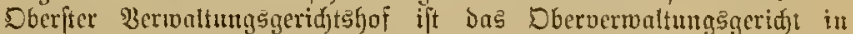

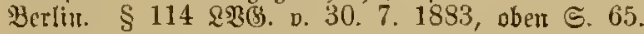

§ 14. Die am Tage des Sntinftretens des (Bericyts=

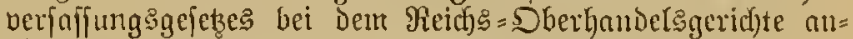
hängigen Sadjen gethen in Der prozeffualifichen Rage, in meldher fie fidf befinden, nuf Das Reidsesgerid)t ïber.

$\S 1 \%$ श Iuf Intrag eimes Bundesftnates und mit $3: 1=$

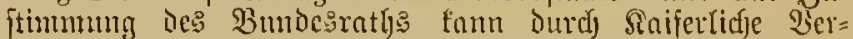

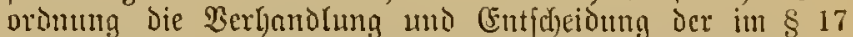
DE: (Serid)t Reić)

Fï Diejengen B̧ubesitaaten, in benen die im $\$ 17$

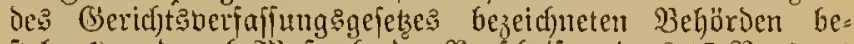

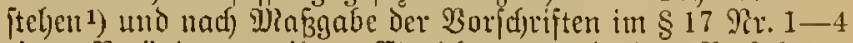

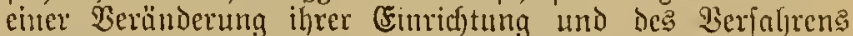
bedürfen, fann bie פeränberung, fofern fie nidjt bis zum

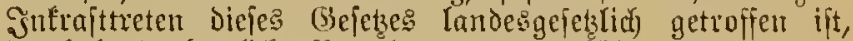
durd) Landesherr(iche Berordnung 1 ) eingefülyrt merden.

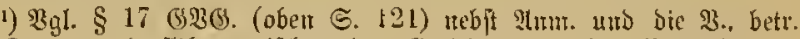
bie Rompetemfonflifte zwifden ben Gerid)ten uno ben Bernoaltungs: beförón v. 1. 8. 1879 (ober 5.98 ).

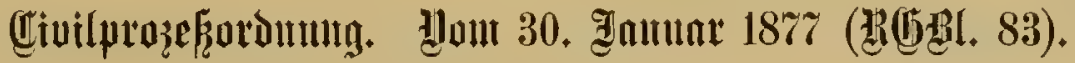

Jul Siraft getreten am 1. Sttober 1879 .

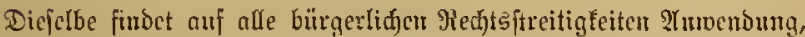
welde vor sic orbcntlideu (serid)te gefören. IIts folde gelten

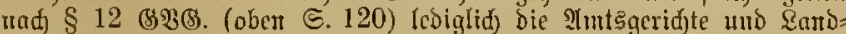

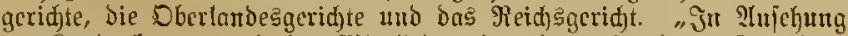
ver Sandesherren uno ber Mitgliever ocr lanbesherrlid)en familien,

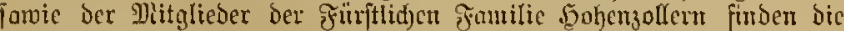

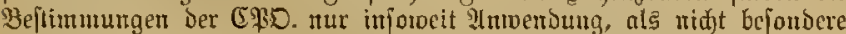

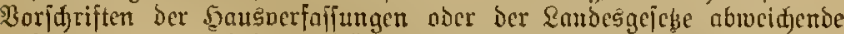
Beftimmungen cuthalten. Fï vermägenకred)tlide Sulprüd) Dritter

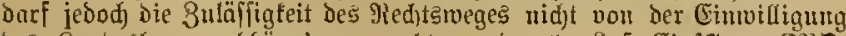

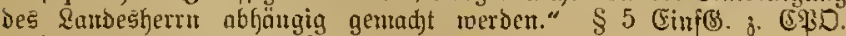

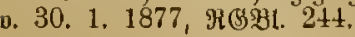

\section{Surgntätiberpant.}

I. Bud). A(lgemeine Beftimunurgen.
I. Bridfte
II. Sarteient
$\$ \S \quad 1-44$
. $\$ \$ 51-112$

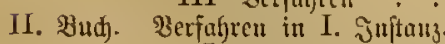

I. Эerfahreu vor ber \&antogeridteu $\$ \$ 230-448$

II. Verfahr'elt vor ben IImtsgeridjten

$\$ \S 456-471$

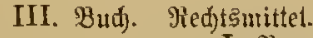

I, \$̧егијurg. . . . . . $\$ \$ 472-500$

II. Renifion . . . . . \$\$ 507-528

III. Beldiwerde : : s\$ $530-535$

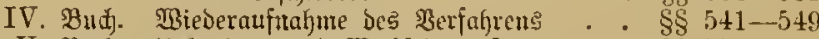

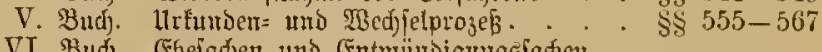

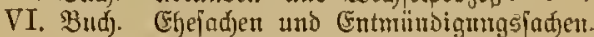

Berjahren in (Ehriadjen.

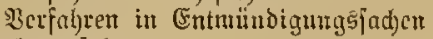

VII. अभน,

VIII. ßud).

Mahnuerfabren

3wangsDollijtrecfututg.

I. AIIgemeine Beftimmungen

II. 3wangsvolf tređung wegent Belio= forderungett

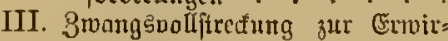
Euttg ber Sercusgabe non Sadjen unb zur Erwirfung von 5amb= Itutgen oder llnterlafi]utgen

IV. Offenbarmaseib und Saft.

V. Anrcit u. cinftrocilige Berfügungen

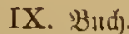
Sิ ufgebot

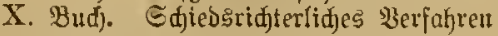

$\$ \$ 568-59 \cdot 2$

\$s $593-627$

$\S \S 628-643$

$\S \S 644-705$

$\S \S 708-764$

\$\& $769-779$

S\$ $780-795$

\$\$ $796-82.3$

\\$ $823-850$

§ $851-872$

Fo hl, Sammlung von Bejeken ac. F. Hoit u. Telegr. 


\section{Buth. Xllgemsint Beffimmunget.}

\section{I. (jeridite.}

\section{Bujtümbigfeit.}

\$ 1. Die jad)lidje Buftändigleit Der (Gerid)te wird ourd) Das (Befels ẗber Die (Seridjtsverfajfung ${ }^{1}$ ) befitimmt.

1) Dben ๔. 130. \$gl. Dort für श̂ntsgeridjte \$ 23; für \&and= gerid)te $\$ \$ 70,71,100$; fïr Dbcrlambesgeridgte $\$ 123$; fïr bns Heids= geriagt $\S 135$.

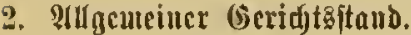

\$12. Das Gericht, bei weldien cime Berfon iljen alfgemeinen (Berichtsitano hat, ift für alle gegen diefelbe zll

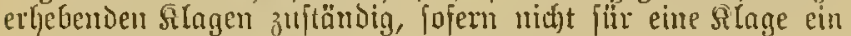
ausfdrlieblicher (Serid)tsptand begritndet ift.

\$ 13. Der alfgemene (Serid)tsfand einer bierion woto

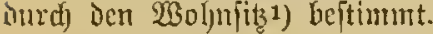

1) voer gewöhnliđjen IIfenthaltsort.

s 19. Der algemeine Beridytsftund der (Siemeinbell, Der

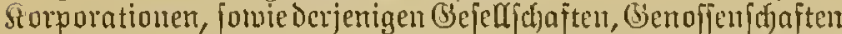
DDer anderen Berionembereine ImD Derjenigen Stiftungen, Injtalten mo Berntögenemajien, told)e ale joldhe betflagt weroen fömun, mird durth den Sits derferben beftummt.

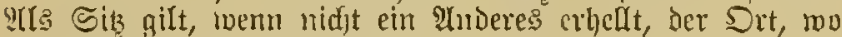
Die V̌erwaltung gefül)rt wird.

Gewertichaiten ljaben den alfgemeinen (Beridytsftano bei Dem (Beridyte, in Defjen Bejirte das Bergmert liegt, Beljörden, ruenn fie als forche berflagt meroen fönmen, bei Dem (Beridfte igres Intşizes.

Reben Dem Durd) die Borjariften diefes Faragraptjen beftimmten (Berichtaftande ift ein durd) Statut oder in anderer Weije befonders geregelter (Bjeridjtajtano zulöffig.

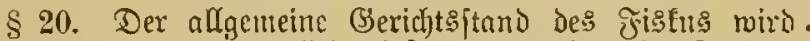
Durd) Den Sitz Der Beljörde beftimmt, meldye berufen ift,

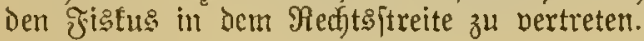

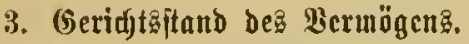

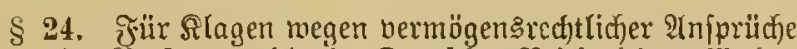

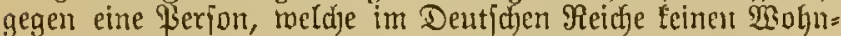

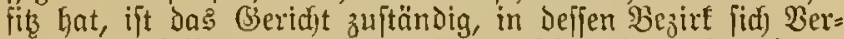

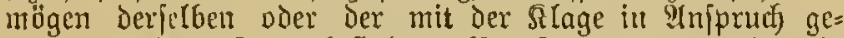
nommene Gegenitand befindet. Bei Forberungen gilt als

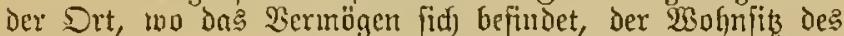
Edjuldners mot, wenn fïr bie Forderung eine Sache zur Sid)erbeit haftet, aud der Drt, wo die Sadhe fidh befinder.

\section{Dinglidjer Geridjtßjtald.}

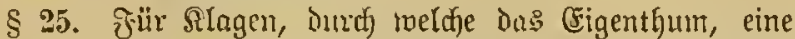
binglidje Belaftung ober bie freil)eit bon einer folchen

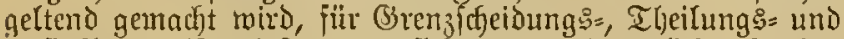
Befibflagen ift, fofern es fidf unt unbermeglidje Sactien

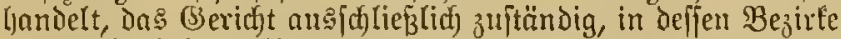
Die Sndje belegen ift.

Bei Den eine Brundoienjtbarfeit oder cine Reallajt be=

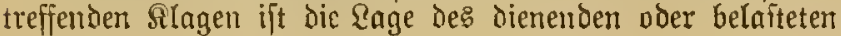
Grundftitcts entidjeidend.

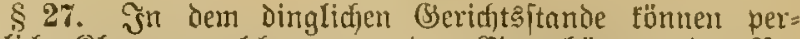
fönlidje Sllagen, weldye gegen den (Sigentfümer ober $\mathfrak{B} e=$ jiker einer unbermeglichen Sache ale jolchen geridjtet werien,

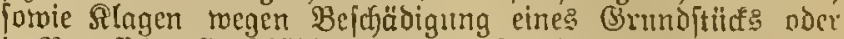
in Betreff Der (Entjäädigung wegen Enteignung cines (Grumb=

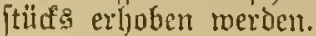

\section{Geridjtaftand ber (Erbjdjajt.}

8 28. Slager, melche (Erbredte, 9tufpriiche aus Ber= mäd)tniffen oder fouftigen Berjügungen anf Den Tonesfall

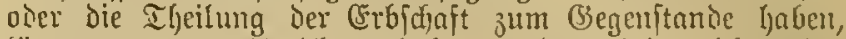
fönnen bor Dem (Seridfte erhoben merden, bei meldjem ber Erblajfer zux 3eit feines Iobez ben alfgemeinen Berichts: itand geljabt ljat.

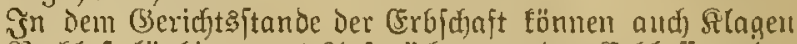

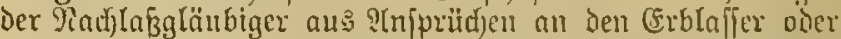
die Erben als foldhe erhoben werben, wem fith ber Parthla

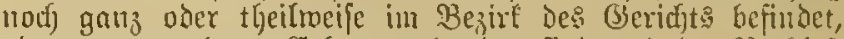
oder roen mehrere Erben borhanden find mo ber Plactlaf; noch) nid)t getheilt ift.

\section{Beriditaftand bce Bertragce.}

§ 29. F̈it Rlagen auf Feflitellung Des Bejteliens oder Nicftbeftebens eines Bertrages, nuf (Erfïfung ober ?luf, hebung eines foldjen, fowie auf (Enticjäbigung twegen 9ich)t=

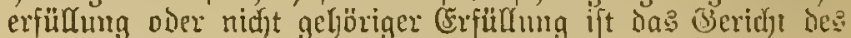

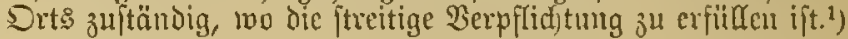

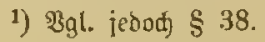

\section{Geridatajtand ber Inerlaubten Şandmug.}

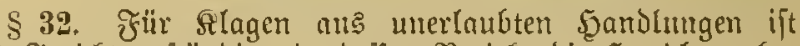

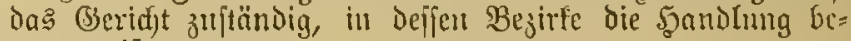
gangen ijt.

§35. Unter melhreren juftändigen Beridjten ljat der

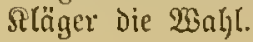

\section{Berciubarmng Hiber bie Butäubigfeit ber Geridete.}

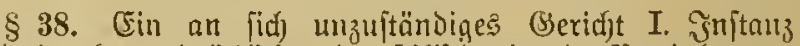

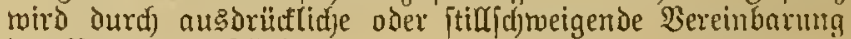
Der ßarteicu zujtändig.

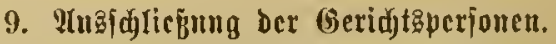

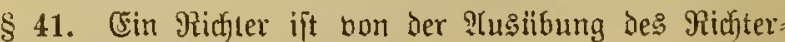
amt: frajt bejetze: ausgefchlojien:

1. in Sadjen, in meldfen er felbit \$artei ift, oler in Injelung welcher or zu einer Firtei in Dem Ver: bäItniffe eines Yitbered)tigten, Mitverpflidyteten, oder Regrejpffirfytigen fteht;

2. in Sadjen feiner (Shefran, audi menn Die Elje nicht mehr bejteht;

3. in Sacten ciner Berjon, mit meltijer er in geraber Sinie bermantot, berfdrwägert oier burdl Iopotion verbunten, in der Seitentinie bis zum 3. (Srade verwandt oder bis zum 2. (Srabe verid)twägert ift,

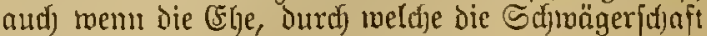
begründet ift, nicht megr: bejteht; 1 )

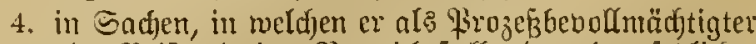
oder Beiftand ciner \$artei beitellt oder als gejeblicfer Bertreter einer Fartei aujutreten bered)tigt ift oder getwejen ijt; 
5. in Sadjen, in welden er nls Beuge oder Sad)= berjtärtbiger bernommen ijt;

6. in Sadjen, in meldjen er in einer fritheren Snftam ober in (d)iedsrichterlid)en Berfahren bei der (Er:= lafiung Der angefocitenen (Entfdjeibung mitgewirft

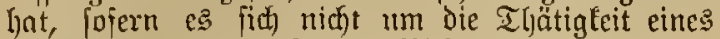
benuftragten ader erfudjten Ridjter hambelt.

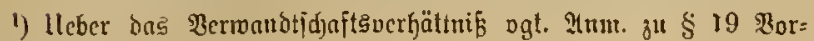
muแถ่ตอ.

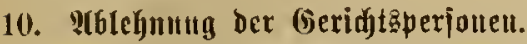

S 42. (Ein Risfter fann fowohl in ben Fällen, in

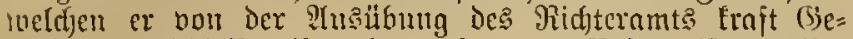

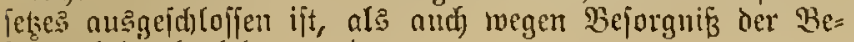
iangentheit abgelelynt roerden.

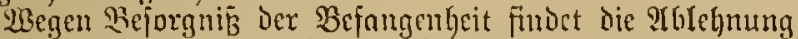
ftatt, menn ein (Brmul vorliegt, weld)er geeignet ift, Mifistranen negen bic lluparteilidfeit cines Richters gll rechtfertigen.

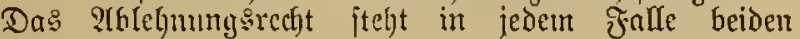
Parteiell zu.

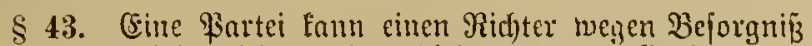
ter Befangenheit nidjt unehr ablehmen, wemn fie bei bem= felben, obne den ily befumnten SLblegnungsgrund geltend zu nradjen, in eine Berhjandlung fid) eingelafien oder 2 Unträge geifelt bat.

$\S 44 . \quad(1) \ldots \ldots$

(2) Der stalelinumgegrund ift glaubhaft zu madhen; der

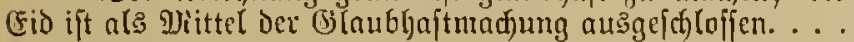

(3) .......

(4) Wird ein Ridjter, bei meldyem die Fartei in eine Berhanthung fich eingelafien oder Plnträge geftell hat, wegen Beforgnip̧ Der Befangenheit abgelebnt, jo ift glaubhaft $z^{u t}$

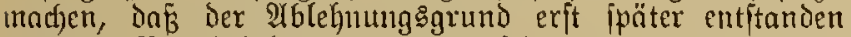
vier der \$rortei betamt gemorden jei.

Die Bcituntuntgen ber $\$ \S 41-44$ finben anf Berichtsjobreiber,

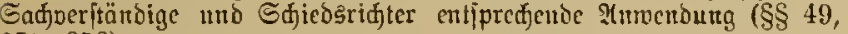
$371,858)$.

\section{II. ঐ̊arteien.}

\section{Prozep̧ähigfeit.}

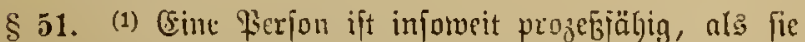
fich Durd) B(rträge berpflifften famm. ${ }^{1}$ )

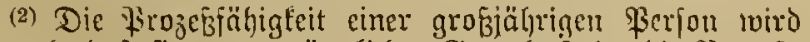
dadurd), onfi fie unter väterlicher (Setwalt ftelt, Die \$rozés=

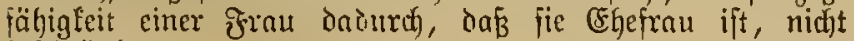
bejd)räntt.

(3) .....

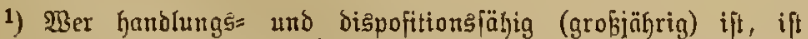

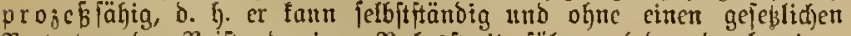

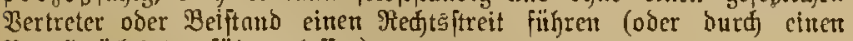
Bcoollmäd)tigten führen laffen).

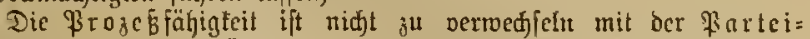

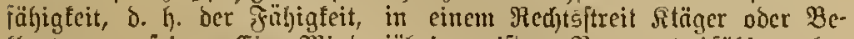
Elagter au fein. Cin MRinberjähriger ijt z. $\mathfrak{Y}$. porteifähig, aber

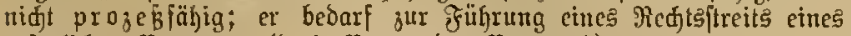

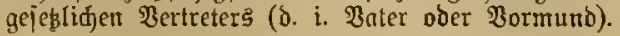

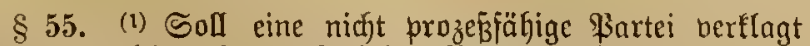
merden, weldje ofyne gefebliden 2 ertreter ift, jo hat Der Borfikenie des \$rozengeridts ierfelben, jalfs mit dem Berzuge (jejaljr berbunden ijt, auf 2lntrag biş zu dem (5in= tritte des gejeklidjen Bertreters, einen befonderen Bertieter z' bejtelfer.

(2) $\ldots \ldots$

2. Streitgenoffenfdjaft.

§ 56. Meljrexe ferjonen tömen ala Streitgenofien ge= meinjajaftich elagen oder verflagt werden, wenn fie in ?u=

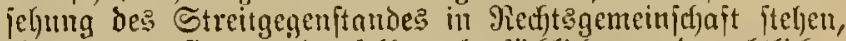

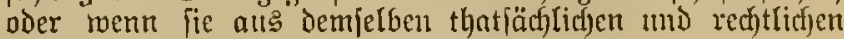
(Grunde bered)tigt ober verpflichtet find.

\section{Juterbentionen.}

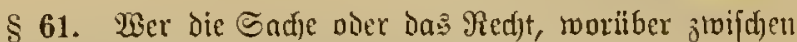

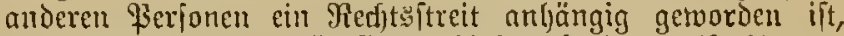

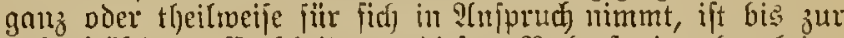

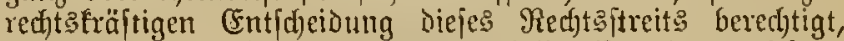
peinen Plufprud burd) eine gegen beibe sisarteien geridftete Rlage bei demienigen (Beridte geltent zu maden, bor

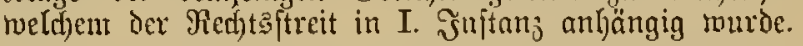

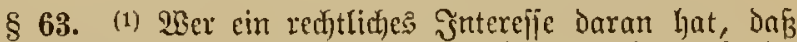
in einem zwijden anderen \$erionen anthäugigen Fed)tsftreite

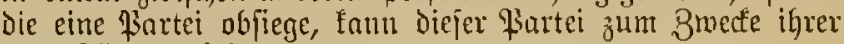
Ilnterftütżug beitreter.

(2) ......

\section{Y)maltzizmang.}

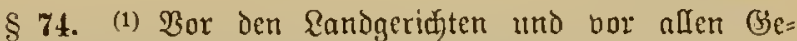

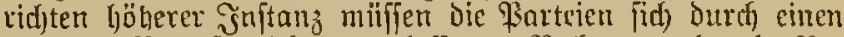

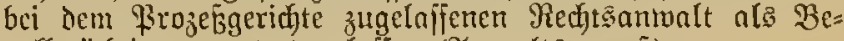

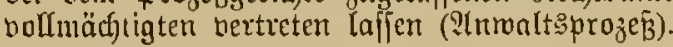

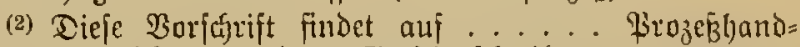

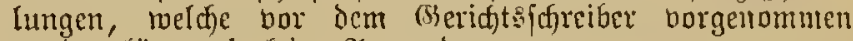
merden fönnen, ${ }^{1}$ ) feine ?ntocndung.

(3) .....

1) 8. B. Buprotofolfetflärungen ic.

\section{Frozę̄bevollmädytigte.}

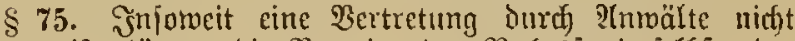
geboten ift, fömnen die Parteien Den Redts siftreit jelfit oder

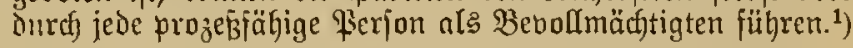

1) $\mathfrak{B g l}$. $§ \S 51,143$.

§ 76. Der Bebollmädytigte hat die Bebollmädytigung Duth eine idfriftlidje Dollmadjt nad)zumeifen und diefe z" Den Sieridftsalten abjugeber.

Fine Bribaturfunde mús auf Berlangen des begners gertatlich oder notariell beglaubigt twerden. .....

Beiptäude.

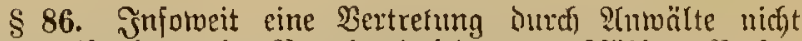

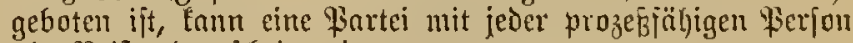
als Beiftano erjucinen. ${ }^{1}$ )

Das von dem Beiftande 3orgetragene gilt ale bon der

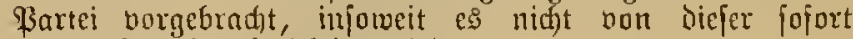
miderrujen oder berichtigt mird.

1) $\mathfrak{g} 1 . \S \S 143,572$ Ab 1.

6. Prozepfojter.

\$ 8\%. Die unterliegende Fartei hat die Roften 1 ) des Rechtōjtreits zu tragen, insbejondere die dem Bienner cr= 
madjenen Rojten zu critatten, forncit diejelben nach freiem

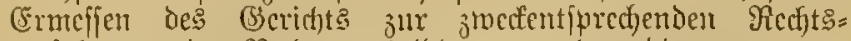
beriolaung ober Redstencrtheidigung notbrendig maren.

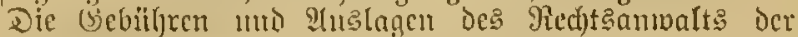
obfiegenden Piartei find in älen Firojeffen zu erftatten, Tieifefoiten eines aแsivärtigen Redjtsambalts jebor) nur infomeit, nls dic Bujieljung nach dcm Ermefien des (B)=

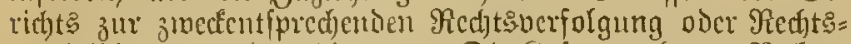

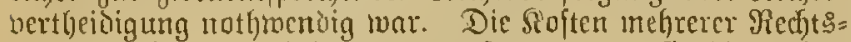

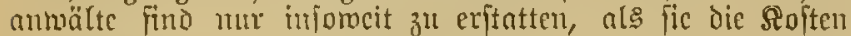
cincs Red)tsantwalts nidbt überfteigen, oder als in icr Rerfon bes Rechtsantualts cin $2 B$ edjecl cintreten muEtc.

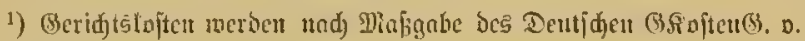

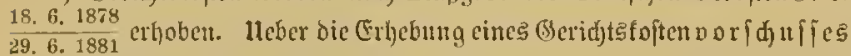
beitimunt bafielbe:

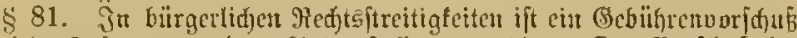

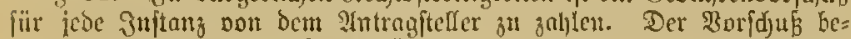
trägt foviel tote bie höd)fte Gebiithr, meld)e fïr einen $2($ ft ber Jnituts

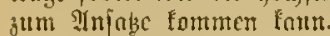

Bei Crmeiterung ber 2tuträge ift ber Woridun und Mafigabe ber Erveiterutug ou erföhen.

\$ 84. TI Bornahme einer 5andutg, mit melder bare Stuslagen perbundert find, cin sur Dedung berfelben hinreidjender \$olidub von bent Intragiteđer zu zablen.

Die Enoung uno sernehnung nou 3eugen ober Sndjverittübigen

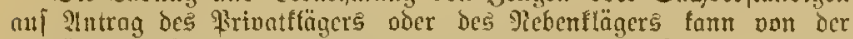

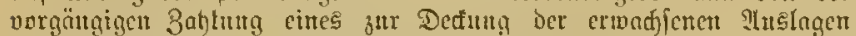

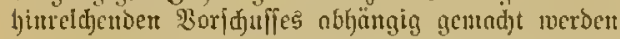

§ 88. (1) Wenn jede Sartei theils obficgt, theils unter= licgt, fo fint bic fioften gegeneinanoer aufzuleben ober ber=

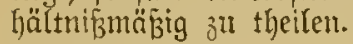

(2) .......

\$ 90. Dic Partei, weld) cinen Termin oder eine Frift 1 )

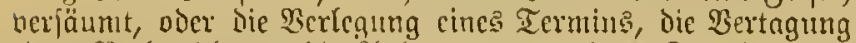
ciner Berbandlung, die Ptrberaumung eines Ternting zur

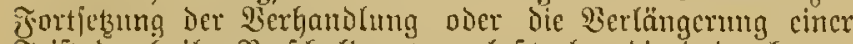

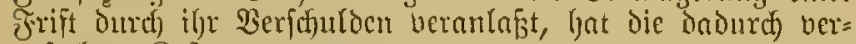
urjachten Soften zu tragen.

1) Berechnung bor Friften $\S \S 199,200$.

\$ 92. (1) Die Roften cincs ofne Exjolg cingelegten

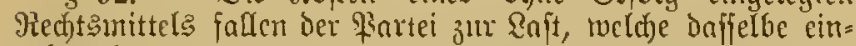
gelegt lyat.

(2) (3) .....

\$ 95. (1) Beftegt Der unterficgende IGcil nus mehreren Serioner, fo baten bieferten für dic Softenerftattung nadi Sopptheilen.

(2) (3) (4) . . . .

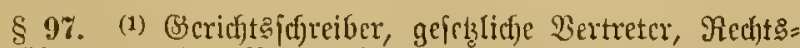
antwälte und anderc $\mathfrak{B}$ evollmähtigte, fowic (Serichtsobazicher

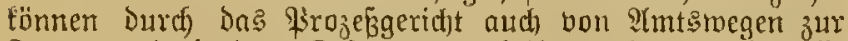
Trngung berjenigen Rojten berntfeilt merten, welche fic burd) grobes Seridulden veranlä̧st Gaben.

(2) (3) . . . .

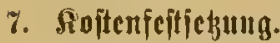

§ 98. Der :Tripruch auf (Erifattung Der firozebtoften fanm nur auf Grund eine? zur 8 mangsooflitrefing geeigneten Titcls gettento gemad)t werdon.

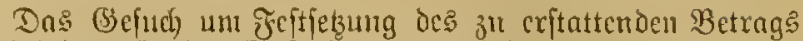
ijt bei bem (Serid)t I. Snftanj anzubringen; es fann vor Dem (Beridftsfd)reiber jn Srototoll erflärt merden. Die

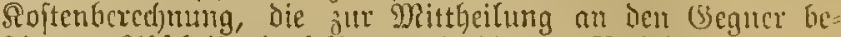

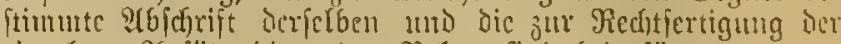

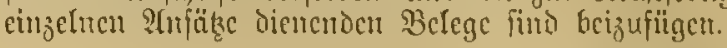

\section{Eithcrlucităteitumy.}

§ 101. Die Befteffung eincr mojeffunlifdyen Sidherbcit

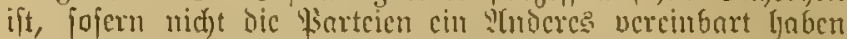

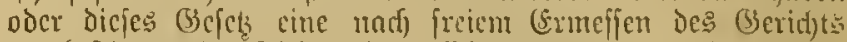

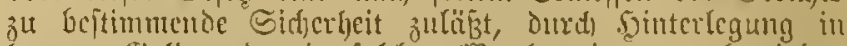

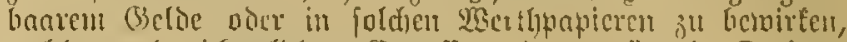
weldie nod) ridjscrlichen (Eruncifen eine geniigente Defung gewäl)rent.

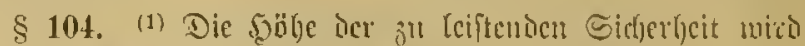

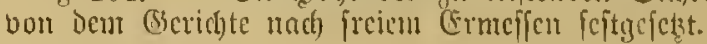

(2) (3) .....

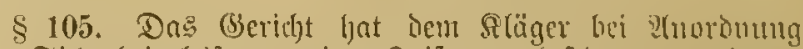

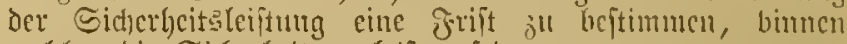
inclder dic Sirfjerheit jul Ieiften fei. ......

\section{2Trutentedit.}

$\$ 106$. (i) $23 \mathrm{cr}$ auficr Stande ift, oljne B̉ccintrödjtigung

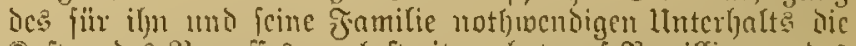

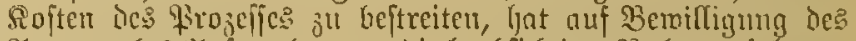

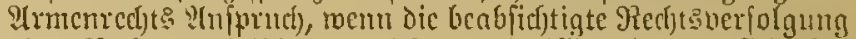

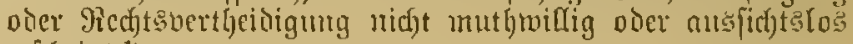
exicheint. ${ }^{1}$ )

(2) .....

1) Der einer armen \$artei beigegebene צ̂tuvalt barf bic $\mathfrak{B e r}=$

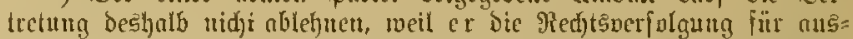

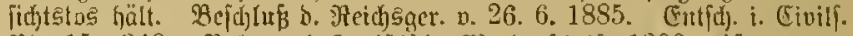
30. 15. 340. 3gl. aud Jurifitidhe 230 nd

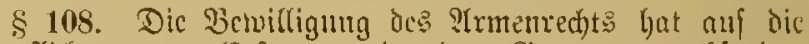
Berpflid)tung zur (Erftattung Der icm Gicgner crmadffenden Soften leincu Cinflufs.

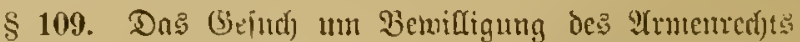

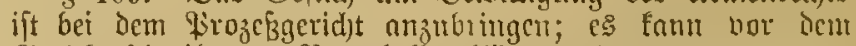

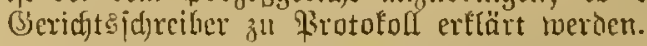

Dent Gefuth ift cin vou der obrigfeitlid)cn bebörde der

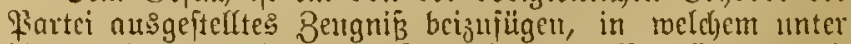
2ngabe des Standes oder (Sicwerbes, Der Bermiögctis= unt

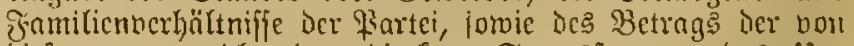
biefer iu entriditenden Direften Staatsiftuern, das lin=

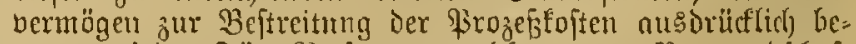
jeugt mird. Fili Firionen, welche unter Bormmof(h)aft oder seuratel ftehen, tant das Zeugnif auch bon ber bor=

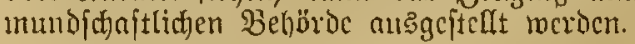

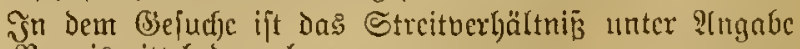
der B̧erveismittel baräulegcn.

\$ 110. (t) Dic Bernilligumg des Prmentect)ts erfolgt für

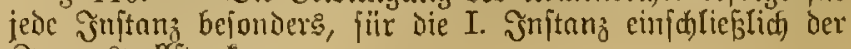
Zmangsuollitrectung.

(2) $\ldots .$.

§ 112. Daz Trmenrecht fam ż jeder Beit entzogen

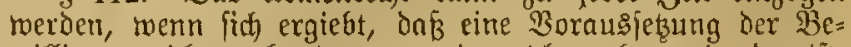
wifligung nidft borfanden war ober nidgt mefor borthanten ift. 


\section{Dexfabien.}

\section{Mtïndidje Berhaublung.}

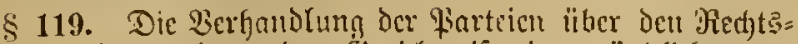
ftreit bor bem erfentucnien Gerichte ifit cine mitndlifje.

\section{Edjriftiätgc.}

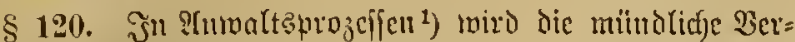

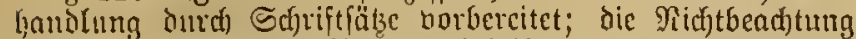

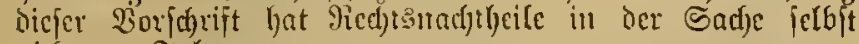

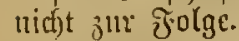

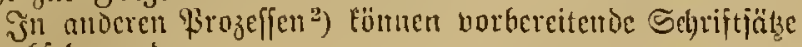
getucd) felt iverocit.

1) sigl. $\$ 74$.

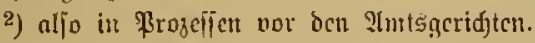

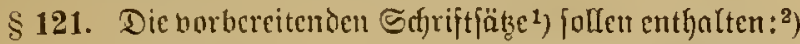

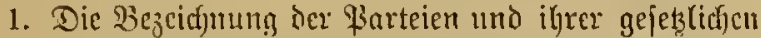
Bertreter nad, Siamen, Stand oder (Setwerbe, 200lju=

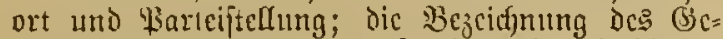
richte uno des Streitgegenitandes; dic Zahl der 2lnlagen;

2. dic ?ntrüge, melde dic Fartei in der (Beridftos= fitzung ju jtellen beabfichtigt;

3. dic ?tngabe ber jur Begrïnoung ber stnträge dicnenten thatiächlicf)en Berljältniffic;

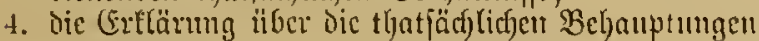

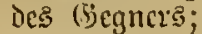

5. Die Bezcidmutg Der Bctwcismittel, meld)er fid) dic Gartei zum Piachtoeife oder zur widerlegung that fächlicher Begauptungen bedienen will, ${ }^{3}$ ) jomie dic Ereflärung itber dic von dem (B)egner bejcicf)neten Bemeismittel;

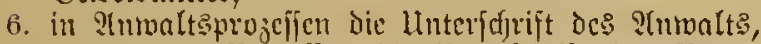
in anderen Projeffen dic lluterjabift der Partei

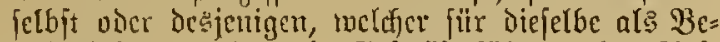

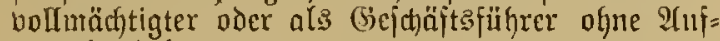
trag handelt.

1) beren 3ujtellutg mindejtents 1 Modje vor ber mündididen $B_{e r}=$ Gastolung ju erfolgen hat (\$ 123).

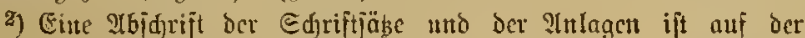
(Berid)tsfdyreiberei niederzulegen (\$ 12t, $\$ 155)$.

3) Diefelben find auf Erforbern vor ber un̈ubliden Berhanding anf ber Beridistifretberei nieberalegen. Der Begner ift non ber Tieberlegung 3น benndridtigen $(\S 125, \S 133)$.

\$ 12\%. (1) Der $\mathfrak{B}$ orjitzente cröffnet und leitet dic miindlicf)e $\mathfrak{B e r h a n d l u n g . ~}$

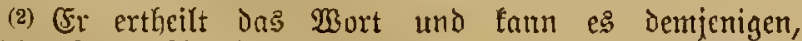

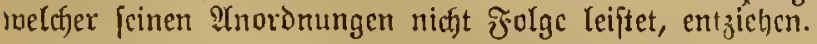

(3) ......

(4) Er fchließzt die Bertyanolung, menn nach P(nficht des (B)eridfts bie Sadje vollitändig erörtert ${ }^{2}$ ) ift, und verfïndet die Ultbcile und Bcidjliiffe Des (Berid)t?.

1) $\mathfrak{R g l .} \S \S 130,464$.

3. Tuträge.

§ 128. Die mündlidje Berhandluna wird dadurd ein= geleitet, das bie Barteien ifye SInträge itellen.
Dic Borträge der Farteien find in freier Redc jull halten; fie ljaben das Strcitucrhältmís in thatfäcfllicf)er uno rechtlicher $\mathfrak{b e z}$ ichung ju unffajicn.

(Fine $\mathfrak{B} c_{j} u g n a h m e$ allf Sodjrittitücfe itatt mündicher Ticrfandlung ìt unzuläjfig. Dic Borlejung von Sd)rift= fittiden findet nur infomeit jtatt, als ç allf den wörtlidjent Jnlyalt berfelben antommt.

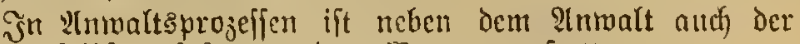
łartei felbft auf Mutrag das wart ju geftntten.

\section{Fragepflidgt und redit.}

$\$$ 130. Der Borfizenite hat Durch Fragen Darauf lin= junvirten, Daß gaben Der geltend gemaditen Thatfadjen ergänzt und die Bemeismittel bezeidjet, iiberhaupt alle für bic ₹reftitellung bes Sacfuertuältniffę erbeblicfen Erfflärungen abgegeben werden.

Der Borfiberde ijat auf die Bedcufen anjmerfjam jull

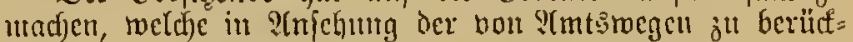
fidftigenien \$iunte vormaltcu.

(Fi hat jedem Mitgliede bes (Gerid)to all Werlangen fu geitatten, Jragen zu ficllen.

$\S 131$. Wirt eine auf die Sadjleitung bejüglicfe $\mathfrak{I} n=$

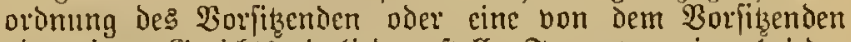
oher einem (Serid)tsmitgliede geftellte Frage von einer bei Der Berbandlung betlyciligten \$ierjon als unzuläjitg beanitandet, fo enticheidet das Bericht.

\section{Beingnifie bes (Beridhts.}

\$ 132. Das (Sericht fann das periönlidic (Erjheinen cincr \$artci zur 24uftlärung des Sact) verbältniffes anoronen.

$\S 133$. (1) Das Beridft fann anordnen, daßs cinc \$artci Die in ihren seänden befindlidfen ltrfunden, allf recldje jie

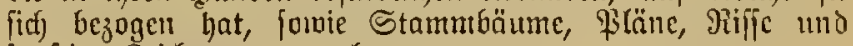
jonftige Beichungen vorlege.

(2) (3) .....

\$ 134. Das (Berifjt fann anordnen, daf die Farteien die in ifrem Befibe bejinolid)en ?teten vorlegen, fomeit die= jelben aus Sduriftitüfen beftehen, wcldhe dic Berbandlung und Entichcioung der Sact)e betreffer.

$\S 135$. (1) Das (Seridjt Lann die (Eimnahme des Ylugen= idfcits, fomie bic Bcgutad)tung duth Sachberftändige an= oronen.

(2) ......

§ 143. (1) Dał Beridyt fann Wartcien, Bebollmäd)tigten

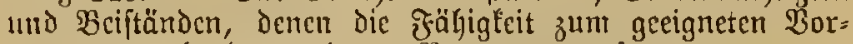
trage mangelt, ben weiteren Sortrag unterjagen.

(2) DaS (Sexicht tann ßebollmächtigte und Bciftänoc,

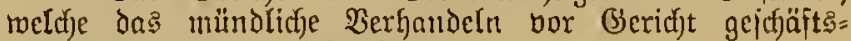
mäßig betreiben, zurücfmeijen.

(3) ......

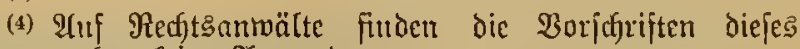
Saragraphen feine Itmendung.

\section{Siłunģ̨ำrotofoll.}

§ 145. Heber die mündlicje Berfandlung nor dem (Bierid)te ift ein Protofoll aujaunefmen. 
Da: Prototoll entfält:

1. Den Dit und Den Tag der Berfandung;

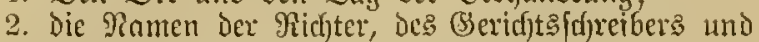
des etrua jugezonenen Dolmetfders;

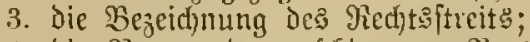

4. Die Pamen Der erffiemenen Barteien, gejetzlidjen Vertreter, Bevollmächtigten mo Beiftände;

5. Die ?tugabe, daf̧ öffentlick verljandelt oder die Deffentlichteit ausigefd)loffen ift.

§ 146. Der Bang Der Berbandung ift nux im all= gemeinen nuzugében.

Durdi) Mlumahme in das Firotofoll find fejtzu[tellen:

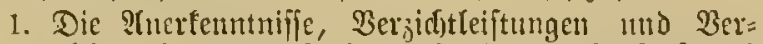

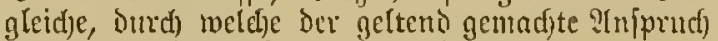
ganz oder theilmeife erledigt mirt;

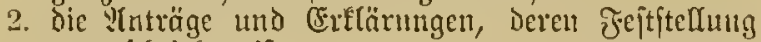
vorgeidjrieben ift;

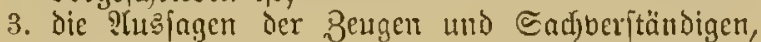
fofern biefclben frither nicht abgeljört twaren oder bou ifrer fritheren ?(us fage abweicfen;

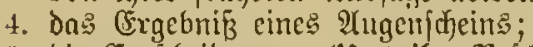

5. Die Entjcheidungen (Utrtheile, Beichlüjie und $\mathfrak{B e r}=$ fïgungen) des (Serichts, fofern fie nidjt dent firototolfe (c)riftlicf) beigefügt find;

6. Die Berkündung der Entfit)eidungen.

Der Tufnalime in Das Grotofolf iteht die Tufnafme in

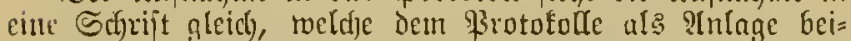
gefiight unt als joldie in iempelben bezeidnet ift.

\$149. (1) Das grotafoll ift non dem Sorfitzenden uno bem (seridjtsfdyreifer zu unterjd)reiben.

(2) .....

\section{3uitellungen.}

§ 152. Dic 3ujtellungen erfolgen outd) (Geridjtäboll= iicher.

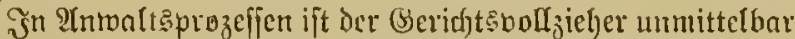
ill beauftragen, in anderel Frozejen nach der Mahl der Fiartei entweder unmittelbar oder unter 2 ermittelung bes

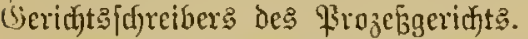

§ 155. Die Fiartei hat dent (Seridjtsondjicher und,

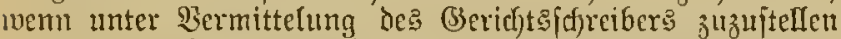

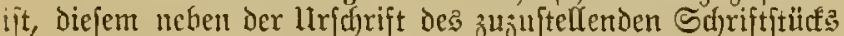
rine ber Bahl Der Ferjonen, melchen zuzuftellen ift, ent=

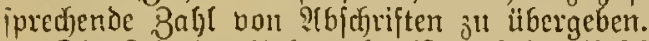

Die Beit der llebergabe ift auf der llriffrift und den

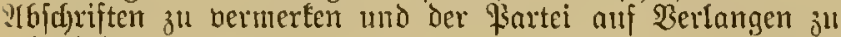
befdecinigen.

\& 156. Die Buitelfung befteht, wem eine $\mathfrak{A}$ tusertigung altgeftellt werden iofl, in deren llebergabe, in ben übrigen Fällen in ber llebergabe einer beglaubigten $\mathfrak{A} 6$ fhrift bes

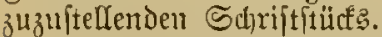

Die Beglaubigung gejchiegt durd) den (Beridgtsvollziehcr,

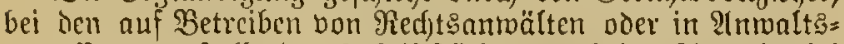

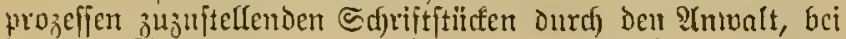

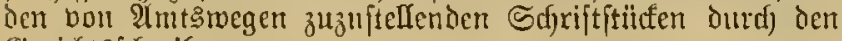
(Seridutâd dyreiber.

\$ 15\%. Die Buftellungen, weldje an eine \$artei berwirlt werben follen, erfolgen fïr bie nicht projefffätigen ţerfonen all die gejekstichen $\mathfrak{B}$ ertreter derfelben.

Bei Beljörden, Bemeinden und Rorporationen, forwic bei Gerfonenbereinen, weldhe alg foldje flagen und berflagt merten fönnen, genïgt dic Buftellung an die Borftefer.
Bei mehreren gejekzlidjen $\mathfrak{B e r t w e t e r n , ~ f o r w i e ~ b e i ~ m e h r e r e n ~}$ Boritefern geniigt bie Zultellung an einen derfelben.

\$ 165. Die Buftellungen fönmen an jeben Drte et= folgen, wo die Gierjon, weldjer zugeftellt werten foll, an= getroffen wiro.

Shat bie Fierfon an Dicfem Srte eine $\mathfrak{B}$ ofnnung oder ein

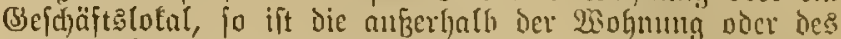
(B)efuäftelofals an fie criolgte Bujtellung num gïltig, wetn bie ?trnafme nicht verweigert ift.

\section{Erjakzuftellungeu.}

\$166. Wirt Die \$erfon, weldjel jugeftelft merben foll,

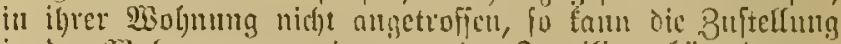

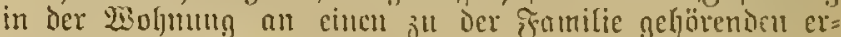

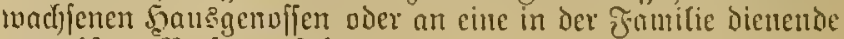
ertuadjene \$erion exfolger.

Weird eine foldje Berfon nicht angetroffen, fo faum die Bnftellung an Den in Demjelben Sallie wohnenten Saus: wirth oder 3 ermiether erfolgen, wenn diefe zur \{mmahme Des Sdhrifttiüt's bereit firto.

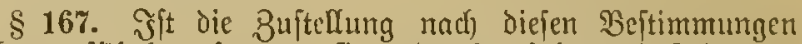

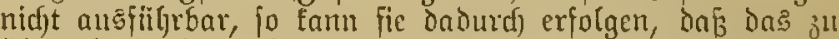

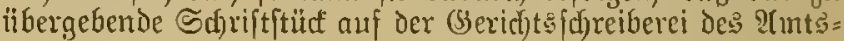
gerints, in Defien Bezirfe der Srt der Znitellung gelegen ift, oder alt diefem Srte bei der Boftanftalt oder Dem (se= meindeborftefjer oder dem Piolizeiborftefer niedergelegt 1 mo bie Riederlequng foroohl Durd) eine an Der Ifyür ier

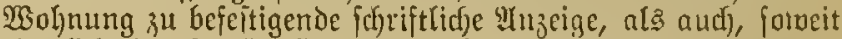

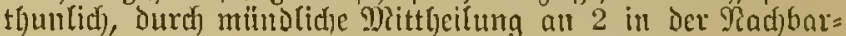
idjaft wohnende Gerfonen befannt gemadjt roiro.

\$ 168. Fुir (Gemerbetreibende, weld)e ein befonderes (je= ichäftalofal hahell, fam, wenn fie in tem Giefchäftalofale nidjt angetroffen twerden, bie Buftellung an einen barin an= wefenden Bemerbegehïlfen erfolgen.

Birb ein Redjtăantwalt, weldjem jugeiftellt merden foll, in

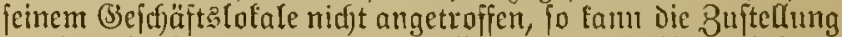
an einen barin anmejenden (Beljilfen oder Sdjeiber erfolgen.

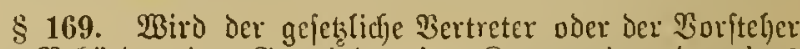
eimer Behärbe, einer (S)emeinde, einer Rorporation oder eine Ferjonenvereins, meldhem zugeitellt werden foll, in Dem (Bes=

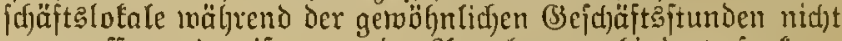
angetroffen, oder ift er an der Ammahme berljindert, fo fann bie 3uitellung an einen anderen in Dem (Bejdjäftolotale an= wejenden SBenmter ober Bedienftetell hewuirft werten.

2Bird Der gefekzlicf) Bertreter oder Der Borfteher in jeiner Wohnung nidit angetroffen, io finden bie Beftimmungen der $\$ \S 166,167$ лur Inventung, wein ein bejonderes (B)efdjäftslofal nicft vorbanten ift.

\$ 170. Wirb bie 9tmnahme der Buftellung oljne gejels=

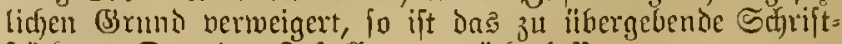
ftiid am Drte der zuftellung zurifitjulaffen.

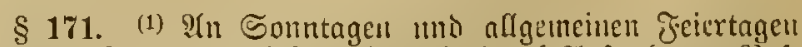
barf eine Buftellung, fofert fic nid)t buref $\mathfrak{A} u f g a b e$ zur Poft bemirkt mirt, nur mit ridterliche: Erfaubnif erfolgen.

(2) (3) (4) ....

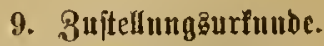

\& 173. (1) Leber bic 3uftellung ift eine Urfunde auf= jumehmen.

(2) $(3) \ldots \ldots$ 


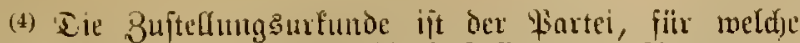
die Buftellung exjolgt, wenn dic Buftellung bou ?tutsmegen

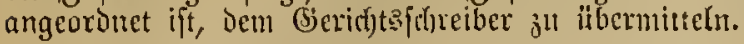

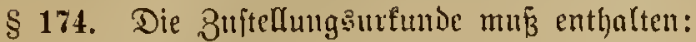

1. Sort und Beit der Buftellung;

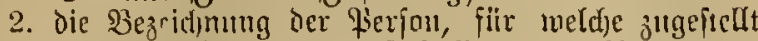

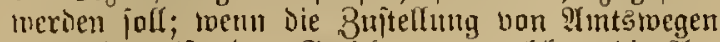
angeorbuct ift, bas (Serifist, bon weld)em die ?(n= orounung nusgelgt;

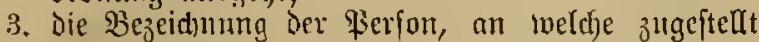
merden foll;

4. Die Zezeidinung der \$erfon, weldyer allgeftellt ift;

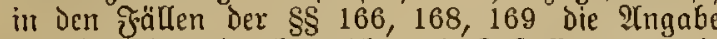
Des (Grmines, durd) meldhen die Buftellung an die bezeidfnete Ferjon gered)tfertigt wird, menn nad) $\S 167$ verfalyren ift, Die Vemerfung, wie bie Durin enthaltenen Borfariften bejolgt find;

5. im Falle Der $\mathfrak{B e r}$ weigerung Der Pnnahne die Cer: wähmung, Daỉ bie ?hmahme berweigert umb Das ju übergebende Sd)riftftilut am Srte der Buftellumg zuriidfgelaffet ijt;

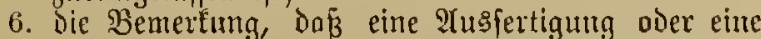

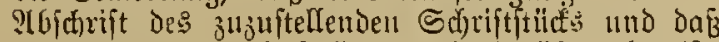

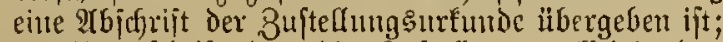

7. die Unterfanrift des die Zuftellung vallzieljenden Beamten.

\section{Buftellung burd bie Poit.} folgen.

§ 176. Buitellungen fömen aud) Dur(f) bie \$ọt er=

\$ 177. Wird ourfy die Soft zugeftell, fo ljot der (be= rid)tsuollieljer einen burd) fein Dientfiegel verfd)loffenen, mit ber शloreffe der Ferfon, an weldje zugejtellt werden folf,

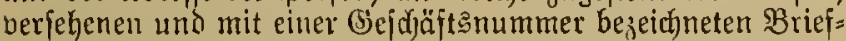
umidjlag, in roelchem die juznlfellende 2 usfertigung oder

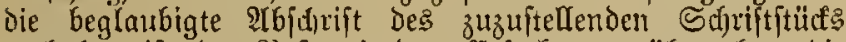
enthalten ift, Der \$oft mit Dem Crrfuchen zu übergeben, dic Buftellung einem Boftboten de: Bepitimmungsortes auf= zutragen. Dá̧ die Uebergabe in der bezeidneten $\mathfrak{A}$ it ge= fhehen, ift bout oem Beridytsondzieher auf ber Uridjrift

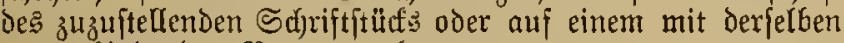
за verbinbenden Bogen zu bezeugen.

\$ 178. Die Buftellung ourch Den \$oftboten erfalgt in Sbemäfheit Der Beftimmungen Der \$s 165-170.

Heber Die Bujtellung ift bon Dem Pojtboten eine Hrfunde aufanefymen, welde Deu Beftimmungen Des $\$ 174$ IR. 1, $3-5,7$ entiprechen und aufrom die llebergabe des jeinem

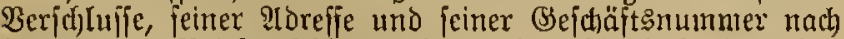
bezeidyneten Briefumichlags, fowie Der 2tojdgrift der $3 \mathrm{u}=$ ftelluagsurfumbe bezeugen mub.

Die Urfunde ift von Dem \$oftboten Der \$oitanitalt und

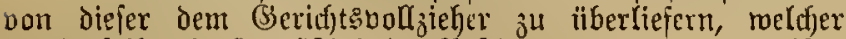

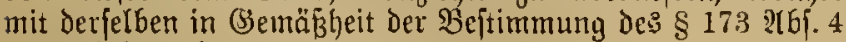
zu berfabren hat.

\section{Defientlidge Buitellung.}

§ 186. (1) Эft Der 2(ufentljalt einer \$artei unbefannt, fo tann die Bultellung Durd) öffentliche Belamutmad)ung erfolgen.

(2)
$\S 187$. (1) ......

(2) Die öffentlid) 3uftellung crjolgt Durd) Qunbeftung

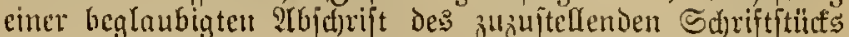

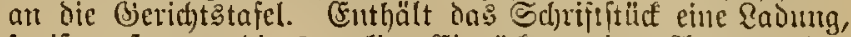

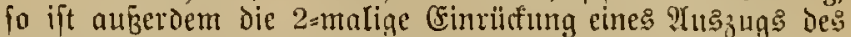

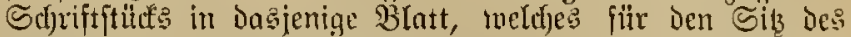

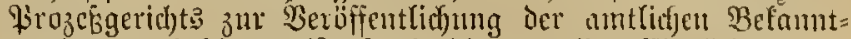
mad)แngen beftimmt ift, fomie bie $1=$ malige Eimriidung bes

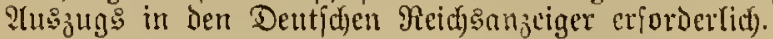

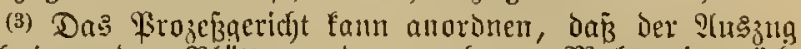
nod) in andere Blätter werbe.

§ 189. (1) Das eine Sabung entljaltende Sdyrijtitüdf gilt als an Dem Tage jugeitellt, an roeldjem feit Der letżen

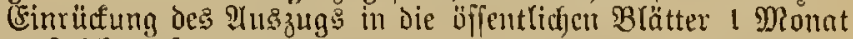
verftricfent ift. .......

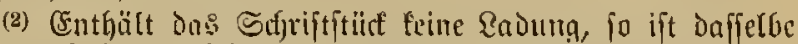
als jugeftell anjufelyen, wenn feit ber stuhcitung ocs Schrift= jitürfs an bie Beridjtstafel 2930 ad)en verftrid)en find.

(3) ......

12. Rabungen.

\$ 191. (1) Die Eaoung ju einem Termin erfolgt burd

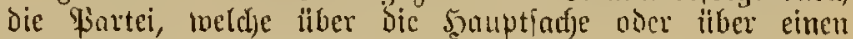
Brwijuenftreit milnolidj ber fandelı mial.

(2) .....

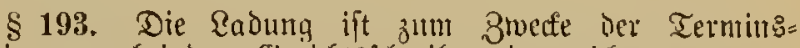
beftimmung bei Dem (Seridftsfdreiber eitlirueidjen.

Die Beftimmung Der Iermine eriolgt bitnen 24 Stunden Durdf) Den $\mathfrak{B}$ arfizzenten.

?(ui Sonntage und allgemeitue Jeiertage fino Termine nur in Rothjällen anzuberaumen.

\section{Sabumgafrift.}

\$ 194. Die Frift, weld)e in einer anthängigen Sadje 3 wifchen Der Zufteffuting Der Ladung und Dem Ierminstage liegen foll (RaDungsfrift), beträgt in Inmaltsprozeffen

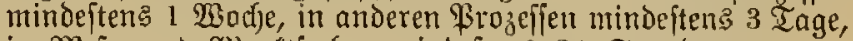
in Mies = und Martifadjen mindejtens 24 Stunden.

\section{Termiute.}

\$ 196. Die Termine merden an Der (seridjtsitelle $a b=$ gehalten, jojern nicht bie Eimnahme eines 2 ugenjugins an Drt und Stelle, Die Berhandhng mit einer am Erfcheinen vor (3erid)t verlinderten \$erfon oder cine jonftige şandlung exforbcrlid) ift, meldye an ber (Serichtşftelle nid)t borgenommen werden fann.

Die Rautosherren und die Mitglieder der landesherrliden Jamilien, forwie bic Mitglieber ber Fïrftlid)en J゙anilie Ђohenzolfern jind niffet verpflicftet, perjüntich an ber (Be= richt:̧iftelle zu erfacinen.

\$ 197. Der Termin Gegimnt mit Dem IIffufe ber Sadje.

Der Termin ift bon einer \$artei berfäumt, suent fie bis zum Sdiluffe deffelben nid)t verhandelt.

\section{Friftell und Deren Beredyung.}

$\S 198$. Der Sauf einer ridjterliden Frift1) begiunt, fofern nidjt bei Fejtiełung berielben ein ?Inderes beftimmt mird, mit Der Bllftelung Des Schriftftituf, in melchem die Jrift feftgefebt ift, uno wenn ez einer folchen Buftellung nidat bedari, mit ber Serfitnoung ber §rift. 


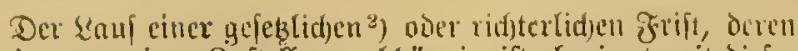
Beginn von cimer Bufteflung abthängig ift, begimut nit biefer audi gegen dicjenige Partei, tuelebe bic Buftellumg hat be= wirten laffen.

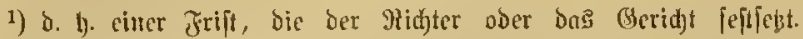
$\S \S 105,820$.

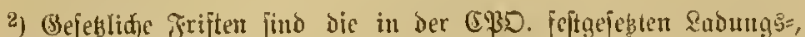

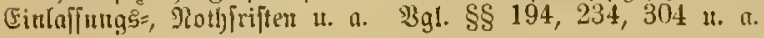

§ 199.*) Bei ber Berectunung cincr Frift, weldje nach Tagen bejtimmt ift, mir' Der Tag nidjt mitgeredjuet, auf

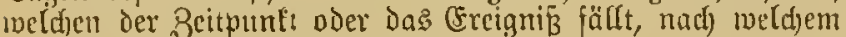
ber ?nfang der Jrift fitf riffen foll.

\$ 200.") (Fine Frift, meldye nad) Wodjen oder Manaten beftimut ift, endigt mit Slblauf Desjenigen Iages Der Iekten

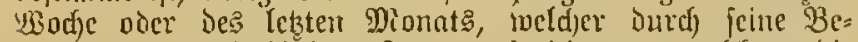
neunung voer Bahl Dem Tage entiprid)t, ant weldem die Strift begonnen t)at; felflt dicjer Tag in bent Letzen Unonate, fo endigt bic Jrijt mit Itblauf Des Iebeten Iages Diejes Monats.

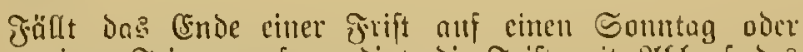
affgemeinen Feiertng, fo endigt bic grift mit ?tblanf bes

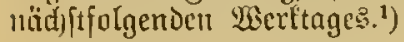

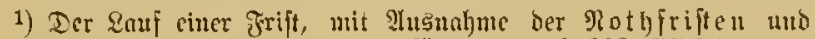

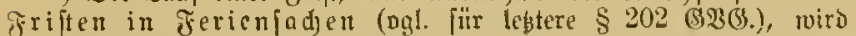
Durd) Die (Beridtsferic u (15. Juli bis 15. September) getemut. -

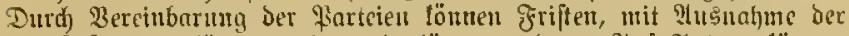
Mothfriften, verlängert ober abgetürzt werben. ?tuf ?tutrag löınen

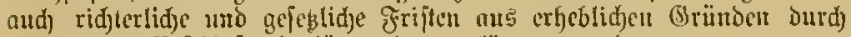
ridjterliden Bejølu[ abgetirzt oder verlängert weroen.

§ 205. Dic \$arteien fömnen die Stufgebung cine? Tcrmins vereinbaren.

BBird die Berlequng cines Termins beantrugt, fo finden bic Bejtimmungen ïber $\mathfrak{B e r l a ̈ n g c r u n g ~ c i n e r ~ F r i f t ~ e n t i p r e d ) e n d e ~}$ ?trivelioung.

\section{Folgen ber Derjättuแutg.}

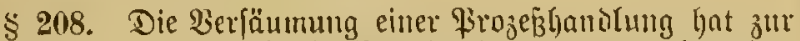
allgemeinen Jolge, daf die \$̧artei mit Der borzunehmenten

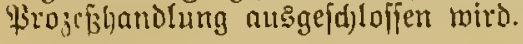

\$ 209. (1) Finer 9noroljung Der gejeblidlyen folgen be: Berfämunng bedarf es nidul; bicjelbert treten bou felloft

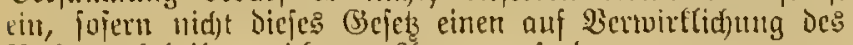

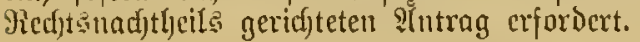

(2) ......

\section{Wiedereinjełung in ben vorigen Etand.}

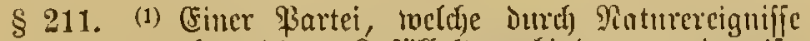

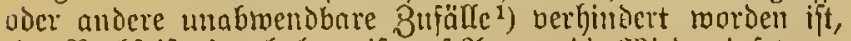

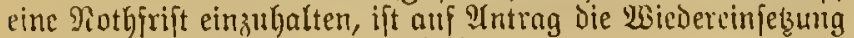
in Den borigen Stand ju ertheilen.

(2) .....

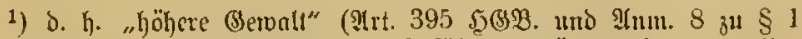

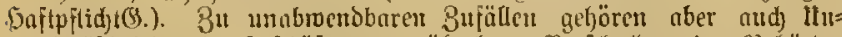

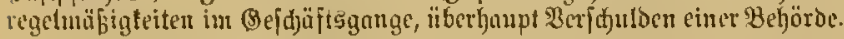

*) Dieje beiden \$aragraphen vertreten jugleich bie $\$ \S 42$ und 43 Der Et\$o.
\$ 212. Die bicbereinjekung mus immethatb ciner 2=lvöhigent f̛rift beantragt werùen.

Dic Jrift beginnt mit bem Iage, an weldyem das Simdernif gehoben ift; fie Eam Durd) Bercmbarung ber Fisarteien nicht verlängert twerden.

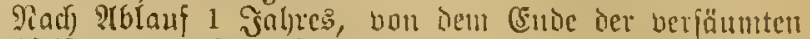

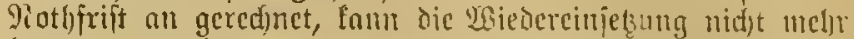
benutragt werden.

§ 216 . (1) (2) . . . .

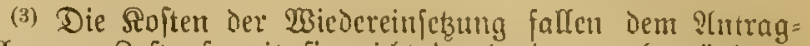
ftelfer zur $\mathfrak{Q} a$ ft, folveit fie nid)t Durd) cinen unbegründeten WOideriprud) de: (Segners entitanden find.

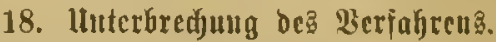

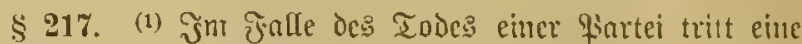

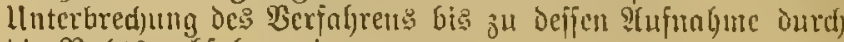
Die Red)t:nadffolget eill.

(2) (3) (4) .....

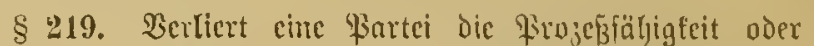

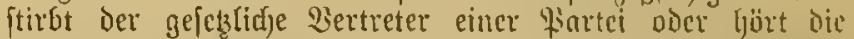
Vertretungsgeftgní bejfelben nuf, ohne daß dic Wartei prozçfäljig gemoviden ift, fo wird Das Berfalyren unter=

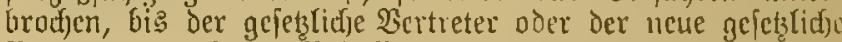
23ertreter voll feiner Beftellung bent (Begner ?4nzeige mad)t,

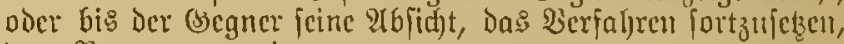
bem Bertreter anzeigt.

§ 222. Soürt in folge cincs firieges oder eincs andercu

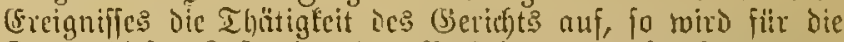
Datuer diefes 3uitandes bas Serịagren unterbrodjen.

\section{24แล์}

\$ 223. (1) Fand in Den Füllen des Iodes, Des Tुer:

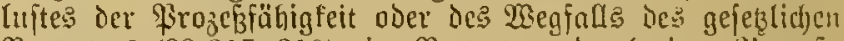

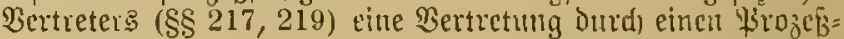
bebollmäbrtigten ftatt, jo tritt eine linterbred)ung Des $2 e r=$ fahrens nidjt cin; das Prozérgerifjt hat jebod) auf ?ntrag Des Bevolfmäd)tigten, im Falle des Todes nud anf Tritrag

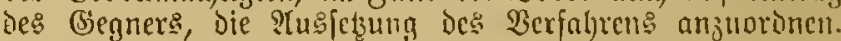

(2) ......

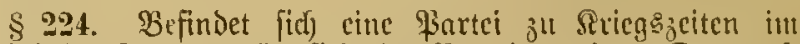
Militärdienfte ober hält fid eine Partei an cinem Drte auf,

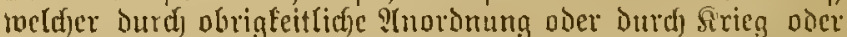

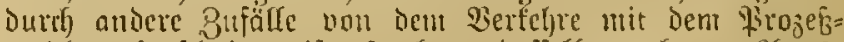

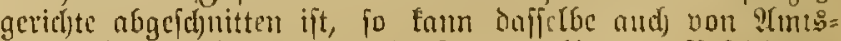
megen dic ?luşetzung bes Berjalprens bis zur Bejeitigung Des Sinderniffes anoronen.

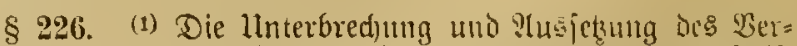
falprens fat die WBilfung, baß der Rauj einur jeden Frijt

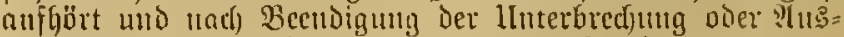
fetsung bie volfe grift bon neuent zu Inufen begimnt.

(2) (3) . . . .

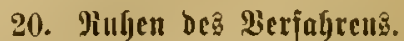

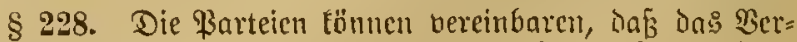
jalyren rulyen jolle. Dic Dereinharung hat anf ben \&auf

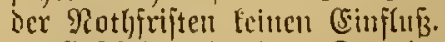

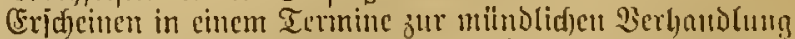
beide Farteien uidjt, jo ruht Das Derjalytu, bis eine fintei

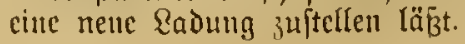


Dns (Seridjt unter 2Bürdigung aller llmitn̈nde nach freicr lleberzeugnng. . . . . .

$$
\text { (2) ..... }
$$

\$ 261. (1) Die von eimer Sartci behauptcten That= fact)en bebürfen infoweit feines Bemeifes, als fie im Sanfe

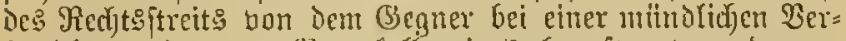
ljandlung oder zum firotofolle eines beanftragten ober $\mathrm{er}=$ furden Pridfters zugeftanden find.

(2) .....

\section{G(aแbhaftmaci)nng.}

\$ 266. Wher eine thatfäd)lidje Beljauptung glaubljaft zut mad)en hat, faun fid alfer Betweismittel, mit S(usnalync

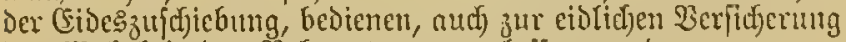
Der $\mathfrak{W a h}$ heit Der $\mathfrak{B}$ ehauptung zugelajjen inerdert.

(Sine Betweisaufnahme, weldje nidjt jofort erfolgen fam, ift unjtatthoft.

\section{Eülneverjud.}

§ 268. Dns Beridjt fann in jeder Rage de: Iiedjt: ftreit? Die güttidje Beilegung Deffelben oder cinzelner Streit=

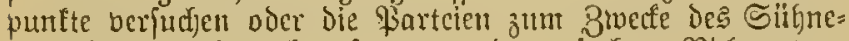

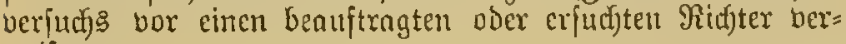
weijen.

Bum Bnedfe des Sillneberjud) tam bas perfönliche Ericheinen der Farteien aligeordnet merden.

\$ 271. (1) Die Farteien fönnen bon den \$iroję̧aften

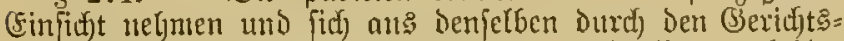

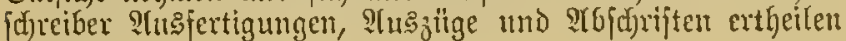
Iaffell.

(2) .....

(3) Die Centwürfe зu Mrtheiten, Befdyliifien uno Ber= jügungen, Die zแn Vorbereitung Dexielben geliejerten ?T-beiten, folvie die Sdfriftitilfe, welde arbftimmungen dier Straf: verfügungen betreffen, merden meder vorgelegt nod) $a b=$ (d) riftlid) mitgetheilt.

\section{Endurtfeil.}

\section{Irtheil.}

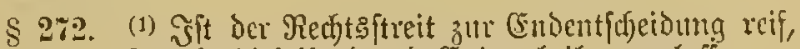
fo hat das (seridyt Dicjelbe Durct Endurtheil ju erlaffen.

(2).....

\section{Ilycilurtheil.}

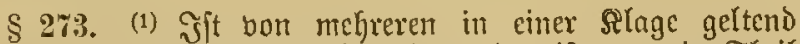

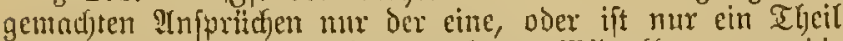

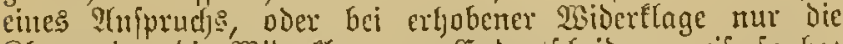

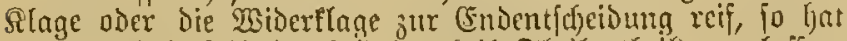

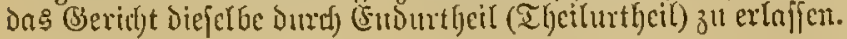

(2).....

\section{3ivijachenurtfjeil.}

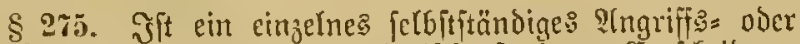
Bertheidigungsmittel oder ein 3 mifdenftreit out Entidcibung reif, jo fann Dic (Entidjeibung Durd) Bwijd)enurtljeif erjolgen.

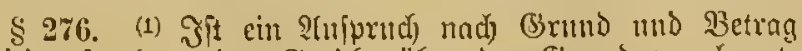
ftreitig, fo fam das Beridjt itber den Grund borah ent= j(d)eident.

(2) . . . .
\$ 278. Crtennt eine Fartei den gegen fie geltend ge= mad)ten S(nfpruch bei der mündficfen Berljamblung ganz

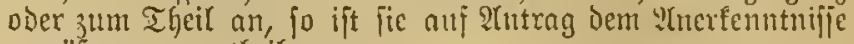
gemäz 3"l berurtbeilen.

\section{Silageantrag it mabgelicuto.}

§ 279. Das (3erid)t ift uidut bejugt, ciner \$artei ctwas juznlprectert, was nid)t beantragt ift. Dis gift insbefondere bon Jrifdeten, Binfen uno anderen 2iebenforderungen.

lleber die Berpflicftung, dic \$rozefzloften z" tragen, lyat Das (Serid)t aud) ofne Alntrag zu crfennen.

§ 280. Das Urtheil fonn mur von Denjenigen Ristern gefällt merDen, tweld)e Der Dem llrtheile zu Sirmme liegcnden Berbandlung beigetwoljnt haben.

\section{Urthcilsิucrfüแถักถู.}

§ 281. Dic Sertüttoung des Untheiţ erfolgt in dem Termine, in meldfem bic mündliche Berljandlung gejefloficu svirt, oder in einen fofort nuzuberatmenten Termine, weldjer nicft über 1 Woche Ginats angejebt werben folf.

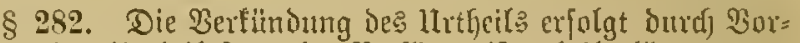

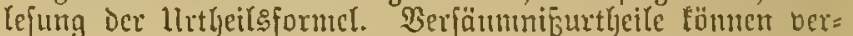
fiubet werden, aud menn bie llutheilsformed nod) nidjt (c)riftidid) abgefäst ift.

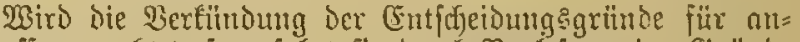
gemeffert crachtet, io erfolgt fie burd) Borlefutg ocr (B)rïmbe ober Durd) miinotidje Mittheilung des incientlidjen Şnthatt?.

6. Juthalt des utrthcils.

§ 28t. Das Ultheil enthält:

1. Die Bezcidfunum der 'jarteien und ifrer gejektidfen Bertreter nacf) 9Ramen, Stano oter (3eroerbe, Wofnort uno Partciftelfung;

2. Die Bezeidjnung Des (Beridfts unt Die Jinmen Det Piidfer, weldfe bei ber Entfdeidung mitgemirlt bahan;

3. cine georängte Daritellung des Sad)= uni Strcit= ftandes nuf Brundlage der mündlidjen Borträge

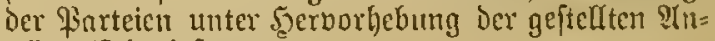
träge (I Ijatbeftami);

4. Dic EntfdyeiDung:gründe;

5. Die von der Daritellut des. Thatbeftandes mut ier (Entfdeidunģarïnde äuserlid) z"t fondernie Ututheifsformel.

Bei Dor Darfellung Des Thatbeftandes ift cine $B c_{j}$ ligy

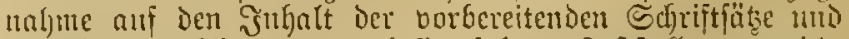
auf Dic jum Silizungsprototoll erfolgten Jeftiftelutugen midat ausigeid)loficr.

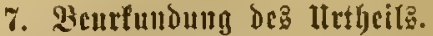

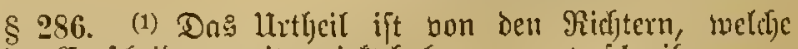
bei ber Entfdyeidung nitgemint haben, zu unterid)reiben. ...

(2) $(3) \ldots \ldots$

§ 28\%. Der Beridjtsfureiber lont die verfïndeten und

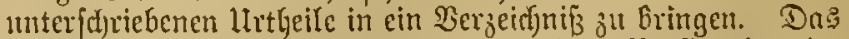
Berzcidynif mird an beftimmten, von ben Borfizenden im borans feftzufekenden isocjentagen mindeftens anf die

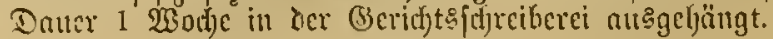


8. 3uitellung be uletheila.

§ 288. Die Buftellung der Urtheile crfolgt anf B̧etreiben Der Barteien.

So lange das Urtheil nidft berfindet milo nid)t unter=

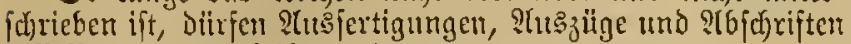
deffelben nidft ertheilt werden.

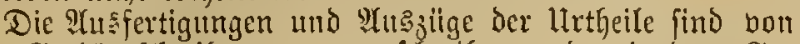

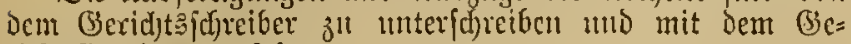
ridftefiegel zul berfehen.

\section{Rechtaftraft.}

\$ 293. (1) ltrtljeile fint Der Red)taltraft nur injomeit

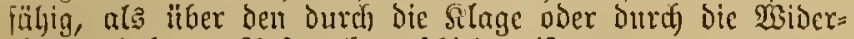
elnge erfjobenen ?(niprudi) entjujieden i[t.1)

(2).....

1) Urtheilc find red)tsträftig, roenn fic mit einem orbentliden Red)tsmittel (Berufung, Revifion) nicht utchr autgefod)ten merocu fönnen. Sit ein Redtsmittel, bezw. cut Einfprud überbatpt nicht zuläijig (3. 3 . im zalle bes $\$ 834$ ), io Iritt bie Redjtsfraft mit ber

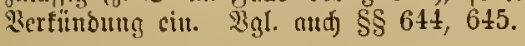

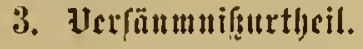

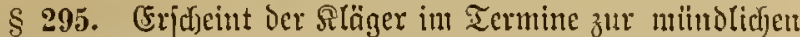

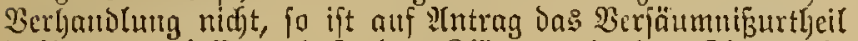
Dahin zu erlafjen, baf̧ Der Rläger mit ber Rlage $\mathfrak{a b}=$ ätweifen jei.

§ 296. Beantragt ber Släger gegen den in Termine

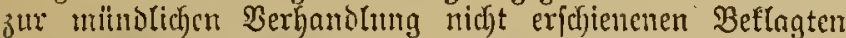

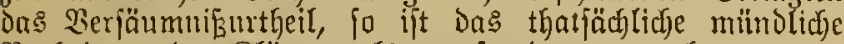
Borbringen Des ふlägers als zugeftanden anzunebmen.

Soweit bafielbe Den Slageantrng recutfertigt, ift nad)

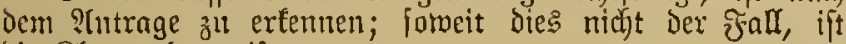
Die ת̂lage abzumeifen.

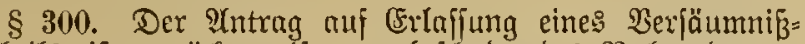
mttleils ift zuridzumeifen, unbefd)a bet Des Rechts Der er= jechienenen Partei, bie Bertagung der mündlicfen Berhandlung jli bcantragen:

1. menn bic erffhienene Partei bie bom (Serichte megen

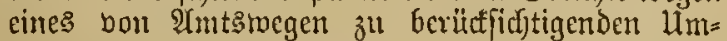
ftandes erforderte gachrweifung nidjt zu beffjaffen bermag;

2. wenn bie nidjt exfdjiencue Partei nidyt oromungs= mäß̄ig, insbejondere nicht rechtzeitig gelaben mar;

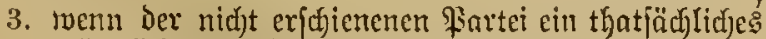
ntïndidjes Barbringen ober ein 2lutrag nicht redft= zeitig mittels Sdjrift\{akes mitgetheilt mar.

Wird Die Verlyanolung bertagt, io ift bie nicht er= [rfjenene Fartei zu Dem neuen Termine zu laden.

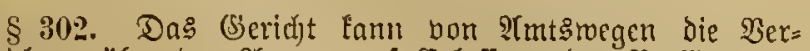

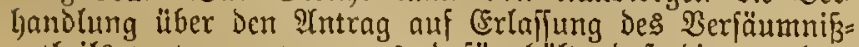
lurtheits bertagen, rent ce bafür hält, baß̧ die bon dem Borfitzenden beitinmte Cinlafiungs oder Rabungsirift zu furz bemejien, ober do $\tilde{B}$ die \$artei Durch Saturereigniffe ober Durch andere umabmendbare 3 ufäf(e $e^{1}$ am (Erjueinen verhindert morben jei. Die nidft erfdienene \$artei ift zu dem neuen Termine zu laden.

1) פgl. Imm. 3и § 211 .

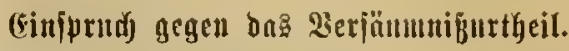

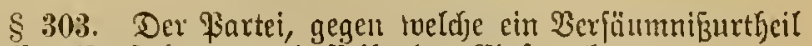
erlafien ift, ftegt gegen Daffelbe ber (Eimprutud zut.

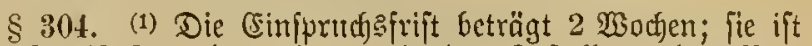
eine Rothfrift und beginut mit ber Buftellung bes Ber=

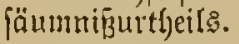

(2) $\ldots \ldots$

\$ 305. Dic sintegung des Einfuructs expolgt durch 3uitelfung eines Sdjriftakses. Derjelbe mus enthalten:

1. Die Bezeid)nung Des Ilttheits, gegen tweldies Der (Einfpruch gerichtet roiro;

2. die (Ertärung, dā̄ gegen biejes Urthcil (sinfprud) eingelegt merde;

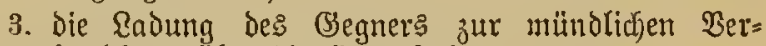
handlung über dic Sauptiac)e.

Der Schriftjas foll jugleich Dasjenige enthalten, twas zur

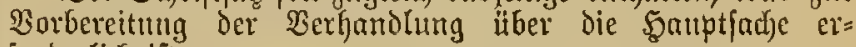
forbertich ift.

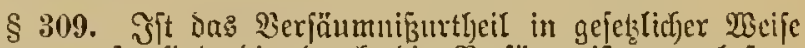

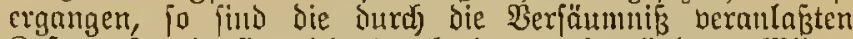
Sojten, forweit fic nicht Durch cinen unbegrïndeten Wider= ipruch) bes (Segner's entitanden find, der fäumigen \$artei auch) bam aufaterlegen, toem in Folge des (Einfprutt) eine aböndernde Entfdecioung erlajfen mirb.

\section{Worbereitendes Werfaljren iu Kedjunggfad)en,

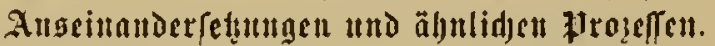

\$ 313. Stellt fich in Rrozeffen, weldf)e Die Richtigfeit

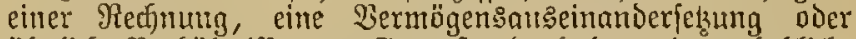
ähnlidfe Serfältmiffe zum (Segenjtande haben, cime erhebliche

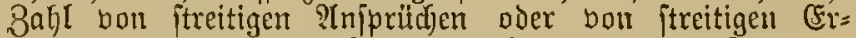

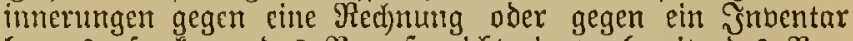
heraus, fo fann bas Brozefigeridgt ein vorbereitendes Ber: fagren bor einem beauftragten Ricjter anorbmen.

\section{3curignufnahme.}

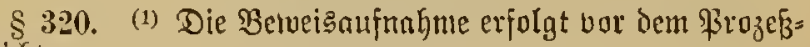
geridjte. ......

(2) .....

\$ 322. Den Farteien ift geftattet, Der Betweisaufunhme beizuwohnen.

§ 323. Frfordert Die Betweisaufnalyme cin befonderes Berfahren, fo ift bafjelbe durd) Berweisbejulus anjuordmen.

§ 335. (1) Erfolgt Die Betweisaujuahme bor Dem \$rozef $=$ gerichte, fo ijt ber Termin, in meldem bic Bemeizaufnalime ftattfindet, follgleich jur Jortfetzung ocr mündlid)en $\mathfrak{B e r}=$ handlung beftimmt.

(2) .....

\section{Bewcis Durd Auncu/djein.}

§ 33\%. (1) Das Frozez̧geridyt faun anoronen, duá bei ber (Einnabme bes 2ugenfd)eits ein oder mehrere Sach)= verftünoige zuzuziehen feien.

(2) ...... 


\section{3entarnlucucis.}

§ 338. Die Sintretıng De: Zeugenbemeifes expolgt Duref Die Benenmung Der Bengen mo Die Bezeichung Der That=

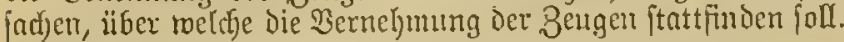

$\$ 339$. Die \$ernehmung neuer Bengen, welde nach

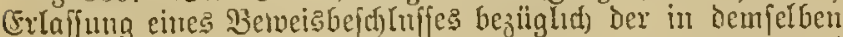
bezeiffreten freitigen Thatjachen benannt werden, ift auf Intrag jurfidjumeijen, menn Durd) bie Bernel)mung bie

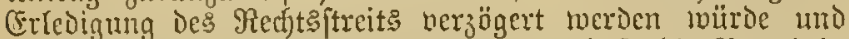

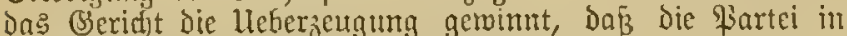

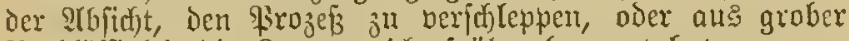
Pandjläffingeit Die Beugen nid)t frtiber betrannt hat.

\$ 340. (1) Die Ilufmalyme Des 3cugenbemeifes foun cimem Mitglicde Des Srozefgerid)ts oder einen anderen (Serid)te übertragen twerden:

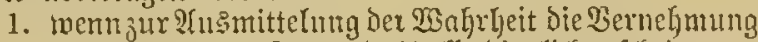
Des Beugen an Drt und Stelle bienlich exfdjeint;

2. menn die Bemeisauinalyme vor Dem qirojebgeridyt erhebliffen Schtwierigfeiten unterliegen witrob;

3. wem der 3euge berbindert ift, vor dem \$rozej= geridite zu eridheinen;

4. menn ber Beuge in grofier Entfermung bon dem Sitze des girozejgerichte fich aulbält.

(2) Die Eandesherren mo Die Mitglieder inex landes=

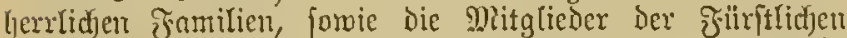

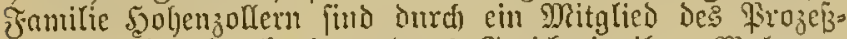

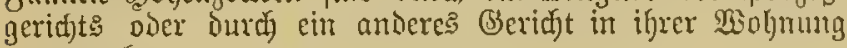
zu bermefmer.

\section{Beautte.}

$\left.\S 34 .^{*}\right)$ Deffent(idfe Beante, ${ }^{1}$ and ment fie nidjt mehr im Dienfte find, diirfen Ḧber llmitänoc, auf meldje

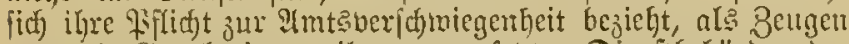
mur mit (senelynigung ihrer borgejetsten Dienftheföroce ober oer ifnen juleşt vorgefest gewejenen Diemftbehöroc ber= nontmen werden. Filix Den Reicfsłanjler bedarf ez Der Ge=

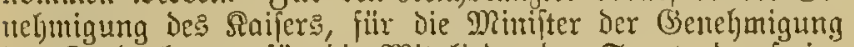
¿es Saniesherrn, fïr bie Mitglieder der Senate der freien Sonieftäbte Der (Benełmigung de: Senats.

Die Sienehmigung Darf nur verfagt werden, went bie

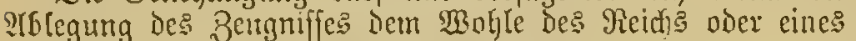

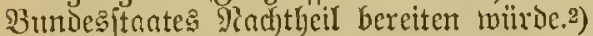

Die (Beneljmigumg ift Durd) das Prozergeridft einzulfolen und Dem Beugen befannt zu madjen.

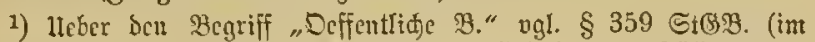
III. Theil). - Ilnmittelbare Etantsbeamte fino in allen fällem einer an fie craethenden aeridjtidifen 3 orlabung als Bengen ober Sndh:

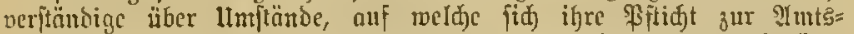
veridwicaenfocit bezicht, verpflidjtet, ifrer vorgciestent Dienftbehörde

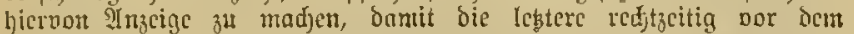

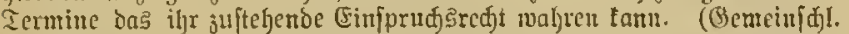

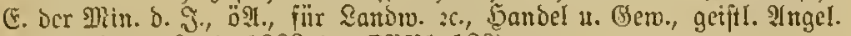

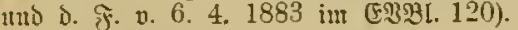

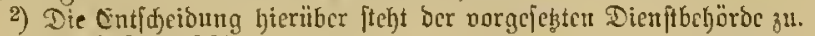
33gl. auta) § $373(367)$.

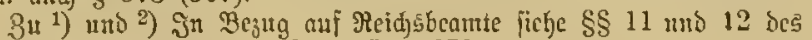

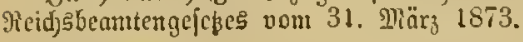

\section{Rabung.}

\$ 342. Dic Rabung Der Beugen ijt bon Dem (Sieridyts=

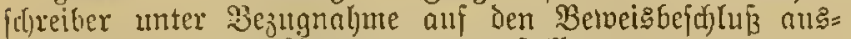
jugertigen und vou ?imtamegen zuß utellen.

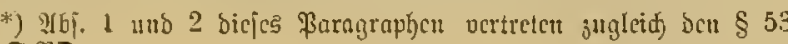
ber Et\$BD.
Die snoung mur entlyalten:

1. Die Bežeichutug Der Fartrien;

2. Die Thatjadjen, ïber weldie bie Sernebmung $\mathrm{er}=$ folgen foll;

3. die Ambeifung, zux Mblegung ies Beugniffes hei Dermeidung Der Durd) Das (Befets angedrohten Strafer in Dem mad) Beit und Sit ju bezeidjnenden Termine ju expdjeinen.

\$34t. (1) Das (Berid)t Eann bie Sadutg Davon abs

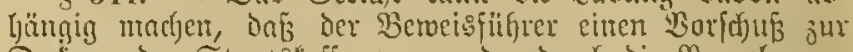
Dectung Der Stantalafie megen ber Durd) bie Bernehurumg Des Bengen crwadjenden ?tustagen binterlegt.

(2) .....

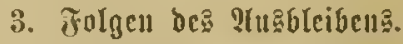

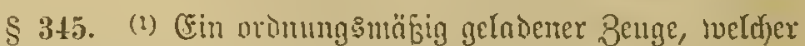
midut erfocheint, ift, ofne daß es eimes Intrages bedarf, in die Durd) has 2 usbleiben verurfadjten Sojten jorvic 3 u ciner

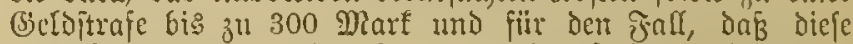

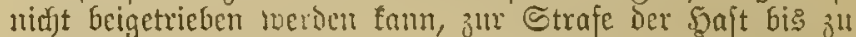
6 2sochen zu vermatheifcr.

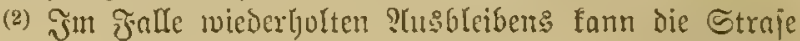

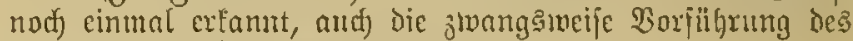
3engen angeoronet meroen.

(3) Begen dieje Bejd)lïffe findet bie Befdyerde ftatt.

(4) .....

\$ 346. (1) Dic Verurtheilung in Straje uno Sroften unterbleibt, ment bas Tnsbleiben des Zengen gentigend entichuldigt ijt. .....

(2) .....

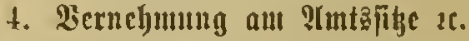

$\S 347 . *)$ Der Reidjêtonjler, die Miniter cines Buntes= jtantes, bie Mitglieder der Senate Der freien Sanjeftïbte,

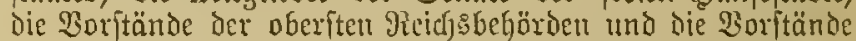
Der Miniferien fitt an ifrem Sintsjitze oder, ment fie fich auberlyalb defjelben aufbalter, an ihrem 2ufentfaltsorte zu bernehmen.

Die Mitglicder des ?ufenthalts nm Sizze bes Bunnesratlys an diefem Sitze, bie Mlitglieder einer Deutidfen gejetzgebenden VerfammLung währent der Sikungaperiode und ihres ?ufenthalts an Srte ber Berfammlung an biejem Drte ju vermelymen.

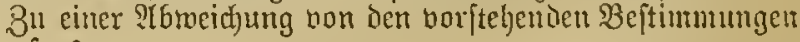
bedarf cas:

in Betreff bes Reid)stanjlets Der (Senchmigung Des Siaijers,

in Betreff Der Minifter und Der Mitglicder dcs Bumbes, rathg Der Benefymigung des Sandesherr,

in Betreff der Mitglieder ber Senate der freien 5anje= ftäote der (3enelymigung Des ङenats,

in Betreff Der übrigen vorbezeidjneten Beamten Der (Be=

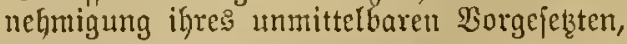

in Betreff der Mitglieder citter gejebggebenion $\mathfrak{S e r j a m u l u n g ~}$ ber Gionelymigung ber Ieţtercu.

\section{3ettguipuerweigerung.}

§ 348. Bur Berweigerung des Zeuguriffes find bered)tigt: 1. Der Berlobte einer \$artei;

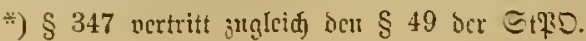


2. Der Ehegatte einer Fartei, audf Ivern Die Elje nidjt mehr beitelyt;

3. diejenigen, weldje mit ciner Fiartei in getnder Sinie berwandt, nerid)wägert oder durf Itooption ner= Gundert, oder in ber Geitenlinie biz zum 3. Gràe vertwandt voer bis zum 2. Birabe berjffrägert find, aut) wenn die (Ehe, Durd) meld)e sic Schmäger= ichajt begrïndet iit, nidjt meljr bejteht; ${ }^{1}$ )

4. Geiftliche in 2nfehurg desjenigen, was ifnen bei

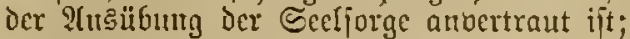

5. Ferjonen, melden frnft ifjes İutes, Standes oder Gerverbes Ijatjadjen anbertraut fino, Deren

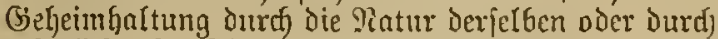
gejetslicfie Vorjdrijt geboten ift, in Betreff Det Thatjacten, auf roldfe bic Berpflicftumg jur $\mathfrak{B e r}=$ idjriegenthcit fidj bejicht.

Die unter $\Re$ r. 1-3 bejeifjneten Perjonen find bor ber

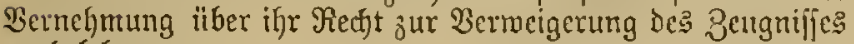
jub belehren.

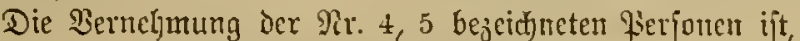
audf roen Das Beugniz nidjt bertweigert wirt, alli That=

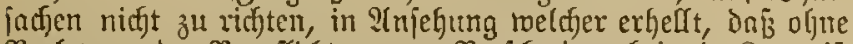

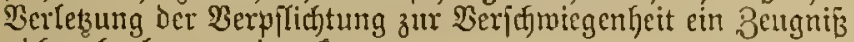
nidjt abgelegt werden fann.

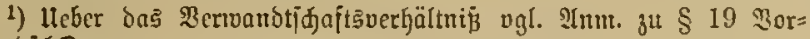

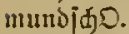

§ 349. Das Zengnifí fant vermeigert werben:

1. über Fragen, Deren Beantwortung dem $8 \mathrm{etugen}$ oder einer Berjon, ju meldjer Derjelhe in cimem

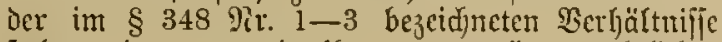
fteljt, cinen unmittelbarer bermögensitedftlidjen Edjaden berurjadjen wilrbe;

2. ïber Jrngen, deren Beantwortung dem Bengen oder einem der im $\$ 348$ शir. $1-3$ bezeidneten शlngehörigen ocjielben zur lltefre gereidjen ober bie (Bejahr itrafgeridtitldjer Sorfolgung zuzichen roilirde;

3. über Fragen, weldfe der Benge nidft mürde beant= morten fonnetr, oljne eit Sturit= oder Serwerbe,

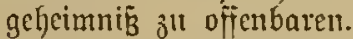

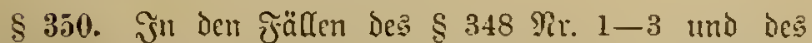

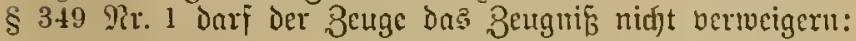

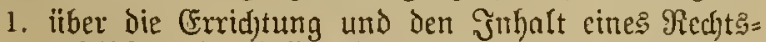
gejdjäfts, bei Dejijen Errifitung er alz Zenge jut $\mathfrak{g e c}_{j}$ ogen war;

2. ïber Geburten, Berbeirathungen ober Sterbejälle bon Familienmitgliedern;

3. ïber Thatjacjen, weldje bie surdy Das Jantilict= berbältnif beoingten Bermögensangelegenbeiten be= treffen ;

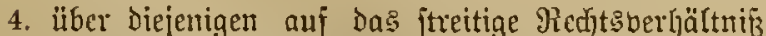
fid) $b_{c}$ iefender Sandlungen, weldie bon ifm jelbjt

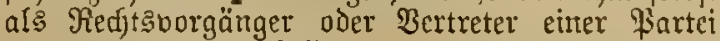
borgenommen jein jollen.

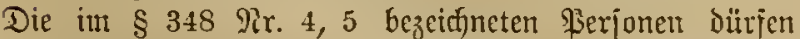

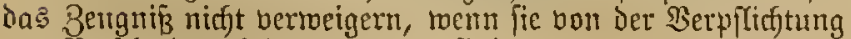
zur Berichroiegentheit entbunoen find.

$\S 351$. (1) Der Zeuge, weldfer Das Zeugnin bertweigert, hat bor Dem zll jeiner Bernehnung beftimmten Iermine

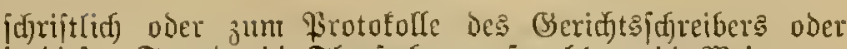
in diejem Termine die Thatiadfen, nuj meldbe er dic $\mathfrak{B e i g e r u n g}$ gründet, anjugeben und glaubhạt zu madben.

(2) Bur Gllaubljaftmadfung geniigt in Den ₹ällen bes $\$ 345$ g?r. 4, 5 bie mit Bermijung alli cinen geleifteten

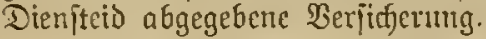

(3) Sont Der Beuge jeine Weigerung idrijtlich oder zum Brotofolle de pflidjtet, in dem zu jeiner Verneljmung bejtimmten Termine olt eriffeiner.

(4).....

\section{Jolgen ber $3 e n g u$ iguerweigermng.}

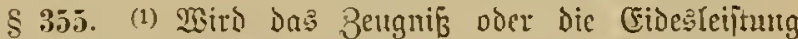

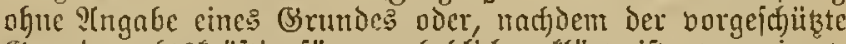

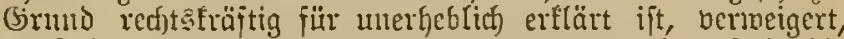
fo ijt oer 3euge, ohue das es eines Antrags bednri, in die burn bie weigerming vermijadten foften jomie ju ciner

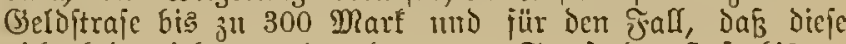
nid)t beigetrieben twerden fantr, zur Straje ber \$̧nf̣t bi: ju 6 wodjen zu bertutheilen.

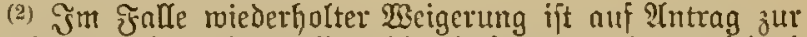
Erzmingung Des Zengmifies die Sajt anjuroten, jedod) nidjt $\ddot{3 i b a r}$ Den Beitpunft Der Becridigung Des Prozejfes in

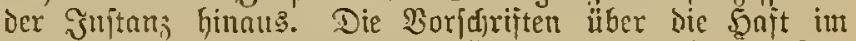

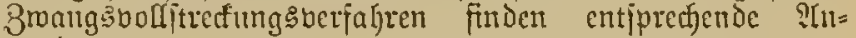
tocribung.

(3) Begen bicje Bejdylitje findet dic Bejdruerbe ftatt.

(4) .....

\section{Baceidigung und Bernefjuntu.}

\$ 3ä6. Feder 3euge iit cinjeln umb bor feiner $\mathfrak{B} \mathrm{cr}=$ nefmung öll bccioigen; dic Bccioigung farn jedod) aus be= jonderen (Srithden, tramentlicf) ment Bedenten gegen ifjec

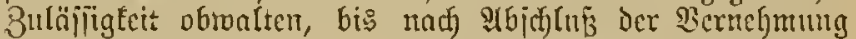
ausgefest merden.

Die Garteien fönnen auf bie Beciligung berjituten.

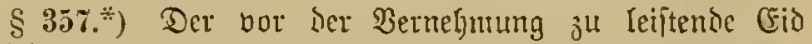
lautet:

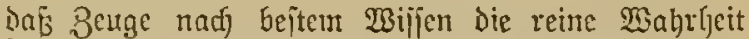
jagen, nidjts verjdjweigen unto ntdjts hinjujeţen merde; det nady ocr Bernebmung zu Ieijtende (Fid Lautet:

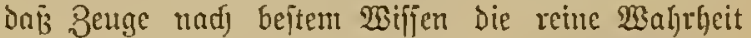
gejagt, nidjt veridjwiegen uno nidjts finzugejestst habe.

§ 35̄s. Unbeeidigt fino ju berrelymen:

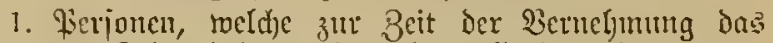
16. Sebensjafr nouf nidft volleniet oder inegen mangelnder Seritandesreife oder megen Veritandes: (id)twädje bon iem 'wejert und der Bedeutung bes Cides feire genitgende $\mathfrak{B}$ orftellung haben;

2. Werjouren, welche nadj Den Beftimumungen Der Straf= sejeşe unfülyig find, als Beugen eidlin bernommen oll roeroen; ${ }^{1}$ )

3. Die nad $\$ 348$ शir. 1-3 utd \& 349 Rr. 1, 2 zur Berweigerung des Zeugnifjes beredftigten Ferjonen, jofern fie von biejem ßiedhte Eeinen Gebraud madjen, die im $\$ 349$ Nr. 1, 2 bejeidjneten \$ierjonen jedodj nur bann, soenn fie lediglid) über foldje Thatjad)en

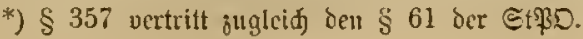




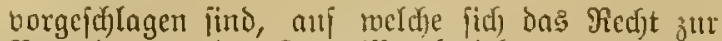
Bertwcigerung des 8cugniffes bezieht;

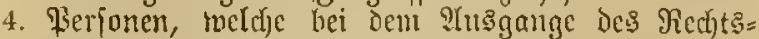
ftreits unmittelbar betheiligt finto.

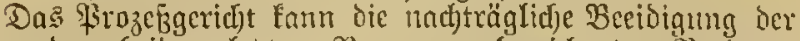
unter ben beiden lekzten Tummern bezeiduneten Pierjonen anoronetr.

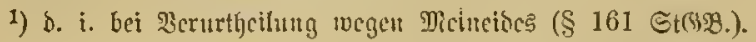

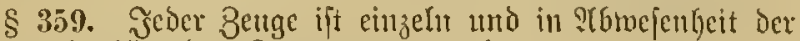
ppäter abăbörnden 3engen ju vernehmen.

Bengen, beren Nusfagen fich widerfpred)en, Ënnen cin= ander gegenilbergejtellt twerden.

\$ 360. Dic Bernchunng begimut Dannit, Daß Der Benge

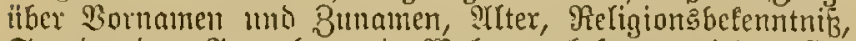

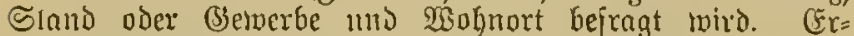
fordertidjenfalls find ifm ofragen ïber foldhe llmitrönde,

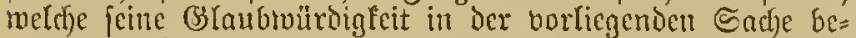

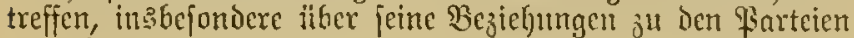
vorzulegen.

\$ 361. (1) Der Benge ift ju beranlaffen, Dasjenige, mas

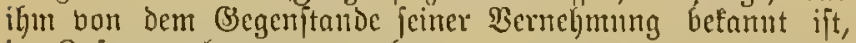
im Bufammentgange anzugeben.

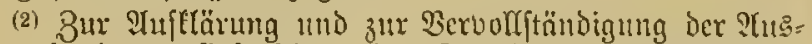

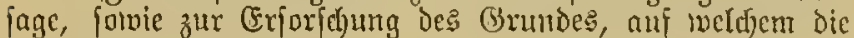

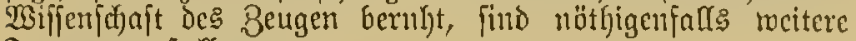
Fragen jull fteflen.

(3) ......

§362. (1) Die Fiarteien find beredtigt, Dent Beugen biejenigen fragen borlegen z"l laffen, meld)e fie jut ?hif= flärung ber Sache ober bex 3erbältniffe Deg 8cugen für. bienlid) cractiten.

(2) Dex Torfitzende fann Den Barteien geitatten min hat ifren :Inwälten auf Serlangen z"l geitatten, an ben Zengen unmitteloar frragen zu richten.

(3) ......

\$ 364. Die gisntei fonn auf cinen Bengen, weldyen fie vorgejdlngen hat, berjidten, Der (begner tam aber bet= langen, Daß ber erfdjienene Beuge bernonnten umb, twenn die Bernefmung bereits begonnen hat, daß̉ diefelte fortgejetst weroe.

\section{Gebilfrell.}

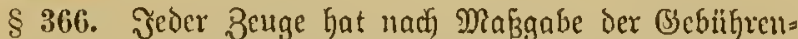

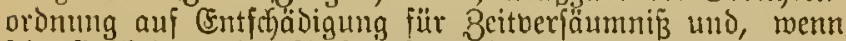

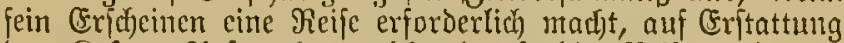

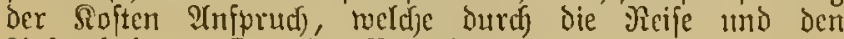
2ufenthalt ant Drte ber Bernefmung verurfacht roerben.

Bgl. (GcbD. für Bcugen uno Sacjocrftänoige v. 30. 6. 1878

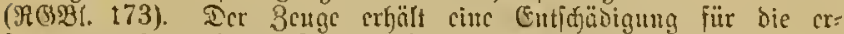

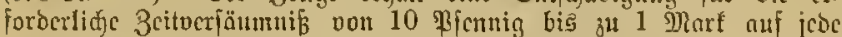
angefangenc Stunbe. Die Entjäbigung ift unter Betüufïd)tigung Des von bem Зeuacn ocrfäumten Ermerbes ju benteffer uto für jeden Ing auf nidjt mehr als 10 હtunbet 3u gewähren (\$ 2 bnf.).

Mubste ber Beuge ober Endjucritämbige ankerhalb oder imerhalb

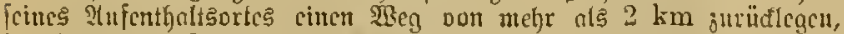
jo ift igu auferbcut cine Enjidn̈bignng für bie seife und für bcn

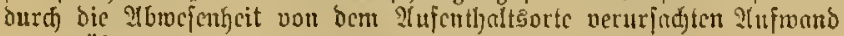
зи gervähren:

a) forocit bie Bemunutg von Tronsportmittelı fïr angemcjicn

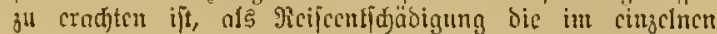

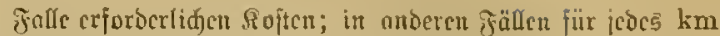
bes Sin= แnd Müdweace 5 Pfennia;

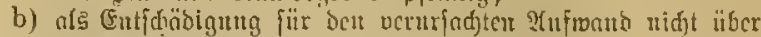
5 Mlarf fïr Den Tng ber S(bmejenlyeit uno nidjt ïber

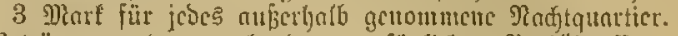

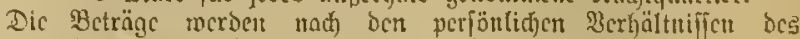

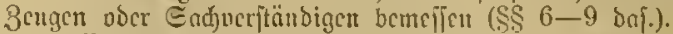

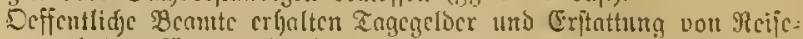
foften nad) ben für Dicufitrcifat geltenton \$orfduriften, folls fic ju= gezogen twerden:

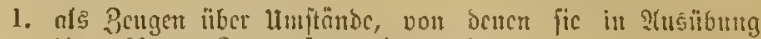
ifres ?intes ficuttuib crhalten l)oben;

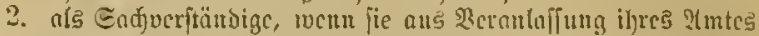

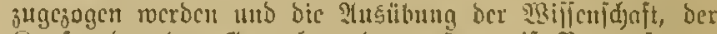

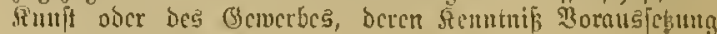
ber 3egutnditung ift, zu Den PFlidften bes oon if,nen ocr= feljeucu stutç gefjöt.

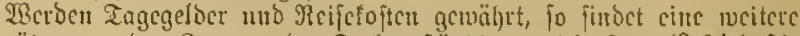
Rergïtung an ben Beugen poer Sadveritandiger nidjt ftatt (§ 14 bai.).

Gebühren der 3cugen utd Sadjuerftändigen merben un nuf

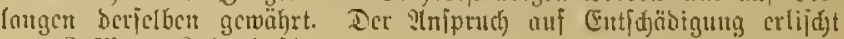
uach) 3 Moth. (S 16 bas.).

\section{Bemcis durd) Sinductitumdiac.}

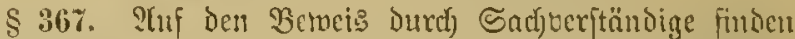
die Borfdriften thacr den Bebueis burd) Bettgen entpredjende

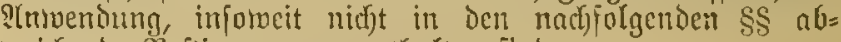
rocidjente Beftimmungen enthalten fint.

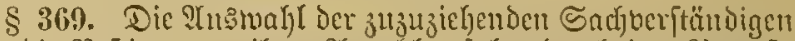

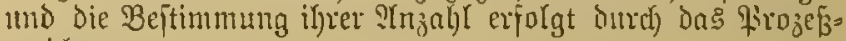
gericht. .......

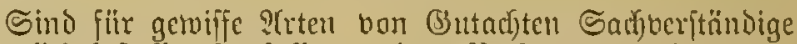
öffentlid) bejtellt, fo folfen andere Berjonen mux Dann ge= mäblt merden, mem bejondere llnijtände es crjorbern.

Das Beridjt fann dic \$iarteien aufforbem, Ficripnen in bezcidfnen, melelje gecignet jimo, als Sacfoerjtändige ncr= nommen zu iverden.

Einigen fidc) Dic \$arteien ïber bejtimmte Perjonen als Sact)verjändige, fo hat Das (Sericht diefer Einiguth Folge 3u geben; das (Bericht fann jedoch die Wahl ber Farteien auf eine bcjtimmte 2 (nģ

1. จด(ch)แng.

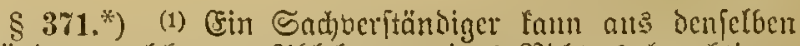
(Brinden, weldhe zur Nblehnung cines Ridter's bercetigen,

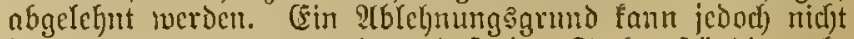

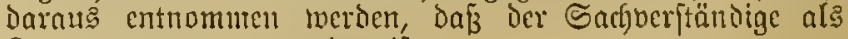
Berge bernommen morben ift.

(2) (3) (4) (5) ....

\section{Piflidit zur criftattumg von Gutachter.}

\$ 372**) Der zum Sner)berftändigen (Ernannte hat der Ermenmung Folgc zu leiften, wenn cr jur Erftottung bon

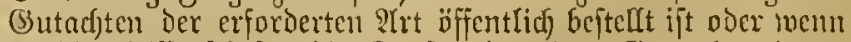

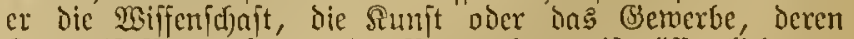
Senntnif Vorausfcksung Der Begutachtung ift, öffentlich jum

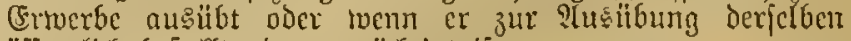
befentlicf) bejtelft ober ermächtigt ift.

Bur (Erftattung des (Butachtens ift and Derjenige ver=

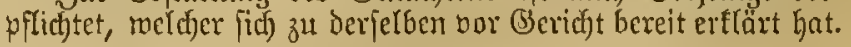

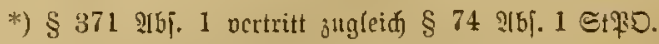

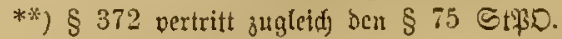




\section{Dicrueigerumg des (Butadtente.}

§ 373.*) Diejelben (Srïnde, weldje eimen 8cugen be=

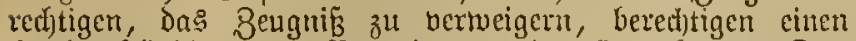

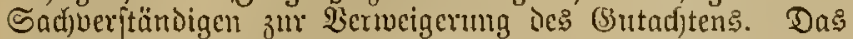

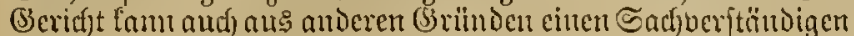
vou Der Verpflidytung 3ur Erftattung Des (Sutad)tet! ent= binden.

Die Bernebunumg eines öffentlidjen Beanten als Gad)= verftänbigen findet nicht ftatt, wenn oie vorgejelzte Behjübe Des Beamten erftürt, dố3 Die Bemebunm den dienftliden Jntereffen Radytheile bereiten wilrbe. $\left.{ }^{1}\right)$

1) গggl. $\S 3+1$ গIbj. 2 (367).

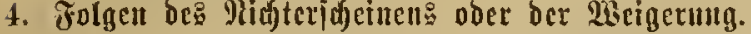

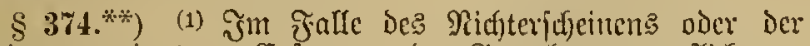
Weigerumg eine: jur Erftattumg Des Gutachtens verpflidyteten Sadjoeritändigen wiro Diejer zun Crifaţe Der fojten mo 3ll emer BefDitrafe bis zu 300 Miart verurtheilt. Sm Falle viederl)olten lingeljorfams fam nod) cimmal eine (Seld jtrafe bis zu 600 Peart crfanmt tucrden.

(2) (Segen ben Befd)luf findet Bejdjwerde ftatt.

(3) .....

\section{Bccidigung.}

\$ 375. Der Sadjocrftündige bat, menn niclit beibe Partcien auf feine Becioigung verzidyten, bor Sritattung Des (G) thad)tens einten (Eid Dahin zu Leiften:

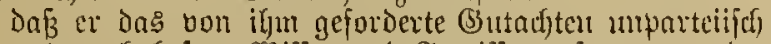

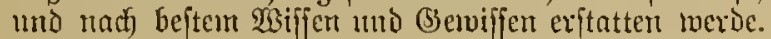

Şt Der Sacfberftändige für Die errftattung bon (Sntad)ten Der betreffenden ?lat im allgemeinen becidigt, fo genügt bie Berufurg auf ben geleifteten sio.

\$ 376. Wird idyriftlicje Begutadytung angeoronet, fo

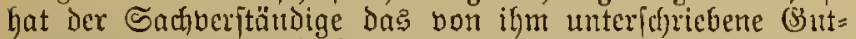
achten nuf ber (Berid)tesfd)reiberci niever julegen.

Das (Sericht fann Das (Exjojeinen Di's Sadfberftändigen antoronen, Damit Derfelbe Das fduriftliche (Sutad ten ertäutere.

\section{Gebïlren.}

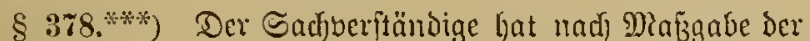

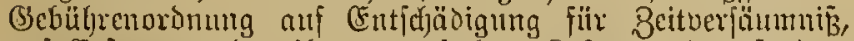
auf (Erfattung Der ifur berurfachten Soften uno auserdem auf angemeffene Bergittung iciner Mrithewaltung ?tnjprudf.

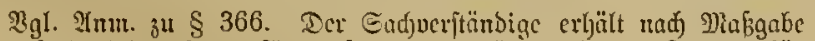
ber erforocrlidjen Beitver[äumniß cine sergütung bis zu 2 Marf für

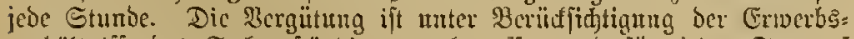
verbältuiffe bes Sadjpcritüntigen zu bemefien mo fïr jeten Tag auf

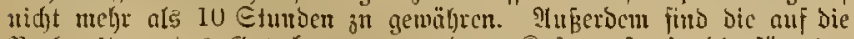
3orbercitung bes Butadftens vernendeten Siojten, folvie bic für einc

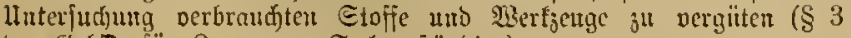
Der BebD. für Betgen tr. Sadjuerftünoige).

\section{Tiewsis Durd Alrkmueu.}

\section{Defïentridje ltutuben.}

\$ 380. (1) ltrfunien, weldje bon einer offentlicten $\mathfrak{B} e=$

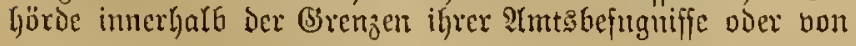

*) $\$ 373$ vertritt 3ugleich bet $\$ 76$ EtæB

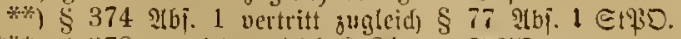

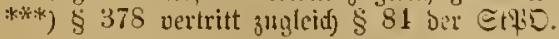

einer mit öffentlidjeu (5jLathen verfehenen Berjon immerfalb

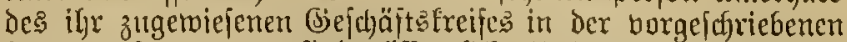
Form aufgenommen fint (öffentlidje llifumben), begründen, wenn fie utber eme vor der Behörbe oder Der llrfundsperfon abgegebene (Exflärung erridjtet find, volfen Scrweis des Duref)

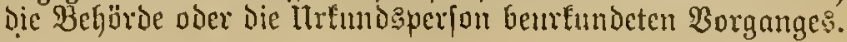

(2) .....

\section{Privaturfundu.}

\$ 381. Fribaturfunden begriinden, fojern fie bou ben W(usftelfern unterf(hrieben ober mittels gerid)tlid) oder notaried beglaufigten 5andzeichent unterzeidyet find, bollen Beweis bafïr, bá̉ die in denjelben enthaltenen Eretärungen bon den 2 tusfteflern abgegeben find.

§ 384. Эnwiejern Dumbjtreidyngen, Rabirungen, (Ein= frjaltungen oder fonftige äubere Diängel die Bemeisfraft eimer Ilrefunde ganz oder theilweife aujheben oder mindern,

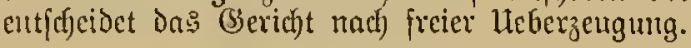

\$ 385. Die ?ntretung Des 23etweifes erfolgt Dutch bie Sorlegung Der HrËแnde. ${ }^{1}$ )

1) Cinte öffentlidge Urfunte fam in Uridgrift ober in ciner bc:

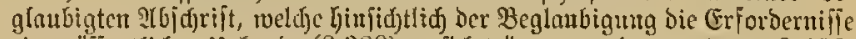
ciner viffentliden Urfutbe (\$ 380) an fid trägt, vorgelegt werden. $\$ \$ 00$.

\$ 386. Befundet fitu Die llrfunde nach Der \$ehauptung

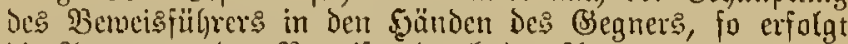

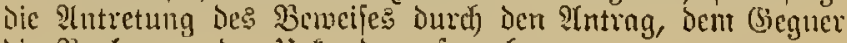
Die Borlegung ber lletunte aufjugeben.

\section{Iltulubencio.}

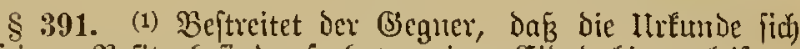

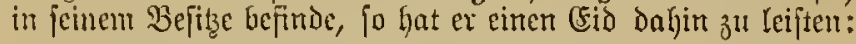

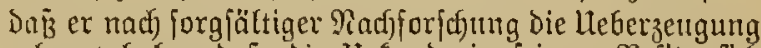
crlangt loabe, daf bic Ilrfunde in feinem Befitze fid

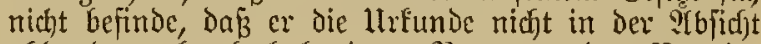
abljanden gebrad)t habe, Deven Benutzung Dent Beweis= fitlyer zu entzichen, Dof er auth nicht riffe, wo bie Ilifimbe jiff befinde.

(2) (3) . . . .

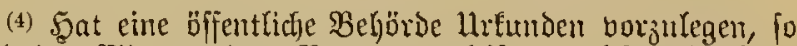

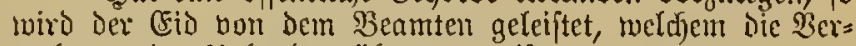
makrumg der ltrfunden ïbertragen ift.

\$ 406. (1) Der Betweis Der Estutheit oder Unect)theit

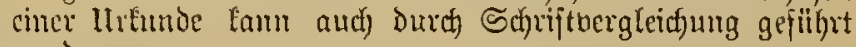
mertell.

(2) (3) (4) . . . .

§ 407. Ileber Das Ergebniß̄ Der Sthriftuergleidyung hat Das (Sericht nad) freier Heberzeugung, gceignetenfafls nad)

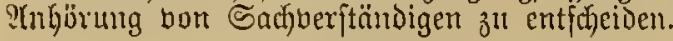

\section{Beweig Durd) EFid.}

1. 3ugejdobener (Eib.

$\$ 410$. Die (Fideszzudjefoung ift nur über Thatianfen juläffig, weldye in Soandlungen des (Begners, feinter Medht: borgünger oder Bertreter bejtehen oder welde (Begenftand ber Wabruebnung dicjer Sierfonen getuejen fint. 
§ 413. (1) Die Bmühfodjicbung Des (Fides ift nu in= pojern zuläfïig, als nad) Den Beptummungen bes $\$ 410$ Die Bufdjiebung deffelben zuläfïg fein twitrob.

\section{(2) ......}

\$ 414. Der Eis lam mu Der Fartei, midft einem

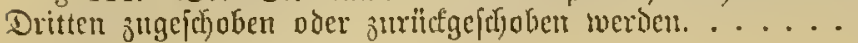

\section{Itebrergeugutugeid.}

\$ 424. Heber eine Thatjadje, weld)e in ciner bondlung Des Cdywurpflichtigen bejeft ober Begenftand jeiner $\mathfrak{B a h r}=$

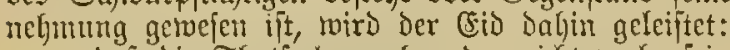

Daf Die Thatfadje maht oder nidjt tualy pei.

Şt eine foldhe Thatjactje bom Biegner des Seflum= pifichtigen beljauptet uno fann bent lesteren mady ben llm= ftämoen Des Folles nidht zugemuthet werden, oaf er die

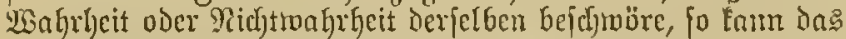
(Serid)t nuf STntrag Die Reiftung Des Eides Dalin anoronen:

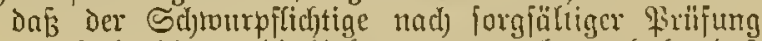

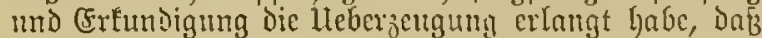
Dic Thatfacie walgr oier nidjt walis fei.

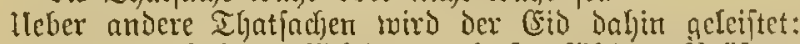

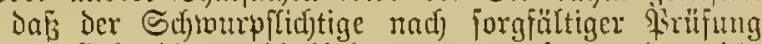
und Crefunsigung bie lleberzengung erlangt ober nicjt crlangt habe, Das bie Thatiadie mahr fei.

§ 428. Dutruf Reiftung Des (Fides wird voller Betwei: Der bejulworenen Thatfacke begritndet.

Der Bemeis des Begentheits findet nur unter denfelben

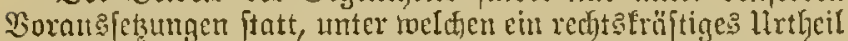

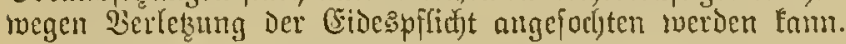

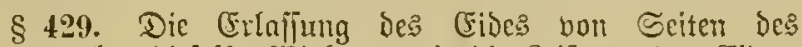
(5egners hat Diefelbe 20irfung, wic Die Reiptmng Des CFides.

Die Sertweigerung Der (Eibesleijtung hat our jolge, Dafs ons (Segentheil ber zu bejdjwörenden Thatjadje nls bolf be= wiejen gilt.

$\S 430$. Crfdyeint Der Scfmmplidftige in Dem zur (Fides= leiffung beftimmten Termine nidit, jo ijt anf ?lutrag ein

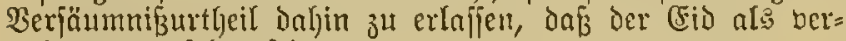
weigert anjujeljen fei.

\section{Midjterlidjer (Eid.}

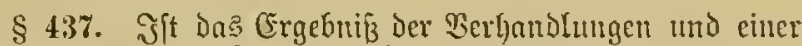

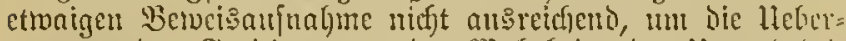

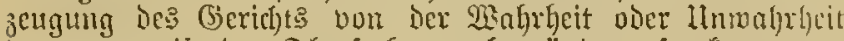
Der zul ertweijenden Thatfacje ju beqritmben, fo fom das (Berid)t Der einen ober Der anderen Firtei diber eine jtreitige Thatjache cinen (sio auferlegen.

Durd Reiftuntg biejes (Eides wirb millyt voller Beweis ber be

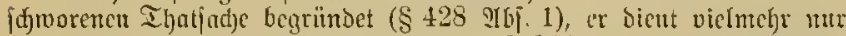

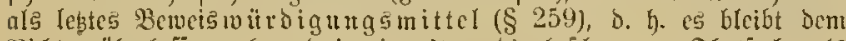

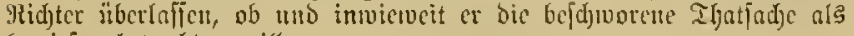
berviefen betradjten will.

\section{IIerfaljen bei Der Abnaljme von Eiden.}

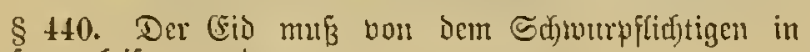
Berjon geleifet werden.

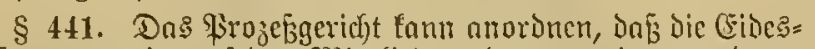
Leiftung bor einem jeiner Mitglieder ober bor einem anderen

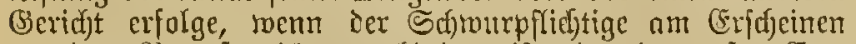
vor Dem Stozeñgerid)te berlindert ift oder in grofier (Ent=

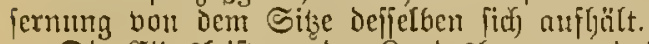

Dic Cibesleiftung Der Eandesherren ntio ber Mitglieder der Landeşbertichen Jamilien, fowie Der Mitglicder Der
Fiirftlidjen Jantilic Szohensolern erfolgt in der Wohnumg derjelfen bor cinem Mitgliede des Prosésgeridgtz ober vor einem anderen (Sierid)te.

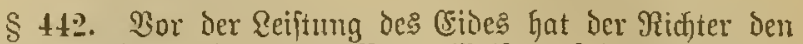
Sflymupflidfigen in angemefiener 20 eije auj Die Bedentung bes Cribes linzuncifen.

\$ 443.*) Der (Fio beginut mit den Wopten:

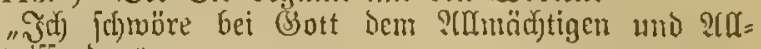
mifienden"

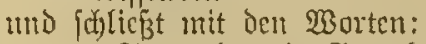

"So walyr mir (Sott helfe."

\$ 444. (1) Der (FiD mird mittels ఇachjpredjen: oder TrGlejeng Der Die Gidesnorm enthaltenden Cidesformel ge= leiftet. Der Sdjwb̈rende foll bei Der CFidesleiftmb Die redjte Şand erheher.

(2) -

(3) Die Enndeglyerren mo die Mitglieder der Landes=

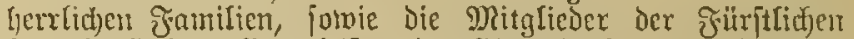

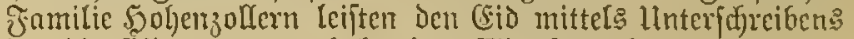
Der bie Eidesnorm entfaltenden CFibesformel.

$\$ 445$. Stumme, weldje fdreiben lömen, leijten den

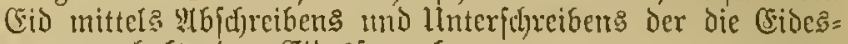
norm enthaltemben Cidespormel.

Stumme, weldye nidht fdreiben Ë̈men, Ieiften den (sid mit seillfe eines Dulmetichers durdf Bcidyen.

$\S 446 . *$ ) Der Eidesleiftung mird gleidfgeadjtet, wem!

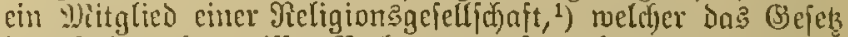
Den (jebrauth gerwifier Betlyenerumgsforneln an Stelle Des.

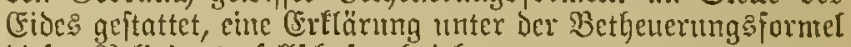
Dicjer Religionsegefelfid)ajt abgicbt.

1) 3. B. Micuroniten.

\section{Sidjermu Deg Brurifrs.}

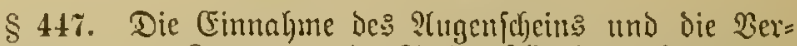
nelymung bon Bengen und Sadjueritändigen foun jux Sid)erung des serweifes exfolgen, twenn ju beforgen ijt, Du[3 Das SBemeismittel verloren odex Die Benthung Deffelben criffinert werbe.

§ 448. Das (Sejud) ijt bei Dem (Beridgt anjubringen,

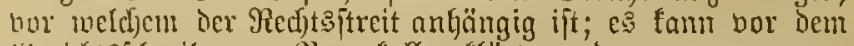

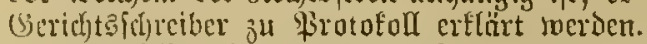

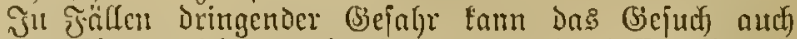

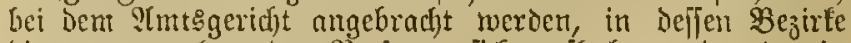

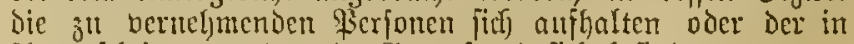
Sfugenffyein ju nehmende (Gegenftand ficf befurdet.

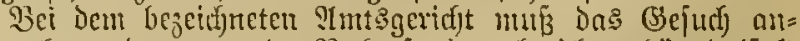

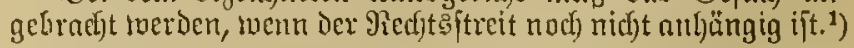

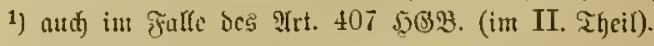

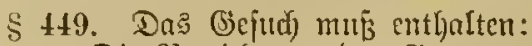

1. Die Bejeidjutung des (Biegner: ;

2. Die Bejeidjunng Der Ifatjadien, über tweldye die Bemeisanfnalyme erfolgen joll;

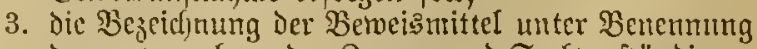
Der zu vernchmenden Zeugen und Sadjberftändigen;

4. Die Darlegung des Grumbes, tweldyer bie Bejorgnił rechtertigt, Daf Das Betweismittel berloren oder Die Benubing Dejelben exfffmert werde. Diejer (Sramb ijt glaublyaft zแ maches.

*) \$ 443 vortritt jugleid ber $\$ 62$ ber StฬD.

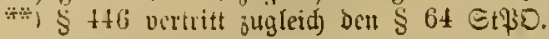




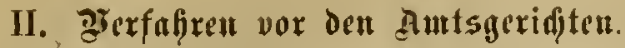

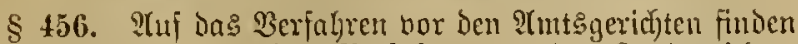

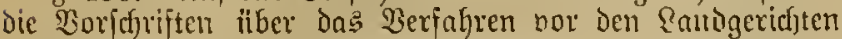

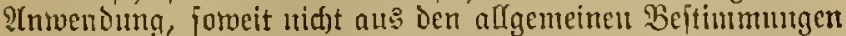

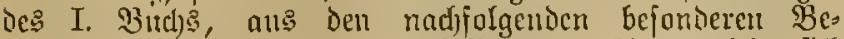
ftimmungen uno als Der Serfaffung Der S(mtsgerid)te fich) (brveid)ungen ergeben.

$\S 45 \%$ Die SIlage tann bei Demt Berid)te idrriftlidj ein= gereicht odcr zum firotololle des (Serid)tefd)reibers angebract)t werdent.

§ 458. Ract) exfolgter Bejtimmung Des Terming zแx

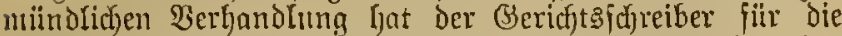
Buftellung Der Rlage Eorge zu tragen, fofern nid)t der Rläger 'erelärt lat, bieles felbjt thim zu wollen.

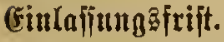

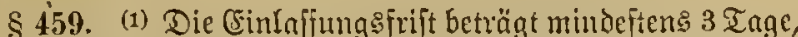

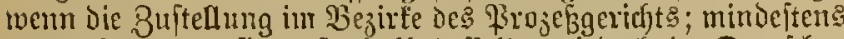
1 Boodfe, wenn fie anfierhalb Deffelben, jedody int Deutidjen Reicf exfolgt; in Mes $=$ und Marftad)en inindeftens 24 Stumber.

(2) .....

$\$$ 460. Die Slage wiro burd) Buitellung der Silage= fidrift ober Des dic Silnge enthaltenden Prototolls errjoben.

\$ 461. 2(n ordentlicjen (Beridytstagen tönne!: dic Bisarteien jur Berlyand (ung des Rechtsftreits ofne Radung und Termins: beftimunung bor (serid)t erfdeinen.

Die (Ertyebung Der Rlage erfolgt in biefem Falfe durd) den niindlid)en Bortrag Derfelben.

§ 464. Bei Der mündidjen Derhandlung hat Das (Bericht Daljin zu wirken, Doñ die Barteien ïber afle erheblid)en

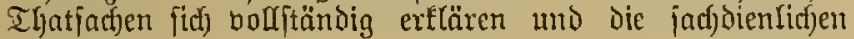
Intrüge ftellen.

471. (1) Wer cine Silage zu erheben beabfichtigt, fanm

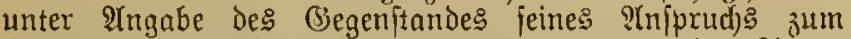
3rocte eines Sïfneberind) Den (Segner bor Das îmte: gerid) Iaben, sor meld)en diejer feinen affgemeinen (Serid)t: itand liat.

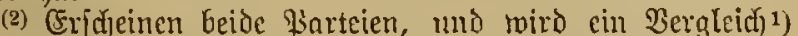

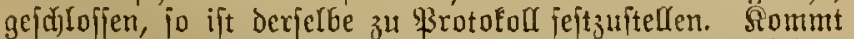
ein Vergleid) nicft jul Stande, fo wiro auf P(ntrag beider \$arteien Der Rechtsptreit fofort perhandelt; Die Crrhebung ber Slage erfolgt in biejem Falle Durd) den mündlichen Bortiag delfelben.

(3) ......

1) Diefer Bergleid) ift volfitređbar (\$ 7029 ?r. 2).

\section{Buch. Medjsmittel.}

\section{I. ב̉ent futg.}

\$ 472. Die B̧erujumg findet gegen Die in I. Jnjtand erfaffenen (Fitdurtheile ftatt.1)

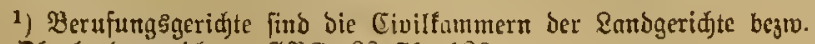
Die Eberíandešgeridte. G2G. $\$ \S 71,123$.
\$ 476. (1) Die Buribfualume der Berufung ift ohne Ëin= willigung des Berufungsbeflngten nur big zum Beainne

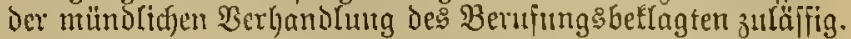

(2)

(3) Die Buruffnalynte hat Den $\mathfrak{V e r l u f t ~ D e s ~ R e d f t s m i t t e l g ~}$

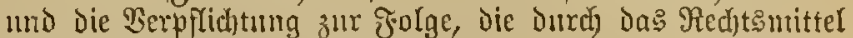
entftanienen §often zu tragen. . . . . .

Berujutgifrift.

$\S 47 \%$ Die Berufm

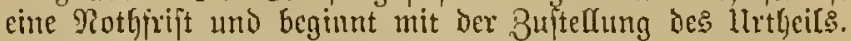

Die Bernfung fann gleidjoeitig mit der 3uftellung des Urtheifs eingelegt twerden. Die Einlegung bor $3 u=$ ftellumg Des lltheils ift wirfungstos.

§ 479. Die CFinlegung Der Berujmg erjolgt ourd) $8 \mathrm{u}=$ itellumg eines Sdyriftiabes.

Dexielbe mus enthalten:

1. Die Bejeidfung des llrtheils, gegen meldfes bie Berufung gertututet roiro;

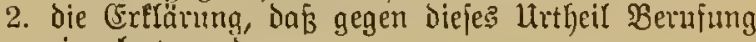
eingelegt werde;

3. Die \&adung deE Djerufung rufungsgerid)t sut mündlidjen Bertandrang iiber die Berufung.

Berujungs̊nanträße.

$\S 480$. Die allgemeinen Bejtimmungen über bie bor=

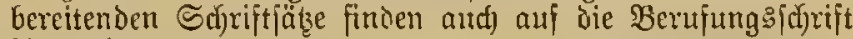
Intwendung.

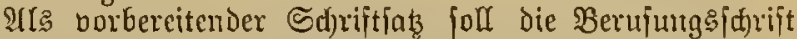

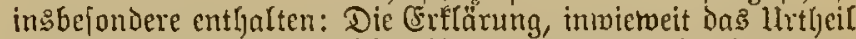

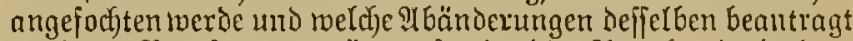
werden (Berufungsanträge), jowie Die S(ngabe Derjenigen neuen Ihatjacfen uno B3etweismittel, weldfe bie \$artei gelteno zu mad)en beabfidtigt.

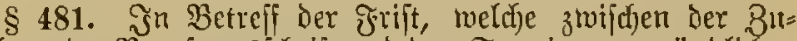
itellung Der Berufungsfd)rift uno Dem Termine zur mündlidjen Berhandhung liegen muß finden die Borfdyriften Des $\$ 234$ entfprechende âduculumg.

\$ 484. Der Berujungsbeflagte hat Dem Berujungstäger dic $\mathfrak{B}$ eantwortung Der Berufung innerhalb ber erften $2 / 3$ ber Beit, meldfe zmifhen der Bujtellung Der Berujungs(d)rift und Den Termine jur mündliden Verhandlung liegt, mittels vorbereitenten Sduriftiatzes juftellen zu laffen.

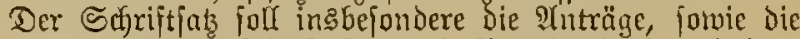
Ingabe der neuen Thatjadien und Berweismittel enthalten, meldje der Berufung:beflagte geltend zt madjen beabfichtigt.

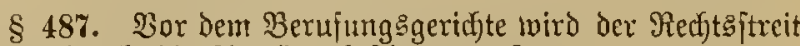
in Den Durd) die Yrnträge beftimmten (Brenzen bon neltem verhandelt.1)

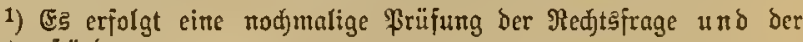
Thatumftänoe.

\$ 489. Cine Renderung Der Slage ift felfft mit Sin= milligung des (Begners unftattlynt.

§ 491. (1) Die Barteien tönnen 2(ngriffs theidigungsmittel, weld)e in I. Jnjtanj nidjt geltend gemadf) fino, insbejondere neue Thatjachen uno Berveimmittel bor= bringen.

(2) ..... 
\$ 497. Das Berufungeggerid)t ljat bou 9(untsuegen zu prijen, of die berufung nut fich ftatthaft nt10 ob fie in ber

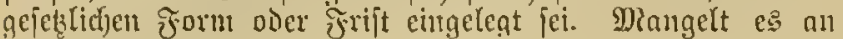

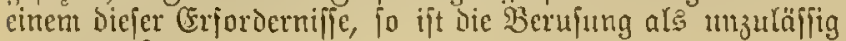
ju berwerier.

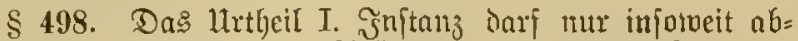
geämbert werden, als eine Abändering Eeantragt ift.

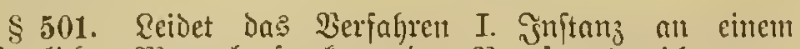
mejentlicfen Diangel, fo fann Das Berufungsgeridt unter Tlufhebung des lirtheile und bes Serfahrens, foweit das leţtere ottrd) Den Dlangel betroffer wirb, Die Sactie an Das

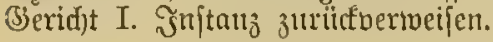

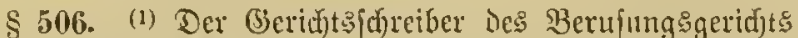

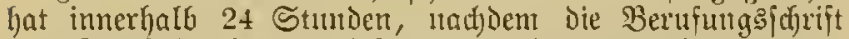
zum Zwede der Termintbbeftimmung cingereicht iit, vort dem (3eridftoffyreiber des (Berid)ts I. Jnftanz die \$rojefzaften einzufordern.

(2) .....

\section{Dievifiont.}

$\S 50 \%$ Die Revifion findet gegen bie in Der Berufungs = injtanj bon den Sberlaubesgerideten erLaffenten (Endurtljeile (tatt. ${ }^{\text {) }}$

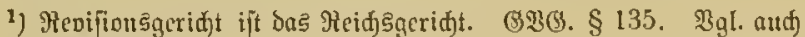

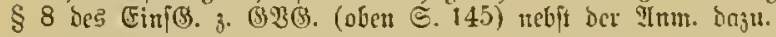

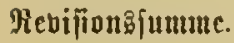

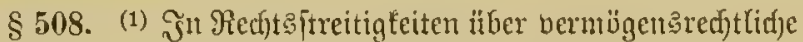
2nfprüche ijt Die Bufáffigfeit Der Revifion Durd einen Den Betrag vour 1500 Miart iberfeigenden Werth des Bejdyerde= gegenjtandes hedingt.

(2) (3) $\ldots \ldots$

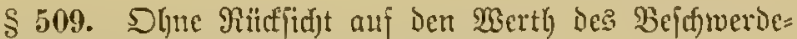
gegenitandes findet bie Rebifion itatt:

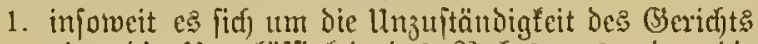
oder bie Unzuläffigfeit des Yied)tsmegs oder die Ulnz̧uläffigfeit Der \$Berttfung lyandelt;

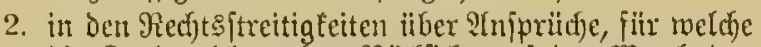
Die Eandgerichte ohne Rüufficht auf den Werth Des

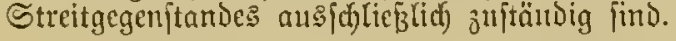

\$511. Die Revifion fann nur Darauj geititist meròn,

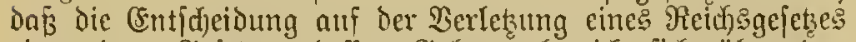
oder eines (sejetzes, deffen (Seltungsbereid) fidh ïber den Bezinf bes Berufungsgerichts hinats erftrecft, berulje.

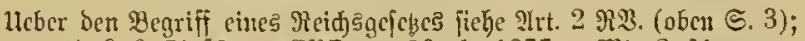

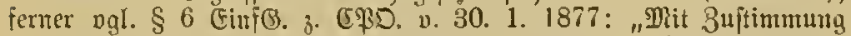

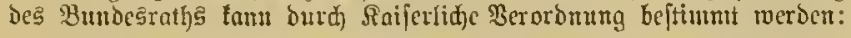

1. Suf bie Berlepuntg von Beicken, obgleid) Deren Beltutggbercid) (id) über ben Begirl bes Berufungsgerid)te finaus eritredt, bie Renifion nicht begrüttbe;

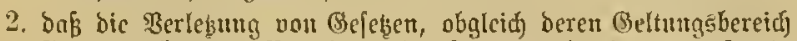

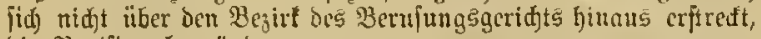
bie গievifion begründe.

Dis anf Brumb Der vorftehcnoen Bep̆timunungen crlaffenen $3 c t=$

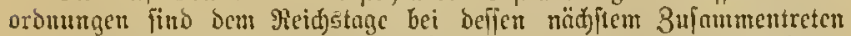
3u: (Benchunigutg vor

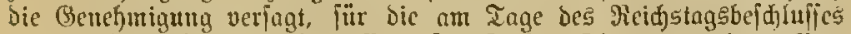

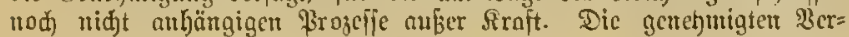
oromungent fönnen un burd Reidsgeję geäntort obcr aufgehobent merben."

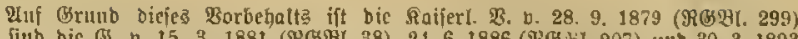

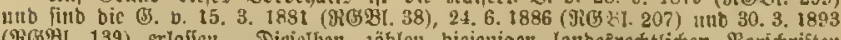

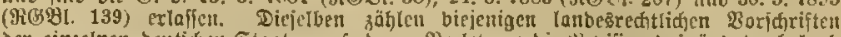

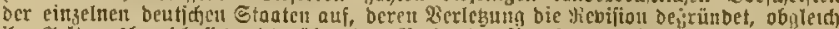

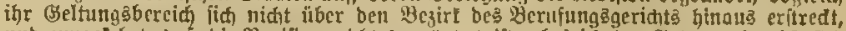

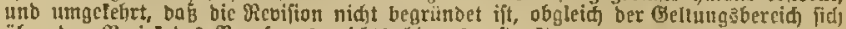

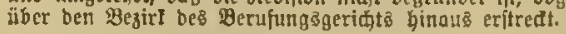

\$ 513. Eine (Entidjeidung ift ftets als auj einer Ber=

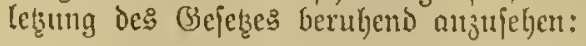

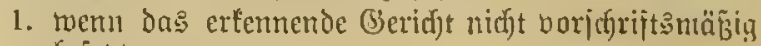
Gejeţt mar;

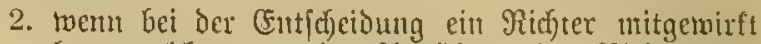
hat, meld)er bon ber ?tugitbung bes Michterants

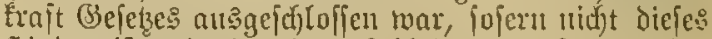

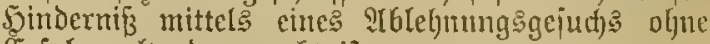
(Frjolg geltend gemad)t ijt;

3. wenn hei Der Entidjeidung ein Ricjter mitgemirft hat, obgleid) derjelthe wegen Beforgnif ber $2 \mathfrak{B}=$ fangenljeit abgelehnt nnd das ?tbrehnutgsgefuct) fiir begründet erflärt war;

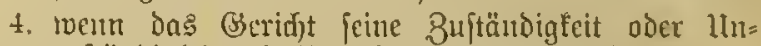
juftändigkeit mit luned)t angenomnten hat;

5. went eite Fartei in Dem Berfahren nidft nad) Borjef)rift Der (Gejesze bertretent war, fofern fie nidjt

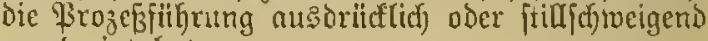
genehmigt lyat;

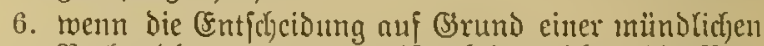
Berhandlung ergangen ift, bei melefjer bie $\mathfrak{B}$ or= fdjrifter über Die Deffentlidfeit des Berfahrens verlekst find;

7. Wenn Die (Entfd)cibung nidyt mit Srïnden bes= jehsu ift.

Mevifitongịnifit.

\$ 514. Die Rebifinnşrift beträgt 1 Monnt; ite ift cine Nothirift und Geginnt mit Der Bujtellung des Untheirs.

Die Revifion Eann gleidzeitig mit Der Zuftellung Des Urtbeite eingelegt merben. Die "Finlegung bor Zuitellung des llttheils ift roirtungshos.

\$ 515. Die (Eiulegung Der Rebifion erjolgt Durd) $84=$ ftellung einte Schriftabes. Derjelbe nutú enthalten:

1. Die Bezeidjnung des llitlyeils, gegen weldjes die Fevifion gerid)tet twito;

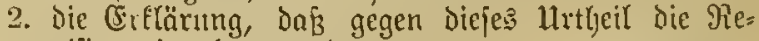
bijian eingelegt werde;

3. Die Sadung Des Revifiongletlagten vor bns Re= vifionsgeridjt zur münolidfen Berbandlung ïber die Mievifinti.

Revi|īon̊̊anträge.

§516. Die allgemeinen Beitimnungen über dic vor= bereitenden ङchriftäbse fuben aud) aut die Renifinnsidfrift TItwendung.

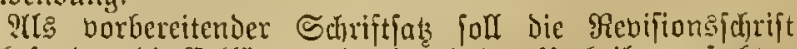
insbejondere die (Frttärung, inmiemeit das llttheil angejod)ten und Deffen Shufbebung beantragt werde (Renifionsanträge),

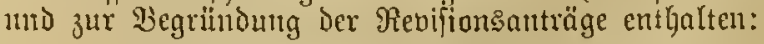

1. injoweit Die Revifion Darauf geftütst miro, daf cine

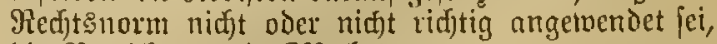

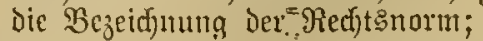

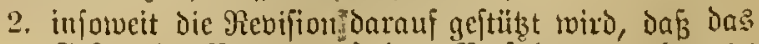

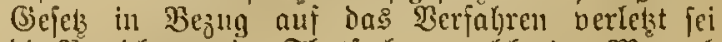
Die B̧ezeidjunt Der Ihatjadjen, wetdje den Mangel ergeben; 


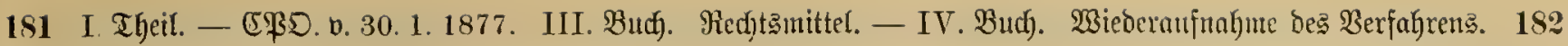

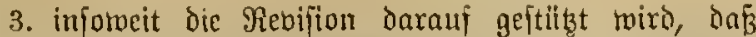
unter Berleţung des (jefetzes Thljatjachen fejtgejtellt, ülsergangen oder als vorgefradjt angenommen feicn, die Bezeidmung diejer Thatfadfer.

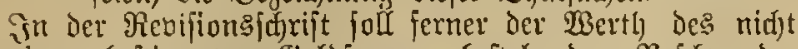
in einer bejtimnten (Beldjumme beftehenden Befdreerde= negenitandes angegehen werden, ment dic Buläfitgleit der Revifion bou diejen $\mathfrak{k e r t h e ~ a b ́ a ̈ n g t . ~}$

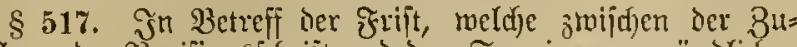
itellumg der Revifionsfortift und Dem Termine jur mündlidjen

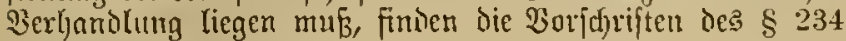
entipted)ende S(ntwendung.

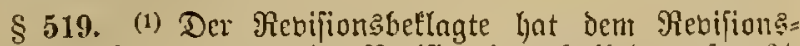

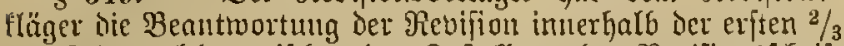

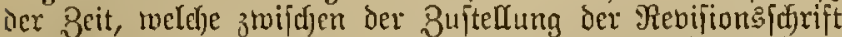
แmi Dem Termime ju münolidjen Berfandlung liegt, mittels vorbereitenden Sdjrijtjaties juiftellen jull Iafjen.

(2) ......

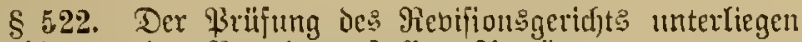
nur bie bon den ßarteien geftellten Ŷnträge.

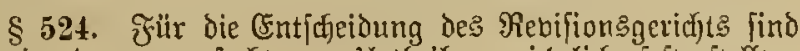
die in dem angejochtenen llatheile geridhtlid jeitgeitellen

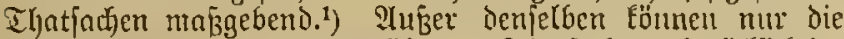

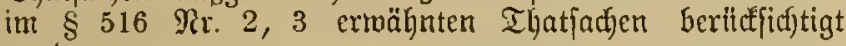
merden.

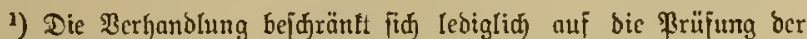
औedtsfrage, int Begenjak jur Berufung (ogl. $\$ 487$ ), bei weld)er

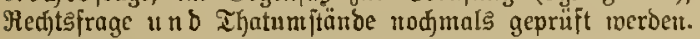

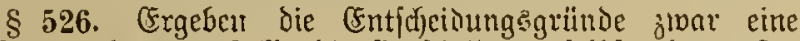
Gejescesverlebzung, ftelft bie (Entjd)eidung felbft aber außser anderen Sritinden fich als ridjtig bar, fo ift bie Revifion jurüc̆́zumeifen.

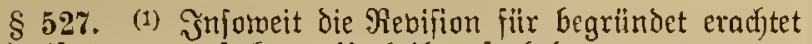
miro, ift das nugefodhtene Urtheil aufatheben.

(2) ......

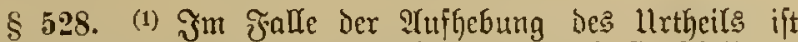

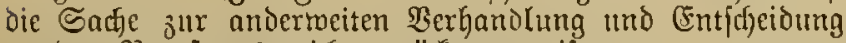

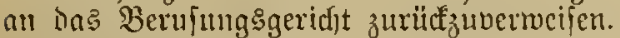

(2) Dajielbe hat iie redftlidje 3 beurtheilung, tweldje der ILffhebung ju (S)tunde gelegt ift, aucf feinet Entidjeioung jul Srunde ơl legen.

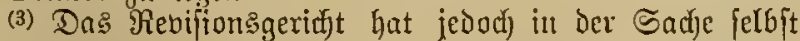
zu entfuction:

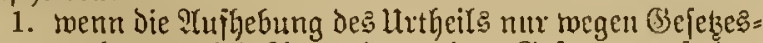
berletzung bei PInmendung Des Gejeķes auf Das jeftgejtelte Sadjberljältniß̧ erfolgt uno uad) letzterem die Sactje ơut (Endentid)cidung reif ift;

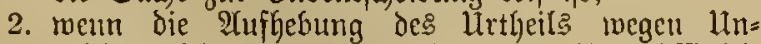
zujtändigfeit bes (Serid)t des Red)tatwegs exfolgt.

(4) .....

\section{Zerfdiwerde.}

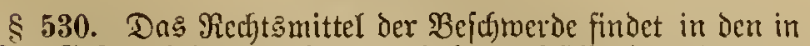
Diejem (Bejekze bejonders herborgehobenen fä̈llen ${ }^{1}$ ) und gegen

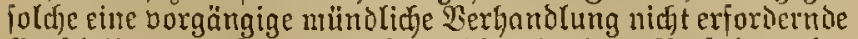
Enticheidungen ftatt, durdf meldhe ein das Berfafject be= treffendes (sefudf) jurǚffgetbiefen ift.

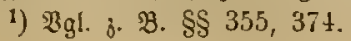

Weitere Bejdjtuerbe.

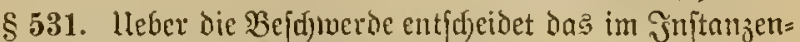
juge junädhft föblyere (Geridft.")

Begen die (Entjdfeioung des Bejdmerdegeridjte ") findet, joweit nidft in derjelben cin neuer jelbftftündiger Beja)merde= grund enthalten ift, eine meitere Befflwerbe nicht ftatt.

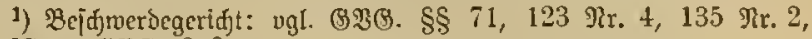

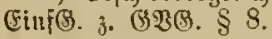

§532. (1) Die Bejufjuerde twiro bei Dem Berifjt ein= gelegt, non weldyem oder bon dejien Borfiţenden die an= gejod)tene Entidjeidung erlaffen ift; fie fann in bringenden J̋̈llen auch) bei dem Bejd)werdegerid)t eingelegt merden. $\left.{ }^{1}\right)$

(2) .......

1) Eime frift ift nidht voracidricben. Eine Frift, und 3mar cinte Mothfrift von 2 शुoden, melde mit ber 3uftelltung bezm. Der Ber=

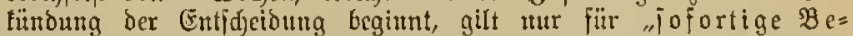

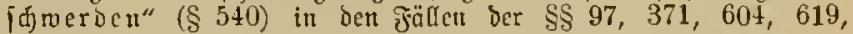
$639,813,829$ แ. a.

8 534. (Erad)tet das (Sericht pier der $\mathfrak{B}$ orfizende, deffen (5ntjheidumg angefod)ten mird, die Befdyerder für begründet, jo haben fie derielben abjuhelfen; anderenfalls ift die $\mathrm{bc}$ jdjwerde bor stblauj 1 23odje Dem Bejdwerdegeridjt bor= zulegen.

§ อ̃35. (1) Die Bejdjmerde ljat nur baun auffifiebende Wirtung, wenn fie gegen eine ber in Den $\$ \S 345,355,374$, 579,619 erroäfhten (Entjijeidungen gerichtet ift.

(2) (3) .....

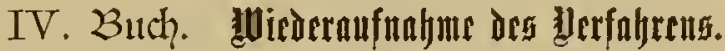

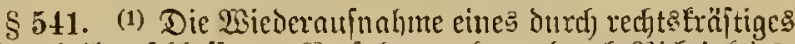

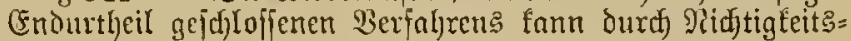
Elage und burdh Reftitutionsflage exfolgen.

(2) ......

1. Ridtigfeitgllage.

$\S 542$. Die Ridtigfeitsellnge findet jtatt:

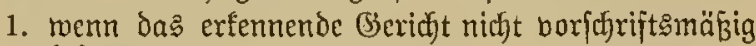
befest mar;

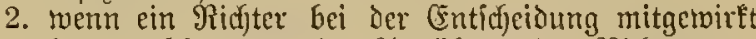

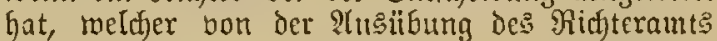
frajt des (sefebes nuspefichlofifen mar, fofern nidjt

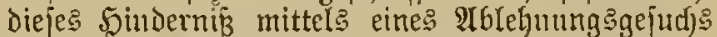
oder eines Rechtsmittels ofne Exjolg geltend ge= madyt iit;

3. menn bei der Entjufioung ein Riffer mitgemirtt hat, obgleich berfelbe roegen Beforgnißa ber $\mathfrak{B} e=$ fangenbeit abgelelint und das Thlebnungsgefuch für begrïndet erllärt twar;

4. wenn eine Bartei in Dem Verfalyren nidyt nadj Borjdrift Der (Sejeze bertreten mar, fofern fie nid)t

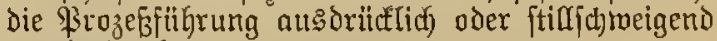
genelymigt hat.

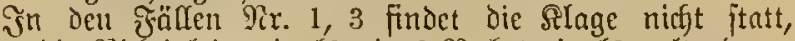
wenn bie 9ichtigleit mittels cines Fect)tînittels gelteno ge= madt werden founte.

\section{Meftitutiongernge.}

$\S 543$. Die $\Re$ is ititution\&llage findet itatt:

1. menn der (Segner Durd) Reiftung eines ßarteicides, auf melche bas Urtheil gegründet ift, fich einer

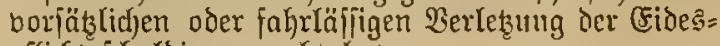
pflidit idfuldig gemad)t ljat; 


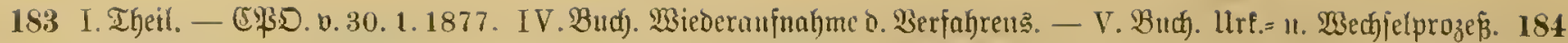

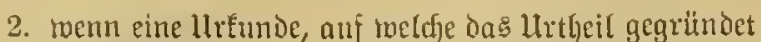
ift, jäljchlict) angefertigt ober berfäljfjt twar;

3. wenu Durdf Beeidigung eines Beugniffes oder eines (Sintadtens, auf meldhe Das llrtheil gegrimbet ift, Der Beuge ober Der Sadjoerftändige fidf einer vor:

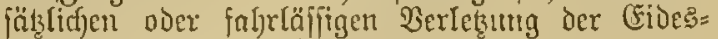
pflicht fouldig gemacht ljat;

4. mern das llrtheil bon den Bertreter Der Sartei ober von beur Gegner ober deffen Bertreter Durcth eine in Beziehung auf Den Rechtegtreit veribbte Sandlung ertvirft ift, melcte mit eincr im $23 \mathrm{ege}$ Des geridgtlichen Strafberfahrens z̆ verhäugenden byfentlicten Straje beoruht ilit;

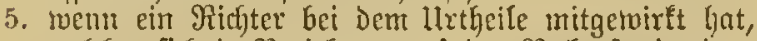
welder fidf in Bejieljung auf Den Rechtâftreit cinter

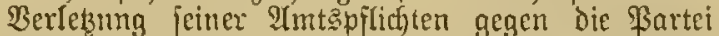
ichuldig gemadbt hat, fofern dieje Berleţung mit ciner in Wege des geridutlidjen Strajberjahrent ju berbängenden öffentichen Straje Gedroht ift;

6. เwent ein frafgeridjtlicfes Urtheil, auf reláses das lltetheil gegrintet ift, Durd) ein anderes redfts= fräfig gemordentes urtheil aufgeljoben ijt;

7. Ivenn Dic Bartei

a) ein in Derjelben Sadje erlajfenes, frïber redyts: fräftig gemordenes Urtheil, oder

b) eine andere lurtunde auffindet oder zu be= mutzen in den Stand gejetzt mird, rbelche eine ihr günjtigere (Entidyeibung berbeigefïhrt haben twürde.

Dieje Beftimmung fommt in dem unter b bezeicf)neten Jalle nidjt zur ?Imbendung, wenn das angefodhtene llrtheil Darauf benht, Daß̧ auf (Gramb ciner Ceideslcítung des (3)egneres die betreffende Ihatjacte oder Deren (Begentheil fïr berwiefen eraditet ift.

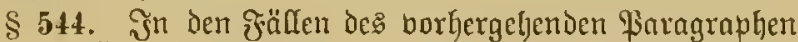

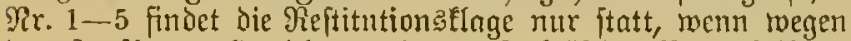
Der ftrafbaren Şandlung eine rentitgfräftige Berurtheirnng ergangen ift, ooer roem die Crinleitung ober Durdffülyrung eines Strafberfahrens aus anderen (S)rittden, als twegen Mangels an Betweis nifft erfolgen Earn.

Der Betweį ber Thatjadjen, weldye die Rejtitutionsklage

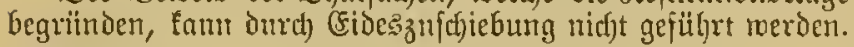

\section{Friften.}

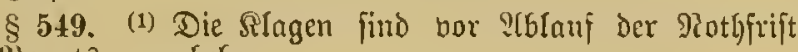
1 Dionats ju crbeben.

(2) Die Frift beginnt mit berr Tage, an melafem die Fartei bon dem Infechtungşgrmnde Renutrif erbalten lat,

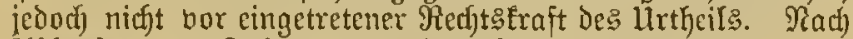

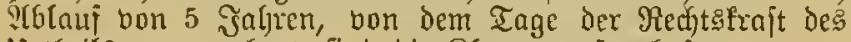
Urtheils an gerechnet, find die 尺lagen unjtatthajt.

(3) .....

\section{Buch. IIrkutdent= und}

\section{Unfunbeuproję.}

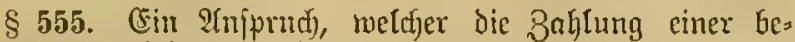
ftimmten Belifunme over die \&eiftnng einer bejtimmten Duantität anderer bertretharer Sachen ober Wertypapiere zum (Begenftande lyat, fann im llrundenprozefie geftend gemadjt werden, wenn die jämmtlicfen gtir Begrindung des

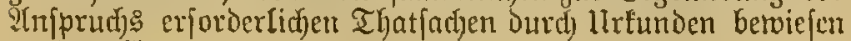
rwerden fönnen.

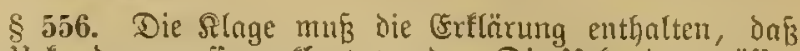
im ltrfundenprojeffe geflagt twerite. Die lluknden mitifien

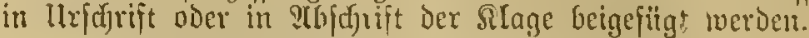

\$558. (1) MiderElagen fino nitft itattljajt.

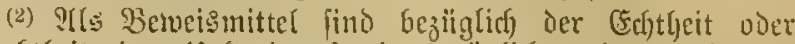
ltureftheit einter llufunde, fomie bejüglidy anderer als der in \& 555 ermähnten Thatfad)en nur ltrtunden mo Eides=

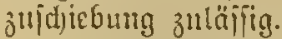

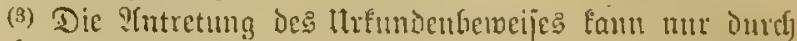
Borlegung Der lltfunien erfolgen.

(4).....

2. 2iecdjelprosể.

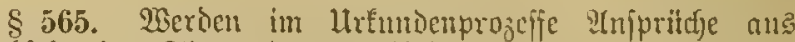
2Bedjfeln in Simne Der Weebfelordnumg geltento gentadt

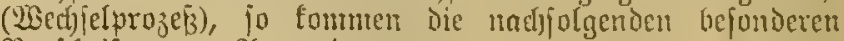
Vorjebriften jut înwendung.

\$566. Wectfelflagen lömen foroohl bei Dem (S)ericfte Dic: Bahlungsorts als bei icm (Serid)t angeftellt verien, bei weldyem Der Beflagte feinen affgemeinen (B)erid)tefftand bat.

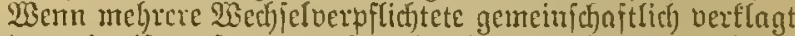
merden, fo ift auber bem (serichte des Bahlungtorts jedes (Beridjt juitändig, bei relehem einer Der Beflagten fcinen allgemeinen (Seridjtêftand hat.

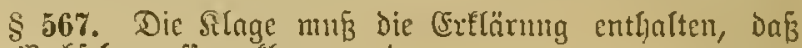
im Wechjelproseffe geflagt merbe.

Die Cinlajfungşrift betrögt, wenn dic Silage ant Sitze des (Berichts jugeltellt wiro, mindeftens 24 Stmmoen; weun iie all einem anderen Drte im Bejirfe des (jeridjt: zu= geftelft twird, mindeitens 3 Tage; wenn fie an einem anderch

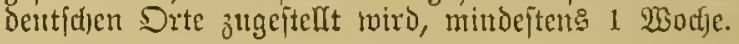

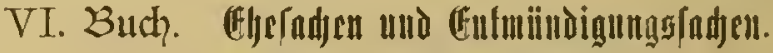

\section{I. כ̧erfafiren in Ëfiefadien.}

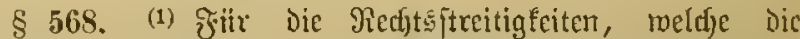
Tremmun, lingültigteit noer Ridntigfeit einer (Ghe noer die Seritellung Des ehelicfen Rebens jum (Segenitante haben (Ehefachen), ift bas Randgeridyt, bei sveld)cm ber Ehemant

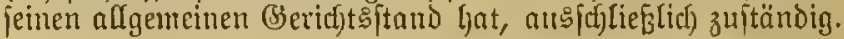

(2) .....

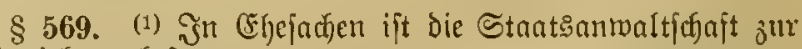
Mitmirfung befugt.

(2) (3) (4) ....

Eiifucueriudis.

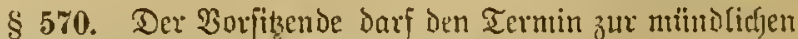
Berbandung über eine CFefdeioungetlage oder ïber eine Rlage nuf seritellung des eljelidjen Rebenz erjt feitjetsen, twenn Den nadjjolgenden Boorjdriften über Den Sühneberjudf geniigt ift.

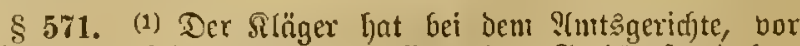
weldhem Dex Ebentom jeinen aflgemeinen Beridhtsjtano hat, Die ?Inberaumnng eines S̈̈ilyneterming ju beantragen uno zu Diejem Termine Den Beflagten ôt laden.

(2) .....

§ 572. Die \$arteien miifjen in dem Süfynetermine

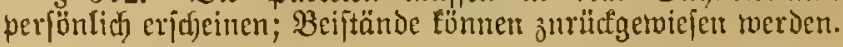


Eridjeint der Släger oder erjodeinen beide Barteien in

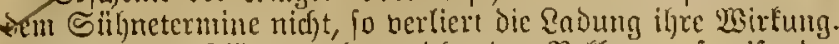
Exjdjeint Der Släger, aber nidfst Der Beflagte, jo ift Der Silgneberjud) nโs mis̆(ungen anzujehen.

8573. Der Sillneverfud) ift nidjt erforberlid\}, wom der ?hifenthalt bes Beflagten unbefount oder in ?uslaute iit, wenn dem Silfoneverjude ein anoeres jofner zu be:

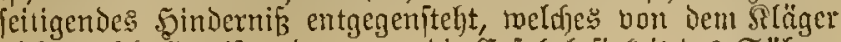
nicfyt verfduldoet iit, oder menn die Crfolglofigteit bes Sühne= verfuth mit Beftimmtheit norausjufelon ift.

lleber Dos Borljandenfein diejer $\mathfrak{B}$ oransjekzungen ent=

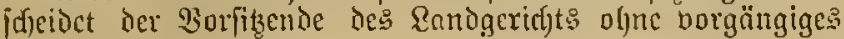
Geljör des Beflagten.

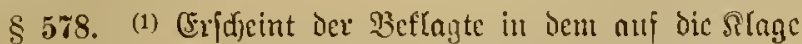

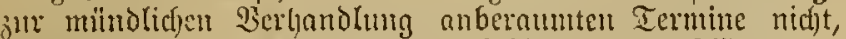
jo fan erft in emem nelten, all sintrang des Srägers j"l beitimmenden Termine berbandelt werden.

(2) (3) (4) (5) . . . .

§579. (1) Das (B)erid)t fann Das perfönluche Exideinen

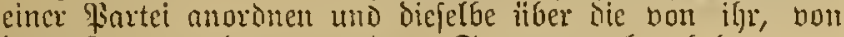
dem (Sisgner ober bou dem Stnatsanmalte behaupteten Ilyatjacfen bernefymen.

(2) .......

(3) (Begen die nidft erfdjienene Fartei ift bie gegen einen im Bernchmungsterminte nid)t erfdyienenen Betgen ju ber=

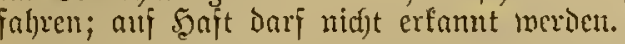

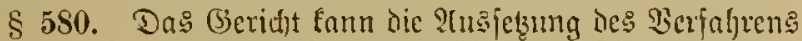

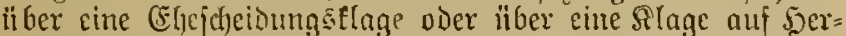
jtellung bes efelid)en Sebens von Thutsmegen anoronen,

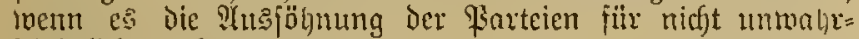
id)einlid) eradjtet.

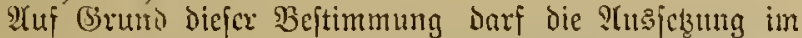

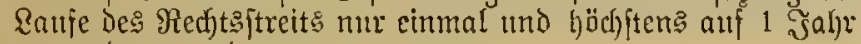
antgeorbnet werdent.

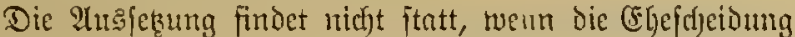
alf Grund cines (Ehebrudfos beantragt ift.

§ 581. Zum Zुwecfe Der :(uprechterfaltung Der (E) Eam

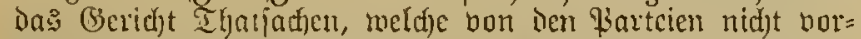
gebradjt fint, berüdfidjtigen mid die TYujnafime von Berveifen

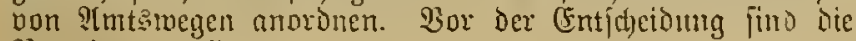
Farteien j"ll hören.

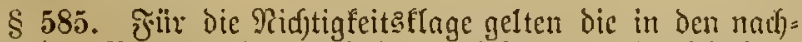
folgenden Paragraphen enthaltenen bejonteren Borfajriften.

$\S 586$. (1) Die flage fann aud) bon der Stantsammalt= idjajt erfoben werden.

(2) ......

§588. Solange dic Chegatten leben, famn die Nidutigfeit cince (E) aus einem (Sirumbe, meld)er aud bon ? geltend gemadyt werden Eann, uur auf (3rund einer Nidjtigkeits: flage ausgejprodjen merben.

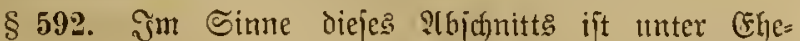

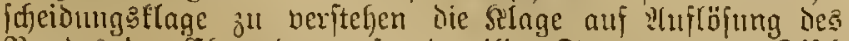
Bandes der (Ege oder auf zeitmeilige Iremmung von Tiff)

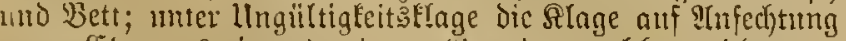

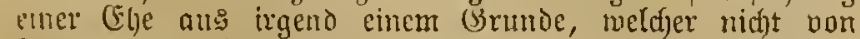

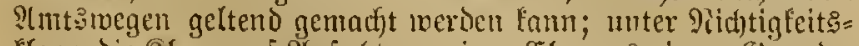
floge bie Slage auf 2lnject)tung ciner (5)e ants einem Grunbe, meldjer aud) bou ?(mtstucgen geltens gentad)t verten fann.

\section{II. Ḋierfafiren in Entmïudigungsfadjen.}

Geifte ŝtrutle.

\$ 593. Cine Ferjon taum fiir geiftesfrant (malynfumig,

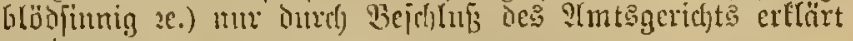
meriten.

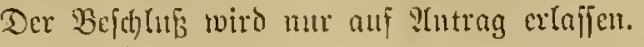

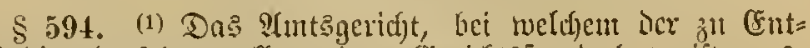

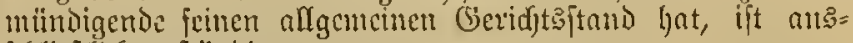
ichlieģlid) jultüntıig.

(2) ......

§ 595. Der Ŝntrag fom bon Dem CGegatten, cinem

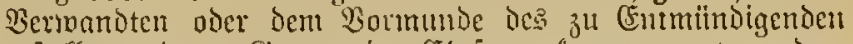

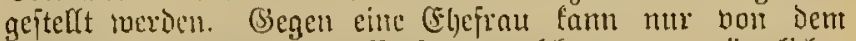
Ëljemame, gegen eine *ierjon, welche unter väterlidjer (Bewalt oder unter Bormutujfjajt itelyt, nutr bon dem Bater

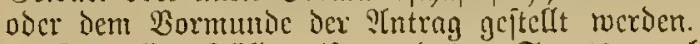

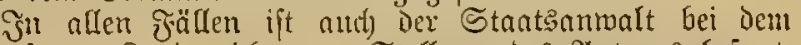
vorgefetzten Eandgerichte jut Stellung Dç Antrags bejugt.

$\S 597$. (1) .....

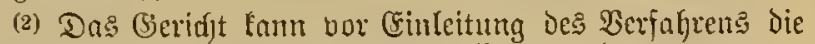
Beibringuth eines ärötlidfen Beugnitjes anoronen.

(3) (4) . . . . .

$\S 598$. (1) Der ju (Entmündigende ijt perjönlich unter 8ujiefyung eines oder mehrercr Sachocritändigen jil ber= neljuten.

(2) . . . . .

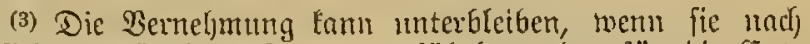

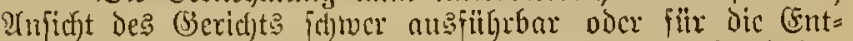

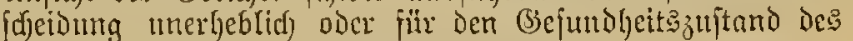
zu Entmindigenden nachtlycilig ift.

\$ 599. Die Entmulinbigung dorf nidjt ausggciprocten Iwerden, Gevor bas (jeridjt einen odcr melyrere Sadjperftändige iiber den (S)ijtez̧ujtand des zu Entmïnoigenden gefört hat.

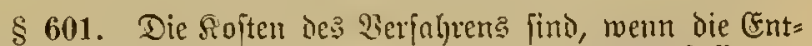
mïndigung erfolgt, von dem (snmilnbigten, anderenfalls von det Sinatîtalie jut tingen.

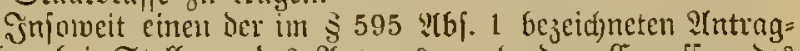
itelfer bei Stellung des ?tntrags thad) dem (Frmefien des (jerichts ein Berfhulden trifft, tönnen demjelben die Rojten ganz oner theilmeije zur Rajt gelegt werdent.

$\S 603$. Der die Gntunindigung ausppredjende Bejuluß

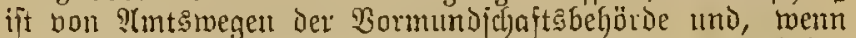

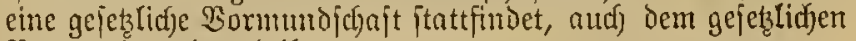
จ้ormunde mitzuthetlen.

Mit Der Mittljeilung Des Bejc)lujes an bie $\mathfrak{B}$ ormund= (d)aftêheljörde tritt bie Entmündigung in wirffamteit.

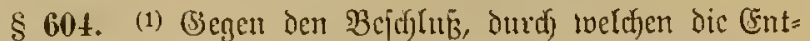
mündigung abgelelgnt miro, ftelft dem SIntragitefler und Dem Staatsanmalte dic jojortige Bejdymeroc ${ }^{1}$ ) zu.

(2) ......

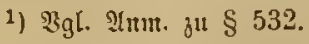

$\S 605$. (1) Dor Die Entmündigung ausfpredfente $\mathfrak{B} e=$

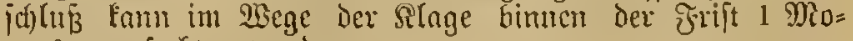
nats angefoditen inerden.

(2) (3) .... 
187 I. Theil. - EPD. v. 30.1. 1877. VI. Bud). Ehejaden u. (Entmitndiguttgąadjen. - VII. Bud). Mahnberfahren. 188

§ 606. Fitr bic Rlage ift Das Ranogeridjt, in Defjen

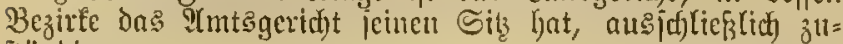
itündig. ridutert.

\$ 607. (1) Die Slage ift gegent Dell Staatsanmalt zu

(2) Erlyebt der Stantananwalt die §lage, jo ift Diejelbe gegen Den $\mathfrak{B}$ ormutud des Centmitndigten als Bertreter Deffelben zu ridjten.

(3) .....

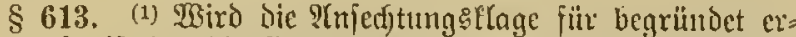

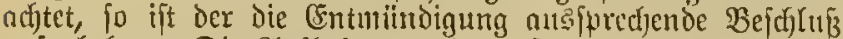

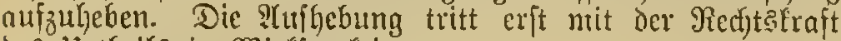
Des Urtheits in Wirffamteit. ......

(2) .....

§ 616. Die Wiederanfbebung Der (5ntmündigung erfolgt nuf Intrag Des Entmïnthigten oder jeines Bormunbes oder

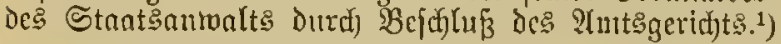

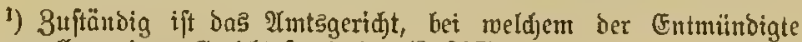
feinen allgenteinen Geriđtsftand hat (\$ 617).

$\S 618$. Die Sojten deక $\mathfrak{B e r f a b r e n s}$ find von dem (Futs miindigten, wenn das Berfahren bon Dem ङtantęnnmalt ohne Erfolg beantragt ift, bon der Staatsfaffe zul tragen.

$\S 619$, (1) (2) . . . .

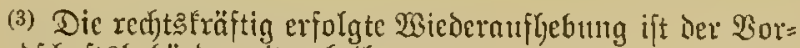

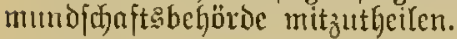

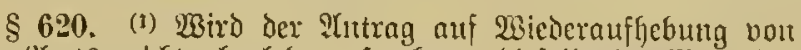
dent 2 (nttsigeridjt abgelehnt, fo fam diefelbe in Wege der Slage beantragt merden.

(2) (3) (4) .....

3uftändig ift bas Rantogeridjt nađ) $\S 606$.

\section{Berjofituentoer.}

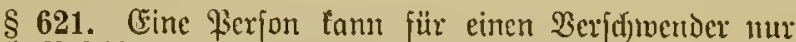

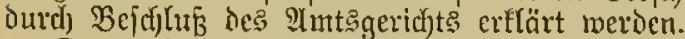

Dex Beidfluf́ mird nur auf Strttag erlaffen.

शtuj Das Berfabren finden die Vorjdyriften der $\$ \S 594$,

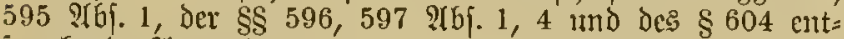
iprectjende Ámmendung.

(Fine Mitwirking ber Staatsantwaltjufaft findet nidft ftatt.

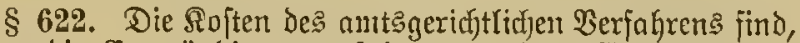
vemn dic Entmündigung exfolgt, bon Dem Cntmtündigten, anderenfalls bon bcm intragitellet on tragen.

$\S 623 .(1) \ldots \ldots$

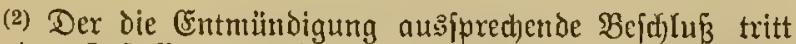
mit Dex 3uftellung an Den Cntmltndigten in Mirffamfeit.

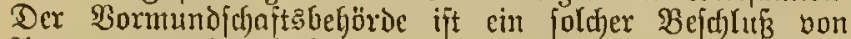
T(mesimegen mitzutheilen.

§ 624. (1) Der bie Entmünbigung antsppredjende $\mathfrak{B C}=$

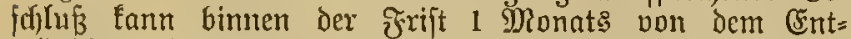
münDigten in Wege der ßlage argefodjten werben. ${ }^{2}$ )

(2) Die Frifit beginnt mit der 3ujtellung des Bejuluffes an ien (5ntmiünigten.

(3) Die slage ift gegen Denjenigen, inelther die Ent= milndigung beantragt latte, falls aber dicfer verftorben, odex fein Itufentlyalt unbefannt odex im Iluslanic ift, gegen Den Stantsanmalt jut tichten.

(4) . . . . .

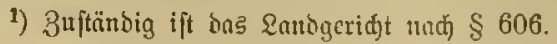

\$ 625. (1) Die 2ric Deraufbebung Der Entunïnoigung er=

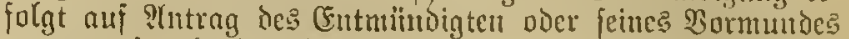

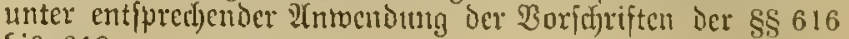
bis 619 .

(2) .....

$\$ 626$. (1) Wird der :Tutrag auf Wicderauflycbung von

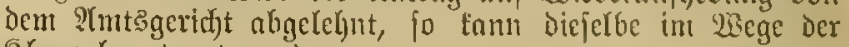
Slage heantragt weroest.

(2) (3) (4) .....

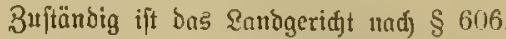

\$ 627. Die Entmündigung einer Fierjon negen $\mathfrak{T} \varepsilon=$ f(t)wendung, fowie die Wicdernufjefuntg einer fold)en (Ent= nuindigung ift bout bem ?Tmtsgeridjt iffentlidf befant zu macjen.

\section{Buch. Bllnhuurerfabren.}

1. 3ahlutugs oshejchl.

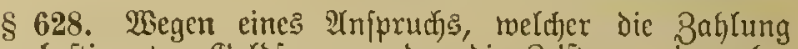
cincr beftinmten Beldojumme oder Dic Sciftung einer be=

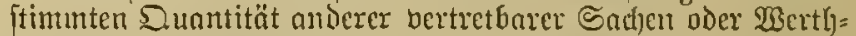

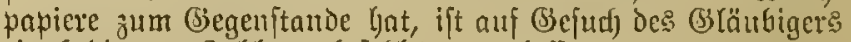

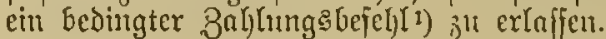

Das Mabnocrfabren findet nicjt ftatt, menu nadf Srnhalt

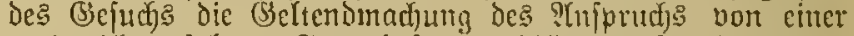
noch nid)t erjolgten (begenleiftung nbhängig ift oder went

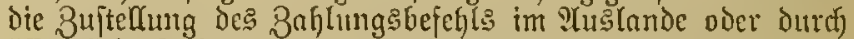
öffentlicfe Befanntntadjung exjolgen müf̧ste.

1) "Bebingt" ift ber Bahlungsbefehi, weil ber Sduldner ein 2Biber\{prudjstedt hat (§ 632).

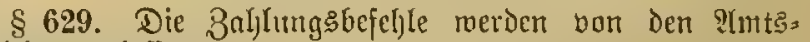
geridftent erlaffen.

QYt Der allgenteine perfönlidie (Serichtsftand oher ber dinglide (Geridfteftath fur die im ordentlidjen 2 erfahren extjobene

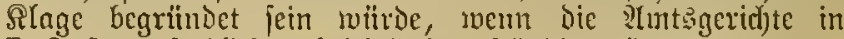

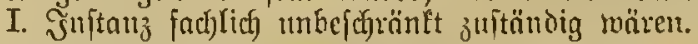

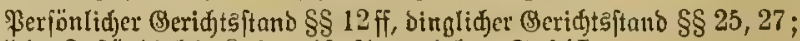
fadjlidge Bufländigfeit § 1 mebit \$inm. (oben S. 147).

§ 630. Das (5efuct) mußz entljalten:

1. die Bezeiffyung der Piarteicn stact) Ramen, Stano oder Bemerbe und $230 l$ nort:

2. Dic $\mathfrak{B c}$ reidıung des (Sertid)

3. Die beftimmte Ilngabe bes Betrags oder Gegen= ftandes und Des (Sirundes des Plripruct)

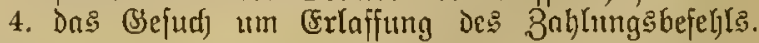

Hnocre Erforberniffe (Formen zc.) fino für bas Befud) nifit vor= gefdrieben. (Ẻ fann aud) mintlid) (\$ 642), fornie Durdj einen $\Re_{e}=$ nuftragten, jebenfalls aber of ue Dritwirfung irgend cines Redts befliffenen, angebradt merben (\$ 643).

§ 631. (Entfpricht Daక (Befu山) nicht Deu Bejtimunungeu Der vorfteliendent Faragraplyen oder crgiegt fidf aus $\mathrm{dem}$

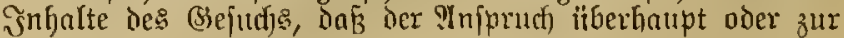

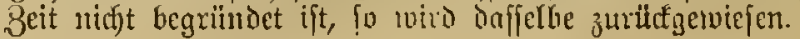




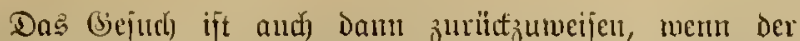

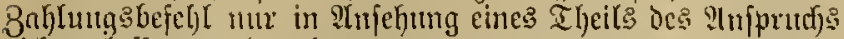
nidft crlaffen merben eann.

Fine 2 Infect)tung Dex jurïfmeifenoen Verfïgung fittoct tiicht ftatt.

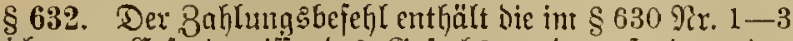

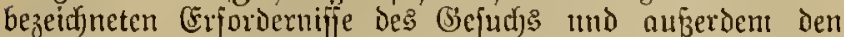
Befeht an tien Srhulduer, bimnen einer vont Tage Der Bn= itellung Laufenden Frijt bon 2 Wुochen, bei Vermeionturg fofortiger Zlvangşbollftrectung, Den (3)lüubiger megen bes QTnjpruchs uebft den dem Betrage nad) zu bezcidjuenden Soften des Berfafjens unt den geforderten Binfen zu he= friedigen oder hei bem (Gerid)te 23ideriprud) zu erheben.

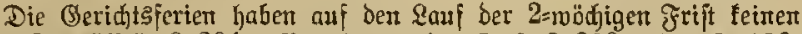

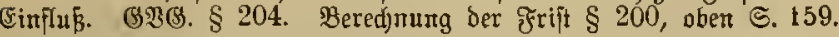

§ 633. Mit Dex Buftelfung Des Bahlungsbejehls an Den Sofjuldner treten die Mirfungen Der Rechtshängigfeit cin.

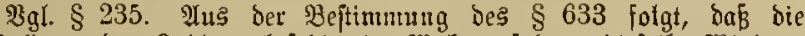

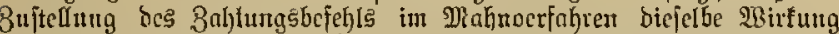

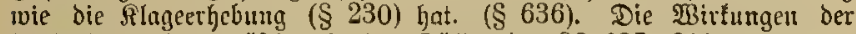

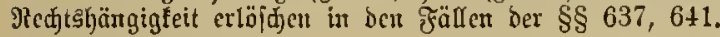

\section{Wibcriprudj.}

\$634. Der Shuldner fam gegen Den T(niprud pder einen Theil deffelben Wideriprud) erbeben, fo lange der $\mathfrak{B} o l l=$

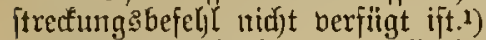

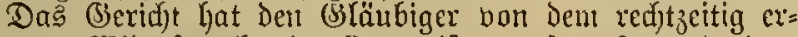

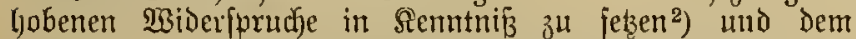
Scfuldner auf Berlangen eine Bejcheinigung darüber zu extheilen, baß̧ er red)tzeitig Widerfprud erboben habe.

Eiver: Burüutweifung Des nidjt redjtzeitig erfobenen

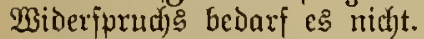

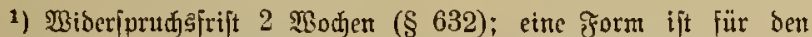
Biberiprud niđt vorgeidrieben, er farts ouch münolid (\$ 642), jowie burch) einen Beauftragten erfolgen (643).

2) (Es exfolgt eine formlofe Mittheilung. Shreibgebuifren merben

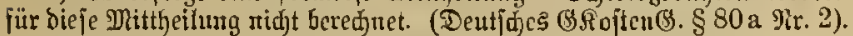

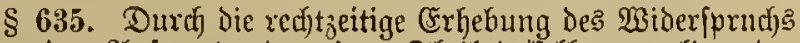
gegen ben SInjpruch ober emen Theil Dejielben berliert Der:

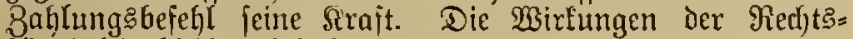
hängigfeit bleituen beftehen."

1) Sie erlöjøen in ben fä̆len der $\$ \S 637,641$.

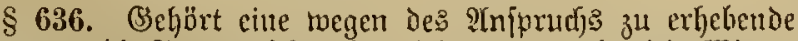
Slage bor bie ?Imtşgcrichte, fo miro, ment redptzeitig Witoer:

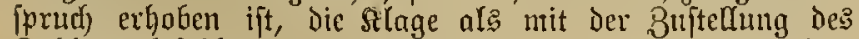
Bahlungsbejehls bei dem भimtsgeridut erboben angejehen, weldjes den SBejebl erlajien (jat.1)

Эe১e \$artei faun ben (Segner zur mündlid)en Berhandlung laden; die Sadungsirift beträgt mindeften 3 Tage.

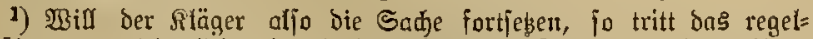

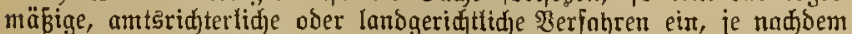

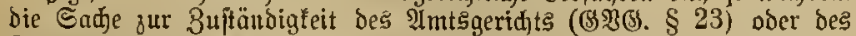

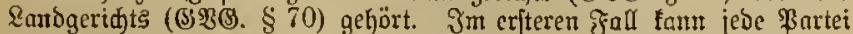

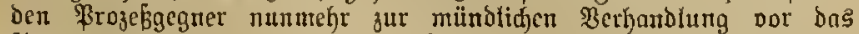

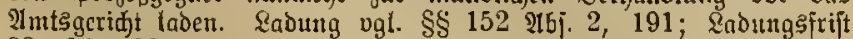
$\S \S 194,199$.

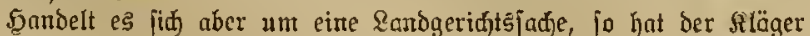

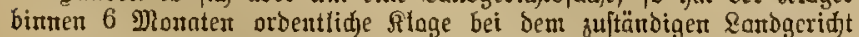

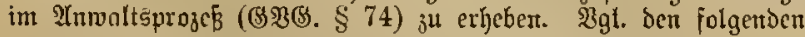

$\S 637$. Beljört eine wegen Des Anjprudjs zu erhebende Slage bor die Eanogerid)te, fo erlöicjen die Birfungen Der

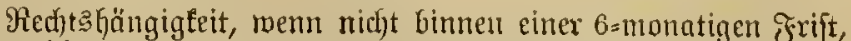
meldye von Dem Tage Der Benad)ridytigung von Der (Fr=

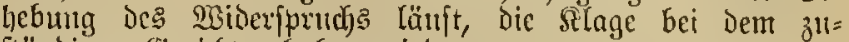
ftändigen (Sericht erhoben mirob.

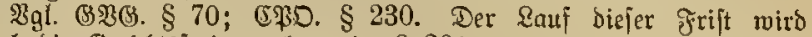
Durd bie Beridtsferien gehemmt. § 201.

$\S 638$. Die Roften des Mahnberfahrenz find im Falle

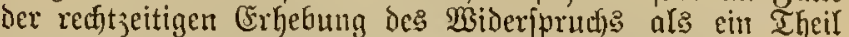

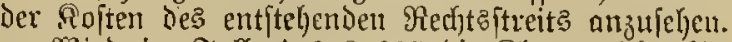

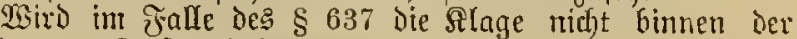
heftimmten Frift erljoben, fo ljat der Glläubiger die Siofter Des Mahnoerfahretz ju tragen.

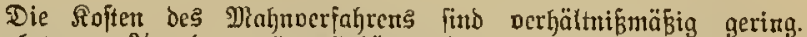
Sie betragen $2 / 20$ ber vollent Gebuht für bie Entjaeibumg uiber Das

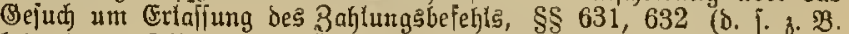
bei cirtem Objefte vou über 200 bis $300 \pi$ eirr[all.; 2,20 $\mathscr{K}$ );

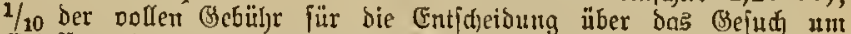

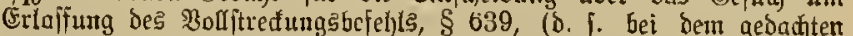

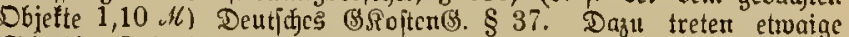
Sdjreib=, 8uftellungs= und \$ojtgebübren.

\section{Bollftreftungăbefefl.}

\$ 639. Der Bahlungşefel)l ift nach 2(blauf Der Darin

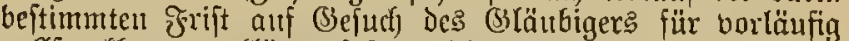
bouftreffbar zu erflüren, jojern nid)t bor der Bolfitrectforfeit: erflärung bon dem Schuloner Widderfprud erboben ift.

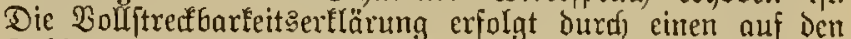

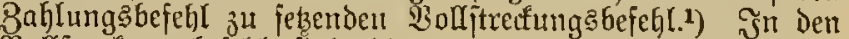

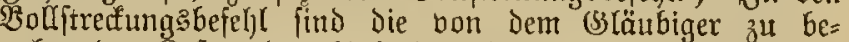

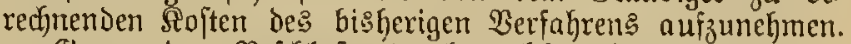

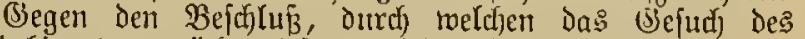
(3) läubigers zurüdfgetwiejen wiro, findet fofortige $\mathfrak{B} e=$ f(t)merde $e^{2}$ ftatt.

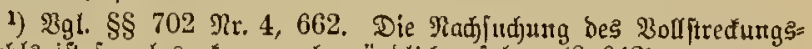

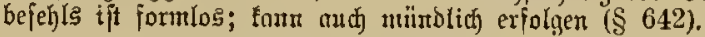

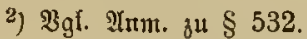

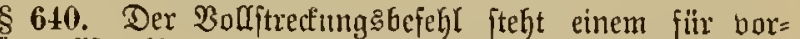

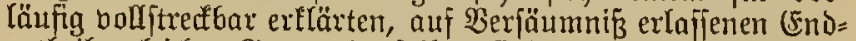
urtheile gleidf. (Sisgen denjelben findet ber (Einjprud) nady Den $\mathfrak{B}$ oridyrifen ber $\$ \S 303-311$ itatt. (Behört Der $2 \mathfrak{A}=$

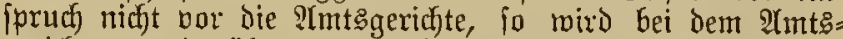
geridgte nur Darüber berlantielt und entidjieden, of Der Cin=

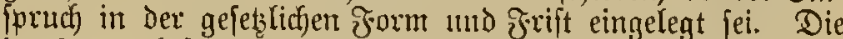
im $\S 637$ bejtimtmte ₹rift beginnt in biefem ₹alle mit ber Reditsfraft Des llrtheils, Durd) weldes ber (Einjpruch fiir zutläfîig crêlärt ijt.

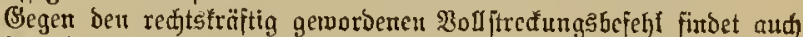
Rítigleits: unt Reftitutionstlage ( $\$ \S 542,543$ ff) ftatt.

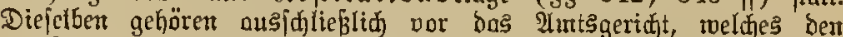
Molftredungsbefeht erlafien hat (\$ 547 ).

$\S 641$. Wird in dem Falle, wern Widerjprud nidft er=

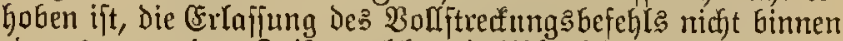

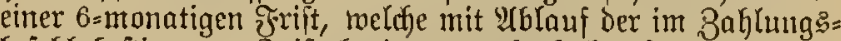
bejehl bejtimmten ofrift beginnt, nadigeiudft, fo verliert der

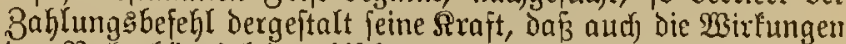

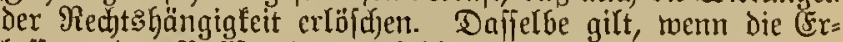

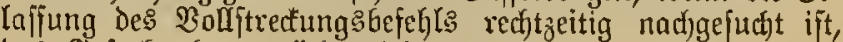
das (Sefuch aber zuritcfgemiejen wirt.

§ 642. Dą̧ Befucf um Erla[jung eintes Bahlungs:

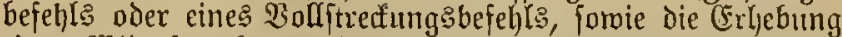
eines Wideripruchs werden der anderen Partei abjobrijtlidj nid)t mitgetfeilt; im Falle ihrer mündlid)en ?inbringung ift die Îfmahme eines grotofolls nidft exfarderlidy. 


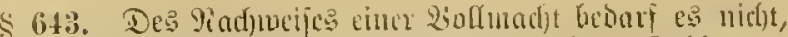

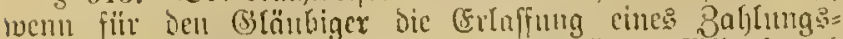

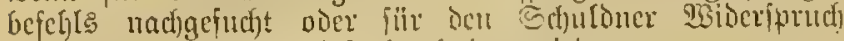

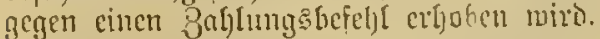

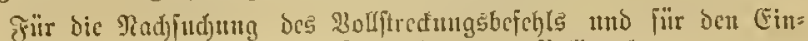

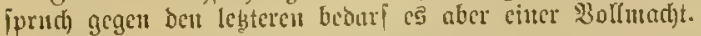

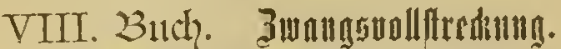

\section{Alfgemeine Zäeftimunugen.}

S 644. Dic Bwangsoolffrectung findet itatt ants Fno urtheilen, weld)e rechtsträftig over für vorläufig volljtrecfbar

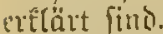

Lutheile in shefadjen dinrfen nicht für vorläufig voll= itrecthar erflärt voerdert.

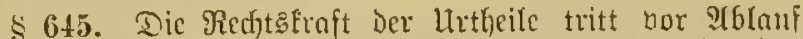

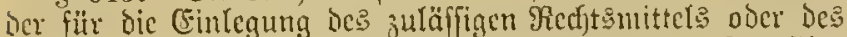

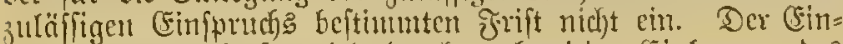

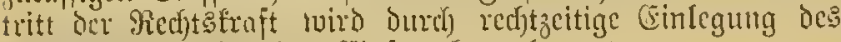

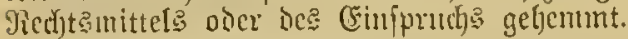

3gl. § 293 nebjt IIm. (oben @. 165).

\$ 646. (1) Beugnifje über die Medjtghruft ber llrtlgeile find auf (Srumb ber Frozefalten bout (Serichtsfdfreiber

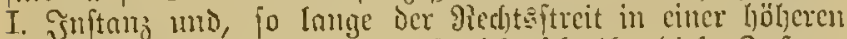

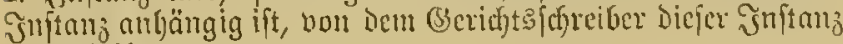
3it ertljcilert.

(2) ....

\$ 64\%. (1) Wirt bie खicoercinferma in ben borigen Stand ober cine Weicteranfnalyme Des Berfalyen beantragt,

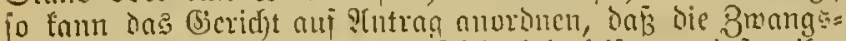
volftredfung gegen ober olye Sidyerheitsleiftung cinftrucilen

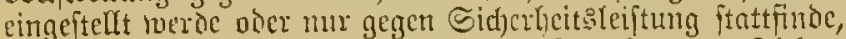

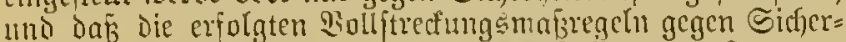

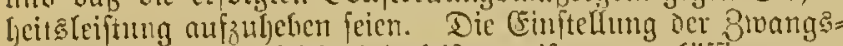

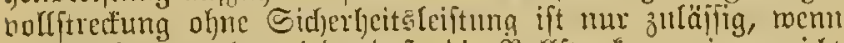
glaubljaft gemad)t wirt, Daß̧ bic Bolrftredung eimen nicht 3 erfetsenticu 9lat)theil bringen mürbe.

(2) .....

\$ 648. 2(uć) ohne sIntrag fino fïz vorläufig volftrecffor ôl crftären:

1. Lrtheilc, wetche auj (simmo eincs ?lnerfenntniffes einc Serutulyeilung ausfpredyen (\$ 278);

2. llutheile, welofe ben Eintritt ber in cincm bebingten Fnourtbeile ausgedrififten jolgen nusiprechen;

3. ein jucites oier ierneres in berfelben snitan gegen biciclle lintei zur jouptjadje crlaffenes $\mathfrak{B e r}=$ iänm

4. Urthcile, weld)e im llrfunden= ode: Wedfelprozelle erlafien tocrden:

5. Llrtheile, ourd) weldje Irrefte ober cinftroeilige $\mathfrak{B e r}=$ fïgungen aufgeboben incroen;

6. Mrtheile, weld)e bie Ricrpf(id)tung zul (5ntridfumg bon शrfmenten ausplect)en, fowcit die Mrimente fïr die Bcit nadj ber Ergcbung Der Silage umd für Das Dicjem Bcitpunft vorauggelgende letzte Viertel= jabr zu entridhten fino.

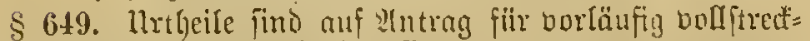
hai sil ertlären, wom fic betreffen:

Ė grhören hier in allgencinen bic in $\$ 23$ (B)B. (oben 5.121 ) aufgefïhrten, jur 3ujünoigfeit ber stuntsgeriute gebörigen Streitig= teiten ber.

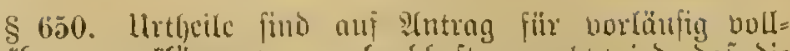

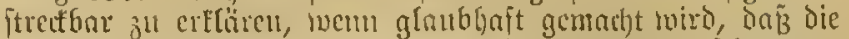

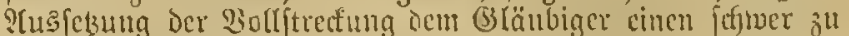
crfetsenten ober cincu folfmer zu ermittelnden 9radtheil bringen wïrde, oder wenn fidj ict (3läubiger erbictet, vor

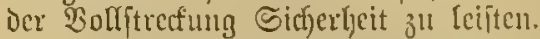

§ 651. 23ird glaubha|t gemad)t, baf dic Sollftectumg

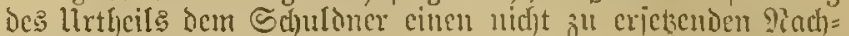

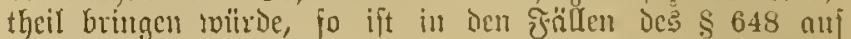

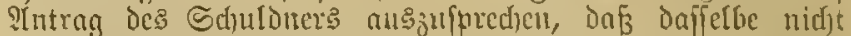

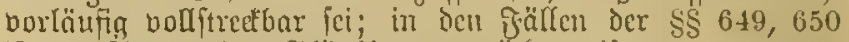

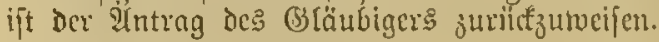

$\S 652$.

(2) Das (Beridft lont nuf IIntrag Dem Sdulbner nad)= zulaffen, Durd) Sicherlycitsleijtung ober Durd) Sinterlegung

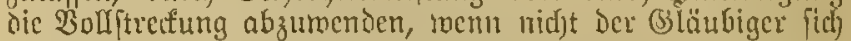

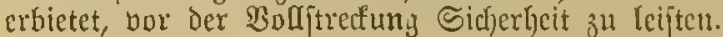

\$ 658. Şit auf Betvirtung einer Fintraguma im (Srund= Doer 5npotgetenbudie ertannt, fo darf Das filr vorläufig bollitrecfbar erflärtc llth heil nur in Der Weife vollzoget

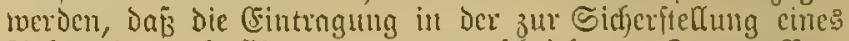
Yuprud) auf (Eintragung porgc|d):iclicuen form (Bor:= merfung, Fivoteftation, nueftatorifd) Berfügung, Dispopitionš bcic)täntung 2c.) crfolgt.

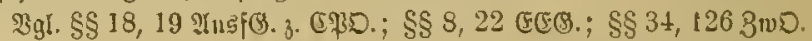

Boljtreffung:laufd.

$\S 662$. Die Zmangsuoditrecfung exfolgt auf (B)

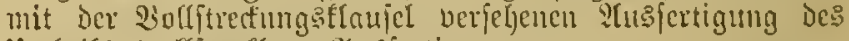
Ulztbeils (bollfrectbare Musfertigung).

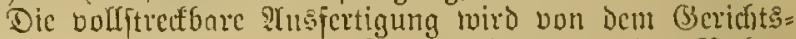

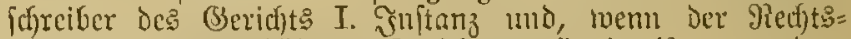
ftreit bei einem ljöljeren (Gericht anbüngig ift, von ben (3) cridjtafdereiber Diefes (Berid)te crtbeilt.

\$ 663. Dic Bollfrectung:tatiel:

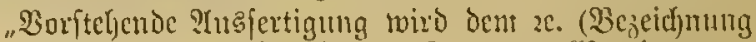

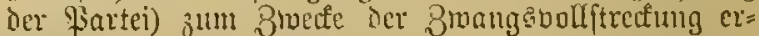
theilt"

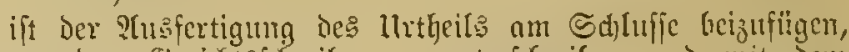

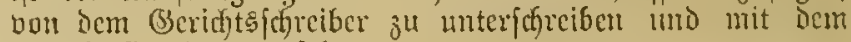
(3)eridytspiegel ju berjehen.

\$671. (1) Die Brongsoullftrecfung barf nut begimen, wenn bie \$erionen, fitr mo gegen meldfe fie itattfinden fork,

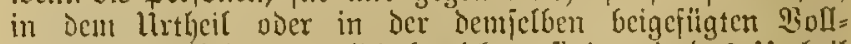
ftrecfungsElaujer nautentlid) bezcid)net find und bas ltrthcil bercits zugeftedt ift ober gleid)zeitig zugeftelft twird.

(2) .....

Geridjt:pollzicher.

\$ 67t. Dic Bwangsoullitrecfung exjolgt, fomeit fic nicl)t

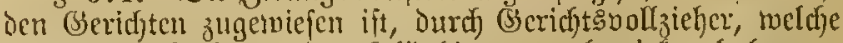

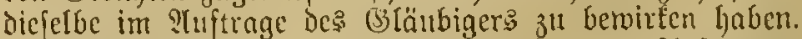

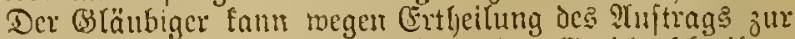

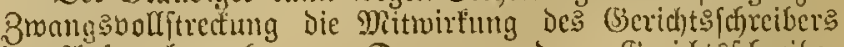
in Sylprud nehmen. Der bou Dem (Serid)teffyreiber

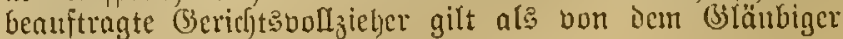
beanftragt.

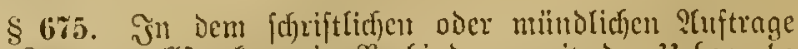
jur 3inanginollitreffung in Berbindung mit Der Llebergabe Der vouftredtbaren Susfertigung, liegt bie Bcautragung des 
(Berichtsuollziehers, die Zahlungen ober fonitigen \&eiftungen in Empfang zu némen, ihber Das Empfangene mirfjam zu

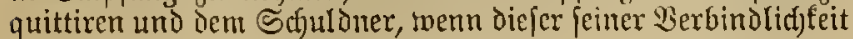

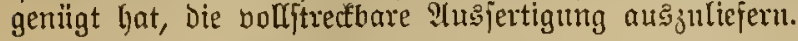

\& 67\%. Der (Geridjtgnolfieljer hat nacf) Empfang Der Seiftungen dem Sdjuldner Die nollitreffbare ?usfertigung nebft ciner Duittung auşulieferu, bei theilweifer Seiftung Dieje anf Der volftrectbaren ?Hejertigung ju benterfen und bem ธaduldner Duittung zu ertheilen.

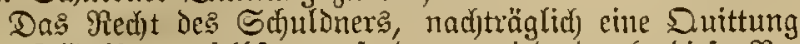
bes (Släubigers felbjt zu jordern, wird durch diefe $\mathfrak{B} e=$ [timumungen nidjt berïhrt.

\$ 678. Der Beridftabolfzieher ift bejugt, Die Woljnung und die Befjältniffe Des Schuldners zu durdjuchen, foweit Der Zmect Der Bolf trectung Dies erfordert.

(Ev ift befugt, bie verfolofieren Saustljüren, Bimmer= thüren und Behăltniffe öfinen zu lafjen.

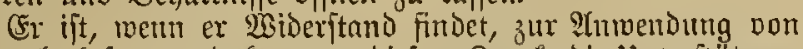

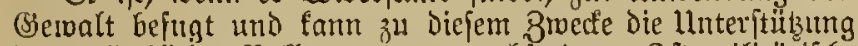

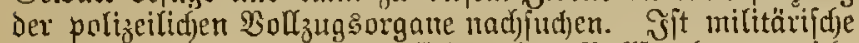

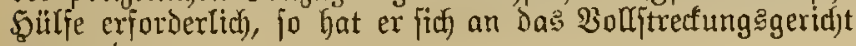
ju twenden.

\$ 679. Wird bei einer Wolfjtrectungshandung Wiberitand geleiftet, ober ift bei einer in ber $20 h n u n g$ des Sd)uldoner erfolgenden Bollitrecfing eine zur Jamilie Deffelben gehörige oder in biejer Jamilie bienende ermath\{ene \$erjon gegentwärtig, jo hat Der (Seridyts. bolfzieljer 2 großjiährige Männer oder einen (Semeinde= oder Bolizeibeamten als 3eugen zuzuzielen.

$\S 680$. Feder ßerjon, reldhe bei dem $\mathfrak{B}$ ollftrectungs= verfalyen betheiligt ijt, mus auj Begehren (Einficf)t der

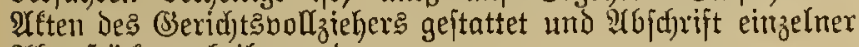
Ifftemptülfe extheilt werden.

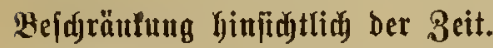

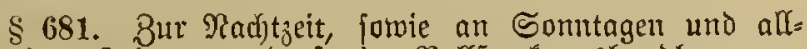
gemeinen Seiertagen darf eine Bollitrectungshandlung mur

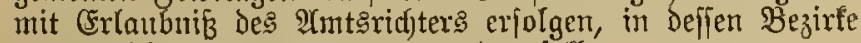
die Sandlung borgenommen werden foll.

Dic Berfilgung, ourdy meldye Die Ertaubrifs ertheilt wiro, ijt bei Der Zmangswolftrectung vorzızeigen.

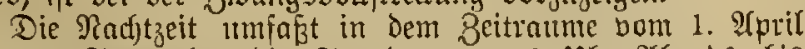
bis 30. September die Stunden bon 9 Uhr Itbends bi: 4 Uhr Morgens und in Dem Beitraum bom 1. Sftober bi:

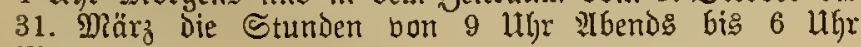
Morgens.

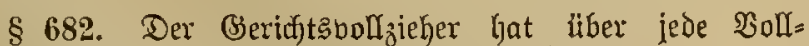
itrecfungshandlung ein Frotofoll aujzunehmen.

Das Grotofoll muß 3 enthalten:

1. Srt und Beit Der Aufnahme;

2. Den Begenjtand Der Borftrecfunghandung unter furzer (Ertwähnung Der mejentlid)en Borgänge;

3. Die Ranten der \$erfonen, mit meldjen berlyandelt ift;

4. Die Unterjotifift Diejer \$erjonen und Die Bemerfung,

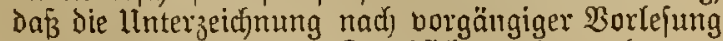
oder Sorlegung zur Durdfficit und nact) vor= gängiger Senehmigurg erfolgt fei;

5. Die Unteridyrift De: (Serid)t: nollziehers.

5at einem Der unter $\mathfrak{R x} 4$ bezeidjneten (5xjorderniffe nidjt genügt merDen fönnen, jo ijt Der (Sruno anzugeben.

\section{(5on}

\$ 684. (1) Die Dell (Berichten sugemiejene :Horonung bon $\mathfrak{B}$ ollptredfungshanblungen und Mitroirfung bei joldben

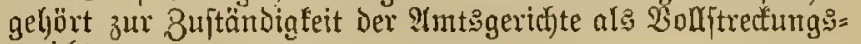
geridfte.

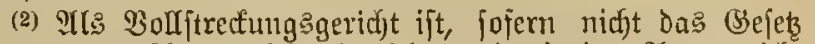
ein allderes :(mtägericht be

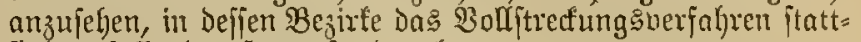
finden jol̂ oder itattgefunden lyat.

(3) -

§ 686. (1) Eimvenoungen, melche Den butrect Das Urtheil fejtgeftellten S(nfprud) jelbft betreffen, find von dem Sdjuldner

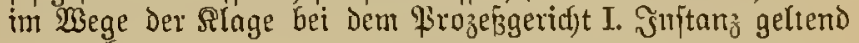
zu madjen.

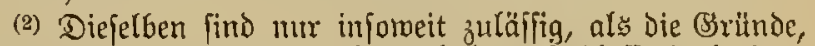

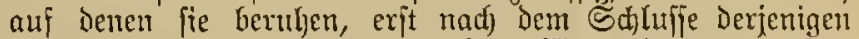

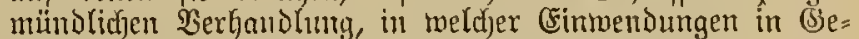
mäßhGeit Der Bejtimmungen Diefes (B)ejeţes fpätejtens hätten geltend gemadjt werden miiffen, entitanden find und burd) (Eimprud nid)t mehr geltend gemadjt rerden fömen.

(3)

\$ 690. (1) Behauptet ein Dritter, Daß

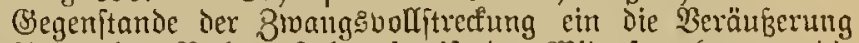

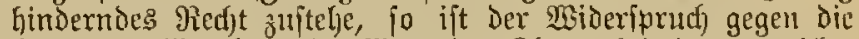

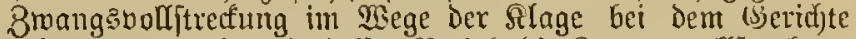

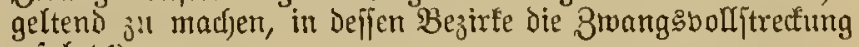
erfolgt. 1 )

(2) (3) . . . .

1) Jnterventionstlage. $\mathfrak{B g l}$ aut $\S 61$ (oben $\subseteq .150$ ).

$\S$ 691. Die 8mangsoolfitrectung ift einzuiteflen oder ju bejuränfen:

1. wenn die Ausfertigung einer bollftrecfbaren (Ent= jufeibung borgelegt wito, aus weldfer fich ergiebt, Dá bas zu vollitrectende llitheil oder befjen vor=

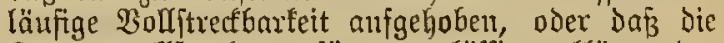
Z̧wangsboljtrecfung für unzuläffig ertlärt ober Deven CEimitellung angeorbnet ift;

2. ment Die 2Hsfertigung einer geridftlicten (5nt= idjeidung borgelegt wirb, auts meldjer fich ergiebt, Dẩ Die einitweilige (Einitellung der $\mathfrak{B}$ olliftrecfung ober einer Solfitrecfungsmansegel angeoronet ift;

3. menn eine öffentliche Urfunde vorgelegt wird, aus welcher fidc ergiebt, Daf bie zur YlEwendung Der Bolfítrectung nadigelaffene Eidjerbeitsleijtung oder Shinterlegung erjolgt ijt;

4. menn eine offentlidje Urfunde oder eine von dent (3) läubiger ausgeftellte Pribaturfunde borgelegt wirb, aus meld)er fidf ergiebt, Daß̧ Der (3läubiger nad) (Erlajjung des zu volfitredenden urtheils bejriedigt ift oder Etundung berwilligt bat;

5. menn eirt Poitfdjein borgelegt mird, aus tweldyem iith) ergiebt, Daf nach Erlafiung bes littheils dic zur Befriedigung Des Bräubigers erjordertiche Summe zu' Wuszahlung an den lebsteren bei der \$ojt eingezalylt ijt.

Sopter.

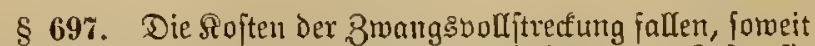
fie nothmendig waren (\$ 87), Dem ङdjuldner zur \&aft; fie find zugleid mit dent zur Zwangsbolfitrectung iteljenden Anipruabe beizutreiben. 
Dic Soften Der Zwangswollftredung fino Den Sdjuldner ju crifatten, menn Das llitljeil, aus welchem bicjelbe erfolgt ift, aufgeljoben wird.

\section{Weitere Fälle ber 3wangåvollitreftung.}

\$ 702. Dic 3ronggvolfitedfung findet fermer ftatt:

1. auะ Bergleidjen, welche nad) (Erbebung Der Slage zur Beilegung des Fiedtsitreits feinen gamzen limfange nach oder in Betreff eines Theils bes Streitgegenitandes bor einem Deutidyen (seridts ab= gejd) (oijen jund;

2. nus Vergleidfen, weld)e int Falle des $\S 471$ vor Dem Imtsgeridft abgefdilofien find;

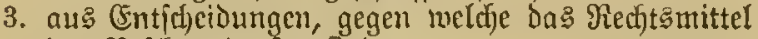
ber Bejdrmerde itattfindet;

4. aus Bollftreftungsbefehlen;

5. aนs Urfunden, weldje bon cinem Deut(d)en (Seridjt oder bon einem deutiden Rotar imertjalb ber Grenzen jeiner $\mathfrak{A m}$ mb befugniffe in der vargejdriebenen Form allgenommen find, fofern die Hrfunde über emen Ŝ(nfprudh erridjtet ift, relduer die Bahlumg einer beftimmten Beldjumme, oder die Reiftung ciner bcitimmten Suantität anderer bertretbarer Sadjen oder Wertlypapiere jum Giegenitande hat, und Der Gduldoner fid in ber Utrunde Der 0 = fortigen Broangsvollitrefung unterworfen hat.

$\S$ 705. (1) Die volftreffbare Aus : Urfunden wird bon dem (serichtsfatreiber des (seridhts er: theilt, meldes die IIrfunde aufgenommen hat.

(2) Dic volfftreffbare Ausfertigung notarieller llrfumben

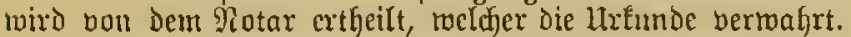
Befindet fidf dic llrfunde in ber Bermahrung einer Behörde, fo hat bicje die volftrectbare ?tusjertigung zu ertheilen.

(3) (4) (5) ....

\section{Zwangsvolfteedung wegen Gectordertngen}

\section{1. in Das beweglide Wermögen (Wfäแdung).}

§ 708. Die Brwanggnolfitreffung in bas bereglid)e $\mathfrak{B e r}=$ mögen exfolgt Durd) Sifänoung.

Sie Darf nidft meiter ausgedehnt werben, als zur $B e=$

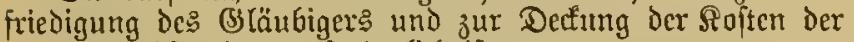
3wangsbolitedung erfordertid) ift.

Dic Ifändung hat zu unterbleiben, wenn fid bon der

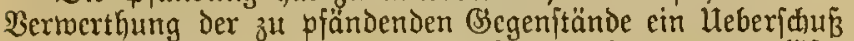

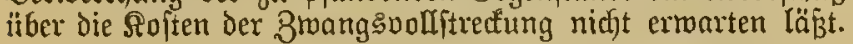

\$ 709. Durd) Dic \$3fänoung erwirbt ber (słäubiger ein 舛fandrect) an dem gepfändeten (Begenftande.

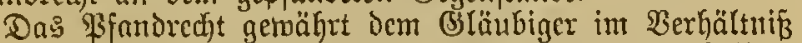

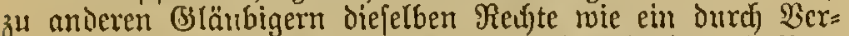

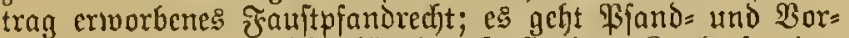

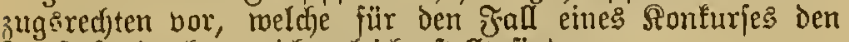

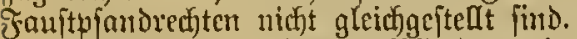

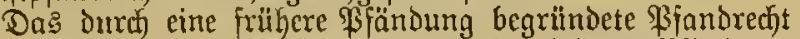
geht Demjenigen bor, meldjes burd cine fpätere ßfändung begritudet wird.

\section{Oifenbarungateio.}

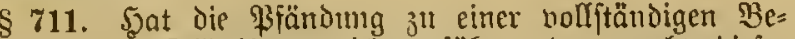
friedigung Des (SIlänbigers nicht gefithrt ober madht bicjer glaubhaft, Dấ ex burd) \$ffändung jeine Becriedigung nidft volfitändig erlangen fönne, fo ift ber Shduloner auf Ântrag

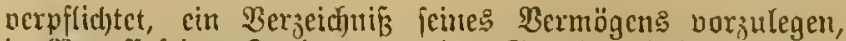
in Betreff feiner Forderungen den Brund und dic Bemeis: mittel zu bejeidnen, forvie den Sffenbarnngseid 1) Dafin 3u leiften:

Daß3 ex fein Bermögen volftändig angegeben un〉 wiffentlid nichts veridyiegen labe.

1) Ueber Itbuahme unb Ergwingung befielben vgl. $\$ \S 780$ ff (unten ङ. 2114).

\section{Sörpertidje Gadjen.}

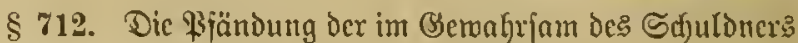
befindtichen förperlidfen Sachen wird ondurd) berwirtt, dấ

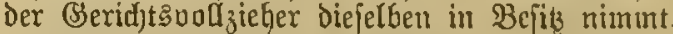

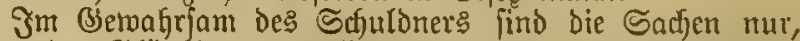
menn der BSläubiger eintwilligt oder wenn ein anderę $\mathfrak{B e r}=$ fahren mit erheblidfen Sdywierigfciten nerbunden ift, ju $b c=$

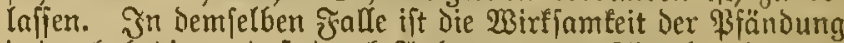
Dadurd) bedingt, daß̄ Durch श्Anlegung von Sicgeln ober auf fonjtige Weife die Bjändung erfichtlich gemadet ift.

Der (Geridhtsuolzicher hat Den Sdjuldner von Der ge=

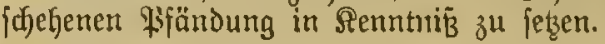

§ 714. Frücyte fömen, aud bebor fic bou bem Bodeu getrennt find, gepiändet werben. Die Pfändung Daxi nich)t früber als 1 Monat bor der getoöhnlichen Beit der Reife exjolgen.

Unpjänbbare Sadjen.

\$ 715. Folgende Sacjen find dex $\$$ fändung nidft unter= worfen:

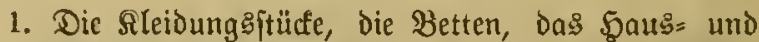

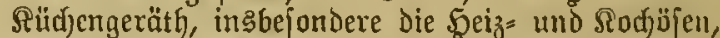
folveit Dieje (Siegenftände für Den Schurbner, jcine Familie und fein (Sefinde unentbehrtich fino;

2. Die für Den Chaldoner, feine Familie und feir (S)efinte anf 2 Wodhen exforderliden Nahrumgs: und ₹euerungsımittel;

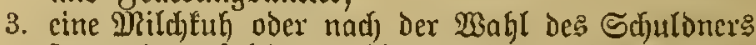
ftatt ciner joldjen 2 Biegen oder 2 Schafe nebit dem zum lunterhalt und zur Streu für diejelben auf 2 Wacten exforderlicten Futter und Stroh, jofern die bezeid)neten Thiere für die (Errährung des Sct)uldners, feiner Familie und feines (Befindes unentbehrlict) find;

4. bei Sïnitlern, Đandwerfern, Gand= und Fabrit= arbeitern, fowie bei Sebammen bie zur perfoulicten

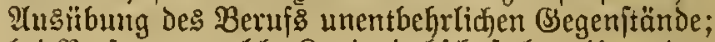

5. bei Ferjonen, weldye \&andwirthidjart betreiben, das

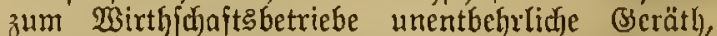

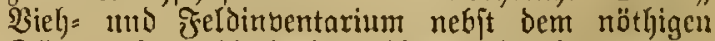
Dinger, fowic bie landwirth(d)aftlidyen (Erzengniffe, weldye zux jortfebung Dex wirthidjaft bis zur nädjiten (Ernte unentbehrlici find;

6. bei Dffizicren, Dedfoffizieren, Beamten, (Beijtlidjen, schrern an öffentlicfien Unterrichtsanjtalten, Red)t:

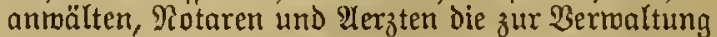

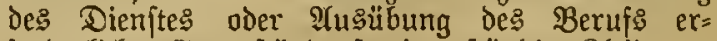

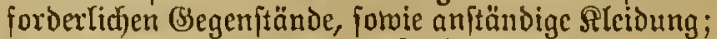

7. bei Difizieren, Dilitärärzten, Decfoff̈zieren, Beamten, (Sciftlidien und Rehrern an offentlichent linterrid)t anftalten ein (Belobetrag, melcher Dem Der Pfändung nichtt untermorfenen Theile des Dienfteinfommen oder der \$enftan für die Zeit von der Bfänoung 
bis zum nächjiten Termine der Gebalts: oder Pienfianţzal)lung gleidffommt;

8. Die zum Betriebe einer Apothefe unentbehrlidjen

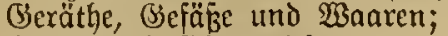

9. Droen und Shrenzeidfen;

10. Die Büdjer, meldje zum (sebraudje bes Sujuldners uno ieiner Familie in Der Sirdje ober Sdfule be= ftimunt jind.

1. Durch Das (5. v 12.6.1894 (GS. 113) ift aud bas geleg= lidic Bfandredit be马 2 ermtether

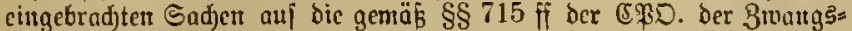
vollftredung unterlicgenden beweglid)en Sadjen eingejdyräntt worben.

2. 3u den urpjä̈bbaren Sađjen gehören aud dic Jahrbetriebsmittel ber Eifen bahner. Bgl. Das nadfolgende

Gejeb, betreffent dic ltuzuläifigleit der \$fäubutg von (Eijenbahufalbetriebsimitteln. Bam 3. 5. 1886 (Ht(6BI. 131).

Die Fahrbetriebsumittel ber Eijenbahnen, meld)e Ferjonen oder Biiter int offentlidjen \$erfegr befördern, find oon ber erften (Finftellutg

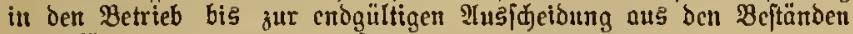
bcr श्änoung nidt unterworfen.

Durd bicfe Beftinmung merben diefelben im Fnlle bes fonturs=

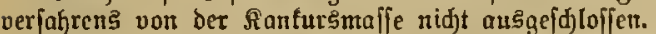

Iuf bie Fahrbetriebsmittel ausländifđer Eifenbahnen finbet bie Reftimmuna bes erften 2lbfabcs nur injoweit Intwenbumg, a[s bic (B)egen \{eitigfeit verbürgt ift. ${ }^{\text {. }}$ )

Dicfes (Scles tritt mit Dem 1. Suni 1886 in Fraft.

Itrlundid) $2 c$.

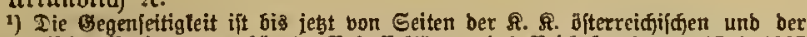

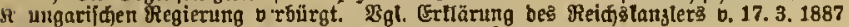

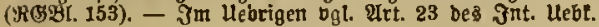

\section{Berfteigerung.}

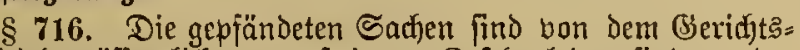
valf ieber offentlid zu berjteigern, Roftbarfeiten find bor Der Berfteigeruแg burd) einen Sadjberftändigen abjufrjäkzen.

Bepfänoctes Belo ift dem Bsläubiger abalieferm. Die wegnahme des (Seldes Durd) den (Seridjtsnollzieler gift als 3ahlung bon Seiten bes Sduldoners, fofern nicht bem

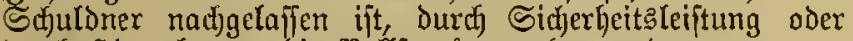
Durdf) Sinterlegung die $\mathfrak{V}$ ollitrectung abzumenden.

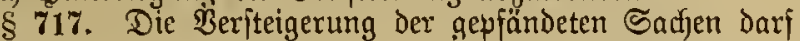
nicft bor Shblauj 1 Wodje jeit Dem Tage Der \$jïnoung ge= idjeben, fofern nidjt der (Släubiger und der Sđjuldner über eine jrühere $\mathfrak{B} e r$ iteigerung fidf einigen oder biejelbe erjorberlidf iit, um die (Sefahr einer beträd)tlichen Werthşuerringerung ter zu verifeigernoen Sacje abzumenden ober um unver: ljältniß̧mäßsige Roften einer längeren $\mathfrak{A}$ ufbetwahrung zu ver= meiden.

Die Beriteigerung erjolgt in Der Bemeinde, in welder

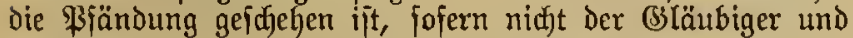
Der Scjuldner über einen anderen Drt fict einigen.

Beit und Sort der Berfteigerung find unter allgemeiner Bezeidyung Der zu verfteigernden Sacjen öffentlich befannt ju machen.

§ 718. Der Buidjlag an den Meiftbietenden erfolgt nadj 3:maligem $\mathfrak{2}$ ufruic.

Die abliejerung einer zugejdjlagenen Sadje darf nur gegen baare Bablung gejujehen.

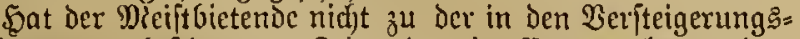
beningungen beitimmten Beit ober in Ermangelung einer

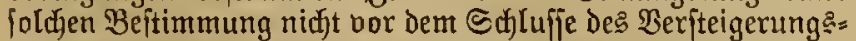

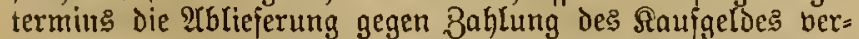
laligt, fo mird dic Sadje andermeit verfteigert. Der Meift= Gictende mird zu einem meiteren (Bebote nidgt zugelajpen; er haftet für ben ?luşall, auf Den Mehrerlös hat er teinen 2(niprutif).
§ 719. Die Berjteigerung wiro eingeftellt, fobald der

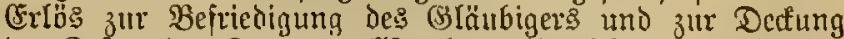
ber Rofteu Der 3mangsoolftrcefung himreid)t.

\$ 720. Die (Empfangualyme ocs (Frlöjes Durd) Den (B̉e=

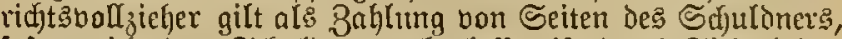

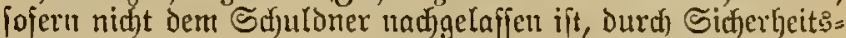
Leiftung ober Dur(f) Sinterlegung bie Dollftedung $a b=$ jumenden.

\$ 721. Gold= und Silberjadjen biirfen nidft unter ihrem

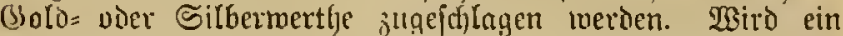
den Bulallag gejtattendes (sebot nid)t algegeben, fo fann

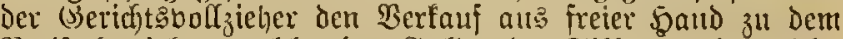
Breife bewitten, weldher Den (S)old = oder Silbermertl) erreidf).

§ 722. Bepfändete Wertlpapiere fint, ment fie cinen Börjen = oder Marftpreis haben, von dem (Beridytsondziefer aus freier Sand zum Tagesturic z"l terfaujen und, menn fie einen foldfen Breis nidjt haben, nad) den allgemeinen Beftimmungen ju beriteigerm.

§ 723. Eautet cin Werthpapier auf গamen, fo fam

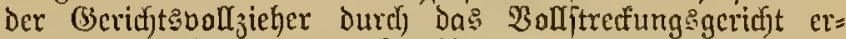
mächtigt werden, bie Umid)reibung auf Den Ramen Des

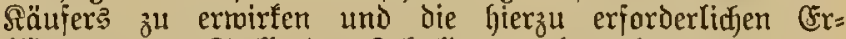
flärungen an Stelle des Êdjuldoners abzugeben.

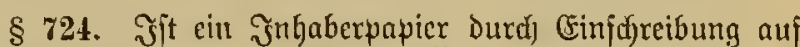
Den Pianten oder in anderer Weife auper Rur's gejetst, jo

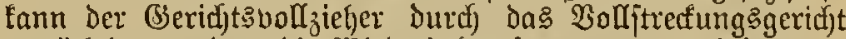
ermäd)tigt merden, bie wiederintursieşung ơ die Gier $u$ crfarderficten Ertflärungen an Stelle des Sdfuldners abzugeben.

\$ 725. Die Berjteigerung gepfändeter, vor Dem $\mathfrak{B a d e n}$

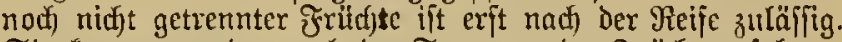
Sic tann oor oder nady der Trenmung ber Früd)te erfolgen; im lebteren Falfe hat ber (Gerid)t3vollzieher bie aberntung bemirfen $z^{u}$ laffen.

\section{P̧ändung von Gelbjorberungen.}

§ 730. (1) Soll eine Beldforderung gepfändet merben, fo hat das (Bericht dem Drittictuldoner zu verbieten, an den Schuldoner z" ,aflen. Bugleid hat bas (Bjeridit an Den Shuldoner das Gebat zll erlaffen, fid jeder Berfühung über bie frorderung, insbejondere der CEinzichung berjelben zu enthalten

(2) .....

(3) Mit Der Buftellung Des Bejulufuffes an ben Drittfduldoner ift die Yjändung als berwirft anzujehen.

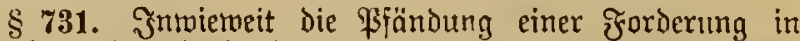
das 5ypothefenbuth einzutragen uno wie eine foldje (Fin= tragung zu ermirfen ift, bejtimmt ficf nach den \&aniesgefezen.

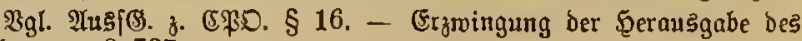
Dohments $\$ 737$.

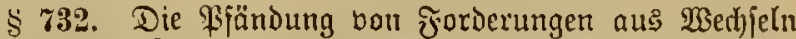

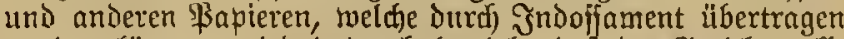

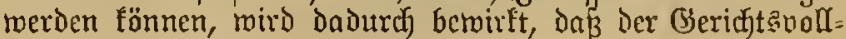
jicher dieje \$apiere in Befik nimmt.

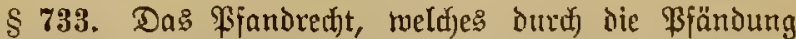
eimer (Behaltsforderung ober einer ähnlicfien in fortlaufenden Bezügen beftehenoen frorberung ertoorben wiro, erjtreeft fid aud) auf bie nad) her Bfändung fällig merdenden Beträge. 
\$ 734. Durnh die Bföndung eines Dienjteinfommens miro audf) Dasjenige (Einfommen betroffen, welufes der

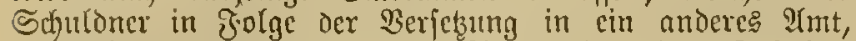
der llebertragung eines neuen 9lmte ober ciner Gebalts= erföhıng zu beziehen 'jat. ${ }^{1}$ )

Dieje ßeftinmung findet ant den Falf der ?tenicrung deక Dienftherrn feine ?ntmendung.

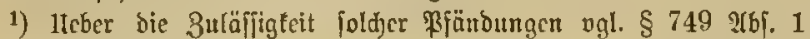

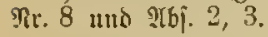

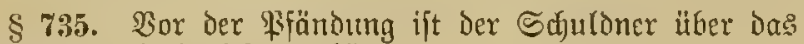

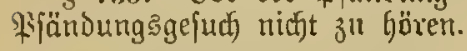

\section{Iteberweifung.}

$\S$ 736. (1) Die gepfändete (ऊeldforderung ift Dcm (3) Läubiger nach feiner Wahkl zur Einziehung odcr an Zahlumgsftatt onm शennmerthe jul ïbermeifen.

(2) Jon leştexen Fralle geht dic forderung nuf den

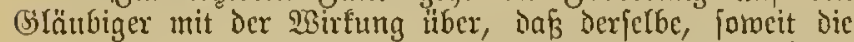
Forbcrung beiteht, wegen feincr Foricrung an den Sdulloner als befricoigt anzujechen ift.

(3) .....

$\S 73 \%$ (1) . . . .

(2) Der Schuldner ijt berpflidftet, dem (s)läubiger bie itber dic ₹orderung vorhandenen lirfunden heraugzugeben. Dic Serausgabe fann bon dem GSläubiger in Wege der 3twang

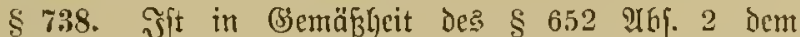
Schuldoner ractgelaifen, Durd) Sicherheitsleiftung oder buref) Sinterlegung bie Solfitrecfung abzumenden, jo findet dic licbermeijung gepfömbetex Geldforderungen nur jux Eirn= jiehung uno nur mit Der Wirkung ftatt, daf Der Dritt= ichnlbner Den Schuldbetrag hinterlege.

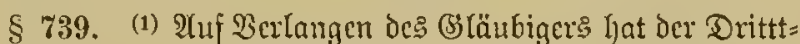

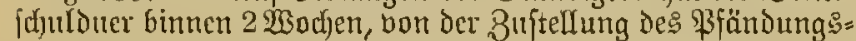
bejdłluffes an gered)net, dem (S)läubigex ju crflären:

1. ob und invierweit ex bic Forderung als begrïndet anerfente und Bahlung ou leiften bereit fei;

2. 06 und toeldfe य̈nfprübe andere \$erfonen an die forderung macken;

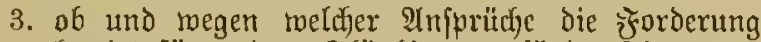
bereits fïr andere Bsläubiger gepfändet fei.

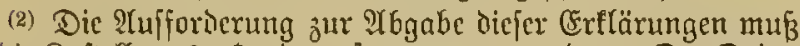
in die Buftellungsurfunde aufgenonment werden. Der Dritt= \{chuloner hajtet dem Gilänbigex fïr den aus dex Richt= crfitllung jeiner Berpflichtung entftehenden Schaden.

(3) ......

\$ 741. Der (Släubiger, weldfer Dic Beitrcifung einer ihm zur Cinzielung ïberwiejenen forberung berzögert, baftet dent Sdjuldner für ben baraus entftehenden Sdjaben.

§ 742. Der (şläubiger fann auf dic burd) Płfändung uno Uchermeifung zut Finziebung ermorbenen Rectite un= befchadet feines Ŝnfprudis berzichten. Dic Berzidftleifung criolgt durd) cine dem Sdjuldner zmujtellende (Erelänng. Die Cretlärung ift auth dem Drittiduldoner zuzuftellen.

\section{Borläufige Befudlagnahme.}

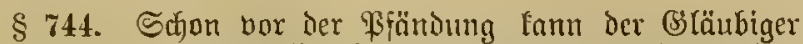
anf (srumd eincs bollitrectbaren Schuldtitels burd) ben

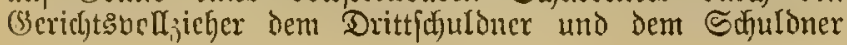

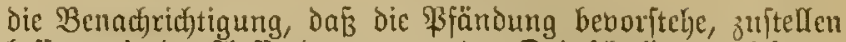
laffen mit ber Xufforberung an Den Drittidfuloner, nidft an

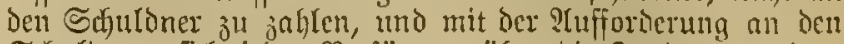

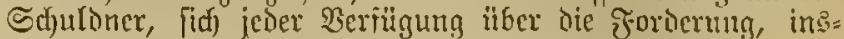
bejondere ber cinziebung derjelben zu entlyalten.

Die Benad)ridjtigung an den Drittid)uldoner lyat die Wirfung eines Prrejtes (\$ 810), jofern Dic \$fänoung Der Jorderung imerlyalb 3 wodjen bervirtt wirb. Die Frrift beginnt mit bem Tage, an sveldyem dic Benad)ridftigung zugeftellt ift.

\section{llupfänobare Foroerumgen.}

§ 749. (1) Der Bfänoung find nicht untertworfen:

1. Der Prbeits = oder Dieniftolnn nach den $\mathfrak{B C}=$

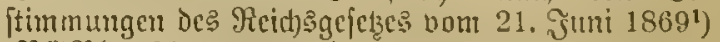
(B3(3ß). 1869, 242 แno 1871, 63);

2. bie auf gejeşlicher \$3orjdyrift beruhenden ?fimenten= forierumgen;

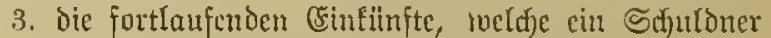
aus Stiftungen oder fonjt all (Srumo ber fïr = jorge mo Jreigebigfeit eines Dritten bejieht, in = forocit der Sdjuldner zur Beftreitung des noth)= diirftigen Unterhalts firr fid), feine (Ehcirau und feine nod) unberforgten Rinder bicjer (sinfünfte bedarf;

4. dic aus Rinnfen=, f̧üljes= oder Sterbefaffen, ins:

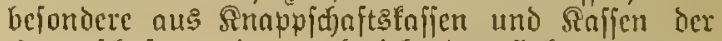

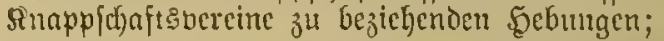

5. Der Sold und die Эnvalidenpenfionen dex Inter= offizicte und der Solbaten;

6. Das Dienfteintonmen Der 9) ilitärperfonen, soeldje zu cinem mobilen Truppentheil oder zur Befaßung eines in Dienit geftellten Airiegsfolyrzentges gebören;

7. die Benfionen der Wittmen und wanifen und bir denjelben aus Wittwen= mo Waaijenfafjen zu= fommenden Bezüge, Die Erzichunģ̧gelder und bic Studienftipendien, fomic dic \$enfionen inbalider Il'beiter;

8. Das Dieniteinfommen der Dffiziere, Militärärz̆te ment Decfoffiziere, der Beamten, der Gerittidjen und ber Sebrer an öffentlichen IInterricjtsanjtalten; dic Fenjion siejer fierfonen nach deren Serfebung in cinftrociligen voer Dauernden Ruheítand, fowie Der nad ibrem Tode den F̧interbliebenen ju gewährende Sterbe= oder (5nadengehalt.

(2) Lleberfteigen in den Fällen $\Re x .7$ und 8 das Dienjt= einfommen, bie \$senfion oder dic fonftigen $\mathfrak{B c z u ̈ g e ~ d i e ~ S u m m e ~}$ von 1500 Marf für Das Jahr, fo ift der dritte Theil des Dehrbetrage der \$ffändung untermorfen.

(3) Der (B̉effalt und Die Dienftbejüge Der in Privatdienjte

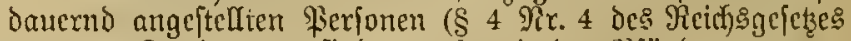
bom 21. Funt 1869) find nur fomeit der \$ffündung unter= moxfen, als Der (Gefammtbetrag dic Summe bon 1500 Dlarf

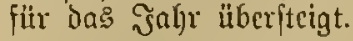

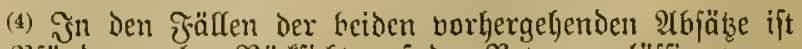

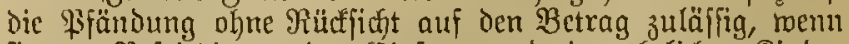
fie zur Befriedigung Der (E) hepran und Der ehelicken Rinder Des Sdjuldners wegen folder arlimente beantragt mird, weldje für die Beit nad) (Erhebung Der Slage und für bne diejem Beitpuntte bornusgehende Lełzte Bierteljahr zu ent= ricften find. 
(5) Die Cinfünfte, tweldhe zur Beptreitung eines Dienft= aufinnudes beftimmt find, und Der Serbis Der Dffiziere, Militärärztc nnD Militärbenmten find meder Der $\mathfrak{B}$ fändung untermorfen nod) bei ber (Ermittelung, of und zu roeddem Betrage ein Dienfteinfommen ber $\mathfrak{B}$ fünoung unterliege, j" berectinen.

1) Daffelfe folgt unten S. $213 \mathrm{fr}$.

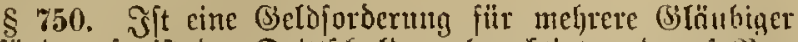
gepfätndet, jo ift Dex Drittjhuldner beredfigt und nuf Qer=

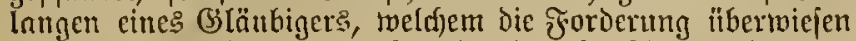
rurbe, verpflidjtet, unter itnzeige ber ङadjlage und unter

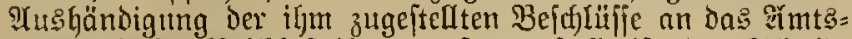

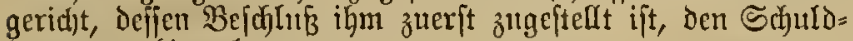
hetrag zu Ginterlegen.

§ 754. TUi die 3wangsvolffrefung in andere $\mathfrak{B c r}=$ möget:Brechte, weld)e uidht Begenftand der Zmangsnolfitrectumg in das unbeweglidie Bermögen fino, finden die voritehenden Beftimmunget entiprechende STrendung.

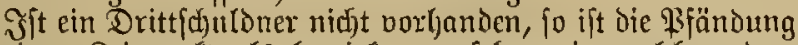
mit dem Beitpunlt als bewirft anzufehen, in welchem dem Sd)uldoner Das (Bebot, fid jeber Serjitgung Ḧber Dns Red)t zu entljalten, zugeitellt ift.

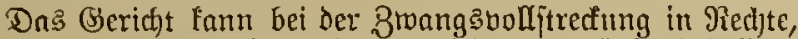

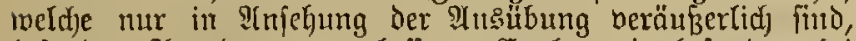
befondere Snoronungen erlafjen. (5) tann insbejondere bei der 及mangsondfitredung in Rutzungsred)te eine Berwaltung

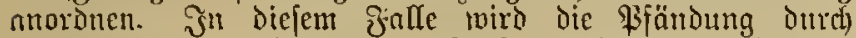
Hebergntie der jot benubenden Sarfe an den Berwalter be= woirft, fofern fie nidft Durd) Bujtellung Des Befdylujpes bereit? vorher betwirft ift.

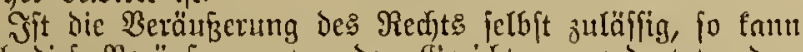

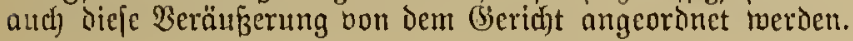

\section{2. in Das แnbeweglide Jermögen.}

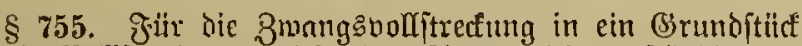

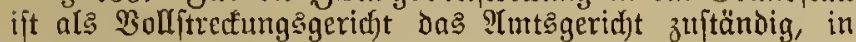

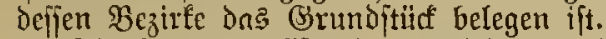

Die Jwangsuolftredtung wird von diefem (serid)t all! Intrag angeoronet.

\& 75\%. (1) Die 3mangevolffredfung in bas unberveglidfe

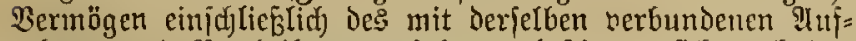

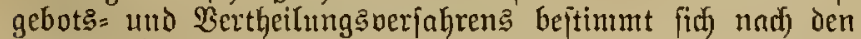
Eanie:gefetzen.

(2) Tiad) Den \&nnbeggefetzen beitimmt fid insbefondere aud, weldfe Sadjen uno Red)te in IN voljtreefung znm unberneglidjen Bermögen gehören, inmiefern

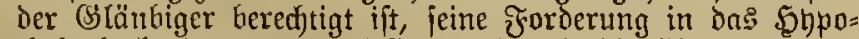
thetenbuth eintragen zu laffen und wie bie Cintragung zu bewirfen ift.

(3) .....

BgI. Preuf. G. Getreffend bie 3roangsvouftrefung in bas unberveglidje Bermögen (8roD.) o. 13. 7. 1883 (BS. 131). Bum unberweg= lih̆en \$erntogen gehören Grandfüde, Berwerfe, Rauffahrteifüiffe zc. einjăl. derjenigen beroeglidgen Begenftünobe, auf melche bns bejüglid

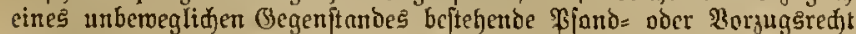

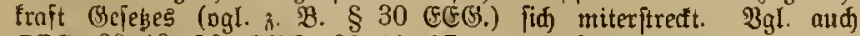

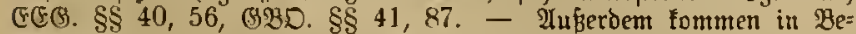

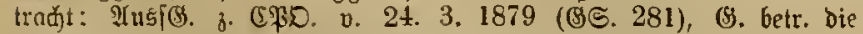
3twangşvolltrefurg gegen Benefizialerben $2 c$. vom 28.3 .1879

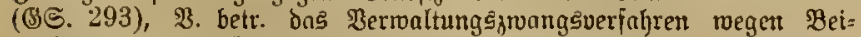

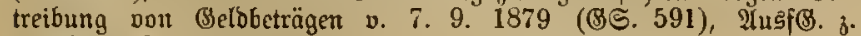
Deutidjen Rontursoronung o. 6. 3. 1879 (अङ. 109).

\section{Wertheilungenerfabreu.}

§ 758. Dos : Vertfeilungsuerfahten tritt ein, menn bei Der 3mangsbolfftrectung in Das betweglide Bermögen ein (Selobetrng Ginterlegt $i f t$, weld)er our Sefriedigung ber be= theiligten (3läubiger nidł) Ginteidt.

§ 759. Dą zuttändige ?(mtşgerid)t (\$§ 728, 750-752)

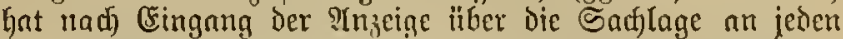
Der hetheiligten Bläubiger die Ŝfufforberung ì erláfjen, binnen 2 Wodjen eine Beredfnntig Der Forterung nn Rapital,

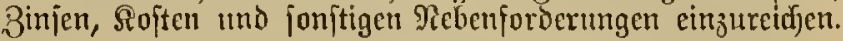

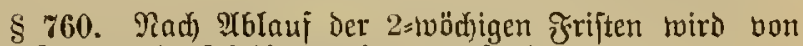
Dem (Seridjt cin Theilungsplnn angefertigt.

Der Betrag Der Roften des $\mathfrak{B e r f a h r e n s}$ ift bon bem $\mathfrak{B e}=$ ftande Der Mrafje bormeg in STbzug zu bringen.

- Die Forberung eines (Släubigers, weld)er biş jur : STn=

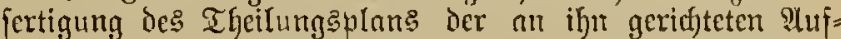
fordermg nidft nad)getommen ift, wird nad) Der $\mathfrak{Y}$ (nzzeige

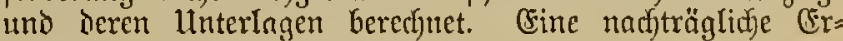
gänzung ier Forderung findet nicht ftatt.

§ 761. Das Beridft Gat jur Errflärnng über Den Theilungaplan jowie zแr Yusflufung der Sertheilung cinen Termin żt Geftimmen. Der Theilungṣplon umuß ppäteftens 3 Tage vor dem Termine auf der (serichtsfethreiberei zur Einficht der Betheiligten niebergelegt twerden.

Dic Radung bes Sduldonere oll bem Tcrmin ift nidjt erforderlidf, werm fie durd) Buftellung im ?tusland oder burch offentliche Buftellung erfolgen müßste.

§ 762. Wird in Dem Termin cin Wideriprud) gegen

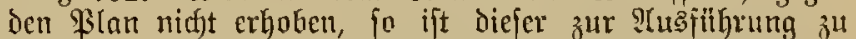
bringen. (Frfolgt ein Widoeriprud, fo hat fid jeber bei Demfelben betheiligte (3)läubiger fojort zu erftären. Bairo ber Wiserjprud von den $\mathfrak{B e t h e i l i g t e n}$ als begrïndet an= erfannt oder fommt anderweit eine Finigung ${ }^{u}$ Stande,

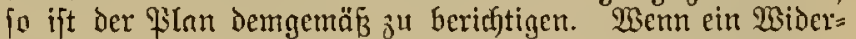

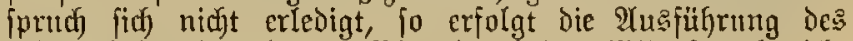
Blans inforweit, als der $\mathfrak{B l a n}$ durd den $\mathfrak{W}$ ideriprutf nicht betroffen wirb.

§ 763. Biegen عiıten Gläubiger, weldher in Dem Termine meder eridfienen ift, nody bor dem Termine bei bem Geridjte Wider frutf erhoben hat, wird angenommen, dof er mit

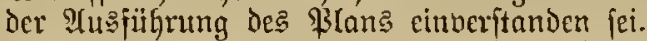

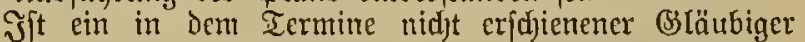

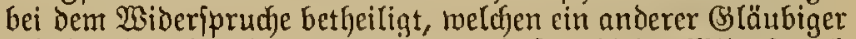
erhoben hat, fo mird angenommen, Dá̧ er biejen $\mathfrak{B i d e r [ p r u d y ) ~}$ nidft als begrïndet anerfenne.

§ \%4 Der mideriprectjende Siläubiger muß ohne vor= herige 2ufforderung bunen einer Frift von 1 Monate, melde mit dem Termintage beginnt, Dem (beridjte nadh:

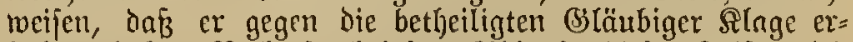

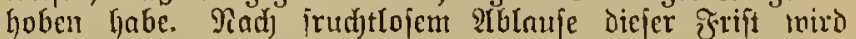

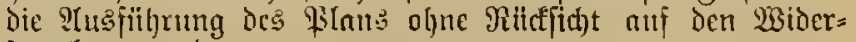
iprudi) nugeoronet.

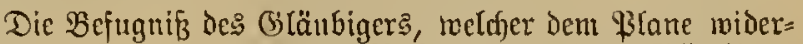
iprocfen hat, ein bejferes Rect)t gegen ben (3läubiger, weldfer cinen (Seldbetrag nad) dem 'Blane erljalten hat, im Wiege Der Rlage gelteno zll madjen, wird Durd Die $\mathfrak{B e r}=$

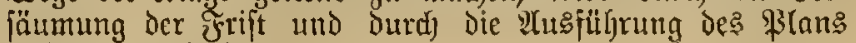
nicht ausgeicjlofien. 


\section{3wangsvofftredung}

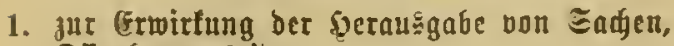 Eñenfarungücio.}

\$ 769. Sat ber Gduloner cine beinegliche Sadje aìer nan bejtimmten bemeglidjen Sadjen eine Zuantität hernus= jugeben, jo find dicjelben bon bem Gierid)tŝollieber ibm megiunehmen unऐ iem Gläubiget ju übergeben.

Wird bie herausjugebende 巨adje nidjt vorgejunden, io

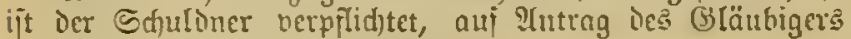
den Ditenbarungseid 1) dafhin jut [eijten:

dats er Die Gadje nidft belitge, and nidjt milic, mo bie Gadie ind befinde.

Das (Geridjt tam cine ber Rage ier Sadje entipredjente

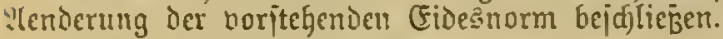

1) Ueber Ibnahme uno Ergringung dep̈elben vgl. $\$ \$ 780 \pi$.

\$ 770. Sat ber Gduloner cine bejtimmte Duantität vertietharer Sadjen ader Werthpapiere zu Leijten, ja findet

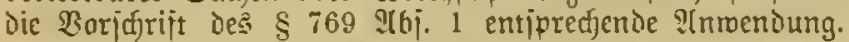

\$ 7i1. (1) Sat Det Sduldner eime unberneglide ミadje ober ein bemofntes Sdifi Gerausigeben, zu überlajjen ober ju räumen, io bat der Geridtsvollieher ben Efulloner ats iem Belitse ju jeken und Den Gläubiger in den Bep̈ts cinzumeijen.

(2) (3) (4) .....

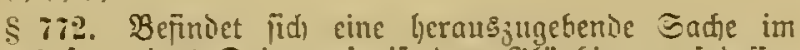
(Getvahriam eines Dritten, jo ijt ben Gläubiger auj belien

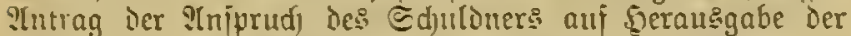
(a)de nad Den Sorjdrijten ju übermeijen, meldje bic Fiändung ciuer Geldjarberung betref̣en.

\section{Jur Frmirtung von Đandlungen.}

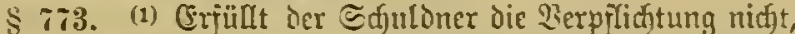
cine Dandung vorjunelymen, Deren Fornabme Durfy einen Dritten eriolgen Eann, jo ijt der Gläubiger bon dem Brozés=

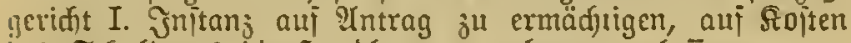

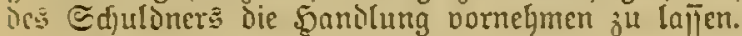

(2) (3).....

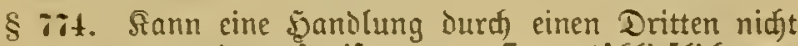

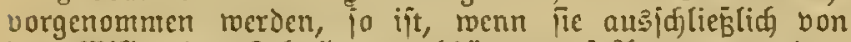

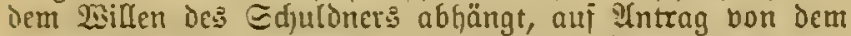
Hirojeggeridit I. Snjtanj iu extennen, das ber Sdjuldner jur Barnabme der Sandung Durd Gelditraien bis zum

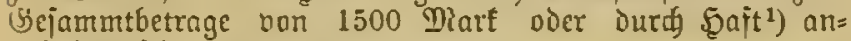
subalten jei.

Dicie Bejtimmung fommt im ₹alle der Berurtheilung jur Cingehung einer Çge nidjt und im Jalle ber $\mathfrak{B e r}=$

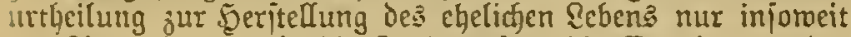
jur $\mathfrak{A n m e n d u n g , ~ a l s ~ d i e ~ S a n d e s g e j e t s e ~ d i e ~ F r z m i n g u n g ~ d e r ~}$

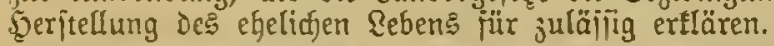

1) Dauer berielben $\S 79 t$. - $3 g[$. (3. betr. D. Gerverbegeridite

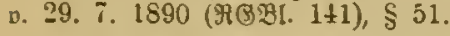

\section{Jut (Frwirfung von llnterlaīungen uno Duloungen.}

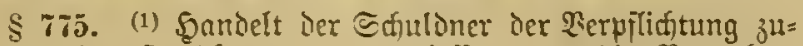
mider, eine Đandlung ju mnterlajien oder die Bormahme cirer fondlung ơ dulden, io jit er megen einer jeden $3 \mathrm{u}=$ miderhnnolung auf :Tntrag bes Gläubiget: von dem \$rojes: gerid)t I. Jnjtanj ju einer (beldjtraje biz ju 1500 Dart oder jur ङtraje oer jajt bis ju 6 Monaten zu verurtbeilen. Das פ? iiberịteiger.

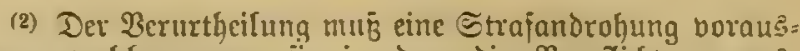
geben, weldfe, wenn fic in bem dic Berpfliditung aus= ipredjenden lirtheile nidit entyalten iīt, auj ?ntrag non bem ૧rozę̈gericht I. J̈njanj crlajien miro.

\section{(3) .....}

S 7\%. Reijtet Der હdjuldnet Wideritand gegen Die Bornalune ciner Donslung, weld)e ex nach ben Bejtimmungen der $\leqslant s ̧ 73,775$;u dulden hat, jo famn der Gräubiger ;ur Bejeitigung de: 20iderjtande: einen Gerid)tsuolfieher ill=

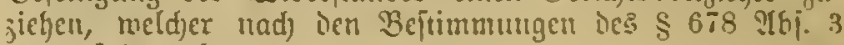
ju verfobren Gat.

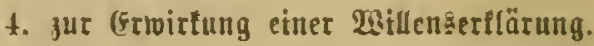

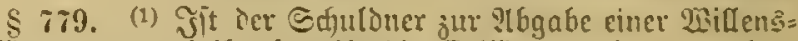
crtlärung nerurtheilt, jo gilt die Frtërung al’ abgegeben, jobalo tas llrtheil die Red)tentrait erlangt bat.

(2) .....

\section{Qffenbaruagseid und Saft.}

1. Eñenbarungšeit.

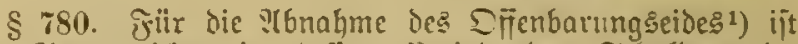
das Xutşgeridyt, in Dejïn Bezirfe Der Cd)uloner im

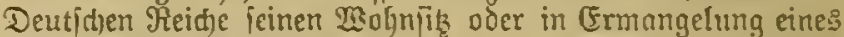
joldjen jeinen ?tujenthaltsort hat, als Bolliredungsgeridjt juitändig.

1) Rormen belielben in $\$ \$ 711,769$.

\$ 782. Giegen den Sdfuldner, melder in Dem jur Scijung Des Stienbarungseides beitimmten Termine nift erifheint oder dic Rciitung des Fides ofne Grund ner= meigert, hat ias (Geridjt zur Erzmingung ber Cidesleītung auj Zlntrag die நajt anjuaronen.

\$ 783. Der verbajtete હduloner fann ju jeder Beit bei bem Imtsgeridte Des Đajtortes beantrageu, ifm den (Fio abzunel)men. Dem Intrag ift obne Verjug itattjugeben.

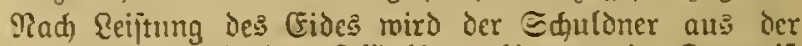

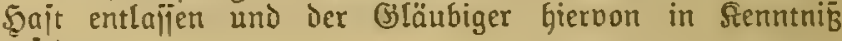
gejetst.

है 78t. Cin ङduldoner, meldjer den im $\$ 711 \mathrm{cr}=$

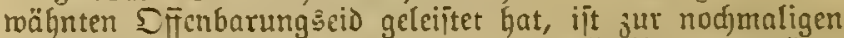
¿eijtung Des (Fìcs auf) eirem anocren (j) läubiger gegenüber mux verpflidtet, menn glaubhait gemndjt wirb, baв ex ipäter Bermägen erroorben gabs.

\$ 785. Dic Şajt ijt unjratthait:

2. \$ait.

1. gegen Ditglieder einer deutidien gejetgebenden $\mathfrak{B e r}=$ jammlung räbrend der Sikungşperiode, jafern nidjt

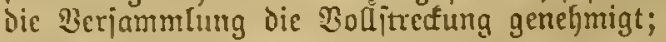

2. gegen Dilitärperjonen, twelde ju einem mobilen Tuppentheif oder jur Bejaţung eincs in Dienjt gejtelten frrieg sajarjeuges gebören;

3. gegen den Edjițer, Dic Ediī̈smanmidjait uno alle übrigen aui einem Eecjdiff angejtelften \$erjonen,

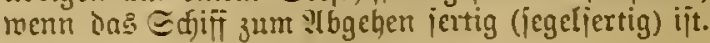

$\S$ 786. Die Sajt wird unterbroden:

1. geuen Mitglieber ciner Deutidgen gejekgebenden $\mathfrak{B}_{\mathrm{er}}=$ fammlung für die Dauer der Siksungsperiode, menn Die Berjantulung Die Jreilajpung verlangt; 
2. gegen Militärperjonen, weldi) зи einm mobiløu Tuppentheil ader ani ein in Dienit geitelltes:

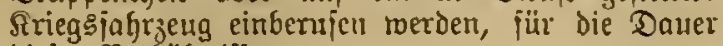
diejer Verbältnijje.

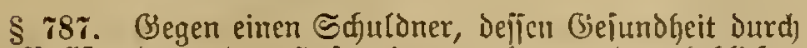
dic $\mathfrak{B o l l i t r e c t u n g ~ b e r ~} 5$ ajt einer nahen und ertheblidjen (Sefahr ausgejekst wird, Darf, jo lange Diejer Zujtand Dauert, bie Soft nidht vollftredt trerden.

\$ 788. Die Sait wirb in einem Raume balfitredt, in meldiem nidjt zugleid Unterfudjung: aber Strafgejangene (id) befinden.

$\S$ 790. Die Berhajtung Deక ๔đuldners erjalgt Durff

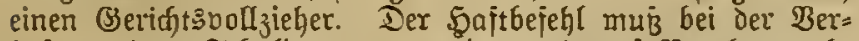
haftung bem ङajuldner borgezeigt und auf Begehren $a b=$ jufrijtlif) mitgetheilt merden.

\section{Beamte.}

§ 791. Wor Der Berbaitung cines Beamten, eines Beijttiden oDer eines Sehrers an offientlidien Unterridt:

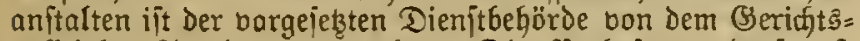
volfieher Anjeige au madjen. Die Berhajtung Dari erit erfolgen, nahdem dic borgejeßzte Bebärde für Die dienjtliase Bertretung des Sduldners gejorgt hat. Die Bejörde ifit nerpflidtet, ahne Perzug die erjorderliden Inoronungen zu

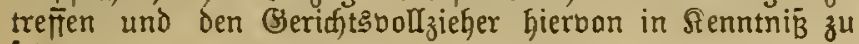
jeß̧en.

\$ 792. Der (3läubiger bat Die Sajten, meldje Jurd)

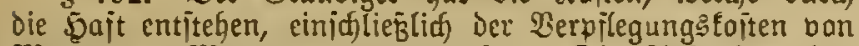
Manat zu Manat barauszuzablen. Die :lufnahme bes

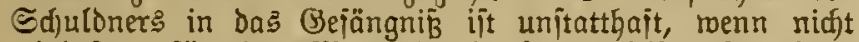
mindeitens fïr einen Manat bie Zahlung geleijtet ijt. Wird die 3ạlung nid)t ipäteitens bis zum Mittage bes leţien Tages ezneuert, für inelden jie geleiftet ijt, jo mird Der ङdhuldner bon Imtamegen aus der Sajt entlajien. Gegen

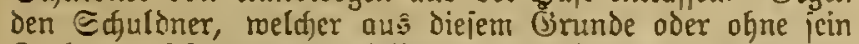
Buthun auj $\mathfrak{A}$ ntrag des Bläubigers entlajjen ijt, findet auj Intrag Delielben Gläubigers eine Grneuerung ber baft nidit jtatt.

\$ 794. Die Sait Dari bie Dauer ban 6 Monaten nifft

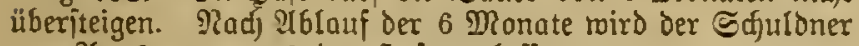
bon 2rmtsmegen aus der \$ajt entlajien.

§ 795. Fin Sdjuldner, gegen weldjen regen $\mathfrak{V e r}=$ weigerung des im \$i11 ertwähnten STர̄enbarungšeides eine Sajt von 6 Panaten bollitreft ifit, Eann aud auj Sintrag eine: anderen Ģläubigers bon neuem zur Reijtung dieie Fides ourch \$ait nur angehalten merden, menn glaubbait gemadit roiro, da $\dot{B}$ der 厄山uloner päter Vermögen er= toarben habe.

\section{Arreft นนd einftmeilige \$ัญerfügungen.}

\section{Arreft.}

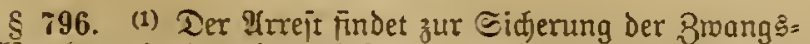
boljtredung in Das bemeglide ader unbermeglidje Vermögen

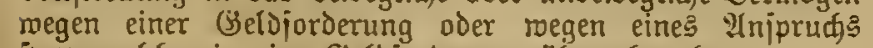
itatt, melcher in eine Beldjarderung übergehen fann.

(2) ......

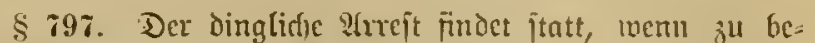

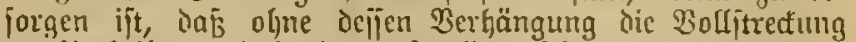
Des Urtheiles vereitelt ober wejentlid) eridjwert werden mürde.

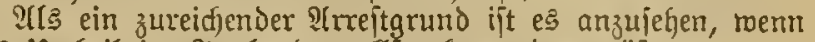
das Urthei! in 2Uslande volftreft werden müBte.

\$ 798. Der perjönliche Gidjerbeitsarrejt findet nur itatt, wenn el erjorderlich ijt, um dic gejährdete Brwang:

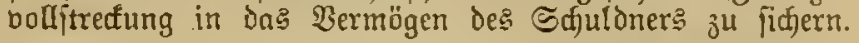

1. Irrejtbejeht.

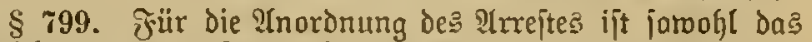

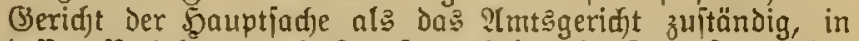
dejien $\mathfrak{B e}_{3}$ irfe der mit 2 rrejt zu belegende Gegenitand oder die in ibrer perjönlidjen ôreigeit zu bejaränfende \$̧erjau iinf) bepindet.

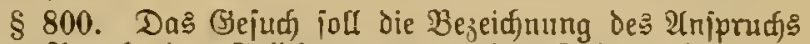
unter Angabe des Geldbetrags oder des Geldwerths jomie die Bezeichnung des Anejtgrundes enthalten.

Der Anjprud) und Der :Irreitgrund find glaublajt zu matien.

Das (Bejud) fam bar Dem (Beridftsjđ)reiber zu ßrotofol erftärt merden.

$\S 801$. Die Entiffeioung fanu ohne borgängige mündlide Berhandlung exjalgen.

Das (Bericft fann, aud rem der ?tnipruch oder der Nrreitgrund nicht glaubgajt gemad)t iit, den \&lreit anoronen, joiern roegen Der Dem Segner Drohenden Pradtheile eine nad jreiem (Frmejien zu bejtimmende Eidierbeit geleijtet

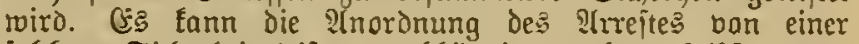
jald)en Siđjerbeitsleijtung ab̧ängig madjen, jelbit wenn der Ânjprud und der IIre ftgrund glaubhajt gemad)t find.

$\$ 802$. Die Entjueioung über bas (Sejud) erjolgt im

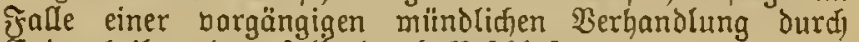
Endurtheil, anoerenjaĺs ourd Bejulus.

Den Bejulu $\bar{B}$, Durd welden ein Arreit angearonet roird, Gat die \$artei, reldje den थrreit erroirft hat, zultellen zu Laijen.

Der Befdfluis, Durd melden Das Irreitgejud zurüct= gemiejen oder vargängige ङidjerheitsleijtung iür erforberlid) erflärt roird, ifit bem Gegner nid)t mitzutbeilen.

\$ 803. Sn dem 2rreitbeiehl ijt ein Geldbetrag jejt= zuitellen, Durd) Deijen Sinterlegung die Bollziehung bes

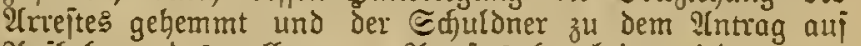

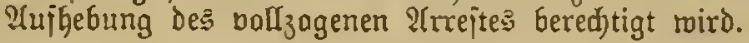

\section{Wiberiprud.}

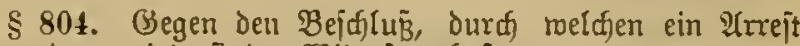
angeardnet roird, findet $\mathfrak{B i d e r j p r u d j ~ i t a t t . ~}$

Die roideriprechende \$artei hat Den Begner unter $\mathfrak{M}$ it= theilung ber Gritnde, meldie fie jür die Tuibebung des Árreites geltend madjen rwill, zur mündlidjen Berbandlung zuladen.

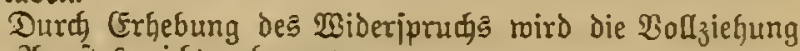
des Arrejtes nidft gehemmt.

\$ 805. (1) Wirb Wideriprud erhoten, jo ift über die

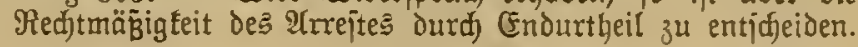

(2) .....

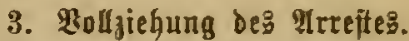

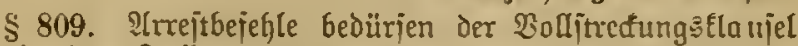
nur in dem fralle, menn nad) Erlajiung der Bejehle eine

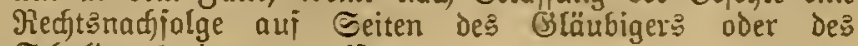
ङduloners eingetreten ijt. 


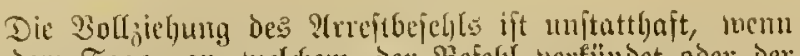
feit Dent Tage, an meldjer ier Befehl verfündet oder Der Bartei, auf deren Bejuch berfelbe erging, jugeftellt ift, 2 Wodien verftridfen find.

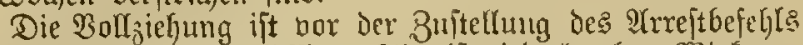
an Den Schuloner zuläfitig. Sie ift jedod ohne $23 i r f u n g$, wenn bie Bujtellung nid)t imnerljalb 1 W3odje mach ber $\mathfrak{B o l f}=$ zielumg uno vor 916lanf Der für biefe im vorthergehenden S(bjatze bejtimmten frift erfolgt. $\left.{ }^{1}\right)$

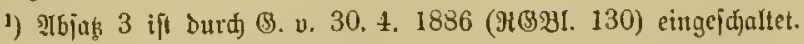

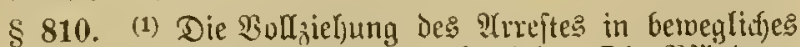
3̧ermögen mird Durch) Ffänoung betwirft. Die \$iändm

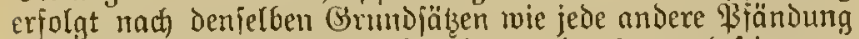
tmo begründet ein qifandred)t mit den im $\$ 709$ beftimmten wixtunger. . . . .

(2) $(3) \ldots \ldots$

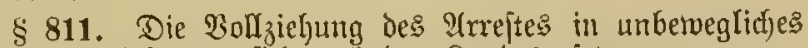
Bermögen bejtimutt fith nad) den Sandesgejetzen.

Es toird auf Intrag des Btäubigers cine Bormerfung in $\mathfrak{U b}=$

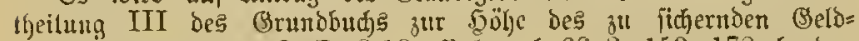
betrages eingetragen. 3roD. §10. 13gi. aud) $\S \S 2,153,178$ ebenda; ferner С્ES. \$§ $22,43$.

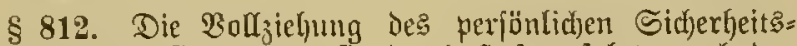
arreites viditet fid), weur fie Durd) Saft erfolgt, nad den Barid)riften Der $\$ \S 785-794$ und, wenu fie durd) fonjtige Befferänfung Der perfönliden Freiljeir erfolat, nad) Den

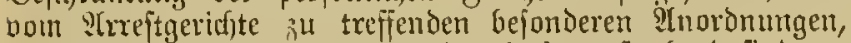
fïr meldje die Bejdränfungen Der Şajt maß̈gebend find.

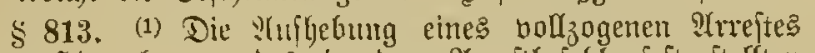
gegen Shinterlegung dos in Den IIrreithefehle fejtgejtelten (Selobetrags erfolgt bou dem 2ollitrectungsgerichte.

(2) (3) (4) ....

\section{Eirttweilige ચerfügungen.}

\$ 814. Finitweilige Berfïgunget in Beziel)ung auf Det Streitgegenitand find zuläfíig, twen zu bejorgent ift, das

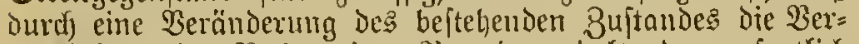

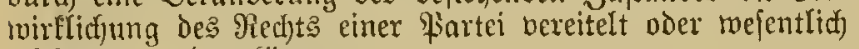
erjchnert werden fönnte.

$\$ 816$, (1) Fïr die Crlaffung einftweiliger $\mathfrak{B}$ erfiigungen ift bas Giericht der Şauptjact)e zuitändig.

(2) ......

\section{Eequeitration.}

\$ $81 \%$ Das (seridft bejtimmt nach) freiem Ermefien, weldje Plnordnungen zur Erreidyung bes Broeffes er= forberlich finto.

Die cimftweilige $\mathfrak{B e r j u ̈ g u n g ~ f a u m ~ n u d y ~ i n ~ e i n e r ~ S e s = ~}$ queftration jomie darin beftehen, Daß̉ Dem Btegner eine 5nandung geboten oder berboten, insbefondere die $\mathfrak{B e r}=$

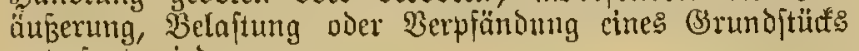
tinterjagt mird.

\$ 818. Pur unter befonderen umptänden fann die Sufhebung einer einftweiligen Berfügung gegen Sicherljeit: leiftung gejtattet merden.

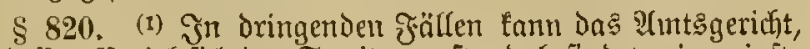
in deffer $\mathfrak{B}$ ejirf fid ber Etreitgegenftand befincet, eirre einjt= meilige $\mathfrak{B}$ erï̈gung erlaifen, inter Beftimmung einer frrift, imterhalb melder der Begner zur mïnofidjen Serljandtung ïber Die Red)tmäßsigleit Der eimftrueiligen Berfitgung bor Das (Serifft det Sauptjact)e zu laden ift.

(2) (3) . . . .

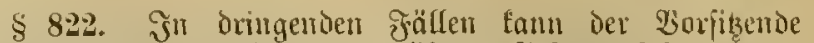
iiber die in diefem abfanitt erivähnten (Sejuche, jofern beren

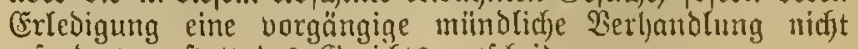
erfordert, anftatt des (Seridjts enticheiden.

\section{Buch. Alufgetuotsuerfalluren.}

§ 823. Cine offentlidfe gerifftlicfje $\mathscr{Y}$ Hfiporderung zur

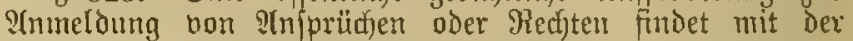
Wirlung, da naditheil zur Folge hat, mur in den ourch das (sejets be= itimmten ₹ällen itatt.

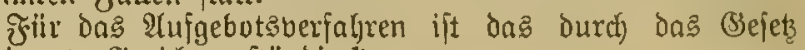
beftimute (Sericht zuftändig. $\left.{ }^{1}\right)$

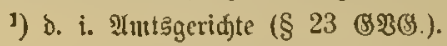

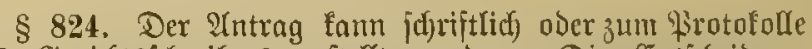
des (s)eridftsfduretbers geftellt merden. Die Enticheidung fann ohne borgängige mündtidje Berbantidung erjolgen.

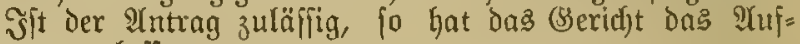
gebot zu ertaffen. ......

§ 825. Die öffertlidje Befamutmad)ung Des QTujgebots

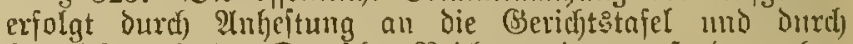
Cimrildung in ben Deutjhen Reichsanzeiger, außzerdem aber, fofern nidft bas (Sejebs für den betreffenden gall eine $a b=$ joidjente s(norbnung getroffen hat, nat) den im $\$ 187$ für Eadungen gegebenten 2 arjaciften.

\$ 82\%. Bwijdjen Dem Tage, an weldjem die CFinrilctung oder bie erjte Cinritfung des 2ufgebots in Den Deutjen

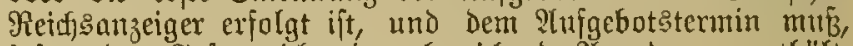

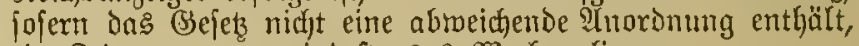
ein Beitraum bon mindeftens 6 Wochen riegen.

\$ 828. (Fine IInmeldung, meldfe nad) Dem Sdluffe

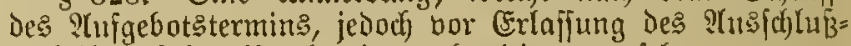
urtheils erfolgt, ift als eine recfitzeitige anzufeljen.

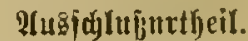

$\S$ 829. (1) Das Yusf(hlußzurtheil ift in offentlicher Sižung auf 9lntrag zu erlafien.

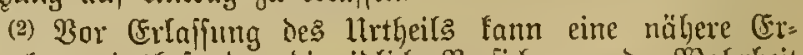

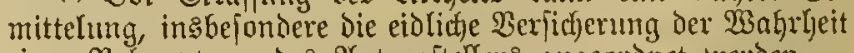
einer Beljauptung Des Întragftellers angeoronet werden.

(3) ......

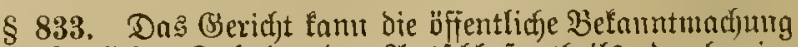

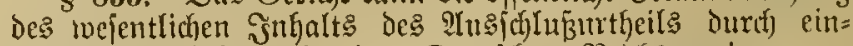
malige (Sinritfung in Den Deutichen Reid)sanzeigcr an= ordnen.

2njedjtung gälage.

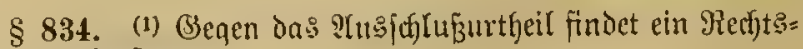
miftel utidft (tatt.1)

(2) ......

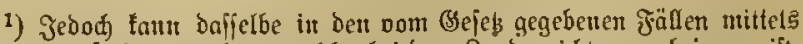

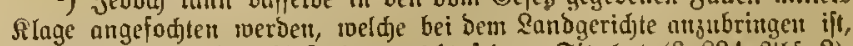

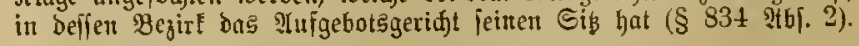

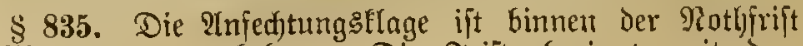
1 Monats zu erbeben. Die ₹ript beginnt mit bem 


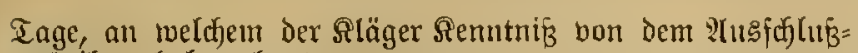
urtheile erhalten hat.1)

Pard ?tblauf bon 10 Sabren, bon bem Tage Der $\mathfrak{B e r =}$

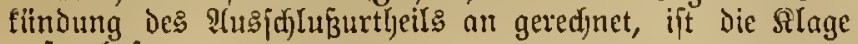
imptatthaft.

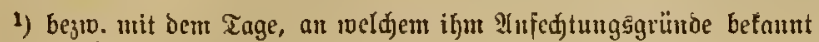
getworben finto.

\section{Iufgebot von 2 edjeln 2 .}

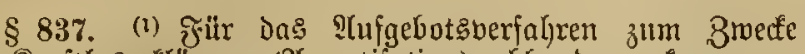
der Rraftloserflärung (2Tmortifation) abjanden gefommener ober bernidyteter Wed fel utio der in den 2trt. 301, 302 bes

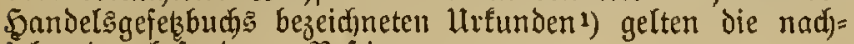
folgenden bejonderen Bejtimmungen.

(2) .....

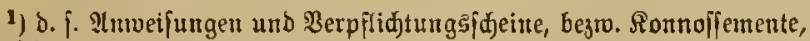
Radeldeine u. a.

§ 839. F̧iir Das 2lufgebotanberfahren ift bas (Serid)t

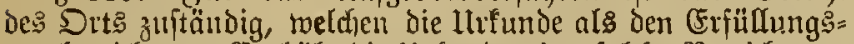
ort bezeidhnet. Enthält die Urtunde eine folche Bezeichnung

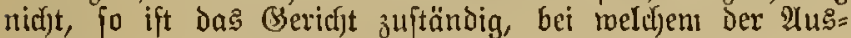
fiefler jeinell allgemeinen (Seridstoftand hat, und in cor mangelung eines joldjen (S)erichts dosjenige, bei weldjent

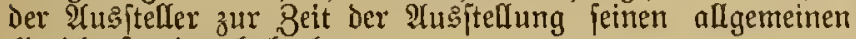
(Serid)têtand gehabt hat.

Sit ber Injprucf, ïber reldfen die Itrfunie ausigeftellt iit, in einem (Srund = oder Shpothefenbutie eingetragen, fo

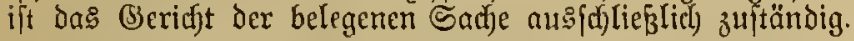

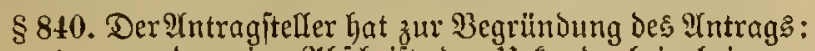

1. entweder eine Mbjudrift Der lltfunde beizubringen, oder den wejentlichen Эnthalt ber urtunde uno alles anzugeben, mas zur vollftändigen (Erfennbarteit derfelben erforberlich ift;

2. den Berluft ber llrfunbe forwie Diejenigen That= fadjen glaubhaft ju madjen, von weldjen feine

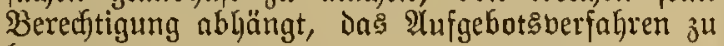
beantragen;

3. fich zur eioficten Berfitferung ber Mahrheit feiner ingaben zu erbieten.

§ 841. Sn Dem 2 A

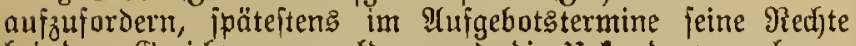
Gei dem Geridgt anzumelden uno die Ilrfutto vorzulegen.

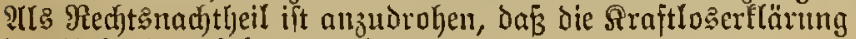
Der litfunde erfolgen werde.

§ 842. Die öffentlidfe Befonntmachung Des YIugebot: erfolgt Durd) Sinheftung an die (Seridftstajel und in Dem Sofale der Bärie, wem eine joldie an Size des ?lufgebots: geridfts beftegt, jomie burch) $3=$ malige (Einrüdung in bie im $\$ 187$ \& $6 f .2$ bezeid)neten 3 bätter.

Das (Sericht fann anoronen, Daß in andere B̧lätter und z" mehreren Malen exjolge.

§ 843. Bei Werthpapieren, für weldje von Beit zu Beit

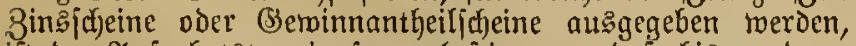
ift der Auigebotstermin fo zu bejtimmen, Daß bis zu bent= felben ber erfte einer feit der Beit des glaubhaft gemtad)ten

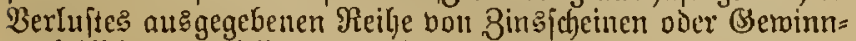

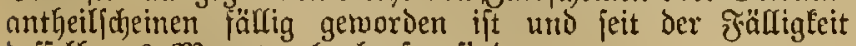
Defielben 6 Monate abgelaufen find.

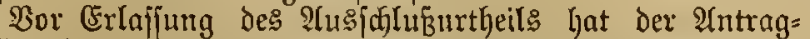
fteller ein nach 21blauf biejer 6=nonatigen frift ausgeftellte

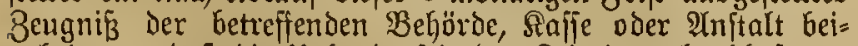
zubringen, dá̧ die Urfunde feit der Beit des glaubhaft ge=

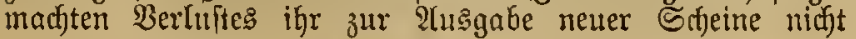

borgelegt fei und baß bie neuen Safeine an eimen als ben Antragiteller nid)t ausgegeben jeien.

\$ 847. Zrwijd)en dem Tage, an meldjem die erite (Fin=

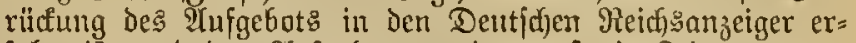
folgt iit, und bem Srufgebotstermine muß ein Beitraum you mindejtens 6 Monaten liegen.

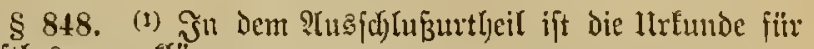
fiajtlos ju erflärent.

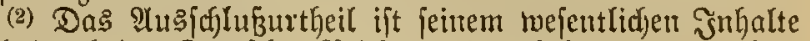

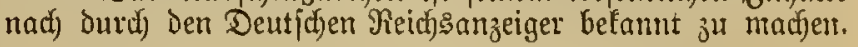

(3)

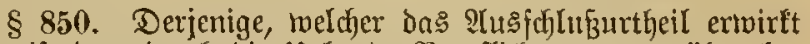
hat, ift Dem durd Die Urftmie Verpflid)teten gegenüber be=

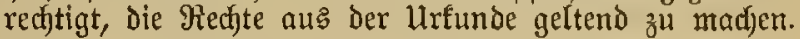

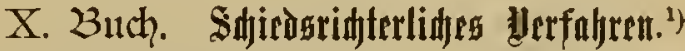

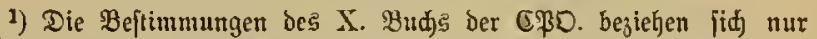
auf prinatredtlid) c Sdjiebsgerid), welden bic Entideibung eittes

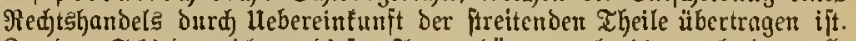
Bu beu Sdiebsgeridten biejer IItt gebören aud bie nad ben all= gemeinen Bertragsbebingungen für bie Insfïhrung vou Reiftusgen

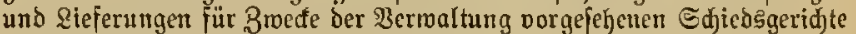
zur (Entjdeidung Don Streitigteiten über bie burd ben dieferunģs= 2c.

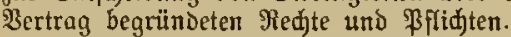

5ierber gehört nidht bas Berfahren vor ऽ山iebsgeridten in

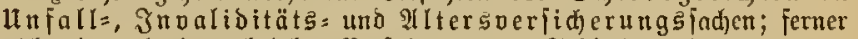
nidjt bas landešredjtlide Berfahren por Sdiedsmännern zur gütlidjen Beilegung oon Beleidigungs= $2 \epsilon$. Rlagen.

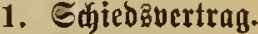

§ 851. Die Bereinbarnng, dof Die (5nticheidung einer red)tsftreitigfeit Durd) einen oder mehrere Schiedsridjter er= folgen folle, hat injomeit red)!liche WBirfung, als bie \$arteien berechtigt find, uber den Giegenftand des Etreits eimen $\mathfrak{V}$ er= gleid) $3^{u}$ f(d) liefren.

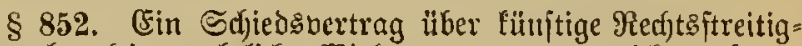
feiten hat teine redhtliche Wirtung, roenn ev nicht auf ein

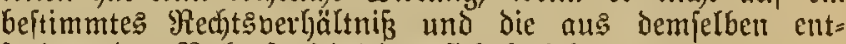

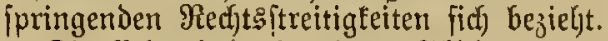

Die Rebenabrede in einent Sdjedsbertrage über Bildung des

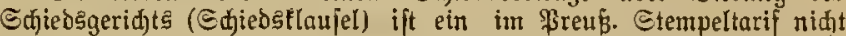

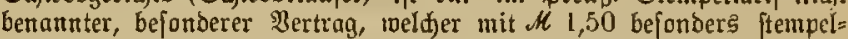
pflidtig ift. Es ift alio bei benjenigen Rieferungsverträgen, toelde nidjt unter bie Beftiumungen des Reidsftempelgejebes fallen, nebou bem \&ieferungsjtempel tood ein allgemeiner \$sertragsftempel (it bars

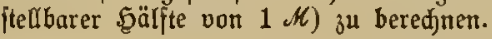

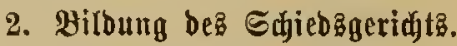

§ 854. Şit in Dem Schiedspertrage eine Beitimmung iiber die Ermenmung der Sdjiebsridfter nidjt enthalten, jo wird bon jeoer \$artei 1 Sajiedsrifjter ernannt.

Furgiren Beante als Sdjiedsridter, fo barf für bie 2 rbgabe eines

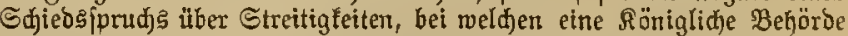
betheiligt ift, in ber Regel eine Bergütung reder angbebungen

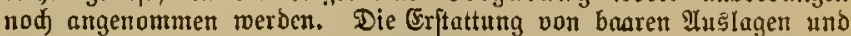

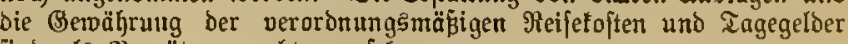
fino als 2̧ergütung matt anzufehen.

§ 855. Stegt beiben Farteien die Ernemmung bon Sdjiedsrid)tern zu, fo hat die betreibende Fartei dem (segner

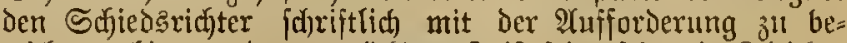
zeidjnen, Ginnen einer 1=mödigen Frift jeinerjeits ein (Sleidjes zu thun. 
Paad) frud)tlojem StGlauje Der Frift wirb auf Intrag der

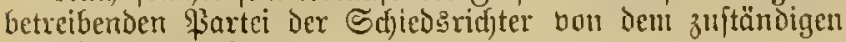
(Sicricht emamnt. ${ }^{2}$ )

I) Das zuftänoige Beridt ergiebt fid aus $\S 871$.

\$ 857. WBenn ein nidjt in Dem Sdjiedsbertrag emannter Sufiedsirichter fitrbt ober aus einem anderelt Grunde reg=

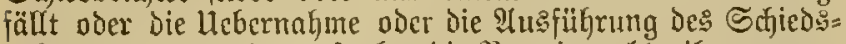
ridfteramts bermeigert, jo hat bie \$artei, weldhe ifnernannt hat, auf Auffordertung Des (S)egners binnen ciner 1=wöchigen Frrift einen anderen Sdiedsridjter zu Geftellen. Nady frudjt= lofem $\mathfrak{A}$ blauje Der Frift wird auf $\mathfrak{A n t r a g}$ Dex betreibenden

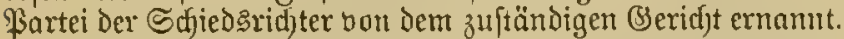

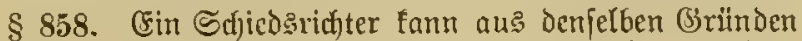
und unter denielken Borauşiszungen abgelehnt werden, meldie zur a(blehnung eines Ridhters bered)tigen.")

Die Şblehnung fam auferdem eriolgen, menn ein nicht in Dem Sdiedsbertrag emannter Shitedsriditer die (5r= fülung feiner Bffichter ungebülur(id) berzögert.2)

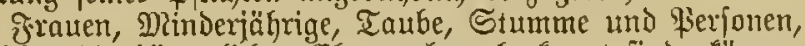
weld)en die bürgerticf)en esgrentedyte aberfamnt jün, fönnen abgelehnt merden.

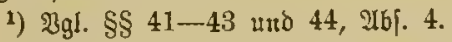

2) Wenn eir in bem Rertrage ernanter Sđjiebsridjter bie

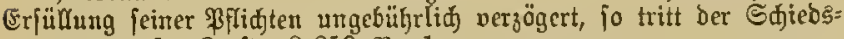
vertrag außer ßraft. $\$ 859$ शr. 1.

\$ 859. Der Sdjiedswertrag tritt auß̄er Siraft, jofert nid)t fïr ben betreffenden Fall Durd) eine Sereinbarung der Parteien Barforge getroffen ift:

1. menn befinumte Ferponen in bem Bertrage zut Sdjiedsridftern ernannt find แno ein Schiedsriditer jtirbt oder aus einem anderen (Grunde regfällt oder die Uebernalyme des Sdjiedstidjterants ber= weigert oder bon Dem mit ifm gefdilofienen $\mathfrak{B e r}=$ trage zurücftritt oder die (5ritiflung feiner Pfflicften ungebuhyrlid vergögert;

2. wenn die Shhicbşridter den Frarteien anzeigen, dẩ unter ihnen Stimmengleidgheit fid ergeben labe. $\left.{ }^{2}\right)$

1) uns aud batn, weru feine abjolute Megrbeit erzielt ifit, $\S 864$.

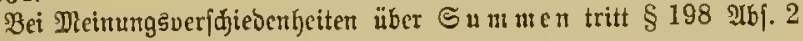
अखB. eit.

§ 860. Die Sdjiedsrid)ter haben bor (Erlafjung Des Sdjiedsfprud) die Firteien zu Gören I) und das Dem Streite

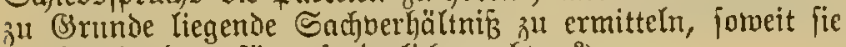
bie (5rmittelung für ex (orderlid) eradjten. ${ }^{2}$ )

Эn Ermangelung eitter Bereinbarung Der \$artcien ïber has Berfafren mird daffelbe bou den Sdjiedstidjern nach freien Ermejpen beftimmt.

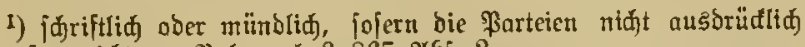

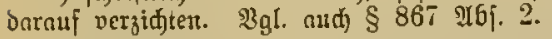

2) Die Labung zи einem Termin jur münolidyen Berbanblurg ge=

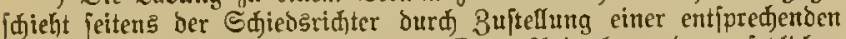

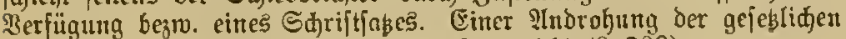

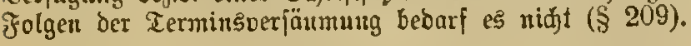

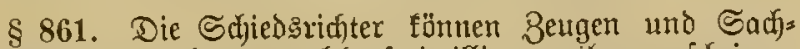
berftänbige vernehmen, welde freiwillig bor ilynen eridjeinet.

Zur Beeibigung eincs Zeugen oder eines Sacjueritändigen

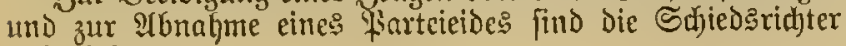
nidfyt befugt.
§ 862. (1) (Sine von Den Sdjiedsrichtern für erforderlid,

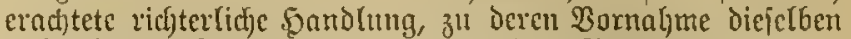
nicht befugt find, ift anf Üntrag eincr Bartei, fofern Der Intrag für zuläffig ernádtet triro, bon dem zujtändigen (Seridjte vorzunehmen. ${ }^{\text {) }}$

(2).....

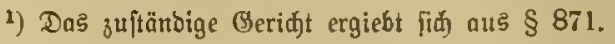

\$ 863. Die Sthiedsridjter fönnen Das $\mathfrak{B e x f a h r e n ~ f o r t = ~}$

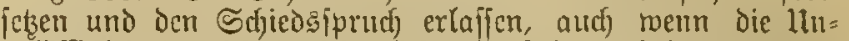

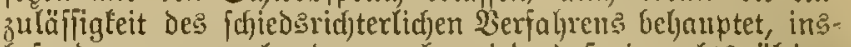
bejondere wenn geltend gemadjt wird, daf ein red)tsgilltiger Scfiedsvertrag nidft bejtehe, daß̧ der Srfiedsbertrag fith auf ben zu entidjeisenden Streit nicht bejiehe ober baß ein

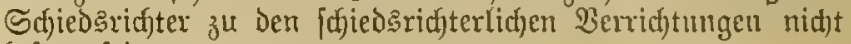
befugt fei.')

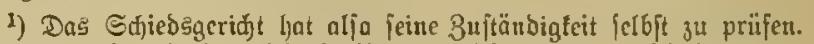

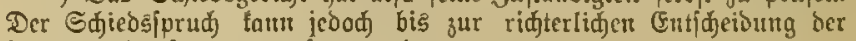

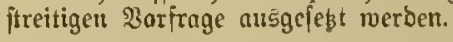

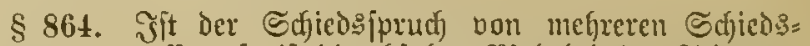
ridatern zu erlafjen, jo ift die abjolute Diehrbeit Der Stimmen

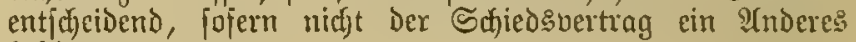
be(timmt. ${ }^{\text {) }}$

1) $\mathfrak{\text { gl. }} \S 859$ গ⿰氵. 2.

\section{Sdjiebsfprud.}

§ 865. Der Sdjiedsipruchi) ift unter $\mathfrak{A}$ (ngabe des Tages Dex $\mathscr{A b f a j j u n g}$ bon ben Edjiedsridjtern ju unteridjreiben, ${ }^{2}$ ) den Farteien in einer von Den Schiedstid)tern unterid)riebenen 2utsfertigung zułuftellen ${ }^{3}$ ) und unter Beifügung Der $\mathfrak{B} e=$ urfundung Der 3ujtellung auf der (Beridjtsjujteiberei de? 3 mftändigen (Seridutes ${ }^{4}$ ) niederzulegen. ${ }^{5}$ )

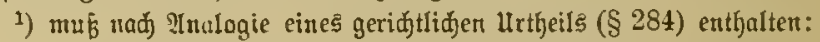

a) bic Bezcidnung ber \$arteient und cuentl. ihrer Bertreter nad) Ramen, Stant oder (Sewerbe unt Wiognort, ben

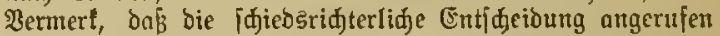

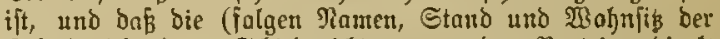

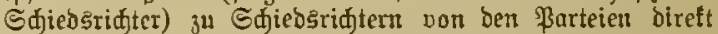
gemähIt aber naw Lebereinfommen bcrielbert burd ber (folgt bic \$egeifnung bes (Ernentrenden) ernant worben find und bei ber Entideidung mitgerwirt! haben,

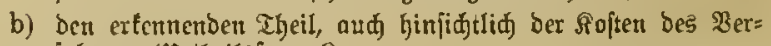
fahrents (Utrtheifşarmel),

c) eine georängte Darftellung bes Thatbeftandes,

d) Die Bründe ber Entifidibung.

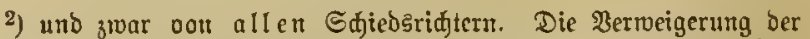

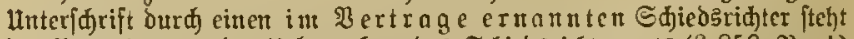

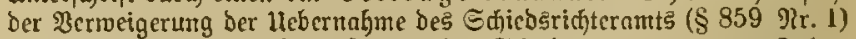

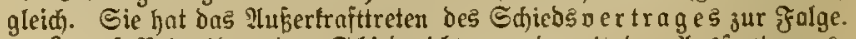

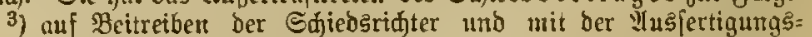

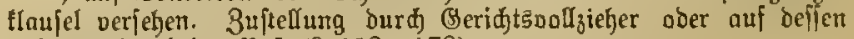
Gripuden burd bie \$olt (\$ $152-178$ ).

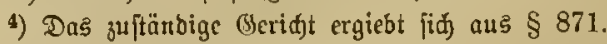

5) Durd einen ber Sdjebsridfter, weldem bie 3ujtellungsurtunde

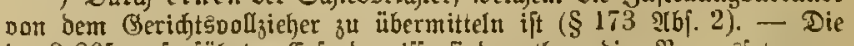
im $\$ 865$ aufgejührten Erforbcrniffe fino nothroendige 3arauşeßungen

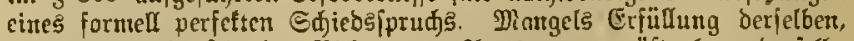

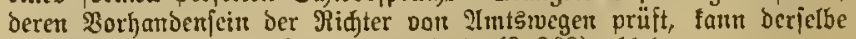

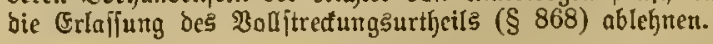

$\S 866$. Dex Shitedsprud hat unter Den ßarteien Die Wirfungen eines redjtsfräftigen geric)tlid)en llathei(s.1)

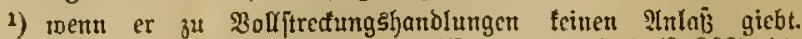

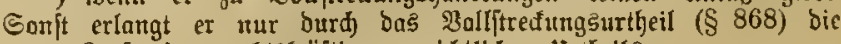
ganze Siraft eines ređtsłträftigen geriळtliđen Urtheils. 


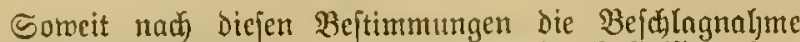
unjuläffig ift, ift andj jede Verfïgung Durd) (ecifion, $\mathscr{A} \mathfrak{n}=$

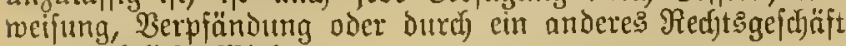
oljne reçjtlidje Wirfung.

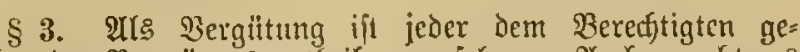
biihrende Vermögensuortheil anzujeben. YUud madjt es feinen Interfdied, ob biejelbe nad) Beit oder Stulde bes rechnet roird.

Y̧it bie Berglltung mit Dem \$reije ober $23 e r t h$ fiir

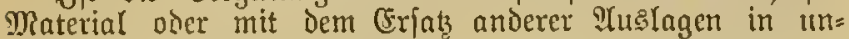
getrennter Stumme bedungen, jo gilt als Vergütung im

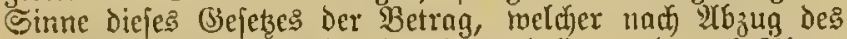
fisteifes oder bes Wertljes Der Miaterialien und nad) थ̉zug oer PYuslngen übrig bleibt.

\$ 4. Das gegentoärtige Befes findet feine Humendung:

1. auf den (Geljalt und die Dienftbezüge der b̈fentlicken Beamter;

2. auf Die Beitreibung der Direften perjönlidjen Staat: = iteuern und Sommunalabgaben (die derartigen ${ }^{*}(6=$ gaben an Sireiss, Sirctien=, Schul= und jonttige Rommunalverbände mit eingefdilofjen), jojern bieje
Stcuern und Ifbgaben nid)t feit länget als 3 Monaten fällig getworden find;

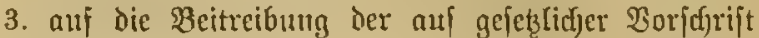

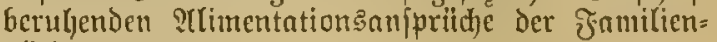
glieder;

4. auf Den Gehalt mo die Dienjtbezinge der im Frivatbienjte douternd angejtellen Ferjonem, fomeit Der (Befammtbetrag dic Summe bon 1500 Dit. ${ }^{1}$ ) jährlid ïberjteigt.

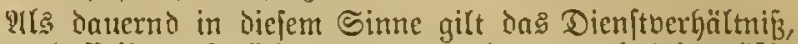

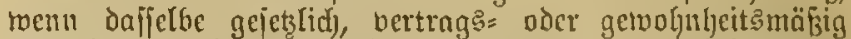
mindeftens auf 1 รalje beftimmt, oher bei unbeftinterter

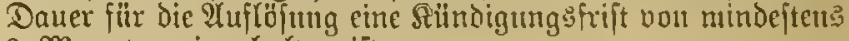
3 Mounten einzuljalten ijt.

1) Jajung, twie fic butd $\S 749$ Ibf. 3 cPD. beoingt ift.

\$. Diejes (Bejeß tritt an 1. श(uguit 1869 in Strajt.

Die bis baljin verfügten, unit den 20rfdjriftent bicfes (Gejekzes nid)t vereinbarten Befdjlagnahmen fino allf ?(ntrag Des Edjuldners nujzuheben oder einzujdjtänfen.

Dagegen finden die Beftimmungen de 2 . ?tb/nkes Des $\S 2$ aแf früherc frälle feine ?\{mmendung.

Urfunolid) $2 c$.

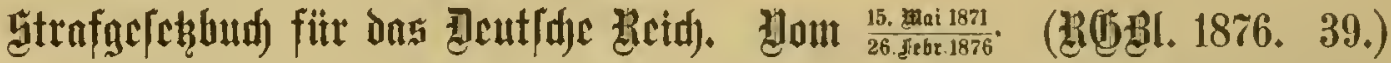

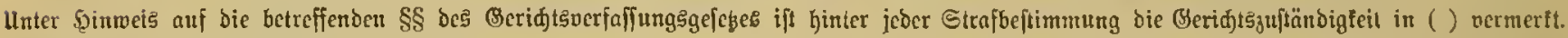

\section{Cintheilung Der ftrafbareu şandungen.}

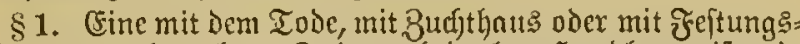
haft bon mehr als 5 Jahten bedrohte fenthlung ift ein Berbrecten.

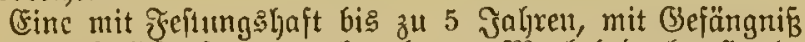
ober mit (3elditraje bon mehr als 150 Miart beorohte \$and= lung ift ein Sergehen.

Fine mit Saft oder mit Selditrafe bis z"l 150 Mart beorohte Scandlung ift eine Hebertretung.

§ 3. Die Strajgejebe des Deutidjen Reidjs finden $2(n=$ menoung auf alle im (sebiete deffelken begangenen itraf:

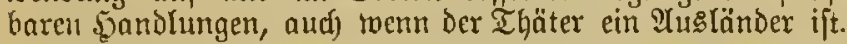

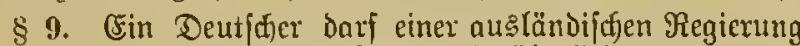
зur Berjolgung oder Beftrafung niabt überliefert merden.1)

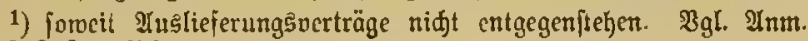
зи § 318 Sเฉ0.

\section{Strajen.}

§13. Die Tonesptrafe ift Durd) Enthauptung zu volftreden.

§ 14. (1) Die Zuduthausftraje ift eine lebenslänglidje ober eine zeitige.

(2) Der Seöchitbetrag Der zeitigen Buththausftrafe ijt 15 Jahre, ihr Mindeftbetrag 1 Jahr.

(3) ......

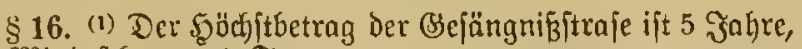
ithr Mindeftbetrag 1 Iag.

(2) (3) .....

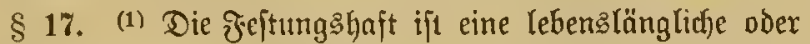
eine seitige.

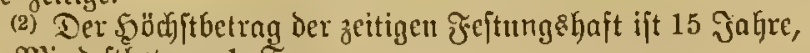
ifr. Mindeftbetrag 1 ऽag.

(3 3 (4).....

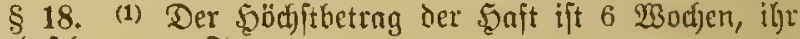
Mindejtbetrag 1 Iag.

(2) $\ldots \ldots$

§ 27. Der Mindeftbetrag der Belditraje ift bei Ber= brecten und Bergehen 3 Mart, bei llebertretumgen 1 Mart.

\section{Bertujt ber bürgerliäen (5hrenredite.}

§ 32. (1) Mieben Der Todesitrafe und der Budhthausftrafe fann auf den Berluit Der bürgerlichen (E) Jremred)te erfant werden, neben der Siejängnisjitrafe nux, wenn dic Douter ber erfantuten Strafe 3 Ponate etreidjt und entweder Das (Gejetz den Berlujt der bürgerlict)en (shrented) ausorïdélid) zuläfít oder die Gejängnif̧itrafe wegen ?tunahme milldernder umptände an Stelle von Budjthausftrafe ausgefprodien miro.

(2) .......

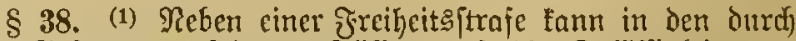

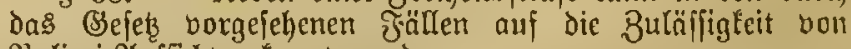
Folizei-2lufficht erfannt werden.

(2) .......

Theilmahme.

§ 47. Wenn Mehrere eine jtrajbare Şandlung gemein=

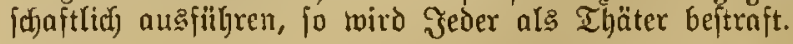

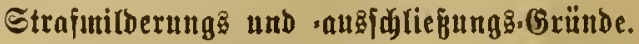

§51. Gine ftrafbare Fandlung ift nicfit borhanden, menn ier $\mathfrak{T h a ̈ t e r ~ z u r ~ B e i t ~ d e r ~ B e g e h u n g ~ i ̀ e r ~ \$ a n d l u n g ~ f i d ~}$ in einem Buftande bon Bermugtlofigfeit oder franthafter Störung der (Beiftestbätigfeit befand, butch meldjen feine freie Willensbeftimmung ausgefdilofien toar. 


\section{Nathweljt.}

§. 53. Cine itrajbare \$ुandlung ift nidft borbanden, soenn die Sandlung durd) Rothroefr geboten war.

Piotbmehr ift Diejenige $\mathfrak{B} e r t h e i d i g u n g$, weldje erforderlidf

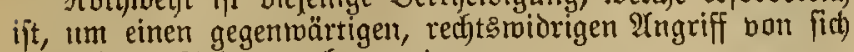
oder einem glnderen abzumenden.

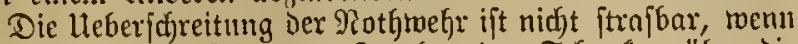
der Thäter in Beftürzung, furdyt oder Safjecfen ither dic (Brenzen ber Bertheibigung hinausgegangen ift.

§ 55. Wer bei Begefgung Jer Şandlung bas 12. \&ebens= jaljr nidjt bollendet hat, fann wegen berfelben nidjt ftraf= redhtlich nerfolgt merden.

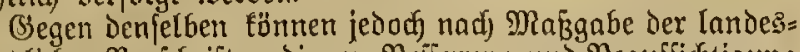
geiekzlidjen $\mathfrak{B o r j d}$ riften bie zur Bejierung und Beaufficjtigung

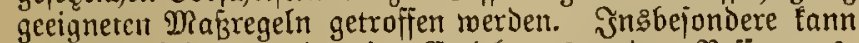
Die Unterbringung in eine Criziehungs: oder Befierungs:

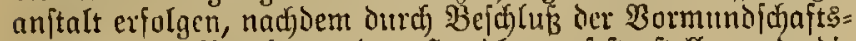
beljörde die Begehung der Sandiung fejtgeftellt und die ltnterbringung für zuläifig erflärt ift.

Bgl. bie Nir. 2 ber Schluß̄bemerfung zur BormunojめD.

§56. (1) Ein ?Ingeffyuldigter, meldfer zu einer 3cit, als er bas 12., aber nidut bas 18. Rebenşafir vollendet hatte, cine ftrafbare Sandlung begangen hat, ilt freizupprectien, wenn er bei Begehung derfelben die zur Crtenntnib ibrer Strafbarteit exforderlidje (sinfidjt nidjt bejaß̧.

(2) ......

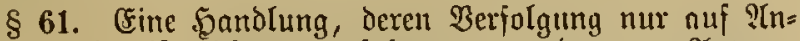

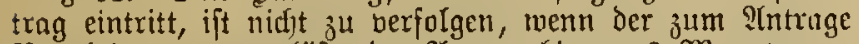
Berech)tigte es unterläßst, den $\mathfrak{A n t r a g}$ binnen 3 Monaten zit ftellen. Diefe Jrift beginnt mit dem Tage, feit reldhem ber jum 2(ntrage Bered)tigte bon der Sandlung und von

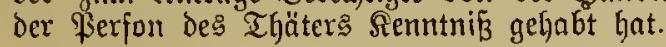

\$ 64. (1) Dic Burïdnafjume Des YMtrages ift nur in den gefeblit) bejonders norgejefenen f̈̈̈lfen und nux bis zur Bertitnoung cines auf Strafe lautenden Urtlyeils zuläfíig.

(2) .....

\section{Berjäljrung: a) ber Gtrafberfolgung.}

§ 67. (1) Die Strafberfolgung von Verbredfen verjährt, jwenn fie mit dem Tode oder mit lebenslänglidfem 3udjthaus beoroht jind, in 20 Sagren;

wenn fie in sobuftbetrage mit einer freiljeitsftrafe bon einer längeren aIs 10=jährigen Dauer Georoht find, in 15 Jahren;

menn fie mit einer geringeren Jreigeitsftrafe kedroht find, in 10 Эahren.

(2) Die Strafberfolgung von Bergehen, dic im $50 ̈$ jjptbetrage mit einer längeren als $3=$ monatlichen $3 e f a ̈ n g n i f j$ trafe be= broht find, verjälyt in 5 Эahren, bon anderen Bergehen in 3 Эafren.

(3) Die Strafuexfolgung von Uebertretungen verjährt in 3 Mionaten.

(4) Die Berjährung beginnt mit Dem Tage, an meldjem dic Şandlung begangen ift, ohne Rüufficht auf den Beitpunft des eingstretenen Erifolge?.

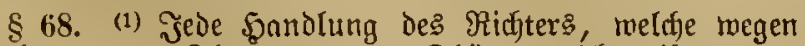
der begangenen That gegen ben Thäter geridtet ift, unter= brifft bie Berjährung.

(2) (3) b) bet Strafoullitredung.

\$ 70. Die Bolljtretfung recht: fräftig erfannter Strajen verjährt, wenn

1. anf Too oder auf IebenIIn̈ngliches Burththauts oder auf lebenslängliche Jeftungshaft erfannt ift, in 30 Эnltren;

2. auf Zudhthaus oder Jeftung ghaft non ntehr nIs 10 Эaliren erfannt iit, in 20 Jahren;

3. auf Budfthaus bis zu 10 Jahyen oder auf Jeftungs: haft bout 5 bis ju 10 Jahren oder (S)efängniß̧ bon mehx als 5 Fahren extaunt ijt, in 15 Jaljren;

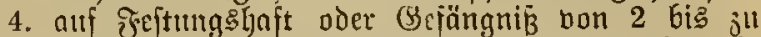
5 Jabren oder aui (seldoftraje bon meljr als 6000 Marf erfannt ift, in 10 Jahren;

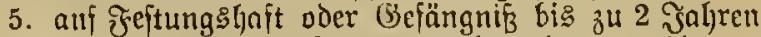
oder auf Gieldjtrafe bon mehr als 150 bis jut 6000 Mart erfantut iit, in 5 S̃aljeen;

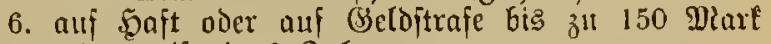
erfannt ift, in 2 Эałren.

Die $\mathfrak{B e r j a ̈ h r u n g ~ G e g i n n t ~ m i t ~ D e n t ~ T a g e , ~ a l t ~ m e l d t e m ~ d a s ~}$ Untheil rechtsfräftig geivorden ift.

Eattbesverrath.

§ 90. (1) Sebenglänglid)e Zud)tfyausftraje tritt im Falle dę $\$ 89^{1}$ ) ein, teerr ber Thằter

2. ....... Britifen, Eifenbahnen, Telegraphen und Iransportmittel in feindlidje (Semalt bringt oder zun Bortlyeile des Feindes jerftört oder unbraudjbar madft;

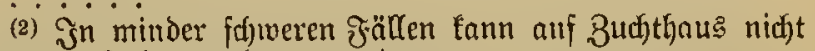
unter 10 รafren erfaunt werden.

(3) ธind mildernde lunftände borhanden, fo tritt §eftung: lyaft nicht unter 5 Jaljren eint.

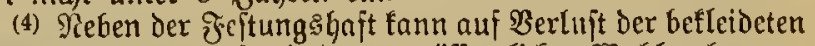
öffentlid)en STemter, fotwie der aus öffentficfen wahlen herbor=

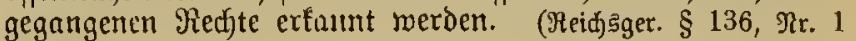
(अ) $3(5$.

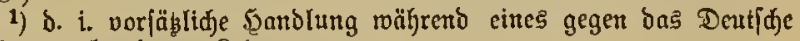
Reid ausgebrodjenen Ŝrieges.

Wideritand gegen bie Staatagewalt.

$\S$ 113. Wer einem Beamten, weldjer zur Bollitrectung bon (Sejetsen, bon Bejeljlen uno Wnoronungen der Ber= waltungebehörden oder bon Mrtheilen und Berfügungen dex

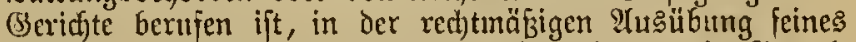
Amtes Durd) (Setwalt oder Durd) Beorolyng mit (Serwalt Biderftand leijtet, oder wer einen loldfen Beamten währeno

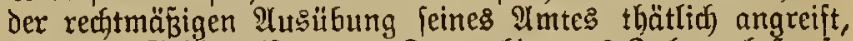
wiro mit Bejängnif́s bun 14 Tagen bis zu 2 Jahren bejtraft.

Sind mildernde lumitände vorhanden, fo tritt Befängnißs= ftrafe bis zu 1 Jahye oder Beloftrafe bis zu 1000 Mart ein.

Diejelben $\mathfrak{B}$ orifdriften treten ein, wenn dic Saandlung gegen \$ierfonen, welche zur Unterftübung des Beamten zu= gezogen waren, oder gegen Mannichaften Der berwaffneten Madjt, oder gegen Mannjd)aften einer Semeindes, Shuts=

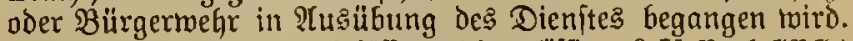

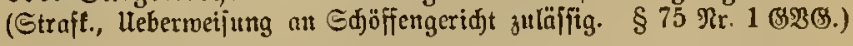

$\S 114$. Wer es unternimmt, Durch) Semalt oder Drobung eine $\mathfrak{B}$ ehpörde oder einen $\mathfrak{B e a m t e n}$ jur $\mathfrak{B}$ ornafme oder $\mathcal{U}$ ter=

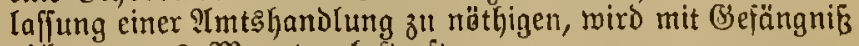
nidit unter 3 Monaten beftraft.

Sind mildernde Umftände vorhanden, fo tritt Befängniß= itrafe bis zu 2 Эahren ein. (Etraft., Heberweifg. an Sđöffeng.

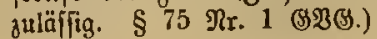




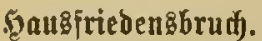

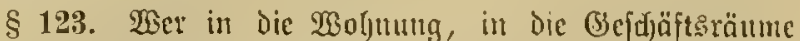
oder in bas heiriedetc Befitsthum eines Anderen oder in abgejd)lofjene Räume, weldhe zum iffentlidfen Dienft be= ftimut find, ${ }^{1}$ miderredftlich cindringt, oder ber, wenu er

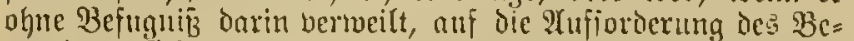
red)tigten fidf nidft entfernt, mirb wegen Sausfriedensbrud)ę mit Şejänguifis bis zu 3 Monaten Dder mit Beldjtrafe bis ju 300 Miarf beftraft. (ङdjoffeng. § 27 9ir. 2 (3)38.)

Die 2 erfolgung tritt nut auf 9 Intrag cin.

Sit bie 5andung bon einer mit $23 a f f e n$ berjehenen \$erion oder von Jieljreren gemeinfdjaftlid) begangen worden, fo tritt

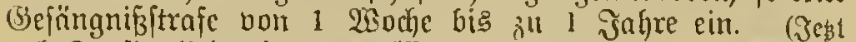

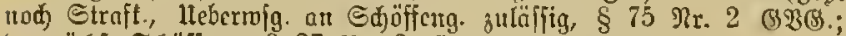

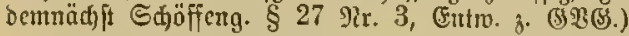

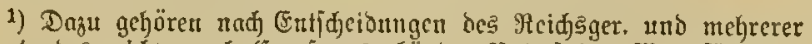

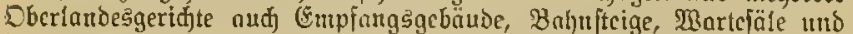

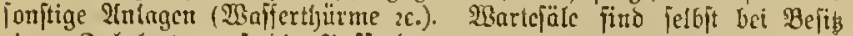

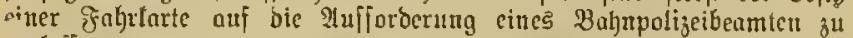
verlajien.

\section{Thtore Berbredfen und Bergehen wiber bie öfifentl. Dromung.}

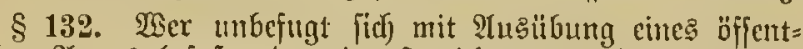

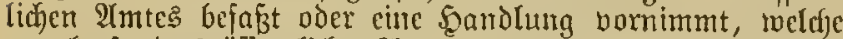
nux fraft eince offentliden 2 (mtes borgenommen werden dorf, mird mit Bsefängni

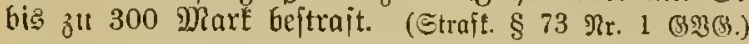

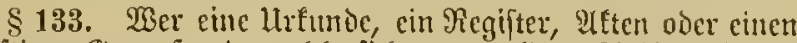

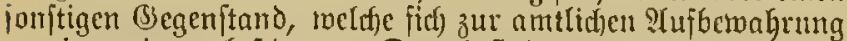
an einem dazll Gejtimnten Drte befinden, oder welche einem Beamten oder einem Dritten auttidy übergeben tworden find,

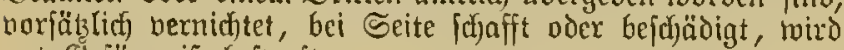
mut Sicjängnifis beftraft.

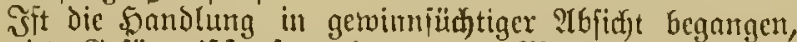
fo tritt (Befüngnisitrafc nudft unter 3 Monaten ciu; aud

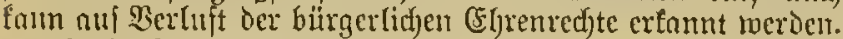
(Stroft. $§ 73$ शr. I (BशB.)

$\$ 134$. Wer öffentlict) angefdylagene Befamntmactjungen, Zieroronungen, Befefle oder \&lnzeigen von Befjörden over Beamten böswillig abreif̧t, beidjädigt ober nerumftaltet, wiro mit Belditrafe bis zut 300 Diart oder mit Befängnís bis zu 6 Monaten beftrait. (Strajt. Heberroig. an ভdjoffeng. zu= läfitig. § 75 Rr. 14 [15] (ङBS.)

$\S 136$. Wer unbejugt cin amtlidjes Siegel, weldjes non einer Befhörde oder einem Beanten angelegt ift, um

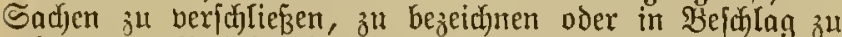

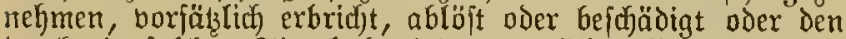
burdf ein foldees Siegel berwirtten amtlichen Berfefluß auf= hebt, mird mit Sefängniß̧ bis zu 6 Monaten beftraft.

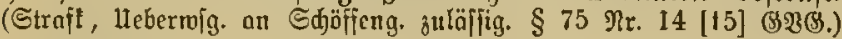

\section{Beleibigung.}

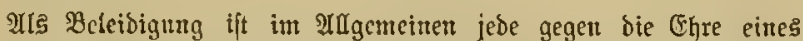
Fnderen geridtetc Rundgebung anjulehen. "Tabelnde Hrtheile über miffenjhajtiche, fünflerijde ober gewerblidje Eciftungen, ingleiden

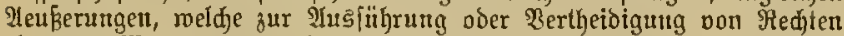
ober zur Mabruchuung beredtigter Yntercjien gemadjt merden, fomte

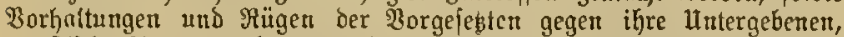
biempttidge PIngeigen ober Unthcite von Seiten eines Beamten uno ähn=

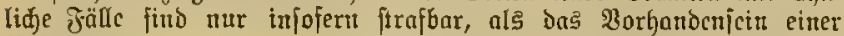
જeleidigung nus ber form ber 2feußserung oder aus ben Unitändon, unter weld)en fie gejdah, herworgeht." (\$ 193 ङt(3:).

Die Betfolgung ciuer Bclcibigung tritt mur anf ofntrag ein. Die

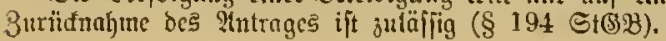

§ 196. Menn dic Bclcibigung gegen eine Beljörde, cincu Beamten, einen Religionsdanct oder ein MRitglied Dex $b c=$

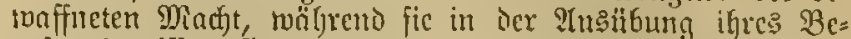
rufes begriffen find, nicr in Beziefung auf ifjen Bernf begangen ift, fa lyaben auber oen unmittelbar Betbeiligten

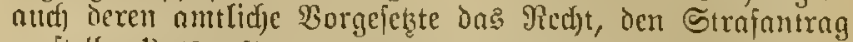

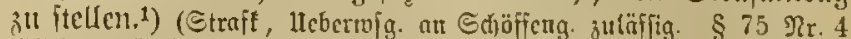

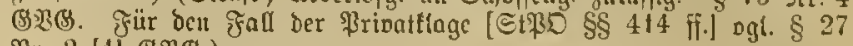

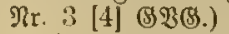

1) BgI. Gemeir|B. \& 20 ,

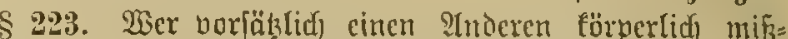
halsoclt oder an ber (Ficfunbheit Gefchäbigt, wird swegen

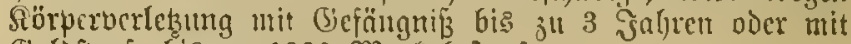
(B)eloftrafe bis zu 1000 Mark bejtrajt.

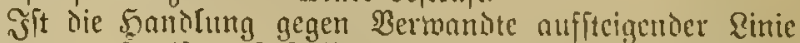
begartgen, fo ift auf (S)cfängnif nicht unter 1 Monnt zu

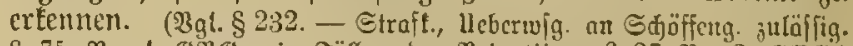

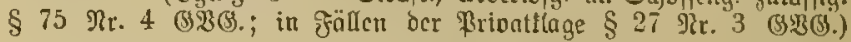

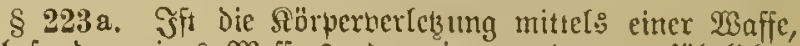
insbefondere eines Meffers oder eines anderen gefülytidjen Werf zenges, oider mittels eines binterliftigen lleberfonds oder bon Pielyzeren gemeinj(d)ajtlid), oder mittels ciner das Rebert

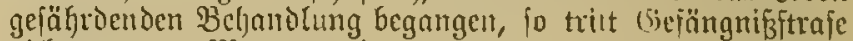
nidyt unter 2 Dionnten cin. (ভtrafz., Hebernog. an Sdjöfieng.

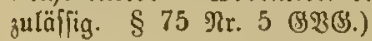

§ 230. Wer Durch Falyrläffigfeit Bie Räpperbertetzung

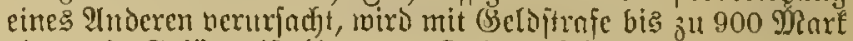

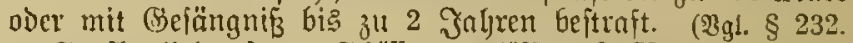

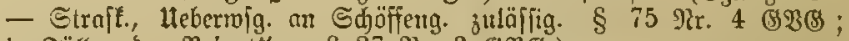

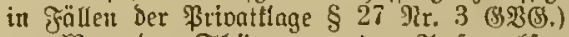

War ber Thäter zu der ?tufmerffamfeit, meldye er aus

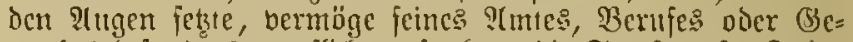
twerbes befonders berpflidjtet, fo fam lite Strafe auf 3 Sabre

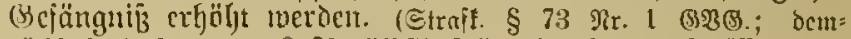

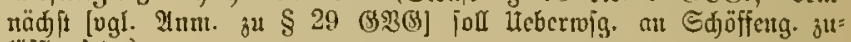
läjfitg jeiti.)

$\$ 232$. (t) Die Berfolgung leidfter vorjäłূliçer, jowic

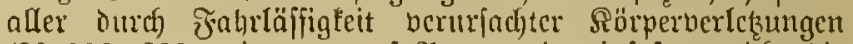
( $\$ \S 223,230$ ) tritt mur auf ?tntrag cin, infoferm nicft dic

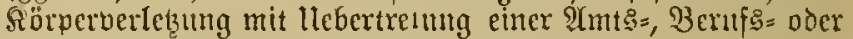
(Betwerbspflityt begangen worden ift.

(2) Silt Das Bergehen gegen cinen Ingel)örigen verübt, fo ît dic Zuritduahme bes vintrages zuläfitg.

(3).....

Sdjwerer Diebftabl.

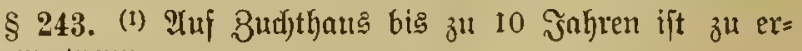
kennen, wenn

4. auf einem offentlicten $\mathfrak{B} \mathrm{ege}$, einer Strnbe, einem öffentlichen \$lakze, einer Wanfferjtrake oder cinter cifenbahn, oder in eirem \$ojtgebiude oder dem Daßu gehörigen \$ofraume, oder auf cinem (Eijenbahn= lofe eime zum Recifegepäaf ober ju nnderen (Segen= ftänden Der Befp̈rderuma geljörende Sarde mittels

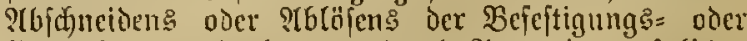
Bermahrutggsutttel, oder burth Antwendung falje)er Sd) litiffer oder anderer jur oronung

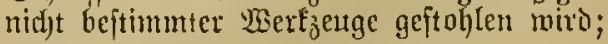

(2) Sind uildomie llmftänie vorlyanden, fo tritt Befäng=

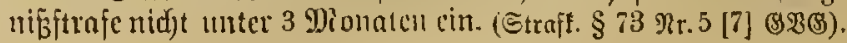


Maub.

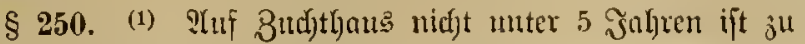
ertennen, inenn

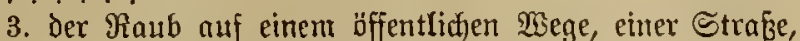

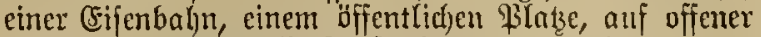
See oder einer Wafjeritraje begangen wird;

(2) Sind milderndellmftände vorhanden, io tritt (Befängnif́ =

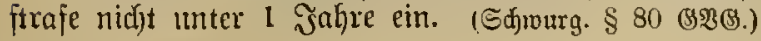

\section{Betrug.}

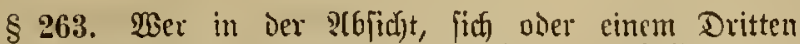
einen rechtsmibrigen 2 ermögensuortheil ju werid)affen, das

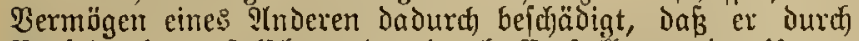
Borfpiegelung falidjer ooer burd) (Entitcllumg oder Unter= brüctung wahrer Thatfachen ${ }^{1}$ ) einen Srrthum erregt oder unterfält, wird megen Betruges ${ }^{2}$ ) mit (Se\}ängnif́ beitrajt, neben weldsem auf (3)eldftrafe bis z̆ 3000 Miarf, fotwie auf Berluft Der bitrgerlidjen (Ehrenredjte erfanut werden faun.

Sind mildermde unifände vorhanden, jo fann aus= id)lieflich) auf bie (seldoftrafe erfannt merden.

Ser Beritth ift itrafbar.

Wer einen Betrug gegen Angehörige, Bormünder oder (5rzieljer begeht, ift mur auf 9lntrag zu berfolgen. Die Burürnalyme des 9lntrages ijt zulälfig. (Sdjüfeng. bis zu

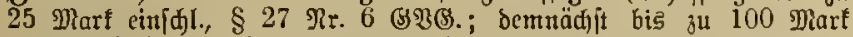

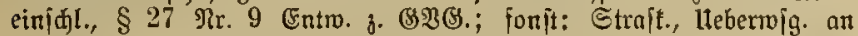

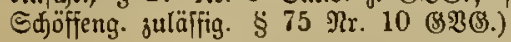

1) Unterbrüünng wafher Thatfachen liegt aud in ber heinulifjen Whitfahrt in eiutem Eifenbahnjuge ohne oder mit ungülttiger Fałrfarte, fowic aud in ber Bentakung einer fremben, als untibertragbar be= zeidneten $\Re$ üd $f \circ \mathfrak{h} r=$ Doer einer 3 eitfarte.

2) Dahin gehören aud unridftige Angaben im fradtbrieje gum

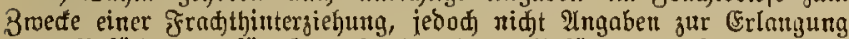
einer ßeförberung für Begenftänoc, Deren Beförderung fonft ausges ¡đ̆lolfen märe.

\section{Sadbeidäbigung.}

$\S 305$. Wer vorfäblich und rectjtsmidrig ein Şebäude, ein Sthiff, eine 23rücfe, einen Damm, eine gebaute Straßze, eine (sijenbahn1 ${ }^{1}$ ) oder ein anderes $\mathfrak{B}$ aummerf, melche fremdes Eigenthum find, ganz oder theilmeije zerftört, mird mit Ge= fängnif nicft unter 1 Monat bejtrajt.

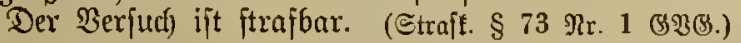

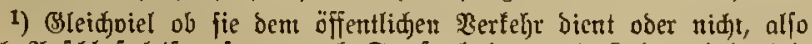

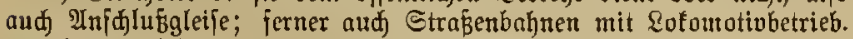

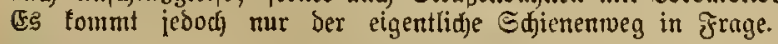

\section{Jügejahriełung von (Gijenbahntrangporten.}

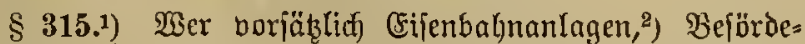
rungemittel oder jonftiges Zubeför Derfelben Dergeftalt

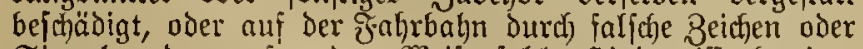
Signale oder auf andere Weife jolche Seinderniffe bereitet, DấB Dadurd) Der Iransport ${ }^{3}$ ) in (Sefahr gejektt trirb, mird mit

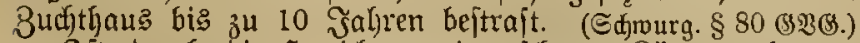

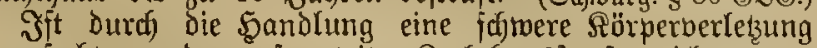
berurfaudt toorden, fo tritt Buchthausftrafe nicht unter 5 Jahren und, wenn der Tod einę Menjajen bermiadjt morden ift, Buchthausitiafe nidft unter 10 Jahren oder

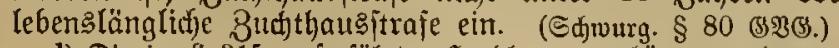

1) Die im $\S 315$ aufgefïhrten bandlungen gehoren zu ben ge=

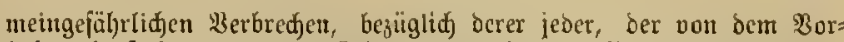
haben berielben zu einer Beit, in welder bie Scrbütung bes $2 \mathrm{er}=$

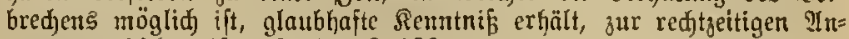
zeige verpflidjtet ift. St(5) \$ $\$ 139$.

2) $\mathfrak{g g l}$ I Innt. 3u $§ 305$.

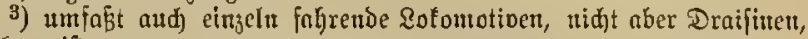
Bahnmeiftermagen $2 e$.

\$ 316. Wer fahrläffigertweife Durd) eine der borbejeidhneten Sandlungen den Transport nuf einer Sifenbahn in (Sejahr

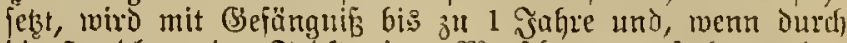
bie Sandlung Der $\mathfrak{T o s}^{1}$ ) eines Menjiden beruriact torden ift, mit Bjeföngnif von 1 Monat biş zu 3 Sahten bejtraft.

(G) eicfe Strafe trifft die zur \&eitung der (Eijenbahnjahrten

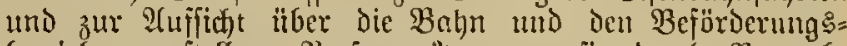
betricb angejtellen \$erjonen, ${ }^{2}$ ) wenn fie Durd Sernafy= läifigung der iljnen obliegenden Bflidten einen Transport

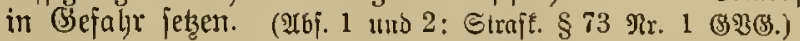

1) Begen ber fahrläffigen $\Re$ örperverleßsung ogl. $\$ 230$.

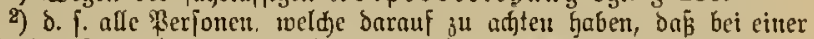

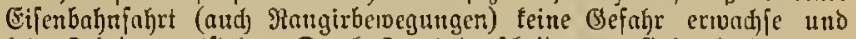
fein Sajaben entftehe. Durd Spezialentj内eisungen find als bağ ge,

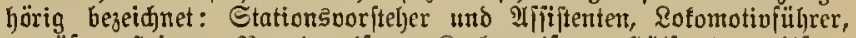

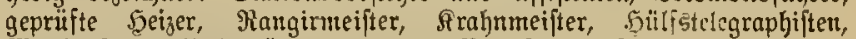

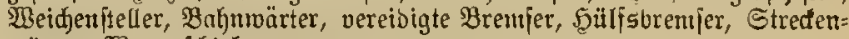
roärter, $\mathfrak{B}$ agenfidjieber.

Bejüäbigung von Telegraphenanlagen.

§ 317.1) Wer vorjäb(id) unذ rechtstwiorig Den Betrieb einer zu offientlidjen 8rwecten dienenden Ielegraphenanlage badurch berhindert oder gefälyrbet, Dẩ er Theile oder $3 \mathrm{~L}=$ behörungen derfelben bejdäDigt oòer 9 keränderungen daran vornimnt, wird mit Sefängni

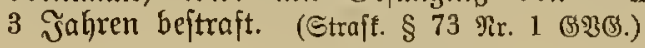

\$ 318. ${ }^{1}$ ) Wer fallrtäjïgerweife Durch eine Der bor= bezeidneten 5̧andlungen den Betrieb ciner ơ öffentlichen 3roefen dienenden Telegraphenanlage berhinbert oder ge=

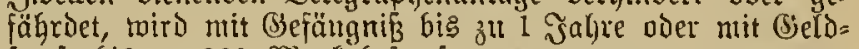

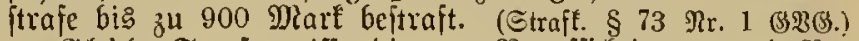

(3) (eid)e Strafe trifft bic jur Beauffichtigung und $\mathfrak{B} e=$ dienung Der Iolegraplenanlaget und iljrer Bubeförungen angeitellten \$erjonen, weun fie Dnrdi) Sernachläfifigung ber ihnen obfiegenden 'sffichten den Betrieb verhindern oder ge=

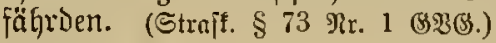

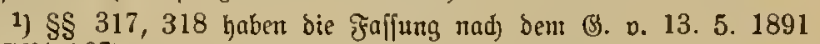

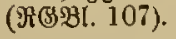

$\S 318$ a.1) Die Dorfuriften in den $\S \S 317$ und 318

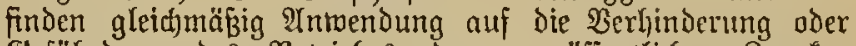
Gefähroung des Betriebes ber zu öffentlicfen 3medfen dienenien Rahrpoftanlagen.

Huter Telegraphenaulagen im Sinne der $\S \S 317$ แmb 318 find テૅernjpred)anlagen mitbegriffen.

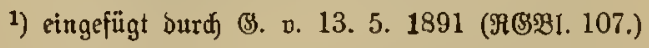

$\S 319$. Wird einer der in Den $\S \S 316$ แnd 318 ex= wähnten Ylugeitellten wegen einer Der in Den $\$ \S 315$ bis 318 bezeifineten Eamblungen berurtheilt, io kann Derfelbe

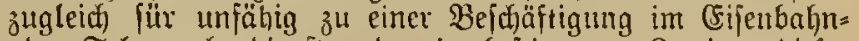
oDer Telegraphendienjte oder in bejtimmten 3meigen diejer Dienjte ertärt werden.

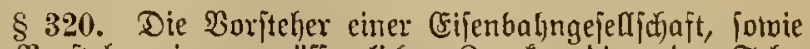
die Borftelger einer za affentlidfen Zwedfen Dienenden Tele= graphenanitalt, weldye nicht fofort nach Mittheilung bes

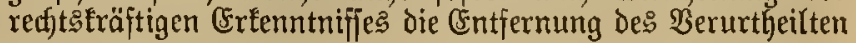




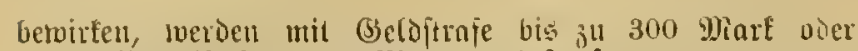
mit Befängní̧ bis zu 3 Monaten beftraft.

(S)leidhe ctraje trifft benjenigen, weld)e fït unfähig zแm Eifenbnlu= ober Selegraplyandenjte erflärt morden ift, wenn ex fich nadher bei einer Fijenbahn oder Selegraphes= anjtalt wieber anftellen läßst, fowic bicjenigen, weld)e ilyn wieber angeftedt bnben, obgleit) ifuen die erjolgte Unjähig=

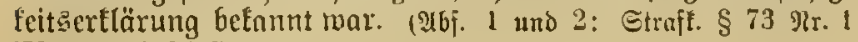
[75 গr. 15] (3\$3).)

\section{ใbjperrumgs:}

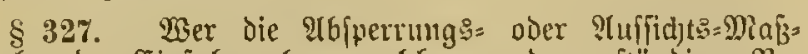
regeln ober (Einjuhrberbote, tweldhe von ber zuftändigen $\mathfrak{B e}=$ börde zแ Berfütumg Des Cinfïfrens oder Berbreitens ciner aujtedenden franlbeit augeordnet toorden fint, mijfentlicf) nerlebt, mirb mit (Sefäugnif̧ bis zu 2 şaren bejtraft. (Straft., Heberrojg. an Edäffeng. zuläfitg. \& 75 शir. 13 [14] (\$शB.)

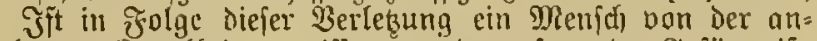
ftedenden Sirantheit ergrifien morden, fo tritt (S)efänguís: frafe bou 3 Monaten bis ju 3 รaljren ein. (હtraft. $\$ 73$ ?r. 1 (BBS.)

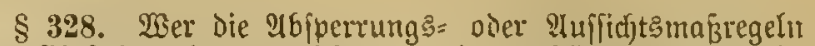
oder Einfuhrberbote, weldje von der zuftändigen Behörde

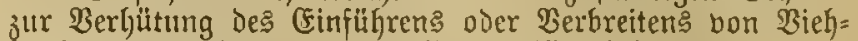
feudjen angeorduet worden find, wiffentlid) berlest, wiro

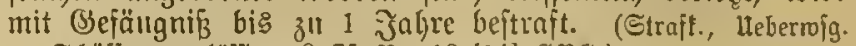

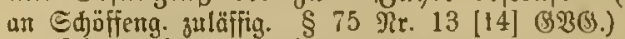

Jit in Folge biefer Berlebung Bieh bon Der Seudje er= griffen worben, fo tritt (Scfängniß̄itrafe von 1 Manat bis

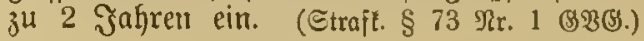

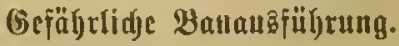

§330. Wer bei Der Reitung oder ?usfführung eines

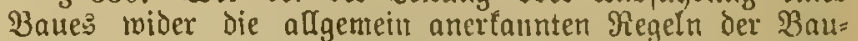
Eunit dergeftalt handelt, Dẩ lyeraus für Indere Ssefahr entiteht, wird mit Geloftrafe bis ju 900 Mart oder mit

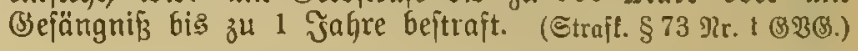

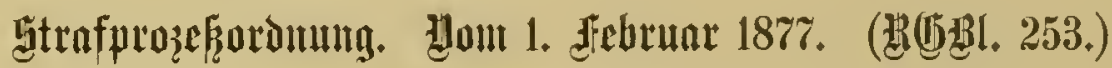

Sit Srait getreten an 1. Dltober 1879 .

Bal. Die Borbenertung jum Bßg oben E. 119. Die:

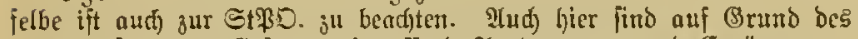
"Entmurís eines Bejeb̧s, betreffeno शenderungen uno Ergänzungen bes Beriditsverfaliungsgejelyes uns ber Strafprogebordutu" - in ber Folge mit (Entro. bejeidjut - cinige midtigere ber beabfidjtigteu Ibänberungen bei beu berreffenden $\$ \S$ vermerft.

\section{3nhalt}

\begin{tabular}{|c|c|c|c|}
\hline I. $\mathfrak{B u d}$ & Illgemeine Beftimmungen . . & . . & $1-150$ \\
\hline II. & Werjahren in I. Suntanj. . . & . & $\S \S 15 \mathrm{I}-337$ \\
\hline II. & Ređtsmittel . . . . . & & $\S \S 338-398$ \\
\hline 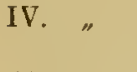 & $\begin{array}{l}\text { Bieberaufnahne eines burd) redjtsträf } \\
\text { Urtheil geidilofienen Berfahrens. }\end{array}$ & & $\S \S 399-413$ \\
\hline$\nabla$ & $\begin{array}{l}\text { Betheiligung des Berlebten bei bem } \\
\text { fahren }\end{array}$ & Ber $=$ & $414-445$ \\
\hline Bud). & Bejondere Irten bes Berjahrens . & & $\$ \$ 447-467$ \\
\hline "I & $\begin{array}{l}\text { Strafoulitrecfung und Ropten bes } \\
\text { fahrens }\end{array}$ & $\begin{array}{l}\text { Ber }= \\
\cdot \text {. }\end{array}$ & $481-506$ \\
\hline
\end{tabular}

\section{Buh. Allgemente Beffimmunan.}

\section{Buftäubigleit ber Geridute.}

\$1. Die fadjlidse Buftänoigfeit her (Seridjte toird Durd) Das (Sejeł liber die (Serid)tgoerfaffungl) beitimmt.

1) Oben ऽ. 119. Bergl. Dort fïr Sdjoffengeridte $\$ \S 27-29$;

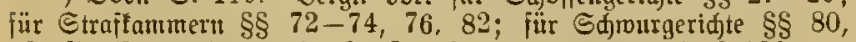

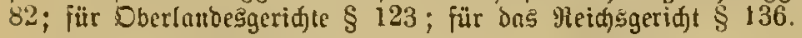

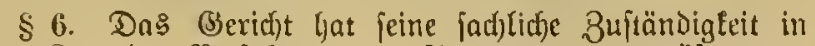

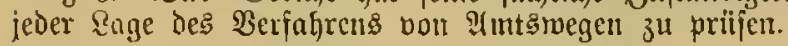

\section{Bseriøtşftand.}

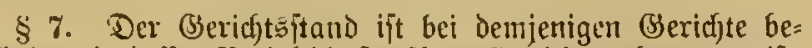
grimbet, in deffen Bezirt die jtrafbare Sandlung Gegangen ift.

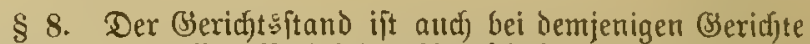

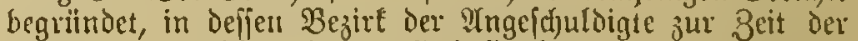
Erthebung Der STlage feinen Wohnfitz hat.

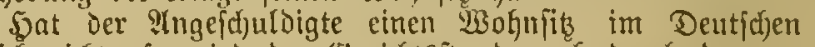
Reid) nidit, io wird ber (Seridftsftand aud) Durd) ien ge=

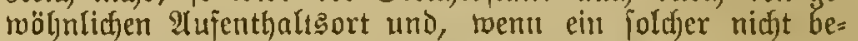
fannt ift, Durd) Den leksten 23ohnfits beftimmt.

I/s neuer $\$ 8 a$ jolf eingefügt reerbett: "Der Beridgtsftand ift nud bei bemjertigen (Beridi)t begrünet, in Deffen Begirf Der Bejduldiate ergriffent roordent ift." (Entw.)

\$ 14. Bejtebt zlviffjen utefreren (Seridjten Streit ïber die Buftändigfeit, fo bejtimmt Das gemeinjaf)aitlid)e obere (Sieridjt Dasjenige (Seridft, weldhes fid) Der Unterfudhung und Entidjeidung zu unterzieben lyat.

\$ 16. Der Ingejduloigte muß̉ den Sinmand ier $l u=$ zuftändigfeit bei Berluft Deffelben bis zum Sdjluffe Der Borunterjud)ung, fađs aber eine joldie nidjt ftattgefunden Gat, in Der Sauptverhanblung bis jur Berleitutg des $2 e=$ idhliffes über bie cröffnung des sauptberfahrens gelteno madjen.

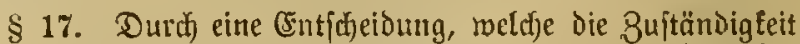

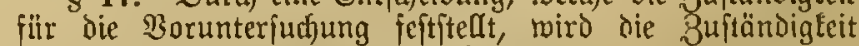
auch) für das Sauptberfahren feftgeftellt.

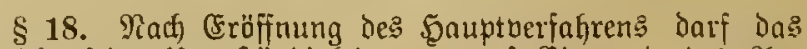
Berid)t jeine Utızuftändigfeit mux auf Eimband ies ?ln= getlagten ausipredien.

\$ 20. Die einzelnen Unterifudumgshandumaen cines

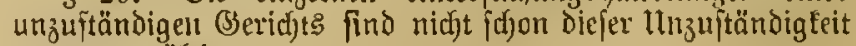
megen ungitltig.

\$21. (Sin แnzujtändiges (Sherid)t bat fidf Denjenigen

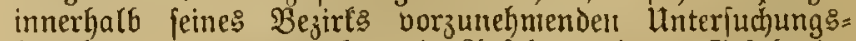
Gandlungen zu ututerziebeu, in ?lnjegung deren (Sefabr im Berzug obtwaltet. 


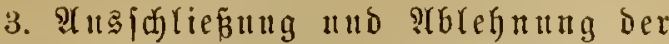 Bericht sperionet.}

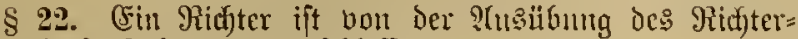
ant? fraft Befekes altigefd)(ofien:

1. went er felbft buref bie frofbare sjandung ver= leţt ift;

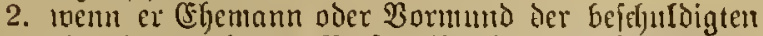
oder der berlebten Berion ift vder getuefen ift;

3. menn er mit dem Beiduldigten ober mit dem $\mathfrak{B e r}=$ letsten in gerader Rinie verwandt, verfchrwägert oder durct Yooption berfunden, in ber Seiten= linie bis zum 3. Brade berwandt oder bił zum 2. (Brode berffowägert ift, audf wenn bie (Elje,

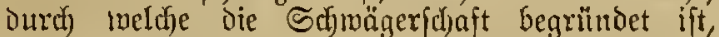
nicjt mehr befteht; 1 )

4. ivenn er in ber Sadje als Beamter ber Stants= anmaltidjaft, als łolizeibeanter, als ?tumalt des Berlekten oder als Bertheidiger thätig gemejen ift;

5. menu ex in der Sache als Zenge voer Sadd)= veritändiger vernommen ijt.

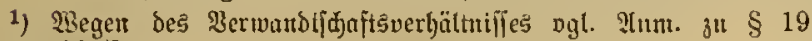
Bormundigho.

§ 24. Cin Ridjter fann folvol, in den Fällen, in denen

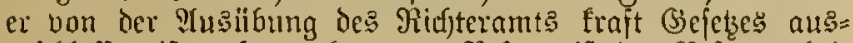
gefd)loffent ift, als audf regen Bejorgniśs der Befangenljeit algelehnt toerdent.

Wegen Bejorgniß der $\mathfrak{B}$ efangenkeit findet die $\mathfrak{X}$ blehnung ftatt, mem ein (Srund vorliegt, weld)er gecignet ijt, Meistrauen

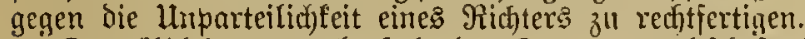

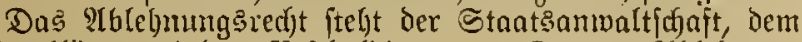
Srivatfläger und Dem Befduldigten zu. Den zur 2lblehnung Berefftigten find auf Berlangen Die zur Mdittvirfung bei der Entfacioung berufenen (Serid)toperjonten nambaft zu madben.

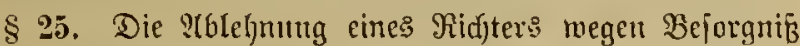
der Befargenleeit ift in Der J̧auptverljandung I. Snitan

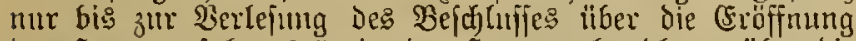

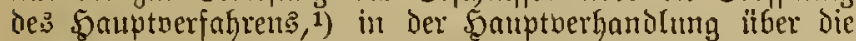
Berufung und dic ßevifion nur bis zum Beginne der Berichterjtattumg juläffig.

1) $\S 242$ IG 62.

§ 26. (1) Das 2tblebnungsgefurd ift bei dem Berid)te, weldhem ier Richter angeljört, anjubringen; es fann bor

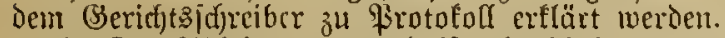

(2) Der 2 blegnunaşgrund ift glaubhaft zu mtadjen; der

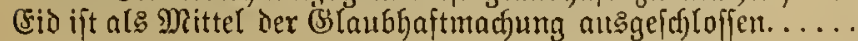

(3) .......

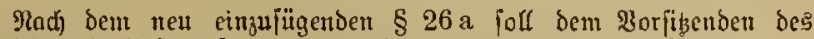

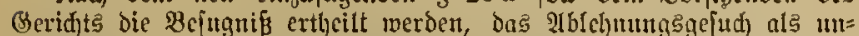

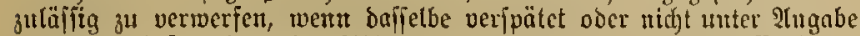

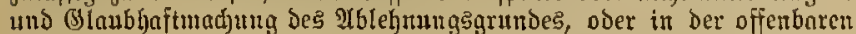
Ibjidst angebradjt morben ift, nur bas \$erfabren zu verjuleppen.

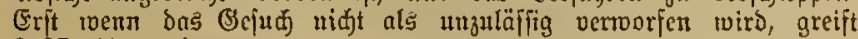
§ 27 \$laß. (Entro.)

\& 27. lleber da: 2(blejnungsgejud entidjeidet Da: (berid)t, weldjem der 2lbgelehnte angefört; wem Dalielbe

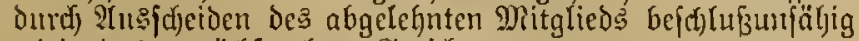
wiro, das zunädjft obere (Gerid)t.

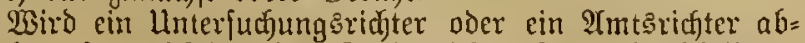

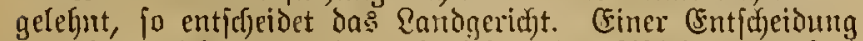

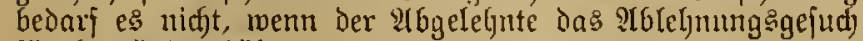
fiil begründet ljält.
\$ 29. CFin abgelehnter Ridter hat bor CErleoigung des ablehnungsgefuchs nur fold)e \$andlungen vorzunehmen, melef)e Eeinest :

\$ 31. Die Bejtimmumgen biejes abjojntts finden auf

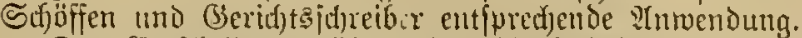

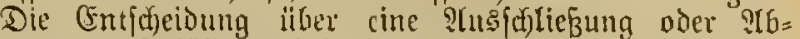

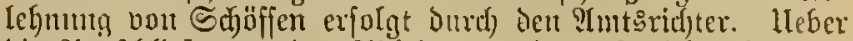

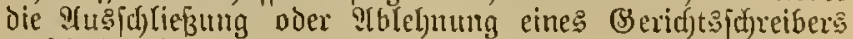
entfdyeidet Das (S)eridft oder Der Ridjter, weldjem Berfelbe beigegeben ift.

§ 32. Die Beftimmungen des $\$ 22$ finden auf Be= idfuorette 1) ?(nvendung. ${ }^{2}$ )

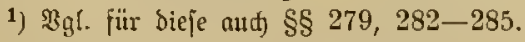

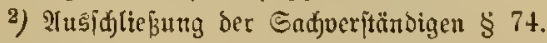

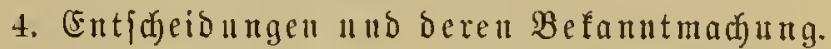

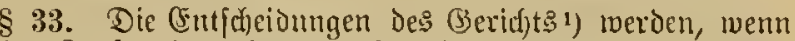

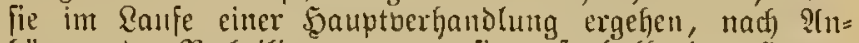
hörung Der Betfjeiligten, menn fie außserhalb einer 5autt= verbandlung ergeljen, nach erfolgter idjriftlifjer oder miindlid)er Ertelärung der Staatsanmaltichaft erlaffen.

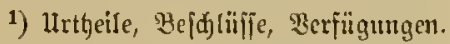

\$34. Die burd) ein Rechtsmitte( 1) alfedt)tbaren (snt= fdecioungen fotwie biejentgen, durd) weldfe ein 2lntrag $a b=$ gelelynt vird, find mit Brilnden zu verjehen.

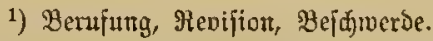

§35. Entfdjeidungen, weldje in 2Uumejenljeit Der dobon betroffenen Berjon ergeljen, merden Derfelben Duref Ser=

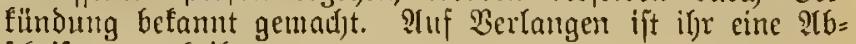
idfrift zu ertfeilert.

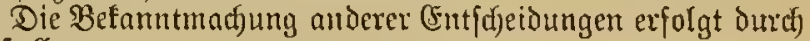
Buttellung.

Dem nicht auf freiem Fure Befindlichen ift Das $3 \mathrm{U}=$ geftellte હd)riftftüct auf Berlangen vorzulejen.

\section{3u[tellung (Bollitredfutg).}

\$ 36. Entidfeidungen, die ciner 3uitellung oder Boll= itrectung bedürjetr, find Der Staatsanwaltichait zll über= geben, weldje das (Evforderlidje zu beranlaffen hat. Thif Entfcheiduttgen, die lediglidf) den inneren Dienjt der (Sertidte voer die Dronung in den Sizzungen betreffen, findet dieje Bejtimmung feine 2Yrmeniung.

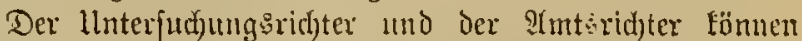
3uptellungen aller Ŝrt fowic bie Bollftreftung bon $\mathbb{B} e=$ ikflitfien umo Berjitgungen unmittelfar veranlafjen.

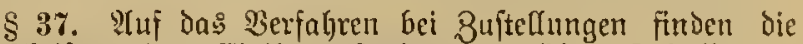
Sorjudriften oer (Sivilprojęoronung 1) über zuftelfungen entiprechende ?tumenting.

1) खgl. bort \$§ $152--189$, ofen 5.155 ff.

\$ 35. Die bei Dem Strafuerialyren betleeiligten Perjonen,

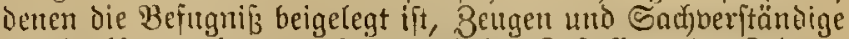
unmittelfar z"l Laven, 1) haben mit der Buftelfutg Der Sadung ben (Serid)tsvollzieher zu beaujtragen.

1) $\mathfrak{B g l}$ u. a. $\S \S 193,219,426$. 


\section{Friften und Wiebereinjetung in ben vorigen ธtanb.}

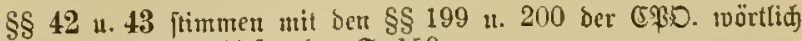
übereit. \$Bgl. Daher dieje oben $\subseteq .159$.

\$ 44. Begen die Berfäumung einer כrift fann dic Wiebercinjet3ung in ben vorigen Stand beanfprudjt merben, tocm der श̆ntragfteller burd) 9iaturereignifje oder nndere

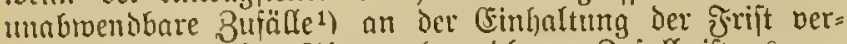
biubert worden ijt. भIf unabmenbbarer Bujall ift es an= zujehen, wenn Der Antragiteller bon ciner Zuftellung obne jein $\mathfrak{B}$ eridhulden feine Semntnib eclangt Gat.8)

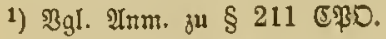

2) $\$ \$ 166-169$ (ङ\$D.

\$ 45. Das (Scjud) um Wicdereinjetzung in ben borigen Stand muß Ginnen 1 $\mathfrak{B}$ ad)e nad) Bejeitigung des Somberniffe Gei demjenigen (Serid)te, bei weldjem bie Frift wahrzumeljmen gevofer wärc, unter ?Nugabe und (Slaubhaftund)ung der Ger [ätmmungägründe angebracht toerben.

Mit Dem (Sefnd) ijt 3ugleid) die verjäumte Şandlnng jelbjt nadjzuljolen.

\$ 46. lleber bns (Sefud) entfacidet Dasjenige (Serid)t, meld)es bei rectijeitig erfolgter 5andlung zur (5ntjokeidung in ber Sarje jelbft bernfen gewejen wäre.

Die Dem (Sicjuche jtattgebende (5ntfdeidung unterliegt feiner $\mathcal{U}$ (nfecftung.

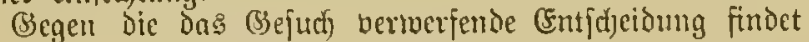
fofortige Beffdroerde ftrtt.

\$ 4\%. Durd Das (Gefud) um Wicdereinfetzung in Den vorigen Stand wird die Bolfitredung ciner geridftidien Sntfdjeioung nicht geljenmt.

Dos Geridft fonm jedod eimen atlotbucn.

\section{Beugen.}

\section{Labung.}

\$ 48. (1) Die Radung icr Beugen geforicht unter Sin=

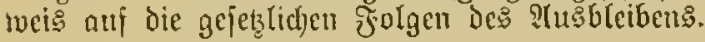

(2) .....

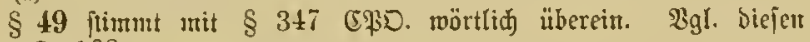
oben ङ. 168.

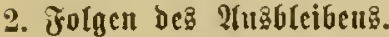

\$ 50. (1) Sin oronungsmäB̈ig geladener Beuge, tweldi)er nidit exidjeint, ift in bic burof bas ?lusbleiben berurjadjten Sioften, jomie zu einer Geloftrafe bis zแ 300 פart, un fï Den Fall, dab bicie nid)t beigetrieben werben fann, zur Strafe ber Saft bis iu 6 Wodjen zu vermtheilen. भud ift die

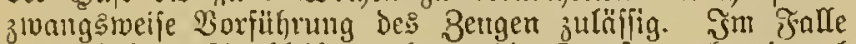
miederholten झुsbleibens tann die Strafe nad) eimmal erfaunt werder.

(2) Die Berurtheilung in Straje und Roften mterbleibt,

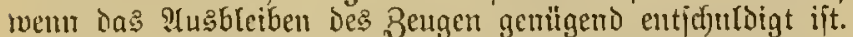
Crifolgt nadjträglid) gentigende (5ntjd)uldigung, fo werden Die gegen den Bettgen getroffenen ?trotontungen wieder auf= gehobetr.

(3) (4) .....

\section{Bertweigerumg bes 3etguifię.}

\$51. Bur Berncigerung des Beugniffes fino beredigt: 1. Der Berlobte des Bejouldigten;

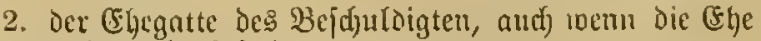
nicht melgr beiteht;

3. diejenigen, weldje mit dem Bejduldigten in gernder Rinie verwandt, beridjwägert oder burd) 2(ouptian verbunden oder in der Seitenlinic bis zum 3. (3rabe berrandid ober bis zum 2. (Srabe verfajinägert find,

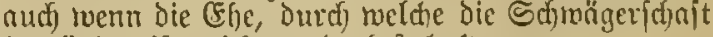
begrïnoct ift, nifft mehre bejtefyt. $\left.{ }^{1}\right)$

Die bezeidfueten \$erfonen find vor jeder Vernehmung

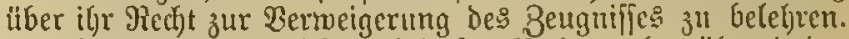
Sie fönnen den Berzidft auj diejes Recfit aud) wälyrend ber Sernefgmung widerrufen.

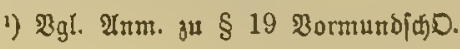

§ 52. Bur פermeigerung desิ Zetigniffes find ferner beredftigt:

1. Beiftlidge in ?tnehung Desjenigen, twas ifnen bei Ausitbung der Seeliorge anvertrant ift;

2. Bertheidiger des Beichuldigten in Mnjehung des= jenigen, was ifnen in biejer iljer (Figenjdjaft nu= bertraut ijt;

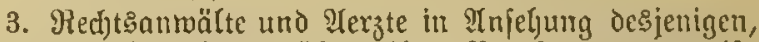
was iGnen bei 2lus̈übung ifhes Berufs anvertrant ift.

Die unter 9ir, 2, 3 bejeifyneten Perjonen dïrfen bas Bengnif nid)t berweigen, wem fie bou ber Serpflichtung ơtu Beridfwiegengeit cutbunden find.

4. Beamte.

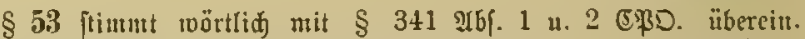
Bgl. biejen oben 5 . 167 . Die Senefmigung ift burd ben bie \&abung 3eranlaffenden nad)зuju內er.

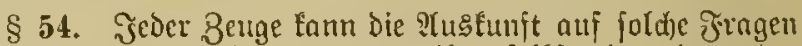
berweigetu, deren sbeantwortung ifm jelGit oder einem der

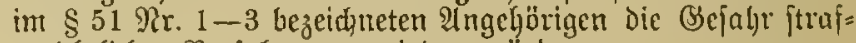
geridjtlidjer Berfolgung zuzieljen würde.

$\S 55$. Die Tlyatindbe, nuf welche Der Beuge bie Ber: reigerung des Zettgnifjes in Den ₹ällen der §§ $51,52,54$ itilizt, ift nui Berlangen glnubhaft zu madhen. (5) genitgt die eidfidje Serjicferung Des Beugen.

\section{Berneljmung und Beeibigung.}

\$56. Unbeeioigt find ju vernehmetl:

1. Berjonen, weldhe zur Zeit der Bernehmung das 16. Sebensiabr norf niaft vollendet ober wegen mangelnder $\mathfrak{B e r}$ tandesreife oder begen Berjtandes= idjuädje von dem $\mathfrak{B e j e n ~ u n d ~ d e r ~ B c o u t u n g ~ i e s ~}$ Csides feine gentigende $\mathfrak{B o r i t e l l u n g ~ h a f e n ; ~}$

2. Berjonen, weld)e nadj den Bejtimmungen ier Straf= gejeţe unfähig find, als Beugen cidfid) vernommeu zu werden; ${ }^{1}$ )

3. Berjonen, reldje Ginfidtlidf der den (Begenftanto Der Luterfudyung bildenden That al: Theilnehmer, $\mathfrak{B e g u ̈ n}$ tiger oder Sgebler verdäd)tig oder bereils ver: urtheilt find. ${ }^{2}$ )

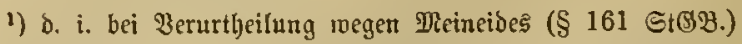

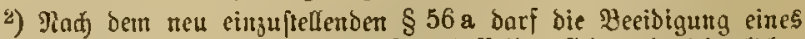

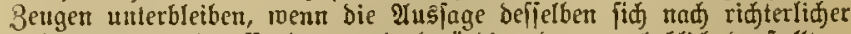
Ileberjeugung als offenbar unglaubrourbig ober unerbebliá) barftellt.

\$5\%. Stehen \$erjonen ju dem Bejchuldigten in eincu Berbältniffe, meldjes fie nad $\S 51$ zur Bertweigerung des 


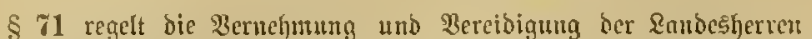

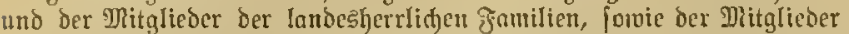

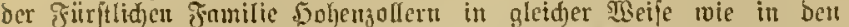

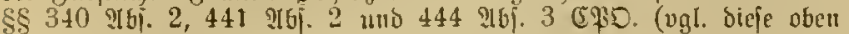
ङ. $167,175,176)$. Bur 5onptverhondung werben biejelben nid)t

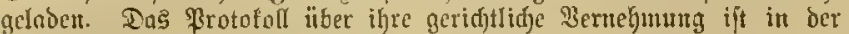
Sauptoerbandlustg zu verlejen.

\section{Sadberittänbige und Augenfdein.}

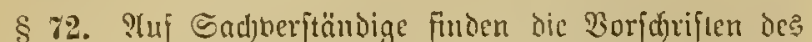
Mbjdjnitrs über Beugen entiprechende ?nmendung, inforocit nidht in den madjpolgenden $\$ \S$ abreichende Beftimmungen ge= troffen fint.

\$73. Die Alusmahl der zuzujiehenden Sachuerftändigen

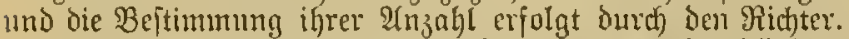

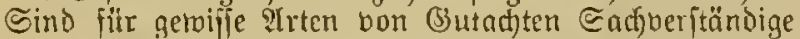
öffentlich beitellt, fo follen andere Berionen nur baun gee toähtt merden, menr bejondere umitände es erfordern.

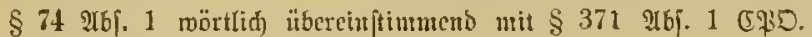
2gl. Diefen oben S. 172.

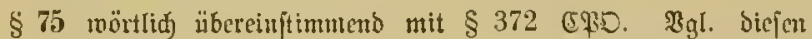
obent ङ. 172.)

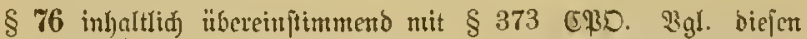
oben ธ. 173.)

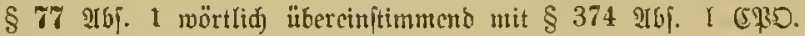
Bgl. biejen oben 5 . 173.

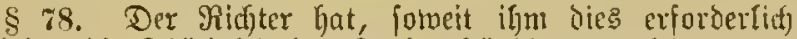

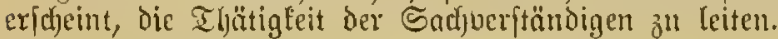

\$ 79. Der Sactueritändige fat vor Erftattung Des (Gutadjtens einen (5id oabin zu leiften:

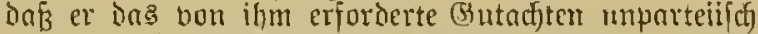

IIII) narf beftem Wiffell und Besviffen erftatten merde.

Sit ber Sactjverftändige fïr die Erftattung bon (3) = adjen ber betreffenden Irt im 2afgemeinen becidigt, jo geniigt die Berujung auf Den geleifteten (5ib.

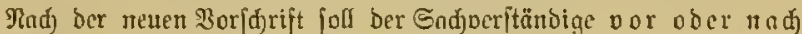
Der Erjpttung bes Butadterts becibigt merbcit.

Der nad) der Begutadjtung bu leifitende Eio lautet:

bob er Das von ibm erjtattete (Gutadten mparteif(d) und und (Gntwo)

beftem Sififen utb Gerwiffen abgegeben habe.

$\S 80$. Dem Sadjuerftändigen lam nui fein Verlangen

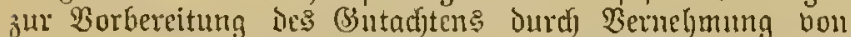

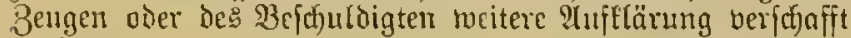
twerben.

Bu Demfelben Bmecfe fann ifm geftattet werden, die offten cinzufeljen, ber Bernelymung bon Beugen oder bes $\mathfrak{B} \varepsilon=$ ichuldigten beizutwolynen und an diefelben ummittelbar Jragen sit itellen.

\$ 81. Bur Borbereitung eines Butadjteng ïber Den

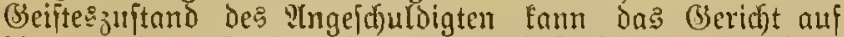
Pntrag eines Sachoerftöndigen nacf Ynförung Des $\mathfrak{B e r}=$ theidigers anoronen, Daf ber ?lngefouldoigte in eine öffent= liche Sirenanjtalt gebracht unt dort beobachtet soerde.

Dem ?Yngefduldigten, weldjer eiten Bertheidiger nidft hat, ift ein foldier out beftellen.

(Begen den Bejdyluz findet poforlige Bejdinerde ftatt. Diejelbe hat aufichicbenbe Wirfung.

Die Dermafrumg in Der Prftalt darf die Daner von 6 2Bodjen nidyt überiteigen.

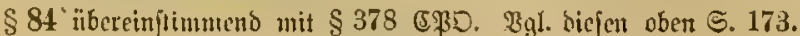

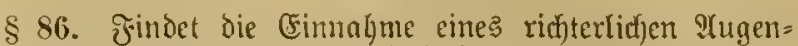
idfeins itatt, io ift in firotofolle ber vorgefundene (Sad)= beitand ieitjuitellen und iarïber ?ustunft 311 geben, iveldie Spuren oder Mertmale, Deren Borbandenjein rad ber be= fonderu Bejchaffenteit Des Jalles bermuthet uerden founte, gefeblt haben.

§ 92. Bei Mainzberbred)en แnd 9ünzbergelyen find Die Më̈nsen ober Bapiere exforberlidjenfalts berjenigen Beljörde

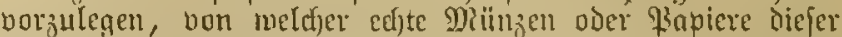
Tht in IImlauj gejetst nerden. Das (3)tad)ten dicjer $\mathfrak{B C}=$

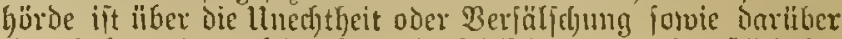
einzulofen, in weidjer शrt dic Jälidfung muthmaflich be= gargen worben ici.

SandeIt es fich un ausländifdue Mänzen oder Papiers, fo fam an Stelle des (Butnchtens der ausländifeljen $\mathfrak{B C}=$ lyörte dasjenige einer beutfácn erforbert rerden.

§ 93. Зur Ermittclunn Der Edjtheit oder llnedjtjeit eimes Sdfriftitüs, fowic zur Ermittelung bes llrljebers deffelten fam cine Sdfriftuerglcidjung mer 8uzielung bon Sadjuerftämbigen vorgendmuen Juerden.

\section{Befdlagualume und Durdfud̆ug.}

\& 94. Begenftände, welche alక Betreisnnittel jür die Unterfud)ung von Redeutung fein fömen oder der (Ein= jiehung unterliegen, fino in 2erwalyrung zu nehmen ojer in anderer weife fidjer zu itellen.

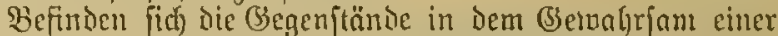
Berfon mo werden diefelben nidft freimillig hernusgegeben, fo bedarf es ber Bejulagnaljume.

§ 95. Wer cinen Begenftand Der norbejeiffuncten 2trt in feinem Betwafyran hat, ift berpflichtet, Denfelben anj (5: forben borznlegen und alts zuliefern.

(5. tam im falle Der Weigerung Dund) die im $\$ 69$ beftimmten Buangemittel hierzu augehalten werden. Biegen Gerjonen, weld)e zur Berveigenung ocs Beugniffes beredytigt find, finden diefe 3wangsmittel feine Trmenbung.

\$ 96. Die Vorlegung oder Huslicjerung von Iften oder anderen in amtlider Berwafrung befindliden Sd)rift= itüafen Durdh Befjöroen und Bffentlidje Beamte onif nicht gefordert werien, wenn beren oberite Dienitbeljürie erflär,

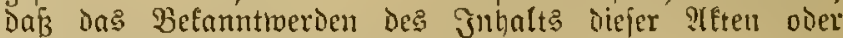

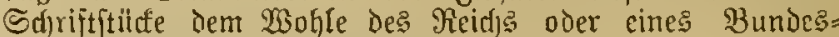
itnates Rachtlyeil bereiten miirde.

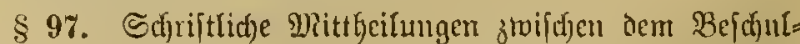
bigten und Denjenigen Pierionen, die wegen ifres Berhält= nifies zu ilgm und $\$ \$ 51,52$ zur Berweigerming des $8 \mathrm{eug}=$ milfes beredftigt find, unterliegen ber Befdjlagnafume nidjr, fađ̧s fie fict in ben soünden ber leßsteren Sistionen befinden und dieje nicht einer İleilnabme, Begünjtigung oder Seflerei verbächtig find.

§ 98. (1) Die Intoromung von Befdhlagnalimen fteht dem

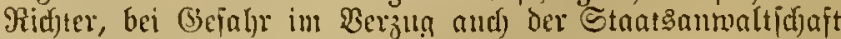

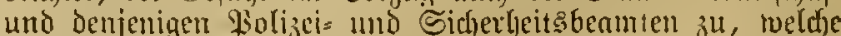

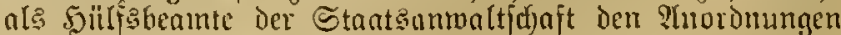
Derfelben Folge ju leiften haber.

(2) Sft die Befdjlagnabme olyne ricjterlidje 21 noronung erfolgt, jo jolf Der Beamte, weldjer Die Bejd)lagnaljue an= georonet hat, binnen 3 Tagen bie ridfterliche Beftütigung

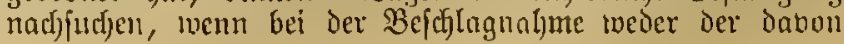


Betroffene nod ein ermadjfener Angeböriger anwejend war, oder wemn der Betroffene und im Faffe feiner Ptbmefenheit

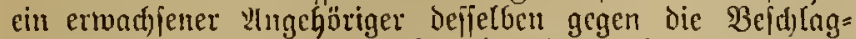
nahme ansorüutliden 2 siderjprud erboben hat. Der $\mathfrak{B} e=$

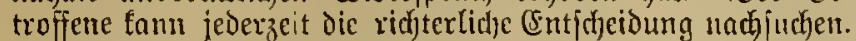
So lange dic öffentlidje $\Re$ lage nod) nicht erljoben ift, erjolgt

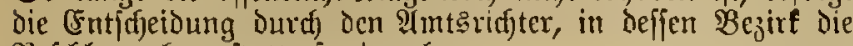
Befollagnahme itattgefunden lyat.

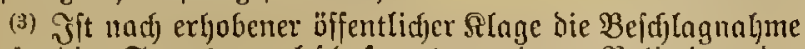
Durd) bic Stantsanmaltidjaft oder einen Bolizei = ober Sidjerfjeitsbeamten erfolgt, io iit binnen 3 Iagen dem

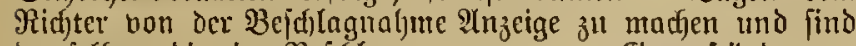
Demielben die in Befdjlag genommenen Begenftände jur Berfügung z̆ ftellen.

(4) ......

§ 99. Zuläifig ift dic Befdulagnahme der an den $\mathfrak{B e s}$ (d)uldigten geridhteten Brieie und Senoungen auf der Wojt jomic ber an ign geridhteten Telegramme auf ben Telegraphen= anjtalten; ocsgleidgen ift zuläffig an den bezeichneten Drten die Beichlagnalyme foldjer Brieje, Sendungen und Tele= granme, in Betreff berer Thatfad)en borliegen, aus iveldjen

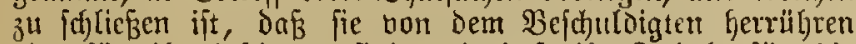

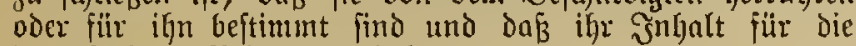
linterfucfung Bedeutung lyabe.

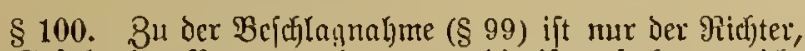
bei (Sejaljr im $\mathfrak{B e r}_{3} u g$ und, wenn die llnterfudfung nidjt blos cine llebertretung betrifft, aud die Staatsantwaltidfaft befugt. Die leketere muf jedod) den ilyr ausgetiejerten begen= ftand fofort, und ztwar Briefe umo andere \$oftfendungen uneroffinet, bem Riditer vortegen.

Die von ber Staatommaltidfaft verfïgte Befd)lagnalyme tritt, auch twenn fie einc Puslieferung nod) nicht zur Folge geljabt hat, alber Siraft, menn fie nidft binnen 3 Tagen bon Dem Ritufter beftätigt wird.

Die Entfaeidung über cine von ocr Stantsambaltidaft

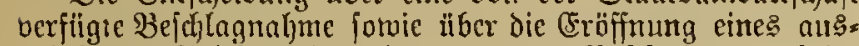
gelieferten Bricies oier einer anieren Poftfendung exfolgt burd) tien zuftändigen Ridjter (§98).

$\S$ 101. Bon den getroffenen Maf̧regeln (\$§ 99, 100) find bie Betheiligten zu benad)ridtigen, jobald bies ohne (be=

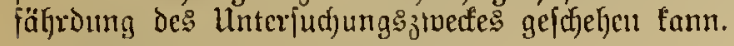

Sendungen, deren Eröffung nicht angeorbnet morben, find Den Betheiligten jofort auszunntworten. Daffelthe gilt, jomeit nach Der Eröffnung Die Zurürfbefaltung nidjt $\mathrm{er}=$ forbertidf ift.

Derienige Theil cines zurüdtbehaltenen Briefeg, Deffen Borenthaltung nicht burd) bie Rüidfid)t auf bie lnterfudumg geboten erfdjeint, ift dem (Empfangsberedfigten abifififtlid nitżttlyeilen.

\section{3uläfĩgfeit ber Durdjuturnung.}

§ 102. Bei ถemjenigen, welder alङ Thäter oder Theil= nehmer ciner ftrafbaren Şandlung ober als Begünjtiger ober

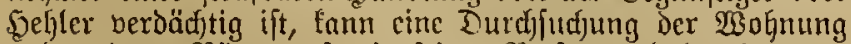
und nnderer Räume, jorvic feiner \$erjon und ber ilym ge= hörigen Sadjen, jowoht zum Zwedte feiner Ergreifung, als auch Daun vorgenommen verocn, werm zll vermuthen ift, daf bie Durchjuctung zur Inffímbung von Bemeismitteln fitfres werte.
\$ 103. Bei anderen Berjonen find Durffiudfungen nux behufs Der Ergreifung Des Befduldigten odcr Gehufs Der Berjolgang bon Epturet einer ftrafbaren 5antolung oder behufs ber Bejollagnalime beitimmter (Segentände und nur tanut juläfigig, toenn Ifatjachen vorliegen, aus denen zll id)lieğen ift, daßz die gejudjte \$erion, Spur oder Sadje fidj

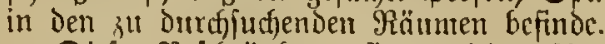

Diefe Bcejutänfung findet feine Ynmenoung anf dic

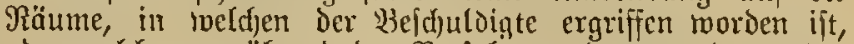
oder weldje ex wälgrend der Berfolgimg betreten hat, oder

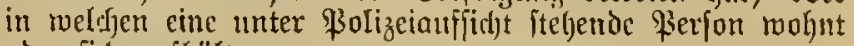
oder fict) aufhält.

\section{Befdränfung hinfịdtlidy ber 3eit.}

$\S 104$. (1) 8 ur Rad)tzeit ${ }^{1}$ ) bürfen Die $\mathbb{B}$ ohnung, dic

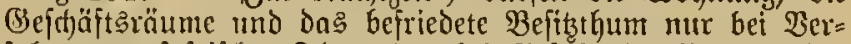
folgung auf frifjer That oner bci Bejaht im $\mathfrak{B} e$ roug ober bam ourd) (uth)t werden, wemn es fich um die 23tederergreifung eines elttwictenen (Sciangenen handelt.

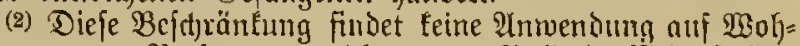
nungen non ßerfonen, welde unter \$olizeiauffitjt fteben,

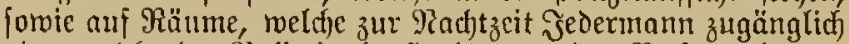
oder weldye Der \$olizei als Setbergen oder Berjammlungs: orte bejtrafter Ferfonen, a[S Nieberlagen bon Sadjen, meldhe mittels jtrafbarer Sondlungen exlang! jino, oder als Sd)lupf=

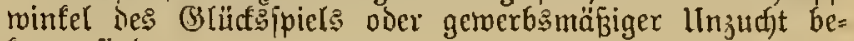
fannt fino.

(3) .....

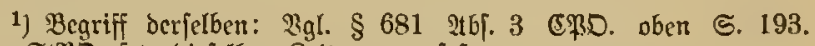
Die ভাßD. Fest biejelben Zeitgrenzen feft.

$\S 105$. (1) Die InorDnung von Durdfjuchungen ftelt Dem Riditer, bei (Befahr im Berzug aud Der Stantsantwaltjdaft und denjenigen "Wolizei= uno Sicherbeitsbeamten zW, roeldje

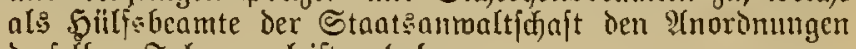
derielben ₹olge zu leiften lyaben.

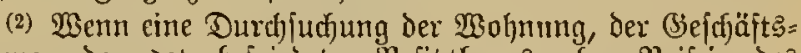
räume oder des befrieveten Befitzthums ofne Beifein bes Ridjters oder bes Stantsanmalts ftattindet, fo find, wenn dies möglich, ein Gemeindebenmter oder 2 Mitglieder der Bemeinbe, in deren $\mathfrak{B e z i r f}$ bie Durdjuludung erfolgt, zuzu= ziehen. Die als Gemeindemitglieder zugezogenen \$erjonen dürjen nidft Polizei= oder Sidjerheitsbeamte jein.

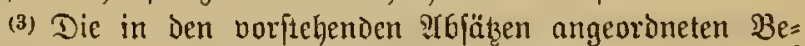
(d) ränkungen der Durdffudtung finden feine 2̈nmendung auf bie im $\S 104$ A6f. 2 bezeid)neten $250 h n u n g e n$ und Räume.

(1) .....

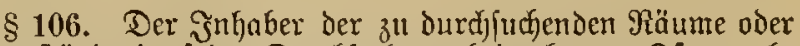
(Begenjtände Darf Der Durdfiud)ung beimohnen. Jit ex $a b=$ welend, jo ift, menn dies möglid), fein Bertreter oder ein

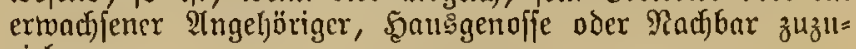
ziehen.

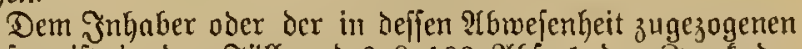

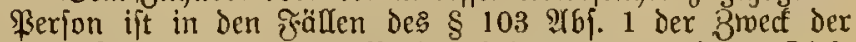
Durffiudjung bor beren 2 eginn befannt zu madjen. Diefe

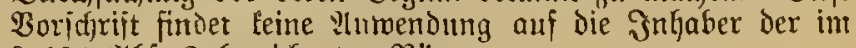
$\S 104$ घ6 f. 2 Gezeichneten Räume.

§ 10\%. Dem von der Durdfuthung Betroffenen ift nad deren Bcendigung auf $\mathfrak{B e r l a n g e n ~ e i n e ~ i d f r i f t l i c h e ~ M i t t h e i l u n g ~}$

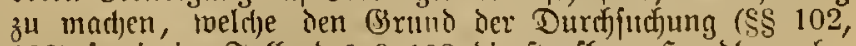

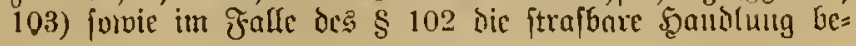




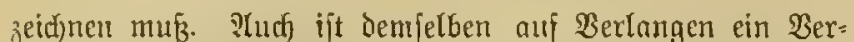
zeidyniz der in Berbahrung oder in Befoding genommenen

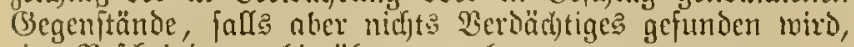
cine Beffeinigung hiertiber z" geben.

§ 108. Werten bei (Belegenfleit ciner Durchjudung (Begenftände gefunden, weldye zror in feiner Bezieljung zu der lluteriud)ung ftehen, aber nuf die expolgte Bertibung einer anderen ftrajbaren Sandung limbeuten, fo find diejelben cinftreifen in Bejd)lag ju nebmen. Der Stantsonmaltidjajt iit bierbon Sienntnifí all geben.

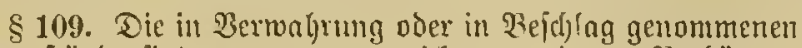
(Gegenjtände firo genau zu verzeict)nen mol zur 2 erfittung von Bermedffelungen durrd) amtlidfe Siegel oder in fonft geeigneter waife tenntlid) z"l madjen.

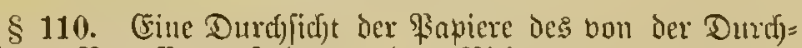
futhumg Betroffenen fiel)t แur Dem Ridjtex zu.

P(ndere Beante find zur Durdfitcht ber aufgefumbenen Fapierc nur daun beftugt, wenn der Jnhaber berjelben die Durcffictet genefmigt. Smberenfalls baben fie die Bapiere, beren Durdfitift fie fïr geboten erad)ten, in einem llmidflage, weld)er in Segenmart Des J̌nhabers mit dem 2lintsifrgel zu wexfchliegen ifit, an Den Ridjter abzuliejern.

Dem J̄nhaber Der ßapiere oder deffen Bertreter ift dic Beidritdung feines Siegels geitaltet; aud ift er, falls Dem= nädfjit Die (Entfiegelung und Durcffict)t Der \$apiere angeorbnet triro, menn dies möglic, aufzuforderu, derjelben beizumohnen.

Der Pideter hat die zu cinct ftrajbaren Somblung in Bejieljung itehenden sapiere der Stant:onmaltidjait mit= zutbeilen.

§111. (segenitände, weld) Durd) die itrajbare somolung

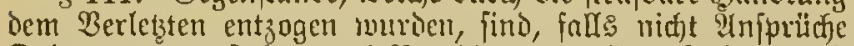
Dritter entgegentehen, nad) Beendigung oer Linteriudung und

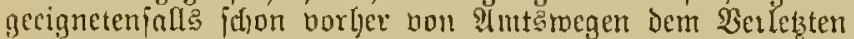
jurtidjugeben, olyue da $\overline{3}$ es cines llrtheils hieriber beunt.

Den Bethciligten bleibt dic Beltenomadiung jeinet rechte int civifnerfalyen vorbehalten.

\section{Berbaftung und vorläufige Feftuabme.}

Berhaftung (\$\$ 114 ff) if Freiheitsentziehung anf (Gruno

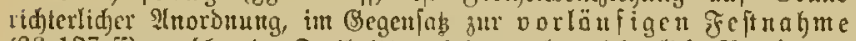

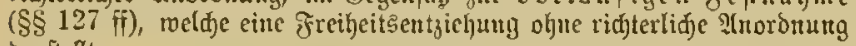
darftellt.

\section{3uläjīngfeit ber $\mathfrak{B}$ erbaftung.}

§ 112. Der ?Ingelduldigte darf nur bann in lunter= judjungehajt genommen werocm, ment Dringende Berdadft: gründe gegen ihn vorbanten find mo entroder er ber §ludbt

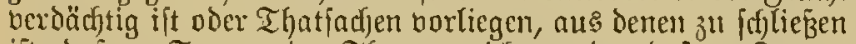
ift, daf, er ভpuren Der That bernirften oder Doß er Beugen

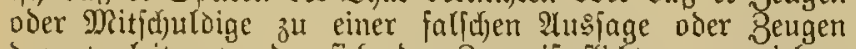
bazu verleiten werde, finf oer Beugrifipflid)t zu entziehen. Diefe Thatjadjen find aftenfundig zu madjen.

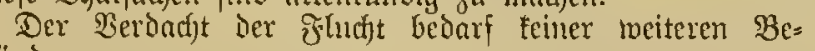
griindung:

1. wenn ein 23erfredjent Den (Biegenjtand der llnter= fucfung bilitet;

2. wenn Dex 2rigejululdigte cin Sceimathlojer oder Eandjtreidjer ooer nicht int Stande ift, fidj iifer feine Berfon auşumeifen;

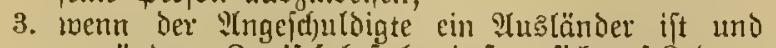
gegründeter Bmeifel beiteht, onfí er fiut) auf Radung

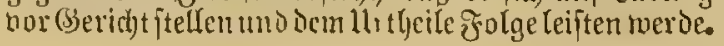

\$ 113. Fit die That nur mit Shajt oder mit Belditrafe bebroht, io oar bic llnter|uchung shaft nur twegen Berdad)t? ber fflud)t mo mIr dann berfängt twerden, wenn Der

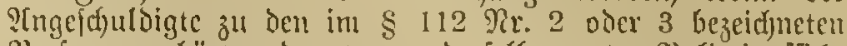

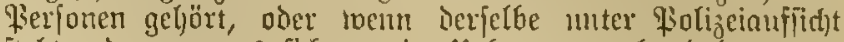
jtelit, ober wenn es fidf) $1 m$ eine llebertretung Gandelt, megen beren die llebertweifung an die \&andespolizeibeljörbe erfannt merben fann.

a) Spaftbejely!

§ 114. Die 23erlyaftung erjolgt auf (Grund eines fdjrift= lidjen frafthefefle des Richters.

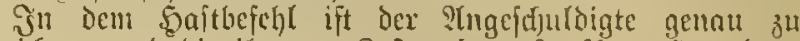
bezcidnen und dic iljm zur \&ajt gelegte ftrajbare sanolung forwie ber Grund der Berhaftumg anzugeben.

Dent SIngefduldoigten ijt Der Sajtheiebl bei Der Berbaftum und, mesu dies nidjt thunlid) ifit, fpäteltens am Tage nad)

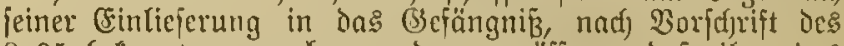
§ 35 befonnt zu madjen und zu eróffuen, da $\sqrt{3}$ iljum ing

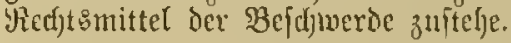

$\S$ 115. Der Berbaftete muß̧ fpätếten’ am Inge nach

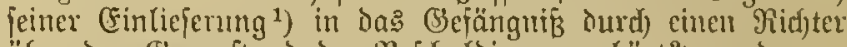
iiber den (Segenftnod der Bejduldoigung geljört²) werden.

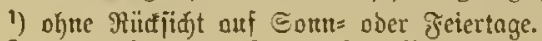

2) Damit ift nidjt gejagt, bof er formlid vernommen werben mú.

b) Unterīư(jung

$\S$ 116. Der Berljajtete joll, jomeit möglid), bon 2htderen gejoniert und nictt iu demfelben Raume mit Strafgejangenen bermaljet merben. Mit feiner Zujtinmung fom bon biefer Borfdyrift abgeislyen inerden.

Dem Berbajteten diirjen mux foldje Bejd)ränfungen auf= erlegt merben, ruclehe jur Gidherung des Zwedfes ber Jafft oder zur Plujechthaltung ber Dronung iut Gefängniffe nothroendig fint.

BequemTichfeiten unt Bejüäfigungen, die dem Stande und ben Vermögcnsocrlyältniffen des : Ver[iafteten entfpred)en, barf ex fid) anf feine Sojten nerf(d)affen, jomeit jie mit beut 3inecfe der Sajt bereinbar find und weder die Dronung im (Gejünguiffe ftören, nod) die Sidjerheit gefährocen.

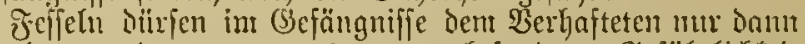
angelegt twerden, roeun es megen befonderer (Befäfrlidjteit

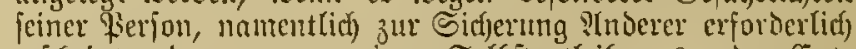
erjacint, oder wens er cinen Selbitentleibungs: oder (Ent= meidfungşuerfuch gemad)t oder borbereitet lont. Bei bei Sauptnechandlung foll er ungefejidt fein.

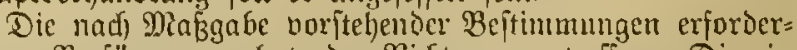

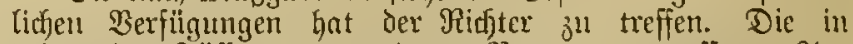

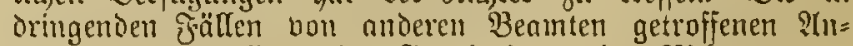
oromungen unterliegen der: Benelynigung des Ridter:

\section{c) Sidjerheitsleiftung.}

\$ 117. (Fin Irgeid)uldigter, ieffen Berbaftung lebiglid) wegen Des Berdadjt: Der Jilud)t angeoronet ift, faun gegen Sidjerheitsteiftung nit ber lunterindjungs(jajt beridjont merden.

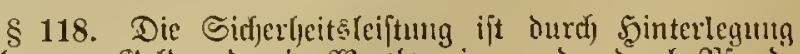
in haarem (Bselde oier in Wertlpapieren oder ourch Prand: beitellung oder mittels Biirgldjaft geeigneter \$serfonen zu bemirten.

Die Söhe und bie Sirt der 3t leif̂tenden Sidferbeit mirt

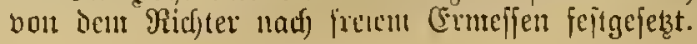


\$119. Ser 2ngcidfuldigte, welder feime \$reilaffung gegen Sidberbeiţleiftung beantragt, i[t, wenll ev nidht im Deut (d)en Reidj wohnt, verpflidftet, eme in Bezint bes zu= ftändigen (Gerifgts mohnhajte Berjon zu Empiangnabme noul Buftellungen zu bevollmähtigen.

\$ 120. Der Sidjerbeitgleijtung ungeadjet ift Der : $:[1=$ geiduldigte zux soaft zu bringen, twenn ex शluftalten jur Fludft trifft, wenn er auf ergangene \&abung obne genügende Entf)uldigung ausbleibt, oder menu ncu ljerborgetretene Umitünde feine Berbaftung erforderlidf madjen.

\$ 121. Sine now ridgt berfallene Sidjerheit miro frei,

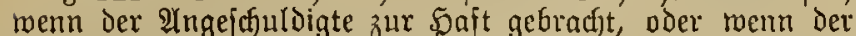
Saftbejehl aupgehoben morden ift, ober menn ber 2lutritt Der ertannten freifitistrafe erfolght.

Diejenigen, melưbe für den Ângefouldigten Siujerbeit geleiftet Gaben, fömnen ifre Befreiumg Daburd Gerbeifitgren, Da $\overline{3}$ fie entmeder binmen einer bom Gericfte zu bejtimmenden

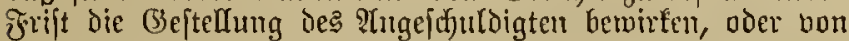

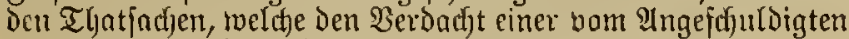

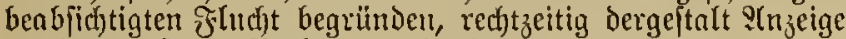

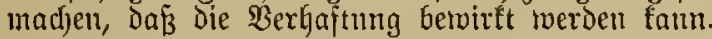

§ 122. (Sine nod nidft frei getooroene Sidjerheit berfäut Der Ctaatstafie, wem der ilngejduldigte fid ber llnter=

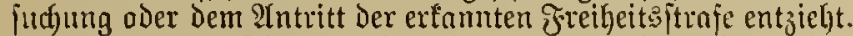

$\mathfrak{B}$ or Der (Fntjofeioung furb der ?lngeidjuldigte forbie bie= jenigen, roelde für ben Angeiduldigten ङidjerbeit geleiftet haben, zu emer Erftärung aujzupordern. Segen die Ent= fojeidung ftelyt ifnen nur die fofortige $\mathfrak{B e f d y m e r d e} 3 \mathrm{u}$. $\mathfrak{B}$ or

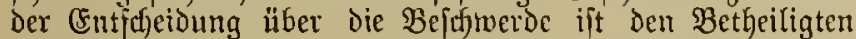

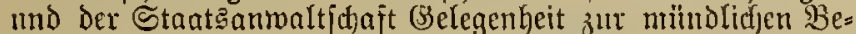

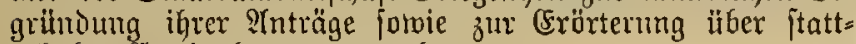
gehnbte Ermittelunger zu geben.

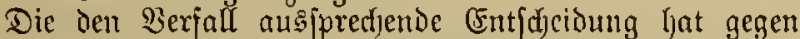
biejenigen, weldye für den : Ingeiduldoigten Sidjerheit geleiftet Gaben, die Wirtungen eines bon Dem Cibifridjter erlajjenen, für vorläufig vollftredfoar erflärten (Endurtljeils, uno nad) Shlauf der Befdrwerbefrift die Wirfungen eines redits: träftigen Civilendurtheils.

\$ 123. Der Snfthefebl ijt aujuheben, wenn ber in Demielben angegebene Sirumb Der Berlyaftumg roggefallen ift, oder wenn ber angejduldigte freigejprodjen oder auber Berfolgung gejebt twiro.

Durd) Cinlegung eines Redjtŝmittels Darf Die Freilafjung bes :ngejduldigten nidyt verzögert meroell.

\$ 124. Die auf die llnterjud Sidjerbeitaleiftung, bezüglidgen Entficheidugen werden vou Dem zuitändigen (seridft erlafien.

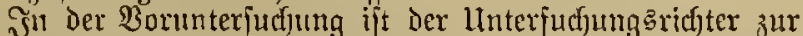

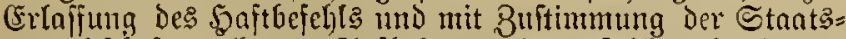
anmaltidjaft aud zur ?tufhebung eines jolden forvie zur Freilaffung bes ?lngeidulbigten gegen Sidjerbeitsleijtung

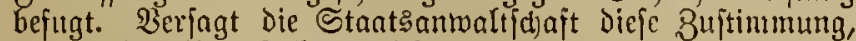
fo hat der Unterjudjungaridyter, menn el die beanitandete

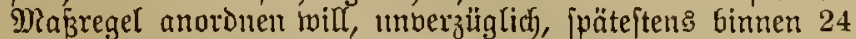
Stunden, die Entidjeidung Des Seridjts nadjujudjen.

Die gleidse Befugnif3 hat nad) (Exöfnumg des Saupt= verfahrens in Dringenden ङällen der Borjizende Des er= fenmenden (Geriffts.

\$ 125. 2ud bor (Ertgebung Der öffentlidjen Slage lann, twenu ein zur Frlajfung emes \$aftbefelyls beredigender (Srund vorbanden ift, vom शrmtsidjter auf ?tutrag ber
Stuatsanmaltjchajt oder, bei (Sefaht in Berzuge, uon

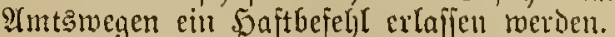

Bur (5rlajiung diefes Saftbefelyls umb Det auf die llnter=

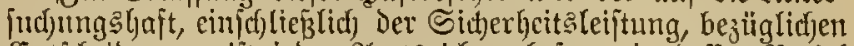

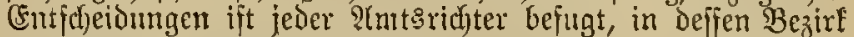

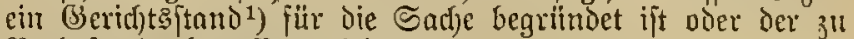
Berlyaftende betroffen suiro.

Die Bejtimmungen Der $\$ \$ 114-123$ finden entipredjende Anmendung.

1) $\mathfrak{B g} ! . \$ \$ 7 \mathrm{ff}$.

§ 126. Der vor Frlyebung Der öffentlidien silage er= lafjene saftbejefl ift aufubeben, wenn die Stantsantortidjait

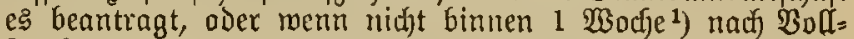
itrectung Des Sajtbefeljls bie öffentlidje alage erboben uno die Fartbauer ber Saft bon Dent zuländigen Ridfter an=

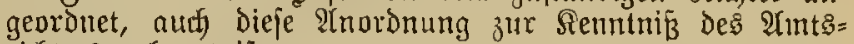
ridjters gelangt ift.

Wenn jur Borbereitung und Erljebung der öffentliaben Slage die ङrift bon 1 Wadje nidit genilgt, fo famn diejelbe

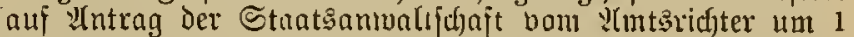
Wadje und, wenn es fich nur ein Berbredjen oder Bergeben yandelt, auf ermeuten ?utrag Der Staatsammultidjait um fernere 2 Wodben verlängert werben. ${ }^{2}$ )

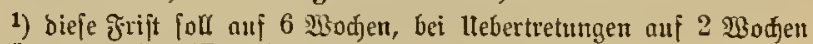
verlängert werben (Entw.)

2) গุbj. 2 wiro gegenjtandslos (Entw.)

\section{3uläfïgleit ber varlänfigen Feftualjme.}

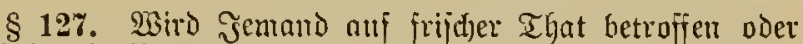
veriolgt, fo ift, wenu er ber \&ludht verbäd)tig ift oder jeine Berfönlichfeit nicfst fofort jeftgeftellt werden fam, seder= mann befugt, ibn aud) obne ridjterlichen Befél borläufig feitzunelyuten.

Die Staatsambaltidfaft und die Balizei= und Sidjer= Geitsbeamten jind audf Dam zux borläufigen Jeftnahme befugt, went die $\mathfrak{B}$ orausfełm und Gejahx im פerzug obmaltet.

Bei ftrafbaren Sanolungen, Deren Bexfolgung nur auj Intrag eintritt, ijt bie vorläufige §ejtnalyme bon der Stellung eines foldjen 2Intrags nidft nbhängia.

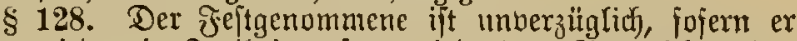

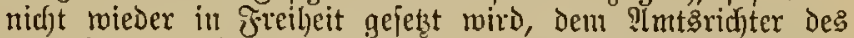
Besirts, in meldjem die jeftnabme crjolgt ift, vorzufilliven. Der :lmtsriduter hat ihn ipätejtens am ₹age nach ber $\mathfrak{B o r}=$ fïbrung ${ }^{1}$ ) z $u$ vernelyment. ${ }^{2}$ )

Sält ber Amtsridjter die Feitmahme nidjt für gered)t= fertigt oder bie Brinde dexfelben fir bejeitigt, fo beroronet er bie Freilafjung. Aluberenjalfs erläjt er einen \$aftbefehl, auf melffen die Beftiumungen des $\$ 126$ शmmenoung finden.

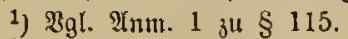

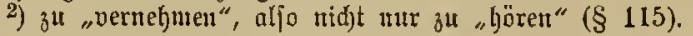

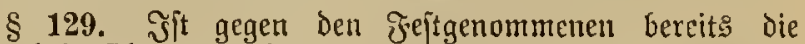
öffentlidje Slage erbaben, jo ijt derfelbe entroder jojort, ober auf Berfïgung Des 9utsridfters, weldiem Derfelbe zu=

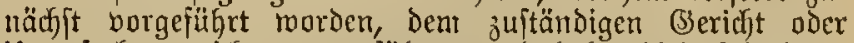
Ilnterjudyungstidfter vorzufiilyren, uno Laben diefe fpäteftens am Sage nad) Der Borführumg ${ }^{1}$ ) über đreilaffung oder Berbaftung bes Feftgenommenen zu entfujetben.

1) \$gl. গงun. 1 zu $\$ 115$.

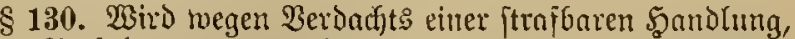
deren Berfolgung mut auf 2 ntrag eintritt, cin Sajtbefeht

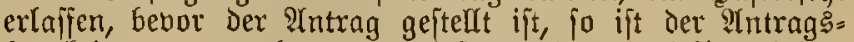
beredtigte, von mefreren menigftens einer Derfelben, fofort 


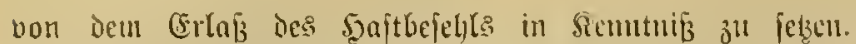
Sul den Safubieht finden bie Beftimmungen des \& 126 gleidjfalls STrwentumg.

\section{a) Stedforieje.}

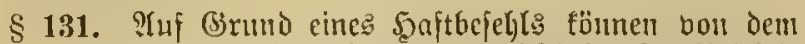
Richter forvie bon Der Stantsanwaltjdajt Stectbriefe's) exlaffen verben, toenn der zu Werhajtente fliidgtig ijt oder fid) verborgen ljält.

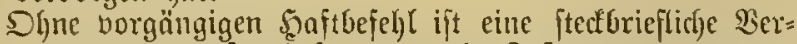
jolgung nur barn itatthajt, bem ein Geftgenommener aus bem (S)efängniffe entrweid)t oder fonft fict) der ßerwachung entziegt. In diefem ffalle find auch die qiolijeiachöroen zur Ertafiung des Steftoriejs bejugt.

Der Stedfbrici foll, fomeit bies möglidf, eine Bej(f)reibung des jul Berfaitenden entlolten und die Demielfen zur \&aft gelegte itrafbare Sandlung forwie dos Befängnifs bezeichnen, in welthes die Mbliefermig zu exfolgen ljat.

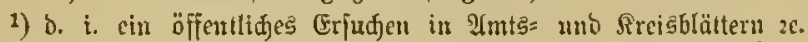

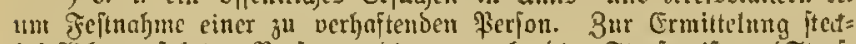
brieflid verfolgter \$erjonen bicten and bie Etrafregiffer (Etraf=

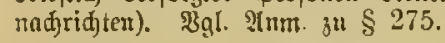

\section{b) Borfïlyung eine (Ergrifienen.}

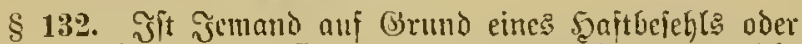
cimes Stecfbriefs ergriffen tworden, und fam er nicf)t pätcftens am Iage nad) oer (Ergreifung vor Den jujtändigen Richter geitellt werden, fo ift er nuf fein Serlangen fojort dem näd)ften Imtsistid)ter vorzufitgren.

Seine 2 ermeljmung ift fpötejtens an Tage und ber (Ergreifung ${ }^{3}$ ) Ind), Das er nidjt Dic berfolgte Perjon, ober dof die Ber= folgung iurd) die zuftündige Behörbe vieber aufgehoben fei,

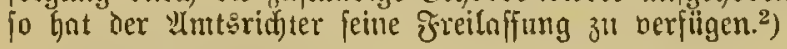

1) 2igl. 2Inm. 1 วu $\S \mathrm{t} 15$.

2) Der Etedbrief wirb, folls er umöthig gemorben, auf bcm= felbent $\mathfrak{B}$ ege, auf bem er erlaffen ifl, wiberrufen (Etectbriefserleblgung).

\section{Bernefmung bes Bejduldigten.}

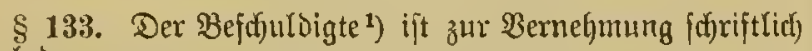
3u lader.

Die Eadung fann unter Der STnorolyung gejdeljen, dẩ

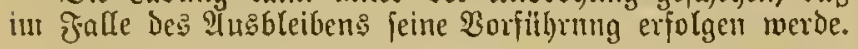

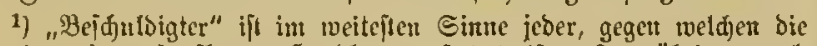

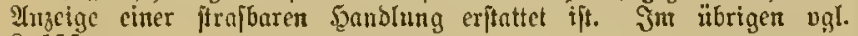
$\S 155$.

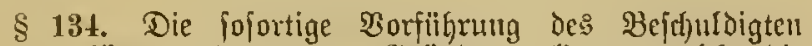

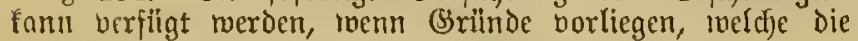

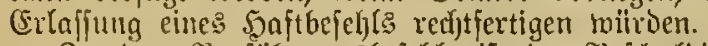

jn dem Sorfithrungôbejefle ift der פejchuldigte genau 3ll bejeidjnen und die iljm zul Saft gelegte itrnfbare

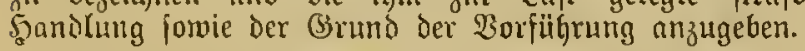

$\S$ 135. Der Borgefulfrte ift fofort bon Dem Riduter zu

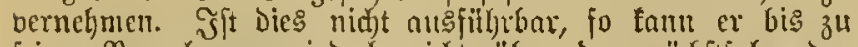
feiner Bernefjmung, jedoch nidyt iiber ben nädfftiolgenden Iag ${ }^{1}$ ) Ginans, feftgeljalten roctien.

1) 3gl. 2tmm. 1 зи $\& 115$.

§ 136. Bci Beginn Der eriten Bernefjumung ift Dem Beithuldigten zน eroffnen, weldye itrafbare Joandung ifm zur Qajt gelegt miro. Der Beffuldigte ift zu befrogen, ob er etrvas auf die Bejdjuldigung erwidern roolle.

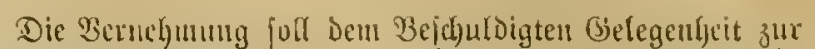

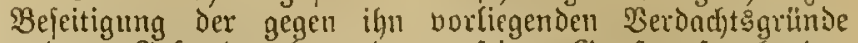
und zur (Seftendmad)ung ber z山 jeinen Bunfen fpredjenden Thatfadjen geben.

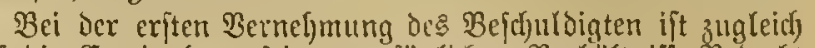

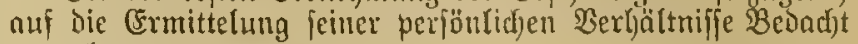
ju แel)men.

\section{Bertheidigung.}

\section{3uläjïgreit.}

\$ 137. Der Bejulduldigte fann fich in jeder Rage des Berfahrens Des Beiftandes eines

Sat ber Beidjuldigte einen gefeslidjen Bertreter, jo fann aucf) Siejer felfftändig einen Bertheidiger wöljlen.

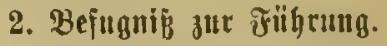

$\$ 138$. Bu Fertheidigern fönnen die bei einem Deutichen

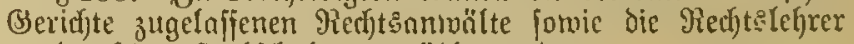

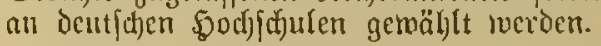

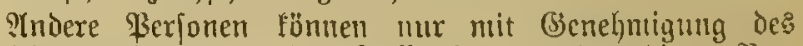
(b)erifgte uns, wem der fintf einer nothmendigen $2 \mathrm{ber}=$ theidigung vorliegt und der (setwählte nidjt zul de

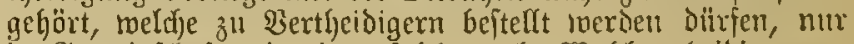
in Bemeinjthajt nit einer foldjen als $\mathfrak{B a h l b e r t h e i s i g e r ~ z u = ~}$ gelaffet metoen.

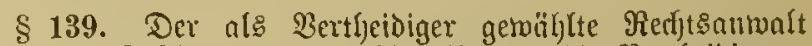
fann mit 3uftimmung Des Angeffagten Die Bertheidigung

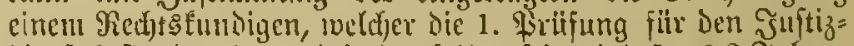
dienft bejtanden hat und in denfelven peit mindeftens 2 Jabren bejchäftigt ift, übertragen.

\section{3. शtothtwendigfeit.}

$\$ 140$. Die Bertheidigung ift nothmendig in Den Sndjen, meldye vor dem Reidjsgerid)t in I. Snftanz oder bor beul Sefwurgerichte zu verhandeln find.

In Sachen, weldye vor dem Sanigeridyt in I. Jnitanz zu berhandeln find, ifft bie Bertheidigung nothinendig:

1. wenn Der $\mathfrak{A}$ ngeffuldigte tallb oder ftumm ift ober bas 16. Eehensjahr nodh nidjt vollendet lyat;

2. Ivem ein Berbrechen den (Begenitnuid ber Unter= judfung bildet und Der Befdruldigte ober fein ge=

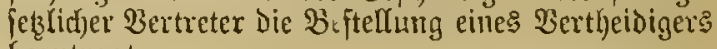
beantragt.

Dieje Beftimmung findet nid)t ?ntmendung, menn bie ftrafbare \$amblumg nur deshalb als cin Verbrect)en fidf barftellt, weil fie im Rlltfoll $b e=$ gangen ift.

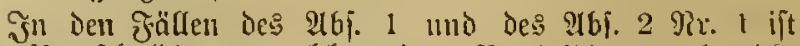
Dem ?tngeidulloigten, weld)er einen Bertheidiger nod) nid)t gemähft ljat, ein foldfer von Ifmtsmegen zu beftellen, fobald Dic in \& 199 vorgeidriebene 2Xfforderung ftattgefunden

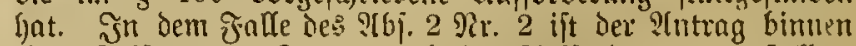

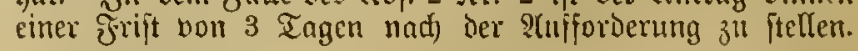

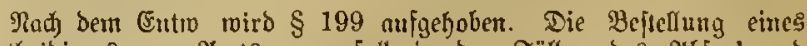

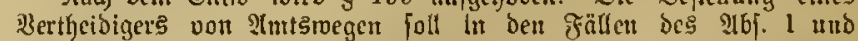

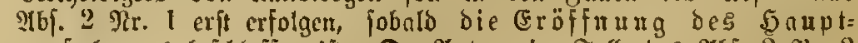

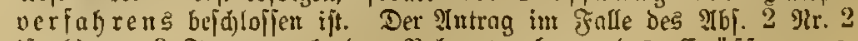

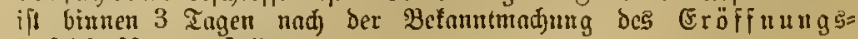
befdinjies zu pellert.

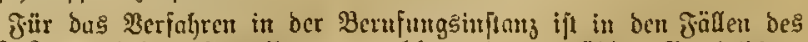

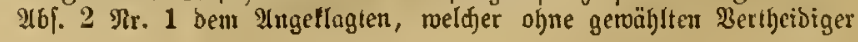




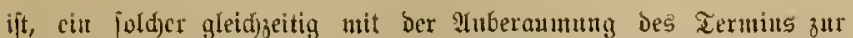

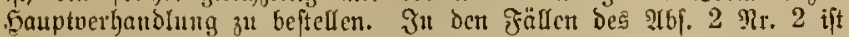
ber Antrag auf Beftellutg eines Bertbeibigers, fojern or nidist f(b)

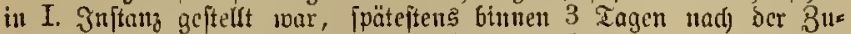
ftcllung ber Sadung zur Souptocrhandurg zu ftelfen.

$\S 144$. Die ?tušmafl Des zu beiteflenten Bertheibigers exfolgt Durd) Den Borfitzenden des (Serichts nus her Zahl

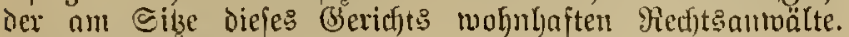
Fin Das vorbereitende Berfahren erfolgt bie Beftellung ourch) Den ?(untsrid)tex.

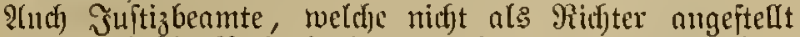

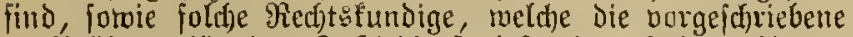

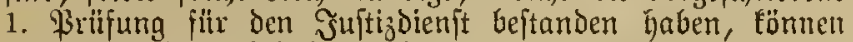
otš Vertbeidiger beftellt werden.

\section{Bertheidiger.}

§ 147. Der Bertheidiger ift nuch Dem Scilufie Der Vorminterfuffung und, wenn einc foldje nidft itattgefunden hat, Jad) Eimreidyung der InElageldyrift bei Dem (Serid)te zur (Finficht der den (Berichte vorliegenden aften befugt.

Schon bor biefem Zeitpunfte ift iljm die (Finfidjt Der geridtlichen Unterjuchungsaften infotweit zul gejtatten, als

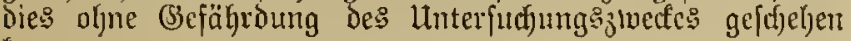
fann.

Die (Finjicht Der Brotofolle über Die Bernelymung Des Bej(f)uldigten, dex (Sintacten der Sachperftändigen und Der Frotofolle itber diejenigen geridjtlidjen Şandlungen, Denen Der Bertheidiger beizumohnen befugt ift, Darf igm leinenlalls vermeigert werden.

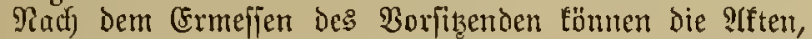

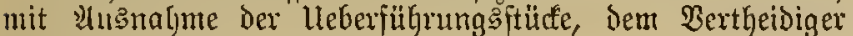
in feine Boblnung verabjolgt werben.

\$ 148. Dem verbafteten Bejfuldigten ift jofriftlidjer แ⿰亻 mündlidjer Berfefyr mit dem Vextheidiger geitattet.

So lange das Jamptwerfafien nidjt cröfinet ift, fann Der Richter (c)riftlidje Mittheilungen zuriicfmeijen, falls deren Einfidit ifm nidut geftnttet roiro.

Bis zu Denfelben Beitpunfte tann Der giduter, lofern die

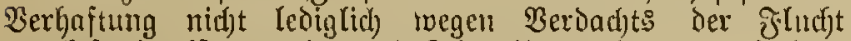
gerenttertigt ift, anordmen, daj den llnterredungen mit bem כertheibiger eine Berichtsperfon beimolyne.

\section{Beiftandổperfonen.}

\$ 149. Der EGemann eirer Ingeflagten ijt in Der

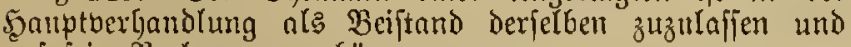
nuf fcin Berlangen zu hören.

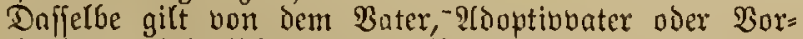
numb emes minderjäfrigen 2 Ungeflagten.

Sn Dem Sorbexfaluen unterliegt bic gulaffung folcher Beiftände Dem ridjterlicfen (Ermefien.

\section{6. (Bebühren.}

§ 150. Dent zum Bertheidiger beftellten Ru(t)tsnnmalte

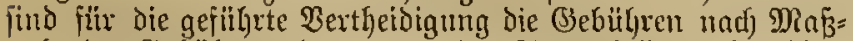
gabe der (Bebulgrenordmm nus der Staatstafie zu bezahlen.

Der Riicfgriff an den in die Sojten verurtheilten $9 \mathfrak{T}=$ getlagten Gleibt vorbeljalten.

\section{Buch. Jerfahren in I. Inttan!.}

\section{Deffentlide $\Re$ lage.}

$\$$ 151. Die (Eröffmung einer gerichtlichen lunterfudfung ift Durd) bie Exljebung einer Slage bebingt.

\$ 152. 3u Erkebung Der öfentlichen Silage ift die Staatsantualtifjaft Germien.

Diefelbe ift, folveit nicjt gejetslid) ein Stnderes beftimmt ift, ${ }^{1}$ ) berpflicftet, twegen affer geridftlidf) (trafbaren und ber: folgbaren Santolugen einzuddreiten, fofern zureidjende that= füct)lithe ?Gurhaltspuntte vorliegen.

1) BgI. beipielstweife $\$ 416$.

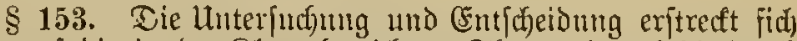
nur auf bie in ber Rlage bejeidjete That und auf bie burd) die Rlage bejululoigten Berfonen.

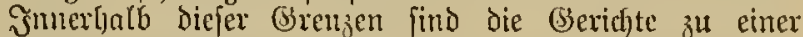
[clbjtändigen Thätigfeit berechtigt unb verpflidftet; ins= bejondere find fie bei ?trmentung des Strafgejeles an die gejtellten ?Yutröge nicht gebunden.

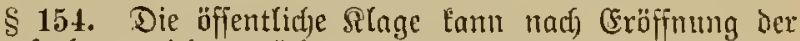
linterfucffung nidft zuridfgenommen werden.

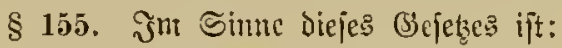

Ingejuduldoigter ber Bejuldigte, gegen weldyen die offentlict)e Silage erfoben ift,

ITngetlogter Der Beffouldigte oder Angeid)ul(Digte, gegen welcten bie Eröffnung des \$auptuerfahrens befdloffen ift.

\section{Borbereitung ber öffentliden Rlage.}

\section{Iuzeige. Strajantrag.}

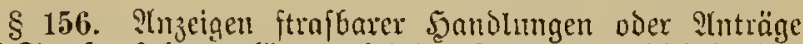
auf Strafbcrfolqung fömnen bei dor Staatsammalticiaft, ben Befjöben und Beamten des Psolizei= und Cidjerljeitzoienftes

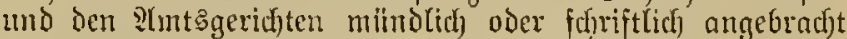
werden. Die mündlich)e ?2njeige ift zu Geurtunden.

Bei ftrajbaren formblungen, deren Berfolgung nux nuf ?Intrag eintritt, muf der ?ntrag bei einem (jeridft oder ber Staatsanmaltfdaft idfriftlid oder zu Protofoll, bei einer anderen Seljörde f(f)riftlich angetrad)t werden.

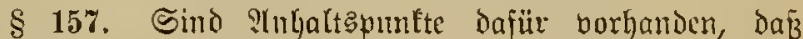
Jemand eimes nidjt natiizlicken Todes geftorben ift, oder wird Der Reidunam eines llnbefannten gefunden, fo find bie Bolizei= und (B)emeindebelyörden zur fofortigen शrnzeige an Die Staatsanwa[tichaft ober an den ?(mesrichter verpflictet.

Die beerdigung Darf nur auf (Brund einer fofriftlidgen

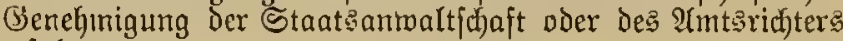
erfolgen.

\section{Borbereitunģverfahren.}

§ 158. Sobalo bie Stantsantwaltidjaft Durdj eine ?trzeige oder aul anderem $\mathfrak{B e g e}$ vou dem Berdacht ciner

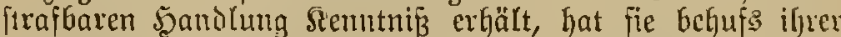
Entfdylię̧ung Daribber, ob bie öffentlidje Selage zu erbeben fei, den Sadjuerbalt zu exforfdyen.

Die Staatsanmaltjchaft hat nidjt blos die zแr Belajtung, jondern aud bie zut Entlajtung bienenden llnitände zu "rmitteln unb fitr die Erhebung Derjenigen Betweife Sorge ju tragen, beren Berluft zu bejorgen jteht. 


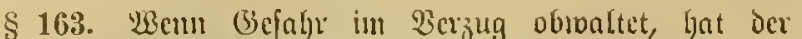

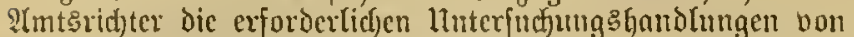
S(untstvegen vorgunehmen.

$\$ 168$. Bieten die angejteliten Ermittclungen genügenden SIrlaß̄ zแx (Erbebung Der offentlidjen Rlage, jo erhebt bic

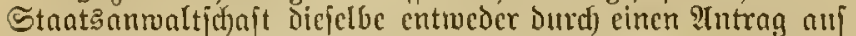

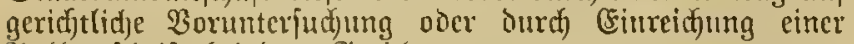
SIntlageid)rift bei bem (Berid)te.

Inderenfalle veritint die Stnatsonmaltifhaft dic sirt= itellung des Berfahrens und jekt hiervon Den Bejpuldigten in $\Re$ enntnißß, twenn er als foldjer bom Ridfter bernommen oder ein \$aftbefehl gegen ify erlaffen mar.

\$ 169. Ssiebt bie Staatsamwaltichaft einem bei iff an=

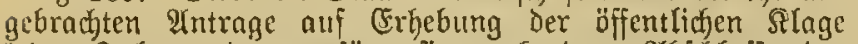

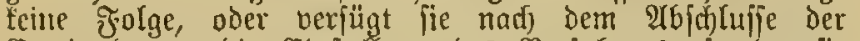
Frmittelungen die Esintellung des Berfafrens, fo hat ite dell Prtragfteller unter Üngabe Der Brithbe zu bejweiden.

\section{Befdywerbe. 2qutrag anf geridgtlidje Entideibung.}

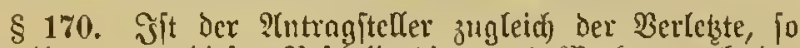
ftelyt ilym gegen dicjen Bejcheid binnen 2 wodjen nadj ber Befanntmadjung die Bejdjwerbe an Den vorgejetzten Beamten

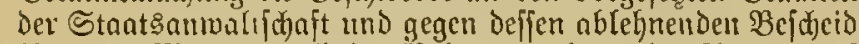
binmen 1 Monate nach Der ibctanntmact)ung der ?attrag auf geridjtliche (Entidjeioung $3^{u}$.

Der Sintrag muß bie Thatjadjen, reldje dic (Exhebung ber öffentliden Silage begründen jođen, und bie Betweis:

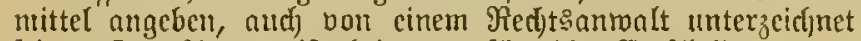
icin. Der SIntrng ift bei dem für die Entid)eidung zu= itündignen (Bseriđgt cinzureichen.

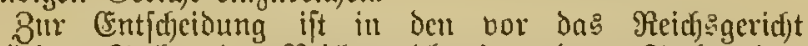
gethörigen Sadjen bns Reid)sgerid)t, in anderen Sadjen ba: ડlicrlandes̈gerid)t jujtändig.

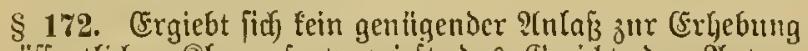
Der offentlidjer Slage, jo verwirft das (Beridht Den Antrag

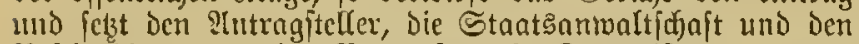
Bejejuldigten bon Der $\mathfrak{B}$ erwerjung in Renntnif.

Sit der Antrag verworien, fo fann die öffentlidbe RInge nur auf (Srutto netter Thatjachen oder Bereismittel erboben werben.

\$ 173. Erachtet bagegen das (Bericht den Autrag fïr

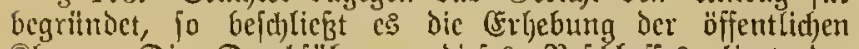

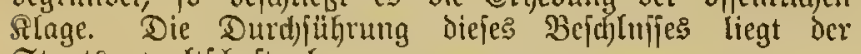
Staatsambaltidant ob.

§ 174. Dem 9lntragfteller fann vor Der (Entid)eidung itber den Sntrag dic Eeiftung einer Sidjerheit fiir die burd

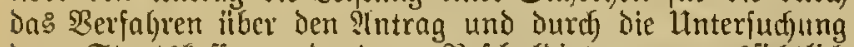
Der Staatsfaffe und Dem Befdulloigten voransfichtlich erwachfenien Soiten durd) Bejchlus bes (Serichts auferlegt twerden. Die Sidjerljeitsleiftung ijt Durd) Sinterlegung in bnarem Belic oder in Wertlpopicren zu becuirten. Dic

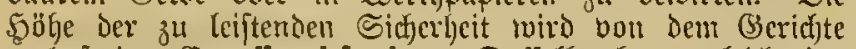
nadi freiem (Entmeffen fejtgejekzt. Dnifelbe hat zugleidy eine Jrift zu beftimmen, bintren meld)er die Sidjerbeit zu leipten iijt.

Bird die Sidjerheit binnen der bejtimmten Jrijt nidjt geleiftet, fo hat bas (B)erifgt ben SIntrog fïr zurtidfgenommen zu erflären.

§ 175. Die Durch Das $\mathfrak{B}$ erfahren über ben 2utrag ber $=$ anlafiten Soften find in Dem Falle Des \$ 172 und Des \$ 174 $\mathscr{1} 6 \%$. 2 bem Antragftelfer aufzuerlegen.

\section{Beridtride Borunterfud)ung.}

$\S$ 176. Die Borunterfutfung findet in Denjeniyen Straf=

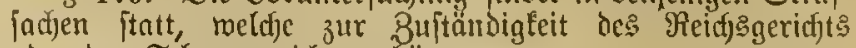
ober der Sd)murgerichte gehören.

Fn benjenigen Straffadfen, we(d)e zur Buftändigfeit der Sanogeridjte geljören, findet die Borunterjud)ung ftatt:

1. wem dic Staatsanmaltjd)aft diejelbe bcantragt;

2. menn Der Angeiduldigte dicjetbe in Semäßheit des \$ 199 beantragt แmb erhebliche (Brinnde geltento madft, aus benen eine Borunterfudumg 3ur $\mathfrak{B o r}=$ bereitung feiner Vertheidigung erforderlid) cefffeint. ")

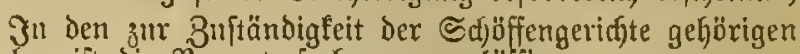
Sndjen ift die Borunterfud)ung unzuläfitg.

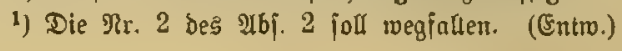

\section{Ilıterjudung}

$\S$ 182. Die Sorunter[u(x)ung wiro bon Dem llnter: [urfungsirithter eroffinet uno gefillyrt.

$\S$ 184. (1) Bei Dem Reidfsgeridjte twirt Der lltter=

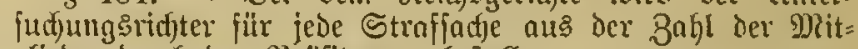
glieder durdf den \$räfidenten bejtelt.

(2) (3) ....

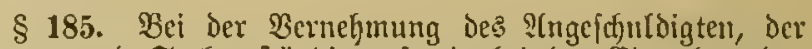
Beugen und Sadfberfändigen fomie bei der CFimnhme des

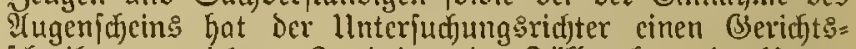

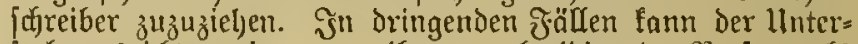
juct)ungsridfter eine von ifjm zu beeidigende \$erjon ats (Berid)tsfof reiber zuzięuen.

\$186. Heber jeoc Unteriudfung ghandlung ift ein \$rotofoll anfanthuten. Daffelbe ift bon dem Unterfudumgsidider und den zugezogenen (Serid)tsfeffeiber z" unterid)reiben.

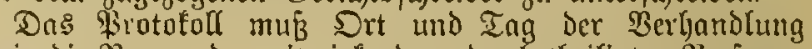

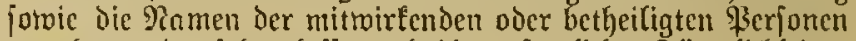

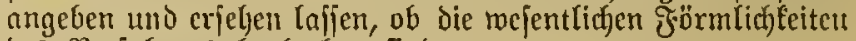
des Berfahrens beobaditet find.

Das \$iotofoll ift Den bei Der Berhandlung betbciligten Berjonen, fotweit es biejelben betrifft, belyufs ber (s)enehutigung borzulefen oder zur eigenen Duraflefurg vorjulegen. Die crforgte Benefinigung ift zu bermerfen, und das \$3rotofoll von den $\mathfrak{B}^{2}$ heiligten entweder $3^{\mathrm{l}}$ unteridjeiben, oder it bemlelben anzugeben, tweshalb die Unterjarift unter= blieber ift.

$\S 190$. Der Ŝlngejduldigte ift in Der Borunteriuchung

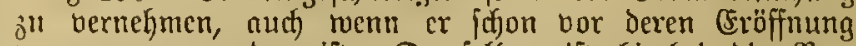
vernommen worben ift. Demfelben ift hierbei dic Ber= fïgung, burcf) weldje bic Borunterfutfung cröffnet roorden, betannt ju madjen.

Dic Bernchmung erfolgt in Mbtoejenheit der Staats= anwalticfaft und des Bertljeidiger's.

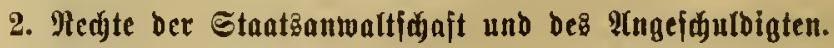

$\$ 191$. Findet die (5inmahme cines Itugcridjeins ftatt,

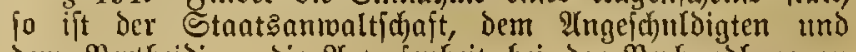

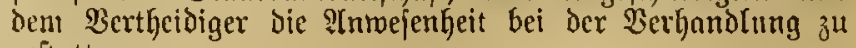
geitatten.

Dafjelbe gilt, wemn ein Benge oder Sadfuerftändiger bernonmen werden fod, weld)er vorausfidtetlicf am Erricheinen 
in der Sauptverhandtung verhindert, oder defien Exfajeinen ivegen grofer Entfernung bejonders exphimert jein wird.

Zon Den Terminen jind die zur 2 (nwejenheit Berectigten vorber zu benadjrid)tigen, foreit bies ohne IYufenthalt für dic Sache gejdehen Eann.

(Sinet 2 (npprud) auf 2 (nnwejenheit hat ber nid)t auf freiem Fube befindliche Ingefduldigte nur bei joldjen Terminen, weldje an ber (Serichtsftelle des Srts nbgehalten werden, tno er fidy in Şaft befindet.

शui die Berleyung eines Termins megen $\mathfrak{B e r h i n d e r m}$

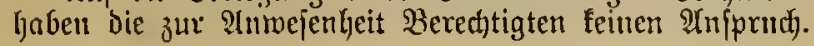

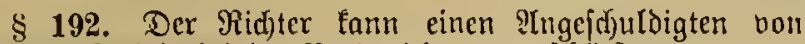

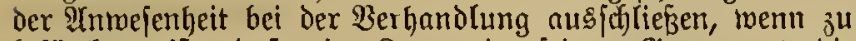
bejürdjten ift, dấ cin Zetuge in feiner Begenmart die Bantreit nid)t jagen merde.

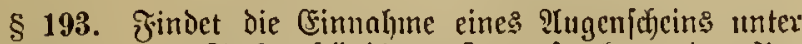
3uzieljung bon Sadjwerftändigen ftatt, fo toun der $\mathcal{A l}=$ gejduldigte beantragen, oaś die bon ifm jür die Salupt= verlyandlung in Borjdjlag ju bringenden Sacfoeritändigen zu bem Termine geladen werden und, wenn Der Richter ben Stutıag ablefint, fie jelbjt laden lafjen.

Ten vou dem ?ngejduldigten bennunten Sadjoeritändigen ijt die Theilunhme am 2lugenifhein und an den eriprderlidjen lluterfutfinngen infomeit zil geitatten, nIs dadurd) bie

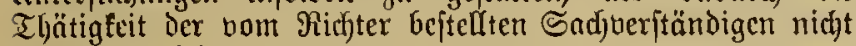
bejintert wird.

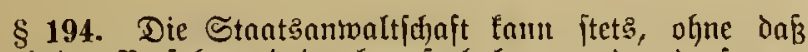
jedod das Berfahren baburd, aufgehalten werien darf, bon Dem Stambe der Vorunterfuclung Durd) (Finfid)t ber Aften

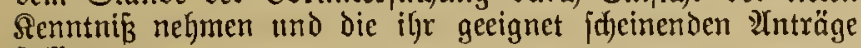
fitellen.

§ 195. (Erad)tet Der Innterfudjungeridjter den 8 mede der Borutnterjudung für crreidjt, jo überiendet er die \$ften Der Stantsanwaltidiaft zur Stellung ihrer YYuträge.

Beantragt die Staatsanmaltfdhaft cine (Ergänzung der Borunter[udjung, fo hat der Unteriud)ungerridfter, twenn er Dem Plntrage nidjt itattgeben will, dic (Entid)eidung Des (Serid)ts einzubolen.

Bon dem Sdjlufie der gorunterfuffung ift der $\mathfrak{A n}=$ gejd)uldigte in Renntrizi zu jeķen.

\section{Eröffung bes Şauptoerfahreng.}

\section{Inflageidurift.}

\$ 196. Sat eine Borunterfutuung ftattgejunden, jo ent= idjeidet Dos (Serid)t, ob bas Sauploerfobren zu cröffuen oder der IIngeffurbóigte auser Berfolgung zu jeşen vier dos $\mathfrak{B}$ erfalyren borläufig einzuftellen jei.

Die Stantşanmaltid̄ajt legt zu biejem Zivecfe bie Ifften mit ifrem Intrage dem (Beridyte bor. Der Ylutrag nuf

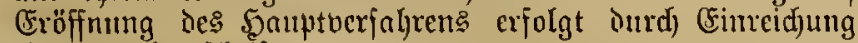
ciner $\mathscr{2}$ Intlagejorift.

$\$$ 197. Erfjebt die Stautsanmaltjăaft, oljne baß̧ cine Borimterjudjung ftattgefunden, die ?intlage, jo ift die $\mathfrak{A n}=$ flage(c)rift mit den खtten, menn die Sache zur Buitändigleit

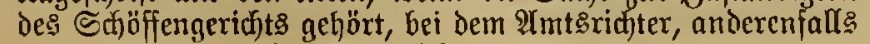
bei Dem Eanogeridjte einzurcididet.

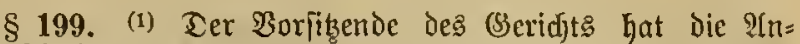
flogefhrift dem Ingeid)uldigten mitjutbeilen und ilyn zugleid)

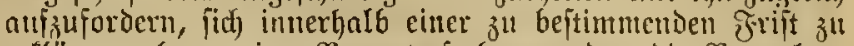
erflären, ob er eine Borunterfudjung ober dic Vornalyme einzelner $\mathfrak{B e m e i s e r h e b u n g e n ~ b o r ~ d e r ~ f o u t p t b e r l y a n d l u n g ~}$ beantragen, oder Cinwendungen gegen bie Eröffnumg de Şauptwerfabretis borbringen wolfe.

(2) (3)

(4) 2(uf die bor Den Srföffengeridyten zu verlyandelnden Sadjen finden bie Bejtimmungeu diejes \$aragraphen teine IItrendung.

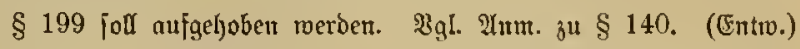

\section{Geridytlidge Befdylüfíe.}

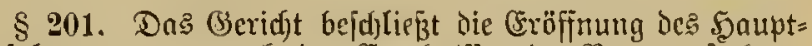
verfahrens, wenn nad) den (Ergebuijien Der $\mathfrak{B}$ orunterjudjung oder, falle cine jold)e nidjt itattgejunien bat, nadj den (Er= gelniffen des borbereitenden Berfaljrens der 2(ngeidfuldigte einer jtrajbaren f̧andung ljinreichent berdäd)tig exjdjeint.

Baar ber $\mathfrak{A}$ ngeflagte ein in unmittelbaren ober mittelbaren Stnats: bienfle jebender Beamter (oder angejtelter einer Brivateijenbahn= vermaltung), fo ifi jofort nad) Eröffung bes Sauptverfafrets unter Mittheilung ber Inflageforift ber vorgejebten Dienjtbeljörde (ober

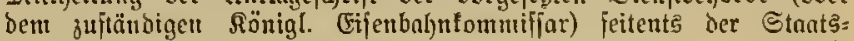

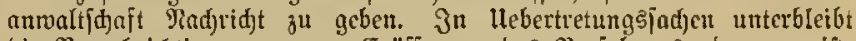
bie Benadjridtigung wegen (Eröfinutug bes setiabrens, bagegen ifl, pofern redtsträftig auf Etrafe erfanni worben ift, bie Utheilśformel

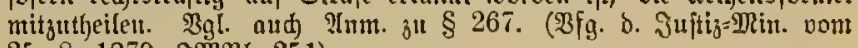

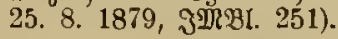

§ 203. Borläufige Einjtellung Des Berfahren tan

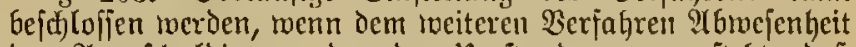
des Angefchuldigten oder der llmitand entgegeufteht, baf derjelbe nad) Der That in Geiftesfrantleit verfallen ift.

§ 204. Tas Geridjt ijt bei oer Bejulusjafjung an die Anträge Der Staatsanmalt/djait nidjt gebunden.

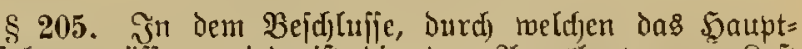
verfahren eröfinet wird, ift die dem ?tugeflagten zur Rajt gelegte That unter Sgervorhebung iljrer geiez̧lidjen Merfmale und Des anjumendenden Strafigejekes, forwic bas (Seridt

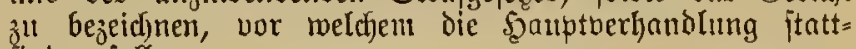
finden foll.

Das (Serid)t hat zugleid) bon 2 mtgivegen über bie 9norbnung oder ₹ortoauer ber Hnterfud)ungehaft fu beid)ließsen.

$\S 206$. (1) $\mathscr{B} \mathrm{em}$ von ber Stantsanmaltjd)aft beantragt

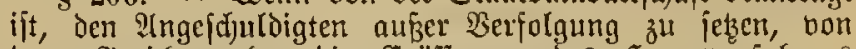
dem Beridjte aber die Froffinung Des Sauptverfahrens bejulofien wiro, io hat dic Etantsanmaltictaft eire dem

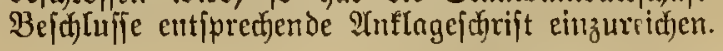

(2) ......

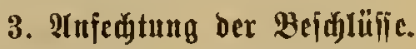

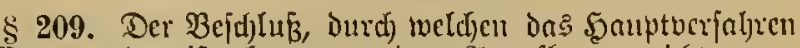
eröffnet worden ift, fann bout bent ?Ingeflagten nid)t ange= foriften merben.

(Segen den $\mathfrak{B}$ cjdjlnß, Durd) weldjen die (5röffrung des 5ृauptverfaljrens abgelegnt oder abmeidjend bon bem $2 \mathfrak{n}=$ trage ier Staatsanmaltidjajt die Berweifung an cin (jerid)t niederer Dronung ausgciprodien morden ift, fteljt ier Stants= anvalificfaft bie fofortige Bejfjwerde zit. 


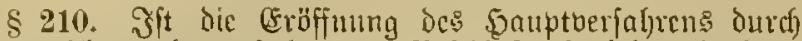

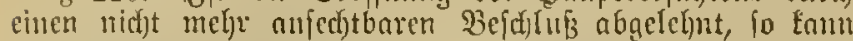
die Silage unt anf Girund neuer Thatfadjer oder Betweiä: mittel roieder aujgenomuter merden.

\section{Befouberes Berfahren vor bem ङdüffengeridite.}

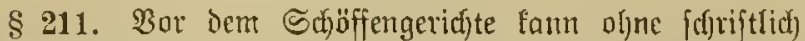

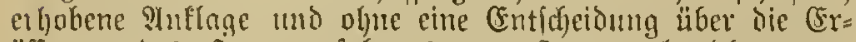
offnung Des Souptberfaljets zur Sauptverbandung ge= fditten meroen, ment der Bjefduldigte entweder fich frei= willig ftellt ober in folge einer vorläufigen Jeftnnlyme dem (3)erichte vorgefiib)rt ooer nut toegen thebertretumg verjolgt mirt. Der wefentliche Jnthalt ber sunflage ift in Den Jällen

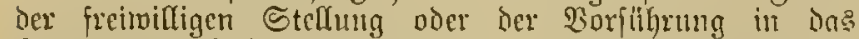
Sibungsprotofoll, anderenfalls in bie Eabung Des Bejchul= bigter nufiumehmen.

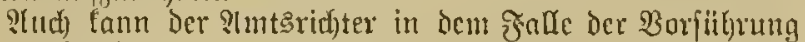

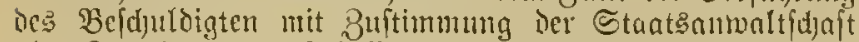
oljne Buziefung von Sd)öffen zแt Şauptoerfandumg (d) reiten, reem der bejdunlìigte unr wegen llebertretum verfolgt mirb uno bie ihut zu: Eaft gelegte That cingeftelt. (S)egen Die im Enufe ter Samptwerhanolung ergehenoen Enticheidungen

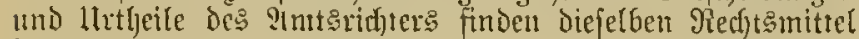

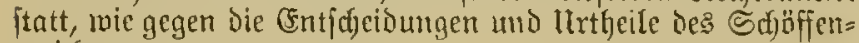
geridets.

Rach bem (Entw. foll dicies abgefürzte Berfahren aud nor anderen

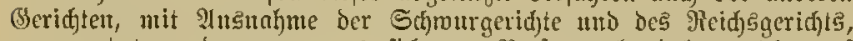
angewentet werben, wenu es fidj um \$erjoutu handelt, meldhe anf

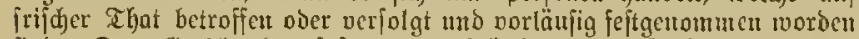
fint. Das (Gerid) hat pofort over ipäteftens ant 2. Tage nad) ber

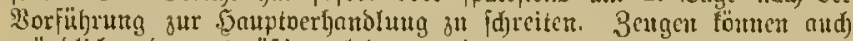

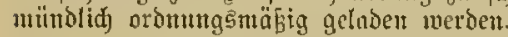

\section{Terutit.}

\section{6. Şanptberhanolung.}

§ 212. Der Termiu fur Sauptberhandung twirb von dem Barfizenien des Bericfte anberanmt.

§ 213. Dic jur Şauptwerhandung exforterlidjen

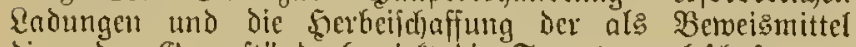
bientenden Gegenftände betwirlt Die Staatsanmaltfuchaft.

\section{Rabungen.}

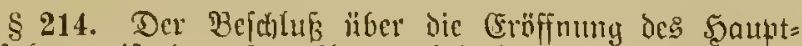
berfahrens ift bem 2tngeflagten fpäteftens mit der \&adung zuzuftellen. ${ }^{2}$ )

1) Deşgl. bie Inflngeidrift. (Entr.)

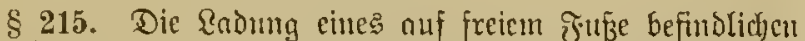

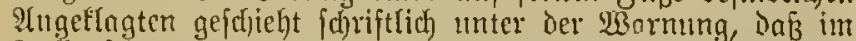
Jalle jeines unentichurbigten ?hableibeng feine Rerbaftung Dier Borführung erfolgen merde. Die Wanunung fann in ben J̈̈̈llen bes \& 231 muterbleiben ')

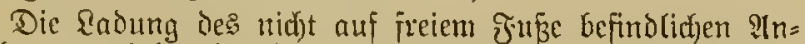

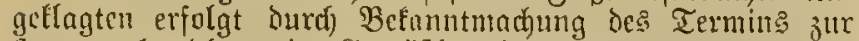
Somproerlyandlung in Bemtn̈beit bes $\$ 35$. Sabei ift ber

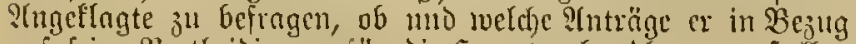
atf feine 2 Batheidigung fiir bic Sauptberhandung atl ftellen habe.

1) Die Sabung foll nur furz unter fimbeis anf bie gefeblithen Folyen nuentiduloigten ?tuśleibens ftatifitoen (Entro.)
\$ 216. 3rvifhen der 3uftellung Der Radung (\$ 215)

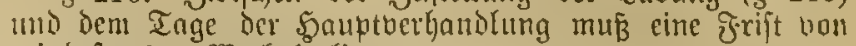
mindeftem 1 (2sod)e $e^{1}$ ) liegen.

Jit diefe frift nicht eingehalten worden, fo foum der

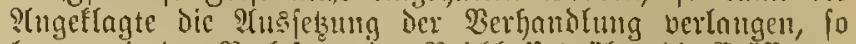
lange mit ber Berlejung bes Bejhluffes über die (Eroffnumg Des Sauptuerfabrens nidht begoumen ift.

1) bei ltebertretungen, von mindeftens 3 Tagen. (Entwo.)

\$ 21\%. Neben Dem ?ingeflagten ift der beftellte Ber=

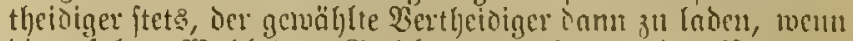
Die erfolgte Wabl demt Berichte angereigt wothen ift.

\section{Inmittclbare Rabung.}

\$218. Ferlaugt ber Pugeflagte bic \&anung bon Bengen

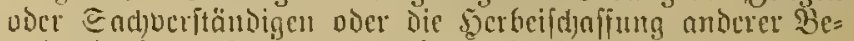
meismittel zur Souptoerlanduma, fo lont er unter ?Ingabe bet Ihatfadjen, über melde ber Seweis erthoben werben foll, feine ?tnträge bei Dcm Borfizenden des Gerichts ju ftellen.

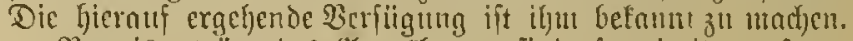

Betweisanträge des Ingetlagten fint, foucit ilyen fott= gegeten ift, Der Etantinammaltid)aft mitjutbeilen.

\$ 219. Schnt Der Borfikende Den Itntrag auf Sabung einer \$erjon ah, fo fam Der 2(ngeflagte bie retztere un=

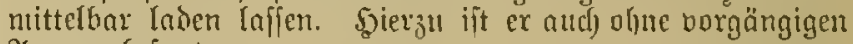
Antrag befugt.

(Fine umbittelbar gelndene Firefon ift nur donn zum

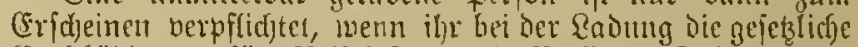

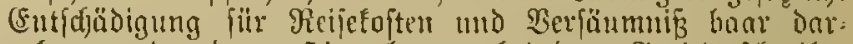
geboteu oder diren Seintertegung bei dem (Berid)tsfchreiber nadjgewicjen bir. ${ }^{2}$ )

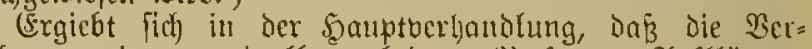

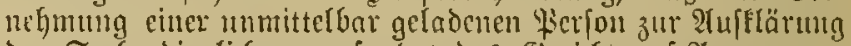

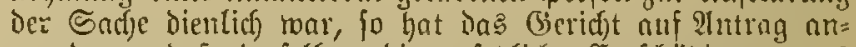

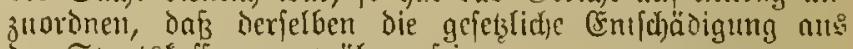
der Stnntsfaffe ju gemähren jei.

1) Soll ein öffentlidyer Beamter ats Eadjuerftändiger gelnden toeroen, fo fomucn nod) $\$ \$ 53$ und 76 in Frage.

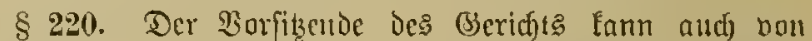
2mtemegen die Rabung bon Zeugen mo Sacjberftändigen

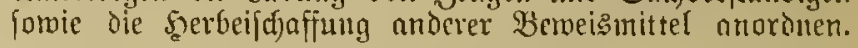

\$ 221. Dor 21ngeflagte bat bic oon ibm unmittelbar gefadenen oder zur Somuptberbandlung jtl ftellenden Beugen und Sachberftändigen rechtjeitig der Stantsanunnltict)aft nambaft zu madjen uno ifren wohn= oder ?lufenthaltsort anzugeben.

Diejelbe Berpflicftung lyat bie Stantsannualtidjnft gegen= über Dem Mngeflagten, wenn fie außer den in Der Plitlage= idrift henaunten oder auf ?lutiag ors ?ingeflagten gifabenen 3eugen Dder Sadjuerftändigen Die \&adung noct) antierer \$ier= fonen, fei es auf aus eigener (sntifflię̧ung, benirft.

\section{Sommiffarifdje Berneljumng.}

\$ 222. Wenn dem (Erfiteinen cimes Beugen oder Sart)=

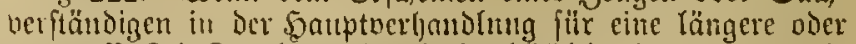

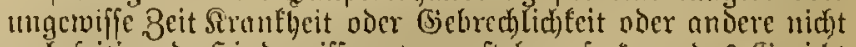
3 befeitigende Sounderniffe entgegenftelen, fo fnum das (Bericht

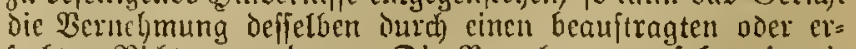
fudjten Ridjter anoronen. Die Bernebmung erfolgt, fomeit dic Beeibigung zuläffỉ ift, cidliç. 
Daffelbe gilt, menn ein Beuge oder Snduberitändiger vernommen merien fall, defien (Erjhjeinen megen grof̧er Ent= fernung bejonters erfsytwert jein witb.

$\S$ 223. (1) ......

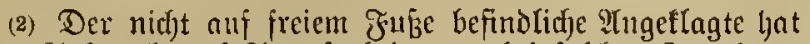

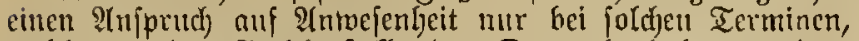
meldye an der Geridts sflelle des Srts ahgehalten merden, two or fidf in Saft befindet.

Reut fommt hinzu, baß̧ oor ber Snuptverfanblung dic Stants=

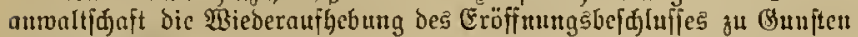
bes IIngeflagten auf (Srumb neu hervorgetretcrter IInjtände beantragen tami (Entro., § 224a.)

\section{Gegentwart.}

\$ 225. Dic 5auptuerfandung erjolgt in ununterbrochener Gegentwart der zur lltheirsfindung berufenen Perjonen fowie

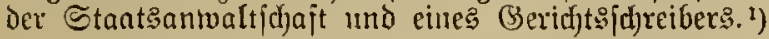

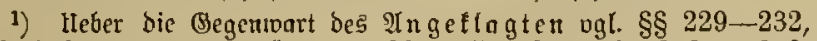
$216,3 \mathfrak{t 9}$; ber Sadjuerftünbigen: $\$ \S 72$ ff, 191, 193, $218 \mathrm{ff}, 242$, 247; bes ஒrivatllägers: \$\$ 418, 425, 427, 431. Die \$er= hinberung bes Bertheidigers giebt, unbejdabet ber झorfdriften iiber bie nothroenoige Nertheibigung (\$ 140), bem Ingetlagten tein Fedjt, bie Ilusjebung ber Berfandlung ôn veriangen. (Ebenjo ift bie Mbrocienteit bes $\Re$ ebentläger verhanoluutg ohne (EinfluE.

$\S 227$. (1) (2) .....

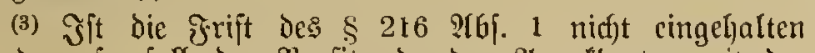
morden, fo folf ber Borfizende den IIngeflagten mit der

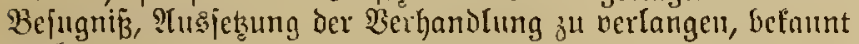
mader.

§ 228. Eine unterbrod)ene fुnuptverbandung muв̈ ipärejtens am 4. Tage nach der linterbrechung fortgejetzt werden, widrigenfals mit bem Berfahren bon neuem zu beginnen ijt.

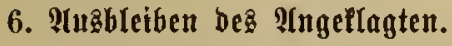

§ 229. (Gegen einen augigebliebeuen 2 Ingeflagten findet eine Sauptoerfandlung tidift ftatt.

Э̃it das 2(uŝleiben des ?Ingeflagten nicht genügeno entid)urdigt, io ift die Borjührung anjurdnen oder cin \$ałtbefegl zu erlaijen.

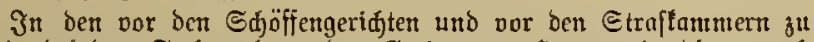
verhandelnden Sndjen tann das Bericht zur bauptverhantutung aud)

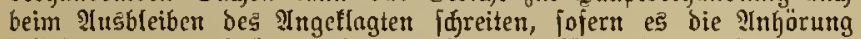
beffelben zutr Aufflärung ber Sade nidft fïr erforberfíf eradtet, (Entr.)

§ 230. Der erjujienene Ingeflagte barf fich aus ber Berbandlung nidyt entfernen. Der Borjibende Eann dic geeigneten Miabregeln treffer, um bie Entfernung ocfjelben ju verfjubern; aud fann er ihn während einer llnter: brectung Der $\mathfrak{B}$ erhandlung in Bemabrjam halten lajfen.

Entiernt Der Ingeflagte fich Dennod, ober bleibt er bei der Jortfesung ciner unterbrochenten Şauptverbandhung aus, fo tonn dieje in leiner शीbmejenheit zu Ende gejübrt

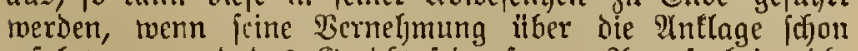
erfolgt twar und bns (Serifft feime fermere ?(mwejenheit nidjt fiir erfordertich eract)tet. ')

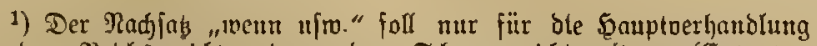
vor bem Reidjsgeridit uno por bem Sdjwurgeriat getien. (ङntw.l

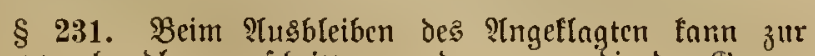
Sauptoerljandumg gejdyritten twerden, wenu bie den Begen= ftand der Unterinthung birdende That nur mit Beldftrafe, 5ुaft oder Eiujifhung, allein oder in Berbindung mit cin= ander, bedroht ijt.

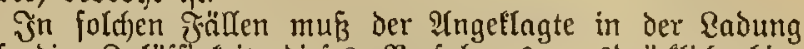

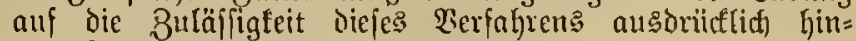
gerwiejen rerden.

$\S 231$ foll aufgeboben werben. \$gl, Inm. హu $§ 229$. (Entw.)

§ 232. (1) Der 2Angeflagte tamn anf feinen Trntrag megen grofer Entfermung feines 2lufenthaltsort: bon Der Berpiliditung zum Erjofinen in der Souptberhandung ent= Gumden werden, wenu nach bem Crmeffen des (Beridyts vor=

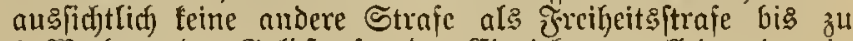
6 Wochen oder (3elditraje oder (Finziehung, allein oder in Berfindung mit einander, ju ertwarten jteht.

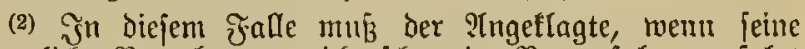
richterlidfe Bernefymung nidft idfon im Borberjahren erfolgt

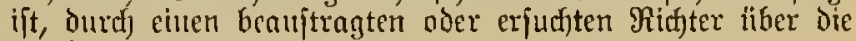
Intlage bernomment merden.

(3) .....

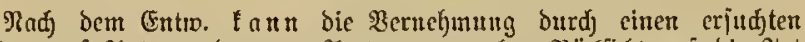

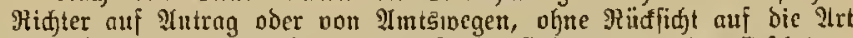

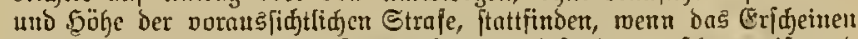
bes Angeflagten wegen groß̈er Entfermung bcjonbers erjofwert ifit uno

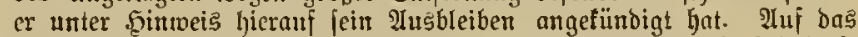

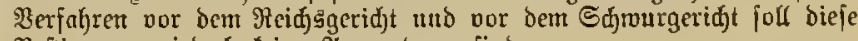
Bejtimmung jedod leine Aีnerioung finden.

§ 233. Fnjorweit dic Fुauptberhandlung ohne ?Inwejenheit Des Angeflagten ftattfinben fann, ijt letsterer befugt, fird) ourd) einen mit idnriftlidfer Bollmadt verfehenen Bertheidiger vertreten zu lajfen. ')

1) nod) bent Entr. unr im Falle bes neuen $\S 232$ (১. h. unter

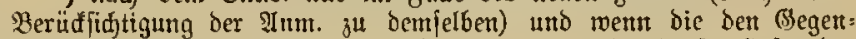
ftand ber llnterfudaung bildende That nur mit Belbftrafe, baft ober Einziegung bedroht ift.

8234. Wat Die Şauptorhanolung ohne Intwejenheit Des Angeflagten ftattgefunden, fo fann derferbe gegen bas

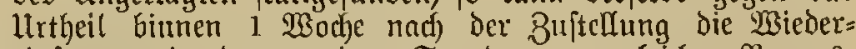
einjetsung in ben borigen Stand unter gleiden $\mathfrak{B}$ ornus:

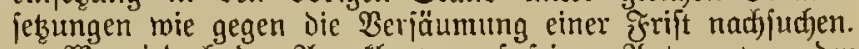

War jedod) der Ingetlagte allf peinen 2ntrag bon ber Berpflicftung zum Eridjeinen in Der Şauptberhanolung ent= bumben morden, oder hatte derjelbe von der Befugniß̧, firf rertreten jul Lafien, (Sebraud) gemad)t, fo findct eine Wieder= einjebung in den vorigen Stand nidit itatt.

§ 235. Das (Berifft ift itets befugt, das perjönticfe Evidjeiten des Wngeflagten anjuoronen und Daffelbe burd)

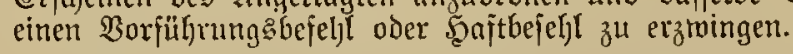

§ 237. Die Reitung Der Berbandlung, die 2ernefmung des Arngetlagten und die Ituftahme des Bemeifes erfolgt Durdf Den $\mathfrak{B}$ orfikenden. ${ }^{1}$ )

Wiro cine auf bic Gadjleitung bejüglidje $\mathfrak{A n o r d m u n g}$ des $\mathfrak{B}$ orfitzenden von eincr bei ber Berhandung betheiligten Berfon als unjuläjifig brantandet, fo enticheidet das (Geridft. ${ }^{2}$ )

1) Derjelbe foll etmäđtigt werben, in einzelnen Sadjen bieje Ges

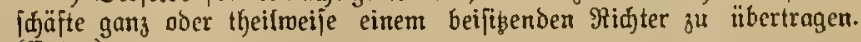
(Entr.)

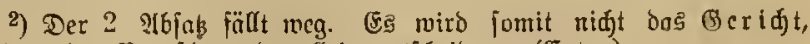

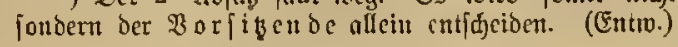




\section{Areujuerfjör.}

\& 238. (1) Die $\mathfrak{B e r n e l}$. antoaltidjaft und Deur Ifrgeflagten benannten Beugen unto Sadwerftändigen ift ber Stnat:anmaltid)aft uno Dem $\mathfrak{B e r}=$ theidiger atf deren Borfikenien z" itberlafjen. Bei Den von Der Stants= ambaltfdaft bennunten Beugen umb Sacfuerftändigen hat Diefe, bei ten bou Dem ?tugetlagten bennunten Der Ber=

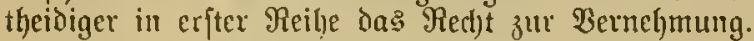

(2) ......

\$ 239. Der Borfitzende loat den beifikenden Ridjtern auf Berlangen zu geftatten, Jragen an die Beugen und Sadjuerftändigen z"I itellen.

Dafiel he hat der Borfizende der Stmatsanualtidjaft, iem

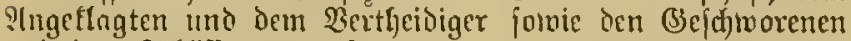
uno den Sdjöffen zill geftntten.

§ 241. 3weifel ïber die Zuläffigteit einer Jrage ent= (d)eidet in allen sällen ing (berid)t.

\section{Beginn ber Şauptwerbanblung.}

\$ 242. Dic Saluptuerfyanblung beginnt mit bem ?luf= rufe der Zengen uno Sadjberftäudigen.

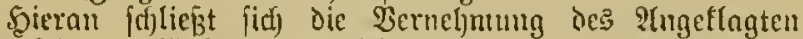

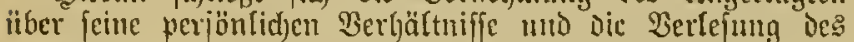
Bejuluffes über Die Eröffnung ies Sauptocrfahrens.

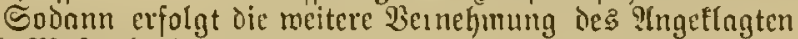
nad) Minganae des \& 136.

Die Berlefung Des Bejufuffes und die Bernebnuug des Ingeflagten geidhieht in :Ifrefenheit ier ju bernchmenden 3eugen. ${ }^{1}$ )

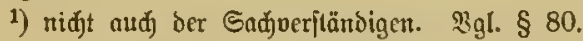

\section{Retweizanfintahme.}

§ 243. (1) Madj Der 3ernefmung Deకె Ingeflagten jolgt dic Bemeisanfmalyme.

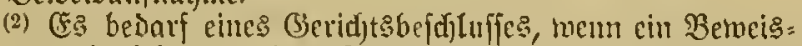
autrag abgelelynt lociden foll, ober weru die Bornalime

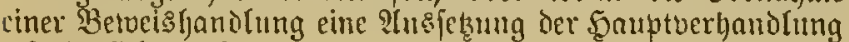
crforderfidf macft.

(3) ......

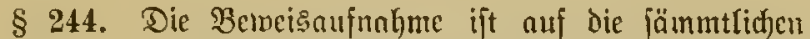
vorgeladenen 3eugen und Sacd)berftänthigen forvie nuf die anderen herbeigeldafiten $\mathfrak{B}$ eweismittel zn erjtredfen. Bon Der (Erbebung einjelner Detreife fam jedodf abgeiehen เverden, ment bic Stantsanmalticjaft uno ber IIngeflagte hiermit einverjtanden find.

Ӭn Den Q3erhandhungen yor den Sdjöffengerichten und vor den Randgeridjten in oer Berufungsinjtanz, fofern bie Terbandung vor Tezteren eine Ucbertretung betrifft oder auf erbobene Bribntflage crfolgt, bejtimmt bas Beridft den llunfang der Belveisanfnafnue, oljne hicrbei Durref) P(nträge, Berjitfite oder frifhere Bejhlüffe gebunden z̆l fein.

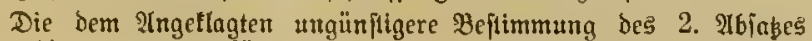
foll allgemein eingeführt merben. Siur in bes fauptoerhandlungen

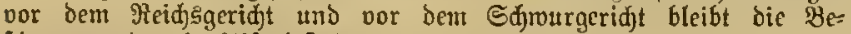
ftimung bes 1. 2tbj. beftehen. (Entr.)

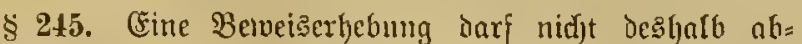
gelehnt werden, meil das Berneisిmittel oder die zu beineifende ¿̇atfadje z" fpät vorgebratift worden fei.
Sit jedod ein z" bernehmender Beuge oder Sad)= veritänbiger dem (3egner des 2Intragitellers fo pä̈t nambaft gemadht oder eine ju betweifende Ifatjadje fo fpät bor= gebrad)t moriden, Daß es dent (B)egner all der jut (Fin = jielyung bon Erfumbigungen erforierlidfen Beit gefehlt hat, to tamn Derfelbe bis zum Stfluffe oer Belveisaufnahme die

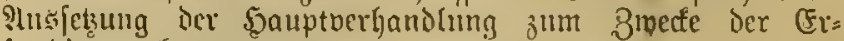
fundigung beantragen.

Diejelbe Befugnifí Gahen die Stnatsanmaltjdjaft und

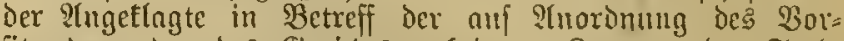
fikenden dier bes (Gerid)t's gefadenent Zengen oder Sad)= veritündigen.

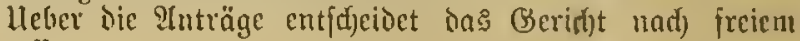
Ermefien.

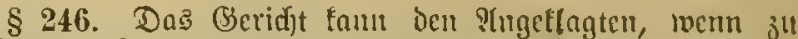
bejiirt)ten ift, onf ein Mitangeflagter ober cin $8 \mathrm{euge}$ bei finer Vernefuntung in Begenmart ies Sfrigetlagten bie Waabrheit nidjt fagen tmerie, mäljend diefer Sernelymung vus bem Sikzungsiummer abtreten Lafjen. Der Borfikende yat jeboch ben Angeflagten, fohald diefer roieder vorgelajfen rorben, von dem wefentlichen Jnlynlt desjentgen ju unter= rid)ten, 1vas ruährend feiner 2tbwejentyeit nusggejagt oder fonit verbandelt morden ift.

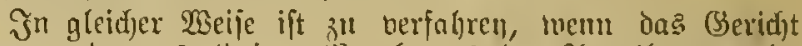
wegen oromumgsmiorigen Wenchment bę 21ngetlngten zeit= weife deficn Entfermung nus dem Sitzungszimmer all= georonct hat.

\$ 247. Die vernommenen Zengen uno Sadfberjtändigen

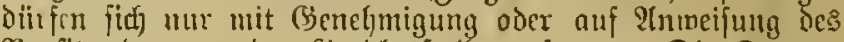
Borfizenten bou der Beridhtsitelle entfermen. Die Stants= anualtidjnft und der 21ngetlagte find vorker ju hören.

\section{Berlefung von Enriftitïden.}

\$ 248. Urfunden und andere ถโลิ Bemeismittel biencnde

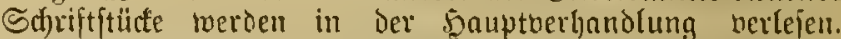
Dies gift insbefondere bon früher ergangenen ङtrafurth-ilen,

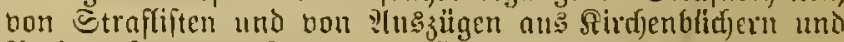
Fierjonenjtanderegiftern und findet and Inmenoung nuf Frotofolle ïber die Sinnahne des ridjterfidjen Qlugen= (d) cins.

\$ 249. Berutht der Brrocis eimer Thatjache auf der Wonbrnebmung ciner Perion, fo ift bie lektere in Der Soupt= berbnolung zu vernehmen. Die Bernehmung oarf nicht burd) Berlefung bes itber eine frïhere Berneijmung auf=

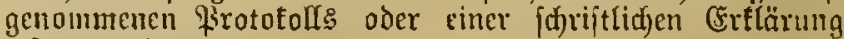
erjąt merben.

§ 251. Die $\mathscr{A}$.

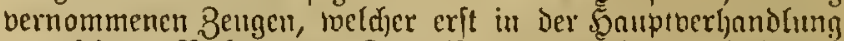

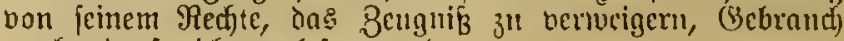
madjt, onrf nicft verlejen merben.

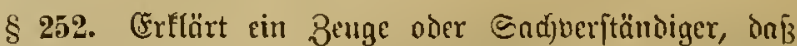
er iid) einer Thntfadje nid)t mehr erimmert, fo tann des hierauf bezilgliche Theil des \$rototolfs über feine frübere

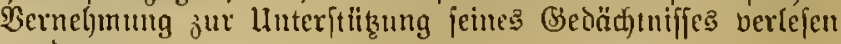
merden.

Dajfetbe lann geidjehen, wenn cin in der Bernebmung

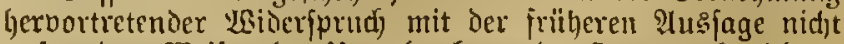

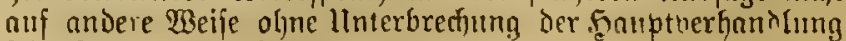
feftgeftellt oiner geboben ineriou fomm. 


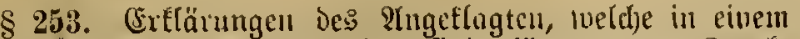
rid)terfidjen Grotolodle enthalten find, tömen zum Zmedfe ber Berbcisaufnahme ïber ein Sejtäniniß̧ berlejen werden.

Daffelbe tann gejfjeljert, wenu eir in Der Bernchmung

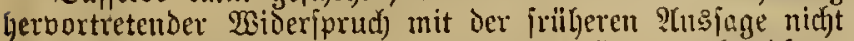

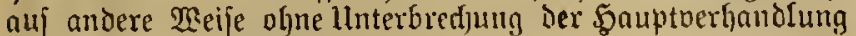
feftgeftellt oder gehoben werden tam.

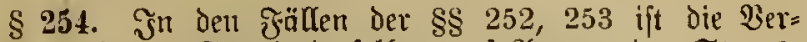
lejung und der Brund derjelben auj Itntrag der Staals: antwaltjúfaft oder des SIngellagten im Srotofolle zu er= wähnen.

8 255. Die ein Beugnif ober ein Gutadten enthaltenden

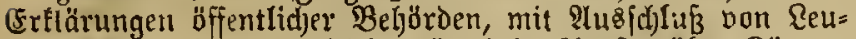

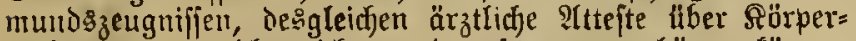
verlebungen, meldje nidb) z"l den (d)weren geljören, fönnen verlejen merden.

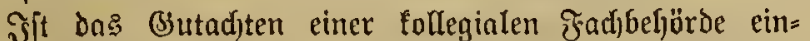
geljolt warden, jo fann tas (Berid)t bie Beförde erfuden, cintes ifrer Writglieder mit ber Bertretung DrE (Gutad)tens in Ser Sauptvertandlung 3 u beanftragen und dem Beridjte ôu bejeidnen.

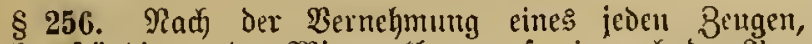
Sachberfändigen oder Mitangetlagten, fowie nad) ber $\mathfrak{b e r}=$ lejung cines feden Sdyriftitüd's foll ber Ingellagte befragt werden, ob er etras zu erflären ljabe.

\section{Edjlup̣oorträge.}

§ 257. Rad) dem Sd)lufje der Betweisauinalyme erhalten die Staatsanmaltid)aft und fodann der ?tngetlagte ju ihren

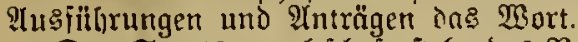

Der Stantşamwaltidjajt iteht bas Redjt Der Crmideruna зu; dem Angeflagten gebiifrt das letzte wort.

Der Ingeflagte ift, aud) twenn ein Bertheidiger für ityn gejprodjen ljat, jul bifragen, ob $\mathrm{el}$ [elbjt nod) etros zul feiner Sertljeidigung anzuführen babe.

\section{Betoolmetidung.}

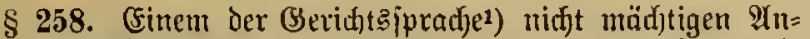
geflagten müffen auక ben Shjluz̧oorträgen mindeiten die

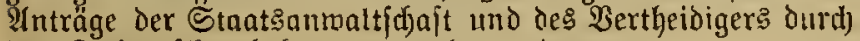
Den Dolmeticher befannt gemadist wirien.

Daffelbe gilt von einem tauben ?lngeflagten, jojern nicht eine (ch)riftliche $\mathfrak{B}$ erftändigung erfolgt.

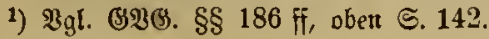

\section{Urtheil.}

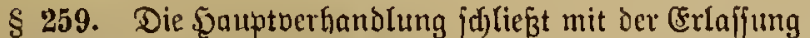
des Urtheils. Toas Hrtheil fann nur auf Freifprechung, Berurtheilung oder Einftellung des Berfahren lauten.

Die Cinftellung des Berfahrens ift auszufpredfen, wenn bei einer nur auf Antrag zu verfolgenden ftrafbaren \$andlung fich ergiebt baf wenn der ?ntrag red)tzeitig zurüufgenommen ijt.

\section{Freie Betweistwïrbigung.}

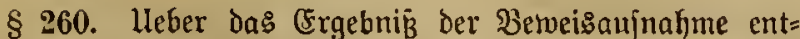
id)eidet Das (Seridft nach feiner jreien, aus bem Эnbegriffe oer Berbandlung gefdjöpften Heberzengung.

\section{Bweibrittheil.Mlehrbeit.}

\$ 262. 8"1 eintex jènen dem ?fugeflagten nadhtlyeiligen (Entidjeidung, weldje die Ed)uldifrage betrifft, ift eine Mefjrheit von $2 / 3$ der (Stimment ${ }^{1}$ ) erforderlid).

Die Sdyltlofrage begrift audj foldje bon bem Straj= gefezze bejonders vorgejehene Umitände, weldje die Straf= barfeit ausfalließzen, vermindern oder erlÿhen.

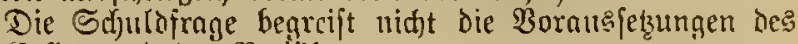
Rüuffalles und Der Verjäfrutig.

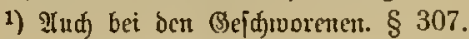

\$ 263. Begenitand der Urtheilsfindung ift die in der Unflage bezeidjnete That, wie fid) Diefelbe nadj Dem (5rgeb= niffe Der $\mathfrak{B e r h a n d l u n g}$ daritellt.

Don Gericht ift an dicjenige Beurtheilung der That,

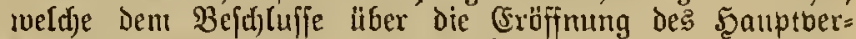
fahrens zu (Brunde liegt, nid)t gebunden.

\section{Beräuberumg ber Inflage.}

$\$ 264$. (1) Sine Berurtheilung ocs ?titncflugten auf (S) rund eines anderen als ies in Dem Bejthluffe iliber die Eröffnung te: Sauptocrfaljrens angefübrten Strafgeietes darf nidft erjolgen, obje bnß Der ingetlagte zubor auj bie Beränberung bes rect)tlidjen (siefid)tipuntte befonders bin= gemiejen und ibm Bjelegenbeit zur Bertheidigung gegeben worden ijt.

(2) In gleidher weife ift z" verjahren, wenn erit in ber Berhanolung foldje vom Strafgeiezze bejonders vorgejehene llmitänbe behauptet werdeu, welche die Strajfarfeit er= böljen.

(3) Beftreitet Der Ingeflagte, unter Der $\mathfrak{B}$ ehauptung auf die Serthcidigung nic)t genügend vorbereitet zu fein, neu hervorgetretene ulnitände, veld)e bie Inmendung eines

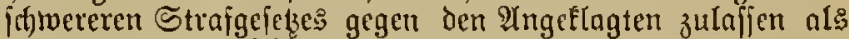
bes in bem Bejdhlific iiber die crioffnung des Saupt=

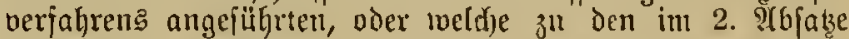
bezeicfneten gehören, jo ift allf feinen 2Intrug die baupt= verhandlung auszu(etzen. ${ }^{1}$ )

(4) Shudf) fonjt hat das (5)eridyt auf ?Intrag oder bon

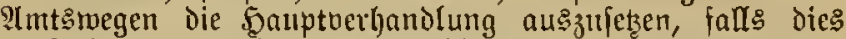

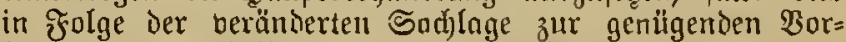
bereitung der ŶAflage oder der Berthridigung angemeffen erjdjeint.

(5) . .

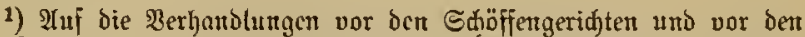

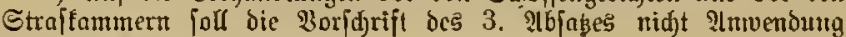
findent. (Entro.)

§ 265. Wird der ?ingeflagte im Raufe der Saupt= verhandlung nodf einer anderen That befduldigt, als wegen meldfer baj Spaupterfahren wider ifn eröffnet worden, fo fann biefelbe alli ?intrag ber Staatsanmaltidyaft und mit 8uftimumung des Ingeflagten zum Segenftande derielben 2lburtheilung geinad)t merden.

Dieje Beftimmung findet nid)t ?tnwendung, ivenn bie That als cin Berfirechen fid) darfiellt oder bie 216urtheilung derjelben die Bujtändigfeit des Beridjts ïberfatreitet.

\section{1\%. Utrtheilągrintue.}

§ 266. (1) Wirt der Ingetlagte berurtheilt, fo mülifen die Urtheilsgriinde bie für erwiejen eradjteten Ihat= 
fadjen angehen, in meld)en die gefetżlid)en Nertmale ter ftrafbaren jonolung gejunten merden. ${ }^{2}$ )

(2) ......

(3) Die Gründe bes Strajurtheits milffen ferner Das

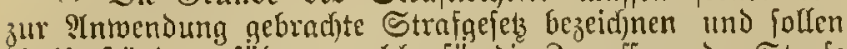
bie llmitände anjüloren, welde fïr die Bumeffung der Straje

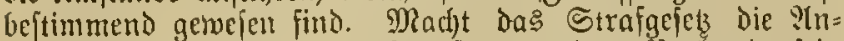
wendung einer geringeren Strafe von Dem Borhandenjein mildernber llmitände im ștgemeinen ab̧ängig, io müfïen tie llth)eilsgründe die fierüber getroffene (Entjcheidung rrgeben, fofern Das Borbandenfein foldjer Umitände an= genommen, vocr einem in der Serhandlung geftellten $21 n=$ trage entgegen verneint wirb.

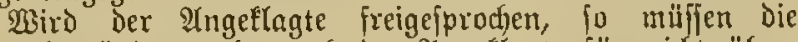
Ilrtheitsgriinde ergeben, ob ber Angeflagte fitr nicht über= fülyst, oder ob und aus twelchen (3ründen die für er= vicien angenommene That für nicht ftrajbar ernchtet worden ift.

1) ebenio bie Gründe, weldje für bie ridferlidje Uebergeugung Leiteno gemejert find. (Entw).

\section{Irtheil[sverfïnoung.}

$\$$ 267. Die Eertïnoung des Urtheils erfolgt durch

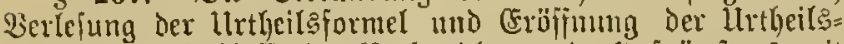
grïnde am Sofluffe ber $\mathfrak{B e r b j a n d l u n g ~ o d e r ~}{ }^{1}$; (pätejtens mit StGlanf 1 Bodje nod Dem Sdfluffe Der Berlyandlung. Die

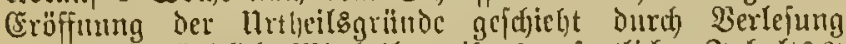

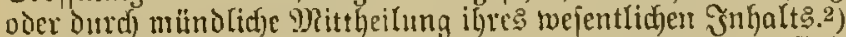

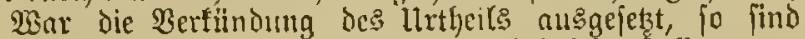
sic llitheilsgründe vor berjelben fdrriftlid) felt gulteflen.

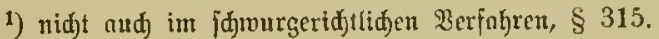

2) $\Im[t$ ber $3 e r u r t h e i l t e$ ein im umittelbaren ober mittelbaren Staatsbicnfte jlehender $\mathfrak{B}$ eamter (ober Angejtellter einer \$rtivat= eijenbabntorwaltung), jo ift bie Jormel bes llrtbeils utmittelbor nach

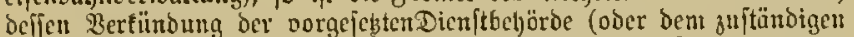

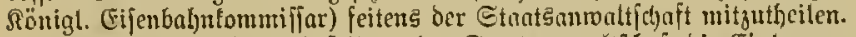
Dnbei ift ju bemerten, ob feitens Der Etaatsambaltjouft bie Einlegung cines Redtsmittels in Ansfid) genoumen fei ober aus veldjen Grünben oon der Einlequno Des zuläjīigen Predistmittels 2lbjtond ge=

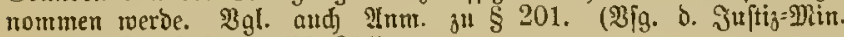
nom 25. 8. 1879, Эฺฺ 251 ).

\$268. llrtheile, Durd) meld)e die Interbringung des Sngeflagten in eine (Fizichungs: oder Beffcrungsanjtalt an= geordnet wird, find aud deffer gejeblichem Bertreter $z^{n}=$

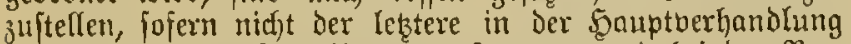
als Seiftano des Angeflagten allgetreten und bei Der $\mathfrak{B e r}=$ fiindung Des thrtheils gegenwärtig gemejen ift.

$\S 269$. Das (sierid)t Dari fich niçt für unzujtändig erthären, weil bie Sache bor cin (Serid)t niederer Sronung gełörte.

\$ 2\%. (1) Stellt ficf) nact) Dem (Ergebniffe der $\mathfrak{B e r}=$ handung die Dem 21ngeflagten zur Enft gelegte That nlg

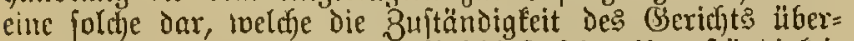

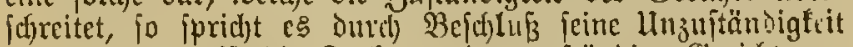
aus und bermeift die Sache an bas zuftändige (Sericht.

(2) (3) (4) ....

\section{Eißjunģ̄prototoll.}

§ 271. Mleber Die Sauptberljandlung ift cin \$rotofolf

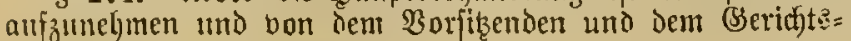
(d) reiber zu unter(d)zeiben.

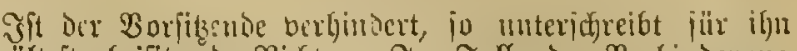
der ältefte beifikende Ridfter. Эat Falle Der $\mathfrak{B}$ erhinderung

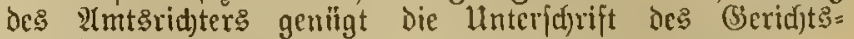
(t)reibers.

\section{§ 272. Das Frotofoll ïber die Sauptoerhanblung} enthält:

1. Den Sort und den Tag der Serljandlung;

2. Die Ramen Der Richter, (Bejdyworenen uno Sdjüfen, Des Beamten der Stantionwaltid)nft, des (Serichts: id)reibers und Des zugezogenen Dolmetichers;

3. die $\mathfrak{B e z e i d} n$ ung der ftrafbaren Sgandung nach ber Intrlage;

4. die Nanten der Angetlagten, ihrer $\mathfrak{B}$ ertheidiger, der Pribattläger, Nebenfläger, gcieţlidjen Bertreter, Bevollmäd)tigten und Beijtände;

5. Die ?tngabe, Dafi offentrich berhandelt oder die Deffentlidjecit ausgefichloffen ift.

§ 273. (1) Das \$rotofoll muţ den Bang und die Frgebniffe der Sauptverhandlung im Befentliden wieder: geben und die $\mathfrak{B e o b a d j t u n g ~ a l l e r ~ w e j e n t l i d f e n ~ f o ̈ ̈ r m l i d j e f e i t e n ~}$ erfidjtlich madjen, audf Die Bezeidjnung Der ber(ejenen Sdjrifts ftücfe, forwie die im \&aufe der Berljandunt geftellten ?In= träge, die ergangenen (Enfid)eidungen und die Uutheilsformel entha(ter. 1)

(2) ......

(3) Sommt Eక్ auf Die Freftitellung eines్ \$orgnngs in

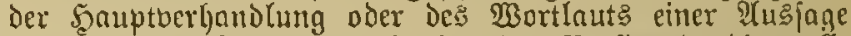

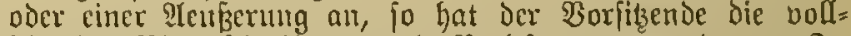

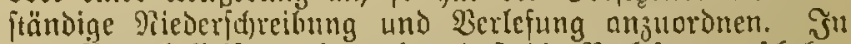
Den Girotofoll ift zu bemerten, daf́ die $\mathfrak{B}$ erlejung geidjefhen unt bie (Sienelynigung exfolgt ift, oder meldye Einmendungen erhoben fint.

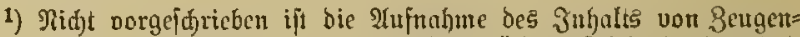
ausjagent in bas \$rototoll. Den Geridtsbchäroen iff jedod) rviedertjolt

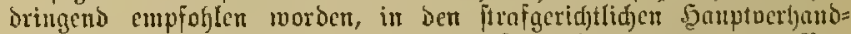

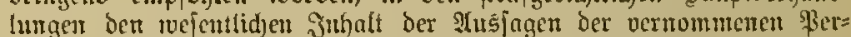

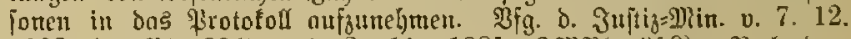

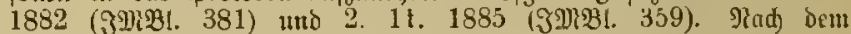

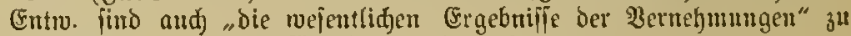
protolodiren. - Eingefiitgt foll werbent ats neuer

\$ 273a: Eriolgt bic Beobadtung ber vorgefdrieberen förmlid)=

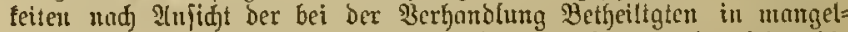

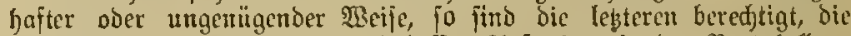
Orejtftellung bes Borgarges uno deffen $\mathfrak{Y}$ Iufnabme in bas Protofoll ju verlangen.

§ 274. Die Beofachtung Der für Dic 5nauptberljandlung vorgeichriegenen \&örmlidfeiten fonn nur durd Dos \$rotofolf berviejen werden. Begen Den Diefe J̈örmlidffeiten betreffenden

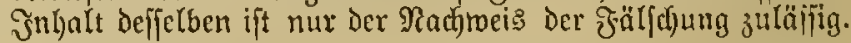

20. Beurfundung beß Itrtheila.

§ 275. Das urtheil mit den Brïnden ift bimmen 3 Ingen nach Der Berfiindung zu Den शlten zu bringen, falls es nidft bereits bolffündig in das \$irotofoll aufgenommen worben ift.

Es ift von den Rithtern, meldye bei Der (Entjd)eidung mitgewirft haben, ju unterid)reiben. J̧it ein Richter ver= hindert, jeine llnterf(b)rift beizujügen, io wird biç unter :Ingabe Des Verbinderungsిgrundes von dem Borfitectideu umD bei Deffen Berfinterung bon dem älteiten beifizenden Midfter unter Dem Itrtbeile bemerlt. Der Unteridyrift ber Stiofffen bedarf es nid)t. 
Die Bezeichntung des Tages der Silzung, fotwie bie

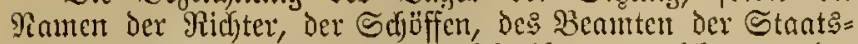

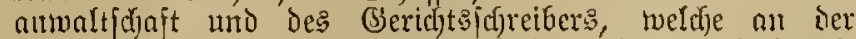
Silzung Theil genomnten Gaben, find in bas Ilrtheil auf= zurelimen.

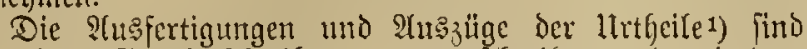
von bem (Beridftofdreiber ju unteridreiben und mit dem Gerict)tsfiegel zu berielyen.

1) Desa!. Strafreaifter (Strafundrid)tem), bie über bejtrafte \$er: ponen bei ben Etantšumaltidyaften gefüht meroen.

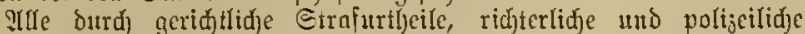

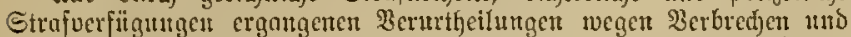
\$ergeljent fowohl als nud) wegen beftimmter liebertreturgen (3.

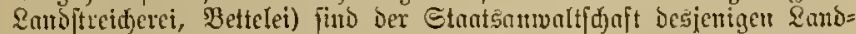

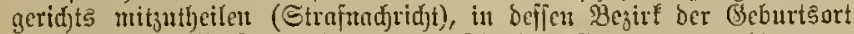
Der bejtraftest Berfon gelegen ift. Jit ber Geburtsout nidut zu er= utitteln ober auberthalb bes gecichşgebietes gelegen, fo erfolgt bie Dit=

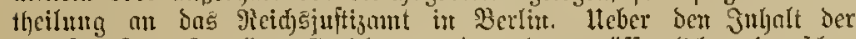
Strafregifter ift alfen Geribten unb anveren öffentlidjen beutjuen Beföroen anf jedes cine befinunte \$erjon betreffende Erfudjen foiten=

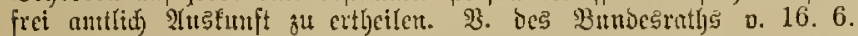
1882, betr. Die Cinridgtumg von Strafregiftern und bie wedffel= feitige Mittheilung oer Strofurtgeile (RCB1. 309).

\section{7. Şauptuerganolung oor ben Sduntrgeridten.}

§ 2\%6. Die Beftimmungen ber beiden borbergehenten

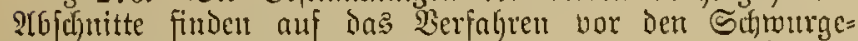

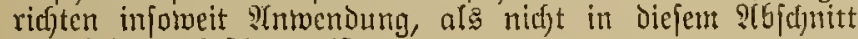
ein ?nderes bejtimmt ift.

§ 27\%. Эar Dem Tage, an weldfem die Santuptber=

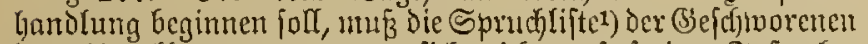
bem ?lngeflagten, wenn er fid) nicfit ant freicm onnfe be=

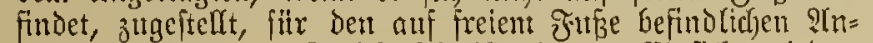
geftagten anf der Serichtêfhreiberet zur Cinficht nieder= gelegt werdert.

Die Ramten fpäter auf bie Spruchlifte gebrad)ter (bse= (d) worener find Dem ÂngeElagten bis zum Beginne der Sauptoerfjanolung mitzutheilen.

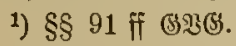

\section{Bitbung ber Gefdjuorenenbant.}

\$ 278. Die Sauptoerfandlung Gegimnt mit Der Biloung

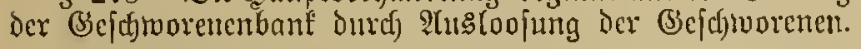

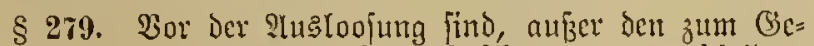

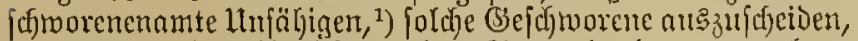

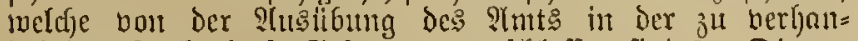

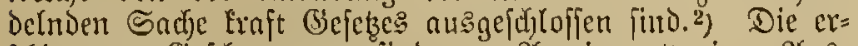
idjienenen (sejd)worenen find zur stracige etwaiger Stus=

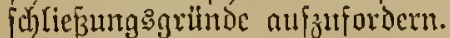

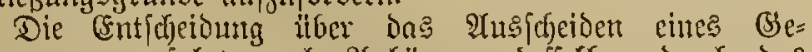

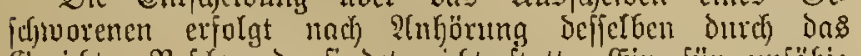
(Seridjt. Befonwerde findet nicjt ftatt. Cin fiir unfähig Ereftärter ift in Der Spruchlifte zu itreicher.

1) $\S \S 32,84,85$ अखु. 2) $\S \S 22,32$ ธt\$0.

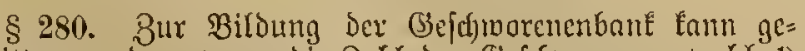
f(f)ritten werden, wenn die $B$ ofjl ber Befdjworenen, meldje ${ }^{1}$ )

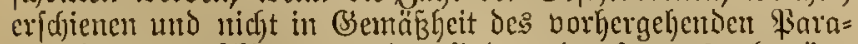
graphen ausgeidjieden worden fino, mindeftent 24 beträgt.

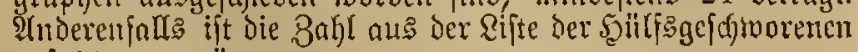
auf 30 zh ergänzen.

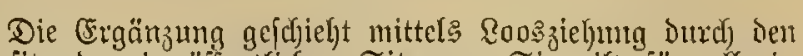
Borfikenten in offentlidjer Sikung. Sie gilt fiir alfe it der Sizungeperiode nodh 3u verhandelnden Sadhen.

Die ausgelooften sutilfsgefduorenen merdent unter Sintweis auf die geicklid)en Jolgen des ?Tusbleibens ge= faben. Shre Ramen find in bie Sprudfilite aufzunefmen.

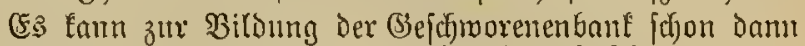
geidjritten werden, twenn in Folge des Erifleinen: von Juthf

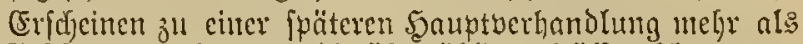

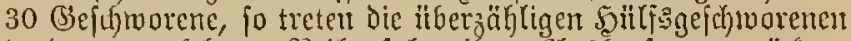

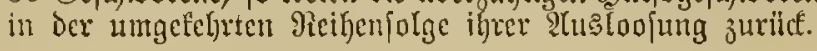

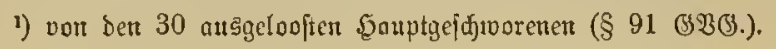

§ 281. Die Bildung dex (sejutworenenbant exfolgt in offentlider Siţunt. Das Roos wiro bon bent Rorfitzenden gezogen.

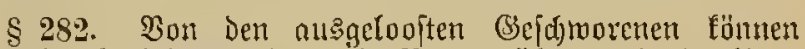
fo viele abgelehnt tuerdent, als Ramen tiber 12 in der llume firct) Gefintinen.

Die cine Bälfte der 2 (blelynungen ftelyt der Stants= antwaltichaft, bie andere dem Singetlagten zu. Dem Stnge=

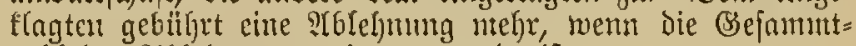
zagl Der shlelynungen cine ungerabe it.

\$ 283. Soliald cin Pame gezogen mo aufgerujen ift,

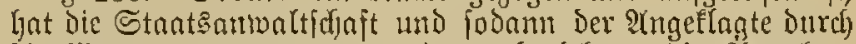

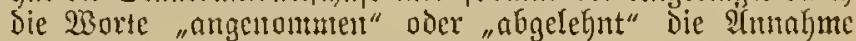

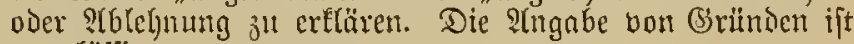
unıuläffig.

Wird eine Ertlürung nidyt abgegeben, fo gilt dics ots Itmualine.

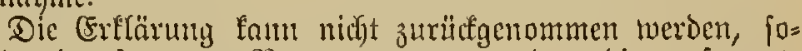
bald ein fernerer Sante gejogen, oder die gefammte Bief)ung fïr beendet erflärt ijt.

\$ 284. Sint bei einer Saauptoerfandlung meljere

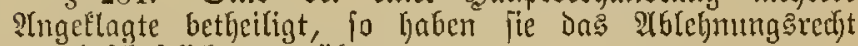

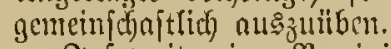

Snpomcit cine Sercinigung nid)t $3 \mathfrak{u}$ Stande fommt,

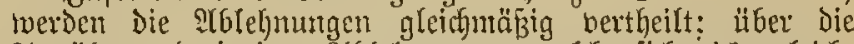

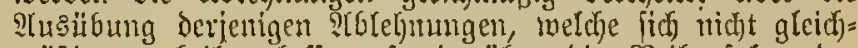

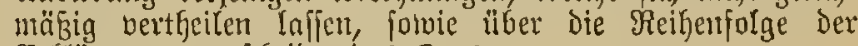
Gritärungen entideidet das Roos.

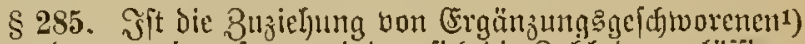
angeoronet warben, jo vermindert fid die 3 aht der zuläfiligen

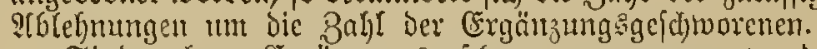

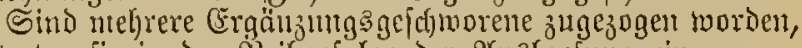
fo treten fie in Der Sieibenfolge Der ?tusloofung en.

1) bei Nergandlungen von längerer Duuer.

\$ 286. Steljen an Demfelben Tage melyere Berlyand= lumgen an, fo berbleibt bie für cine berfelben gebilbete Gecidjworenenbant für bie folgende פerhandlung oder für mehrere folgende Serhandlungen, wenn die dabei betheitigten IIngellagten und Die Stantsanmalt(chaft fick Damit bor Der Becidigurtg Der (Sefdfworenen einverftanden crf(ärt lyaben. ${ }^{1}$ )

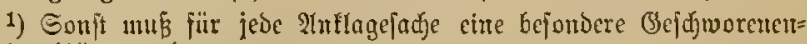
banf gebilbet werber.

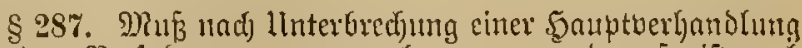
mit dem Berfafyen bon neuent begomen werden, fo ift aud Die Gejdyorenenbanf bon neuem 3น bilden. 


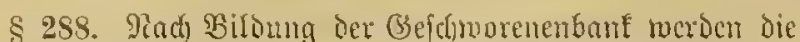

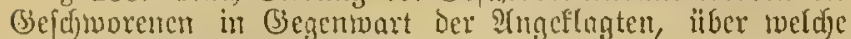
fie ridften folfen, becibigt.

Die Becisigumg erfolgt in befentlidjer Sitzmtg.

Der Borfibentic rid)tet an bie su Becisigenden Die worte:

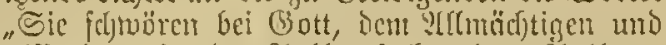

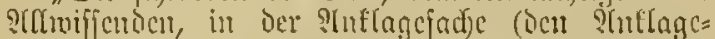

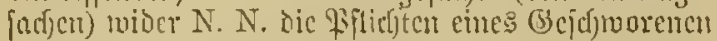

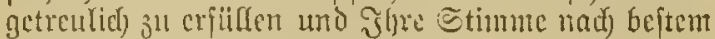
פivifjen uno Bictuifjen abjugebcn."

Die (3)jamprenen leiften den Cio, indem jeder einzeln bic Warte fpricts:

"idf fidwöre ce, fo malyr mir (3)ott ljelfc."

Der Sdjubrende foll bei der Civesteitumg dic rente Somb erfictort.

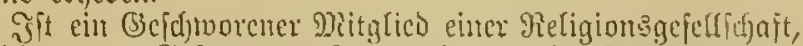

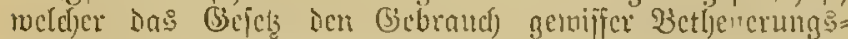
formeln alt Stelle bes cives geitattet, fo wiro dic ?tognbe

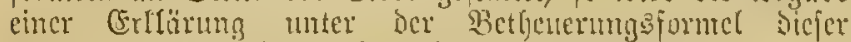

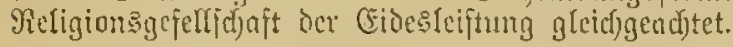

\$ 289. Radi) Der Recidigut der (3efdrotenen erfolgt bie Serfjandlumg in ber Sacje jellif. $\left.{ }^{1}\right)$

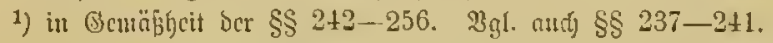

\section{Jeftitelfer Der Jragen.}

\$ 290. Dic Den (Beffjtonemen jul Beantwortung rot= 3ulegenten fragen ${ }^{1}$ ) tocrden bon bem Borfikenden ${ }^{2}$ ) ent= marfelt.

Sind) ben Sdjluje bet Butweisaujualyme twerden bic entworfenen Jragen vertefur. Der Sorfibende fann fic Dent

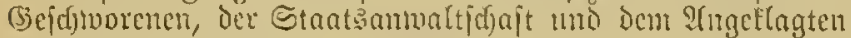
in s(bjo)rift mitt)eilen uno folf eimen bicranf gerid)teten Sintrage cittiprect)cit.

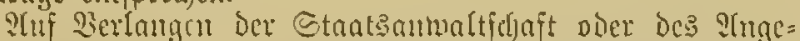

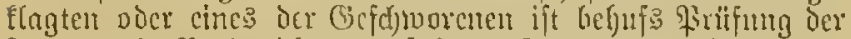
Jragen die Berljandumg auf furje Beit ju nuterbredjen.

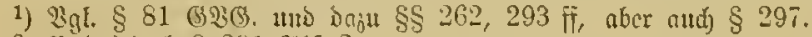

2) 2igl. jcood) \& 291 2tor. 2.

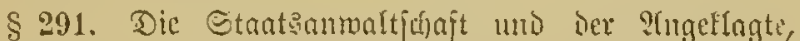
jowic feocr Shefdetvorene ift befugt, alf Diängel in bcr

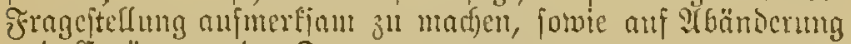
uno Crgäızung der Fragen ausutragen.

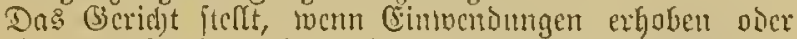

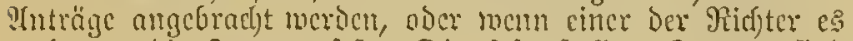
nerlamgt, die đragen fejt. Dic fejtgejtellten Æragen find zli verlejen.

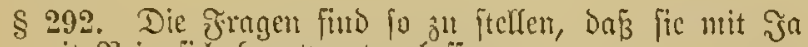
ober mit פicin fid Gcantivorten laffen.

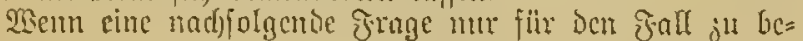

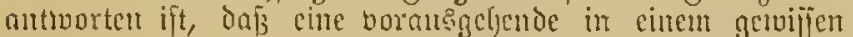
Simme erledigt merice, io ift bies bemerf(id) 3 ir mad)en.

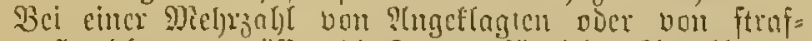

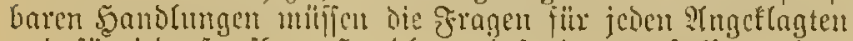
unv fïr jede frajonec santang bejonders geftellt twerden.

\section{a) Scauptfrage.}

§ 293. Dic Srantfrage begims mit Den Marten: "J̧it

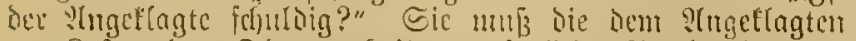

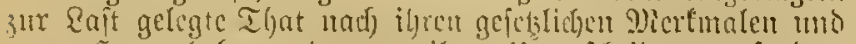

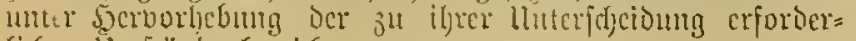
‘içen llmjtände bezeidfnen. b) seillfäfrage.

\$ 294. S5at dic Berfjandung llm[tünde ergefen, nad) wefchen eine bon den Bcfdyluffe tiber dic Croffmung des

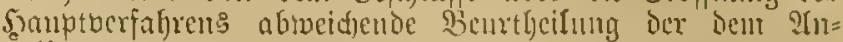
geflagten zur Rait gelegten Ifgat in Betrod)t foumt, fo ift

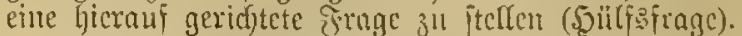

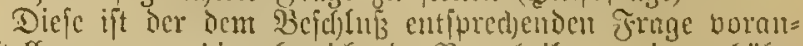

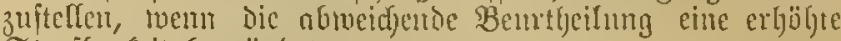
Strajbarfeit Ecgriinoct.

\section{c) Tievenirageu.}

\$ 295. Ilcuer folthe voun Strafgcietse befondors vor:

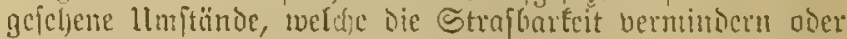

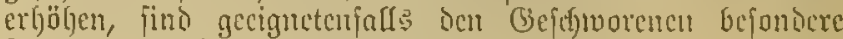
Erngen vorjulegen (9ieticufragen).

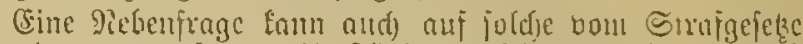
hefonbers borgejeljene llmftämbe gerid)tet werben, ourd) weldje die Strafbarteit twieder aujgeljaben wirb.

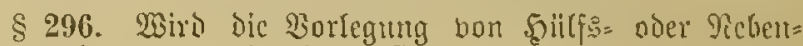

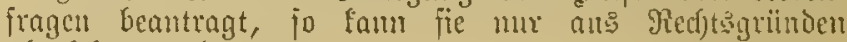
abgeleljnt werden.

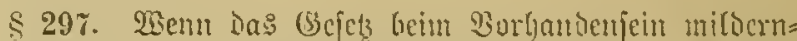
ier llmptände cine geringere Straje anbrolyt, fo ift cine

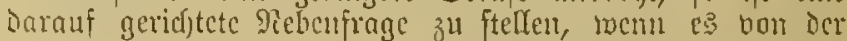
Etuatsanmalticl)aft oder Dem 2lngeflagten beantragt ober

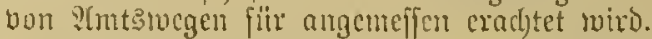

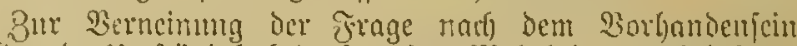

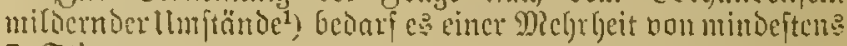
7 Etimmen.

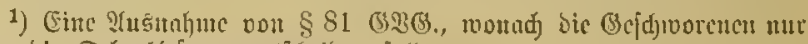

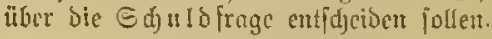

S 299. 5outte ein ?lugeflagter zur 3cit ber That noch

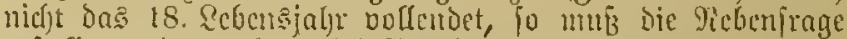
gefteft merden, ob er bei $\mathfrak{B} \mathrm{cgchumg}$ ber That bic jur Er:

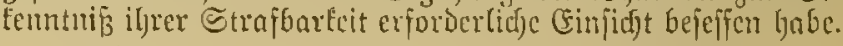

Dasjelbe gilt, wem ein ?lngeflagtci taubitunm ift.

3. Firniboyer.

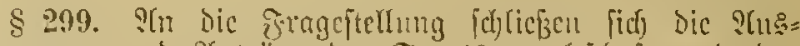

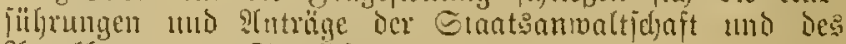
शligeflagten jut Scljuliprage.

\section{Diclebrung bes Sorfijenden.}

\$ 300. Der 2orfiţemoc bclehrt, olne in eine 26ïrbigung Der Bencife cinjugchen, bie (B)idhworenen iiber die red)t=

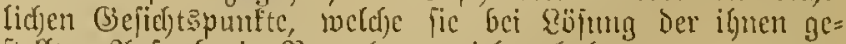

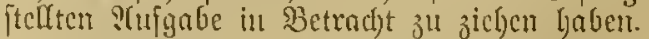

Dic Belefrumg des 3orfitzenden Darf bon feinter Exite einer Crörterung unterjogen werden.

Der nete $\$ 300$ folf lanten:

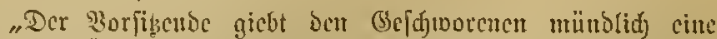

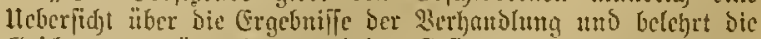

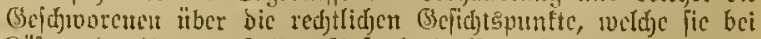

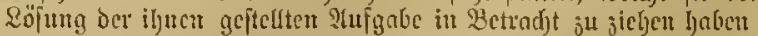

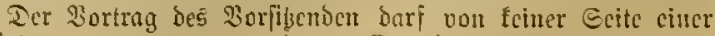
Erörterung unterzogen veroen." (Entro.). 


\section{Bieratljung Der Bejedjworeuen.}

\$ 301. Die F̂rogen werten nou Barfitzenden unter=

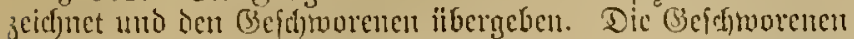

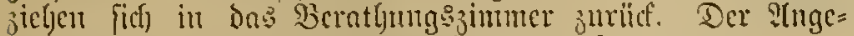
flagte twird ans dem Sitzung juinner entfernt.

§ 302. Gegenftände, melife in der Berhandfung deur

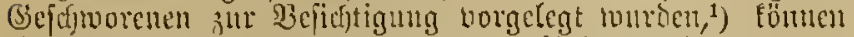
ifnen in dns Berntgungsimuner berabjolgt tuerden.

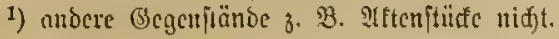

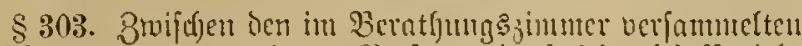
Gejefworenen und nuderen Fierfonen Darf feinerlei Berfelj ftattiniticn.

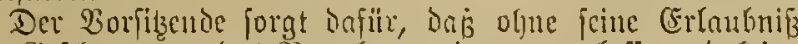

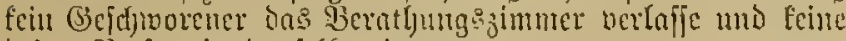
britte Ferion in onsjalloc cintrete.

\section{Somanu.}

\$ 304. Dic Bejdyworenen soählen ifyen Dbutum

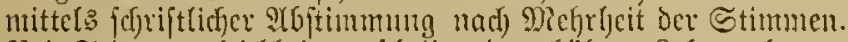
3ei Stimmengleidylyeit entfdyeidet bas ljöljere \&ebentalter.

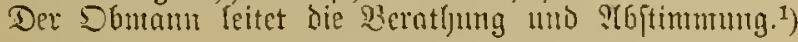

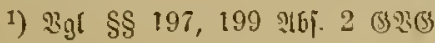

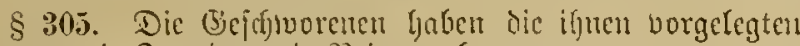
Jragen unit ja oder mit Pein ju beantworten.

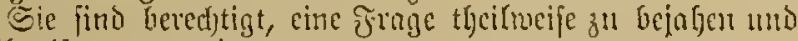
theilucife ju verneinen.

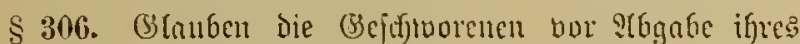

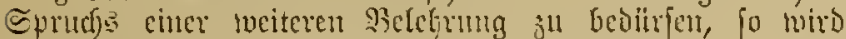
Dieje auf ifjren ?tutrag burd) ien Borfitsenten estheilt,

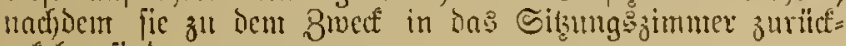
getelnt findo.

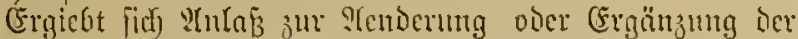

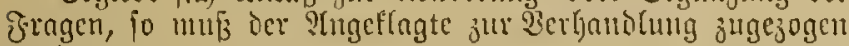
werven.

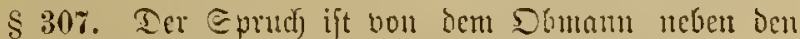

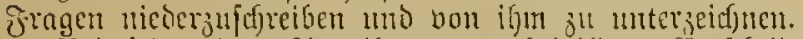

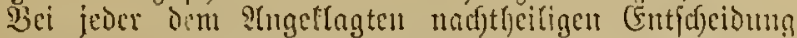
ift aujugebeu, bafis bieiclbe mit meljr nle 7 Etimmen, bei

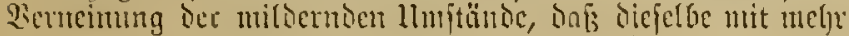
als 6 Stimmen gefart morden ift. Sm llebrigen borif bas

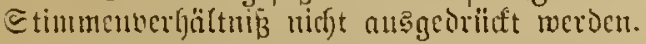

\section{Sictfïubung Dę Eprutfö.}

\$ 308. Der Sprucf) ift in Eitzungisiumer bou Dem

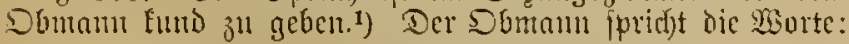

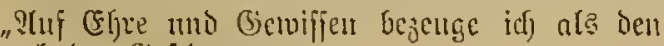
Sprath Der Gefelbmorenen"

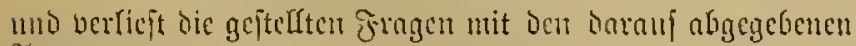
?htworten.

Der berlejene Spruff) ift bon iem Barfizenden mo dem (B)

1) in श6tocjenfeit Des Itrgeflugten, $\S \S 301,313$.

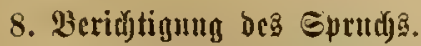

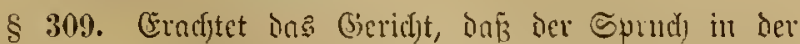

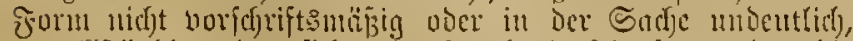

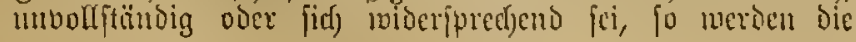

(Sicid)toorenen bon dent Borfitzonden anfgejorbert, fidf in

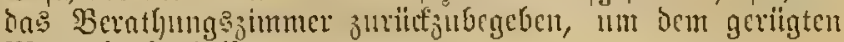
Mlangel abjuljelien.

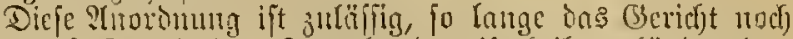

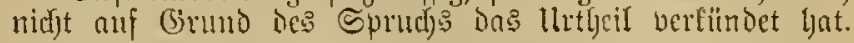

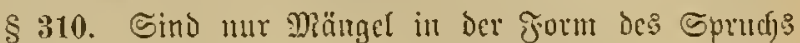
zu beridftigen, fo barf eine factlidje ?tenterung nicht bos= genomutest meroen.

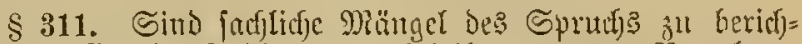

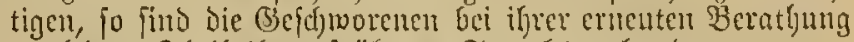
an feimen Ifjeil ifres früljeren Sprudjs gefumoen.

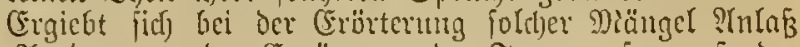

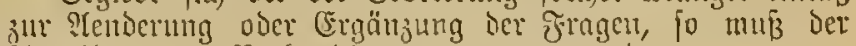
PUngetngte jur Berfontung jugejogen toerben.

\$312. Der beridjtigte Sprutf ift in Der Weife nieder= 3ufdreiben, baf ber fritlere erfenubar bleibt.

\$ 313. Der 巨prudi) Der Beffimorenen wiro dem ?(11= geflagten, nadfoent $\mathrm{er}$ in Das Silzungizimuter wieder eill= getreten ift, our(h) SBerlejung berfïnoet.

\section{Sdjluin ber Berfjumblung.}

\$ 31\%. Sit ber ?(ngeflagte bout Den Gejuluware en

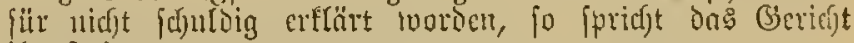
if)ti frei.

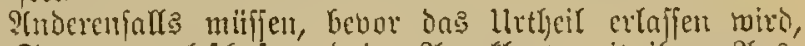

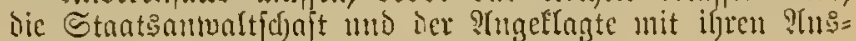
fïhtumger umb ?tuträgen geljört werocn.

\$ 315. Die Derfilndung des Urtfeils crfolgt an Sor)lujie der Serljandlung. ${ }^{1}$ )

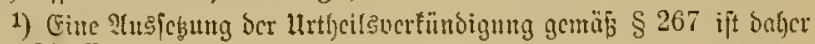
anşgejdjloifen.

\$ 316. Sn Den Gribnden ies llutyeils ift anf Den Sprncl) Der (Sejdjuorenen $\mathfrak{B}_{j} u g$ ju nelgmen. Die llridjrijt

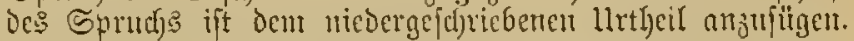

\section{Berwcijung an ein แcut: Sdjuntgeridjt.}

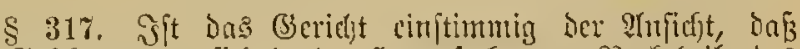

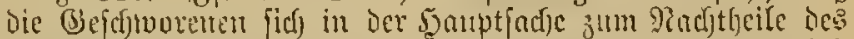

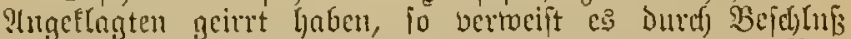

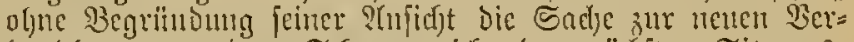

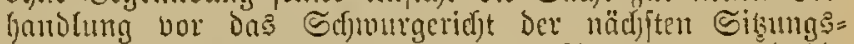
periode. Die Berweijung ift nur bon Plmtônegen und bis 3แr Dertiundung des ltrtheils zuläffig.

Betrifft Das Serjabren nelyrere felbftändige ftrafbare 5anilungen der mehrere Plngetlagte, fo erfolgi bie Ber:

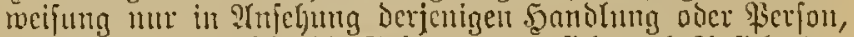

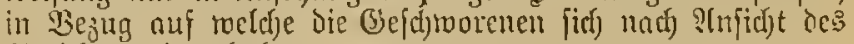
(Gerichts geirrt habert.

Th Der nenen Berhanolung Darf Eein Gefdrworener

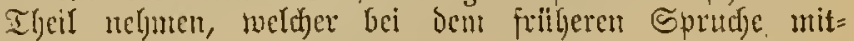
getwirft laat.

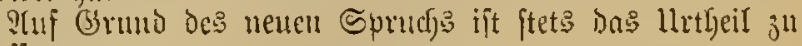
erlafjen.

\section{Berfabren gegen qubefende.}

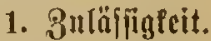

\$ 318. Cin Befduldigter gilt als abtoefend, menn fein

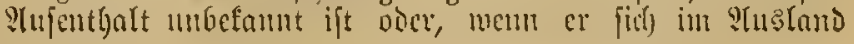


anfbölt und jeine (Geftelfung oor das zufändige Bericht nicfyt

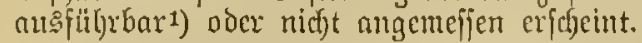

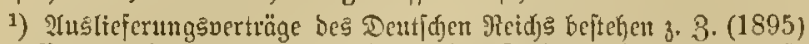

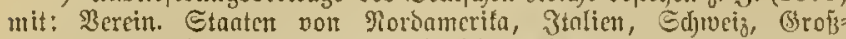
britamien, Belgicn, Suremburg, B̧rajilien, Edjweden unb Rorwegen, Epanien, Itrnguay, Ecrbian, Sildafrif. Repntif (Transuan), fïr Etjak=Qotfringen mit Jranfreidj; ferner mit bem Freiftate Columbien unb bem Rongoptante.

\$ 319. Begen einen 9lbtocienden fann cine 5aupt= berhandung nux banu ftattfinocn, wenn dic Den Segenjtand ber Interfuctyung bilbende That mur mit Geloftrafe oder Einzieljung, allein oder in Berbindung mit einander, bedrokt ift.

Fili das Berfagren fommen dic Borfuriften der $\$ S$ $320-326$ zux Qhmmendung.

\section{Sabung.}

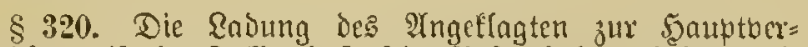
hanilung ift im ङalle, Daf̧ fein ilufenthalt umbefannt ift oder die $3 c f o l g u n g$ ber fïr 3ujtellungen in Pluslande be=

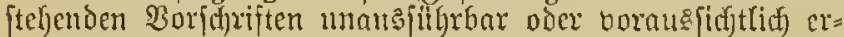
jolglos erfducint, in einer beglaubigten s(b/d)rift an bie (5) ridjtstafer bis zum Sage ber Sauptoerlyandlung anzugeften.

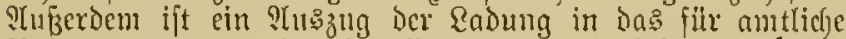
Befanntmadungen bes betreffenden Bejirfs bejtimmte Slant mo nad) Ermejicn bes (Sertd)ts aud) in ein anderes Sblatt

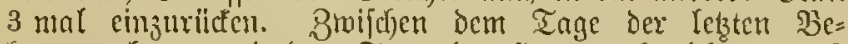
famtmadjung und bem Sage dex jamptoerhanblung mü eine Jrift von mindeftens 1 Monate liegen.

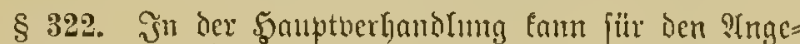
flagten ein Bertlycibiger auftretcn. PUd \&ngeljörige bç Eriteren find, olune daß fie ciner Bollmadyt beditufen, als Dertieter zuzulajjen.

\section{Redjtânittel.}

\$ 324. Die in $\$ 322$ bejeidjncten \$̧erjonen fönnen von Den ocm Befduldigten zuftelenden ९led)tsmitteln (Bicbraud) marken.

\section{2ermïgenabejdjlagualjute.}

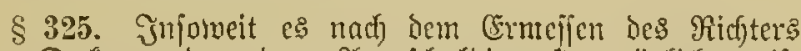
3ux Tedung bex ben Ŝlngefduldoigten ${ }^{1}$ möglicljerweife treffenden bökften (Belditrafe und Der Roften Des Berjalirens erforderlid) ift, fümen cinjelne zum Sermögen Des Ŝlnge= iduldigten geijörige (Gegenftünde mit Befd)lag belegt werden. Sul Diefe Sbefdylagnahme finten bie Sejtmmmngen ocr

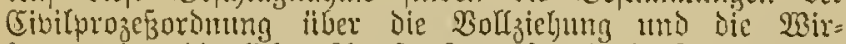
Eungen des binglidjen Trreftes ${ }^{2}$ ) entiprechende ?(umendung.

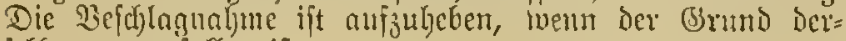
jelben iveggefallen ift. $\$ 155$.

1) Es muß arjo fdjon bie öffentlidje Slage (\$ 168) ertjoben jein.

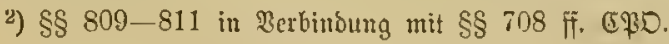

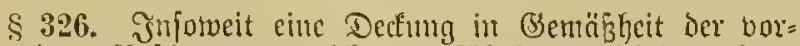

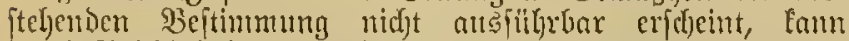
burd) Befdulu des (Beridts Das im Deutjucu Reid befind= licbe Dermügen bes ?(ngefduldigten mit Befdjlag belegt weroen. Der Befflü ijt Durd) Den Dentidjen Tieidian= zeiget uno nad) (Exmeffen des (Seriffts and Durd) andere Slátter zu beróffentliḑen.
Serffigungen, wcld)e òer 9(ngefdruldigte über fein mit Bejud lag belegtes Bermägen naclj Der eriten burd) ben Dentid)en Reidsenzeiger bemirten $\mathfrak{B e r o ̈ f f e n t l i d j u n g ~ d e s ~}$ Bçchluffes vornimmt, find ber Etantsfoffe gegeniiber midjtig.

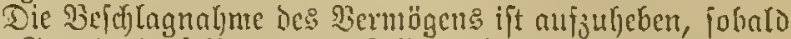
Der Gramo berfelben meggefallen ober bie Dedung Der

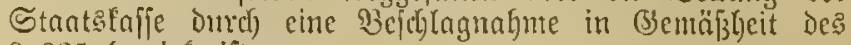
$\$ 325$ bemirtt ift.

Die Pufhebung Der Befdylagnabute ift Durd) biejclben Blätter befannt ju madjen, Durd) weldje bic Bejdhlagnalyme veröffentlicht worien ift.

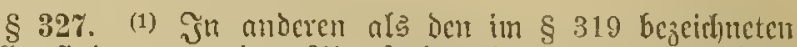
Jülfen findet gegen cinen ?towejenten eine \$̧auptoerbantlung nicht itatt. Das gegen ben \$G befenden eingeleitete $23 e r=$ fahren hat dic Ŝufgabe, jïr den Fall jeiner tilnftigen (se= ftelfung die Bemeife ju fidjern.

(2) .....

\section{Einjeres (5eleit.}

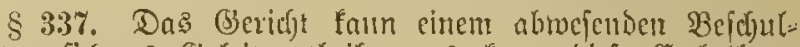
bigten fidjeres Geleit eitbeilen; es fam bieje Ertheilung an Becsingungen lutïpfen.

Das ficjere Gelcit gewäljet Befreiung vou Der ltnter=

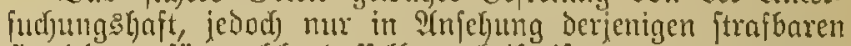
Jjandlung, für weldje inffelbe ertheirt ift.

(5:3 erlifdt, wemn cin auf Jreiheitajtrafe lantendes

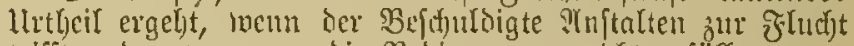

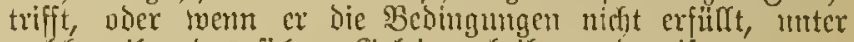
melchen ifm bas fichere (Belcit crebeilt warben ift.

\section{Buch. Jirdjtsmittel.}

§ 338. Die juläfigen Medjtsmittel gegen gerid)tlid)c (Entidjeibumgen fteljen fomohl Der Stantantwaltidyaft als dent Bef(d)uldigten ว̆แ.

Die Staatsanmaltjaft fam von ienjelben and zu (B)umfen des Bejchnldigten Bebrauth machen.

§ 339. Jï den Befdjulbigten fann ier Bertljeibiger,

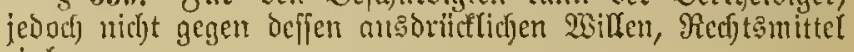
einleger.

\$ 340. Der gefetzlidje 3ertreter cince Bెefdulbigten, Desgleid)en Der (Elycmann ciner befduldoigten Fran fömen binnen der fiiz Den Befdnnlbigten Laufenden frrift felbjtändig

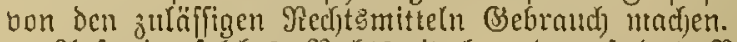

Ituf cin folches Rechtemitrel und anf das Berfaljen finden bie über die Red)tamittel des Bejchuldigten geltenden Sorfdyriften entfprectiente ?Inwendurg.

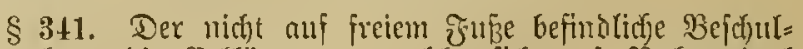
Digte fann bie (Evtlärungen, weldje fich) auf Redhtsmittel

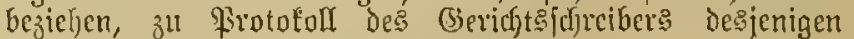
Gerichts gebelt, in deffen (Befängnifs er fid) befindet, und

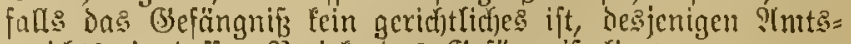
geridjta, in defien şezirte das (Befängnif liegt.

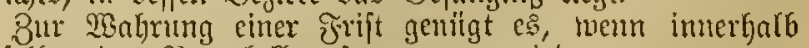
iericlben bas Grotofoll alfgenoumen wird.

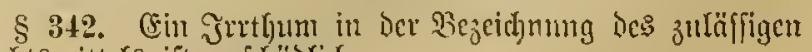

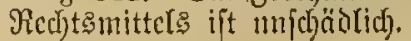


§ 343. Jedes non ber Staatsantwaltfdiajt eingelegte Reditsmittel hat die Wirfung, iaf bic angefad)tene (Ent= f(heioung aud zlt (Sunjten Des Befduldigten abgeändert oder aujgeljoben inerden fann.

\section{3uläị̈gfeit.}

\section{Befdruetoe.}

\$ 346. Die Beffjweroc ift gegen alle bon ben (Bertedten

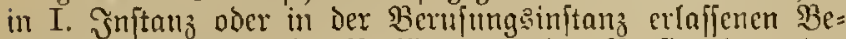

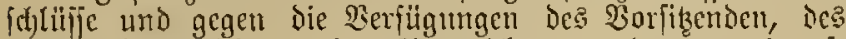

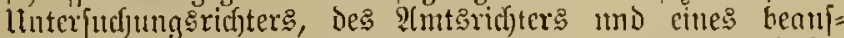

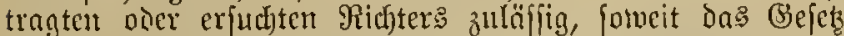

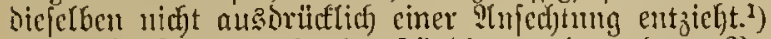

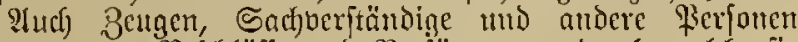
fömmen gegen Bejulüffe uno Berfügungen, Dur(f) melde fie betroffen werden, Befdiwerde erheben.

(S)egen Beidjlüffe mo Berjügungen der Sberlandes=

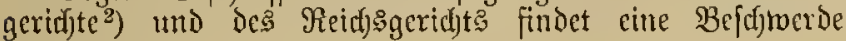
ilidf)t itatt.

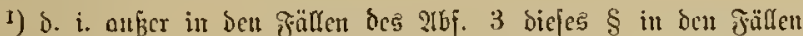

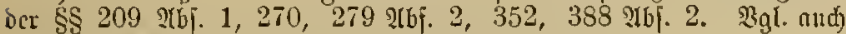

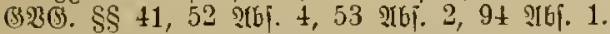

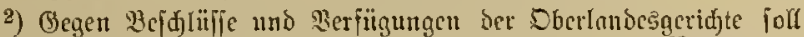

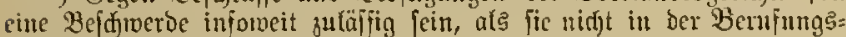

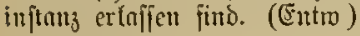

\section{2̧erfahreu.}

\$348. (t) Die Befdjerie mito bei demijnigen (bie= ritute, bon weldfen oiner von deffen Borjizenten die an= gefochtene Enticheibung crlajfen ift, zu Girototoll bes (serichtsjidfeibers ober idfriftlid) eingelegt. Sic fann in

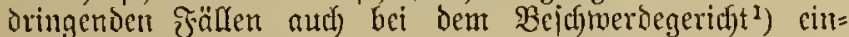
gelegt werden.

(2) (Erachtet das (5erid)t oder der $\mathfrak{B}$ arjizende, deffen (5ntfdeidung augefodften wird, bie Beidjwerde fiir $b c=$ grimbet, jo haben fie berfelben abzuthelfen; anderemjalfs ift Dic Befdutuerde fofort, fpäteftens bor ?tblauf bon 3 Tagen, bem Befdutwerdegeridjte vorzulegen.

(3) $\ldots \ldots$

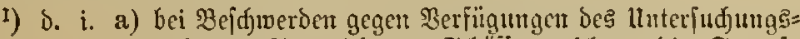

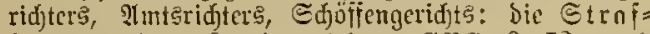

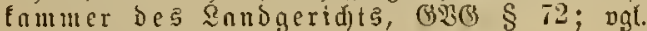
กutd $\$ 77$ ebendon;

b) bei 2icffrmerden gegen Entijeidungen ber Strnf=

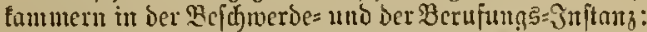

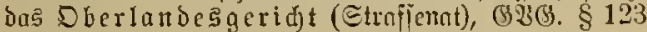
Эr. 5; vgl. aนd \$ 183 शbi. 3 ebento;

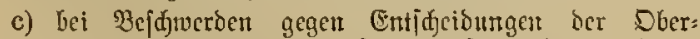

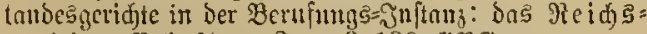

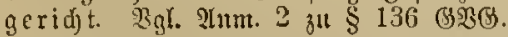

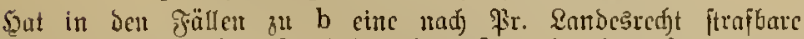

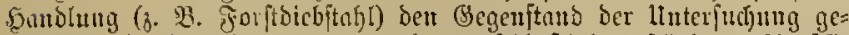

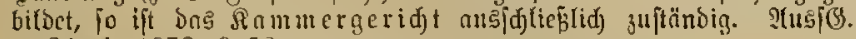
1. 24.4 . $1878, \S 50$.

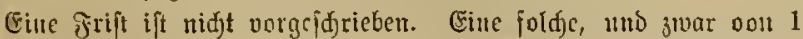

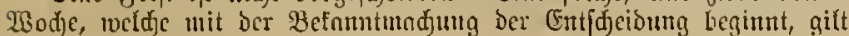

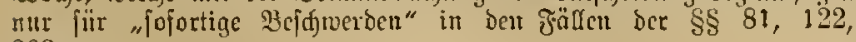
363 น. ก.

\& 349. Durth) (sinlegung der 3 efchmerde wird ber

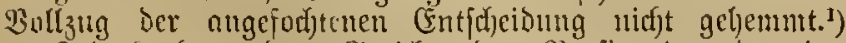

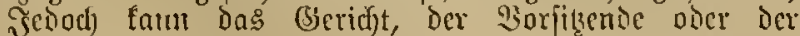

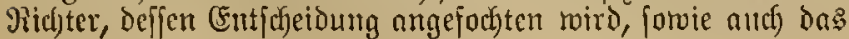

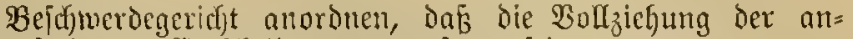
gefoctsenen (Entficheioung auszulfetzen fei.

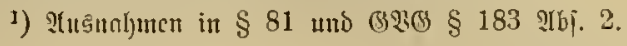

\section{2Beitere Bacidjuerbe.}

\$ 352. Befchlïfie, welche bon bem Randgerid)t in ber B3ejdjwerbeinjtanj crfaffen find, fönnen, infofern fie ber=

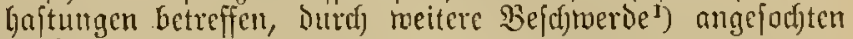
weroen.

Эn llebrigen findet sine weitere s!nfechtung ber in der

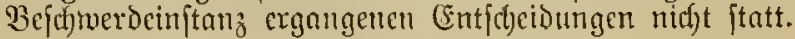

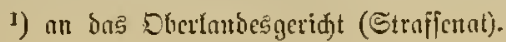

\section{Berufung.}

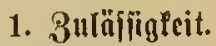

$\$$ 354. Dic Berufung findet ftatt gegen die lirtheile ber Sdyöffengeridfte. ${ }^{1}$ )

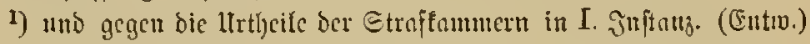

2. Cinlegunty.

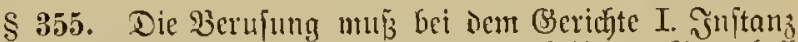
binnen 1 Wodje nad) Bertïnoung Des llttheils $3^{\text {th }}$ \$srotofoll

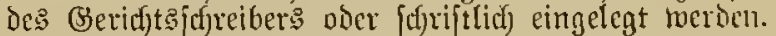

F̧at Die Berfïndung Des llitheils nidft in TImucfentheit des: "2fngeflagten jtattgefunden, fo beginnt juir biefen dic Jrift mit Der 3uftellung.

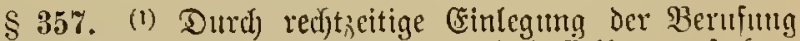
twirb bie Rechtafraft bes lluthcils, foweit baffelbe angejochten ift, geljentunt.

(2) . . . .

\section{Pedrtfertiguug.}

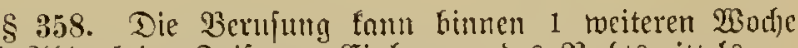
nacl) ?(blall Der Jrift jur (Einlegung Des Red)t:mittels ju

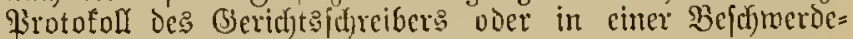
(d)rijt geredytfertigt werden.

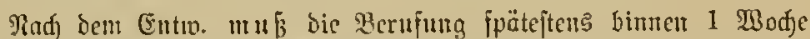

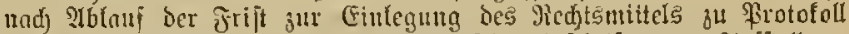

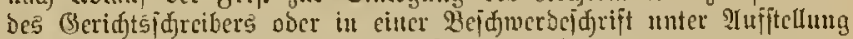
beftumuter Bejbucrocpuntte geredytertigt werbent.

\$360. Ş șt die Berufung veripötet eingelegt, ${ }^{1}$ ) fo hat

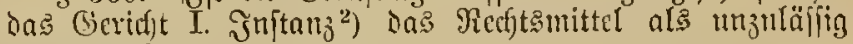
ju vermerfen.

Der Beffiwerdefilfrer faun bimen 1 25od)e noch $3_{11}=$ ftelfung des Befchluffes auf bie (Entfdjcioung des Bernfungs:

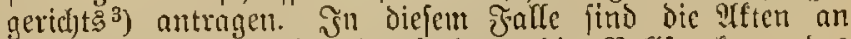

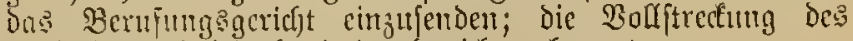
llutheils wiro jeovef bierourd) nicht gehemat.

1) ober nidjt tedstzeitig geredjtertigt (Entro).

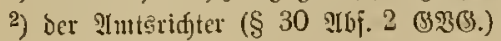

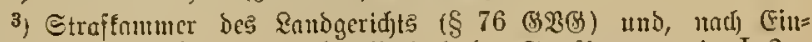

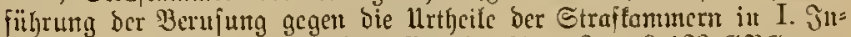

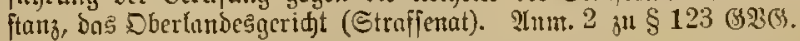

\$ 361. Sit die Berufung recftzcitig cingelegt ${ }^{1}$ ) jo hat

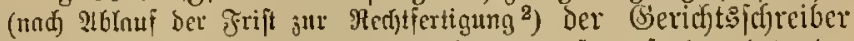

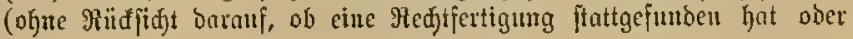


midjt ${ }^{2}$ ) Die 9(Eten ier Staatânunaltidfajt vorzulegen. Dicje

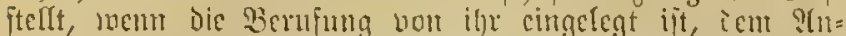

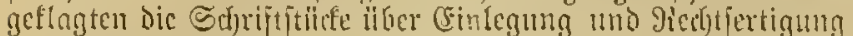
ber Rierujung ju.

2) nut geteditfertigt. (Entw.)

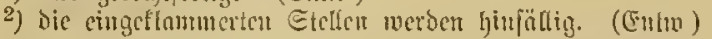

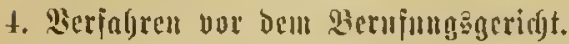

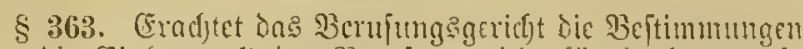

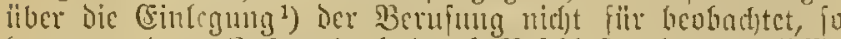

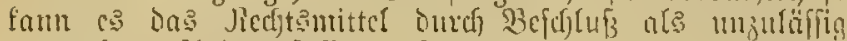

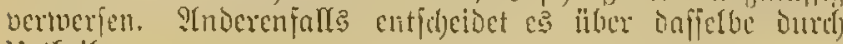
llrtheil. iveroent. ${ }^{2}$ )

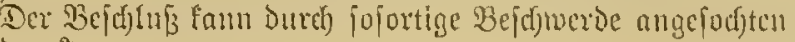

1) ober über bie Redtịertigurg. (Entro.)

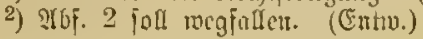

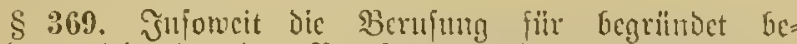
funden loird, lont bas Berufungsgerid)t unter ?(uffebung

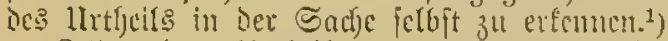

Eeibet bas llatheil an eincm Mangel, weldyer bie

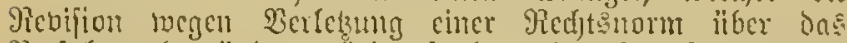

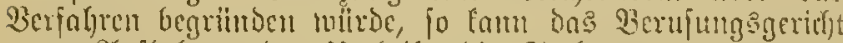

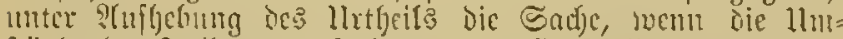

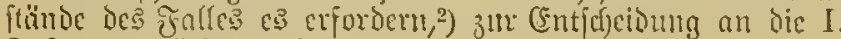
Jnftnul jurihtectumeifen.

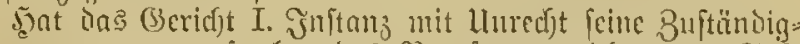

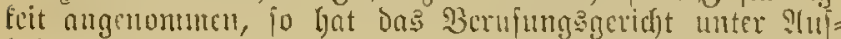

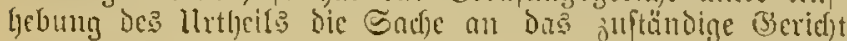
3u bermeifen obcr, wem $\mathrm{ES}$ felbjt in I. Snjtanj juftündig iit, jul erfemen.

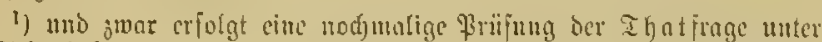

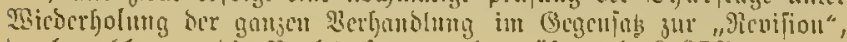

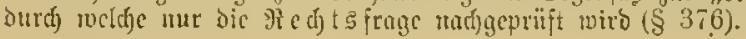

2) 3 .

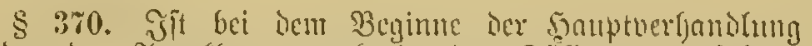
wecoer ber ?tugetlagte, nod) in ten Jülfen, wo jofdbes

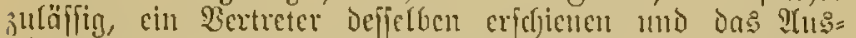
bleifhen nid)t genilgend entfchuldigt, fo ift, injomeit ber ?tn= geffagte bic serulung cingelegt loat, biefelbe fojort zu ber= merfen, infomeit bic Stantanmmattichajt dic Wierufung cin= gelegt hat, Ḧber bicie ju berbantefn ober bic Borfithrumg

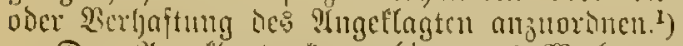

Der Ingeflagte funn binnen 1 Wode nadj ier $3 u=$ fteflumg bes llutheifs die micocreinfetzung in Den vorigen Stand unter den in Den $\$ \S 44,45$ bejeid)neten Burans: (ct)

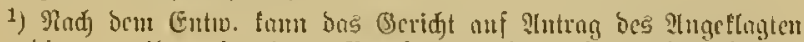

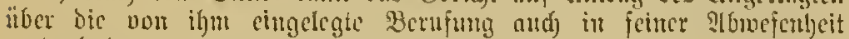
verhantocht.

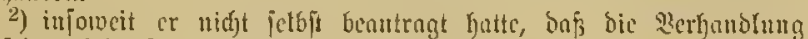

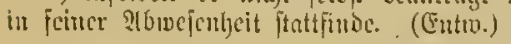

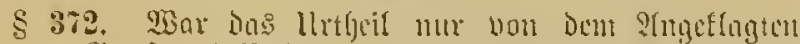

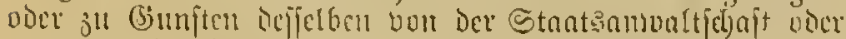

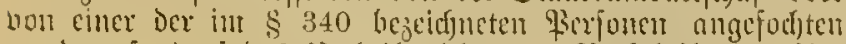

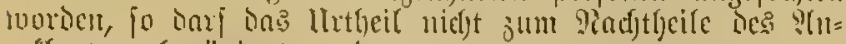
geffagten abgeïndert verien.

\section{3uläijigfeit.}

\section{Revifion.}

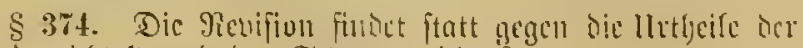
sumbgerichte ${ }^{1}$ ) und ber (E)

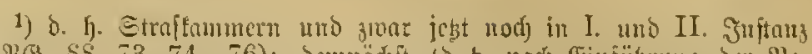

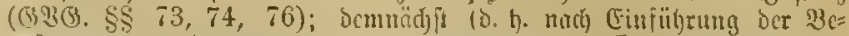
rufung gegen bic Itrthcilc ber Etrnifammern in I. Mmitanj) joll bie gievifion mu gegen bie thetheile ber Stroffoumen in ber II. (BE

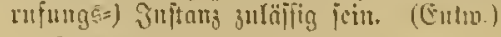

2) (3930. $\$ 80 .-$ Dic gicuifion foft ferner gegen bie ttrtheilc

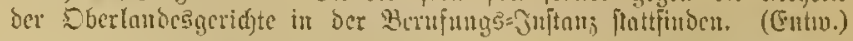

\$375. Det Beutheilung Des gievifionsogericfto unter=

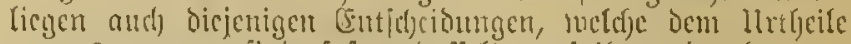
vorangegangen find, fofern dafielbe auf iljuen beruljt.

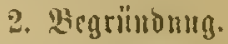

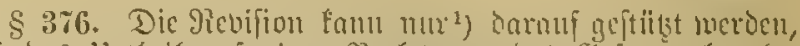

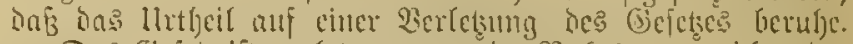

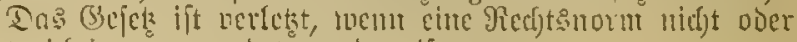
nidjt ridjerg angewendet morben ijt.

1) Eine $\mathfrak{B}$ curtheilumg ocr Thatrnge ift fomit ausgefdlofien

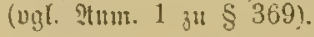

§. 3\%\%. (Fin llutfyeil ift fets als auf einer Berletzumg

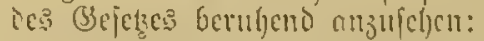

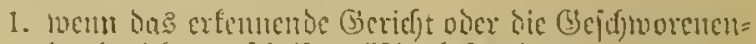

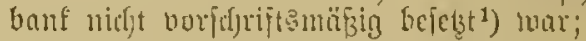

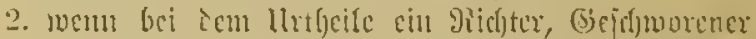

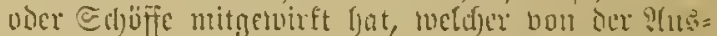

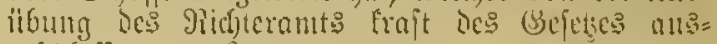
gefurfojien mar;2)

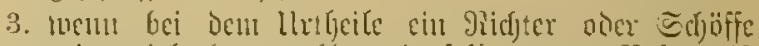

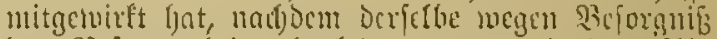
ber Befangenfeit abgele(nut foar, und das $: 16=$

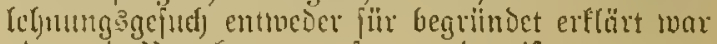
oter mit lluredft berworfen worden ift;

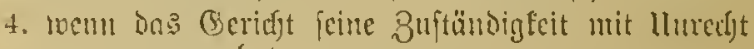
angenommen lyat;

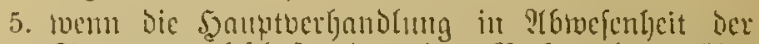

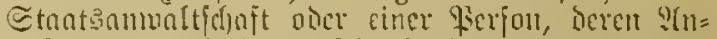

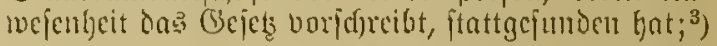

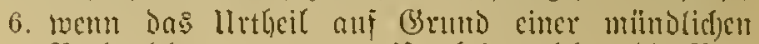

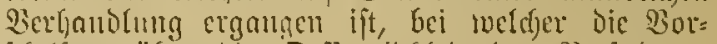
icfriften berleţ̧ jind ;

7. yem bas lutbeil feine Entfacioungegrïnde cutthält;

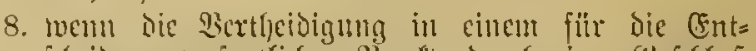

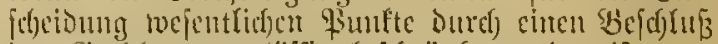
Des Gerichts minuläfig bejdrënet worden ift.

1) $\$ \S 7,81$ (4930. 2) $\$ \$ 22,31,32 \Xi t \$ 0$.

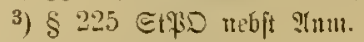

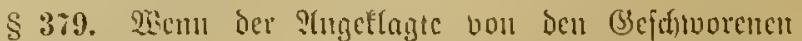

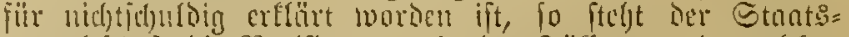

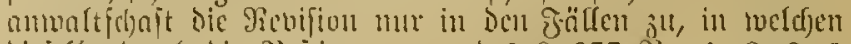

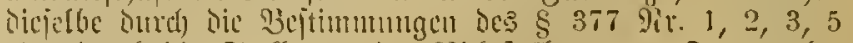

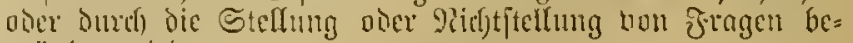
grilitist toiro.

\section{Einlegung.}

§ 381. Die Renifion múz bei ben (Geridste, Defien IIrtheil angefod)ten tvirt, biumen 1 gisod)e nad) Sicteünomng

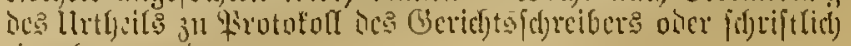
ringelegt merten. 
Şat Dic Berfindoung bes lirtlycils nicft in Sunucienfeit des Sngeflagten jtattgejunoen, jo beginnt für bicien dic Frift nit der Buitellung.

§ 3S3. (1) Durd) redjtzeitige Einlegung ier Micuifiou

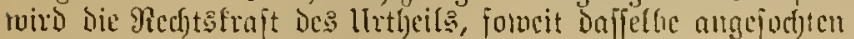
ift, gel)ement.

(2) .....

\section{Vicuipion}

\$3St. Der 23cidmerocfilfrer hat Die Erefïruny $a b=$

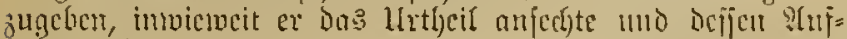
hcbung heantrage (Iiebifionsanträge), unto bic ?futräge jut bcgrümtert.

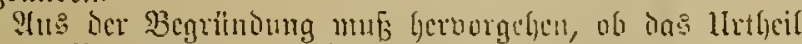
megen Berledumg cirer gicd)tonorm

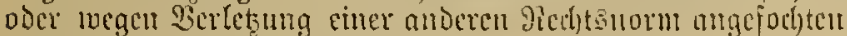

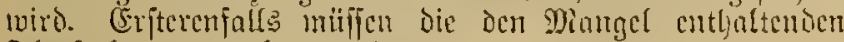
Iljatjachen angegrben werden.

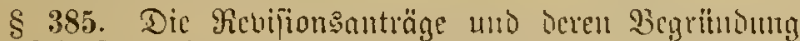

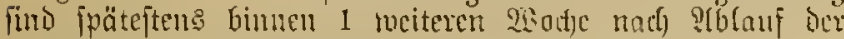
Jrift zur Einlegung des gicchtsmittels bei Dem Gerichte, beficn llutheif angefouten iviro, anjubringen.

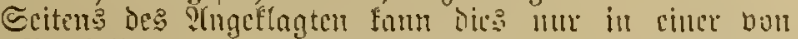

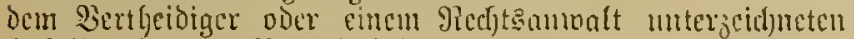

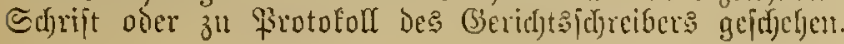

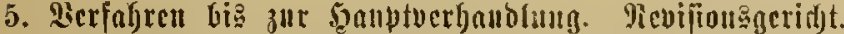

\$ 386. Sit hic Revifion beripätet cingelegt, voer find

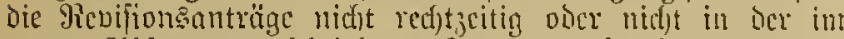

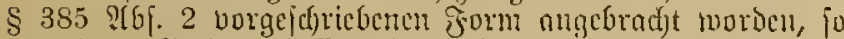

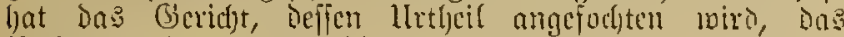

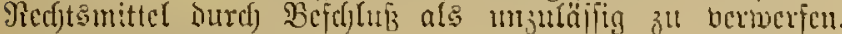

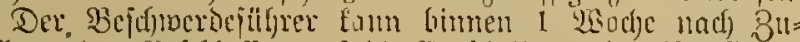

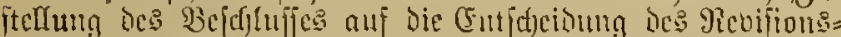

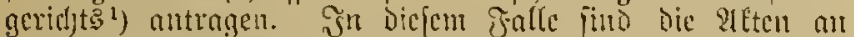

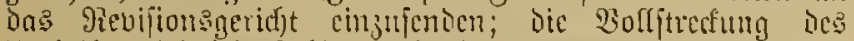

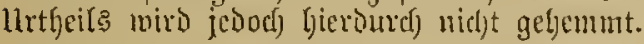

1) o. i. a) Reidsgeridgt gegen alle Itrtheite ber Edymur= acridjte, gegen bic Itrtheile ber Etraftumuernt in

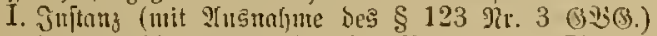
unt gegent bie ttrthcile ber Straftummern in II. Sn=

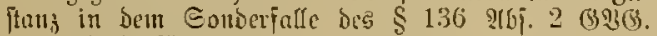
Stad (Einfübrung oer ßुerufung gegen bie ltrtheile ber Eıraftunmern in I. Snitanz tritt nod) bie Ent=

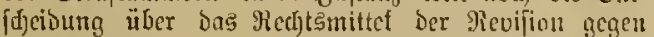

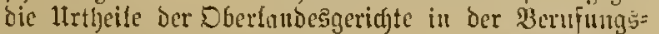

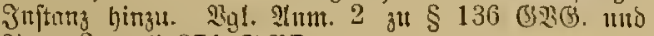

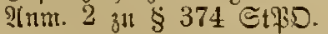

b) Dbertandesgeridte gegen bic llrtheile ber Straf=

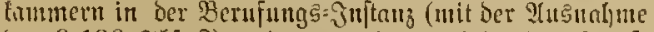
Des \$136 \$15. 2) und gegen Die Itrtfeile der Etruf=

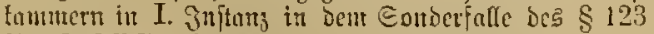

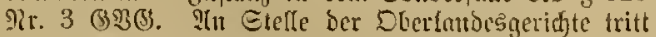
in Freutien in beul falle bes $\$ 123$ gir. 3 ftets uno in beul Folle bes $\$ 123$ Rr. 2, weun cinc nud

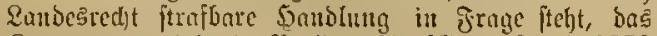
Simmergeridt in Berlin. Titufo. v. 24.4.1878 (ङङ. 230$) \S 50$.

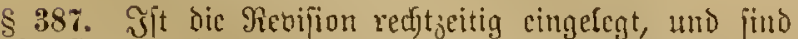
Die 9icvilionsanträge echtzeitig mo in ber vorge doricbenen Jorm angebracjt, io ift die Revifionsichrift Dem Begner des Siejdjwerdcjühters juzuftellen. Dicjem jteljt [rei, bunten
1 23odje einc j(f)riftltd)e (scgenerflärung cinjureicfen. Der

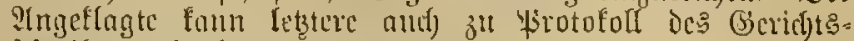
(c)reiber: nogeber.

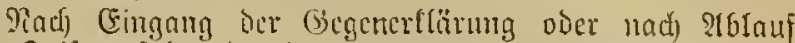

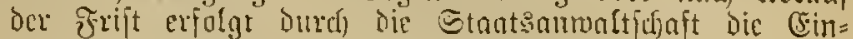
fendung der affen alt das Revifionsingridjt.

\$ 3S8. Findet bus Geridft, an weldfes Die (Finjendung ber Iffen erfolgt ift, Daf bie פerhandung umb Ent=

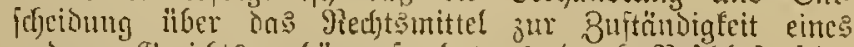

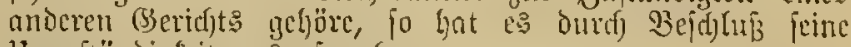
linguftünbigfcit ausujpredfen.

Dicfer bejd)

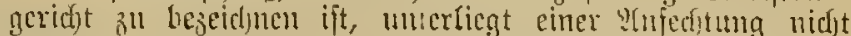
und ift fïr das in Demjelben bejeicluncti Bericht butbent.

Dic Ilggabe Der Iffen criolgt burd) bie Staat: antualticjaft.

\section{Derfabren vor beun Ievijiousegeridyt.}

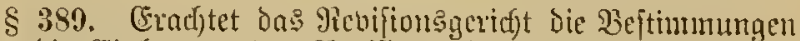
ïber bic Einlegung ier Febiliton ober diejenigen ïber Die

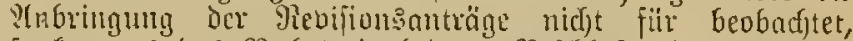

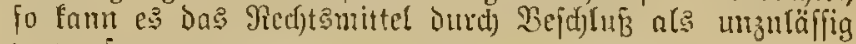
verwerfert.

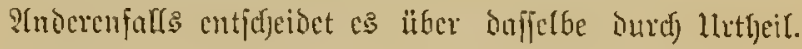

\$390. Der Yrgetlagte ober nuf bejin Serlangen ber 2iertheidiger ift von Dem Tage Der Sanptverhandung ju

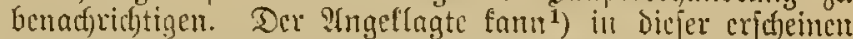

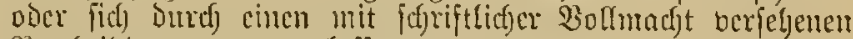
Bertheisiger bertreten lajien.

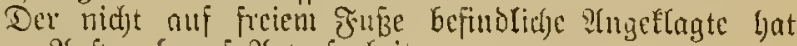
Ecinen ?tnprtut) nuf ?atucienlyeit.

1) Suvejenfecit aljo nidjt uoth wendig.

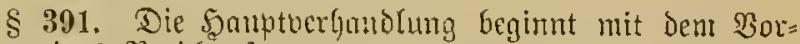
trage eines SBericifterftatters.

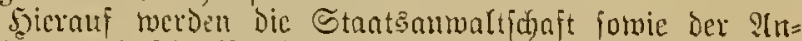
getagte uno fion 2Bertheidigcr mit ifren ?(usfülyrungen uno Tuträgen, uno jwar Der Bcjthmeriejiilgrer juerit, gefört. Dem STlugeflagten gebiil)rt bas lelste Wort.

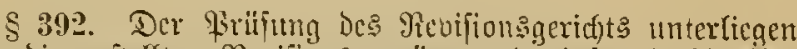

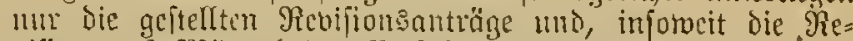

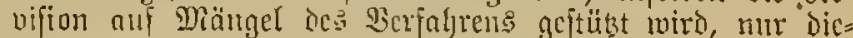

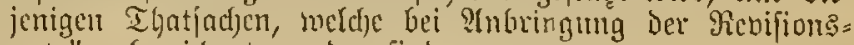
anträge bescidmet borden find.

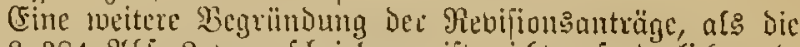

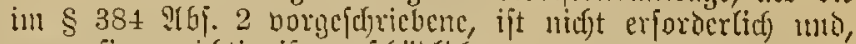

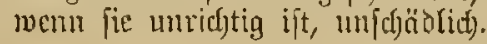

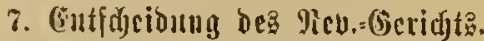

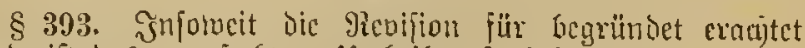

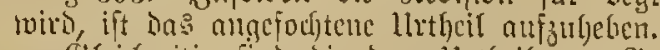

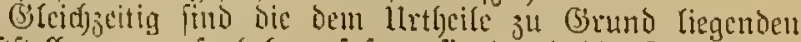

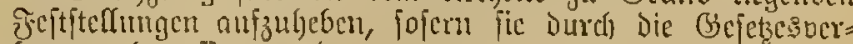
leksung betrofien werden, locgen beren bic Qtuflebung deß lirtljeils eriolgt.

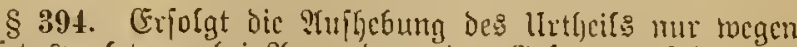

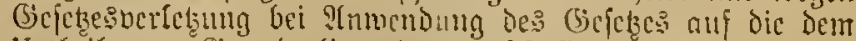

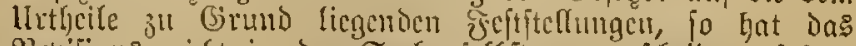
Revifionsgericlyt in ber Sndje jelbjt zu entjobetien, fojern 
ofne meitere thatfädrlidje Erörtermagen nux auj Jrei= fprectumg ober auf Cinftellung oocr auf eine abfolut be= ftimme Strafe zu erfenmen ift, oder bas glevifionsgerid)t in Ilehereinftimmung mit Dest ?ntrage Der Stantsanmalt= f(f)ajt Die gefe(zlid) niedrigite Straje für angenteff'n eradjtet.

Ŝn anderen Sällen ift die Sadje zur nubermeiten $\mathfrak{B} e r=$ lyanolung und Entfdeidung an dos (Serid)t, beffen Itrtheil aufgelyoben ift, ober an ein, Demfelben SBundesftate ange= lobriges, benadbartes (Berid)t gleidjer Srommg zurïufu= beriveifun.

Die Burtibvermeifung fann an cin Bericht niederex Dronmug exfolgen, tocnn vie nod) in Jrage foumende ftrafbare Şandlutg zu deffen Buftändigfeit gehört.

\$ 395. Wird ein litheil anfgeljoben, weil bas (Seridjt

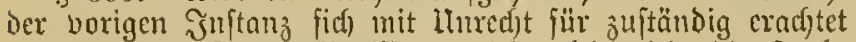
loat, fo bermeijt Das Kenifionsgeridyt gleidjzeitig Die Sache an das zujtändige Beridjt.

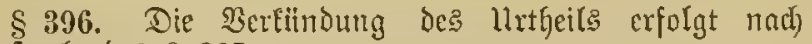
Mā̄gabe Des $\S 267$.

\$ 397. Exfolgt zu (S) onften cines Ingellagten dic

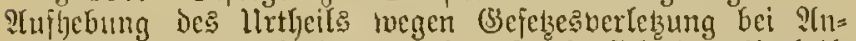

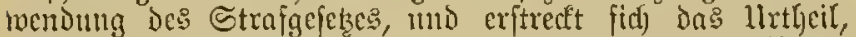
forbcit cs aujgeboben wird, nod) anf andore sugetlagte, weldye dic Revifion nidjt enigelegt lyaben, fo ift zu crfennen, als of fic glcidffalls dic Rebifion eingelegt lättert.

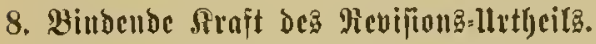

\$ 398. Das (Sicridjt, an Iveldjes dic Sadje zur amber= weiten Berbandlung mo (Enfjd)eidung verwiefen ift, lot die red)tlidge Beurtheilumg, weldye der Qluflebung bes llrtheils zu (Srumb gelegt ijt, aud jeiner Contfdjeidung ju Girund zu legen.

Mar bas lltheil nu vou Dem 2ugeflagten ober zu Giuniter desjelben bon ber Stantsantwaltichaft ober bon einer ber in $\$ 340$ bezeidumeten \$ier[onen angefodjten worben, fo barf das neute litheil cine bärtere ธtiafe, als bie in bem exiteren erfonnte, nidjt berljängen.

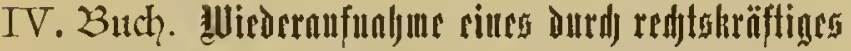

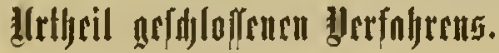

\section{311 (6unfteu be Berurtheilten.}

\$ 399. Die :Bicderaufnahme cinç Durd) red)tôfräftigcs Ilrtheil geidjloffenen Berfahreus zu Binften bes 2Berux= theilten f̈ndet (tott: 1 )

1. toenu eite in ber famptuerhandung zu feiren lin= gunften als edjt vorgebrad)te lirfunde fälfdidid angefertigt oder verfälfdut toar;

2. wenn burif) Seeidigung cines ô feimen lingunjten abgelegten Beugniffes oder abgegebsmen Gutadytens ber Beuge oder Sacjoerftändige fid ciner voriäls= lidjen ober fahrläfitgen Berleţung der Fidespflid)t (d)uldig gemad)t bat;

3. tocnn bei bem Uutheil cilt Ridjter, Befdimorener oder Sodjöffe mitgemirkt bat, welóner fid) in $\mathfrak{B e}=$ ziebung nuf bie Ђadje einer Derlełung feiner

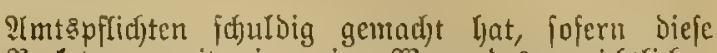
Berlebung mit einer im Wege Des geridjtlidjen Strafocrfabrens zu verbängenden öfentridhen Strafc bebrobt und nidft bout Derurtbeilten felbit ver= anlāst î̄t;

4. wemt ein civilgeridjtlidjes lirtbeil, auf meldjes dos Strafurtbcil gegrtindet ift, burd) cin anderes

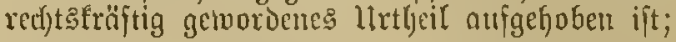

5.2) wenn neue Thatfad)en ober B̧emeismittel beige= brad)t find, welde affein oder in Berbindung mit den Friflyer erfobenen Betweifen die Jreiperedumg bes ?tugetlagten ober in \$nmendung cines milderen Strafgejeizes eine geringere Befurajug ju be= gründen geeignet furd. ऽn Den bor ben Sdjöffen= geridften verbandelten Sachen Eämnen nux jold)e IGatjadjen ober Beweismittel beigebradyt twerden, weldbe Der Berurtheilte in Dem Fribleren Berfabren cinfd) lieflich der Berufungsinftand nicht gefannt fatte oder obne Serfodjulden nidjt geltend madjen Fontite.

1) utio zwar ohuc 3eitgrenje (\$ 401).

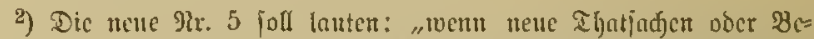
weismittel beigebrad)t fitto, aus weldyen afleit ober in ßerbindung

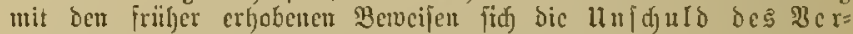

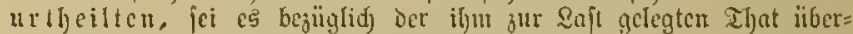

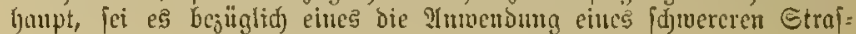
gejęcs begrünondocn Umjtandes, ergiebt. (Entr.)

\$ 400. Durch den Putrag auf Wiederaufunlute Des

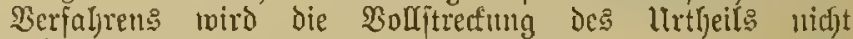
geljemmt.

Das (Berid)t fam jedod) cinen Suffidub joroie eime llnterbred)ung ber Bolffredfung anoronen.

$\S 401$. Der ?ntrag anf Wicderaufualyme Des $\mathfrak{B e r}=$ faljren: toird tocier Durch die exfolgte Strafoolftrecfung

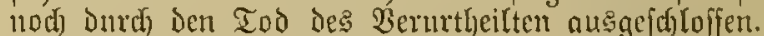

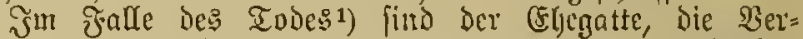
mandten auf = mo abfteigender Rinie forwie die (Gefdjwifter Des 2 erftorbenen zu Dem ?tutrage befugt.

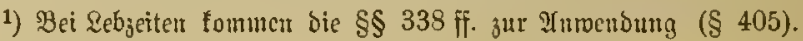

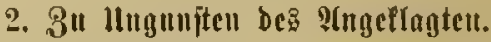

$\S 402$. Die Wicderanfnahme eines Durch red)t llrtheil geidfoffenen Berfabrens zulligulfen Des ?luge= flagten findet ftatt: 1 )

1. wenn eine in Der Jouptberfindulng ju feinen

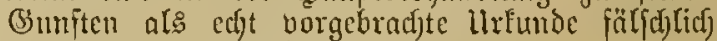
angefertigt ober berfälfdjt war;

2. wein burd) Becibigung eines z"ll feinen (B)unfen abgelegten Bengnifes oder abgegebenen (Butachtens Der Zeuge oder Sadjpertändige fid einer vor=

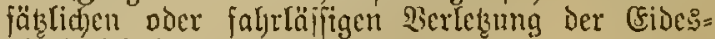
pflidyt ịchuldoig gemad)t ljat;

3. Jvenn bei Dem lirtheil cin Ridyter, (Scid)worener

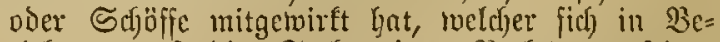
ziegung auf die Sache einer Berlekung feiner P̂tsepftidyten fduldig gemadyt hat, fofern bieje Berlewang unit eitter im Wege des geridftlicten Strufwerfabrens zu berfjängenden öffentlidjen Strafe bedrolgt ift; 


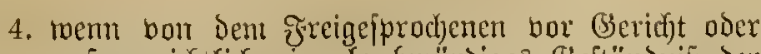
außzergerichtlid) ein glaubmüroiges Beftönonif̧ ber itrafbaren Şandlumg abgelegt wird.

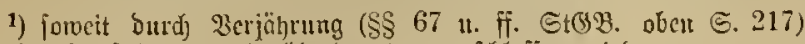
bie Strajuerjolgung mid̆t itherhaupt ausgefdlofien wirs.

\section{Hułuläjïgfeit ber Licoeraufunbut.}

\$ 403. Cine Biedcraufnalynte Des Verfalyens zun 3mefe Der ?lendermitg ber Etraje immerfyalb bes Durct Das=

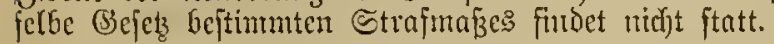

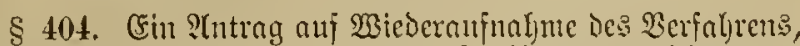

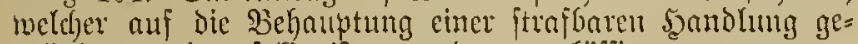
grïndet wevoen foll, ift nut dauts zuläffig, wenn roegen bicier sandung eine rechtsträftige Berurtleilung ergangen ift, ober wenn bie cinleitung oder Durdffülyrung eincs Strafperfalyens aus anderen (Strinden als wegen Diangels an $\mathfrak{B e t w e i s}^{1}$ ) nidht exfolgen fonn.

1) 子. $\mathfrak{8}$. Iob, Itbrejenkeit.

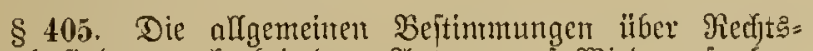

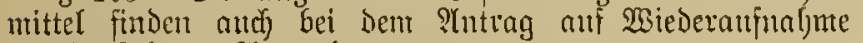
bes : Serfalyens ?numendung.

\section{Begrïnoung.}

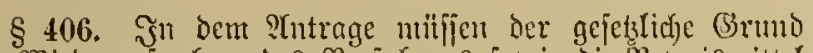

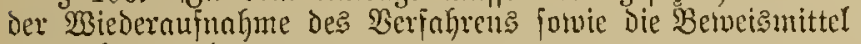
angegeben inerden.

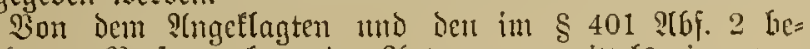
zeid)neten Zierjonen fam icr ?htrag nur mittels einer bon

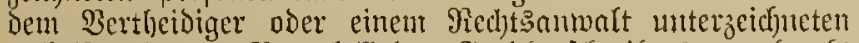

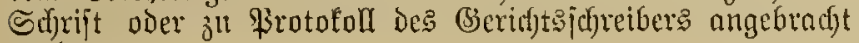
werbert.

\section{3uftüudigfeit.}

\$ 40\%. Lleber die Burafpung des Yntrags auf Wieber:

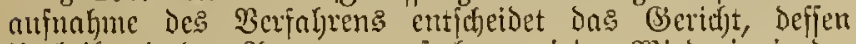

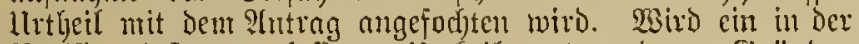
Revifionsinftand exlafjencs Hrtheil aus anderen (Sirüben als anf Brund bes $\$ 399$ शr. 3 oder bes $\$ 402$ शr. 3 angefodjten, fo cntidjeidet das (Sericht, gegent beffen llutljeil die Mevifion cingelegt tuar.

Die (Entjocibumg erfolgt olyne münolid) Serhandung.

\section{2icrfaljen.}

\$ 40S. Sit ber Prutrag nidft in det porgejdriebenen Fornt angebradit, ober ift Darin fein gefeblidber Girund Der Wiederaufmalyme geltend gemadjt obcr fein gecignetes

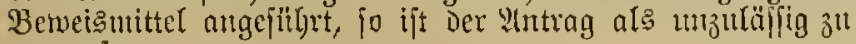
vermerien.

Pnderenjalls ift Derjelbe Dem Begnet bes Intuagiteller:

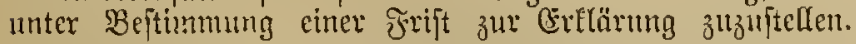

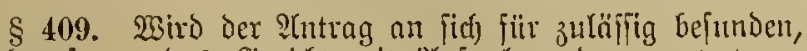
io benutragt Das (Serid)t mit ?hifnalyne ber angetretenen

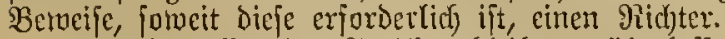

Dem Ermeffen Des Seridfts Gleibt ç ïberlaffen, ob bie Beugen und Sadjoerftändigen eiblicf) verummmen sperden follen. ${ }^{1}$ )

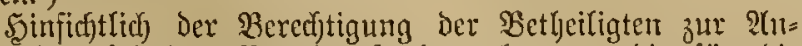
mejenteit bei Der Bemeisaufnabunc fommen die für bie Borunterfudfung gegebenen Borjd)riften zur ?nmendung.
Rach Sdjlús Der Betweisnujuafme find die Staatsant= waltid)aft und der S(ngeflagte unter $\mathfrak{B}$ eftimmung einter

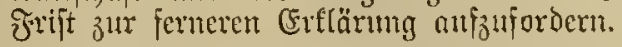

1) Siud Deur Entm. ijt Die Bentebmung ber Bcugen und Sad)= verptöndigen ndat mehr in dos Enmefien bes (serid)ts geftelft, fombern fie erfolgt uno zuwar, foweit die Becibigung juläfig ift, eiblich.

§ 410. Der :antrag auf Wiederaujnahme des $\mathfrak{B e r}=$

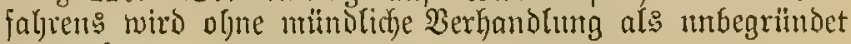
bermorfer,

1. Jwenn Die Darin anfgeitellten $\mathfrak{B c h a u p t u n g e n ~ f e i n e ~}$ gentigende Bejtätigung gefmben haben, ober

2. wem in ben fällen bes \$ $3999 \%$ 1, 2 obcr des

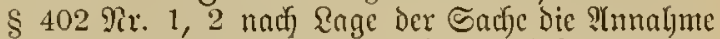
nusgejchlofien ift, baf bie in biejen SBeftintmunget bezeidnete Sandlung auj bie (Entid)eidung (Fimflús geljabt hat. ${ }^{1}$ )

P(nderenfalls veroronet Das Berieft die Wieder= aufrafjue des Berfahrens und die Ermenerung Der jouptberjandlung.

1) $1110 \mathrm{\delta}$

3. went in ben Fället bes $\$ 399$ Rr. 5 (neut 9 Rr. 5) Der

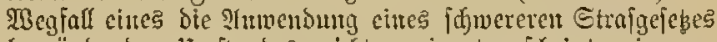
begrundenben IImjtaties nidjt geeignet erjdjeint, eine ge= ringere Beptrufung herbeijufïhren. (Entw.)

$\S$ 411. Şit Der Berurtheilte bereits berjorben, fo hat ohne (Ernenterung Der 5autptbertjandlung bas (Bericht nadf

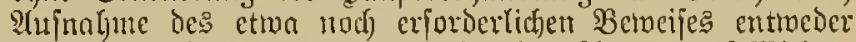

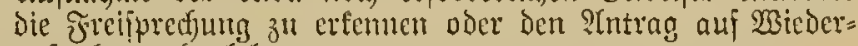
aufnaljme abzuteluen.

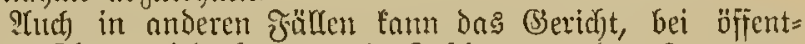

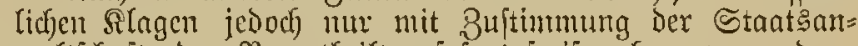
waltict)aft, Den Beruntheilten jojort jreijprechen, menn Dazu geniligende 98 etweife bereit: bor(iegen.1)

Mit dex Jreifpred)ung ift die ?tuffebung des fritheren Urttjeits ă berbinton.

Die Puifeburg ift anf Berlangen Des SYntragiteller: Durch Den Deutjdjen Reicf)snnzeiger betannt zu machen, umb fatul nad) Dem Ermeffen bes (sieridfts aud Durd) andere B (ätter beröffentlid)t merden. ${ }^{1}$ )

1) গIbj. 2 uno 4 jolfen aufgehoben werben (Entw.)

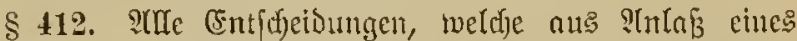

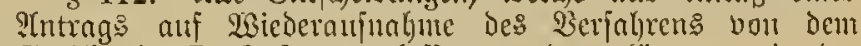
(Seridjt in I. J̄nitanz exIaffen rerben, fönnen mit ber fofortigen Befdimerbe angefod)ten werden.

\section{\%. (sruente şanptuerbandung.}

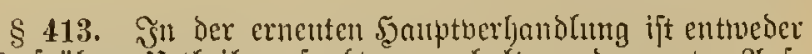
Das früljere IIrtheil aufted jut ju erljalten ober inter ?(uf= gebung beffelben anderweit in ber Sact)e zlt erfennen.

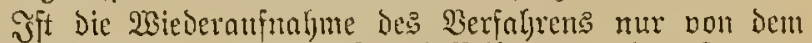

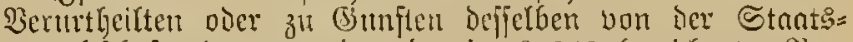
anmaltichaft ader bon einer ber im \$ 340 bejeichneten fier" jonen bentragt worben, fo barf bas neue littheif eine härtere Straje als bie in bem fribljeren erfante nifjt ber= hängen.

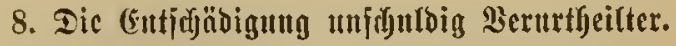

joll wie folgt geregelt werben (Entw.):

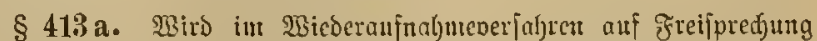
erfaunt, io ijt auf Serlangen bes 3erurtheilten und im ₹ralle bes $\S 411$ mif Berlangent bes 2 nutragftellers bie 2uifebung bes fritger 18 


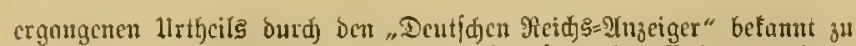

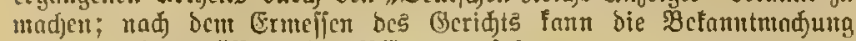
aud in anberen öfficntfidjen B̆lätern crfolgen.

$\$ 413 \mathrm{~b}$. Ferioncn, gegen woldje cine im Straperfahren redits=

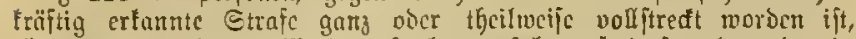

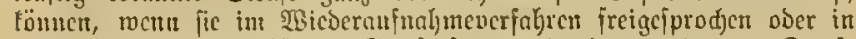
Inwendung cines miloeren Strafgejezes mit einer geringerct Straje

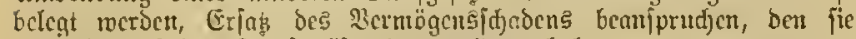
burd) bic erfolgte Strnjollftedutug erlitten Gubet.

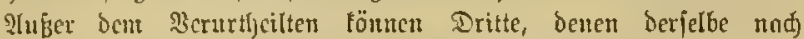

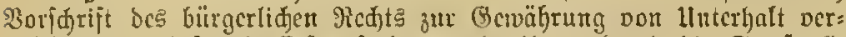
pflightet war, injorneit (Erjats forbern, nls iljnen Durd) Die Strafuolls ftredung ber IJuterbalt entzogen morben ift.

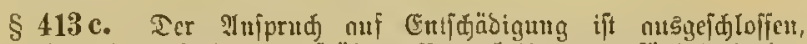

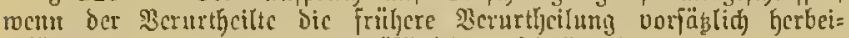
gçïl)rt ober burd) grobe Jaljrläffigtecit veriduldoct hat.

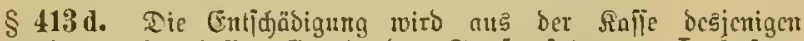
Bunocsjtants, bci scijen (Berid)! bos Ctrafnetjabren in I. Injtanz anhöngig war, obcr, wenn das Reidjgncridft ist expter uno letster

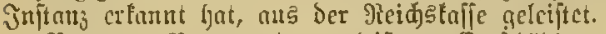

Bis zum Bclrnge ber gelcifleten Entidjäbigung tritt bie $\mathfrak{K a f i c}$ in die Aicd)te cin, weldje ocm Entjdjäbigten gegen Tritte um bcsmillen

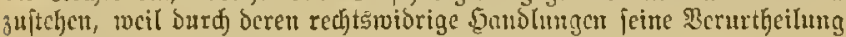
ljerbeigçührt war.

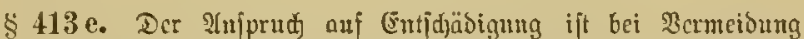

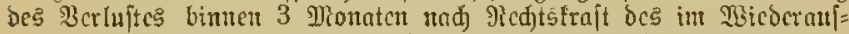

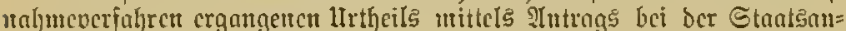

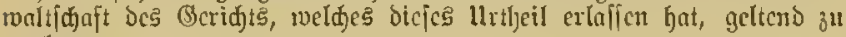
madjen.

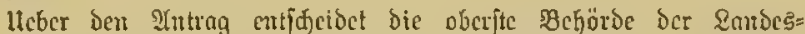

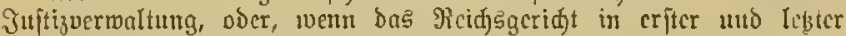

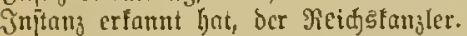

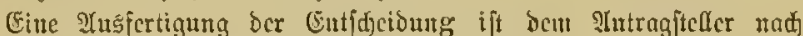

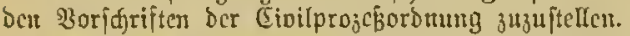

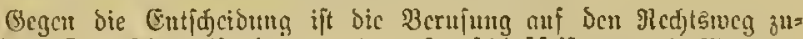

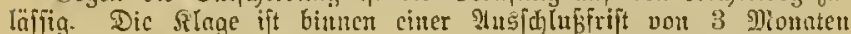

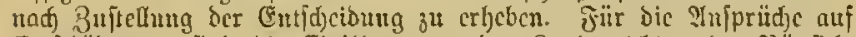
Entidjäbigung find bic Civiltanmern ber Ranogeriajte obne Siüditgt auf Dcu Werth bes Etrcitgegenjtandes ausjdjlieblid) zujtänoig.

§ 413 f. Der Injprud nuf Eutidjäbigung erlifdjt, wertr ber

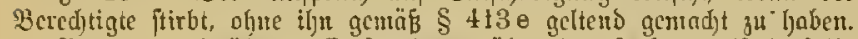

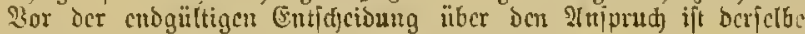

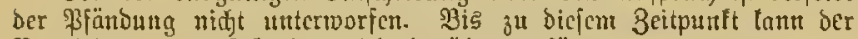
Beredjtigte unter Qebenden nid̆t Sarïber verfïgen.

\section{23udh.}

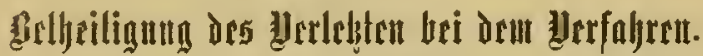

\section{3uläfingleit.}

\section{Privatflage.}

§ 414. Belcidigungen unD Särperberleksungen fönnen, foweit bie $\mathfrak{B e r f o l g u n g ~ n u r ~ a u f ~}$ Antrag eintritt, ${ }^{1}$ ) von bem Berleşter in Taege der \$3ribatflage berfolgt merben, oljne

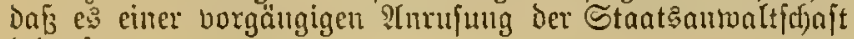
bebarf.

Die gleidje Befugnif̧ iteht Denjenigen z̆ll, weldjen in Den Strafgejetzen Das Riedit, jelbitftänoig auf Beftrafung anzu= tragen, beigelegt ift.

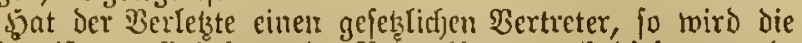

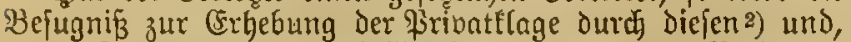
renn Rorporationen, (Sefelffijaften und andere \$erionen=

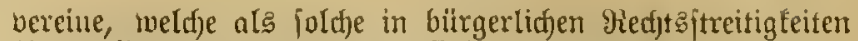
flagen fönnen, die Berletzren find, Durdj diefelten Berfonen

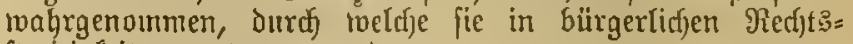
freitigfeiten vertreten werden.

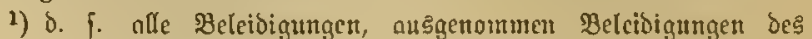

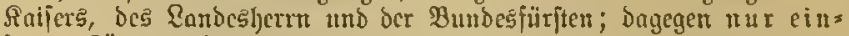
in dj c §örperoerlę̧ungert.

2) Der Beleidigte ober Berleste ift felbiftänoig berchligt, Straf=

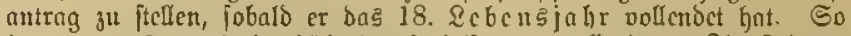
lange er aber minberiäfrig ift (nlio dor volfendetem 21. Rebens:

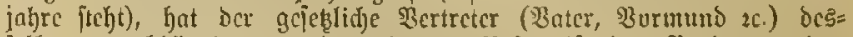

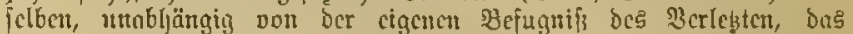

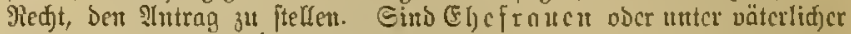

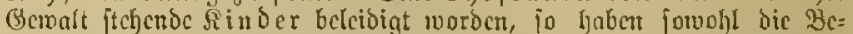

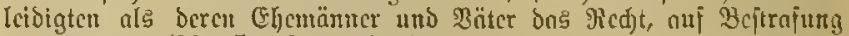

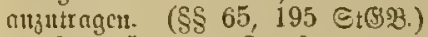

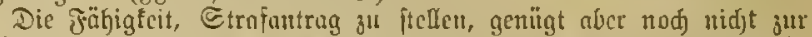
Errgebung ocr \$rivatllagc. (ES fitts viclmchr bic alfgencinen Brunb=

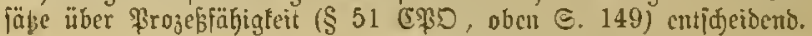

$\S 415$. Sind wegen Derfelben frafbaren Sandrung mehrere Berfonen jur Bribatklage berechtigt, fo ift bei

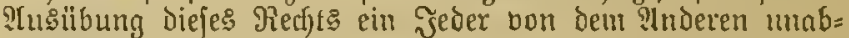
häugig.

Jeat jedoch einer Der Bereditigten die Sribntflage ex= hoben, fo fteht Den übriget ${ }^{2}$ ) nur Der Beitritt z̆ Dem eill= geleiteten Serfahren, uno ztwar in Der Eage zu, in weldfer jid) Daffelbe zur Beit Der Beitrittserflärung befindet.

Эede in Der Eadje lelbit ergangene (Entfdeibung äujert

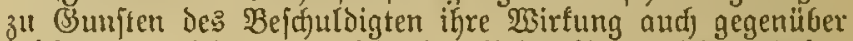
foldfen Beredftigten, weldje die Bribatflage nidjt erboben haben.

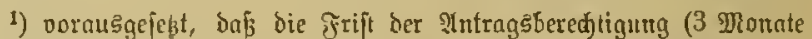
von Dem Tage, nu weld)cu ber zun Intruge $\mathfrak{B}$ crechtigte von ber

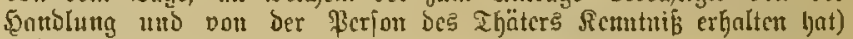
nidft abgelaufen ift.

\section{Etnatżanualtidjait.}

\$ 416. Die öffentliche flage wiro megen der im $\$ 414$ bezeidfneten frafbaren Salndungen non ier Staatsamualt, idjaft nur Dam exloben, menu bies in öffentlidjen Эntereffe riegt.

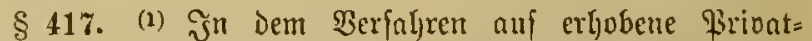
Elage ift die Stantsanjoaltid)aft zu einer Ditmirkung nicht

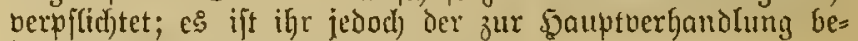
ftimunte Termin befannt zil madjen.

(2) 2(ud) Fonn bie Stantsanmaltifjajt in jeder Sage der Saufe bis zum (Eintritt Der Med) Etraft des llrtheils burd) cine ausorütflidje Ertlärung Die Berjolgung tibernebnten.

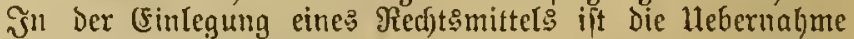
Der Berfolgung entfyalter.

(3)....

\section{Sertretung Des Fiviunteläger:}

§ 418. Der Bribattläger tann im Sciftano eines Gied)tsanwalts eridjeinen oder fidf butd) einen mit idjrift=

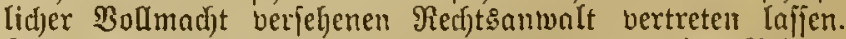

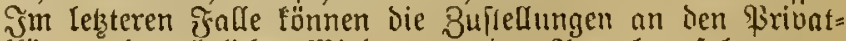
fläger mit red)tlid)er $\mathfrak{B}$ sirtung an Den 2lumalt erjolgen.

\section{Eidjerycitąleiftung.}

§ 419. Der Bribattläger lyat für bie Der Stantstafie und dem Bejduldigten vorausfichtlich ermadjenden Roften unter Denjelben Borautsfeşungen Sidjerheit zu Leiften, 


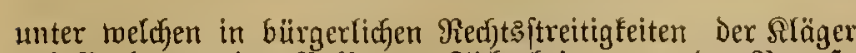
auf Verlangen Des Beflagten Sidferbeit wegen Der \$rozeftoften z"l leiften hat.

Die Sifferbeitsleiftung ift Durd Shinterlegnng in banam Beloe ooer in Werthpapieren 3 th berirfen.

Jiir bie 5öhe der Sidferljeit nno die J̧rift zur Reiftung Derjelben, forwie für Die Berwilligung des Plemenred)t? gelten Diejelben Beftimmungen wie in biirgerlidjent Red)t: fircitigfeitell. ${ }^{2}$ )

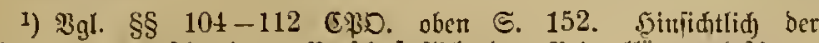

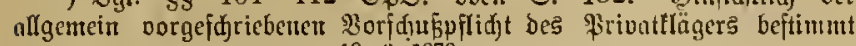

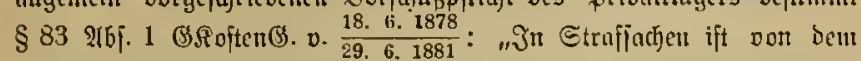
\$rivatfläger ober bemịnigen, welder als \$rivattläger cine \$̧erufung

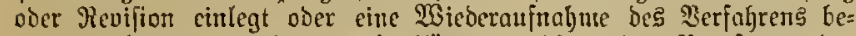

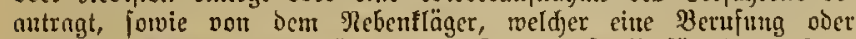

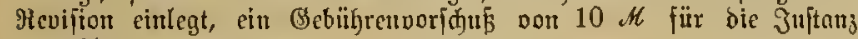
зи jahlen."

Bgl. ferter § 84 Grofoften@s., bei $\$ 87$ ExD. (oben S. 150 und 151) Demerft.

\section{Sïhncucrindy.}

§ 420. $\mathfrak{3 e g e n}$ Beleidigungen ift, injofern nidjt einer

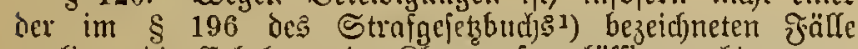

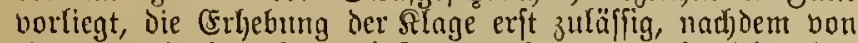
einer burd) dic Randesjuftijocrivaltung zil bezeid)nenden Bergleidjsbehörde2) die Siljne erjolglos verjudte morden ift. Der Rläger hat dic Befdjeinigung hieritber mit ber Silage cinzureitjen.

Diefe Beftimumng fundet leine ?tnmendung, wenn die Barteien nirfit in Demferben Beneindebezirfe wolnen.

1) Beleidigung einer \$ełörde zc. (oben S. 220)

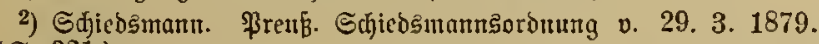
(बS. 321.)

\section{Erfjebung ber PrivatPlage.}

§ 421. Die Crlfebung Der Silage gefdjieft zu \$rotofoll

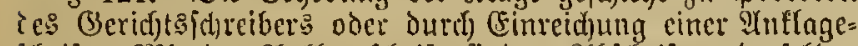
(c) rijt. Mit der InElagef(d)rift find 2 ?(bid)riften Derfelben einzuteidfent. ${ }^{1}$ )

1) Die Slage hat bic bem Befduldoigten zut Raft gelegte That unter fervorhebung ifrer gefeblidjen Merlmale ano bes anjumendenben Etrafgejęes jul bejcidnen, fowie bic Beweismittel und bas Beridt,

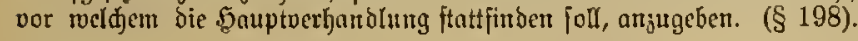

\section{Berjalyren.}

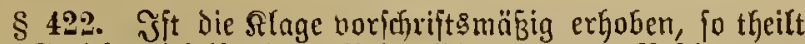

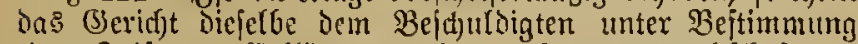

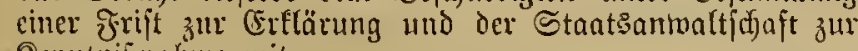
Renntuiģnaljme mit.

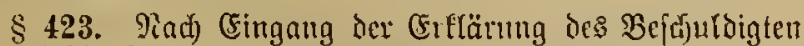

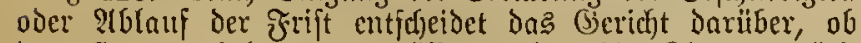
bas Sauptuerfalgren ju eröffnen oder bie Slage jurïf= jumeifen fei, nach Maß̄gnabe ocr Beptinumungen, soclúe bei ciner bon der Staatenanvaltidfaft ummittelfar erhobenen $\mathfrak{i n}=$ flage ?frwentung finden.

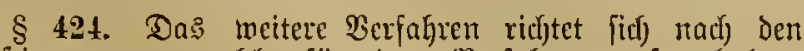
Beftimmungen, welde fïr das Berfahren auf erfobette offentlidje Silage gegeben find.

Bor Dem Édjwurgeridyte fann cine Brinatelagejache nicjt gleidfzeitig mit einer auf bffentfiche Slage antjängig gemad)ten Sadje berbandelt werden.
\$ 425. Эnjomeit in Dem Verjalyren auj erhobene öffent=

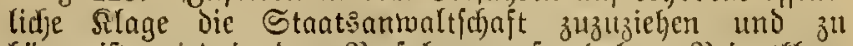
hören ift, wiro in ben 2erfalyren auf erlyobene Firibatflage ber Brivateläger zugezogen uno geljört. Deşgletcten find alfe (Entfic)eioungen, reldje dort ber Stactsantwaltid)ajt befamit gentach)t reerden, ljier dem Frivattläger betannt zu madich.

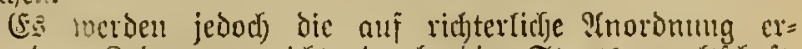
gebenden Rabungen nicht burch dic Stantsambaltichaft, fonbern Durdy den Geriffisfdfreiber bervirft.

Zwifhen Der Zuftellumg Der Eadung Des Fribatflägers

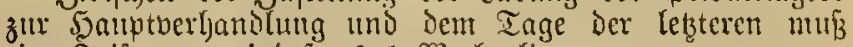

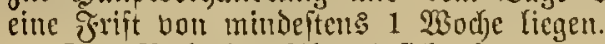

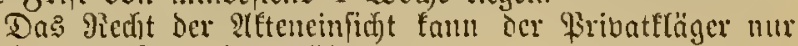
Durd) jeinen ?turalt ausitben.

\$ 426. Der Sorjitzende Des (Geridjts beftimmt, Jueldje Ferjonen als Zeugen oder Sachocritändige zut \$caupt= berfandtum geladen werden folletr.

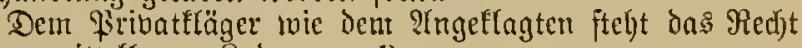
dev unmittelbaren Eabung 3น.1)

i) $\mathfrak{s g l .} \S 219$.

\section{Bertretuug be Pro}

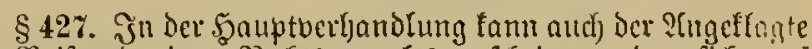

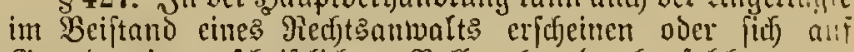

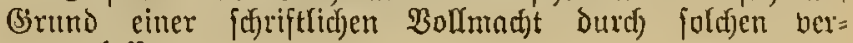
treten Inj]en.

Die Beftimunung des \& 139 findet auf ben ?tmwalt des Slägers mie auf Den bes stngeflagten Thmendung.

Das (Seridft ift befugt, Das perfönlidje Erfojeinen bes Sräger: forvie des atmgetlagten anjuoromen, aud ben ?ln= geflagten borführen zu laffen.

\section{WBiberflinge.}

\$ 428. Bei wedfelfeitigen Beleidigungen oder Rörper=

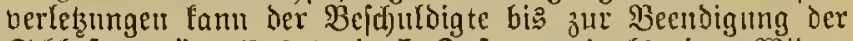

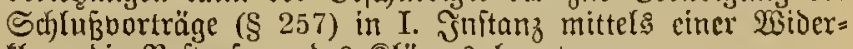
flage bie Bejtrafung des Släger's beantragen.

Heber STlage uno widerflage ift gleid)zeitig zu crlennen.)

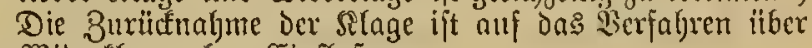
die $\mathfrak{B}$ iderflage ofjne Cinflub.

1) $\mathfrak{B e g e n}$ ber Riotten ogl. $\S \S 500,503$.

\section{Cinftelltug be}

\$ 429. Findet Das (Beridft nad) verhanderter Sadjc,

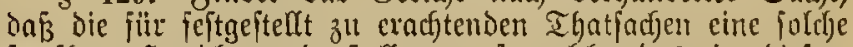
ftrafbare 5anofung darftellen, auf meld)e das in biefent

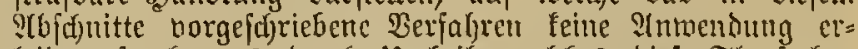
leidet, fo hat es dutud Urtheil, weldjes dieje Iljatjachen lyerborljeben muß, die (Finftelfung de zufprectien.

Die Derkandungen find in biefem Falle der Stant: anmaltidjaft mitzuthcilen.

\section{Medjtamittel.}

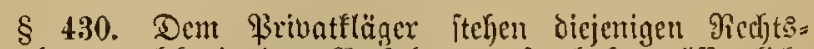

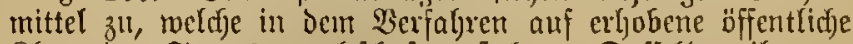
Slage Dex Ctantsanmaltf(haft zuftehen. Daffelbe gilt non

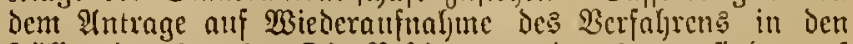

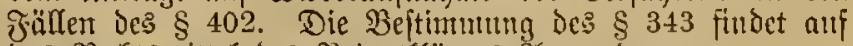

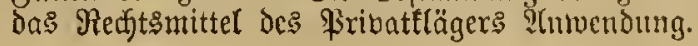




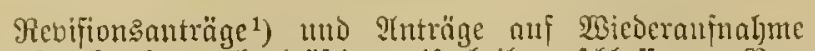

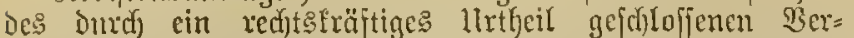

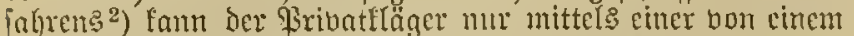

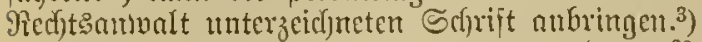

Die in oen $\$ \$ 361,362,387$ nugeoronete 30 rlage 1 mo Einfendung der ?ften exfolgt wie in Berfahren auj er= hobene öffentfiche SInge an mo burd) die Stantanamaltidjaft. Die Zuftellung ier Berufungs: und Revifionsfdyriften an Den (Segner des Befdwerdefïhrers wird Durdf Den Beridfts= iffreifer bemirft.
1) $\S 384$.
2) $§ 406$.

3) Der Ifngeflagte bagegen barf Dicfe Inträge aud ju frotofoll

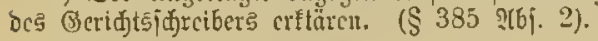

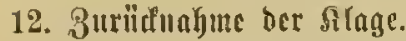

\$41. Dic Privatérage fam Gis zur Berfünong bes

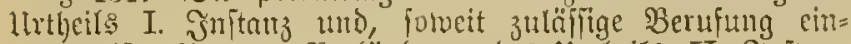
gelegt ift, bis zm: Berfüntoung bes llrtbeils II. S̈nftanz zuruitfgentommen lverden. ${ }^{1}$ )

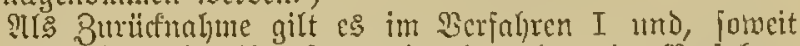
Der 2Ingetlagte Die \$̧erufung cingelegt hat, im Berfahren II. Inftanz, venu ber Firibateläner in ber 5auptberbandhug

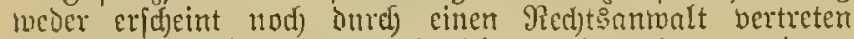
mird, oder in der Sgauptberlyandlutg voer cinemt anderen Iermine ausbleift, ofmolyl das (Bericht jein beriönlicfes (Erid)einen angeorónet hatte, oder eine Jirift nidyt eimbält,

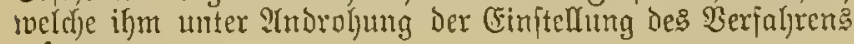
gejelst war:

Solveit Der Brivatfläger dic Berufung eingelegt hat, ift Diejelbe in ₹̧alfe Der borbejeid)meten Sierjäumungen un=

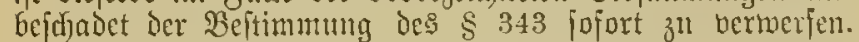

Der Privatfläger fann binnen 1 23odje nad) ber $3 e r=$ fäumung bie פsievereinfetsung in ben borigen Stant unter Den in ben $\S \S 44,45$ bejeicfneten Boransfez̧ungen bean= furtuctien.

ร 432. Die 3urïfgenommene Fribatflage fom nicht bon nenem erhoben werben. ${ }^{1}$ )

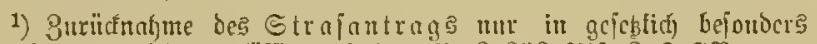

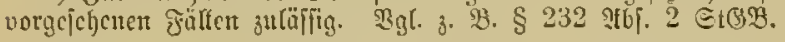

\section{3. llwwererblidjecit ber Privatflage.}

$\S 433$. Der Tod Des qrivatflägers hat die Einftelfumg

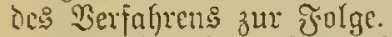

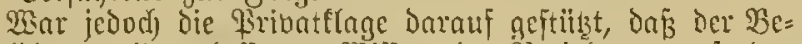

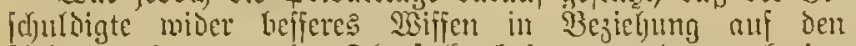
SInteren eine tmbaljre Thatjadje behouptet oder herbreitet

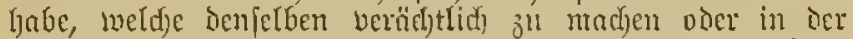
iffentlidjen Meinung herabjumüirbigen geeignet ift, fo fom bie Slage madh bem Tode Des Silägers bon ien EEtern, den Sindern oier Dent Ghegatten Des lekteren fortgejetgt merien.

Die Fortjetsung ift bon iem 3 Beredjtigten bei Berfuft bes Fed to bimen 2 Monnten, vom Iode ies Pribatflëgers ant gerect)net, bei (S)ericht jull erf(ären.

\$ 434. Die Buriafungme Der firibaternge und der Tod Des Fribatflügers, fotvie bic Jortfełututg ber qribat= flage find Dem Befdutloigten befanut ju utadjer.

\section{Bulläijigfcit.}

\section{Rebentage.}

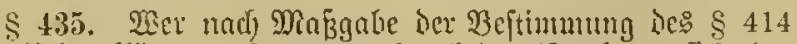

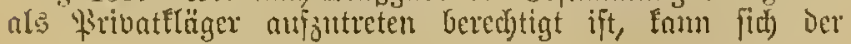

erlobenen öffentlichen Slage in jeder Sage des Berfaljen

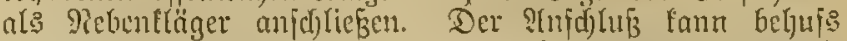
(Einlegung vou Red)tsutteln aud) nad) crgangenem Litheile gefd)eljen.

Die gleidje Befugnif ${ }^{1}$ ) jteljt demjenigen zll, veldjer

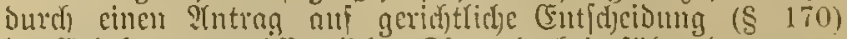
bie (ErIjebung Der offentlichen Slage herbeigefiifyt hat, menu die itrafbare sondolung gegen fein Seben, feine Gejundgeit, feine Jreilycit, feinen ఫierfonenftand ober feime Vermögens: rechte geridjtet war.

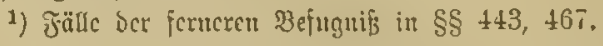

§ 436. Die Înjdfuferelianng ift bei iem Berichte jdyriftlid) einjureidlyen.

Das Icbtere lyat iuber die Rierechtigung Des viebenflägers

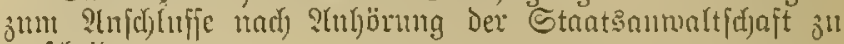
enticheident.

$3 u$ einer Sidferbeitsleiftung ift ier giebentlïger nid)t verpflidxtet.

\section{Gedjte be Meruenfläger}

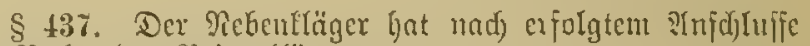
Die Pied)te de: Frivatflägers.

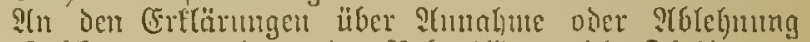
Der Gejchmorenen ninmt ier Rebentläger nidht Theif.

\section{3ucrfeutung ciner Silje.}

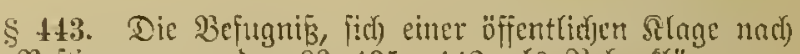

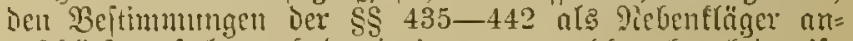
jufch(iejen, fteht oudf demijenigen $3 \mathfrak{u}$, meldfer beredjtigt ift, Die Zuerfennung ciner Buf̣e zu ver(angen. ${ }^{1}$ )

Wser bie Buerfemung ciner Bube in cinem anf erfyobene

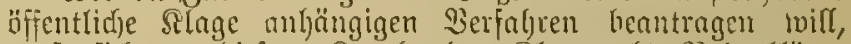

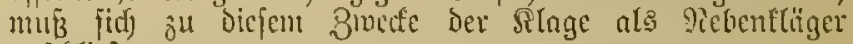
anjol) rię̧en.

1) Dic 3ucrfounung ciner $33 n$ fo fomu vertangt werocn, welu bic

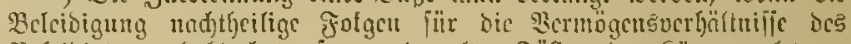

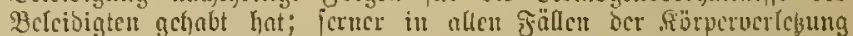
(§§ 188, 231 ङt(58).

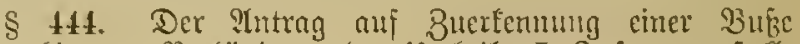

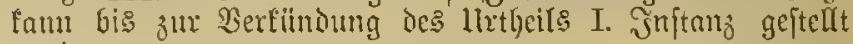
mericn.

Der Stntrag Eann bis zur Serfïnoung ies llutheiโs

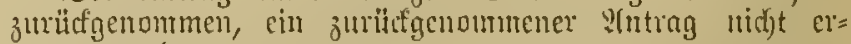
mettert joeroen.

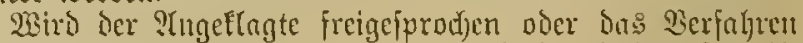
cingeftellt, oder die Sache ohme llutheir ertedigt, fo gilt aud Der 'Antrag oljne weitere (Entfdyeioung fïr crleoigt.

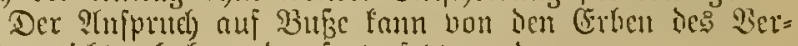

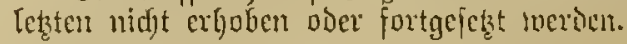

\$ 445. Der Piclenteäger lyat ien Betrag, welden er ats 33 uze verlangt, anjugeten.

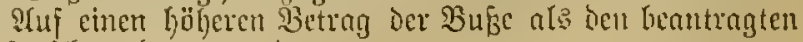
darif nidgt erfonnt werden. 


\section{Buh.}

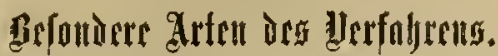

1. Berfahren bei amtarideteridgen Strafbefeglen.

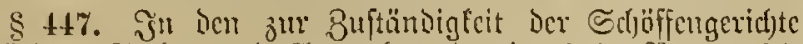

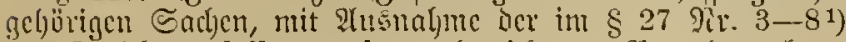

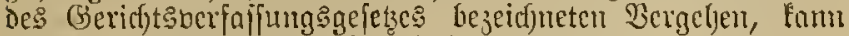
burd) fidriftlidjen Struffefehl des itmtartidters oljue vor=

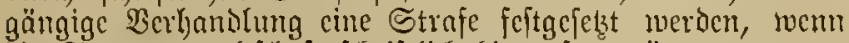

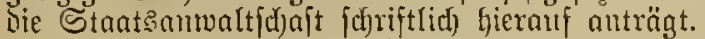

Durd) cincu Etrafbefehl Darf fedoch fcine andere Strafe

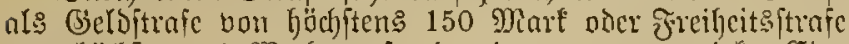

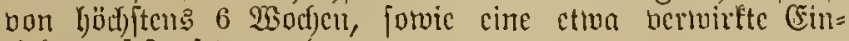
ziclyung feftgciestst wertiert.

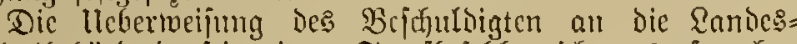

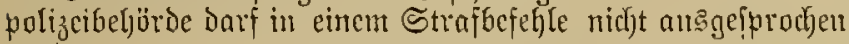
toerion.

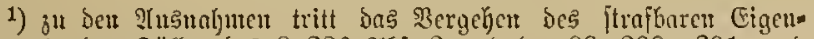

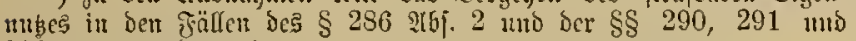
298 હt(3). (Entw.)

\$ 448. Der Ifntrag ift auf eine beftimunte Strafs zul

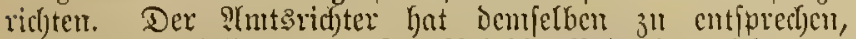

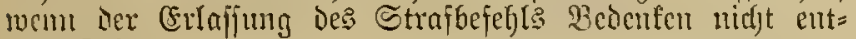
gegenftelyen.

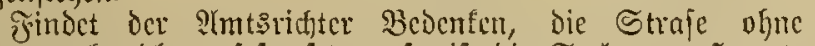

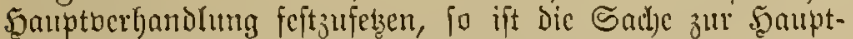

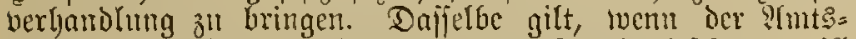

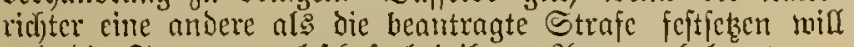
und bic Stantsantwaltidjaft bei ifrem ?tntrage beljarrt.

\$ 449. Der Strafbejcht mur Strafe dic ftrafGare Sandhumg, Dns angewondete Straf=

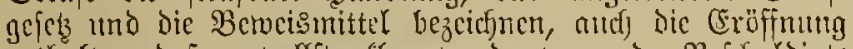

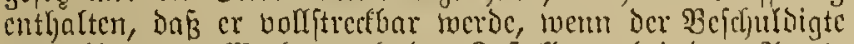

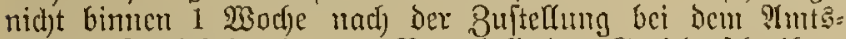

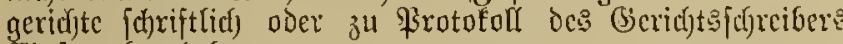
(Einjprutd) erlilebe.

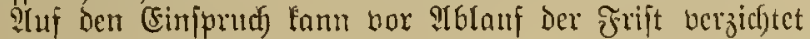
merben.

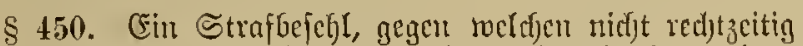
(Einfprud) crfoben worden ift, erfongt bie 2 situmg cincs redftesfräftigen litthcirs.

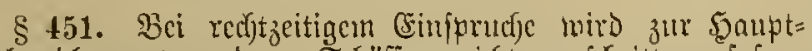

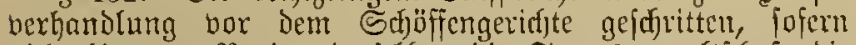

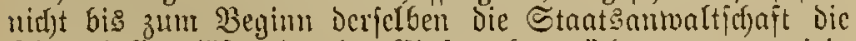

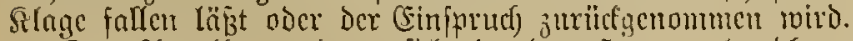

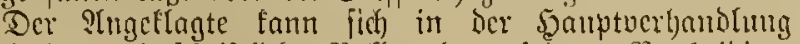

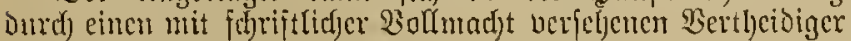
ucrtreten Iaffert. ${ }^{\text {I) }}$

Bci Der llutheilsfäfrung ift Das Gedjöfengericht an den

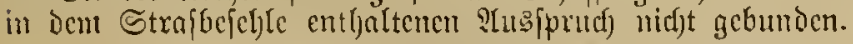

1) (Er fant aber and jum periönlichen (Eriducinen angebalteu werben. (\$ 235). \$3gl. jedod) \& 232.

§ 452. Bleibt Det ?tugeflagte olyne geü̈gente Cut=

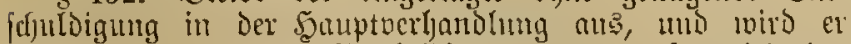
audf micft Durd) cinen Bertheidiger bertreten, fo juird ber Einfpurd) ohue Bemeisaujnalyuc burd) llutlyeil verworfen.

Gin ?ngetlagter, welcfent gegen ben ?lblatf Der Gin=

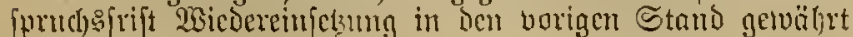
uprocn twar, fam bie lebtere nitht melje gegen bas llatgeil bcanprutuder.

\section{Berfafren nad) vorangegangener polizeilider Strafuerfïgung.}

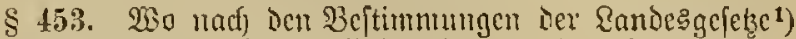

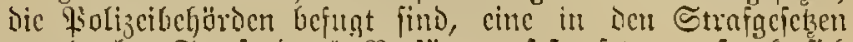

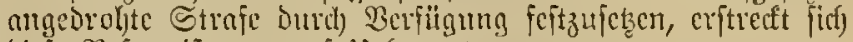
bicje $\mathfrak{B} c$ fugníz nur auf llcbertieturges.

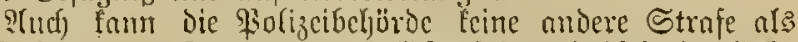
glaft bis zll 14 Iageit ober (Geloftrafe ${ }^{2}$ ) und biejenige \$aft,

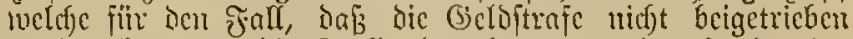
merben famm, an dic Stclle ber lesteren tritt, forwie cine etus vermirfte Cinjiclyung verbängen.

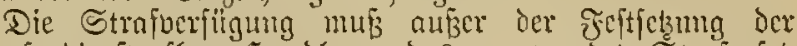
Straje dic ftrafbate Sandlung, bas angetwendetc Stxaigefez

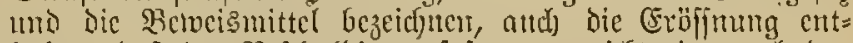

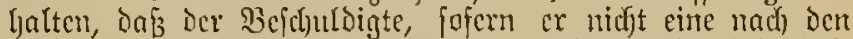

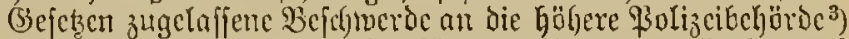
ergreife, geger dic Strajoerfügung bimen 1 Wotfe nad

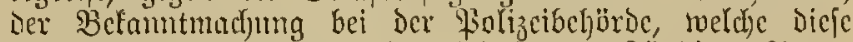

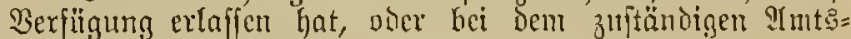
geridjt auf geridbtliche (5ntf(f)cidung antragen fömuc.

Dic Strafocrfïgung wirtt in Betreff Dex llnterbredjumg

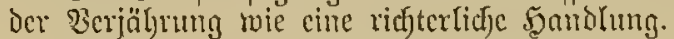

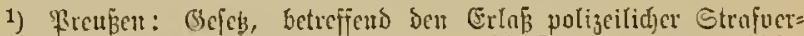
fïgungen wegen llebertretungen o. 23, 4. 1883 (folgt untcu Scite 290).

2) uno zroar in ßrenken mur bis 30 , 1 ober gaft bis ju 3 Tagert. $\$ 1$ 6. v. 23. 4. 1883.

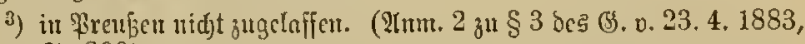
unten ธ. 290).

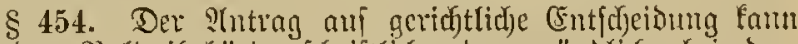

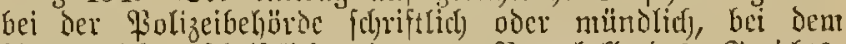

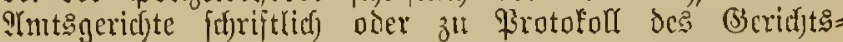
(d) reibers angebradit tocrocr.

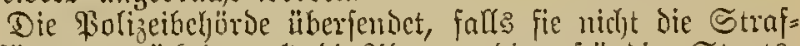

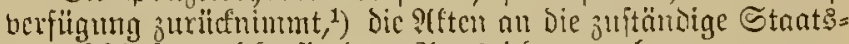

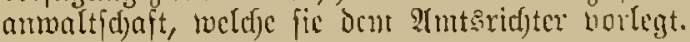

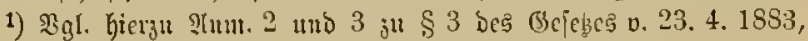
unten ङ. 290.

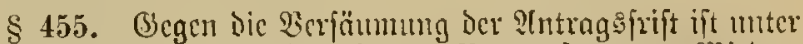

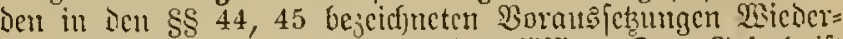
cinjeşung iu Den vorigen Etand juln̈fïg. Daš (Schudf ift

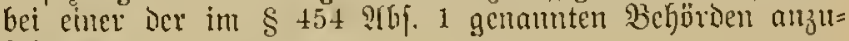
bringen.

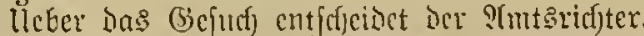

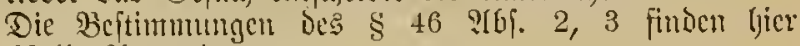
glcich)falls ?(nuvendumg.

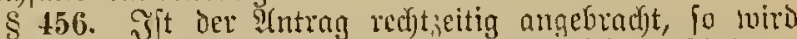

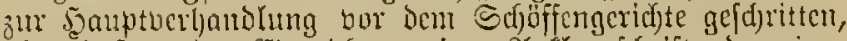

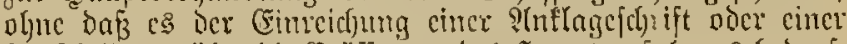

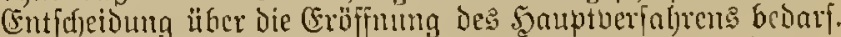

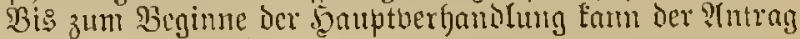
zü̈̈fgenommet mericn.

\$ 45\%. Das berfalyren bor den Sdjoffengeridyt ift

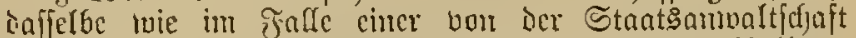

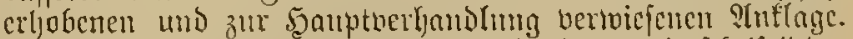

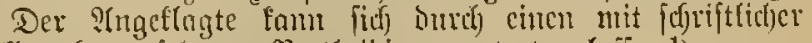

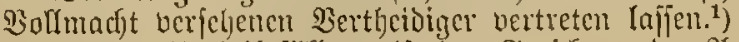

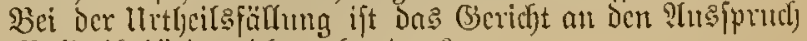
ioc Polizcibcljöroc midjt gebutomen.2)

1) भ(nur. 3แ $\$ 451$ gill and bicr.

3) Es fan aljo andi sinte härtene Strafe verbängetr. 
§ 458. Stellt fid) nad) Dem (ergebniffe Der Samptner= handlung die That des Slngeflagten ats eine foldie har, bei

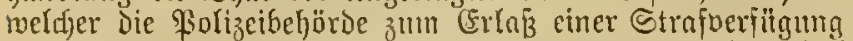
nidft befugt war, jo hat bas (serid)t bie leztere bured llitherl mujulfechen, ohne in ter Sadhe jelbft zu entidjeiden.

3. Berfahren bei Buviberbantungen gegen bie Borfdriften über die Erhebung öfentrider \{łggaben uno Gefälle.

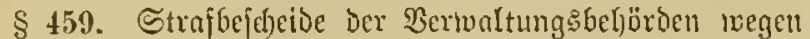

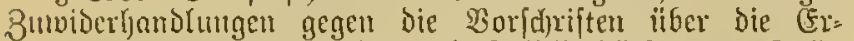
tjebung off entfict)er abgaben und Befälle dinrfen nur Getd= ftrafen powie cine etma berwirfte Cimzielyuta jefteszen.

Der Strajbejdjeid muj auserdem dic ftrafhare Sandhung, ons angetwendete Strafgeles und die Berveismittel bezeichnen, and) Die (Fröfinumg enilyalten, Das ber Befchuldigte, [ofern er nidjt cine nod) Den (Bejetzen zugetaffene Bejd)tuerde an

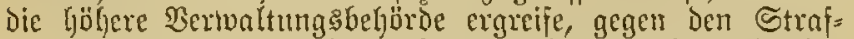
bejheid bimen 1 Bsodje nadj der Betanntmadjung bei Der Bermaltungsbelyörde, weldje denjelben erlafien, oder bei ber= jenigen, weld)e ify betamt gemadht lyat, anf geridallidje (Entfec)eioung antragen fömte.

Der Strafbejcheid wirft in Baetreff Der llnterbrechung ber $\mathfrak{S e r j a ̈ b r u n g ~ m i e ~ e i n e ~ r i d j t e r l i c h e ~ S a n d l u n g . ~}$

\$ 463. Sit die in cinem vollftredfoaren Strafbejdyetde feitgefeste (Belditrafe non Dem Bejchuldigten nicht beizu=

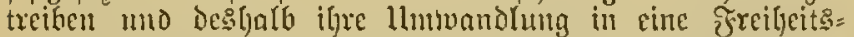

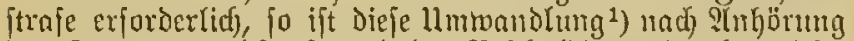

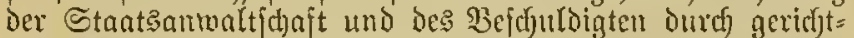

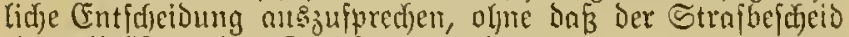
einer Früfung Des (Serid)ts unterliegt.

Die Enticheidumg itter die llutwandang erfolght, wenn

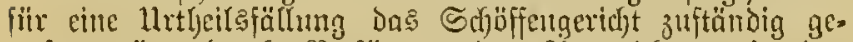

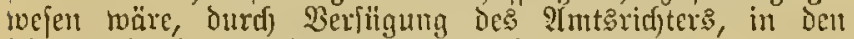

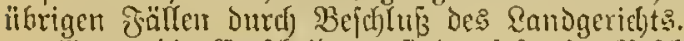

(Segen die (Entjdjeitung findet jofortige Bejdjerde fatt.

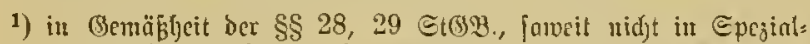
gejegen ein anberes beftimunt ift. (Fine nid)t beizutreibende Beldiftrafe miro in Befänguif und, wenn fie megen siner llebertretung erfount

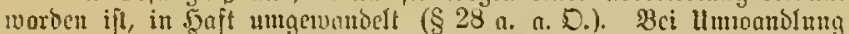
einer wegen einer 1tebertretung crfannten Beloftrafe mirs ber Betrug

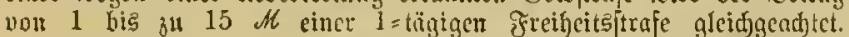
Der Mindeftertrng ber nn Elefle cinter Belditrafe tretendent Jreilgeits=

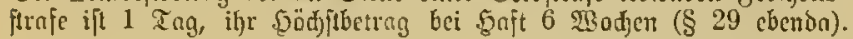

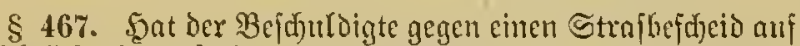
geric)tliche linterfuddung angetragen, ooer hat dic Stants=

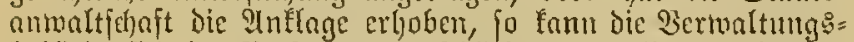

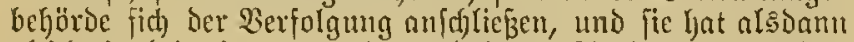
gleidluvie bei einer bon ibr erbobenen STltage cinen $B e r=$ treter zn befteller.

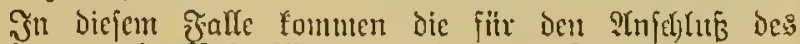

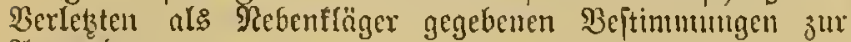
?tnmenoung.

\section{Berfahren bei Einziefungen แnd Berubgens= befwlagnalinen.}

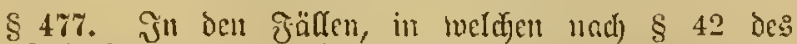

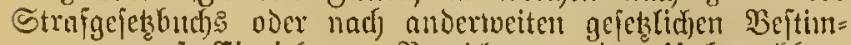

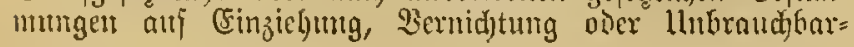

mad)ung von Segenftänden felbftîtündig erfannt werden fann, ift ber PIntrag, folern die (Entjocidung nidjt in Eerbindung

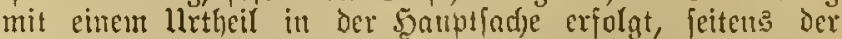
Stnatsanmolt ffaft oder des Grivatflägerş bei bemjenigen (Serid)te zu ftellen, weldyes fiir der Jalf Der Berfolgumg eimer Gejtimnten \$erjon zntiändig fein wïrde.

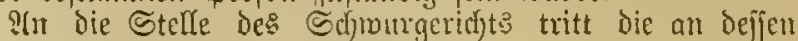
Sibsungsorte beftehende Straftammer.

58 478. (1) Die Berhandhng uno Entfedscioung erfolgt in einem Termine, atf welden oie beftimmungen ïber bie jauptberfondung emipredfende ITnvendung finden.

(2) (3) ....

\section{Budh.}

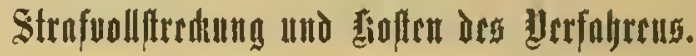

\section{Strafoorfituednug.}

\$ 481. Strafurtheile find nicft bolffrecfbar, bevor fie res(j)

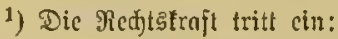

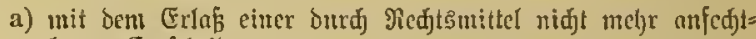
baren Entidjeioung,

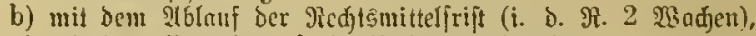

c) mit bent Berjiăt auf cin Neditsmittel und

d) mit ber Burüunalyme beffelben. - Daffelbe gilt von Straf=

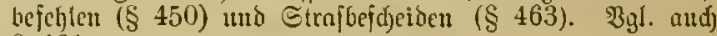
$\S 491$.

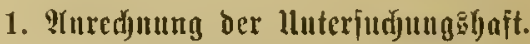

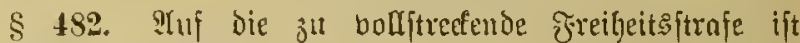
Imverfïrzt bicjenige linterjudumg der ?tugeflagte erlitten bot, jeit er auf cinlegung eine

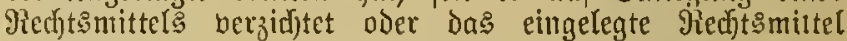
zuridfgenommen hat, ober feitbem bie Einlegungefrift $a b=$ gelaufen ift, obue dá̉ er eine Crelürung abgegeben bat.

\section{Strajoolljtreclende Bebörbe.}

§ 483. Die Strafoollftrefung erfolgt burd die Staats= ammalticjaft auf (Srumb einer bour Dem (Beridjtejdjeciber zu

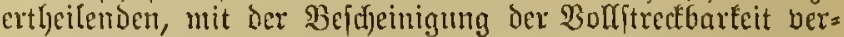

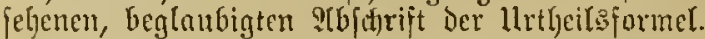

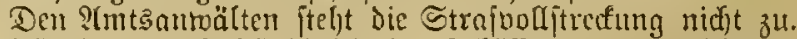

Fitr bie zur Zuftändigfeit her Sdjöffengerichte geljörigen Sadjen fam burd) STnoronumg dex Eandegjuftizbertwaltung

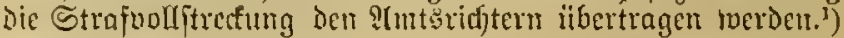

1) Эn Preusen geidjehen.

\section{Begnadigungâtredyt de fiaijer:}

\$ 484. Sn Sadjen, in denen Das Meidjggeridjt in

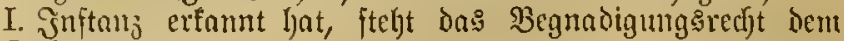
Snijet 3tl.')

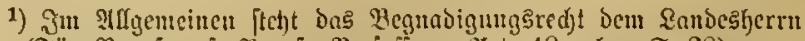

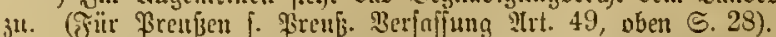

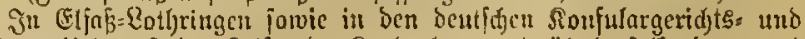

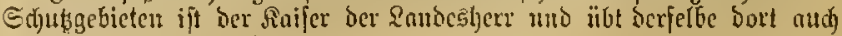

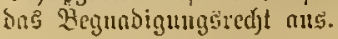




\section{Tobeßiptrafe.}

$\S$ 485. (1) Todessurtheile bedifrfen zu ihrer Balfitrectung feiner Bejtätigung. Die Bolfitreffung ijt jedod) erfit zuläifig, menn die (Entfadliefung des Stantsoberhauptes und in Sadjen, in Denen das Sieid) sgeridyt in I. Jnjtanz erfomnt hat, bie (Entfidfięzung des Saifers ergangen ift, bon beut Begnadigungerechte feinen (Bicbrauth madjen zu wollen.

(2) .....

\section{TItufidub ber Etrafuollitredung.}

\$ 48\%. Die Bollitrefung einer Jrribcitsftraje ift auf=

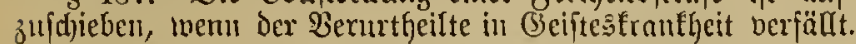

Daffelbe gilt bei anderen Srantheiten, mem von Der

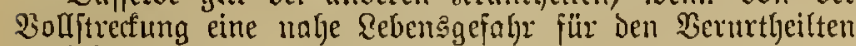
zu bejorgen itelyt.

Die Strafbolfitrectung fam aucic Danu aufgeidoben

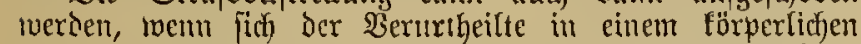
Buitande befindet, bei weIdjent eine jojortige Bolltrecfung mit Der (Fimrid)tung der Strafanjtalt unverträgfid) ift.

§ 488. Tuf Intring bes Berurtheilten fann bie Boll= itrecfung nufgejdoben merden, fofern Durd) bic jojortige Bollitredfung Dem $\mathfrak{B}$ erurtfjeilten oder der ₹amilie defjelben

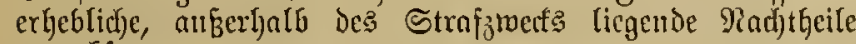
eribadffen.

Der ङtrafauffdub Darf Den Zeitraum bon 4 Monaten nicht iiberiteigen.

Die Bervilligun deffelben fonn an cine Sidjerlyeits= reijtung oder nndere $\mathfrak{B e b i n g u r g e n ~ g e f n i ̈ p f t ~ t w e r d e n . ~}$

\& 489. Die Stantsanmoltjchaft ift befugt, belyufs

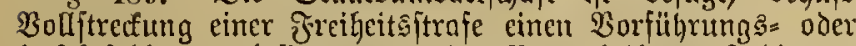
Soajtbefeljl zu crlafien, juenn ber Bernutheitte nuf bie nu ihn ergangene Sadung zum IIntritt der Strafe ficl) nicht geftellt hat ober ber J̛lud berbäd)tig ift.

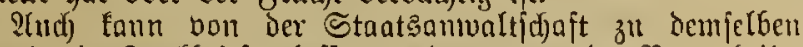
Brwecfe ein Stectbrief erInffen werden, wemn ber Berurtheilte fliuchtig ijt ober fïch berborgen bält.

Dieje Befugniffe itegen im Jalle bes \& 483 भYb 3 aud

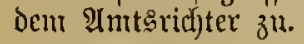

$\S 491$. Saun cine berfängte Beldjtrafe nidft beige= trieben werden und ift Die F̌eitjeţung Der für biefen Fall eintretenden freifeitsftrafe unterlafien worben, fo ift die Geloftrafe nad)träglid) bon dem (Serid)t in die entfpredyende

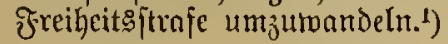

1) in Bemäplyeit ber $\S \S 28,29$ ङ oben ธ. 283.

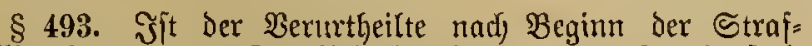
bollftrefung megen Siranfheit in cine voul der Strajanitalt getrennte Sranfenanitalt gefradit morden, fo ift Die Dauer bes Infenthalts in ber Siranfenanftalt in bie Strafzeit ein= zured)nen, wenn nicht der Berurtheifte unit der 2tbfid)t, die Strnfoolfitrecfung zu unterbredben, die sirnnflgeit herbei= geführt hat.

Die Staatsanmoltidjoft hat im Ickstcren Falle eine (Entfdjeidung Des Beridjt: herbeizuführen.

§ 494. (1) Die bei ber Strafuolfitrecfung notbwendig werdenden geridftlidjen (Entjdjeibungen (\$\$ 490-493) reerben

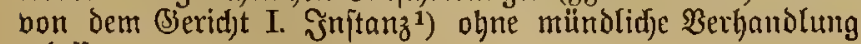
erlafien.

(2) (3) .....
(4) Begen Diefe (Entffreidungen findet, infofern fie nidut

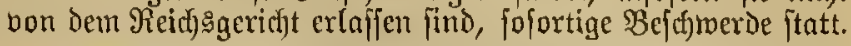

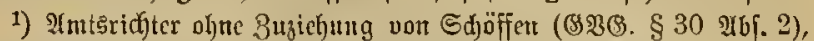

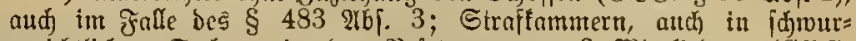

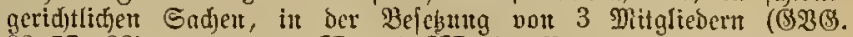

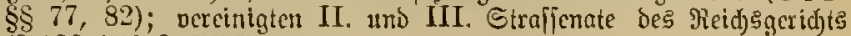
(\$ 138 269.2 (32).).

\section{Bermögen:}

§ 495. Die Boljtredtung ber über eine Bermögens= ftrafe oier eine Bube ergangenen (5ntidyeidung erfolgt nadj ben Borfdriften liber Die Boljtreffung ber llrtheile ber (Eivilgeridte. ${ }^{1}$ )

1) $§ \S 644$ ff. c\$D.

\section{Soften ${ }^{1}$ ) Des $\mathfrak{B}$ erfafreus.}

\$ 496. J̧edes lltheif, jeder Strajbefehl und jede eine Unterfutjung cinftellende (Entid)eibung mura Darïber $\mathfrak{B} e=$ ftimnung treffen, voll wem die Siften des Berfiahrens ôt tragen find.

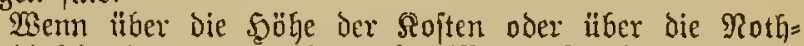
twendigfeit der unter ihnen begriffenten ?tısłagen Streit entiteht, fo erfolgt hierüber bejondere (entid)eidung. ${ }^{2}$ )

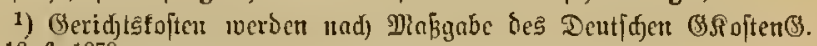
18. 6.1878

v. $\frac{18.6 .1878}{29.6 .1881}$ (

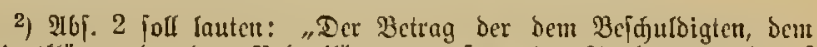
Privattläger ober bem Nebentläger zu erftattenden ?luşlagett wirb auf

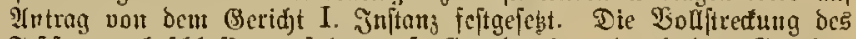

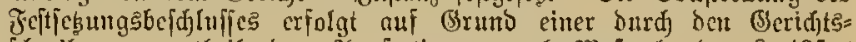

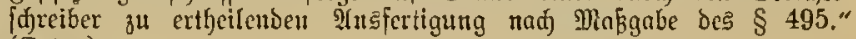
(Entiv.)

\section{Brlidgt zur foftentraguutg.}

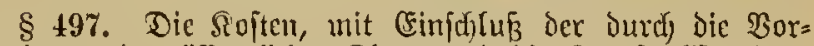
bereitung der b̈ffentlichen ßlage imb Die Strafnodftrectung

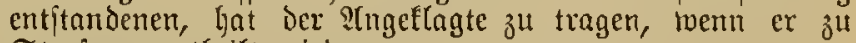
Strnfe verurtheilt wird.

Stirbt ein Berurtbeilter vor cingetretener Red)t:ffrajt

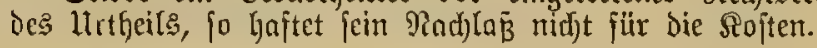

\$ 499. Finem freigefprodjenen oder auber Bexiolgung

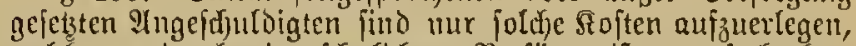

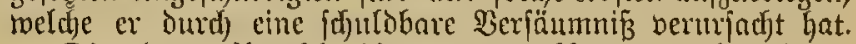
Die dem ?(ngefduldigten erwadfenen notfwendigen Itslagen tömen ber Staatstaffe auferlegt merben.

$\$ 500$. Bei toedffelfeitigen Beleidigungen ober $\Re$ örper= berlebungen wird die Berurtheilung eines ober beider Theile in die Sioften baour(t) nicht nusgejd)loffen, don ciner der= jelben oder beide für itroffrei erflärt werden.

\$501. (1) Sit ein, wenu aud mur außzergerid)tlidjes Berfahren Durd) eine wider befferes wiffen gemndhte oder auf grober Jahrläfïgfeit beruljende Inzeige veranlaßst worden, fo fam bas (Gerid)t dem ?trzeigenden, nadjoem Derjelbe geljört worden, bic der Stnat3kafie umb dem $\mathfrak{B} e=$ ifjuldigten erwadjfenen Sojten aujerlegen.

(2) (3) .....

§ 502. Friolgt eine Einftellung bes $\mathfrak{B e r f a h r e n s}$ regen

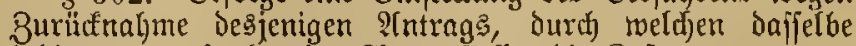
bedingt war, fo hat ber Antragitelfer bie Roften zu tragen. 
§ 503. Sil cinem Berjahren auf erfobene firibatflage

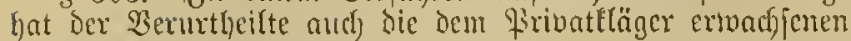
notfymendigen ?tusingen z" exptatten.

Whiro Der Befroldigle außzer Berfolgung gejeţt oier freigeiprocfen, ober wirs das Berfalyen cingeiterlt, jo falfen Den Gribateläger bic Soften be: 2 Serfabren: fowie die Dem

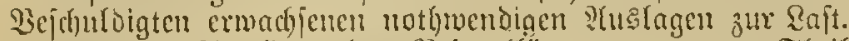

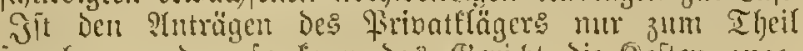
entiprodjen rortien, fo fann das (Berict)t die soften ange= mefien bertheiler.

Dehrere Privateläger und mehrere angellagte hajten als (B) fantmefiduloner.

Ilnter Den nad) Den Bejtimmungen diefes Baragraplen

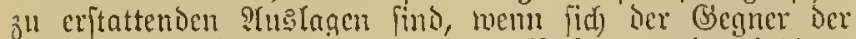

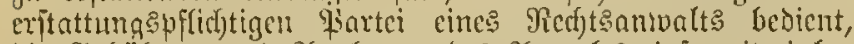

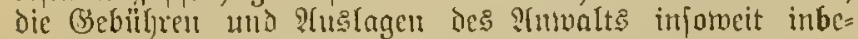
griffen, a[s fold)e nad) ier Beftummung des \$ 87 ber Eivilprozebordmung die unter(iegende Fartei Der obfiegenden zu eritatten Gat.
§505. Dic Soften eines zurüdfenommenem ober er= folglos eingelegten Red)tsmittele treffen benjenigen, Der Das: jelbe cingclegt fot. Wax bns Neditsmittel von der Stants= auwaltict)ajt eingelegt, fo tïnnen bie tem B̉efdruldigten er=

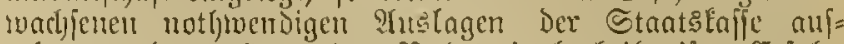

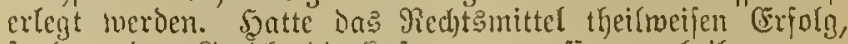

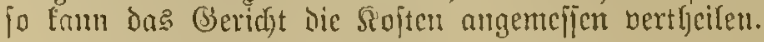

Daffelbe gilt von den Soften, weldye Durd) einen Whtrag

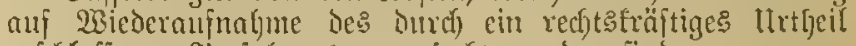

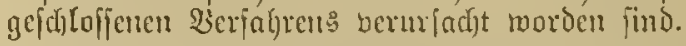

Die Sopten Der Wieterenfetiung in den borigen Stmo follen bem Pntragfteller zur Raft, forweit fie nicht burch cinen

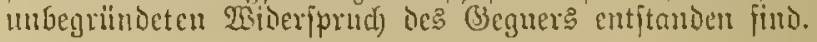

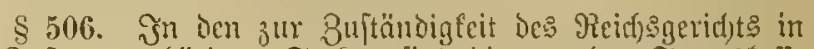
I. Jultanj geljörigen Eachen find bic bou der Etantsfoffe zu tragenden Soften ber Reidfstaffe aufzuctegen.

llrkundich $2 c$.

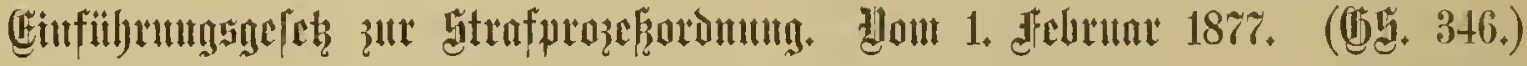

\$ 1. Dic Strafprojelzoronung tritt im ganjen ltmpange

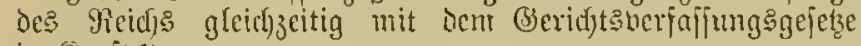
in Siraft. $\left.{ }^{1}\right)$

1) Das war am 1. 10. 1879.

\section{Geltungågebiet.}

§ 3. (1) Dic Strapprozeñoronumg findet auf alle Strafs

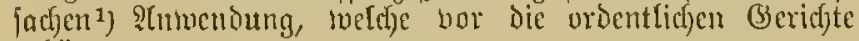
geljüren.

(2) . . . . .

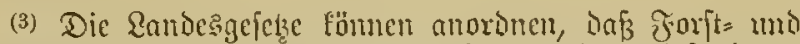
Jelorïgejadjen durd) Die ?tmtsgeridjte in cinem bejonderen

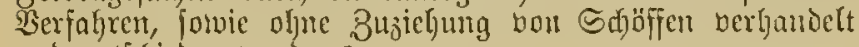
und entfdicten werden. ${ }^{2}$ )

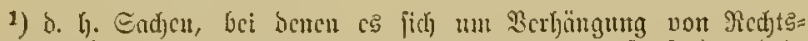

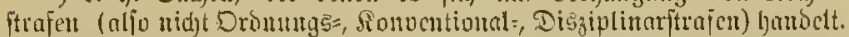

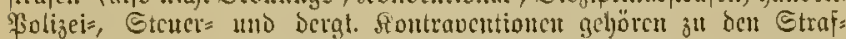
fadjen im Sinne bicjes Bejectes. (\$gl. $\$ \$ 447-467$ ).

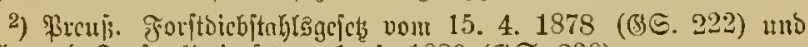
Feld $=$ und Foritpolizeigcich v. 1. 4. 1880 (\$S. 230).

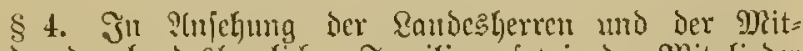

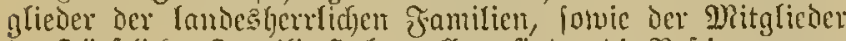

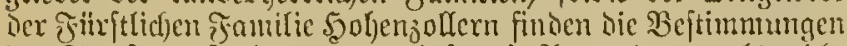
Der Etrafprozeforonung nur infoweit ?tnsenoung, als nidit

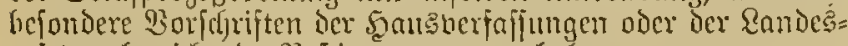
gejetze abrocidjende Bejtimmungen enthalten.

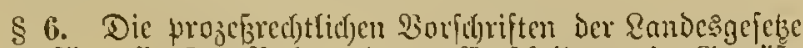

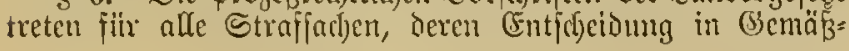

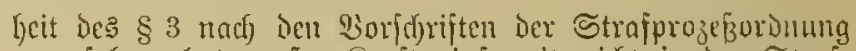
oll erfolgen lyat, aufiser Siraft, infotweit nicht in ber Straj= projeboromung auf fie bermiejen ift.

ltuberifl]xt breiben dic Landesgefeblicten Beftimunungen:

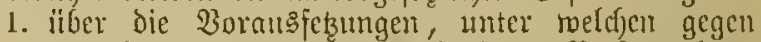
Pritglicder einer gefetzgebenden Berfanmlung während der Dauer eincr Sizungapcriode cine Strafuerfolgung cingcleitet oder fortge ceist verben Insm; ;

2. Hiber Das Berfelyen hei Zutwiderhandungen gegen

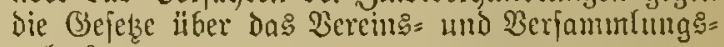
red $\left(t^{2}{ }^{2}\right)$

3. Hiber das Berjaljen im Derwualtungsmege bei llebertretungen, wegen deren die qolizeibehörden 3um Erlâ̧ cince Strafwerfïgung bejugt fims, und bei Bnwiderbandlungen gegen die Borjeriften über

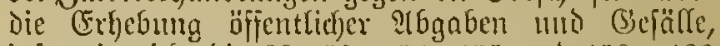
infoweit nicft bic $\$ \$ 453,454,455$ unto $459-463$ der Strafarozefaroronung abändonde Beftimmungen treffen.

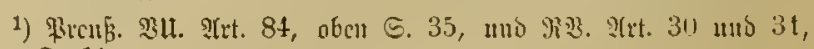
oben 5. 11 .

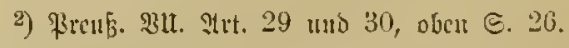

§ 7. Breję in Gimne dor Strafprojef̧ordmung und

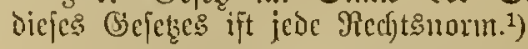

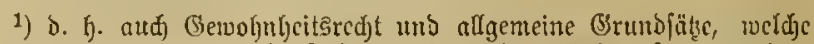

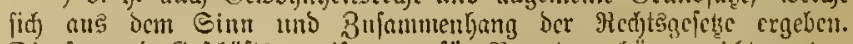
Dienjt: unto Bcidjäftanmeifungen fïr \$cante gefjorch nidjt ful bent Piclytsinornter. 


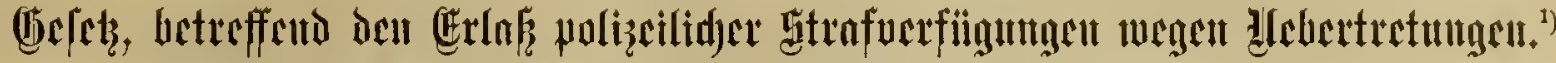

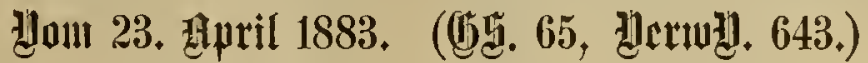

\author{
1) Daffelbe ift auf (Srunb ber $\S \S 453-458$ ऽtগD. erInffen.
}

\$1. Wer bie Folizeiverwaltung in cinent bejtimmten Bezirfe alszuüben (jat,1) ift befugt, inegen ber in bicjem Bezitic veribten, in feinen Bervaltumgabereidy fallenden llebertretungen Die Strafe Durd) Berfitgungen feftzufetzen, fotwie eine etwa berwirtte Einjiełung za berhängen. Dic polizeiliche Strajoerfügung ift aud gegen Bejchnldigte im Âter bon 12 bis 18 sahten julläfiig.

Wird Beloftrafe feitgefelzt, fo ift jugleid) die fiir Den Fall des llnvermögens an bic Stelle ber Gieloftrafe tretende \$nft zil bcitimmen.

Die feitzufekende Beloftrafe daxf den Betrag von 30 Mart, bie Scaft, aud twenn fie an bie Stelle einer nidjt beiju= treibenden Geldftrafe tritt, die Dauer bon 3 Tagen nitft ülierfdjreiteu. (Fradjet Der Prolizeiverwalter eine höhere

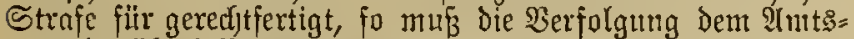
antwalte überlaifen werben.

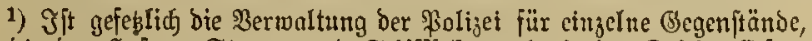

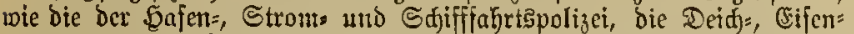
bahns und Chauffieepolizei, nicht ber solizeibehörde Des Sorts, fondern einer befostberen Behärbe übertragen, fo gebiihnt mur bicfer bie \$3efug=

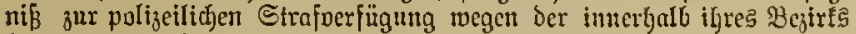

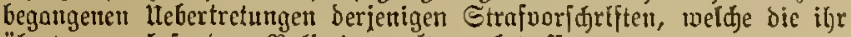
ïbertragetre befordere \$olizcinermaltung betreffen.

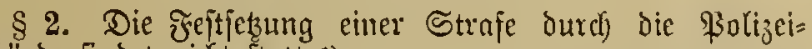
belobrde findet nicht ftatt: 1 )

1. bei Utebertretungen, fiir deren 2tburtheilung die

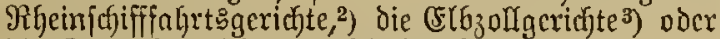
Dic (Semerbegerid̄te ${ }^{4}$ ) jujtändig find;

2. bei Hebertretungen Der Borfhrifteta ïber die (Fr= Gebung öffentlicher $\mathfrak{A}$ bgaben over (Sefälle; ${ }^{5}$ )

3. bei Hebertretungen bergpolijeilicfer Borjdjriften.6)

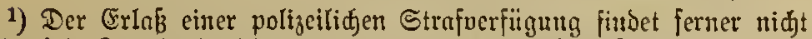
ftatt bei Bunviberhandungen gegen bas forftoicbjtaljisgcies voun

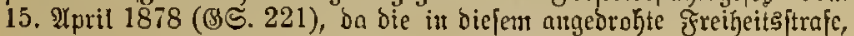

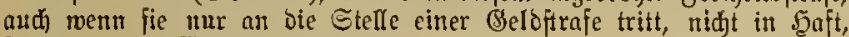
fonbern in Gefüngnif bejteht.

2) उefes v. 8. 3. 1879 (ङS. 129), §6.

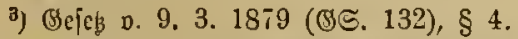

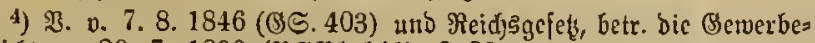

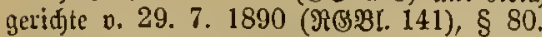

5)

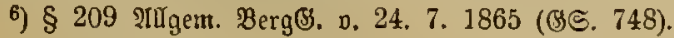

§ 3. Der Befduldigte fann gegen dic Strafberfügung

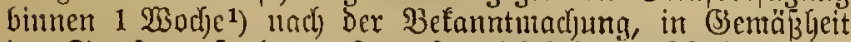
ber Strafproze(3ordmung, ${ }^{2}$ ) auf geridytliche (Eutjudeidung an= tragetl.3)

šit gegen cinen Bejduldigten im $2(1 t e r$ bon 12 bi: 18 sabren eine Strafberfilgung erlaffen, fo laun hinnen

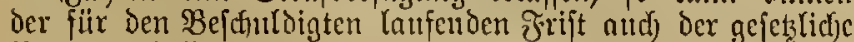
Bettreter beffelben auj geridftlidje (Entfjeibung antragen.")

1) Gegen bie Berfänunung Der IIntrngsfrijt geftattet ber $\$ 455$ ber

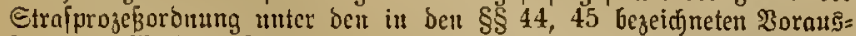
febungen $\mathfrak{B}$ iedereinfebung in ben vorigen Stand. Siernad fann:
1. Die Miebereinfetung in ben vorigen Stand beantragt

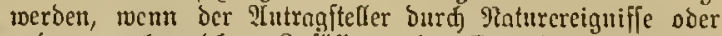
aubere uuabwenbbare Bufälc an ber Cinbaltung ber frift

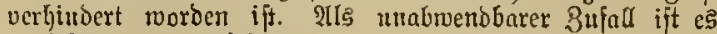
insbejonoere anzufchen, wem ber Intragiteller von ber

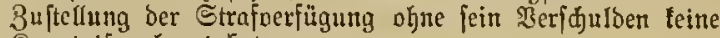

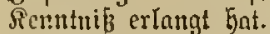

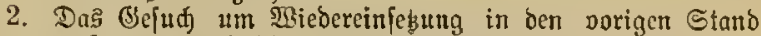

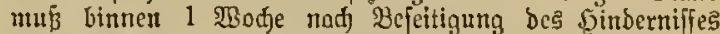
unter शrgabe uno (SIaubl]aftmadung ber Ber[äuntuif: griinbe $(\$ 45)$ bei ber \$olizeibeförbe ober bei bent 2 ints: geriate angebradt merben $(\$ 455)$.

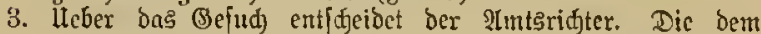
Gejube ftattgebenoc (Entidjeibung unterliegt Eeiner Infedtung;

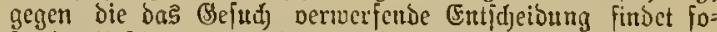

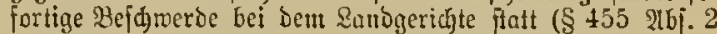
uno $3-\$ 72$ bes Gerifjtsperfaffungsgefeßes vom 27. Januar 1877).

2) Begen bie polizetlide Strafverfügung findet mur ber e)rrtrag

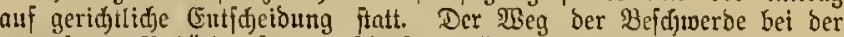

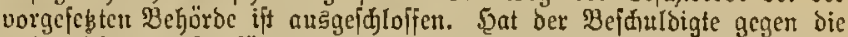

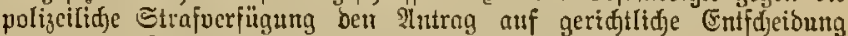
angebradt, fo bat nad) $\$ 454$ ber Strafprojeforonung ber \$olizei= vermalter bie Befugniß̧, anftatt ber Heberjendung ber Berhanolungen

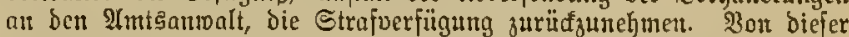

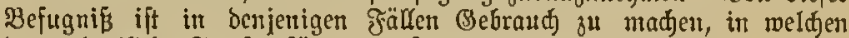
bie polizeitiche Strafoerfügurg auf einen Эrrthum betuft.

3) lleber die Beredftigung ber Bolizeibehörben auf ser $a b=$

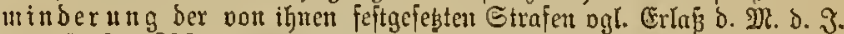
yom 5. 9. 1892. Darad fteht es Den \$olizcibehörben frei, in ge=

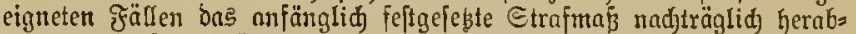
anmindern, fonde überbaupt die Sttaffeffegung aud bann zurüc=

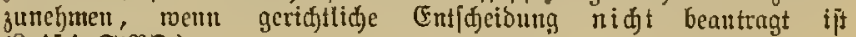
(\$ 454 ๔iPD.).

4) Eitte befondere 3uftefung ber Strafverfügung an bett gefețlidjen Bertreter ift nidjt oorgefórieben.

$\S 4$. Die Strafuerfügung muß̧ auß̧er ber Feftießzung ber Strafe ${ }^{1}$ die ftrafbare Sandlung, Beit und Drt Derfelben, bie angewendete Strafoprjdyrift und bie Betweismittel, fotoic die Saffe bezeidyen, an weldje bie Belbitraje zu zablen ift.

Gie muß die Fröfnung entljalten:

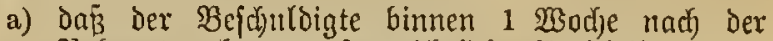
Befanntmadjung allf geridjttidje Entfódeidung an= tragen fönne;

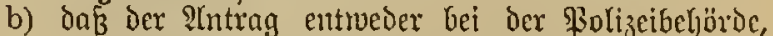
weldie die Strafuerfügung erlaffen bat, oder bei Dem 3uftändigen IImtsgericht anjubringen fci;

c) Daß̄ die Strafoerfïgung, falls inncrhalb ber be= ftimmten Jrift ein Intrag auf gerid)tlid) (5nt= idjeidung nidjt exfolge, woriftredfor werde.

1) Die polizeiliche ßerfügung muई dic im $\$ 4$ bes Befejes be= zeidneten श्ngaben voll fändoig enthalten.

Sift bie llebertretumg nit Geloftrafe ober saft beorolgt, io hat ber Polizeiberwalter nady ben bei ber liebertretsutg obwaltenden llmitänent

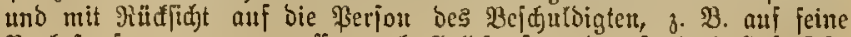
Sorbeftrafungen, zu ernteffen, ob Geloftrafe, ober fogleidg Saft feft. onfegen fei. 


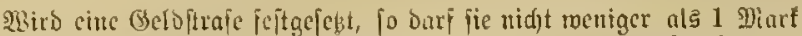
betragen, fofern bic zur Siuweroung tommende Etrafvorfarift ridjt

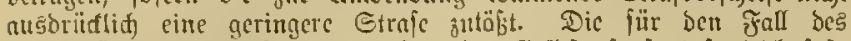

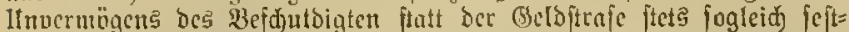

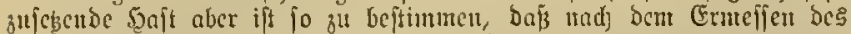
Foliseiverwalters ber Betrag von 1 bis 15 ग)

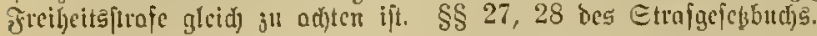

\$ 5. Dic polizcilidje Strafnerfitgung ift nad) Mabs=

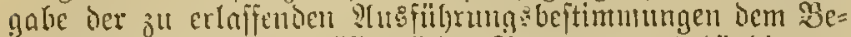

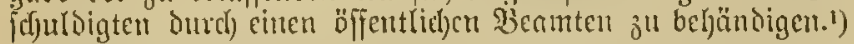

1) Die Buftefung fonn aud burd die Boft ctfolgen. In bicjent

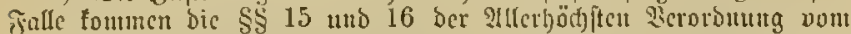

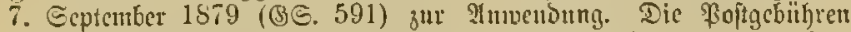
bat bie \$olizeibebötos ju entridten, vorbebaltlid) ber etmaigen (Ein=

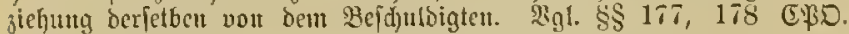
(obeit 5.157 ), weldje beziehenttid) Brficlbe cuthaltest.

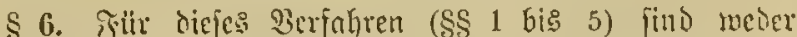

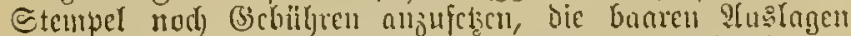

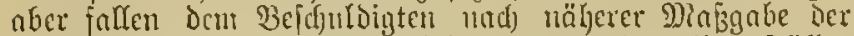

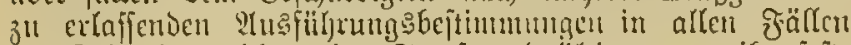
jux Eaft, in weldfen cine Straje cnogulytig gegen ibu foft= gejekst ift. $\left.{ }^{2}\right)$

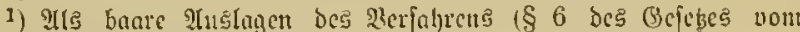
23. \$(prif 1883) buirfer vour bent Dejdur(bigten nur cingezogen merben:

1. \$oitgebührent,

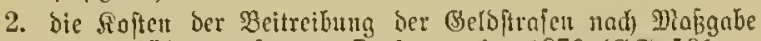
bes Gebülgrentarifs vout 7. Ecptentber 1879 (Bङ.591),

3. Die Soft= und Transportlo[ten, welde Durd) Bollftrectung bicr baft entftejen.

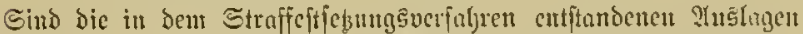
nidit beizutreiben, fo fallen fic als Roften ber Drts=\$olizcinerwallung

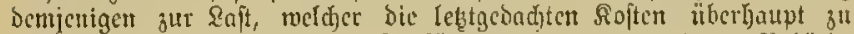

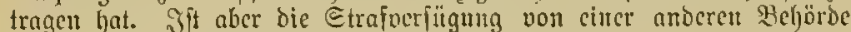

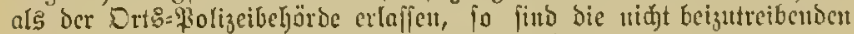

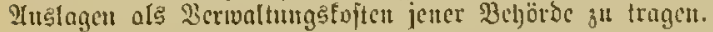

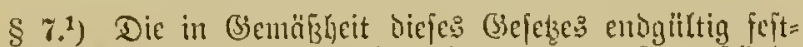
gejetzten Beloftrafen, jowie dic cingezogenen (Segcuptünde fallen Demienigen zu, weldjer bie füd)lidjen Sujten ber Solizcinerwaltung zu tragen hat.

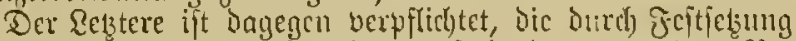

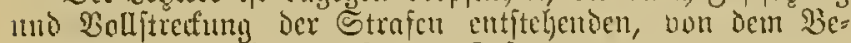
fd)uldigten nidyt beijutreibenden fioften zu tragen.

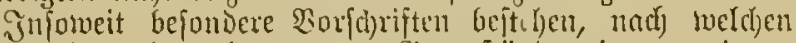
(Belditrnfon oder eingezogene Gegenjtändc cinem nndoren

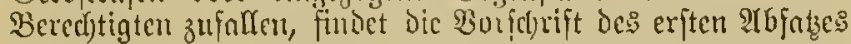

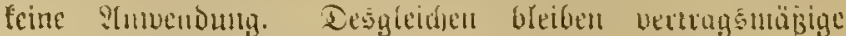
B̧eftimmungen unberilgrt.

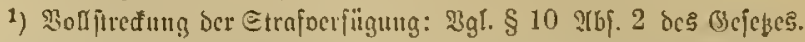

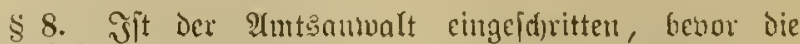
nolizcilide Strafoeriügung Deut Bejúfuldigten Gebändigt

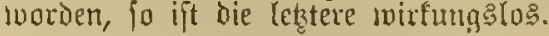

§ 9. Wiro bei Dem 2(mţgeridyt auf gerid)tlid)e Cint=

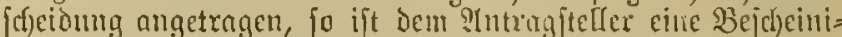
gung hierniber foftenferi zut ertheilen. ${ }^{1}$ )

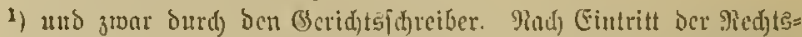

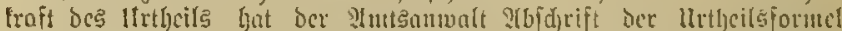

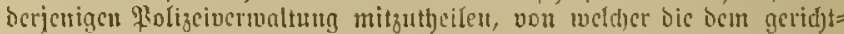

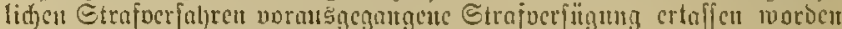
ijt. V̧erig D. Juftizunifters v. 2, 7. 1883.

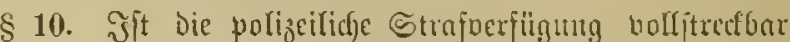

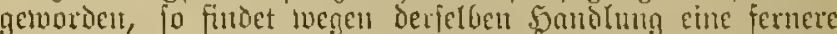

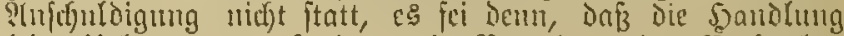
feine llchertretung, fontem ein Rergehen ober Verbrerben

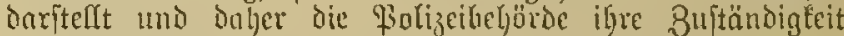
iiberf(d)ritten hat.

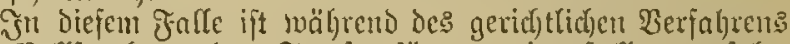
Die Wolfitrecfung ier Strafuerfitgung cinzuftellen; crfolgt

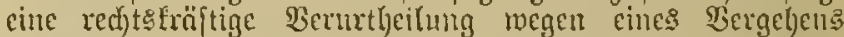
ober Berberd)ens, fo tritt dic Strafoerfïgung aufer froft.

§11. (Siegen Miritärperfonen dür fon die \$olizeibe= böroen Strafen nur wegen foldjer Llebertretungen feftfctzeu, zu beren Y(burtheilung iut gerichtlichen Berfahren Die orbentlidfen (3)erichte zuftöndig find. Fine Jeftfebung von sant für oen Fall Des llnbermögens (\$ 1 YGints 2) findet Durd) Die qisolizeibelörbe nidjt itatt.

\$12. Das gegenmärtige Bejck tritt ant 1. J̋แli 1883 in Siraft umo in Denjonigen Rnudestueilen, in weld)en jur Beit Das (Sefer nom 14. Mtri 1852 Geltung hat, alt die

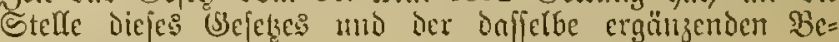
ftimumungen.

Bon Diefen Iage ab find fït Das ineitere $\mathfrak{B e r f a b r e n}$ in benjenigen Sadjen, in weldjen cine polizeitisbe Straf=

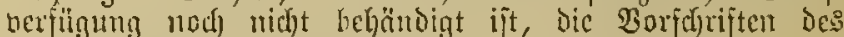
gegennärtigen Gejeł̧es maß̈gebend.

\$ 13. Die Minijter ocs Jnmern mo der Jujtiz lyaben

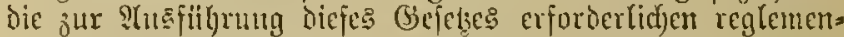
tarifdjen Beftimumugen ju erloffen.

Urtumblid) $2 \mathfrak{~}$.

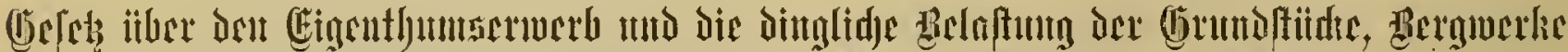

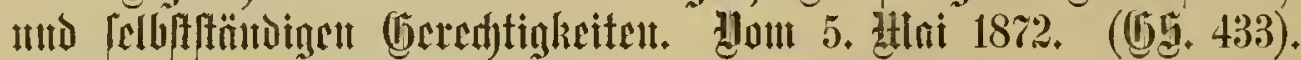

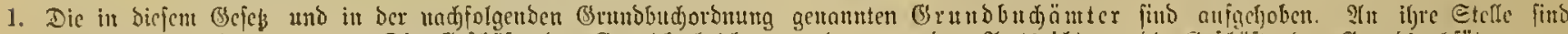

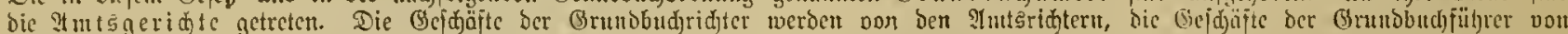

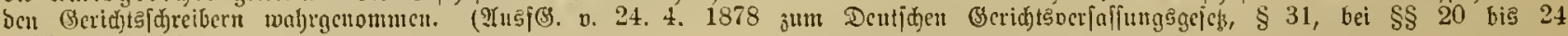
G20. vermerft.)

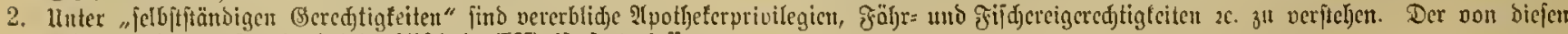

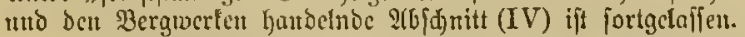

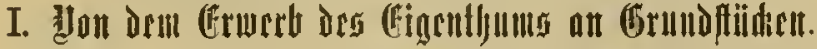

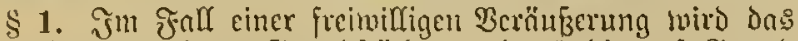

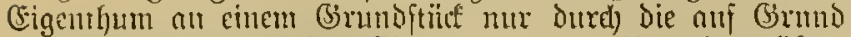
einer Tuflaffung erfolgte Eintragung bes Eigenthumsitber= ganges im (Brurobuch extworber.

৫ß゚. $\S 2,59$.

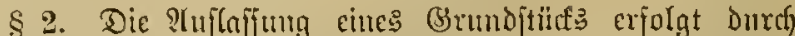

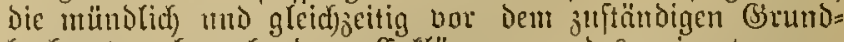
butfamt abjugebenden Erthtärmgen bes cingetragenen Eigenthïmers, bn $\mathrm{B}$ bic sintragung ic: neuen Ertwerbers beivillige unt bes Redzteren, doß er bicke Eintragung be= antrage.

(32D. $\S 30,37,43$. 
§ 3. Ein (Extenntnifs, durd) reldhes der eingetragene

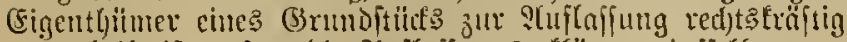
verurtheilt ift, erjetzt dic ?tuflajfung? serflärung deffelben.

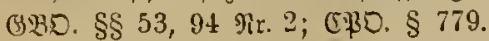

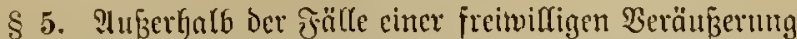

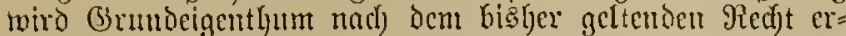
morben. ${ }^{1}$ Das Redjt ber Slufluffung uno Belajtung ocs (3rundftildes erlangt aber ber Erwerber erjt dured jeille Eintragung in (Sirundbutf.

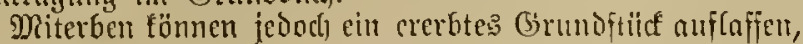

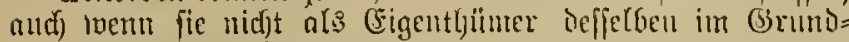
bud eingetragen find.

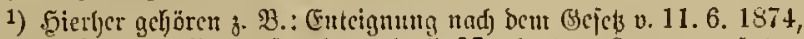

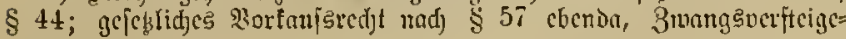
runget น. ส. เก.

§ 7. (1) Der cingetragene Ceigentfjümer ijt frajt peiner Cintragung befugt, alle silngered)te ies Gigentlilimers alls zuilben, und verwflichtet, fidt) alf die gegen ilgn als (Eigen=

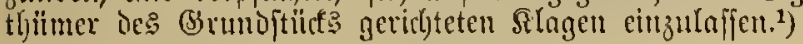

(2) .....

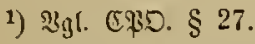

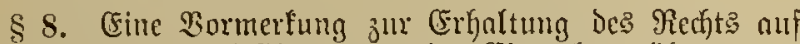
9luflafiung oder nuf Eintragung Des Eigenthumsï̈berganges fam nur unter Bernittelung des Frozežrid)ters 1) oder mit Benilligntutg Des eingetragenen Sigenthïmers eingetragen

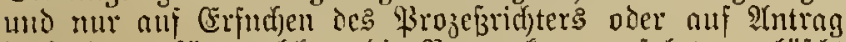
besjenigen, für twelcheu dic פormerfung erfolgte, gelöfdit merden. ${ }^{2}$ )

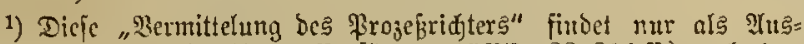
führung cimcr einftreiligen Berfügung (C\$O. $\$ \$ 814$ ff.) nad ber

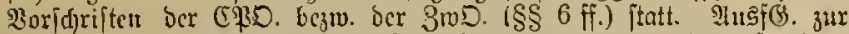
C15. o. 24. 3, 1879 (BS. 281), § 18. "Dic Jurd) eirftueitige Berfïgung angeorbucten (Fintragungent in cinem (Grunb= pober Fupotbetent=

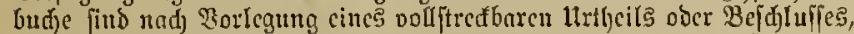
Durd) welde bic einjtwcilige s?crfïgung aufgchoben ift, anf SIntrag

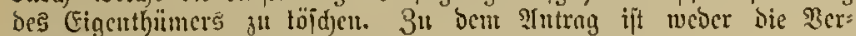

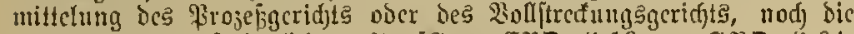

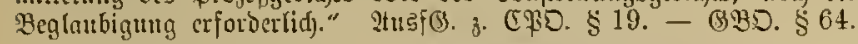

2) Siormerfung über cir cingelcitetes Entciguungswerfahren: Ent-

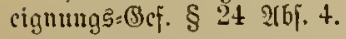

5 9. (1) Dic Eintragung Des Eigenthumsiiborganges

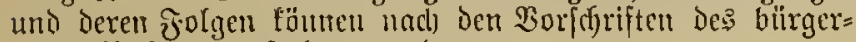

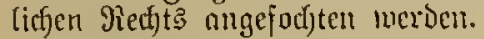

(2) (3) .....

G3D. $\S 64$.

§ 11. Bejưränfıngen Bcs (Eigenthumsired)ts an dcm

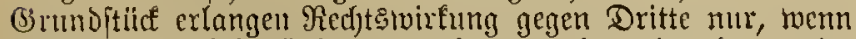
Dicfetben die Befd)ränfungen getonnt lyaben oder leţtere im (3rundbud) eingetragen find.

(3) $\S \S 119$ ?r. 2,51 .

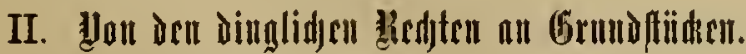

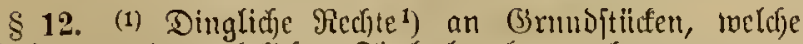
auf cincu privatred)tliffen Titel berulfet, erlangen gegen Dritte un burd) Eintragung $23 i r f j a m f e i t$ und vertieren bie= felbe butd) Eöfdung.

(2) (3) (ii $\dot{\text { ir }}$ i.

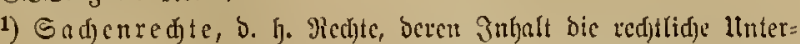
reetfung ciner Sade (aljo bes (srmbjtïđs) ift, im Begenfag zu ben

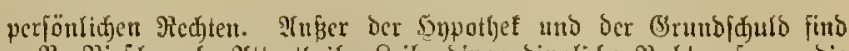

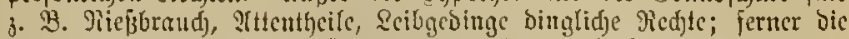

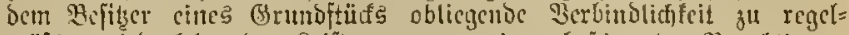
mübig vicoerfef)renoen Eciftungen an eincu bejtinunten Bered)tigten, Sicalajten. Stlle bicie Piectite erlangent gegen cinen Dritten (ocn (Erwerber beg (3rumbfü̈đs) nur burd) bic (Fintragung im (3rumbbudc Trirffamfit.

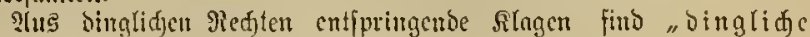
R̊agen", midjt perfönlidje.

§ 13. 3ur Cintragung cines Rechts in ier II. 9(b= theilung ${ }^{2}$ ) Des (5)rundbucfe genilgt der STntrag des einge= tragenen oder feine (Eintragung gleid) jeitig erlaugenden

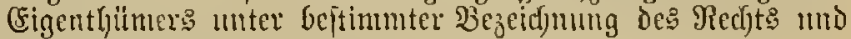
Des 3 erechtigten.

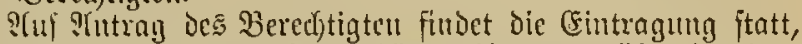
twenn des eingetragene Eigentljïmer $i$ jun gegenüber in cinet beglaubigten lirfunie dic Ceintragung bervilligt hat.

GBD. $\S \S 31 \mathrm{ff}$.

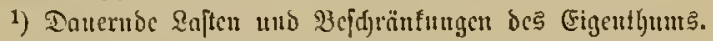

\$ 14. Felyt die Einnillignng ocs Figentfü̈mers, jo

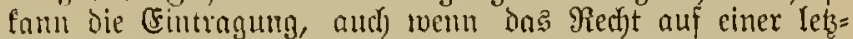

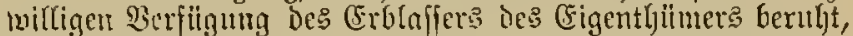

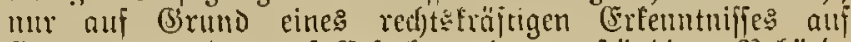

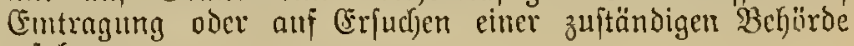
erfolgen.

(330. $\S \S 41,53,92,94,100,117$.

$\S 16$. Eine Bormertung zur (Erlyaltung Des Rechts nuf

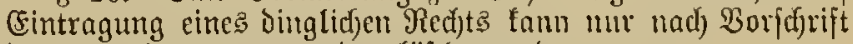
bc \& 8 eingetragen unt gelö/d)t werben.

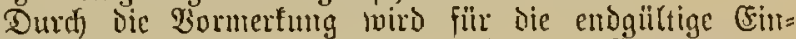
tragung die Stelle in ber Reifenfolge der CEintragungen geficfert.

(53D $§ 64$.

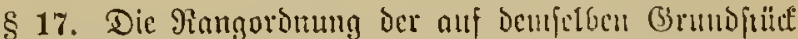

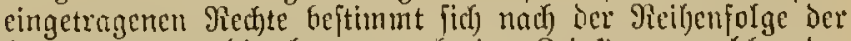
(Eintrngungen, Die (estere nad) Der Beit, ${ }^{1}$ ) jull tweldjer Der :Intrag allf Eintragung dem Grunbbutant borgclegt worden ift.

Eintragungen unter demfelben Datum haben die Rang=

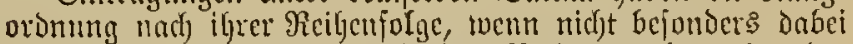

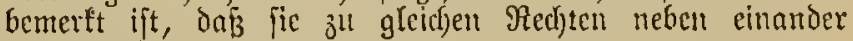
ftehen follen.

(39D. $\S \S 44,45$.

1) $\mathfrak{B g l . ~} \$ 42$ (3BD. ES foumt babci urter Utmfländen auf Stutiven uno Mituten an.

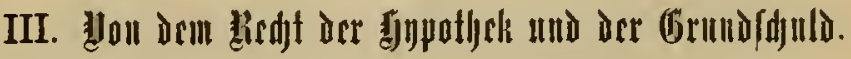

\section{Bon ber Begründug biejer Medjte.}

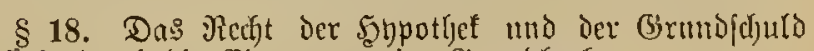
entifeljt durdf) Dic Eintragung im (Grundbud).

§ 19. Dic Cintragung erfolgt:

1. twent der eingetragenc ober feine (Eintragung gleidf)= zeitig erlangende (Figenthütuter fie bemilligt.

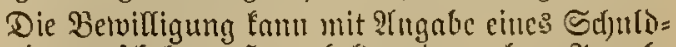
grundes geifjeten (5otpotget), oder oljne stugabe eincs Sdjurogrundes (Srunofd)uld). J゙m criteren Falfe mus die Sdjuldurfunte vorgelegt werden; 


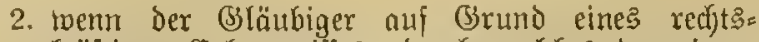
fräftigen (Erfenntniffes, Durch) weldhes ber einge= tragene CFigenthïme: zแt Beftellung einer Sypothef oder Brundichtld verurtheilt toorben ift, bie Cin= tragung beautragt;

3. wern eine zujtändige Beljörde geger den eitnge tragenen Eigenthümer bie CFintragung nadjfudyt.

अBO. §§ 41, 53, 87, 92, 94, 100, 117.

\$20. Der eingetragene (3)läubiger erlattgt Dns Ver pitgung

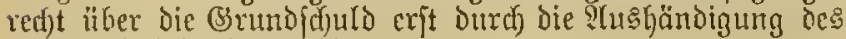
(Brmuldifuld briefs an ifn.

(अBD. § 122.

§ 21. Der eingetragene Miteigenthümer famn auf feinen 2utheil eime Sybpothef oder Grundfdjuld betwilligen; nud fam in 20 ege bes gefetsficjen Bronnges gegen ilju auf feinen Stutheit eine foldse cingetragen werden.

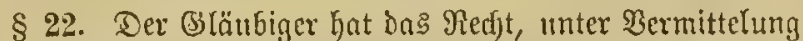

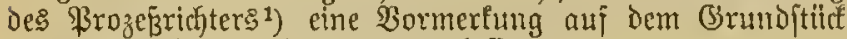
jeincs Sdfuldncrs cintragen z" Iafjen.

2(ud) Dicjenigen Behorden, toeldye bie Cintragung einer

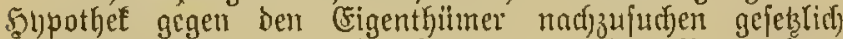
berechtigt find, ebunen die Cintragung eimer Bormerfung verlangen.

Durd) Die Bormerfung roiro für die endghiltige cein=

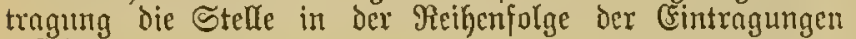
gefictert.

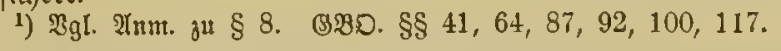

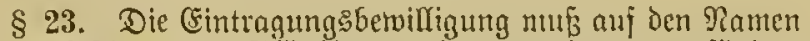
cines beftimmten släubigers lauten, hns nerpiändete (s)rundftitio bezeidnen, und eine bejtimute Summe in gefers=

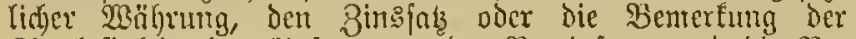

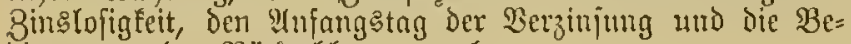
Dingungen ber Rïazoblung nngeben.

अखD. \& 43.

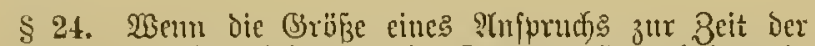
(5intragung nod) unbejtimut ift (Sautions=55tpotbeten), jo

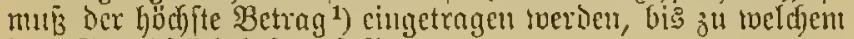
Das Brumbititef lyajten foll.

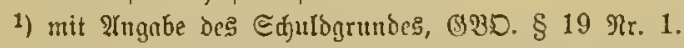

§ 25. (1) Jૈ̈̈r Rapitalien, weld)e zinglos oder mit Binfen

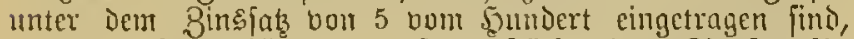

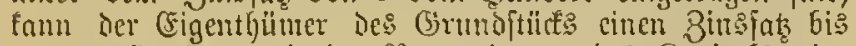
5 bou SJundert mit ick Rangorommg bes Siapitals cin= tragen laffen. Der (Finmilligung Der nad) Dem Tage, an welchem biejes (Befetz in Siraft getreten ift, gleid)= oder nad)ftehend eingetragenen (3läubiger bedarf es nidyt.

(2) .......

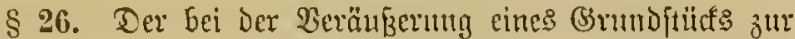
Sicherftellung einer Forderung beoungene $\mathfrak{B}$ orbehalt des

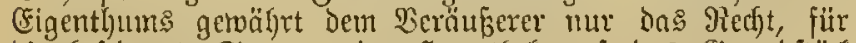
die bcftimmte Sunme cine Sapothef nuf bas Grumbitillf cintragen zu lafjen.

§ 2\%. Der Figenthinter Eam anf feimen ?anten Brund= id)ulden eintrages und fid) (Grnubidultobriefe ausfertigen

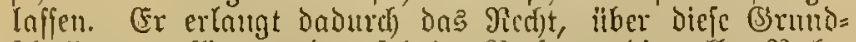
[d)

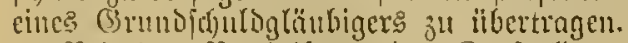

Bei ber Sertheilung ber Satfigcloer in Folge einer

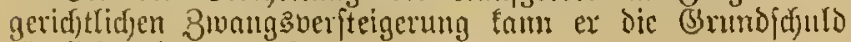
fiiv fidf) geltend madjen.
§ 28. Şat Der (Figenthÿ̈mer Das Figentlyum des Grund= ftiicts abgetreten, fo crlangt $\mathrm{cr}$ an ber auf feinen Famen

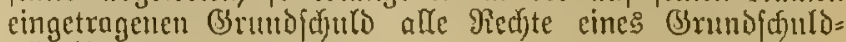
gläı

§ 29. Cine Shpothef fam auf Intrag Des CEigen=

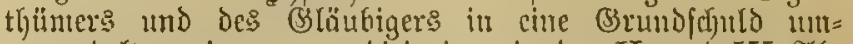
getunndelt werben, toent biejenigen in der II, und III. STb= theilung gleidy = oder nadjeingetragenen Bered)tigten ein= rwilligen, rueld)e vor besn Tange, an weldyem diefes (S)efets in Sirnft tritt, eingetragen find.

\section{Bon Dem Ulmfang Des Sypotgefen= und des} (G) rundiduldoredis.

§ 30. Jür tos cimgetragene Sapital, für bie ein= getragenen Binfen und jouftigen รălyreszahlungen und jür Die Siojten ber Fintragung, Der Sünoigntng, ber Slage tub Beitreibung Kajten:

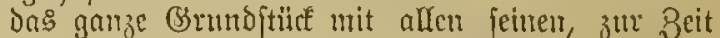
ber Eintragung nicht algef(t)richenen Theilen (Sarzellen, Tremitüicen);

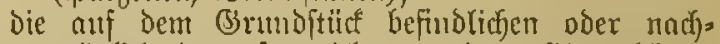
träglid) barnuf erridyteten, bent (sigentbitmer geförrigen Bebäude;

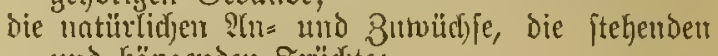
und hängenden frntid)te;

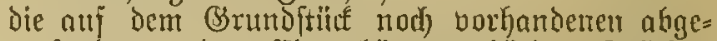

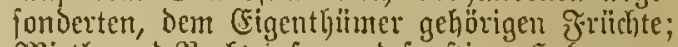
die Miet)= uno \$adtzinfen und ponftigen Sebungen;

die jugefdriebenen unberweglidgen Bubeljörftitefe (Pertinenzien) und Bicrectigfeiten;

bas beweglid)e, beut Eigenthümer gehörige $8 \mathrm{Z}=$ behör, jo lange bis dajpelbe nerüubert und vou deut Girundjtituf räumlich getrennt worden ift;

Die Dem Cigenthïmer mfalfenden Berfid)erungs: gelder fiir Frithte, betweglictes Butbebör tuto abgebramute oder burch Brand bejchäbigte (5) $\mathrm{c}=$ Gände, wenn diefe (Beloer uid)t ftotutemmįgig zur Wiederherftelfung der Bebättio verwethot verden milifien oder bermendet worden find.

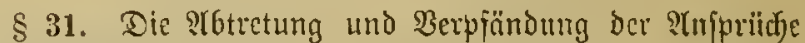

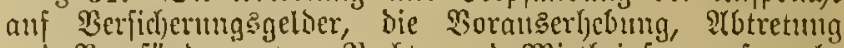

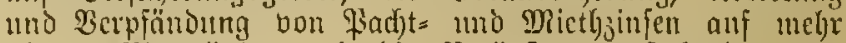
als 1 Qierteljolyr, umb bie Berüußzerung jtefender mo

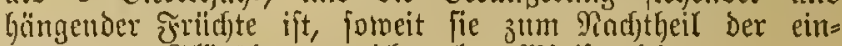
getragenen (5läubiger gereid)t, ohne Wirtfamfeit.

$\S 32$. Werden nad) Der (Fintragung ier Shppothet oder

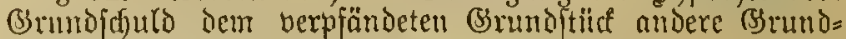
itiiffe als Bubeför zugefdriebeu, jo treten biefe in dic \$FFand. berbind (ichteiten Defielben; es geken jeboch oie utitübertragenen

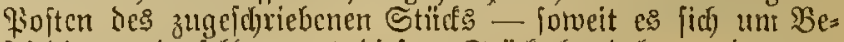
friedigung Derfelben aus biefem Stïd handelt - Den jur Beit ber $8 u\{$ d)reibutug auj Dem Saauptgut cingetragenen bor. (3)D. $\$ \S 65,66,118$.

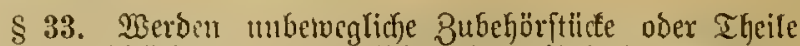

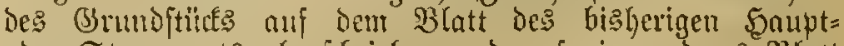
ober Stamurguts abgeidoricben und auf ein anderes Blatt ïbertragen, jo haften fie jï: bic ciutgetragenen Belajtutugen Des hisherigen Snutut= ober Stanmgute mur Dann, wenu Dicje bei ber Prbidsreibung nuf Das andere 3 latt mit= itbertragen morben fimb.

(3) $\$ 0 . \$ 65,66,70,118$. 


\section{Bon der Rangoronung}

ber anf bemferben Bs runbitit haftenden Sgyothefen und Brandidulden.

§34. Die Rangardumg Der anf temielben Grumb=

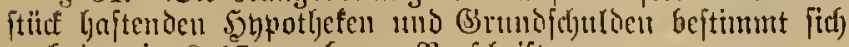
nacly ben in $\$ 17$ gegebenen Vorfdyriften.

(3BD. $\S \S 42,44,45$.

\$35. Fin voreinnetragener (3) red)t einem nad̂fftehenden ciuräumten. Die Cinräumung Des Borredts für das Rapital bezieht fid) auth auf die Rebenleijtungeu. Die Borrechte der Brifchenpofteu werden Gierdurcf) nicht geändert.

अभญ. $\S \S 4,86$.

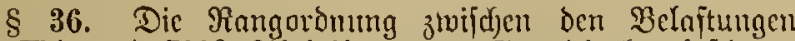
zur II. ${ }^{1}$ ) und III. ${ }^{2}$ ) s(btheilung bes (Grumbbut)s bejtinut (id) nad) Dem Datum ber (Eintragung.

Eintragungen unter bemielben Datum fteljen zu gleidjen

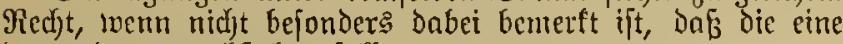
ber anderen nadj]tehen joll.

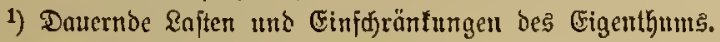

2) Sypothefen uno (Srundjoulden.

ॐㅁ. $\S 42,44,45$.

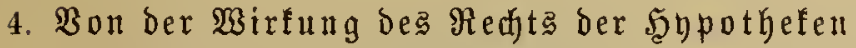 und ber (s)}

§ 37. Durd) Die (Eintragung Der Shpothet umb Der

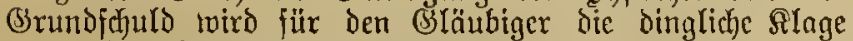
gegen den (Eigenthïner begriindet. ${ }^{1}$ ) Der Eetztere loaftet nur mit Dem (Brunditï(f nad) Masgabe Der $\$ \S 30,32$.

1) b. h. Der (Bläubiger erlangt $21 n$ fprud) nuf Befriebigung nus bem

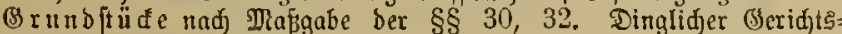
ftand: § 25 ए\$D. vben ङ. 147.

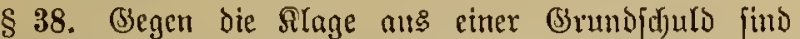
cimreden nur poweit zuläjftg, als fie dent Beflagtell gegen

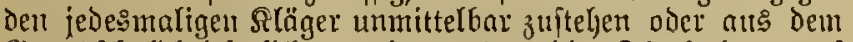
(Brundfduldbrief fid ergeben, oder bie Thatfachen, allf weldje fid Dicjelben gründen, dem ßräger bein Cerwerb der (Sicundjofild befamit getwejen find.

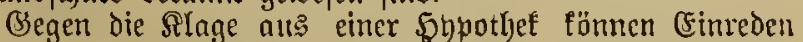
aus Dem perfönlichen Srfuldoerhältnif̧ einem Dritten, weldyer ein Redft auf die Sabpothef gegen (Entgeld ermorben hat, nur entgegengejebt twerden, wern fie ifm norher be= famt gevorden find ober fid) aus bem (Srundbud) ergeben.

(Finreden gegen Das Berjitgungêredjt bes Slägers alls Der Sierjon feines cingetragenen Recftiurfebers (Shutors) find fomohl gegeu die Silage aus ciner (Srumblotild als gegen die aus cinel \$口pothet unzuläfitg.

\$ 39. Begen Die Dingliche Slage alf Rütuftände bon

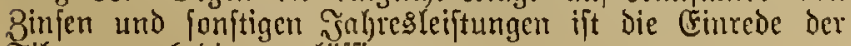
Iilgunt unbedingt zulälitg.

Mit Dem (Srundidfuldorieje tönnen Binsquittung: fifeine rusgegeben merben. Sit bies geidjetjeu, fo ift nur

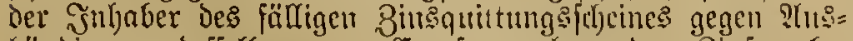
ljändigung defferben jur Empfangualyme der Zimjen be= red)tigt.

(अ, $§ \S 115,128$.
$\S 40$. (3) leich)= oder nad)eingetragene (b) läulitger fömmen

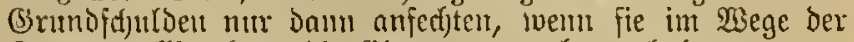
Broangsvolfitrefung bic Eintragung erlangt haben.

\$ 41. Sat Der Errwerber cints Grmoftüçs die auf

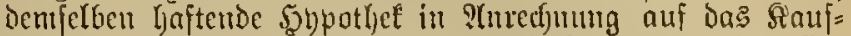
gelo ilfernommen, fo erlangt ier Bräubiger gegen den e $\mathrm{r}=$

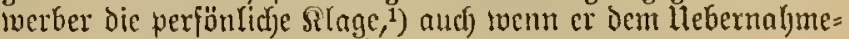
bertrag rididt beigetreten ift.

Der BeräuB̈erer wird bon feiuer per[önlidjen $\mathfrak{B e r}=$ binolidf) feit frei, tnem der (s)läubiger nid)t innerlyalb

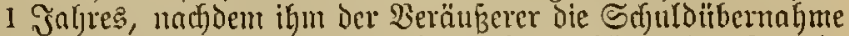

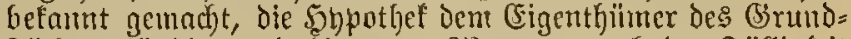
fiülfs getiindigt und binnen 6 Mionnten nad) der Fälligfeit cingeflagt lynt.

Sft bas Rïnoigmggrect)t fïr cine bejtimmte Beit aus= ge[d]lofjen oder an dell Eintritt eines beitiumten Ereigniffes

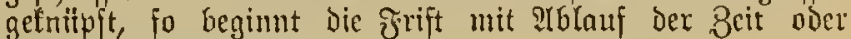
Eintritt Des Creigniffes.

1) Diefe perfönlidje Rlage fann aber in bem "Dingliden Berifteg= [tanbe" erhobent werben, C $90 . \$ 27$ (oben S. 148).

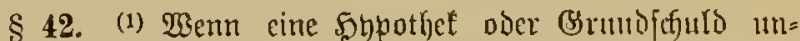
getheilt auf mehreren Bsinnoftïfen haftet, fo ift der (s)äubiger berect)tigt, fich an jedes eimzelne (Brmubjtiict roegen jeilter ganzen Forderung ju halten.

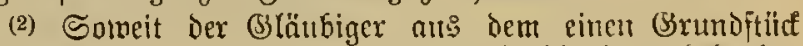
feine Befriedigung erhalten hat, erlifd)t dic 5ypothef oder (Sirundichuld alif bem mitberfafteten Brumbititef. Der Eigenthitmer deffelben erlangt nicht das Red)t, über biefe quojt zil verfilgen, ober fie für fidf zll liquibiren.

(3) ......

(5PD. $\S 78$.

§ 43. Der ljubothefarijace ader (Brundfduldogläubiger, Deffen IInfprudf) bolfftrectbar geworden, yat Das Reefjt, auf geridhtlidge Broangenerinaltung uno gerichtlidfe Zmangs: berfteigerung allzutragen.

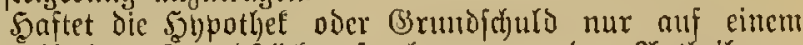

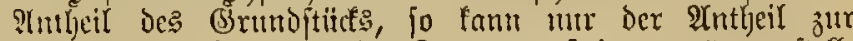
Bivangsverwaltung und Brang sperjteigering ${ }^{1}$ ) geftellt twerden.

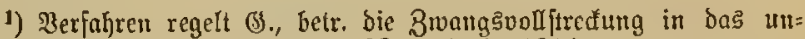
betweglide \$ermögen $\mathfrak{v} .13$ 7. 1883 . (BS. 131.)

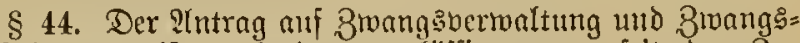
berfteigerung ift and Dann zulüjfig, wenn peit der $311=$ ftellung ber Silage cin Weedjel in Der \$erjon bes erigen=

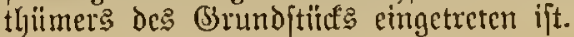

\$ 45. Cin Bertrag zrvifden dem hypotheforifden oder

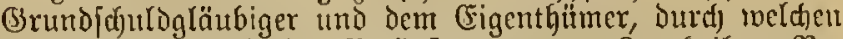

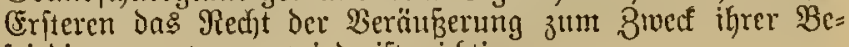
fricoigang entzogen roird, ift nicjtig.

\$ 46. Der (Figentljïmer ift berect)tigt, bei der 8mangs

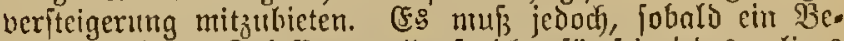
theiligter feiner Bulaffung miderfprid)t, fïr fein jedesmaliges (Sebot in Termin eime Sidf)erheit ${ }^{1}$ ) baar oder in inländifochen üffentlidjen, nicht außer Umlauf gejestent \$3apieren ein=

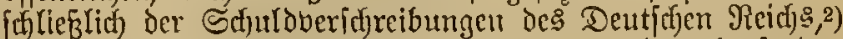
erlegt werben. Dieje \$apiere miijien mit Den laufenden

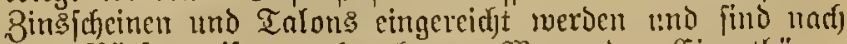
Dem Börfentpreife zit beredfnen. 23ern Det Eigentlüunex ber Meiftbietende geblieben unb cin begrünocter 2 iderfprut) 
nid)t erfolgt ift, fo wiro Durd) Erfemutnif ausgeiprod)en,

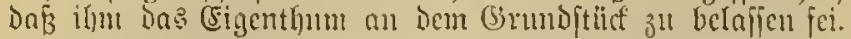

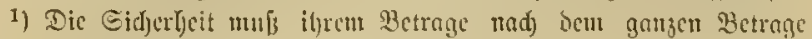

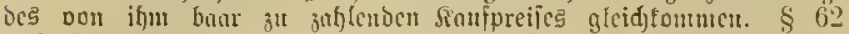

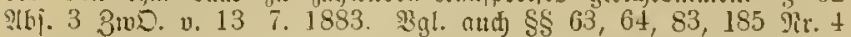
cbenda.

2) vocr anderer Deutjdjer Etanten § 64 \$16;. 1, 3100. v. 13. T. 1883.

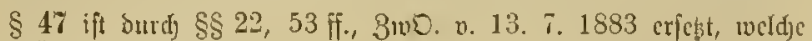
bouptfädtid bejtimuren:

Ohute lkebermbme ober Befricbigung Derienigen Refte,

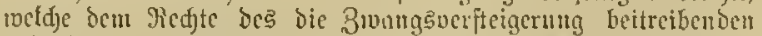

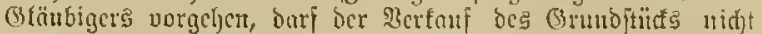
ftatfinden. 3u biefen 3wed wirb burd) ben ßidhter, uölhigen=

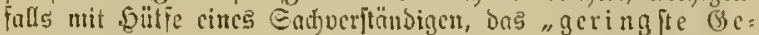

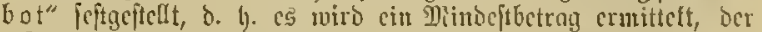
erforberlid) ift, un alle bem beitreibentoct (Stäubiger vot:

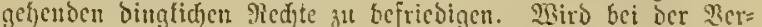

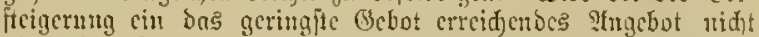
abgegcben, fo wiro ber 3ujhtng nidjt crtheilt. Dic Bmangs= werfteigerung if frudftos verlaufen und Etan nur auf crneuten,

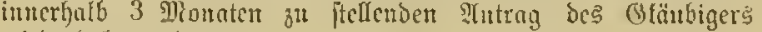
wicberfjolt werben.

Durd bet Setfut wird bas Grumbftiof von alfen bing= fidjen Micdten frei, foncit bicielben oun ben Erfteher nidht übernommen werdon.

§ 48. (Ein Burtrag, Durd) meld)en fid) Det (sigentljümer

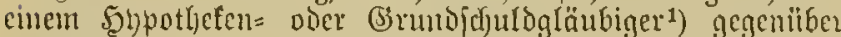
verpflicfetet, dos Grundftilef nicf)t meiter ôtu belaften, ift nichtig.

1) Itnderen ficrfonen gegenüber funu ex fid aber verpflichtent.

§ 49. Bef(f)rönfungen toç eingetragenen Glïubigers in

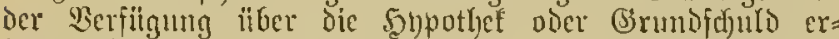
langen Redftsivirtmg gegen Dritle mur, wem Diefelben hei

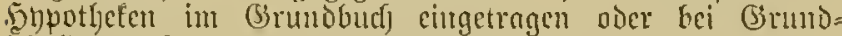

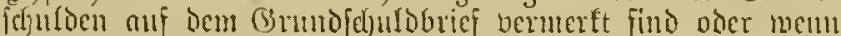

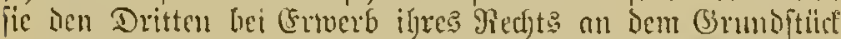
befannt waren.

Die Cintragung erjolyt entweder mit Bemifligumg des

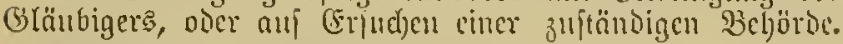

अPD. $\$ 11,41,87,92,100,117$.

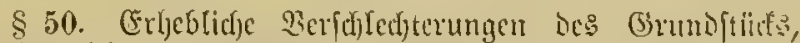

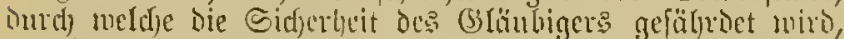

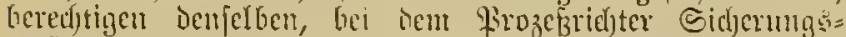

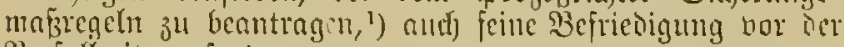
2ैerfallyeit ju fortern.

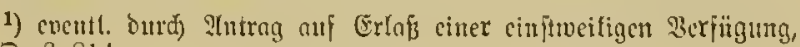
(ำ. § 814 .

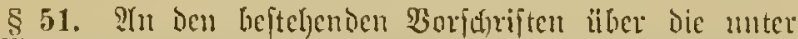

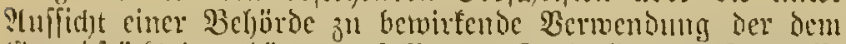

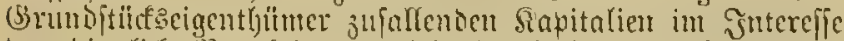

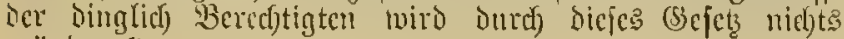
geändert. ${ }^{1}$ )

1) vgt. น. a. Entcigg. v. 11, 6. 1874, $\S \S 37,38,45-49$.

\section{Bon ocm llebergang Der Jghpotgefen mo (3) ruUbid)}

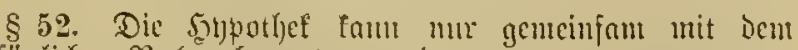
periöntidhen Rerfyt abgetzeten werden.

93iro cine zur Eidfrumg eines periöntidfen 9ied)t

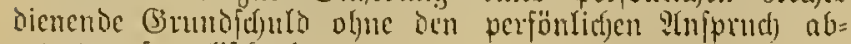
getreten, fo crlijulft Ietzterer.

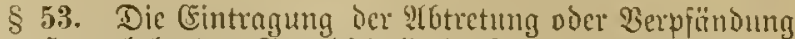

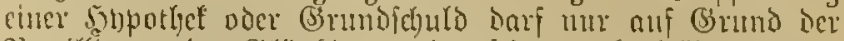

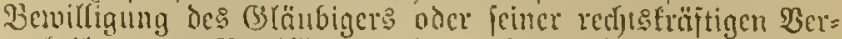

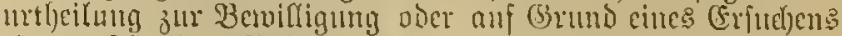

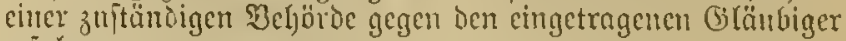
cijolgen.

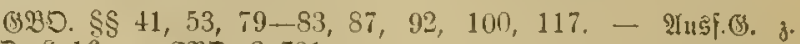
ธ90. $\$ 16 .-$ Eश口. $\$ 731$.

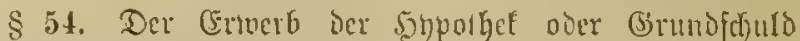

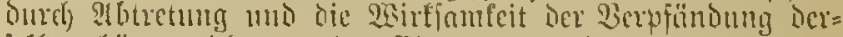
jethen bängt nidut bou Ber Ceintragumg ab.

अ30. $\S \S 79-83$.

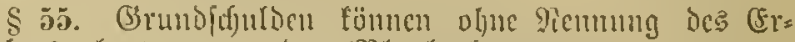
werbers nligetrelen weroen (B3lantonbtretung).

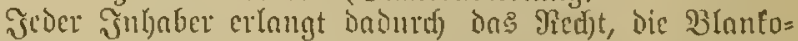

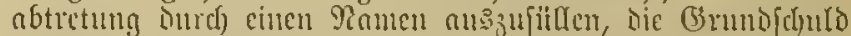
aucl) ohne bicfe ?tusfïllumg abjutreten, und bic binglidfe Singe anzuitellen.

(\$30. § 33.

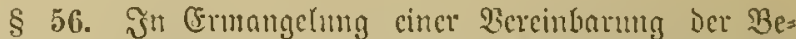
theiligten merben bie Rojten der פerpfändung eines:

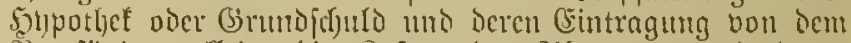
Qu'tufünder allein, Die Sioften ber ?tbtretung und Deren

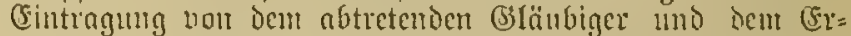
werber jul gleidjen Theilen getrngen; hat jedoct) Der $b e=$

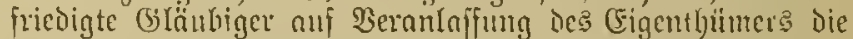

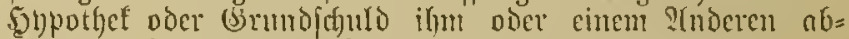
getreten, fo hat ier CFigentfjimer dic Stbtretungs: uno Cintragungafoften zu zahlen.

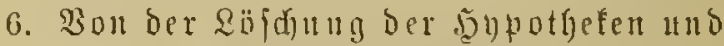 (G)}

\$5\%. Das 5uputhefen= uno (Grundfoulored)t twiro

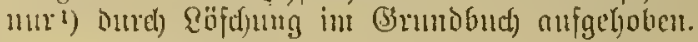

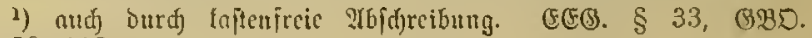
$\S \S 59,118$.

\$58. Die Räj(d)ung crfolgt auf IIntrag des Cingen=

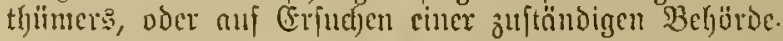

(3)․ $\S \S 33,41,87,92,94,100,117$. PD. $§ 779$.

§ 59. Bormerfungen toerden gelöj(d) 1 1) auf (Erfud)en Der"

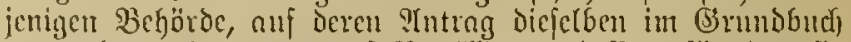
bermerft morden, oder all Berwilligung Deffen, fiir Den fie bermert morden find.

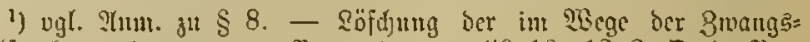

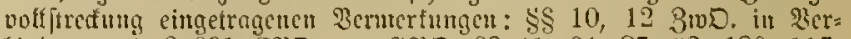
bintont mit $\S 691$ 690. - $030 . \$ \S 41,64,87,42,100,11$.

$\$ 60$. Weigert Der Brlünbiger Dic Bewilligung Der

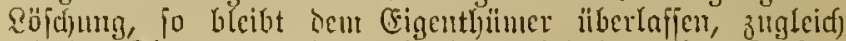

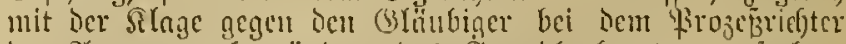

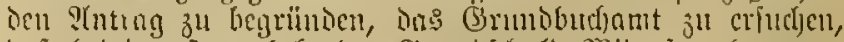

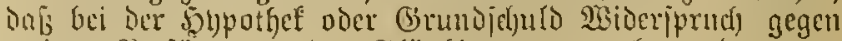
weitere Berfitigungen oes SSläubigers nermerft rerbe.

(3BD. $\S 64$.

§ 61. Die Softeu ber Suittung und \&öfdjung hont bcim Piangel ciner Rereintharumg Der Bietheiligten Der Sd)uloner, bie bejunteren Sioften für ben Tiadjucis ber Beredstigung

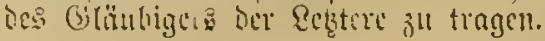


\$ 62. In die Stelfe einer getöjdjten selpothet umb (3irundidjuld barf eine andere nidht eingetragen werden, bielmehr rüufen bie nadj]tel)enten fioften hor.

๒2D. § 118.

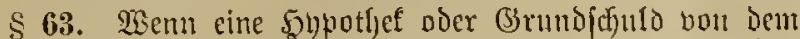
(Figentfümer beznfit ooer muf andere 2 eile getilgt morocn ift, jo ift der bisljerige (Blüubiger nad) ber $23 a b l$ bes

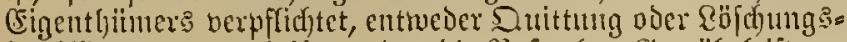
hemilligung on ertheilen, ober bie \$oft olgne Gemälyteiftung abzutreten.

(330. $\S 94$.

\$ 64. Der cingetragene Eigentlyiluer ift berechtigt, nuf (Gruno der Duittuug oder Röj(f)ungshenifligutug bie Fojt

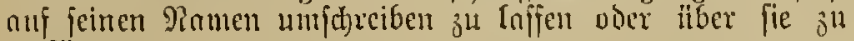
berfïgen.

\& 65. Ein gleidhes Recht bat ber cingetragene Einent=

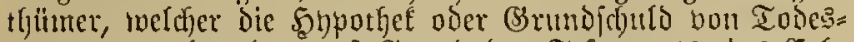
twegent ertworben lont, auf Grmb des Teftaments, bes (E.b= bertrnges ober Der (Erb6eidjeinigung.

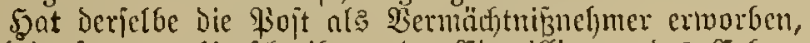

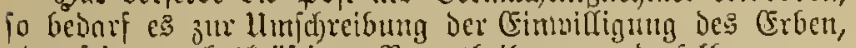
nòer feiner rechtaftäftigen Berurtbeilung zu Derjelben.

(3มD. $\S \S 51,53,94$.

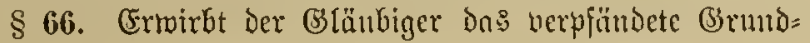

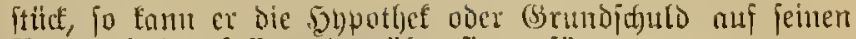
Nomen fteljen Infjen oder itber fie berfïgen.

(3)D. $\S 9+\Re r .3$.

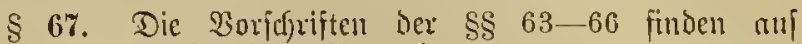
Santionshypotfefen feine ?(unendung.

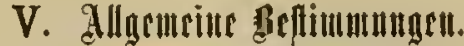

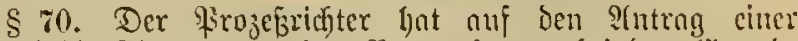
Sartei bie (Eintragung einer Dormerfung ${ }^{1}$ ) hei deut (3rund =

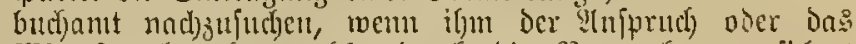
MBiderfprudjertedt, melde burch) Die Bormerfung gefidjert twerden jollen, glaublyaft gentad)t fint.

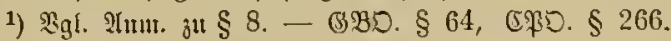

\$ 72. Dieję (Gejełz tritt ant 1. Detobcr 1872 in Strajt. $\left.{ }^{3}\right)$

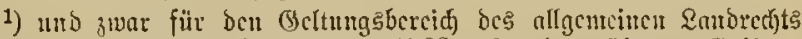

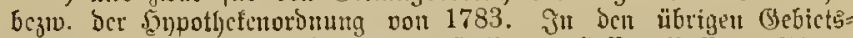

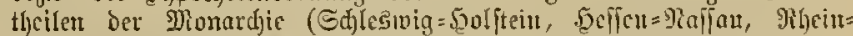

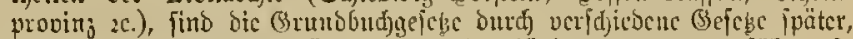

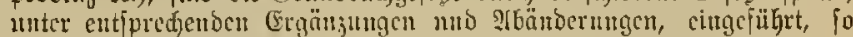

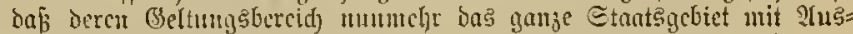

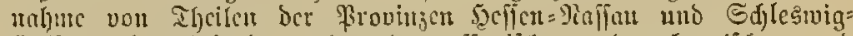

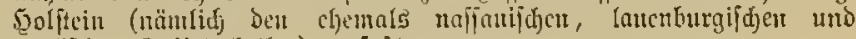

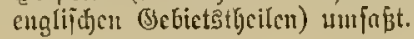

llafunolicf $2 c$.

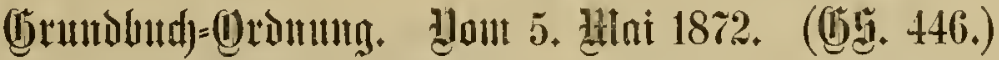

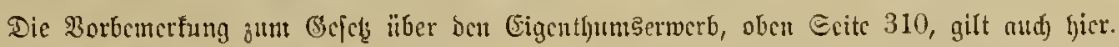

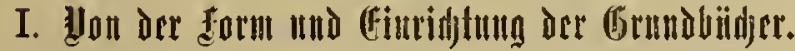

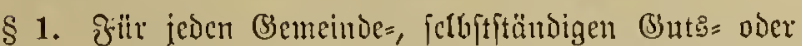
befonteren (Grundfteuer = Erbebungsbezirf werten eit oder

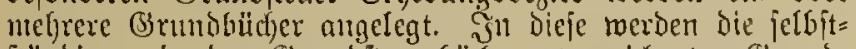
itändigent, in Den (Brunoftenterbiichern berzeichneten (Srumb= fitidfe eingetragen.

Die fintrngung exfolgt in jortlaufender Pammerreifye.

§ 2. Für Domainen mo moere dem Stnat gelyürige

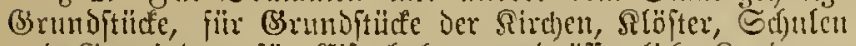

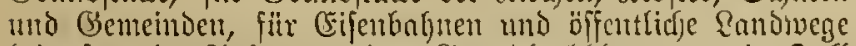
bebarf es der ?tulegung eines (3rintobud) blatts mur im forn ber Bern̈nferung oder Beloftung, ober mem bon Dem Eigentfiumer oder cinem Beredftigten ontruf nugetragen miro.

Die Grunoftüfe Der Eijenbalynen und Die öffentlitien Ranbuege verben boun in dem (5rmubbud) eines jeben Bejitfs $(\S 1)$, in meldem fie liegen, eingetragen.

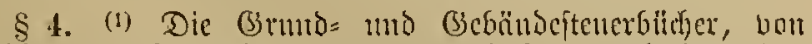

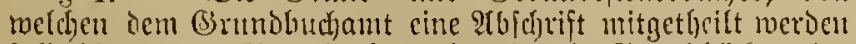

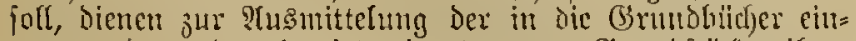
zutringenden ober bereits eingetragenen (Srundftiicfe, ifjer

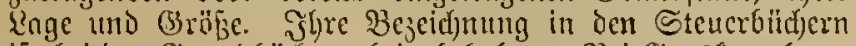

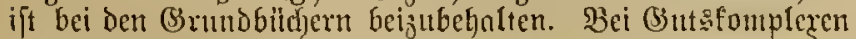

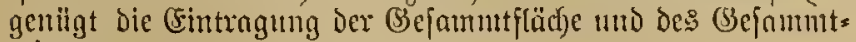
reinertringes.
(2) (3) ....

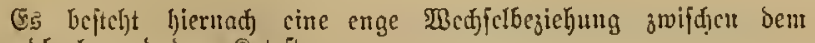
Brumbঢndxe uno Dem Rutafter.

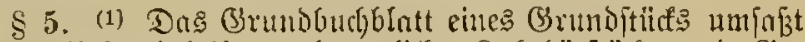
Defjen Beftnnotjeile, unbencglidye Bubetjörftiufe umb Ge= recitigfeitert.

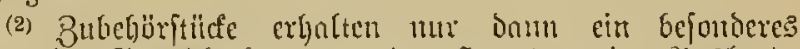

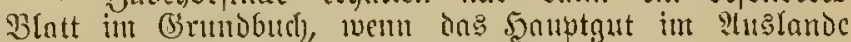
oder in Dem Sejirfe eines anderen (Grundbuctiontes liegt.

(3) (4) (5) ....

EEES. § 32 .

\& 6. (1) Die (Brumbbitther merden, infolveit Diejelben ncu anzulegen oder umjuf(s)reiben fino, nach ben biefent

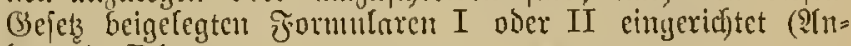
Inge A. B. ${ }^{1}$ )

(2) Dr: (jixumbundyamt lyat zu exmeffen, weldyes ber bciden frormmfare nujubenden ift.

(3) .....

1) Dic FormuIare find bicr uidjt abgeorudt.

§ \%. Эn Dem Formular I erbält jestes Brunoftïct cin

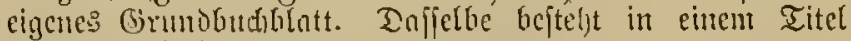
uiti) 3 s(otherilutigen.

\section{\$ 8. Der Titel giebt in Der 1. Spalte nn:}

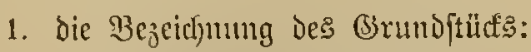

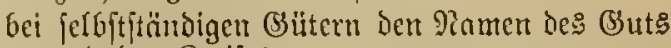
แnid des Sreijes;

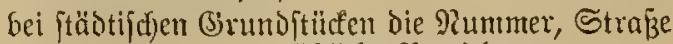
umb fonftige ortsubliche Bejeidjunn; 
bei fleineren länolidłen, zu einer Drtidjajt ge= hörenDen Bütern die Bezeidjnung des Sireifes, ber Ditfdjaft, Der Nummer oder fonftigen Sennzeldjen;

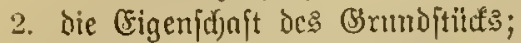

3. die शummer, weld)e das (Grundftiof int Stener= butd) füfrt;

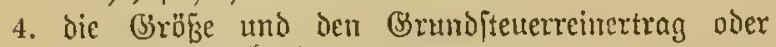
9?ußungsiverth (§ 4);

bei bereinigten Grundftüden $(\S 13)$ die Gröbe

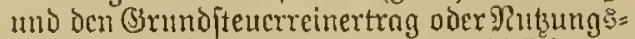
twertl) eines jeden cinzelnen (Sirundiftides.

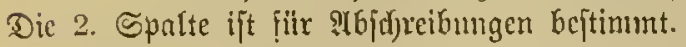

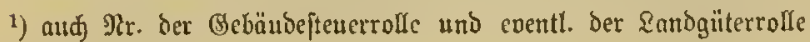
(Heg $=$ Bez. (Eaffel).

\$ 10. In dic 1. Spalte ier I. 9lftheilung ift ein= 3utragen:

Der (Sigentfyïmer mad) $\mathfrak{B}$ or = und Bumamen, nad)

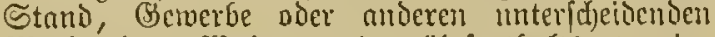
Mertmalen, Wohnort oder Plufentfaltsort; cine juriftifde Berjon mad ifrer gejetzlidjen oder in ocr

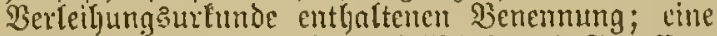

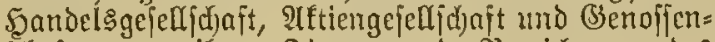
ichaft unter iljrer firma und Sezeidunng des Orts, mo fie iffren Sils hat;

in bie 2. Spalte:

Das Datum Der 2Yufaffumg und der Cintragung, die Şermerfe ïber \&uja)reibungen (\$ 61), uno nuf

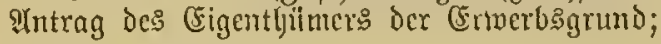

in bie 3. Spalte:

nuf ?tutrag des Cigentlü̈mcrs ber Frwerbspreis,

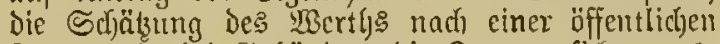
Tare mo bei Gebäuden dic Feuerberfidjerung: fumme mit 2lngabe des Datums.

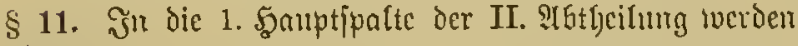
cingetragen:

1. Dauernde Saften uno twiederfefrestoc (Seltio und Raturalfeiftungen, meldje nuf cinem privatredytticjen Titel beruhen.

Bon ber (sintragung find ausgefdrtoffen bie an den Stant zu entrichtenden öffenttichen Âtbgaben und Reiftumgen.

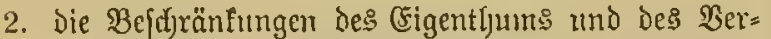
fï̈ungered)ts des (Eigenthümers.

Fn die 2. Sauptipalte "Veränderungen" twerden alfe Beränderumgen eingetragen, melche die in Der 1. Samptipalte

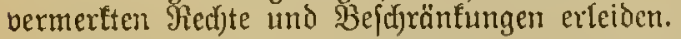

Sit cin in der 1. Sauptipalte eingetragenes Miectit auf= geljoben, fo exfolgt die Söfdurng in De: S2auptfpalte

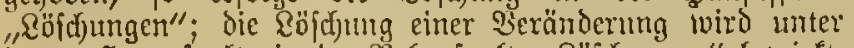
Der 2. Sgauptipalte in Der शebenipalte "Röjdungen" berwirft.

EEEG. §§ $11-14,38,49$.

\$ 12. Sn Die 1. Souptipalte ber III. Ththeifung werden

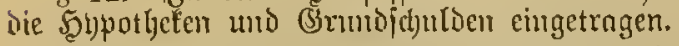

खenn mit foldfen Rect)ten Der Bcjitz und Bemú des

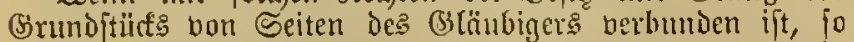

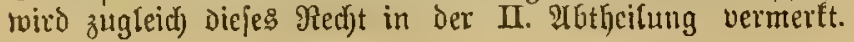

Эn die 2. Sauptipalte "Beränderungen" find alle Der: änderungen der in ber 1. Samptipalte eingetragenen Poften 3t vermerfen.

Die Reberipalte "Söjdungen" in ice 2. Sentutipalte ift fïr dic Röfdung Der $\mathfrak{B}$ eränderungen, die Sonuptipalte

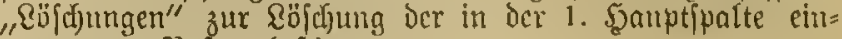
getrogenen \$often bejtimut.

도타. $\S 18$.

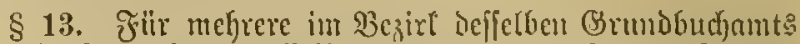
liegente Brumoitüte deffeloen Eigenthiinters fom auj bejen ?futrag ein gemcinf(b)ftlid)es S3lntt angelegt werden, menn

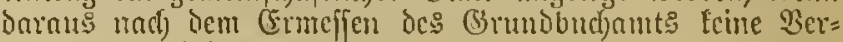
soirrung zut beforgen ift.

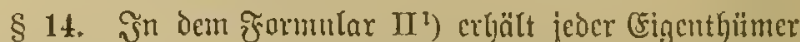
eincn Îrtifel, unter weldhem fämmtliche ihm zugehörige (3):unoftüdfe, iłre Stemerberbältmiffe, ifjre binglicfen $\mathfrak{B} e=$ faftungen und Deren Beränderungen eingetragen werden.

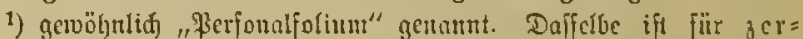
fireuten Gruntobefiz beftimmt. Das formular II beftegt gleidg bent Forumlat I aus eitum Titel mo 3 जlbtheilungen. Der Titel ent:

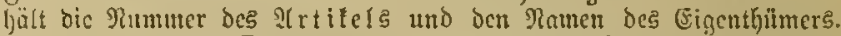

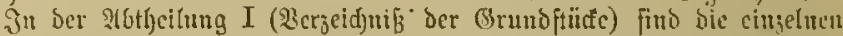

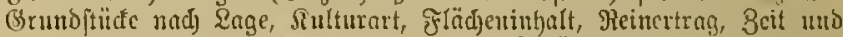

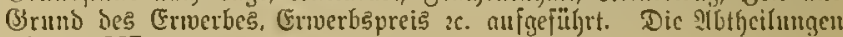
II und III ftimmen im allgemeinen mit ben gleidjet stbtheilungen bes Formular I itberein.

§ 15. Die Irtifel werden in cinem befanderen (Grunt= budf) fiir jeden Bezint (\$ 1) mit Bezeid)mung der virtifel= mummer bes Stenerhudjs angelegt, uno in jedem Artifel dic cinzelnen (Srunditüife mach) fortlanfenden 9?ummern eingetragen.

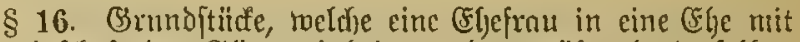
(3emeinjdjaft der (S3ïter einbringt oder twäfremo dexfelben crmirbt, lwerden auf den IYntrag beider Elfeleute in dem Irtifel des Eljemannes cingetragen. Bei Tremmmg ber

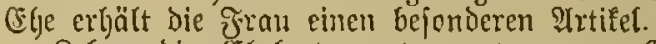

Qeben dic Egleleute inter getrenntem (Süterredist, io crbält zmar bie Egefraut cinen befonderen ?lrtifel, aber init

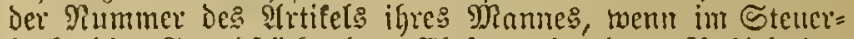

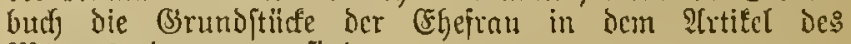
Manues eingetragen find.

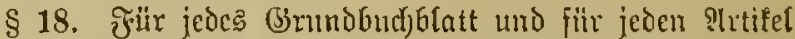
werden befondere Brundaften gefialten. Den Grumbatten

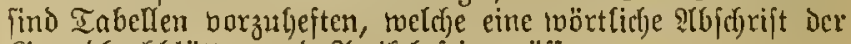

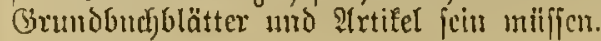

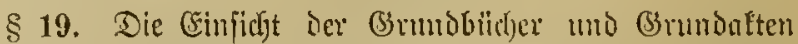

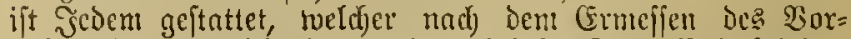
ftefjers Des (S)runobuchants ein red)tliches Şntereffe babei hat.

Deffentticfen Bacjörden und ten bon ifmen bcaujtragten

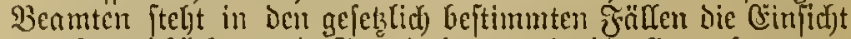
der Sirundbitder und Grondaften mo die (5ntuafme von Bemerfungen nus denfelben frei, audf fint fie lered)tigt, פ̂bid)riften zu verlanger.

(Entrig@s. $\S 24$.

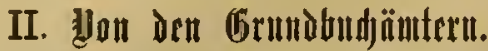

$\S \S 20-24$ fino in Folge ber Beridjtsverfafint vour 1879

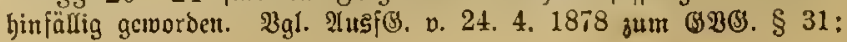


"Die Billoung von Brrunbbudäntern finbet nidt ftott. Die

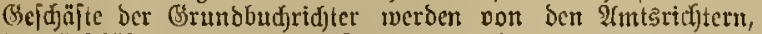

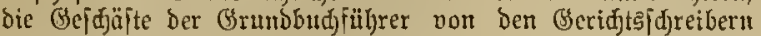
twaljrgetrommen.

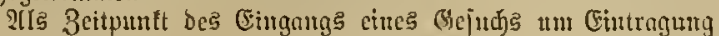

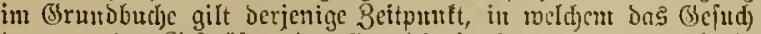
bent mit Den Bejdjäfter bes (Srutnobudrid)ters noer GrunbJud)= fübrers binfidttich bes betreffenden brunbjüdes beajtragten

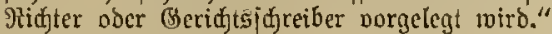

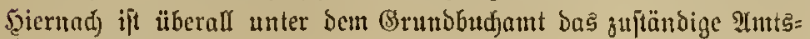
geridit zu verflelyeut.

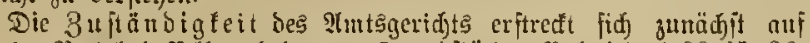

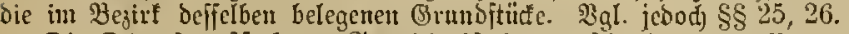

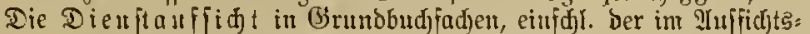
wege zu erlebigenden Befámerben über \$erzögertngen, wirb von ben

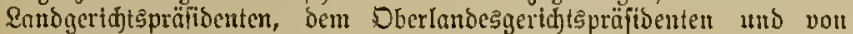
ben Ĭltigminifter ausgellbt.

Sad)lide Bejd)werden gefen an die Civilfammern der Rand: geridte. Begen bie Entfdetoung Des Ranogeridjts findet bie weitere Bejdfweroe an bas Samnergeridjt itatt, weldjes nad) llmitänden an

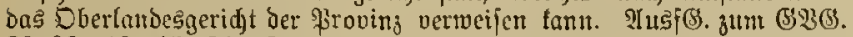
$\S \S 32,40,42,51-57$.

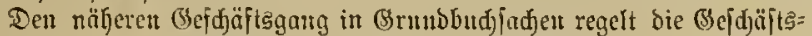

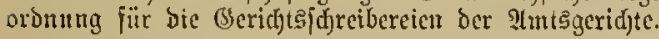

§ 25. Riegen Grundjtïcte, weldje einem einfeitlichen (Butsberbande angehören, in ben $B$ cjirten berjdjedener

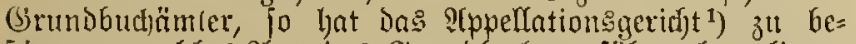
ftimmen, weidles ?

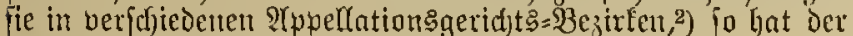
Jnjtizminifter bieje Sbeftinmmutg ou treffen.

\section{1) Dberlandesgeridjt. 2) Dberlandesgeridistäejirfen.}

§ 26. Streitigfeiten über die Buptändigleit melyrerer in

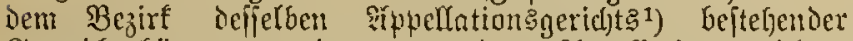
(B)rundbutfämter twerden bon Dem P(ppelfationsogerid)t, 1)

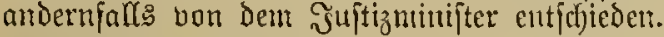

1) Dberlantoesgeridjt.

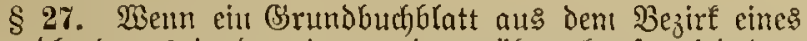
Brundbudjnmts in ben eines anderen übergeht, fo wird beut lebeteren eine bollftändige beglaubigte 2(bjd)rift des

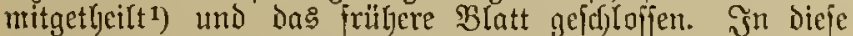

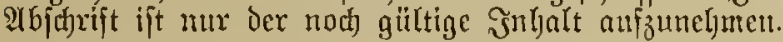

1) ferner werben bie Grundatten an bas uene ?Imtsgeridgt (für

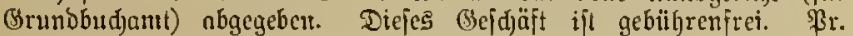

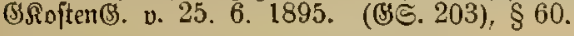

§ 29. Die Beamteut dẹ (BrundbudjamtS haften fïr

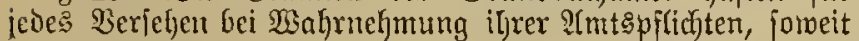
fiir Deu Sejcjübigten bon anderer Seite her (5rfalz uidjt zut erlangent ift.

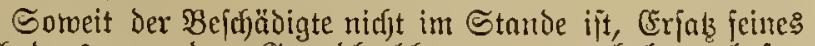
Sdjadens bon bem (Brundbudbbeamten ju erhalten, hajtet ifm für denjelben der Staat.

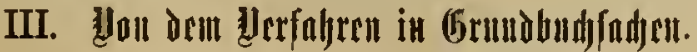

\section{Rllgemeine Beftimungen.}

§ 30. Die Brundbudjämter nerfahren, mit $\mathfrak{T}$.

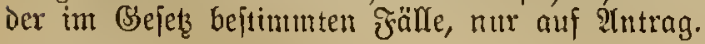

(동. $§ 2$.

8 31. Die Inträge merten mï̈olid) bei bem (Brunto= budjant angeforacht ober fdrriftlidf eingereidyt.
\$ 32. Miündidje SInträge auf Cintragungen oder

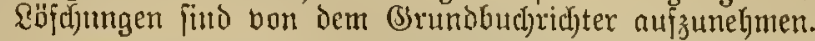

§33. Sduriftlidfe, zn einer (Eintragung oder \&öfdutung exjorderlicfe ?ntröge uno lltfunden milifien geridytlicf oder notariell aufgenommen ober beglanbint feit. ₹evod be= Dürfen frhriftliche ?Luträge, roelchen bie beglaubigten Ulrfunden beiliegen, in octen bie Betheiligten bie benntragte Cin= tragung noer \&bjdjung ictjon bewilligt haben, feiner bejonoeren Beglaubigung.

Der itufnalyme eines befonderen Protofolls über bie Beglaubigungen und det gujiefung von Zeugen bedarf es nicht.

\$ 35. Itrfmoen und Înträge öfientlicjer Behöroen be= bürfen, tocm fie oronungamäpig unterfd)rieben mo unter= fiegelt fino, Eeiner Beglaubigung.

§ 36. Miotare bedürfen zur Stellumg Der 2tnträge feiner befonderen Bollmadjt, menn bie von iluen aufgenommene ober beglaubigte uno eingercichte Urfunde die Sbemilliguth ober Den SIttrag Der Betbeiligter auf Eintrngung oder ¿ä)çung cutbält.

\$37. STndere Berionen, meldye als Bevallmädjtigte

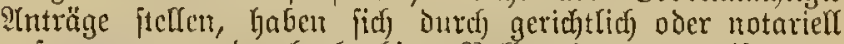
aufgenommene oder $\mathfrak{b c g l a u b i g t e ~} \mathfrak{B}$ ollmadjt augzutweifen.

\$ 41. Dem auf (Fintragung ober \&öfdumg geticjteten

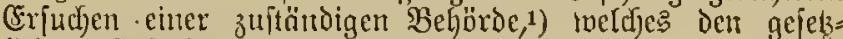
ridjen Erforderniffen entipridyt, insbefonoere aud alle

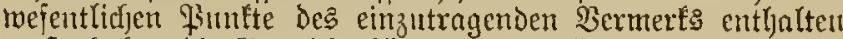

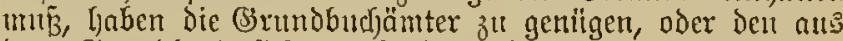

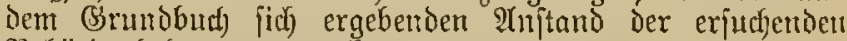
Behörde befannt zu machen.

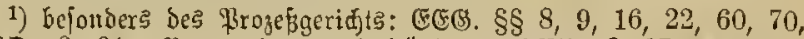

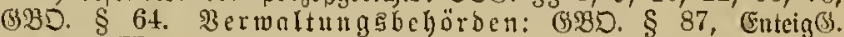

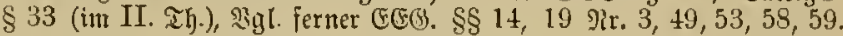

\$ 42. Die 2tuträge fowohl als Die Utrfunden find genau mit dem Beitputut des (Eingangs bou (Brumblud)=

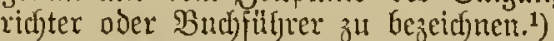

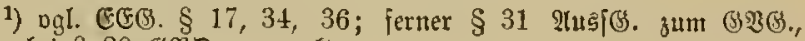
oben bei § 20 GgD. vermerft.

$\S$ 43. Die $\mathfrak{B e r j u ̈ t g u n g e n ~ a u f ~ d i e ~ \Re n t r a ̈ g e ~ f i n s ~ v o m ~}$

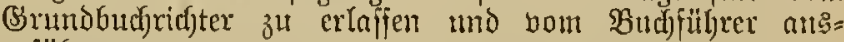
zritifren.

Die Cintragung: sformel ift Dem STutrag gemäß von bem Ridfter mörtlid in ber faffung ju entwerfen, in tweldfer fie in bas (Brumbbud eingetragen werben four.

Rebenbeitimmungen, insbejondere ïber Silndigung ober 3ahlung des Rapitals, find dem Antrag entipredjend in bie sormel aujanefinten.

(घ) ङ § 23.

\$ 44. Bei alfen Einjoreifungen in bas (Srunbbuth ift der Tag ver (sinjdyreibung anjugehen; die in die ПI. und III. Mbtheilung cinzutragenden Sojten find in jeder ?Ib= theilung mit portfantentien शummern zu verfeljen. Die (sinfdreibunget find in (Sirundbud von dem (Brundbuef)=

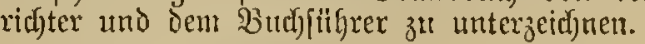

(ङE). $\S \S 17,34,36$.

\$ 45. ?(us melyreten Cintragungşgefuthen für Dafielbe (5r)undftituf exjolgt die (Eintragung in der Durd) Den Beit= punft der Borlegung ber (Sejuche ${ }^{1}$ ) bei bem (Srundobnd)amt bejtimmten Reifjenfolge, uno aus gleidjoeitig vorgelegten (Ge= 


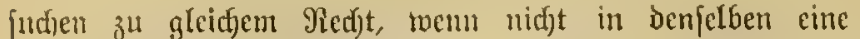
andere Reihenfolge beftimmt ift.

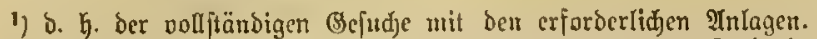

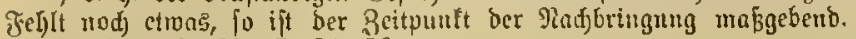
Bgl. atd (E)ङ. §§ $17,34,36$.

\section{Eintragunges Eigenthituer:}

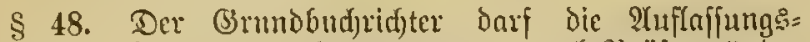
erf(ärung exít entgegemnelymen, wemn er nad) giriifung ${ }^{1}$ ) ber

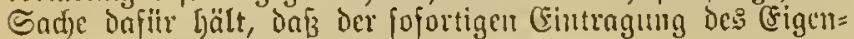

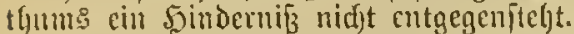

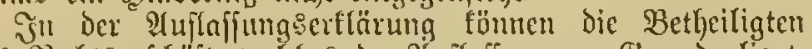

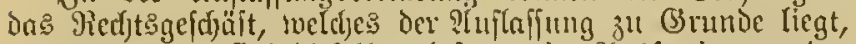
bejeidsnen, und fint diefelben befugt, eine ?lusjertigung ober

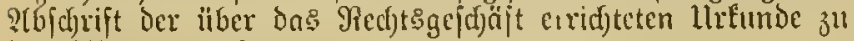
den Siften zu geben.

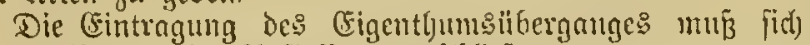

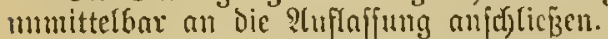

1) zu prïfen fund aud bie perfönliden Erforberniffe ocr

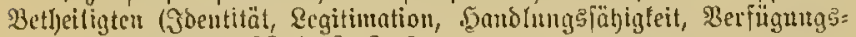
rebt). \$gI. (E) $\$$ (S). \$§ $1,2,3,5$.

\$5. $\mathfrak{W O}_{0}$ Biitergeneinjd)aft unter Elgelenten girt, ift

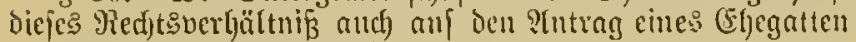
im (G)runbud() ơl vermerfen.

Bei fortge[ekter (Sütergemeinjdjajt ijt ins Miteigenthum Der Rinoer anf Den ?ntrag Des itberlebenten Ehegatten, Der Sinder oder Deren gefelbicher Dertreter eitrzutragen.

(다. $\S 5$.

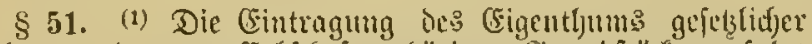
(5rben an den zut (Evbfor)aft gebürigen (3)rundftidefen erfolgt

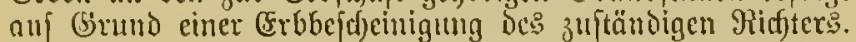

(2) .....

(E) $§ \S 5,65$.

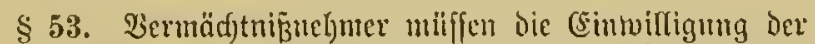
Erben in bie Eintragung ifjes (Eigenthums in beglaubigter

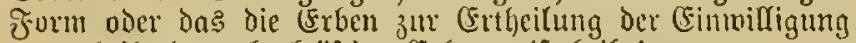

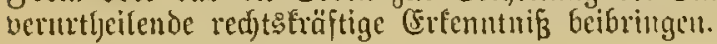

(EES) § $3,5,14,19$ Mr. $2,53,65$.

§ 5\%. Die Eintragung bes Eigentljïmers ift Dem bisher cingetragenen Eigenthiumer und den aus dem (Srund=

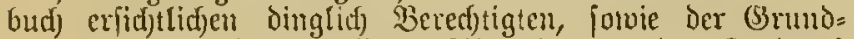
fteuerbelöroe und in falf bon abjweignngen Dem Sandrath oder bem Magiftrat betamit ju madjen.

§58. Wenn ein (5runDitïe, weldyes von einem ein= getragenen (Srumbftice abgezbeigt werben joll, nuf ein

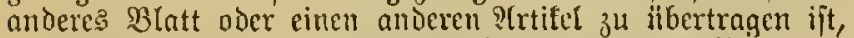

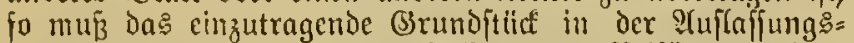
crteärung nad) Dem Steuerbud unter Beifügung einę GegTnubigten 2lusjuges aus Demfelben und einer von Dem Fortid)rcibungşbeanten beglaubigten Sarte, ans meld)er bie

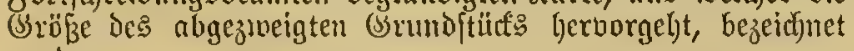
werden.

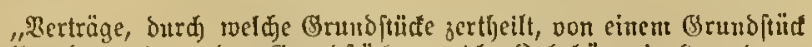
Theile abgejweigt, ober Grunditüe, weldge 3 ubehör cines anderen

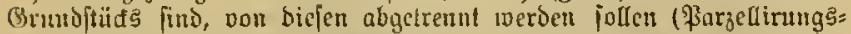
berträge), beoürjen zu ifrer (siuttigfeit feincr anberen form, als bie

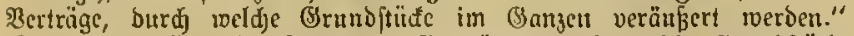
(\$ 1 bes (\$. über bie Form ber Sुerträge, burh melde Brunditïde jerthcilt werden, v. 5. 5. 1872. (\$ङ. 508) - EE(S. § 33.
§59. 23enn cin Theil eines Grunditüts unbelaftet auf

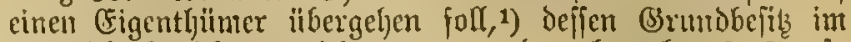

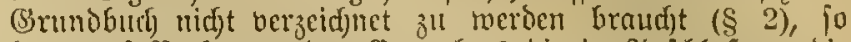

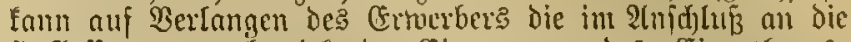
Muffaffung zit besvirfende Eintragung des Eigentfums: ïberganges baburdi erfetst werden, bas anf bem bisherigen

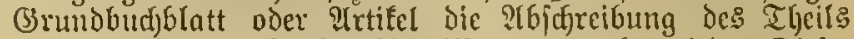
mit $\mathfrak{A n g a b e ~ o e s ~ S n c j u e r b a ̈ l t n i f f e s ~ b e r m e r f t ~ v i r o . ~ D i e j e r ~}$ Sermert hat bie wsirtung des Eintragung bes Eigenthum iiberganges.

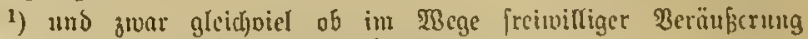

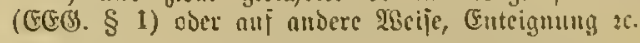

8 64. Der (Ermerber cines Tremnftites foum nod) bor

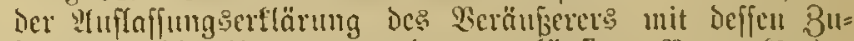
ftimmung bic (fintragung cines vorläufigen Fiermerts der

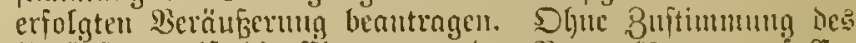
Deränfzerers ift bie Eintragung Des Bermerts nur all Ci:

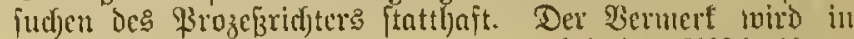
Der II. Stbitfeilumg eingetragen uno bei ber ?(bfor)reifung

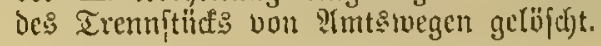

(5\&). $\S 88,9,16,22,59,60,70$.

\$ 65. \$aโtu anf iem \$auptgut nder auj bem gunzen

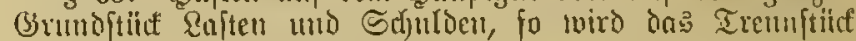
frei bou joldest abgejd)rieben, menn

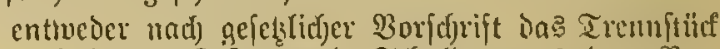
frei bon Saften mo Godulden aus bem Ber= bande bes Souptgutes ausfid)eidet,

oder dic Beredjtigten Das Tremmtiuf aus ber Mithajt entrafjen.

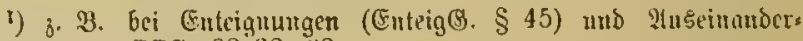
ießungen. -

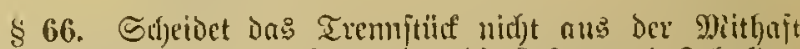
mit bem sjanptgut nus, jo werden bie Saften mo Echulden

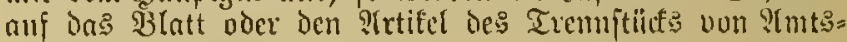
megen ïbertragen. . .....

\$ 70. Dic Eutiafiung Des Trmuftilt: aus Der Mit= laft, fomie die allinige vier antleitsmeife Jafung bes

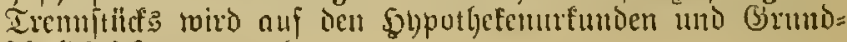
(d) UlD bricien vermerft.

타. $§ \S 32,33$.

§ 72. Grunbbuddblätter oder 2(rtifel merden gejd)lofien, metun fämuntlidje Daraulf eingetragene Grombititife $a b=$ geid)rieben furb.

\section{Berfabren bei Eintragungen in ber II. Mnd III. IY theilung.}

\$ 75. Beldrenten bedirfen Befufs ifrer Eintragung nidft Dex Siapitalifirung, andere ju gerviffen Beiten wicies= fei)rende 2(bgaben uno \&eiftungen nid)t der Şeranfd)lagung in Beld.

EEE(B) $\S 23$.

§ 76. I(tentlyeile ${ }^{1}$ ) werden in Der II. श(btheilung ein=

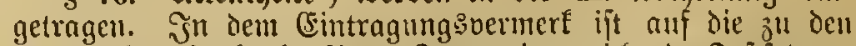
(srundaften in beglanbigter Form einzureid)ento ₹ejtfezung Des Ifltentl)eif ju verbeijen; einer Cintragung Der cinzelten Reiptungen beinif es nidft.

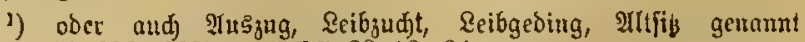

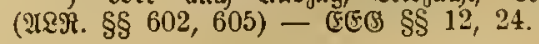


\& 78. Soll eime dauermoe \&nit, eine Shpothef oder eine (3rundfd)uld auf mebrere Brunoftïcfe zur Gejammnthait cingelragen werben, fo ijt auf ben Slatt jedes Srundftülfs bie "yritfaft ber anderen zu bermerfen.

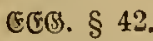

\$ 79. Zur Eintragung der 9 (6tretung ciner Solpothet

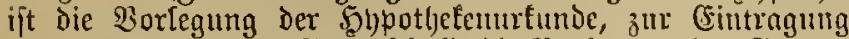

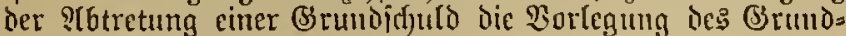
f(c)uldbriej: crforderlich).

๔E્ఠ. §§ $53,54$.

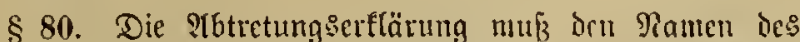
cinjutragenden Eriverbers entfalten. Der ?tunaljme= Es: flärung Des leţteren bedarf es nidf)t.

EEET. § 53.

\$ 81. Bei Der Eintragung ciner STbtretung bedarf es nidft der (Ermähnumg ber Bimifajeninfjaber der Szypothef

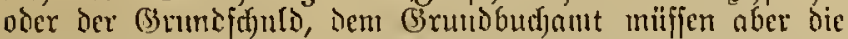
3roijchenabtretungen in ununterbrod)ener Fieibenfolge vor= gelegt werden.

$\S 82$. Dic Eintragung Der Aftretung wird auf ber

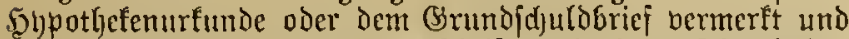
Diejer Bermerf mit Der llnterfdyrift und bem Siegel bes Brundbudfants berfehen. Dic borgelegten Stbtretungs: erflärungen werden bei den (Brundatten entweder in $\mathfrak{l l}^{2}=$ id)rift oder in beglaubigter abfdrift zurürtbeljalten.

§ 83. Erfolgt eine Theilabtretung, fo ift von der

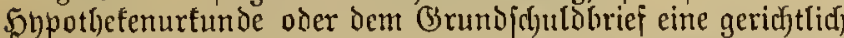
oder notarielf beglaubigte 2(bjd)rift anzufertigen umb zugleidf auf die \$aupturfunde der Bermerf, welder I lacit ber

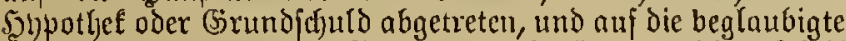
श̂fofdrift der Bermert, für wen und über weldjen Theil derfelben die 2affdrift gefertigt ift, zu jetsen.

Soll bie Theilabtretung eingetragent werden, fo find bie Sanuturtunde und bie Geglnubigte 916fdrift Deut (Grund= buct)ant borzulegrn, und ift die (Fintragung der :Tbtretung gemäв \& 82 nuf beiden lirtunden und neben tiem Cen= tragumgsocrmert auj der Sarupturfumbe zu bermerfen:

nouf) gültig auf (mit श:ngabe ier Summe).

§ 86. Zur Einräumung deక̧ Borrecthts geniigt cine Darauf gerid)tete Erflärung des CFinräunenden.

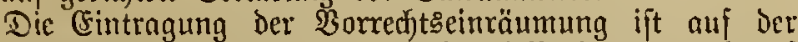
Iltfumbe Hiber bie zurituftretende und auf Verlangen auf auf ber llrEunde ïber die bortretende \$3ojt bon Dem (Srundbud)s amt zu veruterfeut.

통. § 35 .

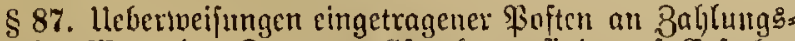
ftatt in $\mathfrak{B e g e}$ ber 3ivangsvoll treefung find auf Erfuchen

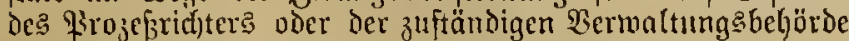
eillzutragen.

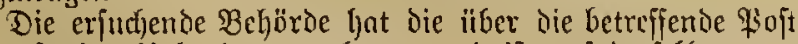
nusgefertigte Urfunde borzutegen, und ift auf berfelben bon

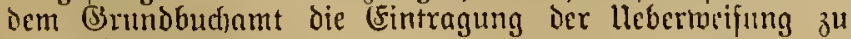
vermerten.

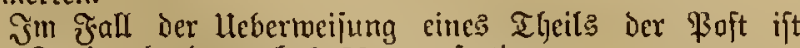
cine 3weigurfunde nac) $\$ 83$ anzufertigen.

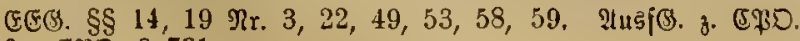
$\S 16$. อPD. $\S 731$.

\section{Söfditngen.}

§ 92. Dic \&öfdung Der Fintragungen in Der II. แnd

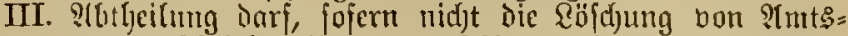
twegen borgejdjrieben ift, nur auf 21ntrag oç im (Brundbudt) cingetragenen Eigenthitmer: Des Srunditüd: oder nuf (5r= fuchen eincr zuftündigen $\mathfrak{B e f j o ̈ r d e}{ }^{1}$ ) erfolgen.

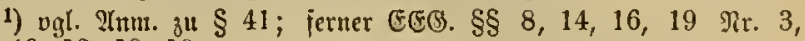
$22,49,53,58,59$.

§ 93. 3ur Begrïnoung Des Röf(f)ungsantrages ciner in Der II. Âbtheilung eingetragenen Raft gentïgt die bon Dem (Sigentfitmer borzulegente \&öjdumgsbetwilligung bes

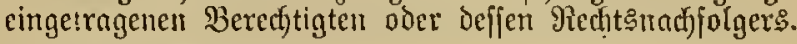

3gl, aud $\mathfrak{C P O}$. § 779 .

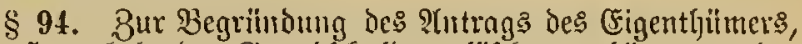

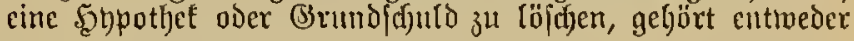

1. Die von Dent Gläubiger ertheilte Suittung oder \&öpthungsbernilligung, oder

2. Der ?iad)weis ber red)toftäitigen Berurtheilung des (Släubigers, die \&üld)umg zu betvilligen, oder

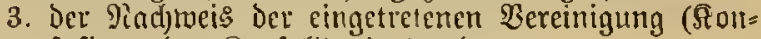
fujion oder Sionfolioation), oder

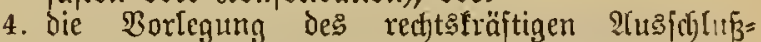
exfenntnifies nad) erfo[gtem Yrufgebot der Pojt, oritr

5. .......

Mit dem întrage muß in den Fällen $1--3$ die die (Fintragung ausggejertigte llrfunde oder bas rect)เgftäftige

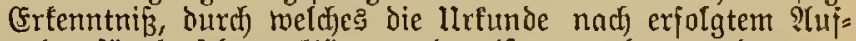
gebot jïr Eraftlos erllärt tworden ift, borgelegt werden.

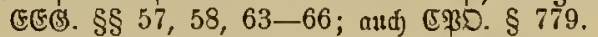

$\S 100$. Die Röf(f)ung ber in ber $\Pi$. शtbtheilung auf Antrag einer zuftänbigen Behörve eingetragenen $D e=$

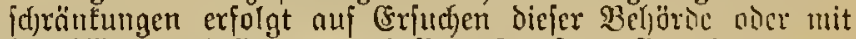
Berwilligurg deffen, ju deffen Bunften fie cingetragen worben, allf 2 (ntrag beg Eigenthiimers.

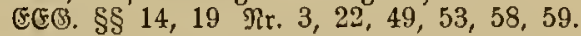

\$103. Die \&b̈jdjung einer im (Brundbud eingetragenen

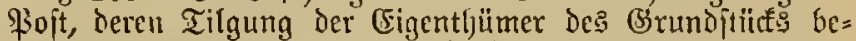
Gauptet, aber ourd) cine beglanbigte Qunittung bes ein=

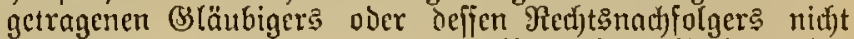
nachweifen tann, weil ifm diefelben ihrer \$erfon oder ifrem ?(ufenthalt nad) unbefannt find, fitloct nut in Folge

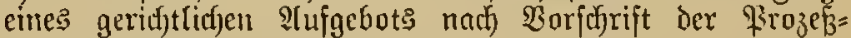
oronung ftatt. ${ }^{1}$ )

1) §S 823 fif. (E\$D., oben S. 220.

$\S$ 104. Das Aufgebot ciner Foft, von welcter ber

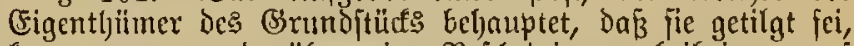
fann, wenn ex bariber eine $\mathfrak{B}$ efdreinigung beibringt, auf feinen 2 (ntrag auch dann erfolgen, wenn ber Snbaber ber Bojt zwar befannt ift, aber als foleber jein $\mathfrak{B} e r$ fitigungered)t nidjt nadjgerwiefen hat.

§ 110. (1) Wem der Jnhaber der \$3oft zwar befannt, auch Suittung zol leijten erbötig ijt, ober wirflid) geleijtet hat, Dic lirfumbe darüber aber berloren gegangeu ift, fo farn bie Röjd)ung mur erfolgen, naffocm bie lirfmbe in

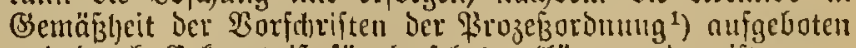
und burch (Erfenntniß̧ jür traftlos erflärt toorden ift.

(2) ......

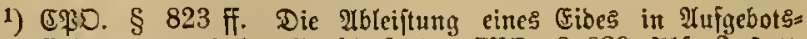

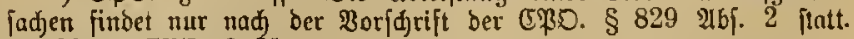

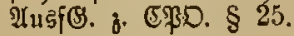


\$ 111. Ebenfo if̣t zu berfahren, twenn Der Bräubiger an Stelle der abhanden gefommenen bie stusfertigung einer

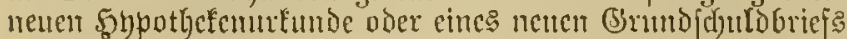
verlangt.

\$ 112. Die netue llifumbe wiro aus einer beglaubigten

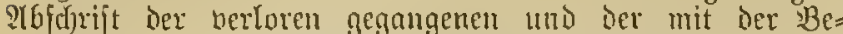

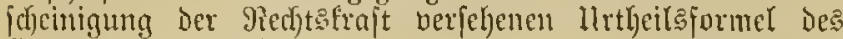
Crtenntmiffes gebilotet.

Die Plusftellung der neucu llrtunde mird in der 2. Saant= fpalte "Perändermingen" bei der Foft bermertit.

§ 114. Die \&öfdyung einer Fojt wird bon bem (Srm! = budjant nuf Der llteunde vermel ft mo ber Cintragungs: bernert auf derfelben dureffftrichen.

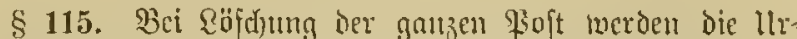

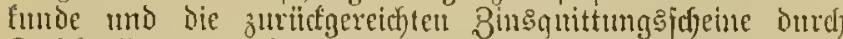
Berffunciden veruidftet mo anf ber angefïgten llefumbe ïber Die perjönliche Berpflidjtıng der borlyandente Cintragungs:

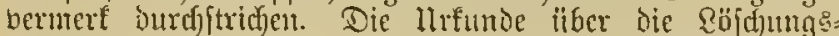
betwilligutg wird bei dem Grumbbuthant juriatbefalten.

(E)

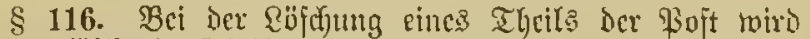
Der zu löjdende Theil von Dem ausgemorfenen Geldbetrag

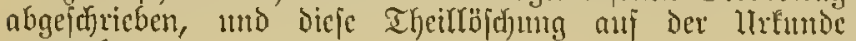
bermerft.

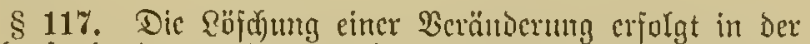
Sebenfpalte der 2. Somptipalte anf ?lutrag oder mit Csin= milligung desjenigen, für vueldhen bie (Einjdreibung gefdjeljen ift, oder auf (Erfuduen Derjenigen Beljöbde, weldye bie Ein= focheibuntg beantragt hat.

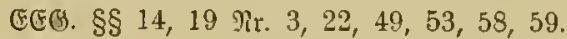

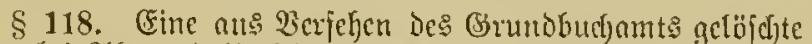

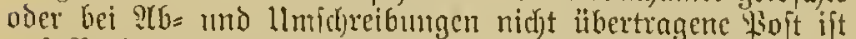

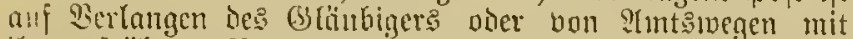

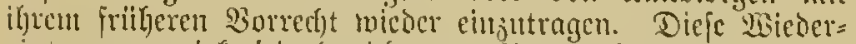
eintragung miret jedoch nidgt jum Siacht)eil Derjeningen, Dic

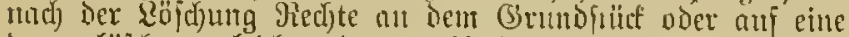

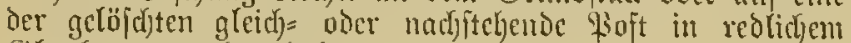
(STanber ermorben bahen.

토․ $\S \S 32,33,57,62$.

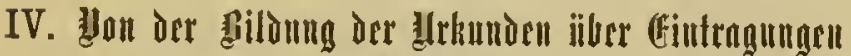 im Grumblond.}

§ 119. Heber bic Eintragumgen in ber I. Imb II. গTG= theitung, hber Berändermugen in ber II. mb III. Qhetheilung unt jiber bic Eintragumgen von Bormerfmigen in ber 1. Srauptipnlte der III. 9(btheilung twerden bejondete Ilthumber nicht angefertigt.

§ 120. Der (Eigent)ümer fanu jeocr eit eine beglaubigte

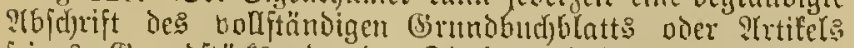
feines Brundoftücts oder ies Titets mo der I. Stbtheilung verlangen.

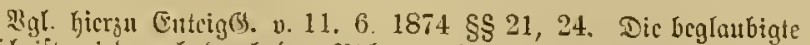

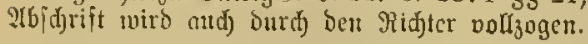

$\S$ 121. Ucber bie Eintragung ciner Bormertung, üher Eintragungen in ber II., Berondoentugen und Röfdungen in
Der II. Ind III. STbtheilung crhalten Die Betheiligten und bic

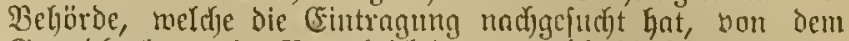

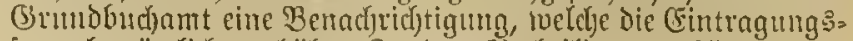
pormel wörtlicl) entljält. Bu den Betbeiligten geljört immer ber cingetragene Eigentjümer.

\$ 122. Heber die Eintragungen Der Sypothefen merden

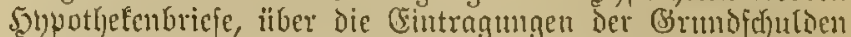
Grundiduldbriefe antogefertigt mo den Eigenthïner bes

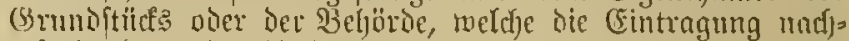

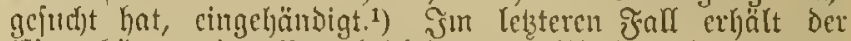
sigentljitmer eine Benadfichtigung. Mit bein Sopotheten=

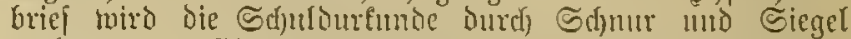
nerbunten. Ein Berzicht auf Die ?tusfertigung Deß

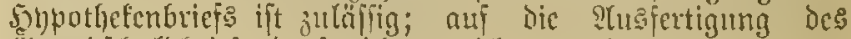
(Srundfdyldobriefs darf nicf)t ver jichtet merden.

(ேㅌ). § 20.

1) $300 . \S 9$.

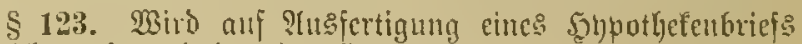

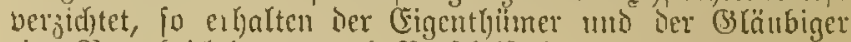
eme Benachrid)tigung na(l) Borfdrift des \& 121.

\$ 124. Der Şbpotheten= แmo der (Srundfduldotief bes fteht alts ber lleberid)rift, Dem bolffändigen Eintragungs:

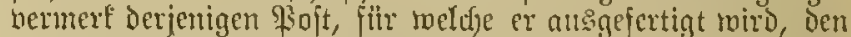

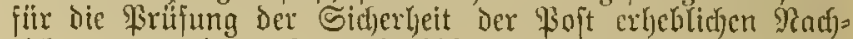

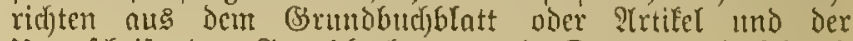
Unterforift des (Srundbuchants mit Datmm mo Siegel.

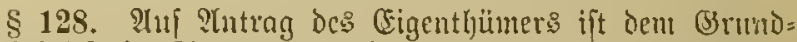
\{d)uldbriej eill 8imsquittungsbogen beizulegen, anf toelchem Die cinzelnen 8utşquittungen fïr einten $5=j$ jährigen Beitranm, mit bem Stempel des (Brundbuchants verjeben, ent= Galten find.

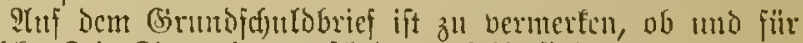
welche 3eit Binzquittungsifd)eine ertheitt find.

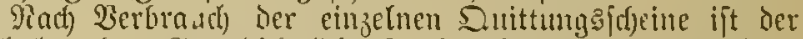

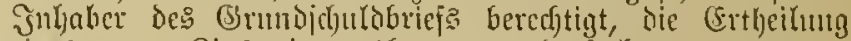

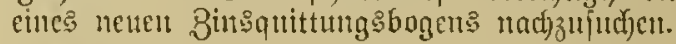

(E⿺𠃊5) § 39 .

\$ 129. Die bei einer Sypothef oder (5rundichulo ein= getragenen Beränderungen umo Röjd)ungen merden bou dem

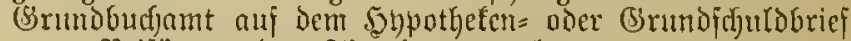
unter Beifilgung Des Siegels bermertt.

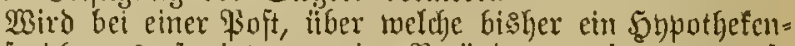
brief nidjt ausgefertigt war, cine Beränderung eingetragen, jo

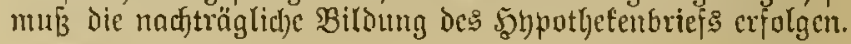

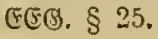

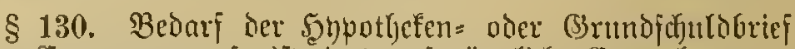
cinet (5rnetterung, fo ift das urfprïnglidfe (Exeutolar bon Deur (Srundbutjamt Durety Bexichneiden zu bernichten und bei ben Grumonften zurid jubchalten. Bei ber ?tusifertignng des netten Eremplars werden Bermerte, die fitr die gegen=

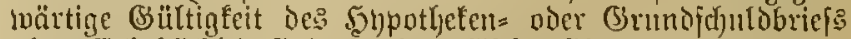
whe Ertheblichleit find, fomic gelöjfote Eitutragungen in Der II. und III. T(btheilum, und ältere Qfbtretungen meggelaffen.

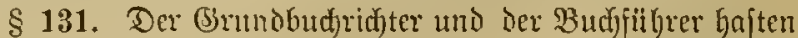

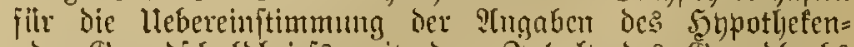

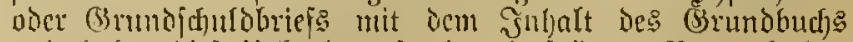
uno haben dieje llrfumben, fomie alle fpüleren Bermerfe des (5rmobuchamts, auf benjelben jul unterfa)rciben. 


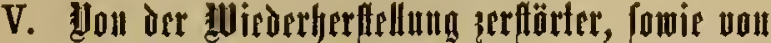 Anleguta ueuter Grutudtiider.}

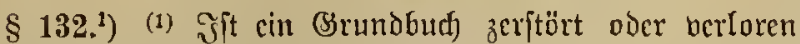
gegangen, io exiolgt Defien Bieocrberjtellung auf (Brund ciner Sönigliden Seroronung.

(2) .......

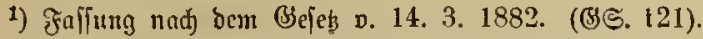

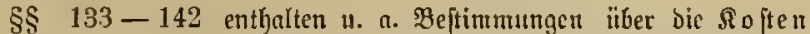
fïr bie Bacarbcitung ber (Srundbudfad)en. Roften in (3runbbud)= und Snpothetenfachen werden leit bem 1. Oltober 1895 nadj beu Brens.

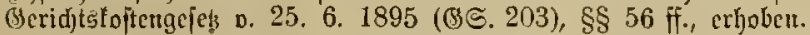

Die Erhebung Der Stempelabgaben für bic bei dem Geridjte

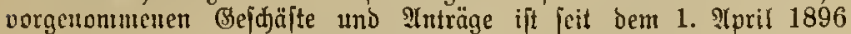
ourd bas ßreub. Stempelftenergeiç uno ben Stempeltarif vom
31. 7. 1895 (6ङ. 413) geregelt. Der Stempel beträgt für Я̂tnf=

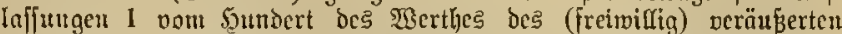

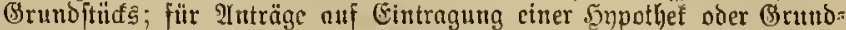

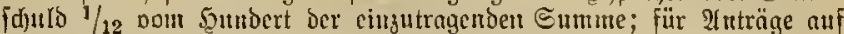
Gintragung ber 2lotretung ciner 5npothel voer Grundiduld $1 / 50$ oom

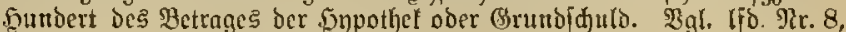

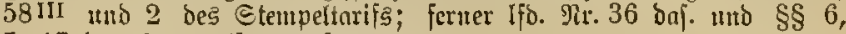
7, 17 bes Gtenupelftenergciebes.

§ 143. Die (Srumobut)ordmung tritt mit bem 1. Dfto= bet 1872 in Sirnit. $\left.{ }^{1}\right)$

Mit biefent Tang merden die Shppothefenoronung vom 20. Dezember 1783 und afle biefelbe ergänjenden imb $n \mathfrak{b}=$ ändomben (serecbe aujgeljoben.

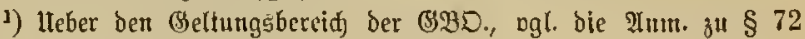
des (E) oben S. 302.

Utrunotirh $2 c$.

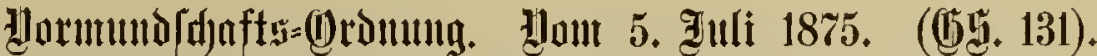

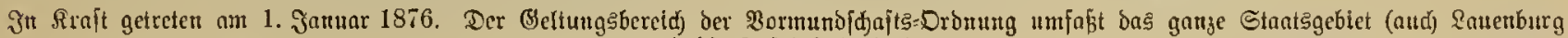
ttto bie Jniel Selgolano).

\section{I. כ̧ormutudrifaftsgeridjt.}

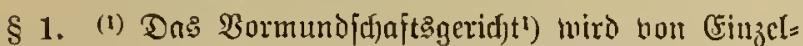

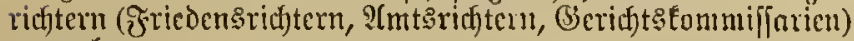
bermaltet.

(2) .....

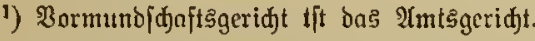

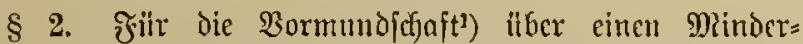

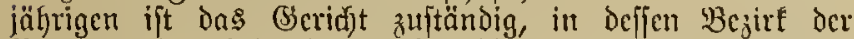
Bater zu ber Beit, in welffer bie Becormundung nöthig getwordent ift, feinen $\mathfrak{B o b n j i t z ~ o d e r ~ i n ~ C r m a n g e l u n g ~ e i n e s ~}$ poldjen feiment îtentigalt gefout hat.

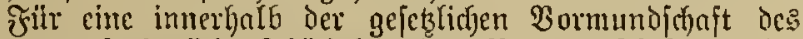

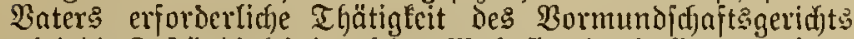

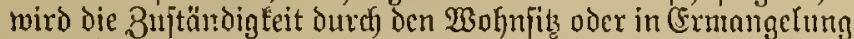

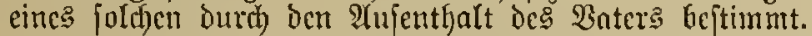

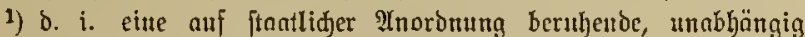

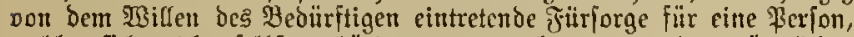

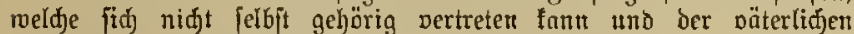
Bemalt nidjt unterfteht (\$§ 11,27).

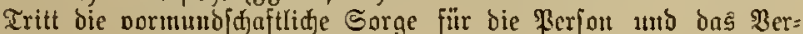
mögen nidjt it vollem ltmfange, fondern nur für einzelute ?lttgelegen= heiten ein, fo liegt eitue "PFlegiøajt" vor $(\$ 86)$.

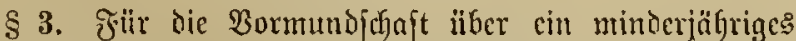
unchelidjes Sind ift dos Sericht zuftändig, in deflen Bezirf

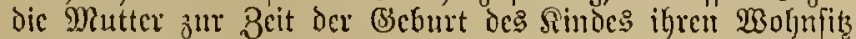
oder in ermangclung cines joldjen igren ?lufenthalt gehabt hat.

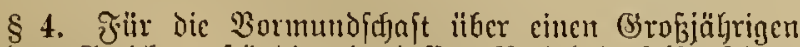
ift do

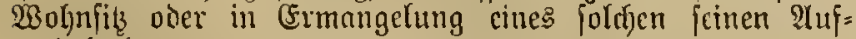
enthalt lyat.

§5. そ̌ehlt ç an einem Der ill ben $\S \S 2$ bis 4 nnge=

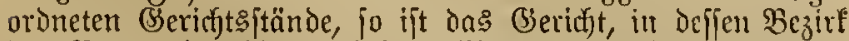
der Bater oder die umeheliche Mutter ooer ocr a bevor= numbende Brofjährige den leţten Wobjnfib gebabt hat, und in Ermangelung eincs foldhen basjenige (S)eridyt zujtändig, weldecs der Juitizminifter bejtintmt.

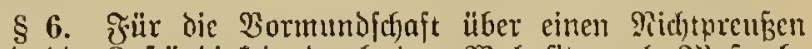
wird die Zuitändigfeit durdf den Wohnfiţ nad) Miafgabe der $\$ \$ 2-4$ bejtimmt.

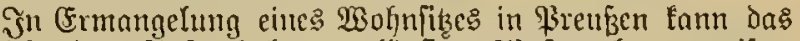

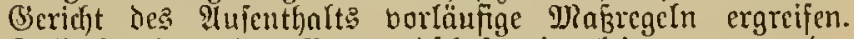
Daffelbe hat eine Sormundichaft cinzuleiten, wenn Der Seimathitaat die Sorge fïr den zu Bebormundenden nidjt übernimmt.

Dic $\mathfrak{B}$ ormumbidfaft ïber einen Ridjtprenfen ift auf

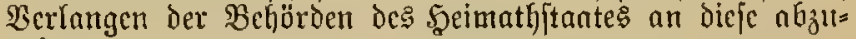
geben.

§ \%. Minderiährige, ocren E⿺tern unbefannt find, merden von dem Geridjt unter Bomumbjenft gefteld, in Defjen Bezirf fie gefuntien murden.

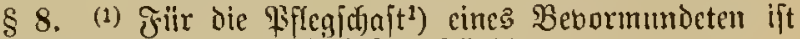

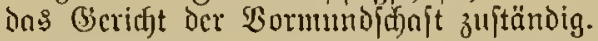

(2) ......

1) 3gl, 2ีtunert. ३แ § 2 .

§ 9. Streitigfeiten iiber dic 3u[tändigfeit mefhrerer

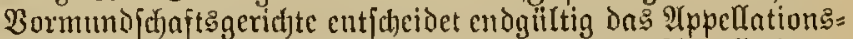
geridf ${ }^{1}$ ) oder, wenn die (seridfte verjofiedenen 2(ppellations:

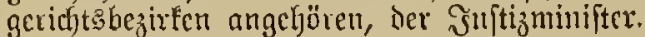

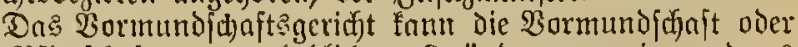
die \$ffegidsaft ats erbeblichen (brïnden an cin anderes

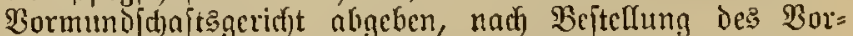

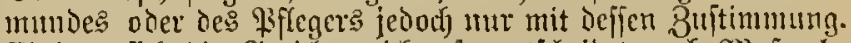

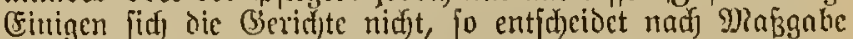

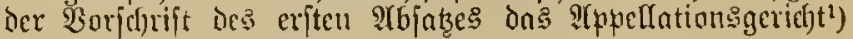

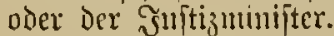

1) Зę̧t Dberlandeşgeridjt.

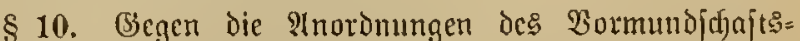
gerichts findet Befdjwerde ftatt. ......

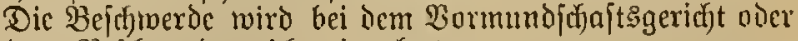
bei dem 23 cid)werbegerid)t eingelegt.

Dic Beidfwerde an das Randgeridit fam oljue Siit=

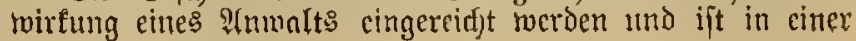




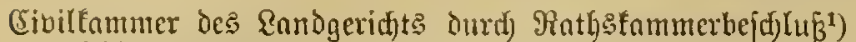
z"l erlebigen.

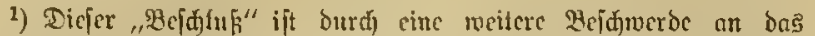
Sammergeridst in Berlin anfedtbar. Die meitere Bejurverde tamt

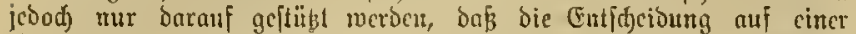

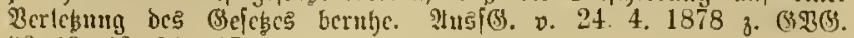
$\S \S 40,42,51-57$.

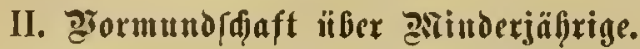

\section{Einleitung ber Bormundfúaft.}

§ 11. Minderjä̧rige ${ }^{1}$ ) er(jalten einen Bormund, menu fie nidjt unter bäterlicjer (Ssmalt fteljen, wemn dic bäterlidje

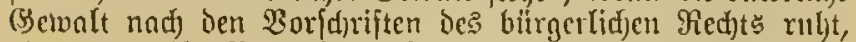
oder ment ifgr $\mathfrak{B a t e r}$ felbft betormundet wird.

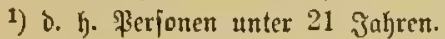

§ 12. (Erlif̧ht bie bäterlidje (Gemalt burd) Berhcirathurg, Dutrd) getrennte Santhaltung oder durd) (Entlaifung des Sindes, ohne das daffelte die Tied)te eines (5rofiährigen crlangt, fo rird ber bisherige Gerwalthaber gejetzlidider Bormund.

lleber ein uneheliches Sind wird ber $\mathfrak{B} a t e r$ ber unchelichen

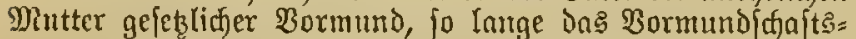
gerid)t nidjt eirten andern Bormund bejtellt.

$\S 13$. lleber einen Mïndel, weld)er in eine unter $B e r=$ maltung bes Stants oder einer Semeindebehörde ftehende Berfflegumgsanftalt aujgenommen ift, hat bis zu oeffen Grofiälurigteit der Borftano der 2 lnjtalt bie Rechte und Bfflidjten eincs geietzlidjen Bornumbes, fo lange das $\mathfrak{B o r}=$ mundidajtegeridht nidjt eincn andern Bormund bejtellt.

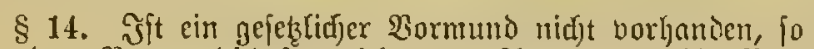

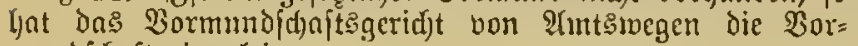
mundid)nft cinzuleiten.

§ 15. So lange eir Bormund nicjt vorhanden oder

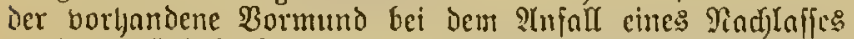

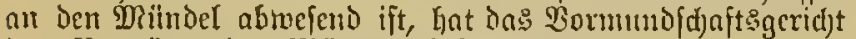
Das Bermögen des Dï̈ntels fidjer zu ftellen.

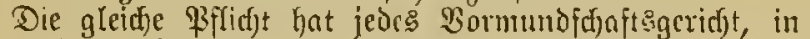

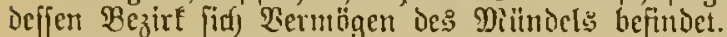

Sind der Bater oder die Mutter des SRündels noce grofjiährige Miteigentlümer anve[end, fo ift bic Sidber= ftellung nidet erforberlicl).

\$16. Wirb dic Einleitung cincr Bormundftaft nöthig, fo find bie Mutter, bie Stiejmutter mnd die grofjiäbrigen (Bejedrnifter, fowvie derjenige, weld)er den Mlündel nn Sinde angenommen hat, berpflicftet, dem Bormundid)aftegerid)t

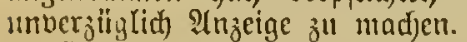

(5iste gleidje $95[$ (id)t jur Strzcige haben die Standes: benmten, wens ifnen ein (Beburts: oucr Sterbefall, weld)er die CEinlcitumg ciner Bormundfdjaft nötljig mad)t, ober Die Beburt eintes uneheliden Sindes angemeldet mirs.

Wirt eine Sebormunoung in Folge eines geridftliden

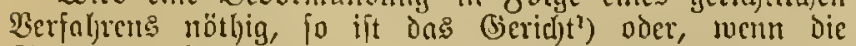
Stantsantwaltidinft in bem $\mathfrak{B e r}$ afjren mitgetvirfte ljat, bicfc

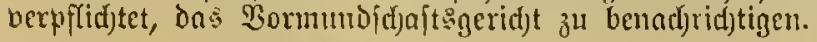

1) $\S \S 603,619,623$ ๔ $\$ 0$.

\section{Reifenfolge ber Berufutg.} berufen:
1. wer ohne bie văterliche Gemalt zu ermerben, den Rïndel an Rindesftatt angenommen hat; ${ }^{2}$ )

2. ver bon Dem Bater in einem Teptament oder in einer geridettidf oder notariell beglaubinten oder eigentündig gejajriebenen mo unterjejricbenen llifunde benamnt ift, fofern der Bater zur Beit feines Todes die väterfiche Germalt über den Mrindel gehabt hat oder unter 'Borausfekung Der bereits erfolnten (seburt deffelben gehabt laben würde,

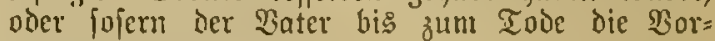
mumb\{d)aft gefülyrt hat;

3. die Miutter ẗber iljre eljelidjen, nidjt an Sindesftatt hingegebenen Sinter;

4. wer bon Der Mutter in Der unter $\mathfrak{R}$ x. 2 beftimmten Form benannt ift, fofern die MRutter bis zun Tode Dic Bormundf(hajt gefïfrt hat;

5. Der Brofzbater bäterficjerjeits;

6. ber (Sropbater mütterlid)erfeits.

Die Mutter ift nidyt berufen, wenn fie mit einem Senderen als dem Bater des Mitndels verheirathet over weun die (5he mit bem $\mathfrak{B a t e r}$ des Miunde(s Durd) llatheil getrennt ift.

Эit einer Eljefrau ein Bormund zu beftelfen, jo barf vor jedent nady diejem Faragraphen Betufenen der Egeman bejtellt werden.

1) เoenn g. B. eine fraumtsperfon eine צtboption vornimmt.

§ 18. Wegen llebergefjung Der nach $\$ 17$ Bernfenen ift die Bcidwerde nur bis zum ?โblanf bou 4 23odjen mad) erhnltener Semntnif bon der $\mathfrak{B e p t e l l u n g ~ c i n e s ~ a n d e r e n ~} \mathfrak{B}_{0}$ :

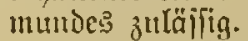

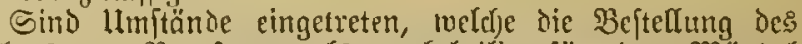
mad) $\S 17$ Bernfenen als nad)theilig fiur ben Miünd erfheinen laffen, io tann bas Bormundidjaftsgeridyt ben Bernfenen mit deffen Zufitimmung ïbergehen. Bei Deffen

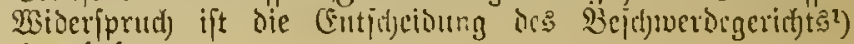
einzufolen.

1) Ranigeridjt.

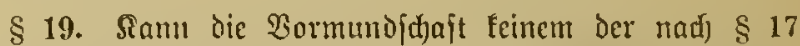
Berufenen itbertragen werden, fo hat oas Bormunofichat:

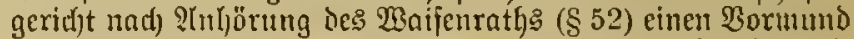

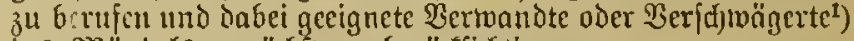

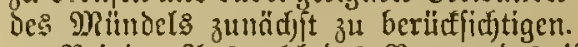

Bei Der ?tuझ̆tunhl des Sormundes ift auf das religiöfe

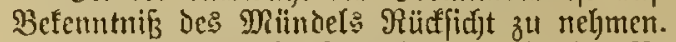

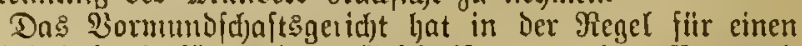
Diïndel, fowie für mehrere (Sejd)mijter nur einen $\mathfrak{B o r m u n d}$ 3n berufen.

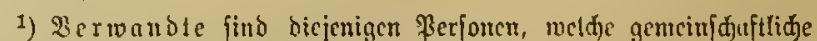

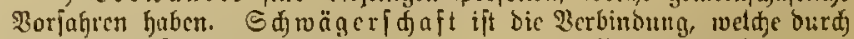
Seirath gmifach einem Ehegatten uto ben Butsverwatem bes

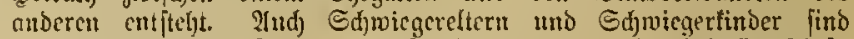

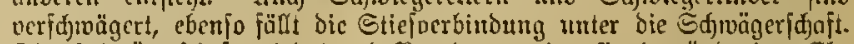

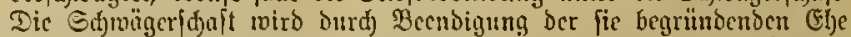

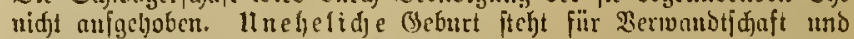

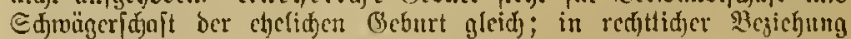
jtehen mefjefide Sinder jedod) nur gur Mlutter und beren Bermanoten, nicht aud) zu ihrem Ergeugcr in cinem Berwandtjualsoerhältnië. Dan Imterfdjeidet Bermanotjdaft (Sd)wäger/daft) in geruber Sinie

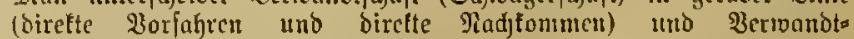

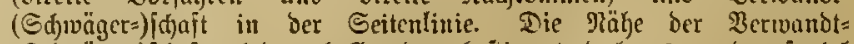

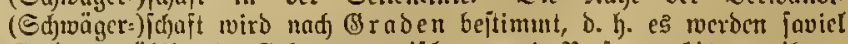
Grabe gezählt a!s Beburten arifon öwci ßerfonen bis gut threm gemeinjamen llriprntnge licgen.

Dic 3 erwandert bes einen Chegatten ftehen zu ben Berwanden

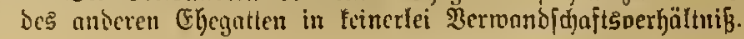




\section{Pflidgt fur Rormundidaft.}

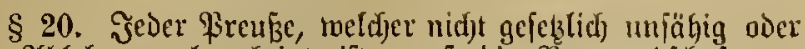

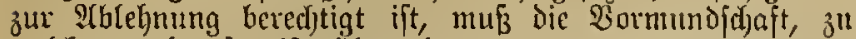
twelder ex berufen ift, ifbernebmen.

BSeigert fid) Der Berufene, fo tann er bon dem Bormmol= idjaftsgerid)te Durd Sronumgs ftrafen bis zum Betrage von

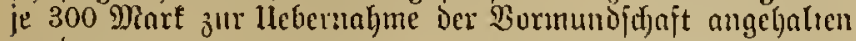
jucroen.

Meljrere Strajen find nur in 3mijdgenrämmen volt minteftens 1 Wodje zu berbängen. Эit 3utal cine Strafe oljne Erifolg verfjängt, jo ift ein anderer Vormumo ju beitellen. ${ }^{1}$ )

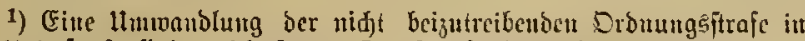
Frciheitspitrafe findet nifti putt. Die Etrafe fum aber mur int Onaben= wege crlafien werben.

\section{Ilnfähigfeit.}

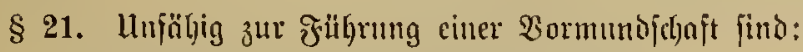

1. Bevormundete oder Scandhunģunfähige;

2. mer Das 21. Lebensjahr nod) nid)t zuridgelegt hat;

3. wer der biirgerlid)en (Elyenured)te berluftig erflärt ift, nach Mlaßggnbe des Strafgejetzbudjs;

4. Bemeinjduloner während ber. Duner bes Sonfur: berfahrens;

5. Iner offenfundig cinen unfittlid)en Sebensivandel fiilgrt;

6. wer vou Dem Dater oder bon Der Mutter nnd Maß̧gabe der in $\$ 17$ fiir bie Berufung eincs Bormmonde gegebenen Burjdyrijten ausgejdy Loffen worden ift;

7. meibfidfe Sierjonen.

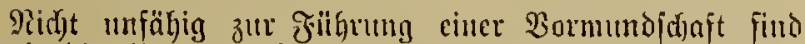
jedod) bie Mutter über ihre eljelidjern, unteleticfen oder angenommenen Sinder und Die Brof3mutter, fofern fie nid)t bei etraiger Trenmung der (Elye fïr Den idjuldigen Theil ertlärt find, jowie biejenigen weiblidfen \$erjonen, weld)e nad) $\S 17$ 9ir. 2 und 4 bernfen find.

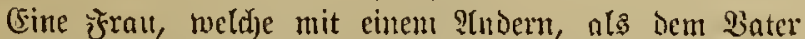
des Mündels verheirnthet ift, burf nur mit Einnilligung bes Eljemannes zum Barmund beftell werden.

\section{Benunte.}

\$ 22. Wer ein Stnatgamt ober cin befoldetes ?rmt in Der Sommunal oder Sirdhenvermaltung befleibet, ${ }^{1}$ bednef zur Führung einer bon dem Bormunojdjaitşgerid)t einge=

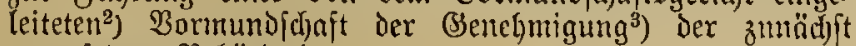
borgcjełsten $\mathfrak{B c l}$ örò. ${ }^{4}$ )

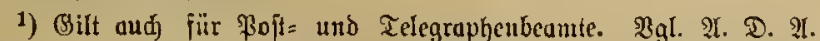

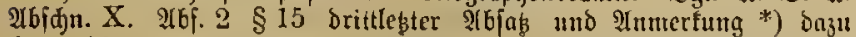
Seite 11 .

2) Bu einer gefes ni⿻it erjorderlid.

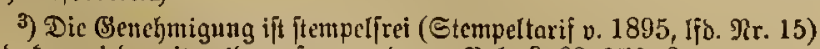

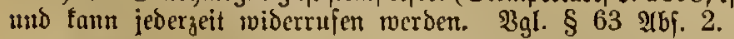

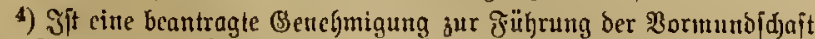
oder (Gegenvormundf djaft von ber Behörbe nod nidjt erlheilt, fo gewährt

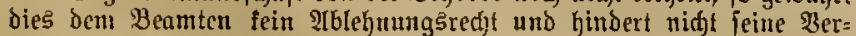

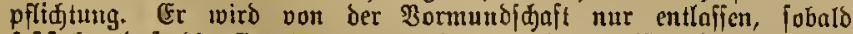

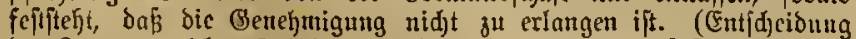

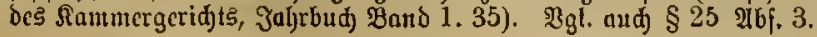

İbleljunng.

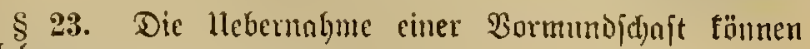
ablebnen:

1. weiblidje Fierjonen;

2. wer ถa: 60. \&ebensjahy überjhritten hat;

3. wer bercits melje als eine Bormundjejajt oder Pflegidjait jührt;

4. wer an ciner die oronungsmäßige frillyrung ber Bormundjaft hindernoen Srantheit leidet;

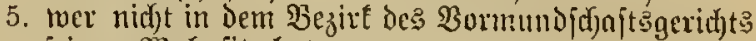
jeinen 20 ohnitis hat;

6. wer nad) Mapgabe Des $\$ 58$ zur Stellung cince Sicherbeit angehalten wird;

7. Mer 5 oder mehr minderjälyrige eljelide stimber ljat.

Die Führung einer Begenvormundichajt pteht im Sinne

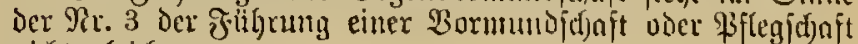
nidjt gleid).

Das 9lblelmungsited)t geht berloren, wem es nid)t bei dem Bormunditajtsgerted bor der Berpflidjtung geltend gemadyt wird.

(Gibcostattlid)e Berpflidjtung.

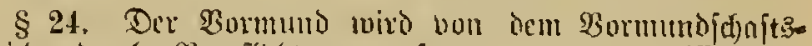

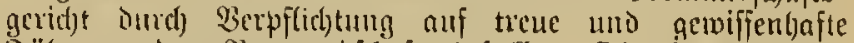

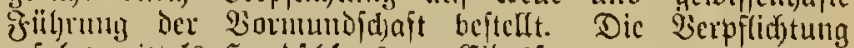
exfolat nittels 5ranojulags an (5ibesftatt.

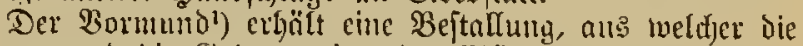
giamen und Die (Seburtşzeiten Der Mitudel, die Tamen des Vormundes, Des Begenbormunoes und Der Mitvormünder, fowie die Plet der ctmaigen Theilung der Serwaltung

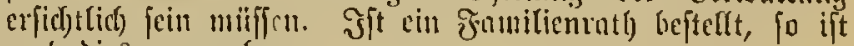
aud bies anzugeben.

Cine Befteflung des gejeblichen $\mathfrak{B}$ ormundes findet nic(t)t itatt.

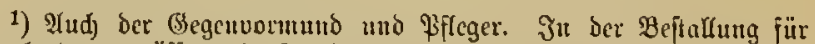

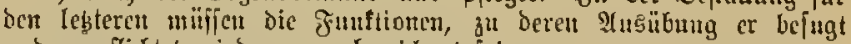
und verpflidjtet wiro, gettan bezcidjnet fein.

§ 25. Wiro cin Şandlungsumjähiget zum $B$ ormuno beftellt, jo ift bie Bejtellumg nictitig.

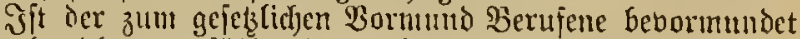
oder handlung sunjähig oder nidyt im Befitz Der bürger(idfen (Egrenred)te, jo tritt die gejetzlidje Borntundidjaft ein.

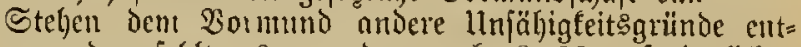
gegen, oder ferjlt es an ber nadj \& 22 erfordertidjen (jeneljmigung, fo fibjt er fein Int, bis er entlaffen wirb.

\section{Gegenvorimuto.}

\$26. (1) ঐeben Dem Bormuno tann ein (Segenvormund beftellt werden.

(2) (Ein Begenbormuno muß bejtellt werben, wenn mit der Bormundidhaft eise Bermögens verwaltung verbuntoen ift und nid)t mehrere $\mathfrak{B}$ ormiinder zu ungetrenuter $\mathfrak{B}$ erwaltung beitellt find.

(3) 3̈übren meljrete Bormiinder Die Berwaltung nad) (5) cidjäitszatweigen getrennt, jo fam ber eine zum (Segen= vormund des andern beftell werden.

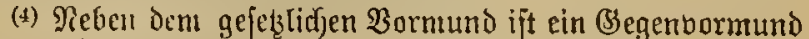
nur zu bcitellen, wenn defien Ynljörung nad) Dinf̧gabe bes \$ 55 erforderlidy wird; die $\mathfrak{B}$ ejtellung erfolgt nur zum 3roedfe der \$rüjung der bon dem Bormumbjdjaftegeridjte zu genebmigenten Şanolung. 
(5) Tuf bie Berniung und Beftellung des (Segenvormundes finden die für bie Berufung und Beitellung Des જ̧ormundes

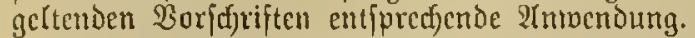

(6) Der $\mathfrak{B a t e r}$ oder Die Mitter fömen nacd) Maß̧gabe Der in § 17 jür Die Berujutg eines Dormundes gegebenen Burjajriften die Bcitelfung cines Begenvormundes unterfagen.

\section{Führung Dex Bormund đdjaft.}

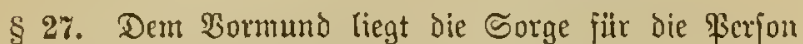

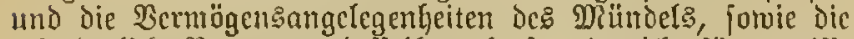
erforderfidje Bertretung deffelben ob, foweit nicht fiir getviffe ?tugclegenheiten cin PFleger bejtellt ijt.

§ 28. Der Mutter DeE Mïndele fteht Deffen Crrichung unter ier Vlufficht bes Bormundes zu. Diejelbe tann ify

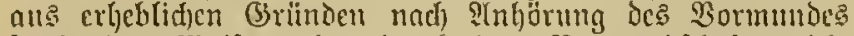

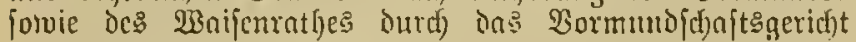
entzogen serion.

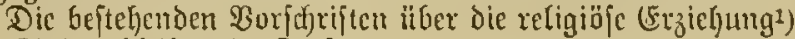
Der Rinder bleiben in Srajt.

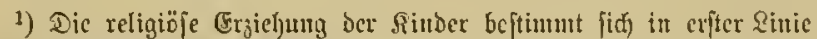
nad) ben Willen ber Eltern. Dieje CFinigung ber (Elterm über ben ifren Sintern ju etheilenden Mcligionsunterridjt bedarf, bejonders in geutifoten Ebeu, feiner ausbrïaflichen Erflärung. Es genïgt ftill= fhucigento 3uitiumung bes einen ober anderen Iheils.

Sint bic Eltern geltorber, bevor bic Ainder bas alter erreid)t haben, in meldem ihnen Meligionsunterridt ertheilt wiro, ober bejtcht eine WBidenscinigung ber Cltern nidt, jo tritt bie 3 oridrift ber Detlaration Rönig friedrid WBirgelms III. vom 21. 11. 1803 ein,

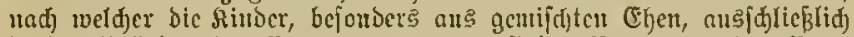

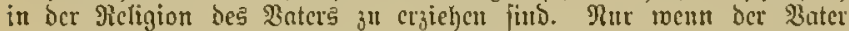

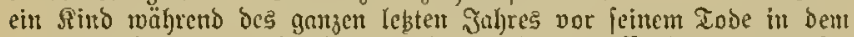
vou bem jeinigen verfdicoencu (Blaubensbefenntnifie ber Diutter hat unterridten lajien, io ift diefer lunterrid)t in derfelben Sirt aud nad)

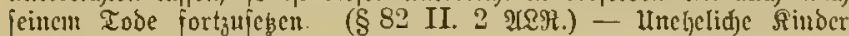
find ftets in dem Granbensbefenntniß ber Mutter zu erzicber.

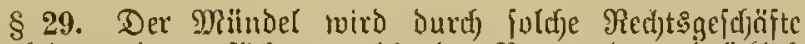

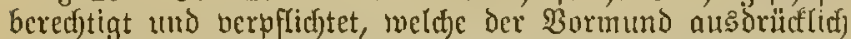
im Sianten des Maindels ober unter llmitänoen abgejd)lof[en

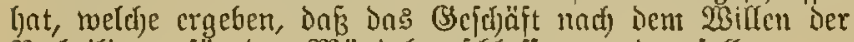
Bctheifigten für den Mändel gefd\}loffen socrden follte.

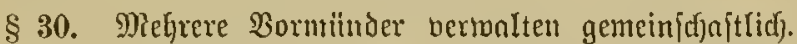
Bei Meinungsoerjajiedenlyeiten ent/dyeidet die Mieljrheit

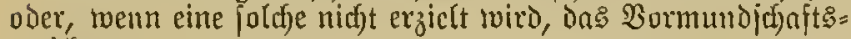
gericfift.

Sit unter mehreren Bormündern bie $\mathfrak{B e r w a l t u n g}$ getheilt, jo verwaltet jeder dic ilym jugetheilten (je) fdjäjte felbitftändig.

Indere Bejtimmungen ihber bie Berwaltung mehrerer

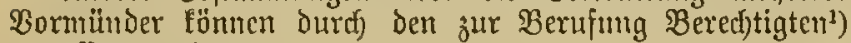
getroffen werden.

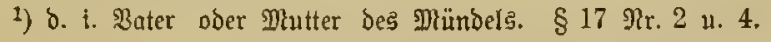

§ 31. Der Begenvormund hat Darauf zu adjten, Daḱ Dic Bermögensverwaltung Des Bormundes oder Des bci

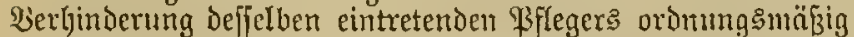
gejüljet trird. Fr lont in den in dicjem (Bejetze bejtinmten

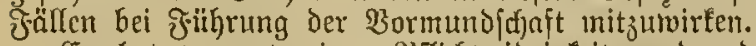

(5r loat bon ctwaigen fiflidftrwistigfeiten oder ber cin=

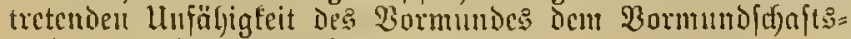
gerid)t $\mathfrak{Q}\left(n_{j}\right.$ eige ju mad)en.

\$ 32. (1) Der Vెormund forvie Der (Segenbormuns Ljaften fïr bie Sorgfalt, weld)e cin ordentlidjer Şausonter auf feine eigenert ?tugelegenbeiten vermendet.
(2) Dic Berentimortlidfécit Des beftellten $\mathfrak{B o r m u n d e s ~ b e = ~}$ giunt mit Dem 3eitpunft Dor Beptefung.

(3) Der Ehemann einer zแm Bormund beftelften frrau baftet, wern er nidft Der 2 neter deg gï̈ndels ift, fiir bic

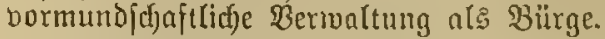

(4) Die Finrede ber Thcilung unter mchreren $\mathfrak{B e r h a f t c t}$ ift nusgcidjloffen.

(5) Die beftehenden Borfdyriften, nad) wecldjen dem Mä̈ndel

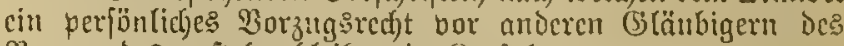
Dorutundes z"iftejt, bleiben in Siraft. ${ }^{1}$ )

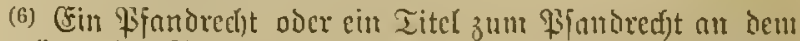
2iermögen des Sormundes entitelyt Durd Die Pormundichajt nitgt.

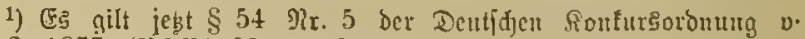

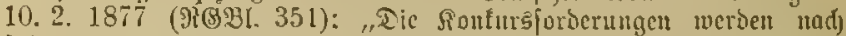

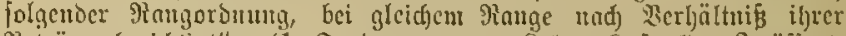
Beträge, bcrichtigt" : (1. Forberungen an Eohnt, Sioftgelo; 2. offeut=

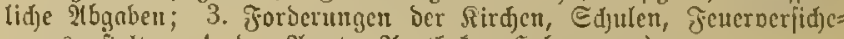
runģanftalten; 4. Ser Iler3te, 2(pothefer, 5cbammen.)

5. "Dic Fornerungen ter fintoer und ber \$plegebcjoljlenen

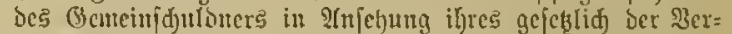
walturg bcifelben untermorfeneu Bermögens; das Borred,t

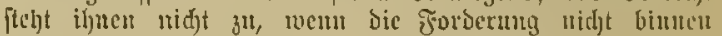
2 Эabren unc) Becubigung ber Bermögentsvermaltung ge

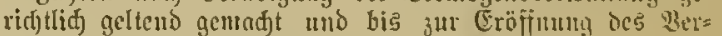
faljens verfolgt worbelt ift;

6. nlfe iibrigen Rontursforbermugen."

Şonorar.

§ 33. Die Burmundidhajt wird in Der Regel unent= gettlid) gejillyrt.

Tuslagen mitffen Den Bormund แmb Dem Begenvormund

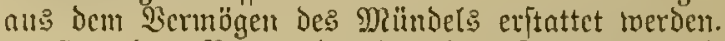

Shat ber Bormund oder der Begenvormund Dienite

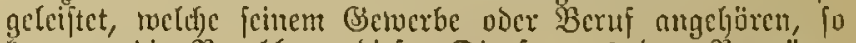
fann cr die Bezahlung bicfer Dienfte aนs dem bermtägen des miünde(s fordern. $\left.{ }^{1}\right)$

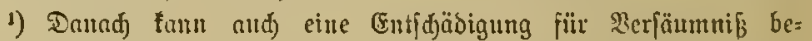
mipprudjt twcroetr.

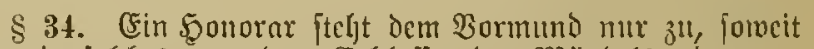
ijum ein foldecs bon dent Erblaffer des Mündels obct non

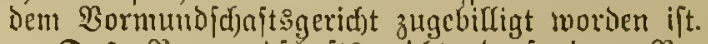

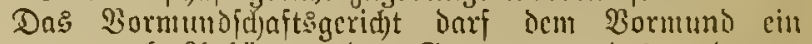
Szonorar nacf) Stuljörung Des (Begenvormuntes nuti nur

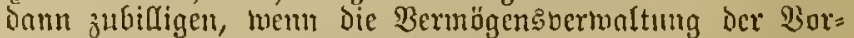
unund (d)ait bejonders umpangreid, ift. ${ }^{1}$ )

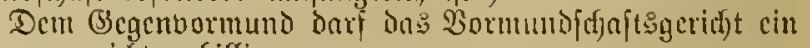
Şanarar nid)t zubilligen.

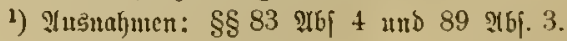

\section{ßermögensิverzeidjuiß̄.}

§ 35. Von Dent hei (Finleitumg Der Bormumb/c)aft bor=

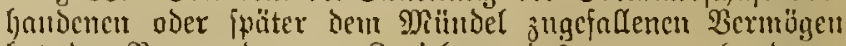

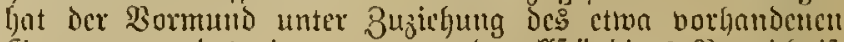

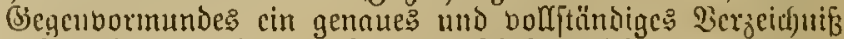

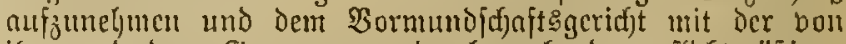

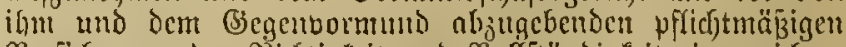

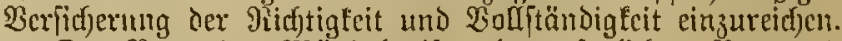

Der Snter des Phündels ift als gefetzlicfer Sormumo bon bicicr Berpflichtung frei.

5at cin Grblaffer des MR̈̈ndets in Der $\S 17$. Rr. 2. beftimmten Jorm Die Dffenlegung Deg Sorzeidjniffes jeines 
Sachlaffes verboten, fo ift Daffelhe won Dem Sornund nach)

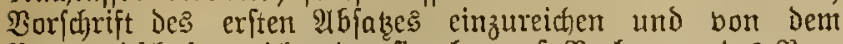
$\mathfrak{B}$ ormundfdyaftsgeridjt einzuftegeln, auf $\mathfrak{B e r l a n g e n ~ d e s ~} \mathfrak{B} o r=$ mundes in Dejien (B)egenmart. Das $\mathfrak{B}$ ormundfdnftzergeridyt Darf nur alts bejonderen (Sründen, über welche Der Dormuno

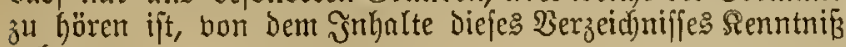
nefmen.

\$ 36. SJat ein Crtblafier des Mïndels über die $\mathfrak{B e r}=$ waltung ober die Beränfierung ber zu feinem Rachlafje ge= Görigen Segenftänve Beftimmungen für den $\mathfrak{B}$ ormund ge= troffen, fo find bieje su bejolgen. Eine शtbmeichung bon Diefen Beftimmungen ift mit (Sienelnutgung Des 20 ormund= \{cjaft gericht's geftattet, menu llmftände eingetreten find, veldie die Befolgung als . nachtheilig fïr den Diündel er: pitheinen lafien.

§ 37. Die Sioften Der Erziehung DeE Mündels hat der গুormund aus ben CEnfünften deffelben zu Gejtreiten. Reidjen die (Eintünfte nicht aus, fo fann Das Stanmbermögen ange= griffen werien.

§ 38. Der Bornumb fann Shjenfungen für den Mündel

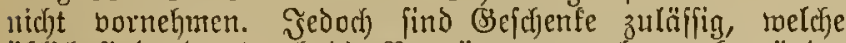

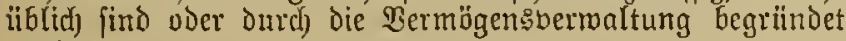
merden.

\section{Bitน:}

§ 39. (1) Gielder, tweldje âl laufenden oder zu anderen

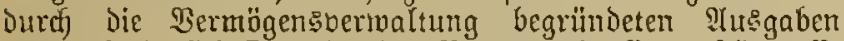

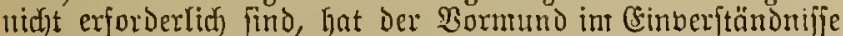
mit dem (Segenbormund in Sabloberidreibungen, melde

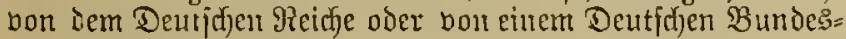

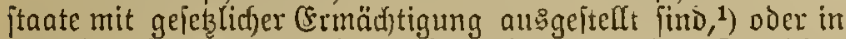
Schuldverjhzeibungen, Deren Werjinjung bon Dem Deutidjen

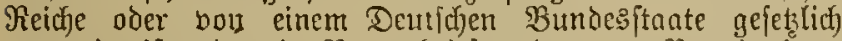

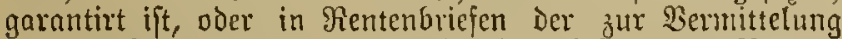

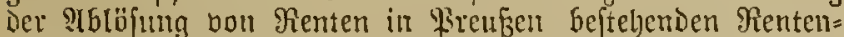
banfen, oder in Sdjulonerid)reibungen, weldje bon Deutjuden fommunater Sorporationen (Provinzen, Sreifen, (Ses:

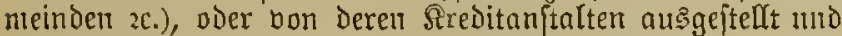
entmeder Seitens der Snbaber fïndbar find, oder einer regelmäß̈igen Amortifation unterliegen, oder auf fithere Sotpotljefen oier (Srundfonloen, zinsbar anzulegen.

(2) Geloer, weldfe in dicier weije nad) den obwaltenden Ilmitänden nicht angelegt merden fönnen, find bei ber

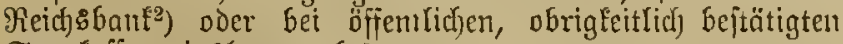
Sparfafien zinsbar ill belegen.

(3) (Eine Sypothef ober (Srumb/chuld ift filt fider zu er= adften, toenn fie bei ländlidjen (Sirundftüufen innerbalb der eriten 2 Dritttheile des Durd) ritteridhaftlidie, Landfdhaft= ridje, gerichtliche ober Steuertare, bei ftäorifden immerlyalb

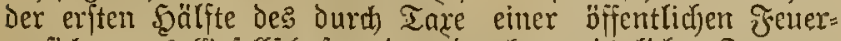
verficherungs=(Siejeflichajt oder Durd) geriduttidje iare $3^{\text {th }}$ ermittelnden Werthes, oder wenu fie innerhalb bes 15 =fachen Betrages des (Srumditetterreinertrages der Riegenjujaft zu fteljen fommit.

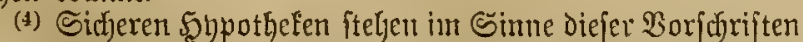
Die mit ftaatlicjer (Benefmigung ausgegebenell PFandobriefe und gleidjartigen Sofuldberjfretbungen foldjer fireditinftitute g[eich), welche Durd) Bereinigung bon (S̈rnobefitsern gebildet, mit Sorporationsied)ten veriehen find und nad ilyren Sta= tuten bie Beleilung bon Grutsptüden auf Die im Dritten IG fats angegebenen Theile des Werthes Derfelben zu be= füränten lyaben.
(5) Berfäumt voer berzögert der Bormund die 9! nlegung von Beldern, fo mus er die anzulegende Summe mit 6 vont 5̧undert jäljrliç berjinjen.

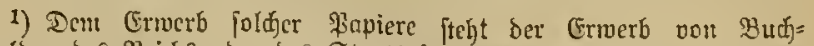

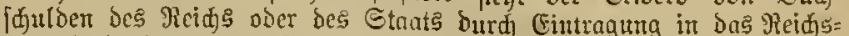

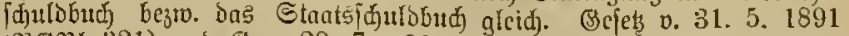

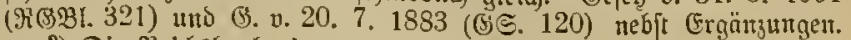

2) Die Reidjsbanf nimut Derartige (Selder tidft mehr an. Be faututntacfuttg v. 3. 12. 1878 .

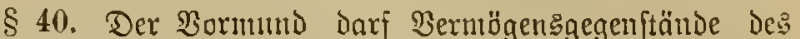

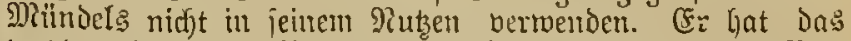

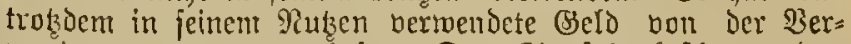

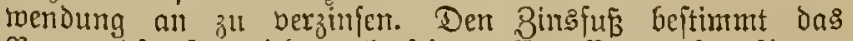
Bormundoftaftsgeridyt nad) feinem Ermefiet auf 8 bis 20 bom Syundert.

Eine Sobpothet oder Brundidfuld, weldie auf einem

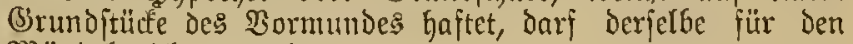
Mitndel nidjt ermerben.

$\S$ 41. Det Beneljnigung Des Giegenbormundes be= Darf ๕ร:

1. zur Beräußerung bon $\mathfrak{B} e r t f p a p i e r e n$,

2. วut Einjtehung, abtretung oder Berpfändung non ßapitalien, fofern biefelben nidjt bei Spartafjen belegt finto,

3. zur Mufgabe oder Minderutug Der für eine for= berung beftellten Sidferlyeit.

Die Benclymigung Des (3egenvormundes fonn Durd) bie

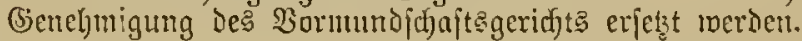

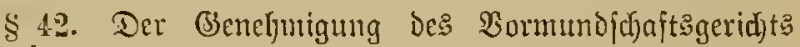
bebatf es:

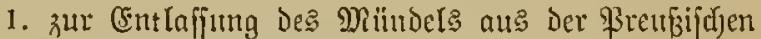
StaatEangelïrigfeit;

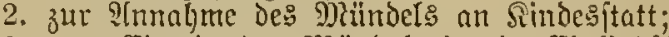

3. Jum (Fintritt Des Mitndels in eine (Einfindfd aft; ${ }^{1}$ )

4. วur Grbauseinanderfez̧urg, foferm Diejelbe nid)t ourch) (Erfenntnif feitgejetzt wird;

5. วur BerăutEertung oder Belajtung unberweglidfer Sacjen, foineit biejelben nicft in Zmangsberfalyren gegen Den Miündel erfolgt;

6. zum Erwerb bon tmbemeglidien Sachen burd läftigen Bertrag;

7. วิน Berpadjtung oder Beruticthung unbelveglidjer Sachen, wenn der Bertrag ïber das Irter ber Grofjährigfeit finaus gelten folf, fowie zur Ber: padtung bon Grmmoftiucten, die ju einem (Brund= fteuerreinertrag von 3000 Mart oder megr ein= gefouatist find;

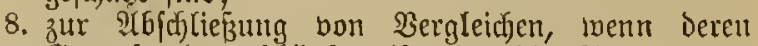
Segenftand unidjätzbar ijt doder die Summe bon 300 Mlart überfteigt;

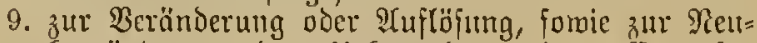
begrünıung voer llebernahme cines Crwerbs: gêdjäfts;

10. zur (Eingehung เoedfelmäßiger Berbittolichfeiten;

11. zur Grtbeilung einer Brokura;

12. zur ?tufnahme bon Darlehen;

13. วิur llebernahme frember $\mathfrak{B} e r b i n d l i d\}$ feites;

14. Jur Entingung ciner Erbjobaft ober cincs Ber= mäd)tnifies.

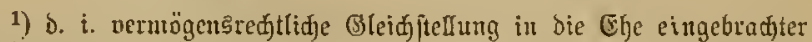
Sinber mit bent leiblidjen findorn Des Eticjuaters over ber Gtief= mutter. 
$\S 43$. (1) $5 \mathcal{G}$ Die 24 seinanderjeksung Ḧber einen dem

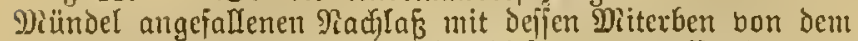
Bormund herbeizujühren fei, hat diejer zlt ermefjen. ${ }^{1}$ )

(2) Dic Erbauteinanderjeksung famn bor Beridft, bor eitrem Notar oder mittelg ßribatidfrift erfolgen.

(3) ......

(4) Der Crrbauseinanderjełung fteht bie Theilung güter=

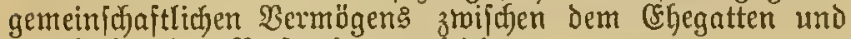
Den Erben des Berjtorbenen gleid).

(5) ......

1) Someit cire গ̛tuseinanderjebung tidjt gejeglid geboten ift.

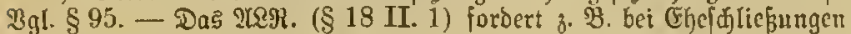

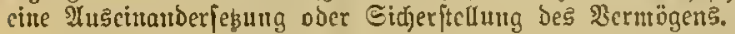

§ 45. Zur (singehung von mectjelmäßzigen Berbind= lidffeiten Darf eine allgemeine Benehmigung ertheilt merben, menn jie Duraj bie bormundjajajtlidje 2 ermögensbermaltung exforderlidi witro.

§ 46. Ein ohne die nach $\S \S 41,42$ erforderlidfe

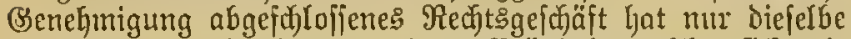
WBirlfamteit, wie ein bon cinem Miünel, welder fidt mit (Benelymigung Des Bormundes berbfichten farm, ofje

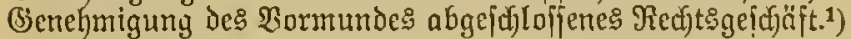

1) Das Befdäft ift unvirfjam. (Es miro aber wirtiam, menn Der Minderiährige nach crlangter Sclbftitändigteit baffelbe anertentt. Derjenige, mit meldem ber Ninberjährige ein megen jehlender

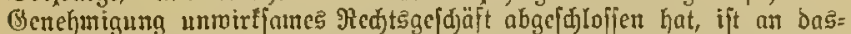
felbe gebunden; er wird non feitter Berbindlidfeit frei, went ber Sormund bie Getrehntigung perweigert. (\$\$ 3, 4 bes (\$3., betr. Dic

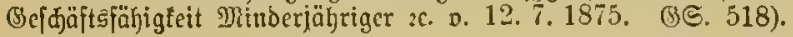

\$ 47. Der $\mathfrak{B a t e r}$ bes Mïndels ijt beredjtigt, in ber § 17 Sir. 2 beftimmten frorm Den von ifm benannten Bormuno von Der Rothmendigfeit Der Genehmigung bes

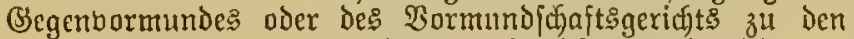
$\S 41, \S 42$ शr. 4-14 und § 44 bezeidneten \$ूanolungen zu befreien.

Jm Falle foldher Bejreiung ijt in ber Bejtallung bie allgemeine (Ermächtigung zur Bormahme ber bejeidfneten Sandlungen zu ertheilen. Dic Befreiung twiro erit Durd) Diefe (Frmäd)tigung wirtfam.

\$ 48. Die bejtehenden $\mathfrak{B a r j d r i f t e n ~ u ̈ b e r ~ D a s ~ C r i o r d e r n i ́ s ~}$

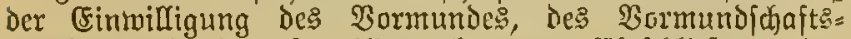

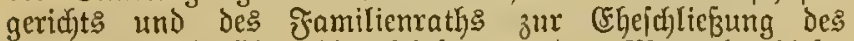
Mündels und über die Wirtungen des Mangels diefer (5inmilligung ${ }^{1}$ ) bleiben mit ber Maßzgabe in Siraft, Daß̧ in

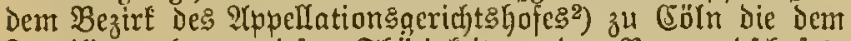

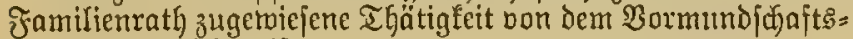
gericht ausిzutiben ift.

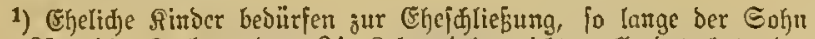
Das 25., bie Todjler bas 24. Rebensjahr nicht pollembet hat, ber

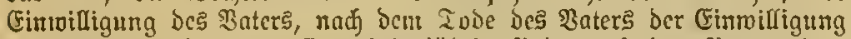

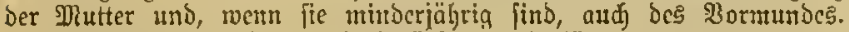

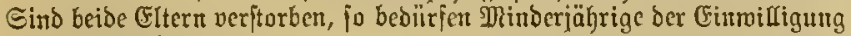
des $3 p r n u t i d s$.

ILf unehelide ßinder firden bie für vaterlofe chelidje Sinber gegebenen Beptimumingen $\mathscr{U}$ nwenburtg.

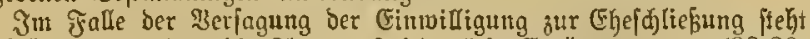

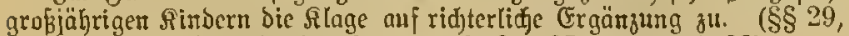

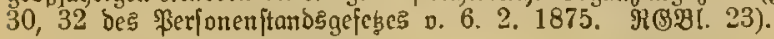

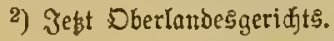

\$ 49. Durd) bie (Benelymigung eineg (Beid)äfts Seitens Des (Begenvormundes wird der 20 ormund, Durch die

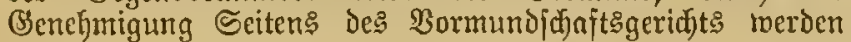

Der Barmund und ber Begentormund von three Saftpflidyt dem Däundel gegenüber nicht befreit.

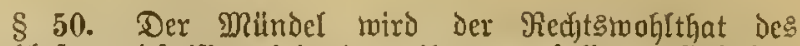
Radjlaf̧erzeidjniffes bei einer iljm angefallenen (Erbffijaft

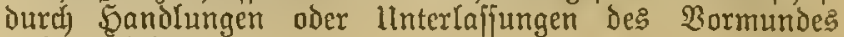
nicht berlupitig.

\section{Beauffidtigung ber Bormundjaft.}

§ 51. Das Barmundjofaftsgeridjt ljat über Die gefammte Thätigfeit Des Bormundes und des Gegenvormundes dic Pufficht zu fïhren.

Das $\mathfrak{B}$ armundjdjaftaggeridjt ift bejugt, gegen ben Bormun und ben Gegenbormuno Dromungsftrajen zu berbängen. (Eine Sromungsitrafe Darf Den Betrag bon 300 Mart nicht it6eriteigen. ${ }^{1}$ )

1) आgl. গงm. วน § 20.

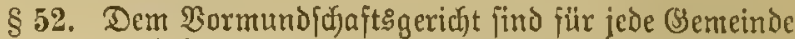
oder für örtlich abzugrenzende Gemeindetbeile ein oder

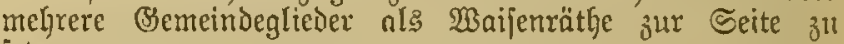
jetzen.

Jit: Genadjbarte (Semeindebezirfe fönnen biejelben fonen zu Waijenräthen beftellt werden.

Das 2Amt eines Waijentatys ift ein unentgeltlidjes Gemeindeant.

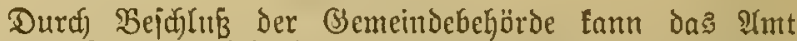
Des Waifenraths befonderen ?tbtheilungen ber Bemeinde= vertwaltung übertragen oder mit fajon beftehenden Drganen ber Gemeindevertwaltung verbunden rerden.

Iuf jelbitftändige Ģutabezirke finden die vorjtehenden Bejtimmungen mit der Masgabe entipresjende Antwendung,

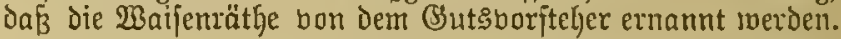

$\S 53$. Der Waifenrath hat die 2tuffidjt über Das

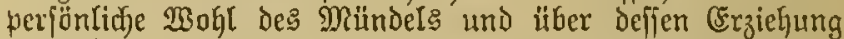

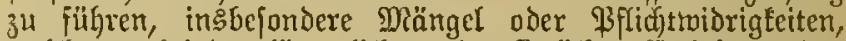
meldye er bei ber förperlidjen oder fittliduen (Erjiehung des Dimoels traljenimmt, anzuzeigen, auch auf (Srjorbern itber

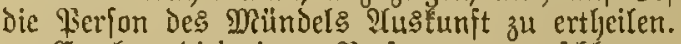

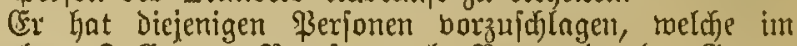
cinzelnen Fralle zur Bertifung als פormumd oder Begen= vormund geeignet erjujeinen.

\$54. Das : bes Bejirt's, in melduem der Miundel moljnt, bon der ein=

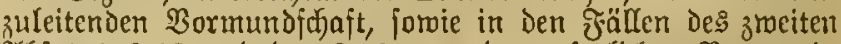

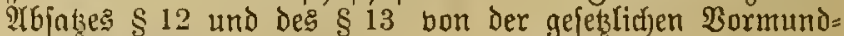
fefjaft Sienntnifz zut geben und den $\mathfrak{B}$ armund nambaft zu machen.

Bon einer $2 e r l e g u n g$ Der Wohnung Des Mitndels in eine andere (Semeinde oder einen anderen Bezirf lyat ber Dortmumd den Wratjenrath zu benadjridfigen. Diejer lyat

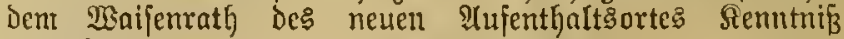
zu geben.

§55. Das Vormundjajafteggeridjt hat bor einer bon

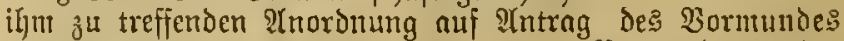
oder des (S)genuormundes oder eines Bermandten oder

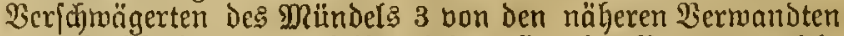

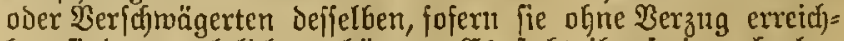
bar find, gutndhtlid) zu ljören. (5: jteht igm jrei, aud oljne

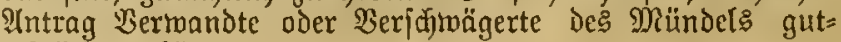
ad)tlidh ju hören. 
Das 2ormunojajajtegerint hat bor ber Entjucioung itber die ju einer Sandlung des Vormundes exporderticfe (3enehmigung ben (Segenvormund zu hören.

Das 20rmumbjajajtsgericht Gat bor ber Entforjeioung über die Șeräuß̧erung einer unbeweglidfen Sadje oder die

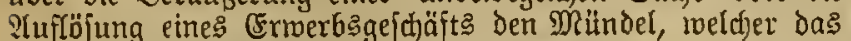
18. Qebensiahr jurüifgelegt hat, zu hören.

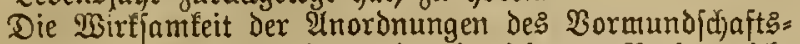
geridfts ift bon ber थnljörung ber bejeidfneten Perion nidft ab̧ängig.

\section{redjmungs̆legung.}

§ 56. Dąs : Vormumd Redmungslegung ïber bie Bermögensbertwaltung ju fordern. Bei Bermaltungen bon geringerem Hmjange

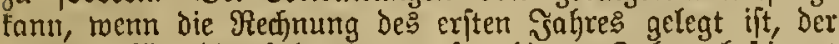
Termin für bic folgender auf 2 bis 3 Jahre bejtimmt merden.

Mefrete zu ungetrennter Bermaltung bejtellte Bormünder

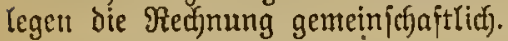

Der Re(f)ung find ein Borbericf) über Den $\mathfrak{A} b=$ und

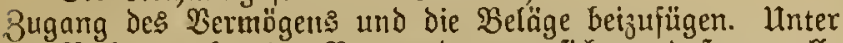

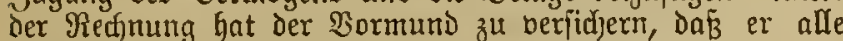

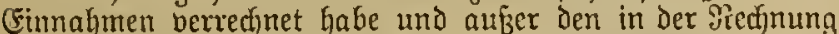

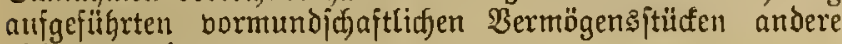
nimbt bertwahre.

Die Recfnung ijt bor ber Eimreidjung dent Begen= vormund unter Radjweijung besి Bermögensbejtandes vor: zltlegen und bon biejem nit feinen Bemertungen zu ber= iefer.

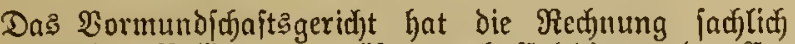
IIId nad) Den Belägen zu prïjen, nad) (Erledigung Der Er: innerungen Dem 20 ormun die Beläge mit eitrem Sermerfe Des elfolgten Gebraudis zurücfugheben, und auf Berlangen

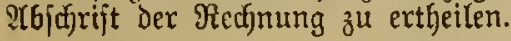

\$57. Der $\mathfrak{B a t e r , ~ b i e ~ M u t t e r , ~ b e r ~ C h e m a n t ~ t m o ~ b i e ~}$

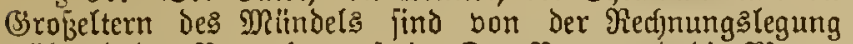
mäl)rend Der פerwaltıng frei. Der $\mathfrak{B} a t e r$ und die Mutter Find beredftigt, in Der $\$ 17$ Nx. 2 bejtimnten form den bon ignen benanten Bormund bon ber Rechnunglegung

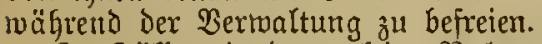

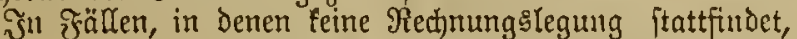

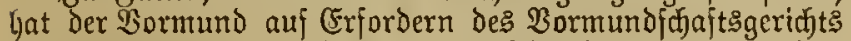
alte 2 Эahre oder in längeren Bwijdjenräumen eine lleber= fid)t des 2ermögensbeftandes einzureichen, meldje borfer

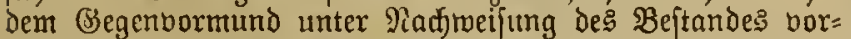
julegen und von biejem mit feimen Bemerfungen ơ berjefen ift. Der $\mathfrak{B a t e r}$ bes Müudels ift bon biejer $\mathfrak{B} e r=$ pffititung frei.

Das $\mathfrak{B e r b o t}$ dex Dffenlegung des Bermögensenezzeid $=$ nifjes ift rücfiftutlicf) des Dabon betroffenen Bermb̈gens al: Befreiung bon Der Re(t)nungstegung und Der (Einreid)ung ter Bermögensิüberficht zu erad)ten.

\section{Eidjerheitaftellung.}

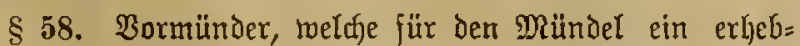
lictjes Vermögen zu vermalten haben, fönnen bon dem Bormund [daftsggeridjte zur Stellung einer Sidjerheit ange= halten merden. Die Art ImD der limifang Der Sicherheit wird nack ridfterlicfen (Ermeffen beftimmt; fie fann jedergeit ergöbet, gemindert oder exlaffen toerden.
Roiten, weldie auts der Ctellung Der Sicferheit ermadjien, jind aus bem $\mathfrak{B e r m o ̈ g e n ~ d e s ~ M i t i n d e l s ~ z u ~ e n t r i c h t e n . ~}$

Die über bie Sidjeritellung zu ertheilende Itrunde ift ftempelfrei.

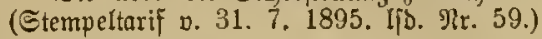

$\S 59$. Der $\mathfrak{B a t e r}$, jorvie die Mutter des Mündels find beredftigt, in ber $\S 17 \Re r .2$ bejtimmten Frorm den bon

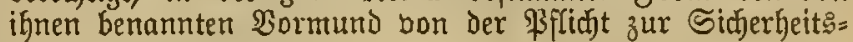
itellung ju berreien.

Die Befreiung fällt veg, wenn linftände eingetreten find,

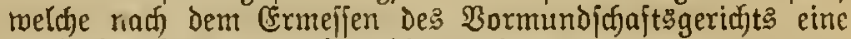
Sidferbeitsitellung nothroendig machen.

Der Fater, bie Mutter, der E⿹ Gemann und bie Brofs= Eltern alE Bormïnder und der Bsegenbormund find bou Der fifficht jur Sidjerbeitŝftellung frei.

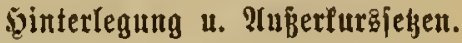

$\S 60$. Das Sormund Berthpapiere Des Miündels, weldje auf Den Ŝnlyaber lauten

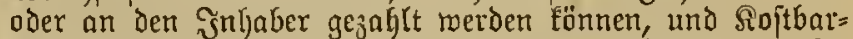
feiten bei ber $\Re e i d j \xi b a n t^{1}$ ) oder bei eirer anderen Dazu be= jtimmten Beförde over Sajie ${ }^{2}$ in $\mathfrak{E}$ erwahrumg genommen

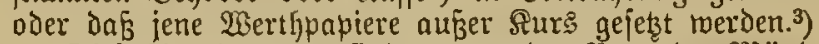

Dieje Ânoronungen finden gegen den $\mathfrak{B a t e r}$ des Münders nIs Bormund nidft jtatt. Sie finden gegen den bon dem Bater benannten Sormund nidyt jtatt, wenn fie bon bem

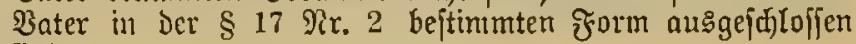
jind.

Daf3 Bormundjdaftêgeriaft muf̧ die Berwahrung ein= treten Lafjen, wenn ber bejtellte Bormund fic beantragt.

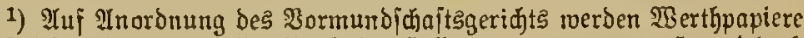

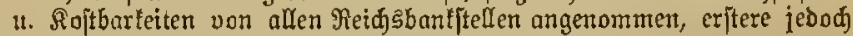

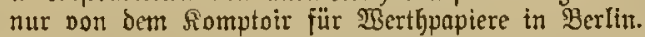

2) Das fund dic Regierungshauptfaj̄en bei ben Bezirfsregierungen, in Berlin die ocreiniate ßonititorial=, Dilitär= und Baufajie. Sinter= legungsoronung D. 14. 3. 1879 (\$ङ. 249) \$§ 1-3.

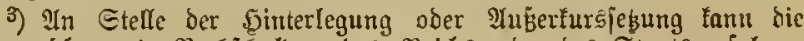

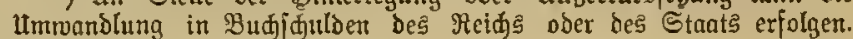
Bgl शlmm. 1 zu $\$ 39$.

\section{Beendigung Der Bormundfかaft.}

$\S$ 61. Die Bormundjđajt hört auf, wenn der MRündel Die Grobjiährigfeit erreicht, wenn er für groß̧iährig ertlärt wirb, wenn er in väterliche Bsemalt tritt, und wenn bas Rufjen der väterlichen Betwalt oder die Bebormundung des Baters aufgört.

Die (Srobjährigfeitserflärung eines Mündels if zu= läilig, twenn derielbe das 18. 2ebensjahr zurüưgelegt hat.

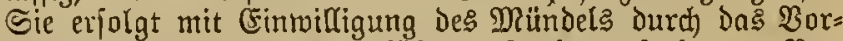
munojdaftsgeridgt nad geführter Sachunterjuffung. Ser= wandte fowie Seridinägerte Des Mündels find nadj Maßs= gabe des $\$ 55$ zu Görctt.

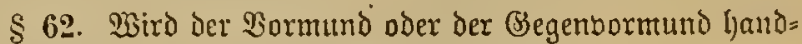
lungşunjäfig, jo erlijøt Dag atmt defjelben.

Mit Der Sufnahme des PR̈̈ndels in eine $\mathfrak{D e r p f l e g u n g} 3=$

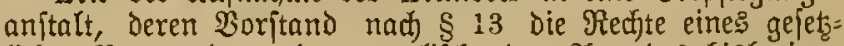
liffen 'Bormundes erlangt, erlifint das Ant Des bisherigen Bormundeg.

$\S 63$. Der Vornumo oder der Begenbormund, tweldyer

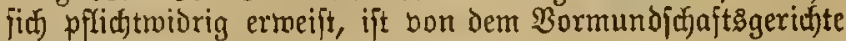
ju entjetsen. 
Der $\mathfrak{B}$ ormund oder der (Segenvormuth, weldher fid) at:

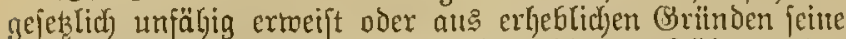

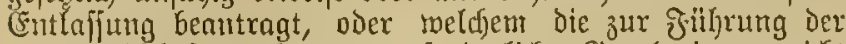
Bormundidajt nad \& 22 exforderlidje (S)enehmigung nidft

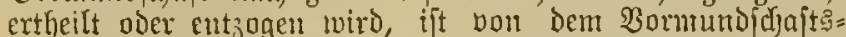

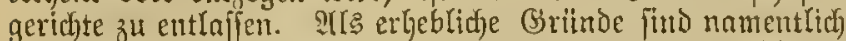

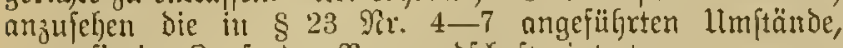

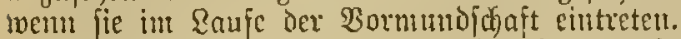

Dieje $\mathfrak{B}$ orjentiften finden audf auf Den gejetglidjen $\mathfrak{B o z}=$ mumb Itnwenoung.

Die Bejuberde gegen die crfolgte Entietsung oder Cent=

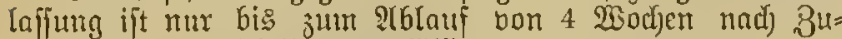
fitellung Dex (Entf(d)eidung zuläffig.

$\S 64$. Werkeirathet fich cirte jum Bormunde beftellte

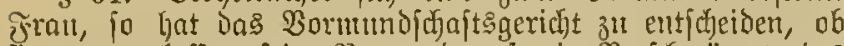
fie zut entlaffer fei. Bermandte jowie Berichmägerte des Mitndels find vorher nach Miazgabe des \& 55 zu hören. Die Beibehaltung ift nur mit Cimvillung Des Chemams 3uläfítg.

\$ 65. Stirbt der Bormuno oder Der Begcnbormund, jo find Der Ueberlebende und die (5rben berpflidhtet, dem Sormundidjajtogeridyte 2(uzeige zu madyen. Die Erben haben fïr Sidjerftellung Der in Dem Siadjlnffe befindlidjen Sermögensftücfe des Miundel zu forgen.

Sind nelyrere Bormünder bejtellt, io mito durdy den S(bgang eines Bormundes dos bormtundjugftlidje ?tut ber ï Grigen nidit nufgehohen.

§ 66. Der Vormund potvie Der Begenbormund hat nact) Beendigung feines SImtes die Beftallung an Das Beridft juriutlyugeben.

\section{Sd)Intedum!g.}

\$6\%. Ter Zormund hat nad) Beendigung feimes ?tutes den bisherigen Ditindel oder Defien Redutsnad)folger oder Dem net beitellen Bormuno dns bermaltete Bermöget

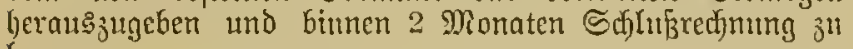
legen.

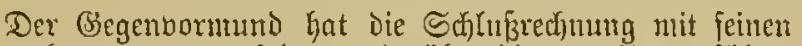
Bemerfungen zut verfeljen und über bie bon ihm gefïhrte (5)genbormundfdaft, pomie über Das bon Dem Bormund

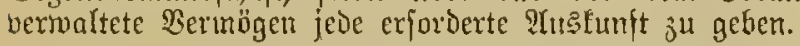

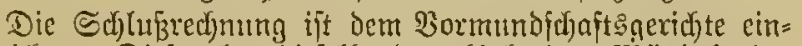
zureiden. Diefes hat diejelbe bem bisherigen Münoel oder

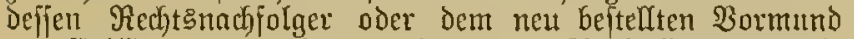
jur Errflärung borjulegen und, wenn ?tisjtellungen nicht gemadyt rerden, bie Entlajtung herbeizufülyen.

Die Pfflidyt jur \&egung Der Sdjluffrednumg geht auf den Serwalter im Sonfureberfahren umb auf bie Erben bes Bormundes iiber. Die $2=$ monatlide Frift beginnt fïr Die Crben bom Todestage Des Bormumes, oder, wenn ifhnen eine lleberlegung פfrift zulteljt, bom Irblauj Der lezteren.

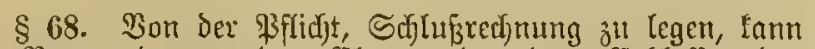
der $\mathfrak{B}$ ormund von Den EEttern ober Dem Crblafjer des Mündels nicht bejreit merden.

\$ 69. Der bisherige MündeL, dejien Rechtannadjfolger und der neu bejtellte Vormund find bereditigt, Behuj:

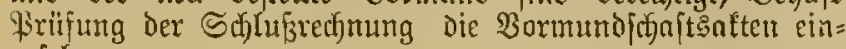
zulehen.
Diejelben find verpflidtet, ocm Bormund und Dem Bes genbormund über tren und ridjtia gefitgrte Sormundidfajt

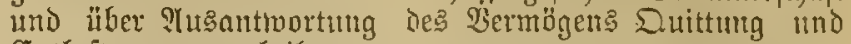
Entlajtung ôt ertheiten.

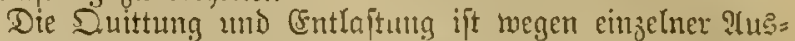
ftellungen nidft ju berweigern. Wiegen biefer darf ein $\mathfrak{B} 0 r^{=}$

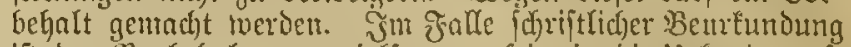
ift Der Borbehalt, um wirkfan ju feit, in bie llrfunde anf= jumehmen.

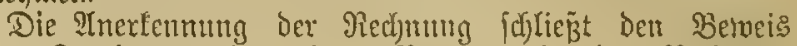

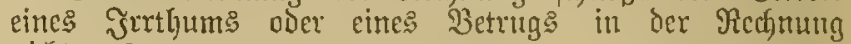
utidyt aug.

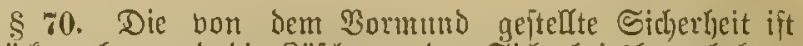
juritefzugeben und die \&bichung Der Sidjerheitshypothe ju betwiffigen, jobald beut Sormund Duittung und Entlajtutig ertheift morden ift. Şit hei Der Duittung unto Entlajtung

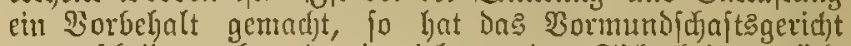
zil entfdfeiden, ob uno wie viel bon ber Sidherbeit zurüct= zubelyalten ooer bon der sypothef befsehen ju laffen fei.

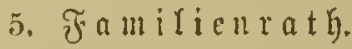

\$ 71. Cin fantilimath i it ju bilden:

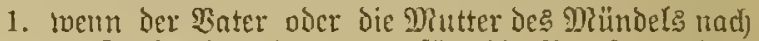
Maz̄gabe der in $\S 17$. für die Berufuttg cine Bormundes gegehenen Borfariften die Bildung angeordnet hat,

2. เoen 3 \$erfonen, toeldye mit Dem Mündel bis 3um 3. (Srave berwandt oder berfojwägert' ${ }^{1}$ ) find Dic 3 iloung beantragen,

3. ment Der Vormumb oder ber Begentornumb bie Bildumg beantragen.

Die Biloung eines Familiemaths unterbleibt, wem fie bon Dem Bater ober Der Mitter nadi Maß̧gabe ber Wor: (4) riften deg §. 17. unterjagt ift.

Zum (Fintritt in ben Famifienrath fann Riemand ge= 3trungen werben.

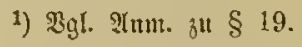

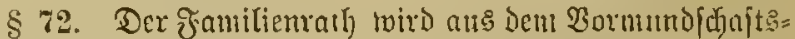
ridjter als Borfibendem und aus Vermandten Doer פer:

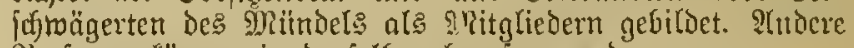
Siserfunen lönten in denfelben bertifen werden:

1. Durdf Den Bater oder bie Mitter nady Maß̈gabe

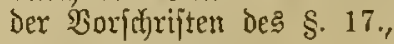

2. Duret) Şefd]lu[3 cines beiteljenden fautiliematys.

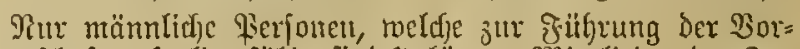

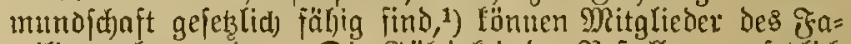
inilienraths merden. Die (Bitltigfeit der Bejtellung gejeţlict) unfäbiger Mitglieder ift tad Den $\mathfrak{B}$ orfdyriften Der $\$ \S 25$, 62 zul beurtbeilet.

Der (Gegenvormuno fann jugleidy Mitglied des familien= rattj̧ fein.

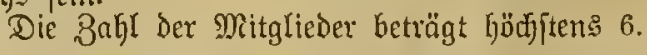

1) Jü̈ Beante ift eine Genehmigung Der vorgcjesten Behjörde,

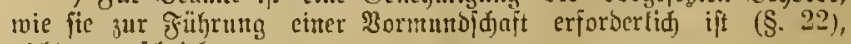
nidjt vorgeidrieben.

§ 73. Spmeit Die Mitglieder des Familienraths nidat Durd) Den Bater oder bie Mutter Germien find, oder die von Diefen Berufenen nifft cintreten oder Mitglieder aus= qujeiden, exfolgt Die Berufung der Mitglieder bis zur ફ̧er= 


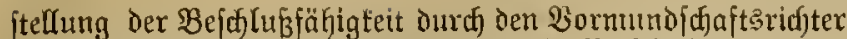
naú Änförung von : Mitndels, jofern diefelbe ohne $\mathfrak{B e r}$ jug gcjdeljen tann.

Daritber, of und weldje Ferjonen auberdem zub berufen find, befdiliest der Familienrath.

§ 7t. Die Mitglieder des Jamilienrathకs werden von Dem $\mathfrak{B}$ nrmundfdjaft

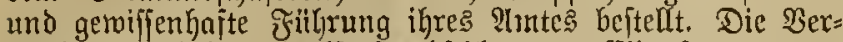
pflichtung erfolgt mittelft Sूandjhlags an (Eideŝftatt.

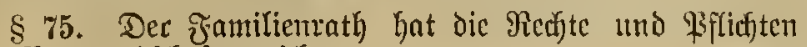
bes Bormundjuffaftşgeridjtà.

$\S 76$. Der Familiemath ift nur bei 2tmejentyeit bes

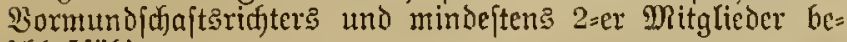

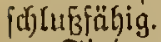

Sino auker Dem Borfitzenden nur 2 Mitglicder bor= hanoen, jo hat ber Jamilienrath 1 ober 2 Erjatsmitglieder ou berufer und bic Reiljenfolge zu beftimmen, in weldher

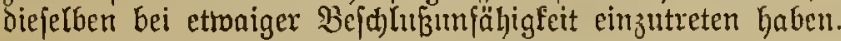

§ 7\%. Der Familienrath wird Duth) den Bormumb= (d)aftsridfter auf ben Intrag $2=e r$ Mitglieder, des $\mathfrak{Z} 0 \mathrm{r}=$ munbes oder des Begenvormundes oder bon Quntswegen jilammengerufen.

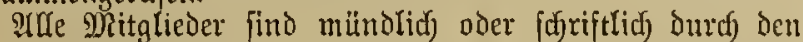
Bormundjchaftšridfter einzulaben.

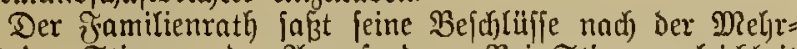
heit Der Stimmen der Anmefenden. Bei Stimmengleidhlyeit

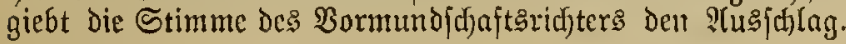

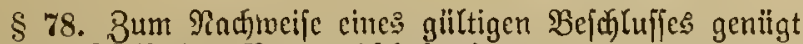

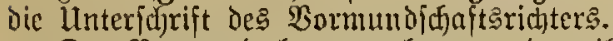

Der Bormund fam berlanger:, daß iljut die Bejdylitife bes ₹ramilienrath

(Segen die Befhlüffe des Familiemraths findet Bejdjwerde mad) Makg gabe Des \& 10 ftatt.

Birb ein fofortiges (Finjidreiten erforderlid), fo hat ber

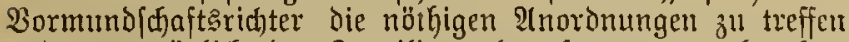
uno unverzüglicf den ₹amilientatl) zu[ammen zu berufen, um biefen bon Der getroffetten Berfügung in ßentrnif̧ z"l jetzen und über bie tweiter z̆ll ergreifenden Maß̄regeln einen

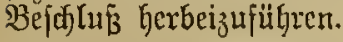

\$ 79. Dic Mitgliedcr des Familientathร fömnen aแs

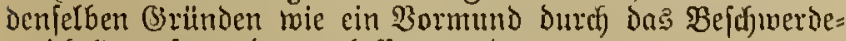
geriffit ${ }^{1}$ ) entfekt oder entlaffer toerden.

(3)egen Mitglieder bes テ̛amilienraths, twelche ohne ge=

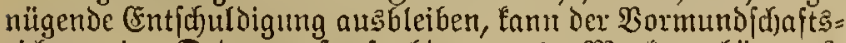
vichter cine Dronungsiftrafe bis jull 100 Mark berfängent. ${ }^{2}$ )

Begen bie Berbängung Der Sronungşfrafe finoet Beidwerde nad) Majagabe des $\S 10$ Ftatt.
1) Sanogeridt.

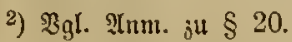

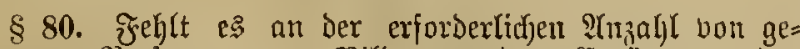
cigneten \$erjonen zur \$Bildung ober Crrgänzung Des

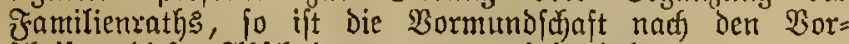

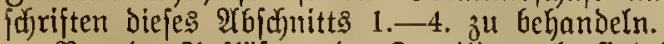

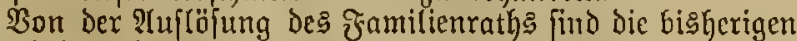
Mitglieder, dex Bormund und der Begenbormund Durch

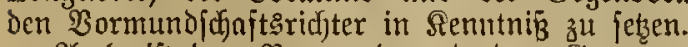

Qud ift Dem Bormund und dem Gegenbormutb eine neue Bejtallung zu ertheilen, dic frübere nber zurït zugeben.

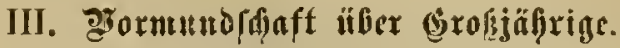

$\S 81$. Brofjährige erhalten cincr જ̧ormund:

1. wenn jie fïr geiftestranf ert(ärt [ind;1)

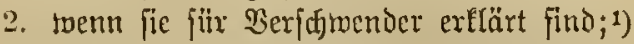

3. wenn fie taub, ftumnt oder blind und lierdurd an Beforgung ifrer Rechtangelegenbciter ge= Gindert fino.

1) lleber bas \$erfahren vgl. $\$ \S 593$ ff.

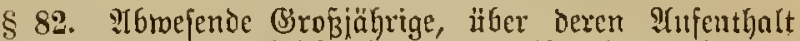

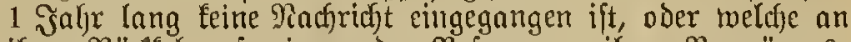
ifrer Rüffelyz, fowie an ber Bejorgung ihrer Bermögents= angelegenlyeiten geljindert fino, exhalten einen Tुormuno jur Bertretung bei ihren $\mathfrak{B}$ ermögensangclegenlyeiten, infoweit fie Daju einen $\mathfrak{B e v o l m a ̈ h t i g e n ~ n i d ) t ~ b e j t e l l t ~ G a b e n ~ o d e r ~ l i m p t a ̈ n d e ~}$ cingetreten find, reldje bie ertheilte Bollmadtt aufleben oder beren Miderruf zu beranlaffen gecignet find.

QHus Dringenden Girinden fann Dcmjenigen, deffen Iujentljaltsort unbefannt ift, audf) bor Mblauf cines Soljres ein Vormumb beftelft werben.

Эeder; weldjer Dem Bormundjdjaftęgeridjt cin Sinterefie

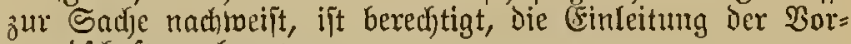
mundjcjaft zu beantragen.

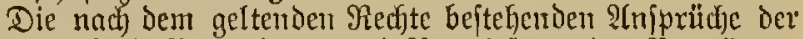

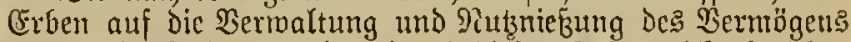

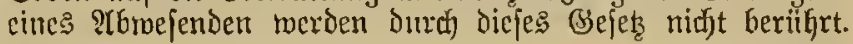

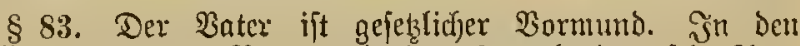

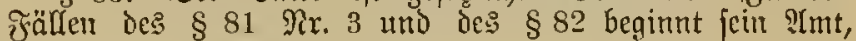

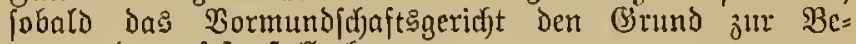
vormundung feitgeitellt hat.

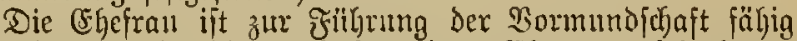
und hat die in biejem Siejeke dem Eshemann Geigelegten Redjte.

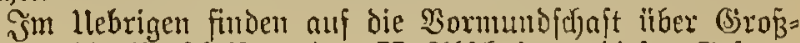

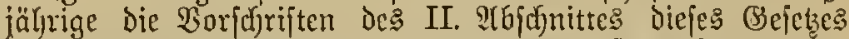
entfpredfende ?tumendung. Fnabefondere ift aud) Der $\mathfrak{V o r}=$ mund cines 9 (brwefenden bered)tigt, fïr denjelben zu erwerben,

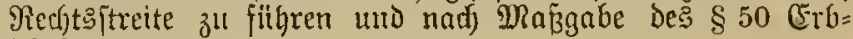
icfoften anzutzeten.

Dem 3 ormund cines Throfenden oder $\mathfrak{B e r f d}$ tuenders

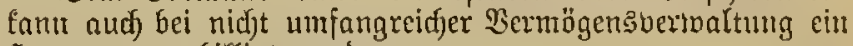
5enorar jugefilligt werden.

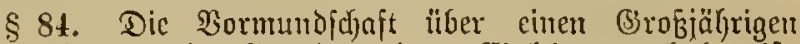
hört auf, ment Der (Srund z"l Deren Cinleitung gehoben ift, bie ïber cinen 1 tbmejenden namentlith aud, menn berjelbc

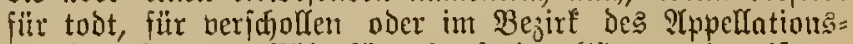

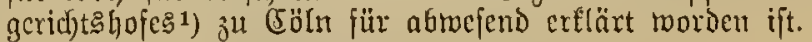

1) Эegt Dberlanbesgeridjts.

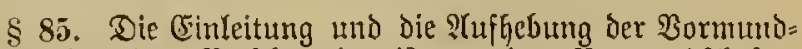

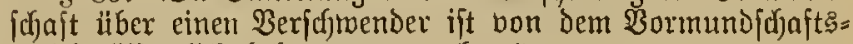
geridjt offfentlidf) befannt zu madjen. ${ }^{1}$ )

1) $3 g$. aud $\S 627$ 厄æD.

\section{IV. ¿’flegldjaft.}

\$ 86. Die in bïterlidjer Betwalt oder unter Sornumb= jd)aft ftehenden \$erjonen erhalten einen \$Pfleger fïr PIngelegen=

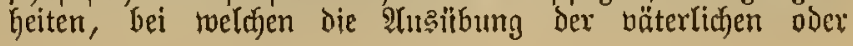


bormundidaftlichen Rechte eriorderlich i it, aber aus that= jächlidjen oder redjtlidjen (jitinden nidjt itattfinden fann.

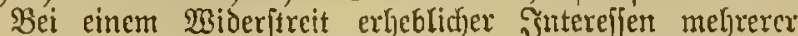
Mündel dejelfen $\mathfrak{B}$ ormundes erfält jeder Mündel cinen Bfleger.

§ 8\%. Wirb bei Bumendmaen an cine in bäterlicher (अe=

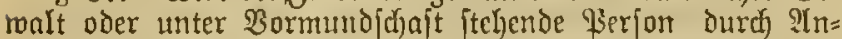
ordnung desjenigen, weld)er bic Buwendung gematht hat,

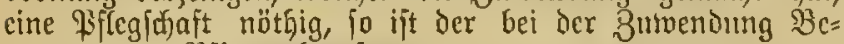
naunte zum \$fleger berujert.

Von der Rechnungslegung twälyrend der Daner der

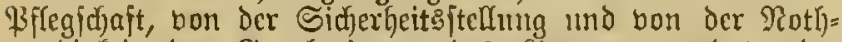
twendigfeit der Benelgmigung des Gegenvormundes oder

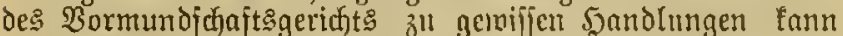
der Fffeger bei ber Buretromng befreit twerden.

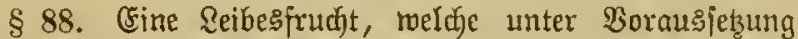
iffer bereits erfolgten (Seburt nicht unter väterlid)er (jetwalt ftehen wiltde, erhält auf IIntrag ber Sdjtwangeren, oder auf Intrag degienigen, defien भichte durch cine mögliche Beburt betroffen roerden, oder in geeiguteten f̈̈llen non Sutsmegen einen \$ffeger.

\$ 89. Sft der Erbe eines Jiactlaffes mubcfannt, jo ift

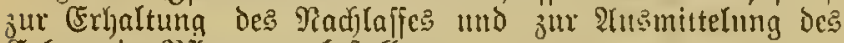
Erben ein $B f i l e g e r$ zu beftellen.

Dic in den einzelnen Eandcstheilen bejtehenden weiteren Bejugniffe diejes berührt.

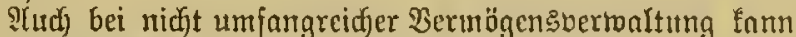
biejem Bffeger ein Seonorar zugebilligt werdent.

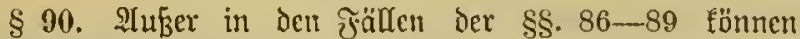
Hierjonten, weldye jelbjt zu bandeln aurer Stande find und ocr bäterlicjen oder bormumb (chaftlichen Bertretung entbehren ${ }^{1}$, für cirzelne 2̈ngelegenfeiten oder für einen beftimmten Sireis von Angelegenheiten einen \$ffleger erhalten.

b) 8. \$. in Falle cinter unfreimillingen $\mathfrak{B}$ erfeţung cines Beamten

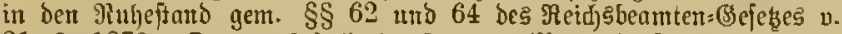
31. 3. 1873. Der jut bejtellende Surntor (PFIcger) ift rifit Don ber Dienjtbejörde, jondern dom

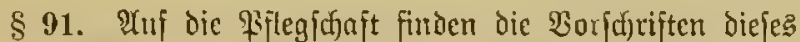

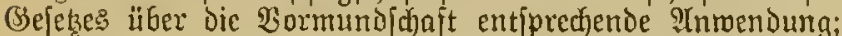
die Beftellung cines Sicgenvormundes ift nicft exforderlich.

Die \$flegichajt hört auj, wenn ber Grund zu beren Crinleitumg gehoben ift.

\section{Sdjhußbeftimtunugen.}

§ 92. (1) Diefes Bejes tritt ant 1. Samtar 1876 in

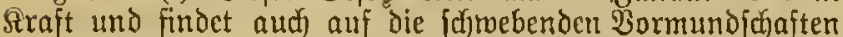
oder Pflegiduaften ?trmenoung, jomeit nidyt in ber nach= itehenden Paragraphen etras

$\left.{ }^{2}\right)$

§ 95. (1) Die Bejugniffe, weldje c5ltern oder (Shegatten

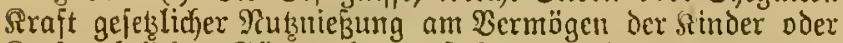

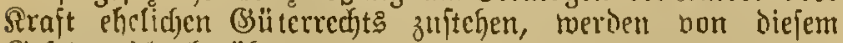
Gefetze nilibt Gerifhrt.

(2) $\ldots \ldots$
(3) Dic in den übrigen Eandegtheilen bejtehenden 3 or

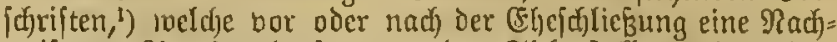
meifung, SUseinanderjebung oder Sicjerftellung des Şer= mögens crforderw, bleiben in Sraft.

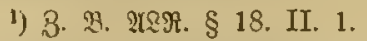

$\S 9 \%$ (1) Dic Brofiährigfcitęctfärung cines in väter=

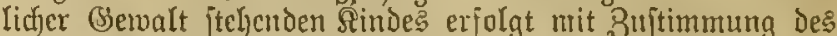

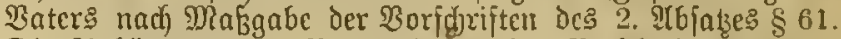
Die 2(nförung vor Bermandten oder Verfajuägerten dę Rindes ift nicht erjorberlid.

(2)

§ 98. (l) Dic für groß̧jährig Ertärten lyaben alle Red)te der Grofją̧̋rigen.

(2) .....

\$ 99. Dic (3roßjjähriafeit tritt als శolge ber $\mathfrak{B e c}=$ Geirathung nicht mehr cin. ${ }^{2}$ )

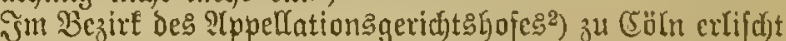
Durd) Derljeirathjung oes Rindes die bäterlicje (Betbalt.

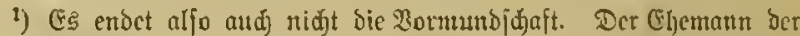

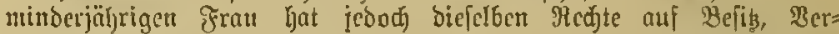
waltung u. $\uparrow$. w. bes Nerntögens wic ber cinter grofiäfriycth. Et= maiges Eonderwermögen ber Frau verwaltet ber Bormuno nto foncit

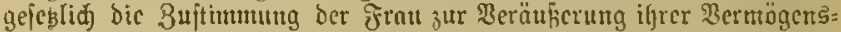
objefte geforbert witb, ift währent ibrer Mittocrjälytigleit bic $\mathfrak{B c t}_{\mathrm{c}}$

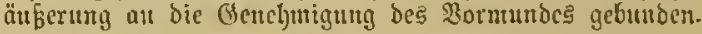

3) Dberlandesgeriduts.

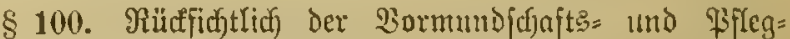

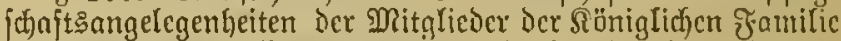

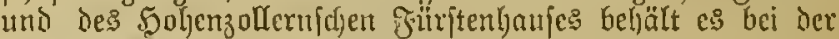
Şanserfajfung (in Bemenden. ${ }^{1}$ )

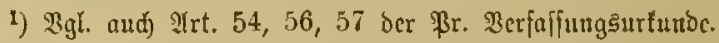

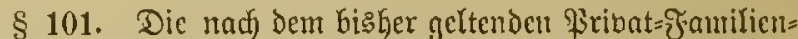
recfte der Sönupter und Mitglieder der \{riiher reichştändijchen

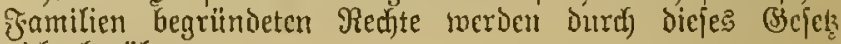
nicht berïljet.

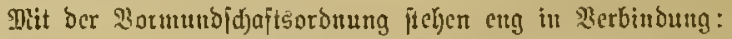

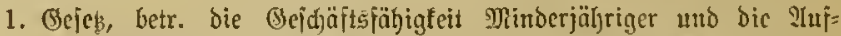
lebunt ber Wistebereinfeibung in ben porigen Stand wegen Plinderjährigfeit vam 12. 7. 1875. (\$S. 518).

Danad) find Minberjährige, welde bas 7. Zebensjaljr

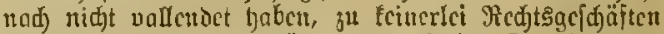

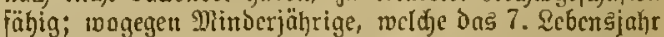
vollenbet haben, obne Benehmigung bes Baters, Bor=

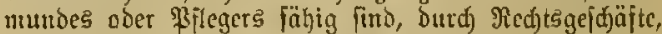
bei welder van ithen feime Begenleiltung itbernomucn

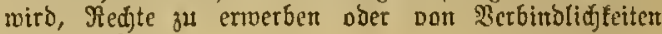
iid) zu befreict.

2. Ge[eb, betreffett bie Unterbringung verwahrlofter Sinder v. 13.3.1878 (\$S. 132), weldics beitinmt:

Wer mad 3olfendung bes 6 . unt oor 30 llentung bes 12. Lebentsjahres einc irafbare banturng begeht, fann ban Dbrigfeitsmegent in eine geeignete framilie ober in

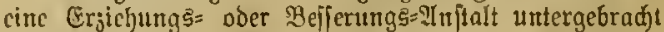

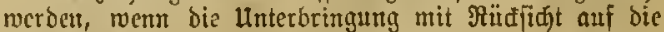
Bejd)affenheit ber fitrofbaren 5andung, auf bic \$cr= fonliđhlcit Der Eltern ober jonjtigen Eraieber Des Sintoç uns auf befien übrige ミebenకverbältniffe zur \$erbütung weiterer fittlidjer Bermahrlojung erforberlicj ip. Die unterbringung zur 3wangserziebung eriolgt, nadbent

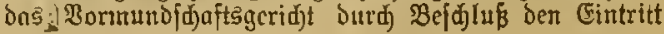


obiger Borausfepungen feitgejtellt mo die llnterbringung fïr erforderlich erflät hat.

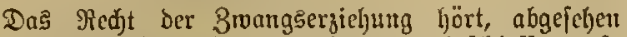

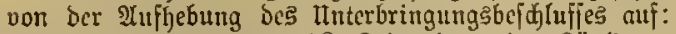

1. mit bem Dollenteten 18. 2ebenjabre bes 3öglings,

3. mit bem Befdlufie ber Entlajiung ant ber 3rangs= crzichung.

1) Bgl. aun ङt@8. \& 55, Dfen G. 217.

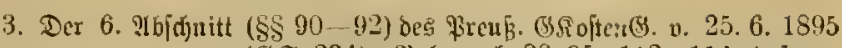

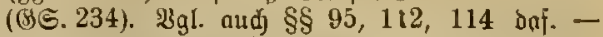
Stenpelabgaben werden nad̆ ben פorjdriften bes Stempelfteuergejebes v. 31, 7. 1895 ((\$). 413) erhobert.

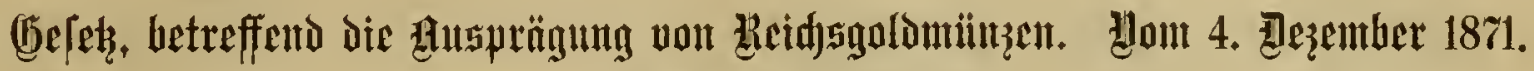

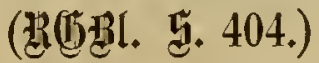

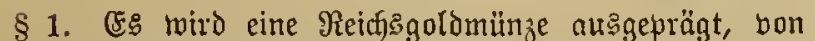

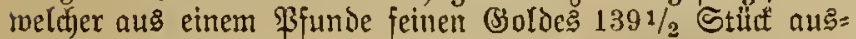
gebracht werden.

§ 2. Der zehnte Theil diejer Goldmünze bird Mart genannt und in hundert $\mathfrak{P}$ fentige eingetheilt.

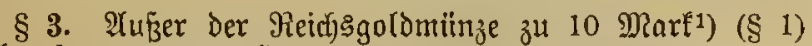
follen ferner ausgeprägt werden:

Retd) eirem Pfunde feinen (Soldes $69^{3} / 4$ Stiuct ausgebradjt merben.

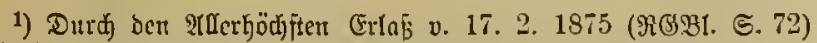

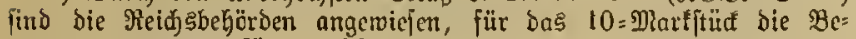
netmung "Srone”, für bas $20=$ Marffítïf bie Benennung "Doppelfrone" anzumenten.

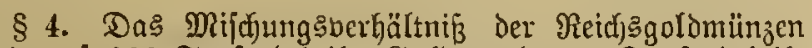
rird auf 900 Taufendtheile (Bold ind 100 Taufendtheile Rupfer feftgeftellt.

(5: werden Demnad):

$$
\begin{array}{cl}
125,55 & 10=\text { Marlfitilfe, } \\
62,775 & 20="
\end{array}
$$

je cin $\$$ ifund wicgen.

\$5. Die Reidjsgoldmitnzen tragen auf der einen Seite

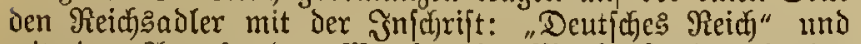
mit der Angabe Des $\mathfrak{B}_{\text {erthe }}$ in "Mark, porvie unit Der

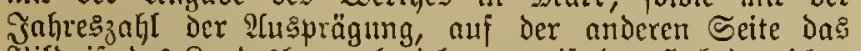

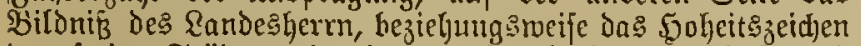
der freien Stäbte mit einer entfpredjenden limidjrift und dem Münzzeidjen. Durdjmeffer Der Mïnzen, Bejdjaffenheit

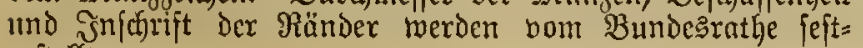
geftelft.

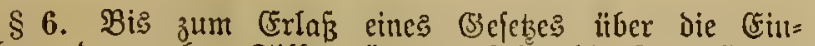
jiehıng Der groben Sifbermünjch erfolgt bie ?lusprägung ber Goldmilinzen nuf Rojter Des Reidje fitr fämmtliche Bundesftaaten auf Den Rünzitätten Derjenigen Bundes= ftanten, meld)e ficf) Dazu bereit ertlärt haben.

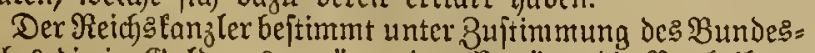
rathes die in Golo auszumtinzenden setröge, die Bertheilung diefer Beträge auj Die einzelnen Münzgattungen und auf Die einjelnen $\mathfrak{P}$ iinajtätten und bie den leţteren für bie Prägung jeder cinjelnen Münzgattung gleich)mäßig zu ge=

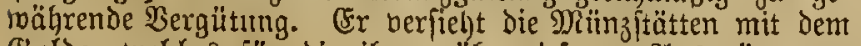
Bolde, meldhes für dic ihnen überwiefener Puspprägungen erforderlich ift.

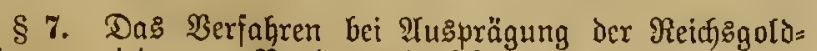
mitnjen wird bom Bumberatlje fejtgeftellt und unterlicgt

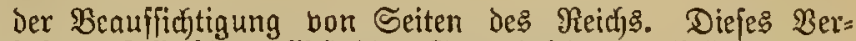
jahren joll bie bolfiändige (Senauigfeit der Münzen nad) Gehalt und Bewidft feifitellen. Sorveit eine abjolute (Ge: ntauigfeit bei dem einzelnen Stürf nicf) feitgehalten werden fann, foll bie ?tbreichung in Megr oder Weniger, im Bemicht nicht melor als awei und cin halb Taufendtheile jeines (Gewidhts, im Feingehalt nicht meht als zwei Tnujendtheile betragen.

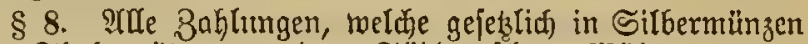
der Thalermährung, der Sübdeutid)en Währung, der

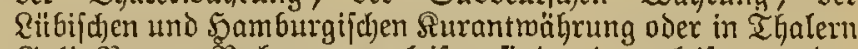

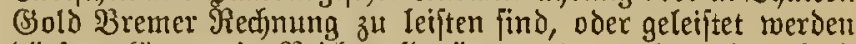

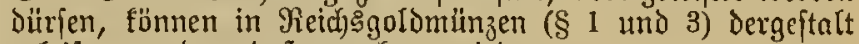
geleijtet werden, dấ gered)net wird:

Das 10= Miarfftidd jum Merthe bon $31 / 3$ Thalem pder 5 హ్l. 50 §r. Sübdeutidher Währung, 8 Marf $51 / 3$ Sditling Rübijder und 5amburgif her Sturant= mährung, 3 1/93 Thaler Gold Bremer Fedinuuti;

Das $20=$ Diartitüd zum Werthe bon $6 \frac{2}{3}$ Thalern oder 11 il, 40 ßr. Sibdeutider $\mathfrak{B a ̈ h r u n g , ~} 16$ Marf $10^{2 / 3}$ Sctilling Rubij(t)er und Samburgijd)er Sutrant=

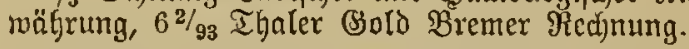

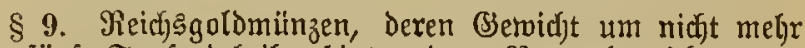
als fünf Taufendtheile hinter Dem शormalgemifts $(\$ 4)$ jurïafbleibt (\$iaffirgetwidyt) und roldfe nicht ourch) gemalt= fame oder gefectwiorige Befchäbigung am (Sewid)t berringert fint, jollen bei aller 3ahlungen als vollwidhtig gelten.

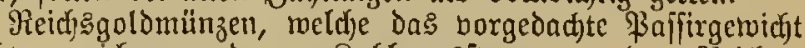
nidft erreichen und an Zahlungestatt bon Den Reidfs:, Staatsa, Provinzial= Doer Rommumaltajien, fomie bon (Seld = und Rrebitanjtalten und Banfen angenommen worden

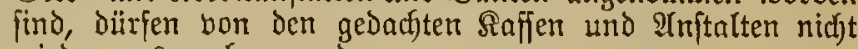
vieder ausgegeben merben.

Die Reid) $g$ goldmïnzen toerden, wenn Diefelben in Jolge längerer Cirfulation und श(bnukzung am (Semid)t fotiel

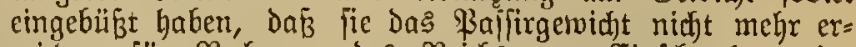

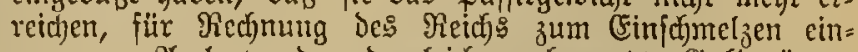
gejogen. शluch werdon Dergleidjen abgenutzte Boldmïnzen bei allen Rafien des Reidjs und Der Bundesftanten ftet? boll j"l demjenigen $\mathfrak{B c r t b e}$;u meldjem fie auggegeben find, angenommen merden.

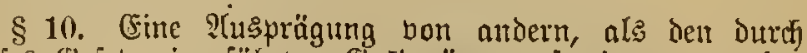
dicles (Sejês eingefübrten Soldmünjen, fomie von groben Silberntitnzen, findet bis auf Weiteres nidj)t ftatt.

\$11. Die zur Beit umlaufenden Ssolomünzen Der

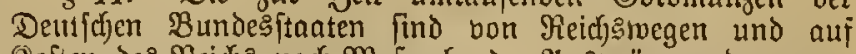

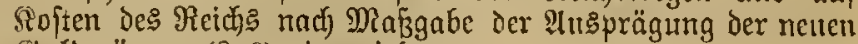
Ğolomitnzen (\$ 6) einzuzieten. 


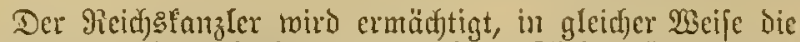
Cinziehung ber bisherigen groben Silberminjen Der Deutjejen Bundesftaatem anzurionen und bie ju biefen

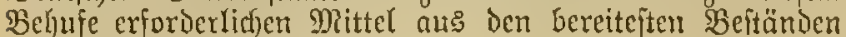

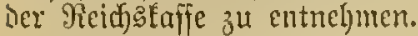

Heber die Stusfïlyrung ber voriteljenden Bejtimmungen ijt Dem Reid)stage alljäbrtich in feiner crften ordentlicben Seffion Rechenjijaft zu geben.

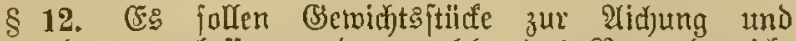
Stempelung zugelaffen werben, melne das Normalgemidft

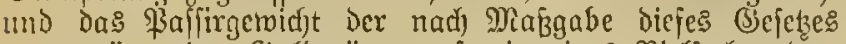

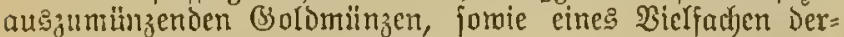
felben angeben. Fith bie 2lichung und Stempelung biefer
(B)encic)tsftiide find bie Beftimmungen ber 2(2t. 10 und is

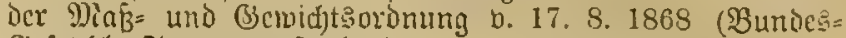
(3ejetzbl. S. 473 majgebent.

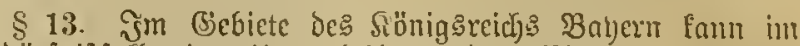

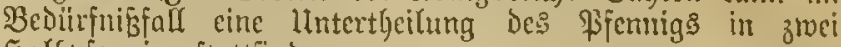
Sothopfermige ftattfinden.

Uifundtith $2 e$.

Begeben Ber [in, Den 4. Dezember 1871.

Willyelun

รiürjt v. Bismarct.

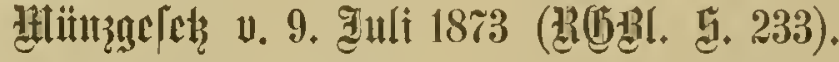

2(rt. 1. IIn bie Stclle Dcr in Deutfdyland geltenten

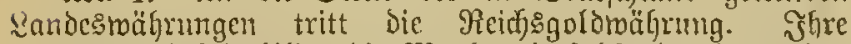

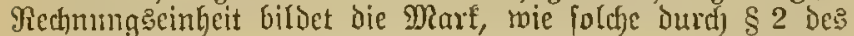
Gejetzes bom 4. Dezember 1871, betrefjend dic 94nsprägung

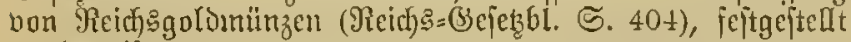
soriden ift.')

Der Beitpuntt, an weld)en bie Reichstvälyung int ge= faumten Yeidjsgebicte in Sraft treter foll, miro Durd eine

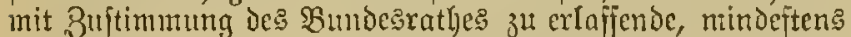
Drei Wionate vor Dem Cintritt Diejes Beitpunftes zu ber= fïndende 2eroronung des fiaifers Eeftimmt. Die Randes: regiermugen fino ermäd)tigt, audh bor biefem Beitpunfte für

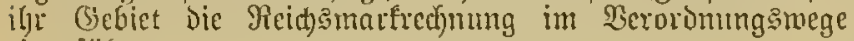
cinjufïligren.

1) Daş vorangẹïhrte (scję, હ. $333 / 334$.

9rt. 2. Tußer Den in Den Gejebe vom 4. Dezember 1871 bezeid)neten Reidjgglomünzen jollen ferner ausigeprägt merDen Reidjgిgolomïnjen zu fünf Marf, von weldjen ans cinem \$funde feinen Gioldes 279 Stüte ausgebradit werden. Dic Bejtimmungen der $\S \S 4,5,7,8$ und 9 jenes Bieferces

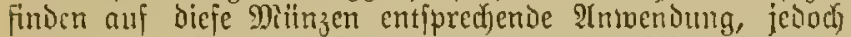

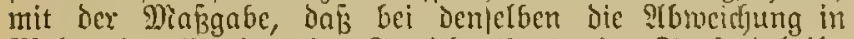
Meljer oder Wieniger im (bemidgt (\$ 7) vier Taulendtleile, und Der Intcriffied amifchen Dem PRormalgewiedst unD Dem

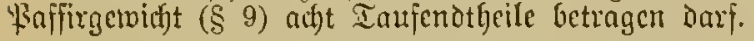

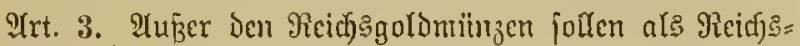
mïnzest und zroar

1. alz Silbermïnzen:

ชันแnfmarfitürfe,

3roeimarfftïcfe,

Einmarfftitle,

Fïnfỏigpiennigitünfe und

3roastzigpfemigitürfe;

2. als 9idtelmiinzer: ${ }^{1}$ )

3ebnvfennigitïlfe und

כัünfpfennigftïcte;

3. aโs Rupferminzon:

Brocipfennigitürfe und

(Eimpfennigftiicte

nach) Miaf̧gabe jolgender Bcitimmungen ausgeprägt werden.

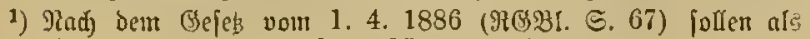
Ricelmüngen aud "3manjigpfentigitïffe" scprägt merben.
§ 1. Bei 2Iusprägung der Silbermünzer wiro da: Fimo feinell Silbers in

20 Fïnfmarkititufe,

50 Zroeimartitiode,

100 Einmartftïcfe,

200 fitinfzigpiemigftïcfe uns in

altsిgebrad)t.

5003 mantigpfennigftitife

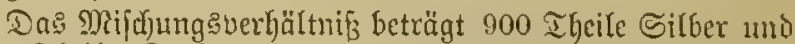
100 Theile Siupfer, fo bẩ 90 Miart in Silberminzen 1 Sifuno miegen.

Das Verfahren bei Ylusprägung biefer Münzen miro vom Bundestath feitgeftellt. Bei ben einzelnen Stinden barf Die melj: als brei Taujentljeile, im (Getridgt, mit singnahme ber

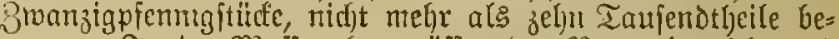
tragen. Sn Der Mafife aber mulfifen das Pormalgemidgt uni ter Siormalgebalt bei allen Silbermilnzen innegelarten merder.

\$2. Dic Silbcrmünjen über cin Mart tragen anf Der cinen Seite den Reid)

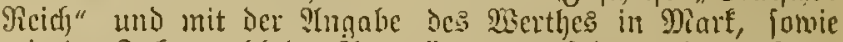

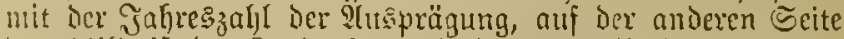

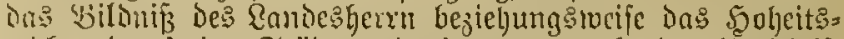

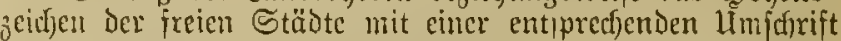
แno Dem Mïnzzeidjen. Durdintefijer Der Münzen, Befdaffen= l)eit und Beraierung Der Ränder Derfetben werden bom Bumbesrathe feitgeftedt.

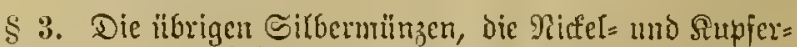
milnjen tragen auf Der einen Seite bie Werthangabe, Die

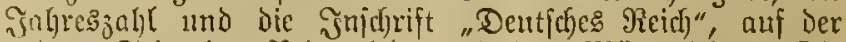

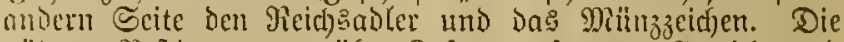
mäleren Beftinmungen ïber Bufammenjeßumg, (Sewidjt und Durchmeijer dicfer Mïnzen, proic über die Serzierung Der Schriftefite แmD Die Bef(haffenljeit Der Mänder werden vom Bundesirathe feitgeitellt.

\$ 4. Die Silber=, Ridfel= mo Supfermünzen merden

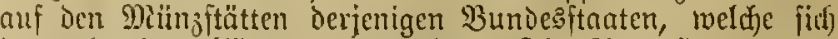

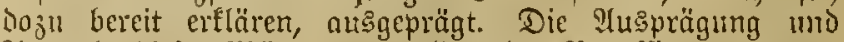

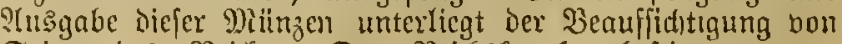
Seiten Des Reidj. Der Reidjäfanzler beftimmt unter

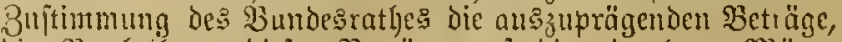
die Bertheilung Diejer Beträge anj die einjelnen $\mathfrak{M}$ iür $=$ 
gattungen แnd auf Die einzeluen Miïnjtätten und die Den leţteren für Die \$rägung jeder cinzelneu Mïuzgattung gleid)mäßzig zu getwäljende Bergïtumg. Die Bejdjaffung

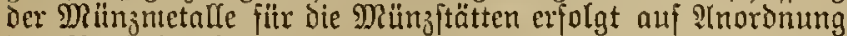

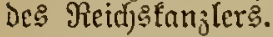

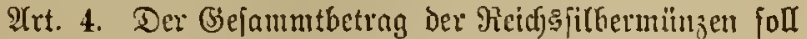
bis au $\mathfrak{B e i t e r e s ~ z e h n ~ M a r t ~ f i ̈ r ~ D e n ~ R o p f ~ D e r ~ B e b o ̈ l k e r t u g ~}$ Des Reidfs nidft überitciaen.

Bei jeder ?(usgabe Diejer Münzen ift eine dem şerthe nad) gleidje Menge ber unlaufenden groben Randesfitlber=

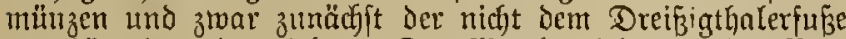
angehörenden einzuzieljen. Der Merth mird nadj der $\mathfrak{B} 0 \mathrm{~L}=$ fdfrift im \$frt. $14 \$ 2$ berect)net.

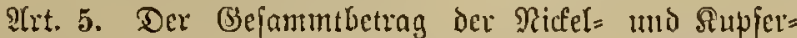
müuzen jolf ztwei und eine halbe Dianf fïr ben Sopf ber Bevoblferang des Reichs nict)t überfteigen.

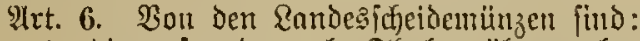

1. die auf andere als Thalerröhrumg lautenden, mit IUEfdjlufs Der baherijdjen Seller und Der medten= burgifdyen nad ben Marfinftente anşgeprägten

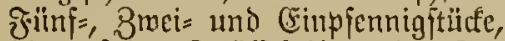

2. Die auf der Bwölftheilung dę (Srofd)en: beruben= den Scheidentimzen z" 2 und 4 4sfennigen,

3. Die Scheidemitnjen der Thalerwährumg, weldfe auf einer anderen Eintheilung Des Thalers, atร Der in 30 (Srofden berulen, mit stusnabme Der Stüdfe in werthe bou $1 / 12$ Tljaler,

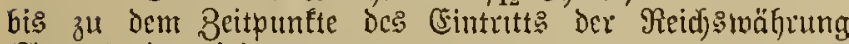
(2rrt. 1) einzuzieljen.

Radh Diejem Beitpunfte ift Riemand berpflidstet, Diefe Scheidemünzen in 3alftung zun nehmen, als bie mit ber Einlöfung Dexfelben beauftragten Saffen.

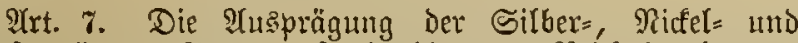

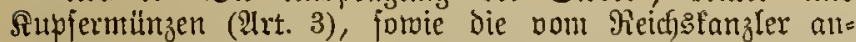
zuordnende Cinziehung Der Randesfiltbermünzen und Randes: jdjeidemilnzen elfolgt anf Redfmung bes Reidfs.

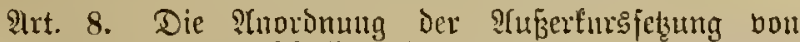

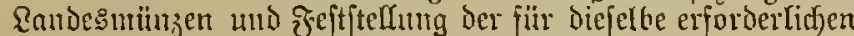
Borjegriften erfolgt Durd) den Bumbestath.

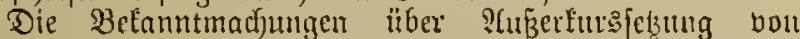
Randesmïnzen find aufer in Den zu Der Beröfifentlidfung von Entrosuctordmungen beftummten Blättern aud burd) Dns Retd)

(Fine Shiserfurşeßzung Darf erit cintreten, weun eine

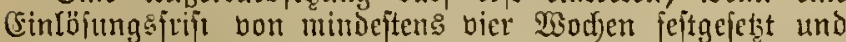
mindeitens drei Monnte vor ifrem Ablaufe durd) bie vo: bejeidjneter SBlätter befannt gemad)t wor'sen ift.

Iit. 9. Riemend ift verpflidfet, Ricidjsfilberutünen im Betrage bour mehr als zmanzig Marf umb Ricfel= und Supfermin̈msen im Betrage bon mehr als einer Mart in 8ahlung зu nelymen.

Bon Den Reicf: münzen in jebem Betrage in 3ahlung genonmen. Der

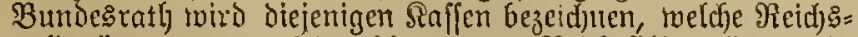
golomünzen gegen (Einzahlumg von Reicfsfitherutünzen in Beträgen bon mindefteng 200 Marf oder bon Niffel= unb ßupfermünzen in Beträgen von mindejtens 50 MarE auf Berlangen veraffolgen. Desfelbe wiro ztgleich bie näheren Bedingungen des llmtnufefes feftfezzen.

2rt. 10. Die Beruflichtung zur 9Annahme und zum Umtaufd) ('Trt. 9) findet auf Durchlöchette und anders, nla burd, ben gemöhntidfen llmlauf im (B)etwidyt verringerte, in

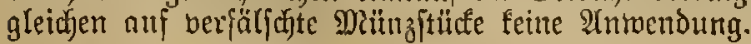

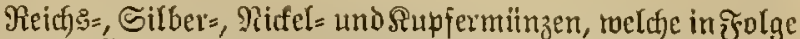

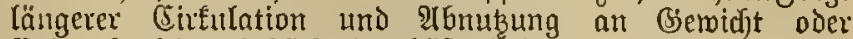
(Erfennbarfeit erheblid) eingebüft haben, werden zwar nod) in allen $\Re$ eidjs: und Randestaffen angenommen, find aber

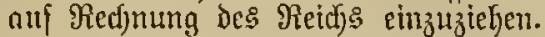

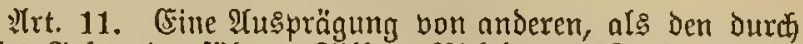
dicjes Befetz eingeführten Silber=, Ricfel= uno Rupjermünzen findet nidft ferner ftatt. Die Durd) Dic Beftimmung im

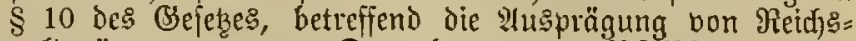

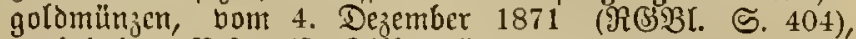
vorbebaltene Befugnif́, Silbermünzen alङ Denfmünzen aus= 3uprägen, erlifd)t mit dem 31. Dezember 1873.

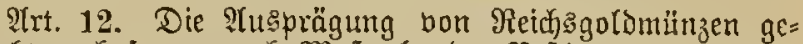
fdjebt nud ferner nad) Maßzgabe der Beftimmung im $\$ 6$

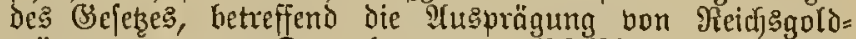

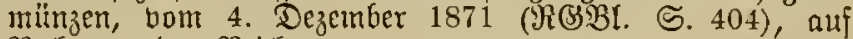
Rechnung Des Reichs.

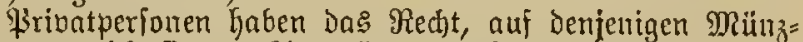

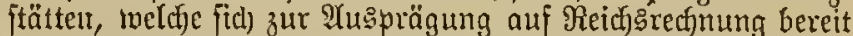

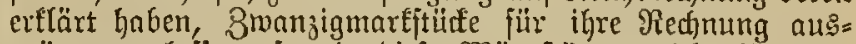
prägen zol lafien, forveit biefe Münzftätten nicfit für bas Reicf beldyäftigt finó.

Die fiir foldje Alusprägungen zu erlyebende Bebully roird

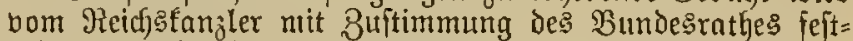
gefiellt, barf aber bas Marimum bon 7 Mart auf Das 和und fein (5) old nidft ïberfteigen.

Die Differenz zrwijd)en diejer (Bebilthr und der Bergütung,

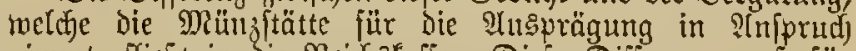
nimmt, fliept in bie Reidfafaffe. Dieje Differenz mur für alle deutidyen Münz\{tätten biejelbe fein.

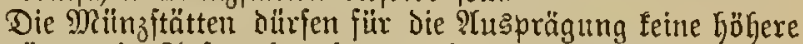

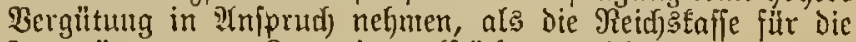
?tusprägrng boul Zmanzigmalfftücfen gewährt.

21xt. 13. Der Bundešrath ift befugt:

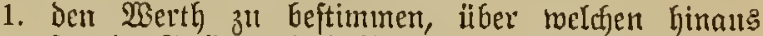
frembe Bold = und Silbermitnzen nidjt in $3 \mathfrak{a h l u n g}$ angeboten und gegeben roerden Dürfen, fowie den Ilmlauf frember פiünzen gänzlich zu unterjagen;

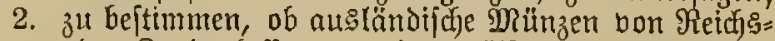
oder Randešaffen zu einem offentlidy befannt zu madjenden Sutrfe im inländijden Berkegr in Baflung genommen werden biurfen, and) in foldiem

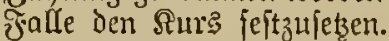

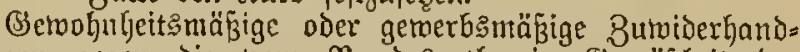
lungen gegen die bom $\mathfrak{B}$ undesratbe in Semäs̆beit der Beftimmungen unter 1 getroffenen 9 (noronungen werbeu beftraft mit (S)eldjtrafe bis zu 150 Marl oder mit \$gaft bi: zu (ech) $\mathfrak{B}$ odjen.

2rt. 14. Bon dem Csintritt Der Reidjgtwährung an gelten folgende $\mathfrak{B}$ orjdyriften:

§1. IItle Bnljlungen, weldje bis dafin in Münsen einer inländifdjen $\mathfrak{B a ̈ h h r u n g ~ o b e r ~ i n ~ l a n d e s ̧ g e f e t s l i c h ~ d e n ~ i n l a ̈ n d i f c h e t ~}$

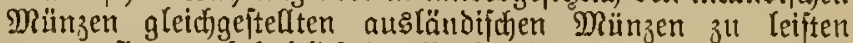
raren, find borbehaltlid) Der Borjoriften ?(rt. 9,15 und 16

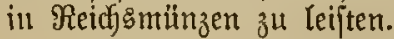

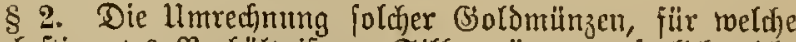

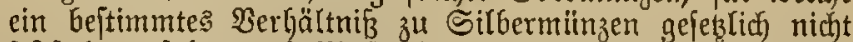
feitfteht, erfolgt nad) Maßzgabe des Berbältnifies bes gefets= richen Jjeingehalts Derjenigen $\mathfrak{D}$ iünzen, auf weldhe die

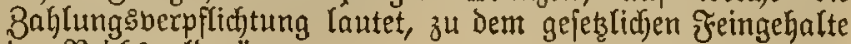
Der Reidjggolomünzen. 
Bei Der Ummed)mung anderer Mï̈zen twerden Der I Ijaler zแm Werthe bon 3 Mart, Der Gulden fïbdentfder Währung zum Wertbe von $15 / 7$ Dinet,

Die Mare liibifder oder hamburgifdjer Surant= wäbrung zum Werthe non $1 \frac{1}{5}$ Mart,

die ïbrigen Mitnzen derielben 2Bägrungen zu entfpreçenden Werthen nad) ihrem $\mathfrak{B} e r(j a ̈ I t m i \tilde{\beta}$ ju den gemanten beredjet.

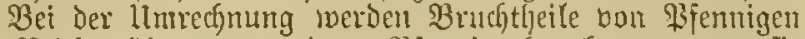
Der Reidfonährung ju cinem Pifennig beredfnet, wenn fie einen balben BSfennig oder mel)r betragen, 3rudjtheile unter eincm ljalben fifeming iverden nidjt gerechnet.

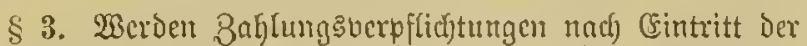

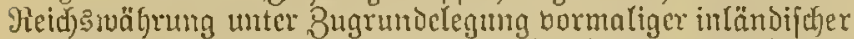

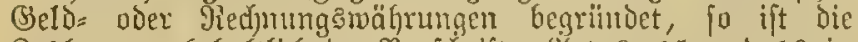
8nhlung vorbehaltlich Der $\mathfrak{B}$ orfderiften Q(rt. 9, 15 und 16 in

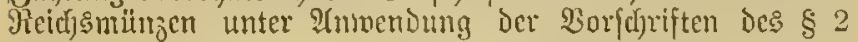
zu leiften.

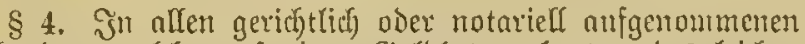
Urfimben, welde allf cinen (selobetrag lauten, Desgleidjen

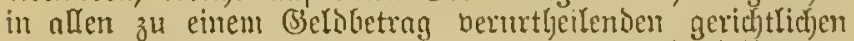
(Entfareidungen ift biefer Belobetrag, wenn jïr Denfelben ein

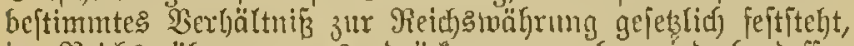

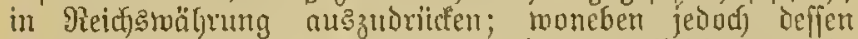
gleichzeitige Bezeicfnumg nach berjenigen wäljung, in velder urfprïnglide bie Berbindlid)leit begriindet $1 \mathrm{war}$, ge= itattet bleibt.

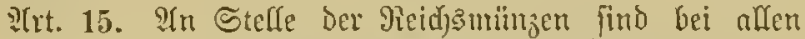

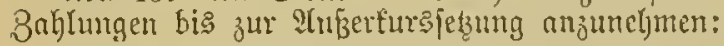

1. in gefanmten Bumbeggebiete an Stelfe afler Reictsmünzen die Ein = und Bweitfaleritütfe Dentficten Sepröges unter Beredhnung Des Thalcrs zu 3 Mart: 1 )

2. im gefanmten Bundesgebicte an Stelle ocr Reidjs: filbermünzen, Silberturantmünjen Dentfden (ses= präges zu $1 / 3$ und $1 / 6$ Thaler unter Beredjumg

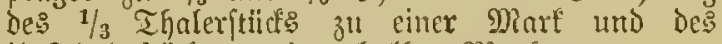
$1 / 6$ I Jaleritutefs zu ciner halben Diarf;

3. in Denjentigen \&ändern, in welden gegentwältig dic

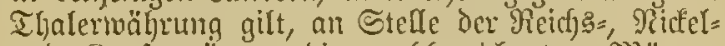
tmb Siupfermin̈zen bie nadjbejeidjuten SRünjen ber I Ijalerwährnng zu Den Dameben bejeidneten 23ertlen:

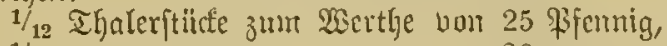

$$
\begin{aligned}
& 1 / 15 \text { " " " } 20
\end{aligned}
$$

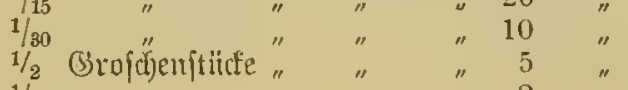

$$
\begin{aligned}
& 1 / 5 \text { " " " " " " }
\end{aligned}
$$$$
1 / 10 \text { und } 1 / 12 \text { " "Qünder", in "meldjen die güülf }
$$

4. in Denjentigen Qändern, in weldhen die 3"ülf = theilumg ies Brofdfents bejtelyt, an Stelle Der
Znölftheilung bes (j)

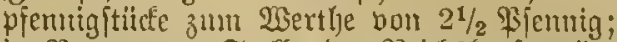

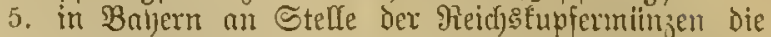
Sellerfticfe 3um 20erthe uon $1 / 2$ PSfentig;

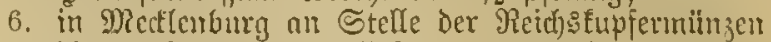
bic nadj ben Marfjuftem ansgeprägten Fiinf= piemrigftücfe, Bueipfentigitidfe uno csimplemtig= itiiffe zmm 2 erthe bon 5,2 mo 1 fifentig.

Die fämmtliden snb 3 umb 4 berzeiduneten 9R̈̈nzen

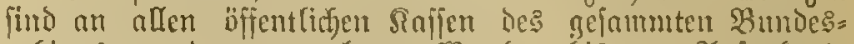

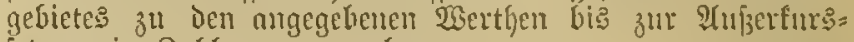
jelzung in Boljlung anzumelomen.

1) gind) bem Gejes v. 20.4. 187t fintoet bic Beptimunung im

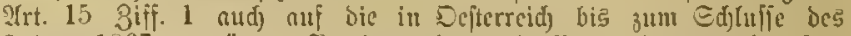

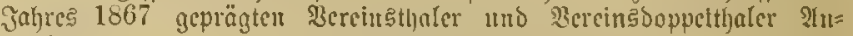
metloung.

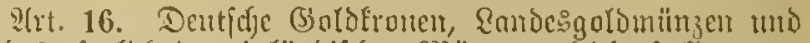

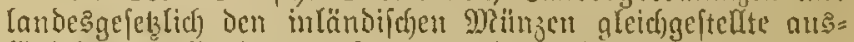

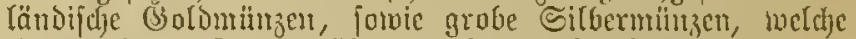
einer amberen \&ambesmöhrumg als oer Thalermähtumg an=

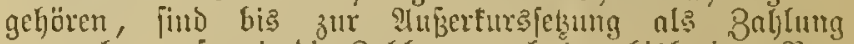
anzunchuen, fotveit die Zahlung nach den Giskferigen $230 \mathrm{r}=$

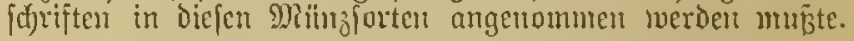

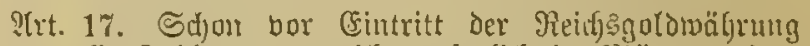

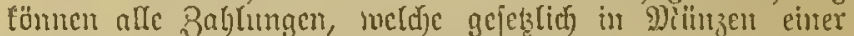

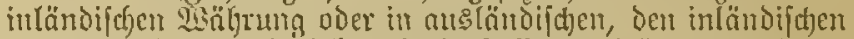

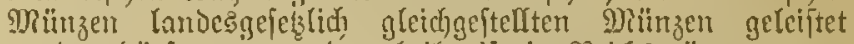

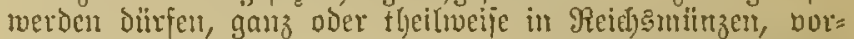
behaltlid) ber Sorjorrift ilrt. 9, dergejtnlt geleiftet wertien,

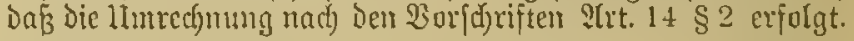

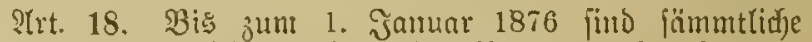
midd)t auf Reid)Eిwälytung Iautenden Roten der Banfen cin=

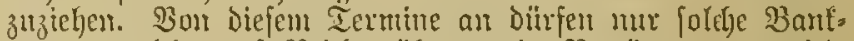

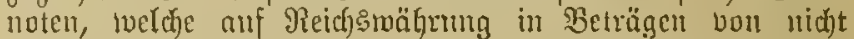
weniger ala 100 Marf Lauten, in llmlauf bleiben oder ansigegeben weroen.

Diejelben SBeftimnnungen gelten für Die bis jedzt bon Sorporationen atigegebenel Sheine.

Dns von Den eirzelnen Bumdeşftraten ansogegebene Fiapiergeld ift \{päteftem: bis jum 1. Santuar 1876 cinjuzicljen mo fuateitens fects Sionate bor Diejem Termine offentlich

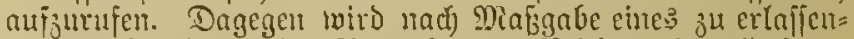

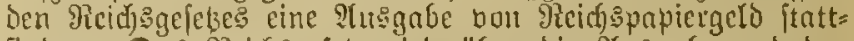

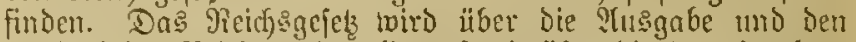

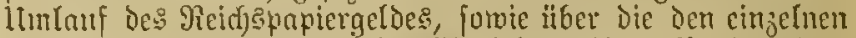

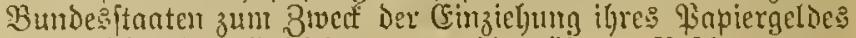
z" gemöljrenden (Erleid)terumgen Die näheren Bcjtimmungen treffen.

lirfundiif $2 e$.

Begebon 23a b cm: den 9. Juti 1873.

2 silgerm.

Fiitrit v. 23ismatit.

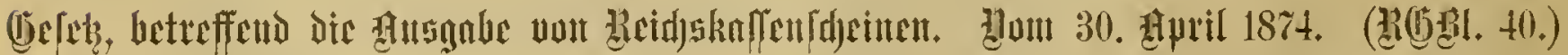

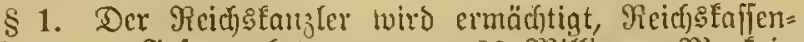
fareine zum Bejaumtbetrage bon 120 Milltionen Mart in ?(bfd)nitten zu 5, 20 und 50 Parl nusfertigen zu Iajjen Imo unter die SBmbesftanten nafj dem Diafjitabe ifrer Durrd Die zählung bom 1. Dezember 1871 feîtgeftellten Bebölferung zu bertheilen. lleber die Vertheilum ies Biefnumbetuges anf bie

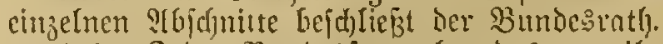

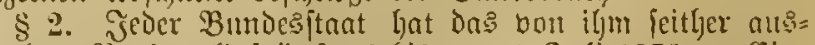
gegehene \$apiergelo fpäteftens bi zum 1. Julli 1875 jul Git= löjung öffentlich anfournfen und thunlich)it f(c)nell einzu= ziefert. 


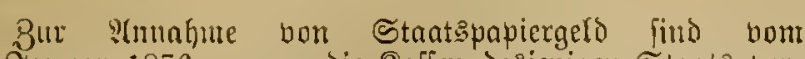

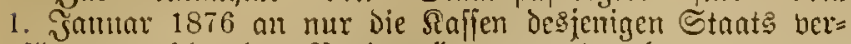
pfliclutet, weld)er das qapiergeld antigegeben hat.

\$ 3. Denjenigen Staaten, Deren \$apiergeld den iljnen

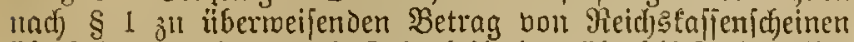

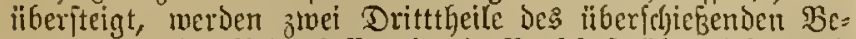

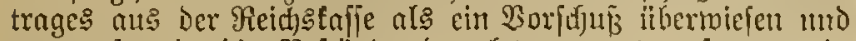
zwar, foweit bie Beftände der Yecteren es geitatten, in brarem (Selde, fomeit fie es ridft geftatten, in Yieidjestafien= id)einen.

Der Reidjs̨tanzler wird zu diefem Zmedfe ermädjtigt, Reidfstajienjcheine itber den im \& I feitgefebten Betrag

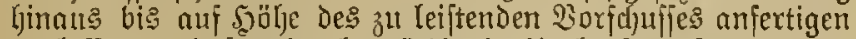

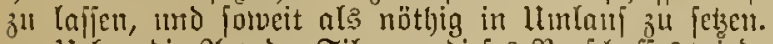

Heber dic S(rt der Tilgung diefes Borfduffes miro gleid)= 3eitig mit Der Dromung Deg Bettelbanfiveien' B̉ejtinmung getrofien. In (Fimangelung einer foldyen Bejtimmung lyat

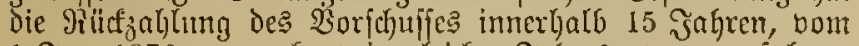
1. San. 1876 an geredjnet, in gleichen Jahresraten zil erfolgen.

Die auf den Borjduß zunächit jur (Eimzieljung Der nac) vorftehenden Bejtimmungen

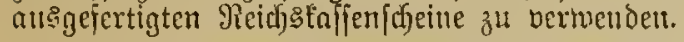

$\S 4$. Diejenigen Bundesjitaaten, tvelde Papiergeld an: $=$ gegeben haben, werben bie ihnen nusgefolgten Reidgtafien= icheine (\$§ 1 und 3), folweit ber Betrag Der letzteren Den Betrag bes ausgegebenen Fapiergeldes nidjt tuberfteigt, mur in deut $\mathfrak{M a ß ̉ e ~ i n ~ U l m l a u f ~ f e k z e n , ~ a l s ~ S t a n t i p a p i e r g e l d ~ z u r ~}$ Firtziefung gelangt.

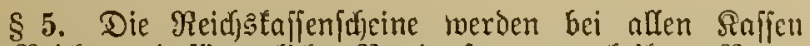

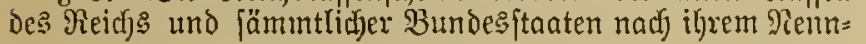

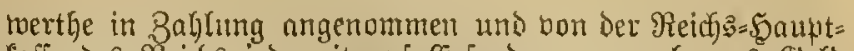

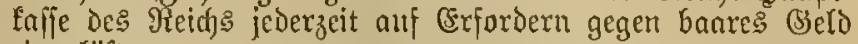
cingelöft.

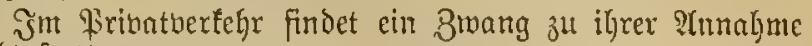
niclut [़tatt.

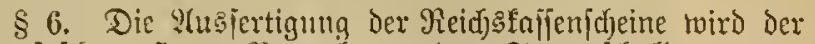

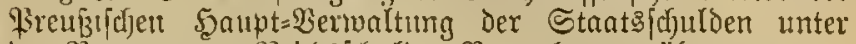

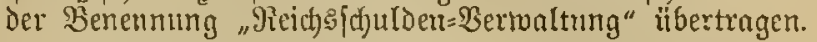

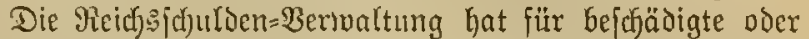

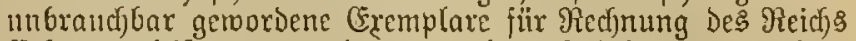
Erfaty jul leiften, wemn Das borgelegte Stitut ju einem echten

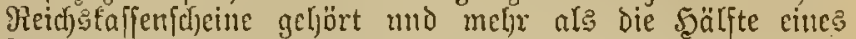

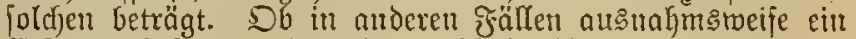

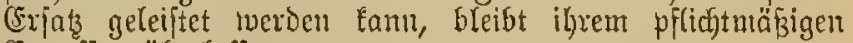
Ermeffen riberlafien.

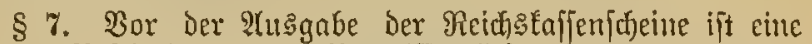
genaue Bejd)reibung ierjelben öffentlicf) befannt zu madjen.

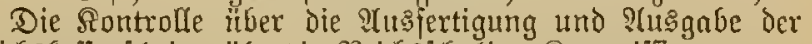
Reid)

§ 8. Bou Den Buttoesftanten Darf aud ferner mur.auf

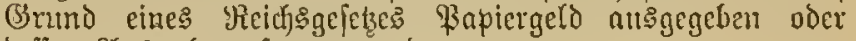
Deffen ?Insgabe geftattet merden.

lirfundich $2 \varepsilon$.

Begebell Berlin, Den 30. STpril 1874.

20irfyelm.

Fiirft b. Bismard.

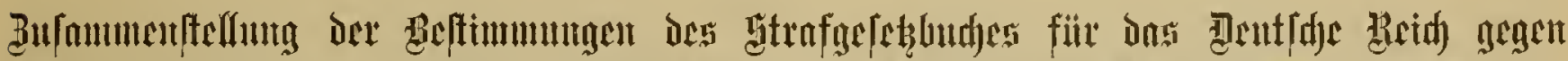

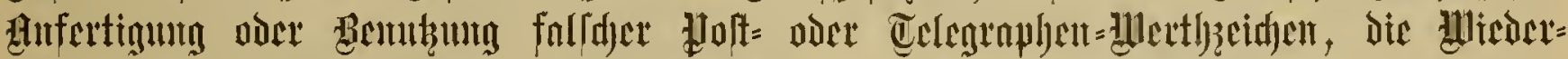

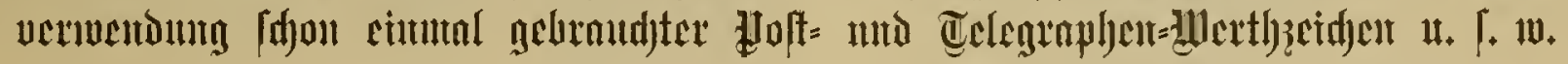

§ 275. Mit Bejängniß́s niç)t unter drei Monaten wird bejtrajt, wer

1. wififentlid) bon falichem oder gefälidjtem Stempel= papier, bon faliden oder gefäliditen Stempel= maxten, Stempelblanfetten, Stempelaborïufen, $\$$ poft= oDer Telegraphen=テreimarfen ${ }^{1}$ ) oDer gejtempelten Brieffuberts (sebraud mad)t,

2. unedftes Stempelpapier, unedjte Stempelmarten, Stempelblanfette oder Stempelaboriolfe für Spicl= farten, \$äjje oder jonftige Drudjadjen oder Schrift= fritfe, ingleidjen wer umedite gsoft= oder. Tele= graphen-Freimarfen doer geftempelte Brieftuberts in Der Affidft anfertigt, fie als edft ${ }^{n} \mathrm{n}$ ber= mendent, oder

3. echtes Stempelpapier, echte Stempelmarfen, Stempel= blanfette, Stcmpelaboriiffe, \$o $1=$ DDcr Ielegraphen= Freimarfen oder geftempelte Brieffuberts in der

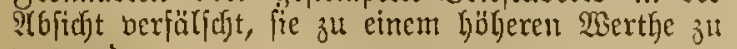
bertuenden.

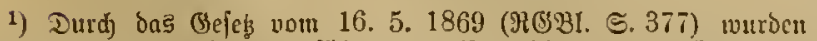
Telegraphen=รrcimarten cingcführt, mittelft rolder bie (Bcbihnten für

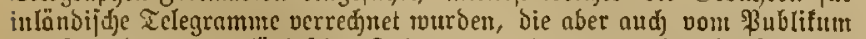

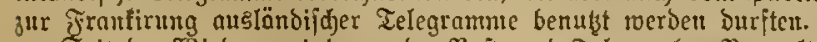

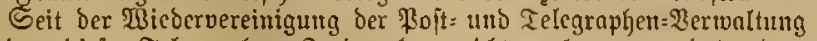
werden biefe Telegraphen = Freinarfen nidjt utehr , vermenbet, bcin

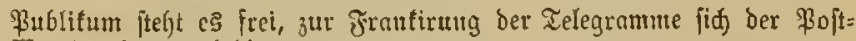

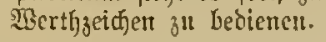

\$ 276. Weer miffentlidj fdjon cinmal zu ftempelpflidjtigen Ilrfimben, Sifriftitiden oder Jormularen bermendetes Stempelpapier voer fofou einmal bermendete Stempelntarten ober Stempelblanfette, ingleidjen Stempelaborïife, weldie zun Beidjen ftattgeljabter Berjteuexung gebient haben, zu ftempelpflidftigen Sdyriftftïden bertwendet, wirb, auber der Strafe, weldje ourd) Dic (Sntzielyung Der Stempelfteuer be= grïndet ift, mit Belditrafe bis 311600 Marf bejitraft.

Sleidfe Straje trifft demjenigen, tweldjer wiffentlid) idjon einmal berwendete Soft = oder Selegraphenwerty jeid)en nach gänjlidjer oder theilmeifer Entfernung bes (Sntmerthungs:

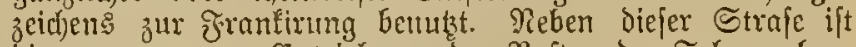
die etmo megen Entzieluung Det \$olt= oder Selegraphen= gebübren begründete (Straje berwoirft. ${ }^{1}{ }^{2}$ )

1) Die 2Tw enoung diefer Strajbejtimmung fest voraus, baj ber

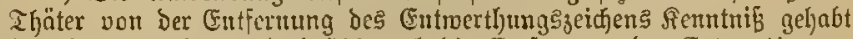
hat; dagegen ift es gleidguiltig, ob bie Entjernung bes Entwerthungs: zeidents vou ihu felbit ober von cinem Dritten bewirtt worben ijt.

2) 1 . nud Soltgeles $\$ \$ 27$ unv 28.

\$ 360. Mit Selditraje bis zu einhmoertjünfzig Marf Doer mit soajt miro beftraft: 
4. mer ohne fdriftlichen STuftrag einer Behörde Stempel, Siegel, Stiche, Blatten oder andere formen, weldje zแน Infertigung von Metall= oder Fapietgeld, ober von foldien Papieren, weldje nach \$ 149 bem \$rapiergelde gleidjgeadtet inerden, oder von Stempelpapier, Stempelmarfen, Stempelblan= letten, Stempelaborituen, \$o[t= oder Telegraplyen= werthzeidhen, öffentlichen Beidjeinigungen oder $\mathfrak{B e}=$ glaubigungen dienen fönnen, anjertigt oder an eirnen Inderen als Die Behörde verabjolgt;

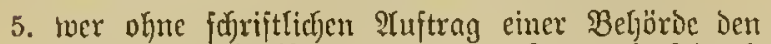
 Stiche, \$ilatten oder Jornten, oder einen Drux́ von Jormularen zu den dafelbjt bezeidneten öffentlidjen Bapieren, Beglaubigungen ober $\mathfrak{B e}=$ jojeinigungen unternimmt, oder ?tboritute an eincn Anberen als die Beförde berabjolgt;

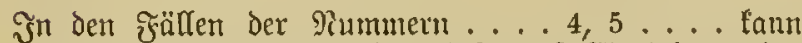
neben Der SEelditrafe oder Der Şaft auf 'Finjiehung Der .... Stempel, Siegel, Stide, \$latten oder anderen

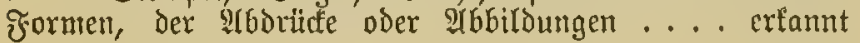

merben, ohne Interjatied, ob jie dem Sermbeilten gefỏren oder nicft. ${ }^{2}$ )

1) ศ. aud Poftgcieg $\$ \$ 27$ unto 28.

2) Die $20 r i \not h r i f t e n$ bes $\$ 360$ Tir. 4 und 5 bejichen fid) fowohl

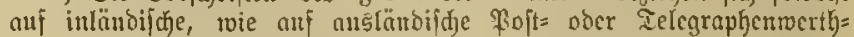
gcidjen, forwie anf bie \$latten ic. zur fecrftellung berfelben.

\$ 36t. Mit Beldftrafe bis jul einfundertfünfig Mark mird bejtraft, wer wiffentlich jdjon einmal berwendetc: Stempelpapier nach gänzlidjer oder theilmeifer Entfermung

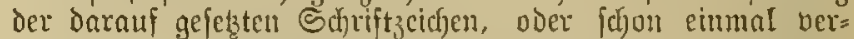
wendete Stcmpelmarken, Stempelblanfette noer ausge= (d) nittene oder fonft abgetrennte Stempelaboribe der im $\$ 276$ bezcidfureten शrat veräufart ober feilfält

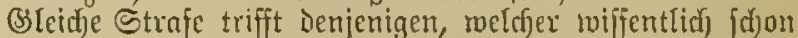
cimmal vermentete 930 its oder Telegrapljenmertbzeidjen nad) gänzlicher oder theilweifer Entfernung des Enmerthungs: zeicjens beränfiert oder feillyält. ${ }^{1}$ )

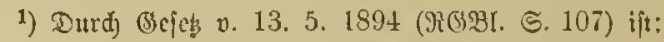

$\$ 276$ ber zwcite $\mathfrak{I} 6$ jaj jugcitigt,

$\S 360$ 9r. 4 in Der frafiumg geäniert,

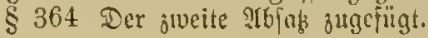

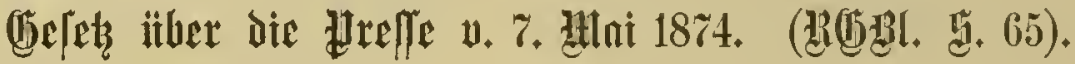

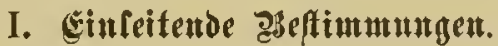

§ 1. Die Frreilycit ber ßreffe unterliegt nux Denjenigen

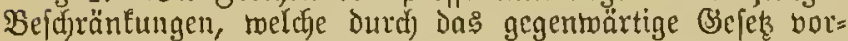
geffjricben oder zugelafjen find.

§ 2. Das gegenmärtige (3ejeł findet $\mathfrak{2 n m e n d u n g ~ a n f ~}$ alfe Erzeugnifje ber $B$ udjorudferprefie, fotwie anf alle anderen, burch medjanifde ober chemijale Mittel betwirtten, zut $\mathfrak{B} e r=$ breitung beitimmten Berviclfältigungen von Sdjriften und bildlicten Darftellungen mit oder ohne Sdjrift, mo bon Mufifalien mit Text oder (Evläuterungen.

Wa? im Folgenden bon "Drusfichriften" verorbnet ift, gilt für alfe vorjtehend bezeidjneten Erzeugniffe.

§ 3. $\mathfrak{A}[\mathfrak{S}$ Berbrcitung einer Drutfid)rift im Sinne biejes

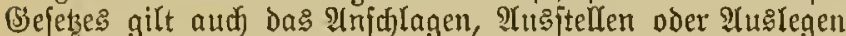
Derjelben an Srten, wo fie der Renntnisnahme durd das Publifum zugänglić) ift.

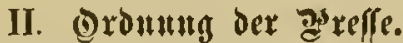

§ 6. Tuf jeder im Bieltungsbereich diejes Bejetzes er=

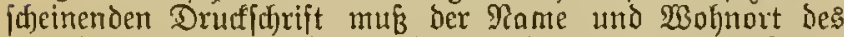
Druffers mtd, ment fie für den $\mathfrak{B u d}$ jhandel, oder jonft zur Berbreitung bejtimmt ift, Der Rame und 230 hnort des Serlegers, oder - beim Selbitbetriebe der Druffichrift Des $\mathfrak{Y}$ erfajfers oder Scrausgebers genannt feit. IIn Stelle

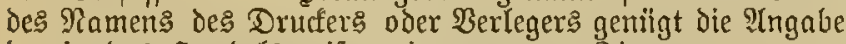
ber in bas Sandelstegifter eingetragenen đirma.

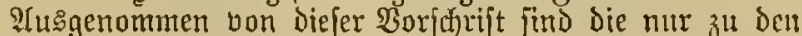
Btwerfen Des (Setwerbes und Berfehrs, Des bäustichen nnd gefeligen Rebens dienenden Drutfichriften, als: ₹rormulare,

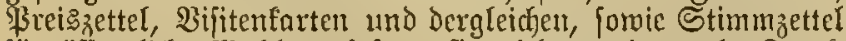
für öffentlid)e ßahlen, lofern fie nidhts weiter als Zmect,

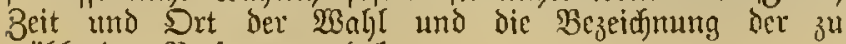
wäljenden ßexjonen enthalten.
\&\%. Beitungen und Beitfdriften, tweldie in mottat= lichen oder fürzeren, menn auth untegelmäß̈igen friften erifheinen (periodijhe (Druffif)riften im Simne diejes (Scjekses), milffen außerbent auf jeder $\Re$ ummer, jedem Stitcte oder

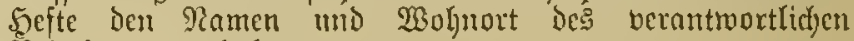
Redafteur's entjalten.

Die Benennung meljerer Ficrionen als verantmortlide Redafteure ift mur zuläfig, menn aus Form und Эnhalt ber Benennung mit Beftimuntheit 3 erfehen ift, fïr weldjen Theil der Druffifjrift jede der betnmmen Berjonen die Redaltion beforgt.

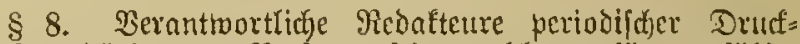

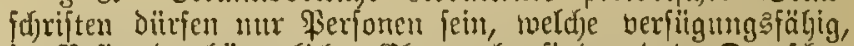
im Befitze Der bürgertichen (Elyrentedyte find und im Deutfdyen

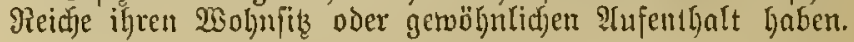

\$ 10. Der verantwortlidje Redaltenr ciner periodiffjen Drucfichrift, belche ?Inzeigen anjminumt, ift berpflicftet, die ihm von öffentlidjen Behörden mitgetheilten amtlidfen Befanntmadungen auf Deren Derlangen gegen Bnflung Der iiblicfen Cimritfungsgebillyren in cine ber beiden mädjiten গ?unmern des s3lattes aujzunelymen.

\$11. Der uerantmortliche Redalteur einer periodiffenen Dructid)rift ijt berpflidftet, eine $\$$ Beridftigung der in lesterer mitgetheilten Thatjad)en auf Berlangen ciner betheiligten öffentlichen Behörbe oder Pirtontperion obne Cinjoljaltungen oder Weglaffungen aujzuneljmen, fofern bie Beridjtigung von bem (Einfenver unterzeidynet ift, feinen jtrafbaren Juhalt

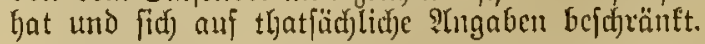

Der Atboruct muts in oer nad) Emplang der Cinfendung nädfitfolgenden, für den Druf nidjt bereits abgefdhlofienen Rummer und zuar in Demfelben Theile der Drutfid)rift

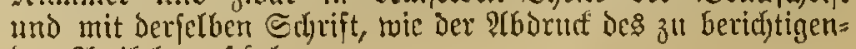
Den Artifels gefchehert. 
Die Pufnahme exiofgt tojtenfrei, formeit nidft die Ent=

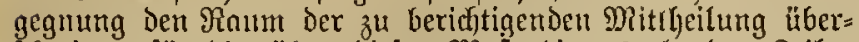

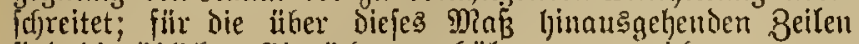
find die viblidfen csimrüungsgebüljen zu entridften.

§ 12. Tuf die bon Den Deutiden Reidf $\xi=$ Staats= und Bemeindebelpobden, bon Dem Reidjestage oder bon Der \&andesbertretm eines deutichen Bundesftants amsgehenden

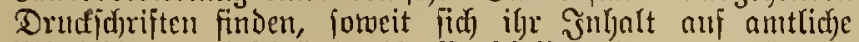

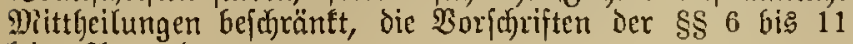
teitte ?tmwendung.

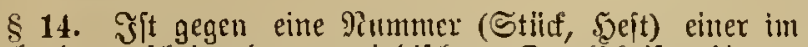
Iustande erfd)einenden periobifd)en Drudfidjuift binmen Jahresfrift zwei Mal cine Serurtheilung nuf Brmmo der \$\$ 41 und 42 Des Strafgefetbudje erjolgt, fo faun der Reichstangler innerljalb jwei Mionaten nach (Eintritt ber

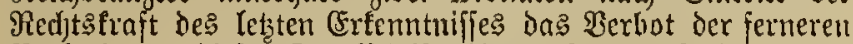
Berbreitung biejer Druffidgrift bis auf zwei Sngre burch öffentliche Befanntmachung ausfpredjen.

Die in ben einzelren Bumbesftanten ant Srrumb der

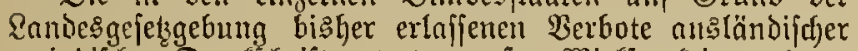

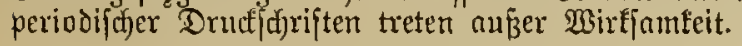

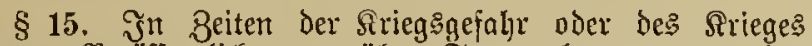
tönnen Beröffentlidungen über Truppenbetwegungen oder

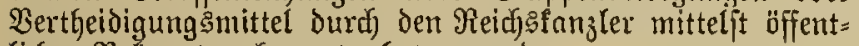
lidfer Betanntmacjung berboten iverden.

§ 16. Deffentliche Pufforderungen mittelfit Der Piteffe 3ur Thufbringung Der megen einer ftrafbaren Sondolung er= Eamten Beloftrafen und Roften, fotwie offentfidje Befdjeini= gungen mittelfit ber Preffie über ben Empfong der zu foldjen Broeden gezahlten Beiträge find berboter.

Das zufolge foldier Yufforderungen Smpfangene oder

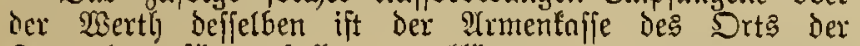
Sammlung jür berfallen ju erflären.

§ 1\%. Die Anflagefdrift oder andere amtlidje Sdjrift= itiicfe cines Strapprozeffes bürjen Durdf die \$reffe nidt eher veröffentlicht merden, als bis diefelben in offentlicher $\mathfrak{B}$ er: handlung fund gegeben worden find oder bas Berfahren fein Ende erreidt hat.

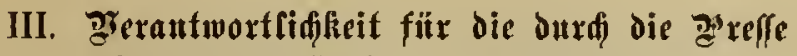 begangenen frafáaren şandrutgent.}

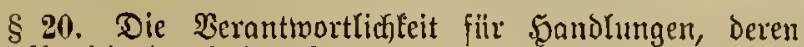

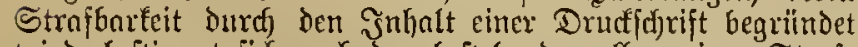
mirb, befitimut fid nady ben befteljenden allgemeinen ङtraf= gejeizen.

Jit bie Drudffdrift eine periobifofe, fo ift ber berant= wortlicfje Redafteur als Thäter zu beftrafen, menu nidjt

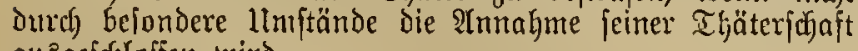
ausigejdjloffen wirb.

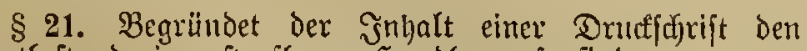
Ihatbeftand einer ftrafbaren Seandlung, fo find

Der verantmortliche Rebattem;

der Berleger,

ber Druffer,

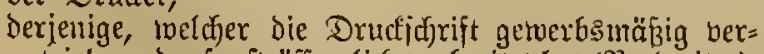
trieben oder fonjt offentlic) berbreitet lyat (20rbreiter), jomeit fie nidft nach $\$ 20$ als Thäter oder Theilnebmer $j^{4}$ beftrafen find, wegen ङabrläffigteit mit Gelditrafe bis zu eintaufend Miarf oder mit Saft ober mit Fejtungshaft ober

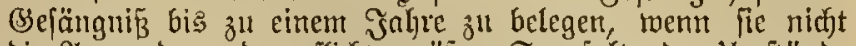

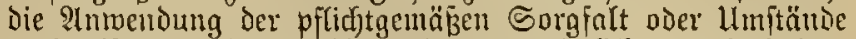
nadjweifen, weldje Dieie ?tnlvendung unmöglich genadjt habent.

Die Beftrafung bleibt jedody fïr jede der benannten

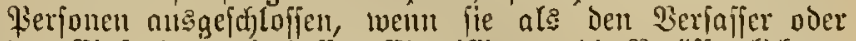
Den (Einjenver, mit Deffen Ėinvilligung die Beröffentlicfung gefibehen ijt, ober, wenn es fidj um eine nidjt periobifdje Druefictrift lyandelt, nts den Sernusgeber derjetbeu, oder als einen ber in obiger $\Re$ eiljenfolge bor ifr Benanuten eine łerjon bis zur Bertindigm des erften llatheifs nadhweift, wercje in Dem Bereich der ridjterlidjen Bewalt cines beutfden Bundesftants fidf befindet, oder falls fie berftorben iit, fidf zur Beit der Geröffentlichung befunden ljat; hinfidjtlidf bes

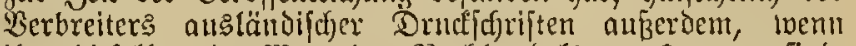

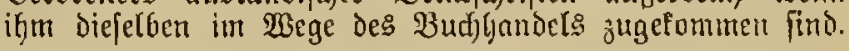

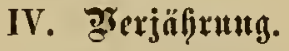

§ 22. Die Strafuerfolgung Derjenigen $\mathfrak{B e r b r e c f j e n ~ u n o ~}$ Bergeljen, tweldye Durd) Die Berbreitung bon Drute= idriften itrafbaren Jnhalt: begangen meroen, forvie der:

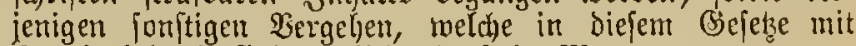
Strafe bedroht fins, berjübrt in fedjs Monaten.

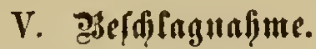

§ 23. Cine Befdflagnabme bon Druffidriften ohne ridfterlidge ?(nordnung ${ }^{1}$ ) findet mur itatt:

1. menn eine Druffidyrift Den Borfdrriften Der $\$ \$ 6$ und 7 nicht entfpridjt, oder den Sorfdyriften bes \$ 14 zurwider verbreitet wiro,

2. twenn Durd) eine Drutfidsift einem auf (sirund des \$ 15 diefes Sefetzes erfaffenen Berbot jumider geljandelt wird,

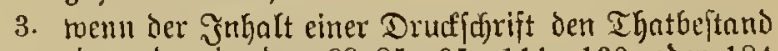
ciner Der in den $\$ \$ 85,95,111,130$ oder 184 des Deutjden Strafgeiejóndys mit Śtraje bedrohten Sandlungen begriindet, in dell Fäflen ber $\$ \$ 111$ und 130 jedoct nur baun, loenu bringende (Sefahr beitelyt, baj bei Berzögerung ber Bef(t)lagnalyme bie Ptufforderumg oder IImeijung ein Berbredjen

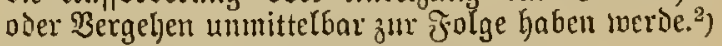

1) Die Beridgte fännen bie Beidlagnaljme vort Druffidriften aud) itt anberell, als belt im $\$ 23$ angeführten ₹älfen Derfïgent.

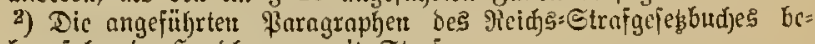
drolgen folgende Sandiungen mit Strafe:

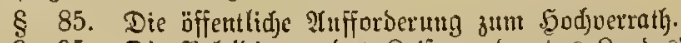

\$ 95. Die Beleibigung bes Rnijers oder Des Landesherrn.

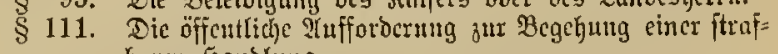
Garen Santrong.

$\S 130$. Die öffentliọc, in ciner ben öffentliden frreben ge=

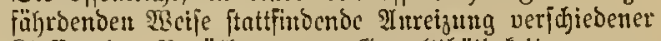
Siaffen ber Devöffertutg ju Gemalttjätigfeiten gegen= einander.

$\$ 184$. Den Berfanf oder bie Berbreitung 2 c. pon unzindtigen Ed)riften, গtbbildungen uto Daritellungen.

§ 24. Lleber bie Bejtätigung oder ?uflyebung Der vor= läufigen Beid)lagnahme hat Das jultändige Beridht ju ent= itheitern.

Dieje Entidjeidung mu[ bon Der Staalsanmaltidjaft bimmen 24 Stmiden nad) Imoronung der Bejd Ingnabme beantragt mito bon dem (Serifft binnen 24 Stumbes nad) Fimpjang des Plntrags erlafien merben. 


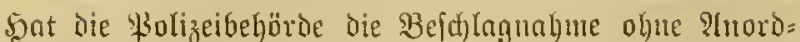
mung Der Stantsanwaltfd)aft berfïgt, fo muß fie die $9 \mathrm{~b}=$ fendung der Derlyndolungen an bie leçtere oljue Verzug und ipätejtens binnen 12 Stunden bewirter. Die Stants=

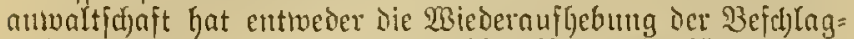
nalme mittelft ciner fojort vollftrefforen Serfïgnng an=

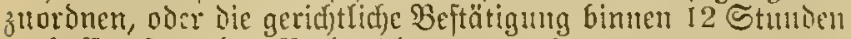
nad) Entpiang Der 9 Berljandumgen zu beantragen.

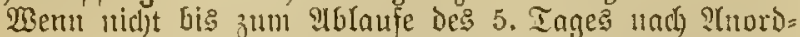

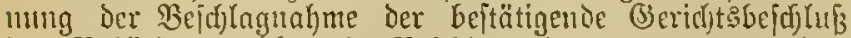
Der Behörobe, ruclche die Befdjlagnalyme angeorbnet hat,

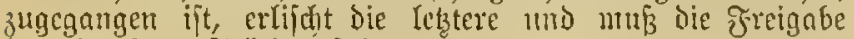
ber einzelnen હtiicfe crfolgen.

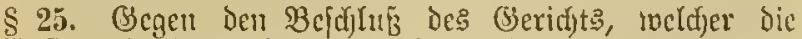
vorläufige Beja)lagmahme auflyebt, findet ein Red)tsmittel nicht itatt.

§ 26. Die vom Beridf)t beftätigle, vorläufige Bejechlag= nahme ift wieber aufzuheben, menn nidjt binnen 2 23odjen nnd) Der Beftätigung die Strnfberfolgung in der Szauptfact)e cingeleitet worden ift.

\$ 2\%. Die Beffulagnalyne non Drucf(d)riften trifft die Exemplore nur do, wo Dergleirfen 3um Brwetfe der $2 e r=$ breitung fidj befitoen. Sie tam fidf nuf bie zur Berbiel= fältigung dienenden ßlatten und Jormen eritrecfen; bei Drucfid)riften in engeren Sime hat auf ?tntrag Des Betheiligten ftatt Bejd)lagnalyne des Sabes das grblegen deg letsteren zu gejdefhen.

Bei der SEejdingnalyme find Die diejelbe beranlaffenden

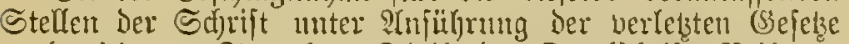
zu bezeid)uen. Tremnbare Theile Der Drutfidyrit (BBeilagen ciner Beitung sc.), weld)e nidht Strafbares enthalten, fund

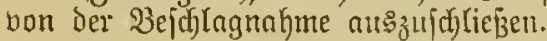

§ 28. Wä̈[jend Der Daucr Der Bejchlagnalyme ift die Berbreitung der von derfelben betroffenen Dintff(d)ift ober Der Wiederaborute Der die Bejulagnahme vernnlaffenden Stellen unftatthaft.

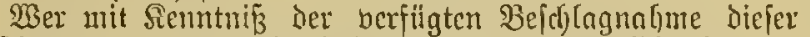
Beptimmung entgegenhandelt, wird mit Belditrafe bis 500 Marf oder mit Gieföngnif bis zu 6 Monaten beftrajt.

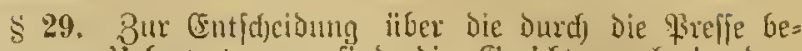
gangenen llebertretungen fund Die Geridfte audf in den=

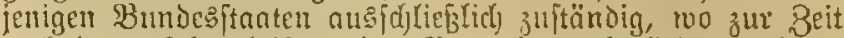

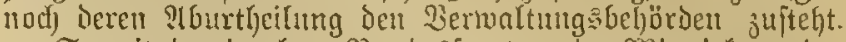

Sotweit in einzelnen Bundesftnaten eine Mitwirfung Der

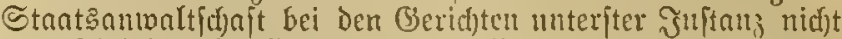

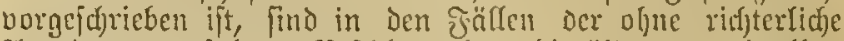

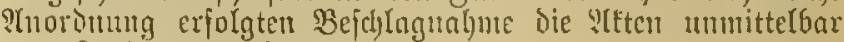
Den (bierid)t vorjulegen.

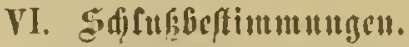

\$ 30. Dic fïr Zeiten Der Sriegsegefahr, des Strieges,

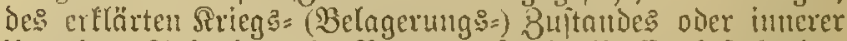

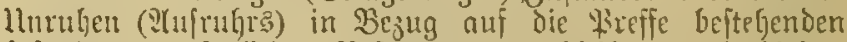
bejonteren gejelzlidjen Bejtinumungen bleiben audj biefem

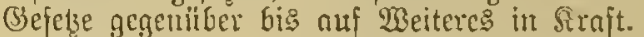

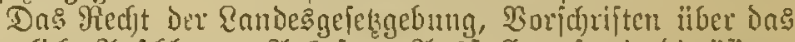

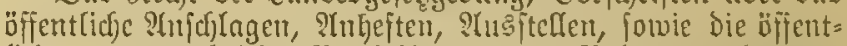
(id)e; uncutgeltlidje Sertbeilung von Befanntmadumgen,

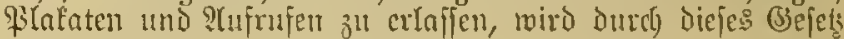
nicht beriilyrt.

Daffelhe gilt won den Boriariften Dex Randeshgefelze über

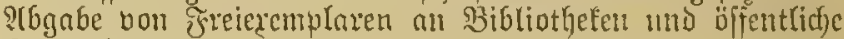
Sammlungert.

Burbehaltlid her anf den Randesgejetzen berubenden affgemeinen Betwerbefteuer findet cine bejondere Befteuerung

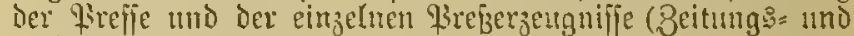
Sialenderjtempel, s:bgaben von šnferaten 2e.) nidjt itatt.

§ 31. Diejes Gefels tritt am 1. Juli 1874 in నraft. Seine Finfiigrung in Elfafs=Eothringen bleibt cintent be= jonderen Befetze vorbelalten.

livfundlid) zc.

Begeben Berlin, ben 7. Maa 1874.

wilbelm.

Fiinft v. Bismard.

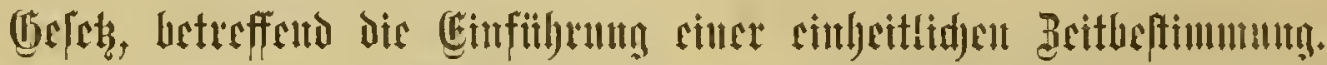

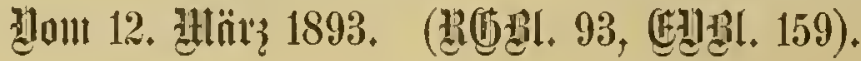

Dic geletblidje Beit ${ }^{1}$ ) in Deutidjtand ift die mittlere

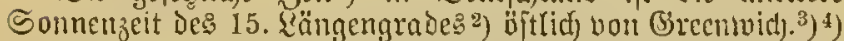

Diefes (Sejes tritt mit tem Beitpuntet in Sirajt, in welchem

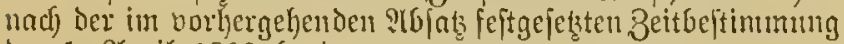
ber 1. 2(pril 1893 beginnt.

1) ๖. i. Die "mitteleuropäifde 3eit" [M EZ]. Tie mittels

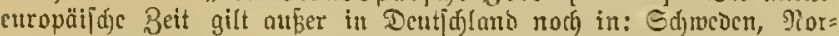

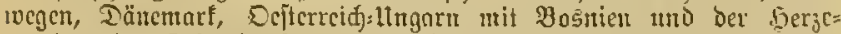
gowitu, Der Sdjweiz, Stalien, Serbien, Dlontencgro и. Briedgculano,

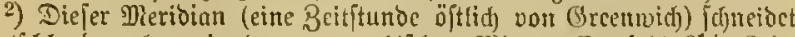
Dentfdland nahezu in der geographijden Mlitte. (Fr jieht $6^{1} / 2$ 3cit=

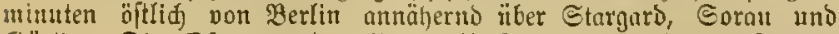

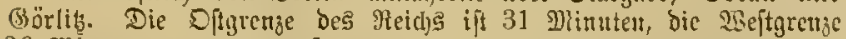
36 Mimuten von ity entfetut.

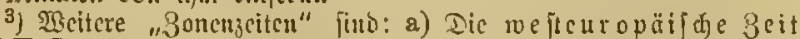

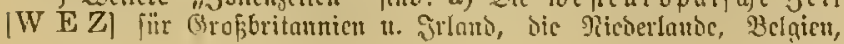

Surcmburg, Franfreich, Spanien u. Portugal. Dicjelbe blcibt 1 ङtunoc hinter MEZ juridf; b) bic ofteuropätide 3 e it [OEZ] fitr

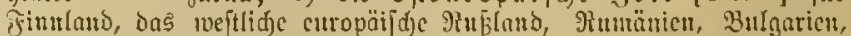

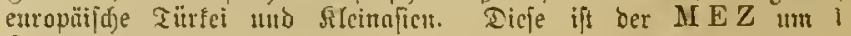
Stunde voraus.

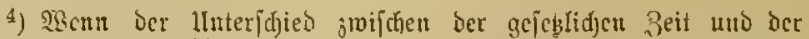

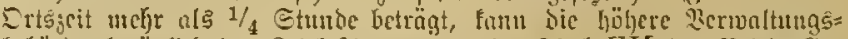

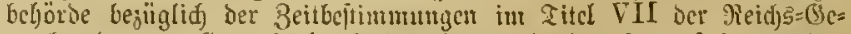

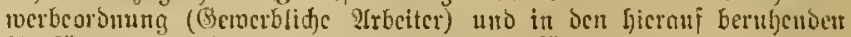

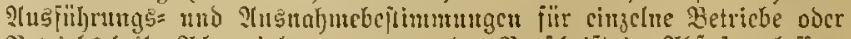

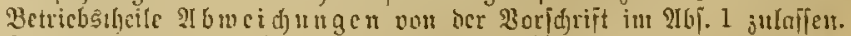

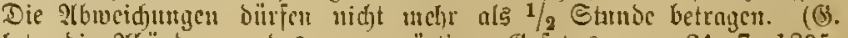

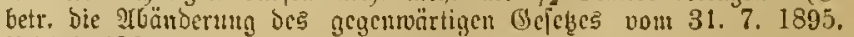

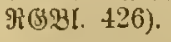

\section{lirfunolid) zc.}




\section{II. $\mathbb{E} \mathfrak{h} \mathfrak{e} \mathfrak{i l}$.}

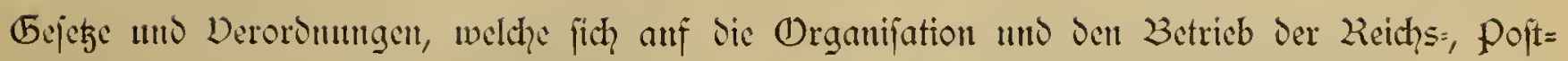

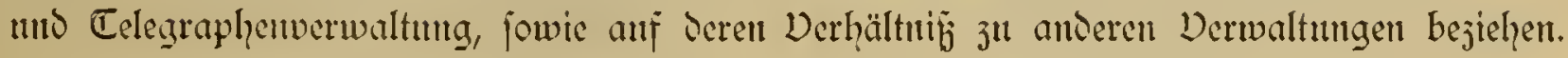

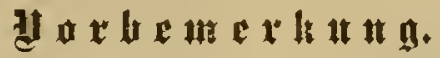

Bei ben in Theil II uno III anfyefïhrten Bejeben ift ber bei allen Preidsgefeben gleidjlautenbe (singang:

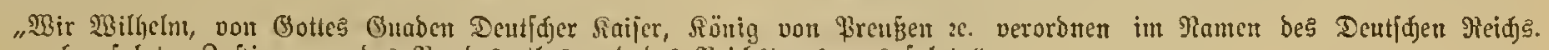
"ttad) erfolgter 3 uftimmutig bes 3 undesrathes uno bes Reidstnges toas folgt:"

jowie ber ebenfalls gleidglantertbe Schluffats:

fortgelafien.

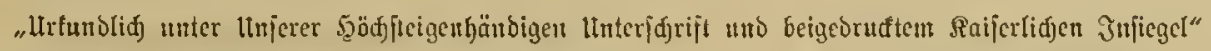

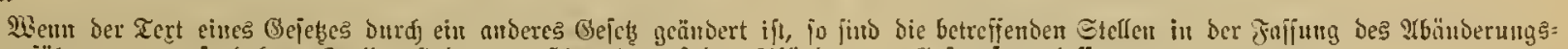

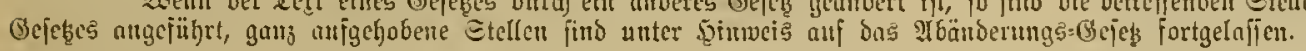

\section{I. (1)rannilation dor dẹnaltumy.}

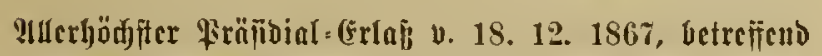

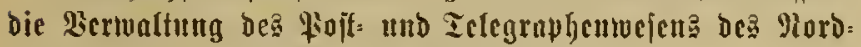
bentidjen Bunbe⿱ vom 1. Jamuar 1865 ab. ${ }^{1}$ )

(B3(923). Mr. 14 Ecite 328.)

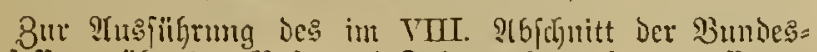
berfaffung tiber das topt = und Telegraphenwejen getroffenen,

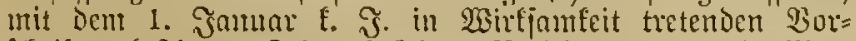

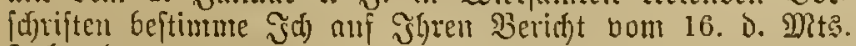
Jolgenics:

1. Die SerwaItung Des: fioit = แแb Telegraphenwejen: Des Bundes nird unter Reitmig des Bundeskanz= lers bon Dem "Beneral=\$Bojtant Des Rordbeutfchen Sundes" und Der "Beneral=Direltion Der Tele= graphen des Mordoeutfdyen Bumbes" gejübrt. Dieie Befjörden fillden die I. Geätv. II, Atheilumg des Buntesfonzler=24mts.

2. Dent Gencral=łjoftamte des Rorddentid)en Bumbes find jämmtlitfe Sber= Boitdireftionent Des Bundes forvie die Dber= Fioftämter in dent freien und Sanje=

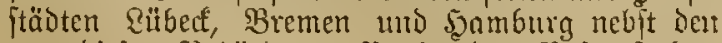
bon diefen Bchörden refforticenden 9 piftanftalten untergeoronet.

3. Der Seneral=Direftion Der Ielegrapljen bes Mord= deutffen $\mathfrak{B}$ undes fitto dic vorbnomen Dber=Teles grapljen= Snjpeftionen, welclje fortan sie Bejeich=

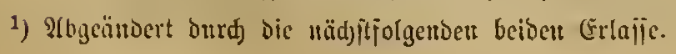

umg "Telegraphen=Direftionen" erhalten, forwie bie Tefegraphen=Direftion ju Sdjucrin nebft den von Denfel ben refiortirenden Telegraplyen=Stationen imtergeoronet.

4. Die Dber=93optoireftionen, Dber=\$3oftämter und jonitigen \$oftanftalten, forvie die Ielcgraphen= Direftionen und Telegrapljen= Stationen erljalten Die Eigenfafjait nou Bumbesbeljörden und twerden Dementfpredjend bezeidjuct.

Berfili, Den 18. Dezember 1867.

\section{Dibilgelit.}

(3i. v. Bismarct=Styönhanfen.

Sh Den Fanjlet des Piorddeutidfu Bundce.

Pallerbödjfe Berorbunng, betreffend die Berwualtung be Poit: und Ielegraphenwejens vom 22. Dejeutber 18\%5.1)

(23(5BL. Mr. 34 Exite 379.)

§ 1. Mit iem 1. Jalutur 1876 wiro bie Bertwaltung des Goft = mid Telegtaphenuafens bom Reffort des Reichstanzler=21mtes getrent und die Reitung De:

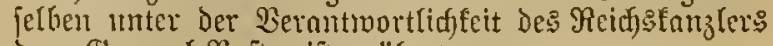
dem Beneral= Fo piptmeifter iibertragen.

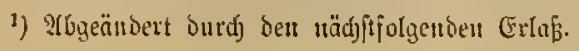


8 2. Dem Beneral=\$3optmeifter itehen ale chei Der Bopt = und Ielegraphen= Bermaltung Diejenigen $\mathfrak{B} e=$

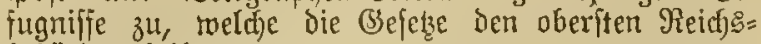
behöroen beilegen.

\$ 3. Unter der Reitumg des CBeneral=\$oitmeifters werden

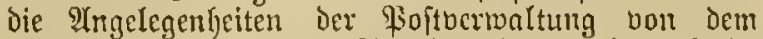
General=7pojtamt, Die ?tugelegenlyeiten Der Iele, graphenverwaltung vou dem Beneral=Telegraphenamt bearbeitet.

\$ 4. Die Sermaltung des Woft= und Telegraphen= melens in Den cinzelnen Bezirfen witd von Reidjs: heljörden aeführt, weldfe att die Stelle Der bisherigen Dber=Poitdirctionen und Ielegraphen=Direftionen treten uno bie 9(mtsbezeid)mung als "Ster=930it= Direftionen" crljalten.

Die Sber=:9ojthireftionen und bie ignen unterge= oroneten Stelfen (Hiojtämter, Telegraphenämter, \$sojt= agenturen) find in Ingelegenheiten der \$oftberwaltung Dein Beneral=93oltamt, in Angelegenheiter ber Tele= graphenberwattung Dem (Seneral= Selegraphenamt $3 n=$ nädjit untergeoronet.

Segeben Berlin, Den 22. Dezember 1875.

WBilferut.

Jiir vout bismard.

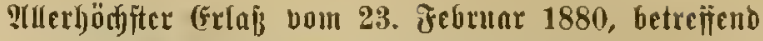

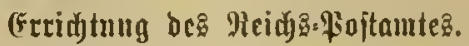

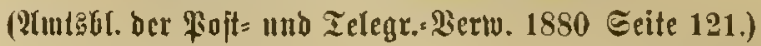

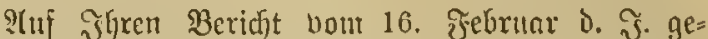

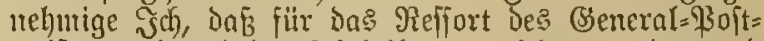
meifters eine dritte 2lbtheilung errichtet merde, und

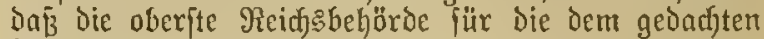
Refijart 3unewiefenen Berwaltungsizmeige fortan die

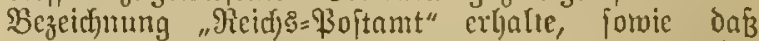
ber (3eneral=\$3oftmeifter gleidf ben anderen, mit ihm

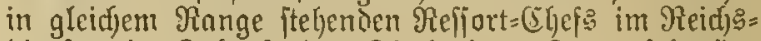
dienjte, in Bufunjt den Titel eines Stantsjetretärs 3u fiilgren bat.

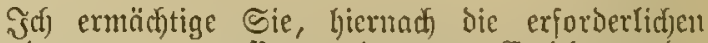
?tnorbmungen zu treffen, und wegen (ertid)tung ber dritten Direftorftelle bie entigitltige J̌eftftellung ourd) den Cetat herbeizufïhrert.

Berlin, den 23. J゙ebruar 1880.

20illyelut.

Fiurft bon Bismardf.

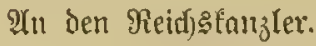

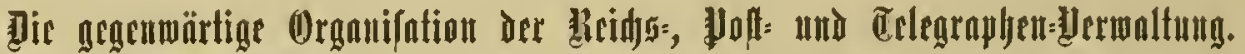

\section{A. Eentral-gुerwaltutu.}

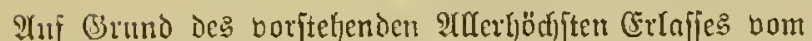
23. J Tebrntar 1880 ift unterm 20. März 1880 folgende Utmtsblatt = Berjütgung De\& GencraL = Pioftmeifters erlafjen worden:

Rx. 45. Bertwaltungs = (Fintid)tungen bei ber oberften

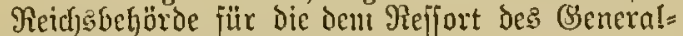
Foftmeifter: zugemiefenen Broeige des Reidjs= berfefrasmefent.

\section{Ber પiu, den 20. Mä̈r 1880.}

Die Pfllerfüd)fte Drore vom 23. Februar 1880 beftimmt,

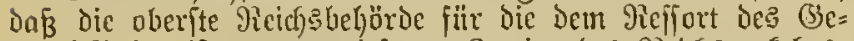

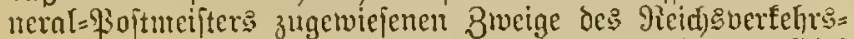

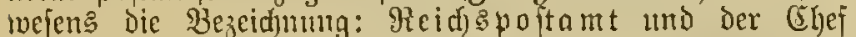

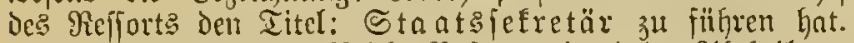

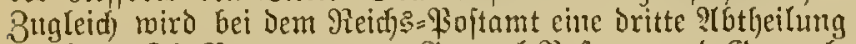
("rridetet. Dis Benenumugen: Beneral=\$3oftamt und Bemeral= Ielegraphenamt fommen in $\mathfrak{B e g f a l l}$.

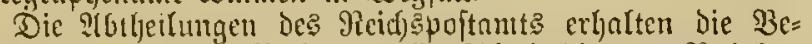

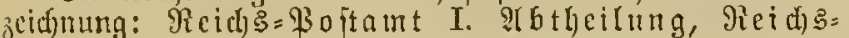

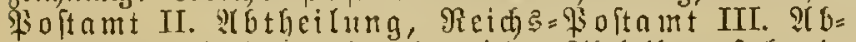

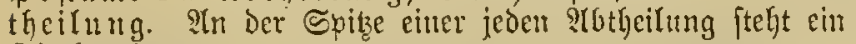
Direftor. $\left.{ }^{1}\right)$

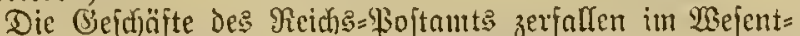
lichen in drei Szauptgruppen. (5) merben bis auf Weiteres jligerniefen:

\section{Der eriten stbtheilung:}

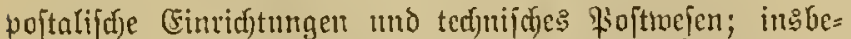

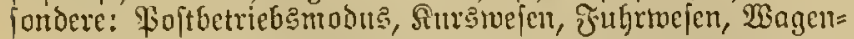

1) Seit bem 1. Ipril 1895 fthyt an ber Evige eimer Slbtheilung

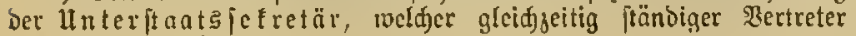
bes Stantşefretärs ift. bau, Eifenbahnpoltberfehr, ซahrpläne, \$3oftonmpfidjiffe, (5r=

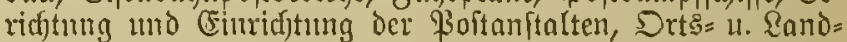

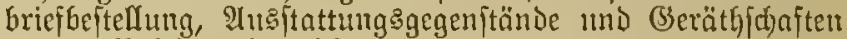

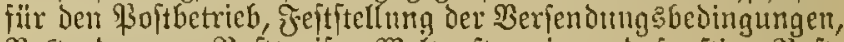
Poftoronnug, Boftturife, Weltpoftuerein mo fonitige goft=

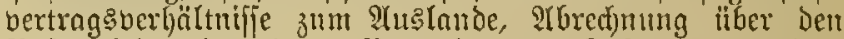

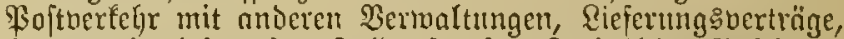

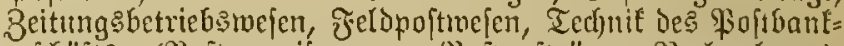

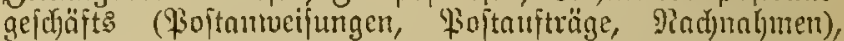

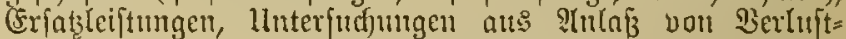
fäßlen, ?tntröge vegen Beichlngnnhute von Bojtiendungen, Foft befrantoationen, Bertragsuerbältniffe nit den Eifenbaljuen, Fortofreibeiten, 2lbuabme ber böheren Softuermaltungs: \$riffung;

\section{Der zueiten 9lbtheilung:}

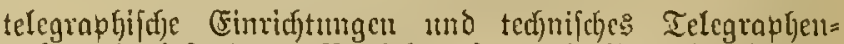
tweien; insbejondece: Betricbancien und Betriebsorduntng, ?tufftellung Der Pläne für Ertweiterming bes Telegraphen=

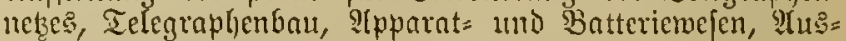
Ftattungsgegenftände uno (Serätljf(c)aften, Tarije, Berträge init fremben Bermaltungen uno Abredumung über Den be=

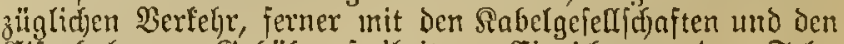

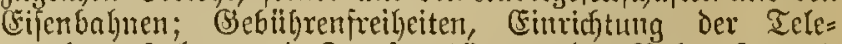
graphenanitalten uno Fernfprectü̈mter, der Fohrpoft= und

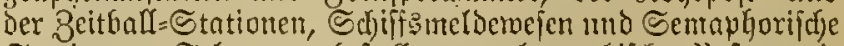
Stntionen, Telegrammbeitcllung, telegraphifdie Hoftanwei= fungen, ?futräge megen Bejd)lagnaljume vout Telegrammen, wifienf(d)nftlidje Frngen und Serfudje, Bezielungen jur

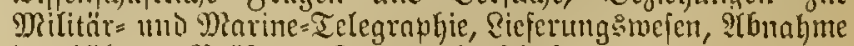
der böberen firrifung, Ielegraphenjdule;

\section{Der oritten $\mathfrak{A}$ btheilung:}

organifde, gefetzliche mo adminiftrative Miajregeln, allge=

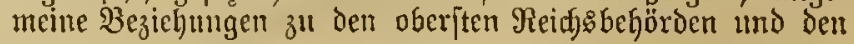


Mrinifterien Dex Bundesftaten forvie zum $B$ undezrath und

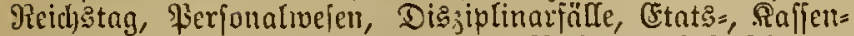

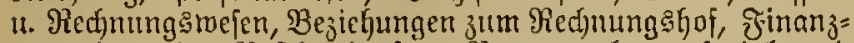
bermaltung des 3 softbanfwefeng, Bauberwaltung, jojiale und

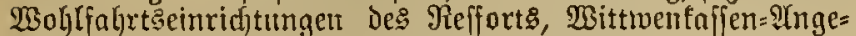
legentyeiten, genfionswefen, Poftipartafien, Weeffelftempel= fteuer, Ingelegenheiten ber Militär=23erjorgungsbereditigten, Mertbzeichenberwaltung, Münzangelegenheiten, Statitit, Scrausgabe der allgemeinen Dienjtanmeijung, Dienjtbe= tleidungsmejen, Betheiligung bei 2tbnafme Der höferen łirü=

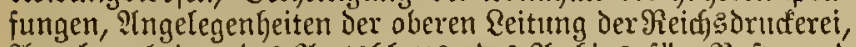

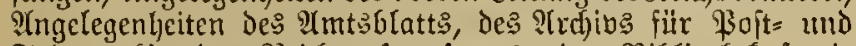
Telegraphie, Des Reidjspojtmujeums, Der Bibliothet forwie Der ßarten= und Modelliammlungen.

Dem Reidjspoftamt jind, antfer den Raifertidfen Sber=

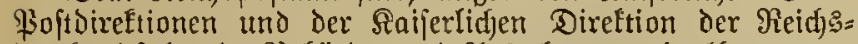
Drufferei folgende Befjörden und ?tnftalten umutittelbar unter= georonet: die Seneral= Pojtfnjie, $\left.{ }^{1}\right)$ Das \$3oftzeitungsamt, Das

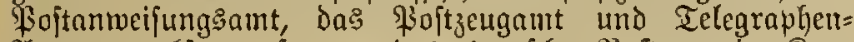
Apparatwertitatt; jerner da: deutid) gioftamt in Sort= ftantinopel. ${ }^{2}$ )

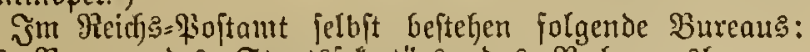

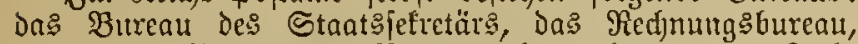

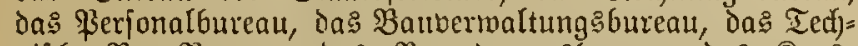

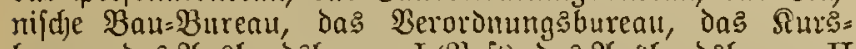

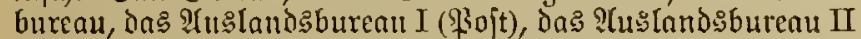
(Telegraphie), das Statiftifhe $B$ uteau, die (sebeme Re= giftratm I, bie Beheime Piegiftratur II (im Telegraphenge= bäube), Die (Seljeine Sanjlei, Das Telegraphenbetriebsbureau, Das Tedjnif che Ielegraphenbuteau, das Telegraphenbau=

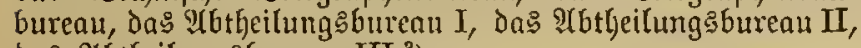
bas 2 btheilung

Someit die (Entfdyidung $\mathfrak{b}_{3}$. Bollzielyung in Den midytigeren Ingelegen heiten u. bei șragen von grumdiäblider $\mathfrak{B}$ coentung bisher dem Beneral= gsoftmeifter vorbefolten wat (vergl.

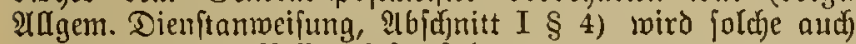
ferner Durdh den Beffortdjef exfolgen.

Die Beridjte Der Raijerl. Sber=\$3oftoireftionen $2 e$. in

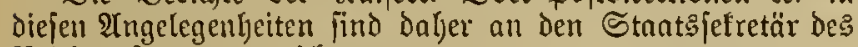
Reidjspoftamts ju riditen.

Jn allen übrigen ?Ingelegenheiten, in melden nach den bisherigen Bejtimmungen nn Das General=\$3oftamt bezm. Das Seneral=Ielegraplyenamt zu beridfen war, ift der be=

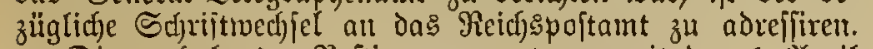

Die vorfiekenden Bejtintmungen treten mit Dem 1. WPpril ๖. $\mathfrak{s}$. in Sinft.

1) Bon berjelben merben zugleidy bie Saffengejdäfte für ben Ober= Paftbireftions=?ezirt Berlin wahrgentommen.

2) (E⿱

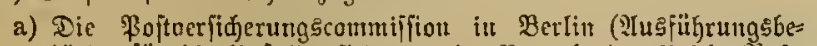

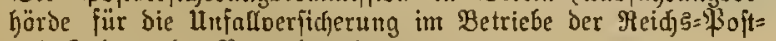
und Tełegraphen=?erwa(tung).

b) Die $\$ a[t=$ und Telegraphen=Inftalten in ben Deutidjen Sahus:

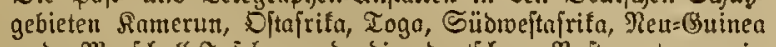

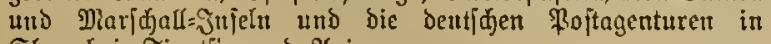
Ȩanghai, Zientin unto ?pia.

3) Daju gelommen: Das Bureau für Ferniprefjuefen uno bas Telegraphen:Э̃ngenieurbuteau.

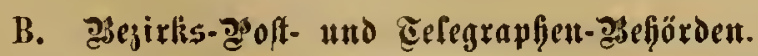

fö̈r bie gemeinfame Bermaltung des Poit = mo Tele=

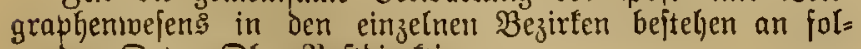
genden Drten Dber $=\$$ oft tireftionen:

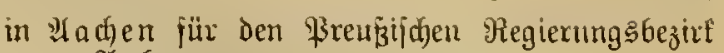
Madjen;

- Berlin für die Şaupt= und Rejidenzftadt Berlin, fomie für die Stadt Charlottenburg uno Burort Wejtend;

Braunichweig fǜ das Đerzogthum Braun=

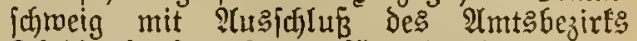
Thedinghaufen, fomie für einzelne Theile Der Freufijden Regierungsbezirfe \$amnover und Silloegheim;

"Bremen jür das (jebict Der Sanjeftadt Bremen,

fiit den lints Der 2 efer gelegenen Theil des \$reukitiden Regierungsbezirf: Şan, nover,

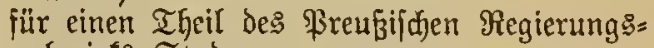
bezirts Stade,

für den Braunfarweigifhen Imtsbezirt Thedinghaujen,

fitr bie Telegraphenanifalten auf den $\mathfrak{B e j e r =}$ leudftthitrmen;

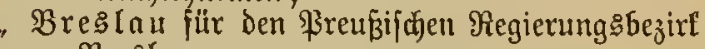
Breslau;

Sromberg für den Breusifiden Regierungs= bezirt Sromberg und die zum ßrenßifanen Regierunģbezirk Marientwerder gehörigen Freije Deutfd)=(Erone, Flatow, Ronib, Shlodjau und Tubjel;

"Caffel für den \$reugij(jen Regierungsbezirf

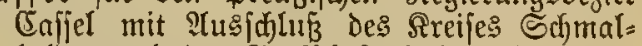
Ealden und der Sorrafichajt Shaumburg,

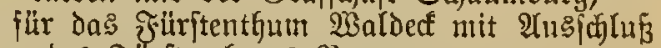
bes ₹urftenthums Sinrmont;

Coblenz jifr den \$reukijd)en Regierungsbezirl

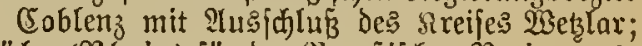

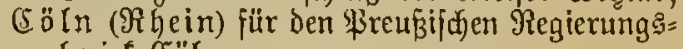
bezirf (Söln;

Cöslin fïr Den ßreufijd)en Regierungşbezite Cöstin;

Danzig für ben ßreußifuen Regierungsbezirt Danzig,

für Den ßreufipijen Regierungsbezirf Marien= werder mit Alusid)luf ber Sreije Deutj(d)= Crone, Flatow, Sonits, Sdjlodjau und Iudjel;

Darmftadt fïr Das (Sropherzagtlum Seffen

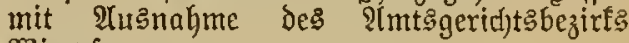
Wimplen;

Dortmund für ben \$reufifiten Regierungs= bezinf Yrrtiberg;

Dreşden für die ङähfifden Sreighauptmann= idjaften DresDen und Bauken;

Düfeldorf fitr Den wreubifiden Regierungs = bejirt Ditffeldorf;

(Exfurt jür den ßreufifden Regierungşezirt Erfurt,

für Den zum ßreußifjuen Regierungşbezirf (Eafjel geförigen Streis Schmalfalden,

für das (Groblyerzogthum Sadjpen=Weimar, für bas \$erzogthum Sadfen=Meiningen,

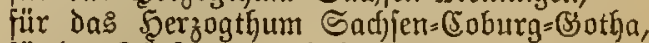

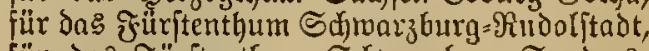
für Das ₹̛̈ritenthum Sajwarzburg=Sonders. baujen,

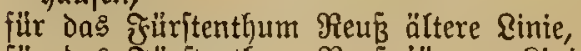

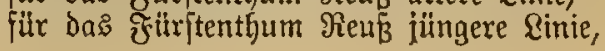


in Franffurt am Main fïr den Brenfijidjen Regierungşbezint $23 i \varepsilon s b a d e n$,

fïr den zum \$rentjifchen Fiegiernuggbezinf (5oblenz gebärigen Sreis Wedzlar;

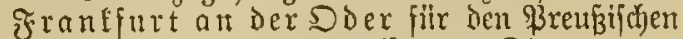
Regierunģbejirt đranlfurt a. Doer;

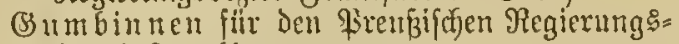
bezirt Bumbinten;

Salle an ber Saale für den Freupificten Regierungshezint DRerfeburt;

5amburg fïr Das (sebiet Der Searjeftadt Sambura,

fiil Das (5ebiet der Samjejtadt Ritbect,

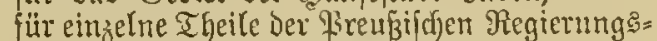
bezirfe Rüneburg und Strode,

für einen Theil der \$rensifanen Provinz Sd) lesmig $=50$ olftein,

für Die Snrfel Şelgoland;

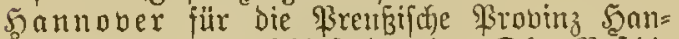
nover mit P(usfich lus Der Den Dher=Foitdi= reftions= Bezinfen Braum duneig, Bremten, Samburg und Droenturg zugerwiejenen (B)= bietstheile;

Rarlsube (Baden) für die Badijchen Sreife MosGnch, Seibelferg, Mambeim, Sart\&rsthe und Baben, fotwie

für einzelne Theile des Sietifes Sffenburg

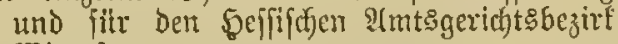
wimpfer;

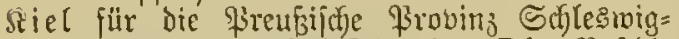

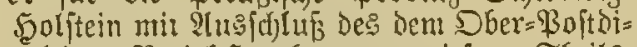

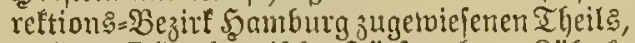

für Das Dloenburgifd)e Fitritenthum Rüberf;

Sönigşberg i. \$r. iï Den Preufifichen Re= gierungabezint $\Re$ önigsberg i. \$r.;

Sonitanz für die Badijhen Siteife Sinftarz, Billingen, Waldshut, Qörach, Jreiburg und einzelne Ilyeile bes Streipes Sffenburi, für bie 5ohenzollernichen Sande;

Seipzig für bie Sädjifichen Rreighanptmann= fic)aften Eeipzig und Zुwitfou, fowie

fiiv Das 5erzogthum Sact) jen=?(Itenburg;

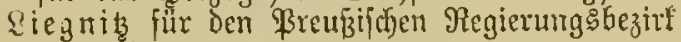
Riegnitz;

MRagdeburg für Den \$reufiptben Regienung bezirt Magdeburg,

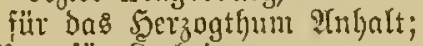

viets für Eothringen;

Mindert in 20 eftaten firr den Freusif(t)en Regierungsbezint Mimben,

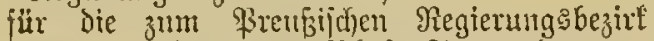
Eafjel gehörige (Brafidjaft Shaumburg,

fïr Das Jilirftentlum Sippe,

für bas đ̛̆ürterthum ธd)aunburg=8ipp?,

für Das zum förftentlyum $\mathfrak{B a l b e d f}$ gefiobrige Fürftenthum \$strmont;

Mënfter in 23 eftalen für den \$renbifden Regierung

Dloenturg für das (3rob̧lyerzogthum Dlden=

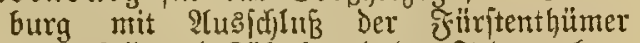
Birtenfeld und Qübect und Der Telegraphen= anftalten auf ber Beferleudytthürmen,

für Die ßreußijidjen Regierungşbezirfe 2(urid) und Dรกnabrita;

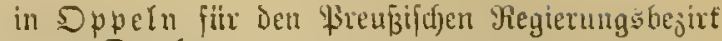
Sppelu;

" Pofer fiir Den Frenpifchen Regierungsbezirf Sojen;

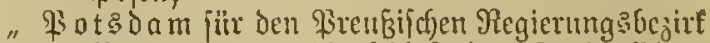

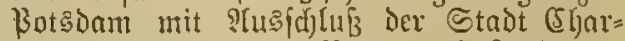
lottenburg umb Deren Bororte 2 Seftend;

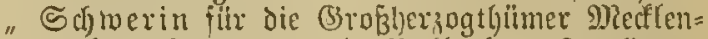

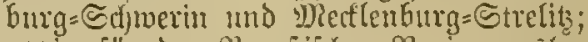

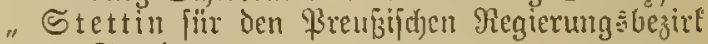
Stettin,

für Den \$reufifichen Regierungşbezin Strals jund;

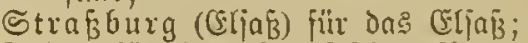

Trier für Den fireufifden Regierungshejirt Trier, forwie

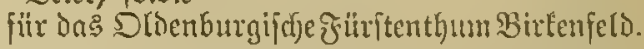

$230 n$ den zu den vorgenannten Bebietsigeilen gehörigen Boftanftalten find einzelne an deren Girenzen belegene alt?

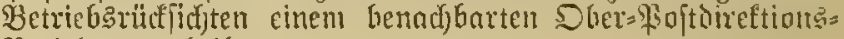
Bezirfe jugetheilt.

\section{Berional der DGer= Poftoireftionen.}

In Der Spize jeder Sber=Bojtbireftion iteftein Dber= \$3 oft direltor, iveld)er Die Sermaltung des \$ojts und Tele= graphentejents in jeinem Bezirfe nad) Magagabe Der (Beicte und Der bom 3eidfs=\$pitamte gegebenen ?tumeijungen felb $t=$ ftändig und unter eigeuer Derantmortlicffeit fithrt, uno

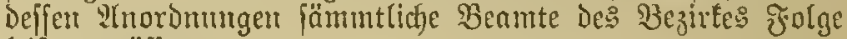
leiften mitijen.

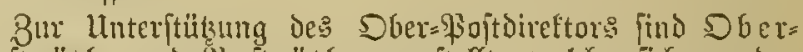
Bofträtbe uno 3 ofträthe angeftellt, meldje fidj an ben

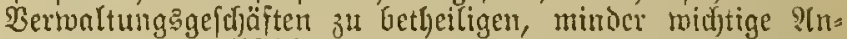
gelegentheiten felGitftändig zu erledigen, Den (B) cinäftsgang in Den Bureants ju regeln, und Dns ignen zunäd)ft unter= geordnete 3 ureabeamten=\$erional z" überwadjen Laben.

Den red)tatundigen Beiftand leiftet cin Recftsoer= ftändiger Deڤ Drtes.

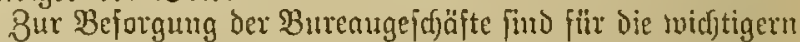
dexfetben Bureaubeamte I. Silaffe (Ober=Pojtdreftions: Sefretäre), für die minder wichtigern, powie fitr die J̃ourmals

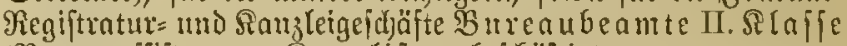
(Bureauafiftenten), Sanjliften Gejdäftigt.

$8 \mathrm{~m}$ peribulichen Beauffiffigung Des Dienftbetriebes

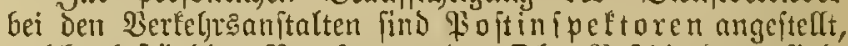
welde Gejtändige Beaultragte des 5 ber-\$softoirettore fino,

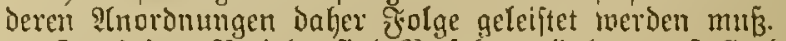

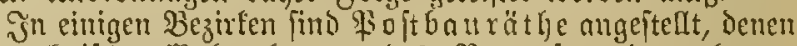

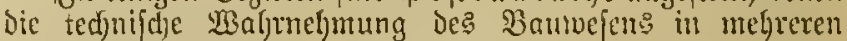
Bejirfen nbliegt.

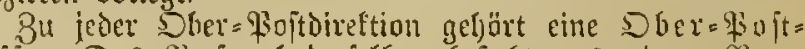
Eafie. Das Ferfonal derfelfen beftegt aus einem $\Re$ en =

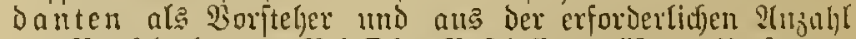
bon $\mathfrak{B}$ ud haltern. Sei Sber=\$ojtfafjen gröberen 1 mafunge: ijt nod) cin Saffirer angeftellt.

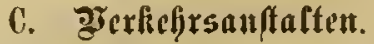

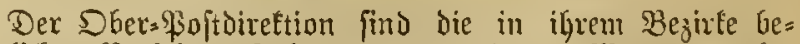
findliden Serfehrsanitalten untergeordnet. 230 inegen bes fonderer Bedinfmiffe die Rotlywendigleit fitf ergiebt, eine. 
Bezirf: =\$oit= oder Telegraphenanftalt einer benachbarten Sber= \$oitotreftion zuzumeifen, wird dies befonders beriügt.

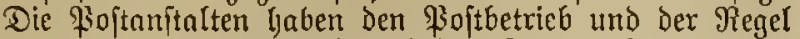
nad) aud) ben Telegraphenbetrieb des Srts wahrzunehmen. Diejelben werden, je nad) Der Bedeutung und bell Umfange Deg Betriebes, in bier ßlaffen eingetheilt:

\section{"Yoftämter I., II., III. und \$softagentriren."}

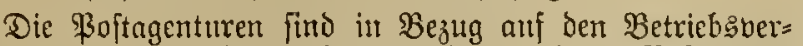
bano und die Redjnunglegung einer anderen \$oftanftalt

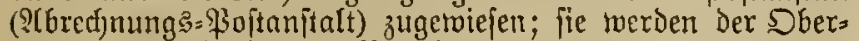
Bojtdireftion Desientigen $\mathfrak{B}$ ezirfes untergeoronet, weldjem die âbrechnungs:=\$Sojtanftalt jugehört, unb yaben eintretenden= falls audf Den Telegraplyenóienjt mahrzunehmen.

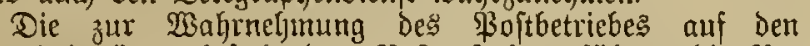

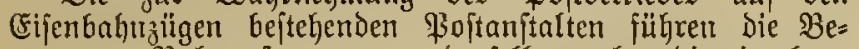
nennurg "Bahnpoitamt"; bon denjelhen gehen die einzelnen Bahnpoiten aus; jener Benennung tritt nod) bie zutreffende

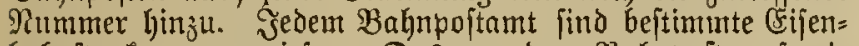
bahnjtrecten zugerwiefen. Das zll Den Bahnpojten jomie zum (Sejuäftäbetriebe bei Dem $\mathfrak{B a h n p o i t a m t ~ f e l b i t ~ e r f o r d e r : ~}$ liche Pierional ift Dem Bahnpoftamt untergeoromet. Fitr cinzelue Eifenbahnjtrecten ift der \$oftbetrieb bejonders be= fitumten Ditspoftämtern zugetwiefen.

Wso Der Befdjäftsumfang es bedingt, befteljen für den Telegraphendienft bejondere Ielegraphenämter, bezro. für Den Stadternjprechdienft befondere Jernjprechämter.

Şit der Jelegraphendienjt mit ber \$ojtanftalt bereinigt,

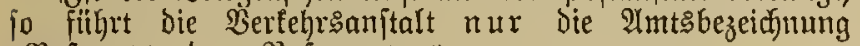
"Poftamt" ober "Poftagentur".

Sämmtlicfe $\mathfrak{B e r f e h r s a n f t a l t e n ~ f t e h e t ~ z u ~ e i n a n d e r ~ i n ~}$

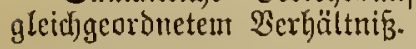

Qufberdem find in bebentenderen Sandorten oljue \$ojt=

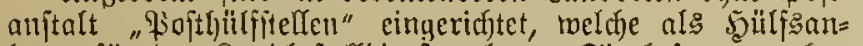
lagen fïr den Sandbeitelloienjt geltert. Sie bejorgen, ohne

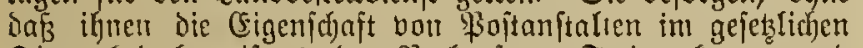
Simle beigelegt ift, 1. Den Verfauf von Jैeimarfent 2e. uno Foftiormularen, 2. die श(nnahme bon gemöhntichen Brief=

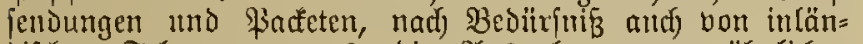

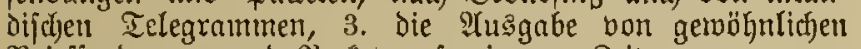
Brieffentungen und \$áteten, fomie von Beitungen.

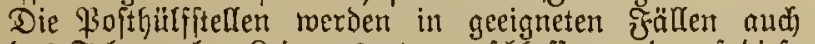
an bas Telegraphen=Reitungshets angefdloffen und auf biefe
Weife gleidjzeitig ale Ielegraphenhülfitellen für bas Bubrifum mubbar gemadft.

BBejtehen an einen größeren Sorte mehrere Boftanitalten, fo merden diefelben Durd) Sinzufügung einer arabif(t)en 3ahf zum Sitsnamen unteriffieden, wobci bie Saatptpoft. anftalt die 尺ammer 1 exhält.

Sind aufer Detn Saupt=Telegraphenamt now etra an der Börie, in einent Shlof 3 , \$alais u. $\{$. r. Teleyraphenan. ftalten vorhanden, jo erhält Das Saupt=Telegraphenamt

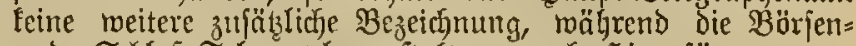

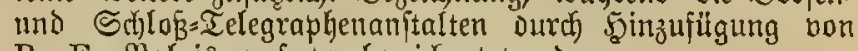
B., E., Balais u. F. to. Gezeichnet werden.

\section{Berjonal der Berfehr:}

Şede Berfehrsanfitalt fteljt unter ber Reitung eines $\mathfrak{B}$ or. ftehers, und führen diefelben folgende Bezeidjnumg:

Bei $\mathfrak{B}$ oftäntern I und Bahnpojtämtern:

"Soitbireftor".

Bei Telegraphenämtern I und Ferniprechäuntern: "Telegraphendireftor".

Bci Pojtämtern II: "Poptmeijter",

Bei Poitämtern III: "Pojtertwalter".

Bei \$ojtagenturen: "Proftagent".

Das gefammte \$erfonal der Berfegrsomitalt ift dem Borfteher ututergeoronet und Defien bienftlidjen Mnoronungen (3)eljoriam iffuldoig.

Der $\mathfrak{B}$ orfteljer hat bie $\mathfrak{A}$ iftalt in allen 9 Ingelegenheiten bes Dienftes an bertreten, Den Dienftbetrieb forvie bie $\mathfrak{B}$ e.

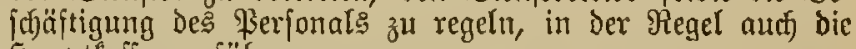
Soupttafje ju führen.

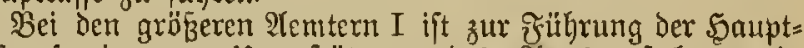

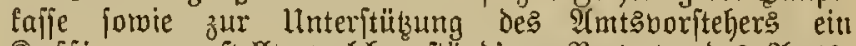

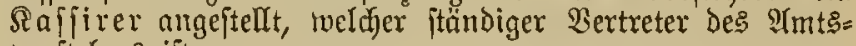
boriteljers ifit.

Ferner find bei bedentenderen Iemtern I Dber=\$3o[t= fefretäre bezm. Sber= Telegrapheniefretäre angeitellt, welche inmerhalb bes ignen zugemiefenen Bejchäftsfreijes ben Amts: borfteher wirffam zal unterfitizen lyaben.

\section{II. (Etigenthum!sted)te Des Zedeides.}

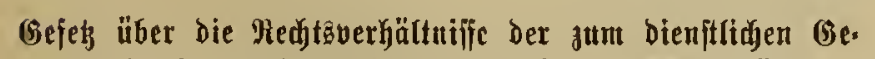
braudje cincr Reidastocrwaltung beftimuten Gegenitänoc. Bom 25. Mlai 1873, (M(GBl. ఠ. 113.)

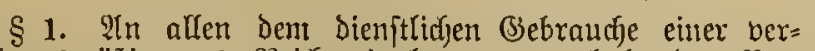

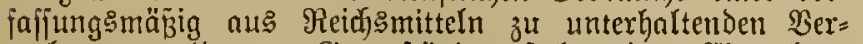
maltung geniometen (Begenftänden itehen bas Cigenthum tind Die fonftiget binglicfen Rect)te, welche detl einzelmen Bundesftaaten zugeftanden haben, Dem Deutjden Reiche zu. Der Beitpunft des lleberganges Diefer Begenjtände in eine foldhe Bertwaltung ift als Beitpunft Des Heberganges ber Rechte auj Das reich anzujehen.

Sinfidytlich der Befreiung bon Stettern und jonftigen binglidyen Rajten find die im Cigentfume des Reidf be: findlicjen (Segenftände den im Eigenthume des einzelnen Stantes befindtict)en gleidjartigen (Segenftänden gleidfgeftelt.
Iuch unterliegt Das Reich bezüglidy Der ihm jugehörigen (3egenftände Der nämlidjen (Seridgtęzuftr̈ndigfeit, meldjer Der Staat, in beffen Bereich jene (jegenftände fïh) befinden, bezuliglich) der ihm zugehörigen gleidjartigen Begenjtände unterworfen ift.

§2. TItsgenommen bon ben ßejtimunngen in $\S 1$ bleiben:

1. joldje beim (5rlajfe biejes Befezes den Zmecten einer Reichsvertoaltung Dienenden Grumbftüfe und Deren gejebslibe 3ubehörungen, melche nadh den in den einzelnen Sundesftaten geltenden $\mathfrak{B} e=$ fitmmungen jur Benulung des Staatsoberfauptes vber ber Îpanagirung ber Mlitglieder bes regierenden Saujes gerwibmet jind;

2. Grunditide, welthe bei bem llebergange it eine Vermaltung des ९Reidje biejer nur auf eine be= 
ftimmte Beit, ober auf Widerruf, ober miethstweife, überlaffen find;

3. Srundftücfe, aน̇ Deren Grlös die zur Ertwerbung oder Bebautung eines im Befíze Derfelben Reid) bertwaltung befindididen (Srunditüt's vou einem Bundeş[taate gemad)ten Uusgaben nad) Den

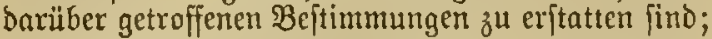

4. Srunditücte, meldje beint llebergange in eine $\mathfrak{B e r}=$ maltung des Reid)s dem betreffenden Dienitzrocige nicht unmittelbar dienten, biclmebr nux infofern mit ifm in einem Bufammerhange jtanden, als bie aus Den Brunditüen auffommenden Cinfünfte bei jenem Dienjtzweige mit verredjnet wurben;

5. Sirundjüde, tweldje zu cinem Theile von ciner Reid) einer Randesvervaltung benutzt werden, fofern ber lezteren die Mitbenuzbung nid)t lediglidi auf eine bejtimmte Beit oder nuf widerruf oder miethsmeife cingeräumt ijt. Pu joldjen Grunditücten jteht Dem

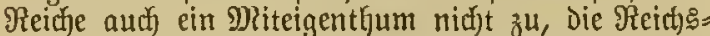
vermaltung befält aber, bis fie mit ber Ranbesoer=

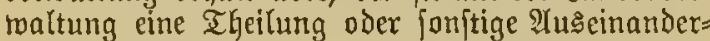
jetzung vereinbart, Das Benumungired)t im bis= Gerigen Untfange.

§ 3. Wenn aus einem in Dasి (Figentlum bes Reid)s übergegangenen Srunbjtüufe, neben ber Benutzung zum

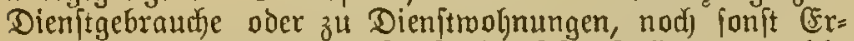
trägniffe gezogen merden, fo ift eine fejte (B)eldrente, weldfe nad Dem nadbaltigen Wertbe biefer Erträgnifje zu ers mitteln ift, an denjentigen Bumbes[tant abzufübren, von welchem das betreffende Srrumbjtüt an Das Reich überge= gangen ift.

$\S$ 4. Die nad Der Beftimmung in $\$ 1$ in Das Cigen=

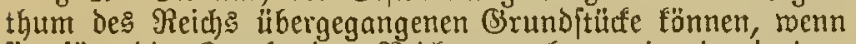
fie für bie 3rocte ber Reidjoverwaltung in Demjenigen Dienitzmeige, dem fie bisher gemibmet maren, entbehr(ic) oder unbraudbar soerben, für Bwete eines anderen Dienjt= grweiges ber Reidsonerwaltung berwendet werden.

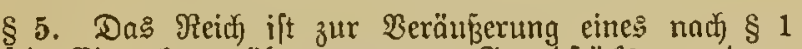
in fein Gigentfum übergegangenen (Srunditüafs nur bann befugt, menn baffelbe fitr bie Yeidjsoerwaltung entbehrlich ober unbraudb)ar wirb, und ber (Erlö's aus feitrem Bertaufe bazu beftimnt ift, burdy bie Grverbung eines andern Srunditüfs oder die serftellung einer anderen Baulid)feit im (Sebiete defjelben Bundesitantes einen (Exjaz für bas entbebrlich) oder unbraudjoar getoorbene (3rumbfüaf zu beja)affen.

\$ 6. Şit für ein entbebrlid) oder unbranthbar getoorbenes (S) cunditide cin Erias nidjt nothmendig, fo ift Daffelbe in bem Zuftande, in toeldyem es fict befindet, unentgeltlict und ofme $5 r j a t z l e i f t u n g$ fïr etroaige Berbefferungen ober $\mathfrak{B e r}=$ (c)ledflecungen Demjenigen Bundeshtaate zurüdzugeben, aus beffen Befíg es in bie Berwaltung Des Reidjs überge= gangen toar.
$\S 7$. Die Rütfgabe $(\S 6)$ fold)er Srunditücfe, meldje ben 3roefen der Mititärbermaltung getoiomet fimo, erfolgt, twemn fie für dicfe Dermaltung entbebrlid) oder unbrauchbar werden, und meder nach \$ 5 cin (Srjas fïr fie zu bejdjaffen, nod) ifre Berwendung fü Buede Der gharine erforder (ind ift.

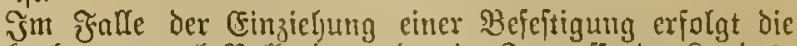

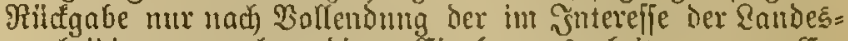
bertheidigung nothmendigen Fincbmungsarbeiten gegen $F_{5}=$ itattung der Roiten diefer Mrbeiten.

\$ 8. Die Sntjdjeidumg Dartiber, ob cin ban Der Reidfs= berwattung nicht weiter vertoenobares (3)runoftüct -

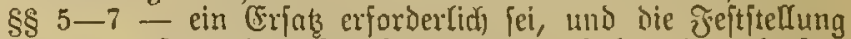
der zu exptattenden (Finebnungsfoften ftelyen ber oberjten Bebörde Derjenigen Reidjsoervaltung zu, in Deren Befitz fid) bas Brumbitüc Gefindet.

§ 9. Durdj Den llebergang besె Eigentlum an ben im $\$ 1$ bezeidjneten mbeweglidien (segenftönden an das Reid) werden nidjt beriiljat:

1. Berfügungen, meldye in Betreff diefer Begenitäude vor Dem 1. Samuar 1873 getroffel find:

2. die Fortbanter bon Bahlumgen oder anderen Reiptungen, meldje bon einer Reidjbermaltung für bie Ein=

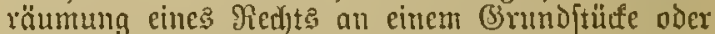

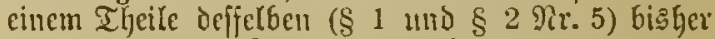
an einen Bumbesftat ju entridyten waren;

3. Die Recthte Dritter, Gejonders der Stantร̧gläubiger. Die zur 2Baljung diefer Redjte in Den Randes= gejeben beftebenden Borfatiften find aut von bem gieidje zll exfüllen.

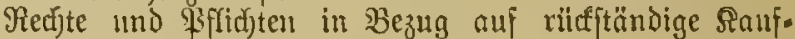
gelder geben auf Das Reid nidjt Hber.

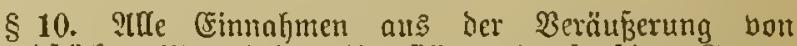
Grmidfülfen, Materialien, lltenfilien, oder fonftigen Gegen=

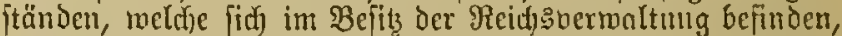
miiffen für jedes Şahr beranfdlagt uno auj den Reidj:

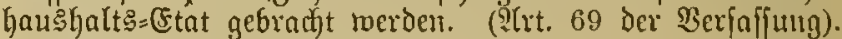
(Fine Radjtweifung Der lleberid)reitungen foldjer (Fimafjue

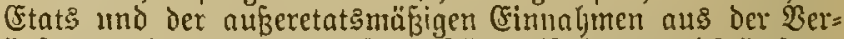
äußerung der erroäljnten (Segenftände ijt jedesmal fpätejtens in Dem auf Das (5tatsjabr folgenden zrociten Safre dem Bundes̉ratl) mD Den reidjstage zur nadjträglidfen (S)e= nehmigung vorzulegen.

\$ 11. Die Cinmafmen aus der Beräuñerumg Der in

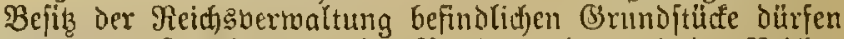
nur unter Sienefmigung des Bundesiatbes mo des शeidjs:= tages verausgabt merden und find, foferm dieje Benelymigung

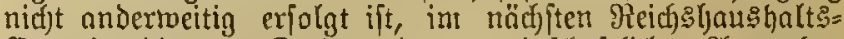
Stat in dic zur Dectung der gemeinfduaftlichen Plusgaben beftimmten Gimnalmen einzuitellen.

\$. 12. Dem Reid)stage ift ein Berzeidnifs Des als figenthum Des Reiches fejtgeftellten Giumbefizes mitzu=

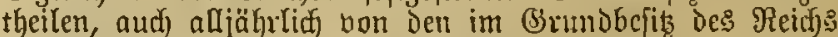

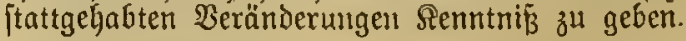




\section{Internationale dertränc.}

\section{Wieltpoft: Bertrag vout 4 . Juli 1891

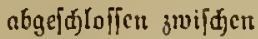

Dentffland und den Delitjuen Sdjulbebieten, den Ber=

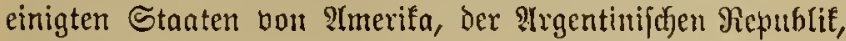
Depterreich=llngarn, Belgien, Bolibien, Brafilien, Bulgarien, Chife, Der Republif Columbien, Dem Unabfïngigen Rango= ftant, ber Republif Cojta=Rica, Dänemart mo ben Dä= niffjen Solonten, der Republif San Domingo, Egypten, Eetrador, Epanien und den Epanijdjen Solonien, Frant=

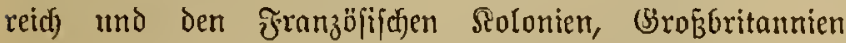
แnd berjujiedenen Britifjen Solonien, den Britifjen $\Re$ olo= nien bon 2(uftralafien, (Eanada, Britifd)= Şndien, Briedjen=

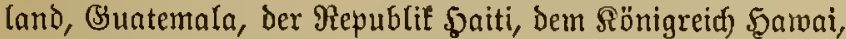

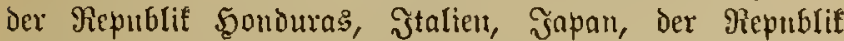
Riberia, Eurcmburg, Merico, Montenegro, Ricaragua, Ror= wegen, Paragutay, ?Riederlano uno den Miederländijofen Solonien, Beru, Ferfien, Fortugal und Den Bortugiefifdjen Solonien, Fumänien, Rugland, Salvador, Serbien, Dem

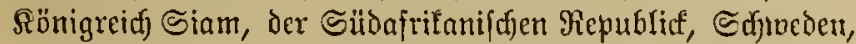

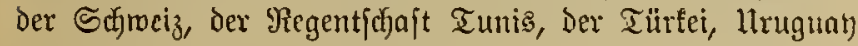
und den $\mathfrak{B}$ ereutigten Staaten bou Benezuela.

Die unterzeifmeten Bevollmäctigten der Regiermugen Der boritelyend aufgefühtten \&änder haben, nadfoen fie auf (5) rund Des 2 rtitels 19 Des am 1. Juni 1878 in Paris $a b=$ gefd)loffenen $\mathfrak{B e l t p o f t b e r t r a g s ~ z u ~ e i n e m ~ S o n g r e ß ~}$ zujammengetreten find, in gemeinj(j)ajtlidjem Einverjtändni仍 und unter Borbehalt Der Ratififation, den gedadjten $\mathfrak{B e r t r a g}$ forvie das barauf bez̧üglidje Enfjaboner 3ufakabtommen bon 21. März 1885 im Wege der Revifion folgendermaßzen $a b=$ geäniert.

Prt. 1. Die am gegentwärtigen Bertrage theilnefmenden, forvie bie Dentfelben foüter beitretenden \&änder birden, für den gegenfeitigen ?(ustaujd) ber Rorrefpondenzen zinifden

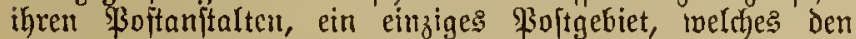
Namen "iselt p oftberein" jübrt.

Art. 2. Die Beptimnungen diejes Bertrages erftreden (idd) auf Briefe, eimfacke Foittarten und \$ofttarten mit be=

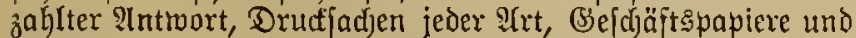
Baarenproben, weldhe aus cinem Der Bereinsländer her = rillyren und nach einem anderen gericjtet find.1)

$\mathfrak{A}$ uch finden diefe Beftimmungen in gleidjer $\mathfrak{B e}$ eife $\mathfrak{A} n=$ wenoung auf deu \$ojtaustauld) Der borbezeidjneten (Gegen= itände zrvifđen SBereinsländern und fremben, Dem Vereine nidjt angehörigen Rändern, jofern bei diefem Tustaujd) Das Bebiet bon mindeftens zroeien der bertrngidfliefenden Theile beriilyrt wiro.

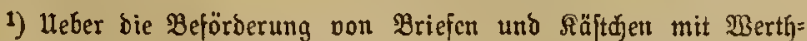

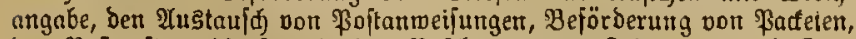

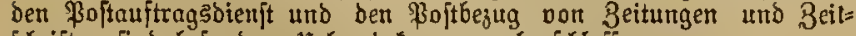
füriften find befondere $\mathfrak{H}$ ebereintommen abgeidiojient.

Irt. 3. (1) Die ßoptbertwaltungen angrenzenier pier joldher \&änder, weldje, ohne find Dex Bermittelung einer

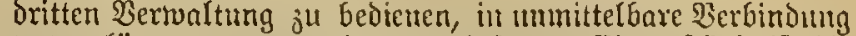
treten föunen, oronen in gemeinfamen Finverftänduif bie Bedingungen Der Beförderung Der beiderjeitigen Briefpojten ïher bie Srenze oder bon einer (Sirenze zur anderent.

(2) Bofern feine gegentheilige 2t6madjung befteht, werden als Reiftungen britter Verwaltungen dicienigen Seebejörde= rungen angejejen, tweldje unmitteloar zwijdjen zmei Rändern mittels der bon einem derfelbet abhängigen Softoampfer oder anderen Sufiffe ausigejiilyt werden. Dieje Beförde= rumgen, fotvie diejenigen, weldje zwijdjen zwei Bojtanftalten eines tmo deşelben Randes durd) Bermittelutg Der bo،

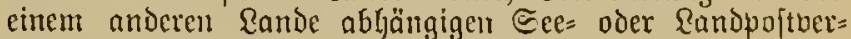
bindungen ausgefïhrt merden, unterlieger den Bejtimmungen des jolgenden Artifels.

Frt. 4. (1) Die Freifjeit des Iranfits ift im gefammten (Sebicte des Berein: gemährleiptet.

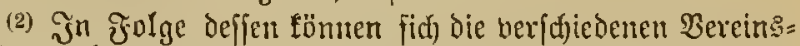
poitbermaltumgen durt) Sermittelung einer oder mel)reres anderer derielben fomohl gefhloffene Briefpoften nIG lofe Sorreppondenzen, ie nadj Dem Sertelrebedurjnif und den Erfordertifien bes \$ojtoienftes, gegenjeitig zufertigen.

(3) Die תorrefpondenzen, weldje zivifajen zmei Bereing= verwaltungen, entweder im offenen Tranfit oder in ge= [d]lofienen Briefpojten mittels Der Wojtberbindungen einer oDer mefrerer anverer Bereingoerwaltungen amşgetauj(j)t werden, unterliegen zแ (S) niten jedes ber ITraulitländer oder Derjenigen Ränder, Deren Foftuerbindungen bei der Beför= berung betheiligt find, ben nadffehenden Tranfitgebüfren:

1. Fiir die Sandbejörderung 2 franfen fïr Das Rilo= gramm Briefe oder Poptenten und 25 Centimen für bas Siflogramm anderer (Begenjtände;

2. fiir die ธecbejörderutg 15 Franten für bas Rilo= granm Brieje ober \$ojtfarten und 1 Franf fïr jedes אilogramm anderer Segenjtände.

(4) Man ift jedodf barüber einverftanden:

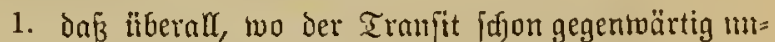
entgelttidf oder unter vortheilf)ajteren Bedingungen

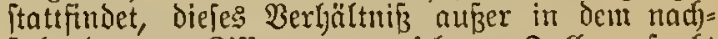
fteljend unter Biffer 3 vorgefeljenen Fall, aujectit: erhalten twiro;

2. Dấ ïberall, too die See= Tramfitgebiihren gegen= wärtig auf 5 đrranten für bas Silogrann şriefe oder \$ajtfarten Imd auf 50 Centimen fïr Das Sillogranm anderer Gegenitände feitgeferst fino, biefe $23 e r g i$ itungsfäze beibefalten twerden;

3. das jede Geebeförderung von nid)t mefr als 300 Eeeneilen unentgeltlid) ftattfindet, womm die betheiligte Bertwaltung für dic betreffenden Briefpoiten oder Rorrejpondenzen fefon die Ber= giitung der Rand=-Tranfitgebütr zu beanfprudjen hat; anderenfalls mird die Beförderung nad) Dem Sake von 2 franfen für Das Rilogramm Briefe oder Fofttarten und 25 Centimen für das Rilo= gramm anderer Gegenftände bezahlt;

4. Dn mehrerer Berwaltungen att ber Eeebejörderung bie See=Iranfitgebilhren für die gefammte $\mathfrak{B e}$ : 


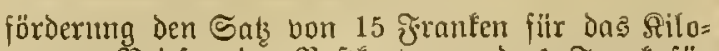
gramm Briefe oder \$oftfarten und 1 Jrank jür

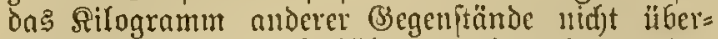
fieigen dürfen; diefe (sebitluren merden eintretenoen Falls z'wifeden ben Gelheiligten Bermaltungen nad) Berbältnif Der ztrü̈dgelegten Stredfen getheilt, unbeidjadet anderweiter $\mathfrak{V}$ ereinbarnngest zmiffien ben betreffenden Bertonltungen;

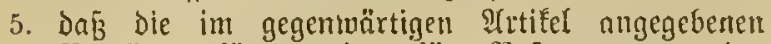

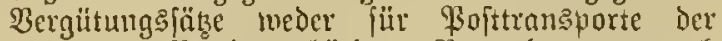
nicht zum Berein gebörigen Sermaltungett, nod)

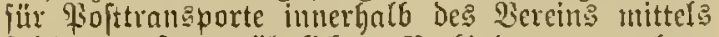

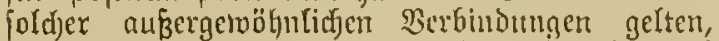
bie bon ciner Bermaltung im Sntereffe oder nuf Verlangen einer oder meljrerer anderen $\mathfrak{B e r}=$ valtungen bejonbers hergeftellt oder unterhalten merden. Die Bebingungen fïr diefe beiden Irten von ßofttrnşporten werden zlwifden den be= theiligten Berroaltungen in freier Bercinbarung geregelt.

(5) Die Tranfitgebüf)en find bon ber Berwaltung hes Sulgabegebiets zu tragen.

(6) Die Stbrectunung ïher dieje (Bebühyen erfolgt auf (3)rund von Radfweifungen, welche alle 3 Salyre während cines Beitraumes bon 28 Tagen nufgeftellt werden, Der

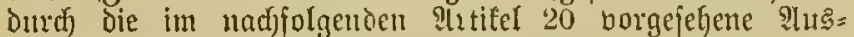
führungs

(7) Der Sdjriftwedffel Der Boftuervaltungen unter ein=

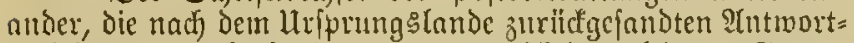
Pojtfarten, nadjgejandten oder unridjtig gefeiteten Biegen=

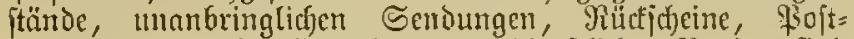

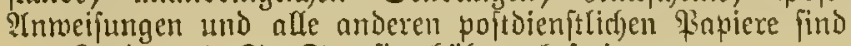
bon $2 a n d=$ und See=Tranfitgebilfrem befreit.

21rt. 5. (1) Dns \$orto für bie Beförderming Der qojt=

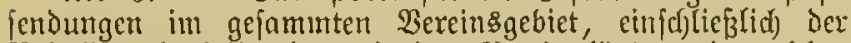
Beitelluttg derfelben in denjenigen Bereins?ändern, in meleden ein Bejtellungảdienft beftẹt oder ipäter eingerid)tet wird, betrügt:

1. Gei Briefen 25 Čcutimen im ₹ranfixumggfalle, anderenfalls bas Doppelte, für jeden Briej uno fïr je 15 Gramm oder cinen Theil vort 15 Gramm;

2. bei Foltfarten 10 (5entimen für sic einfad)e Sarte oder fïr feden ber beiden Theile Der Sarte mit bezahter Rntwort.

Unfranfirte \$oftfartent unterliegen ber Ince für unfintantirte Briefe;

3. bei Dructinchen jeder 2trt, Befchäftspapieven und Wnarenproben 5 Eentimen fili jeden mit ciner befonderen ?tuffdrift berfefenen Gegenftand ober jedes berartige Padfet und fiir je 50 brramm oder einen Theil bon 50 (3) biefer (3egenftand ober biefes giafet weder einen Brief, norf einen geifjriebenten Wermerf entrjält, welcher die eigenjafalt einer eigentlid)en und perfönlichen Sortrefpondenz hat, mo bafis bie

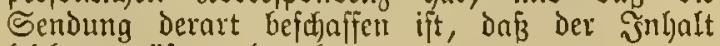
leidft geprüft werden famn.

Die Tare Det (Sefdiñtspapiere barf nidjt meniger als 25 Centimen für jede Sendung, und bie Taze ber Wuaaren= proben nicht toeniger afs 10 Centimen fïr jede Sendung betragen. $\left.{ }^{1}\right)$
(2) STuber Den in den vorjtehenden Paragraphen feft gefetzten Taŗen fönnen zur Erhebumg foumen:

1. fiir jede Sendung, weld) Den See= Tranfitgebühren von 15 J̌tnnfen für don Silogramm Briefe oder Softfarten und 1 frauf fiit das Silogramm anderer (3egenftände unterliegt, und zwar in allen Berfeljrsbeziehnngen, auf toeldhe bieje Tianjitjüze numendbor fint, eine einf(gitfidje Bujd)lagstare, velide 25 (Eentimen fïr bos cinfache Sriciporto, 5 Centinten fïr jede Sarte, und 5 Centimen fïr je 50 Bramm oder einen Theil boul 50 Gromm bei Den nnderen Begenftänden nid)t überfteigen Darf;

2. fïr jeden Begenitand, der mit Poftuerbintungen von uidft zum Berein geljörigen 2iertwaltumgen, oder mit außergetwöhuliden Berbindungen inner= balb Deş Bereins gegen bejondcre (Sebitlyren bes färdert mird, eine zu diefen (sebübren im Berbältnif ftehende Buf(h)lagistare.

(3) Bei ungeniligender franfirung werden Rorrefpondenz=

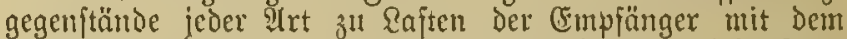

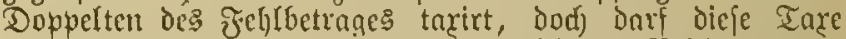
niemals Dasjenige Worto ïberiteigen, weldyes im Beitimmungs: lande fit: Imfranfirte Sendungen gleidjer Batturg fomie gleidfen (semict)ts mo llriprunge erhoben wird.

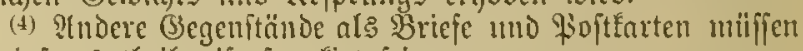
wenigitens theilweife frankirt fein.

(5) Maarenprohenjendungen Dürfen Gegenftände bon Sondelswerth ridjt enthalten; Diefelben follen nidjt ilber

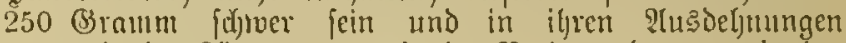
$30 \mathrm{~cm}$ in Det \&änge, $20 \mathrm{~cm}$ in Der Breite tund $10 \mathrm{~cm}$ in ber

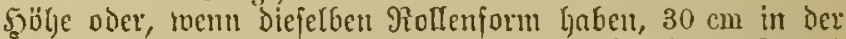
E'änge mo $15 \mathrm{~cm}$ int Durdmeffer nid)t iiberichreiten. Şedod) find die Verwaltungen der betheiligten Ränder ermüd)tigt, in gemeinfdjaftlid)em Einverftänoniß fïr iljen gegenfeitigen Ith die vorbezeicjneten zuzulaffen.

(6) Sendungen mit (Seid)ä[tsyapieren und Drudfachen folfen bas (Servid)t von $2 \mathrm{~kg}$ richt itberfdreiten und an teiner Seite eine ?asdelyumg bon inel)r als $45 \mathrm{~cm}$ loben.

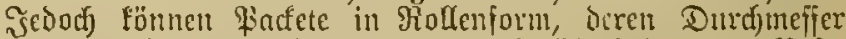
$10 \mathrm{~cm}$ unb Deren Eänge $75 \mathrm{~cm}$ nidft iiberfteigt, zut 930 ft beförberung zugelaffen merden. ${ }^{2}$ )

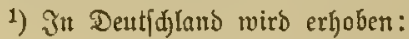

3u 1. 1: Fïr cincu franfîten Brief 20 \$f.

T̈̈r einten unfranfirten Briej $40 \$$.

3u 1. 2: Fitr eime einfade \$oftfnrte 10 \$f.

Fir cine \$oftterte mit 2 ntroort 20 \$F.

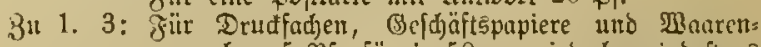
proben 5 gf. Für je $50 \mathrm{gr}$, jedod mindeftems 20 Pi. jür jebe Eettoung vont Brffäftspapicren, 10 \$j. für jede Sendung Don פBarenproben.

2) 3u 4-6: Genbungcn, weldje bicien \$ejtimmungen ntŏhi ent ipreden, merben nidjt bejörbert.

Irrt. 6. (1) Die im शtrt. 5 bejeid)neten Bregenftände fönnen unter (Finjdyreifung beriendet twerden.

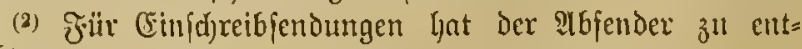
ridfter:

1. Das getoölunlide \$orto Der frnufirten Sendungen gleicher BSattung;

2. eitc Cinfobreibgebühr bon hödffens 25 Centimen

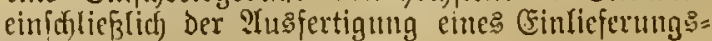

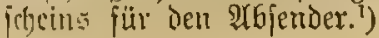


(3) Der Tbjender einex (Einfdreifjendung faum, gegen

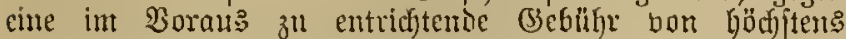

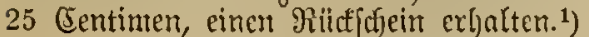

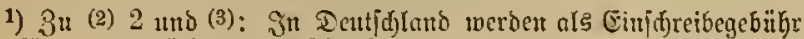

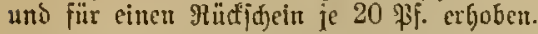

Trt. 7. (1) Die eingeidfricbenen STarefpundenjen fömnen

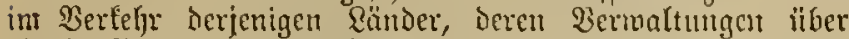
die Cinfilifunt eines fold)en Dienftes fict) veriftändigen, mit Diad)rahme his zum Betrage von 500 Jranten belaitet berfandt twerden. Dieje Gegenftände unterliegen Derfelben Bebandlung und Taritung wie (5injthreibjendungen.

(2) Der vomt Emtpiänger eingezogene Betrag ift nacf)

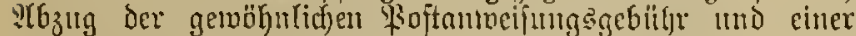
(Einjielungsgebilly bon 10 Eentimen bent शtbenter mittels \$optamtueijung juzujenden.

Wrt. 8. (1) Begt cine Einjerteibjentung verloren, fo hat der গthenter, Dder allf Deffen Berlangen Der (Empfänger,

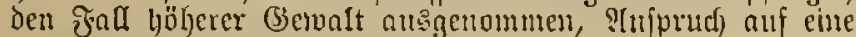
(Ent(d)ädigung bon 50 ₹rtanten. ${ }^{1}$ )

(2) Die Berpflichtung zur Bahlung Des Crrałbetrages liegt Derjenigen Sierwaltung ob, weldjer bie ?lufgabe=\$3ojt anjtalt angehört. Dicjer Bermaltung vird vorbehalten,

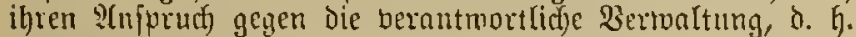
gegen diejenige, nuf deren Bebiet oder in beren Betrieb der Berlujt ftatgefumden hat, geltend zu madjer.

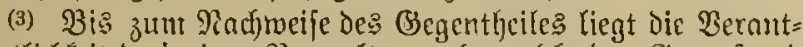
wortlidjfeit Derjenigen Verwaltung ob, weldje Den (jegenftand

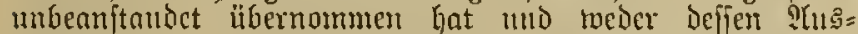
händigung an den (Empfänger, nod), cintretenden ₹afls, bic

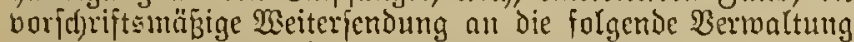
nadjweifen tann. Die Serantmortlichteit für die pojt= Ingernden Sendungen bört anf, pobald diejetben einer ßerion

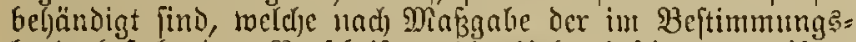
lamo bejtehenden Vorjchriften die llebercinftimmung ifres

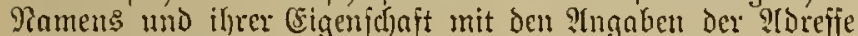
nacjgewieicu bat.

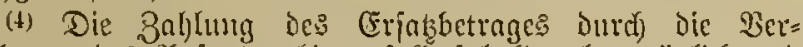
maltung Des ?lufgabegehiets folf fohalj als mögtid mo

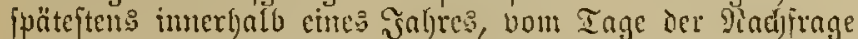
ab geredfuet, itattfinden. Die verantmortlidje bermaltung

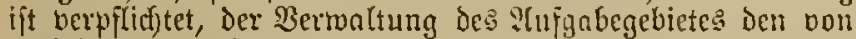
berfelben gezaliten Erfabbetrag ohme Berzutg zu erftatten.

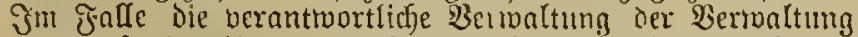

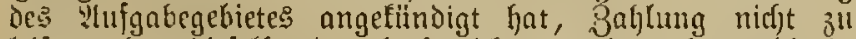
leiften, bat Diejelbe Der leţbezeid)neten Werwaltung bie in Folge her Richtzablumg etwa jich ergebenden foften zu exitatter.

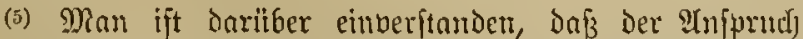

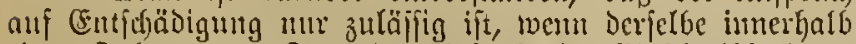

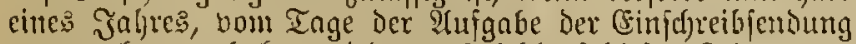
an geredfuet, erloben wird; nad) $\mathfrak{H b}$ lauf diefes Zeitraumes

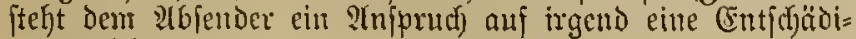
gung micht zut.

(6) Wenu Der Ber[uft bährend Der Reförderung ftatt= gefunden ljat, ohne dofis feitgeftell werden fans, auf ioeldjemt Eandeşgebiete dies geffechen ift, jo niro der Schader vout den betheiligten $\mathfrak{B}$ ermaltungen zu gleiclen Theilen getragen.

(7) Die Erfaberberbindicheet Der Boitnerwaltungen für Einfdarcibjenoungen Gört auf, fobalo ber (Empfangsbered)tigte Duitung ertheilt und bie Senoung übernommen hat.

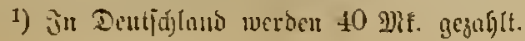

Trt. 9. (1) Der $\mathfrak{A} 6$ fender ciner Brieffendung fant bic= jelbe zurüefnefmen oder igre Pluffchrift abändern laffen, fo lange die Senoung den (Empfänger noch nicft aus: gefiändigt ift.

(2) Das bierauf bezüglidje Berlangen wird entwedel brieflich ober telegraplijid auf Seften Des शtbfenders ïber: mittelt. Eetzterer hat bafiir ju entrichten:

1. Inem bic llebermittelung brieflid) exfolgt, Dic Tare für cinen cinfachen (Sinjc)reibbrief;

2. menn die llebermittelung auf telegraphijeficut Wege gefdieht, Die Tare Des Telegraum: nad) Dem gevöluntiá)en Tarif.

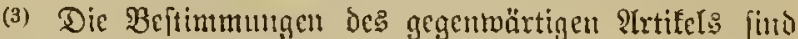
für dicjenigen \&änder nicht berbindfid), Deren Gefesgcbutg dem \{rbfender nicht gejtattet, ïber eine Sendung máhrend

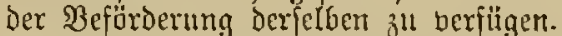

Plrt. 10. Diejenigen Vereinsländer, welche nidht Den Frantes zur Diinzeinheit haben, jetzen die Taxen in ihrer

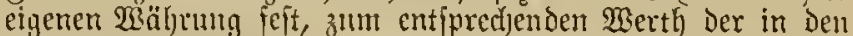
vorhergehenden Q̂trifeln 5 und 6 bejtimmten $\mathfrak{B e t r a ̈ g e . ~ D i e j e ~}$

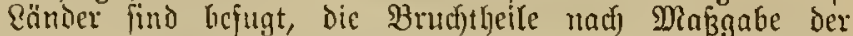
lleberficht nbzurunden, weldye in ber im Irt. 20 bes gegen=

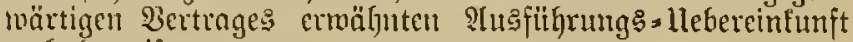
enthalten ijt.

शTrt. 11. (1) Die Franfirung Der Sendungen fam mut mittels ter im ?tuigabeland für die Sribatforrefpondenz giiltigen Fojtwerthjeicfen bemirft werden. Jedoch werden

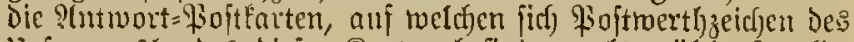
llriprungslanbes biejer Rarten befinden, als gilltig franfirt angefchen.

(2) Şietbon ausgenommen find Lebiglich bie anf dent Fioftoienft bejüglicfen, zwijech den \$ioftberwaltungen aus= getalifiten amtlidjen Sorrefpondenzen, weldje portofrei befördert toerten.

(3) Die anf offenem Meere nittels Sdjiffsbrieffaitens oicr bei den Sdjiffefillyerm nufgelieferten Sorrepondenz= gegenftïnde fönnen nad) dem Tarif uno mit \$ojtmertbzeicfen desjenigen Randes frantirt werden, weldem das Echiff an= geljört òer deffen f̧lagge es filhrt. Wenn die alufticferung an Bord wälseno Des Ilufenthatts am ?tnfange = oder

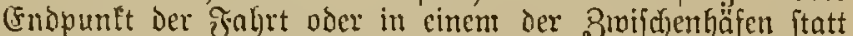
ljat, fam die jrantirung nur nath dem Tarif und mit 26erthzeidjen Desjenigen Eanoes berwirft werden, in Deffen Bsemäffern fict) Das Echiff befindet.

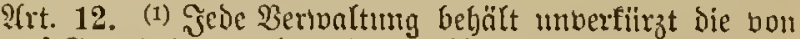
ihe anf (Srund der vorlyergekenden Fit. 5, 6, 7, 10 und 11

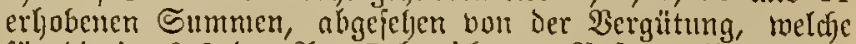
fiir die int $\$ 2$ bes ?[rt. 7 bejeichneten Poftanmeifungen zu zaliter ift.

(2) (5) findet Daher cine IGrechnung Gieriiber, borbehalt=

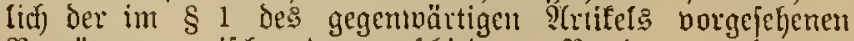
Bergitung, zmifdsen den berfeficoenen Bereinsvermaltungen nicht itatt.

(3) Briefe und andere Poftjendungen dürfen meder in Itriprungs(ande, nod) in Beftimmungs̆lande, fei es zu Eaften Der Ifbjender oder Der C̈mpjänger, einem anderen Porto oder einer anderen Sojtgebitlor untermorfen merden, als in ben borbezeid)ueten ?irtiteln jeftgejetst find.

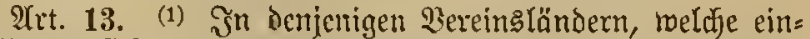
willigen, fidf in ifrem gegenfeitigen Berkehr mit bicjem 


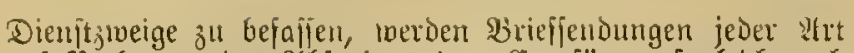
auf Berlangen des खbjenders dem (5mpfänger fogleidf nad) Der Infunft Durd) befoubere Boten zugeftellt.

(2) Diefe Cendungen, weldje "Eilfendungen" genannt merden, unterliegen ciner beionderen Bejtellgebübr, welde nuj 30 Eentimen feftgefetst ift und vou sibjender, neben

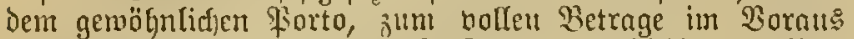
entridjtet merden muß. Dieje Bebïbr verbleibt Der $2 e r=$ maltung bes ?tufgabegebietcs.

(3) Şit Der (Segenftand nad) eiment Drt olyne \$ofitanitalt

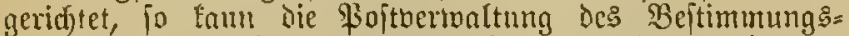

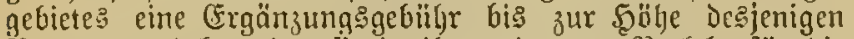
Betrages exheben, den fie in ihrem inmeren 3 erfelyr für die

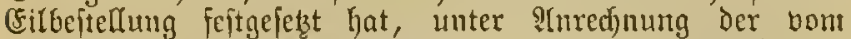
Nbjenber entridjteuten (Bebülyr ober bes entfpredjenden Betrages in Der Wäbrung des die Ergänzungšgebühr erbebenten sanbes.

(4) Eiffendungen, welde nidgt 3wm bollen Betrage Der im Baraus a entridftenden Taxen franfirt find, werben auf Den getob̈hurlichen $\mathfrak{B e g e ~ b e j t e l l . ~}$

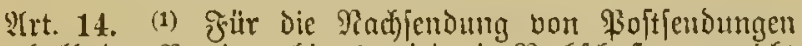

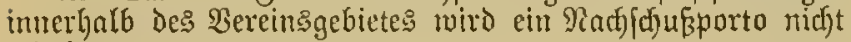
erlyoben.

(2) Bei mbeitellbar gebliebenen Cendungen tritt eine Eritattung ber Den Getgeiligten Bermaltungen für bie erft= malige Beförterung diefer Genbungen zufonmenben Tranfit= gebijtiren ridjt ein.

(3) IInfranfirte $\mathfrak{B r i e f e}$ umb Boptfarten, fotwie unzueidyend prantirte Brieffendumgen jeber ?trt, weldye wegen Ilnbeftell= barfeit ober in Jolge Nadjendung nad) bem SIngabelnude zurücfgelangen, unterliegen Denfelben Tazen, wie gleichartige (S)genftände, meldje unntitteloar aus dem exiten Beftimnungs= lande nadj Denr Ilrfprungelanie verfandt merien.

2(rt. 15. (1) Bwifuden Den Boitanftalten eines Der vertragld)liefsenden לänder mo ben Befeblshabern Der in fremben Gerwäffern meilenden (Siefdrmader oder Sriegsifdiffe defielben Sanocs tömmen mittels oer Rano= mid Seepoit= nerbindungeu anderer Rände: gefdjloffene Briejpoften aus= getnuifict inerder.

(2) Sin Diefan Briefpoften birfen nut joldie fiurtepon= bensen enthalten fein, weldye an die Etäbe und 9)ann= fdjaften Der die Bricipoften empfaugenten beziv. abiendentien (d)iffe geriogtet find bezto. won denfelben berriblen. Die in Unmentung วิt bringenden Tarife und Derjendungs: bedingungen merden von ber Boptbermaltung besjenigen Ranbes, weldjem die Sofiffe angefören, nad) MRafagabe iljtet inländifdicu Berordnungen beftimmt.

(3) 23orbehaltlict) anderer Bereinbarung zwijoten ben be=

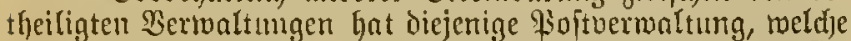
die beregten Sriefpoften abjentet oder enpfämgt, Den tramit=

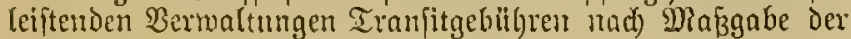
Beftimmumgen in ? Irt. 4 zu zahlen.

शrt. 16. (1) (5) merden nicht bejörbert:

i) Beidäftåpapiere, Mufterienònngen und Drudf= factjen, welche nidjt twenigitens theiltweife frantirt find ober tweldje [idf) nad] Magabe ihrer $\mathfrak{B} e=$ fdoffenbeit nicht leicht auf ifren Snbalt prïfen Iajien;

b) (Begenftände berfelbeu Giattungen, fofern fie die im ?lrt. 5 feftgeietzten Gervicts: und $\mathfrak{a}=$ belymngsgrenzen überidureiten;

c) Waarentroben, reldje einen Sandelsmerth haben.

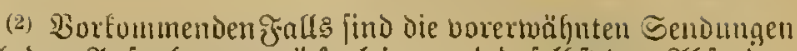

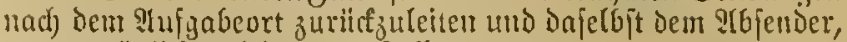
menn möglieh, mieber $z$ ujliftellen.

(3) 6 G ift berboten:

1. mit ier \$ort zu berfenden:

a) Muitericndungen uno andere Siegenitände, toclufe ifjer Ratur madj für die \$ojtbenmten (Sefalyren mit fidj bringen bezto. Die Sorte= ppondenzgegenftände befdumizen oder verderben fönnen;

b) explodirbare, leidjt entzündliche oder gejäbrlidje Stoffe; lebende ober todte Thiere uno surfeftent,

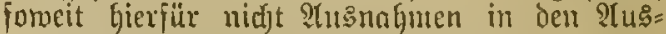
fübrungšbeftimmungen vorgejeben find;

2. in bie getvögnticben oder eingefdriebenen Brieipoit= jenoungen einzulegen:

a) im llmlnuf befindlidje SR̈̈nzen;

b) 3ollpfliditige Bregenftände;

c) (Sold = und Sitberfadjen, (5Delfteme, Sdjmute fachen und andere Enitbore Segenftände, aber

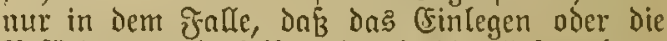
Beförderung Derielben Durd) Die (Sejetsgebung der betreffenden Ränder verboteu ift.

(4) Die Sendurgen, weldie unter die Derbote des vor= lergrlyenden Paragraphen fallen und etrua umridjtig zur Beförderung 3ugelafien worden find, mitifen nad dem

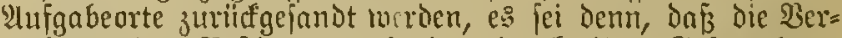
maltung Des Beftimmungslandes Durd) ilfe (Bejebgebung

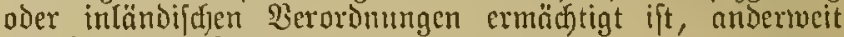
barüber zu verfïgen.

(5) Dex Regierung jehes $\mathfrak{B e r c i n s}$ landes ift librigens bas Recht vorbeljalten, forbohl bie der ermäfigten Taxe unter= sporfenen Giegenftände, in Betreff beren Den beitehenden (Bsefeben, Beroronungen und Borfdriften ïber bie Bedungungen ifrer 2eröffentlicfung ober Berbreitung in Diejem Rande nicht genügt fein follte, als aud Sorrejponbenjgegenftünbe jeder श̂t, meldje augenfdeintid) Benterfungen, Beidjen se. tragen, bie nach den gefezlidfen ober reglementarifden $\mathfrak{B} 0 r=$ fdriften diejes Rnndes unftatthaft fino, bon Der Beförderung

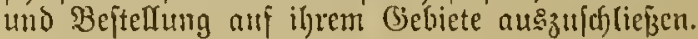

शrt. 17. (1) Diejenigen Bereinsoertwaltmigen, meldje

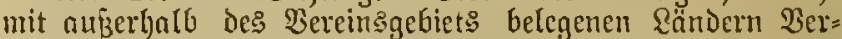
bindungen unterhalten, geitatten allen anderen Berein:

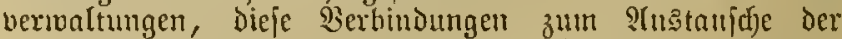
Rorreppondenzen mit den genarnten Eändern z" benuzen.

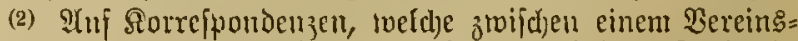
lande und einem dem Berein nicht angebörigen Rande in

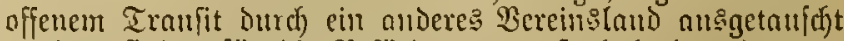
merben, finden fïr die Beförderning aufzerbalb ber (jirenzen

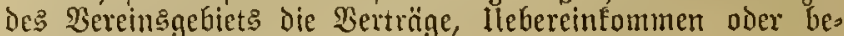
jonderen Beftimmungen RHtwendung, weldje dic Boit= bejieljungen jwifden den Lande und ben nidjt jum Serein gebörigen Lande regeln.

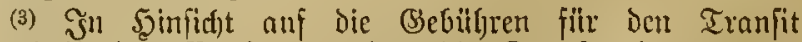
inserhalb des Sereins werben die Rorrefpondenzen aus oder nad) einem fremben Sande den Sareppondenzen aus oder nad) Denjenigen Bereinslande gleidf)geftellt, meldjes die Beziehungen mit eritgedndten Sande unterhält.

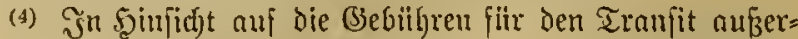
halb der (Sirenzen des Bereins nnterliegen die Storreppondenzen nach einem frembell Innde zu S3unften des Bereinslandesి, 


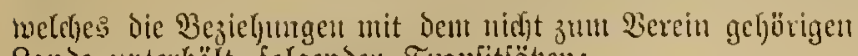
Eande unterljält, folgenden Tramfitjäbsen:

a) iür Die Ceebeförbern!ng au[zerfantb Des Bereins 20 Franfen fiur das $\mathrm{kg}$ Briefe tho Softenten

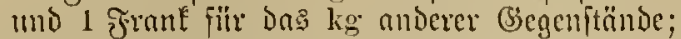

b) fïr die Rnubejörterung auferlyalb bes Sereins vortommenten fralls biejentigen Sicbiiljen jür inas $\mathrm{kg}$, weldye bon Dem Eande, Das Die $\mathfrak{B} e=$ zichungen mit Dem zur Bermittelung bienenten jremien sanic untergält, befannt gegeben merbelt.

(5) Sm Fall zmei ober mefyere Derwaltungen alt ber Seebejörderung theilnehmen, diirjen die Bebulfren Der acjamnten Sechejörderung imerbalb mo nujerbalb Des

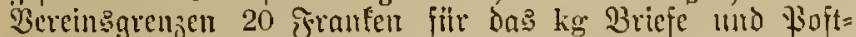

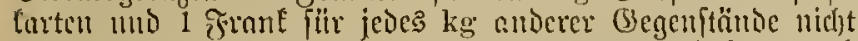
Hiherfteigen. (Eintretendenfalls twerden Diefe (S̈ebiit)ren nad)

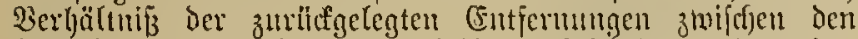
hetheiligten Berwaltumgen getheilt, mbefdiadet anterweiter ŞGuradjunge॥ ber Seţiteren.

(6) Die vorermäfonten (Bebübren für den Tranjit anß̧er= yals des Sercing finden allf alle in offenem Tranjt oher in gejsloficuen Briejpoften bejörierten Sorreiponbenzen ?tumenoung umb find bon der Berwaltung bes ?tufgabe=

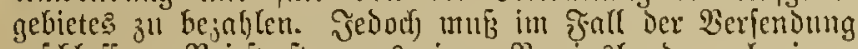

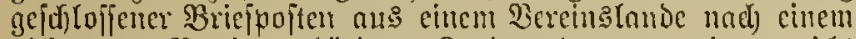
nidut 3um Berein gejörigen sande ober aus einem nidjt

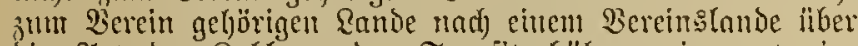
bie 2frt der Zablumg der Tranjitgebiitgren cine zuborige Bereinturung jwifhen ben betheifigten Bertwaltungen ge= troffen werben.

(7) Die Stbreffnung Ḧber Die Tranjitgeblihyen fïr bie swifjen einem Bereinslande und einem fremben Sanbe Durd) Beturittelung eines anderen Bereine landes ansgetnuld ten Sortefpondenzen erfolgt auf Grund bon Rathueifungen, welcfe zur gleichen 3eit alligeitefft werden, wie biejenigen,

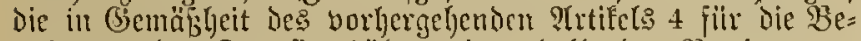
ved)nung ber Tranfitgebilthen inuerbatb des bereing an= jufertigen fino.

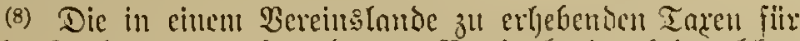
folelje Sendungen nat) mb bom Wereinstande, bei ivelufen die Bermittelung cincs anderen Bereinestandes cintritt, dityen niemals niebriger fein, als die giormalätse bes Bereins. Die Iaxen foumen nungetyeilt Dem Eande 3 , tweldes fic ethebt.

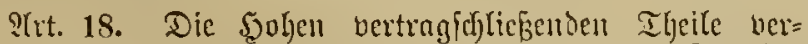

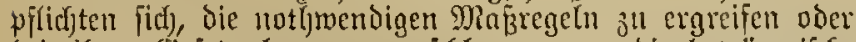

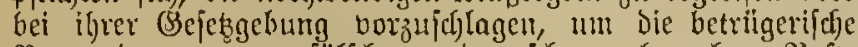
Bermendung bou gefälichteu oder fdjoul gebraudjen tioft = twerthzcichen zur frrantirung von Foftiendungen unter Strafe all fitfen. Sie verpflichten fich gleicherweife, hie nothmendigen Majaregeln zu treffen oder bei ifrer (Sejelz=

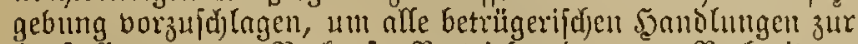
Serftellumg, zum Dertauf, Dertrieb oder zur Werbreitumg

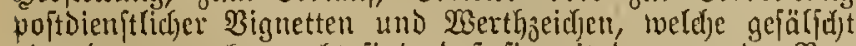

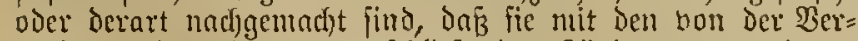
maltung eines der vertragifl)ließerenden Eänder ansgegebenen

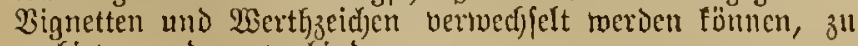
berbieten uns ju verhindern.

9(rt. 19. Der Dienft Det 23rieje und Säftchen unit Werth= angahe, der \$ojtontweifungen, \$ojtpaffete, Rojtanjtröge, der

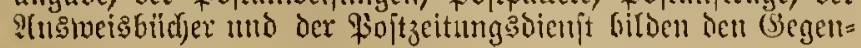

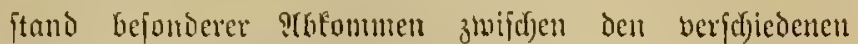
Qändern oder Rändergruppen ic: $\mathfrak{B}$ ereins.

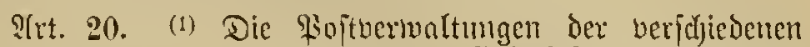

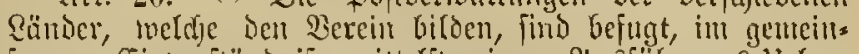

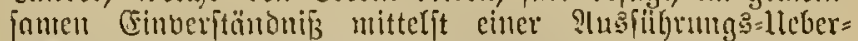
einlunjt affe jiir notgtwendig eraedeten Dienftoorjariften feițuicketh.

(2) Die verjdjicbenen Berwaltumgen föuten aujerdem

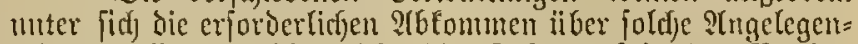
lyeiten treffen, weldye nicht die Gejammtheit Des Bereins

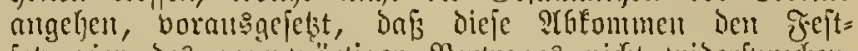

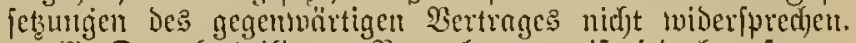

(3) Den betbeiligten Bermaltumgen ift jenod) gejtattet, jich untereinander iiber bie ?tumahne ermäp̧igter Sazen in eimem Ilunfreis noll $30 \mathrm{~km}$ 3ll berftändigen.

9(rt. 21. (1) Der gegenmärtige Bertrag Gerïl)rt in leiner

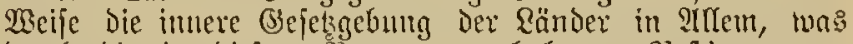
burd) bie in Diejent Sertrage enthaltenen Bepitinumungen mitht borgeifeleu worien ift.

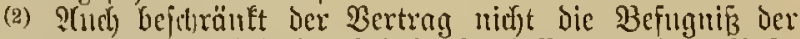

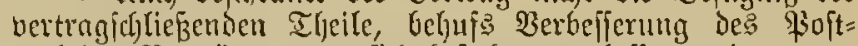
berfelyrs Berträge Imter fid) beftefjen ju laffen und ne॥ jul idj)liefen, fowie engere 23ereine aufredjt ju erbalten oder neu all griïndell.

2(rt. 22. (1) Llnter Dem Ramen internationales $\mathfrak{B u r e a u}$ Des Tieltpoftuereins folf Die Centralitelfe, melche unter ber oberen Reitung ber Sd)meizerifden Foftuersolturg wirft, und beren Soiten von fämuntlid)en Zojtvermaltungen Des Bereins Geftritten werden, allfecljt erfalten bleiben.

(2) Dicjes Sureau wiro nud ferner bic ben inter= nationalen qojtuerfebr Getreffentien bienjtlidjen Mittheilumgen

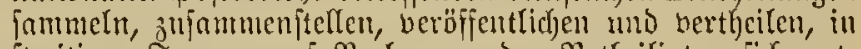
ftreitigen đragen als Berlangeu ber Betheiligten fich) gut=

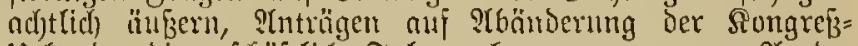

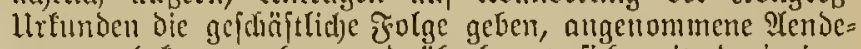
rmugen befonnt geben und über[jaupt fiff mit Denjenigen

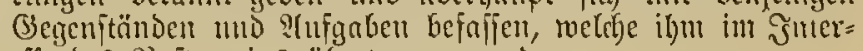
effe des fioptuereins übertragen werden.

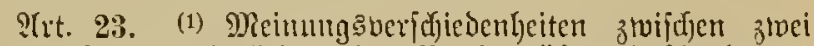
oder mefreren Mitgliedern des \$ercins Des gegenmättigen Bertrage o oder hinfichtlich Der Berant= wortlichleit eimer Berivaltumg im fall des Berlufte: einer Eimf(t) reibjendung follen durd) ein Shicosgerid)t nusgettagen merden, zu meldbem jede ber betheiligten Berwaltungen ein anderes, bei Der P(ngelegenfyeit nid)t unmittelbar betheilightes Bereinsomitglico เnählt.

(2) Das Sdjiedsigericht entf(jeidet nad) einfacher Stimment= melribcit.

(3) Bei Stimmengleichlyeit wäl)len die Theilnelynter des Sdjichsgerid)ts jur (Entid)cidung der ftreitigen Frage cine antere, bei ber 2fugelegerbeit gleid)fatl: umbetbeiligte $\mathfrak{B e r}=$ waltung.

(1) Die Reftimmungen diejes Strtifels finden autf) ?(1)= menoung anf alle llebereinfommen, meldge in Bemäßzheit Des borftebenden STrtifels 19 abgeidflojien fint.

श(rt. 24. (1) Dicjenigen \&ünder, weld)e an bem gegen= wärtigen Sertrage nid)t theifgenoumen haben, fömmen dem= jelben auf ifren strtrag beitreten.

(2) Diefer Beitrilt wird anf Diplomatijef)em $2 \mathrm{ege}$ Der Tiegierma ber Sidjweizerijd)en (Eiogenoifenid)ât angezeigt, welel)e allen Bereing(ändern dabon अad)richt giebt. 
(3) Der Beitritt hat mit boler Red)tsftaft bie Buftimnung zo allen im gegentuörtigen $\mathfrak{B}$ ertrage fejtgejetzten $\mathfrak{B}$ cjtimmungen, fowie die Bulajiung z" allen Durd) Denfelben gemährten Bortbeilen zur ₹olge.

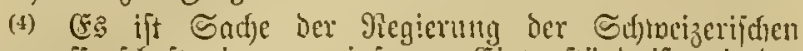
Eiogenoffenjd)aft, im gemeinjomen Einverftönonif mit ber Regierung des betheiligten Eandes die Söbe des Beitrages, ineldjen Die Berwaltung diejes Randes zu den Soften für bas internationale Bureau z"l zollen lont, folvie eintretenden= jallz die Taren zu beftimuten, weldje bon diefer Serwaltung

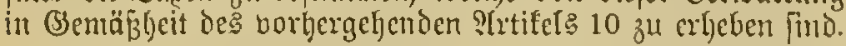

Urt. 25. (1) 9ui Berlangen oder nad) 8nftimunurg bou mindeftens zmei Dritteln Der Regierungen beztr. Ser= Inaltuugen werden, je nad) der \$Bidtigfeit ier zu erledigenden ₹ragen, entrueder Siongreje bon Bebollmäd)tigten der vertrag=

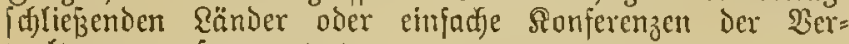
waltungen zu[ammentreten.

(2) Mindeftens alle 5 Jahre foll jedod) cin Songrés $a b=$ geljalten twerden.

(3) Jebes sand fann fid entweder durd cinell osier mehrere Bevollmäd)tigte, ober Duref) die Bevollmädytigten eintes anderen Randes bcrtreten lajien; indē bürjen der ober Die Bebollmädrtigten eines Randes nur mit ber $\mathfrak{B e r}=$ tretung bon ztwei \&ändem, Das eigene \&ano cinbegriffen, beallitragt werden.

(4) Bei den Beraflumgen lat jede: Rnud nur cine Stimme.

(5) Zon jedent Songrę̧ twiro beftimunt, two ber nädyfte Songrefs ftattinden foll.

(6) Fint Die STonferenzen fetzen die Bertwalnmgen, anj Borjalng Des intermationalen Burenus, dent Drt Der Bufammentunft jeft.

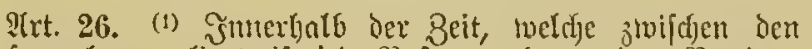
Berfanmlungen liegt, ijt jeoe Poftbcrmaltung eines Bercins: Iandes berectigt, ben antieren $\mathfrak{B}$ ereinsuerwaltungen burt) Dermittelung Des internationalen $\mathfrak{B}$ urean $\mathfrak{B}$ oridhläge in Betreff bes Sereinsucrtehrs zu unterbreiten.

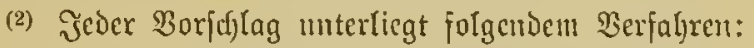

Den Sereinsuerwaltungen wird eine frift bon 5 Mionaten gelafien, um die Borfduläge ju priffen unb um dem internationalen Burean eintretendenfalfs

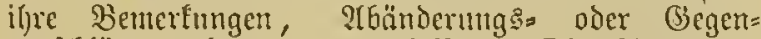

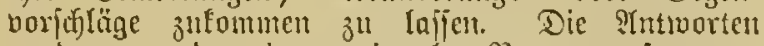
werden bon dem internationalen Burean zujammen=

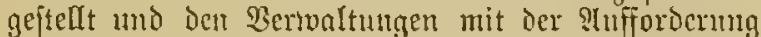
mitgetheilt, fidf fïr ober gegen biefelbe ausjufpredjen. Diejenigen Ssertwaltungen, meldse nidft innerbalb 6 Monate, vom Datum Des ztweiten Rund jureibens ab gerectnet, mit dem dos internationale Burean bie gemad)ten Bemerfungen zli ifrer Remtnif gebrad)t lont, ifre Stimme abgegrben baben, werben als fid entljaltend angefeljen.

(3) $11 m$ bolftrectfor zu verben, müffen die Borfdläge erhalten:

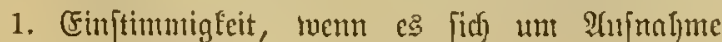

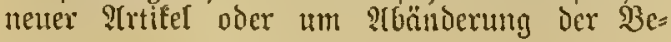

Ftimumungen des gegenmärtigen Trtilete แmo Det borljergel)ender ?irtifel $2,3,4,5,6,7,8$, $9,12,13,15$ und 18 handelt;

2. 3rwei Drittel ber Stimmen, wenn cs fich um bie

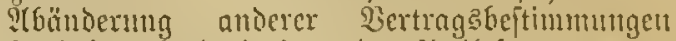
lantdelt, als Derjenigen Der IIrtifel $2,3,4,5$, $6,7,8,9,12,13,15,18$ แnd 26 ;

3. einfadje Stimmenmelyrbeit, wenn es fíf) 1 m bie

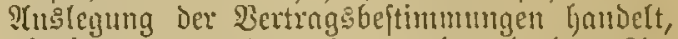
abgefeben un bent im vorlyergelyenden str tifel 23 vorgejegenen sall einer Strcitigfeit.

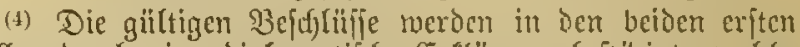
Fä̈len burd) cine diplomatijde (Erelärumg beftäriat, weldye

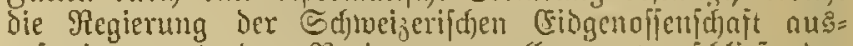
oufertigen und ben Fiegierungen nllex vertragíd)liejenten ¿änder z" ïberjenden bat, im dritten falle Durd) eime ein= fache Befanntgabe bes internationalen Bueans an alle Bereinsuerwaltungen.

(5) Die angenommenen 96änderungen oذcr gefaß̧ten

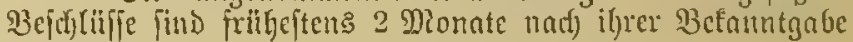
vollftrectbar.

9(rt. 2\%. Soinfidftlicf) Der S(nwendung ber borljergefyenden STrtifel 22,25 und 26 merDen je nady llmptünton al: ein cinziges Snod oder als eine eimjige Bertonltung angejchen:

1. ong Britija)= Snbijd)e Saiferreid);

2. Das Dominium C5anada;

3. Die Befammtljeit Der Britifdyen Solonicu PIIfralafient:

4. Die Gefanmtheit Der Dänif̧chen Stolonicn;

5. die Grejanntheit Der Spanif(d)en Solonien;

6. Dic Gefaumtheit Der frranzififichen Solonien;

7. Die Gejamntheit Der 9icierlïndi d)en Solonien;

8. Die Gejamntheit Der fortugiefifdgen Solonien.

Trt. 28. Der gegcnuärtige Sertrag foll am 1. Juli 1892

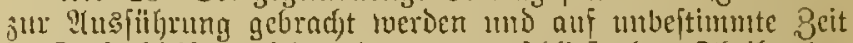
in firajt bleiben; jeber Der vertragfelliebenden Theile loat

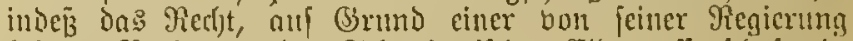
bei ber Regicrung ber Sdfmeizerifden Eibgentifenfd)aft ein Jahr im Sorats gemad)ten Stntindigung ans den Sercin nuszutreten.

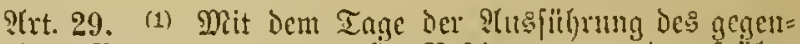
mörtigen Bertrages treten alle Beptimmungen Der friller òvifajen den beriffiedenen Rändern ober Bertwaltungen ab= gejd) Lofjenen Bertrüge, llebereinfommen ober jonjtigen slfte impoweit anfer Siraft, als fie mit Den Feftetzungen des gegenwärtigen Bertrages nid)t im Finflang ftehen und m= bejdjadet ber in vorbergel)enden Ifrtilel 21 vorbelaltenen Red)te.

(2) Der gegentwärtige $\mathfrak{B}$ ertrag joll jobnlo als möglid)

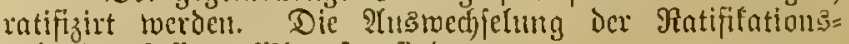
mtumden foll ju 2 ien ftattfinden.

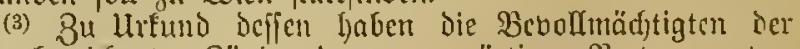
oben bejeirfyneten Ränocr den gegenmärtigen Bertrag unter=

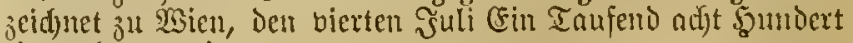
cin und neunzig.

(F̧olgen bie Ututerjdriften ber Bevolmädtigten.) 


\section{b d f it $\mathfrak{B} \mathfrak{p}$ ro f o fio $\mathbb{L} \mathfrak{l}$.}

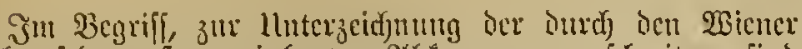

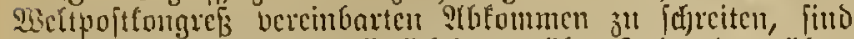
bic unterzeicfneten Bebollmähtigten tiber Folgendes \#̈ber= cingefommen:

I. Sn P(bueid)ung bon der 3citimmung im IIttifel 6 Bes : 25 Cemfmen icitest, ift vercinbart morden, bas dic autincreuropäifdyen Staaten befugt fein jollen, cine gicipt=

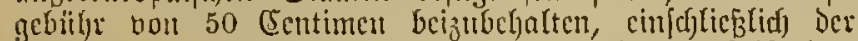

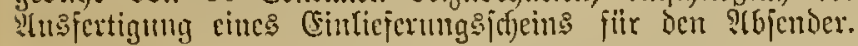

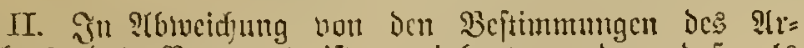
tifels 8 des Bertrages ift vercinbart morben, ton als

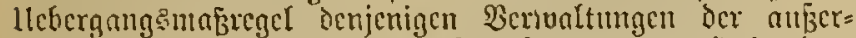

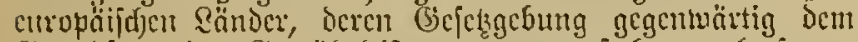

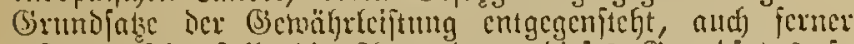

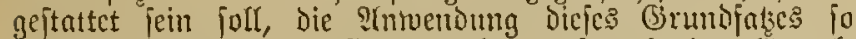
lattge atsoztleben, bis fic von ihrer gejelggebenden (setwalt

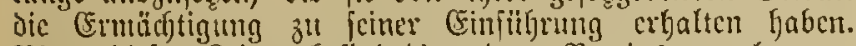

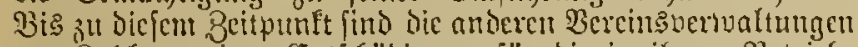

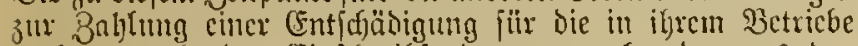
nertoren gebenden (Einfdreibjendungen nad) ober aus den gedadjteu Rändern nicht verhunden.

III. Da Solivien, Elyjte, Cofta=Rica, die Ricpublif San Domingo, Einador, Sariti, Sonturas nud Ricaragua,

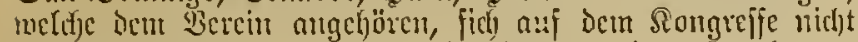

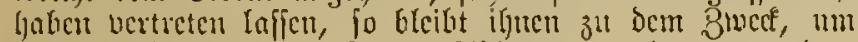
ben dajelgit abgefdlofienen P(bfommen oder mur bcm cinen oder beut anderen Derjelben beizutreten, Das firotofolf vifen.

Das Rrotofoll bleibt chenfalts offen jul (3)uften ber

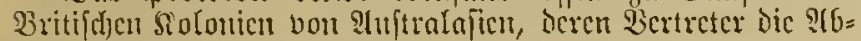
fidjt bicjer Qünder, Dem Wectpoftuercin bont 1. Sftober 1891 ab bcijutreten, crElärt habcu. ${ }^{1}$ )

Dajiclhe bleibt ferner offen für bie Eildafrifantijge

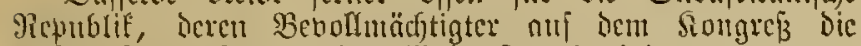

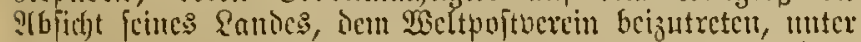

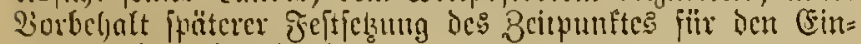
tritt, futbgegcben (jat. ${ }^{2}$ )

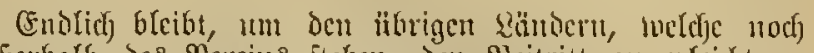

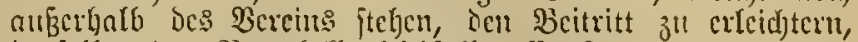

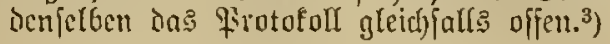

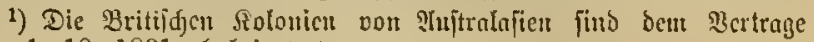
vom 1. 10. 1891 ab beigetrcten.

2) Dic Silbafrifnuifde Itcpublif ift sem פłcrtrang v. 1. 7. 1892 ab bcigetreten.

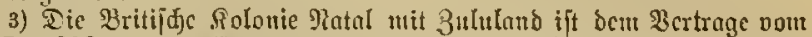

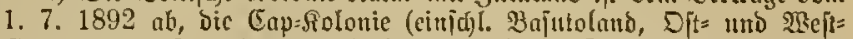

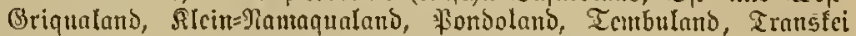

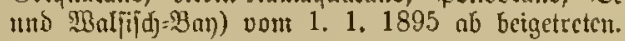

IV. Das grotofolf wirb zn Bunften der Sänder, Deren Scrtecter locute nur ben \$ूauptocrting nocr nut eine getviffe 3afjl ber Durel) Den Songreß bercinbarten P(bfommen unter: zeidjuct haben, offen geljatten, Dantit fie autd) Den übrigen hente unterjeidyeten sibtonmen ober einem des dem nnderen Dexjelben beitreten fönnen.

V. Die in bem voxftehenden Irtifel III borgejeljenen

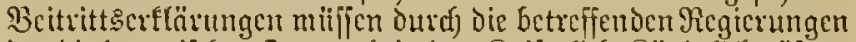
in Diplomatif(f)er Form bei ber Raiferliff) Räniglich öfter=

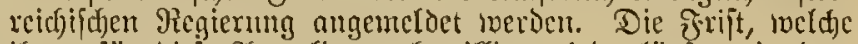
ignen fïr diefe stmmeloumg betwilligt suiro, läuft mit Dem 1. Эัแni $1892 \mathrm{ab}$.

VI. Für Den Jall, Dấ cinç oder mefrete der an den lyeute zu $\mathfrak{B i c n}$ unterzeidyeten 96fommen betheiligten ber=

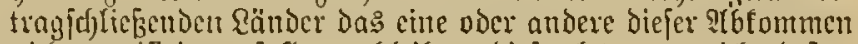
nid)t ratifijiren folten, blciben bicje Ick3teren nid)tobeito= meniger fiit: dic Stanten, buclebe diejelben intifizint lonben, berbinslid).

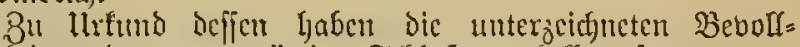
mäd)tigen Das gegentwärtige Schluछprotofoll aufgenommen,

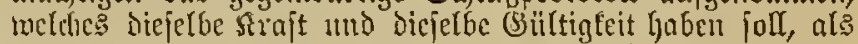
wenn feine Bejtimmungen in den Tert ber betreffenden \$rbfomuren felbft aufgenommen morden wären, und fic haben bicjes Sdjlubprotofoll in einem Eremplar unter=

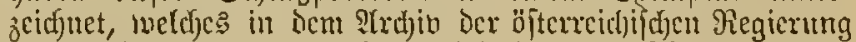

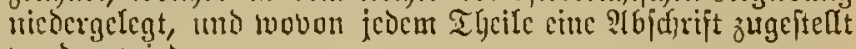
werder juiro.

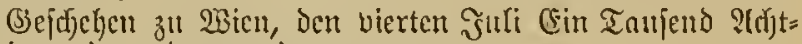
lyubert cin uno ncumig.

(Folgen bic 1tnteridjriften.)

\section{Souffing interuntiounle Joffuertrïge.}

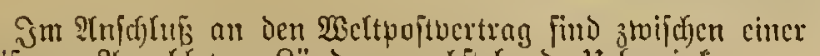

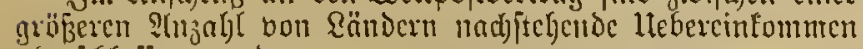
abgejeflofien worien:

1. Das lebereinfommen ${ }^{1}$ ) bou 4 . Jutli 1891, hetreffend

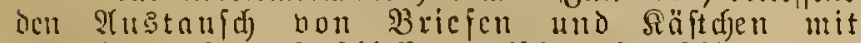

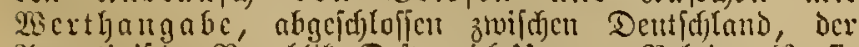

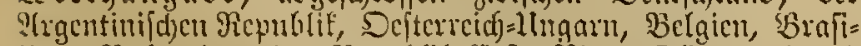

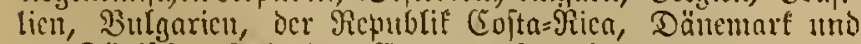

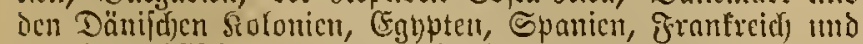

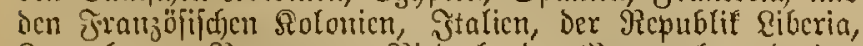
Ruxemburg, शiorvegen, Ricocrlano, Hoitugal und Den

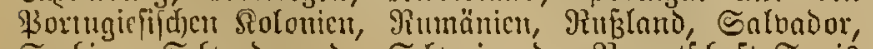
Serbicu, Sdfrueden, der Sdjuciz, bet Pegentjdjaft Iunis und der Tïrfei;
2. Das llebercinfoumen ${ }^{2}$ ) bout 4. Juli 1891, Getreffend

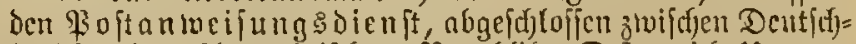

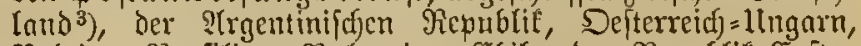
Belgien, Brafitien, Butgarien, Shile, Der Mepublif Copta= Rica, Dänemarf umb Den Dönijou Rolonien, Egypten, Frnnfteidf und Den Franzölifdjen Rolonicn, Stalien, Japan, Der Republif Siberia, Ruremburg, Norwegen, Riedcrlatu แmb Den Ricocrländijden Rolonien, Fortugal unt Den Sortugiclijden Solonien, Rumänien, Salbabor, Dent

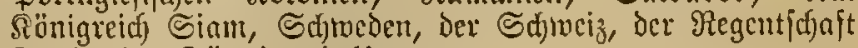
Tunis, Der Türfei und lluguah;

3. Dic 1lebercinfurft \$) bom 4. Jult 1891, betreffend

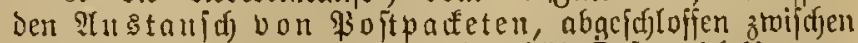

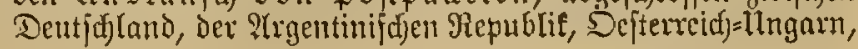


Belgien, Brafilien, Bulgarien, CEgile, dex Tepublif Colun=

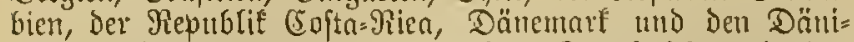
fichen Srolonien, Egypten, Spanien, Frrantieid) und Den

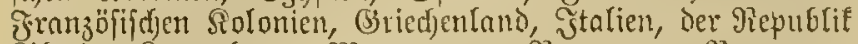
Riberia, Eurcuburg, Rontenegro, Rormegen, \$araguny, Riederland und den Riederländijd)en Solonien, Bortugal und Den Fortugiefff(t)en Rolonien, Rumtäuien, Salvabor,

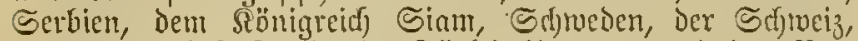
ber Regentidjaft Innis, Der Titrfei, llruguab uno den $\mathfrak{B e r}=$ einigten Staaten bon 2enejuela.

4. Das llebereinfonumen ${ }^{5}$ ) vom 4. Jutti 1891, betreffend

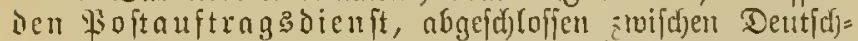
land, Sefterreid)=llngan, Belgien, Brafilien, Der Piepnblif

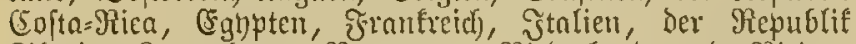
Siberia, Ruxemburg, Normegen, Riehertand uno Rieder= ländifch= Dftindien, F'ortugal und ben \$ortugiefifaen Rolonien,

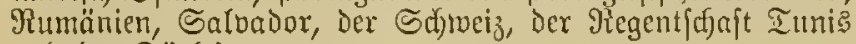
und ber Titrfei.

5. Das llebereinfommen 6 ) bou 4. Juli 1891, betreffend den fo oftbezug vou Beitungen und Beitfdriften,

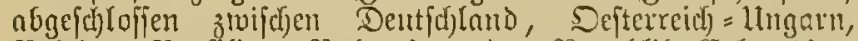
Belgien, Braftien, B̉ulgarien, Der Republit Eolumbien, Dänemart, Egypten, Der giepublif Riberin, Euxemburg,

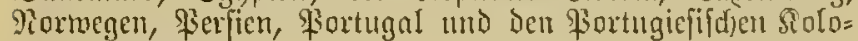

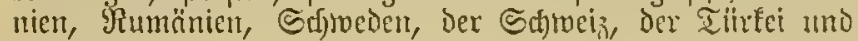
lixuguay.

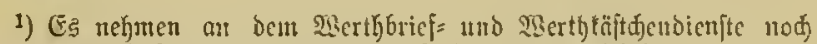

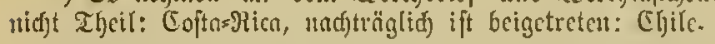

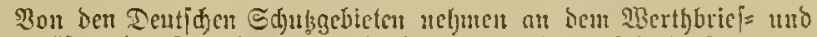

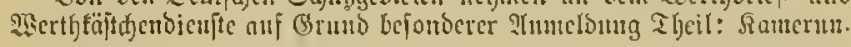

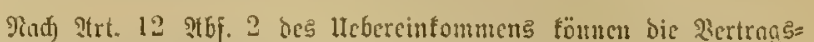

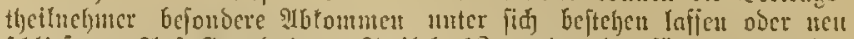

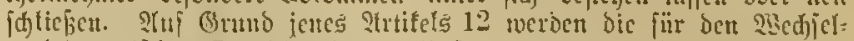

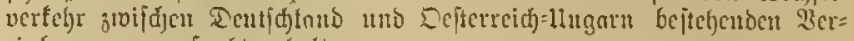
ciubartugent nufredjt erhatten.

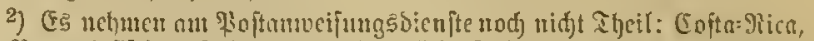

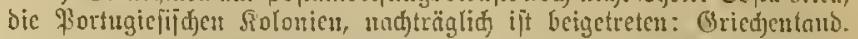

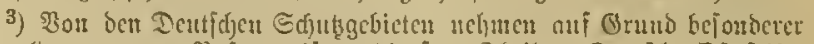

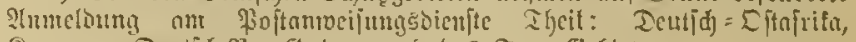

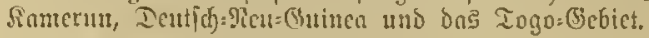

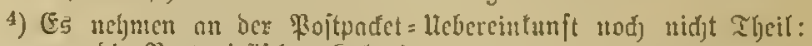
\$uragunn, Dic \$ortugicijijgen Solonient.

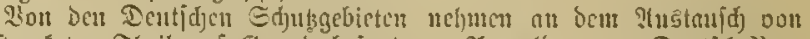

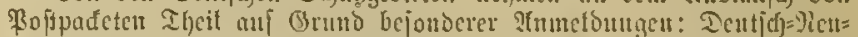

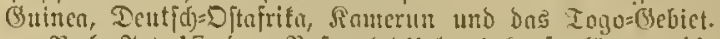

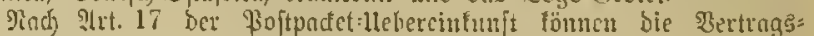
theilnetmer befonbere ?(btommen unter fid) bejtehen tafjen ober neu

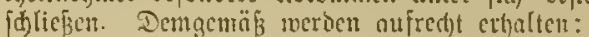

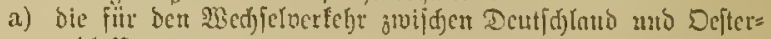
reide=2lngarit,

b) Die für bie Eenoungen aus Dentiglanto und వelgien,

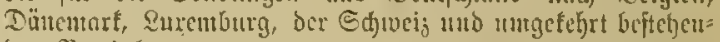
Den 3ercinbartutgent.

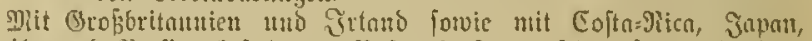

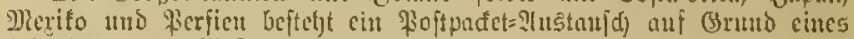

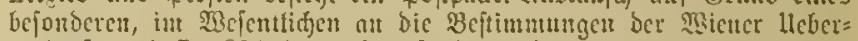

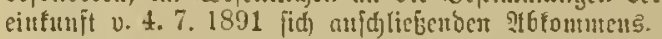

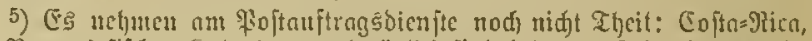

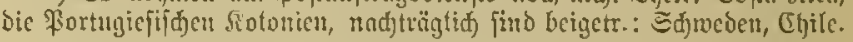

6) Das llebercintoumuen fonumt erft nom 1. Samuar 1893 ob jur গงเร์fitj)rutg.

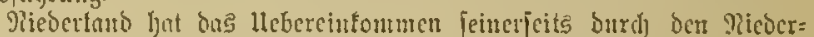

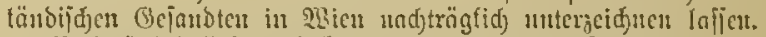

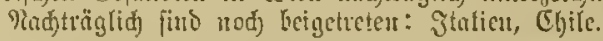

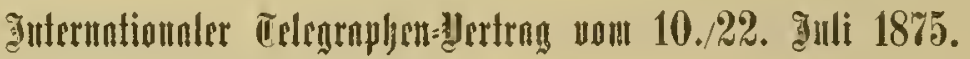

Se. Miajeftät der Saifer von Deutfdjland, Se. Majeftüt

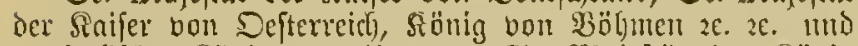
apoftolifher Sïnig bon Itngarm, Se. Minjeität der Siönig Der Delgier, Se. Miajejtät Der אüutig bon Dänewart, Se. Majeftät der Sönig von Epmien, Se. Excellenj der Serr

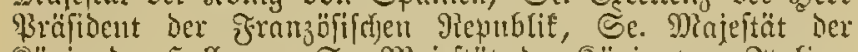
Sïnig der Sellenen, Se. Minjeitüt der Stönig bon Jtalien,

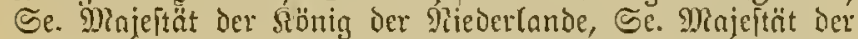
Sdjah bou łerfien, Se. Mineftät der Sönig bou łortugal und Ilgarbien, Ee. Dajeftät ier Siaifer allet Reuben, Se. Majeftat der Rönig bon Scfineden und Formegen,

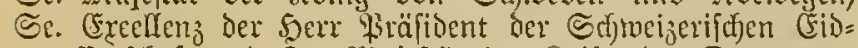

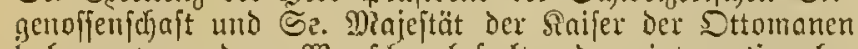

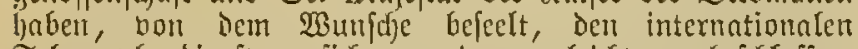
Telegraphendienjt zu fidjern und zu erleidftern, befoldofifen,

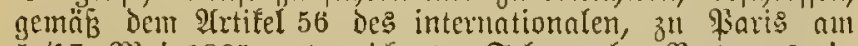
5./17. MRai 1865 unterzeldineten Telegrapljen=Bertages, in diefen $\mathfrak{B e r t r a g}$ Die Durd) bie (Exjaljung eingegebenen $\mathfrak{Q}(\mathrm{b}=$ änderungen und $\mathfrak{B e r b e f f e r u n g e n ~ a u f z u m e l y m e n . ~}$

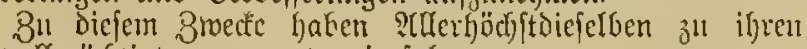
Bebollmäcftigten eluamit, twie folgt:

(grolgen bie sianten :c. ber Bevolmuädftigten.)

reeldye, naib gegenfeitiger Sortweifung ifyrer in guter und geföriger Jorm befmbenen Sivllund)ten, liber bie mach= folgenden iltefifel ibereingefommen find.

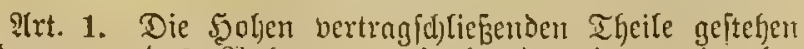
Sedermann Dos Fied)t żtl, mittels ber intemationnleut Ielegraphen 34 forrefpondiren. श1t. 2. Sie verpflichien fith), alfe Minzregeln zu ergreifen,

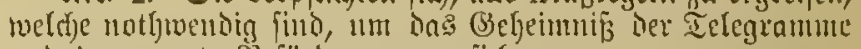
tuto Deren gute Seförderung ju fidjert.

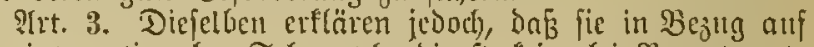
ien internationalen Telegraphendienjt feinerlei Berantwort= [idffeit ïberneljuen.

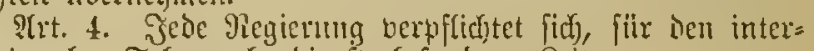
mutionalen Telegraphendienit bejondere Reitungen $3^{\text {th }}$ ber:

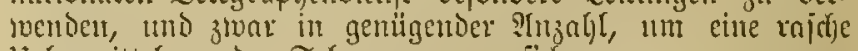
Hebermittelung der Telegramme zu fidjern.

Diefe Eeitungen folfen in Der mad) Den (Erfalyrungen des

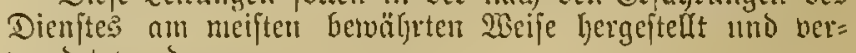
wendet werben.

Prt. 5. Die Telegramme werden in 3 Battungen ciu= getheilt:

1. Stants= Telegramme: i. h. foldje, tweldye bom Stnatsoberlyatpte, von den Pintiftern, den Sber: beiefleghabern ber \&and= ober Seemadyt und Dell diplomatifhen oder Sionfular=?lgenten ber vertiag=

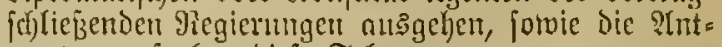
morten nuf eben dicje Telegramure.

2. Dientit= Ielegramme: §. h. Foldfe, tueldye bout don Telegraphenberwaltungen der vertragifhliē̈enden Stanten ausgeljen und fid) entweder anf ben inter= nationalen Jelegraphendient oder auf foldse Giegenftänie tou bffentlid)en J̃ntereffe bejielgent, itber joeldje bie genanten S3ertonltungen fidf ber= ftändigt haben.

3. Arribat= Telegramme. 
Bei Der Beförocrung genieben Dic Stants= Telegramme Den Borzitg bor den itbrigen Ielegramuten.

firt. 6. Die Stants= und Dicnit= Telegranume föment

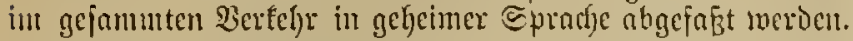

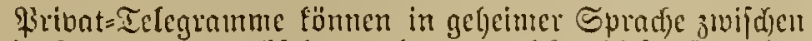
jivei Stanten gewedffelt twerden, tueldfe bieje ?(rt ber Rorrefpondenz zulafien.

Diejenigen Staaten, meldje Pribnt= Telegranme in $g e=$

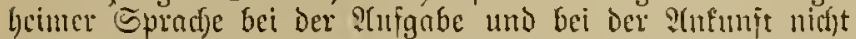
julaffen, milifen biefelten im Tianjit geftntten, fofern nidjt

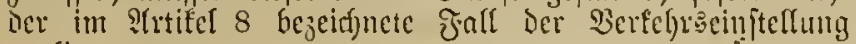
borliegt.

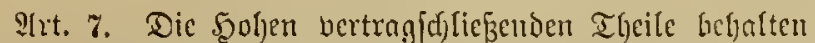

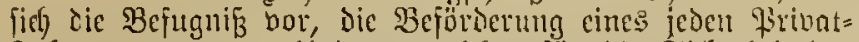
Ielegramms zn verfindern, weldhes für bie Eirferlfeit bes

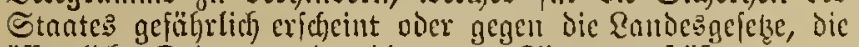
iffentliche Sronung oder die guten Sitten berftöfst.

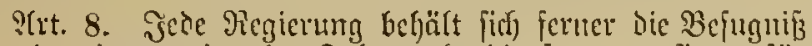
vor, den internationalen Telegraphendicnjt, wenu jie es fiit nothineubig erad)tet, entweder ïberhaupt voer nur auf

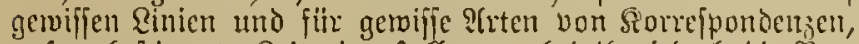

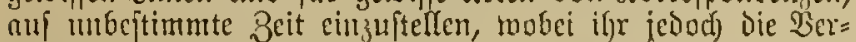
pflicftung oflicgt, fierbon fojort jeder ier itbrigen berting=

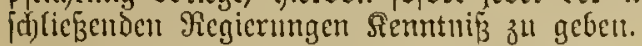

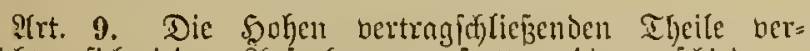
pflidjten fidj, jedem îfugeber jul geftatten, Die oeridjicdenen (Eimriditungen, welche zum Zmeat ier gröberen Sidjerung

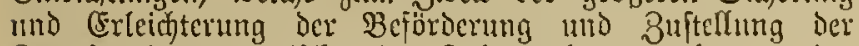
Sorrefpondenzen zwifhen den Telegraphenderwaltungen det

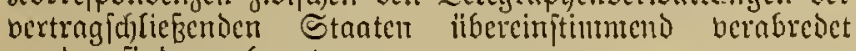
worden find, zit benutzen.

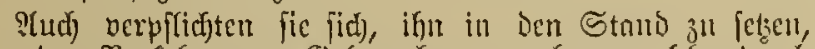
bon ben Borfeljungen Bebrand ju madjen, weldhe Dureth irgend einen allderen Staat hinfiditid) ber Bemulung bout bejonderen (simricftungen fïr bic Bejörocrung unt Bufteflung getrofien und fundgemadjt jind.

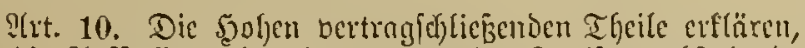
fiir bie ?ufftellung ber internationalen Tarife madjftefenoc Brumblagen anzunelymen:

Dic (3ebultyr foll fïr alle Telegramme, weldje zwifd)en Den Telegraphen=?tritalten bou je zwei ber bertragfhliejen= ben Stanten allf bem näulidjen wege getvedjeclt werben, cinc einfyeitlide fein. Sn (Europa fam jeborl eil und oer=

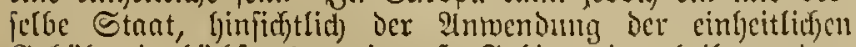
Gebiil)r, in Göchitens jwei groß̧e Bebiete cingetfeilt werben.

Der Bebilyrenfak wiro bon Staat zu Staat im Ein= vernehuen jwifden den Regicrungen ber äuberffen und ber dojwiphen gelegenen Staaten feitgeitellt.

Die auf den telegraphijhen Berfert zuifden Den ver=

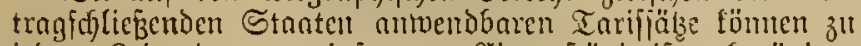

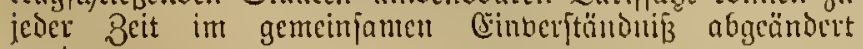
iverocn.

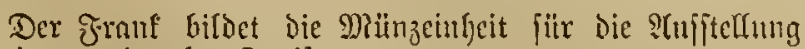
ber internationalen Tarife.

Irt. 11. Die auf den intermationalen Telegraplyendienft

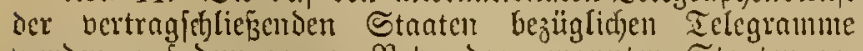
merden all Dem ganzen Tetete Der genamiten Stanten ge= bübrenfrei bcjördert.

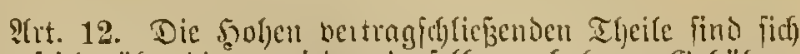

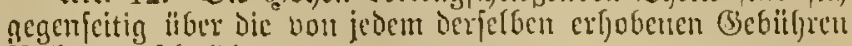
Эied)mmg jdyuldig.

Itrt. 13. Die Beftimumugen Des gegenuärtigen $\mathfrak{B c r}=$

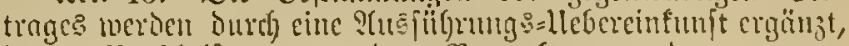
Deren Sorfechiften bou Den Berwaltungen Der liertrag=

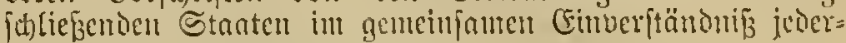
zcit ahgeändert merban fümen.

Slt. 14. Fin Central=Drgan, weld)es unter bie Dber=

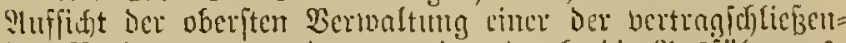

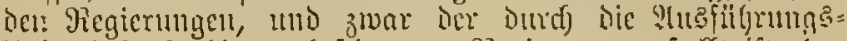
Hebereinfunft lierz"l beftimuten Regierutg, geftellt ift, lyat bic enf Dic internationale Ielegrapgic bejhligliden Siad)= richten jeber ?itt zu fammeln, jufammenzufteffen und ju

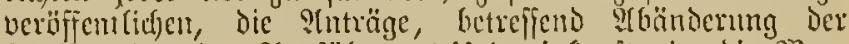

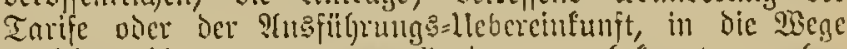
zu leiten, bie angenommenen :Henderungen befaunt zu geben

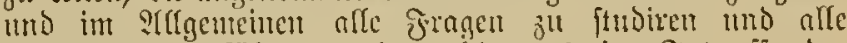
Prbeiten ansufüffren, mit weld)en es int Jutereffe ier intermationalen Ielegroplyic betrunt werden follte.

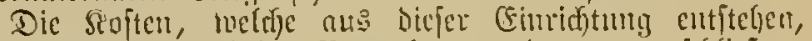

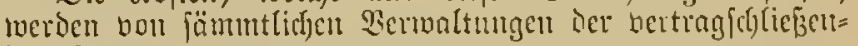
Den Etaaten getragerl.

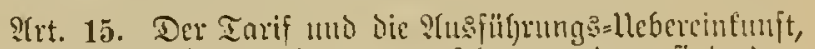
welcf)e in sitetifel 10 mol 13 vorgejel;en worien, find bemt gegenwärtingen $\mathfrak{B}$ ertrage angefelofifen. Diejcloen habent bic gleiche (B)iltigfeit mo treten zu glcidjer 3eit it Sirajt wie Dicjer Ictztere.

Sie werden Rebipionen unterworien, wobei alle Stuaten,

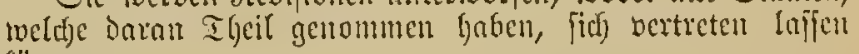
füแmeน.

Zu biejen Beljuje werden bon Zcit ju Zcit $\mathfrak{B} e r=$

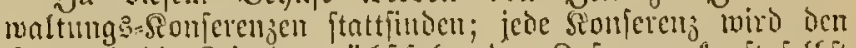

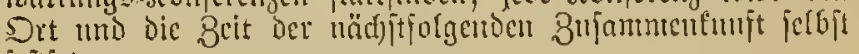
iejtieţen.

Ptrt. 16. Dicje Sinferenzen werien aus ?tgyejanden gebildet, weldye dic Bertwaltungen ber bertragifglicfienden Etaaten bertteter.

Bei den Beratlumgen hat jede Bertwnltung ?trred)! auf eine Stiume, unter Den Zorbelgalte jedod), DaB, foferm es

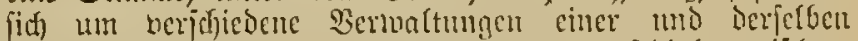

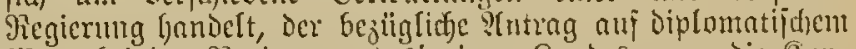
gisege bei ber Rrgiem desicnigen Snots, wo dic Sion= feren fich berfontuteln fol, bor Deren Eroffmungstemin

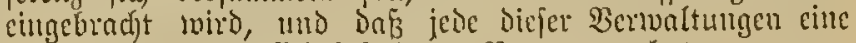
befondere und fïr fid) bejtehende Bertretung hat.

Die ans oen Beratflungen ier Sonferenzen fid) crgebent=

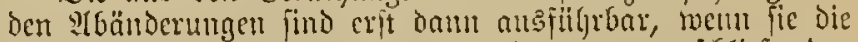
Beftätigung alfer giegierungen Der vertragidflieşzenten Etaater erlangt labcu.

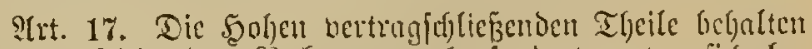
(iid) gegenfeitig Das ged t vor, abgefondert unter fich be= fondere llebereinfïnjte jeder s(rt liber jold)e Theife ies

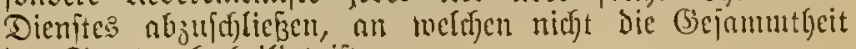
Der Staaten betbeiligt ijt.

\{̂t. 18. Den Stanten, welelye an Den gegenmärtigen Vertrage nidjt Theil genommen hoben, wird auf ifor 9 Ser= langen Der Beitritt zu Denijeroen gejtattet.

Von Dicjem Beitritt wird Demjenigen ber wertragidjliefen= Den Stanten, in bejfen Screidf bic ledzte Stonjerenz flattge= 
funten bat, und Durd biejen Stant alfen Ḧbrigen Stuaten

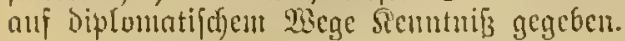

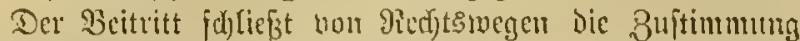

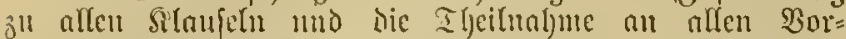
theilen in fid), weldje im negentuärtigen Vertrage feftgejetst ivoriden fint.

Ŝrt. 19. Die telegraphifd)en Biczichungen zu Denjenigen Stanten, weld)e ient gegembärtigen 2ertrage nicht bei= getreten find, ober zu dea Gribatgeielf fuaften werden in

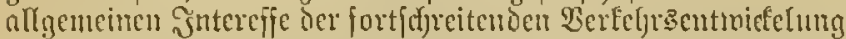
burtl) bic int ?lat. 13 ties gegenmörtigen Sertrages borge= foljene ?tusfülyrung: =ltebercintunft geregelt.

Ŝrt. 20. Der gegenuärtige \$ertrag tritt mit Dem 1. Januar 1876 neuen Style in Siraft mo blcibt anf nu= beftimunte Beit und bis zun ?hlauf eines Saljes von ben Iage ab, an Jueldyen er gefïndigt toorien ijt, in Bit!tigleit.
Dic Siindigumg fommt mux fït Den Stant sm Geltumg, welcher fie ansgefprodfen ljat. Fin die jibrigen vertrag=

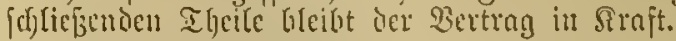

21. mo lekter ?trtifel. Der gegentuärtige Settrag foll ratifizirt werden, und folfen die Fatififationen in möglid) $5 t$

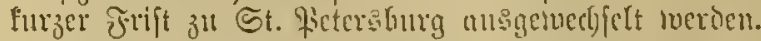

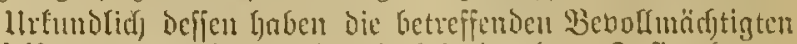
denjelben unterzeiel)net und mit beigedrudtem ̧nfiegel ver= ichent.

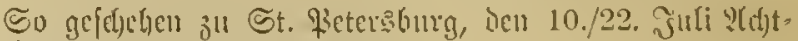
zelynlyundert fïnf uno fiebersig.

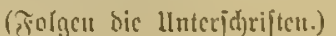

\section{Pratifer gicuijion.}

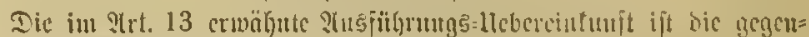

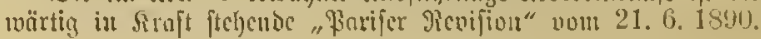

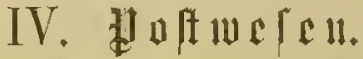

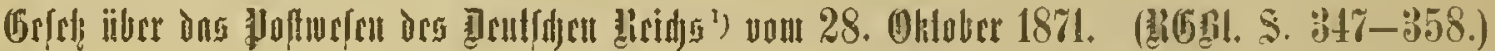
bci (E)

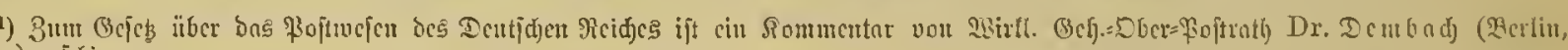

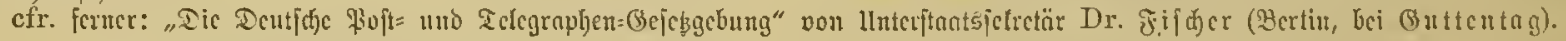

\section{Aurdunitt.}

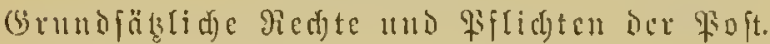

\section{$\$ 1$. Dic Bejörderming}

1. aller berfiegelteu, jugenälyten o der fonft verjdyloficnen Bricic,

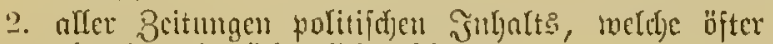
als cinnt mö(t)entlid) erjocinen,

gegen Seznlylumg nou Drten mit einer Bojtanftalt mad) auderen Drten mit ciner Hoftanftalt Des Gn= neer ?us:

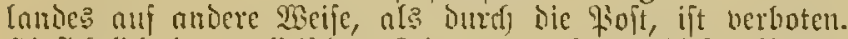

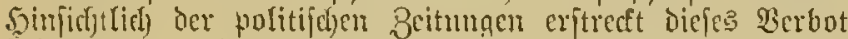

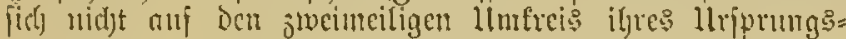
ortes.

23enu Briefe unt Beitungen (9ir. 1 unl 2) bom $943=$ Innde cirngeben und nad) inländif(d)en Srten mit cince Siojtonftalt bejtimmt fino, oder durt) bas (Bebiet des Deutid)en Reidje tranfitiren follen, fo milifen jie bei ber

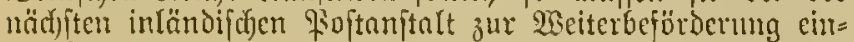
gelicfert incroen.

lltuerfd)Loffene Briefe, meld)e in verfiegelten, zugemälten

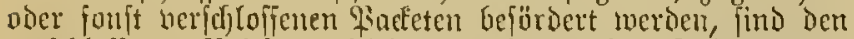

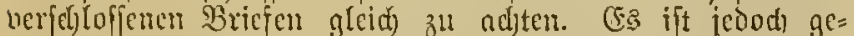
ftattet, beriiegelten, zlugenähten ober fomft verjulofienen

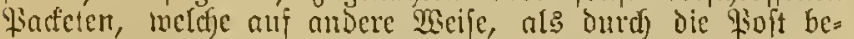

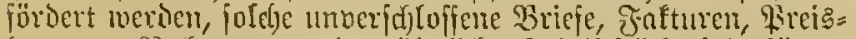
furmute, Jiedjumingen oder äljulidje Sdjriftititute beizufïgen,

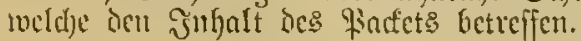

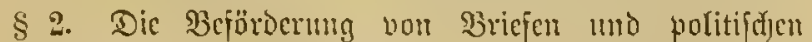
Beitungen (\$ 1) gegen $B e_{j}$ alflung Durefl erprejie Boten ober Julfren ift geftattet. Dod) darf cin pold)er Exprefjer mu

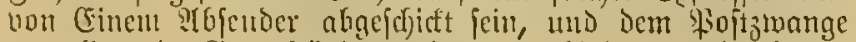

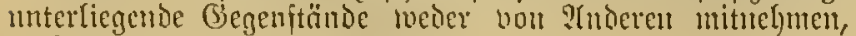
nodf) fiir :Tlndere juriidforingen.

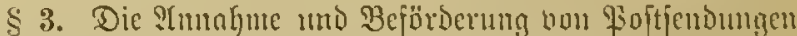

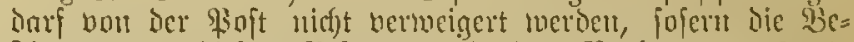

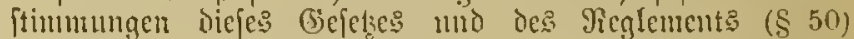

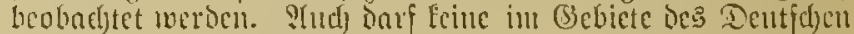

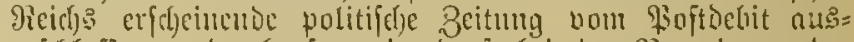
nejc)loffer und ebenfotwenig barf bei ber sionmirumg ber Girobifion, welche jür bie Seförderung und Debitizung der

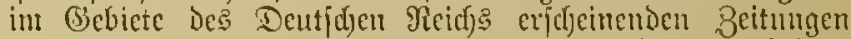

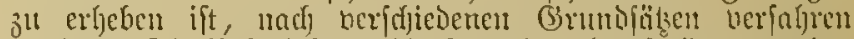

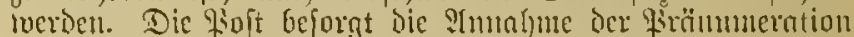
nuf bic Beitungen, founie den gefammen Debit berfelhen.

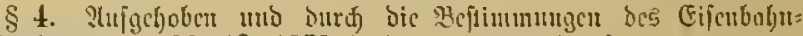
Fofigcictes vom 20.12. 1875 (ogl. weitcr untert) erfetet.

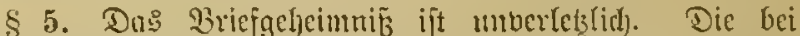

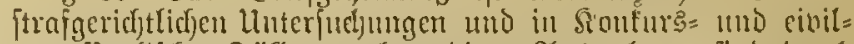

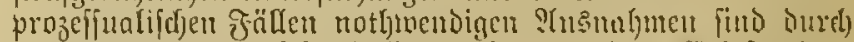

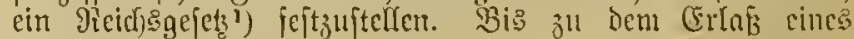
Reic) gejetze beftimut.

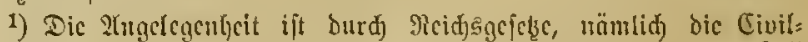

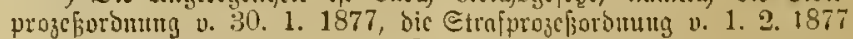
utmo bic fonfursorbutng v. 10. 2. 187\%, getegett.

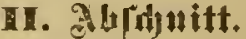

\section{(3) rantic.}

§ 6. Dic Boftuerualtung Ieiftet Dom ?tbjenter in forlte

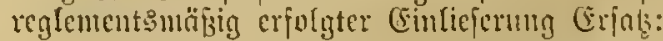

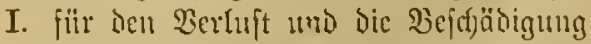

1. Der Bricje mit Wierthangabe,

2. der Warfete mit ober oljue Wertjongabe;

II. für ber Serfupt ber refommandirten Sendungen, benen in bicjer Bezichung Eendungen gleidjgefellt 


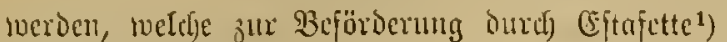
cingeliefert finto.

₹̛̈น einen Durd verzögerte Bejörocrung voer Beftelfung iex unter I. Gejeidjueten Gegenftände entftandenen Sdinden Iciftet die Hoftuertualtung mur Dam Erjak, joem bie Sndje Durd) Die berz̈gerte Beförocrung oier Befteflung verborben ijt, ober ifren $26 \mathrm{erth}$ bleibend ganj oder theifweije verloren l)at. Sluf einc Seränderung ies Surfes ober marftgängigen Freifes roiro jedod) gierbei teine Rüiffid)t genommen.

Die Berbindlichteit der Foftuertualtung jur Erfableiftung bleift nusgejd)lojjen, wenn Der Ver(uft, Die Bejd)r̈digung oder die verzögerte Bejörbernug ober Bejtellung

a) Durdh Die eigene Fahrläffigfeit Des Tbjenders, oDer

b) burch Dic unabruendbaren Folgen encs Siatur=

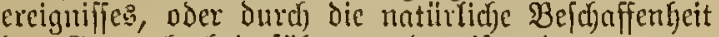
des (3) utes herbeigefiifyrt worden ift, oder

c) auf einer ausmärtigen Bejörderungsanjtalt fïd) $\mathrm{er}=$ eignet hat, für weldye dic Foftuermaltung nicht Durct) Sombention Die (5rjatzleiftung ausoriafflids) Hihernommen foat; ift jeodd in biejem Falle bic Einlicferung bei ciner Dentfden Pioftanftalt er= folgt, uno wifl ber ?tGjender jeine :Infprüd)e gegen

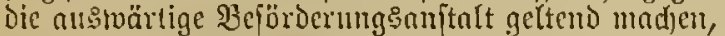
fo hat dic \$oftucrualtung ifm Bciftano ju leifter.

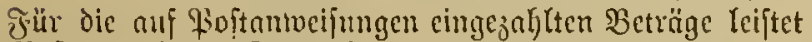
die Foftuersuaftung Giarantie.

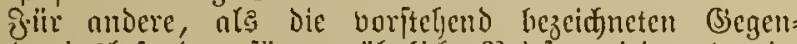
fänbe, insbefondere fïr gewölnliche Briefe, wirb sweocr in Falle cines 20 crluftes oder eincr Bejdöbigung, nod im

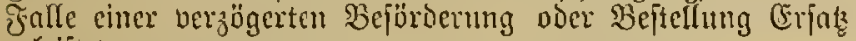
geleijtet.

1) Eine Beföroerung von Eenoungen uittcts Eftafelte fintoct intret= halb bes Reidjs:\$3oftgebiets nidit methr itntt.

§ 7. Wem der Verjectu[ Foft gegetienen (Segenftänoe bei Der शluşändigung an bell (Empiönger äußerfich) unberletzt und zugleid) Da: (5etwidyt mit bent bei der CFinticjermg ermittelten ilbereinftimmeno

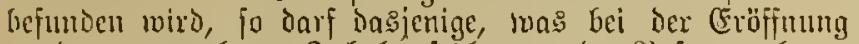
an dom nugegetenen Snhbalte fehlt, bon ber Fojtuermaltung nidht bertreten werden. Dic ohne Erimmerming gefueljene ?(mnalyme cincr Senoung begritniet bie Bermuthum, dof

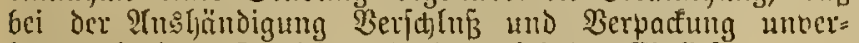

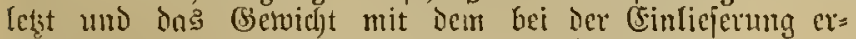
mittelten übcreinftimnend bejunden worben ift.

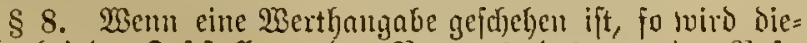
felte bei der Feftiteflung des Betrages des von det Popt= bertualtung zul leiftenden Sifjadenerjakes jum (Brunde gelegt. Bencift jedoch die Fiojtberbaltung, daß ber angegebene Wertly den gemeinen Werth der Sonde iiberjeigt, fo hat fie mui bieien zu erjelzen.

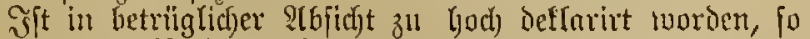

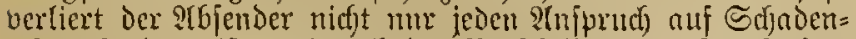
erjots, jondern ift aud) nadi hen Borfdriften der Strafgefetse zll bejtrofen.

\$ 9. WSenn bei Sacteten die Ingabe ocs Werthes unter= blieben ift, jo bergiitet die Foftbermaltung im Falle eines

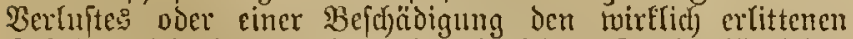
Sthaden, jeodd) niemals melye als (sinen Thaler fïr jedes Fifund (= 500 (Sramm) der ganjen Eendung. \$indete,

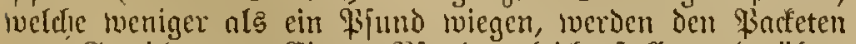
zum (betwid)t bon cinem Sijunde gleid)geftellt mo iiber= fefiejende sifundtyeile fïr (sin sifund gerechnet.
\$10. Fïr eine refonmambirte Sendung, fonie fï

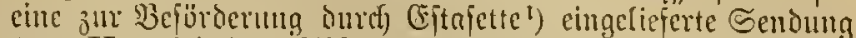
(\$ 6 II) wird dem ?tbjender in zalle bes Berlujtes, ofne

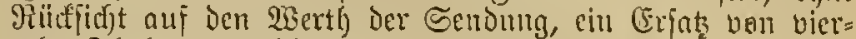
ze[ju Igalern gejaljlt.

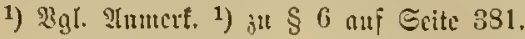

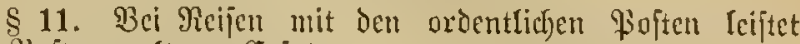
Dic Fioftoermaltutg Crfaks:

1. für den Bertult oder die Befditidigung des regle= mentsmäßig cingelieferten Fafiagiergut: nad) $\mathfrak{M} a \bar{B}=$ gabe ber $\$ \S 8$ uno 9, unt

2. fïr bie erforderlichen Sint= unD Berpflegungstoften im ₹nlle ber förpertichen Bejchäbigumg cines geifen= ben, wenn bicfelbe nidbt enveialich burd lobbere (Selvalt ooer burcl) eigene Fabrläffigfeit des Reifen= ben herbeigefilint ijt.

Bei der Crtrapojtbejüberming rird meder fïr den $\mathfrak{B e r}=$

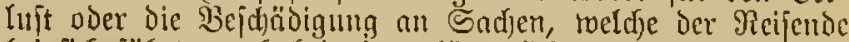

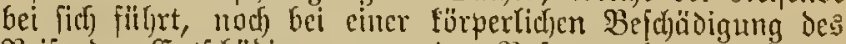
Reijenden Entfchäbigung bon Der Fioftwertoaltung geleiftet.

$\S 12$. Fine weitere, atg bie in den \&s $8,9,10$ แnd 11

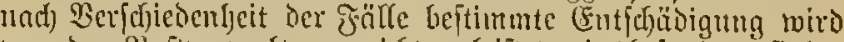
bon Der Pojtnerwaltuig nicht gcleiftet; insbejondere findet

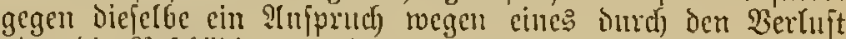
oder bic Beffeübigung cince Eendung entitandenen mittel= baren Schabens oder entgangenen (Selvimes nidft itntt.

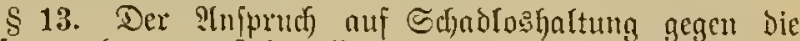

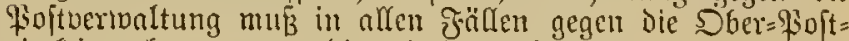
Direftion, bezm. gegen bie mit deren ₹unftionten beaujtragte

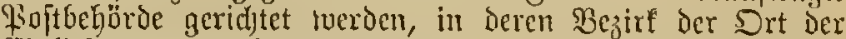
Cinlieferung ber Sendung oder ber Dot der CFinfdreifung UEs Reilenden liegt.

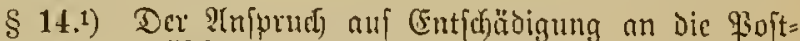
verwaltung erlifat mit Stblauf bon fechas Mionaten, bom Tage der Einfieferung Der Eentung oder bom Tage Der

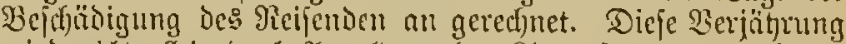

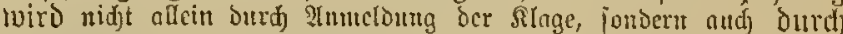
Sfubringung ber ReElauntion bei ber fompetenten Gojt= bebäroe (\$13) unterbrod)en. Ergelft fiermif eine $a b=$ (d) lägige Befcheidung, fo beginnt vont enpfange derjelben cine mene Serjäfrung, weld)e durd) eine Reffamntion gegen jenen $\mathfrak{B}$ eicheid nicht unterbrodjen loiro.

1) Der $\S 13$ bes Bejettes, betreffent bie Einführung ber civil=

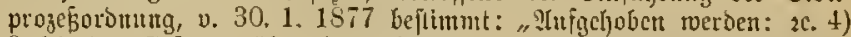

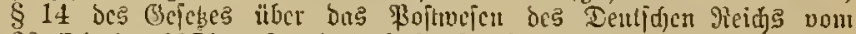

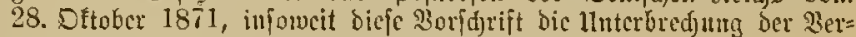

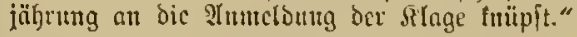

Die tfein gebrufte Stclife ift bemnad) aufgeloben.

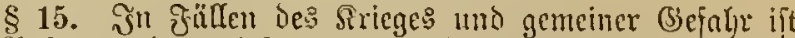
dic fioftbermaltung lojugt, Durch offenttidge Befanntmadfung jeos Sertretung afizulelnen und Bricje, fotvic andere Eachen,

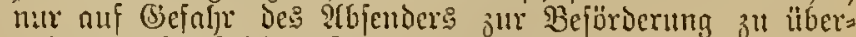

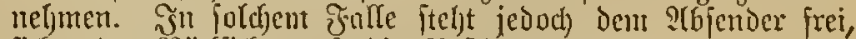
fich obne Ritidfict)t auf bie Seftimmungen Des $\$ 1$ jeder anderen $\mathfrak{B e j o ̈ r d e r u n g s g e l e g e n b e i t ~ j u ~ b e d i e n e n . ~}$

\section{Alridjuitt.}

Befondere Borredte Der Bofter.

\$16. Die ordentlidjen Fiojten nebit deren Beivangen, bie all Soften Des Stantes befürberten Suriere und Eita= 


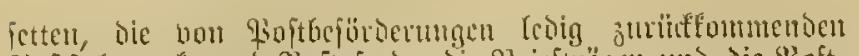

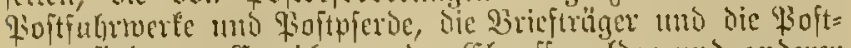
botell find bout Entrichtulig her Ehanjiegefoer uno andorer

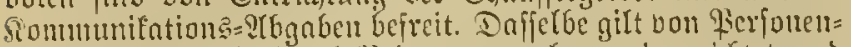

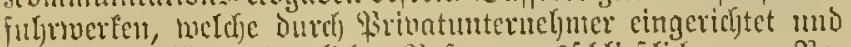

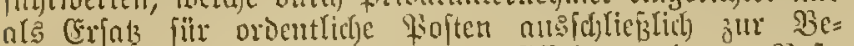
fürocrung von 9ecifentent uno Deren Gffeftent mo von Pajt= fertoungen benutst meriden.

Dieje Befreiung fintet nuch, jetody unbejundet moly

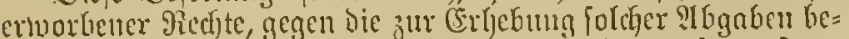

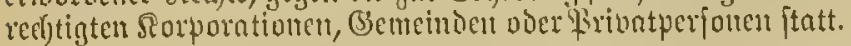

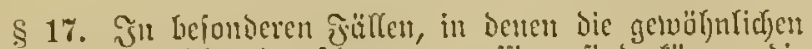
Fofturge gar nidjt ober (d)wer zll paffiren fint), fömen bie

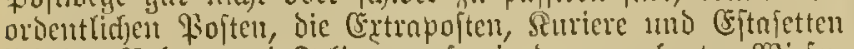

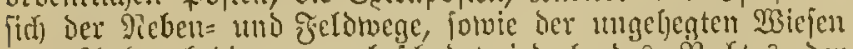

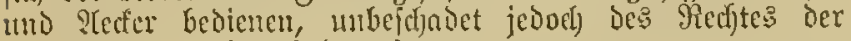
EEigentljïmer auf Edjndenerjats.

§18. Begen Die ordentlidjen Boiten, Extrapolten, Simicre mo Ejtafetten ift feine Sifändung erlaubt; autch barf biefelbe gegen einen lioptiflon nicht geitbt merden, velcher nit deur redigen Gefpnnn zurtütfehrt. Bei Zurnider:

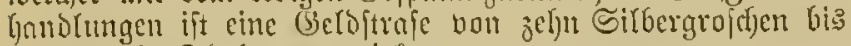
3" jwangig Shaler" bertuirtt.

\$ 19. Эeic: Fulntwerf mus deu oroentlicfen qioften, foule den Ertrabojten, Sureren mb Eftnfetten auf Das

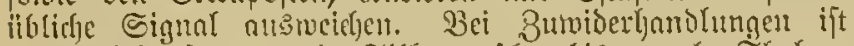

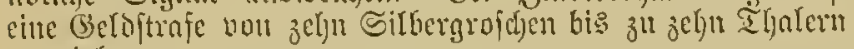
vervierft.

\$ 20.1) Das Snbentarium Der Fopthalterecen borf int

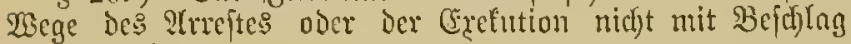
belegt merien.

1) Der $\$ 1$ Der Souftursorobunug v. 10. 2. 1877 befitumnt im $\Re(b=$

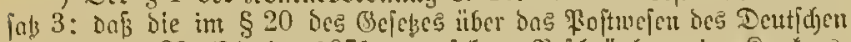
Reids vom 28. Oftober 1871 vorgefelgene Befdräutung im Routurs= verfalyren nidft zur :tuneenbung Foumt.

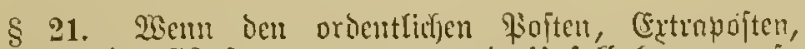
Surteren oder Eftnfetten untermegs ein llufall kegegnet, io jind die s!mvoljner ier Straje verbunen, benjelben dic 3 H

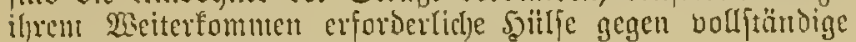

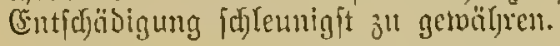

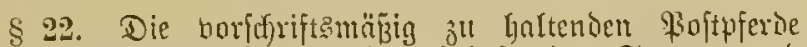

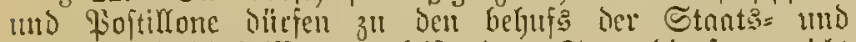
Sommumnlbedibfuifie jul Ceiftenden Spambienjten nidjt lerangejogen werien.

§ 23. Die Thorwadjen, Thor=, Brüfen= und Barriere= benuter find verbunden, Die Iljore und Sdjlngbäume

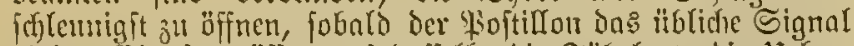

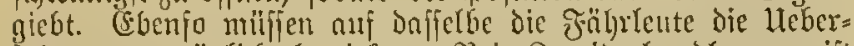

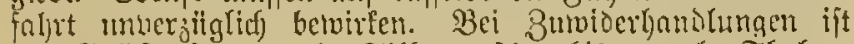

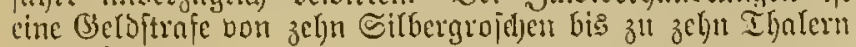
bernirft.

\$ 24. Thf Requifition ber Foftbeljörien haben die

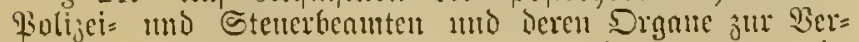
biitung mo Entdeftung bou Fopit=1lebertretungen mit= zurvirfen.

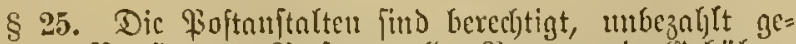

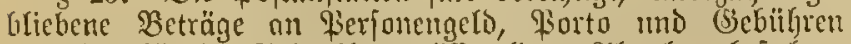
nat) Den für bie Beitreibung biffentliel)er. ?llgghen beftehen= ben Borfduriften ęcefutivifd) einjieljen ju Lnffen.
Die mit Recitreioung excefutionsreifer Forderungen in 2(Lgemeinen hetrauten Drgne find berpflicjtet, bie bon

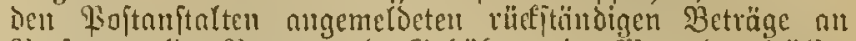

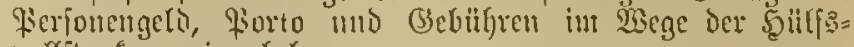
bollftreffung cinjuheben.

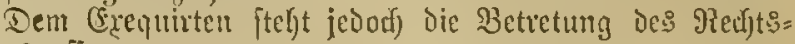
meges offen.

§ 26. Dic 23eitrïge, weldje in einer Sendung entljalten fint, bie weder an ben s(oreffaten bejtelt, noef) an ben

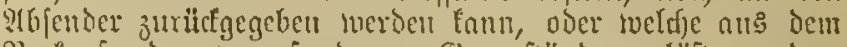
Berfaupe der vorgefundenen Gegenftünde gelöft werden,

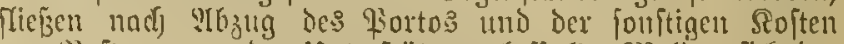

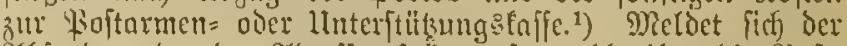

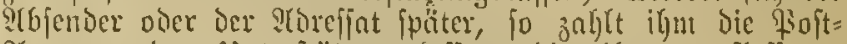

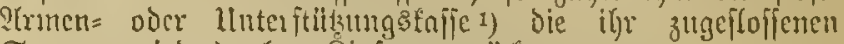
Sitmuten, jeondh olme Binjen, 3uritt.

Nact) gleiclyen (Grundjälsen ift mit Beträgen, tweldye nuf Foltfenoumgen eingejahlt fino, mo mit zuritfgeraffenen Foffagier= Ceffelten zit verfarteren.

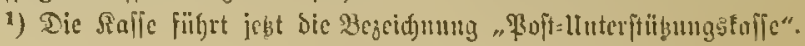

\section{IV. alurdutitt.}

Strafbeftiumungen bei fioft = und Siorto= Dejundiontionen.

§ 2\%. Mit bent vierfachen B3etrage bes Defraubirten Fortos, jebod) niemals nuter einer Beldytrafe bon Einent Thaler, niro beftraft:

1. wet Briefe ober politifje Beitungen, den $\mathfrak{B} e=$ ftiumungen der $\$ \$ 1$ und 2 ztmoider, nuf nndere Weije, als Dutrdy Die \$oft, gegen Bezahlung he= fördert ober verfesicft; erfolgt dic Bejörderntug in berfiegelten, jugenähten ober fonft werfd)lofjenen Findeten, fo trifft die Strafe don \$3eföroerer nur

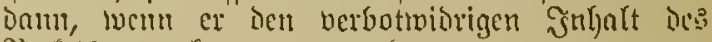
Finefets jull erfernet vermochte;

2. wock fid sul einer portopflifftigen Sentung einer,

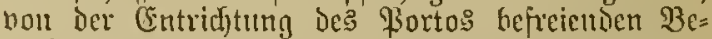
zeidhnung bebient ober eine fordje Sendung in eine andore berpact, rocldje bei ?Tnmentung einer vor= gefdjricbenen Bezeichnung portofrei beföroct Iwiro;

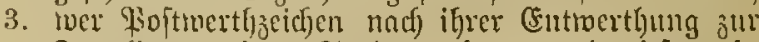
frantirung cimer Sendung benutst; inrwiefert in diefem falle megen himzugetretener \$ertilgung des (Entmertlyungageichens eine ljärtere Strafe ber= wirlt ift, wiro nad) ben alfgenteinen Strafgejetzen beurtheil(t; $\left.{ }^{1}\right)$

4. wer Briefe ober andere Sactjen zur llungeljung der Gortogefälle eiurem qojtbenmten oder Pojtiflon zut Mitmatme itbergicbt.

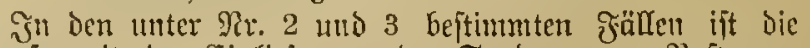
Strafe mit ber Finlieferung Der Sendung zut foft ver= mirtit.

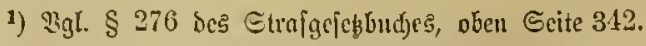

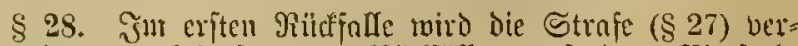
Doppelt und bei fermeren Ribufällent aut Das $\mathfrak{B}$ ierfact) crhöht.

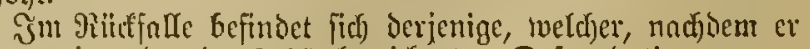
twegen eimer ber int \& 27 Gejeidjneten Defrautationen vout (Berid)te oder int Sicrinnltumngivege (\$§ 34,35 ) beftroft worten, aberutals cime biefer Defrnutiontionen begeht. 
Dic Straferlyöhung megen Tüsfjalle tritt auth cin, toeun die frühere Strafe nur theilweife verbiift, oder ganz oder theilmeife erlafien ift, bleift jebod) attsgefd)lojien, memn feit Der Berbiizung oder Dem Erlajie Der leßzen Strafe bis zut Jegeljung Der neuen Defraubation orei Jafje terfloffen find.

\$ 29. Wer mijientlicf), um der łofttajje das \$erjonen= gelo ju entziehen, uneingeidrieben mit der Fopt reift, wird mit bem vierfachen Betrage des defranditten fierionen= neldes, jedoch) niemals unter cirrer Belditrafe von (Einem Ihaler, beftrajt.

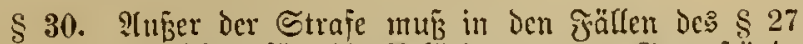

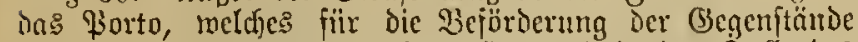

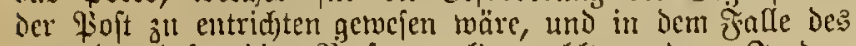

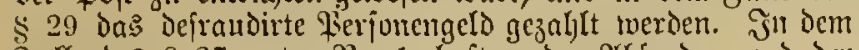

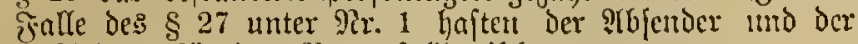
Sejörderer für Das gisorto folidarif(d).

\$ 31. Dic Daner Der Sant, wuche and dic Steffe einer uid)t beijutreibenden (Beldftrafe tritt, ift bom Ritgter feft -

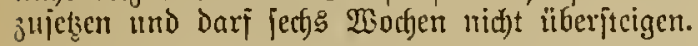

\$32. Die \$oftbéjöroen uno \$ioftbeauten, weldje cinc Depraudation entocfen, fint bejugt, dic dabei vorgejundenen Sricje oder anderen Eacjen, meldje Bsegenitand Der lleber= treturg fiud, in Bejdjlag zu mehmen uno fo lange ganz oder theilmeije zurüffuhalren, bis entweder die ocjraudirten

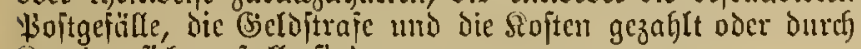
Siaution fidjergeftell fimo.

§ 33. Die in den $§ § 27$ bis 29 bejtimuten (Beloftraf̣en

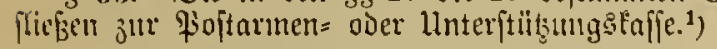

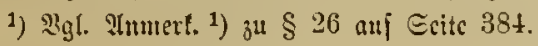

\section{V. albruntt.}

\section{Strafoerfalyen bei Foit = und Porto= Defraubationer.}

\$ 34. Wenn eine Poit= oder Forto= Dejrantation cht=

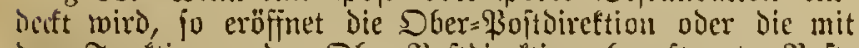

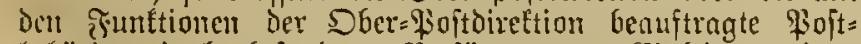

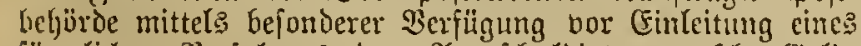

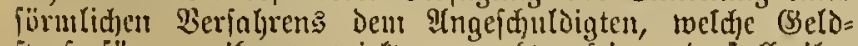

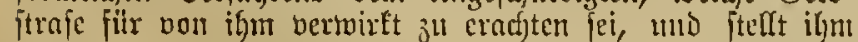
lierbei frei, Das fernere Berfalyren unb die Ertheilmg cimes Etrajeideides burd) Bejahlung der Strafe und Soften imerlyalb einer prällufivifchen ofrift von jeljn Tagen ju ver= meiden. Ecijtet der Angeffhuldigte fierant Die 3 alylumg ohne (Eimrede, jo gillt die Serfügung als redt:

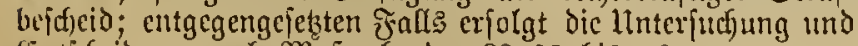
(Entidfeidung nach Majgabe Der $\$ \S 35$ bis 46 .

§ 35. Dic Unterfucjung wiro jummarifod bon Den \$ojt=

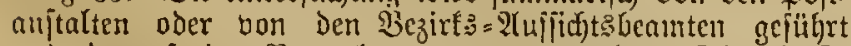
Imo Darauf im Berwaltungsmege bon Den Dber=\$ojt bireftionen $2 c$. cntffiedent. Diefe fömen jedodf, fo lange nodf fein Strafbefdeid erlafien worden ift, bie Siserweijung ber Sadje zum geridjtlidjen Berfahren nerfüigen, und cbenfo faun Der Angeid)uldigte während Der llnterfucd)ing bei ber fivftbeljörde, und Ginnen zehn Tagen präklufivif dier Jrtijt, 1tad) (Eröfinung Des von Ietzerer abgejab̆ten Strajbejdjeides, allf red)tlidfes (Gehör antragen. Diejer ?Intrag ift alt bie \$oftbeljörde ju ridjten. Der Strajbejdjeid wirb alsoam als ridft ergangen angejehen.

Einer ausbritclidien Trmeldung ber Berufung auf

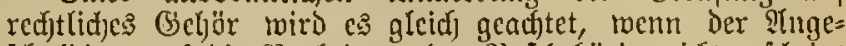

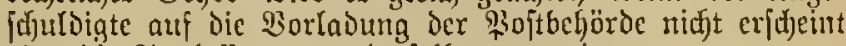
oder die ?tuslajiung vor Derjelben vermeigert.

§36. Bci Den Unterfudjungen im Bermaltungginege

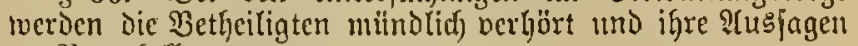
jll Srotofolf genomumen.

§ 37. Die Buftelfungen und Die Borladurgen geideljen Durdf) die Beamten oder Unterbeamten Der Boftanjtalten, oDer auf Deren शiequifition nad) den fïr geridftlid) Snfimun= tionen beftégenden Sorfactiften.

\$ 38. Dic Zeugen fino verbunden, den an fie van den Fojtbehörden ergeljenden Borladungen fsolge zu leiften.

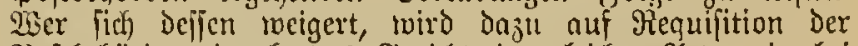
\$softbehörden Duref) das (Seridht in gleidher ?at, wie hei gerid)tlicfen $\mathfrak{B}$ orlaoungen, angehalten.

§ 39. Эn Sadjen, 100 die z"l verbängende (Selditraje

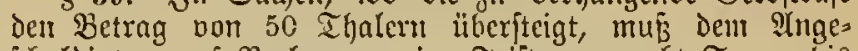
idjuldigten auf Berlangen cine $\widetilde{F i f t}$ bon acht Tagen bis

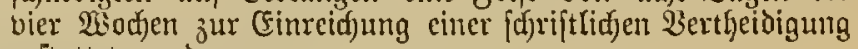
gejtattet werden.

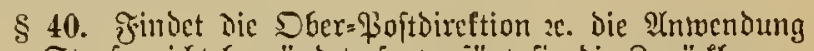

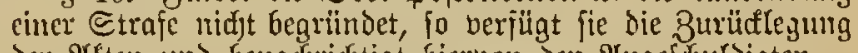

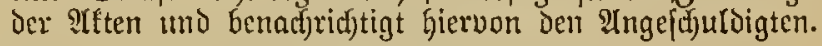

\$ 41. Dem Strajbeid)cide mitijen die (Entjufeidung: gründe beigefügt jein. ?tud) ift barin der श्(ngeid)uldigte fomohl mit den iljut dagegen zuftehenden Recjtsmitteln

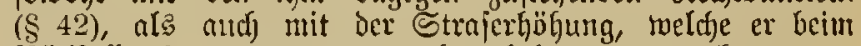
Rüuffalle (\$ 28) ju crivarten gat, befannt zu madjen.

Der Strajhejdeid ift Durd) die \$ojtaritalt bent ?(ut= gcidjuldigten entmeder z"l \$rotofoll zu pubrieiren oder in Der jïr bie Borlaoung borgejdriebenen form ju infinutren.

\$ 42. Der SIngcjdjuldigte fann, wenn ex bon der Befugnif zur Berujung auj ridfterlidje (Entid deioung feinen

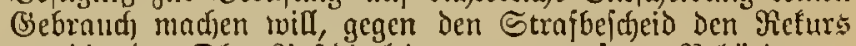
an Die Der Oher=\$ojtoireftion 2e. vorgejetzte Behörde $c r=$ greifen. Die

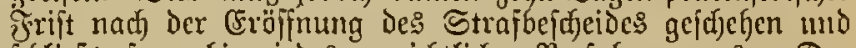
iffliest jernerfin jedes geridjtlidje Berfahren aus. Der

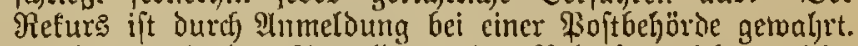

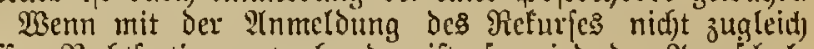

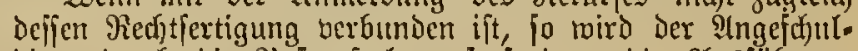

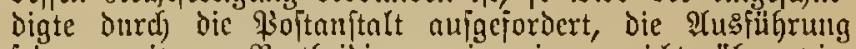

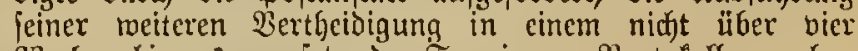
20oden limaus anjujełsenden Sermine z" \$rototoll zu geben oder bi: dahin (afiriftlicf) einjurcicjen.

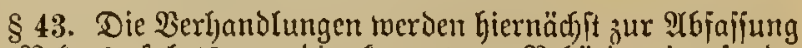
des Refursireplututs an bie fompetente Bejörde eingefandt.

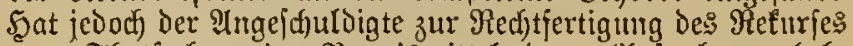
reue Thatfadjen oder Berweismittel, Deren Uujnahme crheb=

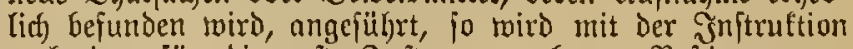
nad) Den fïr die crjte Jnftanj gegebenen Beptimmungen berjabren.

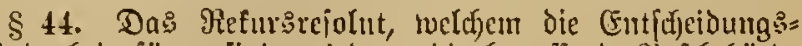
grïnoe beizufïgen find, twiro an bie betrefiente qojtbegörde

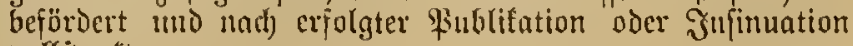
vollitrectt. 


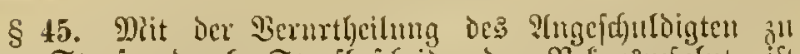
cime: Straje, Durdf Strafbejtheio noer Retmiseclotut, ift juglcid) Dic Sermtbeilung deffelben in Die buaren ?tuslngen Des Derfalpens antijuprectjen.

Bei Der Ilnterfưfung im Vierwaltungsinege fummen, auger den bnaren Shalagen an Forto, Stempel, Zeugen=

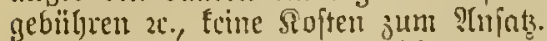

Der Angchduldigte, welder wegen Poit= oder youto= Deframbation zul eimer Strafe grridgtlicf bermatheilt miro,

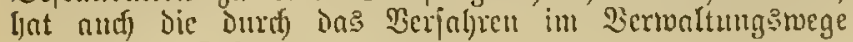
entiftmienen §often zu tragen.

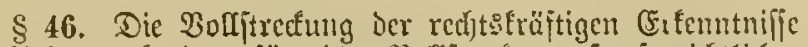
ge[d)icht madj Den fïr Die Bollftrectumg itrajgeridftlidjer

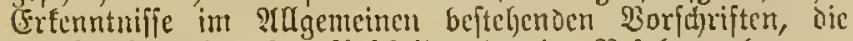

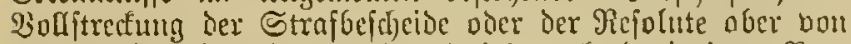

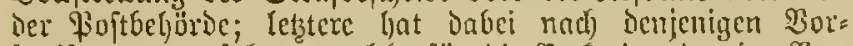
fdurfter zu verfahren, weldfe jür Dic Grefution Der in Ser: waltmingenge feitgejezten (jeloftrofen ertheilt fimb.

\section{Aurdyitt.}

\section{Nrgemeine Beftimmugen.}

\$ 47. Was ein Briciträger ober Foîtbote ïber bie von ifm gejuhehene $B$ cjtellung auj jeinen Dienjteis anjeigt, ift jo lange für roal)r und ridgtig anjumefgmen, bis das siegen= theit itberjeugend nadjgemicfen wirb.

§ 48. Die \$oitnermaltung ift fïr Dic rifhtige Beftellung nicht berantwortlich), swenn der 2(Dreffat crftärt hat, die an ifn eingehenden Poft fenoungen felbît abzugolen oder ablolen

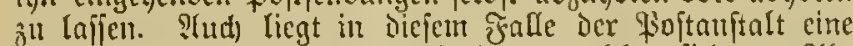

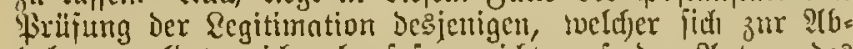
bolung meloct, nicht ob, fojern nich)t anf Den ?(ntrag Des Prorefiaten zwijhen Diefem mo Der Pioftajtalt ein bes: falfiges bejouberes atbfommen getrofien morden ijt.

§ 49. Die Foftbertwaltung ift, nachdem fie Das grormular

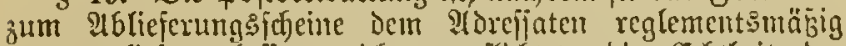
hat ausfiefern laffen, nicht verpflidytet, die (sd)theit Der luterid)rift und bes etwon ljinjugefiiaten Siegels unter bent

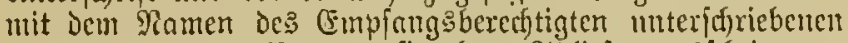

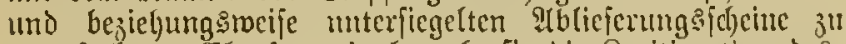

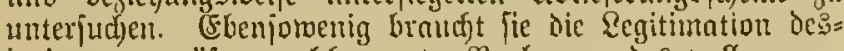
jenigen ju prüfen, tocldjer tmiter Vorlegung Des vollzagenen

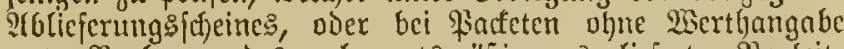

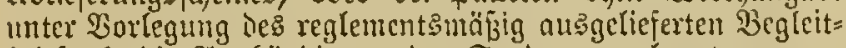
briefes, $\left.{ }^{1}\right)$ Die 2 usföndigung Der Sendung verlangt.

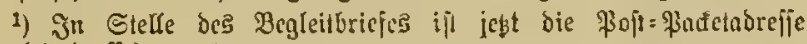
(Begleitabreffe) getreten.

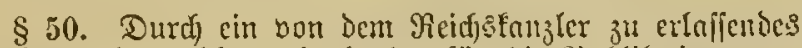
Reglement, ${ }^{1}$ ) tweldjes mittels der fïr die \$ilblifation nutt= Lidjer Befanutmad)ungen bejtimmiten Blätter ju vexöffent= lichen ift, merden bie weiteren bei B̈emulang oer Siojtanjtalt zu heobuthtenten Sorjdjrijten getrofipn.
Dicje Sorjuriften gelten als Beftandtheil ocs Bertrages

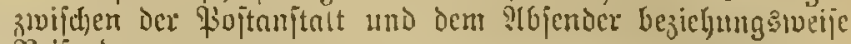
Reifender.

Das Reg(enent') hat ju enthalten:

1. Dic Bedingungen fïr bic Innalyme aller beljuf: der Beförderung Durch dic \$ojt eingelieferten (5iegenitände;

2. Dos Maximalgetwicht Dor Bricje und \$atfete;

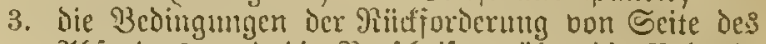
Ifojender: und Dic 2urjefriften thace die Bebano. lumg mueftedbarer Eendungen;

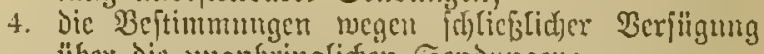
ïber Die mantringlicfen Sendungen;

5. Dic Bezeidinung Der für Bepörocrung Durd die \$oft unjuläjifigen Gegenitände;

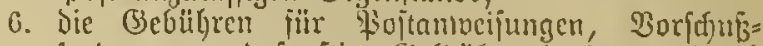
fendungen mo fonjtige (Selobibermittelnugen Durd) die Foịt, jür Sentungen von Drudfachen, Manten= proben und Miuftern, Siurefpondenjfarten, relom= mandirte Genoungen, fïr Buftellung bon Gen=

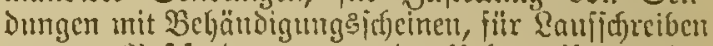
wegen lioftendungen and flebertweifung ier Beitungen;

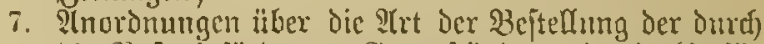
Dic Fojt bejürderten Gegenjtände nno die Gieriitr ju erbebenden (5ebiilgren, insocfondere die Bebühren für Beftellung Der Eapreşicndungen, der Stadt= brieje und Facfete, ber Wertljendnngen, ferner dic Dorid)riften über (5jtafettebeforderung; ${ }^{2}$ )

8. Die Bebingungen für tie Bejörderung der Reifenden unit Den orbentlidjen Fioften oder mit Extrnpoit, die 3eitummung Des Fierfonengeldes unt Der (S)= biibr fitr Bejürterung vou trajiagiergut;

9. Dic nïheren Inoromungen Hibcr Sontirung mo Srebitirumg von Porto, jowic bie bafïr zu ent= ridgtendon (Sebitgren;

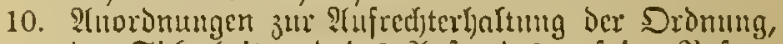
der Sicherbeit mD De: ?!ujtande: auf Den Soften, in den Softiofalen und Paffagierftuten.

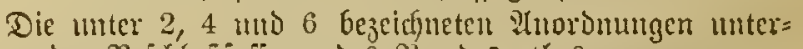

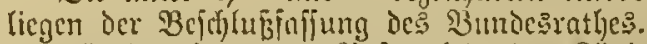

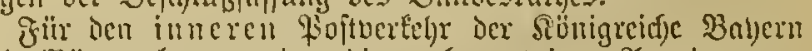
und wiirttemberg merben bie reglementairen Stmordmugen vou Den jultündigen begürden Diefer Etanten crlajjen.

1) Diefes Reglement ift bie vom Reidjstanjler erlailene "\$ofle Dromut" v. 11. 6. 1892.

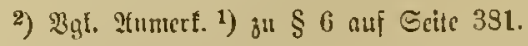

§ 51. จุ(te bisherigen alfgenteinen mi bejonderen Beftimumungen Befelz verfiligt, foweit jenc Bejtinmmugen uidht anf Den mit

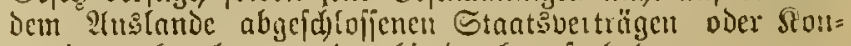
bentionen berulyen, werden lierdurly anfgehoben.

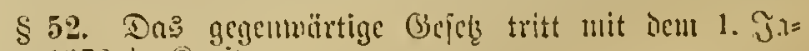
unax 1s72 in Sirnjt. 


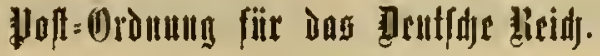

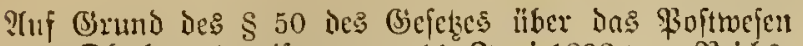

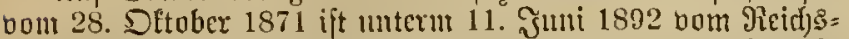

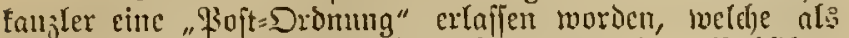

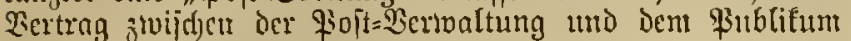
gilt, und ben folgenden Эnljalt ljat:

\section{Alridnitt.}

Po fr fendungen.

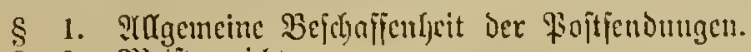

$\S$ 2. Dieijtgetnid)t.

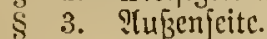

\$ 4. Begleitadreife ju \$acfeten.

$\$$ 5. Mielrere \$infetc ju cincr Begleitabrefíc.

\& 6. จุ(nfidurift.

7. Wcrtbangabe.

\$. Verpadtung.

\$. 2eridulus.

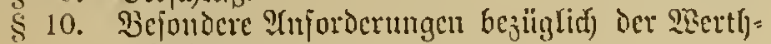
iendungen.

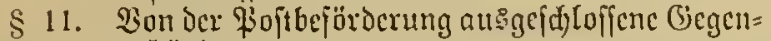
itäride.

§ 12. Zur \$oftbeförderung bedingt zugelajiene Bicgen= Itänoc.

§ 13. Dringenic \$acfetjendungen.

\$14. Rioftfarten.

$\$ 15$. Dructjact)en.

\$ 16. Bur Beförderung gegen die Druffjadjentare bedingt zugelafifene Sd)riftitidte.

$\S 17$. Waarentroben.

$\S 18$. (Einj()reibjendinnger.

\$19. \$oftantweifungen.

20. Telegraphije)e Sojtantweifungen.

\$21. Foftnadjuaburefertoungen.

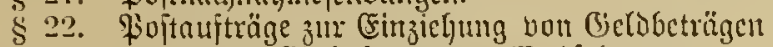
nno jur Eingolung bou Wedjelaceepteu.

\$ 23. \$oitaufträge zu Büd)erpoit fenoungen.

s. 24. Durd) Eitboten zu bejteflende હendunget.

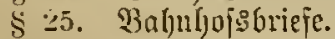

§ 26. 2irieje unit \$oftzuโtellung:

Sั 27. Sehandttng orbunugswiorig bejd)ffener Sen= Dungen.

\$ 28. Beitunģnertrieb.

$\$ 29$. Srt ber Cintiejerung.

30. Bcit der Ëinlieferung.

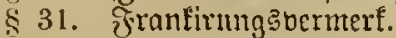

32. Fintiejerung şjucin.

$\$ 33$. Riütefict)ein.

\$34. Reiturng ber Soptiendungenr.

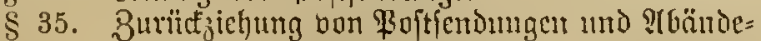
rung bou stufjectriften Durd) den ?(Gjender.

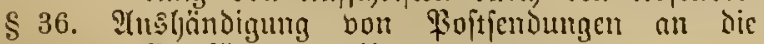
Empfänger an lluternegsorten.

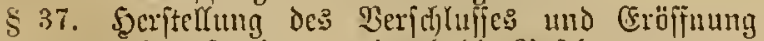
der Eenimmgen duref) dic \$optbeanten.

\$38. 3ejtellung.

$\S 39$. Beit Der Bcitellung.

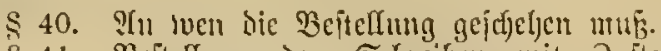

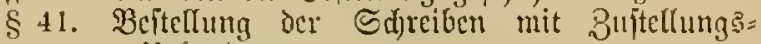
llitumise.

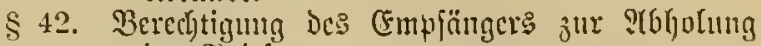
Der Briefe ze.

§ 43. UtushänDigun Det Eentungen nadj erfolgter Beljändigung Der Begleitabreijen mo Der

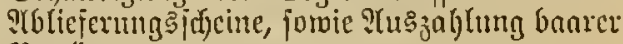
Beträge.

§ 44. Radjenturng Der Boftieniungen.

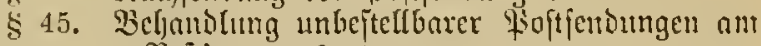
Beptimnumingort.

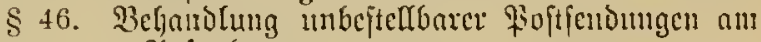
?lufgabeort.

\$ 47. Raufichreibent megen \$oftfendungen.

$\$$ 48. 2ind)lieferumg von Zeitungen.

\$49. Verfauj von \$ojtmertljzeid)ru.

$\$ 50$. Entridntung ocs qortos uno ber fonfrigen (bicbilit)ren.

\section{1. diffuntitt.}

Ferjoncubeförderung mittels der gioften.

\$ 51. Meloung jur Reijc.

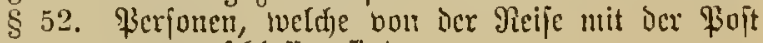
nusgejclutoffar find.

\$ 53. Jabrfatein.

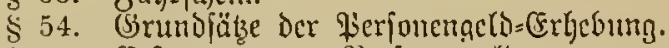

$\$ 55$. Eritattung vou Perjonengelio.

\$5. Verbindlichfeit Der Reijendu in Betreff Der ?tbrcije.

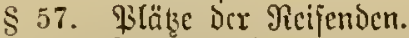

55. गieifegepäck.

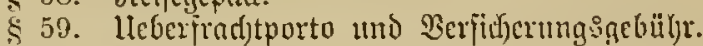

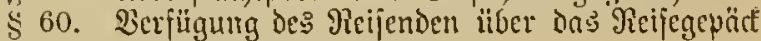
ulttermegs.

\$ 61. Wartejimmer ier \$ojtanjtalter.

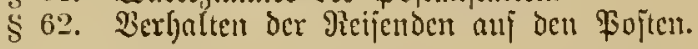

\section{HIT. Xbrdjuitt.}

\section{Gętrapoft = Beföroerung.}

\$63. भIfgencine 3citimnturgen.

$\S 64$. Bablung?

$\$ 65$. Jahlung uno Dltitung.

\$66. Befpomumg.

$\$ 67$. Mbfertigung.

68. 3ejörderumgazeit.

s. 69. ßoîtillone.

$\$ 70$. Dejajwerben.

$\$ 71$. Snfrajtteten.

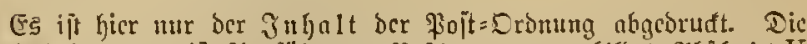

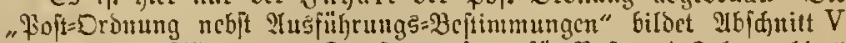

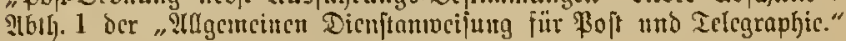




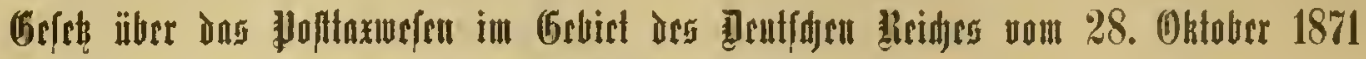 (36?1. Scite 358).}

Porto fïr Bricic.

1. Das fiorto beträgt jür ben franfirten getvöhntidjen Briej auf alle Entfernungen

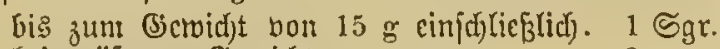
bci größ̈erem (semicjt . . . . . . 2 "

Bei unjranfirten Briefen tritt ein Bujalagporto non

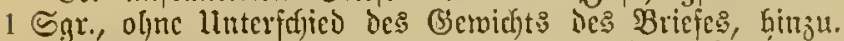
Daficlbe Bujdingporto wiro bei unjureidjend franfirten

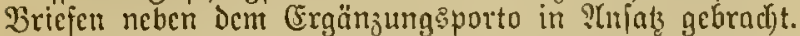

Portapflidftige Dicuftbriefe merden mit Bujd)lagporto nidjt belegt, wenn bic (Eigenjajaft Derjelben als Dicuitjache

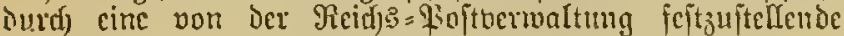
Bejeidnung auf Dem Eoubcrt nor Der Sojtanfgabe crlenntbar gemarift morden ift.

\section{Saceterorto.}

\$2. Dos \$adfetporto miro nadi ber Fintfermumg umo nad) Dem (Getwid)t Der Sendung erljoben. Die (Entfermungen twerden nad) geographifdjen פeilen, ju 15 auf einen Sceuntorgrad beftimmt. Das Poitgebiet twird in quadro tifdje Taxiflder bon hödjftens 2 Mieilen Scitenlängen cin= getljeilt. Der birefte 2tbitano des Diagonaltreuzpunftes Des einen Qlladrats bon dem des anderen Ditadrats billet die Entfermungsftuie, meldye fiï Dic Taxirung ber Sen= Dungen bou Den Foitanitalten Des einen nad) Denen Des anteren Quadrats mašgcbend ift. Die bci den entfermungs: ftujen fid crgebenden Bruchmeilen bleiben unberïffict)tigt.

........

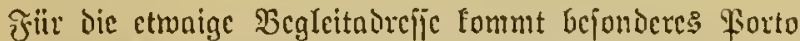
nicht in ?njaks.

Forto und Derjidycrungsgebülr fïr Scudungen mit $\mathfrak{w c r t h o n g a b c}$.

$\left.\$ 3 . \ldots \ldots .^{1}\right)$

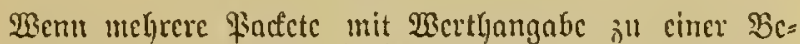

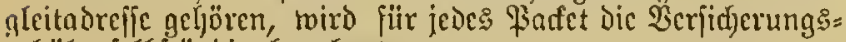
gebiilje felbjtändig bered)net.

1) Dic ur[prïnglid) hier jtchenden Ilbiäbe 3 bis 5 bes $\$ 2$ und IG Seite 393) aufgehober, und beshalb hier iortgclajfen.

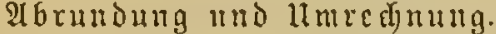

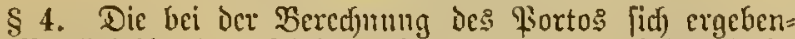
den Brudjtbeile cincs Silbergrofetens merden nuf $1 / 4,1 / 2,3 / 4$ oder ganze Silkergrofofen abgerundet.?

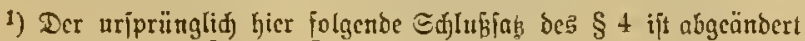
burd) bas (Bejets v. 3. 11. 1874 (Eeite 393).

Couvertiren an bic Bojtanitalten.

5. Werben $\mathfrak{B}$ tiefe oder andere Begenitände bom $\mathfrak{A} \mathfrak{b}=$ fender an cine Foftanjtalt jum Wertbeilen coubertirt, jo
Fonmt für jede im Coubert chtfjaltene Sendung Das tarif= mäßjigc Sorto in ?'nfats.

\section{Iermin ocr $3 \mathfrak{a g l u n g}$.}

\$ 6. Dic Poitanjtaltcu bürfen 23ricfe, Sdjeine, Sachcin :c.

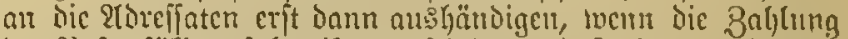

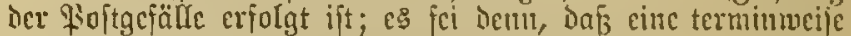

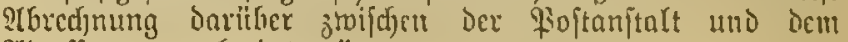
IIscejifaten verabecoet wäre.

\section{Radforocrung bou fiorto.}

$\S \%$. Nadfforocrung an ju merrig bezahitem forto ijt

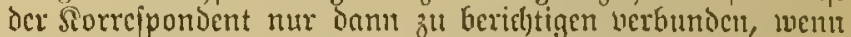

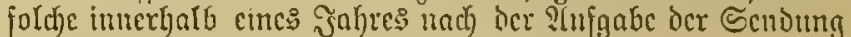
angemeldet twiro.

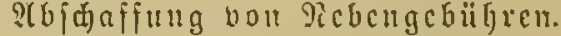

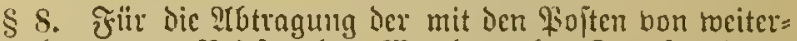
her gefommenen Bricie ofjne 25ertyangabe, Rorteiponienz= fartei, gegeir crmäB̈igtes Porto bejöriterten Drudfjudjen, Waaremprobel oier 2 saarcnmufter, refommandirten Gen= Dungen, Begleitabrefien zu Facfetcu, \$ojtanmeifungen uno

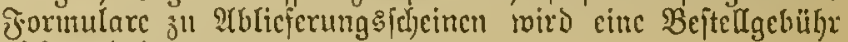
nicf)t erlyoben.

Bebüfren für Fojtidfeine über bic Finlicferung bou

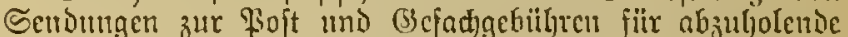

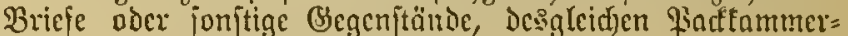
geld, fommen nidjt jur Erbebung.

\section{Vereali bou Foftwerthjeiden ourdy dic Sioftanftalten.}

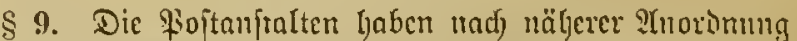

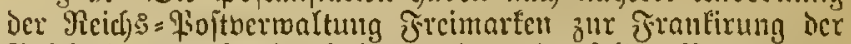
Foftjendungen bereif julfalten und ju bempelben Betrage $a b=$ zulaffen, weld)er burd) ben franloftempel bezeldjuet ift. Dic Siojtanjtalten jolfen crmüchtigt feir, aud) mit Dem ?thjols

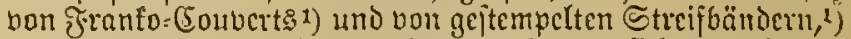
Isoftammeifurgen uno Sorrcipontenjerten fich z"l befajien, jiir toeldje, aufzer bem burch den frranfojtempel bezeidjucter Wertbjetrage, eine den Syerjedlungefojten entfprechende (Ent= fdöbigung cingeljoben tocrocn foun.

1) Seftempelte Briejum[d]läge und Etrcifbünלer verben von bcu Bofiamftalten zut 3eit nidjt verlrieben.

\section{Firobifion für 3eitungeu.}

$\S 10$. Diє Brobifion für Beitunger Getrögt 25 pet. Des Cinfoufspreifes mit dex (Ermägigung auf $121 / 2$ pet. hei 3citunger, bie jeltener als monatlid) vicrmal erfd)einen.

Mindejtens ift jeboch fïr jede abonnirte Beitung jährlich ber Betrag ton 4 ङgr. ju entridjten. 
Tarife für Den Bertelgr mit anderen Foftgebieten.

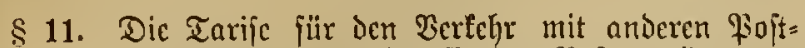
gebieten ridften fid) nadh ben betreffenden Fojtberträgen.

St $1 \mathfrak{j}$ bebung bisheriger Bejtimmungen.

\$ 12. จTle bisherigen allgemeinen und bclonderen $\mathfrak{B} c=$

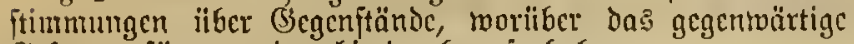
(Sejes berfïgt, merden hierdurd) aufgefober.

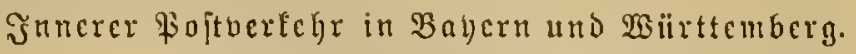

\$13. Dic Beftimmungen bicjes Befelses finden nidjt Inmeniung auf ben intueretr Foftbertefr in Babern und Wü̈ttemberg.

\section{ST úangstermin.}

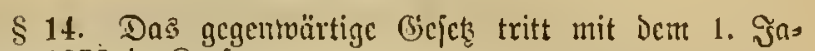
mar 1872 in Siraft.

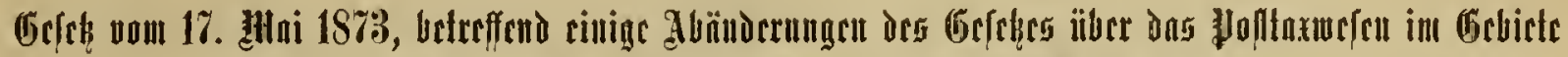

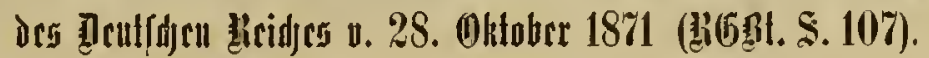

\section{Factetporto.}

§ 1. Da: Forto für \$acfete betrïgt:

1. bis jum (Sictuid)t bon $5 \mathrm{~kg}$

a) auf Entiernumgen bis 10 Micilen cin=

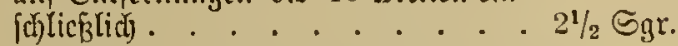

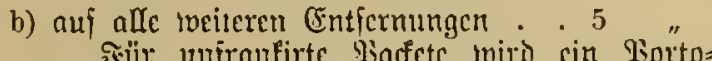
Fïir unirantirte Facfete loird cin Porto= jujd lag bon 1 Sgr. erhober;

2. bcimt Gervitht $\ddot{\text { äber }} 5 \mathrm{~kg}$

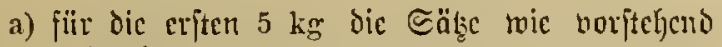
inter 1.,

b) fïr jedcs meitere $\mathrm{kg}$ oder Den ïberfeffiefenten Ifeil cincs $\mathrm{kg}$

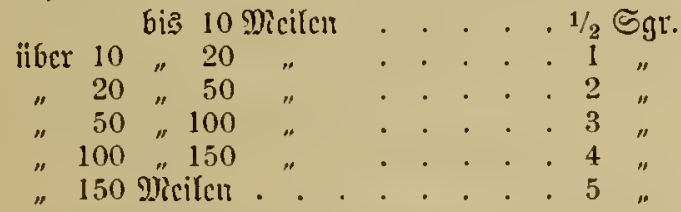

Der Foftuetwaltung bleibt ïberlnffen, fïr jperriges (sut

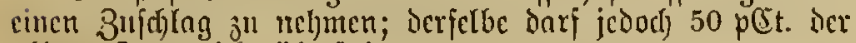
obigen Inare nidjt ïberfteigen.
Porto mu Berficterungsgebühr fïr Sendungen mit $\mathfrak{B a c t h a n g a b c . ~}$

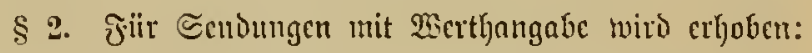
a) Forto, und jtonar

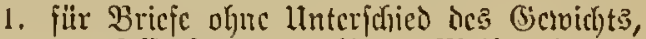
auf Enticumugen bis 10 Mcilen cin=

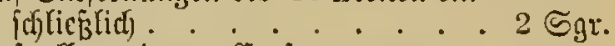
auf alle weiteren Entfermungen . . 4" Fïir minfanfirte Sendungen wird eir Fortazujulag von 1 Sgr. erhoben;

2. fiir Finffete mind dic Daju gehörige Dicgleit= aureffe, ier nach $\$ 1$ fich ergebende Betrag, IIni

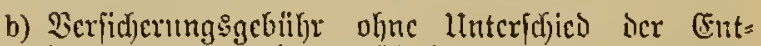

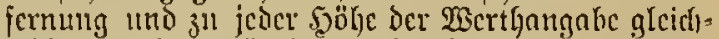
mäisig $1 / 2$ Sgr. für je 100 I Jaler ober cincu Ibcil boul 100 Thalern, mindejtens jebod) 1 Sgr.

§ 3. Das in ien $\$ \S 1$ mird 2 vorgcichene Bufdlagporto twirt hei partapflic)tigen Dienfticulungen ( 1 ics (3)efese: iiber bas Fojttąrwejer bam 28. Sttober 187!) nicht cr= hoben.

§ 4. Das gegentwärtige Bejç tritt mit isem 1. Samuar 1874 in Sirnit.

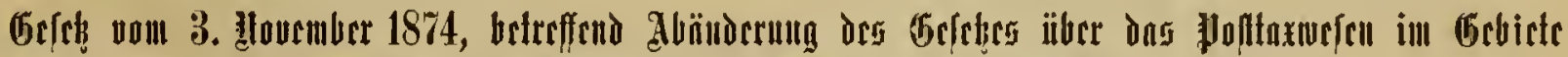

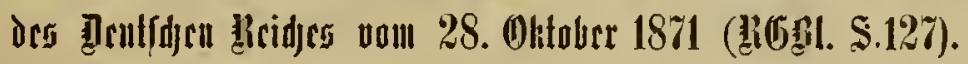

\section{Einjiger Prtilel.}

Der im $\$ 1$ ies Befcics über Das Fofttartwejen int Bebicte ics Dentfden Ricid)es nom 28. Dltober 1871

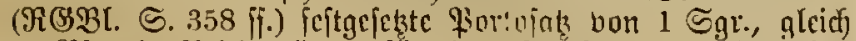

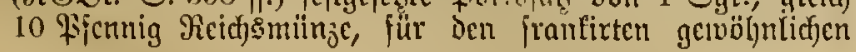

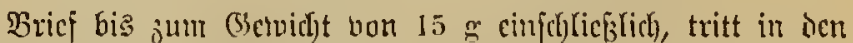
Bebieten Der Sildocutfden Wä̈hrung an ben Tage in

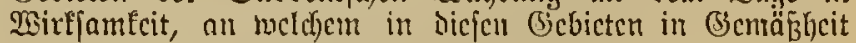

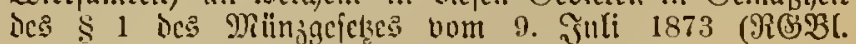

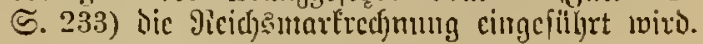




\title{
V. Alorta:
}

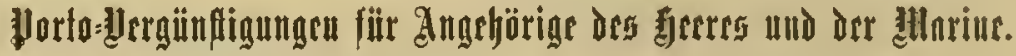

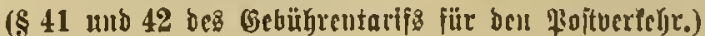

\section{Boftendungen bon ober an Militärperjonen.}

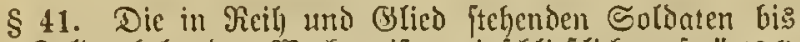

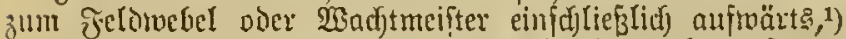
bic Snbaliden in grvalidentfäufern unit eingered)net, ferner dic ill derielben Rang = uno Bejoldung = Berbältnifjen iteljenden nidft itreiterden (SLieber, ${ }^{2}$ ) jorvic aud dicjenigen Eefonde=:eicutenants, weldye joar mit Dem Sicutenants= CGaralter belieben worden jins, aber nidjt in den mit biejer Stellung berbundenen Militärbezügen jtehen, uno bie Bendarmen in denjenigen Staaten, in tweldyen jie zu den Mititärperjonen gerecfnet roerden, jerner bie bei der నaijer= lidjen Dazine im Dienit itehenden Dberiteuerleute und Stenerleute, Dherfenterwerfer und Jetuerwerter, Sberbonts: leute und Bootsleute, Dbermajdiutiften und Majdiniften, Dbermeifter und Meijter, Feloroebel, Sectadetter, Stabs = 23adjtmeifer, Steuermannmaaten, J Jeuermerfemaater,

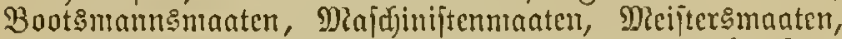

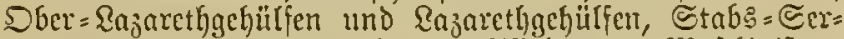

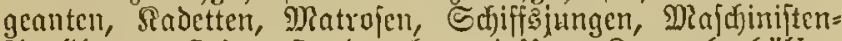

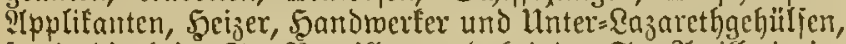
jomie dic beint See=Bataiflon uno bei Der See=?trtilferie im Dienft ftchenden MRilitärperjonen vom Felomebel abrärts, geniefen fiir iljre \$erfon inmerljalb des Dentidjer Reids: Woftgebietes, jowic in Berfeljr jwifden Dem Deutfden

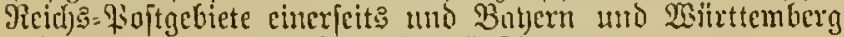
andererfeits folgende \$orto=\$Bergürjtigungen:

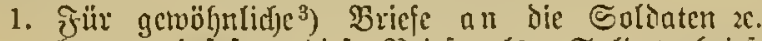
foumt, impofern dieje Bెriefe als "Solbatenturief.

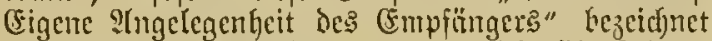

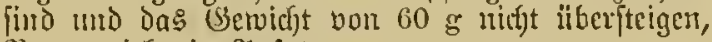
Forto uid t in ?tnjatz.

2. Fïr die an Solonten 2 . gerichteten \$oftantweijungen

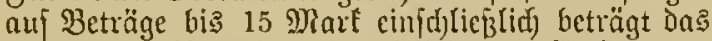
Forto 10 Sf. ofure Unterfdico Der Entiernung. Diefes Forto muß in allen fällen voransbezaljlt merdert.

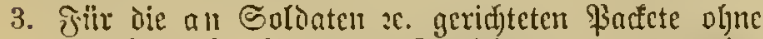
23erthangabe bis jum (Sewicjt boll $3 \mathrm{~kg}$ eirs=

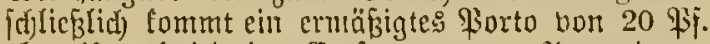
ohne linterfdied Dex Entfernung zur 2Htwendung.

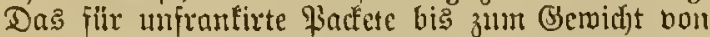

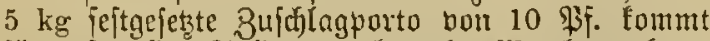

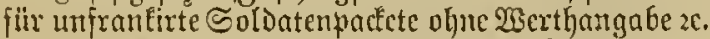
bis zum Gietrid)t bou $3 \mathrm{~kg}$ nidft zur Criljebung.

Die unter 2 bezeidjeten \$oftanmeifungen, forwic die Begleitndreffen zal den unter 3 crmälntten Farfeten müijןen cbenfalls mit Dem Bermerf: "Soldaterffrief. Cigene ?h= gelegenheit des Empfänger:" berfehen feit, und juon muf

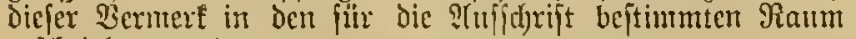
gejefrieben werden.

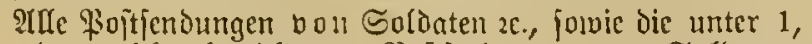
2 und 3 nicht bezeifjneten \$ojtjendungen an Solbaten, unterliegen ber bollen \$ortozaljlung; fiir Fioftunadjual)me. fendunger find ons Forto und die Zorzcigegebilite in ?tnjak zu bringen. Flud) fonmen bie \$orto= Bergünjtigungen zu 1, 2 mo 3 meiter allf beurlaubte Dislitärs 2e., nod) auf eirijäljrig freciniđlige zแr ?tnmendung.

Sendungen, weldje

a) rein gewerbliche P(ngelegent)eiten Des e $m p$ fänger betreffen, 3. B. den Tertrieb cines von einer

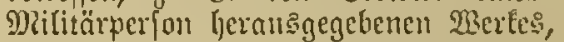

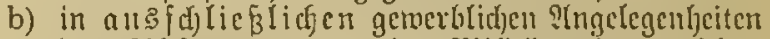
to fint, 3. b3. die 3ufendung budjyänolerifder oder

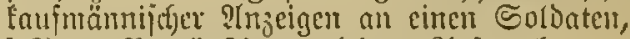

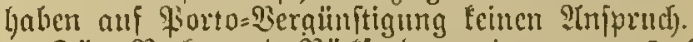

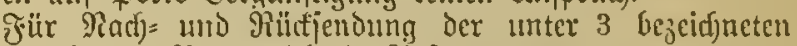
Fartete fommt fiorto nid)t in ?injaty.

1) Dcu zut Dicuttlciftung bei cincr Cidilbchöros abtammandirten Solbaten ftcht cit Stujprud auf Portobcrgünjtigungen uur batt alt,

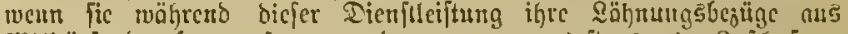
Militärjonos fortempfangen, ober menn menigitens cin 3ujüub z" bem von ber Cioilbchärbe gewährten Eintonum aus Dem Ctat Des Iruppentheils geteiftet wiro.

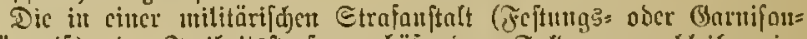

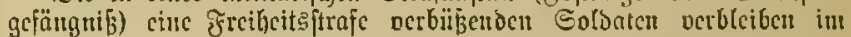
(s)uई Der \$ortouergïn|tigungen.

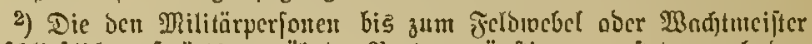

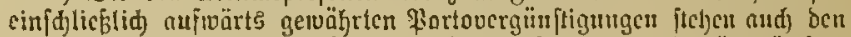

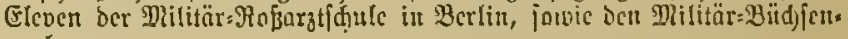

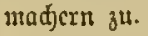

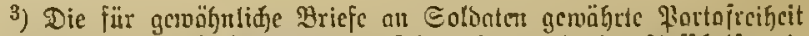

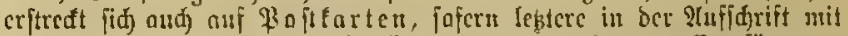

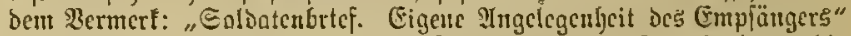
verjefen find. 2Iuf bic it Briefen ober unter fircugbanto nit bic Solbaten geridjteten Drudjadjen (Bcitungen :c.) erftredt fid. Dic Bc= frciung vont \$orto nidjt.

Riribat $=2$ riefienoungen und

Bojtanmeijungen an \$erfonen der Raiferliden

Marine auferhalb Des Deutjocn Reidjes.

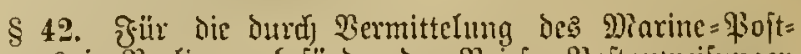
bureaus in Berlin zu beförbernden Briefe, \$ojtantoeifungen tund Beitungen unter Sreuzband an \$erjonen Der Sdjiffs:

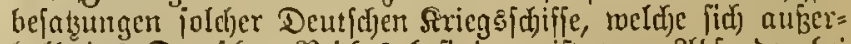
halb des Deutichen Reiches befinden, ift bom ?(bfender bei Der Cinliejerung oul entrid)ten:

1. Gei Cendungen an Dffi iere und dic im Dlf̈jier= rang itelyenden Marinefieamten:

a) für beıt gewölynlicfent Brief bis jum (Bemidyt

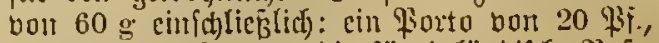

b) fiir \$oftanmeijungen: Die für inlämbifdje \$3uft= ammeijutgen jejtgejelzte Gebüljr $(\S 6)$,

c) Fiir Beitungen unter Sireujband: cin Barto bou 5 Pif. fiir je $50 \mathrm{~g}$ ober emen Theil bon $50 \mathrm{~g}$; 
2. bei Scndmman an Dberfteuerleute mrd Stcuerleute, Dberfeuerwerter und Feuerwerter, Sberbootstente uno Bootsleute, Sbermafdiniften und Majufjiniften, Sbermeifter uno MReifter, Jielducbel, Gecfadetten, Stabs:= mer:smater, Bootรిmannsmaaten, Miaid)iniftent, maaten, Dieiftersmaaten, Dber= \&ajarethgehülfen und \&nzarethgehiulien, Stabs=Sergeanten, SaDetten,

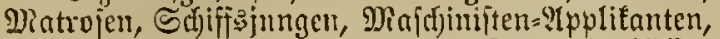
Soizer, Sonnomerter mnd llnter $=$ Eazarethgehïlfen fowic an die bei Der Marine im Dienft fteljenden Mrilitärperfonen vom Feldivebel abmärts:

a) jür Den gemöhnlicjen Srief bi⿱彑 zum (Bemidjt von $60 \mathrm{~g}$ einfétlief̧

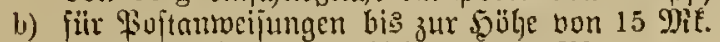
einfd)lieşlid): eine (Bebiil)r nou 10 \$f.,

c) fïr Pojtanweifungen anf B̉eträge bou melj: als 15 Diart: Die gemöhnlid)e (sebuilgr, wie fïr inlïndijclje \$iojtanneifungen (\$ 6),

d) fïr Beitungen nnter Sirenjband: ing unter $1 \mathrm{c}$ fejtgejeste \$orto.

Dic ?tufitfrift Der Sendungen muíz entbalten:

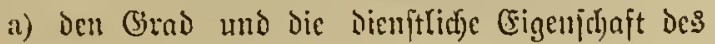

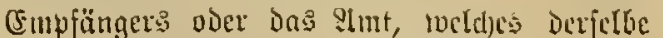
in Der 9 Rarineberwaltung befleidet;

b) den Ramen des Schiffes, an befien Borb Der (Empfänger firch) befindet;

c) Die \$ingabe: "Durdf Sermittelung de: 5̃of= Poptamts in Berlin".

(Einfdjreibfendungen, Radjuahmebriefiendungen, Drutt= facten anDerer ?1:t als Beitungen unter Sreuzband, Waaren= proben, ferner werth) = uno Facfetfendungen, fino oon Der

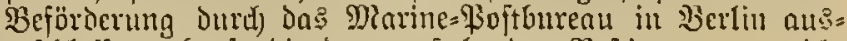
gefchlofien, ebenfo bie den borjtehenden Seftimmungen nid)t entipredjenden Briefiendungen, mithin aud) gevöbulidje Briefe im (Sentid)t voat mehr als $60 \mathrm{~g}$.

Foftanmeijungen Dïrfen aufer Der Ifufjerift mo der Yngabe des Ramens uno 20 olnorts des ?lbjender ander: weite Plittheilunger nicht enthalten.

Diejenigen Sendmgen an Perfonen Der Sefiffabefatungen

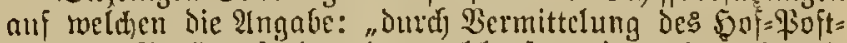
amts in Berlin" feljh, ober melel)e ftatt jener ?tugabe mit iem Srte, wo fich Das Striegsidjiff befindet, bejeidjuet fitro, unterliegen Dent boden tarifimäfigen forto und find umunittel=

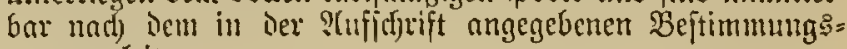
orte jll leiter.

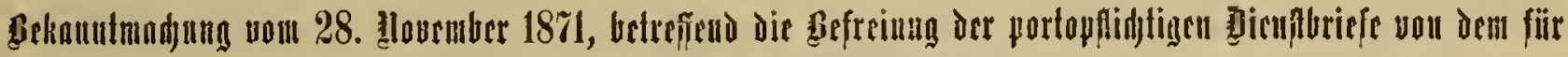

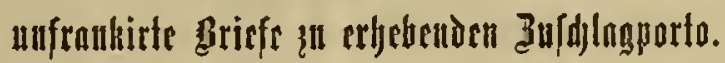

Tac) $\$ 1$ Des (jefetzes jiber Das \$ofttartwefen im (Bebiete

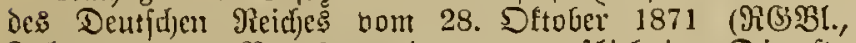
Эahrgang 1871 Pr. 42) twerden portopflichtige Dienft= briefe mit oem fïr unfrantirte Briefe feitgcietsten Bujdjlag= porto ban 1 Sgr. nicht belegt, weun die (Eigenfidjajt berfelben

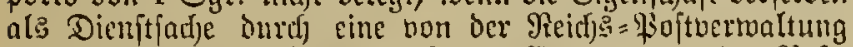

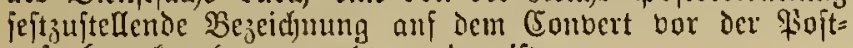
anfgabe ertennbar semad)t roorden ift.

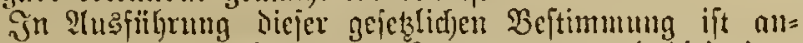
georomet morden, onj bour 1 . Januar 1872 ab dicjenigen portopflidigen unfrantirten Brieje mit Dcm 3ufdjlagporto von 1 巨gr. nidht ju belegen find, weIdje in internen $\mathfrak{B e r}=$

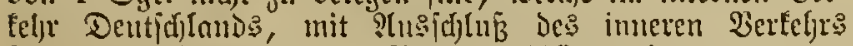
Bnterns und des inneren Vertehrs württemberg?,

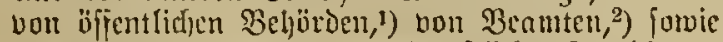
bon (Seiftlid)en ill S(แs̈̈bung dienftlid)er Junftioneu abgejantot und vor der Foftallfgabe

a) allf Der P(Drejie mit Dem Bermert "Porto= pfliditige Dienftiadje" verielen,

b) mit offentlidem Eitget oder Stempe( ${ }^{3}$ ocr: fdllojien merden.

Bon dem Erfordernif Des Berjulupis mittels cincs amtlict)en Siegels oder Stempels (jub) wird nut dann $a b=$

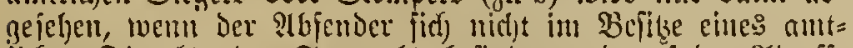
lifjen Giegels oder Etempels befintet und aui ber storeffe unter dem Sermert zu a "bie Ermangelung cines Dimpt=

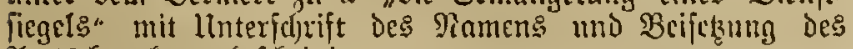
IInt: djorafters befdjeinigt.

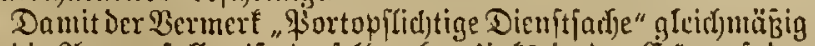
in bic ?lugen falle, ift Derfelbe oben linfs in Der cette nuf Der 9(Drefieite Der portopflid)tigen Dienjtbrieje nieذerjufd)reiben.

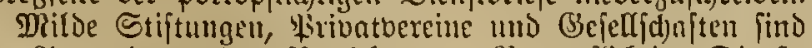

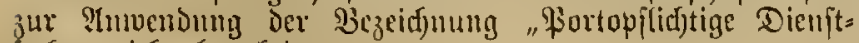
(adfec" nidjt bered)tigt.
Bei Bricien nad) und aus fremden Sändern findet cin (ErTấ3 Des Bufd) (ngportos nid)t ftatt.

\section{Saijerliches (Beneral = Foftamt.}

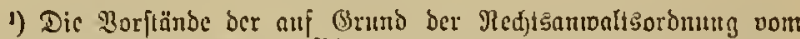

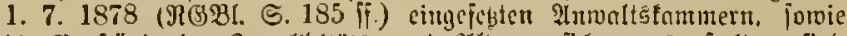

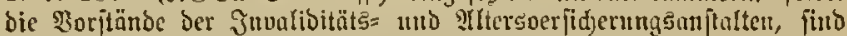
in Eimne biejer Befonntmadung als öfientlidhe Behörden nmjuehen. Dngegen fint bie anf Grut bes Reidjacfeges D. 15.6. 1883, betr.

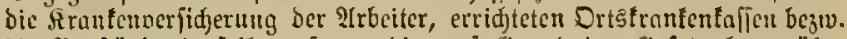
bie Borftänbe Derjelbent, ferter bie auf Grumb der Gejebacbung über dic Ilnjallverfidjerung gebilbeten Berujģenvijenjwuften uno bie Ber=

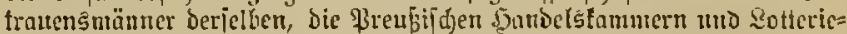

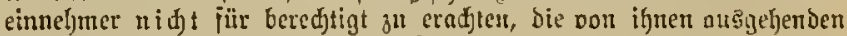

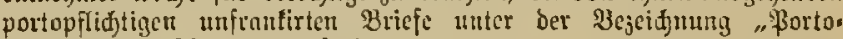
pflidftige Dienjtjod)e" abjulsubeu.

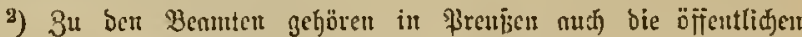
Qehrer. Der Edriftucufjel in itästijuen Eparfafjen=Ingelegentheiten barf jeitcus ber Borfeher sieju Eparfaffen unter ber Bejcidfunng

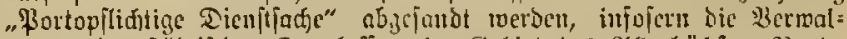

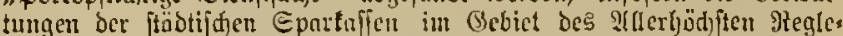

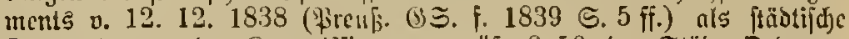
Deputationen oder fiommifioucu gemö̉ $\$ 59$ ber Etäbte=Dromumg v. 30.5. 1853 unb ben gleidjartigen Borjdriften ber Nibejiälijaen uno Rheinifden Stäbte=Dronung bejtellt morben find. Ebenjo ift ben

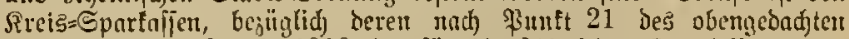

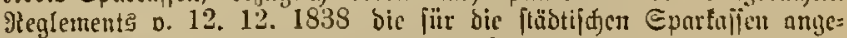

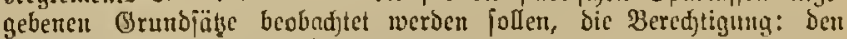

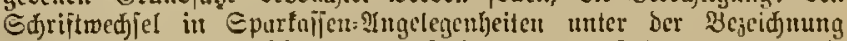
"Portopfliditige Dienitjadje" abjujubes, zuzugejtehen, weut dic

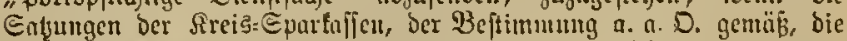

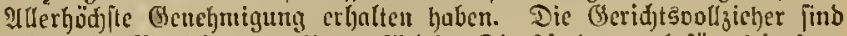

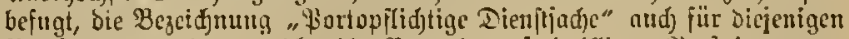

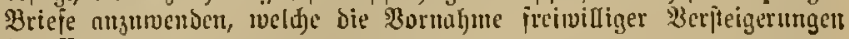
betreffen.

3) Ird) Eiggelutarten Dürfen ocrwentoct wetben. 


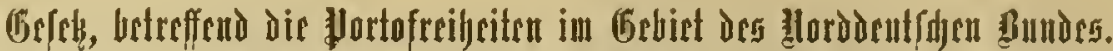

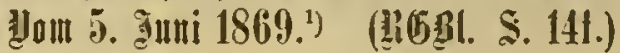

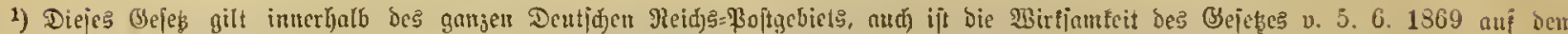

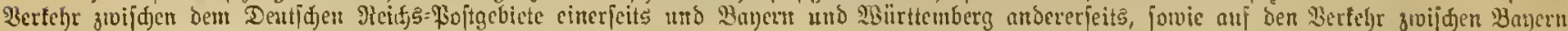

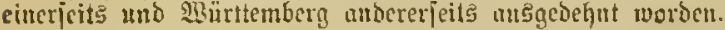

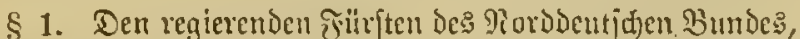
ieren Gemalfiunen und 2 Sittmen berbleibt die Bjejreiung von Fortogebübren in iem bisherigen llmpange.

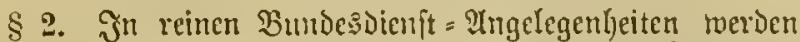

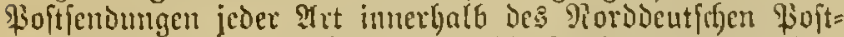
nebietes portofrei bejördert, wenn die Sendungen bon ciner

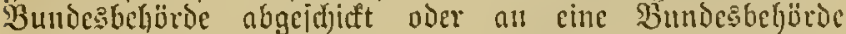

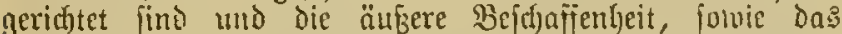
Servidyt der Sendungen Den von der Bundes= Fioft= vertuntung in Diefer bejielung ju erlafjenden befonderen Beftimumugen entfpric)t.

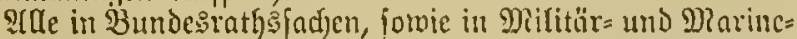
9Ingelegenbeiten, als reinen BundesDienft = QYugelegenheiten, im NorDdeutjden Foftgebicte bisher alfgemein bejtanoenen Fortofreifeiten werden nufred)t erbalten.

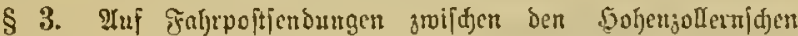

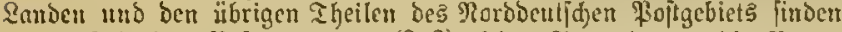

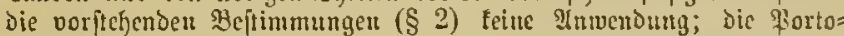

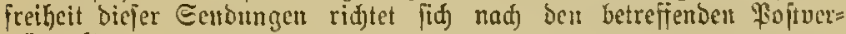
trägen.1) nict)t.

Qhif Stadtpoftfendungen erftreft fith dic Fortopreibeit

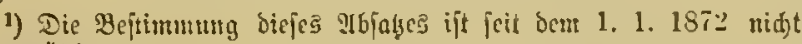
mehr gültig.

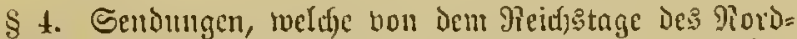

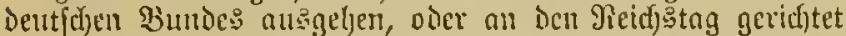
find, metben ben Eentungen von und an Bundeglieljörben gleid)feflandelt.

\$5. Die worto= Bergïnftigungen, welthe ien \$erfonen des Militüritandes und Dene! Der Bundeßs=Siticgsmarine berwilligt find, werben einftweifen aufred)t exthalten. Dem

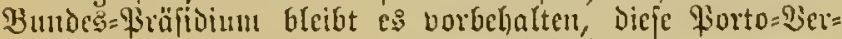
günftigungen aufjubeben ober cinzu|chränfen.

§ 6. Iren übrigen bisher beftandenen Fortofreiheiten uniD Givertvermäbigungen werden nufgeljoben.

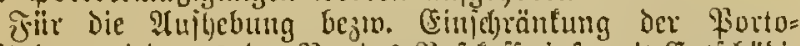

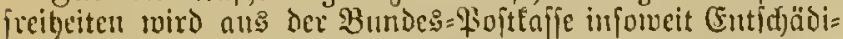

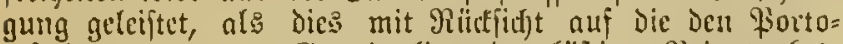

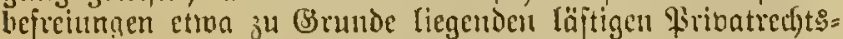
titel nad) Ben Eanoesgejetzen notljuenbig ift.

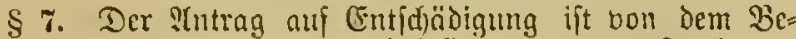
redftigten bei Siermeidung Der \$räflufion bi: zum 30 . Juni 1870

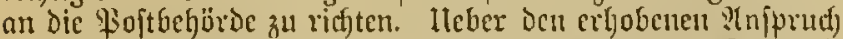
inird vom Bencral= Siofiamt entidjieden. Wenen bas General=

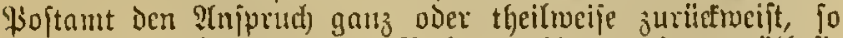

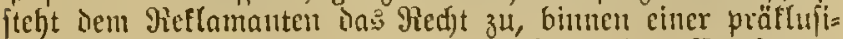
vifanen jrift bon 3 Monaten, nom Iage des Cmplanges

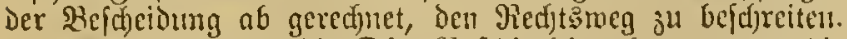

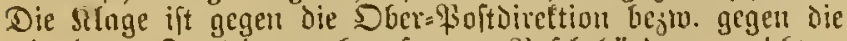
mit deren Futfionen beauftragte Bofthehörde ju rifgten, in Deren Bejirf ber Beflamant fein Domizil bat.

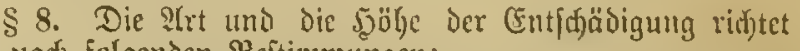
(iid) nadf folgenden 3 eftimmungen:

Der Berechtigte hat nm Sdjluffe eines jeden Jalyre: bie in saufe des Jaljes von iljut (ranfirt abgejdjiften oder

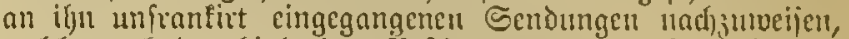
weld)e nad) ien bisherigen Beftimunungen portofeci befördert fein würden. Der auj dieje Sendungen entfaltenoe \$orto=

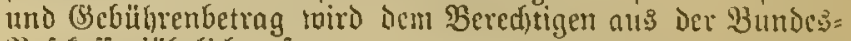
Loftfnife jöhrlich erftattet.

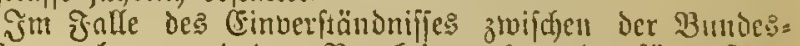
Fojtocrmaltung und dem Berecfrigten Eanu der fïr 1 Jal) feftgejtellte Betrag olye neue (Ermittelung aud fiir melyere

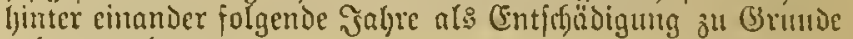
gelegt merden.

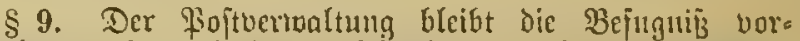

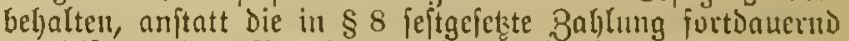
zu leiften, Den Berectytigten Durd) Bahlung ciuter feften Summe cin= für allemal ju entjdä̈bigen.

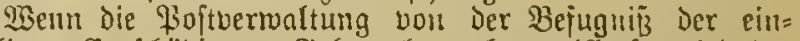
mafigen (Entidjösigung (Sebraudf) madjen mill, fo wird der Betrag, weldjer bem Bered)tigen in Den zuletzt borlyer= gegangenen 3 Salenderjohren in (BemtäBheit bes $\$ 8$ gezablt worden ift, zujammengeredjnet, Der Danad) jite ergethende

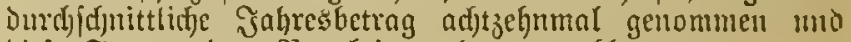
biefe Smmme dem S3eredtigten baar gezablt.

$\$$ 10. Reuc Fiortofreiheiten ober Forto= Crmäpigungen

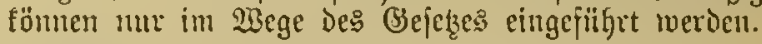

\$11. Der Bundes=\$oftuertwaltung bleibt Dns Rergt

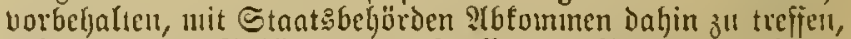

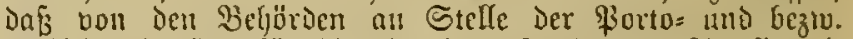
Gebiilsenbeträge fïr bie cinjelnen Eendungen ?locrfionul= fummen an bie Bumbez=\$oftucrmaltung gejahlt metden.

\$12. Fortofreifeiten, welche auf Den mit ben ?tus: lanie abgejd)loffenen Staatsuerträgen oder Sionbentionen berulgen, werden Durd bicfes (Sejes nid)t berïljet. (Fine itrecfentueije portofreie Beförderung findet bei Den in Den $\S \S 2,4$ und 5 ermäfgnten Senbungen von mo mat́) bem Ulushande nid)t ftatt.

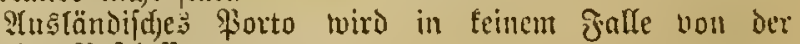
Bunde: $=$ Pojttafie getragen.

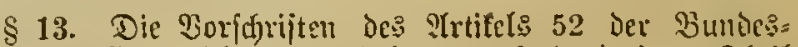
verfaffung jind nidjt ausjubehnen auf Denjenigen Theil

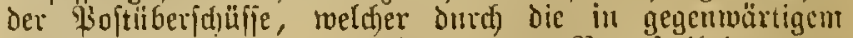
Gejetic angeorinete atujhebung von fortopreiheiten ge= wonnen mird.

Die näj)eren Beftimmungen ïber bie Bered)ung แmo

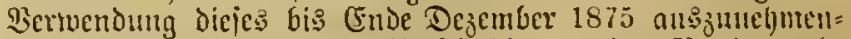

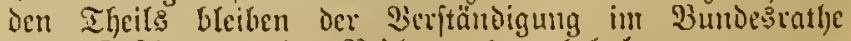
unter Bnjtimunung Des Reid)stages norbelalten.

\$ 14. Då gegenmärtige Gejeb tritt mit dem 1. Jamnat 1870 in Siraft. 


\section{Jirenuntiu ïluer Dir Jortofreilysitrn.}

\section{A. Forlofreifeiten fïr Eendungen innerfyalb des Dentidjen

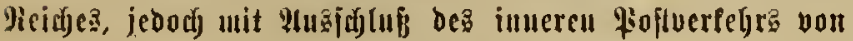 Batjern und Miülleuberg.}

STrt. 1. Die regierenden fö̈rften in Den Glanten des Deutf(f)en Reicfes, fouvie die Bemalfinnen uno $\mathfrak{B}$ ittmen

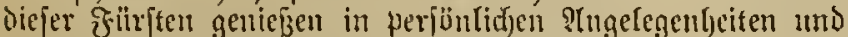

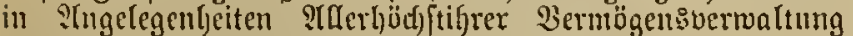

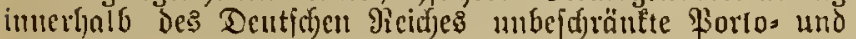
(Sebiiljrenfreiljeit fïr abgehende mo anfoumende \$oft= fentungent.

Diefe Portopreiljeit bejiclyt fidf nidst alfein allf biejenigen

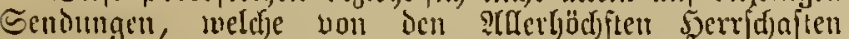

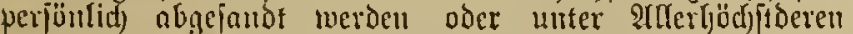
perjönlidjen Sidrejfe cingeljen, fondern nutch alf foldje Sendungen, weldje die SJansminijterien (bejto. Die mit ben betreffenden (Sefdjäften beauftraglen oberifen Stellen), dic Denjelben nadjgentoneten Bertwaltungen, ferner die 500

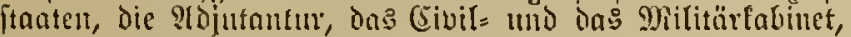
forvie die fonftigen mit diefen Sentungen betrauten Dienft=

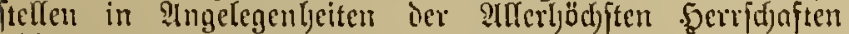
ablaffen oder emplangen.

Die iesifallitgen Sendungen, forweit fie von Den 5 aus: minifterien, den gedact)ten Berualtungen, Den Şaffaaten ze. algelafien toerben, milifen, un bou den Softanitalten als

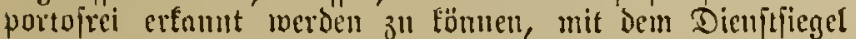

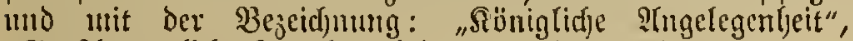

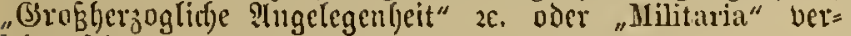
jeljen fein.

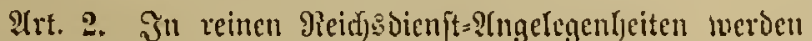

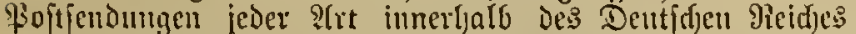
porfofrei bejördert, went die Sendungen bon cinter Reicls: beljöroc abgefdjieft oder an eine Reidjabe(jürde geridjtet find.")

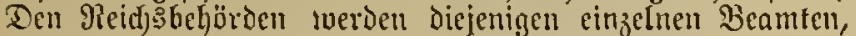
welche eine joldje Behjübe vertreten, gleidh geaditet.

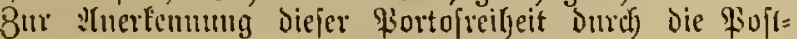
nufialten ift erforderlict), dás die Sendungen:

a) mit amtlidjem Siegel oder Stempel ${ }^{2}$ ) mo

b) in der Plufid)rift mit Deut Portofreiffeitsvermert "Militaria", "Diarinejad)e", "Fojtfadse", "Tele=

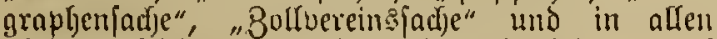
iibrigen Fürten mit den Porfofreiljeilsuermert

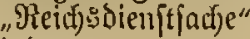

berferyen find.

Son Den (Erjordemíß eines antlidjen Siegers ober

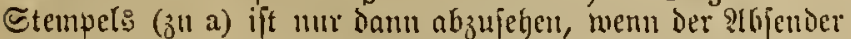
cin unmittelbarer Reidjs= oder Staatsbennter oder cine

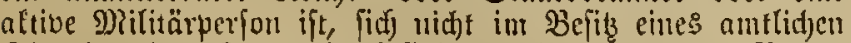
Siegets oder Stempels befindet mino unter beul Porto= freibeitsvermerfe "Die Ermangelung eines Dienjtfiegeles" mit

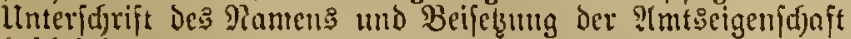
beid)einigt. $\left.{ }^{3}\right)$

Das Betuidt einer portofteien Eenbung in Brief= oder älyulicfer Form foll in Der Pigel iiber $250 \mathrm{~g}$ nicht ljitaus: geben.

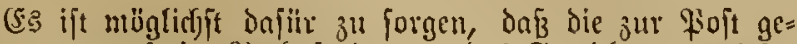
gebenen porfofreien Facfelfendungen bas (3ervidyt von $10 \mathrm{~kg}$ nidjt iiberfleigen.

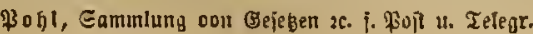

Bei Pacteten, Deren Şnlyalt nitft nus baarem Belde,

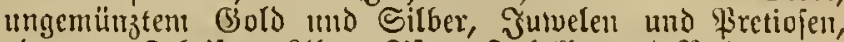
Dber aus Sdjriften, ?(t)en, Siften, Tabellen und Ped)nungen, fondern aus anderen Begenftänden befteht, Darf Das (Servidjt won $10 \mathrm{~kg}$ nid)t ïberjtiegen roerden, twibrigenfalls ba: Die(jrgenicht ber Portozaflung unter(iegt.s)

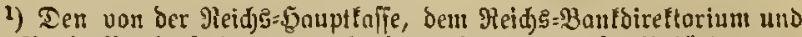
bcu Reid $5=23 a n t a n j$ tulten ausgehenten oder an bieje Bebörden ge= ridteten Scabungeu in reinen $\Re$ eids soien ficht bie \$ortofreiheit ju. Dngegen unterlicgen biejenigen Eendungen,

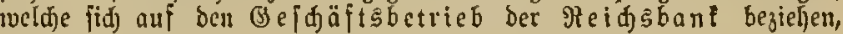
ber Bortoz̧ahlung.

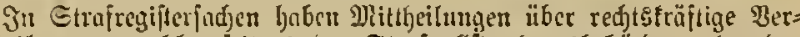
urtheilungen, welde jeitens ber Strofwollitrefungsbefördent ober ber

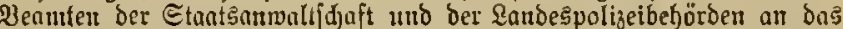

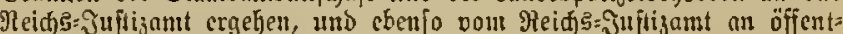

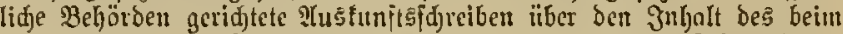

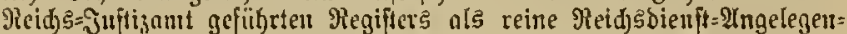

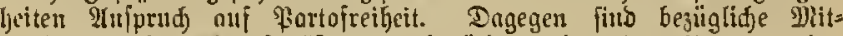
theilungen ber Etrajoolfjuredungsbehörben ober ber Seanten ber

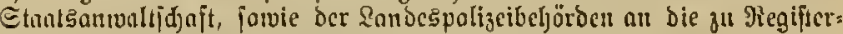

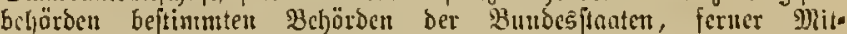
theilungen zc. Der Regifterbeförben ber Bunbesjtnaten an andere

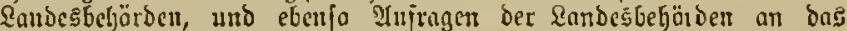

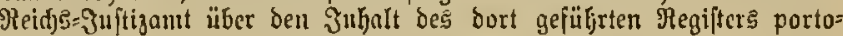
piliditig.

2) श(แ⿰) Єicgelmnten bürfen verwenbet werben. Die Ciegel ober

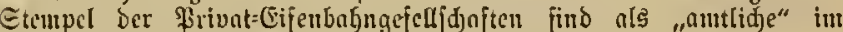
Eiune bcr obiget Sorjorifl anzufeben.

3) Difizicren des BeurYaubtenftandes fiteht als nidit altiven

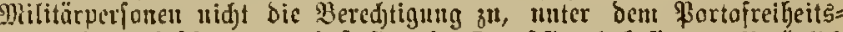

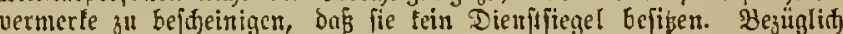
Der von Dffizicren ocs Bcurlaubtenftandes ausgehenden Dienfffendungen

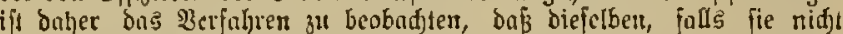

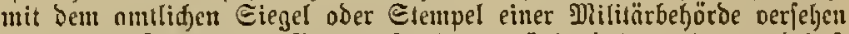

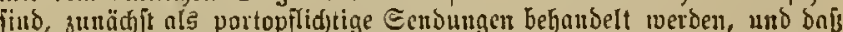

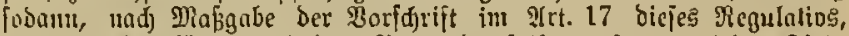
bus vont Enpfünger erhobene \$orto bemfelben erfiattet wirb. Siche

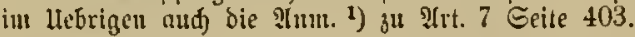

4) Militür=Dien[jpacfete, beren Jnhalt aus Sarten be[teht, muter= liegen binfidjtid bes $10 \mathrm{~kg}$ überfleigenten Mlegrgewidyts nidjt ber

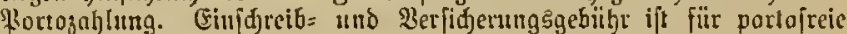

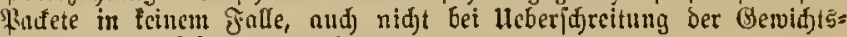
grenzen vout $10 \mathrm{~kg}$ zu erbeben.

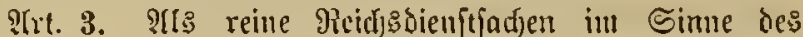
Strifiels 2 find dicjenigen Sendungen nidjt zu berndjten,

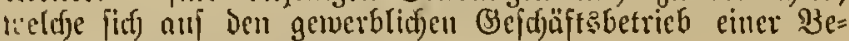
börde oder Stritalt bezieljet.

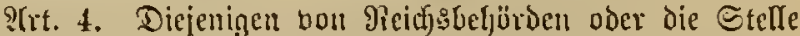
foldier Belyörden vertretenden einzelnen $\mathfrak{B} e n m f e n$ abgefandten bier an fie eingehenden Sendungen, welde Privat=?(ngelegen= beiten gans ober theilweife betieffen, werben nur bann als

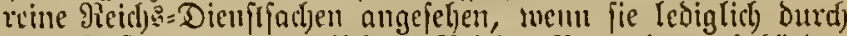

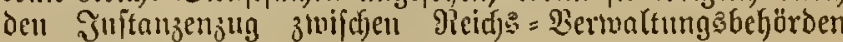
veranlaist finto.')

1) Šn Miltärs und Marinejađen baben biejenigen Eenoungen,

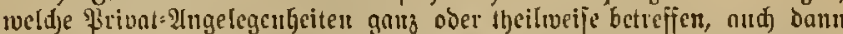

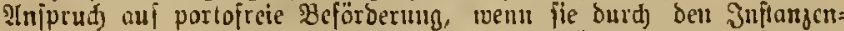
gug zrifden Staat $\bar{s}=$ und (s) emeind cbebörben veranlabt fimo. 
9.t. 5. Sn Buntesathsfachen werben diejenizen Brieic portofrei bejördert, welche bie Bevollmäcthtigten in Bertin zur \$ojt Iiejern, als "Bunies? 3แr Beglaubigung biejes BermerEs entweder mit iljer ginmensunterfurift verfeljen oder mit iljrem Dienfifiegel berid) liepen.

Ebenjo find Dicjenigen Briefe, toclde all Die Şevoll= mächtigten zum Bundesrathe aus anderen Drten des

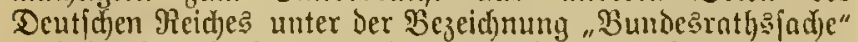
nact Berlin afgefandt serben, portojrei z" befördern.

21rt. 6. Sendungen, weldje bon dem Reidfätage aus: = gehen, oder an Den Reidjstng gericjtet fimb, lverden in Betreff der portofreien Beförderung Den Senoungen von

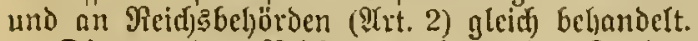

Die bon dem Reidgstage abgebenden Sendungen milffen

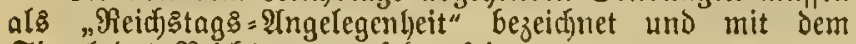
Siegel De: Reidjetags verjehen fein.

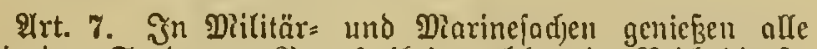

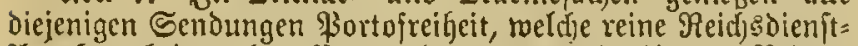
Ingelegengeiten betreffen und bon unmittelbaren Reidbs:-

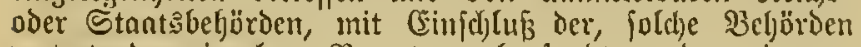
vertretenden einzclnen $B$ camten, abgefanot werben oder an biejelben eingeben.

(5.s miro befonders darauf aujmerfinm gemadt, dos bie Gortofreibeit Der Eendungen in MBilität= แmb Miarime= SIngelegenheilen nicht dabon abbängig ift, Dnf3 bie Sendungen von Peid) beljörden geridjtet find; vielmelyr genteben in bergleichen Trugelegenheiten aud) Die Eentungen bon uni an Etant: beförben bie Fortoficilgeit.')

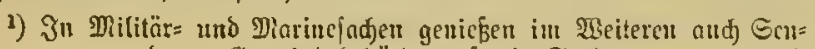
bungen von und an Bemeindebeljörbeu, fomie Eembungen von unb an Benbarmen, ferner Eentungen, melde an ungiftralualifide Barnijons: Bervaltungen geridgtet ober van joldjen aufgeliefert merben, falls fie im llebrigen den ßosidjriften bicjes Miegutatins ?c. entipredjen, \$orto. freiteit.

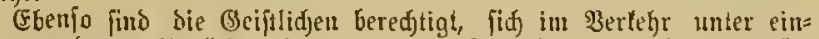

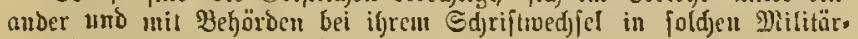

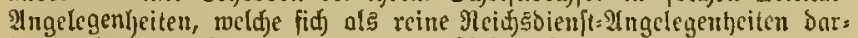
fiellen, Der portofreien Bezeidnung "Militaria" zu beoiencn.

Den von Dffizieren bes Beurlaubtenfiandes ausgebenden bienftliden Eendungen in Militär = und Marinesargelegenheiten fieft bic \$orto= freibeit in bemfelben materieffen lumfange zu, wie ben begilglidjen DienftFendungen ber altiven Difiziere.

Die von bell Bemeindebeljördent auf Brund bes Bejeßes vom

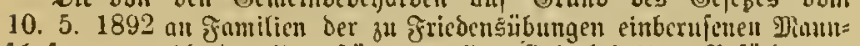

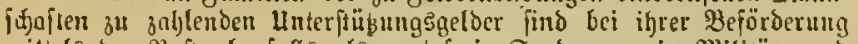
mittels ber \$oft ebenfalls als portofreic Eendungen in Militär= und Dlarines Ingelegenbeiter anjujegert.

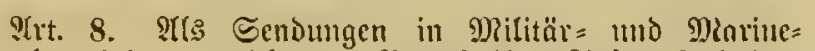

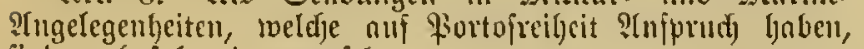
fint aud folgende anjufeljen:

1. Der Edfriftruedjicl und bie Beldjendungen, tweltye badurd) nütlyig berden, Da $\tilde{\beta}$ einjelne Mititör= perfonen oder Militärbenmte bon iljren Truppen. oder Marinetheiten abtommanbint oder Truppen= theile nach anderen Drten verlegt find;

2. (Seldjendungen Der Militür= und Diarinebeljörden:

a) jür Militürtronasporte nn (Gifenbalnn= BertonI= tungen und jür Şorjpam an Srtşbefjörden,

b) für Jutterliejerungen nII Drtsbeljörden,

c) für die bon Jnualiden=STompagnien beurfanten Soldaten, d) fïr Piuljegehülter Der Dilitürs bis sum

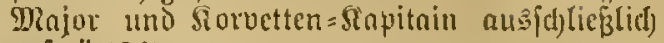

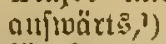

e) jïr beurlaubte Sffizicte und Beamte, iveldye nad) 2(blauf bes lirlaubs Durd) firauflyeit nut ber Riliffelyr ber(findert merden; ${ }^{2}$ )

3. Sendungen mit Rilitür $=$ แnd Dintine $=$ Betleidung: $=$ gegenftänden:

a) Friten: friiferer Sindetten an dus Sadetten=

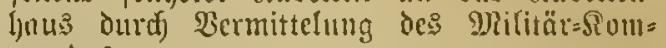
mando?,

b) Feitcus entInffener Solonten uno Marine= Manuifluaften an bie Truppen= und Mrarine= theile, Durd) \$ermittelung Des $\mathfrak{B} e_{0}$ irtajeldovebel: oder einer Bemeindebeljortie;

4. in Jnvaliden=21ngelegentgeiten:

a) Die ant Immittelbare Stnnt: hörden geriditeten (Sejuffe Der Jllvaliden bom đ̧elorvebel abroärts,

b) Jinaliden=llnterftiiksungagelder bei ifjer $\mathfrak{B e r}$ fendung bon eiuer ummittelbaren Stants: Doer Reid)sbehürbe ober Sinffe;

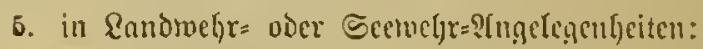

a) IImlaujsbefelle an heurlanbte umbejolocte

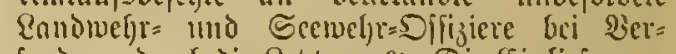
[endung Durd) Die Re(bteren. ${ }^{3}$ ) Dic (EinIieferung muß entmeder Inter Streif= oder Sireujhand erfolgen, oder es muß ein offenter befiegelter 3egleilfalein beiliegen, ans mel(f)ent der (Begen=

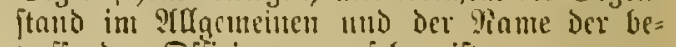
trefienden Sifijiere z" erieljen ift,

b) Meloungen der Rejertiften, ber Enobuelgr= IInI Seewel)mämer, forvic Der jonftigen Minmichaften des Beur'Tnubten Ttnmbes bei iljer vorgefezten Sompngnie bejw. bei den Bezirts. ieldwebeln, tocnn Die Meldungen offen vocr unter Dem Siegel Der Drts= Folizeibeljärde ber= fendet werion,

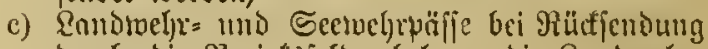
burd) die $23 e z i r t=3$ feld webel an die Randmelyr" uno Seetwebrutänner;

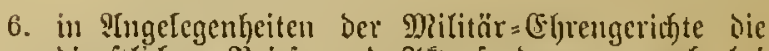
bienftlid)en 3 riej: und 2(ftenjendungen, und, bei Der Berjendung 3twifaten Difizieren nuber Dienjt und beurlnubten Randwelgr= Difizieren. Die $2 \mathrm{Ser}=$ fendung bat in ber unter 5 a angegebenen Beife zu crfolgen;

7. bic Empfangşbefdreinigungen tïber dic nu Sffijicte gejahlten RuhjegehöIter, forvie bie Sutittungen Dor Jnentiden tiber lliterfibizungen $(4 \mathrm{~b})$, bei ber (Ein= jenbung an unmittelbare Stants= oder gicidsobe= böroen;

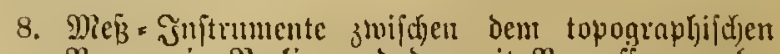
Burcau in Berlin und ben mit Bernteffungen be= aujtrngten Sifizieren fümen in bringenden J̈̈flen! poittïglich bis zumt (Betuid)t von $50 \mathrm{~kg}$ portofrei bejördert inerdert.

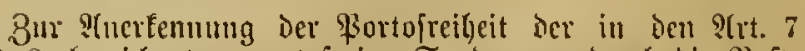
und 8 hejeidneten portofreien Eenbungen Durd bie \$o/t= nnftalten gelten bie im 9 (rt. 2 gegebenen Borfdriften. Fïr

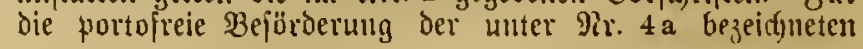




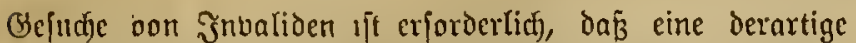

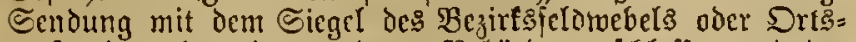
horftantes ober eiuer anderen Beljörde berid) Loffen und der

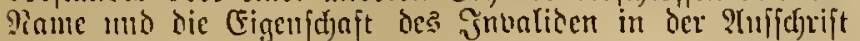
bejeicfuct ift.

1) Dic portofrcic 2lejörderunt findet ond bnun flutt, went bic

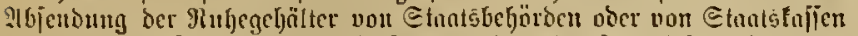

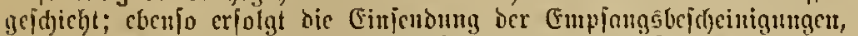

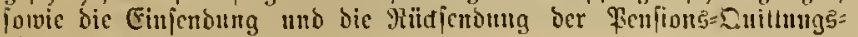
büder portōrei.

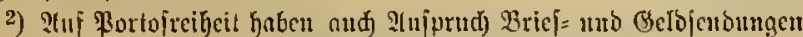

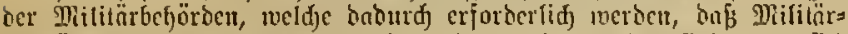

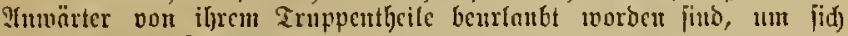
cine Slelle jull fudjetr.

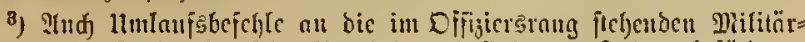
benuten ber Sanbuebr (Dber=?fpotgefer :e.) find portofrei au beförbern.

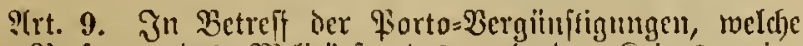
den Fierfonen de: Dititäritandes uns der Sriegsmtarme bevilfint fint, tritt cine stenderung midjt cill.

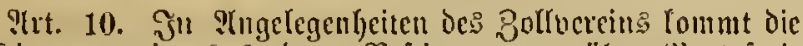
Beffimmung im \$2 ber "Bejtimmungen itber fortoftei= beiten, weldje anf befonteren Bertrïgen bernhen" (ङeite 407)

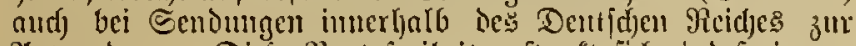
S.umendung. Dieic Bortofreibeit exftreft fid) injes inner= balb des Dentiden Reidjes nur auf ben amfliden Sdrift=

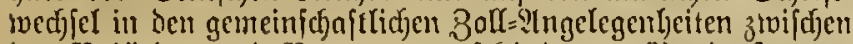
ben Beljörden und Beamten verjdjiedener Sumbesitanten, wogegen der zwijd)en behörten uno Beamten eines mo des felben Bundesftnates in genteinfdunftidyen Bolleslung= legenleiten borfommende Edfrijuvedjef der \$ortojaljlung miterliegt. ${ }^{2}$ )

1) Eenoungcu in Trugclegenbeiten ber llebergangabbaben ge= hören nidyt bu den Senonngen in 3oltoercins[aden unto nutertiegen saber affgemeit ber fiorfojablung.

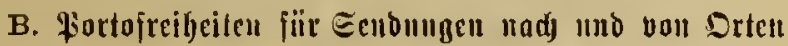 ariberljalo de Dentfden Picitje?}

Sit. 11. Sendungen nad) nice vour Drten nuferlyalb Des Deutfhen Reides iveroen nur infomeit portofrei be= föroert, als fie mad ben befreffenden Stantaberfü̈gen oder Sionventionen bollfen̈ntig portoftei bon iem ?tufgatiearte bis ill dem Beftimmungsortc ju befördocrn finto. Die $\mathfrak{B e}=$ fitmmungen ïber bie biermadj portofreter Senoungen fimo in den "Sieftimmungen üher gsorfopreibeiten weldje auf be= fonderen "Bertrïgen beruljen" (Eeiten 407/408) julanmenge= fiellt.

Eine itrufentmeife portofreie Beförderung findet bei ben in orn ?(rt. 2 und 4 bis 10 erloühnten Eenoungen naर्d) uno von Siten nußzer Jalb des Deuljd)en Reides nidjt ftatt;

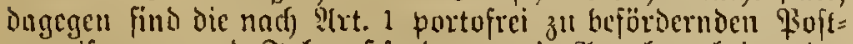
anweifungen und Jahrpoftfenbungen in Itngelegenlyeiten der regierenden Fïrjten in den Stanten bes Deurfajen Pieidjes,

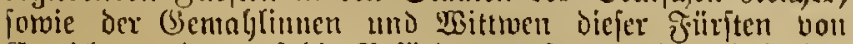
Entrid)tumg des ant bie Beförberungsfirecten innerlyalb bes

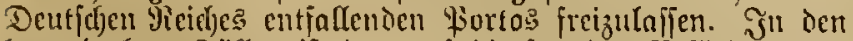

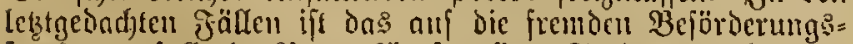
frreden entallembe fiorto für jranfirte Sendungen bei der Eintieferung zu erbeben uno für unfrontirte Sendungen bei

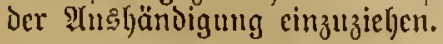

Tusโändif(t)e Forto wird in feirem falle bon ber Reid) $5=9$ : offteffie getragen.

\section{2UIgemeine Beftinmungen.}

2rrt. 12. Wird cine portopflicttige Mittheilung einer portofreien Sendung ljinzugefiigt, oder ein portopfifidtiger (5iegenftand mit cinem portofreien zufnmmengepact, fo iff dic ganze Sendung portopflidstig mo dorf utit bent fortos ireibeitabermert nidjt nerjelyen merden.

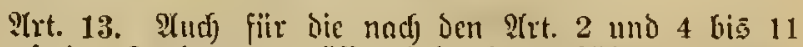
portofreien Senoungen milffen folgende Gebiilgren entrieftet twerbelt:

1. die Buftellungझ̈gebülfr;

2. dic Gebiigr fïr dic Beftellung der won weiterher cingelenden, an Empfönger im Drts: oder Eand=

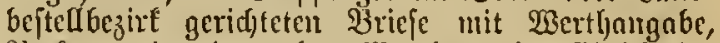
Finfete mit oder olyne werthangabe, (Einfdireib= pacfete und \$oftambeifungen nebjt ben doju ge= börigen Beloheträgen;

3. die Giorto= uni Bebulfrenbetröge fiir Bejorgungen an empfänger im Drţ= oder Sandbejtellbejint be Thijgabe=93oitorts;

4. Dne Girbeitelfgelo;

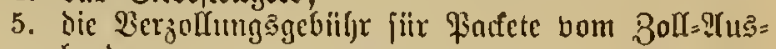
lanile;

6. Die fïr bringende \$indetiendungen bei der Ein= lieferung zu ertyebende befonbere (bebiihr;

7. Dic fiir (Einj() reibjendungen, forvic für getoöhntid)e Bacfetfendungen, weld)e nuÉcrhalb der Dienjtftunden angetommer swerien, im Borals zll entridftende. bejondere (Sebiitgr.

A2t. 14. IInter Bselojenoungen in Simme diejes Regu=

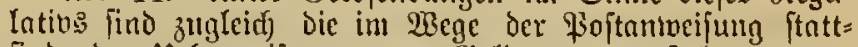
findenien lleberweijungen won Geldern $j^{n t}$ verifeben.

Bei Softanbeifmgen mo bei Begleitnoreffen jul Pacfet=

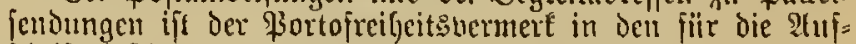
fdrift beftimmten Pinum ju fetzen, unter Beidriidumg cines das amtlidje Siegel vertretenden (antbigen Stempels.1) Sin frmangelung eines eigenen Dienrfítempel\& hat der 2 bjender mter Dem \$ort ofreiheitsucrmerk Die "Ermangelung cines

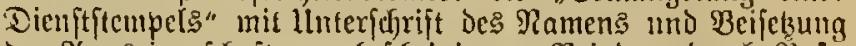

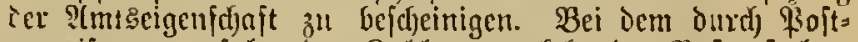

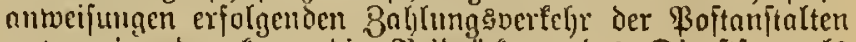

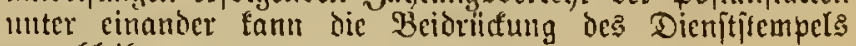
uuterbleibeu.

1) श\{ud) Siegelmarter bürfen vermendet weroen.

Irt. 15. Bei jeder Sendung, für reldfe bie portofreie Seförderung in 2(nifpruch genommen soirb, ijt ju priffen:

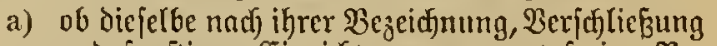
und fonftigen (Einridfung jur portofreien $\mathfrak{B} e=$ förderung geeignet ift.

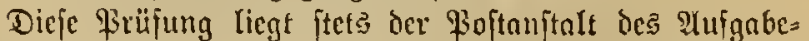
orts 06 . Findet fith ein Mangel in dicjer äußzeren $\mathfrak{B} e=$

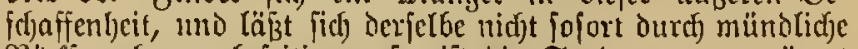
Rivicfpradfe zc. Gejeitigen, fo ift die Eendung unvergögert nlizufenden, jedod) ale portopflidflig zu beljandelir, mid der (Grund hiervon allf Der Borderfeite der Sendurg zu

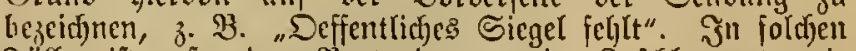

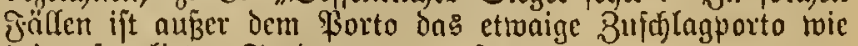
bei unfrantirten Senoungen allujueken.

C.: ift ferner zu priffen:

b) ob dem 9GGender oder (Empjänger ßortopreibeit ïberbalipt juitelyt, und of die Sendung nach 
ilyem (Begenftand (als Bricf=, Bacfet=, Beld=

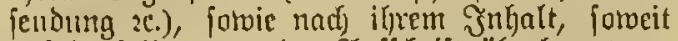
auf benfelben ans der Pluffjrift ilberhaupt ge= fálofien merden Eam, zur portofieien BBeförte: rung gecignet ift.

Diefe Brilfung liegt derienigen Poftamitnlt ob, it deren Bezirt Die zur qortofreifeit heredftigte Beljörde 2e. ifhrent

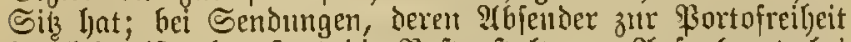
bereditigt ift, lont [tets die Boftanftalt am ?lufgabeart, bei

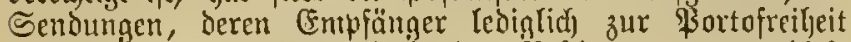

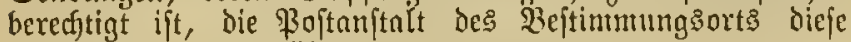
Sriifung (zu b) zul iiben.

Ergeben ficf) bei dicjer \$rüfung (zแ b) begrünoete

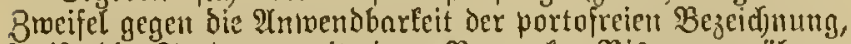
io ift bie Sendung mit bem $\mathfrak{B e r m e r f}$ "Biß zur nöheren Begrïndung der qortojteiljeit" zn berjeljen und, wie zll a angegeben, nls portopflichtig zu behandeln. Damit die $B \varepsilon=$ hörben tmo nutdere Betheiligte nidjt unnöthig beln̈ftigt merden, haben Die Borfteljer der 30 ftanftalten darauf zll

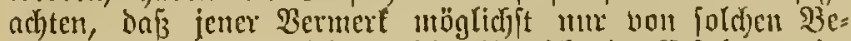

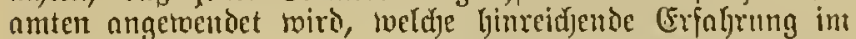
Dienjt bejizen und mit den örtlictien mo 2ierfonalverbïlt= niffen ansereidjend betannt finto.

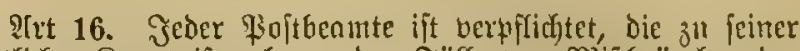

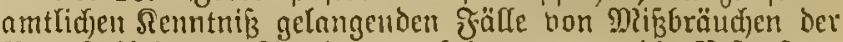
Bortofreihcit 3ur 21uzeige zu bringen, um die Beftrafung

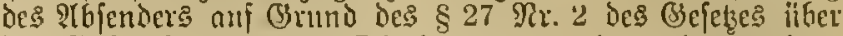
do 3 Gioftwejen vom 28. Detober 1871 und bortommenden= fafle die disziplinarifd)e Rïhge gegen die betreffenden ?: $6=$ fender jull ermögrict)en.

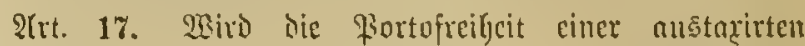
厄entung

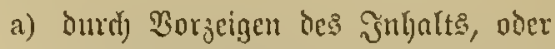

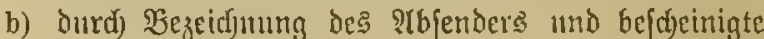
?Ingabe des Jnhalts nuf dem Briefumfdilnge, oner

c) in fonft glaubliafter Wacife

nachtrn̈glid) Dargethan, jo twird bas von dem Empjänger ertobene 93orto demfelben erftattet. Bei Brieffendungen exiolgt dieje Eritattung mur gegen Riüdgabe des Brief:

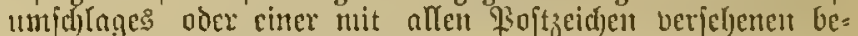
glatbigten ?tbfd)rift beffelber.

Der Briefumidjlag oder bie heglnubigte Ifbidjrift dess

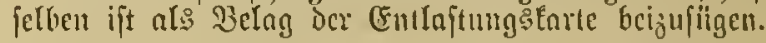

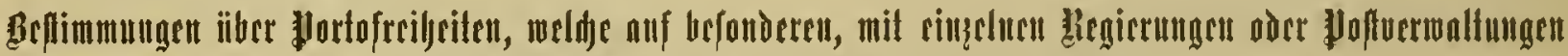

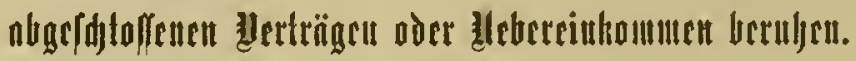

Bortofreithum in \$oftbienft = ?lngelegentgeiten.

§ 1. Der nuf ben Foptoienft bezünlidje, ztwifden den

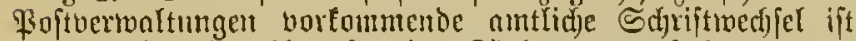
im Berlefre mit alfen frember Ë̈ndern portofrei.

2(ufiscrdem werden portofrei beförocrt:

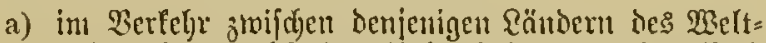
poftbersins, ineldje Dem llebereinfommen, betreffend

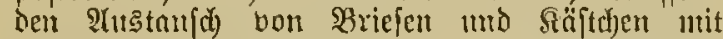
Werthangabe, beigetreten find: Die all den Fojt= dientit begïglichen Briefe zc. mit Werthangabe, meldje die qioftbertualtungen unter firf) austould (d) ;

b) im 2ertefr zlvifă)en Denjenigen Rändern bes Wett= poftuereins, weld)e dem llebereintonmen, betreffent ben Poftammeifungsbient, beigetrcten find: die anf

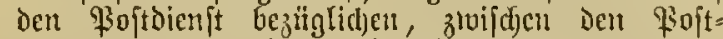
vertwaltungen vorfommenten qoftanveifungen;

c) im Berfehr zrvifichen benjenigen \&ändern deg Welt= poftuereine, weldye dem liebercintommen, betreffeno ben Poftbezug bou Beitungen und Beitfdififten, beigetreten find: Die \$Boftnntweifungen, mittel's weldher bie Y(brectumugen ïber Beitungagelder be= ridjtigt tocrien.

Sortofreitlum in Bortuereins fadjer.

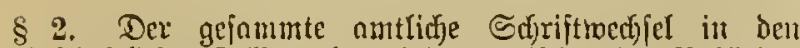
gemeinf(haftlidjen Bollangelegenl)eiten zuifden den Beljörden und Beamten der Bereinsitanten twird im ganzen llmfange

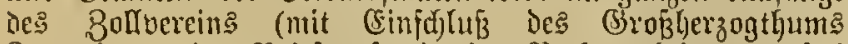

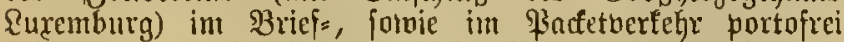
befördert; zur Begrïndung biefer Fortofreiljeit milffen die Sendungen mit ber áuferen Bezeid) "Bung "Bolvereinsfad)e" berfeben metbert.

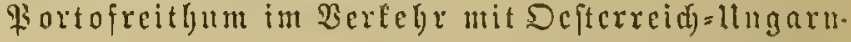

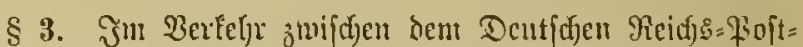
gebiete mind Defteresd) =llngarn lucrocu portofrei befärdert:

1. der Sefriftwedjel zwifden ien Mritgliedern der

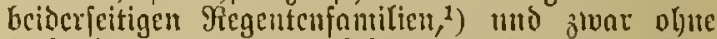
Bejedränfung nuf ein Gejtimmtes (Betwidjt. Den Milgliedern der Regentenfantien merien in Bezug auf die Fortofreigeit fïr Brieffendungen die MRit=

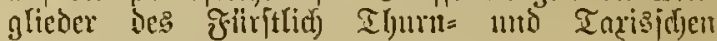
Seanles gleidigefiellt.

Bezuiglidy bex Fortopreibeit für Foftanneifungen, Po[mad)nahmebriefe, WBerthbriefe und Patete der Mitglieder oer Regentenfamilien berbleibt es bi Dett bisherigen Grundjätzen. Dafielhe gilt hezling = lidj ber \$portofreiheit fiit berartige Sentungen Der

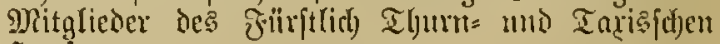
Sanies:

2. Der Selniftmed) [el in Loftoienft= uto in Telegraphen= bien[t=? ngelegenl]eiten;

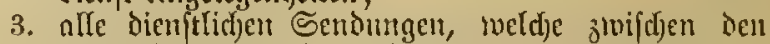
Poftbefjöben und Poptanftalten muter cirander bortommen.

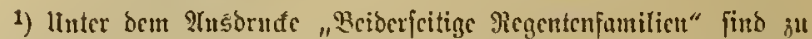

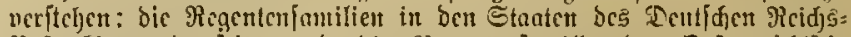

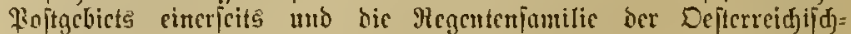
lungarifdocu Minnardjic antoererfeits.

Portofreitym im Berfely mit Der Sdjueij.

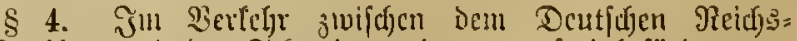
Projtgebiete und ber Sofluei merden portofrei befürdert:

1. Die Sd)riften= und Ilftenpadete in reiren Stants: bienjt=2(rigelegent)eiten zwijd)en Den beiberjeitigen Staatsbehörden; 
2. alle Sendungen, meldje zrijdjen ben beiderfeitigen Boftbeförden uno gioftenftalten im dienftlichen 2ertelyt vottommen.

Bortofreithum im Berfelr mit Ruxemburg.

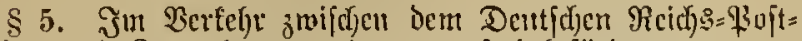
grbicte und Ruremburg iverien portofrei beförbert:

1. Die in ben $\$ \$ 1$ mo 2 Gezciduncten Sendungen;

2. Parfete mit und olne Wertjangabe in Fopitdenfit= ?Ingelegentyeiten.
\$ 6. Cotweit nid)t vorftefend bezügrid) ber äuf̧eren Bejefaffenlyeit der Sendungen bejondere Bejtimmungen ge. troffen find, fommen fït diejenigen Sendungen, melche aus?

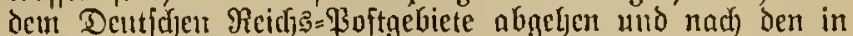
ber gegenvättigen $2(n l a g e$ A bezeid)neten Staaten gerid)tet fino, die Sorfdriften in शlat. 1 und 2 zur Anvendung;

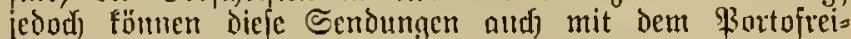

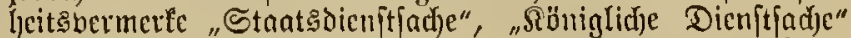

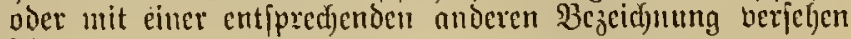
jeilt.

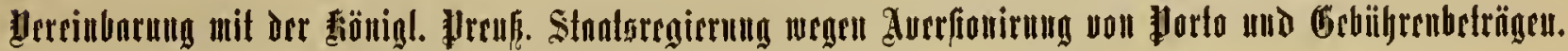

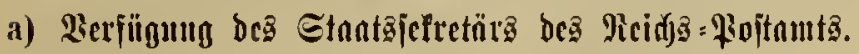

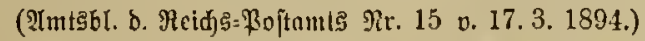

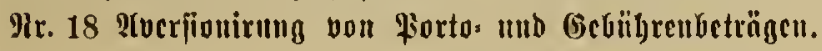

\section{Berliti, 15. Märg 1894.}

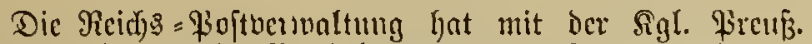
Statêtegierung eine Bercintharumg megen ?t berfionirung inct \$orto 2c. Beträge fïr dicjenigen Sendurgen getrojïn, weldie bou den Sönigl. Preng. Stantsberörten

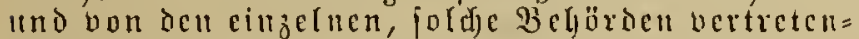
den Beamen franfirt akgefande rerben. Diefe Der=

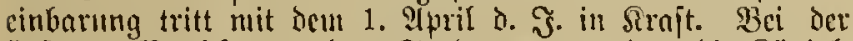
äıberen Bezeid)nung ber Sendungen werten dic Sïnigl. Freuf. Beljörden und Benuten vou bem ermäbnten Beit=

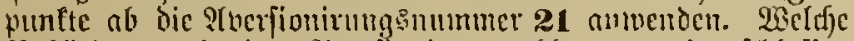

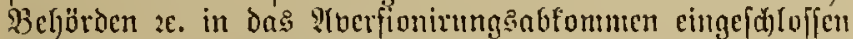
find, with den Goftniftalten bon ien burgefesten Socr= qioftbireflionen mitgetheift merden.

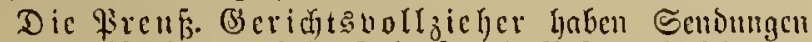

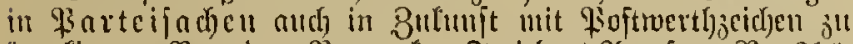

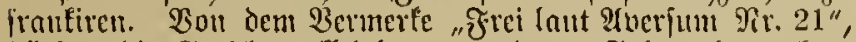

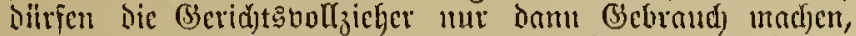

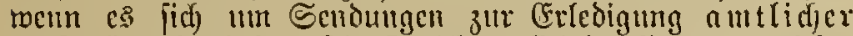

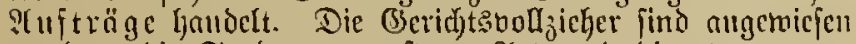
worben, die Sendminen criterer Art nub bie etwa zuge=

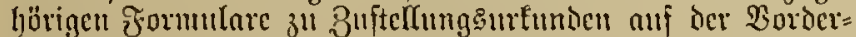

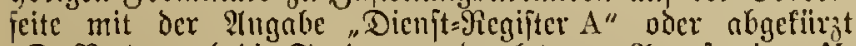

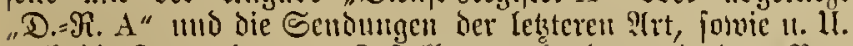

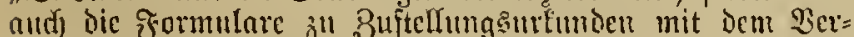

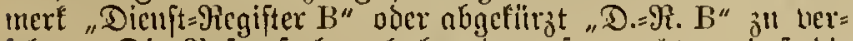

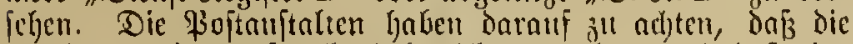
Sendungen dementipred)end bezcid)net iverdon, und baf cine

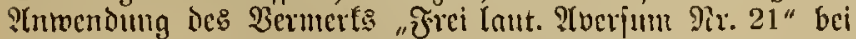
ien Sendungen in Fatteifad)en nicht ftattfinbet.

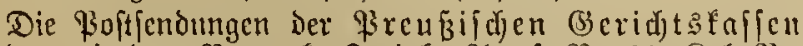

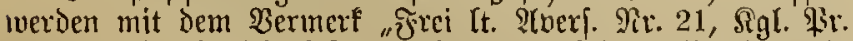
Sintsgerid)t. Seridjtafoftenerbebung" berjeben. Bci derntig

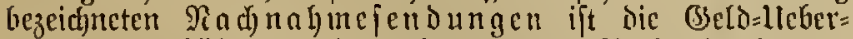
mittelutngsgebiihte von bem eingezogenen Radjunfunebetrage

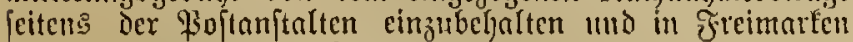

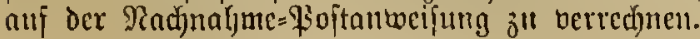

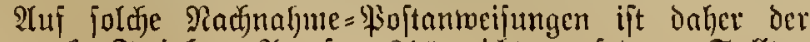
Bermerf "Frrei laut Ifberfun 21" nidbt "z" jeken. Sollten ben (Seridhtatajien gleid)woljl inthjimlid) die eingezogencu Radjnabmen zunt bollen Betrage zugehen, jo werben bie nidjt

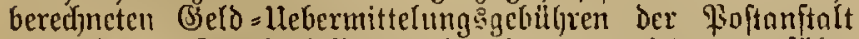

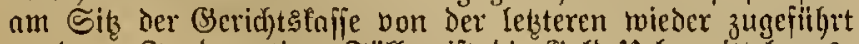
werben. Fn Derartigen Fällen ift bie GelD=llebernittelungs=

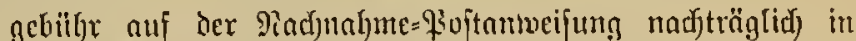
Frtimtaten ju vertedjucti.

Die Sontrolle Daritber, don bie Rachntyme = Foft

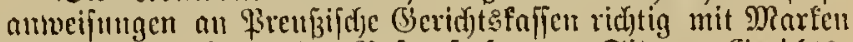
franfirt find, ift von ben gioftanftalten au Sik bon (Beridgt: Eaffet umd bon den \$Bezirforechnumgsftelfen fiir \$oft= anuveifungen ansิzulitbeur.

Went Prenfifide $\mathfrak{B e f j o ̈ r d e n ~ n a d ) ~ d e m ~ 1 . ~ T l p r i l ~ b e i ~ i e n ~}$ Foftanftalten Den lluntaufd) der eribrigten Fojtwocrtyzeidjen gegel banres Gelo beantranen, jo ift dicjen Dicrlangen $j^{11}$ enjpredjen. Dic Bojtanftalten haben dic umgetaufdenten

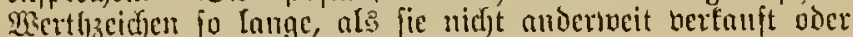
zur frantirumg bon fopticusungen bermendet find, als bante Gielo j" jiilfren.

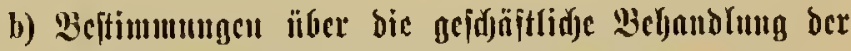 Softicnoungen in Etantäbienit:?(ngelegenfycitcu.

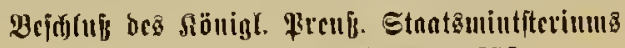 voll 7. Februar 1894. 厄ty. 358.}

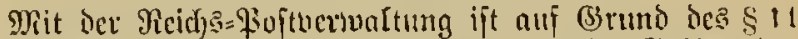
des Befeckes, betreffeno dic Furtofreifeiten im (Bebiete de:

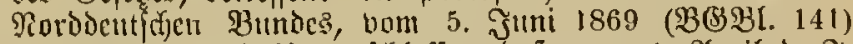
ein s(bfomuen bnljin gejd) ab all Stelle der Fiorto= und bejieljungsincife (Bebïlbrenbe= tröge für die cinzelnen fronfirt abzuldjiffenden portopflick tigen Sentumgen der Röniglidyen Bełjörden und ber einzelı

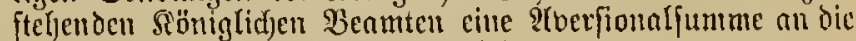

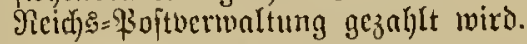

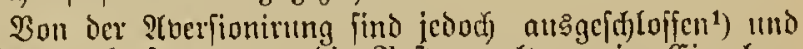
baher andf ferner au bie \$ojtoerwaltumg im Cinjeluen

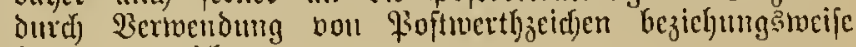
bant z" entricften:

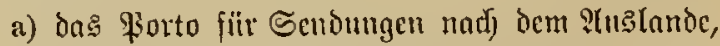

b) Das \$orto für Sendungen, weldje bei den $\mathfrak{B} e$, börden unfranfirt eingeben,

c) Dic Bebiilyr jiit Beftelfung der Sricie mit Werthangabe, Bacfete mit oder oljue Werthan= gahe, Cinfor reibpadete und Foftnurveifungen nebit den baju geljörigen Biclobeträgen,

d) ১กริ (Eilbcitcllgelo,

e) bic Rebengebülyr für bic bou bem Rnubbrief: träger eingejanmelten, zur Weiterjendung mit der Boft bejtinunten Ssegenftände, wenn dic senoung ferbit, nuf welhe ïberhaupt biefe (Sebiil) 2 (nwendung findet, "unfranfirt abge= fanit werden joll, 
f) die Poftanmeifung gigcbilfr fïr bie llebermitte= lumg ter nuf quitautragsiendungen cinge $j^{0}=$ genen who dem ?tuptraggeber ju Hiberjententom Bctrüge.

?!n Stclfe ies Requlatios des Sïniglichen Stant: minifteriuns bom 28. Fovember 1869 treten mun fïr dic

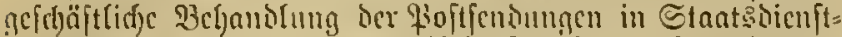

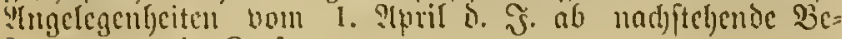
ftinumungen in Sroft.

\section{ग) Ju bic Iocrfiouiruแg find ciubezogen:}

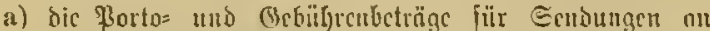
Empjänger im Drts: oser Saubleftellumgsbegirl ocr II ufgabc= Poitanjtait;

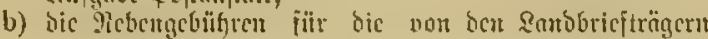

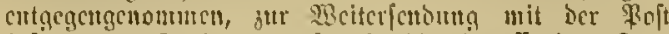

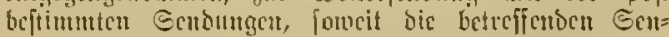

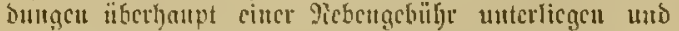
bis sum Bcitimumutgert fratirt merben folfen;

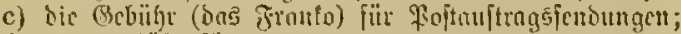

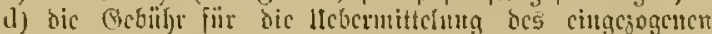
Mandyutumenctrngcs;

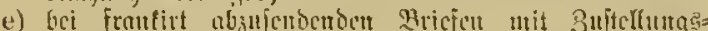

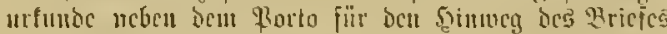

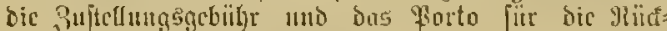

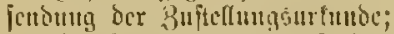

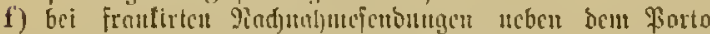

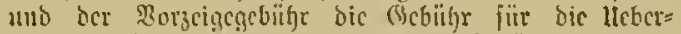
mittctung bor riugezogencn शiod)nuflutuctreträge.

\$1. Frantirt abjufdidfen find alle Fioftienomigen ${ }^{3}$,

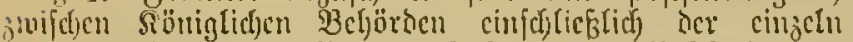

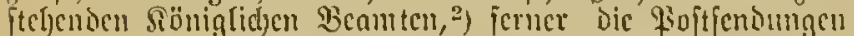
an andore Empjänger, wem bicjelben entmeder:

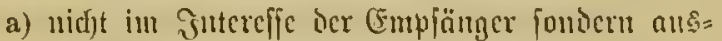

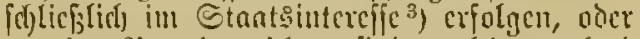

b) an cinc Partci neridstet finto, welde nach ben Gisferigen 3orfdyriften auf portofreic Buftellung cimell Fiechtsinnipruct) hat, ober

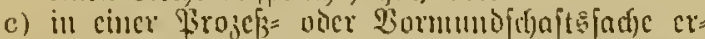

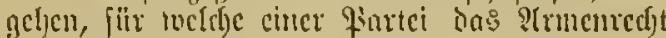
bevilfingt ift.

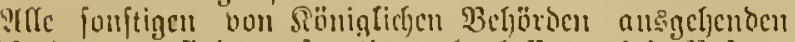
fioffendungen fino minrantint abjulaficn; bei Pojtan=

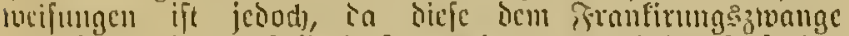

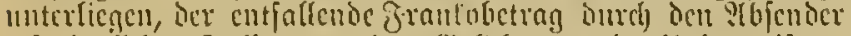
exforberliefen Jafles non bem (Selibetrage der lleberjucijung burmen $\mathrm{ab}_{3} \mathrm{j}_{3} \mathrm{ieg}$ en.

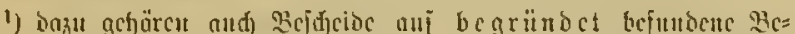

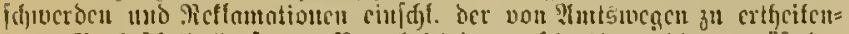

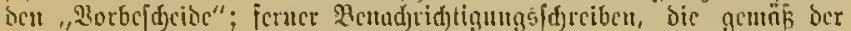

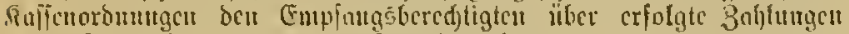
int Zioftanmci[ung

2) natd wenn fic fid auf Dicuptecifen ober auf Urfaub befiubon.

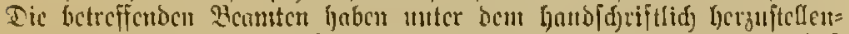

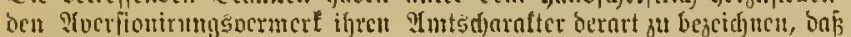

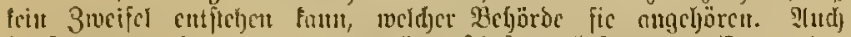

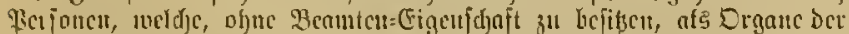

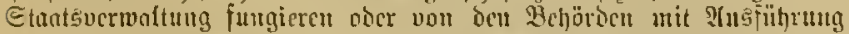

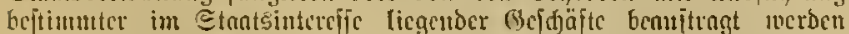
(Fingefbcobod)ter ber Etrombauncruattungen, Bcobod)tes fïr bns metco=

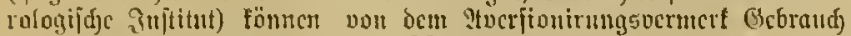

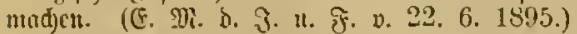

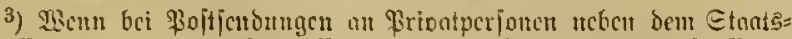

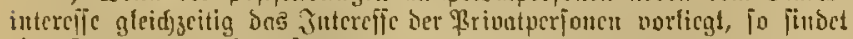
cine frtmatirumy nid)t ftott.

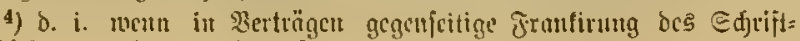
wed) fels vereinbart worben iji.
§ 2. (1) Die franfirt abjujidjefenden Sendungen, jorveit fie ber stoerfionirung unterliegcu, find

1. mit Den Vermetf ,frei Inut ?(berfum $2 \mathrm{k}$. $2 \mathrm{l}^{\prime \prime}$,

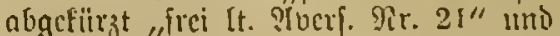

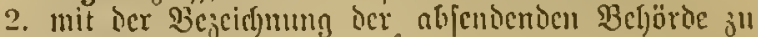
berfeljen.

(2) Der unter I hejeirfuncte Berumert ift anj bic Borderjeite

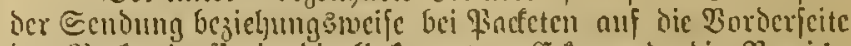
ber findetnoreffe in bic linfe untere (Fife, uno bie $B c_{j}$ cidl)= mung der abjendenden Befjörbe umittelbar unterfjalb dicfes Vermerts ju fekzen.

(3) Slu[serdem mitifen fidj dic Senhungen durd) den $\mathfrak{B c r}=$ ichlnE mittel: bes Dienfficgets oder Dienjtftempels oder mittels Siegelmarten der abiendenden Beljörde im Einjeluen als zur umentgettidjen Befb̈rberung gecignet ersweifen. Sen= Dumgen, meldje offen zux Einficicrumg gelangen, z. B. q30 0

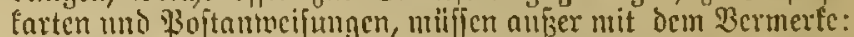

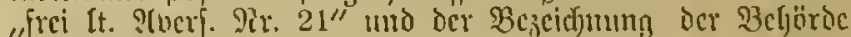

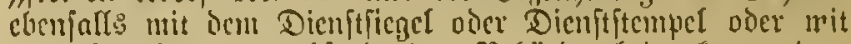

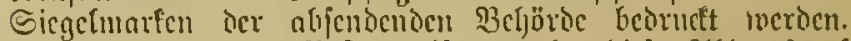

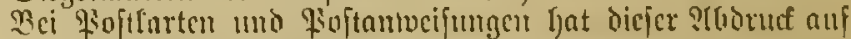

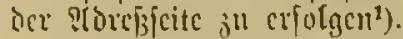

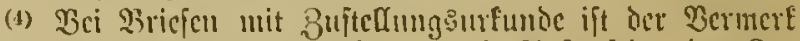

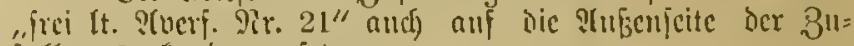
ftellunģ

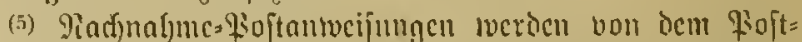
benuten, weld)er dicfellyen nusfertigt, in ber finfen unteren

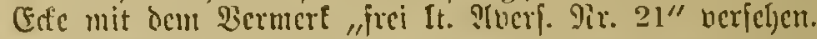

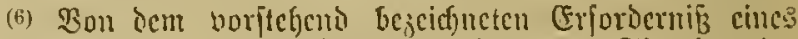
Dienftiegets oder Dienftitempels oier bon Sicgetmarten

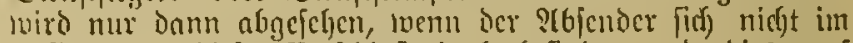

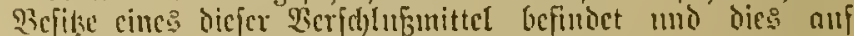

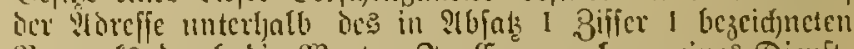

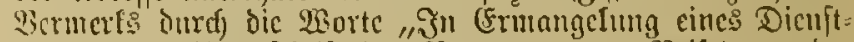

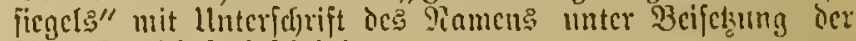
?(nut:igenjajajt bejderinigt.

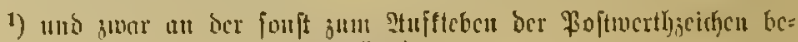
firmutert Etcilc (bic redste obcte (Eds).

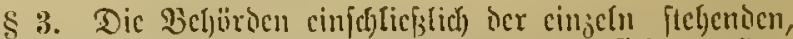

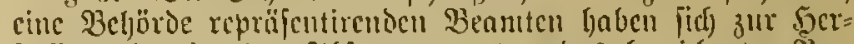

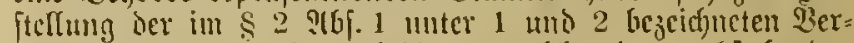
merfe eines Stempels jub bebienen, Imeldyer ber nadjitefjenden Form cottpridst:

$$
\begin{aligned}
& \text { Jrci It. Procrf. Pir. } 21 . \\
& \text { Sigl. Fir. Intsgeridgt. }
\end{aligned}
$$

Dic STngabe ocs Srtg, an meldyent dic Befjörte iffen Silz loat, iff in icm Stempel nid)t erforberlid).

Der Stempel ift in einer gegen unbefugten Bebroud) fichemben Weijc anjabewahren.

(Eiujeln fichende nidst im Befibe cincs Stempels befindfidje

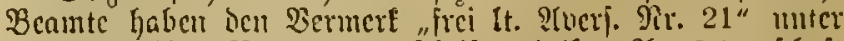

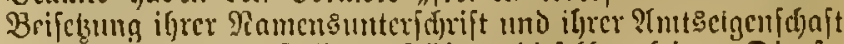

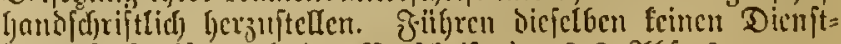

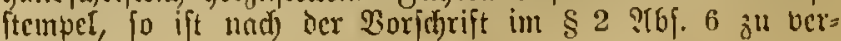
faljren.

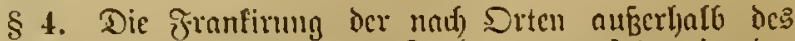
Deutichen Ticidjs bejtinmten Sentungen erfolgt in ocr bisherigen Meife Ourd) Fiontinun! Des Portos und ber fonftigen \$oftgebiil)ren. 
Die hejeiffuten Eenoungen merden bou ber abfrifendeu

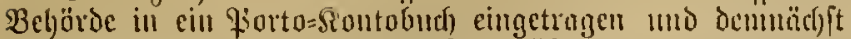

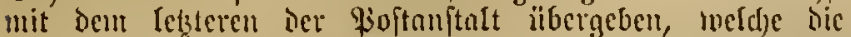

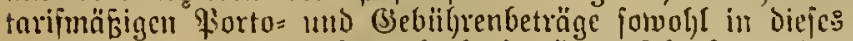

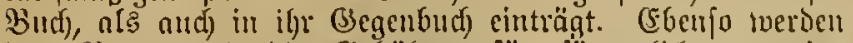
Dn: Yorto uno die (Bscbiil)ren für fämmtlid)e an cine Siöniglid)e Befjörde geridflete Semoumgen, Jveldje unfranfirt eingehen, bei Der slusticjerung Ecitcus der Fioftanftalten in Den bezeicfneten Bïb)ern fontirt.

Sflmonatlid) merien bie fontirten Befanmtbetrïge von Den SBeljörden an Die Foltanftalten gegen Suitumg in Srontobu(f) gezal)(t.

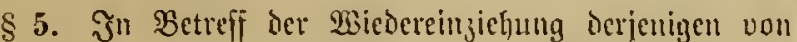

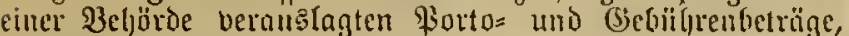
zu beren Grftattung ber 2lbjenter oder ber Empfänger einer Eendung oder ein jonjtiger ฐntereffent verpflidstet iit, bemendet es bei den bejtebenden Worffyriften. ?:und fernerhin

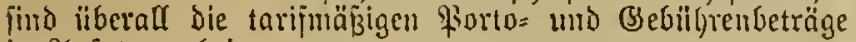
in ? ?n:alz zu bringen.

§6. Dic nad) § 1 mmfraufirt afinlafienten porto= pilichtigen Sendurgen fino auf ber ?toreffe als "porto= pifichtige Dienftfache" zul bejeithnen und mit bem Dienjt= fiegel der abjeridenden $3 e$ jörbe ju berfefen.'

(sinzeln jteljendc Beamte, weld)e ein jold)es nidht fül)ren, haben unter Dem Bermert "portopilidytige Dimffacte" Die "Ermangetumg eines Dienftitegets" mit lluterid)rijt des

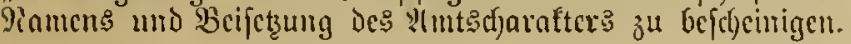

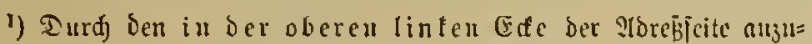

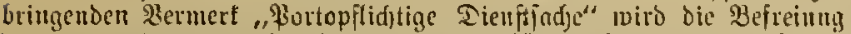
ber portopflidgtigen Briefe von beu fiir unfratirts Driefe ju

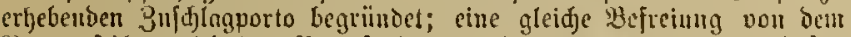

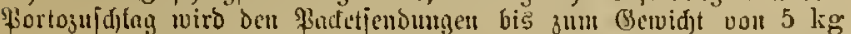

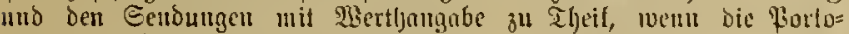

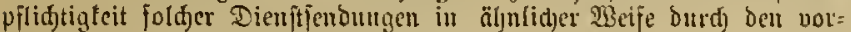

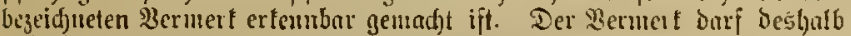
alf den unfrantirt abjulaffenden Rojtienoungen nid)t weggelnfien werber.

Eenoungen an Privatperjunen, die bas \$orto jur Jranfiumy etwa vorber eingefand haber, find unter Berwentung bes cingejdidten Portobetrages nit bem Bernuetf "Portopilidige Dienfijade, frei" zu ocricher.

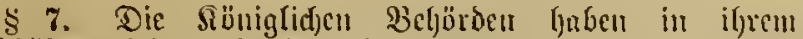

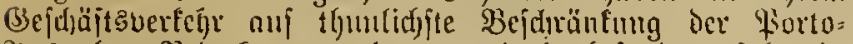
2usgaben Bedatht ju mel)men und insfofoniere folgende Bçtimmungen forgfältig zu bead)ten:

1. Solfen mehrere Briefe gleichseitig an einc storeffe abgefant tocroen, fo find diejetben in ein gemcin= idjajtlid)es (Souvert ä verjid) fießsen.

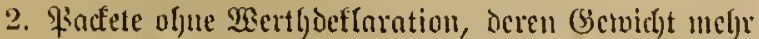

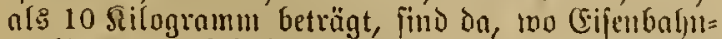
verbindungen beftelgen, jomeit es ofne unverljältuifs= mäß̧ige $\mathfrak{B e r z o ̈ g e r u n g ~ i l j r e r ~ B e j o ̈ r d e r u n g ~ o d e r ~ c i n e n ~}$

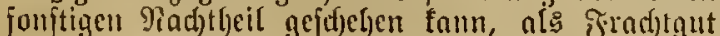
mit ber Eifenbalyn z" verfenden. Dagegen fint

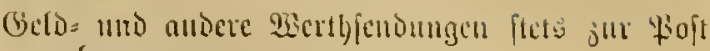
j"ll gcben.

3. 3" Den Fieinid)riften Der Berj̈̈gungen an firivat=

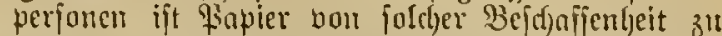

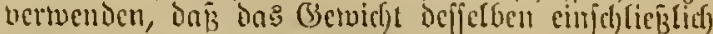

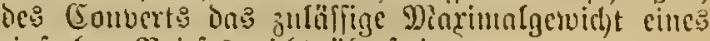
eimfacher Bricjes nicht ziberjteigt.

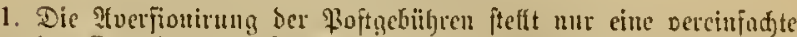
Form ber Entridjung bicjer (Sebül)ren Dar, unb bie Söhe ber von

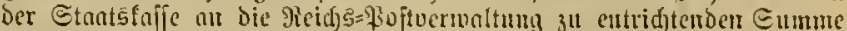

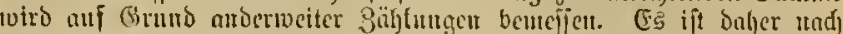

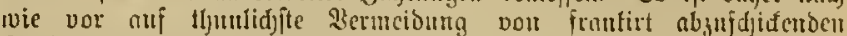
Echoungen und nuf भुbfendung in einer mit thunlifift geriugan (3)bülyren belnfteten Jorm Bebadjt jut uehnten.

Die Briefform ijt bei Eendungen bis ju $250 \mathrm{~g}$ ber Pufetiorm vorgujiebeu.

\$ 8. Die Berredmung ber nidft averïrten Barto= und

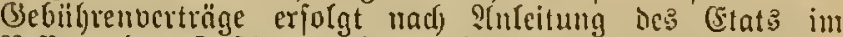

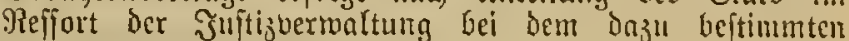

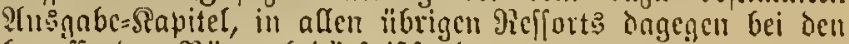
Getreficuben $\mathfrak{B}$ Ḧrenubbürinizionds.

Zeljörben uno cingeln ftelende 3 sante, meldje nidjt mit

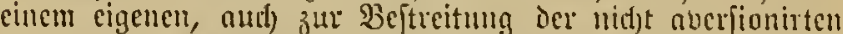
Porto = uns Gebül)renbeträge bcjtimmten Biirenubedintjnifs fonds verfeben fins, lyaben diefe ?tuzgaben zufammen mit Den etwaigen fonftigen Fractjtgebülyen fïr dienftlide

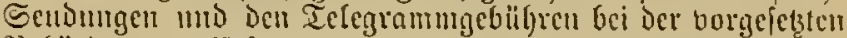

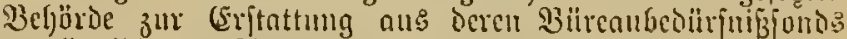
3u fiquibirer. ?tusgenommen find bic Epesialfommiffarc

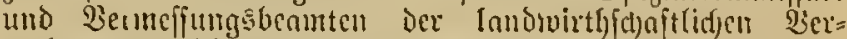
unaltung, weld)e bic ifmer mad) ber ?(verfionirung norf

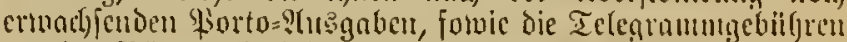

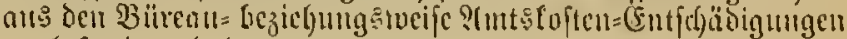
zll beftreiten haben.

\$9. Don cinzehen 9Minifterien blcibt borbchaflen, bic

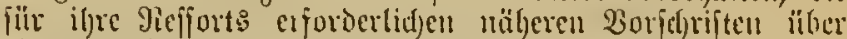
Dic 2 sfï̈lyrung Dicjer Bcftimmungen zu er'affer.

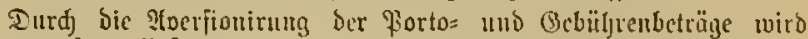

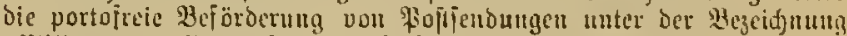

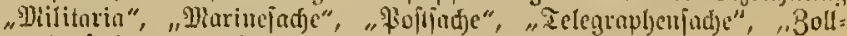

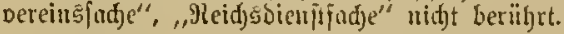

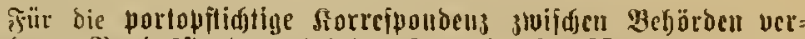

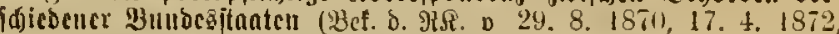
8. T. 1873 (9603t. 1870 514, 1872. 108, 1873. 232)- beş1.

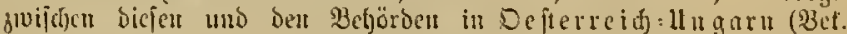

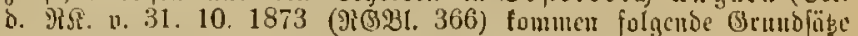
jur SIแuenoung:

1. Porlopflidjtige Embungen find flets von ber abfenbentent

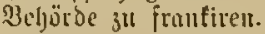

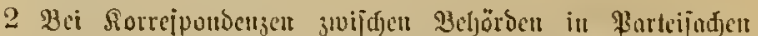
entridstet bie abjendende Etelle das glorto and in juldeu Fällu, in ucthen bie Pillidt jur \$ortojahlung ciner iu (3) cbiete bur empfangenden Ctelle befundidjen \$urtci obtiegt.

3. Die entufangende Etelle iff zuar befugt, ben Portobatrug

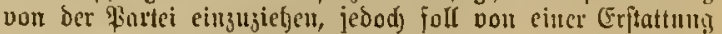
defiethen an bie abjenbende Behörde bes anbercu Etaatis bis auf gliteres शlbftand genommen mertent. 


\section{VI. Ëelegrapljenuelen.}

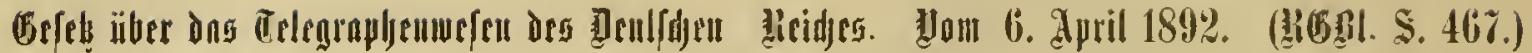

\$1. Das Recht, Telegraphen=?Infagen fïr die Ber= mittelumg von Pindjridjten zu erridjen und zn betreiben,

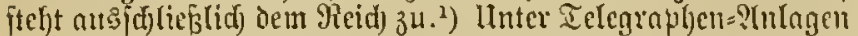
find bie Jernjprect) 2 gnlagen mit begriffen.

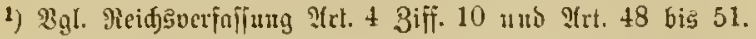

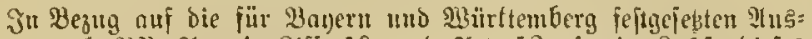

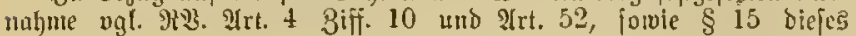
Gepertes.

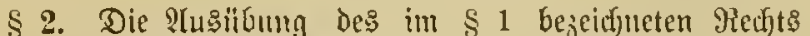

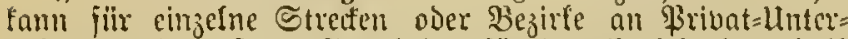
neluner uno muß an Gemeinden für den Berfely. inmerhalb bes Gemeindebezirf: verliefen merden, wem die nodjudjente (3enteinde die genügende Sichertjeit für einen ordnumgs=

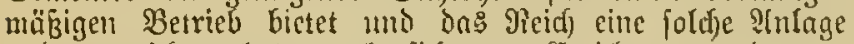
weder erridstet bat, nod) fid jur (Errid)tnng und jum Betriebe einer jold)en bereit erffärt.

Die Berteifung erfolgt Durd) den Reidsfongler ober bic non ifm hierzu ermäd)tigten Behörden.

Die Beoingungen Der SBerteifung find in Der $2 \mathrm{cr}=$ feif)แngšrftunde je|tzuftellen.

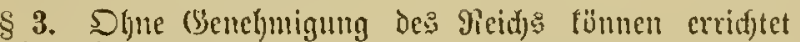
und betrieben neroen:

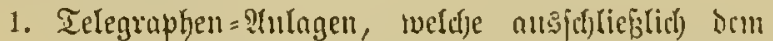
inneren Dienffe bon Randes= und Sommunalbe= ljörden, Deich)forporationen, Siel= und Enttwäjje= rungsherbönden getwidmet find;

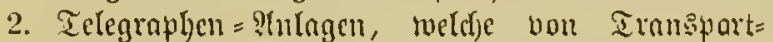

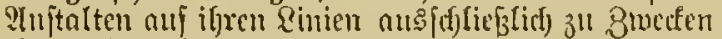
if)es Betriebes oder fïr die Bermittefung von gindjridjten imerbalb ber bisherigen Grenjen be= multz warden; ${ }^{1}$ )

3. Telegraplen=? Inlngen

a) innerhalb der Brenzen cintes Brunditilifs,

b) żvifhen mefjeren einell Befitzer geförigen Doer z"l cinem Betriche vereinigten (Stand= frürfen, deren feinc: bon bem anderen Hbet $25 \mathrm{~km}$ in Der Rufttinie entfunt ijt, menn Dieje

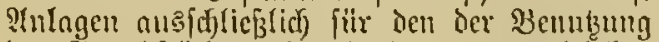

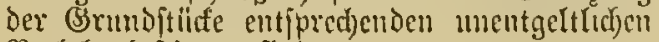
Verfehr bejtimmt find.

1) (Eijerbahn=Telegraphen.

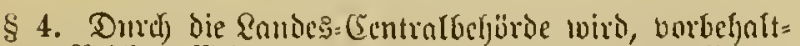

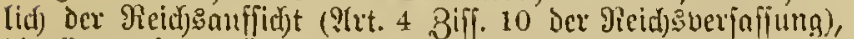

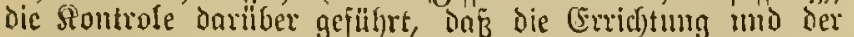
Betrieb der im $\$ 3$ bezeidfuncten Telegraplyen=?(nlngen ficf)

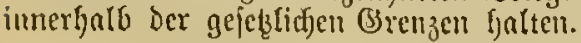

\$ 5. Tedcrmann bat gegen Bablung der (Sebullyren ons

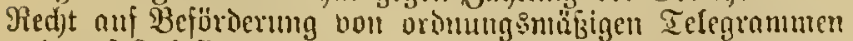

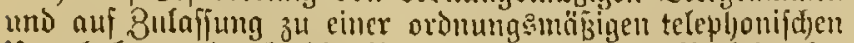

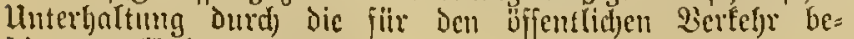
jtinumten Untagen.

Borrechte bei Der Benntzung Der Dent üffentididen Ber=

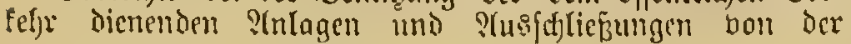

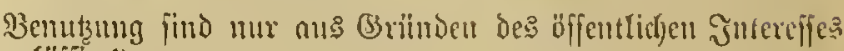
jufäfifig. $\left.{ }^{1}\right)$

1) Stuatš und Tetegraphen= Dicu[ttelegranme baben beftimutung

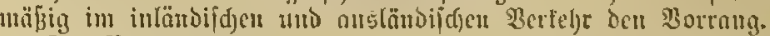

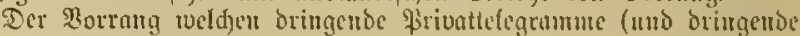

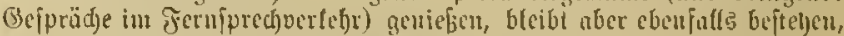

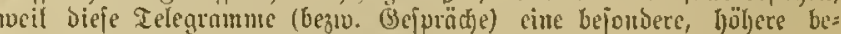

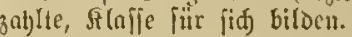

\$ 6. Sino an cinem Dite Telegraphentinien fïr den

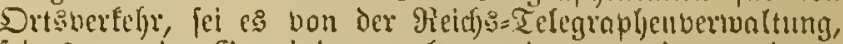
fei es bon der Gemeindeverwaltung oder bon einem andetell

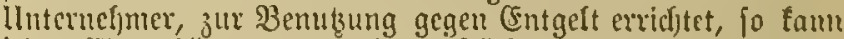

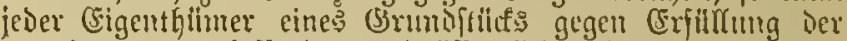

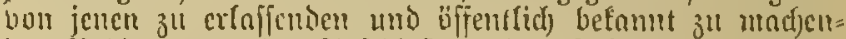

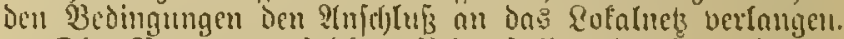

Die Bemutzung foldser \&riuntfteflen Durdi llnbefugte gegen Entgclt ijt mzuläffing.

\$ \%. Dic fïr bie Benutzung vou Rieid) = Telegraphen= und Femprect)=?(nlagen bejtefjenden (B) bithren Ëmmen nur

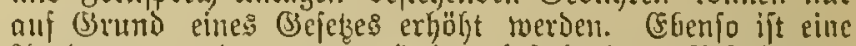
P(11sDelyumg der gegentoärtig bejtefenden Befreiungen un foldjen Bebullyren mu auf Brund eines Befckes zu= 【äffig. 1 )

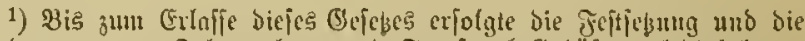

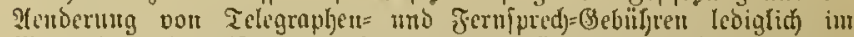

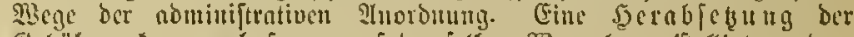

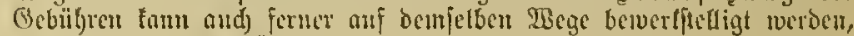
nher uidht eine Erljöbung.

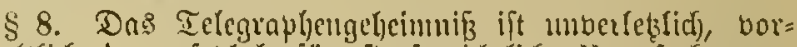
bef)n(tlid) Der gefetslid) fïr ftrofgeridstliche llnterfudjungen, im Sonfurje und in civifprojeffuntifdjen Jällen oder forff

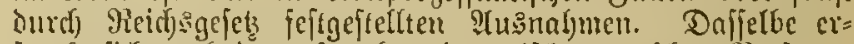

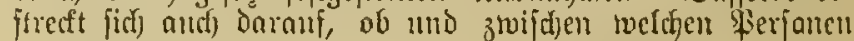

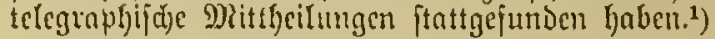

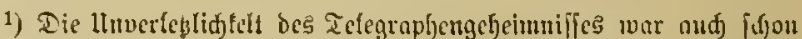

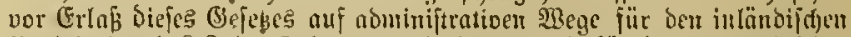

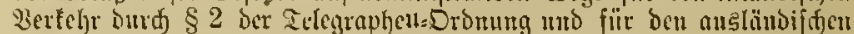

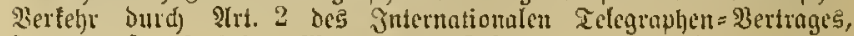

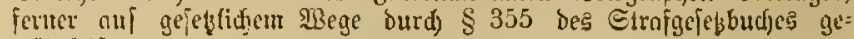
wäbrífiftet.

$\S \S 99$ uno 100 ber @trajprozésoromung jegent bie fälle ber zu=

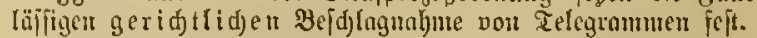

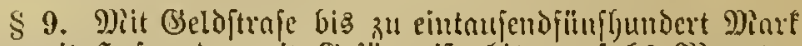

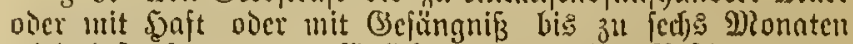
wiro bejtraft, wer borfäłzlicl) entgegen den Beftimmungen

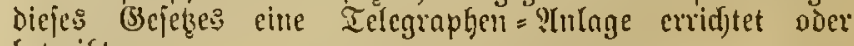
betreitit.

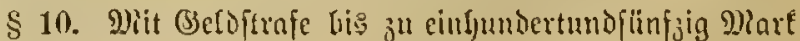
wiro bejtroft, mer Den in Siemäß̧hyeif des $\$ 4$ ertajfenen

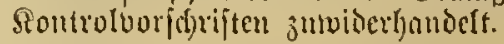

$\$ 11$. Die unbefugt etrid)teten oder betriebenen ?YnTagen find nufer Betrieb z"l fekell ober zll befcifigen. Dell 2 in =

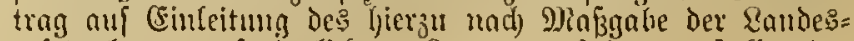
gefectgriung exforderlifjen Brangsberfalyrens ftelft der 


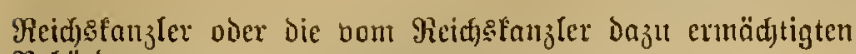
Beljördent.

Der Rechtsweg Gleibt vorbehalten.1)

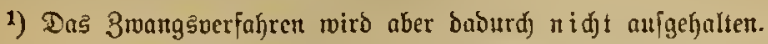

§ 12. EIfftrifde $\mathfrak{A}$ tnlagen find, menn eine Störung de: Betriebes ber eitten Reitung burch bic antere eingetreten ober zu Gefürdyten ift, nuf Sojten desjenigen Theiles, melder durch eine fpätere S(nlage ober ourd) eime fpäter cintretende Plenderung jeiner beftehenden 2 Inlage dieje Störung ober die Befahr dexjelben beranlaßjt, nad Möglidfeit fo aus=

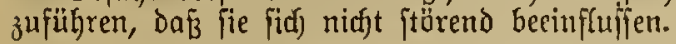

$\S 13$. Die all Brund ber vorftehenden Beftimmung ent= ftehenden Streitigfeiten gehören bor bie orbenttlicjen (seridfte.

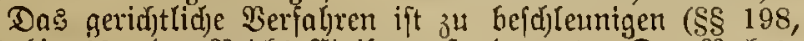

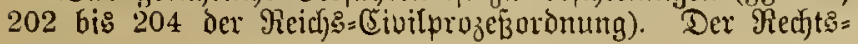

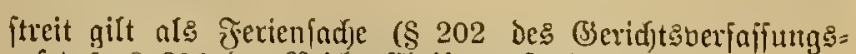
gefetzes, \$ 201 Der Reid)s=(Civilproze[zoromung).

§ 14. Das Reid) erlangt Durd) Diefes Bejes feine meitergehenden als die bisher bejteljenden Sniprithe anf bie Berfügung ïber fremben (Stunto mo Boben, insbefondere itber offentliche Wege und Straßenen.")

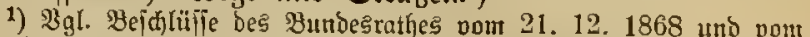
25. 6. 1869 über bie Berpfliðtungen ber Eiienbahnverwaltungen

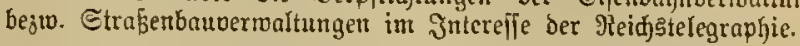

$\S 15$. Die Beftimmungen diefes Brefetzes gelten für Bayern und $\mathfrak{B}$ ürttemberg mit Der Maß̄gabe, daß̉ für ifre

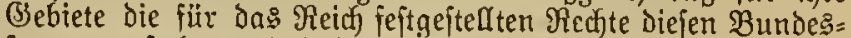
itaaten zuftehen und baj bie SBeftistmungen des \& 7 auf den inneren $\mathfrak{B}$ erfegr biefer $\mathfrak{B}$ undesftanten feime ?lntwendung finden.

Ut fundidf zc.

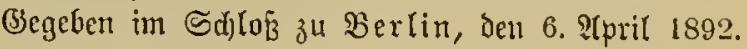

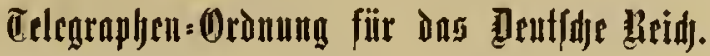

linterm 15. Suni 1891 ift vom Reidjsfonjler eine "Telegraphen = Drbmung für Das Deutiche Reidj" erlaffen wordell, weldje, ebenfo wie die Hojt=Sronung, als Bertrag zivifdjen der Poft \$ithlifum gilt, und die folgenden Э̌nhalt hat:
$\S$ 1. Benutzung Des Telegraphen.
$\S 2$. Wahrung des Telegraphen=(Seheimniffes.
$\S 3$. Dienftitunden Der Telegraphenanjtalten.
\$ 5. Eintheilung Der Telegramme.
$\S 7$. Nulgabe bon Ielegrammen.
$\S 8$. Wortzählung.
$\S$ 9. (Sebithren fiit gewöhnlidje Telegramme.
$\$ 10$. Dringende Telegramme.
$\S 11$. Bezablte Antwort.
$\$ 12$. Berglidjene Telegramme.
\$13. Empfangsanzeigen.
\$ 14. Telegraplifdje \$oftantwcijuttgell.
§ 15. Nadjfendung vou Telegrammen. 4. Srte, nad meld)en Telegramme geridjtet
merden fönmen.
$\S 16$. Servielfältigung bon Telegramuten.

$\$ 17$. Seetelegramme.

18. Weiterbeförderung.

$\S 19$. (Fntrid)tung Der (B) bïhren.

§ 20. Burüffiehung und Hnterdxiifung vou Teles grammen.

s 21. Buftellung der Telegranmte am $\mathfrak{B e f t i m m u n g : =}$ ort.

\$ 22. Unbeitellbare Telegramme.

§ 23. (5etwährleiftung.

\$ 24. Beridjtigungstelegrantme.

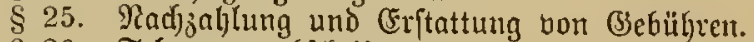

\$ 26. Tclegrammabidjriften.

$\$ 27$. Rebentelegraphen und befondere Telegraphen=

$\S 28$. Bieltungsbereid.

Mie die Poft = Drounug ift aud bie Telegraphen=Dronung unr infaltlid angeriifyt.

Die Telegraphen=Dromung nebft IItsfiührungsbeftimunurgen bildet

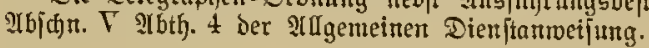

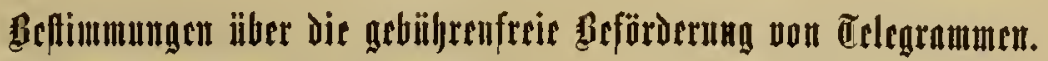

Die Bejtimmungen über die gebührenjreie Beförderung

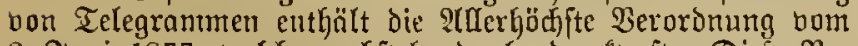
2. Suni 1877 , weldje nadfftelend abgedrucft ift. Dieje $\mathfrak{B} e=$ ftimmungen finden autl) auf biejenigen Telegramme gleid)=

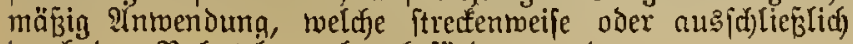
bur(f) Den Bahntelegraphen befördert werden.

\section{פerordutug}

betrefiend

bie gebührenfreic Beförbernag bon Telegramuten.

§ 1. UuI fänmutlidjen Telegraphentinien deş Deutidjen Reidjes genieżen die Bebührenfreigeit:

1. Telegramme, weldje bon den regierenden fölurfen in Den Staaten deE Dentfdfen Reidfes, forwie bon den (Sentahlinnen Itnd Wittmen diefer Füurfen aufgegeben merben. ${ }^{2}$ ) Dieje (Bsebithrenfreiljeit ex= itreeft fich aud auf bicjentigen Telegramme, welche im 2Luftrag Der genanuten श氏ferbödjiten und 5ूödjten Serridjaften bon Den $\mathfrak{B}$ eanten, ber $\mathfrak{U} m=$ gefung, bem Befolge oder Den \$ofitaaten zur Arujlieferung gelangen;

2. Telegramme, tweldje von Den Bevollmädjtigten zum Bundešrath twährend ifrer Answefenteit in Berlin in Bundesratbis=? Ingelegenheiten aufgegeben merben, vider weld)e an bieje Bevolmähtigten aus anderen Drten Des Deutfichen Reiffes in Bundesrath: Ingelegenheiten eingehen;

3. Telegramme von bem Reidjstage und an denfelben in reinen Reidf)

4. Telegranme von oder an Reidsbehörden in reinen Reictsbienft=21ngelegenlyeiten;2)

5. Telegramme yon oder an Militär $=$ und Marine=

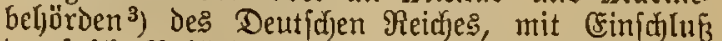
bex foldje Befjörden vertretenden einzelnen Dffiziere und Beamten, in reinen $\mathfrak{M}$ ilitär $=$ und $\mathfrak{M}$ arine $=$ Dienft 
Stngelegenheiten; im f̧all einer Miobilmachung aud bicjenigen Telegramme, weldje bon cinzelnen mit

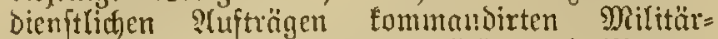
berionen ober Beamten Der Militär $=$ und Marine: berwaltung des Deutidjen gietches in reinen

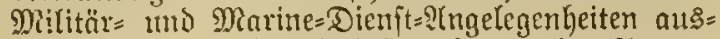
gehen oder ant foldhe Militärperfonen oder Beamte gerict)tet find;

6. Telegramme der Cijenbalynnerthalturgen, Eijenbahn= itationen und Cifenbahnbeamte an vorgeletzte $\mathfrak{B} C=$ hörden über vorgefommene lunglüdsfä̆le und Betriebsfttörungen.

Welche Telegramme der Etjenbahnuermal= tungen $2 c$. auferdem gebührenfrei zu befördern find, ift burch befondere Bereinbarungen feftgefest.

1) Die non Sc. Saijerlidjen und Röntalidjen Sohcit bent Sratt= prinzen bes Deutfon Reidfes ausachenden Delegramme genicken auf

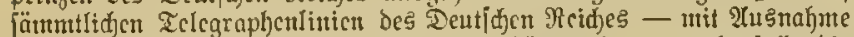

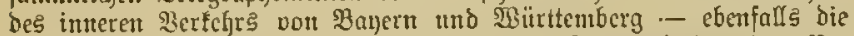

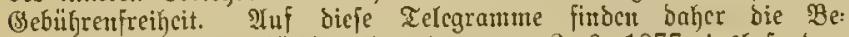

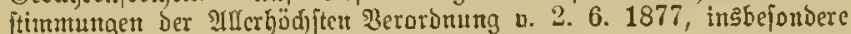
$\S 1$ Ir. 1 und $\S 4$, entiprechende IItuentoung.

2) Die an গ̂l ben Baft = und Den Meidsbantanftalten Dorfammenden Telcgramme iind acbiifyenfrei.

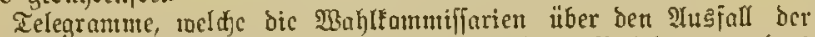

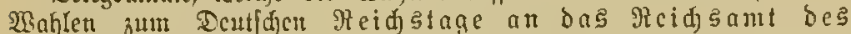
Inncrn riđten, geniçan bie Bebihgrenfreiheit, Dagegen find bie

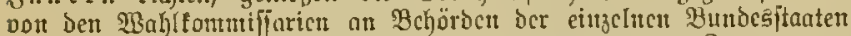

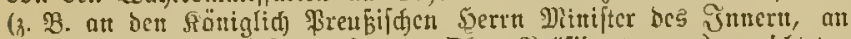

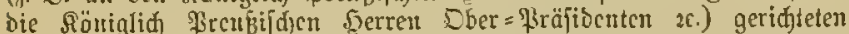

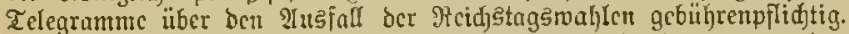
Ebenjo untcrlicgen bicjeniger Telcgranme, mittels deren von ben

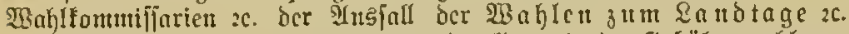
cinc $5 \mathfrak{B}$ u

3) $3 \mathfrak{3}$ bicfen Behöroen gchören and) dic (Eivilvarfigenden ber Erjaţ⿻上丨miffionen.

§ 2. Die Bebillyrenfreiljeit Der Telegramme erftrectt ficf) nur auf die Telegrobhirunggెgebüfren, nidyt aber auf die baaren 2 ttölagen für 2 eiterbeförberung über die Tele graphenlinien Ginaus.

Die baaren 2(ušlagen find vielmehr nad) den betreffen= den veroronungämäfigen Beftimmungel entweder von den aufgebenien qerfotten umo Bebärden oder von den (Empfängern jut entrich)teut.

Staottelegramme geniegen Die (B)ebührenjreifgeit nidft.

Gebilfrenfreikeiten, welde auf den mit dem शluslande

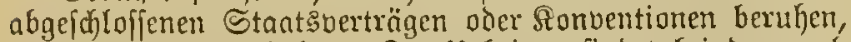

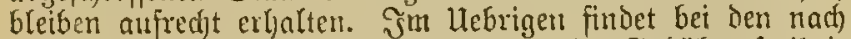
dem P(uslande gerichteten Telegrantmen eine (Sebührenfreiheit fïr bie Beförderungsftrecfe innerhalb des Deutichen Feiches

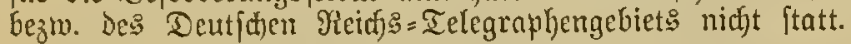

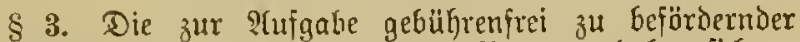
Telegranume befugten Befjörden und Beauten haben fith zu ibrer amtlicfen Siorrefpondens nur in Det ividytigiten und Dringendften Füllen Der Telegraphen zul bedienen und die Telegramme in georängtefter Ritrze mit Dermeibung aller entbegr (ichen Titulaturen $2 \varepsilon$. a $b_{3} u f a j e n$.

\$ 4. Bur 9fnerfenum der Bebübrenireibeit durch bie Telegraphennuftalten ift erforderlich, dä bie Telegramme

a) mit amtlichem Siegel ober Stempel, ${ }^{1}$ ) b) mit einer die Beredytigung zur Bebüfrenfreiheit

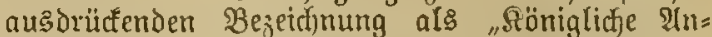
gelegentyeit", "Broßßlerzogliche 2Ingelegenheit",

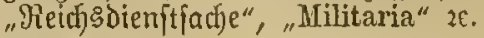
verfichen find.

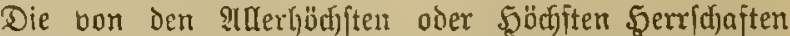
herritfrenden Telegramme furb, aud menn fie bon sierionen anfgegeben merden, weldje zu Dem Befolge oder Den \$ुofftaaten gefjören, fofern über die ßerfon DeG 2Afigebers nder bie Erftheit feiner Pamentsunterfdyrift bei den Telegraphen= anitalten fein Broeifel obroaltet, ofne Beglaubigung burch Siegel oder Stempel, forvie ofne meitere Bezeichnung zux Beförderuna anzunehmen.

Die gebilfrenfret zu befördernden Telegramme bon Civils

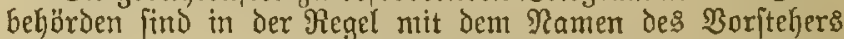
oder eines der leitenden Beamten der Behörte zu unter= zeichnen, töunen aber entretendenfalls yon dem mit der Ifufertigung beaufragteu Beamter Dahin beglaubigt fein, bas fie von dem Borfteher Der $\mathfrak{B e h o ̈ r d e ~ a u s ̧ g e h e n ~ u n d ~ i n ~}$ feinent ?uftrage mit feiner Ramensunterfortift berfeljett worden (Hiro. ${ }^{2}$ )

Bei ben von Den Militär: und Marinebchörden aus= gehenden, aebïhrenfrei zu befördernden Telegrammen genïgt, neben der Bezeid)nung "Militaria" tno Der Beidriidfung Des antlidhen Siegels oder Stempels, als Unteridurift die Jirma

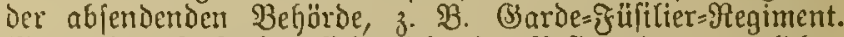
Weum der ?lufgeber fidf nidjt im Beftik eines amtlidien Siegels oier Stempels befindet, fo hat derfelte in "(Fx= mangelung eines Dienft ftempels" mit Unteridfrift Des ఇantent

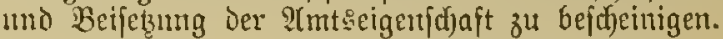

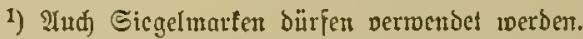

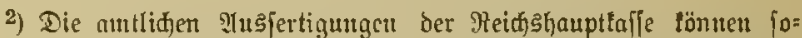

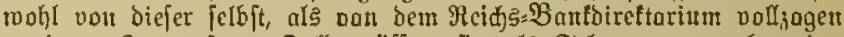
rocrobn. Im erfteren fall miifien fic als Telegrantme neben ber Lutterjdrift bes Borftchers dicjer Bejajäftabtheilung ober feines ges arbucten Bertreters uno ber llnterjărift cines berjelben angehärigen

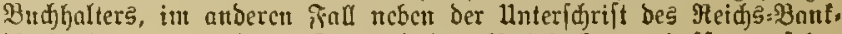
bireftariums mit bem Stempel ber Heidghauptenffe berfehen tocroett.

§ 5. Эn allen fällen, in Denten aus dem Telegramm herborgeht, das in materteller oder formeller Sinficht eine

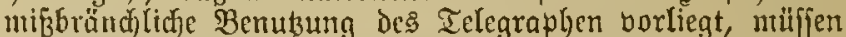
folde Telegramme yon den Telegraphenamptalten an die

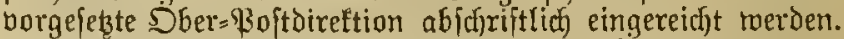

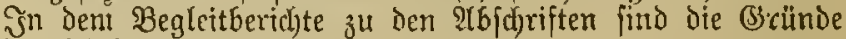
ber cinfendung näher ở erörtern.

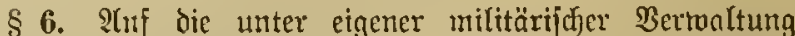
Ftelenden Telegraphenlinien finden die Beftimntungen biefer Beroromung teitte $\mathfrak{A}$ moendung.

§ 7. Bjegentärtige Beroronung tritt mit bem 1. Juli biefes Sahres in Siraft. Mit diefent Tnge verliert Die $\mathfrak{B} e r=$

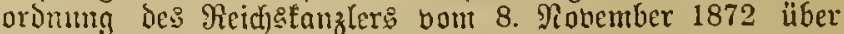
die gebührenfreic Befötoerung telegraphiffer Depefden ihre Gültigfeit. Die Beftimnntungen Diejer $\mathfrak{B}$ eroronung finden nuf den inneren Bertegr in Sabern und $\mathfrak{B u ̈ t t e m b e r g}$ feine ?trumentung.

Urfuntblich $2 \varepsilon$.

Begeben Berlin, den 2. Sunt 1877. 


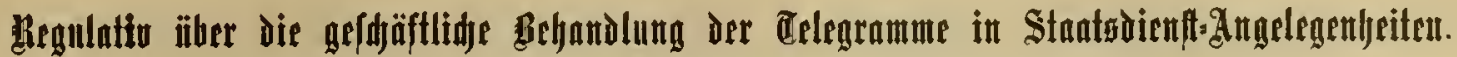

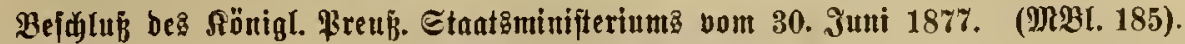

Rardjom Dutch Die Raiferlidje Beroronung bom 2. Jumi

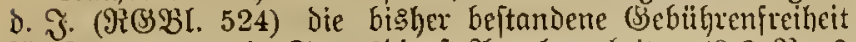
fiir Telegramure in Stantobienjt=9Tngelegenbeiten $(\$ 292.3$

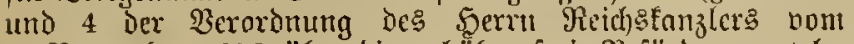
8. Nonember 1872 über bie gebühyentreic Beförbertutg tele=

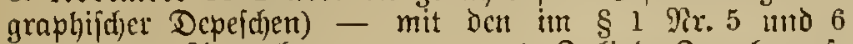

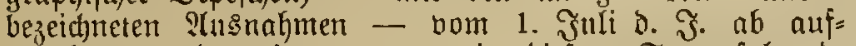
achoben rorben in, treten mit diefem Inge folgende Beftimmungen über die gefoäfftliche Beljandlung Der ge= Dachten Telegramme in Sraft.

§ 1. Den Telegrammen in Stantedienft = ?fugelegen= heiten berble:bt, in ocr Befürderung, der biskcrige bortang bor 93ribattelegrammen. Sie find Daher bon der abjemien= Den Behörde wie bisher (\$ 8 der Telegraphen=Drdmung für

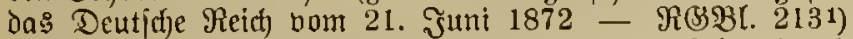
als Stantstelegramme zu bezeidinen, tmo als folcte iurd) Siegel oder Stempel zu Geglaubigen.

1) jekt Telegraphenoronung $\mathfrak{0}, 15.6 .1891, \S 5 \mathrm{I}$.

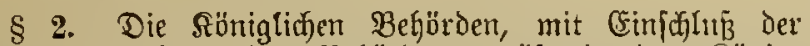
cinjeln ftehenden eine Behörde repräfentirenten Röntg= lichen $\mathfrak{B e a n t e n , ~ h a b e n ~ d i e ~ T e l e g r a p h i r u n g s i g e b i t h r e n ~ f i ̈ r ~ b i e ~}$ von ifneu in StantşDienjt=21ngelegenteiten abjujendenden Telegramme:

a) weun Die Rufgabe bei eimem Reidjstclegrnphen= Simte erfolgt, entrueder in Wiege Der Contirung oder in jedem einzelnen ङaffe baar unt zioa: Dutrd) Bermendung bon Tioft= oder. Telegraphen= freimaten ober Durdh Einzahlung beim Telegraphen= nute, ongegen

b) Inenn die Sufgnbe bei eimer Eijenbahn= Telegraphen= ftation erfolgt, it allen Fä̈fen Durdy baare (Ein= zaljlung bei der betreffenten Station ou ent= riditen.

\$ 3. Dic unentgeltliche (Sontinung wird jeder $\mathfrak{R}$ öutg $=$

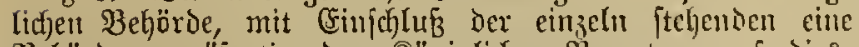
Behört̀e repräjentirenden ßäniglichen Beanten, auf die: jäßligen ?(ntrag bon Demjenigen Saijerlichen Telegraphen= Imte zugeftanoen twerden, bei meldjent, nach Der urtlidfen Lage, bie Telegramme der betreffenden Behöride regelmäß̈g jur ?lufgabe gelangen. (Fin folder Plattrag ift nur in bem

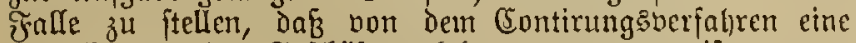

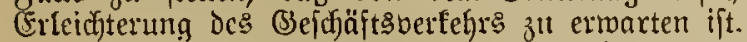

Die abjendende Befjörde hat Den Beitimmungsont und den (Empfänger Des Telegramms in Detn (5ontobudt)e z"I berzeid)nen und podann das Telegramm mit biejem Budfe dem Telegraplen=2lmte zu ïbergeben, welches darin Die Telegraphirungsgebilgr und Die etwanigen baaren ?tus: lagen bermert. (5benjo merben ?tuslagen, reld)e auj einem nu die Bchörde 2e. cingeljenden Telegramme haften, feitens Des Telegraphen=?lutce in bem bezeidyneten Butche fontint. Rach siblauf cincs Monats merden bie fontirten

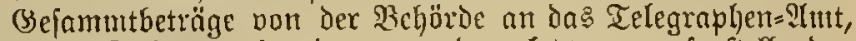
gegen Duittung in einer bou bem lezteren aufzuftelleniten Rect)mung, bezahlt.

§ 4. Die Berrectunung Der von Röniglithen Bebörben und eiuzeln ftehenden Röniglichen Beanten fii Telegramme in Stantsoicnit=?lngelegenheiten 3 entrid)tenden (Selobeträge bei den Staatsfaffen tmo die Erftattung ber von Den be= zeichneten Behöroen und Benmten vernuslagten Beldbeträge für Telegramme der gedacftel \%lut erfolgt in Derjelben Weife, wie es hinfitfytlich ber \$3ortobeträge für \$oftiendungen in Staatsoiemifiachen nach den bejteljenden $\mathfrak{B}$ oridoriften zu gefolden hat.

§ 5. Die Wiedereinzichtng derjenigen für Telegramme in EtaatsDienfts? Ingelegenlyeiten verauslagten Beträgc, 3" Deren (Erifattung cin 3 etheiligter berpflichtet ift, bat madh

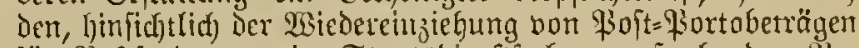

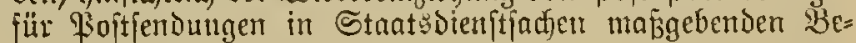
ftimmutngen z̆ł erfolgetr.

\$ 6. Telegramme in Stantsdenjt=?lngelegenheiten fitu nux in den midjtigiten mo Dringenditen Fïallen, oder meun es ausbrüctlich borgeffrieben ift, abzufenden und in ges

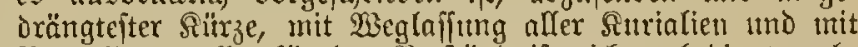

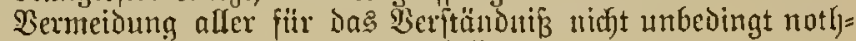
rendigeu situlnturen $2 \varepsilon$, abzufaffen.

Der झुortlaut eites Dicnjtelegramms bejteht aus Ilorefie, Juljalt

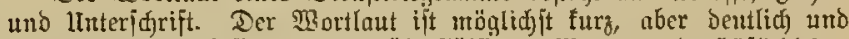

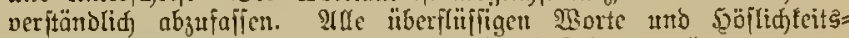

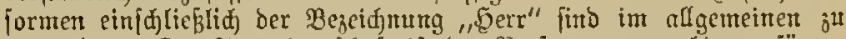

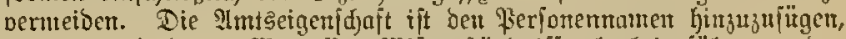

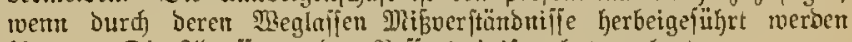

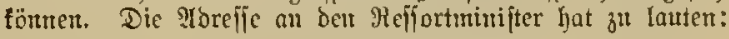

$$
\text { פerrn STbeiţminifter }
$$

Berlin.

§ 7. Den einzelnen Miniftericu bleibt überlaffen, bic füx ifren Reffort erforderlidfen näheren Beftimmungen ïber Die 2tusführung Diefes Regulatios zu treffen.

\section{Röniglid)es Staats= Drinifterium.}




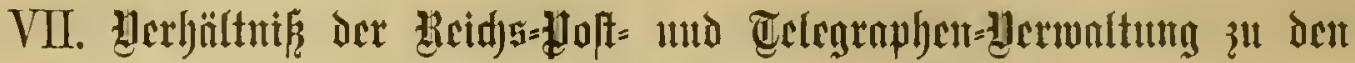

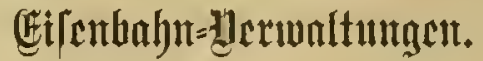

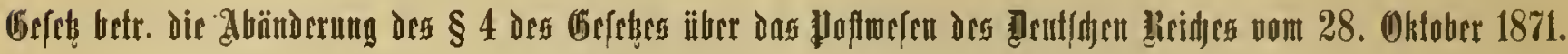

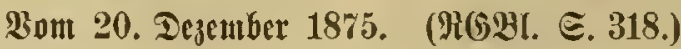

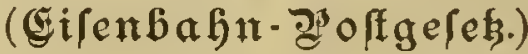

Einziger Baragraply.

Yn die Stelle des $\$ 4$ des Seletses Des Deutfiden Reidjes bom 28. Detober 1871 (Reid) $\$$ (3ejebl. S. 347) treten die nadfolgenden Bejtimmungen:

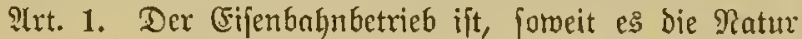
und die Erforberniffe deffelben geitatten, in die nothwendige Hebereinftimmung mit Den Redurfniffen Des \$ojtoienjtes zu bringen.

Die finlegung befonderer Büge für die glwete des Poftienftes fam jedoch bon ber \$oftberwaltung nicht be= anjprudt merden.

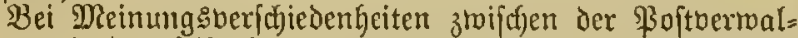
tung und Den (Eifenbahnverwaltungen ïber die Bedürfniffe des Poftoienftes, bie Ratur und die Erforderniffe des

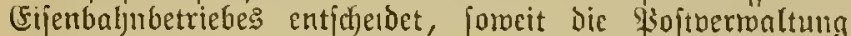

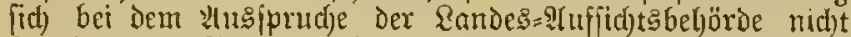

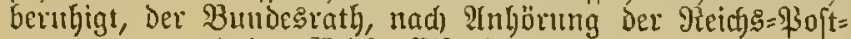
verwaltung und bes Reid)

2rt. 2. Mit jedem für Den regelmäffigen $\mathfrak{B e f o ̈ r d e r u n t g s : ~}$ dienft der Bahn beftimmten 3uge ift auf Berlangen der

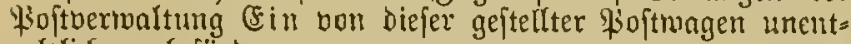
geltlich z"l beföroern.

Diefe unentgeltliche Beförderung umfä̧t:

a) Die Briefpoftendungen, Beitungen, Bielder mit

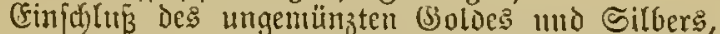

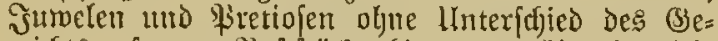
mid)ta; ferner Zioftftücfe bis zum (sinzelgewidht voll $10 \mathrm{~kg}$ einfd)ließslid);

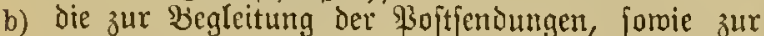
Berridjtuttg des Dienftes unterwegs exforberlidjen \$3oftbeanten, aud) wenn diefelfen bout Dienfte zurücffehren;

c) Lie Beräthf(c)aften, deren die Bojtbeamten unter= wegg bebitifell.

Für Bofititücfe, weldje nidyt unentgeltlid) zu befördern find, hat die \$oftoerwaltung eine Jrachtbergütung zu jeflen, meldise nad) Der (Befammtmenge ber auf Der be= treffenden eifenbahn fich betwegenden zohlungspplichtigen Fojtftitcfe fiir bas IIt)

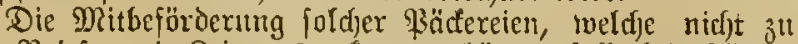
den Brief= แnd Zeitungspacfeten geljören, folf bei Bïgen, Deren ₹rahrzeit befonders furz bemeffen ift, befdräntt oder ausgefichloffen werden, wenn bies non ber Eifenbahn Muffichtebehörde zur 20 ahrung der pünftliden und ficherent Beförderung der betreffenden Büge für nothnendig eradhtet mirb, und andere zitu Mitnahme der ßäcfereien gecignete Biige auf ber betreffenden $\mathfrak{B a h n}$ eingericftet find.

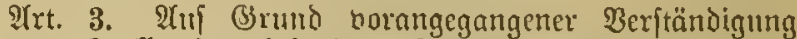
fanm an Stelle eines befonderen gistmagens eine ?tbtheilung cines Eifenbahnwagens gegen Erftattmng Der fïr Seritellung und Wicderbejeitigung ber fïr die Bmecfe des \$ojtoienfes erforderlidjen (fimvidfungen bon Der (Eifenbahnverwaltung aufgemendeten Selbftlojten, fomie gegen 3nhlung einer Mietbe jiir Sergabe und linterlyalung benubst werden, tweld)e uad) ?trt. 6 stbj. 5 zu bered)nen ift.

Irt. 4. Bei foldhen für den regelmäb̆igen Befärderungs: Dienjt der Baljn beftimmten Bügen, weldje nicht in Der in

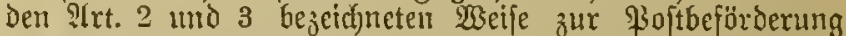
benutzt roerden, fann die \$oftberwaltung entmeder, infoweit Dies nach dem Ermeffen Der (sifenbahnvertwaltung zuläffig ijt, Der Lebteren Briefbeutel, fornie Briefs und Beitung: pactete zur unentgeltliden Beföroerung durd) das Bug= perfonal iiberweifen, ober de Beförderung von Bricfbeuteln, jomic Bricf= unD Beitungspndetent Durd) eimell Bojtbeautten beforgen laffen, roeldjem der erfordertiche \$lats in einem (Eifenbahnwagen mentgeltlid) eirruräumen ift.

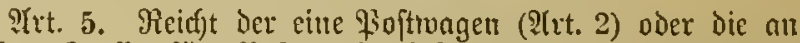

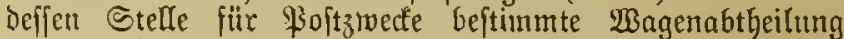

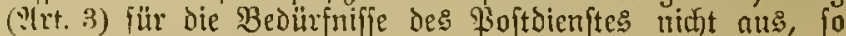

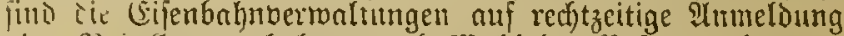
oder Bejtellung gebalten, nad) Babl ber Pojtberwaltung melyere \$oftmagen zur Beförderung zuzulaffen, oder Der Pojtbermaltung zur Befriebigung bes Miefrbenitrfuiffes geetgnete (B)ütermagen oder

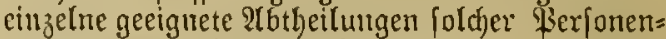
twagen, deren übrige 2tbtheilungen in dem be= treffenden Buge für Eifenbahnzmecte vermendbar fino, zu geitellen,

oder endrich die ifuen boul der Boftuermaltung übermiefenen Boftfendungen zur eigenen $B_{e}=$ förderung zu tibernehmen.

Bei Bügen, auf denen dic Bejötberung von ßojt=

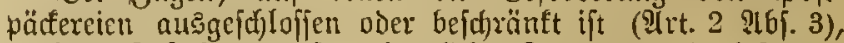
Darf die Beftellung aufzerordentficfer Iransportntittel feitens

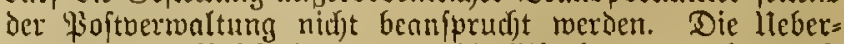
meifung you \$oftjentungen an bie Cifenbabnbermaltung ift mux infomeit zuläffig, als lekztere fich bei bem betreffendem Buge mit der Beförderung von Biitern (\&il= oder ₹rned)t= giltern), befaßst und die zu überweifenden Boftitüre niefst in (Geld = oier $\mathfrak{B}$ erthfendungen beftefen.

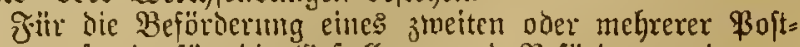
magen, forvie fïr die seftellung mo Beförderung Der ex=

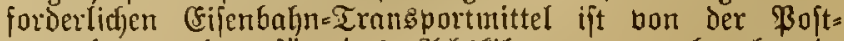
berwaltung eine fitx Das Ad)afilometer zu berecjnende 
Bergütung, für die Beförberung ber überwiefenen \$oftitücte aber bie tarifmäßige (5ijenbahu= (5iljradjtgeblibr zu zahlen. Jiix die झnitbeförderung bes etma erforberlichen \$oit= begleitungşperfonals uno Der Bern̈th\{dfaften für beu Dienft mird eime Bergütung nid)t gezahlt.

அrt. 6. Die für den regelmäßigen Dienit erjorberlidjent (Sijenbahn=\$o[tmagen werden für Rechnung der Bojtnex= maltung beidjafft.

Die Cifenbahnbertwaltungen find berbumben, die llnter= haltung, äußere Reinigung, Das Sdjmieren und das Ein= und Pltsiangiren diejer Wagen gegen eine Den Selbjtoften entipredjende Bergittung zu bewirfen.

Wenn die im regelmäß̧igen Dienโt befindridjen Gifenbahtu= Poftragen während des Stillagers auf Den Bahnhöjen der Endftationen im Freien jtehen bleiben, fo ift oafür eine Bergïtung nid)t zu zahlen. Setzteres gilt aud für die Pläb̧e auf den Bahnhöfen, weldje der \$oftuerwaltung zux

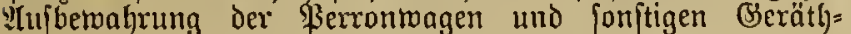
idjajten fïr bas Berlabungsggejääft angemiejen werben.

Ilnbelabene \$oftrongen find gegen Erftattung der fiir

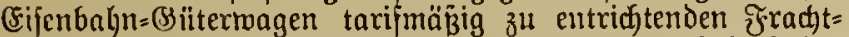
gebülyr zu beföroern. Für die Beförderung zur Eifenbaln= Heparaturmerffatt uno zurüd findet eine Bergütung nidijt jtatt.

Wenn (Fijenbahn=\$oftmagen bejuäbigt oder laufunfäbig merden, fo find die Eijenbahnbermaltungen gehalten, ber

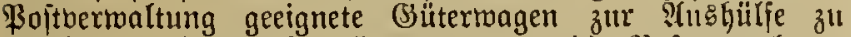
überlafien. ₹ür dieje (Stiterwagen hat dic \&oftbermaltung bie nämliche Mlietbe zt bejahlen, inclde die betreffende (5ifenbahnbermaltung im $\mathfrak{B e r f e b r}$ mit benadjbarten $3 a b n e n$

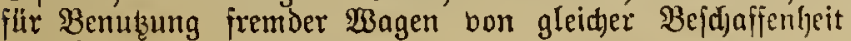
entrichtet.

Dessgleidien find die theilmeije bon Der \$pojt benulzten (5ifenbahmtwagen (Plrt. 3), menn fie laufunfähig werden, von Den Cifenbahnberwaltungen auf ilre sopten burds andere zit exfetzen.

Yrt. 7. Bei Srridjtung netter Balynljö|e oder Stations= gebäude find aul Berlangen Der \$ofítermaltumg die bured) ben Cifenbabnbetrieb bebingten, füix die Broece bes \$3oft= dienftes erforberlichen Dienfträume mit den für den \$ojtoienft etma exforberliden befonderen baulidjen Irtlagen vou ber

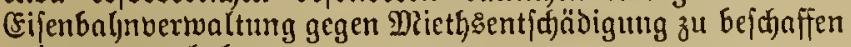
und zu unterhalten.

Doffelbe gilt bei Dent Um= oder frmeitermaşbau beftebender Stationsgebäude, injojern Durcf die Den Bau veranlajfenden Derbältuifje eine Ertweiterung oder Berände= rung der \$oft dienjträume bebingt miro.

Bei dem Dangel geeigneter Bribatmolnungen in ber शähe ber Bahnböfe find die Eijenbahnverwaltungen ge=

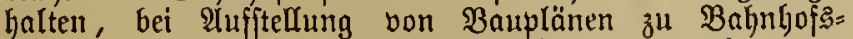
nulagen und bei Dem $17 \mathrm{~m}=$ oder Ermeiterungşbau von Stationsigebäuden auf dic Befánaffung von Dien|trohnungs: räımen für bie \$soltbeamten, tweldje zur Berridjtung Des ourd) Den (Eifenbahnbetrieb bebingten \$oltbienftes exforderlich find, Rücficht zu nehmen. Heber Den Umfang diejer Dienjt=

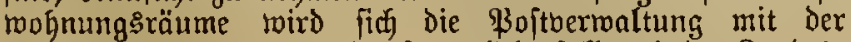
Eijenbahnbermaltung und erforderlidjenfalls mit ber Randes=

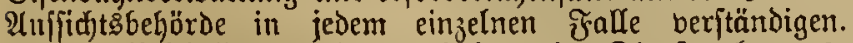

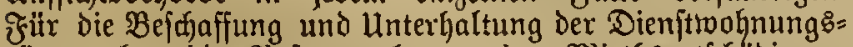
răume hat die \$oftverwaltung eime Mriethsentfdábigung saç gleichen (Srundfäbsen wie für die Dienfträume auf Den Babnb̆ben zu entridten.

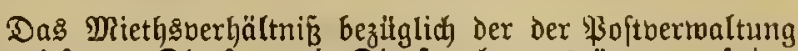

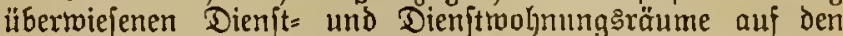
Bahnhöien Eann nur Durd) Dasె (Sinberftänonif beider $\mathfrak{B e r}=$ waltungen aujgelöft werben.

Werben bel Grricjumg neuer Baljnhojsanlagen, jomic bei Dem Um= oder Ermeiterunģ口bau beitehender Stations: gebäube zur Unterbringung von Dienit= ober Dienjtmog= mungsinäumen auf Serlangen der \$ojtbehörbe bejondere Gebäude auj den Bahnhöfen berqejtellt, jo ijt ber exjorder= liche Bauplas bon ben Eifenbahnverwaltungen gegen Gritattung Der Selbitfojten zu bejdjaffen, der Bau und dic Unterhaltung berartiger Sebäude aber aus ber Poittajie zu bejtreiten.

Wrt. 8. Wenn bei dem Betricbe einer Eifenbahn ein im Dienft befindlidjer \$oftbeamter getödtet oder förperlich berlekt worden ift, und dic (Fifenbahnberwaltung den nad) den Esefesen ibr obliegenden Sdjabeneriats dajur geleiftet hat, jo ift die \$ojtbermaltung verpfliditet, dexjelben Das Geleiftete zu exjesen, falls nid)t ber Tod voer die Sürper= verletzung durfy eit Dexidulion des (Fifenbaljnbetriebs: Unternehmers oder einer der im Fifenbalubetrieb berwendeten \$erfonen herbeigefilbrt morben ift. $\left.{ }^{1}\right)$

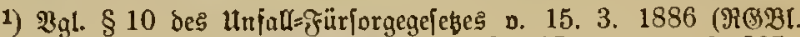

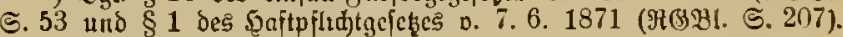

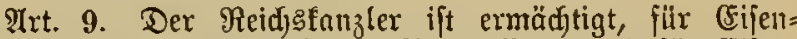
babnen mit jomalerer als Der Rormalfpur, und fïr (Eijeu= bahnen, bei weldjen megen ilner untergeoroneten Bedeutumg Das Bahnpolizei=\$leglement für die Sifenbahnen Deutjdjlanos nicht für anmendbar eradjet ift, die vorfteljenden $B e r=$

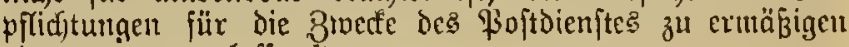
odcr ganz zu erlafien. ${ }^{\text {) }}$ )

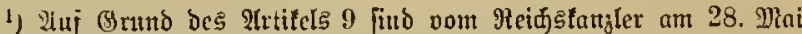
1879 bie Beftimnutngen, betreffeto bie ßerpflictungen ber Eijen, bahnen untergeoroneter Bebeutung zu Eciftnttgen für bic 3wedc bes Pojtoienftes (fiche Seite 437), criffien worben.

2(xt. 10. Durd) Die bon bem Reidj:Fanzler, nadj $9(n=$

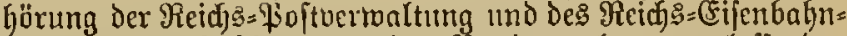

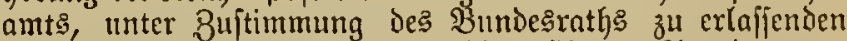

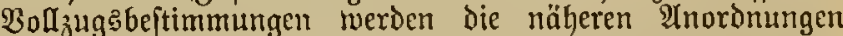

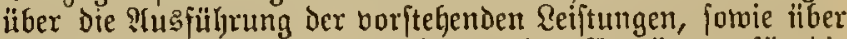
bie ₹eftfetzung und die Beredjmung Der Bergligung für dic gegen Entgelt 3u gemährenden Reiftungen getroffen.

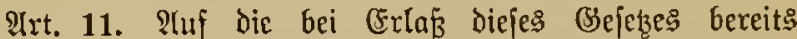
fonzeffionirten fifenbahngefellichnften und beren zuflinftig fonzeffionirte (Frmeiterungen Durd) Neubauten finden bie

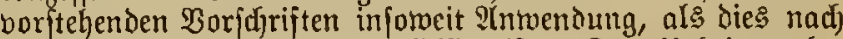

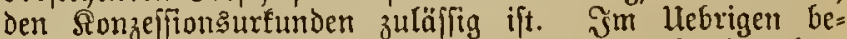
wendet es für die berbindlidjeiten der bereits fon= zeffionizten (Fijenbaljngejelidjajten bei den Bejtimmungen ber SonzejionsurEmben, und bleiben inşbejondere in bicjer Beziehung die bis dahin zux ?lnwendung gelommenen $\mathfrak{D o r}=$ forriften üher Den llmfang Dem \$soitzmanges und tifer bie Berbinolicffeiten der Gijenbahnbermaltungen z Reijtungen für die Zroecfe des \$oitbienftes maß̈gebend.

Die bereits fonzeffionirten (Sijenbahngcjellidjaften find jedod) beredigt, an Stelle der ignen folljefifionsmäß̈ig obliegenden Berpflidjtungen fïr dic Brocfe Des \$oftoienftes bie Durch bas gegenmärtige (S)fets angeoroneten Reijtungen zul übernehmen.

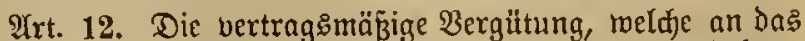
Brob̧berzogthum Baden für Scijtungen jeiner Staatæbabnen 
zu den zroeden des \$ioptoienftes zu entrideten ift, wiro, fofern nicht eime andertbeite Bereinbarung erfolgt, bis zuni 2hblauf Des Jahres 1879 weiter gezahlt. Bis baljin bleiben fiir die Reiftungen der babifden Statshahnen zil Buecten

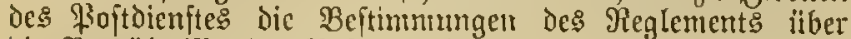
die Berbältniffe der Boft zu Den Stantsecifenbalnes vont 1. Samuar 1868 maß̧3gebend.1)

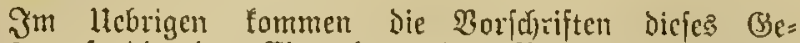

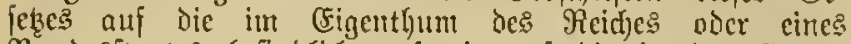
Bundegitantes befindliclien, forvie nuf die in Das (Figen= thum bes Reidjes oder cines Bumbesffantes ïbergehenden

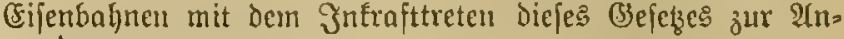
twendung.

1) Seit bem 1. 1. 1880 findet bns Eijenbahn=\$o[taefes neb/t dent zugebörigen Bolfuggbejtimmungen aud auj bie Eifenbahnen in (Groß= herjogthum Baben Inmenoung.

Irt. 13. Diefes Befes tritt mit Dent 1. Januar 1876 in Sraft. Daffelbe findet auf Babern und Württemberg ecine Irnucnoung.

lixfindlich) $2 c$.

Begeber Berlin, Den 20. Dezember 1875.

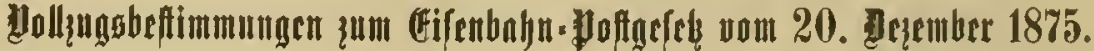

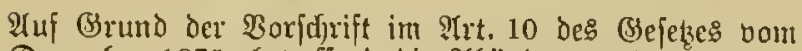
20. Dezember 1875, betreffend die 2tbänderung Des \& 4 des (3ejebes 28. Sttober 1871, werben, nad) erfalgter IYnjörung Der

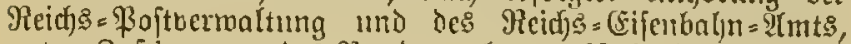

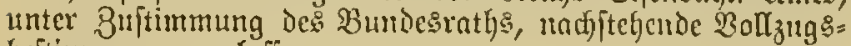
beftimmungen erlajien.

I.

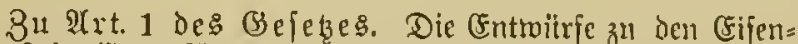
balminjahrplänen für bie Perfonenbejörderung, fomic fïr bie,

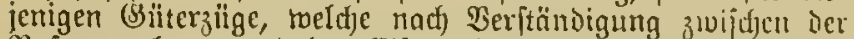
Fojtuerwaltung und Der (Fijenbahnberwaltung zur Beförile= rnng ton Boftpäefereien benutzt merben follen, fint ber eriteren zur 20 ahrung ilgrer Snterefien redjtzeitig mitzutheilet. Die Feftitellung Der ङabrpläne geidjeht unter Mitwirfung Der ßoftuerivaltung.

Die feitgeitellten ₹ahrpläne find von den Eifenbahn= berivaltungen ofhe Verzug Der \$softverwaltung mitzutheilen, meldye Diejenigen cinzelien Büge bezeidnet, Die fie zur Boft= beförderung benuizent miro.

\section{II.}

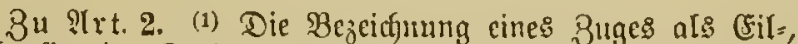
Schnelle ober Ŝrrierzıg reicht an fich nicht auts, um dié Pojtpädfereien von der Beförderung mit Demjerben böllig auszuid) lię̧en.

(2) Die Baffl der \$oftheamten, weldye 3ur Syegleitumg Der Boftiendungen, forwie jur Berridjutng deg Dienftes unter= wegs bei jedem Zuge regelmäfig nitgehen follen, wird von Der goftuerwaltung beftimmt und ber Eijenbahnuermaltung

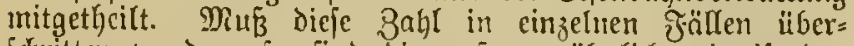
fohritten merden, fo firti bie au[sergetwöhnlich mitreifendent Boftbeamten feitens ber Bojtoermaltung mit bejonderen, auf Die einzelnen ₹ahrten Lautenden Regitimationsforten ju verieber. ${ }^{1}$ )

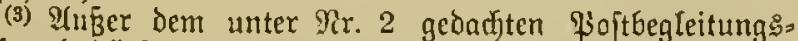
perjonal bïrfen nux ber jedesmalige Boriteber Desienigen \$oftamts, welchem der $\mathfrak{B e t r i e b}$ allf Der $\Re$ oute zugerwiejen

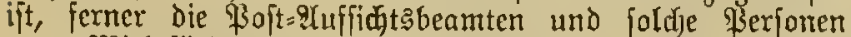
zur Mitbeförderung in Den Boftragen oder 23agen= Adbtheilungen zugelaijen merden, weldje aus poftoienjtlichen

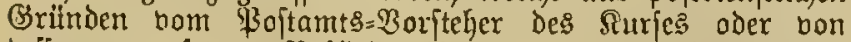
Defien vorgefester Behörde hierzu mit (5rlaubnifjacteinen verjehen find. Ferjonen, welche auber Dem \$oftbegleitungs: perjonal $(\Re, 2$. 2) in ben \$oftragen oder \$oftragen. Abtheilungen mitueifen, müffen Das \$erjonengeld für die zmeite $\mathfrak{B a g e n f l a f f e}$ des betreffenden Zuges, und jofern
Diejer mur Wagen exiter Slaffe fillyrt, Da: Jaljucheld erfter Ølaffe entridjten. Die Eilenbahnuerwaltumg ijt befugt,

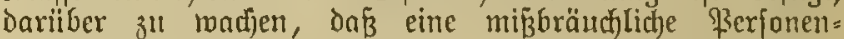

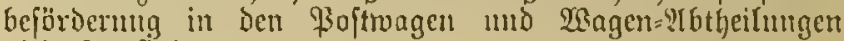
nidj) ftattfinic.

(1)2) Dic Fracht für Beförderung zahlumgsిpf(id)tiger Boptfendungen wirb, mie folgt, berechnet:

Jür einen Zeitraum bon 14 Tagen wirb ermittelt, roie

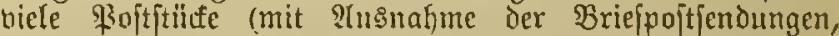
Bcitungen und (Sielder) in (Finjelgemidit von mehr al\& $10 \mathrm{~kg}$ unt judem Buge bon jeder Etntion bĭ zutr nädffts folgenien beförbert morber fino, mo miebiel bas (servidst Diejer zal)hungspflidytigen \$oftftìfe non Station zu Station betragen hat. Dieje Ermittelumg miro Durdj die \$soft vermaltung bemirft, und zmar abivedjeend für bie erften

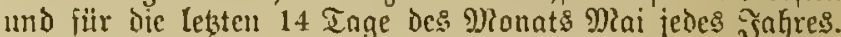
Dic Cijenbalyuerwnltmig fteht dic Mitmirfung bei ber $\mathrm{F}_{\mathrm{r}}=$ mittelung frei.

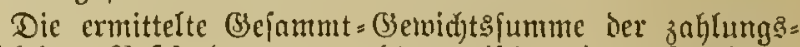
pflicjtigen \$oftienoungen, meldbe zuijden ie 2 Stntionen bejördert worien find, mird mit der Silometerzaljl dex Stationsentfermung vervielfältigt, und bie gejundenen

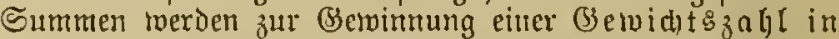
Silogrammen für das Silometer Der Baljnlänge zufammengerectinet.

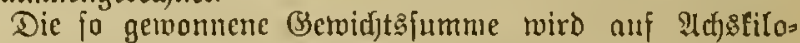
meter zurïf(fgefüfrt, invem je 1000 Rilogrammlilonteter auf Da id

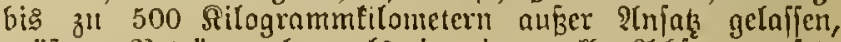
gröfere 3eträge aber als je eine bolle ?tchie angejetst werden.

Die frrad)tbergütung wiro nach Dem Sake von 0,20 MRe. für das ?(d)stilometer bered)net. Durch Bervielfältigung Der fiernad] gefundenen Bergïtnngsflumme mit Der $3 a h[26$

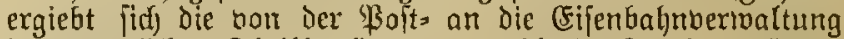
in monatlichen Theilfeträgen zu zaklende ₹ract)tbergitturg fïr das laufende Rechnımgşahr.

Fiir dic Stationglänge fommt die wirtlich ausgemejifene Entjernung (nid)t bie zu Torifzmecten abgerundete Rilometer=

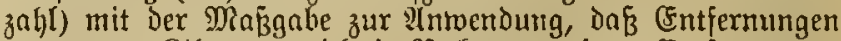
unter 0,50 Rilometer nicfit in Redfnung gejebt, (Entfermungen bon 0,50 bis 0,99 silometer dagegen für ein bolles sillo= meter geresfinet mer Den.

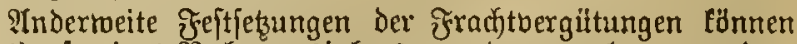
im saufe eines Rechnungsijahres un dann verlangt reerben, wenn in Der Benułung der $\mathfrak{B a h n}$ zu Zroecfen Des Boftdienftes erhebliche Beränderungen eingetreten find. 
Bei Eröffnung neuer Strefen ifton beftelyender Balnen fann bie Ermittelung im heiderfeitigen Einverftänonifie it Der 9 rt bemirft merden, Doß 3 nur für die nett eroffrnete Streffe die 8ngl Der Sillograinmfilometer berted)net, diefe Zahl der $3 a \mathfrak{h l}$ der Silograumfilometer für bie übrigen Bahnitrecfen hinzugeredfnet und foldhergeftalt bie Bahl ber

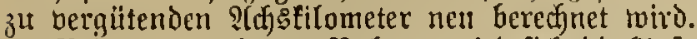

Bei neu angelegten $B$ ahnen wird fidf die Goftuermaltung mit der Eifenbabunermaltung iiber Den Beitpunft Der Er: nittelung für Das Recfinungsjahr, in weldhem die Betriebs: exőffinung erfolgt, in jedem eingelnen Falle berftändigen.

1) $3 \mathfrak{u}$ ben auFergemöhnlida mitreifenden \$ojtbeamten find aum folde \$ofthenute zu zählen, welde behufs Crlernung bes Bahnpoft= bienftes als Begleiter mitzufahren habent.

2) Tie Beftimnungen unter II Biff. 4 und unter III Biff. 2 haben durd bie Seroronung bes Meidstanglers vom 24. Desember $188 t$ die obige Faffung erhalten, und zwar znit ber IDBirlfamfeit vom 1. Ipril $1881 \mathrm{ab}$. Die Beftimmungen unter III Biff. 3 find bei

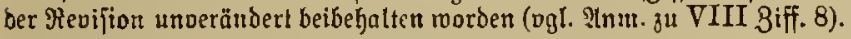

\section{III.}

8u 2 rt. 3.) (1) Der (Einftellung vereiniqter Boft $=$ und

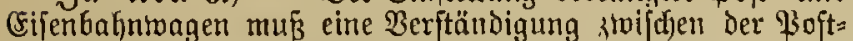
und Eifenbahnverwaltung äber die Bröbe und die Sin= ridjtung Der fïr die \$oft zu beftimmenten Räume, jomie iiber bie Zahl und (Sattung non Eifenbahnwagen, in meldben dicje Räume herzuftellen find, borkergehen.

(2) 1) Sofern bie innere Aluştattung Der fiir goftzmeafe beftimnten P(btheilung und Deren Demnärffilige $\mathfrak{B}$ ieder: entfernung in ciner $\mathfrak{W}_{\text {Serfftatt }}$ der betreffenden (Eifenbaljn= vermaltung exfolgt, fönuen

a) Die berwendeten Materialien mit dem Selbftejten= vreife 11110

b) die Ptrbeits[öfne mit dem roirflid) aufgemendeten Betrage

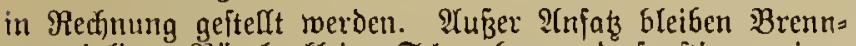

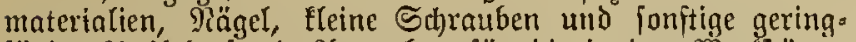

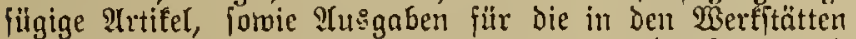
3II allgemeinen Berridjtungen verwendeten Bebienfteten und STrbeiter. ₹fï bie hiernad) nid)t liquidirten Reiftungen foll

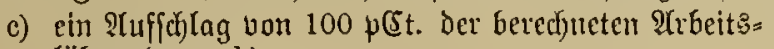
löhne (unter b)

zunt I(njałz fommen.

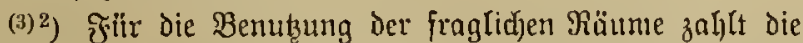
Poitbermaltung eine Miethe, meldje, fo lange das feit bem 1. Mai 1875 gültige Regulatin für Die gegenfeitige $\mathscr{B}$ agen= Genubung im Bereidje Der Deutidjen (Eifenbahnen $\mathfrak{l n}_{n}=$ wendung behält, Gei Berwendung von Bjüter o oder Bepäcf= wagen an $\mathfrak{Q}$ alf miethe 0,01 Marf jür Das Rilometer und ail 3eitmietge 1 Mart für ben Taq, bei Bermendung von 3erfonentwagen aber an \&aufmiethe 0,02 Miarf für bas Silonteter ${ }^{3}$ ) und an Beitmiethe 2 Mart fïr Den Tag mit Der

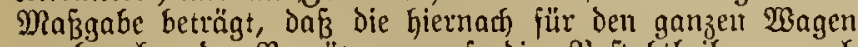
3"1 beredfmende Bergitung allf bie Poftabtheilung nad)

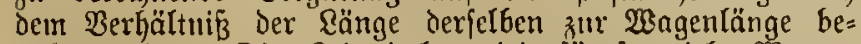
recfinet mird. Die Beitmietle twird für fo biele wagen,

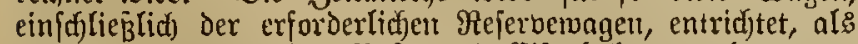
nad) der zwijden Der \$oft = und (Eijenbahnbermaltung ges mäs $\mathfrak{A r} .1$ getroffenen SBerabredung fiir Den regelmäbigen \$oftberfehr auf Den Strecten Der Eijenbagnuermaltung wirtich eingerictet find.4)

Fin diefer Miethe find die Sojten für die unterhaltung,

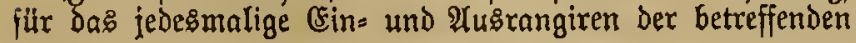

Magen in bie Bïge und aus den Bügen, für bie äufere Reinigung und fitr bas Shtnieren mitbegriffen. Für die innere Reinigung, fotwie für die etwaige \$eizung und

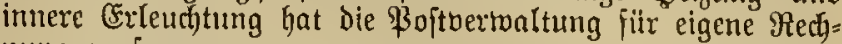
murg zu jorgen.

Solweit die Wagen auf den Bahnen berfuchiedener Eifenbahmberwaltungen durdjbemubt twerden, tritt bie \$oit= verwaltung ïber die zt zahlende Miethe nur mit (simer Eijenbahnoerworltung in a(bred)uung.

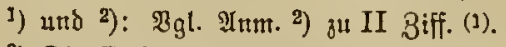

3) Die Entfermungen werden bei Berednung der Bergütungen für die im Intereffe bes \$oftbeförderungsbienftes von der Fijenbahn aus:

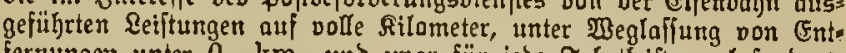
fernungent unter $0,5 \mathrm{~km}$, und zroar für jebe Fahrtfeiftung bejonders, abgerundet.

4) Die nämlidgen Sätse an গুagenniethe merden für (cifenbahn. wagen=21btheilungen ( ohne für ben \$oftdienft befonders cingeridtet zu fein, auf beptimmten Streden und in beftimmten Bügen regelmäbig zur Beförberung pon Foftentoungen betubt merben; in folden Fällen find auberbem bie für Seizung, Erleudutug uns innere Reiniguttg ber von ber Poft

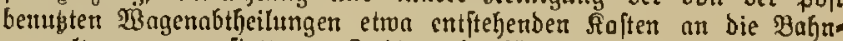

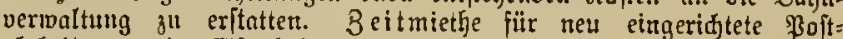
abtheilungen in Gifenbahmmagen wirs oon bem Tage ar berednet,

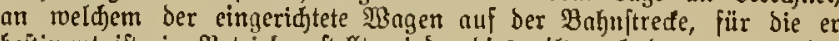
bejtimmt ift, in Betrieb geftellt virs; dies gilt and ban, menn der in Betrieb geftell te Magen niđt fojort von ber ßoft in Benubung genoument wirb.

İn Fall ber Sergabe von Erfapmagen an Stelle laufunfähig ge: morbener vereinigter \$opt = und Eifenbahmwagen ift es juläflig, da bie $\&$ a tifmicthe night mit bem Betrage, roelder füt lepteren zur (5r= hebung gelangt fein würbe, fondern mit bem Betrage, weldyer auf bie wirflin hergegebenen (Erfaprongen ober fïr ben zu \$oftzmeden überviefenen Theil derfelben entfält, gezahlt wirb, fopern bie Eifen. bahnvermaltung dies verlangt. Bezügtid ber Beitmiethe bingegen ift baran feftjuhalten, bá biejethe uur für bie laufunfähig gemorbene Magenabtheilung, ohne Hüffidt auf dic Bröße bes anshülfsmeife für ßoftzmede hergegebeuren $\mathfrak{B a g e n r a u m}$ gezahlt merde.

Die fofter, welde burd bie Uttterhaltung ber fur innereu ftattung ber \$optabtheilungen in Eifenbahnmagen erforberlidjen Begentitände, wie insbefondere ber \$ei $=$ und Beleudtungsanlagen, Spinde,

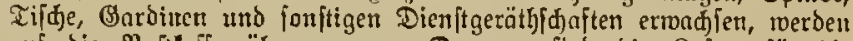
auf bie Boftalfe ïbertommen. Dagegen fitto bie Fopten für die

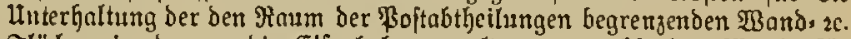
Fläd)en it ber an die Eifenbahtwerroaltung zu zahlendeu Piethe für Sergabe und llnterhaltung der \$oftabtheilungen mit inbegriffen. Sierbei fommen namentlid, in Betradt: bie Solten für ltnterholtung ber Fenfter, Thüren, Thürdjlöfier, Thürgriffe, für ben inneren uto

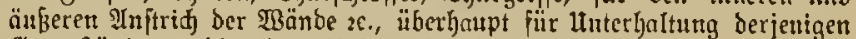

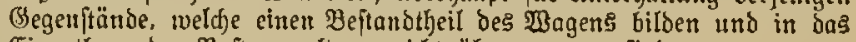
(Figenthum ber \$oftoerwaltung nid)t ïbergegangen find.

\section{IV.}

8" 1 r.t. 5.1) (1) Die anfergerwöbnlicjen Transports mittel find bei der (sifenbahnverwaltung ifitiftlid) zu be= ftelfen. Die Beftellung mus möglidjy zeitig nor ber be= ftimuten $\mathfrak{x}$ bfahrtszeit ber Bilge gefdehen.

(2) ${ }^{2}$ Die für die Sergabe uni Bejörderung aufer= ordentficjer Transportmittel bon Der \$ojtbertwaltung zu

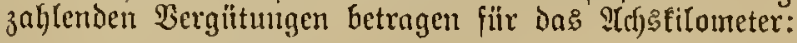

a) fiir fioftragen . . . . . . . $0_{108}$ Mart,

b) für (S)ïtermagen oder P(btheilungen von

\$erjonermagen....... $0_{10}$

Jn den borjtehenden Säłzen find die Bergütungen "für

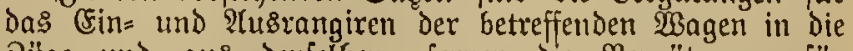
Büge und aus denfelben, fermer die Bergiłtungen für

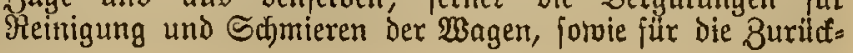


\{djaffung Der ber (sifenbaljuberwaltung gehörigen aufer, ordentlichen Transportmittel mitbegriffen.

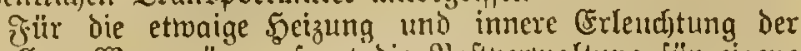
acfellten Wagenräumc forgt bie \$oftuermaltung für eigene Recfunng.

(3) Die \$oftuermaltung Darf verlangen, onf $\mathfrak{3}$ ihr die Benutsung der für fie auf einer (Eifenbalin geftellten aufer= Dritentifien Tlanspormittel, namentlid) der (Eijenbahn= (siiter: uno der Boftwagen, aud) ïber den Bereid diefer Bafjn hinaus, und zwar infomeit gejtattet werbe, als im Silembahndienite felbit eine Durdjbenutzung ber Wagen auf anid) liesenden Bahnen ftattfinden fann, und als nukerdem eine Ulmladung Der \$ojtgüter an Den Heberganggpunften nicht ohne Beeinträbtigung לes regelmäß̈igen Banges ber \$3oftgüter zu betwirken jeir toürde.

Die Bahlung Der Shergafes und Beförderungser, gittungen findet der Regel nach an jede (Eijenbahnberwaltung, auf berer $\mathfrak{B a h n}$ auperordenttidje Traneportmittel benubst worden find, zum bollen Betrage und ohne Rüdfidst Darauf ftatt, ob bie benubten $\mathfrak{B a g e n}$ erft auf ber betreffenden $\mathfrak{B a h n}$ cisgeftellt, oder fotion von meiterfher durchgenommen worden find. Sede Eifenbafnverwaltumg, deren Magen über Den Bereid ifrer Bahn hinans benntat rerden, hat fid daher wegen der ifgr für die $\mathfrak{B e i t e r b e f o ̈ r d e r u n g ~ z u f t e h e n d e n ~ D i e t h e ~}$ mit Denjenigen Berraltungen unmittelbar zu beredfnen, auf deren Bahnen die Wagen meitergegangen find.

(1) Die llebermeifung bon $\mathfrak{B}$ oftifendungen an bie (sifen=

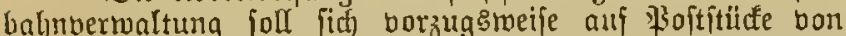
größerem Umfange uni (bewidg)t beffjränfen. Die Heber= weifung gefuieht mittels doppelt ausgefertigter Bet fendungspancine, bon denen die Cifenbahnvermaltung ein Erentplar mit Der Suittung üGer Den Empfang der einzeln berzeid)neten Stïde żuriägiebt, während fie bas andere Eremplar zurïđ

Fiir jede 2lblieferungştation mitfjen bejondere ßer=

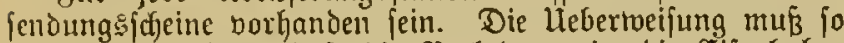
fritlyeitig erfalgen, dẩ die Berladung in die Csifenbahn= wagen bor 2 rbgang des Buges mit Dronung betwirft werden tann. Šlt zur Berladung genilgende 3eit vorhanden, worüber ber (Gijenbahn= Etationsoorjteher in Differenj= fällen enticheidet, io barf jeitens der Cijenbahn bie Mit= beförderung mit dem betreffenden Buge nidht berfagt berden. Bei der Ablieferungesftation ift es Eache Der \$ojt, bie Begen. ftände von der Eifenbahnvermaltung mieder abzufordern. Dabei twiro von der goft in dem, in den Sgänden ber

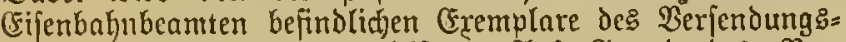
fcheines Begenquittung geleiftet. Yuf (3rund bes $\mathfrak{B} e r=$

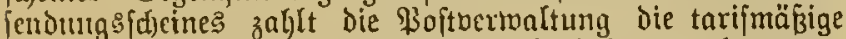
(Eiffradjtgebithr nad) beil bont ber (sifenbahnuermaltung er= mittelten (Sejammtgetwidhte, wobei die Sentungen nadu) jeder ?lblieferungsftation befonders tarifirt merdent.

1) Etehe oite $2 \pi m .{ }^{3}$ ) zu Irt. 3.

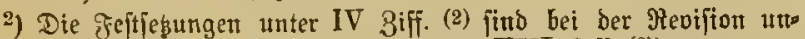
veränbert beibehalten morben (vgl. शి(nแ. วn VIII 3iff. (8)).

\section{V.}

Bu ?trt. 6. (I) Den $\mathfrak{B a u}$ Der ßoftrongen bermittelt bei den Stantgbahnen bie betreffende Eijenbahndireftion, bei \$rivatbahnen die zunächft die श(ufficht führende Behörbe.

(2) Die zum (3ebraudje nuf einer (sijenbalyn bejtimmten Boptragen werden ber Csifenbahnberwaltung überwiefen. Eetertere lyat bie Berpflichtumg, für Den fortgefegt betriebs: fähigen Buftand Der übermiejenen \$ojtwagen und ïberbaupt dafür, dấ diejelben it guter Beidhaffenteit bleiben, in

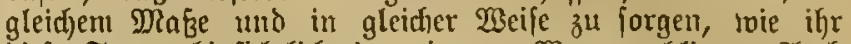
biefe Sorge hinfidttlid ber eigenen Wagen obliegt. Aud)

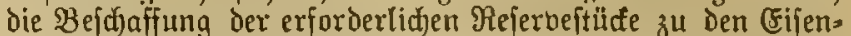
bahn=\$oftragen mird bon der betreffenden (Fifenbahn=

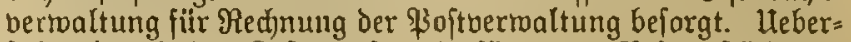
iteigt jedoth der Roptenaufmant fiir neue Rejerbeftihte in Einzelfalle den Betrag bon 1500 Mart, jo ift zubor eine Ber'tändigung mit Der \$ojtberwaltung erforderlich. Die Eifenbalnnermaltung forgt ferner fïr das Cinrangiren ber \$oftragen in bie einzeltren Büge, fonvie bafür, daß bie $\$$ oft vertwaltung in jebem 3uge, bei meldjem ein \$3oftragen mit= gehen imußs, folchen redjtzeitig borfinde. Dagegen tann fie berlangen, daß übermiejen werde, als nach den für ben (5ijenbahnbetrieb bejteljenden Brumdjätzen zur Decfing des Bedarfï er: forberlidy ijt.

(3) Sind ßojtragen jum Durfflaufenden (sebraudf auf mel)reren, unmittelbar aneinander fallięenden (Eijenbahnen zugleid) beftimmt, fo merden diejelben der Bermaltung einer biejer $\mathfrak{B a h n e n}$ ïbermiejen. Sebtere übernimmt alsDann, mon die Unterhaltung der \$oftragen in Reparatur betrifit, die vorftehende Serpflicftung fïr die 2lubdefnung Des Rurfes, und ljat fid über bie 2art und Weife, in der die Ber= maltungen ber librigen Bahnent hierbei mitłumirfen haben, mit diejen zu berjtändigen. Fïur das Sintangiren der $B$ ojt

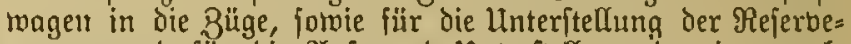
magen, und fïr die $\mathfrak{A} u f=$ und ltnterftellung Der im regelmäß̈igen (Bebraud) befird dicfen Wagen an Den (Endjtationen hat jeic Bertwaltung an iljrem Theile zu forgen.

(4) Tie Sijenbahnverwaltung läß̧t bie nothmendig werdenden Revifionen ber ihr übermiejenen (Fijenbahns $=$ Softwagen und

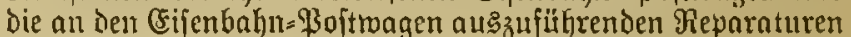
in ifrell eigenen oder fonft dazu geeigneten $\mathfrak{B e r f f i a ̈ t t e n ~ b e = ~}$ forgen uno empfängt dafür von Der ßoftvertwaltung die

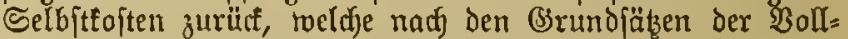
zugşbeftimmungen zu 91rt. 3 berechnet toerden fönnen.

Die betreffenden \&iquidationen müffen mit IItteften ïber

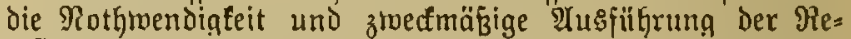
bifionen und Reparnturen und über die Argemefientyeit ber Freije verieken jeit. Das bei Reparatur der (Eijentbahn. Poitmagen etwa entbefyrlia) getwordene alte Material mird bon ber (Sifenbahnberwaltung entroeder nad, Den (Bebraud) s: twerthe vergütet, vder in Der Meife in Rectumung geftellt,

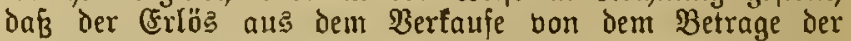

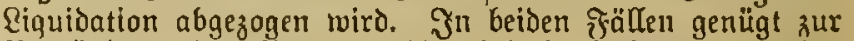
Begründung des $\mathfrak{B}$ etrages die einfache Befdeinigung ber (Fifenbahnberwaltung.

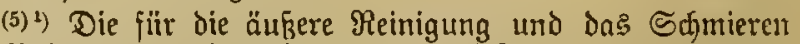

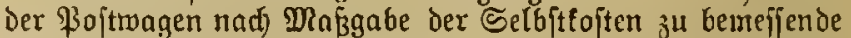
Entichädigung miro in einer Befammtveraiitung entridtet, reldje für das lnufende 2ld) sfilometer 0,80 \$fennig beträgt. Für die Reinigung im Ynnern der $\mathfrak{B a g e n ,}$ fowie fïr Derent innere Ertentfung und beizung forgt die \$oft. berwaltung auf ihre eigene Rechnung.

föur die 2lufftellung ber nid)t im regelmäfigen Dienft befindtichen Bojtwagen auf den Bohnhb̈fen im ofreien hat die $7_{3}$ jitbermaltung eine $\mathfrak{B}$ ergütung bon $0_{11}$ Dlarf fïr Den

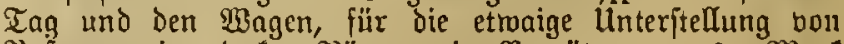
Bojtwagen in gedectten アäumen eine Bergütung bon 0,55 Marf für den Tag und ben $\mathfrak{W a g e n}$ ju entriditen.

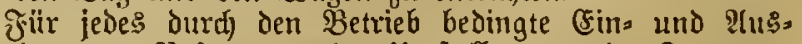
rangiren bon \$ojtwagen oder Umittllen bon im Buge ber= bleibenden \$softmagen hat die \$oftuerwaltung als ben Selbft= 
fojten entfpredjeno Den Betrag bon 1 Marf ju intridften. Beriffiebungen ber Poftwagen mit betu Buge, forwic bas llmfetsen bout \$oftwagen, wefdje fidf in auf Der Fahrt be= griffenen Zügen befinden, toerden als z" bergütende ßangir= bewegungen nicht betrachtet.

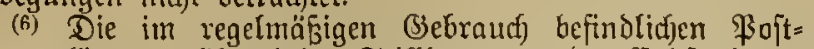
wagen Ënnen trährend des Stialagers an Den Ertoptationen im freten ftehen bleiben, foler"t nidgt Belegenheit zur Unter: frelung borfartien iit, ober die borlyandene Belegenfeit fïr (Eijenbahutwagen nicht benust wiro. Rejerbe=\$3oftrogen

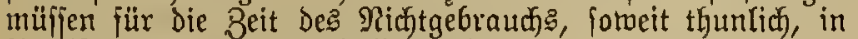
Remifen troden untergeftell twerden.

(7) Für die Beförderung bon, zul \$softoienjtzmeden nidft benutgten, zurütfgehenden \$oftmagen wiro eime frrarftgebühr nidjt gejahlt, roenn die Gifenbahnbermaltung diefelben, was ihr freifteht, für ihte Brvecfe benutst.

(8) Die im Bejeb Plit. 6 9yb. (5) beitimmte Bergütung tritt aud in aller benjenigen Fâfen ein, to ausnahns meife an Stelle der regelntäß̧ig mitgehenden \$oftragen (Eifenbahntwagen hergegeben merden.

1) Dis Beftimmungen unter $V$ Biff. 5 fino bei ber Revijion uns verändert beibehalten worben (vgI. YInm. zи VIII Biff. 8). Weaen

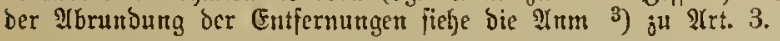

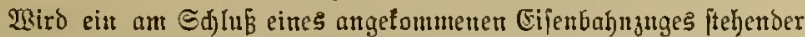

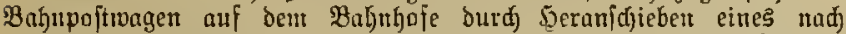

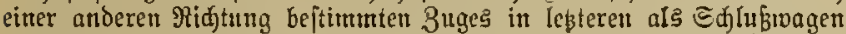
aufgenommen, fo ift bies als eine, ber Gebühr (bon 1 Mart) unter.

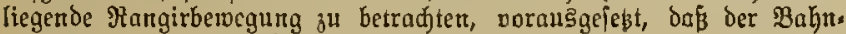
poltragen allein auf biefe $\mathfrak{B}_{\text {eife }}$ aus dem frehenden in ben heran= geidjobenen 3 ug aufgenommen mird. Berber bagegen nod zugleidy Eifenbalynuagnen aus bem argetommenen ftegenden 3uge bem nad

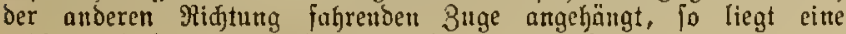

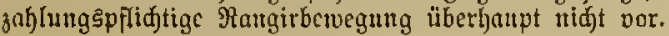

\section{VI.}

Bu $\mathfrak{A}$ rt. 7. (1) Bei 2 (ufitellung der Bauprojefte zu Den

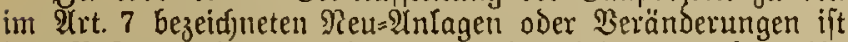
Der Boftbertwaltung reditzeitig Selegenheit zu geben, ilyr Bedürfnif an Dienft= แแto Dienftwolunuggräumen an= mmelden.

Die Benehmigung Des Bauplanes fteht Der Eifenbalyn=

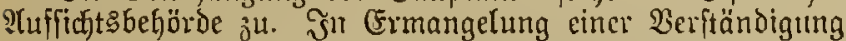

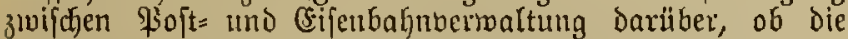
bon der Foft berfaugten Dienjträume ooer befonderen bau= lichen Inlagen Durd) Dell (Eifenbahnbetrieb bedingt find, und ob die (sifenbahnuerwaltung zur miethisweifen Befit)affung bon Dienfroohnungşäumen anzuhalten ift, forvie endlid) über Die Sage uno Einridjtung Der \$?oftoienfträunte ell: = idfeidet Der Bundesiath narf Magante der Beftimmungen iII $\mathfrak{A}$ rt. 1 des Befexes.

(2) Die von der (Eijenbahnberwaltung beja)nfften \$iojt= Dienjt= bezw. Dienftwohnungs räume find der \$oftuerwaltung in einem zur beabfidtigten Sermendung geeigneten, gefraud) jäfigen 8uitande zu übergeben.

(3) Die Gaufiche Unterhaltung der Der \$oft übermiefenen

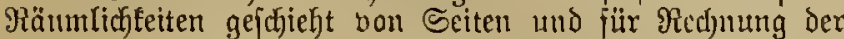
Fijenbahnoermaltung. Bur baulichen unterfalturg ijt hier: bei jedodj bie Altsjithrung foldjer Reparaturen $2 \varepsilon$. nidft :u red)nen, welde nad dert in Dem betreffenden Staate geltenden $B$ eftimmungen itber die llnterhaltung bon Dienjt= wohnungen der Staatßkeamten fitr Rerfunung der Snljaber

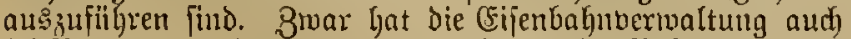

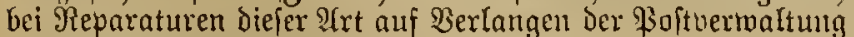
die Bermittelung zu ïbernefmen; die Solten find aber der \$oftbertoaltung in Red)rung ju fteLlu.

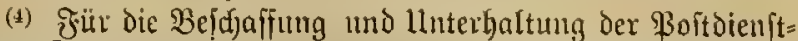
beztw. Dienjtwolnungeräume zahlt dic Foftbertoaltung an Die (Eifenbahnoermaltung eine jährlidje Mietljgoergätumg bon fieben Projent Des Baufapitals.

IIE Baufapital gilt ber Betrag ber Seritellungstoiten

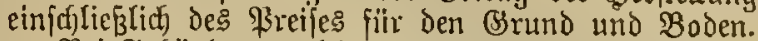

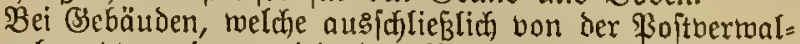
tung benubt werden, twiro bas Baufapital ungetheilt zur Beredhnung gezogen.

Bei folchen Bebäuden dagegen, in denen die ßoit= vertwaltung mar einen Theil ber borhandenen Räumlich= feiten benutzt, miro berjenige Theil des Bautapitnls des ganzen (5ebäudes in Urjats gebradt, melther auf bie bon der \$3oftbcrwaltung benutsten Räumlidffeiten nadh bem Berhältníz des Raumes derfelben zu Dem Raume des ganzen Bebältdes entjäat, und ift Dabei ber Baumerth Der gemeinf(c)aftlich benuţten flure, Treppen und Bodentäume auf die (sifenbahn= und auf die Poltbertwaltung nact) Deut

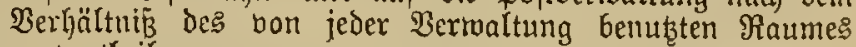
zu bertheilen.

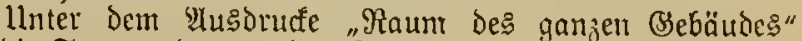
ift die Summe des quadratiffhen Şnhalts der lidjter Räume fämmtlicfer (Etagen, unter Sinzured)nung des Bodenraumes zu berjtehen. Ban biejer Befanmtinmme ift bortweg Die Summe der auf die gemeinichaftlich benuterten f̧lur:, Treppen = unt $B$ odenräume fallenden Duabratmeter in

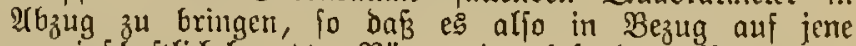
gemeinfdiaftlich benubzten Räume einer befonderen Repartition nicht bedarf.

(5) Die Reinigung, (Frleudftung und 5eizung der zil

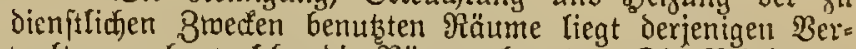
waltung ob, meldye die Räume bemutzt. Die Reinigung,

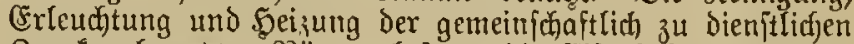
Bivefen benubster Räume beforgt die Eifenbahnberwaltumg gegen Erftattung der Şälfte eines zu berechnenden Roften= Baujchquantums.

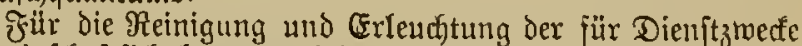
gemeinfdjaftlid) benutsten Flure und I reppen merden nur die im Эntereffe des \$oftoienjtes etwa entitehenden Gefonderen शlufmendungen bon ber Foftuertwaltung eritattet.

Die Reinigung und (Fileur)tung der Flure und Treppen ber Dienftmohnungstäume Der 9 softbeamten liegt Der Eifen= bahnbermaltung nicht of.

(6) Dic für die Eijenbaljnreijenden beftummten Wartefäle fönnen audf bon ben \$oftreifenden benutgt merden, und 3'war unter benjenigen Bedingungen bezüglich des $\mathfrak{Y} u f=$ enthalts in benjelben, melche für die Benubung der $\mathfrak{B a r t e}$ fäle burch die (Eifmbafnteifenden algemem borgej(d)rieben find. Sotweit ben Eifenbahnen Durh bie Aufmahme der Fojtreifenden in den Wartefälen Der (sijenbahn nadfmeistidje Mehrfojten entfitefen, find biefelben von ber Poptoerwaltung zu exjtatten.

(7) Die Stellen, wo Boftiffilder und Brieffaften anzu= Gringen find, werden bon der \$oftbertwaltung nad) bor= Geriger Berftändigung mit der Eijenbahnbertwaltung befitimmt.

(8) Ueber die Baupläne für die Gefonderen \$oftgebäแbe

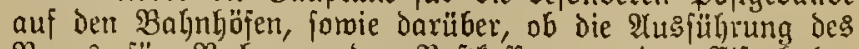

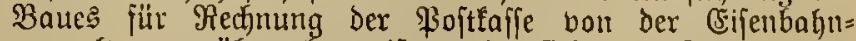
vermaltung ju übernebmen ift, merden fid die \$oftocrmaltung und die Eifenbafnnermaltung in jedem cinjelfall verftändigen.

(9) Wenn die Cifenbahnbermaltung Beränderungen Det

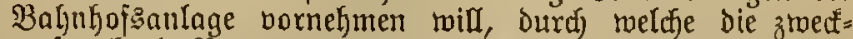

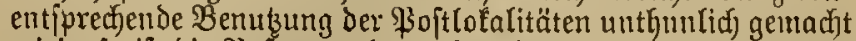
wirb, fo ift die \$oftberwaltung bered)tigt, bie leşteren zurüct. 


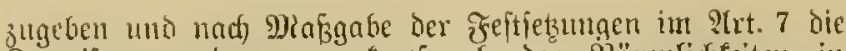
Bubeifung anderer zwetfentprect)ender Päumliçfeiten in S(nfprutch zu nehmen. Dieimungsverfhicbenheiten barüber, ob ein foldyer Fall worliegt, werden auf ben im st. 1 des (Sefetzes vorgeffiriebenen Wege exlebigt.

\section{VII.}

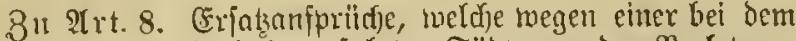
Betricbe ciner Gifenbabn erfolaten Iobstung oder Berletzung eines in Dientit befintidyen Gioftbeanten ethoben werien, wird dic betreffende Sifenbalyuberwaltung alsbald zur fennt= niß der \$oituertoaltung bringen.

Berben foldhe Eriasaniprüdie im wege des Brozefies verfolgt, fo miro bie Eifenbaljnverwaltung nad, Buitellung ber

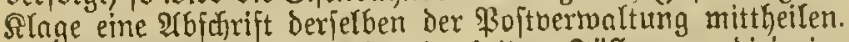

Die Mittbeilung exfolgt in beicen fällen an biejenige Saiferlide Sber=4Boptoireftion, in secen Bezinf der linfall (iid) ereignet gat.

$$
\text { VIII. }
$$

\section{argemeine $\mathfrak{B}$ eftimmungeu.}

$8 u$ Irt. 10. (1) Die Beanten ber heiberjeitigen $\mathfrak{B} e r$ : maltungen find berplidytet, bei Wabrnelymung ibres Dienites dergeftalt 5ano in Sand zu gehen, Dafi bas Snterefie beider

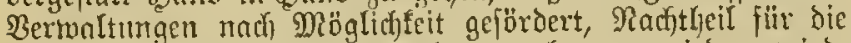
eine oder die andere Germaltung aber vermienen miro. ธoneit foldjes mit den Finereffen ber eigenen Bermaltumg verträg(id) exfdeint, milifen die Beamten in allen $\mathfrak{B}$ or: fommnifien des Dienftes den Wuinjdyen ber Benmten der anberen Bertweltung fich willfährig bemeifen.

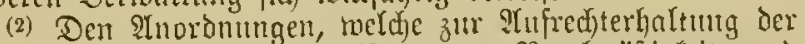
Dronung auf ben Babuljöfen, ter Regelnäbigteit uno Sidferbeit im (Bange der (5ifenbalynzlige, formic auf (Grund

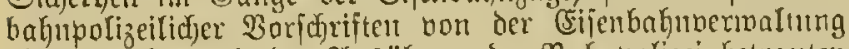
ober bon ben mit der A̛silbung ber Bahupolizei Getrauten (5ifenbabnbeamten getroffen serben, find aud) bie Poit= beantes nadizufommen berbunden.

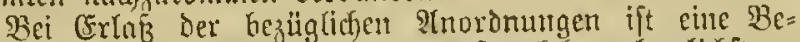

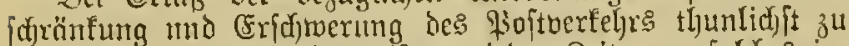
berntiden. जnskejondere ijt ju jeder Beit, wo foldhes im \$oftintereffe nothmendig erfodeint, ber Bugang zu ben auf Den sBahnhöfen befinolichen 3 oftbureaus offen zu erhalten;

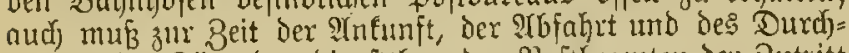
ganges Der Büge den bienfthluenden $\$$ Softbeamten der Butritt zu bes अartons geftattet werben, imgleidyen aud bem die Brieffaiten an den Poitmagen bentisenden \$̧ubrifum, info= fen nidft die Eifenbahnbermaltung aus befonderen Gründen bas Betreten tes Perrons zu hefdrünten genötligt ift mo

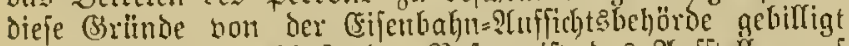
merden. Den anfwliebenden Soften ift bas Thfitellen auf ben Babnhöfen an gecigneten Stellen, foroeit foldje vo: Ganden fino, zul geftatten.

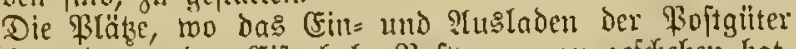
in bie und ans ben (5ijenbahn= Sioftwagen zu geforjeben lont,

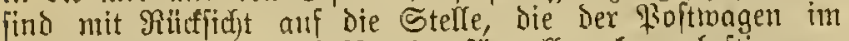
Buge einninmt, nögliaglt cin= fïr allemal zu beftimmen. Dic \$räze find, mo bies tluunlicf erf(t)eint, fo zu mählent,

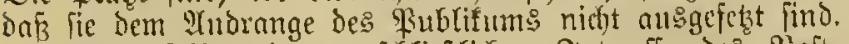

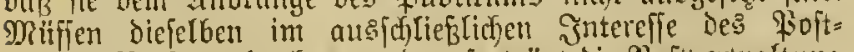

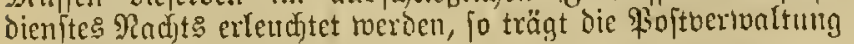
die Soiten.

(3) Die Foftbeanten find verbumben, alle Borfidgt an=

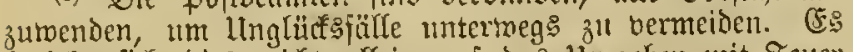
bezieht fich bies nidyt alfein allf bas llmgehen mit Feuer und Richt, auf Das (Sd)liefzen und Deffinen ber Wagen= thïren ze., fondern audy ganz befonders aul die 2(rt des Berladens Der Boftgüter. Die einzelnen Ad ffen der Boịt= wagen müffen möglid)ft gleidbmäß̄ig belnjtet, jebe lleberlajtung nber muf3 forgfältig bermieben iverden. शRimmt der Fifen= Galy = Stationsooriteher cine lleberlajtumg bes ganzen 23agens oder eines Theiles deffelben roahr, fo ift ex be. red)tigt und berpflictet, fofortige Befeitigung biejes llebel= ftandes zu berlangen.

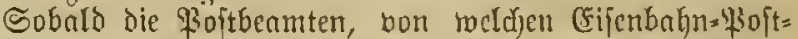
transporte begleitet merben, untertwegs eine Sd)abhaftigfeit an ben Soptruagen mahrnehmen, haben fie dabon in ge=

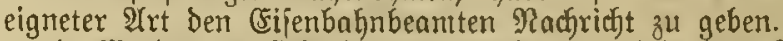

(1) Werden an Eifenbahnbaltejellen, mo bejondere $\mathfrak{B o i t =}$ anftalten fich nicht befmben, bon der \$3oftbertbaltung Brief = tajten aufgejtellt, fo wirb bie Eijentiagnbertbaltung, forweit dics ofme Beeinträchtigung ber Sicherheit bes Betriebes zuläfïg ift, nadj Bexftänoigung mit ber \$3oftuerwaltung den C5ifenbahubeamten, roeldyem die Wahrnebunng des Dienftes an Der Salteftelle obliegt, berpflid)ten, fidf Der Beaufficftigung bes Brieftaftens zu unterziefen, Denjelben furz vor Durré)= gang jedes Buges zu eröfnest und die barin befundlichen Briefe den Poftbeamten, meld)e die Bitge begleiten, wäbreno bes ?alualtens derielben zn übergeben.

IInter ben gleidfen Borantsjełungen wirb die Gifenbalnt= bermaltung ben Silenbahnbeamten ciner joldien Salteitelle aud) beaufragen, die Insmed)feluna ber\{d) Loffener 3 rief=

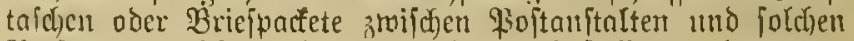

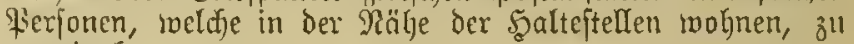
vermitteln.

(5) Dic Eifentalyn= Ctationsporftelyer find berplidjtet, ben Roritebern ber Drts=98oftanftalten vour allen Störungen im Eifenbahnbetriebe, welfie auf ben \$optbienit bon Ginfußz feit Eönnen, forvic von der exfolgten Befeitigung folcher Ctörungen unzerölalich Mittheilung ju mad)en.

(6) Bei Betriebsjtönugen, weldue dic Weiterbeförterm! Des Poftwagens nidht geitatten, find bie Briefpoit mo die

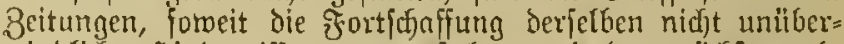
windlidje joinderniffe entgegenftehen, mit bem nächften $a b=$ gehenden 3uge weiterzbefördern. SBei gänzlicher Semmung Der \$ajjage auf der Cijenbahn ift es Sache der Bojtbermal= tung, fiir Die Bejörberung ber \$oftjenoungen Durch \$opt= betriebsmittel zu forgen.

(7) Şede (Sifenbahnberwaltung tritt in $\mathfrak{B} e z u g$ atif ifre gefammten Jorderungen an Die \$optbertmaltung in Der

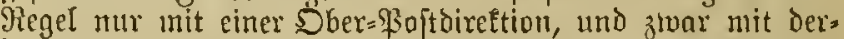
jenigen in $\mathfrak{A}$ Gred)trung, in beren Bezirf ber Drt gelegen ift, an meldjer die Cijenbahnbermaltung ibren Sits hat. Die

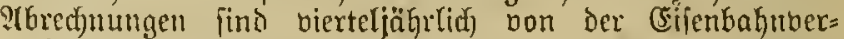
maltung aufjuftellen. Die Ballung der Beträge exfolat,

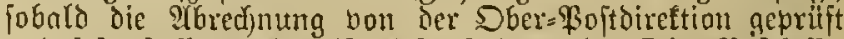
und feitgeftellt worden ift, foftenfrei aus oer Dber=93oftfaffe.

(8) Die Bcftintmungen unter II Biff. 4 find nach YYblauf pon 2 3abren und semmäđjlt mit ben Beftiumungen unter III Biff. 2 und 3, unter IV Biff. 2 uో unter V Biff. 5 nad) Iblauf von

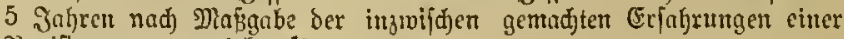
Revifion zu untergiet,en. ${ }^{1}$ )

1) Die Revifion hat ftattgefunden und ift erlebig!. Die $\mathfrak{B e}=$ frimmungen unter II Biff 4 und III Biff. 2 fino burd) geroromung

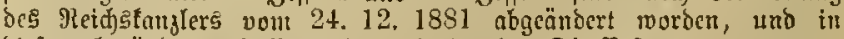
bicjer abgeänberten fraffung hier ahgebrudt. Die Beftimmungen unter III 3iff. 3, IV Biff. 2 uno $V$ Biff. 5 find unverändert beibefalten worben.

Berliu, Deแ 9. Februar 1876. 


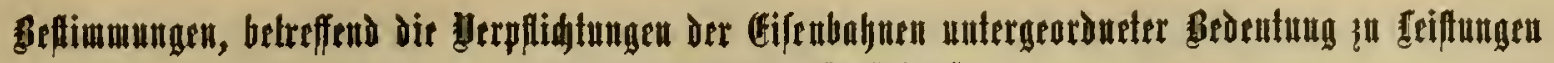 fiir dit 3wente Drs Jlofttientiftes.}

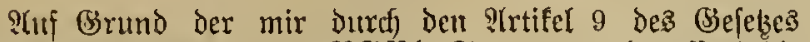

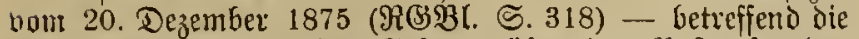

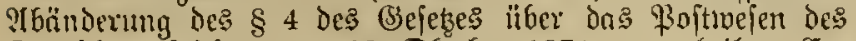
Deutfifen Peidfe vom 28. Sftober 1871 - ertheilten (Fr= mäuftigung beftintme id hierdurd), was folgt:

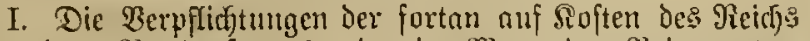

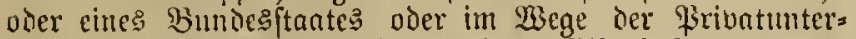
neljum zu Strlage fommenden Eifenbahnen unter: geordneter Bedentung zu Reiftungen fitr bie Bmecfe des foroftoienftes regeln fid) nad) bem borbezogenen (Befelse vom 20. Dezember 1875 und den Daju geljörigen

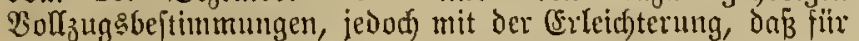

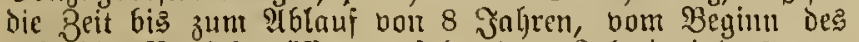
auf bie Betriebseröffnung folgenden solenderjahres, an Stefle der bie nadjftehenden Bcitimmungen treten:

Die Bafneerjorltung ift berpiliditet, in jebem für ben

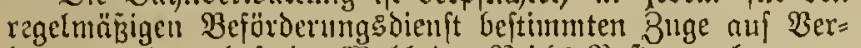
langen und nad) freier Wabl Dex Reich

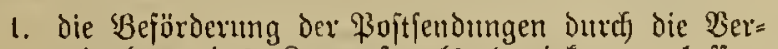
mittclung Des Bligperfonals berwirfen zu lafien, wooilir Die \$oftbermoltung eitue Bergiltung vot 1 Pijennig für den 3entuer und dag Rilouteter der Beförderung:streffe nadh dem monatliden Gefommtgewiffte der von Station zu Station

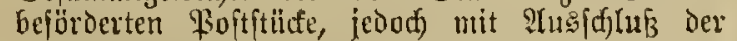
nutentgeltlid) zu befördernden Briefbeutel, Brief= uno Beitungspacete, cnlrid)tet. Die Softoermaltung $^{3}$

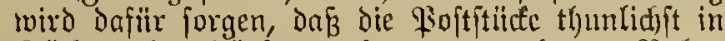
Eüffen oder sïrben zufammengepacft zur Bahn= beförderming übergeben werben;

2. Briefbeutel, fotwie Brief= und Beitungapactete mit

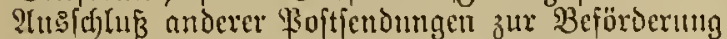
burtf) Das Bugperjonal gegen eine Entichäbigung von 25 gif. für jeden in dicfer Weife bertukten

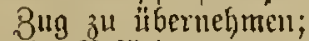

3. bic Befördenung von Briefbeuteln, forvic Briej=

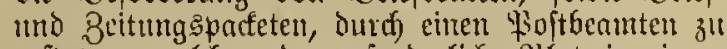

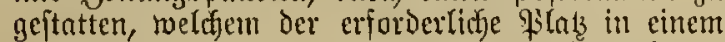
Hierfonentwagen Dritter Slaffe gegen Entridftumg cines fahrgeldes bon 2 Pf. Für Das Filometer cinz

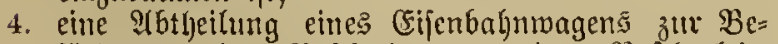
förderung der Poftenoungen, des Poftbegleit= perfonals und ocr exforderlidjen Poftoienitgerätlje gegen die in 2Trt. 3 bezm. 6 bes (Fifenbahn=? oft =

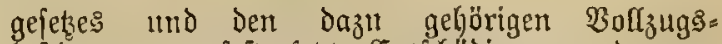
bejtimnungen feitgejezte (sutjojabigung und gegen Entrichtung ciner frrachtnergütung bou cinem halben bfennig für Den Bentner tub das Rilo= meter nach dem gemäs Der Beftimmung za 1 zu

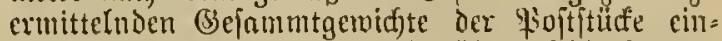
zuräumen. Die Entfcheidung Dartiber, of bie Waggen= abtheilung in einem Perjonen= oder in einem Siuter= wagen einzuridften ift, fteht der \$oftberwaltung ju;

5. einen bon ber Boftoermaltung geitelten Eijenbabn= Boftwagen mit Den Derin Gefindficfen \$ojtfendungen, deen \$ojtegleitperfonal unt Den erforderlichen Foftoienitgerätben gegen (Fntrid)tung elnter Jirad)t= bergüttmg von eimem halben \$seunig für ben Bentner und bas Rilometer nad) dem gemü $\bar{B}$ Der Beftimmung zu 1 zu ermittelnoen (Sefaumtgemichte Der Poftitid a at befördern.

Soferm imlerbalb Des borbezeichneten Beitraumes in den Verfältniffen der $\mathfrak{B a h n}$ in Folge von Ermeiterungen des

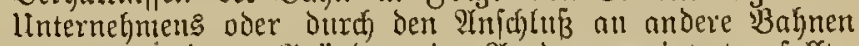
oder aแs anderen (Sriltnden eime Ylenderung eintreten folfte,

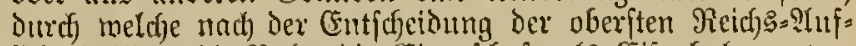

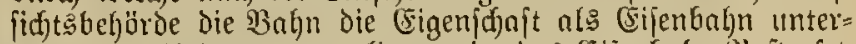
geordmeter Bebentung verliert, tritt dos Eijenbahn=\$Softgefed mit Den dazu gehörigen $\mathfrak{B}$ olfzugsbeftimmungen ohne Ein= fifgränfung in :Invendung.

II. Ilnter den (Eijenbahnen untergeoroneter Bedentung iur Sintne Der vorftehenden Beftimmungen find biejenigen verftanden, weldhe mit fdmalerer als ber Rormalfpur ge= baut find, jomie bicjenigen, auf welche bermöge iljer unter= georoncten Bedeutumg bie Beftimnungen bes Bahnpolizei=

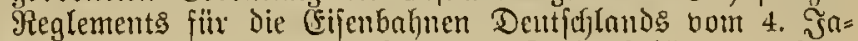
muar $1875^{1}$ ) bou der zuftändigen Randes6eljörde im (sin=

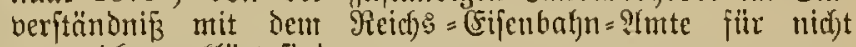
anmendbar ertlärt find.

गuf die jux Beit bereit: im Betriebe oder Ban befind= (icfen Eijenbaljuen untergeoroneter Bedentung roie auf beftehende Eifenbalmen, denen fïnjtig Der Sharafter einer Eifonhahn untergeordneter Bedeutung beigelegt werden mödnte, finden die $\mathfrak{B}$ eptimmungen unter I - vorbegaltich meiner $b e=$ jonderen Berwifligung int Eingelfall - feime 2Tmentomg.

Berlin, den 28. Miai 1879.

Der Mcidzfazler. v. Bismartef.

1) Unterm 30. 11. 1885 ijt ein neues Bahnpolizei=9ieglement für bie Eifenbahten Deutjd)lands erlaffer mordent.

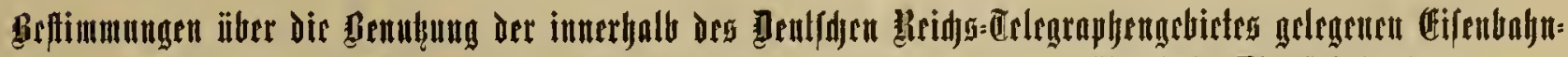

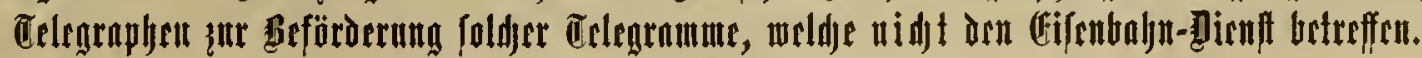

\section{(Pleglement vou \%. פiäry 1876.)}

§ 1. Sämmtliche Stationen der innerhalb des Dentid)en Reidj: Innahme uno Bejörderung foldfer Telegramme, weldje nicft den Eifenbahndienft betreffen, nach) Magsgabe der $\mathfrak{B} e=$ fitimmungen biejes Reglements ermächtigt.

§ 2. Die (Eifenbahn= Ielegraphentationen dürfen $T$ Iele= granme annebmen: a) trenn feine গeidj: jelben Drte ift: von Jeocrmann;

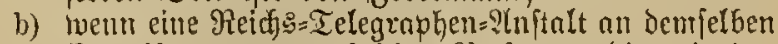
Drte ift: nur bon foldjen Sierfonen, bie mit ben Buigen anfommen, abreijen oder Durdreifett.

§ 3. Die telegraphifde forrefpondenz ift, olgne Rühfidft

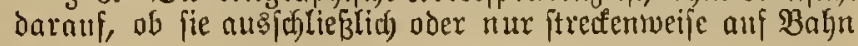


telegraphen ihre Beförberung erfält, Den Beftimmungen Der jedesmaligen Telegraphen=Dronung fï bas Deutide Reid) untertworfer.

§ 4. Die auf Den (Fijenbnhn=Betriebsodienft bezüglidjen Telegramme Gaben in ber Bejörberming allen anderen Telegrammen borzugehen.

§ 5. Die Eifenbaln= Telegraphenjtationen gebören der Regel uad) zu den Stationen mit bollem Tages=

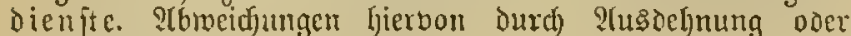
Bejdyränfung Der Dienjtitumben toerden zur öffentficfen Sentutniz gebradjt.

§ 6. Die bei Den (Eifenbahn= Ielegraphenftationen an= genommenen Selegramme, weldje nad) Srten des Deutidjen

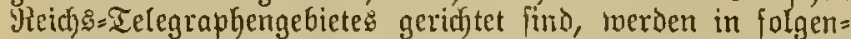

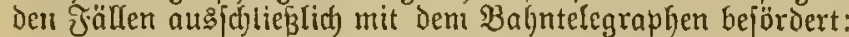

a) wenn fie bon der Tujgabe an bie Rorefjitation direft, o. h. ohne jede llmtcleyraphirung gegeben meroen fönten, wobei es teiren linterfofied maryt, ob an Drte Der Ildreß̧itation eine Reich $s=$ Iele= graphen=:Anjtalt beftebt oder nidjt;

b) renn fie auj bem Wege bon ber शujgabc= bis sur IDreß] tation nicht melyr als e ine llmtelegraphirung zu erleiben Gaben, und am Dite der glorebitation

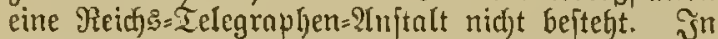
nllen anderen Jällen find die Telegramme an bie näufte zur Bermittclung gecignete Reid)

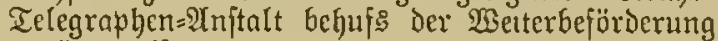
zu tibertweifen.

Sine dirette Beförderung von Telegrammen über die (Sienzen des Deutfofen=Telegraphengebietes mit dem Babu= telegraphen darf nidjt gejd)eben. (SE blcibt jedoch bor= befalten, für diejenigen Babnen, meldise zum Theil in anderen (Staatggebieten liegen, 2tbroeidumgen cintreten $z u$ lajpen.

\$7. Die Reidjotelegraphen fino jum Buerte und ju Befd)letmigung Der Telegramm = 2(usmedfelung mit Den Babn= Ielegraphen deffelben Srtes, forneit es tljunlidf ift, outch Reitungen zu verfinden.

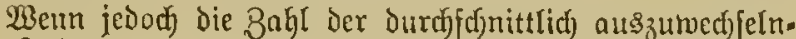
Den Telegramme oder die Sntfermung zuvijden den beider. peitigen Stationen eine febr geringe ijt, fo fann von ber

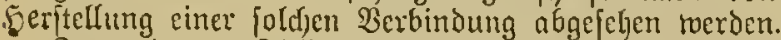

šn geeigneten ởllen jollen aud foldhe Srte, an welden cinerjeits nux eine Reidjs=Telegraphenanjtalt, andererjeits nux cine Babntelegraphenjtation borhanden ift, telegraphijó verbunden und die Berbindungleitungen it gevöhnlicher

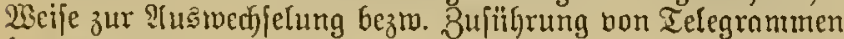
benutzt weroen.

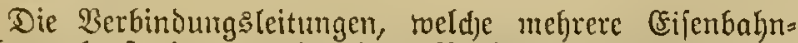

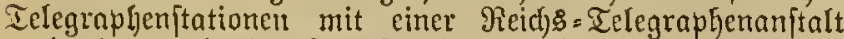

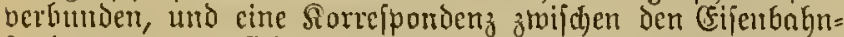
ftationen unter fïch ermöglichen, dürjen unter Siontrolle Der Reichs: Telegraphenanftalt zu Galundieniflidien Mits theilnngen benubst merben. Dagegen Dïrfen Bribat=Sele. gramme stwijen den Eifenbahn-Ielegraphenftationen auf poldjen Seitungen nicht gemedjiclt tverden.

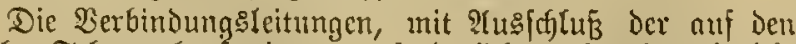
Babn= Telegraphenftationen erforberlidfen Stationseintricf) tungen (Mpparate, Batterien 2e.) trerden für Red)nung Der Reidjs-Telegraplie hergejtellt und unterbalten, forweit ein

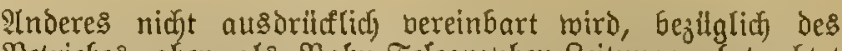
Betriebes aber als $B a\} n=$ Ielegraphen=Reitungen betrachtet und nad) den bei deu (Eifenbahubermaltungen beitchenden Inweijmmen bon ben beiderjeitigen Beamten bebient.

Die Eifenfabnverwaltungen madjen Demgemäs den

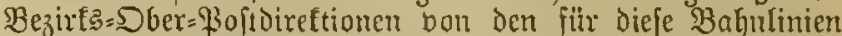
beftebenden Dienitlidjen RImeifungen behufs der Bend)tung fritens Der Reid)s=Ielegraphenanjtalten Dlitthcilung.

§ 8. Die Thtowed)

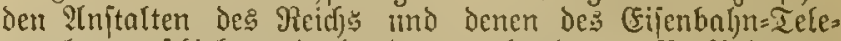
graphen gefficht nittels ber borbandenen Berbinoung: leitung und, falls cine joldje nidft borljanden oder nidjt betriebsfäling ift, ourda Boten. (FE Gleibt jedod) Den beider=

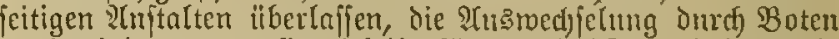

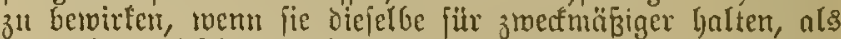

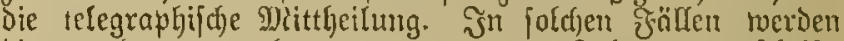

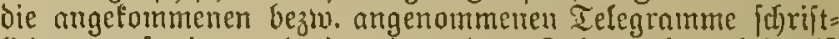
(id) anzgejertigt mo in ciner bas Telegraphengeljeimní̋ fidjernden Weife (fei $e^{s}$ in einem $1 \mathrm{~lm}$ id)lag, auf weldjem die Bafl ber darin enthaltenen Telegramme angegeben ift, fei

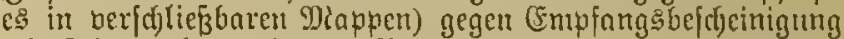

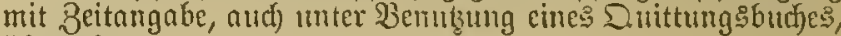
ïbergebelr.

\$ 9. a) Jitr biejenigen Telegramme, Deren Beförterung

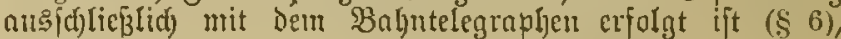

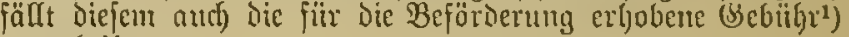
ungetbeilt zu.

b) $\mathfrak{B e r i o n}$ Telegramme ftrecfenmeije mit dem Reidjsిs telegraphen uno itrectentweife mit Dem Barlyntelegraphen

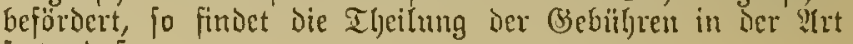

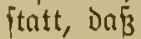

1. jür hie innerhalb dę Sentidjen Reidjo und Quxemburg: Geförderten Ielegramme die Picid) Ielegraplertbermaltung $3 / 5$, Dic Gifenbabn= Tcle= graphenbermalturgen $2 / 5$ Der erlyobener (5ebilibr erljalten, แmD baß̄

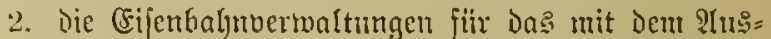
Iande getvethjelte Ielegramm 50 Pfennig für je 50 Warte ober den ïberfádejenden Barudjtheil, jes bod) nidft mefri als den eigenen (sebïbrennutheil Der Reid)

c) sit ber Telegrapl von megr als Finem Babngebiet zir Benubung getommen, fo mirt ber madf Dbigen auf den BBahntelegrapljen enifallende Bebührenantheil zroijachen

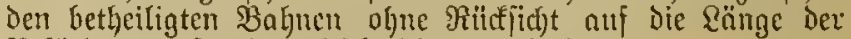

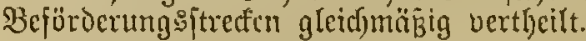

d) Zür ein Telegranm, toeld)es bci einer Babn= Tele= graphenjtation aufgegeben und der an demielben Drte

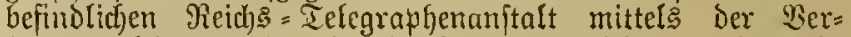
bindungsleitung oder durel) Boten zuge[iigrt worben ijt, erbält der Babntelegraph 25 Pfennig fitr je 50230 te oder

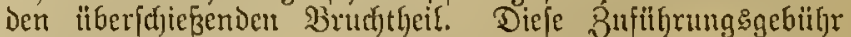
wird bei Telegrammen, seldfe nachfer wieder vom Reidf: telegraphen auf ben Bahntelegraphen beffelben ober cines anderen Bangngebiets ïlergeben, nach Der Bejtinumug unter c Dicjes Faragraphen in Rechum gebracht.

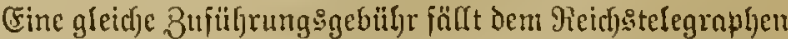
зu, roem ungefel)t Ielegramme bei einer Reidfs= Ielegraplyen= anftalt aujgegeben umb der an Demielben Drte befindididen Baljn = Ielegraplenftation mittel Der Berbindungsleiturt ober ourdh Boten zugeführt morden fino. 
Riegen die Reidjs: Telegraphenanjtalt uno die nädjpte Bahn=Telegraphenitation an berjutedenen Srten und find beide duref eine Seitung telegraphijich berbunden, is fann diefe $\mathfrak{B e r b i n d u n g g l e i t u n g ~ b e n u k t ~ t o e r d e n ~ z u r ~ B e j o ̈ r d e r u n g ~}$ aud) (oldher Telegramme, weldhe bet der Reidf anjtalt aufgegeben und an bie Bahn=Telegraplenitation gerichtet find und imgefehrt.

:on der nad) Dem geröbntiden Tarif zu erbebenden Gebiligr erhält bie zufïhrende Yujtalt die unter d diefes

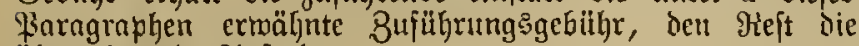
iibertrebmente 2 inftalt.

P) Bezahlte Rillfantworten und CEmpinngsanzeigen find

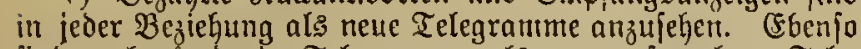
find nad)julendende Telegramme als net aufgegebene $\mathfrak{T} \in l_{e}=$ gramtme zu behandeln.

f) Die Gebüfren für Berbielfältigung, Zurïtfziehung

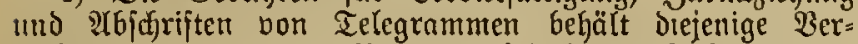
waltumg zum ganzen Betrage, bei beren Mnftnlten bie Erkebung itattgefunden hat.

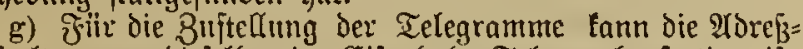
anjtrlt, menn diejelbe eine Eijenbahn=Telegraphenftation ift, ind der Drt, ju reldfem biejelbe gehört und wojin daś Telegramm geridytet ift, weiter $a[s 2 \mathrm{~km}$ von ber $\mathscr{B} a \mathfrak{l} n=$ itation entiernt ijt, eine 2ustragegebiifgr bis zut 50 Biennig erbeben. Befindet fidj jedoch) an Demjelben Drte zugleid) eine Reidjs=Telegraphenanjtalt, jo erjolgt Die Zujtellimg entweder burdh bie lezztere, meldjer die Ielegramme itt ber im $\& 8$ borgejpiriebenten Beije zugejübart toerden fönnen, oder gebitilyrenjrei bezw. gegen (Erbebung bes nad) Maß̈gnbe der Zerarbutung bom 24. Samuar 1876, ${ }^{2}$ ) betreffend $9(6=$ änderung und (Figänzung der Telegraphen=Drdnumg, zit= läffigen Beftellgeloes burd die Bahn-Telegrapheujtatun.

Sind die Bebühren für die 2 setterbeförderung iex Telegramme mittel: Eiłbeftellung bom 2 ufgeber Ginterlegt, jo rerben fie Derjenigen Berwaltung überwiefen, derell Anftalt dic Weiterbeföberung der Telegramme alţzl= iiifren Gat.

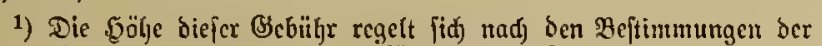

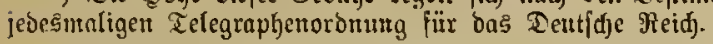

3) פez̧n. nađ ben Beftinumungen ber geftenden Tefegraplent= Dronung.

\$ 10. Die Beptiummungen, weldje ïber die gebïlytenfrete Bejörderung von Telegranmen bom Reid) Skatzler exgehen,

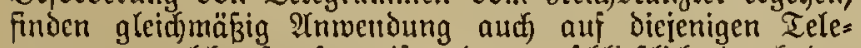

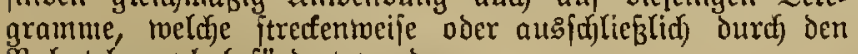
Bahntelegraph befördert merden.

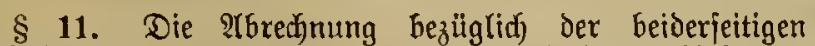

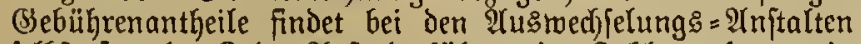
felbit itatt. ${ }^{1}$ ) Jede 2 nitalt fïhrt cin Baflungsifonto, in weldjes alle an bie andere 2 nitalt abgegebenen, und ein Forderungstonto, in welches alle bon ber anderen $\mathfrak{A}$ nffalt itbernommenen Telegramme nad der Beitfolge einzutragen

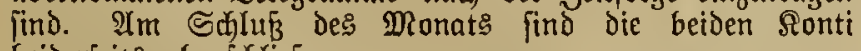
beiderieit: abzujd) lieken.

Das fich ergebende Saldo wird fofort ausgezahlt. Die auf den Zahlungsfonti auszuftellenden Duittungen mulffen ïber den bollen Betrag diefer Ronti lautent.

Sollter Den (Eijenbahn = Telegraphenftationen bon den Bahnpoitanitalten Ielegramme äberwiejen merden, für meldye die (Bebühr mit Telegraphen= oder \$optrocthzeidjen entrichtet worden ift, io find dernrtige Ielegramme fiur jedes $\mathfrak{B a h n =}$ gebiet zu lammeln und mit einem Forberungsnadineije ber bon der Eifenbahnberwaltung beanjpruditen (Bebulhren= antheife an diejenige Dber=\$3optoireftion einzureichen, in beren Bezirf fid ber Sits der (Eifenbahnberwaltung befindet.

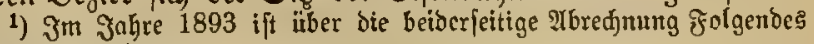
beftimmt worben:

Bur Beit findet fortlaufende abred)mung mur nod) mit ben Stationen wentiger Eifenbahnen ftatt. IIn Stelle berfelben ift folgendes \$erfalyen getreten:

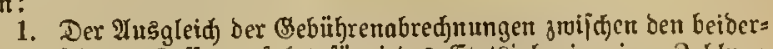
feitigen Fैaffen erfolgt für jebę Etatsjahr it einer Bahlung am 1. Itprit.

2. Die Эahresforderung ober Bahlung wirb badurd) ermittelt, baह fïr bie erften 15 Tage bes Februar unt bie exften

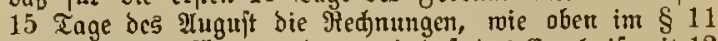
beftimmt ift, geführt werden, und bas bas Ergebnis mit 12 vervieffältigt miro.

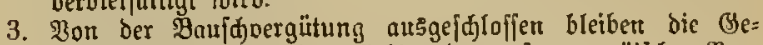
bithren für bie nad bem Bebiete bes aubereuropäijđen Bor= [dififtenbereidjs geridftetes Telegramme. Heber berartige

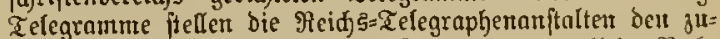
führenden (Fifenbaljn=Telegraphemftationen monattidge Red)= mungen zum भinerfentrnib ju, bie fodann gefantmelt uto bei Belegentheit Der Bablung ber Baufdoergintungent am 1. Iprit ausgegliden merben.

4. Die năheren Mereinbarungen über bic IIusführutg ber vor=

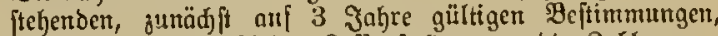
namentlien bie शBaht ber Rafienftellen, wo bie Bablung ju erfolgen hat, bleiben den betbeifigten finaferliden Dber=\$3oit=

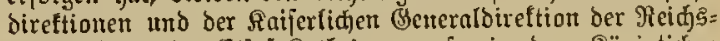

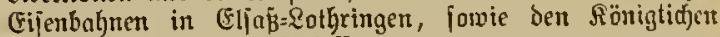
Eifenbahndireftionen itberlaifen.

5. Sollte bic Erfahrung ergeben, ba B̈ cin wejertlidjer lluter=

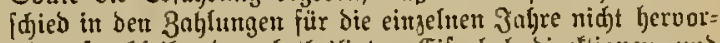
tritt, fo bleibt bent bethciligten EFifenbahabireftionent unb Ober= \$oftsireftionen iiberfaffen, von ben 30 -tägigen $\mathbb{E}^{2}=$

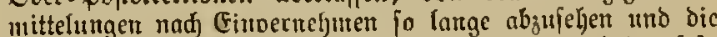
jährlide Bablung nađ beut Durdjöntitt ber 3orjahre feft= anjegen, bis bejondere Brütbe mieder eine Ermittefung er= forbertid) erfdjeinen faffen. (Ebenfo famm dout ber Cinjel= verrechnung ber ansereuropäiø̄ent Telegranme abgejehen

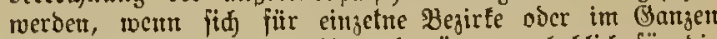

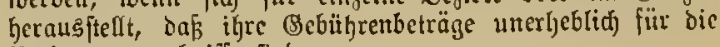

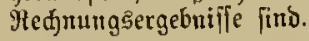

§ 12. Die für berlangte Rüdfantwort Imb Cmpjang: anzeige eingezaljlten (Sebithren fimo der itberneljmentoen ?tritalt voll zu übermeijen. Daffelbe gilt von ben von dem STifgeber erbobenen Bebüfren fitr die Weiterbeförderung ocr Telegramme mit der Bujt oder mittele des See=Telegraphen.

Die Sioften jïr die Beiterbeförderung mit Eitboten ober (EFtajette ${ }^{1}$ ) werden berred)net, jobald der $\mathfrak{B e t r a g}$ diejer Sioften gemeldet morden ift.

Die bezügliche Mittheilung, mieviel Boten= bežn. (Eita= jettenfoften berauslagt find, hat entmeder in der (5mpiangs= anjeige, oder, twenn ę fid) um gemöhnlitide Telegraume itmerhalb des Deutidjen Reidjes ljandelt, Durch bie \$3ojt mittels portofreten Dienitbriefes za erfolgen. In jedem

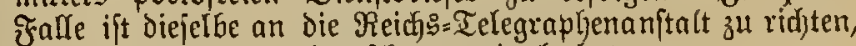
weldhe bie Urjprungsoepejdje berntittelt hat.

1) Eine $\mathfrak{B}$ eiterbeförderung der Telegramme mittets Efftefte inner=

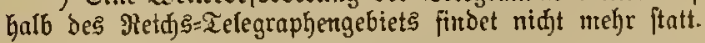

§ 13. ₹̛̈u (Bebübrendejefte Gaftet diejenige Reid) bezw. Bahn=Telegraphenanftalt, bon weldyer ons Ielegramm all den $\mathfrak{B} a l y n=$ beztw. Reichs=Telegraphen itbergegangen ift.

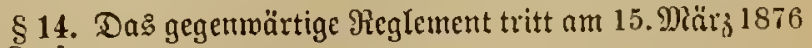
in Sraft.

Berlin, den 7. März 1876.

Der $\mathfrak{A} \in \mathrm{i}$ d Эür\{t b. Bis?mard. 


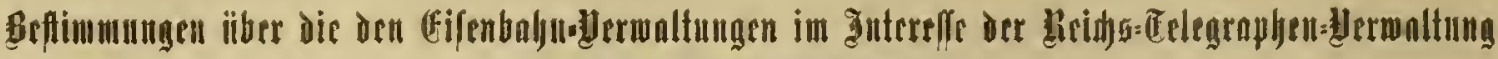 oblirgenden ऐerpelimtnugen.
}

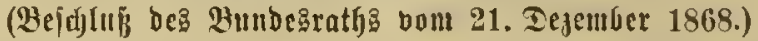

(1) Dic Eifenbalynbermaltung hat die Benuţung bes

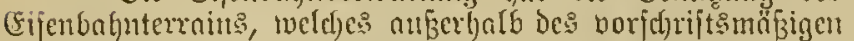

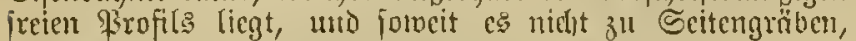

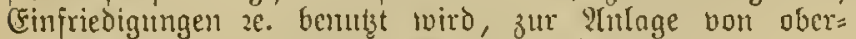

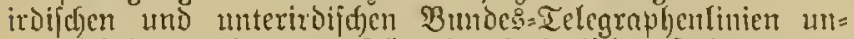
cutgeltlid) zu geitatten. Fill bic oberirbifden Telegraphen= linien folf thunlidgit entfernt bou iden Babugeleijen nad Bedinfnif cine einfadje oder Doppelte Stangenreibe nuf Der cinen Seite Des B̉nhrolnmumb aujgeftelft tocrden, weldje von ber (Eijenbafmberwaltumg zan graplyenleitungen unentgeltlict) mitbenutzet werden bar.j. Zur :Inlnge Der unteriroifcten Telegraphentinien foll in Der Regel diejenige Seite Des Babnternins benuţt iverden,

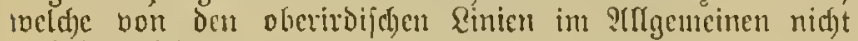
berjolgt twird.

Der erite Trnft der Bumdes.Telegraplyculinicn wird bon

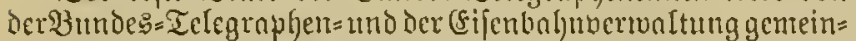
jejaftlich feitgejebt. S(enderungen, iveldje durd) Den BBetrieb ber $23 \mathrm{abnen}$ nadyweis(id) geboten find, erfolgen auf Sioften der Bundes=selegrapljenbermaItma, bezm. Der (Filembalyn;

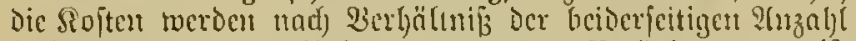
Dräbte reparirt. Heber andertucite Beründerangen ift beiderjeitiges (simberittindnifi, crjoricrlid) 1110 merben bic=

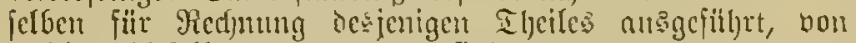
melel)em diejelben antsgegangen find.

(2) Die (Eijenbalumertunltung geftattet ben mit ber ?tulnge mo llnterfaltung oer Bundes= Telegrophentiuten bearjirngten

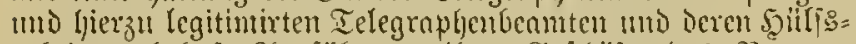

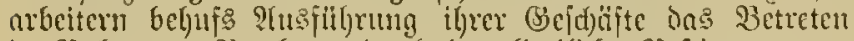

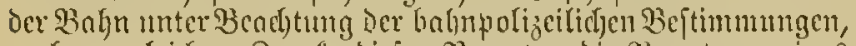
antl) zu gleidfem Buecte Dicien Benmten Die Benutzung eines Schnffnerfizes ober Dientfoupces anf alfen Bügen, eins

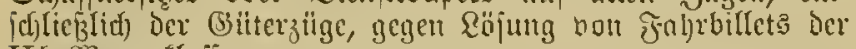
III. Wagentfaije.

(3) Die Cifenbalunertwaltung hat Den mit der Stulage

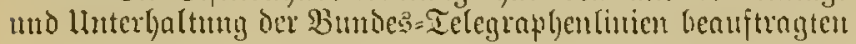

und legitiminten Telegraphenbeanten nuf deren Requifition zum Transport tout Eeitungsmaterialien, dic Bemnţung von Baf)nneifterwagen unter baljnpolizeificher ?tufficft gegen eine Bergïtung bon 5 Syx. pro Wingent unt Tag mo bon 20 ङgr. pro Tng ocr Auffid)t z" geftaften.

(4) Die Eijenbaljnoerloaltung Gat dic Burbes= Ielepraphen= anlagent ant ber inlln iegent eine (Entithäbigung bis zur

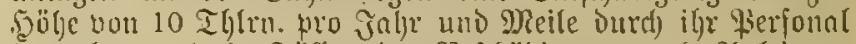

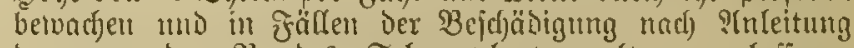
Der bon Det Ḋunoes = Ielegrophenverwaltung exlaffenten

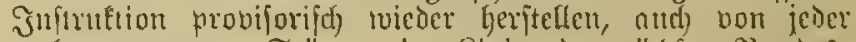

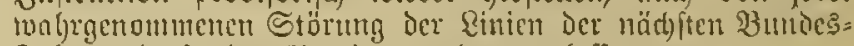
Ielegraphenftation ?lnzeige madjen z"l Infien.

(5) Dic Eijenbalmuermaltung hat dic \&ngernug dic zur Unterlyaltung Der Sinten erjorderliben Borrätbe von Stangen auf ben bazu gecigneten $\mathfrak{B a b n b o ̈ f e n ~ u n e u t g e l t l i d ) ~}$

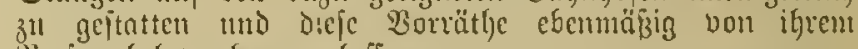
Herjonal bemacljen jull laffen.

(6) Dic Eifenthabuncrwaltung gat bei boribergebenden

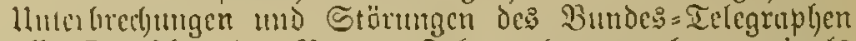
alle Depefthen oer Bundes= Telegraphentuerwaltung mittels

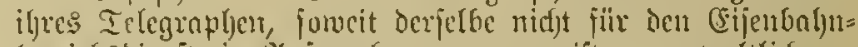

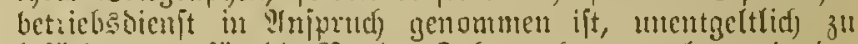

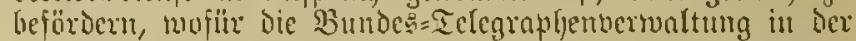

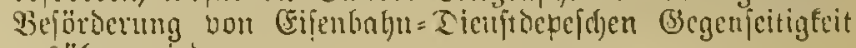
aแtsitibct toiro.

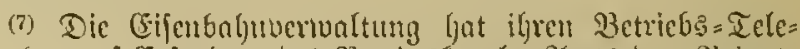
graplen auf Erfordern des Bundesfanjler:?

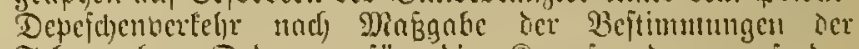
Telegraplen = Sromuth fiir bic Surtefpondens auf tent

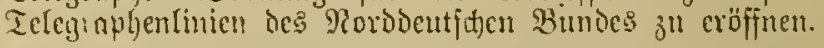

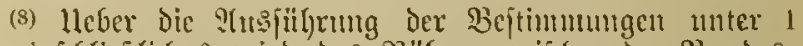

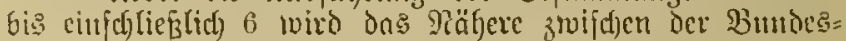

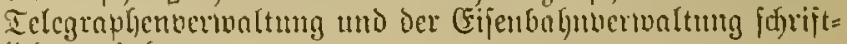
(ich) vereinfart.

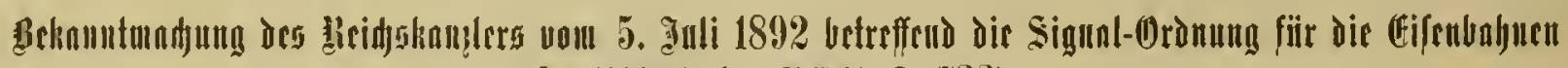

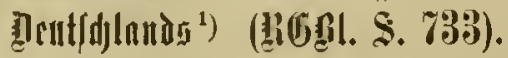

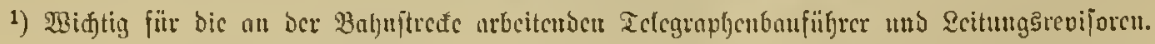

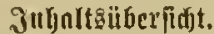

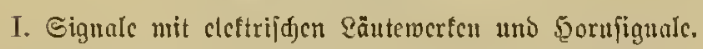

II. Sonbfigute ১cr Thärter umb Enchibenfigualc.

III. Signale an Eignalmaite.

IV. Boritigulc.

V. Sigrale an Tiajןcrfinahucu.

VI. Meidjenfigutc.

VII. Eigrtalc ant 3 mạc.

VIII. Signale bes 3ugperionats.

IX. RargirfignaJe. IIgcmeinc Bcftimntungen.

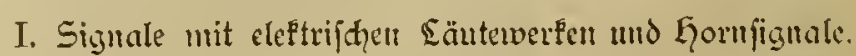

Die Signale mit eleftrifden \&äutewerfen find zu geben wic folgt:

1. Ier 311 gelyt in ber Midjtung wou A uard) B (2(6. meldefigutal):

Einmal cine befimmte 2 (njal)l bon BSlocten= ichlägen.

2. Der 3ug geft in ber Ridutung vou B nad A (21b. melbefigual):

Brocimal dicjelbe 2nzahl bon Blodenjdylägen. 


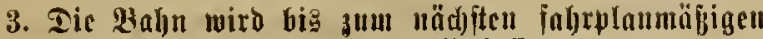
Buge niclut meljr befagren (Miubefigual):

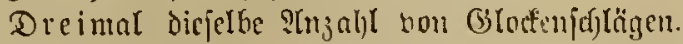

Diefes Sigunl foun aud) angewand twericn, um anju= zeigen, dấ ein fignalifirter Bug nicht fontmt.

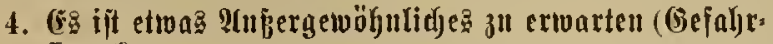 iignal):}

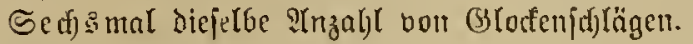

Diefe Signale fönnen nuferbem auth mit dem forn gegeben werden wie folgt:

1a. Ginual bic Toufolge lang, furz, furz, lang.

2a. 3wcimal bie Tonfolge lang, furs, furj, lang.

3a. Ginmal vier lange Tönc.

4a. 3weimal vier furze Töne.

II. Gandfignale der Wärter und Sđ̆eibenfignale.

Die 5 and jignale ber $\mathfrak{B a ̈ r t e r}$ fino zu geben wie folgt:

5. Der 3 ug foll langiam faljren:

\section{bei Tage:}

D以 $\mathfrak{B a ̈ r t e r ~ b a ̈ l t ~ i r g e n d ~}$ eimen Gegenftand in der Pirt)= tung gegen bas Biteis. bei Dunfelyeit:

Der Wärter hält die Şand= laterue mit grïucu Qid)t bem Buge entgegen.

\section{Dex 3»g joll balten (baltịnal):}

bei Tage:

Der Wärter fditwingt einent Gegenftand in Sireije Gerum.

\section{bei Dunfelyeit:}

Der Wörter idfivingt feine Sandaterne in Sreife herum, weldje, fofern es die Beit ex= laubt, roth) ju hlenden ift.

In Stelle diejer Gignale tömen aud) $\subseteq$ dje cibcujignale gegeben merden bie folgt:

\section{5a. Der $3 u g$ foll lautgfau faljen:}

\section{bei Tage:}

Stm thifang und ant ende ciner Langian jul Durd)= fahreniden Strecfe ind runde Stockidheiben aufgeitellt. Dem foumuenden Buge àugetefrt

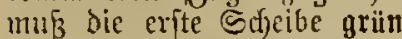
mit weipeu Mambe geitrichen unio mit A bezeictinet, bie lezte weib geitrid)en uno mit $\mathrm{E}$ bezeidfunt fein.

\section{6a. Der 3ug joll halten (Saltịgual):}

\section{bei Tane:}

Bor einer unjahrboren (b) leisftrede fins redftedige Stoufid)eiben aujgeftelft. Dem tommenden 8uge zugetehrt murs bie Sdjeibe roth mit sueipem Plande geftrifjen fein.

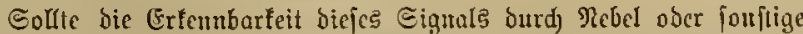

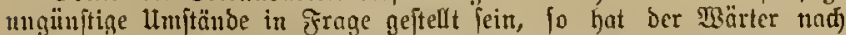

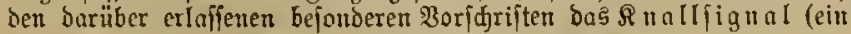

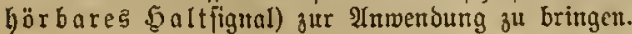
B) leisftrectefind Stofflaternen aufgeitellt. Dem fommenden

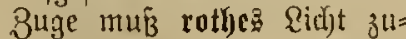
getelyrt fein.

III. Signale am Signalmafte.

Die Siguale am Sigunlmaite find $3^{\prime \prime}$ gehen wie jolgt:

\%. Salt:

bei Taģe:

Sigualarm madi redis ts wagered)t geitellt.

\section{Frcie Fahrt:}

bei Tage:

Signalarm fduräg red)ts nach oben geitellt (unter einem Wintel bon etra 45 (Brad). bei Dunfelyeit:

Rothes Ridjt Dex Signal= lateme.

(Frfidjeint es erforderlidf, dic Stellung des Signals bei Dunfelheit aud) nad) ritfivärts ertembar zu mad)en, fo

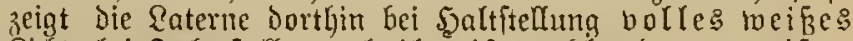
Sidft, bei Jahrtitellung theilweife geblenbetes weifes Sidft (Sternlidft oder mattweises gint).

WOo es für nothwendig eradtet wird, die ?hblentung Der Büge bom burtfgel)enoen (sileife ourd) Signale an einem uno demielben Eignalmajte fenntlid) zu madjen, erhält Der

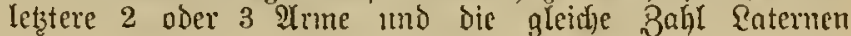
iiber einnnder. Die unteren STrme und Saternen merden 3ur Signalgebung nur berwendet, went eine 2tblenkung vom durd)gehenden (3) Leife ftattfinden folf; beiut Saltfignal uno beim Fahrïgnal fïr dos durdigehende Bhleis fino bic unteren arne fenfredft geftellt mo zeigen bic unteren Saternen fein Qidjt.

Die bem Buge entgegen rothes oder fein Sidjt seigenden Saterner miffer nach riidmärts volles weises sidjt mol bic Dem Buge entgegen grün lcudytenden Qaternen müfjen nad) rücfmärts theilmeife geblenbetes weines eirht (Sternlicht oder mattweifzes Sidjt) zeigen.

Die Signale am Signalmafte mit mehreren strmen fint ju geben wie folgt:

\section{9. Şalt fïr das burdjuchende und abjweigenoc Gleis:}

bei Tage:

Sheriter Signalarm nadf rect) ts magered)t geptellt.

\section{Faljert frei fïr bas durdjgeljende (sleis:}

bei Iage:

Sherfter ङignalarm idjüg rectis nad) oben Beiterlt (unter cinem $\mathfrak{B}$ infel bou ctiva 45 (Grad).

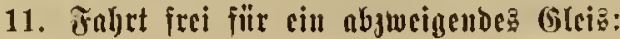

bei Iage:

Bivei (bezielyungsmeife die beiden oberen) Eigunlame idjrïg recht: nad) oben geftellt (unter eirent $\mathfrak{B}$ intel bour etwa 45 (Srad). bei Dunterheit:

(Briiuc Sicht ber beiden (bejielunngsweife der beiden obercir) Eignallaterner. 
12. Fahrt frei fïr cill andere abjocigende (Gleiz:

$$
\text { bei Tage: }
$$

Stlle òrei Signalarme fofräg redits nad) oben geitellt (unter einem $\mathfrak{w i n f e l}$ von ctwa 45 (Sirab).

Die Signalc 7 bis 12 Dienen als Cinfahrtsfignale, S(usfal)rtsfignalc, Blocffignale, forvie innerthalb der Stationen zut Dectung cinzelner (Bleife odcr Blcisbezirfe lind auf freicr: $\mathfrak{B a h n}$ zur Dectung von $2 \mathfrak{b} z$ meigungen, Drehbrücfen und fonftigen Gefahrpunften.

Die Anbringung bon Signalen für entgegengejetzte faht= ridfungen an ein und bemjelben Signalmajte ijt geitattet.

\section{Dorfignale.}

Wo es fïr nothwendig eradjtet wiro, die Stellung des Signals an einem Signalmaite idjon in einer gemiffen (snt= fernung bor deffen Standort fenntlid) zu madjen, ift ein unit jencm Signal in Abłängigfeit jtchendes Borfignal auf=

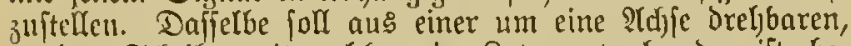
runben Sdheibe, mit meldfer eine Saterne berbunden ift, bc= ftelgen. Die Signale find Damit zu geben wie folgt:

13. Das Signal am Signalmafte zeigt 5ुalt:

\section{bei Tage:}

Die volle rumbe streilhe Dem Buge zugeteljet. bei Dunfelyeit:

Grïnes Ridyt dem Zugc entaegen.

Tiant) rüđfroärts zeigt die Saterne bolles weipes Sidjt.

2al. Boridriften über bic Inwentung oon Rnallignalen. Reblere lommen in frage, wenn vorhanbene Bejahrpuntte burh ander=

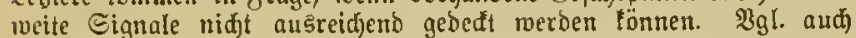

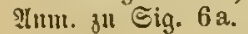

14. Das Signal am Signalmajte zeigt freie Faljt:

\section{bei Tage:}

Dic Scheibe parallel zutr Balju oder wagered)t geftellt. bei Dunfelheit:

Macipes \&idjt ber Raterne bem Buge entgeger.

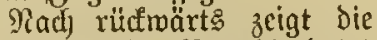
Saterne theilweile geblembete weipes didjt (Sternlicht oder mattroeifes عicht).

\section{Signale an Wafferf́rahnen.}

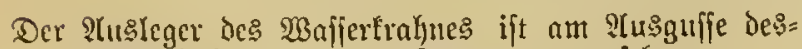
fethen bei Dunfelheit mit ciner Eaterne zu berichen.

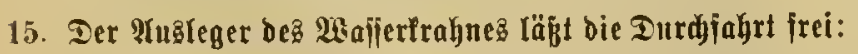

- bei Tage:

Der Plusleger fleht paraffel jut Rid)tung DC: (S) Leifes. bei Dunfelgeit:

Weiper Sidjt ber an bem 2lußleger Des Wafferfrahne: befindichen saterne.

16. Der Mus:

bei Tage:

Der ?lusleger itelht quer zแm Ridjtung Des BSLeifes. bei Dumfelbeit:

Mothes Richt ber an Dem

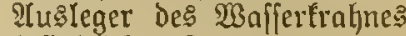
befinslidjen Raterne.

\section{Weiđ̧̨nfignale.}

Die Signale an ben $\mathfrak{B}$ eidjen müfien fotnoht bei Tage als bei Dunfelheit Durd ifre form erfennen lafjen, ob bie Weidje auf bas gerabe (shleis geitellt ift, oder nad) weldher Seite die $\mathfrak{A b l e n f u n g}$ exfolgt. Das rothe und bas grüne Signallicjt find jür die $\mathfrak{B e i d f e n f i g n a l e ~ n i c h t ~ z u ~ b e r w e n d e n , ~}$ jojern biefelben nidyt im einzelnen Jalfe zugleich als salts fignal oder Ranglamfahrfignal bienen follen.

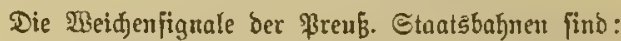

A) Die ascidie ift auf bas gerabe (BIets geftellt. Redjtectige reike Edjeibe.

B) Die Meinge ift auf bas getrümmte (Bleis geftellt.

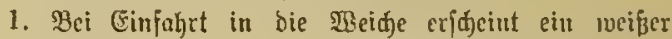
Pfeil mit ber oberen Spike nad der Eeite der श्tblenkung gerididet.

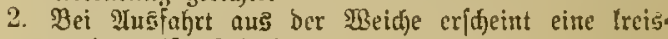
rumbe reiße ङdueibe.

C) Die Iusfaht ift geöffuet.

1. Yus bem lințjeitigen (Sleije eincr inmutretrijuen

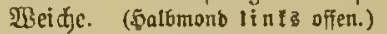

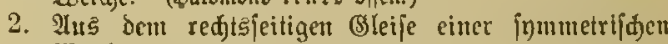

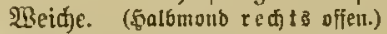

D) Die (Einfalyxt in bie beiben getrü1umeten Gleife tiner boppelten Siteujungsiocide ift geöffuet.

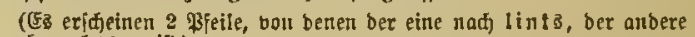
nach $r e() !$ a weift.)

VII. Signale am Jüuge.

Die Siguale am 8 uge find zu geben twie folgt:

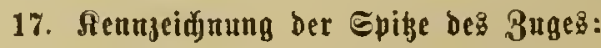

a) twem Der 3 ug auf eingleifiger $\mathfrak{B a h n}$ ober auf bem für bie Falytridhtung beitimmten BSTeife einer zmei= gleifigen $\mathfrak{B a h n i t r e c t e ~ f a ̈ l y r t : ~}$

bei Tage:

Sein befonderes Signal.

bei Dunfeltheit:

Bmei weip Yend)tende $\mathbb{R} a=$ termen born an ber Lofo= motibe.

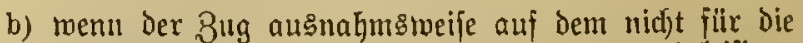
Fahrtrifftung beftimmten BSleife einer zmeigleifigen Balyntredfe fährt:

bei Iage:

Cine roth und weipe runde Saljeibe vorn an ber \&ofo= motibe.

Befindet fid) in :Tuڤnahmeiären die Rofomotive nidjt an ber Spitze Des 3uges ober jährt biefelbe mit Dem Ielloer voran, fo find die Sigllale am Bordertheil Dez vorderjten ङahrzeuges anzubringen. 


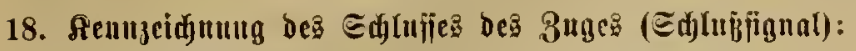
bei Tnge:

2n der Seinterivant des weipe runde Stheibe. bei Dumfultyeit:

In Der Syintertuand de? letblen $\mathfrak{B a g e n s}$ in ungejährer Söhe der Suffer eine roth letzten 23 ngens cine rotly und leuffente saterne (ङd)lufs. (aterne) mo auberbem ant lebien $\mathfrak{B a g e n}$ jwei mad) vorn griin ntllo mact) finten roth leudftende Raternen (Dber: Wagenlaternen).

Fiit einzeln faljende folo= motiben auf freier $\mathfrak{B a h n}$ ge= niigt einte roth (eud)tende $\mathbb{E} \mathfrak{a}=$ terne und bei Betwegumg der Rofomotiben auf Stationen die ?tnbringung ie ciner $\mathbb{E} n=$ terne mit weipean Ei(f)t boin an ber Rolomotioe mo ljinten am Tender, bei Tenderlofo= motioen oorn uno hinten.

19. (E⿱ folgt ein Sonber3แg แad): bei Tage:

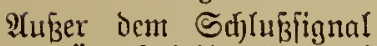
eine grüne Sdjeibe oben auf dem lebten Wagen oder ju jeder Seite defielben.

bei Duntelkeit:

Signal 18 mit Der ?tb $=$ ändcrumg, dafs cine Der beiden borgefdriebeneu \&atemen aud) nach binten grïlte seicht ieigt.
Für eingeln fahrende Qotor motiben genitgt die $2 \mathbb{T}=$ bringung einer griï (eut)= tenden Eaterne hinten antiger ber rothen Swhlü̧laterne.

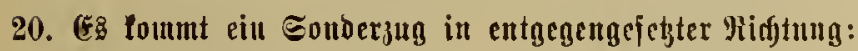
bei Tage:

Fine arüte runde Sheibe born an der Eofoutotioe.

\section{Die Telegraphenleitung ift ju unterfud)en:}

bei Tage:

Fine toeipe runde Sdjeibe born an der Rofomotive oder an jeder Seite des 3uges.

22. Der Bafubärter foll jojort feine Strefe unterfunen: bei Iage:

(5in 8 ug fedienfteter fajmingt

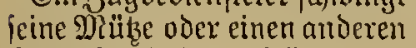

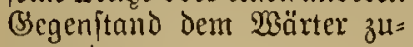
gemendet.

(Fin Bugbedienjteter fdiningt feine Saterne dem 230 ärter 3 แ getwendet. bei Dutnfellyeit:

תein bejondcres Signal.
Eine grüu leutctende $\mathfrak{E} a=$ terne über den wcifiß leut)= tenden Ratermen born an Der Sofonotibe.
VIII. Signale des Jugperionals. jolgt:

Die Signale Des 3ugperfonals fino ju geben mie mit der Dampipfeife:

23. Ildjtung :

Fin mäßsig langer Ton.

\section{Bremieu anjiegen:}

a) miäzig: Şin furzer Ion.

b) ftar: Drei furze Töne f(thelf hintereinander.

25. Bremịn Loslajien:

Bmei mäß̧ig lange Töne idfnelf ljintercinander.

Die Gignale 23, 24 und 25 Ë̈mmen auf einjelnetl Stretfun แno Stationen mit Benelymigung dex znftändigen

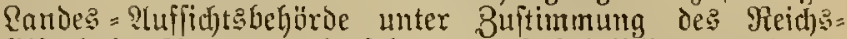

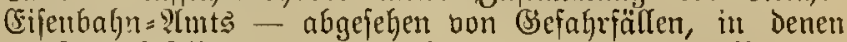
die Dampfpfeife anzumenoen ift - aud mit Signalgömern gegeben werden.

mit ber $\mathfrak{M}$ un bpfeije:

\section{Das 3ugperfonal foll jeine Präłge einnelymen:}

Čin mäß̈ig langer Ton.

\section{2\%. Y(bjahrt:}

3wei mäß̧ig lange Töne.

\section{Rangiritignale.}

Die Rangiriignale mit Der Mundpleife oder bem Sorn fint zu geben ric folgt:

\section{8. borziehen:}

Eit langer Ton.

\section{3uriidơriiden:}

3mei mǟ̧ig lange זöne.

\section{Salt:}

Drei furze Tönc fdfucll hintereinander.

Die Mangirfignale mit dem $\mathfrak{A} x$ me find zu geben wie folgt:

\section{8a. Sorjiehell:}

bei Tage:

Senfred)te Bewegung des Trmes bot oben nad) unten. bei Dunfelheit:

Genfrect) Bemegung ier Sandlaterne bon oben nud unten.

\section{9 a. 3uriicforïifen:}

bei Iage:

Wagereilte Belvegung Des Arme ljin und ber.

\section{0a. Salt:}

bei Tage: Sireisförmige Bewegumy ics शrmes.
Gei Dunfelfyeit:

Wageredjte Bewegum ber 5 andaterme lin uno ljer.

\section{bei Dunfelfyeit:}

Sreisförmige Bervegung Der 5̧andaterne.

\section{2fllgemeine Bejtimmungen.}

1. Die vorjtehend fitr einen 8 ug gegebenen Beptimmungeu

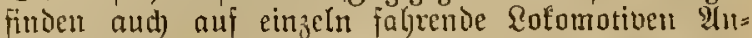

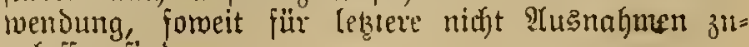
gelajfen find. 
2. (Eine P(bweidfung in Der Daritellung ber Signale bon

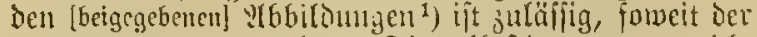
26ortlaut der einzelnen Signalbejtimmungen nicht entgegenfteht.

1) Sint firer nicht nbgeorudt.

3. Diefe Signaloronung tritt mit den 1. Jamune 1893 in Straft; fie findet ?hmendung auf allen Sanpteifen= bahnen Deutjdlands und auf den Riehoneifenbahnen, jomeit bei ben letzteren Signale zur ?trmendung formmen. Stusnaljnen Ënuren unter bejouberen Ber=

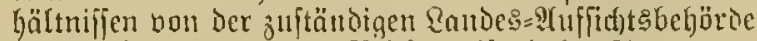

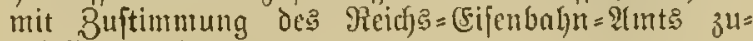
gelaifen merden.

Disfe Signnloronung wird Durd) Das Reid) blntt beröffentlicl)t.

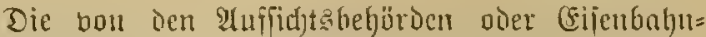

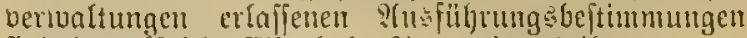

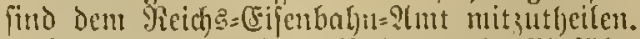

4. Sojern nuf cinzclnen Balynen die (Einfülurung der Signalemrichtungen obne befondere Sel)micrigteiten bis zum 1. Januar 1893 nicht zu bewirfen ift, fömen el fiir den ?tusfififung von der betreffenden Entiose

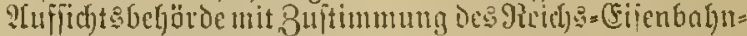
?tuts nugeneffene च̛riften beivilligt werben. Bercit: besvilligte \$ejriftungen tuerden ljiervon nidjt beriigrt.

5. Fint die an den Srenzen Dentigfands gelegenen

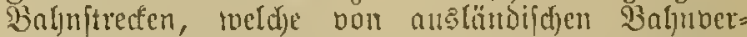
waltungen betrieben merben, fönnen ?(bueid)nngen bon dicier Signalorsmung non Der betrefienden \&anoes.

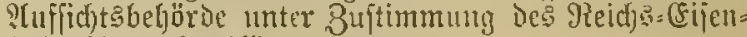
bahn=? ?ntts berwifligt weroen.

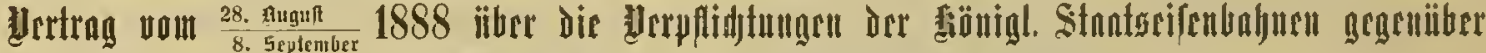

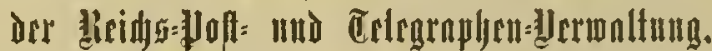

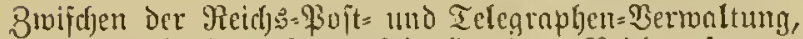
vertreten Durd den Stnatsiefretär des Reidispoftamts,

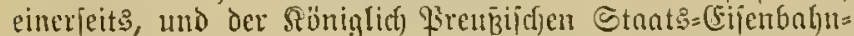
vervaltung, bertreten Duth ben 9Rinifter Der offentlid)en

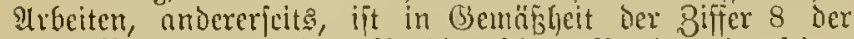
boun Bundeşrathe des शiordientichen 3untes in feiner Sikung bout 21. Dezember 1863 Feftgeitellten Betpflichtungen der CEijenbahnen im Snterejie Der Suntes: Telegraplyen= Berwaltung ${ }^{1}$ ) folgender Bertrag abgejd) (ofjen worden:

1) 230 rfteheno Seite 443 abgebruct.

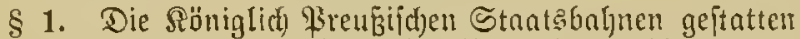

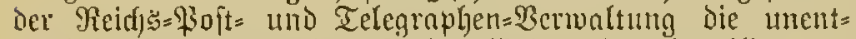
aeftliche Benutzung Des B̈alyngeländes ber jeweilig von

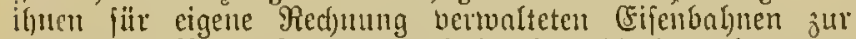

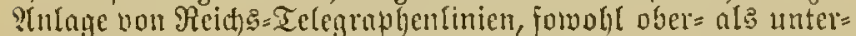

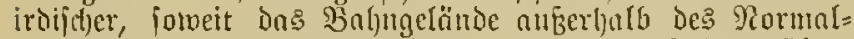

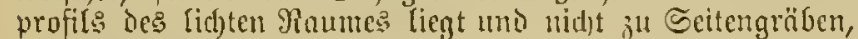
Einfriedigungen und fonftigen für Die Bablu notfwendigen AnItalten benutst wiro.

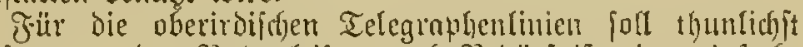
entient bon Den Balyngleifen nach Bedirfuib eine einfache oder doppelte Stnngenreifie nul ber einum Seite des Baljn= plnums aufgeitellt werben, weidfe bon der Eifenbahnoer= maltumg zur Befejtigung ifjer Telegraphenleitungen unent=

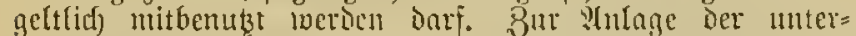
irdijchen Telegraptentinien foll in Der Regel Diejenige Seite our Bahn bentibt werben, meldje von Den oherimoifchen Einien im 2(llgemeinen nicht berfolgt wird.

Bezilglicf der Engeftelfe ber Siabel fintet gegenjeirige Beteinbarung ftatt.

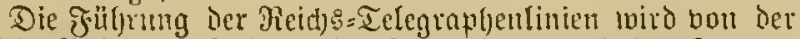

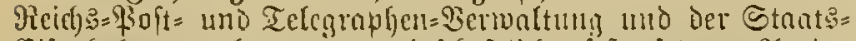

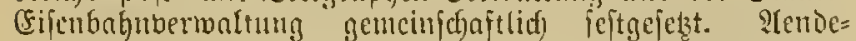
rungen, wefd)e burd) Den Betrief ber Sahtuen nadjmeistid)

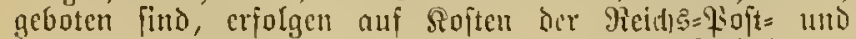
Ielegraplen = Sermoltung und der Etaats = Eifentalyner= maltung nach) Berbältnits Der fierbei in frrage ftefenden beidrieitigen SInzahl Diähte. Ll'ber anderweite Serände=

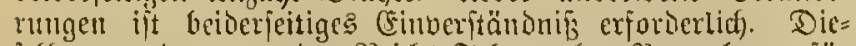
jelben iverden von der Reid) $3=$ Telegrnphen=3erwaltung für Pied)ung desjenigen Theites ausgeführt, bon iveld)cu fie ausgegangen find.
§ 2. Die Stants = Eijcubnfmbermaltung üherlägt bas

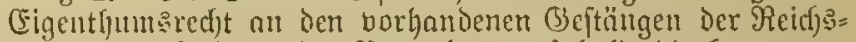
Foit = und Telegraplen=Bernaltung, jobalo bie leţtere an Dicjun (5)eitürtgen Reidfy= Telegraphenleitungen anlegent wifl, gegen (Frftattung Des bon beiberieitigen 3evollmäd)tigen gemeiuf(hajtlich zli ermittelnden Beitwertbes nnd unter ber

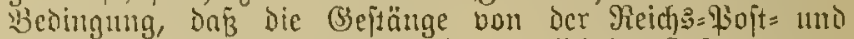
Telegrnplen=Bermaltung auf deren alfeinige Foliten unter: Galte:, bou ber CFifenbahnderwaltung aber mit der fïr fie nothinendigen ?tuzaljl Reitungen unentgeltlid) mitbenubzt merden.

Bici Serftelfung neuer Bafnlinien wirb die Staats=

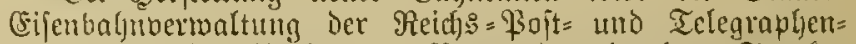
Berwaltung Den $B e$ ginn des $\mathfrak{B}$ autes Der einzelnen Streffen 1und Den Beitpuntt, bi: zu belchem die Fertigftellung in S(t:Fifidt genommen ift, red)tzeitig mittlycilen.

Die gicich $5=$ Pojt $=$ und Telegraphen $=$ Bertwaltung hat ficf Darauf zu erffären, ob fie die neuen Bahmitrecten zu $\mathscr{X} n=$

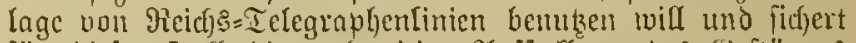
fiit Dieien Fall dic red)tzeitige ?uffitellung Des (sieftänges

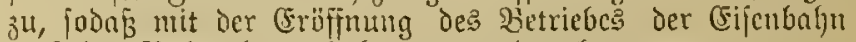
auri) der Babntelegraph benubt werben fann.

Falls bie Picid) $3=930$ t $=$ und Telegraphen $=$ Bermaltung bie Benutzung eines in ifrem (Eigentfum befindichen, bon beiten Bermaltungen gemeinjdynjtlid) benuisten (beitänges nufgeben jullte, Datnfis Das (Beftänge mur Den 3 medfen Der Stants=

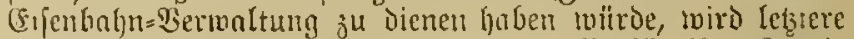
Denjenigen Theil bes (Seftänges, Defien fie für igre Brocte Gedori, gegen Erftattung Des bon beiderfeitigen Seboll= mächtigten gemein (d)aftlid zu ermittelnden Beitwerthes als (5igenthum ertwerben, ober bis ju einent zmijden beiden bertragidfliefsenden פerwaltungen zu bereinbarenden 3eit= punfte fïr ifje Reitungen ein eigence (Beftänge jür ifjee

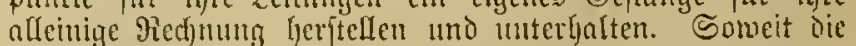
Stnats=(Sijenbolnnbertmaltumg Das (3ieptänge nicht galla voer

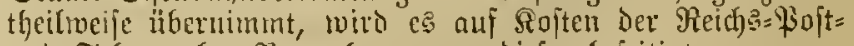
und Telegraphen=2ermaltung bon biefer bejeitigt.

\$ 3. Die Reids: $\$$ soit $=$ uno Ielegraphen= Serwaltung ift

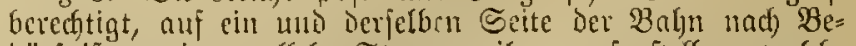

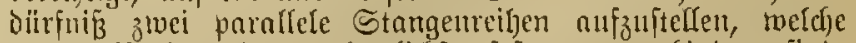
ourd) verfuppelung thunfidjit fejt $3 u$ verbinder fino. Sollten die ortfichen Berfyärtnifje an einzelnen Etellen bie 
Inlage einer boppelten Stangenreihe nidyt ge tatten, fo bleibt den beiderfeitigen ted)nifd) Bevollmächtigen die $\mathfrak{B e r}^{2}$ einbarung Hiber eine nnderweite fHithrung Der \&eitungen an dicjen Steller überlaffen.

§ 4. Die Stangen weròen naud den bon der oheriten Telegraphenbehörtoe vorgefdriebenen (Srumbjäłzen auf alleinige

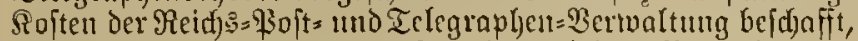
aufgeftellt und unterljalten. Sie Dienen beiDen Berwaltungen gemeinjdaftlid) zur 2(ubringung ifrer Draljtcitungen.

Die \$läke zur Slnbringung Der Bafnleitungen werden

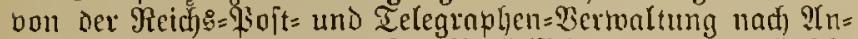

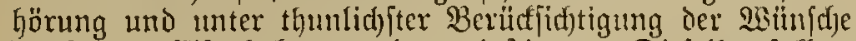
Der Staats= Eifenbahroerwaltung beftimut. Diejelben jollen, jomeit thunlich, auf Der den Bafngleifen zugefelyten ङeite Det Stangen und nicft niebriger als 2 गPeter über Der CErde angelegt torden.

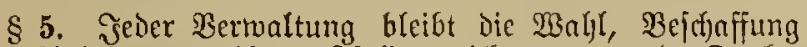

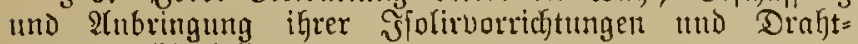
leitungen überlalfen.

§6. Dic zur Jiifrung der Reitungen ourd) Tumnel erjorderlichen Telegraphenfabel merden bon jeder Bertwaltung alif ilfre eigenen Sojten bejoffift, eingelegt und unterlyalten.

Berden für die ơ̈hrung Der Telegraplentafed durd)

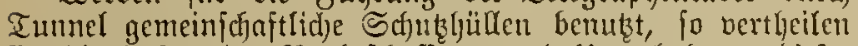
(iid) die Sioften Der Neubefd)affung und linter(jaltung diejer llmbintungen auj bie beiden Verwaltungen nact) dem $\mathfrak{B} e \mathrm{l}=$ ljältnif̧ der ânzaljl der beiderfeitigen Sabel.

\$ 7. Die Stants = Eijenbahnuerwaltung geitattet der

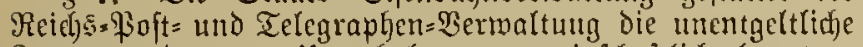

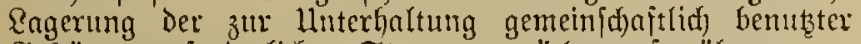
(Beftönge erforderlichen ङtangenborräthe auf näber anzu= meijenden Filäzen der dazu geeigneten Băhnljöfe.

Diefe Stangenuoräthe merden, gleid) wie bie (Eifenbaljn= Banumaterialien, Burd) Die Bahnbeamten mit beauffichtigt

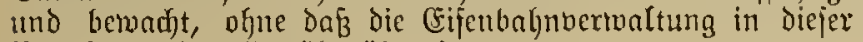
Beziehnng eine (Getwälir übernimmt.

§ 8. Bux (5mittelung Derjenigen Stnngen, reld)e im Sauje ber Beit fdjadjaft werden, und behuja Eidjerung fo= wohl Des $\mathfrak{B a h n = ~ a l s ~ d e s ~ b e i d e r f e i t i g e n ~ T e l e g r a p h e n b e t r i e b e s ~}$ wird bie Reid)s=\$oit= und Telegrapljen= Berwaltung jüljelid) mindeftens cinmal eine bejondere firtifung jeder cinjeluen Stange Durd) ifre tedyijdjen Beamten vornefymen und bic hierbei fich als nothwendig ergebenden ?lusbefferungen an

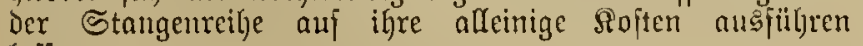
laffer.

§ 9. Die Stant: = Sijenbafnberwaltung fjat dic $\mathfrak{B} e=$

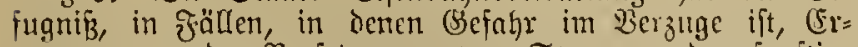
netierungen oder $\mathfrak{B}$ erjetzungen bon ๔tangen oder fonitige Zutsbefferungen an der Etangenreilje felbititändig bor: zunehmen und die zu Diefem Zuvecfe erforderlid)en Stangen

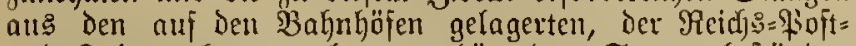
und Ielegraphenverwaltung gehörenden Stangenbejtäuden zu entnelymen. Dicjelbe verpflidtet fid) jedod), dic (Eijen= bahn=Ielegraphenmeifter anzumeijen, bon allen felfititändig beivirtten Crneuerungen, Berjețungen ober fonjtigen $\mathfrak{Q} u s=$ befierungen der Reid) Reid): Telegraphenanftalt unter gleid)zeitiger lleberfendung einer Suitung über Die auङ Den Beftünoen entmommenen Stangen Mittheilung zu madhen. Die der Stant = (Eifen= bahnberwaltung erwachjenden Roften jür 2(ushefierumgen an

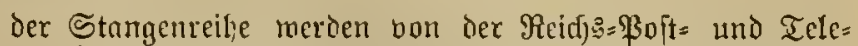
graphenocrmaltuta auf (Bruno der bon Der Eifenbahn=

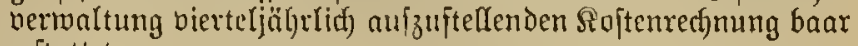
critattet.

\$10. Tuf BerIannen der Stant $=$ Sifenbafnbermaltumg

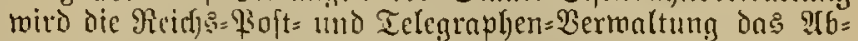

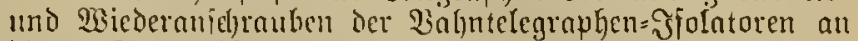
bie zur ?tışwerf)felung ge[angenden Stangen mit Den übrigen Arbeiten gleid) ieitig utsiülyen laffen und der (Eijenbahn= berwaltung bafür den Betrag non $10 \%$ F. Für den ŞFolator

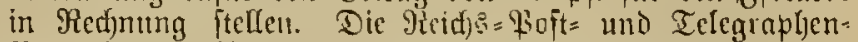
Berionltung beljält fid jeiod bor, ljöljere foften in forberung nachjumeifen, falls jifl bei slumentung fdyerigerer Siolir= Rorridytungen lyeransftellen follte, onfiß ber borgenannte $\mathfrak{B} e=$ trag die Selbfttojten nid)t dect.

$\S 11$. Die Stant: = Sifenbabnberwaltung geftattet den

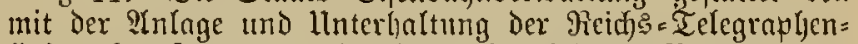
finien beaufragten und ljierju beted)tigten $\mathfrak{B e n m t e n}$ der Reid): $=\$$ oft $=$ und Ielegrapljen=Berwaltung, ien Reitung: $=$

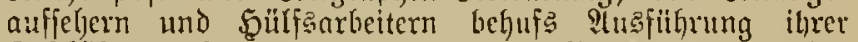
(Bejchäfte das Betreten Der Bahn, unter Bend)tung der bahn= polizeilichen Beftimmungen, auch zul gleid)em 3mete dieien Beamten und Den Reitungsaufielyern Die Benutung cines Ect)affnerfities oder cinces Dienjtfupees nuf allen Biigen

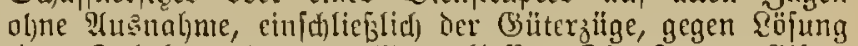
einer ₹rabrfarte ier III. Wingeuflaife. Die Stantes= (Eifen=

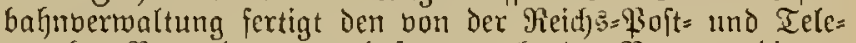

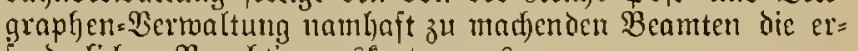
proerfiden Beredtigung farten att?.

Die unentgeltlid)e Mitfübrung bon Berfzeugen und 9)aterialien it den Supees ift infoweit geftattet, ale bie Mitreifenden dodurch nidjt beläjtigt merden.

§ 12. Die Staat: (Eifenbaljnermaltung berpflichtet fid), den mit der sinlage und ilnterbaltutig der Reiches= Tele= graphenlinien beauftragten und hierju bered)tigten Beamten begufs Beförderung von Einienntaterialien auf (Eriuchen die nötfigen Strecfentongen unter bahnpolizeilicfer Beauffichtigung

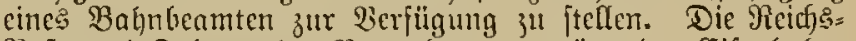
Fioft= und I Ielegraphen=Berwaltumg bergïtet Der Eifenbahn= Sermaltung fïr jeden foldjen Wanger 50 \$f. für jeden audj nur angefangenen Tag der Benutzung uno für den beauf= fichtigenden Baljnbeamten Tagegeloer botn 2 Mart für jeden aud) nur angefangenen Ing der Bsauffidtigung. Diefe Bergütung meift dic Stant: = Cijenbalynoermaltung auf (Brund

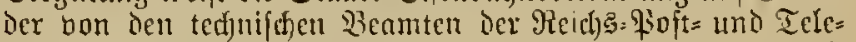
graphenverwaltung ausgeftelten Beineinigungen viertel= jöhrtich in Forderung nadt).

§ 13. Die Stantä=Eifentaljuvermaltung läß̈t die Reichs: Telegrapljenanlagen an Der $\mathfrak{B a l m n}$ gegen cine (Entfd)öbigung bis zur Şöhe bon 4 Mart jür Dae Jahr und Das Silo= meter durd ifle Fierfonal bewadfen und in Fällen der $\mathfrak{B c}=$

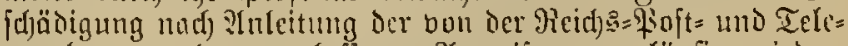
graphenocrwaltung erlafienen ?trmeifung vortüufig wieder= (jerftellen, aud) bon jeder roaljrgenommenen Störung der

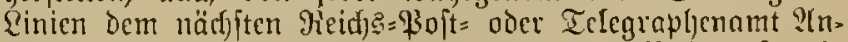

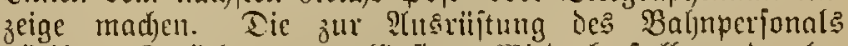
nöthigen Geräthe zur vorläufigen waicochferitelfung Der be=

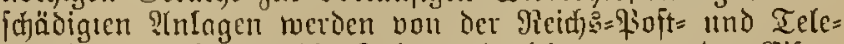
grapljenvermaltung, die Telegraphenleitern bon der fifen. bahnberwaltung bejd)afft und unterbalten und bleiben Figenthum Det llnterfaltungspflidytigen. Die Benukgung diejer Bregenftände fteht beiden $\mathfrak{B}$ ermaltungen zu. 
\$14. Die Banrnuslagen fütr Tagelöl)ne mo Materinlien,

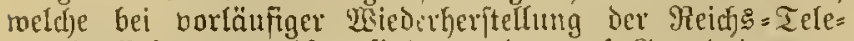
graphenlinien ertondfor find, werden nuf (jrund ice bon ber Stants= (Eijenbalnuerwaltung aufjufteflenten, gelörig

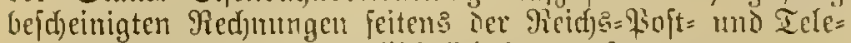
graphen= Bertoaltung vierteljälyrlicl) bnor erftattet.

Den mit der endiültigen Wicterheriftellung benuftrngten

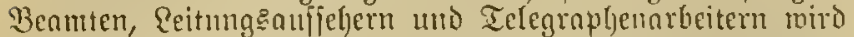
jeitenక der Bahnbeamtell nuf Erforbern bei bie\{m Giejcjäfte

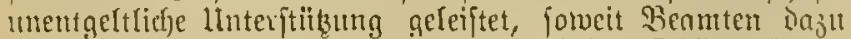
ohne Belfinderumg ifjer joriftigen autlidfen Dbliegentheiten im Stande find.

§ 15. Behuf: fdneflerer Frmittchung mo Befeitigung non Störungsurjadjen follen die beiden (5ifenbnhnfationen, juifd)en melden ein Fehler in Den Reichs=-Telegraphentinien eingegrenzt ift, mitte[g Telegramms Duref) Das Siniferlide Telegraphen= oder Fojtamt von dem Beftehen biejes Jehlers

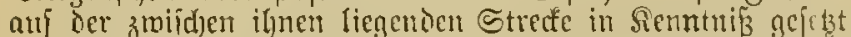
mo gleichseitig um YKblnjfung bes jïr bergleid)en Störungen vorgeidhriebenen 8 ugfignal ${ }^{1}$ ) erfucht merdert. Diefes Signal mird bon jeder ier beiden Eijenbahnitationen den nädjiten beiden, die feblerjtrecte am Iage Durdffahrenton $B a b n j u ̈ a c n$ oder Minjainen mitgegeben, inent injwifdjen nidjt bereite die cbenjalls mittels Dienittelegramms jul beloirfente Mittheifung von Der Bejeitigung des Ĵehlers eingegangen jein jollte.

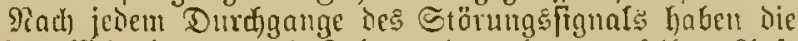

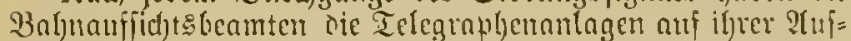
fidtegftreffe einer genauen Befichtigung jull untermerjen und etwa vorgefundene fellet nad) der im \$ 13 gennaften $9(1=$ weifung zul befeitigen.

Damit nber das ?luffidjt:aperfonal dor fehferiteien Stretfen nidjt unnöthig benndyrid)rigt wird, foff diejenige ber vor=

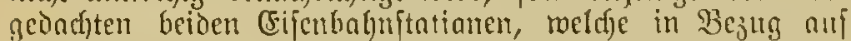
bie Jahrtrichtung Des th: Sigunal jüljrenden Buges an Endpunte der F̌ehleritrecte liegt, Die Mlbnalyme de Eignnls berwirfen.

1) Bgl, Signalordmung, Seitc 449.
\$16. Die Ctant: =Eifenbahnnermaltung miro bei var=

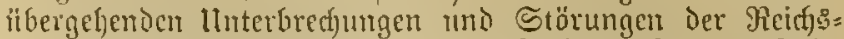

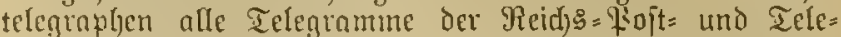
grapten= Bermaltung mittels ifjre: Telegraphen, jotweit diejer

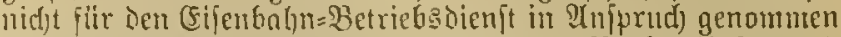

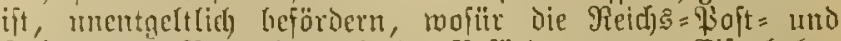
Ir Eegraphen=Berwaltung in Der Beförderung von Eifenbahn= Tienîttelegranmen (Begenfeitigfeit aušitgen mirò.

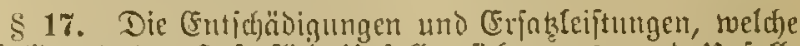
nuf (Bruts ier Sogitpflicht llnfaftoerficferung

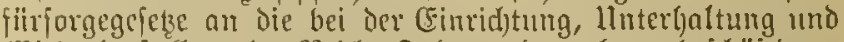

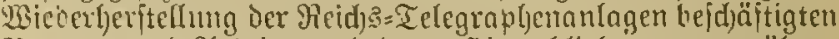
Benmten und ?hbeiter und Deren Sinterbliebene zu gemähren

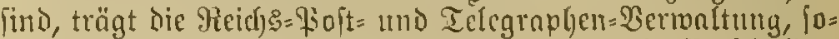
fern fie nicht nnchmeift, Dof incr Llnfall burd) eit Berjd)ultoen ber (Eijenbahnuerwaltung oder einer der im (Eifenbahnbetrieb vermendeten fierjonen ljetbeigejiifut ift.

\$ 18. Licher ctmaige in Saufe ber 3eit erjorderlide Senterungen Der jefifeţungen des gegentuärtigen $\mathfrak{B e r t r a g e}$ wirt eine befonderc Sereinborung vorbeljalten.

\$19. Der borjteflende, von beiden Theilen genehmigte uno unterfichiebene und hoppelt nusgefertigte Bertrag tritt nut 1. Dftober 1888 in Beftumg.

Sn̈mmtlide jux Beit nod) beiteljende, Den gleid)en (Begen=

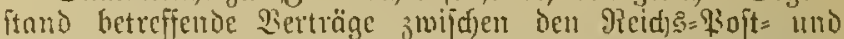
Telegraphentebörtien einerjeits uno Den Röniglid firengildjen Stnat = Cifenbalnbehöriden antererfeits treten mit bem gleidyen Beithunlt nufjer Siraft.

Berlin, deu $\frac{28 . \text { Stugurt }}{8 . \text { Eeptenter }} 1888$.

Der Stantäffietär des

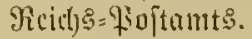

von Stephan.
Der Minifter der öfferttict)en 2(rbeiten.

$\Im \mathrm{m}$ Ituftrage:

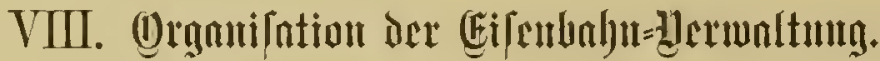

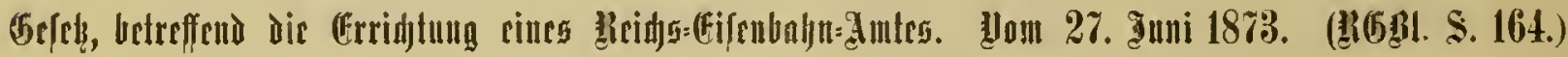

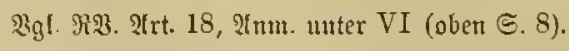

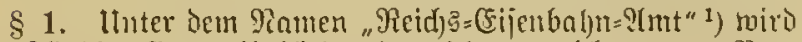

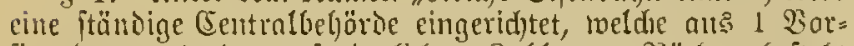

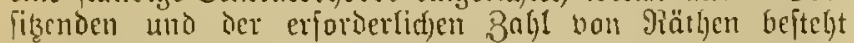
und ituren Sik in Berlin hat.

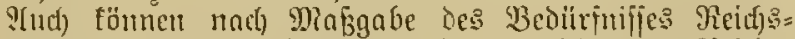

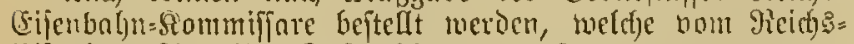

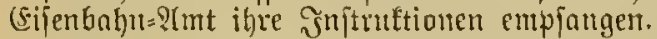

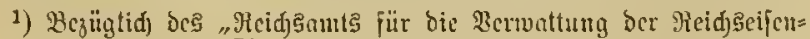

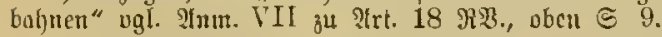

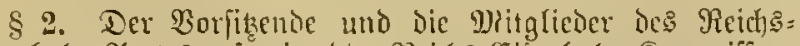

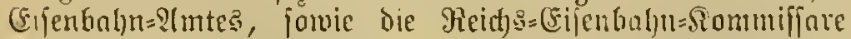
merden bom Siniier, die Subaltern= und Iluterhenuten werden bou Reichsfanzler ermannt.

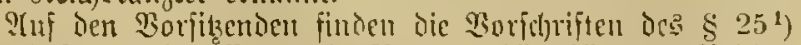

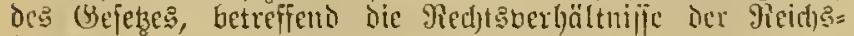
beamten, vom 31. Diär 1873 , ?tmuendung.
Berjonen, weldye bei der Berwaltung einer dentidfen

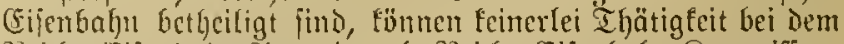

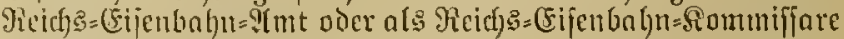
กแเïibcr1.

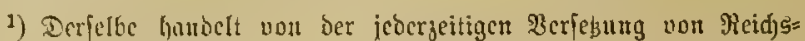

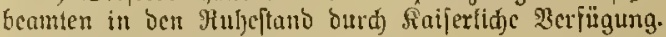

§ 3. Vorbehaltlich der Beptimmung im $\$ 592 x, 4$ jührt

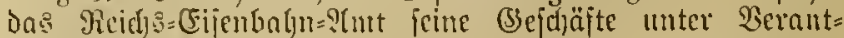

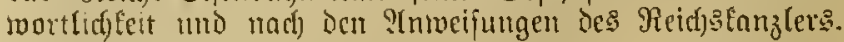

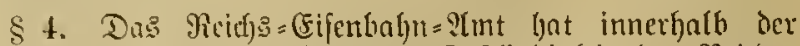
durd) bic Serinjiung beftimmten Zujtändigfeit des Reidy:

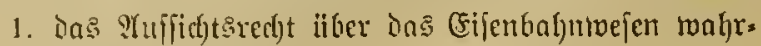
imelymen;

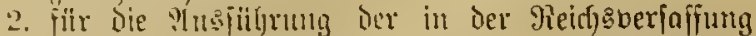
cutbaltencu Beftimmungen; fotwie ber fonftigen nuf 
Dag Eifenbahnmeien bezïgliden (Sejebe nud vers faffung:mäßzigen Sorj(t)riften Sorge z"l tragen;

3. auf 2 bjtelfung der in 5inficht auf bas (Eijenbalun= mejen hervortretenden פiängel แmo Mişitände ljin= zutirfen.

Dafjelbe ift berecfigt, innerlyalb feiner Bujtändigfcit iiber alle Einridytungen uno Dingregefn bon Den Eijenhaljnverwaltungen ?tu\&Eknft à erforDern oder nael) Befinten

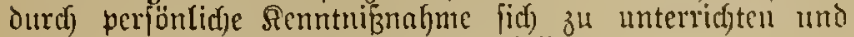
hiernady das (erfordertidye zu veranlaffen.

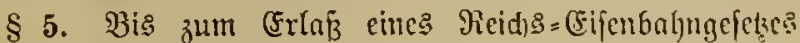
gelten folgende $\mathfrak{B}$ orjdyriften:

1. In Bezua auf Die Grivatcifuthaljnen fteljen Dem

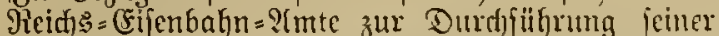
Berfügungen dicjelben Befugniffe ju, weldje den

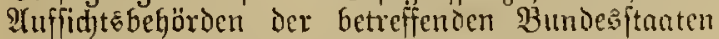
beigelegt find. Werden ju biefern Bmede Brvang: maßregeln erfordertia), fo find die (Fiferbalyn=?hip= (id) to befjörden der einjelnen Rumbesftanten gehalten, Den Deshalb an fie ergehenden Fequfitionen 3 "t entipred)en.
2. Staats = Eifenbahnoermaltungen find nöthigenialls 3แt CErjüffung Der ifnen obfiegenden $\mathfrak{B e r p f l i d}$ tungen

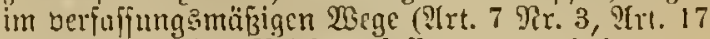
und 2(rt. 19 Der Fieicfsnerfajiung) anzuhartent.

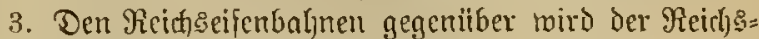

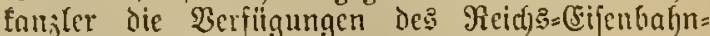

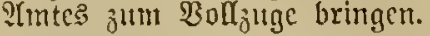

4 Whir aegen sine bon bem Reids berfiigte $\mathfrak{M} a$ äregel Begendoritellung erloben auf (Brund Der Behauptung, Daß̉ jene MaErecgel in Den Gejetzen und redtesgitltigen Borichriften nidft begrindet fei, fo lont bas burd) Buzieljung bon

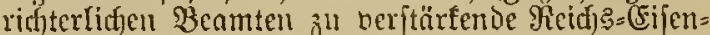
bahn:? ?mt liber bie Gegenvorftellung immer felbit:= ttändig und unter eigener $\mathfrak{B e r a n t m o r t l i d j e c t ~ i n ~}$ follegialer Beratl)ung uno Beid)luşaffung zut be= fimber. Bu Diefem Biwede mird der Bundeszath cin Regulativ erlaffen, weldye (c)äftsyarg oronet umb Die bicrbei bem Pröfidenten zuftekenden Befuguifie regelt.

Ultfund(ict) $2 e$.

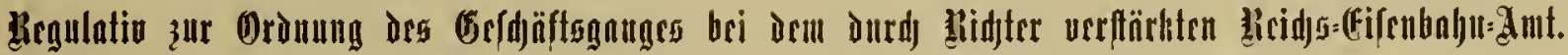

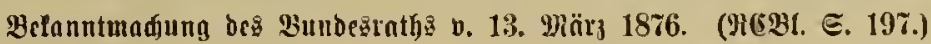

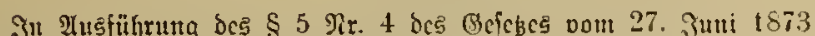

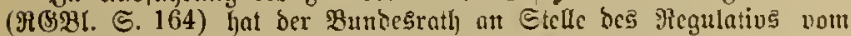

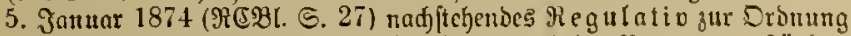

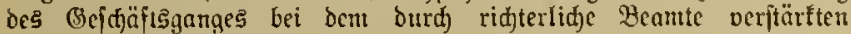
Reidjs=(Eifenbabn=Itmt erlaffer:

\$ 1. Wirt gegen cine bom Reid) fügte Mafregel (3)genvorftellung auf (5runo ber Bebauptung

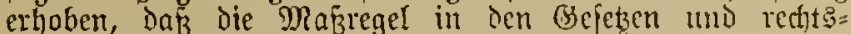

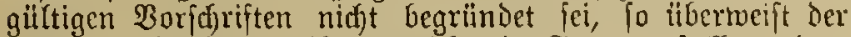
Peichsfanzler die an ihn zis ridjtende Begenvorftellung Dem berftärften Reid) $\xi=($ Sijenbahn=2(mt.

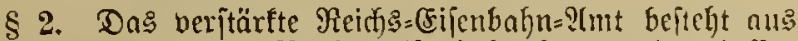

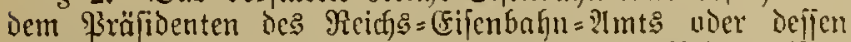
Stellbertreter als Borjizenben, 2 Räthen des Meid):(5ifen= bal)n=?(mts und 3 riaterlid)en Beamten. Fitr letglere werien für den Fall der Belinderung 3 Steflucrtreter ermannt.

Das bei dex früberen Shearbeitung ber Sad) als

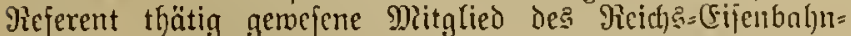

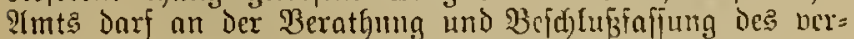
itärtten Reidge=(5ifenbahn=21mts nidft theilnchunen.

\$ 3. Ergiebt fid bei Der frriffung ber angebraditu

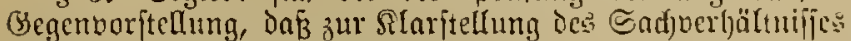

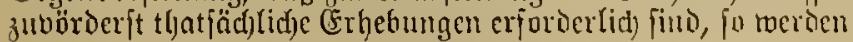
bieje vom Präfidenten angeoronet.
\& 4. Sind Die nad) \& 3 macordneten Erbebungin er jolgt, oder lyat ber firräfident meitere Erlyebungen nidgt fiir nötljig crachtet, fo wird bie Carbe zur follegialen Beratbung und Befdulüfafjung gebradjt.

Bu Diefem Ende ermennt Der Riräfibent einen 1. uno cinten 2. Beridfterftatter.

(Finer dicjer Berid)terftatter nutß aus Den rid)terfidjen Benmten gervählt werben.

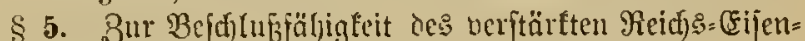

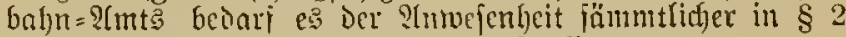
aufgefüfrter Mitglicber ober Deren Stelfuertreter.

Der $\mathfrak{Z} a r f i k e n d e$ leitet die Berbandungen und die $\mathfrak{B C}=$ rarlun in ben ङizungen. Er itellt die Jragen und fammelt dic Stmmen. Das Rolleuium entidyeidet nad) Stimmenmelyrjeit. 23ci Stinmengleidj)cit giebt die Stimme

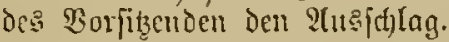

S 6. Beit)lient Das Sollegium cine meitere Frmittelung ober Berbandung, fo meroen die erforderlichen ?hordnungen vom sirüibenten getroffen.

$\S \%$ รm Eingange Dç unter Deul Sicyel des Reid):

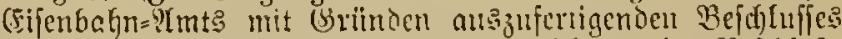
find die Mitglieder des Rollegiunts, weldse an ber Beictuff fafiumg theilgenommen habem, anf3ufïhren. Dic ?Hsfertigung ift von bem $\mathfrak{B}$ orfibenten ju unterf(t)teiben.

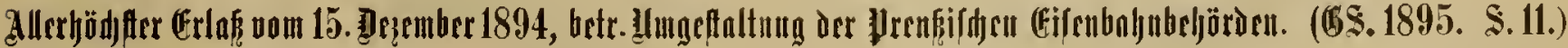

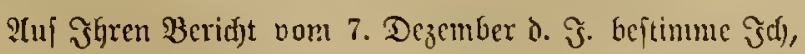
doß́ am 1. Tlpril 1895:

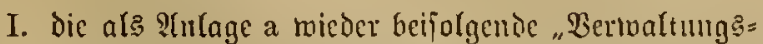
ordnung fïr die Stant:eijenbaliu'n"'

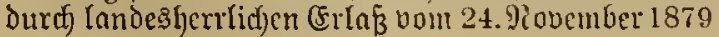

genehmigten "Siganifation Der Bermaltung ber Stantseijenbahnei und der bom Staate bertoalteten Gribatbahnen" eiugefübrt toird,

II. bie zur ?(usfüh)rung her bisherigen Drganifation eingejezten Eijenbalunbirclionen und (Fifenbahn= betriebsämter aufgelöft werìen, 


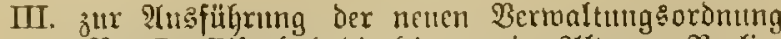
(9ix. I) Eijenfaljndirettionen in शlttona, Berlin, Breslau, Bromberg, (5affel, Ëöln, Danzig, Elber= feld, Erfurt, Effen a. Rubr, Franffurt a. Diain, Salle a. Sale, 5annober, Siattowik, Sönigs: berg i. \$r., Magocburg, Mitufter i. Weitfalen, Pojen, St. Fohann= Sanzbrïden und Stettiu mit den fid) cus Der Unlane $b^{2}$ ) ergebenoen Bejuten erticftet werbeu,

IV. Das (Eijenbahnfommifjarint zแ Berlin nufgelöft toirt.

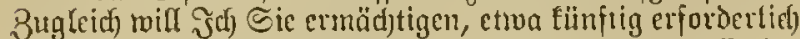
mertende Aenterungen der : Termaltmigsoronumg zu $\mathrm{I}$, in = jormeit fie nicht grundfäklicher Tatur find, zu veranlaffen.
Diefer Grlấ ift Durdf die Bejez= Sammlung zu bet= öffentlicfien.

Retç Palais, Den 15. Dezembet 1894.

Willy ellu. Thiclen.

PU den Pinifter der öffentlisluen शrbeiten.

1) Tadiftchend 5.459 abgebrudt.

2) Ridt nufgenommen.

2ulage n.

Merwaltumngordmung fiir dit Stantarifentahnen.

\section{Zlllgemeine Dermaltung.}

\section{(Gijenbaljmertwaltungăbehöroen.}

\$ 1. (1) Dic Berwaltung Dex in Betriebe fowic ber im Baue befindlichen Stantseifenbaljnen und bom Staate bermalteten Brivateifenbalynen erfolgt imter ber oberen

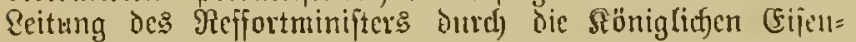
Galgndireftionetl.

(2) Werben für bejonbers umfangreidje Banausjïlorungen

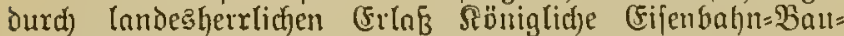
fommitfifonen eingefeßst, fo trifft Der Minifter über beren (Sic-

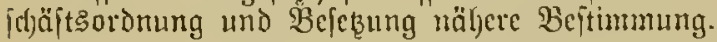

(3) Die §öniglichen (Fifenbalynbireftionen find bem Dinifter

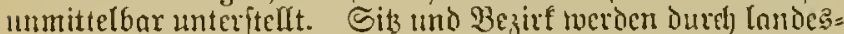

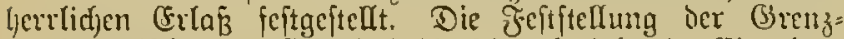
punfte zroijd)en Den Eijenbaljudireftionsbezirfen im Finzelnen ift Dem yrinfifer ïberlnffen.

Bezüglid ber Drganifation beg Mintferiums vgl. Ptım. IX ju

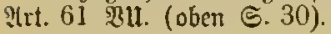

\section{Borbeharte bes Minifteræ.}

1. šn orlgemeineแ.

\$ 2. (1) Dem Minifter bleibt Dic cinfeitlidje Regelung tes Dienftes innerfalb des gejanmten Bereidfes Der Stant: =

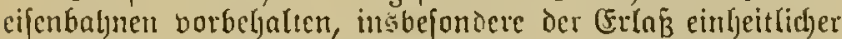

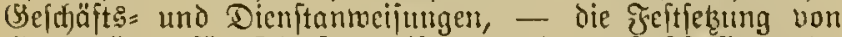
(S)undzügen fïr Dienftantweifungen, deren Jeftftellung im Firzelnen den Röniglidien (sijenbabndireftionen für ihren

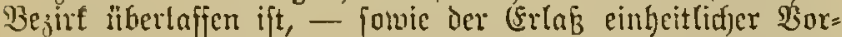

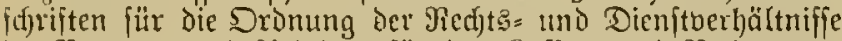

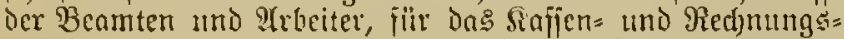
wejen und bie cinzelnen Dienjtzlveige im Betricbe und im 2̧aue der Stanticijenbatnen.

(2) Der Minifter entflycidet tiber die gegen die $\mathfrak{B} \mathrm{er}=$ jügungen und Befchlïffe $(\$ 7$ ) Dex Rönigliden (sijenbalun= bireftionen uljobenen Befdiverden. (Segen die auf $B:=$ idjmerde ergangenen Berfitgungen der fiöniglichen (Fifenbal)n= diuftionen fteht Den Beamten eine Berufung nicht zu.

\section{Bezüglich der Betriebsocrualtung.}

\$ 3. खlbgefehen von der für bejondere fälle vor= gefdricbenen höljeren (Senchmigung fleibt Den Thiniftr be= z̈iglich der Betriebsuertoaltung botbehalten:

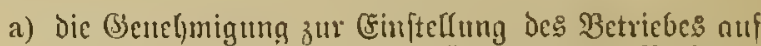

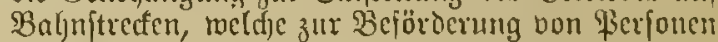
oder (Sittern im b̈ffentlidjen Berfehre Dienen แnd

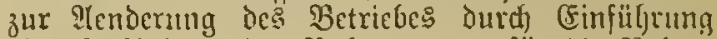
oder Muffebung ber Bafnorinung fü die Reben= cijenbaljuen Deutfólands;

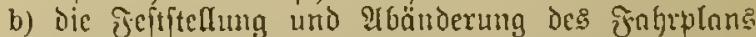

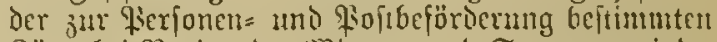
Büge bei Beginn Der Winter= und Sommerperiode, jowic die (Geneljnigung Der in Der Broifdenzeit beabjidftigten alenderungen, wenn baburef die $Z_{\mathrm{ahl}}$ und Gattung ber Bïge fertibrt wirb, oder menu cine Sinigung ber betheiligten Eifenbahnberwal. tungen uno foftbehörden nidjt erzielt woresn ift;

c) bie Jeftitellung und \&enderung der Tarife fiir Ferjonen, Gïter, lebende Thiere mo Sciden, fourcit Die SBcftimmung darüber nicht din siönig= lidben Cifenbaljndireftionen überlaffen wird;

d) Dic Bsenclyntigung bon Bausansfïbrungen, fïr

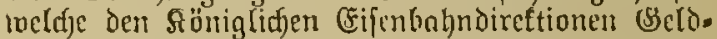
utittel nidft zux Berfügung geftellt find;

e) Die ₹eftitclung Derjenigen Entwïrfe und Roften= anffiläge, beren Soiten den Betrag bon 50000 PRarf in (Finjelnen liberfteigen, fomeit nicjt die feft= freflung fïr Bauten bon höherem Werthe den Sïniglicfen Eifenbabudireftionen befoniers itber: tragen wirt, forvie dic Jcitftellung ber (5ntmiixfe uno Softcnanfdläge füt Bauten bon geringerem Wertbe, fïr wolde Dic höhere \$ixüfung mo $\mathrm{cnd}=$ giiltige Jeftftellung bei Uebertoeifung ber Gell= mittel norbeljalten ift;

f) Dic Jeftitellung uno Nenderung ber Rormalent= milufe and giormalnnordunngen für baulidbe und majobinelle 2lnlagen, fowic für Betriebsmittel und mect)nnifude Betriebseinrichtunges;

g) die CFrmädjtigung zum 2b[çluß freibändiger

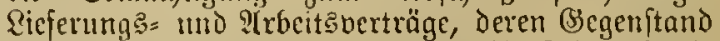
Den Werth von 50000 Miart überfteigt, fowic 3แ* Bujellagsertljeilung in öffentlidfen und engezen Beroingusngen bei (Begenttänden - jedes 200s für fid) geredfnet - von mebr als 150000 Marf.

\section{B̊czüglid) Der Rcubaubermaltung.}

\$ 4. Эut gleidjer $\mathfrak{B}$ eife bleibt tem Minifter bezüglid) der Reubauberwaltung batbehalten: 
a) die 9tnordmung der affgemeinen und ausführ(ichen

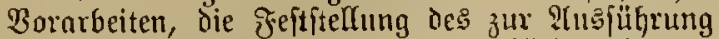
beftimuten (Entroufs und des zugeljörigen Saupt=

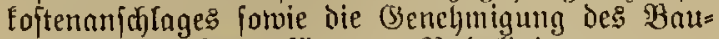

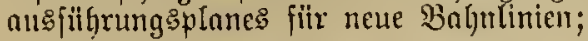

b) Die Feftitelfung derjenigen Gntmürie und Sioften= anf (d) läge, Deren Sộten Den Betrag vou 50000 Mart

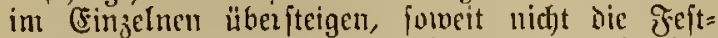
ftellung jïr Bauten voll loblyerm Werthe den Söniglidjen (sifenbahndireftionen bejonders iiber= tragen twitb, jowic bic Feftitellung der Euttwürfe III0 Roftenanld)läge für Bauten von geringerem Wexthe, für weldfe die höhere Brüfung mo end= gïltige Jeftftellung bei heberweifung Der Beldmitrel vorbehalten ift;

c) Die Jeftftellung und Ilenderung der Pormalent= würfe tund Normalanoromungen fïr banficke und

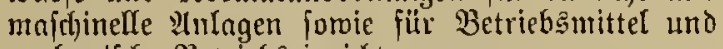
med)anif(d)e Betriebseinrictungen;

d) Dic Cröffnung Des Betriebe: auj jertiggeftellten

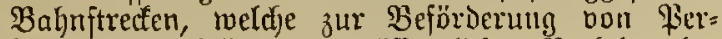

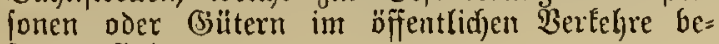
ftimmt find;

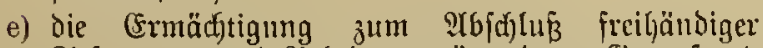
Rieferungs: = und Qh:beitsverträge, Deren (Begenitano den Werth bon 100000 Miart itberfteigt, jomic zur Bulfhlagsertheilung in offerttlicfon und engeren 3eroingungen bei Begenftänden - jebes Qoos fiir fich geredhut - bon mehr als 300000 Diarf.

\section{Bezüglich Der $\mathfrak{B} e x f o n a r i e n$.}

\$5. Bezüglick der Berfanalien der Stantseifenbalyn= bermaltung bleibt Dom Minifter borbehalten:

a) Dic Âfitellung, Berjetzung, Entlaffung fomic die Regelung Der Bejoldung

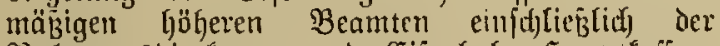

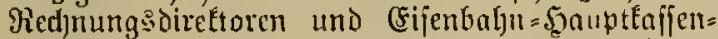
rendanter, fowie Die Heberweifung Der diätarifdjen höberen Beamten an die Röniglid)en (Ejijenbahn= oireftionen;

b) Die Beriebung bon Beamten atts dem Bejirfe

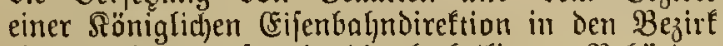
einer anderen, fomeit die betheiligten Behörden verfdjiedener פ̂einung find;

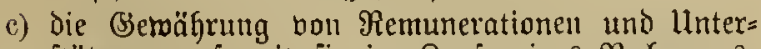
ftiitzungen, foreit fie im Entlfe eincs Re(t)nungs: jahres Den Betrag bon 300 MarE überịteigen;

d) die Gervälyung bon Urlaub über 4 Worfjen an. die unter a bezet(f)neten, über 6 Wodjen an bie übrigen Beamten.

\section{Die Sïnigliden (sifenbahmbireftionen.}

\section{(5ejđäftgbereid) Der $\Re$ öniglidjen (Eifenbahn= Direftionen im arlgemeinen.}

§ 6. (1) Den Röniglidfen (Gifenbafndireftionen obliegt mit Den den \$rovinzialbeförden zugerwiefenen Recjten uno Piftiçten die Bermaltung alfer zu ifrem $\mathfrak{B}$ ezizte geförigen, im Setriebe oder im Baue befindididen Sijenbahniftrecten.

(2) Die Rönigliden Gifenbahndirettionen Gejtefen aus einem \$täfidenten, den mit der ftändigen Bertretung des
Bräfibenten beauftragten beioen Mitgliedern ( $D$ ber $=$ Re

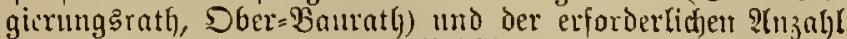
meiterer Mritgfieder. Der Gräfident niro vom Rönige eruant.

(3) Die Stelfnertretung des \$räfidenten douref bie onmit benuftragten Mritglieder der Röniglichen (Eijenbahndireftion regelt Der Mrinifter.

(t) Die Röniglichen (Fijenbaljndireftionen entfcheiden über die gegen die Verfïgungen und P(nordonungen Der Beritünde

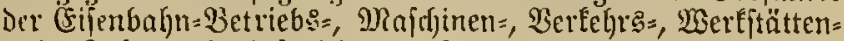
und Telegrapheninfpeftionen fowie der Bauabtheilungen (\$ 9) erljobenen Befitwerden. Sie vertreten in alfen Q $11=$

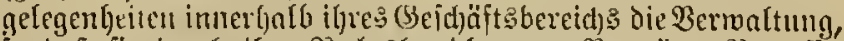
fo don fie burd) iffre Bechtshandlungen, Berträge, \$rojefle, Bergleidfe 2e. Für die Berwaltung Re(t)te erwerben unD Betpflichtutgen iibernehmen.

(5) Dem Minifter bleibt borbehalten, die Erledigung beftimmter hier子u geeigneter (Sefd)äfte fïr mehrere (Eifenbahns direftionsbejirfe oder det gefammten Staatseifenbahnbereidf Einer seöniglidgen Eijenbalyndireftion zu übertzngen.

(6) Die Fräfïdenten Der Rönigliđen (Gifenbahndireftionen,

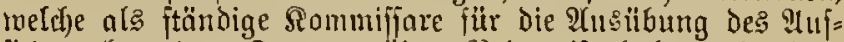
fidtesectis des Etnates uber Pribareijenbahnen in Dem ignen bom Minifter zugemiejenen Wuffidtsbezirle beftedt fino, habetr in Bemeinfodaft mit oen als ibre ftändigen Bertreter bejtiumten beiden PRitglieden der föniglichen

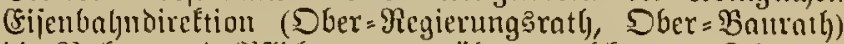

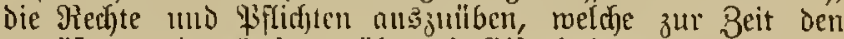

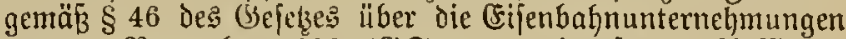
vom 3. Ronember 1838 (ङऽ. 505) eingejekten IIffichts: organen übertragen find.

\section{Befondere Derwaltungsjweige. \\ 1. İm îfgemeinen.}

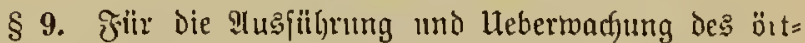
lidjen Dienftes nad) den ?(noromungen Der Röniglidjen (Eijen= baljnoireftionen fino Betricbs:, Majesinen=, Bertehrs=, BerEftätten = uno Telegrapheninipeftionen, jomie jïr die

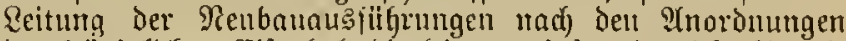

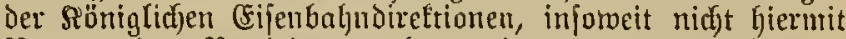
Beamte det Betricbsonermaltung betraut merden fönnen, Bauabtheilungen einjuridten. Den Borjtänden der Şn= fpeftionen und der Bauabtheilumgen fann bon Dem Minifter die Befugnif̧ zu borläufigen Siafjenanreifungen, zur $\mathfrak{B} e=$ urlaubung ber unterftellten Beamten mit bermaltungsieitiger

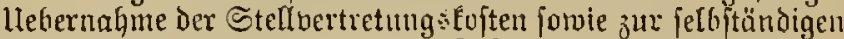
Vergebung bon Arbeiten und Eiejerungen ertheilt werden.

\section{Jut Bejoutorett.}

a) Betriebsinfpetionen.

$\S$ 10. (1) Den Betriebsinfpeftionen obliegt:

a) Die Susfiil)rung nnd Ueberwachung Des Betriebs: dienftes, injorweit nicitt einzelre 3roeige den $\mathfrak{M a}=$ idjineninipettionen (\$ 11), Berkegrsinjpettionen $(\S 12)$, Wertftätteninfpeftionen (§ 13) oder $\mathfrak{T} e l e=$ grapheninipeftionen (\$ 14) jugerwiefen find;

b) Die llnterfaltung und Beauffichtigung der im $\mathfrak{B e}=$ triebe befinolidien Streffen forvie die Bertwaltumg

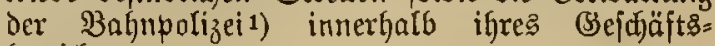
bereidg. 
(2) Bezirf uno Beidiäiţanucijung der Boritände ier Sijenbahn=2Betrithinjpeftianen beftimmt ber Minijter.

(3) Dem Boritande ber (Eijenbahn=Betrieboinjpeftioner fann non dem yJinifter hie Befugnif jur jelbitändigen Berpac)tung Der Dispofitionslänbeteien, Ragerplätze, (Sias: mutzungen, Liflanjungen 2c. beigelegt weroen.

1) Dit ber Berwaltung Der Rahupolizei ift bie Bçnguib Derbunden jur Berfolgung แno Beftrajung von Bahnpolizei=lleberfretungen in Sime bes Gejeßses vom 23.4 1883 (ङ. 289) in Rerbindung mit bem

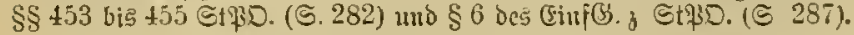

$$
\text { b) Majuineninipettionen. }
$$

§ 11. (1) Den Mafdineninfpeftionen obfiegt: die ?tus= fiif)rung uno lleberwact)ung Des Majd)inen= uno Betriebs: werfitättenoienjtes.

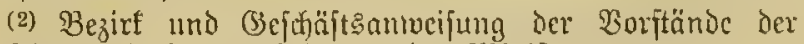
Majdineninfpeftionen beftimmt der Minifter.

$$
\text { c) Berfebrinipeftionen. }
$$

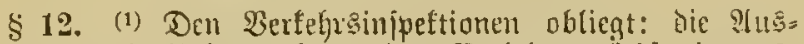
jïfrung und Llebervactung des Verfelyr:, itbjertigung: und Raficndicnftes.

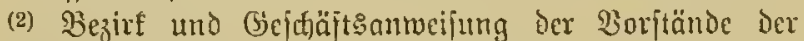
Berfefresinjueftionen beftimmt der Minifter.

(3) Die Borftänoc Der Berfelnesinipeftianen find befugt, nad) näherer Beịtimmung des Mrinifters bis zu ciner von

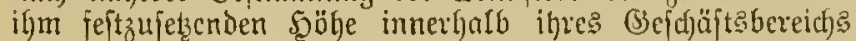

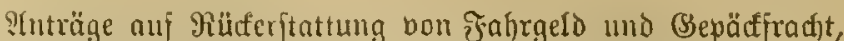
fowic auf Erfatzo oder Entfoäbigungsteiftung aus bem Frnd)tbertrage felbitändig zu cutf(d)eiden, aud) die anf (Srrund

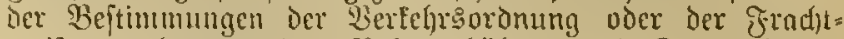

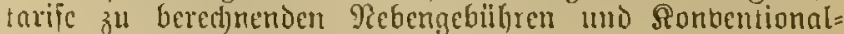
ftrajen ganz oder zum Theil ju erlajien.

\section{d) Werteftëteninipeftionen.}

$\$$ 13. (1) Den Werfftätteninipeftionen obliegt: Die \$4

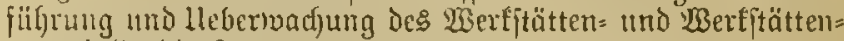
materialiendienftes.

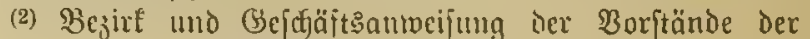

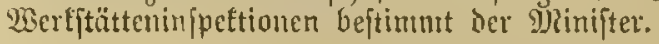

\section{e) Telegrapheninfpettionen.}

§ 14. (1) Den Telegrapheninjpeftionen obliegt: bie Unter=

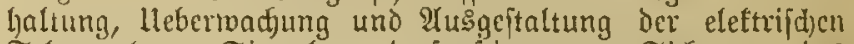
Telegraphen=, Sigual= und fontigen zur Sidjerung des (Gijembalunbetriebes dienenden eleftrijhen श̂nlagen.

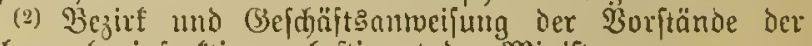
Telegrapheninfpettionen bejtimnt ber Minifter.

\section{f) Banabtheilungen.}

$\S$ 15. (1) Den Bauabtheilungen obtiegt: die Reitung ber Reubauausiül)rungen.

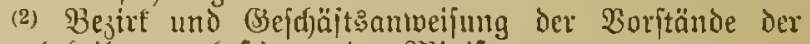
Bauabtheilungen beftimmt Dex Mrinifter.

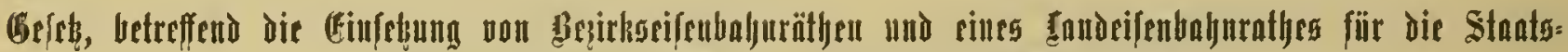

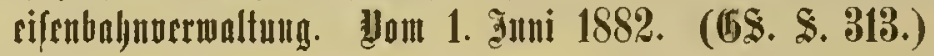

\section{Einleitende Beftimmungen.}

§ 1. Zu beiräthlidjer Mitmirfung in (Eifentahumerfehr: fragen $(\S \S 6,14)$ merben bei den für Redfunng Des Staates verwalteter (Fijerbahjen erricjtet:

a) Bezirfseifenbałnräthe a[s Beiräthje ber @tunts= eijenbagndirettionen;

b) ein Ranteseijenbahntath als Bciratl) ber (Sentral= vermaltung Der Stantseijenbahnen.

\section{A. כẻegirkseilenGafintütfie.}

\section{$8 \mathfrak{a b l}$ l.}

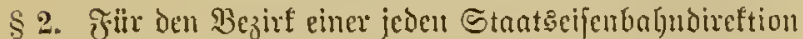

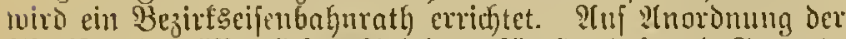
1) Rinifter ber öffentfidjen Arbeiten, fïr Soandel und Serwerbe

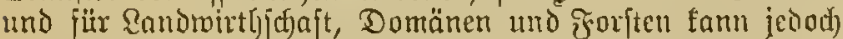
ausmahmancife ftatt defjen der Bezirfseifenbalymath für mehrere Staatseijenbahnoireftions = Bejirfe errid)tet werden.

Bezir

1. in B̈rauberg für bie Direftionşbejirte Bramberg, Danzig,

2. "Ser「in

3. "Magoeburg Rärigsbergi. \$r.;

t. "Sannaer " Den Direttionsbezirl Dagoeburg; die Direftinnsbejirfe Samnoner und श)

5. "frattiurta. MR.

FrautFurt a. Mi. uno caliel;
6. " ᄃே̆

7. "Erfurt

8. "BresIau

9. "M I tou

fïr bie Direftionsbejirfe Cöln, Erberfeld, Efien a. o. Ruhr, St. Yohantn= Saar= briiden;

Grfurt u. Ђallea. . Breslau, Rattowis, Bofen

" den Direftionsbezirf આItora.

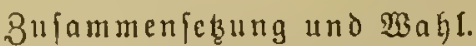

§3. Die Bূzirtseifenbahntäthe werden aus Vertretern Des Dandeleftandes, Der जnduftrie, Der \&aub= und Forft= ivirthidjaft zulantmengejetst.

Dic Mitglicder, fomie die in Falle der Befinderung bun Ditgliedern eintretenden Stelfuertreter tocrden bon den Fुarbelsfammern, faufmäunijefen Sorporationen und den Ianomirtbidfajtlidjen \$rovinjialvereinen (Eentralbezirfsver: eimen), folvie bon anocren, burd) bie Minifter der öffentficjen IIrbeiten, für Sandel uno (sicwerbe und für Eanowirthjojajt, Domänen uno ₹oriten zu bejtimmenden Siorporationen uno Bereinen auf 3 ร̧ahre getoählt.

Die 8 anl ber Mitglieder und Stelfbertreter, fowie deren Bertheifung auf Die berjdiedenen Sntereffentenfreije beftimmen die MRinifter der öffentlicten Irbeiten, fïr Sandel und Be= twerbe und fïr Randwirtbidjaft, Dontänen und Forften.

\section{Bulnfing auzerpreufijuer Theilnegmer.}

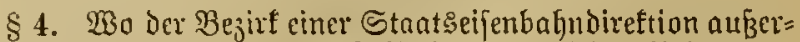
mreufifd)es (sebiet - innerhalb Des Deutjd)en Reict)es -

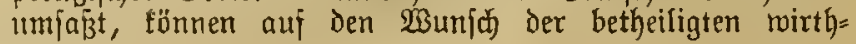


(c)joftlidjen Streife Inter Buftimmung ber betreffendon Re=

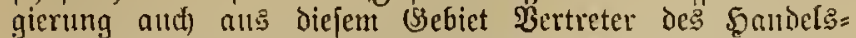

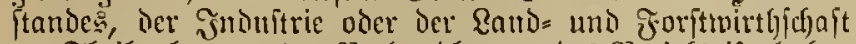

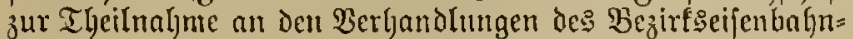
rathes zugelafjen merden. Die IInzahl Derjelben und die ?ht ifrer (Finlabung beftimmt ber Minijter der öffentlidjen Irtbeiten.

$$
\text { Tน }
$$

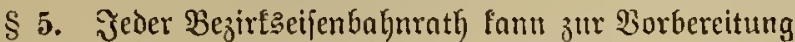

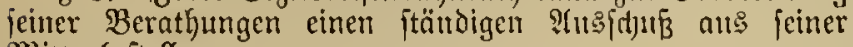
Mitte bejtellen.

$$
\text { Buf̂tänoigfeit. }
$$

\$ 6. Der Bezirfseifenbahmath ift von ber betreffenden Siantseifenbahndireftion in allen die $\mathfrak{B e r f e h r s i n t e r e f f e n ~ d e s ~}$ Bezirfes oder einzetrer Diftrifte beffelben beriibrenden widstigen

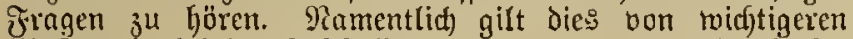

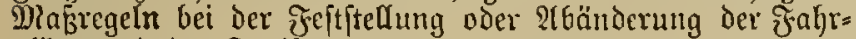
pläne und der Tarife.

Der Bezirfseifenbahnrath fann in Stngelegenlyeiten Der vorbezeicf)neten Irt auch (elbititändig 2(nträge an die Stants= eifenbahndireftion rid)ten und bon diejer 2(usfumft berlangen.

Wenn die Eifenbahndireftion regen Bejahr im 3 erjuge

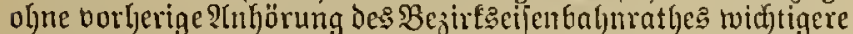

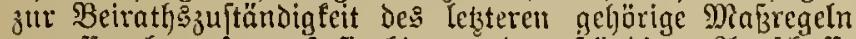

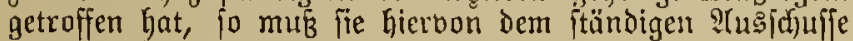
(§ 5) und bem Bezirtseifenbabnrathe bei deren nänftem 8ufammentritt Mittheilung maden.

\section{(S) $\{$ chäftรoronung.}

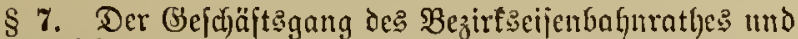

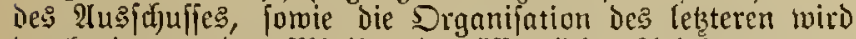
burd) ein bon dent Minifter Der öffentlidjen $\mathfrak{T}$ rbciten 3 ll ge= nelunigendes Regulatio, meldfes der Bejirfseifenbahnrath entwirft, georonet.

Das requlatio hat aud bie exforderlidien $\mathfrak{B}$ eitimumungen

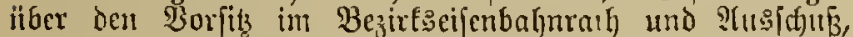
folvie ïber die periobijdjen Sibungen bez erfteren zu treffen.

(5) muß cine wenigftens $2=$ mal im Эabre ftattfindende Bufanmenberujung des $B$ ezirfscifenbahniathes anorbnen.

Buziehning anderer Gifentahnberwaltungeu mi Staatsbehörden.

§ 8. Den Sibzungen des Bejirkeijeubahurathę Ëunen allf Finlabung Desิ \$räfidenten Der Staatseijenbahndireltion aud) Bertreter anderer (Eijenbahnocrmaltungen oder Stants= beböroen beimohnen.

\section{Borerhebunger.}

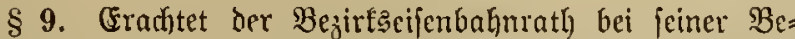
fd) lufffaffung Borerbebungen fïr erforderficf), fo erfolgen bie= felben burch) die betreffende Staatseifenbahndoireftion.

\section{B. Sandescilenbafiuratf.}

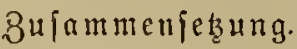

$\S 10$. Der Eandeseifenbalymath befteht:

a) aus 1 Borfizunden und defien Stelluertreter; Diefelben werden bom Rönige und ztwar allf bie Dauer bon 3 Эahren ernannt;

b) aus 3 von bem Minifter für Randmixthichaft, Dos mänen und foroften, 3 non dem Minifter für Sander und Bemerbe, 2 von Dem Minif́ter der Finanzen, fowie 2 bou bcm Dinifter Der offentlidjen ?Trbeiten fitt Die Dauer bon 3 Эahren berufenen Mitgliebert, nebft einer gleidfen 2lnzahl bon Stelluertretern;

alteggeidjtoffen find unmittelbare Staatzbeamte;

c) aus je 1 Mitgliede für Den Regierungsbezirf Caffel, Den Piegierungsbezirf $\mathfrak{B}$ iesbaden, dic Stadt Bertin und die Stait Jranffurt a. MR.;

ante je 2 Mitgliedern fïr die Srovinzen Ditpreusen, Weitpreuber, fiommern, Brandenburg, Fojer, Siflesimig= Solitein, Snamnober;

aนล je 3 Mitgliedern für die ßrobinzen Scflefien, Sadj $\{$ en, Bejtfalen und die Rheinprovinz,

nebit einer gleidjen $\mathfrak{A} n_{z} a \mathfrak{l}$ bon Stelluertretern.

Diejelben werden Dumb die $\mathfrak{B}$ ezirfseifenbalyntäthe aus Den Sreifen Der $\&$ and = und Forftwirtbichaft, der Jnduftrie Doer Des Fandelaftandes innerhalb der \$rovinz, bejiefungs= roeife Des Regierungşbezitts oder Der Stadt allf die Dauer

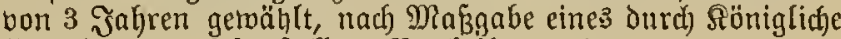
Beroronung 1) feitgeitefften Bertheilungsplanes.

1) v. 31.12 .1894 (ซङ 1895 , ङ. 1).

\section{Buzielung bou Sadberjändigen.}

§ 11. Dem Minifter ber öffentficf)en Prbeiten bleibt es vorbehalten, in geeigneten Fällen Spezialfacjuerftändige bei den $\mathfrak{B e r a t j u n g e n ~ b e h u f : ~} \mathfrak{A}$ usfunftertheilung zužziehen.

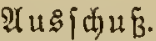

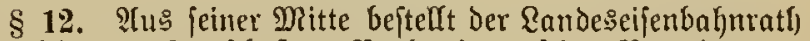

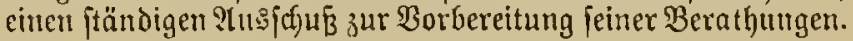

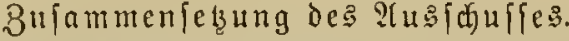

§ 13. Der Tusid)uß bejteht aus dem Borfizenden des Eandeseijenbahnrathes oder deifen Stellvertreter ( $\$ 10$ Litt. a), und 4 von bem Randeseifenbahnratbe aus feiner MRitte er: wäglten Ditgliebern und 4 Stelfoertretern.

3uftändigfeit des Randeseifenbalunathes.

§ 14. Dem Sandeseifenbahnratbe find zur Reußzerumg burjulegen:

1. bie bem Entwurf des Staatshaushalts=ertats bci= zufïgende Ueberfitit) Der Rormaltransportgebühren jür Berjonen und Bsüter;

2. die Sllfgemeinen Beftimmungen über die Antwendung

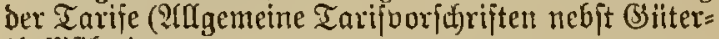
flafififitation);

3. die 2lnoromungen togen 3ulajiung oder Berjagung von ?tusinafme= Imo Differenzialtarifen (untegel= mäß̈ig gebildeten Tarifen);

4. Inträge auf allgemeine Aenderungen der Betriebs: und Bahnpolizei1)= Reglements, foweit fie nicht tech)tif hje Beftimmungen betreffen.

श(ud) hat Der Raubescijenbahmath in allen widftigeren, das öffentlidje $\mathfrak{B}$ erfehrswejen der Eifenbahnen berïhrenden Fragen auf $\mathfrak{B e r l a n g e n ~ d e s ~ M i n i f t e r ~ D e r ~ o ̈ f f e n t l i c h e n ~} \mathfrak{A}$ rbeiten fein (3utad)ten zu erjtatter.

Der Randeseifenbahurath tann in Ingelegenheiten der

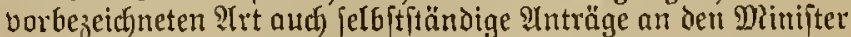
ber iffentlid)en $\mathfrak{A}$ rbeiten ridften und bon biejem ?(ustunft verlangen.

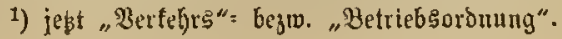


Berufung des Randescifenbaljurathes.

§ 15. Der Randesecifenbal)ntath wiro bon Dem Minifter

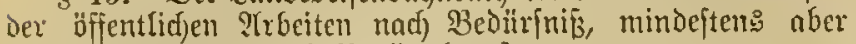
$2=$ mal in Saljre, nad) Berlin berufen.

Die Tngesoromm fitr bie Sikungen, infomeit dicjelbe

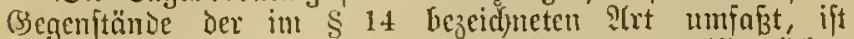
minseftens 8 Tage vorlyer von Den $\mathfrak{B}$ orfitzenden zur öffentlichen Semntuis zu bringen.

গa d)träglid)e Mittlyeilung borläufiger ?troronungen ber Statisegierung an ben \&nndes:

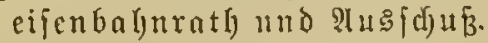

$\S 16$. Dic nou her Stnatsregierung bei Bejahr im

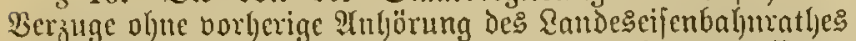

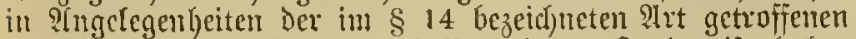
SToromungen find den ?lusjdjulfe und dem \&andeseijenbahn= vatbe bei Dem nürbiten 8 ufammentritt mitzutbeilen.

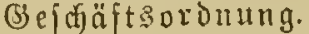

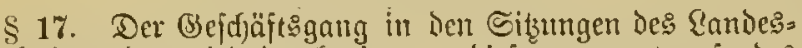
eifenbahnrathes mird Durdf ein von biejem zu entwerfendes und von dem Staatsminifterum ju genel)migende $\Re$ egulatio georonet.

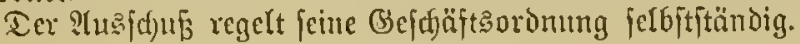

Borerhebungen.

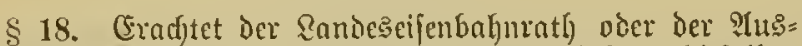
(d) uf Borerlyebungen fiir erforderfid), fo erfolgen diefelben

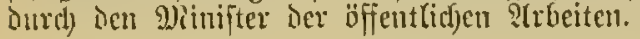

Dittheifung Der Terhandungen de: Randescifenbalurathes an ben Sandtag.

§ 19. Die Werlundlungen des Sandeseijenbahmathes werten von Dem Minifter Der öffentfidfen \$rbeiten unter Beifïgung einer Hiberfictlid)en Darftellung Des (Ergebnifjes und Der Darauf getroffenen (Entfheidungen ebenjo toie bie Rormaltransportgebülyen für \$erjonen und Bitter Dem Sandtage regelmäßig mitgetheilt.
Feitfetung der Rormaltransportgebilfren.

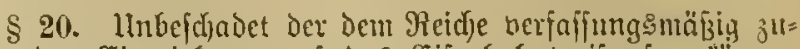
ftehenden cinwirfung auf ias (Gifenbalntentifwefen fönnen

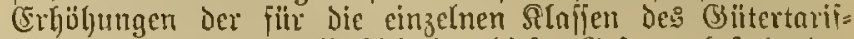
(d)emas zur Beit der \$3ublitation bicies (3ejetzes bejtehendin Rormal= (श2arintal $\Rightarrow$ Traneportgebithem, lomeit fie nid)t 3um Btvecfe Der 5erftellung Der (5)leich)mäßigteit der Tarife oder in Jolge von Penverungen des Intiffichemas vor: genoument werden, nur Durd) Sejes erfolgen.

\section{Freie ঔahrt und Diäten.}

\$ 21. Die Mitglieder bes Randeseifenbafuntathe: Imo

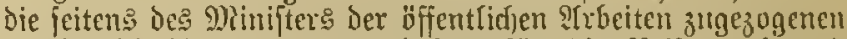

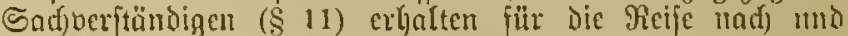
von bcm Srte der Siz̧ung, fowie für Die Dauer Der Sikzung tïglid) je 15 Marf, joweit biejelben nidjt idjout nnoerweit Diäten nus der Staatskaffe beziehen.

ILud erljalten biefelben jorvie audf die Mitglieder Der Bezirtseifentalyntäthe belufg, Theilnaljue nu ber Sibung freie Jaljet in beliebiger $\mathfrak{B a g e n t l a f f e ~ f u ̈ i r ~ d i e ~ \Re e i f e n ~ t a d ) ~}$ uno bou beu Sorte ber Siz̨ung.

\section{Erlöfden der MRitglicdfdaft im}

Bezirfacifenbalunathe und Randescifenbaluratge.

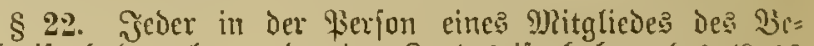
jirfseifenbalynathes, oder deg \&nndeseifenbahnrathes (\$ 10 Litt. b und e) eindretende limptand, durd) weldyen bafiflle 3u Befleisung öffentlid)er 2(emter bauerno oher ant Beit

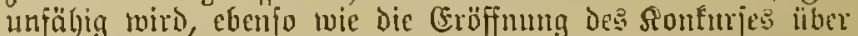

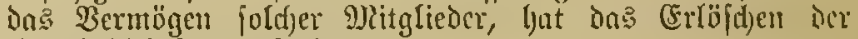
Ditgliebjd)nft zur Folge.

Scheidet aus biejer Seranlafjumg ober burdf Too oder

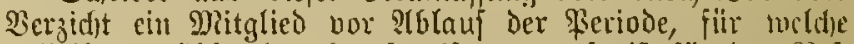
Daffelbe gemälft oder berufen ift, alls, io ift fïr isu Meft Der qieriode ein ncues Dlitglied zu wäblen beztw. zu berujen.

§ 23. Diefes Gejes tritt am 1. Januar 1883 in Sraft. llifundicf) $2 c$.

\section{IX. 람ältni}

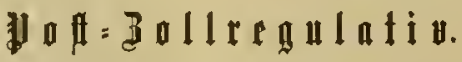

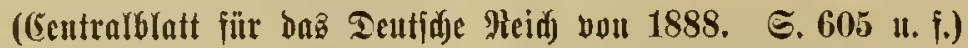

\section{Alr rdunttt.}

Affertigung DCr in Das Bollgebiet eingehenden (j) genftïnde.

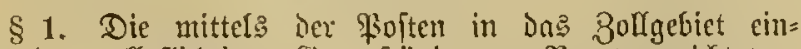
geljenden zollpflichtigen (segentände zum Bruntogemidft bou utehr als $250 \mathrm{~g}$ mïjien mit ciner Deutlid gejdbriebenen, vifen beiliegenden Ĵnhaltererflärmng (Deflaration) begleitet jein, aus welcher fich exjeben läst:

a) Der Pame Des S(Drefiaten;

b) Der Drt, twogin die Sendung beftimnt ift; c) die Bahl Dex einzelnen zu der Sendung getjörtyen Wioftitüfe, jomie die Beidfen unt Tummern jede: einjelnen;

d) Die Bsattung Der in jedem Bojtftüté enthaltenen (siegenftünne nad) deren handelsil blidfer oder fonjt [prađjgebräudjlidjer Benemnung;

e) Der Dot uno der Tag Der Thêfellung ber Ĵnfalt: Grtlärumg mo

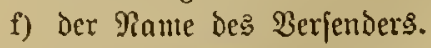

§ 2. Dic Bcifïgung ciner Эnljalţertlärung ift midjt erforderlid): 
1. bei Briefbeuteln und Faljrpoftbeuteln, fonie bei den an Stelle dexielben zur Intwendung fommen= ben Brieppacfeten und Jahrpoftpacfeten;

2. Бei Beitungsipadfeten und Drudfadien;

3. bei SielDfäfiern, Gelofiften, Belobeuteln tnd Geld= pardeter;

4. bei \$Boftienoungen, meldye unter bem Sicgel ciner Etaatzbehörde oder eines eine foldjc Beljöroc repräfentirenden Beamten cingeljen und an cine Stantąbebärde bezm. cinen dicjelbe reprä|entirenden Beamten geriatet find;

5. Gei $\mathfrak{W a n r e n p r o b e n ~ u n o ~ M a f t e r n ~ z u m ~ B r u t t o g e r v i c t ) t ~}$ vout $250 \mathrm{~g}$ oder meniger, meldje unter fireuzband oder in foldjer Weile berpadt cingeben, dafis liber den sonbalt fcin Broeifel cntftehen tann.

Siegt (Grumb zu ber Bermutlyumg vor, Daf̧ nit Den Briefpoften àllpflid)tige (S)genftänbe in zollpflictjtiger Mienge cingefityrt werden, io find die $804 \pi=$ mo Stenerbeanten befingt, in ben Dienftlofalen ber betreffenien Fioftanitalten ber Eröfrung Der $\mathfrak{B r}$ ref= und Fahrpoftbentel oder = Parfete beisumohner, um bon ben Snlpate lleberzengung zu nelymen; dic etroa vorgefundenen Bricje ober Hadetc, Eci weldyen fich die Bermuthung jollpflidjtigen Şnl)nlts redit= fertigt, forvic zollpflidjtige Wancenproben bon mehr als $250 \mathrm{~g}$ find der zollamtrichen Borabfertigung (\$\$ $4 \mathrm{ff}$. ) $3^{11}$ unterwerfen.

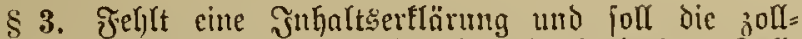

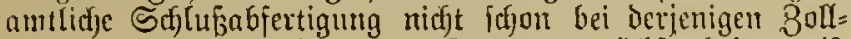
ftelle crfolgen, melct)e der (Srenze zuiädjft belegen ift (§ 4), fo twird bon Der letsteren Bolltelle bei Dem Eingmige ier Sendung cine Revifiontinote gefertigt, weldje, menn der

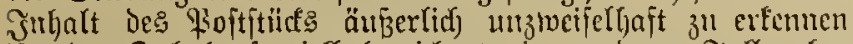

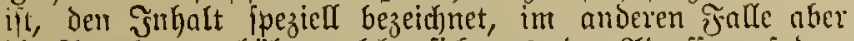

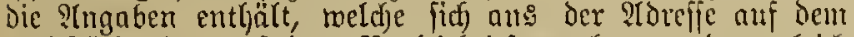
lioptitiuf oder auf dem Begleitbricf ergeben, und zugleid) bejdjeinigt, baf die Eendung zux zollamtlidjen Bebandumg vorgelegen habe.

Die Rebifion Sendung dic Stelle der șnhaltsertärurg. Diejclbe fam jederzeit mb bis zur Bornahne der jollamtlicjen

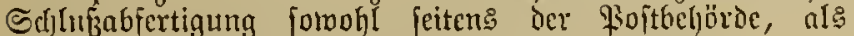

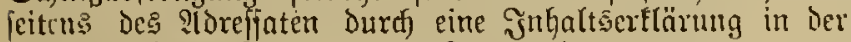

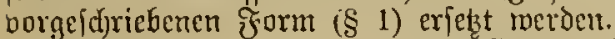

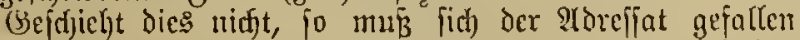
lafien, Daß die gebörig deffarirten Sendunger bei Der Ecflubaffertigung vargejogen merben.

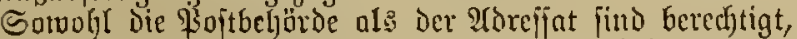
cine bercits vorliegende sonljaltserllärung, injolange einc

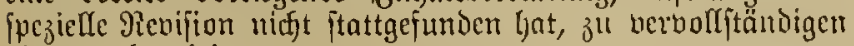
ober ju beridjtigen.

\$ 4. Die nac) Dem Srte ber Bollitelle alt ber (Birenze beftimmten, Desgleidjen biejenigen Eendungen, weldje nuf dem Wege nach dem Beptimmungsorte cinen weiteren Drt, an melchem eine $30 \mathbb{L}=$ oder Stenerftelle fich Gejände, nidyt berilbten, werden von ber Ballitelle an Der Brenze fojort

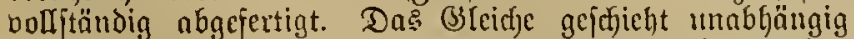
bom Beftimmungsort ber Sentung auf bas Berlnugen bes

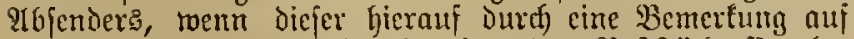
ber srrbaltserflärung oder in einer das Poittüuf offen be= gleitenden Rote ausorüuflidg Den Antrag geftellt lont.

Die in bem $\$ 2$ unter $\Re 2.4$ aufgefúlyten \$ofititiufe der Beförien, infofern Deren S̈nhalt aus iffen oder Sdjriften beitegt und dies auf den betreffenden Begleitbriejen oder

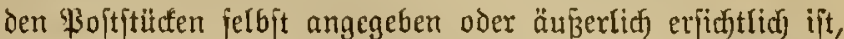
ferner die in dem $\$ 2$ unter $\Re \mathrm{r} .1,2$ und 3 aufgefübrten Segenitände ber \$Boftadung find in ber Regel Den $80 l l=$ beamten an ber Grenze nur zur allgemcinen Befidjtigung boralegen uno einer weiteren jollamtlicfen Beljandlung nicht unteriorifen. (5benjo findet bei ben in $\$ 2$ unter

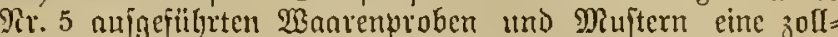
amtlidje Sornbjertigung an ber Srenje nidht itatt, vielmeljo merden biejelben crit am Beftinmmingorte vou der \$ojt=

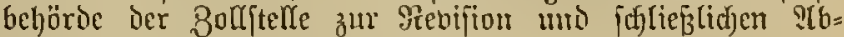
fertigung ( $\$ \$ 6 \mathrm{ff}$ ) vorgefittrut.

YIlle ponftigen eingebenden \$3optftïde unterliegen, folveit Diefelben Dns 3 ruttogetwidft bon $250 \mathrm{~g}$ ïberiteigen, bei ber= jertigen Bollftelle, weldbe der (B) tenge aunächjt belegen ift, einex zollomtlidjen Bornbjertigung (\$ 5). Die jefliçzlidic Ubfertigung (\$§ 6 ff.) crfolgt am $\mathfrak{B e f t i m n u m g s o r t c ~ o d e r , ~}$ wem fid Dafelbit cine $B$ all= oder Steucritelle nicht befindet, bei einer gecignet gelegenen $80 \mathrm{fl}$, oder Stenerftelle, deren

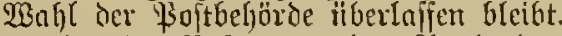

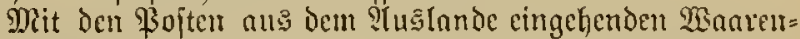
icnoungen in B̧ruttogenidft von $250 \mathrm{~g}$ und meniger fint als zollfrei auch bon jeber zollamtlidjen Behanblung befreit.

Bon Det Bollbcireiung des $\$ 4$ lit. a bes Bolltnii = gejetzes werben ausgefdjloffen:

a) Diejenigen $\mathfrak{W a n a t e n}[\mathrm{end}$ ungen in Fingelgewidjte bon Grutto $50 \mathrm{~g}$ und Daribber, Deren Cimfuh mit ber Foit über die Brenjen gegen Defterreich=Ilngarm ober bie Bolfantsid)lïfle erfolgt, foncit dieje Sen= oungen cinem Bolliats bon 100 Miart oder melur fitr $100 \mathrm{~kg}$ unterliegen;

b) Die ïber bic (Srestzen gegen Defterteid)=IIngazn

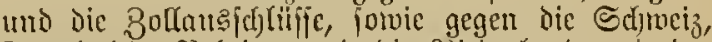
Franfreid), Belgien mo die 9icherlande mit ber Foft eingeljenten Wantenjentungen, forveit dic= jelben Tajotjenuljen, Werle mo (Sebäuje zu joldjen enthalten. Die zu a und b bezeidneten Sendungen unterliegen ber şnlualsertärumg und ber zoll= amtliden Sebandlung nadj Den Beftimmungen bes borliegenden Riegulatibs.

\$ 5. Dic zollamtridje Borabfertigung (\$ 4) befpteljt in Folgenten:

Durdj Diejenige Bollitelle, weldje ber (Sirenze sunäd)it belegen ift, fimb dic emgcljenden Poititiofe

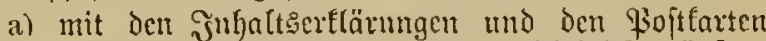
oder nach Bediirfmif̧ mit Den Begleitbriefen änf̧er: (icf) ju bergícidjen, etwaige 9lbroeid)ungen in den

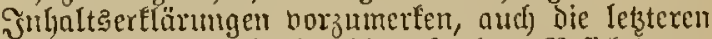
mit cinem Demerf зu veriegen und fehlenic Snljaltserflärungen Durd) Revifionsmoten $(\S 3)$ ju crietsen;

fodann

b) diejenigen Foftitüde, meldye ber Borabjertigung unter= regen haben, jun Beidjen ber noch borbehaltenen

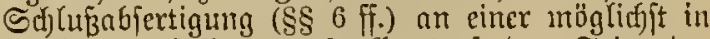
dic Rugen fallenden Stclle (auf ber Scite ter

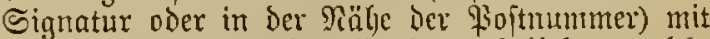
einer Marfe bon rothem \$3apier zu beleben, toeldie cince jdyrotzen Uborud des Dientiftempels ber

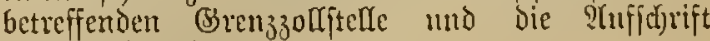
"Bollfilict" trïgt.

Dieje Beljandlung findet auch bei Den in $\$ 2$ unter शr. 4 aufgefüfrten Soptiendungen bann 2lnmendung, menn

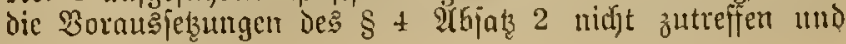


Diefelben beskalb einer weiteren zollamtlidjen Thfertigung unterzogen werden milfien.

Dicjenigen \$oftitücfe, Deren Эnllalt als zollfrei fofort ertannt worden ober deren Sd)lufabjertigung gleid bei der erften 8ollitelle an ier Birenze erfolgt ift, treten in ben freien Berfehr, bedïrjen baher aud) ber Bezeichnung burd) eine Marfe (lit. b) nidjt.

Desaleicten ift bon bem unter lit. b borgefdyriebenen Berfahren 2tbftand zu nehmen, wemn mefrere Sendungen nady einem Srte, on reldjem eine $80 l l=$ oder Stenterftelle ifren Sitz hat, fartirt find, und in berfdhliez̧bare Wagen= abtheilungen, Rörbe, F̌eleifen, Bentel oder fonjtige Behälter berpacft werden, weldie alsbann unter zollamtlidjen $\mathfrak{B e r}=$

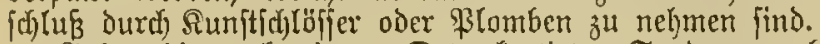

(Sehen Dic nad cinem Drte lartirten Sentungen be= reits bout $\mathfrak{A}$ (uslande in berjd)loffenen $\mathfrak{B}$ agenabtheilungen ober fonftigen Behältern ein, jo hat fich die Bolftelle an ber (Srenze anf die Artlegung eines zollamtlichen Berjetluffes an den $\mathfrak{B a g e n a b t h e i l u n g e n ~} 2 e$. zu befd)ränfen.

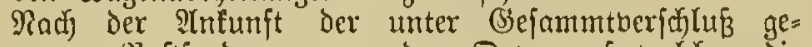
nommenen Hoftjendungen an bem Drte, auf welden bie Pojtfarte lautet, hat die bortige 30 ll = oder Steueritelle in Bezug anf die reitergebenden Stǘte dic zollamtidye Bor= abfertigung dem Borfteljenden entjprechend borjunefmen, bez̧w. nacf der Beftimmung lit. b zu ergänzen.

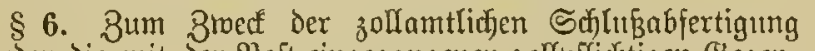
merben die mit ber \$o/t eingegangenen jollpflidftigen (Segen= ftände mit den Daju gehörigen Snthaltsertlärungen Dder Revifionsmoten den betreffenden 3oll= oder Steuerftellen (§ 4) übergeben. Die 2lbfertigung exiolgt nach) ben alf= gemeinen gejezzlidten Boriftyriften.

Das :Berfahren ift indeffen ein berfdjiedenes, je nadjoem

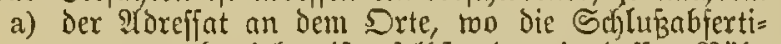
gung zu betwirken ift, felbit oder in deffen शähe fich befindet und beshalb der शtbfertigung perfönlidy beitwohnen fann, oder

b) die Sendung ofme Zuziehung Des 9dreffaten zoll= amtlict) abgefertigt mo Dann zแm Zmect der Weiterbeförderung an biejen der \$ojtjtelle zurüdf= gegeben werden muf.

§ 7. Befindet fich) Der Sldreffat an Dem Drte jelbft, too die Schlufabfertigung ju bewirten ift, oder in defien 9ähge, fo merden die Begleitbriefe (Begleitadreffen) oder, menn foldje nidft borhanden find, Sb(d)riften der auf den $B_{0}$ oft ftilden befindlidjen Idreffen, mit Dent Eingamgsftempel Der Bojtitelle berfehen, Durch Die letztere an den idorejiaten bejtellt;

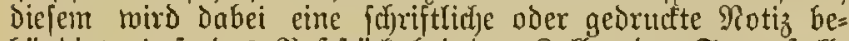
Gändigt, onfiz das gioftititu bei der 30 ll = oder Steuerjtelle in (Empfang zu nel)men iei. Sactie des Adoreffaten ift es

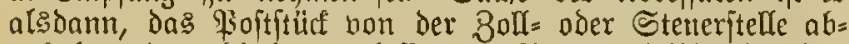
zuholen oder abjolen zu laffen, nadjdem er felbjt oder fein Beauftragter dort Durch Qorzeigung des abgeftempelten Begleitbriefes (Begleitadreffe), bezrw. Der abgeftempelten

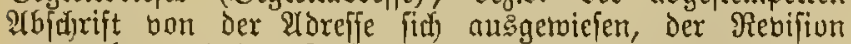
angetwohnt und den 80 oll entridftet hat. Das Begleitpapier

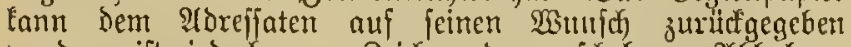
merden, ift jebocf zum Beidjen der gefdehenen Itbyolung

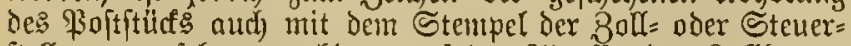

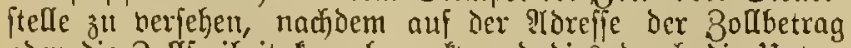

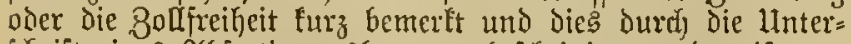
fidrift eines 2(bfertigungsbeamten bejdecinigt morben ift.

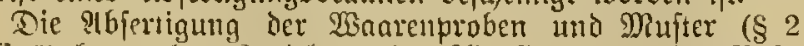

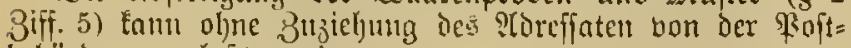
behörde veranlāist werden.
\$ 8. Soll dic Boftfendung, entfernt von dem Wohnort des Tldreffaten, ol)ne Deffen Zuziehung, fei es bei ber Zoll= Ftelle an ber Grenje oder bei einer ber Dem Bejtimmung:

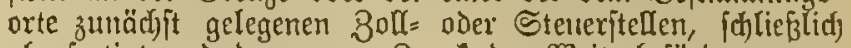
abgefertigt uno bann zum Zroed ber Weiterbeförderung an den ât reffaten der sioft telle zuriffgegeben werben, jo begiebt fich ein ßoftbeamter zu der betreffenden Zoll= oder Stenteritelle, weijt fidf bort als zur stbfolung beaufragt aus Durch $\mathfrak{B}$ orjeigung des $\mathfrak{B}$ egleitbriefes (der Begleitadreffe), oder in (Frmangelung eines jold)en burd) eine mit Dem (5itl=

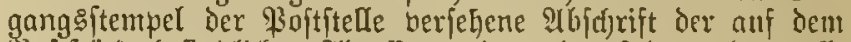

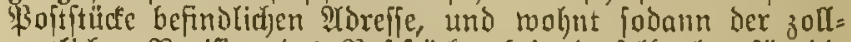
amtlichen Revifion Des \$ojtftüufes bei; Derjelbe hat für die Deffnutig deş Rollo uno Die Darlegung der Waaren zut Rebifion, fowie fiir deren Wiederberpacfing Sorge jut tragen, und entrichtet den Bolf gegen Bolquittung.

Die Detfiegelung des zollamtlin abgefertigten Foptitiofes hat darauf burch die gioft und die Zoll= ober Steuterftelle

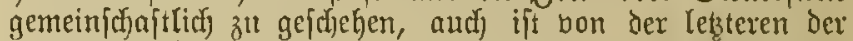
vorgezeigte Begleitbrief, bezw. Die TDrefie jum Zeichen der gefdebenen Berzolung deg \$ojtitürt's mit ifrem Stempel

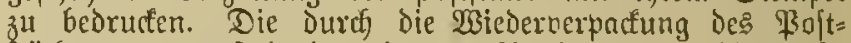

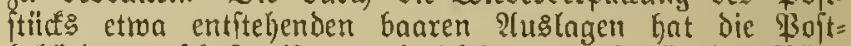

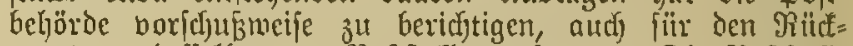
transport befielben zur \$oftitelle ju forgen. Die \$oftitelle

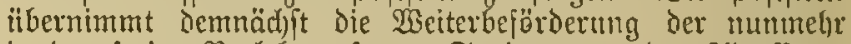
in ben freien Verfefir gefesten Sendung an Den ?loreffoten und zielyt bon bieferm die bei Der Bollabfertigung entitandenen baaren ?tuslagen an 80 ll mo Serpadungsfopten ohue

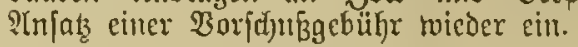

\$ 9. Die ßoftitelle wie Die Boll= oder Stenteritelle find befugt, and) in foldfen Jैälen, in weldjen der थDreffat fidf nid)t am Drte ober in beffen 9?ähe befindet, bie ?(nwejenlyeit Des afdreffaten oder cines mit fidrifitidjer 2ollmad)t ber: fehenen $\mathfrak{B}$ ertreters beffelben bei der Revifion ju berlangen.

Dies Berlangen muş insbefondere bann gejtellt rerien:

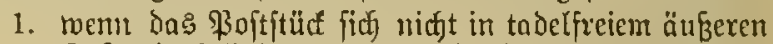
3uitande befindet und wenn desgalb das Garantie= verhältnif̧ der \$3oftbertwaltung mit in ₹rage fommt;

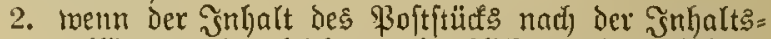
erflärung in leidft jerbrectlictjen oder poldjen (Segenjtänden bejteht, die einer bejonderen funit= bollen: Berpactung bedürfer.

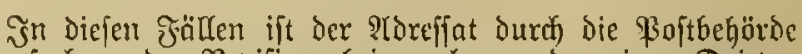
ju erjuthen, Der Revifion beizuwohnen oder einen Dritten

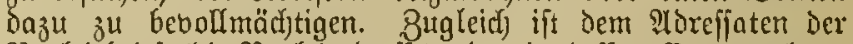
Begleitbrief (dic Begleitadreffe) oder in Deffen Ermangelung

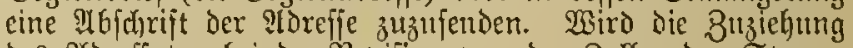

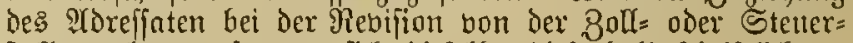
jtelle verlangt, to hat fid biejelbe bieferbalb fdjriftlidf an die Poftftelle zu wenter.

Das Berlangen der Buziehung des P(dxeffaten fann aud) Dann ausgeiprod)en werden, wern Die Beranlaffung hierz" fich) erft bei Der Revifion in (Begentwart bes Poftbeamten ergiebt.

Someit bezïglid ber im $\S 2$ unter $\mathfrak{i r .} 4$ bezeidneten

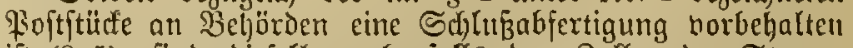
iit (\$ 5), find diefelhen ebenfalls den 3oll= oder Steuer=

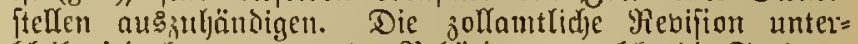
bleibt jedody, wemu bour ier 3 Behörde, an tweldje die Sendung

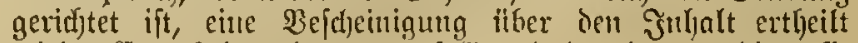
ibird. (5) exfolgt alsoann auf (Siumi dex lekteren bie zoll= 


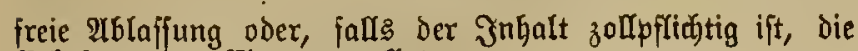
Erhebung Des CEingangs zolles.

$\S 10$. Die Verzollung exfolgt jedesimal nach dem (Ex. gebnis des Revifionsbefundes.

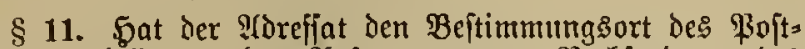
ftiids berlaffen, aber ?luftrag wegen Findfendung bes (B)egenitandes gegeben, oder wiro bon ihm die Beiterfendung beffelken ohue vorkerige Eröffnung und Revifian beantragt,

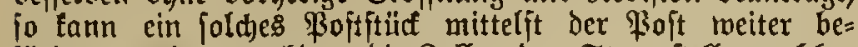
fördert werden, nachdem die Boll= oder Steuerftelle, weld)er

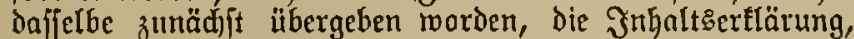
bezm. die Revifiongnote mit einem entfpredjenden Bermert

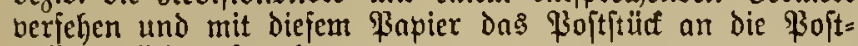
itelle zurïngegeber hat.

Эft der neue Beptimmungsort im Ballgebiet belegen, jo miro bie Senoung nebft Эnhaltserflärung oder Revifions: note der Boll = oder Steuerftelle jenes Drts burd die \$oft jugejiifitr.

Siegt ber neue Bejtinmungsort auf̧erhalb des Boll,

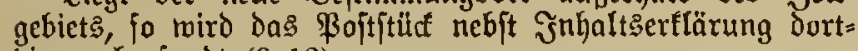
hin radfigejandt (\$ 12).

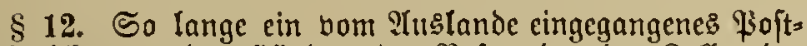

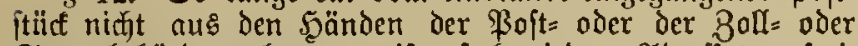
Steuerbehörde gefommen ift, fteht jedem adreffaten frei, defien Ifmahme abzulehren.

Bei Sendungen, welche, meil der श̂defjat die ?tmahme verweigert hat oder nidht $\mathfrak{u}_{\mathrm{u}}$ ermitteln ift, unbejtellbar fino,

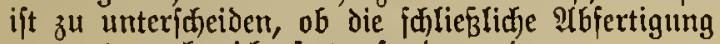

a) nodf nidht jtattgefumben, oder

b) bereits ftattgefunder hat.

Im Jalle zu a ift die Boll= oder Steueritelle, weldfer das Boptftüct übergeben worben, bon ber Boftitefle, unter Borzeigung des mit Dem Bermert über bie Hnbejtellbarteit und Die zu betwirfende Rüfjendung berjehenen Begleit=

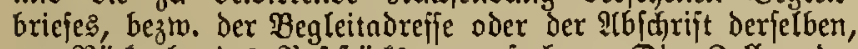

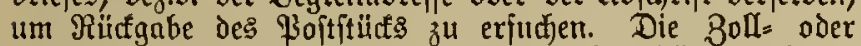
Steuerftelle verfieht hierauf die Jnhaltşerflärung bez̧m. Rebifionsinote mit einem entfprechenden Bermerf und giebt

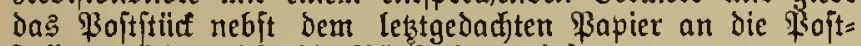
ftelle zurüt, tweldhe die Rülefiendung bejorgt.

Эm ₹alle zu b hat die ßoptitelle bas in freien Berfegr gejezt gemejene ßoftitül Der 3oll= oder Steueritelle, bon welder bie Schlubabjertigung geidjehen war, nebft dem, mit Dem Vermert über die llnbertellbarfeit und bie zu be= mirfende Rürjendung berjebenen Begleitfrieje, bezrn. ber Begleitndreffe oder der abjajrift Derfelben, mieder vorzulegen. Sie empjängt nlędann ben gezallten EFingangszon gegen Rürfgabe Der Ballquittung zurüt, nadjdem dieje von ber

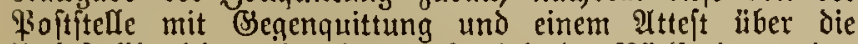
Ilnbeftellbarfeit und die zu bewirfende Rüffendung bes Boptftïcts beriehen worben ijt. Die Boljtelle überzeugt fin

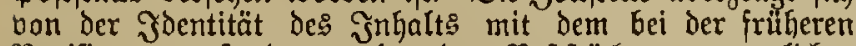
Rebifion vorgefundenen, legt bas Boftftüf unter amtfiffen Serjefluß und giebt dafjelbe, bon einer offenen Inthalts:

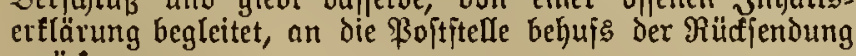
zurüić.

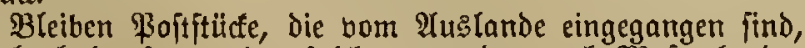
unabgeholt, fo werden folde entroder nady Makgabe der

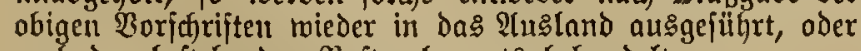
nad) Den beftehenden $\mathfrak{B}$ oftreglements behandelt.

Эิm ₹alle fie innerhalb des 3ollgebicts verbleiben, ift van Denfelben der tarifmäßige (Fingangszoll z"l entrid)ten.

\section{Xurdjutt.}

Abjertigung ber aus bem Bollgebiet mit ben Boften ausgehenden segenfände.

§ 13. Solleu ausgangşzolpflidtige Begenftände de freien $\mathfrak{B}$ erfehrs nus bem 30 dlgebiet mittelft Der Boften nad dem Bollaustande berjendet merben, fo liegt bem ?tbjender ob, vorher bei der Zollbehörbe den $\mathfrak{A}$ tugangsazoll z" ent= richten.

Die bariber erljaltene Duittung muß der Ibiender dem Poftitiofe offen beifiigen. Die Foftbehörde nerfieht diefe Quittung mit einer Bejajeinigung über den Zuftano des Bactets und übergiebt biefelbe der \&usgangszollitelle.

$\S 14$. Wenn unverzollte $\mathfrak{B a a r e n}$ aus einer Ricderlage mitteljt der Bojten in das Bollausland gejandt twerden jollen, jo roiro bem stbjender barüber ein Begleitjofein oder

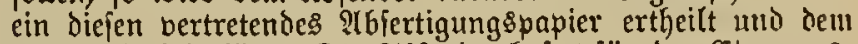
Boftftüfe beigefügt. Der $\mathfrak{X}$ bfender haftet jür den (Fingangs:zoll nad Den geietzliden Borfffriften. Auj Dem Begleitbrieje, bezw. Der Begleitadreffe muß jeitens des \$lbjenders vermerft jein: "nebft Begleitjdjein."

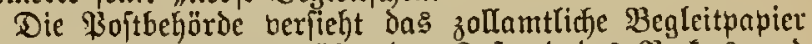
mit einer Befdeinigung iiber den 3 uftand bes Fantets und

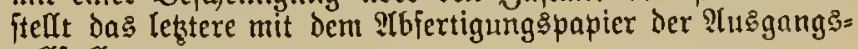
zollitelle zu.

\section{Altrdyitt.}

Abfertigung bon Begenftänden, welde mit ben ßoften durd das Bolfgebiet durdgeführt merden.

§ 15. Den zur Durdfiihrung Durd Dne Zollgebict be:

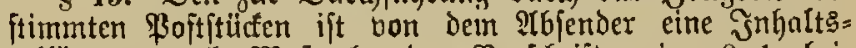
erflärung nad) Daafgabe der Dorjfyrijten im $\& 1$ bei= zulügen.

Die Bofjtüufe merden beim Fingang in bas Bolfgebiet zollamtlid eberio behandelt, wie foldes im $\& 5$ rürffid)tlidf ber im Bollgebiet berbleibenden \$oitjtüffe borgefdrtieben ift. Beim A̛sigang werden Den abfertigenden Bollbeamten

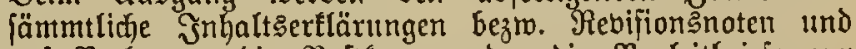
auj Berlangen die \$oftfarten oder die Begleitbricje zur Bergleid)ung mit Den ausgehenden \$oftftücfen vorgelegt.

Der Bollbehörbe bleibt borbehalten, auf foldjen Siurien,

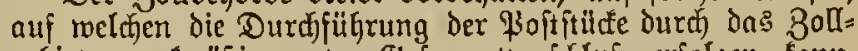

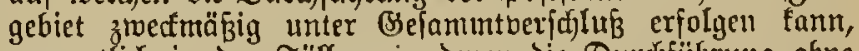

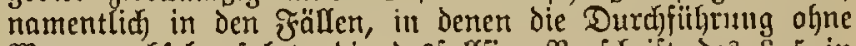
Bagenwerfjel exjolgt, die deşfalligige Borfthrift des \$ 5 in ?Tmendung zu bringen oder aud ftatt bes (Sefammts verfd)luffes antlidje $\mathfrak{B}$ egleitung eintreten jull lafien.

\section{Ahrinmitt.}

Abjertigung bon $\mathfrak{B}_{\text {optiendungen, }}$ welde aus cinem Drte oes 3ollgebicts durd) das 3ollausland nad) einem anderen Drte des Bolls gebiets gehen.

§ 16. Bei (Segenjtänden đes jreien Berfehrs, weldje von zollinländijdjen \$oftamitalten aus Drten des Bullgefiets durd) Das Bollauśtand nad) Drten Des Bollgebiets befördert 
merden follen, bedarf es ber Beifïgung bon sulhalts= crflärungen nid)t. Die jum Durd)gang Durd ong $80 l l=$

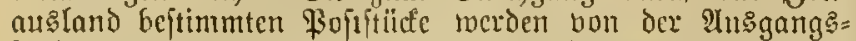

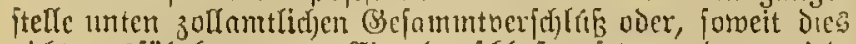

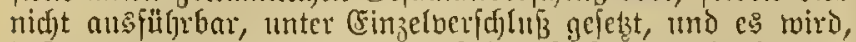

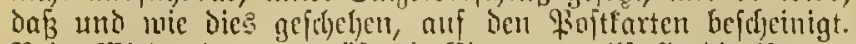
Beim $\mathfrak{B i e d e r e i n g a n g ~ H r i f f t ~ d i c ~ E i n g a n g : ~ z u l l f t e l e ~ b i c ~ l l n v e r = ~}$

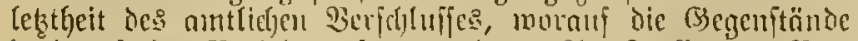

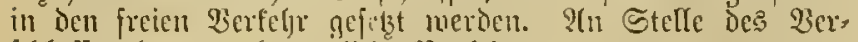

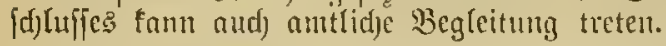

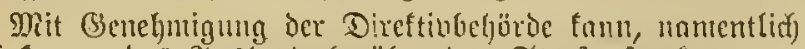

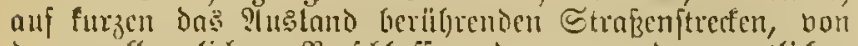

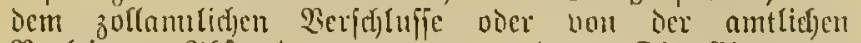
Begleitung Stbftano genomuen weroen. Die Eingangż

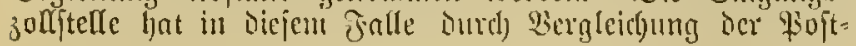

fitücfe mit den \$ojtfarten oder den Begleitbriejen von ber

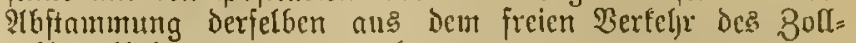
gebict: lleberzeugung, z"l nehmen.

\section{V. alurduttt.}

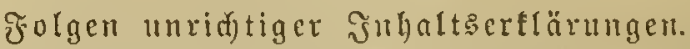

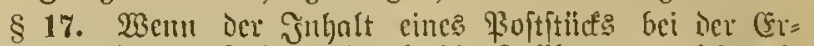
offinung uni linterfuefung Durdf bic Bollbeanten nid)t nit

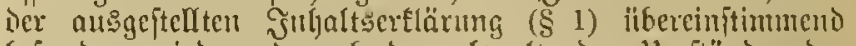
befunden wiro und nad) den obnaltenden llmitänden ber Berbad)t ciner benbfidfigten Defraubation begrindet cr: (d) cint, jo mirb nady den megen unriditiger Deflaration iu

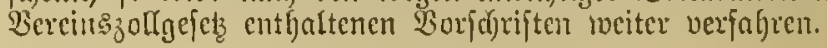

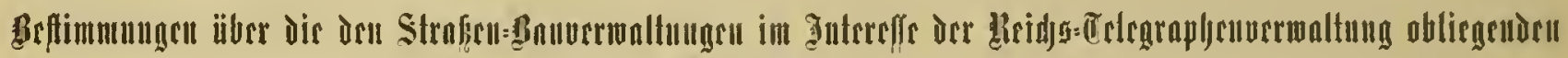 界rrpflintumgen.}

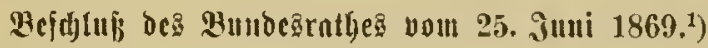

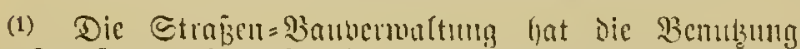

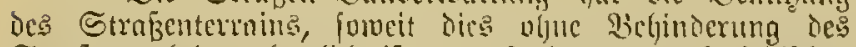

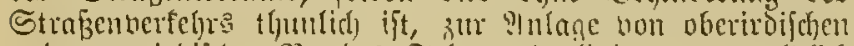

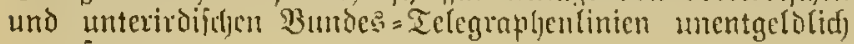
jul geitatten.

Die Stangen fiir Die oberitbijden Ielegraplyenlinien merden tlyunliefft entfernt bon ben Banmanfilanzแngen aufgeftellt.

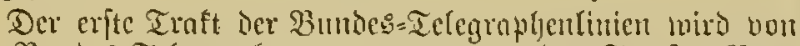

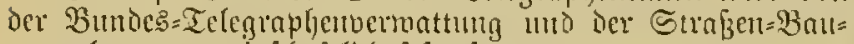
bermaltung gemeinfel)aftiel] jeftgejetst.

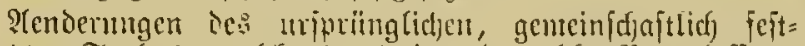
gejezcten Traftes, weldje durd) ingeno tocldje 2 cranlaffung

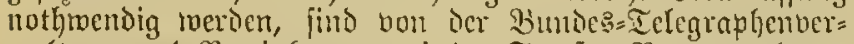

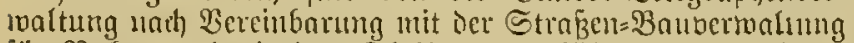

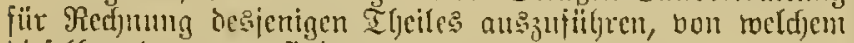
diejelben beantragt fimb.

(2) Dic Gtrafien= 3aubertonltung ljat die Bunbes= Tele=

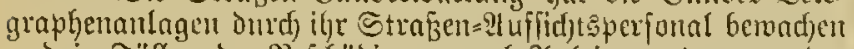

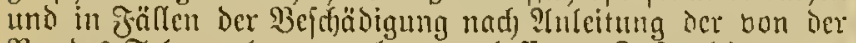
Bundes= Ielegrapljenberwaltung erInjpenen Sintrution pro= biforifd) wieder lyeritellen, nudf bon jeber twaljgenommenen

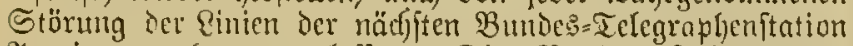
2tnjeige madjen zu laffen. Die Bumbes = Telegrapljen= bermalumg zaljt Den mit ber Beanffichtigung und provifos rifden Wienerberitellung der $23 u n b e s=$ Iclegraplenlinien beauitragten Straben=?(uffid)t

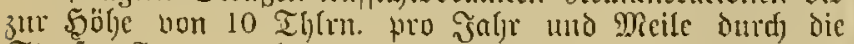
Strajen= Baubermaltung. Dic 9icmunctationen werben bou ber Bunies= Selegrapljentuermaltung imerhalb ber borbe= jeidjneten Grenze fïi Dic cinzeluen ?uffidjtsbcamten nad Maßjgabe ber bon denfelbcu im Sntereffe bes Bmbes= Ielegraploen geleifteten Dienjte fejtgejetst.

(3) Die Strabcu= Baubermaltung lyat ocn mit ber $3 \mathrm{c}=$ feitigung vou Befdäbigungen Des B̈mbes = Telegrapljen beauftringten mo alg joldfe legitiminten Telegraphen= beanten anf Erjordern und forveit dies thunlich ift, die bei

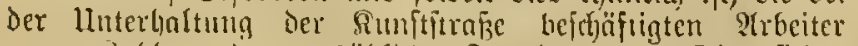

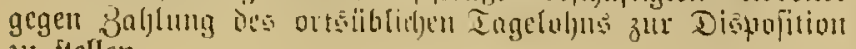
ou fleller.
(4) $11 \mathrm{~m}$ Störungen ber Bumbes= Telcgraphentinien butel) Berïhrungen der Qcitunggorähte mit Den Straßen= \$In= pflanjungen zu vermeiden, hat bie Straf3en=Bambertoaltung

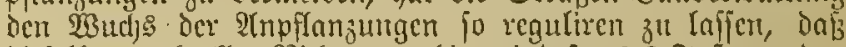

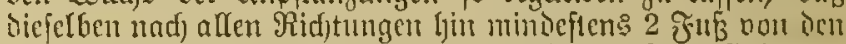
Ecitungsobrähten des Buntes=: Telcgraphen entfernt find.

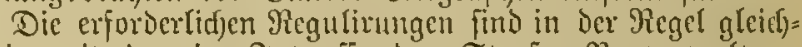
zeitig mit den in Jnterefic oer Strafen $=$ Banvermaltutg

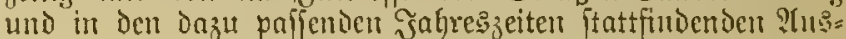

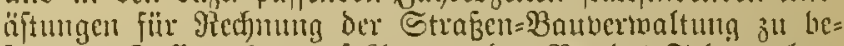
forgen. Fath aber auf ?tntrag Der 23 umbes=Telegraphen=

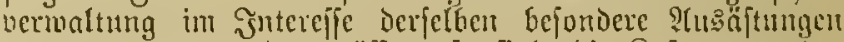
vorgenonmen werten muiffen, fo fund die Roften non ber B̈undes= Telegraphenbertualtung 3 tragen.

(5) Falls bei ber Wnlage mno ltuterljaltung der Bundes=

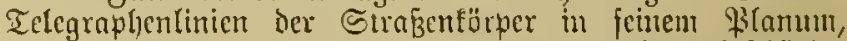
jeinen $\mathfrak{B}$ öjdungen voer zugefjörigen Bräben bejdäbigt mirb, erfolgt die Wicoerlyeriteffurg rad) Thuneifung ber

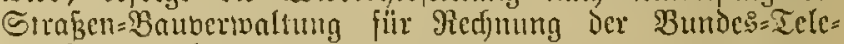
graphentuermaltung.

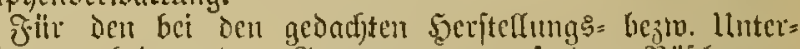

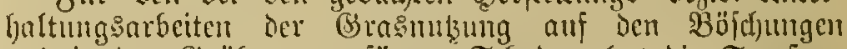

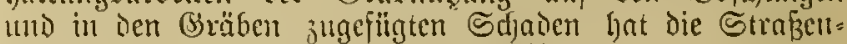
3aubcrwaltung Snfprud) auf (Entjhäbigung nicht ju $\mathrm{er}=$ ljeber.

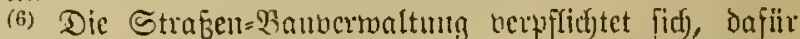

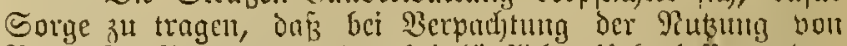
Baum=?tupilanjungen ober bei fäuflid)er lleberlaffumg ber= jelten die betheiligten Berfonen nor Bejujäbigungen Der Bundeg= Telegrapljenaulagen mit dem Benterfen gematnt

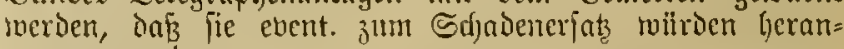
gezonen werden.

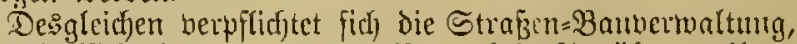

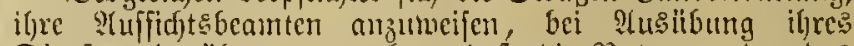

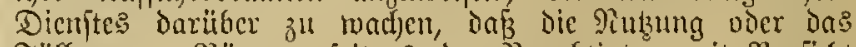

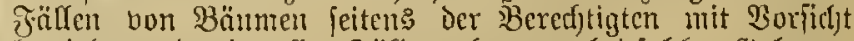

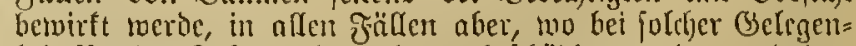

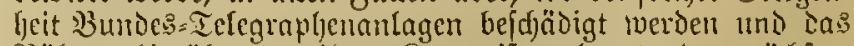

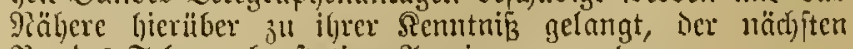
Bumbes= Telegraphenitntion ?luzeige zu madjen.

1) Die unter 1 bis 6 entlbaltenen 3 erpflidhtungen find nath bem 8 c

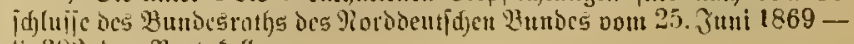
$\$ 302$ der Brotofolle - 


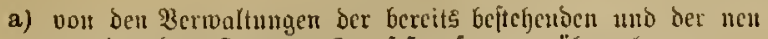

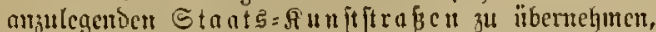

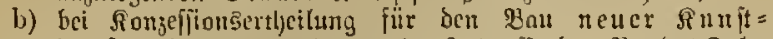
ftraben beu Internchmern int Sntereffe ber Bundes=Tcle= graphonverwaltuttg aนfänerlegen, แแb

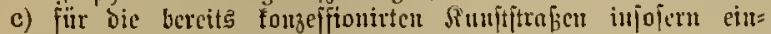

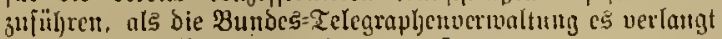
und dic Ronzcfítions=llrtunden es geftatten.

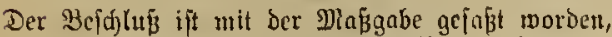

1. Daf bic fragliden Boridriften auf Straben inuerlyals ber Stäote fid nidt begiehen follen,

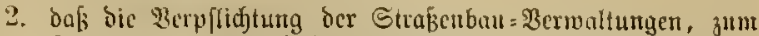
Bued ber Llicberberitellung bejdjäbiater Telegraphenleifunacn

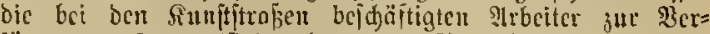
fïgung sut ftellen (Fiche oben unter 3), auf wirflidhe ?lotb): fälle beld)rätlit blcibt, uno

3. bn $\tilde{B}$ bie Beftimunnugen unter 1 bis 6 injoicrn eine mur

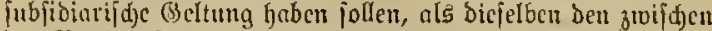
Der Bambes=Telegraphenverronltung uno einzeluen Burnoes: ftanten beftehenden Berträgen über den Begenftand biejer Bejtinturungen nid)t cutgegenftchen.

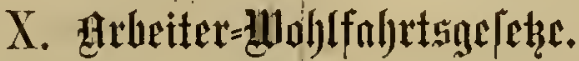

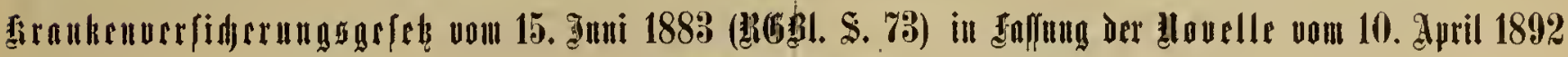 (द⿱⺈⿻コ一心}

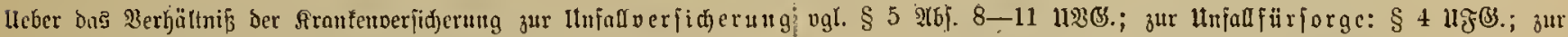

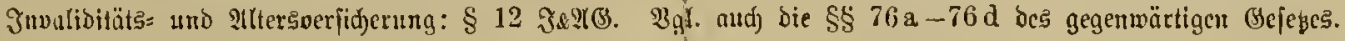

Die nad)folgenocn \$(rbeiterverfïderungsgejege pflegt man unter bem

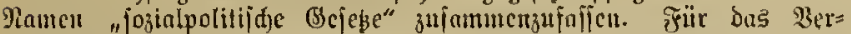

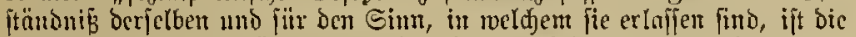

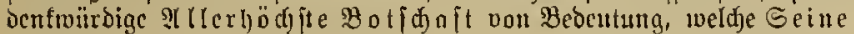
Mi aje tät ßaifer 13 ilgelm I. am 17. Sovember 1881 ducd

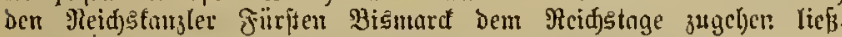
(Es beifit barin:

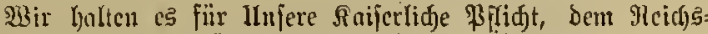

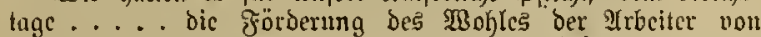

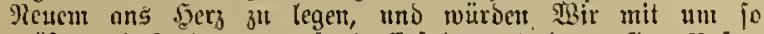
aröberer Sefricoigung auf alle Erfolge, mit benen (Gott linferc gegierung fidtlid) ge(egnet hat, zuriübliden, soenn cs lins

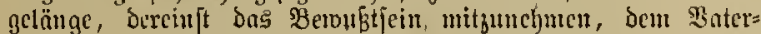

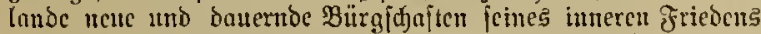
unb Den sülfşbedïrftigen gröpere Sidjerheit uns Ergicbigtcit

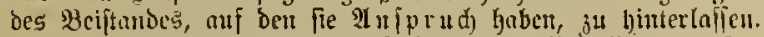

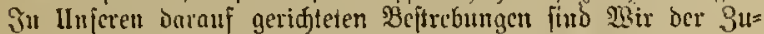
ftimumug alter verbumbeten Regicrungen gervib umb. vertrauen auf bie Interftibung bes Reidstags obue llnterfojico ber

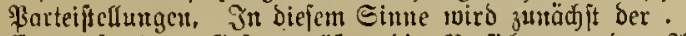
Entrurf eines Sejebes über bie \$scridjerung ber Irbeiter gegen $\mathfrak{B}$ ctriebsunfälle..... vorbereitet. Ergänzend

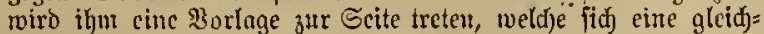
mäpige Drgarijation Des gewerblidjen franfenfafientwejen

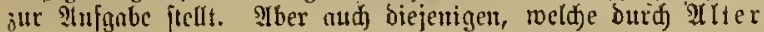
oder invalibität crwerbsumfäbig werben, haben ber be= fammtheit gegenüber eitch begründeten Injpruch auf ein-höhereśs

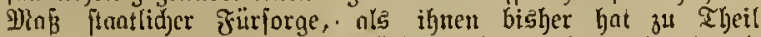
merden föntrn. Für bieje Fürforge bie redten Mittel und शुege zu finden, ift eine.jojwicrige, aber aud eine ber hödjten ?tufgubert jedes Bentintwejens, weldyes auf ben fittliden

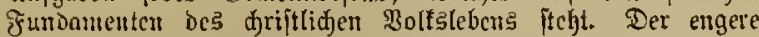

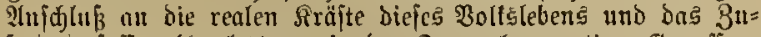
famutenjoffen ber legteren in ber frorm forporativer Genofien= idaficu unter ftantlidjem Sdus und ftnatlidarer föroerung werden, ivic Wir hoffen, bie Röfurg aud) von. Ilufyaben möglidi) madgen, benen bie Staatsgeroalt allein in gleidjem llmfange nidjt gewadjen jein rö̈rbe.....

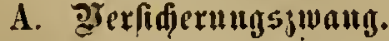

§ 1. (1) \$erfonen, welife gegen Geljalt oder Boljn be= idjäjright fint:

1. in Bergnerfen, હalinen, slufbereitungsanftalten,

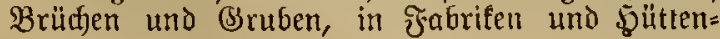

inerten, beim (5ifenbalyn=, Binnenfeliffalyrt: $=$ uno Baggercibetriebe, 1 ) anj $\mathfrak{B e r f t e n}$ unt bei Bauten,")

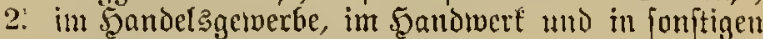
fleljenten Sierwerbebctrieben;

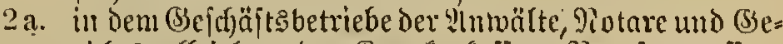
ridjtaboll jieber, Der Rranfenfafien, Berufsgenoffen= ichafien uno Serficherungsonftalten,

3. in Betrieben, in Denen Dampifeffel Dier Durd) elementare Siraft (Wind, waffer, Dampi, Bas, l)cib̧e \&ujt 2c.) betwegte Irtiebuerfe zur Berwendung

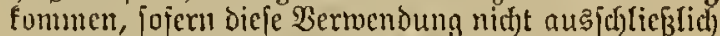

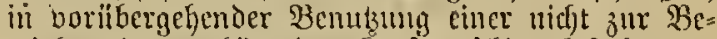
triebsanlage geförenden siraftmajujue bejteht,

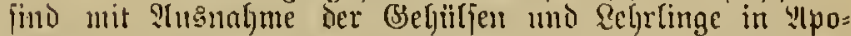
thefen, forvic ber im \& 2 unter Biffer 2-6 aufgejïlyrlen

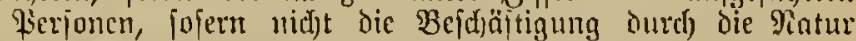

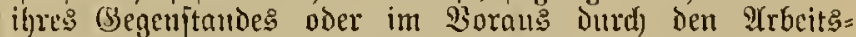
vertrag anf cinen Beitraum bon wentger als 1 Wodbe be= (d)ränft ift, nad) Maß̧gabe der Borjdjriften diejes (Befezes gegen Sirnuffeit zu berjidjern.

(2) Daffelfe gitt von Berjonen, weld)e in dem gefammten

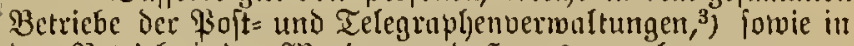
Den Betrieben der Marine= มno Sectrberwattungen gegen

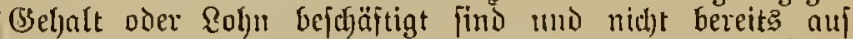
(S)rund ber borjteljenden Bejtimmungen der Sranfenberficfe= sung $\mathfrak{s p f ( i d ) t ~ u n t e r l i e g e n . ~}$

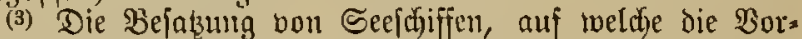
fidriften der \$s 48 mnd 49 ber Seemanmsoromung bom

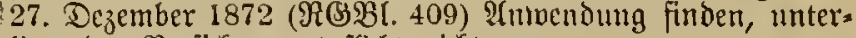
liegt der Berficherung spffict)t nicf)t.

(4) Şandlungsgeljüljen und = Qefrringe unterliegen ber Verfidjerung:pflickt nur, fojern ourch Sertrag die ifjnen

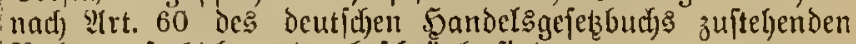
Redite nujgetjoben oder bejchräntét find.

(5) Itrs Gehalt ooer Sohn im Sinne "biefes Bejebes gelten aud Tantiemen und $\Re$ aturalbejilge. Für die letzteren

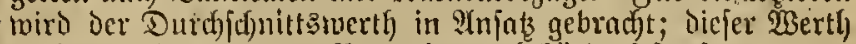
mird bon der unteren Verwaltungsbeföroce feftgejekst.

2) Der Begriff Des Betriebes ift hier ber algemeine bes $1 \mathfrak{B}$ s.

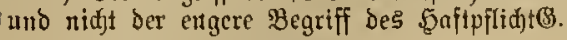

2) $3 \mathrm{gl}$ § 69 nebit $\mathfrak{A}$ m. 


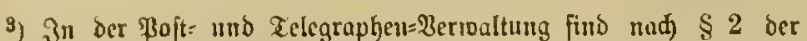

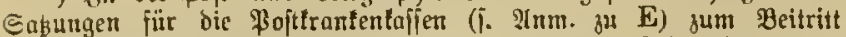
nerpflidict alle in ber Bermaltung gegen Sscholt ober 2ohn

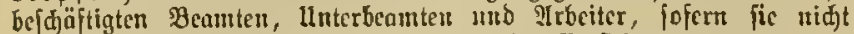
zum Eintritt nur beredtigt, ober Don ber Berjiderung ganz aus= geidhlofien fint.

A $u$ Sgefd loffen find alfe Perjonen, beren jührlidjes (Fintommen 2000 D)R. ïberjtcigt.

Bum Gintritt beredtigt, aber nid)t verpflidtet find (nornusgejebt, oas ihr jährlidjes (cintommen 2000 Mit. nid)t überiteigt):

a) bieienigen Perjonen, beren Bejdäftigung auj einen 3eit= raum Dou veniger als einer Wodje belfrönlt ift;

b) alle Perjanen, Denen in Rrantheitşälfen die Dientberüge mindeftens fïr 13 Woden fortgewährt toerden;

c) Die Popttllane ber reidjseigenen Pofthaltereien.

(5) find fonad zum Beitritt oerpflid)tet:

a) $20 \pi$ im geamtenderhältnib ftehenden Perjonen biejenigen, denen bei Erfrantungşällen Bejüge niđt ge= röbst werben, uno juat:

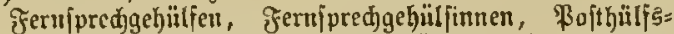
beamte, \$ojtgebüljen anf Bergütung, Telegraphen=

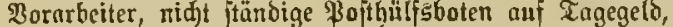
ßofthülishoten ouf \$ergütung, \$ajthülfs5oten ouf Tage gelo und Vergütung, bei meldhen ber Hmiang ber Bejdäftigung auj Tagegelo bas Dlindejtmaई für die

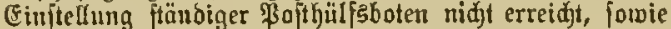

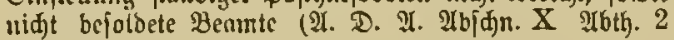
\& $147 \mathrm{e})$;

b) Dounid t im genutenoerbältnif ftehenden \$er= forten:

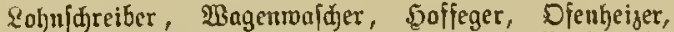
Eampenreiniger, unmittelbar aus der ßaptlafie bezahlte außergemöhnlide Bgegleiter von Fopten oder Lanopoft= fahrten und Beiboten, zur গuझhjilfe herangezogene juacndlidge Perjonen (Sd)reibhülfen uno Detlebejungen). Zelcgraphenarbeiter, porvie Bauarbetter, roelden oer Eohn unmittelbar aus ber \$ajitnffe gezablt wiro, un= mittelbar aus ber ßaftlafie bezablte Edjeuerfrauen, 5anbwerfer ber reidjseigenen \$ojthattereien.

\$ 2. (1) Durdf italufarifd)e Beftimmung einer Bemeinde für ihten Bejirf, oder eines meiteren Sommunalverbande:

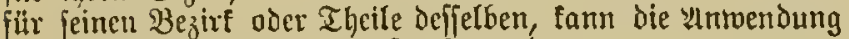
ber Borifjuriften Des \& 1 erftrect twerden:

1. allf biejenigen im \& I bejeichneten ßerjonen, deren Befdjäftigung Durd) die Siatur ifres (Segenftandes oder in Boraus Durd) Den 2(rbeitseertrag auf cinen Beitraum bon weniger als 1 Wodje bes (id)ränft ift,

2-6’ hetreffen Rommunulbetriebe, Familtenangehörige von Be. Iriefsunterneljmern, felbittändige Berverbetreibende, 5ond:

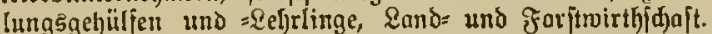

(2) Die auf (srund diejer Borfdrift ergegenden ftatutarifhen Beftimmungen mitfien die genaue Bezeidfnung derjenigen

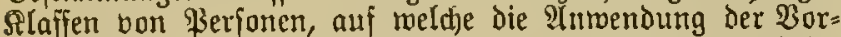
id)riften des \& 1 eritrect merden foll, und in ben föallen Der: Biffern 1 und 4 Beftimmungen üGer die Berpflidstung 3ur ใี Finzahlung Der Beiträge enthalten.

(9) Sie bedürfen ber Benehmigung der göheren $\mathfrak{B e r}=$ toaltumgsbelöbde und find in Der für Betanntmad)ungen der Gemeindebehörden vorgejuhriebenen oder ïblichen Form zu beröffentlichen.

\$ 2a. Die 2Inwendung Der Borfduriften des § 1 fanu audi) auf (olde in Betrieben oder im Dienite des Reidjs oder cines Staates bejdjäftigte \$erjonen exftredt merden, weldfe ber Siranfenberficherungspflidjt nidjt bereits nad) $g^{e}=$ feslicien Beftimmungen unterliegen. Die Erfitectung erfolgl Durch Berfilgung Des Reidjsfanzlers beziv. Der Zentralbehörde. \$2b. (1) Betriebabbamte, Werfmeijter und Ted)nifer, Sandfungsehülfen und = Sehrlinge, forvie die unter $\$ 1$

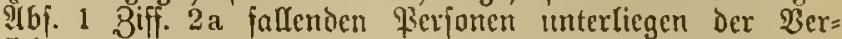

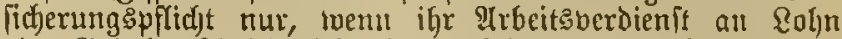
oder Behalt $62 / 3$ Marl für den Ulrbeitstag oder, jojern \&ohn oder Sehalt nach größeren Beitabjunitten bemefien ift, 2000 Diarf für Das Jahr geredjut, nicht überiteigt.

(2) Daffelbe gilt bon anderen unter \& 2 शtb. 1 Biff. 2 und $\$ 2$ a falfenden Berjonen, fotweit fie Beamte find. ${ }^{1}$ )

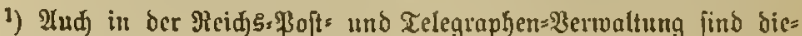
jenigen Perfonen, beren Eintommen 2000 MR:. Überfteigt, oon ber

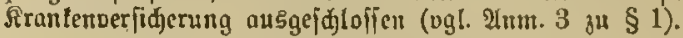

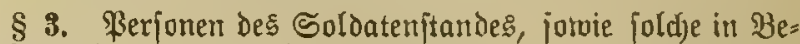
trieben ader im Dienite des Reidfs, eines Staate: oder

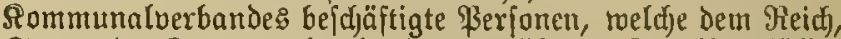
Stat oder \$ommunalberbande gegenüber in Stantheit:äallen Anpruch auf Fortzahlung des (Sehalts oder Des Eoljnes mindeftens für 13 23odjen uad) der (Ertranfung oder auf

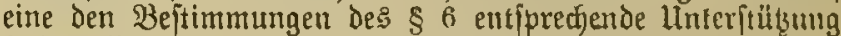
Gaben, find bon ber $\mathfrak{B}$ erfickerumgspflicht ausigenommten.

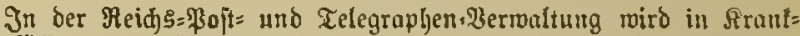
heitsfällen etatsmäßig argepleften $\mathfrak{B}$ camten und $\mathfrak{U n t e r b}$ cainten, aud Poftagenten, Ielegraphemberwaltern im Rebenant und llm[pann= aufiehern unter Hebernahme ber Bertretungatoften auf bie \$ofttufie,

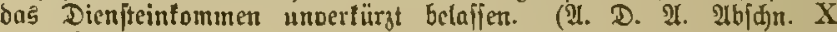
216th. 2 \$147 a).

Bis zu 13 פoden bleiben im unverfürzten Benuffe des Dienfit= einlommens:

1. Die unmittelbar aus ber \$oftlaffe bejoldeten nidit etatร=

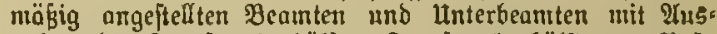

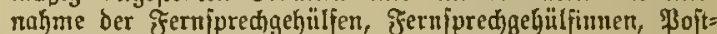
Guilisbeamten, nidgt fitänoigen \$ojthülfsboten, Telegraphent= vorarbeiter und \$oftillone reidiseigener \$oflhaltereien;

2. Diejenigen nidbt ftäubigen ßoithülişoten nuj Tagegelo,

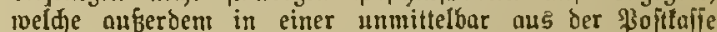

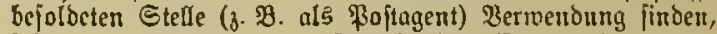
fojern fie burd ihre poitbienftliden Obliegengeiten in

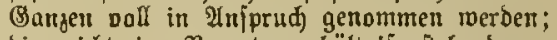

3. bie nidut in Beamtenverhältni $\beta$ Ptehenden, aushülfşweife und auf bejdräntte ober unbejtimmte Beit bei Den Poft= bauten ober in ben Bureaus ber Ober=Boitbireltion bee [djäftigten Baumeiffer, $\mathfrak{B a s}$ [ïl)rer, fonftigen $\mathfrak{I}$ rdjiteften, Banauffeher und Banzeidner, Fofern fie unmittelbar auร ber \$opittalie bezajlt fino.

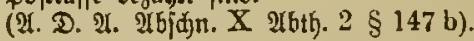

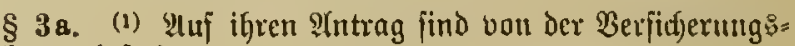
pflidift zu befreien:

1. \$erfonen, weldje in folge bon ஒerlełuntgen, (Sse= bredjen, chronifden Srantheiten oder alter nur theilmeife oder nur zeitweife erwerbsfähig find, wenn Der unterftüzungępflichtige Qtrmenterband der Befreiung zuftimmt,

2. \$erionen, weldjen gegen ihren ?trbeitgeber für Den

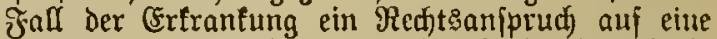
den Befimmungen des $\$ 6$ entfprectende oder gleict)= merthige llnterftüţung zujteht, fofern Die feiftung:

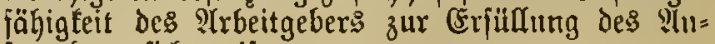
(prudf) se geficifert ift.

(2) Wird Der Antrag auf Befreiung bon Der Bertvaltung Der Bsemeinde=Sranfenverfidjerung oder von dem $\mathfrak{B}$ orjtande Der Sranfentaffe, reickjer der Intragjteller angegären wittrde, abgelehnt, fo enticheidet auf "surufen des Intragitellers die 2tuffichtsbeförde endgulttig.

(9) (t) ..... 


\section{B. (Gemeinde- Sirankenverfifferung. ${ }^{1}$ )}

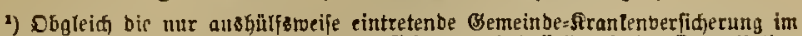
Seleb zuerft behandelt yoirb, liegt bod ber Gdiwerpunft befferben in ber Oryantiation

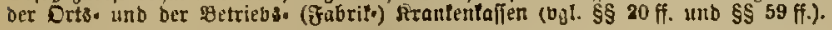

§ 4. (1) Fïr alle berjidjerungsppflid)tigen \$erjonen, weldbe nidjt einer Sotsfranfenfaffe (§ 16),

einer $\mathfrak{B e t r i e b s = ~ ( \Im a b r i f * ) ~ S t r a n f e n f a j i e ~ ( § ~ 5 9 ) , ~}$

einer Bau=§ranfenfajie ( $\$ 69)$,

ciner Э̌ınungs:= Strantenfaffe (§ 73),

ciner Snappfajaftsfaffe (\$ 74)

angeyören, tritt, borbegaltlich ber Beftimmung Des $\S 75$, Die Semeinde= Rranfenberficheruug eir.

(2) \$erfonen Der in $\S \S 1-3$ bezeichneten 2 rtt, meld)e Der Berfidjerungspflicht nicht unterliegen und beren jührlidjes (Sefammteinfommen 2000 Darf nidjt ïberfteigt, fotwie Dienfthoten find beredfigt, Der (semeinde=siranfenberfidjerung ber Bemeinbe, in Deren Bezirf fie befacaftigt find, bei= zutreten. ......

(3) (4) ....

§ 5. Denjenigen ßexjonen, für roldje die Bemeinde= Siranfenberficferung eintritt, ift bon Der (Semeinde, in beren Bezirf jie bejdjäitigt fino, im Falle einer Sirnmfheit oder Durch) Srantbeit herbeigejührten (Ermerbsunjähigfeit Rranfen= unterftüłzung zu gewähren.

Bon Denfelben hat bie (Semteinde Sranfenverfid)erangs: beiträge $(\S 9)$ zu crlgeben.

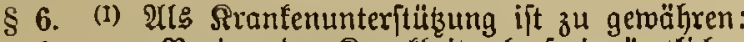

1. vom Beginn Der Pranffeit ab freie ärztliche $\mathfrak{B e}$, Ganolung, $\mathfrak{A} r z n e i$, fowie Brillen, Brubjbander und ühnlicje \$eilmittel;

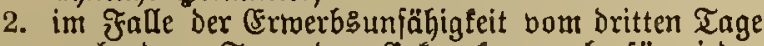
nach Dem Tage Der Erfranfung ab für jeden Urbeitstag ein Sranfengeld in Söhe Der Salfte des ortsibblicfen Tagelohnes geröbnlicher זage= arbeiter. ${ }^{1}$ )

(2) Die Rranfenunterftüßzung envet ipäteitens mit dem Mblauf Der 13. Wodje nad) Beginn Der Srantheit, im falle ber Ermerbsunfäbigfeit fpäteftens mit bem arblauf ber 13. Wodje nach Beginn bes Seranfengelobezuges. (Endet ber Bezug des Srantengeldes erit nach Mblauf Der 13 . Worfee nad) Dem Beginn Der Rranfbeit, fo endet mit Dem Bezuge Des Sranfengeldes zugleich autif ber Unfprud auf bie im IGG 1 unter Biffer 1 bezeidfueten Reijtungen.

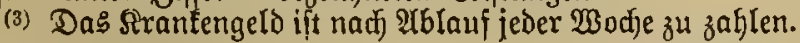
Bgl. $\S \S 20,64,72,75$.

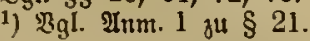

\$ 6a. (1) Die Bremeinden find ermächtigt zu befdjlięen:

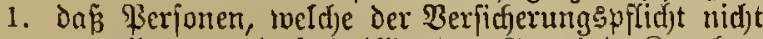
unterliegen und freimillig Der Bemeinde=Sranfen= verfidjerung beitreten, erit nad, গTblauf eimer auf

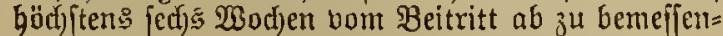
Den Frift Sranfenunterftïßzung exhalten;

2. Daf Berficferten, weld)e Dic (Semeinde $=$ Sranfen= berficherung burd) eine mit Dem Berluft ber bürger= licfen (Efrenred)te beorolyte ftraffare Sandlung gejdjäbigt lyaben, fiir dic Dauer bon zmölf Monaten jeit Begehung ber Straftljat, forwie baß3 Berfidjerten, meldye fidf eine Srantfeit vorjätzlid oder Durd)

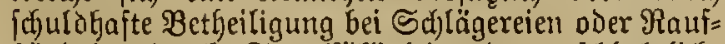
händein, ourd) Trune[äldigfeit oder gejd)led)tfict)e 2usfinweifungen zugezogen haben, für biefe Arant= heit Das Sranfengeld garnicht ober nux theilmeife zli getwähren ift;
3. Daß3 Verfifferten, meldfe bon Der Bemeinde die Sranfenunterftitkung munterbrochen ober im Raufe cines Beitraumes von zivölf Motnaten für Dreizeht Wocfert bezagen haben, bei Sintritt eines metlen llnter[tï̈zungsfalles, jofern biefor Duruf bie gleidfe, nidgt gehobene Sinnlfheitsuriat)e beranlafst ift, in Qaufe ber närditen zmölf sl?onate Srantenunter= ftïtsung nur fïr bie Befanmtoauer von breizelpn Wodhen zu gewährent ît;

4. Dafi Siranfengeld alfgentein oder unter beftimmten 23oransfetzungen fdjon bom Tage des Cintritts Der

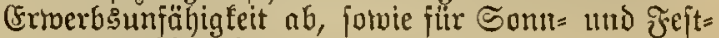
tage zu zaflen ift;

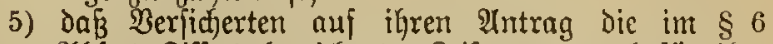
श(b) 1 Biff. 1 bezeidjneten Reiftungen aud für ihre Dem Seranfenberfidjerungs żmange nidft unter= liegenden Familienangehörigen zu genälten find;

6. Daß bie ärztliche Behandlung, die Rieferung Det Irgnei uno bie Sur und Berpflegung nur durct) beftimmte 2(erzte, Ifpothefen nino Rrantenhäufer zu

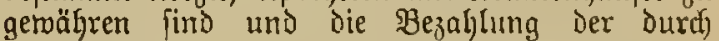
Jnanfprudfnahme anderer :Terste, ?ipothefen und Rrantenfyäufer entitandenen Sioften, bon dringenden Jälfen abgefchen, abgelef)nt werden fann.

(2) Die Bremeinden find fermer ermähtigt, Borichriften

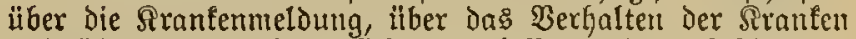
und über die Stranfellauffigt zu erlaffen und zu beftimmen,

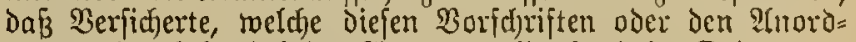
nungen des Gehandelnden $\mathfrak{A r}_{\mathrm{r}} \mathrm{tes}$ jurviderfandeln, Dronung ftrafen biş zu ztwanzig Marf zu erlegen haben.

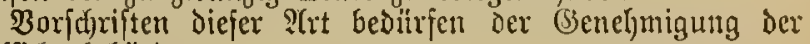
Iuffijd)tsheljörde.

$\S 7$. (1) Un Stelle der im $\S 6$ vorgejdriebenen Reiftungen fann freie Sur und Berpflegung in einem Sranfenbaulfe ge= mährt roerden, und zwar:

1. für Diejenigen, reldhe berfeirathet find oder eine eigene Souslyaltumg Gaben, ober Mitglieber der 5ausgaltung ifrer Familie find, mit ihrer $8^{4}=$ fimmung, oder umab̧ängig von Derjelben, went Die 2 rt ber Stranffeit $\mathfrak{A} n$ forderungen an bic $\mathfrak{B} c=$ handlung oder Berpflegung ftellt, weld)en in ber Framilie bes Erfranften niajt genügt trerden fam, oder twenn bie Stranflyeit eine anftecfende $i$ t, oder wenn der Erffrantte roicderholt dent auf Brutid des

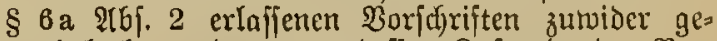
handelt hat, oder wem dejien Bujtand oder Ber= balten eine fortgefebte Beofaditung exfordert;

2. für fonjtige Crtranfte unbebingt.

(2) Sat Der in einem Sranfenljaufe Untergebradjte 21n= gehörige, Deren Unterhalt er bisher aus jeinem 21rbeits= berbientt Geftritten hat, fo ift nefen der freien S?ur und Berpflegung bie S̆älfte des im $\& 6$ als Rranfengelo feit. gejeuster $\mathfrak{B}$ etrages frï Diefe Antgehöriget ju zahlen. Die 3ahlung fann unmittelbar an bie शingehörigen erjolgen.

Bgl. $\S \S 20,64,72,75$.

§ 8. (1) Der Betrag Des ortsiltffidjen Tagelohnes ge=

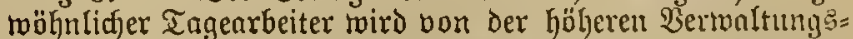
behörde ${ }^{1}$ ) nad) S(nhörung der (Semeindebehärde feitgejekt und burd, bas für ifre amtlidjen Befanntmad)ungen be= ftimmte Blatt veröffentlidjt. Tenoerungen ber ₹refticbung treten erft 6 Monate nact) Der Verbffentliffung in Rraft.

(2) ......

1) ঠ. i. Megierungşpräfibent. 
\$ 9. (1) Die bon den Bemeinden zu exhebenden Ber= ficjerunggbeiträge follen, folange nidjt nach Maşgabe des $\$ 10$ etroas anteres feftgejekt ift, einundeintalb \$rozent des ortsüblicten Tagelohnes (§ 8) nidft überfteigen und find mangels befonderer Befidlußnahme in diefer Söbe zu ex=

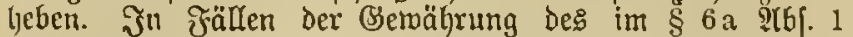
3iff. 5 bezeidfneten befonderen Reiftungen find bejondere von Der Semeinde = Sranfenberficjerung alfgemein jeftzujez̧ende Bujaz̧beitröge zu erbetien.

(2) Die Beiträge flię̧en in eine befondere Sinffe, aus reldjer aud) bie Sranfenunterjtüksungen 34 bejtreiten find.

(3) (4)

\section{Q)rts - drankenkafen.}

§16. (1) Die Semeinden find beredftigt, für die in ihrem $\mathfrak{B}$ ezirt befdüftigten berjidjerungapplidjtigen \$erjonen Srtis=Strantenfajien zu erridten, fofern die Bahl der in der seaffe zu berfidjernden Perfonen mindejtens 100 beträgt.

(2) .......

(3) Die Drts=Яranfenfaffen folfen in der Regel für die in einem Gemerbszmeige oder in einer Betriebsart be= jajäjtigten \$erjonen erridjtet merden.

(4) (5) ......

$\S 20 *$ ) (1) Die Drts. đrantenfajien follen mindejtens geroähren:

1. im falle einer Pranfheit oder Durd) Sranfheit Gerbeigeführten Crrmerbsunfähigfeit eime Sranfen= unterftüzzung, weldye nad) $\S \S 6,7,8$ mit der $\mathfrak{M l a \beta}=$

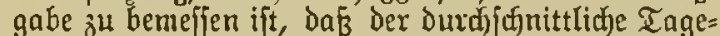
logn Derjenigen \&lafjen der Berjidjerten, für meldje die Raffe erridjtet mird, jomeit er 3 Paarf für den Mrbeitstag nicht überjafreitet, an bie Stelle bes ortsüblidjen Iagelohnes gerwöhnlidjer Tagearbeiter tritt;

2. eine Unteritütung in \$öhe des Sranfengeldes an Wöd)nerinnen, tweldje innerhalb bes leżten Jahres, bom Tage ber Entbindung ab gerednet, mindejtens 6 Pionate hindurdi einer auf (Srund biejes Be= jekes errichteten Rajfe oder einer Bemeinde= Rranfen= verfitherung angeljört haben, auf bie Dauer von mindeftens 4 Bodien nadi ihrer Riederfunit, und forweit ihre Bejdjäftigung nadj den Bejtimmungen Der (B)emerbeoronung für eine längere Beit unter= fagt ijt, für diefe Zeit;

3. für Den Todesfall eines Mitgliebes ein Sterbegeld im zwanzigfadien Betrage des Durchjidnittlidjen Iagelohnes (3iffer 1).

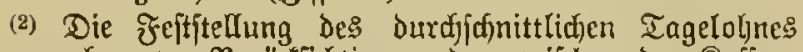
taun audf unter Berïffictitigung ber zwifhen Den ßaffen= mitgliedern hinfidtlid der Sohnhöhe beftefenden $\mathfrak{B e r j a j i e d e n = ~}$ lyeiten flaffenteife exjolgen. Der burdjidjnittliche Tagelolgn

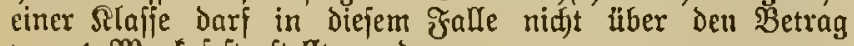
von 4 MRark feitgeftellt werden.

(3) Berftirbt ein als MRitglied ber Safje Grtrantter nach Beendigung Der Rranfenunteritiłtzung, jo ift das Sterbegelo ju gewäbren, renn die Frmerbsulähigfeit bis zum Tode jortgedauert lyat, und Der Tod in Folge Derjelten Srantheit vor \$Iblauf cines Jahres nad) Beendigung ber \$ranfenunter: jtüßzung eingetreten ift.

(4) Das Sterbegeld ift zunädjft zur Decfung Der Sioften Des $\mathfrak{B}$ egräbniffes beftimmt und in bem aufgewendeten $\mathfrak{B e}=$

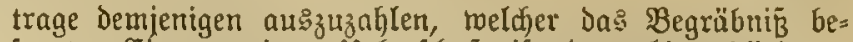

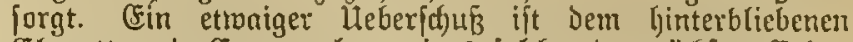
(Ehegatten, in Frmangelung eines joldjen den täuh)ten (Frben

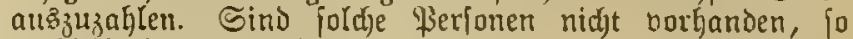
berbleift der Ueberiftur ber Siaffe.

$\S 21 . *$ (1) Fine Frböhung und Erweiterung der Reiftungen der Drt3s=Srantentaffen ift in folgendem llmfange zulöffig:

1. Die Dauer Der Rranfenunterftüzung fann auj einen längeren Beitraum aโs 13 TOod)en bi: zu einem Эahre feftgejełst merden. ${ }^{1}$ )

1 a. Das Strantengeld fann allgemein oder unter bes ftimmten Borausfetsungen idjon vom Tage des Fintritts der Erwerbsunfähigfeit $a b$, fowie für Sonn = und Fejttage gemährt merben, fofern bieję fomohl bon der $\mathfrak{B}$ ertretung der zL Beitühgen ver= pflid)teten ?(rbeitgeber (\$ 38) al: aud) vout ber= jenigen Der Berfidjerten bej fhloffen roird, oder foferu

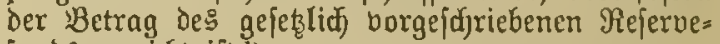
fondes erreidjt ift. ${ }^{1}$ )

2. Das Stanfengeld fnnn auj einen höheren Betrag, und $z^{\text {mar bis }} z^{3} 3 / 4$ des Durdffonittlidjen Tage= Lohnes (\$ 20) feitgefezzt merden; neben freier ärztlidjer Behandlung und $\mathfrak{i}$ rznei tönnen aud andere aโร die im $\$ 6$ bezeidjneten §eilmittel getwährt werben. ${ }^{\text {) }}$

3. Neben freier §ur und Berpflegung in einem Arantentaule fam Rranfengeld bis zu $1 / 8$ bes Durdjidjnittlidjen Tagelohnes ( $\$ 20$ ) aud joldjen berwidigt rerden, weld)e nidjt den lintergalt bon Ingebörigen aus ifrem Sohne bejtritten Gaben.

3a. F్̈ü bie Dauter eines Jahres bon Beendigung der

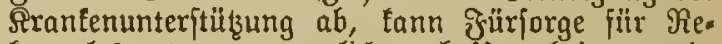
fonvalescenten, namentlich aud Interbringung in eine Refonvalescentenanitalt gemährt merden.

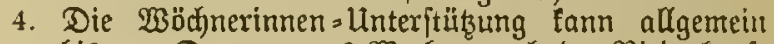
bis zur Dauer von 6 Bodjen nad) Der Riederfunit erjtrect werden.

5. Frete ärztlidje Behanolung, freie $\mathfrak{T}$ (rznei und jonftige Jeilmittel fönnen für erfrantte Familienangehörige Der Raffenmitglieder, fofern fie nicjt felbit Dem Iranfenberficherungszmange unterliegen, auf bes jonderen 2 ntrag oder allgemein gerwährt werden. Unter Derjelben $\mathfrak{B}$ orausfekung fann für (F)ejrauen der Safjenmitglieder im Falle ber Fntbindung Die nach) Biff. 4 juläffige Unterftüßsung gewährt werdcn.

6. Das Sterbegeld tann auf cinen höheren als den zraanjigfadjen Betrag, und zroar bis zum vier jig= fachen Betrage des Durdjidjnittlichen Tageloljnes (\$20) erföht merden. ${ }^{2}$ )

7. Beim Tode Der (5hejrau oder eines Rindes eines Saffenmitgliedes fann, jofern dieje Berfonen nidyt felbjt in einem gefezzlidgen Berfidferung saerbältnif jtehen, auf (Srund Defjen igren Sinterblieberen ein Inpprudi auf Sterbegeld zujteht, ein Sterbegeld, und zmar für eritere im $\$$ etrage bis zu $2 / 3$, für lețtere bis zur Sälfte des für bas Mitglied fepto gettellten Sterbegeldes gemährt werden.

(2) $\mathfrak{A}$ uj tweitere Unterjtükungen, namentlid) auj Jnvaliden=, Bittwen= und Waijenunterftülz̧ungen, dürjen die Reiftungen Der Drts=̊rantenfaffen nicft ausgedehnt merden.

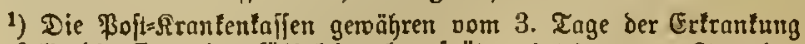
ab, falls bie Ermerbsunfäbigleit aber fpäter eintritt, vom Tage des 
Fintritts berjelben $a b$, auf die Dauer oon 26

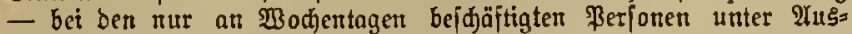

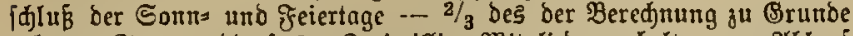
gelegter Tagesoerbienjtes. Freimillige Mitglieber erhalten on $\mathfrak{A b l a u f}$ her 6. Wodje bis zum Yblauf bes erften Jalbjahres ihrer Mitglied.

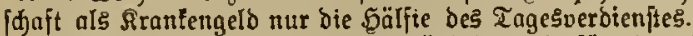

Das Rrattengelo viro nadträglid) aud für ben ₹ag ber $\mathcal{E}_{r}=$ tranfung unb bis beiben folgenben Tage tndgezablt, went die

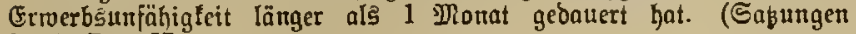
$\S 10$, I. u. II.)

2) Die \$oft=firanfenfafien aewähren ein Sterbegelb in föhe bes vierzigfaden Betrages bes ber Beitragsberedunung zu Grumbe gelegten Tagesarbeitsverbienites, renn aber bas 3ranaigfadje bes ortsüblidett ragelohnes geroöhnlider Tagearbeiter mehr beträgt, in söhe bicjes Betrages. (Sapungen $\S 13$, I.)

$\S 22 .{ }^{*}$ ) (1) Die Beiträge zu Den Drts=Srantentajien find in \$rozenten Des Durdjidjnittlidjen Tagelohnes (§ 20) jo zul bemefien, Das fie unter Einrectinung Der etroaigen fonitigen Cimnahmen der Safje ausreicfen, um die ftatuten= mäßigen Llnterittiłzungen, die Bermaltungsfoften und die zur

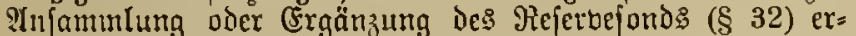
forderlidien Riidtagen zu Deffen.

(2) Sirantenfaffen, welthe die im \& 21 Stbf. 1 Biff. 5 bezeidhneten bejonderen Reiftungen allf INntrag getwå̉)ren, find und) Beptimmung des Statuß befugt, für diefe Eeiftungen von Saffenmitgliebern mit Familienangehörigen einen be= jonderen, allgemein feitzujez̧enden Zujakbeitrag zu erheben."

1) Die Mitglieber ber $\$$ Sabunger befugt, ihte Ehcirauen und Sittoer unter 15 Jahret gegen Entridfung eirres 3 nfapbeitrages gu verfidern.

§ 23.*) (1) Für jede Drts= Rrantenfaffe ift von ber (S) meindebehörde nad "Unhörung Det Betheiligten oder von Sertretern Derjelben ein Rafienjtatut zu erricjten.

(2) Daffelbe muf Beitimunung treffen:

1. über dic Rlajfen der Dem Rrantenverficterung: zwange unterliegenden Berjonen, weldje der Rajie al\& פTitglieder angebören jollen;

2. über IIt und Umjang der Unterftübsungen;

3. über die Şähe der Beiträge;

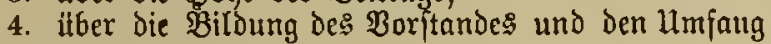
feiner Befugniffe;

5. ïber bie Bufammenfegung und Berufung Der (seneralberjammlung und über die शirt igrer Bejdfluşfafiung;

6. iiber dic 2(bänderung Des Statut: ;

7. über die 2lufftellung und \$rüfung der Jahres: rechinung.

(3) Das Statut Darf teine Beftimmung enthalten, meldje mit Dem Broef der Saffe nidjt in Berbindung jteht oder geleblichen Borjưfiften zumiderläujt.

§ 24.*) (1) Das Safjenftatut bedarf der Benehmigumg Der Göheren Berwaltungsbehörde. ${ }^{1}$ ) Befdjeid ift interhalb 6 Wodjen zu ertheilen. Die Benelymigung Darf nur berfagt merden, wenn Das Statut den 2Unforderungen diefes (Se = jebcs nicht genügt ober menn die Beftimmung itber bie §laffen von \$erfonen, weldje der Raffe angehören follen (§ 23 2b斤. 2 Ziff. 1), nit den Beftimmungen bes Statuts ciner anderen Saffe im Wideriprud) fteht.

(2) Abänderungen des Statuts unterliegen der gleidjen Borjatrift.

(3) Эedes Mitglied erhält ein (Eremplar des Safienftatuts und etruaiger 2 bănderungen.
(4) Den Beitpunft, mit weldjem dic Safie ins Reben tritt, beftimmt die höhere Berwaltung $\$$ be hörde.

1) Die Sakutgen ber \$oft:Sranfertaffen finto nom Staatsjefretär

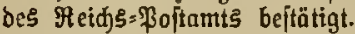

§ 25.*) (1) Die Drt: = Aranfenfajie tann unter ihreut Ramen Rethte erwerben und Berbindliffeiten eingeben, vor (Seridft flagen und berflagt twerden.

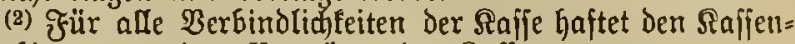
gläubigern nur das Bermögen der Raffe.

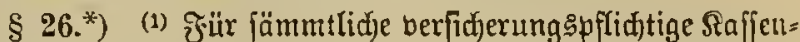

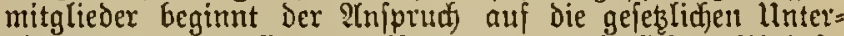
flübungen ber §affe zum Betrage der gefeblicten Mindejt= leiftungen Der Safje (\$ 20) mit Dem Beitpunfte, in weld)em

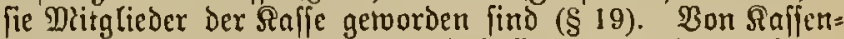
mitgliedern, weldje nadjweijen, Daß fie bereits einer anderen Stranfenfajie angehört oder Beiträge zur Gemeinde=Stranfen= berficjerung geleiftet haben, und daß ztwifden Dem Beit= punte, mit toldfem fie aufgehört haben, einer fold)en Stranfenfaffe anzugehören oder Beiträge zur Bemeinde= Sranfenterfitierumg zu leiften, und Dem 8citpuntte, in reldjem fie Mitglieder Der Drts=Sranfenfaffe getworden find, nidft mehr als 13 Worfen liegen, darf ein Fintrittsgeló nicfit erfoben werden.

(2) Siafienmitglieder, toeldje aus Der Bejejäftigung, ver= möge toeldjer fie Der Staffe angehörten, behufs cErfïllung ihrer Dienftpflid)t im Seere oder in Der Marine ausgefdjieden find und nad Erfüllung Der Dienftpflid)t in cine $\mathfrak{B}^{3}=$ fujäftigung zurüdffefren, vermöge weldjer fie der Raffe wieder angefören, erwerben mit dem Beitpunfte des $23 i e d e r e i n t r i t t s$ in die Raffe Dns Recft auf die bollen ftatutenmäßsigen Unterftübungen derfelben und Ënnen zur Bahlung eine: neuen Fintrittsgeldes nifft verpflidtet werben. Dasfelbe gilt bon Denjenigen, weldfe einer seffe bermöge ber $\mathfrak{B} e=$ fdäftigung in einem (Setwerbszrweige angehört haben, deffen Ratur eine periodifaf miederfehrende zeitveilige Cinjtellung des Betriebes mit fiff bringt, wenn fie in Folge Der leţteren

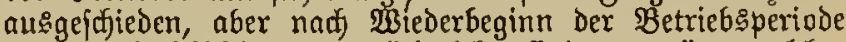
in eine Beffeäftigung zurüdgefehrt find, bermöge tveldfer fie trieder Mitglieder derfelben Rajfe twerden.

(3) Sotweit die boritehenden Beftimmungen nidft ents

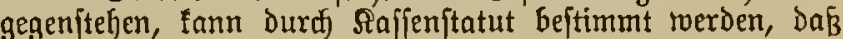

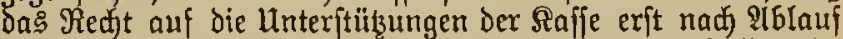
einer Rarenjzeit beginnt, und bā neueintretende Raffenmits glieder ein Eintrittggelo zu zahlen haben. Die Rarenzzeit Darf Den Beitraum von 6 Momaten, Das Cintrittsgeld barf den Betrag Des für 6 Wodjen zu leiftenden Raffenbeitrages nicht itberfteigen.

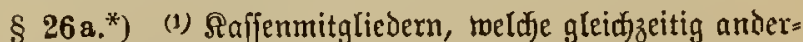
reitig gegen Sranflfeit berfidjert find, ift bas sranfengeld foweit zul fitrzen, als dasfelbe zufammen mit bem aus anderweiter Berfidjerung bezogenen Rranfengelde ben bollen

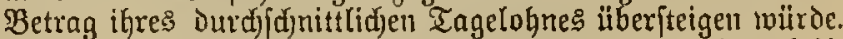
Durd Das Safjenftatut fant dicje Rürzung ganz oder tgeil. weife ausgejdjlofien werden.

(2) Durdf da: Siaffenftatut fann ferner beftimmt merden:

1. Daß̉ die Mitglieder berpflidjtet find, andere von iłnen eingegangene Berfid)erutgsonergältuiffe, aus welden ibnen Sinfpritde auf Sranfenunteritüksung zuftehen, fofern fie zur 1Beit Des Cintritts in bie Safie bereits beftanden, binnen einer Wodje nadj Dem

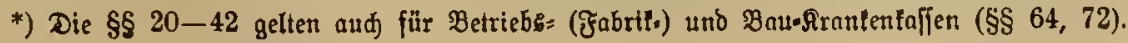


(Fintritt, fojern fie jpäter abgejuldolien werden,

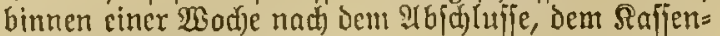
borftande anzuzeigen;

2. Daß $\mathfrak{M}$ itgliedern, weldje die Saffe burdf cine mit bem Verluft ber bitrgerlidjen (Eljremedjte bebrol)te frrajbare Sjanilung gejüäbigt haben, für bie Dauer bon 12 Mionnten, feit Begehung der Strnfthat,

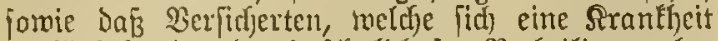
norfätslich oder burdh fduldbafte Betheiligung be=

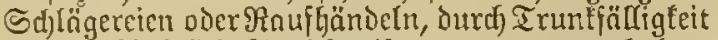
oder geidfledtlidje ?lusfdfmeifungen jugezogen hnben, fïr Dicje Stranklycit Dą jtatutenntäßige Sranfengelo gar nidjt ober mur theilmeife z"l gemähren ift;

2 a. daf DRitglieder, meldje der gemäf Ziff. 1 getroffenen

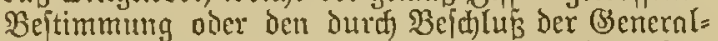
verfanmlung ïber dic firanfenmelonng, Das Ber= lualten der Sranten und Die Sranfenauffid)t er= lajienen Borjafriften oder Den ?Tnordnungen des behandelnden Prates zumiderhandeIn, Dronung: itrafen bis zil 20 Mart zu erlegen haben;

2b. Daß̧ Die ärztlidje ß̧eljandung, bie Rieferung ber Irjuci und die Sur tmo $\mathfrak{B}$ erpflegung nur Durdh bejtimmte ?arzte, 2Apothefen uno Siranfenbäufer 3"ll gewähyren find und die Bezalylung der durd)

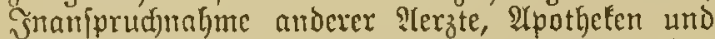
Srnnfenljäufer entitandenen Soften, bon Dringenden Fällen abgejehen, abgelehnt werben eann; ${ }^{2}$ )

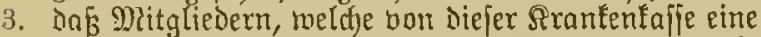
Siranfentmerftitkung ununterbrodfen ober im Raufe cines Beitrnums von 12 Ponaten fïr 13 Mocten bezogen baben, bei Gintritt cines nelten Unter= jtïbungsifalles, fofern biejer burdf die gleidje nidjt geljoheme Siranfbeitsurfadje veranlafst morden ift, im Raufe der näbfften 12 Monate Sranfenunter= itilzzung nur im gejeţlid)en Mindeptbetrage (\$ 20) แmo nur für bie (Seiammtoauer bon 13 wadjen zu getwäbren ift; ${ }^{3}$ )

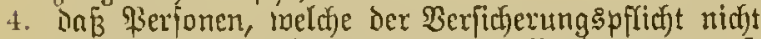
unterliegen und freimillig der sajfe beitreten, exit itach 2(blauf eincr atf Gödjiteng 6 Modien bom Beitritt $a b$ zu benteffenden frift Srantenunter= (tützung erbalten; ${ }^{4}$ )

5. Lafis auth ambere als bie in den $\S \S 1$ big 3 ge. nannten S3erfonen als Mitglieber ber Saffe auf= genommen werden fömnen, fofem iljr jührlicfes

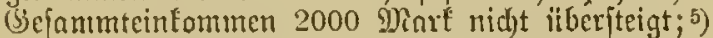

6. Daf̧ Die Unteritülizungen und Beiträge itatt nad) Den Durchidunttlidjen Tagelöhnen (\$20) in \$iro= zenten des twirffidjen ?lrbeitsverdienftes der einzelnen Berjicherten feitgefebt twerden, foweit diefer 4 Mark fiir Den ?Trbeitstag nidyt ïberfteigt.

(3) Die unter 2 a bezeicf)neten Bejdjlüfie Der Beneral

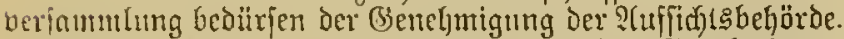
Heber Befduerden gegen die Berfagung der Benefmigung entidecidet bie nädfit vorgejelste Dienjtbebjörbe endgültig.

(4) S(bätocrungen Des Êtatuts, Durd) tocld)e die bis= jerigen Snjfenleiftungen berabgeletst merden, finden auf foldfe Piitglièer, weld)en bercitg zur Zeit Der ?tbänderung ein

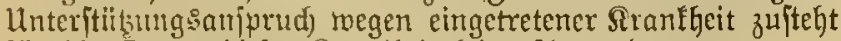
fitr die Danter diejer Srantlyeit feine P(nwendung.

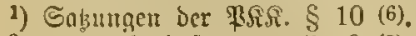

2) cbentoi. \$ू 9 (2) bis (7).

3) cbendaj. $\$ 10$ (7).
}

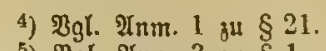

5) இgl. Inm. 3 jit $§ 1$.

$\S 27 .^{*}$ ) (1) Safjenmitglieder, trelcte nus der die Mit=

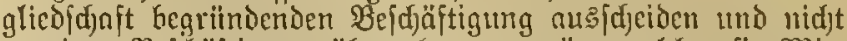
zu einer Bejdjäftigung iibergehen, bermöge beldjer fie $\mathfrak{D}$ Rit= glieder einer anderen ber in ben $\S \S 16,59,69,73,74$ bezeidineten Sranfenfoffen twerden, bleiben io lange Mit=

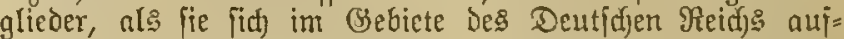

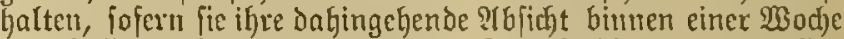
em Raffenvorftand e anzeigen. Die 3ahlung der vollen

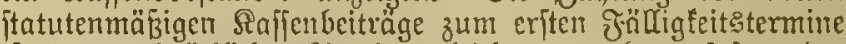

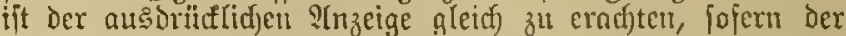
Fälligfeits termin inmerhalb der fïr Die lekstere borgeidhriebenen einnoüfjigen đrift liegt.

(2) Die Mitgliedidraft exlijdyt, wenn die Beiträge nn zmei auj einander folgenden Bahlungsterminen nidjt $g c=$ Ieijtet werden.

(3) Durd Rafienftatut fann beitimutt merden, da[j fïr nicft im $\mathfrak{B}$ ezinf der Sranfenfafie ober eines für Die Zmecfe

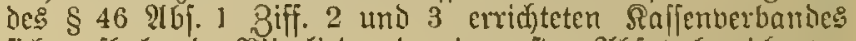
(iid) aufbaltende Pitglieder der im erften Thfał bezeidneten

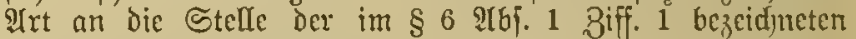
Seiftungen eine $\mathfrak{B e r g u ̈ t u n g}$ in Sö̈he bon mimbeften ber Saälfte bes Rrantengeldes tritt.

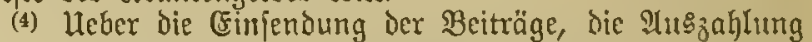
der llnterittïzungen und bie Siranfentontrole für bie nid)t im Bezirf der Gemeinde fich aufhaltenden Fierfonen hat das Sajienjtatut Beftimmung zu treffen.

§ 28.*) (1) \$erfonen, meldye in folge sintretender (F) twerbslofigleit aus der Sajie ausldjeiden, verbleibt der Aripruth nuf die gejeblichen Mindejt teijtungen Dex Rafje in Unterftüburggfäßlen, meld)e rährend ber Errverbslofigteit und innerbalb eines Beitraumt von orei Wadjen nad) dem

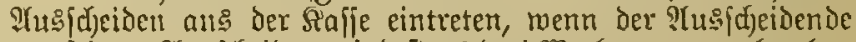
bor feinem 2 Hajdjeiden mindeitens brei $\mathfrak{B o d j e n}$ ununterbrodjen einer auf Brund biejes Bejezes errifteten Arantentafle angehört bat.

(2) Diejer SInjprud) fällt fort, wenn der Betheiligte fïh

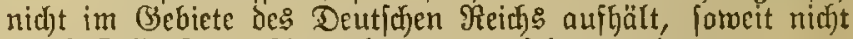
burcf) Rafienitatut ?(usిnahmen vorgefehen werden.

§ 29.*) (1) Die Mitglieder find der Raje gegenüber

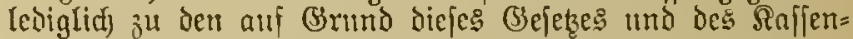
ftatuts fejtgeitelfter Beiträge berpflidytet.

(2) 34 antheren 8 medfen als den ftatutemmäßzigen Unter=

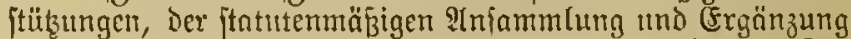
DeE $\Re e j e r v e f o n d s$ und der Deffung Der Serwaltungstoften dürfen weoer Beiträge non Pritgliebern erhoben merden, nad) Bermendungen auts dem Bermögen der Sajie erjolgur.

§ $30 .^{*}$ ) (Entitelien Bmeifel darifber, ob die im Saffen= ftatut vorgenommene Bemejiung Der Beiträge der Injorde= rung bes \& 22 cntipricht, fo ljat die höhere Bermaltungs= beförbe vor der (Extlyeilung oer (Benelymigung cine (ad)= veritändige \$rriffung herbeizujühren und, falls diefe die Unzulänglicfleit der Beitrüge ergiebt, bie (Ertheilung der (3enef)migung von einer (Erhjobung Der Beiträge nder einer

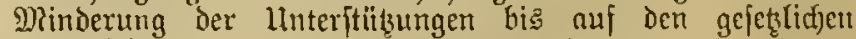
Mindejtbetrag (\$ 20) abhängig zu machert.

§ 31.*) (1) Bei Der (Frrifftung der Sajie dïrfen Die Beiträge, jomeit fie Den Rajienmitgliedern jelbjt zur \&ajt fallen (§51), nid)t ïber $2 \%$ besjenigen Betrages, nad)

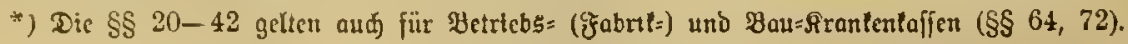


meld)ent die linteritiţ̧ungen zu bemejien fint (\$S 20, 26a 3iff. 6), feitgeietst merien, pofert jold)es nidjt zur Decfung der Mindejtleiftungen ber Siafie (\$ 20) erforberlid) ift.

(2) Cine fpätere (5rhöbung Der Şeiträge ïber biejen

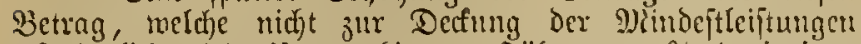

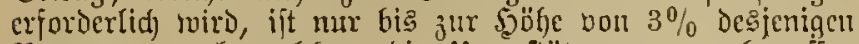
Betrages, nad) sneldjem die liuterftübungen zu bemefien

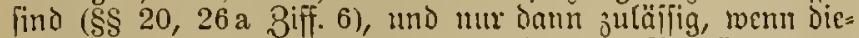
jelbe fotwohl votr der $\mathfrak{B}$ crtretung Der zu Beiträgen ber:

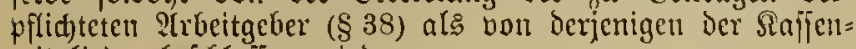
mitglieder beichlofifen roiro.

§ 32.*) (1) Die Srts= Rrantenfaffe hat einen Rejervefonds

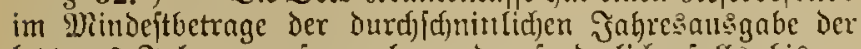
lekster 3 Jahre anzmjammeln und erforderlichenfals bis ju Diejer \$̧öbe zu ergänzen.

(2) Solange Der Rejerbejonds Diefen Betrag nidjt etreid)t, ift deutielben mindejtens $1 / 10$ des Jabresbetrages ber finfjul= beiträge zuzujühren.

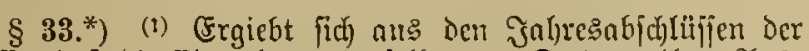

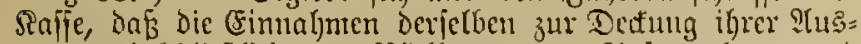

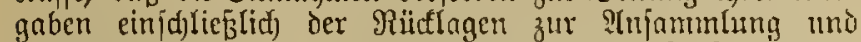

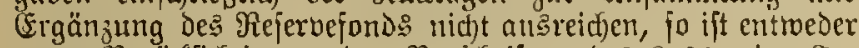
unter Berüficutigung Der Boriduriften des $\$ 31$ eine (Er= fölyutg Der Beiträge ober cine Minderung Der Rajfen= leijtungen herbeizufiibren.

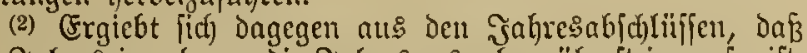

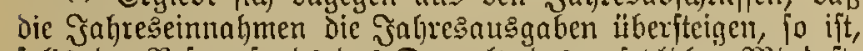

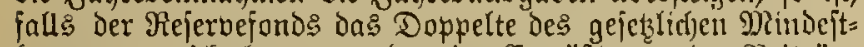
betrnges erreifft hat, entweder eine Ermäß̧igung Der Beiträge oder unter Berüufichtigung Der $\mathfrak{B}$ orjechriften Der $\$ \S 21$ H. 31 eine Ertjöhung oder (Erweiterung der Safjenleiftungen herbei= zufübren.

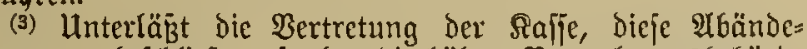

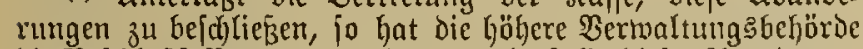
die Bejdlusfafiung anjuoronen, und, fals bieier ?tnoromung feine Jolge gegeben roiro, ihrerfeit: die erforderlidje $\mathbb{S}(\mathrm{b}=$ änderung des Safjenjtatuts von 2(mtsimegen mit rectits= verbinblinger Wirtung zu volfiehen.

(4) Wirb zur Yufreefterhaltung oder Wiederberjtelfung

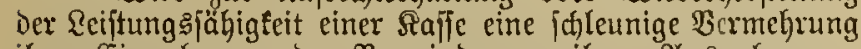
ihrer Cinnahmen oder Berminderung ifyrer YHagaben er= forberlidf, fo Eann die höfjere BertwaltungsGehöroc, yorbehalt=

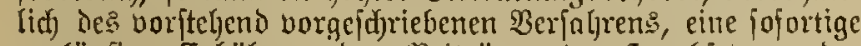
vorläufige Grhöhung Der Beiträge oder serabjełung der

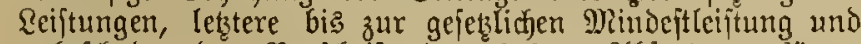
unbeidjadet der Vorjabrift des \& 26 a $2(b .3$, bertitgen. Gegen dieje Berfïguttg ift bie Bejdiverde an die Bentral= behörde zuläjïg. Diejelbe hat feine aufichiebende $23 i r f u n g$.

$\S 34 .^{*}$ ) (1) Dic Sajje mū̄ einen bon Der (Beneralver=

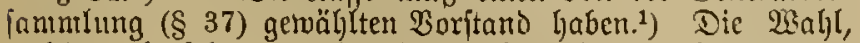
welde, abgejeben von Der Den irbeitgebern nad) \& 38 zu= itehenden Sertretung, aus ber Mitte Der Raffenunitglieder erfolgt, fundet unter Eeitung Des Sorftandes fott. Siur bic

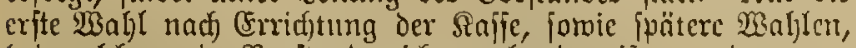

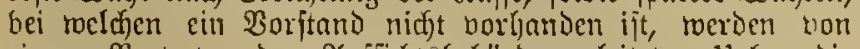
cinem Bertreter der ?luffichtebljörbe geleitet. Heber bie Bafloerhandlung ift ein Srototolf aujzunelyen.

(2) Der Boritano hat über jede Tenderming in jeiner

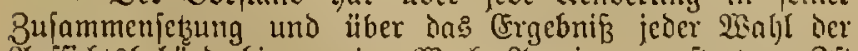

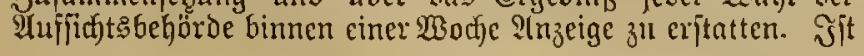

dic Ingeige nicht erfolgt, jo fonn die Tenderung Dritten \$erjonet un Dam entgegengeję̧t merden, toenn berwiejen wirb, bafí fie leketeren befant mas.

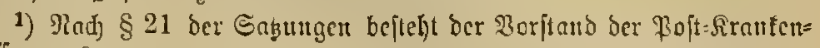
taffer aus:

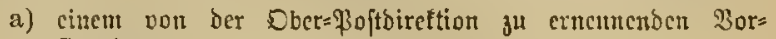
Fifertion:

b) Drei Beifipern, meldye it ber orbentlident Bencralverjantu=

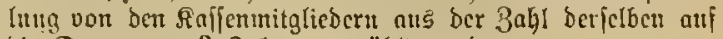
bic Dauer von 3 3ahren gewählt werben.

$\S 34 a^{*}$ ) (1) Die Mitglieber bes $\mathfrak{B o r f t a n d e s ~ b e r m a l t e n ~}$

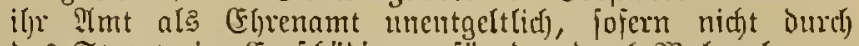

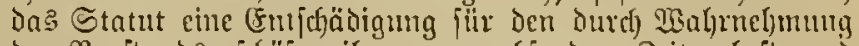

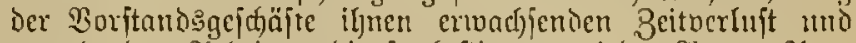
entgebendeu Strbeitsperdienjt bejtimmt mird. Baare ?tus: lagen werten iljnen bou der Rafie erjekst.

(2) Die ?tblelunung Der $\mathfrak{B a h l}$ jum $\mathfrak{B}$ orftandsmitglied ift

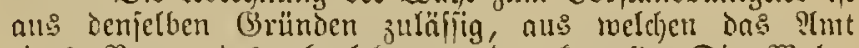
eines $\mathfrak{B}$ armundes abgeleljnt werden fam.1) Die Wahr= nelymung eitles auj Grund Der llufaltorfitjerung nud ter Jnbalibität3berfid)erung übernommenen (Elyennant jteljt ber

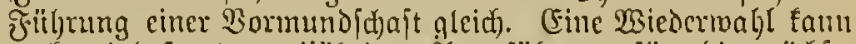

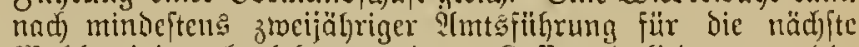
Wablperiube abgelehnt merDen. Saffenmitgliedern, meld)e

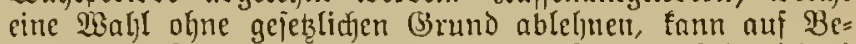
(d)luf Der Beneralverjammlung für bejtmmte Beit, jedod) nid)t Der: Generalverjammlung entzogen roerden.

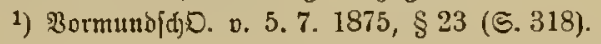

$\S 35 .^{*}$ ) (1) Der Borjtano vertritt die Rajpe gerichtlich uno außergeridhtlich uno fülyrt nach Diaģabe des Saffen= jtatuts die laujende Berwaltung derjelben. Die Vertretung erjtrecft (ich) aud auf Diejenigen (Sejuäjte und Red)ts: bandlungen, jür weldfe nad) Den Bscjeben eine Spejial= volfmadft erforderlicf ijt. Durch Das Statut faum cinem Mitgliede oder mehreren Mitgliedern des Borjtandes bie Bertretung nad amben iibertragen wersen.

(2) Bur Regitimation des Borjtandes bei allen Redjt: =

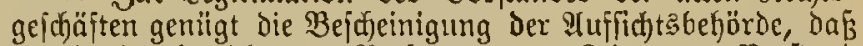
die darin bejeidneten Perjonen zur Zeit Den Borjtand bilden.

§ 36. ${ }^{*}$ ) Sotweit die Waljrnefmung Der 2 ngelegenheiten Der Saffe nicht nad) Worjdrift Des (Bejęce ober Des Statuts Dem Boritande obliegt, jteht bie Bejd)lubmagme Darïber Der Seneralverjammlung zu. Derjelben muई vorbeljalten bleiben:

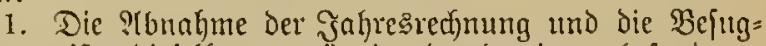
nif́, biejclbe vorgängig burd) einen bejonderen

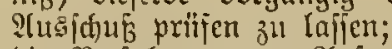

2. Die Berfolgung vou ?(niprüitien, weldie der Saffe gegen $\mathfrak{B}$ orftandsmitglieder aus Deren ?Imtsjïlyung ertoadjen, Dard) Bcaujtragte;

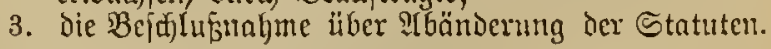

§ 37.*) (1) Die (Seneralverjammlumg beiteljt nad) $B$ ftimmung Des Statuts entweder an: fämmtlidjen fafien= mitgliedern, weld)e gró̧jül)rig und im Bejitse ber bitrger=

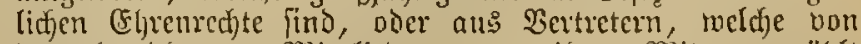
ben beseichneten Mitgliedern aus igrer Mitte getwäblt werdet1. $\left.{ }^{2}\right)$

(2) Die Beneralverfammlung mus aus Bertietern be=

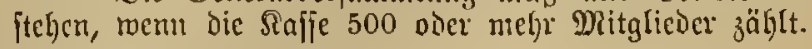


(3) Bejteht die Beneraloerjannulung aus Bertretern, fo find bicfe in acheimer $2 \mathrm{Wahl}$ unter Reitung des 20 orjandes

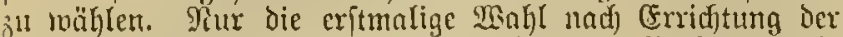

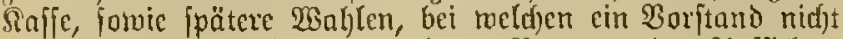
vorbanden ift, werben bou einem Bertreter der 2luffichts. beljöribe gelcitet.

1) Jrauen Gaben, fareit fie Mitglieber ber $\mathfrak{A a f f e}$ find, gleides Stimmredt rvie die Maanner.

\$ 38.*) (1) 2rbeitgeber, weldhe fït bie tuon ifnen be= idüftigten Mitglicier curer Drtšsraufentaffe an dieje Bei= trïge nuङ eigenen Ditteln zu zaljlen berpflidjtet find $(\$ 51)$, baben vluporuch auf Rertietung in Borftanoc und ber Benctalberiammlumg ier Siafie.

(2) Die Bertretung iff nad) dem Berljältniß̧ Der bon ben Prbeitgebern aus eigenen Mitteln zu zal)lenoen Reiträge zu iem Seiammtbetrage det Beiträge zu bemefjen. Mebr als $1 / 3$ ذer Stimmen Darf Den Plrbeitgebern toeder it Der (Gonernlverfammlung nod) in פorftande eingeräumt merden.

(3) Die Walles der Bencrnlberfammlumg zum Borifande fini) acheim und werien getrent bon Qurbeitgebern unb Saljenmitglicdern vorgenommen.

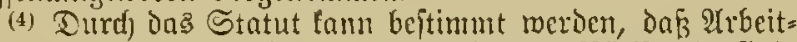
geber, weld)e mit Bablutng der Beiträge im Rücfitande fino, von der Bertretung und Der Wablbered)tigung anşzufdließzen jitid.

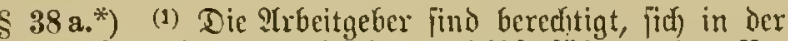

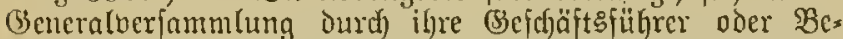
triebsbeamen bertreten zu lajien. Bon Der Bertretung ijt bem Sajfentworfande bor Beginn ber Benerolverjammlung Injocige zu madhen.

(2) Die $\mathfrak{U}$-beitgeber find ferner bered)tigt, zu Mitgliebern ber aus Bertretern beftelienden Beneralverfammlung mo

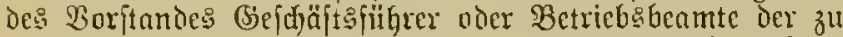
Beiträgen berpflid)teten Q(ibeitgeber a wäblen. (Sine Ber:= tretung ber gewäblten Mitglicoer ber (Senetalverfammlnttg ober des Borjtandes findet ridit ftatt.

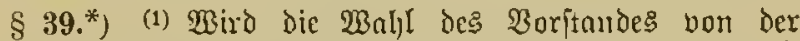
(B)eneralverjammlumg oder die $\mathfrak{B a l}$ l der Bertreter zur (B)eneral= verianmlung durb die Wablberechtigten berweigert, jo tritt an ifje Stelle Ernenum Der Mitglieder des Boritandes

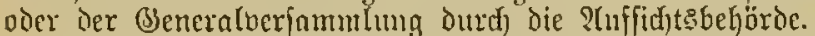

(2) Şaben bic $\mathfrak{A r b e i t g e b e r ~ a u f ~ d i c ~ i l y n e n ~ 3 u l t e b e n d e ~} \mathfrak{B e r}=$ tretung in Der Beneralberjammlung oder im Borftante ber= zichtet, fo Ënnel fic bicie Bertzetumg mu mit Mblauf einer Baljlperioise miescr in 2 upruch nehmen.

\& 40.*) (1) Die (Finualumen und ?tusgaben ber faffe

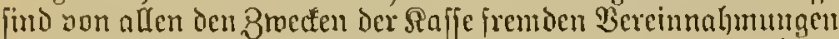
แmb Berausgabungen getremt jeftzuftelfen; igre Beftände jinc gejondert zu bermabren.

(2) Werthpapiete, Ivelde zum 2 etmögen Der Sinije ge=

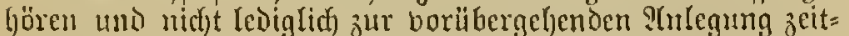
weilig verfügbarer Betricbggelder für dic Siafe ermouben

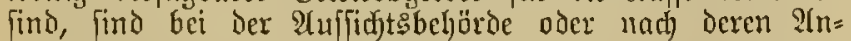
meifung bermalgrlid) niederzulegen.

(3) Berfügbare (Selder dürfen mur in öffentlictgen Spar=

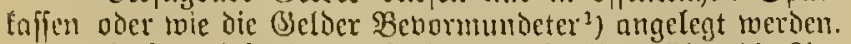

(4) Cojern bejondere gefetzlid) Borf(t)riften ïber bie ?In= legung der (Belder Bcoormumber nid)t bejteben, fant die Inlegumg der verjügbaren (Belder in Sd)uldner dfurcibungen, meldje bon Dem Deutideu Reid, von einem Deutiden $\mathfrak{B}$ undess

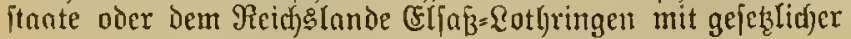

Ermäd)tigung ausgeftellt find, oder in Sduldoberjdyreibungen,

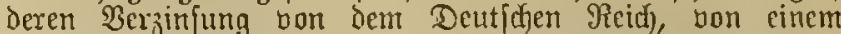

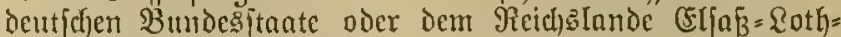
ringen geietzlid) garantirt ift, oder in Gduldoerforeibumgen, welche bon Deutfiden fommunalen Rorporationen (\$3rovinzen, Sicifen, (Semeinden 2c.) oder bon deren Areditanitalten ans=

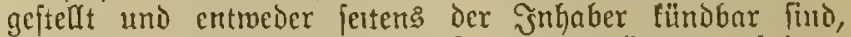
oder einer regelmäßzigen PImortifation unterlicgen, erjolgen.

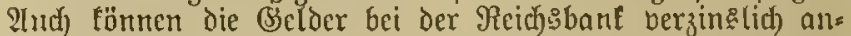
gelegt merden.

(5) Die Bentralbebörde farm die \&nlegung verjügbarer (Gelder in amberen als ben borftehend bezeidneten zins: tragenoen \$avieren, fotwie Die borübergeljende Ynlegung zeit. weilig verfügbarer Betricbsigcloer bei anderett als ben vor= bejciduneten Ricditanjtalten widerruflich geitatten.

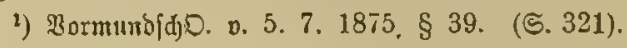

\$ 41.*) (1) Die Saffe ift verpfliditet, in den bor:

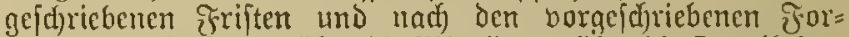

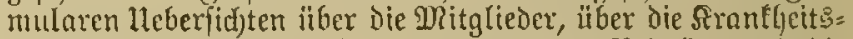
mm Sterbefälle, $\ddot{b}$ ber Die vercinnalmenten Beiträge uno die

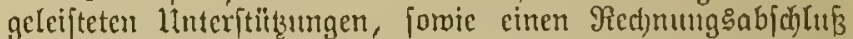
Der Suffidstsbeljörbe einzureidjen. ${ }^{2}$ )

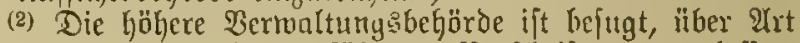
und Form ber Redinungşübrung Borfdriften zu exlaffen.

1) $\Re \mathrm{gl}$ § 79 .

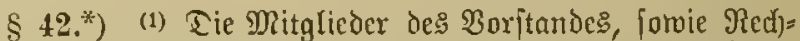

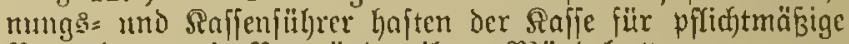
Bertualtung wic $\mathfrak{B}$ ormïnder ifien Mï̈nde(n.2)

(2) Bermenion fie verï̈gbare Belder ber fafje in ibrem

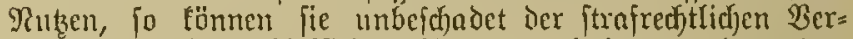
folgumg durd) dic ?luffidfţbehörde angehalten weroen, das in ifiem ?luben bermendete Seld bon Beginn der Ber= wenoung an zแ berzinjen. Den Binsint beftimmt dic ?uf fidhtsbchöroc nacf iljem (Ermefien auf 8-20 bom 5̆mbert.

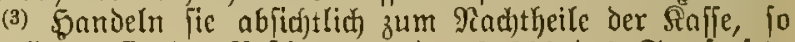
unterliegen fie der $\mathfrak{B e p t i m m u n g}$ des $\$ 266$ des Strafgejets= butfs. ${ }^{2}$ )

1) BormundføD. จ. 5. 7. 1875. §\$ 32, 49 น. a.

2) ":Begen ltstreue merben mit Befängnif, neben meldem auf gerluft ber bürgerlidjen Ehrenredte erfannt werden fann, beftraft:

1. Bormünber..... twenn fie abfidtlidf jun Sadjtheile bor ifrer Fuffïht anvertrauten \$erfonen ober Saden bandeln; ..... girb bic Untreue begangen, um fid aver einem Inderen

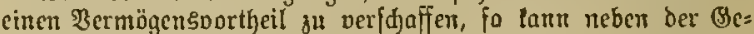
färgnififtrafe auf Belbitraje biș zil 3000 th erfannt werden."

$\$ 44^{*}$ ) Unter Dberauffidt der Göheren Bertoaltungs:

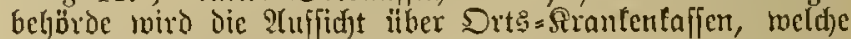
fïr Den Bezinf ciner Semeinde bon mehr als 10000 Ein= molynern errid)tet find, durd) dic (Semeinbebeljörden, bei allen übrigen Drts= Sirantenfaffen durdf dic feitens der Randes= regierungen zu beftimmenden $\mathfrak{B e h}$ örden wabrgenommen.

Bgl. $\S 84$ भbf. 3 .

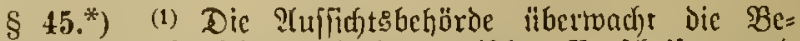
folgung ber gejetzlidfen und ftatutarifonen Borfáriften und

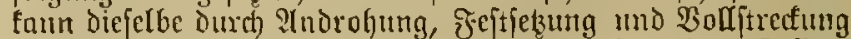
von Dronmugftrafen gegen die Mitglieder des Raffen= borftandes crzwuingen.

(2) Sie ift bchugt, bon allen Berbandlungen, Büdjern und Red)nungen der Saffe (Sinfid)t zu nehmen und die Rafje зu revidiren. 
(3) Sie fam bie \$erufung Der Raffentorgane zu Siłzungen verlangen und, falls biefem Berlangen nicht entfprodien wito, die Sitzungen felbjt anberaumen.

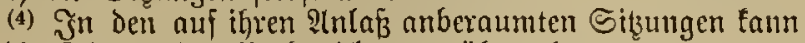
fie die Reitung der Berbandlungen libernehmen.

(5) Solange Der Borftand oder Die Beneralberfammlung nidat zu Stande fommt oder die Srgane Der SRafie bie (Fr. fïllung ifrer geieţliç)en oder ftatutenmäßsigen Dbliegentyeiten

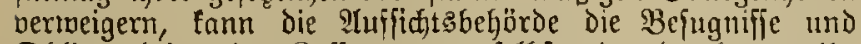
Dbliegenfeiten Der Saffenorgane felbit oder Durch von ily: ju beftellende Bertreter auf Soften der Saffe wabuefinten.

\$\$ 46, 46a, $46 \mathrm{~b}$ Ganbeln von Rranfenfajien = Berbänben,

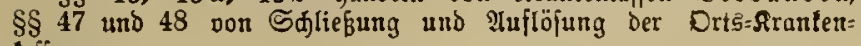
faifen.

\$ 48 a.*) (1) (5rgiebt fich, daß cinem Staffenitatut nact) \$ 24 शbi. 1 die Sienehmigung bätte veriagt werden milffen,

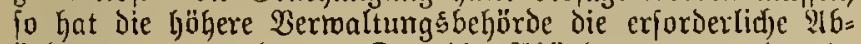
änderung anzuordnen. Der die Mbänderung anoronende Befdicid fam auf dem in $\$ 24$ TbF. 1 bejeitineten Wege angefacfiten merden.

(2) Ilnterläßt die Bertretung Der Raffe, die endgültig an=

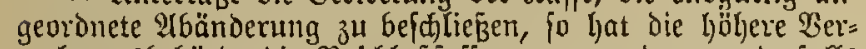
maltungsbeb̆bod die Beffjluffaffung anzuoronen mo, fals diejer ?̂noronung teine Folge gegeben wiro, ifrerjeits Die

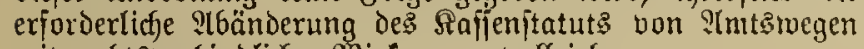
mit rect)tsverbindlidjer Wirfung zu bolfzieben.

\section{Gemeinfame ßeftimutungen für die Gemeinde-

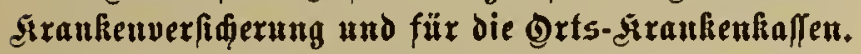

$\$ 49 .^{*}$ (1) Die Arbeitgeber haben jede bon ibnen be= idjäftigte verfid)erungspfliditige \$ierjon, meldje meder einer Betriebs: (₹abrif $=$ Sranfentaffe) (\$ 59) Bautrantenfalfe

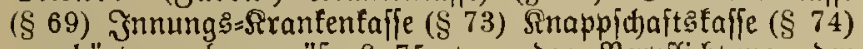
angehört, nou gemäß $\$ 75$ von oer Berpflichtumg, oer Semeinde=Sranfenberficjerung oder ciner Drts=Sranfenfalfe anzugebören, Gefreit ift, ipäteftens am Dritten Tage nad) Beginn der Befääftigung anzumeloen und fpäteftens am dritten Tage nad Beendigung derjelben mieder abzumelden. Beränderungen, durd) meld)e während Der $\mathfrak{D a u e r}$ der $\mathfrak{B e}=$ fdjäftigung die Berfidjerungspflidjt für joldje \$erfonen be= gründet toird, die der Verficherungspflict auf (Srmut ibrer Bc\{cfäftigung bišljer niđbt unterlagen, find ipäteftens am Drittel Tage nach ibrem cintritt écnialf anjumelden. Das (3leidie gilt bei Nenderungen des Mrbeitsvertinges,

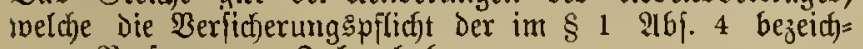
meten \$erfonen zur Folge Gaben.

(2) (3) (4) (5) .....

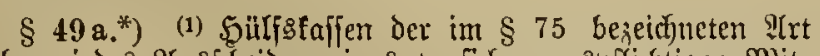
haben jedes Yugfojeiden eines berfidjerungspflidjtigen Mit= gliedes aus der fiaffe und jedes Uebertreten cues joldaen in eine niedrigere Mitgliedertlaffe innerhalb Monatsinijt bei Der gemeinfamen Meldeftelle oder bei Der Uufficftibebörde Desjenigen $\mathfrak{B}$ zirfs, in welchem das Mitglied jux Beit der lebten Beitragszahlung bejchäftigt mar, unter ?Ingabe feines Uufenthaltsortes und feimer Befdäftigung zu Diejer Beit idjriftlidf anzuzeigen.

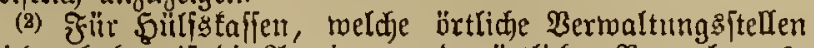
erricftet haben, ift die ?Inzeige bon ber b̈rtlicfen Bermaltung: ftelle zu erftatten.

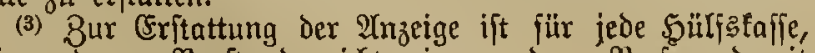
fofern deren Borftano nidjt eine andere Berfon damit

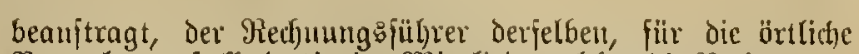

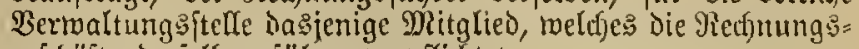
gefdüfte Derjelben fïljt, berpflidjtet.

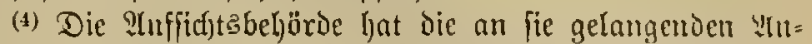
zeigen Der Bermaltung Der (3emeinde=Rrantenverfid)erung oder Dem Borftanic der Drtesiranfentafie, welder Die in Der Hnjeige bejeidfuete Herfon nad ber in Derjelben an=

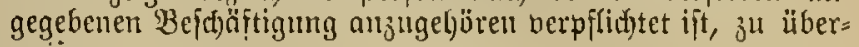
tocilen.

\$50.* (1) Strbeitgeber, toeld)e der ibuen nad $\$ 49$ obliegentien thmeldepflict botfäblich oder fabrläjfigertucile

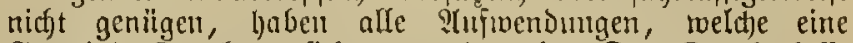

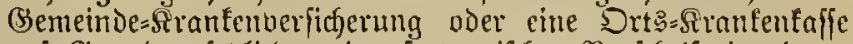

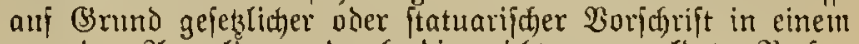
bor Der ?tumeloung Durdj Die nidft angemeldete \$ierfon beranlafiten Unterftitungsalle gemadit hat, zu exftatten.

(2) Die Berpftidntung jur Entriatumg bon Beiträgen für die Beit, während weldjer die nidyt angemeldete oder nidft angezeigte \$ierion Der (S)meinde=Rranfenfajfenberiidje= rung oder Der Drts= Sranfenfaife anzugebören verpflidtet toar, wird fierdurch nidjt berilbrt.

$\left.\S 51 .^{*}\right)$ (1) Die Beiträge zur Rranfenberjicterung ent= falfen bei nerfitierungapflicjtigen \$erjonen zu $2 / 3$ auf dieje, зu $1 / 3$ auj ibre 2rbeitgeber. Eintritt引gelder belaften nu Die Berfiderten.

(2) Durd) ftatutarijace Yegelung (\$ 2) fann beftimmt merben, daß̧ $\mathfrak{A}$ beitgeber, in deren $\mathfrak{B}$ etrieben Dampifeffel oder bur(f) elementare אrajt Gervegte Triebroerfe nid)t ver= wendet und mefr als ztvei Dem Srantenverficherungszuange unterliegende Berjonen nicht bej(f)äjtigt merden, von Der Ber= pflidtung zur Reijtung bon Reiträgen aus eigenen Mittelı beireit find.

$\left.\S 52 .^{*}\right)$ (1) Die Urbeitgeber find verpflichtet, die $\mathfrak{B e i =}$ träge uno Fintrittsogelder, welche fïr die bon ignen be=

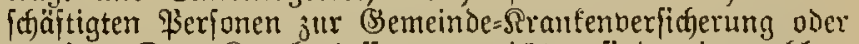
ou cimer Drts= Sranfentaffe ju entriditen furd, eirzuzablen. Die Beiträge jind an die Bemeinde= Rrantenberfidjerung, $f 0=$ jern nidjt Durd) Bemteindebe\{d\}lū andere Bablungstcrmine jeftgejest find, twödjentlid) im Dorans, an die Srts=Sranfen= Eaffe zu Den Durd Statut feftgejetzten Bablungsiterminen einjuzablen. Das Eintrittsgeld ift mit Dem exften fäligen Beitrage einzuzahlen. Die SBeiträge jind folange fortzuzhlen,

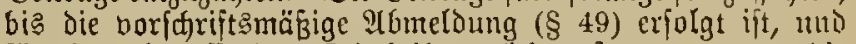
für ben betreffenden Beittbeil jurücfueritatten, toenu die redjtzeitig abgemeldete \$erfon innerlyalb ber Bablung soperiole aนฐ Der bisherigen Bejdjäftigung auşđjeidet.

(2) Went Der $\mathfrak{B e r f i d j e r t e ~ g l e i d f z e i t i g ~ i n ~ m e b r e r e n ~ d i e ~}$

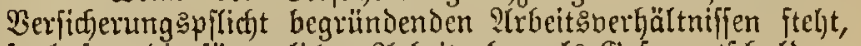

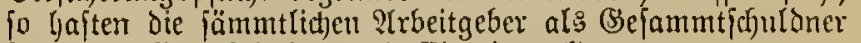
jür die vollen $\mathfrak{B}$ eiträge und Fintritţ̧gelder.

(3) Durd) Bemeindebejdy fidisbehöroe oder Durch Raflenitatut fann Geftmmt merden, dấ die Beiträge jtets fül volle Wochen erboben und zurüct= gezahlt werden.

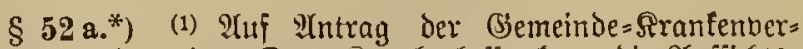
jidjerung oder einet Drts= Sranfentalfe fann dic Yujichts.

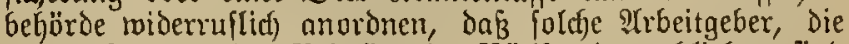
mit $\mathfrak{Y}$ bjührung der Beiträge in Kücfitande geblieben find

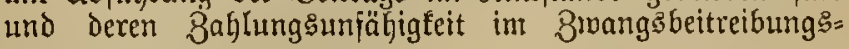


be:fafyen feftgeitellt morden ift, mur den auf fie felthft als 9trbeitgeher entfaflenden Theil ber. Beiträge, weld)e fïr bie

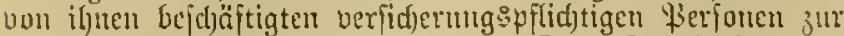

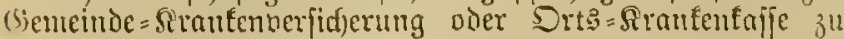
entrid)ten find, eitzuzahien haber.

(2) WBirb bies angeordnet, fo find die bou folden ?tebeit= gebern befuäitigten verfidjerungapfidjtigen Gerjonen ver= pilidftet, die Eintrittsgelder jomie beu anf fie felojt ent=

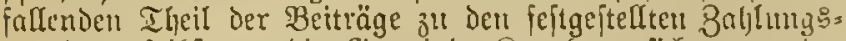

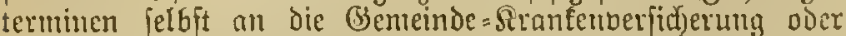
Sirartentaffe einzuzahlen.

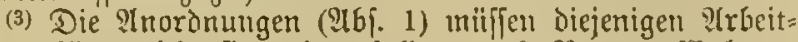
geher, für weldje fie gelten jollen, nad) Namen, Wsoljnort แnD (sejajäjtsbetrieb Deutlidj bejeidjnen und find biejen S?rbeitgebern (d) riftlich) mitzutheiโent.

(4) Die von joldfen Inoromungen betroffenen 2 Trbeitgeber find verpflidjtet, Dicjelben ben bon igmen bejdäftigten, in ter (Scmeinde= Sranfenverfictierung oder Drts=sranfentajie ver: fidjerten verfidjerungspflidftigen Ferjonen durch onuernien Tus̆lang in ben Betriebsjtätten befannt zu madjen und bei jeder Sohnjaglung die von ifnen bejchäjtigten bes=

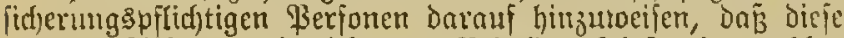
die im ?tbfaz 2 bejeidjneten Beiträge felbft cinzuzahlen l)abetl.

(5) Begen die im $\mathfrak{A} b[.1$ bezeidneten $\mathfrak{A}$ norònungen findet bimen 2 Moden nad) der Bujtelung Die Bejfrwerde an

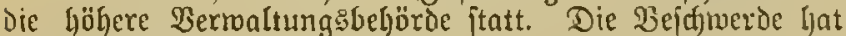
teine auffajiebende Birtung. Die Entjajeioung ber ljöberen Bermaltungşebörde ift enogültig.

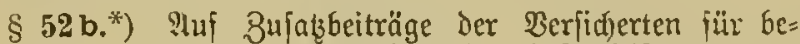
jondere auf Antrag zu getwährende Rajfenleijtungen an

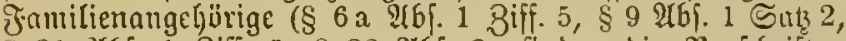

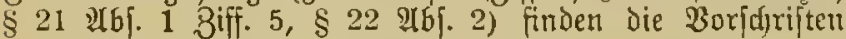
ber $\$ \S 51$ und 52 feine anmentung.

§53.*) (1) Die Vierficherten find verpflichtet, die (Fin=

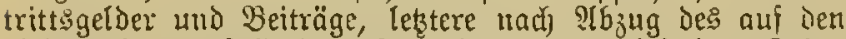

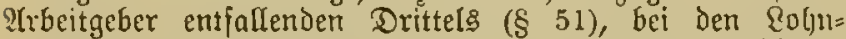
zaljlungen fidj einbelgalten zu laffen. Die Irbeitgeber dürfen

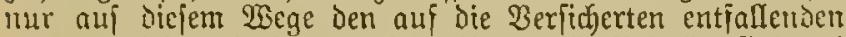
Betrag mieber einjieben. Die Ŝlbjïge fïr Beiträge find auf dic Rohnzahlungspertoden, auj weldie fie entfallen, gleidg=

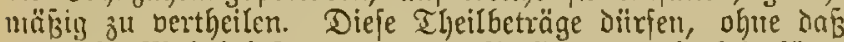
daburch Melnbelaftungen Der Berfiderten herbeigefülyt ivertell, auf volle 10 wjennig abgerundet twerden. Sino

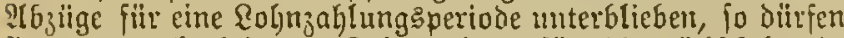
fie nur noth bei der Iolynzahlung für die närfjiffolgende Sohnzahlungsperiode nadjgeholt merden.

(2) (3)

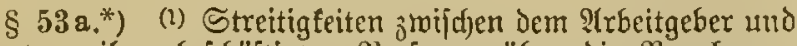
den von ifm bejfräftigten Berionen ibber die Berectinung und SInrec)nung Der bon diefen zn leiftenden Beiträge toerden nadj den Boriduriften des (Sefebes, betreffend die Serwerbe=

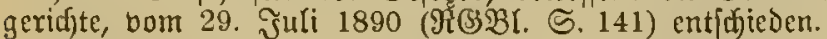

(2) Die Boridjriften des Letzteren Bieietzes finden aud) auj Streitigfeiten jowi\{hen den bezeidneten Berjonen über

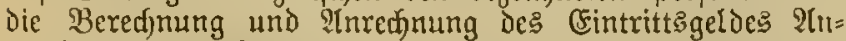
mendung. Bur Entidjetbung diefer Streitigfeit find aud bie auf Brund des $\$ 80$ jenes Gefezes fortbejtehenden Be= merbegerichte zu[tändig. ${ }^{1}$ )

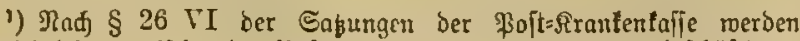
Streitigleiter zroijđen ber ßoptbermaltung uno ben von igr bejळäjitigters

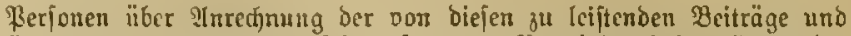
Eintrittşaclocr cutweder auf IItrufen einer Bartei burd) ben Semeinbe:

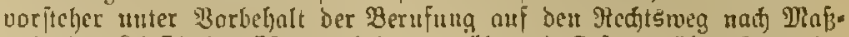
gabe ber $\$ \varsigma$ il bis 75 des (oben crwäbnten) Bejeges über Benderbe= geridjte vom 29. 7. 1890 obcr jofort in orbentlidjen Redjtsmege ent= iojtionen.

Etreitigfeiten zrijden den finjennitglicbern unb dem frafjens

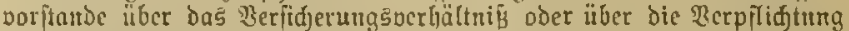
jur Reijung oder Einzahlung vou Eintrittggeloern unb Beitrügeu und

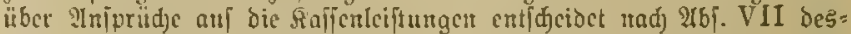

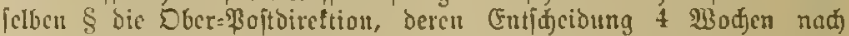
Deren 3 uftellung in orbcntliffen Redtsivege (fouveit aber lanbes: gejeblitj joldje Etreitigfeiten ben Bermaltungsftreitoerfabren übers

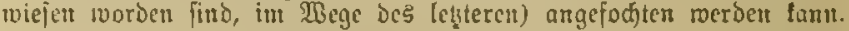

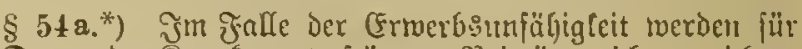

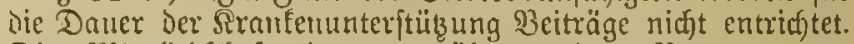
Die Ditglied/c)aft dauert twährend des Bezuges bon Srantentunteritüßzung fort.

$\S 55 .^{*}$ (1) Der Infprud auf (Eintrittsgelder uno Beis träge berjähtt in 1 Jahre nad) ?lblant des Salenderjahres, in tweldjem ex entfíanden ift. Rü̈fitändige Cintrittsgelder und Beiträge merden in berjelben $23 e i f e$ beigetrieben, roie Gemeindenbgaben. Die dajïr beftehenden landeşred)tliden Borjabriften finden aud infofern stmendung, als fie tiber die aujicjiebende Wirtung ctraiger gegen die Baljtungs: pflidyt erhobener (Finmendungen ibeftimmung treffen. Die rücffändigen (Fintrittggelder und Beiträge Ljaben Das Bor=

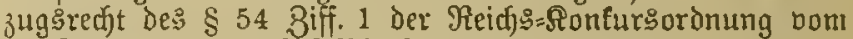

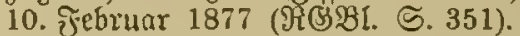

(a) Sofern nacf Biemeindebejcjluß oder Raffenftatut Der Einteitung Des Beitreibungsberfahrent ein Mahnberfahren vorangelyt, lam von 2ibeitgebern, meld)e die Eintritışgelder und Beiträge nidyt zum Fäligfeitstermine eingezahlt haben, eine Malungebühr erhoben uno roie die Rüufftände beigetrieben werden. Dic focitiebung des Betrages der Mahngebilihr

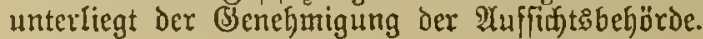

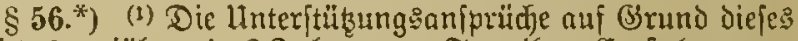

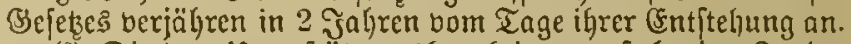

(2) Die dem llnterftüßsungsbered)tigten zuftehenden Forde= rungen fönnen mit rectitlicher ssirfung meder verpjäubet, nod) iibertragen, nod) für andere als die im $\& 749$ श bi. 4 der

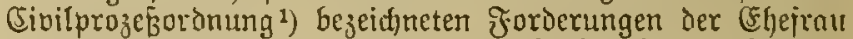
und eljelichen Sinver und bie des erjabberedftigten ?trmen= verbandes gepfäniet merden; fie dürfen nur auj gejdjuldete (Fintrittsgeloe: und SBeiträge, weldhe von dem Unterjtüßzung: bereditigten felbit einjuzahlen maren, forvie auf Beldjtrafen, meldfe er burd) Zurwiderhandlungen gegen bie auf (Srund bes $\$ 6$ a 26 . 2 oder $\$ 26$ a 20 6 . 2 Biff. 2 a erlaffenen Borjchriften verminft hat, aufgeredinet merden.

1) oben S. 200.

$\left.\S 56 a^{*}\right)$ (1) $\mathscr{Y}$ uf $\mathfrak{A}$ (ntrag von mindejtens 30 betheiligten Verficherten fanu die höhere Bermalungsbehörde nad) ?[n=

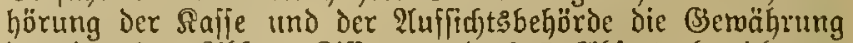
Der in $\S 6$ ?tb 1 Biff. 1 und $\S 7$ श्tbi. 1 bejeidneten Seijtungen Durff meitere als bie bon ber ßaffe beftinmten

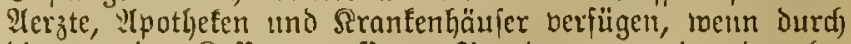
bie bou der Saffe getroffenten Pnoronungen einte dent be= reditigten :(nforocrungen Der Berfidjerten entfpredfende (Be. mährung jener Reiftungen nidjt gefid)ert ift.

(2) WBito einer foldhen Berfügung nidjt bimnen ber ge=

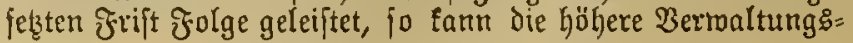

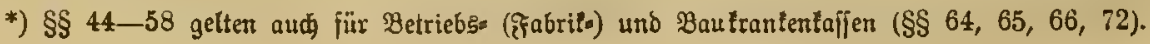


beljöroe die erforberlichen ?tnoromungen ftatt Der zuĩtändigen Saffenorgane mit verbindlidfer Wirfung für die Saffe treffen.

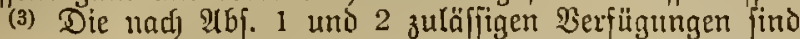

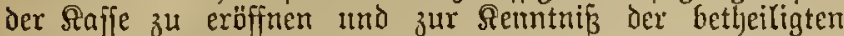
Berfidjerten zu bringen. Die Berfügung her Gäleren Ber= maltungsteljörde ift endgültig.

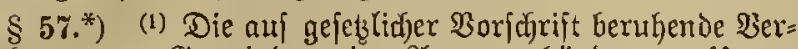
pflidjtung bon (Semeinten oder Trmenberbänben zur Unter= ftitbung hitf şbedüritiger \$erjonen, jomie dic a uf (Sejek, ${ }^{1}$ ) Bertrag oder lez̧tmilliger Anoromung beruhenden ?Injpriidye ber $\mathfrak{B e r}=$ jicherten gegen Dritte merden burdid diejes (Bejebs nicht berührt.

(2) Someit auf (Brund diefer Berpflidftung IInteritübungen jïr einen Beitraum geleijtet find, für weldjen dem Unter= jtüzten auf (Srund diejes (Sejebes ein lunterftübungsaniprud) zufteht, geht oer letztere im 3etrage der geleifteten linter= ftübung auf bie Biemeinde oder ben Irmenterband itber, bon roeldeen Die ltnterftüksung geleiftet ift.

(3) Das Sileidje gilt von den Betriebsunternelymern und Seffen, welde bie ben bezeidineten (5iemeinoen und Armen= berbänden obliegende Berpflidftung zur Unteritübung auf (Brund gefeblicher Borjdyrift eriült haben.

(4) Sit von der Semeinde=Sranfenberficherung oder von der Ortšsiranfenfajje Unteritübung in einem Siranfbeitsfalle geleijtet, für roldden Dem Berfict)erten ein gejebzlidjer (Fnt=

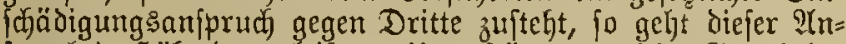
pruch in 5ूöhe ber geleifteten Unterftutyung an die (Sentcinte= Sranfenverfidjerung oder Die Ortš= Sranfentafje über.

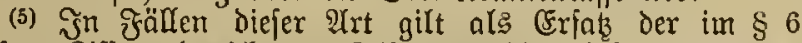
乡bj. 1 Ziff. 1 bezeichneten \&eiftungen die Sä̈lfte des gejeg= lidjen Mimdejtbetrages Des Siranfengeldes.

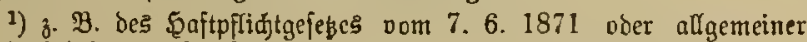

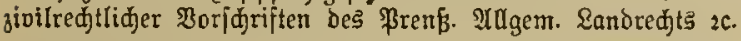

§57a.*) (1) 2uf (Erjordern einer Bemeinde= Siranfen= berficherung oder einer Orts= Sranfenfafje ift Den bei ihr

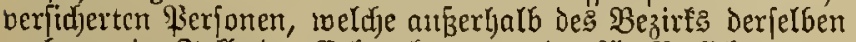
mohnen, in Falfe Der Erfranfung bon ber für Berficherung: pflidjtige dejielben Bemerbajtmeiges ober Derjelben Betriebs: art beftehendell Drt: =Siranfentafje oder in Ermangelung einer joldjen bon ber Bemeinde = Stranfenberfidjerung de? Wohnortes diefelbe linterftübung zu getwäl)ren, weldhe ber Erfranfte bon Der (Semeinde= Sirantenverfid)erung vder Drts= Sranfenfaffe, Der er angehört, 3 u beanfpruden lyat. Dicje baben der unterftützenden Drts=Srantenfajje oder (Semeinde= Aranfen= berficherung die bieraus ermadjenden Sojten zu erftatten.

(2) Daffelbe gilt jür Berfidjerte, meldje mährend eines porübergehenden Iufenthalts auB̉erhalb DeE Sezirts der (Siemeinde = Sranfenberfidjerung oder Sorts= Stranfenfaffe, der fie angebören, etfranfen, fofern oder folange ihre lleber= fï̈rung mad ihrem 230 hnorte nidjt erfolgen fann. Eines beionderen शntrages der (Bemeinde=Seranfenberficherung be= Darf $e^{3}$ in Diefen Füllen nidjt.

(3) Erfolgt die Erfranfung im Atuslande, fo hat ber Betriés eitte Ueberjührung in bas Эnland nicht exfolgen fann, bie= jenigen Unterftütżungen zu gemähren, meldje ber lekztere von ber Semeinde= Siranfenverfidherung Doer Der Drts= Aranten= Eaffe, ber er angehört, zu beanjprachen hat. Dieje bat dem Betriebsunternebmer die ifm hieraus ermachjenden sojten zu erftatter.

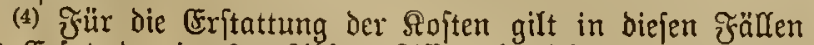
ats Criją der im $\$ 6$ 2tbi. 1 Biff. 1 bezeidnteten \&eiftungen die \$älfte bes §ranfengeldes.
$\S 57 \mathrm{~b}$. *) (1) Streitigfeiten zwifden (Şemeinde=Sranfen= verfidjerungen mo Drts=siranfenfaffen oder zwifthen Drts= Rranfenfajfen über die Jrage, weld)er bon iljnen die in einem Giemerbszmeige oder in einer Betriebsart oder in einem einzelnen Betriebe bejhäitigten \$erjonen angefören, merden bon der högeren Bermaltung sbehörde entfdieden.

(2) Begen bie (Entfheidung fteht den Betheiligten nur die Bejatwerde alt die Centralbehörde ju. Die B̧efanerde ift biunen 2 Wodjen nach) der Eröfinung der Entjdyeidung einzulegen.

(3) Frgeljt die Entidjeidung bahin, daß berfidjerung: pflichtige Fierjonet einer anderen Siaffe, als Derjenigen, bei tweldher fie bisher thatjäcjlich berfichert raren, anjugefjören haben, fo ift in Derjelben der Beitpunft zu beftimmen, mit

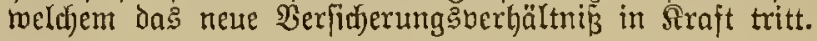

$\S 58 .^{*}$ ) (1) Streitigfeiten, welde 3twifden den auf (5irund biejes Befeses zu verficjertden Berjonen oder ifren Prbeitgebern cinerfeits und Der Semeinde= Aranfenberfict)erung oder der Drtg=Sranfenfajpe anderer\{eits ïber bas VBerfidje= rungšberbältnif ober ïber die Berpflifftung jur Leiftung oder Einzablung bon Cintrittsgeldern und Beiträgen oder ̈̈̈ber Unterftüßzungßanjprüdje entjtehen, jowie Streitigfeiten

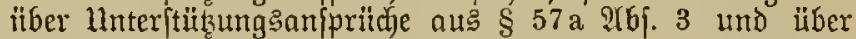

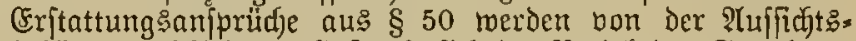

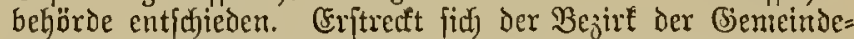
Sranfenberficferung oder der Srtes=Sranfenfafje ïber mehrere (Bemeindebezirfe, fo fann burd) die Bentralbejörde die (Ent= fdeidung anderen Behörden übertragen merden. Die Ent= Idjeibung fam binmen 4 Wodjen nadj Der 3njtelung ber.

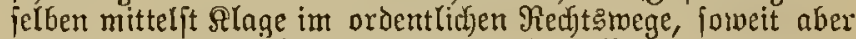
landesgejetich foldje Streitigfeiten dent Berwaltungsftreit= verfahren übermiejen find, im 2 ege des lekgteren angejorbten twerden.

(2) Streitigfeiten über dic im $\S 57$ भดj. 2 u. 3 bes zeid)meten P(njpribche, Streitigfeiten über critattungsanjprüche auร $\S 3 \mathrm{a} 2 \mathfrak{2}\{.4$, $\S 3 \mathrm{~b}$ und $57 \mathrm{a}$, ferner Streitigfeiten z'wifden (Bemeinde: §ranfenberfidjerungen und Rranfentaffen

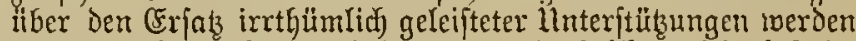
im Bermaltungsftreituerfahren, mo ein foldhes nidjt bejteht,

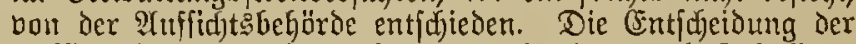
Auffidjt\&behörbe ${ }^{1}$ fann binnen 4 Wod)en nad) Buftellung

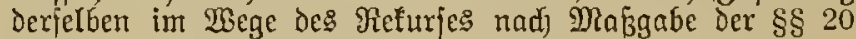
Into 21 der (Semerbeorinung angefodten merden. ${ }^{2}$ )

(3) (4) ....

1) welde "vorläufig oodftredbar" ift (§ 58 Ibf.4).

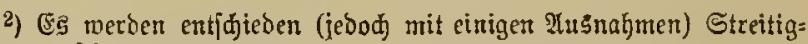
leiten a swijden:

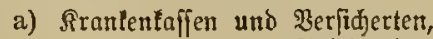
$\mathfrak{A}$ rbeitgebern (Utnternefmern)

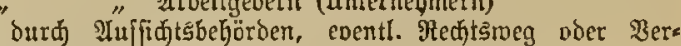

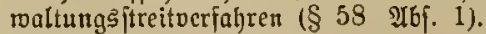

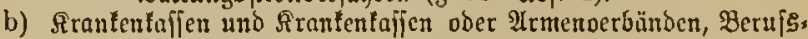
genofjenjdiaften :C.,

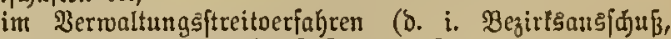
Oberverwaltungsgeridt) $§ 58$ $2 \mathfrak{b}$. 2 ;

c) SRranlenlaffen uno entfoubigungspflidtigen Dritten,

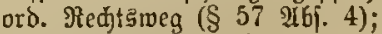

d) Arbeitgebert (Intermehmern), und \$erijierten,

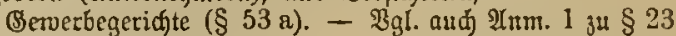
(B)B. (oben ङ. 122).

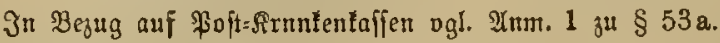

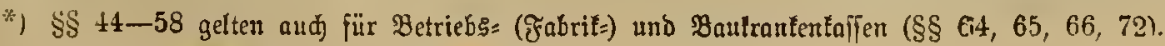




\section{E. Zֶetriebs- (đ̌abrik-) Stranfienfial/en.}

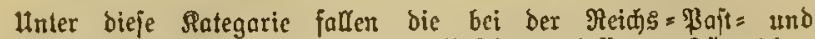
Telegraphenverwaltung eingeriateten \$ojttranlettlafien. ₹ür jeben OPDBejirl ift eine Salle unter ber Begeidsung:

\section{"Poft $=\Re$ ranfertafie für ben Bejirl ber Raijerl. Ober=\$ojtbireftion in NN"}

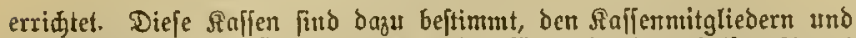

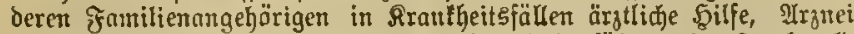
uno 5eitmittel, Frantengelber und bei Tobesfälen eil Sterbegelo nad) Ila gewähren.

§ 59. Irantentaffen, rocldje für einen ber im $\S 1$ be= zeidjeten Betriebe oder fïr mefrere diefer Betriebe gemein=

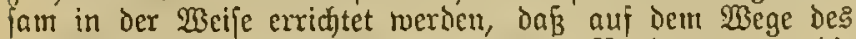

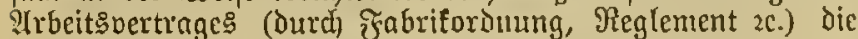
in bem Betriebe bejdjäftigten ßerjouen zum Beitritt ver= pflid)tet werden, unterliegen ben nadjolgenden Boridriften.

$\$ 60$. (1) (5in Unterneljmer, twela $)$ er in cinem Betriebe oder in mehreren Betrieben 50 oder juchr Dem Sranten= verficherungszmange unterliegende Perjonen bejajaftigt, ift bered)tigt, eine Betriebs= (

(2) (5x fann bazu Durd Inoronung ber föberen Ber=

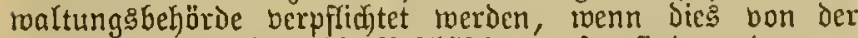
Gemeinde, in weldjer Die Befdäftigung ftattindet, oder bon Der Sironfentaffe, welcher bie bejajätigten \$erjonen ange= lören, beantragt wird. Bor Der Inorbunng ift Dem Unter=

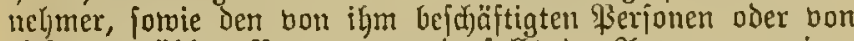
Diefen gewäblten Bertretern und, falls Der $\mathfrak{Y}$ ntrag bou einer Dits= Sranfenfaffe ausgegangen ift, aud ber Bimeinde z"t ciner Y्Aeußerung Darüber Belegentheit zu gebetl.

$\$$ 61. (1) Unternefmer einc: Betriebes, roeldjer für die barin bejääfigten \$erfonen mit befonderer frantheits= gejabr berbunden ilt, fönnen aud bann, wenn fie roeniger als 50 Perionen beföäftigen, zur (Erridjtung einer Betriebs: (jabrit $=$ ) Srantentajie angehalten werden.

(2) Unternebmern cines Betriebes, in weld)em weriger als 50 \$ierionen bejöäjtigt werden, fam die (5tridjtung einer Betricbs= (Fabrif $=$ ) Strantenfafie gejtattet merden, wenn die

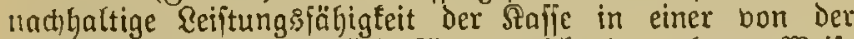
böberen Sertwaltungsibehörde für ausircidjend eradjteten Weije fidjergeftellt ift.

\$ 62. (1) Unternebmer, weldbe Der Berpflidytung, cine Bitriebs = (Fabrits) Srantenfaffe zu crridten, innerhalb dex

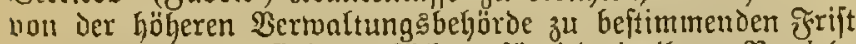
nidjt nachfommen, find berpflichtet, für jebe in ibrem Betriebe bejdäjtigte, Dem $\mathfrak{B e r f i c j e r u n g s ̧ j u n a g e ~ u n t e r l i e g e n d e ~ F e r j o n ~}$ Briträge bis zn $5 \%$ des berdienten Rohnes aus eiquenen. Dritteln zur Semeinde= frrantenberfidjerung oder zur Drts= Stantentajie zu leijten.

(2) Die Söhe Der zu leiftenden Beiträge mird nad̀) $\mathscr{X}$ = förung Der Semeindebebörde bon Der höberen Bertwaltung behörbe endgültig feftgejezt.

\$ 63. (1) Berjitherungsppfidytige \$erfonen, weldje in

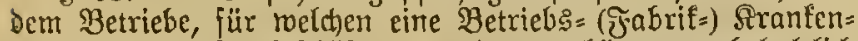
Eajie erridjtet ift, bejudütigt werden, gebören borbebaltich Det Beitimmungen Des $\$ 75$ mit Dem Iage bes Fintritts in die Bejdäftigung Der Safje als Mritglieber an.

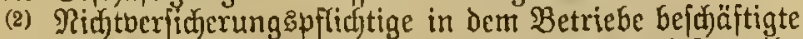
Berjonen haben Das Redjt, Der ßalje beizutreten, fojern ihr jährlidjes Sejammteintommen 2000 Dart nicht überiteigt.
Der Beitritt erfolat durdy fdriftlidje oder mïndlicije Inmel= Dung bei dem Saffenboritande, getoäbrt aber teinen S(njpruch auf Interftükung im ₹alle einer bereits zur Beit diefer Anmeloung cingetretenen Frtranfung.

(3) Die Saffe ift beredfigt, nidftberfid)erusgspflidftige Berjonen, meldje fid) zum Beitritt melden, einer ärztlichen Unterjudiung unterziehen zu lajien und ibre Aufnabme ab= zuleljuen, roen die Unterfudiung eine bereits befteljende Sirankeit ergiebt.

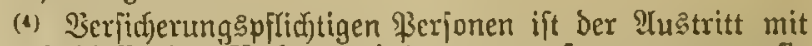
betit Schlufje des Recfuungsjahres zu geftatten, roenn fie denjelben mindeftens 3 Monate borher bei Dem Barftande beantragen und vor Dem Xustritt nadbiteifen, daß̄ fic

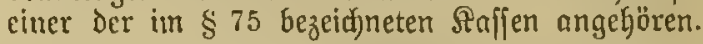

(5) Ridjtberfid)erungspfliçtige Berjonen, weldye die $\mathfrak{B e i}=$ träge an zroei aufeimanderfolgenden Bal)lungsterminen nicht geleiftet ljaben, fojeiden damit aus der Safje ans.

\$ 64. Die für Drtbs= Sranfenfajien geltenden Bejtim= mungen der $\S \S 20$ bis 42,46 bis $46 \mathrm{~b}, 48 \mathrm{a}$ und $49 \mathrm{a}$

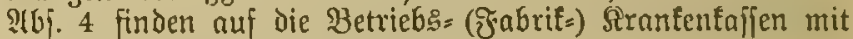
folgenden $\mathfrak{A b a ̈ u b e r u n g e n ~} \mathfrak{A n t w e n d u n g : ~}$

1. Das Sajpenitatut ( $\$ 23)$ ijt Durá) Den Betricbs: unternclimer in \$erion ober burdy einen Beauf= tragten madj Inbörung ber bejachätigten ßerjonen oder der bon denjelben geruählten Bertreter zu erriditen.

2. Durd) daక Rafienitatut tann Dem Betriebsunter. neljmer oder einem Bertreter deffelben Der Borfit3 im Borftande und in ber Beneraloerfammlung übertragen merden. ${ }^{1}$ )

3. Die Rechnungs: und Raffenfübrung ift unter $\mathfrak{B e r}=$ antwortlichfeit und auf Soiten Des Betriebs= unternebmers durch einen bon demielben $z u$ be: ftellenden Rechnung: und Raffenfübrer mahr = zunehmen. Bermenoungen bon Saffengeldern in den Ruben Der Betriebsunternebmer fallen unter

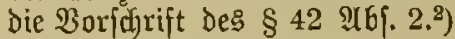

4. Reichen die $\mathfrak{B e}[$ tände einer auj Grund Der Doridyrift Des $\$ 61$ erriduteten Betriebs: ( nicht aus, um die laufenden 2 usgaben berfelben zu becten, fo find bon dem Betricbsunternelymer

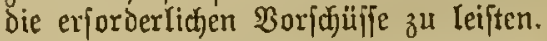

5. Dic aus dem Betriebe ausgejojiedenen ßerjonen,

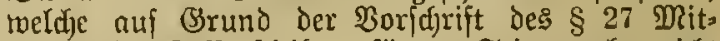
glicoer Der Safje bleiben, fönnen (timmred)te nicht ausitiben und Raffenämter niḑt bctleiden.

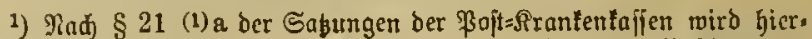
nad) ber Borfibende bes Raffenvorjandes von ber Ober=\$ajtoireltion crtannt.

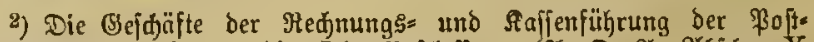

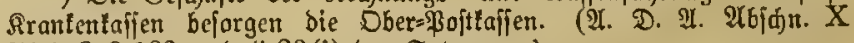
शtbth. $2 \S 102$ und $\$ 23(1)$ ber Saţungen.)

\$ 65. (1) Die Betriebsunternehmer find berpflichtet, Die ftatutenmäß̧igen Cintrittsgelder uno Beiträge für die von ifnen bejdöftigten berfidjerungşpflidjtigen Saffenmitglieber zu Den Durd) Das Raffenjtatut feftgejetzten Baflungsterminen

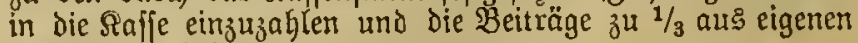
Mitteln zu Ieiften.

(2) Werden die geiezliuben Dindeftreijtungen ber sajje (\$ 20) Durd Die Beiträge, naçbcm diefe für Die Berficherten

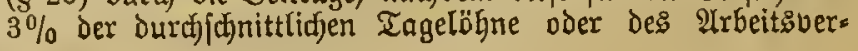


Dienjtes erreidyt habcr, nidft gedectt, fo hat der Betriebs: unternefmer die zur Dectung Derjelben erforberlichen Bujfjüjfe auษ eigenen MRitteln zu (eilten.')

(3) Die Bejtimmungen Des $\S 52$ 20j. 3 und der $\S \S 52 \mathrm{a}$ bis $53 \mathrm{a}, 54 \mathrm{a}$ bis 58 finden aut) auj Betriebs= (ร̌abrif=) Sranfenfafien entiprectende Inmendung.

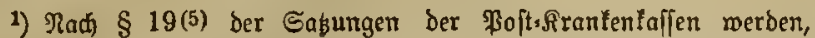

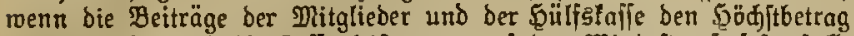
exreidt haber unb bie falfenleiftungen auf bas Mindeftmá fejtgejtellt finb, bie bann etra nod feḩlenden Beträge ber Saffe als aukerorbent= line Bufdüffe ber \$oltfalfe zugejührt.

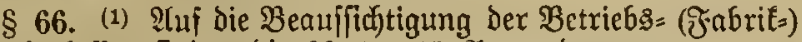
Sranfentaffen finden bie $\$ \S 44,45$ Anwendung.

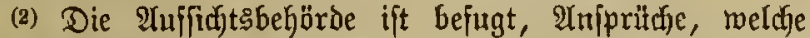

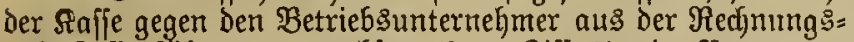
und §affenführung erwadjen (\$ 34 Ziff. 3), in Sertretung der Saffe entweder felbft oder durch einen bon ify zu bes ftelfenden Bertreter geltend zu madjen.

$\S 67$. (1) Wird der $\mathfrak{B e t r i e b}$ oder merden die Betriebe, für melche bie Safje erridjtet ift, zeitweilig eingejtellt oder

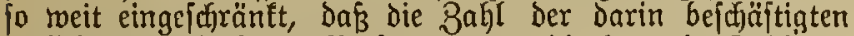
berfifjertungspflicfitigen ßerfonen unter die doppelte Zahl der itatutenmäßigen $\mathfrak{B}$ orftands mitglieder finft, fo tann bie $\mathfrak{B e r}=$ maltung bon Der Aluffichtabehörbe übernommen merben, meldhe biefelbe durd cinen von igr zu bejtellenden $\mathfrak{B}$ ertreter mahrzunehmen bat.

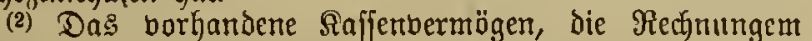
SBüher und fonjtigen 2 ftenjtüice der Rajfe fino in biejen, Jalle ber Iluffitftsbebörde auszuliefern.

(3) Borftebende Beftimmungen finden feine 2lntwendung, wenn bie zeitmeilige (Finftellung oder Finjohräntung eine Durth die alt bes Betriebes bedingte periodifd roieder= fefjrende $i \mathfrak{i t}$.

$\S 67$ a. (1) Siebt bon mehreren Betrieben eines Unter= nehmers, für welche eine gemeinfame Betriebs= (Jrabrif $=$ ) Sranfenfaffe bejteht, einer in Den $\mathfrak{B}$ ejits eines anderen Unternefmers über, jo fujeiden die in dicjem Betriebe be= idä̈ftigten \$erjonen auj den INntrag eines ber betheiligten Unternegmer aus ber Rajie aus.

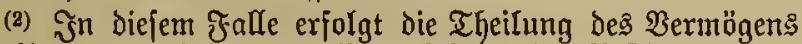
der bisher gemeinjamen safje nach folgenien Bejtimmungen:

1. Ergiebt fich nac) Beriditigung Der etwa borhandenen Sajulden und Dectung ber bor dem Beitpunfte bes

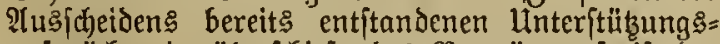
anjprüd) cin überjujésendes Bermönen, jo ift Der Theil defielben, meldfer dem Berhältnifs der Babl Der 2 uEjcheidenden zur (scjammtzaht Der bisherigen Rafjenmitglieber entfpricjt, Derjenigen Rrantenfaffe zu übermeijen, swelther die in Dem ausfdfeidenden Betriebe bejoäftigten ßerjonen fortan anjugelören haben.

2. (Ergiebt fidf ein Feblbetrag, fo ift derielbe, falls Der Tntrag bon bem Unternebmer des ausfúfeiden= Den Betriebes geftellt roorden ift, bon diejem in Dem. unter Biffer 1 feitgejęzten Berhältniß̄ zu becfer.

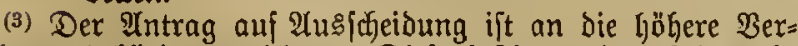
raltunggbeförde zu riaten. Dieje bejtimmt ben Beitpuntt,

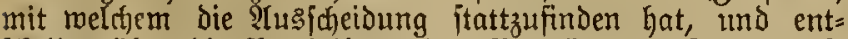
icjeibet iiber bie Bertheilung dez Bermb̈gens. (Begen dieje Entidyeidung itefyt den Betheiligten binnen 2 20od)en die Bejabrerde an die Zeutralbejörbe zu.
§ 67b. Bei Beränderungen in Der Drganifation einer öffentliden Betriebsberwaltung fann auf Deren Untrag bie

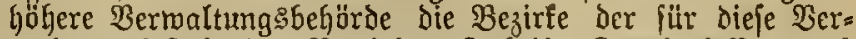
maltung beftefenden Betriebs= (Ĵbbrif $=$ Stranfenfaffen nad) Infjörung der Rafienorgane andermeit Feftietzen. Dabei finden die Boridfriften des $\S 67$ a $\mathfrak{Y G} 6$. 2 und 3 entiprechende Intoendung.

\$ 67c. (1) Mebrere Betriebs = (Fabrit=) Siranfentaffen fiir Betriebe Defielben IItuternehmers fönnen mit 3 ujtimmung ifrer Beneralverjammlungen zu einer Siajle bereinigt werden.

(2) Die Bereinigung erfolgt Durdj Erridjtuttg eines Raffenjtatuts für bie vereinigte Safie nadj $20 x$ rithrift des

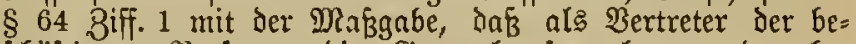
jdäftigten ßerjonen die Sieneralverjammlungen ber $b e=$ ftehenten Saffen gelten.

(3) Mit Dem Beitpunte, zu weldjem die bereinigte Raffe ins Reben tritt, gehen auf biejelbe alle Rechte und Ber= Gindrichfeiten ber bisherigen Љaffen über.

$\S$ 68. (1) Die Saffe ift zu frjliegen:

1. menn der Betrieb oder die Betriebe, für welcje fic errichtet ijt, aujgelöft merden;

2. Tomeit nidjt auf den Betrieb, für weldfen die Raffe

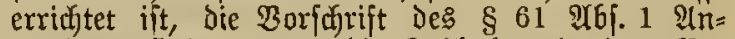
menoung findet, wenn die 8 ahl der in Dem $B E e=$ triebe bejüäjtigten verficherung gpftidjtigen ßerjonen Dauernd unter bie gefeblicke Mindeitzahl (\$60) fintt und bie dauternde \&eijtungsjähigteit der Saffe nicht genügend jibjergeitellt wird ( 61 2)6j. 2);

3. menn der Betricbsunternchmer es unterläßät, für

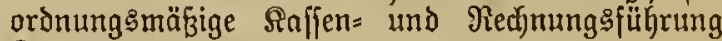
Sorge zu trager.

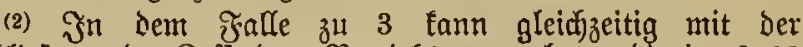
Sthlięung Der fiajpe Dem Betriebsunternehmer Die im $\$ 62$ vorgefehene Berpflidftung nujerlegt und die (Erridjtung einer

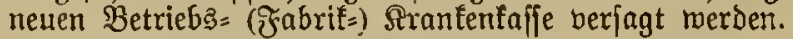

(3) Die Rafie fann nad) INfjörung Der betheiligten (Se= meinden aufgclöit merden, wenn Der Betriebsunternehner unter Buftimmung Der Beneralberfammlung bie \&uflöjung beantragt.

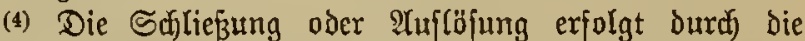
höhere $\mathfrak{B e r m a I t u n g} g$ behörbe. (Segen Den biejelbe ausppredjen= ben oder ablebmenden Bepdjeid, in weldjem die Bründe $\mathfrak{m}=$ zugeben find, fam Ginnen 2 Wothen nadi) ber Buftellumg Bejufficerde an die vorgejeste Beförde erhoben twerden.

(5) $\mathfrak{A} u$ bas $\mathfrak{B e r m o ̈ g e n ~ d e r ~ g e i d j l o f f e n e n ~ o d e r ~ a u f g e l o ̈ f t e n ~}$

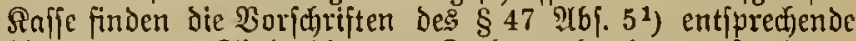
Unmendung. Sind die zur Decfung bereits entftandener

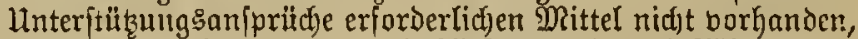

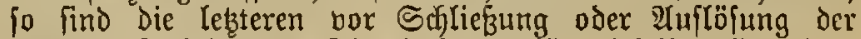
Rafie aufabringen. Die \$laftung für biefelben liegt bem Betriebsunternehmer of.

1) Derfelbe lautet:

"Dą etroa vorhanbente Bermögen ber Fafie ifit in biefem

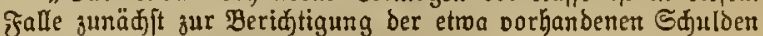
unb zur Deffung ber vor ber Sdliebung ofer Inlläjung be reits entitanbenen $11 n t e r i$ ï̈surgsariprïd) zu vermenden. Der ßeft fäßt Denjenigen Drts-Srarfenfajien, forvie ber Bemeinte=

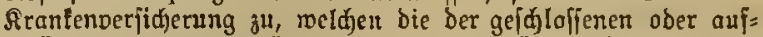
gelọ̈ten Rafie angehörenden ßerfonen überwiejen merbet.

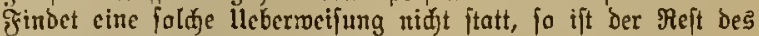
Dermögets is ber bett bigherigen Bmed am meiften ents pprefjenden Beije zu Derwenden." 


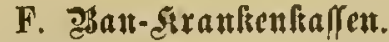

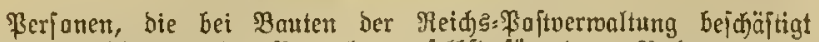

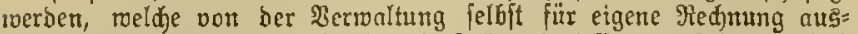
geführt rocrben, werben bei ben \$ofto 8 rantentafien verfibert. (\$2 TLFF. IV ber Sał̧ungen).

$\S 69$. Fü dic bei (Eijenbafn=, Ranal=, Weges, Strom=, Deid $=$ und Feftungsbauten, jowic in anderen borubergeben= Den Baubetrieber bejuäftigten Berjonen haben die Bau= herren auf 2Lnoronung Der höheren Berwaltungşbeförbe Bau=Sranfentafien ju cridjten, wenn fie zeitweilig cine gröbere 3 ahl bon ?(ibeitern beịhäftigen.

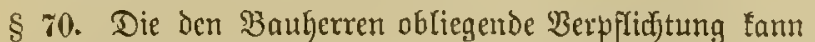
mit (3eneljmigung ber böheren Berwaltungsbefjorbe auf cinen oder mehrere llnternehmer, toclde die ILtoführung bes Baues oder eines Theiles deffelben fï eigene Rectinung ïbernoumen haben, übertragen merben, menn diejelben jür die (Erfitlung der Berpflidtung cite nad) Dent Urtheil ber höljeren $\mathfrak{B} e r$ toltungşbehörde ausiscidjende Sidjerheit bejtellen.

\$ 71. SBaulerren, weldye Dex ihnen nadj $\$ 69$ auf= erlegten Berpflidtung nicht radffontulen, haben den bon iljnen bejdfäftigten \$erjonen für Den Jall einer Sirantheit

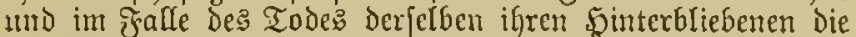
im $\S 20$ vorgejdricbenen Lnterftübungen aus eigenen MitteIn ju leiften.

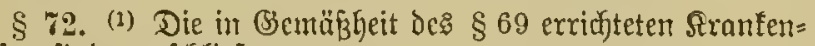
fajjen fint zu fidfliç̧en:

1. menn Der Betrieb, filr weldjen fie errifjet find, aufgelöft wiro;

2. menn Der $\mathfrak{B a u h e r r}$ oder Unternefmer es unterläßt,

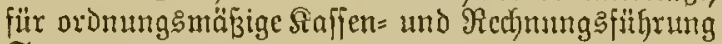
Sorge zu tragen.

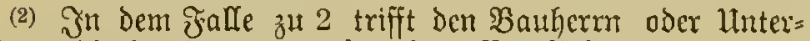
nchmer bic im $\$ 71$ ausigefprodjene Derpflidjtung.

(3) Jm ltebrigen finten anf Die in (Semäßheit ocs $\$ 69$

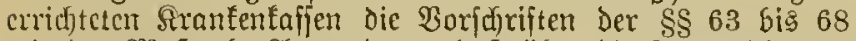

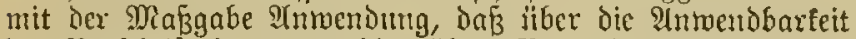
ber Borjurift des \& 32 bic höhere Bermaltung\$behöroe bei (Senclynigung des Siafienitatuts,

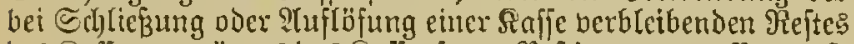

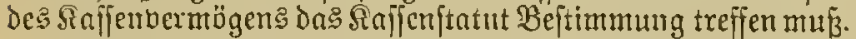

(4) Cine Berwendung ju Bumften des Banferm vier Ilnternehmers ift ausgejulojien.

?Iuf Streitigfeiten ïber Unterftütżnngs̊anjprüudje, meldde alif (Srund bes \& 71 gegen Den Baulerrn erhoben merden, findet die Vorichrift des $\$ 58$ शโb 1 Antendung; auf Streitigfeiten über Erfataniprïtche, weld)e auj Grumo Des $\S 71$ und Des \& 57 2[6\%. 2 gegen Den Bauherrn erfoben

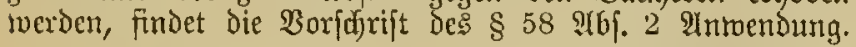

\section{H. इ̇erfälfnif (oer sinappldiaftsliaffen und)

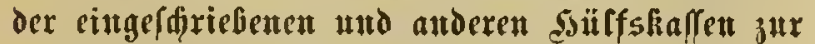 Siranfenverfidierang.}

§ 75. (1) Mitglicier der auf Brrund ics Befetzes über

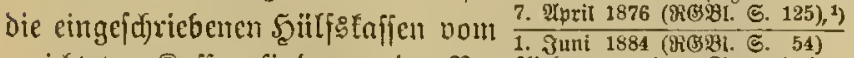

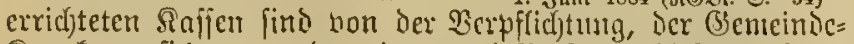

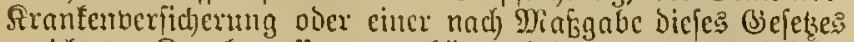
erridyteten Sranfentafje anzugchören, befreit, wenn Die \$ö̈lfs=
Eafie, weldyer fie angeljören, allen ihren verficherungspflichtigen Mitgliebern oder Dod) derjenigen Mitgliederflafie, zu tweldier der Эerfidferungspflidjtige gefört, im \$ranfheitsfalle mindeftens

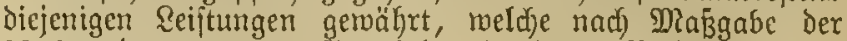
$\S \S 6$ und 7 von Der Senteinde, in beren Bezirt Der $\mathfrak{B e r}=$ fidferungspflidytige bejdäftigt ift, zu getwähren find. Die durch) Saffenftatut begründeten Bejd)rünfungen ber unter= itiikungganjpridd)e fduliegen bie Befreiung nidjt aus, twenn

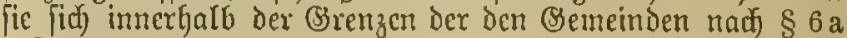
geftatteten Be[d]räufungen balten.

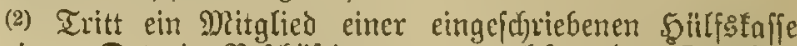
an cinem Drte in Bcjubäftigung, an reIdjem Das Rranfen= geld der Mitglieberflafie, der es bisher angehörte, finter bem bon Der Ģemeinde=Sranfenberficherung zu getrährenden Srantengelde zuritéblcibt, fo gilt bie Befreiung nodf fitr bie Dauer von 2 Modjen. Die Meldepflid)t bes 2rrbeitgeber:

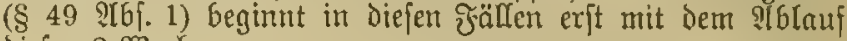
Diefer 2 Wonten.

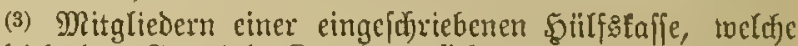
3uglcid) de: (Semcinde=Sirantenverfidjerung oder einer auf Grund dicjes (Siefetzes erriffteten Sranfentafje angehören, fanut an Stelle ber freien ärzttidjen Beljandlung und $\mathfrak{A}$ rznei

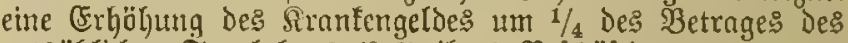
ortsibblichen Sagclobnes (§ \&) ifres Befüftigungsortes ge= mährt twerden.

(4) Die vorjtehenden Bejtimmungen finden auch auf Mitglieder foldjer auj (Brund landesrecthtlidjer $\mathfrak{B}$ orjoriften

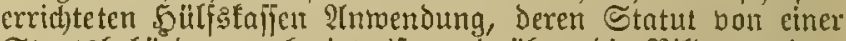
Staatsbeljörde genehmigt ift und über die Bildung cires Rejerbefonds Den $\S \S 32,33$ entfprechende Beftimmungen enthält.

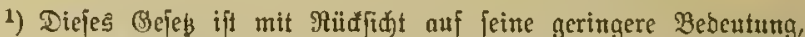
bie es nach (Eitrïhrung des Rrantenderjiderungs fronnges bat, nidt

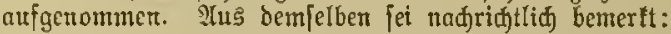

Safjer, weldic bie gegenjeitige linterftübung ifrer Mitglieber für

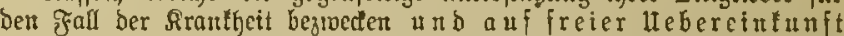
beruhen, erbalten bie Rechte einer eingejdriebenten Süljataffe. Die Raffe hat einen bejtimmten গamen anjunehmen mit ber zufäblidien

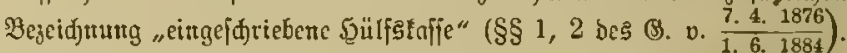
Э̧hre innere (Fintifitung wirb burd) ein Statut geregelt, weldhes ber Beftätigung burd) bie hähere Berwaltumg §behärbe unterliegt. Die Rafie wiro mit Rorporationsredten ansgeflattet. Bgl. bie folgenben $\S \S 75$ a $14.75 \mathrm{~b}$.

§ 75a. (1) Den eingefudriebenen Sülfsłafien, fowie ben

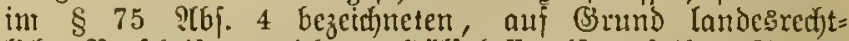

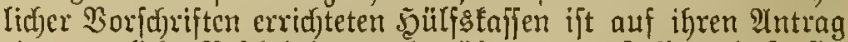
cine amtlidje Bcjdjeinigung barüber auşzujtelen, Da $\bar{B}$ jie,

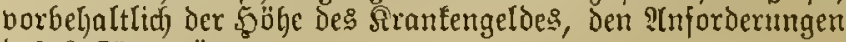
bes § 75 genitgen.

(8) Die Bejucinigung wird ausgeftellt:

1. fïr Sajien, Deren $\$ 3$ zzirf über die Brenzen cines Bumbesitaates nidft hinausieidft, bon ber Bentral= beljörie,

2. fïr Rafjen, Deren Bezirf Ḧber die Brenzen cintes Bunicsftaates Ginansreidyt, bon Dent Reidfsfanzler.

(3) Mirb die $\mathfrak{B} e j$ jeinigung berfagt, fo fino bie Bründe mitzutheilen.

(4) Tritt in Dem Statut ber Raffe eine Menderung ein,

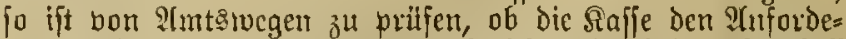

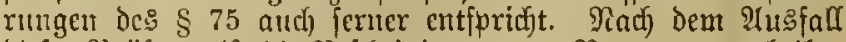

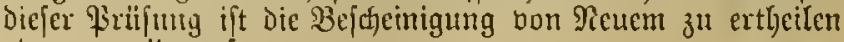
oder zu widerufen. 
(5) Die Befdjeinigung und beren Widerruf find in bem Falle zu 1 burd) Das für bie amtlid)en Bctanntmachungen ber Bentralbeförde beftimmte Blatt, in ben Falle zll 2 Duref) den Reidf

§ $75 \mathrm{~b}$. (1) Bei Streitigfeiten über Die Bejreiung eines Mitgliedes ciner Şülfstaffe vou der Berpflicftung, einer Bsemeinde=Srantenverfidjerung ober einer auf Sruno biefes Befebes errifjteten Sranfenfaffe anzugehören, ift fïr bie

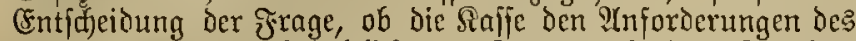
§ 75 genitgt, vorbehaltlich Der Frage, ob Das firanfens

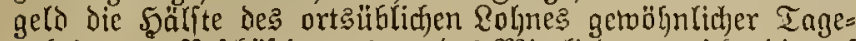
arbeiter am Bejujäftigungsonte bes Mitglicoes erreidjt, bie auf Grund dcs $\$ 75$ a ausgeftelfte Befdeinigung majgebend.

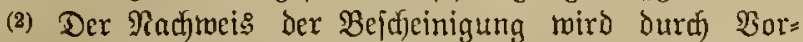
legung cines Eremplars des Saffenftatuts gefithrt, in weldhem Das die Befanntmadjung enthaltende Blatt nadf Sahrgaug, Nummer und Seitenzahl angegeben ijt.

§ 76. Die Beftimmungen Der $\S \S 57$ und 58 श็f. 2

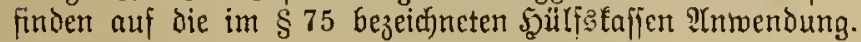

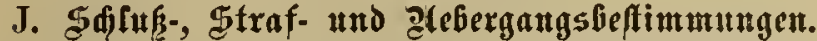

§ 76a. (1) Die Serwaltungen ber Bemeinde= Sranfen= berficterung, fowie bie Barftände Der frantentafien und Der im $\$ 75$ bezcicjneten Şülfätafien find berpflichtet, Den $\mathfrak{B} e=$ Görden bon Gemeinden und Armenverbänden, iwelche auf Srumd der ifnen obliegenden gejestidfen Serpflichtung zur

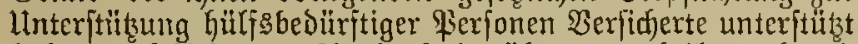
haben, auf Erfordern श̂sfunft Darïber zu ertheilen, ob und in roeld)em ltmfange biefen \$erjonen gegen fie llnterftübunggs: anfprüb)e auf (Srumb diefes Gejetres zujtehen.

(2) Die Berwaltungen Der (Bemeinde= Srantenverficherung, forvic dic Borftände der Sirantentafien und Der im $\$ 75$ be= zeidfneten Sülfsfonjen jumb ferner berpflidftet, Den auf Grund Der Unfallberficherunggefeze beftehenden Berufsgenoffen= fdaften, forie den auf Grund des Gefekses, betreffeno die

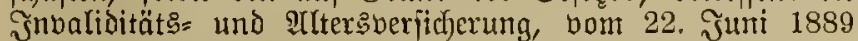

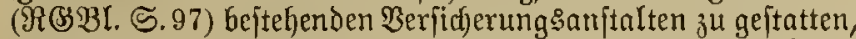
zum Zwed Der Ermittelıng Der von ihren Meitgliedern bejw.

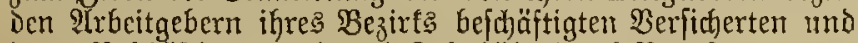
Deren Befajätigungazzeit und \&ohnhöhe Durd) Benuftragte bon den Bütjern und Siften dex Safje in Deren (Sejejäftgräunten mährend der (Sejc)äftşftunden (Eimficht ăll rehmen.

(3) Die Mitglieder Dex Berwaltungen Dex Bemeindes Sranfenverficjerung und ber faffenvoritände tömnen jur Erfüllung der ifnen durd) borjtebende Bejtimmungen anf= erlegten Berpflidjtungen von Der 2uffichtebebörde burd Geldftrafen bis zu 20 Marf angehalten werben.

§ 76b. (1) Die Bermaltungen Der (Bemeinde= @ranten= berficjerung, fomie bie Boritc̈nde ber Rrantentaffen und der im $\$ 75$ bezeidfneten Şülfstaffen find berpflicjtet, jeden (Erfranfungsfall, weld)er Durd) einen nad) Den Llnjal= verfifjerungsgefcken zu entfoübigenden unfalf herbeigefïhrt ift, fojern mit Dem 2 blauf der vierten $\mathfrak{B}$ odje der Srantlycit die Ermerbsfähigfeit des (Erfranften nod) nid)t miederfergeftelt ift, binnen einer Wodhe nad) Diefem Beitpunfte Dem Borjtande der Berufs̈genofijenffjajt, bei weldjer der Ertrantte gegen llnfall berfidjert ift, anzuzeigen. Šit die Bernjggenoffen= fdjuft in Seftionen getheilt, 10 ift bic 2tuzeige an ben Seftionsworftuno zu riditen. Bur Eritattung ber IInjeige ift, fofern Der Siorftand Der Bemeinde oder Der Sranfentafife nicft eine andere Berjon Damit beaujtragt, der Redfmungs= füfrer, für örtlidfe Bermaltungsjtellen der eingefdriebenen Şülfsfaffen basjentge Ditglied, welches bie Rechnung: gefçäfte derfelben fithrt, verpflid)tet.

(2) Die Unterlaffung der $2 \mathfrak{n}$ zeige fann bon Der Stufficht: $=$ beljörde mit Dromungeftrafe bis zu 20 Mark geabndet merben.

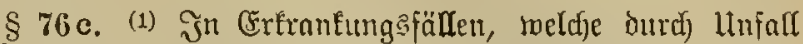
herbeigefiihnt merben, ift die B̈ernfägenojienfudaft berechtigt, Das Seilverfabren auf ibre fioften zn itbernehmen. Som Tage Der llebernahme an Gig jur Beendigung ies Seit= berfalreng oder bis zum ?tblauf Der 13. Wod)e nadf Begim

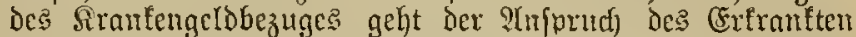
anf Rrantengeld auf bie Bernfsgenojienfethajt liber. Auj Dieje gehen Dagegen für denfelben 3eitraum alle $\mathfrak{B e r}=$ pflidftumgen über, weldje ber Srantenfaffe bem Erfranften gegentiter obriegetr.

(2) Streitigfeiten auŁ Diejent $\mathfrak{B e r h a ̈ l t n i f ̧ ~ m e r d e n , ~ f o w e i t ~}$

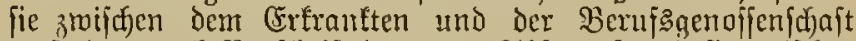

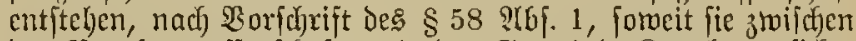
Det Berufägenoffenfdjaft und Der (S)eneinde= Rranfenberfidje=

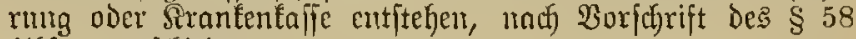
:K5. 2 entfohieden.

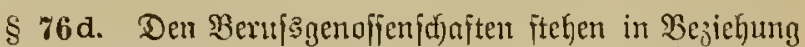
anf Dic Ynmentung Der $\$ \S 76 \mathrm{a}, 76 \mathrm{~b}, 76 \mathrm{c}$ Das Reicf, bie Staaten Imb biejenigen Berbände gleich, meldje madf den Beftimmunger der linfalverfiderungsgefebe an die Stelle Der Berufägenofienidjaften treten.

\$ \%6e. (1) Gegen die Strafuerfitgutugen, melche attf

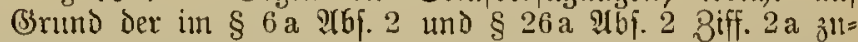
gelaffenen Beftimmtungen getroffen worden jino, ift bimmen

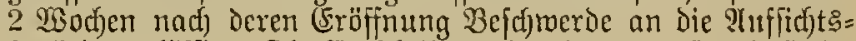

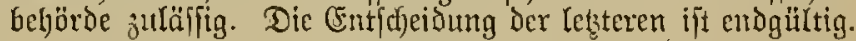

(2) Begen die anf (Srumb der $\S \S 76 \mathrm{a}$ und $76 \mathrm{~b}$ ge= troffenen ङ大trajberfügungen ift bimmen 2 20 odfen nack Deren Fröffnung Befdymeroe an die nädjft borgejetzte Bebörde ju= läfifig. Die Entfdyeioung der leţteren ift endgültig.

§ 77. Die auf (Srund diefes Sefełzes gemälntent Reiftunget, fotvie die Unter(t)̈̈ţungen, weldfe nad) Maşgabe des $\S 57$ গtb 2 und 3 exfelit find, gelten nid)t als öffent= licke 9 (rmenunterftït女̧ungen.

§ 78. (1) Die auf (Srumo diejes befelzes berficherten Perfonen find in Streitigfeiten über Unterftüşungsanfprïcje

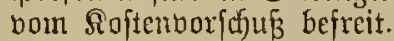

(2) :Itmtlicje Befojeinigungen, weldfe zur Regitination

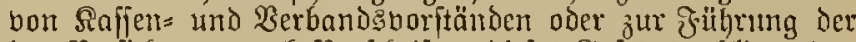
den Berjidferten nad) Borfdyriften diejes (Befetzes obliegenden श्adfweife erforderlief werden, find gebühren= und ftempel= [rei. $\left.{ }^{1}\right)$

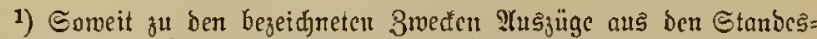
amtsregiftern crforberlid) fint, werbon folde zur Berminderung bes

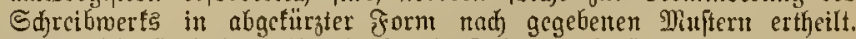

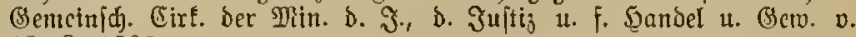
18. 8.1893.

§ 78a cuthält Borfdriften über bie Bercdunung ocr int bicfem

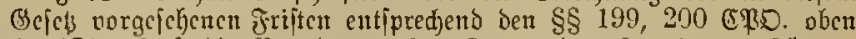

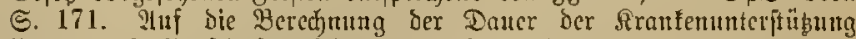
finden bicj: Yoridriften jebod) feine Inwertoung.

\$ 79. Dic Jriften und Formulare fïr die in Den $\S \S 9,+1$ borgejdriebenen Hebcrfidten und Rectnung 
abfdiliffe merden nom Bundesrath ieitgeitcllt. Mindejtents von 5 zu 5 Jafren findet cine cinljeitlidje 8 ufanmenftelung

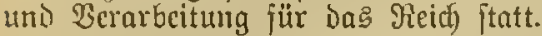

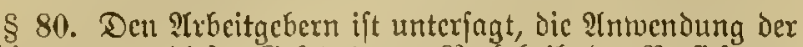
Beftimmungen Diefeg (Bejebes zum Raditheile der Berfidjerten inuch Berträge (nittelft Beglements ober bejonderer leber:

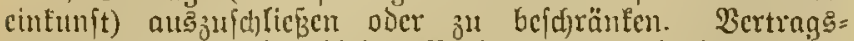
beftinmunget, meldie bicicm Berbote zutwiberlaufen, habeu feine redflidic Wirfing.

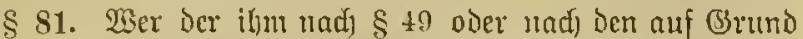

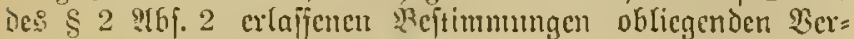

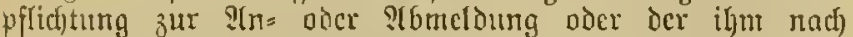
$\$ 49$ a obliegenden $9(n z c i g e p f(i d) t$ nid)t nadjfommt, wird mit (S)loftrafe bis zu 20 MRart bejtraft.

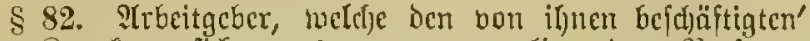
Den Sranfenverficherungszivange nterliegenden Perfonen bei der Rolnzahlumg borfäblid bölere als bic nad

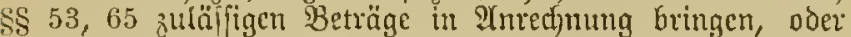

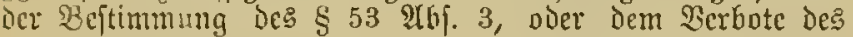
\$ 80 crtgegentjandeln, werben, fofern ricfit nad) anderen gefestidjen $\mathfrak{B}$ eftimmungen eine bärtere Strafe eintritt, mit (s)loftrafe bis ju 300 syarf oder mit Saft beftraft.

\$ 82a. (1) Die 2trbeitgeber find befugt, bie Erfüllung Der ifuen Durd) bicies Befetz auferlegten Berpflidjtumgen foldjen fierfonen ju übertragen, sweldje fic zur Reitung ilgres Setriebes oder cimes Theiles Deffelben oder jur Beauffidyti= gung beftellt bahen.

(2) Gint bic in bicfent (3ejebe gegebenen Borfdriften son jolchen Perfonen ïbertreten morocn, fo trifft die Strafe die Ictzteren. Der 12 beitgeber ijt neben Denfelben itrafbar, swent Die Buviderhandung mit feinent Sormijen begangen ift, ober menr er bei der nadi ben Verbältniffen möglidjen

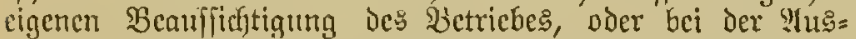

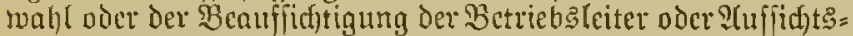
Herponen es an ber erforburlidyen Sorgfalt bat feljlen laffen.

(3) Für Den Eritattungsanjprusf auङ \$ 50 【jaftet neben Dent jur \$Immeloung etma verpflidfteten Betriefsleiter oder 2ufjeher in aller f̧ăllen aud der Irbeitgeber. Mehrere Berpflid)tete Gaften dabei als (Sejammtjufuraner.

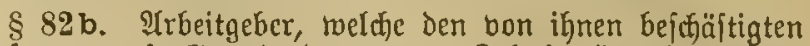
Berfonen auf (Srund des $\S 53$ \&ohnbetröge in 2tbzug fringen, diefe Beträge aber in Der $\mathscr{A} b j i d f t$, fid oder einem

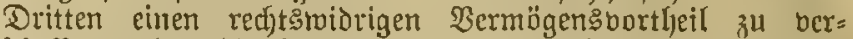
fdjaffen, oder die beredjtigte Bemeinde=Siranfenverficherung odcr Rranfenfaffe zu füäoigen, Den Iekteren borentbalten,

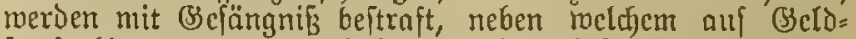
frrafe bis zu 3000 Marf, fowie attf Berlufit der bürgerlidjen (E) Grenred)te erfannt rocrden fann. Sind mildermoe lumitände vorljanden, fo fann ausfjblieslich auf Beldjtraje erfannt merden.

$\S 82 c$, Die auf (Brund der $\S \S 81,82,82$ a berljämgten (B) cloftrafen flicken Derjenigen Srts=, Betriebs: (F̧abrits),

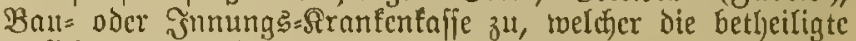
ucrfidherumgspflidtige Ficron angehört, in Frmangelung ciner foldhen Saffe der (Semeinde= Srnmfenverfidjerung.

§ 84. (1) Die Beftimmung Darüber, melche Behörden in jedem $B$ undeşftate unter Ssemeindebehörde, höhere $\mathfrak{B e r}=$

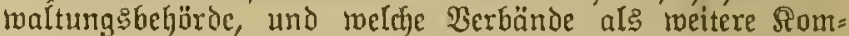
munaloerbände im Sinne diejes (Gejełzes zu berftefen find, bleibt den Randeŝregicrustgen mit der $\mathfrak{P a B g} g a b e$ überlaffen,

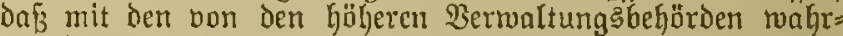
zแnehmendon (Bejdäften diejenigen höheren Bermaltungss beljördell zu betrauen find, weldic nadj Randesired)t die Puffictit odcr Dberaufficht in (Bemeindeangelegentheiter waht: 3urfymen haben.

(2) Die auf (Srund diefer Borfdrift erlaffenen Be= jitimmungen find befarnt zu machen.

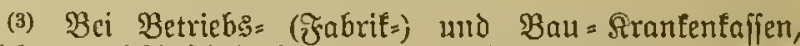

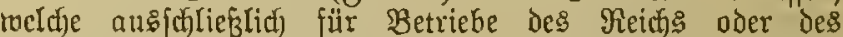
Staates crridutet rocrden, fönnch die Befugniffe und $\mathfrak{D b}=$

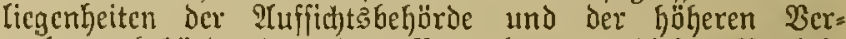
waltungsfebörde den den Berwaltungen diejer Betriebe vorgejetzten Dienftbehörden übertragen werden.

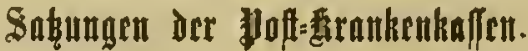

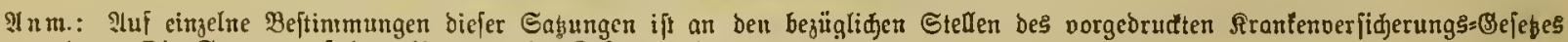
hingeriefer worben. Die Sabungen folgen hier now in Bujammenhange.

3nhaltäslleberifint.

Rame, Sib und Bwoef Der Raffe.

Berpflidtung und Berechtiaung zum Beitritt

Begirm uno Dauter ber Ditgliedjळaft

Eimalynen Der Riffe.

Fintrittsgelo

Sauferbe Beiträge ber Mitglieber umb ber ßoftfaffe

Pefervefonds.

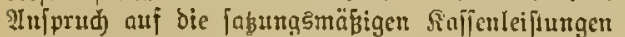

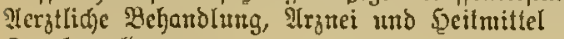

Srantenaclo

Rrantenthatspiflege.

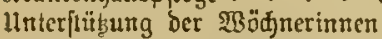

Sterbcgeld

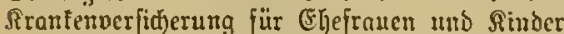

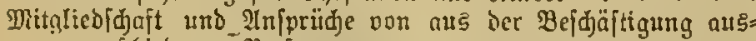
aciofiednen Perjonen

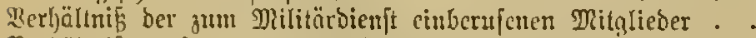

Berbältniß zur Irmenpflege und zu (Frjaganjprüd)en geget Dritte

Bortedte ber forberungen auf bie Rajlenleifungen.

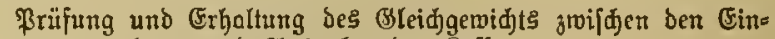
nahmen und Itusgaben ber Raffe

Bermaltung ber Raffenangelegenheiten

3ufommenjetsung und Bahl des Baritandes

Berjammlungen und Befugniffe bes Borftandes

Red)rungs: und Raffenführung.

3erhandlungen und \$efugnifie ber Gererolnerfammlung

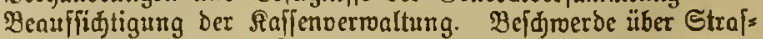
verfügungen. Streitigteiten

Ybänderurg ber Sabungen .. . . . . . . . . . \$27

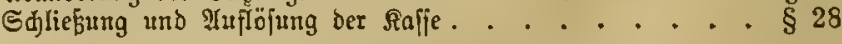

\section{Rame, Sttz und Broef der Stafie.}

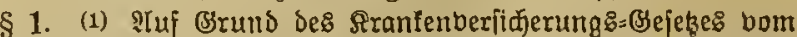

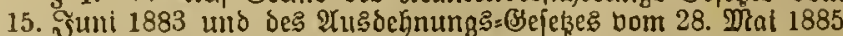

bejteht für ben Bezirf der Raiferlidjen Dber=\$3ojtolreltion in - i) eine Sranfenfafic, roldje ben Tamen Dber=\$ojtsireftion in ......1)
"Hojt = Sranfenfaffe für ben Bezht ber Satierlldent 


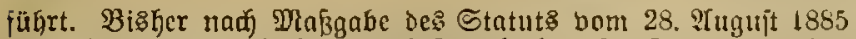
bermaltet, nimmit biefelbe auf Grund ber $\$ \S 23,36,6 \frac{1}{6}$ ber

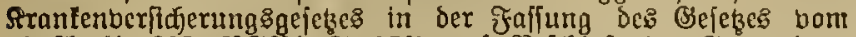

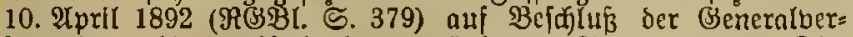
fanmlung die nadjitchenden beränderten Gałzungen au. Dic: jelben treten bom 1. Jauluar 1893 ab in Srajt.

(2) Dle Saffe hat ifren Sitz in .......

(3) Dlefeibe tann Inter ibrem Ramen Red)te ermerben uno Berblndlidjeiten eingefen, bor Gertat flagen mins bertlagt rerbelt.

(4) Fiir alle Derbindlid)leiten ber Saffe hajtet ben Saffen= glăublgern nur ఏas Bermögen ber Saffe.

(5) Die Saffe lit beftimunt, ben Saffenmitgliedern in Sirant=

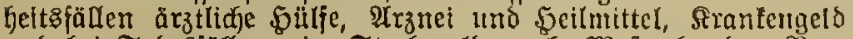

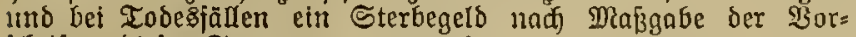
jajriften biefer Sakzungen zu gemähren.

(6) Dle Mitglieber finto oer Raffe gegentiber ledigliff zu ben

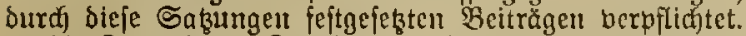

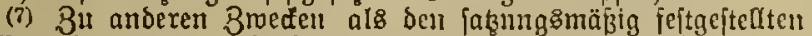

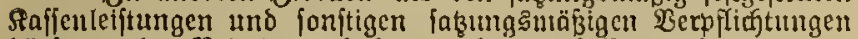

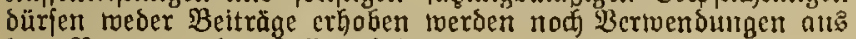
bem Bermögen ber §affe exjolgen.

1) Sib ber betreffender Dher=\$oftoireltion.

Berpfltchtung uð Bered)tigung zum Beltritt.

§ 2. (1) Bum Beltritt berpf(id) tet $t^{1}$ ) find alle im Dienjte ber Reld $5=\ngtr$ o[t $=$ und Ielegraphenbermaltung bei ber Saiferlidjen Dber $=$ Foftoireltion in .....2) ober einer berjelfen nadige= oroneten Dienjtitelle gegen (Bchalt oder $20 b n$ bcjdjäitigten $\mathfrak{B} e=$ amten, Unterbeamten und Irbeiter, fojern fie nicht nach bent folgenoen Beftimmungen zum Beitritt mur beredjtigt ober bon ber $\mathfrak{B e r j i d j e r u n g ~ a u s g e j d ) l o f i e n ~ f i n d . ~}$

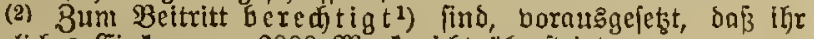
iăhrlidjes (Finfommen 2000 Darf nidjt überiteigt,

a) Diejenigen Ferfonen, deren Befdjäftigung burd ble গatur ifres (Gegenitandes odcr im Boralis burch bcn Arbelt8bertrag auf eimen Beitraun bon weulger als einer Wodje befajränft $l f t$,

b) alle ßerjonen, Denen In Rranfheitsfällen die Dieujt= bezüge beitlmmutng mäsig mindeftens für 13 खadjen fortgemäfrt merben,

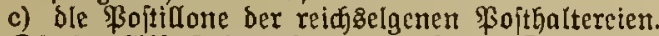

(3) Die im $\mathfrak{A}$ f. 2 bezeldueten Ferfonen fins bon ber $\mathfrak{B e r}=$

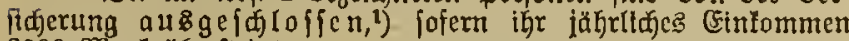
2000 Marf überiteigt.

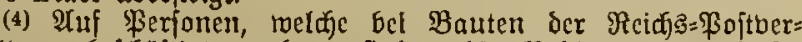
maltung bejäaftigt werden, finden ble Beftimmungen bicfer Sazzungen nur fomelt Ynmenoung, ais diefe Bauten bon ber

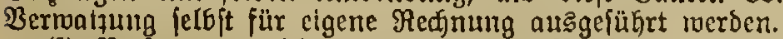

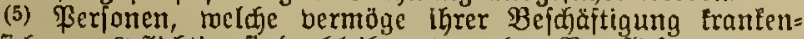
berfidjrungspflichtig find, bleiben bon ber Bervflidung 3un

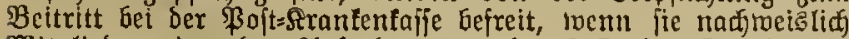
Mitglieder ciner ben Unforderungen bes $\$ 75$ bes Sirantenber: ficjerungsgejeses genügenden Đülistajle fiuto. Sat ch foldjes

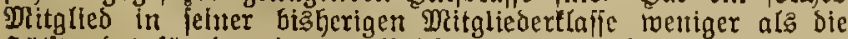
\$älfte des für ben jeşlger Bejajäftigung ort fejtgejesten orţ: üblidjen Iagelobns gewöhnlider Tagearbeiter ( 8 beş Pranten= berfiderung gefezes) als Strantengelo zu beanfprndicn, fo bauert

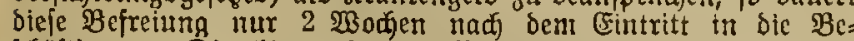

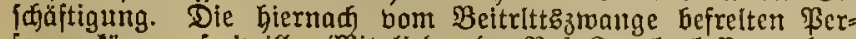

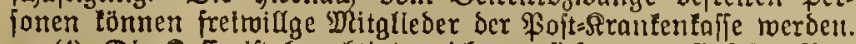

(c) Dle Seffe ift beredjtigt, nidjt berjidjerung spplidjtige $\mathfrak{B e r}=$ fonen, toeldose fid zum Beitritt melden, einer ärztlidjen Unter= fudung Interzieben zu laffen und thre $\mathcal{A}$ ufnahme abzulchneı, wenn bie Unterjudung cine berett: bejtebende Srantheit erglebt.

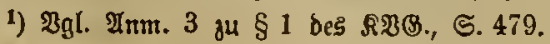

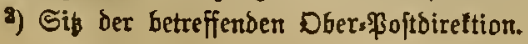

Beginn und Dauer ber Ditgltedfaft.

\$ 3. (1) Die Mtitgltedføaft bei ber Raffe beginnt für ole zur

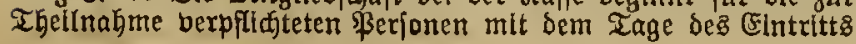

in sie bie Mitgliedjdjajt begrïndende Bejdjäfigung, ${ }^{1}$ ) für bie zur

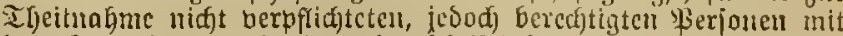
Dem Tage Der münolidjen oder fdriftlidjen Qnmelontng bet bem Rafienboritanoc.

(2) Sofern Der Safjenboritans binnen 3 Tagen nad bem

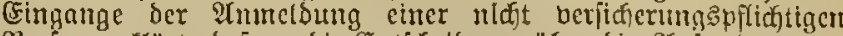

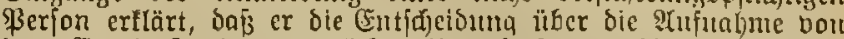

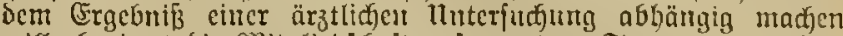

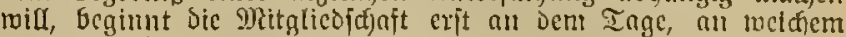

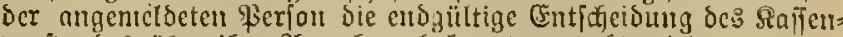
voritandes itber ifre 2 mmafme betannt gemagt toird.

(3) Jesem Iten ciutreterion Ditgltede miro ein Erentalar ocr

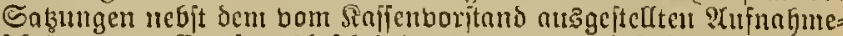

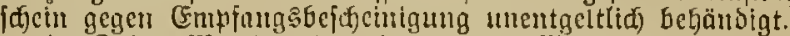

(4) Jebes פeltglied hat bimen einer Wocfe nad Beginn ber

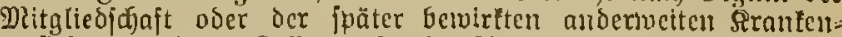

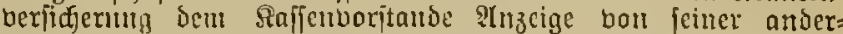

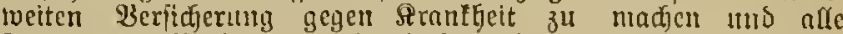

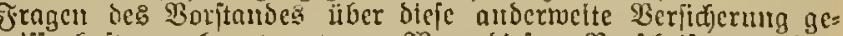

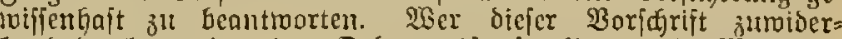
Gandelt, tann in cine Droumugsjtrafe bis zu 20 शart ge= llommen berden.

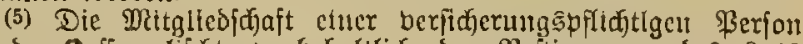
bel der Seafic erlifdit, vorbefialtlid) ber Bejtimmmg des $\$ 15$

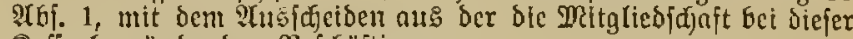

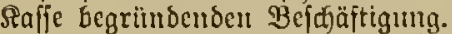

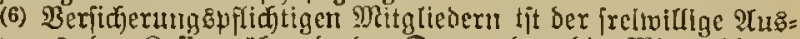

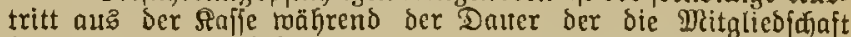

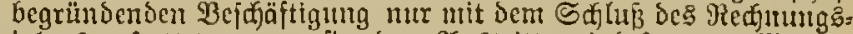
jahres geitattet, weun fie den Pustritt minoejtens 3 Monate borker bei bem Borjtande beantragen und onr bem Uustritte

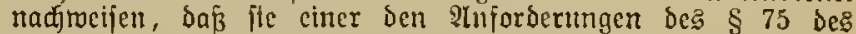

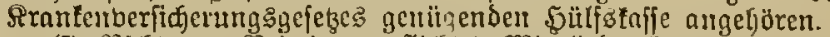

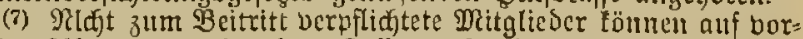
Gerige

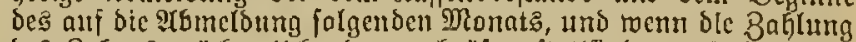
bes Rohnes twörfentilú oder nod) öfter ftatfindet, mit bent $\mathbb{B} c=$ ginne ber auf bie Ylomeloutg folgenton Wodje ausfobeider.

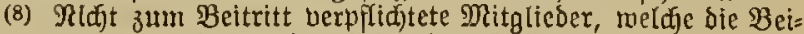
trăge alt zovei auf eimanber folgenden Zahlumgsterminen nidit

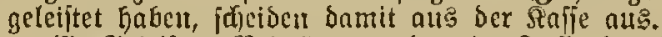

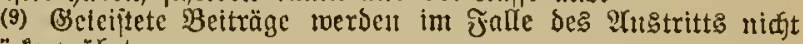
3arïđffgemăbrt.

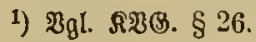

Einnathen ber Raffe.

$\S$ 4. (1) Die Elnnahmen der Rafie bejtehen in ben Cintritts: geloern, Den laufenden Beiträgen ber Ditglicber und Der Foittalfe

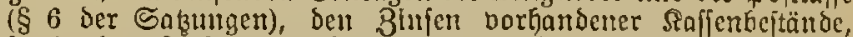
fatwie des fonjtigen fiafienbermögens, ben Belditrafen, meldje gegen die Saffenmitglieber bom Rafienborjtande (\$§ 3 थ็j. 4,

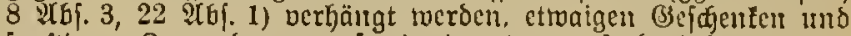
fonjtigen 3uracndungen, forie in etroa erforderlidjen auper=

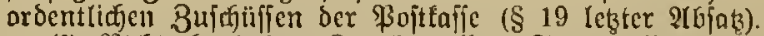

(2) Nid)t abgehobente Rrantengcloer, Sterbegelder unb jonitige

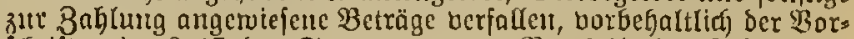
(d) riften im \& 17 ber Saţugen, jum Bortheile ber Saffe.

\section{Eintrittåge}

§5. (1) Bon Sen freimillig Geitretenden Mitgliedern toiro ein Cintrittsgeld in Betrage bes für 6 Modjen 31 leijtenden vollen Raffenbeitrages erfoben. ${ }^{1}$ ) Berfidjerungafflidjtige Mit= glieber zablet cin Eintrittsgeld nicht.

(2) Befrelt bon Der Bahlung Des Fintrittoneloce find die:

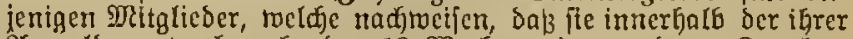
Anmeldung borbergehenden 13 Wodjen eimer anderen Siranten:

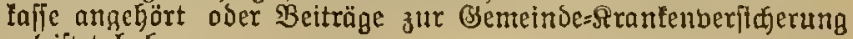
geleiftet baben.

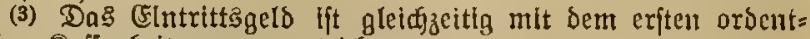
lidjen Rafjenbeitrage zu entridfter.

1) $\mathfrak{g l . ~} \S 26,3$ คश円. 
Ranfende Beiträge oer Mitglieder uo oer goft faffe.

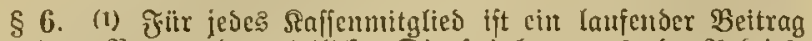

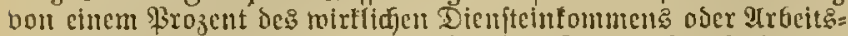
verdicnftes, fotbeit biefe 4 Mart für ben Iag nidjt überfteigen, зu Raffe zu entriditen.

(2) Zum Dienteinfommen oder Arbeitsoerdienft find alfe

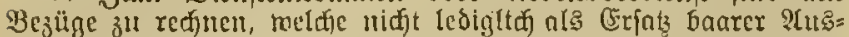
lagen anzufeben fino. Bon beat Jahrt= mo lleberlagergehitbren ber im Babmboftoienfte Gefoüftigten \$ierfonen totrs bie salfte

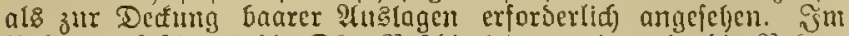
liebrigen beitnment bie Doer=\$oitoireltton, wie meit bie ieben=

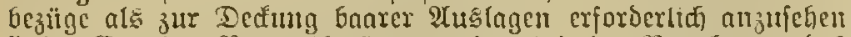

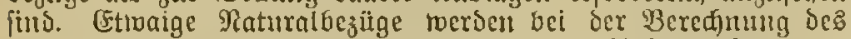

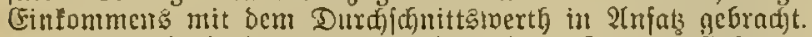

(3) Der laufende Beitrag woird für jesent Iag Der Erlyebungs:

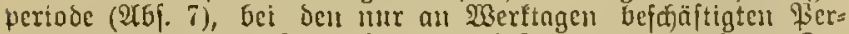

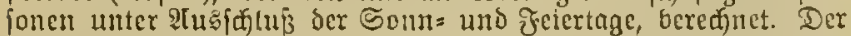
Tagešnerdienjt wird in ber Weije gefunden, bas ber Bejammt= letrag Des in Der (Erlhelumgapertode zH zallicnden Dienits

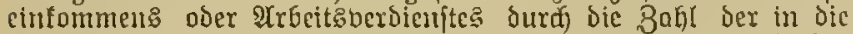

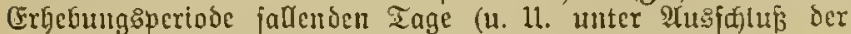
Soun = und Freiertage) getheilt roiro.

(4) Der Beitrag toiro für jedes Mitglied nud jeden Erhebung: ternin forveit anf bolle \$fennlg aufrodrts abgermbet, bis cr burdf bie Babl 2 theilbar ift.

(5) Fitr die Beit ber burd ferantheit ober Serleţug her= beigeführten Erroerbsum|ähigteit cines Mitgliedes miro ber Beitrag Jiưt beredurt.

(6) Die zur Iheifnabme an ber Saffe berpflidjteten Mitglieder baben die Sälfte des nad) boritehenden Bejtimmungen bereff)= neten $\mathfrak{B}$ sitrage oder $1 / 2$ \$rojent des Dienjtcinfommens oder bes

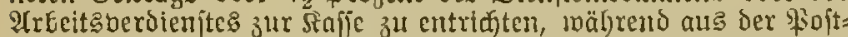
faffe ein Zuj bes Dienteinfomments genäbrt wirs. Die zur Theilnabme nidgt verpftiáteten Mitglieber haben ben vollen Beitrag oder

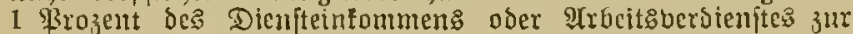
Safic zu entridter.

(7) Die ben Ditgliebern zur Lait fallenben Beiträge nerben an ben fitr bie Bahlung bes Bebalts oder des 2obnes be: ftimmten Terminen แnto zmar, forveit die Witglteder ihr Ein=

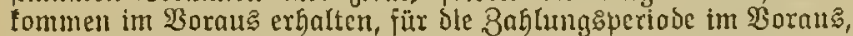

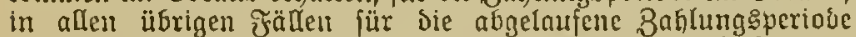
bon ber zabienden Stelle einbehalten. Sotweit benjelben bie \&öbnung öfter als wöod)entltod cinmal gezaflt roird, findet die

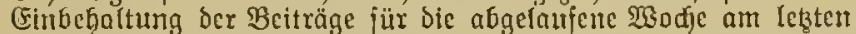
möd)entriớen Bahlungstage ftatt.

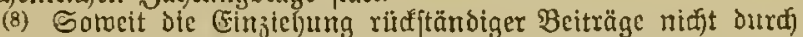
Einbehaltung Des Dienjteinfommens, bes \&ofns oder bon $\mathfrak{B C}=$

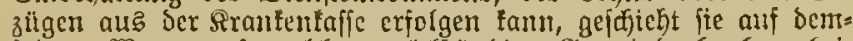
jelben $\mathfrak{B} e g c$, auf meldyem rücfitändige Ssenteintocabgaben bet= getriefen merden.

\section{イc ferbcfonds.}

\$ 7. (1) Die Rafie hat einen Refervefonds im Minocjtotrage

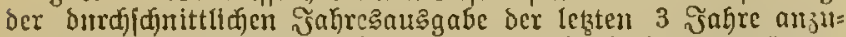

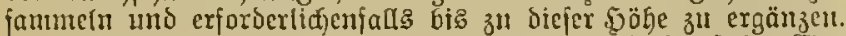

(2) Dem Rejervefonds ift ber alljälyrlidje lleberfdunf ber Cin= naljmen tiber bie S(usgaben ber Raffe, mindeiteus jedoch), fo

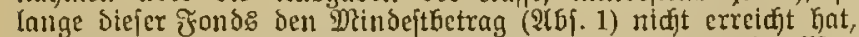

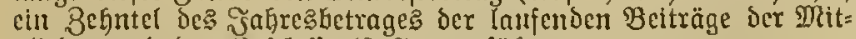

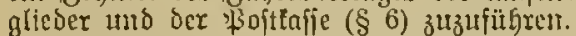

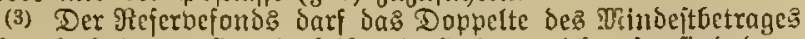

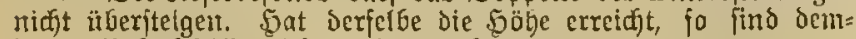

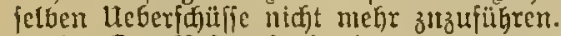

(4) Der Refervefontos Dient borzugstweife als jülfşanelle in foldjen Beiten, in meldien der Safie Durdf befontore Srantfeits= gefahr (ist Jolge bou Seudfen uro bergleid)ert) auß̈ergemöhnlidje ঋusgaben ertwadjien.

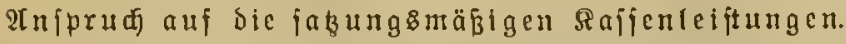

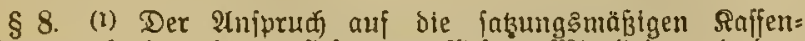
leijtungen beginnt für verfidjerungepfliditige Maitglieber mit bem.

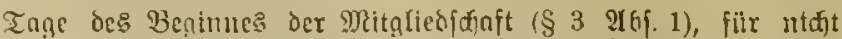

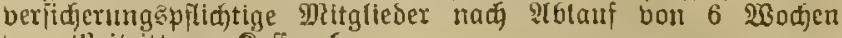
bom seitritt zur Raffe ab.

(2) lluter Erftanfungen find and) Bertesungen embegriffen.

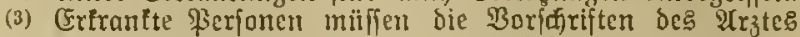
gemificulfait befolgen; fie dürfen toeber 2 rbeiten, meldje nad)

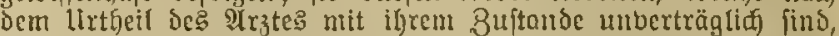

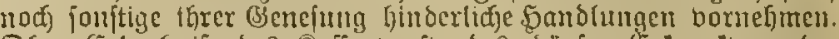

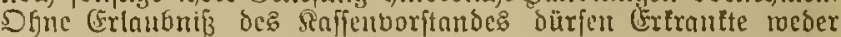
B̈ffentfict)e Solale noch Sdjantitätten bejudjen, nodi Ermerbs: arbeiten vornefmes. Sobals cine \$erjon, weldie Seranfengeld bezicht, mieder ermerbsfähig twirs, oder fobald der $\mathfrak{A r}_{3} \mathrm{t}$ cine crfrantte \$erfon für genejen crElärt, Gat diefelde eine थ́nzcige

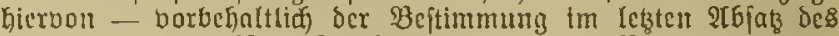
\$ 15 - bem nädj) Den Deuftuorucfesten zur Bermittelung an ben Raffenborifans cinzuretdjen. Der Sajfenboritans fam Inter=

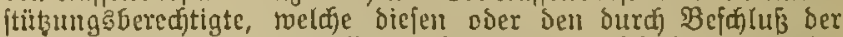
Bencralverfammlung erlaffenen jonjtigen Worfdjetfen über bic

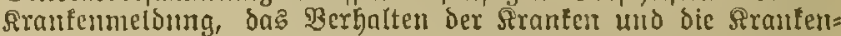
aufifid)t zutwiderhandelu, in ehte Strafe bts 20 Marl nebutr.

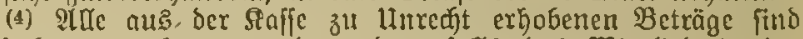
berfelben zu erjtatten sutb meroen, falls bas Dritglicb in ber Befääftiqung berGleift, bon bem Serotenjte getürzt.

(5) Mit ben श्Ausfdeiben aus oer bie Mitgliedfaft be=

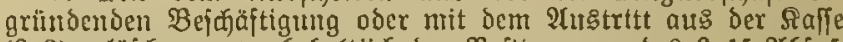

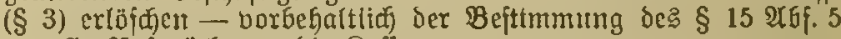

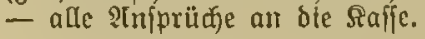

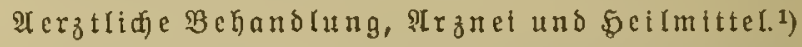

§ 9. (1) Dic Safije getwährt ifren Mitgltedern bom Beghm ber Srantheit ab auf bie Dauer bon 26 $\mathfrak{B}$ odjen - ober wenn

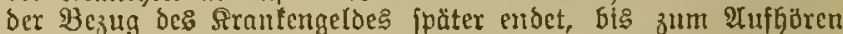

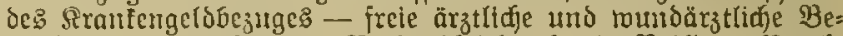

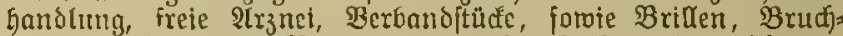
bänder und ähalide : Borridgtungen ober \$ellmtttel, roldje zur feilung Des Grfranten oder zur 5erftelung Jtid Erfaltung ber Ertwerbiäbigteit nad) beensigtem Sei(berfahren exforberlid) find.

(2) Der Safienboritand tam für bejtlnunte Bezirfe mit Be=

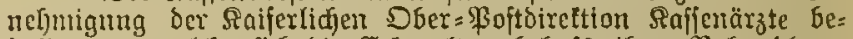
ftelfen, an meldje fid die Erfranften behnfs ihrer Behandung

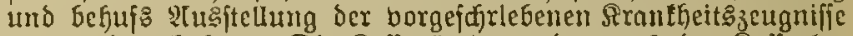
3! twenden Gaben. Die saffenärzte merden alts ber Saffe be= folbet. Name, शBobnort und Bezirte der Raffenärzte toerden vom Safjentoritand befannt gemaht.

(3) Ditglicbern, meldje fid im Bezirt eines bon einer anderen ßojt = Siranfenfajle befteliten Irgtes nuffalten, wird bie freic ărztlidie Bebanolung durch ben für biefen Bezirf beftellten $\mathfrak{O r}_{3}$ зแ Thell.

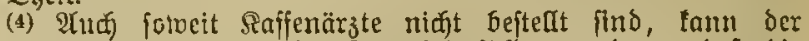

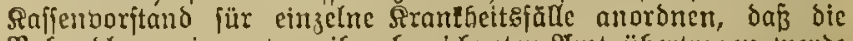
Befandlung einem bon ibm bezcidjeten Irzt übertragen merbe

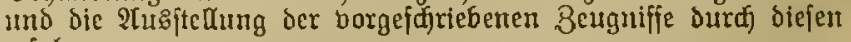
erfolge.

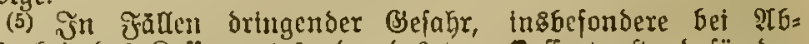

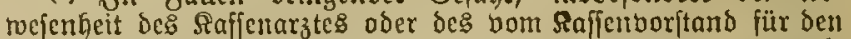
cinjelnen fall beftimmten 2Trztes, erftattet die Saffe die noth: mendigen Sojten bes eriten $\mathfrak{B}$ cfudis und exjordertidjenfalls aud

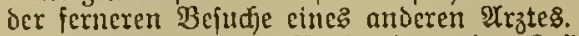

(6) Someit boul Borftande weder Saficnärzte bejtell find, nod) die Bujlefung eines bejtimmten anderen êrstes bor. gefdricben ifi, ftegt Den Erfranften bie Wagl unter ben nädiften gectanetel $\mathfrak{A}$ ersten fret.

(7) Die Mitglieber Gaben die Dülfe ser Nerjte in deren

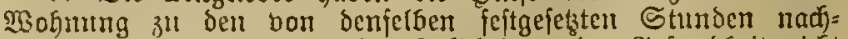

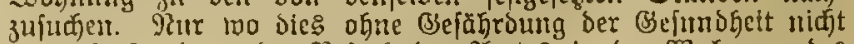

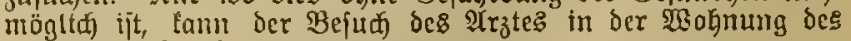
Ertranlten beanfpriajt rocrsen.

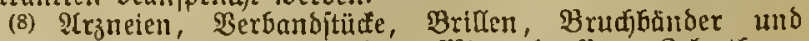
ähnlidje Đeilmittel, inbefondere Dineralmaffer, Rebertlyran, Bäber, jotole medianifae $\mathfrak{B}$ orridjtungen, toeldje jur Serjtellung und Grbaltung ber Grtwerbsfäbigteit nad beendigtem \$eil= berfabrest erforbertida find, werbent nur bann bon ber saffe be= 
ftritten, toenu bicfelfes boun शrzte beroronet werben. Der Raffenborjtant fann für getwiffe Bezirfe ble $\mathfrak{A}$ pothefen und bie Qieferer, bel denen biefclben zu entnefmen ftro, beftimmen. Rame, Wohnort und Bezirfe biefer Berfonen find bom Raffen= borftand befami zu madjen. Dle Soften ber bezeidneten Seil= mittel reroen alsoann, bon oringendes fällen abgejehen, nur

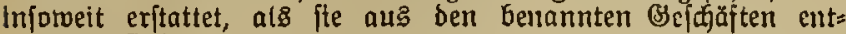
nommten fino.

(9) Someit ole Behandung nifit ourd elnen Saffenarzt

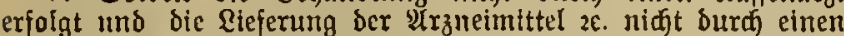
bom Safienboritano allgemein bezeidneten Rieferer gejajeben ift,

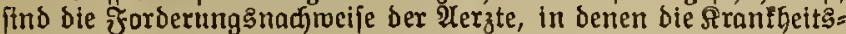

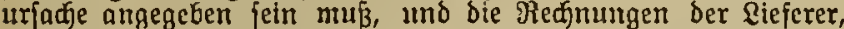
benen ble ärztlidje Beroronung beizufügen ift, borbebaltidi ber Beftimmung im letsten $\mathfrak{X} b\{$. Des $\$ 15$, bet bem nädfiten Dienjt= borgejetzten bes Ertranten zur llebermittelung an den Saffen= boritano einzureiçen.

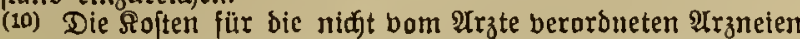
und Setlnittel, forote für çrauben, $\mathfrak{B}$ eine und bergleidjen zur Stürtung bienende Mittel, für Baberetfen und fonjtige grȫ̧ere Suren fallen ber Saffe nidit zur \&ajt.

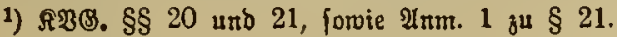

\section{Srantenge( 8.1$)$}

\$ 10. (1) Den burff Rranthett oder Berlekung erwerbsunfähig getoordenen Saffenmitgliedern getö̈brt bie Saffe bout britten Tage

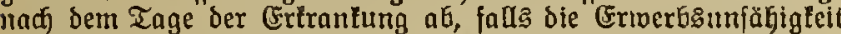
aber päter eintritt, bom Tage bes (Fintritts berjetben ab, auf ble Dauer bon 26 Wodjen für jeben Tag - bei ben jur an

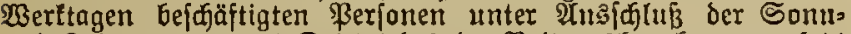
und Feiertage - zwel Drittel bes ber BeitraģGeredinnng zulest zu Brunde gelegten Tagesverdienites (\$ 6 शैG. 1 bis 3). Jret. willige Mitgiteder erbalten für ble Belt vom 2 blanf ber fechiten

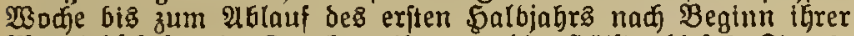
Mitgliedfđaft als srantengelo nur bie §älfte diejes Tages= veroienjtes.

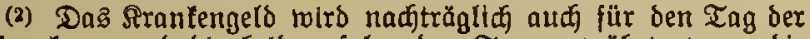
Ertrantung und ble Gelden folgenden Tage gemäht, went bie Frmerbsunfäbigleit länger als einen Monat gebauert bat.

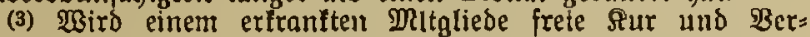
pflegung in eincm §ranfentanfe zu Thell (\$ 11), und bat bas= felbe Jrantlienangebörige, ocren unterbalt es nad)weistich ganz oder gröftentheils ans feinem Arbeitsuerbienjte bejtritten hat, jo ift neben ber freten Fur mo bon der §älfte des bem Mitgliede jonjt zujtehentoen Betrages zu zablen. Die Bnhlung tann unmittcibar an die 2rngebörigen exfolgen. Soat oas Mitglieb foldje Familienargehörige nidjt, fo erbält es metien ber freien Sur und Berpllegultg cin firantengelo

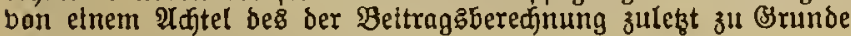
gelegten Tagesberolenftes.

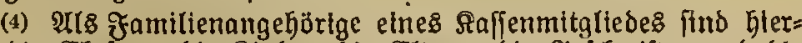

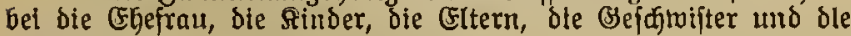
ธकtwiegerettern beşelben anzujeben.

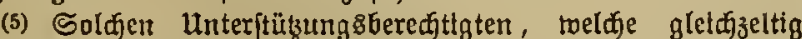

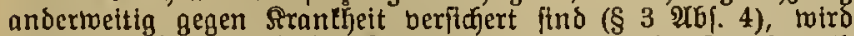

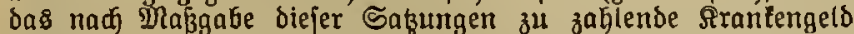
joweit gefürzt, als eq zufanmen mit bem aus anderweiter $\mathfrak{B e r}=$ itcherung bezogenen Rranfengelde ben bollen Betrag ifres ber

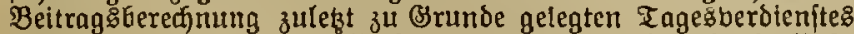
üterfteigen twürde. Bet ßerjonen, weldje bei ber Reidjs=ßoit= berwaitung nidit boll befajafitigt find, findet eine Sïrzung nur infotveit jtatt, als fonit der bolle Betrag bes ber Beitrageleiftung zu Brunde gelegten Tagesoerdienftes zuzüglla bes auts ander=

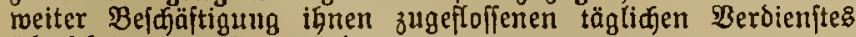
überjaritten werden würbe.

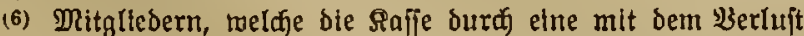
ber bürgertidjen ङhrenredite bedrobte ftrafbare 5andinng ge: idjoblat baben, wird für ote Dauer bou 12 Monaten feit $\mathfrak{B e}=$ gehung oer Strafthat, Berfinerten, weld fta cine Sirantheit

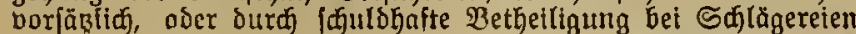

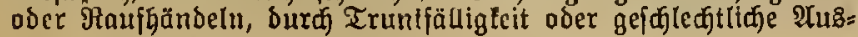

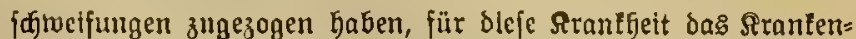
gelo nidgt gewäbrt.

(7) Mltgltedern, weldje von ber Sajfe cine Sranten= unteritïbung imunterbradien oder im Saufe eincs Beitraums ban 12 Tonaten für 26 Wodjen bezogen Gatien, wiro bet (5in= tritt eines nenen linteritüßnngsfalles, jofern otefer ourd bie

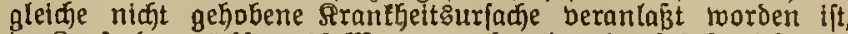
im Raufe der näditen 12 Manate neben Den im \$9 bezeidfneten Reiftungen nur ein Rranfengeld im Betrage der \$älfte des der

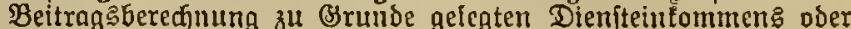

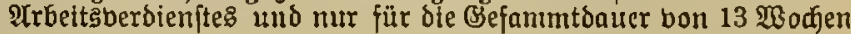
getoührt.

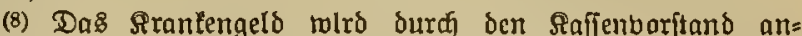
gemiejen. Die Bahlung an die cmpfangsberedtigten erfolgt

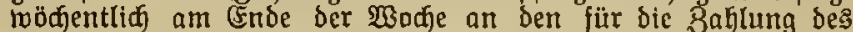

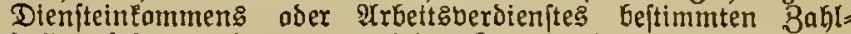
ftellen, fofern redjtzeitig bor jebem Termine dem näditen Dienit borgefetsten zur Bermittelung an ben Saffentaritand bas bon

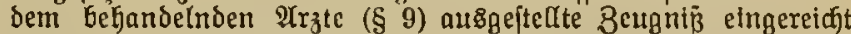
wiro, ln meldjem Beginm, Irfacje und Dauer der Grmertis unfähiglelt bejकeinigt find. Šit bas Beugniß niaht bon cinem Rafienarzte oder einem burdf ben Rajienbaritand bezeldineten

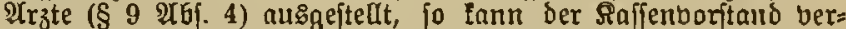

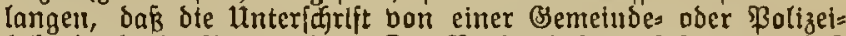
behörde beglaubigt werde. Der Baritand fann beittmmen, daß

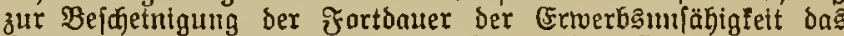

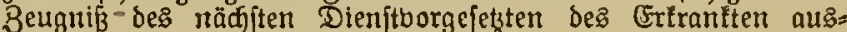
reidit.

(9) Für Erfranfungen bon Saffenmitglicbern an Drten, in benen थerzte nidit borhanden ftnd, tann ber Boritand be= ftimmen, Daß̧ aud zur Bejdeinigung beş Beginns, ocr Uriađje

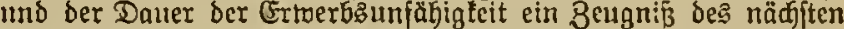
Dienitboraejesten des Erfrantten genügt, fo lange bie Ermerbs = unjäbigleit niajt bie Dauer bon 14 Tagen ïberjteigt und nidjt

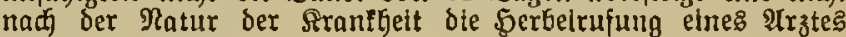
nothtwendig twird.

1) $\mathfrak{B g l . ~}$ આrtm. 1 ชน $\S 9$.

\section{Sranteuhauspflege.}

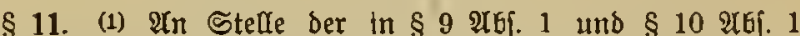
vorgefekenen \&efftungent getwährt die Safje bis zar Dauer von 26 iBodien, bom $\widetilde{T} a g e$ nad $\mathfrak{B}$ cainn ber frtranfung oder bom Tage des Beginns ber (5rtwerbsunfäbigfeit, falls bicfe erft fpäter eintritt, ab gerednet, freie Rur and Berpflegung in etnem Srautenfauje, menn eln crfranttes Ditglted auf Xnordmung dcs Sajienborjtandes in einem Stanferbauje untergebradit mird. Die Roiten der Bcförderung elnes folden Mitgliebes zu dem Rranten= baule werden bon der Saffe getragen.

(2) Bet Erfrantungen foldjer \$erjonen, weldje berbeiratbet fino oder eine eigene 5aubbaltung baben oder Mitglieder ber Бaubhaltung ifrer Famille find, lit der Faffenboritand nur Dann beredjtigt, die Uuterbringung in etnem Srantenfinje 311 beriangen, wenn bon bem erfrantten Mitgliebe zltgeftimmt woiro,

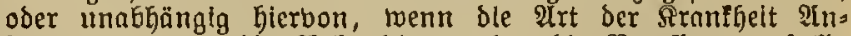
forderungen aut ble Behandlung oder bie Verpilegung itellt, weldjen it der Familie des Errtantten nidft genügt werden fam, ober wenn die Siranffeit eine anjedende ijt, ober menn ber Frfrante toiederbalt ben über bie stantenmeldung, über bas $\mathfrak{B}$ erbalten ber Stanfen und über bie Srantenanffidit er= Iaffenen Borfdriften zumidergebandelt bat, oder wenu beffen Bujtand oder $\mathfrak{B}$ erbalten eine fortgejekste $\mathfrak{B}$ eabadiung erjordert.

(3) Sefnt ein Ertranter, Deffen Itnterbringung in einem

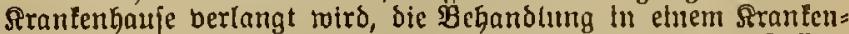
Gaule ab, oder nimmt ex ein anderes als bas bom fafjen=

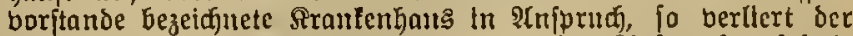

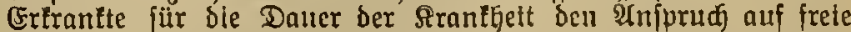
ărztlidje und mundärztlidje $\mathfrak{B}$ ehandlung, freie $\mathfrak{A r z m e i}$ und ફeil= mittel uno auf bas srantengels, fojern uno folveit bastette

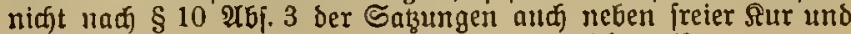
Berpflegung in cinem Simutenthanie jul getoăgren ift. 


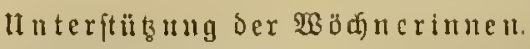

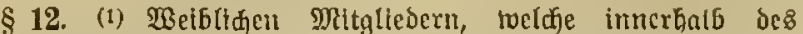

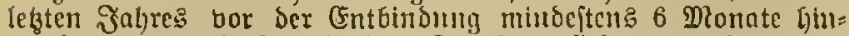

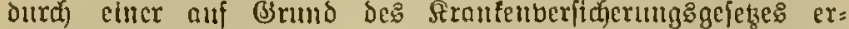

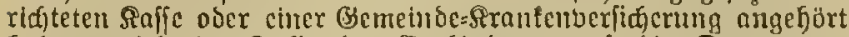
Gaben, wiro in Falle ber Entbinbung all bic Dauer bon 4 Wodjen eine llnterjtüßung in \$öbe ses̊ Sranfengeldes getoäbrt. Erfranfungen, weiffe bet ber (Entbindung ober väl)resto bet

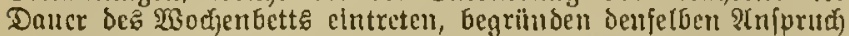
auf Rranfemuteritütsung toie ansere Erfranfungen.

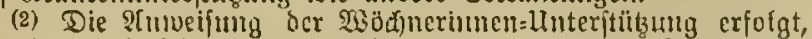
fooald eine Bejueintgung bes Standesamts über bie Eintragung

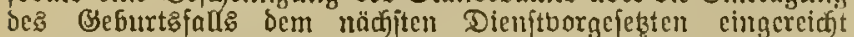
toorocu lif. Bezüglich oes Bcitpunftङ ocr Bahlung finden die Beftimmungeu im $\$ 10$ 2(6j. 8 शโnmentung.

\section{Sterbege(d.1)}

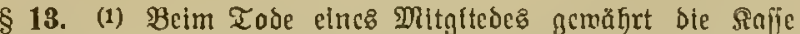
eill Sterbegeld in \$öhe des vierzigfochen Bctrages bes der Beitrag

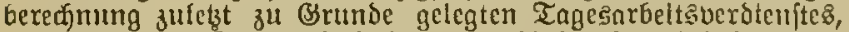
menn aber bas \$wanzigfache bes ortbublichen Ingelolinjaßes ge= wöhnliđfer Tagearbeiter mehr beträgt, in Бöle bicję Betrages.

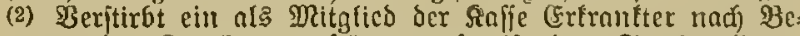
endigung ber Sranfenunteritüßı!g, fo ijt baß Sterbegelo zu

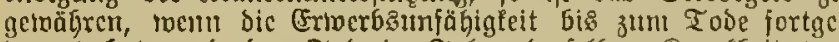
bauert hat, unb ber Tod in Folge berfelben Seranfgeit bor

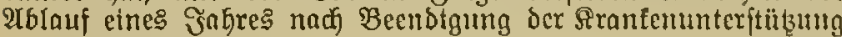
cingetreten $\mathrm{fft}$.

(3) Bom Sterbegelde toiro gegen (Finlicjerung Der itnubes: nmtfichen Sterbeurfunoe ber zur Dedung ber Begräbnif3 fojten alfacwendete Betrag demjenigen ausgezahit, welđher dos Begräb.

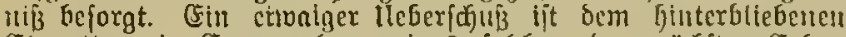
Ebrgatten, in Ermangelum ches pidfen ben nädjiten Erben ausjujablen. Sint foldhe Ferjouten nitht borfindent, fo ber= heitit ber Ueferiffuf der Raffe.

(4) Der Borjtand ift beredfigt, Dle Becroigung bcs $\mathfrak{B} c r=$

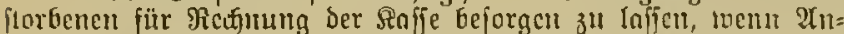
neförige, weldyc bie Beerdigung beforgen, nidjt borbanben find.

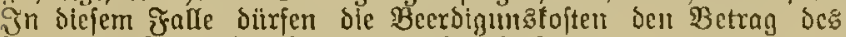

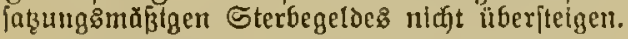

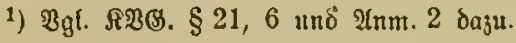

Srantenberfiderung für Egefraneu und Riuber.

$\$ 14$ (1) Die im $\mathfrak{B o j t =}$ und relchraphendienjte befanaftigten rafjenmitglieber fönmen gegen Fntrichtumg eines Bnfatzbcitrage

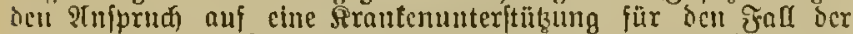
Gifratiung ifrer (5hefrau ober ifrer efclidjen Rinder, folveit fie

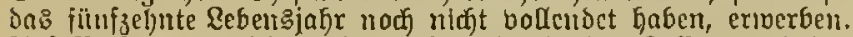

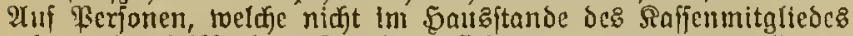
leben, ober felbft $5 \mathrm{~cm}$ Srantentorficherungszmange unterliegen, critrecft fich bieje Beredftigung nidft.

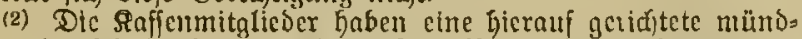

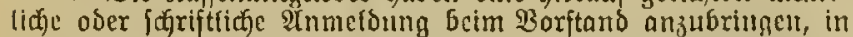

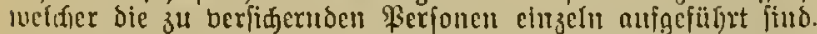

(3) Bimten 3 Ingen nad) Bingang ber थnmeloma farm der

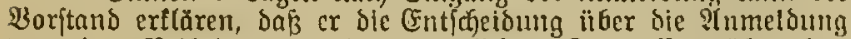
boun ber Belbringung cimes ïrztfidjen Bengnifies ïber ben

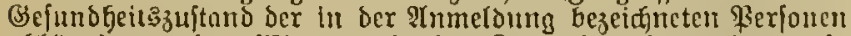
abbänglg made. Wiro cin foldes Benguifs nid)t berlangt, fo

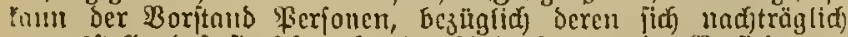

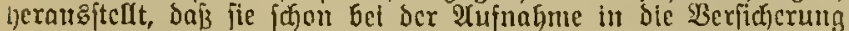
ail elmer chronifchen stanffeit gelitten haben, nachträgfich bou

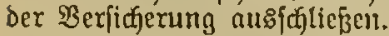

(4) Für bic berfitferten $\Re e r j o n e n$ weroen in Ertrantungsfallc auf bie Dauer der Sranfbcit, hödjitens nuf 13 Wodjen, vour Beginn oer Rranthelt ab, freie ärztfidje $\mathfrak{B e h a n d l u n g , ~ f r e t e ~ O r z m e i ~}$ und fonftige beímittel in bemfeibcn Majse, wie für erfranfte

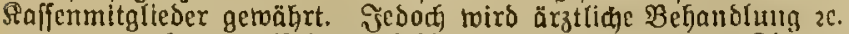

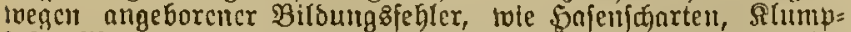

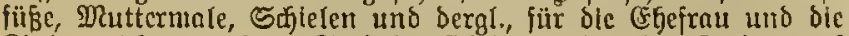
Rinber nifht getnübrt. Sind bie Ehefrau oder bie Rinber auf

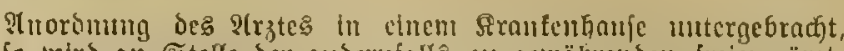
fo wiro an Stelfe ber auberufalls zu gemährenden freien ärzt=

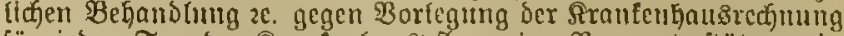

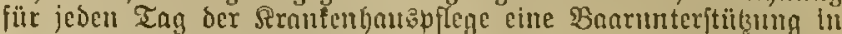

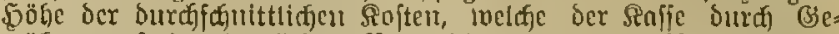
wäfrung freler ärztlicher BeGanolung 26 . erwachjen, gezahit.

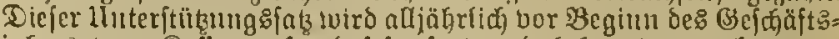
jafres bom Rafienborftons feftgejetzt und Gefaunt gemadit.

(5) Dns Fed)t nuf bie Getoäbrung der Unteritübung für bic Egefraut und ble \$inder fegimt nach \$lblauf bou 6 Wochen bom

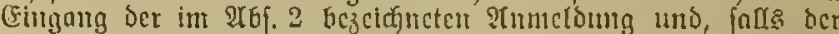
Barjtand Die Beifringung cines ärztfidjen Zeunniffes angeoronet

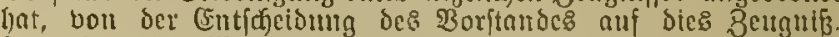
EF cribet ohne Weiteres mit bem Tobe Der Egefrau ober bes

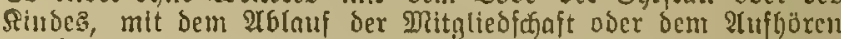
ber Befääftigung im Fojt= und Telegraphendienit, ferner auf

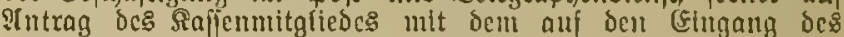

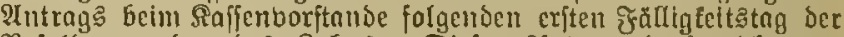
Bcfoldun ober Des Qohns. Diefer PUntrag barf nidit bor

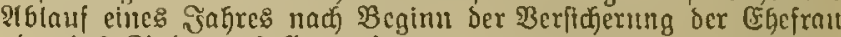
oder bes Rinbes geftellt werbent.

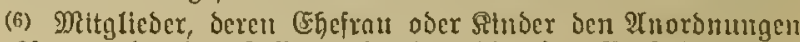

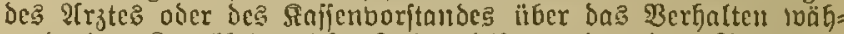
reno ber frantheit nicht Jofge leiften ober ben Plrzt trot criolgter Sarmung wieberholt ofue genügende Beranlaffumg

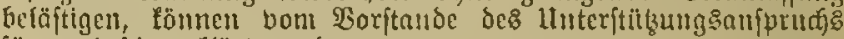
fiì verlujtig er?tärt toerden.

(7) Bur Empfanguahme der Unterftitzungen für bie Egefrau

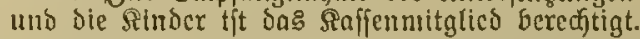

(8) Der bom Raffenmitglics z" znflende Bufatzbeitrag wird

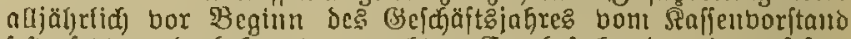
fejtgefebst mo befaumt gemadst. (5x bejteft in einer feiten Summe, meldje für jebe berfiderte \$jerfon zu zablen ift; er

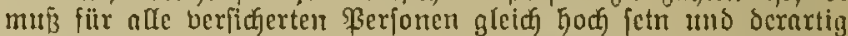

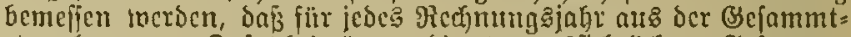

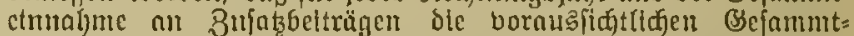

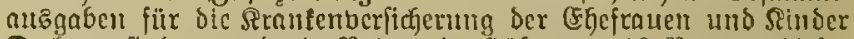
Dectung finden, und cin Betrag in 5obe bou 10 srozent dicfir

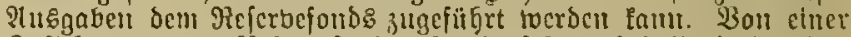
Buführumg zum Aeferbefonos hit abzufeben, fobald bicier ben gefetrificuen \$ödfitbetrag erreicht hat $(\$ 7)$.

(9) Der Zुnfaţbeitrag ift fowohl mährend ocr Dauer ber

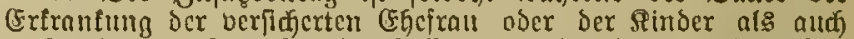

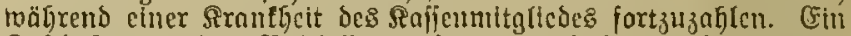

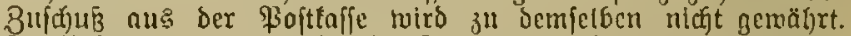

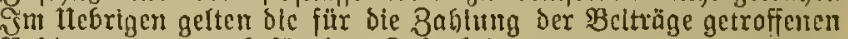
Beptinmmugen and für ben Bufntzbcitrag.

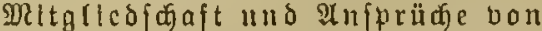

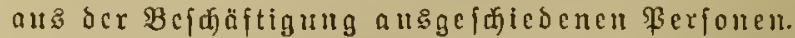

§ 15. (1) Raficumitglteder, wuclac aut ber Die Mritgliedfchaft

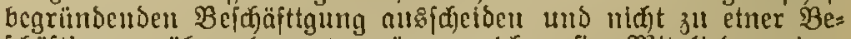
fdüftigung übergchen, vermöge meldfer fie Dlitglieber einer Ortitranfenfaje, cincr auberen Betrieb = ober ctuer Jabrit= 2aut=, Jumungstraulentafje ober ciner Snappfdofisfafie tverben, breiben fo lange, als fie fich in Bebiete bes Dentfach Fecich auffaften, Mitglieder der Saffe, fofern fte iffe botin gefiento

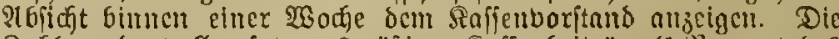

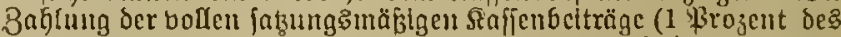
Zagesuerdienfte

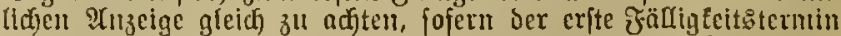

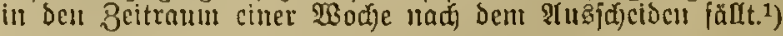

(2) Jür bic Beitragşbered)nung tit berjentge Zagcỏverdienjt

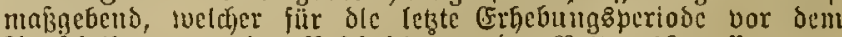

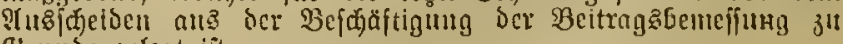
Grunbe gelegt ijt.

(3) Die Beiträge müfjen tojtenfrei an Demjentigen Tage an

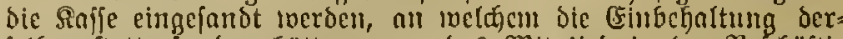
felben ftnttgcfumben Gätte, wenn bas Mitglico In ber Bejüäft= ginig berblteben toüre. 
(4) Die Mitglledfajaft foldier ßerfonen erlifat, inenn die Betträge an ztoei nuf eimanber folgenben Bablungsterminen utcht geletftet merden.2)

(5) Mitgliebern, welche in Folge eintretenoer Ertwerbstopinteit aus ber Snife ausfáseiden und fid im Bebiete bes Dewtidien

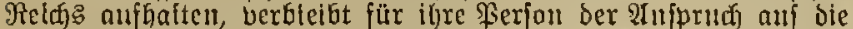

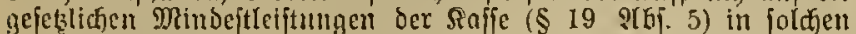

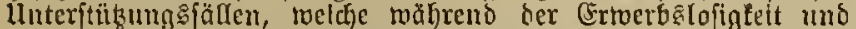

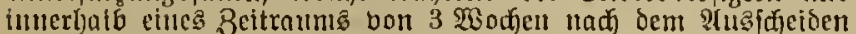

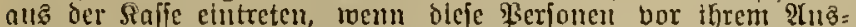
icheiben minbeftens 3 शुochen แnuterbrodien ener nul (S) rumb

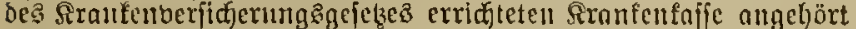

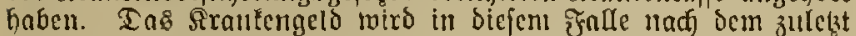

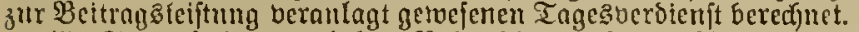

(6) Statt freier ärztlldjer Bebanolusg, freier $\mathfrak{A} r$ zuci und Sellmittel tann deu aแล ber Befdäftigung auछgefdiebcutn Unteritübungäberecitigten ber Im 26.1 bezeiduneten शrt, meiche fich) ntaft int $\mathfrak{B}$ ezlrf ber Saffe aufbalten, cint um bie Sälite des ifnen ohuchtı zuftehenden Betragez erföhtes ferutengelo bou Borjtand gemäfirt toerden.

(7) Die Bahlung bes Brantenoctses an bic auB ber Beiffäfti=

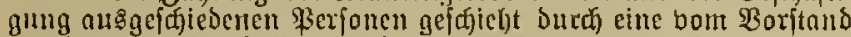
3u bejeiduende Saffe an ben IInterftübugsbereditigten oder

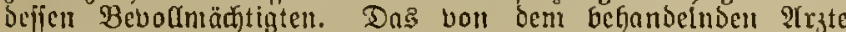

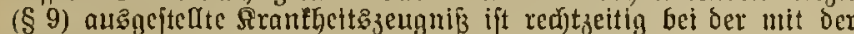

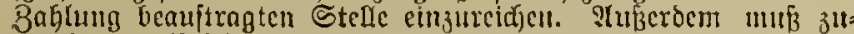
gleid) eine Bejajetnigung ber (Semeinbebehörbe bes berzeitiacn Sulent5altsortes beigebradit toerden, burch weldje dargetbast

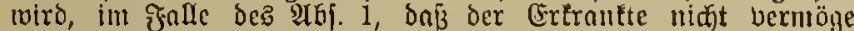
feiner $\mathfrak{B e j}$ däftigung gejeblich ciner nuberen fronfenfofje ange-

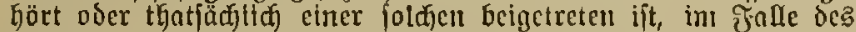

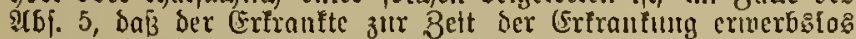
war ober fortoaternd erwerbstas ift.

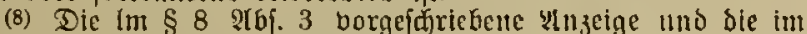

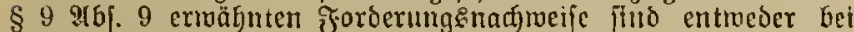

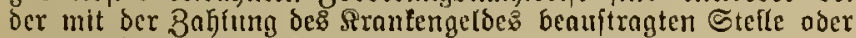
unmittelbar bei bent faffertbarjand eilıureidfen.

1) $\mathfrak{R} B(s . \S 27,1$.

2) ebendaf. $\$ 27,2$.

Ber Mitglleder.

§ 16. (1) Werber Rafienmitglieder zur शbleiptung ifger

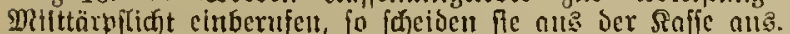

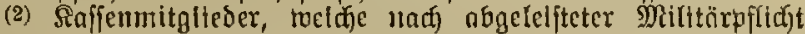
zeitmeilig zu militärifdjen Dienftieiftnngen einberufen toerden,

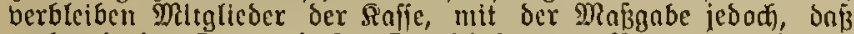

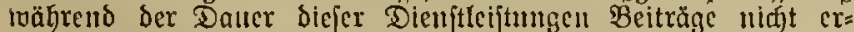
Goben werben und nlle IInfprüh) auf bic S̊affenleiftungen ruben.

Berbättnifz zur armenpflegc und zu Erfaz= amprïben gegen Drittc.

\$ 17. (1) Sotoeit bon Bemetnden und Irmenberbänoen in

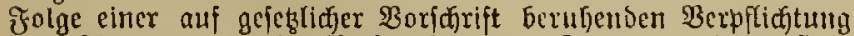

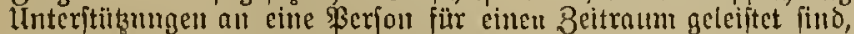
fïr toeldien derfelben auf (Srund ber $\$ \S 8$ bis 15 biejer

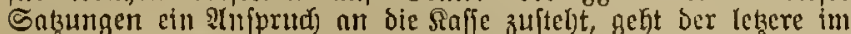
Betrage der gefelfteten Interftütrumen auf die Scmeinde oder

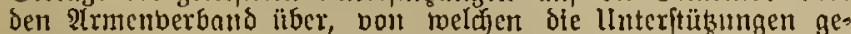
leiftet find. Die Interitiibten find verpflidftet, hierbon binnen

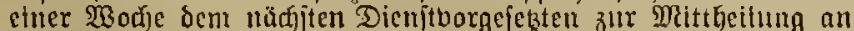

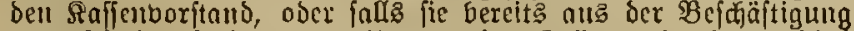
auşgcidichen find, Immittclbar an Dell Raffenborftand mündlid oder ifjriftlicf) 21 zeige zn macicu.

(2) Siud die jnßungsిmäßigen fafienleiftungen cinent unter=

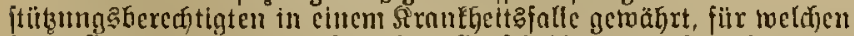

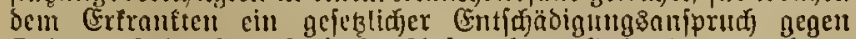
Dritte zuịteht, fo aeljt biejer S(nfpruch in Söbe ber gemährten Saffenleiftungeu auf bie Raffe über.

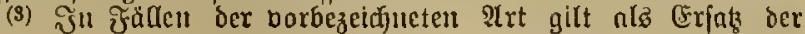

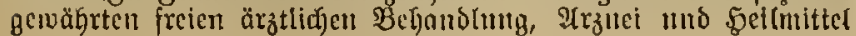

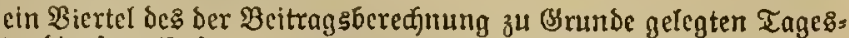
berdienftes (\$ 6 ).

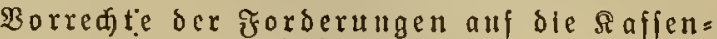

$$
\begin{aligned}
& \text { leiftungen. }
\end{aligned}
$$

§ 18. (1) Die Den Unterftüţunģбered)tigten gegeı ble Saffe

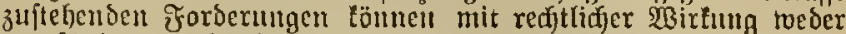

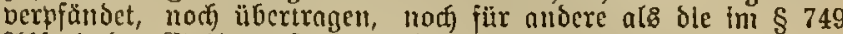

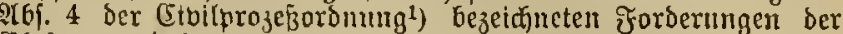

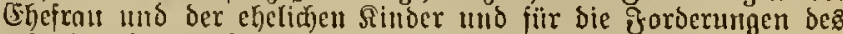
erfatsberect)tigten Armentuerbandes gepfändet toerden; fle bürfen nur anf gejuldoete cintritts̈nelder ind Beitrăge, ivelche von bent Dritgliede felbjt einjuzablen waren, folule nuf Beloftrafen,

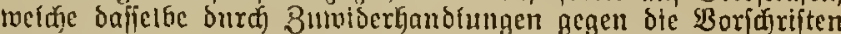

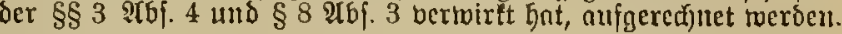

1) Dben $\subseteq .200$.

Prïfung แnd Erhaltung dez (SCleidgetolfts

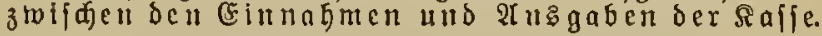

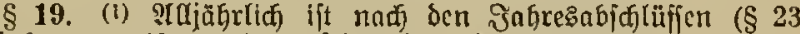

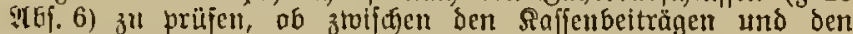

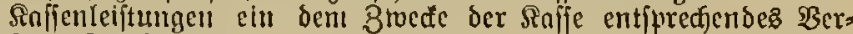
fältuí̧ befteht.

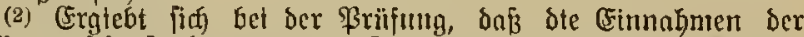

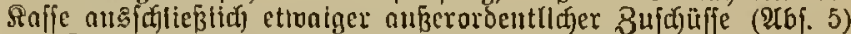

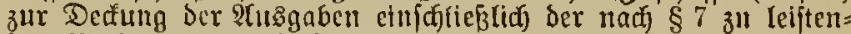

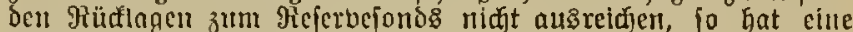

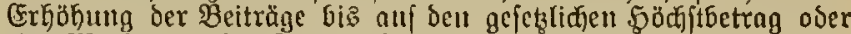

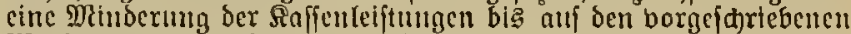

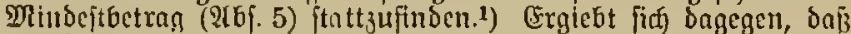

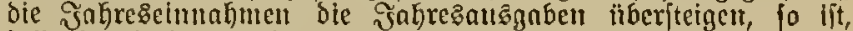

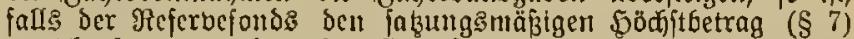
erretdit hat, entroeber elne Crmäßigung ber Beiträge ober eine Erbobung oder Cerweiterung Der Raffenleiftungen bis auf Sen

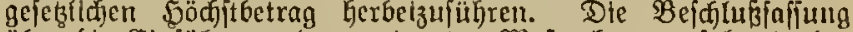
ïber bie Cufübrmug oer geeigneten Maßzuabmen erfalgt in der inr \$ 27 borgejdriebenen $\mathfrak{B}_{\text {eife in }}$ ber (Seneralberfammlumg. ${ }^{2}$ )

(3) lluterläst die (sencralverfommlung, dieje Mafnabnten 34

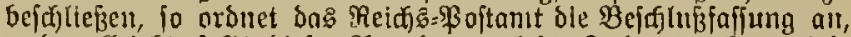
und volfzicht, falls btejer Arnordnung tellte Jolge gegeben twiro,

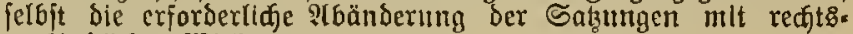
berbindfictier $\mathfrak{B i r f u t u}$

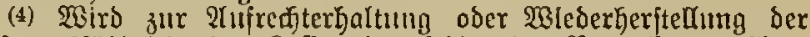
Reiftungşäblgfett ber fafte eine ialermige Bermehrung threr

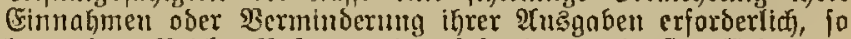
tanu bas Reids = \$ojtamt cine jofortige boriäuftge (Erböbung ber Beiträge ober Sernbjetzungen Der Reijtungen, leţtere bis zum borgefifriebenen Dlinseftbetrage (श6. 5) berfïgen.

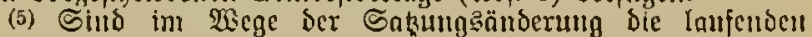

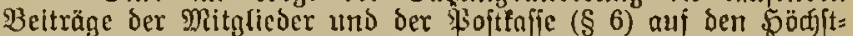

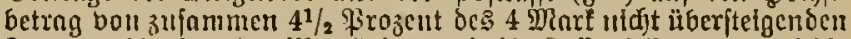
Ingesverdienftes ber Mitglieder uto bie Raffenlelftungen auf ble Minoe[tletitumgeıt, nămilict):

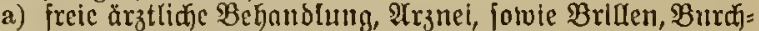
bänber uno ähnlidje Seilmittel $(\$ 9)$ für ole Mil= glieder auf ole Dauer bon 13 WBodjen,

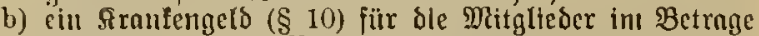
ber 5 älfte beg zutr Beitragßleifung veranlagten Tages: berbientes, oder §rantenhaußpflege (\$ 11) auf gleiffe Dauer,

c) cine Unterftïßuแ an $\mathfrak{Z}$ ödjnerinnen im Bctrage ber

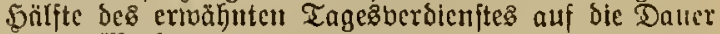
bon 4 isadien,

d) cin Sterbegelo für ben Todeşall eines Mitglieves in 20:facjen Betrage bes ber Bettragsherefinmm zu (Srunde liegenden Tagesberoienites

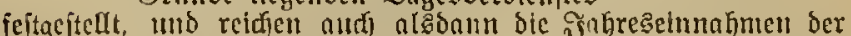

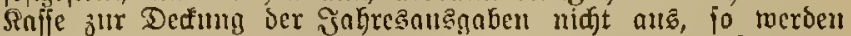
ber Raffe die feflenden Beträge als außerordentliçe Bufebilfie aแs ber Poittaffe zแnefülyrt.

1) $\mathfrak{R} \mathfrak{B}(\S 33,1$.

2) ebenda. $§ 33,2$. 
Berwaltung Der Raflenangelegengeiten.

$\S \Sigma 0$. (1) Die Angelegenfeiten ber Saffe merben von einem

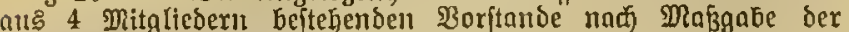
Borfanjiften siefer Satzutugen bermaltet.

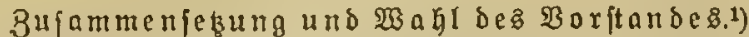

§ 21. (1) Der Saffenborftand befteht aus:

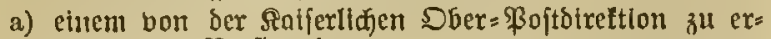
nenuenden $\mathfrak{B o r f i t g e n t e n , ~}$

b) 3 Beiftzern, treldje in ber orbentlidfen Beneral= berfammiung (\$ 25 थbf. 1) bon ben Raffenmitgltedern nus ber Bahl ber lektteren auf bte Dauer bon 3 Э̌ahren gewählt merón.

(2) Dle Wahl ber Beifiker ift ctne geheime. Sle exfolgt

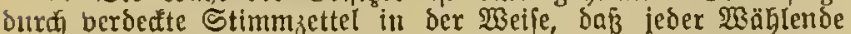
fo vicle Ramen auffétrelbt, als Beifiżer z" mählen find. (अe= mählt find biejenigen, velche dic meiften Stimmen erhalten. Jn einem bejonderen $\mathfrak{B a h l g a n g e}$ werden in derfelten $\mathfrak{B e t f e}$ in jeber ordentlifien Beneralberfamnilung 3 Erfakmänner nuf dte

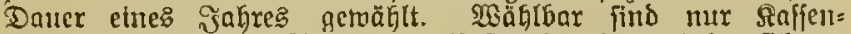

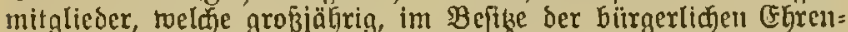

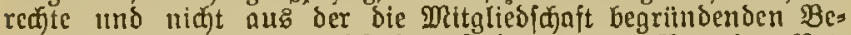

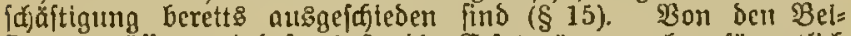

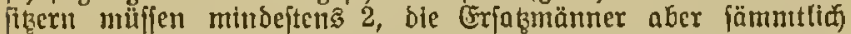

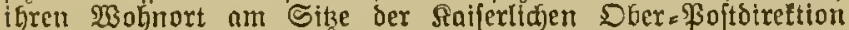
oder an cinem tn ber Näfe besfetben belegenen Srt haben.

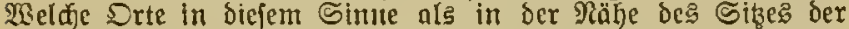
Saiferliden Sber=Foftbireltion getegen nuzufegen find, miro bon Der lekteren vorher beftimmt. Stintmen, weldfe auf nidft mähl= barc Ferfonen follen oder die (Bemähiten ntdit dentlide) be= zeidneu, wexben niđft mitgezähtt. Bei Stimmengleidgeit ent= fđjeibet bas bon dem Borlikenden ber Benernโberjammlung zu

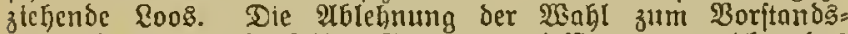

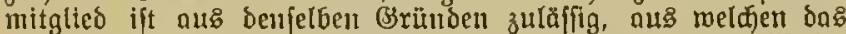

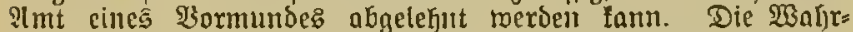
nefmung eintes allf (srund der Unfalfuerfidjermg ober ber

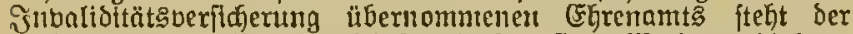

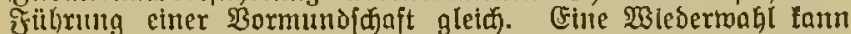

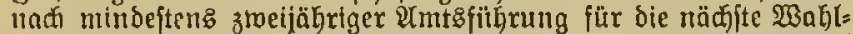
pertode abgelehnt twerben. Raffenmitgfiedert, weldie eine $\mathfrak{B a h t}$

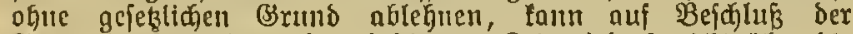
Bencralverfanmlung (iïr beftimunte Beit, jedod) nidit iiber bie Dater ber Wabluerlobe, bas Stimmrectit in ber Beneral= verfamnulung entzogen werdent.

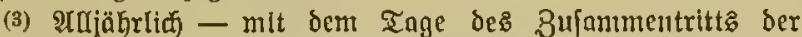
orbentlidfen Beneralberfammlusg (\$25 2tb. 1) - fajelot elner

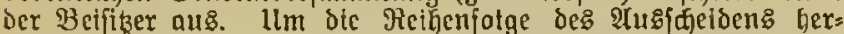
zuftellen, entfodeibet unter ben tand Errtaitung ber Sinfe zuterft gewählten Mitaliebern iiber ble Dauer ber Mitgliedifinft eines jeben berfelten dos vom Sorfizenden der Beneralberfammlutsg

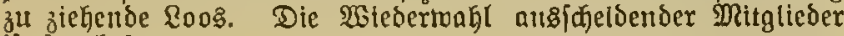
ift jtatthajt.

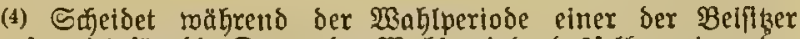
ans, fo tritt fïr bie Dauter ber $\mathfrak{B a h l p e r l o d e ~ b e s f e l t e n ~ e i n e r ~ b e r ~}$ Erfaţmänter an fehter Stelle in den $\mathfrak{B o r j t a n d}$ eht. In welfjer

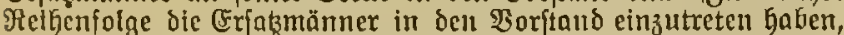

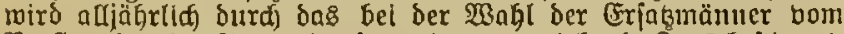
Borfisenden der Beneralberfammlung ju ziehende \&ooß bejtimmt.

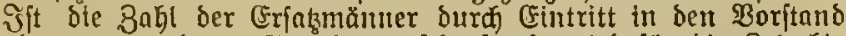
oder aus nnderen Brituden eriföpit, fo wird für bie Beit bis zur näđften Beneralverfammlung bie erforderlid)e $3 \mathrm{ahbl}$ bon

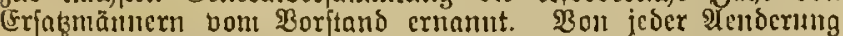

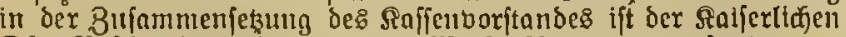

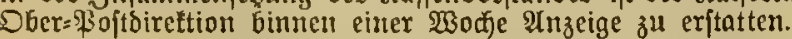

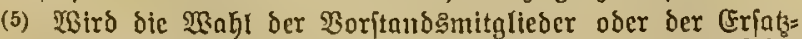
mämuer berweigert, fo tritt an ifre Stelle Ermenum burch die

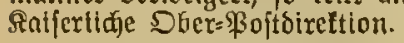

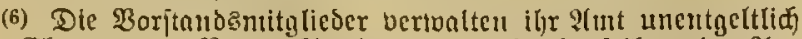

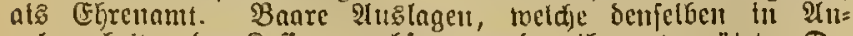
zelegenbeit'n ber Sajie erwadjen, werben ifuen bergittet. Die

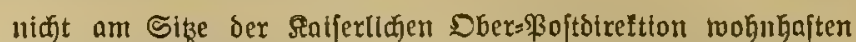

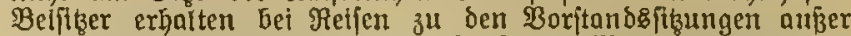
dem Exfak der nothmendigen Reifefojten 3 Marf בagegelder.

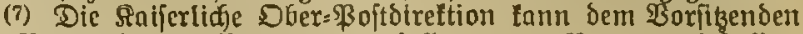

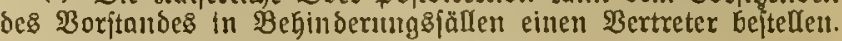

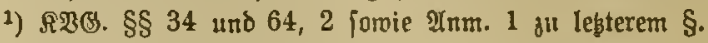

Berfamm fungen und Befuguife des

§ 22. (1) Dle Bexfammlungen des Raffenborftandes finden

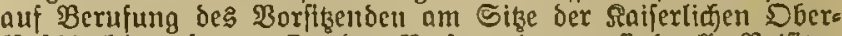
Bofibireftion ftatt. Bul ben Berfamminngen find alle Beifitber

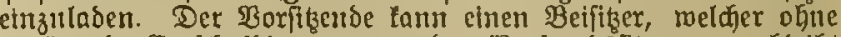

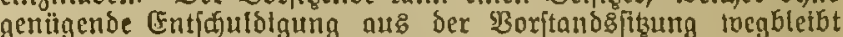

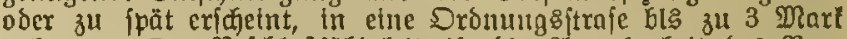

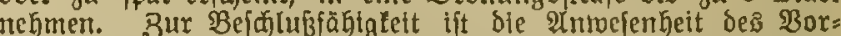
fikendent nito zweier Beiftzer erforberlith. Die UGjitimmung über $\mathfrak{A}$ ngelegenheiten Der Lautentent Berwaltung fann auf

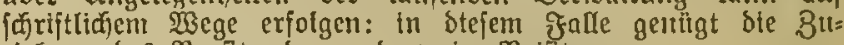
ziehung des Boritisenden und ztoeter Beifiker.

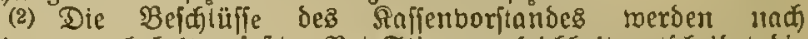
Stimmenmehrheit aefaß̧t. Bet Stimmengleidheit entidieidet bie

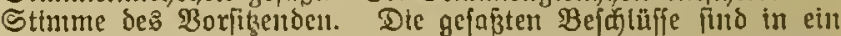

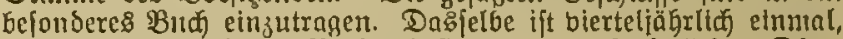

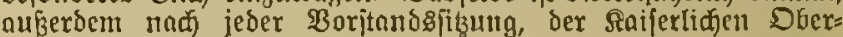
Poitsireftion borzulegen.

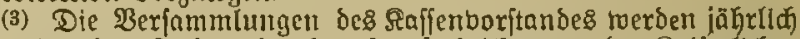
einmal mis auferdem berufen, fo oft foldies von ber faifertichen

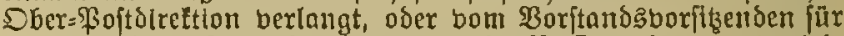

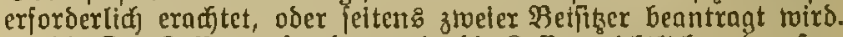

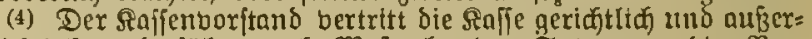

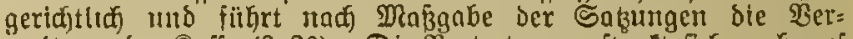

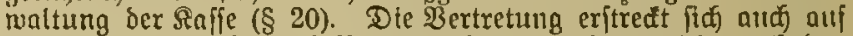

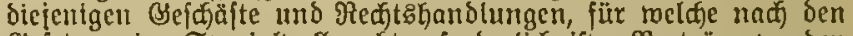

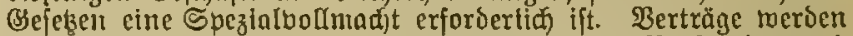

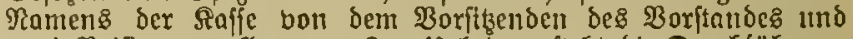

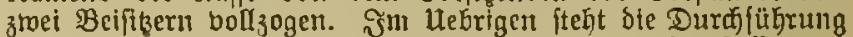

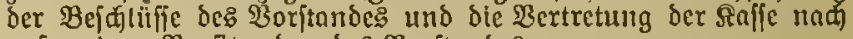
aufen Dem $\mathfrak{B}$ orifikenden de\& $\mathfrak{B}$ aritandes zu.

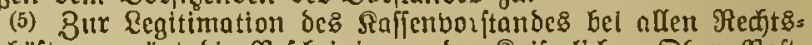

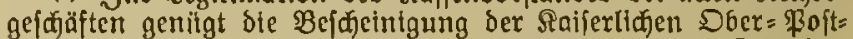
Dtrettion, baß̧ die darin bezeldfueten Ferjonen zur Beit bent Boritand ber Saffe bildent.

(6) Dic Mitglieder bes Borftandes gaften der Saffe für

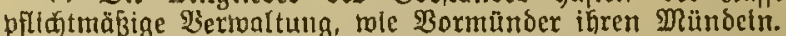

(7) Der $\mathfrak{B o r j t a n d}$ ift befugt, fla nuf bienfflidjem Wege ble theberzeugumg bou bem Befundbettszuftand ber als frant ges

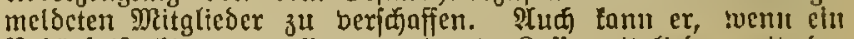
Bedürinip̧ hierzu vorliegt, geetgnete Raffennitglieber unit ber Fontrole erfranfter Berfonen beauftragen.

(8) Der Raffenborftand ift berpflidtet, in ben vorgefdiciebenen

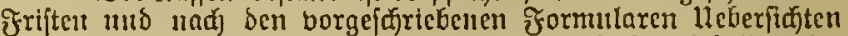

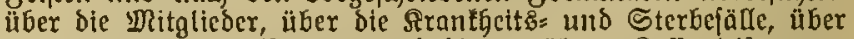

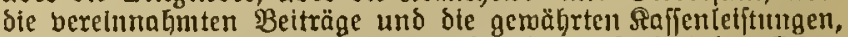

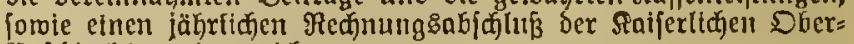
Poftsireftion einzuretaen.

$$
\Re c \text { ๘) }
$$

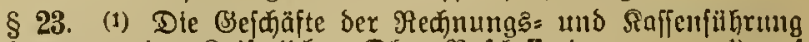

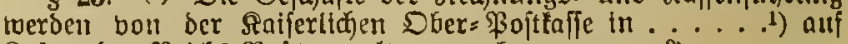

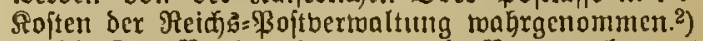

(2) Die Bercimnahnumg uno Berantagabung bou Saffen: geldern exfolgt anf bie vom Borftand8vorfisenden volzagenell Iflutweifungen.

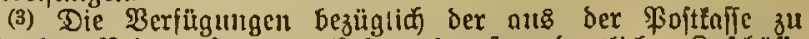

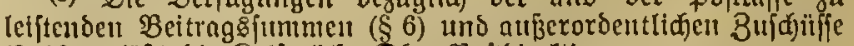

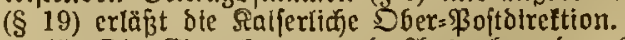

(4) Die Einnatmen und Yusgaben der Sranfentaffe find

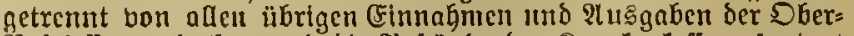
Boft taffe zu butfien und bie SBeftäude ber sranfenfafje geiondert nad)zuweifen. ङ̌n Mefrigen wird über bie 2lrt uno form ber

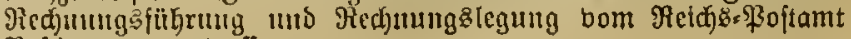
Beftimmung getroffen. 


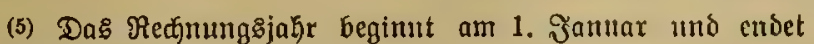
am 31. Dezenber.

(6) Anjähríă Innerhalb ber erjten belben Monate bes neuen

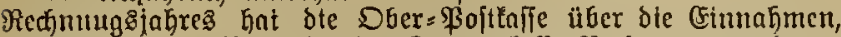

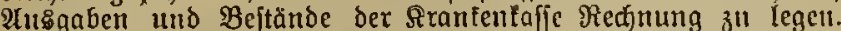
Die Redfunng mird bon Rafjenvorftande geprüit und nach 5 r. ledinm etwaiger (Erinnerungen ber aljäbrlid itattfindenden

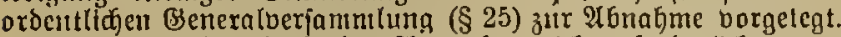

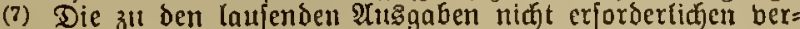
fügbaren Belder ber Sranfentaffe find auf ben Ranten ber leşteren nad Borfdrift des $\$ 40$ A6j. 3 bis 5 des Sranfel= berfidjerungsgejekes anzulegen.

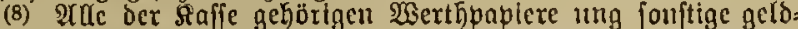
werthen Urfunden werben bou ber Dber=\$oftlaffe aufberabrt.

1) Sib ber betreffenden $O P D$.

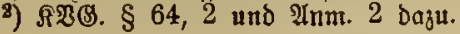

Bujammenfetung der Beneralberfammlumg.

\$24. (1) Dic Beneralherfammlung befteht auts bem $\mathfrak{B e r}=$ treter ber Reids = \$oltberwaltung uno iänmtiticien Raffen

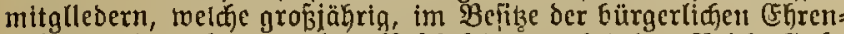

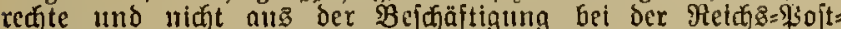
bermaltung bereits ausgefditeden find $(\$ 15)$.

(2) Bebören bex Bofttranfenfafie mebr als 500 Mitglieder au, fo befteht bie Benerafberfammlung aus bem פerteter ber

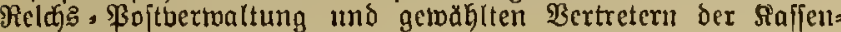
mitglieder.

(3) Dic $2 B a h l$ ber Bertreter ber Safjenmitalieder erjolat für die Daner breier Rechmungsiabre Surd $\mathfrak{B a h l b e r b a ̈ n b e , ~ w e l d h e ~}$ bom $\mathfrak{B a r i t a n d e}$ mit Bujtimmung ber Ratjerlictien Dber = Boit= sirckton für räumlich begrenzte Bezirte nuter Bezeichnumg eines Bororts gefilbet werben. Sebem $\mathfrak{W a h l b e r b a n d ~ m u ̈ f i e n ~ m i n ~}$ beitens 50 mahlberedigte Rafienmitalieber angehören. šeber Wablverband toühlt für ie 50 mahlberechtlgte Rafjenmitglieder eineu Bertreter uto 2 Grjabbertreter. Sit bie $3 a b l$ joidfer Rafjenmitglieder nicht ourd bie 3 afl 50 theilfar, lo find für bie

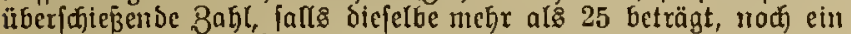
Bertreter und 2 Erfałzertreter zu twählen.

(4) Die $\mathfrak{B a h l}$ exfolgt fïr jeben $\mathfrak{W} a h$ lberband bejonders an defien $\mathfrak{B}$ orort $z_{4}$ Dem bom $\mathfrak{B}$ oritand bejtimmten Beitpunft uner Reitung eines bajelbit twohnfaften, bom Boritand at be= ftinmenden : nur §affenmitglieder, toeldie grofijährig, im Befize ber bürger:

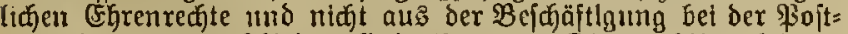
berwaltung ansgefaleden fino (\$ 15). Die wablberedigtent

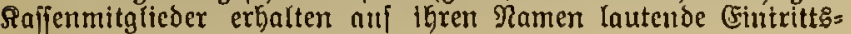
farteı zux $\mathfrak{W a h l b e r j a m m l u t m g . ~}$

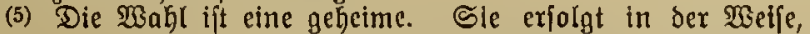
daß̧ jeder Wäblenoc auf ben Stimmzettel fo viele Namen füreibt, als Bertreier zu wählen find. Berbäblt futo diejenigen, meidfe bie meiften Stimmen exhalten. Stimmen, tocidfe auf nidjt wählbare Berfonen fallen ober bie (Sewählten nich)t beutlia bezeiduncn, werben nidit nitgezäblt. Bei Stimmengleidheit entfucidet bas bom Wablborjeber zu ziehende Loos. Jัn ber = jelben Welje und für btejerbe Belt wiro in cinem befonberen Wablgange die exforberitac $B a b l$ bon Grjabuertetern getwählt.

(6) Shbeidet währeno ber Wahlperiode einer ber :ertecter nแts, fo tritt für bie Dauer ber Wablneriode etuer Der Eriats= vertreter an feiner Stelle ein. जัn velder ßeibenfolge bie Erfakbertreter einzutreten haGeu, wirs burch bas bei iGrer Waht bom $\mathfrak{W} a$ hlooriteher zu zichende $200 s$ bejtimmt.

(7) Raffenmifglieber, toeldie niđt eridgeinen, fönneu ibre Stimuse ourfh lleberweifung ibrer Gintrittalarte allf andere Mitglieber übertragen. Der Befizer ber Cintritt:larte gill al:

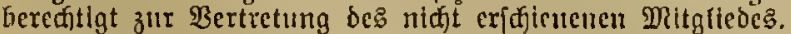

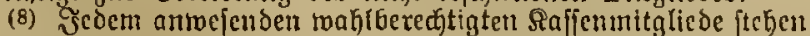
it ber $\mathfrak{B a h l b e r l a n m f u n g ~ a t f e r ~ b e r ~ S t i m m e ~ f u ̈ r ~ b i c ~ e i g e n e ~}$ Berjon nod fo biele Stimmen zu, als ç ङtimmberedigte bertritt.

(9) Die üher die Berhanolung ber waftberbände auf: zunehmende 2 erhandungs/difif ijt bon bem 23 abloorjteher 311 unteridgretben und bem siaffenvoritande zu itberjenden; ber Saffenvorfand bat bierbon, jowie bon jeber Penderung ber getoähtten $\mathfrak{B e r t r e t e r ~ b e r ~ S a i f e r l i d j e n ~ D G e r = \$ 0 | t o i r e f t i o n ~ I n z e i g e ~}$ zu madien.

(10) $\mathfrak{A}_{n}$ Safienmitglieber, weldje an ber $\mathfrak{Z}$ ahlberjammlung in Berfon theilnebmen, wiro elne Entichäbigung für ben ifnen ctma crmachjenden Etnfommentsausffall ober für aufgemendocte Reijetoften nidyt getvährt.

(11) Ẇlto bic Wahl ber Bertreter ober ber Brjatzertreter bermeigert, fo trltt an ibre Stelle Crnemmung burd ble Saljer= liafe Dber $=$ Poftoirettion.

Berbaudurgeu und Befugnifie oer (Beneral= veriamm $\{$ ung.

\$ 25. (1) Einc ordentliche Bencralberjammlumg bat alliäbr= (ich, in ber Reget im erjten SBierteljafr, fpäteftens tu ber erjten

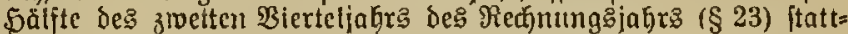
zufinden. $\mathfrak{A} u \mathfrak{s e r b e m}$ find Bencralberjammlungen zu berufen,

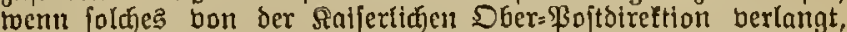
in einer Beriammlung des] Raffenboritandes einjtimmig bejofiofien oder minbeitens bon bcm bierten Theile ber zur Thethabme an ber Beneralverjammlung berechtigten Rafjenmitglieder (\$ 24) beantragt miro. Die Beneralberjamntungen finden am Sike ber Raiferifiden Dber=\$oftsireftton itatt.

(2) Der für bie Generalverjammlung bejtimmie Tag uno Drt lit vom Saffenboritande minbejtens ctue Wodje borber unter Mittheilung ber Tagesoronung ben zut Theilnabme an ber Berjammlung bereditigten Safjemmitglicberu befannt zu madien. Eestere erbalten auf ibren Ramen lantende Eintrittşarten zur Beneralveriammlamg.

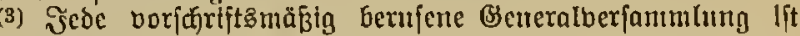

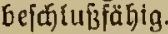

(4) Die Antrăge für die Beneralberjammlumg gehen aut: bon

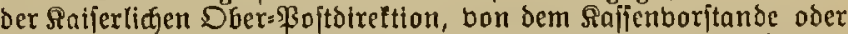
vour ben jur Theirnahme an ber $\mathfrak{B e r j a m m i n n}$ bereditlgten Raffenmitgliedern. Puträge bon einem Senffennitglieb mitffen von 10 anderen Ritgliebern, $\mathfrak{A}$ träge von einem genäbiten Rertreter von 2 anderen getodgiten Vertretern unterftüst uno 2 Wodjen vor ber Beneralberfammlung dem Rajpenborjtande cingercidjt

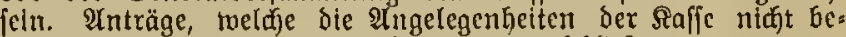
treffen, find bon ber Tageşoronung aušzufकliefen.

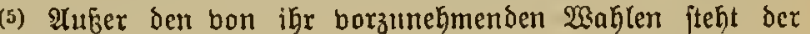
Beneralberjammlumg zu:

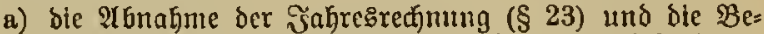
fugnī $\bar{B}$, biejelfe borgängig burch einen bejonberen

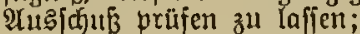

b) Sle Berfolauna bon Anfprïtien, welche ber saffe

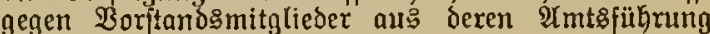
ermadien, Durch Beauftragte;

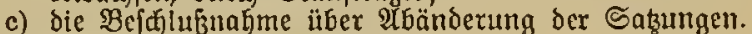

(6) Die Beneralberfammlung witd bon bem Borjanosbor:

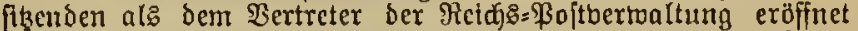
und geleitet. Эัn ber Beneralverfammlnng bürien nur foldbe

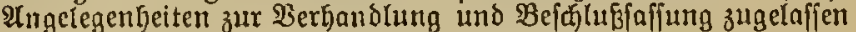
twerben, meltie auf ber Tagesorontmg ftehen.

(7) Mitglieber, weldie in ber Beneralverfaninilung nidjt er:

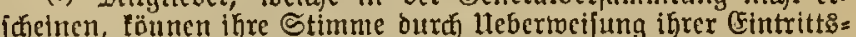
farte auf andere Mitglieber übertragen. Der Befizer ber CEln=

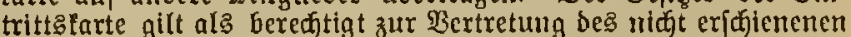
Mitgliebcs. Bejtebt jedod bie Beneralverjammlung aus $\mathfrak{B e r}$. tretern ber Saffenmitglieber, fo fundet eine Bertretumg ber geroäblten Mitglieber der Benernlberfammlung nidgt ftatt.

(8) sebem antwejendeu Mitgliede der Beneralberfammlung fteben in berjêtben nub̄er ber Stumme für bie eigene Ferjon nod fo biele Stimmen zll, als er Stlmmberechtigte bertritt.

(9) Der Borftzende fïbrt in der Beneralberjammlung bal6 jo biele Stinmen, als in berjelben berjicherungspfliditige Saffent= mitglieber vertreteu find. Bejtebt die Beneralverjammiung ants getwähften Sertreterı, fo fteft 1 hm cin Drittel ber Stimmen= zahl 3.1, wethe ben erjobicnenen getwäbiten Bertretern jufommt.

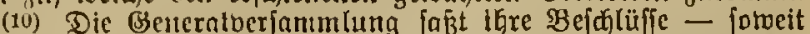

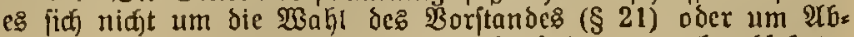
änderungen bex (akumgen (\$ 27) Ganbelt - nac) abfoluter 
Mebrhett fämmtliđjer in der Beneralberjammlung vertretenen Stlmmen. Bel Stimmenglethbcit entideidet die Stimme des Sorftizenden.

(11) Leber de Berfandungen der Beucralberfammfung ift eine Berhandfungb(d)rfft aufzunchmen, meldje bou bem Bor= fißzenden und 2 Pitgltedern ber Berfammlung zit vollziehen ift.

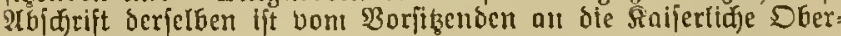
93oitoireftion einzurciden.

(12) थ́n Safferumttglicoer, welüe an ber Bencralverjammlung

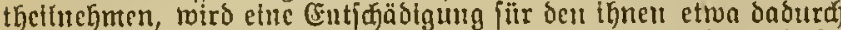
verurfactiten Ginfonmensaugfall oder für alifgetwendete Reife= lojten nidjt geluährt. Die gemählten Bertreter der Sajfen= mitgfteber, melfie nidjt an Sitz ber Satjerl. Dber-\$ojtoireftion wohntgaft find, erbalten auber bem Crfał ber nothivendigen Retjefoiten 3 Marf Tngegeloer.

Bcauffldigung ber Saffenbervaltung. Befdiveróc über Strafuerfügungen. Streitlgeiten

\$26. (1) Die IIuffdit über bie gejammte Raffenbernaltung

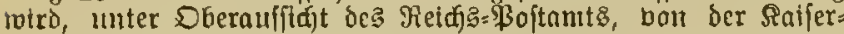
(idjen Dber=9soitoireftlon wabrgenommen.

(2) Die Satjerliđic Dber=\$ojtolrettion übermadit ote $\mathfrak{B e}=$

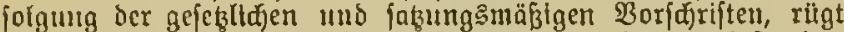

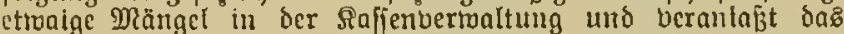
(Becignete an Deren Bcjeittgung. Sic lift insbejondere alld be= fuat; bou allen Berhanolmger, Büdjern mo Redjungen der Sajic (Einftift zu nehmen uno ole ßaife zn rebioiren.

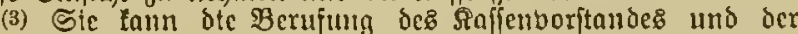
Bencralberiammlung berlangent und in ben anf thr nnberaumten Siłmugen die Qeitung ber Berhanbhugen mebmen.

(4) So lange der Saffenvoritanó ober bic Bencralberjamntumg

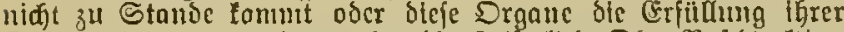
Sbliegenfeiten berwelaern, hat die Sulferlidie Dber $=$ Bojtoirction die Befugniffe und Dbliegentgeiten ocr Saffenorgnute felbit toabr=

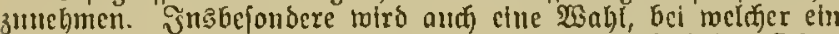
Rajienvoritand nidjt borbanden ift, bon der Raiferlicjen Dber= Boftsirction angeordnet und burd) $\mathfrak{B c a u j t r a g t e}$ derfelben geleitet.

(5) Begen Strafberfitgungen bes Raffenborftandes ift bunten 2 Woden nad beren Groffnumg Befdwerde an bic Dber=\$oit=

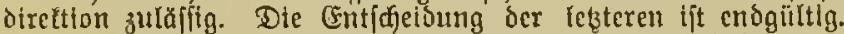

(6) Streitigleiten zrofficn der gioftoerwaltung und ben bon

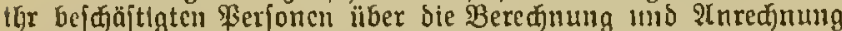

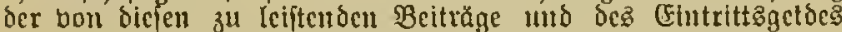
werben entweber auf Slnrufen elner Partel dura ben Bemeinde: boriteber unter $\mathfrak{B o r b e h a l t ~ D e r ~ B e r n f u n g ~ a u f ~ d e n ~ R e f i t s m e g ~ m a d f ~}$ Makgabe ber $\$ \$ 71$ big 75 bcs (scjebes jiber bic Bclverbegeridte

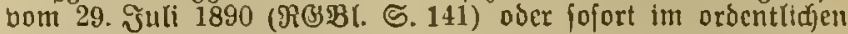
Rechtsిmege entiditedcn 1)

(7) Streitigfeiten, weld)e ztotjdjen oen Saffesmitgllebern mo

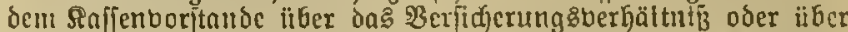

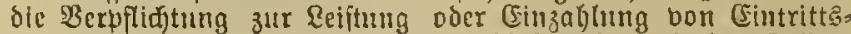

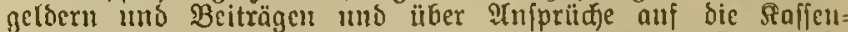
lciftumgen entitehen, tocrben bon ber Seniferlidjen Dber=\$3oit= bireftion entidfleoen. Die Cntiđetoung ijt borläufig bollitrectbar,

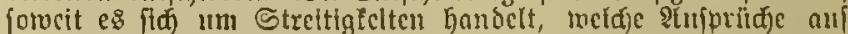
bie Saffenteiftungen betrefin. Die Sntjdjeloung fant bimnen 4 Wadjen nad deren Buftellumg mittelit Slage im ordentlidjent Redjteroege, jomeit aber fanbeggeicblid) foldje Streitigfeiten bem

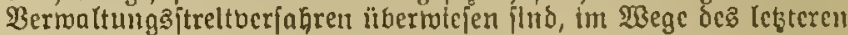
angefoditen twerden.

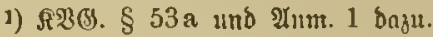

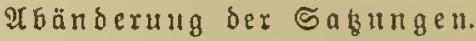

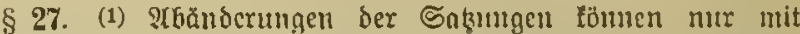
elner Prebrjeit bou bier ङ̈unfteln ber in oer Bencralverfamm. lutg bertretcicn Stlutnicn beidfofifen werben.

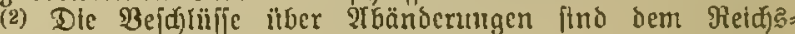
Bojtant zur (B)nebmiging cinzureid)cut.

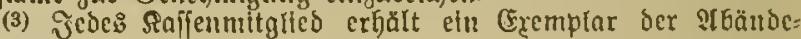
rumgen.

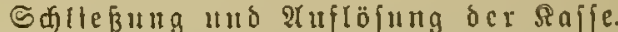

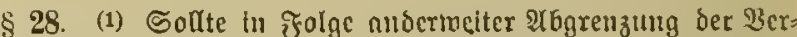
matungêbeztrfe ch größserer Theil ber Mitglieder aubichetben,

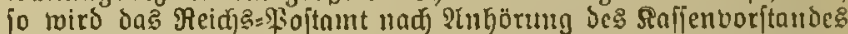
orriber Beftimmung treffen, ob uno zu toddjem Beltpuntte die

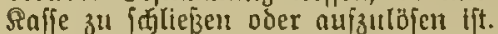

(2) Begen btc bie ङdjliç3ung oder 2tuflofung ausfpredjende

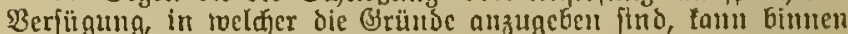

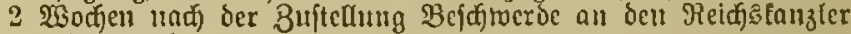
erfoben twerocut.

(3) Das borhandene Sermögcm ber Saffe tijt im Jafle ber

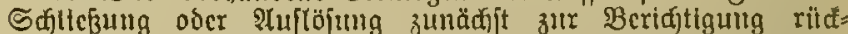
itänoiger Bablungen uns zur Dedung bereits entitandoner

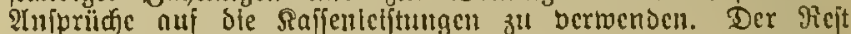

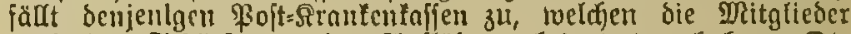

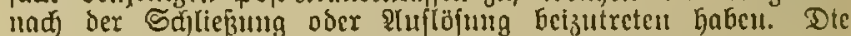
Bertbellung crfolgt und der Roplzahi ber Mitglicber.

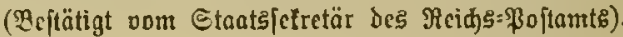

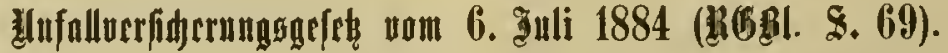

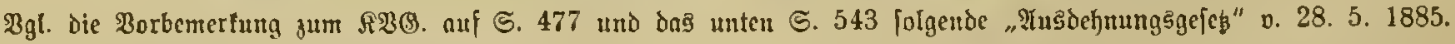

\section{I. ¿llgenteine Beftiutungen.}

Umiang der Berfiderung.

§1. (1) Itlfe in Bergiverfen, Salinen, Ttufbereitung: anitalten, Steinbrür)en, (Sräbercien (Brruben), auf Weriten mo Bauljöjen, jorwic in sabrifen und Soüttenwerfen be=

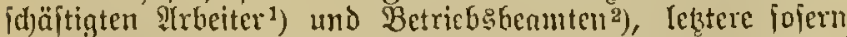

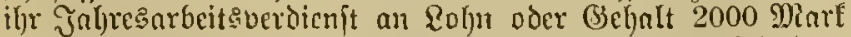
nid)t iiberifeigt, werben gegen bie Folgen ber bei dem

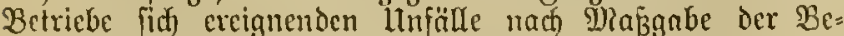
ftimmungen diefes Gejetzes verfidjert.

(2) Daffelbe gilt von Itrbeitern und Betriebsbennten, meldie von einem (Setwerbetreibenden, icfien Bewerbebetrieb

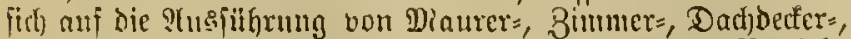

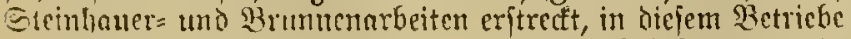
beidjäftigt werden, fumie bon den im Sod)ornfteinfegergemerbe bejouâtigten ?(rGeitern. $\left.{ }^{3}\right)$
(3) Den im :Tbf. 1 nujgefüfrten gelten im Sinne biejes (Befekes dicjenigen Betriebe glcid), in Jueldjen Dampifeifel oder Durd elemtentare Sinft (wind, 2Eaffer, Dampf, Bas, beife $2 u f t$ zc.) bemcgte Triebwerfe jur Bermendung tommen,

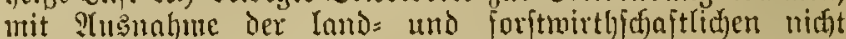

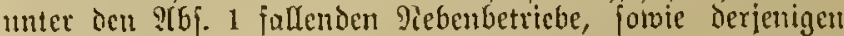
Betriebe, fïr Ineldye mur voritbergebend eine nidft zus Betriebsanlage gebörende Sraftmajujine benut wird.

(4) Эm Hibrigen gelten nla gabrifen im Sinme diefes (3cjezes insbejondere dicienigen Betricbe, in meldjen dic

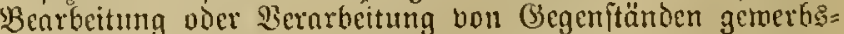
mäpig ausgefitlyrt wirt, und in weldjen ju biefem Broet mindeiteng 10 Stbeiter regelmäBig bejchäftigt werden, forvie Betriebe, in meldien Explofinftoffe oder criplodirende Begen=

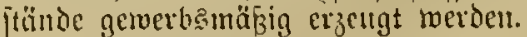

(5) Weld)e Betricbe auferdem als fabriten im Sinne 


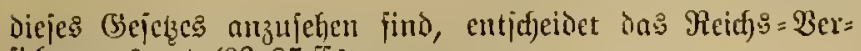
ficferungsamt ( $\$ \S 87$ fi.).

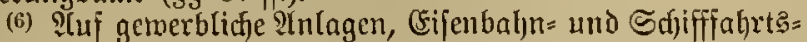
betriebe, melche wejentliche Bejtandtheile eines ber nor:

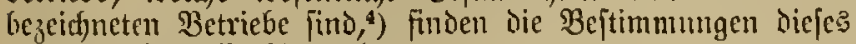
(S)efetse ebenfalle İntwendung.

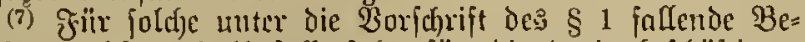
triehe, welche mit llnjallgejahr für dic Darin bejdäitigten

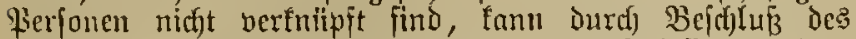

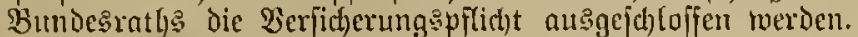

(8) STrbeiter und Betriebsbeante in anieren, nidjt unter

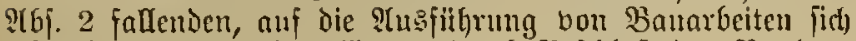

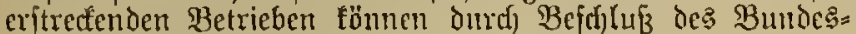
ratbs für berficterungspflichtig erflärt twerben. ${ }^{5}$ )

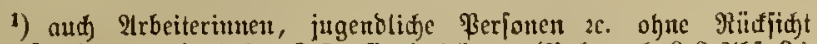

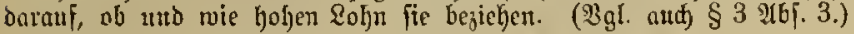

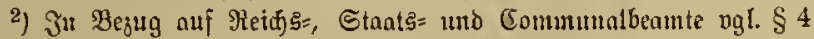

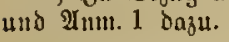

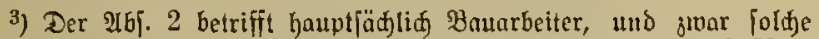
Banarbeiter, welde int generbliden 5odbaubetriebe beidäpigt

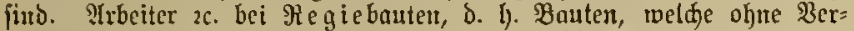

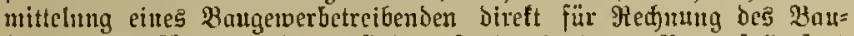
herru nusgeführt merden. fino erit burd bas "Baumfallgefeb"

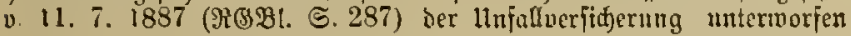
worben.

4) $\mathfrak{I}_{11}$ ben (Fijenbahnbetrieb als foldhen (jomeit er aljo nid) $\mathfrak{B} e=$ ftunbtheil cines anderen Betriebes ijt) ift bas lt23. erit burd bas "Husdehutugsge [eß" vout 28. 5. 1885 ausgedehnt worden.

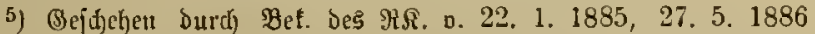
11. 14. 1. 1888 (betr. Tüud)er, Berpuger, $\mathfrak{B a n t i j d}$ ler, Baujd loffer zc.)

\$2. (1) Dutch itatutaxifhe Beitimmumg (\$§ 16 ff.) fann die $\mathfrak{B e r f i d j e r u n g s p f l i d f t ~ a u f ~ B e t r i e b s h e a m i t e ~ m i t ~ e i n e n ~}$ 2000 MarE ïberjteigenden Salhesarbeitsnerdienjt exjtrectt merden. Sn diejem Jafle ift bei ber ifeftftellung ber Ent=

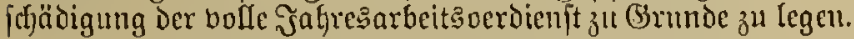

(2) Durd) Statut faun fermer beitimmt merden, da 3 uto unter weld)en Bedingungen llnternebuer der narf $\$ 1$ ber= fiderungspf(icftigen Sietriebe beredftigt find, fidf felbft oder andere nad) \& 1 nidyt berficferungspflichtige \$erjonen gegen die Jolgen bon Betriebsunfällen zu berfithern.

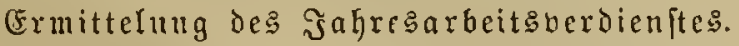

§ 3. (1) Thrs (Behalt oder Sohn im Sinne diefes Befebes gelten audf Tantiemen und Raturalbezüge. Der $\mathfrak{B e r t h}$ Der

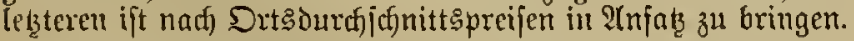

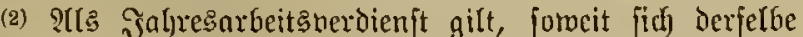

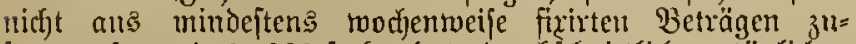

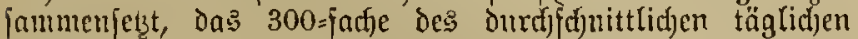
Qtrbeitsperdienftes. Fïr ?trbeiter in Betrieben, in melden die üblid)e Betriebsweife für den Das ganze Эaljr regelmäß̧ig hejdn̈ftigten 2lrbeiter eine höhere ober nieorigere Zaht von

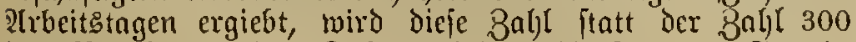
Der Berechnung des Sahresarbeitsoerdienftes zu (5runde gelegt.

(3) Bei jugendlidjen $\mathfrak{A}$ rbeitern uno joldjen Perfonen,

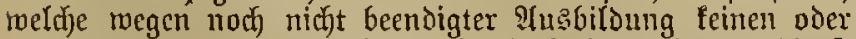
einell geringen \&ohn beziehen, gilt als Jahresnatbeitsnerdienjt

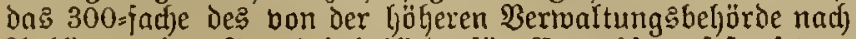

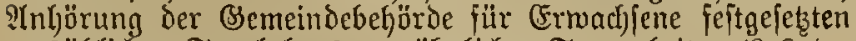
ortsitblid)en Tagelohnes gemöhnlicher Tagearbeiter (\$ 8 bes frautenverftherunggge [eges pom $\frac{15.6 .1883}{10.4 .1892}$ ).
Reid) $s=$ Stants= mni Rommunarbenmte.

§ 4. Tluf $\mathfrak{B e a m t e}$ meldhe in Petriebsverwaltungen des

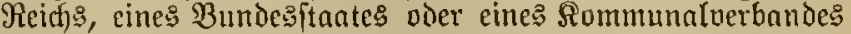
mit feftem (3ehalt uno Wenfionsberechtigung angeftefft jind, findet biejes (Bejebs teiue ?(nmendung. ${ }^{\text {) }}$

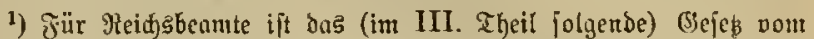

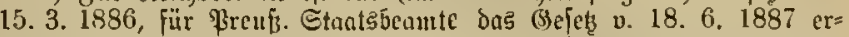

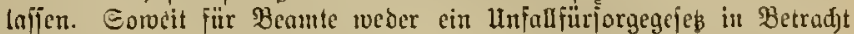

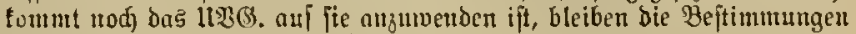

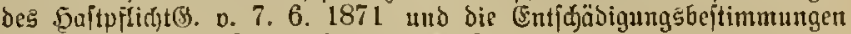
ocs थ2ง ., bes code civil zc. in frajt.

\section{(3) egenftand Der Berfiderung nnd Umfang Der (Entffjädigung.}

§ 5. (t) Begenftand der $\mathfrak{B e r f i c j e r u n g ~ i f t ~ b e r ~ n a d ~} \mathfrak{M a} \bar{B}=$ gabe Der nadjfolgeuden 3ejtimmumgen zu bemejiende Erjats des Sdhadens, weldjer durd siörperverletzung oder Tödtmg entiteft.

(a) Der Sdjadenserfatz foll iun Jalle Der Berleţung be= iteljen:

1. in Den Soften bes Seilverjahrens, weldie bom Beginn Der 14. 23 adje1 ${ }^{1}$ ) nadf (Eintritt des ltujall: an entitchen;

2. in ciner dem $\mathfrak{B e r l e b t e n ~ v o m ~ B e g i n n ~ d e r ~} 14$. $\mathfrak{W}$ achet) nacf) (sintritt des llnfalls an jür die Dauer Der

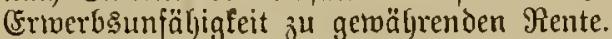

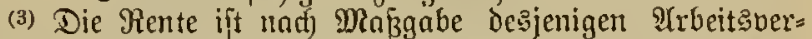

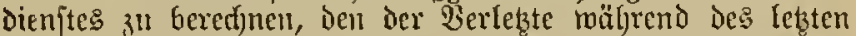

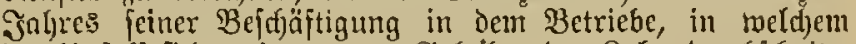
Der IInfall fid) ereignete, an (3ehált oder Lohn durdfichnitt= lid) fïr Den QYrbeitstag bezogen lyat (\$3), mobei der 4 Marf überiteigende Betrag nur mit $1 / 3$ jur sfured)unug fommt.

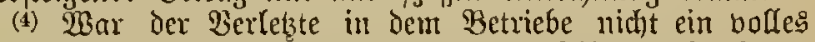

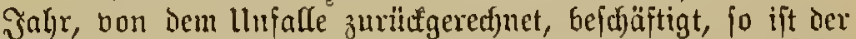
Betrag ju (srunde zu legen, meldfen während diefes Beit= raumes Mrbeiter derjelben ?̂rt, in demfelben Betriebe oider in benadfbarten gleidjartigen Betrieben burchfonnittlich $b c=$ zogen haber.

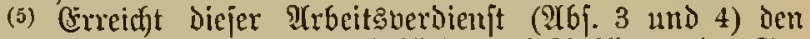
bon ber föheren Bertwaltungsbefjörde nad) ?tnförung der (Bes=

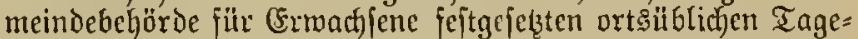

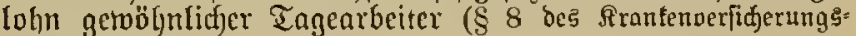

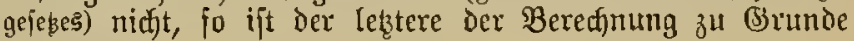
zu legen.

(6) Dic Rente beträgt:

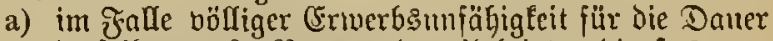
derfelben $66^{2} / 3$ \$rozent des Mrbeitsverdienftes;

b) im Falle theiltweifer Grinerbsmpähigfeit für die

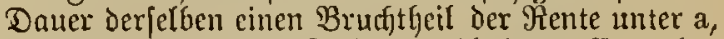
weldjer nady bem Maße der verbliebenen (Erwerbs: fäbigfeit zll bemeffen ift. ${ }^{2}$ )

(7) Dem $\mathfrak{B e r l e t z t e n ~ u n d ~ f e i n e n ~ S i n t e r b l i e b e n e n ~ i t e h t ~ e i n ~}$

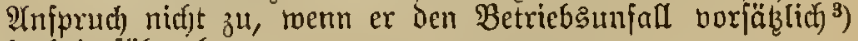
herbeigefïhrt hat.

(8) Die Berufigenoffenfortaften (§ 9) jind bejugt, ber Srnnfenfaffe, melcber der Berletete angehört, gegen (Er)tattung

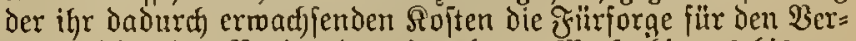
lekgten iiber den Begimn der bierzelnten $\mathfrak{W}$ acfe hinaus bis zur Beendigung des Scilverfahrens zu übertragen. Jn biejem

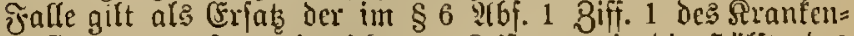

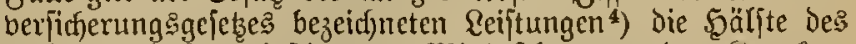
in ienem sejebe bejtimmten Mindeftbetrages des Sranten= geldes, fofern nidjt Göhere Sufwendungen nachgewiefen werden. Streitigfeiten, weldhe aus $\mathfrak{A}$ Iafá biejer Bejtimmung 
3rwifden den Berufsigenoffenf(t)aften und Den Sraufenfnffen entjtehen, merden nad) Maß̧gabe des $\$ 58$ 2(6. 2 bes Srantenberfitjerungsigejebes entidjieden.

(9) PSon Beginn Der 5. Wod)e nad) (Eintritt des Unfalls bis zum গtblauf Der 13. Wache ift das Sranfengeld, weldjes ben Durd) einen Betriebsunfall verletzten \$erfonen nuf (S) runo des Franfenverficherung:gefebes getrährt wird, nui mindeften $2 / 3$ Des bei der Berechnung Defielben zu (S) runde gelegten 2(rbeitslognes zu bemteffer. Die Differenz z'vifd)en biefen zwei Dritteln und Dem gejeszlich oder ftatutengemtä $\tilde{B}$ zu gervährenden niebrigeren Sranferigeloe ift ber betheiligten Siranfenfajpe (\$łemeinde=STranfenberfid)erung) von Dem linter: nehmer desjenigen Betriebes ju erftatten, in tocicfem der

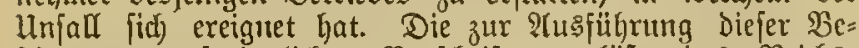
ftimmung exforderlidjen Borjdriften erläßt das Reidjs: Berjidjerungsamt. ${ }^{5}$ )

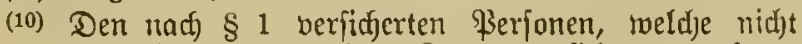
nad) Den Beftimmungen des Rrantenverfidjerungsgefetzes verfichert find, hat der Betriebsunternebmer bie in Den $\$ \S 6$ und 7 bes Sranfenverjicherungsgejebes borgejehenen unter= itübung einjol. des aus dem vorbergehenden 2tbjatze jid) ergebenden Megrbetrages fïr die eriten 13 Madjen all eigenen Iitteln zu leilten.

(11) Streitigfeiten, weldje aus Y̛nlnáz ber in Den beiden vorbergeljenden $\mathfrak{a b f a ̈ b e n ~ e n t h a l t e n e n ~ B e f t i m m u n g e n ~ u t t e r ~}$ den SBetheiligten entitelen, werden narf Mafignabe des $\$ 58$

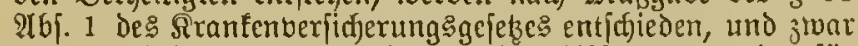

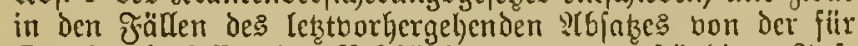

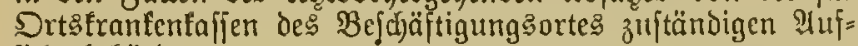
ficht

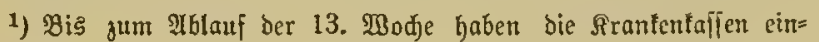
zutreten.

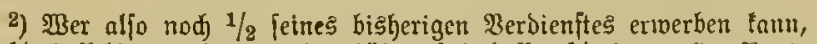
hat $1 / 2$ beffelben verloren und erhält infolgedefifen $1 / 2$ ber vollen Rente ober $1 / 3$ Des für ighn beredfneten bisherigen Jahres̆arbcitsoerbienfics.

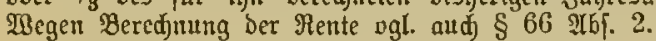

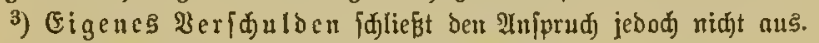

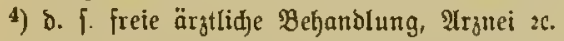

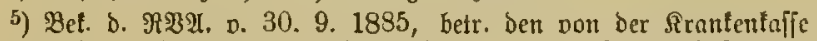
in ber Beit von der 5 . bis jur 13. शुode nad bem lunfall zu leiftenden, jeitens bes Betriebsunternehmers ju exftattenden Diebrbetrag an

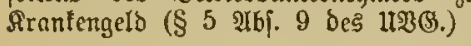

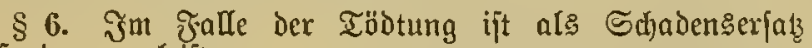
aufierdem zu reipten:

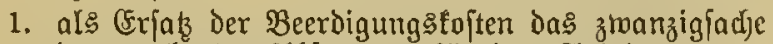

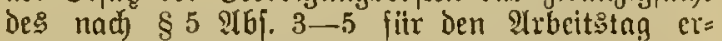
mittelten Serdienftes, jedod) mindeitens 30 פintf;

2. eine den Sinterbliebenen Des Getöbteten vom Todes: tage ant zu gemährende Rente, roeldie nact) dent

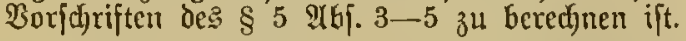

Diefelfie beträgt:

a) fïr Die Wittme des (Betöbteten bis zu deren Tode oder Wiederverheirathung 20 Frozent, fïr jedes hinterbliebene vaterloje Sind 1 bi: zu beffen zurülffgelegtem 15. Rebensigalre 15 \$rozent und, wenn das אind aud) mutterlos ift oder wird, 20 łrozent Des ?trbeitšberbienjtes.

Die Renten Der Wittren und Der Sinder Dürfenzufammen 60 \$rozent Des Arbeitsocrdienjtes nidft überfteigen; ergiebt fich cin höherer Betrag, io werden bie einzelnen Renten in gleidhem Berbăltniffe gefürzat.
Fin Falfe der Wiederberbcirntfung erfyält die 2 ittrue den $3=$ facten Betrag ifrer Jahres: rente als afbindung.

Der 21nfprud) Der Wittwe ift autge[d]lof[en, menn die (she erft nadj bem llufalle gefaldolien worden ift;

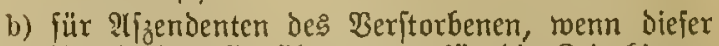
iht einziger (srnährer mar, für die Beit bis zu iljem $\mathfrak{I}$ ode oder bis zum $\mathfrak{B e g}$ jall Der Bedürtig= feit 20 Srozent Des itrbeitsberdienftes.

Wenn mebrere Der unter b benannten $S B e=$ rectigten borhanden fimb, fo wird die Rente Den (Eltern vor den Brobeltern getwäbrt.

Wenn die unter b begeidjuten mit den unter a bezeidneten Berechtigten fonfurriren, fo baben bie er[teren einen 2niprudf nur, foreit

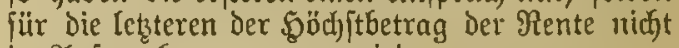
in 2 (n)prud) genommen twiro.

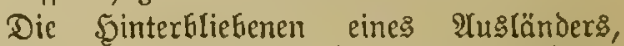
weldje zur Beit bes llnials nidjt im Jnlande

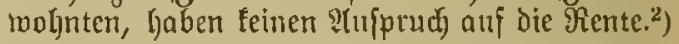

1) Uncheliđa Rinber cines verunglüdten Irbeiters finb ridjt rente= berchtiat; unehclidje finder einer verunglüđten Irbeiterin bagegen find rentebereditigt.

2) $\mathfrak{B g l}$. $\$ 67$.

§ 7. (1) 9In Stelle der im $\$ 5$ borgejdriebenen Reiftungen fann bis zum beendigten ફूeilberfahren freic §ur und Berpflegung in einem Sranfenthaulje gewäh)t weròn, uno zrwar:

1. Für ஒrerunglüctte, roeldhe berheirathet find òer bei einent Mitglicde iffer Familie wohnen, mit ihrer Bujtimmung oder unabhängig von berfelben, wenn Die 2Trt Der Berleb̧ung 2nforderungen an bic $\mathfrak{B} e=$ handlung oder Berpflegung Ftellt, denen in ber Jamilie nicht genügt werden fann;

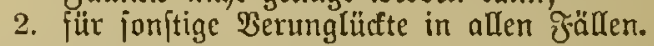

(2) Fïur Die Beit Der Berpflegung Des $\mathfrak{V}$ erunglücten in Dem Sranfenlanufe fteht Den in $\$ 6$ Biff. 2 bezcid)neten ?trgehörigen defielben die dajelbit nngegebene Rente impoweit zu, als fie auf diefelthe im Falle des Todes Des Berletgten cinen S(nfprud) haben würoen.1)

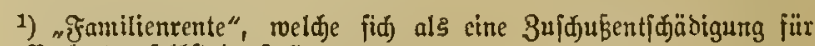
ben Berlebten felbjt barftell.

Berlältní̄ zu Sranfenfaffen, צrmenverbänden ze.

\$ 8. (1) Die Berpflictung her eingeichriebenen Fुtil fajjen, fowie Der fonftigen Rranfen =, Sterbe=, Fnvaliden= und anderen lunterjtiiłzungefaffen, Den von Betriebsunfällen betroffenen 2libettern und Betriebsbeamten, jomie deren

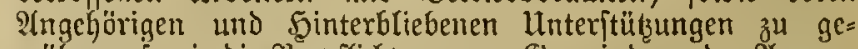

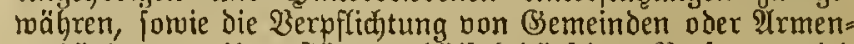
nerbänben zur Unteritübung hülfsbedürftiger \$erjonen wirb Durd) Dicjes (Sejets nidyt beritbrt. Sorweit auf (Grund lold)er Verpflichtung lunteritübungen in fïllen getuälyrt fino, in weldjen dem linteritiibten nadj Maßzgabe biefes Gejebeś ein Entfdäbigungs̊njprud) zufteht, geht ber lebtere bis zum Betrage der geleifteten Interftilbung auj Die Saffen, die Gemeinden oder die Armenverbände üher, bon reld)en bie Interftüłzung getwährt worden ijt.

(2) Das (SLeidje gilt von den Betricbsunternelynern uno Saffen, meldje bie Den bezeidyneten Bemeinden und Armen= 
verbämben obliegente Berpilichtung ỏแr linterftük̨ung auf (Srutnd gejebfiduer Worfdrift erfitllt Ljaben.

Träger ber Berficherung (Berufsgenoffenj d)aften).

\$ 9. (1) Dic $\mathfrak{B e r f i c h e r u n g ~ e x f o r g t ~ a n f ~ B e g e n j e i t i g f e i t ~}$ omed) Dic Ilnternehmer ber unter $\$ 1$ fallenden SBetriebe,

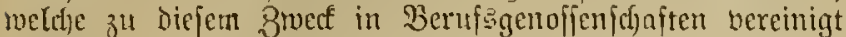
merden. Dic Berufagenofienfafaften find fïr bejtimmte

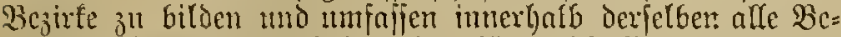

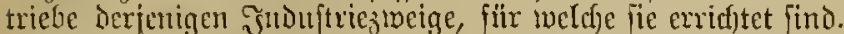

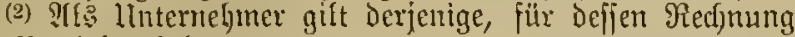
Der Betrieb erfolgt.

(3) Betriebe, weld)e mefentliche Beftandtheile veridjieden= artiger Jnouftriejweige umfajjen, find derienigen Berujs= genofjenịdjajt zuzutheilen, meldjer Der 5auptbetrieb an= geljürt.

(4) Die Birufägenofjenichaften fönnen unter ifjem Bamen gicd)te erwertien und Serbinblichteiten eingehen, bor Gericht flngen und berflogt werden.

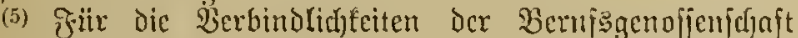

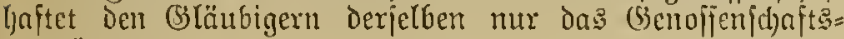
verüügen.

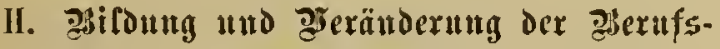 genolferlddiaftell.}

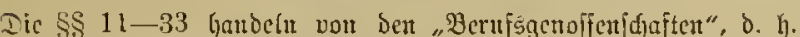
ben a

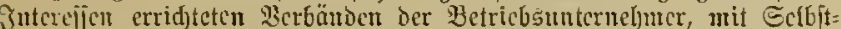
ncrvulturg und auf (Scgenjeitigfcit. Dic Bitbung erfotgt anf bem SBege der Sircinburung unter 8uftumung bes Bunbesratljs. Dic intere Berwaltung miro Inrch Etatut geregelt.

\section{Zֶertretutg der girleiter.}

\$ 41. (1) Bum Broet Der Wangl von Beifit3ern jum Erfiedsgeridft (\$ 46), Der Begutadjtung Der zแm $\mathfrak{E}$ erhütung non llufäflen zu erlaffenden Borfariften $(\$ \$ 78,81)$ uno

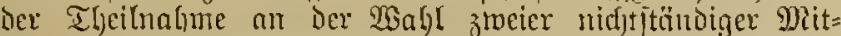
glieder De? Reid)

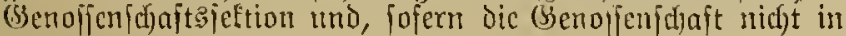
Seftionen getheilt ift, fiir die Benoffenfliaft Bertreter ber ?rbeiter gewäl)lt.

(2) Die Bahl der Vertreter nut Der Bahl der von Den Betriebsunternebmern in Den Barftand ber Seftion bejw.

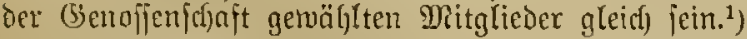

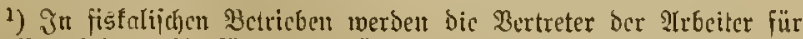

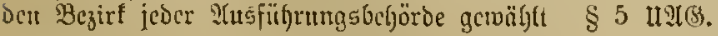

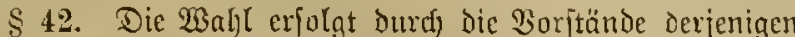

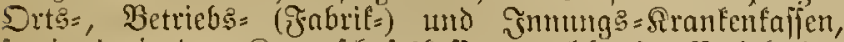
forvie derjenigen Snnppl(h)atsfoffert, weldye im Bezirfe der Seftion bezn. Der Genofieniffaft ifren Sib laben mo

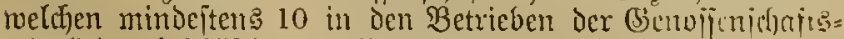
mitglicber bejajäfigte verfiderte \$erjonen angebören, unter

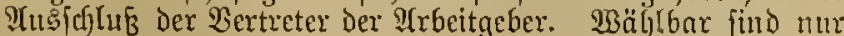

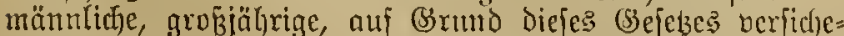
rungsprfictige אaffenmitģlieder, weldje in Betrieben Dex (Sic= noflerichaftamitgfieder und im Sesirfe Der Seftion bezı.

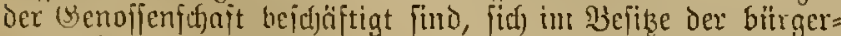
lid)en (5hrenred)te befinden und nicht burd) rifjterlidje $\mathfrak{Q}(\mathrm{n}=$

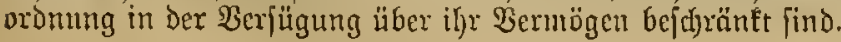

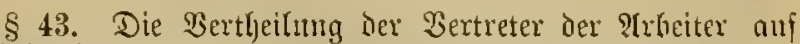

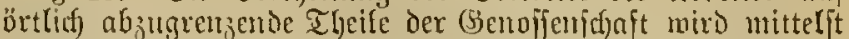

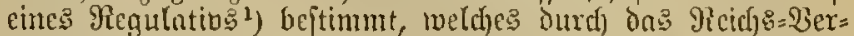
ficherungsont vier, jofern es fid) um eire (Benofienjidaft oder Seltion bandelt, weldie iiber bie Srenzen eimes Sandes

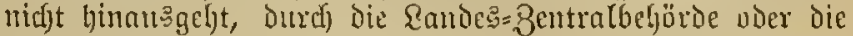

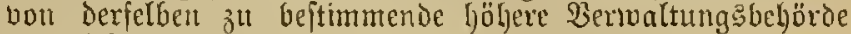
zu erlafien ift.

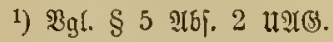

$\$ 44$. (1) Die $23 a h l$ Der $\mathfrak{B}$ ertreter Der 2 rbeiter erjolgt

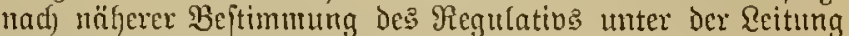

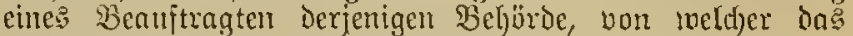
Regulatio erlafien worden ift.

(2) Fiir jeden Bertreter find ein crifter und ein ziveiter

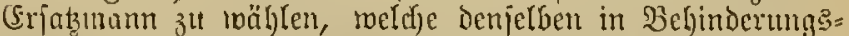

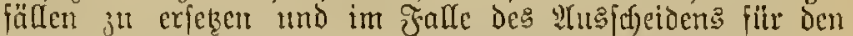

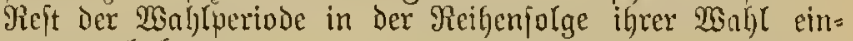
jutreten Gaben.

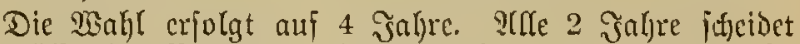
die 5ällfte ter $\mathfrak{B}$ ertreter und Erratznänner aus. Die erit=

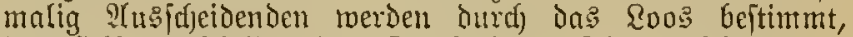
Demuädjft entfdeidet das Dienftalter. Die Tusffheidenden tönnen micdergetnäl)lt twerben.

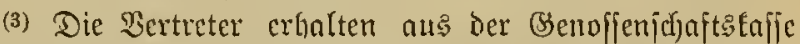
auf S(nweifung des (Senoffenfdiaftsvoritandes nad) den Durel] do

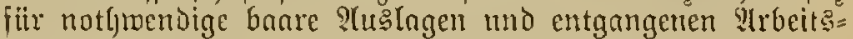

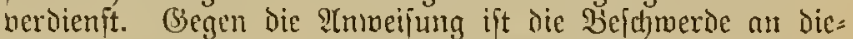
jenige Beljörde, weldye Das Regulativ erlaffer: hat (\$ 43), julüjilig. Dicjefbe enticfeidet endogitttig.

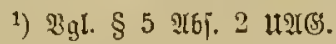

§ 45. (1) Dic Voritände der Siranfenfajien uno der Sinappfchaftsfaffen, weldjen mindeftens 10 in Den Betrieben

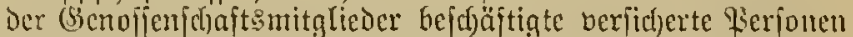
angehören, wählen alle 2 Jahre aus Der Zaht der Sajpen=

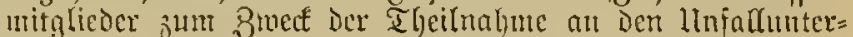

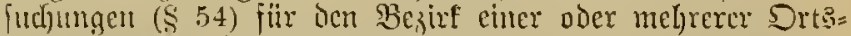
polizeibeljörden je cimen $\mathfrak{B}$ evollmäd)tigten und 2 (Exjasmänncr, dercn Rame nut Wobnort Den betheiligten Srtapolizei= belyöroen ${ }^{1}$ ) mitjutheilen ift.

(2) Die Dem Boritande Der Salie antgeljözenten Bertreter Der Irbeitgeber nefmet an Der W3ah)! nidft I Theil.

\section{Sdjiedsgeridite.}

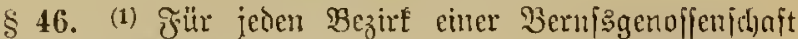
oier, fofern dicjelbe in Seftionen getheilt ift, einer Seftion, wiro ein Sdjiedsnericht errichtet.

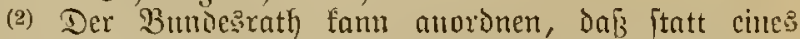

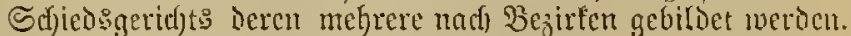

(3) Der Sitz des Sofjedsageridyts wirb von Der Bentral= behörde des Bumbesftantes, gehört, ooer, jojern ber B̉ejirf über die (3)enjen emes V3uncsitantes hinausgeht, im Einbernehmen mit ben be=

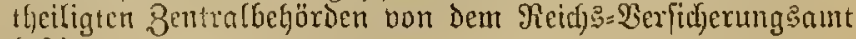
Geitinmt.

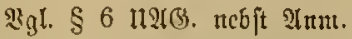

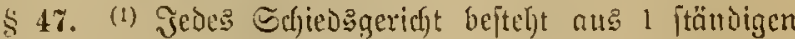
Yorjikenden und atts 4 Beifizcrn. 
(2) Der Borfitzende wird aus der Baldl Der öffentlid)en

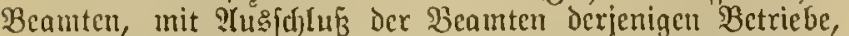
rvelche unter diejes Bejés fallen, von Der Bentralbeljörbe Des Sandes, in weldyem der Eizz des Sdjiedsgeridyts belegen ift, crutant. Für Den פorjizenden ift in gleidjer $\mathfrak{E}$ eife cin Stelfbertreter zu ernemen, meldjer ifgn in Beljinderungs: fällen vertritt.

(3) Brwei Beifizer werden bon der Benojien[dfaft, oder jojern Dic (Benofienf(d)ait in Seftionen getfeilt ift, von ber lnetheifigten Scftion getwählt. Ẅäl)lhar fino dic ftimm:

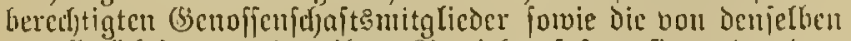

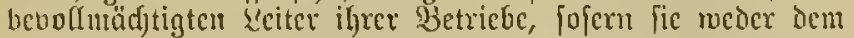
Borftunie der (Senojiemf(haft, nodf) Dem Sorftande der Seftion, 110() den Bertzauensimännern angeljören uno nid)t Dured)

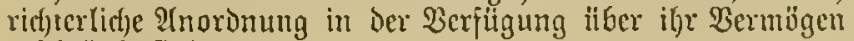
bclc)ränlt find.

(4) Die beiden andezen Beiftzer werden naud) näljerer Beitimunu des Regulatibs ( $\$ 43$ ) bon bcu im $\S 41$ be=

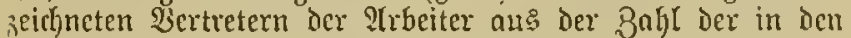
3etrieben der Benoffenfdiajt beldjäftigten, Dem Ir.bciter= ftande angefjörenden berfidjerten Fisefonen, weldie den im $\$ 42$ genantiten Sajien angeljören, geroählt.

(5) Fï jeden Beifizer find ein erfter und cin zrmeiter Stclfbertreter zu mählen, melche ihn in Behinderungsfällen zlt veruretelt haben.

(6) Die SBeifitier uno Stellocrtreter werden auf 4 Jafre

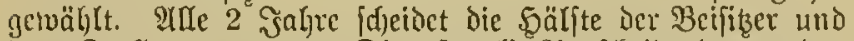

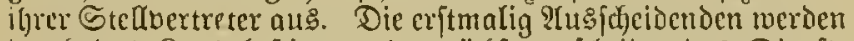

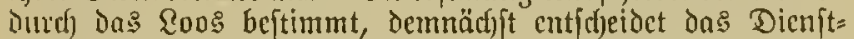

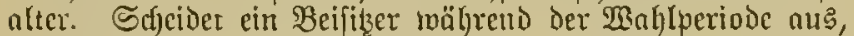

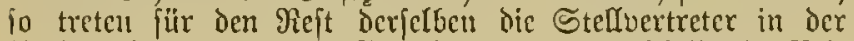

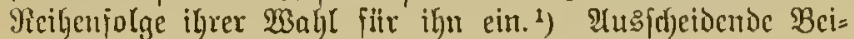
fiker und Steflbertreter find wieder wöflbar.

1) aljo für ben ausjdjeibenden Seifiper befien 1. Stelluertreter, für belt lesteren ber 2. Etellocrtreter. Das Iultüđen Der Stell= vertreter sarf nidit baburd verhinbert werben, baj bie vor ifuen ent= jebende Rüđe burd eine Reuvabl ausgefüllt worb. Eie baben bas

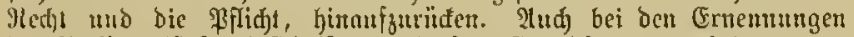

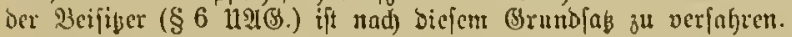

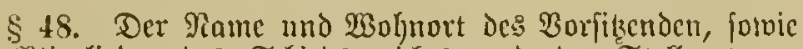
Der 9yitglieder Des Schiedsgericfte uno Der Etelloertreter

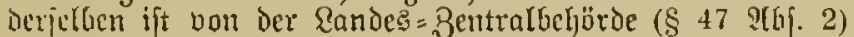
in Dem ju Deren amtlidjen Veröffentlidyungen Gejtimmten 3̧atte öfientlicf) befannt zu machen.

\$ 49. (1) Der Borfibende und deffen Stefluertreter, die Beifitser uno deren Stellocttreter find mit Bezichung auf ifl. ?lut zu becidigen.

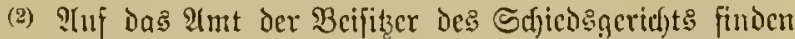

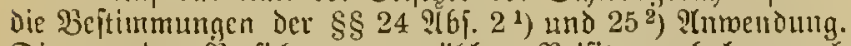
Die von Den 2 erfiderten gewählten Beifiker crfalten nad) Den Durd) Das (Senoffenflyaftsftatut ju beitimuenden Säzen ${ }^{3}$ ) Erjats für don ibnen in Folge ibrer Theilnafme an den

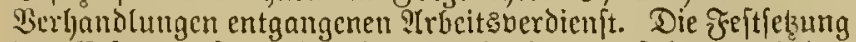
deş (Eriakzes, fomie Der baaren शtuslagen erfolgt burd) den Burfitzenten.

(3) Die Bchjörde, meldye das im $\$ 43$ vorgcichene Regulatio erlafien hat, ift bercdytigt, Die llebermalyme und die wahrnelunung der Sbliegenheiten des Whts eines Bei= fizer: voer Stelluertreters Durth (seldftrafen bis jull 500 Diart

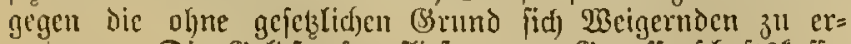

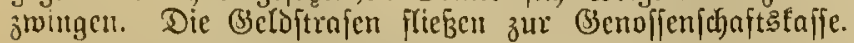

(4) Benveigern Dic Bemählten alcid)wohl ihre Dienft= leiftung, oDer fonmt einc WSabl nicht zul Stande, jo lat, jo Lenge uno fowcit dię der Fall ift, Die untere Verbaltung: behörde, in Deren Bezint Der Sik ies Sdjiedsgeridft: be=

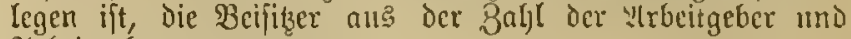
?trbeitnefmer zll cinemen.

1) Derictbe lautet: "Die IIblehrurg ber פKahl ift nur ous benjelben

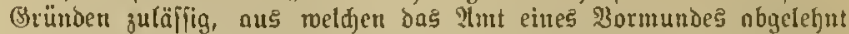
roerden fann. (Eire Wiederwabl tann abgelehnt roerden." Bgl. \$ 23 ber शłornunofdD. obeu ङ. 318.

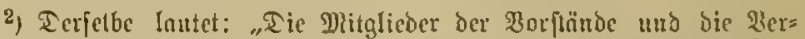

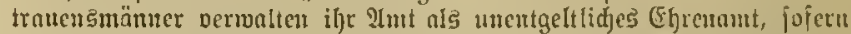
nidjt burd bas Etatut cine (Entjdäbigung fïr ben ourd) 2labrnelymung ber Genoifenidaftsgejdäfse iljnen cruabjenden Bettuerluft befitimut wirb. Buare ?tuslagen werben ihnen von ber (Bendifenfduft erjebl,

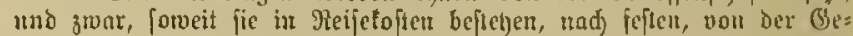

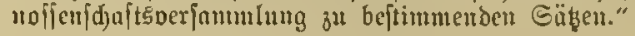

3) ঔgl. $§ 5$ आbj. 2 แ2(G.

\section{Berfagren bor dem Sdiedsgeridyt.}

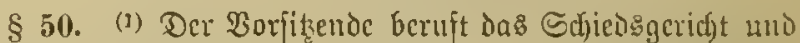
leitet bie Berfjandlungen beficlben. Das Schiebsgeridjt ift bciugt, denjenigen Theil ies Betriebes, in meldyen tocr

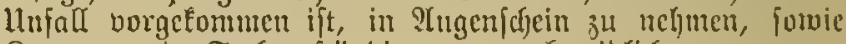
3cugen und Sadjberftändige - aud eid tich - zll ver: nchmen.

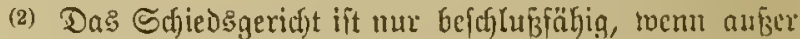

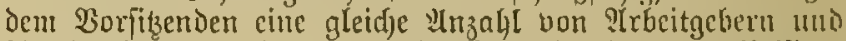
?trbeitmel)mern unb zwar mindeitens je eimer als B̉eifiker: mitwirfen.

(3) Die (Entidycidungen Des Sdjiedsgerid)t: erfolgen nad) Stimmenmefy:beit.

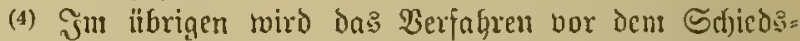
gericht burd) Seaiferlicfe 2 serordmung mit Buftummung brs

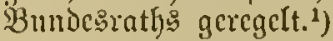

(5) Dic Roften des Schicisgerithts, fowic dic Roften bes Berfahrens yor Demiclben urägt dic (Senofienjid)ajt.

(6) Dem Borfikenden Des Schiedsageridtes uno icficu Stelluertreter darf cine Bergittung voll ber Bendifenjelujt nicht gemäl)t twerden.

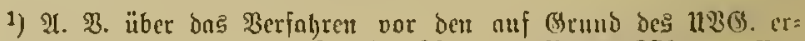

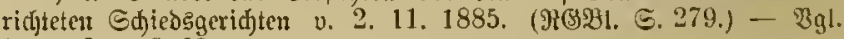
आกน. 2 зแ $\S 62$.

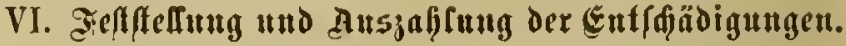

\section{*Izzeige und unterfud)ung der unfärle.}

\$ 51. (1) Bon jeicm in cincm verfidjerten Betricbe vor= fommenden Unfall, Duref weld)en cine in iemiclten be= fdjäftigte Berfoul getöbtet wird oder eine Rörperberleksumg crleidet, bcldje cine Arbcitsunfähigfeit bon mchr als 3 Tagcu oier Den Tod zur F̌olac hat, ift von bem Betriebsunter.

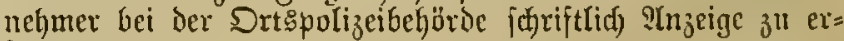
itatten.

(2) Diejelbe muj binnen 2 Tagen nad bemt Tage er= folgen, an meld)em der $\mathfrak{B e t r i e b s u n t e r n c l y m e r ~ b o u ~ d e m ~ U n f a l l ~}$ Senntuif erlangt hat.

(3) J̈̈̈ Den Betriebsunternelymer fann derjenige, meldfor zur Beit des Unjalls den Betrich oder Den Betrichstheil, in meldyem ficf ber Unfall ereignete, zu leiten Gatte, Die 2lnzeige

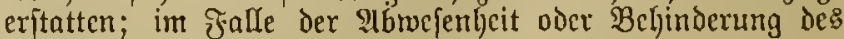
Betriebsiunternehmers ift er Dazu verpflichtet.

(4) Da: Jornullar für Dic ?lnzeigc riro vom Reid): Berficherumgsamt fcitgeftellt. 
(3) Wixb der angemelocte Entffjäbigungsanjprud) an=

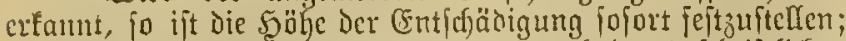

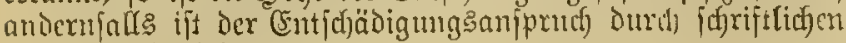
Becfjeid abzulehnen.

(4).....

\$ 61. Lleber die Feftitellung Der Cutjdjöbigung hat ber

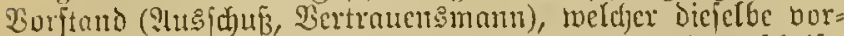
acuommen ljat, Dcm Entidjöbigungesocechtigten einen idf)rift

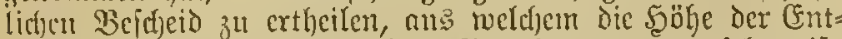
idübigung und bic ?[rt ifrer Beredinumg ju crichen ijt.

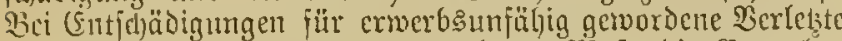
iit namentlid) anjugeben, in weld)en Dinßze Dic Crmerbs= unjübigfeit anßenommen worden ijt.

\section{Bertifung gegen die (Entjdeioung ber ß̊chöroen und Genoficufdunfţorgane.}

\$ 62. (1) Begen ben Becideio ber unteren Werwaltungsbchöroc,

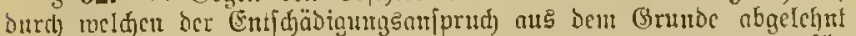
juirt ucil ber Retricb, in meldhen ber llnfalf fiú ereignet hat, fïx nid)t unter ben $\$ 1$ falleno erachtet wird $(\$ 59$ ?(bj. 4), itcht ism

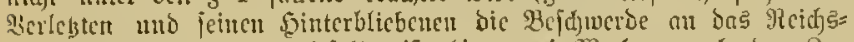

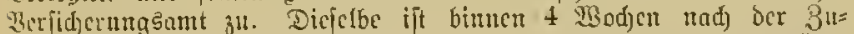

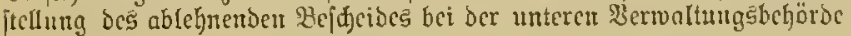
cinzulegen. ${ }^{1}$ )

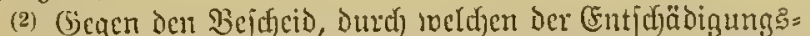

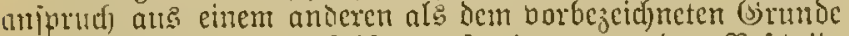
abgelıl)t wird (\$ 59 ?lbf. 3), jowie gegen den Rejcheid, Dritd) welchen dic (smij)äbigurg fejtgeitellt wito (\$ 61), fintet bie Berufung auj icficostichterlide Entidjeioung itatt.

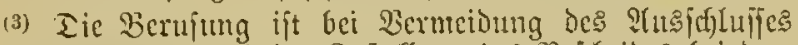
binner 4 Woden mad ber Bujtellung Des SBejdjeides bei ben Wurfilienden besjenigen (Sd)iedsgeridjts (\$ 47) zu erheber,

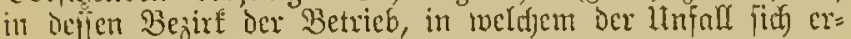
eignut luat, belegen ijt. ${ }^{2}$ )

(4) Der Befáfeid muß bie Bezeidymug Der für Dic Be=

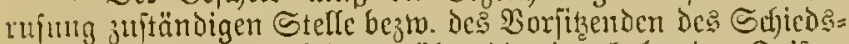
gerid) ettlluallen.

\section{(5) Die Berufung lyat fcinc auffoficbetide Wittung.}

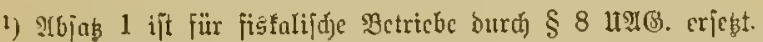

2) Tie Berulung an bos Edicosgeriđt ijt foriftlid unter Bci=

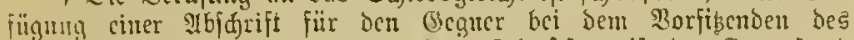

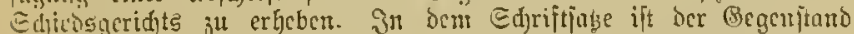

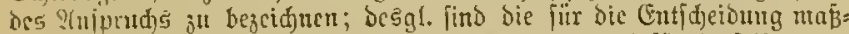
achenocu Thatfaden unter YIngabe ber Berbeißnittel für biciclber an=

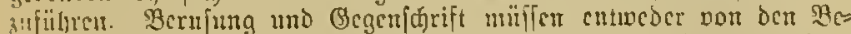

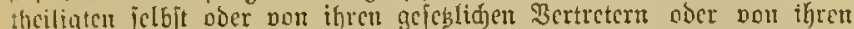

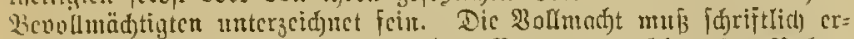
thcilt merben. Dus Schicosacridt tann Bertreter, welde, obne Redyts=

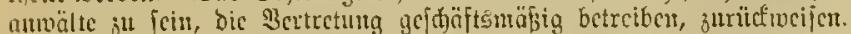

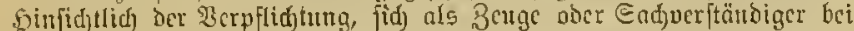
crachunocr Qaoma bes Gdicosgeridhts vernchnen ju laffen, finben bic

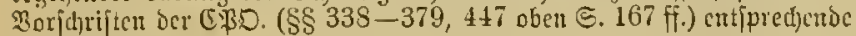
?ุmenoung.

Entfdeidung des Sdficdsgeridts. Returs an bas Reidf

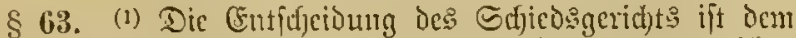
Berufenten und iemjenigen Genofjenjefajtsorgane, weldes

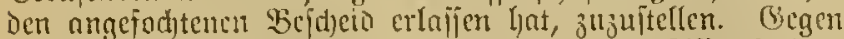
Die (enticheidung itcht in den stüllen bes \& 57 Biff. $2^{1}$ ) $\mathrm{cm}$ Ferfertern nicr dejien Sinterblicbenen, forvic dem (Sentifen= ichafisuoritande binnen eitter jrift von 4 Wodjen nadj ber
Buftelfung Der Entidfeidung Der Refurs an ias Reichs= פerficherung:amt ju. Derjelbe hat keine aufichiebende Wirfumg.

(2) Bildet in Dem Jalle bes $\$ 6$ Biff. 2 die ?tnertennung

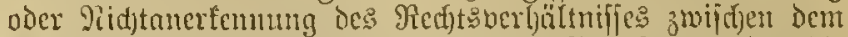

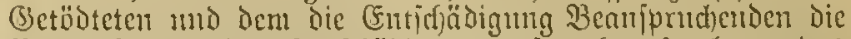

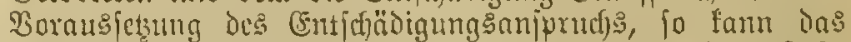

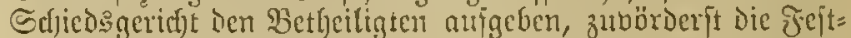

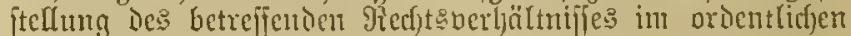
Rec(j)tsmege herbeizuführen. In Diejem Jjalle ift dic filnge

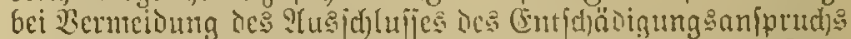

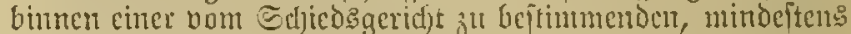

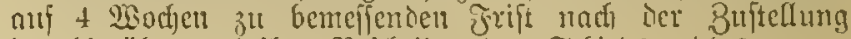

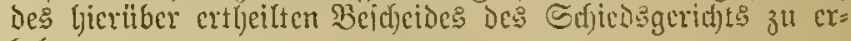
hebeit.

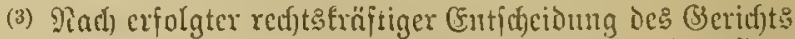

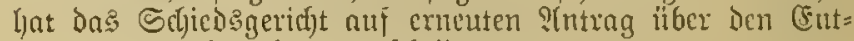

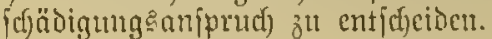

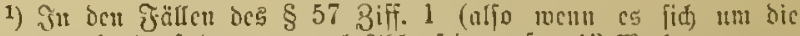

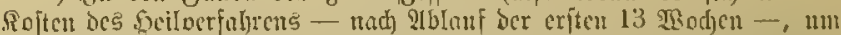
Becroigmtgsfoitcu unb um vorübergehende (Frmerbsunfähigfeit lonbelt),

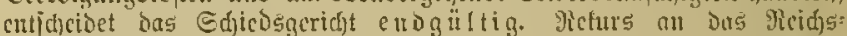

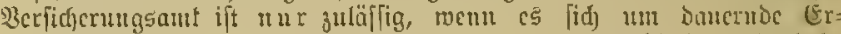

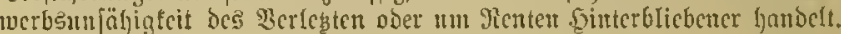

\section{Bercd) tigung}

\$ 64. (1) gind) erfalgter Jejfftellung Der (Enticjäbigung (\$ 57) ift Dem Bered)tigten bot Seiten Des Gemoffenfiffaits=

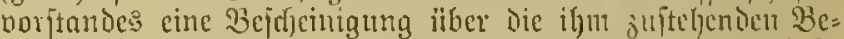
züge unter Sargabe ser mit der 3ablung beauftrugten Fopt=

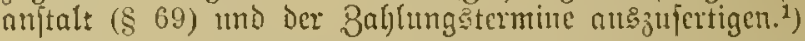

(2) Whito in folge des idjedengeridjttidjen Berfaljrens Der Betrag der Eutfáfäbigung geändert, fo ift ben Ents

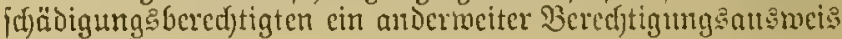
ju erthcilen.

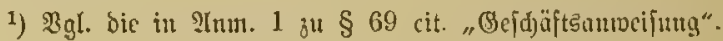

\section{Beränderung Der $\mathfrak{B e r}$ hältuije.}

$\S 65$. (1) Iritt in Den $\mathfrak{B e r l j a ̈ l t n i f j e n , ~ r o e l d f e ~ j u ̈ r ~ b i c ~ J e c i t = ~}$

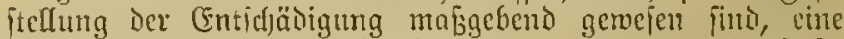

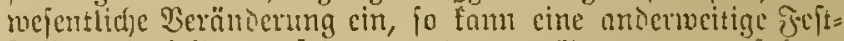

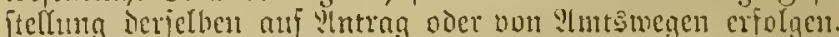

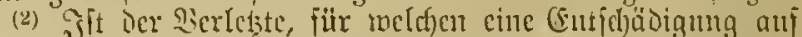

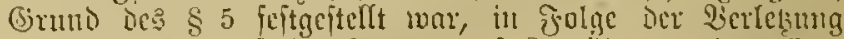
gefturben, io mur Der Stntrag auf Gemälirung einer Ens idjäbigung fitr bic Sinterblichenen, falls beren Jefiftellung

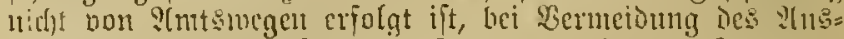

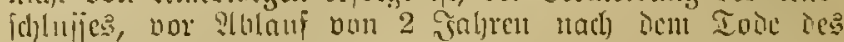

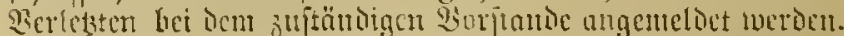

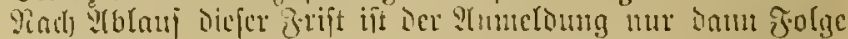

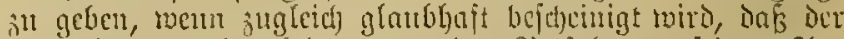

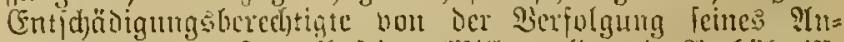

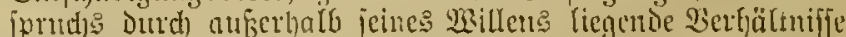
abgeljalten morden ift. Jim ïbrigen finden nuf Da: $3 e r=$

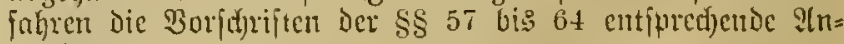
twenduna.

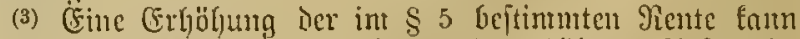
nur für dic Beit stad) Plumeloung Des ljäljeren ?(njprud)ร gejorbert meriten.

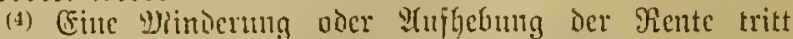
bon dem Tage ah in isirffamfeit, nu weldfem Der dicjelbe

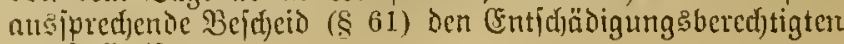
jiggejlellt ift. 


\section{そ̋̈lligfcitstermine.}

$\S$ 66. (1) Dic Sojten des Şcilberjaf)rens (\$ 5 Biff. 1) und Dic Soften der Bcerdigung (\$ 6 Biff. 1) jumb binnen

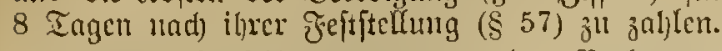

(2) Dic Entjujäbigungsirenten ber Sicrfebten uno ber Sointerbliebenen ber (Setöbteten fimo in monatlidfen Raten

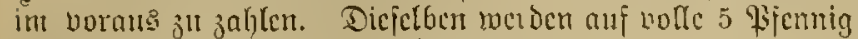
fiir Den Mionat nad) oben abgerumbet.

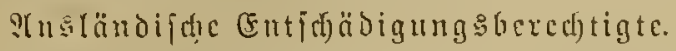

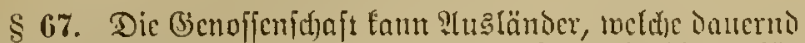

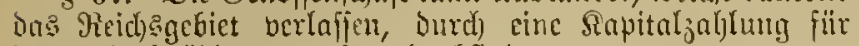
iljren (Entjd)äbignngsanfpruct) abfindon.

\section{Ilupfänbbarfeit Der (Entidäbigungsforderunger.}

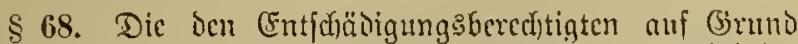

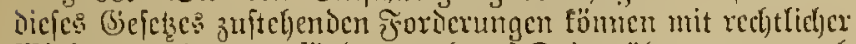
פirtung wedez berpiändet, nod) anf Dritte iibertragen, nod) fiir moere als die im $\$ 749$ 9lbf. 4 ber Civilprojeboromm bejciffucten Forbazungen ocr (Ehefrau uno chelichen Sinocr nuil dic Des erfabebereftigten Armenuerbandes gepfünoct jucrien. ${ }^{1}$ )

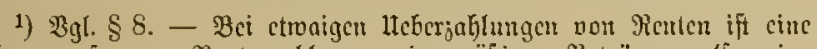

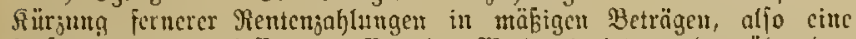

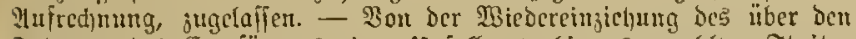
Tooestag ocs Empfängers einer llnfaffrente bintus gezaljten Theiles

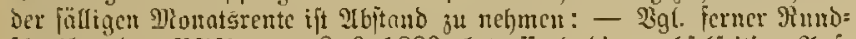

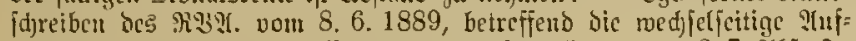

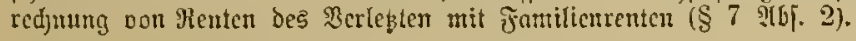

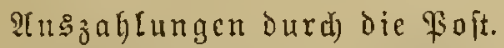

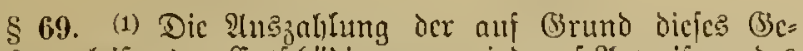

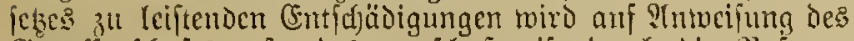

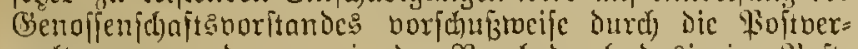

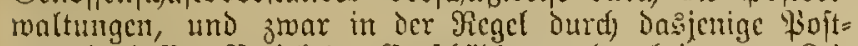

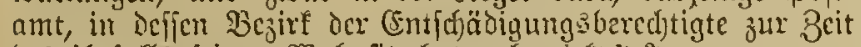

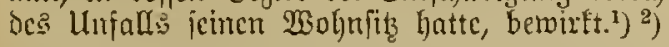

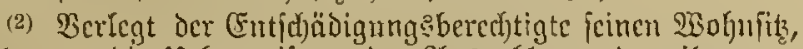

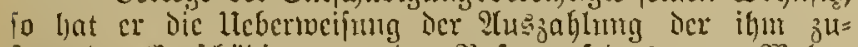

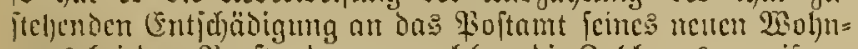
ortes bei bcm Sorftande, bon treldyem dic 3ahlungsanweifung crloffen wortoen ift, ju beantragen.

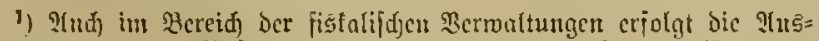
3alyluna Durd) bie Poit mo nidjt etwo burd Dic Epczialfofifer jence

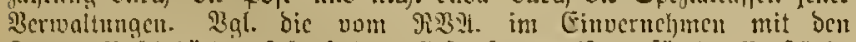

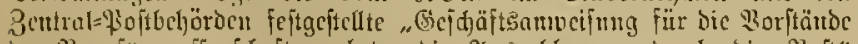

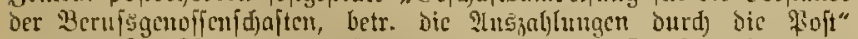

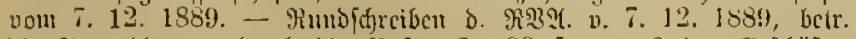

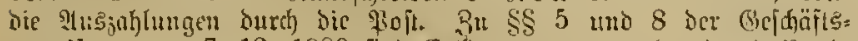
aumeijung vom 7. 12, 1889 finv Ertünterungen gegeben ourd) Minno. fdjreiben bes $\Re 22$. v. 27. 4. 1892.

2) Mleber bie reduncrifde Behandung ber 3ahlungen Eeitens ber

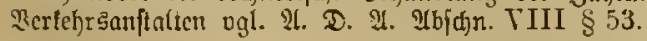

\section{Riquibationeu ber Pojt.}

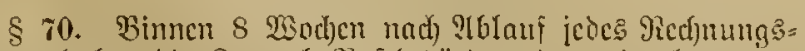
jahres haben bic Bentral= $\$$ oftbeljöroen Den cinjelnen (vic=

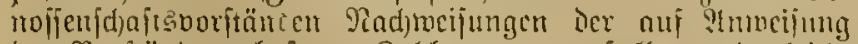
Der Forftändc geleifteten 3ahlungen jujuleclen mo gleid)= zeitin die fioltfafien ou bezeidnen, an wold)e bic ju $\mathrm{cr}=$ ftattcuocu Beträge cirjuzalien finto.

\section{Ybfülyung Der Beträge an die \$s ofteficn.}

§ 75. (1) Dic (Genoffenfffaft suorftände haben dic bon ben

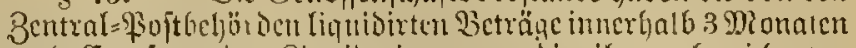

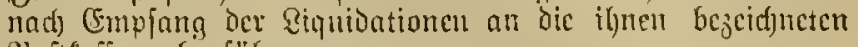
łioftfaifen abjufïhren.

(2) (Begen (Senvificnidfaften, melde mit der Erftattung ber Beträge im Rilidftande bleiben, ift auf Stutrag der

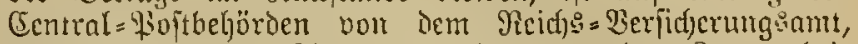
vorbchaltfich Der 9 citinumungen ies $\$ 33$ Das Bmangsbei= treibunģoerjaluren einzuleiten.

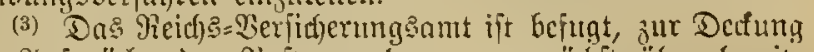

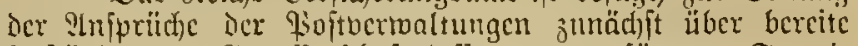
Beftänie Der (Bendfienjajajtêfaficn ju berfïgen. Somcit

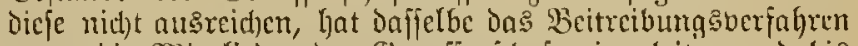
gegen bie Mitglieocr ier (Benoffenjt)ajt cinjulciten mo bis

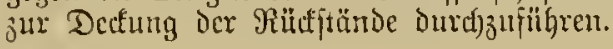

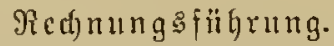

§ 7\%. (1) Ucber dic acfammten Rcufumg geracbnifje cincs

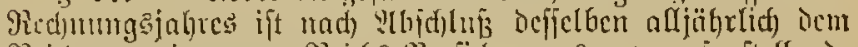

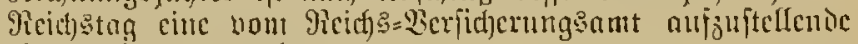
Piaclucijumg vor julcgen.

(2) Beginn und Ende ocs Yect)nungejalires mird für alle

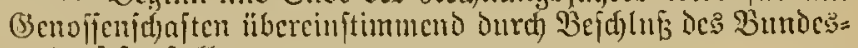
ratl]: icitgcitcl(t.1)

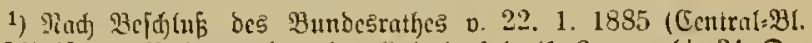

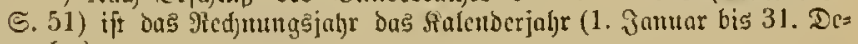
jember).

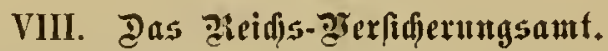

\section{Drganifation.}

§ 8\%. (1) Dic Benoficujajaten unterliegen in Bejug anf bic

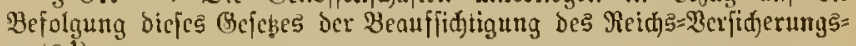
amis.)

(2) Das Rcidjs= Berficherumģamt hat jeinen Sik in Bcrlin. (Es Geftcht ans mindeftens 3 ftändigen Ditglicocru,

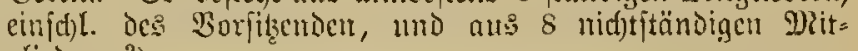
gliedern. $\left.{ }^{2}\right)$

(3) Der Borfitzen內e und Dic übrigen ftäntigen Mitgliècr

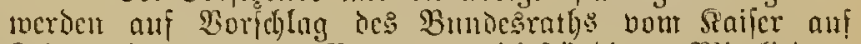

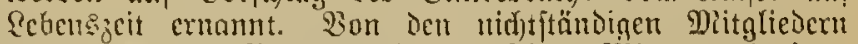
merder 4 bom Bumbestatb ats feincr Witte, nuo ic 2

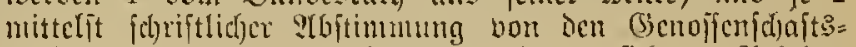

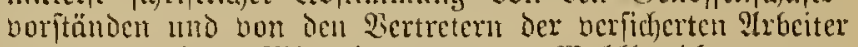
(\$ 41) aus it)er Mitte in getrenuter $\mathfrak{W a b}$ )handlumg unter

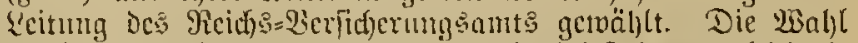

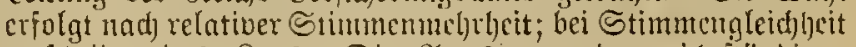

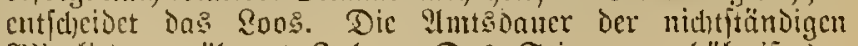
Mitglicder wäljut 4 Şaljre. Das Stmmenberlültmif̧ Der

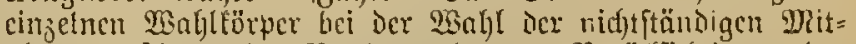

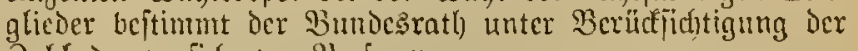
Zahl der verfictjerten Zierfonen.

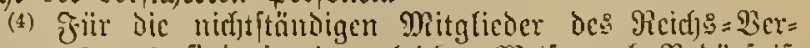
fidherungsamts find in oer gleidfen Meife nad) Bcolirfinifs Stelfnertreter ju beftellen, meld)e dit MRitglicder in $\mathfrak{B} c=$ hindormigs fäthen ju vertreten haben. ${ }^{3}$ ) Edfeitet (in foldjes

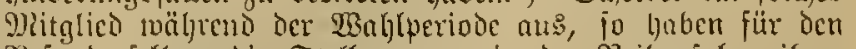

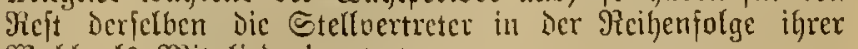
WBntl als Ditglicd cinjutreten. 


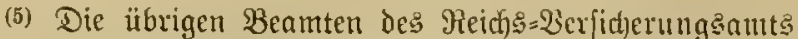

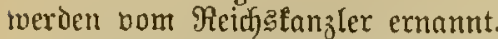

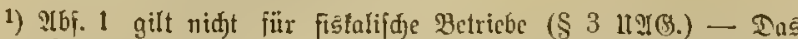

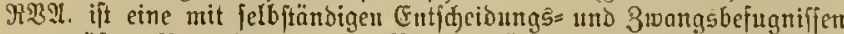

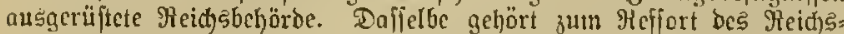

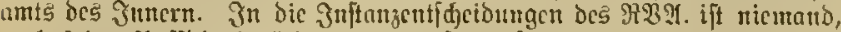
aud) feite Nuffichtsbehöroc, einzugreifen bejagt.

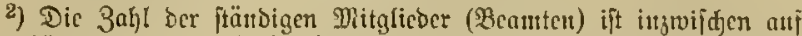

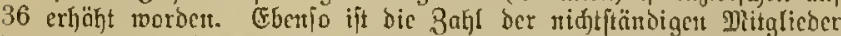

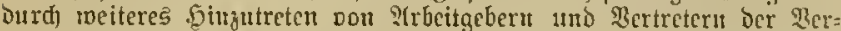
jidgerten auf 16 vermehri. \$gl. autb $\$ 90$ \$bi. 3 .

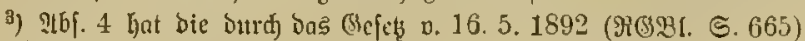
vorgejdricbene \&afjung.

\section{Suศtändigleit.}

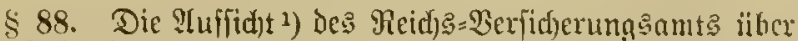
ben Bejaäitßbetrieb ber (Benofjenfdjaften ljat fid) auf dic Beobadtung Der gefetzliden und ftatutariffen Borfdrijten

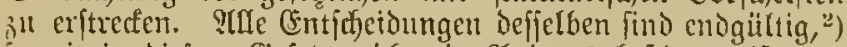

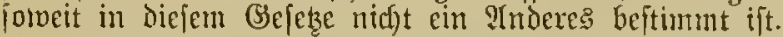

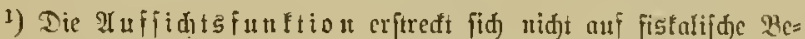
tricbe. Dieie unterfehen vielmeht ber ?tuffidut ber vorgejeteten Dienft=

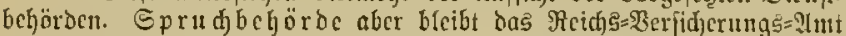
aud fïr bicje Behörde $\mathfrak{B g l .}$ aud $\$ \S 3,5,8$ Uश(5.

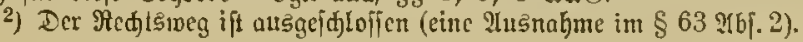

\section{(S) $\{$ d) äftgingng.}

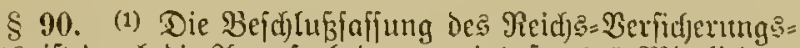
amts ift Durd die Qnuefenheit von mindejtens 5 Plitgliedern (einfd)l. Des Borfitzenden), muter benen jitd) je 1 Vertreter oer Genoffenfdiaftšborftände und ber QT-beiter befinden müffen, bedingt, wenn es fid) handelt

a) $\ldots . .$.

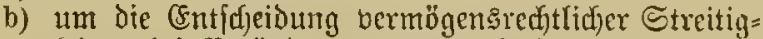
feiten bei Beränderungen Des Beftandes Der Ge: nofienictjaften (\$32);

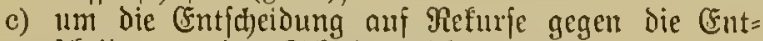

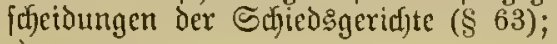

d), e) ......

(2) Solange die Wabljl der Wertreter Der Bienofienfduaft: norftände und Der $\mathscr{A}$ rbeiter nidjt zu Stande gefommen ift,

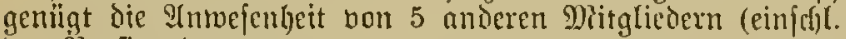
Des Sorfitzenden).

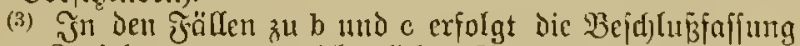
unter 3uziehung bon 2 richterlid)en 2icamten.

(4) Jm itbrigen twerden die frormen bes Verfahrens und

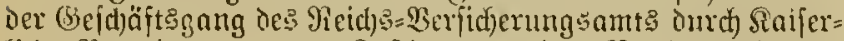

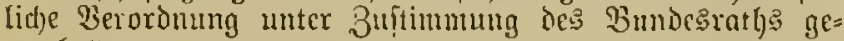
regelt. 1$)$

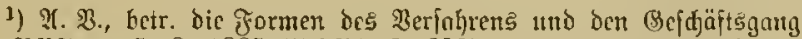

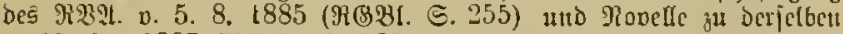

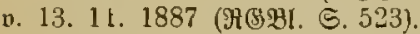

\section{Soften.}

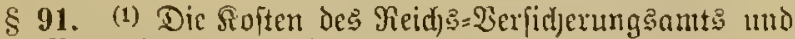
feiner Vermaltung rägt das recich.

(2) Die nidhtftändigen Mitglicher erhalten fiir bie Theil=

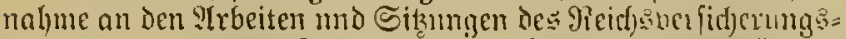

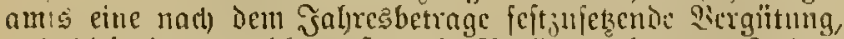

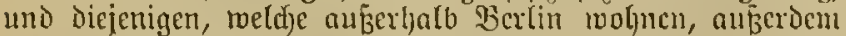

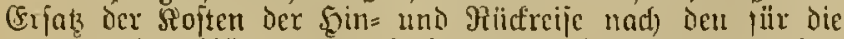
vortragenden Räthe der oberften Reichsbehjöben geltenden

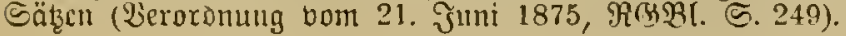

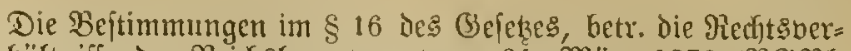

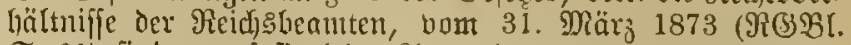
ङ. 61) finden anf fie feine ?tnwendung.

\section{Eandez=Berfidgerunģämter.}

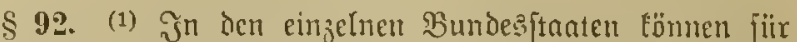
Dos (Siebiet uno anf Roften Derjelben \&ande : Berficherungs:= ämter bon den Santeŝtegicrungen errid)tet werten. ${ }^{1}$ )

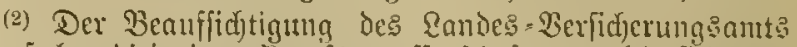
unterftehen diejenigen Berufsgenofienf(haften, weldje fidt) uidjt iiber das Gebiet des betreffenden Bundesftanteg hinaus $\mathfrak{c l}^{2}=$

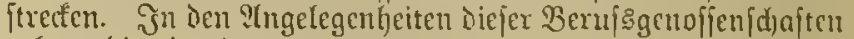
gel)en die in ben $\$ \$ 16,18,20,27,28,30,32,33,37$, $38,39,40,62,63,73,75,78,80,83,85,86,88,89,106$

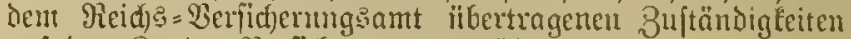
auf Das Lanteš=Berficterungsamt über.

(3) Someit jenod) in Den Fällen der $\$ \$ 30,32,37$ und

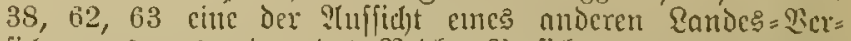

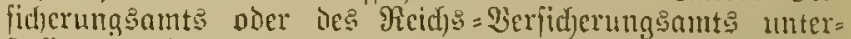
fteffe Berufsigenoffenf(haft mitbetheiligt ift, entid)cider Das

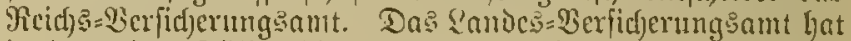

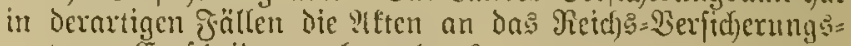
ant jur (Entfaciontug abjugeben. ${ }^{2}$ )

(4) ......

1) Ranbes= Berfidjerungsäuter find u. a. errichtet in Banern, Gadj|cu, \$ï̈rttemberg, Bnden, Sceffen.

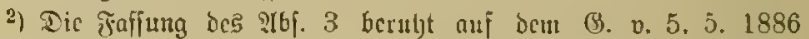

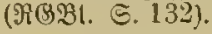

\section{Sdifnk- แnd Strafbeftimunngen.}

\section{Şaftpflid)t dex Betriebsunternelmer mo Betriebs=} beamter.

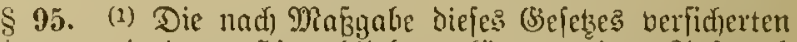

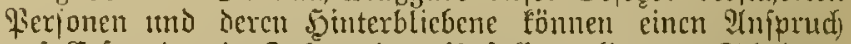
anf Erfats des in Folge eines llnjalls extittenen Sd)adens nur genen Dicjenigen Betricbsunternehmer, Bevollutüchtigten voer Yiepräfentanten, Betriebs = oder Itrbeiteranffeher geltend

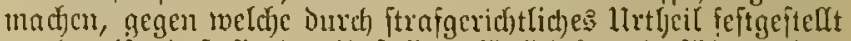
worden ift, Dafs fic den llnfall vorfätzlich herbeigejührt ljaben.

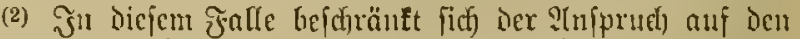
Betrag, um meld)en die ien $\mathfrak{B e r e d}$ tigtell nad) Den bejtelfenden

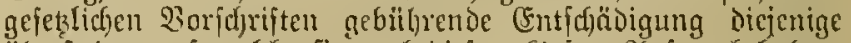
iiberfteigt, auf weld)e fie nady dicfem Bejetse ?tupprudy baben.

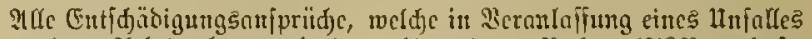

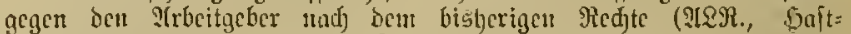

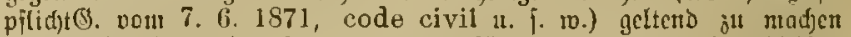

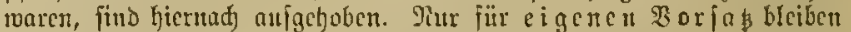
bie Untemegner fornie bie Betriebsbeanten aud ferner verbajtet. Der

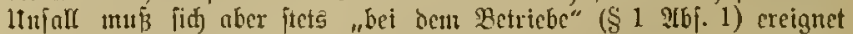

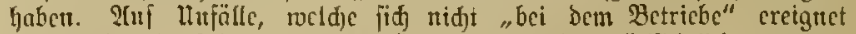

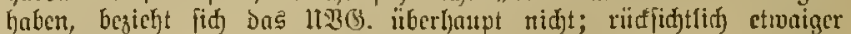

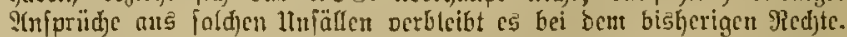

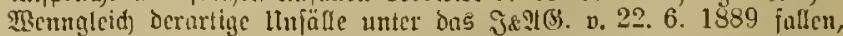

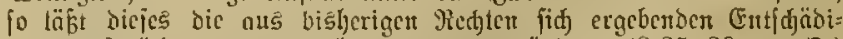

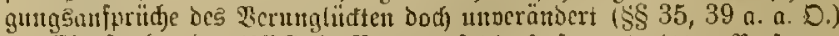

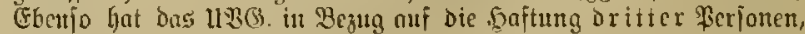

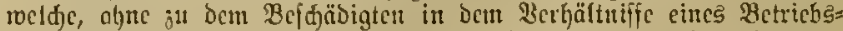
unternelumers gu ftehcn, cincu llnfall Dorfübliff ober burd) Beriळulden

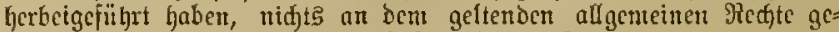

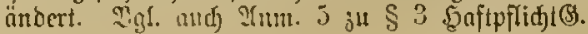


§96. (1) Diejenigen Bctricbsomternehmer, Bebollntäc)= tigten poer Repräjentanten, Betriebs= obcr \$libcitcrauffeljer, negen meldye Duref \{trafgerichtliches Urtheil feitgeitellt worden

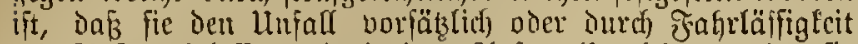

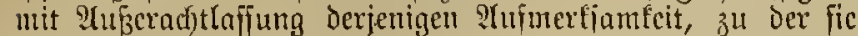
necmögc ihres Imtes, Berufes oder Bemerbes befonders verpflichtet fino, herbeigciïhrt haben, haften fïr alle $9(u f=$

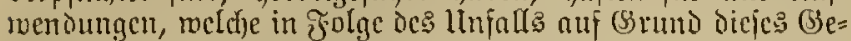

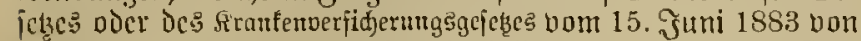

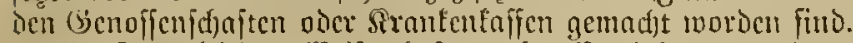

(2) Sn gleid)er Weije haftet als Betricbsunternebuner

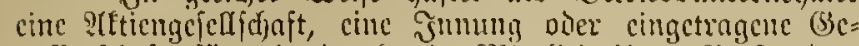
noffenid)ajt für Dic Durd) cin Mitglico ihres Burftandes,

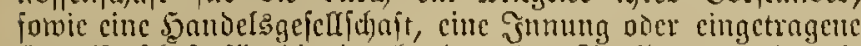

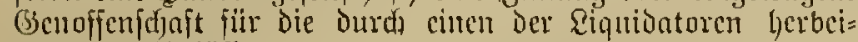
gciiil)rten Unjülle.

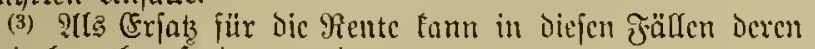
Rapitalwerth gciordert werden.

(4) Dev 2unpruch beriäfyrt in 18 Monaten von Dem Inyge, an weld)em das ftrafrecf)tlidje Urtbeil red)tsträftig gevorion iff.

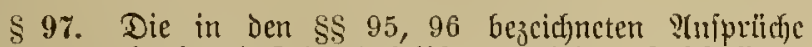

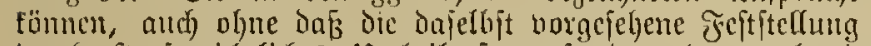
Dutr(f) ftrafgerichtliches Urtheil ftattgejumben hat, gelteno gemadist werden, falls dicje fisciftellumg wegen bes "Iodes nier der stbrefenfeit bes Betreffenden Doer nus cincm anderen in der Gerfon deffetben liegenden Girunde nicht $c r=$ folgen falıt.

\section{Sgaftung Dritter.}

\$ 98. Dic Şaftung Drittcr, in Den \$\$ 95 mo 96 nid)t

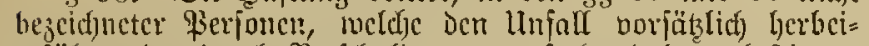
gefiulyt woer durd) Berfdulden verurfadyt haben, beftimut

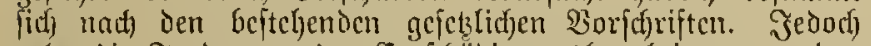
geht dic fordcrung Der (Enidjöbigungsbered)tigten an Den Dritten auf dic (Sienofjenfhaft infoweit iiber, als dic $\mathfrak{B c r}=$

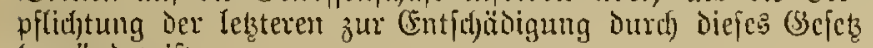
begrünoct ift.

3gt. शैum. zu \$ 95. Dic vorftehenben Bejtinmungen werben auj

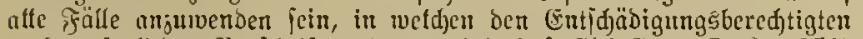
nad) gejessidien 3orjdriftert (momentlid) Soitpflidjt(s. v. T. 6. 1871) ein Sdjabenserjakanjprud) gegen Dritte jufteht. Benu bie Cijen=

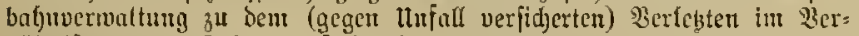
hältuif eines "Dritten" iteht, b. ฤ. wenn ber bein Betricbe be: (Eifenbal)n \$erlebte (als \$affagier, anf bem Babufjof bejđäftigter 2rbeiter irgend cistes \$rivatmanucs) nidyt in Diente Der Cifenbahn= vermatturg bejdäftigt war, ift er nidjt auf Grumb Des llufallocrifide-

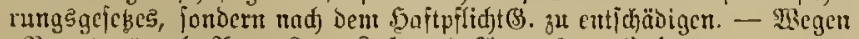

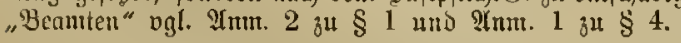

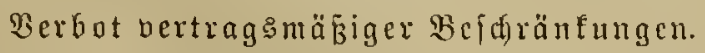

§ 99. Den Beruiggenoffenid)aften fowie Den Betricbs:

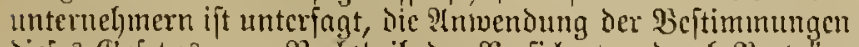

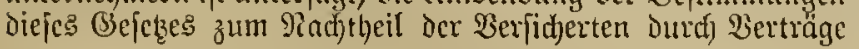

(mittelft Reglement? ober befonderer Hebereinfunft) aus=

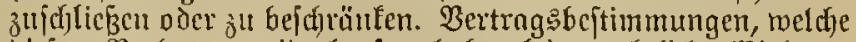

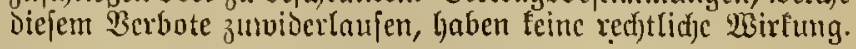

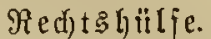

\$ 101. (1) Dic üffentlicfjen Befjörocu find nerpflicfjet, Den im 'Boflunge dicfes (Scjetzes an fie ergehenden Erfuchen des

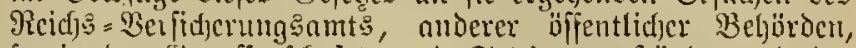
forvie der Genofienidjaits= und Settionsuorfände mo der

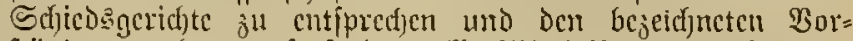
ftänden aud) unaufgcicrdert alle Dittheilungen zuloumen

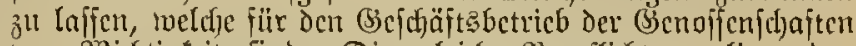
non widftigfeit fillo. Die gleiche Berpflichtung liegt ben Drganen Der Genoffenifhaften untercinander ob.

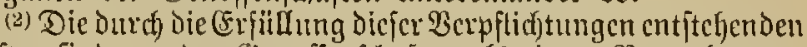

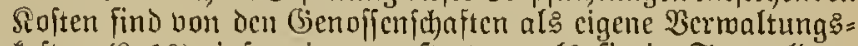
foften $(\S 10)$ infoweit $3^{\mathfrak{u}}$ crftatten, als fie in Tagegeldern umb Reifefoften von Bcamten Docr (Bsonoffenfd)ajtsorganen, fomie in (Sebüfren iür 3eugen und Sadjoerftändige nder in ponjtigen baaren 2 (uslagen bejtehen.

\section{(5) ébülren=und Stempelfreiheit.}

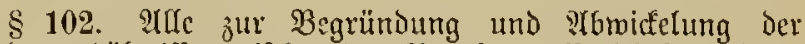

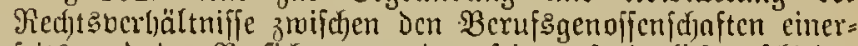

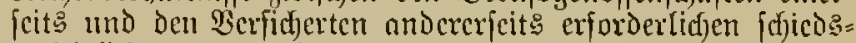

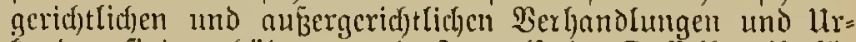
Eunden find gebüliten = und jtempelfrei. Daffelbe gilt für die beluf Đertretung von Berufsgenofien ausgejtelten prinaticfriftlicfen 20 fllmachter.

\section{Buftändige \&andesbehörden. Berroltungsexctution.}

$\S 109$. (1) Die Bentralbeböroen Dor \$Bundesftaaten be= Ftiminen, bon weldjen Staats= ober (Senteindebeljörden bie in biejem Gcjeze Den höljeren Berwaltungsbeljöben, den unteren פerwaltmisheljörden und den Drtæpolizeibeföroen

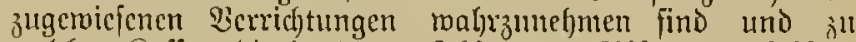

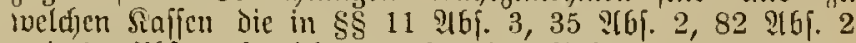
unl 85 ?(b). 2 bejeidjueten Strafen fließzen. Dicje, fomic Die auf (5rmul Der $\$ \$ 49$ 9lbF. 3, 103-105 cifannten Strafen, Desgleidfen Die von Den Borftänden Der Betriebs:

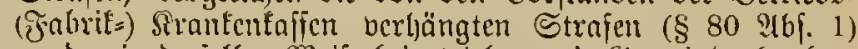
werben in derjelben 2 cije bcigctrieben, twie (Scmeindeabgaben.

(2) Dic von Den Bentralbehörden Der Bundesftaaten in (Se. mäß̈beit vorfteljender $\mathfrak{B}$ orldjrift erlafienen Beitimntungen fino Durch Den Deutidyen Reicjsanjeiger befantt ju madjen.

\section{Buftellungen.}

\$ 110. Zujtellungen, weldic Den \&auf bon Friften be= dingen, erfolgen Durd) die qsoft mittelpt eingefdricbenen

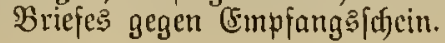

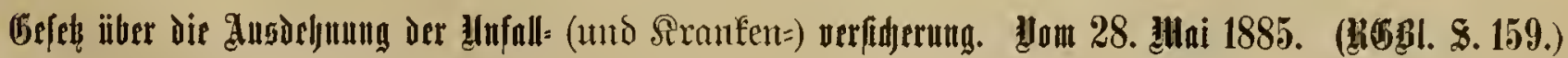

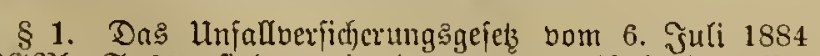

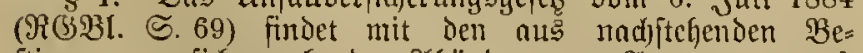
ftimmungen ficf crgebenden ?(6änderungen Inwendung auf

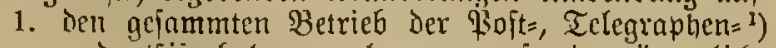
tmo (Eijentonljnbersualtumgen, jowic lämmtlidje Betriebe Der Marinc= unt 5eetesverwaltungen, und 3war cinjol. dex Bauten, weldje von Diejen Ber= maltungen für eigene Rect)mung ansgefithrt werden;

2. Den $\mathfrak{B a g g c r e i b e t r i e b ;}$

3. Den gcmerbsmäßzigen fufrmet

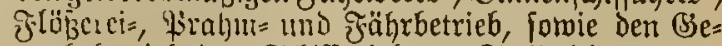
rerbebetrieb Des Sdiffisziehens (Ireidelei); 


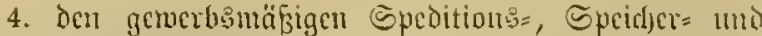
Rellereibatrieb;

5. Den (3)werbebetricb der Büterpafer, Bülerlaber, Sdjaffer, Bracter, Wäger, Micfer, Sdjaucr unt Stauer.

1) Im Bercidge ber ßoptnerwaltutg unterfiegen ben Beltimmungen

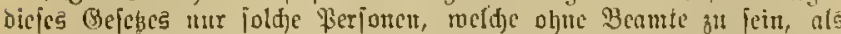
Irbeifer im Betriebe ber Bermaltung (einfdichlide oct fïr cigene Rednung berfclben, niđt für SRedunng cines thternchmers ausgefïfrten Bauten) bef(täftigt find.

Eś geljören Dngu iusbejondere:

1. Dic Telegraphenarbeiter;

2. Die Mrbciter in ben für Mednung ber Telegroplentoc: waltuny betricbencu Stangenzubereitunasanftalten;

3. Dic in Betriebe verroendeten Tushelfer;

4. bic Edreibhüllen;

Berfonen, weidje Iediglid) Jur Berribtung hätslider Dienfte per=

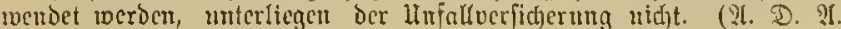
Ibjut. X $\mathfrak{A}(b+\mathrm{b}) .2 \$ 358$.

\section{Reidy = und Staatsbctricbc.}

§ .. (1) Für bie \$oft=, Ielegraplen=, Miurine= umD Seercsuctwaltmingen, fomie für die vom Tieid) oicr von cinem Bundesftaate fiir Reidjs= bejw. Stnatsred)mung nel"= maltcten (Gifenbahubetriebe, fümmtlid) einfd)l. Der Banten,

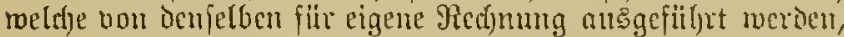

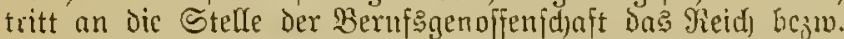

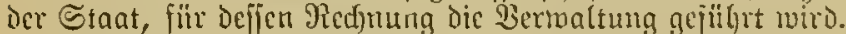

(2) Daffelbe gilt linficttlid) Der vom Neid) oder von

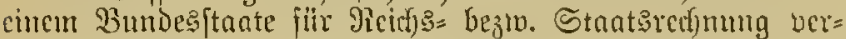

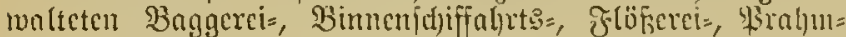

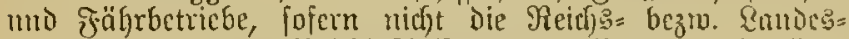

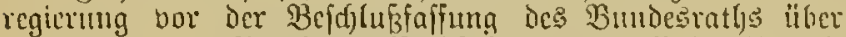
die Silloung Der Berufünenoffenfchajten (\$\$ 12 fi. Des lhnjall=

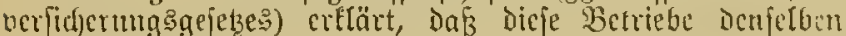
angehören foller.

(3) Somcit Gicmact] das Ticich ober cin Bumbesftant an

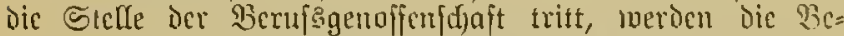

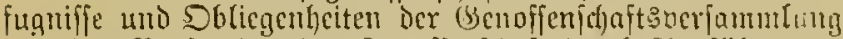

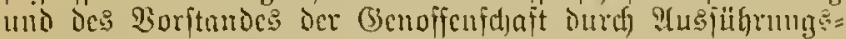

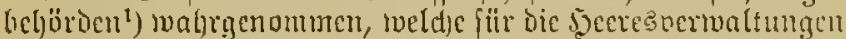
vou Der oberffen 9 it itärverwaltumgsbeläroc ocs Slontingents,

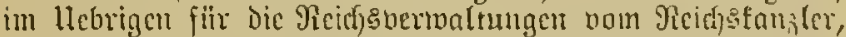
fiir Dic Rambesnerwaltungen oon ocr Randes=3critralbchörde

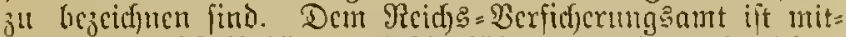

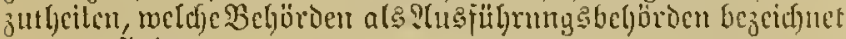
worien find.

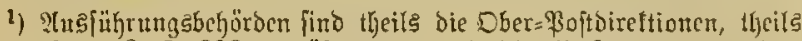

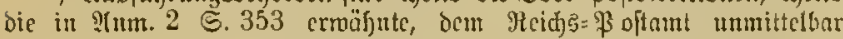

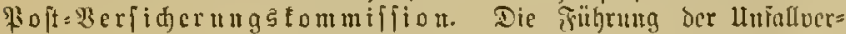

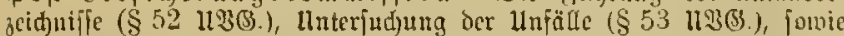
Die Fefitebung ber Entidäbigungen, forveit ç fid un bic nad) $\$ 5$

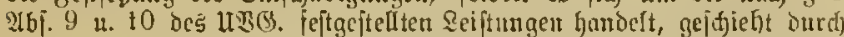

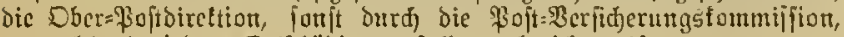
an welde in jedem Entjö̈bigungsfalle ju berifften ijt.

8 3. Solweit Das Reidf oder cin Bundesftant an bic Stelle der Berufeggenoffenfuffaft tritt, finder dic \&\$ 10 bis 31 ,

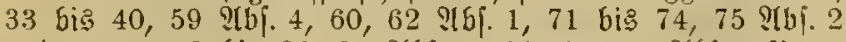

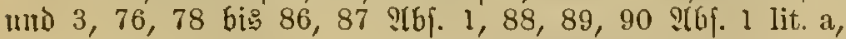

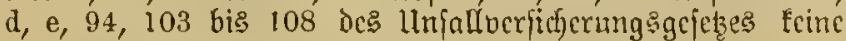
(ntwendung. ${ }^{1}$ )

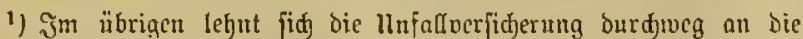

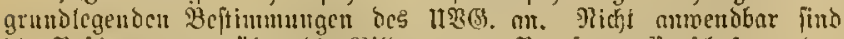
die Bcitimmungen über die Bildung von Bernfsgenolïnjajajten, bas

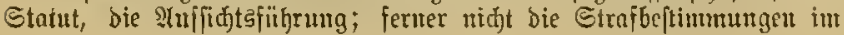

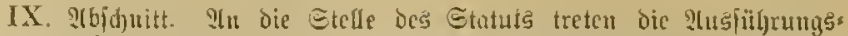

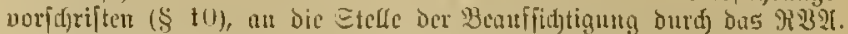

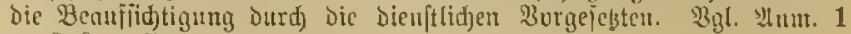
34t $\$ 831190$.

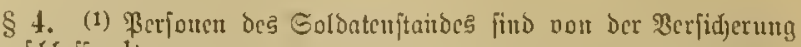

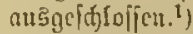

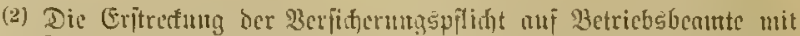

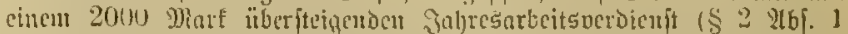

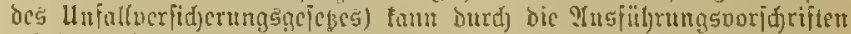
criolgen, foweit dicje itcanten nif)t nad) $\$ 4$ a. a. D. von ber ?lu=

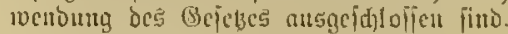

1) Gï̈r Ferfonen bes Soldntentandes gilt \$aร (im III. Theil abgeorutte) Gejey nom 15.3. 1886 (2) (932. G. 53).

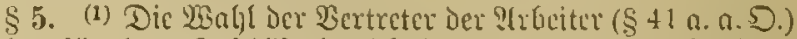

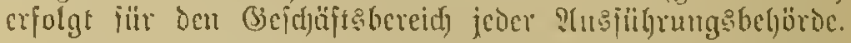

(2) Dns Ficgulatio (\$ 43 a. a. D.) Ivird ourd dic für

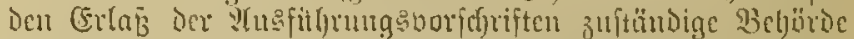

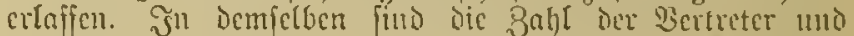

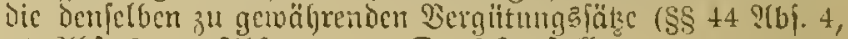
49 :Ibf. 2, 55 Ibf. 1 a. a. D.) icitzuftellen.

(3) Lleber Streitigfeiten, welthe fiefs anf Dic Buittigfeit

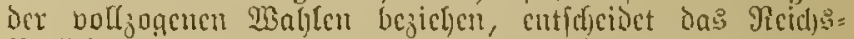

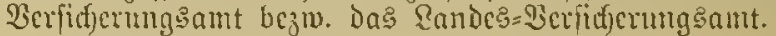

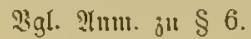

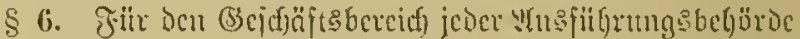
ift miniefen's cin Sdjiedsgeridjt (\$ 46 a. a. D.) jul cr= ridfert. Dic in $\$ 47$ श(b). 3 a. a. D. Gejeiduneten B̉ci=

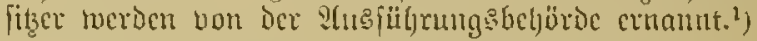

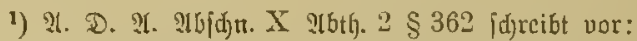

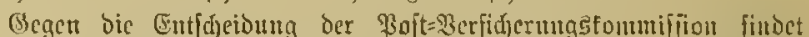

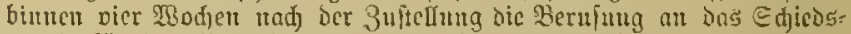
geribt für ben Betrieb ber Seidjg:Yloftocroultung ftatt, weldhes jeinen Eib in Berliu luat. Dalfelbe beftebt nus Dem Z3orfigenden mo nier Beifizern. Der Borfigende und fein Elefluetreter werbent Durd ben

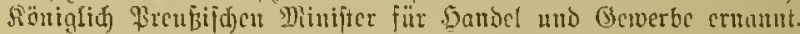

3wei Beifiger umb für jeben Beiftzer ein erfter und cill jueiter

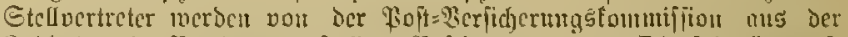
Babl ber in Berlin nugefteflen \$optbeamten bom Dberjeltetür anf= wärts ermannt. Die Erncmung erlijdt, ment Der Beifiber ans bem

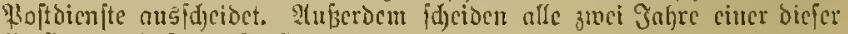
23eifiber und icine Etellucrtteter aus.

Die bciben nubcren Bcifiter uto Deren Etelfoctuter find unter

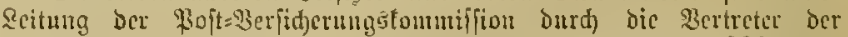

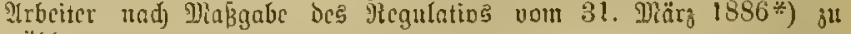
wühlert.

Die Bergütungen, weldhe ben pon ben Bertretern ber ?trbeiter

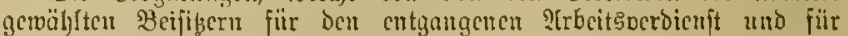

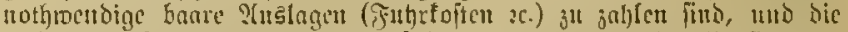

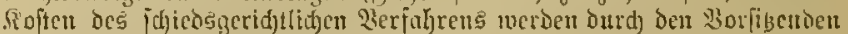

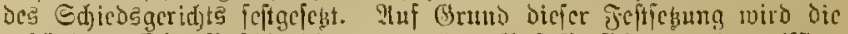

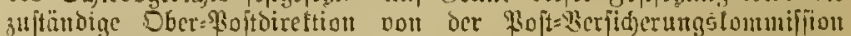
jur 21nweijung Dex 3ablung peraula jit.

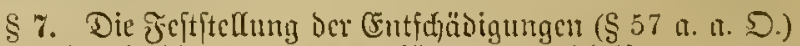

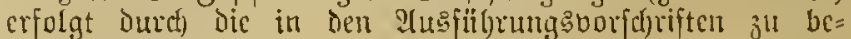
3cid)ncnoe Befjörde.t)

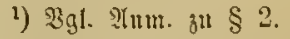

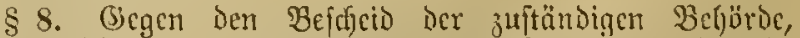

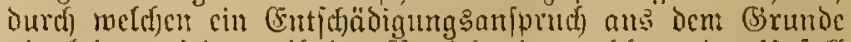
abgelef)nt mird, weil Der Betricb, in welefem Der llnfall (iid) creignet hat, fïr nidjt unter Delt $\$ 1$ falleno erad)tet twird, fteht Dem $\mathfrak{B e r l e s t e n}$ und feincn Jjinterbliebenen Dic

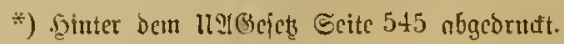


Befcimerde an das Reich Serficherung:ant zu, weldje bet Demielben binnen 4 Wodjen nach Der Buftellung Des ablelynenden Befdeides cinzulegen ijt. ${ }^{1}$ )

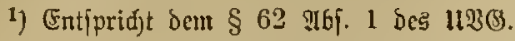

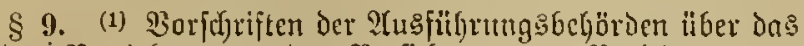
in Den Betrieben von Den Berfifjerten zur Berbütung von Ilrjällen ${ }^{1}$ ) ju beobachtende $\mathfrak{B e r h a l t e n ~ f i n d , ~ f o j e r n ~ f i e ~ S t r a j = ~}$ bejtimnumgen enthalten follen, bor dem Erlafis mindeptens

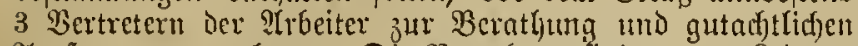
Seuferung vorjulegen. Die Berathung findet unter Seitung

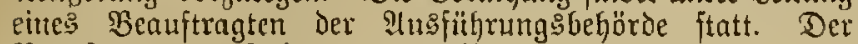
Beaujtragte darf fein unmittelbarer 23orgefebter Der $\mathfrak{B} e r=$ treter der ?Trbeiter fein.

(2) Die auf Brtund foldher Borfdriften verbängten (Seld= frrajen fliefzen in Die Serantenfajie, welcher Der zu iffrer Zahlung Berpflichtete jut Beit ber Buwtoerhandlung an= gehört.

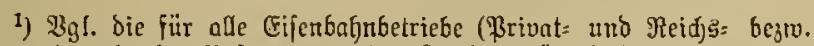

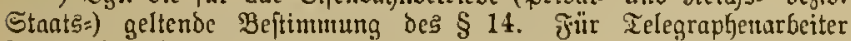
find in Ser "Drbmung" vom 13. 7. 1894 bejonbere Llnfallocrfidjerungs= voridjriften enthalten.

$\$ 10$. Die zur Durdffüfrung Der Beftimmutgen in

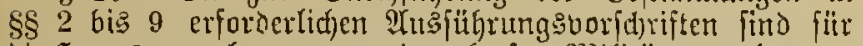
die Secresnerwalthtngen von der oberiten Mrilitärverwaltung : beförde des Sentingents, im Hebrigen fiir Dic Reidys=

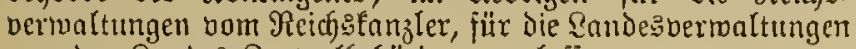

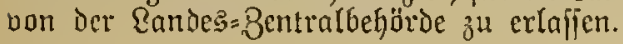

\section{Bribatbetriebe.}

$\S 11$. Someit nicht bie $\S \S 2$ bis 10 SInmendung finden, erjolgt die Berfid)erung Durd Berufggenoffenidaften nadf Den Beftimmungen de: llnfallverfidjerungsgefełes. Bei Der

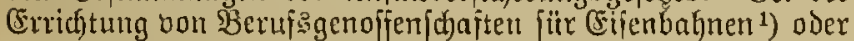
bie im $\$ 1$ Biff. 3 bejeidneten $\mathfrak{B}$ etriebe tamm von der $\mathfrak{B e}=$ jtimmung des $\$ 9$ des Unfaldverfitjeringsgefetzes abgefeljen merden, monad) die fïr einen beftimmten SBezirf gebildoten Berufgagenoffenforafter innerfalb beffelben alle Betricbe Des: jenigen J̧nduftriegtweiges umfaffen mitifen, für toeldhen fie errid)tet finto.

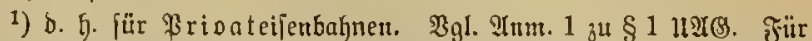

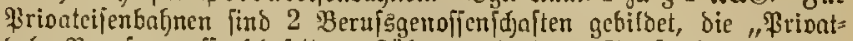

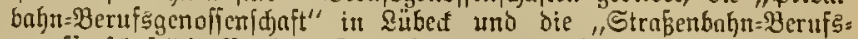
genofjenjofof " in Berlin. 3ur erfteren gehören siejenigent Eijenbabnten,

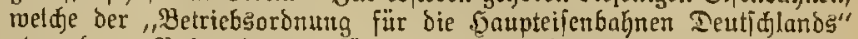

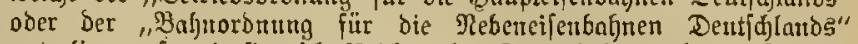

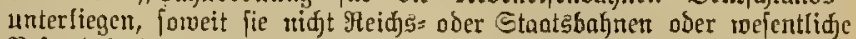
Bcifanblheile eines anderen unfalloerfidjerungspplidftigen Betriebes finto.

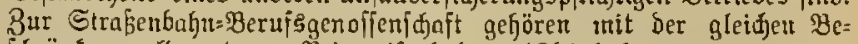

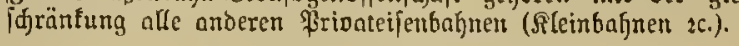

\section{(Semeinfame Beftimungen.}

§ 13. (1) Ereignet fid ein Itnfall auf Der Frafrt, fo ift

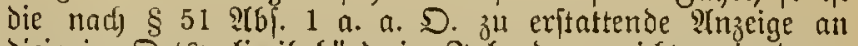
Diejenige Sortspolizeibeförde in Şntande zu riditen, in Deren De jirf fich ber llifall ereignet hat oder ber erfte Sufenthalt nadj Demielben genommen wiro. ${ }^{1}$ ) Dic Unterfunfing Des llnfalts (\$ 53 a. a. D.) erfolgt Durch Diejenige Drtspolizei=

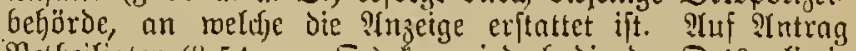
Betlyeifigter (\$54 a. a. D.) fann jeodd Die Der Sortspolizei= beförde vorgejekste Befjörde bie Interfuchung Durf eine andere Drtspolijeibegörde Gerbeifüfgren. ${ }^{2}$ ) Die zur F̈̈̆hrung der llnterfuthung berufene Drtspofizeibegörde hat Der Stranfen= fajfe, twel(f)er ber Berledste angehört, rechtzeitig bon bem Beit= punfte, in reldjem die linterfuthung vorgetrommen werden mith, Renttnif ju geben. Der Voritand hat Das Redjt,

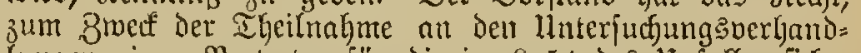
lungen einen Bertreter für die im $\$ 54$ des Unfalloerficese rungşgelekę bezeidgneten Bevollmäd)tigten zu beftellen und ift hiterbei nidft auf Den ßreis Der ßaffenmitglieder befdränft.

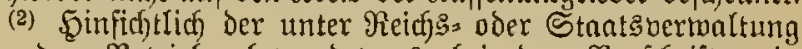
fteljenden $\mathfrak{B e t r i e b e}$ bewendet es bei Den $\mathfrak{B}$ orfafriften in $\S 51$ ?โ6โ. 5, 52, 56 a. a. D.

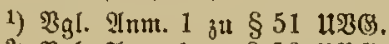

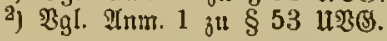

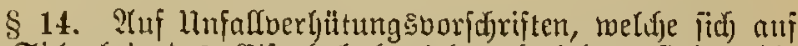
die Sirherlyeit des Eifenbahnbetriebes bejiélen, finden Die Bejtimmungen des $\$ 9$ dicjes Bejekes, folvie Der $\$ \$ 79,81$ des Unjaflverficjerungsgefetes feine $\mathfrak{A}$ mentung.

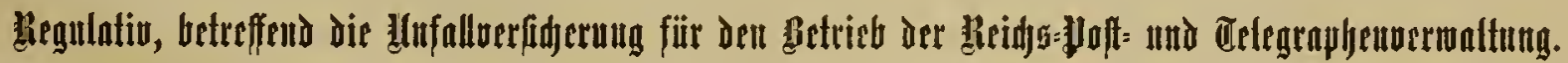

In Stelle bç Miegulatios vom 30. Septentber 1885

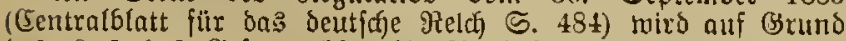

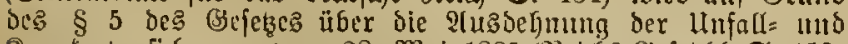

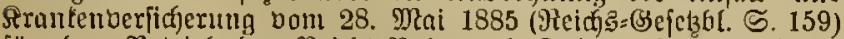

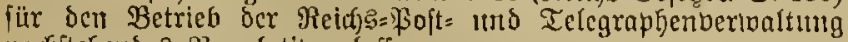
nacjjtefjendes Regulativ crlaffen.

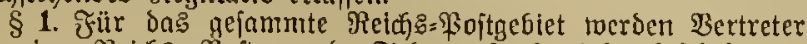

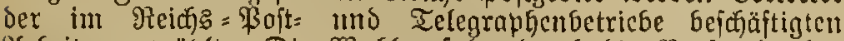
Urbeiter gemählt. Die Wagh erfalgt outrdj Sic Borjtände ber

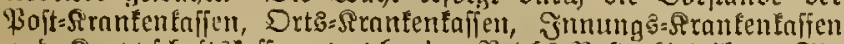

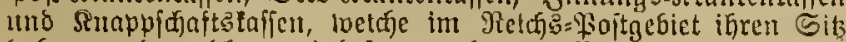

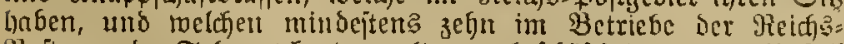
Foitz und Telegraphenberwaltung beidäitigte gegen Ilnjall veritgcrte \$erjonen angehören. Die Borfibenden ber \$ojt= Sranfentaffen und sle sem Borjtande cher antocren bahl=

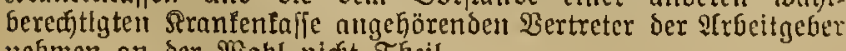
nefmen an ber $\mathfrak{B a h l}$ nicht Theil.

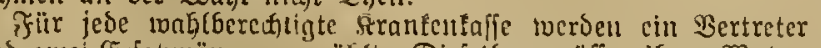

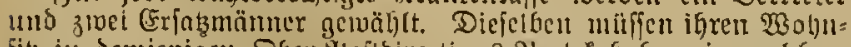

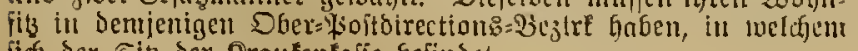
ita) Der Siz ber Sraufentaffe befindet. \$l! gegen llufan berifigert im Simne diefes Regulative

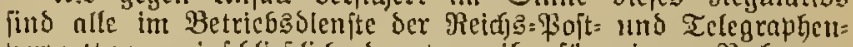

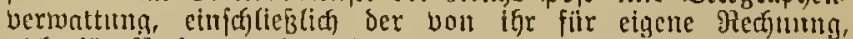

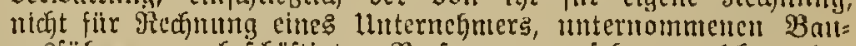
ausfiufrutugen, bejoüftigten ßerfonen anjufegen, weldje, ofmt

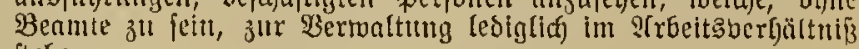
iteher.

§ 2. Dic $\mathfrak{W a h}$ ber $\mathfrak{B}$ ertreter Der $\mathfrak{A r b e i t e r}$ und ber Erfatis: männer hat zum erften $\mathfrak{R}_{\text {al }}$ in ocr erifen 5älfte bes Mronats

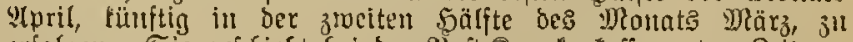

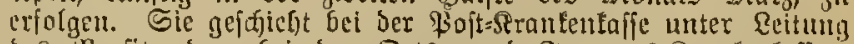

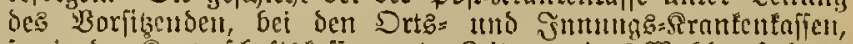

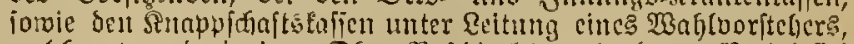
melefer von berjentigen Obcr. Foftoirettion, in Deren Bczirt fidf

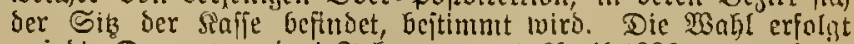
anf bie Dauer bon ie 4 J̃abren, voln 1. ?lpril 1886 an gereefmet.

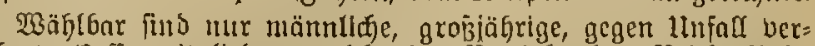

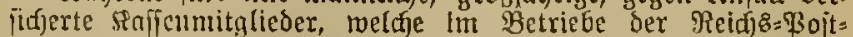

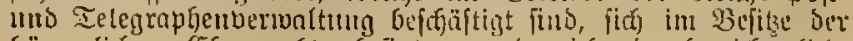

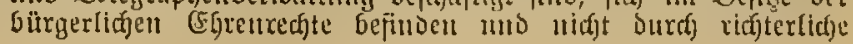




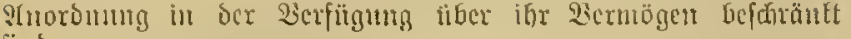
fiito.

Dic Walst crfolgt fïr jeocn Bertecter umo fïr jeben be:

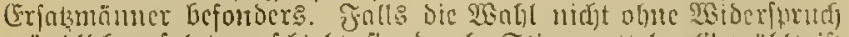
münblaf erfolgt, gefdyicht fic burch Stmmzettel. (semälit ift sericuige, locldjer dic meiften Stimmen crhält. Stimula,

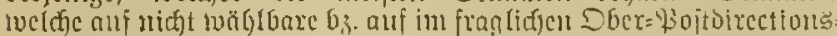
Bezirf nidft wobuljafte Ferjonen frllen, ober bie Bemäblten

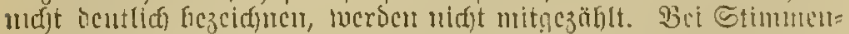

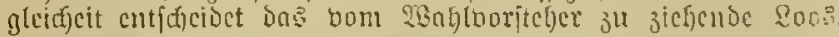

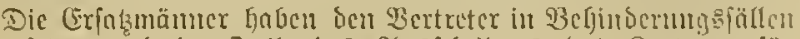

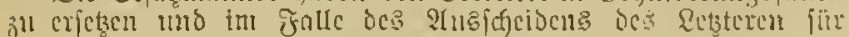

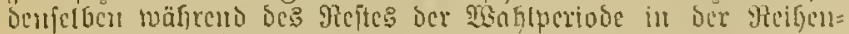
folge ifjer $\mathfrak{B a b l}$ cillzutreteu.

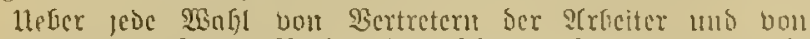

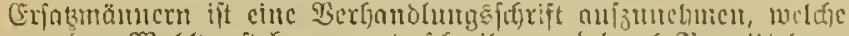

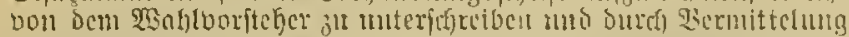

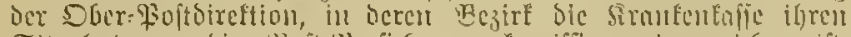

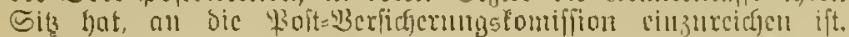

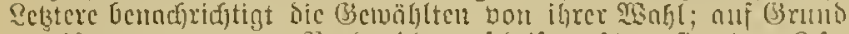

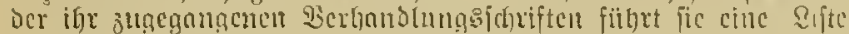

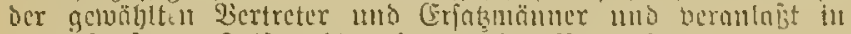

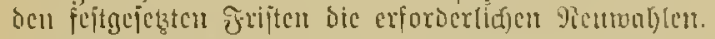

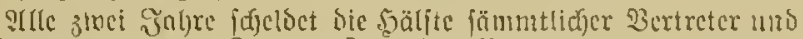

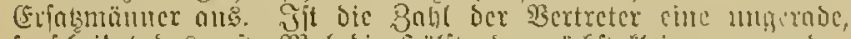

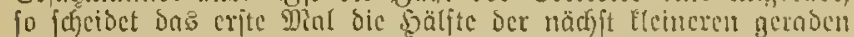

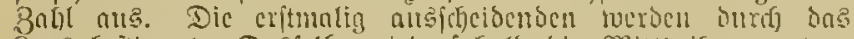

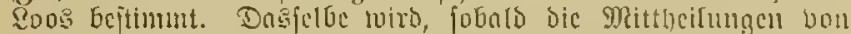
Den erfolaten 2 bahlen cinnegangen fins, burd cinen Benuten bex

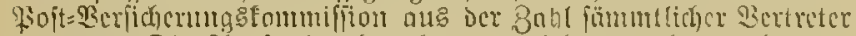

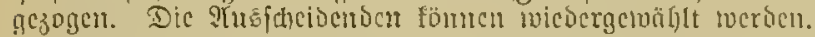

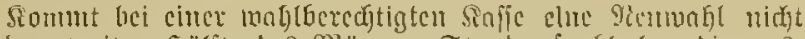

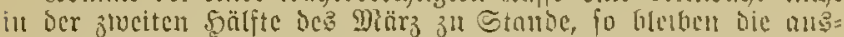

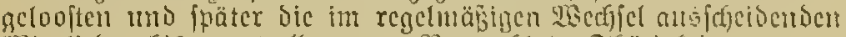

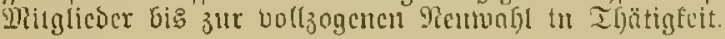

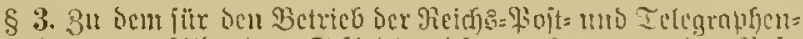

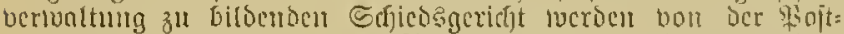

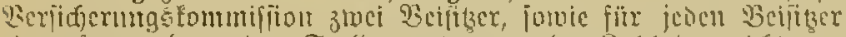

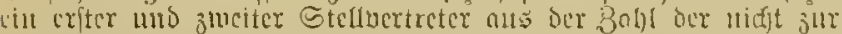

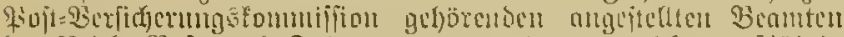

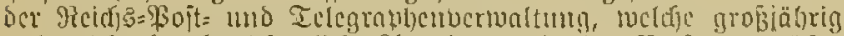

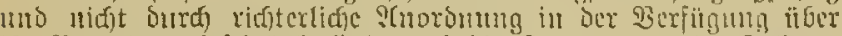

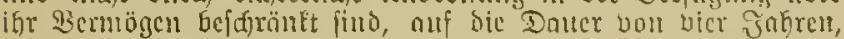
vom 1. PTpril 1896 an geredinct, crunant.

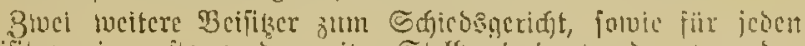

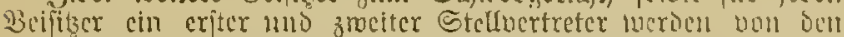

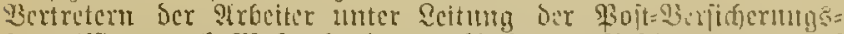

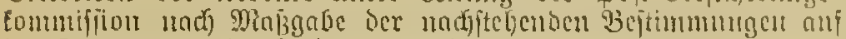
bic Dalter bou bier Jabeen gewäglt.

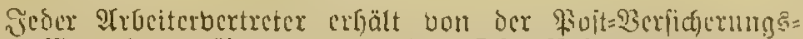

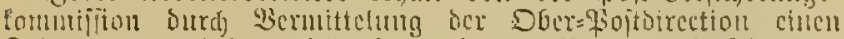

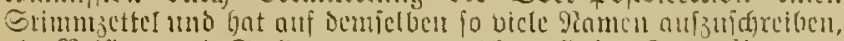

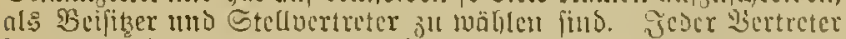

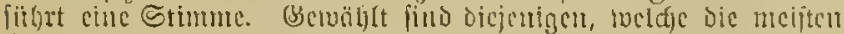

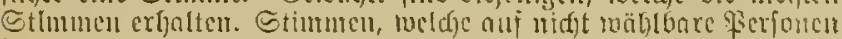

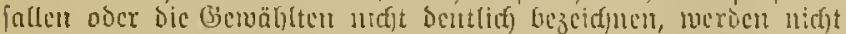

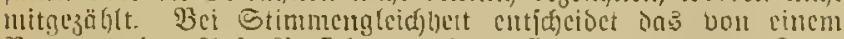

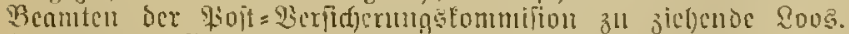

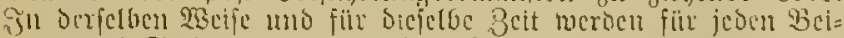

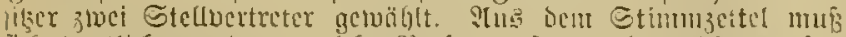

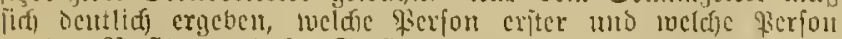

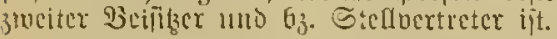

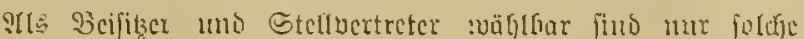
grosijährige, ocr sicichs:

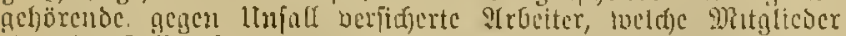

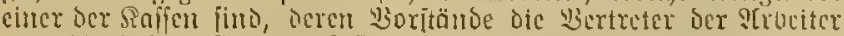

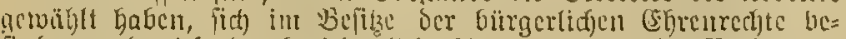

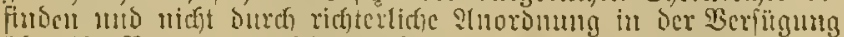

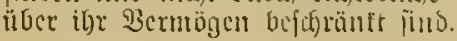

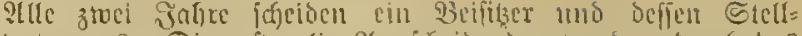

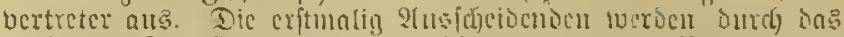

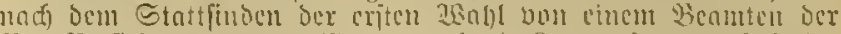

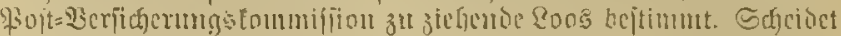

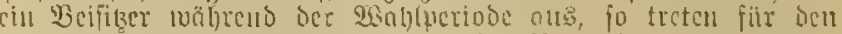

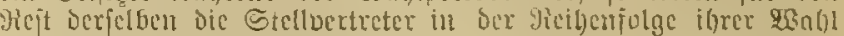

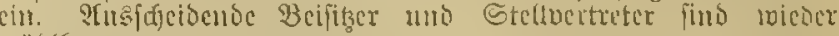
toül)lont.

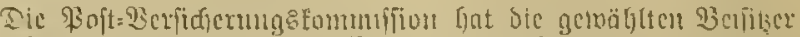

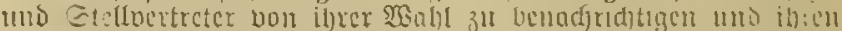

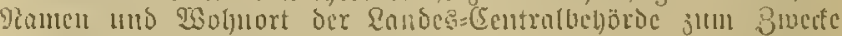
ber 3 ¿röffentlidjutiz atijujcigen.

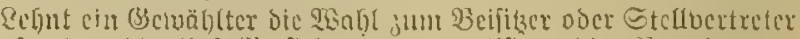

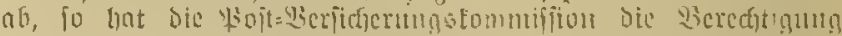

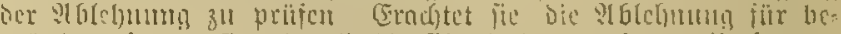

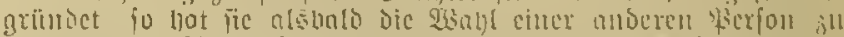

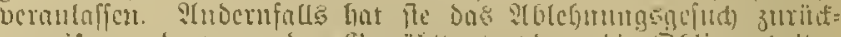

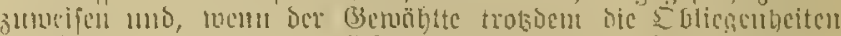

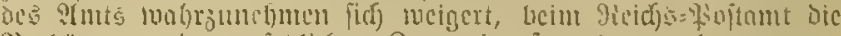

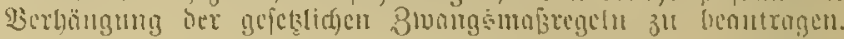

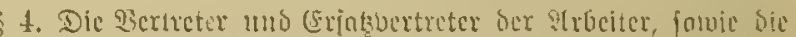

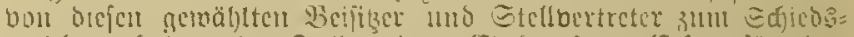
ucrid)t crbaltel in Falle cincr Einberufung Erfab für ocn

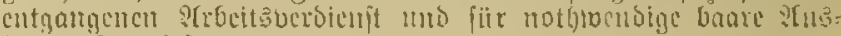
lagen (jub) toiten :c.).

Soferu bie Berteter in folge inter finferufung cinen

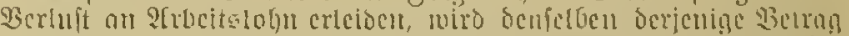

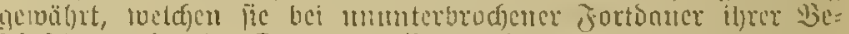

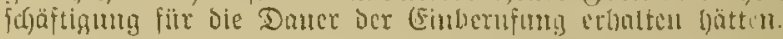

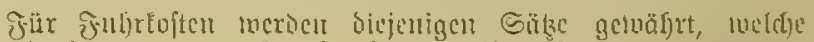

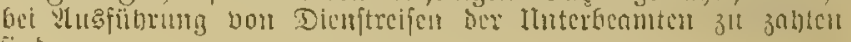
jints.

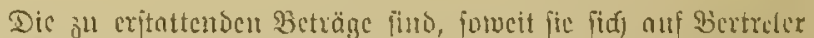

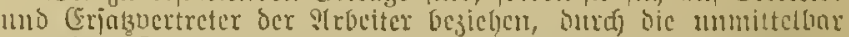

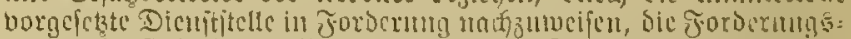

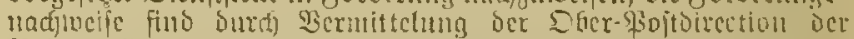

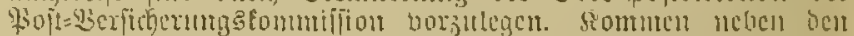

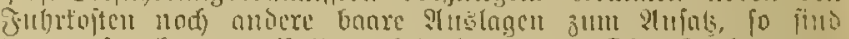

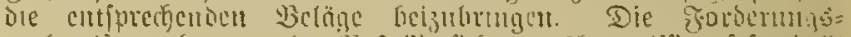

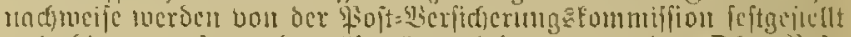

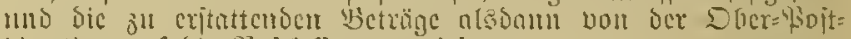
birection anf Dic \$sojtfnfic anyenicjent.

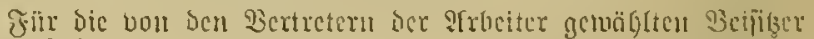

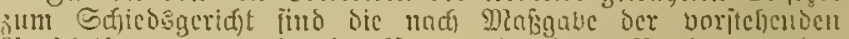

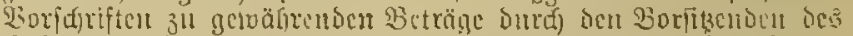

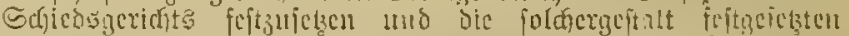

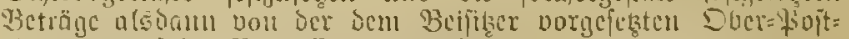
bircction anf bic Bojtuffe anzแndeifen.

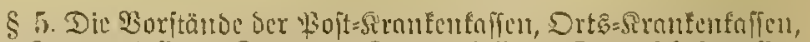

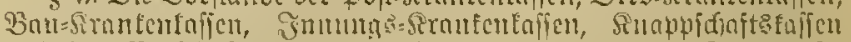

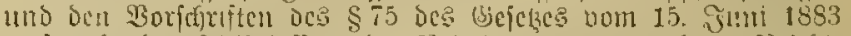

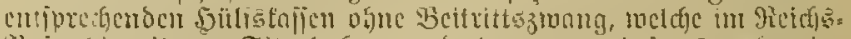
Hojtgubet ibren Sib baben mo denen mudejtens jehn im

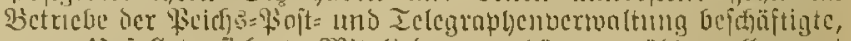

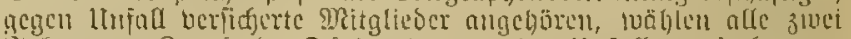

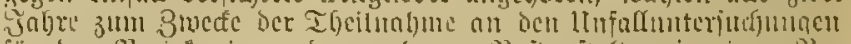

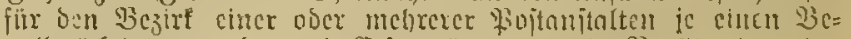

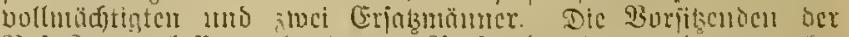

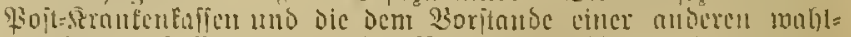

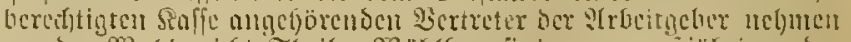

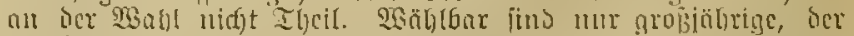

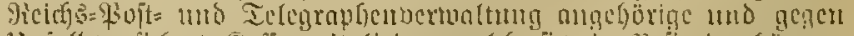

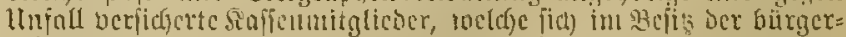

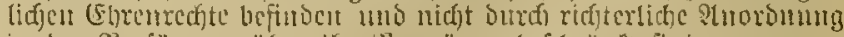

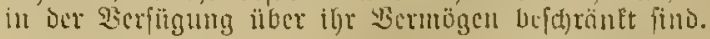

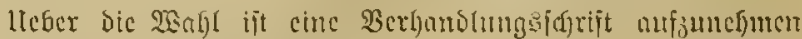

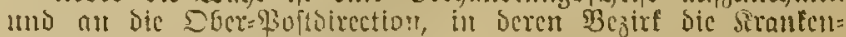
infic igren Eits bat, chumadicn. 
\$ 6. Dem Reun[Imädjtigteu Ser Sirnutentaffe, weldicr au Der

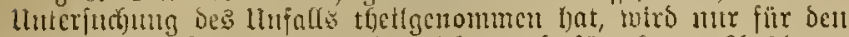

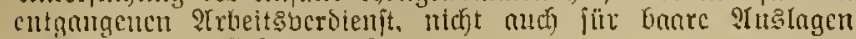
(Jibrejoitcu ac.) Erjalz geleijtet.

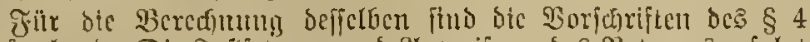

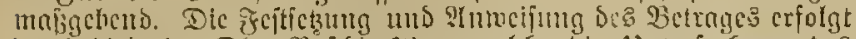

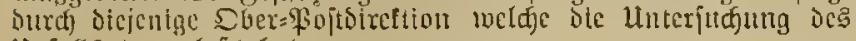
llufalla verantafst lout.
§ \%. Dics Picgulativ tritt mit ben 1. Upril 1886 in Rraft.

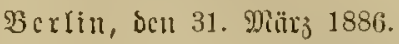

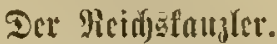

Jొ1 Sicrtretung:

bon Stcplin.

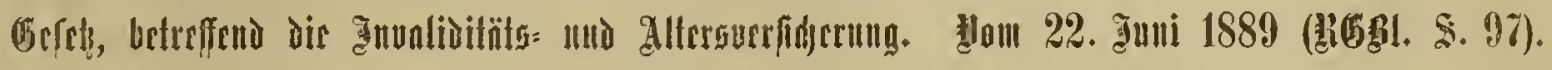

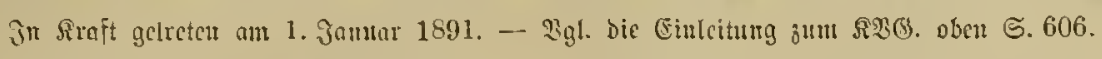

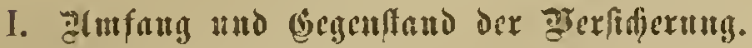
Berfiderungspflit)t.

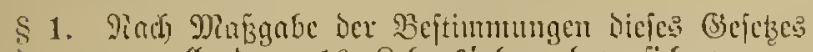

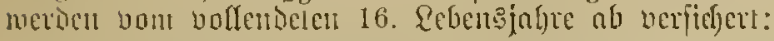

1. Ferfonen, melche als strfieiter, Getjülfen, Gejelfen, Rebrlinge oder Dienftboten gegen Rohn oder Gebalt hejuäjtigt merden;

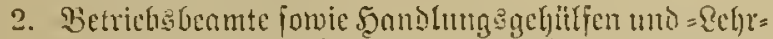

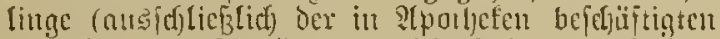

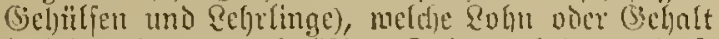

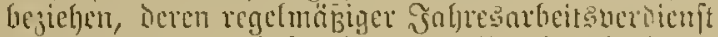

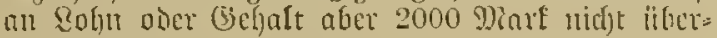
itcigt, jonic

3.

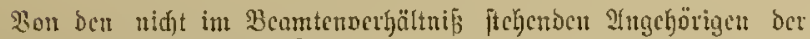
Roftnermaltumg finto zu verfict)ern:

1. Dic Schrcibhülicu,

2. dic Solntidreiber,

3. Dic ?tusheffer,

4. Dic Telegraphenurbeiter cinffjl. Ser Trbeiter an Elungen= aubcreitungsamftalten,

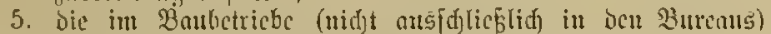

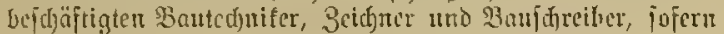

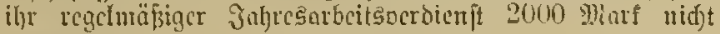
iiberitcigt,

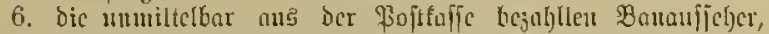
Bauvë d)ter แno Banarbcitcr,

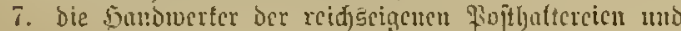

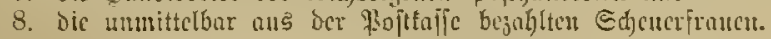

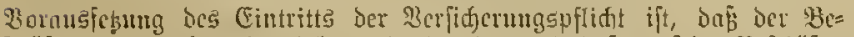

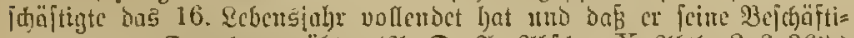

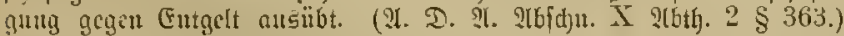

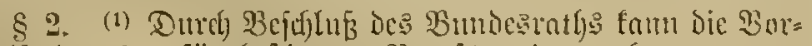
idjrift Des \& 1 für befimmte Berufsjolncige aud

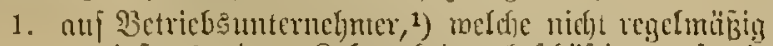
wenigftens cinen Rofnarbeiter befdüfitigen, jotnte

2.

erjtrect swerden, und jmar ze.

(2) $\ldots \ldots$

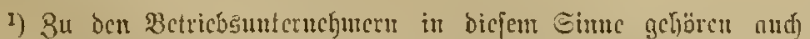

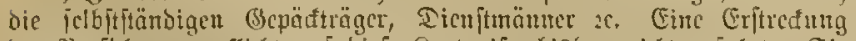

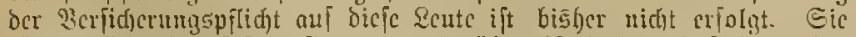
fömens fidg aber, jofern fie nod̆ nidgt itber 40 Jahre alt finto, in ber Zoljutlafie II jetbit verficjern (\$§ 8, 120).

\$.3. (1) SแL Sohn oder (bieljalt getlen and Tanticmen

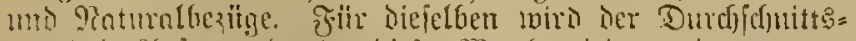
merth) in stujnts gebracht; Dicjer $23 e r t h$ wird won ber unteren Serwaltungegefjorde ieftgcietst.
(2) Cine Bejdjäftigung, für tweldfe als (Entgelt nur freier llnterhalt gewälytt wirt, gillt im Simne biefes (Sefebes nidft

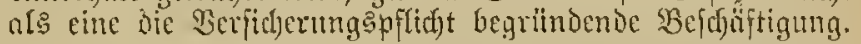

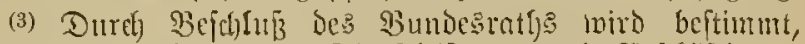

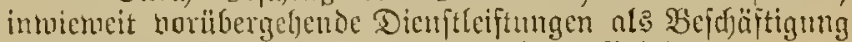
in Sinte diefes (Sejedses nidyt anjujelyen find. ${ }^{1}$ )

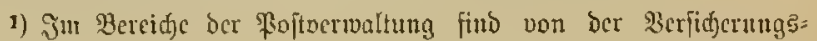
pflicht bejreit:

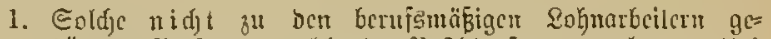

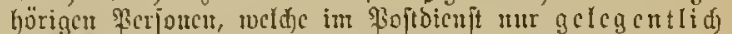

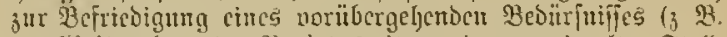

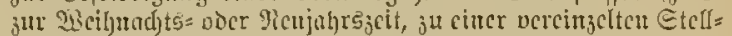

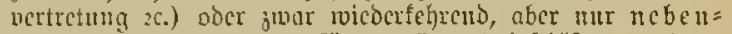
bei uno gegen ein geringfïgiges (Entgelt beidältigt werbent;

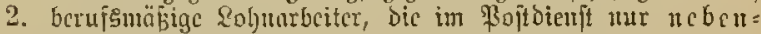
bei bejojoftigt weroen, foforn fic auf Brumb iljere Soupt= beichäftigung bei eincu aubcren Irbeitgeber verfiderungs= pfliditig finto;

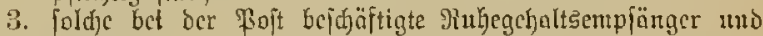
Empfänger vou ltufallerenter, wethe Durd eine Bejdeini= gung ber unteren Berwaltungsbehörde iffre Befretung nachipcifon $(\$ 4,3)$;

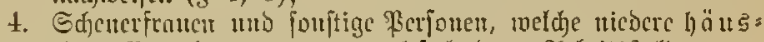

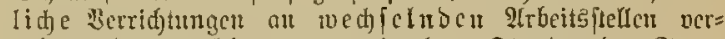
ridfen, D. h. woclde mur an cinjchren Etumbent des Tages

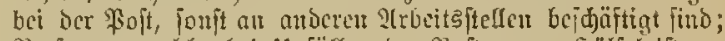

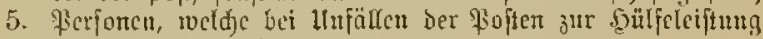
hermigezogen werden;

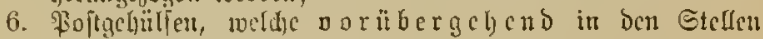
als Engreiblülfen Rtermendung finben.

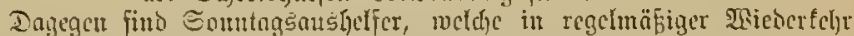

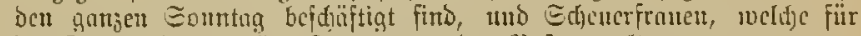

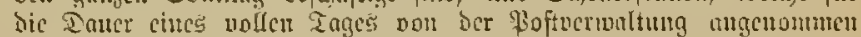

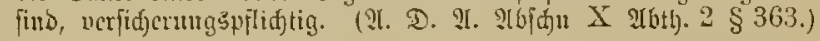

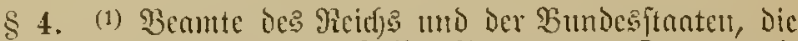

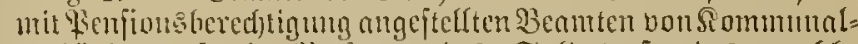
berhänten, fomie yiserionen des Soldatenftandes, melche

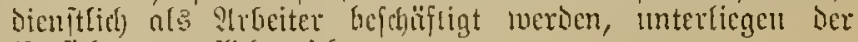

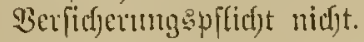

(2) Tic Berfidjerungapflidft tritt für biejenigen \$erjonen nidft ein, mulffe in Jolge ifjec förperfidjen oder geiftigen Buftnoes Dauemb nidgt meljr in Stande find, Durd) cine ibren Sräften mo Jäbigfeiten entfpredfenoe Solnarbeit

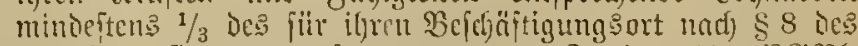

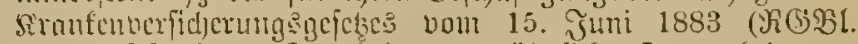

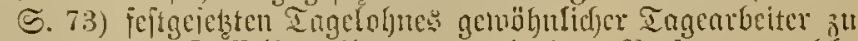
verdienen. Dajfelbe gift non denjentigen Perfonen, beldje

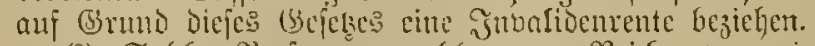

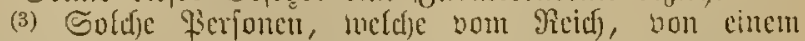

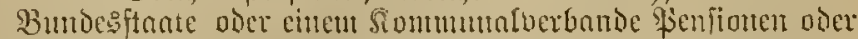

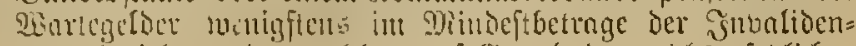

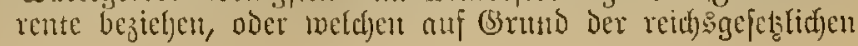


Beftimmungen über lunfalfberficherung der $\mathfrak{B} e_{z}$ ng einer jäl)r=

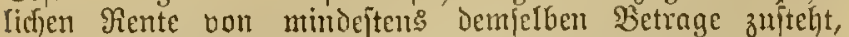
find alf ifyen Untrag bon Der Berfitherungspflicht $3 \mathrm{u}$ be= freien. Heber Den Q1ntrag enticheidet Dic untere $\mathfrak{B e r m a l t u n g} g=$

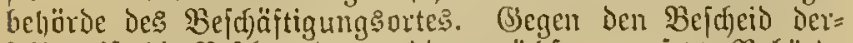
fellen ift die Bej(j) merde an die zumädjit borgejetzte Beljörde

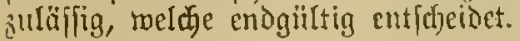

\section{Bejondere Rajenemridtungen.}

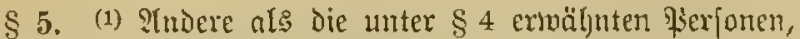
tueldye in Betrieten bes Reich) einc: Sommunalverbandes be[däftigt twerden, genügen ier

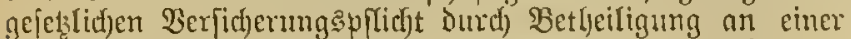
fïr Den betreffenten Betrieb befteljenden ober zu erridjtenden befonteren Safjencinricftung, Durd) weldfe ithuen eine Den

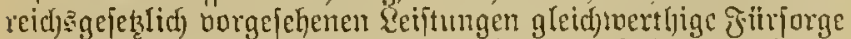
gefid)ert ift, fofern bei der betreffenden Raffeneinridtung folgende ছorauşetzungen zutreffen:

1. Die Beiträge Der Berficyerten dürjen, forveit fie

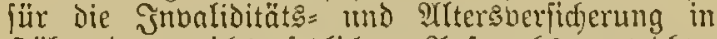

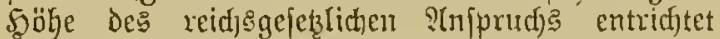
merden, Die Själite değ für Den lethteren nad) $\$ 20$ zu erhebenden beitrag Beftimmung findet feine ?tnuendung, fojern in Der betreffenden Saffencimidftung Die Beiträge nad) cinem bon der Bered)ntmgsiveife des \$2 20 ab=

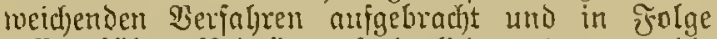
Deffen höhere Beiträge erfarderlid) twerden, um die

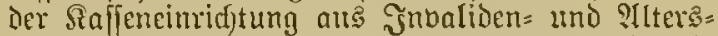

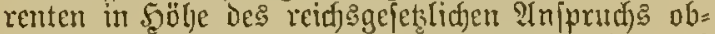
liegender Eeiftungen ju dedfen. Gojern liernad)

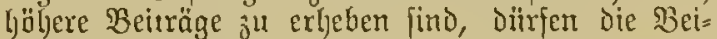
träge der Verficherten Diejenigen oer 2rbeitgeber nid)t itberiteigen.

2. Bei Berechnung Der Wartezeit und ber Rente ift Den bei foldjer Seffifeneinridytungen betheiligten Pier=

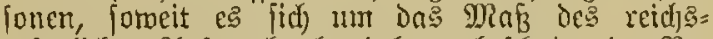

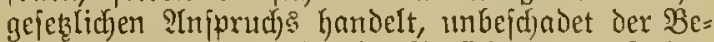

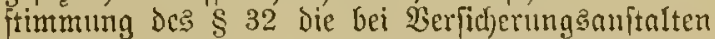
$(\$ 41)$ zuritufgelegte Beitragşzeit in 2(nxed)nung zu bringen.

3. Lleber ben $2(n[p r u d)$ dex eimjelnen Betl)eiligten auf (Servährung vou Invaliden = und Mltcrestente muß

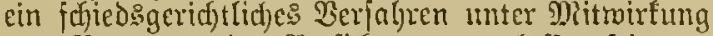
bon 2 ertretern Der Berjicherten zugelafien fein.

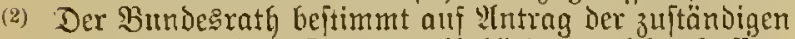

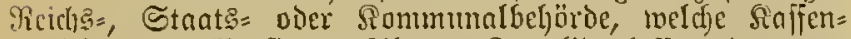

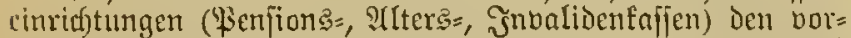

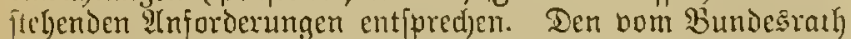

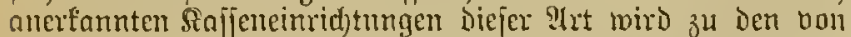

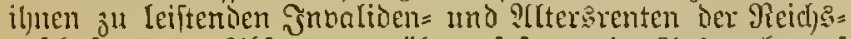

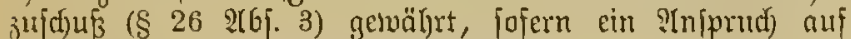

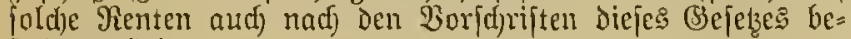
jelyen milide.

\$ 6. (1) Ton Den Infraftreten dicjes (Sejetses ab iniro

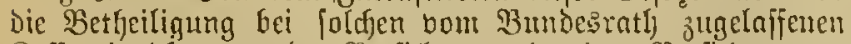

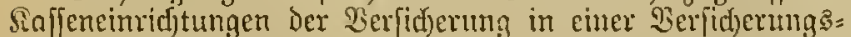

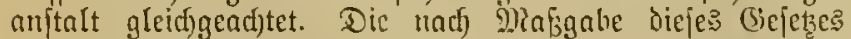

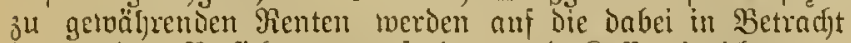
fomnenden 2 erficferungsanjtalten und Siffeneinridjtungen nach näherer Bejtimmung ber $\$ \S 27,89,94$ vertbeilt.

(2) Wenn bi einer folffen Riaffeneinrichtung die Bciträge nidgt in ber nad) $\$ \$ 99$ ff. borgeidriebenen form erlyoben werden, hat der Boritand ber Raffeneinxidjtung Den aus Der

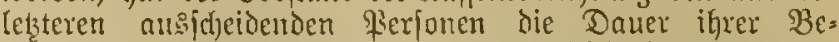
theiligung und fïr diejen 3eitraum die Şähe des bezogehen Soljues, die Bugehörigfeit ju einer Rranfenfaffe, fomie bie Dauer etmaiger Siranfljeiten (\$ 17) ju bejdjeinigen. Der

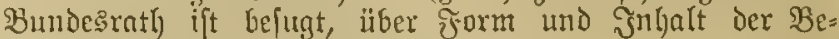
(d)einigung Borfduriften zu erlofier.

\section{(3)egenftand Det Bexfiderung.}

§ 9. (1) (Begenitand Der Berfidjermig ijt ter Infprud)

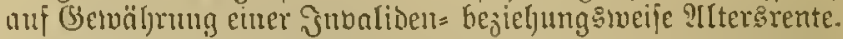

(2) Inbali alter Derjenige Derfid)erte, twelduer Dauterno ermerbsిunfäljig

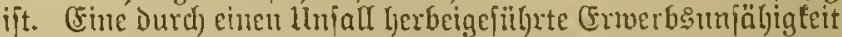

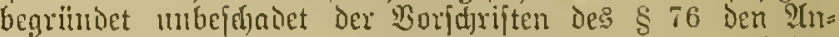
iprud) anf Эnoalidemente mur infoweit, als nicht nad) den

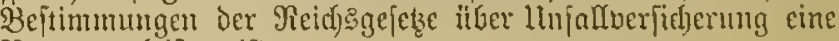
Rente zu leiften ift.

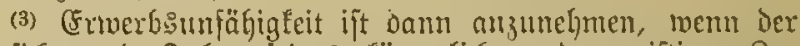
Berfieferte in đolge feines förperlicjen voer geiftigen $Z_{41}=$ ftandes nich)t mefyr in Stande ift, Durch eine feiner Sräften und Fähigfeiten entiprechende sohnarbeit mindeftens cinen Betrag in berbienen, weldjer gleid)fommt Der Summe einte

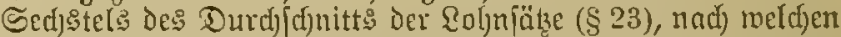

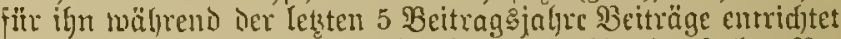

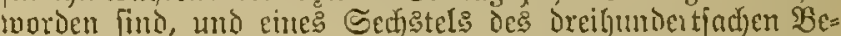
trages des narf) \& 8 Des fironfenberfidjerungsgeickes voun

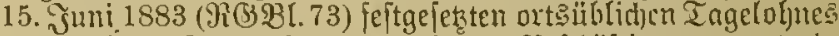

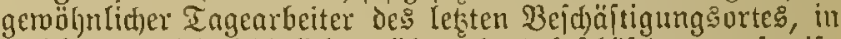
weldjem er nid)t lediglić) vorübergehento bejdjäftigt gewejen ift.

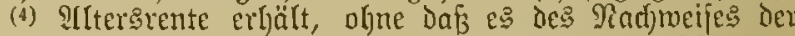
(Ermerbesunfähigfeit betari, derjenige berficjerte, weldjer bas 70. Eebensiahix bollendet hat.

$\S 10$. Invalidenrente erhält aud derjenige nidjt Daterno erwerbsunfähige $\mathfrak{B e r f i c f ) e r t e , ~ m e l d ) e r ~ m a ̈ l ) r e n o ~} 1$ Faljres un= mnterbrod)en ermerbsunjäbig gemejen ift, fiir die weitere Dauer jeiner Ermerbsumjähigfeit.

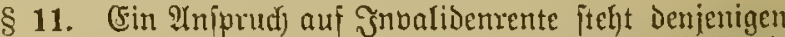

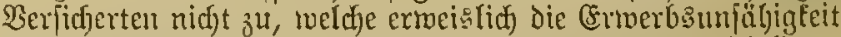
(iid) borjütalid) over bei Begeljung eines durch itrafgerid)tliches

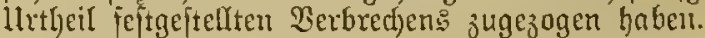

\$12. (1) Die Vierficherungsanftalt ift bejugt, für cinen

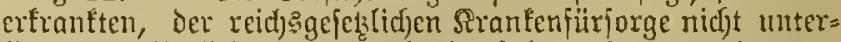
liegenden $3 e r f i d j e r t e n$ das Seilverjahren in dem in $\$ 6$ शTbF. 1 Biff. 1 Des Franfenverfidferungsigejetzes bejeichneten

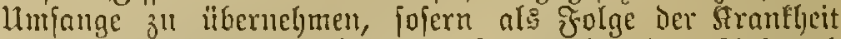
(5rverbsunjähigfeit zu bejorgen ift, melche cinen ?(njprud)

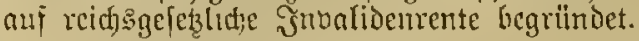

(2) Die Berfidferungsanjtalt i[t ferner befugt, zu ver=

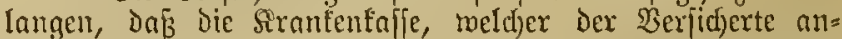
geljät oder zulekgt angeljärt hat, die fönrforge für benielben in demjenigen llmjange iibernimmt, weld)en bie $\mathfrak{B e r j i d j e r u n g s : ~}$ amitalt für geboten eradjet. Die Roften diejer bon iljr Geaniprud)ten Firrjorge hat bie Berfidjerungsanftalt zu ex=

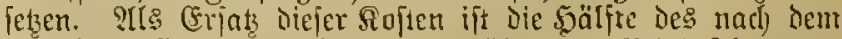

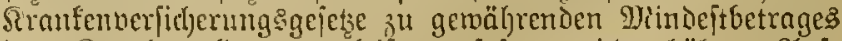
De: Sranfengeldes ju Ieiften, fofern nid)t böl)ere $\mathfrak{A} u f=$ wendungen nachgemiejen merden.

(3) ......

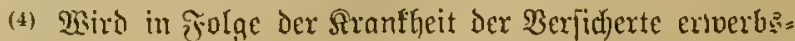
unjäbig, jo verliert er, jalf er fid) den im $\mathfrak{T b}$. 1 umb 2 


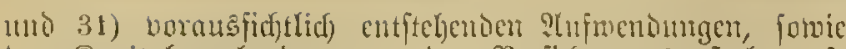

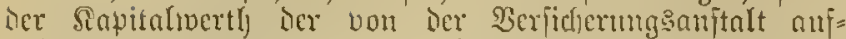
jubringenoen Sntheile an is enjenigen gienter, melde in

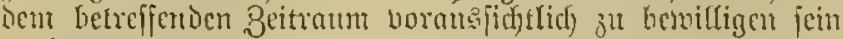
merien.

S 21. (1) Die Rüitflngen зum Refervefonds find für die

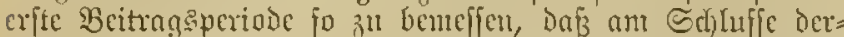

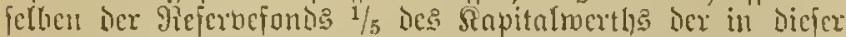

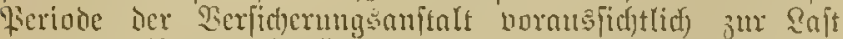

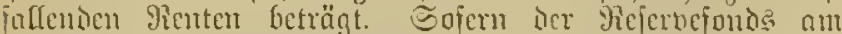

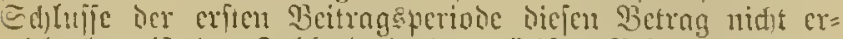

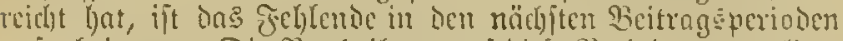

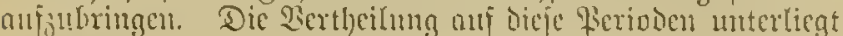

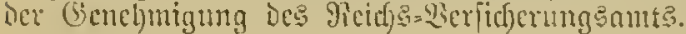

(2) .....

(3) Der Rejeruefonds forwic defien Binjen bürjen, folange

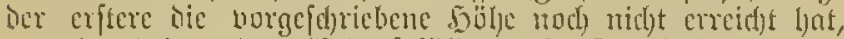

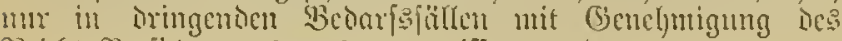
gicid)

\section{Rolitelaffen.}

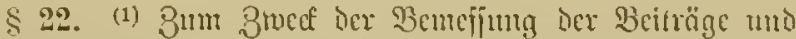

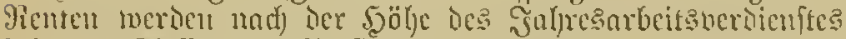
folgende Stafien ier Sicrfidlexten gebiloct:

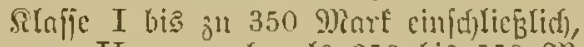

"II von mely als 350 this 550 Miarf,

" III bon meljr nls 550 bis 850 Diart,

" IT vou mrelp als 850 Mart.

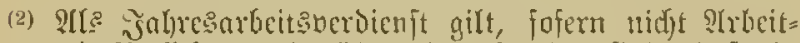

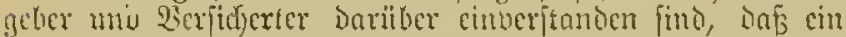
büljerex Betrag ju (Brmbe gelegt mirt:

4. für Mitglicoer ciner Drts=, Betricbs $=($ Fabrif $=)$,

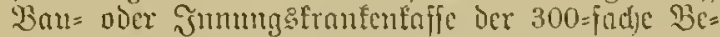

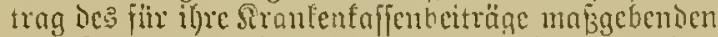
Durdjid)niteliden Tngelolmes (\$ 20 des Siranfen

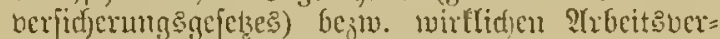
bienftes (\$ 64 Biff. 1 a. a. D.);

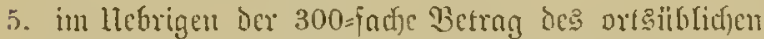

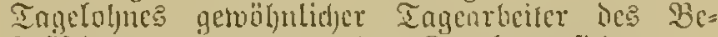
id)ôftigungsortes (\$ 8 ics Siranfenverfid)erumg gejetic:

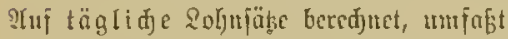

Solmuttaffe I cincu Tugelohm bił ju $1,16 \%$,

" III " " " von mebr afs 1,16 ", bis 1,83 .t

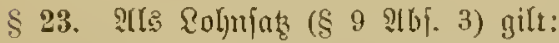

fïr Die Rohnflaffe I Der Snkz bon 300 Mart,

" " "

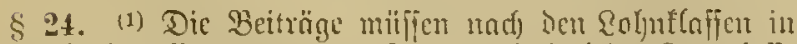

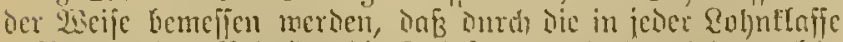
nuffommenten Beitrn̈ge dic Beloftung gedeckt mirt, melthe Der Perfiderungsonjtalt ourd) bie auf (Brmmi ticjer 3 Bei=

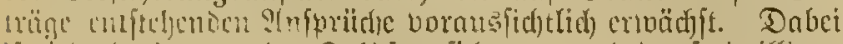

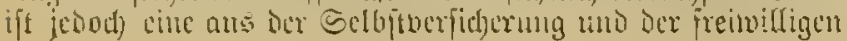

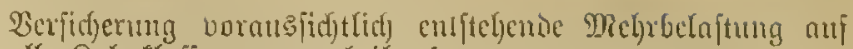
alle Soljnflafien jut wertheilen. ${ }^{1}$ )

(2) ......

1) Dur Deitrag für bic Salenberwodye belänit fid): für dic Sohntlafic I auj 14 \$i .

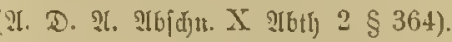

" " " III II " 24 "

\section{Bered) Uu Der Renten.}

\$25. Dic Sienten meroen für Snlenterjabre bereduet.

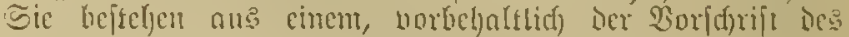

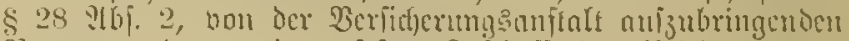
Betrage mo nus cincu feiten Buichuffe des Reiclys.

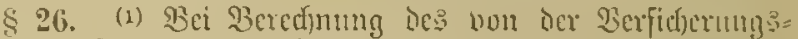
antalt anfubringenden Theifes ber Junnlidentente wirt

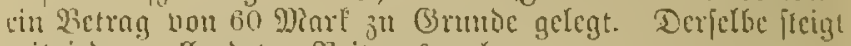
mit jeder volfentefen SBcitrngsivod)e

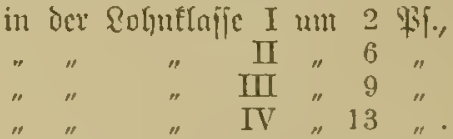

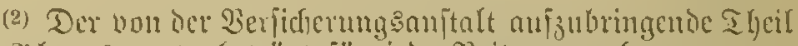
ier : Iltersiente beträgt fïr jecte B̉eitragsumadje

$$
\text { in RoLnelajic I } 4 \text { \& \$f., }
$$

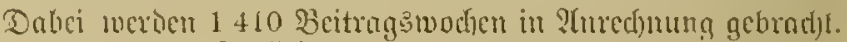

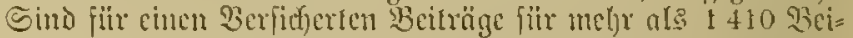

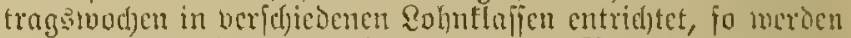
jitr Dic Beredjnmmg Dicjenigen 1410 Beitrigsmodyen itt

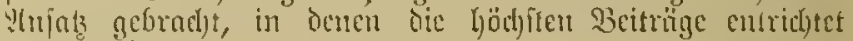
worben itmot.

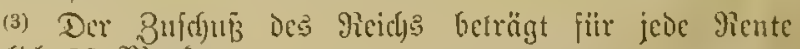
jülyrlid, 50 Diàt.

(t) Die Renten find in monatlidfen Theilfeträgen int

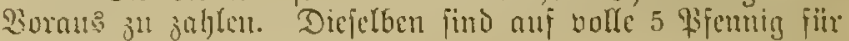
Den 2lionat math ofen abjuminem.

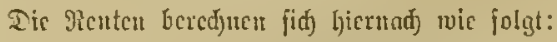

$$
\text { A. Jutonibenrentc: }
$$

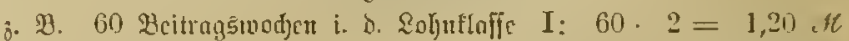

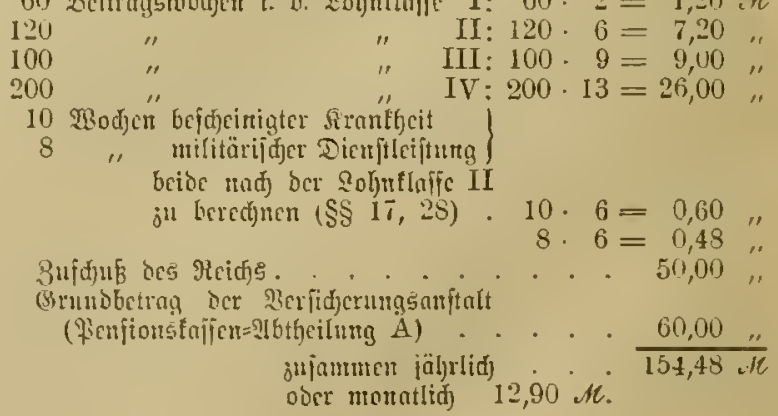

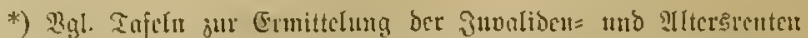

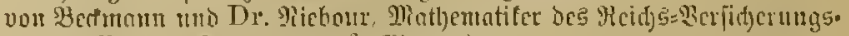
amts. Bertin (Eiencurvih) \& SBzorms). 


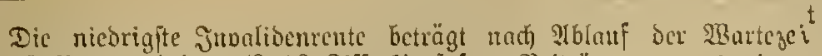
von 5 Beitragğaljen (\$ 16 3iff. 1), joferu Bciträge mut aus citue r Soljulajic in Betradyt fommen, jäbrlido:

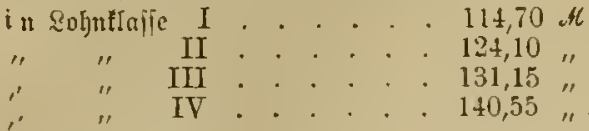

Cincu cigentlifen sönitbetrag aic5t ç bei ocr juvalibemtente

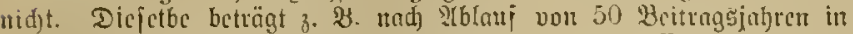

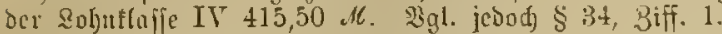

\section{B. Mltersirente:}

Der nicurigite Betrag ift (1410 Beitrags= woifen in ber Dobuttulle I) $1+10.4$

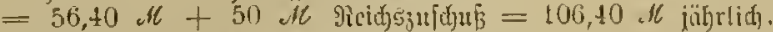

Der \$öd) itbetrag ift (1+10 Beitragswodfect in Der Robutlafic IV) $1+10 \cdot 10=1+1,00$ M

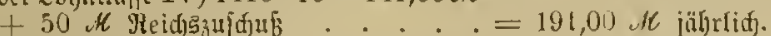

Sierzu treten ïberall bie \$brumbungen ber monatlid)en Theil= beträge anf volle 5 \$ुeming.

3uijhen bicjen Buträgen werben bic Einjelrenten ïberants ver=

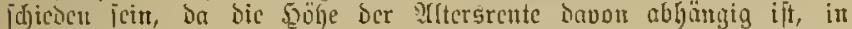

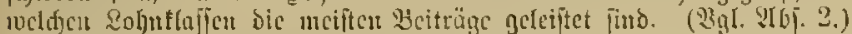

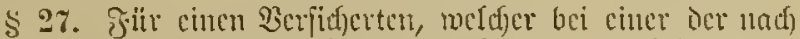

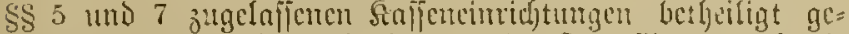

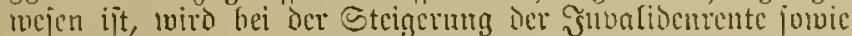

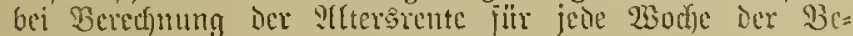

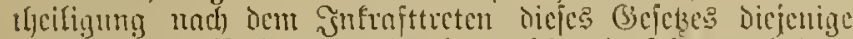

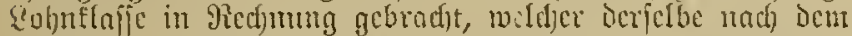

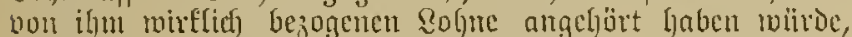

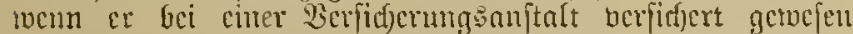

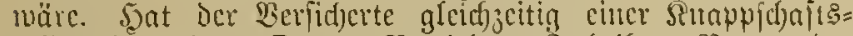

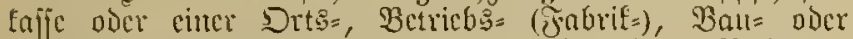

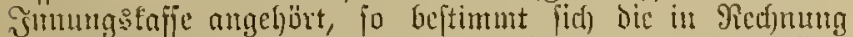
itl bringende Eohnflofie nadj ben Beftumumgen ber Biff. 3 beju. 4 des \$ 22 Ibf. 2.

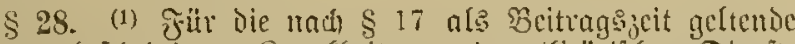

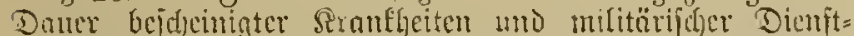

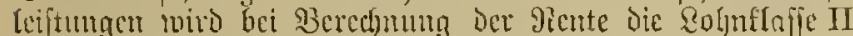
ju (3rimbe gelegt.

(2) Don nuf Dic Dauer militärifder Dientteiftungen

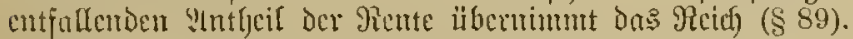

\$ 29. (1) Dic Snbalioenrente beaimnt mit bem Tage,

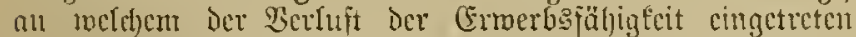
iff. ?lls Dicicr Beitpunft gilt, jojern nidjt cin anterer in ber (sntidgcioung feftgcfteflt wiro, Der Iag, an mefd)ent Der

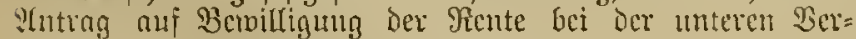
waltumgabehörde geftellt worben ift (\$ 75).

(2) Dic ?Iterstente Gegimnt frübejtens mit Dem 1. Iage Des 71. Ecbensjalies. Diejelbe fontmt in Fortjall, pohalo

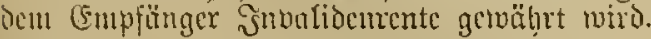

\section{Eritattung bon Beiträgen.}

\$ 30. Weiblidien Fcrionen, weldfe eine Ëge cingelyen, bevor fic in ben (senufs cincr Ficute aclangt fino, ftelt cin

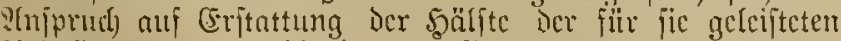

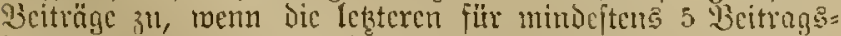

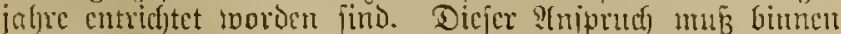
3 9Ronaten nadj Der Berfjcirntlyung geltend gentadft werden. S)it ner (Frftattung ertifofit dic Durd) bas iriibere Ber=

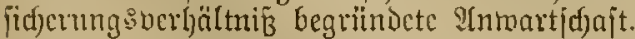

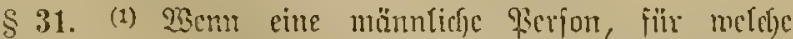

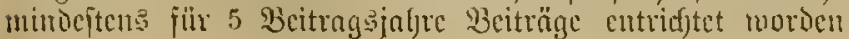

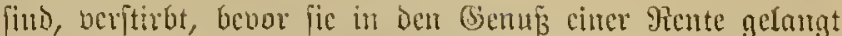
ift, fo ftel)t ocr linterlafienen 2 ittwe voder, falls ciuc jolthe nidfte borbanden ift, ben hinterlaffenen efeficlen Sindern

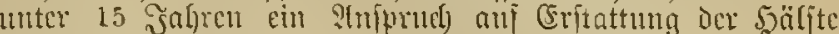

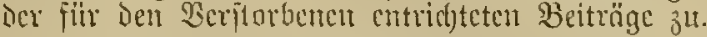

(2) Wenn cire meiblicfe Ficrfon, fïr weldye ntindeftens fü: 5 Bsitrags bevor ite in isn Gemis eirer Siente gelangt ift, jo ftebt Ben

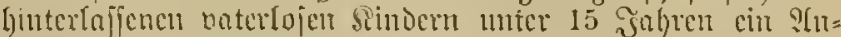

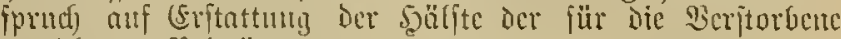
entrichtetcn $\mathfrak{B c i t r a ̈ g e ~ a ̀ ~}$

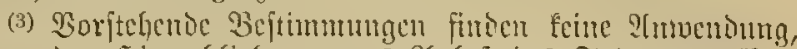

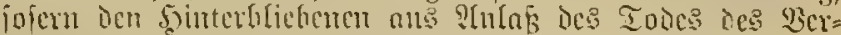
firlfirten auf (brumb bes llnfolfocrfit)erungagefetzes cine giente gemähnt miro.

\section{(Erlöjcher ber ?tumartidaft.}

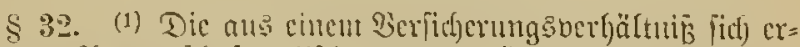

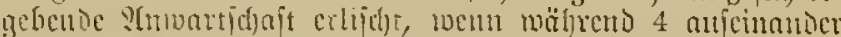

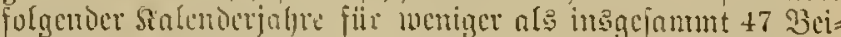

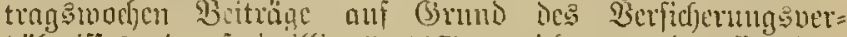

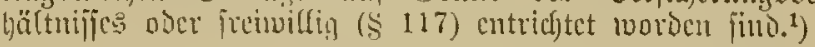

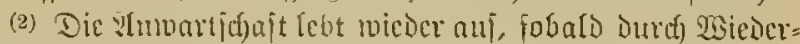

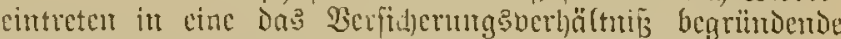

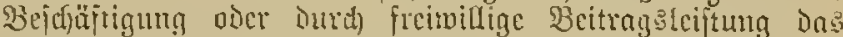

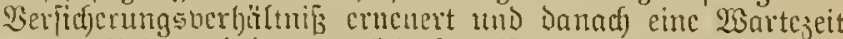
bour 5 Şcitragsjaljren jurüdgelegt iit.

1) Sontrole Darüber wirb surd) bie Dutttungsfarte (\$ 101) bejw.

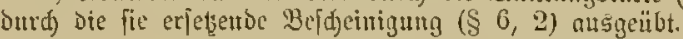

\section{Veränderung Der $\mathfrak{b}$ er}

\$33. (1) Tritt in Don Berfältniffen des Empfänger:

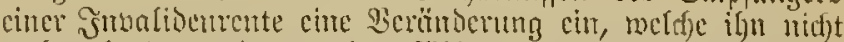
mefr a fant bemiclfor bie Pente cntzogen werben. ${ }^{1}$ )

(2) Die CEntzichung ber Pente tritt bon Den Tage ab

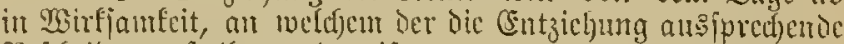
Bcjefjeid zugeftellt woriden ift.

(3) Mird dic Rente bou Rencm berwilligt, jo ift Dic Bcit

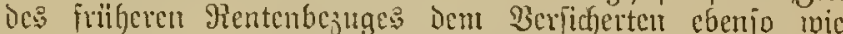

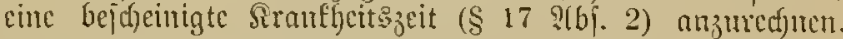

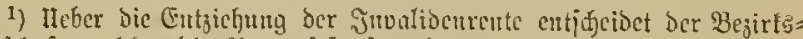

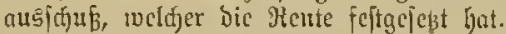

§34. Der nad Manggabe Dicjes Sicjelzes ermorbenc infpruch auf Rentc ruljt:

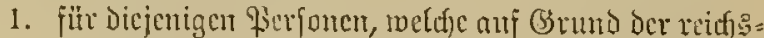

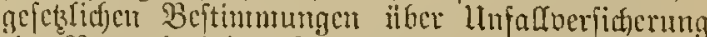
eine giente bezichen, folnuge mo porecit dic $14 n$ fall= rentc unter Somzuredfunng Der diejen Ferjonen uad

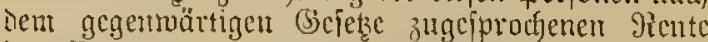
ben Betrag bon 415 Diatf überiteigt;

2. Für bic in Den $\$ \S 4$ unD 7 bejeichmeten Beranten uni Ficronen bes Soldaterftondes, jolange umb jomeit die icnjelfen gemüfrten Gerfionen oder 20artegelder unter Sinjuredmung Der ifnen nadj Dem gegenwärtigen Sejetse jugeiprodjenen Rente Den Betring bon 415 Mart itberfteigen;

3. Folange der Bered)tigte eine dic Dauet bon 1 Monat überfteigende Jreibeits jtrafe berbitist, oucr jolange cr in cincm ?trbetshauj oder in einer Befferungs aujtalt untergebradut ijt; 
4. jolange der S3eredhtigte nidjt in Snlanie twolint.

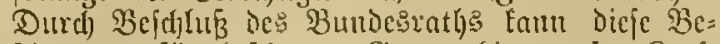
fitimmung fïr beftimmte Brenzgebiete amber Rraft gejekzt tocrben.

Berbältuib zu aroeren Ŝnprïden.

$\$ 35$. (1) Die nuf gefetzlidfer Borfdyrift beruljente Ber= pflichtung bou Geuteinden und 9/menberbänben zu* llnter=

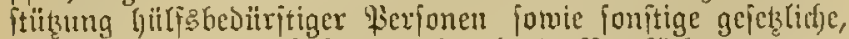

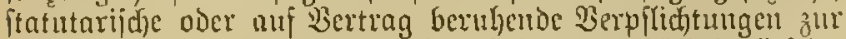

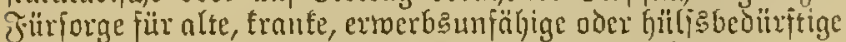

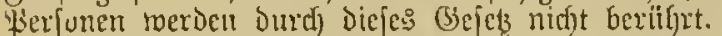

(2) Someit pon ciner Bemembe ober cincm 2trment= verbande an hülfgbedïrftige Perjonen llnterftïßzungen jïr einen Beitranm geleiftet find, für reeldjen diejen giserfonen ein ?(nfprud) auf Ynbaliden= oder S(Iterstente zuftant, gel)t

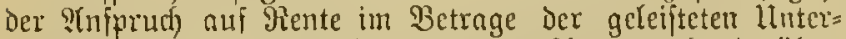
ftït)mg auf bie Bemeinde oder den ?trmenberband ïber. Das (Sleid)e gilt für Betriebsunternefymer uno Rafien,

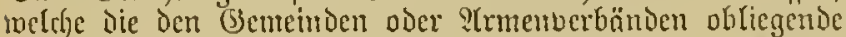

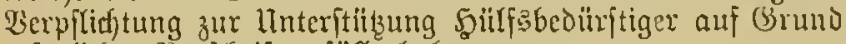
gefchslicfer Joridyrift erjüllt haben.

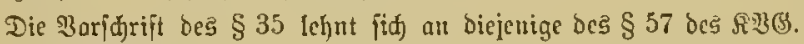

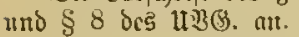

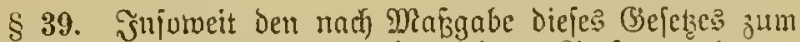

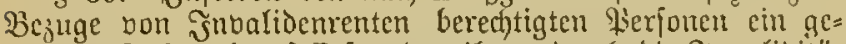

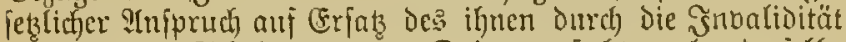
enffandenen ङdhadens gegen Dritte miteht, geht derjelbe auf Die Berficherungsanftalt bis zum Betrage Der von Dicfer 3u gewährenden Rente über.

\section{Borredjte Der Renten.}

$\$ 40$. Die Rente Eant mit rectitlidjer 2 Birtung meder verviätndet, nodf übertragen, noch jür anoere als die im $\$ 749$

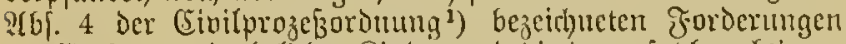
Der (Chefrau und shelichen Sinder und die der erjałzberedjtigten (Semeinden oder S(rmenberbände gepfündet twerden.

2) aber S. 200.

\section{Organifation.}

Serjidjerungsanjalten.

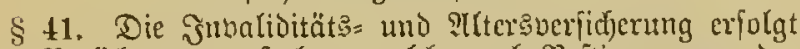
Durd) Berfidjerungsanftalten, weldye nady Beftimmungen der Eandesregierumgen für mcitere Rommunalverbände ifre?

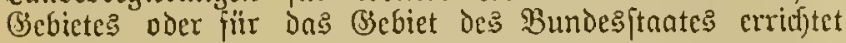
werden.

?lud) fann fïr melyrere Bundesftaaten oder Bebicts= theile derfelben, fowie für mehrere weitere Rommunclver: bänve eines Bundesftaates eime gemeinjame Terfidjerung: anftalt errichtet weroent.')

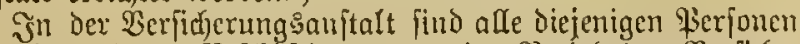

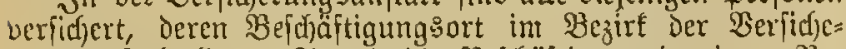
rungsanftalt liegt. Soreit die $\mathfrak{B} e$ cidjäftigung in einem $\mathfrak{B} \mathfrak{C}=$

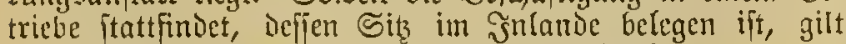
als Bejuäftigungsort Der Sitz des Betriebes. $\left.{ }^{2}\right)$

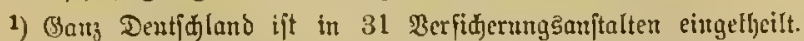
Iuf bas Rönigreid \$reusen entfallen Davan 13, who zrwar bilben

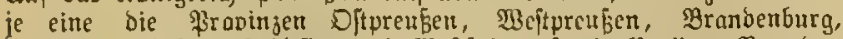

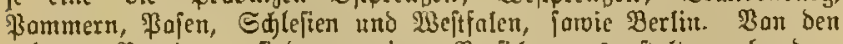
unberen Pravinjen firto ju einer Berfidjerungsanfalt Derbunden:

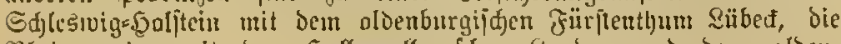

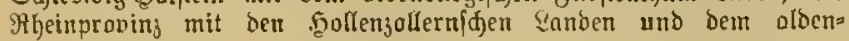

burgijळen fïrfenthum Birfenfelo, Sadjen mit dem 5ergogthun

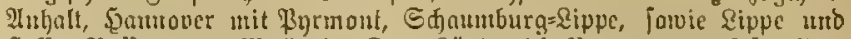

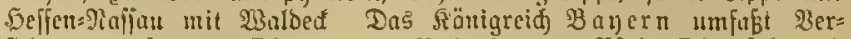
fidferunģanjtalten: Oberbanern, Riederbanern, \$FFls, Dberpjalz uno

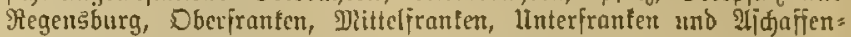

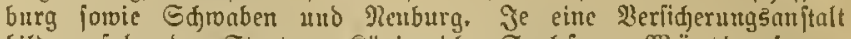
bilden falgenbe Stauten: Rönigreidje ङadjen, $\mathbb{B}$ ürttemberg,

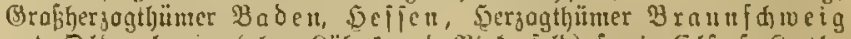

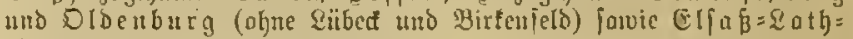
ringeut.

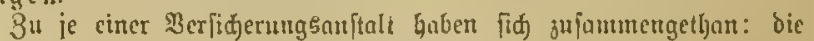

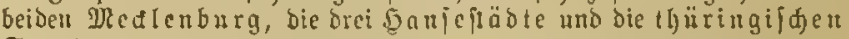
Stanter.

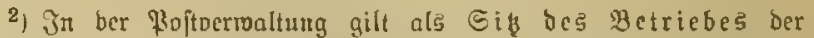

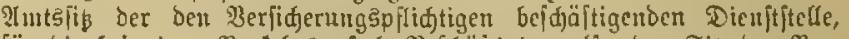

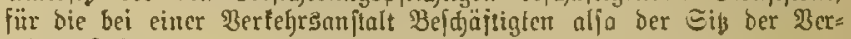
fehrsanjtalt.

Fïrir Dic bei Serftelung uno IInterhaltung ber Telegraphenantagen

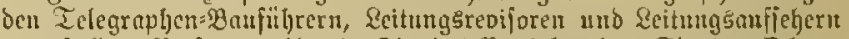

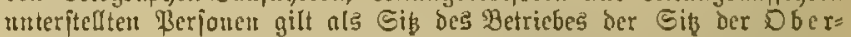
Bajtbireftian. Soweit jeDad die 2usfïhrung bon linterbaltungs= arbeiten an ben Stadt=Telegraphen= oder Stabt=Fermpredantagen unter Reitung eines Beamter ber ortliden Ielegraphenauftalt gejdjeht, iit ber Sitz ber Telegraphenauftall als Eis bes Betricbes anju= jeherr.

Fïr Irbeiter ber Stangengubereitungsanftalten ift ber Sip ber

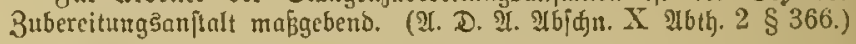

§ 43. (1) Der Sib3 Der Berfidferungsonftalt wird Durd) bic Sandesregicrung beitimmt. ${ }^{1}$ )

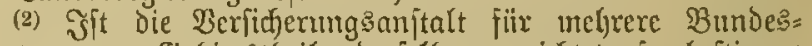
itaaten ooer Bebietstbeife Derfelben erridftet, fo beitimunt

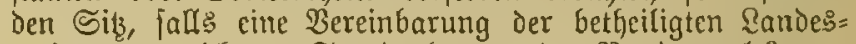
regierungen nidft zu Stande tommt, dex SBundesirath. ${ }^{2}$ )

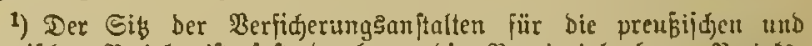

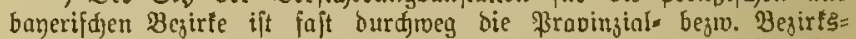

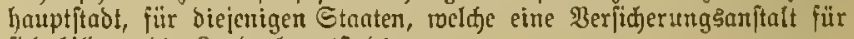
fidi bilocm, bic 2andeshauptitabt.

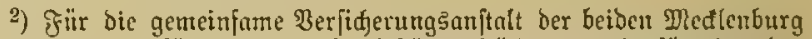
ift Sducrit, für bie der Sanjeftübte \&itbed, und für bic ber thïringijđen Śtuaten 23 ci mar beftinmt.

\& 44. (1) Dic Berfict)erungsanftalt Eaun unter ifrem

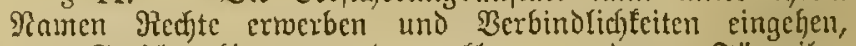
yor (Seridt flagen mo verflagt werden. Für iljre

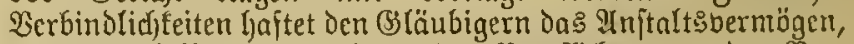

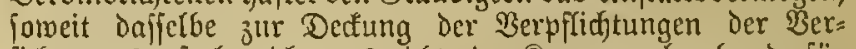
ficherungsanftalt nidyt ansreidyt, ier fommunalberbano, fïr

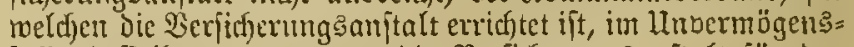

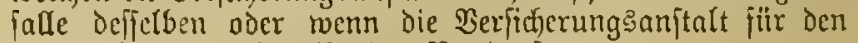
Bundeš faat errichtet ift, Der Bundespitaat.

(2) (3) (4) ....

\section{Borftano.}

\$ 46. (1) Dic Berficferungsanjtalt twiro Duredy eincur Foritand bermaltet, foreit nidft einjelne 9ugelegenfeiten

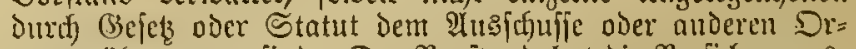
ganen ïbertragen find. Der $\mathfrak{B}$ oritand hat Die Berficherung: anjtalt geridjetidf und aufergerifjtlidf) $z^{u}$ vertretent. Dic Vertretung eritredt fidf ande auf diejentigen (sejchäjte mo

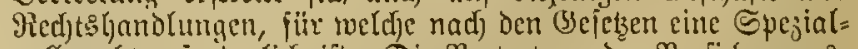
volfmadyt erjorderlidy ift. Die Bertretung Der Berfidyerming: anjtalt gegenüber Dem $\mathfrak{B o r j t a n d e ~ m i r b ~ D u r d ) " d a s ~ S t a t u t ~}$ geregelt.

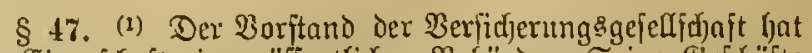

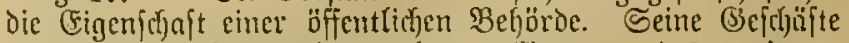
merben bon einem ober melyreren Beamten bes tociteren 
Rommunalberbandes oder Bundesftaates, fïr meldjel die Berficherungsanftalt errid)tet ift, wahigenommen ......

(2) Durdy bas Statut fann bejtimntt werden, daj bem Boritande neben den borgenannten Beamten nodj andere Perjonet angehören follen. Diejelben tönnen nach) $\mathfrak{B e}=$ itimmung des Statuts bejoldet oder unbejoldet jein....

(3) ......

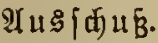

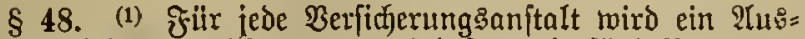
jaduß gebildet, weldjer aus mindeftens je füni Bertretern Der ?trbeitgeber und der Verfiderten befteht. Die Ball ber Bertreter wiro bis zur (Senefmigung Des Statuts ourd) die Randeşzentralbehörde, ipäter burfi das Statut bejtimmt. Die Inzaht der Bertreter der $\mathfrak{A r b e i t g e b e r ~ u n d ~ d e r ~} \mathfrak{B e r}=$ ficjerten mus gleid) fein.

(2) Diefe פ̉ertreter merden von ben Boritänden der im Bezirf der Berfitherungsanitalt borhandenen Drts=Betriebs:

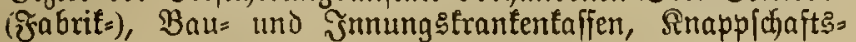
taffen, Secmannstajien ...... geroühit .....

$\S 49$. (1) .....

(2) Filr jeden Bertreter find cin erfter und żweiter Erfaţ= mann zu mählen, meldhe Denfelben in BeGinderungşällen

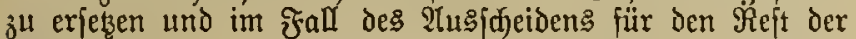
Bahlperiode in ber Reihenfolge ifyer $\mathfrak{B a h l}$ cinzutieten haben.

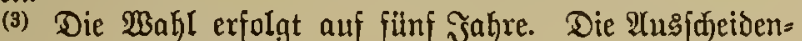
den find roieder wählbar.

(4)

\section{Weitere Drgane.}

§51. (1) Durd Das Statut farn die Bildung eines

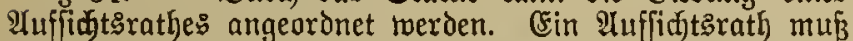
gefildet werden, menn nach dem Statut dem Boritande Bertreter Der 2trbeitgeber und Berfidjerten nidjt angehören.

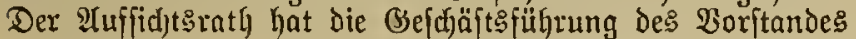
zu ïberwadyen und die ifm duref bas Statut auferdem übertragenen Dbliegenheiten zu erfülden.

(2) .......

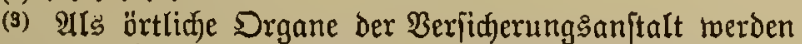
Bertrauensmänner aus dem Rreife der Probeitgeber und der Berfidjerten beitellt.

(4) Die Ditglieder des Auffict tşrathes und die $\mathfrak{B e r}=$

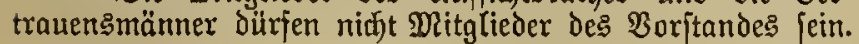

Statut.

§ 54. (1) Für jede Berfifferungsిanitalt ift ein Statttt

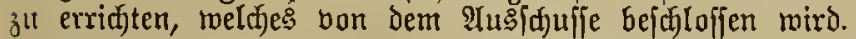

\$6. (1) Das Statut bedarf zu feiner Bsiltigfeit ber

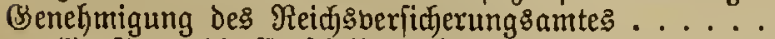

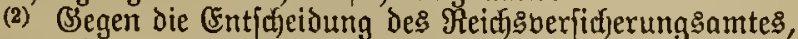
Dur(f) meldhe bie Benehmigung berfagt wiro, findet bimen einer Jrift bon bier $\mathfrak{W}_{\text {odjen }}$ yom Tage der Buftellung an detl Borjtand ab, die Befdumerde an den Bundesirath jtatt.

(3) (4) (5) $\ldots \ldots$

\section{Staatstommifiar.}

§63. (1) Für Den Bejirf ciner jeden BerfidjerungsanftaIt wiro zur $\mathfrak{B a h r u n g}$ bcr Эntereffen ber itbrigen $\mathfrak{B}$ erficherungss anftalten und des $\Re$ eichs von der Randestegierung im

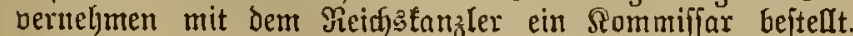
Derfelbe ift insbefondere befugt, allen Berbandlungen der
Drgane der Berfifjerungsanftalt mit berathender Stimme und den $\mathfrak{B}$ erhandlungen bor den Sdjiedsgerid)ten beizutwohnen,

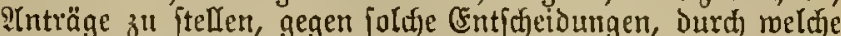
Die Crrmerbsunfäfigteit anerfannt oder eine Rente feftgelest wiro (\$§ 75 uno 77), die zuläffigen Red)tsmittel eirrzulegen

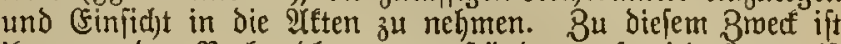

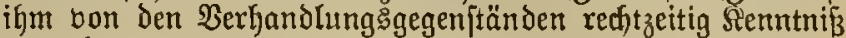
zu geben.

(2) Dic Thätigfeit des Rommiffars erftrefft fid) aud auf biejenigen nad) §§ 5 uno 7 zugelafienen Raffeneintidftungen, weldbe im $B$ ezirfe bes Sommififars ihren Sit haben.

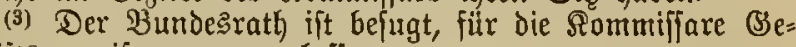
fáäjt:anmeifungen zu ertafjen.

\section{Sufiedsgeridite.}

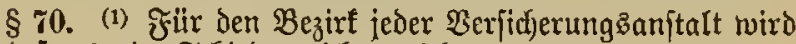
mindeftens ein Sdjiedsgeridfit erridjtet.

(2) .....

§ 71. (1) Эedes Shitedsgeridjt beiteht aus 1 ftändigen Borjikenden und aus Beifikern. Die Bahl der Beifiker muß mindeftens je 2 betragen.

(2) Der Borfitiende wird aus der Bahl der öffentlicten Beamten bon der Zentralbehärde Des Bundeşitaates, it weldhem der Sitz des Shiedsgeridht Jür den Sorfitzenden ift in gletder $\mathfrak{B e i f e}$ ein Stellbertreter zu ernennen, weldjer ifn in Behinderungsfällen vertritt.

(3) (4) .....

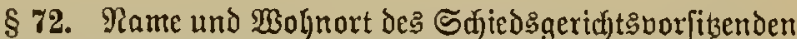
und jeines Stellvertieters, folwie der $\mathfrak{B e i f i z e r}$ find bon der Randes = Bentralbehörde in dem ju deren antlidjen $\mathfrak{B e r}$, B̈ffentlidjungen beftimmten Blatte befannt zu marjen.

\$73. (1) Der Borjitzende und deffen Stelluertreter, forwie bie Beifizer find auf die gewifjentafte Erfülung der Dbriegenfyeiten thres 2 mts ciotici) zu berpflidjten.

(2) .......

(3) Wjerionen, weldje die Wahl ohne zuläffigen (Srumb

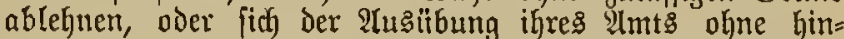
reid)ende (Entidutidigung ent 3 iehen, werden bom Borfizenden mit Seldftrafe bis zu 500 Mart belegt.

(4) Rommt eine $\mathfrak{B a h l}$ nidft zu Stande oder bermeinern die Berrählten ilire Dienftleiftung, fo hat, folange uno fo= tweit dies der fall ift, die untere $\mathfrak{B}$ erwaltunģbehörde, in deren Bezirt Der Sitz Des Shjiedsgeridts belegen ift, die

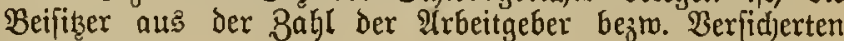
zu ernenmen.

§ 74. (1) Der Borfţ̧ende beruft das Sfjiedsgertat und leitet die Yerhandlungen defjelben. . . . . .

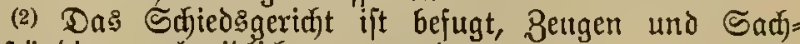
beritändige, auch eidlid, zu bernehmen.

(3) Das Sdjiedsgeridyt entidjeibet in der Bejebung von 3 Mitgliedern, unter denen (id) 1 Itrbeitgeber und 1 Ver = ficjerter befinden mus.

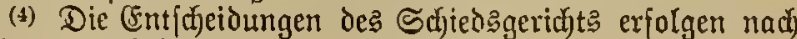
Stimmentmebreit.

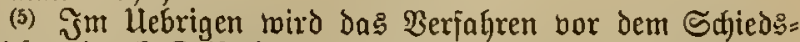
geridjte durd) Raiferlidje Berordnm mit Buftimmung des Bundeeraths geregelt. 


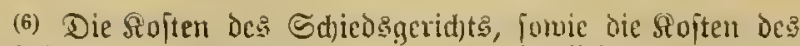
Derfahrens bor Denjelben trägt Dic Berfitherungsanitalt. Das Sedjedsgerid)t ijt jedod, hejugt, Den Betheiligten foldhe Roften des Berfahrens zur Qaft zu legen, weldje Durd) un= Gegrïndete Betweisanträge derfelben veranlab̧t wotoen find.

(7) Dem Vorjitsenden Des Erficdsagerid)t und Deffen Stell= bertreter darf einc Bergïtung bon ber Berfid)erungsanftalt nid)t gewäbrt werden.

\section{IV. כ̋erfafiren.}

\section{Jeftitelung der rente.}

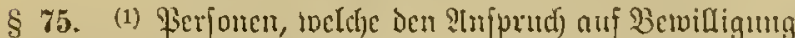

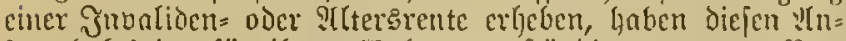

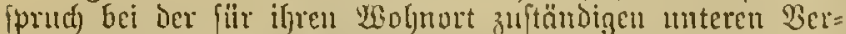
valtungsbeljöric arjunelden. Der 2mmetoung find Die Duitungsfarte forvie die jonftigen zur 3 egrïmoung des

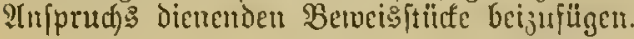

(2) .

(3) Wiro Der angemelocte 2 (nfprud anerfamt, fo ift bie 5öhe Der Rente fofort feitiultellen. Dcm Empfang beredjtigten ift jobatm ein (d)riftlid)er Befdeio zu ertheilen, ans tweldiem dic 2 ret Der Bered)mung der Piente zu erichen

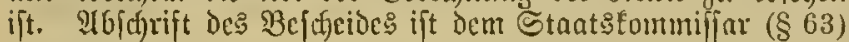
з山zนftellen.

(4) WBird Der angemeldete Infpruch nich)t ancrfannt, fo

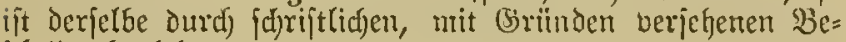
ficscio abjulelynen.

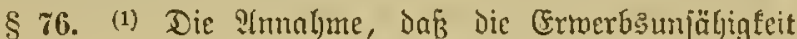
Durd) einen nad) den llnjalfberfidjerungesgejeçen ju ent=

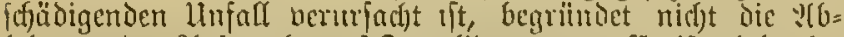

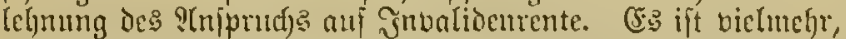

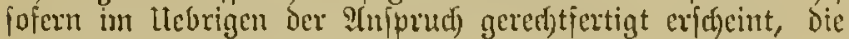
Jubaribenrente jeftujutellen.

(2)

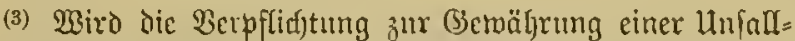
entfdjädigung beftritten, fo ijt oaritber in Dem durch) $\$ \$ 62$

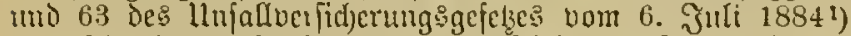

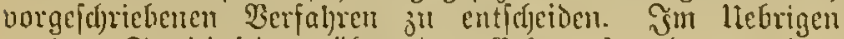
werden Streitigfeiten tiber den Erjatzanimrud) bon bem orbeik(id)en $\Re$ idjer entidjieden.

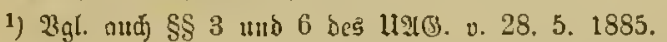

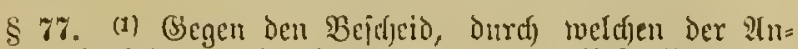

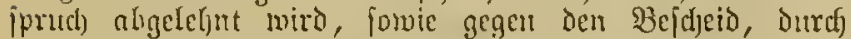

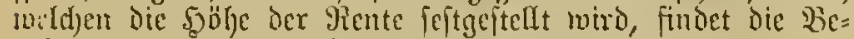

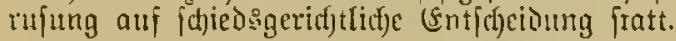

(2) Der Bejdjeid muß́B dic Bejeidjnung Der Berujunģ: frift und des fïr dic Berufung Jutändigen Sdjiedsgerithts, fowic Yamen und Woljurt des Sorfikenden des lebterent embalter. Dic Berufung ift bei Germeidung de: "lus= (d) (uifes bimmen 4 worhen nad) Der Buftelung Des $B e=$

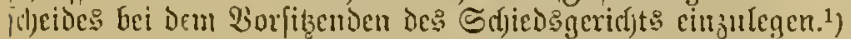

(3) Die Berufung hat feine aufidjebende Wirtumg. ${ }^{2}$ )

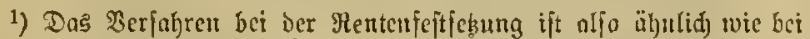

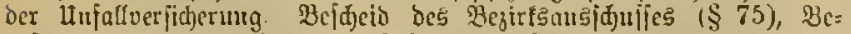

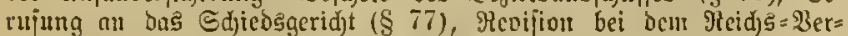
fiderungsont $(\$ 79)$. Die Revifiont ift jebod in \&ugenteiten un

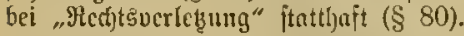

2) Sandelt ę fid) unt (5rftatuug vou Beiträgen gemäß $\$ \$ 30$ usto 31, io Gnben bie Red)tsmittel (פerufung utt Mevifton) auf= fifiebende Birfung ( $(95)$.
§ 78. Cine Yusfertigung Der Fntflucioung des Schieds: geriffts ift Dem Berujender und Dem Borjtande Der Ber=

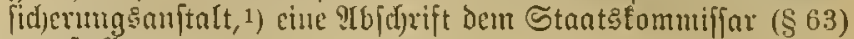
$j$ แjuाteflen.

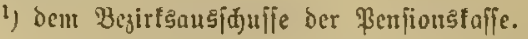

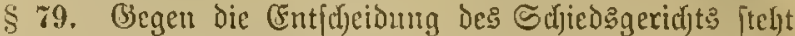

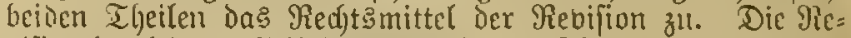

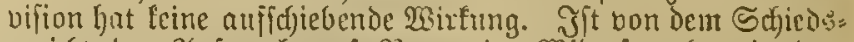

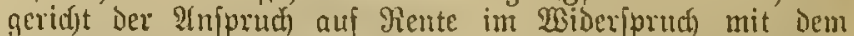
Borftambe der Berfidjecungsan[talt ${ }^{1}$ ) anerfannt und nidjt

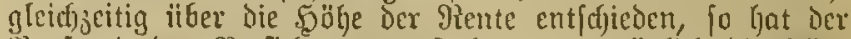

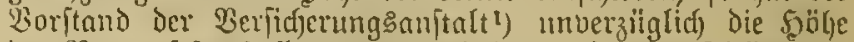

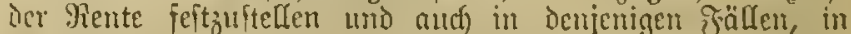
weId)en bas Mied)temittel ber Revifion eingelegt twird, fofort

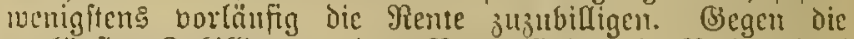
vorläufige Bubilligung einer Rente findet ein Rechtsmittel tiid)t itntt.

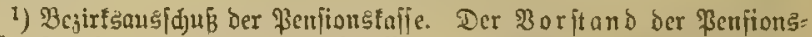

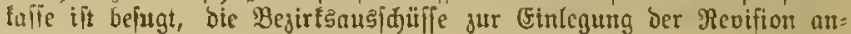
zuncijes.

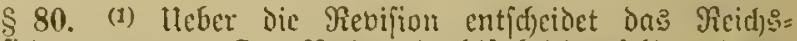
Brrfiderungsant. Das Red)tsmittel ift bei Demfelben himmen 4 wodjen nadi ber Buftellung der (5ntfdjeidung Des Sdjicds. gerilif)t: einjuleges.

(2) Die Revifion fann nur barauf geftübst merden:

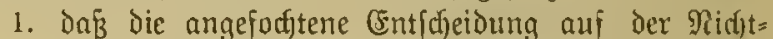
anmendung oder auf Der unridftigen ?Tmendung

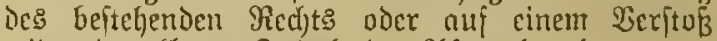
wider Den Elaren Snljalt Der :Iften beruhe;

2. Dấ Dą̉ Berfaljren an wejentlidjen Mängeln leìe.

Die Bejtumungen über bic Stevifionsgrünbe beden fid) übrigen

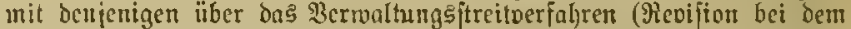

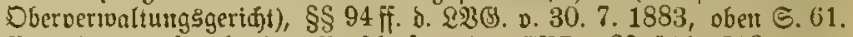
3on ben entipredenten \$orjdriften ber $5 \$ D$. ( $\$ \$ 511,513$, ober ङ. 179) weidjen fie bagegen ab.

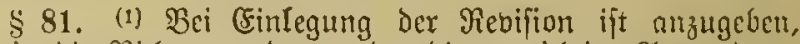

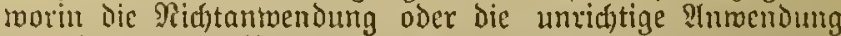

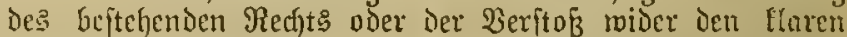
Jnljalt Der Iffen oder morin bie Gel)anteten Drängel bes

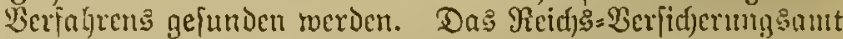
ijt bei feiner (Entfdjeidung an biejenigen (Brünbe nidjt ge=

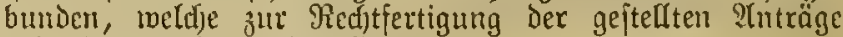
geltend gemacht roorden find.

(2) Fichlt Die Ingुabe foldjer (bründe oder ergiebt fitf

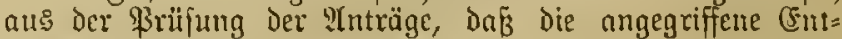
idfeidung nidit auf Der Niditanvenoung voer untidftigen

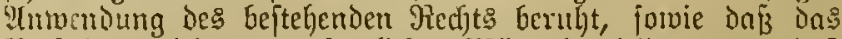
Berfabren nicht an bejentlidfen Mäugeln leidet, mo Daß̉

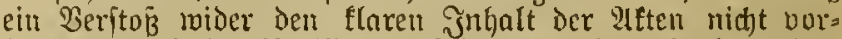
liegt, oder ift bie Revifion beriphitet eingelegt, fo fum inß

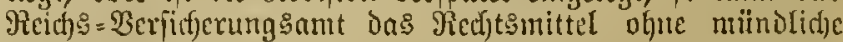

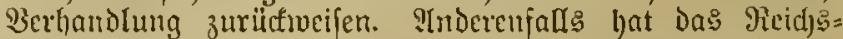

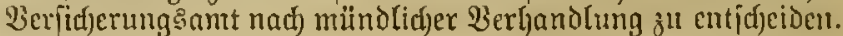
WBiti Das angefochtene Urtheil auigeboben, fo fam ins Jietds:-2erfidjerungsant zugleid) in der Sache felbit ent= idjeiden pier biecelbe an Das Sofjiedsgeridjt oder an den

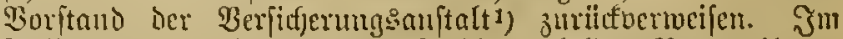
Fafte Der Buriudnerweijung ift Die red)tlidfe Beurtljeilung,

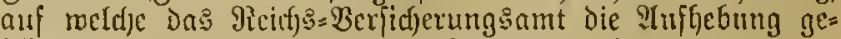
ftitizt ljat, der Entidjeidung zu (Brunbe zu legen.

1) ber Penfionstafje. 


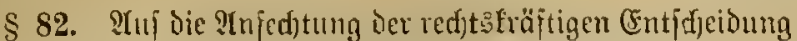

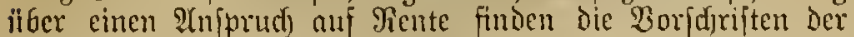

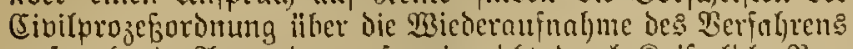

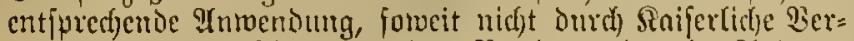

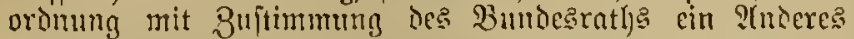
bejtimmit wiro.

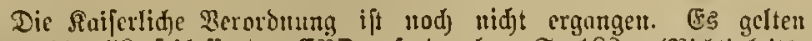

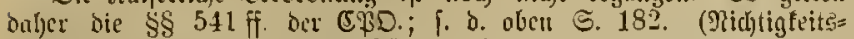
flage, Mefitutionstlange.) Buftärbig ift algemein biçcutge Etelle, berent chntideiourg angefochten wiro.

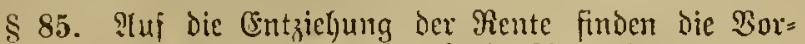
ic)riften ber ş 75 bis 84 entfprefjende ?(nnendung.

Bgl. $\$ 33$. - Der Borftand ber Penfionatafie ift bejugt, die

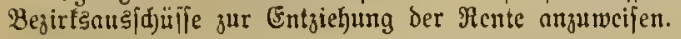

\section{Berect) tigung: a}

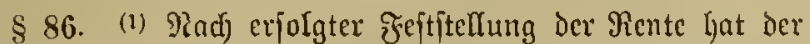
Boritano ier Berfidjerungsanjtalt dem Beredjtigten eine

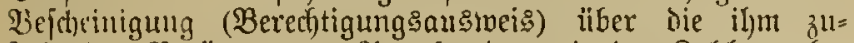

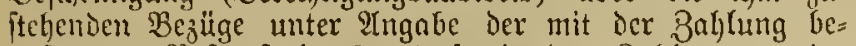
auffragten \$ojtanftalt $(\$ 91)$ jomic oer 3ahlungstermine

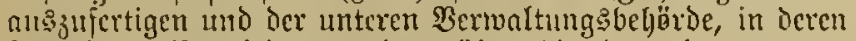

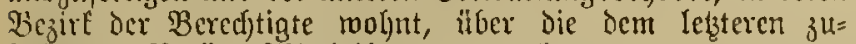

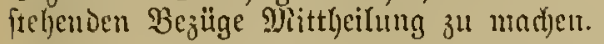

(2) Wird in Folge des weiteren $\mathfrak{B e r j a l j r e n s ~ d e x ~ B e t r a g ~}$

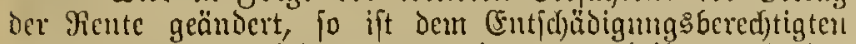
ein anderer Bered)tigungsausmeis zu ertheilen und ber unteren Dermaltungsheförde peines Wolnortes von ber Ilenderung Sienntnifi ju geben.

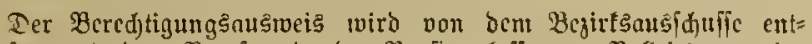

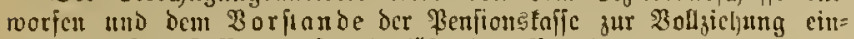
gejandt. Der Raffenvorftand läßt ben Berchtigunģansucis und

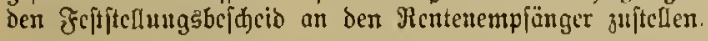

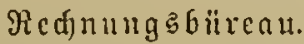

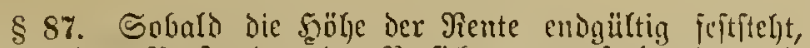
ift bon bem Borfinnic ${ }^{2}$ ) Der Berjicherung:anftalt eine mit

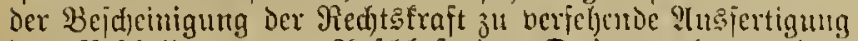

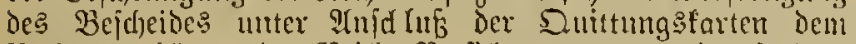

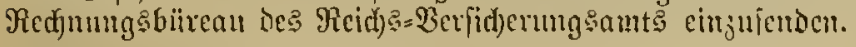

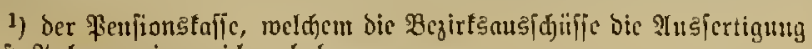
nebft İnlagen cingurcid)en haben.

§ 88. Das Red)mungsbüreau hat alle bei Dem Reid): Berfid)ernugsamt nad) Maggafe isejes (Bejebes norfommenden

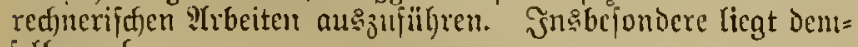
jelben of:

1. Die $\mathfrak{B e r t b e i l u n g ~ D e r ~ \Re e n t e n ; ~}$

2. dic Mitroirfung bei den im Bollinge des Gejełes berzuftellenden ftotiftifichen Irbeitert.

§ 89. Daร Recf)nungshüreau vertheilt bic Renten auf

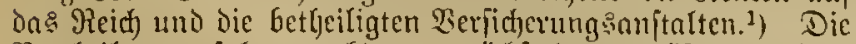
Bertheilunn erjolgt, nad)nem zunäd)ft der gemäß \& 26 Dem

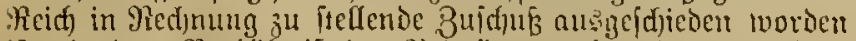

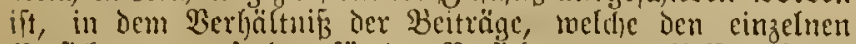
Berfid)erung sanjtalten für ben Berfidjerten jugefloffen, bezı.

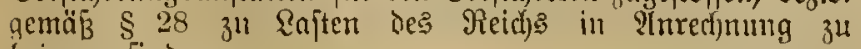
bringen fint.

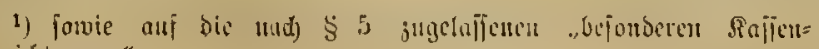
eimridfungen".
§ 90. (1) Die Bertheilumg iff ben Borftänden der be=

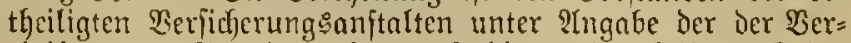
theilung ju Grunde gelegten $3 a$ j)len mitjutheilen. F̌eder hetheiligte Boritand ift befugt, binnen 14 Tagen nad) Der Buftellung gegen dic Bertheilung (Finjprudy zul erbeben.

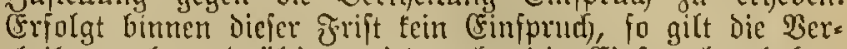
theilumg als endgülttig; wiro red)tzeitig (Einjprud) erhoben, to enticheidet ïber denjelfen nad) 2(nljörumg Der $\mathfrak{B}$ orfitände

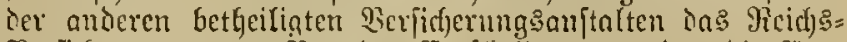
Berfidjerungsamt. Şon ber Entfdecioung werden die Sor= ftänte in Sienntnis gejetst.

(2) Sobalo die auj Die betheiligten Berfidjeruntgsnnjtalten

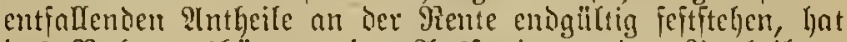

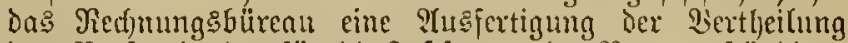
Dem Borftande der für die Feftfeţung Der Rente zuftändigen Berfidjerungsanftalt zu ïberjenden.

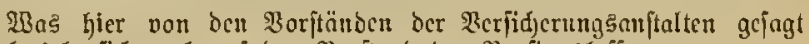
ijt, bezicht fidj aud auf ben \$orftand ber \$enfionstafie.

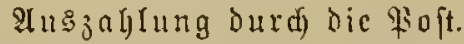

\$ 91. (1) Dic 2luzzalylung der Renten wird auf $2(n=$

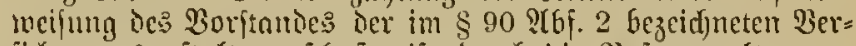

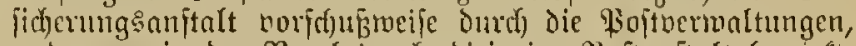

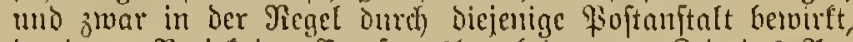
in Deren $\mathfrak{B e z i r f}$ der Cmpfangaberentigte zur Zeit bes ?tn= trags auf Bewilligung oer Yente feinen Wobntits loatte.

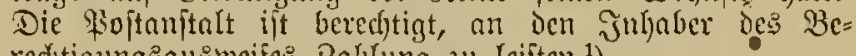
red)tigungennsismeifes 3aljlung ju Icijten. ${ }^{1}$ )

(2) Berlegt der Empfangsberedfigte feinen $\mathfrak{W o f n i t}$, fo

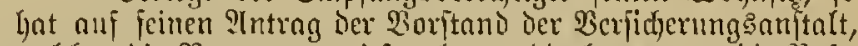
weld)er die Rente antgervicien hatte, dic Yebtere an Die Projt=

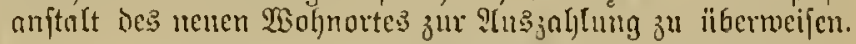

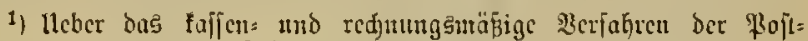

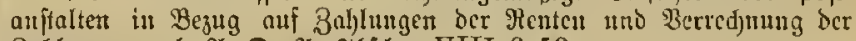

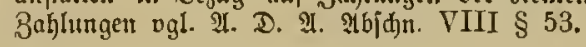

\section{Exftattung ocr Borfditffe ber Boftuertonltungen.}

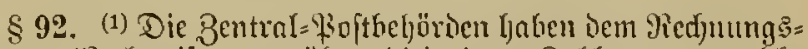
bïreau Sind)weifungen liber dicjenigen Ballumgen, veldje auf Grund der Mnmetjungen Der Verfidjerungsanftalten ge=

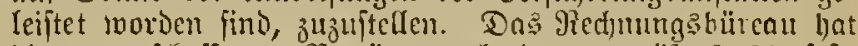

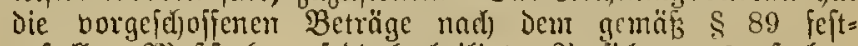

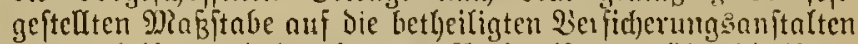

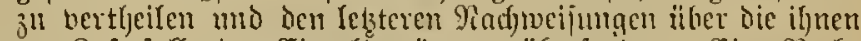
jur \&aft fallenden (Einzelbeträge zu ïberienden. (Fine Rad)= weifung üfer die deut Fieid) zแt Enit follenten Beträge ift

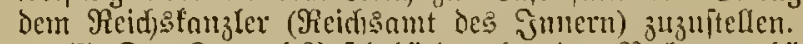

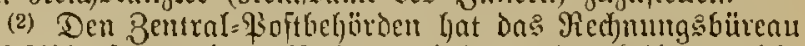

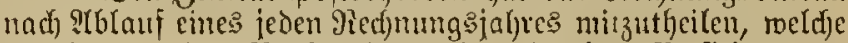

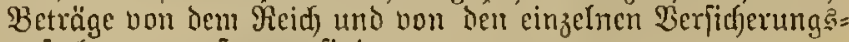
anftalten zu eritatten find.

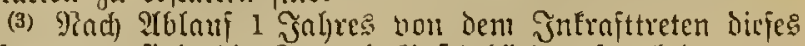
(Bejesces an find die Bentral = Poftbehörtien bered)tigt, von jeder Berfidjerunģanjtalt einen Betriebs fonds cinjuziefjen.

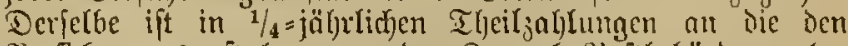
Derfifferungsomitalten non der Bentral= fiofthebörde ju be= zeidnenten Sajfen ahzufïfyen nut Darf Die für bie

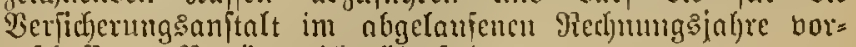
gefđoffenen Beträge nicht ïberfteigen.

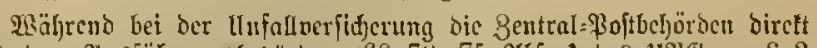

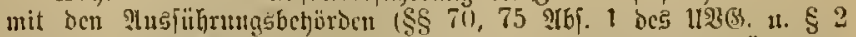

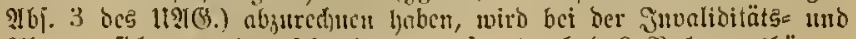

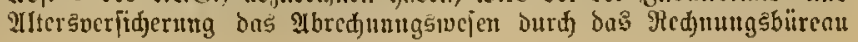




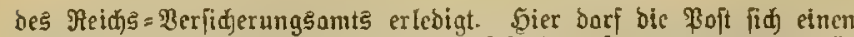
Detriebsfonds (I6j. 3) cinzichen, bort muß fie bie erforberlidjen (Selber fïr

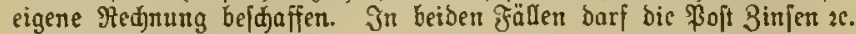
nidt beredyer.

\$ 93. (1) Die Berfidjerungsanitalten haben bie von den \$ojtberwaltungen borgeidfoffenen Beträge binnen 2 Wodjen

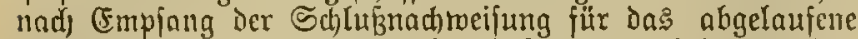
Recfnung:jahr zu erjtatten. Die Erftattung erjolgt aus ben bereiten S?itteln ber Unitalt. Sind folche nicht vorbanden und bietet aud Der Rejerbefonds foldje nidjt Dar, fo hat Der weitere Sommunalberband bezto. Der Bundes/taat bie $\mathfrak{e r}=$ forberlidjen Beträge vorzuldjießsen.

(2) (segen Berifherungsanjtalten, weldhe mit der (Ex= itattung Der Beträge im Pitufftande bleiben, ift auf Antrag

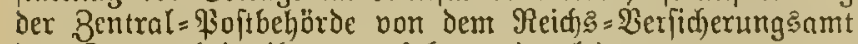
das Bmangsheitreibungsuerfahren einzuleiten.

§ 94. (1) Die $\mathfrak{B e j t i m m u n g e n ~ d e r ~} \S \S 79$ bis 82,86 bis 93 finden auf die nadj $\S \S 5$ und 7 jugelnifenen siafien= einrid)tungen entipredjende unmendung. Den lelzteren ift

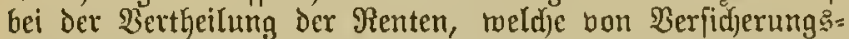
amftalten feitgejtellt find, Die gleidje Summe bon Beiträgen

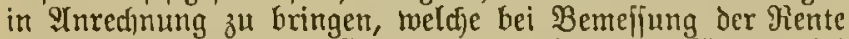
für dic Dauer der Berjidjerung des Rentenempfängers bei einer Salfencinridjtung nad) $\S 27$ in ?(nred)nung gebrad)t ift. Die Vertheilung von Renten, weldje bon ciner Sajien= cinrichtung fejtgeftellt jino, erfolgt, fomeit ein ?(njpruch auf

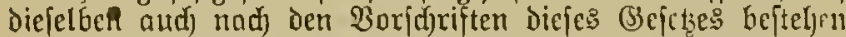

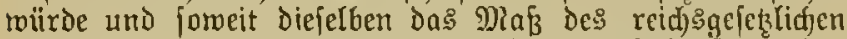

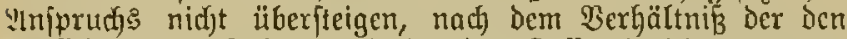
Verfidjermugsanftalten und Der Den Sajieneintidjtungen zu= gęloffenen B̉eiträge, leţterer, jorweit fie jür bic Berwährung

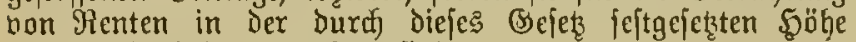
jür exforberlich zu eractiten jind.

(2) Someit dieje Saffeneinridjtungen die von ifnen feft= gejetzten Renten ohne $\mathfrak{B}$ ermittelung Der \$3oftanitalten felbit

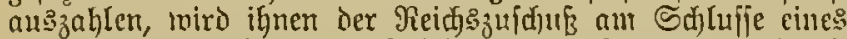
jeden Redfumgsjahres auj jedesmalige Riquidation birett itbermiefen. Die Berficherungsanftalten, all melefje Theile der bon folden Sajieneinridjtungen gezahlten Renten ent= fallen, lyaben bieje Intbeile nach beren Jeftftellung durd

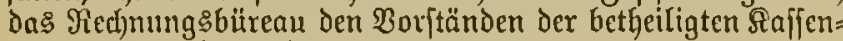
einrid)tungen jägr(id) zu erjtatten.

\section{CErftattung bon Beiträgen.}

$\S 95$. (1) Der 2 (nfprud) auf (Exitattung von Beiträgen (\$§ 30 uni 31) ift unter Beibringung der zur Begründung

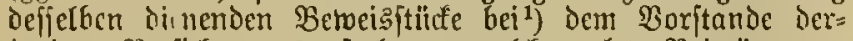
jenigen Berficjerungsanftalt, an weldje zuleşt Beiträge ent= rid)tet wordu find, geltend zu maden.

(2) ? ?11 Das Berfalyren finden die Borjuriften Der $\$ \$ 75$

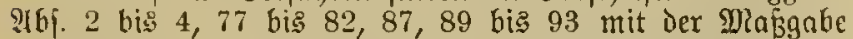

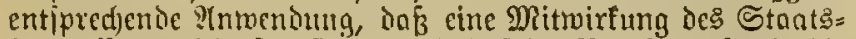
fommiffars nidjt frattfindet und daf bie BBerufung jomie die Rebifion auffobicbende Wirfung haben.

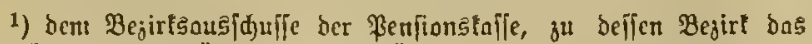
Mitglieo julę̧i gehört hat ober gehört.

\section{Şöhe Der Beiträge.}

§ 96. Siit Die erifte Beitragaperiobe $(\$ 20)$ fino in

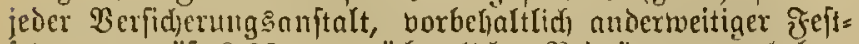
feşung gemäß $\$ 98$, an wobd)entlid)en Beitrïgen zu erlyeben:

in Qohntlaffe I 14 Pfennig,
$"$ "

\$ 97. (1) Fiir die ferneren Beitragsperioden hat der

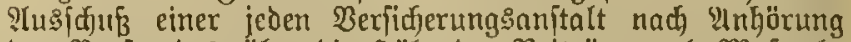

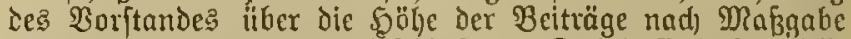

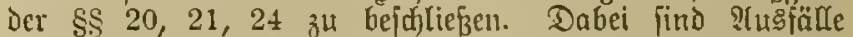

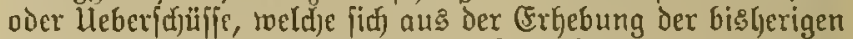
Beiträge red)uungsెmäfig hercusిgejtelft haben, in der Weife

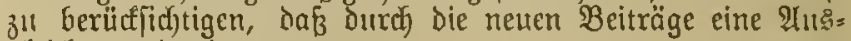
gleicjung eintritt.

(2) Der Befd)luß̧ bedarf Der Benehmigung Des Reidjs: Berfidjerungsamts. Э̧t die Beitragsperiode bis auf einen

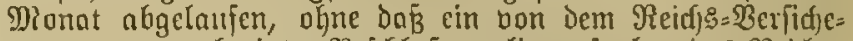

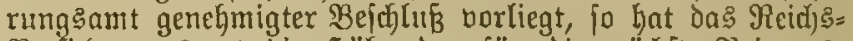
Berfirderungsamt bie 50 öhe der für die näd)fte Beitrags:= periode zu erbebenden Beiträge fïr alfe in der $\mathfrak{B e r f i d j e r u n g s ? ~}$

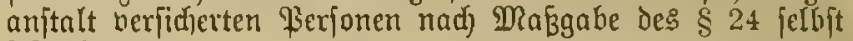
feit żufetzen.

(3) Die Syöhe Der Beiträge, fomic Der Beitpunft, bon ineldjem $a b$ biefelben erfjoben merben follen, ift durch dic, jenigen Blätter, Dutd) meld)e die Befanntmaduungen ber \$erfidjerungsanftalt zu erfolgen haben, z" beröffentlidjen. Die Befanntmadjung muf minbejtens 2 23odjen bor bem= jenigen Beitpunfte erfolgt fein, von melchem ab der Beitrag in ber feftgeftellten Sëbe erhoben rerden foll.

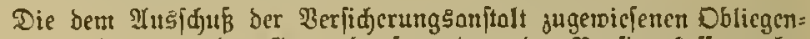

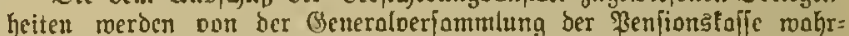
genommen. Die Benebmigung wirb burd ben Minifter ber öffeniliden Atrbeiten ertheilt. Beröffertlituangen erfolgen im Eifenbagnveroronungs: blntt und in bett Direftions=2Imtsblättern.

§ 98. Die $\mathfrak{B e r f i d ) e r u n g s m n j t a l t ~ i f t ~ b e r e d i t i g t , ~ f d o n ~ f u ̈ r ~}$ Die erfte Beitragsperioie oder innerhalb derfelben an Stelle ber im $\$ 96$ feitgelebten Beträge für ifren $\mathfrak{B}$ ezirf andere Bcitragşözze unter $\mathfrak{B}$ eaditung der $\mathfrak{B e f t i m m u n g e n ~ d e r ~} \S \S 20$,

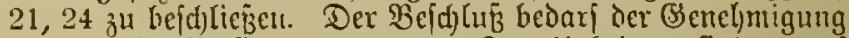

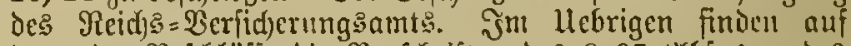

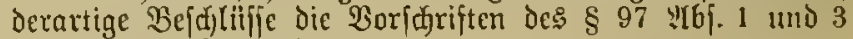
entiprechende ?trmendung.

BgI. \$ูกm. zu $§ 97$.

\section{Darfen.}

§ 99. (1) Buแ Bıeđt ber Erbcbung ber Beiträge werben Don jeber Berfichcrungsanitalt für bic cinzelnen in ifrem Begirle dor=

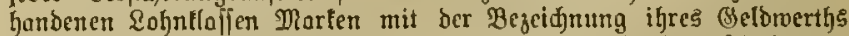

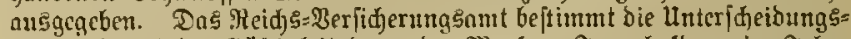

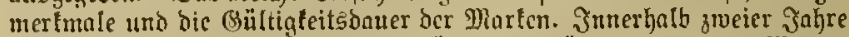

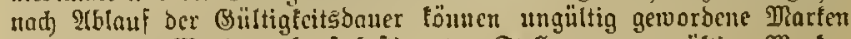
bei bea zum Marfendertauf beftimmten Etellen gegen gültige Marten unugetaujabt merben.

(2) Die Mlarten ciner Berfidjerungsanftaft fönnen bei allen in

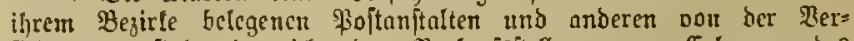

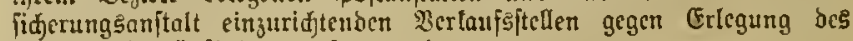
Nennoerths fäuffidj ermorben merben.

\section{Entridtung Der Beiträge.}

§ 100. (1) Die Beiträge Des fitferten find bon Demienigen 2 rbeitgeber zu entrichten, weldjer Den Verfidjerten wäbrend der Salendertwodje beidjäftigt hat.1)

(2) Findet die Brfddäftigung uid,t wägrend der gauzen Salemoerwodle bei iemiclben illbeitgeber ftatt, fo ift oon 
demjenigen Irbeitgeber, meldher den Werfidjerten zuerft be= ichäftigt, dex volfe Modjenteitrag z" entridfen.

(3) ......

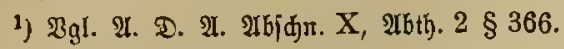

\section{Duttungstarte.}

§ 101. (3) Dic (Entrid)tung Der Beiträge exfolgt durt) (5intlehen eines entipred)enden $\mathfrak{B e t r a g e}$ von Marfen in dic Duitfungstarte des $\mathfrak{B e r f i f f e r t e n . ~ S i t ~ d e r ~} \mathfrak{B e r f i d f e r t e}$ mit ciner Duittungsfarte nidft berfeben, fo ift ber ?Irbeitgeber berectigt, für Rechnung des $\mathfrak{B e r f i d j e r t e n ~ e i n e ~ f o l c h e ~ a n = ~}$ zu[d]affen und ben berauslagten Betrag bei ber näcfiten Pohnjallung einzuhehalten.

(2) Die Suttungstarte enthält Das $̧ a h x$ und den Tag ihrer ?tusgahe, dic üter Den (sebrauch der Duiffungstarte erlaffenen Beftimmungen (\$ 108) und die Strafooridyrijt des \& 151. Jm llebrigen beftimmt der Bundegrath ifre (simridytung.

(3) Die Sopten Der Quittungstarte trägt, forweit fie nied)t

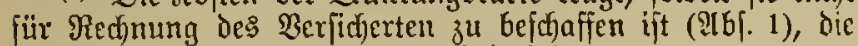
Berfichermiggnftalt des :Itisgabebezirts.

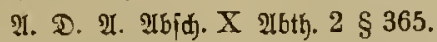

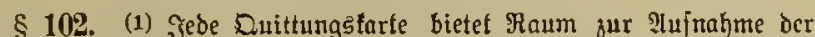
TRarten jür 47 Beitragsmoden. Die Sarten find jür jeben $\mathfrak{B} e r=$

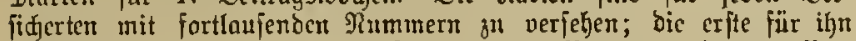

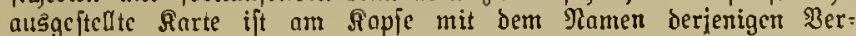
fiderumggarifalt, in deren Bezirt Der Berfidjerte zu biefer 3eit be= id)äftigt ift, jeoe folgende mit Dem গamen berjentigen Berfiderungss anftalt, welde fin auf ber nädjituorhergehentoen Siarte vermertt finbet,

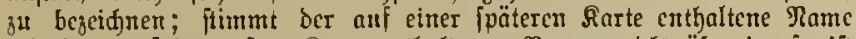

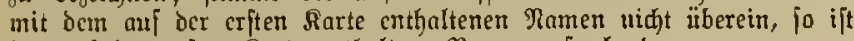

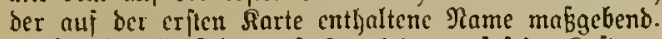

(2) Der Rerfiderte ift berchtigt, auf feine Roiten ju jebcr Bcit bic

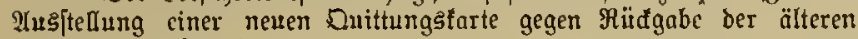
Rarte zu beanjpruden.

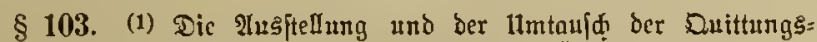

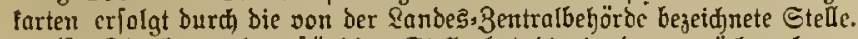

(2) Tie hiernad zuftändige Etelle bat die in ber zurïđgegebenen Sarte eingetlebten Marfen Derort aufauredinen, dás erfidtlich mird, wieviel Beitragsmoden fïr bic cimzelnen \&ohntlafien dem Inthaber der Duittungs?arte anzuredmen finb. Bleidzeitig ift bic Dauter ber $b c=$ ideinigten Sranthetten forvie der miliffärifden Dienfitleiftungen an=

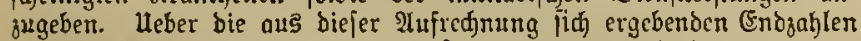
ift bem Inthaber ber Farte eine Be[deinigung ou ertheilest.

\$ 104. (Fine Duittungglarte verliert if)re Bültigfeit,

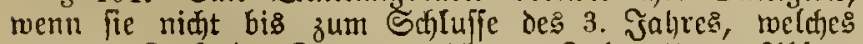
dem am Sopfe Der Sarte berzeidneten Jaljre (\$ 101 Thf. 2) folgt, jum umtaufde eingereidft tooroen ift. Jit die $\mathfrak{A} \mathfrak{n}=$

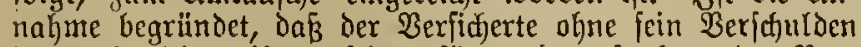

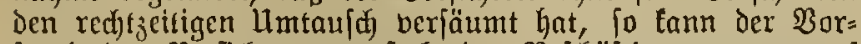
ftand Der Berficherungsamptalt des Bejádäftigung sortes auf den Antrag des Berfingerten die fortdauernde (Bültigteit der Quittungstarte anerkennen.

$\S 105$. Werlorene, unbraudbar gemorbene ober zerförte Quittungs: tarten find burd neue zu ericber. In bie neue Quittumgsforte fino

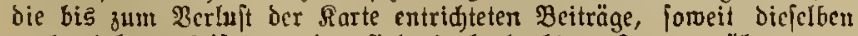
nndmeisbar geleiftet morden find, in beglaubigter form gu übertragen.

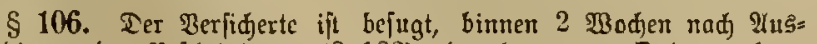
händigung der Befđeinigung ( $(103)$ aber ber neuen Quittungstarte

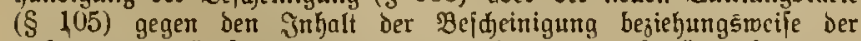
llebertragumg (Einipruc) gn erheben. Gegen Die 3uriiđweilung bes

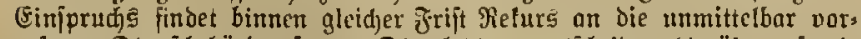
gcieble Diculibehörbe ftatt. Die leğtere entfóneidet gierïber, forwie

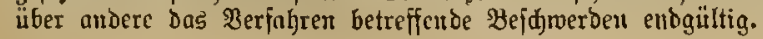

$\S 107$. (1) Die abgegebenen Duittungstarten find an bic Bcr= fidcrumģanjtalt bes Bejirfs ju überjenden und von dicjer an bic= jenige $\mathfrak{B e r f i c h e r u n g s a n f t a l t , ~ D e r e n ~ N a m e r ~ f i c ~ t r a g e u , ~ z u ~ ̈ ̈ b e r w e i f e r . ~}$

(2) Der Bundeşrath hat bie Barassjekungen zu bejtimnen, unter benen bie Rernidtung von Duittungsłarten ju erfalgen hat.

$\S$ 108. (1) Die Eintragung eincs Utrtheils über bie Fithrung obcr

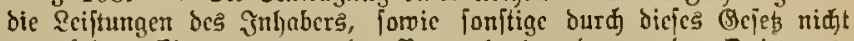
vorgcjehene Eintragungen oder Bermerfe in ober an ber Duitungs= farte find unzuläifig. Duittungs?arten, in welden derartigc Ein= tragungen ober Bermerle fith vorfinden, firto von jeber Bebörbe, welder fic zugchen, cingubehalten. Dic \$3chärbe hat die Erickung

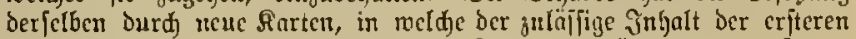

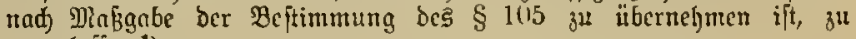
veramlafien. ${ }^{1}$ )

(2) Denm Hrbeifgeber jomie Dritten ift unterjagt, bie Duittungšs

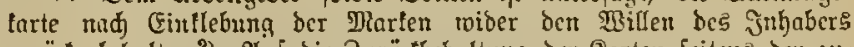
zurü̈đubehalten. ${ }^{2}$ ) Ilıf hic Burüđbchaltung Der farten feitens ber zu=

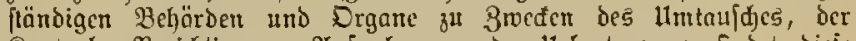
Sontrale, Beridftigum, 2ujređuung ober \lebertragung findet bicjc gejtimuntrg feine 21 ntwenbung.

(3) Suiftung zurüđbehalten vocrben, finto burd die Drtspoli

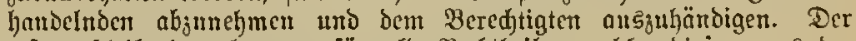
crftere bleift bent lebteren für alle Fadtheile, welde biejen aus ber 3uviocrbandlung ermadjen, perantmortlid.

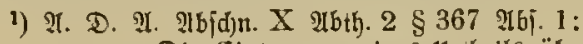

Dic Eintragung cinces 11rtheils über die fö̈hrmtg obcr Die Eciftungen bes inhabers, fowie fonftige ourd) bas

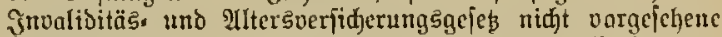
Eintragunger ober 3 ermerle in ober an ber Dnittungs= tarte fino umbuläjfig."

Bgl. aud $\$ 151$ biejes Gejefres.

2) 2 เb. 2 bes in $\mathfrak{A n m} .1$ angezagenen $§$ ber $\mathfrak{A}$. D. $\mathfrak{A}$ :

"Die Quittungstarten find bei ber lohnzablenden Stelle

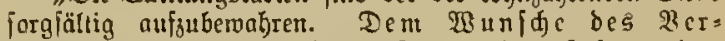
fiderten, bie histerlegte farte einzufehen oder zurüdzuergalten, ift jebergeit zu entipreden."

Bgl. aud $\S 148$ biejes Bejetęes.

$\S 109$. (1) Jn die Dutittungstarte hat der ?lrbeit= geber bei der Rohnzahlung zu dem nach $\$ 100$ zu Geredfnen= den Betrage Marfen Derjenigen ?trt einjufleten, weldye jür

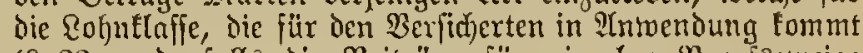
$(\S 22)$ und, falls die Beiträgc jür cinzelne Berufzzmeige veriffieden bemefien find (\$ 24) für den betreffenien Berufä: zweig, bon der für den Bejujäftigumgsort zuftändigen $\mathfrak{B} e r=$ ficherungennftalt ausgegeben itt. Die Plarfen hat der Prbeitgeber aus eigenen Mitteln zu erwerben. ${ }^{1}$ )

(2) Die Mlarten müfjen auf oie Quittungstarte in fort=

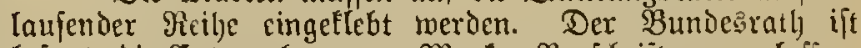
befugt, die Entwerthung von Marfen $\mathfrak{B}$ orjdriften zu erlafjen, und deren Ridftbefolgung mit Strafe zu bedrohen. ${ }^{2}$ )

(3) Die Irbeitgeher find berechtigt, bei der Solnzahlung den von ihnen bejäjftigten Perjonen bie Sälfte Der Beiträge

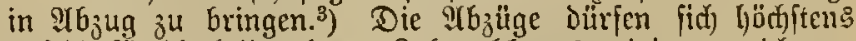
auf die für die Geiden leţten \&uhnzahlungapperioden entridteten Beiträge exftredten.

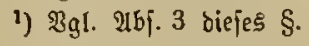

2) IUf (brumb biejer Bejtimmung hat ber Bumbestuth in ber Sigung 0. 27. 11. 1890 jolgende Borjdrifter erlafien:

1. Sojern aul Brund ber $\S \S 112$ ober 114 bie Einziehung ber $\mathfrak{B}$ citräge Durd Drganc von Sramtentaffecu, burd Bc= meintebchorben ober burch andere von der 2andes=(Central= behärbe bezeidnete nocr vont ber serfidjernuggamifalt cin= gerififtete Stellen (bebejtellen) exfolgt, taum die Ranbese Eentralbebörde anoronen, baf von der bic Bciträge ein= giehenden Stelle bie ben eingegogenen Bcifrägen entfpredjen= 
ben Marfen alsbald nad ocren (Finflebung zu cntmethen

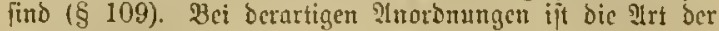

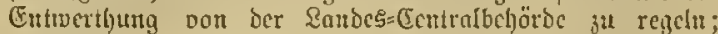
babci barf bie Ingahe bes Entwertbrtages vorgejdricber twerbent.

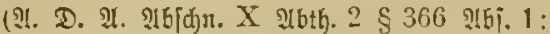

"Die Beiträge find burd bicjenigen Etcllen, velde beu Rohn zahlen, an entridter Dicfelben honbeln bierbei in Injebung ber Mlitglicber ber Bofttrautentafien als Dran ber lesteren.") 2. QIrbcitgeber, welde bic Minrfu cinfleben, fouvic Berfidget fino befugt, bic in bic Duitumgsfatten citogellebten Mlarfen in ber Wieife zu cutwerthen, baß bic cinjeluen Datfen hanbid)riftlid ober unter 3 ermendutg sines Etcmpels mit

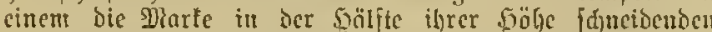

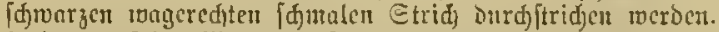
Inbere aul bie Miarfer acichte 3eiden aciten, jolanas bic bic Marten cutholtertoe Enitungsturte rod) ridt zum Un=

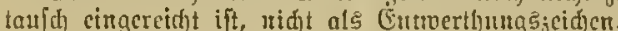

(21.D. I. Ib[du. X Ibth. 2 \$ 366 Itj. 8, Beridftigung 52.)

3

4. Heber bie Form ber Entmerthung ber Marfen in Den f̧ällen bes \& 117 IGF 4 und bes \$ 120 tann bic Snnbes= Eentralbchörbe bejontere शีrorbunng treffest.

5. Marfen, melde utidt bercits anbermeit entwerthet worben ïiv, ntiffen entwerthet uncrocu, nudbem bic dic Diarf'n cut=

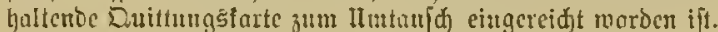

6. Rei ber Entwerthung birfen bic Marfen nicht unfeutlid

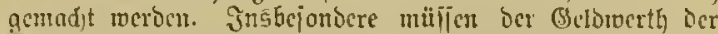

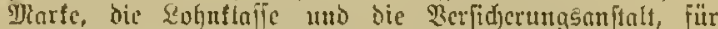
meldhe bie Martc ausgcacben ift, bei Doppclmarten aute) dic Semaciden ber 3ulabmatfe erfentuar bleifen.

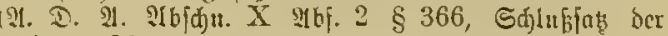
Beridgtigung 52.)

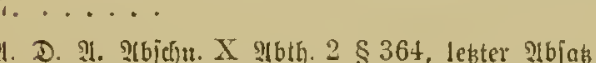

"Dic Beiträge find von ber \$oftocrmaltung uno ben Berfitherungspllidtigen zu gleiden Iheilen zu tragen."

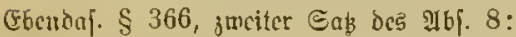

-3rgleidh mit ber Cinflcbutug ber Marten ijt bie

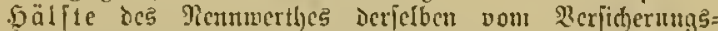
pflidjtigen vam Sofne einzubebalten.

\section{If brunduแg.}

\$ 116. (Ergeben fid) bei den zmifden ?rbeitgebern unD

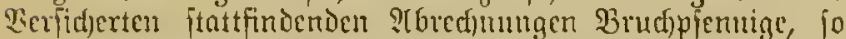

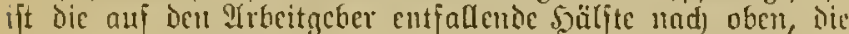
auf ien Berfidyerten entfalfenoc seälfte nact unten auf volle fifennige abjurunden.

\section{Freiwillige Fortjetzung des gerfiderunge berl)ültniffes.}

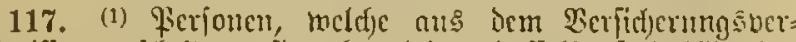

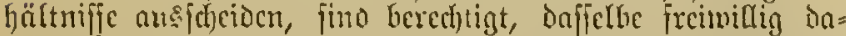

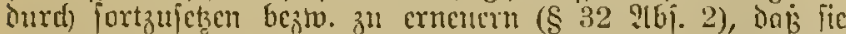
Die fiir dic Sohntlaffe II jeitgciesten Beiträge in Dintten

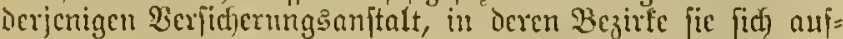

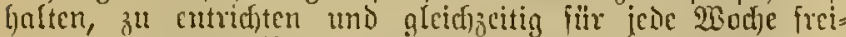

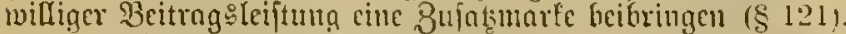

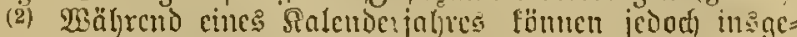

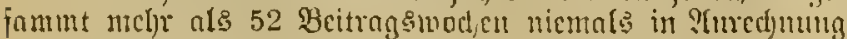
gebrad)t uerden.

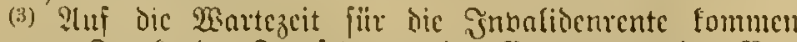

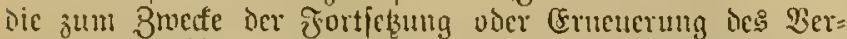

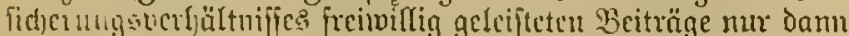

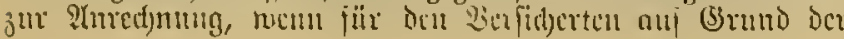

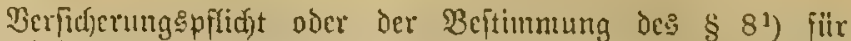
mindeftens 117 Beitraggmod)en Bciträge geleiftet morbcu find.

(4) Die gemäñ $26 f .1$ bermendeten Marfen find zu ent= werthen. Dic (Entmerthung erfolgt Durd) die non doc Sances=(Eentralbelörde ju bejtimmenten Steflen uno barf nur dom borgenommen werden, luen der cutjuredjende Betrag an Bufatzmarfen beigebracht morden ijt.

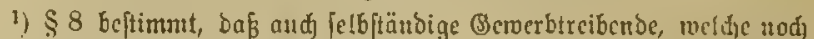

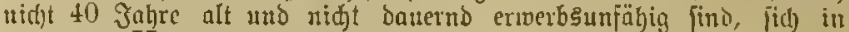
Qohntlofje II jelbft verfidjern bürfert.

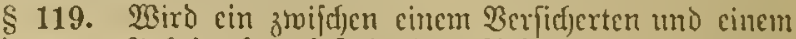

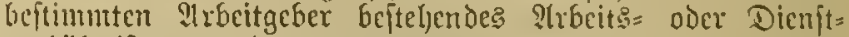

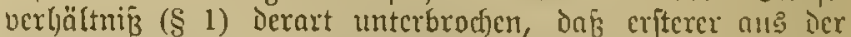
Berfifferungepflicht borübergebend nusf(f)eiset, fo fann fïr

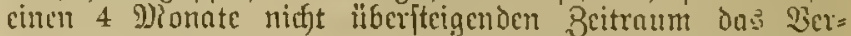

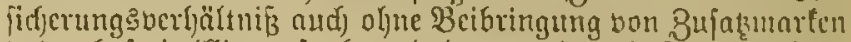

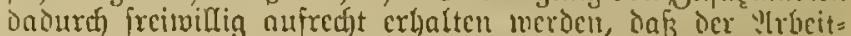
geber ober ber Berfidjerte dic bisherigen Beitröge fort= entridftet.

\section{Bujałูmarfer.}

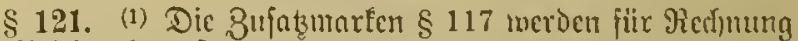

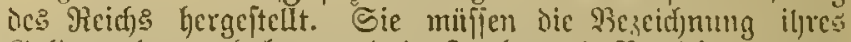

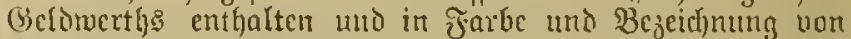

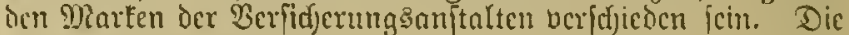

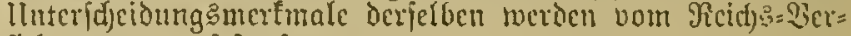
fidferungsoint icitgcietbt. 1)

(2) Dic Zujatzmarten fömmen bei allen \$softanitalten, foumic bei denjentgen Étellen, tweld)e vou den Berficherungsnnftolten zum Bertrieke iljer Miarfen erricjtet worben find, gegen

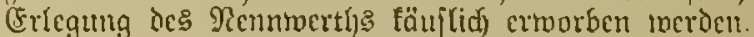

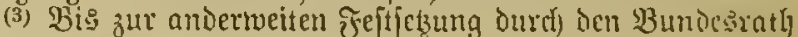

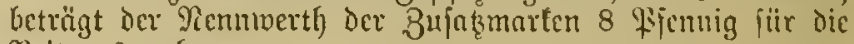
Bcitragsinodjc.

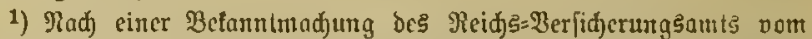
9. 9. 1890 wird von 5critellung bejonderer Bufanmarten abge= fehen, und merden itatt beficn für jebe Berfitherungsanftalt Doppel=

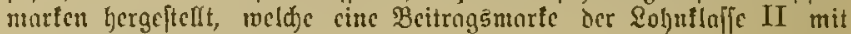
ciner 3 ufabmarfe verbinden.

\section{Streitigleiter.}

§ 122. Streitigfeiten zmije)en Den Srģanen Der Ber=

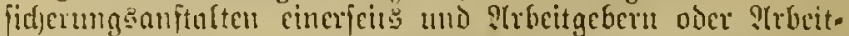

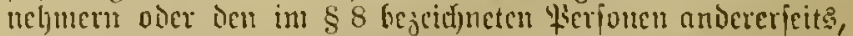

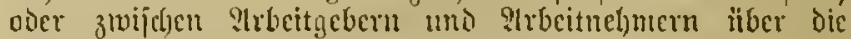
Frage, ob oice zu weld)er Berfidjerungennftalt, in melder

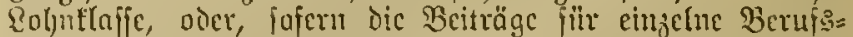
zmeige verjdjeden bentejen find (\$ 24), jür meldjen Berujs: zweig Bestrüge ju entrichten fint, weroen bon der für Den

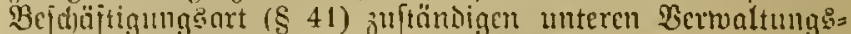

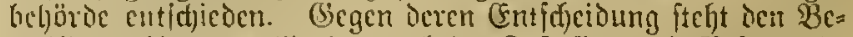

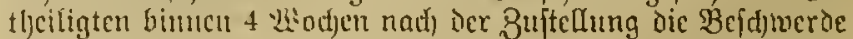

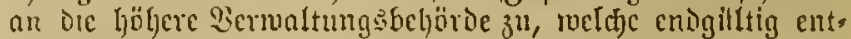
jofjetiet.

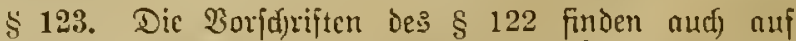

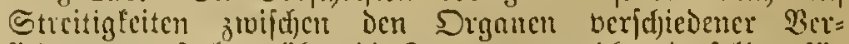
jid)crungsanjtalten Ḧber Dic Jrage, zu welcher Derfelhen für

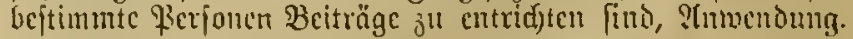

§ 124. §on Ucbrigen werion Streitigteitem jwifd)en Dem "Irbeitgcher mo Den won iłm bejdäftigten Ferfonen über

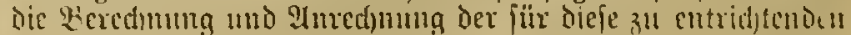

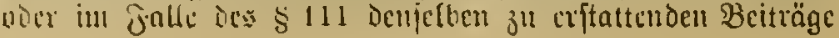


von Der unteren Bernaltungabeljörde (\$ 122) enogürtig ent= jujieden.

§ 125. (1) Rach enذgültiger Grledigung Diejer Streitigfeiten

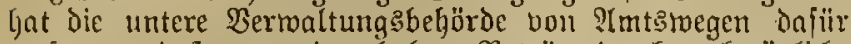

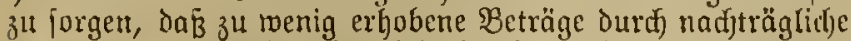
Sermenoung von Marfen beigebract)t merden. $8 \mathrm{u}$ viel el= jobene Beträge find auf ?ntrag bon ber Berfiderung: = anjalt wieder einzuzichen und nad) Bernidjung der in bie

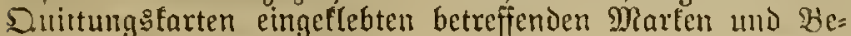
rid)tigung ber 2lnfred)mungen an die betbeifigten 2rbeitgeber

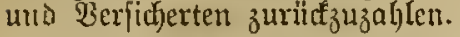

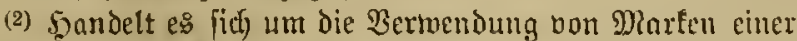

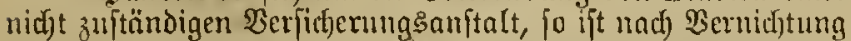
Berienigen Miarfen, meld)e irrthïntidf beigebrad)t find, ein der 8nhl ber Beitragstodjen entfprechender Betrag von Miarten der zujtändigen Berjicherungşamtalt beizubringen. Der Betrag der vernichteten Marfen ift von Der Berfidye= rungsanitalt, weld fe fie ausgeiteflt hatte, wieder einjujeljen uno zwifden den betheiligten âbeitgebern und Berficherten entiptedjend zu theilen.

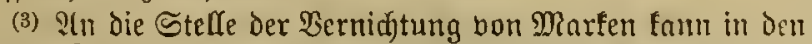

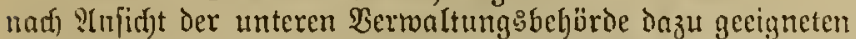
Fäflen bie (Einziehung Der @uittungsffarten uno nad) lleber=

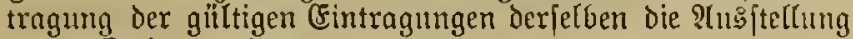
neller Sluittungstarten treten.

\$130. (1) Dic Terfidjerungsanjtalten find berpflidjtet, Den

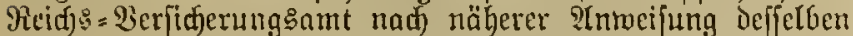
und in Den von ihm borzujajreibenden Friften lleberjidten iiber ifye (Sejajäft: und Red)nungsergebniffe cinjurcidjen.

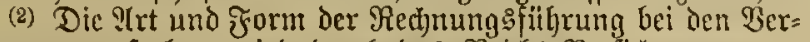

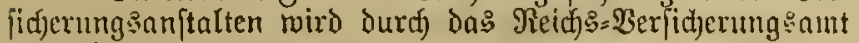
geregelt.

(3) Das Red)nungsjahr ift das Salenderjaljr.

\section{V. Ånffidit.}

\section{Reichs= Berficferungsిamt.}

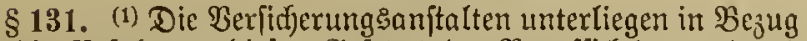
all die Befolgung diefes (Bejezes der Beauffictigung durth Da: Reicfis=:Berficherungsamt. Das ?uffichtsrectit Des lekteren erftrect fich auf bie Beobadftung Der gejeblicten und ftatutarifden Boridriften.

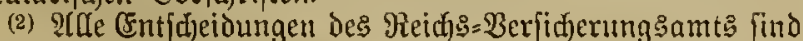

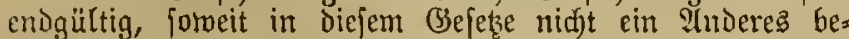
jtimumt ift.

(3) Das Reidfs=Beriiderungsomt ift bejugt, jederzeit cine Brififung Der (Sejcfäftsführung Der Beritderungsanftalten burzunebmen. Die Pitglieder der Borftände und fonjtigen Srgane der פerficferungsanjtnlten fino auf (Exfordern bes

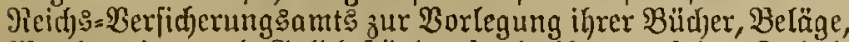
Werthpapiere und Geldbeftände, forvie ifrer auf ben Fntjalt

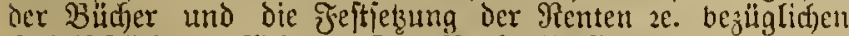

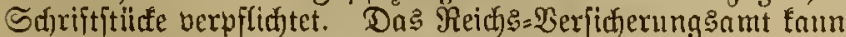
Diejelben ljierzu fowie zur Befolgung Der gefezlidjen uno ftatutarijdjen Borjdriften burd) Geldoftafer: bis zu 1000 Mart anlyalten.

§ 132. (1) Daڤ̊ Reid) befdiadet Der Rechte Dritter, über Streitigfeiten, meldhe (itd) auf die Redjte und \$3flichten der Drgane der Berficherung: anftalten forvie der MRitglieder biefer Drgane, auf die $2(4:=$
Legung der Stotutem mo auj Dic Bjültigfeit der volfzngenen

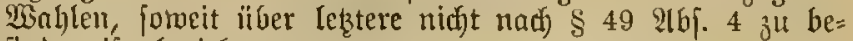
finden ift, bezicljer.

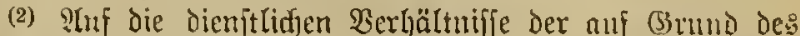

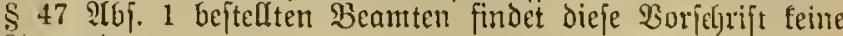

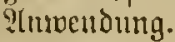

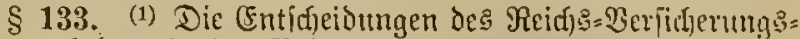
ant erfolgen in Der Befelbung bon minteftens ? ftündigen und 2 nidutftündigen Mritgliedern, unter weldien lïh ie 1 Bertreter oer ?trbeitgeber und der Berfidjerten befinden muf3, und unter Bujichung bon mindeftens 1 richter(id)en Benmten, toenn es fich handelt:

1. un die (Entidjeidung auf Revifionen gegen bie (Snt= (d)eidunget Der Schiedsgeridyte,

2. um Die (Entideidung bermögenorechtrifjer Streitig= feiten bei $\mathfrak{B e r a ̈ n d e r u n g e n ~ D e s ~ B e j t a n d e s ~ d e r ~ B e r = ~}$ ficherungsanjtalten.

(2) ?LE Bertreter der Irbeitgeber und der Berficherten gelten aud) für Den Bereid) Dicjes (Sejeţes dic auf Brund der

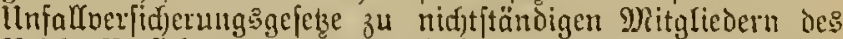

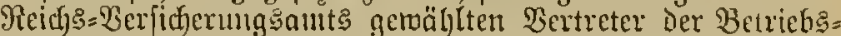
unternehmer und Der !) (rbeiter, ohne Bejofränfung auj die :Ingelegenteiten ifjes belonderen Berujsztweiges.

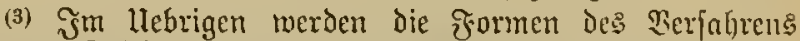

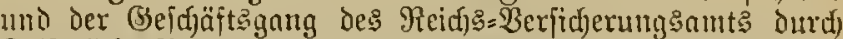
Saijerliche 2erordnung unter Bujtmmung Des Bundestaths geregelt.

\section{Sdifure, Straf- und Zlebergangsbeft iunungen.}

\section{Sranfentajfen.}

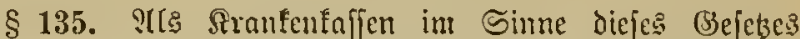

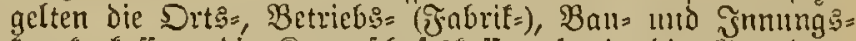
tranfenfafien, die Inappidjajtsfoljen fotwie die (semeinde=

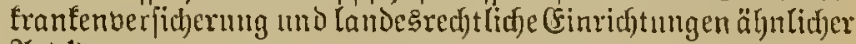
2(rt. $\left.{ }^{1}\right)$

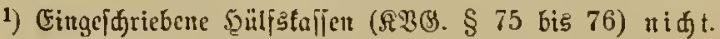

$\S 136$ entţält bejonbere Beftimunutgen für Sceleste.

\section{Beitreibung.}

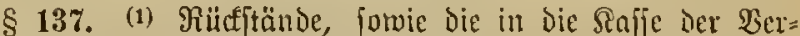
ficherungeanjtalt frieźzenden Strajen twerden in dirjelben 2iseije beigetrieben wie Bemeindeabgaben. Ritcfitände haben

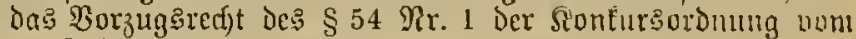

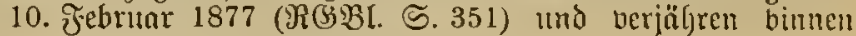
4 Fathren nadf ber Fälligleit.

\section{3uftändige Randesิbehörden.}

§ 138. (1) Die Centralbehörden der Bumbesitaten be: itinmen, weldje Berbände als tweitere Slommumaloerbänie anzufeljen, uno von weld)en Stants= oder (Bemeiniebeljördeu bejw. Bertretungen, die in diejen (Bejeke den Stants: 1110 (3) meindeorganen, forwie den Bertretungen der meiteren Siommunalverbä̈de zugemiefenen Berridfungen valjrält= melumen find.

(2) Die yon den (Eentralbefjörden Der Bundesftanten in (Bjemähbeit norjtehender Borichrift exlaffenen Beptimmungen find bured) den Meidjsanzeiger befanut jull madjen. 


\section{8uftellungen.}

\$139. (1) Buitellungen, weldfe den \&auf bon ₹riften be=

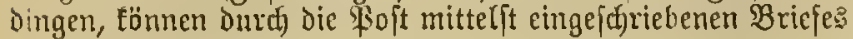
erfolgen.

(2) Berjonen, weldje nidys im Jnlande wohnen, tömen bon ber zuiteนenden Beljörde aufgeiardert jverden, eineu $8^{u=}$ fteffurgabevollmädftigten ju beftelfer. Wird ein folchjer inner=

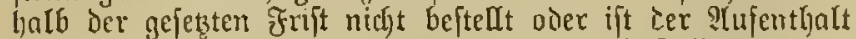
jencr Perjonen unbetanut, fo fann die 8 uitelfung ourd)

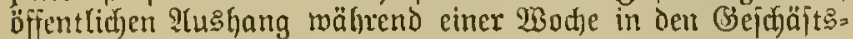
räumen Der zuftellenden Behöroc oder ber Drgane Der $\mathfrak{G} e r=$ fictyerung

\section{(Gebühren= und stempelfreigeit.}

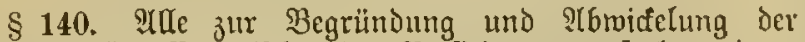
Rechtsverhältnifje żwijüjen Den Werjidjerungsanjtalten ciner= feits und den irbeitgebern oder 2 erjidjerten andererfeits er=

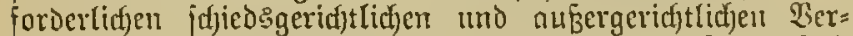
halldungen und llifunoen find gebühren= und itempelirei. Dajfelbe gilt für privatf(f)riftlicje Bolmachten und amtlidje Befdheinigungen, suelche auf Brund diefç Bejeşes zur

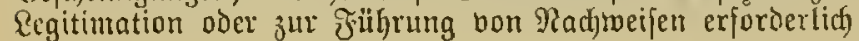
werdell.

\section{Rech)tğülfe.}

\$141. (t) Die öffentlicten Begörden find verpflicjtet, Den im Bollinge diejes (sejetzes an fie ergefenden (Erjud)en des

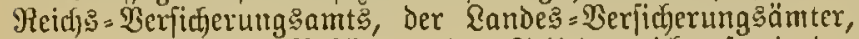
anderer öffentlidfer Beförden, der Sdfiedsgerichte fonie der Borjtände und Srgane Der Berfitjerunganatalten ju ent= ipredjen und ben bejeidnneten Borftänden auti unaujgefordert nthe Mittheilungen zufommen zu lajjen, melche für den (be=

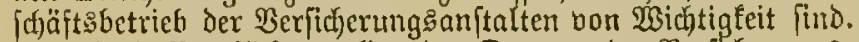

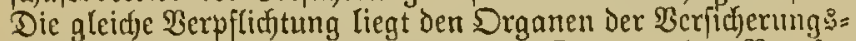
anftalten unter cinander fowie den Drganen Der Beruis= genoffenf(d)aften und der Rranfenfajien ob.

(2) Die burch die (Erfüllung Diejer Berpflididtungen ent= ftehenden Sojten find bon Den Berjifjerungsanjtalten a[? eigene Sermaltungstojten inloweit zu erftatten, als fie in Tagegeldern uno Reifetojten bon Reamten oder von

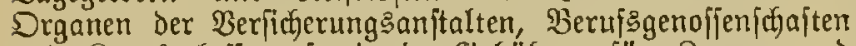
uno Siranfentaffen, forwic in Sicbühren für Zeugen und Sadjueritändige oder in fonjtigen baaren Uluslagen be= itchen.

(3) IIf die nach $\$ \S 5$ und 7 zugelajienen Rajieneinrid)tungeu

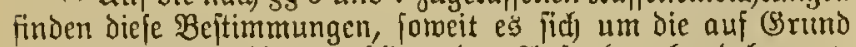
ifrer 3ulafiung iljnen offlegenden $\mathfrak{A} u f g a b e n$ Gandelt, ent= ipredtende Intwendoung.

\section{Strafbeftimmungen.}

\$ 142. (1) 2rabeitgeber, meldye in bie bon ifnen auf

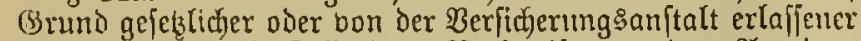

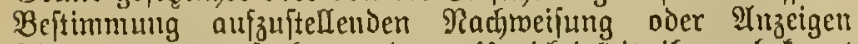
Fintragungen aufnehmen, Deren Unridgtigteit ifnen betannt war, ober bei gehöriger $\mathfrak{X}$ ufmerffamteit nidjt entgehen fomnte, fömen bon Dem Borjtande Der Berfidjerungsanjtalt mit Dronung:

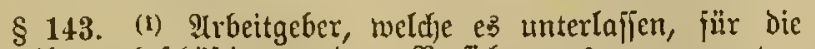

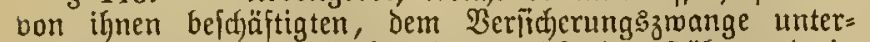
liegenden \$erfonen Marfen in zureidjender Sö̆he uno in

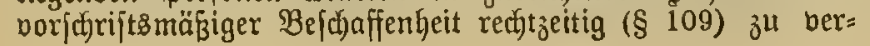

menden, fümuen bon Dem Borftande der Berficferungsanitalt mit Dronung: ftrafe bis zu 300 Mart belegt verden. Fine

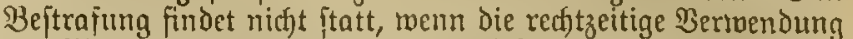
Der Diarfen vou cinen anderen ?(rbeitgeber oder Betriebs=

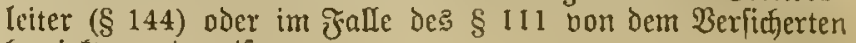
bewirtt worden ift.

$\S$ 144. (1) Der Irbeitgeber ift befugt, bie ÎUffellung

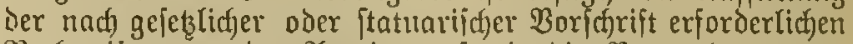

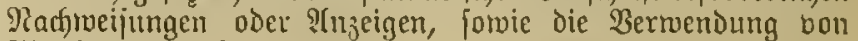
Mlarfen auj bebolluädjtigte Reiter feines Betricbes z" itbertragen. )

(2) Nane und Wohnort bon foldhen bebollmädytigten Betriebsleitern find dem $\mathfrak{B}$ orjtande der $\mathfrak{B}$ erficherungsanitalt mitjutheilen. Begegt ein Derartiger Bebođnürdjtigter eine in Den $\S \S 142$ bezm. 143 mit Strafe beorolyte Şandlung, fo finden auf ifn bie in biefem Saragraphen borgefelyenen Strajen Anmendung.

1) Die Bertebrsanftalten, \&eitungsreviforen 2c. find nath ber 2t. D. I.

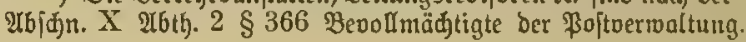

\$ 145. (1) Begen die auf (Srund diefes Befekes oder Der Statuten bon Den Srganen Der Berficferungsanftalten oder Den Scfiedagerichtsporfizenden erlajienen Strafber: fügungen findet bimnen zroei $\mathfrak{W}$ odjen nad) Deren 3u[tellung

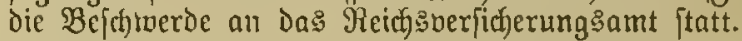

(2) Die bon ben borbezeidjneten Srganen, forie bon ben

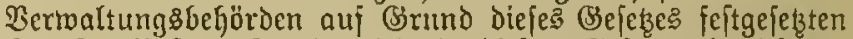
Strafen fliefren, fomeit nicht in diejem Bejebe abrveicfende

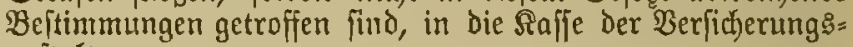
anjtalt.

§ 146. (1) Berjonen, weldte eకs unterlajןen, im falle Der Selbitwerficherung oder der freimilligen Berjicherung ( $\$ \S 8$ und 117) die borgejefrichenen Zufakmarfen zu berwemDen, fömnen, fofern nidjt nach) anderen (Se feben cine böhere Straje berwirft ift, Durd die untere Bermaltungsbeljörbe ibres Bejcjäftigungsortes mit Dromungsjtraje bis zu 150 Met. beftrajt twerden.

§ 147. (1) Den 2 (rbeitgebern und ifren 2 ngeitellten ift unterjagt, ourd) Hebereintunjt oder mittels arbeitsoronung

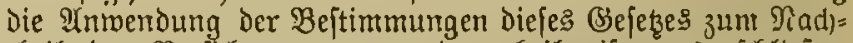
theil Der Berfinjerten ganz oder theilmeife auszuld lieben oder biefelben in ber llebermahme voer 2 hajührung eines in

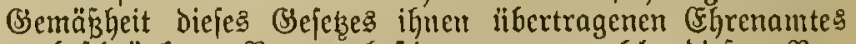
ju befdränfen. Bertragsbefitimmungen, weldje diejem $\mathfrak{B e r}=$ bote zurwiderlaufen, haben teine recfitliche Wirfung.

(2) 21rbeitgeber voer Deren Ingeitellte, weldje berartige Berträge abgejdyloffen haben, werben, jofern mid)t nach) anderen gejeß̧lidjen Borfdjriften cine härtere Strafe cintritt, mit Belojtraje biz zu 300 Marf oder mit §aft bejtraft.

$\S 148$. (1) Dic gieidje Strafe (§ 147) trifft:

1. Mrbeitgeber, meldfe den bon ifnen bejduäftigten,

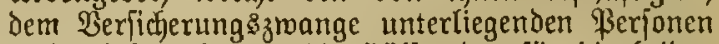
wiffentlich mehr als die ફ̧älfte des für die beiden letsten Rohnzahlungsperiodel berivendeten bezrw. in Denfelben fäulig gemordener Betrags an Marfen bei Der \&ohnjahlung in Stured)mung bringen (\$§ 109 Ab 3.312 2(b. 2);

2. Angejtelte, weldye einen joldjen gröferen शtbzug wiffenlich bemirfen;

3. diejenigen \$erfonen, toelüe Dem Berechtigten eine

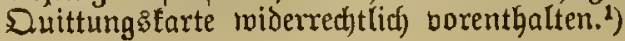


(2) Die unter Biffer 1 und 2 norgejegenen Straj= beptimmungen finden auf den ₹rall bes $\$ 119$ teine ?!ne wendung.

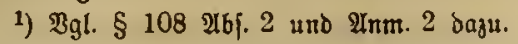

\$ 149. (1) 2(rbeitgeber, meldje trijisntlid andere als die borgeidrielienen Marfen berwenden, fowic Angeftefle uns

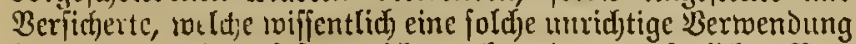
betwirten, werden, fofern nidjt nad anderen gejeklidjen Bor= idjriften eine härtere Straje eintritt, mit Beloftraje bon 20 bis 1000 Mark oder mit Sefängnifí bejtraft. Sind mildernde Umjtände borhanden, fo fann bie Strafe bis allf 3 Mart oder einen Iag \$aft ermäBigt werden.

$\$ 152$. (1) Wer in Duittungstarten Fintragungen oder Bermerte mad)t, meld)e nad) $\$ 108$ unjuläffig Fino, , twird nit Beldjtraje bis zu 2000 Mlart oder mit Ssefängnif bis zu bै Donaten bejtrajt. Sind milldernde llmitände bor= handen, fo fann ftatt der Befängnif̧ftrafe aul Şaft erfannt merden.

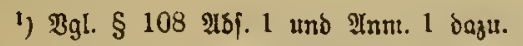

\section{Uebergang go beftimmungen.}

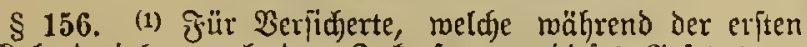
5 Salenderjabre nad dem Jntraftreten diejes Bejetses er: merbsunfähig merden und für woelde wälyrend der Daner

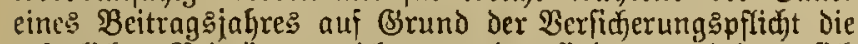
gejeßslichen Beiträge entridjtet morben find, vermindert fich

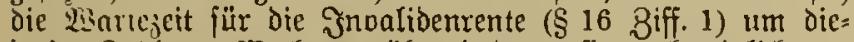
jenigi Zutll non 230 djen, während deren fie nadjmeislict bor

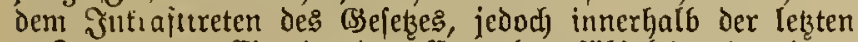
5 Jalire vor sintritt der Erwerbsumïh̆gfeit, in einem

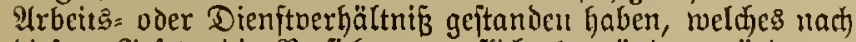
Diefem Befełze Die Berficjerungṣpfid)t begrümoen toürbe.

(2) Dieie Beftimmung findet auf bic im $\$ 8$ bejeidyneten Berionen feine Ultmendung.

(3) Bei Ernittelung Des Durdjpdynittlidjen Rohnjakes is 9 Ibj. 3) wird fïr diejentge Beit, um weldje fid bie Wartezcit bermindert, die exite \&ohnflajfe zu Brunde gelegt.

(4) ......

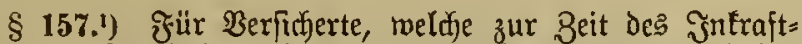
tretens diefes (Bjeletes bns 40. Rebensiahr vollendet haben

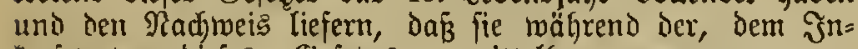
frajttreten biejes Sejeb̨es unmittelbar borangegangenen 3 Ralenderiahre insgejammt mindejtens 141 Wodjen bin= ourd) thatfählid) in einem radj diefem (sejeke die $\mathfrak{V} e t=$

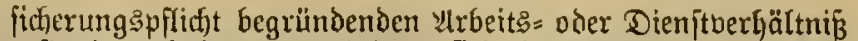
geftanden haben, berminoert fid die Wartezeit für die Mftersirente (§ 16 Biff. 2), unbefáadet ber Borjariften bes $\S 32$, um fo viele Beitragsjahre und überichießBende Beitrags? wodjen, als ihr Rebensalter am 1. Jamuar 1891 an Jafhren und nollen Bodjen Das volleniete 40 . Rebensiahr über= jitiegen hat. Dnbei werdeu für jedes nollendete Rebens:

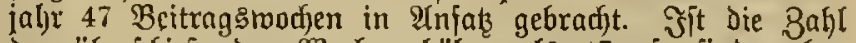

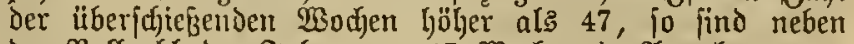

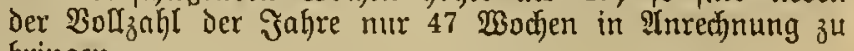
bringen.

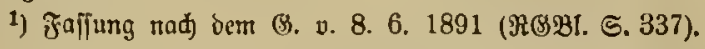

$\S 158$. Fine unter $\$ 17$ IUbf. 2 [alfende Sranfheit oder militärijale Dienjtleiftung wiro auth in ben ₹fälen ber

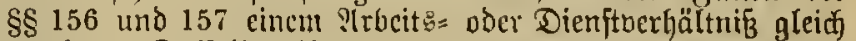
geadtet. Daffelbe gilt von der Interbredjung bes Arbeit: Dder Dienjtberfältniffes in dem ₹rafle des \& 119 , infomeit bieje Unterbredjung rälyrend eines アalenderjahres ben Beits raum bon 4 Monnten nid̈t überjteigt.

§ 159. Bei Bemeffung der auf Brrund Des $\S 157$ zu

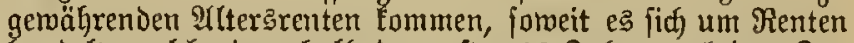
handelt, melde innerhalb der erften 10 Эahre nadj bem Эn= Erajttreten des Befekes zur Entitelyung gelangen, für die bor bcm Intraittreten des Seferses liegende Zeit bie Steigerungsjäßze derjenigen Lolynflafie in Anredfnung, welda)e

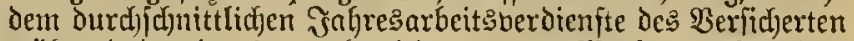
mährend ber im \$ 157 bezeidjneten 141 Wodfen entiprechen, minicitens aber dic der eriten Eolnntlaffe, jür bie nadj dem Fntraittreten des Gejetzes liegende Beit dngegen die den wirffid) entrid)teten Beiträgen entfpredjenden Steigerungs: jäbe (\$ 26 9(6). 2). Bei den nad शtblauf jener 10 Jahre zur Entftehung gelangenden Renten merden jowohl für bie bor, als aud fitr bie nad) dem Jintrafttreten bes (Sefezses liegende Zeit die Steigerungşäz̧e zu (Scunde gelegt, weldje Den nach dem Jnfrafttreten bes (Bejebes entridteten $\mathfrak{B e i}=$ trägen entipredjen, und jtor, wenn die Beiträge in ber= fojiedenen Qohnflaffen entridytet find, nad bem Berhältnifs der $B a \mathfrak{h l}$ der in den einzelnen Qohnflaffen entridjteten Beiträge.

$\S 161$. Die in $\S \S 157$ und 160 bejeidmeten Radjweife jino durd) Bejheinigung der fïr die in Betracht fommenden Beidjäftigung sorte zujtändigen unteren Berwaltungşbchörden oder Jurd eine bon einer offentlidjen Beljörde beglaubigte Bejdjeinigung ber Arbeitgeber zu fübren.

\section{Doftordnung und đelegraphenoromung. *)

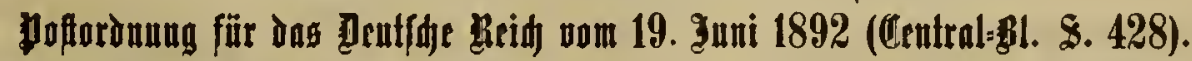

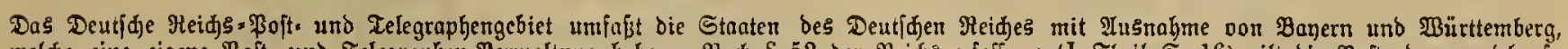

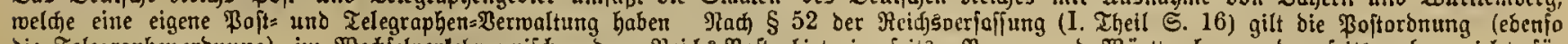

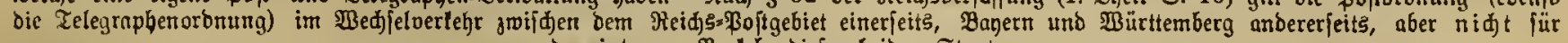
ben intermen Bertehr Diejer Deiden Staaten.

\section{Inbalts.lleberfidt.}

I. भסjdn.: ßoitfendungen.

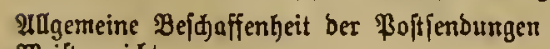

Teijtgemidjt.

थuB Enjeite

Begleitabreffe zu \$acteten

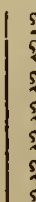

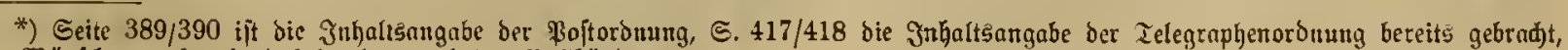

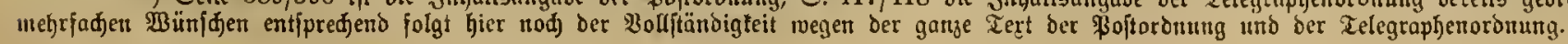


3ur \$oftbeförderung bedingt zugelafiene Begenfäutoe

Dringende Radetfendungen

Bofttarten

Druffaden.

Bur Beförberung gegen bie Drudjadentare bebitrgt gugelafiene Edjriftitüte.

\$antenprobert

Finfidreibfenbungen

\$ojtanmeifungen

Telegraphijde \$ojtanmeifurger .

Boitnadinahmelendunger

\$oftaufträge zur Einziełung oon Belobeträgen uno zur (5in= bolung von Medjelaccepten

ßoftaufträge zu Büdjerpoftjenbungen .

Dura) (Filboten ju beftellende Senbungen

Bahnhofsbriefe.

Briefe mit Paftzufteluingsurlunde

Behandlung oronungsmibrig bejŏnffener Gendungen. . . Beitungsoertrieb

Drt ber Firlieferung .

3ett ber Finlieferung.

franlirungsిpermert

Finlieferungşdjein .

Püdiळein.

Seitung oer Popjendungen

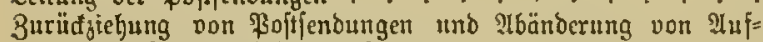
fdriften burd ben ?lbfender..........

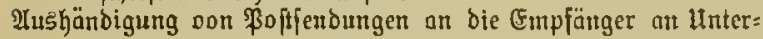
roegsorter

Gerftelung des Berfdulufes und Fröfinung ber Senoungen burd bie \$oftbeamten

Beitellung

Beit ber $\mathfrak{B}$ eftelfum

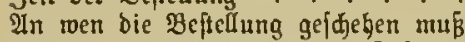

Beftellung ber Edretben mit Buftellungsurfunde

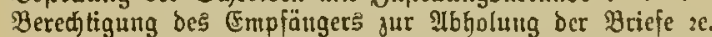

Aushänbigung ber Sctiounget nud erfolgter Beljündigung ber

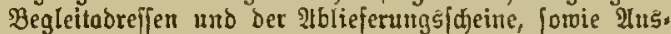
gablung boarer Beträge.

গahfertoung ber \$oftfenoungen

Bebandlung unbeftellborer Poftienbungen an Beflimmungsort Beljandlung unbeftelbarer \$oft fenoungen am 2lufgabeort.

Raufidhreiben vegett \$oftiendungen

Rad)liejerung oon Bettungers

Berfurf Dot \$oftroerthgeiden

Fntridtung bes ßortos and ber jonjtigen (S)bübren.

II. Abfdn.: ßerfonenbeförberung mittels ber \$often.

Meldung zur Reife.

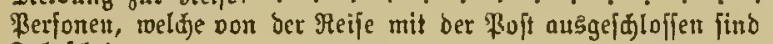
fahrijhein

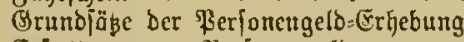

Grftntung vou \$erjonengeld

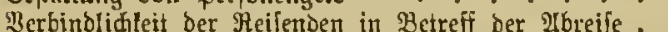

ஐlä

Reijcgepäđ . . . . . . . . . . 558

Ueberfradtporto unס Berfiderungsgebühr . . . . . . . $\$ 59$

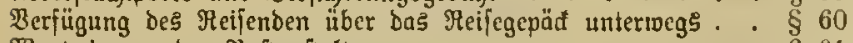

Wartegintuter ber \$oflanftelten . . . . . . . . . \$61

Berbalten ber Reifenden auf Dett ßoften . . . . . . $\$ 62$

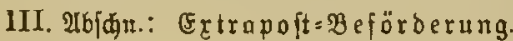

WIgemeine Beflimmungen

$\$ 63$

3ablungsfäke

Baflung und Ruittung

Beppnnmung .

Ibjertigung .

Bepörberutgsgeit

\$oltillone

Pefdiwerben

Jitlraftireten

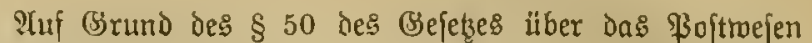
bom 28. Ottober $1871^{1}$ ) twiro nadjftehende \$oftoronung er!aifen. ${ }^{2}$ )

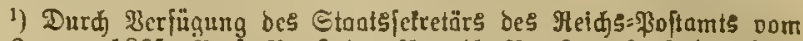

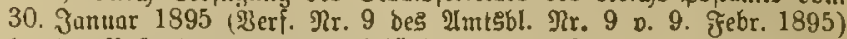
hat bie $\mathfrak{p}_{0}$ ftorbnung eittige Mbänderungen erfahren, weldhe in ben Tert hier mit anfgenommen finb.

2) Bgl. Inm. jum Cingang ber Telegraphen=Oronung.

\section{I. abrdyutt.}

Poftiendungen.

\section{Igemeine Beffaffenteit Der Boftfendungen.}

\$ 1. (1) Die \$3oftjendungen müfjen ben rachjolgenden Bepitumungen entfprectiend berpact, verffiflofien und mit I!uffurift berfegen fein.

\section{Meift getwidjt.}

\section{§ 2. (1) (Es beträgt dns Meiftgemid)t:}

eines Briefes 250 (Sramm, ciner Druffiactie 1 Rilogramm, ciner Waarenprobe 250 Bramm, cines Bafets 50 stilogramm.

\section{$\mathfrak{A}$ ußenfeite.}

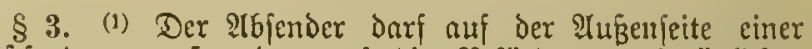
Foifjendung aufer den auf die Beförderung bezüglid)en Ingaben noth feinen Ramen und Stand, feine Firma, forwie fine Mohnung bermerten. Bei Briefen fömnen roeitere IIngaben uno 9rbbildungen, meldye fing auf Den Stand, Die Jitma oder das Bejcjäft des șbjenders beriehen, unter der

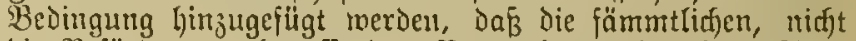
Die Befürderung betreffenden Bermerfe 2e. in ifrer ? debnung etwa den fedjften Theil Des Briejumfdrlag: nidft iibericjreiten und am oberen Rande des Briefumichlags auf

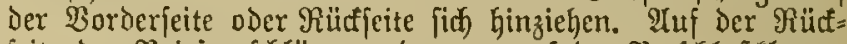

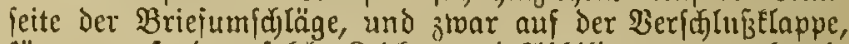

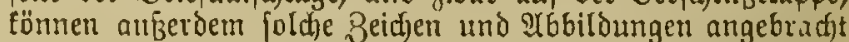

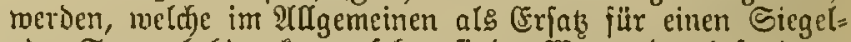
oder Stempelaborud anzufehen find. Wegen der befonderen Beitimutungen für $\mathfrak{B} 0$ oft= Bacfetndreffen, $\mathfrak{B}$ oftfarten, Drudf= fachen, Waarenproben und \$oftanmeifungen fiebe $\S \S 4,14$, 15,17 und 19.

(2) Die Freimarfen find in die obere rechte (Fafe der 2uffid)riftfeite, bei Factetfendungen an gleidfer Stelle auj die \$oft=\$acfetadrefie zu tleben.

\section{Begleitadrefie zu ßafeten.}

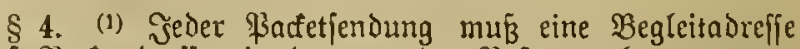
(\$oft $=$ \$acfetaorefie) in Der bon ber \$oftoerwaltung vorge= (id) riebenen form beigegeben fein.

(2) Formulare ju \$olt=\$actetadrefien fömen burd) alle Poftanjtalten bezogen merden.

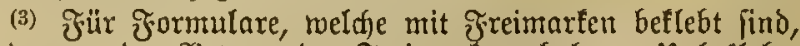
mird nur der Betrag Der freimarte erhoben. Unbeflebte Formulare merden zum \$reije von 5 \$f. jür je 10 Stitcf abgelaffcri.

(4) Formulare, meldje nidft bon der $B o f t$ bezogen werben, müffen in (Sröß̈e, Farbe und Stärfe des \$apiers,

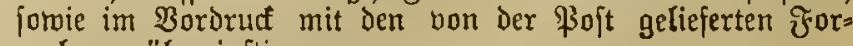
mularen übereinjtimmen. 


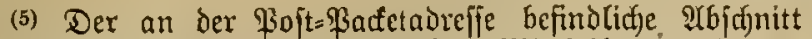
tann zu (d)riftlidjen oder gedructen Mittheilungen benutzt werden. 1 )

(6) Die Boft bes Fiactets alt die Boptnriftalt oder an den beftellenden Boten zurücfgegeben, Der $2(b j d$ nitt fant jebod) abgetrennt und bom cimplänger zultüafbefinlten merden.

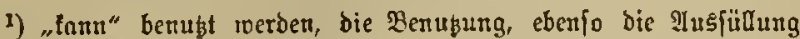
bes Rorbrudes "Name, Mohnort 2 . bes Ilbjenders" ift garg in bem Belieben des IIbiender' anbeimgeftedt. Der frnutinumgsoermerf ift

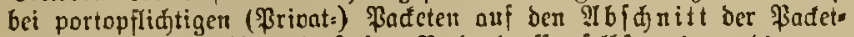
abrefic nieberzufheiben (auf ber ßafetabrejie felbit zeigen bie ver= wendeten Marten bie Frantirumg an), dic \$orto(reigeit 2c. begründen=

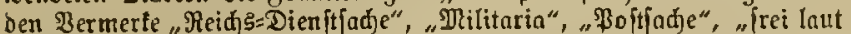

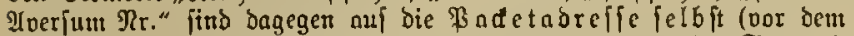
Borbrud "Beitimumugsort"), bie aur Beglaubigung dienenden Stempcl=

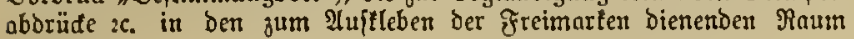

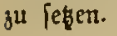

\section{Mehrere Pafete zu einer Begleitadrefie.}

§5. (1) Mehr als brei Facfete dürfen nid)t ju einer Begleitadreffe gehören. Auth) ift es nidft zuläfiftg, Pactete mit Werthangabe und jolde ohne $\mathfrak{W e r t h}$ jangabe mittels einer Begleitaireffe zu verjenden.

(2) Befb̈ren mehrere ßacfete mit Werthangabe zu einer Begleitadref]e, jo muE auf derjelben der $\mathfrak{B e r t h}$ eines jeden Facfets befonders angegeben fein.

(3) Эedes Rachnahmepactet muß́ von einer bejonderen Pojt= Bacfetadreffe begleitet jein.

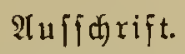

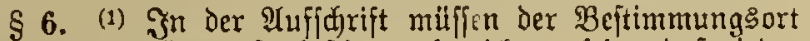
uno der (smpfänger jo bejtimmt bezeid)et fein, baf jeder Ungeminheit vorgebergt wird. ${ }^{1}$ )

(2) Dies gilt aud bei fold)en mit "pojtlagerno" be= zeidfneten Gendungen, für relde die $\mathfrak{B}$ ojt "Semähr àl Ieiften hat. Bei anderen Sendungen mit dem Bermert "pojt=

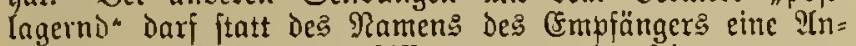
gabe in SBudjitaben oder Biffern angerwendet jein.

(3) Bei Poitieniungen nad) Drtidjaften olyme \$ojtanftalt ift in Der ?lufichrift außzer bem eigentlichen Beftimmungs: orte nod) biejenige ßoftanitalt anzugeben, bon roeldfer aus die Beftellung der Sendung an ien Empfänger berwirft merden, oder die Abholung expolgen joll. Wenn der $\mathfrak{B} e=$ ftimmungsort zwar mit ciner Foftanjtalt verjehen ift, aber nicf)t zu den ẩgemeiner befannten Drten gehört, fo ijt jeine Sage in ber 9lufid)rift nod) näher zu bezeid)nen.

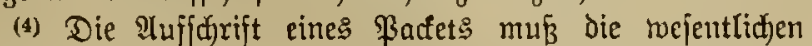
Ingaber der Begleitadrefje enthalten, fo DaÉ nöthigenfalls bas \$adet nudi ohne die Begleitadrefie beftellt merden faun.

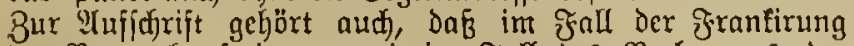
oer Bermerf "frei" 2e. und in Fall des Berlangen der Eilbejtellung "Der Bermerf "Durd (Filboten" 2c. angegeben mird. Rad)nal)mepactete müffen in Der ?(ujjdjrift mit Dem

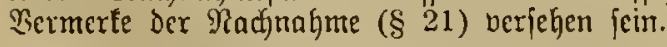

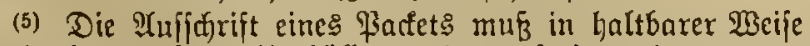
ummittelbar auf der ltmbülung voder auf einem Der ganzen isläche naú aujgeflebten oder jonft unlösbar barauf be= fejtigten ßapiere ze. angebradjt reerden. Sft dics nidjt aus= jithrhar, fo ijt jür die $\mathscr{A}$ ufjurijt eine haltbar befeftigte Jahne von \$ruppe, Fergamentpapicr, Jol; niner fonftigem feften Stoff ar benuten. Befonders grof und dentlich muF
Der Name deg Bejtimmungsorts mit unoerlöfd)licjem Stoff gefdirieben oder gedrutft jein.

1) Die Folgen ungenauer oder unridtiger Ilbreifirung hat ber $2 \mathfrak{b}=$ fender ou tragen. 3 gl. \$oftgef. § 6 a unb $\$ D$. \$ 27 (3)

\section{Werthangabe.}

\$7. (1) Wenn der Werth einer Sendung angegeben twerden foll, fo muj Derfelbe bei Briejen in ber suffid)rift, bei mberen Sendungen in der 2ufjurrift Der $3 e g$ leitadreffe

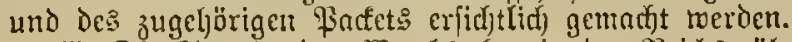

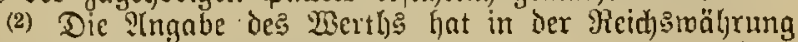
z11 erfolgen. Der alugegebene Betrag foll den gemeinen Werth) Der (Eenoung nidjt itberfteigen.")

(3) Bei der Deriendung von furshabenien \$apieren ift Der Sursmerth, meld)en diejelben zur Beit der Eintiejerung haben, bei der Berfendung von bypotlefariffen gapieren, Wedfieln und ähulticjen Dofumenten Derjenige Betrag an= zugeben, weldfer vorausfidytlidf ju vertwenden fein wilrbe, um eine neue red)tミgültige $\mathfrak{A} 1$ se fertigung des Dofument: zu erlangen, oder um Dic Şinderniffe zu befeitigen, meld)e fith Der (Finzichung Der Forderming entgegenftellen würden, wenn Das Dokument berloren ginge. (Entipricht die Wertl)angabe Den boritehenden Regeln nicht, fo fann die Sendung zur Beridytigung zurürfgegefen werden. 2 us einer irrthümlith 3u Gohen Werthangabe darf ein T(niprud) auj (Erjtattung Des entiprechenden Theiles der $\mathfrak{B e r f i c f j e r u n g}$ gebühr nidjt her= geleitet merden.

(4) Der Bermerf ïber Boftnadjnahme gilt nidjt als Wertfangabe. Radinaknejendungen merden bałer nur bann als Werthjendungen befandelt, wenn auf Der Sendung aufer

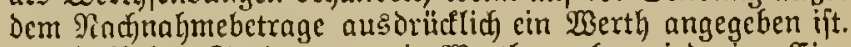

(5) Uleber Sendungen mit Werthangabe wird cine (Fin= 〔icferung:bejtheinigung ertheilt.

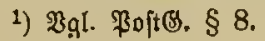

\section{Berpafung.}

\$8. (1) Die Berpactung Der Sendungen mus nach Maß̉gabe der Beförderungsftrefe, Des lumfangs der Sendung tund Der $\mathfrak{B}$ cidjaffenheit des Jnhalts haltbar und fichernd cingeridtet jein. ${ }^{1}$ )

(2) Bei (Begenjtänden bon geringerem Werth, meldfe nidft unter Druct leiden und nidgt Jett over Feudftigfeit abjetsen, ferner bei Iften = ober Sd)rifteniendungen genügt

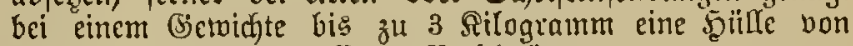
Bacfpapier mit angemejener Berjobnürung.

(3) Edjwerere (Gegenftände müffen, injofern nidjt ber

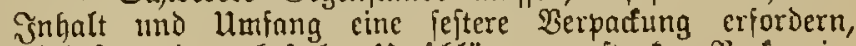

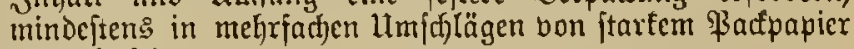
berpadt jein.

(4) Sendungen bon bedeutenderem Werth, insbejondcre

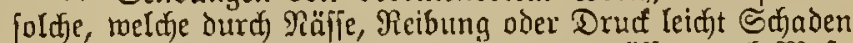
leiden, 3. B. Spiben, Seidentwaaren 2c., müfjen nach $\mathfrak{M} a \mathfrak{E}=$

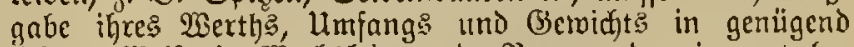
Fitferer Weije in Wadjetemwand, Pappe oder in gut be= jđaffenen, nad) llmitänden mit ?einen iiberzogenen Riften :c. verpact jein.

(5) Sendungen mit einem Snhalte, weldjer anderen \$ojt.

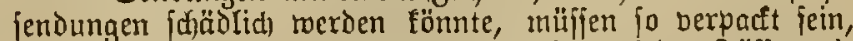
Daź eine foldje Reidjäbigung fern geljalten mird. Jääfer mit

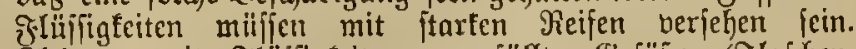

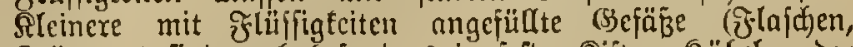

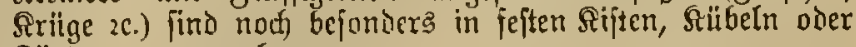
Siörben zu verwahren. 
(6) $\mathfrak{B e n n}$ in Folge fehlerhafter Berpacfung einer Sendung mäfrend Der Beförderung eine neue Berpacfung nöthig twiro, jo twerden bie Soften dajür bon Dem çmpjänger eingezogen, oemiclfen aber erftattet, wenn ber Mbjender die Entridjtung nadjträglid) übernimmt.

1) Ehenfo mie die Folgen ungenauter Abreffirung $(\S 6(1))$ hat ber 2rbfentor auth bie folgen nimit haltbarer Berpadung ju tragen, bie Boftoermaltung hajtet nidt für Befdjäbigungen ber \$adete, Terlufte

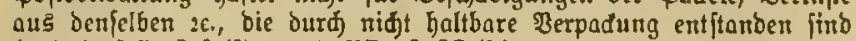
(ogl. \$oft(s. $\S 6$ (2) a und \$D. $\S 27$ (3)).

\section{Berfका}

§ 9. (1) Der Berjaluß

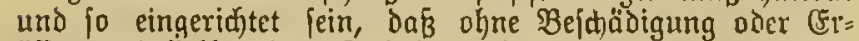
offinung Deffelben Dem Э̂nlyalte nifft beizutommen ift. ${ }^{3}$ )

(2) Bei $\mathfrak{B a c t e t e n}$ mit Mertlyargabe lyat die Befeftigung ber Sd)lüffe ftets burd) Siegellact mit Irborud eines ordent= lidien \$?etid)afts ftattzufinden.

(3) Bei \$arfeten ohne Werthangabe faun bon einem Beridhluß mittels Siegel oder Bleie abgeichen werden, wenn burd) Den fonjtigen $\mathfrak{B e r}$ (d) lus oder burd) die Untheilbarkeit

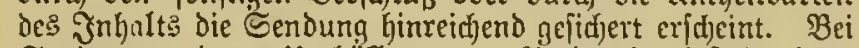
Senaungen, deren umbtillung aus Yiafpapier bejtelt, fann Der Berihlūis mittels eines guten silebjtoffes oder mittels Siegelmarfen hergeitelt merden. S(uch bei anderer Ver= pactung fömmen Siegelmarten in 2nmenoung fommen, fojern damit cin halt6arer Berfd) luß̧ erzielt mird.

(4) Bei Reifetafden, Soffern und Riften, melde mit Stylöffern beriehen find, porwie bei gut bereiften und feft beripundeten J̈äfiern, aud fejt bernagelten §iften, bedarf es

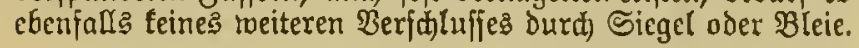

(5) Deşgleidjen fönnen gut umbülle Majdinentheile,

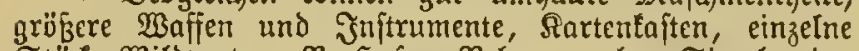
Stüfe Willopret, z. B. Sajen, Rehe 2c., ohne Siegel= oder sBleiberidiluß angenommen werben.

1) Bgl. 2 Irm. 1 зи § 8 (1).

Befondere Anforderungen bezüglid ber werth= fendungen.

§10. (1) Briefe mit $\mathfrak{B e r t h a n g a b e ~ ( \$ o l d , ~ S i l b e r , ~}$ Bapier= gelo, 28 crthpapicre 2e.) müffen mit einem haltbaren ümidjlage berielyen und mit mehreren, Durd) Dafjelbe \$etjdaft in gutem Sncf hergeitelten Siegclaborüden bergeitalt beridjloffen jein,

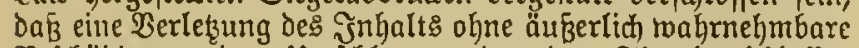
Bejuäbigung des Hmidlages oder des Siegelber(h)luffes nid)t möglidi ift.

(2) Belditüfe, weldje in Briefen berfandt merben, milfien in Papier ober bergleidhen eingefhlagen und innerhalb bes Briejes fo befejtigt fein, Daß̧ eine Beränderung ihrer Eage während ber Beförberung nidyt ftattfinden fann.

(3) Sdywerere Beldjendungen find in \$actete, Beutel, Siften oder Fäfier feft zu berpacfen.

(4) Scnoungen bis zum Betwicht bon 2 Rilogramm ditfen, fofern ber $\mathfrak{B e r t h}$ bei \$apiergeld nidtt 10000 Mar: und bei baarem (jeld nid)t 1000 Mart überjteigt, in Pacfeten bon ftorfem, melirfad) umgeid)lagenem unb gut beridnürtem Fapier cingeliefert merden.

(5) Bei [dfmercrent (S) wid)t und hei grögeren Summen

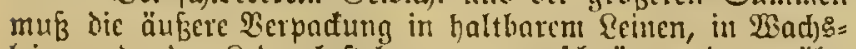
leinmano nicr Scter bejtchen, gut umijdyürt und vernäht, fomie dic giaht binlönglid) of̣t berfiegelt fein.

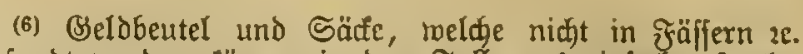
verfandt rerben, tönnen in bem ₹̧alfe aus einfadier ftarfer Seinmand bejtchen, weun bas (seld darin gehörig eingerollt oder zu Päcthen vereinigt enthalten ift. Andernfalls müfien die 5 Beutel aus tonigfters boppelter Reinmand bergeftellt fein.

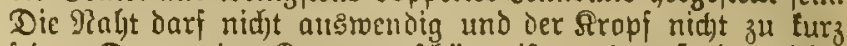
fein. Da wo Der Snoten gejdjilrzt ift, und außserdem über beiden Sffnurenden muß fein. Dic Sdjnur, reldie den frop umgiebt, muß Durch) den Sropf felbft hindurd)gezogen merben. Dergleid)en Sendungen jolfen nidjt über 25 Ailogramm fdroer fein.

(7) Die Belofiften müfifen bon ftartem Solz angejertigt, gutt gejiigt und feft bernagelt fein, oder gute Snjlöfier laben; fie dürfen nidt mit itberftehenden Decfeln berjeljen, Dic Fijenbejoläge mülfen jeft uno bergeftalt eingelafien jein, Da $\bar{B}$ fie andere (j)egenftände nid)t zerjdjeuern fönnen. Ueber 25 §illogramm jdjwere §iften mulffen gut bereift und mit Şandhaben verję̧en fiein.

(8) Die ऊeldfäffer müffen gut bereift, die ङdjlußreifen angenagelt und an beiden $\mathfrak{B} 00$ ben bergeitalt berfonnürt und

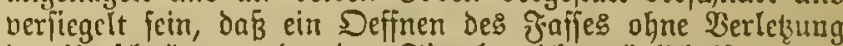
Der Umidgnilumg oder Des Siegels nidjt möglich ifft.

(9) 3 ci \$acteten mit bnarem Beld in größeren Beträgen

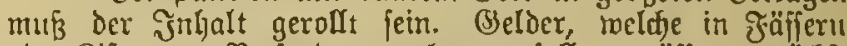
oder Riften zur Beriendung gelangen follen, müffen zunädift in Beutel oder Findete berpact werden.

\section{Bon der Boftbeförberung ausgefdoffene Begenitände.}

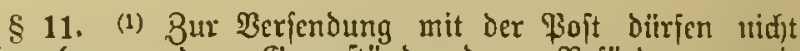
aufgegeben werben: Begenitände, Deren SBeförderung mit (3efalgr berbunden ift, namentlid) alle Dur(f) Reibung, \&uft= zuorang, Drudf oder fonjt leidjt entzündtidjen Sadjen, forie ązende گ̧üiffigfeitent.

(2) Die Boftanftalten find befugt, in Fällen bes Werbadts, Daß̧ bie Sendungen (Segenjtände Der obigen $\mathfrak{U}$ rt enthalten,

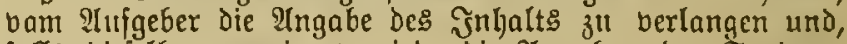
falls diejelbe berweigert wirb, Die Innahme der Eendung $\mathrm{ab}_{\text {zulehnen. }}$

(3) Diejenigen, meld)e Derartige Sađen unter unridjtiger Ingabe ober mit Serichmeigung bes Jnhalts aujgeben, haben - vorbehaltlich der 2 ciftrafung nad den Bejeken für jeden entftebenden Sđjaben zu hajten. ${ }^{1}$ )

(4) Die Boftanftalten tönnen bie Innahme und $\mathfrak{B} \varepsilon=$ iörderung von \$ojtiendungen ablehnen, fojern nad) Maşabe Der borhandenen \$oftoerbindungen und \$oftbeförderungs= mittel dic Zufüljrung berfelfen an Den Bejtimmungsort nidgt möglid ift.

1) ভtrafgefebbu西 $\S 367$ :

"Mit Beloftrafe bis ju cinhundertfünfrig Marl ober mit baft wirb beitraft:

5a. Wer bei Berfendung ober Beförderung von leidit

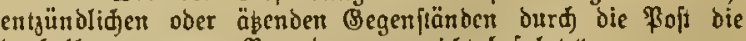
beshalb ergangenen Berordnungen nidjt befolgt."

Die hier angebrolte Etrafe ift fion oerwirft, menn ein ßadet mit berartigem Snhalt nur unter unriditiger Singabe oder Ber[đmeigung

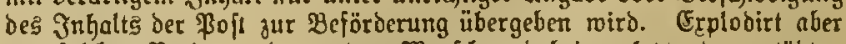

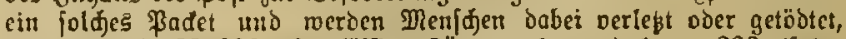
fo treten die $\$ \S 230$ (fabrläffige Görperperlegung) begro. 222 (finhrs

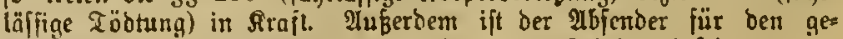
fammten burd) bic Explofion sc. entftandenen હdaßen haftbar. 
3ur Poftbeförderung bedingt zugelaffene (5)egerftände.

§ 12. (1) Flüifigteiten, Sadjen, die Dem fannellen $\mathfrak{B e r}=$ berben und her F̧äulnif ausigejekt find, unförmfich grofe

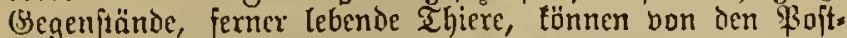
anitalten zurïdgemiejen merben. Bei Sendungen mit lebenden Thieren ijt bom Ilbjender burd) einen fowohl auj die Beglcit= abrefie, als auf die Sendung jelbft zu fekenden Bermert baribber Beitimnung zu treffen, roas mit ber Sendung $g e=$ idjehen foll, menn die ?tmmahme derielgen durd ben

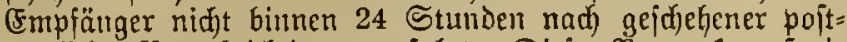
amtlidfer Benadjridytigung erfolgt. Diejer Bermert mußs, je nadf Ber Wahl Des :lbfenders, ber nadffehenden Faffitug entiprecteen:

1. Wenn nidjt fofort afgenommen
(oder: melu nidjt fofort bezogen), zurüct!

2. Wenn ridjt fofort abgenommen,
(oder: menn nid)t fojort bezogen), verfaufen!

3. Wenn nidft jojort abgenommen telegraphifdje (oDer: menn nidft jofort bezagen), Rachricht auf meine

f̧ür Die Behandlung Der Sendungen mit Iebenden Thieren an $\mathfrak{B e f t i m m}$ ungsort ift die getroffene $\mathfrak{B e r f i t g u m g}$

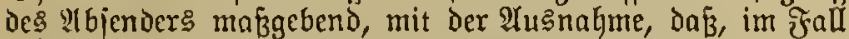

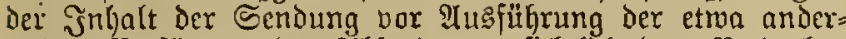

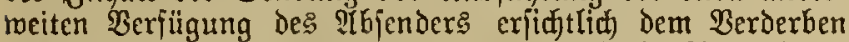
ausgefęt ift, die Beitimmungen de? $\S 45(5)$ in $\mathfrak{A}$ nmendung zu tommen haben.

(2) Fït dergleidhen (Begenftände ze., menn diejelben dennod jur Beförderung angenommen werden, forwie fïr leidjt zer= bred)lidse (Segenftäude 1 mo für in Sdjadjteln verpacte Sadjen, leiftet die Poftoermaltung feinen Exjaz, menn Durch Die Ratur tes Snljalts ber Sendung oder burd bie Beidjaffengeit der Terpactung mährend Der Beförderung eine Beidiäbigung oder ein Berluft entitanden ift.

(3) Zur Bermeniung fïr Sand=Sdjußrmaffen bejtimmte Bündbuitdjen, Bündipiegel und Metalpatronen, jowie $\mathfrak{F}_{\mathfrak{B}}=$ tronen aus ftorfer \$appe mit einem jum Stfut der \$ulber= ladung dienenden B̊lef)mantel müffen in Siften oder Fäfier feft von autien und innen verparft und als foldfe, fotwohl auf der Begleitabrefie, als audj) auj der Sendung felbit, be= zeidynet fein. Die \$atronen müffen fiir (Sentralfener be= fimmt und aukerdem Derart bejufffen jein, daf meder ein Ablöjen Der Sugel oder ein Serausfallen ber Strote, nodi

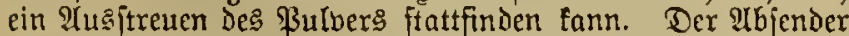
ift, wenn er bieje Bedingungen nidht eingehalten hat, für Den als etwaiger (Entzüniung entftandenen Sd)aden Gaftbar.

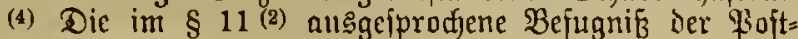
anftalten tritt audy in foldjen Jö̈len ein, in meld)en (brund zu der Innahme borliegt, baß dic Eendungen flitfifigfeiten, Dem iđjnellen Berderben und Der Şäulnif̧ ausgejekzte Sact)en, lebende Thiere, Bündgütchen, Bünofpiegel oder Batronen entGalten.

\section{Dringende Pactetiendungen.}

$\S$ 13. (1) Die \$oftbermaltung übernimmt es, oringenie,

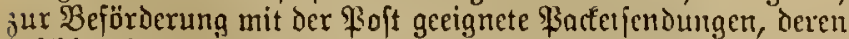

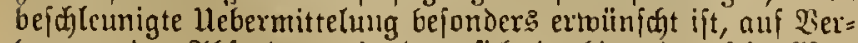

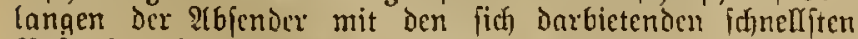
Boftgelegenheiten nach icm Beftimmungsorte zu bejörtern. Das Rerlangen der Einfdjreibung oder cinte Werthangabe ifit bei Driugenden \$actetjendungen niçt zuläffig.
(2) Dic Sendungen müffen bei der Fintiejerung jur Sioftanitalt äuferlid) Durd) cinen farbigen Bettel, meld)er in fettem fdymarzen rypendnuf oder, bei bejonderent fällen, in grofen hancidurijtlidjen Bilgen die Be;eidanumg

\section{"Dringend"}

und Darunter eine furje $\mathfrak{A n g a b e}$ des Snthalts trägt, hertuor= treteno Eimutlich gemrad)t fein. Die 3ugeböriģen Begleit= abreffen find mit Deur gleiden Bermerfe zu berichen.

(3) Dringende \$acfetjendungen miiffet bou Dem ?: 9

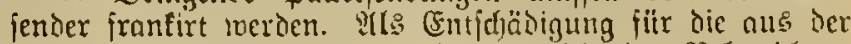
beborzugten Bejörocrumg uno der abmcichentien Beljandtung

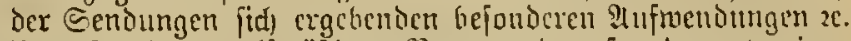

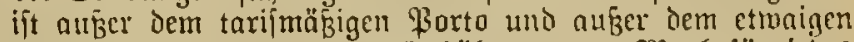
(Eilbeftellarloe (\$ 24) eine (53ebiithi voul 1 Mart fïr jcocs Stïc bei ber Einlieferung ơlu entrichten.

\section{Boftearter.}

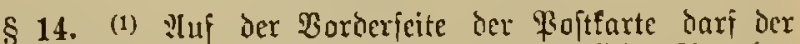
Stbjenter anker den auf die Bejörderung bezüglichen ?lugaben nocf) feinen Namen und Stand oder feine Firma, jolvie

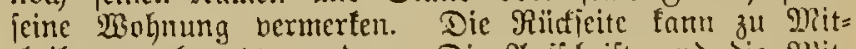
theilungen benutst merden. Die ?hifid)rift und die Dite theilungen fömen nnit Tinte, Bleifeder oder jazbigent Stift geicjrieben merden; nur muÉ bic Edjrijt ljajten uno beut= (id) jein.

(2) Foitfarten, aus Deren Snlyalt dic ?tbfid)t der $\mathfrak{B} e=$ leibigung oder einer fonit frrafbaren fyandlung fich ergicbt, ferner $\mathfrak{3}$ oftfarten, melde nad) Bejeitigung ber uriprïng=

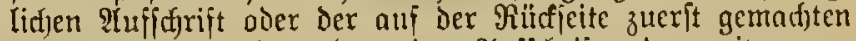
Mittheilungen mit andermeiter 2luffajrift voer mit neuen MRitheifungen verjehen zur \$ojt gefiejert merem, efrejo Bojtfarten mit Beflebung, 3. B. mit aufgetlebten \$hjoto= graphien und Pofttarten mit angejügten $23 a$ aremproben fino von ber \$ojtbejörderung ausgefulofifen.

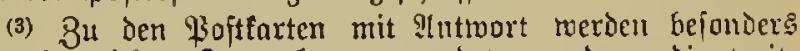

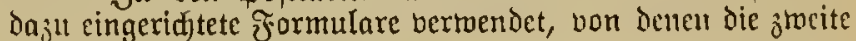
ફülfte zur 2intmort dient.

(4) \$oftfarten müffen franfirt merden. Fiir \$oftforten

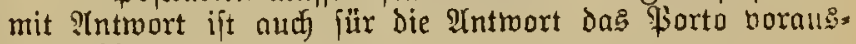
zubezahlen.

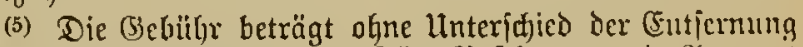
5 \$ij. für jede loftfarte. Für \$3oftfarten mit itntivort meroen 10 \$if. erlyober.

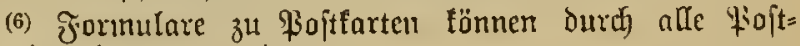
anjtalten bezogen merden.

(7) Ungeftempelte Formulare zu Poftfarten merden jum

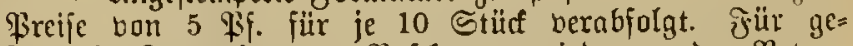
ftempelte formulare zu Pojtfarten witb nur der Betrag Des Stempel erhoben.

(8) Formulare, weldje nidit von der \$ioft bezogen merden, müffen iौ (Sröfize und Stärfe des Sapiers mit ben bon der \$oit geliejerten übereinftimmen, audh auf der Sorberjeite mis ber georudten ober gefdyriebenen lleberjejrift "Fojtfarte" berfehen jein.

(9) Unfiantirte Boftfarten und fold)e ßoftfarten, meldue den äuģeren :Inforocrungen rid)t entiprecten, unterlicgen Dem fiorto für unfrantirte Brieje. F̋̈r unzureidgent frantirte quaftarten mird Dem Eimpfänger Der boppette Betrag bes feblenden Bortotbeils in Injak nebradit, toobei Brudtheile ciner Mart auf eine surth 5 ibcilbare

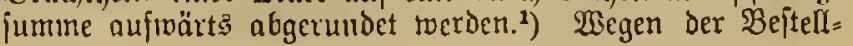


farten für bie 2lbholung von Bacfeten burch die \$acfet= befteller jiehe $\$ 29$ (3).

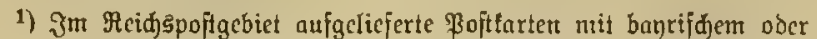
vürttembergifden 2 Berthzeiden, bie $\pi$ id $t$ nah) bemijenigen Bebiete abrefitrt find, weld)en bas $\mathbb{B}$ erthzeidien angehört (olfo cinc bancrifđe

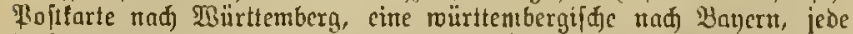
berfelben nach bem Reichspoftgebiet) merben gegen Erhebung oon

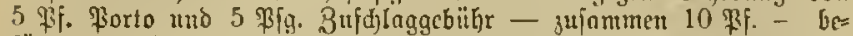
pörbert. Jit bie \$oftente aber nah Demienigen Bebiet abreffirt, woldcm bas 2 ertheidfen angehört (aljo ciuc bayerifdje farte nad) Banern, eine württembergifde ttad 2 ituttemberg), fo finb nur 5 ßj. cintuzichen.

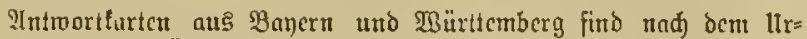
iprungsgebiet gcbührenfrei zu befördert.

\section{Drudfachen.}

\$15. (1) Begen bie für Drudffadjen fejtgefez̧re ermäfägte Inre tötmen befördert werben: alle burd) Budjorud, Supferfitid), Stahl(jtich), \$olzidnnitt, Qithographie, Metallo= arapljie uno Bhotographie nervielfältigten Begenftäntie, meldje nady iljer form und fonftigen Befdjaffenheit zur Bejörderung mit der Briefpoft gecignet find.

(2) Die Scndungen tönten entwèer unter Der :Lfufjurijt

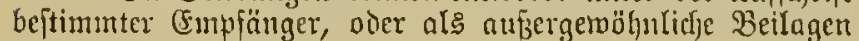
joldjer Zeitungen und Beitjictiften, deren Bertrieb die \$̧oft bejorgt, zur Einlieferming gelanget.

\section{a) Bei ber (Cinlieferung unter ber PLffd)rijt beftimmter}

\section{(Empjänger.}

(3) Die Senoungen müffen offen, แnd zmar entweder unter Streif= oder Sreuzband, ober umidjuitut, oder in citen offenen llmidjlag gelegt, ooer nber dergeitalt einfach 3 us=

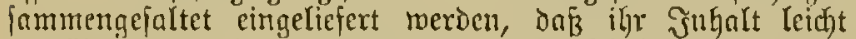
geprïft werden Lann. Unter Band (Beridnüirung) fönnen aud) Büdher, gleid)biel ob gebmnden, gefalzt ober geheftet, werfand merden. Das Band mufs dergeftalt angeiegt fein, on der Sentung auj (Segenftände, beren Serjendung unter Zino geftattet ift, leidft erfannt merden fann.

(s) Drutfiadien find aud in Form offener Sarten zu=

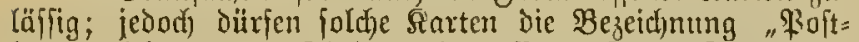
Earte" nidgt tragen. Sino mit Den offenen Sarten Formulare 3u SIntrootstarten berbunden, fo diinfen dieje Doppel= farten gegell das Druffachenporto nut bann verfandt werben, wenu auf den : Iutwortgfarten fidx Poftmerthjeidjen nidjt befinden.

(5) Die Genoung tann eine innere, mit ber äuf̧eren iibereinftimmende 2 luffarift enthalten.

(6) Meljrere Drưffachen bürfen unter einer Itmbïllung berjendet merden, die einjelnen Gegenftände dürfen aber nicht

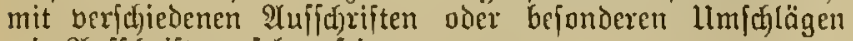

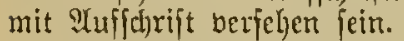

(7) Die Berfendung bon Druffindjen gegen die ermäß̈igte Taxe ift unzuläffig, wenn diejelben, nad) ihrer そrertigung

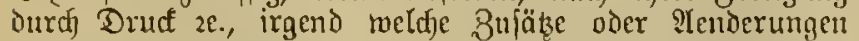
am Fnhalt erhalten haven, toobei es feinen Unterichied madht, ob die Bufätze oder ?(enterungen gefd)rieben oder auf andere $\mathfrak{B e i f e}$ bemirtt find, z. B. Durd Stempel, Durd Drud, burch) Heberfleben non Wörtern, Biffern oder Beichen, Durd)

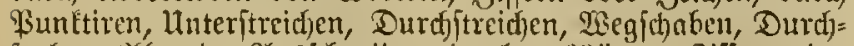

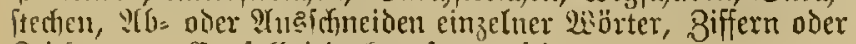
Beidjen ze. (Es foll jedod) gejtattet fein:
1. auf ber $\mathfrak{W}$ (1) nadf $\S 3$ (1) bei Briefen zuläffigen Bermerfe $2 c$. unter den bort borgejdriebenen $\mathfrak{B e d i n g u n g e n ~ a n = ~}$ zubringen;

2. auf gebrudten Bifitenfarten die SInjangshudjftaben iiblid)er formeln zur (Erläuterung Deg Zroed Der Heberjendung Der Sarte Gandforiftlid) anjugeben;

3. auf ber Drucfache ferbit den Drt, den Tag der STbfendung, Die Ramensunterjdyrift oder Firma=

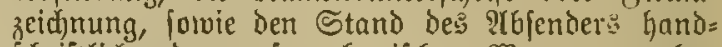
idjriftlid oder auf medjanifjen $\mathfrak{B e g e}$ anjugeben ober abzuändern;

4. Den Rorrefturbogen das Manutript beizufïgen und in Denjelben 2enderungen und Bujäke itt machen, meldje die Sorreftur, die Form und den Druf betreffen, foldje Bufäze nud in (Ermangelung Des Raumes auf befonderen Betteln anzubringen;

5. Druffehler zu berichtigen;

6. gemilife Stellen des gedrutedten Iertes zil durd)= frreidyen, um biefelben unlejerlich z" machen;

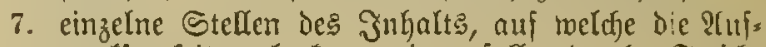
merfjamfeit gelentt werden jod, Durd) Stridje tenntlich zu madjen;

8. Gei ßreisliften, Börjenzettelu und Şandelgkireularen die Breife, fotwie den Ramen des Reifenden und den Tag feiner Durdjreife Gandjdifitlid Doer auf medjanifhem Wege einzutragen ober abzuändern;

9. in Den $\mathscr{Y}$ zacigen über bie 2 bfahrt bon Gduiffen den Ing Der थbjahrt hanof(f)riftlid anzugeben;

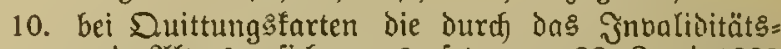

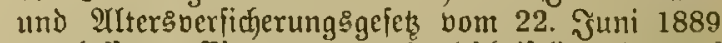
zugelaffenen (Fintragungeu handf(friftlid) oder auf medjanifacm Wege vorjunchmen, die Beitrags: uno die Doppelmarten aufzutleben und bic anf= getlebten Darfen zu entwerthen oder zu ver= nicften;

11. in Die Sendungen mit B̈̈đjern, Mnjifalien, Beit [dyriften, Randtarten und Bildern cine Wiomung hanof(hriftlidf einzutragen, aud diefen Sendungen eine auf Den Preis Der überjandten Bregenftände bejüglidje Rechnung beijujügen und lectstere mit

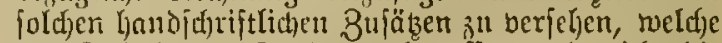
den Şnljalt iex Sendung betreffen und nicht die Eigenithaft einer bejonberen, mit biejem in teiner

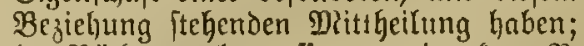

12. bei Büdjerzetteln (offenen gedrudten $\mathfrak{B}$ eftellungen auf Büder, Beitjdriften, ஒbilder und D(ufitarien) die beftelten ober angehotenen Werfe auf der Riüdjeite hanofd)rift(id) zu bezeichnen und ben $\mathfrak{B a r}$ iruef ganz oder theiltweife zu Durdjitreidfen oder zu tunteritreidjen;

13. Nodebilder, Eandearten 2c. atşumalen;

14. hei Drudfacjen, weldje bon Berufignenoffenf juaften nier :Serficherungsanftalten oder von deren Drganen

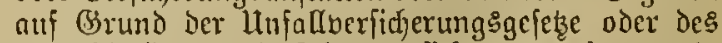

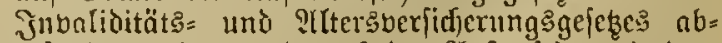
gefandt merben und auf der ?Lusenjeite mit Dem Famen der Berufsgenoffenfidaft oder Der Berfidyes rungsanftalt bejeid)net find, Zablen ober Viamen handidbriftlid) oder auf medjonijacm $\mathfrak{B e g e}$ einju= tragen nder abzuändern und ben Borirnt ganj voer theilmeije zu burchitreidjen. 
(8) Druoffacten miifjen frantizt feiu. Das Borto be= trägt auf alle Entfernungen:

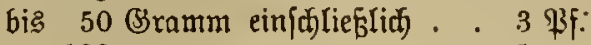

über $50 " 100 " .5$ "

" $100 " 250 "$ " ". 10 "

" $250 " 500$ " . . 20 "

500 Sramm biš 1 Silogramm einfófl. 30 "

(9) Für unzureidfend franfirte Drudffarten mird dem Empfänger Der Doppelte Betrag des fehlenden Fortotheils in ?Injałz gebraht, wobei Brudtheile einer Wlart nöthigen= falls auf eine Durdi 5 theilbare \$fennigiumme aufwart? abgerundet werben. Drudfachen, weldje ben fonjtigen vor= itehenden Beftimmungen nidjt entiprechen, oder unfranfirt fino, gelangen nicht zur 2 bjendung.

\section{b) Bei ber Cinlieferung als aunergewöhulide 3eitungsbeilagen.}

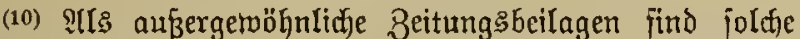
Den Beftimmungen unter (1) entfprediende Drudfactien an= zufehen:

1. welthe nad) Frorm, Bapier, Druff oder fonjtiger Befdraffenheit nicht als Beftandtheile derienigen Beitung oder Beitjdyrift eradftet merden fönnen, mit ber bie Beriendung erfolgen foll;

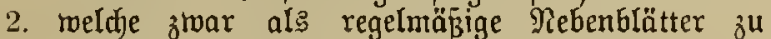
Beitungen eridfeinen, aber aud unabjängig bon Der Şauptzeitung für fich allein bezogen werden tönnen.

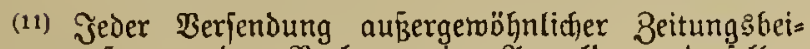
lagen mú bon bent $\mathfrak{B}$ erleger eine Anmeldung derielben bei der ßoitanftalt des 2 ufgabeorts und bie (Entridftung ocs Bortos für fo vicle Exemtplare, als der Beitung ze. bei= gelegt merden follen, norhergeben. Das ceinlegen in die eillzelnen Beitungs: 2 . Eremplare ift Sache des Berlegers.

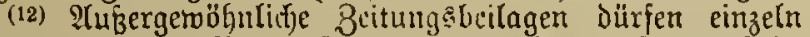

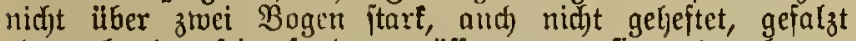
oder gebunden fein, fondern müffen, ment fie aus melyreren Blättern beftehen, in Der Bogenform zufammentängen. Die \$ajtanjalten find zur Zurüweifung foldjer Beilagen befugt, weldje nadj Srö́ze und Stärfe des \$apiers oder nach igrer fonftigen $\mathfrak{B}$ efdaffenheit zur Beförderung in Den Beitungspadeten nidjt geeignet erjojeinen.

(13) Das Borto für Druffiacten, meldye als aufer=

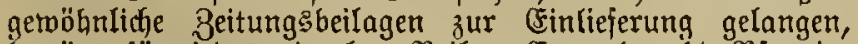
beträgt für jedes einjelne Beilage= (Ecemplar $1 / 4$ Pfennig. (Fin bei Berecfmung des Bejammtbetrages finf ergebender Bruchtheil einer Mart riro nöthigenfalls auf eine burdh 5 theilbare Pfennigfumme aufmärts abgerundet.

\section{Bur Beförberung gegen die Drudfadentare bedingt zugelaifene Shriftitü ofe.}

$\S 16$. (1) Begen die für Dructiactien im $\S 15$ (8) jejtgefeste ermǟigt Tare tönnen ferner befördert werden: bie mittels des Settographs, \$apyrographs, (Ehromograph: oder mitte!s eines ähnfichen lumbrucfuerfahrens, nicht aber mittels der

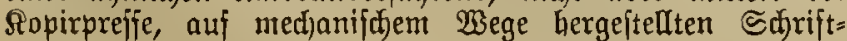
ftücfe, tweldje nach ifrer Frorm und jonjtigen Bejuaffenbeit zur Beförocrung mit Der Briejpoft geeignet find.

(2) Die Cinlieferung der borbezeidyneten Begenftände, altf reldt)e im Hebrigen die Beftimmungen bes § 15 (3), (4)

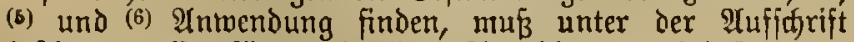

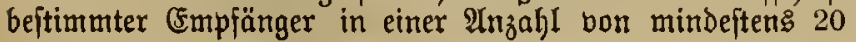

bolffommen gleidflautenden Exemplaren am Fioftfdilter exfolgen.

(3) Die Segenftände dürfen nah ilyrer Fertigftellung

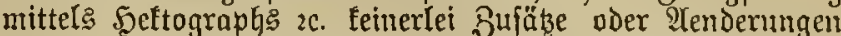
am Jnhtalt erhalten haben, fei es, daß̉ diefe 3 ufäbe hand= f(d)riftich nachgetragen, oder in (Seftalt bon georucten $2 e$. 3etteln beigeliugt oder eingeflebt find.

(4) Scftographien 2e., weldhe borfdriftsmiorig Jurdf bic Brieffaften oder in nidjt genügender $8 \mathfrak{a l} \mathfrak{l}$ zur (sinlieferung

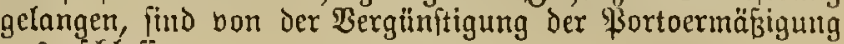
ausgejeftoffen.

\section{Warenproben.}

§ 17. (1) Bjegen die fïr Waarenproben feftgejekte er= mäß̧igte Tare werden nur foldje Wharenproben zugelajien, bie feinen Sondelsmerth haben und nact) ihrer Befdaffentheit, ₹rorm und Berpadung zur Bejörderung mit Der Briefpoft

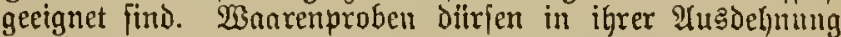
30 Centimeter in Der Eänge, 20 Centimeter in Der Brcite und 10 Eentimeter in Der Soblje nifft überidgreiten. Sriolgt die Cinlieferung in Rollenform, fo dürfen fie teine größere Ausobhnumg haben, als 30 Sentimeter in Der Sänge und 15 (Eentimeter im Durchmejier.

(2) Sinfict)t? der Berpaffung gilt als Bedingung, daf Der Snthalt ber Sendungen als in Waarenprotien Gejtehend (cid)t erfannt werden tann. Die Berpacfung fann unter Band in offenen Briefumjølägen oder in säftchen oder

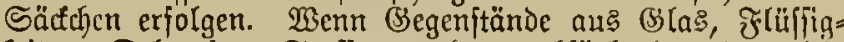
feiten, Dele, fette Stoffe, trocfene, a ffärbende ober nid)t a ffärbende \$3ulver, fomie Iebente Sienen als waarenproben verfanot soerden folfen, io muis ifre Berpactung den bon ber \$oftuertoaltung borgefdyriebenen Bedingungen entipredjen.

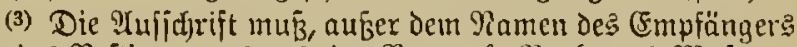
uno des Beftimmungsorts, Den Sermert "Broben" ("Pujter")

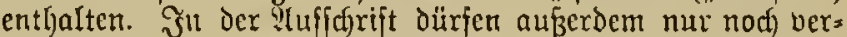
merft fein:

der Rame oder bie Firma des Itbjenders,

bie Fabrif= pder ફ̧andelझzeithen,

dic গiummern,

bie झreije uni

Angaben bejifglich Des (jemidhts, Des Mafizes uno Dex \{uŝdehnung, jomie der berfügbaren Menge, ber Serfunit und ber Ratur ber $\mathfrak{B a a r e t .}$

Dieje IIngaben bürfen ftatt in Der 2 uffiffrift bei nder an jeder \$robe für fich enthalten fein.

(4) Die $\mathfrak{A} u f i d f r i f t$ darf nidft auf einer fogenannten ङ̌ahne der Sendung angehängt, jondern muß auf biefer jelbft angebractit feim.

(5) Den Waarenproben dürfen Briefe nitht beigefdyloffen oder argehängt merden. Mehrere Waarenproben ditrien unter berjelben Umbjülung berjandt werden, die einjelnen Hroben bürfen aber nidht mit beridhiedenen Itufidyriften ober $\mathfrak{u}$ mforlägen mit 2luffdjrift berfegen fein. Die Bereinigung bon Drudfiadjen mit $\mathfrak{B a a r e n p r o b e n}$ zu einem $\mathfrak{V}$ erjendung $3=$ (Scgenitande bis zum (Setwich)t von 250 Bramm ift geftattet; Die bejüglich der 2tusbefnung gezogenen (3) renzen furden

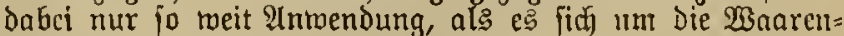
proben felbjt handelt; Die Drucfjadjen müfjen den $\mathfrak{B e}=$ jtimmungen des $\S 15$ entiprect)en.

(6) Die Sendungen müljen franfirt feit. Das \$orto beträgt, gleidjviel ob die Waarenproben für fich allein ber= fande merden, oder ob Druffjacten damit bereinigt find, ofne

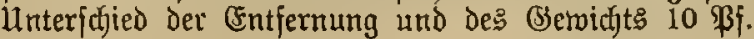


(7) Fีär unzureidjend franfirte $\mathfrak{B a a r e t i p r o b e n ~ w i r d ~ d e m ~}$ Eimpfänger Der doppelte Betrag des fehlenden \$3ortotheil in III a gebrad,t, mobei Bruththeile einer Darf nöthigen= falls auf eine durd) 5 theilbare \$iennigiumme aufwäts algerumbet werben.

(8) Waarenprohen, weldye den voritehenden Beftimmungen nicht entfprecten, oder unfranfirt fino, forbic oicjenigen Waurenproben, we[d]e einen 5andelgworth haben, oder ieren Bejörberung mit Rad)theil oder (Sejahr berbumben iein

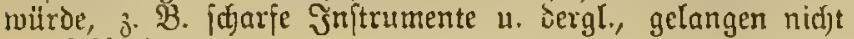
зนr शrbjendung.

\section{(Einjhreib\{endurgen. ${ }^{1}$ )}

\$18. (1) Briefe, Boftfarten, Druffadjen, $23 a$ arenproben,

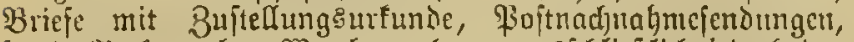

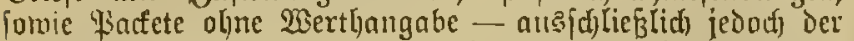
dringenden Fiactete $(\$ 13)-$, fönnen unter (Einfdreibung bejürdert und mïifen zu diejem Zmecfe bon dem StGjender mit der Bejeidinung "Ginf(d)reiben" verieben werden. Dei Bacfeten ofme 2Berthangabe muß dieje Bejeidjnung auf ber Beglcitaidreffe utto alif iem Bacfete angegeben jein; Die Birtung der (Finj)reitung in Bezug auf oie Bemährleiftm erftrecti fict) in biejem Falle nur auf bas \$actet uno nictjt zugleid) aud) auf Dic $\mathfrak{B e g l e i t a d r e f f e . ~}$

(2) Uleber eine eingejintiebene Sendung wiro eine Fin. lieferuutgebcid)einigung ertfeilt.

(3) ₹iti eingejujriebene Sendungen mird, auser dem

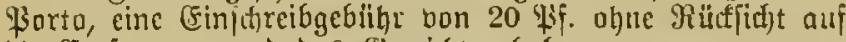
die Crntiermung und das (Semiat erhoben.

(4) Eine Werthangabe ift bei (Einjugreibjendungen nidft зuไäfïg.

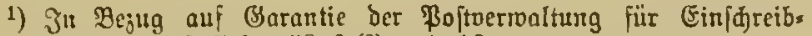

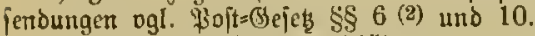

Die bort feltgeleßte Entj山äbigung von 42 Mar? wiro aber nur bei oolfïärtbigem Bcrlujt ber ganzen Seroung bezahlt, nid)t bei theilwcijem Berlujt, oder bei Bejdäbigung ze.

\section{Boftanmeifungen. ${ }^{1}$ )}

§ 19. (1) Die \$oitnermaltung übermittelt im $\mathfrak{B}$ ege Der

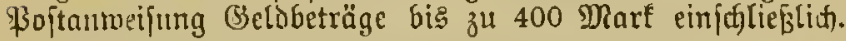

(a) Boitantweifungen müjjen franfirt roerden. Die (Ge= bitlyr Geträgt ofue llnterfafied ber Entfernung:

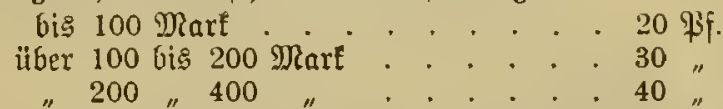

(3) But Softanmaijungen büren nur Formulare benutst werden, meldye von den Fioitanitalten bezagen find. Den Pbjendern ift nidjt gejtattet, fïr eigene Redumng bergejtellte

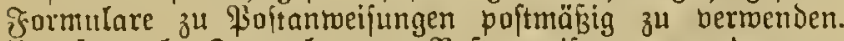
Ingeftempelte Formulare zu \$optanmeifungen werden van den Hoitanitalten in Mengen bon mindeitens 20 Stüd zum Fireije von $10 \mathrm{gj}$. für je 20 Stüa verabjolgt. Für geftempelte Formulare mird nur Der Sketrag Des Sttempel erboben.

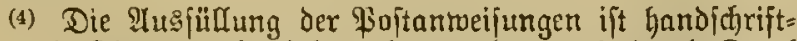
lid) nuit Tinte zu berwirfen, fann aber aud Durd) Drudf geidjeben. Die शingabe des (Seldbetrages hat in ber Reidjs: mährung ju erjolgen. Die Marffumme muF in Zablen und in SBudjtaben auggedritut jein.

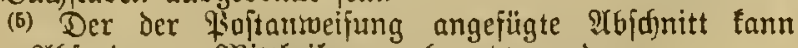

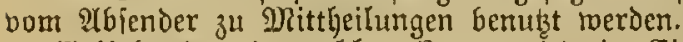

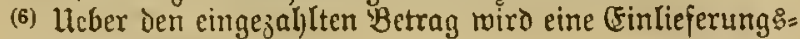
befareinigung extheilt.

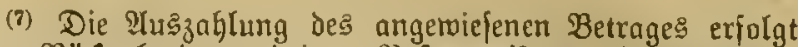
gegen Rücfgabe Der quittirten \$ojtantweifung. Der Mbichnitt ber Poftanmeijung fann bom (Empiünger zurütbehalten merden.

(8) Die Crifhebung des Gelobetrages bei Der Boftanitalt am Beftimmungson't mú, jojern Der Betrag nidjt Durf) ien bejtellenden Boten ïberbracht roird, fpätejtens innerbalb 7 Tage, vom Tage der 2luşbändigung der \$oftantweifung gered)net, erfo[gen. Anderenfalls viro die Rüuzahlung des Seldes an den 2 ufgeber eingeleitet, oder, fofern Derjelbe nid)t z̆u ermitteln iit, dag fïr unbeitellfare Sendungen vor=

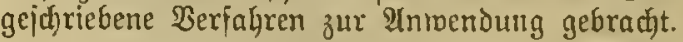

(9) Stehen Der Poftanftalt am $\mathfrak{B e f t i m m u n g s o r t ~ b i e ~ e r = ~}$ forberlidjen Geldmittel augenblicflid) nidjt jur Berfïgung, fa faun die SIugzahlung erit berlangt werden, nach)dem die Befct)affung der Mittel expolgt ift.

(10) Wenu deut Empfänger eine \$ojtanmeijung abganden gefommen ift, fo hat Derjelbe der Boftamitalt am $B_{e}=$ ftimmungsort bon dem Verlujte Mittfeilung zu machen. Zon biejer Hoitanjtalt wird alsdann bei etwaiger Bor= legung der 2rnmeifung die Bablung bis auf Weiteres aus: gejetzt. (Es ift Sadje des (empiängers, Durd 2ermittelung bes 2rbjenters bei der ?lufgabe=\$ojtanjtalt die llebrrjendung eint' nom Tbjender auşufertigenden Doppels ber Fioft= anrveifung ju erwirfen. Bei Der (Finfieferung des Dappets mū bie bei der 2 Lufgabe der ablanden gefommenen qojo $=$ anweijung ertheilte Cinliejerungsbejacinigung von Dem Tufgeber vorgelegt merden. Die Beriendung Des Doppels von dem S(ufgabe, nad) Dem Beptimmunggoorte erfolgt Enftenfrei.

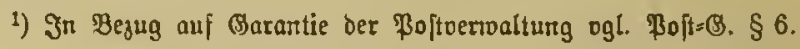

\section{Telegraphiface Boftantocifungen.1)}

\$20. (1) Die llebermeijung auj \$ojtarmeijungen ein= gejahlter Beträge tamn auf Berlangen des $\mathfrak{A}$ (jenders durd) Bermittelung des Telegraphen erfolgen, menn zwijden der Sojtanitalt am Itufgabeort und Der \$oftanitalt am $\mathfrak{B}_{C}=$ ftimmungsort oder auf einem Theile des $\mathfrak{B}$ eges telegraphija)e Berbinduntg beiteht.

(2) Falls ein folches $\mathfrak{B e r l a n g e n ~ a u s i g e i p r o d j e n ~ w i r d , ~ l i e g t ~}$

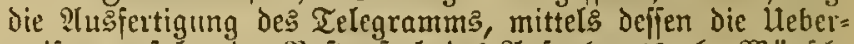
meifung erjolgt, Der \$ojtanitalt des 2Tufgaheorts ob. WBünid)t Der Mbjender Durd diejes Telegramm meitere, auf die Ber= fïgung über Das (Seld bezüglidje Mittfeilunger zil madjen,

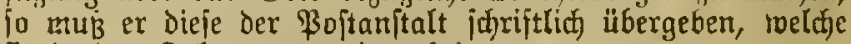
fie in bas Telegramm mit aujnimmt.

(3) Bei telegraphifichen \$oftantweifungen, weldhe an Drten ohne Telegraphenanjtalt jur \$ojt gegeben werden, wird das Telegramm bon der Annahme=\$ojtanjtalt mit der

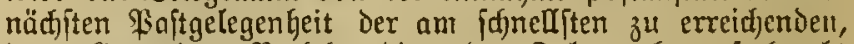
Dent allgemeinen Berfehre dienenden Ielegraphenamjtalt als (Finjachreibjendung jugejülyt. ${ }^{2}$ )

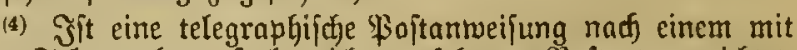
einer Telegraphenamitalt nicht berfehenen \$ojtorte gerichtet, jo erfolgt bic 2 Beiterbeförderung DeS Telegramms von Der lekzten Telegraphenanitalt bis zur Bejtimmung $=$ Pojtanjtalt ebenfalls mit der nädfiten \$oftgelegengeit als (sinjajreib. fendung.

(5) Der Aufgeber hat zu entrichten:

1. die \$oftanmeifungs̊gebühr,

2. die Gebüfr für Dag Telegramm. 


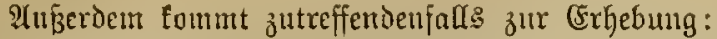

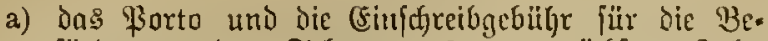
föroerung des Telegrammes jur nächjten Teles graphenaujtalt, joferu am Ifufgabeort eine dem allgemeinen Berfehre Dienende Telegraplyenanitalt nictit borkanden iff;

b) bas Giorto und die (Einjajretbgebühr für bie $B c=$ fürderumy des Telegramms bon der leţen Tele= graphenanjtalt bis Jur Beftimmung $=$ B oftanitalt, falls die telegraphiface Boftanmeifung nady einem mit ciner Ielegraphemanjtalt nidht berjehenen ßojts orte geridhtet ifit;

c) infoferm die Ifnweifung niffyt mit dem $\mathfrak{B e r m e r f e}$ poltlagernd berjehen ift, Das (silbeitellgeld für die Beftellung an Deu Empfänger am Beftimmung: ort oder für bie Beftellung von Der Iebten foit= anitalt narh Dem $\mathfrak{W o l j n o r t e ~ d e s ~ ( 5 m p f a ̈ n g e r s ~ ( \$ ~ 2 4 ) . ~}$

Die Bebühren unter a find ftets bom 2 fbjender voraus: zubezaljlen; dagegen bleibt es in jein Belieben geftellt, ob er die (5ebüfren unter b und c ebenfalls vorausbezaglen

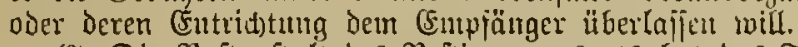

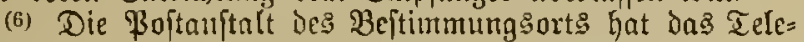
gramm gleid) nadf der 2(ntunft dent (Empfänger durch einen bejonderen Boten zuzujtellen. Die YGajzahlung des angewiejenen Betrages erjolgt gegen Piüfgabe bes mit ber Duittung des cEmpfängers verjehenen Teleqramms.

(7) Die Telegraplyenanjtalter find ermädtigt, in $\mathfrak{B e r}$ tretung ter \$oftarftalt Beträge auf Poftammeifungen, meldye auj telegraphifdyem $\mathfrak{W}$ ege überwiefen werden follen, bon den 2 bjendern anzunehmen oder an Beptimunumgort aus: z"zahlen.

1) 刃gl. Telegraphen=Dronung $§ 14$.

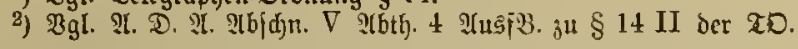

\$o jtnadjnabuejendungen.

§21. (1) \$oitnathnafmen find bis zu 400 Mart ein.

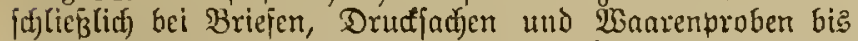
zum (Setvidjt bon 250 (Sramm, fotwie bei \$offfarten umo Facfeten julläflig.

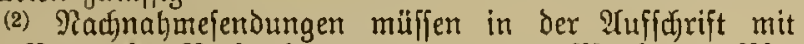

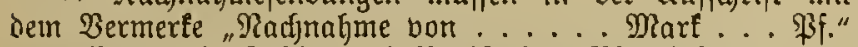

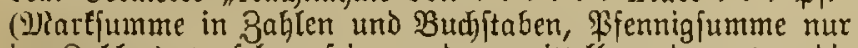
in Baflent berfeljen fein, und unmittelbar datunter die

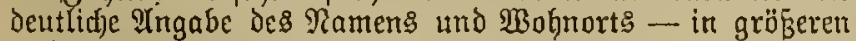
Stäbten aud die $\mathfrak{B} 0$ nung - bes $\mathfrak{a b}$ [enders enthalten.

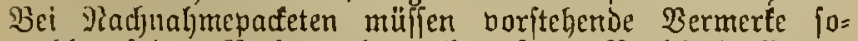
mohl auf Dem Bacfete als audf auj Der Begleitadreffe an. gebrad)t fein.

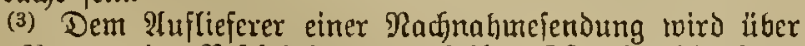

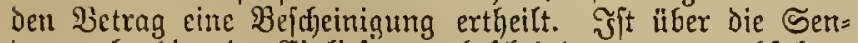
oung ofmehin eine Einlieferungsbejojeinigung zu verabjolgen

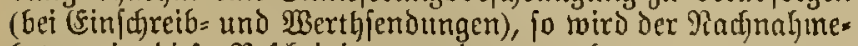
betrag in diefe Befdeinigung mit vermerft.

(4) (Fine 2adf)nahmefendung barf nur gegen Beridjtigung des গachnahmebetrages ausgehändigt werden. Wiro die Senoung nidht immerhalb 7 Tagen nad) Dem (Eingange ein.

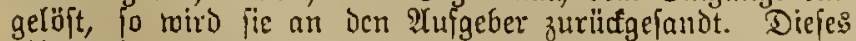
gilt aud von Den Radnahmefendungen mit Dem Bermerfe

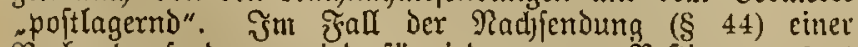
Rachnabmefendung wiro für jesen neuen Beftimmungsort eime bejondere (sinlöfungsirift bon 7 Iagen bereffnet.

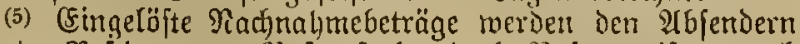
bon der $B$ ejtimmutigs=\$3oftanitalt mittels \$oftanmeifung nach)

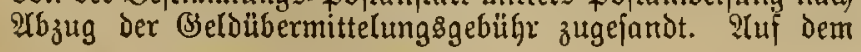

\$obt, Gammlung von Bejesen ac. f. \$oft u. Telegr.
T(b) behalten fam, wird poltfeitig vermert, auf toeldje Nach)= naljmefendung fitf die qoftaumeifung bezielyt.

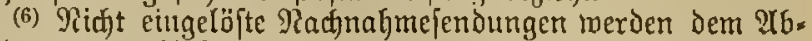
jender gegen Ritidgabe Der unter (3) erroähnten Bejdjeinigung mieder autsgefändigt.

(7) Für Radjnahmefendungen tommen zur Erfyebung:

1. Dass \$orto für gleidjartige Sendungen ohne Radt)= naline.

Falls cine Werthangabe oder (Finfhreibung ftattgefunden hat, tritt dem ßorto dic Berficjerungs: gebiihr oder (Finjd)reibgebühr hinzu.

2. Finte Borzeigegcbühr von 10 \$F.

3. Die Bebühren für Hebermittelung des cingezogenen Betrages an Den ?tbiender, und ztwar:

$$
\begin{aligned}
& \text { bis } 5 \text { Mart . . . . } 10 \text { \$F } \\
& \text { über } 5 \text { " } 100 \text { " . . . . . } 20 \text { " }
\end{aligned}
$$

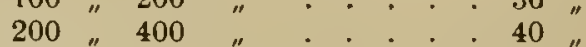

(8) Die Borzeigegebütyr wiro "zugleidj mit Dem \$orto erboben und ift aud Damn zu entrichten, menn bie Sendung nicht eingelọ̈t toiro.

\section{Poitaufträge zur Einziefung oon (Seldbeträgen zur Einfolung von $\mathfrak{B e d f f e l a c e p t e n . ~}$}

§ 22. (1) $\mathfrak{m}$ Wege des \$3oftauftrags tömen

a) Belber bis zum Betrage von 800 Marf einjulief $=$ (id) eingejogen, oder

b) 2Bectjel an Den Bezogenen befufs Einholumg det Irmahme= Ereflärung berjendet toerden.

(2) Dem \$oftanftrage find die einzulöfenden ßapiere

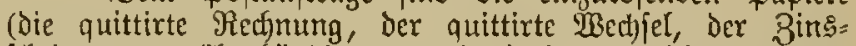

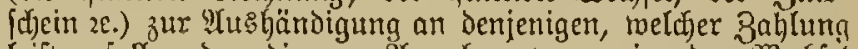
leiften joll, oder bie zmi Annahme vorzuzeigenden $13 e d f$ fel

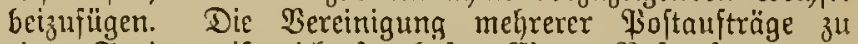
eimer Sendong ift nidjt ftatthaft. (Einem groftauftrage zut

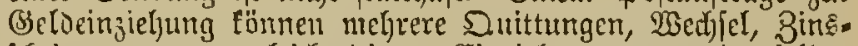
(d) 3al)lungspflidytigen beigefïgt werben; die Bejammtfumme Des einzuzichertien Betrages Darf lebod) 800 Marf nidjt überiteigen. CGemfo fönmen einem \$oftauftrage zur : Fecept= eintolung mehrere wedfjel beigefïgt werden, wenn fie auf

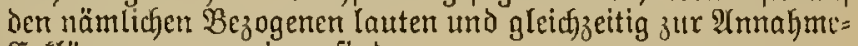
Ertelärung vorzuzeigen find.

(3) $3^{4}$ den $\mathfrak{P}_{0}$ taujträgen für Beldeinzieljung und für

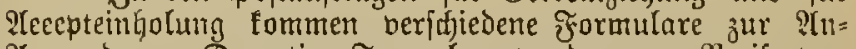
IInvendung. Terartige Formulare werden zum \$reife bou 5 \$f. jür je 10 Stüut bei fämmtlicfen \$pộtanjtalten zum Berfouf bereit gehalten. Den YGjendern ijt nicht geitattet,

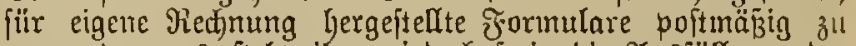

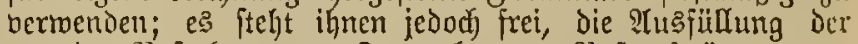
bon der \$oft bezogenen Formulare zu \$oitaufträgen gailz oder theilmeife Durdf Drud bewirfen zu laffen.

(4) Der Muftraggeber hat auf Der Borderfeite des Jormulars anzugeben:

Den Ramen und Wohnort des Baflungsppflidjtigen oder Dę Bezogenen,

Den eirzuziehenden Betrag oder Den Betrag Des

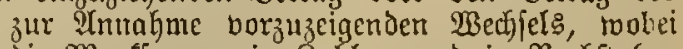
die Marfjumme in 3 ahlen und in Budjftaben ausigebrücț feir muß,

Den eigenen (des stuftraggebers) Pamen mo Bohnort. 
Bei den Boftaufträgen zur Beldeinjiehung ift aup̃erdem Die Zahl Der beigejügten 2̂nlagen cinzurüffen. Ferner ift bei biejen 2tuftrügen geitnttet, im ?iiftragsformular dos Datum Deşjenigen Tages anjugeben, nn meldjem die (Fin: ziegung des Betrages erfolgen joll. Dicjer 3eitputnft ift bann für die Borjeigung oes Bojtauftrags mafgebeni.

Bei Del: \$oftanfträgen jur 2lesepteinfholung bleibt die :

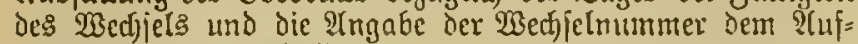
traggeber anljeimgeitellt.

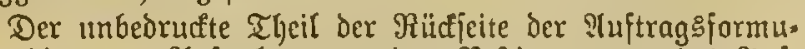

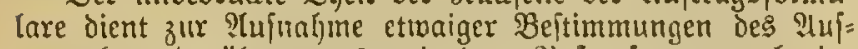
traggebers darüber, was mit dem \$ijtauftringe nad) eins

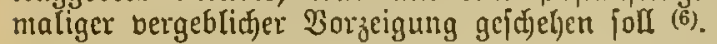

(5) $\mathcal{B u}_{\mathrm{u}}$ idfriftlicjen Mittheilungen an Den Bahlung:

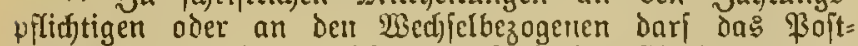

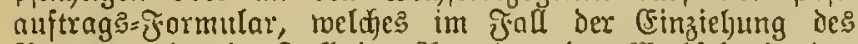
Betrages nder im Jall Der Afmnahme deg $\mathfrak{3 e c h j e t s ~ i n ~ b e n ~}$ Sönden der \$oft verbleift, nid)t benukgt werien. Brieje

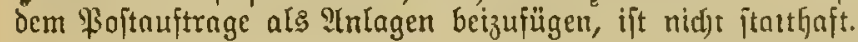

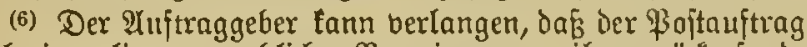
nath einmaliger vergeblict)er Borjeigung an ign zurüctgefandt ober nach einem innerhalb bes Deutjhen Reid)es belegenen Drte, nidht aber nadj Dem Itufgabeorte des \$oitauftrags, neitergefandt werde. Dicfes $\mathfrak{B}$ erlangen ift durd den $\mathfrak{B e r}=$ mert "Sofort jurücf" oder - unter genauer Bezeidjnung eines anteren (Empjängers - durch Den Vermert "Sofort an N. in N." nuj der Rüucfeite bes \$ojtauftrags= Formulare

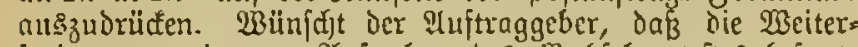

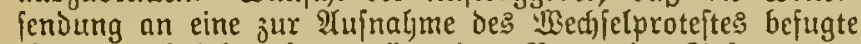
Fierfon gefditebt, fo genitgt der Bermert "Sofort zim Froteft" auf ber Riucfeite bes \$oltauftrags= Sormulars, ohne dá Ferion bedarf.

(7) Der Iuftraggeber hat den \$oftnuftrag unter ber=

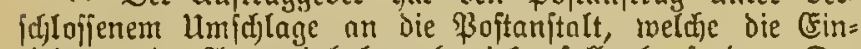
ziebung oder ICcepteinlyolung bewirfen fon, abzufenden. Der Brief ift mit der "lufichrift "Boftauftrag nach.

(Tame der \$ojtanjtalt)" zu berfehen. Eoll bie Borzeigung an einem beftimmten Tage gefhehen, dann darf die Eins lieferung bes \$optauftrags nidjt früber ats 7 Tage vorber erfolgen.

(8) Ueber ben \$optaujtragsbrief wird cine Finlieferung: befdeinigung ertheitt.

(9) Bei Bojtaufträgen zur Geldeinziehung erfolgt die (Finziel)ung Des Betrages gegen Borzeigung des Poftauftrags

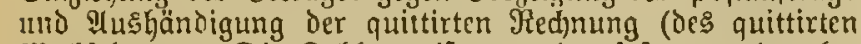
23edffels 2e.). Die Zahlung ift entweder jojort an den be= jtellenden Boten ober, wern oer 2uftraggeber nicjt eine andere $\mathfrak{B e f t i m m u n g}$ (18) getroffen hat, bimen 7 Tngen llad) Der Borzeigung de: \$ojtauftrags bei der einjieheriden Gojtanjtalt ju leiften. Die 7 tägige \&agerfrift ift von bem: ienigen Tage $a b$ zu redjun, meldjer auf den Tag des eriten itattgeljabten Berfud)s der Borjeigung jolgt. (Erfolgt Die 3ahlung inmergatb biejer orift nicht, fo wiro ber \$oft=

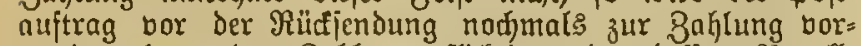
gezeigt; hatte der Znhlungapflidftige ober beffen Beboll= mähtiger bereits bet der eriten $\mathfrak{B o r z}$ eigung dic Finlöfung cnogulttig vermeigert, fo unterbleibt die nodmalige Bor:

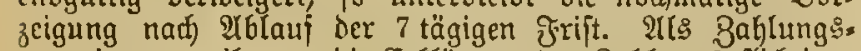
nerweigerung gilt nur bie (Erflärung des 3alylungšpflid)tigen felbjt oder Deffen Beballmädtigten. Theilzahlungen merien nid)t angenomtmen.
(10) Der eingejogene Betrag, nad) 2tbredhnung Der $\mathfrak{B}$ oft

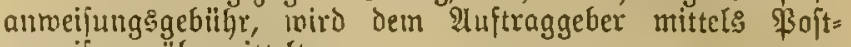
anmeifung übermittelt.

(11) Dem $\mathfrak{B}$ เlieben Des 2uftraggebers ift eร überlafien, tem \$ojtauftrage das ausgefitnte formular der \$oft ambeifung beizufïgen. Soldje ßoftanweifungen find bis zun Meiftbetrage von 800 MRart zuläffig. Die (Sebüljr für cinc Foftauftrages=90ftanmeijung im Betrage von mehx als 400 D)art ift nact) denfelben Säben zu berechnen, wie für zınei \$oftanmeifungen bis 400 Diart. Jn bem beizufügen= ben Poftanmeijungs=Formulare darf nur derjenige Fetrag tier Forderung angegeben merben, meldjer nach $\mathfrak{A b z}_{\text {zug }}$ ber Fioftantreifungsgebübr übrig bleibt.

(12) Bei łoitnufträgen jur Areeptcinholung exfolgt dis

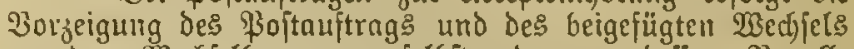
an Den Wectfelbejogenen felbjt oder an defien Beboll=

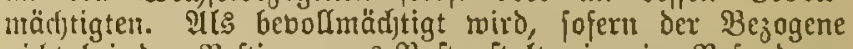
iidft bei der Beftimmungs=\$oftanfalt eime im Befonderen auf Die ?'(nuahme bon W3edffeln lautende Bollmad)t nieder: selegt hat, poftjeitig jede foldhe \$erjon ange[eljen, meldje jur (Empjangnahme von 2tblieferungsf(t)einen ither Sendungen Init ciner 3 erthangabe im Betrage bon mehr al: 400 Marf für ben $\mathfrak{B}$ ezogenent bered)tigt ift.

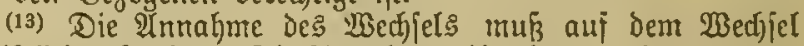
f(f)riftlich gejdehen. Die Sinnalyme gilt als berweigert, toenn bicjelbe mux auf einen Theil ber $\mathfrak{B}$ edjfelfumme erfolgt, oder

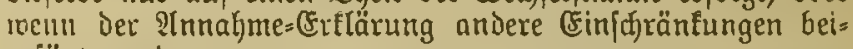
gefügt merben.

(14) Der angenommene Wedfiel wiro von ber Beptims

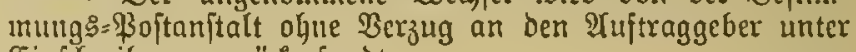
Finfitrcibung zuriidgefandt.

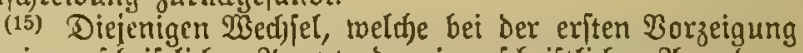

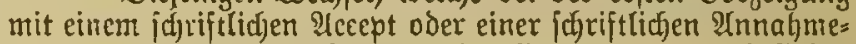
bermeigerung nidft berjehen morden find, merden nad fieben Tagen nodjmals borgezeigt, falls nifjt Der $\mathscr{X}$ uitraggeber

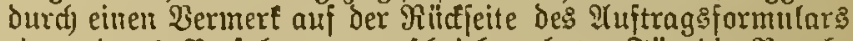
ein anderes Berfahren vorgeldrieben hat. Fiur die Bereft)= nung der fiebentägigen \&agerfrift gelten bie Beftimmungen unter (9).

(16) $\mathfrak{U}$ Sonntagen uno an allgemteinen Freiertagen findet die Borzeigung bon \$oftaufträgen nicht ftatt.

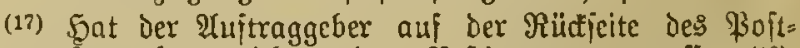
auftragsformtulars nidjt andere Beftimmung getroffen (18), fo ift ber \$ojtauftrag nebit ?Inlagen an ihn zuriüfulenden, fobald feftiteht, Daß̧ ber Zahlungs̆pflidtige oder ber $\mathfrak{B e d j j e l s ~}$ bezogene nidft ju ermittelm ift, over bos bie zahlung und

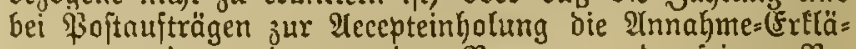
rung berweigert, oder bon dem Bezogenen oder feinem $\mathfrak{B e}=$ vollmähtigten eirte die Berweigerung der YYnnahme nus=

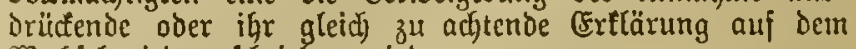
Bed) fel niedergefarieben roird.

(18) Ulle ßoitaufträge, auf weldhen für ben fall der Rid)teinlöjung oder der bertweigerten 2(nnal)me dic fofortige Rü̈fiendung, bie $\mathfrak{3 e t t e r j e n d u n g ~ a n ~ e i n e ~ a n d e r e ~ \$ e r f o n ~ o b e r ~}$ Die 23eitergabe zur \$rateitaujnahme berlangt ift, werden fofort nad) ber eriten bergeblidjen Vorzeigung bezm. nad) Dem eriten vergeblict) gebliebenen Berfuthe Der Borzeigung,

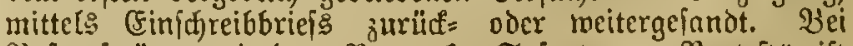
\$ojtaufrägen mit Dem $\mathfrak{B}$ ermert "Sufort zum \$roteft" ift mit det Weitergabe des \$oitauftrags und Defien 2lnlagen

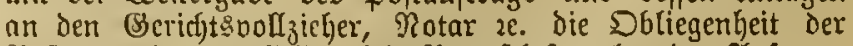

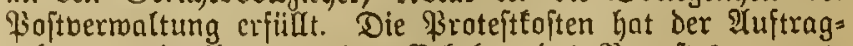
geber unmittelbar an den Erbeber des \$rotejtes zu ent= ridfter. 
(19) Die ßojtbermaltung haftet für eine \$ojtauftrags: fendung twie fïr einen eingejacicbenen $B$ rick, für den ein= gezogenen Betrag aber in beniflben Umfange, mie für bie auf \$ojtantweijungen eingejablten Beträge. Eine roeiter= gebende Bemähr, insbefondere für red)tzcitige $\mathfrak{B}$ orzeigung oder für rechtzeitige Rüct= mid Weitcrfendung des \$oft =

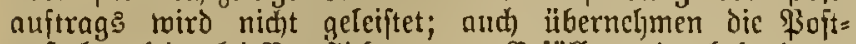

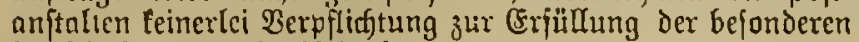
Borfdfriften des 2 echjelredts.

(20) Jïr cinen \$oftauftrag fommen folgende Bscbühren in $\mathscr{2}$ nfatz:

1. Borto für Den \$ojtauftragşbrief mit 30 \$斤.

2. a) bei \$oítaufträgen zur Seldeinzichung die torif= mäßige \$ojtantweifungs̊gebühr fïr bie Ueber= mittelung bes eingezogenen (S) elobetrages;

b) Gei Boftaufträgen zur Irceepteinholung \$orto für bie Rüdffendung Des angenommenen $\mathfrak{W e d f f c l s ~}$ mit $30 \mathrm{Bf}$.

Das \$orto unter 1 ift bom Ahftraggeber borauşu= bezaljlen. Die \$ojtanmeifungsggebühr $(2$ a) miro boul dent cingejogenen Selbbetrage in $2 b_{3} u g$ gebract.t. Der Porto= betrag unter $2 \mathrm{~b}$ mirb Dem Aujtraggeber bei Hebericndung des angenommenen $\mathfrak{B e c h j e l}$ angered)net.

Şit die 3ahlung des (3)ldbetragę oder die 2lnnahne Des $23 c c h$ fels vermeigert toorden, fo mirt bie Rücfiendung ies 2luftrags und dic Weiterfendung ieffelben an cinen anderen (Empfänger oder an eine zur भufnalyme Des Wed) felprotefte? bejugte Perion ofne neuen sebübrenanjał berirtt.

\section{Poftaufträge zu Büberpoftienoungen.}

$\S$ 23. (1) Den Büdjerpoft fendungen, $b$. i. Den Sendungen mit Büd)ern, Mufitalien, Zeitfhriften, Randtarten und

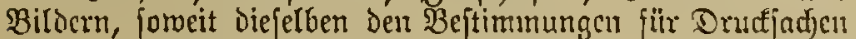
(§ 15) entiprecten und ein (Semicht von mehr als 250 (Sramm laben, Darf gegen Zahlung Der jür Drudfiachen fejtgeicksten ermäfigten Taxe und einer bcfonderen, bom 21bjender zu entrid)tenden Bebitigr von 10 PF. ein ßojtauftrag jur Ein= ziehung ber bie Sendung betreffenden Redjnung beigefïgt meroen.

(2) Dic भUfichrift Der Cendungen hat zu lauten: "Poft=

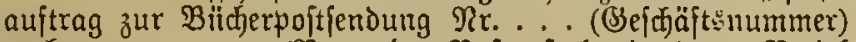
nnd ......... (Name der Poltanftalt, in deren Bezire Der (Empjänger mofint)".

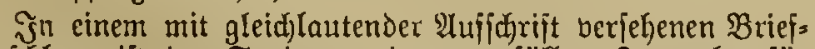
um[ablage ijt ber Sendung cin ausgelüntes formular fitr Boitaufträge zur Einziełung bon Belobeträgen, fotwie ein ausgefiiltes Poitantwcifung šsormular fo feit beizufügen, daÉ untermegs fich fein Iheil bon Der Sendung trennen fann. 2tuf dem Iuftragsformular muf Der Ueberforift "Poftauftrag" oer Bermert "żur Bïderpoftjendung" zuge= lekgt und Dahinter die Geldjajtşnummer wicderfiolt fein. Das Verlangen Der $\mathfrak{B}$ eitergabe oder $\mathfrak{B e i t e r}$ endung ijt bei diejen \$oftanjträgen nicht zuläfifig.

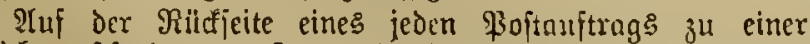

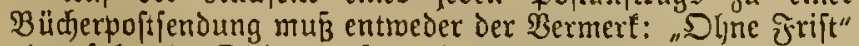
oder folgende Quittungsformel niederge(d)ricben fein: "Die QUllagen diejes \$ojtauftrags habe id) ohne Bahlung Des um= itehend angegebenen (s)eldbetrages empfanger. ..."

(3) Ueber B̧äd)erpoftfenoungen mit \$poftaujtrag mirò eine (Einliefermgsbejdeinigung nid)t ertheilt, fofern oer 2 bjender

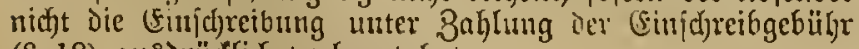
(§ 18) ausorüuflich) verlangt hat.

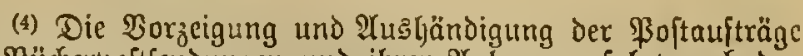

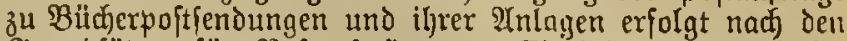

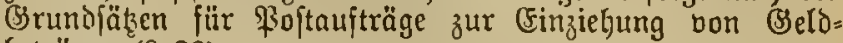
beträgen (§ 22).

Wird die Innahme fofort nermeigert, fo mirb dic Gendung an ben ?ibjender toftenfrei zurüffgejandt, unb z'war unter (sinfd)reibung, menu fic bei der (Finliejerung einge d)ricben worden war. (Fin (S) Feidjes tritt cin, wern bei folden Sendungen, Deren Foftauftrag den Vermerf: "Sline frrift" trägt, bei der erften Borjeigung die $\mathbb{B}$ ahlumg

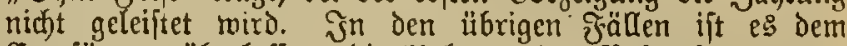
Empiänger ïberlaffen, die sInlagen deg \$Boftauftrags ents meder unter Bahlung des vollen Sseldbetrnges, weldher auf leţterem angegeben i ît, oder unter dem Berlangen ber ipäteren Beridjtigung diejes Betrages anzunehmen.

Wird ber Betrag nidjt fofort berichtigt, jo werden dem

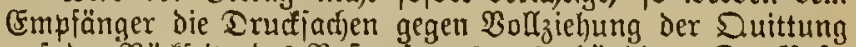

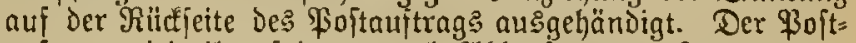
auftrag wird ihm joonn nad) T(Glauf bon 7 Tagen nod)= mals befures $\mathfrak{B c r i c h t i g u n g}$ der Âjtragsfumme vorgezeigt. Die fiebentägige Eagerfrifi jit bon Demjenigen Tage ab ju $^{11}$ recfinen, weldjer auf den Tag oes erften itattgehabten $\mathfrak{B} e r=$ fudj) ber Borzeigung jolgt. Sit and bei biefer zweiten Borzeigung bie 3nhlung nid)t zu erlangen, fo mirb ber mit entipredender Bejhcinigung des beftellenden Doten zu ber: feljende Moftanftrag fammt beigefügtem gioftonmeifungs: Jormular ohme Tnjojeiben aIs \$oftjadje an den ?lbjender zurïfgefandt. Crine Burüdnalyme ber Drudfadjen feitens

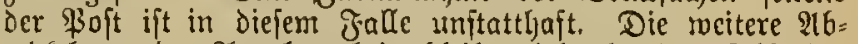
mictelung Der Stngelegenljeit bleibt bielmehr dem 26jender nnd (Empjänger iiberlafjen.

(5) Die für Bütferpoftienoungen mit Poftauftrag bc=

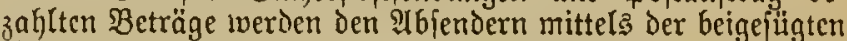
joftnnmeifung übermittelt, und ztwar unter Berechnung bes tarijmäßigen đ̧rantos für lektere.

(6) Jïr die auf Biidjerpoftiendungen eingezogenen (B)eld= beträge haftet die \$oftberwaltung wie fïr die anf \$oft= anrueijungen cingejabltels $\mathfrak{B}$ eträge. (Eine reitergehende $(5)=$ toähr, insbejondere gegen $\mathfrak{B}$ erlujt und Bejwäbigung der $\mathfrak{B}$ iidjerpoftiendungen, fowic fïr red)tzeitige $\mathfrak{B}$ orzeigung, $\mathfrak{B} \varepsilon=$

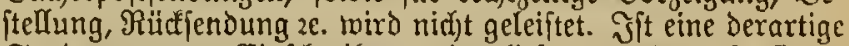
Sendung unter (Finjd)reibung eingeliefert roorden, fo findot Geroügrleiftung in gleidjem Umfange wie für (Finfdhreib= jendungen ftatt.

\section{Durdf (Eilboten zu beftellende Sendungen.}

§ 24. (1) Sendungen, weldhe jogleid) nnch der 2untunft Dem (5mpfänger befonders zugejtelt merden follen, müffen in ber $\mathfrak{A} u f f(c) r i f t$ einen $\mathfrak{S e r m e r t}$ tragen, weldjer unzmeideutig Das Berlangen auşdrtitft, onf Die Beitellung fogleich nad) Der Infunft Durf) befonicren Boten eriolgen polf (\&it= beitcling). Diejem 3meaf entfpredfen folgende, bom 2 Ib= fender durdf Itnteritreichung heroor 3 ulgcbende $\mathfrak{B}$ ermerfe: "Durd Eilboten", "Duref bejonderen Boten", "befonders z" "bejtellen", "fofort zu bejtellen". Bezeid)nungen, wie "cito,

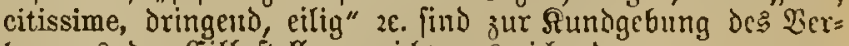
langens der (silbejtellung nicht ausiteidend.

(2) Jm శalle der Boraugbezahlung deş Botenlolng hat

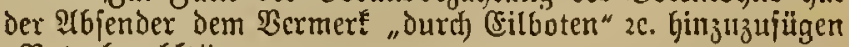
"Bote bezahlt".

(3) Bei Seubungen an Empiänger, die im Drtšs oder

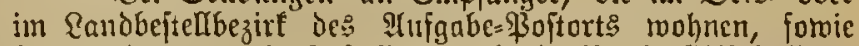
bei Sendungen mit Zuitellungsurfunde ijt dic Filbeftellung ausgefdifofien. 
(4) Semöhnlidje und eingcidriebene Brieffenoungen, \$̧oft= anmeifungen nebft ien Gribbeträgen, अadfete ohne Werth= angabe biङ zum Gicwidjt von 5 Silogramm und Sendungen mit Werthangabe bis jum Betrag von 400 Marf und bis jun Giemidht bon 5 fillogramm werben Den Eilboten mit= gegeben. Bei jdrwereren \$iarfeten, forwie bei Sendungen mit Göberer Werthangabe erjtreft fich die Berpflidjtung jur Beftcllung auf die Begleitabreffe ober den Ilblieferungsidjein.

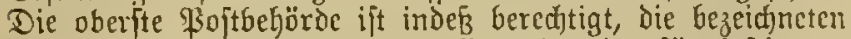
Scroidsts= und Werthgrenjen nUgenein oder für beftimmte Srte Dauernd oder borúbergeheno zu ertweitern und bie unter (5) jejtgejeßzten (Sebühren entiprechend zu erböber; cbenfo fann dic \$oftbchörde, fomeit es fich um Werthfenoungen, 界oftantweijungen ober \$acfete bandelt, die Eifbejtellung fïr

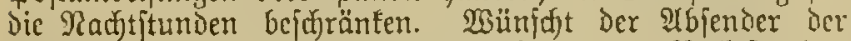

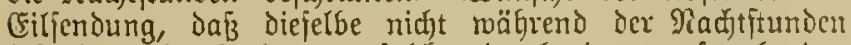
beftellt merde, fo fann er foldjes burdy einen entipredjertion Bermert in Der $\mathscr{U}$ ufforrift beftimmen.

(5) Für die (Filbeftelung find zu entrid)ten:

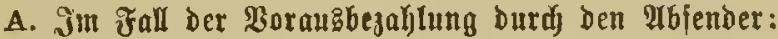

a) bei Sendungen an Empjänger im Drţ̧bcitellbczirt der Poitanjtalten, und zrvar:

1. Gei gemöhnlidben und cingejariebenen Bricf= fendungen, fowie bei Bricjiendungen mit Nad), nahme, \$oftantweifungen nebjt den Beträgcn, Briejen mit Werthangabe bis 400 Mark, $\mathfrak{U b}=$ lieferungsfäeinen über Belobriefe mit höberer Werthangabe und Begleitadrefien ofme die ju= achörigen \$actete: für jede Gendung 25 \$SF.;

2. bei Bacfeten ofne Werthangabe mo mit $\mathfrak{B}$ merth= angabe bis zum $\mathfrak{B}$ ctrag von 400 Dart, went die Gendungen jelbjt bejtellt merben: für jedes \$adet 40 \$F.;

b) bei Sendungen an Empfänger in Sanbbeftellbezirt ber \$oitanftalten, und zmar:

bei Den unter a 1 genannten Segenjtänden fïr jede Genoung 60 Ұ\$F., bei ben unter a 2 be=

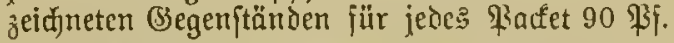

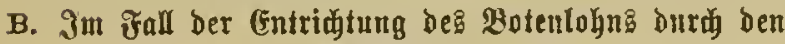 (Empjänger:}

bei allen Sendungen die wirflich ermadjfenden Botenfoiten

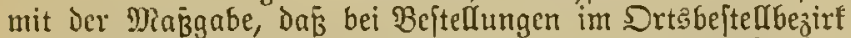
für jeben Beftellgang mindeftens 25 \$j. und, menn \$actete abzutrager find, mindejtens 40 \$jj. in injaks fommen.

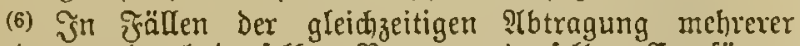
Sendungen Durch Denjelben Boten an denielben (Empfänger mird bas Botenloly nur zum einfadjen Betrage eihoben. Sind mit Filbriefen zugleidf Filpactete abjutragen, fo fommen

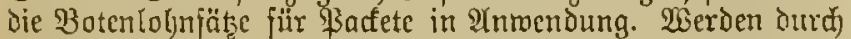
Deniclben Boten an Denjelben (5mpfänger gleidjảtig joldje Gilpoitfendungen abgetragen, für velcje bas (Eilbeftligelo im Boraus bejahlt ilit, und foldje, bei meldien dies nidht Der ङुall ift: fo ift bom Empfänger bas wirtidje Botenlohn abzühlid Der im Boraus bezahlten Beträge ju entrichten.

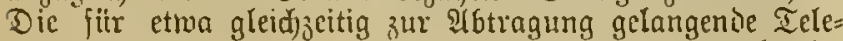
gramme in פoraus bejablte Beftellgebühr blcibt bicrbei aufier Betradjt.

(7) Reidien bei Sricjendumgen, vneldie im Brieftaiten borgefunden roerden, dic vermenteten đreimarfen zur Detung des fiortos und Der filbeitelfgebïbr nidjt aus, fo fommen

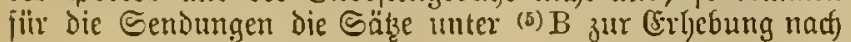

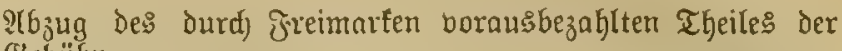
(Bebilitr.

(8) Derweigert Der (5mpiänger die Baโlung des Boten= Iohns, io ijt dic Gendung als unbejtelbar zu behandeln.

(9) Einc SBcjöroerung bon Ecudungen mittels Filboten bon (Finlicicrungsort nad) cinem anderen Poftorte findet micht jtatt. Dagegen fann auj Berlangen Der 9्lbfender dic hejondere Beförderung von Eendungen, welde einer \$iojt= anftalt bon weiterlyer zugehen und nach einem anderen \$iojt= orte geridytet find, Durd Filboten ftattinden, toenn die Cintfernung juijufen den beiden Poftanftalten nidft ïber 15 Sillouncter beträgt. Dic ?luffchriften Derartiger Sendungen uitffen unter Der Ŷngabe ies Beftimmungsorts Den Bermerf entljalten: "Don (Bezeicfnung Der Boftanftalt, vour roelder art: Die Bcförberung Durch (Eilboten erfolgen joll) ourd) (cil= boten". Für derartige (Filfenoungen find burdjmeg, alfo

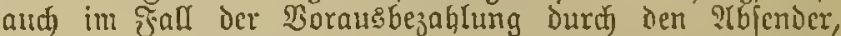
die wirflid) ermadjpenden Botenfoften, mindeftens aber dic unter (5) A b bejeicfneten Säbze, zu entridjten. Der $\mathfrak{A b}$.

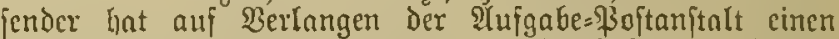
angeneffenen Betrag zur Dedung diejer Rojten zu hinter= 【egen. Bertociger't der Empjänger die Babluma des Boten= lohns, io wird ifm die Sendung gleid)mohl Gehändigt, wenn

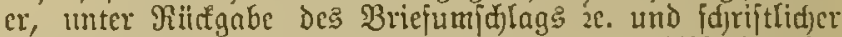
Inertennung ber Bahlungsverweigerung, Den शlbjender bc= zeiffnct. Die Roften Der Beftellung find alsbann bon Dem Reşteren zu tragen.

\section{Bahnhojzgriefe.}

§ 25. (1) Wünjŭt cin Empjänger Brieje von cinem beftimnten $\mathfrak{A} b$ fender am Bahnhoi ummittelbar nad) Intunft

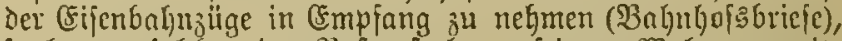
fo bat er joldjes der \$3oftarftalt an feineur Wobnorte mit= zutheilen. Die Roftanjtalt ftellt dem Empfänger gegen (Entridtung Der im $\mathfrak{A b j a t z ~ ( 4 ) ~ j e i t g e j e t s t e n ~ ( S e b u ̈ h r ~ e i n ~ d u r d ) ~}$

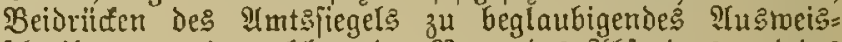

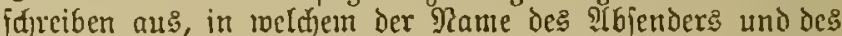
Crmpiängers, ber @ijenbahnzug, mit meldjem dic Bricie regelmäß̆g :

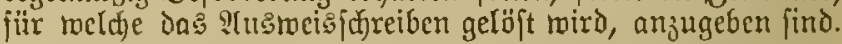

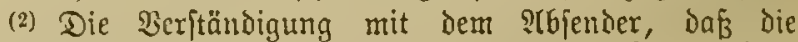
Bahntofabricfe ftets ou demjelben Buge aufgeliejert werben, licgt Dem Cinipänger ob.

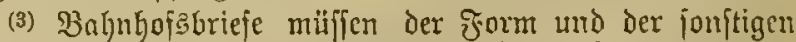

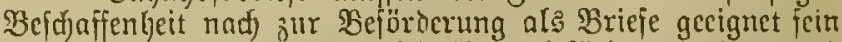
und Dïrfen weder unter (Finfdreibung beförbert werden, nod

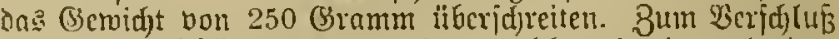
find Briefmidjläge ju verwenben, weldje mit cimem breiten rothen Ranbe verieben fimd und asn Ropf in grofen Bud)= ftaben dic Bejeid)nung, sBabnhofabric" tragen; auf ber

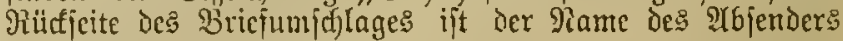
auzugeben.

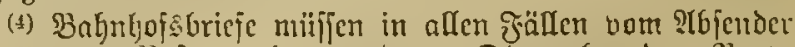
pranfiut zur 将oit gegeben merden. Die neben bem \$orto

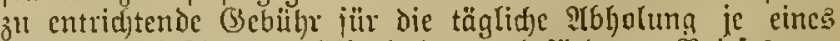
mit cinem heftimmten Eifenbahnjuge bejöroceten Briefes non

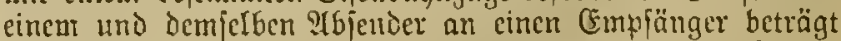

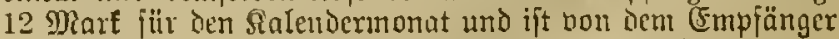
mindciteng jür cinen Pionat im Boraus zu jchlen.

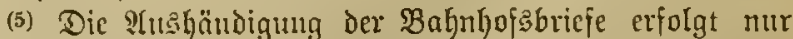
gegen Vorzeigung Des UHEిneisfd)reibens. Deldet fid) Der whboler nidit red)tzeitig, fo merben bic SBricfe gegen die im $\$ 24$ (5) unter B jeftgejetzte (Gebüly durd) (Filboten bejtellt. 


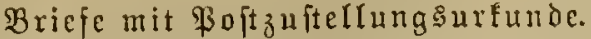

§ 26. (1) Wä̈nfdt der Mbjender cines getwöhnlicjen oder eingefdriebenen Briejes liber die erfolgte Beftellung

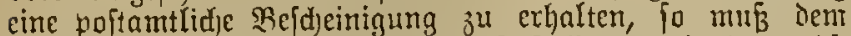
Brieje eine gehörig ausgefitâte Bujtelfungsurfunde nebjt

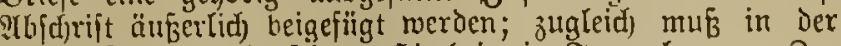

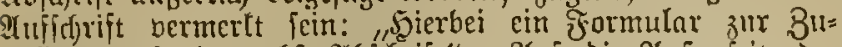

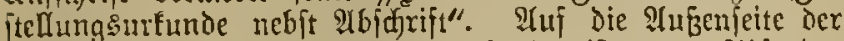

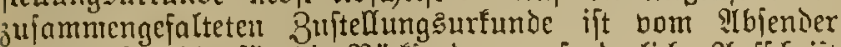

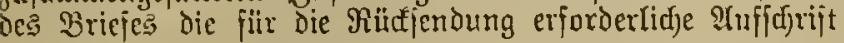
3̆

Эิn B̧etreff Der Beftellung 2c. Der Briefe mit Buftellung: urfunde fielie $\$ 41$.

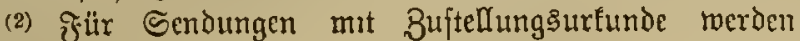
exthoben:

1. Das gemöljnlidje Briefporto,

2. eine Bujtellung:gebühr von 20 \$广.,

3. das \$orto bon 10 PF. für die Ritffendung der Bufte(1)

Wird die (Finfdreibung berlangt, fo tritt den ßarto zu 1 die (Finjdreifgebithr bon 20 \$F. hinzu.

(3) Jormulare, meldie jomohl zu Uridgrijten als audj zu S(bjd)riften von Buftellung:urfunden berwendbar find, tönnen Durd die Poitanjtalten zum \$reije bon 5 PYi. für ie 10 Stïd bezogen merden. Die \&ieferung bon formularen an (Serid)te, Seridhtsonolzicher und Beridjtsid) reiber exjolgt unentgeltlidf).

1) Bei Briefer mit Bụtellungsurfurde ar cinwohner bes Drts=

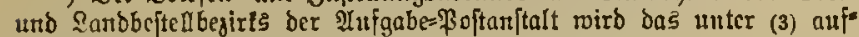
geführte ßorto für bie Rüđjeridung ber Bujtelungsurlunde ridit er= hoben (ogl. (Bcbithrettarif fïr ben \$oftvertchr, §10).

\section{Behandrung oronungsiorig befduffener Sendungen. ${ }^{1}$ )}

§ 27. (1) Gendungen, reldje nidft den borjtelenden Beftimmungen gemäß berpadt und berfd]loffen 2e. find, fönnen Dem Einlieferer zur Serftellung der borjdurijtsmäß̈igen Beidaffenheit zurüdgegeben merben.

(2) Berlangt jebodh Der (Finlieferer, Dex ifm gejdechenen Bedeutung ungeadtet, die Bejörderung oer Sendung in ihrer mangelhaften $\mathfrak{B} e$ ejaffenheit, io mü die Beförderung gefdehen, wenn aus den gerüigten Miängelu ein Padjtheil für andere Pojtgüter oder eine Störung der Dronung im Dienjtbetrieb nidht zu bejürdyten ijt, ber (Einlicjerer audj auf

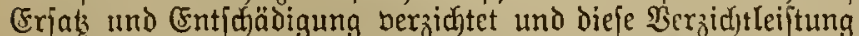

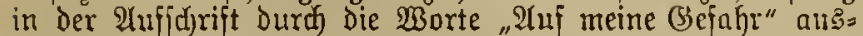
brüft und unterforreibt. Wiro über die Sendung eine (Finlieferungsbejcheinigung extheilt, fo hat dic Fojtanjtalt ulber die Berjidjtleiftung Des (Einlicjerers in ber Befdyeinigung

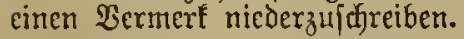

(3) 2(ud) wenn die Innahme der Sendung nidjt regen mangelhajter Bejdjaffenheit beanjtandet moroen ijt, hat

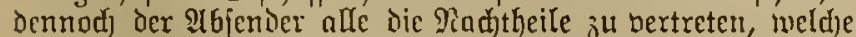

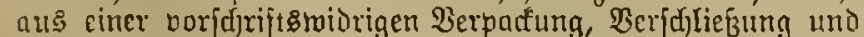

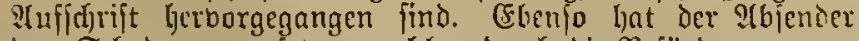
ben Sdjaden zu crjeken, melder Durdh dic Beförderung von (5)egenftänden entfteht, die bon ber Pojtbeförderung aus: gejulojien oder zur f'ojtbejörderung nur fedingt zugelaffen find ( $\S \S 11$ und 12).

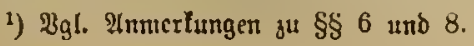

\section{Beitungsoertrieb.}

§ 28. (1) Soll eine Beitung der \$ajtvermaltung jum Bertrieb übergeben werien, fo hat ber $\mathfrak{B}$ crleger cine ent= ipredfende jdjriftlidje (Erklärung nad) Miajgabe der von bir Pojtbermaltung vorgeidriebenen Jaffung bei der \&ojtanjtalt nicderzulegen.

\section{Drt der cinlieferung.}

\$ 29. (1) Die Einlicjerma ter mit der Fojt jull be

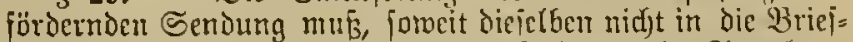

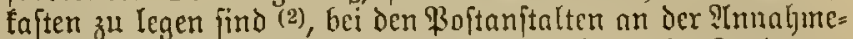
frelle gejđjehen. Dic als Frgäujungsonlagen in Eanobrten

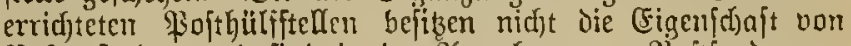
\$oftanftalten und find in der S(nnahme bon \$oftjendumgen beichränft (7).

(2) Эniofern ber Umfang und bie jonjtige Bejujaffenlyeit der (s)egenftände nidft ein Inderes bedingen, find grwöhnt = licfe Briefe, gleidjuiel, ob franfirt ober unfrantirt, ferner

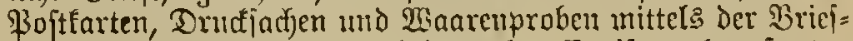
falten zur (Einlieferung ju bringen. ${ }^{1}$ ) (5s ift aud) neitattet, derntige Sendungen ben Foftbegleitern, Boftillotien utto Beförderern bon Botenpoften, menn diejelben fid) unterweg? im Dienjt hefinden, fotvie hen Jührem der z Hoftzmeden dienenden Primat=\$erjonemfuhrverte, 3 itbergeben.

(3) Эn Stäbten, in weldhen mit Facetbeftelfahrten bejtehen, dürfen den qactetbejtellem

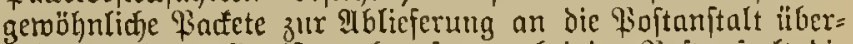
geben werden. (Es ift auch gejtattet, bei der \$ojotanitalt die Abholung bon Fiacteten aus ber 20 ohnung jufriftlic) zus beitellen. Füur Derartige Bejtelfidjriben oder Bejtelfarten fommt eine (Bebrilye nid)t sur (Erbebung; dicjelben fönnen in die Brieffaften gelegt oder Den beftellenden Boten mit= gegeben werden.

Den Randbriẹträgern dürfen auf ifren Beftellgängen zur Ablieferung an die $\mathfrak{B}$ oftanitalt oder zur Beftellung untermegs die nadbezeidneten Sendungen übergeben merden:

gemöhnlidje oder einzudjreibende Briefe, \$oftarten, Briefe mit 3 utelungsurfunde, Drudfachen und Waaremproben,

Foftarmeifungen, geroöhnlidje qiadete,

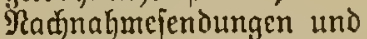

Sendungen mit $\mathfrak{W e r t h a n g a b e , ~ i m ~ E i m z e l n e n ~ b i s ~}$ zum Betthbetrag boll 400 Marf.

Bur Mitmahme bon Fiadeten find dic Randoricitrïger วu ờ untergebracf)t merden fönnen, und unzuträglid)feiten - fei es in Betreff Der Beförderung oder Bejtellung Der fonfitigen Sendungen - nidjt zu bejorgen fino.

(4) J̧eder Randbricjträger jührt auf feinem Bejtellumg: gange ein 2 mnahmebud) mit fid), in meldjes er bie von ilm

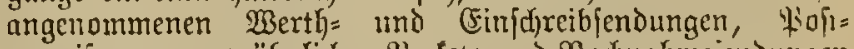
aumeijungen, gewögnlid)en Fadete uno Rad)nahmejenoungen einzutragen hat. Bum (sintragen diejer Sendungen ift auth)

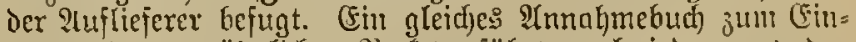
tragen ier getwölntidjen Fiadete fülgrt auch jeder nad) ien Beftimmungen unter (3) jur ?Tunahme gemöhnlidjer fuctete ermähtigte tiacfetbeiteller auf (ciner Beftellfahrt mit fidf).

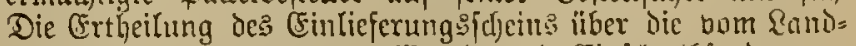

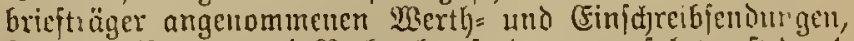
Fioftanmeifungen und Tad)nahmejendungen erfolgt erft Duret) Die Fojtanftalt; der Ranibricjträger ijt verpflichtet, Den (5in= lieferungêf(t)ein dem Pluflieferer, wern möglidy beim nächjten Beftellgang, zu überbringen. 
(5) F̧ü Die von Randbriefträgern auf ifren Beftellungs: gängen eingejammelten portopflifftigen (sinjd)reibbrief=

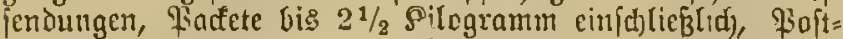
amveifungen und Briefe mit Werthangabe (3) fommt, wetur dicie (Begenjtände jur Weiteriendung Durde) die Foftanitalt

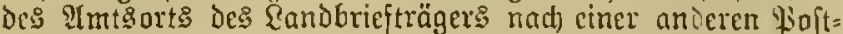
anjtalt beftimunt find, aufer bem fiorto und Den fonjtigen Gebüfren, eime Rebengebiifr von 5 \$i, melde im Vorats

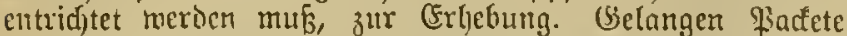
non höherem (Semid)t als 21/2 Silogramm zur Sinfammlung,

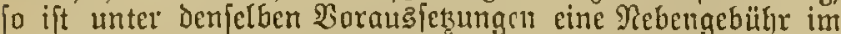
Betrage der fïr gleidf fámete fiactete fekgefetzten Sanbbeftell= getiih) (\$ 38 (7)) zu entrid)ter.

-(6) fürx die bon den Facfetbeftellern auf ihren Be. ftcllungg్fahrten eingejammelten getwöhnlicfien Tiacfete (3)

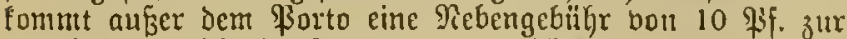
Erljebung, weldje im Boraus zu entrid)ten ift.

(7) Bei Den \&oithülfitellen dïrfen getwöhulide Brief= fendungen uno bei denjenigen Foithülfitellen, ineld)e bon Der vorgejebsten Sber = \$oftoireftion zur ânaljme von Fiafeten ermädftigt find, audf \$adfete obne Werthangabe

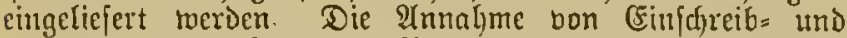
Werth)(endungen, forvie bon Sioftanmeifungen gehört nidjt ju

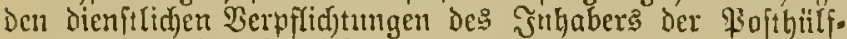
ftelle. Fïr die Einliejernng ban Sendungen bei cinct

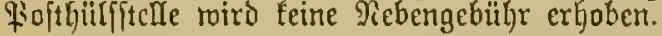

1) Bur Jrantirung ber voritehento aufgeführten, burd bic gricfs Enjien cimzuliefernoen Begenftäntoe finto Briefmarten zu beumben, fofern ridjt bem begenftande felbft das Franlirungsgeiden eingebrudt ijt ( $($ poittarten)

\section{3eit ber Einlieferung.}

§ 30. (1) Die Finliejerung bei den \$oftanitalten muß mälirend Der Dienftitunden uni, wenn bie Berfendung Des eingelieferten (Begenftandes mit ber nädj[ten bazu gुeeigneten

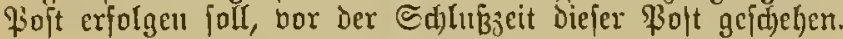

\section{a) Dienititunden.}

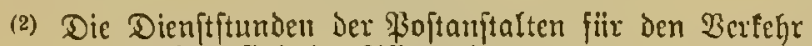

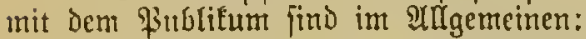

1. in Dem Sommer=5albjahr (bom 1. Ipril bis lekten September) von $7 \mathrm{Hhr}$ Morgens bis $1 \mathrm{uhr}$ Dittags,

2. in Dem Winter = Salbjalyr (bom 1. Detober bis Iebten Miärz) bon 8 uhb (Morgens bis 1 llhx Mittage, und

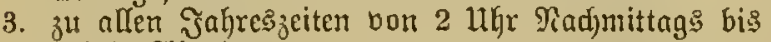
8 llin: Yxbends.

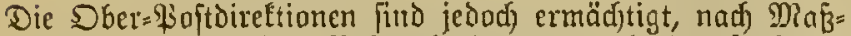
gabe der bejtehenden Pojtuerbindungen und ber fonftigen

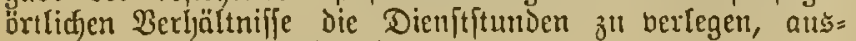
zuichnen" oder zu befduränfen.

(3) 2ku Sountagen uns an alfgemeinen freiertagen fallen die Dientitunden bon 9 llhr Mrorgens bis 5 luhr giad)= mittags ats. Bmifdjen 5 uno 8 uhbr radjurittags findet mindeftens toährend ciner Stunde und längitens rährend jmei Stunden ber Dicnftberfely mit dem unterbrad)en ftatt. $\mathfrak{A}$ uf meldyen Bcitraum innerhalb vor= ftefender (Brenzen Der Sdjalterdienjt (idd) zu erjtreden lyat, twird für jede Poftanftalt Durdh die vorgejetzte Sber=Fojt= diref́tion nad bem örtlidjen 2 edintrfiffe beitimmt. Die

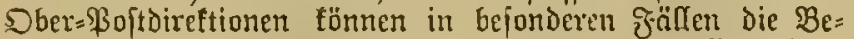
id)räufung Der Dienftftunden an Somntagen und alfgemeinen Jeiertagen zeitweife ganz oder zumi Theil aufbeben.
(4) Die bon den Sber=\$3oftdireftionen in Bezug auf die Dienjtitunder ber \$oftanjtalten getroffenen Fejtjełungen müfien zur SenntniÉ des \$ublifums gebradt werden.

b) Shlufzeit.

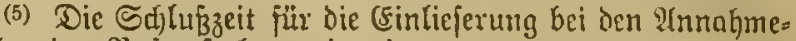
[tellen der \$ojtanjtalten tritt ein:

1. Jür Briefe, Bojtfarten, Drudfadjen oder : Eaaren. proben, über welthe dem 2 Xbjender eine Sinlieferung: bejdeinigung nidft zu ertheilen ijt:

eine biertel bis eine halbe Stunde bor dem plan= mäßigen গlbgange oder Weitergange der \$oft.

Bei Boptanftalten auf ien Eifenbabuböfen tritt jür Die bezeicfjneten (Segenftände die SdiluB= zeit erft fünf Minuten bor dem planmäßigen 2Thange Des Zuge: ein; aud fönmen bicfe (3egenjtände bis unmittelbar vor bem slligange bes Zuges, forveit Der Bahnjteig zugängliech ift, in die Brieffaften Der Bahnpoftwagen gelegt merden.

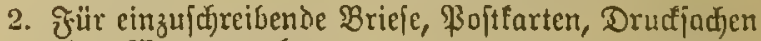
oder Waaremproben:

eire biertel bis etue halfe Stumbe bor Dem planmäßzigen YYbgange oder Weitergange Der Sioft; jedod) fino (ämuntlidue Sioftanjtalten be. red)tigt, im frall durdy denfelben 2lbfender mel)r als orei (sinfdyreibbrieje zugleid) eingeliejert rerden, eine Sd)[ußzzeit bon einer Stunde in IIniprud) zu nefmen.

3. Für alle anderen Segenftände:

eine Stunde bor Dem planmäßjigen Tlogange oder Weitergange Der \$oit.

(6) Falfs bie oromungsmäß̈ige Bearbeitung ter Sen= bungen inmerhalb der boritehend bejtimmten Sdjluz3eiten

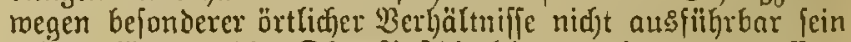
jollte, E⿺辶nnen bie Sber=\$jojtoireftionen eine angemeffene Berlängerung Der Suflubzciten eintreten laffen.

(7) Ĵn jeben Galle merben bei \$ojtbeförderungen auj (Fijential)nen die Sd)lüzeiten un jo biel berlängert, als erforberlidj ift, um bie Sendungen bon Der \$oftanitalt uad) Dem Bahnhofe zu bejörbern und auf bem Bahnhofe felgjt ïberalnden.

(8) för Fioften, die auberlyalb der gemöhnlichen Dienit= ftumben abgel)en, bilbet der Yblauf der Dienftitunden bie Sd)lußzzeit, injofern ridft nad) Masgabe Des Abgangs ber

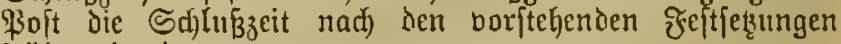
fribler cintritt.

(9) Die an ober in Den Fiofthäujern befindlidien Briej= faiten müfien bei (Eintritt Der Sd)luBzeit jeder \$oît, und zu Den augerljalb der gemöbnlidjen Dienftftunden abgeljenden Hofren aud nod) bor deren 9logang, geleert merden. Bei Sendungen, weld)e in Brieffaften ferm vom \$ofthaus gelegt meròn, ijt auj Ditbejörderung mit ber zunächjt abgehenden Fojt nut inforweit zu redjen, als bie Sendungen nad) ber geroblyntidien Zeit Der Reerung Der Saften bor Sdjluß́ ber in Pietrad)t fommenden Fiften zum \$oịthaufe gelangen.

(10) bei Denjenigen ßojtanftalter umo jelbftftändigen Telegrawbenanjtalten, reldhe non Der Fojtbehörde hierzu bejondere ermäd)tigt find, dürjen (Einjudreibbriefifendungen zu [oldjen Foptbejörderungšgelegenteiten, roeldje auBerbalb oder Eurz nad) Beginn ber fïr Den Werfehx an Shalter be= [timmten Dienffitunden fidh darbicten, auf Berlangen aurd) auficrbalb der Dienitfunden angenommen merien. Worats:

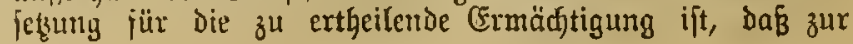




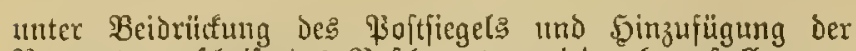
Tameniunterfdyrift des \$oftbeanten wieder hergeftellt.

(2) Şit Duraf) die gäuzliche \&öfung des Siegels oier anierweiten Berid)lujfe: einer Sendung mit baarem Belo

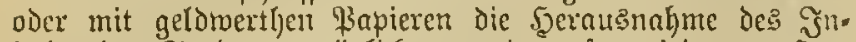
halts der Sendung möglicf) geworden, fo mird bor Ser=

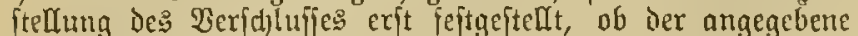
Betring der Sendung nod) vorbanden ift.

(3) Bei \$oftanitalten, bei meldjen zwei oder meljece Beante zugleidy im Sienft anmefend find, rvird jutr $5 \mathrm{er}=$

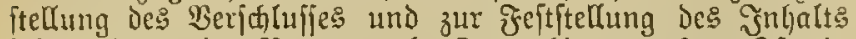
fojort ein zmeiter Beaunter als Benge hinzugerufelr. Şit ein zweiter Beamter nicht im Dienjt, jedod) eill gojtunterbeamter zugegen, fo wird biejer als Beuge hinzugezogetr.

(4) Sat nady den boriftehenden $B$ efitinmungen ein ander= reiter berfd)lus der Sendung ftattgefunden, jo ift - wern es fich um Sirieje mit Werthangabe oder um \$arfete mit ober olyne $23 e r t h a n g a b e$ ljandelt - bei Strfunft der Sendung

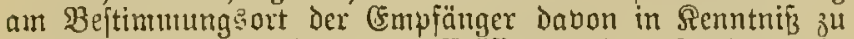
fedzen und ju erjudjen, zur Crubffnumg Der Sendung in Gegenmatt eimes \$ojtbeamten im \$oft denftzinmer inner= Galb Der zu beftimmenden Frift fich einzufinden. Stmaige

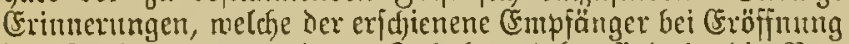
Der Sendung gegen beren Эnhalt erljebt, find in bie $2 e r=$ bandlung aufamelymen, Durch weldje der Befund feftgejtellt wird. Eeciftet Der Empfänger dem (Erfuchen feine đrolge, ober berzichtet Derjelbe ausorürtlicf) auf (Eroffinung Der Sen= Dung, jo ift mit beren Beftellung und Slusbändigung nad) Makgabe der folgenden Borjariften zu verjahren.

(5) Die \$oftbeanten müffen fidj jeder über den Brwect Der (Exoffmung Ginauggehenden (Finficht der Sendung ent= halten; aud) mū über bie gejdjehene (Eröfinung eine $\mathfrak{B e r}=$ ljandlung aufgenonmen merdem, in welher bie Beranlaffung Der: Diaßregel, Der Jergang bei Derielben und Das Ergebnis niebergufthreiben find.

(6) Sendungen mit Drucffachen oder mit Waarenproben zum Brod Der Girüfung iiber Die Buläffigfeit Des ermäß̈igten biortos zu öfinem und einzufeljell, find die \$ojtbeamten auch ofje weiteres gerfahren bejugt.

\section{Beftellung.}

\$ 38. (1) Die Berbindlichfeit der \$oftuerwaltung, die

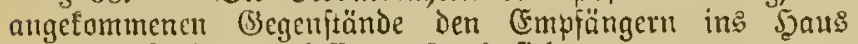
fenoen (beftellent) zu Lafjen, erjtrecft jidf:

1. auf gemöhnlid) แnd eingefdyriebene Briefe uno Bopttarten,

2. auf gewöhnlidfe und eingefdicticbene Drudfacten und waarenproben,

3. auf \$oftanmeijungen,

4. alif \$ojtanfträge,

5. auf Begleitadrefien zu getwöhnliefen Bacteten,

6. auf शbliejerumgSfffeine (Begleitadreffen) über Sen= Dungen mit werthangabe und über (Finitureib= padete.

Die für Şerwolner bon Ranoorten mit Bofthyülfgitelle beftiututen gewoölnlidjen Brieffendungen und, jotweit thun= (i(i), aud) Die \$adfete ofne Werthangabe werden der \$ojt= hǘlfitelle zugefüljrt, und hier entrweder Durdy den Jnhaber Der Qboitlittlfitelle abgetragen, oder zut abholung bereit ge= halten $(\$ 42)$. Wenn im leţteren frall die Sendungen bis zur närffiten Stnfunjt des Eandbriefträgers bei Dex \$oftgülf = ftelle nicht bon Dem (Empfänger abgeholt find, jo exfolgt die Bejtelung Dur(f) Den Randbriefträger.
(2) Someit Die \$oftwermaltung die Beftellung nicht über= nimmt, müjfen Bricfe mit $\mathfrak{B e r t h a n g a b e , ~ B a c f e t e ~ m i t ~ u n d ~}$ obute 2 serthangabe, fomic Einfchreibpadtete uni jerner die

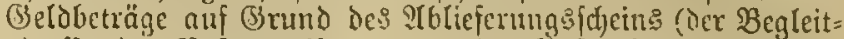
adreffe, Der \$oftanmeifung) bon ber Foft abgeljoft merDen.

(3) Fïr Die Beftellung Der gemöhnLirfen \$arfete und der (sinjdyreibpactete in Drtsbejtellbezint rerden erjoben:

1. bei Dem \$joftämtern I. Яlajie:

a) fïr \$actete bis 5 silogramm einfdhl. . 10 Bf.,

b) fïr jdinerere \$adfete $15 "$

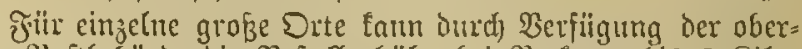
ften \$optbehärde bie Bejtellgebüht bei ßacfeten bis 5 Rilo=

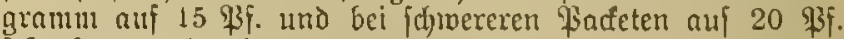
feitgeiezt werden. ${ }^{1}$ )

\section{Gei den übrigen Bojtanitalten:}

a) für ßacfete bis 5 Silogramm cinjøl. . 5 \$f.,

b) fiir fdrwercic \$adpete 10 "

Gehört mehr als ein ßactet 3 u ciner Begleitadreffe, fo

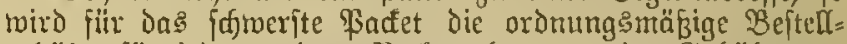
gebihlyr, für jedes roeitere \$acfet aber mur eine Sebuligr bon $5 \mathrm{Bj}$. erhober.

(4) Fï Die Beftellung Der Briefe mit Wertljangabe und Der Padete mit Werthangabe im Drtsbejtellbezirt werden erhoben:

1. fiir Bricje mit $\mathfrak{B e r t h a n g a b e : ~}$

a) bis zum Betrage bon 1500 Mart.

b) im Bettage bon mehr als 1500 ind bis 3000 Mart.

2. jür Bafete mit Werthangabe:

die Sätze für Bejtellung gernöhnlidyer \$adete, mindeitens aber die Säbe unter 1.

(5) In Drten, no Sendungen mit höherer Wertljangabe als 3000 Marf beftellt werden, ift dafür eine Beitellgebithr von 20 \$F. zu erkeben. Jür großze Drte farn die oberfte

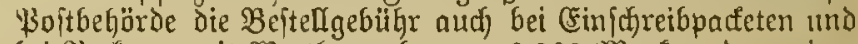
bei \$adfeten mit Wertljangabe von 3000 Marf und sneniger auf 20 \$F. fejtieben.

(6) Fïr Die Beftellung von \$oftantweifungen nebit Den

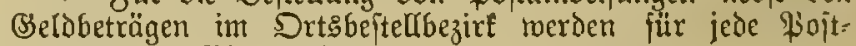
anveifung 5 Pf. ertoben.

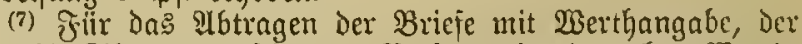

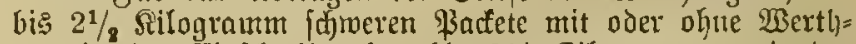
angabe, ier cinfdhreibpactete bis $2 \frac{1}{2}$ Silogramm und de? Boftanmeifungen nach dem Randbejtellbezirfe werden Durd)= tweg 10 \$F. für das Stüd erljoben. Selangen \$adete von höherem (Setvidtt alE $2^{1 / 2}$ Silogramm zur Beftellung, fo be= trägt das $\mathfrak{B} e$ ftelfgeld 20 \$f. für das Stüaf.

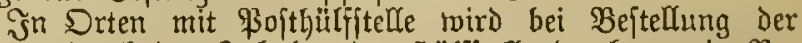

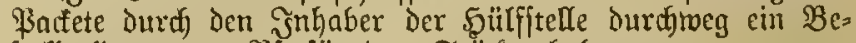
ftellgelo von 10 SF. für das Stüce erljoben.

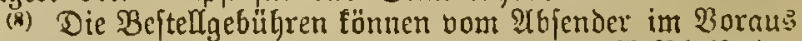

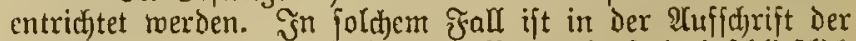

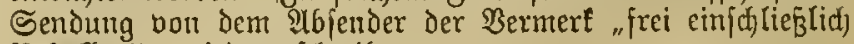
Beitellgeld" niederzufdjreiben.

(9) Die Beftelgebühren werden audi bon portofreien Sendungen erhoben.

(10) 2 In Einwohner im Drts= und Sandbeitellbezirt des

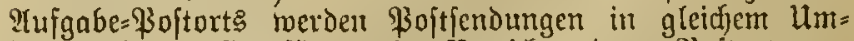
jange wie an (5mpiänger im Bereid) anderer \$ojtorte an= genommen. Wegen Der 2(usnahme in Betreff der burd) Eilboten zu beftellenden Sendungen fiehe \$ 24 (3). 


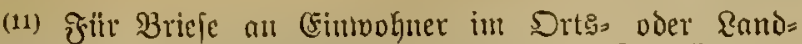

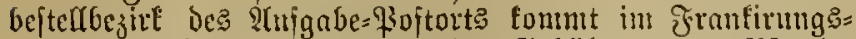
fall, fowie jür Dienjtbriefe, eine (S)bïlgl bon 5 \$s.., in

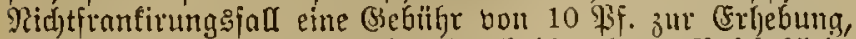

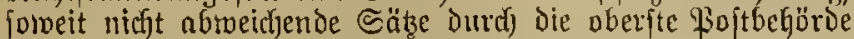
angeoronet find. Bei Briefen mit Bujtellungaurfunde roiro

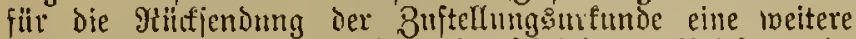
(bebühr nid)t erljoben. Bei eingejdriebenen Briejen tritt

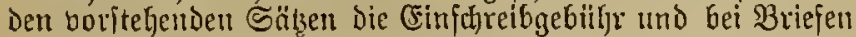
mit \$oftnad)nahme bie Borzeigegebiligr ljinzu.

(12) शrtle iibrigen Sendungen, weld)e an (Finmolyner im Drts = oder \&anbbeftellbezirf bes \&ufgabe=\$30ftorts eingetiejert

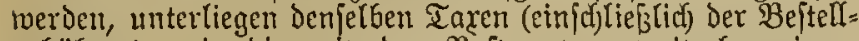
gebübren), bie die mit den $\mathfrak{B}_{0}$ ften bon weiterher einge: gangenen gleidfartigen Sendungen mit Der MRaßgabe, baß̧, jomeit bei Den Taren die Entjernung mit in Betradt fommt, Der fïr die geringfte Entfernungejtuje bejtimmte Salz in Atnmendung zu bringen ijt.

(13) Eine Porto= uno (3ebuifrenfreigcit findet bei $B c=$ forgungen an (Sinmolyner im Srts= oder \&anbbejtellbezint

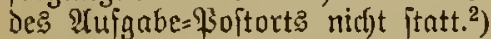

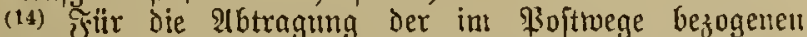
Beitungen uno Beitj(f)riften find fowoljl nact dem Drt: = beitellbejirfe als audf nad) Dem \&nobejtellbejirfe für jedes (Sxemblar jährlid) ju entrid)ten:

a) bei Beitungen, beldye mödhentliel) eimmal oder feltener bejtellt werden.

b) bei Seitungen, weldje zmei= oder brei= mar möchentfidy beftelt werden

c) bei Beitungen, welche mefrmals, aber nid)t öfter als einmal täglidj) beitellt ruerden

d) bei Beitungen, weldje täglia melurnals erfoct)einten, fïr jede tägliçse Beiteflung.

e) jïr die amtlicfen Berordmunģ6lätter MiE. 0,60 , $1,-$ 1,60, $1,-$, 0,60 . Das Beitungsheitellgelo twird für osnjenigen Beitraum im Borau erfoben, für meldfen die Buraubezaflung des Bezugझpreifes für die Beitung erjolgt ift. Die Bahl ber Beftelfungen ridhtet fid) danad), wie oft (Belegenheit zu: Beftellmg borfanden ift. Der bei Beredjung des Bejtelfgeldes fich ergebente Brtdftheil einer Marf ift eintretendenfalls

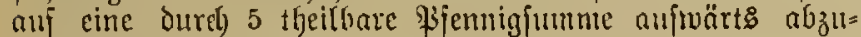
runden.

1) Dieje [jöl)cre Beflellgebühr ift für folgende Drte angeorbutet:

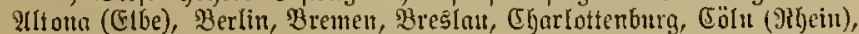

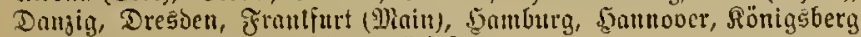

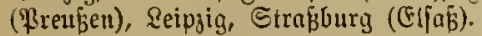

2) Bgl. (scjeß über \$ortojtciheiten v. 5.61869 § 3 (ङeite 390).

\section{Beit der Bejtellung.}

§ 39. (1) Die Foftbeljörde bejtimmt, wie vit täg(id) unto in weldhen Friften bie eingegangenen Briefe u. $\{$. w. zu bejtellen find. Wegen der (siljenoungen fielje \& 24 .

(2) Sendungen mit dent Bermerfe in ber 2tuffdrift:

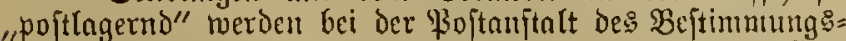
orts aufbemafit (\$ 45 (1) \$iult 3 und 4) und bent (Em= pjänger befändigt, wenn jidh Derjelbe meldet tmo auf (Er= fordern austweift.

\section{Atn ren die Beftellung gefdeben mub.}

$\S 40$. (1) Die Beftellung erjolgt an den Empjönger jelbjt oder at deffen Bevollmädbtigten. ${ }^{1}$ ) Bojtiendungen, melche an berforbene \$erfonen gerichtet fino, bürfen ben
(Erben ans̊gefjändigt werden, wenn diefelten fid) ala fold)e Durrf) Borlegung des Teftaments, Der geridftliffen (5rb= bejdsinigung ze. auggetviejen haben; jo lange biejer Radjweis

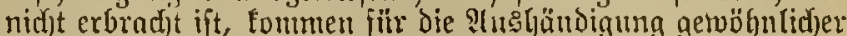

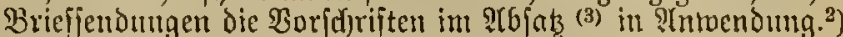
Bjoftientoungen an (Sejellid)aften oder Bertine, ober an

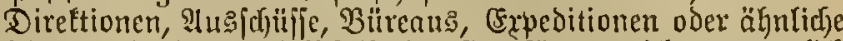
Firmen, in Deren 2(uffid)rijt Der (Fmpjänger nicht namentlid bezeid)tet ift, find an biejenige \$erfon auşuljändigen, welde der Foftaritalt als Direftor (Borjteher, Snnhaber) bes Ber.

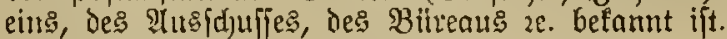

Der (Empiänger, weldjer einen Dritten zur Emplang= nalume der an ifn zu bejtellenden Sendungen bebollmächtigen

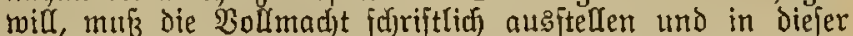
bie (Sattungen ber Sendumgen genan bezeid)nen, zu beren Empfangnahme der Bebollmädjtigte belugt jein folf. Эnjofern bie (Gefebe uidjt eine bejondere テ̛orm Der Bolmadjten vor

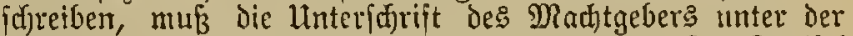

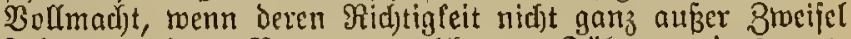
iteht, von einem Beanten, weldyer zur J̈̈thrung eines amt= lidjen Siegrl: beredhtigt iff, mnter Beidrïrfung desjelben, beglanbigt feir. Die Boflmadyt mnß̧ bei Der \$ojtanjtalt,

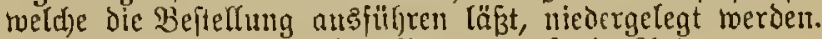

(2) Sít außger bem (Empfänger nod) ein ?tnderer, menn auch) แur zur näheren Bezeichnumg der Wobnung de: (5m= pfängers, in der Ŝufichrijt genamt, 3. $\mathfrak{B}$. an A. bei B., jo ijt biejer z'meite (Empfänger aud) ohne ausorilfflidje (Frmäd)ti= gung als Bebollmäd)tigter be: eritgenannten Cimpjünger: zur Empfangnahme bon gewöhnlichen Briejen, Boftfarten,

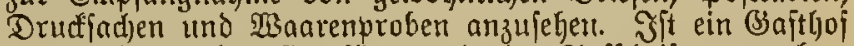
als Woljnung bes (Empfängers in der 2uffahrift angegeben, fo fann die Beitellung Diejer (3egenitände an Den Bajtmirth aud) Daml erfolgen, lvenn der (Empiänger nod) nid)t ein= getroffen ift. Sind bei \$ojtaufträgen melrere Berjoner

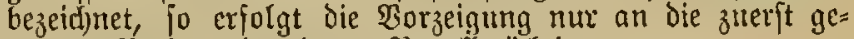
nannte \$erjon oder deren Bebollmächtigten.

(3) W3iro Der (ampfänger oder beffen nadf den bor= fteljenden $\mathfrak{B}$ eftintmungen beftellter $\mathfrak{B e b o l l m a ̈ h}$ tigter in peiner

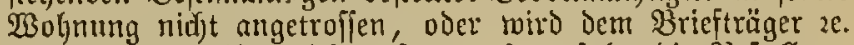
Der 8utritt zu ifju nidjt geftattet, fo exfolgt bie Beftellung

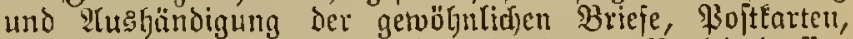
Drutfjadfen und Waarenproben, folvie oer Begleitadrefjen zu gewöhnlidjen \$acfeten und der Fiadete felbft, jerner ber Inlagen Der \$3ojtaufträge zur Einjiehung bon (seldbeträgen, fofern ber Dafür eistzujielende Betrag jogleid beridjtigt wiro, an cinen Ђaus(\$eichäft引) beamten, ein erwadjenes Familien= glieo, einen jonftigen SIngebärigen, oder an einen Dienjt. boten de: (smpfängers bु. Des Bevollmähtigten desfelben. BBird Niemand angetroffen, an Den hiernad) die Beftellung

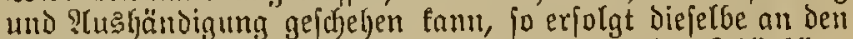
Sausmirth, an den Wobnungggeber oder an den I Ijitbilter de? รูaนfe.

(1) Sat Der Empjänger oder defjen Bevolfmäd)tigler (1)

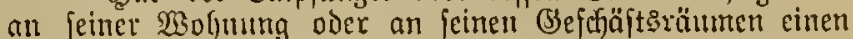
Brieffaften anbringen lafien, fo twerden gewöhnlidje franfirte Brieje, \$oftfarter, Druffadjen uno Waarenproben burd) Die beítelenden Boten injotmeit in den Briejtaften gelegt, als deffen Befdjaffenheit foldjes gejtattet und andere פierab: redungen nicf)t bejtehen.

(5) 1. Einff]reibiendumgen,

2. Bojtanweifungen,

3. Telegraphijche \$oitanmeijungen,

4. Wrblieferungsidjeine ïber Sendungen ntit einer Wertbangabe bor je 400 Marf, 
5. Begleitabreffen zu eingefdrebencu tiadeten uno zu Siacfeten mit einer Werthangabe boul je 400 Mrarf fino an Den Eupfänger oder bcffen Bebullmädıtigteu ferbit 3ll bejtellen. Wirb ber Gupfänger nder beffen Bevoll=

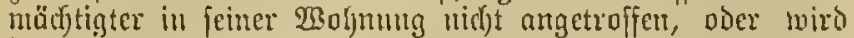
ben Briefträger voer Boten der Butritt 34 ifm nid)t ge= ftattet: fo fömuen die bezeid)neten (Segenftändo aud) an cin

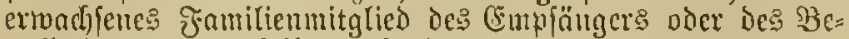
vollmädtigten besfelben befterlt werben.

Foftantweifungen mu telegrapljifde \$softammeifungen won mebr al: 400 Marf, Mblicierming mit einer Werthangabe von mebr als 400 Marf, folvic Begleitabreffen zu Pacteten mit einer $\mathfrak{W e r t b a n g a b e ~ b o n ~ m e l y : ~}$ als 400 Marf milffen an Den Empfänger oder Deffen $\mathfrak{B e}=$ bollmäutigten felbit beftelt werden.

Die Bejtellung Dex Ginfdreibjendungen, Der \$oftantoci= fungen, ber telegraphifdjen \$oftantweifungen und ber $\mathfrak{a b}=$ lieferungsfd)cine, ferner der Begleitabrefien zu cingefdriebenen Badeten und 3 \$3acteten mit Wertbangabe bat ftets an den Sutpfänger felbit itattzufuben, wenn die Sentoungen vom צbjender mit Dem Bermerfe "Sigenljändig" ver"= jeben find.

(6) Rautet bei gelob̈hnlidfen Fiaffetfendungen, bei Gin= fhreibfendungen, bei \$oltanmeifungen, bei telegraphijdyen \$oftnutueifmngen nub bei Senoungen mit Wertyangabe bie श)iffurift:

\begin{tabular}{|c|c|}
\hline 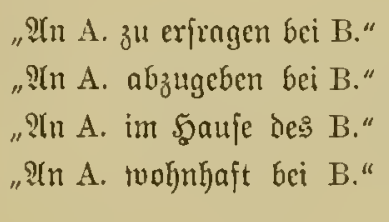 & 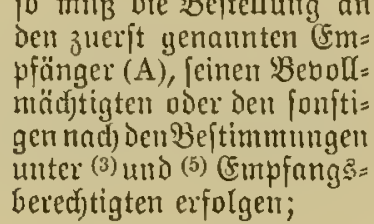 \\
\hline
\end{tabular}
Inutet Die Ruff(f)rift Dagegen:

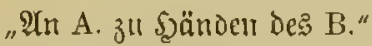
"श्? A. abzugeben an B."

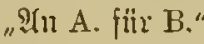

"भ̂n A. per Adresse des B." fo Darf die Beftellung fo= mohl an den zuerit ge= mannten (Smplänger (A.), als aud) an beil zulebt ges namten (B.), Deren $\mathfrak{B e n o d =}=$ mäutigten oder Den fonfiti= gen nach denßeftimutungen unter (3 und (5) Fmpfongs= berectigtign exfolgen.

(7) Senoungen gegen Rübfjein bïrien nur an Den Sinpfänger felbft oder deffen Bevolfutädjtigten beftellt werden.

(8) Die Beitellung von Sinf(j) ciffiendungen, von \$3oft= anmeifunģbeträgen und bou Sendungen mit werthangabe, forvie bon \$acfeten olyne Wertbangabe genen Pücfichein, barf

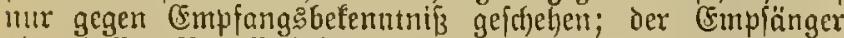
oder Deffen Bevollmädtigter ober başenige fantlienglied, an weldjes bie Beftellung erfolgt, loat den Qlblicjerung ŝfjein

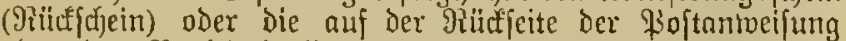
ober ber Begleitabrefie vorgebrudte Duittung ju unter= idfreiben.

(9) Dic Beftellung Der \$ojtiendungen an Betoofner bon Schlöffern regierender beuticher fïrften, an Militärperfonen, fotvie an Böglinge von Srjiefungsanftalten, Benfionaten $2 c$. erfolgt auf Girumb der mit Den zuftändigen Beljüroen oder ben $\mathfrak{B}$ orftebern der (Exziclyunganfta!ten getroffenen bejonderen

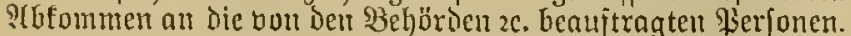

(10) Die an Siranfe in D̈ffentididen Sitanfenanftalten ge= riditeten \$Boftiendungen Dïrjen an Den Boritand ber Sranten= anftnlt behändigt werDen, foferm dem Briefträger oder Boten Der Butritt zu dem Siranfen nicft geltattet toiro.

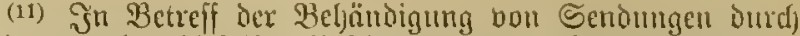
Eilboten gelten diefelben Beftimmungen, lvelde bezüglid) Dez im getvöbulid)en Wege zur Be[tellung gelangenden Sendungen majgebend find.

(12) Bolfpflichtige \$poftienoungen werden sum Brod ber

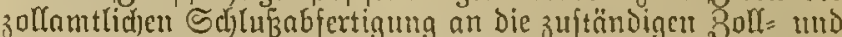
Stenerftellen ïbergeben. Die Saftpflicht ber Hoftuermaltung

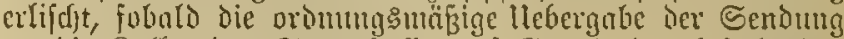
an die $30 l[=$ oder Steuerftelle nuf (Sirund ber beftebenten Burforififen ftattgefunden bat.

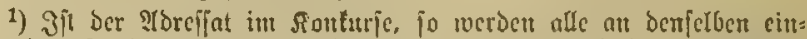

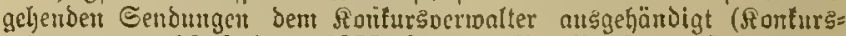
oronung vom 10. Februar 187i, § 111). Nur Brieje mit Bulteflungs: urfunde werbent nidjt befiellt, jondern mit eittem entiprechenden Jer= mert zurïdgeiands.

2) Briefe mit Buftellungsurfundc an Berftorbene IDerden nidjt an bie Crben beftcat, fordern mit entipredendem Bermerf jurïfgejondt.

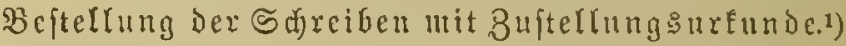

$\S$ 41. (1) Iuf Die Bejtellung von Gdjreiben mit $8 u=$ ftelfungsurfunde finten bie Beftimmungen in Der $\$ \S 165$ bis 174 und 178 der (Sivilprozeforonung für das Deutfde

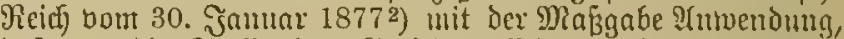

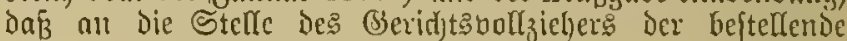
Bote Der Boftanitalt tritt.

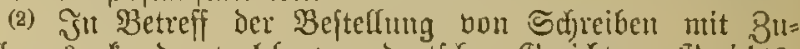

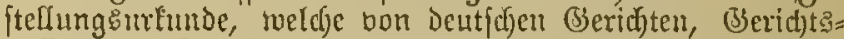

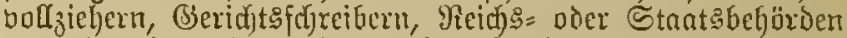
ansgelyen, bervendet es bei den hieriiber beftehenden befonderen Beftimmungen.

(3) Die Porto = und fonjtigen Beträge fïr ein Schreitien mit Buftelfungesurfunde milffen fämmtlid] entroeder bou $216=$

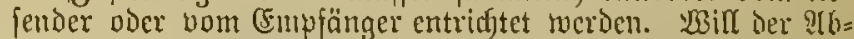
fender bie Bbebithren tragen, fo zahlt er bei der Einlieferuttg

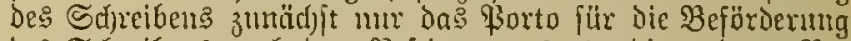
Des Sd)reibens nad) Dem Bejtimmungsorte, bie anderen $B e=$

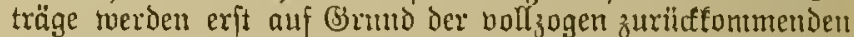

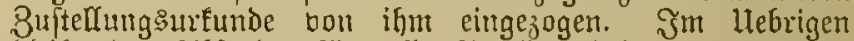

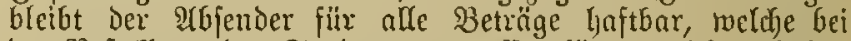

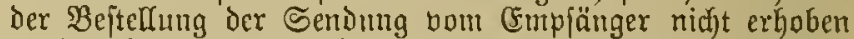
werDen fömen. Falls jebod bic Zufteđung nidjt ausgefiil)rt werden Eamn, foumt rur das \$lorto für die Beförderung Des Sd)reiberis nad) Dem 2 ejtimmungsorte zum ?(njakg.

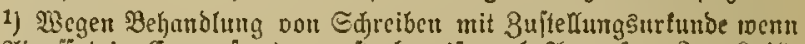

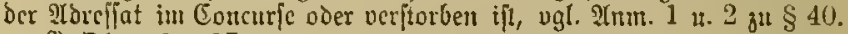

2) Oben ङ. 157.

\section{Berextignng Dę Empfängers zur 2tblolung Der Bricje 2c.1)}

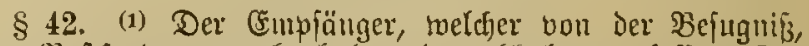

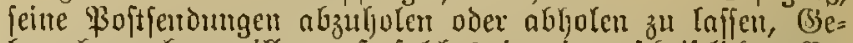

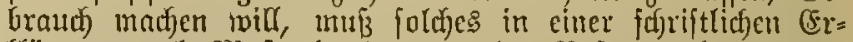
flärung nach Mafigabe ber bon ber Foftuermaltung vor= gefid)riebenten ₹raffung ausfpred)en und diefe Ertlärung bei

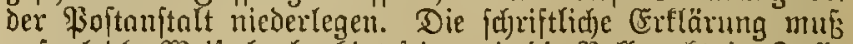
auf gleid)e 2 cife beglnubigt fein, wie die $\mathfrak{B}$ ollmadft im Jొnlle oes \& 40 (1). Die 2lushändigung exfolgt alsonm imerhala

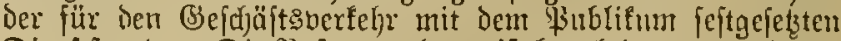

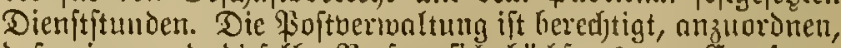

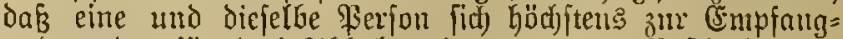
nalime oer filt brei \$oboler eingegangenen \$oftentoungen melden barf.

Die MbColung von \$oftienoungen bei \$ofthüliftellen ift

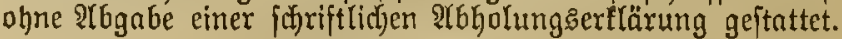


(2) Tnjomeit bie ßoitvermaltung die Beitellung bon \$acfeten ofne $\mathfrak{B e r t h a n g a b e , ~ b o n ~ e i n g e f d i c i e b e n e n ~ ß a d f e t e n , ~}$ von Sendungen mit Werthangabe oder bon Geldbeträgen zul Foftnmweifungen ïbernommen hat, find bezüglich ber Beftellung:

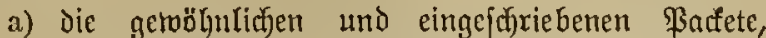
fowie Die \$acfete mit Werthangabe und tie Begleits abrelien, jouve etwaige atbliejerungsf(t)eine,

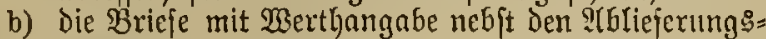
fdjeinen

c) die \$3ojtanmeifungen neбft den Beldbeträgen je als eine zujammengeljörige Sendung anzujeljen.

(3) Die mit Den Bojten anfontmenden gemöhnliden Sricfe, Sojtfarten, Druffacten und Waarenproben milffen fuir die Stbholer eine halbe Stunde nad) der IInfunft zur Stubnabe geftellt werden, vorausgejebt, bas die Ilbholungs: zeit in die gemöhnlidjen Dienjtitunden jällt. Sine $\mathfrak{B} e r$. längerung jener ofrift ijt mux mit (Senehmignng ber oberften Foptbehöroe zuläpitg.

(4) Bei eingejdriebenen Briefen uno Briefen mit $\mathfrak{W e r t h}=$

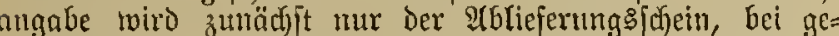
möhnticfyen lano eingeffyriebenen Bacfeten, jowic bei Bacteten

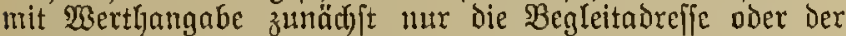

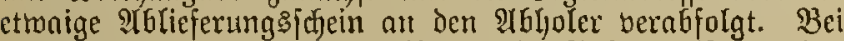
Boftanmeifungen mird zmmähfit num bie Gioftantweifung ohne ben Betrag bem $\mathfrak{Y}$ (Gholer ausgeljändigt.

(5) Die Beftellung erfolgt jedodf, der abgegebenen (Ers flärung Des (Entpfängers ungeachtet, Durch) Boten ber \$ojts anftalt:

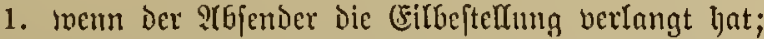

2. twenn cs alif die Bejtellung von Bricjen mit $\mathbb{B}^{\mathrm{u}=}$

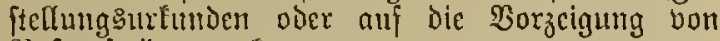
Goftaujträgen anfommt;

3. wenn Der CEmpfänger Den zu beftelfenden Biegen= Ftand nicht ant כage nad) Dem Eingange, bei Sendungen mit lebenten Thieren (\$ 12) nicht fimmen 24 Stumien mad) Dem Eintreffen abholen läpt.

1) $\mathfrak{B g l}_{\mathrm{g}}$.

Aughändigung der Sendungen nad) exfolgter Behändigung der Begleitadrefien und der stb=

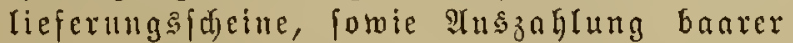
Beträge.

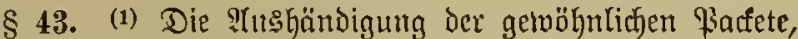

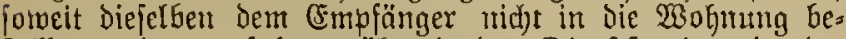
ftellt werden, exfolgt wähend ber Dienfftunden in der Boftanftalt an benjenigen, weldjer fid zur Abholung meldet und die zu bem \$saffete gehörige Begleitabreffe zurïcfgiebt.

(2) Eingcidyricbene Sendungen und Sendungen mit Werthangabe, ferner bei Woftantveifungen die Beldbeträge, werbert, infofern bie abfolung von der \$ojt exfolgt, an denjenigen anzgefjändigt, welcher der fioftanftalt den mit

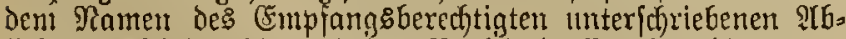
licferungsfdyein, bie quittirte Begleitadreffe oder bie unter= idfriebene \$oitantweifung überbringt und ausłänbigt.

(3) Cine IInterfuffung iiber bie (Ed)theit Der Ututerf(hrift

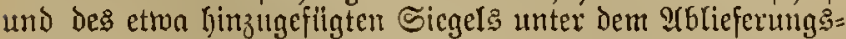
icheine 2e., jolvie eine meiterc \$stufung Der Berechtigung Des: jenigen, weldjer diefen Schein $2 c$. Hberbringt, liegt Der \$ioft $=$

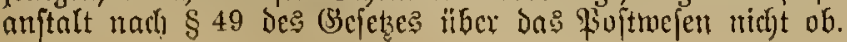

\section{Rachfendung Der $\mathfrak{B}$ oftfendungen.}

\$ 44. (1) Sat der Gmpfünger feinen Iufenthalts= oder Wohnort berändert und ift fein neller Áfenthalts: ober Wohnort befannt, fo werben ihm getwöhnlidje und ein= gejdriebene Briefe, Poftfarten, Drutefadjen und Wanten= proben, ferner \$softanmeifungen nactigcjendet, swenn ex nidft cine andere. Beftimmung getroffen hat. Dafjelbe gilt bon

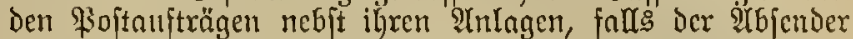
nidjt Die fofortige Rücfendumg ober bie W3eitergabe zur Sirotefterhebung oder die Plbjenoung an cine andere, nament= (ich) bezeid)nete \$er[on berlangt hat. ${ }^{1}$ )

(2) Bei Pacfeter und bei Briejen mit $\mathfrak{B e r t h a n g a b e ~ e r = ~}$ folgt die Nachlendung anf Berlangen des Stbienders obcr, bei borhandener Sicherheit filr bas \$orto, altet) bes (E) pföngers.

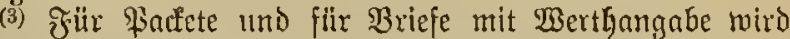
im Fall der Rachfendung das \$orto mo bie Berficherungs:

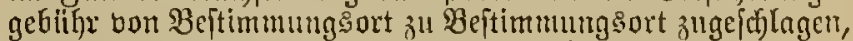

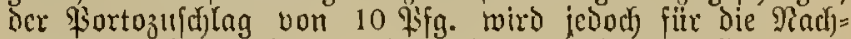
fenoung nicft erhoben. Fin andere Scnoungen findet ein

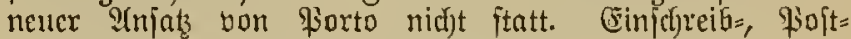

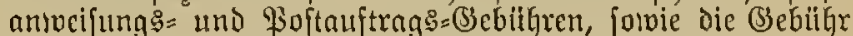
bon 1 Mark fiir oringende Bactetfendungen und die $\mathfrak{B} o r=$

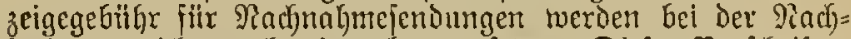
jendung nidht nod) einutal angejetzt. Dieje Borjefriften fommen nurfy bei Nadjfendung Derjeniger (Segenjtände,

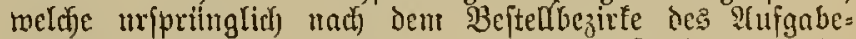

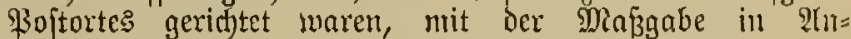
wertoung, Dof

a) bei unfrnnfirten Briefen die fiix die berinchte $\mathfrak{B} \in=$ ftelfung an bie Empfönger im Bejtellgezirt des

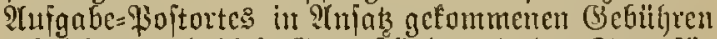
geftridjen, und diefe (Segenftände mit Der Tare fïr unfrantirte Sendungen nad) der nenen $2 \mathcal{B}$ [timutungs: Goftnirfalt Gelegt werben; jerner, daj

b) bei franfirten Sriefen das vou dem QTGfender ent=

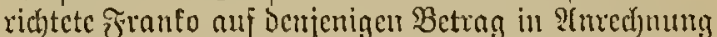
gebrad)t wiro, weld)er fiir Den (S)egenftano zu ents richter icin witrde, fafts derfelbe bei ber nad)= iendenden Soitanitalt als franfirter nen zur 2 huf= gabe läns; die 2Imwendung bon Bulchlagporto oder bic Sebandlung als unfranlirte oder uma reichent franfirte Schoung findoct Daber nidje itatt; Der fehlende Frantobetrag wird Dem cimpfüuger als \$orto angcjezt.

(4) Bann eine Perfon, meldie cine Beitung bei ciner

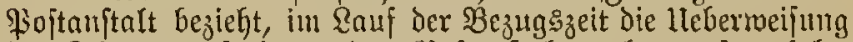
Der Beitung anf cine andere $\$$ softanjtalt verlangt, io erfolgt bie lleberweifung gegen cime Bebrigr von 50 \$5. Die lleberneifungsgebügr tommt ebenfo oft in ?tnjaz, wie Der

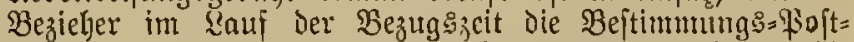

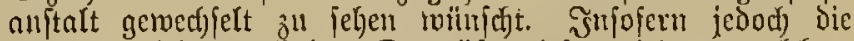
Beitung wieder nach dem Drte ithermiefen wird, an melchem Der Bezug uxpprïnglich) itattgejunden hat, ift für dic lleber= meifung eine nodjmalige (Scbilfre nidyt 314 erfeben.

1) Briefe mit Buftellmgğnffunden, weldhe pon Beridftşeförben ober Beridjtsperfonen abgejanto fino, bïrfen tur bam radjgcianot

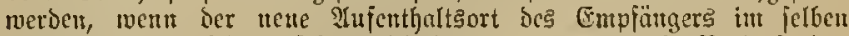

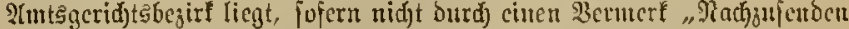

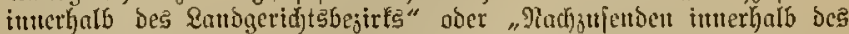

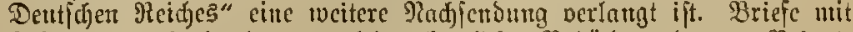

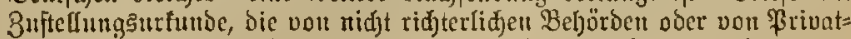

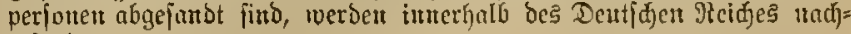
gefautot. 
Bebandrung unbejtelfbarer $\mathfrak{B}$ ojtiendungen am Beftimmungsort.

$\S 45$. (1) Boftfendungen find jür unbeftelloar zu er= actiten:

1. menn der (smpfänger am Beftininuungsort niḑ\}t zu ermitteln und oie Radjpendung nadj den $\mathfrak{B} 0 \mathrm{r}=$ idfriften im \& 44 nidft möglidf) ober nidjt z"= läijig ift;

2. twenn die $\mathfrak{A}$ nnahme berweigert mird;

3. twetm die Sendung mit bem $\mathfrak{B}$ ermert "poftngernd" berfehen ift und nidjt inner(jalb eines $\mathfrak{M}$ onat Tag des (Eintreffents an gered)net, bei Sendungen mit lebenden Thieren (§ 12) nicht fpätejten zo zmei Tage (b. i. 2 nal 24 Stmmben) nady Dem Cintreffen voll der \$3oft abgeholt wiro; ${ }^{1}$ )

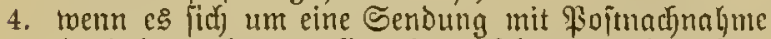
hanbelt, auth wenn fie mit "poitlagerni" bezeidfutet ift, und bie Sendung nid)t innerbalb 7 Tage nad ih)er 2nfunft am Beftimmungerort cingeläft wird;

5. menn bei \$ojtantweifungen innerfalb 7 Iage nad ifrex Tteghänoigung ber (3eldoctrag nid)t in Empiang genonimen wird;

6. Ivenn bie Sendung Rovje oder Stnerbictungen zil cinem Bliäfsfpielc entfölt, an weld)em der (En=

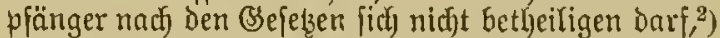
und wenn eine jolrbe Sendung fojort nad) ge=

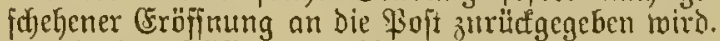

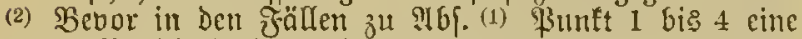
mit einer Begleitaoreffe verfebene Sendung alङ unbejteflfar nad) dent Aufgabcorte sttritfgeleitet wird, ift cine Hnbejtell=

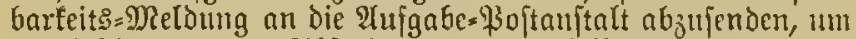

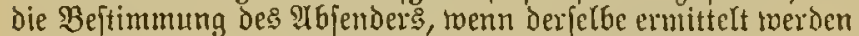
fann, über Die weitere Befjandlung des \$actets eirjuhulent.

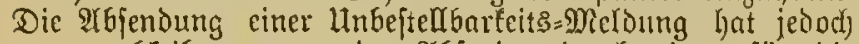
zu unterbleiben, menn der Itbjender burth einen fïr bie Bejtimmung: 9 sojtanjtalt berftänblichen Bermert auf Der Vorderfeite der $\mathfrak{B e g l e i t a d r e f f e}$ und in Der ?Luffedrift Des Bacfete bie jofortige Rittefendung Deffetben nach Dem eriten

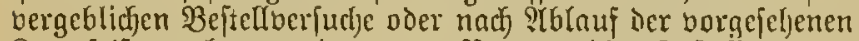
Eagerfrift berlangt oder zum Boraus die Buftellung an einen nnderen 5 mpfänger, jei eg an demfetben oder an einem anderen Drte des Deutjuden Reides, norgefdyricben bat.

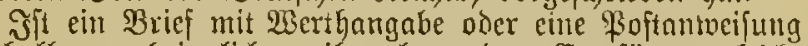
beshatb unanbringlid), weil melyrere dem (Empfänger gleidy= benannte Berfonen im Drte fid) hefinden, nint der twirftidle (Empfänger nidjt fidjer zu unterfdjeiden ift, fo muß ebenfalls

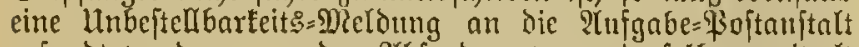
gejandt rerben, un den Stbfender, roenn derfelbe ermittelt

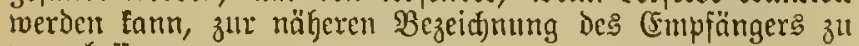
beranlafjen.

Fitr die Beförderung jener Unbejtellbarfeits= Melouttg unb ber zu cetheilenden Sintwort an bic \$spitanjtalt am Beftimmungsort der Senbung bat der 9bfender 20 Pi. Forto an Die 2lufgabe=\$ojtanjtalt baar zu entridjten.

(3) lleber ein unbeftelbar genteldetes Sacet fann Der 2tbjender bahin berjügen, ba $\overline{3}$

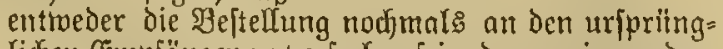
lidjen (Emplänger zu berfudfen fei, oder an eine andere Berfon unb, bergeblicjenfals, an cine britte \$erion erfolgen folle, oder bafi dos piactet an ifjn felbft zurǚfogefondt rerbe.

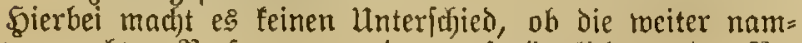

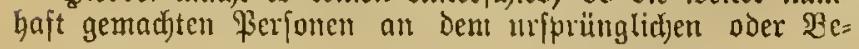

ftimmungsorte oder an einem anderen Srte des Deutffien Reiches, toohin eintretendenfalls die Weiterfendung zu be= twirfen ift, mohnen.

Şt bie Beftelling an bie bom 2 bjender auf Grund Der linbeftellbarteit = Meloung naunhaft gemad)ten \$erfonen nidft

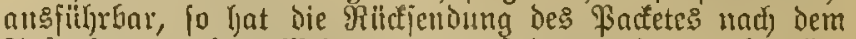
Plifgabeorte ofne Weiteres zu criolgen; cine nodjuntige llmbejtellbarkeits=Meloung wiro nid)t erlaffen.

Der S(bfender fann bic Sendung aud Durch \$3reisgabe.

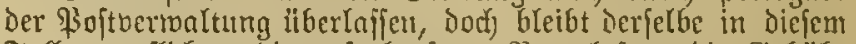
Falle berpflichtet, bie aufgelaufenen Bortofoften, die (Sebiitgr

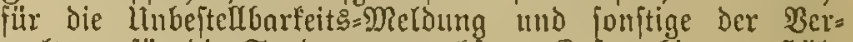

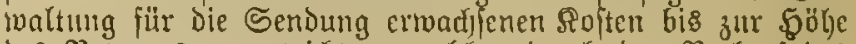
Des Betrages zu entridjten, weld)er Durdf den Berfanf Des Sactets nicht gedectt trirb.

(4) Berweigert der 2LGfender die Bahlung Des ßortos

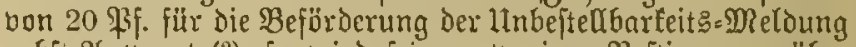
nebjt ? Intmort (2), jo wird jeirter etmaigen Bejtimmung Hiber Die Sendung feine Folge gegeben, die Sendung bielmeljr nach Dem Rufgabeorte zurițgeleitet.

Das (3) leidje lyat zu gefdjeben, wenn der 2afjender feine (Ertlärung nid)t innerhalb 7 Tage nad) (Empiang ber $\mathfrak{B} e=$ nadfricftigung bei ber Pufgabe=\$oftanftalt abgiebt.

(5) STlle cnderen Boftfendungen find, menn fie als un= beftellbar erfannt roorden, ohne SBerzug nach Dem Slufgabe= orte zurühzufenden. Nur hei Sendungen, dic cinem fonellen

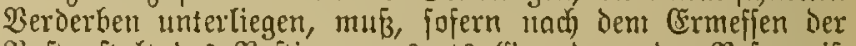
Foftanftalt Des Beftimmungent: (Srund zu Der Bejorguifs

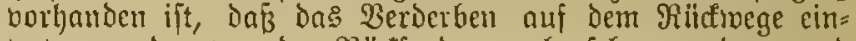
treten werde, bon der gituffendung abgejefen merben, und

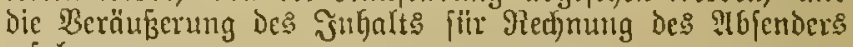
erjolgen.

(6) Ӭll allen vorgedachten fällen ift Der Grumd Der Buritefendung oder eintretendenfads, daß̧ und tweshalb dic Bern̈uBcrung erfolgt jei, autf deut Sriefe oder aul ber $\mathfrak{B e}=$ gleitabreffe zu vermerfen.

(7) Die zurüufufendenien Brgenftände bïnfen nidjt $\mathrm{er}=$ öfinet fein. (Eine Der unter (1) 6 bezeidjneten Briefe, famie bez̈̈̈glidj berjenigen Sriefe, weldhe bon einer mit Dem (5mpfänger gleid)namigen Ferfon ixthiimlid) geöffnet wrurben. Bei Briefen Der lez̧teren ?(rt ift thunlidfft Daljin zu wirfen, daf bie Pierfonten, weldyc Dic Eröffnung inthümlid) betwirft Gaben, eine bezitglidie

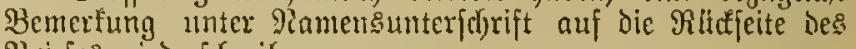
Briefes niederidfreiben.

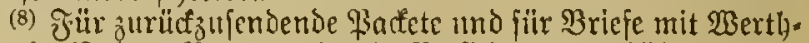
angabe ift das Gorto und die Berfid)erungsgebilgr fïr bic

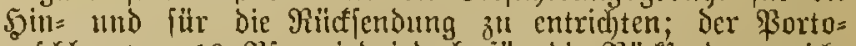

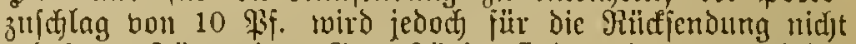

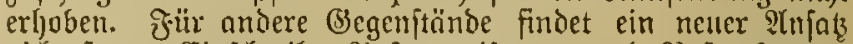
nidf) Itatt. (5infdyreib=, Poftantweifungs= Ind Poftauftrags=

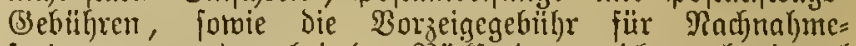
fendungen werden bei ber reïeffendung nidft nod) eimmal angefejt. Dagegen mird für jurüđzujendende dringendc

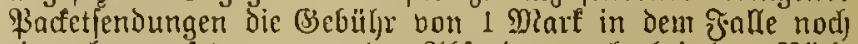

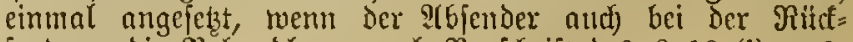
jendung bie Beljandlung nach Borfidrift bes \$ 13 (1) nus: orituflict) berlangt bat.

1) Ibrveident giervon find die Engerzeiten feftgelept:

a) für poftlagernoc Telegramme 6 TBoden ( $20 . \S 22(2)$ );

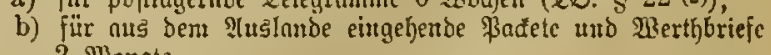
2 Mionatc.

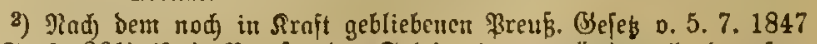

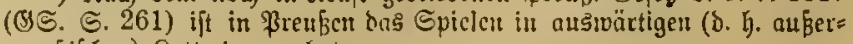
preubifdyen) Rotterien verboten. 


\section{Behandung unbeftellbarer Woftendungen am 2 ufgabeort.}

$\S 46$. (1) Die nad) Man̄gatbe des $\$ 45$ unbeftellbaren unt beshalb nach dem शrgangsorte zurïfgehenden Sen= dungen werden an Den Thjender zurïtgegeben.

(a) Bei der Beftelluutg uno Bebändigung einer zurücf getommenen Sendung an ben STGfender wiro nad) den fïr Die Beftellung und $\mathfrak{A}$ Heghändigung ciner Sendung an ben

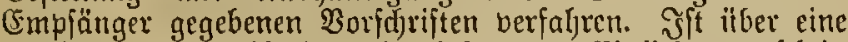

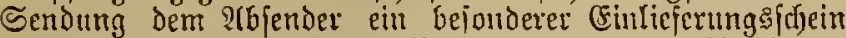
ertheilt worden, fo muß̄ Derfelbe bei der $\mathfrak{B i e d e r a t s h j a ̈ n d i g u n g ~}$ ter Sendung zuritugegeben merden.

(3) Saum bie Boftanitalt am ?fGgangsort Den ?tbfender nicft ermitteln, fo wirb bie Sendung an dic vorgejegte Ober = \$oftoireftion eingefand, mela)e diefelbe mittels Stembels als unbeitellbar zu bezcidjnen und durdf (Eröffnumg den S(bfender zu ermitteln hat. Dic mit her Eröffnung be= auftragten, zur Beobad)tung ftrenger Ber [afwiegenlyeit befonderş berpilichteten Bcamten nehmen Renntnißs bon Der IInterfdrift und bon Dem Drte, milffen jedod) jeder weiteren

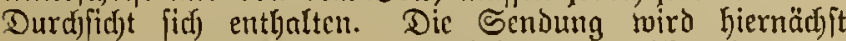
mittels Siegelmarfe odcr Dicnftfiegels, weldje eine ent= iprechende Snfdurift tragen, wieder berid)lofjen.

(4) Wenn Der Áf ender ermittelt mird, derielbe aber bie Innahme vermeigert, oder innerbalb 14 Tage nad) Behäudo gung der Begleitadrejic oder des Mbliejerungsfdeing oder der \$poftanoeifung die Sendung oder den Beldbetrag nicht abholen läbt, fo tönnen Dic Begenfüude zum Bejten bet Bopt=llnterftübungéfaffe nerfauft oder vermendet, Bricje und dic zun Bertauf uicht geeigneten werthlofen Begenftänbe

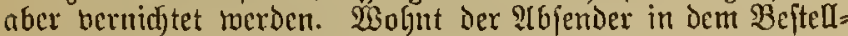
bezinfe ciner anderen 730 tanjtalt ale derjenigen, bei weldjer dic ?lufgabe exfolgt war, fo ift bie Sendurg der anderen

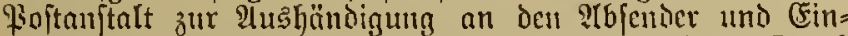
ziefung ber barauf hajtenden Beträge zu überjenden. Durclj

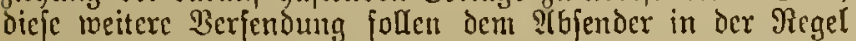
fcine Mehrfoiten ertoadjen. Sandelt es firf icdod) um un. bejtellbare gewöhnlidje Briefe, meldje uriprïngLid) nadj bem Beftellbezinte Des ?lufgabe=\$ojtortes gerithtet waren, fo wird bei lleberweifung ber Brieje an dic andere Fojtanftalt bas Borto nad) Borfdrift in $\$ 44$ (3) bered)net turd erljoken.

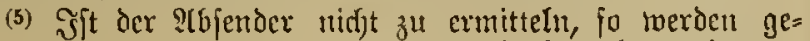
wöhnlidje Briefe und dic zum Berlaul nidjt geciguteten wertblofen (Begenftände nad) Berlauf bon Drei Manaten, nom Tag des Eingangs Derfelben bei der Dber=\$softoireftion gered)net, vernidstet; dagegen wirs

1. bei eingefdrictenen Sendungen, ferner bei Briefen nit $\mathfrak{B e r t h a n g a b e , ~ o d e r ~ b e i ~ B r i e f e n , ~ i n ~ D e n e n ~ f i d ) ~}$ bei ber crofffnumg (Begenftänie bon $23 e r t h$ borge= funden lyaben, ohne daf dicfer angegeben toorden mar, forvic bei \$oftanmeifungen,

2. bei Fiafeten mit oder olyne Wertljangabe

ber Itbjender öffentlid) aufgefordert, innerhalb vier worffen die unbeitellbaren Begenitände in crmpfang zu neljmert. Die zu erlajiende öffentlidje 21 ffforderung, tweldje eine genaue Bezeidinung des (Segenftandes unter Ingabe des Ytbgangs. 1uio Beftimmungsorts, der ßerfon des Empfängers und Des

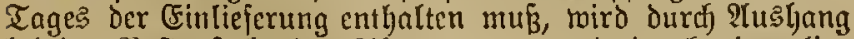
bei der Poftanitalt des ?thgangsorts und durd) einmalige Finrüifung in ein bazn gecignetes amtliches $\mathfrak{B}$ latt betannt gemadt.
(6) Jnzmifden lagern die Sendungen auf Brefaht des 2rbjenders. Sachen, weldje bem Berderben ausigejest find, fönnen jojort vertauft rerden.

(7) פ⿹leibt bie b̈fentliche ?lnfforderung ofne Erfolg, fo werden dic Sadjen bertaujt.

\section{Sauffureiben wegen Poftendungen.}

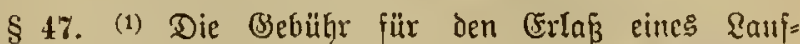
(d)reibents bezüglich ciner zur \$ojt gelicferten Sendung be= trägt 20 \$i .

(2) Fïr \&aufidjeiben wegen gewöhnlidjer Brieje, \$ojt= farten, Bruffjacter oder Waarenproben foll dicje (Sebülyr erft nacfträglich und mux in Denjenigen ₹ällem erljoben weroen, in toeldyen bie ridjtig crfolgte Itushändigung ber Senduitg an den Empjänger feftgeftellt miro.

(3) Für Rauffejreithen inegen anderer Senbungen ift dic (Sebüllr vor dem (Erlaife des \&auffdreibens zu entridjten;

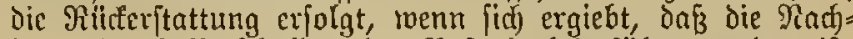
frage Durd) Berjoulden Der \$ioft ljerbeigefïhrt morden ift.

(4) Fïr Eauff(jreiben, meld)e portojreie Sendungen be= treffen, wiro eime (3ebilhr nicht erhoben.

\section{Rad)licferung von Beitungen.}

§ 48. (1) Wenn bei berfpätet erfolgender Beftelung ciner Beitung der $\mathfrak{B c z i c h e r}$ die Padjlieferung ber fitr bie

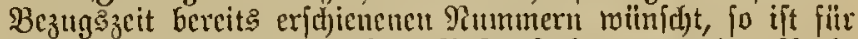
das an die Beitungeberlags= \$oftanftalt tregen ber Rat)= liejerung abjulaffende bejondere $\mathfrak{B e j t e d j c h r e i b e n ~ b a s ~ F r a n t o ~}$ bon $10 \mathrm{BF}$. zu entridjten. (Ebenfo ift, menn Begiełjer von Beitungen die nod)malige Sieferung einzelner ifjnen fehlender Rummern der Zeitung berlangen, für das dieferhalb an bic Berlagg: \$3oftanitalt zu rid)tende poftantliate Schreiber dos Jranto von 10 \$f. z"l erlegent.

\section{Bertauf von Boftwertheident.}

\$ 49. (1) Die Freimarfen, jowie die geitempelten 'Bojt= farten und Boptanweifungen werden zu dem Rentwerthe Des Stempets an Das \$3tublifum abgelajien.

(2) Dic Inftalt, in welther bie Boftwerthzeidjen fjergeftelft merden, Hiberninmt dic 2(bjtempelung bon \$oftenten mit Dent Freinarfenitempel fiir das ßublifum unter Der bci jeder \$3oftanftalt zu erfragenden näheren Bedingungen.

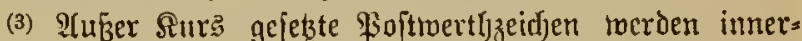
halb Der Duref den Deutfdjen Reidfis=2Inzeiger und andere öffentlicf)e Blätter befannt zu madjenden ₹rifit bei den \$ojt= amftalten zum Renntwertly gegen gïltige \$3oftwerthzeidjen umgetaufd)t. Rad) S(blauf Der Frift findet ein limtaufd nidft mehx ftatt. Dic Reichs=\$Poftocribaltung ift nicft ber= bunden, Foftwertlyzcid)en baar einzulöjer.

(4) Die Berlvendung der aus geftempelten \$30it $=$ anmeifungs = Formularen und Bojtfarten autgejunittenen Frantoitempel zur Franfirtung bon Boftferdongen ift nidft zuläffig.

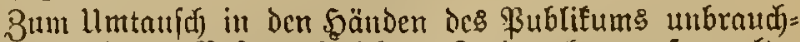
bar gewordener $\mathfrak{B}$ oftwerthzeiffen (ङreimarken, gejtempelter

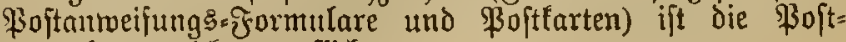
bertoaltung nidjt berpflicjtet.

1) Bgl. Pofttnz=(B) 


\section{Entrichtung des \$ortos und der fonjtigen (3) ebitgren.}

§50. (1) Die Boftiendumgen fönnen, jofern nidft dos

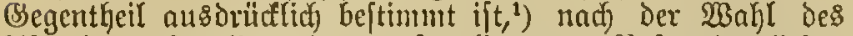

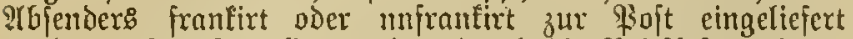
werden. Bur Franfinumg der Durel die Briejtajten einzts=

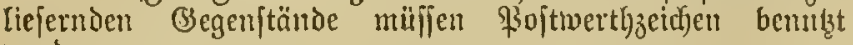
tocroen.

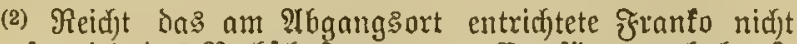

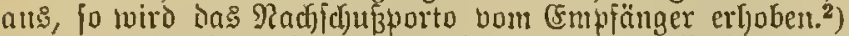
Bei gemöhnlidyen Briefen, Bojtfarten, Drucffadjen und Waarenprobell, fotwie bei alfen Sendungen vom STußland

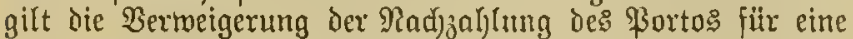
Zerweigernng Dex $\mathfrak{A}$ malyme Deß Briefes 2c. Bei anderen Sentoungen fann der Empfänger die Ilustieferung ofne Portojablung berlangen, wenn ex den NGiender nambajt madft und den Briejumidhlag ober cine 2Lbichrift Dabon zurïd zunehmen geftattet. Der feblenie Betrag wird alsonn vom ?tbjender cingezogen.

(3) Woiro die sunnabute cincr Sendung von Cimptänger bertweigert, oder foun ber smpfänger nidft ermittelt werden,

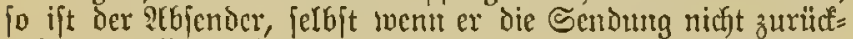
nelmen will, berbunden, dag Borto und bie Bebihgren zu zahlen.

(4) Fïr Sendungen, weld)e erweiglid) all ber Pojt ver= loren gegangen find, wirb fein $\$$ sorto gezahlt und ons etwa gejaljlte eritattet. Daffelbe gilt bon poldien Sentungen,

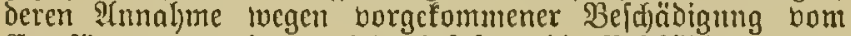
Empfänger wermeigert twird, injofern bic scjéfjäbigung bon ber Foftoertoaltung ou bertreten ift.

(5) Sot der Empfänger die Senoung angenommen, fo ift $\mathrm{cr}$, fofern im Woritehenden nicht ein S(noeres bejtinmt ift, zur (Entrid)tung Des Fortos und der (Bsebillyren vers

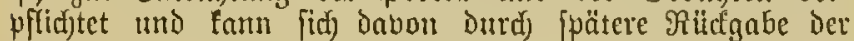
Senoung nid)t beireien. Die Reidjs= mo Staatsbefjörben find jebocl bejugt, and nad) erfolgter IImnalyme und (5r. offnung portopflidftiger Sendungen zum . Bweaf Der nachträg.

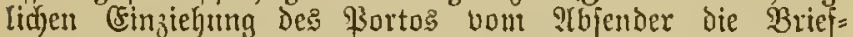

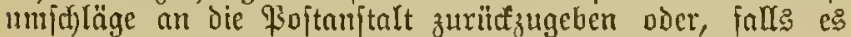

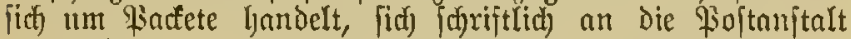
zit twenden.

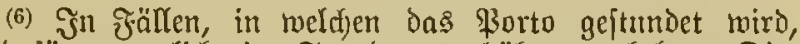

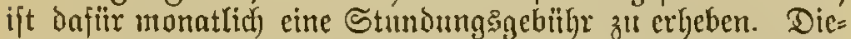
jelbe beträgt 5 \$if. jür jede Marf oder den itberjchieźenden Theil ciner Marf, mindejtens aber 50 \$F. Wenn in einem Monat \$orto nidjt zu itunden gewejen ijt, fo wird eine (ङebülyr nicjt erhoben.

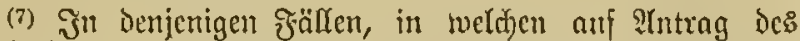
Betljeiligten zur Bermittelung der Ilbgabe ber für ifn ein= geljenden oder der Cinlieferung der bon iljn abzufendenden getwöhntidfen Brieje, \$ojtfarten, Drucfjadjen, Waarenproben uno Beiturgen mit Den borbeifahrenden PBoften berfolofiene Tajejen bejördert werden, ift fïr bieje Bermittelung cine (Sebilfr bon 50 \$f. für ben Mlonat zu exheben.

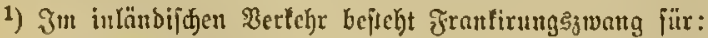

Dringettoc Findete

Bojturten.

Drutiaden : :

Waarenprober

Poftanweifungen

\$of̣tau|trägc

\section{¥D.}

$\S 13(3)$

$\$ 15(8)$

$\$ 17(6)$

\$క 19 (2) น. 20 (5)

$\S \S 22(20)$ u. $23(1)$
2) Bgl. In ßezug auf:

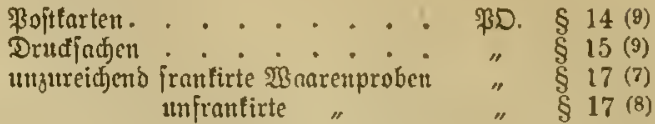

\section{Abrijuttt.}

Ferfonenbejörberung mittels ber Fojten.')

1) $\mathfrak{i t}$ Dezug auf Garantic vgl. \$ofts. \$ 11.

\section{Meldung zux Reife.}

§ 51. (1) Die Meldung zแr Reife mit den ortientlidjen \&often fann itattfinden:

a) bei den Poitanitalten, oider

b) bei Den unterwegs belegenen Salteitellen, tweldic von den Dber= \$3oftoirettionen ïfientlid, betannt ge= madit werden.

a) Bei den \$ujranitalten.

(2) Bei ben \$oftanftalten fann bie Meloung friigejten: am 20 d)entage vor oer Stbreife und fpäteftens bei Schluß der Pioft jür bie therjonenbeförderung gejdjeben.

(3) Der Gdjlnß̧ der Poft für die Fierfonenbeförocrung tritt cin:

wenn in Sauptwagen oder in ien bercit: geftellten Beiwagen nod) siläţe offen find:

5 Dinuter, uno

roenn biejes uidjt ber Fall ift, jonbern bie bies

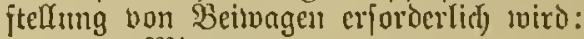
15 Minuten

bor ber fejtgefeczten IlGgangszeit oct fioft.

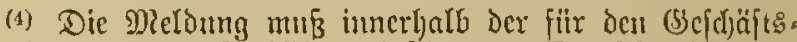
verfel)r mit dem giublifum beftinmten Dicuitfunden ges idjeben, fann aber, wemn die \$ojoft auferbalb Der Dienjt= ftumben abgehts, alld nod) gegen bie Beit der 2tbfertiguttg Der Poft crfolgen. Lebrigen: barf die Meldung - itber bic

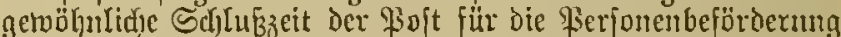
hinaus - ausnahusmeije noch unmittelbar bis zum 96. gange der Pojt jtattfinden, injofern badurd) Die piinftliclye Q1bjendung Derfelben nad bent Exmefien der \$oftanftalt nid)t berzügert wiro.

(b) Erfolgt Die Meldung bei einer Piojtanftalt mit Station, fo fann die SInnaljue nur Dann iwegen mangelnden \$lazzes beanitandet iverden, menn zu Der $\$$ pojt Beimagen überhaupt nidft geitellt werden und dic \$läßc im Santst. wagen fahon vergeben oder all ben Itnternegs:=Stationen bei ?tufunft der \$ojt fdton bejest find, oder toen anf Der Station nur eine bejduränfte Beftellung bon Beinongen jtatt. findet.

(b) Erfolgt die Mieldung bei ciner \$oftanjtalt oljuc

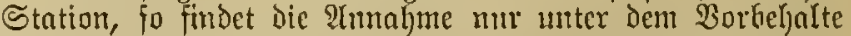
ftatt, bas in bear 5auptwagen und in Den ettna mittommen= ben SBeirvagen nod) unbeletste SBläţe vorbanden find.

(7) Bei joldjen \$ojten, zu weldjen Beiwagen ïberhanpt

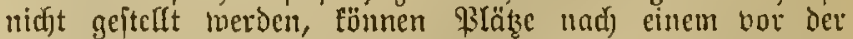
närthjten Etation belegenen Bwifichenorte nur injomeit ber. gebel iverden, als fid bis zum stbgany ber \$ojt zu incn borbandenen ßräzell nidft ßerionen gemeldet ljaben, meldre bis zill näd)ften Station ober dariiber Ginaus reifen roollen. Dod) fann der Reifentio cinen vorbandenen Plats fid bas 


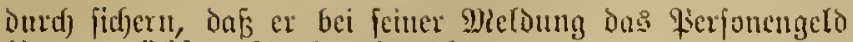
bis zur nächfiten Station bejahlt.

\section{b) श्tn Saltejtelletr.}

(8) Die Meldung an Saltejtellen tann mux Dam be=

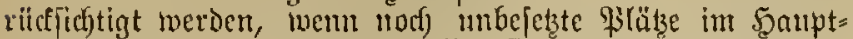
magen oder in ben Beimagen offen find. Bepä́ct von joldhen Reifenden faum mur injorweit jugelaffen werden, als bajfelbe ofne Beläftigutg der nuderen Peifenden im Ferjonenratm leicht untergebracht werden fann. Die Bacträume Des WBngen: biirfen niddjt geöffnet werden, aud ift jebes längere ?Inljalten der gioft unjtatthaft.

(9) 2Bünjchen Reifende fich Die Beförderung mit der Bojt von einer \$3oftanitalt ofye Station oder bon einer \$alteitelle

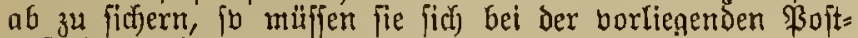
nuitalt mit Station melden, bon bort ab einen şata nehmen und das entipredjende झ̈erfonengeld exlegen.

Berfonen, welde bon ber Reife mit der \$ojt ausgefdjlofien find.

\section{§52. (1) $\mathfrak{B o n}$ der Reije mit der łopt find ansge=} \{uff)lofien:

1. Sirante, weldye mit epileptifcjen oder Bemittbs= reiden, nit anftecfenden oder Efel erregenden Uebelu behaftet find;

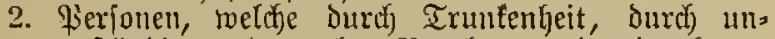
anitändiges oder rohe: Benchmen, oder Durch un=

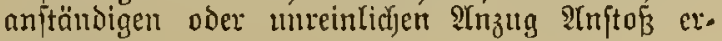
regen:

3. Sejangene und

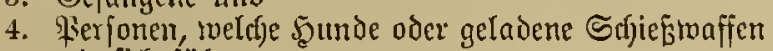
mit fich füfren.

$$
\text { Jaদrifhein. }
$$

\$53. (1) (3efdjieht Die Mieloung zur Reife bei ciner S3oftanftalt, fo erfjält der Reifende gegen (Entricftung des

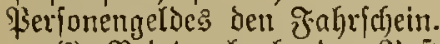

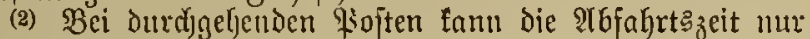

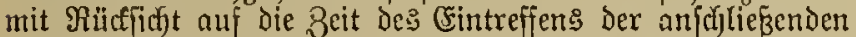
\$often oder (Fifenbalinzïge angegeben werden, uno es liegt

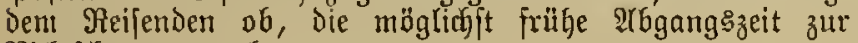

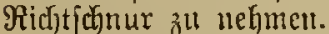

(3) Die Rummer des ₹rafridjeins ridftet fidf nach De:

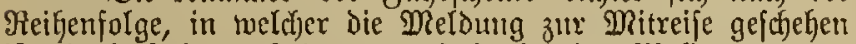
ift, Docf) fteljt es J̌edermann frei, bei der Meloung unter:

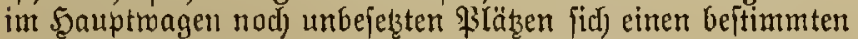

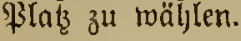

(4) \$erjonen, bie fick an 5altefteflen gemeldet haben und

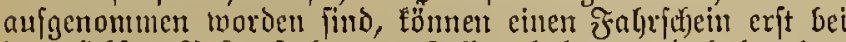
Der nächiten \$oftanitalt ausgeftellt erljalten, und haben bas Berfonengeld bei biefer Bojtanftalt oder, wenn fie nicht

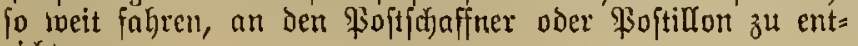
richten.

(S)rundäze der Berjouengeld= Erhebung.

\$54. (1) Dns \$̇erfonengelo wird exhoben, ${ }^{1}$ ) entweder

a) nacf Der bou ben Reijenden mit der \$ojt zuriiff= zulegenden Cntfermutg, unter Anmenoung dę bei ठcm Surje jür Das నilometer angeoroneten Sazzes, oder

b) nach Dem für einen beftimmten Surs angeoroneten bejunderell ऽabze.
(2) Das Fierfonengelo fommt bei ber Metoung bis zum Seftimmungsort jur Erhebung, fofern Diejer auf Dem Surfe liegt mid fidj Dajelbit eine \$ojtanitalt befinoct.

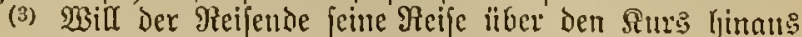
oder auf eimem Seitenfurfe fortfełen, fo taun Das Ferfonen= gelo mit bis ztl dem Enopunte oder his zu bem lleber= gangspuntte des Siurje: erlegt werden; der Feifende fanm

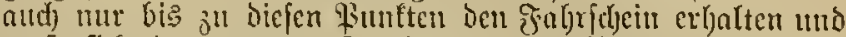
muß ficf Dort Iuege: Fortfebung Der Reife bon Reuem

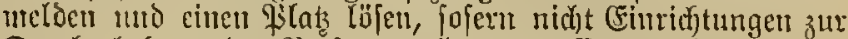
Durtherljebung des Pierfonengeldes getroffen worden find.

a) Bei Reifen nach Brwifchenouten.

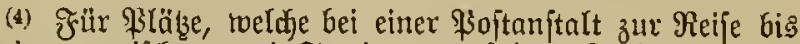
zu einem zwifchen zmei Stationen auf Dem Surfe gelegenen Drte (3wiffjenorte) genommen twerden, fommt, gleidjbiel, of fid) in biefem Zwifhenorte eine \$ojtanjtalt befindet oder midjt, bas Ferfonengelo nach) der wirflid) zurïf zulegenden Silometerzaljl, mindejtens jedoch der Betrag von 30 PF. zur Crrljebung.

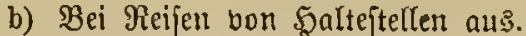

(5) Fiir bie Beförderung bon \$ूalteftellen ab ivird, fofern die dort jugeljenden Perfonen firf nid)t etrwa einen \$lats bon ber vorliegenden Station ab gejictert haben, das \$erjonen= gelo nach) DRafgabe der wirflichen (Entfernung bis zur nä(s)jten Station, ader, wenn bie Reijenden idjon vorher

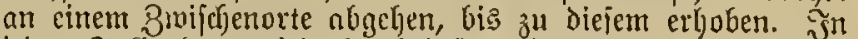

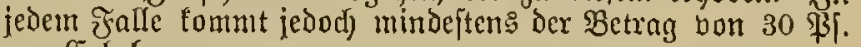
zur Erhebung.

(6) 230 llen an Soltejtellen jugegangene ßexponen mit delfelben Bojt bou ber nächjten Station ab meiter bejördert merden, fo haben fie dort den \$lab für die meitere Reife z"l löjen.

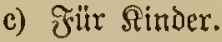

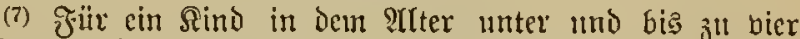
Jahten wird Serfonengeld nicht erhoben. Das Sind Darf

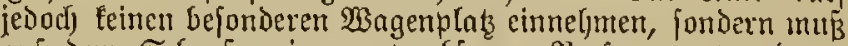

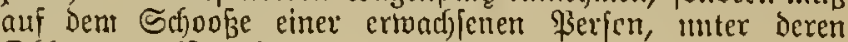
Sffint es reift, mitgenommen werden.

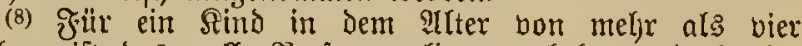
Jahren ift das bolle \$erfonengeld jul exheben uno ein bes fonderer \$lats zu beftimmen. Sehmen jedoct) ઍamilien einen

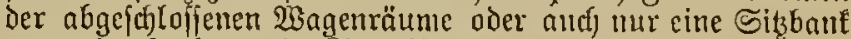

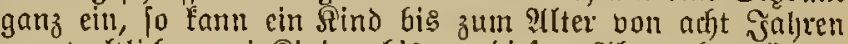
unentgeltlicf), zmei Rinder bis zu biejem I(ter aber föntmen fiir das \$serfonengelo für nur eine \$erfon bejörbert werden, infofern bie framilie mit den ßindern ficf auf die bon ibnen bezahlten Sitzplởze beja)ränft. Dieje Berginjtigumg fann nur für den Scauptroagen unbedingt, fïr Seiwngen aber nux infoweit jugeftanden werden, als auf Beibcljaltumg Der urfprïnglidfen fiäłze zแ rec)nen ift.

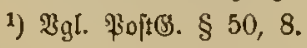

\section{Eritattung bon Berionengelo.}

\$ 55. (1) Die Eritattung von ßerjonengelo an die

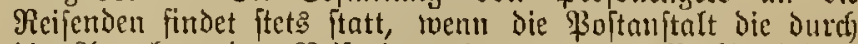

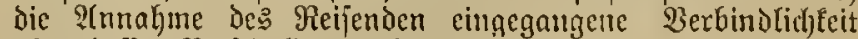
ohne Deffen Eerjutulden nicht erfïllen fant. Die Erjtattung bon \$erjonengeld foll aud Domn zuläffig fein, went Der

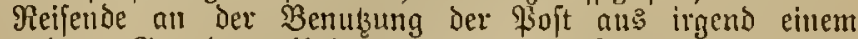
anderen Brunde verGindert ift mo dic Erftattung mindeftens 15 Minuten bor dem plaumäzigen P(bgange Der \$ojt be= antragt. 


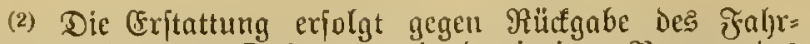
icheins und gegen Dunittung imit Demijenigen Betrage bes Gerfonengeldes, meldeer von dem Reifenden jïr bie mit der Foit nod) nidjt jurürfgelegte Streffe erboben moriden ijt.

\section{Berbindicfect der Reifenden in Betreff Der Rbreije.}

\&56. 1) Dic Rcifenden mitifen bor dem Piofthanfe oder an den fonjt Dazn beftimmten Stellen Den $\mathfrak{B a g e n}$ bes fteigen und an diejen Stellen zu ber im ₹ahrid)ein bezeid)=

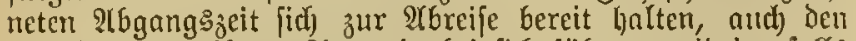

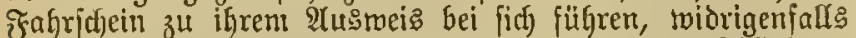

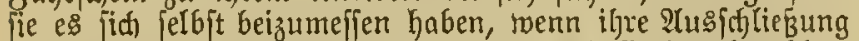
bon der Mits oder Meiterreije erfolgt, und fie bes bezahlten ßerfonengeldes berluftig gehen. Saben folche \$erjonen

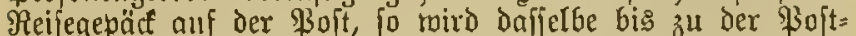
anjtalt, auf welche ber Fabrifchein lautet, Geförbert und bis zum Cingang Der meitezen $\mathfrak{B}$ ejtimmung jeitens ber zurilif= gebliebenen \$erjonen aufberongrt.

\section{giäze der Reifenden.}

\$ 57. (1) Die Sromung der \$läkze im Santptragel er:

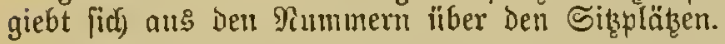

(2) Beziiglich Der Jolge Der \$̧läke in Dell Beimagen gilt

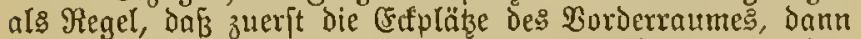
Der BorDerbaut und Der Rürtbanf Des Mittelraumes, zuleżt in Derfelben Reihenfolge die Mittelpläkse fommen.

(3) Behen untertwegs Reifende ab, fo rücfen bie nach) ifjen folgenten \$erfonen in Şauptwagen und in Den Beis magen Inm fobiel Rummern vor, als łlätze frei roerden.

\section{a) Bei Dem Bugange auf ciner untertwegs gelegenen \$ojtanjtalt.}

(4) Die bei ciner untermegs gelegenen Siọtanjtalt hin= zutretenden ßerjonen jtelien Den vom Surje fommenden und meiter eingeffiriebenen Reifenden in Der Reihenfolge Der ঔ[äkูe nad].

b) Bei Dem Hebergange auf einen anderen Surs.

(5) Reifende, welche von einem Rurje auf einen anderen iibergehen, jtehen Den fiir ben Leteteren Surs bereits einge= fafriebenen Reifenden hinfinttid) des \$latges nad).

\section{c) Bei Reifen nach Bmifdyenorten.}

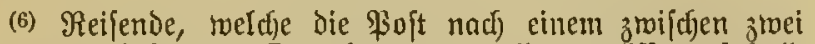
Stationen belegenten Srte benuben volfer, müfjen, jobals burd) ifren Arbgang unterwegg ein Beimagen eingehen fam, allen bis zแr nädjiten Station cingejdriebenen Reijenden nachjtelyen und die \$läke in dem Beitwagen einnelymen.

\section{d) Bei Reifen bou \$altejtellen ณuเ.}

(7) Reifende, weldje bon Den \$3oftichaffnem oder \$3oftillomen untermeg: an \$olteftellen aufgenommen worden find, jtehen bei Der Weiterreife über die nädjfte Station hinaus den bei

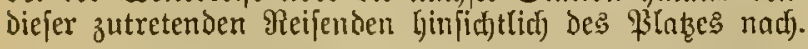

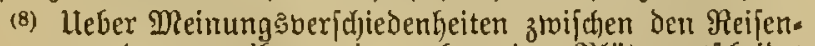

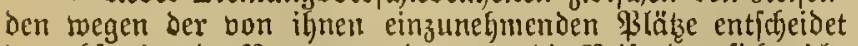
Der abfertigende Beaunte, und, wenn Die Reifenden fidj nid)t

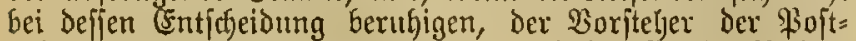
aujtalt. Der getroffenen Enticheioung haben fich die Reijen= ben, borfehaltlich ber Brfunerde, zul untermerfen.

\section{Reifegepätf.}

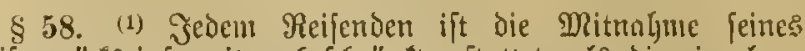

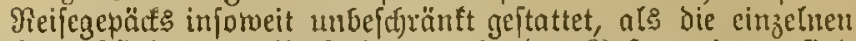

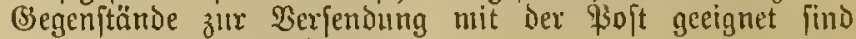
(vgl. $\$ \S 1,2,11$ und 12).

(2) Sleine Begenjtände, weldje Dljne Beläftignng Der

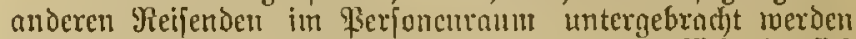

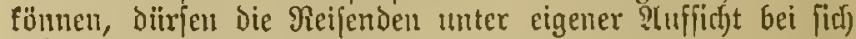
fübren.

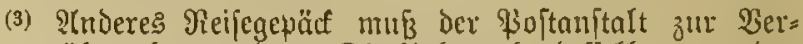
labung tibergeben werden. Die llebergabe Deffetben bon den Reifenden an \$oftichaffner und \$oftillone ift an Drten, an

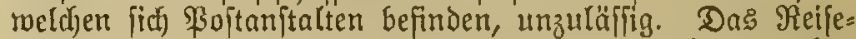
gepäaf muß, twenn dafiir ein befimmter 20 erth angegeben wird, den fïr andere mit Der \$ojt zu verfendende $\mathfrak{B e r t h}=$ gegenitände gegebenen $\mathfrak{B} e$ itimimungen entipredjend berbact, berfiegelt uno bezeidynet fein; die Bezeifymung mura, nußer dem Worte: "Reifegepät", Den Ramen des Reijenden, Den Drt, bis zu weldfem die Cinfdjreibung erfolgt ift, und bie Werthangabe enthalten. Bei Reifegepäaf obne $\mathfrak{B c r t h a n g a b e}$ bedarf es ciner Bezeidjung nidft. ${ }^{1}$ )

(4) Das Reifegepädt, fomeit daffelbe nidjt alts Eleinen Reijebedïrjnijien befteht, muis fpätejtens 15 MRinuten nor

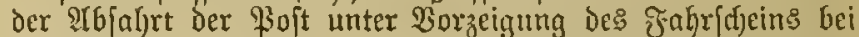
Der \$ojtanftalt eingeliefert merden. Erfolgt die CEinliefermung fpäter, fo hat der Reifende auf bie Mitbeförderung des (Be= päcfs nur Dann zu red)nen, mern Duref deffen QInnahme und Verladung der abgang der \$oft nicht verzögert wird. Solweit Reifende von ciner \$ojt anf bie andere oder bou cinem Baljnzuge anf bie \$ojt nnmittelbar übergelyen, roiro

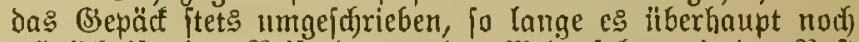
möglich ift, den Reifenden zu der Weiterfahtt mit ber \$ajt ofne Berfä́mmiz anzunefmen.

(5) Der Reifende erfält iiber das eingeliejerte Reife=

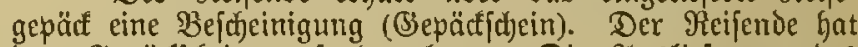

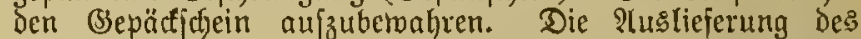

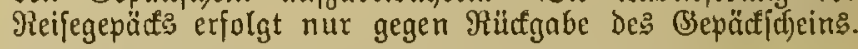

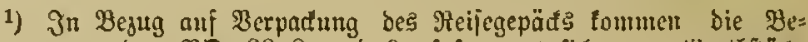

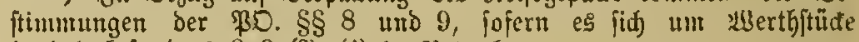
handelt befonders \& 9 (2), (4) in Setrant.

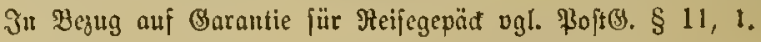

lleberfradjtporto und Beriacherung gagebülr.

§ 59. (1) J̌edem Reifenden ift auf bas der łopt über=

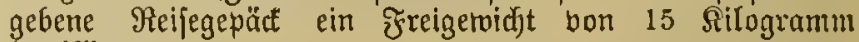
berwilligt.

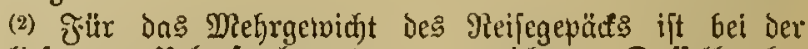

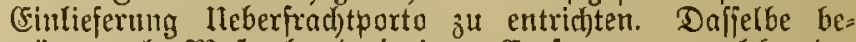
trägt nad) MRasgabe Derjenigen (Entfermung, weldje ber Serjonengeld= (Erfebung ôt Srunde gelegt miro, für jede: silogramm oder den überfdbiefenden Theil eines Silo= grainms:

1. bei Beförderungen bis 75 Silometer 5 舛., minde= iteng 25 Pf.

2. bei Bejörderungen über 75 ßilometer 10 \$̧., minde= ftens 50 Pf.

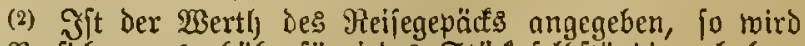

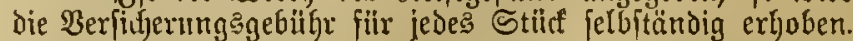
Dieje (Bebiil)r beträgt oljne unterjhieo ber Entfermutg und zu jeder Şähe der $\mathfrak{B e r t h a n g a b e ~} 5$ وf. für je 300 Mart Dder eimen Theil von 300 Mare, mindejtens jedoch 10 \$F. 


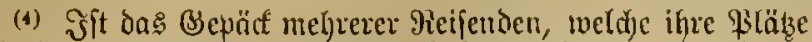
auf einen Fahrfchein genommen haben, zujammengepart, jo ift bei Ermittelung Des lleberfrachtportos bas Jreigewidht für bie auf Dem Frabricheiue vermerfte Inzahl von ßerfonen nur Dann von dem (Sejammitgemid)te des (sepäcts in Itbzug zll bringen, toem die Sierfonen zu einer uno derjelben

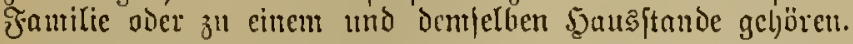

(5) Die Criftatung van Ueberinadjtporto und Berfiche= rungsgebübr regelt fid nard) benfelben (Srundjätzen, wie dic Erjtattung bon \$ierfonengeld.

\section{Berfïgung des Reifenden über das Reife. gepäu untertoegs.}

§ 60. (1) Dem Reifenden Kant die Berfitgung ïber das

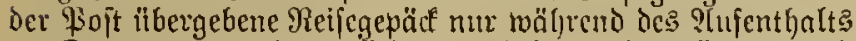

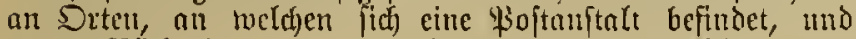

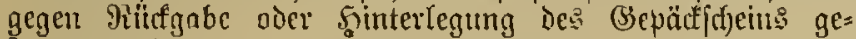
itattet trerden.

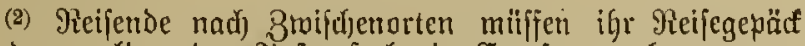
uci ber borliegenden \$oftanftalt in Empiang nebmen, bon

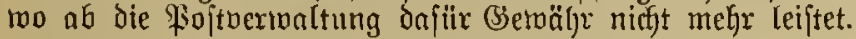

\section{Wartezinuer der Boftanfalten.}

§61. (1) Bei den \$oftanftalten werden nad) Bedürfníß Wartezintuter unterljalten. Der $\mathfrak{A}$ ufenthalt in den Warte= zimumern Der \$ojtanjtalten ift den Reijenden gejtattet:

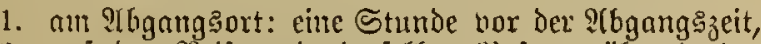

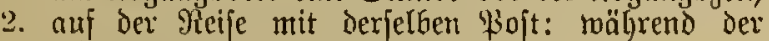
Trbjertigung auf jeder Station,

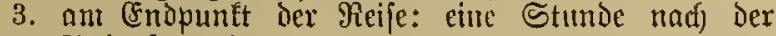
Infunft, und

4. bei Hebergang von eitter Foit auf die andere: während 3 Stumben.

(2) Bierjonen, meldie die Reifenden jul Fojt begleiten,

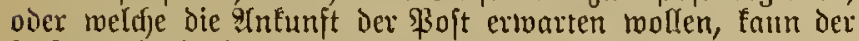
Aujenthalt in den Bartezimmern nur attonahmsesmeife und in geringer $8 \mathrm{al}$ l $\mathrm{gej}$ tattet werden.

\section{Bergalten der Reifenden auf ben Boiten.}

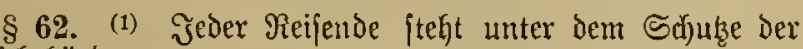
Poftbehärden.

(2) Ilndererfeits ift es die ßfficht eines jeden Reijenden,

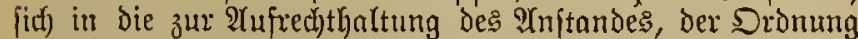
und ber Sicherkeit auf den ßoften und in den Wartes zimmern getroffenen $\mathfrak{2}$ moronungen zu jügen.

(3) Dą̧ Randfen im \$ojtwagen ift nux gejtattet, wenn

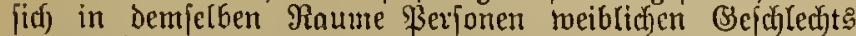
nicht befinden und bie anderen פitreijenden ifge 8 uftimmung zum Raudjen gegeben haben.

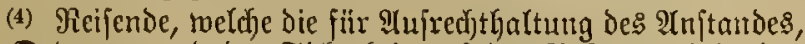
der Dronung und ber Sidjerbeit auf den \$ojten und in den Wartezinmern getroffenen Plnoromungen berleken, ヒ̈̈nnen vorbeljaltlich der Bejtrafung nad) dent Sandesgcfetsen - von ber \$ojtanitalt, unterwegs bon den \$ojtfdiaffner, von der Mits = oder Weiterreife ausgefdiflofen und aus Dem \$ojtmagen

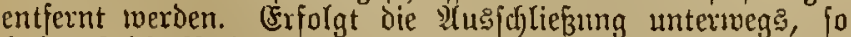
Gaben folche Reijende ihr Bepäct bei der nähjten \$ojtamitalt abzutholen; fie gehen Des gezahlten Perfanengeldes und des etroaigen Ileberfrachtportos verluftig.

\section{Aluridyitt.}

\section{Crtrapoitteförderumg.}

Prlfgemeine Beftinmungen.

$\S 63$. (1) Die Brefteflung von Extrapoftpferden tam mur auf denjenigen Straßzen berlangt werben, auf weldfen Die \&oftbertwaltung es ïbernommen hat, Reijende mit Extra= poitpferden zull betördern.

(2) Yuf Diefen Strafien erjtrecft fich die Berpflidftung der Pofthalter zur (Seftellung bon Ertrapoftpferden nur auf bie Beförderung bon Reifenden mit igren Bsepäct.

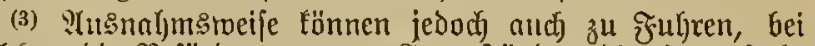
ineld)en die Bcjörderung bon (Gegenftänden bie Somptfache ift, Errtrapoftpferìe geftellt merden, jofern die Biegenftände bon einer Perfout begleitet und benuffidgtigt werben und igre Bejörderung iiberljaupt oljne Befafr und Rachtbeil betoert= ftelligt werden fonn.

(4) Die \$3opthalter find nicht werpflicftet, zu den eigenen

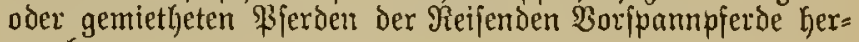
zugeben.

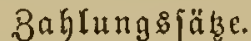

a) Friir die \$̧Ferde.

§ 64. (1) थ̂n Bferdegeld find für jedes Extrapojtpferd und fïr jedes Silometer 20 \$f. zu zallen.

\section{b) Wagengeli.}

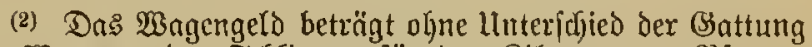

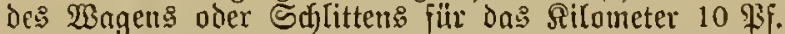

(3) Siöfere, als vierfitzige Wagen oder Schlitten her= zugeten, find die Bofthalter nicht verpflichtet.

(1) Die Befugnif, \$ofthaltereimagen zur Beiterreife

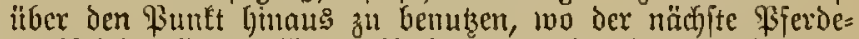

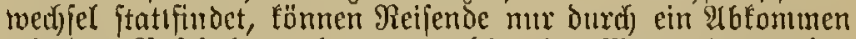
mit dem $\$ 3$ ofthalter erlangen, melder den Wagen herzugeben jid) bereit finden läs̆t, uno beffen Sorge ez ïberlnfijen bleibt, Die Ritufefördertung des lebigen Wagene nuf feine Roften jull berwirken.

\section{c) Beftellgebühr.}

(5) Das Beftellgeld beträgt für jeden Extrapojtmagen auf jeder Station 25 \$F. YUt anderen \$untten, als den wirtlicfen Stationer, findet die Erhebung ber Beftellgebülyr. nicfit ftatt.

d) Sdjmiergerd.

(6) ₹̛̈ix das Sdfmieren eines jeden Wagens, der nidft von der \$ojt geftellt ift, find 25 95 . zu zahlen.

\section{e) Beleuditutugâtoiten.}

(7) :Lf Berlangen der Reifenden find die Boithalter ver=

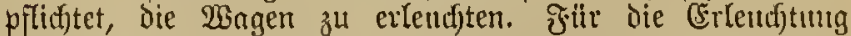
zmeier Saternen werden 20 \$j. Für jede St::ude der vor:= idjrijtemäß̈igen Befördorung: Minuten werden fïr eine halbe Stumbe geredinet. Die

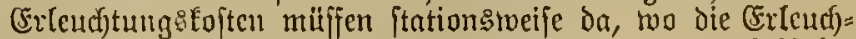
tung nerlangt wird, von ben Reifenden vor ber Abfafirt mit den anocren Bébiligren beridgtigt werden.

\section{f) Wregegeld und fonftige $\mathfrak{B e g e}=2 c$. 2Yogaben.}

(8) Da: etwaige $\mathfrak{W e g e g e l d , ~ f o t w i e ~ d i e ~ f o n j t i g e n ~} \mathfrak{B e g e}=2 \mathrm{c}$. Abgaben werben nach der zur bffentlidjen Sentntis ge= brachten Iarijen erhoben. Itnentgeltlid, hergegebene Miehr. 


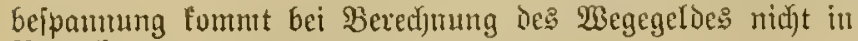
Betract)t.

\section{g) Sioftillonstrinfgelo.}

(9) Das Boftillonstrinfaclo beträgt oljue llnterjdied der Befpanmung fïr jeden fortillon für bas Silometer $10 \mathrm{HF}$.

\section{h) Rïfbenubung einex (5xtrapojt.}

(10) Ertzopojtreijende, bic jich an Beftimmungsout ifjer Reife nicht über 6 Stunden aufjalten, haben, tverm fie mit den auf Der Sjimeife bermbten Siferden und $23 a g e n$ einer

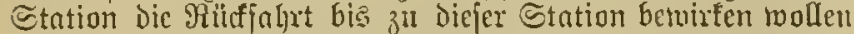

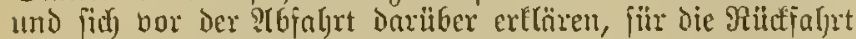
Inur Die Sälfte Der nach den Säben unter $a, b$, c uno g fich ergebenden જetrïge, mindeitens jedod fiir die ganje Falyet dic Soften für eine Sintefibidernug bon 15 Silometern

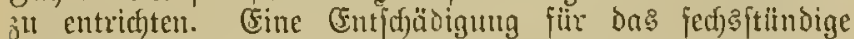
Etilllager des (Gefpants tutd des Foptillons ift ricf)t zut

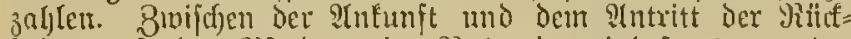
falprt mus den gjerden cine Mubezeit mindejtens van der Dauer Ber cinfadjen Beförderungegrift gemölfurt merden.

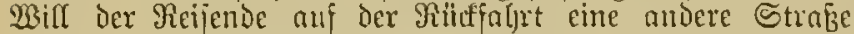

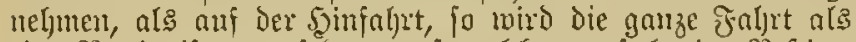
eine Mundreife angeieljen, anf weldye boriteljende Beftim= mungen nidft ?tumentung findert.

\section{i) Boraugeftellumg von Extrapoftpierden.}

(11) Reifenie Ë̈men Durd) Saufzettel (Extrapoitsferde vorausbeftellen. Die Wirfung ber Giferbebeftelfung beidräntt (id) auj 24 Stmmben, fiir welde ber Reijende aud bei

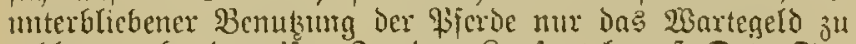

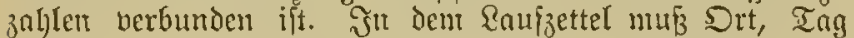
und Stumbe Der ?tGiahrt, die Bahl der Bjerde und der gieiferweg mit Sెenenumg ber ভtationen angegeben, audj bemerft merben, ob die Reife im eigenen $23 a g e n$ exfolgt, ober ob ein Dffener, ein ganz= oder halbuerdecfter Stations= magen berlangt wird, fowie ob und mit meldyen llnter=

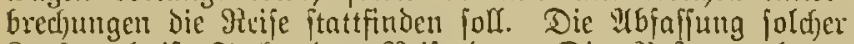
Raufzettel ift Sache des Reifenden. Die Foftuerwaltung loält fich an denjenigen, weldfer den Eaujacttel unterjefricben hat. Sft der gieifende nidft nut Drt amjäjig oder fonft niclyt ljinlänglicf) befannt, fo muर $\mathrm{Ex}$ feiren Stand und Boljnort angeben. Für Bejörderung cirres Raujzeltels mit Den Gioften jur Borausbeftellutg von Ertrapojtpierden ift eine (S) bübr nidjt zu entridjter.

\section{k) Wartegeld.}

(12) Seder Gxtrapoftreifende, welcher jith nut einem unter= megs gelegenem Dite länger als eine halbe Stmude auf= lonlten widl, ift berpflid)tet, hierbon ber \$oftanftalt bor ber

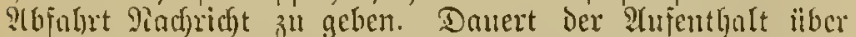
eine Stunde, fo ift von der fïnften Biertelftunde an cin 2Sartegeld bon 25 PF. Für Giferd und Stunde an entridften. (Ein längerer 2Ufenthalt als 24 Stunden darf nicht ftatt= finden.

(13) đ̧ür borausbeftellte fiferde ift, ment bon denielben nidft su der Beit (Bebroud gentad)t wiro, fïr meld)e die Beftellung erfolgt ift, fïr \$fero und Stunde ein 2 sartegelo

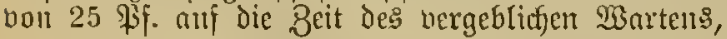

a) bei meiterher tommenden Reijenden bon der fieb= zelynten $\mathfrak{B i e r t e l f t u n d e ~ a n ~ g e r e c h n e t , ~}$

b) bei im Sot befindlidjen Reifenden bon Der fünjten zu entricften.

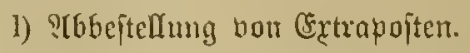

(14) Benukzt cin im Sort befindicfer Reifender die be= ftellten Ertrapoitpierde uricht, fo ljat derfelbe, incmu die

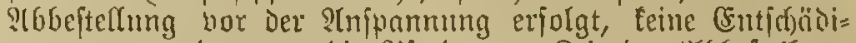
gung, wenn dagegen die \$ferde zur Zeit dex Urbbeftellumg hereit: angefpannt waren, Det Betrag des beitimmungs= mäbigen Ertrapoft=, Wragent= und Trinfgelies fïr fïnf Silo= meter, fowic bic seftellgebilitr als (Entjdäbigung zu ent= richten.

m) Entgegenfenoung vou Extrapoftpferoen uiri) 23 ngen.

(15) Der Reifende tann berlangen, baß̧ ihm auf langen ober jonft bejdmerlidfen Stationen anf borljergegangene (c)rifylidfe Beftcllung \$Fierde und Weagen entgegengefandt

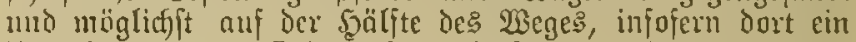
lluterfonmen äl finden ift, aufgeftedt merden. Fïr bie 93eförderumg foldjer Beftellungen mit Den Bojten iff eise

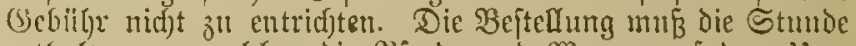
enthalten, ju joclcher dic \$ferde und $23 a g e n$ auf Dem Um=

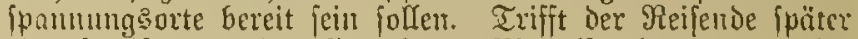
cin, io ift bou der fiebjeljuten Bierterftumbe an bas be=

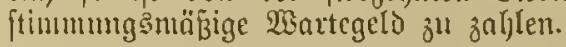

(16) Fitix entgegengejandte Extrapojten wird erfoben:

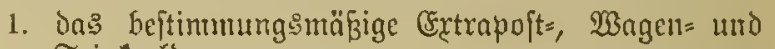
Trinfigeld,

a) wenn dic (Entfermung bon einem PfFerdemedfjel zum anderen 15 Seilometer oder meljr beträgt, nach) der wirflicfen entiernung,

b) wenn folche reniger als 15 silometer beträgt, marly bem Salze fir 15 Silometer,

2. Die einfadje Bejtellgebügr, weldye bon Der qioft = anjtalt an Stations. Mbgangsort ber Extrapoit z" berechnen ift.

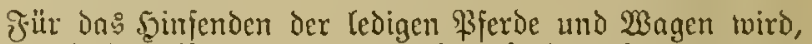
wenn mit Denfelben die Faljrt nad) Derjenigen Station, 100=

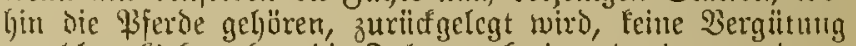
gezaljlt. (Bcht aber bie Fahrt nach irgend einem anderen Site, gleidfuiel, ob auf einter \$sojtitrafe oder anferbalo der= felbell, fo müfjen entridftet meroen:

1. Für Das Şinfenden der ledigen ßFerde und Wagen von der Station bis zum Drt Der Mbfahrt dic

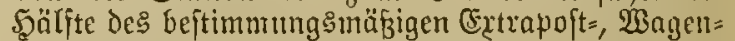
uno Irintgeloes nach der wirtlichen (Entfermung,

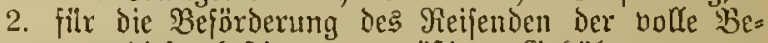

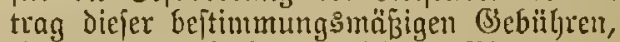

3. für Das Burüffgehen der ledigen \$ferde und Wagen von Dem Drte $a b$, mohin bie Exrtrapoit gebradjt worben ift, bis zu Der Station, zu weldyer die Piferde gehören, dic Şälfte des beftimmungs: mäkigen Crtrapojta, $\mathfrak{B a g e n}=$ und Trinfgeldes jü Denjentigen Theil des Riüfrueges, ber itbrig bleibt, wems die Entfernung abgetedhnct wirb, auf meldier dic Extrapojtbejörderung ftattgefunden Gat.

\section{n) Ectrapoiten auf Entfermungen unter 15 Sillometern.}

(17) Jin (5xtrapofter auf Entfernungen unter 15 Silo= metern werden die (Gebiif)ren für eine Entfermung bon 15 Rilontetern erhoben. 
o) Ertrapoiten, weldfe ïber cine Station hinaus benuţt werden.

(18) Wenn die Meife an einem Srte enbigt, reldyer midst itber 10 Siloneter Ginter oser feitmärts ciner Station licgt,

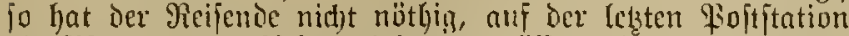

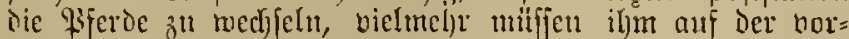
Ictsten Station die \$iferde gleid) bis jum Beftimmungeort gegen (Entridjtung der vorgejd)riebenen Säkze fïr die tvirt: (id)e (Entfermung, jedoch mindoftens fïr 15 Silometer, ge= geben werden.

(19) (3eljt bic Faljet bon ciner Station ober bon eittem (Gijenbafn=5altepunft ab und über eine Station binaus, weld)e nidjt itber 10 Siloneter nom ?(bFahrtsort entiertst liegt, fo fann ilber bicje Station ohne Pferbemedffel eben= falls gegen (Entrichtming Der borgejdriebenen Sätze für bie mirflid)e (Entfernung, jedod) mindeftens fïr 15 Silometer, hinatsgefahret roerden.

\section{p) Errtrapojttarif.}

(20) Эin bem \$oftoicritzimmer ciner jeden zur Beitellumg bon Ectrapojtpicrden bejtimmten Station befindet fich cin Ertrapofterif, Deffen Borlegung der Reifende berlangen mo aus meldyem derielbe det fitr jede Station zu zahlenion Betrag bes Softgelics und afler gicbentoften erjeben fann.

\section{$8 \mathfrak{h l u n g}$ und Duttung.}

§ 65. (1) Die Bebülyen fïr die Ertrapoftreifen müifen mit 2 (uș gelegter Jahyrt Dem \$ojotillon gezaljlt zu merben brautht, in

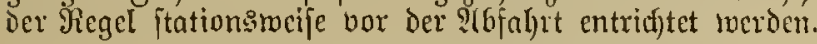

(2) Э̌odem Reifenien muÉ über Die gezalylten Extrapojt=

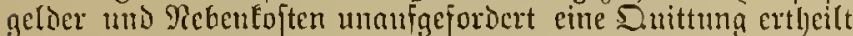

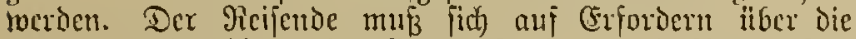
gejd)elyene sbezalylung Der Ertrapoitgelder und Rebentopiten burd) Borzetguttg ber Duittung ausincifen und bat foldhe

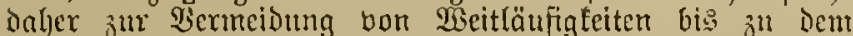
Drte bei fick zul führen, bis rofjin dic Sioften bejahlt jind. Ilnterläßat er joldyes, fo hat er ituter llmitänden zu ge=

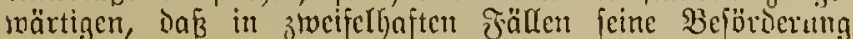

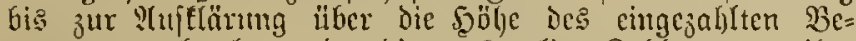
trages unterbrod)en, oder bic nod)malige Bahlung bou ihm verlangt mirb.

(3) Dic Entridtung ber Ertrapoitgelier fïr alle Stati= onen cines gemiffen Surjes anf eimmal hei der 2Hbalyet am श(bgang regen Der Borausbezahlumg bicranf beredhete (Eimridungen bejtelyen.

(4) Miad)t Der Reijende von einet folchen Bergïnitigung

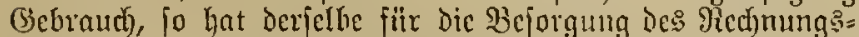
gejdjäfta, und zmar fïr jede Beförderung, welche dic 2(us=

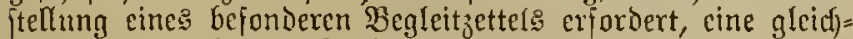
zeitig mit dem (çtrapoitgelde ju erhebende Bebuthr zu zallen.

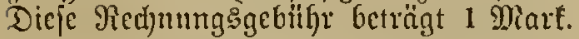

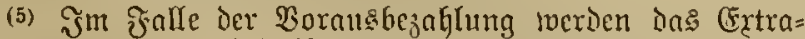
poitgelo und jänmtliche Rebonfojten, als Wagengeld, Bejtel= gebiihr, $\mathfrak{W e g e}=$ Damm $=$ Briffen = und Fuăbrgeld von Der

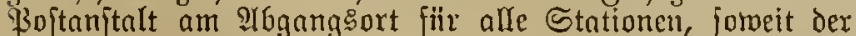

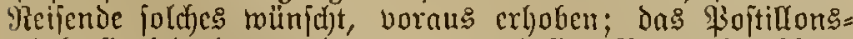

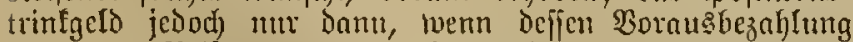
un bem Reifenden gemtïrift wird. Das Sethmiergeld und bie (Erleurdtungstoften werden da bejaljlt, wo ber

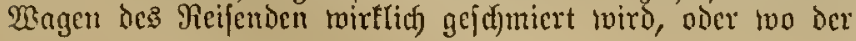

Poitljalter auf Berlangen dę Reijenden fitr (Erfeuthtung De? $\mathfrak{B a g e n}$ jorgt.

(6) Findet Der Rcijende fich beranlaf̧t, unterjwegs den mriprünglid) beabjict)tigten $\mathfrak{B e g}$ bor Der 9 nfumft in dent

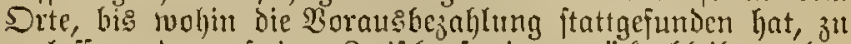

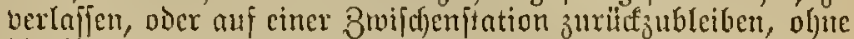

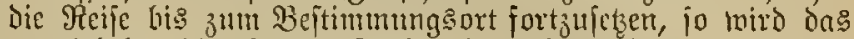

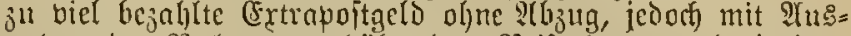
naf)me der Rechnungsgebiihr, bem Reifenden von Derjenigen

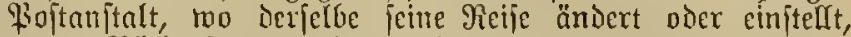
negen Ritiffgabe ber iljnt ertheilten Duittung mo gegen (Empfangsbejc)einigung itber Den Betrag, erftattet.

\section{Bejpannug.}

\$66. (1) Die Beppanmung ridjtet (iid) nach Der $\mathfrak{B e}=$ idfaffenlyeit Der $93 \mathrm{ege}$ mo Der Wagetr, forvie nad) Dem llmfange mo ber Sodjwere der \&ndung.

(2) Findet ber Poffichaffner ober ber Fofthalter bie bon

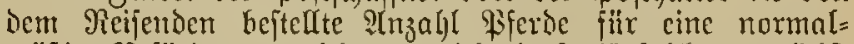

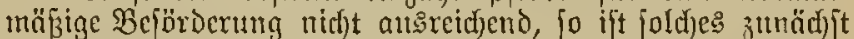
dem abfertigenden 3 cauten und non Diejem Dem Ricijenten vorjufteffer. Sommt feinte Bereinigung zu Stande, jo ftelgt bem Sorjteler Der Goitunitalt Dic Entfdecioung à, und bei biejer bebült es, mbejdyaiet Des fowohl Dem Reijenden

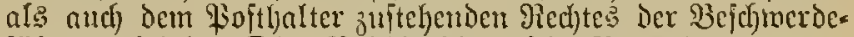
füfrung bei Der Dber=\$30|toireftion, fein Bewenten.

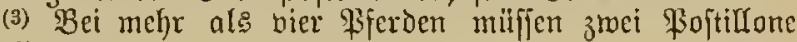
geftellt merien.

\section{If bertigung.}
a) Bei norausbejtellten Extrapoiten.

\$ 67. (1) Sind Dic \$ijerve und Wagen vorausbejtellt

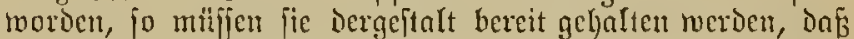
zur heftimmen 8cit abgefalyren werden tantr.

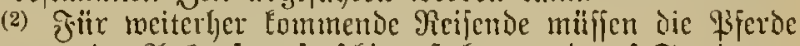

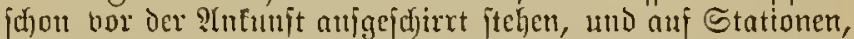

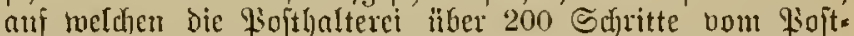

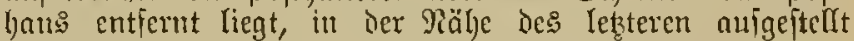
twerden.

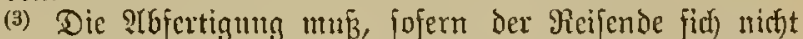
länger aulhalten mid̆, bei vorausbejteflten Extrapoiten imterbalb 10 Mimuten exfolgcn. 23iro ein Stationsmagen verwendet, fo tritt biejen đrijten nod) jo biel 8cit binzu,

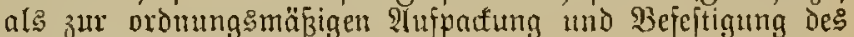
Reifegcpäcfez erjorberlitu ijt.

b) Bei nicft borausbejtellten Extrapojten.

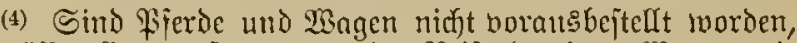

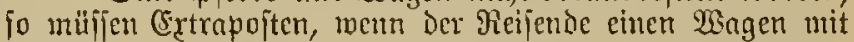
(iid) fiit)rt, intuetfalb cincr Biertelitunde, und menn ein Stationswagen geftellt swerden muß̧, innerhalb ciner halben Stumbe reiterbefïrdert werten.

(5) SInf Stationen, bei meldfen felten Extrapoiten bor=

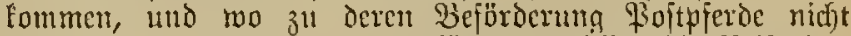

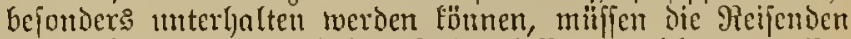
(iid) Denjenigen Ŝjuentljalt gefallen lafjen, weldjer zur $\mathfrak{B} e=$ idfaffung Der Bjerbe nothipendig ijt.

\section{Beföberungajeit.}

\$ 68. (1) Die Befördertutg unE innerbalb her Friften,

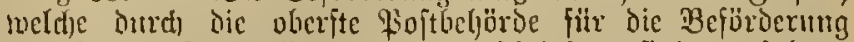
der Extrapoiten allgemein vorgefdrieben fino, erfolgen.

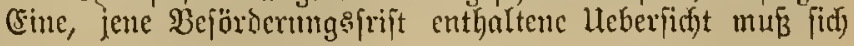


in Dem Dienftzimmer einer jeden zur (Beftellung von Ertra= puftpferden beftimmten Station befinden und bem Reifenden allf Berlangen zur einfidut vorgelegt werden.

\section{a) Beförderungşzeit bei nicht normalmäßziger} Beppannung.

(2) Şat auf Berlangen Deక̧ Reifenden eine (Finigung Dahin itattgefunden, Daß ber Reifende Durd eine geringere SInzalf von Siferben befördert mirb, als nadj Dem llntange Der Sadung, fomie nad) der Beffiaffentheit der $\mathfrak{B}$ ege und der $\mathfrak{B a g e n}$ eigentficf) erforberfid) twaren, fo fann berjelbe auf bas Cintjalten ber normalntäpigen Beförberungęzeit teinen 2ิnfpruch) mad)ert.

\section{b) QInhalten untertuegs.}

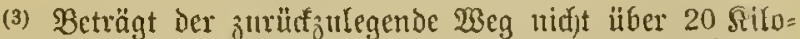
meter, po barf der \$oftillon olyne Berlangent des Reijenden untermegs nidjt antalten. Bei gröfserer Entfermung ift ihm ztoar geftattet, zur (5rholung der siferde cimmal anzulalten,

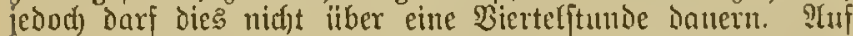
dicjen 2lufenthalt ift bei Feitftellung Der Beförderungsfrift

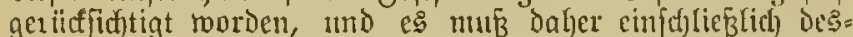
felben die borgefatriebene Beförderuntgszeit eingebalten

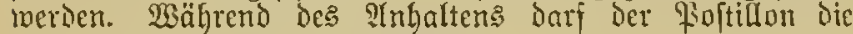
Bferde nidjt ohne Slufficht lajpen.

\section{Boftillone.}

\section{a) Dienfteleioung.}

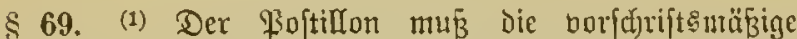
Dienjtfleidung tragen und mit Dem \$softhorn berfeken fein.

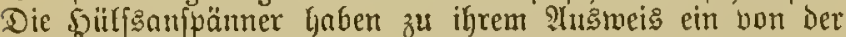
oberften \$ojtbebörde feitgefekstes ?tbjeicten zu tragen.

\section{b) Sits des \$oftillong.}

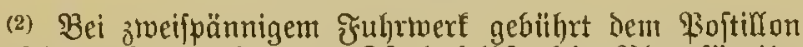

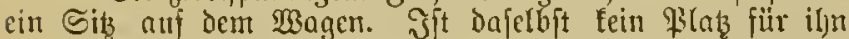

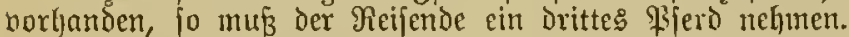
Bei ganz leid)tem Futhrwerf und wenn bar leid)te Wangen etwa nur mit eintm Reifenden bejest ift, Der Eein nunfang=

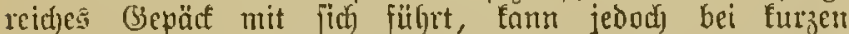
Stationten einte jwcifpänntige Beförderung aud, bant ftatt= finden, wenn ber fioftifnon bom Sattel fahren muf. Bei

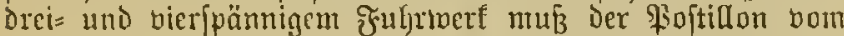
Sattel fahren, menn ifm der Reifende Eeinen Slats anf Dem Wogen gejtattet. Bei einer Befpannung mit mehr afs vier Bferden muis itets lang geipannt uno bom Sattel ge= fahren merden, injofern nidid der Reifende bas Fahren bom Badf verlaugt.

c) Weet) $\{\mathrm{eln}$ mit den ßjerdert.

(3) Das Wectfeln der Bferde mit entaegentommenden Boften Darf gar nidjt, bei fid hegegnemien (E्trapoften aber

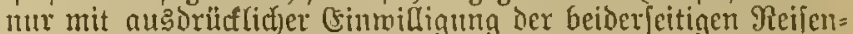

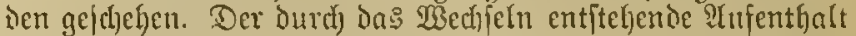
muß bei der ₹raht wieder eingeljolt werden. Das Trint= geto erljält Derjenige \$softillon, welcher ben Reifenden auf Die Station bringt.

d) 2orfahren beim \$opt = oder (Bajtyaufe.

(4) Der Reifende hat zu beftimmen, ob bei der 2Anfunft auf Der Station beim Foptljaus oder bei einem (3)afthaufe oder bei cineut Bribathaule vorgefaljen werien foll. Misid nicht heim fiofthaus borgefaljern, fo mur der Boftiffon,

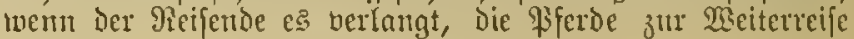
beftellen.

e) Jülyrung der Bfferde.

(5) Denl \$softillon allein gebülyrt es, die Siferde jul jühren. Wenn ber Reijende oder deffen Reute aut dem Softillun Ihätlichteiten beriben, fo hat der gioftillon die

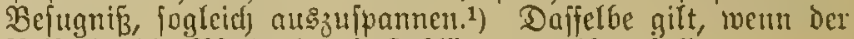
Reifende die Ziferde Durdf) Edyläge antreiben pollte.

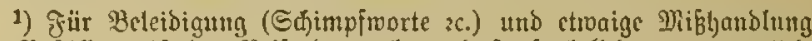

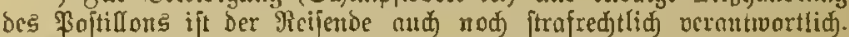

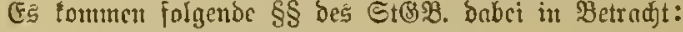

$\S 185$ (Beleidigung),

\$196 (Bcleibtgurtg eincs gheanten in Stusibung foncs \& 223 (aeruöburliche),

$223 \mathrm{a}$ (gejührlidje) unt

$\S 224$ (idmere Rörperverlekung).

\section{Befdrerden.}

\$ 70. (1) Sofern Der Ertrapoftreifende Tlulab zur Be= fdumerie ljat, ift er berectitigt, Diefelbe in dest Begleitzettel einzutragen.

\section{Jufraftreten.}

\$71. (1) Begenmärtige Poptntonung tritt ant 1. Suli diefes Sngres in Sitaft.

Berlin, den 11. Juni 1892.

\section{Der Reiñoffanzler.}

3. शु.:

v. Stcphan.

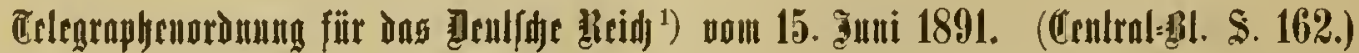

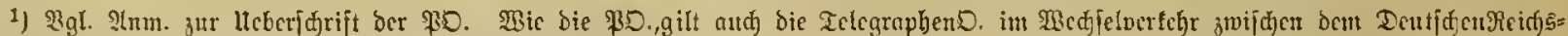

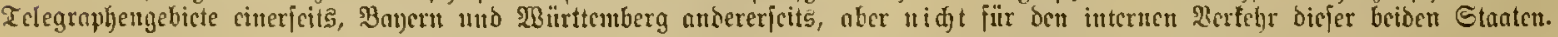

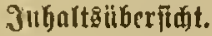

Bentuung bes Telegraphen

Mahrung Des Telegraphengehcimniffes

Dientitunden Der Talegraphenanitaiten

Orte, nad weidgen Telegramme geridfet werben fönucn

Eintheilung Der Tolegramme

Illgemcine Erforberniffe der з befördermben Ieleqramure. .

Iufgabe von Ielegrantuncn............

Mortzäb̆lung .
Bebiihren fïr gewöhulidje Tclegramme

Dringende Tclegramme

Wezahilte IItutroort

3̧rglidjente Ictegranme

Empiangsanzcigen .

Ielcgraphifdje Foftantuei[ungen

Radforting vou Tdegrammen

Bervidfältigung non Telegrommen

Eeetelcgrautme.
$\S 9$

$\S 10$

\& 11

$\$ 12$

13

\$ 14

\$ 15

$\$ 16$

\$ 17 
Wुeiterbeförberung

Entridjung ber Gebitgren

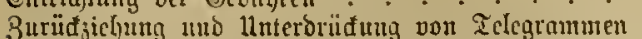

3uitellung der Telegramme aut \$ệtimmungsort

lnbeftellbare Ielegramme

Bewölyrleiftung

Berid)tigungstelegramme

Radjzohlung uno Erffattung von Bebïfrers.

Iclcarammabfdrifter

Rebentelegraphen und bejondere Telegraphenaulagen. Fern. [predjeinridtutugen

(Geltungśbereidu) .
$\$ 19$

$\S 20$

$\$ 21$

$\$ 22$

\$ 23

$\$ 24$

$\$ 25$

$\$ 26$

$\$ 27$

$\$ 28$

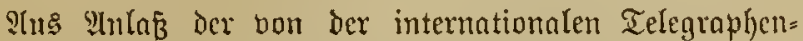

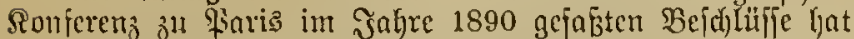
dic Iclegraphenordnumg, weldye auf (j)und des ?Trtifele 48 oer Reidjencerfaffung erlaffen tworocn ift, 1 ) Renderungen crjahren. (F) trift Daher, unter शlufhebung der Telegraphen. oronung bom 13. श̂guft 1880, bom 1. Juuli 1891 ab die nachjtefjende

in Sraft.

\section{Eelegrapfenoronung}

1) Bgl. Den afmeidenden Eingang gur \$oftoromung.

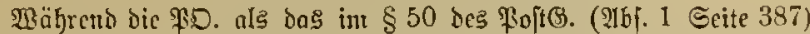
angefürbigte "Reglement" bezeiduet wirb, ift bier angegeben, baß̈ die 25. nuf Gruto des Mrtifels 48 ber RY3. crlaffen iff. Der llnter=

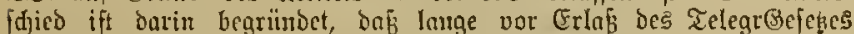
TclegrDronungen (wenn aud in anberen Faffungen als in ber 3.3.

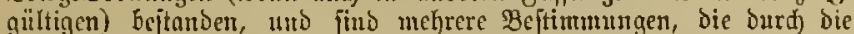
ID. auf aominiftratioem Bege erlaffen waren, erlt fpäter burd bas TelegrGe广. vom 6. Slpril 1892 (ङ. 415) aud nod gefeblid) ieft= gelcgt porben.

\section{Benuzung des Telegraplen.}

\$ 1. (1) Die Benukung der fïr den öffentlichen $\mathfrak{B e r f e h x}$ beftimmten Telegraphen ficlyt Sedermann zu. ${ }^{1}$ ) Die Sier= waltung bat jeboch ins Fed)t, ihre Sinien und Telcgraplen= amitalten jeitweif ganj oner jum Theil für alle ober für

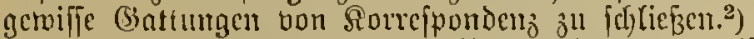

(2) Der sibfender cinces Piribattelequmms ift ber= pflicjtet, auj desfallfiges Berlangen fidl) ïber feine qierjön= lichfeit auszumeifen. (5) jtcht demfelben jeinerjeits juci, in feim Telegramm die Seglaubigung [einer lluterjd)rift auf= के unehmen. ${ }^{3}$ )

(3) Fribnttelcgramme, deren Sinhalt gegen dic Befeke

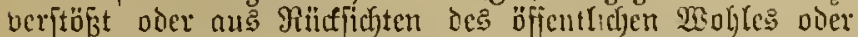

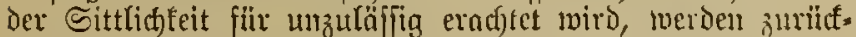
gemicjen.4) Die (Entjcheidung iiber die Buläjfigleit Des

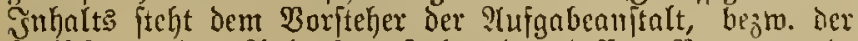
3rifdjen = oder 2(nfunftsanitalt oder Deficn Vertreter, it

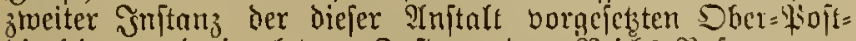

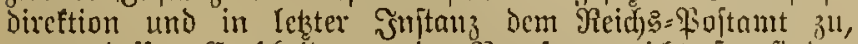
gegen befien Enticheioung cine Berufung nidht fiftfintiof. Bci Stantstelegrammen iteht den Ielegraphenanjtalten cine

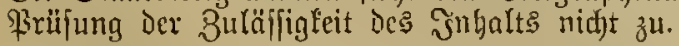

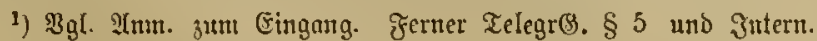
Telegr Bertr. \$Irt. 1.

2) 3. $\mathfrak{B}$. in Niriegśseiten.

3) $\mathfrak{B a S}_{\mathrm{S}}$ in bas Telegraum aulgenommen wirb, if taxtpflidtig, allo

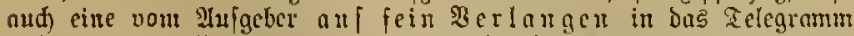
aufgenonmene Beglaubigung Der 11nterfdrift. Eine von Der Telegr:s

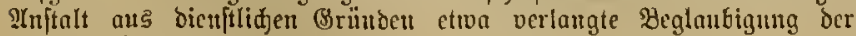
1tnteridrift ift jebod gebübrenfrei.

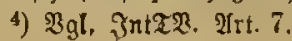

Wahrung Des Tclegraphengeheimuiffes.

§ 2. Die Ielegraphenverwaltung wiro Eorge tragen,

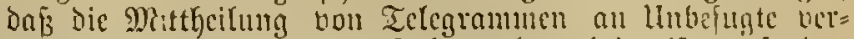

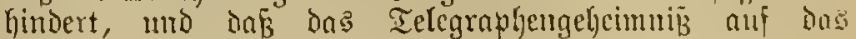
Sirengite gemalyt werde. ${ }^{1}$ )

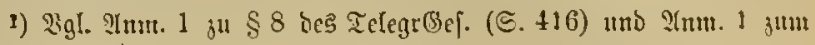
Eirgnnge.

\section{Dienftituden der Telegraphenanftalten.}

\$ 3. Die Telegraphenamitalten zerfallen rücfficftlict) Der 3eit, mäl)rent meldyer fie fïr Den Bertehr mit Dem \$ublifum offen zu halten fins, in bier §laffen, nämlich):
a) Inftalfen mit ununterbrod)enen Dienjt (Tag und Nad) $t$ )
b) Sิnftalten mif verlängertem Inges̉otenft (bis Ditter= nad)t),
c) Iinftalten mit bollem Iagcesdienft (bis 9 llyx Uhends)
d) 2tnftalten mit beffuränttem Tagesoienit.

Dic Dierfiffunden Der ?hifalten unter b und c begimucn in der Beit bom 1. ?(pril bis (Enve Eeptember แum 711 ) Morgene, in Der Beif noun 1. Dttober bis Ende Miär's um 8 uhr Morgens. शtu Eom= und Jejtanch twiro jedoch

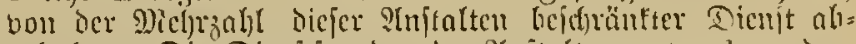
gehorten. Dic Dienjtftumden Der ?tnifalfen unter a uecrien, Den b̈rtlid)en Bebdirriniffen entfpredjend, für jeoen Drt be= fonders fejtgejtellt.

\section{Drte, nad welden Ielegramme geridetet toerden fänuen.}

\$ 4. (1) Telegramme föunen mady alfen Drten aufgegeben werden, nad) melden bie vorhandencu Telegrapleuber=

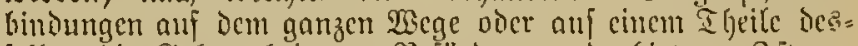
felben Die Belegenlect zur Beforbersung Darbieten. Sit am 23eftimmungert eine Telegraplenanitalt nicht borfonien,

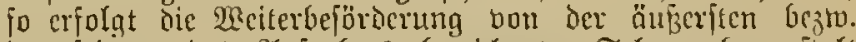
ber feitens des $9(u j g$ gebers bejcidnueten Iclegraphenanjtalt

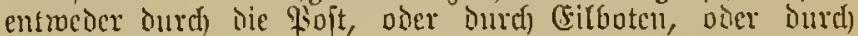

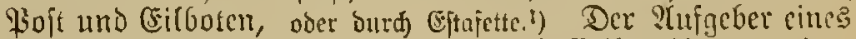

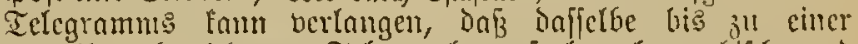
bon ifm bezcichneten Telegraphenanftalt teleqrapljifd und

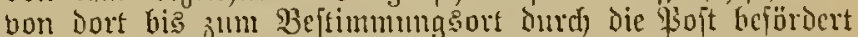
merde. Die 2icrwendung bon Eilboten zur Bejöroterung bon Telegrammen zwifden Dorten, in toelden Telegraplen= anifalten beffelien, ift ingegen ausgejd)lofien. Sit teine Beftimmung iiber die $\mathfrak{A}$ rt der 2 eiterbejörderung getroffen,

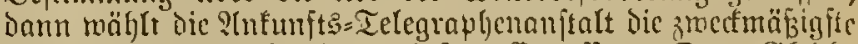

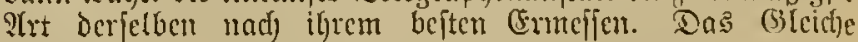
finiet fiatt, tom die bom Slufgeber angegebene Sitt ber

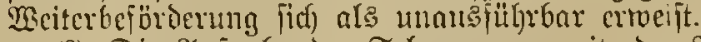

(2) Die $\mathfrak{P}$ fugnbe der Telegramme mit Der 23 ejeichnumg "telegraphenlagerno", "poitlagernd" oder "Gahnllyollagerno" ift zuläifig.

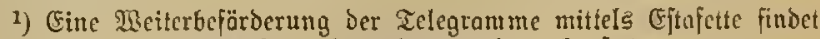

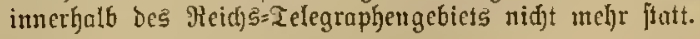

\section{Eintheilung ber Telegramme.}

\$5. (1) ') Die Telegranme zerfalfen rï̈ffichtlid) ifyres Behandlung in folgende Siattungen:

1. Stantstelegramme, 
2. Telegraphen=Dienftelegramme,

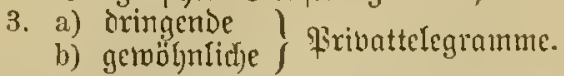

Bei der B̧eförderung geniefzen Die Stratetelenranme,

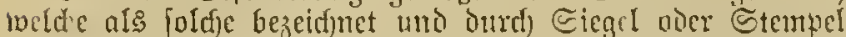
beglanbint fein mitfien, bor ben ïbrigon Telegrammen, Die

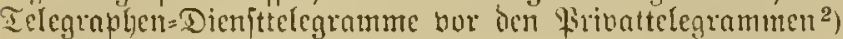
und die bringenden Pribnttclegramme nor ben gewöhnlicfen Wribattelegrammen den Burrang.

(2) $\left.{ }^{1}\right)$ Эin Bezug auf bie T(bfaffung find z" unterid)eiden:

1. Telegramme in oficner Spratfe,

2. Ielegramme in gebeimer Spradje,

Dic gehcime Spradte fdecidet fid in

a) berabredete Spradie,

b) duiffirte Sprache,

c) cine Spradfe, iveld)e nus $\mathfrak{B} u d$ ft $a b e n$ mit $g e=$ beimer Beocuturg beitel)t.

(3) Fribattelegramme, deren Tert entweder ganz

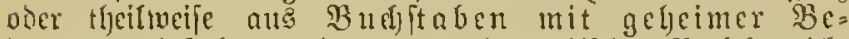

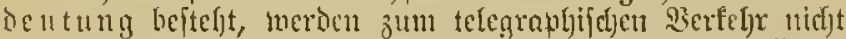
3uglafien. Suf Stants= unto Dienftelegramme findet Dicie Beftimmung ingeget feine ?(nmentuna, ${ }^{4}$ ) ehenfomenig

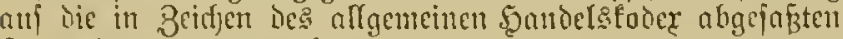
Sectelegramme (ogl. \$17).

(4) Ilnter "Telegrammen in offener Spradfe" mes ben jolfje Ielegramme berftanisn, weldfe in einer ber

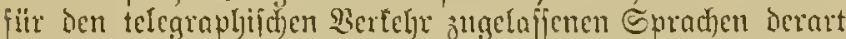

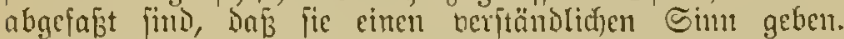
weld)e Spradjen neben ber dentjelen fïr Telegramme in offener Eprache geftattet jimb, wire bon der Telegraphen= nermaltumg befannt gemadft. Fitr Telegramme, meld)e

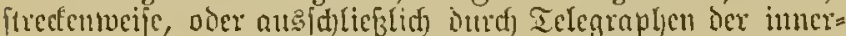
balb des Dentidjen Reidjes belegenen Cifenbahnen zu be=

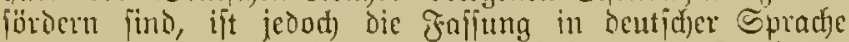

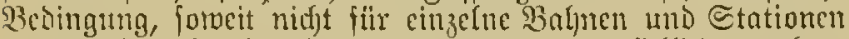
ta: (setrand) fremder Sprad)en ausoriteflicl) nacf)ge= geben miro.

(5) $:$ If "Ielegramme in berabreieter Eprade"

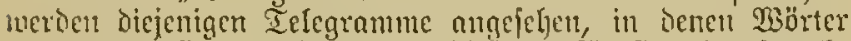
nutgemendet (ino, weld)e, obwoly jebes (itr fich cine (mracf)= lic)e Bedentung loat, feine fïr Die betheifigten Dienftitellen nerftönolicfen ธäke bilden.

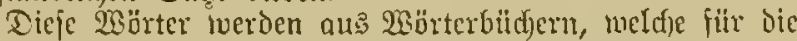
Sorrefpondenz in berabredeter Sprache jugelnjfen fino, oder

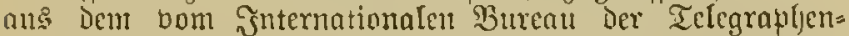
berwaltungen antlid) aufgeitellten 'Börterbuch entrommen.

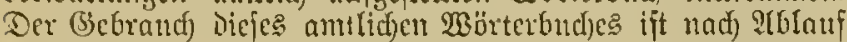

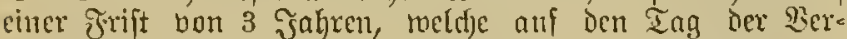

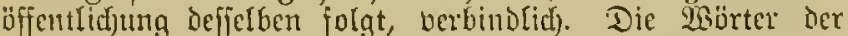
berabredeten Spradje diirfen hädjiten 10 Budfjtaben ent= baften uno milffen einer oder mefreten der nadfgenanten

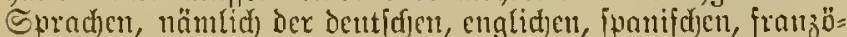

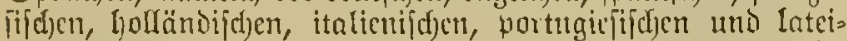
nifhen Sprad)e entnommen fein. Eigennanen birrfen bei

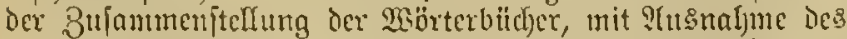
bom Эnternationalen Bareau Dex Ielegraphentuermaltungen

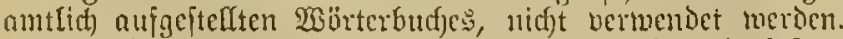
Sie werten in Den in verabredeter Spradje abgefoften

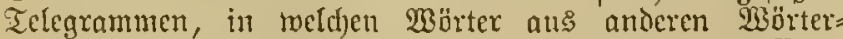

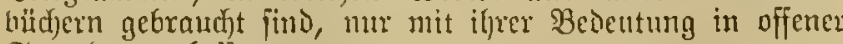
ङprache zugelaffen.

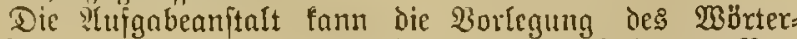

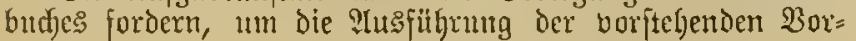

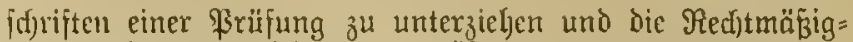
feit ber benulzten Wörter zu prïfen.

(6) Unter "I Ielegrammen in diffrirter Spradic" ber= fteht man diejenigen Telegramme, Deren Tert gänzlicf) Dder zแm Theil aus (Gruppen oder nus Reifen von Biffern mit geljemer Bedeutumg bejteft. Der ediffrirte Iext Der Brinat=

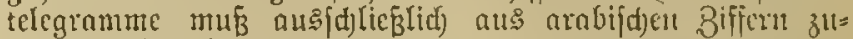
fammenge jekt fein.

Эn Stnatstclegrninmen fann dex Text ourd) 3iffern

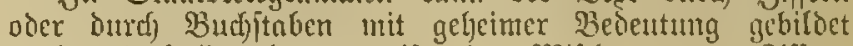
werton (bgl. (3)); Dagegen ift eine Miffutung bon Biffern แnd $\mathfrak{B}$ uchjtaben nicht zuläffig.

1) Man unterfojeidet ferner

A. 3n Bez̧n anf bie Behandiung:

1. gevöhnlide Telegranme,

2. befondere Telegramme.

3 औen rę̧tcren gegören:

a) oringertoc Telegramme,

b) Telegramme nit bezahlter Itntmort,

c) Telegrantme mit begablter oxringentor ?Intuort.

d) verglidjene Telearamme,

e) Telegramme mit Empianģanzeige,

f) пadjuf cribenie Telegramme,

g) offen an bejtellende Telegramme,

h) eigenhändig zu befteflente Telegramme,

i) telegraphifdje \$optanmeijungen,

k) zu vervielfältigende Telegramme,

1) Eectelegramme,

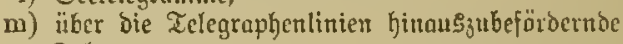
Ielegrantme.

B. Эn Begng anf bas Bemegunggebiet:

1. inläubifde Telegranme, weld)e nur bie Rinicn bes Reids:

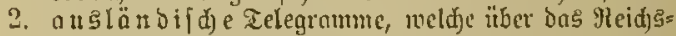

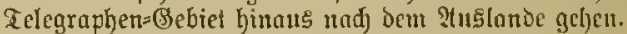

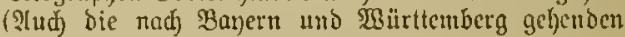
Telegrantme gehören hierher.)

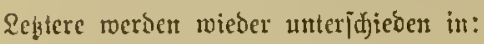

a) europäijđe Telegramme,

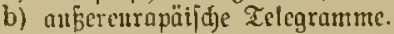

2) Unter llujtänoen haben Telegr. Dienfitclegrantme and por Etantstetegrammen ben Sorrang. Ein Telegraphen-Dienftelegramm 3. 3. itt welden cine it 5 Minuten ftatfinbenoe Sfolitung einer ge=

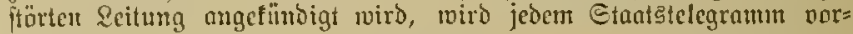
gezogen.

3) Telegranme in gebeimer Eprađe find unłuläffig rad): Bosntens Serzegaviuto, Sulgarien, Miantenegro, MuElant, Türtei.

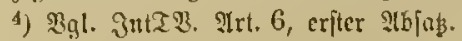

\section{Tllgemene Erforderniffe der zu befördernitu Ielegramme.}

\$ 6. (1) Die Mrjd)rift jedes ju bejürdernien Tele=

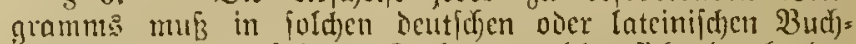
itaben bejw. in foldjen Beidjen, tweld)e fidf Burch ben Telegraphen miedeigeben laffen, [eierfid gefdrieben jein.")

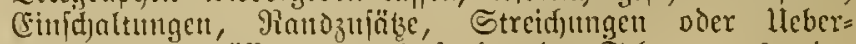
id)retbungen mitifen bout झlufgeber des Telegramms oder non feinem Beauftragten bejoeinigt merden.

(2) Die cinzelner Theile, aus iveldjen ein Telegramm beiteht, miifien in folgender Sronung aufgefiilurt merden:

1. Die bejonderen ?tngnber,

2. Die Ifuffertift,

3. Der Tert und

4. Die Itnteridjrift. 
(3) Die etwonigen bejonoeren 2 ngaben bezïglid Der Beftellung an Beftimmtungsort, Der bezablten Antwort, ber (5mpiangenazige, Der Dringlichfeit, Der Bergleiduung, Der ?Rachfentung, der Weiterbeföroctung, ber offenen oder Der eigenl)ändigen (nux on den Smpfönger lelbjt ôu bewirfen= Den) Beftellung des Selegramms zc. niiffen nom :1ufgeber

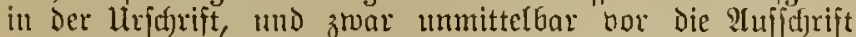
niedergeidrieben toerden. Jïr dieje Bermerfe find jolgende, jwifdjen Silammern zu jetsende ${ }^{2}$ ) S(bfïrjungen jugelafien:

(D) für "oringendes Telegranm",

(ST) für "gebülgrenpflichtige Dienftuotis",

(RP) für "Selegramm mit bezahlter :Hutionort",

(RPD) füi "Selegramm urit Dringendex bezaljltex Qntioort",

(TC) fïr "Tclegramm nit Derglcidyung",

(CR) fïr "Telegramm nit Eัmpfanģanzeige" mo für "Empfattganzeige",

(FS) für "nadjựendendes Telegramm",

(PP) für "\$soft bezalylt",

(PR) fïr "\$joit eingeid)rieben",

(XP) fïr "Eilbote bezalylt",

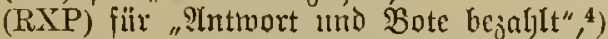

(EP) füt „Eftafette bejahlt",5)

(RO) für "offet ju belteflendes Telegramm",

(NIP) für "eigenljündig วu beftelfendes ácle= gramm".7)

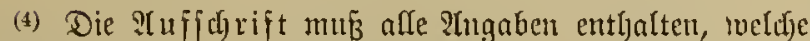
nötgig fino, um die llebernittelung des Telegramms an deffen Boftimnumg zu fitferm, mo fermer fo bejdjaffen feim,

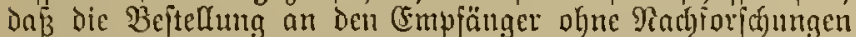

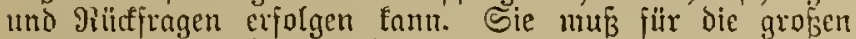
Stäbte die Strabe und dic Sausిmmmer nadjweticn oder

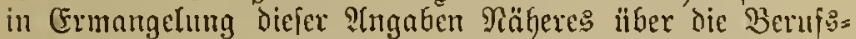
art bes Empfängers oder andere zmedentipredjende Mits theilungen enthalten. Selbit fïr flcinere Drte ijt es

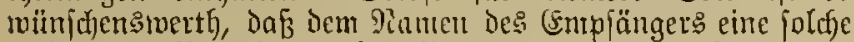
ergänzende B̧ezeidunung beigefügt wiro, unt im Fall ciner Entftellung Des Figentamens der Beptimmungsanjtalt für dic Crnittelung des Cimpängers einen Nnhalt ju gerwähten. Die genaue Bezeidinung ber geographiffien Rage des $\mathfrak{B e}=$ ftimmungsorts ijt exforberlid, fofern cin Broeifel über bie dem Telegramm zu gebende Rid)tung beftchen tam, nannentidf bei gleidjlautenden Drţbezeidynungen.

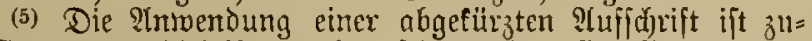
läplig, ivenn diejelbe vorber jeitens des Empfängers mit ber Telegraplyenanitalt feines 20 oljnortes vereiubnrt morden ift. Demjenigen Sorrejpondenten, welcher eine mit Det Iclegraphenanftalt bercimbarte abgefürzte 2(uffarift binter.

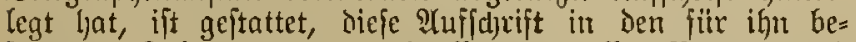
ftimmen Selegrammen an Stelfe des bollen शamens uno bet Wohnungsangabe anmenten zu Iaj̄en. Der Rame Der Beftimmungs=Selegraphenanjtalt muß auferdem nngegeben oerben.

(6) Jür die Sinterlegung und 9-nmenoung cinet abge=

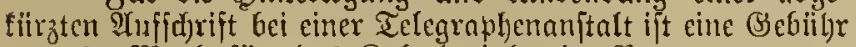
bon 30 Mart fïr bas Salenderiabx in Boraus zu ent=

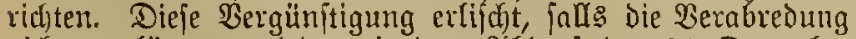
niduft berlängert wiro, mit Dem Slblauf Des 31. Dezentber deฐ Şatres, für weldhes dic (Sebülyr entridtet worben ift.

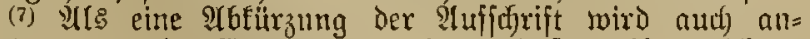
gejehen, wemn ber (Empfänger berlangt, Dẩ an iłn geriơ)tete Telegramme, ohne diesbezüglid)e näbere (ngaben in Der গluffdurift, zu gerviffen Beiten in beftimmten Botalen, z. B. an Wochentagen in Dem Sichäitslofal, an Sonntagen in
Der Woljnung, pier au gewiffen Stundeu in ien Romtoir, 3u anderen it ber Wohnung ober ber Börfe regelmägig bejtellt twerden folfen. Die rierfitr in Soraus all ent= entrichtende (Gebülyr beträgt ebenjalls 30 פart fît Das Ralemberjolj:; fie fommt aud Dant zur (5rfjebutg, svenn bir betreffende Roizefpondent fïr die all ibn geridjteten Iclegrantme mit Der Selegraplyenanjalt eine abgetïr;te ?tufidurijt vercinbart ljat.

(8) Telegrantute, Deren Iufferift Den in borfteljendocn Piunten vorgejeljenes \&nforderungen nidft entiprifift, folfen 3war Dennod jur Bejörderung angenommen merben, jc=

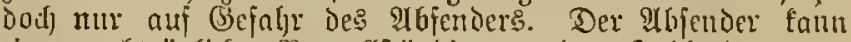

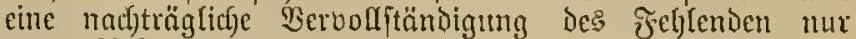
gegetr 2lufgabe uno $3 c_{3}$ ljlung eines neuen Selegramm beanipructien.

(9) Die Ilufgabe von Telegrammen oljue Text ift zuläffig. Die Interforift fam in abgefilizter Jorm gejurieben oder weggelaffet merden. Die etwaige Beglaubigung ber luter= iafrift ift linter diejelbe zu jeken..$^{8}$ )

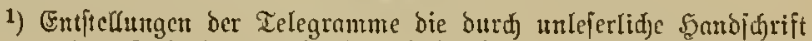

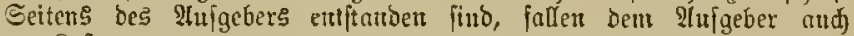
jur Eajt.

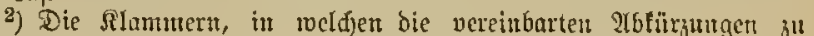
jegen fund, werben weber mitgezählt nod mittelegraphirt. Die per=

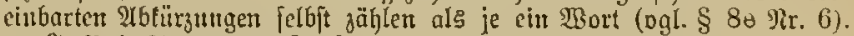

3) Bgl. 2Im. 1 zu $\S 10$.

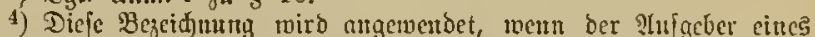

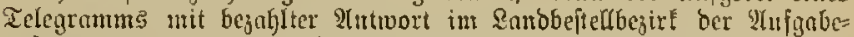
anjtalt wohnt, uno er wifl bas Botenlohn für bic voransbezahlte, nad)

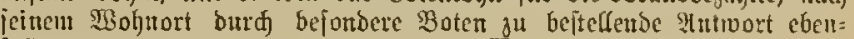
falls vorasbezahlen (I. D. I. গูG ber TD.)

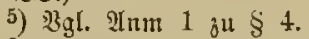

6) Difen zแ beftellende Ielegramute futo unzuläjig nad): Sroß̧= britantrien, Suremburg, Biontenegro, Rubland, Serbien.

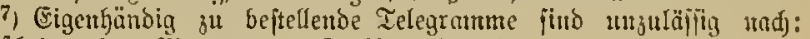
Broburitanten, Diontenegro, Eerbien, Spanten.

8) $3 g$ I. SInt. 3 ; $\$ 1$.

\section{Tufgabe bon Telegrammen.}

§ 7. (1) Die Stufgabe non Telegranmen tam bei jedcr für den Telegraphenverfelyr eröffueten Telegrapljenanitalt (aud) brieflich) erfolgen.

(2) Telegramme fömnen aud bei Den B̉almnpoiten, แmb

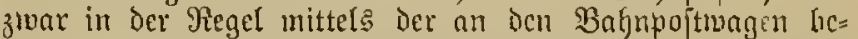

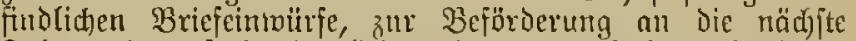
Ielegraplyenanftalt cingelicjert, famie den Telegrapljenboten utio Den Ranbbriciträgern bei Der Beftellung bou Zele= grammen oder \$3oitfenoutgen zur Bejargung Der âtugabe itbergeben werden.

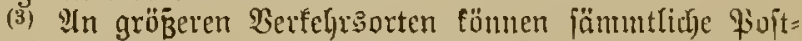
anjtalten, audj menu mit diefen eine Telegrapljenbetrieb3= frefle nid)t berbunden ift, zur !lumalyme bon Ielegrammen ermärbtigt, aud faum die Bentbung der Brieffajten str

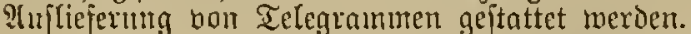

(4) Bei Der 9itualune Der Telegramme Dutuf bie Tele=

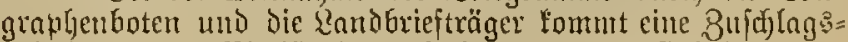

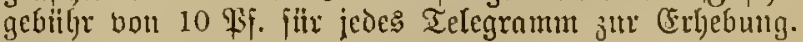

\section{Wortzäglung.}

§ 8. Bei Ermittelung Der $\mathfrak{B a r t z a h l ~ c i n e : ~ T e l e g r a n m ~}$ gelten bie folgettoen Regeln:

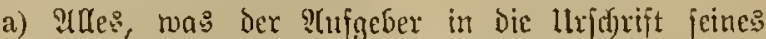
Telegramtuls zum Brect der Bejörderung nieder= iffreibt, twird bei Der Bered)nung der (sebülgren 


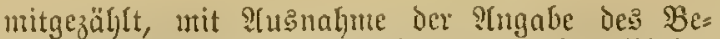
förderungsheges, oer linterf(heidungszeichen, Binde= jtridje, 21poftrophe mo \$tbfazjeidjen.

b) Der Rame der Plggangsanitalt, der Tag, dic Stunte mo Minute der ?tufgabe werben bon 9utşmegen in die ben (Empfänger zuzufteflende

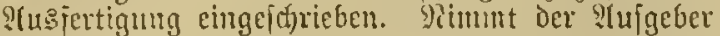
Dieje 2ugnben ganj ober theifmeije in Den Tert feines Telegrammes atf, dann werden fie bei der Wortzählung mitgered)net.

c) Dic gröfste Sänge eites Tarmortes in offener Spradje ift anf 15 Butdffaten nact) dem (ourct)

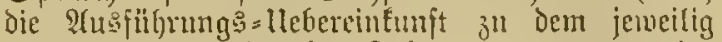
gitltigen internationalm Telegranfenbertrage ein= gefiifjrten) MJorje=?(Iphabet feftgejetst. ${ }^{1}$ ) Der lleber=

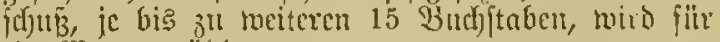
cin $\mathfrak{S o r t}_{\text {gezä́lt. }}$

d) Dic gröfte \&änge eines Inroortes in verab. rebeter Spradje ift anf 10 butdjitaben feitge= geiest. Die Wörter in offener Spradje, welde in Tert cines gemifdeten, aus $\mathfrak{B}$ örtern ber offenen mo ber verabredeten Spradje jufammengejebten Telegramm enthalten fino, tocroen bis jur söbe von 10 Buchftaben fitl ein W3ort gejäglt. $30 m$ etwaigen lleberfduf wird jeoe Reihe bis an

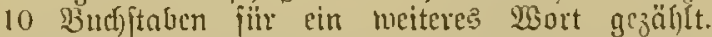
Wemn Dieje: gemijefte Telegramm aujerdem einen

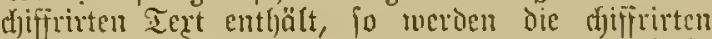
Stellen nah) den Beftimmumach muter b gejäflt. werm ton gentiffte Telegrnmm mur cinen Tent in offener und einen foldyen in dyiffrirter Sprache entbält, fo werden die in offener Sprache afgefōbten Stelfen den Beftimmungen unter c, und Der in rfiffirter Sprache abgerafiste Text Den Sor= idjriften unter h entiprechend gezöhit.

ө) 24ls je ein Wort werden gezählt:

1. Der Mame der Bejtimmungsonjtalt, des be= ftimmungelandes und der Unternbtheifung Des (3)ebiets, aber nur in der Telegramm: auff(f)rift, ohne Rü(ffid)t auf die Bahl der zu

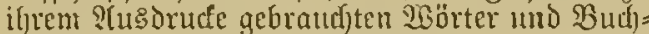
itrben, unter Der Bedugung, Da $\bar{B}$ Dieje Wörter fo geidjrieben find, wie fie in den amt= lichen $\mathfrak{E e r j e i d n i f j e n ~ e r f a j e i n e n , ~}$

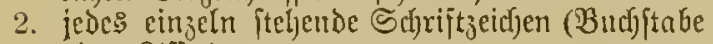
oDer Siffer),

3. Da: Unterftreichungszeichen,

4. Die Ŝlammer (die beiden Zeidfen, meldye zu ifrer Bifdung Dienen), ${ }^{2}$ )

5. die ?Inithrungszeiclett (die befonderen Beid)en an ?tujang und (Ende einer einzelnen Stelfe),

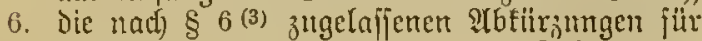
bie befonderen ?Ingabent bor Der Telegramms anfictifrift.

f) Die Durd) einen Bindeftrid) berbundenen ?(u3brücfe

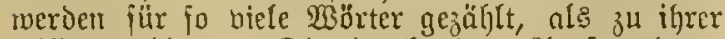
Birdung dienen. Die Durrf einen ?twojtroph ge= trennten Märter werben jür ebenfo biele cinjelne WBörter gesällt. (Es tönnen jedod) die in Der englijehen uti jrarzöjijichen Spraelje vorfommenden zllammengejezten Wobrter, Deren (Bebräudblichteit

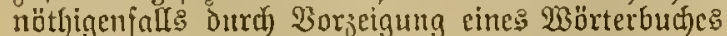
nachgemiejen werben muß3, al\& ein $\mathfrak{B o r t}$ gejdyrieben und Den Beftinmungen unter c entfpredjend tarirt werden.

g) Dem Spradjgebrantfle zumidertaupmoe Bnjammen= jichungen ober BerünDerungen von Wärtern twerben

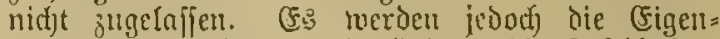
namen von Stäbten und Qäudern, dic (Bejchlechts:= namen, die Ramen bon Drtichajten, filäłen, Boulcurdos, Strajen ${ }^{3}$ ) $2 x$., die ?amen bon Sdiffen, ebenjo wie die gans in Burfjtaben gejdyriebenen

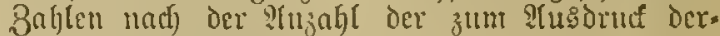
felben vom Stufgebe: gebraudten wörter gejöglt.

h) Die in Biffern gejdyriebenen Bahlen werden fiir fo vielt wörter gejühlt, als fie je 5 Bifferm ent=

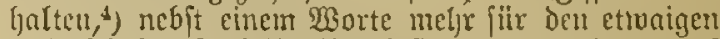
Iteberidjus. Diejelbe Regel findet Invendung alf die Bählung non Budfftaben=(3ruppen in Strats= telegrammen, ebenjo audf auf Gruppen bon Bud]= ftaben thlo Biffern, welche entrueder alş SJandets: Mtarfen oder in ben Scetelegrantmen angemvendet roerden (bgl. $\$ \S 5$ (3) und $17^{(1)}$ ).

i) F̛̈̈r je eine Biffer werden gezählt: Die zur Bildung Der Zahlen Genutzen \$unkte und Simmata, forvie Die Butudjitriche, jerner Die Budjftnben, weldje Deu Biffern angehängt twerden, um fie nis Dro= nungşallen zu bezeidjnet. ${ }^{5}$ )

k) Sofern cin SBriuattelegramm, den Beftimmungen im $\$ 5$ (6) entgegen, zufällig cine (Bruppe von nicht anwendbarcn Budffaben oder ein sGort entjält, weldies feiner ber fïr den intemationalen Bierfehr zuläffigen Spradjen angehört, fo twird dicfe Buct)= ftabengruppe oder diefeg $\mathfrak{B}$ ort gemä́ den $\mathfrak{B} E=$ fitmmungen unter h des gegenrärtigen \$aragraphen gejählt.

1) Die Wortzäglung Dex Tujgabeanftnlt ift für dic Bebilfrenbered)nung dem Ilufgeber gegenitber ent= idjeidento.

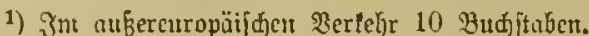

2) $\mathfrak{B g l} \mathfrak{A}$ แnm. 2 วน $\$ 6$.

3) Jn englifider uno frambofif

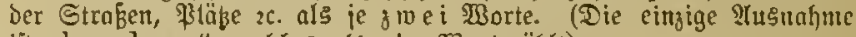

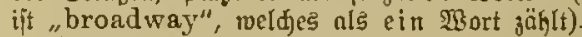

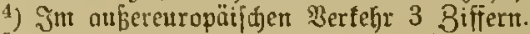

5) $13,7-12.15-7$ ter $-41 \frac{1}{3}$ jählen jedes für ein $2 B a r t$, 3ifferngruppen wie: " $1 / 25$ " Dagegen als zroci 230 orte.

\section{(3) bithren für gemöhnlidie Telegramane.}

§ 9. (1) F̈ï das getwöhnlidje Telegrantut wirt auf alle Entfernungen cinc Gebühr bon 5 \$if. Für jedes $230 r t$, mindeftens jeboch ber Setrag bon 50 \$f. erfjoben.

(2) Fiin geroöljnlidje Stadttelegramme, weldje in fol(t)en Stäbten zugelaffen twerden, imertyalb beren Bacidjbifo mehrere unter fid burch Telegrapljenleitungen betbundene Telegraphenauftalten Den Berfehr geöfuet jund, woird eine

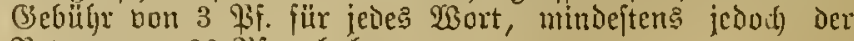
Betrag non 30 qif. erlyoben.

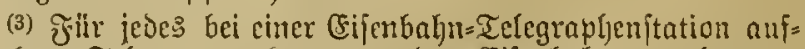
gegebene Telegramm fann bon den Eifenbahnbermaltunger ein Bufdhlag bon 20 Pif. bom \$lnfgeber erlyoben werden. 2.uFerdem find dic (sijenbalyn= Telegraphenftationen berechtigt, fiir jedes bon ifjnen beftellte Telegram vom Empjänger ein Beftellgeld von $20 \mathrm{gF}$. zu erheben. Beides zufanten Darf aber fïr bie augfdjließ̧(id) mit dem SBahntelegraphen 
beförderten Telegramme nidjt exfoben twerden. Fitir diefe Telegramme ijt vielnuelyr nur die (5rhebung der Bicjtellgebüryr bon 20 PF. geftattet.

(4) Die fiir Den telegraplif(jen $\mathfrak{B e r f e h r ~ m i t ~ d e m ~} \mathfrak{A}$ Lande mab̧gebenden Tatife tönnen bei oen Telegraphen= anftalten cingefelyen werden.

(5) (5in bei Beredjunung Der (sebityren fié) ergebender, burdf 5 nidjt theilbarer Pfennigbetrag ift bis zu cinem joldjel aufwärta abjurutocn.

\section{Dringende Telegrantur.}

§ 10. Der 2Ufgeber cinc: \$ribattelegramus fann ben Borrang bei Der Befötocrutg und der Beftellung bor oen gerwölunlichen Privattelegrammen erlangen, menn er bas Wort "Drimgend" Dder abgefiirzt Die Siezeid)umng "(D)" vor

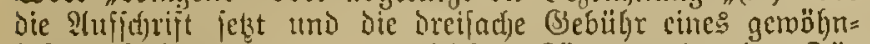
lidjen Telenramms bon gleidher sänge exlegt. ${ }^{1}$ ) F̈̈r dringende Tulegramme mird demmadj eine (Sebillyx bon

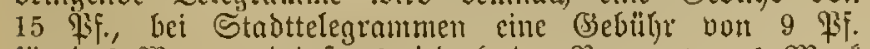
fiir das 23ort, mindeftene jedod, Der Betrag bon 1 Mart

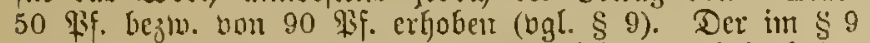
muter (3) angegebene 3ujdhlag jür die bei einer Eifenbaln= itation aufgegebenen Selegramune fommt dagegen nur ein= (ach) - inie fiir getwöljnlidge Iclegramme - zar (Erhebung.

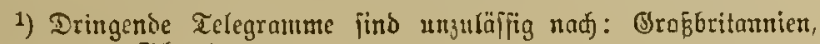
Drontenegro, 厄diveis.

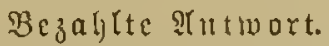

\$ 11. (1) Der ?tufgeber faum bie Intwort, weldye er vou dem Emplänger nerlangt, vorutşbejal)Ien; die Boraus= bejalylung Darf irvorfien die Bsebüfr cines Telcaranms irgent eincr 2 (rt bon 30 खärtern nicht überidneciten. ${ }^{3}$ )

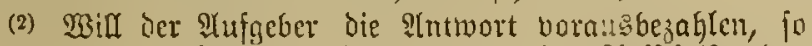

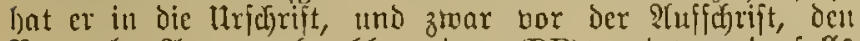
Sermert "Intwort bezalit" oder "(RP)", eintretendenfalls unter Beifügung einev Yngabe iiber die voraubbeahlte Wortzahl, niederzufdreiben und ien entipredjenden Betrag imnerbalb ถer Durd) Die Beftimmung zu (1) gejogenen (5renze

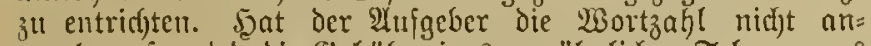
gegeben, jo wird die (Sehiil)r cincs gewöhnlid)en Telegramme von 10 mbörtern ertjoben. Der Stufgeber, welder eine Dringende Intwort voransbejalylen will, hat oen unter

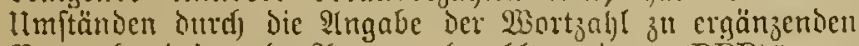
Bermerf "dringende Ifntwort bezalitt" oder "(RPD)“ nor

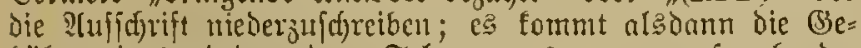
biigr eines oringenden Telegramm von entfpredjendur 93ortzaljl zitu (Ethebung.

(3) IIm Beftimmungsort ü6erfendet dic 9ullunft:anftalt Dem Empfönger mit Der Telegramunausfertigung cin ?̂nt= mortsformular, weldyes demiclben die Befugnif ertheilt, in Detr Grenzet der vorausbegalten (Sebillyt ein Telegramm an eine beliebige Beftimmung interljalb 6 lisochen, bom Tage der $\mathscr{H}$ (ustellung des formulars ab gered)net, unent= gett(id) antfugeben. ${ }^{2}$ )

(4) $23 e n n$ die für ein STntroortetelegramm ju entrichtende Bebillyr den Werth des für dafjelbe borausbezalyten $\mathfrak{B} e=$ trages überiteigt, fo ift das Mebr Der (Bebithr baar zu

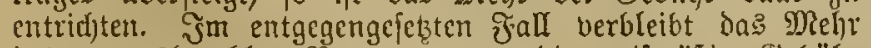
des votausbezahlten SBetrages gegen die tarifntäfige (Shebül)r Der Telegraphenvermaltung.

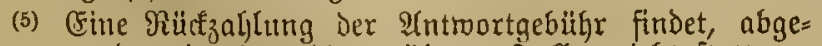

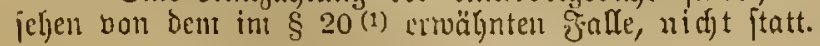

(6) Ram Das IIrfprungstelegramm bei der Infunft nidyt beftellt jwerben, bann twird dic int $\$ 22$ borgejefene tele= graphifthe Micloung über dic Uubeftellbarfeit an die ?Iufgabe= anjtalt jogleidf eritattet. Wenn feine Beridytigung erjolgt, benachridytigt die 2fnfunftsanftalt den ?lufgeber von ber Unbejtellbarteit burdy eime dienftliche Meldung, weldhe bie Stelle ber İntwort bertritt, fobald bie zur IIuffindung des

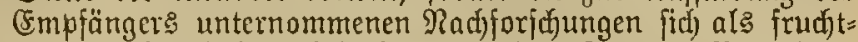
los erroiefen haben, fpöteftcrs nad) 8 Tagen. Bermeigert

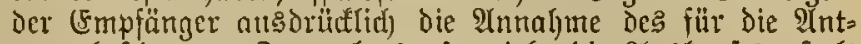
wort beptimmten jormulars, fo giebt bie शtustumfts̊amitalt Dem Shigeber ebenfalls Senntnis durch cine Dienftlidfe Meloung, weldje gleidffales die Stelle der 2(ntwort bertritt.

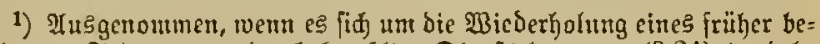
förberten Zelcgramms burd bejahltes Dienfitelegramm $(\$ 24)$ handelt.

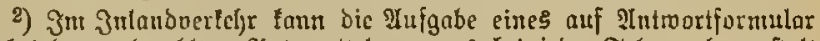
geid)riebenen bejajitten \{ntroorttelegramms bei jeber Telegraphenanifalt

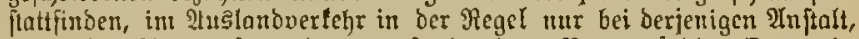

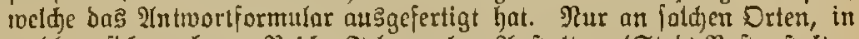

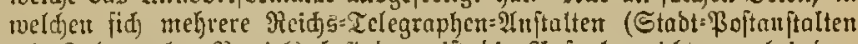
mit Telearaphen=\$etrieb) befinden, ijt bie \$Ilugabe nifjt nur bei ber=

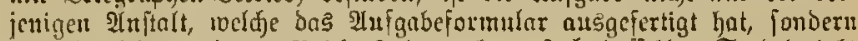

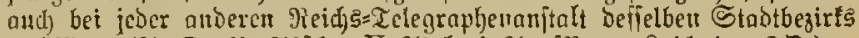

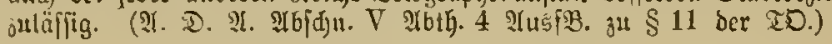

\section{Berglichene Telegramme.}

§ 12. (1) Dor ?ufgeber eines jeden Telegramms bat dic

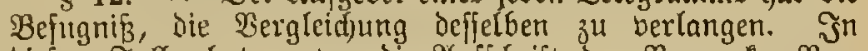

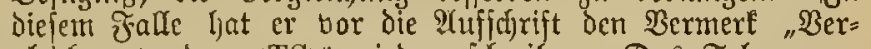
gleid)ung" Doer "(TC)" nicderzuld)reiben. Das Telegramm ift bann bou den verjofiedenen Inftalten, weldje bei feiner Beförderung mitwirteu, bođftänoig zu bergleiden.

(2) Die Bebülgr für dic Bergleidung eines Telegramms ift gleich cinem Biertel der (sebiillr für cin geroühnlidfes Ietegramm bon gleicher Sängc.

\section{Empfangzanzeigen.}

§ 13. (1) Der গ̂lufgeber cines jeden Telegramm: fann berlungen, dab ifun der Tan und die Stunde, ju weldjer Das Iclegran!m Den Empfänger zugejteft worden ift, un= mittrlbar nad) elfolgter Beftellumg telegraplif(d) angezeigt merde. (Er bat ill dicfem falle bor die ?tuff(d)rift den Ber= merl" "Empfangsanzeige" oder "(CR)" zu fŕf)reiberl.

(2) "Fïr die Cmpfangsanzeige ift diefelbe Bebiigr, twie für ein gewöhulidics Telegramm bon 10 wörterm zu entrichten.

(3) Sant Das Telegranm bei Der Anfunft nicht beftell werden, dam wird die in $\S 22$ borgejehene Utnbefteđbarfeits= meloung jogteich crlaffen. Die Empfungsanzeige wird

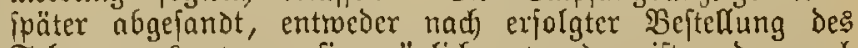
Ielegramms, wenn fie möglid) getworien ift, oder nad) 24 Stmnien, wenn fie nidht hat Itattinden fönnen; in biejem Jalle zeigt fie oen (Srmo der Unbejtellfarfeit an.

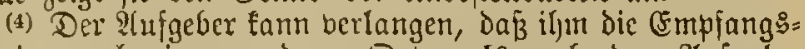
anzeige nach rinem ander'n Drte, a[s nach ocm Rlufgabe= orte D:S llifprung 3 telegranms 11 bermittelt merde, infofern er bic dajtl crforderticjen $\mathfrak{A}$ ngaben in bas lurprungs: telegramm aufnimmt.

\section{Telegraplijuge \$oftanmeifungen.}

\$ 14.1) (1) Die Telegraphenanftalten an joldjen Srten, an Denen eine $\mathfrak{B}_{0}$ ftanftaft befteft, find ermädjtigt, in $\mathfrak{B e r}=$ treturitg der Drtspoftanftalt Beträge auf Poftantoeifungen weld)e aul telegrapliffyen Wege überwiefen werden follen, bon den Abjendern entgegenzunehmen. अuf Eifenbahn: 
Ielegraphenftationen findet dieje Bejtimmung feine $\mathfrak{A}$ n= mendung. ${ }^{2}$ )

(2) Stuch find die Telegraphenanjtalten, mit Susnahme der (Eijenbahu=Telegrapljenitationen ${ }^{2}$ ) ermäd)tigt, menn bei ifnen Boitanmeifungen auf telegravhiftiem 93 ege eingehen, Die 2 Lşzahlung an Den Empfänger in Bertretung Der Dits:

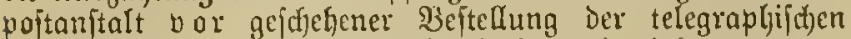
Boftanmeifung an Die Drtepoftantalt zu bewirfen:

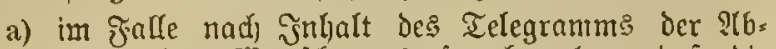
fender ben 2 unjid ausgejprochen hat, bas die शโuszahlung Durd bie Telegraphenantalt ge=

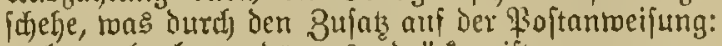
"telegraphenlagerno" aน 3 judrücfen ift;

b) im ofall der (Beldenufänger, indem er die tele= graplifiche \$oftaumeijung erroartet, der Telegraphens amitalt den $23 u n j$ d ausgedrüuft ljat, bie Baljlung gleid) nach der ?tnfunft der Arumeifung bei ber Ielegraplenanftalt in csmpfang z"l nehmen.

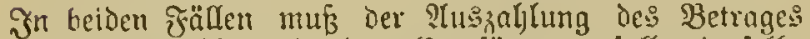

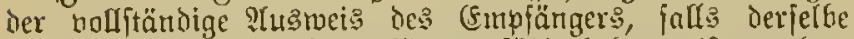
nidht werjönlicf und als berfügungsfähig befannt ift, borlyers gefen. ${ }^{3}$ ) Die telegraphifhe \$3oftanweifung ift alşDann von der Telegraphenan[talt mit dent (vorzulfhreibenden) Duittung: vermerke zu nerfeken, diefer von (5mpfänger zu unter füreiben und die Unteridurift burd) bic Telcaraphenanitalt mit Dem Bufatze zu beglaubigen, DaßB Der Empfäuger befant jei, ober bafis und in welet)er weife er ben Mustweis ge fiithert habe.

1) $\Re g !$ \$O. $\S 20$.

2) Die (Eijunbahn=-Telegraphenitationen, welde anderen Berualtungen

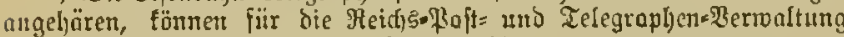
weder (Belder erheben nod) meldie auszahlen.

Dagcgen ift zuläffig, daß̧ bie Eifenbahn=Telegraphenfintionent das lleberweifungstelegramm beförbern, meldges ifnett übergeben twerden taun, wenn nit ber IInnağmepoftanftalt eine Telegraphen= sBetriebsftelle nidjt nereinigt ift, aber am jelben Drte fing cine Eijen-

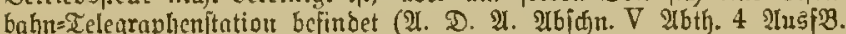
3u \& 14 ber TD.)

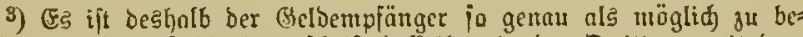
aeidnen, und mus Die lunter[driff beffelbent in ber Quittung mit bem im lleberweijungstelegramm angegcbenen Ramen genau übers cinftimmen. Die \{imbenoung ahgetiitgter, pereinbarter Ilorefifen

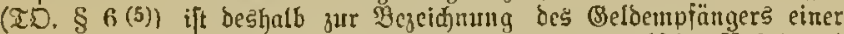

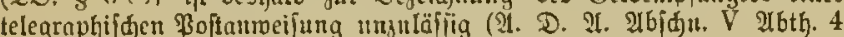

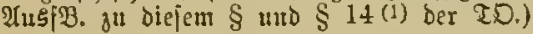

\section{Nachfendung von Telegrammen.}

\$ 15. (1) Der 2luigeber eines Telegramms fann, indem er bor die Aufidurift oen Bermerf "nad)jufenten" oder "(FS)" niederffereibt, berlangen, Daf3 baffelbe fufort nady ber nergeblich berfuchten Buitelung von ber Beîtimmungs:

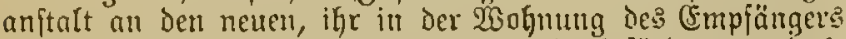
befaunt gegebenen Beitimmungsort weiterbefördert werde. ${ }^{1}$ )

(2) Der Bermert "nadizulenden" Doer "(FS)" Eann aud

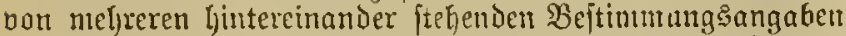
begleitet fein; bas Ielegramm bird Dann nadeinander an jeden ber angenebenen Beftimmungsorte, nöthigenfalf bis 3uut lebten, bejördert.

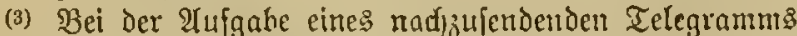
iit nur bie auf Die erfte Beiörderung E్frecte entialfende (Sebiligr

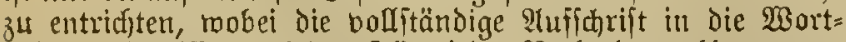
zahl eitubegriffen wird. Fin jede Radjtelegrapljirumg an

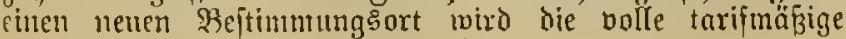
(sebübr bered)net und bom (Empfänger exhoben.
(4) J̌dermann fann nach gebörigem $\mathscr{U}$ ustweis verlangen, Daß̧ die bei cinter Telegraphenanftalt antommenoen uno in deren Beitellbezinf ilym zuzuftellenden Telegramme an eine von ilym angegebene 2 oreffe beftellt ober reiterbejörbert merden. Die bezliglichen $\mathfrak{A}$ nträge find id)rijtlich zu ftellen.

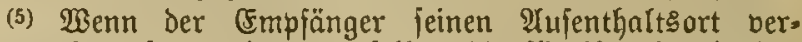
ändert hat, fo merden bemielben die fïr ifn cingehenden Telegramme an den neuen Slufenthaltsort, nadjelegraphirt,

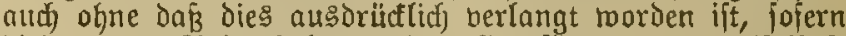
Dieier neue 2ufenthaltzort des Cimpiängers unzmeifelhaft befannt iif, innerljalb Deutjhlands liegt, und fich am ur. iprüngliden toie am neuen \&ufenthaltsort 2 nitalten ber Reich s=: Telegraplenbermaltung bezm. Der Staat: =Telegraplen. vertoultung Baberng ober Württembergs befinden. $\left.{ }^{2}\right)^{3}$ )

1) Radjentoung bon Zelegrantmen finbet nur im europäifjen Berlebgr fitt.

2) Wie jebes andere Telegramm tönteri nud telegraphifde \$opt= amveijungen nađtelsgraphirt werठen.

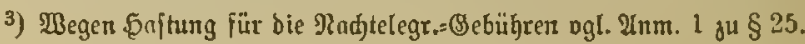

\section{Bervielfältigung von Telegrammen.}

$\$$ 16. (1) Die Telegramme fönnen geridtet rerden entweìer an mefirere Empfänger in einer Drtfchaft oder in berjajiedenen, aber in den Beitellejirf einer und derjelben Telegraphenanftalt fallenden Dertlidfeiten oder an einen und Denfelbell (5mpfänger nad) berfifiedenen Wohnungen in terielben Drtichaft'1) mit oder ohne Weiterbeförderung Durdh Moit, (Eilboten oder (5itafette.

(2) Der Tlufgeber cines zu berbieljättigenden Telegramms

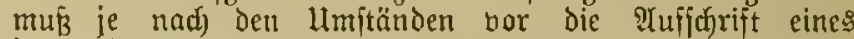
jeden (5utpfängers die befonderen Angaben (bgl. \& 6 (3))

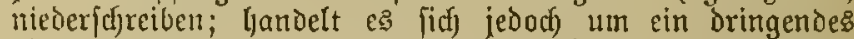
oder zu vergleitfendes Telegramm, melchę zu bervielfältigen ijt, fo genilgt $\varepsilon$, menn Die 2(ngabe ber erften 2 uffic)rift voranjtefit.

(3) Went ein zu vervielfältigendes Telegramm a॥ meGrere (Empfänger gerid)tet ift, fo Dari jede 2luşfertigung Deg Telegranms nur die ihr zufommende Shuficjrift tragen, es fei Dent, das der Mufgeber das (Segentheil verlangt

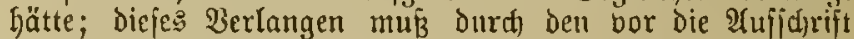

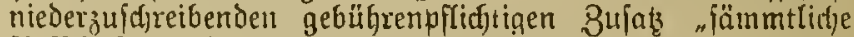
S(ufid)riftes mitzutheilen“ ausgedrüft merden.

(4) Das zut vervielfältigeno Telegramm wirb als eit eitujges Telegramm tarirt, mokei alle शhufidriften in bie

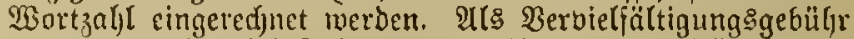
merden danchen bei Telegrammen bis zu 100 wörtern für die zheite und jede meitere $2 / u g$ jertigung 40 \$j. erfober. Bei längeren Telegrammen erhöht fich dieje ऊebühr fïr jede weitere Reilge oder den Brudhtheil einer Reihe vou

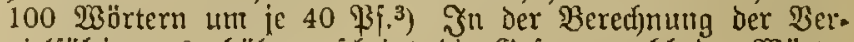

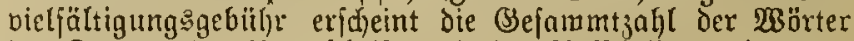

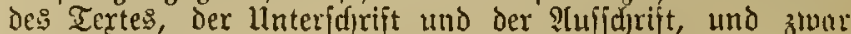
Ivird die Gebilht fiir jede $9(6)$ d)rift bejonders feitgeitellt.

1) Das zu vervielfältigende relegramm darf thur naw eincr Telegraphenanftalt geridtet fein, offo nur cinmal telegraphifd be: förbert werbet, uno toiro banu bervielfättigt. Die Đervielfältigungeu tönen bann per \$oft oder (Eitbote soeiterbeförbert merden.

8) ВgI. Iกm. 1 ди $\S 4$.

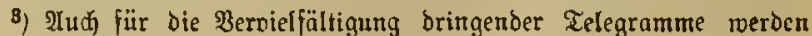

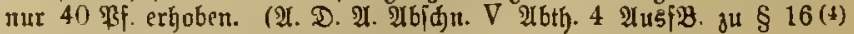
Der 20.$)$ 


\section{Seetelegramme.}

§17. (1) Telegramme, welde mit den Sdjiffen in See mittels der an Der ßüfte gelegenen Seetelegraphen geruedfielt merden, müfifen entweder in Deutfffer Spradje, oder in Beidjen

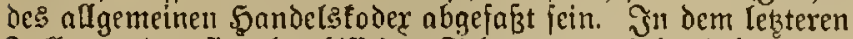
Falfe werden fie als diiffrirte Telegramme behandelt.

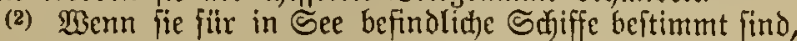

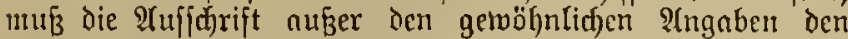

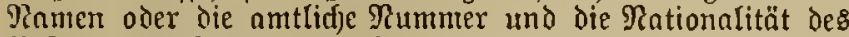
Beftimmungeffiffeses enthalten.

(3) Dicjenigen Telegramme, welche durd) die See=Tele= graphenanftalten imterhalb 30 Tagen nach) ifjer Slufgabe (den Tag Der $\mathscr{A}$ ufgabe nidft einbegriffen) den Beftimmungg: ¡dfiffen niff) haben übermittelt merden fönnen, merden als unbeftellbar zurildeđgelegt.

Jit das Schiff, fuir weldes ein Sectelegramm beftimmt ift, innerhalb 28 Iagen nidf)t angctommen, io giebt bie Sees Telegraphenanitalt dem 2 (ufgeber hierbon am 9/orgen des 29. Tageb Durth eine dicnfttidye Meldung Renntnißz. Der

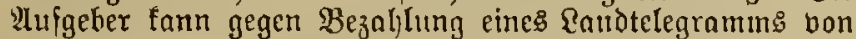
10 थRörtern verlangen, das die See=Telegraphennnitalt fein Telegramm während cines meiteren Beitraums von 30 Tagen für bie Buftellung bereit halte. Beht cin foldfes Berlangen nifht ein, fo miro das Telegramm bon Der See=Telegraphen= amjtalt $\mathrm{nm} 30$. Tage als unbeftellbar zurïtfgelegt.

(4) Die Bebühr jür Telegramme, meldie burch $\mathfrak{B e r}$ : mittelung einer See- Telegraphenanftalt mit Schiffen in See altsgeweedfelt werden, beträgt 80 \$F. Für ong Telegramm. ${ }^{1}$ ) Tiejelbe mird Den nach den fonftigen Beftimmungen $z^{u} \mathrm{cr}=$ hebenden (Sebülhren finzugered)net. Dic Befanmtgebithr fiir die an bie Sdjiffe in Eee geridfteten Telegramme wird nom ?lufgeber und für die bon dent Sdjiffen formenden Ielegramme bom cemplänger erfoben.

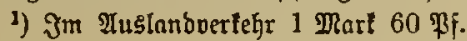

\section{Weiterbeförderung.}

§ 18. (1) Die W3eiterbeförderutrg bon Telegrammen iiber bie Telegraphenlinien himaus erfolgt nady wounfd des ?tofenderes entmeder durd die \$oft oder Durd (Eiffoten, $\left.{ }^{1}\right)$ nder Durrd) \$oit und (silfoten, ober burd) Eitafette. $\left.{ }^{2}\right)$

(2) Der 2 lufgeber hat die ?trt Der bon ihm verlangten Beiterbeförderutug in eittem taxpflidstigen Bufake vor ber थuffadrift anzugeben (bgl. \$6 (3)).

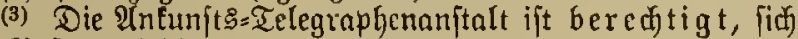
der Boit zu bedienten:

a) twenn in dem Telegramm die 9trt Der WBeiterbe= förderung nidft angegeben ift,

b. wenn eg fich um cine bon Dem (5mpfänger zи bes zahlende $23 e i t e r b e$ förderung handelt, und biefer fid friffer geweigert hat, Ruften Derfelben 2(rt $z^{u}$ bezablen.

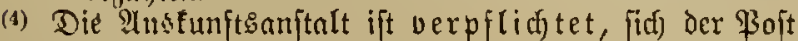
zи bedienen:

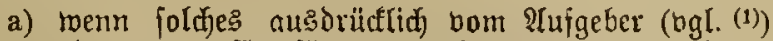
oder bom (ङmpfänger (bgl. $\S 15^{(t)}$ ) berlangt worden ift,

b) wern diefer 2Injtalt fein fafnelleres Beförderungs= mittel zu Bsebote jteht.

(5) Telegramme jeder Îrt, welde Durdi Bermittelung der Bojt an ihre Beftimunung gelangen, alfo autf foldede, weldde pofftagerno niedscrgelegt merden follen, swerden von Der Infunftgonftalt in der Regel ohne Roften für den ?luf= geber und fïr den (Empfänger al\& gerwöhnlidje Briefe zur 3ojt gegeben. 24usgenommen find jedoch folgende frälle:
1. Teleytanme, weld)e als cingefdriebene Brieje zu: \$oft gegehen werben follen, find mit ber bor die

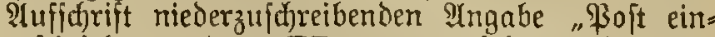
geffirieben" oder "(PR)" zu berfelyen und unter= liegen einer vom STugeber zu entridjtenden (Fin= fdreibgebilfr von 20 'sF. Diefe Sinfdreibgebülyr bon 20 \$f. fontmt nud) bei ber $\mathfrak{A}$ fuflicjerung aller Telegramute mit (Empiangsanzcige, roelche unit der \$oit meiterbejördert, oder poftiagernd niedergelegt merden jollen, zur Crljebung, da dieje Telegramme ftets als eingeldricbene Briefe zur \$oit gegeben merben.

2. Für Telegramme, welche bou ber beutfdyen $\mathfrak{B} e=$ ftimmungsanjtalt werben follen, hat Der Yujgeber die \$oitgebüfr zu entridjteıt. Diefelbe beträgt:

a) rack Dem europäifdjen ?(uStande und nad denjenigen liberfeeijchen Sänocru, meldje den Weltpoituereine angebören, 40 \$if.;

b) nach den bem Weltpoftbereme nicht angeljörigen

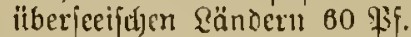

3. Telegramme, weldje einer an der Brenze gelegenen deutfhen Telegraphenanjtalt zur Wheiterbeförocrung mit Der Psoft nad) Dem Nachbargebiete und Daviiber

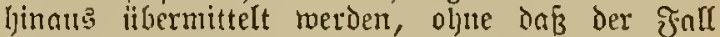
ciner lluterbreffung der liber bie Brenze fithrenden Telegrapljemberbinoungen borliegt, fino als un= frantite Sriefe zu bebanielı; das \$sorto fält den Empfönger zur Rajt.

(6) Die Solten fits Dite Buitellung bon Telegrammen mittels Cilboten an (5mpfänger auperbalb bes Drtsbeftell= bezirf: bex Beftimmungs=Telegrablitunitalt fönnen bom Tufgefier durd) (Entridftung eincr feften (Sebüb: bon 40 ४if. fïr jedes Telegranm norausbezahlt tocrden. Der Aufgeber hat it diefem Falle den Bermert "Filbote bejahlt" oder "(XP)" vor die Telegranmmuffdrift zu feben. Fin weiteren jteht es dem ?tufgeber cines Telegramms mit bezaljlter 9trt. joort irci, die etroa entfelonde Eilbeftellgebiin fitr Das

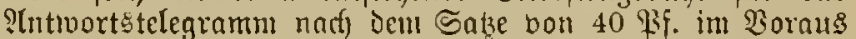
bei der 2ujgabe des Uriprungstelegrammts z entridten.

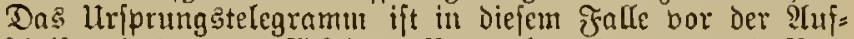
idyift mit hem taxpflidftigen Bermerfe ":Intwort und Bote bejalylt" oder "(RXP)" zu verieben.

Ginbet Die Roran bejaflung bes Silbotenlohnes nicht ftatt,

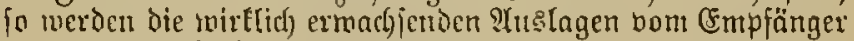
ober bont Puigebcr eingezogen.

Die Roiten jür die Weiterbejörderung Durch (Sftafette find ftets bou sufgeber zu entrichten. ${ }^{2}$ )

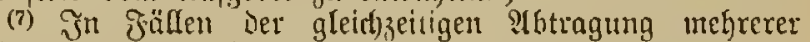
Selegramme durd) Deniclben Boten an Denjelben Cempiänger findet die vorftebenic Beftimmung unter (6) gleid)mäß̈ig Îln= mendung. Werden im llebrigen burst denfelben Boten an Denjelben (Fmpiänger gleid)zeitig foldje Telegramme $a b=$ getragen, fïr weld)e das Butenlahn in Boraus bezahlt ijt, 11nd foldace, bei weldjen dies nidjt der Fall ift, jo ift bom (Empfänger das erroadffene Botenlohn, abzitglicf der im Borau bezablten Beträge, zu entridjten. Die auf etiva gleid)zeitig zur I!btragnng gelongende Eilpoltjendungen im Boraus bezahlte $B$ eftellgebühr bleibt lierbei auber Betratit.

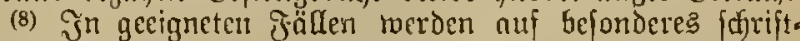
liches Betlangen bes Crnpiängers dic fïr ihn cingeljentent Selegramme feitens der Ielegraphenanftalt nidft dureh (5il= boten beftell, fouderu den Boten Des Empfängers gc= legentlidi der jedesిmaligen Mlbljolung bon \$oftfendungen 
mitgegeben. Unzuträglidjéteiten, weldje etroa aus diejer (Fin= ridjtung entfteben, hat bic Ielcgraphenvermaltung nicht z"t bertretert.

1) Die Weiterbef̈̈rberurg burdj Eilboten über bic Brenzen bes

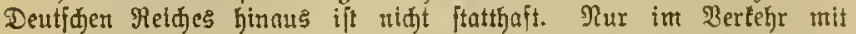

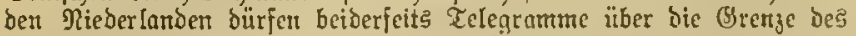
eigenen Etaates hinaus burd Boten bejtelft werbelt, aber audj mur

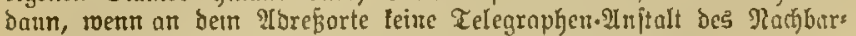
itantes bejtegt.

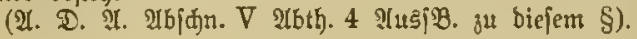

2) $\mathfrak{B g l}$ Inm. 1 зи $\S 4$.

\section{(Entrichtung der Gebligren.}

§ 19. (1) Sämmttliche betannte (sebühren find bei ?luf, gabe des Telegramms im Boraus zu entridjtcti.

(2) (5s twerden jedoch bom (Empfănger am Beftimmung ort erhoben:

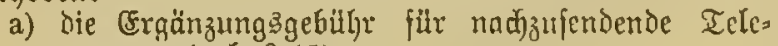
gramme (ugl. \& 15),

b) eintretendemfalts die weiterbeförderungsgefilfren (vgl. $\S 18$ ),

c) die (Sebtihren für bie burd) bic Sectclegraphen= anitalten bom Diect her bejörderten Telegramme (ogl. \& 17).

Эn allen Fällen, to cine Bebübrenerbebung bei der Beftellutg ftattzufinden hat, toird das Telegramm dem (Empfänger mur gegen (Frifattung des f(t)uldigen Betrages auघgehändigt.

(3) Die (Entrifftung der Bsebübren fann bei den Tele= graphenamitalten mittelo Werth $_{3}$ cicjen ${ }^{1}$ ) oder baar - bei den (Eifenbaln= Telegraphen[tationen mur baar ${ }^{2}$ ) - erfolgets. Fine Befdeinigung ẗber die erhobenen Bebiithen wird tur

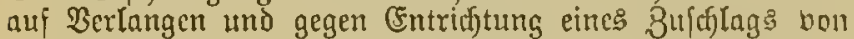
20 PF. ertheilt. Bei gebihtenfreien Stantstelegrammen ift auf Berlangen eine Befdreinigung über bie Euflicfernng unentgeltlidf zu ertheiler.

(4) \$erionen, meldhe (id) Des Telegraphen häufiger bedienen, lann auf ifren ?tntrag geftattet merden, die Ge= büfgren für die bon ihnen bei Telegraphenamitalten aufge= gebenen Telegramme monatlid) zu entridyten. Sie baben

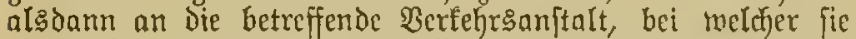
ihre Ielegranme aujgeben mollen, einen entfprectenden $\mathfrak{B a r}=$ jchuß cinjuzahlen, und aIs befondere Bergüttung für bic burdj)

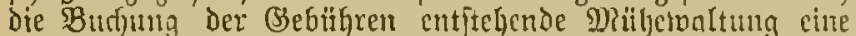
Gebühr von 50 \$i. für Den Salcndermonat und nußserdem fïr jedes Telegramm, defien Gebülgren geftuniet merden, 2 gif. 3u entridjten. SItuf (Fifenbahn= Telegraphenflationen finbet diefe Beftimmung feine ?lntondung.

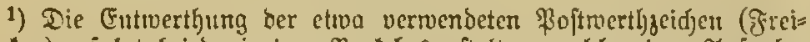

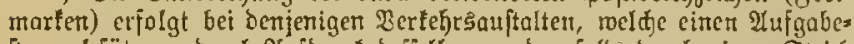
fitempel fütren, burd Ruforud deffelben, anderrifalls burd) cinen Strid)

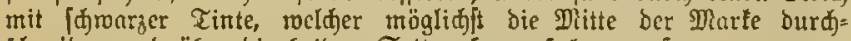
¡̈neiden und ziber bie beiben Seiten berdorjtehen mus.

2) Weir biejelben anderen Berronltungen argehören, bie 2 Berth= geiden ber Pofts und Telegraphenderwaltung fiir fie bather teine Bültigleit habert.

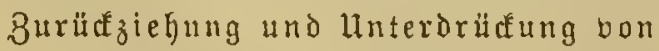 Telegramen.}

§ 20. (1) Jedes Telegramm fann von bem ILGfender,

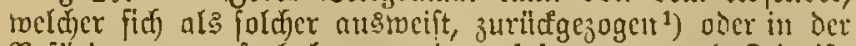
Bejördernmg nufgehalten toerben, fojern es nod) Beit ift. Wenn in einem folden ₹alle bie Beförderung de Tele= gramms thod) nid)t begonmen bat, fo werben bemt ?lbfenter die (Bebilfren narf) ?(bzug bon 20 Bi. ${ }^{2}$ ) eritattet. ${ }^{3}$ ) Sat dic 2tbtelegraphirumg bercits begoumen, fo nerbleiben die Be= bilhren Der Telegrapljenvermaltung; toratsosczahlte Beträge fiir Weiterheförderung, bezal)lte ?tntwort, Fmpiang:

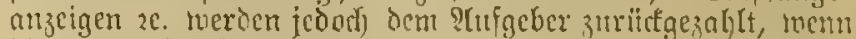
die borausberaflte Éciftung uiclit ausgefithrt worden ift.

(2) Fin Telcgranm, voeldes Durdh Die llrfurungsanjtalt bereits tejördert worben iît, fann nur aui Grund eincs

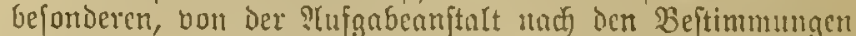
im § 24 zu erlafienden Telegrantm: angegalten mo net=

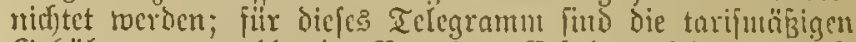

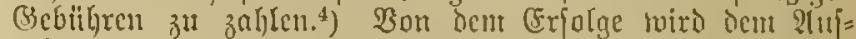
geber mittels unfranfitten 23riefes Renntnifs gegefien. Ber=

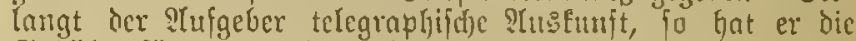

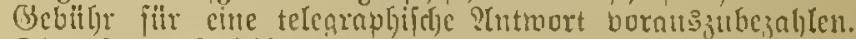
Die crlegten Bebilfren fït Das Ielegramm, Deffen Beftellung auf Berlangen unterdriteft miro, werben nidgt zurïfgezalit. Bei jedent dernrtingeu Berlangen hat Der IIntragfteller bas

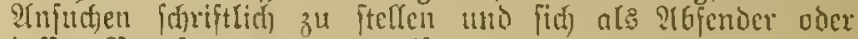
deffen Beaujtragter ausioumeijen.

1) Der 2rufgeber tont anth bie 1trfdrifi beङ Telegramms jelbft zurüđerbalten, roen baliclbe not) nid)t beföroert ift.

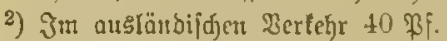

3) Der $\mathfrak{A}$ ufgeber quittirt über den zurüderljaltenen Betrng entweber auf bet $\mathfrak{A}$ fgabetelegramm oder auf sinem bejonberen Blatte. Tic Berreditutg erfolgt butd) dic Entlafumgstarte.

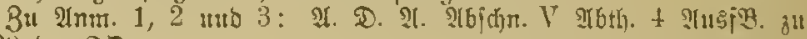
$\$ 20$ ber TS.

1) Dieje Telegramme gelören au ben "gebührenpflidtigen Dienjt. notigen (St)" und find frets von ber \$!ufgabe.Telegraphenanftalt $a b=$ zufaffen. Die etroaige (brieflide ober telegraphtfde) Untroort ijt bes= balb aud on bie Ilugabeanftalt, nidjt an bea Hufgeber felbit gu riłhter.

\section{Buftellung der Telegramme am Beftim mung ort.}

$\S 21$. (1) Die Telegrantme merocn bei ber Itufnalyme

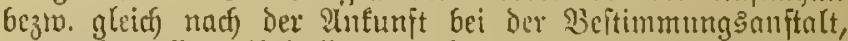
wenn Die offene Beftelfung nidjt ansoriiffich berlangt ift, verfdylofien.

(2) Diefelfen merden, ifrer Ifufichrift entipredjend, ent. weder nach der $930 h n u n g$, ben (3jejdjäftęlotale $2 e$. Deg Empfängers heftellt besw. auf fonltige Meife ueiterbejördert oder pofttagerro oder telegraphentagerno niedergelegt. Jొut Weiteren Ë̈men dic angefoumenen Telegramute ben

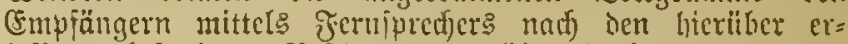
Iaffenen bejonderen Beftinmungen Ḧbermittclt merdocn.

(3) Die Beftellung oder \$iserterbeförderung Der Tele= gramme gefdieht mit thumlichfter $\mathfrak{B e c}$ d. Reibenjolge ifrer ?tufnahme und ihres Vorranges. (28egen IIebergabe der Telegranme an bie $\mathfrak{B}$ oten bes (Empfänger: vgl. \& $18(8)$.

(4) Staat: $=$, forvic Dienft= und dringende Bribattele= gromme metben mit Borrang bor anderen Telegrammen

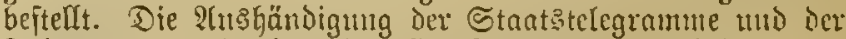
Telegramme mit Gezahlter Empiangsanjeige erfolgt gegent

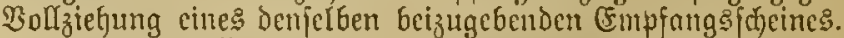

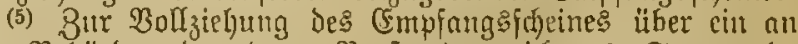
eine Behörde oder Deren Boritano geridftetes Staatstele= gramm tann, wenn utidgt cine befondere fudriftlitbe Beriügung Darïlier getroffen ift, mur der 2 arftand ber betreffenden 3efjörde, Dder, in deffen STbrefenhcit, jein Stelloertreter als bcred)tigt angejelen werden.

(6) Bribattelegranume, jowie bie nidft aul cine Bebörde oder beten Borftant gerishteten dienftlisfen Ielegramme find 
bagegen im fantl her 2 (bmejenljeit des (Empiängers an ein

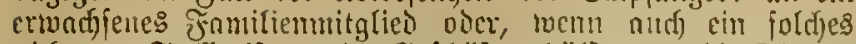

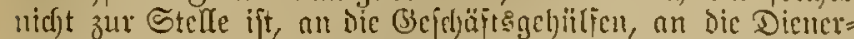

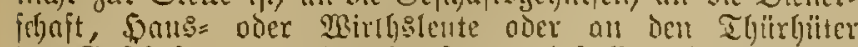

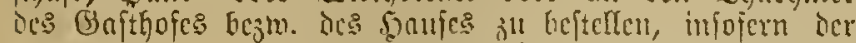
Empfänger fiir Derartige đ̈n̈lle nicht einen befomberen $\mathfrak{B}_{\mathfrak{e}}=$

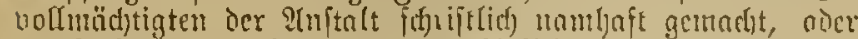

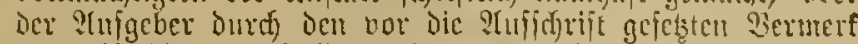
"cigenländig zu beftellen“" over "(MP)"1) vertnugt ljat, bnf

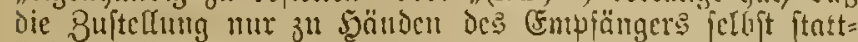
finden foll.

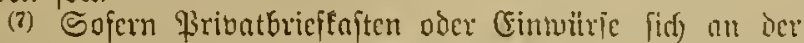

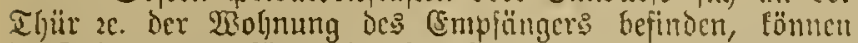
bic Tricgramme, fï tweldhe (Empiangsidgeine nirjt abzugeben fint, in jeme Briefteften 2c. geftept mericn. Telegramme, meldse ocn Bermert "cigenfänoig zu beftefleu" oocr "(ISP)" z)

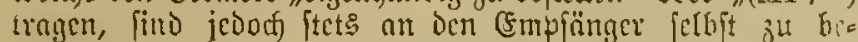
ftellen; cbenjo werden poftIngernde oucr telegraphentagernte Telcgramme mu Dem Entrfänger oder feinem Y3enolt=

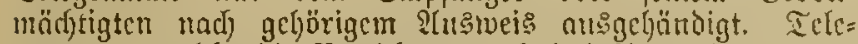
gramme, reldhe bic $\mathfrak{B} c$ jeidjung "bafnhoflagerno" trager, werden an den Bahnhofsuorfeker oder deffen ভtelfuertreter abgegebert.

(8) Die an Reifende rad) sinent (Safthoic gerichteten Telegramme werden, wenn der (Empfänger nod) nicht cin= setroffen ift, an Den Wirth 2e. Des Softlofes mit dem

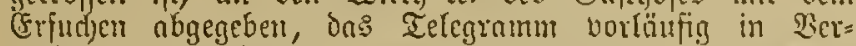
malyung ju nelmen mo Dent Empfänger bei fincm Esin=

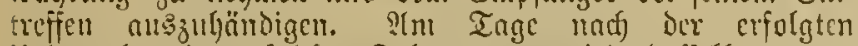

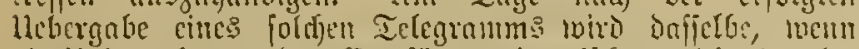

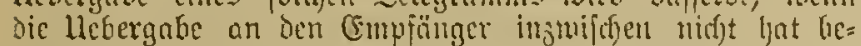
birft merden Ënmen, Durel eincu Boten gegen Sinterlajimg

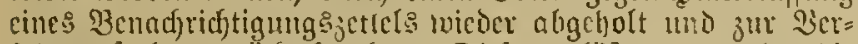

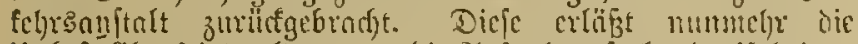

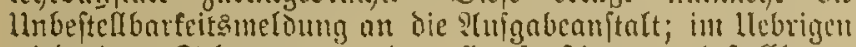
wiro Dos Telegramm wic alfe jonftigen mulhefelfharen IcIegramme betjandelt.

(9) Ĵt meder Der (Fnpiänger nod) fonft Jemand auf=

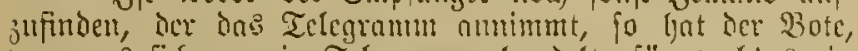

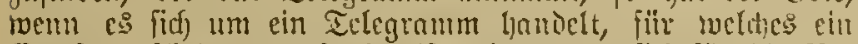

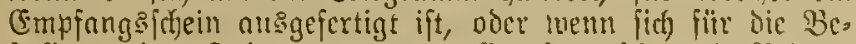
fellung eincs Telgrammes oder Bmpfangefdeen ein litivat=

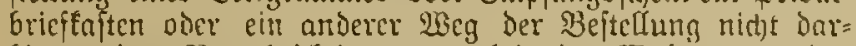
bietct, cinen Benndridftigung 5 jettel in Der 20 ofjumn $2 e$. Deß

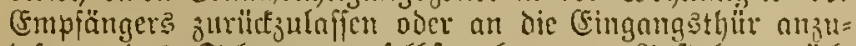

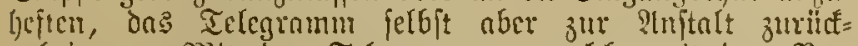
jubringen. Dhit den Telegrammen, weldje mit dem $\mathfrak{B e r}=$ merfe "cigenfändig zu beftellen" oder "(МIP)" berjeben find, iit in "gleidjer Wreije ju verfahren, "wem ber bejeirfuncte (Empjänger fe(bit niç)t nngetroffen wiro.

(10) 4 Benn Der Bote bei Der Bejtellung bou Tele=

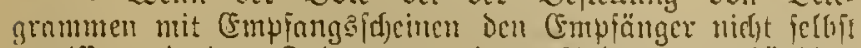
antrifft und das Telcgramm cinem ?ludercn aushänbigt, lyat ber Sekzterc in bem Empfangsfdyeine feiner eigenent

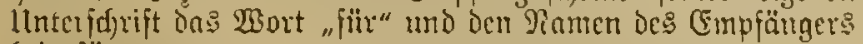
beijuifigen. fagt. $\left.{ }^{2}\right)$

(11) Dem Boten ift bic S(mmahne bon Gefdjenten urter=

1) Iuf bic 2ermerfe "MP", cbenfo auf ctwaige Bermerte "RO" ift ber befteffenbe Bote befontors aufmerfiam zu inadjert.

2) Bon bcm Motell chna einjujichende (Bebül)ren (Botenlohn. MRad)=

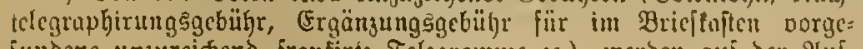

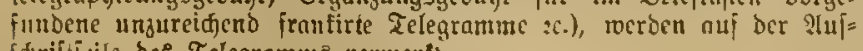
id)rifticile bes aelegramms vermerti.

\section{llnbefteltbare Telegrame.}

§22. (1) Bon der llubejtelbarteit cincs Idegranms und den Grïnden der llnbeftetharteit twirb ber ?hufgahe= nmftalt telegraplifid) gicloung gentadjt. ${ }^{1}$ ) Siegt fiit bic Itnbejteflharfeit cimes Telegramm: ein (Srund vor, melder nidft oljue Beitercs nus bienfilisfer Beranlaffung heicitigt

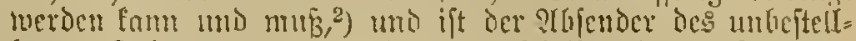
buren Telegramm nus der ltuteridurift oder anl andere Weife mit genïgenier Sidferheit hefamnt: Donn wirb bie

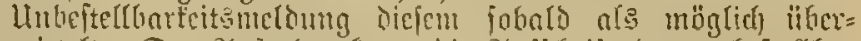

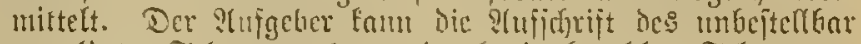
gemeldeten Telegramme nut durly cin bejaljles Telegramm uerbol[tänDigen, heridjtigen ober beftätigen. ${ }^{3}$ )

(2) (Fin Telegramut, weldyes von bem abtragenden Boten

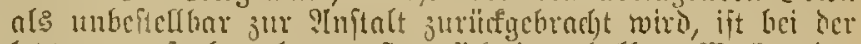

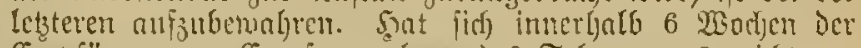
Empfänger jur Empjangrahne de Telegrammes nid)t ges

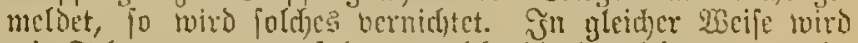
mif Telegrammen verfahren, meldje dic şejeidjunng: "telc=

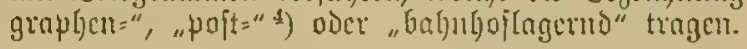

1) Dic Inbeftellbarteitsmeldung muf enthntten:

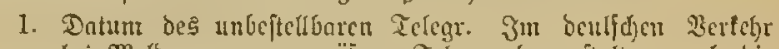
bei Peltoungen an größere Telegrapljentanitalten madj bie Sufgunbezcit.

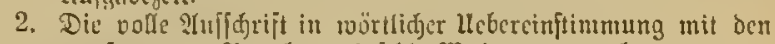

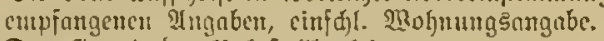

3. Dent Brund Scr llubejtectborteit.

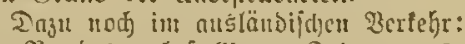

4. Tic Mir bes unbeftellhoren Telcgramms.

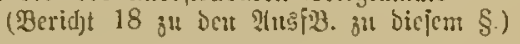

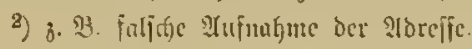

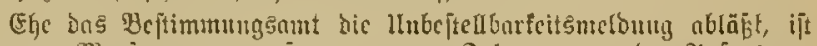
bei nut Dlorjeappnrot aufgenonumenen Telegrammen ber stufrnbmes

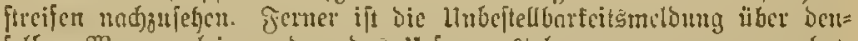

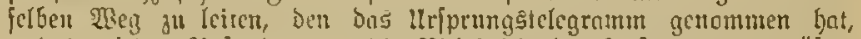

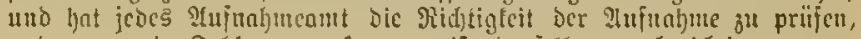

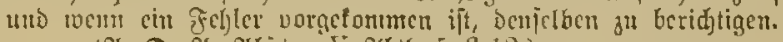

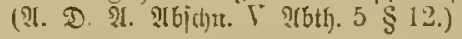

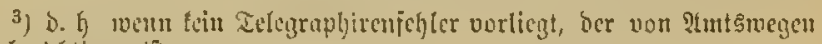
3ut beridgtiget ift.

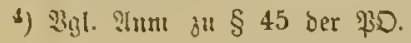

\section{(5) rö̈rreifung.}

§ 23. (1) Die Telegraphentermaltung leiftet für bic richtige Aleherfunft Der Telegramme voer dercu lleberlumit

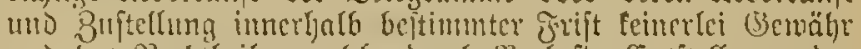
und lyat Pindtheile, weldie burd) Berluft, Entfelfung oder Serjpätung Der Telegramme entfehen, nitgt ju vertecten.

(2) Die entrichtete (Sebilfyr wird jedoci) exftattet:

a) jiïr cir Telegrumu, wclffes Durch Sdfuld des Telegraphenbetriches gar nidjt oder mit bedeuten= ber Werzügcrung in die ફände bes Empfängers getantit ift,

b) fïr cin nerglidjenes Telegramm, welufes in Folge

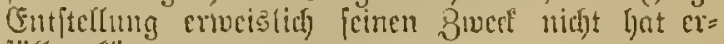
ïแllen fömucn.

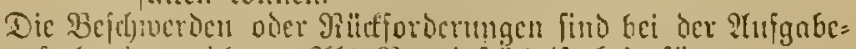

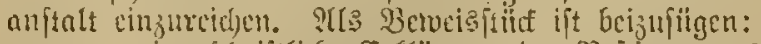

cine id)riftlich) (Frflärung der Bejtimmungsonfitult oDer Des Cempfängers, wem Doక Selegramm nicht angefonment ijt,

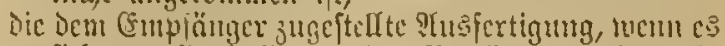
firf) แm (Entitllumg oder Berzögcrung handelt. 


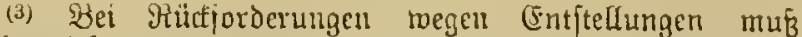

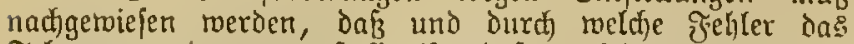
Telegramm derart entitelft ift, ina hat erfüđen tömen. ${ }^{2}$ )

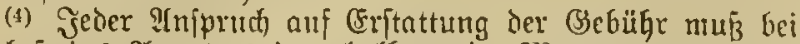
Berfuft des ?nrechtes innerlyalb zrocier Manate, bom Tnge ber Erbebung an geredgnet, anbängig gemant twerden.

(5) Die Erftattung bezieht fich Tediglich auf die (G) bithr

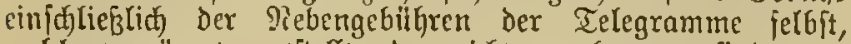
ineldye verzögert, entftellt oder nidjt angefommen find, und auf dic Bebühren ber int $\$ 24$ vorgejefenen Telegramme, nicht aber auf bie (Sebül)ren fold)er Telegramme, melde etwn Durd) die Berzögerumg, Entitellung oder Ridft= anfunft jener Telegranme beranlafít oder nublos gemadjt worden find.

1) Mts erheblid vergögert ift ein Telegramm anzulehen, weun taffelbe:

a) im inIän১ifden Berfehr bem Mdrefinten fpäter zugeftelt wirb, als es bei Poftbeförberung gefhehen weäre,

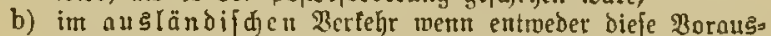

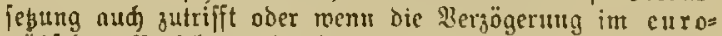

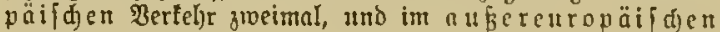
Bertehr, fechsmol 24 Stunden beträgt.

2) Rur bei verglidenen Telegrammen. 2gl. (2) b im jetben §

\section{Beridftigug gatelegramme.}

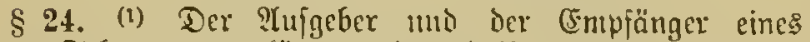
jecten Telegramm fömen imerhalb ciner Jrift non 72 Stunden, welde ie nady dem falle der aluftiefermng oder ber SInfunft dicies Ielegramms jolgt, auf telegranhifdem Mege ?hisfunft verlangen oder (Frläuternmgen geben, tweld)e (iid) anf das in der Hebermittelung befindlicle oder bereits bejörderte Telegramm beziehen. Sie tönnen aud zum Broet eirer Beridftigung cin Telegramm, weldfes fie auf, gegeben oder erbalten haben, entmeber durd) die Beftimunungs=

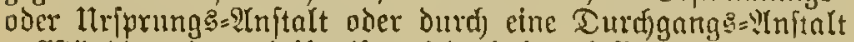
nolftändig oder theilmeife twiederlyolen laffen. Sic baben folgenie Beträge zu hinterlegen:

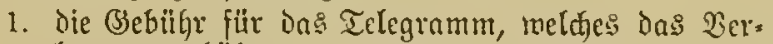
langen enthält,

2. Die (Gebühr für cin 21ntrourtotelegramm, menn rine telegraplijiffe ITntwort getuilnjdjt wird.

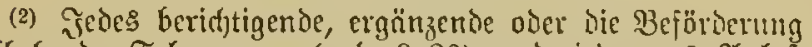
auffebenie Telegramm (ogl. \$ 20) und jede auङ PInla cines bereits beförderten oder in der $\mathfrak{B e f u ̈ r d e r m m g ~ G e g r i f f e n e n ~}$

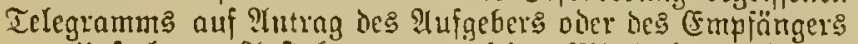
von IInftalt zu Inftalt nusgetnuid)te Diittheilung ift cin Dienfttelegramm, tweld)es nad) dem gemöbnlidjen Tarife taritit wird. ${ }^{1}$ )

(3) Die fïr die Betidhtigungstelegrnmme erhobenen (b) $=$ bilhren werben auf desfalfigen IIntrag zuriddgezahlt, wenn Die Wiederholung ermeift, onáz das oder tie miederholten Wörter im Uriprungstelegramm unridytig riedergegeben morben find. Wenn im llriprungstelegrnmm einige wötter richtig uno einige andere wbürter umridytig twiebergeneben morden fino, fo twird die (Bebüfr für diejenigen wïnter

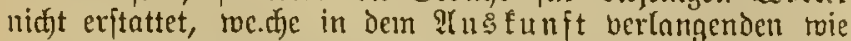
in dem Itntworts= Dienftelegramm die im Urfprungs: telegramm ridjtig twiedergegebenen 3 b̈rter bezcidjnen.

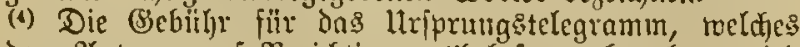
3'l bem Sintrage auf Berid)tigung "InInf gegeben hat, wird nidit zurikfgezahlt.
(5) Dem Intrage auf Beridfigung eines beföroberten oder in ber Beför derung begriffenen Telegramms barf bon den Telegraplenamitalten nur dann Folge gegeben werden, menu der \&utringiteller fidc) alg ?lufgeber oder (5mpfänger des betreffenden lirfprumgstelegramms oder als Beboll. mädjtigter cincs dexfelthen ausgeroiefen hat.

1) (Ein bezahltes Dien[ttelegramm, St.

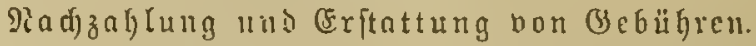

\$25. (1) Gebillyren, melde für beförberte Telegramme z"ll menig erfoben fint, oder deren (Finziefung bom (5mpfänger nidat erfolgen tonnte, - fei $є \mathcal{E}$, Dn

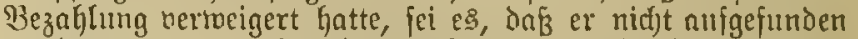
morden war, - ljat der ubjender auf Derlnngen nach= zuzaflen. ${ }^{1}$ ) Эrrthitmlich zu viel erhobene (Sebitfren merden dem Itrfgeber zurïftgezahlt.

(2) Der Berng der nom Tufgeber zu biel nermendeten Werthjeidjen mird jedocl) nur auf jeinen ?(ntrag erftattet.

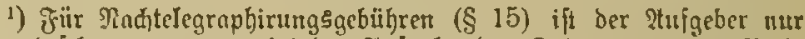
bann haftbar, wenn er bei ber 2tufgnbe bes Telegramms bie शad): tetegraphirung verlaugt hat. 5ot ber Empfänger Die Mudutelegraphirung

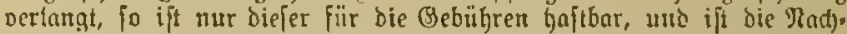

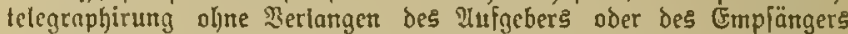
erfolgt, io merden die uneimbiehbaren Gebuifren auf bie Reidstaffe

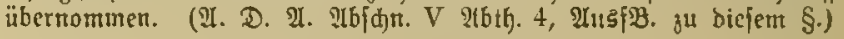

\section{Telegramutabidifiten.}

§ 26. (1) Der ?tufgeber und der Empfönger, falls fie ficf als foldfe gelörig ausmeifen, find berecftigt, fich bes glaubigte 9tbidjriften ber bon ignen nufgegebenen und ber an fie gericfteten Telegramme nusffertigen zulaffen, menn fie Srt und Tng der Plufgabe genau angeben fönnen, und

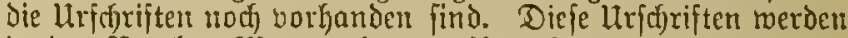
in ber Regel 6 Manate lang nufferonhrt.

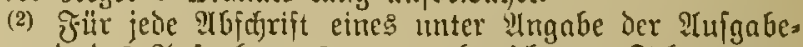
zeit und des ?(ufgabeortes genau bezeid)neten Telegramms

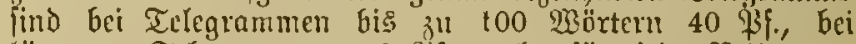
längeren Ielegrammen 40 \$f. meljr für jede Reibe bon 100 Wörtern oder einen Theil derjelben zu entridften. Bei ungenau bezeidjneten Telegrammen find auser Der Sd)reib= gebilfhr bie burdy die Aluffuchung des Telegramms entftehen. oen Rojtel zu zaljlen.

\section{Rebentelegraphen und befondere Telegraphen. anlagen. Fernipred)intidungen.}

\$ 27. Die Bedingungen für Rebentelegraphen und bes jondere Telegraphenanlagen, fowie für die f̧ernjpredeinriđ. tumgen werden nom Meid)

\section{(G) eltung}

$\S 28$. (1) Die voritehenden Beftimmungen gelten, fotweit

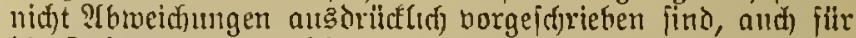
die Telegramme, melthe unter Benukung bon Eifenbalyn. telegraphen bejördert roerden.

(2) In Bezug auf den telegraphifden Bertefr mit dem Tuglnnde fommen die Beftimmungen der bezügliden Tele. graphenverträge zur 2luwendung.

Berlin, den 15. J゙mi 1891.

\section{Der Meidał Inanler.}

3. ஒ.:

ท. Stephan. 


\title{
III. $\mathbb{E} \mathfrak{h} \mathfrak{e} \mathfrak{i l}$.
}

Gejetse uno Deroromungen, welche fith auf die Beamtenverhältniffe bejtehen.

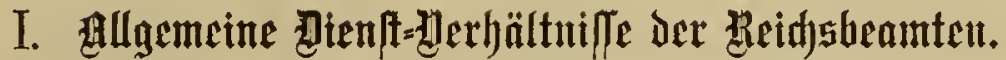

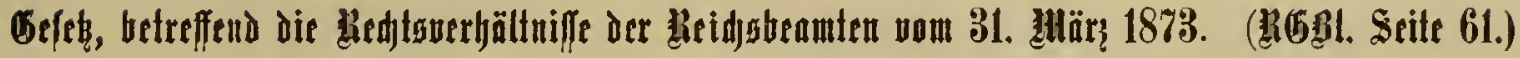

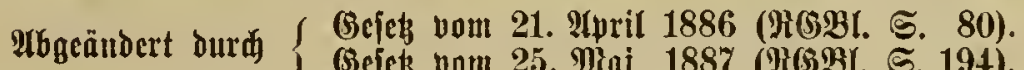 \\ ( Bejeb vom 25. Mai 1887 (M(5) S. 194).
}

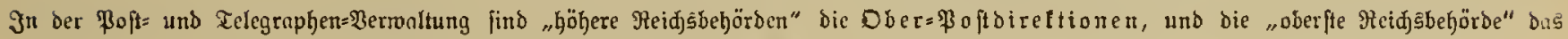
Reids. Boftamt. (Siege Amm. jum Sd)lubparagraphen 159.)

\section{Argemeite $\operatorname{Be}$ itimmungen.}

§ 1. Reidsbeamter im Sinne diejes Bejebes ift jeder Beamte, weldjer entweder bom Raifer angeftellt ober nad) Boridjrift der Reidjsoerfaffung Den Tnardnungen des Raifers ङolge z"l leiften berpflidftet ijt.")

1) Welde Beante ber Bopt= und Telegraphenoermaltung burd ben Saijer, toeldhe burdi bie Bunbestegierungent anjuftellen finb, beftimnt Itrt. 50 ber औeidfsperfaffung (oben S. 15).

Iuf Grund dicjer Bejtimmung jowic auj Brumb bejonderer Ber= träge werber ermantt:

1. Die Ober = Boftoireltoren, Dber = \$ofträthe, Fofträthe uno Poitbattäthe pam Rnijer.

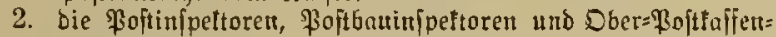
renbanten in Ranten bes Raifers pom Stantsjecretnir bes Reichspoitantes,

3. bie \$oft=umb Relegraphendireltoren, \$oft= und relegraphen=

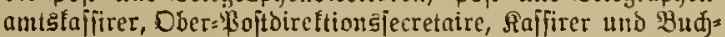

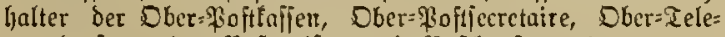
graphenfecretaire, Boftueifter und \$ojtbaujecretaire

a) inmerbalb bes (Grobhergogthums Dloenburg (mit $\mathfrak{A} u 5=$

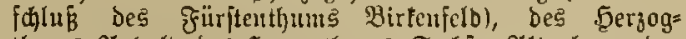

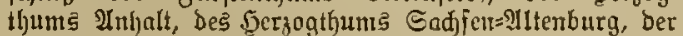
Etaatsgebiete ber freien Sanfefübte Bremen, 5amburg

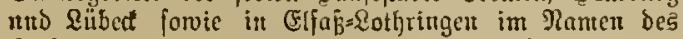
Paijers Dom Stantsjecretair bes Retds=\$oftamts,

b) iu den übrigen Stantsgebieten von den \&anbešregierungen.

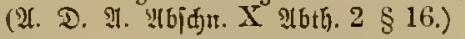

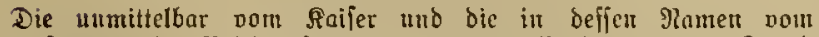
Etaotsjecretair bes $\Re$ eidspojtunts crnannten, aljo bie unter 1,2 uno 3 a aufgeführten Beanten find unmit te lbare, bic von oen Bunbes= regierungen ernaunten, aljo bie unter $3 \mathrm{~b}$ aufgejübrten $\mathfrak{B}$ eamten, fino mittelbare Reidsbeaute.

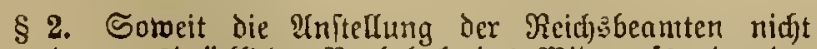

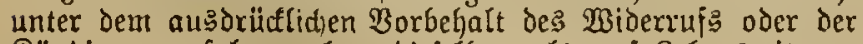
Ründigung erfolgt, gelten diefelbet als auf Rebenzzeit an= geftellt.

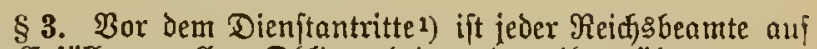
die Crfülung aller Dbliegenheiten de

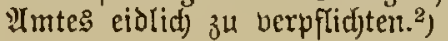

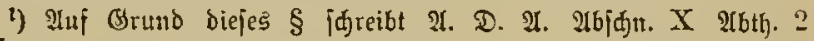
$\S 7$ por:

"Die Beauten und Unterfeamten müfifen, beoor bie $34=$

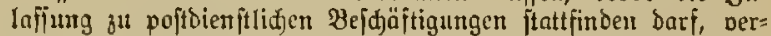

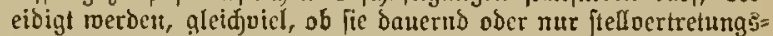
meije oder aushülfisweife in Roftbienfte vermendet werden follen."

2) Dic fapintg bes Dienjteibes der unmittelbaren Reidis=

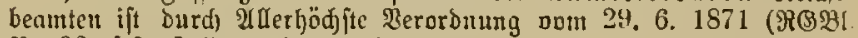
গir. 32) feftgeftedt worben, unt lautet:

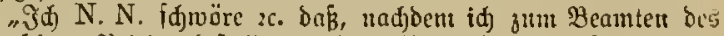
Dentider Reidja beftelft worben bill, id in biefer meiner Eigenjめait Seinter Dlajeftät bem Deutiden Raijer treu und

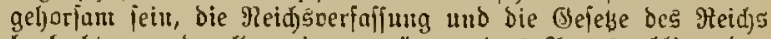
beobadtell unt alle mir vermäge meines Intres obliegendon Pflidten nad beftem $\mathfrak{B}$ Biffen uno Bewiffen genau erfüllen roill, jo toafie :e."

Dieje Cibesformel tommt zur 2(nnentung:

1. bei ben in 9 Inut. 1 ju $\$ 1$ unter $I$ und 2 oufgeführten Beamten, menu biejelben in ben ifhnen übertragenten Etellen

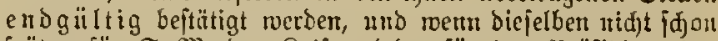

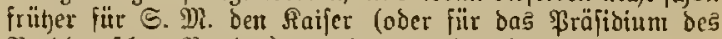
Tarboentidjen Bantes) vereibigt tworben find,

2. bei ben, in nen unter 2 a aufgeführten Etaatsgebicten ne॥ eintretenden ßennten, mo wem Beamte aus anderen Gebieten bes Dentiden Meidjes in bieje Stantsgebiete neriest

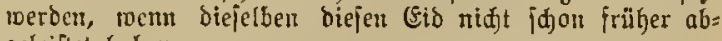
geleiftet habent.

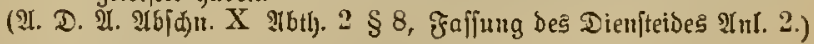

Bei bent in anderen Stantsgebieten neu eintretenden Beamten er= folgt bie Bereibigung und) Mlakgabe ber Ronbçgejekgebung. Sn bent Dienfteib ift an geeigneter Stelle der 3 ufał auffunchmen:

"Dos ber Beamte fid verpllidte, ben Inorbunungen Seiner Dajeftät bes Deutfden Saijers Folge zu leiften." (ebendaj. §9.)

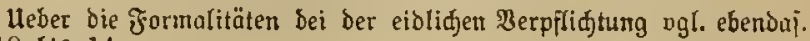
$\S 10 \mathrm{bis} 14$. 


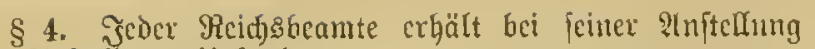

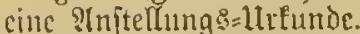

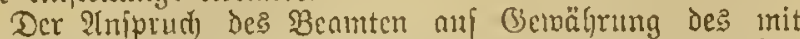

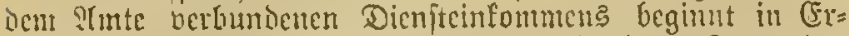
ntangelung bejonberer FFeftfekungen mit bem Tage be? Omtantritts, in Betreff ipäter bewilfigter Bulagen mit bcm Tage der Bewilligung.

§5. Dic 8nhlung des (Befralts criolgt monatlid) im Burnus. Dem Buniestath blcibt vorlichalten, Dicjenigen Reanten in befimmen, an weld)e dic Seljaltszablung vierteljähr(ic) ftattiuben foll. ${ }^{3}$ )

Beamte, weldye bis aum Erlaffe dicjes Befelzes ilyr (Ge= halt viertcliägrtid) bejogen haben, folfen inffetbe jedenfalls bis zu ij)er Bejörberming in cin höheres ?tmt in glcidjer Weije jortbesichen.

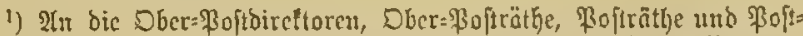
bauräthe wiro bas (sey)alt vierteljährlion, an alle nuberen Beamten

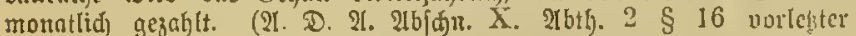
Itofok.)

\$ 6. Die Reid)sbeamten tönmen ben auf bic Ballumg unn Dienjtcinfünften, W3artegeldern ober \$senfionen iljnen

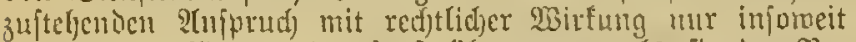
ecoiren, berpiänden oder foult iifertragen, als fie der $\mathfrak{B C}=$

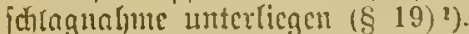

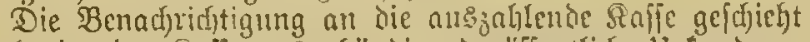

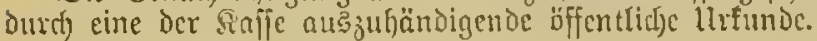

1) ßgl. § 749 c\$D. (oken 5. 200).

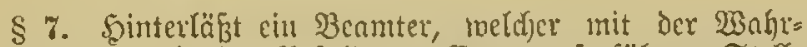
nef)ung einer in ben Bejoloung: (Etats nujgefübrten Stelfe

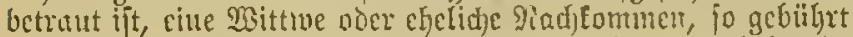
Den Syinterbliebenen fiir ons auf ien Sterhemonat jolgende

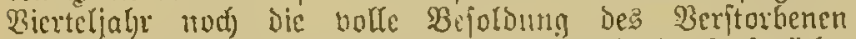

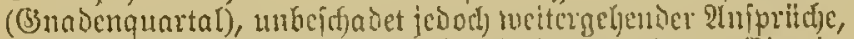

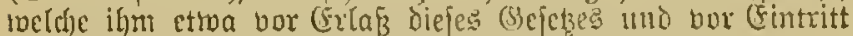
in ben Reichstienft zugeitanden loorien find. 3ul $\mathfrak{B C}=$ foldung im Simnc ber vorjtehenden Bejtimumung gelören

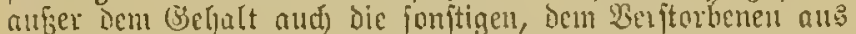

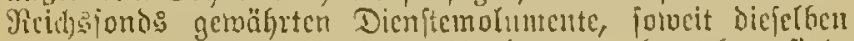

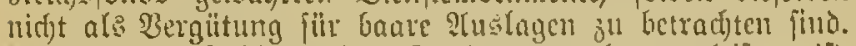
II Ecjtimut die vorgeleszte Dieniptbehbrde. ${ }^{3}$ ) Das (Snndene quartal fam nidjt (Segenftnud ber Befdrlagnal)ute jein.

1) Für Bcante ocr Pleids=\$oft= und Iclegraphen=\$ermaltung ben fimmt biefes, fofern cs fif um 3ablung un bie 2rittwe oder chelident

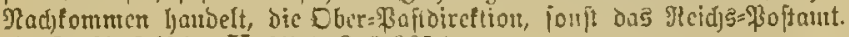

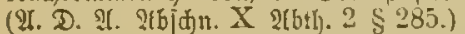

\$ 8. Die Gemälyrung bes Bmadenquartats fam in Ermangchug ber in $\S 7$ bejeichneten . Sinterbficbenen mit

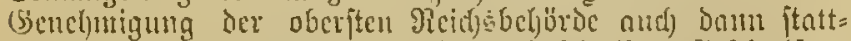

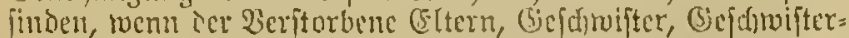
linder oocr Wflegetinter, oeren Emälyer or mar, in $B \mathrm{BC}=$

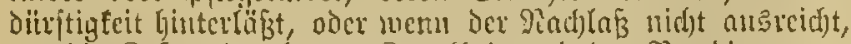

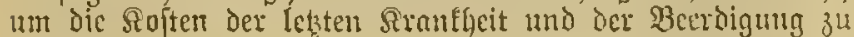
iscfen.

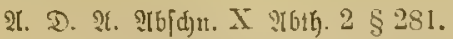

§ 9. Эn Dem Genuife der bon dem berfturthenen $\mathfrak{B e}=$ anten berofhnten Dienftwolnung ift die binterbliebene Samilie nad) ?tblauf deE Sterbeunnats nod) 3 jernete Monate zu belajien.

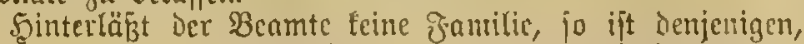
auf jveldje fein Tadjlá̉ übergefit, eine bom Todestnge an 3u recljnende 30 tägige Frift zur Räumung der Dienjt= moljnung z̆ gewähren.

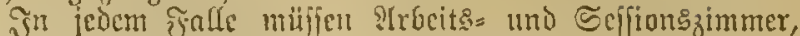
jomie fonjtige für Den antlidjen (Bicbraud) bejtimmte Eotali= täten fofort geräumt weròn.

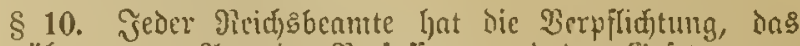

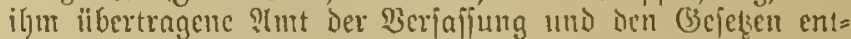

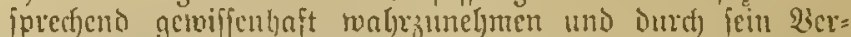

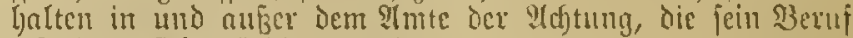
erfordert, fing witrbig zu jeigen.

\$ 11. Heher Dic vermöge jeinc: Thte iljm lictannt

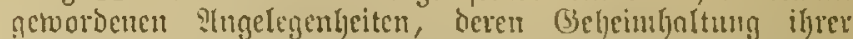

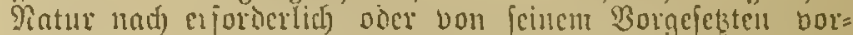

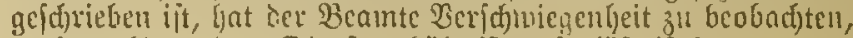

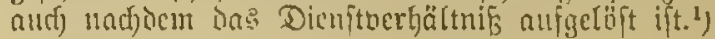

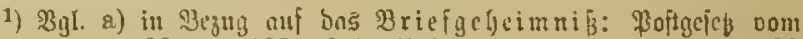
28. 111. 1871 \$ 5, \$ु० = Drontura vom 11. 6. 1892 $\$ \S 37 \nabla$ und t6 III, Strajgeictbud $\$ \S 354$ แno 358.

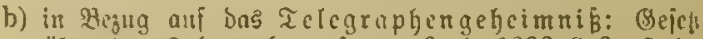
übur Dos Telegraplenmefen o. 6. 4. $1892 \& 8$, Tele graphenoromag v. 15. 6. $1892 \S 2$, Strnigciesbudi $\$ 355,358$.

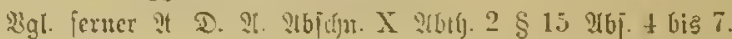

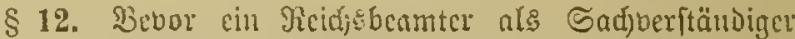
cin aufergerid)triches ') (Butadjten abgiebt, hat berjelbe baju die (3enebmigung fcincr vorgejetzten Bebörbc einzulyolen.

(56cnfo haben Reidjsbeamte, aud) menn fie rid)t meljr im Dienfte find, ilgr Beugnifs in Betreff Derjenigen That=

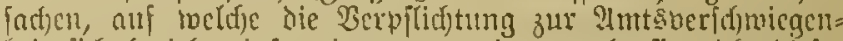
beit fids bezicht, injomeit 3t1 bermeigem, als jie nicf)t Dicjer Serpflidfung in dem einzelnen folle ourdy bie iljnen vor=

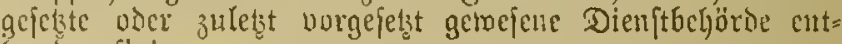
butten fins.

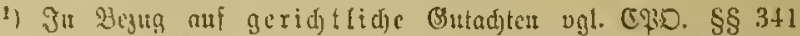

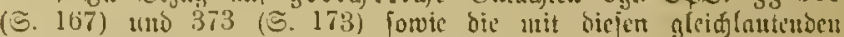
\$ ber St90 53 (ङ. 228) utt 76 (ङ.231).

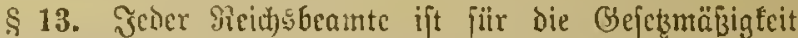
icinct antlid)en Sand (ungen bcrantwortlich. ${ }^{1}$ )

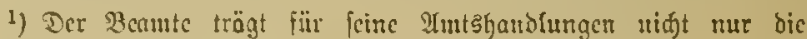
bienftide, fomberm aud bie volle ftrafredtlide mo cioil. $r e$ ditlidje serantwortung.

§ 14. Die Siorfdriften Hiher ben Utaub der Reidj:3= Genmten und deren Stefluertretung werdel vom Saajer erlafien. $\left.{ }^{1}\right)$

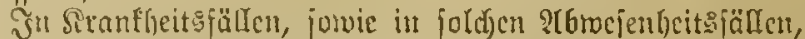

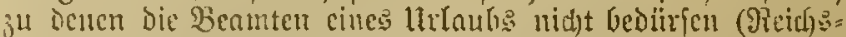

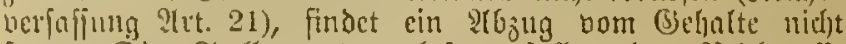

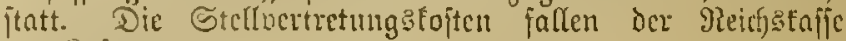
3ilt Qnit.

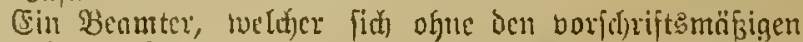

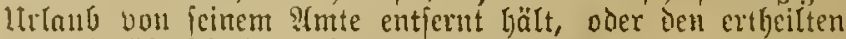
lirlaub ïbcrfá)reitet, ift, wenn ifyn nidjt licjondere (Ent= jef)uldigungsgründe jur Seite ftehen, für die Zeit Der un= crlanben entfernung feines Dienjteintonnens verluftig.

1) $\mathfrak{B}_{3}$ [. AIfrrgöd)fte Berordung v. 2. 11. 1874, madffteheno S. 703.

\$ 15. Die vom Siaijer angejtellten Beamten Dïrjen

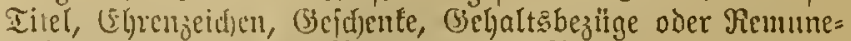
rationen bon nuberen Regenten over Regierungen nur mit

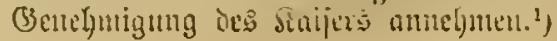


Bur Ynnahme von Gefdjenfen oder Belohunngen in Bezug auf fein ?Imt bedarf jeder Reidjsbeamte der Bre= nebmigung der oberften Reid)sbeförde.

1) 2ud nidit vom eigenten Randesherrn.

§ 16. Siein· Reidj引beamter Darf olye vorgängige Gic=

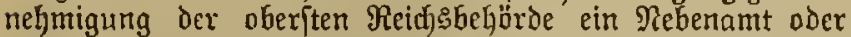
eine গebenbejujäftigung, mit weldjer eire jortlaufende Mentuneration verbunden ift, ïbernebmen ober ein (Serberbe betreiben. Diejelfe Benefmigung ift zu dem (Fintritt eines

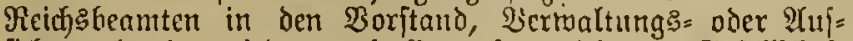
fidfterath einer jeden auj (Frwerb gerideten (sefellfdaft erjordertict. Sic darf jeboch nicht extheilt werden, fojern die Stelle mittelbar oder sumittelbar mit einer Remunes ration verbunden ift.

Die ertheilte (senehmigung ift jedergeit twiderruflich.

Auf $\mathfrak{B} a \mathfrak{l} l$ fonjuln und einjtweilen in den $\Re$ uheftand ber= febste Beaute finden dieje Beftimmungen feine Anmendung.

§ 17. Titel, Rang und Uniform Der Reicfgbeamten twerden burd) Raiferlicke Berordnung beftimmt.

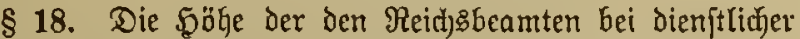
Beidjäjtigung aukerbalf ifhes Wohnortes zufteljenden Tage=

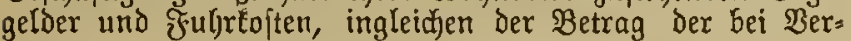

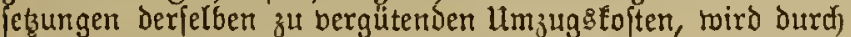
cine im Cinvernehmen mit dem Bundešrathe zu erlaffende Seroldung Des Raifers geregelt.1)

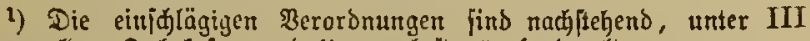
"Tagegelder, f̧ufrloften und Un

\$ 19. *Uf die Rectitsucrbältniffe der aftiven und der

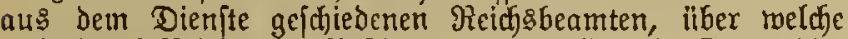

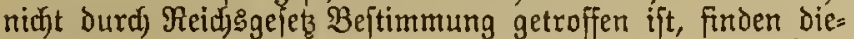

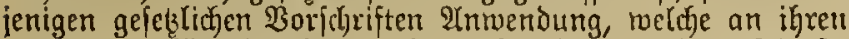
Boljnorten fïr die aftiben, bezm. fiir die aus dem Dienftc

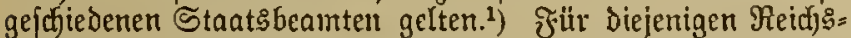
beamten, deren Bohnort auferhalf ber Bundesitaaten fidf Gefindet, fommen himficttlich diefcr Medfosverhältniffe vor Deutjajen Befjörocn bie gefeblichen Beftimmungen ihres Seimathsftates (\$ 21) und, in Ermangelung eines

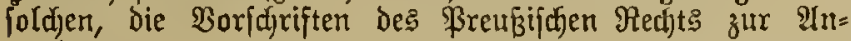
toendung.

Diejenigen Begünitigungen, weldje nady der (Sejebgebung der einzclnen Bundesftanten Den finterbliebenen der Staats= beamten hinfichtlid) der $B$ efteuerung Der aug Staatsfonds ober aus öffentlichen Berjorgungętajjen denjelfen getwährten \$enfionen, Unterftübungen oder fonftigen Burwendungen zu= itchen, finden aud zu Gunften der Sinterbliebenen von

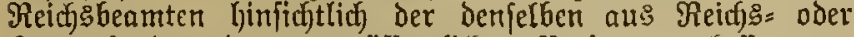
Staatsjonds oder aus bffentlichen Berjorgungstajfen zu= fließ̄enden gleidjartigen Bejüge ?nmendung.

1) Sierna genieben die im \$reubifden Staate bejdäftigten un= mittelbaren und mittelbaren, aftioen uno nidit aftiven Reidsbenmten bie in ber ßerorbnung v. 23. 9. 1867 feftgefęte Bergïnjtigung, fur Romnunalbefteuerung nur mit bem halben Dienjteinfommen heran= gezogen zul werden.

§ 20. Ӭngleicfen fteben bezüglict):

1. der Mitroirfung Gei der Siegelung des Rachlajjes eines Reidjsbeamten,

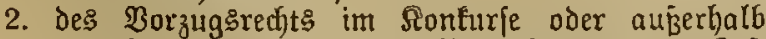
Deffelken wegen Der eirnem Reidfsbeamten zur \&ajt fallenden Defelte aus einer bon demjelben ge. füfrten Rafjen= oder jonitigen Bermögentuermat= tuing

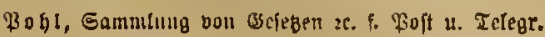

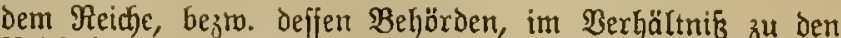

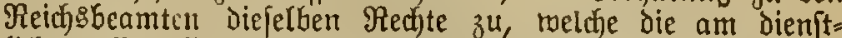

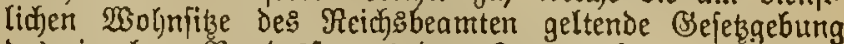
des cinzclnen Bundesftaates Dem Staate, bezm. Deffen $\mathfrak{B e}=$ höroen Den Staatşeamten gegenüher gevährt.

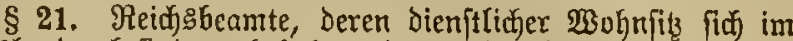
TItslande befindet, beGalten den ordentlidien periönlidien Geridjtsfand, meldjen fie in ifrem Seimatgsitante hatten. Jn Ermtangelung eines foldjen (Sieriditsitandes ift ihx ordentlicher perfönlicfer (Seridftsftand in der Şauptftadt bes Seimathsftantes, und in Ermangelung eines seimaths: ftates vor bem Stadtgeridt zแ Berlin') begrïndet. Jit bie Sauptitadt in mehrere Berichtshezirte getheilt, jo wiro

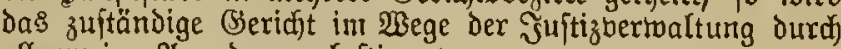
allgemeine Anoronung beftimmt.

श्tuf Wahlfonjuln finden bieje Beftimmung feine $\mathfrak{A n}$. rendung.

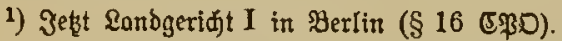

§ 22. Befindet fich ber bienjtlidfe Wohnfits des Beamten

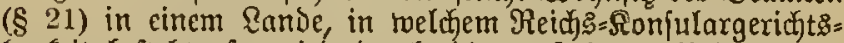
barkeit befteht, fo miro durch bie boritehende Beftimmung nid)t altsge(d)loffen, daf

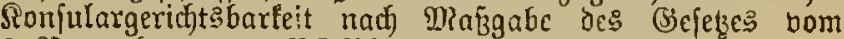
8. 20bember 1867 (BS(SBL. (5. 137) $)^{1}$ ) unterliegt.

1) $\mathfrak{A n}_{n}$ Stelle diejes Gefetses ift leit dem 1. Dttober 1879 dos (Se=

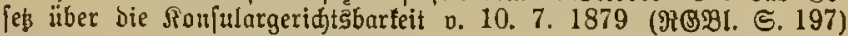
getreten.

\section{Berfetung in ein anderes $\mathfrak{A m t}$.}

§ 23. Jeder Reichbeamte muß Die Berlekung in ein anderes $\mathfrak{U}(\mathfrak{m t}$ von nid)t geringerem $\Re$ ange und etatsm möfrigem

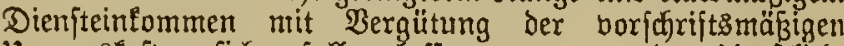
lumzugstoften fith gefallen laffen, toenn es bas bienftliche Beoutixinif exiordert.

Wrs eine Berfürzung im (Finfommen if́t es nid)t anzufebeu, menn die Gelegenheit zur Bertvaltung bon Rebenämtern entzogen rird, oder bie Drt\$zulage ober endtich bie $\mathfrak{B} e=$ jieljung dex füx Dienftunfoften bejonder: ausgefekten (Finnahmen mit diefen Untoften fortjälft.")

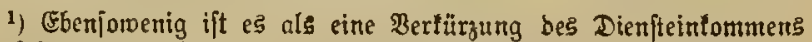

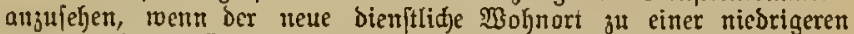
Seroistlaffe gefjört, bent verfepten Beamten benmad) ein geringerer

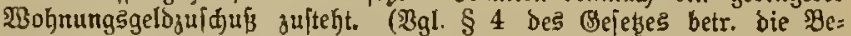

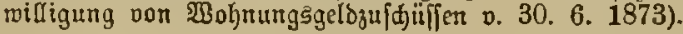

\section{Einftreilige Berjetung in den Rugeftand.}

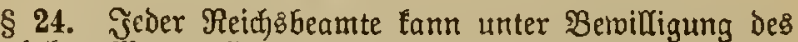
gefeblicten $\mathfrak{B}$ artegeldes einftweilig in den Ruhe tand ber:

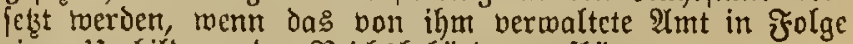

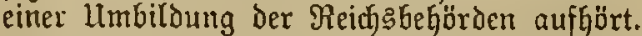

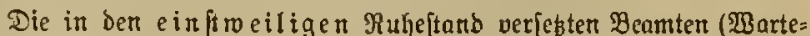
geldempfäuger) twerben als nod) im Dienfte befindlide Beamte ange, fehen, bie nur jeit we ife bienfitiag niajt befajaftigt find. Folgento für aftioe Beamte geltende Bejtimmuntgen find aud für $\mathfrak{B}_{\text {artegelds: }}$ empfänger gültig:

1. Unter benfelben Borausfebungen, unter benen aftive \$eamte

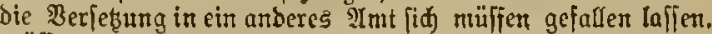
mirffen $\mathfrak{B}$ artegeldempfätrger ein ifuen übertragenes Reid̈s: aurt antrefnetl (\$ 23);

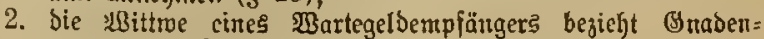
quartal (\$23);

3. bei Hebertritt in den ba u ert ben Rubeftand (Penfionirung) mirb bie ßartegeit als Dem 
4. Die Borjđriften über förmlidjes Disziplinaroerfabren (\$ 84 bis 119), potoic

5. Die über zmangšmeife ßenfionirung ( $(60$ a u. f) geIten anch) für Tikartegcldempiänger.

Dogegen ift ber 2 artegeldempfänger, do berfelbe ein geritrgeres Einfommen bejieht als Der aftive Beante, eine anbermeite Bejün̈itigung

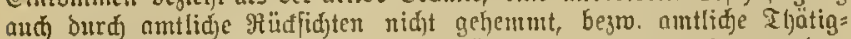
teit burd) auferamtlidje nidht becinträdtigt mirb, in einer ander= seiten geminnbringendon $\mathfrak{B} e[$ jäftigung, bie ber altive Beamte nađ́)

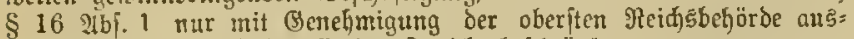

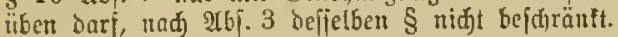

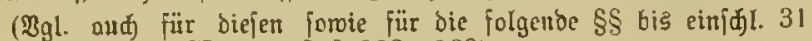

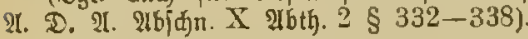

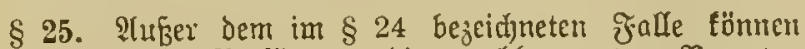
durch eniferlidie Berfügung die nadjbenamnten Beamten jederzeit mit Gervährumg bes gejetzlidfen Wartegeldes ein= meilig in den Rutheftand berjebt werden:

ber Reidjstanzler,

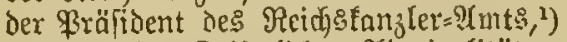

Der Che Der Raiferlichen Slomiralität,

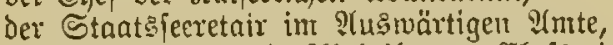

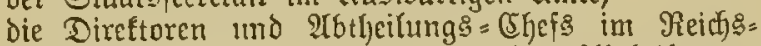

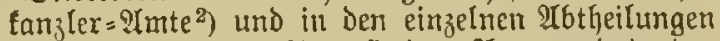

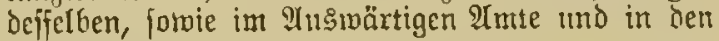
Minifterien,

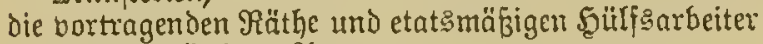
im 2Tugnärtigen ?Tmte,

Die Militärs und die Marine= Sntendanten,

die biplomatifjen Agenten eimfolieflid) ber Ronfuln.

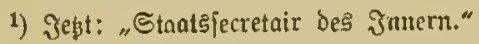

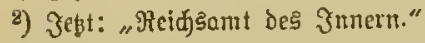

8 26. Daş Wartegeld beträgt hei Befuältern bis zน 150 Thli. ebenjobiel als das Behalt, bei höheren (Behältern diei Biertheile bes (Sebalts, jedoch) nidht meniger als $150 \mathfrak{T h l x}$.

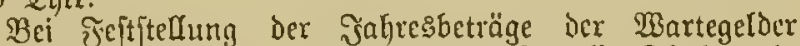
werden germitioct.

Der Jafreşbetrag des Wartegeldes fann 3000 Thlr. nicjt überjteigen.

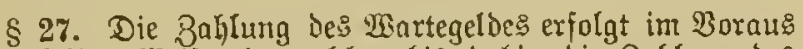

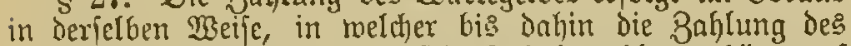
(Behalts ftattgefunden hat. Die Belyaltszalylung hört auf uno Die Baflung Des Bartegeldes beginnt mit Dem Mblaufe Des Biertcljalyres, weldies allf oen Monat folgt, in meldfem

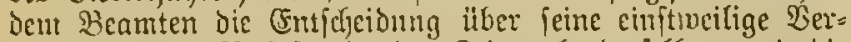
fetzung in Den Fuhejtand, der Beitpunft derjelfen und die Souble des 2 artegeloes befant gemadt morden ift.

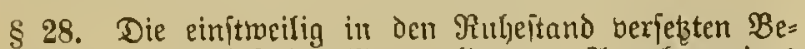
amten find bei Berluft Des $23 a r t e g e l d e s$ zur Anmahme eines

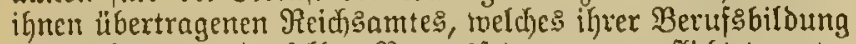
cintpricht, unter denfelben Borausjetzungen berpflicjtet, unter

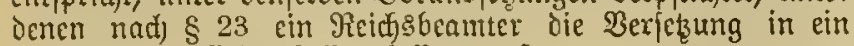
anberes 2lmt fid gefalten laffen mur

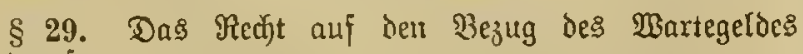
Gört auf:

1. wenn der Beamte in Bicidfosdienfte mit einem dem frither bon ifm bezogenen Dienfteinfommen mindes ftens glcidgen Diemiteinfonmen mieder angeftelft rird,
2. mern Der Beamte Das Deutjuje Fnoigenat vertiert,

3. went der Beamte ofne (Bentelynigung Des Reidjs: farjlers jeinen Mohnfiz auferhalb der Bundes: itaaten nimmt,

4. herrs der Beamte des Dienftes entlaffen wird.

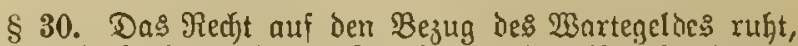

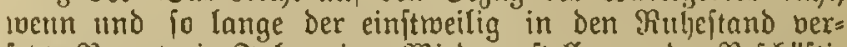
feste Beamte in Jalge einer $\mathfrak{B i e b e r a n f t c l u n g ~ o d e r ~ B e f d j a ̈ f t i = ~}$ gung im Reidfs: ober im Staatsoienfte ein Dienfteinfommen bejieht, infomeit als ber Betrag biefes neucn Dienft= cintonmens unter f̧injuredinumg des Wartegeldes den Betrag Des bon Dem $\mathfrak{B} e a m t e n$ bor Der einjtrueiligen $\mathfrak{B} e x=$ fełzung in Den Rubeitand bezogenen Dienfteintommens iiber= fteigt. Fijindet die Befdjäftigung Des Beamten vorübergehend gegen Iagrgelider ober eine andermeite Entidjäbigung itatt, po wird Demielben Das Wartegeld für die erften 0 Monate biejer Befdjäftigung unvertïrjt, ongegen vom 7. PRonat ab nur zu bem nad ber vorfteljenden Beftimmung juläfifigen Betrage gemährt.

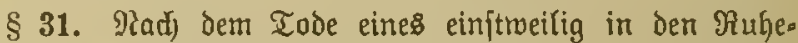
ftamb verfekzten Beamter erfolgt die Bemährung des Bsnaden. quartals bom Wartegelde an die Sinterbliebenen nad) Den in Den $\S \S 7$ und 8 enthaltenen Brundjäzzen.

\section{Entlaffung der auf Probe, Sinndigung oder auf Biderruf angeftellen Beamter.}

§ 32. Die Gntlafiung Dex auf ßrobe, auf Sündigung oder [onjt auf Wriderruf antreftelften Beamten exfolgt burd) diejentige Behörde, melefe Die Anjtellung berfügt hat.1)

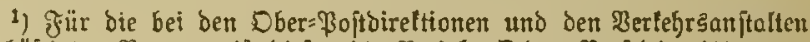

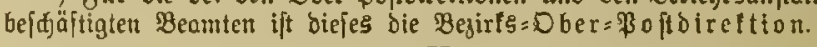

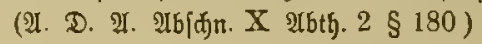

\section{Wiedetanftellung ausgefdiedener Beamten.}

§ 33. Zur Wiederanftelfung von Beamten, weldje au:

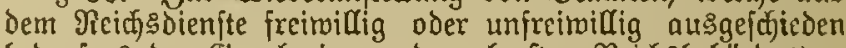

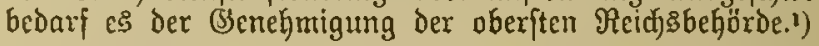

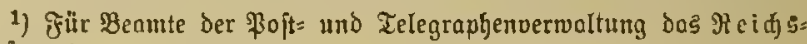
Poftamt.

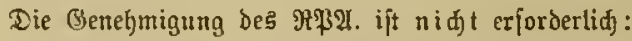

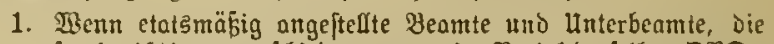
freivillig ansgejdieben waren, im Bejirt berfetben OBD.,

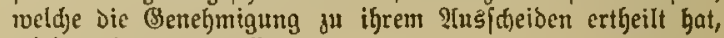
wieber eintretent mollen;

2. wem penfionirte Beante und Unterbeamte als Poftagenten atrgenoumen merben;

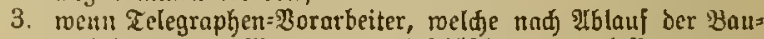
periobe wegen Mantgel an Bejwäftigung entlaifen rocen, beim Miederbeginn ber Bouperiobe wieder eingeftell reerben.

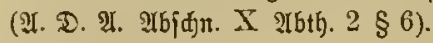

Benfionirung der Beamten. Infprud) auf ßenfion.

§ 34. Şeder Beante, weldjer fein Dienfteinfommen aus

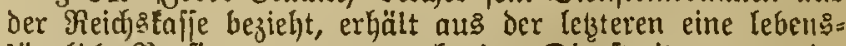
länglide \$enfion, wern ex nach einer Dientzeit von wenig. Fteng 10 Jahren in Folge eines förperlicfen (Bebredjens oder

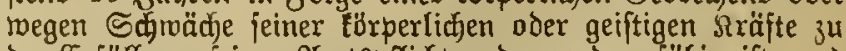
Der Eriẗlung peiner 2(mtspflid)ten bauernd unfähig ift, und Deshalb in den Ruheftano verjekt miro. $\S 307$.

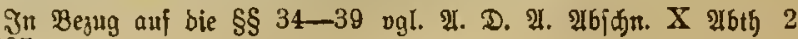


\$ 34a. ${ }^{1}$ ) Bei benjenigen, aus dem Dienite fifeidenden Beamten, reldje bas 65 . Rebensjahr bollendet haben, ift eingetretene Dienjtunfähigleit nidft $\mathfrak{B}$ orbedingung beg $\mathfrak{I} \mathfrak{n}=$ iprudfs auf \$erfion.

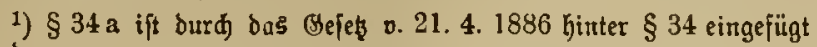
morben.

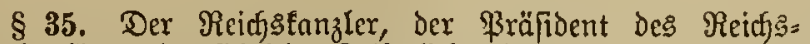

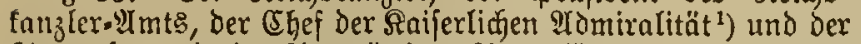

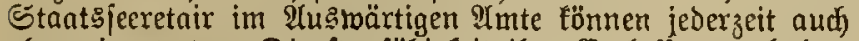
obne eingetretene Dienfturfähigfeit ifre Entlafiumg exhalten und fordern. Der Utriprudf auf ßenfion beginnt, mern ber Ilusgefdiedene mindefters 2 Jahre bas betreffende $91 \mathrm{mt}$ be= fleidet hat. Der Mindejtbetrag Der ßenfion ift ein Viertel

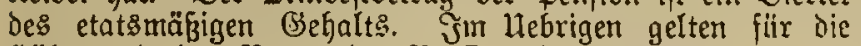
5öhe und ben Bezug Der ßenfion die Borjuriften diejes (⿶) efetzes.

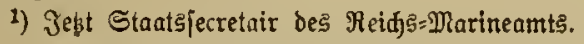

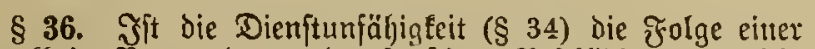
Srantheit, : Berwundung oder jonjtigen BejdjäDigung, melche ber Beamte bei 2 usübung Des Ditenites ober aus $\mathfrak{B e r}=$ anlaffurg beffelben ohne eigene Bcrfduldung fid zugezogen bat, fo tritt die Benfionsberedtigung auth bei fürzerer als 10 jähriger Dienftzeit eim.

刃gl. and $\S 39$.

\$37. Die unter Dem Borbehalt des Biderrufs oder ber Ründigung angeitellten Beamten haben cinen PInfprud) auf ßenfion nad) Maßjgabe biejes Beietzes nur bann, menn fie cine in Den Bejoldungsetats aufgeführte Stelle befleiden; es fann ihner jedoct), wenn fie eime foldje Stelle nitft be=

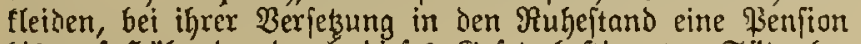

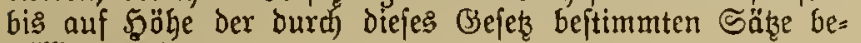
willigt werben.

§ 38. Reid)sbeamte, beren Beit und Rrófte Durch bie ifnen übertragenen Giefääfte nur nebenbei in 2Ynjprud) ge= nommen, oder meld)e ausbrüctlicf mur auf eine bejtimmte Beit oder für ein feiner Ratur nad) vorïbergehendes (Se. iđfäft angenommen werden, erwerben teinen 2 rnfprud auf eine ßenjion nach den Beftimmungen diejes Bejeşes.

Darüber, ob eine Dienjtitellung eine foldhe ift, oa $\bar{B}$ fie bie Beit und bie Sräfte eirtes Beamten nur nebenbei in Infprud nimmt, entifjeidet bei ber Dienftübertragung bie Dem Beamten borgejez̧te Dienftbejörde.

§39. Wirb auß̧er bem im $\S 36$ bezeidyneten ₹alle ein Beamter vor Sollendung des zehnten Dienftjahres bienft= unfäbig umb deshalb in ben Ruljejtand berjegt, jo fann Demielben bei borhandener Bedürftigfeit Durd Bejdjuß des Bundesrathes eine Benfion entweder auf beftimute Zeit oder lebenslänglich bewilligt merden.

\section{Inipruch auf $\mathfrak{M}$ mugstoften.}

\$ 40. Sat Der in Den Ruhejtand oder in Den einft= meiligen Rufyeftand verferte Beamte jeinen bienftlicjen Woknfits im ?ltslande, jo find demfelben die Rojten des

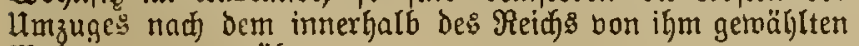
Wohnorte zu gemähren.

\section{Betrag Der Benfion.}

$\left.\$ 41 .{ }^{1}\right)$ Die ßenfion beträgt, wenn bie Berfetzung in Den Ruheftumb nad, bollendetem zehnten, jedod) vor voll= endetem elften Dienftjahre eintritt, ${ }^{15 / 60}$ und fteigt von bn ab mit jevent weiter zurücfgelegten Dienjtiahre um $1 / 60$ bes in ben $\S \S 42$ bis 44 beftimmten Dienfteinfommens.

Heber den $\mathfrak{B e t r a g}$ bon ${ }^{5} / 60$ diefes Cinfommrns hinaus findet cine Steigerung nidit fitatt.

In Dem im \& 36 erwägnten Falle beträgt die Penfion

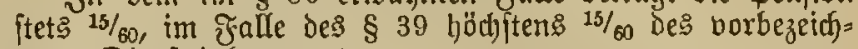
reten Dienfteinfommens.

Bei jeder ßenfion twerden überffiefende Thalerbrüctje auf volle Thaler abgerumbet.

1) Durd Das Bcfeł vom 21. 4. 1886 abgeärterte ₹raffung.

$\left.\S 42 .{ }^{1}\right)^{2}$ ) Der Berectinung Der ßenfton mird bas bon Den Beanten zuletzt bezogene geiammte Dienfteinfommen, fonecit es nidjt zur Bejtreitumg bon Repräjentations: oder Dienftaufmandstoften gemährt wirb, nach Maß̧̧abe der jolgenden näljeren $B$ eftimmungen zu Grrutrde gelegt:

1. Fefiftehende Dienftemolumente, namentlid freie Dienftmolnung, forvie bie anitatt Derfelben ge=

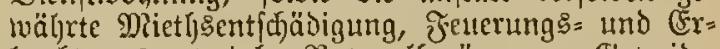
leuchtungsmaterial, Raturalfezüge an Sictreide, Winterfutter 2e., forie oer Ertrag von Diemit= grimoftïfell fommen nur infomeit zur ?tnrecfinung, als deren Werth in den Befoldungsetats auf die Gelobefoloung des Beamten in Redinumg geftellt oder zu eirem beitimmten (Belobetrage als an= red)mungsjäbig bezeifjnet ijt.

2. Dienftemolumente, weldje ifrer $\Re$ atur nady fteigeno und fallend find, rerben nad) ben in den Befoldurg: etats oder fanft bei Berleifung DeE Rechts auf biefe (5malumente beshalb getroffenen zeftießungen

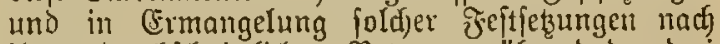
ibrem Durdffdutttidjer Betrage mährend Der Drei letsten Etatsjahre bor Den (Etatsjahre, in weldjem die \$enfion feitgeictzt wirb, zur Anrechmutg gebrad)t.

3. §olos zufädlige Dienfteinfinfte, wie miderruffidje

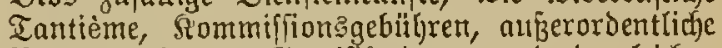
Remunerationen, Gratifffationen und bergleidfer fommen nid)t zux Beredimung.

4. Bei Den fervisberechtigten Militairbeamten miro ber mittlere Etellen= bejieljungsmeife Chargen= (Perjonal $=$ ) Serbis als Theil Des Gehalts be= tractitet.

5. Das gefammte zur Beredfunng zu ziekende Dienjt= eintommen ciner Stelle harf Den Betrag des böd) ften शomalgebalt bericnigen Dienttesfategorie, zu melder die Stelle gehört, nidjt itberfteigen.

Dhne dieje Befdräntung fonmen jedoch joldie (Sebaltatljeile oder Bejoldung julagen, meldfe zut Wusgleithung cines bon Dem betreffenden Beamter in früberer Stellung bezogenen Dienfteintommens Demfelben mit łenftonsberedtigung gewähxt find, zur vollen 2 (nredinung.

6. Wenn Das nad, Den Beftimmungen dicjes \$ara= graphen ermittelte (Finfonmen eires Beamten insgefammt mehr als 4000 I haler beträgt, mird bon Dcm überidfieß̧enden Betrage nur bie \$älfte in $\mathfrak{I}$ mred)nung geforadit.

Die ßenfion fir bie eiritweilen in ben Ruhejtand ber: fezten Beanten mird bon Dein zur Zeit ihrer Berjekzung in Den Rubeftano bezogenen gejammten Dienfteinfommen heredfnet.

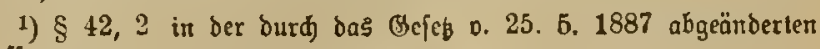
Şaffung.

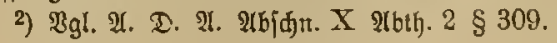


\$43. Fin Beamter, weldfer frither ein mit einem Gäheren Dienfteinfommen berbundente ?(mt befleidet und biejes (Einfommen menigitens 1 Jabr bezogen hat, erbält, fofern der Fintritt ober Die Berfesung in ein 2tmt bon geringerem Dien[teinfommen nidft leobiglid) auf jeinen im eigenen Jntereffe geftellten Sintrag crfolgt, oder aber al: Straje auf Brund des \& 75 gegen ign berljängt ift, Gei

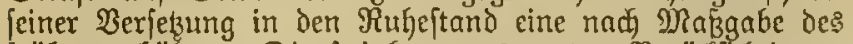
irtiheren höheren Dienitcinfommens unter Barüdefid)tigung der gejammten Dienitzeit beredjnete Benfian. Sedoch foü

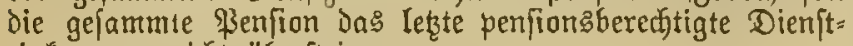
einfommen richt liberjteigen.

ม. D. I. I6j

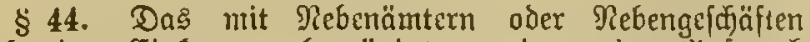
verbundene (Finfommen begründet mur dann einen $2(n$ iprutf) auf \$enfion, wenn eine etatsimäsige Stelle als Rebenamt bleibend berliehen ifit.

\section{Berednung der Dienftzeit.}

$\S$ 45. Die Dienjtzeit wird vom Tage der er[ten eidlidjen Berpflid)tung für ben Reidysbienft ant gered)net..')

Sann jedod cin Beamter nadyeifen, Dấ feine $\mathfrak{B e r}=$ eidigung erft nad) feinem (Fintritte in ben Reidgbienft [tatt= gefunden hat, fo wird bie Dienftzeit bon Dem lezteren Beit= punfte an gerechnet. ${ }^{2}$ )

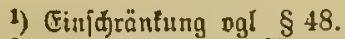

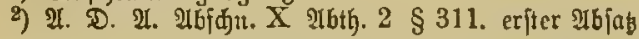

§46. Bei Berechnung Dex Dienjtzeit fommt nud bie Beit in 2(nredfunung, während tweldjer ein Beamter

1. unter $\mathfrak{B}$ ezug bon $\mathfrak{B a r t e g e l d ~ i m ~ e i n f t w e i l i g e n ~ \Re u h e = ~}$ ftande, oder

2. im Dienfte einesి Bundesftaates oder Der Regierung eires zu einem Bumbesftaate geljörenden Sebiets (iid) befunden hat, oder

3. als anjtellungsbered)tigte ehentalige Militairperfon nur borläufig oder auf \$robe im Cibildotentite

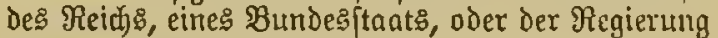
einesิ zu einem Bumbesftante gehörenden Bebiets bejuäfigt morden ift, oder

4. eine prattijäje Bejujäftigung auß̉erhalb des Dienjtes bes Reibjs oder eines Bumbesitantcs ausitbte, injofern und injomeit bieje $B$ ejüäftigung bor $\mathbb{F} r=$ tangung der Ânftellung in einem Reidys unmittelbaren Stantsamte behufs der tedinifden 2usbildung in den \$rüfungsooridififten aus? brürffidi angeordnet ift. $\left.{ }^{2}\right)$

Sm Jalle der Rr. 2 mird die Dienjtzeit nad) dcn jür Die Beredjung Der Dienftzeit im Reidjebienfte gegebenen Beftimmungen berectinet.

1) (5s werben ferner angeredgint:

1. Die \$optitlonsoienjitzeit,

2. Dic Beit, in velder \$oftaegülfen oder \$oilhülfsboten nidgt unmittelbar ous ber \$ofittofie fordern aus einer bem \$ojt=

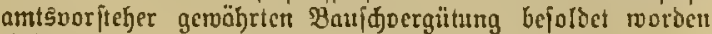
fino;

3. Die por den 1. Itpril 1894 fallenbe Seit, in welder Poft=

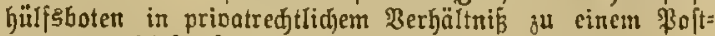
agentert vollbefoüfigt getwejen fino.

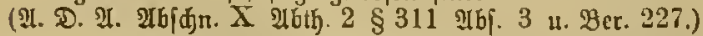

Die in ben Deutjacn હdubgebietent (Togo, Ramerun, Deutid)=

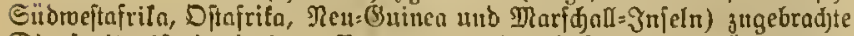
Dienitgeit ift benjenigen Beamten, meld)e bajelbit eine längere als cinjährige Bermendung gefunden lyaben, mad) cirtun auf (Sruno bes

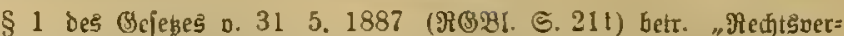
hältniffe ber Saijerl. Beamten in ben Cđupgebieten" nom Rumbess: rotbe gefaften Bejblufjes boppelt in Inredntung jut bringen (eberioni :Ber. 12).

\$4\%. Det Cibildienitzeit roiro die Zeit Desి aftiben Mifitairdien\{tes hinzugerechut. ${ }^{2}$ )

1) Heber bie Grundäbe, welte bei ber Berednntng ber Militör= bienjacit in ben burd bie Bepeßse v. 20.9. und 24.12. $1866 \mathrm{mit}$ ber \$reußifden Monardic vercinigten Sonbestheilen zur Intuendung getonmen fino, f. Mlinijterid = Blatt für bie gejamute innere $B e r=$

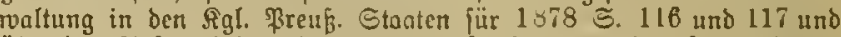

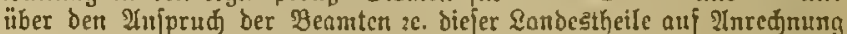
ber frelbzüge in Den J̄ahren 1848, 1849 und 1850 als Rriegsjabre

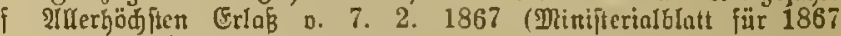

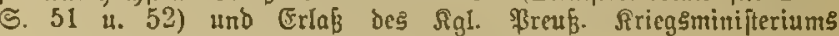

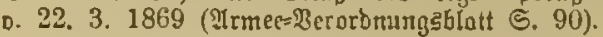

§ 48.1) Die Dienftzeit, meldfe vor den Beginn des 21. Le. benşjahres fält, Gleibt aufzer Berechnung.

Nur dic in dic Domer cines Rrieges fallende und bei cinem mobilen oder Erjatz= Truppentheile afgeleiftete Militär =

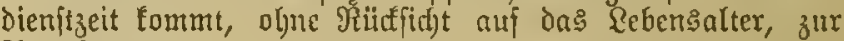
Anrechnung.

MLa Sriegszat gilt in Diejer Beziehung die Zeit bout Inge einer angeoroncten Mobilmadjung, auj melebe ein Sitieg folgt, bis zum Iage Der Demobilmadjung.

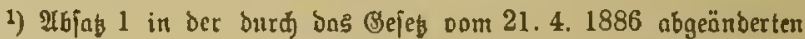
Faiflung.

\$ 49. ₹̛̈ir jeden Jeldzug, an tweldjem ein Benmter im Reictshecre, in Der Raiferlidjen Marine oder in der

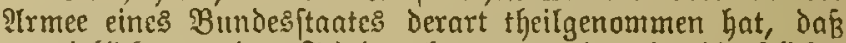
er wirfliff bor ben freind getommen, oder in dienftlidjer Stellung den mobilen Truppen in bas? F్ld gefolgt, oder auf cinem zur Dertwendung gegen den テreind bejtimmten Sd)iffe oder Fahrzetge ber Raiferlidfen Marine cingejdifft gerwejen ift, mird demjelfen zu der mirffidien Dauer Der Dienjtzeit ein Salgr Ginzugeredinet. ${ }^{2}$ )

S6 eine militärifite lunternefnumg in dicier Beziehung als ein feldzug anjufehen ift, und inwiciern bei friegen bon

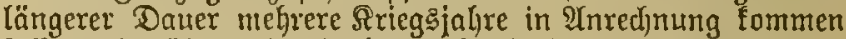
follten, dariber wird in jedem Falle Durd Den Saifer $\mathfrak{B} e$ s ftimmung getroffen. ${ }^{2}$ ) foit bie Vergangenheit betwendet es bei den bierüber in den einzelnen $\mathfrak{B}$ undespltaaten getroffenen Be(timmumgen. ${ }^{3}$ )

1) Bgl. at. bie erweiterten Beftimmungen bes Irtitels 17 ber

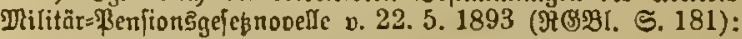

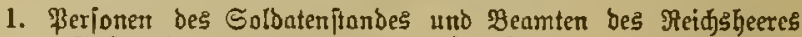
uno ber Saijerliđen Marine, melde aul פgefehl eiлem felozug

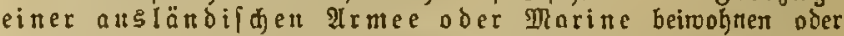

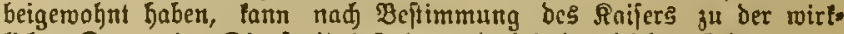
lifen Dauer ber Dienitzeit 1 Jahr und bei bergleiđen Artiegen von längerer Dauer ein Zeitraum von 2 oder mehreren Jahren zugerednet

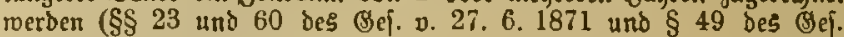
Dom 31. 3. 1873).

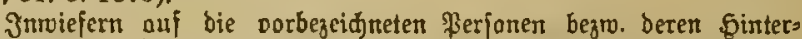
bliebene bie für bie Thailnehmer an eintem Daterländifđen F̧elbsuge und beren Sinterbliebene gegebenten Boridriften in 21troendung gu bringen find, barüber riro in jebem falle bur由 den §aijer $\mathscr{B}_{e}=$ finimung getroffen.

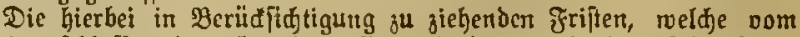

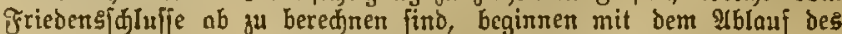

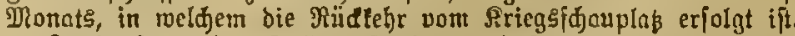

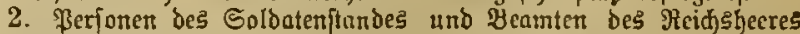

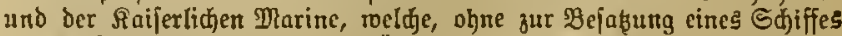

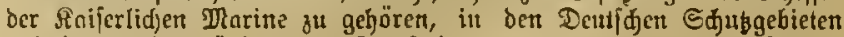

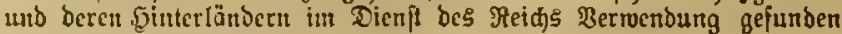


haben, wirb bie bafelbjt jugebradte Dienttzeit bei ber ßenfiontrung boppelt in 2Inred)nung gebrađt, fofern fie minbejtens 6 Manate ohne Interbredjung gebauert hat. Seercifen auberhalb ber Oft unb Rorb=

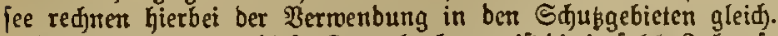

Utusgenommen von biefer Doppelrednung ift bie in foldhe Jahre fallende

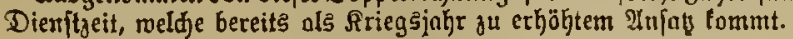

2) (Es lommets folgende IUllerhödjte Crlaffe in Betrabt:

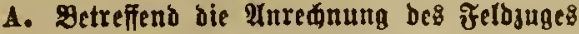 von 1866 als Ariegsinghr.}

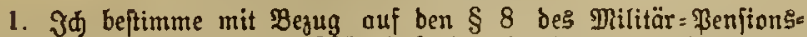
Reglements pom 13. Juni 1825, baß ber biesjährtge Felozug ben babei Betheiligten bei Berednung ihrer Dienftzeit als cin Nriegsjahr in Anrednung lommen foll. F̧ü bie Betheiligtes ift ber ftatuten= mäbige Yeft bes burd Meine Drore vom 20. September b. J. ge= ftifteten Erimerungsfteuges maßgebend. Das Staatsminifterium hat hiernad bas 2 Beitere ga veranlafien.

Berlin, ben 6. November 1866.

2. Iuf Brunb ber Beftimmungen bes $\S 23$ bes Bejebes, betreffend bie Betrfionirurg unb Berjorgung ber Militärperfoner $x$, vom

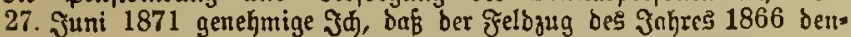

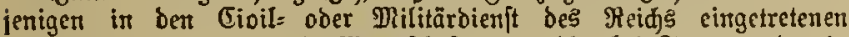
Offizieren, Beamten und Mamnjaften, welde bei Truppen ber in jenem Jahre in friege befinblid gemejenen Deujden Stoaten ges ftanden haben, ols Frtegsjahr augurednen ift, jojern biejelben an einem Sefedt aheil genommen ober behujs 21 sfïhrung von Opera= tionen zu eriegerifden 3roden bie (8renzett ihrer bamaligen Seimath. Iänder verlaffen Gaben. Diefer Mein Erlabs hat rüđmirtende Rraft für alle feit bem Jahre 1866 penfionirten \$erfonen ber genamten Rategorient.

Berlin, ben 11. Jebruar 1875.

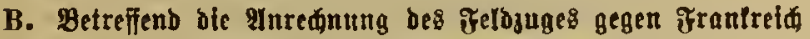 von 1870/71 als Arteggotenitzcit.*)}

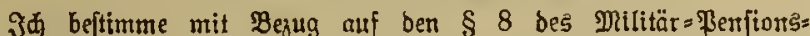

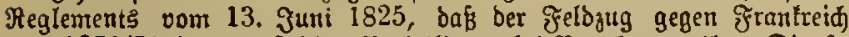
von $1870 / 71$ ben an folden $\mathfrak{B}$ etheiligten bei Berednung iffer Dienft=

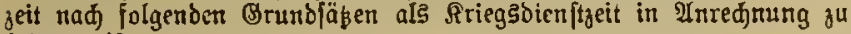
bringen ift:

1. benjenigen Betheiligten, meldye in jebem ber beiben vors bezeidneter Jahre an einer Ş̣ladt, einem (Befed) bezm. einer Belagerung Theil getrommen, ober melde je zreet Ronale aus bienftlider Beranlailung in Granfreidj zu= gebradt haben, lommen zruei frriegsjahre in $\mathfrak{A}$ tred)

2. Denjenigen bagegen, welde bieje Bebingungen mu in einen ber Jahre 1870 ober 1871 erfült, pomie Dertjenigen, melde ohne an einem Rample Theil gu nehmen, nur in beibets Jabren zulammen amei Monate fortlaufenber Beit aus bienftlider SEeranlafiung in Franfreid zugebradjt habett, ift mur ein Friegsjahr in Inrednung zu bringett.

Die Inrednung Des Jahres 1871 als Rriegsjabr für Diejenigen, melde in biejem Jahre tidjt an einem Rample betheiligt gervejen, findet icood ijberhaupt tur in bem falle ftat,, renn bie getrefferben bis zum 2. DRärg biejes Jahres minbefterts 2 Monate aus bienftliđjer Beranlafiung in Franfreid anmejenb maren.

Berlin, ben 16. Mai 1871.

*) Begen gnabemreifer Bervilligung von ßenjionşu[düifen für

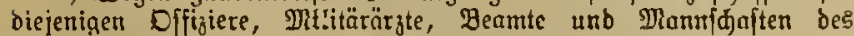
Deutjaen நeeres unb ber Railerliden Marine, welde in folge

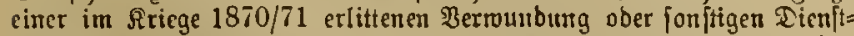
bejđäbigung verfinbert waren, an ben weiteren linternchmungen bes Felozuges theilgunehmen, uns buburd ein jocites, bei ber \$enfionirung ju ber wirflidjen Dauer ber Dienftjeit jtzureduendes Dienitjat: ju

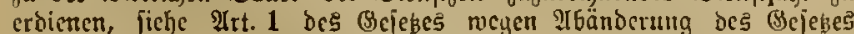
р. 23. 5. 1873, betreffend bie (Brünoung und Berwaltung bes Mcints:

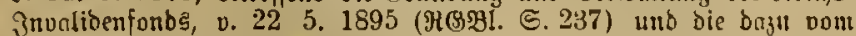

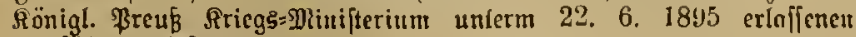
Ausfiihntnasbeftimmungen.

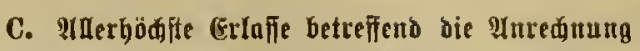

bet miliłärifácu Internebmungen in Iritila uno auf ben Samoa.

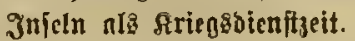

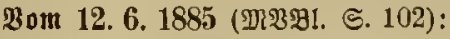

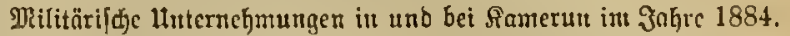

இom 19. 11. 1889 (গูญญl. ؟. 83):

a) Miritärifđe :ftion o. 6. 9. 1888 bis 10.7. 1889 an ber Dit= füjte Afrifus für ben Stab bes Rreuzergefdmabers unb bic Bejobungen ber Frenjerfregatte "Ecipjig“, Der Rreuzerforvetten "Sophie" und "Carola", ber fireuzer "Ilöoe" unb "Shtwalbe" uno bes Ivifo "Pfeil".

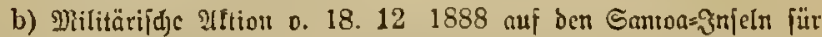
dic Bejakungen ber freuzerforvette "Olga", Des fireuzers "Idbler" und des Ranonentotes "Eber".

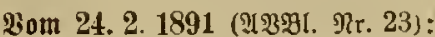

Militärifde গItion in Ditafrila $1889 / 90$ für bie Brfałungen bet

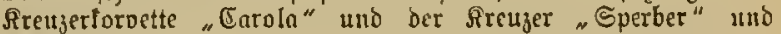
"Sમnwalbe".

Bom 24. 10. 1891 (MPßI. S. 265):

Militärifक) Itnternehmangen ber Truppe bes Ricidsfommiffors Fïr Ditafrila 1889 bis 1891. Tö̈ biejenigen aus bem Seere oder ber Marine ju biejer Truppe ïbergetretenen Mannidniten, Die in ie eincm ber rokre 1889,1890 und 1891 au einem Gefedt theilgenoumen habelt, ober sine fortlaufenbe Dienjtgeit von zroci Miontaten in je cinent Jahre butdgemad) haben, fommt je eit Siriegsighr in Ŷtrednung.

\$om 5. 9. 1892 (간. ․ 195):

Theilnahme am Befcht bei Miung (Ramerun) am 18. 10. 1891.

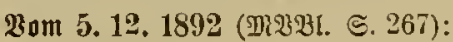

Expebition ber Sđubtruppe für Dentju)=Ditafrila gegen die 20hahehe 22.6. bis 1\%.9. 1891 unb gegen bic Diafite 16. 8. bis 12. 9. 1891 .

Boin 17. 4. 1893 (றҢ: Expebition bcr Sduptruppe für Dent d):Dftufrila in bas Sinter= land oou finterut in Эahre 1892.

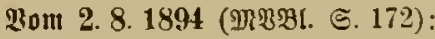

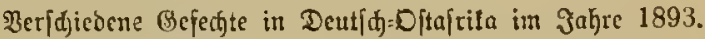

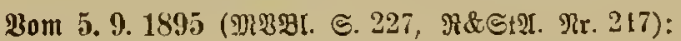

Theilnaljne alt folgenben Befedten ber Eduthtuppe füt Deutfd)= Dftafrila:

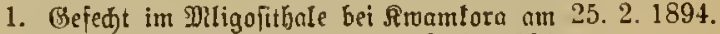

2. (3)fent bei Dun= Pafunda am 6. 3. 1894.

3. Einnahme ber B̧ora beş Şäuptlings Ribula von Ritara am 1. 4. 1894.

4. Befedt bei Mamudie an 11.6. 1894.

5. Gefed)t bei Himmit am 13.6. 1894.

6. (Sefed)t bei Runbaj ant 2. 8. 1894.

7. Straferpebition gegen bas Sultartat Bulima v. 30. 7 . bis 6. 8. 1894.

8. Befedt bei Rilma=Riminbie an 7. 9. 1894.

9. Bejeht Gei Ronfo am 13. 10. 1894.

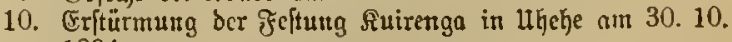
1894.

11. 1leberfall burd bie Wahehe bei Diege am 6. 11. 1894.

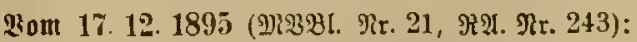

Für dicjenigen Militärperjonen, bie in Der ङळustruppe ber

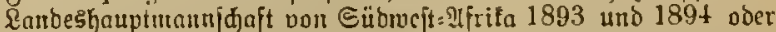

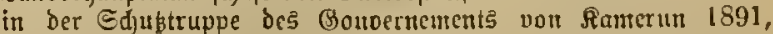
1892, 1893 unb 1894 in jebem 3abre an cimem Befedt theil= acrommen haber ober cine forthufende Dienfigeit oon zimci Wonaten in ie cinem Jahre ourdgentad)t habes, fommt je cin

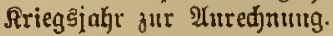




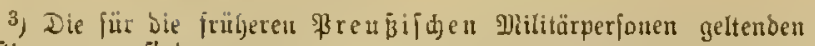
Bepitimmungen find:

a) Für bie Sämpfe in Sdlesిvig=5oljtem, ber Bialj, Baben,

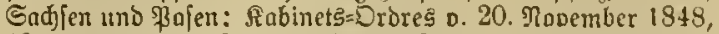
13. Fobruar uno 6. शabember 1849 und 19. Tautuar 1850 ,

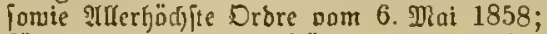

b) für ben firieg gegen Däncmart: Yucrfödjite Drore vom 18. Desember 1864 .

Beamten und Interbcamten, welde nIS Salbaten ber pormaligen

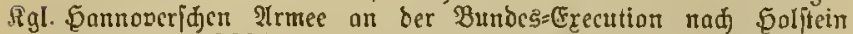
uno Raucrburg 1863/64 thsilgenommen haben, ift aus bicjem शnlajie cin frriegsjahr in Inrsdnung su bringen, wenn biejclben an cintem (Sefedt betheiligt gewsien finb.

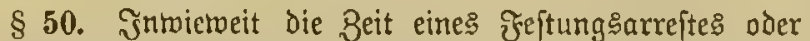
ciner Sriegsagefangenfdjaft angerechnet werden tänne, ift nach Den für Die \$enfionirung der Militärperjonen des Reidf?= heeres und der Raiferlidjer Marine gettenden gefestiugen Beftintmungen zu bemeifen. ${ }^{1}$ )

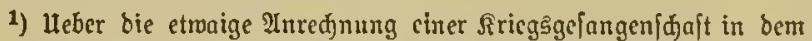
Felozuge gegen frantreid, fiche खllerhödjite Drores vont 18. 5. 1871 unb 17. 5. 1872 (शtrmte = \$croronungsblatt für 1871 ङ. 113 un für 1872 S. 183).

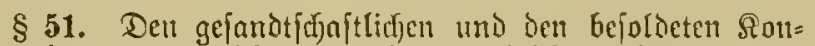
fulatsbeamten, weldie in ausercuropäiffien Qändern cinc längere nlg einjäbrige Bermendung gejunden haben, wirt dic Dojelbyt zugebradte Dientzeit bei Sermenoung in Spt = und Drittelafien, Mittel= und Sïdomerifa bei ber Penfionirung Doppelt in Anredfuning gebrad)t.

Bei Bermenoung von gejandtjdaftlidjen oder won bes foldeten Ronfulatsbeamten in anderen ausereuropäijoden

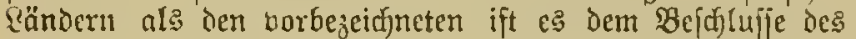
Bundegraths borbeljalten, detn Borfteljenden entfpredende Beftimmungen zu treffen.

§ 52. Mit (Senehmigung Des Bundesrathes') fam nad) Mafiggabe der Beftimmungen in bell $\$ \$ 45$ bis 49 bie Bcit angeredfuet rerden, während weldyer ein Beamter,

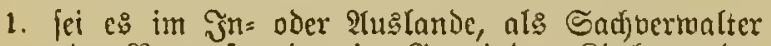
oder Ratar fungirt, im (s)emeindes, Rird)en= oder Schuldienfte ouer im Dienfte ciner landeshyertidyen

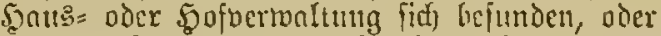

2. im Dienfte eines tem Peidje nidjt angeljörigen Staates gejtanden hat, ode:

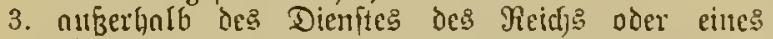
Bumbesftantes praftifd) befchäjtigt gewejen ift, int= fofern tuto injomeit dicje Bejejäftigntth vor \&r= longung Der \&njtellung it cineut Reidf: $=$ obcr mnittelbaren Staatsante herfömmlid) mor.

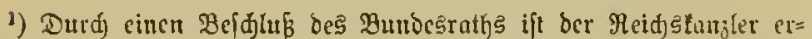
mädftigt worben, ben in ben Ruheftand tretenben, au s ber Silafie ber Militärantö̈rter heroorgegangenen Peidgbeanten ofuc

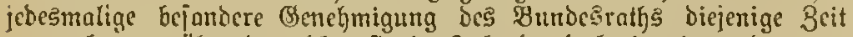

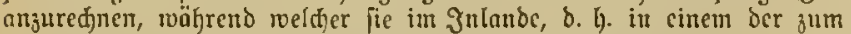

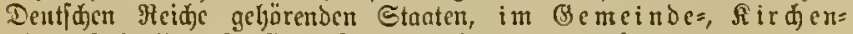
ober Sduldienfte fid) befunden haben, ooransgejest:

a) Doß bie Diurjtigtcit bes Bcauten brideintigt ijt,

b) baś ifre Stelung it bem bezïglidjen Dicufte niđt leobiglid in eimer nebenamtliden Bejuäftigung bejtanden hat, uno

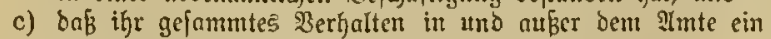
pfliditircues gemefen ift.

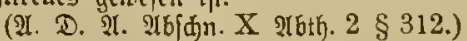

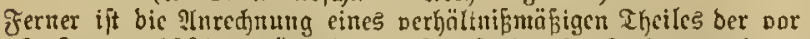
dem 1. Januar 1891 zuridgelegten Dienttzeit afs Telegraphen=

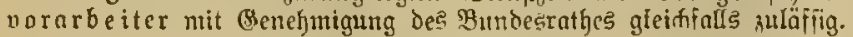

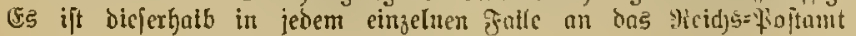

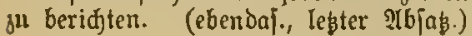

\section{Radrueis der Dienjtunfähigfeit.}

§53. Zुum Eimeije der Dienitunfähigfeit eines jeine Berfezung in Den Pufeitand nadffuchenden Reidjebeamten ift die Creflärung Der deurfelben mmittelbar borgefebten

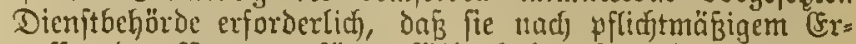
mefien den Beanten für unfähig halte, jeine Imtspplidenten ierner zat exfitten.

Snmietweit andere Betweismittel z"l exjordern oder der Erfäutung Der unmittelbar borgejełzten Behürde entgegen fïr

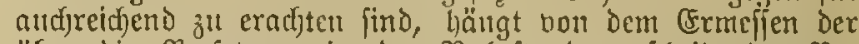

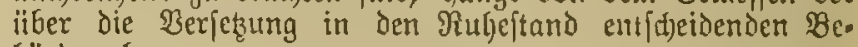
hörde $a b$.

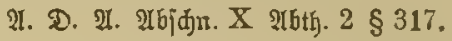

$\left.\S 54 .{ }^{3}\right)$ Die Beftimmung daribber, ob und zu weldhem Beitpunfte dem Intrage eines Beauten nuf Berfebung in den Pulbeftant ftattzugeben ift, forvie ob und roldye Berfiton Demiclben zufteht, erfolgt Durch Die oberfte Reich\&behörde, meldje bie Befugnif zu fold)er Beftimmung auf bie höhere

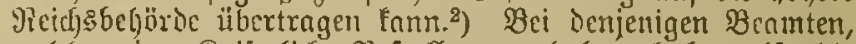
weld)e eine Raijerlicf) $B$ eftallung erbalten haben, ift dic

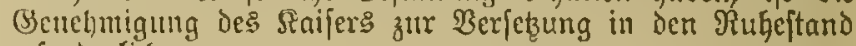
crforierlid).

1) Эn ber burd bas (beję̧ v. 25. 5. 1887 abgcätrocrten faffung.

2) 5iernad) crfoigt bie Beftimmung:

1. Durd bas $\Re$ eidjspoftamt: bejüglid Der Beamten oom

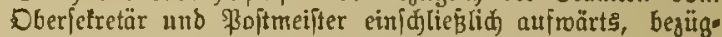
liđ ber übrigen $\mathscr{Y}_{\text {camten }}$ unb ber Hnterbeamten in ben unter 2 bejeifgneten bejonderent ซäallen.

2. Durd bie Ober= Poftbirettion: begüglid ber etats:

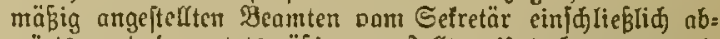
märts und ber etat3mäßig angefsclten lunterbeanten, mit

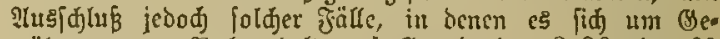

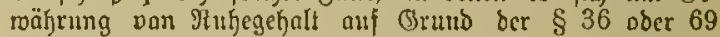

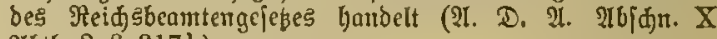
刃bth. 2 \& $317 \mathrm{~b}$ ).

\section{Bahlbarleit der \$enfionen.}

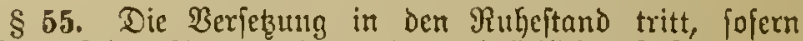
nicft auf den 2Intrng oder mit augbrüuflicfer Buffimmung Des Reidjecamten ein frïherer Beitpunft feitgejekst twirb, mit bem शrblauf des Bierteljohres cin, meldies auf Den Manat folgt, in weldjem Dem Beamten Die Enticheidung

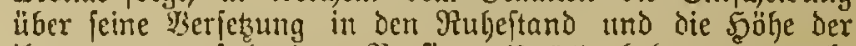
ihm etwa zuleb)enden \$etrition (§ 54) befannt gemad)t morden ift.

§ 56. Die \$enfioneu werden monatlich im Boraus gezahlt.

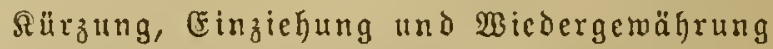
der Benfionen.

§57. Das Recht nuf Den Bezug Der \$enjion ruft:

1. toenn ein \$enfionär das Deutfaje Эndigenat ber: liert, bis zu ettoniger Wiedererlangung deffelben;

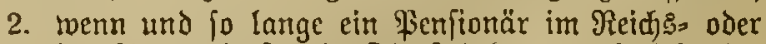
im Staatsdienfte ein Dienfteinfommen bezicht, in. foweit, als ber Betrag diefes netten Dienft,

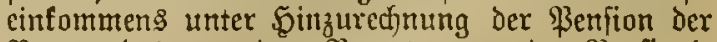
Betrag Des von deu Beamten vor der Rienfioni. rumg hezogenen Dienjteinfommens überjteigt. 
$\S 58$. Ein ßenfionär, tweldyer in cine an fidf jur ßenfion

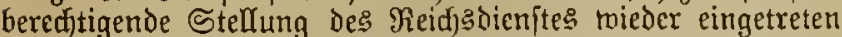
ift $(\$ 57 \Re r .2)$, exwirbt für den ₹all des Burüdtretens in

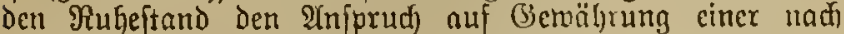
Daß̧gabe feiner nummehrigen berlängerten Dienjt; jeit nud Des in der nenen Stellung bezogenen Dienfteinfommens Gerechneten ßenfion nur Dann, wenn Dic nen hinjutretende Dienftzeit menigftens 1 Эăhr betragen bat.

Dit Der (Setwährung eiter ljiernad) neu bered)neten

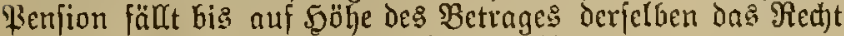
auf den $\mathfrak{B e z} u g$ der früheren

§59. Froient ein Fienfiomär, meld)er in eine an fid zur \$enfion berectitigende Stellung Des Staatsdienjtes ein= getreten ift, in Diejer Stellung eire ßenjion, fo findet uchen Derjelben Der Furtbejug der auf (Srund diefes (3ejesces gi= währten \$enfion nur in Dem Duref) $\S 57$ Nr. 2 begrenzten llmiange jtatt.

§ 60. Die Einzicljung, Sïtrzung aber Wiedergemälyrung der Benfion auf Brund dir Beftimmungen in ben $\$ \$ 57$ bis 59 tritt mit dem Beginn desjenigen Mionats cin, weldyer alf das cine foldhe Beränderung narh fich zichende (Freignî̉ folgt.

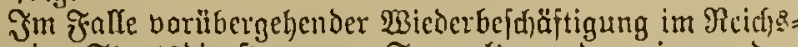
over int Stantshienle gegen Tagegelder oder eine ander=

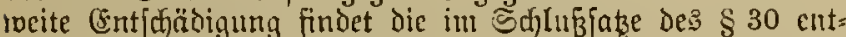
baltene Borfdrift Âtuendung.

\section{3rongstreife Berickung in ben Rubeftand.} (I. D. I. গtb

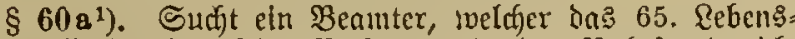
jafy bollendet hat, feine Berjebung in den Ruheftand nidjt nach, fo fann biefe nad) ?Inhörung te: Beamten unter Beobacftung Der $\mathfrak{B a r f d j r i f t e n ~ D e r ~} \S \S 53$ ff. in Der nämlicfen Weife verfügt twerden, wie tvenn der Beamte feine \$senjioni= rung felbft beantragt hätte.

1) $\S 60$ a Durd das Befes vom 21,4, 1886 hinter $\S 60$ ein= geidjaltet

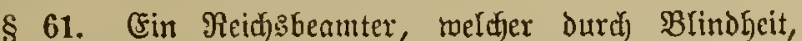
Taubleit oder cin fonjtiges Éprperfiches (sebrechen oder

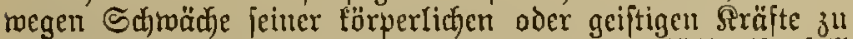
Der (Frfüllung feiner 2(mtspflicten bauernd unfähig ift, foll

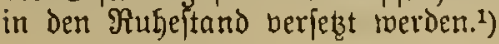

1) ßgl. $\S 34$.

\$ 62. Sucht der Beante in einem foldsen Falle feine

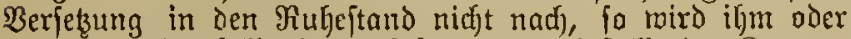
feinem nöthigenfalls Gicrzu befonderş zu beitellenden నuratar

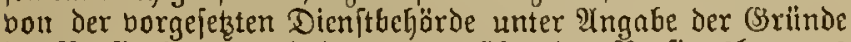
der ßenfionirung und des zu gewährenden \$senfionşbetragę

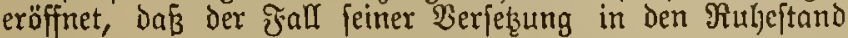
borliege.

§ 63. Wenn Der Beamte gegen die ihm gemadte (Fr: offrnung $(\$ 62)$ innerljalb 6 शुothen feine Cinnendung erhoben hat, fo wird in berfelben weife verfügt, als wenn er feine Penfionirung felbit tadjgefudft ljätte.

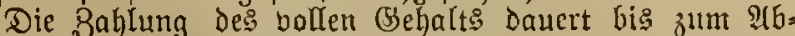
laupe Desicnigen Bierteljahrez, weldjes auf den Mionat folgt, in dem ifm die Berfügung riber die erfolgte Berfetzung in Den Rutheftand mitgetljeilt ijt.

$\S 64$. Werden von Dem Beamten gegen Die Ber\{ełung

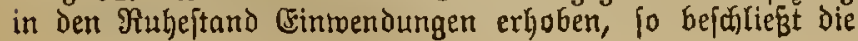

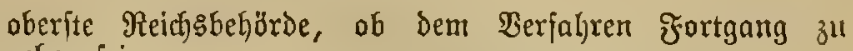
neben ici.

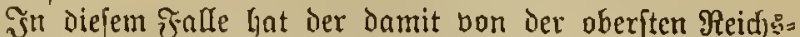
Gehourde zu beauftragende Sheamte die ftreitigen Thatfaden zu erörtern, bie erjorderlid)en Beugen und Sadjoerîtändigen eiolich) zu vernehmen, no dem zu penfionirenden SBeamten oder iejfen Ruratar z" geftatten, Den Bernehmungen bei= zuwahnen.

Bum Salub ift der z" penfionirende Beamte oder deffu Surntar (Erfflärung und jeinem afntrage zu ljören.

$8 u$ den Berkandungen ift ein vercideter Frotofolfiïlyer zujuzieljen.

\$ 65. Die gefflolofienen SIften merten Dex oberiteu

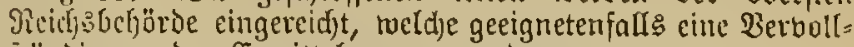
jtïnbigung Dex Ermittelumgen anoronet.

Die baaren Mlnslagen jür die durd die Sduld des ju penfionirenden Beanten veranlā̧ten erfolglojen Ermtitc: lungen fallen demieltien zur \&aft.

\$66. Şat Der Beamte eine Siaiferlidje Beftallung er= halten, fo erfulgt die Enticheidung über die Berfebung in den Plubeftand vom Saifer im Finbernehmen mit Dem Bundesirat).

Эn Betreff ber übrigen Beamten fteht bie Entfdeidung der oberiten Reichsbehörde zu. (Segen dieje (Entfijeidung hat Der Beamte bimen ciner (j)rift bon 4 WBod)en nad) Deren

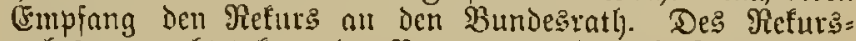
rechts ungead)tet fom ber $B$ camte bon Der aberften Reichs: beförde fofort ber weiteren întsoverwaltung borläufig ent= hoben merden.

\$ 67. Die Znhlung Des bollen Behalts dautert bis zum शtblauf des SBierteljahres, das anf Den Monat folgt, in meldem dem in ginheftand berfebten Beamten die Ent= ¡djeidung bes Saijers ader ber oberíten Reidjabehörde zu= ge(tellt worden ift. ${ }^{1}$ )

1) $3 g$ I. $\S 63$ Ibf. 2.

$\S 68$. Şt ein Beanter vor Dem Beitpunfte, mit toeldfem die \$enfionsherect)tigung für ifn eingetreten fein würte, bienjtunfäljig gemorden, fo fann er gegen jeinen Willen nur unter Beobad)tuny derjenigen Formen, weldhe für Das förm= lidfe Diş3iplinarverfalyren bargefdrieben find, in den $\Re u h e=$ ftand berjetzt rerden.

Bird es jedod bon Der oberften Reicfsbeljörde mit Buftimmung bes Bundeşraths angemefien bejunden, Dem seamten eine fienfion zu dem Betrage zu Gelvilligen, weldyer ifm bei Erreidutig des vorgedadyten Beitpunftes zuftehen mürbe, fo fann dic \$enfionirung Deffelben nad ben Bar= fufriften der $\$ \S 61$ bis 67 erfolgen.

\section{Berolligung für Şinterbliebene.}

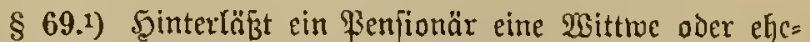

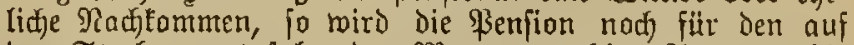
ben Sterbemonat folgenden Monat gezahlt. ?in wen bic

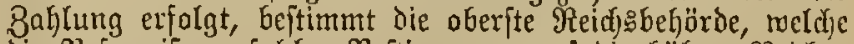

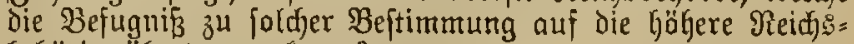
beförde übertragen famn. ${ }^{2}$ )

Die Zahlung Der ßenfion für den auf den Sterbentonat folgenden Monat fann mit (Senefmigung der oberften Reicfs: behörde audf Dann ftattfinien, menn ber Berftorbene (Eltern, Bejcjwifter, Befdywiftertinder oDer \$flegefinder, Deren (Fr: näbrer er gemefen ift, in Bèürftigleit hinterläß̧t, ober menn 


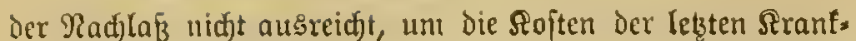
lecit und Der Beerdigumg zu decten.

Der iiber den Sterbemonat hinaus gemährte einmonat=

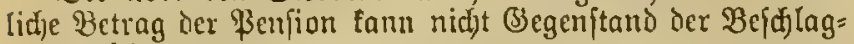
nal)me jein.

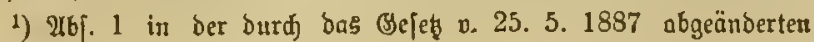
Foliung.

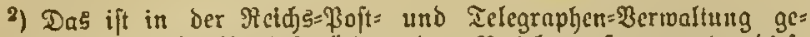

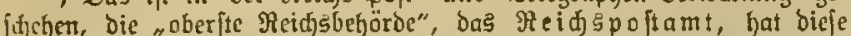

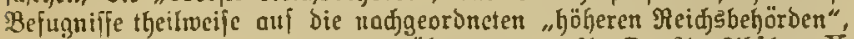
die Dber= Boftoireltionen, ïbertragen. II. D. 2t. Ifbidn. X Abth. 2 \$ 285 oronet an, Dais bic Beffimmung, an wen bic Bablung

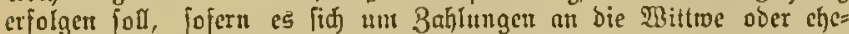

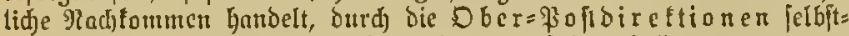

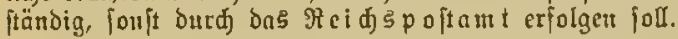

\section{Tranjitorifde Beftimmungen.}

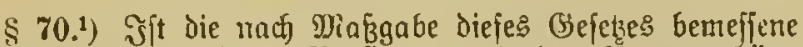
Benfion geringer als die \$enfion, weldje dent Beamten hätte getwährt werden müffen, rean er bor bem Erlaffe diejes (s)eietes nad den Damals für ihn geltenden Beftimmungen penfionirt worien wäre, fo mirb bie letztere \$enfion an Stelle ber erjteren betrilligt.

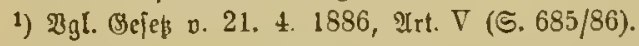

8 71. Эnjofern bor der Щebernahme eires Beamten in

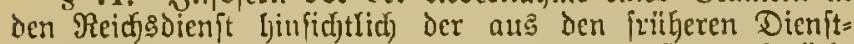
berbältuiffen demfelben ertwadjienden Fienfronsanfprïbe mittels cines vor Dem Extaffe diefes Gejetzes abgefortoffenen Staatsocrtrages bejandere Jeftetsungen getroffen find, follen dieje ₹eftfetzungen aud) fïr dic Bered)nung der jenem $\mathfrak{B C}$. amten zunîh

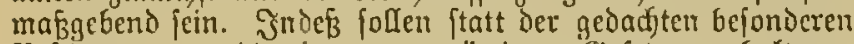
Beftimmungen die im gegenturitigen (Se feke enthaltenen Borfd)riften infoweit ?luwendung finden, als fie für ben Beamten günftiger find.

\section{Argemeine Beptimmungen über Dienftuergehen und deren Bejtrajung.}

§ 72. (Fin Reidjebcamter, weld)er die iljm obliegenden Bflidjten $(\S 10)$ verlekt, begeht ein Dienftuergeben und hat dic Diszziptinarbeftrafung vertwitft.

§ 73. Die Diszziplinarftrafen bejtelen in:

1. Dronungstrafen,

2. Entiemung aนร Detn ?mte.

§ 74. Dronungsitrafen fino:

1. Barnung,

2. Bertweis,

3. Belditraje,

bei bejoldeten Beanten bis zum Betrage Des cin= monatliden Dienfteinfommens, bei unbefoldeten bis zu dreifig Thalerm.

(3eldftrafe fam mit Sertweis berbunden werden.

§ 75. Dic Entjermung aus bem Samte fann befteljen: 1. In Strafuerjebiung.

Diefelbe erfolgt Durd) Berfebung in cin anderes $91 \mathrm{mt}$ von gleicfem Range, jedod) mit Berminderung Des Dienjtein= tommens um lö̈hifens 1/5. Statt Der Verminderung Des Dienfteinfonmens fam eime Geldftrafe verljängt werden, meldje $1 / 3$ Des Dieniteinfommens eines Эahres uid)t über: fteigt.

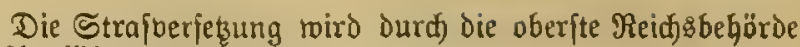
in Мนร์fübrung gebracht.

\section{2. Эn Dienftentlaffung.}

Diefelbe hat ben Berluft des Titels und \$enfions: anfprud)s von Recht:inegen zur Folge. Sat vor Beendigung

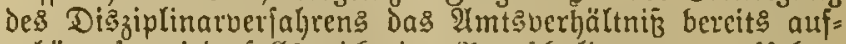
gehört, fo twiro, falls nicft ber inngeifjuldiate unter lleber= nalime der Soften freiwillig auf Titel und \$ienfionsanjprud\} verzidftet, auf deren Berluft an Stelle der Dienftentlaffung erfannt.

(Befjört Der ?tugefduldoigte zu Den Beanten, weldje einen Suppruch auf ßenfion lyaben, und Iafjen Gefondere Umitände eine miĺbere Beurtleilung $z u$, fo ift die Disziplinarbefjörbe ermächtigt, in ilyter (Entfd)eioung zugleid) feitzulesen, bob dem 2lngeiduldigten cin Theil des gejebliden ßenfions: betrages auf Rebens:zeit oder auf gemiffe Jabre zu be= laffen fei.

§ 76. Bcldje ber in bell $\S \S 73$ bis 75 beftimmten Strafen anzumenden fei, ift nad) Der gröberen oder ge: ringeren (stljeblichfeit Des Dienftuergehens utit befonderer

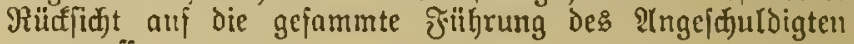
zu ermeffen.

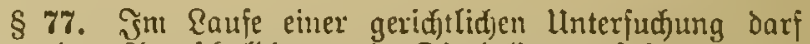
gegen den 2Ungefduldigten cin Dişziplinarverfahren rogen Der nämlicjen Ilyatfadjen nicd)t eingeleitet werden.

Benn im Eaufe eintes Disjiplinarberjahreng wegen Der nämlid\}en Ihat\{aden eine geriditlid\}en Unterfudjung gegen

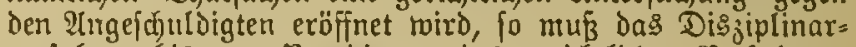
berfahrer bis zur Beendigung bes geridttichen Berfahrens altsgefebt werden.

§ 78. Wenn von ben getoöhnlicyen Strafgeriduten nuf

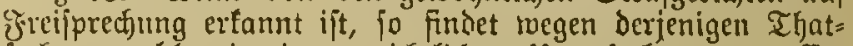
[adjen, welde in ber geridytlid)en Unterfudjung zur (Fi: örterung gefommen find, ein Sisziplinnrberfahren nur nod) injofern jtatt, als diefelben an fid) und ohne ihre $\mathfrak{B}$ czichung zil Dem gefetzliç) Thatbeftande Der ftrajbaren \$andlung, weldye Den (Segenitand ber Interfudung bildete, ein Dienft. vergehen enthalten.

Şft in einer geridytlid)en unterfuchung eine $\mathfrak{B}$ erurtbeilung ergangen, weld)e den Berluit des 2(mte? nidyt zur folge gehabt bat, fo bleibt berjenigen $B$ chjörde, tweldje über Die Einleitung De: Disziplinarberfahrens zu verfügen hat (\$84 26f. 1), Die Sntfdeidung Darüber vorbehalten, ob auferdem ein Diszziplinatberfahren einzuleiten oder fortzufezen fei.

\$ 79. Spricht dos Giejetz bei Dienftuergeben, weldje (B)egetrftno eines Disziplinarberfaljens werden, bie Ber: pflichtung zur Bicberciftattung over zum Stfabenserfatse oder eime jonftige eibilredjtlidye $\mathfrak{B e t p f f i c f t u n g}$ aus, fo gehört die Nage ber betlyeiligten bor Jas (Sibilgerid)t. Die $\mathfrak{B e}=$

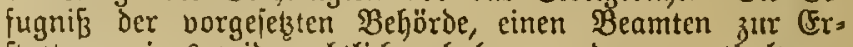
ftattung cines rvideried)tlicf erhobenen ober borenthaltenen Berthbetrages anzuhalten, twiro hierdurd) nicht ausige= (d) loffert.

\section{Bou Dem Digziplinarberfahren.}

$\S 80$. Эeder Dienftuorgefetzete ift zu 2 Barnungen und Serweijen gegen Die ihm untergeoroneten Reidbseamten befugt.

\section{§ 81. Beldftrafen fönnen}

1. von Der vberften Picidjübeljörde gegen alle Reidjs: 
beamte, InD żwar bis jum hödften zuläffigen Betrage (\$ 74 Nir. 3),

2. Don Den Derfelben unmittelfar untergedroneten $\mathfrak{B} e=$ hörden und $\mathfrak{B}$ oriteljem bonBehörden bis zแm $\mathfrak{B e}=$ trage bon zehn Thalem,

3. von Den ben lekteren untergeordneten BehörDen und Borftehern bon Behörden bis zum Betrage bon drei Thalern

berljängt werbent. ${ }^{1}$ )

1) 3u 1: Das Reidjs=

3u 2: Die Dbers=\$oftoireftionen.

Bu 3: Die Borjteher ber \$oit= und Telegraphenauffalten.

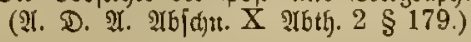

\$ 82. Bor Der Berbängung einer Drdunnggftrafe ift Dem sbeamten (Stelegenlyeit zu geben, fich) über bie ihm zur Eaft gelegte Berleţung feiner amtlichen \$iffichten zu ver= antworter.

Dic Serhängung Der Dronungsitrafen erfolgt unter Ingabe Der Brümbe burch fdriftlidje Berfitgung oder z"l Brotofoll.

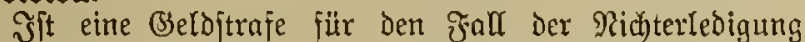

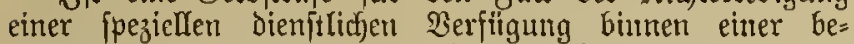
timmten ₹rift angedroht, fo tam nach श(blauf ber frift bie (3)eldjtrafe ohye Weiteres jeftgefetst merben.

§ 83. Benen die Berhängung von Drdmungsitrnfen findet mur Bejuberde im Inftanzenzuge jtatt.

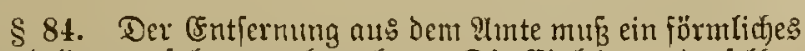
Disziplinarberfafyen vorhergeher. Die Crinleitung desfelfen wirt bon ber oberiten Reidjobehöroe verfïgt.

Das Disziuliuarberfahren bejtelyt in einer fidjriftichent Borunterfuchung und eimer mündliden Verfand hntg.

$\S 85$. Die ober:te Reicjsbehörde entunt den unter= [udfungsführenden Beamter uno dicjenigen Beamten, welche im Raufe Des Disziplimarberfahrens Die Berridtungen Der Stantỉantwaltidjaft mahrzunehmen haben.

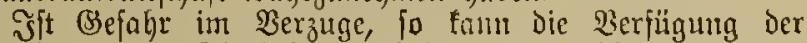
Finleitung Des Disziplinarberfabren: und bie Frmentung Deร Interfudungsfithrenden Beamten borläufig von einer Der in \& 81 unter 9ir. 2 bezeichneten Beljörden oder eimem ber bort bezeidfreten Beamten autsgelien. (s) ift alsoann

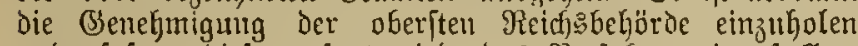
und, fofern biefe verfagt wird, Das Berfahren einjujtellen.

§ 86. Die entifjeidenden Disziplinarbehörden, welche je nach Bedürfuif zufammentreten, find

1. in exfter Э̧nitanz die Disziplintarfanmern,

2. in zweiter Snftanz der Disziplinarlyof.

$\S 87$. शn folgenden Drten:

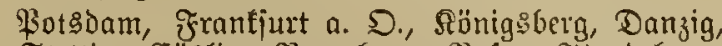
Stettin, Cöstin, Bromberg, \$ofen, Mingdeburg,

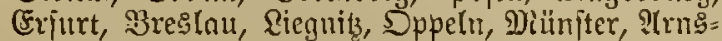

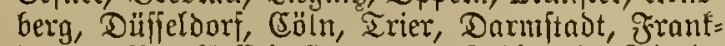

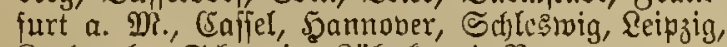
Sar(Iruhe, Shlwerin, Ritbed und Bremen

mird je eine Disziplinartammer errichtet.1)

Der Disziplinarhof tritt am Sitze Des Reicfs:Sher= Gandelsgericht52) zufammen.

1) Es ift nod) erridgtet eine Disjiplinarlammer in Strabburg

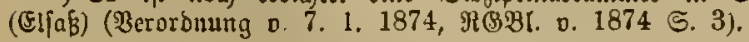

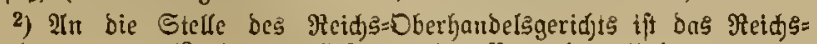
gerid)t getreten (\$ 1 Des (seję̧ç, betreffend ben Hebergang von

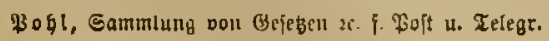

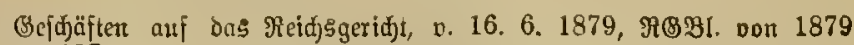
ธ. 157).

§ 88. Die Bezirfe Der Disziplinarfammem merden bom Saifer im Einvernehmen mit Dem Bundešrathe ab. gegrenzt.

Bultändig im einz̧elnen ₹alle ift Die Dişziplinarfammer, in Deren Bezinf Der IIngeiduldinte zur Beit Der Einleitung des jörmlidjen Disziplinarberjahrens jeinen bientitlidjen 23ohnfit hat, und wern biejer Wohnfis im Slustande fid befindet, bie Dişziplinartammer in Fotsoam.

Streitigteiten ỉber die Buftändigfeit beridbiedener Dis= ziplinarfanmern werden bom Disziplinaryof entfhieden.

\$ 89. Э̌ede Dişziplinarfammer Gefieht aus fieben $\mathfrak{M i t =}$ glicbern. Der Proúfibent und renigitens orei andere MRitglieder milffen in richterlicher Stellung in einem $\Re$ Bunde: ftaate jein.

Die mïndtiche Berhandung und Entffreidung in Den einjelmen Disjiplinarfachen erfolgt burd) fünf Mitglieder. Der Borfizende Imd menigitens zmei Beifitzer milifen zu Den richlerlichen MRitgliedern gehören.

\$ 90. Wenr auf ben \{tntrag bes Beamten Der Staats= aumaltidaft oder Des Ângejduldigten Der Disziplinarhof

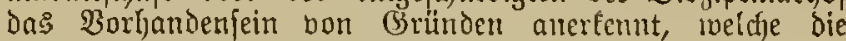
Unbefangenljeit Der zuitändigen Disziptinartammer zweifel= haft maden, fo tritt eine andere burd) Den Disziplinarhof ermannte Disziplinarfammer an beren Stefle.

\$ 91. Der Dişjiplinarhof Gejteht aus 11 Mitgliedern, von benen weningitens 4 zu Den Bebollmäd)tigten zum

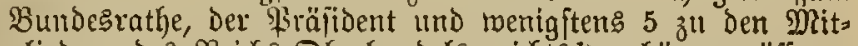
gliedern De' Reicf

Die mïndlide $\mathfrak{B e r h a n d l u m g ~ u n d ~ ( E n t j o b i d n n g ~ i n ~ b e n ~}$ einzelnen Disjiplinarjacfen erfolgt Durd) 7 Mitglieder. Der Borfizende und menigitens 3 Beifizer mitffen zu ben ridfterlichen Ditgliedern gehören.

1) $\mathfrak{B g l . ~ 2}$ (nm. 2 zи $§ 87$.

§ 92. Die Sefduäftooronung bei den Dis̊ziplinar= beljörten, inşefandere die Befugmiffe des Sräfidenten und bie Reiljenfolge, in weldjer bie ridjterlicjen Mitglieder an Deu cinzelnen Sitzungen theilzunehmen haben, wird burch cin Regulatio geordnet, welches Der Disziplinarhof zu ent= werfen und Dem Bumbesrath zur Beftätigung einzureichen hat.

§ 93. Die Mitgliçer der Disziplinarfammern und bes Disziplinarbojs merden für die Dauer der zur Beit ihrer

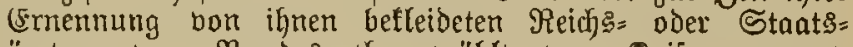
ämtern bom Bundesrath gewoählt, bou Saifer ernannt, und fïr die Crrfülung der DGfiegenheiten ihres Amte berpflicftet.

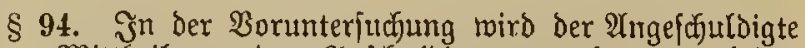
unter Mittheilung Der Infdhuldigumgspumtte vorgeladen mo ber Benmte ber Stantsantwaltfujaft zrigezogen. Die= jelben merden, menn fie erid)einen, mit ibren (Ertlärumgen und Ânträgen gebört. Die Beugen merben, nach Befinden ciolid), bernommen, und die fonjtigen Betweife erboben. Den Berneburungen der Beugen Darf weder ber Beamte der Staatsanmaltichajt nocf) Der 2(ngefduldigte beibohnen.

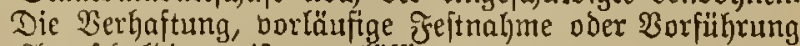
des QYigeichuloigten ift unzuläffig.

§ 95. Heber jede Unterju(fungshandlung ift ourch einen

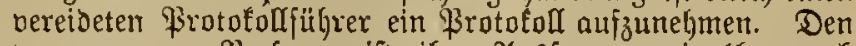
bernommenen \$erfonen ift ifre 2 (usfage ummittelbas nad) 
Der Brotolollirung vorzulcien, um Denfelben Belegenheit zur Veridjtigung und Ergänzung ju geben.

§ 96. Wenn Der Borunterfudungsbeamte bie Bors unterfuchung fïr gefdloffen erad)tet, fo theilt er die Ifften Dem Beamten ber Stantsanmalticjaft mit. Şält ìcjer eine Cargänjung ber Boruntcrjurlym! für erforderlid), fo hat er Diefelbe bei Dem $\mathfrak{B}$ orunterfudumgsbcamten z" beantragen, wel(f)er, went er entgegengejetzter 2unficht ift, die (Entidjeibung Der oberjten Reidjabehöroc einzuholen lyat.

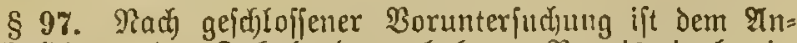
gefduldigten Der Эnhalt ber exhobenen Bemeismittel mit= 3utheilen. Darauf twerden die steten an bie oberite Reidfs: beljöbe eingefendet.

§ 98. Die oberfte Rcidjsbeljörde fam mil Rüdfitut

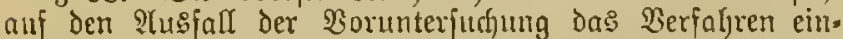
fitelfen und geeignetenfalfe cine Dromungsiftrafe berljängen.

Der Ingejhulbigte erlyält 2(usfertigung Des Darauf be züglichen, mit (Sründen zu unterftriß̨ertoen Befchluffes.

§ 99. Die Wicderaujnahme des Disziplinatberfafren megen Der nömfidjen Anjd)uldigungspunte ift nur auf (S) rund nener Berveije und toährend eines Beitraums bon

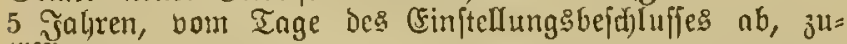
läfifig.

War eine Dromungsftrafe berlängt (\$ 98), jo findet eine Wiederaufnahme des eingeitellten Disziplinarverfahrens nicht jtatt.

\$ 100. Die Cinftellung Des Verfahreng muf expolgen,

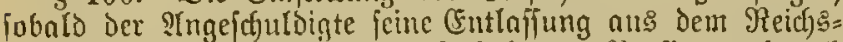
dicnite mit Berzicht anf Titel, (Behalt und \$senfionsanfprud)

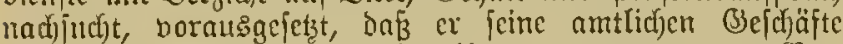
bereit: erlebigt und uber cine ihin etroa anvertraute $\mathfrak{B e r}^{2}=$

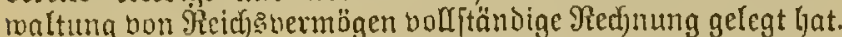

Die Berljängung einer Sronungsiftrafe ift in diejem

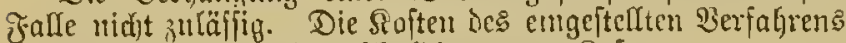
(\$ 124) jaflen bent 2(ngcid)uldigten zur Eajt.

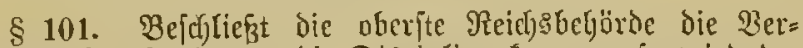
meifung ber Sadje bor bie Disjiplinarfanmer, fo twird der Angeiduldigte nach Fingang ciner bon bem Beamten ber

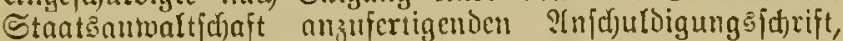
unter abfdyriftlidfer Mittleilung ber Iebeteren zu ciner bon dem Borfitenben der Dibiplinarfammer ztl bejtimmenden Silumg, jur mündlidjen Berhandlung vorgeladen.

Der Yrrgejudjoigte fam fidj des Beiftandes eine: Tldofofaten oder Redfitsantontts als Vertleibigers bedienen. Dem Eebteren ift bie (Finfid)t Der Borunterjudungafaften fll gejtatten.

\$ 102. Dic münolidje Werhandlung findet ftatt, alidf

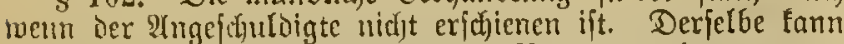
(id) Durch einen ?tobofaten ober Rechtsanmalt bertreten Inffen. Der Dis,iplinartammer ficht es jedody, fofern Der

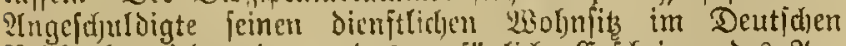
Preicte hat, jederzeit zu, bas perfönlidfe (Erjejeinen des $\mathfrak{A} n=$

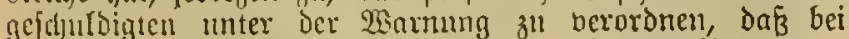
feinem Susbleiben ein Bertyeibiger ju feiner 2ertretung nidjt werde zugelajien reerden.

§ 103. Die mündlidfe Berhandung ift öffentlid. Die

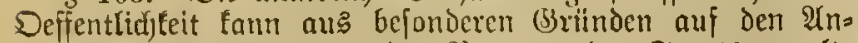
trag bes Plngejdulloigten, des Bcamten ber Staatsanmalts

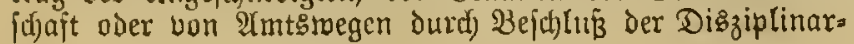

fammer auggejdhlofien odcr auf beftimmte \$erjonen bejd)ränft

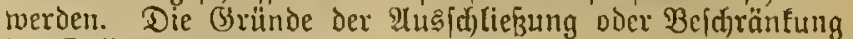
ber Defientlidffeit miiffen aus Dem Sizung sprotofoll herbor: geljen.

\$ 104. Bei der mündlicten $\mathfrak{B e r h a n d l u n g ~ t w i r d ~ b e r ~}$

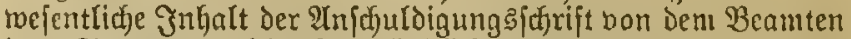
ber Staatsantwaltidjaft mïndlidf borgetragen. Der $21 \mathrm{n}=$ geidjuldigte wird vernommen. (Sejteht Der fatbe Die Den Gegenftand bildenden Thatjacten ein, und walten gegen die Glaubroürdigfeit feines (Seftändnifjes feine Bedenten 06 , fo

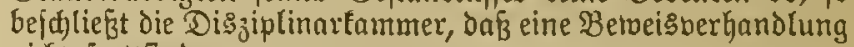
nicfit ftattinde.

Mnderenfalls giebt ein von dem Borfizenden der Dis: ziplinarfammer aus der $3 \mathrm{ahl}$ der Mitglieder ermannter 3erichterfintter auf (Brund Der Gisherigen Berhandlungeu cine Daritelfung der Berweisaujnaljme, porweit fie fidc auf

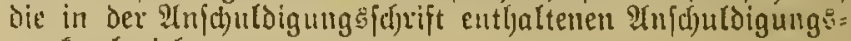
punfte bezielt.

Bum Schlub wiro Der Beamte der Staatsantwaltichaft

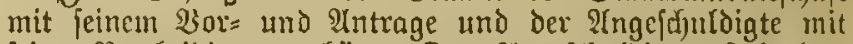

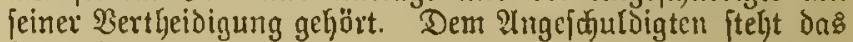
lekste Wort zu.

\$ 105. Wenn die Digziplinarfantmer vor oder im \&auje der mïndichen Berbandfung auf Den Intrag bes 2 in= gefduldigten oder Des Beamten der Staatsantonltidjaft, oder von Putbinegen die Bernehmung bon Bengen, fei es bor Der Disziplinarfammer oder Durdj einen beauftragten Beanten, oder bie flerbeifthnffung anderer Bemeismittel für. angemeffen erad)tet, fo erläB̆t fie die erforderfidje $\mathfrak{B}$ erfïgung und verlegt nöthigenfalls bie Fortjetung der Berhandlung

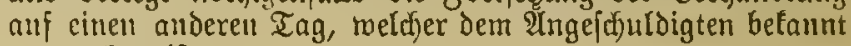
zu madjen ift.

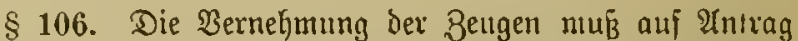
bes Beamten der Staatsanmaltidfaft oder des Mngeidildigten in Der mündfichen Berhandfung erjolgen, fofern die $\mathfrak{Z}$ ljat= fadjen erbeblidj find, ïber weldye die Sernehmung [tattinden Foll, uno die Dişiplinarfammer nicht die lleberzeugung ge. wonnes Gat, dnß ber ?Yntrag nur auf Beridjleppung ter Sadje abjielt.

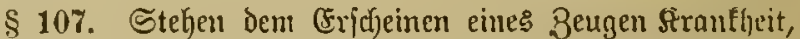
groß̈e Entfermung odcr andere unabwendbare Sindernifie entgegen, fo ift von der Disziplinarfammer defien Ber= nehmung Durdj cinen Dantit benujtragten Beamten unter Beiladung der Stratsanmaltidjaft uno des ?ngejduldigten anzuoronen.

ALS grofe Entfernung im Sinne dicies Befetzes ift es nidjt anjujeljen, wenn ber Beuge fidj im Bezirte ber ent: icheidenden Diszziplinarfammer aujgält.

§ 108. Bei der (Entfcheidung hat die Diszziplinartammer, ohne an pojitibe Beweisregeln gebunden zu jein, nath ihrer freien, aus Dem Эnbegriffe der Berhandhungen und Bemeife gejdiópften lleberjeugung zu beurtheilen, inmietweit bie $\mathfrak{A n}_{\text {. }}$ idjuloigung fïr begründet zu eradjten.

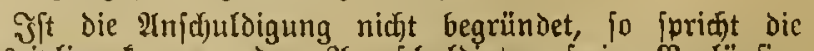
Dişsiplinarfammer Den Angeiđuloigten frei. Borläufige ₹reifprechung (ङntbindung non Der Jुnitan\}) ift nid)t ftatt= hajt. (Segen ben freigeiprod)enten Ingeiduldoigten barf wegell Der nämlidjen den (Segenftand Der Ânjaldigung bildenden 5̧andlung ein Difziplimarverfahren: nidjt wieder eingeleitet weriden. 
Jit die ?(nic)uldigung begründet, fa tann die Entfheidung aud) auf cine blofie Sronungeftraje lauten.

Die Entflyeidung, meltfe mit Brïnden verfchen fein

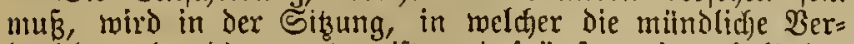
Landung beendigt worden ift, und fpäteftens innerhalb ber barallf folgenden vierzelyn Tage vertïndet. Eine Plusfertigung der Entidbeidung roird dem stngefduldigten ertheilt.

§ 109. Leber die mündiche Berhandlung mird cin Firototoll aufgenonmen, weld)es bie Ranten ber Stnmejenden und die wejentlicfen $\mathfrak{P a m e n t e}$ ber Berbandlung enthalten mus. Das Brotofoll wird bon dem Barfizenden und Dem Protatolfführer unterzeidfnet.

\$110. Biegen die Entiheidung Der Disిziplinarfammer fteht die Berufung an Den Disiziplinargof jomohl Dem Beamten der Staatsanmalt(d)aft als Dem 2(ngeffyuldigten offen.

Reue Thatjactien, weldye dic (Srundlage einer anderen Bejdjuldigung bilden, dürfen in ber Berufungsinftanz nidft vorgebradt twerden.

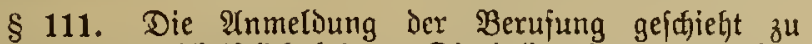
Fratofoll oder fobriftlicf bei der Disziplinartammer, melche die anzugreifenbe (Entfacidung crlaffen hat. Bon Sciten Des 2ingeldfuldigten tarn fie and durd) einen Bebollmächtigten neichetien.

Die Frrift zu biejer Anmeloung ift eine viermödjentlidje. Sie beginnt für den $\mathfrak{B e a m t e n ~ d e r ~ S t n a t s o n n w a l t f d j a f t ~ m i t ~}$ Dem 2hlaufe bes Tnges, an reldfem die Entfajeidung ber= fündet, für Den Ingejhuldigten mit Dem Itblaufe des Iages,

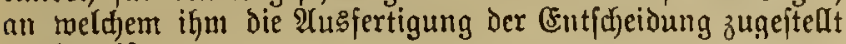
worden ift.

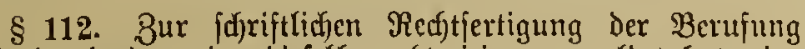
fteht Demjenigen, Der biefelte redjtzeitig angemeldet hat, eine vierzehntägige frift, boun Thlauje ber Mbmeldungsfrift ge= rechnet, offen.

\$ 113. Dic 2Inmeloung Der Berufung uno die etwa

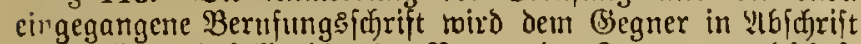

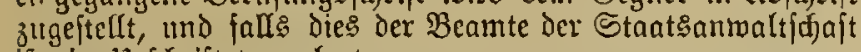
iit, in llr r(d)rift borgelegt.

§nnerhalb vierzehn Tagen nad) erjolgter 8uftellung oder Barlegung fann Der (Begner cine Beantwartungefdyrifit ein= reidjen.

§ 114. Befindet fich Der Angefduldigte im 2 Uslande, fo hat die Disziplinarfanmer dic Jrititen zur 2tumeldung und Red)ticrtigung foiner Berujung und zur Beantwortung ier $\mathfrak{B}$ trufung des Beamten Der Staatsanwaltidjaft mit Ritcficht auf Die (Entfernung Des Dienftlicfen $230 h n$ fibes des Ungefduldigten von Antervegen zu erweitern mo bie be= treffende $\mathfrak{B}$ erjügung alcichzeitia mit Dem llrtlyeil bezm. mit Der Inmeloung der $\mathfrak{B} e r u j u n g$ De $\mathfrak{B}$ Beamten Der Staat: antwaltijuaft Dem Ingefdjuldigten zuzuftellen.

\$ 115. Die Friften zur Rerftfertiqung und $\mathfrak{B}$ eantwortung der Berufung (\$§ 112 biß 114) fönnen auf $\mathfrak{A}$ (ntrag bon der Disziplinarfnmmer berlängert merden.

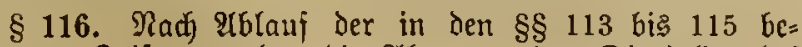
itimmten Griften merden die Aften an den Disziplinarljof cingejandt.

Dex Disziplinarhaf fann die zur 2 uffelärung der Sadje etro erforberliçen Berfügungen crlafien. Fr bejtimtnt jodann eine Sikzung zur mündlidjen Berbandlung, zu twelifyer
Der 2tugefduldigte vorzuladen und Der Beamte Der Staats= anmaltinaft zuzuzieljen iit.

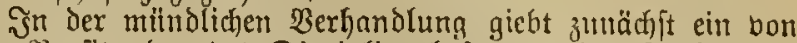

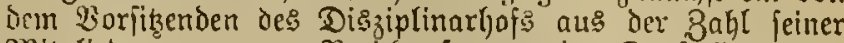
Ditglieder ernannter Rericfterftatter eine Daritellung der bis bahin itattgcjundenen, auf bie in ber Anjhuldigung: ichrift enthaltenen 2Infouldigung opunte bezüglidjer $\mathfrak{B e r}=$ handlungen.

Jim llebrigen wird nady Maß̄gabe der in den $\S 101$

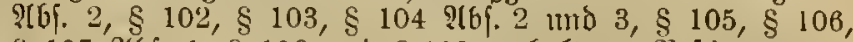
$\S 107$ \{bf. 1, § 108 und $\$ 109$ enthaltenen $B e f t i m m u n g e n$ berfahren.

§ 117. CFin anderes Rectjtsmittel, alsి die Berujung, insbejondere aud) dag Redistsmittel Des (Finfprud) (Dppo= fition oder Rejtiturion), findet im Disziplinnrberfabien nicht ftatt.

§118. Der Saifer hat bas Recht, dic von den Dis= ziplinarbeljörden berbängten Strafen ju crlaffen oder ju mildern. $\left.{ }^{2}\right)$

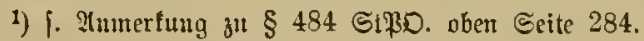

§ 119. Die Borjdyrijten Der §§ 84 bi: 118 gelten nud in

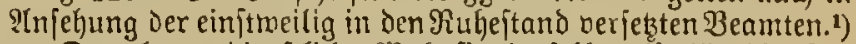

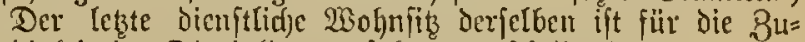
ftätroigfeit int Dişziplinarberfahien entfheidend.

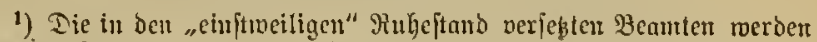
in Gegenjas ju ben it beat "Dauernoen" Pinheftano verfesten (penjios nirten) Beanten immer nod) als im Dienfte befindich angefeljen.

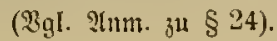

Befondere Beftimungen in Betreff Der Benten Der Militairberwaltung.

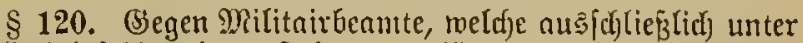
Dititnirbefehlshabern ftehen, berfügt Der tommandirende

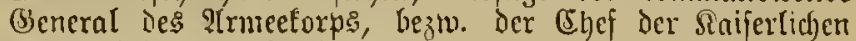

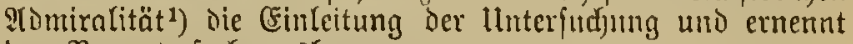
Den Borunterjud)ungsberntten.

1) Эest: Der tommanbirende Adomiral.

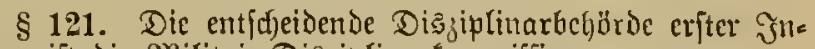
ftan ift bic Militnir=Disziplinartommiffiton.

Jü jeles Plmeeforps tritt die Militair = Dişziplinnt= fommifition am Garnifonorte des Benernlfommandos $j^{\mathrm{H}=}$

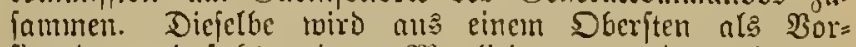
fitzenden und fedfs anderen Mitgliedent, van denen drei zu den Stabsoffijieren, 5auptleuten oder Rittmeiftern, dic iibrigen 34 Den oberen Benten Der Mifitnirverwaltung gehören müffen, gebildet.

Die Mrilitair=Disiplinartonmifitonen fïr bie Marine laben ifren Sik an den hetreffenden Marime=Stationsorten und beftelyet ans einem Rapitain zur See als Vorfitzenten uno fert) anderen Mitglicuern, bon denen drei ju bell Stabsoifizieren ber Diarine oder zu Den Sapitän=Eieutenant:, Dic jibrigen zil ben obcren Beanten der Mlarineberwaltung gehöben müfjen.

Die Mitglieder der Rommiffion werden bou ber oberịten Reichsbef̧örde ernantt.

§ 122. Die Berrichtungen Der Staatsammaltjitjajt bei Den Difitail= Disgiptinartommiffionen twerden bon Dem Salps= Muditeur, bezro. Dem Marine = Stationsanditeur twabr= genomment. Jm Behinderungsfalfe wird voul der oherften Reidsbeförde cin anderer ?luditeur mit ber Stelloertretung beallftragt. 
$\S 123$. Begen Militairbeamte fommen in Betrefi der Berfügung bon Disziplinarjtrafen, bie nicht in der Ent= fernumg aut dem 2 mte bejtehen, Die auf jene Beamten be= züglicten bejonderen Beftimmungen zur ?lumendung. Dass felbe gilt bon der ?tmtsjuspenfion aller Beamten der Dilitairvermaltung im falle des Srieges.

\section{Roften des Disziplinarverfahrens.}

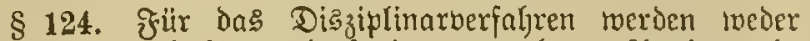
(Bebuifren, noch Stempel, jondern nur baare 2tulagen in Infate gebrad)t.

Snloweit im förmliffen Disziplinarberfahren (\$ 84) der Ingejduldigte berurtljeilt wird, ift er fdjuldoig, bie baaren

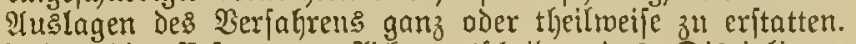
Ileber die Erjtattungsppfint ent\{theidet das Dišziplinar. (Erfenntnif.

\section{Borläufige Dienftenthebung.}

$\S 125$. Die borläufige Dienjtentlyebung eines Reict) beamten') (Suspenfion bom 2lmte) tritt traft des (Sefetzes ein:

1. wenn im geridtticfen Strajnerfahren feine Ber= haftung hejhloffen, oder gegen ilgn ein nod) nicht rechtsträftig gewordenes llitheil erlajien ift, weld)es

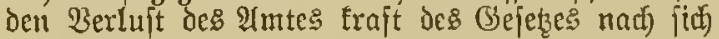
jieht $;^{2}$ )

2. renn im Disziplinarberfahren eine noch nisft rechts: träftige (Enticheidung ergangen ift, welche astf Dienjt= entlaffung lautet.

1) Die Suspenfion vom Imle ift feine Straje, fondorn eine im

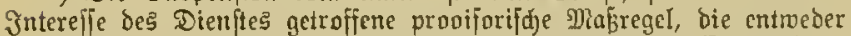

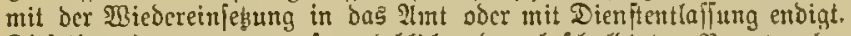
Diejelbe tritt cin, wenn fo erheblidj, ber bejduldigten Beamten be=

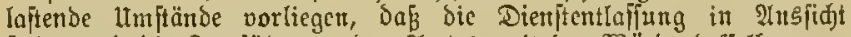

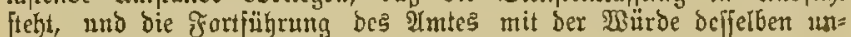
verträglid ift.

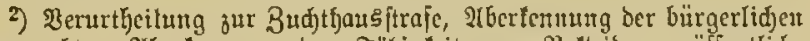

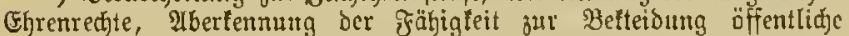

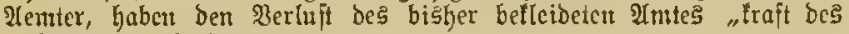
Bejepes" our folge.

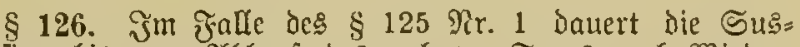
penfion bis zum Mblauf des zehnten Tages nach Wieder" aufhebung des Berfaftung sbefdilufies oder nach eingetretener

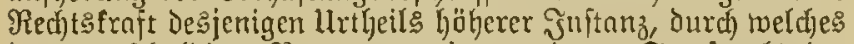
Der angefufuldigte Beamte zu ciner anderen Strafe nl: Der bezeidyeten berurtheilt viro. ${ }^{1}$ )

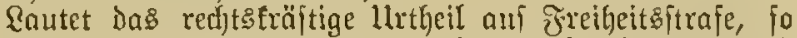
dnuert die Suspenfion, bis das llttheil nodjtredt ift. Wito

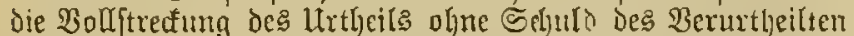
aufgehalten oder unterbrochen, fo tritt für die Beit Des Aufentbalts ober Der linterbredfung eine Bebaltatilizung (\$ 128) nicht ein. Daffelbe gilt fiir die im eriten Mbfake diefes 93aragraphen ermähnte Beit bou zehn Ingen, menn nidft bor Yblauf derjelben Die Suझpenfion bom Imte int Wege des Dişiplinaruerfahrens bejuflofien wird.

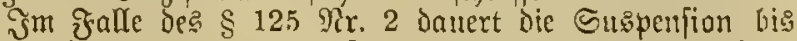
zur Rechtsfraft ber in Der Disziplinarjache ergehentien (Ent= iffieidung.

1) Rie jehntägige Frift foll einmaf verhindern, baß̄ ber Beante

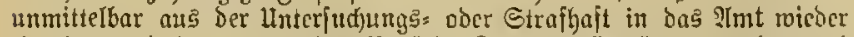
eintritt, utto banst audh ber Bebärbc Beit jut (Frruägung gcbent, ob nidjt bas Dişiplinnrperfahren cinzuleiten und $\mathfrak{A}$ tnt5juspenfion auf=

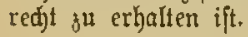

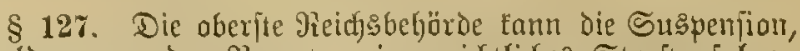
fobald gegen den Beanten rin geridytlidje: Strafberfabren cingeleitet oder bie Finleitung eines förmlichen Dişziplinar= berfalyrens (\$ 84) verfitgt mird, oder anch Demuabuit in Sanfe des einen ober anderen Berfahrens bis zur recht: fräjtigen (Entjheidung verfügen.

$\S$ 128. 2Bährent der Suspenfion des Beamten wird bom 2Lblauf des Monats ab, in welchen biejelbe berjïgt ift, die Särlte feines Dienitentonmeng inmebehalten.

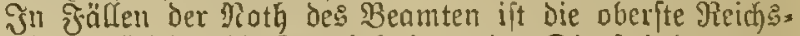
behörbe ernüb)tigt, die S̈nnebehaltung Des Dienftcinfomment auj Den bierten Iheil Deffelben zu bejchränfen.

2uf die für Dienftumfoiten befonder angejebter Beträge ijt bei Berechnung Des innezubehaltenden Theile vom Dienjt=

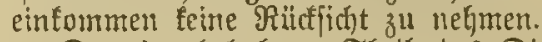

Der innebelyaltete Theil des Dieniteinfammens ift zu

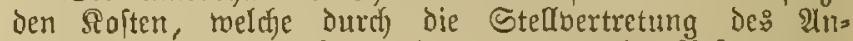
gejfuldoigten berurfadjt metien, Der etwaige Rejt zu Den Interfuchungstojten (\$ 124) ju berwenden. Sinen roeiteren Beitrag ju den Stelloertretungefoften ju Leiften ift bex Beante nidft berpf(id)tet. ${ }^{1}$ )

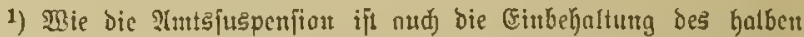
Dienftcintonmens rähteno berfelben fcine Strafe fortbern cite Sidjet=

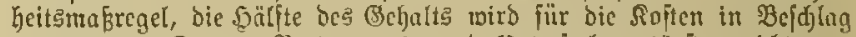

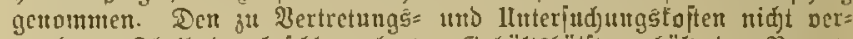
wenteten Theil ber hejajlngnahmten Bebältşhälfte crhält ber Bcante

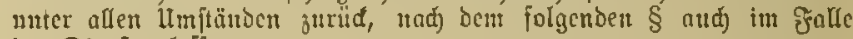
ber Dicuftentloffung.

$\S 129$. Der zu den fioften (\$ 128) rid)t verwendete Theil des Finfonmens twiro dem Beanten autfin in ient

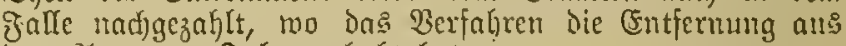
dem ?tmte jur Folge geljabt hat.

Dem Beamten ijt auf Berlangen ein Rachtweis über dic Berwendung zu ertheilen. Erimerungen gegen bie $\mathfrak{B c r}=$ wendung tö̈nnen in Rechtênege nidht geltend gemacht wetden.

$\S 130$. Wird der Bcamte ireigelprochen, fo muß jhm Der innebehaltene Ifeil des Dienfteintommens vollftändig nadjgezahlt twerben.

Wirb er nur mit einer Dronutugsftrafe belegt, fo ift ifm der intubehaltene Theil injomeit nodjujahlen, als berjelbe nicht zur Deffung ber ifgn treffenden llnterfudjumgstoften uno der Sromungeftrnfe erforterlich ijt. (Ein ?tbzug rogen ber Stelloertretungstoften findet nicft ftatt.

8 131. Wenn (Befaly im Werzuge ift, fann cinem Beamten auth bon foldten $\mathfrak{B}$ argeferzten, die feine Suspenfion zแ berfïgen nicht ermäd)tigt find, Die $\mathscr{Y}$ L verrichtmingen vorläufig unterfagt verien; es ift aber Darüber fofort an die oberite gieicfisbeljörde zu beridjten.

Diefe llnterjagung lyat eine Sïrzung Des Dienjteinfommens nicht jur jolge.

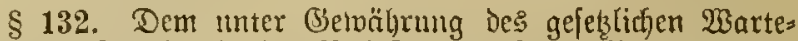
geldes einjtrueilen in den Ruhejtand nerjesten Beamten twird ein Biertel des Wartegeldes innebehalten, wenn im Dis.

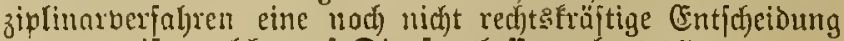
ergangen ift, melche nuf Dienjtentlafiung (autet.")

Wegen Der Radjahlung Deg innebehaltenen Theils bom Wartegeloe lommen Die Grmujäke Der $\$ \S 129$ und 130 zut ?Invendung.

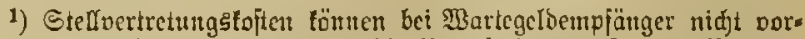

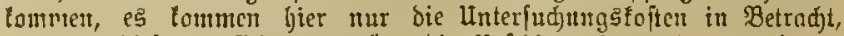
uno un biefe fu fidern gentigt die Bejhlagnahme cincs geringen Theiles bes Martegetoes. 
§ 133. 2afle nad den Beîtimmungen der $\$ \S 61$ bis 132

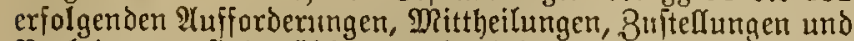
Vorladungen find gilltig und bewirken den \&anf der Jriften, wenn fie unter Beobadftung der für gerid)tlidje Jufintation in Straffadjen borgejdjriebenen formen Demjenigen, an Den iie ergehen, zugeitelt find. Die vereibeten Viermaltumg : beamten haben dabei den (slauben der Beridjt:buten.

Sat ber Ingejduldigte feinen dienftlident $\mathfrak{B}$ ohnlik ver= Iaffert, ohne daf jeine vorgejetzte Behörde Senntitis von feinem 2 ufenthalt hat, jo erfolgt die Эnfmuation in ber

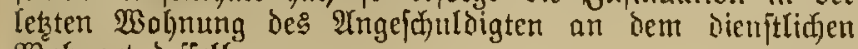
Wohnort deffelber.

\section{Befondere Beftimmungen über die Defelte Der Beamten.}

§ 134. Die Feftitellung der Defefte an öffentlidjem oder \$rioatbermögen, melde bei Reid)sfoffen oder anderen Reich)sverwaltungen entiecft werden, ift zumädfit von ber= jenigen Behörde zu bemirfen, zu beren Geidjäptsfreife die unmittelfare Aluffidst über bie Saffe ober andere Bermaltung gehört.

§ 135. Bon Diejer Bebörde ift zugleid) fejtzuftellen, $a b$

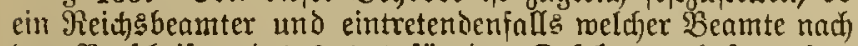
Den Voridriften des \$ 141 für den Defeft jul haften hat, und bei einem Defeft an Materialien, auf wie hod bie ju eritattende Summe in Belde zu beredjnen ijt.

$\S 136$. Ebenjo (\$§ 134 uno 135) bat die unmittelbar vargejetzte Behörde die Defette aut joldjem öffentlidhen oder

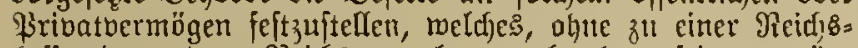

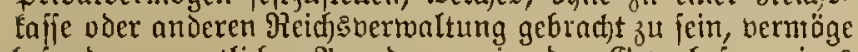
bejonderer amtlidjer ?tnorbmung in den Serwahrjam eines Reidjberamten gefommen ift.

$\S 13 \%$. Heber der Betrag des Defefts, die Berjon des jum Erjałz berpflidjteten Beamten und den Brumo jeimer Berpftidytung ift von ber in Den $\$ \$ 134$ und 135 bezeid)neten Behörde eill motivirter Befd Luß abjufaffen.

§ 138. Nach Sefinden der Umftände fann die Behöride auch mehrere Beich] üffe abfalfen, wenn ein Theil des Dejett: fofort Elar ift, der andere Theil aber nad) meitere (Ermittes lungen nothmendig macts, ingleid)en, menn unter mehreren Berfanen die Berpflidfung der einert feiffteht, die der anderen nod) ztweifelhaft ift.

§ 139. Şat die Behörde die Eigenidjaft ciner höheren

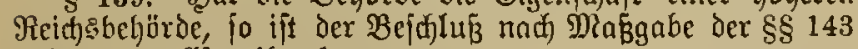
แni) 144 volfitrectbar. ${ }^{1}$ )

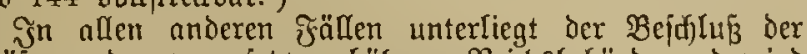

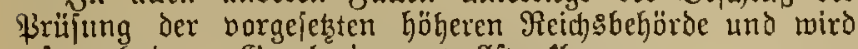
erit rach beren Benchmigung bouptrectbar.

Bon Dem Beidlulje ift Der oberiten Feidsbehörde tII= vergüglich Renntniß̈ zu geben.

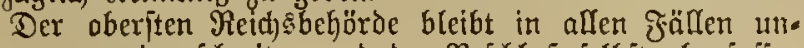

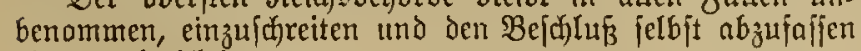
oder zu beriditigen.

1) $3 u$ ben "höheren Reidsbehörben" gehören bie Ober = Bojte

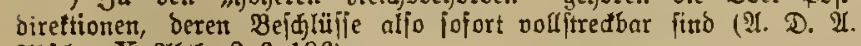
2tbid)m. X 2bth. 2 \& 196).

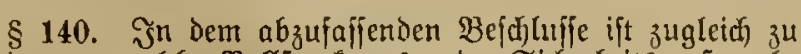

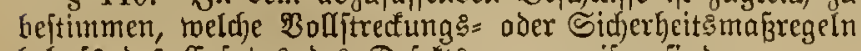
hehufs des Erjatzes des Defetts zu ergreifen find.

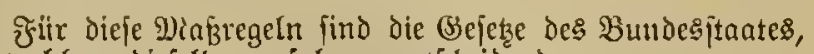
in weldjem diefelben erfolgen, entiheidend.

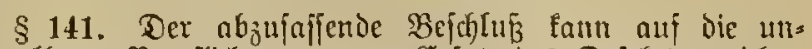
mittelbare $\mathfrak{B e r p f l i d}$ tung zun Erjats des Defefts geridtet twerten:

1. gegen jeden Benuten, weldjer der Unterfidlngung al Thäter oder Theilmefymer nach) der Heberzetgung der Reidsobljörde itberfitgrt ift;

2. a) gegen dicjenigen Beamten, reldjen dic Siffe 2c. zur :ermaltung übergeben toar, und zwar auf \$ölje des ganzen Dejeftes,

b) gegen jeden anderen Beamten, der an der Einnahme oder 2tusgabe, der Erhebung, der Iblieferung ober ben Iranzport bon Rafien= geldern odex mioren (Begenjtätrden vermöge ieiner bienftlidjen Stellumg theilzunehmen hatte, jedonf nux auf Şöhe des in feinen Gemahrfam gefommenen Betrages,

jofern der Defeft nad) der lleberzetigung der

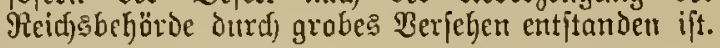

(5éten bies gilt gegen bie int $\$ 136$ genannten Beamten in Den Dafelbit bezeichweten §ällen.

\$ 142. Sino 3enmte, gegen beldhe die juangsiveife Sinziehurng des Dejelt: bejdloffen twird, in der Berwaltung ibres Imtes, wojitr fie cinc 2luttatantian gejtellt ljaben, be= lafien morben, fo foben biejelben toegen Erjatzes des Dejefts andermeite Sidjerheit z"leiftell. Erfolgt die Sicher=

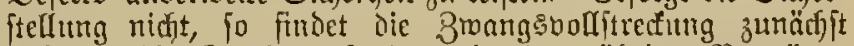
nidyt in bie Snution, fontern in das übrige Sermögent jtatt.

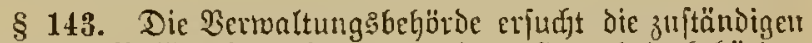
(B)erid)te, Bolftrectungsbeamten oder \$ypothetenfehörden

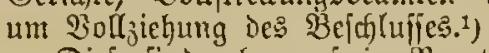

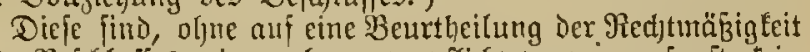
Des Befdilufies eitzugehen, berpflidjtet, wemn foujt feit 2Injtand obrwaltet, fallemig, ahne vorgängiges Bahlung:

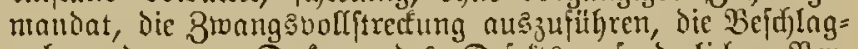
nahme Der zur Decfung des Dejefts exforderliden $\mathfrak{B e r}=$

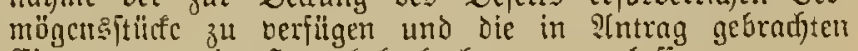
(Fintragungen im Sypotbefenbudje ơ veranlafier.

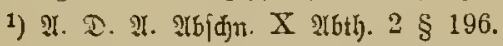

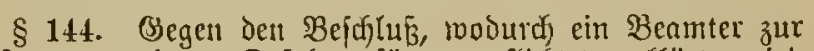
(5ritattung cines Defefts für verpflichtet ertelärt mird

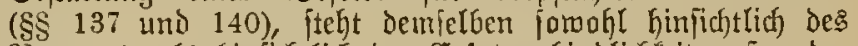

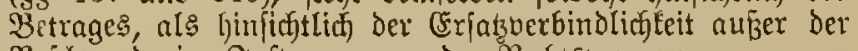

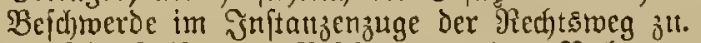

Dic frift zur Beja)reitung Des Redtęmeges beträgt

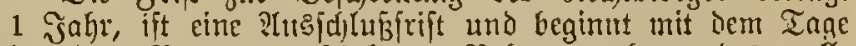
der dem $B$ cauten gejdehenen Befanntmadung des voll= ftreefbaren Sicjhluffes, oder went der Beamte an feinem Walnort nicft ju treffen ift, mit Dem Iage de abgefaß̧ten

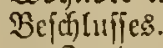

Jn Deni auf die Rlage des Beamten entftandenen Rechts: frreit hat bns (Seridgt über die Wanlyrheit der thatjädflid)en Bebauptungen Der \$arteien nach feiner freictn aus dem

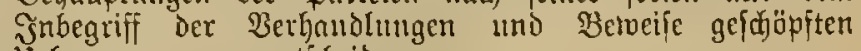
Heberzeugung zu entid)eiden.

$\ldots 1$ )

Sob einer \$artei über die Waljrheit oder Untalyrheit einer thatfäblidjen Behaulptung nod ein (Eid aufauerlegen, bleibt den Ermeffen des Seriats iiberlaffen. 
Itt Der Inegent Dis Defefts etro cingelciteten linter= furfung bleiben dem Beamten, injofern c⿱ a a die Beitrajung

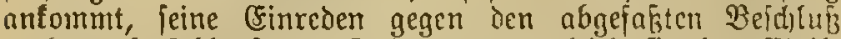

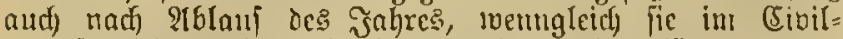
prozé nidjt mehr geltend gemad)t werben tönnen, bor= behalten.

1) Der $\S 13$ bes Befeteses, betreffend bie CEnfïhrung Der (હ)O. v. 30.11877 beftimmt:

Itufgehoben merben: $2 c$.

"5) § 144 ILF. 4 Des Bejęes, betreffend die Rectitsuer. hältniffe der Heidsbeamten, v. 31. 3. 1873.

\$145. Das Berifft hat auf Intrag des $\mathfrak{B}$ eamten

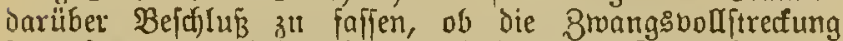
jortzufezen oder einjtmeilen cinzuftellen jei. Dic einjtmeilige Einftellung exfolgt, menn ber şeamte glaubhaft mad)t, baf

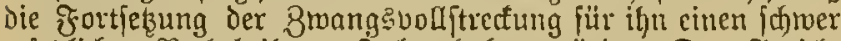
eriezlidjen Radtheil zur Folge haben mürde. Das Bsericft ift jebod) verpflidftet, falls es bic (Finftellung Der Brwangs= volfitrefting beroronet, an Stelle derfelben auf Sutrag ber

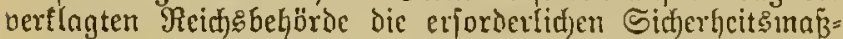
regeln behuje Des (Exjałes des Defefts herbeizuführen.

\$ 146. Wenn cine mafe und dringende (Befalje nat= handen ift, Dafis ein Beaunter, gegen welchen dic Bmangs=

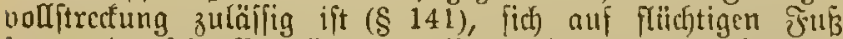
feben oder jein Wermögen der Bermendung zum Erfał bes Defefts entziegen werde, jo faur dic unutittelbar vorgejebte Beljörde, aud) wenn fie nicht bie (Figenjdjaft einer höheren

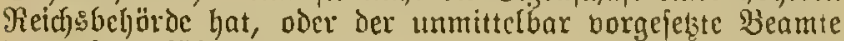

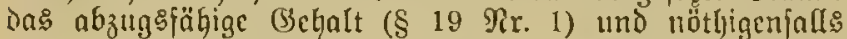
הas übrige benegludje Bermögen tes im Eingange bezeid = neten Beamten vorläufig in Befchlag nclymen.

Der vorgefekten höheren Reichsbeljörde ift ungefüumt 2rrzeige dabon zu madjen und beren Benehmigung eill= jutholen.

§ 147. Şt vout den vorgefekten Belgörden oder Beamten gemän \& 146 cine Beichlagnahme crfolgt, fo hat tos (seridft, in deffen Bezirf die Bejdlagnalume ftattugfnnion hat, auf SIntrag Des van derjelben betroffenen Beunten an= zuoromen, Daj bimen einer zu beftumendet Frift ier in

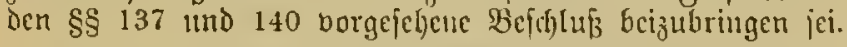

Wirt Diefer Inoromung nidjt Folge gelciftet, fo ift auf weiteren IIntrag bes $B$ camten die Beichlagnahme fofort aujzuheten, anderenfalls toumen die Beftimmungen des \$ 144 zur 2trmendumg.

§ 148. Für ถas Defeftenverfafren im Bermaltungsmege rerden Giebiibren und Stempel nidjt bereffut.

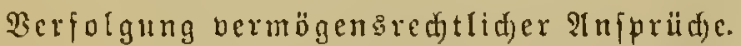

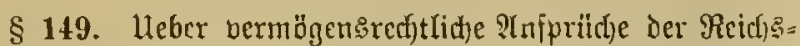
beamten aus ifrem Dicnituerbältnis, inghejondere über ?[n= \{prüdje auf Bejoldung, $\mathfrak{B}$ artegeld oder Fenfion, fotvie über bie den Sisterbliebenen der Reidfsheamten gejeblidg gee

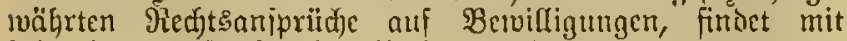
jolgenden Maǵgaben Der Recjtsmeg ftatt.

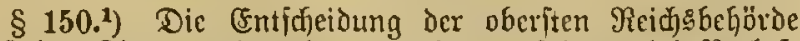
mußB Der אlage vorhergehen uno Iekctere fodann bei Berlujt ics Slageredits innerhalb 6 Dionaterl, nadjent icis $\mathfrak{B} e=$ theiligten Die Entfacidung jencr bichöroc befunt gemacht tworben, angebracft merden.

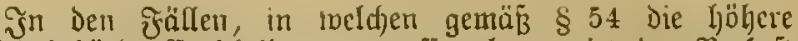
Reid̄sbehöroce (Entfcheidung getroffen hat, tritt der Berlujt ies Slagerechtes aud) barn cin, menn nidyt bon bem $\mathfrak{B} \mathfrak{e}=$ theiligten gegen Dicic (Entidheidung binnen gleidjer Frift dic Bejdyerde an Dic oberjte Reidjebeljörde erhoben ift.

1) \$rb. 2 zugefügt burd bas bejeł v. 25. 5. 1887.

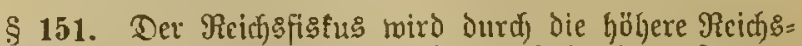
behörde, unter meldycr Der Reidfebeamte ftelt odcr geitanden hat, oder falls er direft nuter Der oberiten Pieidjobebörde fteht oder geftanden hat, Durd bic oberfte Reichsbeföroc bertreten.

Die Slage ift tei demjenigen (Beridjte ${ }^{1}$ ) anzubringen, in deffen Bezirfe die betreffende Bebörbe ifren Siz hat.

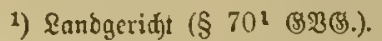

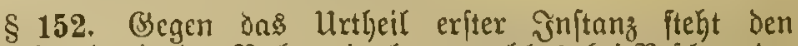
Barteien dasjenige Rechtsmittel zu, weldje: bei $\$$ Bejd)merde: gegenftünden nom hörfften Werth ftattfindet. Y(uef) die $\mathfrak{T}$ M.

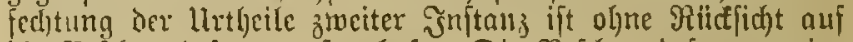

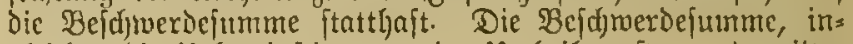
gleidyen die llebercinftimmung der Urtbeile erfter utt jwiter Jultans fommt nut infomeit in Betracfit, als dabon die (Fnt= (d)eidung Der Jrage nbhängt, weld)c: bon mehreten nad) den Eandesgcjeben etiva zuläfígen Reç)tsmitteln itattfindet.

DaE Reid) $=$ Dherhardelsgericft ${ }^{2}$ ) entf(heidet an Stelle

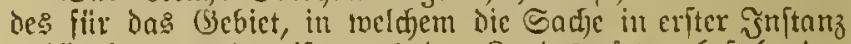
aubängig getworden ift, mad) Den \&andesgefetzen bejtchenden oberften (S)erichtshofes, und zwar in letzter Juftanj. Soweit nid)t ?6f. 1 Des̆ gegenmärtigen Saragraphen abrueidjende Borfdriften enthält, werden die Beitimunurgen des Befezes, betreffend die (Errid)tung eines obcriten Beridtshofes fïr 5andelşjact)en, vom 12.6. 1869, fomie Die Frgänzungen bejjelben auf Die im $\$ 149$ bezeicf)neten bürgerlicfen Rechts: jtreitigfeiten ausigedefint.

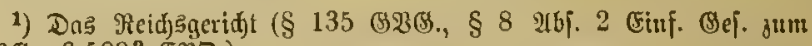
अख(G., § $509^{2}$ 巨शD.)

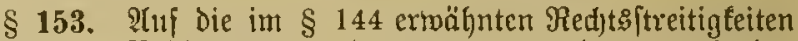
finden Dic Beftimumungen Der $\S \S 151$ und 152 mit ber

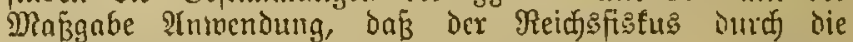
höhere Reidgofeförbe vertreten wird, weldje Den Defeft=

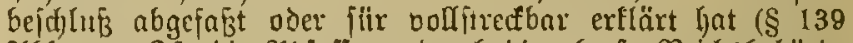

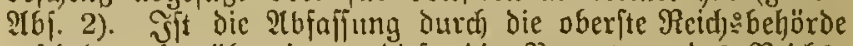

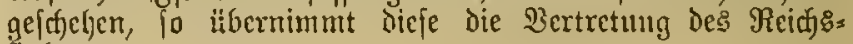
fịfuล.

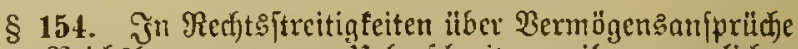
gegen Reidfgbeamte megen lleberjd)reitung ifrer amtlidjen

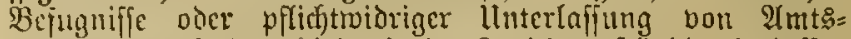
handutugen ift fowohl Dasientige (Berid)t zultändig, in befien

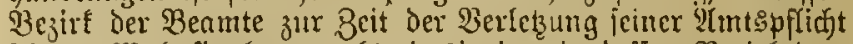

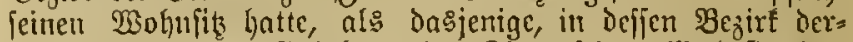
jelbe zu Zeit Der Erhebung Der Rtage fcinen Woljnitz hat.

Die Buläffigfeit Der Recffismittel, die Zulftändigfeit des

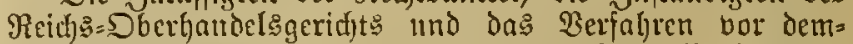
felben ridjten fich nach) den im $\S 152$ gegebetten 30 ifdriften.

§ 155. Die (Entfd)cioungen dex Disziplinar= und $\mathfrak{B e r}=$ raltungsbehörden darüber, of und von meld)em Zeitpuntte

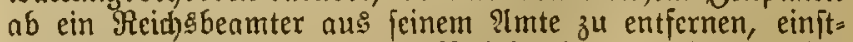
meilig oder definitib in Den Rubeftano zu verfeksen, ober vorläufig feines Dienjtes ju entbeben fei, und itber bie Berljängung oon Dromungşitrafen find für bie Beurthcilung der bor dem (Berichte gel tend gemad)ten vermögens rechtlichen ?ruiprït) majagebend. 


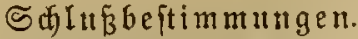

§ 156. Die Reidjstagsheamten haben die Rechte und Pflichten Der Reidjsbeamten.

Die Anftellung der Reidfstagşbeamten exfolgt durd)

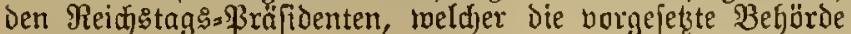
derielben bildet.

$\S 15 \%$ : 1 uf \$erjonen des Soldatenjtandes findet diefes Brefetz nur in den $\$ \$ 134$ bis 148 ?trmentung.

\$ 158. Die Beftimmungen diefes Befezes itber bie Verfetzung in ein anderes ?tmt, liber dic eimitweilige und

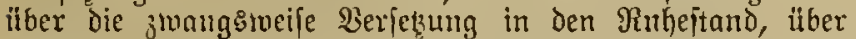
Dişipfinntheftrajung mb iiber vorläufige Diententbibung

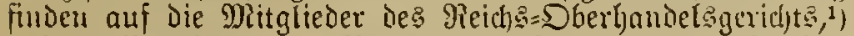
auf die Mitglieder bes Bunvesant? für bas Sgeimathmefen, auf die Mitglieder des Redjumgshofes bes Dent|chen Reid) menoung.

Thferdem baben fïr Dit Mitglieder Des Reid

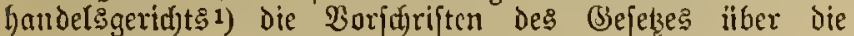

\$enfionirung und über den Berluft der ßenfion feine Geltung.

1) Bgl. Itnu. 1 ju $\S 152$.

§ 159. Die Aftsfithrung diefes (bejetzes regelt eine Dom Snijer zu exlaffende Beroxduung, burd) weldhe namentlidf biejenigen $\mathfrak{B e h o ̈ r d e n ~ n a ̈ l j e r ~ з " ~ b e z e i d y n e n ~ f i n d , ~ m e l d h e ~ u n t e r ~}$ den in dicjem Gejeke ermäljten Reidjsbejörden veritanden jein jollen. ${ }^{1}$ )

litfundtidy $2 \varepsilon$.

(Begeben Berlin, Den 31. Diärz 1873.8)

1) (Es gehören:

a) zu ben oberften Reidjsbeförden:

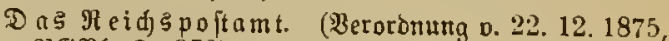

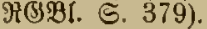

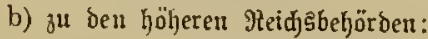

Dic Dber= Bofticeftionen (खeroromuth nom

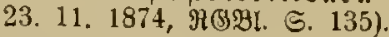

2) Das Bejeb ift am 11. 4. 1873 Dertündet worben und an 18. 4. 1873 in $\Re$ raft getreten.

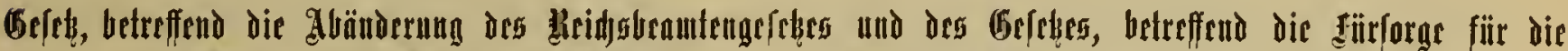

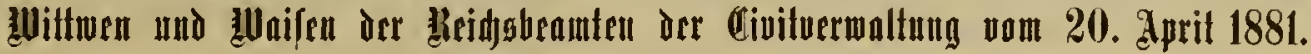

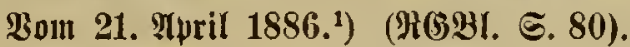

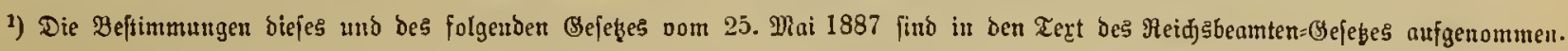

Ixt. I. Sinter \& 34 Des Reid)ąbenutenge[ebes vom

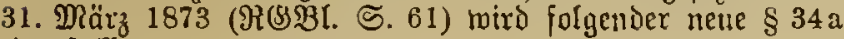
eingeftellt:

Bei denjenigen aus den Dienfte juheidenden Beamten, meld)e das fünfundfectsjigite Rebensiahr bollendet haben, ift eingetretene Dienjtunjähigfeit nidjt $\mathfrak{B o r}=$ bedingung des 2 (n)pruct)s auf $\mathfrak{B}$ enfion.

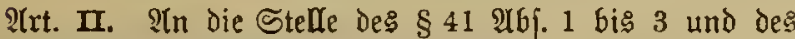

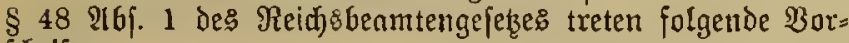
idj)rijten:

\section{$\S 41$.}

Die ßenIion beträgt, wenn die Berieksung in Den Rubeftand nad, bollendetem zehnten, jedod, vor boll= endetem elften Dienjtjahre eintritt, ${ }^{15} / 60$ und fteigt von da ab mit jedem tweiter zurücfelegten. Dienftiahre um $1 / 60$ des in Den $\$ \S 42$ bis 44 beftimmten Dienjt= einfommens.

Ueber Den Betrag bon $\mathbf{4} / 60$ diejes Cinfommens hinaus findet eine Steigerung richt flatt.

In dem int $\S 36$ ermähnten ₹alle beträgt die

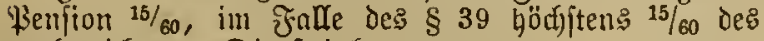
borbezeid)neten Dienfteinfoumens.

\section{$\S 48$.}

Die Dienftzeit, weldje bor den Beginn des ein= undzmanzigiten Sebensjahres jält, bleibt außer B̉es rectinung.

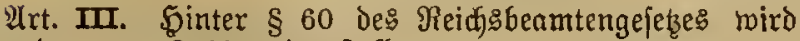
folgender neue $\$ 60 \mathrm{a}$ eingeitellt:

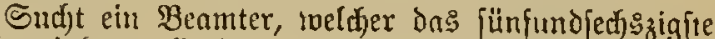
Rebensiahr bollendet hat, peine Berjęuma in den

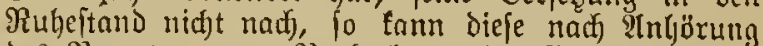
Des Beamten unter Beobadjtung ber Boriduriften ber §§ $53 \mathrm{ff}$. in der nämlid)en Beije berjügt werden, wie twenu Der Beamte feine Benfionirung felbit benutragt hẩtte.

Art. IV. Den Beamten, welche in Der Beit nom

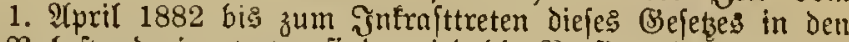
Rufeitand eingetreten find, mird bie Sienfion, den Wittwil

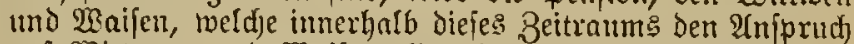
auf Wittmen = und Waifengeld erlangt haben, das Wittwen= und Waijengeld vom 1. T(pril 1886 nad) Maß̧gabe bes Itrtifels II Diejes Gejekes exhöht.

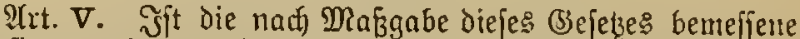
Benfion geringer als die Penfion, weldye dent Beamten hätte getwälyt berden müijen, wenn or am Tage vor dem J̄nfraftreten diejes (Bejeßses nad) den bis dahin für illn geltenden Beftimmungen penfionirt worden wäre, fo wiro diefe lebstere ßenfion an Stelle ber erfteren bemilligt.

2) VI. Diefes Befetz tritt mit dem Tage fimer $\mathfrak{B e r}=$ filnoung in sirajt. ${ }^{1}$ )

1) Dos Befé ift am 28. Stpri! 1886 verkündet roorden.

Ifrt. VII. Diejes Bejer findet auj dic Mitglieder De: Reiffigerichts feine Inmenoung.

Urfundlich ze.

(3)egeben Berlin, den 21. April 1880. 


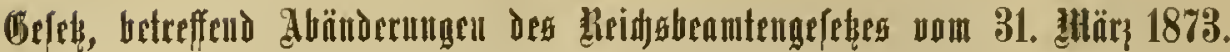

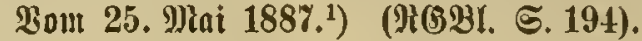

1) Bgl. Inmerfung zutn voritehenoen Bejebs.

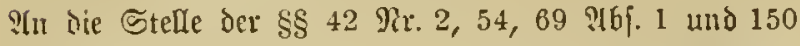

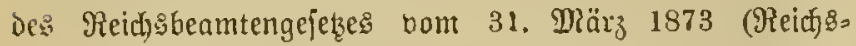
(3) ejetzbl. (5. 61) treten jolgende Vorjidriften:

\section{$\S 42 \Re \mathrm{r} .2$.}

Diemftemolumente, weldhe ilyer Ratur nad iteiģend und fallend find, werden nad Den in ben Befoldungs. etats oder fonft bei Berleiljung bes ßechts auf die Cmolumente Deshalb getroffewen Jeitieksungen und in

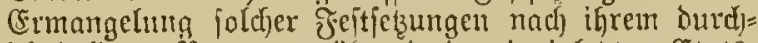
[chnittlichen Betrage mäl)rend Der drei leżten (Etatis jahre bor dem (Ftatsjahre, in weldhem die Henfion jeftgejetzt wird, zut ?turedjumug gebrad)t.

\section{$\S 54$.}

Die Beftimmung onrilber, of und zu reldyem

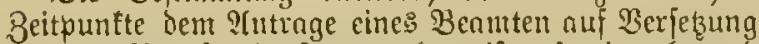
in ben Piulseftanto itattzugeben ift, jolvie ob und roeldie Benfion Demielbcu zuiteht, erfolgt Durdh die oberite Reidjgbeljörde, relche die Befugnif́ zu foldfer

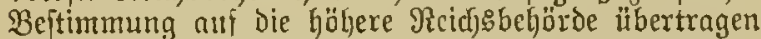
farn. Bei Deujenigen Beamten, weldje eirte Raijer= lidje Beftallung erhalten haben, ift die Benebmigung

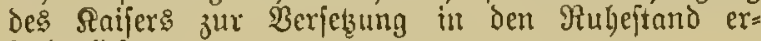
forderlich.

\section{$\S 69 \mathfrak{I b}[\mathfrak{a b} 1$.}

Sinterläßst ein ßenjionair cine $\mathfrak{B}$ ittwe ober ehelidje Madjtommen, io roird bie \$enfion nod) fïr ben auj den Sterbemonat folgenden Mionat gezahlt. ") wen bie Bahlung erjolgt, beftinmt die oberite Reidjs: behörde, melche die Bejugníz zu foldfer Bejtimmung alif die ljöhere Reichabehörbe ibertragen tamn.

\section{$\S 150$.}

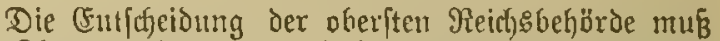
Der Rlage borbergeljen uno lebtere fodaun bei Berluit des Silagered)ts innerfalth jedjs Monaten, nadjoent bem Betheiligten die (Entfojeioung jener Behöró befannt gemadjt morden, angebracht werdelt.

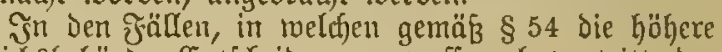
Meidshejörde Entjacidung getroffen hat, tritt ber Berluft des $\mathfrak{A}$ lagerecht: aud dann ein, wenn nid)t bon bem Betbeiligten gegen bicfe Entffyeidung bimmel

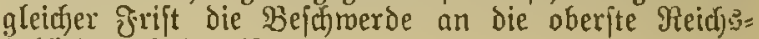
behörde erhoben ijt.

Utrfundtich $2 e$.

(Siegeben Berlin, Den 25. Mai 1887.'1)

1) Dns Befes ift an 2. Juni verfünbet worben, am 16. Suni 1887 in Sraft getretest.

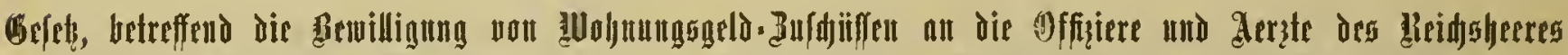

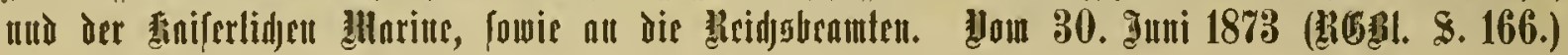

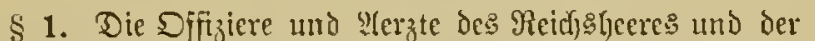

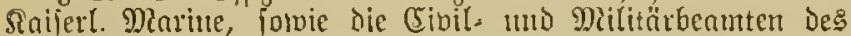
Reiches erhalten, menn fie ibren bienftliden 20 ohnitis in Deutfifland haben, cine etatgmägige Stelle befleiden und

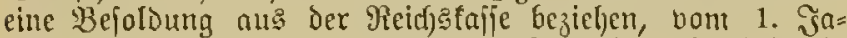

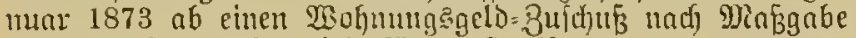
des in bicjem Bsejebe beigejügten Tarifs.

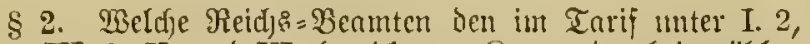
IJ. 2, III. 2, V. und VI. bezeidjneten Sintegorien beijuzählen Find, wird in Den Salfen 1873 unto 1874 Duref Raiferl.

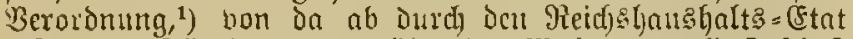

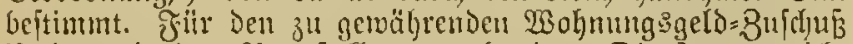
ift der mit der ?Imssitelung verbundene Dienftrang, nidht Der cinem Beamten etma perjönfid) beigelegte ljöbere Rang maß̧gebento.

1) folgt unten S. 690 .

§ 3. Jür die Cintlycilumg Der Drte in Servistlajjen, auf weldje der Tarif Bezug nimmit, ift bis 3 th andermeiter

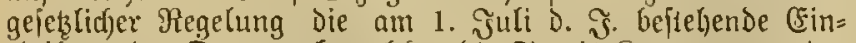
theilung Der Srte, nach meldjer die Eetris:sompetenjen der MRifitär=\$erionen bemejfen twerden, mafzgebend. Bei $\mathfrak{B} e r=$ änberultgen in ber Slaffeneintbeilumg tommt von demt auj die Rubrifation Derfelben jolgenden Ralender= Duartale $a b$

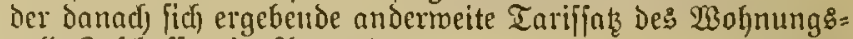
getr. Zufduffes in Thmendung.

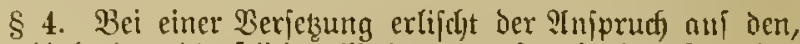
Dem bisherigen Dienjtlidjen $\mathfrak{B}$ ohnort eutiprectjenden Sntz bes

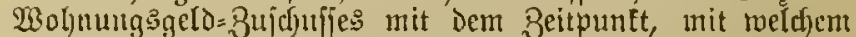
ber Bezug Des (Siehalts der bisherigen Dientittelle aufgört.

Soat Die Berfekung an eimen Drt, weldyer zu einer nieorigeren Servištlaje gehört, eine Berminderung Des B3olyung

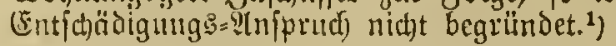

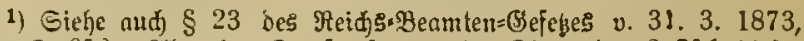
oben 5.658 . 2tls eine Strafoeriegung im Sinne bes $\$ 751$ biejes

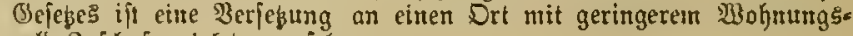

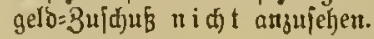

§ 5. Difiziere, ?lerzte ober Beamte, tweldje melyr als

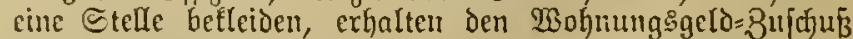
mur ein Mal, und jwar für biejenige Stelle, weldhe auj den Göchptet Sals ?Infpruch gicbt.

§ 6. Wirb eine Befoldung theils ans Reichsmitteln,

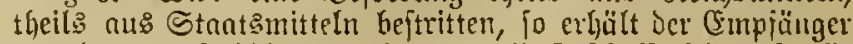

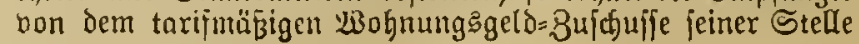


(§ 1) nur eine Dem auf die Reidfstafie ïbernanmenen Befoldungstheile entipredjende Duote.

§ 7. Difizieren, Ierzten und Beamten, weldje eine Dienftrohnumg inne baben aber anjtatt derfelben eine ifnen befonders bernifligte Miethsentichäbigung bejiehen, wird der

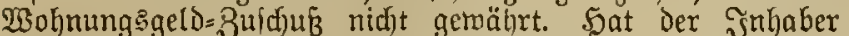
einer Dienjtmoljunng eine Mietljşergütung zu entridten, fo mird die Iez̧tere bom 1. Sanuar 1873 ab fomeit erlaffen,

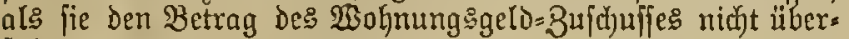
fteigt.

§ 8. Bei ₹refftellung ber Unzuggfoften= Bergütungen

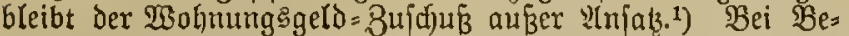
meffung Der Sienfion twird der Durchidynittsfatz des $\mathfrak{W o h}=$

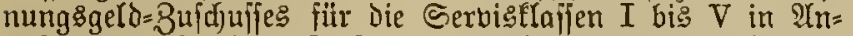
rectunung gebracht. Diejer Sas gilt aud jür biejenigen Dffiziere, Uerzte und Beamten, weldje eine Dienftmohnung inne haben, oذer eine Miethgsentfdyäbigung (\$ 7) beziehen.

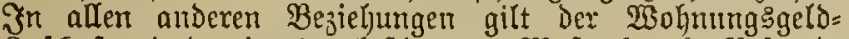
8ujajuß mit der im § 4 beftimmten Maßjgabe als Bejtand= theil ber Befoldung.

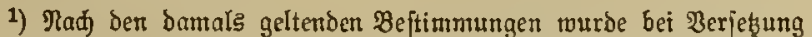
in ein 2 mt mit größerem Eirtommen bie Sälfte ber jährlichen Ein

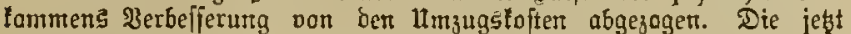

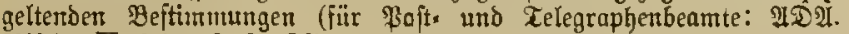

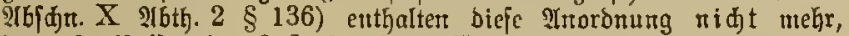
der erfte ßafius bes $\$ 8$ ift aljo hinfälig geroarben.

§ 9. 2Uuf Die Beamten der Reid) findet diejes Befeb leine Intwendung.

Urfundtich $2 \varepsilon$.

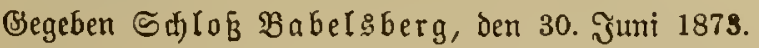

\section{(1) a if.}

Bezeidumy ber Ehargen

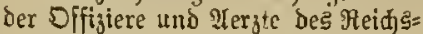
beeres utio ber Raiferlidien Marite,

fomie ber Rategorien ber Reidjbeamten.
Iabreabetrag

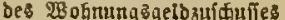
in ben Drten ber Serbistlafie:
I. 1. Didifion $5=$ Sommanbeure, Brigabe = Romtmandeure uno Dfriziere in Dienjt= Itellungen biefes ßanges, Mtarinte Stations = Chefs und Ilomirale fomie ber (B)eneral : Stabsarzt ber Irmee

2. Direftaren ber oberften ReiçGbebörben . . . .

II. 1. Ctabsoffiziere mit $\Re_{e}$ giments : Rammandeur. Rang, Rapitäte zur See, Senerals?lergte . . .

2. Bortragende अäthe ber obcriten ßeidjbehöben .

III. 1. Stabsoifiziere, Rornetten= Sapitünc, §ouptleute ( titt= meifter), Siapitän= Sieute= nants, Dbar = Stabsärzte, Stabsärzte

2. Witglicber ber übrigen

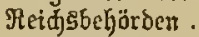

IV. Sieutenants unb 2 [fffteng= Ierzte . . . . . 140

V.

VI.

Subaltern.Deamte.

unterbeante

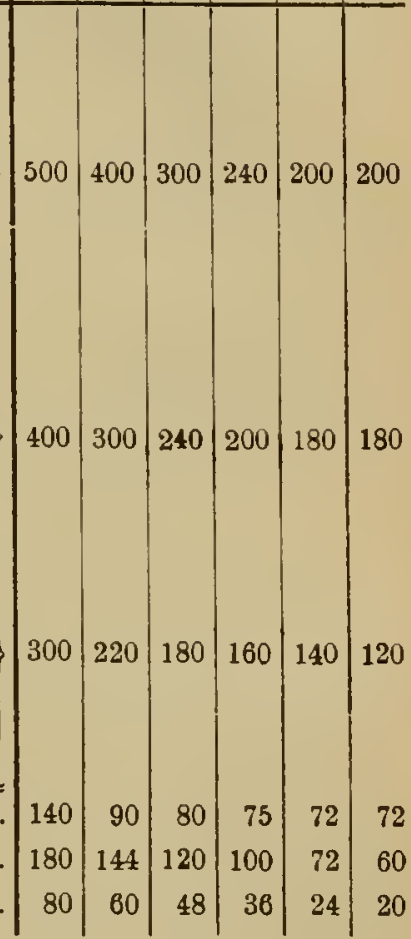

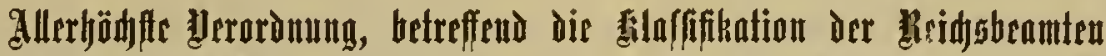

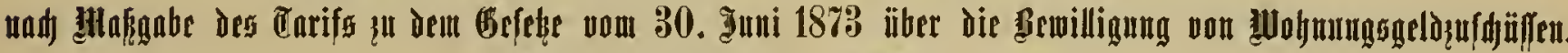

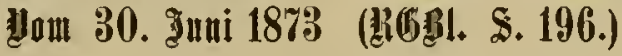

\section{Einziger $\mathfrak{A}$ rtifel.}

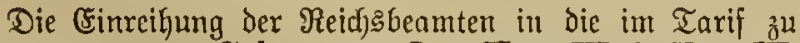
Dem vorgenannten Sejeke unter I. 2, II. 2, III. 2, V. u. VI.

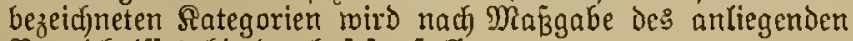
Verzeidinifies hierdurch jeftgeitellt.

Urfundlid) $2 \epsilon$.

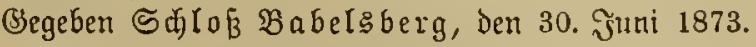

\section{Direltoren ber oberften Meidabläb̈rben.}

6. Beneral= $B$ oftoireftor.1)

7. Beneral= Telegraphen=Direftor.1)

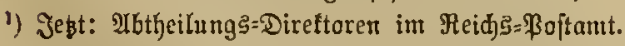

II. Bortragenbe Räthe ber oberifen Meidjąbłörben.

G) \$so ftuermaltung:

1. Vortragende Räthe beim General=\$3ojtamt. ${ }^{1}$

2. Sber=? oft Direftoren.

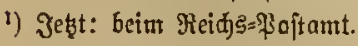

Botl, Sammlumg von (Befeser ac. f. \$oft u. Relegr.
III. Mitglieber ber übrigen Meidgobehörden.

H) Roftuermaltung:

1. Sber=\$Softräthe und Bopträthe.

2. Baurath beim (Seneral= Boitamt. $\left.{ }^{1}\right)$

3. Seheime expedirende Sefretäre und Saleula= toren, Sseheime Regiftratoren uno Sanzlei= Direftor beim (sieneral= $\$ 30$ [tamt. ${ }^{2}$ )

4. Rendant und $\mathfrak{B}$ orjtefrr des Boft= Beitung samts.

5. Fnipeftor des \$Boit=3eitungsamtes.

6 . Direftor des \$3oftzeugamtes.

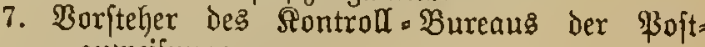
ammeifungen $2 e$.

8. Boitoireftoren. ${ }^{3}$ )

9. Foftinfpeftoren.

10. Rendanten bei den Dber= \$ofttaffen.

1) Dafür jebt: Die \$aitbauräthe bei ben Ober=\$oftstrettionen.

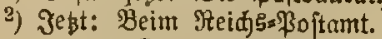
Daju getammen:

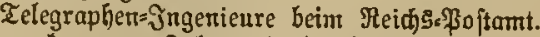

3) Dazu gefommen: Telegraphentireltoren. 
IV. Subalternen.

H) Pojtoerwaltung:

1. Beheime Ranzletfecretaire beim Benetal = \$oft= amtc. ${ }^{1}$ )

2. Regiiptratur u. Sanzlei=\$lffititenten beim (B)eneral= Poftainte. ${ }^{1)}$

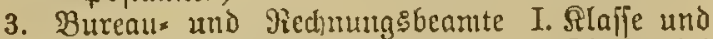

4. Bureau= uno Red)nungsbeamte II. Slaffe bei

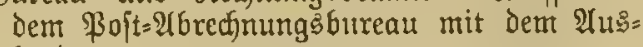
lande.

5. Sontrolleur,

7. Siaffrer,

8. 2⿺ffiftenten,

9. Bureau= und RedinungşGeamte

10. Desgl.

11. Ranzliften

I. アlaffe

II. Slaffe $\}$ Boft=

12. Buchialter, )

13. Raffirer, $\}$ bei ben Dber=\$opttaffert.

14. Siaffirer Gei den Dber= ßoftanftalten. ${ }^{3}$ )

15. Expeditions=:Borfteher bei größ̈eren Poftämtern (Dber= $\$ 30$ ft fecretaire). ${ }^{\circ}$ )

16. Borfteher der $ß$ oftucrmaltungen (\$oftmei[ter), 5 )

17. \$oft jecretaire.

18. Secretariats. IIffiftenten.6)

19. Borfteher von \$oft=Erpeditionen (\$oft= Erpe= bitelire. ${ }^{7}$ )

20. Bojtamt:

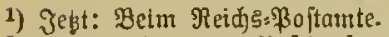

2) Daģu getommen: \$oftbaufecretaire.

3) Dber=98oftanjtalten giebt es nidjt mehr.

Dafïr jebt: Raffirer bei ben \$oftämtern und Telegraphenämtern I.

4) Die Bezeidnung "Erpebitions=\$orfteher" für bie Ober-\$oft= iecretaire ift in 2 egfall gefoument.

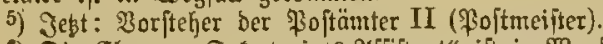

6) Die (Sharge "Eelretariats=2ffiffent" ift in $\mathfrak{M e g}$ fall gelonmen.

7) Эest: Morfiteher ber \$oitänter III (

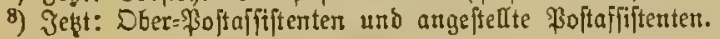

\section{I) Telegraphenberwaltung: ${ }^{1}$ )}

7. Telegraphenfecretaire. ${ }^{2}$ )

8. Dber=Telegraphiften und Telegraphifter. ${ }^{3}$ )

9. Telegraphen=(3eljülfinnen (imt Groß̧herzogthum Baden). ${ }^{d}$ )

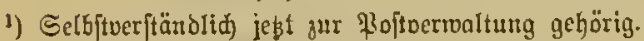

2) Dazu: Dber-Telegraphenfecretaire.

3) Jest: Dber-Telegraphenaffifterten und Telegraphenafiiftenten.

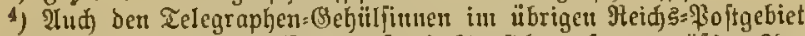

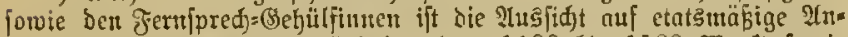
ftellurg und Degurg eintes (Segaltes (von 1100 bis 1500 MRart) forvie

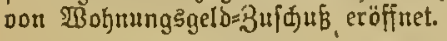

\section{$\nabla$. Unterbeamte.}

\section{H) Poftbermaltung:}

1. Die Saltellane, Botenmeifer, Sanzleidiener, Fortiers, Sausdiener 2c. Beim Reirfispoftamt.

2. Dic Unterbeamten bei den Dber= \$oft tirettionen.

3. Briefträger im $D_{1+t}=$ Brici= und Telegramm= Beftellungsdienjt.

4. Boftichaffner im Bacfetbeftellungsoienjt, im inneren Dienft und im Begleitungedoienjt.

5. Sandbriefträger.

6. Angeftelfte Seitungsauffeher. ${ }^{1}$ )

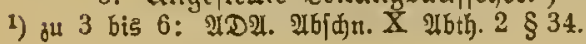

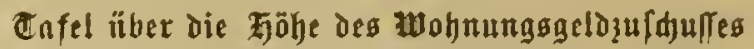
für Beante

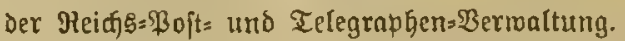

\begin{tabular}{|c|c|c|c|c|c|c|c|}
\hline \multirow[b]{2}{*}{ 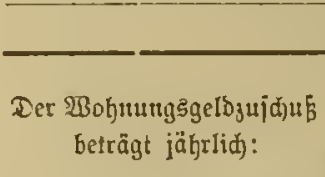 } & \multicolumn{7}{|c|}{ ¡̈̈r die Eervistlafie: } \\
\hline & $\begin{array}{l}\text { A. } \\
\text { TRt. }\end{array}$ & I. & $\begin{array}{l}\text { III. } \\
\text { 9R: }\end{array}$ & $\begin{array}{l}\text { III. } \\
\text { IRt. }\end{array}$ & $\begin{array}{l}\text { IV. } \\
\text { פt. }\end{array}$ & $\begin{array}{l}\text { v. } \\
\text { me. }\end{array}$ & $\begin{array}{l}\text { Durdidgnizt } \\
\text { ber } \\
\text { Alafien } \\
\text { I bis Vי) } \\
\text { פit. }\end{array}$ \\
\hline
\end{tabular}

1. [ür Ibtheilungs=Diret: torent in Meids $5=$ \$olt. amte (I. Fategorie)

2. Fïr bic Dortragenden

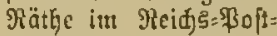
aut formie für Dber= \$optoite?toren (II. Sia. tegorie) . . . . Pojträthe, \$oftbauräthe, Poptoireltoren, Tele. graphendireltoren, \$ojl. injpettoren, Tele. grapheninipettoren, \$opt= bautupeltoren, uno Rertoanten der Dber: ßopttaffen (III. $\mathfrak{F} a=$ tegoric) . . . . graphenomt 3 fofirer,

Dber - \$oitoireltions: fecretaire, Sajpirer und Budbalter ber OberPoitlaifen, Dber=ßo[t= fecretaire, Dber = Tele: graphenjecretaire, $\mathrm{B}$ oft= meifter, Boftbaufecres taire, ßojtjecretaire, Telegraphenjecretaire, Dajúfinentureifter für bie Mohrpolt, Büreals= affiftenter, Randififen, Boptbau[d)reiber, ßoft= bauzetujuer, Dber=\$o|t affiftenter, Dber-Tele. graphenaffiftenten, Poft. peridalter, angeftellte \$ojt und Telegraphen= affiftenten, Dafadiniften

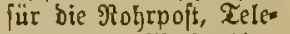
graphen = Medaniler, jomie bie Relegraphen= gebülfinnen in (Brob= herzogthum Baben ${ }^{2}$ ) (V. Rategorie) . .

5. Für bie llnterbeanten (VI. Rategorie)

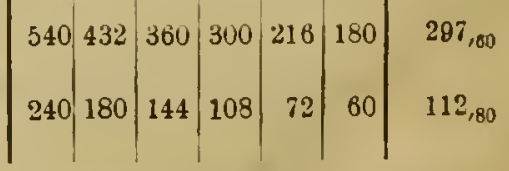

1) Der it ber Spalte: "Durdfdanitt ber Rlafien I bis V" an=

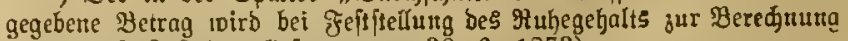
gezoger ( $j$. $\$ 8$ des Gejepes vom 30.6 .1873 ).

2) 2ứ für bie übrigen angeitelten Telegraphengehülfinten. 


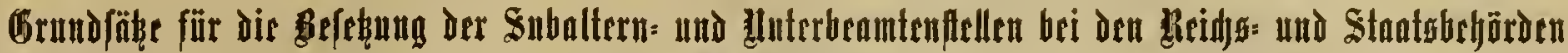 mit Militärnunuärtern.}

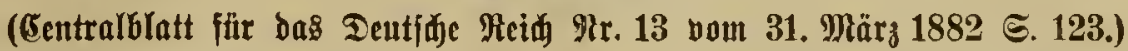

\$ 1. Militäranmärtex im Sinne ber nachftebenden Brundjäbe ift jeber Jnhaber des Civilberjorgungsidjeins.

Der Cinilberjorgungsifdein vird Denjenigen łैerfonen,

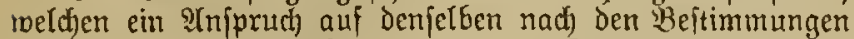

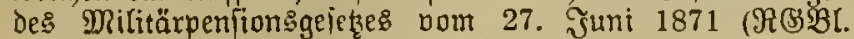

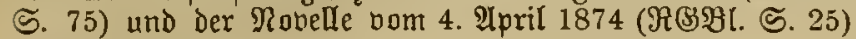
zu(teht, ertheilt. ${ }^{1}$ )

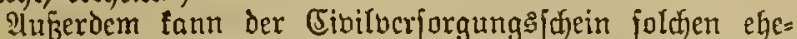
maligen Unteroffizieren ertheilt merden, weldye nadh mindeiten neunjährigem, aftinem Dienft im Seeere oder in ber Marine in militairijo organifirte (Bendarmerien (Randjägerforpg) oder Sdjukmannidjaften eingetreten und Dort als Jnvalioen ausgefditeden find ober untcr (Finted)nung der im Seere oder in ber Marine zugebracteten Dienjtzeit eine gefammte aftibe Dienftzeit von zmölf Эahren zurüffgelegt haben. Der Civilberjorgunggichein ift in diejen Fällen nach Junlage B

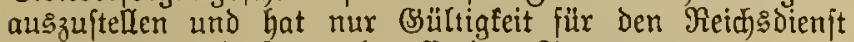
und ben Cibildienit des betreffenden Staates.

Sind in eine militairifh organtifirte Bendarmerie (Eand: jägerforps) oder Schutzmannichaft, in (Ermangelung geeigneter Unteroffiziere bon minoejtens neunjähriger attioer Militair= dienftzeit, Unteroffiziere pon geringerer, aber mindeftens (ed) sjäkrigex attioex Militairoienftzeit aufgenommen morden, jo Darf Denjelben dex Eibilberforgungsidhein nach 2 anlage C berlichen werden, wenn fie entweder eine gefammte attine Dienftzeit bon fünfzehn Gahren zurüdgelegt haben oder nach igrem llebertritt in die (sendarmerie oder Shutzmannjujajt burd) Dienjtbejdjäbigung oder nad) einer gefammten aftiben Dienjtzeit bor 8 Jabren inbalide gemorden find. Dicjer Shein hat nux Gültigfeit für Den Civildienit deg $b e=$ treffenden Staates.

Die Ertheilung Des Eibilberjorgungsffeines exfolgt in

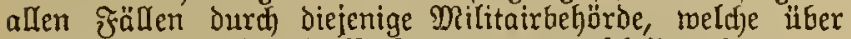
Den 2Ynipruch auf dieje Berjorgung zu enticheiden hat.

Die auf Brund der bisher geltenden Borjdriften er. theilten (5ivilanftellungsidjeine find fortan innerbalb ihres bisherigen (Silltigfeitsbereides den (Sivilverjorgungşidetnen gleid zu ad)ten.

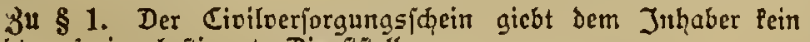
Reçt auf eine beftimmte Dienftitelle.

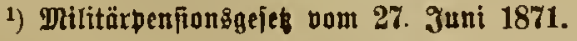

§58. Die jur Rlaffe ber Unteroffiziere und Gemeinen gehärenden \$erioner bes Soldatenftarides haben Mniprud auf Groaliden= verjorgung, menn fie ourd Dienftbe[jübigung ober nad einer Dienftzeit oan mindeftens 8 3ahren invalioe gewarden find. Saben biefelben 18 jahre ober länger aftio gebient, fo ift

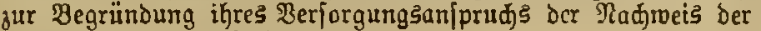
Znnalidität nidjt erfarberlid).

§ 75. Die als veriorgurgకbeređtigt anerlanten Snvaliben erhalten, renn fie fid gut geführt haben, einen Civiloerjorgungsjīen. Die Banginualiben erhalten diefen Sdein neben Der ßenfin,

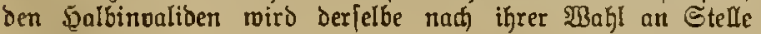

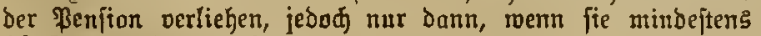
12 马ahre gesient haben.

Rovelle vom 4. Thril 1874.

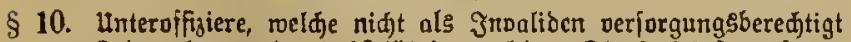
find, erlangen burá) 12=jährigen aftiven Dienft bei fortgejester

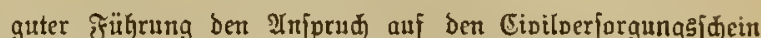
(\$S 58 und 75 bes Bejebes oam 27. Juni 1871).

1trteroffiziere urd Matulechaften bes Beurlaubtenitandes er=

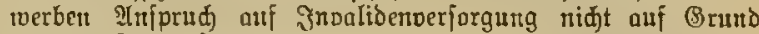
der Dienitseit, fondern nur burd eine im Militairdienite er= littene Dierftbef̧äobigung.

§ 2. Die Subaltern= und Unterbeantemitellen bei Den

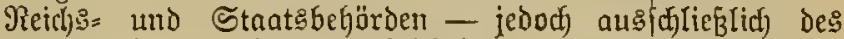
Fraritoienftes - find, unbefdjabet der in den cinzelnen Bundesfftanten bezüglich) Der $\mathfrak{B e r j o r g i n g ~ D e r ~ M i l i t a ̊ r a n t = ~}$ wärter im Sivildienjte erlaffenen weitergehenden Bejtim= mutngen, nach Map̈gabe dex nachjtefenden (Srumbjäze vor= zugs̆neife mit Mititairantärtern z"l beję̧en.

3u § 2. Gemeindedienfitellen fullen nidit unter die Beftim* mungen des Entwurfs.

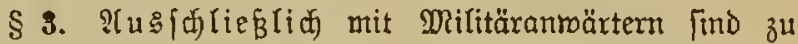
bejeţen:

1. in allen Dienftżmeigen und bei allen Behörden,

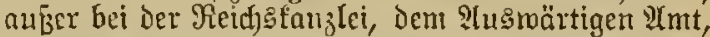
ien Mitmifterien ber auşrärtigen 2(ngelegenheiten,

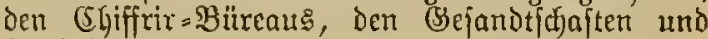
Sonfulaten:

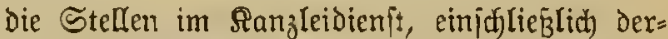

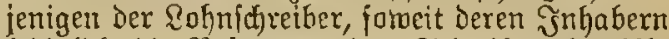
lebiglid) Die Beforgung De: Sd)reibmert' (âb= fareiben, Mundiren, Rollationiren 2e.) und Der mit dentelben zufammentängenden Dienjts berrichtungen obliegt;

2. in allen Dienjtzmeigen und bei allen Behöroen, auß̧er bei den (Sejandtjajajten und Ronjulaten:

fämmtlidje Stellen, Deren Dbliegenheiten im Wejentlicfen in mectjanijhen Dienitleijtungen be= itehen und feine technijoten fienntnifje exfardern.

3ா \& 3. 1. Stellent oder Derribtunaen, welde als Kebenamt, verichen werdert, fallen nidht unter die Beftimmungen des Entwurfs; diejelben find Duher den den Militäranmärtern porbehaltener Stellen nidht jujujählen.

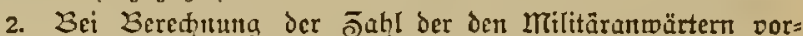
3ubehaltenden Stellen find dicjentiaen Stellen nicht in Betracht $3 u$ jiehen, bejüglich welळer den Anjtellumgsbehörden freie Eand ge. laffen itit.

§ 4. Mindeftens zur 5̧älfte mit Militäranmärtern find zu bejeşen:

in allen Dienjtzmeigen und bei allen Behörden, auker bet Den Miniterien und jonjtigen Sentral= beljörden, forwic bei den Befnndtidjaften und Son= julaten:

die Stellen der Subalternfeanten in Büreau=

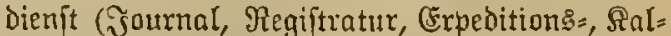

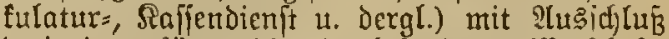
Derjenigen, für welde eine bejondere miffenf(hajt=

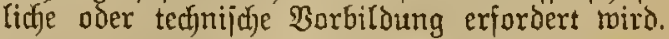

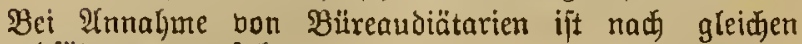
(3rundfäzzen zu berfafien. 
§ 5. Эn reldem umfange die nitft unter die $\S \S 3$ und 4 fallenden Subaltern = und IInterbeamtenjtelfen mit Militairanmärtern zu bejeken find, ift unter Berücfifftigung Der Anjorderungen des Dienjtę zll bejtimmen.

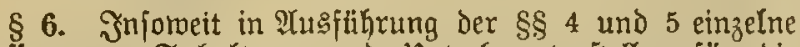
Slajien bon Subaltern = und llnterbeamtenjtellen für die Dilitairantwärter nidjt mindeitens zutr Sälfte borbehalten

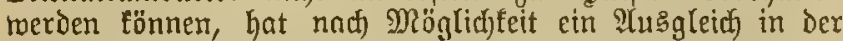
Weife ftattzufinden, Dafis nndere Derartige Stellen beffelben Befföftsbereidys in entiprechender Bahl uno Dotirung bor: behalten werden.

§ \%. Heber die gegentwärtig vorhandenen Subaltern. und Interbeamtenftellen des Reichs: und Staatsdienjtes, melche nach $\S \S 3$ bis 6 für Die Militairantwärter borzubehalten find, werden Berzeidnifife angelegt.

(Sleidfartige Stellen, meldhe in Bufunft errichtet werden, unterliegen Denfelten $\mathfrak{B} e$ ftimmungen.

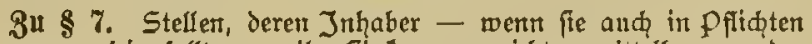
genommen fein follten - iḩr Einfonmen nidht unmittelbar aus der Staatsfaffe beziehen (Privatgehzillfen), brauḑent in dic nad̨ § ? anzulegenden Derzeid̨niffe niक̨̧ aufgenommen ju werbert.

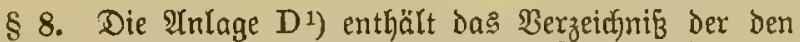
Militairammärtern our Beit iur Reidjsoienjte borbefaltenen Stellen.

Die Berzeidfnifie bezuliglid) des Stratabienftes merden bon den einzelnen Bundesregierungen aufgejtellt und dem

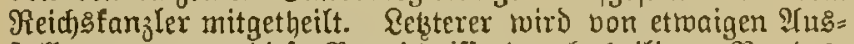
jtellungen gegen biefe Berzeid)nifje den betheiligten regierungen Sienntnif́ geben.

Die Berzeidfniffe, pomie etmaige Rachträge z" Denfelben, merben durch Das (entralblatt für bag Deutfche Reid) bers offentlict)t.

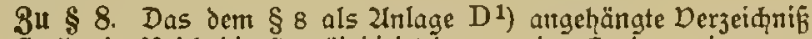
der Stellen im Reidssoienft präjudizirt den von den Sandesregiernngen aufzuftellerten Derzetकृniffen niḑ̨t.

1) Seite 703 abgeorufft.

§ 9. Die Den Dilitairanmärtern vorbehaltenen Stellen dürfen nit anderen Berfanen nidjt bejekt merben, jofern fich Militairanmärter finden, meldye zu deren llebernabme be= fäbigt und bereit find.

(EE madjt Dabei feinen Unterjuted, ob bie Stellen Dauernd oder nur zeitmeife bejtehen, ob mit denjelben ein etats= mäpiges (B)ehalt oder nur cine biätarifd)e oder andere Rer mumeration berbunden ift, ob dic 2InItellung auf Rebenszeit, auf Ründigung oder jonit auf Biderrmi gejdjeht.

Bu borübergehender Bejdjäftigung als Şülfşarbetter ober Vertreter fönnen jedod, auth $\Re$ idjtberjorgunggbered)tigte an= genonmen werden, falls qualifizirte Mititairanmärter nicft borhanden find, beren Csintritt ohne unberbältnif̧äß̧̈igen Beitberluft oder Sioftenaufmand herbeigefitfrt werden fann.

§10. Эnfoweit Borjuriften beftehen oder erlajien merden, nach meldijen bie Bejetzung erledigter Stellen erfolgen fann, oder borzugstreife ju erfolgen hat,

1. mit Beamten, welde cinftroeilig in Den Ruheftand beriest find und Wartegeld oder dem gleich zu er= actitende (simnafymen beziehen, oder

2. unit joldhen Militatrperjonen int Dffizierrange, welchen bie 2 (usfidut auf Wnftellung int Cibildienfte berliehen ift, 1 )

finden jene Borjifriften aus auf bie Belekung ber ben PRilitairanmärtern borbehaltenen Stellen ?Tmenoung.
Auch fönnen die den Militairantwärtern borbehaltenen Stellen berliehen twerden:

3. foldjen Beamten, soeldhe für ifren Dienft unbraudjbar oder entbehrlid) getworden find und einitmeilig noer

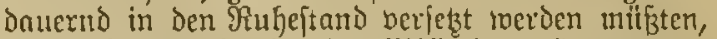
meun ihnen nicht eine ben Militatranmärtern var= beljaltene Stelle verlieben mürde. Bon joldjen Serleihungen ift dem zuftändigen Siriegsminifterium Senntnís zu geben;

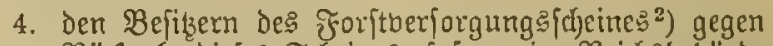
Rïifgabe diefes Scheines, jofern eme Reichsbehörde oder eine Beförde des betreffenden Stantes bon Der Injtellung eines mit diejem Sdjein Beliehenen einen bejanderen Bortheil für Den Reidf $8=$ oder Staatedienit ermartet;

5. (oldijen ehemaligen Militairanmärtern, melcje fid )

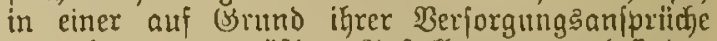
ermorbenen etatsmäßigen $2 n$ ftellung (\$ 13) befinden ober in Folge eingetretener Dienitumjähigfect in den Riuleftand beriezt worden find;

6. jold)en eljemaligen Militairperfonen, meleyen der

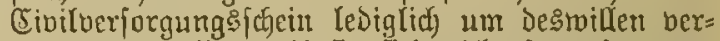
jagt toorden ift, weil fie fird nidjt fortgejejzt gut gefuhnt haken und relche bon der zuftändigen Militairbehörde (§ 1) eine Bejuljeinigung nach $\mathscr{A} n=$ lage $\mathrm{E}^{3}$ ) erfyalten Gaben;

7. Fonftigen Berionen, welchen, fofern es firt) um den Reidjüienjt oder Den Dienft Der Randesbermaltung bon (Elfaß $=$ Rothringen Gandelt, Durd) Erlak Des

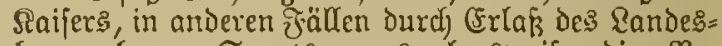
herru bejm. Senats, cusnaljmstweife die $\mathfrak{B e}$ rechtigung zu einer 2 njtellung berliehen borben ift. Dergleitfen Berleibungen jollen jedoct) nur für cine beftininte Stelle oder für einen beftinimiten Dienjtzroeig und audi mur dann beantragt merden, menn ein bejonderes dienftliches Jnterefie dafür geltend zu madjen ift. Die Anträge find, roenn Die Anftellung im Reid)gDienft oder im Dienft der

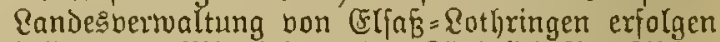

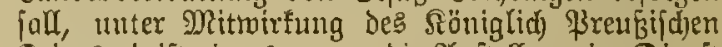
Sriegsminifteriums, twenn die QYiftellung im Dienjt cines Bundesifaates mit eigener Mititairbermaltung oder in ber Mrilitairberwaltung Deffelben erfolgen foll, unter Mitminfung des zuftändigen Srieg: ninifteriums zu jtellen. Jn Den übrigen Bundes= ftanten hat Den IInträgen cine Dittljeilung an Die oberite Militaitbejörde desjenigen Erjakbejirfes, immerhalb weldies die stelle befetzt werden joll, boranzugehen. 2tudg ift diejer Militairbeförde bon Den ergebenden Cntfdjeibungen, fotwic bon etraigen ohne Antrag erfolgten Berleihungen ber Ninjtellung: bered)tigung Renntnif zu geben.

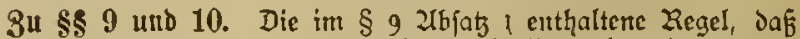
die den Mitilitairanmärtern vorbehaltenen Stelfer mit anderen per. forten utiąt hejetst werden dürfen, fofern befähigte und jur Heber. nahme der Stellen bercite Mitlitairanmärter vorhanden find, fteht abgeichen von Jen Uusnahmen Des $\$ 10-$ Jer Unwendung der Beffimmungen in $\S 22$ 2bfat 3 mid in $\S 30$ nibut entgegen. Uud bleibt Dert Landesregierungen dic Befugnif, Derjetjungen von Beamten (Bebienfteten in weiteren Sinne) non Stelle ju Stelle vorzunchmen. Eitre folde Derfegung in eine Den Militairantwärtern vorbehaltene Stelle darf jedoh mir bann erfolgen, went badurh eine den Militairantwätern rah Mą̧aabe diejer Brundätze ju. 
eine foldje Wiederfolung unterlaffen wird, find in Dem $\mathfrak{B} e r$. zeidyniffe zu itreichen; fie föntren demnäbjt, auf erneuertes STfuden, mit Dem Datum Des (5ingangs Der netuen Reldutng, tnieder eingetragen merben. ${ }^{2}$ )

1) Midft mit ahagedrudt.

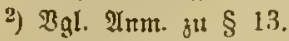

§ 16. Stellen, fiir meldje Stellenantwärter nicht notirt

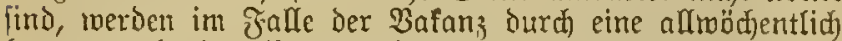
Germis?zugebende sifte ("Vafanj̧ifte") befannt gemacht.

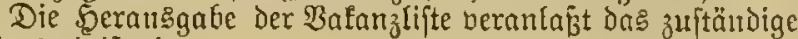
Sriegsminifterium.

Die Aufnahme der Stellen in die Rifte bermittelt eine für Den Bereich cines oder mehrerer (Erfabbesinte befonders bezeidnete Militairbeljörde - Vermittelung sbe hörde -, roeldfer zu biefem 3toef feitens Der 2rnjtelfungsbefärben Nachmeifungen nach ?tnlage $G$ zuzuicnden find.

3u \& 16. Die DermitteIntrgshehörden weroen von dent in bent

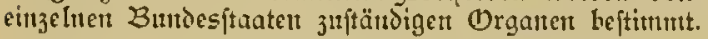

$\S 17$. St innerhalb einer frift bon 5 wodjen nach Abjendung Der Ract)weijung cine Berverbung bei der $\mathfrak{A}(n=$ itelfumgshehörbe nid)t eingegangen, io hat diefelhe in ber Stellenbefersung freic frand.

$\S 18$. Die Reilgenfolge, in tveldjer Die (5inberutung ber Stellenanroärter" z̆l erfolgen hat, beftimnt fich nach folgenden Grundfäłzen:

1. Bei Cinberufungen für Den Dienft einc: Bundes. ftantes fanm Den diefem Staate angeljörigen oder aus Detr Rontingente Deffellet lyervorgegangenen Stellenammärtern bor allen ïbrigen Der Borzug gegeben merden.

2. Bei Einberufungen für ben Sees, Siliten= uno Seehafendienft find Unterofifiziere der Miarine bar Den Itnteroffizieren des Qandheeres zu berïrof= pidftiget.

3. Jnfomeit die (Sinndfäßze unter 1 und 2 feinen Borzug begriinden, find in 1. Feife Unteroffizicte

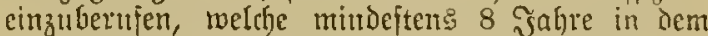
Seere oder in der Marite aflio gedient ljaben. शిtbroid)ungen hiervon find nur in Thusna\}mefällen

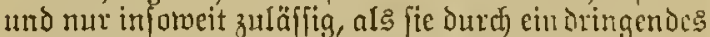
dienftliches Sntereffe bedingt werden.

4. Jnncrhalb ber einzelnen Siategorien non Stellen=

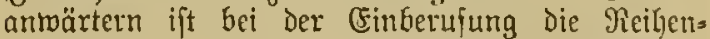
folge in iem Bergeichnifs (\$ 15) in Dectrad)t ju ieherr.

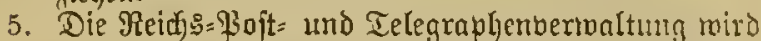
bei itren ?lnftellungen borjugstweife dic Stellen= anmärter desijenigen Staate berücffititigen, in meld)em die Bafanz entitamben ift.

3u \$ 18. Uls aus dent Kontingent Elja gegangent weroen alle Diejenigen betrahtet, weldhe einent it Elfafi. Sothringent garnifonirendet đruppentheil angehört habeıt.

§ 19. Die Unftellung cincs cinberufenen Stellenan= märter fann zunädjit auf \$irobe erjolgen ober bon einer Frobedienftleiftung ab̧ängig gemadit metden.

Einberufungen zur Girobedienftleiftung merden nur er= folgen, injomeit Stellen ( $\$ 9$ atbf. 2) offen find; eine Cent= laffung Einberufener megen mangelnder Batanz wird nirft ftattfinden.
Die \$robezeit joll, norbehaltritf Der Ubfürzung bei

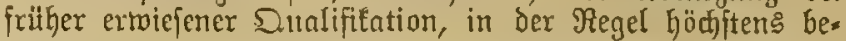
tragen:

a) fïr Den Dienft als Pojt= oder Telegraphen= affiftent 1 Faljr, ${ }^{1}$ )

b) für Den Dienft in Der Eifenbahnuermaltung ntit

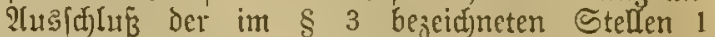
Sahr,

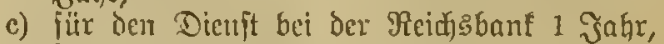

d) fïr Deu Dienft in der Şermaltung der Bölle und indiretten Stenern ein Эahr,

e) für den Dienft in Der Straß̧en= und Wafferban=

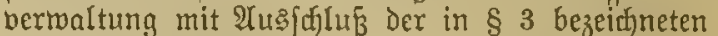
Stellen ein Эalur,

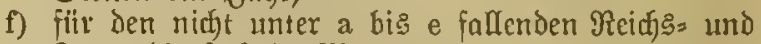
Stantsoienft fechs Monate.

Späteftens bei Beettdigung der \$robezeit hat bie $\mathfrak{A} n=$

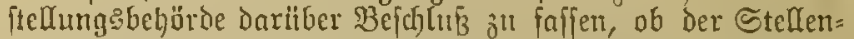
atrwärter in feiner Stelle zu bejtätigen, bezm. in den Cibil= bienft zu übernefunen, ober tvieder zu entlaffen ift.

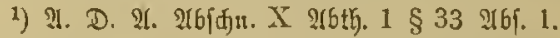

\$ 20. Stellenantwärter, weldhe fid nod) im aftiben Dititairbienft befinden, merder auf Beranlaffung der \$ln: itellungsfehörde Durch die vorgefecte Difitairbehörde für bie Dauer der \$robezeit abfommandirt. Eine Berlängerung Der Iekzteren ïber bie im \$ 19 bejeidnneten friften binaus

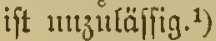

1) Berfouten bes altiven Militairftandes lönter im Civilbienf proberbeife augeftellt werben, menn cinerfeits bie anftellento Civil= behörbe es dent 3nterefie des Dienftes für entfpredend bält bezm. eine folde Inftellung por IIbleifturg bes \$robedienfteß nađ forfigen 3orifriften überhaupt erfolgen barf, uno wenn ambererjeits bie be:

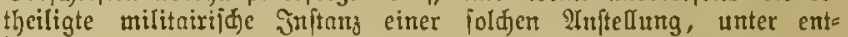

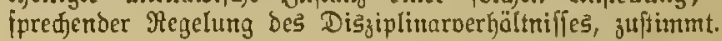

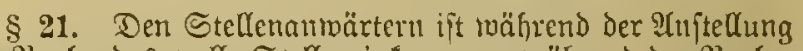
auf Đrobe das volfe Stellencintommen, während der \$robe= dienitleiftung cine jortlanfende Remuneration bou nidft meniger als Dreiviertheil bes Stellencinfoumens zil ges mähren. ${ }^{1}$ )

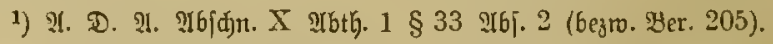

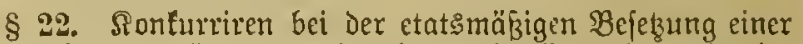
Den MRilitairanmärtern borbehaltenen Stelle melurere bereits einberufene, aber nod) ni(f)t etatsmäżig (\$ 13) angeftellte Stelfenanwärter, fo finien Dic im \$ 18 feftgeftellten (5rtund=

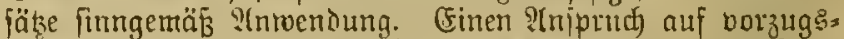
weije Beritteffit)tigung haben jedoch bie chemaligen, mindejtens acht Salye gedienten Ünteroffiziere nidjt denjenigen Stellen= antö̈rterı gegenilber, deven (Sefonmtbienftzeit (attive Miti= tairdienfizeit und Dienftzeit in dem betreffenden Dienjtzmeige) bon längerer Dauer ift, als die vort ifnen felbjt jurüd= gelegte.

Ticjtberiorgungsherectitigte, welche fiir cine ben Militair=

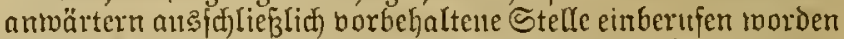
Find, weil fein geeigneter Stelfenanmärter vorhanden twar, find bezüglich der etatsెntäsigen Mnftellung den Stellen= antoörtern, weldje ridjt nad) mimbeftens adjtjähriger aftiver Dienftzeit aus Detn Seere oder der Mrarine als Itnteroffizier

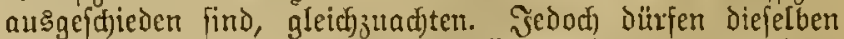
nicht bor foldhen qualifizirter Stellenanmärtern etatsmäs̄ig angeftellt werden, melidhe in demielben Dienjizmeige eine gleiche oder längere Dienitzeit zurilafgelegt haben. Dafjelbe gilt fïr bic im $\S 10$ $\mathfrak{R} .7$ bezeidneten Pierfonen, fofern 
\$28. Eriolgt das ?lusjujeiden aus der Stelle freiwillig, aber ofine \$senfion, jo ijt dies gleidfjalls in dein

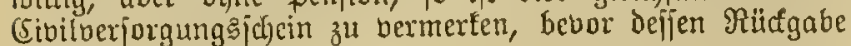
erjolgt.

$\$ 29$. Der (Sivilueriorgungsfdein erlijeft, jobalo fein

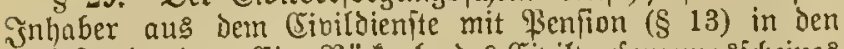
Ruheftand tritt. (Fine Ritifgabe bes Civilberforgungsidjeines Findet in biejem Falle nicjt ftatt.

§ 30. Rereits ermorbene IInfprüd)e werden durch bor= itehende Brumdjätze nidat berihbrt.

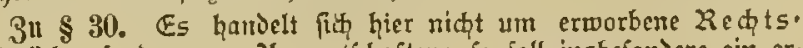
anjprithe, fortiern un Umwartidaften; fo foll insbejondere ein er. morbener $\mathcal{Z}$ nfpruch dann als vorhanben angenommen werden, went fïr gewiffe Dienftzmeige die Priffung beftanden oder der Dor. bereitungsoienft jum gröperen Cheil abfolvirt ift.

§ 31. Worftehende Srundjäze treten mit dem 1. Oftober 1882, für \&lfaj̧= \&othringen mit bem 1. Sttober 1884 in Sraft.

Berlin, Den 25. März 1882.

\section{Der Meidgatangler.}

3. B.:

b. Boettidjer.

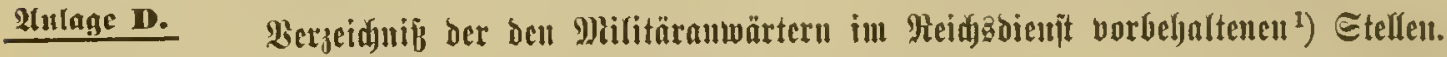

\section{( $\mathfrak{A} u \& z u \mathfrak{B}$.}

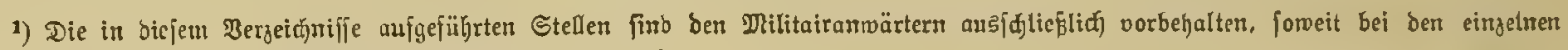
Rategarien von Etellict etmas anderes nidjt auboriiđlici bemerft ift.

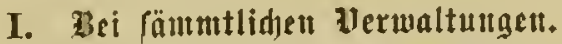

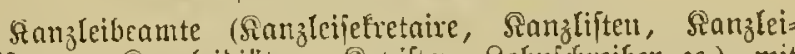

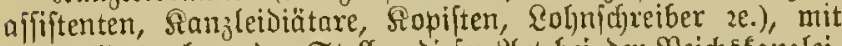

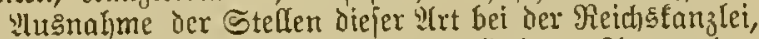
dem Shifirirbitreau Des 2lusmärtigen 2 mts, den (3)iandidjaften und finjulaten, fowic der Stellen Det: Diätarien und des vierten Theiles Der etats= mäßigen Setretäre ber Beheimen Sanzlei des 2uts= wärtigen $\mathfrak{i}$ mts

Botenmeifter,

Puffeher (Magajin=, Bau= und andere थिufieher),

Diener (B̈̈reaus, ,̧aus=, Sanzlei=, Siafien= und andere Diener und $930 t e n)$,

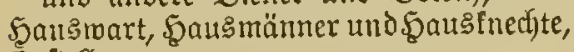
Saiftellane,

\section{Difenkeizer,}

Fortiers, \$förtner, Thïrfteher,

Wäd)ter utro Ract) tnäduter,

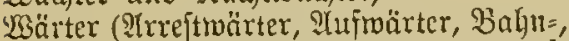

Barrieren=, Brürfentuärter, Şaนรณuๆ= märter, Rajernen=, Sranfen=, Lampen =, Eanf $=$, \&azareth $=$, $\mathfrak{T}$ unnel $=$ und andere Wärter),

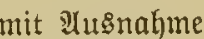
Der Stellen biejer Irrt bei Den Gejandt= ichajten und Somjulaten.

\section{Reidi=}

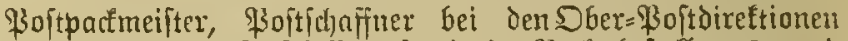

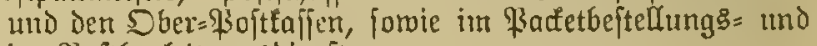
im \$ojtbegleitungsbienjte,

Sandbricjträger, \$ojtboten,

Pofticjaffner im innern Dienjte bei den

Yoft = beztw. Telegraphenämtern, Brieftrïger,

Büreau= und Redynungsbeamte II. アLajןe bei ben Sber=\$Boftbireftionen (Bitreau= affiftentem),

minde\{tens 子u 2 Dritteln,

$\left.\begin{array}{l}\text { Sber= Telegraphenaffiftenten, } \\ \text { Telegraphenaififtenten }\end{array}\right\}$ zи 2 Dritteln, Sber= \oftaffiftenten,

Poitafififenten

\$oftuerwalter,

mindeitens zur Şälite,

1) Die Stellen für Telegraphen=Reitungşaufieher gehören nidit 孔и ben ben Militairanwärtern vorbehaltenen Stellen.

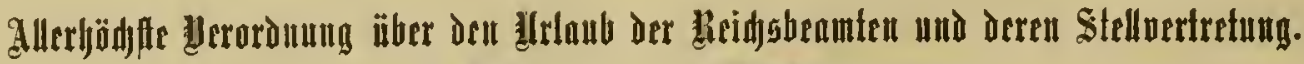

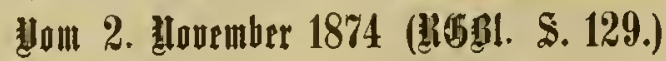

Mir Wilfyelm 2c. veroronen im Ramen des Deutjctien

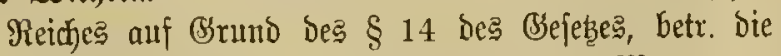

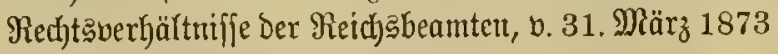

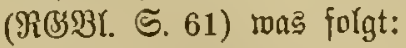

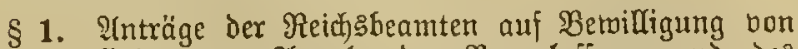
Urlaub, find unter İngabe der Berallajiung uno Des 3 medfes der unmittelbar borgejebten Bebörde oder Dem un= mittelbar borgejelsten Beamten einzureichen.
§ 2. Der Reidjątanzler beftimmt die Stellen, weldje zur Critheilung bon Hrlaub berectigt find, fomie bie Beit= räume, für melcje bon denjelben Urlaub gerwährt merden barf.1)

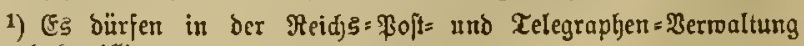
urlaub bemilligen:

1. Die Dber=\$oft bireftionen:

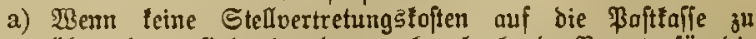
ïbernehuten find ober ber ju beurlaubende \$peante für bie Dauer bes Utlaubs auf jein Dienjteinfommen oerzidtet: an alle uadgearoneten $\mathfrak{B}$ eamten und Unterbeamten bis ju 3 Mounaten; 
b) unicr Ucbermahme der Stellvertretungstojten:

1. Den etatsmä̈ia astgeftelten Benmten: bis qu 14 Tagen,

2. Den Poitproftifonten uno nid)t etatsınäbig angeftellten Polt= und Telegraplyctoififtenteu, ben gegen \$er giitung bejöäftigten, nidgt 3 ben Bernfsbcamten ge=

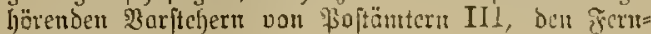
fpred)gchülfintmen und ben etatșmäbì angeftellten Huterbcamteu: bis s̆ 10 Ingen;

3. in bejonbers begrintocten Jüflest ben \$afteleven, \$ojt= uno Telegraphenanvärtern, Telegraphen:Sülf̈mecha=

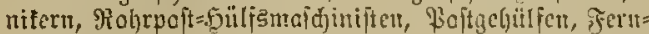
ipredgehülfen uno \$̧ojthülisbeanter, ferner ocnicuigen Softugenten und Telearaphenocrwaltern in sicbenaint,

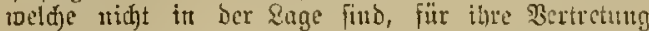
felbit zu forgen, fomie oct trid)t etatsuäfig auge=

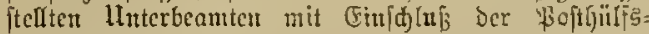
boten auf Bergïtung: bis zu 7 Taģen.

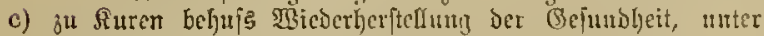
liebertahme Der Stelloertretungsfajten: an alle nuaj)geord:

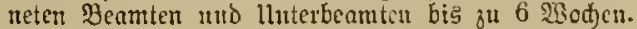

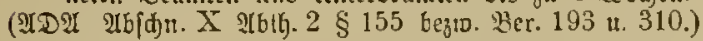

II. Die Borfeher ber Bertehrsanftalten:

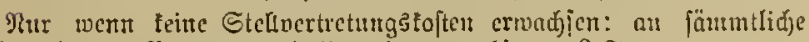
nanjgeorometen Bcanten uns llnterbeantest bis 3 น 3 నagen.

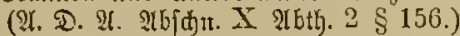

§ 3. Wird ein 1trlaub jur Wiederheritellung der Bejurd: beit nadjgelucht, fo ift Demt ?(ntrage eime ärzttiche Bejcheinigung beizufügen. ${ }^{\text {) }}$

Die Stelle, meldjer die (Entidfeidung über ben Intrag 3ufteht, ift berechtigt, die Beibringung ciner folchen Bejcheini= gung ausinathmsmeile zu erlaffen. ${ }^{2}$ )

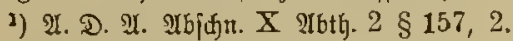

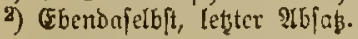

\$ 4. Der beurlanbte Beamte Gat Dajür zul forgen, Da $\mathfrak{B}$

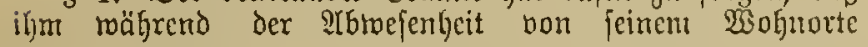

Berfügungen der vorgeieşten Behörde zugeitellt merben (önnen. $\left.{ }^{1}\right)$

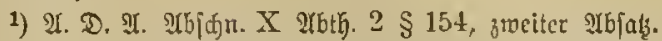

\$ 5. Siti bic 23ertretung cimes Gourlaubten Bcamten ift zunäthit von ber Stelle Sorge zu tragen, weldje ben ltrlanb ettheilt.

Dicielbe jekt jugleich feft, intwietweit die dem Beurlauben

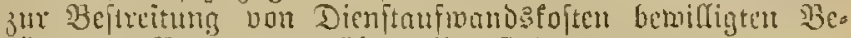
jüge Dem 2 ertreter ju thberweijen fino.

\$6. Bur Decfung von Stellnettretumg toften findect,

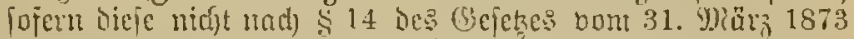

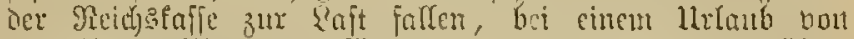
$11 / 2$ bis 6 Mionaten, fïi ben amoerthatb Mionate ïber: fteigendu Beirnum ein ?lbjug bou Dem Dienjteinfonmen de: Beurlautoten im Betrage Der Själfte iefiethen itat:; bei fermerem LrTaub wiro bas gunze Dienjtcintonmen ein= belialten..2)

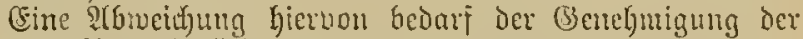

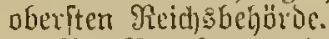

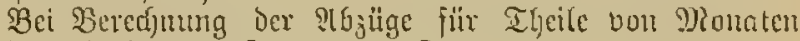
werben Die Łeßzleren ftet: 3แ 30 Tagen angenommen.

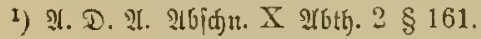

\$ 7. Dic llrlaubsbemilligung fann jederzeit jurüct=

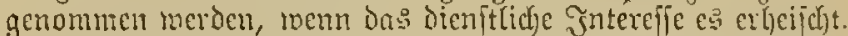

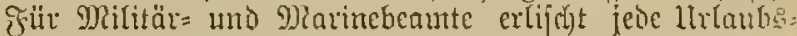
bernilligung, mem die Sriegsbereitfthaft oder Die Diobil=

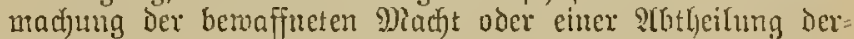
felben angeoronet ift, mit ber Befanntmachung bicjes Inorduming.

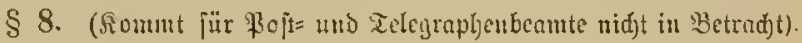

Ilitumolid) $2 c$.

Segeben Berlin, dan 2. Pouembu 1874.

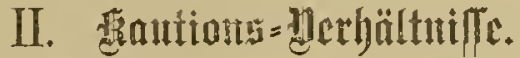

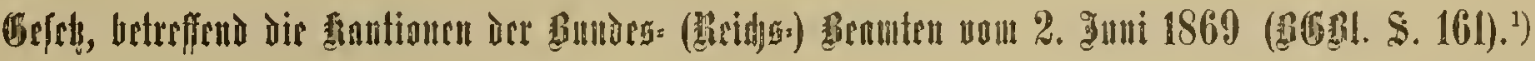

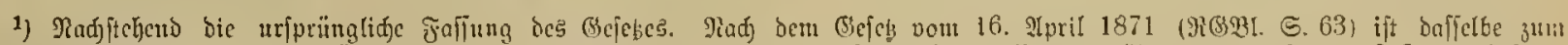

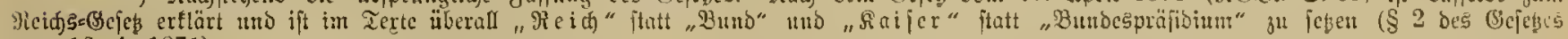
voin 16. 4. 1871).

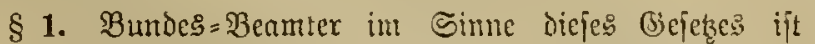
jeder $\mathfrak{B}$ camte, weldyer entweder vom Bundes=\$räfidium an= gejtellt, oder uad) Boridhrift der Bumbes-Berjajiung ben

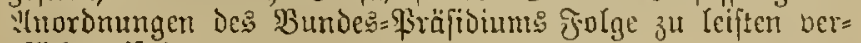
vif(idatet ift. ${ }^{\mathrm{I}}$ )

Thi Gierfonen des Soldatenftandes finder dics Bejers feine Antwendung.

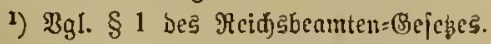

§ 2. Sicamten, weld)en dic Werwaltung einct bem Bunde geljörigen Síaje oder eines dem $\mathfrak{B}$ unde geförigen Magazins, oder dic ?(unaljme, Die ?lufbemaljrung, ober Der Transport vou, dem Bunoc gehörigen ober ilju anbertrauten Geldern oder gelomerthen (Segenftänden obliegt, Gaben Dem Bunde für ifgr Dienjtberhältnif Raution zu leijten.1)

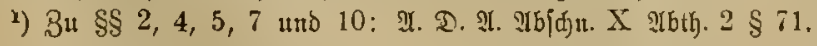

§ 3. Die Silaffen bcr zur Santionzleijtung zu ver= pflichtenden Beamten und die nach Maß̧̧abe der berichiedenen

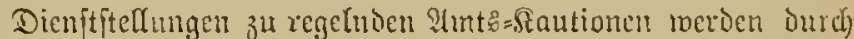

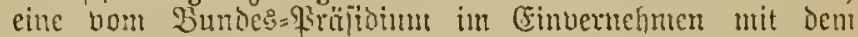
Bundestatlye ju erloffende Betoronung bejtumat. ${ }^{2}$ )

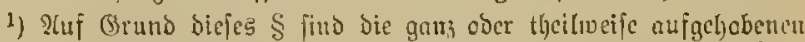

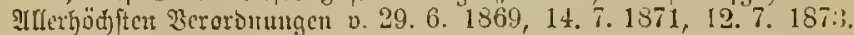

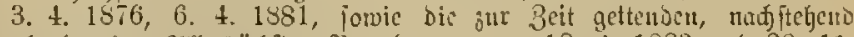

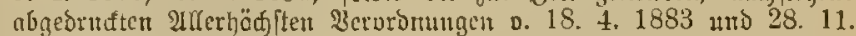
1895 crInjīent doordett.

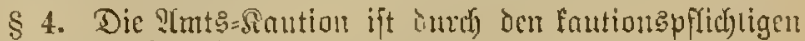
Beamten ju bejtellen.

Die Bejtellung Derjelben burdif eine andere Ferjon it

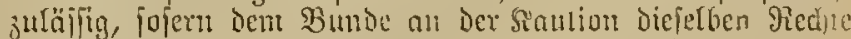
gefidjert merden, melefe igm an einer huth ben Beant $n$ felbit geftelten Sontion zugeftarden Gaben roilion.

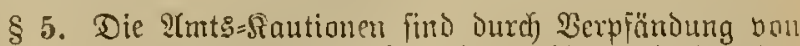

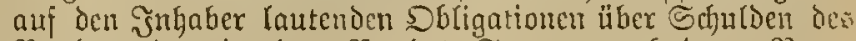
Bundes over cinzeluen Bundes = Staaten natf beren Renn= werthe zu Ieiften. 


\section{Die Berpfändung cxiolgt ourch Hebergabe zum ₹̃auft= piandc. ${ }^{2}$ )}

1) Ueber eine andermeite Mirt ber Sautionsftellung, burd) Beffellung eines Fauftpfandoredites an einer in einen Sdjulbbudje bes Reides oder etnes Bundesftaates eingetragenen forberung, ogl. Das tadj= folgend (ङ. 713/714) abgeoructe Befes v. 22.3.1893.

§6. Die Siautionen find bei Denjenigen Saffen, meldje

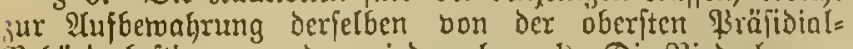
"Betpörde beftimmt merden, niederzulegen. ${ }^{1}$ ) Die Plieder (egung ier Werthpapiere erjolgt cinjalieflich des baju geljörigen Talons, bezı. Desienigen Zinsfaleines, an beffen Jnljaber bie neue Bingf (d)ein=Serie ausgereidyt wird.

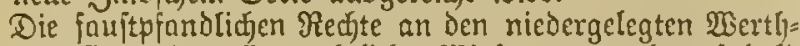
papieren find utit boller rechtlicher Wirfung ermorben, fobnlo ber Fmpiangsiduein über die Riederlegung ertheilt ijt.

Die Zingfdeine für cinen 4 Jaljre midjt jiberfteigenden Beitranm werden dem Santions=Befteller belafjen, bezm.

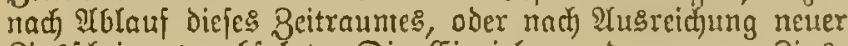
Binsfdyeime berabfolgt. Die (Finjiegung ber neuen Bims: jujeine exfolgt burád bie Saffe.

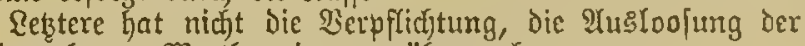
niedergelegten Berthpapiere ju übertoadjen.

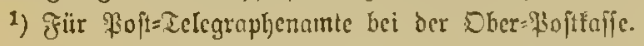

§ 7. Die Beftellung Der 2 (mts $=$ Saution ift bor ber CFin=

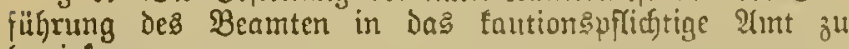
berwixfen.

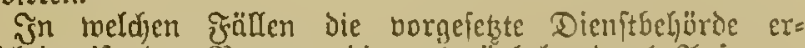

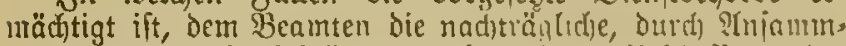

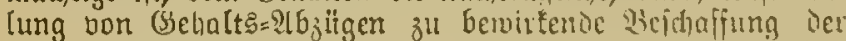

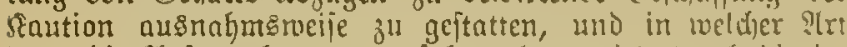
Dann bie $\mathfrak{A}$ nfaumlung 3u erfolgen lyat, wiro ourd) Die im \$ 3 errähnte \$räfidial=seroronumg beftumt.

\$ 8. Bermaltet cin Beauter gleidjjeitig mel)rere fautions pflichtige Bumbe:stemter, io geuligt bie Beftellung cinct staution zu dem für eines diefer : Vlemter vorneffiriebenen Betrage. Sind die für bie cinzeliten 2 (emter borgejajriebenen Sautionsfätze beridjicoen, fo ift bie Raution nad bem

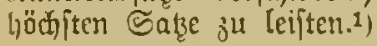

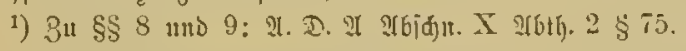

89. Bertualtet cin tautionspfliditiger 23 undes:Beanter nleid) Burdesftantes, jo fann die für lełsteres $\mathfrak{A}$ mt bejtellte Rantion,

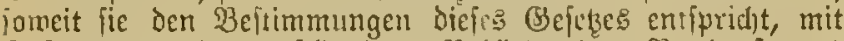
Buftimmung der zuitändigen $B$ eljörde des Bundesitates und nnd) borgöngiger Bereinbarung inrilber, miebiel von Dem Gefammbetrage der Siaution auf jedes der beiden ?lemter zu red)nen ift, zugleid) für bas foutionspflid)tige Bundesamt nugendmmen wesden.

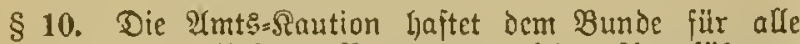
uon dem fautionspflicttigen Beamten aus jeirer Stutsführumg iu bertretenden Sffäden uno Mängel an Siapital umo Zinfen, forwie an geridytliaben und aubergeridftliden siofen jur Ermittelung des Stjadens.

§ 11. Steht eire ber na(t) $\S 10$ aus der Raution zu Defenden Forderungen zur Ereeution, fo ift bie dem fautiolls=

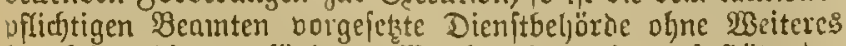

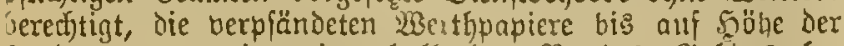

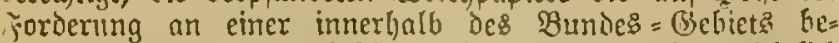
isgenen, von ithr zu beftimmenden. Börfe aurergeridjtlid) ierfaufen zu laffen. Der Rautionsbefteler ift in folchen Falle zur Untantwortung der ihm belaffenen, nod) nidjt

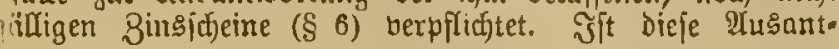

mortung bon iljur nifit zl erlangen, jo fann er zur $\mathbb{F} r=$

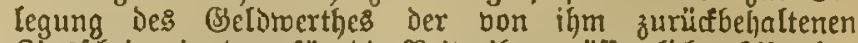
Binsficheine in bem fitr bie Beitreibung offentlid)er Î́gaben borgefdjriebenten $\mathfrak{B e r f a b r e n}$ jmangsmeife angehalten werden.

Der Bund ift nicht berpflid)tet, im falle bes Senfurfes dic verpfändeten 2 serthpapiere in dic Sionfurgmmaffe cinzulicjern.

§ 12. Dem Bunde fteben dem fautionspflictiger Burdes: Beamten gegenüber alfe গiechte zu, meldje an Dem Drte,

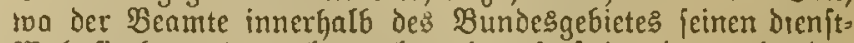
3ohnfits hat, ooer zulekt geljabt ljat, fiaft der dort geltenden Enndes=(Sejekgebung Dex Ennies= Piegierung den tautions= pfliditigen Benmten gegenüber beigelegt fino.

Siegt Der betreffende Drt in SBundes=21ustande, fo fino

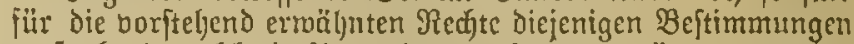
mazgebend, welde in itntwendung gefommen wären, renn ber Beamte jeinen dienjtlidjen $\mathfrak{B o l j n f i b ~ i n ~} \mathfrak{B}$ erlin gehabt bätte.

\$ 13. Raci) Beendigung des fnutionspfliditigen Dienit=

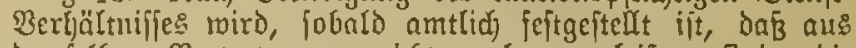
Demfelben Bertretungen nidjt melyr zu leiften find, die

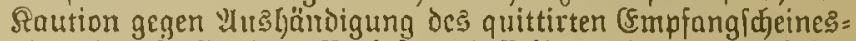
oder in J్lle des Berlujtes Deffelben, Des geridttlidjen I(mortijations: Dofument8 jurïdgegeben..$^{1}$ )

Von der Beibringung Des gerid)tlichen emortifations: Dofunents fam rach Dem (Ermejien Der Dem fautions= pflidftigen $B$ eanten borge fetzten Dienjtbehörde abgejęen merden.

1) ม. D. I. Mbidu. X 2 bth. $2 \$ \$ 92 \mathrm{t}$, g, h.

\$ 14. Dicjenigen Stautionen, weld)e bor dem (Erlafje

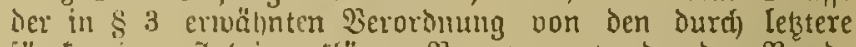

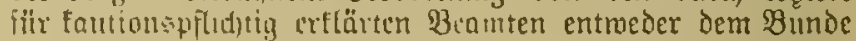

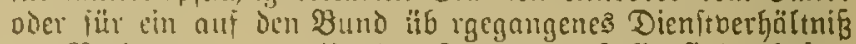

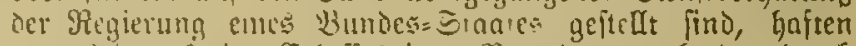
nom jeitpunt de Frlajes forer Beroronung $a b$, dem durd) die Bentmmunen diejes Bejetzes bejeidjneten Umfange.

\$ 15. Die Dem Bunde nor dem CrLaffe der im $\S 13$

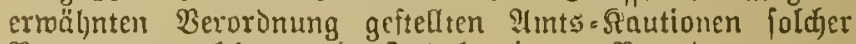

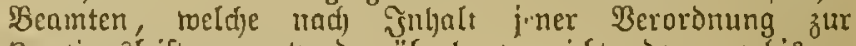
Srautionsleiftung entroeder überl)aup nidjt oder nur bis zu einer geringeren 5jöle verpflichtet find, werden zuriidgegeben, $\mathfrak{G e z}_{\mathfrak{z}}$ w. auj den in Der Berordnung beftimmten Betrag ermäßsigt.

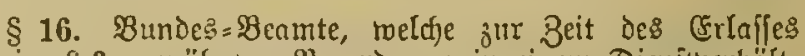
ถer im $\$ 3$ ermähnten Beroronung in einem Dienituerbält= niife fteben, filr meldies es der Fantionsleiftung nadf Den bis dahin gelterioen Borjadjriften entroeder überthaupt nidjt, oder nur in einer geringeren 5eöbe, oder it einer anderen als der in biejem (Sefeke vorgefátiebenen art bedurjte, fönnen, fo lange fie in derfelben dienjtlicjen stellung ohne (Behaltê: Erthölyung verbleiben, wider ibren willen nicht daju angehalten werden, nad) Draßggabe der Bejtimmungen diefes (Sejebes und Der Beroronung (\$ 3) eine Raution zu itellen, oder bie gefiellte fraution zu erljöhen, bejto. Durch eine Den Borjdirifen diejes Bejekses entiprectende Saution zu erjezsen. snniemeit ein jolder Beamter bei eintretender (Sebalts. (Erljöhung berpflichtet ift, den Mehrbetrag Des Behalts gan oder zum Theil zur Ânjammlung der Raution zu berwellden, wirb Durd die im \& 3 erivähnte \$räfidial=:Berord. rung bejtimmt.

§ 1\%. Die vor dem Erlaffe der im $\S 3$ ermähnten Berordmung gejtellen $\mathfrak{A}$ ints= Rautionen, weldye Den $\mathfrak{B o r}:$ jdyriften diejes (sejekes nidjt entipredjen, merden, fobalo fie burd) anderveite אautionen exfeßzt find, zurücfgegeben.

lirfundiid) $2 \varepsilon$.

(Segeben Sfflö́ 2 abelsberg, den 2. Suni 1869. 


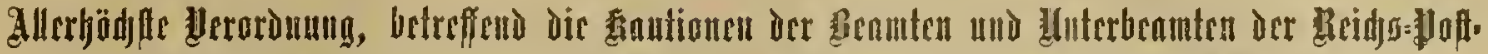

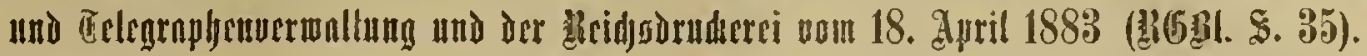

Wir $\mathfrak{B i l h e l m , ~} 2$. 2 .

berorinen in Ramen DeE Reidf auf (Grund Der

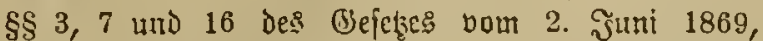
betreffend die Sautionen der Bundeşbeanten (BSBSL. 5. 161), nad) (Finvernelmen mit Dem 3undesiratl), twas folgt:

F(rt. 1. Bur Rautionsleiftung find die nachftefyenden Beamtentlajien berpflichtet:

I. Эm Bereidje der Pofts und TelegrapheneBerwaltung:

a) Die bei ber (Seneral=\$3oftaffe, Den Dber=\$3oftaffen und den Boftanftalten angeitellten oder bejtäftigten Beamiten urd lluterbeanten, einidylieşlid) Der im Bertragşuerhältnif́ ftel)enden Unterbcauten und die Boriteher Der Telegraphenämter;

b) Die übrigen im Reich $E=230$ ft, und Telegraphen= Dienfte angeftelften oder befchäftigten $\mathfrak{B}$ canten und Unterbeamten, fojern denfelben bie Ilmahme, bie Iufberafrung oder dic Beförderung oon Beld, Daterialien oder jonftigen geldmerthen Begen= ftänden obliegt;

b) bie Jiifrer von ßoftdampffatiffen.

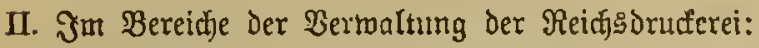

der Rendant, die Betriebsinfpeftoren und Dicjenigen Beamten und Unterbeamten, denen Dic Berwaltung oder $\mathfrak{Y}$ ufbetwahrung bon Geld, Matcrialien over fomptigen geldwerthen Ssegenftänder obliegt.

21rt. 2. Die ફöhe der bon den borbezeidfneten Beamten= Elaffen zu leiftenden Siantionen beträgt:

I. Im Bereiche der $\mathfrak{B}$ oft= und Telegraphen=Berwaltung:

1. Für den Direltor des ßoit= Beiturgsamt? und die Rendanten Der Beneraloßofteaffe und ber Dber-\$oftfaffen

$9000 \mathfrak{D R}$.

2. für Rontroleur und Saffirer bes Boft= Beitungsamts, fïr Rajfirer dex Benteral. \$ofttaffe und ber Dber $=$ Boftfaffen, den

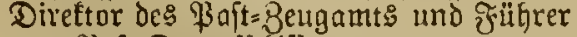
Don \$3oft=Dampfithiffen . . . . 3000

3. für den Borfteher der Telegraphens

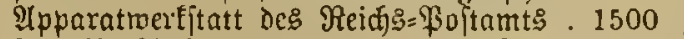

4. fuir Buthalter dex (Beneral= \$Boftaffe und Der Dber = Bojttajien . . . . 2400

5. für Borfteher von \$oftämtern I. gröberen Utmangs oobr von Wahn= \$oltämtern aröferin llmfangs . 9000

6. für Borfteher von Boitämtern I. uittleren

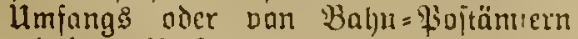
mittleren Umfang?

7. für Borftcher bon Fojtämtern I. ge ringeren Umfangs .

8. für $\mathfrak{B}$ orjteher von $\mathfrak{I}$ clegraplemämtern gröberen llmiangs.

9. für Borfteher bon Telegraphenämtern mittleren $\mathfrak{H}$ mfangs.
10. für Borfteher von Telegraphenämtern geringeren llmfangs. . . . . . 1500 M.1)

11. fiit Faffirer bei gioft oicr Tclegraphen= äntern . . . . . . . . 2400 "1)

12. fïr Bewerbec an ber Bahl veriorgung: berchtigter Dffizicre um Unftellung als

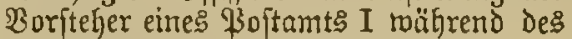
Borbereitung $:=$ und Probedienftes . . 900

13. Für 23orjteher von \$oftämtern II . . 1500

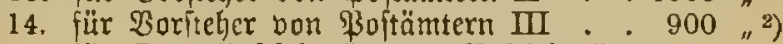

15. für Dber $=\forall$ oftfefretäre und \$oftiefretäle 1500

16. für Sber=Ielegraphenfetretäre unt Tele= graphenjefretäre

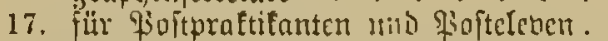

18. fï: Burcauafiftenten, Dber-Poftafifiten= ten, Dber: Iclegraphenafifitenten, \$oft = affiftcuten, Iclegraphenaffiftenten und Ielegraphenutedianifer

19. für Jjoftanvärter, Ielegraplenanmärter und $\$ 3$ oftgebilien

20. fïr \$oltagenter . bis

21. jür Unterbcaute (einfdylishlich) Der im Bertragguncrbältnifs ftehenden) . . bis 600 " $\left.{ }^{3}\right)$

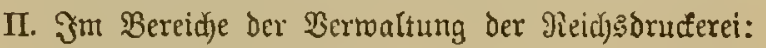
1. für den Renoanten
9000 றִt.
2. für Betriebsinfpeftaren
6000
3. fïr dic übrigen Beamten
bis 3000
4. für Unterbeamte
bis 600 "

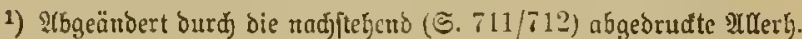
Beraromung ๊. 28. 11. 1895.

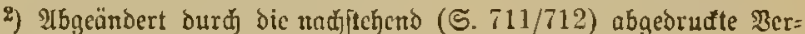

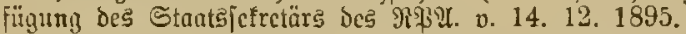

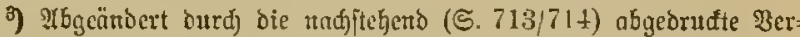

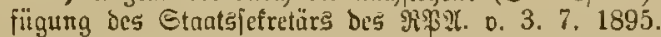

PLit. 3. Die Cintheilung ber \$oftämter, Bahn= \$oft= ämter mo Telegraphenämter ( $\mathfrak{A}$ rt. 2 inter I, 5 bis 10) jomie die Bejtimmung ber 5öble der nady Hrt. 2 unter $I$, 14, 20 mi 21 und II, 3 mid 4 zh beftellenden Rautionen

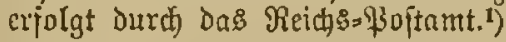

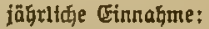

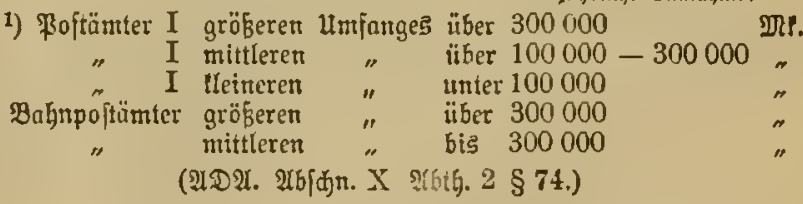

21t. 4. Beamten uno Interbeamten, weldje bei ber Tufunhte in den Feidjsdienft oder bei Dem Einrüden in cine mit Saution:pflicht nerbundene Dienftftellung Die ex= forierliche Saution auf cinmal zม beføaffen aufer Stande fint, fant bun Dem gicicjs=\$softamt bejw. Der von biefem Daju ermähtigten Dienjtbehörde ausnahmsmeije geitattet

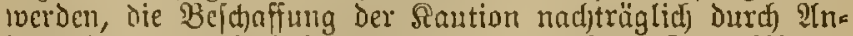
inmmlurg bon Schaltsabjügen z" beroirten. Dicfe Plbzïge Dürfen bei Beamten nicft toemiger als 150 Mge. jährlicf, bei Unterbeamten nidjt meniger als 3 glf. monatlid) betragen. 
Ohne bicje Beft)ränfung fann Ielegraphenbeamten, wedde in Folge Der Vereinigung Des Telegraplentuciens wit ber Goftuertwaltumg eine mit Sentionsplicht, be ziehent= (id) mit häherer Sautionspflidst verbundene Dienftiftefung

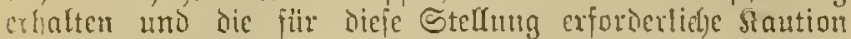
auf eimmal zu beichaffet anfer Etamie fimb, bon oen Dber= Bojtoireftionen Die nadjträgliche Beichaffung Der Saution (umd) Snfammlutg von angentejenen (Beljaltsabjigen ge= itottet mericut.

Tuf Benmte, welche an ber Sermaltung bur Sencral=

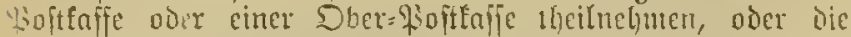

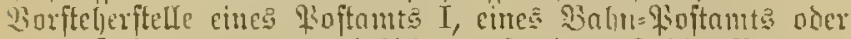
cines Telegraphenamte befleiteu, fonie auf Die Z3eamten

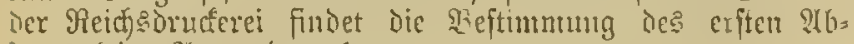
inties teite (nnwendung. ${ }^{\text {) }}$

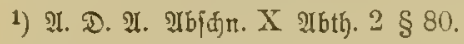

2(tr. 5. Beamte, weldje in Dem in $\$ 16$ Sab 2 ies $\mathrm{er}=$

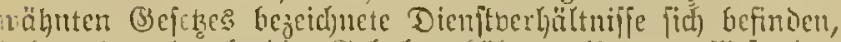
(jahen ben Burd) Die (Seljaltserbölyung iljnen suffiefenden Mehrbetrng Des Gehalts ganz zur ?tufanmilung ber fiaution

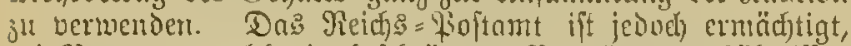
bei Beamten, welche in bejđränften Bermögenesuerhältuiffen

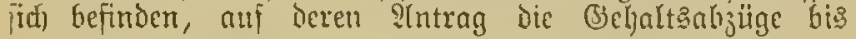

auf die Şälfte Des Betrages ber Gchaltserböhung zu cr. ntä(Bigen. ${ }^{1}$ )

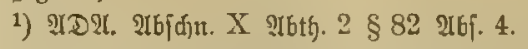

2(2t. 6. Dic Tnjaumlung uno $\mathfrak{A} u f$ betwafrung der Bes

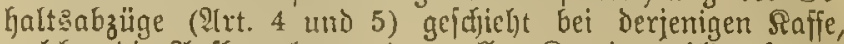
mekcher Die 2uffemal)rung der vollen Sattion obliegt. ${ }^{1}$ )

1) Bei ben Dber $\$$ Buftaffert.

Trt. 7. Diejenigen Ielegraphenbeanten, meldje nor dem 1. Sftober 1882 angejtellt find, und bei Foftanftalten befchäftigt merden, fömen von ber şinterleguntg Der faution enthunden werden, fo lange fie in ifrer Dienititellung mit

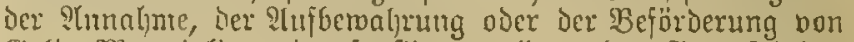
(3eld, Matcrialien oder fonftigen gelomerthen Bsegenjtänden thatfäd)lidj feine Bejajpung baben.

:rt. 8. Dic anf bas Rautionsmejen ber \$oft= uni Telcgraphenbeamten be jüglichen Beftimmungen ber Beroromung

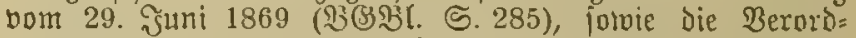

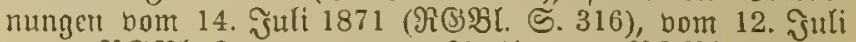

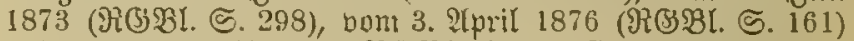

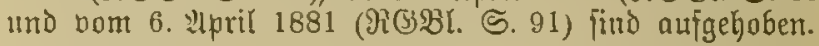

lirfundlid) $2 \varepsilon$.

(3egeben Wieşa den, den 18. 2Tpril 1883.

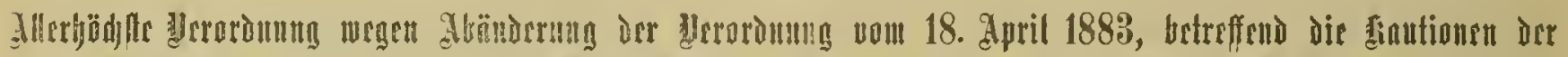

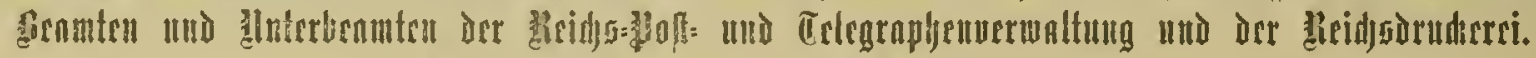

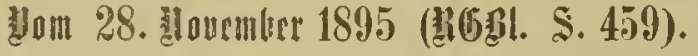

Mir Withchu 2c. veroronen in: Ramen ocs Ticidj: auf

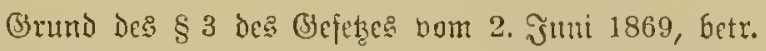

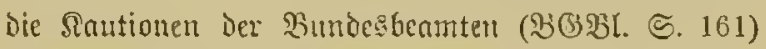
in Ginbernelymen mit bem B̉mbesrath, wons folgt:

รm ?trt. 2 Der Veroronung bom 18. Thril 1883, bctr. Die Rautionen Der $\mathfrak{B}$ canten und linterbeamten ier Yicicl)

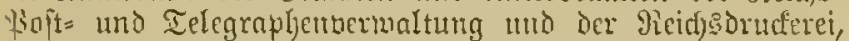
treten an Die Stelle òcr IIngaben unter 1, 5, 6, 8, 9, 10, 11, 19 die folgenden Brftimnumgen:

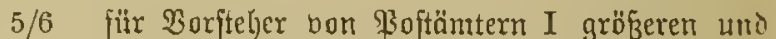
unittleren llmfangs oder vou Bahnpoftämtern gröberen und mittleren limfangs. 3000 Dit.

8/10 für 2orfteher bon Telegraphen= ämtern . . . . . . . 1500

11 für Saffitret bet \$ojtämtern. . 2400

11 a für Saffirer bei Telegraphetuänteti 1500

19 Für \$oltanmärter, כelegraphenan= märter, Telegraphenhill smectanifer und :oftgebüfen.... 300

litfundlid) $2 \varepsilon$.

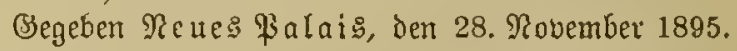

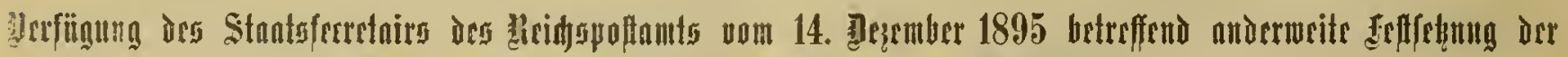

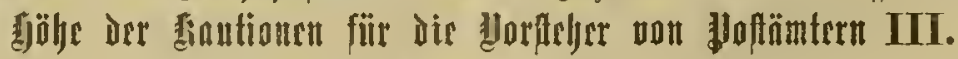

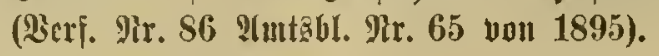

Berโin, 14. Dezember 1895.

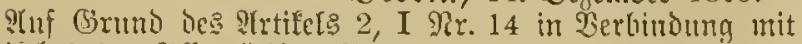

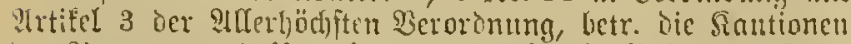
Der Beamten unb lluterbeamten Der Reidjesioft= mo Tele=

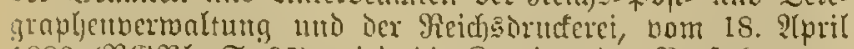

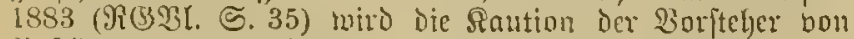

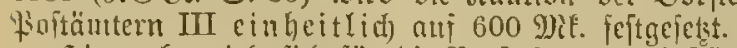

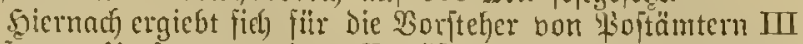
grö̈eren llmfange: eine Ermüfigung ihrer bisherigen

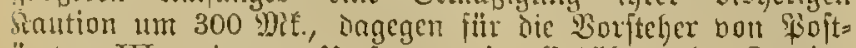
ämtern III geringeren ltmfanges eine (Frböhung oer Raution um ber gleidjen Betrag. ${ }^{1}$ )

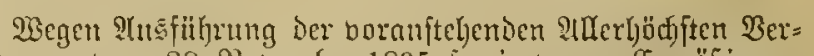

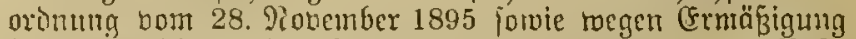
bejto. (Erhp̈hung der Siautionen ber Borfteber bon \$oft= ämtem III auf Den Betrag bou 600 Dit. roird all bie Dbet= Fioftirettionen bejondere $\mathfrak{B e r f i ̈ g u n g}$ ergelyen.

\footnotetext{
1) Dic Rautionen betrugen für Borftefer von Fofitümtern III grö́ceren tluffangę $900 \mathfrak{M E}$.

mittlereu " 600 "

geringeren " $300 "$
}

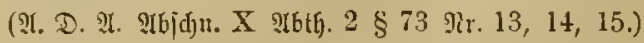




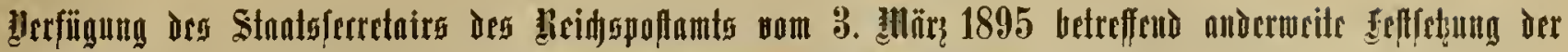

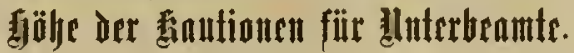

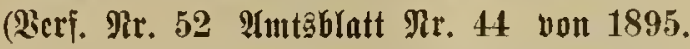

Berlin, 3. ̧uli 1895.

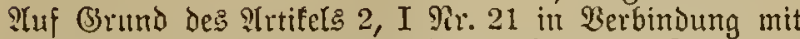
?trtifel 3 ber s(xerhödfften $\mathfrak{B e r o r o n u g , ~ b e t r . ~ D i e ~ \Re a u t i o n e n ~}$

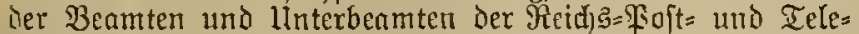

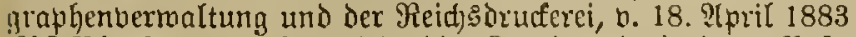

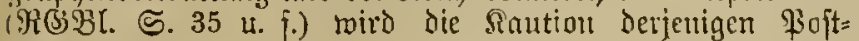
Ilnterbeamten, weldje nadi den bisherigen Borfdyiften eine joldise bon 400 Iit. zu beftellen hatten, auf 200 gRe. Gerab.

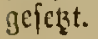

Der Rautionsfat bou 200 Mif. gilt demmad) finjtig fiir fümmtlicfe lluterbeamte iोer Foftbermaltumg. Someit $\mathfrak{B}_{\ell}=$

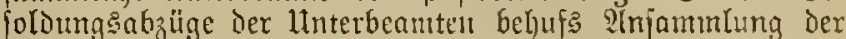
Saution tiber den Betrag von 200 Mif. Ginaus cintehalten

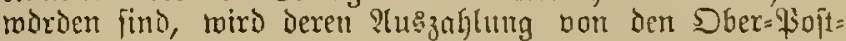
direftionen angeoronet merder. Wistemeit die giücfgabe ber Wher 200 ME. Gimaus borbandenen Werthpapiere erfolgen fann, wird burch bejoniere Berfïging an bie Dber=\$ojt= direftionen bejtimmt werden.

\section{$\mathbb{C} \mathfrak{a} \mid \mathfrak{x} \mathfrak{l}$}

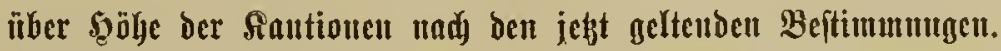

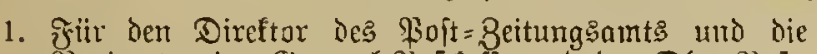
Mendanten der Beneral=\$sojteffe umo der Sher=\$3oit =

fafjen ......... 9000 MiE.

2. Fैü Rontrolleure und Saffirer bes \$ojts Seitungşants, für Raffiter Der Beneral= Wipttaffe und Der Sber=\$oftfajfen, den Direftor Des \$oft jeugamts und Führer von \$oftonmpfichiffen.

3. Fï̈ Den $\mathfrak{B}$ orifteljer Der Telegraphen=

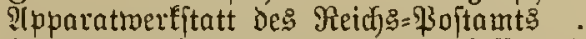

4. Fiur Bud) halter der (seneral=\$3oftfaffe und Der Sber $=\$$ poittaffen

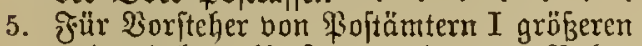
und mittleren Ulmfanges oder bon Babn= poftümtern größzeren und mittleren $\mathfrak{u m}=$ fanges

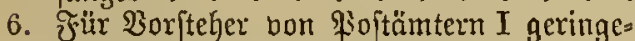
ren Unfanges

7. テٓür Boriteher von Telegraphenämtern

8. ङ̈̈r Salfirer bei \$̧oftämterm
3000

1500

2400

3000

1800

1500

2400
9. ऊür Raffirer bei Ielegraphenämtern

10. Fु̈tr Soritelyer bon \$oftämtern II .

11. Fitir Boriteher bon Softämtern III

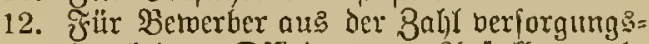
berentigter Difiziere um 2inftellung al: Borfteher eines \$ojtamts I röherno des Borbereitungs: uno Probedienftes.

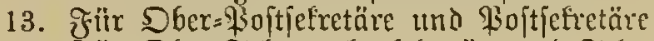

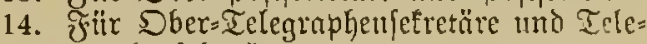
araphenfeftretäre.

15. Cittir Poftpraftifanten und \$ojteleven.

16. Ifïir Bureanaffijtenten, $\mathfrak{D} b e r=\$ B$ oft $=$ mito Sber = Ielegraphenaffiftenten, Woft = und Ielegraplyenaffiftenten mo Telegraphen= mectjanifer.

$1500 \mathfrak{M C}$

1500

600
17. ₹̧ür \$ọtanmärter, Ielegraphenanmärter,

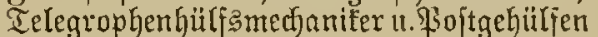

18. Fiir \$ojtagenten.

19. Jैü Unlerbeamte
900

1500

900

900

600

200

200

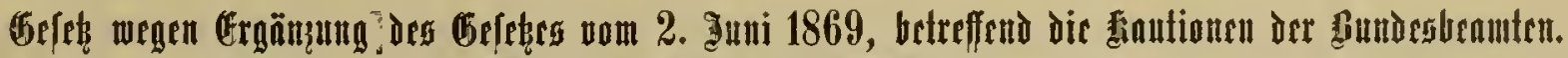

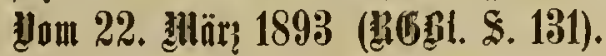

§ 1. 2Imtsfautionen im Sinne des Gefezes bom

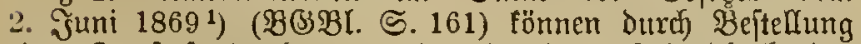
cines Fauftpfandred)tes an einer in einem Sdjulobudie des

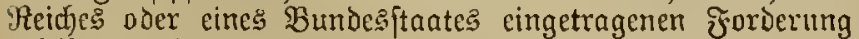
geleiftet merden.

Die Beftellung exjolgt Durd) Eintragung eines der $\mathfrak{B} e=$ ftimmung im $\$ 10$ des bezeidfneten (Sejebes entfprectenden Bermerf: iu S(f)uldobuche. ${ }^{2}$ )

Das Recft zum Empfange Der Binjen der eingetragenen Forderung, mirb Durd bie Fantiongbejtellung nidjt beringrt.

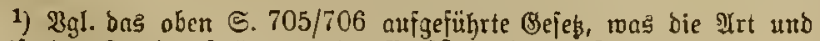

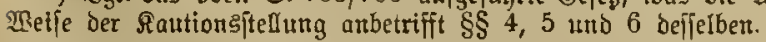

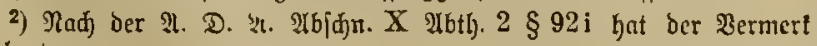
ou lauten:

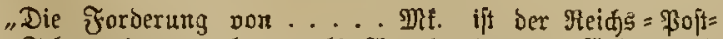
und Telegraphentverivaltung als STmtštaution oerpfändet und haftet für alle van bem Bläubiger (ober von Dent mit शanten und Dienjtftellung au begeiduenden Beanten, fojsrn bas Fauft= pFanoredyt an Der Forberung eines britten beitellt ift) aus

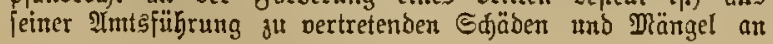

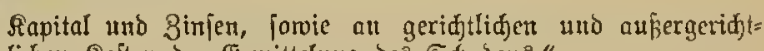
lidjen Roften Der Ermittelung Des Edadens."

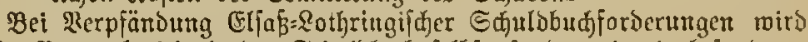

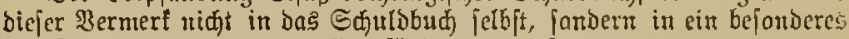

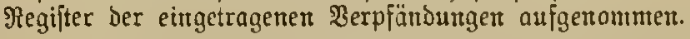

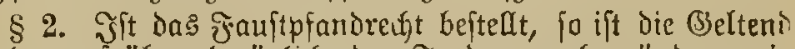
madjung früber bezüglid, Der テorberung begrïndeter, in

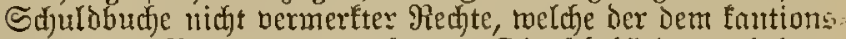
pflifftigen Seamten vorgejekten Dienftbeförtde unbefamint maren, iljr gegenüber auggejofhloffen.

§ 3. Sobald für cine aus ber Saution sull decfends Forderung ein volfftredfbarer Titel borliegt, if̂t die deni fautionspflidytigen Beamten borgefebte Dienfibelobrde befunt,

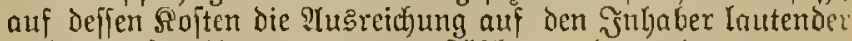

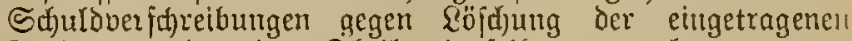
₹orderung oder eines igheiles derjelben zu berlangen.

(Segenüber Der Shuldenvertwaltung bedarf es Des શart: meifes des bolftrectbaren Titels nidi)t.

Die ausgereidften Souldber [hreibungen gelten als jun: 8rwecf der fautionsleiftung beitelltes ₹auftpfand. 
§ 4. Sobald amtlich feftgcitellt ift, dof aus bem

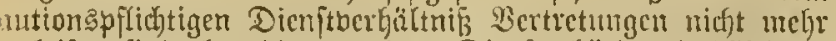

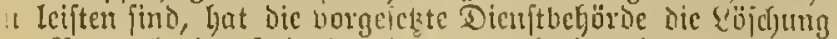
is. 2ictnterfs in Edjulobudje ju genclymigcu. ${ }^{1}$ )

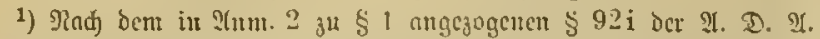

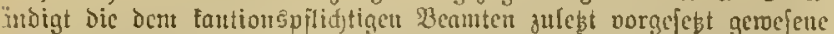

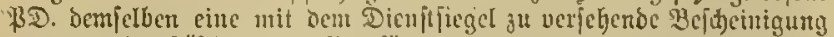

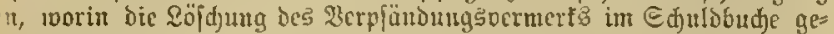

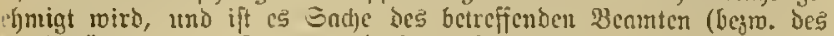

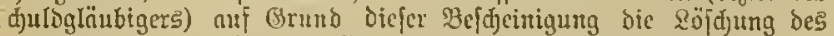

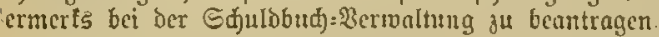

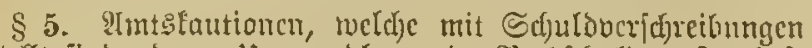
cjtellt find, deren llutwandlung in Budbfonulden ftattljaft it, fönnen zh Sautionsmaffen bereinigt und anf beren

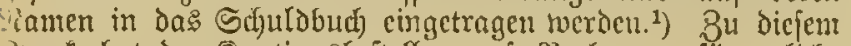

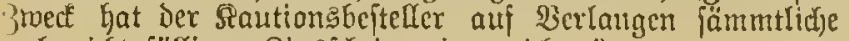
:ud) nicjt fälligen Binsfid)eine cimzureidjen." )

Mit der 2(uflialyme in dic Sautionsmajp gehen bie

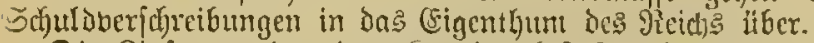

Die Zinjen rerden dem Siantionsbciteller bein (Fintritt

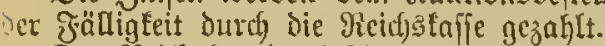

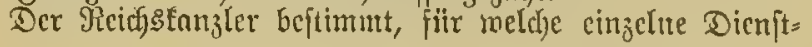

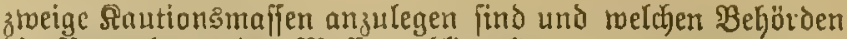
oic Berwaltung ber Mafjen obliegt. ${ }^{1}$ )

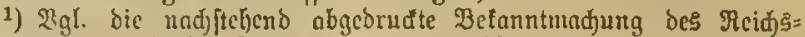

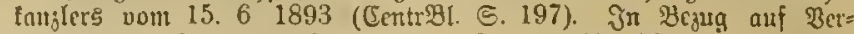

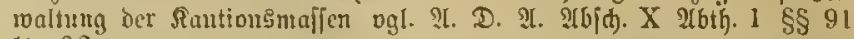
bis 920.

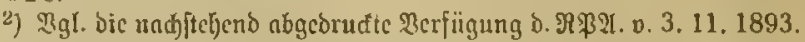

\$. Wird cine in die Maffe aufgenommene Saution aus berjelben mieder ansgeforicden, jo find $\mathrm{dcm}$ frautions:

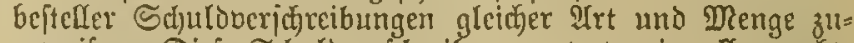
sutueifan. Dicje Sdjuldoerfarreibungen treten in allen redtst=

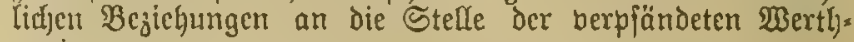
papiere.

§ \%. Bon ber 2ufnafme der Sduldoerfdyreibungen in dic Sautionsmafic (§ 5) und bon der Zumeifung andercer

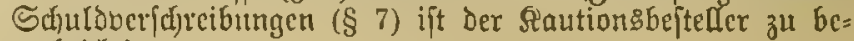
nadjridtigen.

§ 8. Şjt cinc in die Mafje aujgenommene Raution

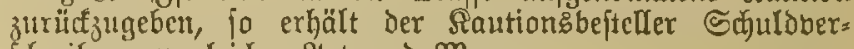
idjecibungen gletcjer Strt und Denge.

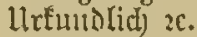

(Segcben Berlin Schloß̧, ben 22. März 1893.

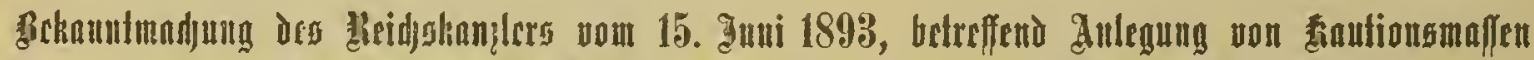

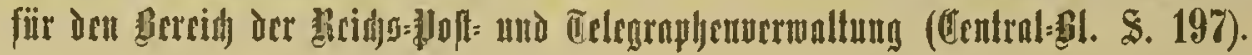

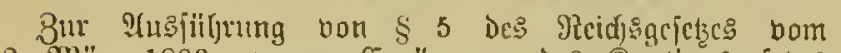

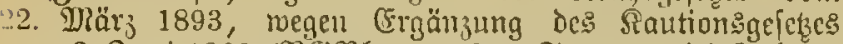

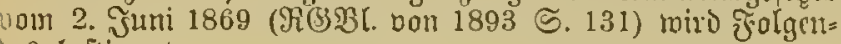
îs beftiumt:

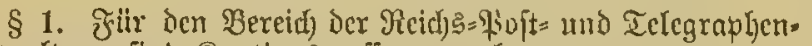
uerwaltung find Rautionsmaffen anzulegen:

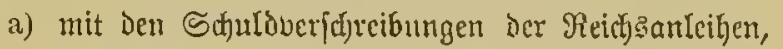

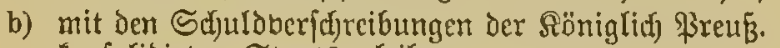
Eonjolidirten Stantsanleiljen.
§ 2. Die Berwaltung biejer Siautionsmaffen liegt den Dber=\$3oftbireftionen, einer jeden Ginfichtlich des in ihrem Sెefiz befindlid)en Theils, ob. Bu Inträgen auf Fintragungen oder \&öf(t)tngen in ben Sdjulobüchern, fowie zum (Empfang

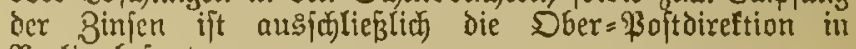
Berlin befugt.

Berlin, den 15. Juni 1893.

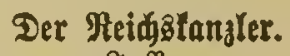

๖. Stephan.

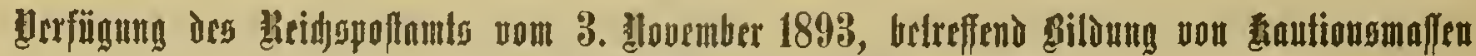

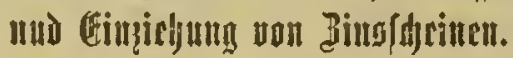

\section{(2erf. Pir. 85 :(mtą̧latt Mir. 63 voul 1893.)}

Berlin, den 3. Nobember 1893.

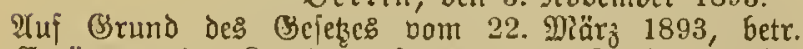

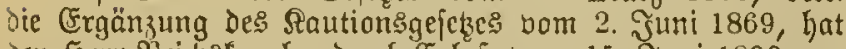

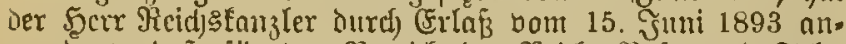

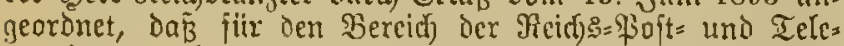

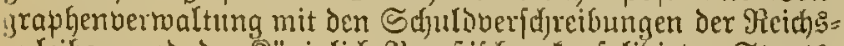

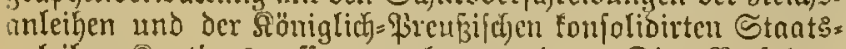
anleifyen Sautionsmaffen angelegt socrden. Dics Berfabren tritt mit Dem 1. Samuar 1894 in Sraft.

Die in 4 prozentigen, $3 \frac{1 / 2}{2}$ projentigen und 3 projentigen

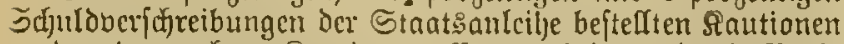
berben bemmad) zu Sautionsmafien vereinigt und als $\mathbb{B} u t)=$ (d)ulden unter bem 9amen der Rautionsmaffe Der Reidfs:

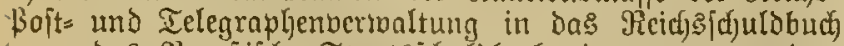

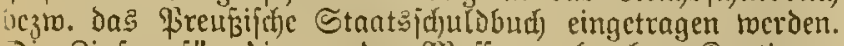
Die Zinfen für Die ju den Mlajien gebradten Sautionen ollen jur Beit der Jălligfeit - erfmalig am 1. Itpril 1894 — von den Berfehrsanftalten, in Deren \$ezilf bic Sautions. befteller twoljnen, an bie (Fmpjangsbered)tigten baar aus: gezahlt merden.

Эn die Rautionsmaffe fömen die \$apiere nur dann aufgenommen merdct, went ifnen fämmtlide, nodj nid)t jäđligen Bingfdjeine beiliegen. Daher werden fillnftig bic

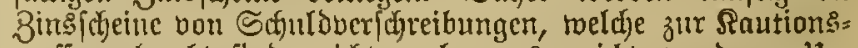
maffe gebradjt fino, nidjt mehr ausgereidjt werden. Um Die Uleberfithrung ber bereits beftellten Sautionen in bic Rautionsmaffen zu bejojleunigen, haben die Berfehröämter igre Beamten und Unterbeamten, fameit für fie die Saution mit $4,3 \frac{1}{8}$ und 3 prozentigen ङchuldverid)reibungen Der

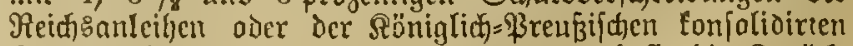
Staatsanleifyen bejtellt ift, zu bepragen, ob fie bie Zuriid. lieferung Der bercits jur Uusgabe gelangten, nad dem

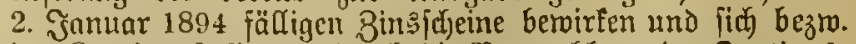
den Sautionsftellern badurd) Die Baarzahlung der Sautions. jinjen firfern wollen.

$$
\text { u. โ. } \text { เo. }
$$




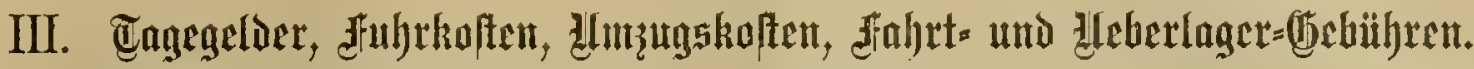

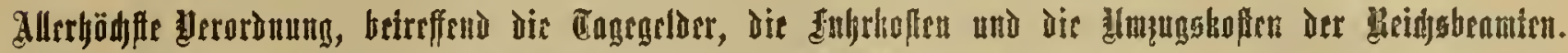

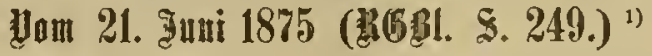

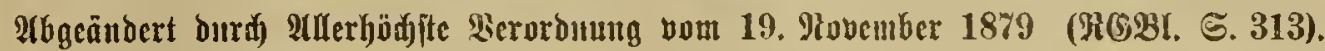

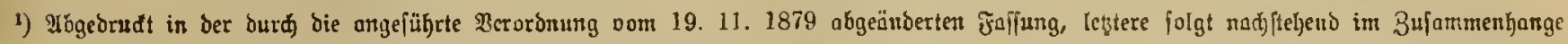

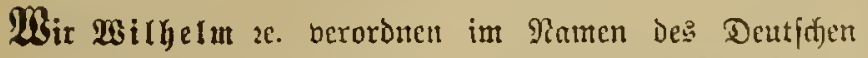

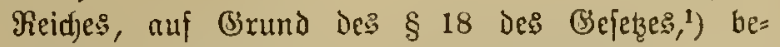

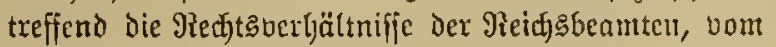

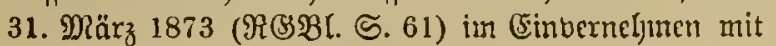
Dem Bunbesratl), toas folgt:

1) Bgl. ob́er Seite 657 .

$\S$ 1. Die Reidjgbcamten exhalten bei Dienjtreifen Tage= gelder nad) den folgenden Sätzen:

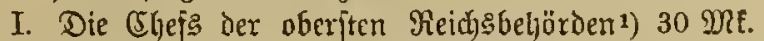

II. Dic Direftoren Det obcriten Reidsbes böroen ${ }^{2}$ )

III. Die bortrngenden Räthe ذer oberiten

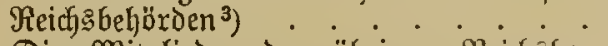

IV. Die פitglieder der übrigen Reidf höroen ${ }^{4}$ )

V. Die Secretaire der höberen Retctsbe: hörden ${ }^{5}$ )

VI. Die Subalternen Der übrigen tremsbe= Göroen ${ }^{6}$ )

VII. Die linterbeamten 24 18

1) Der Stantêfecretair bes Reidకిpoitamts.

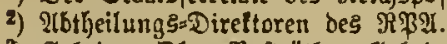

3) (Beheime Ober=\$oiträthe, Beheime \$oftröthe (als oortragende

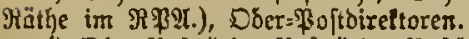

b) Ober=\$oiträthe, \$oiträthe, \$oftbouräthe, \$o[t= uno Telegraphen= Direltoren, \$o[t= und Telegrophen=Inipettoren, Rendanten ber Dber. Boptluffen.

5) \$ofthffirer, Ie'egraphenantstaffirer, Ober.\$oftoirettions.Secre= tatre, Raffirer uno Budhalter bet ben Dber-\$ofttajen, Dber= \$ojt= uno Dóers: Telegraphenfecretaire, Poftmeifter, Bopt= und Telegrapljenfecretnite.

5) Bureauafiftenten und Ranjliften ber DPD., DGer=\$ojts uni Dber-Telegraphenafiftenten, Bojt. und Telegrapherafififtenten, Bojt= verwalter.

§ 2. Fiforbert eine Dienftrcife cinen aujzergemöbuličen Rojtenaufwand, fo fam Der Tagegelderjats (\$1) bon Der oberften Reidjôbhörde angenteffen erhöht roerden.

§ 3.') (Etatzmäsig angeftellte Reid)gbeamte, weldje atferlyalb ihres Wohnortes länger als einen Dionat be= idjäftigt werden, erbalten neben ifrer $B$ efoldung fïr ven eriten Monat die im \$ 1 jeftgejesten Sagegelder. Fitr dic folgende Beit einer joldben Bejhäftigung etatsmäßig ange= itellter Beamten, fowic in ism falle, wem nicf)t ctatse =

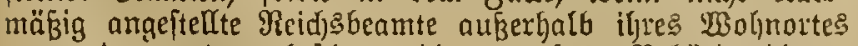

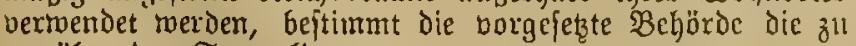
getwährenden Tagegelder.

Für die Dauer der Sin= und Rüureife lyaben die $\mathfrak{B} E=$ amten in jedem $\Im a l l e$ auf die in $\$ 1$ jeftgejetsten Tagegelder aniprud).

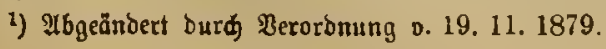

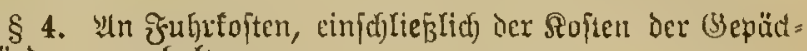
beföroerutg erfalten:

I. bei Dienftreifen, welche auf (sifenbalynen oder Dampfidiffen gentad)t toerben tönmen:

1. Die im $\$ 1$ unter I bis $V$ bejeidneten und dic iljnen nadj $\$ 19$ gleidgeitelltell Bcamten für bas $\mathrm{km} 13 \mathrm{PSF}$. tmid für jeden $8 \mathrm{H}=$ und

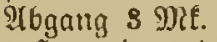

Sat einer Der im $\S 1$ unter I bis IV bes zeidyneten Benuten ciren Diencr auf die 乌eije mitgenonmen, io tann er für icnfelbeu 7 \$f. fïr Das $\mathrm{km}$ bcaniprudjen.

2. Dic ill $\$ 1$ unter VI bezeidjeten Imto dic ifjnen nad) \& 19 gleidgeitelten Beanteu fïl

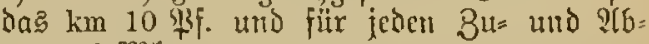
gang 2 Mf.

3. Dic Unterbeanter für Das $\mathrm{km} 7$ \$f. unb für

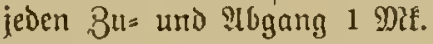

II. Bci Dienftreifen, weldye midjt auf Dampffuiffen oder Fifentonfuen zurittgelegt werden tönnen:

1. Die in $\$ 1$ unter I bis IV bezcidjmeten unt dic ilynen naud $\$ 19$ gleidjgeitellten Beanteu 60 TSF.

2. Die im \$ 1 unter V und VI bezeidineten und dic iljnen tadi $\$ 19$ gleidjgejtellten Bcamten 40 \$).

3. Die Unterbeamten 30 \$3F.

fiir Da: $\mathrm{km}$ Der näd)ften fahrbaren Straf̧enberbin= Dutig.

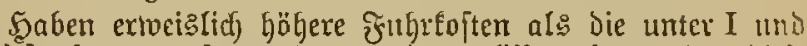
$\amalg$ fejtgefezten aufgemendet werden mifffen, fo werben bicic erjtattet.

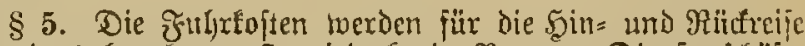
befonders beredjet. Sat jedodj cir Beamter Dienjtgeidjäft" an berfdiedenen Diten unmittclbar nadj cinaldocr alsge

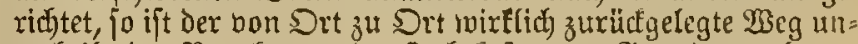
getheilt Der Beredjning Der Jufrfoften zu Srumie zu legeu.

$\left.\S 5 a^{1}\right)$ Jïr Begefrecten oder Hmmege, welche lediglid) zum Bmedfe Der Uebermad)tung nad) anderen Drten als Den Drte des Dienitgejdjäftes gemadjt werden müfficn, fiti an Stelle der borftelyenden Sergïtungsföze in Den (Biren, Derfelben dic etwa verauslagten Juhbrfopter zu exjtatten.

i) 3ugejest burd Beroromung o. 19.11. 1879.

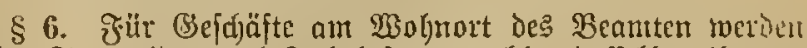
weder Tagegelder nod) Fulytoften gejahlt; Daffelbe gilt wou (Scjudaften aujerljalb des 2 obnortes in geringerer cent. fernung als $2 \mathrm{~km}$ bon Demjelbets. War ber Beamte duru

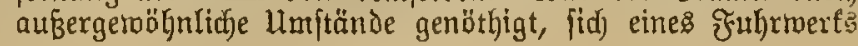


"11 Gesientu, noer maren fonitige notbromoige Unfoiten, wie

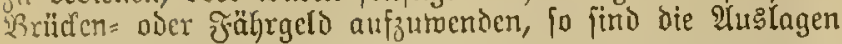
ju elftatten.

fit cinzelue Drtidjaiten tann burd ben Reidjstanzler

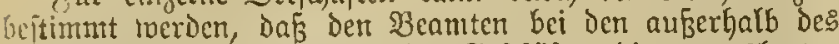
Dienjtgebät)es borzunehmenden (Sejdjäften die berauslagten Julurfoften zu erftatten find.

\$ 7. Bei Berechnung Der Entfernungen roird jedes angejangenc filometer für ein bolles Rilometer geredjnet.

\& 8. Beamte, weldye aum Bmed bor Reifen innerljalb

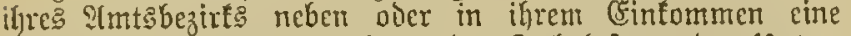
Baufofjumme für Tagegelder oder Jubrfoften ober lunter= haltung von ङratriverf oder \$ferden bezieljen, erhalten Tagegelder und Fuljufoiten nad) Mafjgabe diejer Beroronung

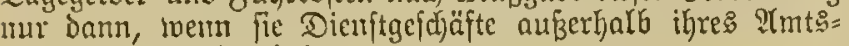
bezirf? auggeführt haben.

§ 9. §ür Dienftreijen bon Beamten, weldje fiff im Barbereitutigsoienfte befinden, ${ }^{1}$ ) toerben Tagegeloer und Jubrfopten Dann nidft gewälyrt, twenn dic Reifen lediglid) zum Broef der Ausbildung dic|er Beamten erfolgen. \$b Qebteres ber Jall ift, entidjeioct bie Bchörde, von weldjer Der \&ujtrag zur Reife ertljeilt wiro. $\left.{ }^{3}\right)$

1) Pofteleven uno \$ojtgebülien.

2) Die Dber= Poptoireltionen.

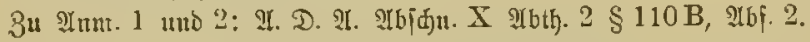

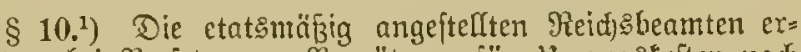

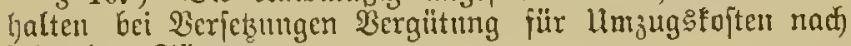
folgenden 巨äłen:

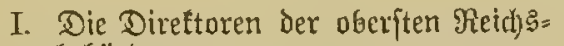
behörocn

II. Die bortragenoen läthe ber oberfen Reicjsbeföriter

III. Die Mitglieder Der Güberen Yieichs: bejörden

IV. Die Mitglicoer der itbrigen Meidt) behärden

\begin{tabular}{|c|c|}
\hline $\begin{array}{l}\text { auf } \\
\text { allgemeine } \\
\text { Rofter }\end{array}$ & $\begin{array}{l}\text { auf Irants } \\
\text { porltoftert } \\
\text { furr it } 10 \mathrm{~km}\end{array}$ \\
\hline $\mathscr{H}$ & $\mu$ \\
\hline 1800 & 24 \\
\hline 1000 & 20 \\
\hline 500 & 10 \\
\hline 300 & 8 \\
\hline 240 & 7 \\
\hline 180 & 6 \\
\hline 100 & 4 \\
\hline
\end{tabular}

V. Die Seeretaite Der bäberen Sietdys= behörden

VI. Die Subalternen Der übrigen لieidjs= befiörden

VII. Dic Unterbeanten

100

Yufzerdem ift Der Miethzins zu vergülen, melthen der

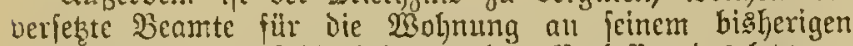
Sufentljaltsonte auf dic Bcit bon bem Berlajien des Letzteren his zu Dem Beitpunft hat aufmenden müffen, mit weldyen

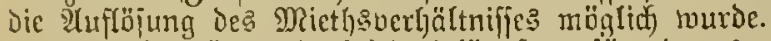

Dicie Bergittung burf jedod längitens fïr cimen 9 monat= lichen Beitraun gemälyt werben. Sgat der Beamte int

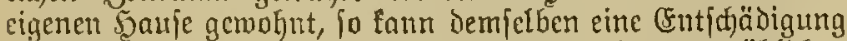

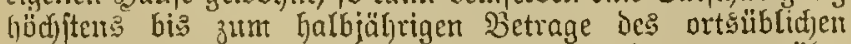

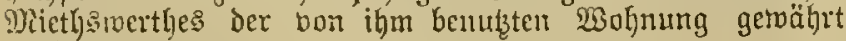
werben.

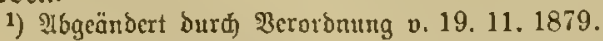

§ 11.1) (Fine Bergütung auf ltruzugstoften fittet nidjt flatt, wenin bie \$erfez̧ung leoiglio' auf ben Intrag bes Beanten eifolgte.

1) Nufgetobell burch Berorboning b. 19. 11. 1879.
§ 12. Beamte ohne Familie erfalten nur bic Şälite ber ract) $\& 10 \mathrm{I}$ bis VII feftzuietenden Bergïtung.

$\S 13$. Bei Bereffnung Der Bergütung ift Die Ent= fernurg zwif(t)en den Diten, bon reldfem und nad) meldjem bic Verjełururg ftattfindet, nad) der türzciten fafubarcu

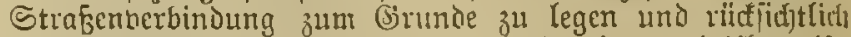

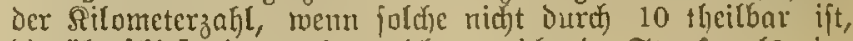
bie tiberfdjiefende, $10 \mathrm{~km}$ nidjt erteidjende Strede al: eime Entferumg bou $10 \mathrm{~km}$ zu rectnen.

$\S 14$. Bon den Bergütungsjäßen ift berjenige in ?ฺn= menoung zu bringen, welefen bie Stellumg bedingt, als weldjer - nicht in reldje - Der Beainte verfebst ruird.

$\S 15$. Die zum $\mathfrak{B e z u g e ~ e i n e r ~}$ Sergütung fïr $\mathfrak{H m}_{\text {zug }}=$ foften bereditigten Beamten erfalten auBer bicfer $\mathfrak{B e r g i i t u n g}$ für ifye \$erfon Tagegelder und Jufrefoften nad) Maßsgabe Der gegenmärtigen $\mathfrak{G e r o r o n u n g . ~}$

\$ 16. Die nicht ctatsmäß̧ig angeitelften Reichsbeanten

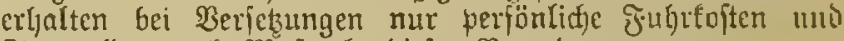
Tagegelder tack) Diafgabe biejer Derorbnung.

§ 17. Shat cin in den Ruheftard ober in ben eimft =

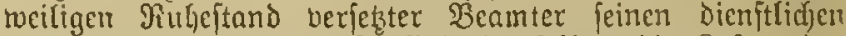
Wolnfits in ?lus̆lande, fo find demfelben bie Soften bes

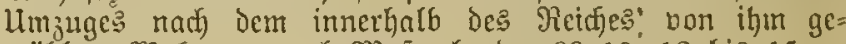
wältteı Wohnorte nach Maß̧gabe ber $\$ \S 10,12$ bis 15 z"l getwälgreti.1)

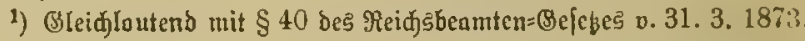

$\S 17 a .1)$ Die cimftmeilig in den Ruheitand verjeksten

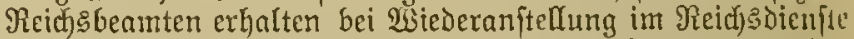
Bergütung fïr Umzugstoften nadj den Beftimunutuen ber $\S \S 10,12$ bis 15 . Der $\mathfrak{B e r e d}$ nung ift die Entfernun!? awifden dem bisherigen $\mathfrak{B a h n o r t e}$ und dem neuen 2 mt fitse ju Grumbe ju legen.

1) Bugefügt burd Berorbuung D. 19. 11. 1879.

$\S 18 .{ }^{1}$ ) ßerionen, weldje, ohne vorker im Reidfsodienfte geftanden zu Gaben, in denfelben übernommen merden, taut cine Duref Die oberíte Reidjgbehörde feîtzufezende Wergütult Für bie Dienftantrittereije und in falle ber bauernden Uebernabme cine in gleidfer Weije feitzulescende Bergittung für Ulnguggtoiten gemöhrt twerben. Dieje Derguitungen follen nur ausnalymsmeife bemilligt twerdell und bürfen Dic Säke nidft überfteigen, welche die Stellung bedingt, in welet)e Der Beamte berufen wird.

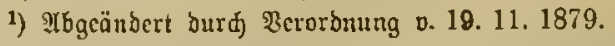

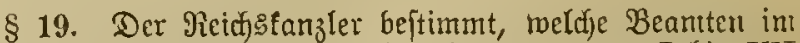
Sinne diejer Beroronung zu den im $\$ 1$ unter I big VII und im $\$ 10$ unter I bis VII genannten Beamtentlaffen ge= hören oder Denjelben gleidjzuftellen fint.1)

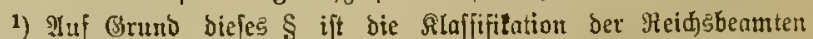

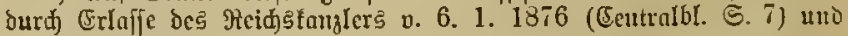
v. 13. 2. 1886 (CentralbI. E. 35) erfolgt.

§ 20. Begenmärtige Berorbmung tritt mit dem 15 . Juli ঠ. รaljres in Siraft.

Urfunditd) $2 c$.

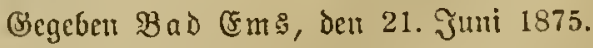




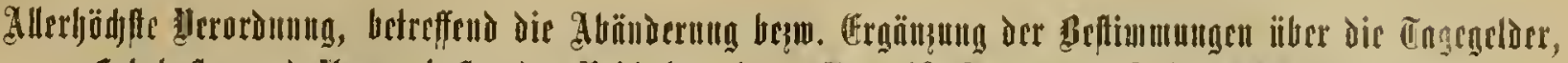

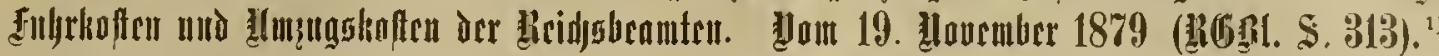

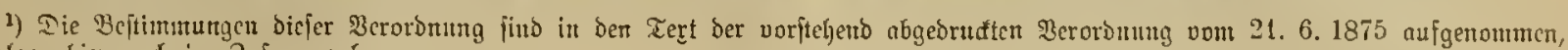
Dicjelber folgen lier nod im 3 funumenharge.

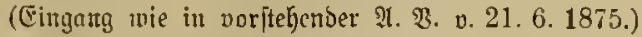

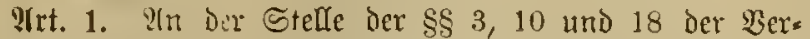
ordumg bctreffend dic Sagegelder, dic Jubrtoften und die

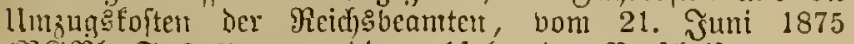

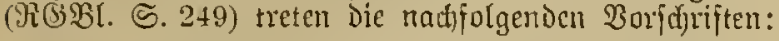

(5ier folgen bic in ben ?ext ber voritehenden Berorbung aufgenomntent $\$ \$ 3,10,18$.

2rt. 9. Sinter $\S 5$ und $\$ 17$ der Beroronung vom 21. Suni 1875 find folgende Beftimmungen einzufochalten:

(Folut Tert ber $\$ \$ 5$ a uno 17 a).

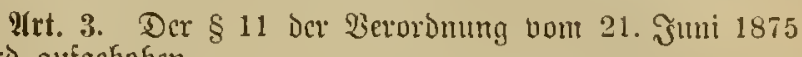
Iviro aufgehoben.

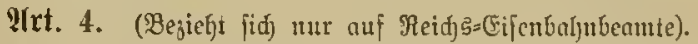

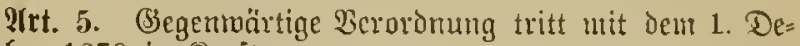
zember 1879 in Siraft.

Urfundidid) $2 c$.

Gegeben Berlin, Den 19. Rovember 1879.

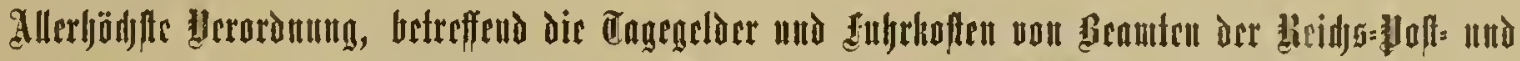

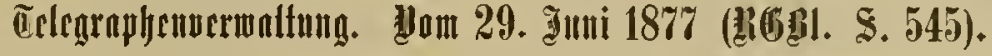

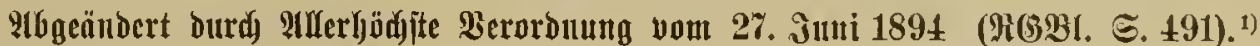

1) श:adjiteheno Seite $723 / 724$ abgebrudt.

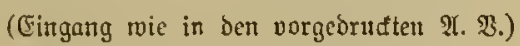

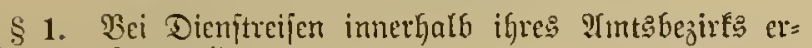
balten an Tagegeldern:

1. Dber=\$3oftoireftoren . . . . 15 Dif.

2. Foft= Imo Telegrapljeninipeftoren 99

werben bie Reifen auf Eifenbahnen oder Dampficjiffen

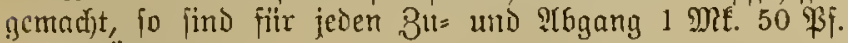
ju bergüter.

Softinfpeftoren und Telegrapheninjpeftoren erljalten,

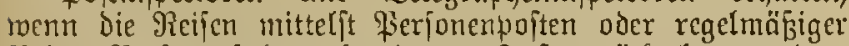

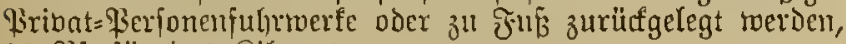
20 \$斤. fïr Dns Silameter.

§ 2.1) Die int \& 1 für \$oftimpeftoren und Tele= grapheninfpeftoren beitimmten Bergïtungen erbalten auch) 3orfteher bon Balnopoitäntern uno bon $\mathfrak{B}$ ojtämtern exiter

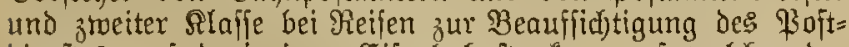
bienjtes auj denjenigen (Eijenbahujtrecfen, auj meldfen ber Bojtbetrieb ifjer Reitung unteritellt ift.

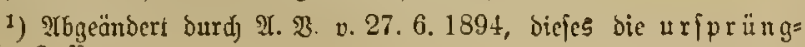
lidie Ærafiung.
§ 3.1) Die $\S \S 1$ und 2 finden auf Beante, meldbe cinen Der Dort bejeidfucten 3 eamten bertreten, ebmfalle

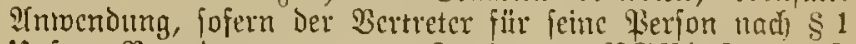

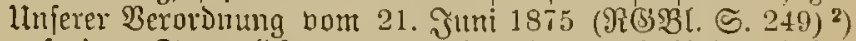
auf einen Tagegeldjak bon mel)r als 6 Mit. 21 nipruch hat

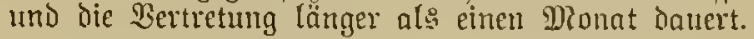

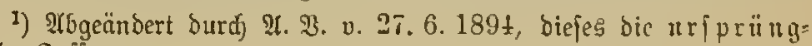
liche farfung.

2) Die S. $717 / 718$ vorgebruđte $\mathfrak{1}$. $\mathfrak{B}$.

$\S$ 4. Sotweit in Borftebendem nicht andertweite $\mathfrak{B} c=$ fimmungen getroffen find, finden auj Die Tagegelder uno Julfrefojten die pben bezeidfneten Beamten aud) bei Dienjt=

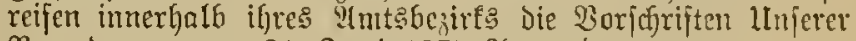
Beroromeng vom 21. Suni 1875 Ifntwenoung.

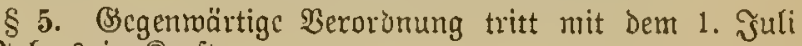

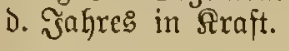

Urffurtolici) $2 c$.

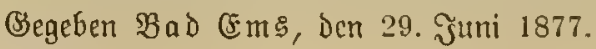

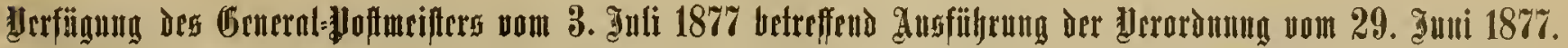
(शrmtäbratt vou 18\%\%. Є. 235).

Berlin, den 3. Juli 1877.

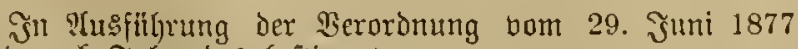
wirb nodj Folgendes bejtimnt:

1. Dienftreifen der Beamten in den Der Sber=9soit direftion Des eigenen Bezirf's unteritellten $\mathfrak{B a h n}=$ poften nach Drten in frember Bezirfen find zu Den Dienitreifen innerbalb des 9 amtsbezirfs zu rectinen.
2. Wiro bei Dienjtreifelt zrwifdyen Srten des eigenen $\mathfrak{B}$ czirfs ein frentder Bejirt herithert, fo find -

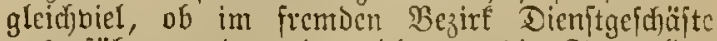
auggeführt merden voer nicht - Die Tagrgelder nad) Den Säzen ber Beroronung vom 29. Şuni zahlbar. Daffelbe gilt bei Diemitreifen behuis Uebernachtung im fremben Bezirf, fowie bei Dienjt. 


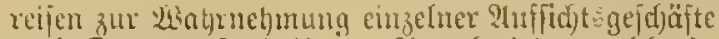

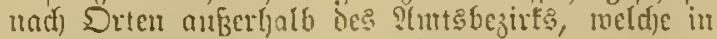
ถer গiälye ber Bezirtsgrenze liegen.

3. Solveit bei Reifun jur Erleoigung nou Dienit=

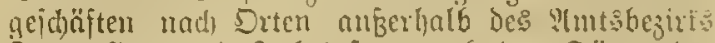
Ingrgelier und Juhrfoften nad den Sätsen or $x$ Sinijerliclen Rerurdmung bom 21. Tun 1875 ahl= har fint, fommen die höberen Săke an Iagac: aclocrn bercits für Den Tag, an melden oic

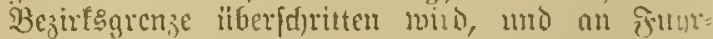
toften fïr die Strecfe bom Brenzorte Des ?mts: bejirfs bis zur Rüdtelyr in den exften Grenjout Des $B \mathfrak{e}$ jirt: zur Tnuvendutig.

4. Dienftreifm, veldse wou den Snfpettoren ze. nuf

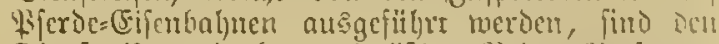
Dienftreifen mittel: regclmäß̈ger 93 ribat=23erfonen= jubrwerfe im Simne des $\$ 1$ abf. 3 तer Berordmung vom 29. Tumi gleid);uact)ten.

5. Die Sber=quptoirettoren mo die Rioptinipefturem,

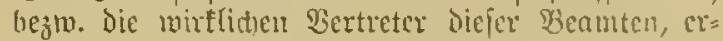
balten bei Diemitecifen innerljalb iljes atutes= bejirfs freie Beförberung nittelo Extrapoftplerde mu auf Denjeniget Etationen, bei weldien die Fofthalter auf (S)rutio älterer Derträge jur ment= geltfidjen (Sefteflumg bon Ertrapoftpierden ber=

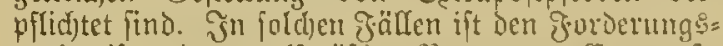
nad)weifen der tarijmäpige betrag an Gxtrapofs= pierdegeld, weld)er ani die mit unentgeitlid) geftellten \$ferben zurïffgelegten $23 \mathrm{geftretfen}$ cut=

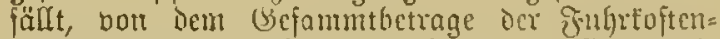
bergüttungen in ?163ug 311 bringen. (5) mad)t Dabei in SBetreff Der mirtlidten Stelluertreter teinen Intericties, ob diefelben mur noribergehento Sber=

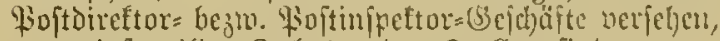
voer einftroeifige Snhyabe: oer Stellen fins.

för dic Bantzung von Grtrapolt alf Etationen

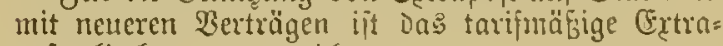
poftgelo baar zul entrid)ten.

6. Die \$optinfpeftoren und Die Selegrapheninipeltoren haben bei Der Benutzut ier Yerjoncupoften ing qerfonengeld baar jur Foftlaffe ju entrichen; dic

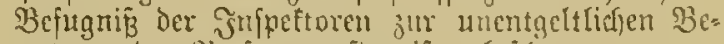
mubung ber Hierfonenpoften ift exloj(t)en.

7. Die 3nhlnng Der Tagegelder und Juhgrfoften nad) Den Eäken Der Beroronumg vom 29. Tuni findet jufolge Der Beptimmung im \$ 3 nid)t mu bei Dienptreifen bon $3 e(n n t e n$ ftatt, melche probemeife oder cinftrueilig mit ber Eermaltung von Dienft. fteffen Der in be'n \$\$ 1 แmb 2 ber Berordmung be= zeidfueten Benmten betrus fino, fondern aud) bei Dienftreifen, dic bei Ertrantungen, Beur=
Laubungen 2c. joldfer Beamten bertretumgstocije nou anderen Beamten ausgefiifert merben, fojern Die 2iertrettung länger als cinen J)onat bantert uno Der Bertreter fü feme fierion anj cinen Tagegelojats von mebr als 6 glt. ?(mprud) hat.

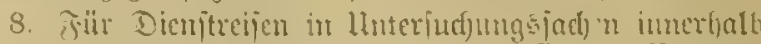

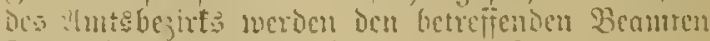

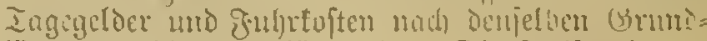
jütcen gezahlt, yoie fitr andere Dienifreijen inner= holb des ?tmtsbejut:

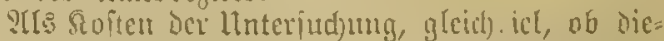
ielhe von ฐnjpettoren ober bon anderen Beanten

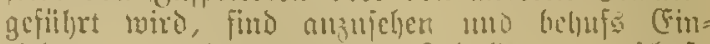
jeljung vou Dem ctwaigen Sefuld gut norichus= ivcife ju verrecfnen:

a) Tayegeloer bom Iage ber ?thrife bom Wohn= arte vere bon benicuigen Dote, mo der unter=

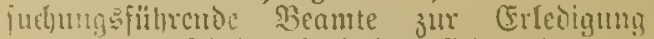
andocer bicnjtlid)er ?(ufträge iid) inleşt be= fumben ljat und wäfreno der Iage ber linter:

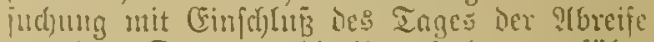
non bem Drte, too Die Itnter|uch):แg gefïf)r morocu ift, jonvic

b) istufrefojten fiir dic Reife nad) Dem Stte Dex Iluterfud)ung uno, mum nad) Beendigung Der lluterfudhung ninft etton in Demfelben Sorte andere Dienitgefchäfte zu exlebigen find, fïr Die 23 eiterreife bis sul bem Sule, two dic andermeiten Dienftgeichäfte beginnen.

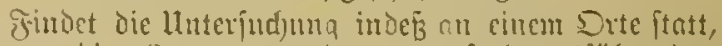
wo bic (Segentwart des unterfuthumgsfül)renden 23eanten fdjon andermeiter Dienitgefdjäfte inegen nothimendig ift, uno too Die Retateien bic Syampt: bef(c)ätigung bilden, fo find als linterfudifungs: foften nur bie Tagegelder wölfrend ber Tage ber linterfud)ung, nidjt aber aud foultopten in Injats 3" bringen.

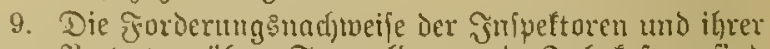
Vertreter ilber Tagegelder und Futlyrtoften fint monatlicf) aufisuftellen.

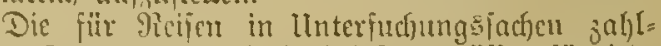
baren Tagegeloer und Frufirtoịten inülfen für jede lluterfud)ung bcfonders in fiporocrung nadjgewiejem werben.

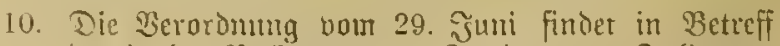

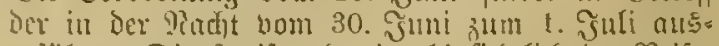

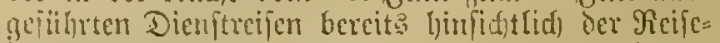
frreder ?tnmendung, weldye nad) 12 llhr Madjts aurïfigelegt fino.

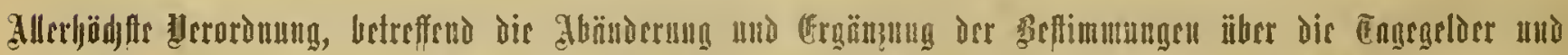

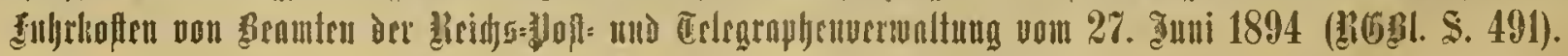

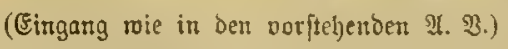
Artifel 1 .

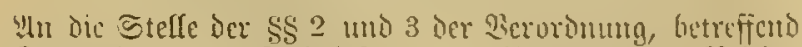

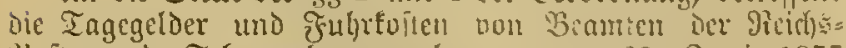
*3oit = MnD Telegraphenvermaltung nom 29. Smu 1877

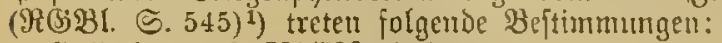

1) 2orftebeno S. 721/722 abgeorucit
§ 2. Die in § I für Poptinjpettoren und Tele= graphenufueftoren beftimunten SBergütungen erbalten

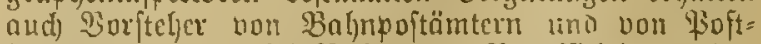
ämtern I und II bei Reijen jur Beanffichtigung Des Gioftbienfte: auf Denjenigen (Fijerbaluntrecter, auf weldien Der Foftbetrieb ifger Reitung unteriftell ift. Daffelbe gift - aubigenommen nen Tagegelojaz - 
fiir die gleidfurtigen Reijen der Borfeber non \&oft= ämtern III.

§3. Dic $\$ \$ 1$ uno 2 finten anf Benmte, weldfe cinen ber bort bezeiduneten Beanten bertreten, falls dic Bertretung länger als cincm 9)ionat dancrt, voun

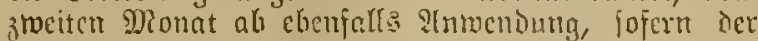

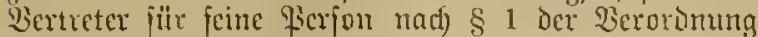

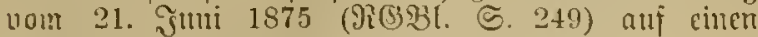
Tagrgelofats bon mely als 6 MRE. ?miprudd hat.

\section{Irtifel 2.}

Jinter icm $\$ 3$ find polgende Beftimmmugen einju= il)attell:

\$ 3a. Dic bei ber jerftellung und linterhaltung

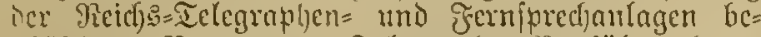
ichäjtigten Beanten - Telegraphen='Baufübrer bejw. Seitungarcuiforen uno Deren Bertreter - pomie Bic augeftellen Telegraphen=seitunganatjeher crhalten bei

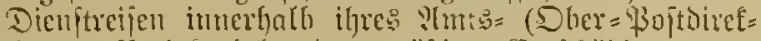
tion: $\Rightarrow$ Bejufs folgente ermärigte Entjuäbigungen:

1. Kai Den Reifen auf Eifutulnen oier Dampi= filififen:

$$
\begin{aligned}
& \text { Dic Telegraplen = Baufüfret und Seitung: } \\
& \text { reviforen . . . . . . Mit. 1,50 } \\
& \text { Dic Reitungsauffeljer . . . . . " } 0,50 \\
& \text { jïr jeden } 8^{\mathfrak{u}=} \text { und ?thgnag. }
\end{aligned}
$$

2. Bei den mittele Ferjomempoften oder regelınäsiger

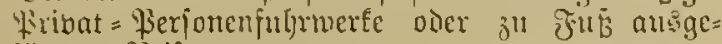
fiilyrten Meifen:

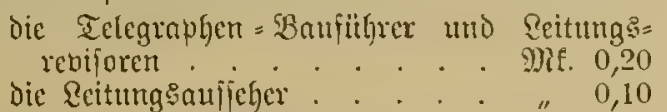

für bng Stilometer.

Fitir die Dienftgänge auf ber 2 trbeitsftrecte und

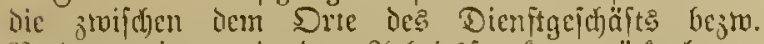
Tiad)tquartier und ber ?rbeitsftreffe juritafgelegten Wege find fullyrtoften nicht jalylbar. Th Stelle der: felten miro diejen Beamten fitr dic Datter iffer

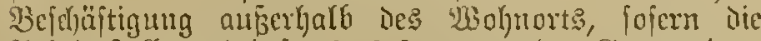
STrbeitsifelle mindeftens $2 \mathrm{~km}$ woul der (birenze des: iefocu entfent ift, cine non ber oberfen fiofsbehäroce mad) Dher= bergiiturg getwährt, und ztwar: den Telegraplen=Bauführern und Reitungs: reviforen von 1 bis 2 ME.

Den Reitungsouffehern bon 50 bis 75 \$f. fiir jedeı ?Trbcitstng.

Dic nad) ber boritehenòn Beftimmungen ben an= gefrellten Reitumg̨auffelern gebillurenden Zergütungen find aud) thenjenigen angeftellten llnterbeamten ju ge= mälren, melche vertrctungs: ober aushülistoeife ism Scitumgsanfieher= Dienfte nermendet merden.

Die nicl)t angeftellen Reitungsauffeber und bic Ielegraphenoorarbeiter erhalten bei ifrer Befdäftignng anberbalb dos 230 hnortes neben dem Tagegeld ein

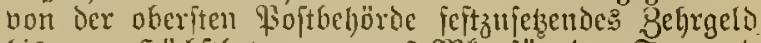

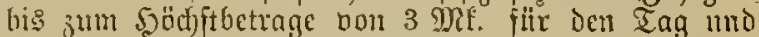
anferdem eine Entidübignng für die stuslagen an šabrgelo in 5obhe der wirélid aufgemendeten Beträge

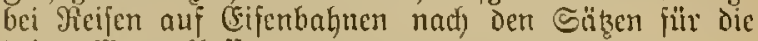
Dritte $\mathfrak{W a g e n t}$ taffe.

\$3b. Den bei der Sccritellumg und IInterlyaltung der Telcgraphen= mo F̌stuprechanlagen Gefchäptigten

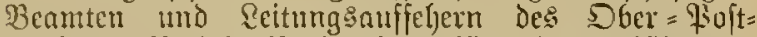
Direttions=23çinfs Berlin fteht für dic Bejuäftigung immerbalb diejes Bezirfs cin Trnjpruch auf Tagegelder

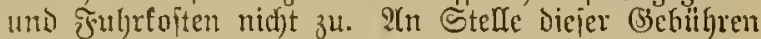
und jur Beitteitung Der Mehransgaben für Rleidung

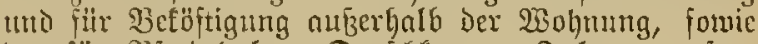
Der fïr Riferdebalyn=, Drojeffen= 2c. Fahnten aujzu=

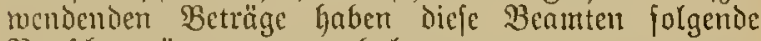
Baujdyergütungen zu erbalten:

Dic Sberjecretaire und Secretaire Mit. 4,50 Die Dheraffiftenten uno : iffiftenten " 3,50 Die Reitungsaurijeher. . . . " 1,20

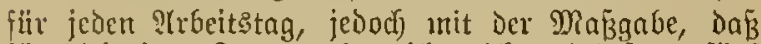
fïr diejenigen Iage, aนf tocldye nid)t mindeitens füuf

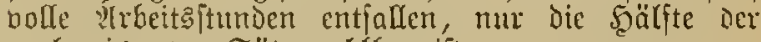
vorbejeichneten Säłze zahyshar ift.

\section{Pritifel 3.}

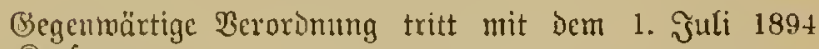
in Sirnft.

\section{lltunolich) $2 \varepsilon$.}

(3)egeben an Booro $\mathfrak{R}$. Y. "Sెohenzollern",

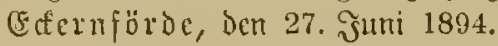

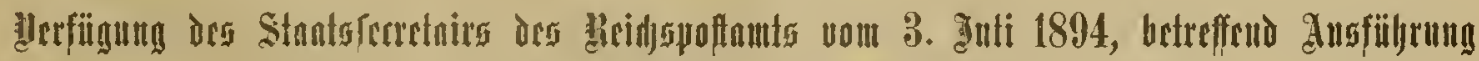

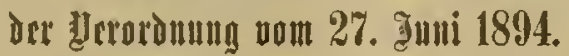

\author{
(2ierf. Mir. 42 PInt
}

Berlin, Den 3. Şuli 1894.

Durd) bie machftehens abgedrudte, am 1. Suli in Sraft getretenc Saiferficle Veroronung*) bour 27. Sumi, betreffeno

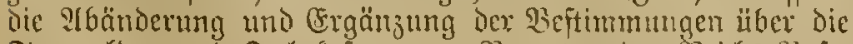
Tagegelder mo Futgrfoften non Beamten der Feid) $3=$ Foft

*) Die hier voritehen s abgebructe Sialerliche 3eroronung.

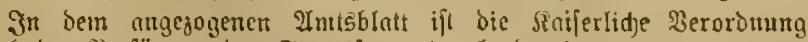
nad) ber गुerfïgung bes Etant5]eretais abgeoruft.

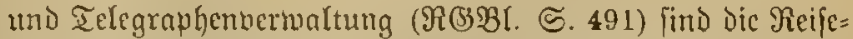

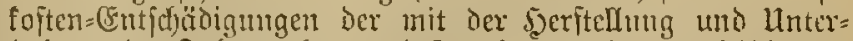
haltung ver Telegraphen= und Jerniprechanlagen befdjäftigten BBeamten und llnterbenmten aniermeit geregelt worden. SYuferdem ift Durd) jenc Berorduntg dic den Borftebern bon Foftämtern III bei Reifen zur Benuffichtigung Des

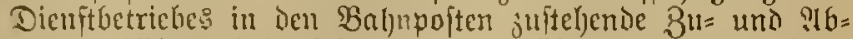
gangsgebüft auf benfelben Sał ermäßigt toorden, meldjen bie boxfeljer der ilbrigu Woftümter bei den gleidjartigen 
Reijen futun bisher auj brund des \& 2 Der Verotomng

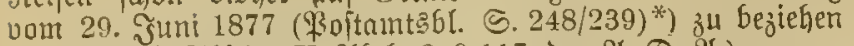

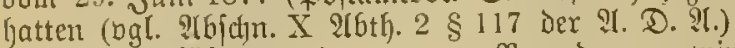

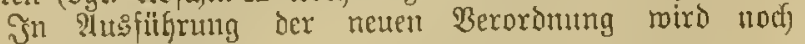
Jolgendes beftimmt:

\section{Irtifel 1.}

§ 3. ఫür die Anwendung der Borfdrift diejes Baragraphen, durd) weldjen ber Snthalt Des früheren \$3 ber Berordung vou 29. Suni 1877 nidjt berïbrt, pondern nur deffen Bortlaut in eine andere, jeden

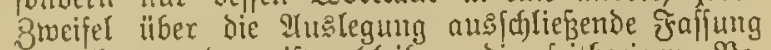
gebradyt worden ift, bleiben bie feitherigen $B e=$

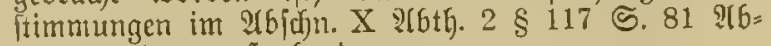
jats 2 uto 3 majgebend.

\section{3u $\mathfrak{U}$ rtifel 2.}

§ 3a. Juhrtoften=\&ntfäbigung ber Tele grapben=Baufübrex, Seitungsreviforen und angeftellen Reitungsauffeger.

1. थโ Dienitgang auf ber 2 rbeitsftrecte ift das Burifulegen bot 2egftreden an ben für die fithrung bon Selegravhen = mod Jernjpredjlinien beftimnten oder bereits benuzten Straf̧en 2c. nnzufeben, fotneit diefe (Szänge burd) die ?usführung des auf Die betreffende Rinie fich bezichen=

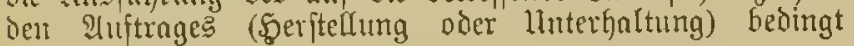
werden.

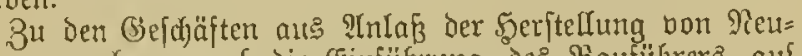
anlagen rectumen auf Die Sinfüfrung Des Baufibrers auf

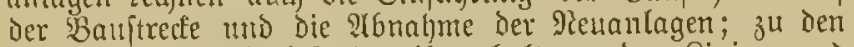

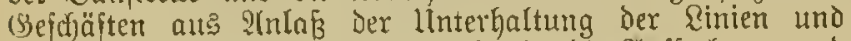
Reitumgen and bie Sorredifion porvie die $\mathfrak{A}$ uffutdung und Befeitigung von Betriebştörungen in Denjelben.

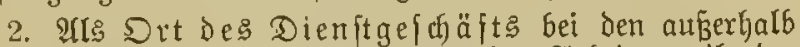
rines gejulofienen Drts auszufibrenden Urbeiten gilt der

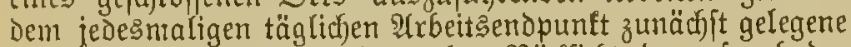
Drt (Dorf, Flecten, Stadt), ogne Rücfidut Darauf, ob ber Benmte in diejem ober in einem anderen, entfernter ge= legenen Srte Radjtquartier nimmt.

3. Die für die Dienjtgänge nuf ber Urbeitsfrecfe fotwie fiix bie Mege zwiffyen Dem Drt Des Dienftgefdäits oder den ?adytquartier und der 9 rbeitsitrecfe zn gewälytende Baufdjoergütumg ift, fobnlo die Irbeitsitelle mindeftens

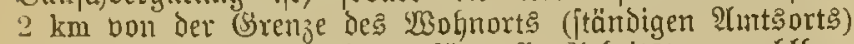
bes Beamten entient liegt, für afle श्रrbeitstage zablbar, gleichoiel, ob bie Arbeitsftelle fich aug̈erhalb eines Srts auj freiem Felde, dem Bafnförper $2 c$, Doder innerbalb eines ge= id)lofjenen Drtes befindet. Jiti diejenigen Sage, an welctien die Bau= und snftandjełungsarbeiten mben (Som = mo Jeiertage, powie Regentage) und fitr foldje Iage, an toeldyen a

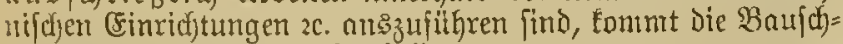

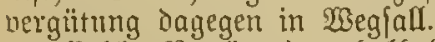

Welde Beträge immerfalb der Durd bie Raiferlide $\mathfrak{B e r}=$

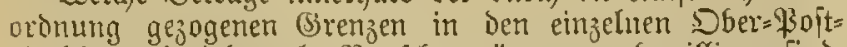
Diretions=-Bezirfen al’ Saujdjbergütung zu bewilligen find,

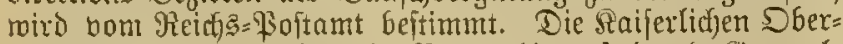
fioptoireftionen erljalten in Bezug hietauf Durd) Beneral=

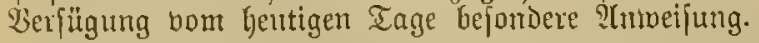

4. Die beroronungsmäßigen Gubrtoften, gegebenenfalls nad) Den Dutu die Dorfdriften im $\$ 3$ a ermäfigten Säßen,

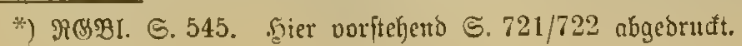

werden gemälut, oorausgefezt, oa $B$ die Entfernung bis zum Reifejiel roenigiteng $2 \mathrm{~km}$ beträgt:

a) für die bor Beginu ober nady Beendigung ber Bauarbeiten (5erjtellmg oder IInterhaltungs: arbeiten) ausjufülytenden Dienftreijen jrifichen dem Wofynort des Benmten und Detn Pnfangs: oder Endpunft der SIbeitsitrede, und in Denjenigen

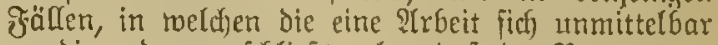

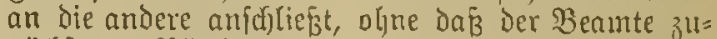

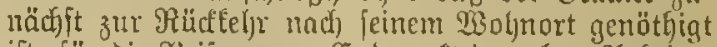

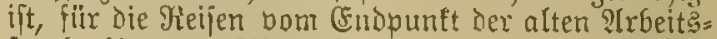
frecte bis zum Ilbgangspuntt Der nenen Strecte;

b) fïr bic nad) (Sinfülung des Baufilthers auf der Bauftrecte auszufübrende Rüctreije nach dem Unfangspunft der Bauptiecte oder zu Dem ?hifent= Galtsort des 9lrbeitertrupps;

c) für die ausinalymstorife nady anderen Drten, als bem Drt des Dien|tgejüäfty oder Tachtquartier, zurücfzulegenien Wege, beren ?(usfilbrung nur cine zeitweife linterbrecfjung ber Dienjttljätigfeit bes Benuten auf Der eigentlidjen Bauptrecte zur Folge lyat.

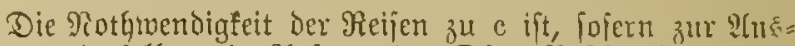

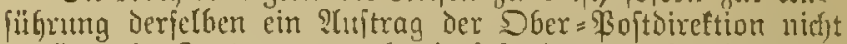
borliegt, im Jorbermmg nadfrueis bejonders zu begründen.

Bei derartigen Reifen trito die Baufdjoergütung mu fïr foldje Sage, toeitergemälyrt, an Denen Der Benmte auf jeiner eigentlidgen ?trbeitsfrrede nur mähreno cines Sheiles

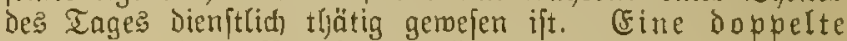
3ahlumg der Baufdoergütung fïr einen und Denlelben ?rbeitstag ift indeß unbeoingt ausge= fdi) o l fert.

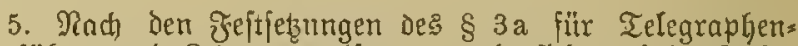
Bautifigrer und Reitungareviforen regeln fic auch bie Fubr= fojten = Sntjäjöigungen derjenigen Beamten, meldje ber=

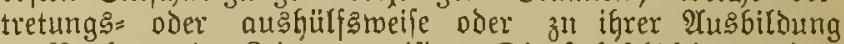
im Reubau oder Reitungşrebifions= Dienft bejdäitigt merden,

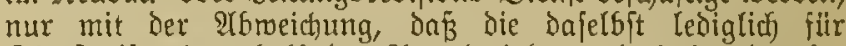
Dienfreifen innerhalb des ?mtsbezirts - D. i. Der Der be= treffenden Dber = Yioftirettion zugetheilte Rinien = Snitand=

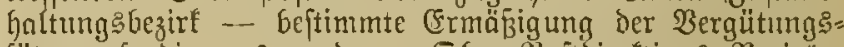
fä̉ze auf die nus anberen sber= \$softoireftions = Beairten

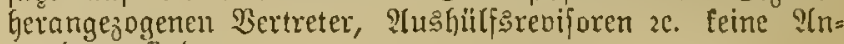
toending fincet.

6. Wenn Beamte mit ifren $\mathfrak{A}$ rbeitern in Der Rähe des Wobnorts bejäjätigt find, fo Gaben diejelben fid Sonnabends

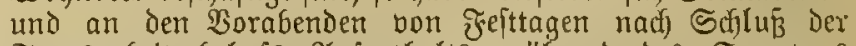
Tagesarbeit belyufs Aufentbalts mähreno des Sonntags oder während der folgenden feittage nad ifrem Wohnort zu begeben, falls die Jufrtopten titu die Reife mad dem 'Bobnort uno bou diejem an näd)ften Werftage zurürf nach ber Irbeitsftelle zujammen geringer find, als bie auf Den Sonntag oder auf bie Jeftage entfallenden Sagegelder, und wenn in Rütffict all die benuzbaren Beförberungsmittel, morunter aud) Pribatfulyrwerf zu verjtelien ift, die Siöglich= feit borliegt, Dá bie Seamten fíf am nädjiten $\mathfrak{B}_{\text {erftag }}$ Morgens jul der je nach Der Sabreszeit für Den Beginn Dex

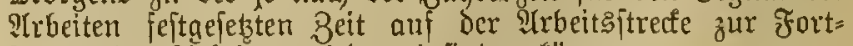
jeksung Der Srbeiten bieder einfinden E⿱艹mnen.

7. Jü die Beredynung Der Jufreften bei ben unter 4

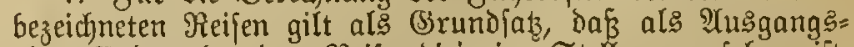
voer Endpunft einer Rcife diejenige Stelle anzuleben ijt, 
von meldjer bie Reife angetreten oder mo diejelbe beendet wiro, mithin in denjenigen fällen, in melchen ber 2 ntritt oler die Beendigung eimer Reife bon der Bauftrefe auț oder atif berjelben erjolgt, die in steien belegene ?rbeits= ftelle, in allen ibrigen f̧ällen aher ber Drt des Dienjt =

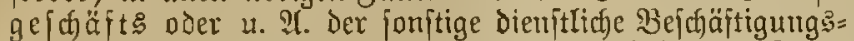
ort. Werden die 2 trbeiten auf der uriprïnglicten Baujtrecte

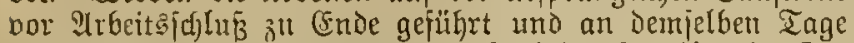
แuj verjejiedenen Sauftreden bierjtthätig, io gilt als Sit De: Dienjtgefdäjts lediglicf) der Dem ચrbeitsendpunte auj

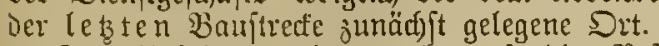

$\mathfrak{J m}$ llebrigen roiro nod auf die Beitimmung im

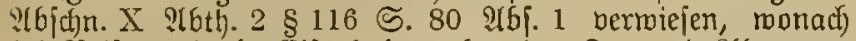

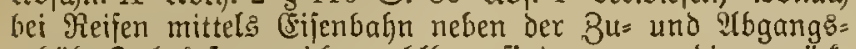

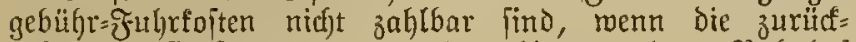
julegende Entfernung von ober bis zu dem Bahnlof ineniger als $2 \mathrm{~km}$ beträgt.

Jैür die Entiffeidung der Frage, ob bei einer Dienft=

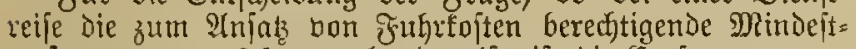
entfernulg bon $2 \mathrm{~km}$ borlanden ift, ift die Entfermung von iev Srtşgrenje des 2tbgangsorts bis jur Mitte des Beitimumig Stelfe aufizerhalb eintes Srte angetretert oder an einer folchen beendet wird, die Entfernung bon biejer Stefle pder biz jut dexjelben maß̈gebend. Wiegen Des Begriffi "Drtsgrenje" ugl. \$(bid). $X$ i(bth. $2 \$ 122$ ङ. 86.

8. Die Bevechnung der Entfermumgen bei Reijen allf Sanoregen bat, jonseit angänglich), auj (Srund der Koft= und (Eijenbaluntarte, im llebrigen aber nat) dett an den wegen befindidjen Stations= oder Pummeriteinen ftattju= finden; find Derartige Merléfteine an Den $23 \mathrm{egen}$ nich)t $\mathrm{vol}=$ handen, jo hat Der Seamte im forder.mgsnadiweis an den

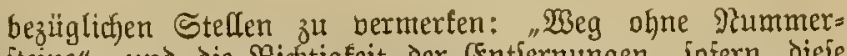
jteine", und die Richtigfeit Der Entjernungen, jojern bieje nicjt aus ponjtigen amtlicjen (Entfernumgsnacturijen (Specialtarten, Bejueinigungen von Wegebaubehörden 2e.) heroorgeben, in forderumgsnactmeis bejonders ju $b e=$ idjeinigen. '̧n allen fällen, in weldhen bei Reijen auf Qandwegen zwijwen geid)loffenen Srten bie \$ojt= uno (Eijen=

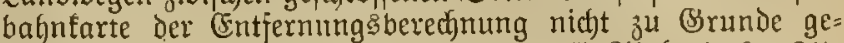

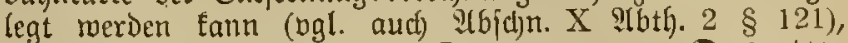
werden die Jubrtojten bon Ditsgrenze zu Drtamittc vergütet

(Enticfädigungen der nidut angeitellten seitungsaufefer und der Telegraphenvor: arbeiter.

9. Die bisherigen Borfdriften megen der \$ुb̈he der Reife= Tagegelder bleiben unberändert.

Wegen Der Yietjefojten=(EntjuäDigungen ber nicht ange=

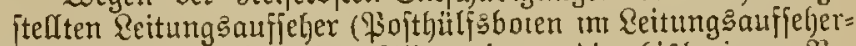
Dienjt), für melde im \&llgemeinen die bisherigen $B_{E}=$ fitimmungen in Sitaft bleiben, und wegen der 3ufolge Der

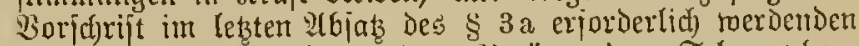
andermeitigen Regelung Der Wezüge Der Telegraphen= norarbeiter erhalten bie Siaijertichen Dber= 130 ptoireftionen

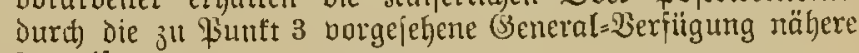
Untoeijumg.

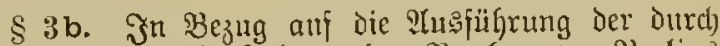
Den $\$ 3$ b für Die Ielegraphen= Baubeamen Berlits getroffenen 2lusnalmebejtimmungen ergeft an die Saijertidue Dber=\$3ojtbireftion in \$erlin bejondere Ber= jiigung.

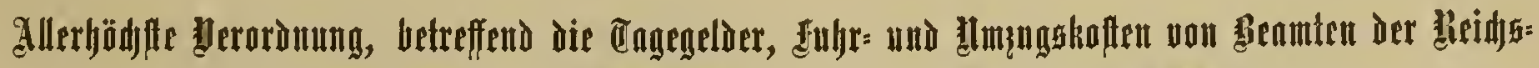

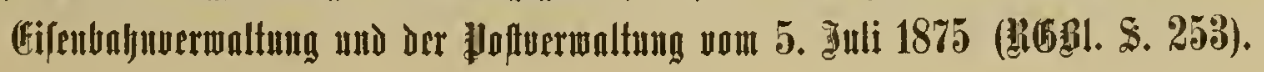

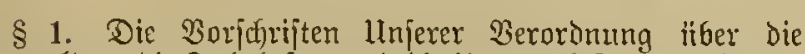

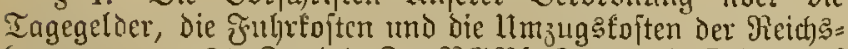

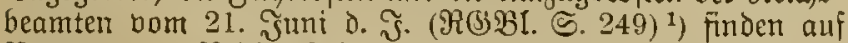
Beamte Der Reiths: = Eifenbahnvermaltung und Der Boit= berwaltung nack Miaggabe dex folgenden bejonderen $\mathfrak{B e}=$ ftimtmungen $\mathfrak{2}$ (n)menoung.

1) \$orfteh̆end Seite $717 / 718$ abgedruffit.

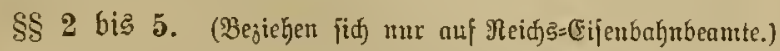

§ 6. Rofomotib= und Zugbegleitungsbeamte exhalten für ifre Befoüjtigung im Jahrbienjte, Bahn =?luffichtsbeamte für die Begleitung von Material und P(rbeitżüligen an

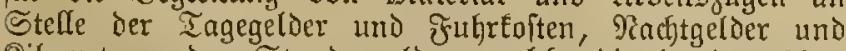
filometer = Dder Stundengelder, meldye die in Den $\$ \$ 1$

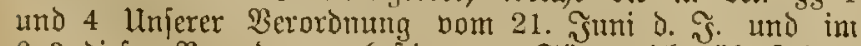
$\S 3$ diefer Beroronung bejtimnten Sätze nicd)t überfteigen

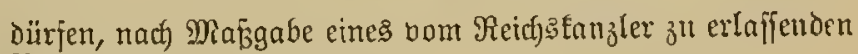
Reglements.

̧n denjelben (Sienzen uno auj demjelben

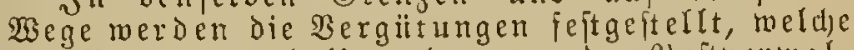
Den Beamten und Interbeamten der gioftormal= tung bei Reifen oum 8 wed Der Beforderung und Expedition non Boitfendungen an Stelle bon Tagegeldern und Fubrtoftel zu gemähren jind.

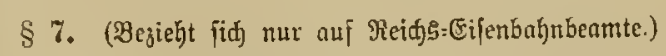

\$ 8. Begenwärtige Berorbnung tritt mit dem 15 . Sull D. $\mathfrak{S}$. in Sraft.

Ilrfunolicf) $2 c$.

(B)geben Çoblenj, den 5. Suli 1875. 


\title{
(E⿱

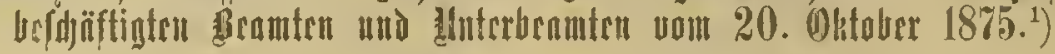

\author{
(2turtäblatt voll 1875. @. 393.)

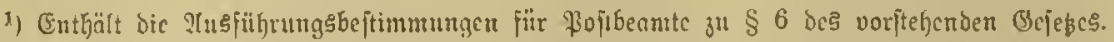

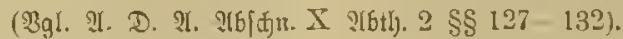

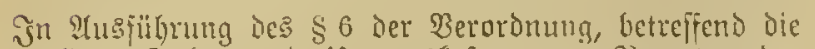

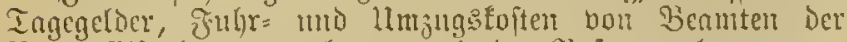
Reid) = (5ijembahnuerivaltumg mio Der Lioftuermaltung bom

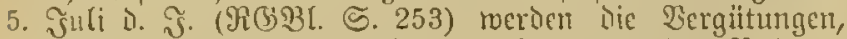
welde den Beamten und llnterbeamten der ReichsHoltoermaltung bei gieifen zum Binede der be=

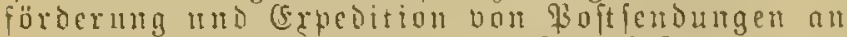
Jtelle von Iagegelderu und fultefofen ju ge= mähren fint, von I. Noventber 1875 ab, wie folgt, fejt= gefectst:

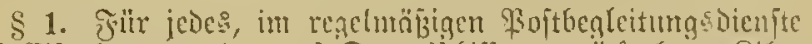

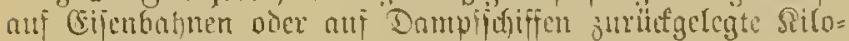
miter erbalten:
Dic Bcamten
dic \$oftictafiner
0,8 bis 1 Bjennig
0,6 bis 0,7

als gabrtgebühren.

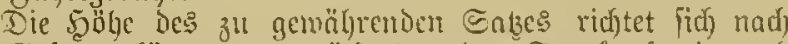

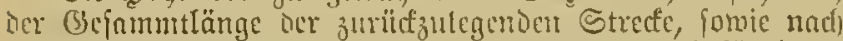

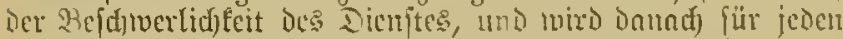
Siurs bezm. jede Jnhyrt bou Der betreffenden Sher=4ioft= Direftion feitgejetzt uno nadl limitänden net geiegelt.

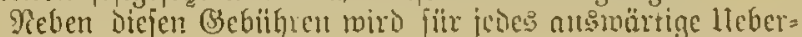
lager, meldfes 6 Stunden oder lönger Dauert, eine fefte Bergiitung

gerwährt.

an Die Beamten an bic \$ojtidjnffner

bon MiÉ. 1,50 bon "1,

§ 2. Bei der rege!mäbigen Begleitung von Foften auf

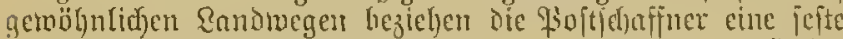

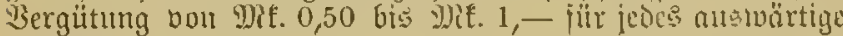
lleberlager, melctes

1. wenn es in bic Piadtzeit fällt, mindeftens jedjs Stunton;

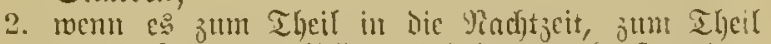
in die Ingegzeit fällt, mindeften: ndyt Stumben, tind

3. wenn es ganj in dic Inges̊jeit fält, mindeftent: 3elun Stunden

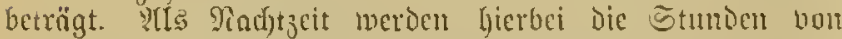

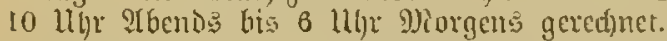

Die söbe des ju gemährenden Satzes wird bou den

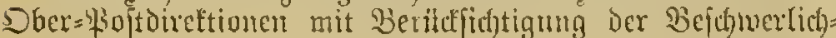

Ecit iç Dicnftes und Der Roftjpicligfeit Deş nusonärtigen ?lifinthalts feftgejebt und narf llmitänoen neu geregelt.

Someit nach sen borftehenien Bejtimmungen lleberlager=

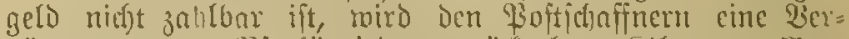

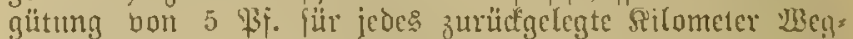

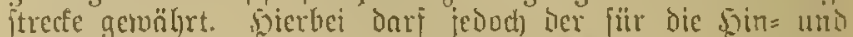
Fiid(figl)t fich ergebende (Scjammtbetrag dic 2ergütung nidft liberfteigen, meldye fïr ein eimmaliges lleberlnger zu zahlen fein mitirbe.

Bei $\mathfrak{B}$ egleitumg bon Babnlyojäalyrten wiro dicje $\mathfrak{B e}=$ gïtung mur Danu gewölfrt, toent dic (EnIfermung bum Drte Det Gioftanjtalt bis zu Dem anzerlyalb befielben belegenen Bahnlyofe, wou ber Drtagrenje nb geredict, minde=

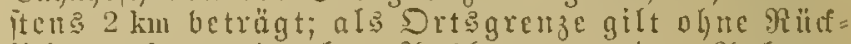
fid)t nuf bereinjelte atsonuten oder ?tulagen bic It oder cingefriedigten Grundtü efen eingenommeneu Theils bes betreffenden Drtes. ${ }^{1}$ )

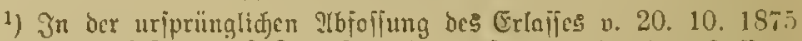

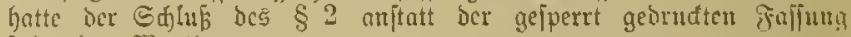
folgerben \$ortlunt:

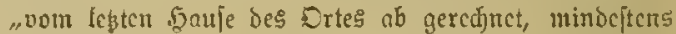
$2 \mathrm{~km}$ beträgt."

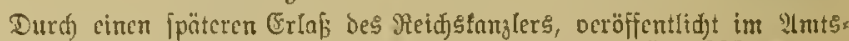

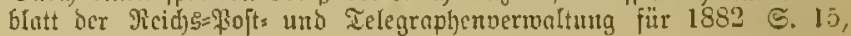
ift bic jefige zaffinug vorgeidrieber worbcr.

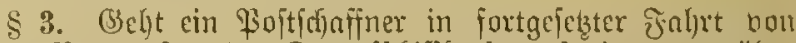

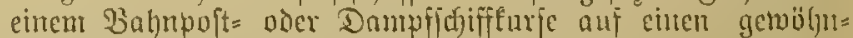

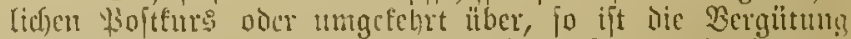

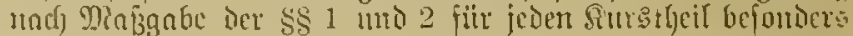
jtl bercelinetr.

\$ 4. Werien Beamte oder llnterbenmte, weldye niclyt

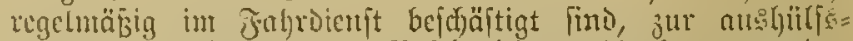

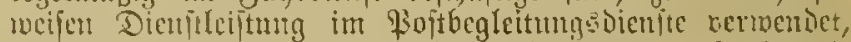
in tom denielben bei cimmaligen Begleitungen jomic mit (Senel)migung Des (General=\$3oftants ${ }^{1}$ ) bei mehrmaligen Begleitungen in jujammenl)ängender Reihenjolge unter he=

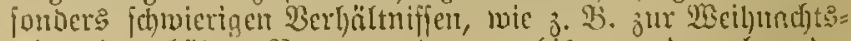
zeit, eir erhöhter Betrag und zluar bis jum boppelten ber

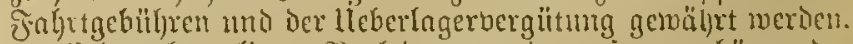

Bei melymoligen Begleitungen in stlummentyängender

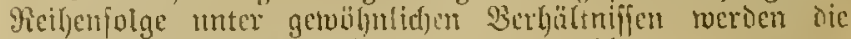
Bergütumgen zum einjact)en Betrage gezaltt.

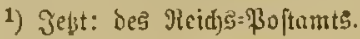

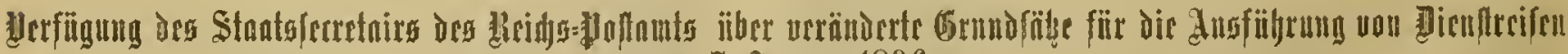 vout 7. 3nutur 1896.}

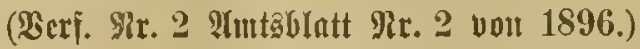

Bertin, Der 7. Fonuar 1896.

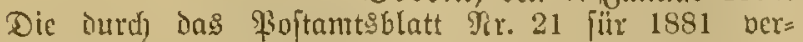

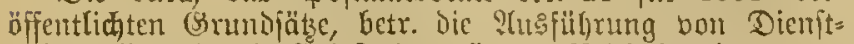
reifen, find Durd) Ertáz des foern Meidjstanzlers bom

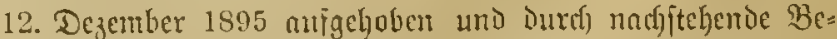
fitmunngen erfect woroen:

1. Diemitreifen fub, fofern dic $8 \mathrm{ahl}$ ber $\Re$ cifetage Dadures beeinflufst werder follte, und wem 
nitut bejonbere dienjtlid)e - enentl. in ber Riqui= iation fur: zu erlänternto - llmptände ober die

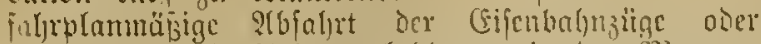
Damplfoffiffe ein ?nderes bebingen, in ten Diorgen= itmoen, D. q. in Den g)ionaten ?(pril bis Sentenber

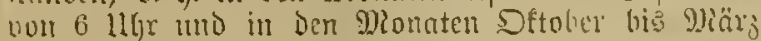
แou 7 แhr Morgens ab, anjutreten.

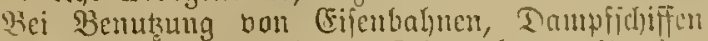
ober fiofuerbinoungen ift als Beitpunft ics :) (nutits

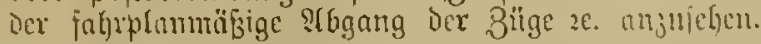

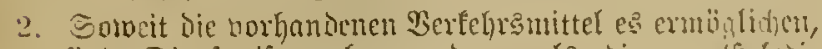

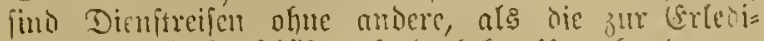
gung ber Dienftgeidräfte crforderludjen linterbucd)ungeu juritidjulegen.

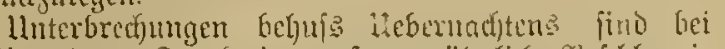

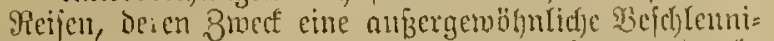

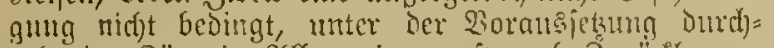

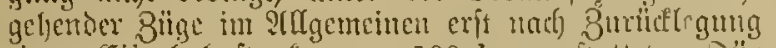
ciner Cijenbahnftrecte von $500 \mathrm{~km}$ geftattet. Jifr

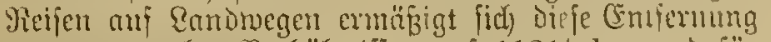
muter normalen Berhältniffen auf $112 \frac{1}{2} \mathrm{~km}$ mo für Reifen auf Dantplidififen auf $375 \mathrm{~km}$.

llnterbred)ungen, weldje Durd) Sirunflyeit voer ardere bejondere llurftänoc nothtwentin iverben mo auf bie $3 a b l$ ber Jeife= und ?lticntlalts=

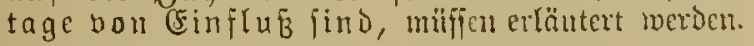

3. Beamte, melche fïr die mittels Der Gijenbalyn smritu= zulegenden Dienitreijen an șuljtoftin 0,10 th oder mehr fitr das seilouteter ill beamprucher lyaben, find

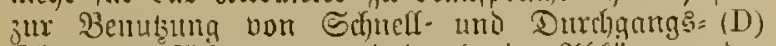
Bügen berpfliditet, menn baburd) cine ?tofitumbng der クeifedmer crmöglifit toird oder llnterbred)ungen ber Heife vermieien toerden.

4. Die $\mathfrak{L e c t e r}=$ bejw. Rüfreife, nanentlid bei füzeren

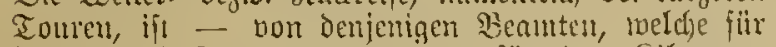

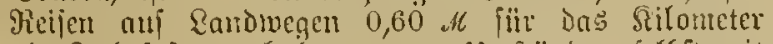
als §ulfrejten erhalten, unter Umitänben jelbit mit
Benubuny von Srtrapoft - mad) beendetem Dienit= geidiäit möglidjt nod) an Denfelben Tage anzutretcu.

Sonben bie Dienitgeichäite bejro. die joinreife mo

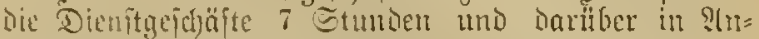
ip:ud) genvmmen, fo socrten unter fürzeren Touren fold)e (sutfermmgen veritmon, weld)e nit ber fiojt,

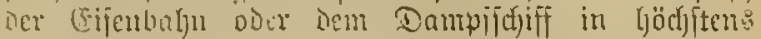
2 Stunden juridefgelegt werden tömen.

5. Dic Berethung der Reipetoiten erfolgt olyne Rüdfidyt baran, weld)en $2 \mathrm{Beg}$ her Reifenbe thatfäblid) einge:

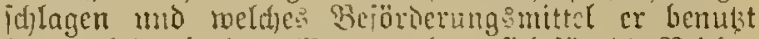

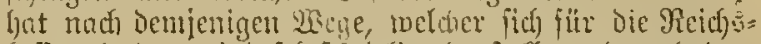
Eaffe als ber mindefteftipielige baritell mo nad) Dem Broef der Sieife mo Den llmitänden des bejonder'n

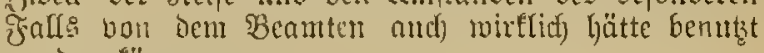
twerden fö!nneu.

6. Tuझ̆ualynen bon voritehenden Beitimumugen (1 bis 5) fümmen nad) Del (Entideidung Der Die Reijefoiten=

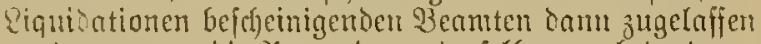
merden, went die 2lmwendung berfelfen ju bejonderen

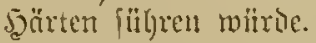

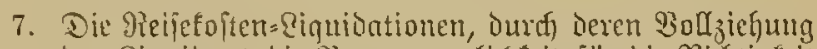
ber Siquidnnt dic Derantroortlicffert für Die Ridjtigfeit

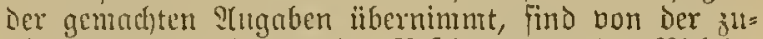

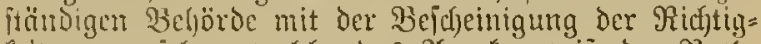

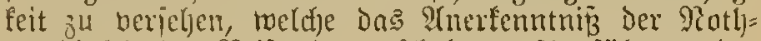

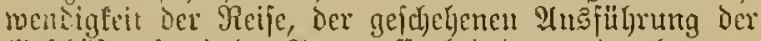

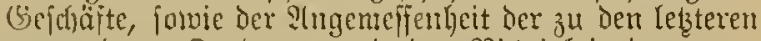
werwendeten Betbaner und ber Ridutigkeit ber ange= gebenen Daner übeulgaupt in iid) begreift.

8. Vuf Dienfreijen Dex gejandtidjajtidjen uno Sanjular: beanten fincen dic voritelyendon Beftimmungen Eeinte

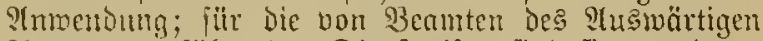
PImts auszufiifyenden Dienfteifen find fie mux Dam mägebeno, wenn ?.Tinng interhalb des Reidigebiets liegen.

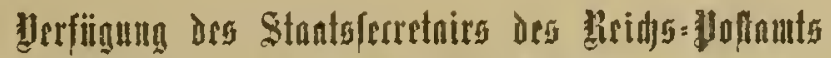

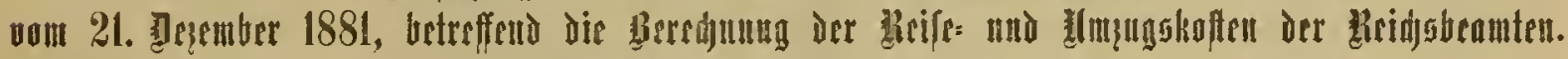

(2lutb̆blatt you 1881, Scite 390).

Berrin, den 21. Dejember 1881.

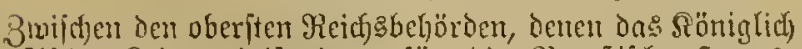

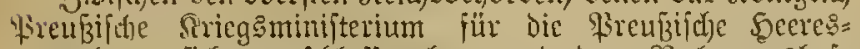

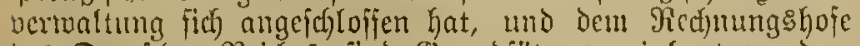
Des Deutiden Reicjes find Sinundiäke vereinbart morben, nact meldfer bei Berect)numg Der Reije= und IInjuggfojten Der Reicfebeamten fortan allgemein $z^{\text {th }}$ berfaliren ift. Die Bujammenftellung diefer (Srundjäkse vird nachftehend mit= getheilt.

A. Bemegt fid die Dienitreife eines Beanten, meldjem

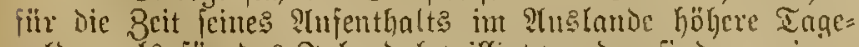
gelder, als fïr bas Snlano bemillignt toroton fint, an eincm Inge innerhatb mo anferhalb Des Reidjegebiets, fo toito fiir ben Tag des lleberganges in ons ?Ls:and Der höhere,

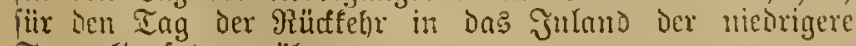
Tagegeloerfats getoüljrt.

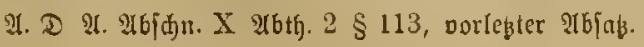

B. 1. Bei (3efdäften auberhalb des 23ohnorts, Der

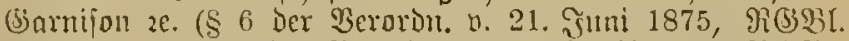

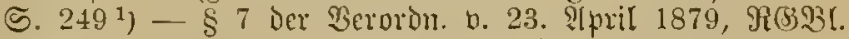
(5. $127,{ }^{2}$ - $\$ \S 3$ bis 5 ber Gerordn. b. 20. Mai 1880,

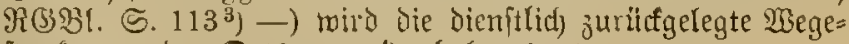
ftrecfe von ber Drtsigrenzes) ab berechnet.

3) §gl. oben S. 718 .

2) Betr. Tagegelber 2c, von gejandidjaftliden und fionjulntbeamten.

3) Betr. Tag̣egetser ic. von Beanten ber Mititär= und Narine= verwaltung.

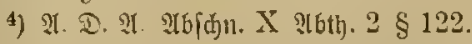

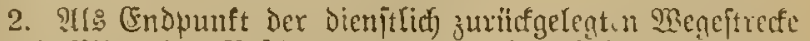
gilt bie Mritte Des Bejtimmung ontes ober, ialls dic Dienft= reije mittels (Fijenbaljn oder Damplictiff gentatht merden tam, der betreffente Bahnljof oder Mlnlegeplats, borbehaltlid)

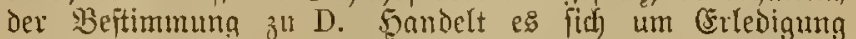
eitre: Dienjtgejuäjtes an einer bejtimmten Stelle außerbalb 
eines Drtes, jo ift dicje Stelle alక Enopuntt Dex Dienftreife allzunelymen.

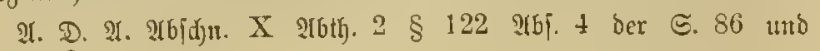
अer. 243.

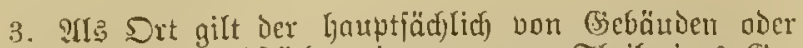
cingejriedigten Grumbftüfen eingentomene Theil cines Gie=

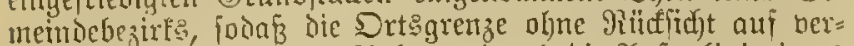
cimzelte P(usbauten oder Anlagen Durd) die ?lufenlinie jenes Rezinfstlyeils gebiloct mird.

Beitel)t cin (Semeinbebejirf (Barmifonberband) ans mehreren Drffdjaften, fo ift als Drt in Sinne Diejer B̉es fitmmung nidjt dic cintiselne Drtfdjaft, fondern Der (Semeinde= bejirf (Sarmijonverband) anzulehen.

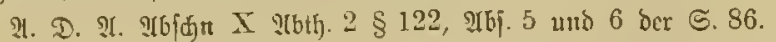

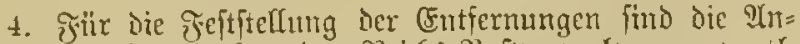
gaben bes Rursbutfes Der Reidfs=? ber amtlidjen gioftEarten mafgebeno. Jeljlen fold)e 2 lngaben,

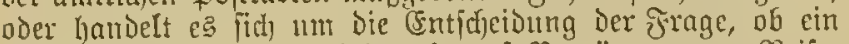

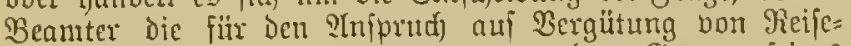
Eoften mafgebenter Entfermung bou ber (Srenje feines

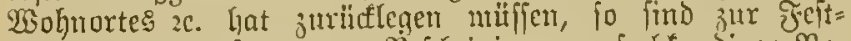
Ftellung Der (Entfermungen Bंcjocinigungen fact)tumbiger $\mathfrak{B} e=$

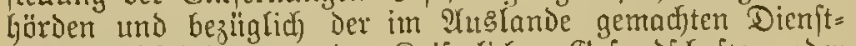
reifen Befoheinigungen Der Saiferlidjen Befandjchaften ober Sonfulate beijubringen.

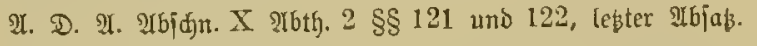

C. 1. Bei Dienifreijen, melde mittelg (Fifenbaln oder

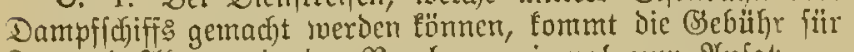

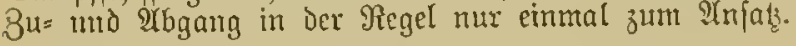

2. (Fin mehrfad)er Imfatz Dicjer (Bebühres findet ftatt:

a) wert an Zipifjentorten ïbernachtet werden muf;

b) wem die (Eifenbahn noder Dos Dampfictiff an Broifdenortent Dienftgeffuäfte halber verlafien werden mufi;

c) twenn an cinem Brwifuchorte ein Bahnhof oder

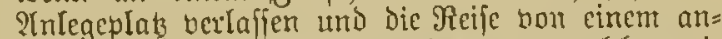
Deren Bahthof oder Inlegeplats ars, welcher mit Dem erjeren nicht in unmittclbarem Bufammentange iteht, fortgejebt werden muE, fofers Der Ulebergang bon Deu cinen zum andernt Bahnflofe nidft mittel Duref)gekender ober unmittelbar anjd)ließ̧ender Büge

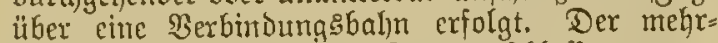
facje ?anfats ber (Sebuilyr ift ausgejdyloffen, went au einem Bmildenorte ein llebergang yon einer Bahn auf Die andere ober non cinem Dampfiddiff auf Dag andere ftattfindet, olyne Daj́ baju Det Bahnhof oder ?Inlegeplaş zu verlafien ift. Die mit ltcbergängen Der lekteren Yirt ctma verbundenen

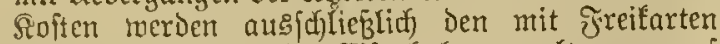
reifenden Beamten Der Eiferbahmbermaltungen auf (S) rund fpecieller $Y$ ngaben eritattet, Deren 3 elegung nidyt erforoerlidy ift.

(Fine alphabetifd georonete Factjmeifung Derjenigen Srte Dentfdilands, an weldjen melyrere räumlich bon einander

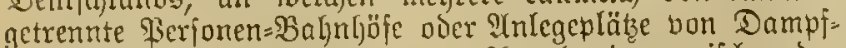

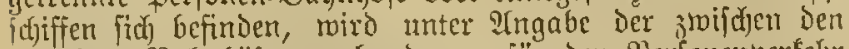
einzelnen $\mathfrak{B a h m b o ̈ f e n ~ v o r h a n d e n e n , ~ f u ̈ r ~ D e n ~ F i e r i o n e n b e r f e l j e ~}$ benutbaren Serbindungsbalinen Durd) Da: Rursbud) Der

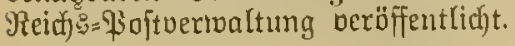

3. Beamte, weldje bei llnterbredfung einer żแm Zroefe Der Bereijung einer Balnnlinie, zur Befidftigung oder

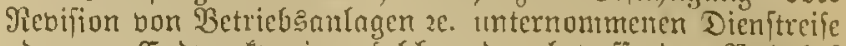
Doder an CFnopunft einer fold)en Den hetreffemien $\mathfrak{B a l j u l j o f}$ oder das Balnngehiet Dienjtgejouäite halber ju verlaffen

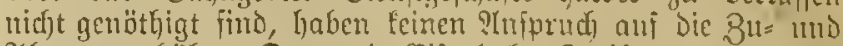
Q1bgangsgebishr. Den mit Sifenbahn= Jreifarten reifenden Beamten werden in joldjen fjälfen bie banten 》ehenfoften nad) Mafigalie ier Beftimmungen unter Biffer 2 e eritattet.

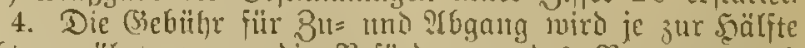

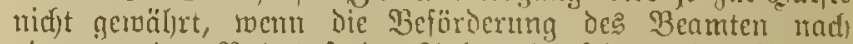

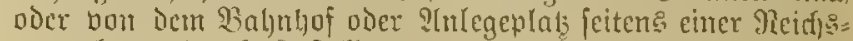
berwaltung Dutef Gicitellung cine: Jithrmerte erfolgt.

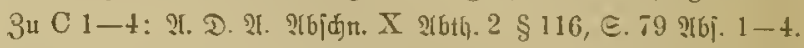

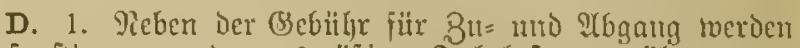

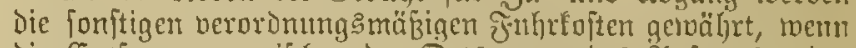
dic (Entjerntung zmifhen Der Srtsarenze Des ?tnfang: oder Endpunfts Der Reife und Dem B̉alnnlyof oder Qlnlegeplats $2 \mathrm{~km}$ vocr mehr beträgt.

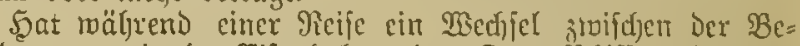
föroerung mittels (Eifenbahn oder Damptichiff und einer

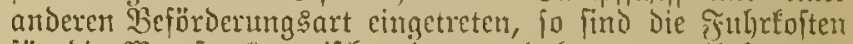
fiir bie Wregejtrecte swifher bem nadl besw. vor llebergang auf bie Gifenbahn oder Das Dampffefiff junädjjt bezrw.

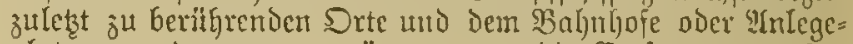

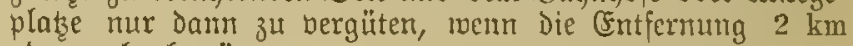
ober melgr beträgt.

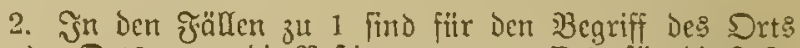

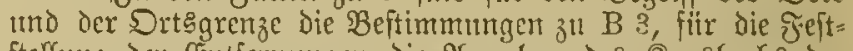

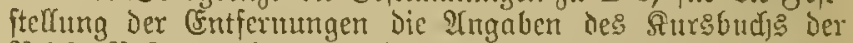

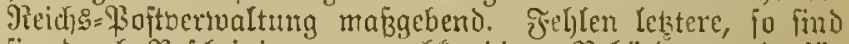
fie Duref) Bejefeinigungen ladflundiger Beljörbent unt fï: Das शి idhafter oder Sonfulate ju erjełzen.

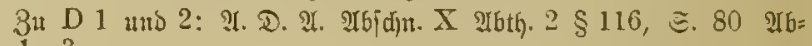
jags $1-3$.

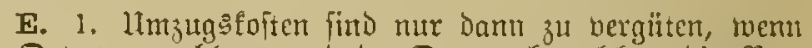
Der Drt, won welchem, und Der Drt, nadf reldeent Die Ber=

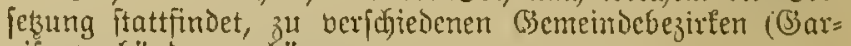
nifonverbänden) gehören.

2. D. அ. 2 b

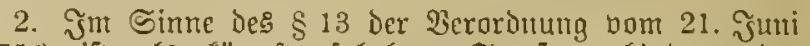
18751) ift als fitrzefte fabrbare Strafenverbindurg der fitrzeite falyrbare Eanomeg anzufeljen.

Wenn jevod) der Sort, von meldjent, und Dex Sort, nact)

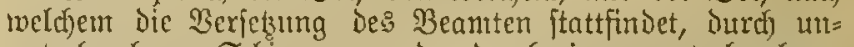
unterbrodjenen Sdjenentog oder Durch eine umunterbrodjene,

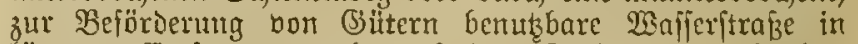
fürjerer Fntfernung, als auf dem Eantowege, berbunden Find, fo gilt Die lürzefte Derartige Berbindurg als fürzefte fahrbare Strafenberbindung.

Behuf Grmittelnng der fürzeiten folyrbaren Straben = verbindung find Dic $2 \mathrm{~km}$ oDer mehr betragenden (Ent= fermungen zwifden dem QInfangs: oder Endort bes ltmjuges umb Dem zugehörigen gleichnamigen Bahnthof ols Sdjienen= weg, foldhe Sheilftreden, auf reldjen beladene $\mathfrak{B a g e n}$ mittels

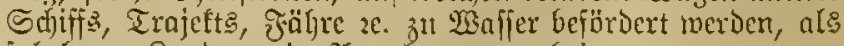
fahrbarer Sanomeg in Arredinutrg zu bringen.

1) Sben ธ. 720 .

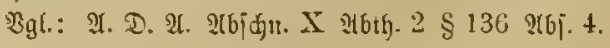




\section{(4) $\mathfrak{a} \mathbf{f} !$}

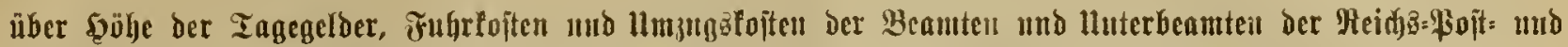
Telegrapljenverwaltuntg uad) ben jur 3eit beitehenden Deitimmungen.

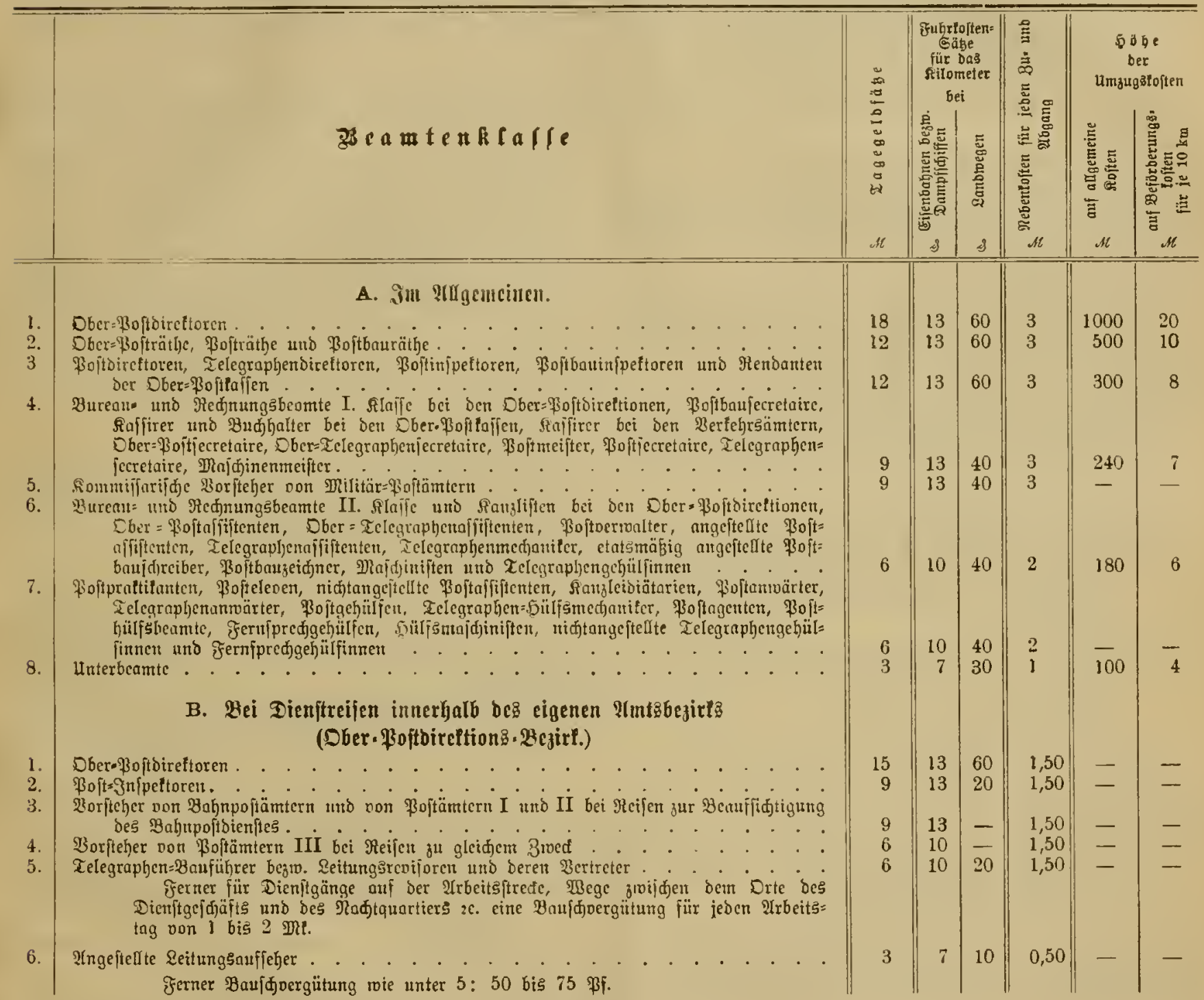

\section{IV. diirr/orge für geinterbliebente.}

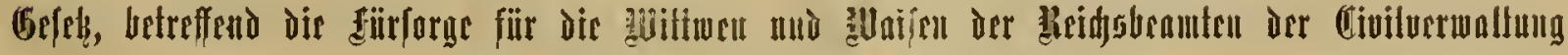 voult 20. April 1881 (\$101. \$. 85).

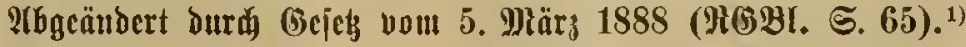 \\ 1) Radjfteherib (ङ. 741/42) abgebrudt.}

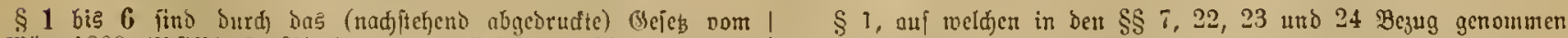

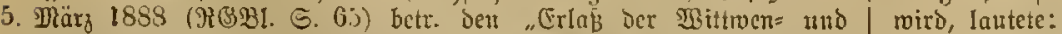

Waifengelobciträge non Mngehörigen ber Reidjs = Civilncrwaltung :c" gegenftandslos gemorocn.

Beamte ber Civilvermaltung, weldje Dienjetnfontnten ober

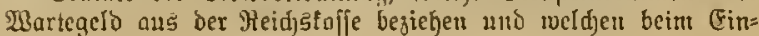


tritt der Barausießsungen ber Berfebung in ben Rubejtant nađ (Erfüfung Der erfarberliden Dienfizeit \$enfion aus ber Reidstajie gebühren würbe, fowie in ben Stuheftand verfegte

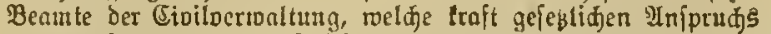
nder auf Grund des $\S 39$ Des Heidzbenmtengeieses Dam

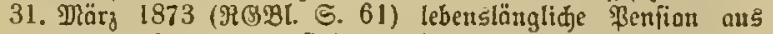

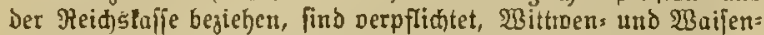

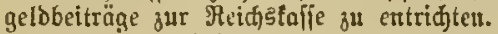

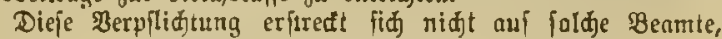
welde nur nebenamtlid in Reidsbienjt angeftelt fint.

$\$ 2$ bis 6 fełten bie böhe ber Beiträge (3\% bes Dienjt cirlammens), ber 3ablungsిmobus, bas (Erlöjen ber Berpfliçtung zur 3ahlung ic. feit.

\$ 7. Die Wittwe und die hinterbliebenen ehelidjen oder durd nadjgefolgte (Ehe legitimirten Rinder eines zur Beit jeines Todes zur (Entrichtung oon Wittmen= und Waifer= geldbeiträgen berpfliç)teten Beamten erbalten aus oer Reid) tafje Bittwen= und Waijengeld nach Maß̈gabe oer nach)= folgender Beftimmungen.

§ 8. Das Wittmengeld bejteht in ben Dritten Theile

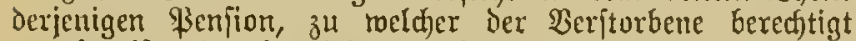
geveien ift, oder beredigt geiveien jein miirbe, wenn er am Todestage in den Muljejtand beriebt märe.

Das Wittmengeld joll jedoch, vorbehaltia der im $\$ 10$ beroroneten Bejuräntung, mindejtens 160 Marf ${ }^{1}$ ) betragen und 1600 Dart nidit liberiteigen.

1) Siehe 2 nm. zม $\$ 12$.

§ 9. Das Waijengeld beträgt:

1. für Rinder, Deren Mutter lebt und zur Beit des Todes des $\mathfrak{B e a m t e n}$ zum Bezuge bon Wittmengeld bereditigt war, ein Jüritel bes Wittwengeldes für jedes Sind;

2. für Sinder, beren Mutter nidyt mefr lebt oder zur Zeit Des Todes Des Beamten zum Bezuge bon UBittwengelo nicht bered)tigt war, ein Drittel des Bittrengeldes für jedes Sind.

$\$ 10$. Wittmen = und Waijengeld dïrjen weder einzelt rod) zujammen beti Betrag Der \$enjion überiteigen, zu meldier ber Beritorbene berechtigt gerveien ift oder beredigt gerbejen feil nürbe, roetrn er am Tobestage in den $\Re$ hue= ftand verietst wäre.

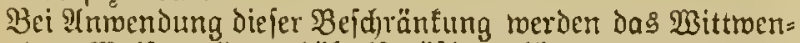
und das Waifengelo verlälmißnmäßig getürjt.

§ 11. Bei Dem 2usidyeiden einę Wittroen= oder Raifen= geloberechtigten erhölut jid) das wittwen= ober Waijengelo Der verbleibenden Beredjtigten bon dem nädjitjolgenden Dionat an inforoeit, a[s fic fich nod) nid)t im vollen (Senub oer ilgnen mach ben $\S \S 8$ bis 10 gebührenden Beträge be= finden.

§ 12. War die Wittwe mehr al\$ 15 Jahre jünger alङ ber Beritorbene, fo wird das nady Maßjgabe der $\$ \$ 8$ und 10 berednete $\mathfrak{B i t t m e n g e l d ~ f i i r ~ j e d e s ~ a n g e f a n g e n e ~ J a h r ~ b e s ~}$

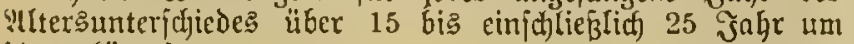
$1 / 20$ getürzt. ${ }^{1}$ )

भ्य Den nach $\$ 9$ zu berectinenden Betrng Des Waifen= geldes jub dicje Sïuzungen bes Wittmengeldes ohne Finfluß̄.

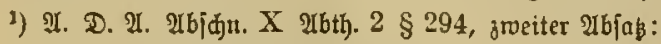

„Bei Inmentung biefer Beftimmungen ift bas Wittmen= geld erfardertidenfalls aut unter Den Dinbefibetrag vout jübrliç 160 Dart herabjufegen."
§ 13. Reiuen $\mathfrak{A n j p r u d ) ~ a u f ~}$ Bittroengeld hat die Wittwe, wenn die Che mit Dem verftorbenen SBeamten innerhalb breicr Monate bor feinem Qbleben gejalojien und bie (5) idjliç̧ung zu Dem Zroefe exfolgt i it, um Der Wittme den Bezug bes Wittmengeldes zu verjojaffen.

Reisen ख्याprud auj Wittmen= und Waifengerd baben Die Wittre und dic Ginterblicbenen Rinder eines penfiouirten Beamten aus folder (Ehe, weldhe erft nadj ber Beriełung des Bermen in Den Rubeftand gejolofijen ijt.

\$14. Stirbt ein zur (Entrid)tung bon Wittroen= und Waijengeldbeiträgen berpflidjteter Beamter, weld)em, went

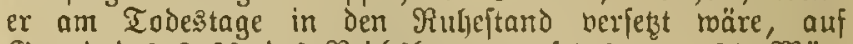
Grund des $\$ 39$ des Reid) sbcamtengejetzes vom 31 . März 1873 eine Pienfion bätte berwilligt werden fönnen, ${ }^{1}$ ) fo tann oer Wittme und den Waijen bejfelben Wittwen= uro Waijen.

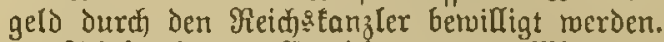

Stivbt ein zur (Entriditung von Wittwen= und $23 a i j e n=$

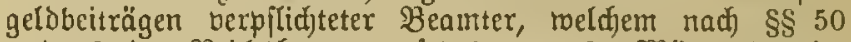

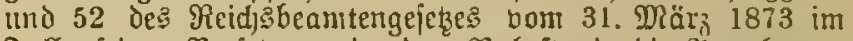

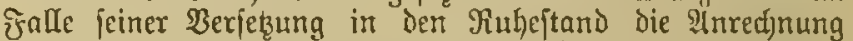
gewiffer Beiten auf Die in Betradjt Eommerdo Dienjtseit bätte betwilligt meroen fönmen, ${ }^{2}$ ) fo ift Der Reid)

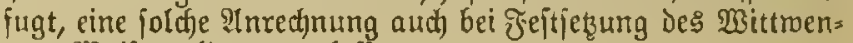
und Waijengeldes zuzulajien.

1) Siehe Seite 661.

3) Siehe Seite 667.

$\$$ 15. Die Bahlung Des Wittmen= und Waijengeldes beginnt mit dem @blauj des Ginadenquartals oder bes (S) nabemonats.

\$ 16. Das Wittwen = und Waijengeld wird monatlid im Boraus gezablt. Un wen die Bahlung gültig zul leiften

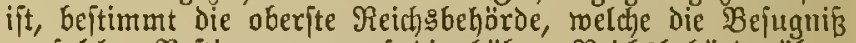
zu fold)er Beftimmung auf bie böhere Reidjbehörde uber= tragen (anm.1)

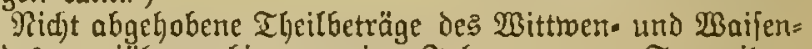
geldes verjühren binmen viex sabren, vom Tage ihrer Jälligteit an gered)net, zum Bortheil ber Reid)stafie.

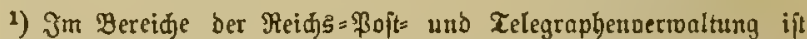

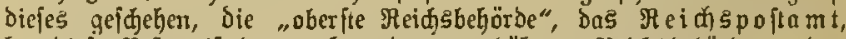

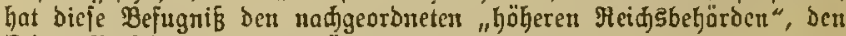
Ober-\$oft birettioner übertrager.

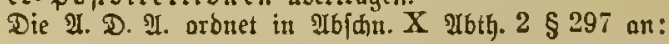

"2u wen bie 3ohlung ber \$ittwen unb शुaifengelder gïltig su leifter ift, bejtimmt burळroeg bie jujtändige Dber= Moftoireftion"

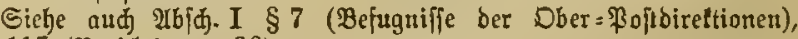

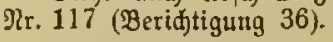

\$ 17. Daฆ Wittmen= und Waijengeld farn mit rect)t= licher Wirtung weder abgetreten, nod) verpfändet oder jonft übertragen merben. ${ }^{1}$ )

1) Siebe aud (E\$O. $\$ 749,7$ I. Theil Seite 200.

$\S$ 18. Das Reদt auf Den Bezug Des Wittwen- uno Barijengeldes erlifift:

1. für jeden Berectigten mit bem $\mathscr{U}$ blauf des Monats, in toeldem er fid berbeirallet oder ftirbt;

2. fiit jede $\mathfrak{B a i j e}$ auBerdem mit dem Mblauf des Ponats, in weldiem fie das 18. Rebertijabr voll. endet.

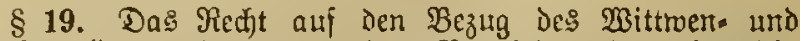
Waijengeldes ruht, mests der Beredtigte das Deutide 
Indigenat berliert, bis zur etmaigen Wiebererlangung bes: jelben.

§20. Mit Den auङ $§ 14$ fich ergebenden Mlaşgaben exfolgt die Reftimmung dariber, of und meldies mittmenl= uno Waifengeld dur $\mathfrak{W}$ intme uno den Waifen einez Beamten zu[teht, Durd) Die oberfte Reidşbeljörde, weld)e die Bejugnif

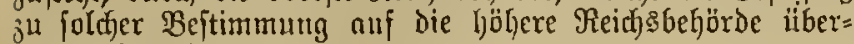
tragen farm. ${ }^{1}$ )

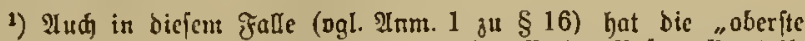

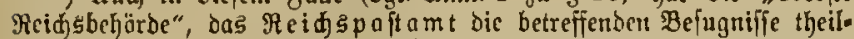

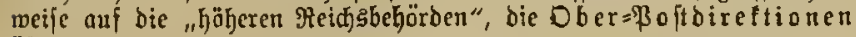
ïbertragen.

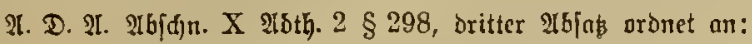

„Das Mittwen= und Waifengeld für bie Sinterbliebenen folcher Beamten zc., meldhe den Ober=\$oftbireftionen unter= ftelt find, wirb butrd bie Dber= Boftoireftionen, für

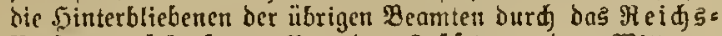
Boftamt ieftgejept. Bor der Feiffeckung bes Bittwen= und Baifergeldes für bie Sintertitebener berjenigen im

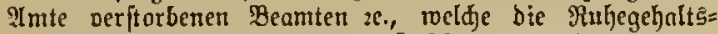
beredtigung auf (Brutto Des $\$ 36$ Des Reidgbeamtetrs gejeges (bet einer fürgeren als $10=$ jährigen Diemitzeit) er. langt haoben, ift bie Benchmigung Des Reids: \$ojtamts einguholen.

§ 21. Das Den Sinterblieberen eines Beanten zu be= milligende Writtwen= oder Waifengelo Darf nidst hinter Dem= jenigen Betrage zurïtfleiben, weldyer Denfelben nach den bis jum Snfraftreten bieies Sefetses für fie geltenden Beitimmungen aus ber Reidjatafie ljätte gemährt merden mitffen, roenr ber Benmte bor dicjem Beitpunft ge= ftorben märe.

\$ 22. Beamte, melche nach den Beftimmungen dieje: Brejeres Wittmen= und Waijengeldbeiträge zu entridjten haben, find nidyt verpflichtet, einer Militär= ouer Landes= Beamten=2Bittwentafie oder der fonjtigen Beranjtaltung eines Bundesftantes zur Gerjorgung der Sginterbliebenen von $\mathfrak{B} c=$ amten beizutreten.

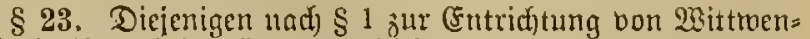
und Waifengeldbeiträgen berpflictteten $B$ eamten, weldje Mit= glieder einer ter im \& 22 bezeidfueten Eandesanftalten und derfelben nidgt erft nach der Werfündung diefes Befekes beigetreten find, bleiben, metn fie binnen brei Monaten nach

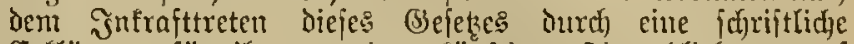
(5rtelärung für ihre etmaigen tünftigen jinterbliebenen auf Dos in Den $\S \S 7$ ff. beftimmte 2 Bittwen= und $23 a i f e n g e l d$ berjicften, bon (Entridjtung der im $\& 3$ beftimmten $\mathfrak{B i t t m e n =}$ und Waijengeldbeiträge befreit. Inderenjalls find fie be=

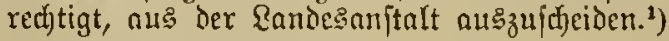

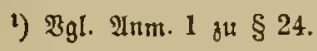

§ 24. Diejenigen narh $\S 1$ zur (Entrichtung von Wittroen= und Waijengeldbeiträgen verpfliditeten Benmten, meldhe vor Der Berfinndung diefes (Bejetses und während fie in Dienfte

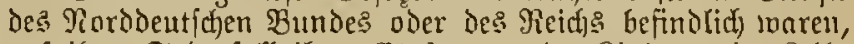
auf ifren Todesfall ihren (5hefraten oier Sinderm eine Reib= rente oder ein Siapital oder ihren geieblicten frrthen ein Sapital bei einer Bribat=Berficherungsgefellic)ajt berfidjert haben, fönnen, falle diefe $\mathfrak{B e r f i c h e r u n g ~ z u r ~ Z e i t ~ D e s ~ S n t r a j t = ~}$ tretens diefes (sejebes noch) bejteht, und wenn fie hinnen Drei Dionaten nact) Diejem Zeitpunfte Durd) eine (d)riftlief)e Erflärung für i็re etmaigen Eünftigen Sinterblicbenen nuf das in den $\$ \S 7$ fi. beftintme Wittroen = und Waifengeld

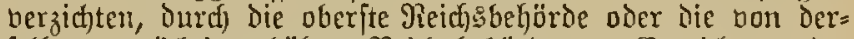

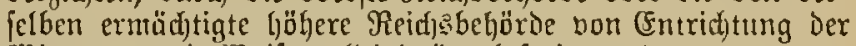
Wittmen = แnd Waifengel beiträge befreit merden.

Die näl)eren Borausiekzungen, unter Denen eine foldje

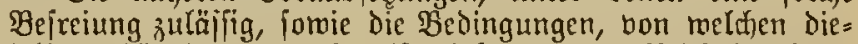
jelbe abljängig zu madjen ift, bejtimmt ber Reidjsłanzler.')

1) Die $\S \S 23$ und 24 find nad 3 nfraftreten des Befeges vom 5. 3. 1888 aud gegenftandslos geworben (ogl. IItt. II $\S 1$ bcs ge= nannten (Beickeses).

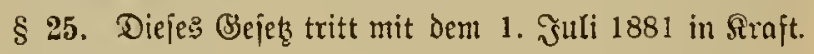
Urfundlid) $2 \mathfrak{e}$.

Begeben Berlin, Den 20. 2Tpril 1881.

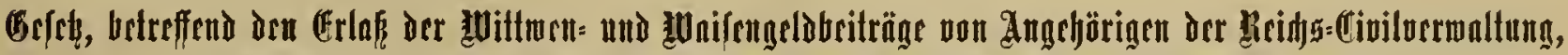

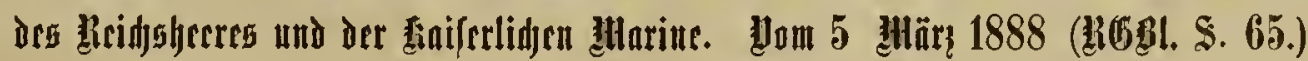

\section{Irtifel I.}

Die Wittmen= und Waijengeldbeiträge, welde auf (Srund

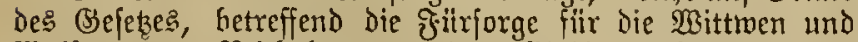
Waifen Der Reidisbeamten Der Civilbetwaltung, bom 20. Aprit 1881 (RESBC. S. 85), jomie Des (Siejekés, be-

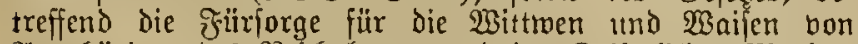

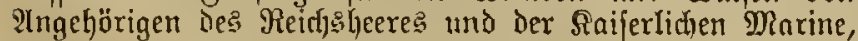

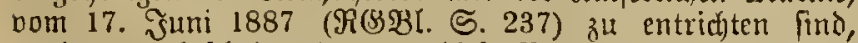
loerden, unbejdiadet des an dieie Berpflifftung gefnüpiten

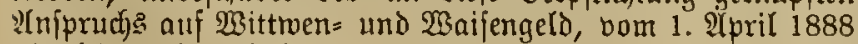
ab nicht mehr erthoben.

\section{Irtifel II.}

$\S 1$. Berzidfte auf 2 Bittmen= und $23 a i j e n g e(d$, melche auf (B) runo der $\$ \& 23,24$ Des Seietzes vom 20. Xpril 1881 oder ber $\$ \S 26,27$ des (refęes bom 17. Jutni 1887 crflärt

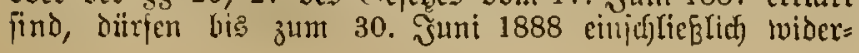

rufen werden. Iluf Rechtšnadjfolger geht dieje Bejugnif́ nifft über.

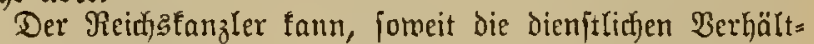
nijfe Der Betheiligten es erfordern, die Ærijt angemeffen verlängern.

§ 2. Der Widerrujende hat denjenigen Betrag an

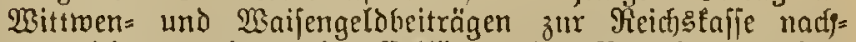
juentrichten, melcher ohne (Extlärung des $\mathfrak{B e r j i c h t s ~ b o n ~ i h m ~}$ hätte entrid)tet werden müffen.

Die Tilgung diejer Srfuld gefficlt in Theilbeträgen von 3 pCt. des Dienfteinfommens, des 2 Bartegelda oder Der Fenfion, nadi den für die Erthebung der $\mathfrak{B i t t m e n}=$ und Waifengeldbeiträge beftehenden $\mathfrak{B o r f d}$ riften, nit der $M a \tilde{B}=$

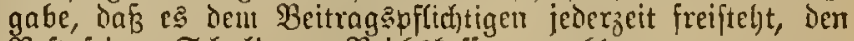
Reft feiner Sdjuld zur Reicjattaffe zu zablen.

Der nad) dem Tode De: Beitragspflidjtigen etma noch ungebedte Betrag wiro bon Den zunädjit fälligeu 
Raten des Wittroen= und Waijertgeldes borweg in utbug gebract.t.

\$ 3. Mifgliedem einer Der im \$ 22 des Bejetzes bom

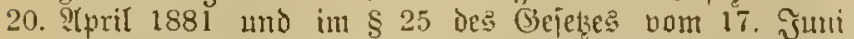
1887 bejeidfueten Eaniesanjtalfeli, weldje gemä̈s \& 1 Den Verjidjt miderrufen uni gleidjzeitig aus der Sandesanjtalt ausidheiden, fino bie an die letztere feit der Serzid)tleiftnng entridjteten Beträge auf die nad) \$ 2 zu madjenten Tiacj= zahlungen anzuredjnen.

§ 4. (Sehört Der Widerrufende einer Militär=Wittmen= fajie als Mitglied an, jo ift die (sthölyma der von ifm bei ber lesteren berfict)erten fienfion umzuläffig mns, fomeit Fie nad) dem 30. Smi 1887 erfolgt ift, ofme wirtung.

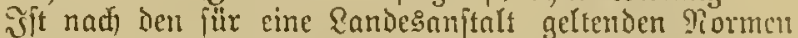
Die Jobhe Der Beitragapflidft, forwie Der Wittrwen= mo
Waiferpenfionen but Dien!beit, Simptrang oder Dienft= cinfommen abbängig, po toerden für die fernere Beitrags: pflidjt des Widcrujendent ôur Sandesanftalt und Bereduung der won biejer ju leijtenden Wittmen = und Waijerpenfitonen Dicmijeit, Dicnftrarg mi Dienfteinfommen nur infeneit in ?triaks gebrad)t, als fic nm 1. Jult 1887 erreicf)t maren.

\section{STrtitel III.}

Die Beftimmungen Dicjes (Bejetses fommen in Babern nad, Mañgahe des Bündrif̧ertrage? nom 23. November 1870

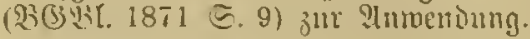

Uirfundidis :e.

Gegeben $\mathfrak{B e r l i n , ~ D e n ~ 5 . ~ M a ̈ ̆ r z ~} 1888$.

\section{Jiitrorge bẹ dednfülllen.}

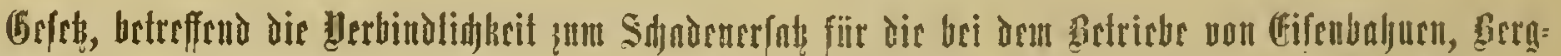

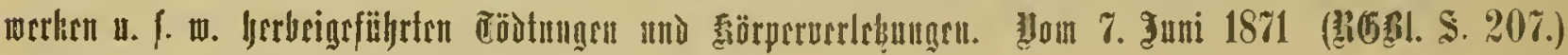

Das Inmeroungsgebiet bicjes fur als "softpflidtgefes" bejcith=

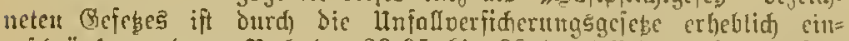

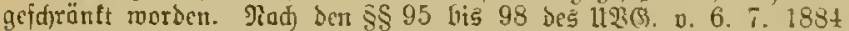

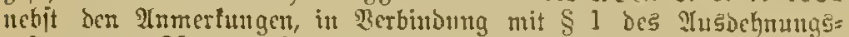

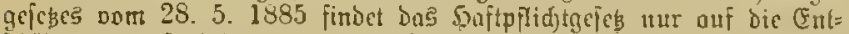
idjöbigunganjprüde Dritter Ferjonen, aljo insbciondere in Injehung ber Meijenden 2tnmendung, mogeget bejüglid ber im Detricbe Der Eijenbahnen jelbft bejdäftigten ßerfonen bas ltufallnerfiderumgşacies gilt. - Heber Den Edjnbenerjas an einen bei bem Betriebe Der Fijen= bahn ocrunglüdten \$oftbeamten ogl. \$rt. 8 bes (Ei enbaln=\{ojtaciebes oum 20. 12. 1875 (oben 5.426 ) no $\$ 10$ bes (nud)fteljend bier

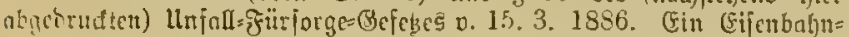

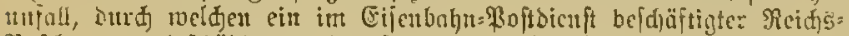
Pojtbcamter beidäbigt mirb, ijt ein "int Dicute ertittener Retriche=

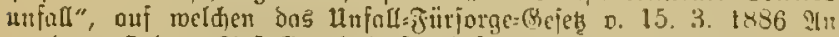

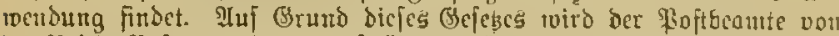

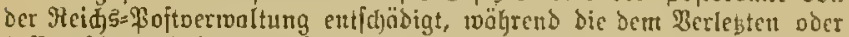
befien Sinterbliebenen auf Grunb bes "Softpflidtgejeges geqen Eijen

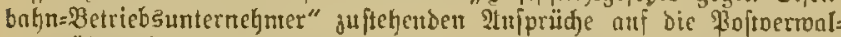
tung iibergehen.

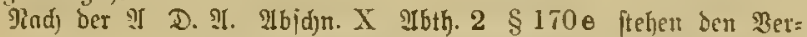

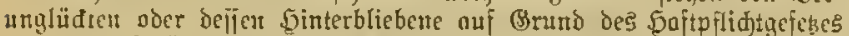
weitere IInprïde gegen ben Eijenbohubetricbsunternehmer ut bunn 311, menu ber cifenbahnbetricb, bei weld)em fid ber llnfall ereignet

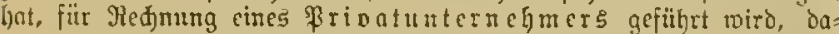

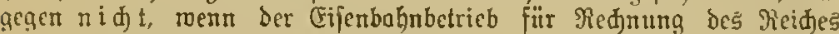
oder eines Bundesftnates gejührt mirb.

§ 1. 2aenn bei dem Betriebe') einer (Fijenbaltr ein Menic) getübtet oter löbperfid) berlekt ${ }^{2}$ ) wird, fo hajtet ber Betriebsunternelmer ${ }^{3}$ ) für den daDurd) entftandenen Schaien,

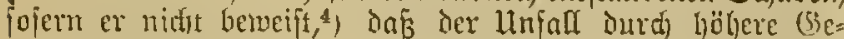

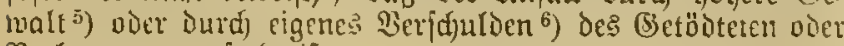
Berleksten berulfadst ijt.

1) Der Begriff bes Eifenbohn=Beiticbes ift hiet cin engerer ols

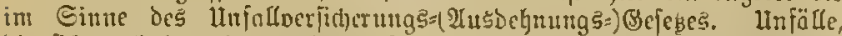
bic fich and bei einer anderen IItulnge ereignen tönnen, follen nidt unter bos Softpflidtgefes. Inbererfeits erftredt fid Dnilelbe auf alle

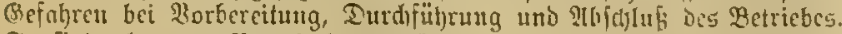
So fino als zum Bhetriebc gehörig eradtet morbert: Das lleber

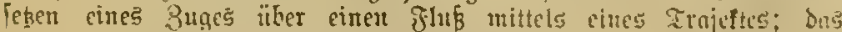
Tiangiren mitcls Dampffroft zur Bufammenftelung cines Eifcrbatut=

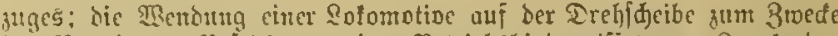

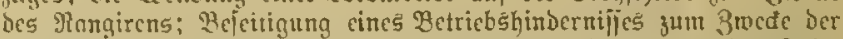

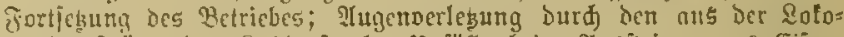

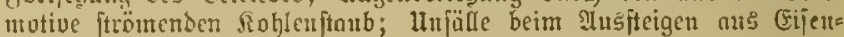
babniougen.

Tie Duldung ber jortbewegung oon Eijenbahnungen auf bent (Brije zum Buved ber Entlabung ourd) anbere als Balutarbeiter be:

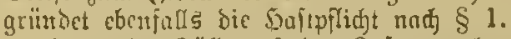

In vielen Fällen ift ber Bujammenhang bes linjalls mit ১em $\mathfrak{B}_{e}=$

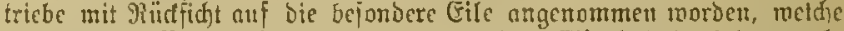
bei ben betreffenten Snanblunger megen bes (Eijenbahnbetriebes noth= mendia wor, jo oei In

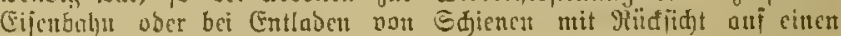
betunnhenden Eijenbahnjug; bei ber Bebienung eines Sigual: apporots; hei bem (Eitloden van (sütern in cinen mur turze Bcit auj ciner 3roijuenftation haltenden Büterjug.

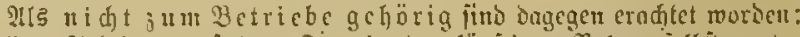

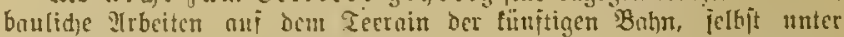

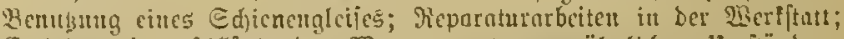
Enfladen eines ftilftehenden Magens unter gewöhnlithen lintënden;

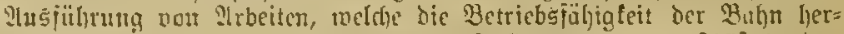

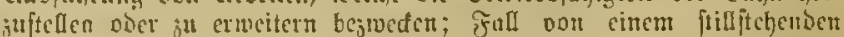

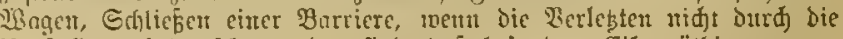

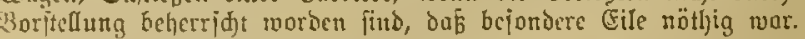

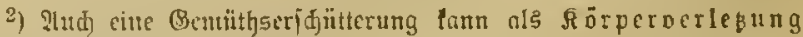
ungejeljen werben.

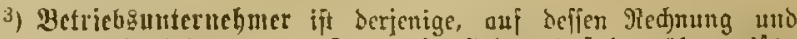

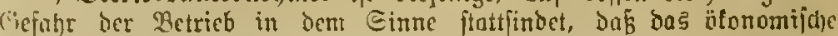

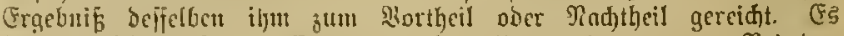

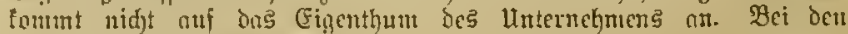

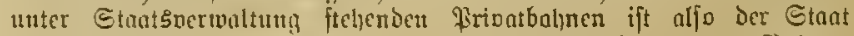
Betricbantenchmer. - Bei Ionfurtrendem Retricbe mebzerer Bahnen auf Derielben Etrede Guitet Dicjenige Bahn, Durd) Deren Betricb ber

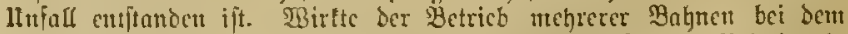
tlufall jufommen, io baften fic jämutlid folionrijd. - Bei burd)= gebenden Bïgen ift, menn jwilden den betheiligteu solhnen teite

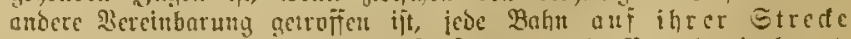

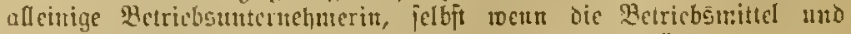
dus 3ngperfonal ciner anderen Balysvermoltung angehörett.

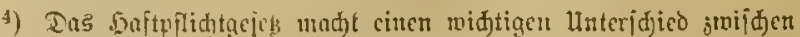

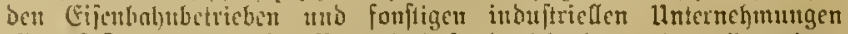

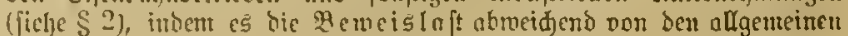




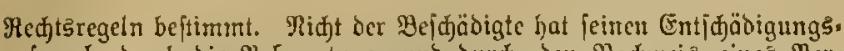

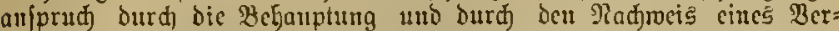

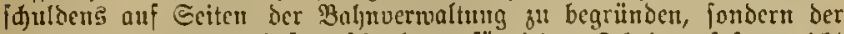
Betrichsuuternehnter buftet fdichthin für jeden Edaben, jojern nidit

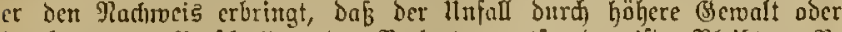

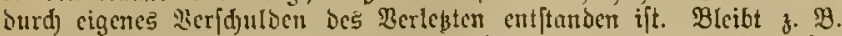
unaufgeflärt, moburd) ber હçabeu (linjall) cntitunoen ift, fo haftet ber Betricbsuntermehmer ficts. 2tnoers liegt die Eadje in Jalle bes \$ 2. Der llnternehmer bajtet fier nud, aber ber 2 temeis bes Ber

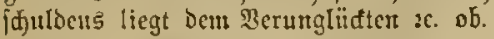

5) ఏöhere Gemalt (vis major), ๖. h. 3 fälle, melde über ons Má̉ berer, welde im Rerlant bes Untemehmens als biejem eigen= thïnlid mehr ober minder häufig sorzufommen pflegen, hinauggehen,

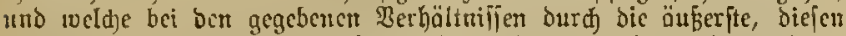
llmfätroeıt nugemeficte Sorgiult und burd) Mittel, deren 2Invendung bem Şaftpflid)tigen vernitnjtigermeije jugemuthet werben burfte, nidit ahgevendet merden tömen (elementote Ercignifje, frantheit, Jrrfinn,

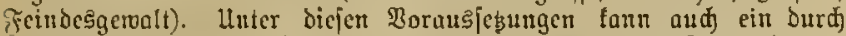

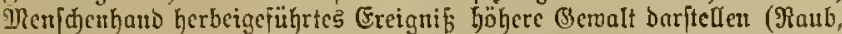
Brandififtun 2e.), nicmals bagegen die Birfung ber gefährbenden Matur bes linternehmens felbit, ober bie Jandlung eines (Eifenbahns bebienfteten. Der Begriff ber höheren Semalt ift nidgt allgemein zu

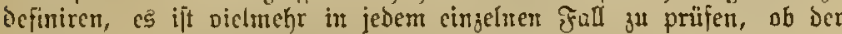

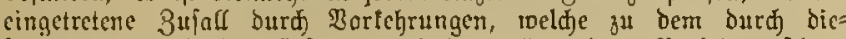
iciben зи erreidjenden Erfo!ge nad, ber allgemeinen Berfebrइanidau. ung in vermünitigem Berbältuif ftehen, Dermicten merben fonnte ober nicht.

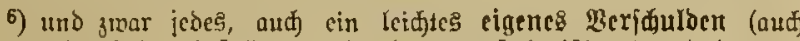

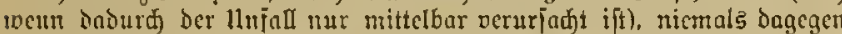

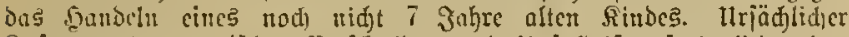

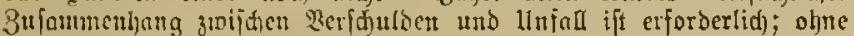
jothen genïgt uid)t dic bloke Ilebertretung ber Betriebsordnung fïr dic Saupteiferbahnen Deutihianos bezm. Der "Bahnoromung". Heber= tretutug eincr Dienftoorīrift ijt bon tein eigenes Berjळulden, wenu dicjetbe regelmäsig oder mit Bifligung ber Borgejestert ftatt= gefunden hat.

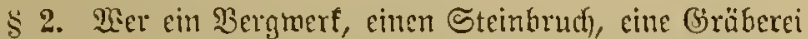
(Grube) nier eine Fohrif betreibt, bajtet, wenn ein :evoll= mäd)tigter vier ein Repräjentant, ober cine jux Reitung oder

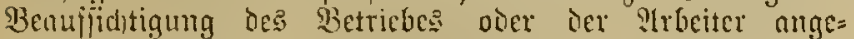

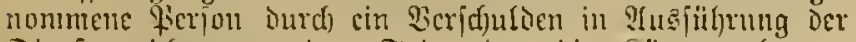

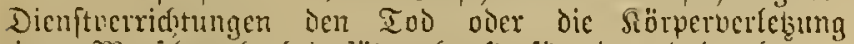

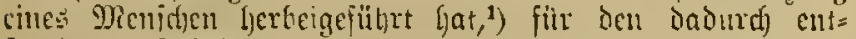
îtanituen Eethider.

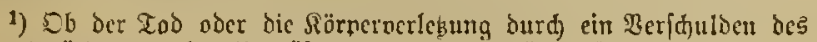

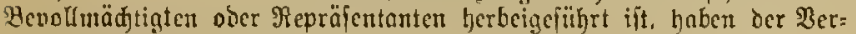

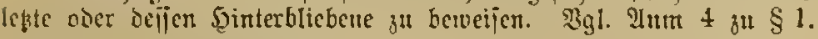

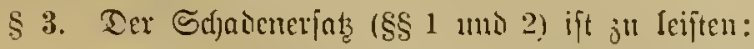

1. im ₹alle der Töbtung Durd (Friak der Soiten cimer berfuchten Seeilung ${ }^{1}$ ) uno Der Becroigung,

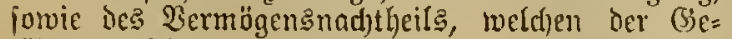
tödtete während der Stranffyeit duri) (Frmerbs= unföhigfeit oder Ţerminderung der Erwerbs= föhigfeit erlitten ljat. War der (Betioitete jur

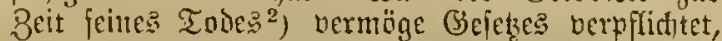
ciucm :!niern lunterljnlt zu getwähren, ${ }^{3}$ ) fo funn diejer injomeit (Erjakg ${ }^{4}$ ) forbern, als iljm in Folge de: Todesfalle: der llnterbalt entjogen worden ift; 5 )

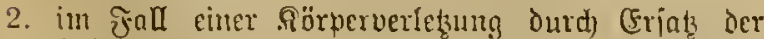

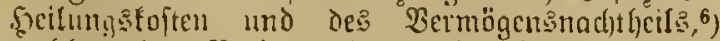
weld)en der Berlekzte turd) eime in folge der Berlekung eiugetretene zeitmeife ober bauernie

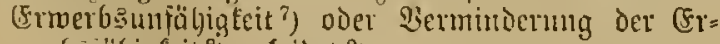
werbsiöhigf(cit ${ }^{8}$ ) erleidet. ${ }^{9}$ )
1) Die geforberten $\Re 0$ ften fint als that[üd]lid aufgeroendet rnads= zumeifen. 3u ben 5eilurgstoften achören aud bicjenigen ber ner=

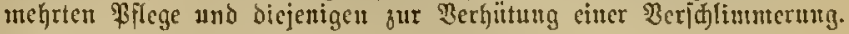

2) alio nidit zur Seit bes Itrialls.

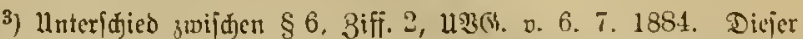
billigt nur ber Trititwe ans eirter vor dem thujall gejकlofienen (E)he,

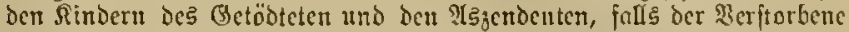

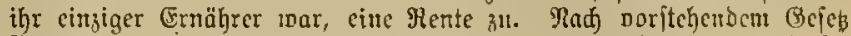

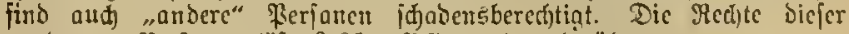

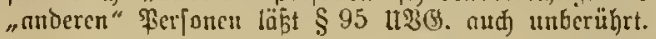

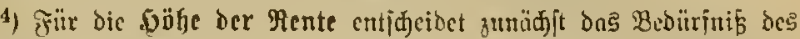
Berchtigtert. Es foum bie fröhe des Ermerbes bes Betöbteten in getrad)t und bas Dia gewährung im Stanbe nar. Dabci Darf beriidfigtigt merocen, menn (iid) nad einer fhou beim Iobe des Ertährers feftitehenden

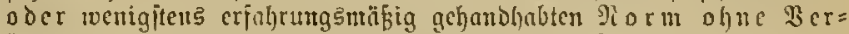
änderung der Arbeitsmobalität im Laufe ber Beit der Ber=

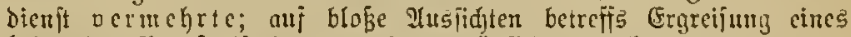

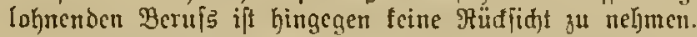

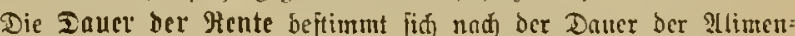
tationsberechtigung (\$ 7 Itbf. 2). Daher miro bei munündigen Rindern

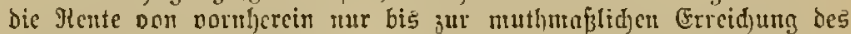

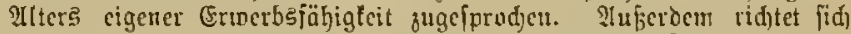

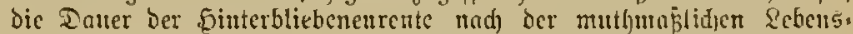

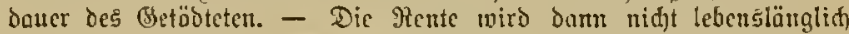
jugejproden, memz der Erwerb ogne Eintritt des llnfalls nut bis zu

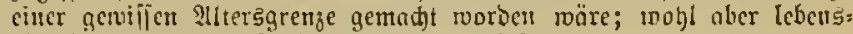

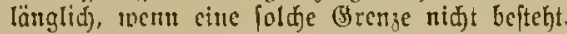

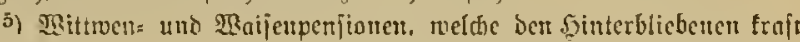

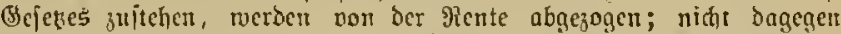

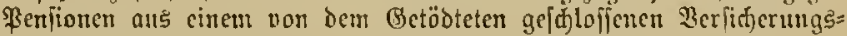
Dertruge.

6) Cin Sdjmergensgeid darf niemals gefordert rerden.

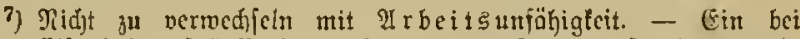
einem Eijenbahnunjull Bertebter fann einen Eknabencriab bann nidit

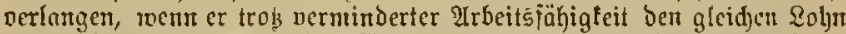

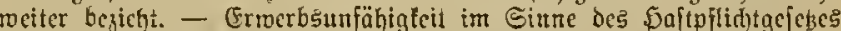

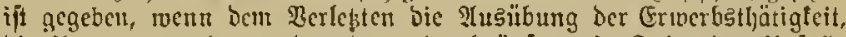

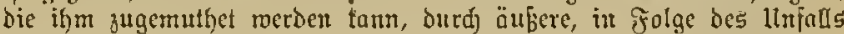

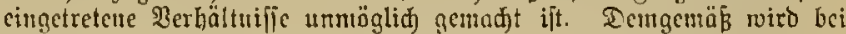
Untähigteit zur Fortjegurg des bisherigen Berujs donernde Ermerb unfähigfeit angenommen. 9lernuag ber Berleste aber burf cine andere Thätigfeit nod) cinen (Erwerb, wenn aud cinen minder lohnenden fid)

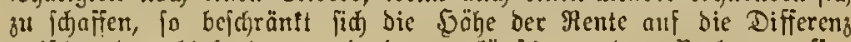
zmifhen Dem bisherigent unv bem zutünftigen, Dent Berlegten offen itelyenden Erinerbe.

8) Die llmatände, burch welde ber lumang einer an fich be= grïmbeten Edadenserfappflid)t gemintbert mirb, aljo aud bns ßorlicgen

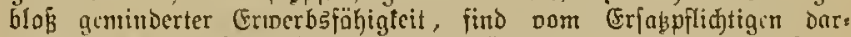
juthum Etcht fêt, Das oic Ermerbşähigfeit nur ncmintoert ift, jo

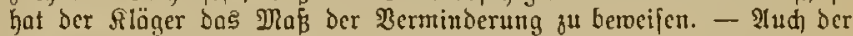

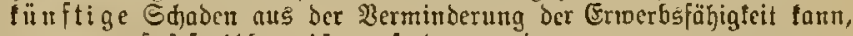
rent er feftitellbar ift, gefordert werben.

9) Bei Bemeijung ber Entifäbigung ift barauf Tiüđfint zus nchmen. dós der Berleģte aud ohne ben lunfall beu fritheren Ermocrb nad beftimmter Beit nif̆t mehr hätte ergielen tötuen.

§ 4. War ier Wetödtete oder $\mathfrak{B e r}$ Tetzte unter Ditleiftung• bon Brtëmien ober anteren Beiträgen durd) ien Betriebs:

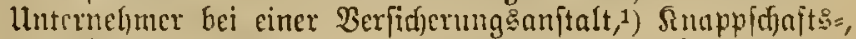

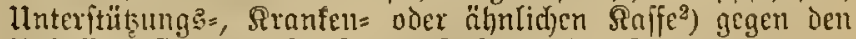

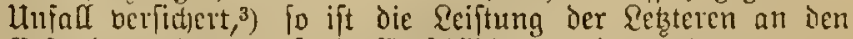
(Frj̄oţbercd)tigten auf die (Entj(jäbigung einzured)nen, woun

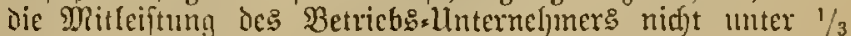
Der Gejumtenteiftung beträgt.

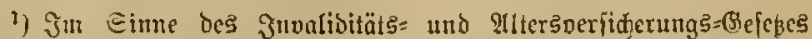
pom 22. उuni 1889.

2) aud) ax[ ßenfionstafien anrombbar. 
3) oarausgejęt wiro eine regelmäbige uno buacrmos Diticifung tes Internchmers, aus roelder auf cine bleibende, bie Reijtungsjähig=

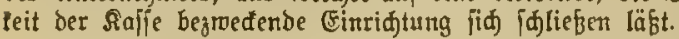

$\S 5$. (1) Die in Den $\$ \S 1$ und 2 bezeidjneten linternelymer find nicht befugt, die शmrondung der it den \$\$ 1 bis 3

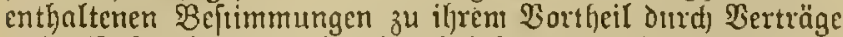
(mitteljt Reglements oder burd) hejondere Hcbercinfunft) im

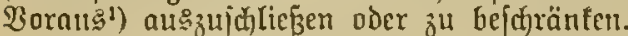

(2) Bertragşbeftimmungen, toeld)e Diefer Barfdrift cnt= gegenjtelon, haben feine red)tliche Wirfung.

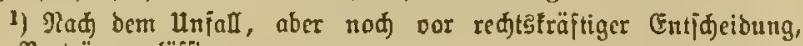
fino Berträge zulälïig.

$\S 6$ ift burd bie Cidilprogeborbung $(\$ 13$ 3iff. 3 bes cinfor.

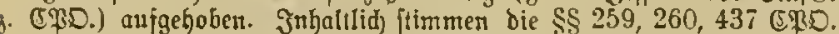

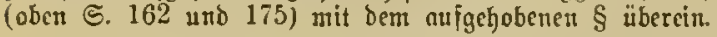

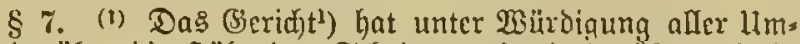
jtände über die \$öhe Des Sdjadens, fomie Darüber, ob, it welcher 2lrt und in tweldyer Söhe Sidherbeit zu beftellen ift,

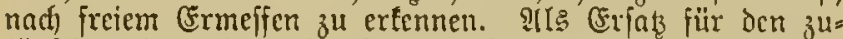
fïnftigen Unterlalt oder (Erwerb ift, toenn nicht beide Theile iiber die Ilbfindung in Rapital cinberitanden find, in der

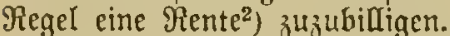

(2) Der Berpflichtete fann jederzeit ${ }^{3}$ ) die 2 (ufhebung oder Minderung Der Rente fordern, wenn diejenigen Berbältuiffe,

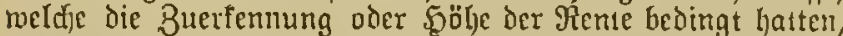
inzroijdjen mejentlich berändert find.") (5benjo faun ber Berlebte, dafern er den Infpruch auf Shadeneriak inner= halb ber Derjäfrungs[rift (\$ 8) gelteno gemad)t hat, jeder.

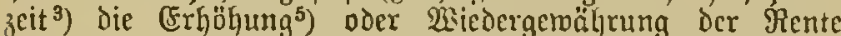

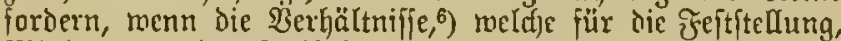
Minderung oder शuffebung oer Rente mafgebeno maren, weientlich berändert find.?)

(3) Der Beredjtigte fann aud nadjträglid) bic Bejtellung einer Sicherheit oder (Erhöhung Derjelben jorbern, wenn die

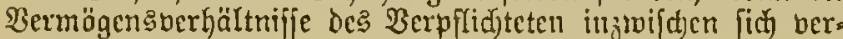
f(d) Iextert haben.

1) bas ordentlide (Beridt (\$ 12 (Bशु(\$). Das 5aitpflidtgejes beruht auf bem cioilredtliden Grundas im Gegenjas gu ber

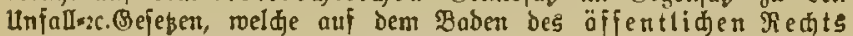

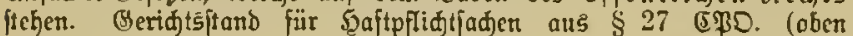
Seite 148).

2) Der Erfas bes Sdabens in Rentenform bilbet bie Regel. Wenn nljo nidjts Dereinbart ift, wirb bas Geridjt immer eine Rente

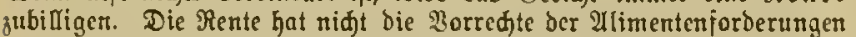

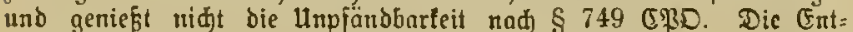

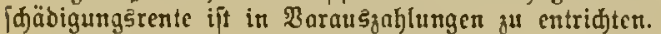

3) Maggebender Bcitpunft ift niđt ianan bie Zeit bes thatjädlidjer

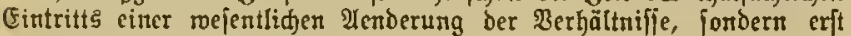
bie Beit ber filagejujtellung.

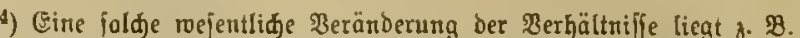
oar, roenr ber Berleb̧te bie Făhigłeit unb Belegenheit ju eintem

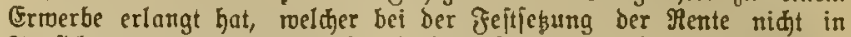

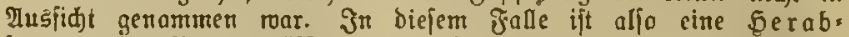
fє bung ber Rente zuläifig. - Dic Buerfennung ciner freibetłsjtrofe

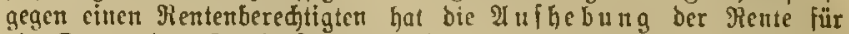
Die Dawer ber Strafhaft gur Folge. - Bieberverbeirathung

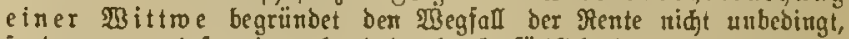
joubern nur infomeit, alక baburd thatjädid bas linterholtungs: bebürinif fid Derminbert ober regiällt.

5) Erhöhungsgruno ift g. B. Das fidher gu erroartende IInfüden in eine hähere (Sehalts, ober Lohnllafie, falls bie \$erlebumg bic fort.

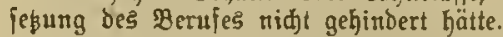

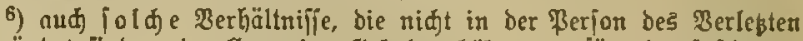
begrimbet firo, wie allgemcine Bchaltserhöhungen fiir eitue bejtimmte

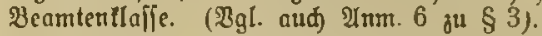

7) มื|ał 2 gilt nur auf burd geridtlidges urtheil feftgejtcute

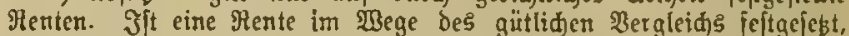
fa bat meder ber Berpflidtete nod) ber Beredjtigte nadjträglid etroas anberes ju forbert. \$arbehalte gemad)t werben.

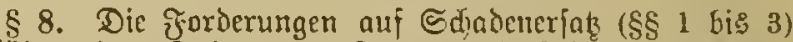
verjöhren in 2 Jahren vom Tage Des Unjall an.') (3egen oenjenigen, welchem der Betöbtete Unterhalt ju gerwöhren hatte ( 3 Rr. 1), beginnt die Beriährung mit dem Todes: tage. Die Berjährung läujt auch gegen Minderjährige und biejen gleidjgejtelte ßerjonen bon denjelben Beitpunften an,

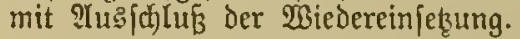

1) Der Tag bes unfalls miro nidt mitgeredjet. - Es ocrjährt

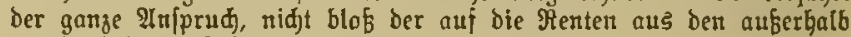
ber अerjäbrungsfrift liegertber Jahren.

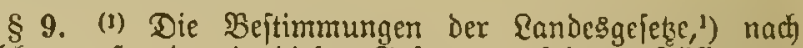

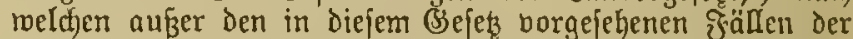
Unternehmer einer in den $\S \S 1$ und 2 bezeidneten 1 ntage oder cine andere \$ierfon, ingbefondere megen eines cigenen Berf(j)uldens für den bei Dem Betriebe der 2Inlage burd) Töbtung oder Rörperberletrung eines Dienfaben entjtanienen Schaden hajtet, bleiben unberührt.

(2) Die Boridjriften der $\S \S 3,4,6$ bis 8 finden aud

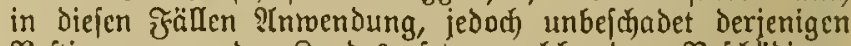

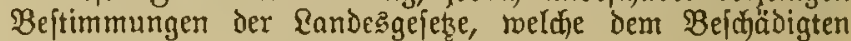

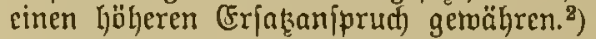

1) $\operatorname{cod} \theta$ civ. Art. 1382 ff.; Gifenb(B. D. 3. 11. 1838, § 25.

2) Die günfliageren $\mathfrak{B} n$ ridjrifiten bes Rarbesredts über ben Urifang ber Entidäbigung fommen aud barn zur IImmendung, rent bie

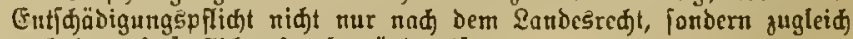
nad bem Softpflidigejes begriintet ift.

Urfundlich $2 c$.

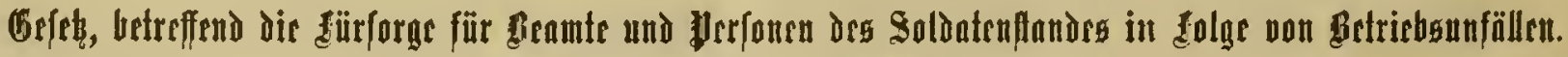

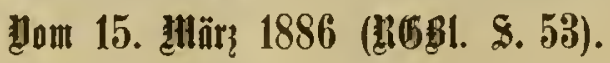

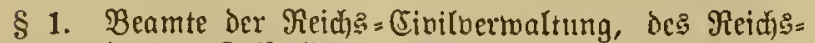
heeres und der Raiferlichen Marine und \$erionen de? Soldatenitandes, reldhe in reidjegciezlich der Unjalnnerfid)e= rung unterliegenden Betrichen bejdjäftigt find, erhalten, wenn fie in ₹rolge eincs im Dienfte erlittenen Betriebs: mialls') bauerno dienftunfähig roerden, als \$enfian fectiss imbjectzigjmeidrittel \$rozent ifres jübrlichen Dienjteins fommens, fotweit innen nidht nach) andermeiter reid) Boridjrift cin höhorer $\mathfrak{B e t r a g}$ zuiteht. ${ }^{2}$ )

Berjonen Der vorbejeid)neten Irt erhalten, wenn fie in folge eines in Dienfte erlittencm Betriebsunfalls nidit doucrno dienftunfälig gemorden, aber in ihrer (Ermerbs: fähigfeit becinträchtigt morden find, bei ihrer fentlaffung aus Dem Dienfte als Benfion: 
1. im ₹alle völiger Erwerbsిunfähigfeit für Die Dauer derfelben den im eriten Mbfaze bezeidineten Betrag;

2. im ₹alle theilmeijer Grmerbsunfäbigfeit für bie Dauer Derfelben einen Brudjtheil ber voritebend

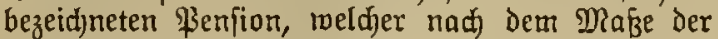
verbliebenen (Frmerbsfähigfeit zu bemeffen ift.

Stebt joldjen łerfonen nad) anderweiter reidjgejebclidjer Borjarift ein höberer Betrag zu, fo erbalten jie biejen. ${ }^{3}$ )

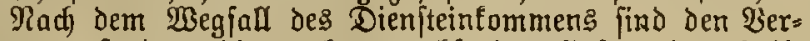
lez̧ten auperdem die nod ermadfenden soften bes seil= verfahrens zu erfeben.*)

1) Das (Bejeb bejiebt fid) nur auf $\mathfrak{B e t r i e b s u m f a ̈ l l e , ~ b . ~ h . ~ a u f ~ f o l d e ~}$ Un[älle, meldje mit bem eigentlichen Betriebsbienfte in unmittelbarem oder mittelbarem 3 ujommenhang jtehen. Die gewähnlide 2 brusurg Der Rräfte burd) Den Dien[t gilt ridjt als Infal $\mathfrak{A}$ uf Perjonen, beldfe lebiglid mit SRegiftrotur= ober Bureauarbeiten ober nit ber

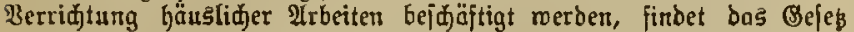
te ine Inmenbung. Dogegen begrünbet es für bie Anmenbbarfeit bes (sejejes feinen Unterjojied, ob Die Beamten ober Interbeamten cime in ben $\mathfrak{B}$ ejolbungs=(etats aujgefübrte Stelle befleiben, oder ab fie gegen felte Bergütung ober gegen Tagegelber bejuäftigt werben, ab fie ihr Dieniteinfommen ummittelbar aus ber $\mathfrak{P o j t f a j e}$ ober burd) eimen

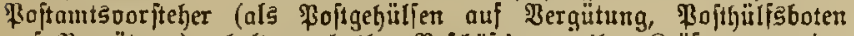

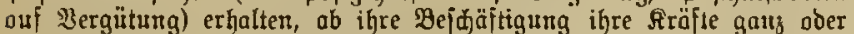

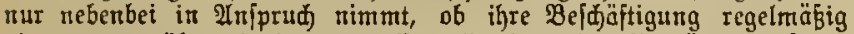
ober nur varübergeherb, gegen (Entgeld ober obne Bergütung eriolgt. Iud) für bie \$oftillone ber reidjseigenen \$olthaltereien gilt bas Bejes.

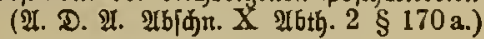

2) (E.tendaf. $\$ 170 \mathrm{~b}$ unb $\$ \S 326$ bis 331 .

3) Ebendal. $\$ 170 \mathrm{~b}$.

4) Ebendaj. §§ 171 und 172.

§ 2. Die Đinterbliebenen folder im $\S 1$ bezeidneten

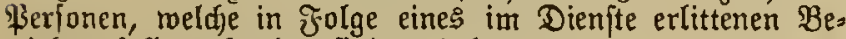
triebsunfalls gejtorben find, erhalten:

1. als Sterbegeld, ${ }^{1}$ ) fofern ihnen nidjt nad) ander. weiter Beftimmung ?Iriprud auf (Snadenquartal oder Bnadenmonat jujteht, den Betrag Des ein= monatigen Dienfteinfommens bežl. Der ein = monatigen Penfion des Berjtorbenen, jedod) min. Deftens 30 :Rf.;

2. eine Rente. ${ }^{1}$ ) Diejelbe beträgt:

a) für die $\mathfrak{B i t t r e}$ bis zu deren Tode oder $\mathfrak{\text { Bieder= }}$ torbeirathung zmanzig Frozent des jährliałen Dienfteiufommens bes Berftorbenen, jedod nidjt unter 160 Daaff und nidjt mehr als 1600 Mart;

b) für jedes Rind bis zux Bollendung des adt= zehnten \&ebensiahres oder biz zur etraigen früberen Berheirathung, jojern die Dutter lebt, fünfundfiebzig \$rozent der Wittmenrente, und jofern bie Mutter nidit lebt, bie bolle Wittwenrente;

c) für $\mathfrak{A f c e n d e n t e n ~ d e s ~}$ Berftorbenen, wenn diejer ihr einziger Ermährer twar, jür bie Zeit bỉ 3u ifrem Tode oder bis zum Wenfall ber Bedürftigfeit zranzig \$rozent Des Dienjt= einfommens des beritorbenen, jedod) nidit unter 160 Mf und nidit mehr als 1600 Mf.; fins mehrere berartig Beredigte borhanden, fo wird die Rente Den EItern vor Den Erofis" eltern gemährt.

Dic Renten dürfen zulammen jedjzig ßrozent bes Dienit= einfommens nidjt überfteigen. (Ergiebt fïh) ein höherer $\mathfrak{B} e=$ trag, fo haben bie $\mathfrak{A}$ [cendenten nur injumeit cinen 2 njprud, als Durd) Die Renten Der $\mathfrak{W}$ ittme und Der Rinder der $50 ̈$ offt betrag der Rente nidjt erreid)t wird. Someit die Renten der Wittro und Rinder den zuläffigen Födjitbetrag über= id)reiten, rerben die cinzelnen Renten in gleichem $\mathfrak{B e r}=$ hälıniffé getürz̧t.

Steht rad andermeiter reidsgefeblidjer Dorjdjift ben Sinterbliebenen ein höherer Betrag ju, fo erhalten fie diejent.

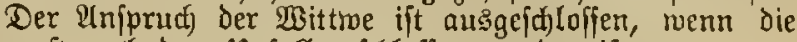
(5)ge erft nad) Dem unfall gefdloffen rorden ift.

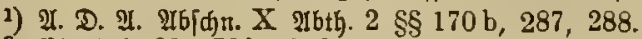

2) (Ebenboj. $\$ \$ 170 \mathrm{~b}, 302$ bis 306 .

§ 3. Crreicht Das Dienfteinfommen nidjt den bon der

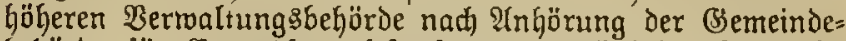
behörde für (Frwachjene feitgejeşten ortz̈̈blidjen Tagelohn gemöhnlid)er Tagearbeiter (\$ 8 des Bejekses, betreffend die Sranfenberjicherung Der Arbeiter, vout 15. ร̌uni 1883,

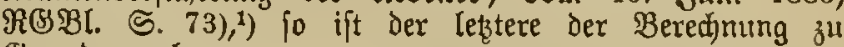
(Brunde zu legen.

Bleibt bei Den nifjt mit ßenfionşberentigung angeitellten Beamten (§ 1) bie nadf borjtehenden Beftimmungen Der Beredinung z̆ Brunde zu legende Summe unter dem niedrigften Dienfteinfommen berjenigen Stellew, in weldhen jold)c Beamte nad) den bejtehenden (Srumdjößzen juerit mit Genfionsberedigung angejtelt toerden fönnen, fo ift ber lez̧tere Betrag der Berechnung zม (Srunde zu legen. ${ }^{2}$ )

1) Oben S. 482.

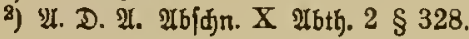

§ 4. Der Bez̧ug Der Penfion beginnt mit dem $\mathfrak{B e g i a l l}$

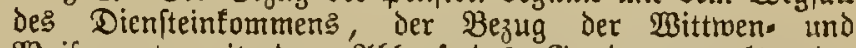
Waifenrente mit Dem Ublauf des Snadenquartals oder Gnadenmonats, oder, forweit joldje nidjt gemährt merden, mit bem auf den זodestag deక Berunglüuten folgendeul Tage.

(Gefört der Berlez̧te auf Brund gejeţlider oder ftatuta= rijder Berpflidjtung einer Siranfenfalfe oder ber Bemeinde=

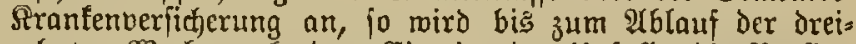
zehnten Wodje nad Dem Eintritt des unfalls die Penfion und ber Crifat ber Rojten bes Seilverfahrens um den $\mathfrak{B e}=$ trag der van der Aranfenfajfe oder ber Bemeinde= Sranfen= verfidjerung geleifteten franfenunteritülzung gefürzt. Der Infprud) auf das Sterbegeld (\$2 26f. 1 Siff. 1), und bom Beginne der vierzehnten Bodje ab aud Der $2(n$ iprud auf Die \$enfion und auf den Erjats Der Roften bes Seilver= fahrens (\$ 1) geht bis zum Betrage Des von der Siranfen= faffe gezahlten Sterbegeldes bezro. bis zum Betrage Der bon diefer gemährten reiteren franfenunteritübung auf bie

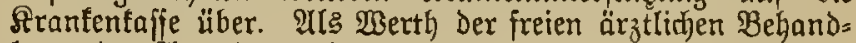

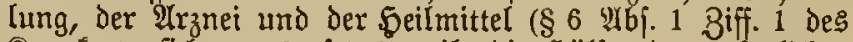

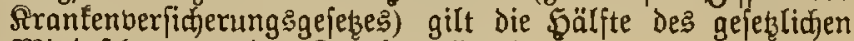
Mindeptbetrages des Rranfengeldes.1)

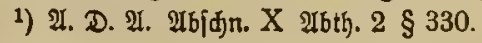

$\S 5$. (Fin 2 nnfprudi auf die in den $\S \S 1$ und 2 bezeid)= neten Bezüge befteht nicht, menn der $\mathfrak{x e r l e k t t e ~ d e n ~ U n j a l l ~}$ (§ 1) vorjäblid oder durd) ein Berjdulden herbeigeitifhrt hat, regen defien auf Dienfentlaffung ober auf Berluft des Titelङ und ßenfionsanprudjs gegen ifn erfannt oder megen Deffen ifm die ₹̛ăhigfeit zur Bejdjäftigung in einem offentlidjen Dienftzweige aberfannt worden ift. ${ }^{3}$ )

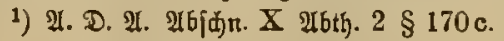

§ 6. Iniprïd) anf (Brund diejes Bejetzes find, foreit

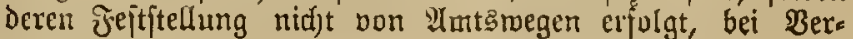




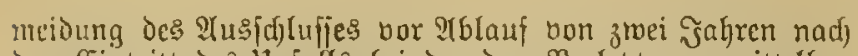
Dem Cintritt des Unfalls bei Der dem Verlekten unmittelbar warnejesten DienftGeljörie anzumelden.

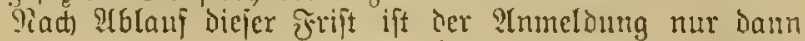
jolge 3u geben, wenn zugleid glaublyaft bejdurinigt wirb,

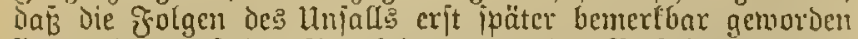
fini, oder dẩ Der Beredftigte von der Berfolgung feincs

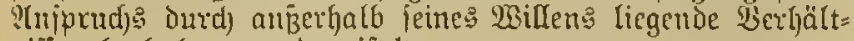
niffe abgefalten worden ift. ${ }^{1}$ )

Seber Unial, weldier von 2lmtimegen ober burd) 2!n= meloung Der Betheiligten ciner vorgejeßzten Dienitbchörde befannt wird, ift fofort ju unteriuden. Den Betheiligtu ift Belegenheit zu geber, jelbjt oder Durd) Bertreter ihre sinterefien bei der linterfudjung zu walyen.

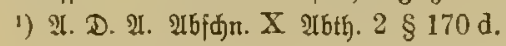

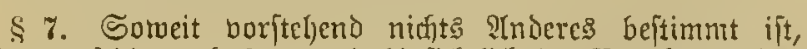
finocn auf Die nad) $\$ 1$, und hinfidytlid Der \$Beredjunng De's Dienjteinfommens aud auf bie nad $\$ 2$ zu gemäbrenben Bezïge die für Die Betheiligten geltenten Beltimmungen

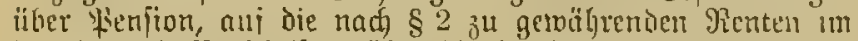

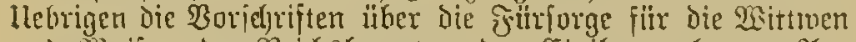
IInD Waifen Der Reidisbeanten Der Civilucrtbaltung, 2(n= twendung. Šedoth erfolgt die Beftimmung Hiher bie Baljlung Der Senten an Sinterbliebene ciner amm Yieidjolyeere gehörinen

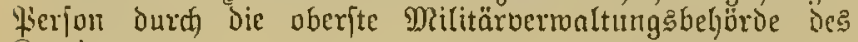
Rontingents.

$\S$ 8. Die in den $\S \S 1$ und 2 bejcidjneten Fierionen tönnen eimen ?tuprud auf (Frjaz Des Durd) Den Unjall (\$ 1) exlittenen (S)abens gegen die Betriebsoertoaltung, in Deren Dienjt fic Den Unfall erlitten Gaben, überbaupt nid)t, mnd gegen deten Betriebsleiter, Bebollmäd)tigte oier ßic= präjentanten, Betriebs= ober ?rbeiterauffeljer nur Dann geltend ntachen, toenn Durd ftrafgeridjtlidges llutheil jeftge=

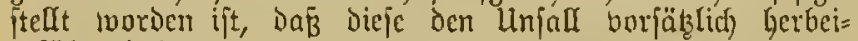
gefïlitt haben.

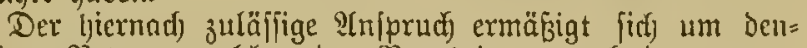
jenigen Betrag, weld)er ben Berechtigten nad) Dem gegen= wärigen Gejetze juịteht.

\$ 9. Die in Dem $\$ 8$ bezcidjneten IIniprïd)e fönnen, audh olue baß bie bajelbit vorgejebene Jejtitellung oud) itrajgeridftlidises llitheil itattgefunden bat, gelteno gemadjt merden, falls dicje Jeitjellung megen Des Todes oder Der Ubtwejentyeit des Betreffenden oder aus einem andercu in ber fierfon deffelben liegenden Grunde nidyt exfolgen tam.

\$ 10. Die Dem Berietzten oder Dejfen Sinterbliebenen auf (Srund Des $\$ 1$ des (Sejęes, betreffend die Berbindlid)= teit jum Sdjabcnerjats fï die bei dem Setriebe bon Cijen=

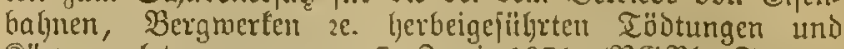

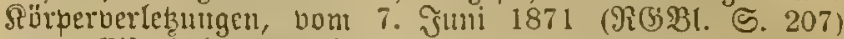

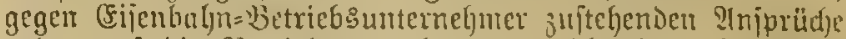
geljen auf bie Betrichsoermaltumg, welel)e den Berlebten ober deffen sojuterbliebenen auf Girum des gegenuärtigen (5)efelzes oter andermetter reid)sgejedzlid)er 2orid)rift (\$S 1 und 2) Hertionen, אoften des Seilberfalyens, Renten oder Sterbegeloer zu zahlen hat, in 5öbe diejer bejüge und vor: behaltlid) Der Beftimmungen ics Mrtitels 8 Des (Bejetses

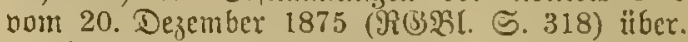

Weitergehende ?tniprübe alo auj dieje Bejüge ftehen

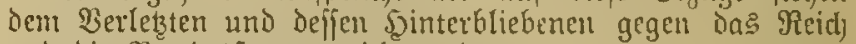
mi die Bundeş\{taaten nidft $u^{1}{ }^{1}$ )

Die Saftung anberer, in Dem \$ 8 nicft bejeidfneten ßerjonen, weldje den Unfall vorjätzlid lyerheigefiulyt oder

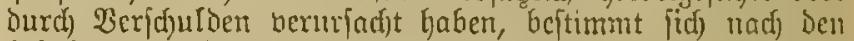

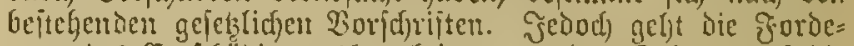
rung Des Enticjädigungsuered)tigten an Deu Dritten auf die Betriebsberwaltung injomeit über, als fie zu Den im शIb= jab 1 gedadsten Bablungen anj (Sirumb Diefes Gejetzes ver: pfliditet ift.

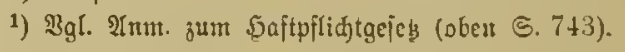

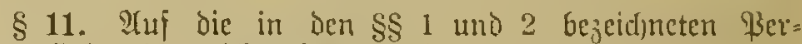
fonen finden die reid)ggefelzlicten \$eftimmungen über ltujall= berjicherung tcine IImventung.

\$ 12. Staats= und Rommumalbeamteu umo beten Sinterbliebenen, für weld) Durd) die Randesgeietzgebung ober ourd) ftatutarifdje Fetzfetzung gegen bie folgen eines im Dienfte erlittenen Betriebsunfals eime Den $B$ oridriften Der §§ 1 bis 5 Des gegenmärtigen (Bejeşes mindejtents gleich)= fommende Fürjorge getroffen ift, jtelyt megen eines fold)en

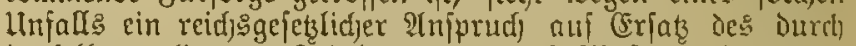

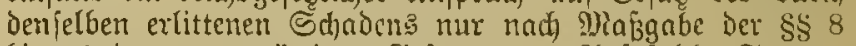
bis 10 des gegentun̈rtigen (Sejetzes zu. Iuj joldje Staat: und Sommunalbeamten unb deren Sinterbliebene funden die

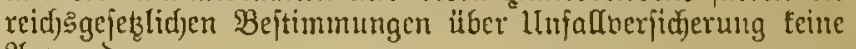
Inmenoung.

\$ 13. Dies Bejeł tritt mit Dem Tage Der Bertïndung

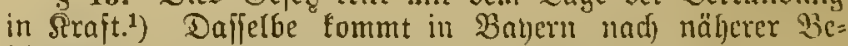

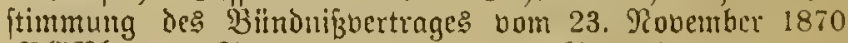

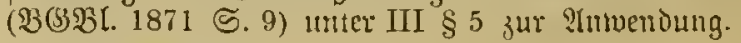

Ilitunotidf) $2 c$.

Begeben Rerliı, \eı 15. Mär 1886.

1) Das Bejes ijt am 20. Närg 1886 verlündet worbent.

\section{Gitrafredtlide Eeftimmutugen.}

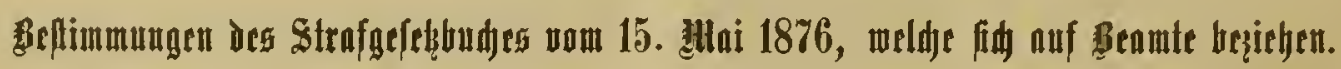

\section{(Cithex Aurdjuitt.}

\section{Berlujt be ?intę.}

$$
\text { Straien. }
$$

§31. (1) Die Berurtlyeilung jur Budjthausftrafe hat die Dumernde Unfäligfeit zun Dienite in bem Deutfden Seere

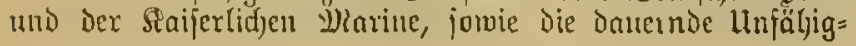

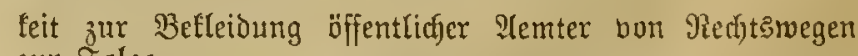
jur §olge.

(2) Unter äffentlidjen $\mathscr{L} e m t e n$ in Sinne dieję Straige=

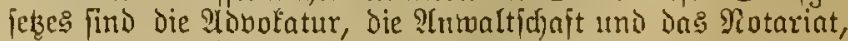

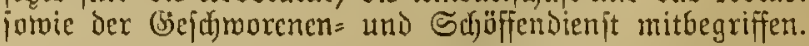

§ 33. (1) Die Iberfennung Der bürgertiden (Ghrenred)te Gervirft Den Dauernben $3 e r l u j t$ der aus öfientlidjen $23 a$ Glen 
für Den Berurtheilten Gervorgegangenen Redjte, ingleichen den bauernden Berluft der offentliden 2temter, Würden, Titel, Drden und (sthrenzeidhen.

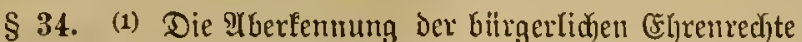
betwirft ferner die llnfähigfeit, mährenb Der im littheile be= fimmten 3eit

1. Die Randestofarbe zu tragen;

2. in Das Deutfhe \$ूer oder in die Siaiferlidje Marine einzutreten;

3. öffentlidye Remter, 2Bürden, Titel, Drden und (Ehrenzeichen zu erlangen;

4. in öffentlichen Ifugelegenheiten ju ftimmen, ju wählen oder gewählt zu rerden;

5. Beuge bei Plufnalyme bon llthumen z"l fein;

6. Sormund, Rebenbormmo, fitrator, geridhtlicher

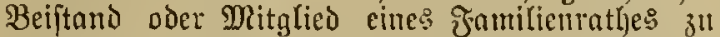

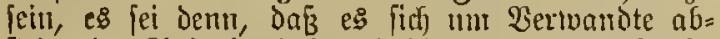
Fteigender Rinie handele und die oberbormumbjchaft. liche Behörde ober der đamiliemath) bie (Stenehmi= gung extheile.

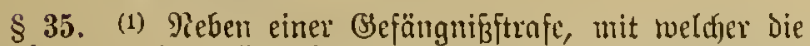

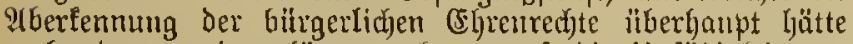
verbunden werden fönnen, faum allf die lnnfähigteit jur Befleibung offentlider Yenter auf bie Daner bou einem bis ju jünf Safren erfannt werden.

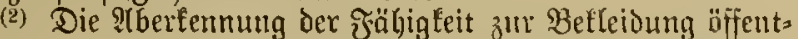

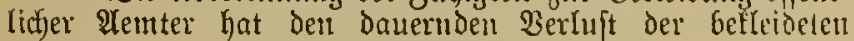

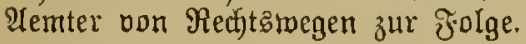

\section{Fedjltex alurdutt.}

Widerftand gegen die Staatzgeralt.

\section{Biberitandsleijtung.}

§ 113. (1) $\mathfrak{B e r}$ einem 8 eamten, twelufer jur פูolf=

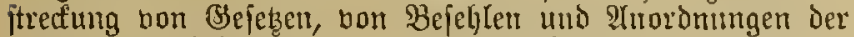
Bermaltumgšbehörden oder von llatheilen und $\mathfrak{B e r f i i g u n g e n ~}$ der Beridute berufen ift, in der recftmäbigen ?lusitbung feines 2(mtes burdh Bemalt oder Durd Bedrohung mit (Se= walt Biderftand leiftet, oder mer einen joldfen Beamten

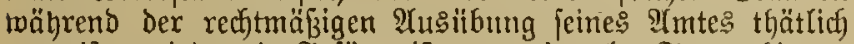
angreift, mird mit Befängnis bon bierzehn Tagen bis zu zwei Jahren beftraft.

(2) Sind mildernde Lumftände borljanden, fo tritt (Sejäng=

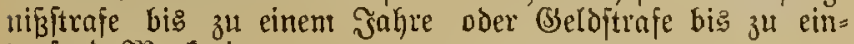
taufent Marf ein.

(3) Diefelben Strafuorfariften treten eir, rwem die Jandhung gegen \$erjonen, meldje zur llnterititzung ber Beamten zugezogen waren, oder gegen Mannidhajten ber bemaffneten Madht oder gegen Mannffaften einer Bemeinde=, Schuts: oDer Bürgerweht in 24usitbung Des Dienjtes be= gangen wird.

\section{Möthigung.}

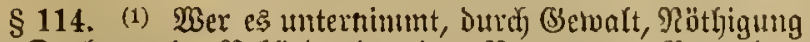
oder Drohung cine Bebörde oder einen Beamten jur Bornalyme

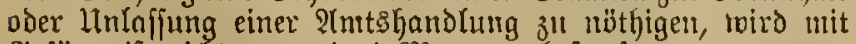
Bejängniß̧ nidut unter brei Monaten beftrajt.

(2) Sind mildernde Umitände borljanden, fo tritt Gejäng= nipjptrafe bi: zu ztwei Эahren ein.

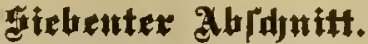

Berbreden und Bergehen rober die offentlide Dronung.

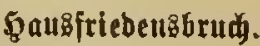

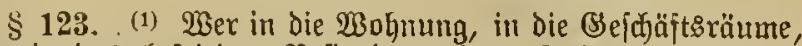
oder it bas befriedete Befizthum eines Anderen ober in

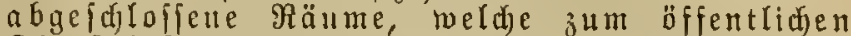
Dienfit beftimut find, miderredgthid) eindringt, oder toer,

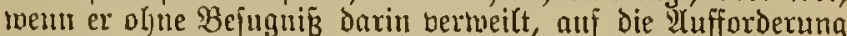
Des Bered)tigten fid nid)t entiernt, lvird roegen Saubfriedens:

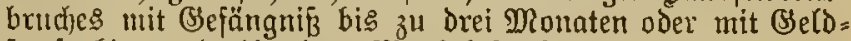
jtraje bis ju breifumbert Mark bejtrajt.

(2) Die Berfolgung tritt mur auf Antrag ein.

(3) Sit die Shandlung bon einer mit Waffen beriehenen Berfon oder bon Mehreren gemeinfdaftlid begangen worben,

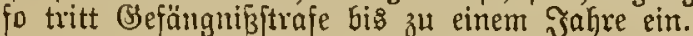

ฟืgl. aud) $§ 342$.

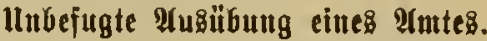

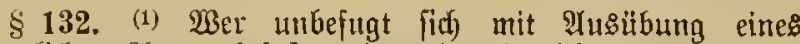
offentlidjen 2 mtes befaß̧t, oder eine Sandlung bornimmt,

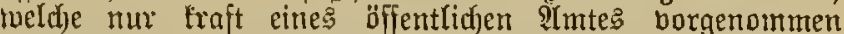
toerden Darf, wird mit Gejängnī̧ bis zu einem Jahre oder mit Belditrafe bis ju oreihumbert Mare bejtraft.

\section{Beijettefuafiung von Urtunben ic.}

§ 133. (1) 23er eine ütfunde, ein Regiffter, Iften oder eimen fonjtigen (Begenftand, weldje fich zur amtlidjen $\mathscr{A} u f=$ bewahrung an einem bazu beitimmten Srte befinden, oder melcje einem Beamten oder einem Dritten amtlich übergeben worden find, borfäzlidy bernichtet, bei Seite idjafft, oder bee fchäbigt, miro mit (Sefängnīß beftraft.

(2) Şt die Sandlung in getwimnjüc)tiger Sandlung be= gangen, fo tritt Bjefängnīiftraje nicht unter brei Dlonaten ein; audf tann auf Serlujt Der bürgerlichen (Shrenrechte er" fannt werden.

Brudu amtlidiner Siegelung.

$\S 136$. (1) Wer unbefugt ein amtliches Siegel, weldhes von einer Beförbe oder einem Beamten angelegt ift, um Sachen z" berjfjlięen, zu bezeidfnen, oder in Bejulag zu nehnet, vorfäblid erbridjt, ablöt, oder bejdäbigt, oder den

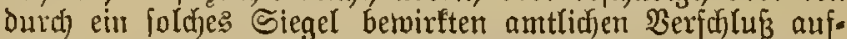

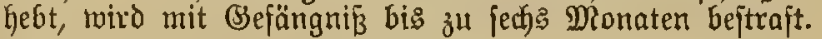

\section{deteuntex Aurdjuitt.}

Deineid.

Meineib.

§ 153. (1) Wer einen ifm zugejdjobenen, zurüdgejobobenen, ober auferlegten (Fid roiffentlid falid) fabmört, miro mit Buththans bis zu zefn Jagren beftraft.

Dienfteib.

$\S$ 155. (1) Der ableijtung eines çides mird gleid) geo adjtet, twenn

1. ..... 
2. .....

3. CEin Beamter eine amtlicje $\mathfrak{B} e r$ fidjerung auf feinen Dienjteid afgiebt.

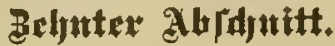

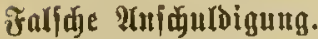

§ 164. (1) Wer bei einer Behörde eine Inzeige madtt, Durdf meldye er Эemand twider befferes 2 Wiffen ber Begehung einer

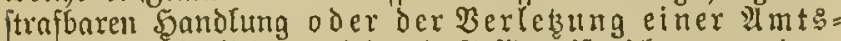
pflid) befduldoigt, wiro mit (sefängni Dionat bejtraft; nudf Eann gegen benfelben nuf Berluft ber bürgerlidjen (şrenredte erfannt werden.

(2) So lange ein in Folge ber gemad)ten THzeige ein= geleitetes જ̧erfahren anhängia ift, foll mit dem Serjahren und mit der Entfdeidung ïber bie falfdje Ifnjofuldigung inne gehalten twerden.

\section{niltexthuter aldidutt.}

\section{Peleidigung.}

Beleidigung.

§ 185. (1) Die Beleidigung wiro mit Sieldjtrafe bis zu fectshumbert Marf oDer mit S2aft oder mit Befängni zu einem Sahre und, wenn die Belcidigung mittele einer IGätlidjeit begangen woird, mit Bseldftrafe bie ju eintaufend= fünfGundert Marf oder mit Sefëngnifis bis zu zroei Sabren beftrajt.

\section{Mügen von Sorgejebten zc.}

§ 193. (1) Tabelnde Urtheile itber miffenfdajatlidje, Eïnjt= Ierifdye oder getoerblidje Reiftungen, ingleidjen Peuserungen,

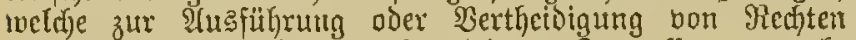
ober zur Wahrnefmung beredigter Jntereffen gemadjt werden, fomie $\mathfrak{B}$ or haltungen und Rügen der $\mathfrak{B}$ or: geferten gegen ibre lintergebenen, dienfticte 2 n zeigen oder llrtheile bon Seiten eimes Beamten find nur infofern ftrafhar, a[S Das $\mathfrak{B}$ orhandenjein einer $\mathfrak{B e}=$ leidigung aus Der form Der SeuBerung, oder aus ben Unt= itünden, unter meldjen fie gefdah, herborgeht.

\section{Strafantrag.}

\$ 194. (1) Die Berfolgung einer Beleidigung tritt nur

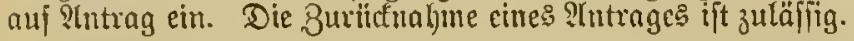

\section{Etrajantrag bei Reamtentelcibigung.}

§ 196. (1) Wenn die Beleidigung gegen eine Behörde, cinet Beamten, einen ReligionsDiener oder cin Mitglied Der betuafineten Madjt, während fie in der MHsitbung ihres Bernfes begriffen find, oder in Beziehung auf ifren Beruf begangen ift, jo Kaben auß̈er Den unmittelbar Betheiligten audf beren amtlidje $\mathfrak{B}$ orgejetste bas Redht, den Strafantrag ju jtellen.

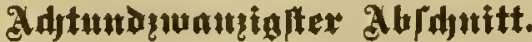

Berbreden und Bergegen im amte.

\section{Itunahue voแ Gejüenlen.}

§ 331. (1) (Fin Beamter, reld fer für eine in fein I(mt

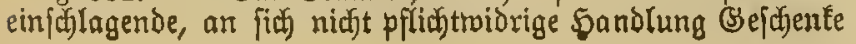

oder andere Bortheife amimmt, fordert oder fid berfprecten läst, wird mit Belditraie bis zu dreihundert Mharf oder

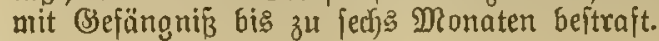

Beftedung.

§ 332. (1) Fin Beamter, weldher für eine 5̧andlung, bie eine $\mathfrak{B e r l e t z u n g ~ c i n e r ~ a l m t a ~}$ (d)ente oder andere BortGeile aunimmt, fordert oder (ich) veripredjen läßst, twiro megen Bejtedjung mit Zudjthaus bis zu fïnj Jahren Gejtraft.

(2) Sind mildernde Umitände borlyanden, fo tritt (Sefäng. niß̧̧ trafe cin.

§ 333. (1) Wer einem Beamten oder cinem Dritgfiede Der bewaffueten Madjt (Ssejd)enfe oder andere Bortheile anbietet, verfpricht oder gemährt, um ifn zu einer Sandlung, die eine

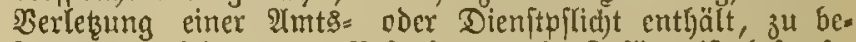

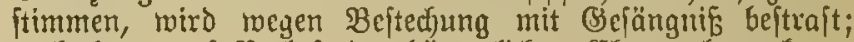
audf) Eann auf Berluft der bïrgerlidfen (Egrenredgte erfannt - merden.

(1) Sind mildernde lumitände vorhanden, fo farm auf (Seldjtrafe bis zu eintaujendiinfhundert Dart erfannt werben.

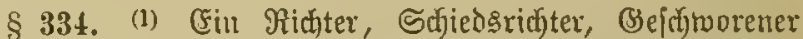
oder Scubffe, meldjer (sejdjente oder andere Bortheile fordert, annimmt, oder ficf) berfprechen läß̧t, um cine Redjtş fadje, Deren Reitung ober (Entfdjeioung ifhm obliegt, fu Bunjten

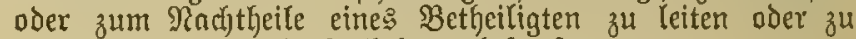
entfueiden, wiro mit Budjthaus beftraft.

(2) Derjenige, weldjer einem Ridfter, Sdjiedsridjter, Be= fdrworenen oder Sdjoffen zu Dem borbezeidjneter Zlveufe (Bjeidsenfe oder andere Bortheile aubietet, verfpridyt over ge. währt, wird mit Budjthaug bejtraft. Sind mildernde ltu= Ftände borkanden, fo tritt Biefängniß̄jtrafe eir.

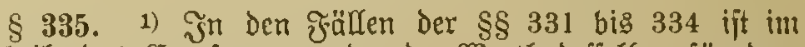
Utrtheile das Cmpjangene ober Der Werth deffelben fitr dem Staate verjallet zu erthären.

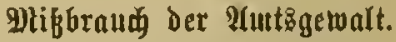

§ 339. (1) (Fin Beamter, welder ourch Mişbraud feiner

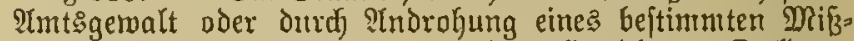

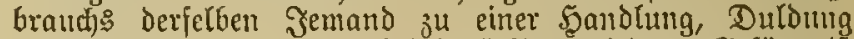
ober linterlaffung roiderrechtlid) nöthigt, wiro mit (sefängnifs beiptrajt.

(2) Der פerfud ift ftrafbar.

(3) .....

§340. (1) Fin Beamter, weldjer in 2 (4)

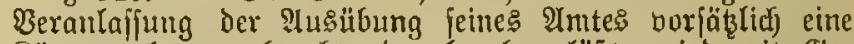
Rörpervertebung begeht ober begehen läßst, wiro mit (Bes füngnif́s nicft unter orei Monaten beftrajt. Sind mildomde Limitände vorhanden, fo fann die Strafe auf einen Tag Sefängnif ermäß̧igt oder auf Belditraje bis zu neun= Gundert Marf erfannt werden.

(2) Эit bie Rörperbertekzung eine fdjwere, fo ift auf Budthausftrafe nidyt unter zwei Jafuren zu erfemmen. Sind mildernde Umftände vorhanden, fo tritt Befängnißífrafe nidft unter Drei MRonaten ein.

§ 341. (1) (Fin Beamter, weld)er vorjäblidy, ofne bierzu beredutigt зu fein, eine Berfaftung oder vorläufige Ergreifung

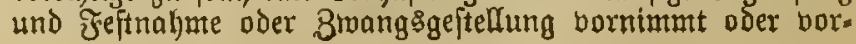


nehmen läft, oder bie Dauer einer Freiheitsentziehung bers längert, wiro nach) Doridurift oç $\$ 239,1$ ) jedoch mindeften mit Sefängnif̧ bon brei Monaten beftraft.

1) Diejer $\S$ oroht an:

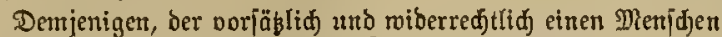
cinipert ober auf andere 20 eije bes Bebraudes ber pers förliđien ģreiheit beraubt: Befängnißjitrafe.

\$Benn bie Orreiheitsentziekung itber cine Bodje gebauent hat

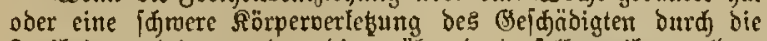
freiheitsentziefjung oder bie währento berielben thn wider= fafrene Behandung verurjadt morben if: Budjthats bis zu

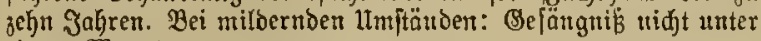
einem Monat.

Jit ber Tod des (Beifäbigten verur[acht: Budjthaus nidjt unter brei ̧ahren. Bei mitbernden Itmitänden: Befängniß nidft unter brei Monaten.

§ 342. (1) Cin Beanter, der in der Ausilbung oder in

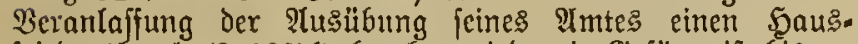
friebensbrud) (\$123) ${ }^{1}$ ) begeht, toiro mit (S)efängnif̧ bis zu cinem Šnhre oder mit Bseldftraje bis zul neunhumbert $\mathfrak{R}$ arf beitrajt.

1) ஐgl. § 123, oben S. 754.

$\S 343$. (1) (5in Beamter, weldfer in ciner Unterfudfung Brwangsmittel antwendet ober anwenden läßjt, um Be= ftänoniffe ober IHÊagen zu erprefien, wirb mit Budfthaus bis zu fünf Jahren beftraft.

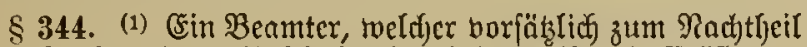
ciner \$er\{on, deren llnidjuld ifm betannt ift, die Eröfnnumg oder Jortfeksung ciner ltnterfuctung benntragt oder befoliefst, mirb mit Budfthaus bejtraft.

$\S 345$, (1) (SIcidje Straje trifft Den Beamten, roldjer vor-

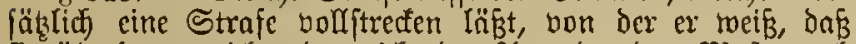

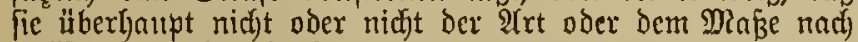
volffrect werden darf.

(2) Şit bie Sandlung auss Fafyrläffigfeit begangen, jo

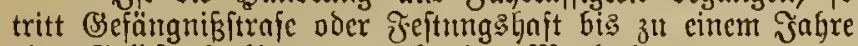
oder (Beldjtrafe bis zu neungundert Marf ein.

§ 346. (1) Ein Benmter, weld)er verntöge jeines :(ntes bei 2 fusübung ber Strafgetwalt DDer bei Bolftrecfung ber Strafe mitzumirten bat, wirb mit Buchthaus bis zu fünf Jahren beftraft, wenn er in der Thfidt, Jemand der gefestidjen

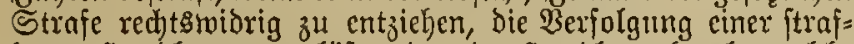
baren Syandlung unterläß̧t, oder eine Şandlung begeht, tweldae geeignet ift, eine Jreifprechung oder cine bein (Sejekse nicht entfprechende Beftrajung zu bemirfen, oder die Bodftreefung der ausgejprodjenen ङtraje nicf)t betreibt, ober cine getindere als die crfaunte Strafe zur 30 oftreffung bringt.

(1) Sind mildernde lluritände borbanden, fo tritt Sejäng. niß̧̧⿸丆口

\section{Interidglagung in IImte.}

\$ 350, (1) Ein Scamter, weldfer Belder oder andere Sadjen, bie er in amtlid)er (Eigenfd)aft empfangen oder in

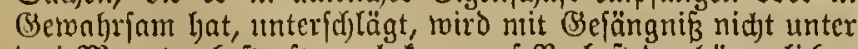
orei Mionaten bejtraft; aud tann auf Berlujt ber bürgerlicfen (shrenred)te erfannt reerden.

(2) Der Berfud) ift ftrafbar.

§ 351. (1) Sat der $\mathfrak{B e a m t e}$ in Bezicljung auf bie linter= fiflagung Die zur Eintrngung oder ßontrole der Cinnahmen

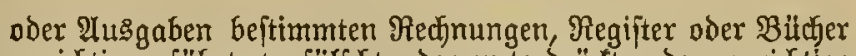
unridftig gefübrt, verjälfát oder unterorïaft, ober unridfitge

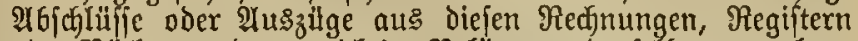
oder $\mathfrak{B u}$ it jern, pder unricttige Belöge zu denjelben vorgclegt, oder ift in Beziehung auf Die llnteridjlngung nuf J̌affern, Beuteln oder Badeten der (secloingalt fäljulide be: zeidjnet, fo ift nuf 8udjthausftrnfe bis zu zehn Jahren zil erfennen.

(2) Sind mildernde llmitände borfanden, fo tritt Bejängs niहfitrafe nicht unter fectis Monaten ein.

§ 353. (1) Sin Beamter, welcfer Steuern, Befälle ober andere A6gaben jür eine biffentlicje Safie zu erheben lyat, twirb, wenn ex 2l6gaben, bon denen er weif, baf der Bahlende fie überbaupt nidjt oder mur in geringerem $\mathfrak{B} e=$ trage veriffuldet, erbebt, und das redjtsmidrig Erbobene ganz

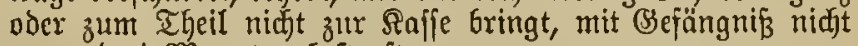
unter Drei Monaten bejtraft.

(2) SIciche Strafe trifft den Beamten, weldjer bei amt= lidjen \&uşgaben an (Seld oder Raturalien Dem Empfänger bor=

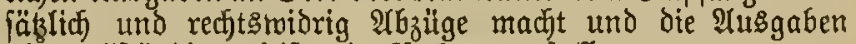
als bolftändig geleiftet in Redmung ftellt.

\section{Cröffnumg uno Interbrïdung von Boitfendungen.}

§ 354. (1) Ein \$oftbeamter, weldjer die ber ßoft an, bertrauten Briefe ober sadete in anderen, als nut den im

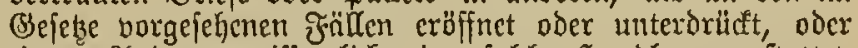
cinem ?inderen wiffentlidy cine foldje Sandlung geitattet, oder igm babei wiffentlick Sülfe leiftet, wiro mit Ssejängniß́s nicht unter brei Monaten bejtrajt.

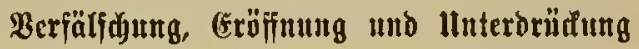 von Telegrammen.}

§ 355. (1) Telegrapljenbeamte oder andere mit ber $\mathfrak{B}_{\mathfrak{C}=}$ auffictitigung oder Bedienung einer $3 \mathrm{u}$ öffentlidjen Zlvedfen dienenden Ielegraphenamitalt betrante ßerjonen, weldje die einer Telegraplenanftalt anvertrauten Depefden berfälidjen oder in nnderen, als in den in Befebe borgefelyenen fुn̈lfen eröffinen ober unteroridfen, oder von ihrem Jnhalte Dritte rechtsmidrig benadjridjtigen, oder cinem Inderen wiffentlid)

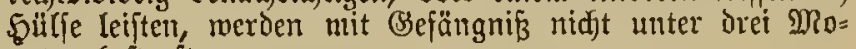
naten beftraft.

\section{Berleitung Der Intergebenen.}

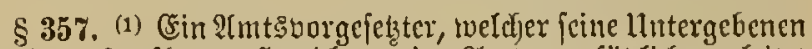
3u einer ftrafbaren Şandlung im ?tmte vorfäłzlich verleitet DDer zul berleiter unternimmt, oder eine foldje [trajbare Sandlung jeiner Untergebetten wiffentlidy gejdelsen läßst, hat die allf dicje ftrafbne Şandlung augedrohte Strafe vermir.

(2) Diejclbe Beftimmung findet auf eincn Beamten ?:n= mendung, weldjem cime Iurfifd) oder Pontrole ïber die Amtミgejdäfte cines andoren Beanten ïbertragen ift, fofern bie von diefent letsteren Beamten begangene ftrafbare Sandlung bie zur Iflfficht oder Fontrole gehistenton (B)= idjäfte betrifft.

Berluft be 21ute

§ 358. (1) Rebent ber nad Borjurift Dex $\$ \S 331,339$ bis 341,352 bis 355 und 357 erfannten Bsefängnif́ftrafe

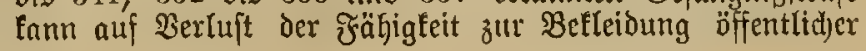


2emter auf die Dauer bor. einem biß зи fünf Эahren er= fannt werden.

\section{Begriff ber Beanteneigenfduaft.}

§359. (1) Unter Beamten im Sinne diefes Strafgefetzes find zu beritehen alle im Dienjte des Reidhs oder in un= mittelbarem oder mittelbarem Dienfte eines Bundesftantes nui Eebenşzet, auf Beit oder mut borläuffig angeftellte \$ser= jonen, ofjne Unterichied, ob fie einen Dienjteio geleijtet Gaben oder nidjt, ingleidjen Notare, nidjt aber Midbolaten 1mo Inmalte.

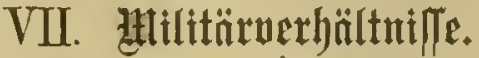

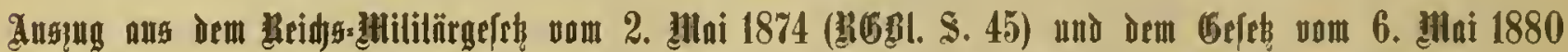

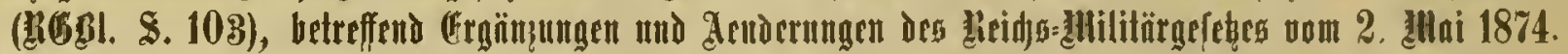

\section{V. abjumitt.}

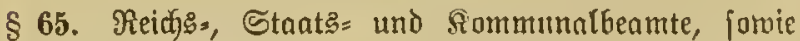
Ingeftellte Der (Sifenbahnen, weldje der Referbe oder Rant= wehr angebören, dürfen für den Fall cincr Mobilmachung oder nothroendigen Berftärfung des Seeres binter den älteiten Jahrgang ber Ranowebr surüfgeitellt werden, wemu ifre Stellen felbit boritbergebeno nid)t offen gelaffen werben tönnen und eine geeignete Bertretung nidjt żt ermiäg= likgen ijt.

§ 66. Reta) 5 s, Stantsి = und fommumalbeamte follen burdy ihre Finbertfung $31 \mathrm{~m}$ Militärbienit in ibren bitrger= lichen Dienftberhältuiffen feimen Sachtheil crlciden.

Şhre Stellen, ihr perjönlict)es Dienfteinfommen aus den= felben und ihre Ineiennetät, fotoie alle fidc) Dnzaus ergeben= ben $\mathfrak{A n}$ ipribde bleiben ifnen in der Beit ber Cinberufung zum Militärdienjte geronhrt. Crhalten diejelben Dffizier= befoloung, fo fann ihnen Der reine Betring Derfelben nul dic Cibilbejoloung angerednet werden; denjentgen, soeldie einen

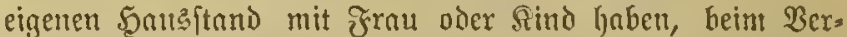
laffen ihres Woljnortes jedodi) nur, wenn und forneit bas

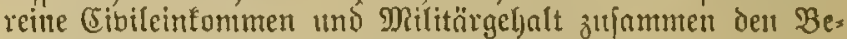
trag bon 3600 Mart jüljrtid) ïberfteigen.

Pind benfelben Girmbfäzer find penfionirte oder nuf Wartegeld ftelende Civilbeamte ljufidjtidf igrer Benfionen oder Wartegelder z" beljandelu, went fie bei ciner gjobil= utadjung in den Sitiegshienjt cintreter.

Sbige Bergionftigumgen fommen nad atsogeprodjencr

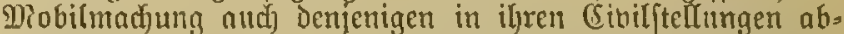
fönmlichen Reid) $\$=$ und Stantgbeamten zit gitt, meldye fich freituillig in bas Seet nufrebutuen laffen.

Die nälexen Beftummungen bleiben den cinzelnen Bundes. regiertugen ïberlnffen.

\section{Edjlufbeftututungen.}

§ \%1. Dic 2(usfibling fdjnitten II, IV und V deş Befetses erläbt der Sntfer.

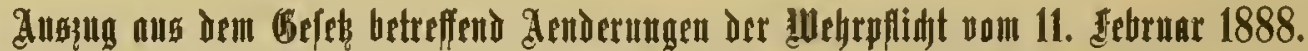

\section{Zroeiter $\mathfrak{X}$ bidnitt.}

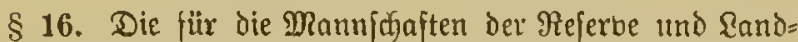
wehr gegen Zurüdftellung hinter bie lețte Jahresflaffe ber Rejerbe bezm. Randwehr getroffenen $\mathfrak{B}$ ejtimmungen finden auf bie Criakrejerbijten entipredjende \&nmendung. Die Zaht Der auf Grund häuвlidjer und gewerblidjer Berfältniffe hinter die lebte Jahrestlajfe Buritfgeftelten darf in Eeinem

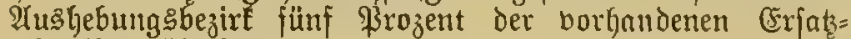
rejerbiften überfteigen.

\section{Dritter 2 b fidnitt.}

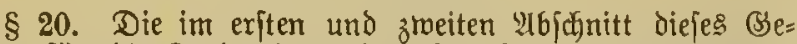

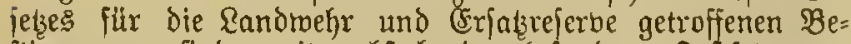
ftimmungen finden mit nadjitehenden befonderen హeltfebungen nuf die Seetrefr und Marine $=$ Frfatzreferbe finngemäbc Ifumendung. (Die befonderen Ærekietzungen betreffen nicht die Buriaffiteflung vom Waffendienft.)

\section{Bierter 2 bidinitt.}

$\S 29$. Die Bejtimmungen Der $\S \S 64,65$ und 66 bes

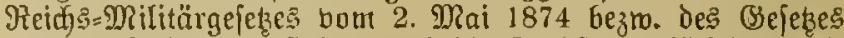
bom 6. Mai 1880 finden auf die Randfturmpflidytigen mit

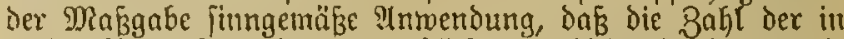
Folge fäuslidjer ober getwerb̆lidjer $\mathfrak{B}$ erbältniffe hinter dic

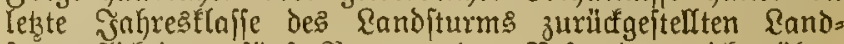
fturmpflidgtigen fünf \$rozent des $\mathfrak{B}$ eftandes nidft über= fteigen barf.

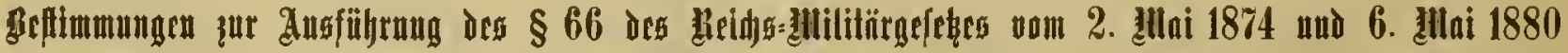

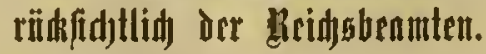

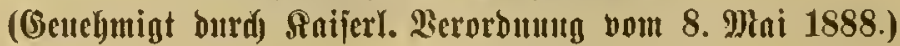

I.

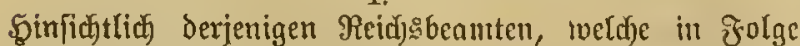
einer Dlobilmadjung in bas Speer oder den Randjturm zum Militärdienjt einberujen werden oder, jojern fie in ihrer
(Eibilitellung abfömmlid) find, freimillig cintreten, fommen folgende Rejtimmungen zur ?̂rmendung:

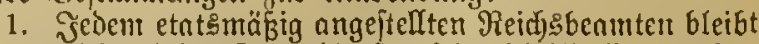
währeno des Ariegsdienftes feine cibilftelle gerungrt. 
2. Den etatsmmäßig angeitellten oder ftändig gegen (Entgelt beidiä)tigten Feid)\$beamten wird während der Dauer bes Ariegsoienites ifr perfönlicjes Dienfteinfommen unberfitrzt fortgemährt.

Bit dem perjönlidfen Dienteinfommen gefören Behalt, fixirte diätarijote Remuneration, Srt $\$=$,

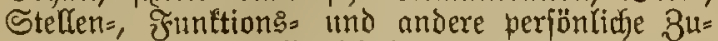

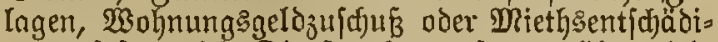
gung, jofern nid)t Diemptwohnung fortgenöhrt wird, penfionsfätiges (Finfommen nus cinem Rebenamte und der penfionsfähige Betrag folcher Dienjt = emolumente, relde ifrer $\Re$ atur nach fteigend und fallend find. Der lektere Betrag ift fit die Dauer

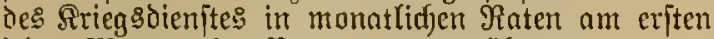
jedes Monats in $\mathfrak{B}$ oraus zu gemähren.

Bn dem perjönlidfen Dienteintommen werden Repräfentations= und Dienftaufmandsgelder, foric dic jogenannten Manfogelder ber Raffenteranten nidjt geredjnet.

3. Fryält der Beante bie Bejoldung cines Sffiziers oder oberen Beamten der Militärbervaltung, fo wiro der reine betrag derfelbet, als weldyer fieben Beljntel der Sriegsbefoldung nngefeben merden, auf das Siviroieniteinfonmen angered)net. Das Dienfteinfonmen eines Unteroffiziers in einer vafanten Eientenantsiftelle gilt nidjt als Dffiziers: bejoldung.

Sat dex Beamte Familienangehörige, welthen er im eigenen Sautsftande 230 lnung und Unterfalt auf Girund einer gejeshlidfen oder moralifajen Ilnterfitibungšnerbinolidy feit gewäljrt, oder hat der= felbe bie Bemirtjuaftung eines Dienjtandes jort= 3fitifren, fo findet fïr bie Dauer jeiner Mbtwejen= heit alts dem 20 ohnorte die Anrechnung nur infomeit itatt, als bas cibilbienfteinfommen und fieben 3egntel Der Rrieggbejoldung zufammen ben Betrag ton 3600 MRare jägrlich itberjteigen. Dienftwohnungen oder Miiethäentjüäbigungen werden hierbei ftets anm tarifmäßigen Betrane bes Wofnungsgelojuldulfes angerefinet. Die (5in=

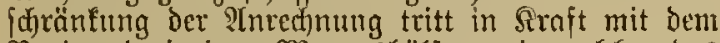
Beginn berienigen Monaterbälfte, mit weldjer bas Seriegsgehalt zahltar mird, jedodf nidjt bor Beginn Des Monats, in welchem Der slbgang aus dem W3ohnorte erfolgt, und endet mit dem Salulus des Monats, in meldem die Riudfehr in ben Wohnort fittfindet.

llnter framilienangeljörigen in Sinne des vor=

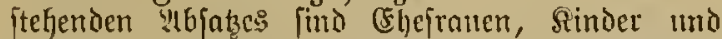
Seltern, fowie andere nalje Bermandte und Bflege= finder ju beritehen.

Beamten, weld)e als ohere Beamte ber Militär= bermaltung in immobilen Steflen Bermendung finden, wird die mit orei Zwanjigftel ader brei Behntel des Friedens= Maximalgelialt's zaglbare 3ulage nidft angerectinet.

4. Die Beptimmungen unter $\mathfrak{N}$. 2 und 3 finden atif penjionirte ode auf 23 artegeld itehende Reidfs= beante Ginfidgtlid igrer. Benfionen und $\mathfrak{\text { Bartegelder }}$ ?trwendung.

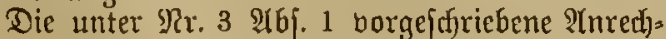
numg findet indefifen nur infotweit fatt, als fieben 3elintel Der §riegsbejoldung und Die ßenfion oder bas Wartegetb zujammen das bor ber \$emfiontrung oder Stellung auf Wartegeld bezogene Civildienfteintommen itberiteigen. Pluth die hiernach erfolgendo Pnrectinumg tritt fedod) in Den Füllen des $9(6=$ fazes 2 Der $\Re$ r. 3, pofern bas jrühere Cibildienjt= einfommen 3600 Mare ober weniger betragen bat, nur in dem dofelfit borgefehenen geritigeren $11 \mathrm{~m}=$ fange ein.

5. Den imentgeltlich oder zwor gegen (Entgelt, aber nur boritbergchend bejuäftigten Reich \$beamten foll

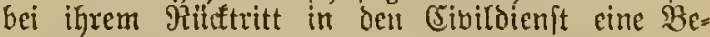
fchäftigung möglidjt gegen Entgelt gelvährt merden.

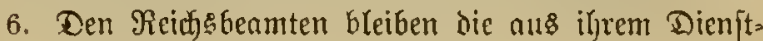

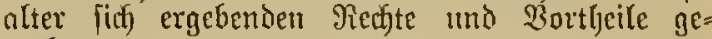
mahrt.

Den in $\mathfrak{B}$ orbereitumgsoienite befinorid)en Reidjs: feamten foll bie Beit bes friegsoienjtes mady be= ftambener Friifung bei \&ejtftellung ibes Dienft= alters zil gute gereefjnet merden.

Waar Die Bulafiung zur Fritjung bereits ber= fiigt, fo foll ihnen die zur Stblegumg der Ysriffung erforberliche ₹rift, fomeit die Militüruerbältniffe es gejtatter, berwilligt werben.

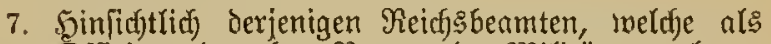
Sffiziere oder obete Beamte der Militärvertonltung in den Siregsoienft eingetreten find, ift der Cibil= belyörde bon Âtemegen mitzutheilen:

a) die Söhe dess Betrages, meldyen der Beamte als Sriegstojoldung eventl. Zullage bezicht;

b) der Beitpunft, von weldjem ab biefe Bezuige getwährt merden.

Fintretende $\mathfrak{A}$ enderungen, jotwie der Beilpunft, mit melujem bie $\mathfrak{B e z u ̈ g e ~ a u s ~ M i l i t a ̈ r f o n o s ~ a u j g e s ~}$ Gört haben, find gleidhfalls ber (Sivilbehörde mit= zutheilen.

Dieje Mittheilungen madjt derjenige Theil ics 5reeres, des Eanofturms oder ber Mifitärver = woltung, in defien Berpflegung bie oben erjuäfnten Ferfonen actreten find, iofern derfelbe eine eigene Salfenberwaltung hat, andernjalls die mit der $\mathscr{U} 11=$ weiftung ber Militärgebithrniffe befafiste Sntendontur.

Die Mittbeilung ift zu ridjten an die vorgejetste Beljörde berjenigen sajfe, roeldje iiber bns civil= dienjteintommen, die ßenfion oder bas Wartegel des Beamten Redinung 3il legen ljat.

Boritehende Mittheilungen find als Beläge zul den Das Civildienfteinfommen, die łienfion oder

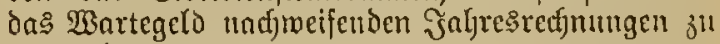
berwendert.

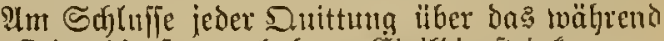
des Friegedienjtes erfyobelte Eivildienitemfommen hat ber Beante anzugeben, in tweld)er militärif(jen Dienftitellung er fid befindet und, went cr bi: Bejoloung eines Sffiziers oder oberen Beamten der Militärberwaltumg bezieht, auf roie had fir: feine Rriegşbejoldung beläuft.

Die Siaffe lyat, menn dieje Tingaben det Quittung fehlen oder mit deun Sulualte der geDadyten Mittheilungen Der Militärbehöròn niđjt übercinftimmen follten, ifrer borgejekten Befärdc ljerbon, nadf erfolgter 8 ahlung, $2\left(n_{j}\right.$ eige z̆l madjen.

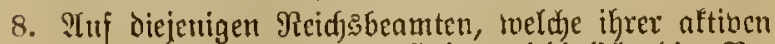
Dienjtpflicht geulïgen, findent leoiglia die $\mathfrak{B} \varepsilon=$ ftimmungen unter 6 , und zwar nur himfichtlict der: 
jenigen Beit Intwendung, während deren die Be= amten itber die Dauer ifrer gejetslidjen Friedens:

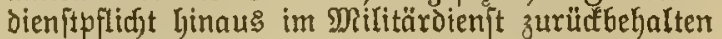
rorders.

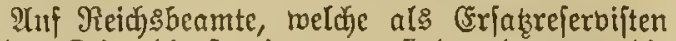
in Den Sriegsoienit eintreten, finden Dagegen die Bejtimmurgen tunter $\Re$ r. 1 bis 7 unbejudräntte TIntwerdoung.

\section{II.}

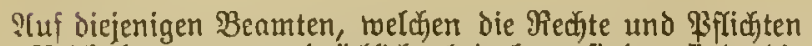
Der Reidssbeamten ausbrïtfich beigeleat find, find bie unter I getrofferen ofeftfeşungen gleidufalls anzutwenòn.

\section{III.}

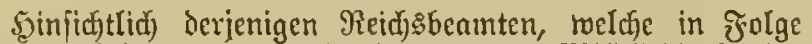
cince Mobilntadung in die Marine zum Militärbienft cin= berujem merden oder, foferm fie in ifrer cibilftellung $a b=$ fömnific) fino, freiwillig eintreten, finden bie oorftehenden Beftinumungen mit folgender Raß̧̧abe Tumendung:

a) Den fieben Befnteln Der ßriegsbefoldung ftehen in

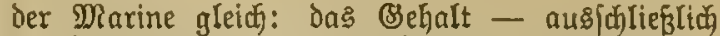
des barin liegenden Servištheiles -, der Bebalţ:

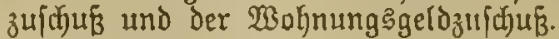

b) Someit Dem Beamten eine Sriegşzulage oder cine gleidjartige andermeite Zulage auts Marinefonds nid)t bereits gewährt wiro, erhält er aus jeiner Cibilkefoldung den Betrag der reglementomäß̈igen Shargentriegsizulage.

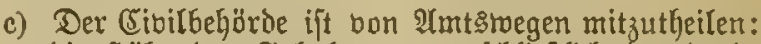

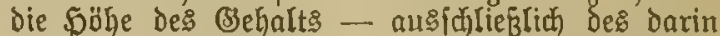

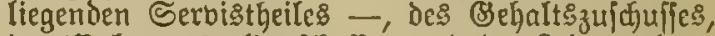

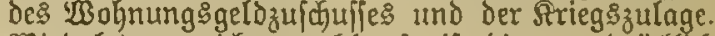

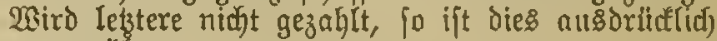
zu crtwähnen.

d) Die voritekeno unter c beregte Mhittheilung ift bei denjenigen Diarinetheilen, meldic einer Stations= oder Barnifontaffe angefalloffen find, feitens des Rechnumgsamts des betreffenden Marinetbeiles ju madjen.

\section{Gateuern und Aghgaben.}

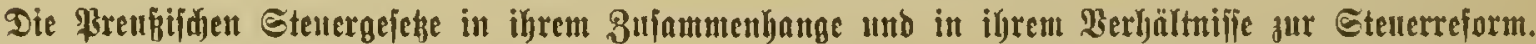

Die hter abgeoructen nicr Befeßpe:

Dos Einfommenjtcuergelep o. 24,6. 1891

Dos Erä̈rangefteuergeies v. 14. 7. 1893

Das Belek regen IIfhebung birelter Stantsftenern vom 14. 7. 1893 (अ.5. (5. 119 )

Das Fommunalabgabengeles v. 14. 7, 1893,

foroie bas bier ni $\mathbf{t}$ abgebrudte Befes:

Dns Bemerbefteurgefç D. 24,6.1891 (\$ङ. ङ. 205)

fithen im 3 ufammenhange und bilden zufammen die "Steuer= reform", meldie fdfon feit längerer Beit als nothrocndig anerlannt,

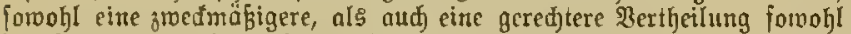
ber ftantlidem, als aud ber fommunalen श口gaben, und nantentlich Entlajtung ber "woirthjupaftlid Sdyronden" bejwette.

\&ebiglid biefen Broed periolat bas Gemerbeftentergeies nom 34. 6. 1891, weldes vernltete, mit ber neuerer wirthjuatlider Ent=

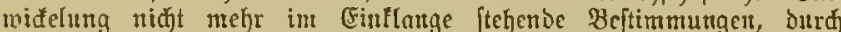
neuere, bett jegigen Berbältniffen angepajte Bejtimmungen erjebte, und bie fleineren Betriébe entlaftete, in ben bie gröberen geverbliđjen Betriebe füärfer herangezagen wurben, obthe ba $\bar{B}$ jebod ber Gefommertrag ber Gewerbefteuer erböht wurbe. (NB. Dic fonftigen $\mathfrak{B}$ eftimmungen bcs (Bewerbeftenergejebes liegen auferbalb

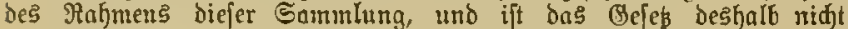
mit abgeorudt.)

Das (Eintomntenfteuergejes vom 24.6. 1891 verfalgte bagegen cinen mefrfachen Sivect. Bumädjit tourben veralfete Beftimmungen

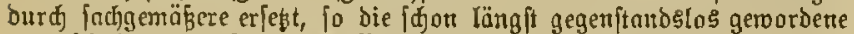
lluterfdeibung zroifhen "SIaffenjteuer" (bis 3000 Mf. (Finfommen) und "flaffificirter Cinlommenfteuer" (über 3000 Int. Cinfontunen) arf= gehoben, und beibe Gteuern ju einer cimigen, ber "Cinlonmenfteuer" perjømolzet. Dann wurde fomohl bie Stenerderanlagung als aud

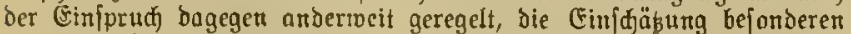
"Vorein[めäßungštommiffionen " uno "Beranlagungsfomuiffionen" übertragen, bie \$rüfung und Erledigung ber Cinfprüdje gegen bie

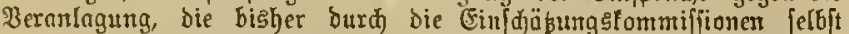
bezro. Durd) Begtrfslonmiffionet oder burd bie Reaierung erfolgte, rourben den Bermaltungsorgatten entragen, und bie Entfdeidung ïber Cinfprüde in erfter Эnftanz (Berufuna, $\$ 40$ ) den Berufungstom=

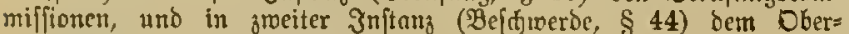
Dermaltungsgeridjt überwiefer.
Sobam ift aud in bem Cinfommentenergeles bos Prinip, Cuts laftung ber geringerett und ff̈ärferen Seranjiejung ber böheren Ein. fommen, burdigefïgrt toorden.

Mie ber Steucrtarif $(\$ 17)$ auझmeift, merbet bic Cittommen oon 100000 Mi. und barüber mif $4 \%$, foldje von 10000 Mi. ntit $3 \%$ befiteuert und fält ber Steuerfaş von da $a b$ з̆ ciucm Cinfommen von über 900 Ml. bls nuf $2 / 3 \%$ (6 Ml.), wäbrento Einfommett unter 900 Ml. gatt fteuerfrei fint.

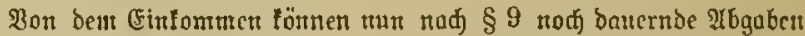

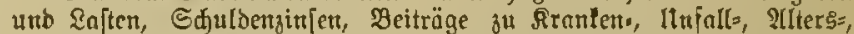
Jnoalibetr, MBitmen=, $\mathbb{B a}$ a

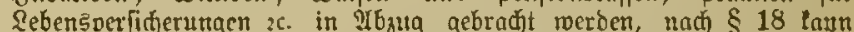
bei einem Eintommen von unter 3000 Mf:. für jebes framilienmitglieb unter 14 Johren von bem fteuerpflidtigen Einfonmen 50 Me. in

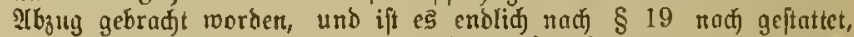
bei einen Einlommen von unter 9500 MRe. bejondere, bie Seiftungs =

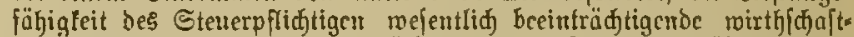
liche 2erbältniffe berart ̧u berüdfidtigen, dab cise Ermäßigung bis a brei Stufen gerwährt metoen laut.

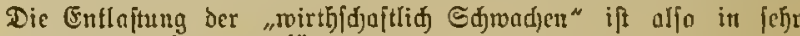
weitgejenber शुeife burdigeführt.

Endich follte aber and die reorganifirte Ginfommenftenter höhere Erfräge abmerfen, um, wenigitens theilmeife, bie Dlittel zu lieferm, andere Staafjiteuern (bie Srunds und (Gebäubefteuer) entbefrlid) madjen und ben Iommunalen হerbänden übermeifett zu tönnet.

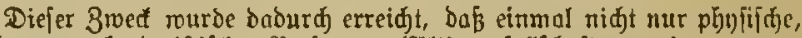
fondern aud juriftifde ßerfoner (Altiergefellfdafter, cingetragene Genofien[daften, forfumpercine 2e.) zur Steuer herangezogen murben,

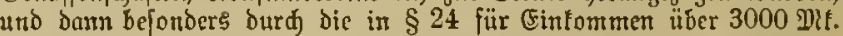
vorgefariebene obligatorifaje Eelbiteinfajäßung. Bei ber Cinfääpung Durd britte \$erionen warett naturgemäß bem Einldäbenden Diele Eintuhmert des Steuerpflidtigen entgangen (wie $\jmath^{\circ} \mathfrak{B}$. Binfen non

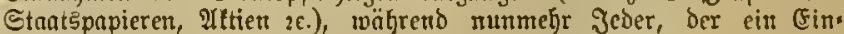

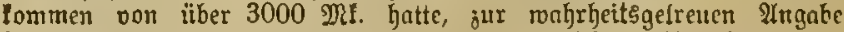
feines Cinfommens perpflidtef toar, und umriøtige IIngaben unter fitenge Strafe geftellt murben (\$ 66).

Das Cinfommenjteuergefes murbe (ebcnjo wie bas Bemerbefteur. gejes) vom Eastotage ber Mtonardile angenommen, am 24. Juni 1891

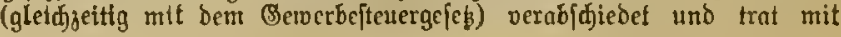


Beginn des Etatsjahres 1893/94 in Srajt. Die zur Erhöhung ber Erträguiffe getraffenen Minßregels batten Erfolg, es ergab

bis erfte Einfonmenjteueroeranlagung für $1892 / 93$ ein gejammtes Beranlagungs. foll von

124842848 DI.

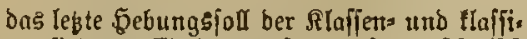
ftcirten Einfomment|tener für $1891 / 92$ Gatte betragen. . . . . . . .

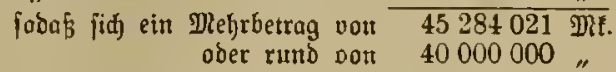

ergab, ber fur Reorganifation ber Rommunalbeftenerung verwendet werben lonte.

Die Sommunalbefteuerung hatte fid forou lange als gand be= jonbers reformbebüritig cruicjen.

Die Bebürtiffe ber Semeinben rutber bisher, abgejchen vott

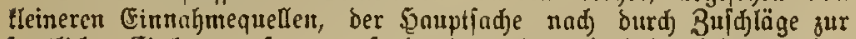
ftaatlidjen (Eintontmenfteuer aufgebradt, und wurbe baburd in mand)en

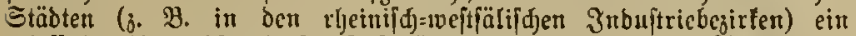
folofinales slnwadjen biefer Bujdjläge, ber fid bis ju $600 \%$ fteigerte und faft unerträglid tourbe, beivirft. Fs wurbe beshalb Seitents

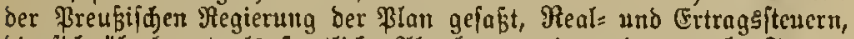
bie fich überhaupt als ftaatlidje Ibgaben weniger eignen, als Staats= ptenern зи bejeitigen, ut ben Bemeinden als Eimahmequellen zu* zumeifert.

(ङ) wurbe nut ein

\section{(5ejeb wegen Thfbebung direfter Etantsiteuern}

bem Randtage oorgelegt, ronad als Stantइfteuern auker \$ebung ge= fegt und ben Bemeinben überwiefen merben folter.

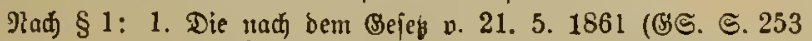
uno 317 ) veranlagte (Srutb= unb (Bebäubefteuer;

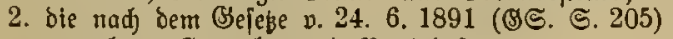
Deranlagte Bemerbe: und Betriebsfteuer;

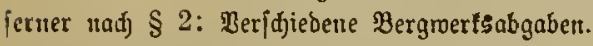

Der Staat vergidtete (anch Dem ßoramfdlage für 1892/93) ju (3)unften ber Gemeinden auf folgende Steuereimahnest:

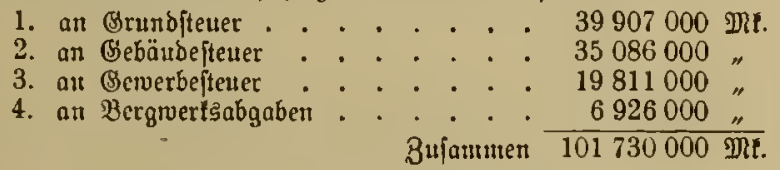

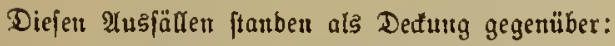

1. Dhebrertrag ber (Eintoumenfteuer (und)

40000 Or)0 $\mathfrak{D l t}$.

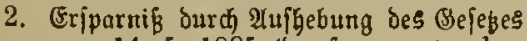
vom 14. 5. 1885 (der fogetranten lex Huene)

3. Erfparnif ठurd) Bejeitigung ber ben Bemeinden für Beranlagung unb Ers hebung von Staatsfteuern bisher Seitenక bes Staates gezahiten 刃ergütungen. .

3ufammen 66940000 IRt.

(55 blieb fottad) nod) eill \&eglbetrag von rutb 35000000 Dlt., auf weldjen ber Stant nidjt Derjidjten founte, gu beưen, und biefen syetrag ju ergänzen, ift ber finastzielle Broede bes "Ergänjungs: iteuergefebes.

Dieje brei Bejepe:

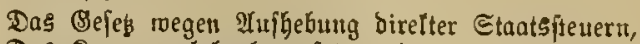

Das Rornmuntalabgabengefcs, und

Das Crgärzungsftetuergẹeß,

ftehen alfo in intgliem 3 nammenthange, afle orei fiub gleidjoitig bem Rambtage Dorgelegt, gleidjzeitig am 14. Juli 1893 Derabidjiebet, unb and gleidjzeitig mit bem 1. IXpril 1895 in iraft getreten.

Durch bie (Ergänzungsfitener folfte mun midjt nur ber freblbetrag in bent ftatlidjent Einnafmett ergängt rerben, fondern es follte auch eine (Ergängung in ber gered) ten Steuerdertheilung ftattfinden, injofern, als bus jogenantute "Funbirte" Einfommen gegeniiber bem "unfundirten",

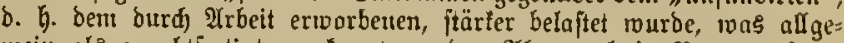
meitr als geredtiertigt atterfanut wurbe. श्रber aud in $\mathfrak{B}$ ezug auf bie ErgängungSfteuer ift ber Brunbjats "Shounng ber Schrodjen" burd)=

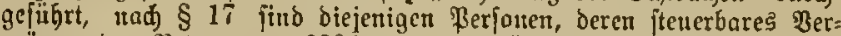
mügen bert Betrag von 6000 DIt. nidjt ïberfiteigt, unter allen um. ftänden fteuer[rei, ferner biejentigen ßerjonen, beten Bermögen nid)t mehr als 20000 Mf. beträgt, went ihr jottitiges, nad Magaabe bes Einfommenjtenergeickes zu bered)menocs (Einfonmen ben Betrag von

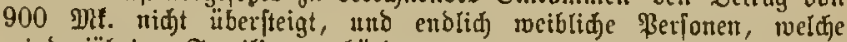
minderjährige familienangehörige gu unterhalten haben, vaterloje

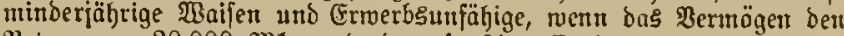
Betrag vor 20000 Mnt. und bas jonjtige Einfommen ben Detrag Don 1200 IRl. nidt überiteigen.

Wie bereits ermährt, follte bie fommunalbcfteuerung auf anderen, als ben bi弓ger geltenben \$rinjip ber Buị)läge ju ber Stant3einlommenjtener aufgebaut roerben, und geht bas fiomumuals abgabengeles beshalb, nachiem ben bemeinden bisher (taatlide Stenerqueller übervicjen firb, von bem Brumbgebanfen aus, bas ber \$ebarf an Gemeindeeintommen möglidft burd andere Finnahmen (bie in $\S \S 2,4$ bis 11 cc. angeführt finb) gebedt roirb, unb baß bie Bemeinben von ber Befugnif Steuern zu erheben, nur infomeit Be= braud maden bürfen, als bie fonftigen Eintahmen fur Defung ber

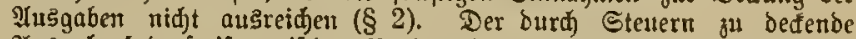

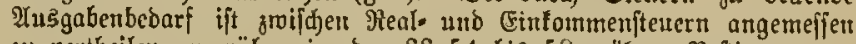
gu vertheilen, morïber in Den $\$ \$ 54$ bis 58 nähcre Beftimmungen getroffen find, bie von ben (Brundjaßs ausgehen, bab́ bie Realjteuern als fommunale Steucrquelfen möglidf auszubilben find. um bie

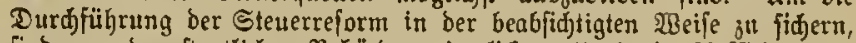

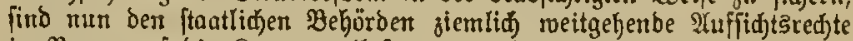
in $\mathfrak{B}_{\mathrm{e}}$ utg auf bie fommunalbefteuerung eingeräumt morben, worüber bie $\$ \S 77$ und 78 fith ausppredcr. So bedar Neueinfübrung ober Beränberung birelter ober inbirefter (Semeinbeftenern, Sbroeidung von ben ßertheilungstregeln zrifdjen Real= unb ßerjottalfteucri, fowic Bufdläge über ben vollen Eas ber cinfoumenfteuer hinans ber

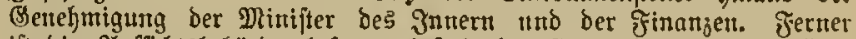
ift bie Afuffintsbehörbe befugt, beftehenbe Semeinbeoronungen über

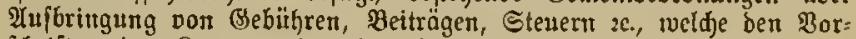
¡driften beక Rommunalabgabertgefebes jumiberlaufen, abänbern unb ergänzen zu lafjen.

Fiir Staats: und Reidsbeamte von bejonderem Intereffe ift ber $\S 41$ bes fommunalfteuergeipeses, worin ber Erlab eines befonderen

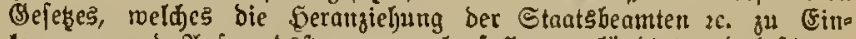

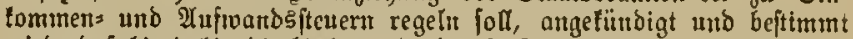

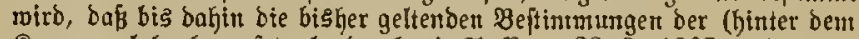
Rammunalabgabengefes abgedrudten) II. ‥ v. 23.9. 1867 reiter zur Inwentung fommen follen, soonad) bie Staatsbeamten (und nad)

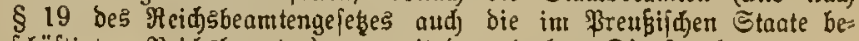

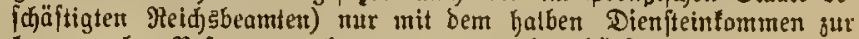
fommunalen Befteuerung heratigegogen werben büfen. 


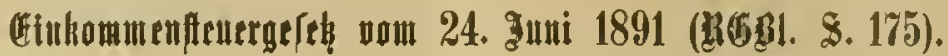

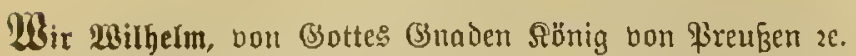
berorbnen mit Buftimmung beiber Säujer des \&and= tags Unferer Monardfie, für den Llmfang derfelben,

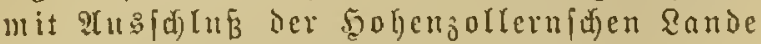

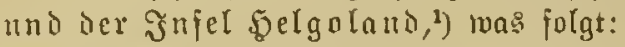

1) Demjelben Eingang babeu bie nadjplgent uod) abgebruften (Hejebe:

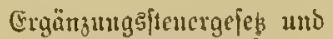

Rommutalabgabengcjeb.

methe alio, ebenio wie das Einfommenitencraejes, in bem Sobcn= jollernidjen Sanben und it Selgoland feine Seltung haben, was it ber Befonderhett bet bortigen Stetterverbältniffe feinten (Bruno hat.

\section{Gitencruflidjt.}

\section{Subjektive Steuerpflifit.}

$\S 1$. Cinfommenteucrpflicutig find:

1. die prenßiijacn Staatsangehörigen, mit 2(usnahme derjelligen,

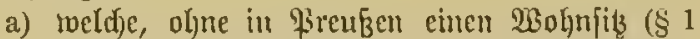

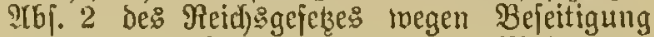
Der Doppelbeiteuerung vom 13. Mai 1870,

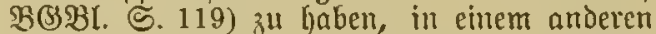
Bundesftate ober in einem beutichen Schuts gebiete mohuen oder fid auflualten;

b) weld)e neben einem Wobnfits in Breusen in einem anderen Bundesfitante oder in einem deutidjen Schutgebiete ihren bienftlidjen $\mathfrak{W o h n}$.

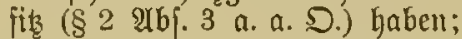

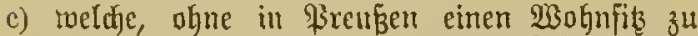

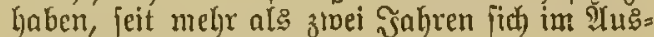
lande dauernd aufhalten.

ItIf Reich: Imo Stantsbeamte, beldhe im

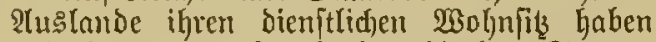
und dort zu entiprechenden direften Stants. fteuern nicht herangezogen toerden, findet bie Ausnahme unter c feine Yntwendung.

2. Diejenigen Ângeljörigen anderer B̧undęitanten,

a) ivelche, ohne in ighem Sgeimathgftaate einen Wohnfits zu haben, in Breufen wohnen oder, olje im Dentidjen Reidfe einen Wohnfits ơ Gaben, fid in \$reugen aujgalten;

b) roeldje in \$renßen ifren dienftlidjen 20 ognfitz (§ 2 Ibj. 3 a. a. D.) haben.

3. Diejenigen $\mathfrak{A} u$ länder, weldhe in \$reusen einen Wohnfib haben oder fid) Dajelgft des CErwerbes wegen oder länger ars ein Jahr aufbalten.

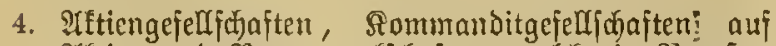
Iftien und Berggetwerfidiaften, weldbe in Freusen einen Sib haben, jotwic Dicjenigen eingetragetten

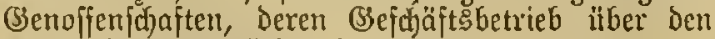
Siteis ifrer Mitglieder ljinausgeht.

5. Ronfumbereine mit offenem saden, fofern biefelben

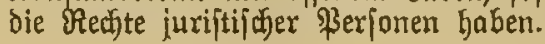

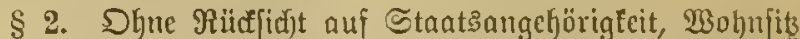

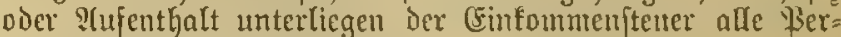
fonen mit dent Einfonmen

a) aus ben bon ber preufifiden Stantsfaffe gezalyten Befoldungen, \$enfionen und Wartegeldern;

b) ans preusifdem (Srundbefits mo aus preubijd)en (B) emerbe oder Syandelsantagen Dier fontiget ge= voerblic)en Betriebsftätten.

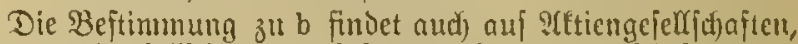
Rommanditaejelfichniten anf ?fftien, Berggemerfichajten mó bie im \$ 1 Nr. 4 und 5 bezetchneten cingetragenen Benofien= fd)aften Antuendung.

\$3. Bon Der Binfommenteuer fino befreit:

1. Die Mitglieder des tönigliden 5aufes und Des Бobenzollern[dien Jürftenljaujes;

2. Die Mitglieder des bormaligen hamnoverjuden Sönigshaujes, des vormaligen furbefiifden und bes vormaligen berzoglid) naffauifochen Jüurften. haujes;

3. Die bei bem Sraijer und アïnige beglaubigten $\mathfrak{B e r}=$ treter frember Märdte und die Bebollnächtigtell

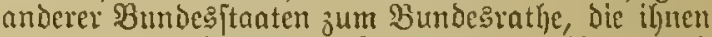
ăgewiefenen Beamten, fowic dic in ilyren und ifrer Beamten Dienften fteljenden \$erfonen, forweit fie $\mathfrak{A}$ u\&länder find;

4. biejentigen \$ierjonen, denen fonft nach bölferredit= lidfen (Sruntojäben ober nadf befonderen, mit anderen Staaten getroffenen Bereinbarmaen ein श्tiplud) auf. Befreiung bon der Cinfommenfteuer zufommt.

Die Bejreiungen zu 9 ir. 3 und 4 erftrefen fid) nidft anf bas nad) $\$ 2$ iteuerpfliditige Einfommen und bleiben in Denjenigen अ̈ällen ausgejchloffen, in weldben in den betrefien= Den Staaten (Segenjeitigfeit nid)t gewährt wirb.

\$ 4. Die \$äupter uno Mitglieder Der Fnnilien vor=

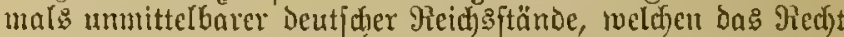
ber Befreing bon ordentlichen Berionaliteuern 3uftelyt, merben ju ber Einfommenftener von Dem Beitpunfte $a b$ herangezogen, in meldyem Surdh hejonderes Gejets Die Ent= jojädigung für bie aujuhebende Befreinng bon ber Ein= fommenfteuer geregelt fein twirb.

\section{Q) ljelitine \$teuterpflidit.}

\section{A. 2rilgeucine (ormubjälge.}

§ 5. Die Stenerpilidft beginnt mit einem Cinfommen von mel)r al: 900 MRf.

§ 6. Bon ber Befteuerung find ausgefdilofen:

1. Das cinfonmen aus den in anderen bentidjen Bundesftaaten oder in einem Deutfdyen Sdjutgebiete belegenen Brunditidfen, ben Dafelbit betriebenen Betwerben, fotwic aus Befoldungen, ßienfionen und Wartegelbern, weldbe Deutjche Mititärperjonen und Civilbeamte, fotwie deren Sinterbliebene aus ber Rafie eines anderen Bundesftaates bezichen (\$ 4

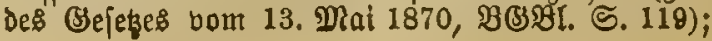


2. Das (Sinfommen ber uad) $\$ 1$ গx. 3 fteuer=

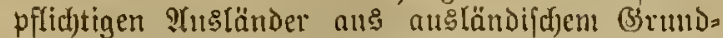
befis oder Benerbebetrieb, fofern diefelben nidjt des Ertwerbes wegen in \$ireuß̧en einen Wabnfits haben oder fid Dafelbft auflunlten;

3. Das Militäremfoumen ber Pierfonen Des llnter= offizier: 1111 S Semeinenftandes, folvie mälyend Dev Bugebörigfeit zu einem in ber Siriegsformation befindidjen Theile des 5ceres oder Det Marine dns Militäreinfommen aller ?tngeförigen bes aftiven \$eeres und Der aftiven Marine;

4. Der das perfönliube penfiansberedigende (Beljalt itherfteigende Theil des dienftlidjen Finfommens Derjenigen Staat: $=$ und Reichsbeamten mo Dffizicre,

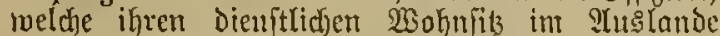
juben. Solern Diefelben in 2luslande zu cnts iprechenden direften Stantsitenerm Gerangerogen werben, bleibt aud Dos perföntidje penfion: bereftigende Sebalt frei;

5. Die auf (Srund gejeblidier Borfdrift den firiegs. invalioen gesvïhrten Fienfonserböhungen un Berftümmelungşzlngen, forvic die mit Sriegs: Deforationen berbundenen Ëhrenjolde.

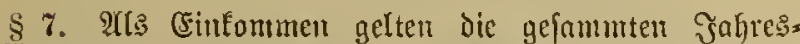
cinfinjte der Stcuerpftidjtigen in Gero und (Seldesmertl) aเtย :

1. Sapitalbezuögen,

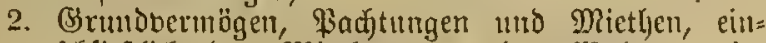

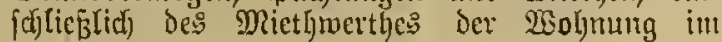
eigenen Sautie,

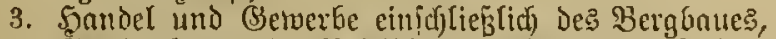

4. Setvinnturingender Bejdöîtigutg, fomie nus Redjten auf periodifde \$eburgen und Bortheile irgeno voeldier Irt, fotveit Dieje Cinfünjte nidjt fdoun unter Rr. 1 bis 3 Gegriffen find.

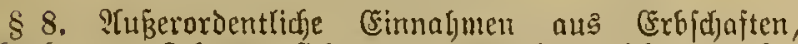
Schenfungen, Rebeninerficherungen, aus dem nid)t gewerbs:

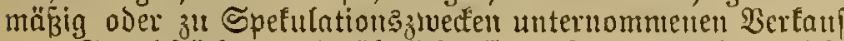
ban Sinndfitcfen und ägnlicfe (Frmerbungen gelten nicht als ftenerpflichtiges (5infommen, fondern als Dermeljung des Stanmbermägens und fommen ebenfo wie Beruntude: rungen Deפ Stammbermögenฐ แux infofern in Betracht, als bie (Erträge Des lesteren Daburd) bermefrt oder bermindert werden.

\section{§ 9. I. Bon Demt Cinfommen (\$ 7) find itr MLbjug zu} bringen:

1. Die зur Ertwerbung, Gidjetung und Ertjaltung bes

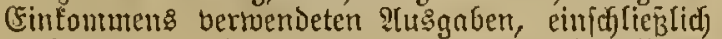
and) Der unter ben Sommunalabgaben begriffenen Deidjlaịten;

2. Die bout ben Stenerpfliditigen zu zalylenden Sdjuldenzinfer und Renten, folveit biejelben nicht auf Einnaljmequellen lyaften, weldje bei Der $\mathfrak{B e r}=$ anlagung auber Betrad)t zu Laffen fub (\$ 6 शr. 1 IIกס 2).

(Sritrent ficf Die Beftentung Lediglicf) auf Das iui \$2 bezeidurete Einfounten, fo fins nur bie

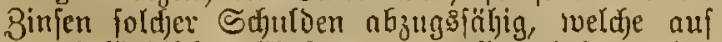
ben inländifd)en (Finfammen:quellen hajten oder fit: deren Ertwerb alligenomnten fint;

3. Die auf befonberen Red)tstiteln bershenden bauern= Den Raften;
4. die boll dem (Srundeigenthume, Dem RergGau und dem Bemerbebetriebe zul entridjenden direften Staatsfteuern, farwie foldje indirefte Ilbgaben, weldje zu Den Sefdöftsuntofiten zu rechuen find;

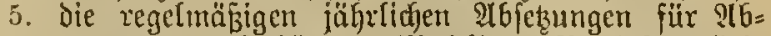
mubung bon (Gebäubet, Mafdimen, Betriebsgeräth= ichaften 2e., jolveit folche nicf)t bereits unter ben Betriebsausgaben berred) fuet find;

6. Die bou ben ङteuerpflichtigen gefeł: oder vertrags:

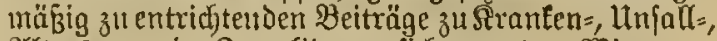

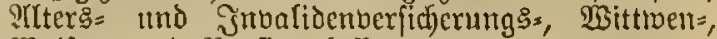
Waijer = uno Fenfionstajien;

7. Berficterumgsprämien, melche fitx Berfidjerung Des Steuerpfliditigen auf den Todes= ober ReGengfall gezahlt metden, jorweit diefelben den Betrag von 600 ME. jäbrlid) nidjt ilberjteigen.

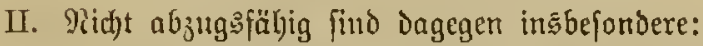

1. Bertwendungen zur Berbefjerung und Bermeljrung

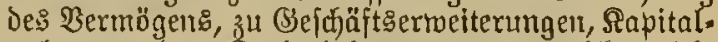
anlagen oocr Sapitalabtragungen, welde nidjt lebiglich als ourd) eine gute Wirthy(d)ajt gebotene

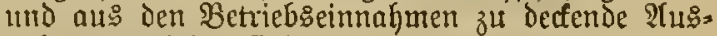
gaben nnzuleben find;

2. Die zur Bejtreitung Des Saushalts ber Steuer: plichtigen und zum linterhalte ihrer Argehörigen gemaditen 2 usgaben, einfoflieglid) des (Seldmerthes Der zu Diejen Zुwedfen berGraudften (Frjeugnifje uno 26 maten des eigenen lambruirtbidjaftlidjen ober ge. verbliden Betriebes.

\$ 10. Jeftftchende (Finnabmen find nad) ifrem Betrage fiu Das Steuerjafix, ifrem Betrage nad) unbeftimmte oder formantende (sinnabmen, jomie Das fteuerpfliditige (sins

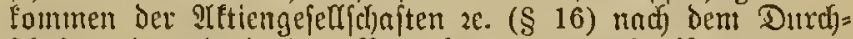
(df)nitte Dex Drei Der Beranlagumg unmittelbar boran. gegangenen Эaljre, jedod) bei der nach diejem (Sejebe

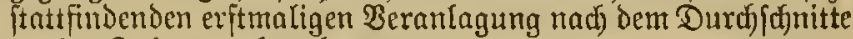
zoeier Saljre zu berechnen.

Wemn (Finnahmen der lestgebadften 2 rt nod) nidyt fo latige beitehen, fo find fie nad) Dem Durdjidnitte Des Beit=

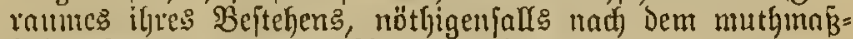

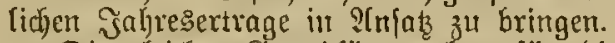

Die gleiden (Stundjätze gelten fïr die Bered)unng det

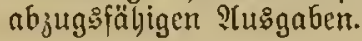

\$ 11. Befufs Der Steuerberanlagung ift Dem (Fin=

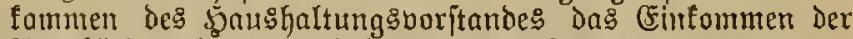
Ingebörigen der 5aushnltung ऊuzured)men.

Sierfonen, welde mit Geljalt oder Sohn zu Dienft. leiftungen angemommen find, forwie ßojtgäuger, lintermietljer uno (d)lajftellenmiether meroen nicht zu ben ?tngehörigen ciuer Sausgaltung gezälylt.

Selbftitündig zul beranlagen find:

1. Eljefrnuen, ment fie bauerno van bem Egemtane getrennt leben;

2. Sittoer und andere ?lugeförige der \$aushaltung, soent fie ein der Berfitgung des 5aubignltungs = boritande: nidyt unterliegendes Cinfonimen aus

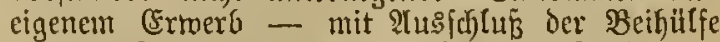
in dent (Siejchäft bes \$aushaltungsovoritandes oder aus anderen Duellen bezicben.

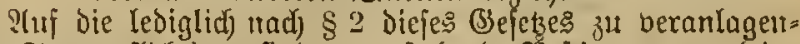
den Steuerpflicftigen finden vorftehende Beftimmungen teine Unmendung. 


\section{B. Bejonbere Bejtimmungen.}

a) Einfommen aus Rapitalvermögen.

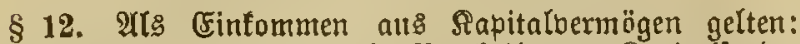
Binjen, Renten und geldmerthe $\mathfrak{B}$ ortheile aus Sapitalforde= rungen jeder $\mathfrak{A}$ rt, foweit joldje $\mathfrak{B}$ ezüge nicht bei $\mathfrak{E} a n d=$ wirthjefaften, Sandel und Semerbetreibenden behuj: 24:s: mittelung Des fteuterpflichtigen (Finfommens aus (Brund= vermögen, \$ad)tumgen, Sandel Doer Semerbe (\$§ 13, 14), als Theife bes (Seichät'sertrages in Red)nung zu bringen jind.

Mit biefer Maß̧gabe gelten als cinfommen aus Rapital= bermögen insbejondere:

a) Zinfen aus «nleihen und fonftigen verzinstidhen Stapitalforderungen jomie aus verzinslich gemorde=

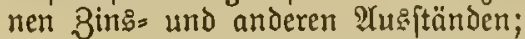

b) Dibidenden und Binjen, 2usbeuten und jonjtige (seminnantheile von 2ftiengejelfichajten, Sommandit= Bejellichaften auf IIftien, (semerficjaften, (Ermerb: = und Wirthjchafisgendifen;djaften und bon einer

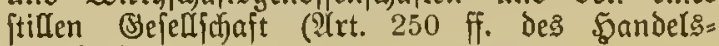
вejeछburis);

c) Sinfen, weldye in berzinslid)en Rapitalforderungen, bei Dener ein höheres als das uriprünglidf ge= gebene Sapital zurüufgemäbrt wiro, eimbegriffen find;

d) bereinnahmte Beminne aus der zu Spefulationss zroeden unternommenen $\mathfrak{B e r a ̈ u f e r u n g ~ v o n ~} \mathfrak{W e r t h}=$ papieren, Forberungen, Rentell 2e., abzüglid etwaiger Berlufte bei Derartigen (Bejd)äfen.

b) (Einfommen aus (Sirumbermögen.

§ 13. Das CFinfommen aแร Grumbbermögen umfäst die Erträge jämmtlidjer Grunditücfe, meldhe bem Steuer= pflidftigen eigenthümlid, gehören oder aus benen igm in Эolge bon Berechtigungen irgento tweld)er 2 trt ein (Finfonmen zufliebt.

Bon (Brumbftuten, weldje berpactitet ader vermiethet find,

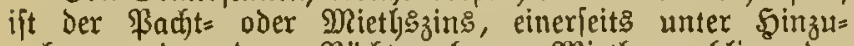

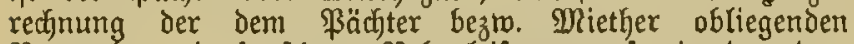
Natural= und fonftigen Rebenleiftungen forvie ber bem Berpäd)ter bezro. Bermiether borbehaltenen Nukzungen, andererfeits unter Xrbechnung Der dem \&ez̧teren verbliebenen abzugsiähigen \&aften als çinfommen zu berechnen.

Jैür nicht bermiethete, jondern bou dem (Eigenthümer bezw. Nuksnieber felbit bewohnte oder fonft benutzte Be= bäude ift das (sinfontmen nadf) dem Miethsinerthe zu

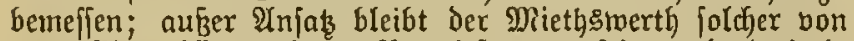

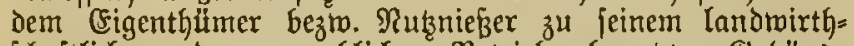
(d)ajtlichen oder gewerblichen Betriebe benutzten Bebäude

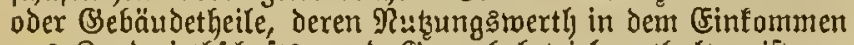
aus \&anomirthidjafts: und Bsemerbebetrieb enthalten ift.

Bei Sefäbsung des (Finfommens aus nidjt berpachteten Befitzungen ift ber burch die eigene Berwirtbichaftung erzielte Reinertrag zu Srumbe zu Iegen. Die Berantagung folcher Betriebe, bei meldjen bie Erträgniffe der Subjtam bes Bodenః entnommen merden, forvie die Seranlagung länd,

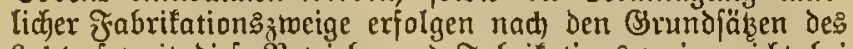
\$ 14, foreit Dieje Betriebe uno ₹abrifationgztweige nidyt bei ber Ertragsermittelung des \$nauptbetriebes, zu meldem fie gehören, berücfficfitigt twerden.

Der Serwin beim padjtwcijen Retriebe Der Sandwirth= idfaft ift in gleidjer $\mathfrak{B e i f e}$ zu "ramislagen, wie beim $\mathfrak{B e}$. triebe auf eigenen Brundjtïden, unter ફinzurechnung des Miethsmerths Der mitberpachteten Bohnung.

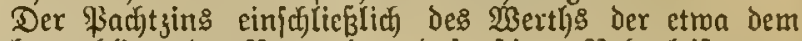
ßäctster obliegenden Ratural = und fonftiger Rebenleiftungen ift babon in 2 fozlig zu bringen.

c) Finfommen aus şandel und Bemerbe ein =

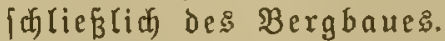

\$ 14. Das Finfommen aus 5ुandel und Semerbe ein (d) fieşlid bes Bergbaues befteht in dem in Bemäßheit der

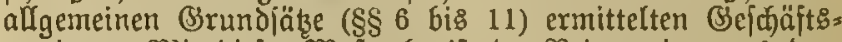

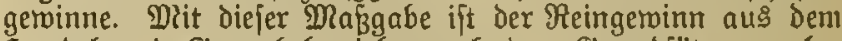
Sandel und Semerbebetriebe nach Den Srumbjäben zu be. rectinen, wic foldfe für die Inventur und Bilamz durch Das

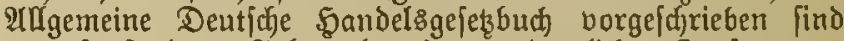
uno fonft bem Sefrauche eines ordentlichen Seaufmannes

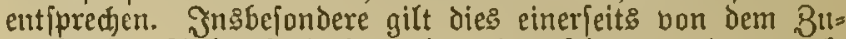
madis des Inlagefapitals und andererfeits bon ben regel=

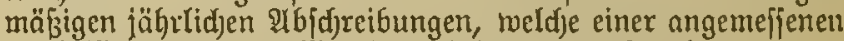
Berüfffidjtigung ber $\mathfrak{B e r t l y p e r m i n d e r u m g ~ e n t i p r e c h e n . ~}$

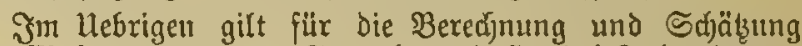
des (Finfommmens aus (Semerbe und Sूandel Falgendes:

1. Die Zinjen des in \$andet $=$ oder (5erverbebetrieb angelegten eigenen Sapitals des Steuerpflichtigen

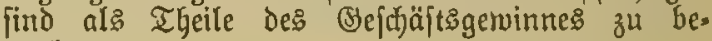
trad)ten.

2. Der bon einer nicht nach $\S 1$ Nr. 4 und 5 iteuer= pflidjtigen (Frmerbsgejelfidjajt erzielte (Sejd)äfts: gerwimn ift den einzelnen Theilfabern nack) Mafs= gabe iffres Antheils anzurectinen.

3. Der Setwinn aus den zu Spefulationszzecfen abgejofloffenen Bejejäjten, abzüglid) etroaiger $\mathfrak{B e r}=$ lufte bei berartigen (Sejejäften, uni aus der $\mathfrak{B}_{\ell}=$ theiligung an berartigen (Sejejäften, ift aud bei foldfen Steuerpflidftigen, meldfe nidjt zu ben Syandel = und Bemerbetreibenden gebören, nad) den für Das Einfommen aus Shandel und Biemerbe maß̧gebenden Srundjäkzen zu berectjent.

d) Cinfommen aus (seminn bringender Befdüftigung und aus Rechten auf periodifde 5ebungen ze.

§ 15. Das Finfommen aus SSetwinn bringender $\mathfrak{B e}$

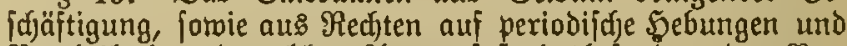
Bortheile irgend meldjer ârt umfaßst insbefondere den $\mathfrak{B e r}$ bienft der Alrbeiter, Dienftboten und Bemerbegehülfen, die Befoldung bon $\mathfrak{D}$ ilitärperjonen und Beamten jeder $\mathfrak{A}$ rt, ferner Den seminn aus idhriftftelferifder, fünitlerifher,

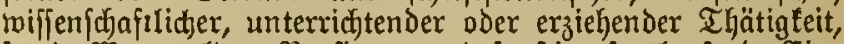
fowie $\mathfrak{B a r t e g e l d e r , ~ B e n f i o n e n ~ u n d ~ f o n f t i g e ~ f o r t l a u f e n d e ~ G i n . ~}$ nahmen, melde nicht als Jahresrenten eines bemeglidyen oder unbermeglidjen ছermögens anzujehen find, enulidj joldhe Rentenbezüge, tweldje an bie Berjon bes (Empfangsbered)= tigtell gefnitpft find.

Das (Finfomuten aus Dienftroljnungen ift nach bem ortşüblichen Diethsmerthe, jedodj nicht höher als mit fünf= zeln von Sundert des baaren Sehaltes bes Berechtigten in $\mathfrak{A}$ njats 3 bringen. Sorweit Dienjtwohnungen bermiethet find, ift ber Miethకిzins nach Maßgabe ber Beftimmung im $\S 13$ थbi. 2 arzurecinen.

Bei MRititärperjonen, ReicjEbeamten, unmittelbaren und mittelbaren Staatobeamten, (B)eiftliden und Eehrern an 
Bffentlifjen Unterrichtsanitalten ift Der zur Beitreitung Des Dienftaufrondes bejtimmte $\mathfrak{I}$ heil des Dieniteintommens aufier :Injał zu laffen.

e) Cinfommen der Iftiengeferlidaften ze.

$\S$ 16. 2โร [teuerpflidttiges Einfommen ber im $\S 1$ Rr. 4 itnd 5 bezeidneten Steuerpfliditigen gelten unbejd)adet

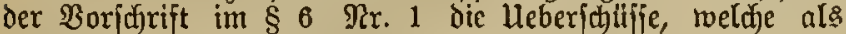
Iftienzinjen poer Dividenden, gleid)viel unter melder $\mathfrak{B} e=$ nennung, unter die Mitglieber bertheilt und ztwar

unter Sinzurectinung ber zur Tilgung Der Sdibldon oder des (Srundfapitals, zur Berbefferung oder Bes

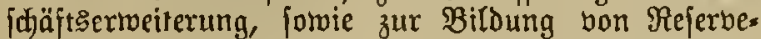
fonds - jorveit joldje nidjt bei den $\mathfrak{B e r f i d j e r u n g s : ~}$

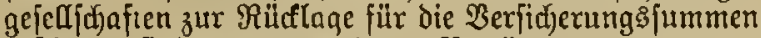
bejtimmt find - bern ndeten Beträge,

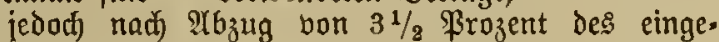
zahlten Iftientapitals. In Stelle des Yekteren tritt bei eingetragenen Benoffenjidaften bie Summe der eingezahlten Befdüflsamtheile der Mitglicder, bei Berggenverfidjaften bas aus dem Erwerbispreife tmo den Siojten der Unlage und cimridatung bezro. (5r= meiterung des Bergwerts fich ju|ammenfekende Srund = tapital ober, folmeit diefe Solten vor dem 1. Ipril 1892 aufgerwendet find, nad) zmanzigfardje Betrag der im Durdujidjnitt der leţten vier Jahre bor bem Sntrafttreten diefes Bejetzes ver. theilten 2 usbeute.

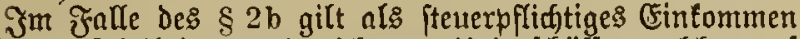
derienige Theil der vorbezeidjneten lueberjafilife, meldfer auf den (Seichäftabetrieb in ßretlßen bezm. auf das Cintommen

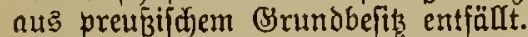

Der Rommunalbejteuerung ift bos ermittelte Cinfommen ogne den शtbzug bon $3 \frac{1}{2}$ Brozent zu Brunde zu Yegen.

\section{Gitewerrätze. \\ 1. Steutertarif.}

$\S 17$. Die (Einfommenfteuer beträgt jährlid bei einem Eintommen:

\begin{tabular}{|c|c|c|}
\hline $\begin{array}{l}\text { oon mehr als } \\
\text { Mif. }\end{array}$ & $\begin{array}{l}\text { bis einjhließlid) } \\
\text { Mft. }\end{array}$ & $\mathfrak{M E}$. \\
\hline 900 & 1050 & 6 \\
\hline 1050 & 1200 & 9 \\
\hline 1200 & 1350 & 12 \\
\hline 1350 & i 500 & 16 \\
\hline 1500 & 1650 & 21 \\
\hline 1650 & 1800 & 26 \\
\hline 1800 & 2100 & 31 \\
\hline 2100 & 2400 & 36 \\
\hline 2400 & 2700 & 44 \\
\hline 2700 & 3000 & 52 \\
\hline 3000 & 3300 & 60 \\
\hline 3300 & 3600 & 70 \\
\hline 3600 & 3900 & 80 \\
\hline 3300 & 4200 & 92 \\
\hline 4200 & 4500 & 104 \\
\hline 4500 & 5000 & 118 \\
\hline 5000 & 5500 & 132 \\
\hline 5500 & 6000 & 146 \\
\hline 6000 & 6500 & 160 \\
\hline 6500 & 7000 & 176 \\
\hline 7000 & 7500 & 192 \\
\hline 7500 & 8000 & 212 \\
\hline 8000 & 8500 & 232 \\
\hline 8500 & 9000 & 252 \\
\hline 9000 & 9500 & 276 \\
\hline 9500 & 10500 & 300 \\
\hline
\end{tabular}

Sie jteigt bei höberem Einfommen

$\begin{array}{cccc}\text { von mehr als } & \text { bis einjal. } & \text { in Stufen von } & \text { um je } \\ \text { Mll. } & \text { MRl. } & \text { MR. } & \text { MRl. } \\ 10500 & 30500 & 1000 & 30 \\ 30500 & 32000 & 1500 & 60 \\ 32000 & 78000 & 2000 & 80 \\ 78000 & 100000 & 2000 & 100\end{array}$

Bei (Einfommen bon mehr als 100000 Mart bis eins (d) fiéflid) 105000 Marf beträgt die Steuer 4000 Marf und fteigt bei böheren (Finfommen in کtufen bon 5000 Mart unt je 200 Mart.

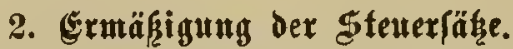

$\S 18$. Für jedes, nidjt nad) $\S 11$ felbitftändig zu vers anlagende Familienmitglied unter 14 Эngren wird von dem fteuerpflichtigen Fintommen des 5aushaltungsboritandes, jofern daffelbe den Betrog bon 3000 Marf nid)t überfteigt, der Betrag von 50 Mart in $\mathfrak{A b}_{3} u g$ gebrad)t, mit ber $\mathfrak{M a k}=$ gabe, da $\sqrt{3}$ bei $\mathfrak{B}$ orhandenfein von brei oder mehr familien=

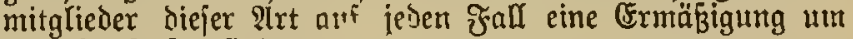
pine Stuje itattindet.

§ 19. Bei der $\mathfrak{B}$ เranlagung ift $\mathfrak{c}$ ge gerattet, bejondere,

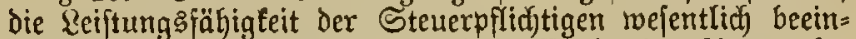

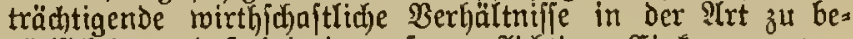
rürfiditigen, daß̧ bei einem iteuexpflidtigen Eintommen von nid)t mehr als 9500 Mart eine Ermäkigung Der im $\S 17$ vorgejdjriebenen Steuerjäzse um hödjitens 3 Stujen ges währt wiro.

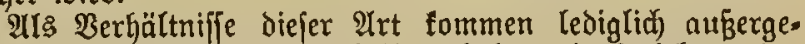
röhnlidxe Belajtungen burch Unterhalt und Erziehung ber Sinder, Berpflichtung zun Unterhalte mittellojer İngehöriger, andouernde Sirnnfheit, Berjajuldung und bejondere lunglïfs: fälle in Betradft.

\section{Zilexanlaguttg.}

\section{O)rf dex \$eranlagutug.}

\$20. Die Beranlagung exfolgt in Der Regel an Dem Srte, wo Der Steuerpflidtige zur Beit der Alufnahme des \$erjonenjtande: $(\S 21)$ jeinen $\mathfrak{W}$ ohnjits oder in Ermangelung eines fold)en feinen aluenthalt hat.

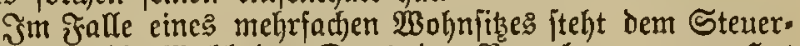

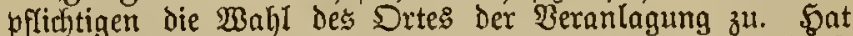
ex: bon biejem Wahtrecht Eeinen (Bebrauch gemadht, und ift die Beranlagung an mefreren Drten exfolgt, fo gilt nutr die Beranlagung an bemjenigen Drte, an weldjetn bie Cin= jidjäłzıng zu dem hödj)iten Steuterbetrage ftattge [unden hat.

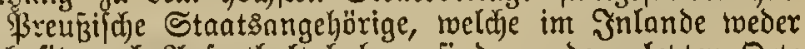
Wohnfits nod Sufenthalt haben, find an dem leegten Sorte

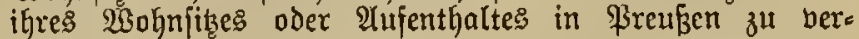
anlagen.

Die Beranlagung dex im $\S 1$ গ $x$. 4 und 5 bezeidnneten Bejellidjaften und (Senofferifhaften exjolgt an Dem Orte, wo diejelben in Breuben ifren Sits haben.

Die Beranlagung Der int $\S 2$ bezeidfineten Steuter. pflidftigen gefdieht an dem Srte, too der Sirundbefits bezm. bie getwerblidbe oder Sandelsanlage oder bie Betriebsftätte liegt, oder ber bei der Stellerberwaltung etwa beftellte $\mathfrak{B e r}$.

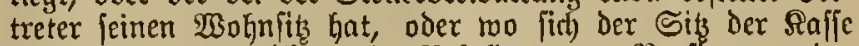
befindet, bon weldjer die Befoldungen, Benfionen oder wartegelder ausigezahlt merden. 
Die bezüglid des Beranlagungsortes weiter erforder= lidjen etnordmungen exläßt der ङinanzminifter.

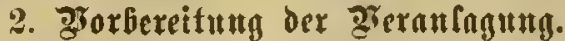

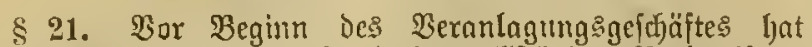

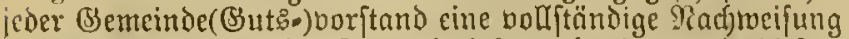
afler in dem Semcinde=(S)ut:s:) bezirfe borljandenen, in biefem (Bejek als fteuerpflidtig bezeidjneten \$erfonen, Beferfichaften und (Sienofienfifaften, folmie ter nach \& 2 die Steuerpflidft bedingenden Grundbefikungen uno gemerbficfen llnter= neljmingen aufzunehmen.

\$ 22. Seder Bejitzer eines betnolynten (B)rundftind? oder ieffen $\mathfrak{B}$ ertreter ift berpflidftet, der mit ber ?tufnahme des Herjonenftandes betrauten Belyörbe die auf dem Sinndo ftiide borhandenen ßerfonen mit Ramen, Bernfs: oder Ertwerbsart anzugeben.

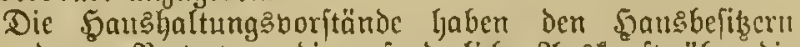

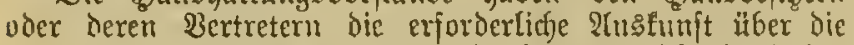
zu ifrem 5ausftande geljörigen \$erjonen einjodlieflidj Der linters und Sallaffellenmiether z" crtheilen.

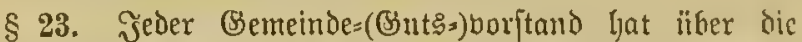
Befis=, Bermögens= =nd fonfigen (Einfommensoberbältniffe Der Steuerpflidtigen des Semeinde.(Buts=) bejutes, fotwic iiber etıaige bejondere, dic Reijtungsfähigfeit berfelben be= dingende wirthjchaftliche Ẻerbältnifie $(\S \S 18,19)$ möglichjt

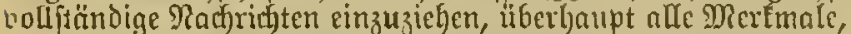
melche ein ltrtheil über bie Beftenerung z" begründen ber: mögen, zu fammeln.

Tuf (3rund Der bon ifm angeftellten Crmittelungen hat

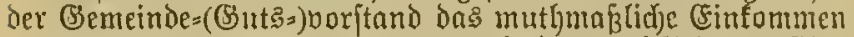
der Steuerpflidtigen, getrennt nach den berfafiedenen (Fin= nafmequelten $(\S 7)$, in eine (Einfommensnadjweifung einzus tragen.

Dic auf ben Bemeinde=(B)uts=)borftand felbjt bezüglidjen Eintragungen find bon den jeitens der Regierungen ljerfï Geftimmten Perfonen zu betwirfen.

\section{Steuererklärnngen.}

\$24. Şeocr bereits mit cinem (Finfommen bon mehr ats 3000 Mart zur Einfommenfteuer beranlagte Stenter pflicjtige ift auf bie jäfrlid duref offentlicke Befnnmtmacjumg exgeljerde :Hufforderung zur Abgabe ciner Steucrerflärung berpflicjtet. Rektere ift innerhalb Der allf mindefteng

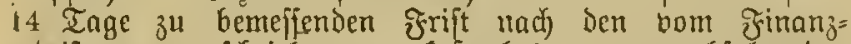
minifter borgefdriebenen, fojtenlos zu berabfolgenden Formularen bei Dem Sorfizenden der Vieranlagungs: fommiffion (\$ 34) fefriftlicf) oder 3l \$3rotofoll, unter Der Berficherung abzugeben, baßs bie s(ngaben nact) bejtem $23 i f f e n$ und Berviffen gemadjt find.

Aftiengefellidaften, Sommanditgefellidaften ouf 2iftien, 'Berggemertidjaften und eingetragene (senofienjdfaften fino

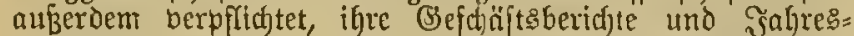

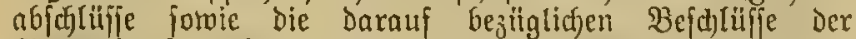
(B)eneralberjammlungen nack den nảberen Beftimmungen deş Jinanzminifters aljälytich bem Borfizenden ber $\mathfrak{B e r}=$ anlagıngsfommiffion einzureichen.

\$ 25. 2ndere Stenerpflidtige find jur ?tbgabe einer Steuererflärung berpflichtet, fobalo cine befondere ?tup. forderung deకి Borjizenden der Beranlagungstommiffion $(\$ \$ 34,35)$ an fie ergeht. Sie find, falls \&ebsteres nicht

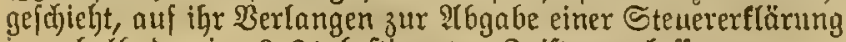
imnerfjalh ber im \$ 24 beftimmten frift zuzulaffen.
§ 26. 1. J̄n Der Steutererflärung ift der Befammt= betrag des Cinfommens (\$ 10) getrennt nad) den im $\S 7$ vorgejehenen Einfommensquellen nnzugeben.

2. Das Einfommen vort Dem aurierhath bes $\mathfrak{B e r}=$ anlagungsbezirfes belegenen Brunbbeitze oder Bemerber betriebe ift befonders nufanfiitien.

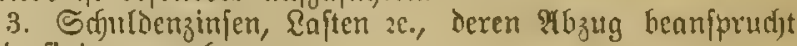
twitt, find anzugeben.

\$ 27. Dem Stenerpflidtigen foln auf feinen :Intrag, jomeit es fid) $1 \mathrm{~m}$ nur Durd Sdjäłzung zu ermittelndes Einfommen handelt, geptattet trerden, in die Stener= erflärung ftatt ber ziffermäfigen 2 ingntic des Cinfommen biejenigen ఇadjmeifungen aufjunehmen, deren die $\mathfrak{B e r}=$ anlagungstommiffion zur Sdfritzung deffelben bedarf.

\$28. Die Aufforderungen jur ?tfgabe der Stener: erftärungen müffen Den ફ̧intociă auf die im $\& 30$ ange= broljten Mrectsmadytheile, formic auf die Strnfheftimmungen bes $\$ 66$ enthalten.

§ 29. Die Steucrertlärungen find fïr \$ierfonen, Iveld $)$

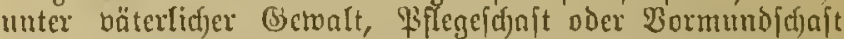
ftehen, fomic für dic im \& 1 9ir. 4 mnd 5 bezeidjeten Steuerpflidjtigen bon beren Gertretern, fiir Efyefrauen, fofern fie nidjt felGifftändig veranlagt find, bon beren Ehemännern n๒з $u$ ge

Fith Ferfonen, reldje afiwefend oder fonft berljindert fino, die Steucrerflörungen felb ft abzugeben, Eümen fold)e burch Bebolfmäclytigte erfolgen.

Die Crfüßung Der Stenererftärungępflid\}t feitens einę bon melyreren Bertretern Gejreit die ubrigen Berpflidfeten von iI)rer BerbindIidjét.

§ 30. Wecr die ifjm obfiegende ङtcuererflärnng nicht inmerbalb ber borgejaricbenen frift abgiebt, berliert die

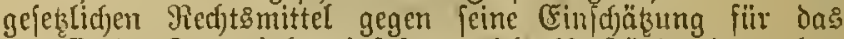
betreffende Steuerjahr, imfofern nidft limptände bargethan werden, weldje die Ser\{äummis ent\{d)uldbar madjen.

Wer bie Stcuerertlärung, zu Dercn (Fimreidjung $\mathrm{er}$ ge= fekslidf) berpflicjtet ift, nidjt längftens immerljalb 4 23ocjen nad) einer nodfualigen an ign zu ridjenden befonderen Stufforberung, welde autf nach gejejehener Berantagung ergeben fann, abgiebt, hat neben ber beranlagten Stener einen Bufdrlag von 25 Brozent zu derfelben zu zablen mo aujzerdem die burd feine llnterfaffung dem Staate ent= zogene Stenter zu entridjten.

Dic Jefffetung Des mit Der veranlagten Stener $311 \mathrm{ent}=$ ridftenden Buld)lages bon 25 \$rojent ftelyt Der Regierumg

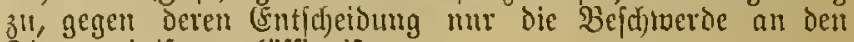
Jinamzminifter zutä́fíg ift.

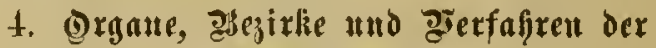

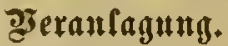

§ 31. Der $\mathfrak{B e r a n l a g u n g ~ d e r ~ S t e u t e r p f l i c h t i g e n ~ g e l j t ~ c i n e ~}$

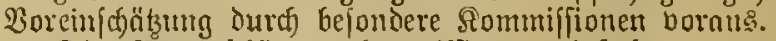

Die Boremfchäţungstommififionen hefrehen aแs dem (s)emeintevorfande als Borfitzenden und aus einer von der Regicrung zu beftimmenden 2(nzagf bon Mitgliebern, iveldfe

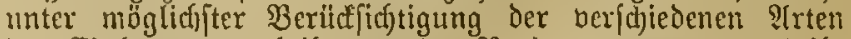
Des Einfummens theils vou ber Regienung ernannt, theils bon der Bemeindeberfammlung beztw. Bemeindebcrtretung getwäljlt verber. Dic Zahl der ernaunten Mitglieder ein=

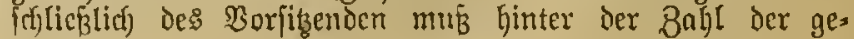


mälyten Mitglieder zurürffleiben. Die Regierung fann bon ber Ermennung bon Mitgliebern abjehen.

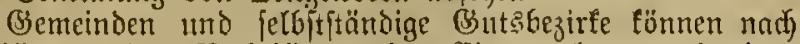
Shlförung der Betheiligter in (5inbernelynen mit dem

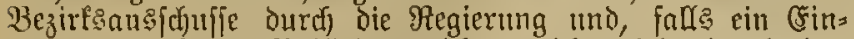

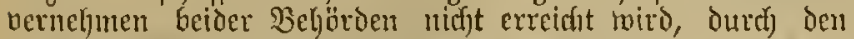
Sberpräfidenten mit benarfbarten Bemeinden zu einem Soreinfichäbung be jirfe bereinigt werden.

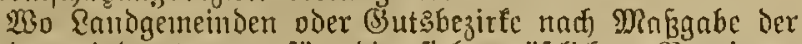

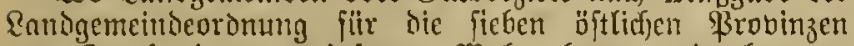
jum Brvede der gemeinfamen 2 aljruebmung einzeluer $3^{11}$ ilyrem Wirtungstreife geböriger Sommmalangelegenljeiten jth Gefonderen Berbänden bereinigt fitto ober bereinigt

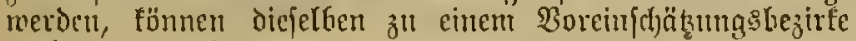
berbution berten.

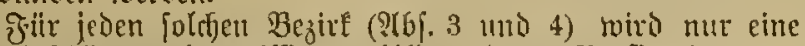

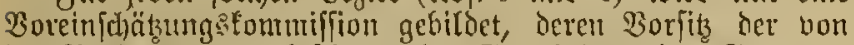
Der Regierimg zu beftimmende (Senteinde= oder Bintsbor=

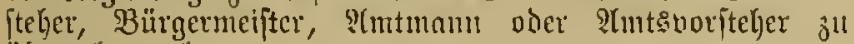
itbernetymen gat.

Die $8 \mathfrak{a l l}$ ber ju mählenden Ditglieder einer foldjen Boreinferjäkungstommiffion wirs nuf bie einjelnen (Ge=

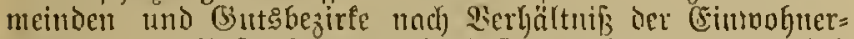

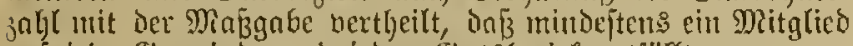
nuf jede Bemeinde und jeden Gutsbezirf entfält.

Sitr Biutsbezirfe treten die Boriteber hezı. Deten Stell= bertecter oder dic boul ilutu zul ertuentenden Eimmohner des

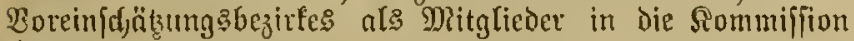
cin.

\$32. Dic Borcinfdhäkungsfommiffion unternirft dic

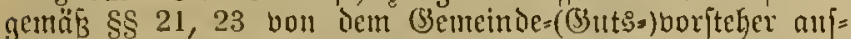
geftellten Rad)meifungen einer genauen \$ribfung und trägt bie fïr die cimselnen Steuerpflichtigen ermittelten Erin= fommengbeträge bis zll 3000 Mart, fomie die bor ifgr für

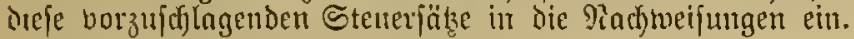

§ 33. Behufg Beranlagung Der Stenerpflictigen bildet jeder Sereis einen Beranlagungshejirf. Der Regierung jteht die $\mathfrak{B}$ ejugnif̧ zu, innerfalb deffelben Rreijes die Bildung mefyrerer $\mathfrak{B}$ eranlángungsbezirfe alıuordnen.

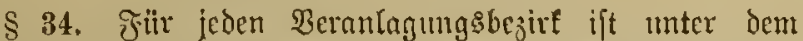
Borfiţe des Ramorathe oder eutes bon Der Regierung zu ernennenden Romntiffars cine Veranlagungstonmiffion $z^{4}$ Gilden, Deren Mitglieder theil: bon Der Megierung ernannt, theils bon Der 尺reisbertretung und in Den Stadtfreifen bon der Bemeindebertretung all $\mathbf{B}$ den Einwohnern des $\mathfrak{B e r}=$ anlagungsbezirf? unter möglicfjter Berücfficftigung Der bers jejiedenen 2hrten des Esinfomments anf die Daner bon fech: Jafren getwähtt werden.

Die Bagl Der ermannten mo der getwäglten Mitalieder

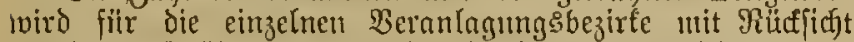

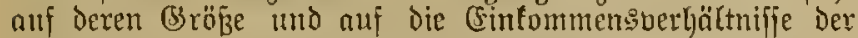

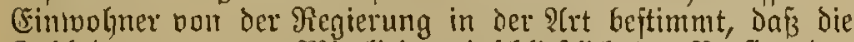

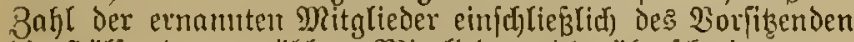

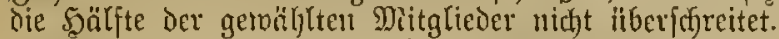

श्tle drei Jahre fefeidet je die Scäljte der ernannten und Der gemählten Mitglieder und jwar bei ungerader Bahl das

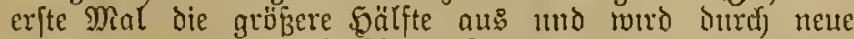
(Frnemungen bejtw. Waljen erfebt. Die bas erfte Jial

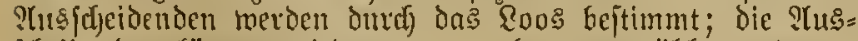
idfeidenden föment mieder exnannt bezlv. getwählt twerden.

§ 35. Der Borfizende der Beranlagungstontmiffion, veldher zngleid) die Jnterejfen des Stantes bertritt, hat

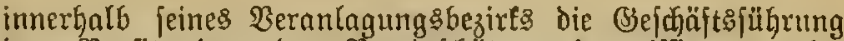

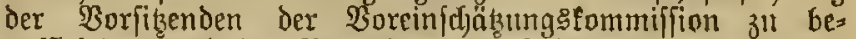

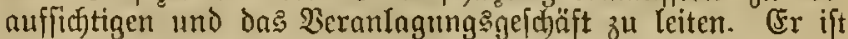
Dafilir berantmortlidé, da $\bar{\beta}$ die gefanmte Beramlagung in

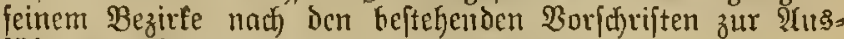
fiiffrung gelangt.

Der Borfitzende hat inshejondere die Berfonenftands:

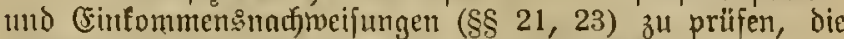
öfrentlidjen Befanntmad)ungen ruegen ?tbanbe ber Stenc: erflärungen zu erTaffen (\$ 24) InI biejenigen nicf)t keteits? mit cinem Einfommen bon melg als 3000 Marf ber= anlagten Stetuetpf(ichtigen, bei weldhen ein diejen Betrag ïberjeigendes (Einfommen anjumelymen ift, zur $彐$ togabe bezm. Ernenerung der Steuerertlärming bejonders anfänorbern. Die fämmtlid)en eingegangenen Steneterflärungen find non ify zu priffen.

3um 3recte der ridjtigen Beranlagung der Steuer=

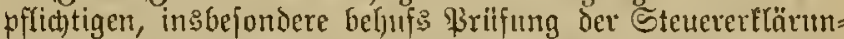

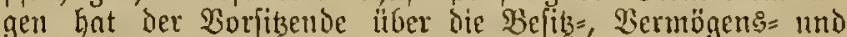
Einfommensverbältniffe der Stenerpflid)tigen möghtidj]t voll=

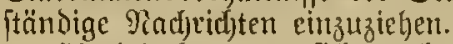

Sierthei foun er fict) nact) feinem ermeffen der Mit= svirfung der Gemeinde $=($ Sutg $\Rightarrow$ borftäube nnd Der $\mathfrak{B e r}=$ maltutgebeljörben bedienen, weldye feituen ?Iufforderungen

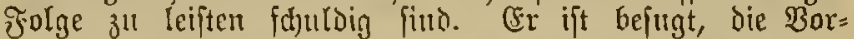

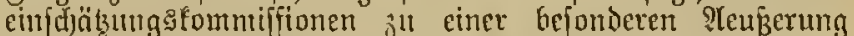
itber die Befitz=, Sermögens und (sintommensberfültniffe einzelner Stellerpflicjtiger zul veranlajjen.

Der Borfizende fann den Steuerpflichtigen all ?tutrag oder von 2Imtsivegen Belegenlyeit jur perjönlicfen $\mathfrak{B e r h a n d}=$ lung itber die fitt dic Beranlagung erbeblidfen Thatfadjen ımo Berbältniffe gemäljren.

Sämnttlidje State $=$ und Sommumalbefördon haben die (5infirf)t aller die Einfommensoverhältniffe der Steuer= pflidjtigen betreffenden SBütder, 21kten, Mrfunden zc. zu ge= jtatter und auf Exfucfen 2ibjurijten aus denjelben ju ertbeilen, fofern nicht befondere gejeglidje Bejtimmungen oder bienftficfe Ritufictiten entgegenftefen. Die (Finjidft der

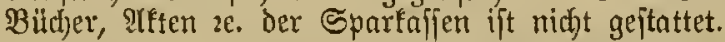

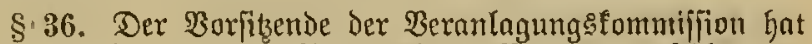
die non der Boreinfoüzunngatommifition borgejhlagenen Steuer äßze (\$ 32) zut priffen unt, forweit diefelben nicht bou ilym beanftandet merben, feftzujezen.

In Betreff berjenigen Steuerpflidftigen, bejüglicf) meldyer

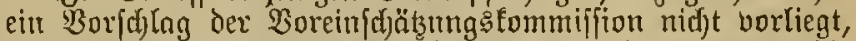
oder ber Boridhlng bon ify beanftandet wird, hat er bie Berbandlungen der Beranlagıng fajpung vorzulegen und zu biejen Beljufe das nad) feinem (Ermeffen fiir jeben Steuerpflidftigen zutreffende (Finfontmen, getrennt llad) ben berjdiedenen Duellen, in bie (Sinfommens=

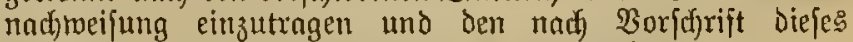

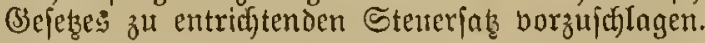

\$ 37. Tem Voritzenden Der Beranlaaumggfommiffion tönnen zur $\mathfrak{B e a r b e i t u n g ~ b e r ~ ( E i n f o m n t e n t e n e r j a d ) e n ~ b o n ~ i e r ~}$

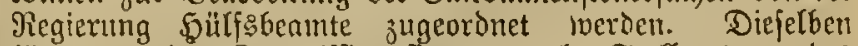
fötmen an den Rommiffionsfitzungen alङ Stellvertreter bes Borfitzenden oder mit berathender Stimme Theil nefmen; ihre fonftigen Rect) und Pffidjten werden nadf den hier= itber bon dem f̧inanzminifter zll exlajpender allgemeinen 2lnmeifungen bou der Regiernng feftgefekst.

\$38. Die Beranlagungstommiffion unterwirft die ein= gegangenen Steuererflärungen fotwie die Perjonenjtands: 
utto Einfommensinadjweifungen ciner genauen P3riffung.

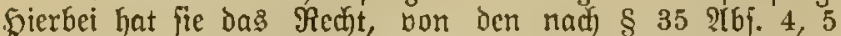

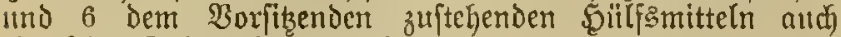
ifrerfats (Bebranch zu madjen.

Wiro eine Steuercrflärung burch) bie Veranlagungs: tonmiffion oder den Boritzenden beanftandet, fo ift dem Steuerpflidjtigen Giervon unter Mittheilung Der Srïnde mit ber Anfforderung Senntniß z"l geben, fich binnen einer frift

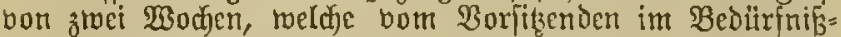
falle auf bier wodien verlüngert werben tann, ïber bies felben oder beftimmte an ifn geftellte Fragen zu ertären. Ilnterläß̈st dics Der Steuterpflidtige, oder merden die $\mathfrak{B C}=$

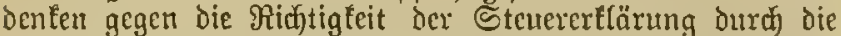
Crrläuterung oder Ergänzung fcitens deffelben nid̄t $b c=$ ljoben, fo ift bie Beranlagunggfommiffion bejugt, bie Ber= nehmung von Beugen und Eactyeritändigen umo fonjtige,

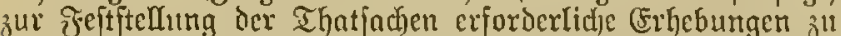
beraulaffen. Die zu bernehmenden Serjonen dïrfen bie

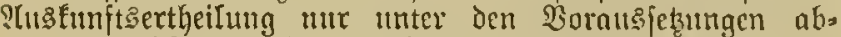

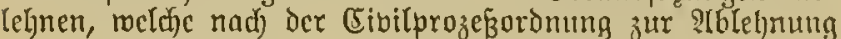
cines Zeugniffes bežw. (Sutad)tens beredjtigen.

Bleiber troksdem die Zroeifel an Der Richtigteit der Stencrerffärung beftehen, fo ift die Sommiffion bei Schäłzung des (Finfommens an dic IIngnben ies Steuerpflidjtigen nicht gebunden.

Die Sommiffion fezt ben nadj ifrem (Frmeifen itt= treffenden Eteuerjats auf (Srumd der ftattgehabten (Er= mittelungen fejt.

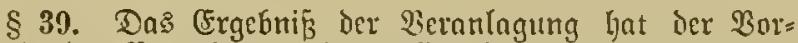
fikende ber Beranlagungstoutuiffion feocm Steuctpflichtigen mittelft ciner, zugleidf cine Belefrumg ïber das Reditg= mittel ber Berufung entljaltenden 3ufdrift befannt zu mactien.

\section{Ziedifmittel.}

a) Berufung.

$\S 40$. Becgen das Ergebni mohl dem Steuerpflichtigen als audy Dem $\mathfrak{B}$ orfitisenden der

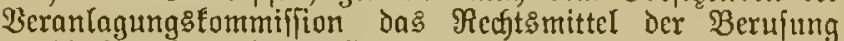
an dic ß̊cufungstommiffion zu.

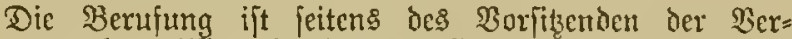
aulagungsfommifinton bei Dem Borfibenden ber Berufungs: fommiffion, feiteng der Steuerpflichtigen bei dem $2 \mathfrak{o r}=$ fibenden der פeranlagungafommiffion binnen einer Wh!sfd)lußfrift bon 4 Wodthen einzulegen, welche für ben Borfizenden der Ietzteren bom Tage Deg angefodftenen Befoluffifes, füt den Steuerpflicltigen bon dem auf dic Buftellung ber Benaddrid)tigutug (\$ 39) folgenden Iage $a b$ lainft.

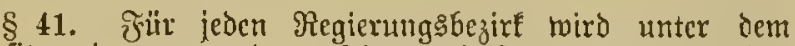
Borfibe eines bon bem Jinanzminifter jul ernennemben Regierungstommifiars cine Berufungstommiffion gebildet,

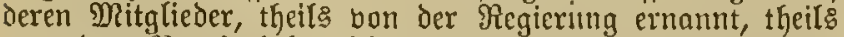

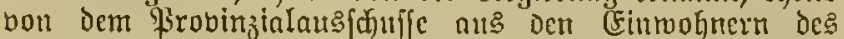
Regicrungşbezirf? unter möglichfter Berüdfichtigung ber veridjicdenen ?trten des C5infommens alt die Dauer von jedjş Jahren gemählt werden.

Die Mitglieder Der für die Sgatpt= und Refidenzjtadt Berlin zu bildenden Berufungsfommiffion werden theilg von dem finangminifter ernannt, theils von dem Magiftrat und der Stabtueroronetenverfammlumg in gemeinfdjaftidjex Siķıng unter dem Borfiz̧ des Bïrgermeifters gewählt.
Die Bahl Der Mlitglieder ber Berufungsfommiffion mird für jeden $\mathfrak{B} c$ zirt von dem finanzminifter nad $\mathfrak{M a E}$; gabe ber Vorjdjrift im \& 34 2(bjałs 2 feftgejezt. Die $\mathfrak{B} e=$ ftimmungen im $\S 34$ Qbjąs 3 finden entfprediende $\mathfrak{2}(n$. mendung.

§ 42. Der Borfitzende der Berufungstommiffion ift in Bezug anf die ridjtige ₹reftitellung ber Steuer Der Bers treter der Stantsintcrefien für jeinen Bezirt. \$ֲ̧m liegt bie obere Reitung des gejammten Beranlagungsgejdiäft im Bezint of. Er hat die gleidhmäß̧ige Alnmendung Der Veranlagungs grumbjäze zu ïberwadjen, bie (Bejdäftsfithrung ber Borfitenden Der Beranlagungstommiffionen zu beauf: jidftigen uno für bie rechtzeitige Bollendung bes $\mathfrak{B e r}=$ anlngungsigef doúfts zu forgen.

$\S$ 43. Dic Berufungstommiffion entfreeidet über alle gegen das Berfahren und die Entideidungen der $\mathfrak{B e r}=$ anlagungstommiffionen angebradten $\mathfrak{b}$ efdjmerden und $\mathfrak{B} e$ s ruftugen.

Behufs \$rriffung ber Berufungen tönnen die Berufungs: fommiffion und Deren $\mathfrak{B}$ orfikender eine genaue ک̧effftellung Der Vermögens, แnd Cinfommensverfältniffe ber Steuer = pflicktigen beranlaffen. Dabei find fic befugt, von ber zu

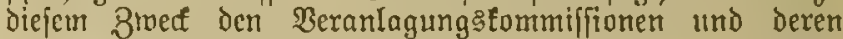

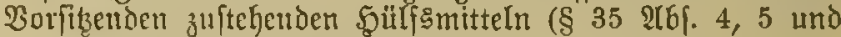
$6, \S 38$ ) (sebrauth zu machet.

Die Berufung:tommiffion und Deren Borfizender tönnen ferner bie cibliche Befräftigung des Bengniffes oder (S)t= achtens der vernommenen Bertgen bezm. Sadjberitändigen bor dem jujtändigen 2 lmtsgeria)t erfordern.

Dic Berufungstommiffion hat die Berionenftands: แno Eintommensnachmeifungen forgfältig zu prïfen; dic bon ifr gezogenen Erimnerungen find bei ber Beranlagung fïr bas nädjfte Steuerjobr z̆ beadjten.

\section{b) Befdutwerde.}

§44. Begen dic Gntfdjeidung ber Berufungstommiffion

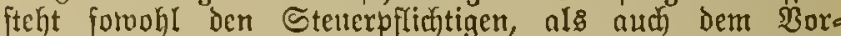
fitzenden Der $\mathfrak{B}$ erufungsłommiffion bie Befdjwerde an bas Sberverwaltungsgerid)t zut. Die Beffywerbe ift imnerhalb Der in $\S 40$ bejtimmten frrift, feiten $\$$ bes Borfizenden der Berufungstommiffion bei bem Dberberwaltungsigeridjt, feitens oer Steuerpflichtigen bei bem $\mathfrak{B}$ orfitzenden der $\mathfrak{B e}=$ rufungafommiffion anzubringen und fann nur barauf ge: ftützt werden:

1. Daß̧ bie angefodjtene (5ntforeioung auf Der Nicht= antwendung oder auf ber unridtigen ?(ntwendung bes bejtelienden Rechts, insbefondere nud ber bon Den Behörden innerhalb ifrer Bujtändigfeit er= lafienen Veroronungen berulje;

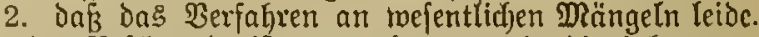
Stl Der Beidjwerbe ift anjugeben, rorin bic behauptete 9ididtantwendung oder unriditige Inwendung bes beftehen: ben $\Re e c h t s$, oder morin die behaupteten Mängel bes $\mathfrak{B} e r=$ faljrens gefunden rerden.

$\S 45$. Der Borfizende ১er Berufungstommiffion über. reidjt dic bei ifm eingegangene Bejtuwerde bes Steuer= pflicftigen mit jeiner Bsegenerflärung, fotoeit er jolche für erforderlich eract)tet, bcm Dbervervaltungggerid)t. Die $\mathfrak{B} c=$ idjuerde des Borfizenden ber Berufungstommiffion miro dem Stcuerpflichtigen zur fơriftliçen Segenerflärung innerhalb eimer beftimmten, bon einer bis zil bier Wodjen zu bemeffenden Frift zugefertigt. 
§ 46. Das Sherberwaltungsgerifft erläf̧t jeine cint=

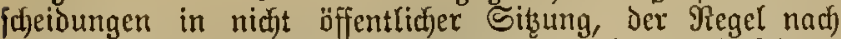
ohne borherige mündlidje Iuförung dę Steuerpflichtigen.

(Es fanu jedoch Dem Stenerpflichtigen von 21mtsmegen

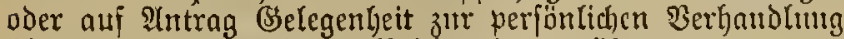
über den Gegenftand Der Befdrwerbe gewähren.

Bei feiner crntfocidung ift $e^{2}$ an diejentigen Gründe nidjt gebunden, meldfe zur Red)tfertigung Der gejtellten $2(n=$ träge geltend gemadft worden fimb.

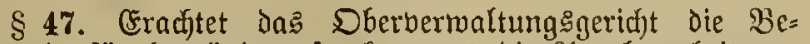
idfwerde für begrïndet, jo fann es bie PIngelegenteit zur anderweiten Fnticheioung an Die Berufungatommiffion zurüdfgeben oder jelfjt bie Steuerfeftetzung beridjtigen. Jm

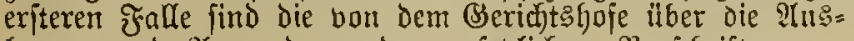
legultg utto 2(nmendung Der gefestictien Borjofriften ge= gebenen 2 seijungen $z^{u}$ bejolgen.

§ 48. Heber Befdwerden, roldje das Berfahren des

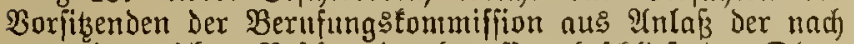
$\S 44$ eingereidften Befdwerden betreffen, bejd)liejt bas Sber: bermaltungsggerifjt.

§ 49. Эm Hebrigen finden auf Das Verjahren zum

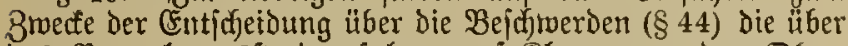
Das Bermaltungsftreitverfaljen auj ßlagen vor dem Dber= verwaltungsgeridfte bejteljenden gefezlicjen Beftimmungen, insbefondere diejenigen über die allgemeine Sandesver=

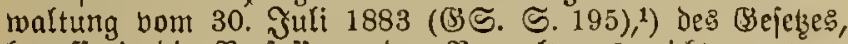
Getreffend die Derfajiung Der Berwaltungsgericfte 2c. voin

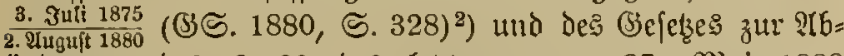
änderung Des § 29 des leţteren bont 27. Miai 1888

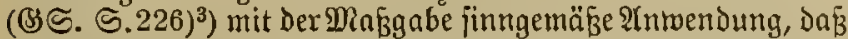
Die (Erbebung eines Faujd)quantums aud) Dann ftattfindet,

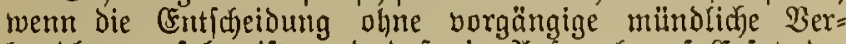
handlung erfolgt ift, und das ein Aniprud) auf Erfats ber Ânwaitsgebübren nidft ftattfindet.

1) ober S. $41 / 42$ u. ff. $\quad$ 2) oben S. $77 / 78$ แ ff.

3) § 29 ift oben $\subseteq$. $79 / 80$ in ber Fafijung bes Bejetęes vom 27. 5. 1888 abgebrưt.

\section{Gerdä̈ftsordun! der stouniffonen.}

§50. Für jämmtliaje 3 orfizende und Mitglieder ber Borein[d]ätzungs:, Beranlagungs= und Berujungsfommififionen find Stelluertreter in gleicher Weife twie die Borfitzenden oder Mitglieder zu ernennen bejw. zu rählen. Die $\mathfrak{B} e=$

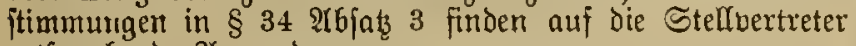
entipredjende $\mathfrak{A n w e n d u n g . ~}$

Begen Annahme und ablefnung der nady den $\mathfrak{B}$ or $=$ ithrifter diejes Seietzes jtattindenden Grnennungell unt Wahlen finden Die Beftimmungen Der $\S \S 8,25$ Der Rreis: oronung vom 13. Dezember 1872 (G5ऽ. S. 661) finngemäße 2(nwenoung.1)

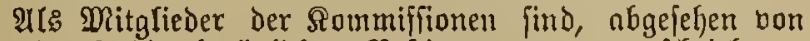
den buref die bezügticfen Bejtimmungen borgejdjriebenen bejonderen Sorausjetzungen, nux joldje \$3erjonen mäbrbar, weldye das 25. Rebensiahr bollendet haben und fich in $\mathfrak{b e s}$ fizze Der bürgerlidjen (Ehrenred)te befinden.

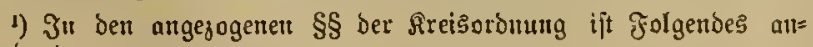
georonet:

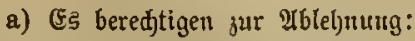

1. anthaltende Strantheit;

2. Bejgäfle, bie eine jäufige ober lange antouernde

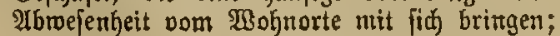

3. Das 9lter von 60 Эahren und barüber;

4. Die Bernaltung eines unmittelbaren Stantsantes;

5. foujtige bejondere Berbältnifie, welde cine gültige Entidulbigung begrünoen.

b) SBen bie 2tmlsbauer mehr als brei Jahre beträgt, fo tam Da马 IImt nad) brei 3ahren niedergelegt merden.

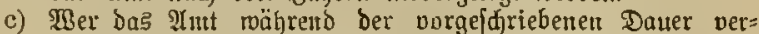
waltet hat, fann Die Hebertuhme beffelben oder eintes gleidjartigen IImtes für bie nädjten brei Jahre ablehnen.

Iuf unbegrïnoete Yblehnung ift uls Rechtșnadtheil gelest:

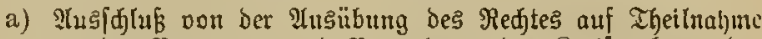

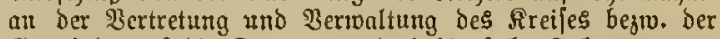
Bemeinte auf bie Daner von orei bis jed క̧ahren;

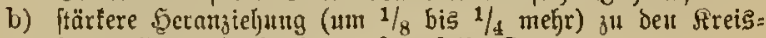
beziv. Sencindenbgaben auf diciclbe Dauer.

\$51. Die Borfiţenden der Rommiffionen lyaben die Ietzteren zujammenzuberujen, deren (j) juäfte vorzubereiten แnd zu leiten, forvie bie nidgt von ifnen burd Cinlegung

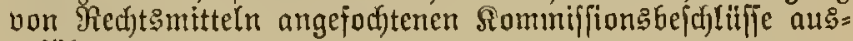
juführen.

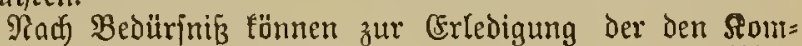
miffitonen obliegenden Bsejdäjte lunterfommiffionen gebildet merben.

Dic Rommiffioner beziehungstmeife Unterfommiffionen jaffen ifre Bejdlüffe naw Stimmenmehrheit. Dem $\mathfrak{B a r}=$ fiscenden fteht bolles Stimntredht 3u. Bei Stimmengleidffeit entrdheidet die Stimme des $\mathfrak{B}$ orjitzenden.

So lange über bie Einjuäţung oder Berufung eines Sommifitionsmitgliedes oder feiner Bermandten oder. Ber= [ajwägerten in auf = uno abjteigender Sinie oder bis zum oritten Srade Der Seitenlinie berathen und abgeptimmt wird, ljat dafjelbe abjutreten.

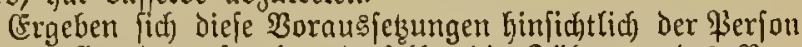

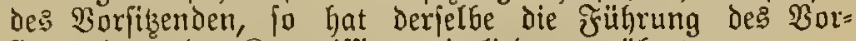
fikes einem der Sommiffionsmitglieder zu übertragent.

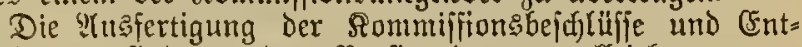
idfeidungen find von dem $\mathfrak{B}$ orjizenden zu bolfziehen.

\$ 52. Die Mitglieder Der Sommiffionet haben Dem Borjitzenden mittelit Sandidjlages an (Eidesftatt ou ge= loben, Daß́ fie bei Den Rommifitonswerhandlungen ofne भin= jehen der \$ier[on, nadf beftem Wiffer und (s)erwifjen vel= fahren und die Berhandungen fotwie die hierbei zu ihrer Sienntuifs gelangenden Berbältniffe der Steuerpflichtigen itrengitens geheim halten werden.

Das gleide Belöbnif haben bor einem bou ber Re= gierung ju ernemenden Sommijiar diejenigen Bor[itzentell abjulegen, weld)e uidjt idjon als $\mathfrak{B e n m t e}$ vereidigt jint.

Die bei der Steterberanlagung betheiligten Beamtelt find zur Seheimljaltung der Sonmiffionsverhandlungen $j=$ wie der z"l ifrer Senntnifs gelangenden Berljältnilfie der Steuerpflid)tigen traft Des bon ifnen geleifteten Amtgeides verpflidetet. Die Steuertlärungen find unter $\mathfrak{B} e r[d$ f fuß auf zuberwahren und bitrfen, ebenjo rie bie Sommiffions=

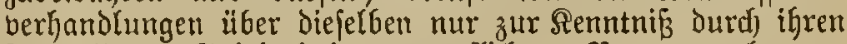
2(mtseid jur (Sel)eimfaltung verpflidfteter Beanten gelangen.

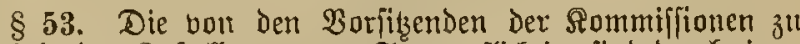
Gervirfenden Buftellungen an Steuerpflichtige find Durdf einell öffentlidjen Benmten unter Bejdjeinigung der Befändigung

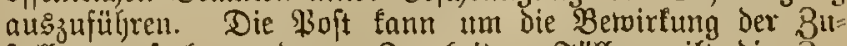

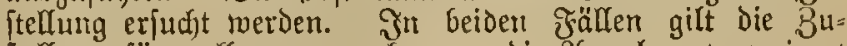
ftellung fïr bolfogen, aud) went die Antahme verweigert wird. 


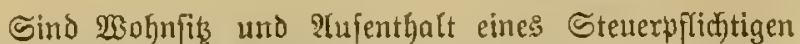
unbefannt, fo tann die Buftellung an denfelben ourd) 2โn=

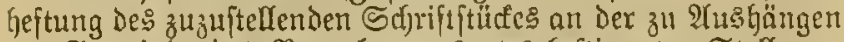
ber Bemeinde des Beranlagungsortes beftimmten Stelle er jolgen. Die 3ujtellung gilt für bolfzogen, went feit der

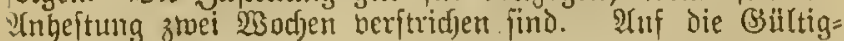

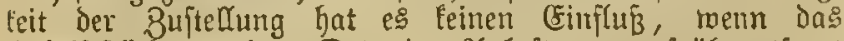
Sdjriftftuid bon beut Drte der ?(nlyeftung zu frilh entfernt viro.

Die außergalb \$reußens зu betwirfenden 3nitellungen fönnen mittelft eingefdricbener Briefe erfolgen. Die $B^{u=}$ ftellung gilt mit der stiffgabe zur \$oft fiir volljogen.

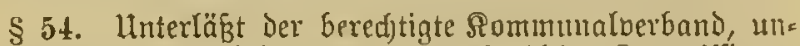

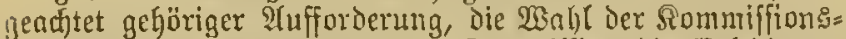
mitglieder, oder berseigert eine Rommiffion Die Erlebignng der ifrr übertragenen Gefdjäfte, fo find diefe für bie be= treffende Beranlagungsperiode nuf $\mathfrak{B e r f i t g u n g}$ der 9 (uffict)ts.

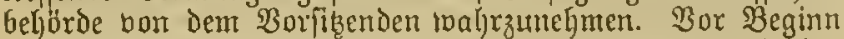
des näd)ften Beranlagungsgefdjäft: hat eine Reutwahl der wäglbaren Sommiffionsinitglieber zu erfolgen.

\section{OHexanflidjt.}

§55. Die oberfte Reitung des Beranlagungsagejuäjt: im Staate gebührt dem Finanzminifter, meld)er zugleid, über Bejdmerder gegen das Berfahren Der Berufungstommifítonen

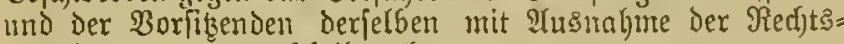
mittel (\$ 44) zu entfajeiden lont.

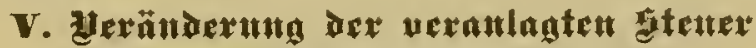

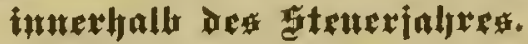

§56. Die Beramlagung Der Cinfommenfteter exfolgt für jedes Redjnungsjały (Stencrjahr). ${ }^{1}$ )

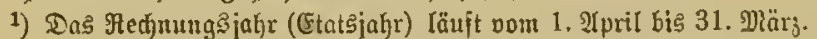

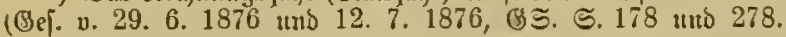

§57. Die Bermehrung des Finfommens während des Laufenden Steuerjafres begrtindet feine Beränderung in Der f(f)on exfolgten Beranlagung. Tritt bie Bermehrung in folge eines (5rbarjalle ein, jo find die Erben entfpredtend ber Bermehrung ifres Fintonments nndertweit zu beranlagen und zur (Entrid)tung Der Steuer bon Dem Beginne Des auf Den Anfall Der Erbfdyaft folgenden Dionats ab verpflidjtet.

§ 58. Wird nadgetwiejen, daß wähxend des laufenden Steuerjahres in ₹̊lge des $\mathfrak{W e g f a l l e s ~ e i n e r ~ ( 5 i m m a h n e q u e l l e ~}$

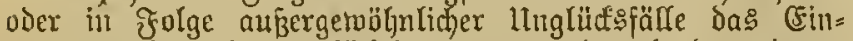
fommen eines Steuerpflid)tigen um me(j) als den vierteu Theil bermindert morden ift oder das ruegfallende (5in= fonmen anderweit zur Einfommenfteuer herangezogen wird (\$ 57), fo fann vom Beginne des auf den Cintritt Der (Finfommengberminderung folgenden MRonat: ab cine Dem verblicbenen (Eintonmen entipred)ende (5rmäfigung Der (Sit= foumenfteuex beanfprudft werden.

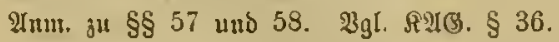

$\S 59 . \Im m$ llebrigen tritt innerhalb des Steuerjaljres eine Beränderung in ben Stenerrollen mur ein entweoer in

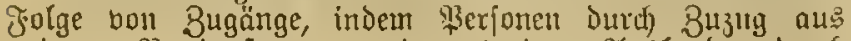
anderen Bundesftaaten und aus dem अ(uslande, Durd)

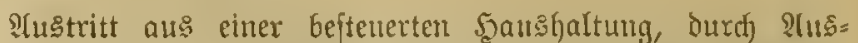

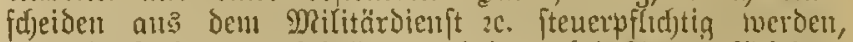
Dder in ₹olge bon ?lbgängen, indem bei Stcuerpflidytigen die Sorausfetzungen, an welche die Stenterpficht gethipft ift, erröfdten.

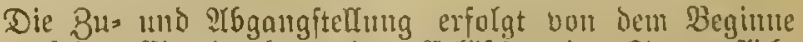
des anf ben (Sintritt Geztv. Das Grlöfdjen Der Steuterpflidyt folgenden 9) ionatis ab.

$\S 60$. Lleber die Cteuerermäbigung (§ 58) hat die Regierung auf ben bei dem Borfibenden Der Deranlagumg: fommiffion zu ftellemben ?tutrag zu befinden. Begen ihre (Entf(heidung fleht dem Steuerpflid)tigen binnen ciner ?hus:

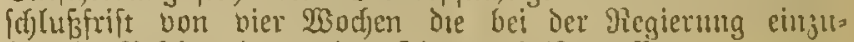
legende Befdjwerde an Den Jimanzuninifer offen.

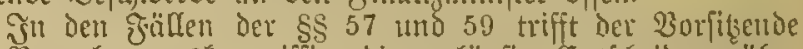
Der Beranlagumgafoumiffiton die vorläufige (Entfd)eidung Den zu entridftendon Stenerfatz und den Zeitpunft ber Zus uni) \$!logangsftellung.

Die Jectitelluttg der Ttbgangstiften, weld)e in Den vom

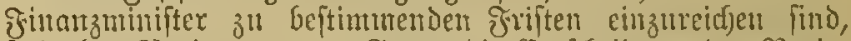
fteht ber Plegierung zu. (Segen Dic Entfdecioung ber Regie= rung ift die Bejchiverde nad) Maşgabe der Beftummung im 2tbfats 1 geftattet.

Die Beranlagung bei Zugangftellugen mo Steuer" ertjöhutgen erfolgt halbjälyrlich.

Die Steuerpflidytigen find mod) Maz̄gabe De: § 25 jur RGgabe von Steuererftärungen bered)tigt hezłw. berpf(id)tet.

\$61. Stenerpflidftige, meldhe in \&aufe Des Steners jahres ihren 230 hnfit verändern, haben fid) bei Dem (Bemeinte:

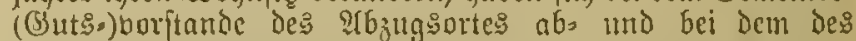

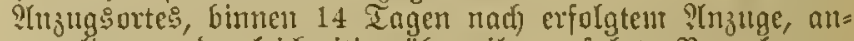
zumelden uno gleidzeitig itber ihje erfolgte Beranlagung zแ Cin Eommenfteuer auş juweifen.

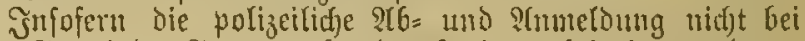
Dem Genteinde=(Buts=) borftande, fonden bei einer anderen Beljörde itattzufinden Gat, vertritt Die $9(b=b e z m$. Tumeldung

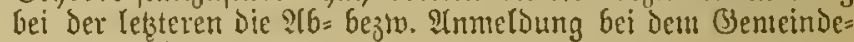
(B)

Den (Senteinde=(\$it:s=) voritïnden liegt uad) Den bom Finanzminifter Gieriber ju treffenden ?lnordnungen Die

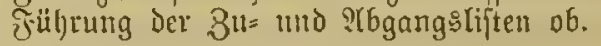

\section{Etenteretjeluthon.}

\$ 62. Die veranlagte Steuer ift in vierteljälurlidjen Beträgen in Der eriften Şälfte Deß zmeiten Monat: eine: jeden Tierteljahres an die bon Der Steuerbehörde zu be= zeidjnende (smpfangsftelle abzufïbren.

(5) fteht Dem Stenerpflichtigen frei, Sic ifu auferlegte Stener auf melirere Bierteliahre bis jum ganjen sabres. betrage im 20raus zit zaljlen.

\$ 63. Die Zallung Der beranlagten Steuer viro outr(t)

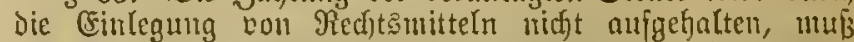
vielmeljr nut 20rbefalt fpöterer Crrftattung in ben borge= (d)riebenen ङriften erfolgen.

\$ 64. Beranlagte Cinfomnienfteuerbeträge fönuen in

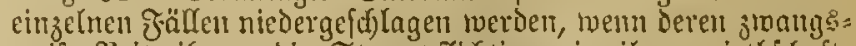
weije Beitreibung Die Stenterpflidigen in ihrer wirthid)aft=

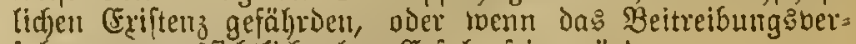
fahren borausfidjtidid ohne Erfolg fein voitrde. 
$\S 65$. Die veranlagte Steucr ift uid)t ju ethetent:

1. bon Der Interoffizieten uno Mamfdhaiten de: Beurlaubtenftandes, weldhe mit einem fintommen bon nidft mefr als 3000 Marle veranlagt firi), fïr Dicjenigen Nonate, in Denen fie fidf im aftiven Fientite befinderi;

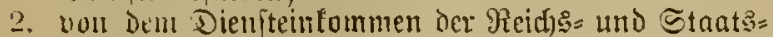
beamten uno Sffizicre währeno der Zugchörigleit Dericlben zur Bejałsung eines jum ausmärtigen Dienjt beptimmten Sdiffs oder faljrzeugeg Der taiferl. Marime, und jwar bom Erften desjenigen Monats $a b$, reldjer auf icri Mionat folgt, in rweldjem dic heimifden Bewäffer verlafien merden, bis jum ablauf des Plounts, in meldyem die Rïfffehr in biejelben erjolgt.

\section{Straftreftimuนngen.}

\$ 66. Wer miffentlich in der Stenererflärung oder bei Bcantwortung oer von jujtändiger Scite an iłhn gerichteten Jragen oocr jur Begriindung eines $\Re e c h t s m i t t e l s$

a) ïber fein iteuerpflidjtiges Einfommen oder über das (sinfommen ber bor ifm iu vertretenden Steuerpf(idftigen unridjtige oder unvolftändige Angaber madt, rocldie geeignet indo, jur $\mathfrak{B e r}=$ fürzung der Steuer zu jüfren,

b) ftenertflictiges (Einfommen, weldjes er Had) den Boridififten biefes Befectes anzugeben verpflid)tet ift, berid)weigt,

mird, wenn eine Verfilizung des Staatce ftattgcjunicn hat, mit bem $4=$ bis lojadjen Betrage Der Berfitizung, andern= falls mit bem $t=$ bis 10 fadjer Betrage der Sahresfteucr, un weldje der Staat berfürjt merden follte, mindejtens aber mit einer Geloftrafe von 100 Mart bejtraft.

Un die Stclle diejer Strafe tritt cine Belditrafe bou 20 bis 100 Mark, toenn aus Den llinftänden zu entnehmen

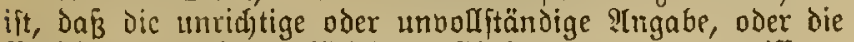
Berfdyweigung fteuerpflichtigen finfommens zmar wiffents lich, aber nicht in ber 2lbfitht ber Steucrfinterzichung er= folgt ift.

Derjenige Steuerpflidtige, meldier, bevor eine Inzeige exjolgt oder eine linterfucfung eingeleitet ift, jeine Ingabe an zuftändiger Stelle berichtigt oder ergänzt, bezlw. Das verid)micgene (Einfombien angiebt und die borembaltene Stener in Der ifm gefezten Strift entrid)tet, bleibt ftraffirei.

$\S 67$. Die Finjtelung der hinterzogenen Steuer erjolgt neber uno unabfängig von der Strafe.

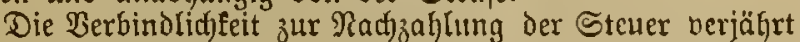
in 10 sabren und geht auf die Erben, jedod für dicje mit einer Berjährunggfrift von 5 Fahren uno mur auf $50 ̈ h e$ ihres (Frbantheils, über. Die Serjäl)rungşrift beginnt mit IGlauf des Steuerjahres, in weldjem die Şinterziehnno begangen rourde.

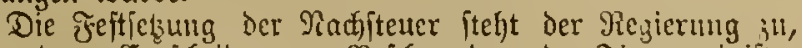
gegen deren Emffjeidung nur Bejdjwerden den Finanjminifter zuläfiig ift.

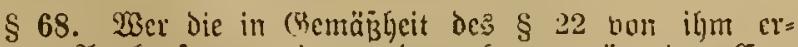
forderte Ru\&funjt vermeigert oDer ofun geniigenden Ent=

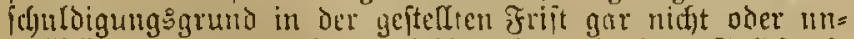
volfitändig oder unvichtig crtbeilt, wirt mit cirer Gelojtraje bi: 311300 Darf beftraft.

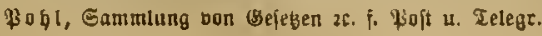

Wer der in $\S 61$ oorgeldriebenen จierpflithtung zur श( $n=$ und stbuieloung nidft redftzeitig nadflommt, wird mit einer Selojtrafe bis zu 20 Marf bejtraft.

$\$ 69$. Dic bei ber Steucrberanlagmig betheiligten $\mathfrak{B} c=$ anten fotwie dic Mitglicoer der Siommiffiotien werden,

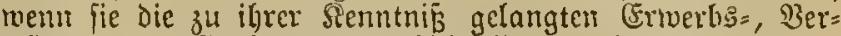
mögens= oder (Einfommensnerhältniffe eines Steuerpfliditigen, inşbefoniere audj den Shljalt einer Steneterflärung oder ber bartïber gepflogemen Berhandlungen mbefugt offen= hareir, mit Bselditrafe bis zll 1500 P̉?art oder mit Gyes fängnís bis zu 3 Monater bejtrajt.

Die Berfolgung findet nur auf Intrag der 9Regierung oder ies betroffenen Stcuctpfliffingen itatt.

$\S$ 70. Die auf Grund Der $\S \S 66,68$ und 69 feit $=$ zufekentoen, aber unbeitzeiblichen (Selditrafen find nad) $\mathfrak{D} a \bar{B}=$ gabe Der für llebertretungen geltender Bejtimmungen des Strajgejetzbud)es fiir das Deutjd)e Reich (\$§ 28 und 29) in Soaft unzurwanteln.

Die Itnterfutfung und Entfdeidung in Betreff Der in den $\S \S 66$ แ⿰ 68 bezeidjneten itrafbaren 5yandlungen iteht

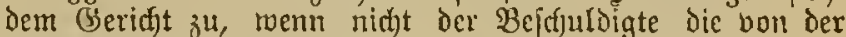
Regicrung vorläufig fejtgefeßzte Beloftrafe melfit Den durch) Das Berjahren gegen iln entFtandenen Roften binnen einer ifjm befount gemadten Frift freivillig zablt.

Die Regiermugen find ermähtigt, fierbei cine mildere als die im $\$ 66$ vorgejuriebene Straje in \$trmendung $3^{\text {la }}$ bringer.

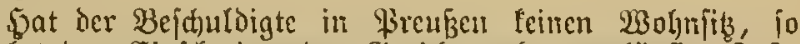

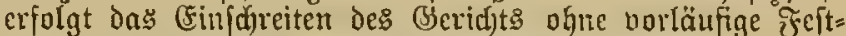
fetzung der Strafe durdh bie Regierung. Daffelbe findet ftatt, wenn die Pregicrung all: jonftigen (Srïndeli von der vorläufigen fecitiekzung der Strafe gibjtand zu nefmen er. tlürt oder der Ingefajuldigte bierauf berjidjtet.

Die Fitfifidioung wegen ber hinterjogenen Stener ber=

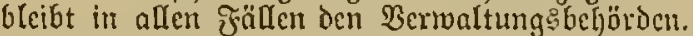

Э̌n Betreff Der Buwiderlyandlungen wegen Der Ber. pflid)tung jur Befeimbaltung $(\S 69)$ filidet nut das ge= riditlides Strafoeriagren ftatt.

\section{ERaften.}

§ 71. Die Soften der Steucrberanlagumg und (E) =

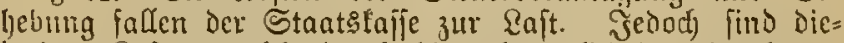
jenigen Sejten, meldje durdf die gelegentlid) Der eingelegten Re(t)tsmittel erfolgenden (Ermittelunger veranläst werden,

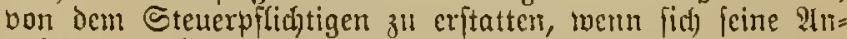
gaben in mejentlidjen 3 sunten als umridig erweijen. Die

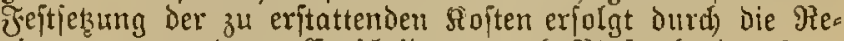
gicrung, gegen Deten (Entf(heidung nad) Diakgabe des \& 60

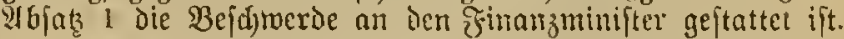

\$ 72. Dic Mitglicder der Siommiffianen erljalten Reife= uno Tagegelder nad) Maggabe ber Beroronung. betrefiend dic Tagenelier und Reifefuiten 2e., vom 20. Dezember 1876 (अ). 1877 ङ. 3).

Dic (bcbühren für Beugen und Sadjnerjtändige (\$ 38)

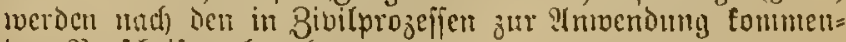
Den 93orfduriften bereffunt.

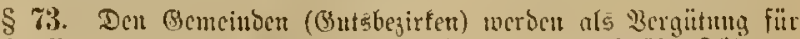
die bei entrgegantgentu Etener gewoüf(t.t. 
Sinfid)tlidy der örtliclen (erlgebung oer Steuer verbleibt es bis anf 2 eeteres bei den bejtelenien Beftummungen mit

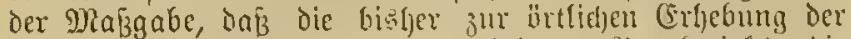

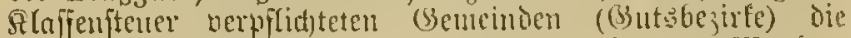
Etener bon (Einfommen bon nid)t melyr als 3000 gharê zu erlyebent haben.

Diejenigen Bientumben (Gutąbejirfe), weldhen dic Steuer=

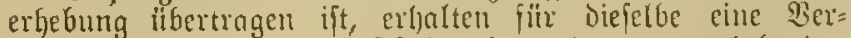
gütung von $2 \%$ der Siteimaljue oer öl ertebenden (Steuert. ${ }^{2}$ )

1) $26 j .1$ dicjes $\$$ anfachobcu burti) $\$ 16$ भbi. 1 bcs (jejeges

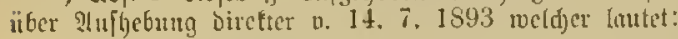

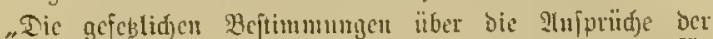
Gencindon (Bhtsbejitfe) nuf ben S3ezuly von sergïtungen fï bie bei Bernnlagme Der Besucrbeftener uno ber Finfommen=

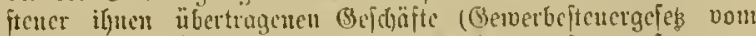

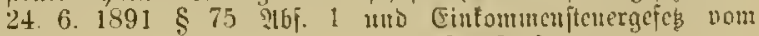

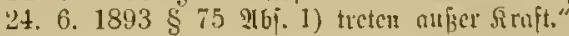

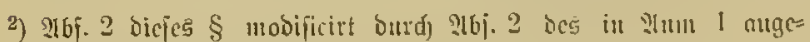
zogenen \$, socldjer lautet:

"Durd) Röniglidge Beroronung fimu din Bemeinden uno iclbitfündigen Butsbezirfen bic Berpflid)tuna anferlegt werbeu, in ihren Bejirfers dic Elententurethehung ber fämntlidjen

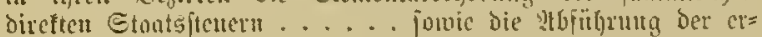
hobeneu SHeträge an bic juïtübigen Etuntstuffer obme Bcr= gaitung zu bewirten."

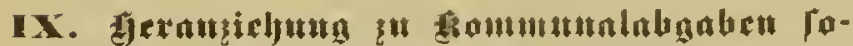

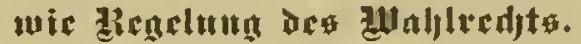

\& 74. Sind zu Den Beiträgen mo \&a[ten, weid)e tom=

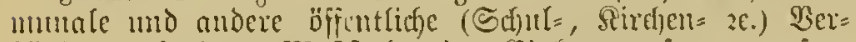

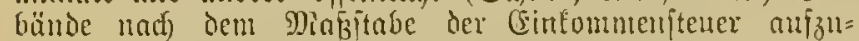
bringeu bejw. ju bertbeilen haten, fierjonen mit Cein=

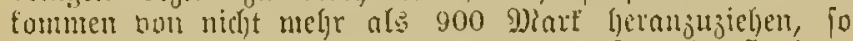
erfolgt deren Beranlagung auf (Brumb nachitel)ender fingirter Tiorntalíteuerjäke :

bei cinem Э̧oljresecintomunen

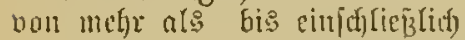
$-\mathfrak{D i}$. +2093 .

$2 / 5 \%$ des ermitteltem ftemel $=$ prlidftigen Sinfoumens his 3แun 5ödjitbetrage bou $1,20 \mathfrak{M}$.

420 " 660 " $\quad 2,40$ M.

Die borbezeiqueten Perjonen tömren, menn Die Decfung

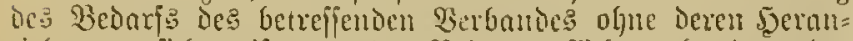
jiclumg geitchert ift, bon der Bcitragspflidit entbunden ober mit einem geringeren firojentiake als Das ljöbere Ein= fummen Gerangejogen weroen; ilje forelaffung muв er= inlgen, joirn un Wege ber befentlid)en wrmenplege forts liufende lluterftïlizung exlyalten.

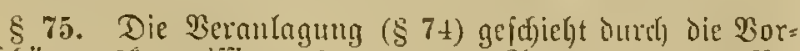

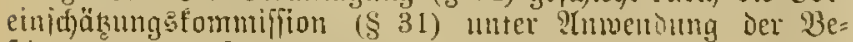
jtimumungen dicics Bcietzes.

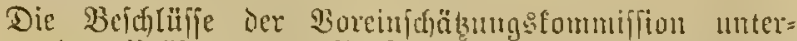
liegen Der Hriffung Des Boritienden ber Reranlagungs:

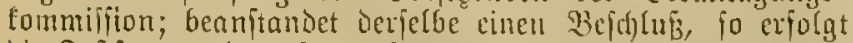

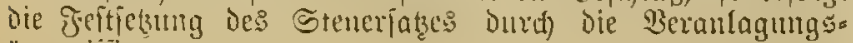
tomminjion.
Tie icitgeietzte Steuerlifte ijt 14 Tage lang öfrentlid)

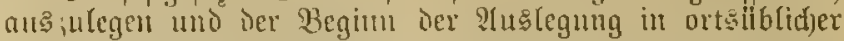
Ziseife befamt zu mad)en.

(Segen bie Weranlagung fteljt Dem Steuerpflidgtigen

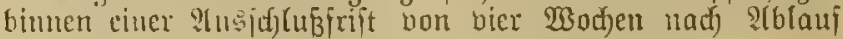
det ?llstegungsfrift die Berufurg ju und juar

a) ment dic Seranlagung Durd die Borempdjäzumgs: foumiffion olune Beanitaroung exfolgt ift, an bie DeranlagungsE Enmiijion,

b) weun die Jeftfetung bes Steuer\{azes durdy die Beranlagungsfommifion itattgefunden hat, an die Berufungsfommiffion. ${ }^{1}$ )

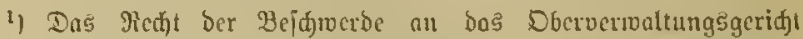

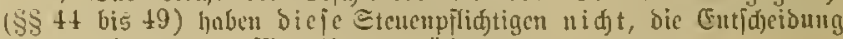

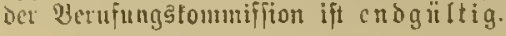

76. Fiit Dic Feftfellung Der nad) Dem Daaßjtabe Der

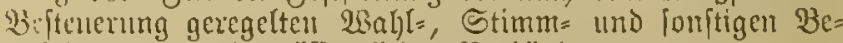

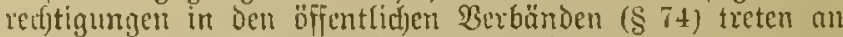

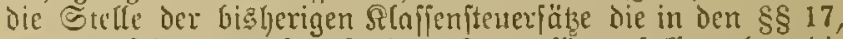
it vorgejeljenen entfprechenden Steuerjä̌ze, jalls aber bie

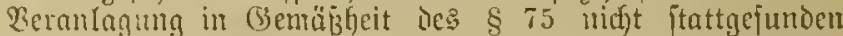

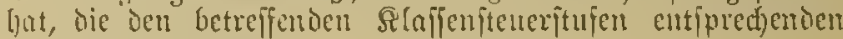
Ginfommensozäige.

\$7. Someit nad) Den bejtehenden Beitimumugen in Stad = แmb Randgemeinien bas Bürnerredt hezro. Das Stimut = mind Walfred)t in Gemeindeangelegentyeiten an bie Bedingung eines jäfrlicfen ßTaffenjtenerbetrages von 6 Whark gethilipit ift, tritt bis zur anderweitigen gefetzliden Regelung

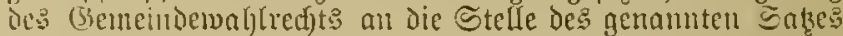
Der Steuerjaţ von + Mart bezro. ein (Finfommen von melnt als 660 Miat' bis 900 M)

Sn denjenigen Eandestheiten, in melden fïr die Bese

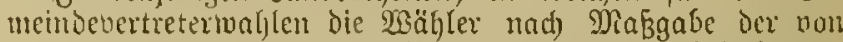

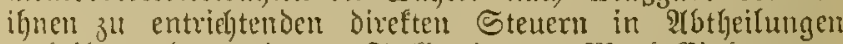
getheilt weroen, tritt an Stelle cines 6 Mart (Fintommen=

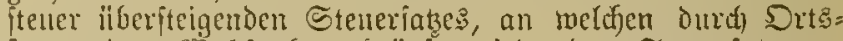
itatut das wablrefijt geEnilpjt mird, der Steuerjatz bon 6 Diart.

Wo poldje Drtsitatuten nady beitchenden frommunal=

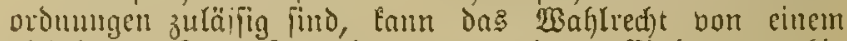
niedrigeren Steuerjake bejlv. bon einem Einfonmen bis 900 sjlark nбljängig gemad)t werden. EFine (Fihöhutg ift niç)t zuläifitg.

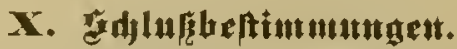

\$ 78. Die in Diejem Bejeke Den Regierungen zuge= viejencu Befugniffe und Sbliegenfjeiten juerden für bie Sorupt= unb Refidenzitade Bertin von der Direttion für die Bertunltung der bireften Steuern in Berlin malyrgenommen.

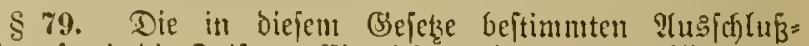

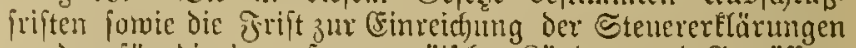
werien für Die in nuzerentropäifichen Qändern und Bewäffern 9tbuejenden anj 6 Monate, für andere außserljalb bez

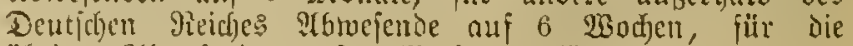
ïfrigut ?(bmejenden aแj 323 od)en berlängert.

§ so. Steuerpiliditige, weldie, entgegen ben Borjuriften dicfes Bcieces, bei der Beranlagung übergangen oder fteneiprei oder sul emer ifremt wirtlidjen (Finfommen nidgt entipredienden niebrigeren Eteueritufe beranlagt toorden

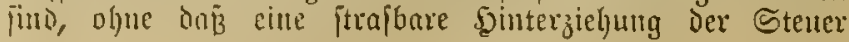


Ttattgefunden föttc $(\S \S 66,67)$, find 3 ur (Entrid)tung des Jer Staatsfafie entzogenen Betrages verpiftictet. ${ }^{1}$ ) Die Ber: pflidtung eritreft fich nuf Dic Drei Steucrjofre zurüd,

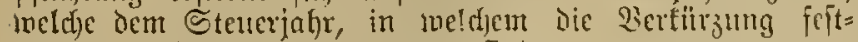
geftelt morben, vornusgegangen fints.

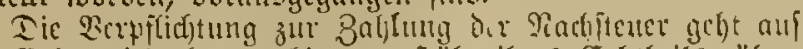
die Erben, jeboch nur bis jur söbe ihres (Erbtheils, hiber.

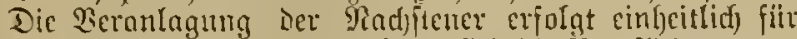

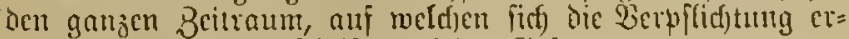
frredt, nard) oen Borfdyriften diefes (sejeczes.

1) Erhält cin Bcamter vom 1. Stpril ab ciute Geljaltsulnge,

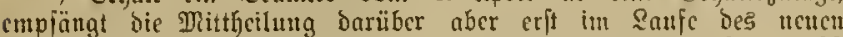

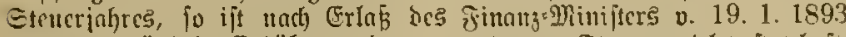
cinc nnd)träglidje (Erböhuug ber veranlagter Etcuer $n$ itht ftutthaft. (Ditth). ans der Berwnltung ber sirctten Etcucrt, Seft 26 ङ. 29.)

\$ 81. Someit bas gegenmärtige (Sefck abmeidfende

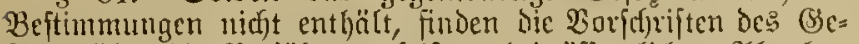
frace Uiber die Beriährungsfriften bei offentlichen Itbgaben

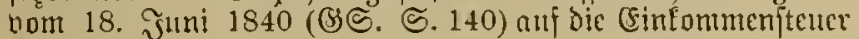
itnuendung.

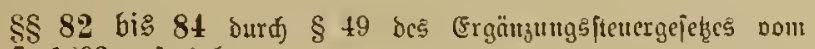
14. 7. 1893 anjgehober.

§ 85. Dex Finanzminiftex miro mit dex झuşührung dicfes Sicjetes beauftragt.

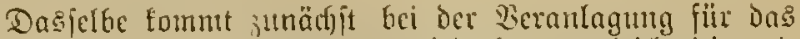

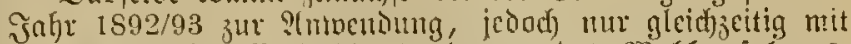

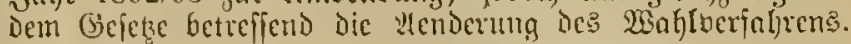

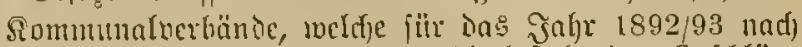
Maß̈gafe Der neuen Seranlagung die beftelienden Bufdrläge

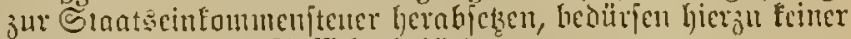
(s)

Mit Dicjer Magigahe und vorbebaltlich der Snwendung

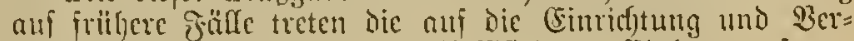
anlagung ber Staffin= uno Elaffifizirten Eintemmenitener

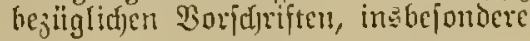

Das (Biciets bou 1. Mai 1851 (హ). (. 193),

Das (Gejeł non 25. Mai 1873 (ఆङ. S. 213 ,

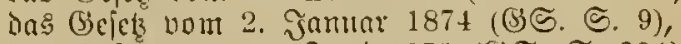

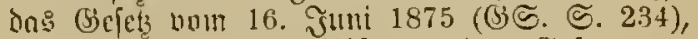

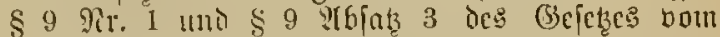

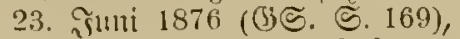

Strtifel III und IV des Scjęces bum 12. Miärz 1877 (अ). ङ. 19),

am 1. จItpril 1892 nū̧ex Sraft.

llttundrid) $2 \epsilon$.

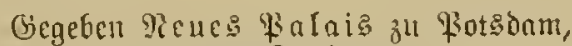
den 24. Эıแแ 1891.

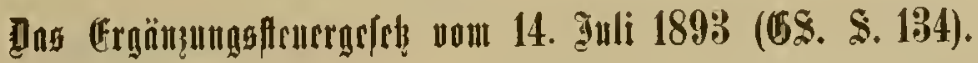

Eingang wie beim Einf St(5). (obcu @. 767/68.)

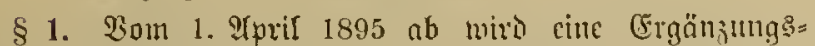
jener nact) Maßsgabe ber folgenden Bejtinumungen erljuben.

\section{I. steutcrpflidit.}

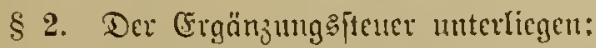

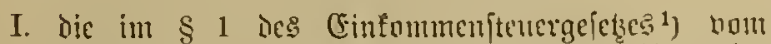

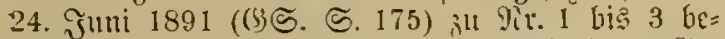
jeidjucten phefijdyen fierjonen ${ }^{2}$ ) nadj bem (B) $=$ faumtmenthe ifjes itcuerbaren siernögens (s 4).

.II. ofne Rüuffid)t auf Stantsangelörigfeit, Wisohnfitz oder sufenthalt affe whyjifden tierfonen ${ }^{2}$ nad) nem werthe

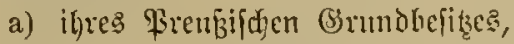

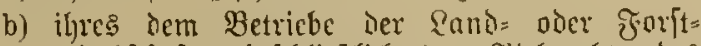

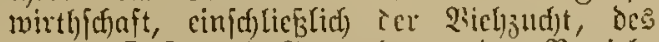
Wein $=$ Dojt= mo Bartenbauce, dem Betriche ies Bergboues oder eines ftelendon (Betwerbes in Preuben Dienenden ?tulage= und Betricbs: fapitals.

1) Bgl. bicjen $\S$, obcn $\Xi$. 767 .

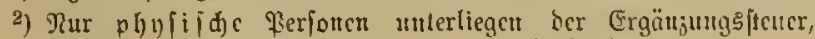

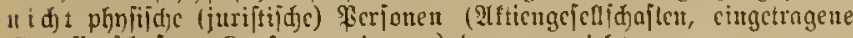

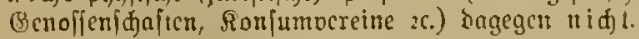

\$3. (1) Bejecit von Der Ergänjungsfteucr find bie ge=

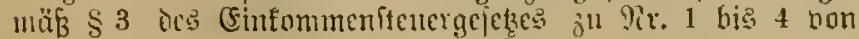

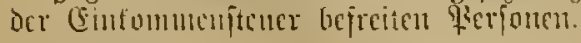

(2)

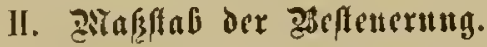

\section{Ctenerbare Beruögen.}

§ 4. (1) Der Befteucrumg unterliegt bos gefamute be=

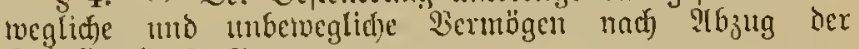
(ธd)uItoen ${ }^{1}$ ) (S 8 ).

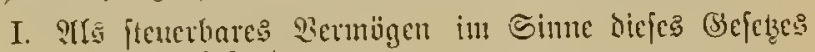
gelten inşbejonitere:

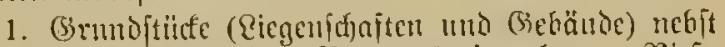
nllem Buhchör, Bergmertseigenthum, Riçs=

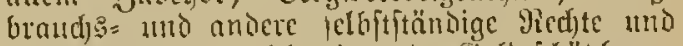

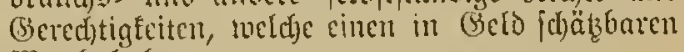
Werth haben;

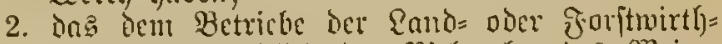

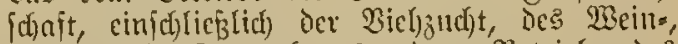
DGjt= 1mi Gartenbauts, bem Betriebe de Berghanes votr cines (3emertes dienende Inlage= und Setricbetapital (\$ 6);

3. ing ponjtige Sapitalvermingen (\$ 7 ).

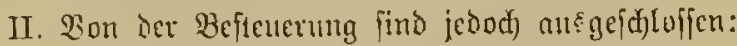

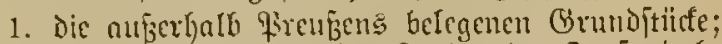

2. Das bem Betricbe der Sand= Diner Fol [tmitth= id)ajt, ocs Bergbates oder cines fichenden (Sic=

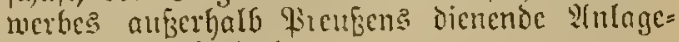
uno Betriebstapital.

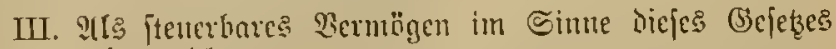
gelten nicht:

Piäbel, frans ratly und andere bivegliche törper: lidje ミadjen, injojern biejelben nidjt als Bubejör

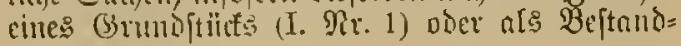


theil eincs :InIage = und Betrieb) anzufeben find.

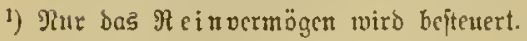

§5. Behrje der Stenerveranlagung werden Linzuges rechinet: ${ }^{1}$ )

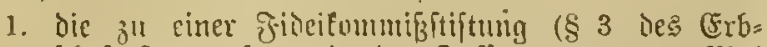
id)afteftenergefekes in der faffung bom 24. Mai 1891, (\$S. S. 78) gehörigen Bermögen oder

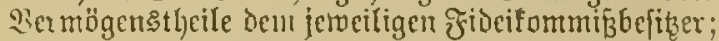

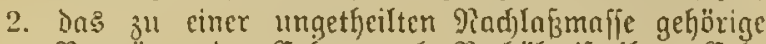
Bermögen Der (Erben nad) Berlyältnif̧ ifres (E)b= theils;

3. Die zum 1 lnlage = und betricbsfapital einer nicht gemäв § 1 Rir. 4, 5 Des Ginfommenftuergejetre ber Einfommenteuer unterliegenden Ertwerbs: gejellifjaft gelörtigen $23 e r t h e$ oent einzelnen Theil. babern nad) Magagabe ihres ?utheirs;

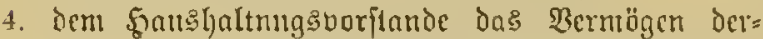
intigen Şaughaltungsangehörigen, deren CFin= fommen iljm gemäßs § 11 des Centommenjteuer. gefesces bei Der Beranlagung jur Cinfommenjteuer hitzuzแtediten i[t.

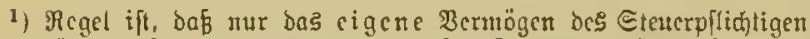

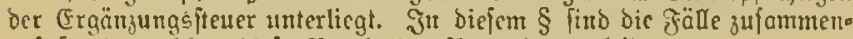

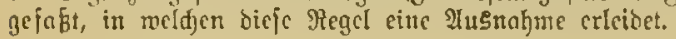

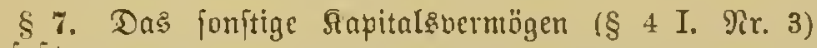
แmfกตBt:

a) berzinslide und unberzinsliche, verbriefte und un= verbriefte Sapitalforderungen jeder $\mathfrak{A}$ :t, einjuliežs

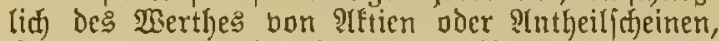

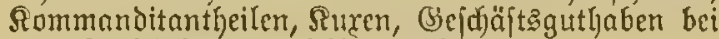
(3) enoffenjwaften, Bejadäft:antheilen und anderen (Sejellidjajt:einlagen;

b) Gaares (Seld deuticher Währung, fremde Beldjorten,

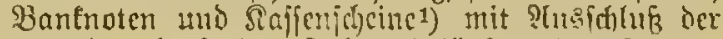
aus den laufenden Jahrescintünten des Sicuer: pflidtigen (\$ 7 ies (Einfommenftenergefeßses) bor: handenen Beftände, fowie (3)old unt Eifler in Barren,

injomeit die $\mathfrak{B e r t h e}$ ju a und b nidjt als Theile

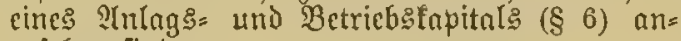
jufehen find;

c) Dell STapitalmerth der Red)te auf R(panagen, Reuten,

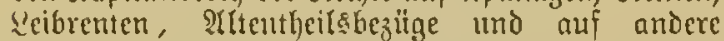
periodijue geidmertlye Sebungen, welche dent Etcuerpffictigen auf feine Rebenzzeit poer auf die Qubenzzeit eines ?Inderen, auf unbejtimmite Zeit ober anf bie Daucr von mindeftens zefn Jaljell,

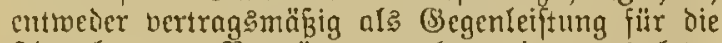
Simgabe non Sermögensmerthen ober nus Ictit= miffinen Rerfügungen ober Fnmilienftiftungen vier nemöge lous:gefeklicher Beftimmung jujtehen.

Die Beftinumg ju c findet feine ?tumendug a

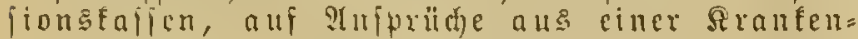
oder llnfaIl=,2) oder ber gefetzliden Jnnaliditäts: oder getersoerficherung, auf fenfionen, welde mit Rüffidt auf cill iriberes ?luctes= oder Dienfthälaib gezablt werben, fomic auf gituten,

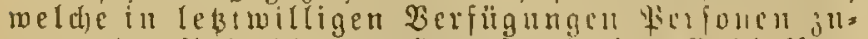

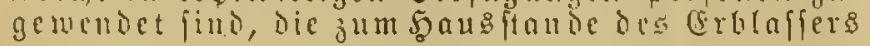

gelört und in einem Dienjuerbätnif zu dem= ferben geitanden baben.

1) Pur turrentes Selo, feine Düngammlungen.

2) (ES mad) bier teinen llnterihied, ob cs fich un eine gejestid

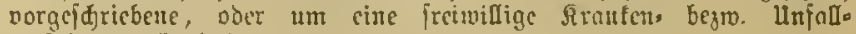
verfidjerting handolt.

3) 3n dicfem galle tamm dagegen nur dic gejeslide, b. h.

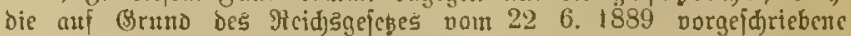

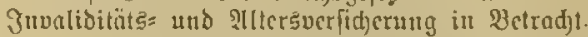

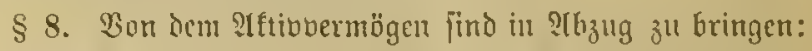

1. Die dinglid)en und perfönlidfeu Sapitalfe)ulden des

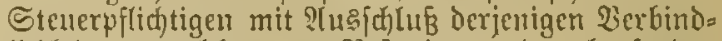
(ide)feiten, voeldje zur Beftreitung ber Inufenien Sousl)altungsfojten eingegangen find (Fons:

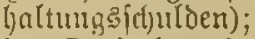

2. Der fiapitalmerth ber nom Stcuerpflichtigen oier

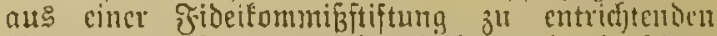
Ylpanagen, Renten, Ritentheile und fonfsigen periodifden, geldwerthen Reiftungen, all meld)e die

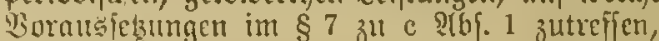

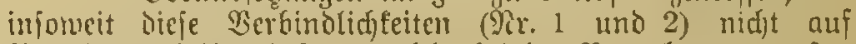
Sermögenstheilen 'Gaiten, melche bei der Beranlagung nufer Betrndjt jut Iajpen find (\$ 4 III).

(Erftrent jich Die Befteuerung lediglide auf bie im $\S 2$ II zи a uni b bezeidneten Bermögenstheile, fo find mur dicjeni=

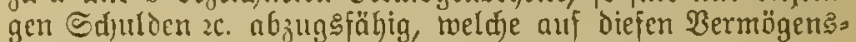
ibeilen baften oder für beren Ertwerb aufgenommen fino.

Berbindtidfféten, meldje ungetheilt zugleidy anf fteuer. faren und nid)t fteuerbaren Bermögenstheilen hajten, fommen bou dem erfteren nur nach dem $\mathfrak{B e r h j a ̈ l t n i f f e ~ d i c j e s ~}$ Theiles zu dem Bejammtbermögen in $\mathfrak{A b z u g}$

\section{Werthbeftinumung.}

§ 9. Bei Beredjnun und Sdjäłung des fteuerbaren Bermögens wird der $\mathfrak{B}$ eftand und gemeinte $\mathfrak{B e r t h}$ der cins zelnen Theile deffelben zur Beit ice Beranlagung (2ier: mögensangetge) ih (Srunde gelegt, foreit nid)t im शiad). iteljenden etwas ?tnderes beftimmt ift.

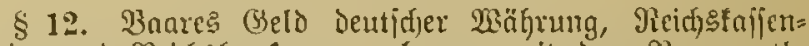

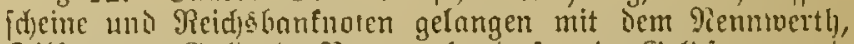
Silber und Bsold in Barren, forwie frentive Belojorten mit Dem Berfaulstwertl) in Injaţ.

Эn llebrigen find werthpapiere, twenn diejelhen in Deutffland einen Börienfurs baten, nad) dirjem, anderen= falls nad) ifrem Berfaufswerthe zu beranjd)lagen.

?llle fonftigen sapitalforderungen und Sfullen find mit Doun Pennwerthe in ?lufatz zu bringen, infojern vidjt die

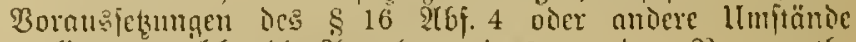
norliegen, weldhe dic ?tunalyme eines un dem gimumerthe abweidyenten vierfaufsuerthes begrïmben.

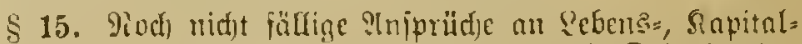

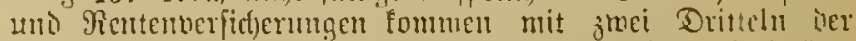
Eunme Der eingezahlten Srämien ober Siapitalbinäge, falts nher Der Retrog nadgerviejes wird, für melden bie

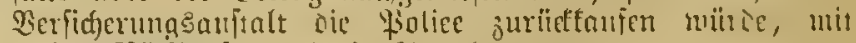

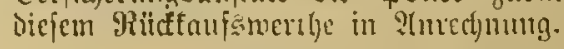

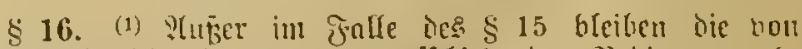

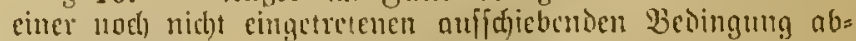
hängigen Sied)te mo Sajtcn außer Betradjt.

(2) (3) .....

(1) Llnbeitreibliche forternugen bleihen aufer Infaz. 


\section{Beftencrung grenze.}

§ 17. Bux (Frgänzungsteuer werden nicht Gerangejogen:

1. diejenigen \$erjonen, deren ftenerbares $\mathfrak{V e r}=$ mögen ben (Gefommtwerth bon 6000 Dinet nid)t ïberiteigt;

2. Diejenigen lierfonen, deren nad) Dinzgnbe des (5infommeniteuergejeses zu bered)nen= Des Sohreseinfommen den Betrag voll 900 Jiare nidit überfeigt, infofern ber (S) jammerorth ibres jteuerbaren $\mathfrak{B e r}=$ mögens nidgt mehr als 20000 Mart bes trägt:

3. meiblide fierfonen, weldye minderjährige familienangebörige zu unterbalter gaben,

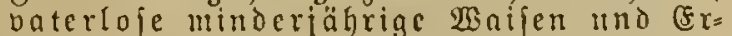
werbsunfälige, infofern bas fteuerbare Fermögen Der bezeidneten Fierjonen den Betrag von 20000 Rare und das nof Deaśabe des Einfommenitenergefebes ju beredinende Jabreseinfommen derjelben Den Betrag oon 1200 Daré nid)t über= iteigt.

\section{Steuerfärąe.}

\section{Stcuertarif.}

§ 18. Die Ergänzแngsfftcuer beträgt bei cincm fteucr= baren Bermö̈gen von

\begin{tabular}{|c|c|c|}
\hline meljr als & 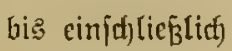 & jälırlict) \\
\hline Dif. & $\mathfrak{M f}$. & $\mathfrak{R} \mathfrak{k}$ \\
\hline 6000 & 8000 & 3 \\
\hline 8000 & 10000 & 4 \\
\hline 10000 & 12000 & 5 \\
\hline 12000 & 14000 & 6 \\
\hline 14000 & 16000 & 7 \\
\hline 16000 & 18000 & 8 \\
\hline 18000 & 20000 & 9 \\
\hline 20000 & 22000 & 10 \\
\hline 22000 & 24000 & 11 \\
\hline 24000 & 28000 & 12 \\
\hline 28000 & 32000 & 14 \\
\hline 32000 & 36000 & 16 \\
\hline 36000 & 40000 & 18 \\
\hline 40000 & 44000 & 20 \\
\hline 44000 & 48000 & 22 \\
\hline 48000 & 52000 & 24 \\
\hline 52000 & 56000 & 26 \\
\hline 56000 & 60000 & 28 \\
\hline 60000 & 70000 & 30 \\
\hline
\end{tabular}

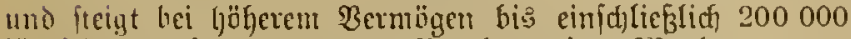
für jedc angefangene 10000 Piarf um je 5 griarf.

Rei Rermögen bour meln als 200000 Mart bis cin= isfliefblid) 220000 Mart betrïgt dic Steuer 100 giart und freigt bei lyäherem Dermögin fiir jebe nngejangencu 20000 Jianf un je 10 Siart.

\section{Bervildfid)tigung bejonberer Berłältrifïe.}

\$19. Berjuncl, Deren Rermögen 32000 giat nicht überjtrigt, merden, ment iie nicjt zur (Einfummunteuer

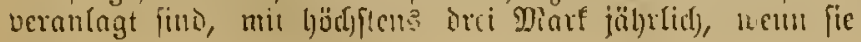

3t Den erften vier Stufen derjelben veranlagt find, hödjiteng mit cinem um juei $\mathfrak{M a r f}$ unter ber bon ilunen zu zahlen= den Einfommenftcuer verbleibenien Betrage zur Ergänjı!ng = fteuer herangezogen.

Etencrpflictigen, meldjen auf (binnt des $\S 19$ bes Einfommenjteuergejesces cilte FrmäB̈igung der crinfommen=

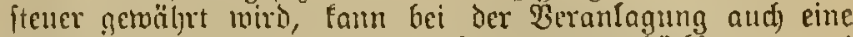
Ermäвigung der (Ergänßzungefteuter um höch)ten? zwei Stufen gemälert werden, jofern das iteuerpflid)tige $\mathfrak{B e r}$. mögen nicf)t mel)r alz 52000 Marf heträgt.

\section{IV. Ḋicranlagıng.}

\section{Drt uto Borbercitung ber Peranlagung.}

$\$ 20$. (1) Die Beranlagumg erfolgt an Demjenigen Drte,

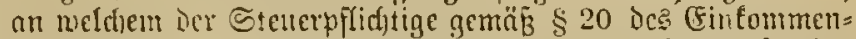

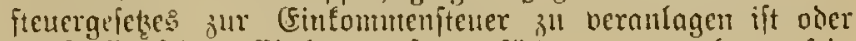
im Jalle feiner (sinfommenfteuerpflit)t zu vernalagen fein mïrde.

(2) .....

§ 21. (1) Die ßerfonenftands̊anjnalgme (\$ 21 des (Fin=

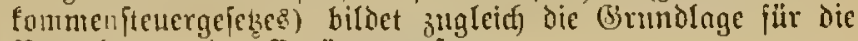
Beranlagung der (Ergänzungsftcuer.

(2) .....

\section{Beranlagunggoerfahreu.}

§ 22. (1) Dic Beranlagung der Steuerpflicftigen erfolgt gleidjzeitig mit Der Beranlagung der (Finfommenjteucr inrren

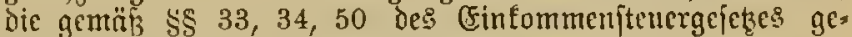
bildeten 2eranlagungstommififionen.

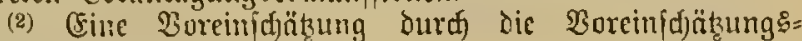
fonmiffion findet nidjt ftatt.

§ 23. (1) Jïr jeden Beranlagungsbejirt wird ein

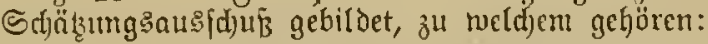

1. Der Borfitzende Der Veranlagungsfommiffion oder ber von Demfelben zu bezeidjnende Stelfuertreter;

2. mindeitens bier Mitglieder, von meld)en żoci ftündige dıtth die Negierung ernnnnt, die übrigen aus ien gemähIten Mitgliedern (ifelfoertretenden

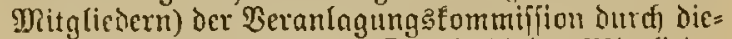
felbe ahgeoronet merden. Die Bahl ber Ditglieder beitimnt der Finanzminifter.

(2) (3) .....

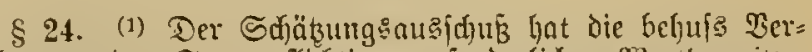
anlngung ber Stenerpflidjtigen erforderliden $23 e r t h e r m i t t e=$

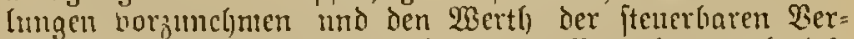

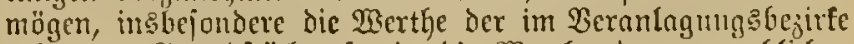
helegenen Grunditïtfe, fomie die Werthe der gemerblidjen 2nlage = mo Retricbstapitalien ju begutadsten.

(2) (3) ....

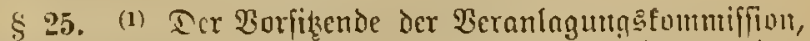
meldier zugleid) bie Эnterefien ies Strates vertritt, hat das Beranlagungsuefd)äjt ju leiten und ift Dafitix nerantwortlicf), dof die gcjamme Beranlagumg in jeinem Bejizf mach ben

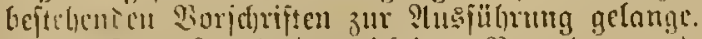

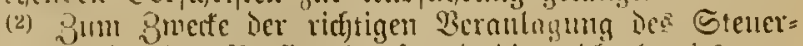
bffichtigen loat der Borfikenile, foldeit dies nicht berrits zum

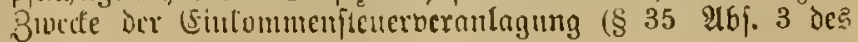




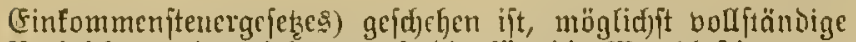
Nad)ridjten cinzuziehen, auf Dic für bie Werthbejtimmung ber ftenerbaren Bermögensttheile erforierlidjen llnterlagen 3u bejichaffen.

(3) (4)

(5) Sämmtlicje Stnaţి= แmo Sinnmunalbeljörden uno Beamte, mit 2โnznahme ier Tiotare, haben die (Finfid)t aller dic Rermögensuerbältnific der Steuerpflidtigen be= treffenden B̈̈djer, Offen, Mlfunden $2 c$. jll geftatten, und auf

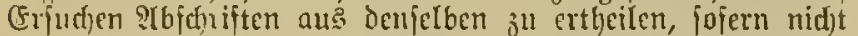

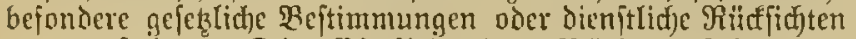
entgegenfteben. Die (Einjidit der Büder, Aften $2 \varepsilon$. ber Spartafien ift nidft geftattet. ${ }^{1}$ )

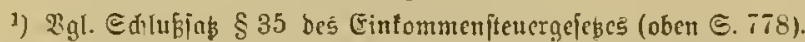

\$26. (1) Die Steuerpflidtigen find be= ledtigt, ${ }^{1}$ ) behufg der Beranlagung dem $\mathfrak{B}$ orjiken= den ber Beranlagungetommiffion ifr fteucrbares Bermögen anzugeben oder diejenigen thatiäd)= (id)en Mittheilungen zu maden, beren die Ber. anlagungefommiffion zur Sdäßung des 2 er mögeus bedarf (

(2) 8 u Bermögensิnnzeigen fiir ßerfonen, weldje unter bäterlidjer (3emalt, Ziflegidjajt oder $\mathfrak{B}$ ormundfdyaft fteljen, find deren gefeşlidje Bertreter befugt.

(3) .....

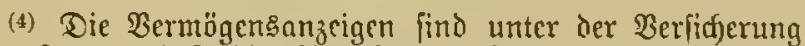
3u eritatten, das bic ?(ngaben nad) beftem Wiffen und (Serwiffen gemadit find.

(5) .....

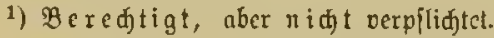

\$ 31. Die Rommiffion fetst Den nach ifrem (Frmeffen jutteffenden Steuerjaz auf Sirund der ftattgehabten (Ex= mittelungen feft.

§ 32. Das Ergební̄ ber Beranlagung bat ber Bor= fikende der Beranlagungsfommiffion Dem Steucrpflidtigen mittelit einer jugleid) eine Belefrung über Dos Red)tEmittel der Berufung enthaltenien Bujdrift befannt zu madjen, toeldie, fofern audf) die Beranlagung zur (Finfommenitenter ftattgefunden ljat, mit ber Benadfridftigung ïber Diejelbe (§ 39 des (Fintommenfteuergejeses) berbunden werden faun.

\section{Reditgimittel.}

a) Berufung.

§ 33. (1) Begen bas (Ergební̉ der Beranlagung fteht jotoohl Dem Stcuerpflidtigen, als and Dem Vorfizenten

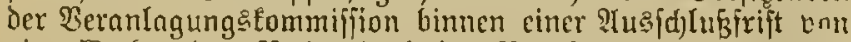

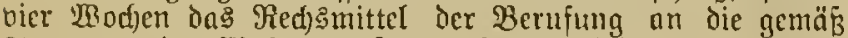
$\$ \$ 41,50$ bes (Finfommenjtcuergefetes gebildete Berufungs: fommiffion zu.

(2) Die $\mathfrak{B o r f d j i f t}$ im $\$ 40$ शtbi. 2 des (Einfommenjtencr= gejekses findet finngemäßze 2Tnsendung.

(3) Dic Berujung faum nrit der etmaigen Bernfung gegen die Cinfommenteuerberanlagung in denifelben Sdyrift= fake angebradjt merden.

\$ 34. Der Borfitzente ier Bernfungefommiffion hat

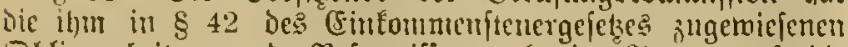
Soficgenteiten mo Befugniffe nud in vezug auf die Ergänzungsfifener malyzumelymen.
\$35. (1) Dic Berufungäfommiffion entfdecidet über alle gegen Daะ Berfahren und die Entidjeidungen der $\mathfrak{B e r}=$

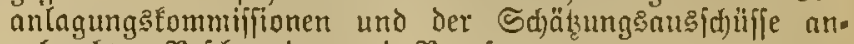
gebradten Befdrerden und Berufungen.

(2) (3) .....

(4) Die Berufungstommiffion hat die Bermögenenad)= meifungen forgfältig ju brüfen; die bou ifhr gejogenen Erinnerungen find bei ber nädjften Veranlagnng (\$ 37 ) zu beadten.

(5) .....

\section{b) Befdiverde.}

§ 36. (1) Brgen die (5ntfdecidung der Berufungs: fommiffion fteht fowohl dem Steuerpflichtigen als nud dem Borfitsenden ber Berufungstommiffion dic Beidjoerbe an

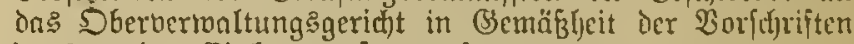
im $\$ 44$ des (Fintommenteuergejetzes jul.

(2) Die Bejdjmetde fann mit her etronigen Beidjuerde bezüglid) der (Finfommen jteuerberanlagung deffelben $\$$ sflicfrigen in dem näntlidjen Śd)riftjalze angebrad)t werden.

(3) .......

(4) Эm llebrigen finden auf die Bejdwerben und auf bas Verfahren zum 3twedfe ber (Fntjdeinumg berfelben dic §§ 44 bis 49 bes (Finfommenfteuergefescs ?tntocndung.

\section{V. Žranlagungsperiode und Žerändenung der veranlagten Steuer interfialo oerfelben.}

§ 3\%. (1) Die Deranlagung Der Ergänzungsftencr ex= jolgt für eine \$eridde bon drei Steuerjahren, zum eritel Male jebod fiir die Beit bom 1. 2lpril 1895 bis jult 31. März 1896.

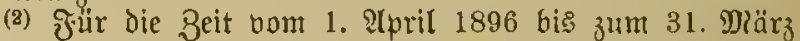
1899 crfolgt Die J゙eftieţung Der Beranlagung Durch) Riönig= licfe Beroronung.

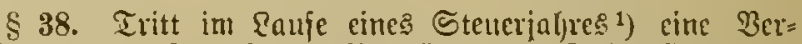

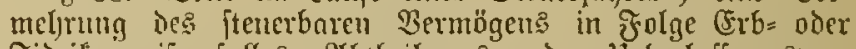

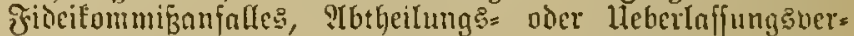
truges zwijelen Eltern uno Sindern, Edjenfung oder $\mathfrak{B e r}=$

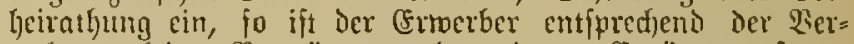

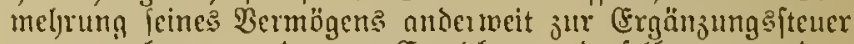
zul beranlagen und zur Entridftung derjelben bon dem

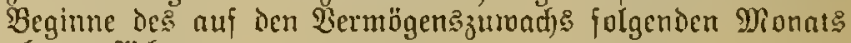
$a b$ berpflict)tet.

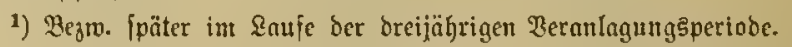

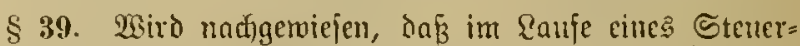

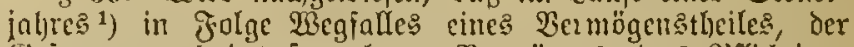
(3ejammtmerth des fteuerbaren Vermögens eines 13 flid)tigen um mel) als ten vierten Tlyeil hermindert worden ift, oner da $\bar{B}$ der megfallende Theil ic 2 Bermögens andermeit jur (Ergänjungsiteuer herangezogen trird, fo fann bon Beginn des alf den (5intritt der Permögensuerminderung folgenten Monate ab die Ermäfigung der Ergänzungefftener anf den tem veıbliebenen Bermögen entipredjenden Steuerfats be= aniprud)t werden.

1) $\mathfrak{g}$ [. 9 Inm. ] зи $§ 38$.

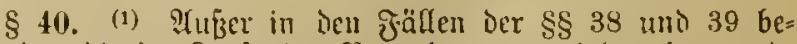
grintiet die in Ennje Der Beranlagungsperiohe cinnetente

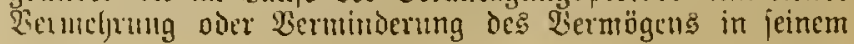


Beftande oder Berthe teine Beränderung in der fdion ex= folgten Beranlagung; ......

(2) ......

\$ 41. (1) Wegen Deక Berfahrens bei den Steuer= ermäbigungen (\$ 39) und bei Den 2 bgangştellungen finden

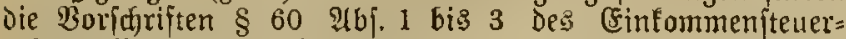
geiebes finngemäß̈̌ ?lnwendung.

(2) (3) .....

\section{Stemererfefoung.}

\$ 42. (1) Die Grgänzungs̊fteuer twird gleidfzeitig mit der Cinfonmenjteuer erhoben.

(2) ......

(3) Die Borifuriften $\$ \$ 62$ bis 64 des (finfommenltener:

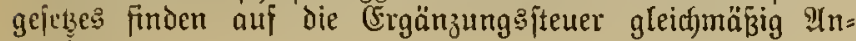
เoendung.

(4) $\ldots \ldots$

\section{Straffieftiutututg.}

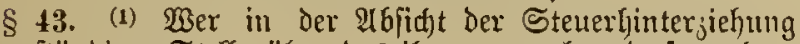
an zultändiger Stelle über Das ilym zuzuredhnende jtenterhare

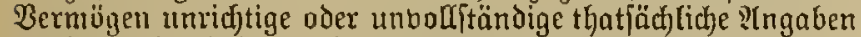
mad)t, wiro mit dem zehn= bis fünfundzmanjigfadjen Betrage der Э̧aljesfteuer, um melche der Staat berfïrzt roorden ift oder verfiurzt werden jollte, mindejtens aber mit ciner Geloftraje voll hundert Marf bejtrajt.

(2) Эit eine unridjtige Ifngabe, weld)e geeignet ift, eine Berfiirzung der Steuer herbeizuführen, zwar wiffentlid, aber nicht in der \&hfiegt der Stenterhinterziehung erfolgt, fo tritt (Seloftraje bon jwanzig bis hundert Mart ein.

(3) Strafirei bleibt, wer feine unridtige oder unvolls ftändige IIngabe, bebor ŜInzeige erfolgt, oder eine Unter= jutd)ming cingeleitet ijt, an jujtändiger Stelfe beridgtigt oder ergängt uno die vorentlyaltene Stenter in der ifm gefetzten Jirift entridftet.

\$ 44. (1) Die CFinzichung der hinterzogenen Steuter erfolgt neben und unabhängig von der Strafe.

(2) Die $\mathfrak{B}$ oridriften $\& 67$ श.6j. 2 und 3 bes Eintommen= itenergeietzes finden finngemäßze STmendung.

\section{Sณ fufbeftimmungen.}

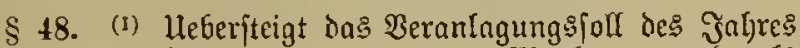
$1895 / 96$ ben Betrag bon 35000000 Marf um mehr als 5 Brozent, fo findet in dem Werhältnis des Mehrbetrages zu Der genannten Sirmme eine Serabjeķung der fämnt= lichen im \& 18 bejtimmten Stcuerjätze ftatt.
(2) Diefe 5ुerabjełzung wird in angemeifener 2thrundung omrdj Söniglidfe Berordnung feitgeftellt. Die in der Letzteren beftimmten Säksen find für das Steuerjahr 1895/96 und die folgender safie majgebend.

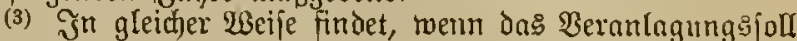
des Эahres 1895/96 hinter bem Betrage bon 35000000 Mtarf un mefir als 5 grozent zurïdébleibt, eine entipredjende (5igöhung ber im $\$ 18$ dicies Sejebes beitimmten Steuc:

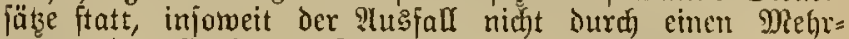
extrag ber Einfommenfteuter für das รahhr 1895/96 ilber die Summe bon 135000000 Marf und Dnth die Binfen Der im § 49 bezeidyneten Uleberidülife gededft roird. Dieje

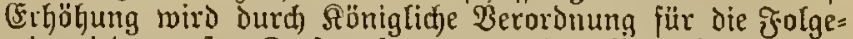

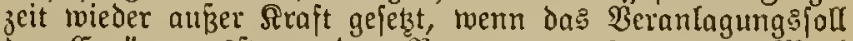
ber (Ergänzungsftener den Betrag von 35000000 Marf zujüglid eimer Steigerung bon 4 Brojent fïr jedes auf 1895/96 folgende Steuerjabr erreid)t.

\$ 49. (1) Meberjteigt dic Simnahme an Finfommenjteuer

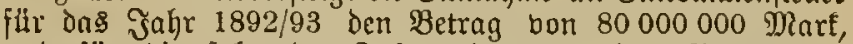
und für die folgenden sahre eimen nut je 4 \$rozent er= högten Betrag, fo find die lleberidjiffe und deren Binjen

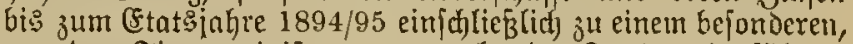

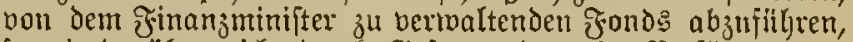
fomeit daritber micht burd) (Sejes nuderweite Berfïgung ge= troffen ift.

(2) $\ldots . .$.

(3) Dex Fonios felbft ift am 1. 2Tprit 1895 zlt den all= gemeinen Staatsfonds 3u bereinnahmen.

(4) Die $\$ \S 82$ bis 84 bes cinfummeniteuerge etses treten mit der Bertündigung bicjes (jejetzes außer §raft.

\$50. 2ugejefen bon der bejtimmung in $\S 48$ ift cine Beränderung der (Ergänjungsfteuerjätze mur bei gleid\}zeitiger

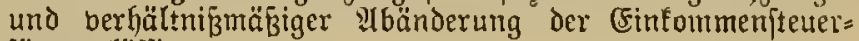
fätze zuläplitg.

§ 51. Bei Der $\mathfrak{B e r t h e i l u n g ~ u n d ~}$ Pujbringung öffentlidjer Enften nach Maggnbe direfter Staatsfteuern fommt die

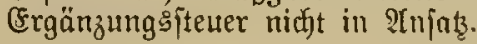

§ 52. Diejes (Sejek tritt nur gleicfzeitig mit Dem (Bejeks

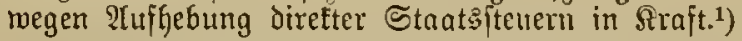

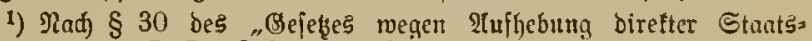

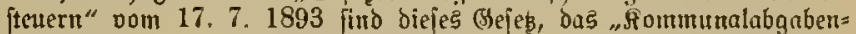
geję" und bas "Ergänzungsjteuergefę" ain 1. Âpril 1895 in Rraft getreten.

§ 53. Der Jinanzminifter wird mit der ?(usfïl)rung diefe: Bejekzes beauftragt.

Lirfundlidf $2 \varepsilon$.

(3egeben Reues ßalais, den 14. Juli 1893.

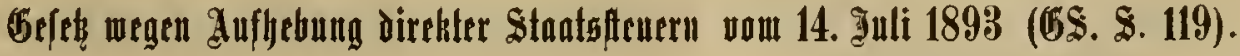

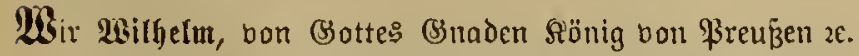
veroronen mit 3nitimmung beider ร̧äujer bes \&and= tage: unjerer Monardfie für den Umfang Derjelben

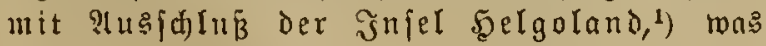
jolgt:

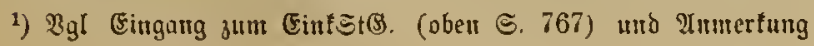

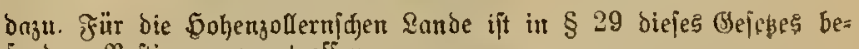
fonbere Beftimmung getroffen.

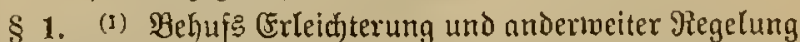
der öffentlidien Eajten der (Semeinden (Gut:sezirfe) twerden die folgenden bireften Stenern gegeniiber der Staatsfaffe nufer saebung gefezt:

1. Die nach Den Bejęzen bott 21. Mani 1861 (BSS. 
ङ. 253 mo 317) fotnie nady ben hierzu ergangenen ergänzcuden und abändernthen (Sejeken beranlagte (3)rund = แno Bebäudefteuer,

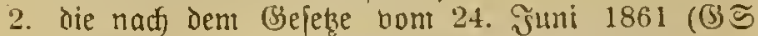
5. 205) veranlagte Bewerbe = mond Betriebsitener.

§ 2. (1) F̌erner toerden anger Sूebung geję̧t:

1. Die non Den Bergmerfen in ien älteren redit $t=$ rheinijhen Sandestljeiten zu entridjtende ?uffid)t: ifeuer und Bergmertsabgabe

2. Die in den ïbrigen Randestbeilen zu entridtende Bergreettiabgabe . . .

§3. (1) Die Borjdriften Der in den $\S \S 1$ und 2 be= zciducten (bejeßze bleiben, fomeit nidjt in Dem gegenmärtigen Scicke und in Dem Sommunalággabengefeze Plbmeidjendes bejtimmt ijt, in Frajt.

(2) Die Beranlagung uno Berwaltung der Brumb=, Sebäude= und (Serwerbejteuer rwird, forweit nid)t in dem

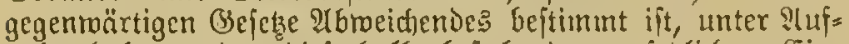
red)terhaltumg Der diejerhalb bejtehenden gejeżliden (Eit= ridjtungen boin Staate für dic Broeffe der fommumalen Bejteuerung ausigefïhrt ......

§ 5. (1) Die beftehenden gefeblidjen $\mathfrak{B e}$ timmungen, meldec bon der $\mathfrak{B e r a n l a g u n g}$ der im $\S 1$ Nr. I uno 2 be= zeiduneten Steucrn oder von einjelnen derjelben andermeite

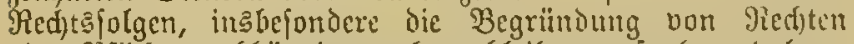
oder Bflidten abfängig mad)en, bleiben aufred)t erbalten; Foreit hierbei Die Entriffung foldfer Steuten boransgejetst wiro, treten an die Stelle der zu entrifjtenden die beran= lagten \$Beträge.

(2) 2 uf die Beịtmmungen im $\S 9$ I $\mathfrak{N}$ r. 4 drs Csin= fommenitenergejetses bom 27. Jumi 1891 (3ङ. ङ. 175) findet dieje $\mathfrak{B}$ orjebrift feine 2 (nwendung. ${ }^{1}$ )

(3) ......

1) oben 5. 779 .

$\S 11$. (1) (2) ....

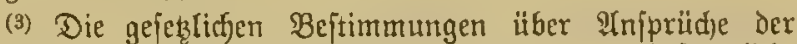
(Semeinden auf Mitverwaltung ifrer faffen durd) ftaatlid)e Saffenbeamte merden aufgehoben.

§ 14. (1) Dic Soften Der Beranlagung uno Berraltung Der Steuern retben, forocit fie nid)t bured die den (jemein= den hierbei übertragenen (Bejuäjte entjtehen, aus der Staats= faffe bejtritten.

(2) Das 2uffommen an (Gebühren, Soften und Strafen

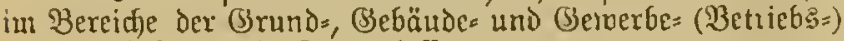
Steuer fliest in die Staatsfajie.

(3) ......
\$15. (1) Die Sojten ber 5ebung und Beitrcibung der Steuern (\$§ 11,13) find von Den Bemcinden zu tragen.

(2) ......

§ 16. (1) Dic gejeblidjen 3 cjtinnnungen über die $2 \mathrm{~ns}$ fpriide der Bemeinden (Butsbejirfe) auf Den Bejug vout Bergiitumgen fiir die bei Beranlagung der Betwerbejteuer unD Der (Emtommenifener ifnen ïbertragenten (jejhäjte

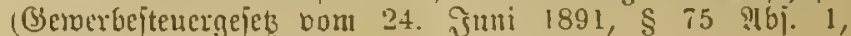

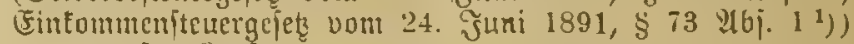
treten auzer firajt.

(2) Durd) R̈öniglide $\mathfrak{B e r o r o m u n g ~ E a n n ~ d e n ~ ( B e m e i n d e n ~ u n d ~}$ feloftftändigen Gitsbejirfen die Berpflicftung auferlegt veroen, in igren Bezirfen die (Flementarerbebung der fämunt= lidjen direften Stantşiteuern, der Domïnen=, Rentenbant=

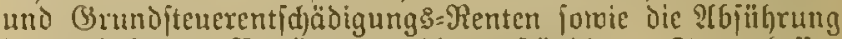

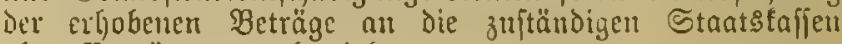
ohne Bergütung zu bemirfen.

1) Dben s. 786 .

§ 28. (1) Das Gejez, betrefiend llebermeijung von $\mathfrak{B e}=$

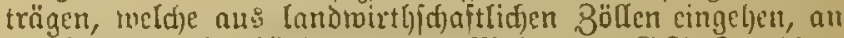
die Rommunalverbände, vom 14. Mai 1885 ((5). (5. 128)') tritt auḡer seraft.

(2) ......

1) Die fogenante lex Huene.

§ 29. (1) Tie Beftimmungen der $\S \S 1$ bi: 27 finden auf Die 5ohenzollernidjen Rande teime Ulmmentung.

(2) Die Ungeitaltuth Des Syftems der Direften Stenem in Diejen Randen bleibt einem bejonderen Bejebe vorbehalten.

(3) Bis zum Erlajie eines pldyen Gejetzes twird für die 5ohenzollernjuen \&ande vom 1. 2lpril 1896 ab ein fefter Эafjresbetrag bon 62020 DRarf aus Der Staatstajie ilber: wiejen.

(4) ......

§ 30. (1) Das gegentwärtige Bejets tritt mit dem 1. S(pril 1895, jeood) mur glcid)zeitig mit den $\Omega$ rom= munalabgabengejeţe und dem Ergänzungejtenergejełse in 尺ra $\left.{ }^{1}{ }^{1}\right) \ldots \ldots$

(2) Die $\mathfrak{B e r a n l a g u n g}$ fïr die 3mecfe der tommunalen

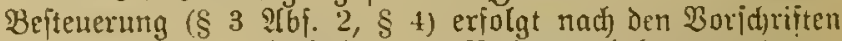
dicjes (3ejeţes junädjit fiir das Fedjunngsjahr 1895/96.

(3) .......

1) शุe orei (Befęe fino am 1. 4. 1895 in Fraft getreten.

§ 31. (1) Die Minifter Der Finanzen uno des Jnuern werden mit der ?lusführung diejes Befetzes beauftragt.

Urtundlid) ze.

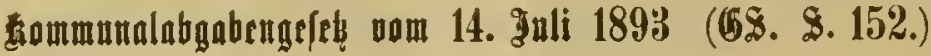

EFingang wie beim EintSich. (obert 5 767/68).

\section{abeit I. Gemteindeabgaber.}

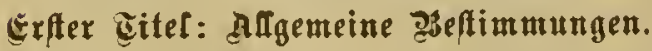

§ 1. (1) Die Gemeinden fins bered)tigt, sur Dectung

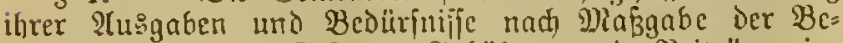

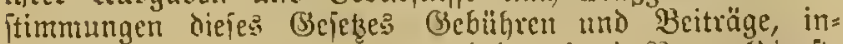
birefte und direfte Steucrn ju erhehen, forvie Raturaldienite zu fordern.
§ 2. (1) Die Bemeinden dürfen bon der Befugniß̧, Steuern zu erheben, nur injomeit (Bebraud) mad)en, als die foritigen (Finnahnen, insbefondere aus iem Gemeindeber= mögen, als (Behïlbren, Bcirrägen uno boun Stante oder bon meiteren fonmumalberbänien den Bemeinoen ïber=

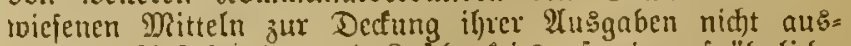

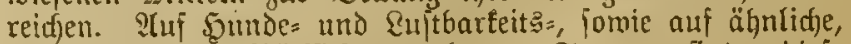
Dur(i) bejundere Riulfifiten gebotene Stenern findet Dieje Bejtimmung teine ?(umendung. 
(a) Durd birefte Steuern dari nur der Betrag aujge:

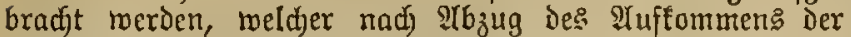
indireften Steuern bon dem gefammten Steuerbedarje ber= bleibt.

§ 3. (1) Benerblidje llnternelymungen Der (B)meinden find grundfäķlich io zu vermalten, baf̧ durch bie (Fin= nahmen mindefterts bie gefammten burd) bic Unternehmung

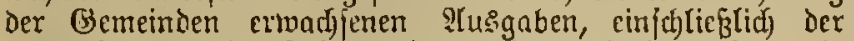
Berjinfung und der Tilgung des Sinlagetapitals, aujgebradt toerden.

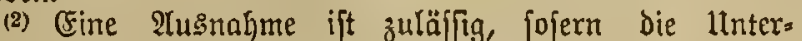
nefrnung zugleich einem öffentlichen J̦nterefie dient, weldfe: andermaals nicht bejriebigt wird.

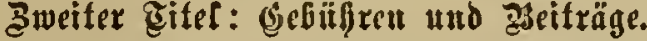

§ 4. (1) Die Bemeinden fönnen für die Benuburg

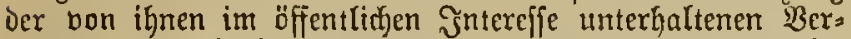
anftaltungen (Înlagen, IInftalten umb (Fimrid)tungen) bes jondere Bergütungen (Ģsbübren) erbeben.

(2) Die (Erhebung von (Bebühren hat zu eriolgen, twenn die Beranftaltung einzelnen Shemeindeangehp̈rigen oder cinzelnen SIaffen von foldjen vorjugsmeije zum Sortheile gereid)t, und fotneit bie $\mathscr{A}$ usgleidfung nid)t Durch Beiträge oder eine Mehr = oder Minderbelajtung erjolgt. Die Ge. bührenjäßze find in Der Regel jo zu bemeifen, das die $\mathfrak{B e r}=$ maltungs: und Ilnterljaltungsfoften der Beranitaltung,

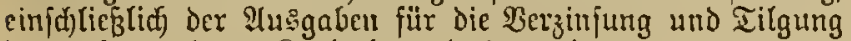
bes aufgetwendeten Seapitals, gedect rerben.

(3) ......

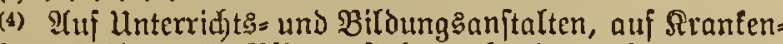
bäujer, Şeil= uno Piflegeanjtalten fotvie auf borztig: meije den Bedüriniffen der unbemittelten Bolfstlafien bienende $\mathfrak{B e r a n j t a l t u n g e n}$ finden boritehende $B$ eftimmungen

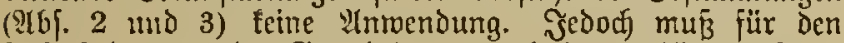
Befud) der von den (Semeinden unterhaltenen böheren Rehrs

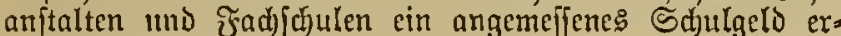
boben werben.

(5) (6) .....

§ 6. (1) Die Semeinden, Imtọhezirfe, 2(emter und Landbürgermeiftereien find bered)tigt, fïr die (Senefunigung und Beauffïbtigung bon Reubauten, Umbauten uno andere baulichen Serjtellungen, jorvie für bie orbunnģ= und feuer: polizcilidje Scauffid)tigung von Meffen und Märften, von Mifitaufiubrungen, Schauftellungen, theatralifaen Bor= jtellungen und fonjtiget \&ujtbarfeiten Bebüloren zu $\mathrm{cr}$. heben. Die Erhebung von \&ujtbarteitsiotenern idjließst Die Er hebung bon Sebühren für Die Beaufitiftigung Der \&ujt. barteit aus.

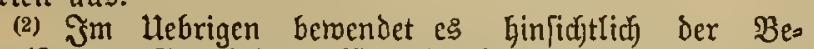
fugnif ber Bemeinden, für einzelne Saandungen ifrer Drgane (Sebühren (Bermaltungsgebütgren) zu erbeben, bei Den bejtehenden Beftimmungen.

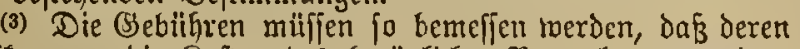

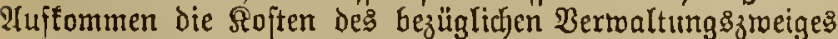
nicht überiteigt.

§ 7. Sebüfren find im Boraus nach feften Rormen uno Säken zu beftimmen. Fine Berücfifidtigung Unbe=

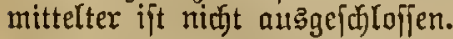

§ 11. (1) Die Borfahriften des Bejetzes betreffend Die Frhebung bon Darttitanogeld, bom 26. 2⿰亻pril 1872 (SSS. ธ. 513) bleiben unberibut.
(2). EGenfo behält ę bei Den Bejtimmungen der Bscictic

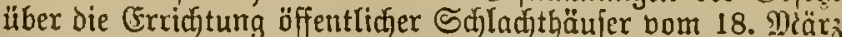
1868 (ङङ. ऽ. 277) und 9. März 1881 (ङ3ऽ. ऽ. 273)

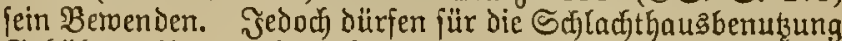
Gebühren bis zu einer foldjen \$öblje erhohen raerden, Da burch ifh jöfrtidjes 2luffommen Die Soften Der Unterhaltung der Inlage und bes Betriebes forie ein Betrag von 8 \$rozent des Inlagetapitals und Der etroa gezahlten fsnt= jdjäbigungsfumme gederft werden. . . . . . .

(3) ......

§ 12. Эn Badeorten, flimatifdjen und fonftigen §ur= orten fönnen bie Semeinden für bie Serftellung und Unter=

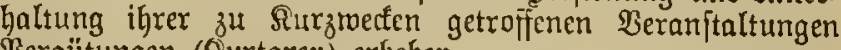
Bergïtungen (siurtaren) erheben.

\section{Dritter Eifel: Gemeitbefteuern.}

\section{Erfter 2lbj ḩn.: Indirelte Bemeindeftenern.}

\$13. (1) Die Genteinden find zur Erhebung indirefter Steuern innerfalf ber Durd) bie Reichsgelebe gezogenetl Srenzen bejugt.

(2)

§ 14. (1) Steuern auf Den Berbraud bon Fleijd, (Setreide, Mehl, Bactwerf, Sartoffeln und Brennftoffen aller श्रt bürfen nidjt neu eingefïlfrt oder in igren Sätzen erb̈̈bt merden. Die CFinführung einer wildoret= und Beflügel=

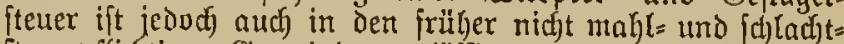
fteuerpfliçtigen (Gemeinden zuläffig. Die Steuerjätze fönnet afmeidend bon ben Borfdriften Des ErLaffes vom 24. Afpril 1848 (ङङ. ङ. 131) bemefien werden.

(2) Megen Forterbebung der Sd)ladjtiteuer betoendet es bei den Beitmmungen deg Bejełes bom 25. Mai 1873. (अS. ऽ. 222.)

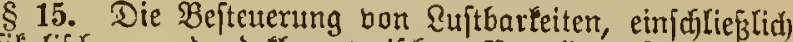

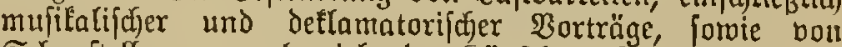
Sd)auftellungen umberjichender Siünfter, ijt den (S)emein= den gejtattet.

\$16. Die Bemeinden find befugt, das Salten bon Sunden ju befteuern. Die in biejer Beziefjung zur Beit befteljenden gejekglidjen Borjdriften werden aujgeljoben.

$\S$ 1\%. Die bejtelenden Borjariften über die Berwen= bung des 2uffommens indirefter Steuern für hejtimmte 3medfe (Sioften der Armenpflege u. f. w.) werden aujgehoben.

§ 18. (1) Die Cinführung netter und die \$Berönderung beftehender indirefter (Semeindejteuern fann nur Durd) Steuer= ordnutugen erfolgen.

(2) Die Stcueroronungen bedürfen der SSenehmigung.

§ 19. Wegen Der Bejreiung Der Miritärpeifeeinrid)= tungen und äbnlidjer'Militäranjtalten bon Den $\mathfrak{B}$ erbraucfis: fteuern berwendet es bei den beftehenden Beftimmungen.

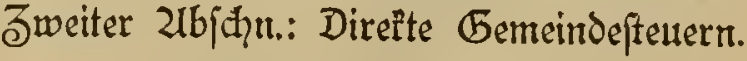

\section{Arlgemeine $\mathfrak{B e f t i m m u n g e n . ~}$}

$\S 20$. (1) Die bireften Gienteindefteuern find auf alle ber Befiteuerung unterworfenen Pjficjtigen nach feften und gleicf)= mäbigen Ojrundjätzen zu vertbcilen. 
§ 23. (1) Die direften Semeindefteuern fönnen bom

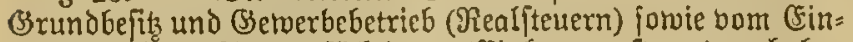
fommen bes Steuerpflidtigen (sintommenftuer) erboben toerden.

(B) Die Cinfommenfteuer tann zum Theil burch $\mathfrak{X}$

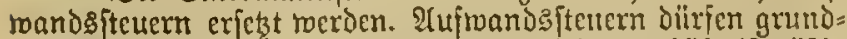
fäblich bie geringeren Cintommen nidjt berljältnifmäß̧ig böber, als bie gröberen belaften.

(3) Mieth's= und Bolunungsfteuern ditrfen nid)t neu ein. gefiithrt merben.

(i) Die Geftefenden Mieths: und Wohnungsfteuern find auf ihre Ulebereinjtimmung nit Den borftehenden 3 efteuerung grumbfäzen und Den fonjtigen Bejtimmungen diefes Sejeţes zu prüfen. Sie bedüfen erneuter, an bie 3uftimmung ber Minifter bes Šnnein und der Jinanzen getundener (je= nefmigung und treten auEer Sraft, wem Die Benehmigung nidjt bis zum 1. Ylpirl 1898 erfolgt ift.

(5) Die (sinjührung neuer und Die Seränoerung beftełen= Der birefter (Semeindefteuem, weldje nidjt it Yirojenten Der bom Staate beranlagten Steuer erhoben roerden, fam nux Durdy Steneroronungen erfolgen.

(6) Die Steueroromungen beoürjen ber (Senehmigung.

\section{Befondere Beftimungen.}

\section{Ricalfteuerit.}

a) Bom Girunobefiz.

\$24. (1) Den Steuexn bom (Brundbefits fino die in der (Semeinde belegenen bebauten und unbebauten (Srund=

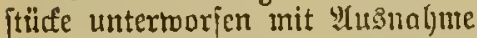

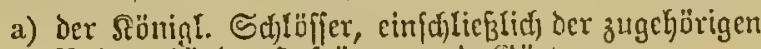
Rebengebäude, \$̃ofuäume uno (Särten;

b) Der einem fremien Staate gehörigen (3rundftücte, aui benen Botidjafts= oder (Sejandtid)aft şgebäude erridftet find, einf(hlieglid) Der auf ibner esrichteten Sebäude, fofern yon dem fremben Staate Biegen= jeitigfeit geroälyrt roird;

c) Der Dem Stante, Den Provinzen, den Sreifen, den Gemeinden oder fonfitigen fommunalen : Der fünden gehörigen (srunoptücte und Bebäude, fojern jie zu einem b̈fentlidjen Dicnfte oder Bebraudfe beftimmt find;

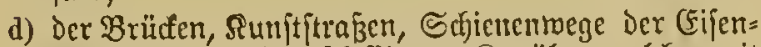

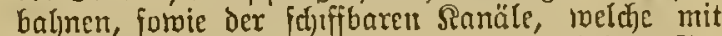
Genehmigung Des Staates jum öffentlidjen (B) braudje angelegt find;

e) Der Deidjanlagen Der Deidyberbände uno ber im öffentlidjen Snlereffe ftantlidf unter (Sd)au geitell =

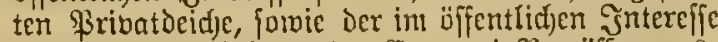

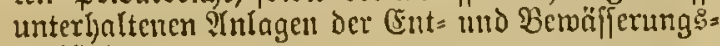
berbände;

f) Der Univerfitäts: und anderen zum öfientlidfen lunterridfte beftimmten (jebäude;

g) Der Sirchen, Sapellen und anderen Dem öffentliffen (3) ottesdienfte gerviometen (B) bü̈rde, forwie Der gottes= Dienjtyicfen (Sebäude oer mit Siorporationsred)ten berjegenen Religion:gejed[ (d)aften;

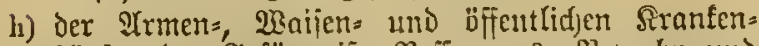
Ђäufer, der (Befängnifo, Bcī̄erung: $=$ Betwahr = und Derjenigen $\mathfrak{W o l t h a ̈ t i g e i t s a n f t a l t e n , ~ b e l d j e ~ b i e ~} \mathfrak{B e}=$ wahrung bor Shutzlofigfeit oder fittlicifer Bejahr

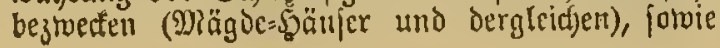

der Gebäude, wcldje milloen Stiftungen angelyören und für deren Brecfe unmittelfar benulzt werden; burd) (Semeindebefd)Lu[ fümen aud andermeitige (3ebäude foldjer milden Stijturgen, treldje nidjt blos zu (Sunjten beítimmer ßerjonen und Jamilien befteljen, freigelajien werden;

i) Der (Srunojtutte ber unter $f, g$, h aufgejübrten 2(njtalten und Sïrper\{fiaften, jomeit die (Brund: ftücfe für beren Bwecfe unmittelbar benutzt werden.

k) Der Dienjtgrund ftüffe und Dienftrohnungen Der

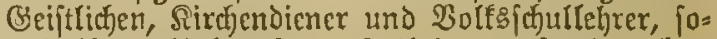
tweit ifjen bisfyer Steucrireiheit zugeftanoen hat.

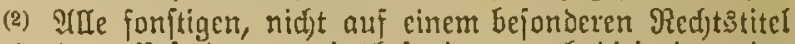
beruljenden 23efreiungen, insbejondere aud dicjenigen der Dicnftgrmbjtilfe uno Dienftwohnungen oer Beamten, find aufacloben.

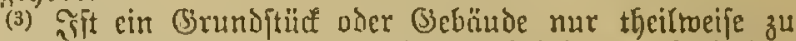
cincu offentfichen Dienjte oder Gebraudj beftimmt, fo bezicl)t fitif Die Bsejrciung nur auf Diejen Tlyeil.

(1) ......

$\$$ 25. (1) Den Bemeinden ift die Einfülyrung befouderer Steuern vom Grundfeits geftattet.

(2) ......

\$ 26. (1) Sind bejondere Steucrn bom Grumbefite mid)t eingefülyt, fo erfolgt die Befteuerung in Grozenten Der bom Staate beranlagten (Srund. und (3ebäuvefteucrts.

(2) (3) (4) .....

§27. (1) Die Steucin vom (3runtbefits find nadi gleid)en গormen mo હäßzе zu bertlyeilen.

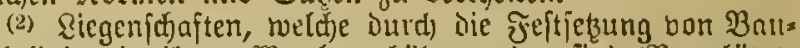

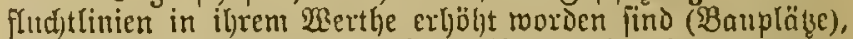

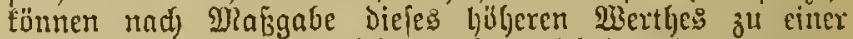
Güberen Steuer als die übrigen Riegenjüaften berangezogen toerden. Siefe Befteuerung mufi Durd) Steueroromung ge. regelt werden.
b) Som Serretbebetrieb.

§ 28. (1) Den Bewerhefteuern unterliegen in beit (Be, mecinoen, in benen Der Betrieb ftattfindet,

1. Die nach dem (Semerbejteuergefeb bom 24. Jumi 1891 (\$ङ. 5. 205) 3u beranlagenden fteberioen Berwerbe;

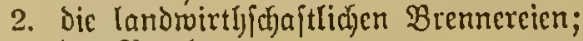

3. ier Bergbail;

4. Die getwerbimäßige Bcminnung von Bernitein,

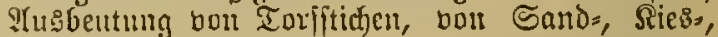

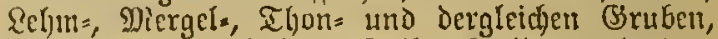
ton Stein=, Sdjefer=, Sialf=, Sircide= und dex= glcicjen Brüd)en;

5. die (Seroctbebetriebe fommunaler und anderer b̈ffentticher Berbände;

6. Dic (Semerbebctriebe Des Staates und der Reidssbant.

(2) Diejenigen zu $\Re$ r. 2 bis 6 bezeidineten Betriebe, Gei

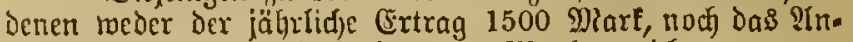
lage = und Betriebsfapital 3000 Dlarf errcid)...... Gleiben von Der Bemerbefteuer befreit.

(3) Der Betrieb der Staataeifenbahnen und ber ber Eijenbahnabgabe unterliegenden \$ribateifenbabuen ift $\mathfrak{g} \mathfrak{e}=$ soerbeftenerfrei.

(4) Der (jewerbebetrieb im Umherjiehen ift der Berverbe: fiteucr in ben (Bemeinden nidjt untermorjer. 
§ 29. (1) Den Bemeinten ijt Dic Cinführung bejonderer (Serverbejteuern gejtattet.

(2) .......

§ 30. (1) Sind befondere Bjetwerbefteuern nidjt cinge= fiithrt, fo erjolgt die Bejtenerung in Prozentet Der vont Stnate beranlagten Bemerbejteuer.

(2) (3) .....

\section{Bemeinbeciufomutenfteucr.}

a) Steuerpflict)t.

toorien:

§ 33. (1) Der Benteindecinfonmenfeucr fino unter=

1. diejenigen $\mathfrak{B e r j o n e n , ~ w e l c h e ~ i n ~ b e r ~ ( b e = ~}$ meinde einen $\mathfrak{B O}$ ol) nitiz (\$ 1 des Cimfonmen.

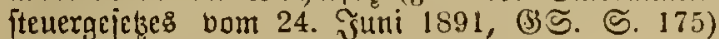
haben, hinfichtich ibres geiammen intuer. halbundauferhalb des Breufifden Stants. pebictes gemonnenen Einfommens, foucit Daffelbe nidjt von der Bejteuerumg freizulaffer ift;

2. Diejenigen Berjonen, weldje in Der Gemeinite, oljne in Devielben einen 230 hriftz z̆ haben, Brumoner: mögen, Samdels= oder gerverblicje ?tulagen, cin= fejliefflich der Bergiverfe haben, somiel oder (Betwerbe oder auperhalh emer (Beweifidajt $\mathfrak{B} \mathrm{crg}=$ bau betreiben oder als (Sejellidiafter an bem ltuter: nehment einer Bejedj jjaft mit bejd)ränfter Saitung

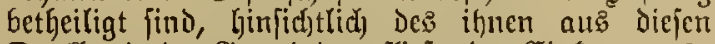
Queller in der Bsemeinie zuffieženden Einfommens:

3. Stftiengefelf(d)ajten, fonmanvitgcielfichaften auf Ifftien, Berggemertjajajten, eingetragenc (Bendijen= idjaiten, Deren (Beidjäftsbetrieb über Den Sireis il)rer $\mathfrak{P}$ itglieder Ginamselyt (insGejondere Ronjum= bereine mit nffenem $\mathrm{EaDen}$ ) und jurijtijefe $\mathrm{F}_{\mathrm{C}} \mathrm{e}=$ fonen (instejondere aud) Gemeinden und tweitere Sommumalverbänic), wocld)e ill der (Semeinde

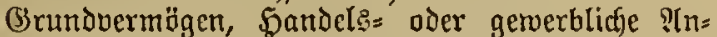

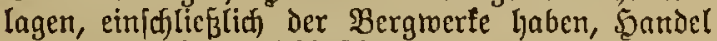
oder (semerbe einidflieflid) des Bergbaues be= treiben oder als Bejellichajter an bem llnter= nehmen einer (sejcljdjoit mit bejd)ränfter \$aftung betheiligt find, linfidjlid) des innen aus diejen Duellen in ber Bsemeinde zufliefenden Cinfommens.

4. Der Staatsfistus bezüglid feines Einfommens aus den bon ifm betriebenen (Eifenbahn=, Berg: bau= und jonjtigen gewerbfichen Unternefmungen, forvie aus Domänen und ઉorften.

(2)

(3) (4) ......

§ 36. (1) Bremeindefteuern bom Finfommen dürien,

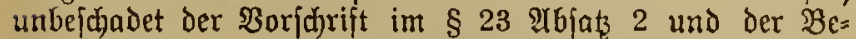
jtimmungen über die Beranlagung bon Theileinfommen (\$\$ 49 biß 51) mur auf Brund der Beranlagung zur Staatseinfommenfteuer und in der Regel mur in Der Form bon 3uláflägen erhoben merden. Dieje Bujchläge müfjen

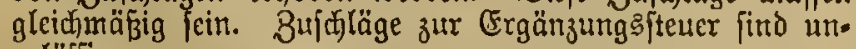
zulärlig.

(2) Э̧̃t das gemeindefteuerpftidtige Cinfommen ganz oder zum Theil zur Staatseinfommeniteuer nidyt beranlagt, fo ift Der dem 8urfjlage zu (Srunde zu legende Steuerjaz, $j \mathrm{D}=$ fern fick aus ben $\S \S 44$ bis 46 nidjt ein श्tnderes ergiebt, nath Den für die ßeranlagung Der Staatseinfommenjteuer geltenden Borfdriften zu ermittelr.
(3) Die ouf (Srund Der Finlegung bon Redtsmitteln, jowic bic anf (Srund der $\S \S 57,58$ des Cinfommenfteuer= gefeucs vou 24. Suni 1891 erjolgte (Exhöhung oder (5x. mäßzigung ber beranlagten Staatseinfommeniteuer ziegt bic entipred)ende Abämderung des Semeindezujalages ma(t) fid).

§ 37. (1) Bejondere Bemeindejteuern find nur aus be: fonoeren Bründen gejtattet und bebürfen der Benefmigung.

(2) (3) $\ldots \ldots$

\$ 38. (1) Steuerpflidytige mit einem Einfommen bon nicht melyr als 900 MarE roerden, jojern in Den Steuer= oronungen nidjt abrweicjende Bejtimmungen getroffen find,

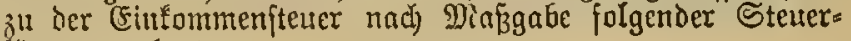
jüke vernulngt:

1. bei einem (Einlommen bon nid)t mefor als 420 Marf nach einem Steueriatze von $8 / 5$ bom \$umbert

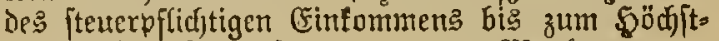
betrage Des Steuerjatzes bon 1,20 Miarf;

2. bei einem (Einfommen von mehr als 420 Mart

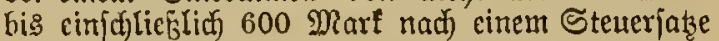
bon 2,40 Mart;

3) bei einem (Finfommen bon mebr als 660 Mlart naci) eintm Steuerjatze von 4 Mart.

(2) Steucruffidytige mit eincm Einfommen bon nifft

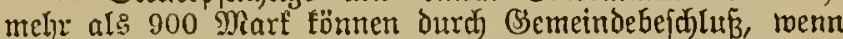
Die Dectung des Bedarl: der Gemeinde ofnefin gefichert ijt, bon ber Beitragspflidjt entbunden oder mit einem $g e=$ ringeren Brozentiatze Gerangezonen worden. Der Beintü

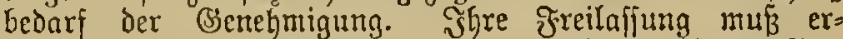
folgen, fofern fie im $\mathfrak{B e g e}$ ber offentlidjen âdrmenpflcge jortlaufende Unter[tïßsung erbalten.

§ 40. (1) Bon der Bemeindecinlommenfteuer find befreit:

1. Die Mitglicoer des Räniglicjen Saujes und die Dohenzollernj(t)en fïurftenthaufes:

2. Die bei Dem Saijer und Sönige beglaubigten Bertreter frember 9 iäd)te und die $\mathfrak{B} \in$ cuollmächtigten anderer Sundesftaaten zum Bundesirathe, die ifnen zugerviejenen Beamten jorvie die in ibren und ifrer Beamten Dienften ftehenden Berjonen, forveit fie IUsländer find,

3) diejenigen ßerionen, Denen jonit nad) bölfer. redhtlidjen Grundjäzzen, oder nach bejonderen, mit anberen Gtaaten getroffenen Bereinbarungen ein Injpruif auj Bejreiung zufommt.

(2) ........

(3) Dic Bejtimmungen z̧น 2 und 3 exjtrecfen fich nicht auf bas in $\S 33$ Nr. 2 bezeidjnete Finfommen und Gleiben ausagefdyloffen, fofern in den betreffenden Staaten Begen: jeitigfeit nicht gemährt mird.

\$ 41. (1) Die Seranzichung Der unmittelbaren und mittelbaren Statsbeamten, Beamten des Rönigliden Sofes, Der (Beiftliden, Rirdendiener und Elementarjdullegrer, fotwie ber Wittren und waifen diefer perionen wird durch bes jonderes (jejes geregelt. Bis zum Erlajje diefes Befetzes fommen die Beftimmungen der $\mathfrak{B e r}=$ ordung, betreffend die Seranziefung der Staats. biener zu den $\mathfrak{R}$ ommunalaulagen in ben neu er= 
worbenen Sambegtheilcu bour 23. September

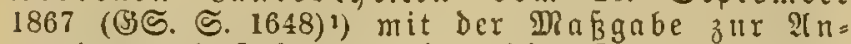
toendung, daß̧ das nothtoendige Domizil aúzer Berüffidtigung bleibt.

1) Ginter biejem Gejeb, S. $811 / 12$ abgedrudt.

§ 42. (1) Sinficftlich Der Seranzichung Der Militür= perfonen su ben auf bas (Finfommen geleaten Semeinde: abgaben bewendet es bei den beitchenden Beitimumaen?).

(2) Die Mitglieder ber Bendarmerie gelten nla Dilitär= perfonen im Cinne diefes Geferzes. befreit.

1) Danad find Dilitärperfonen von Romumulcistommenjteuern

\section{Bertheilung bes Steterbebarfa auf bie beridjiebenen Eteuerarten.}

\$ 54. (1) Die bom 5 taate veranlagten Realfteuern fino

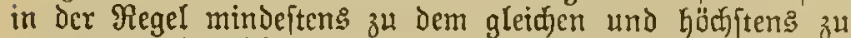
einem um die Sälfte höheren \$rozentjake zur Sommunal.

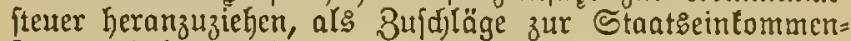
teuer erhoben werden.

(2) So lange die Realiteuern 100 \$rojent nidft über= jteigen, ift Die ऊreilafiung Der Finfommeniteuer oder cine Seranziehung Derfelben mit einem geringeren als Dem im erjten 2(bjaze bezeidjneten \$rozentjaze zuläijtg.

(3) 2Berben mebr alક 150 Pirozent ber ftaatlich beran= lagten Realjteuern exhoben uno ift die Ctanţeinfommen= fteuer mit 150 Brozent belajtet, fo fönnen bou dem Melur= betrage für jedes \$rozent Der ftaatlid) beranlagten Real= fteuern 2 Prozent Der Gtaatieinfommenjteuer erboben toerden.

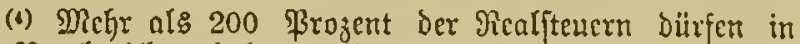
Der Regel nicht exhoben merden.

\$55. (1) Buifläge tiber der vollen ऽał der Staats= cinfommeniteuer Ginaus, foric $\mu b$ toeidjungen bon den im \$54 enthaltenen Borfidriften beditrien ber Senebmigung;

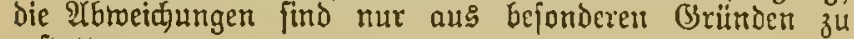
geitatten.

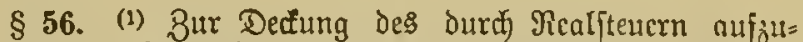
bringenden Steuerbedarfs find die beraulagten (Srund., (3ebäude = und (Setwerbefteuern in Der Regel mit Dem gleidien Brozentfake heranzuziefen.

(2) (3) (4) (5) .....

\$ 59. (1) Heber Die Bertheilung des Steuerbedarf\$ nach Den boritebenden Beitimmungen ( $\$ \$ 54$ bis 57) hat

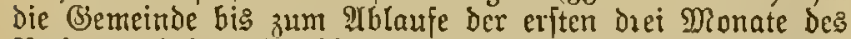

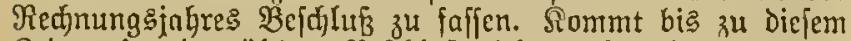

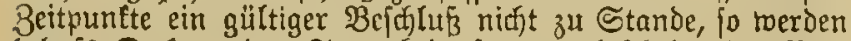
behufs Dectung Des Steuerbedarfs - unbefdidet der Dor:

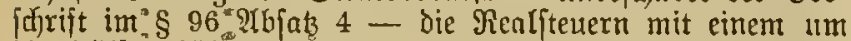
dic Soälfte Göberen 9 srozentjałe als bie Finfommenfteuer, unter fich nad gleidjen \$rozentfäzen herangejogen. Die Xuffiditsbehörde ift jedod befugt, die Dectung des Stcucr= bedarfs nad Maß̧gabe ber $\S \S 54,55$ anzuordnet.

(2).....

\section{Beitride Begrenjung ber Steuerpflidyt.}

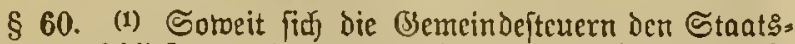
fteuern anfifließen, und etroas शnderes nixjt beftimmt ift, gelten für Den Beitpuntt des Beginnes und des Erlb̈|d)ens der Stetterpflidgt die für bic cntipredjende Staatsifteuer be= itelyenden $\mathfrak{B}$ orjadriften.

(2) Şm Ulebrigen gelten finfidtlich der Dauer Der Stetter. pflicit folgende $\mathfrak{B e}$ [timmungen:

1. Dic Cteuerpflidjt beginnt:

a) fotoeit fie bon Der Begründung cincs Wohns fitses oder Gitses in einer (Semeinde nbljängt, mit Dem criten Tage des anf dic Begrünoung

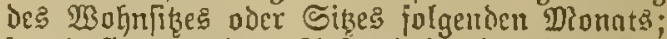

b) forveit fie bon $\mathrm{dcm}$ Iufentljalte in ciner (Se. meinde ablängt, mit bem erften Tage bes nach)

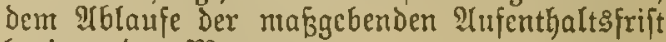
beginnenden Monats;

c) forveit fie Durch Grundoermögen, Betricb bout Snndel und Bemerbe, einfdicticlid des Berg. baucs bedingt ift mit Dem eriten Tage bes auf dem Frwerb des Srumbermb̈gens oder ben Beginn Des Betriebes folgenden Monats.

2. Dic Steucrpflidyt erlifdyt:

a) Dura den $\mathfrak{I} D$ des Steuerpflidtigen mit dent $\mathfrak{A b l a u f ~ D e g ~ M o n a t s , ~ i n ~ t o e l d i c m ~}$ Der Tod erfolgt ijt;

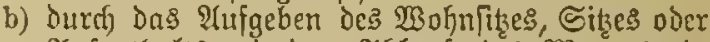
Rufenthalts mit Dem Yblaufe des Monats, in meldiem der Wofnitz, Sił oder 2ufenthalt that [äd)(id) aufgegeben morben ift, fofern jebod) bis zu biefem Beitpunfte der (Ssemeindebe. höroe hierbon feime Inzeige erftattet ift, exft mit Dem ?lblaufe des jolgenden Momats;

c) Durch die Veräuberung Des (Brundbermögens Geziclyngstweife die Cinjtellung des die Steuct: pifidft bedingenden Betriebes bon Sandel oder

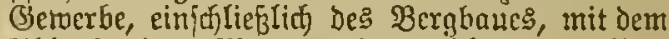
Mblatife des Manats, in welatent die Ber: äuberung bczichungstocife die Cinftellung des Betricbeg erfolgt ijut.

\section{Beranlagung unb Crhebung.}

§ 61. (1) Dic Beranlagung erfolgt Durch den (Semeinto. borjtand oier cinen befonderen Steuerausfhuf Der Benteinde.

(2) .....

§ 62. (1) Dem Bemeindeboritande (Steueraus[d)uß) finto von den zuftändigen Staatæbehörden diejenigen bei ber Beranlagung oder F́eftieszung der ङtantsfteuern befamit=

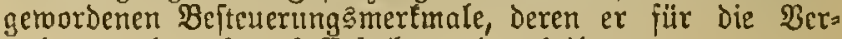
anlagung bedarf, auf (Erjuthen mitzutbeilen.

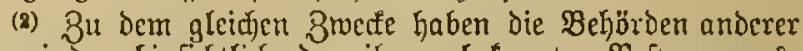
(Gemeinder hinfiditlidf) Der ifjnen befaunten Bejteuerungs:

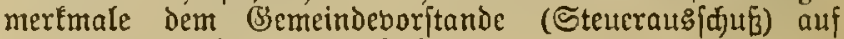
Erffordern ILustunft zu extheilcn.

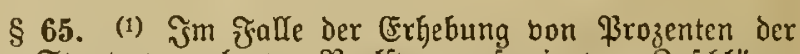
bom Staate beranlagten Realitenern fowie bon Bujdjlägen zur Staatseinfommenfteuer erfolgt Die Befanntmadjung der Stcuern Durch Den (Semeindeborjtand für biejenigen Steucr. pflid)tigen, Gejuglify Deren die jtaatlich beranlagte Steuer die unberänderte (sirundlage Der \$rozente oder 3 ux folläge bildet, burd) eine in ortsïblidjer Weife zu bemirfende $\mathfrak{B e r}=$ ïffentlichung der zu erhebenien \$rozentiäze, für andere Steuerpflidtige Durd befondere Dittheilung.

(2) (3) (4) .... 
\$66. (1) Rad) erfolgter Befanntmadinng $(\$ 65)$ ijt die Stcuer in den eriften adjt $\mathfrak{I} a g e n$ cimes jeden Monats zu entridten. In Stelle bes Monats fann burch (Semeinde. bejulus cine ztwei- oder oreimonatlictje feebeperiode einge.

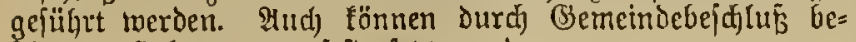
ftimmte Sebungstage feitgefekt roerden.

(3) Dem Sifliftigen ift itets die Barausbezahlung melyrerer Raten bis zum ganzen Jahresbetrage geitattet.

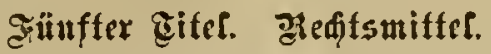

\$ 69. (1) Dem 1 bgabepflidfigen iteft gegen bie Scran= ziehung (Beranlagung) zu (Gebühten, Beiträgen, Steuern uno giaturaldieniten der (Finfprud) zu. Das Red)tsmittel ift binnen einer frift bon vier Wodjen bei dem Bemeinde. burftande einjulegen.

(2) Der Lauf Der frifift beginnt:

1. Foweit die Befanntmadfung durd, ?tuelegung ber Sebeliften erfolgt ift, mit dem eriten $\mathfrak{T}$ age nad) Ŝ̉blauf ber Yluslagefrift;

2. jotweit eine bejondere $\mathfrak{D i t t h c i l u n g ~ v o r g e i c j ) r i e f i e n ~ i f t , ~}$ mit dem erjten Tage nad erfolgter Mittheilung;

3. in allen übrigen fällen mit Dem erften Tage nad) ber. Mufforterung zur Bablung beziefungsweife Eeiftung.

(3) Finfpridue, weldye fid gegen den ber Beran= lagung zu Grunde liegenden Staatsiteueriaks ( $\$ \$ 26,30,36,38)$ und bei bejonderen (Bemeindecin. fanmenfteuern gegen die \$̧öhe des zur Staatzein. fommenftener veranlagten Finfommens riditen, Eind unzuläfig.

(1) $\ldots \ldots$

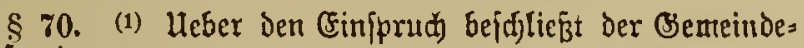
borjtand.

(2) (Begen den Beidjlu[ jteht dem Pfliditigen binuen einer, mit dem eriten Tage nach eriolgter Buftellung be= ginnenden frift ban zwei $\mathfrak{B}$ odjen bie STage im Bermaltungs.

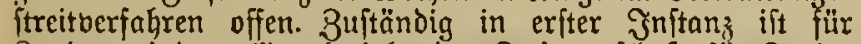

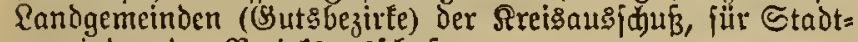

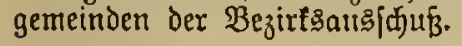

(3)

\$ 75. Durd) (Einfprud tnd Rlage wird die $\mathfrak{B e r}$,

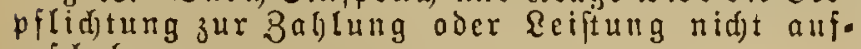
geidoben.

\section{Sedffter giter. duffidit.}

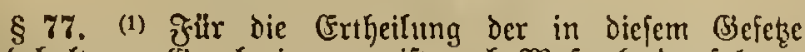
norbehaltenen (Seneljmigungen ift nad) Dafigafie der folgen.

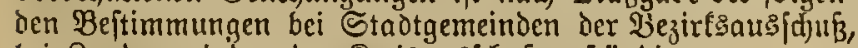
bei Randgemeinden Der 尺reisausfajuß zujtändig.

(2) ...... meldye

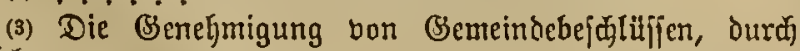

a) bejondere dirette oder indirefte Genteindejteuern neu cingeführt, oder in igren Grundjäzzen ber= ändert,

b) Îbreidhungen bon den im $\$ 54$ vorgefdriebener Bertheilungsregeln, c) Buidjläge über den vallen Sakz der Staatąein. tommeniteuer ginaus (\$ 53) angeordmet twerden, bebarf ber Zujtimmung Der Minifter deg Jnmern und ber Fुinanzen. Den Minijtern ift geptattet, die Ertl)eilung der Buftimmuna auf dic ignen untergeordneten ?luffichts: beförden böberer Эnitanz zu ïbertragen.

(4) .....

§ 78. (1) Beftefen bei dem Эnfraftreten des (Befelzes in einzelnen Bienteinden Dronungen jiber die stufbringung bau Gebülyren, Beiträgen, inbiretten, biretten Steuern oder

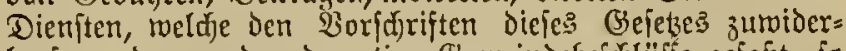
laujer, oder merien derartige Bemeindebejulüfíe gefojt, jo

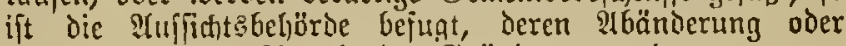
Ergänzung unter Ingabe der Śrtinde anzuaronen.

(2) ......

(3) Die Einfïlyrung neuer und die Eryjähung beftehender indiretter Steuern barf nidjt angeordnet werden.

(1) (5) (6) ....

\section{siebenter gitel. Strafeu.}

§ 79. (1) Wer in ber 96fict) ber Steuerhinterjiehung an 3uftändiger Stelle die an ifn geridteten frragen oder bei ber Begrtindung eimes (Finfpruches unridtige oder unvoll= fändige S(ngaben mad)t, wiro mit dem vier bis zehnfadjen Betrage Der ftattgehabten oder beabfictigten Berfiirzung, mindeltens aber utit einer Beldjtrafe bon eingundert Diark bejtrnit.

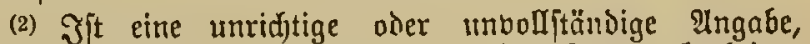
meldfe geeignet ijt, eine Berfürsung oer Stetter herbeizu= fïhren, 3twar wiffentlid, aber nidft in der 2(bffd)t der Steuerhinterziefung erfolgt, fo tritt Gelojtraje bon orei bis einfundert MRark ein.

(3) Straffrei bleibt, wer feine unridftine oder unbou, ftändige Ingabe, bebor $\mathfrak{I n}_{j}$ eige erfolgt oder eine Unter. juchung cingeleitet ift, an zujtändiger Etclle beriajtigt oder ergängt und die vorenthaltene Steuer in ber ihm gejetsten Jrift entridhtet.

ఇgl. Cin!StG. $\S 66$.

$\S 80$. (1) Der Semeindeborftand beziehungsిmeife die Mitglieder des Semeindeboritandes, die Mitglieder der Steuerausjajilije, forvie die bei der Beranlagung betheiligten Beamten werden, wenn fie die zu ihrer ßenntnif aelangten Ermerbs=, Bermögen: oder Finfommensverfältniffe eines

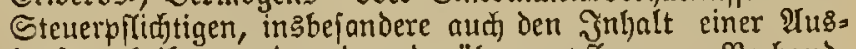
funftsertbeilung oder ber barüber gepflogenen Berband. lungen unbefugt offenbaren, mit Gelditrafe bis zu ein.

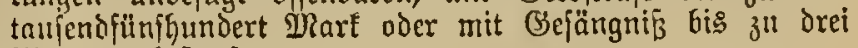
Monaten beftraft.

(2) Die Berfolgung findet nur auf Intrag des (Bemeinde: borftanbes oder des Steuerpflideltigen bejiegungsmeije dejien Bertreters itatt. S̃it das Bergehen ban Dem Gemeindevoritande oder von Mitglicdern des Gemeindevorftande: be=

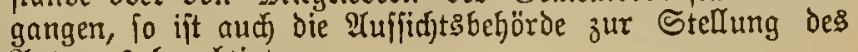
Antrages beredtigt.

Bgl. Eintऽtô. $\S 69$.

$\S 81$. (1) Die auf Brund der $\$ \S 79$ und 80 feftge= gefezzten, aber unbeitreiblidjen Geldftrajen find na两 $\mathbb{P a}$ : 
gabe ঠer für Uebcrtretungen geltenden Beftimmungen der

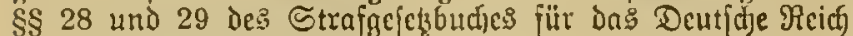
in 5 aft umjurandeln.

(2) (3) (4) ....

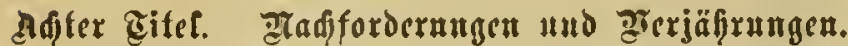

$\S$ 83. (1) Die (Finjichung biuterzogener dircter Steuern (\$ 79) zur Gemeindetaffe crfolgt neben und unubfängig von der Strafe.

(2) Die Berbindlichteit zur Nadjzallung der Steuer ver. jährt in zehn Jahren und geldt auf die (Frben, jedod) fïr bicie mit einer Berjährungsfrift bon fünf ̧̧ahren und nur auf Soühe ifres Erbanthcile ïber. Die Serjäbrung beginnt

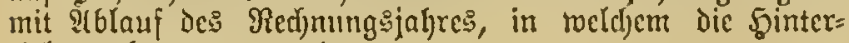
zichung begangen wurde.

(3) .....

\$ 84. (1) Stcuerpf(icitige, weldje entgsgen ben $\mathfrak{B}$ or= (d) riften bicies Befezes oder der nuf Grumb ieffelben er= lafienen Steueroromungen bei ber $\mathfrak{B e r a n l}$ lagung dircter (Semeindefteucrn übergangen oder ftetcrirei geblieben find, obne onfs eine ftrafbare Sinterzichung ber Steuer itattge= funden hat, jind zur Entricftuna De: Der (B) emeiniefajfe entzogenen Betrages verpflidtet. Dic פocrpflichtung erftrect

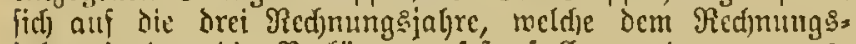
jaljre, in dcm bie Serfürjung feitgeftelt borden, borauss gegangen find.

(2) (3) .....

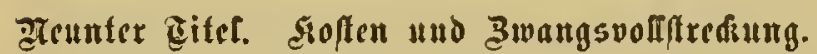

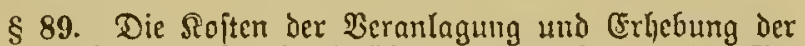
Tbgaben fallen, infoweit hieriiber nid)t durd) $\$ 14$ des (Ge. fekes megen Shif hebung Diretter Staatsfteuern andermeitige Beftimmung getroffen ift, ber Bemeindefaffe zur Lajt.
Fedad) find dicjenigen Soften, melde durch dic gelegentlid) eiucs (Finfprudjes erfolgenden (Ermittelingen beranlafít merden, bon bem 2T(bgabepflid)tigen zu exftatten, menn firf)

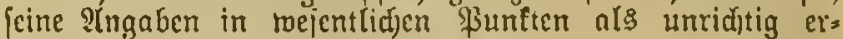
meifen. Dic Feftictzung dicjer Sioften tann nur in Der Cant= idfeibung über Den Cimfprudj erfolgen.

§ 90. (1) Biebiifren, Bciträge, Steuern und Rolten,

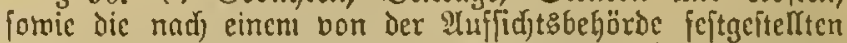
Tarije erfjobenen $\mathfrak{B}$ ergütungen (Sturtaren น. F. wo.) unter: liegen der Bcitreibung im Berwaltungsimangsucrfahren nad) Paßgane Der Beruromung bon 7. Eeptember 1876 (ङ) ธ. ธ. 591)

(2) ......

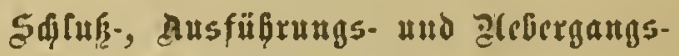 beftimmunger.}

§ 95. (1) Das Rechnungsijahx für ben (Gemeindebants Galt begiunt mit dem 1. QPpril uno idjliegst mit bem 31. Märrz. (2) Der Beffylu[jaffung der Bemcindebeljörden bleibt

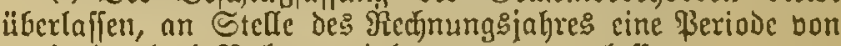
zrwei ober brei Redjungsjahren treten zu Laffen.

§ 96. (1) Das gegentwärtige (5)ejeţ tritt gleid) zcitį mit dem Gejeke rocgen ifuffebung Diretter Stantsifteucri in Srajt $\left.{ }^{1}\right)$.

(2) (3) .......

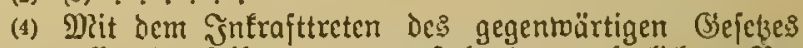
treten affe demielben entgegenjtefjenden gejekstidjen $B_{c}$ ftimulungen aujser Sirajt.

(5) (6) ....

1) Beide Befebe, uno als brittes bas Ergängungsftenergefeb (ogl. § 52 beffelben) find gleidjeitig am 1.4. 1895 in Rraft getreten.

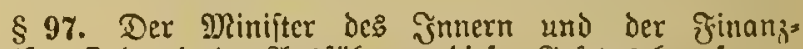

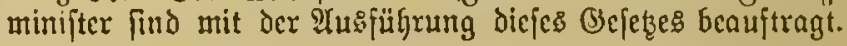

Ut:fundidi) $2 \mathfrak{c}$.

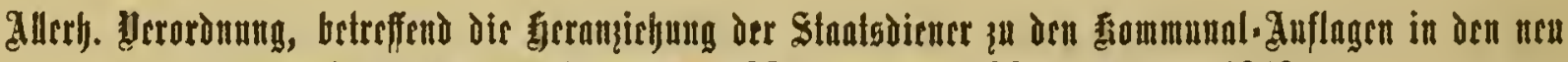

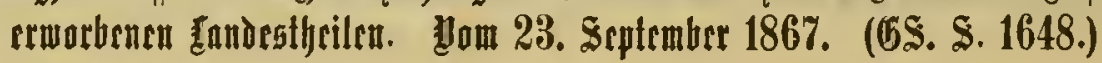

Wir Millyelun, von Bottes Ginaden Rönig von \$reusen zc. verordnen für Die Durd) die Befetze vam 20. Septent= ber und 24. Dezember 1866 mit linjerer Monardjic bereinigten Randestheile, mit 2 usnaljme des (3emcinde, gebietes der Stadt đrantfurt a. M., um die Staats= diencr in diejen \&andestbeilen bezüglid) ifrer Beitrags= pflidjt zu den Sommunalbedürfniffen den Staats= dicnern in Der übrigen Monarcjic nach Maǵgabe des (Sejeczes vom 11. Juli 1822*) gleid) zuftellen, auf ben Intrag lnjeres Statsminijteriums, toas folgt:

§ 1. Bon affen direften Sommunnlauflagen, fowohl Der einzelnen biirgerlicfen Stadt= und Randgemeinden, af: Dex weiteren fommunalen నörperid)aften (?Imtsbezirfe, Diftrifts.

*) Die Scftimmungen diejes, f. 3. für die alter \$rovinzen ers la|jenen Gejepes ftimmen mit bem 3nhalte biejer Beroronung infalt: lid überein, und ift bas Bejeb beshalb nidjt abgebrudt roorben. gemeinden, Trmendiftrifte, Wegeberbände u. f. to.) und der treis=, fommunal= und provinzialftändifden Berbände, find volftändig bejreit:

1. Die ferbisberedftigten Mifitürperfonen bes aftiven Dienfittandes, himfichtlidi ibres dienftlidjen, als forftigen Finfammens; nur zu den auf Den Grirund= befis oder Das ftelyende (jetwerbe, oder auf bas aus Diefen Qunellen fließzende Einfommen gelegten תomutunaliaften müfijen audy fie beitragen, weun fie in Dem Rommunalbezirf Grutbbefiz haben oder ein ftehendes Bemerbe betreiben.

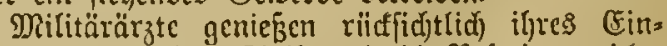
fommens aus ciner Bibilpraris dic $\mathfrak{B}$ efreiung nicht;

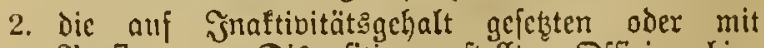
Penjion jur Dispofition geftellten Difiziere hins fidflich ifrer Behalts= oder fonftigen dienftlidjen Bezüige;

3. Die Geiftlidjen und (Elementarlehrer himidatlid ifrer Befoldungen und Emolumente, einjoflieflid 
der Rulegeljälter, ingleid)en dic unteren Sirdjen= diener, too und fomeit den lezteren eitse Derartige Befrewng [either redjtigültig zuge्tanden hat;

4. die verabjdjiedeten Beamten und nidjt z"I ber Sa. tcgorie unter $\Re$ r. 2 gehörigen Militärperfonen fjinjichts ilyer aus Gtaatsfonds ober fonjtigen öfentlidfen Sajien zablbaren Sienjionen und laulen: Den Unterftüzungşbzüge, ebenjo die Beamten l)tn= fidjt: ifjer Wartegelder, fojern oer jährlidje $\mathfrak{B} e=$ trag foldier Bezüae für einet Fmpfänger die Summe bon 250 Ihalern nicfst erreicht;

5. Die Ginterbliebenen खittwen uno Waijen ber unter 1-4 genannten \$erjonen Ginfid)t: ifrer aus Sfaatifonis oder aus ciner offentlid)en $\mathfrak{B} e r=$ forgungstaffe zablbaren \$enfionen und laufenden unterfiüzungen;

6. die Sterbe= und Ginadenmonate;

7. alle diejenigen Dienjt= Smolumente, weldje blos als Erfatz baarer ?โuslagen zu betradjten futb.

\$2. Bu ben Beamten im Sinne dicjer Berorbnumg gebören alle, in ummittelbaren Dienjten bes Stants oder ber bemielben untergeoroneten Dbrigfeiten, Sollegien, fom= munalen und jtändifden Rorporationen itehende, mit fejter Bejoldung augeftellte, bejiclentlich in Rubeftand getretene

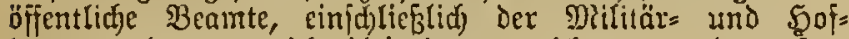
beamten; Dagegen nidht Diejenigen, toeldje nur als aujer: ordentlidje (Sehülfen borübergeberd in öffentlidjen Dienfte befduätigt merden.

\$3. Die Beamten (\$ 2) fönnen von iGren Dienjt= eitfonmen cinf(d)liefslid) Der 2 arte = und Rubegefälter, eben= fa die Qlilitätperjouen bon ifren \$enfionen - menn nidut ein ริall der gänzlidjen Bcjreiung naw \$ 1 vorliegt - zu direfien Sommunal=QXfuflagen $(\S 1)$ nur injomeit berange= zogen merdem, als bieje bon allen Piflidtigen nach bem Dásftabe Des perfömlidien Einfommens erhoben toerden.

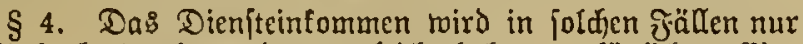
balb jo hod), als anderes gleidi hohes perfötlidjes (sin= fommen der Steuerpflid)tigen veranlagt.

Wenn die Seranlagung nidjt unmittelbar den Ein= fommen̊̊betrag zur Srumblage bat, jo ijt, unter (Sic= nehmigung ber 2 (uffidsts behörbe des bejteuertiden fommunalen Berbandes, Das Ginjofäbungsverjabren Dergejtalt bejonders zu regeln, Dafi Der vorftehende Grundfaz analog zur थn= wenoung fommt.

Das Dieniteinfommen bon sujäligen Emolumenten mird gleid Dem fejten (Sebalte befteuert; zu diejem Befufe mird nöthigenjals Der Betrag Derjelben in runber Summe ouraf die vorgefeste Dienjtbebörde feftgeftellt.

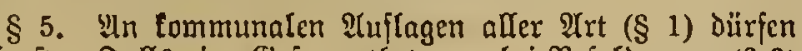

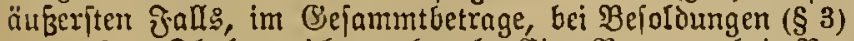
unter 250 Ihaler richt mebr als Ein Prozent, bei $\mathfrak{B C}$ : joldungen bon 250 bis 500 Thaler auşjd)lief̧lid) nidjt mehr

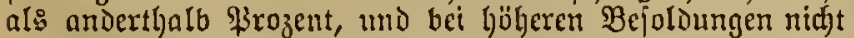
melx als zmei \$irozent des gejammten Dienjteintommens jäbrlich) geforbert werdett.

Die biernad) etwa nöthige Ermäpigung der nach) $\$ 4$ bereducten Steuerbeträge trifft, im ₹all ber Soufurrenj

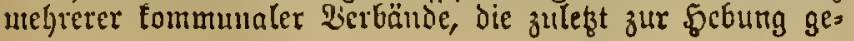

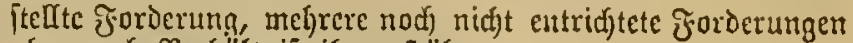
aber nad) Berbältmiß̈ igrer §öbe.

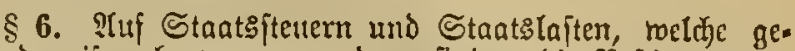
meindemeife abgetragen merben, finden die Beftimmungen Dicjer Berordmung feine

§ 7. Die gemäß $\$ \$ 3$ bis 5 Dent Staatgodenern obs liegende Beitragspflicht zu ber Rommunalabgaben erjtrecft (id) auf alle diejenigen Beträge ber lebteren, meldbe inner:

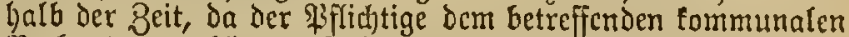
Berbande angebört, auf ign bertheilt und auch jäßig werden, nicht aber auf jpäter fällige.

\$ 8. Seder Beamte ift bezïg(id) Ber fiomnumalbciteue. rung jeines Dienfteinfommens als (sinwohner Desjenigen (B)emeindebezirts 3 betradjteu, in meldjem die Bebörde, Der er angelört, iljrett Sił bat.

§ 9. Don ifrem etmaigen beionderen : aud) dic nad) $\$ 3$ begünitigten Staatsdiener, cbenfo die Diffziere der unter $\$ 1$ Sr. 2 bezeddineten Rategorien, bie Geiftlidjen umb Elementarlebrer, ihre Beiträge zu Den

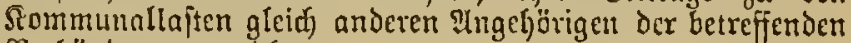
Vetbände zu entrituten.

\$ 10. Durd) die radj den voritebenden Beftimmungen 3u bentejenden (Selobeiträge find die \$flid)tigen zugleich von perjönliden fommunalbienjten frei. Cins fie jebod Befitzer von (brumbitiden, oder betreiben fie eiu ftehendes (Seroerbe, io mlifien ite die nit diejem (Sirundofitz oder Semerbe ber: bundeneu periönlidfen Dienfte entrveder jelbft ober Duth Stelluertreter liciften.

(Beiftlicye und Glementarlebrer bleiben von allen ber= fönlid)en Gemeinbedienjten, fotweit dicjelben nidut auj ihnen gehörigen Ssrumbjtüuen lajten, bejreit; untere Rirdbendiener

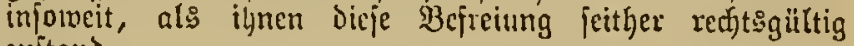
з山โtatio.

\$ 11. Bu oen indiretten (S) Die nad) $\S \S 1$ bis 5 begïnftigten \$erjonen gleid) anderen (Semeinde=(Finwolntern beitragen. Sie find nidjt bejugt, mas fie bierauf entridjten, bei ifren diretten Rommumal, beitrëgen in Olnred)um zu bringer.

Die Militär=Speijes (Einrid)tunger und ähnliche Yujtalten bleiben indefien bon Berbraudjofteuern in Dem, in bet alt: preufijuch Sandestbeilen bejtehenden llmfange bejteit.

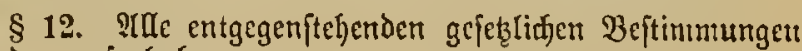
twerden aufgehoben.

Bo jedoch weitergehende Smmunitäten fïr Beamte,

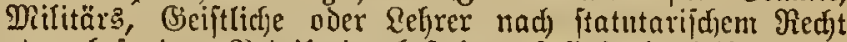
oder bejondcre \$rivilegien beftehen, foll in Denfelben hier= Durd) nicfts geändert toerden.

$\S$ 13. Begentwärtige Berardnung tritt mit Dem 30. Sep= tember $D$. S., utter 2intwendung auf alle bon diejem Tage on zur 2usidfreibung gelangenden biretten Sommunal= Iuflagen, in Rraft.

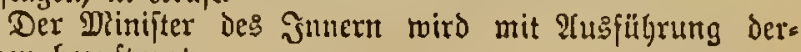
felben beauftragt.

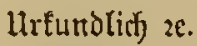

Gegeben $\mathfrak{B} a$ den=Baden, den 23. September 1867. 


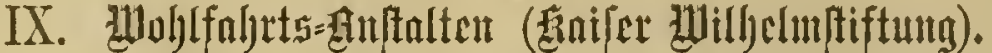

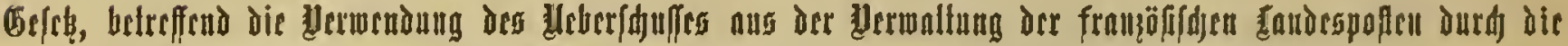

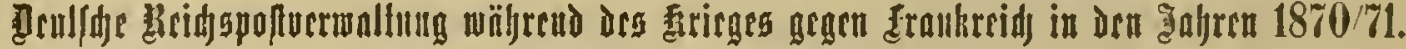

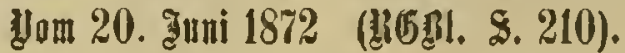

\section{Einziger Pinragraph.}

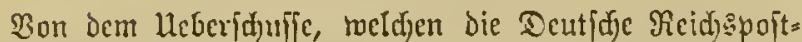
berwaltung mährend des Stieges gegen franfreid in Den Jahren 1870/71 Durd Wnhrmelimung bes Foptoienites in Den oftupirten fromjöfifden Gebietstheilen bis zum

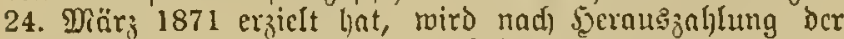
auf Babern und Wiürttemberg falfenden, mact bem $\mathfrak{B e r}=$ bältnifie oer Bafl der babcrijhen und mürttembergifachen

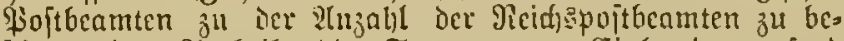
ftimmenden Antheile die Summe von (Finlunderttaufend Thalem dem Siaifer zur Berfügung geitell, um cine Stiftung zu gründen, Iveld)e Dic Beitimmung hat, bie Wohlfahrt Der Ângehörigen der Deutiden Reidjspojtoer= rwaltung ju jördern, insbejondere den Senmten biejer Ber.

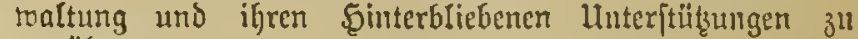
geväbren.

Die Verwnltung dicjer Stiitung und bie Berwendung Der auffommenden (Frträge erfolgt durd) dos Genernl= poitamt Des Deutjuen Reichs nad MRägna ber bon dem Senifer genchmigten Stifungsurfunde.

Der nod) (Erridftung Der Etiftung und nod lleber: weifung ber nuf $\mathfrak{B a b e r n}$ und $2 B$ ürttemberg falferden ?lutheile bon bun gedndjten lleberidjuB bleibende Tieftbetrag miro bon Dem Sseneralpoitnmte zu Remuncrationen an Fioft= benmte bertwendet, reldje jich mährend des Sirieges befontors verdient gemadit haben.

urfundrit) :e.

Gegeben Shlof̧ Babel:berg, ถen 20. Şแni 1872.

\section{allertjödffite (1)ròre vout 29. Aluguft 1872.}

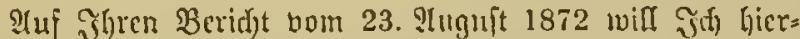

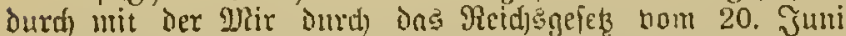

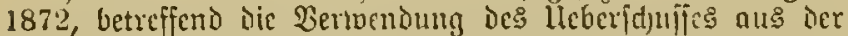
Berwalumg der Franzöfifichen Randespoiten Durdi Dic Dentid)e

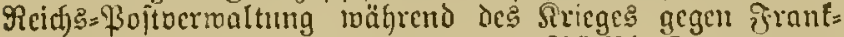

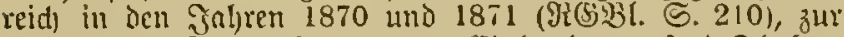
Berïühung gefteliten Summc bon Einhmoertnufeno Thalern eine Etijtung begründen, meldje den Broed lyat, dic $\mathfrak{B}$ ohl= fabrt Der Angehörigen Der Neid) insbefondere ben Bcamten Dicjer Derwaltung, igren

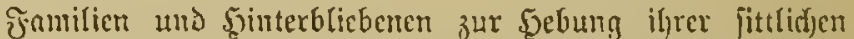
und geifyigen Bildung, furvie zur f̈ötocrung ibre:

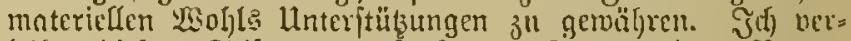
Leife Dicjer Stifung auf Shren ?intrag den ramen "Siaifer Willyclm=Stiftung für Dic Îngehürigen der Deutjdeu Peidjs. Foftuervaltung un ertheile Bem antiegenoen Statute Derjelben hierdurd) Meine (Senchmigung. Dicje Mleine Drore und das Statut Der Stiftung find Durd) da: Reid)

Regenş

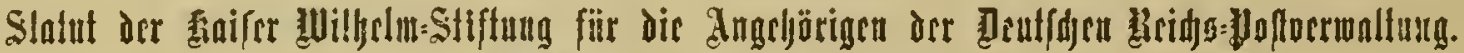

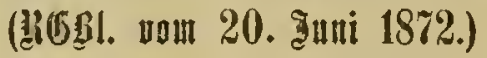

Dic Stiftung fübrt ìn Ramen:

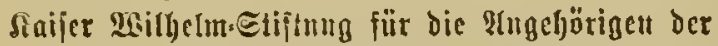
Deutfden Meidjs: Foftuetwonltung. ${ }^{1}$ )

Sic hat Domijil in Berlim und (Scriclytsfand bor bem Berliner Stnotycridft. ${ }^{3}$ )

1) ఇgl. I. D. v. 4. 3. 1876 (ธ. $819 / 20$ ).

2) Jckt Ranogeridjt I begı. Ilmtรgeridjt I.

\$ 2. Brwet ber Stiftung ijt: bic Woblfoljut der :Hngeförigen der Deutiden Reidis= Yoitvermaltung ju fürdern, inshefondere den Benmten dicjer Vertonltung, ihren Jamilien und ifren Sinterblicbenen ju: Spebung ihrer fitt= lidjer und geifitigen Bildung, potwie zur förderung ihres materiellen Wohls ilnterjtükungen zu ge= wähten.
§ 3. Bur Thcilnalme an Den Wohlthaten der Stiitung

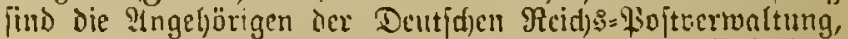

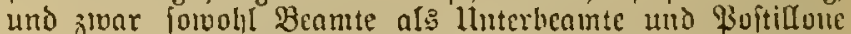
in und nuser Dienften, jowie die Jamifien und fointer= bliebenen Derfelben nad $\mathfrak{D}$ anggabe Der varhandenen Mittel bejühigt. $\left.{ }^{1}\right)$

1) :gl. U. D. v. 4. 3. 1876 (S. 819/20).

$\S 4$. Die Bermaltung Der Stiftung mird Durch bns (Bencral= Sojtamt ${ }^{1}$ ) unentgeltlich betwirtt. Daffelbe hat Dic Stiftung nad) angen zu nertreten und für die fidjere zings. bare Aulegung bes Stiftungs̄nermögent, fomic jür die bcjtimmungsnuäsige Bermendung Der Stijtungscinfüujte ju jorgen.

1) Эełt Reidg=ßoftamt.

§ 5. Das Stiftungsvermögen mird aus ber burdy bns

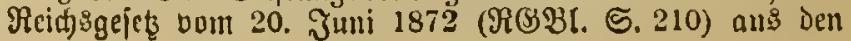


Heberfefiuffen ber BertwaItung Der Framzofifiden Eandes=

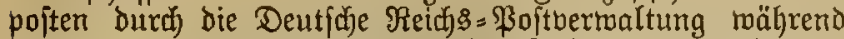
des Arieges gegen ₹rantreid) in ben Jahren 1870 und 1871 itberwiejenen Summe bon Eimbunderttunfend Thalern ge= bildet.

Dem Stiftungşbermögen madfjen zit:

1. tïnftige Bumendungen uno Bejatente, meldfe der Stiftung gemadist rerder, fofern bon Dest Donas toren nid t ausoriudefich eine andermette Bermendung angeoronet ift;

2. Stiftungseinfünite, meld) Dem Stiftungg̨bermögen übermiefen merden (§ 10).

§ 6. Das Stiftungsbermögen barf zur (Frreidfung Der Stiftungszmecte in jeinem Rapitalbejtante nidjt angegriffen werben.

§ 7. Das Stiftungsvermögen ift anjulegen:

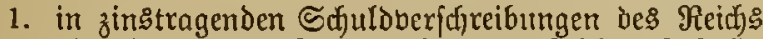
oder ber Bumbesitanten, bezw. in joldhen Schuld:

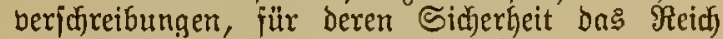
oder ein Bundesftaat Barantie leiftet;

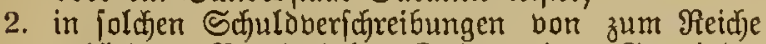
gehörigen \$robinzial=, Rreiss. ober Gemeinde=

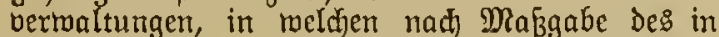
Berlin geltenden (Sibilrecht: Das geridjtlicf) ber= waltete Sermögen bebormundeter \$erjonen angelegt merden barf;

3. in Sypotheten auf Brundftücfe zu pupillarifater Sicjergeit.

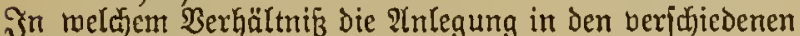
zulälfigen $\mathfrak{B e r t h o b j e f t e n ~ e x f o l g t , ~ b e f t i m m t ~ b a ̨ ~ ( E r m e f f e n ~ D e r ~}$ Bertualtung.

(Fin naij dem (Exmefien der Bermaltung zu beftimmender Theil des Stiftumgoermögens

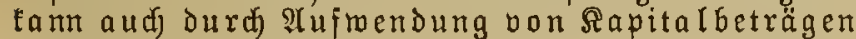
zur Begründung bon ₹reiftellen für Ỹngehörige oder Sinterbliebene bon Angebörigen ber Reids= \$oft = und Telegraphenverwaltung in geeigneten Verforgungs: oder Erziebungsanftalten angelegt werden. ${ }^{1}$ )

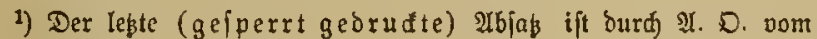
27. 9. 1883 zugejest rorden.

\$ 8. Die geldreerthen Dofumente und der Baarbeftand des Stiftungsvermögens werden bei ber Dber=\$ofttaffe in Berlin nach den $\mathfrak{B}$ orffyriften über die Bermaltung ber Dber $=$ \$oftfaffen aufberaaljt.

§ 9. Bur Berwendung für die Bmecfe der Stiftung find Die Stiftungseinfünjte bejtimmt.

Diejelben beftehen:

1. in Den Binfen des Stiftungsvermögens;

2. in foldien Zumendungen und Bejhenten, meldie bon ben Donatoren ausibrüuffich zur Bermendung unter den Stiftungşeinfünften beftimmt werden.

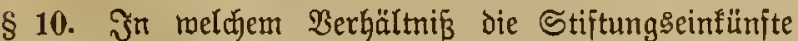
zur (Erreichung der Stifturgszrocfe zu bermenden find, unterliegt Dem Ermeffen Der Etiftungsverwaltung, forweit nicht itatutenntäbig oder von Den Donatoren ausobrüctliche Beftimmung getroffen iit.

Die Stiftungsvermaltung hat baribber zu enticheiden, ob und intwiemeit Stijtungseinfünte, meldfe im \&aufe bes

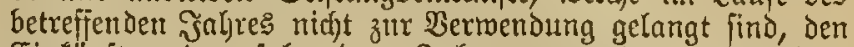
Einfünften dex folgenden Эahre zuzurechnen oder Dem Stiftunggovermögen zur Beritärfung des Rapitalbeftandes zu ilbermeifen find.

§ 11. Die $\mathfrak{T u s m a h l ~ u n t e r ~ b e n ~ z u r ~ T h e i l n a h m e ~ a n ~ d e n ~}$ W3ohlthaten der Stiftung befähigten \$erfonen bei Berwillgung von Unteritükungen jteht Der Stiftungsverwaltumg $z$ u.

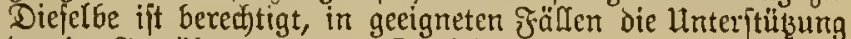
Durch Bewährung bon Darlehen aus Den Stiftung: cinfünften eintreten zu lafien.

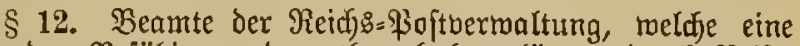
befondere $\mathfrak{B e f a ̈ h i g u n g ~ d a r g e t h a n ~ \zeta a b e n , ~ E ̈ o n n e n ~ D u r c h ~ \Re e i f e = ~}$ itipendien a:ts Den Stijtungseinfünften in Den Stand gejest

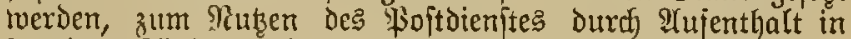
fremben Sändern ilje Spracjkenntnijie ju ermeitern uno

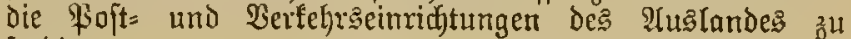
itudiren.

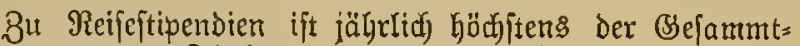
betrag von 800 I Thalern zu bermenden; jeboch lam, wern diefe Sumute im \&auje eines Jahres nifft erreinft morden ift, der Mlinderbetrag in ben folgenten Эathen ofne $2(n=$ redjung auf Den Sabresbetrag ausgefdüttet merden.

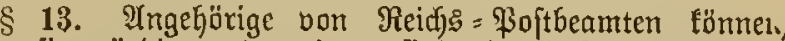
monn fie mürdig und geeignet find, burd Stipendien aus den Stiptungseinkünjten in ifren Studien auf Uniberfitäten oder anderen Göheren miffenjafifticten, tedjnifden oder artiftiffien Sehranftalten unterjtütst merden.

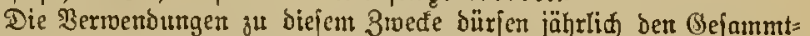
betrag voll 800 Thalern nidt überjteigen. ${ }^{1}$ )

Bei fortgejekter $\mathfrak{B u ̈ r d i g k e t ~ u n d ~}$ Bedürjtigfeit tönnen den Benefiziaten bie Stipendien auf zmei Jahre, umb aubs= uafmstweife unter ganj bejonderen Umftänden auf brei sahre verlieben werden.

1) Durd $\mathfrak{A}$. D. v. 30. 10. 1876 ift bie befchräntende Beftinmung in গ⿰冫广. 2 bes $\$ 13$ aufgehoben roorden.

§ 14.1) $\mathfrak{1}(\mathfrak{n}$ (ngehörige jomie an Sinterbliebene bon

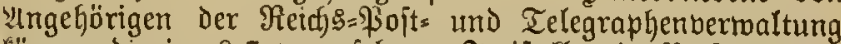
tönnen bie im $\S 7$ vorgejehenen Freiftellen in Beriorgung $5=$ oder Erziefhumgsanftalten vergeben, jonie Beihülfen zur $\mathfrak{A} u j=$ nahme in Derartige 2 njitalten getwährt roerden.

1) Tert biejes $\S$ in ber burđ $\mathfrak{A}$. D. v. 27. 9.1883 fejtgejejten Faाiurg.

$\S$ 15. Durch bie ipecielfen Feftetzungen der $\S \S 12$ bis 14 follen andere Arten der $\mathfrak{B}$ erwendung Der Stiftumg: einfünfte zur (Erjüllung Des im $\$ 2$ autsejprodjenen Broetes der Stiftung nidit ausgefdifloffen jein.

§ 16. Heber die Bermaltung des Stiftungsిvermögens, forwie über bie Bermenoung Der Stiftung̨einfünfte miró jährlich von ber Dbers?3oftfafje in Berlin $\Re$ ect)rumg gelegt.

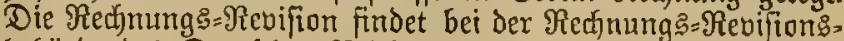
begörbe Des Deutidjen Reidjes ftatt. 


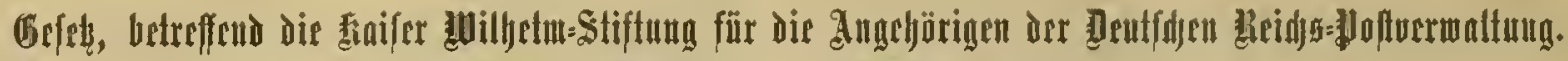

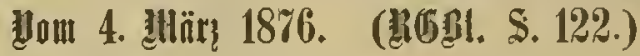

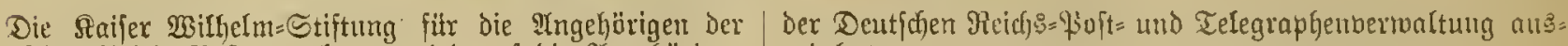
Deutichen Reidfs:

urfundich 26 .

(Begeben Berfill, Den 4. Wiär 1876.

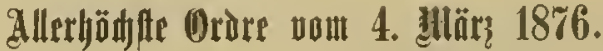

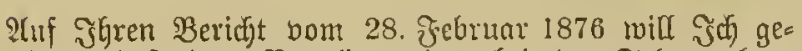

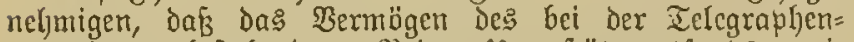
verwaltung bejtehenden "\$iribat =Llnteritübungsfonde" mit Dem Rapitalbermögen ber" Raijer Wilhelm=Stiftung für bie

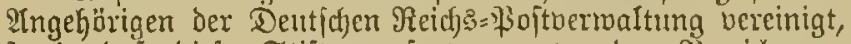
fornie daß̉ bieje Stijtung fortan unter der B̉ezeichmung ।
„Saifer Willgelm=Stiftung fïr die Ingefjörigen Der Deutf(t)en Reidf: $=9$ oit= und Telegraphenberwaltung" bon Dem Beneral=

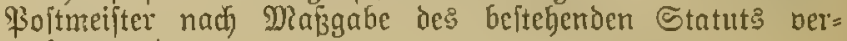
maltet merde.

B̧erlin, ̀en 4. Mlärz 1876.

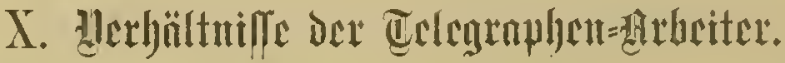

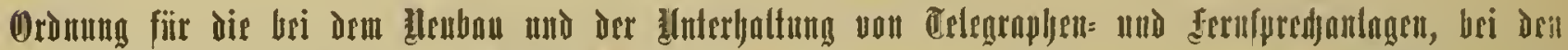

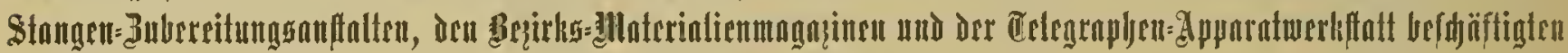

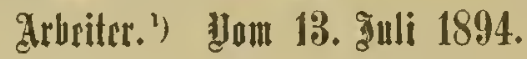

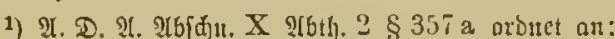

.Die Dienitnerhältniffe berjenigen bei bem 9leubau unb ber unter= haItung von Telegraphent uno JernipredautIagen, bei ben Stangen= Bubereitungsanftalten, Den Beçirtsmaterialien * Mingazinen unto ber Telegraphen=2Ipparatwerffitatt befwäftigten Irbeiter, beren Belळäftigutrg nidht pon vorntherein auf bie Dauter von wentiger als einer M3odje

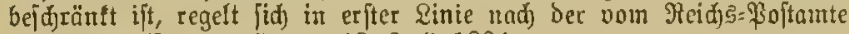
exlaffenen "Drommt" Dom 13. ऊuli 1894.

Die Drontung ift ben Telegrapgeturbeitern sc. gegen Dnittung ou ïbergebent.

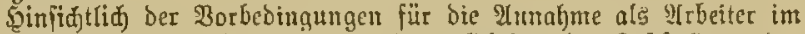

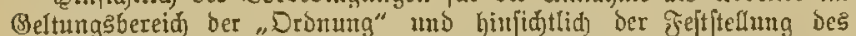
Borhaubenjeins biefer Erfordernifje gelten folgende Beftimmungen:

Die anzunehmenden Peripnen müfen:

a) Für bie ihnen zuzunetfenden Itrbeiten bie erforderfide

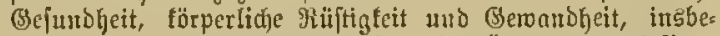
\{onbere ein hinfänglidyes Eeh= and börvermögen befiłen und burdjans irei non Epilepfie unb bergleidjen (Bebredentr fein ;

b) fid) in ifren bisherigen Rebensocrhältniffen adttbar uns unbeld olten geführt haben, fowic

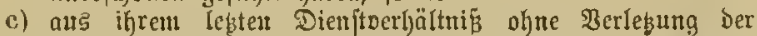
etron eingegangenen vertraglidjen Berpflid)tungen ge[d]ieben fein.

\section{Urigemeine $\mathfrak{B}$ oridfrijer.}

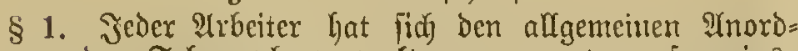
mungen ber Telegraphenberwaltung ju unterwerfen, ing= bejondere jidf mit den jux Sicherung gegen Gefabr getroffenen Bejtimmungen befanmt zu nachen und Diefe ju bejolgen.

Det 2 rbeiter hat (id) innerhalb mid nuberbalb des Dienftes adjtbar und egrenthaft ju fülyren und fid bon ber Theilnahme an ordnungefeindlidjen $\mathfrak{B}$ ejtrebungen und $\mathfrak{B e r}$ einen fernzuljalten.

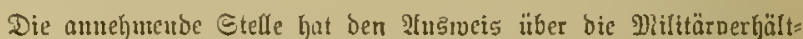
nifife, [ouvie ju b Die Borleguntg einer polizeilichen Befdeinigung ou perlangun unঠ für bie Befdaffung ber IIน

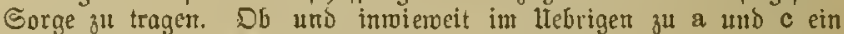

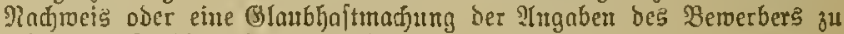
erfordern ift, bleibt ben Ermefien ber amelymenden Stefle im Cingel. folle an iiberlaffer.

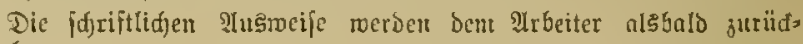
gegebent.

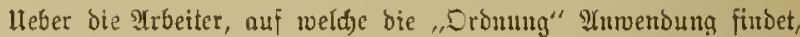

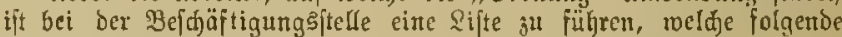
:Ingaben entlbaltent murf:

1. Den Manten (Bor= unb 3 unamen),

2. Drt und Beit Der Beburt,

3. Bejeinumung ber vorgelegten Beugnifife,

4. Tng bes Dien[teintritts,

5. Siumner Des IInfualmeicheins ber Bopttrantenfaife,

6. Den Rokning,

7. Strafen, Beit unt Bruts derfelben,

8. Tag bet Entloffung uno Brutto Derjelben,

9. Benterturgen (Salyt und Tag ber \$efäroerung buแ 3orarbeiter) น. \{. w."

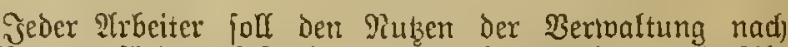
Sräften zu förbern beftrebt, bornehmlich aud 1 m bie $2(b=$ mendung von Unglübtésfäller, Brand/d)aden und jonftigeu Gefahren und Radhtheilen bom Bau und Betriebe ernjtlid) bemitht feir.

3ur getoerbsmäB̈igen ßornalyme bon \$3rivatarbeiten jeder

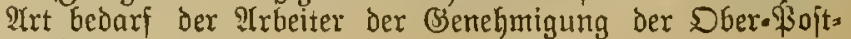
bireftion.

(3ejucje und jonjtige Eingaben an bie Dber=\$jojtoreftion find durd) Bermittelung des̆ zunächft vorgefekten Beamten 


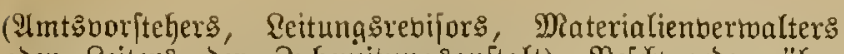
ober Seiters der Zubereitungsanftalt), Bej(htwerden über Diejen unmittelbar einzureidjen.

\section{Befondere Dien teflidjten.}

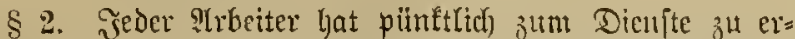
(d)einen und bie ihm Ḧbertragenen \&ltbeiten jeglicher ?(rt,

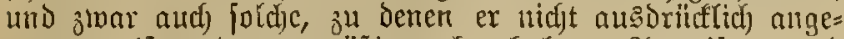

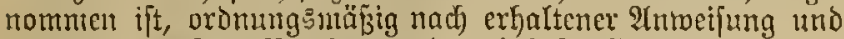

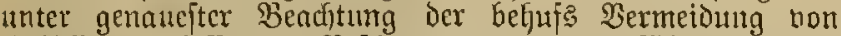

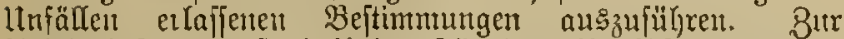

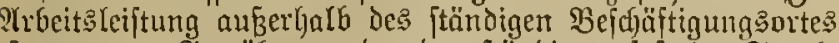

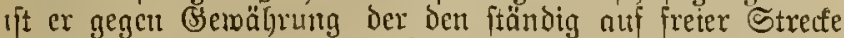
bejojäftigten $\mathfrak{U}$ ibeitern bon gleidfem Dienftalter zugcbilligten Bezitge berpflidftet. (S) Darf während der feitgefenten

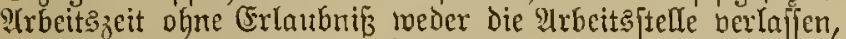
nod) Răume, in Denen er feine ?(rbeiten zu berrichten hat, betretcli.

Indere, als die ifm bom Dienftorifteher ober Dejien

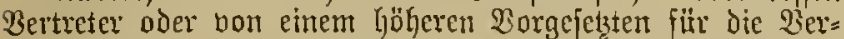

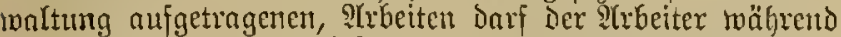
der ?robitszeit ohne befondere Benehmigung nidjt bor= nehmen. Shne eine joldje Crrlaubnif ift itsbefondere ber boten: dic Sornalyme gemeinfdhaftlidjer $\mathfrak{B} e[p r e d f u n g e n$, jotwie bą Bortejen, Subbieten, Der Berfauf und die fouttige $\mathfrak{B} e x=$

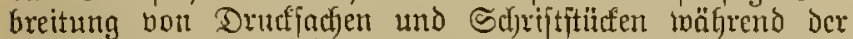

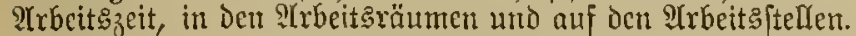

Der Strbeiter Yjat fid gegen feine Worgefetzen ftets bienft=

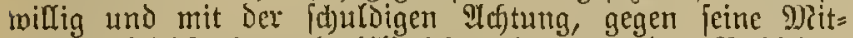

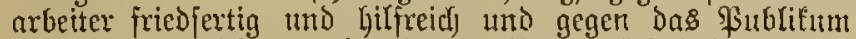
höflich und gejällig zu benehmen. Diamentlich loben die im Jernfpred)bau bejdäftigten ?(rbeiter gegenüber ben Refitzern

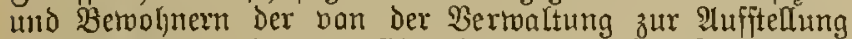
von (Seftöngen oder zur (Finrichtung bon Fermprechitellen

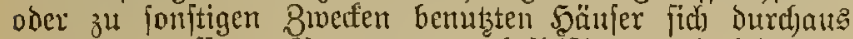
eines angemejfenen 23etragens zu bejteibigen und jede un= nöthige Störung oder Beeinträchtigtmg peintid) zu bermeiden. Trinfgelder zu beanprudjen, zi erbitten oder anjunchmen, ift berboten.

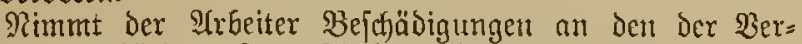
maltutng gehberigen Giegenftänden odcr nn Dem ifm bei Der

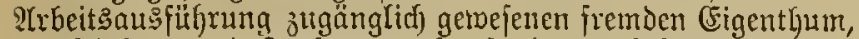
an Däcjern und Jentern toahr, fo hat er, jobald al: mög= lid), feinent ummittelbaren Dienjtborgefebten Dabon IInzeige zu exjtatten.

\section{Sdubeinxidytungen, Beräthe, Materialien.}

§ 3. Bon Der Telegraphenberwaltung fitnd die Betriebs:=

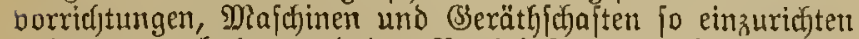
und zu mnterhalten und Der Betrieb fo zu regeln, dấ die :Irbetter gegen (Sefahren fïr \&eben uno (S)epunbkeit forweit

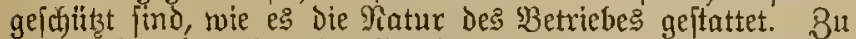
biefent Bmecfe haben bie Baubeamten bie jür Den Dicnjt=

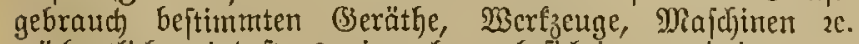
twödjentlicf) minveftens einmal zu befidjtigen und in ange= meffetter Beife auf ilgre Braudjoarfeit zu priifen.

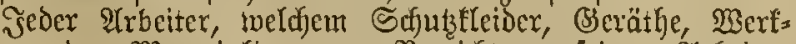
zeuge oder Materialien, zur Ferridftung feiner शrrbetten itbergeben imerden, ljot für diefe aufautommen; er hat fie jorglidf und in bex borgejdriebenen Weife zu behandect und nacf beendigter $\mathfrak{U}_{2}$ beit an Dem bazu beftimmten Drt aufabemalyen. (5r barf aud) nicht die den Mitarbeitern

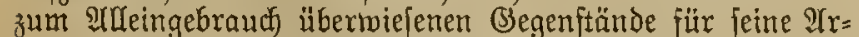
beit bermenden. Ricft exforderlicfes Material, powie un= braud) bar oder mangelfaft getwordene Beräthe und $\mathfrak{B e r t s}$ zenge find zurïrfulieferm.

Die unbefugte Entnahme non Materialabfällen irgend melcher ?.rt ift berboten. Butwiderhandlungen merben un= nadfficf)tlid) mit pojortiger (Entlaffung geahndet und in Den

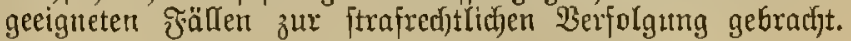

$$
\text { llnfalluerhutungsoorfdutften. }
$$

\& 4. Die 9rbeiter Yjaben die bon Der Bertwaltung er,

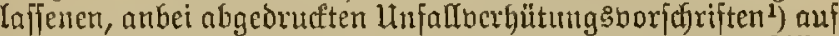
bas Sorgfältigfte zu beobnd)ten. Sie ljaben ferner alles żl bermetben, twas ju einer Sainderung oder: Störung bes Betriebes ber Ielegraphenanlagen fïliren fönnte. Buwider. handlungen gegen diefe Bfficht werden unter limjtänden Ftrafred)t tid gealyndet.

1) unten $5.827 / 828$.

\section{Jernbiciben bou Diente.}

§ 5. Die 2rothtwendigfeit, megen Rranflyeit bon Der IUtreit megjubleiben, ift möglichjt frübjeitig Den Dienjtvorfteljer oder feinem Bertreter mitzutfeilen. Jö̈ andere beabfidjtigte शirbeitsumterbreduntgen ift rechtzeitig bei ifgnt ll:taub nad żujuchen.

\section{Thzeigen bon Sïrperverlezungen.}

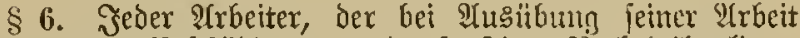
Berlebungen, Befjuädigungen oder fonjtigen Piadjtyeil erlitten hat, oder bon foldien betroffen zll jein glaubt, lyat ofne Verzug Dem Dienitnorfteher oder defien Bertreter babon Mittfeilung zu macjen und bie erforderlidjen Bemeife bei= zutbringen.

\section{Borgejetste.}

$\S \%$ Dem $\mathfrak{A r b e i t e r}$ find jeine Vorgejekten zu bezeiffnen; beionders ift ilnt mitzutheilen, wer die Befugntís zux $\mathfrak{B e}=$ itrafung und zur (5ntlaffung mit oder ofne 9luftündigung hat.

Sobald Srbeiter eines Dicnjtzmeiges in den Bereid eines anderen Dienjtzmeiges eintreten, Gaben fie Dent Unorontungen des betreffenden Dienftborftehers oder jeines $\mathfrak{B}$ ertreters Folge zu leiften.

\section{Irbeitzjeit.}

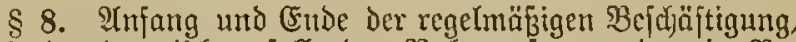

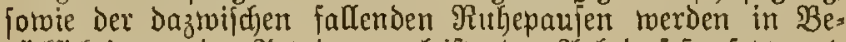

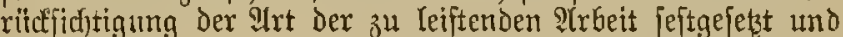
ben SMbeitern in geeigneter weife befannt gemadit; bet auferordentlidjem Bedurfutiffe ift indé jeder pflichtet, aud über bie ein= jür a llemal bejtimmte Irbeitg= zeit hinnus, powic aud) zur ungetwöhntidjen Beit, insbejondere

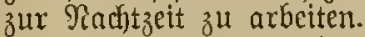

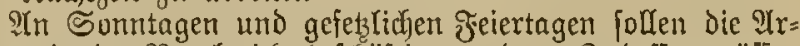

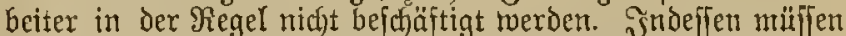
auf Berlangen aud an Som= und Feiertagen bon ben ?rueitern verridjtet werden:

a) Trbeiten, welche nach Der Ratur des Telegraphen.

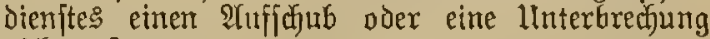
nicht gejtatten,

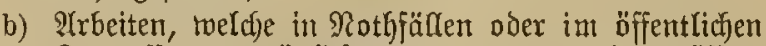
Эntereffe unverzüglicf borgenommen werden müfjen,

c) Die Bemacfung Der Bauten und Bెetriebsanlagen,

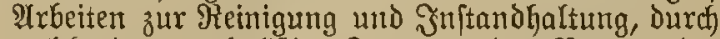
welche der regelmäß̈ige Fortgang bes Baues oder 
Betriebes bedingt ift, forwie 2 rbeiten, bon twelchen die Wiederaufnahme bes bollen merțthätigen $\mathfrak{B} e=$ triebes abjängig ift, jofern nicht diefe Irbeiten an Werftagen borgenommen toerden fönnen,

d) unter derfelben Borausfeksung Irbeiten, weldje zur Berhütung des Serderbens von Materialien oder Des Miflingens von Irbeiten erforberlich find.

Irbeiter, weldhe twiebertebrend an Sonntagen bejääftigt werden, müffen cntweder an jedem dritten Sonntag zนH= fammen mit dem borangehenden Dder folgenten $\widetilde{T} a \mathrm{~g} u \mathrm{n}=$ unterbrochen 36 Stunden ober an jedem zweiten Sonntag von $6 \mathfrak{B}$. bis 6 श. bon Dex Irbeit freigelaffen merden.

\section{Söhnung.}

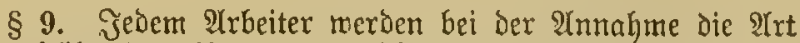
und Söhe des ifnt zut gewährenden Rohnes, ebenfo die Friften und Formen, in weldjen bic Bablung erfolgt, mit=

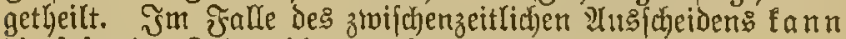
die fofortige \&ohnzahlung geftattet toerder.

Der Rohn Darf feinesfalls in Sdjant= oder WBirthghäujern

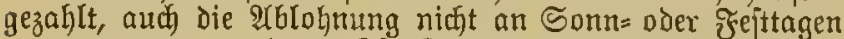
vorgenommen merden. Şit Resteres ausmahntimeije nicht zu vermeiden, fo mú der Seitpuntt der Lofnzahlung fo

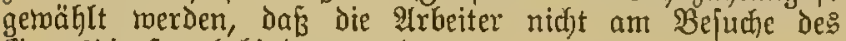
(S) ottes̉denftes beljindert twerden.

Fintwendungen gegen die empfangenen Sohnbeträge find innerhalf der nädjften orei Iage beim Dienftuorfteher an= zubringen.

Wünjojt der 2trbeiter bei einer Bejdäftigung auserhalk feines $\mathfrak{W o h n o r t s , ~ d a f i ~ e i n ~ T h e i l ~ b e s ~ R o h n e s , ~ D e n ~ e x ~ v e r d i e n t ~}$ hat, feiner Familie übermittelt werbe, fo hat der utit ber Sohnzahlung beauftragte Beamte den Selobetrag anzunehmen

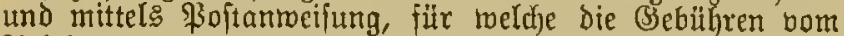
Arbeiter zu entridften find, Der ₹ramilie zu überjendent oder Dem $\mathfrak{Y}$ rbeiter bei ber $\mathfrak{A}$ usfertigung der \$oftanmeifung be= lïlflid) zu fein.

Der Den Sohn zahlende Beamte ift ferner berpflidetet, von jedem Arbeiter auf deffen Berlangen an jedem Bahltage Eriparniffe anzunehmen, Darüber in einem $\mathfrak{B} u d)$ bem $\mathfrak{A} r=$ beiter zu quittiren, ben $\mathfrak{B e t r a g}$ aufaubetoahren und foldien an jedem 3ahltage auf Berlangen des \$Trbeiters ganz Dder

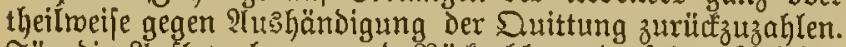

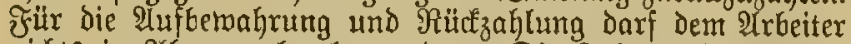
nidjts in $2 b_{z} u g$ gebradt twerden. Die Telegraphenbermat=

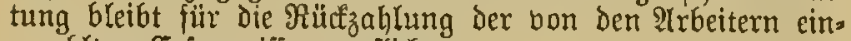
gezahlten exparniffe verpflichtet.

\section{Arbeitgoverfäumnif̧ แnd Heberftunden.}

$\S 10$. Der Tagelohn miro für biejenigen Tage getwährt, an melden der Arbeiter bienjtlidf thätig getwelen ift; etroa geleiftete Heberftumden werden bejonders bergütet.

Für berjäumte Beitabjofnitte fant, abgejehen bon Der

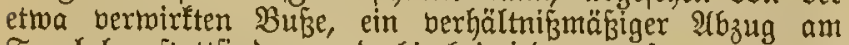
Tagelohn itattfinden und hierbei jede angefangene halbe Stunde boll geredinet merden.

F̆̈̈r Sonn= umb f̧eiertage, an denen nidjt gearbeitet wirb, und für foldje Tage, an weldjen Das Wetter zur Unterbrechung der Prbeit nöthigt, fann in Stelle des fort= falfenden Tagelofnes ein Behrgeld in Söhe Der bälfte des Tagelohnt getoährt merden. Sh bie Bahlung von Behr $=$ gelo itattfindet, wird für bie einzelnen $\mathfrak{B e f d a j a t i g u n g e n ~ i m ~}$ Boraus beftimmt.

\section{Erfabpficht.}

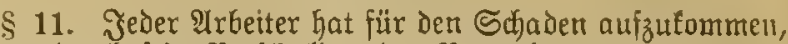
Den er burd fein Berfdulden der Bermaltutng an den voul

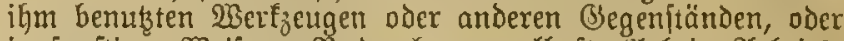
in fonjtiger Weife, z. $\mathfrak{B}$. Durch mangelhafte Urbeit, ?trbeits: einftellung $2 c$., verurfact)t.

\section{Bugen.}

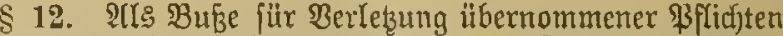
fönnen gegen Den ?trbeiter bon der vorgefebten Dienftifelle

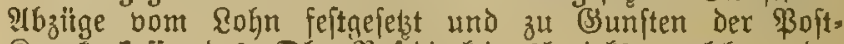
Rranfenfaffe Des Dber:ßoftdireftionebezirfs, meldjem ber Arbeiter angehört, einbehalten roerden.

Die 2Ymtsoorjteher, Bauführer, \&eitungsirebiforen, Reiter von Stangen=Z3ubereitung Bermalter haben die Bejugnif, folche $\mathfrak{B} u$ bell bis zum $\mathfrak{B} \varepsilon=$

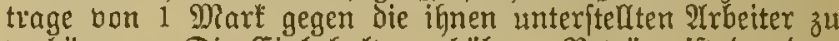
verhängen. Die (Einbehaltung höherer $\mathfrak{B}$ eträge ift Der Dem Imtsuorfteher, Banführer, \&eitungǧrevifor 2e. borgejebten Dienftitelle vorbehalten.

Die Şöhe eitter verhängten $\mathfrak{B}$ ube foll ben $\mathfrak{B}$ etrag bes

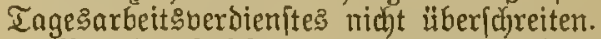

Bor der Jeftietsung einer Bube ift Dem Srbeiter durch verhandlungs(d)riftliche Bernehnung Belegenheit zur Recht= fertigumg ă geben, und der Thatbeftand, forweit nothroendig, Durd 2lnhörung bon Beugen oder andere Betreiserhebung f(u)riftlid) feftzuftellen. (Segebenenfalls ift die Bube ohne Berzug feftzufetsen und bem 2(rbeiter zur Semtrif̧ zu bringen.

J̃ede $\mathfrak{B}$ uge twird bei Der näbjten \&ohnzahlung einbehalten.

Gegen bie Berhängung von $\mathfrak{B u b e n}$ fteht dem Yrbeiter die Bejumerbe an Diejenige Dienftftelle 311 , meldte der bie Bufze fejtietzenden Stelle zunähjit borgejekst ift: bie Conts inheidung Diefer Behörde ift endgültig.

$$
\text { Sohnabzüge. }
$$

$\S 13$. Bom Sohne fönnen einbehalten werden:

1. Bufen (§ 12),

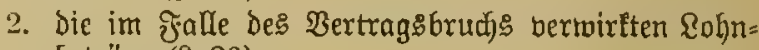
beträge $(\S 20)$,

3. Die ftatutenmäf̧igen ßeiträge zur ßoft=ßranfen= Raffe;

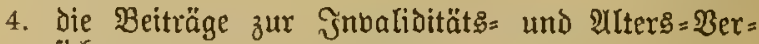
fidjerung.

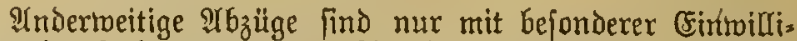

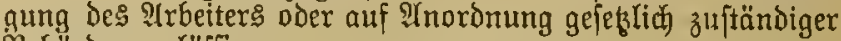
Behörben zuläffig.

\section{If zzeidyen.}

\$14. 8um Tragen einer Uniform find die $\mathscr{A}$ rbeiter nid)t beredytigt. Dagegen find fie verpflidftet, cine nad, Doridjrift gefertigte Dienjtmüke mit bem borgejariebenen Dienftabzeiden und der jedem Finzelnen zuzumeifenden Rummer zu tragen. Müze und Dienftabzeicten hat der शrbeiter auf eigene Rolten zu bejudaffen; Die Nummern werden geliefert.

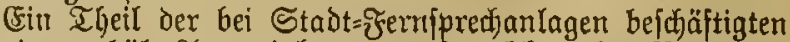

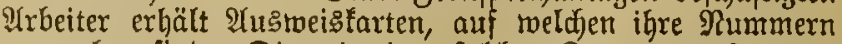
angegeben find. Die mit einer folchen Sarte ausgeftatteten Nrbeiter haben jie im Dienfte ftets bei fich zu führen und Dem \$̧auseigenthümer ze. unaufgeforbert vorzuzeigen. Die 
Rarte ijt auj das Sorgfältigite aujzuberoabren. Sollte fie Dem 2rbeiter abhanden fommen, jo hat diejer feinem Dienjt. vorfteher unberzüglid, Davon Mittbeilung zu machen. Ract)= läffigfeiten beim $\mathfrak{B e r m a l ) r e n ~ D e r ~ f a r t e ~ w e r d e n ~ m i t ~ ( S e l d b u ß e ~}$ geahndet.

Die $\mathfrak{B e j t i m m u n g e n ~ d e s ~ v o r j t e h e n d e n ~} 2$ tbjakes finden aud auf Dicjenigen Arbeiter, weldhe behufis felbjtändiger Erledi= gung bon STufträgen Babnaulagen betreter millifen, ent. iprectiende ?tnmendung.

\section{Beitritt zur $\mathfrak{B} o[t=\Re r a n f e n f a j i c$.}

§ 15. Der gelesticfen Srantenberficterungspflidft haben die Yrbeiter bei ber zujtändigen ßoit=९rantenfajpe zu ge= nitgen. Sie bleiben von ber Betheiligung an dieje salife auf Arntrag nur bann befreit, wenn jie nadineisticy $\mathfrak{R}$ itglied einer den SInforderungen deछ $\$ 75$ Des Bejezes bom 15. Juni 1883 , in Der ₹Fajiung Der Tobelle bom 10. Tlpril 1892, gentigenden Saullfatajfe find. ${ }^{1}$ )

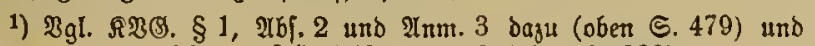

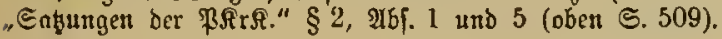

\section{Beendigung des Dienftberhältniffes.}

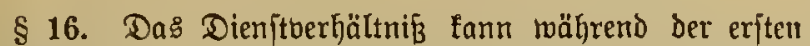
vier Wodjen ron beiden Theilen jederzeit fojort, nad) diejer Beit, auger im Jalle bes beiderjeitigen CEmberjtänonifjes, nux Durd eine jedem Theile ireiftehende, 14 Tage vorher

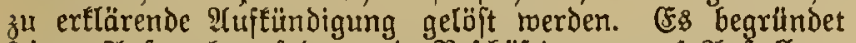
feinen $\mathfrak{A}$ (n)pruch auf bauernde Beffiäftigung, auf Injtellung im \$oft = ober Telegraphendienjt oder auf (setwährung eines

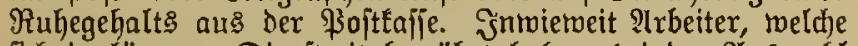
(itc) in längerer Dienjtzeit betwährt haben, bei ber Áubmahl ber lunterbeamten zu berüdfidjtigen (ind, rid)tet fid nad) den hieribber bom Reid) $=$ Bo|tamt getroffenen allgemeinen Be(timmungen. ${ }^{1}$ )

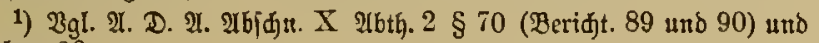
Inlage 30.

\section{Sojortige entrofiung.}

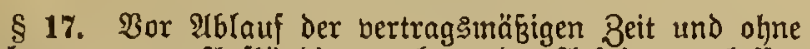
borhergegangene 2luffündigung fam der 2 rbbeiter entlajfen werben:

a) negen miederholter Truntentheit im Dienfte;

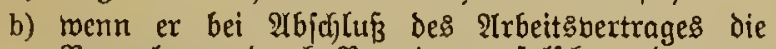
Berwaltung Durd) Borzeigung falf(fer oder bers

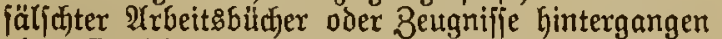
oder fie itber das Bejtehen eincs anderen, ign gleidzeitig berpflichtenden Arbeitsvergältniffes in einen Jrrthum beriezt gat;

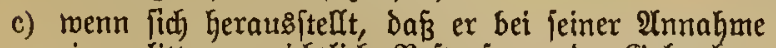
eine exlittene geridjtidje Beitrajung ober Bsebredien, wie Shmindel, Epilepite ze., verheimlidyt hat;

d) tuenn er fid eines Diebitabls, einer (Entwendung,

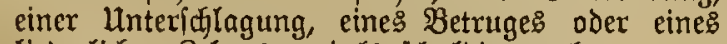
liederlidjen Rebenswandets juuldig madjt;

e) wenn er bie Arbeit unbefugt verlajjer hat oder fonft den nact) Dem arbeitsbertrag igm obliegenden Berpflidtungen nadjzufommen beharrlid) ber: meigert;

f) menn er, der Berwarnung ungeadidet, mit ‡euer und Richt unoorfidjtig umgeht ober bie lunfall= berblitungevorjadriften beharrlid auber 2(d)t läßst; g) menn ex fiđ Thätlichteiten oder grobe Beleidi. gungen gegen feine Borgejekten oder beren $\mathfrak{B e r}$ : treter zu Sdulden fommen läßst;

h) wenn er einer vorjäkzlicten und rechtstoibrigen Sadjbejwäbigung zum Nadtheil Der Berwaltung oder eimes Mlitarbeiter

i) wenn er MRitarbeiter zut Sandlungen berleitet oder zu verleiten jutht, melche wider die Bsejetze ader bie guten Sitten veritoben;

k) menn er zur frortfebung der Irbeit unjäfig oder mit einer abjefrectenden Srantheit behajtet ijt.

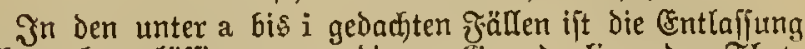
nidit mehr zuläffig, menn die zu Grunde liegenden That = fadjen auf Sruns glaubhajter :Tingeige der Bermaltung länger als eine $\mathfrak{B a d h e}$ befannt find.

Es ift bem $\mathfrak{A}$ rbeiter borker Sielegenheit zu geben, fith verbandlungsfadriftlid] zu ertëren; ber Thatbejtand ift, foweit nothrendig, burd Bernefymung bon Beugen und andere Berweiserbebung fóriftlid feitzuitellen.

\section{Sofortiger Austritt.}

\$18. Vor Ablauf Der vertraggemäвigen 3eit und ołne Pluftindigung fann ber 2rrbeiter die 2rrbeit berlaffen:

a) wenn er zur Fortję̧ung Der Mrbeit unjähig wird;

b) rwenn Borgejeste oder Deren Bertreter fid Thätlich: Eeiten ober grobe Beleibigungen gegen ifn z" Sfuuldon fommen laffer;

c) menn Borgeletete oder Dexen Bertreter ihn zu Sandlungen verleiten oder zu berleiten futhen, weldie wiber bie Sejeke ober bie guten Sitten laufen;

d) wenn ihm ber idfulbige Rohn nidjt in ber be= dungenen weije auggezahlt oder bei Stüfflohn nicht für feine aubreidjende Befdjäftigung geforgt wirb, oder wenn ein Borgejester fid miderrectit= lidjer Ueberbortbeilungen gegen ifn ífuldig mact;

e) menn bei Fortjeksung Der भrbeit jein Leben oder jeine Bejunbheit einer erweislichen Befahr ause gejetzt fein wilide, weldje bei (5ingehung bes 2rbeitsvertrages nidjt zu erfennen war.

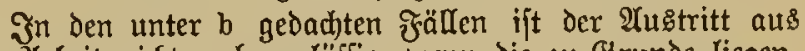
ber $\mathfrak{A}$ rbeit nidgt mehr zuláfig, menn bie zu Grunde liegens den Thatfactien dem 2̂rbeiter länger als eine Wodje be: tannt find.

\section{Befugní̄ zur bertoaltungşeitigen âflofung des Dienftuerhälnifies. Befdruerde gegen die leztere.}

\$ 19. Bur berwaltungsifeitigen $\mathfrak{A}$ uftöfung Des Dienft=

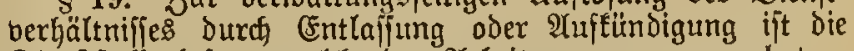
Dienitftelle befugt, weldje den भrbeiter angenommen hat.

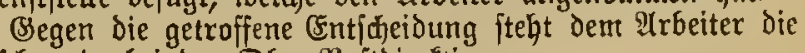
Befdiwerde bei Der Sber=\$oitdireftion $z^{u}$.

(5ntidäbigung wegen ungeredtfertigter Entlafjung und wegen redistoidrigen Berlaffens ber $\mathfrak{A r b e i t .}$

§ 20. Fine Entijäbigung für unbegründete jofortige Entlajiung findet mur bis zur söbe bes bem Entlaffenen fitr die Dauer der 尺ündigungefrifut entgangenen \&ohnes jtatt. 
Wirb Die Befannerde über jofortige (5ntlafiung begründet befunden, fo wird dem 2Abeiter für die Daner ber fïndigung: frift der bertragsintảbige Sohn nadjgezahlt, jolveit er mäbrend ber ङrijt einen folchent nidfit anderneit verdient hat.

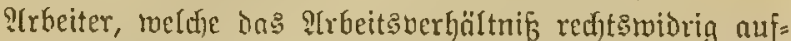

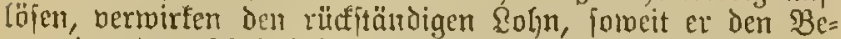

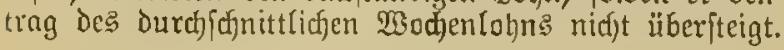

खqf

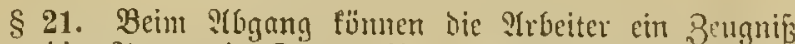
itber dic 2l't แnd Dauer ifjrer Befdäftigumg fortertu. Diefes Zeugnif ift von dem Seiter des Betriebes nusjuftellem

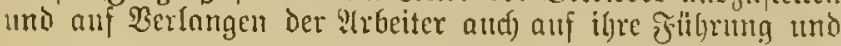

ihre Reiftungen forte auf den Brund Der :luflöfung des

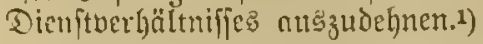

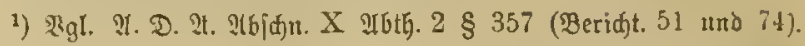

Rü ffleferung Der dienftliden Gegenjtände.

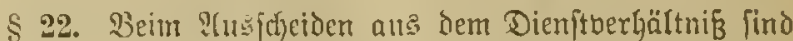
jämmeliç)e dienjtlicf) itberwicferen (Segenftäude, a[s Dienft= antreifungen, Beräthe, Wertłacuge, Schukteteider, Daterialien

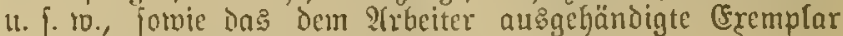
Der gegentoärtigen Dronung zurüufuliefern.

Bertin W., den 13. כัul 1894

Reid)

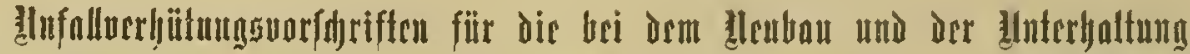

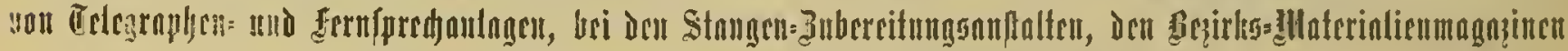

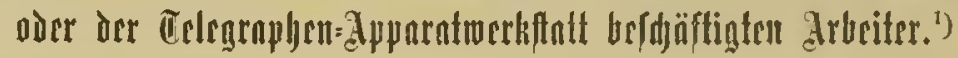

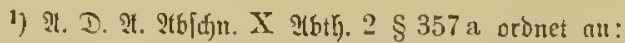

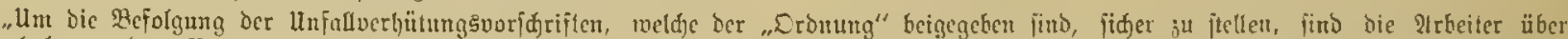

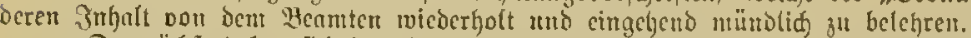

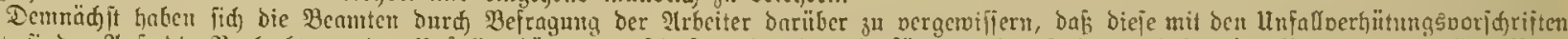

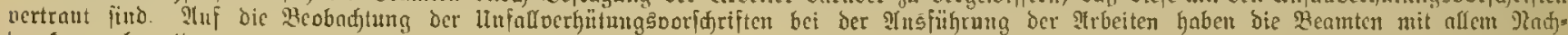
bruff ju ndjter."

\section{Algemeines.}

Jeder Ieleqraphenarbeiter iff uerpflichtet, fofern ifm nicf)t unter bejonderen Derljälunifien vour feinen unntele

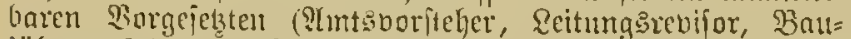
iithrer, Seitungenaffeber nder 23 orarbeiter) abweidjende $\mathfrak{A}_{11}=$

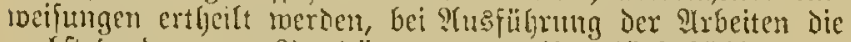

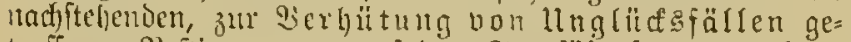
troffenen Beffinmumgen auf ons Sorgiältugfte jul beachten.

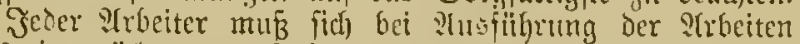
itets in nüd)terneut Buitande befinden. Bei gleidgeitiger

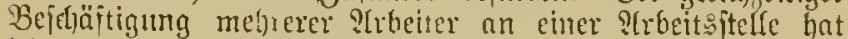
jeber cingelne nidht mur anf fidf jelbit sul achten, fonbern

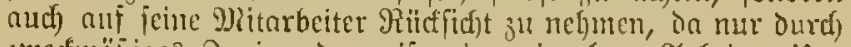
ivedmäbiges Snctuandergreifen ber eill jelneu ?trbeiten lln jällen witliom norgebeugt werden fann.

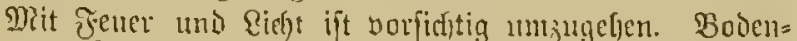
räume u. f. w. mit offenem Qidft in hetreten, ift unterfagt.

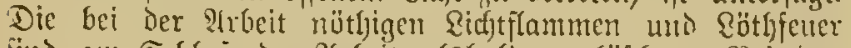

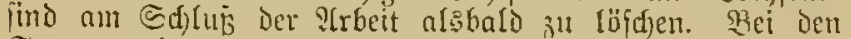
Stangenjubercitungsanftalten ift der Jenertorb nie in un= mittelbarer Piähe von Schälfpänen und itets auf der dem leerfachion 2 simde abgemendeten Seite aujujteffen. Teben

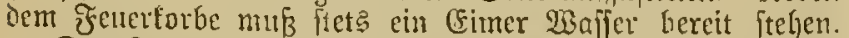

Den ?trbeitern ijt bei Der :Beidjäjtigung auf Böben oder in Bimmen, fomie immerhalb ถer Etangenjubereitunganan= ftalten Dos giaudjen unterjagt.

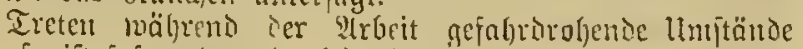
ein, fo ift fofort Dent bauleitenden Beanten ?tuzeige zu er= itntten, mo es ift an ber betreffenden Stelle mur madi mäherer $\mathscr{Y}$ nmeifung bes leşteren reiter ju nibciten.

Befondere Borfid)t ift bei Den ?rbeiten an Denjenigen Telegraphenleitungen ju beobadsten, rweldje in ier Niähe von Startftromleitungen verlaufen, domit Berührungen

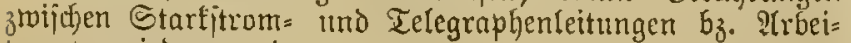
tern vermieden merden.

\section{Befichtigung Der (s)eräthe.}

Der Urbeiter hat fid mit Der praftifonen 5andjabung

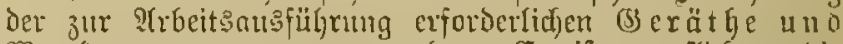
Werézeuge vertraut ju madjen. (5r ift berpflicftet, die ifm ïberniejenen (3erüthe, insbejondere dic Reitem, Sidjer=

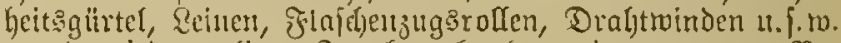
bor Der jedesmalizen Jngebrauchnahme ciner genanen $\mathfrak{B} e=$ fidftigung zu unter jeben; er hat ferner zu priffen, ub Die Sä̈mmer, Beile, \&öthfolben n. F. w. Feft auf dent Stielen auffitzen, ob bie Rniebebeltemmen genügend tief aufges hauen find. un oen eingelegten Draht fejt fafjen zut tönnen

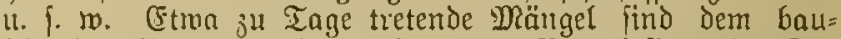

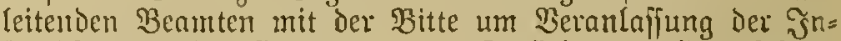

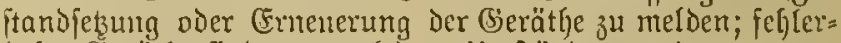
hafte Seräthe find unter keinen Umftänden reiter ju ver= menden. Jeoent Strbeiter roird inşbejondere zur Pfficit gemadjt, fofort anjuzeigen, wenn Duref) Unnoorfidftigfeit oder 3ujall die Sidherheitsgïrtel ober Sidherheitslemen mit Säuren beneßzt jein jollten, ba Derartige biegenftände ojt audf danu nocly böllig unberfehrt ausfehen, neen fie fdon mit Reidjtigleit jerriffen toerden tömen.

\section{Befteigen der Eeitern.}

Dic Seitern fino beim Bebrauch mit den eifermen

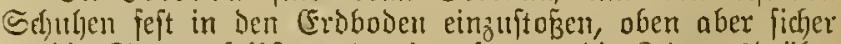
an die Stange jelbft, und niemalg an Die Reitungsorähte anzulegen. Beim Suffteffer auf Steiuplatten, feft gefrorenen

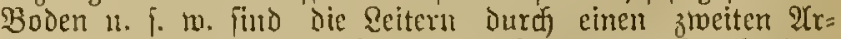
beiter zll halten. Die Scitern mitjien in entfpredjendem Winfel ju ben ङtangen น. F. w. aufgeftelft werden, fo dn $\bar{B}$ fie wever bei ju fteiler Stellung umfallen, noch bei ju

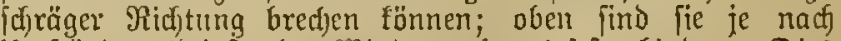
IImptänden (bei jtar Een Wimbe u. F. w.j feftzubinden. Dies

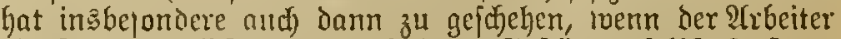

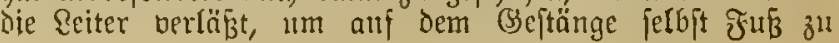




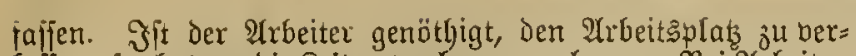
laffer, fo hat ex die \&eiter borher umzulegen. Sei $\mathfrak{A}$ rbeiter längs der (sifenbahn find bie \&eitern thunlidjit anf ber

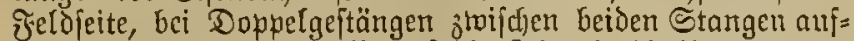
jujtelen; auf feirten Jalf boxf bie Reiter in bie 1Tmgrenzung des lidjten Raumes hineinragen. Beim Serannahen eines 8uges find aufrecht ftehende Reiteru, fojern fie nidft ange= bunden fins, umzulegen.

Bei Irtbeiter an Eanditrafzen hat die Ilufitellung ber Seitern eberfalls auf ber J̌eldeite zu exfolgen; two bies nidjt angängig ijt, fowie an berfelyrerreichen Siten, ijt die Qeiter Durd) einen zweiten 2 (rbeiter zu halten und gegen

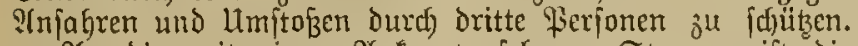

Un Die mit einem 2 nfer berfehenen Stangen ift Die Reiter thunlichit auj derfelben Seite der Stange, auf weldier Der âfer angebrad)t ift, an bie mit einer Strebe ber= jegenen Stangen auj Der Der Strebe entgegengefertiten @eite

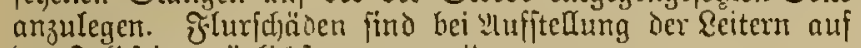
ber ₹eldicite möglidjft ju bermeiden.

sit die Reiter on eine angefaulte, durd) Streben u. f.w. nidit bereits genügend berfiz̈rtte Stange anjulegen, fo ift lebtere Durch) (segenjtemmeu einer zmeiten Reiter, einer Babel u. i. w. zu itüzen.

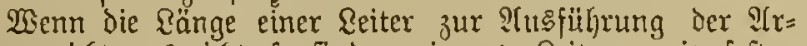
beiten nicft ausareidit, fo find zmei gute Reitern mit feiten

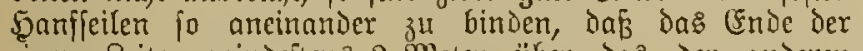
cinen Reiter mindeftens 2 Meter ïber das der anderen Seiter ju liegen fontmt.

Bei Bermulumg jeljr langer oder zufammengefezter \&ei= tern find biefe oberhalb der 9litte nod befombers a u fitutselt, um bem Senmanfen uno Brechen borjubeugen.

$\mathfrak{B e i}$ Den ?trbeiten auf ber Reiter oder auf den (B)= ftängen felbjt hat fid ber S(rbeiter Duted SInbinden alt ber Stange oder in jonjt geeigneter Weife gegen yrbgleiten zu fithern. Sfit der 2 Irbeiter hierbei gentithigt, fid) an einem

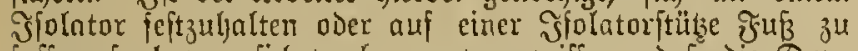
fafien, fo hat er fid borker zh vergervifferm, oaf dte Dops pelglodfe oder die Stütze, meldje den Salt gewülyrent foll, unbejuäbigt ift, und namentlid) Daß Die Etüke feit int

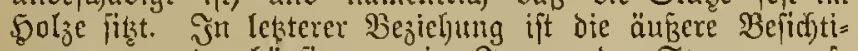
gutrg megen der häufig mur im Sumern der Stangen auf =

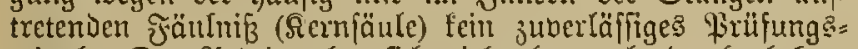
mittel. Der P(rbeiter (jat (id) bie(mehr aud) Durd) behut= fames Bieben an Dem Jiflator bour deffen guter Befeftigung lueberzergung ju berifyaffen. Steht bie Stange, an welfier gearbeitet vird, in ciner Sirümutug, fo fat der 2(rbeiter, namentlic) wenn Reitungen umgelegt werden u. F. w. feimen Standpunt an ber bem Drabtzuge abgefebrten Seite zu nefmen, Damit ex nidjt.bon eimem losjdueflenden Drahte getroffen wird. Röthigenfalls ift der Draht aud nod durd $\mathfrak{A n b i n d e n}$ an Der Stange feftzulegen. (Eine Seiter barf niemals Durch mefrere 2frbeiter zugleidy beftiegen werben. Das Bepteigen einer freiftehenden \&eiter, aud went fie von mefreren Irrbeitern gehalten wird, ift ftreng= fters unterfagt. Sofern bei einer Reitung biejenige Stelle, an weldjer gearbeitet werden fol, meder bon Dem @tüts= punft aus nod auf andere Weije zu erreiden ift, mus der Reitungsoraht Durt) 1 bnelimen non den Doppelglocfen tiefer

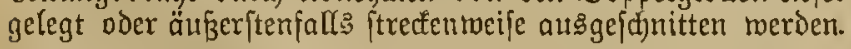

4. Serfellen bon Stangenlödern, Sezen, Austedfeln und llmlegen bon stangen 2 .

Die Stangenläber miiffen geniigend meit fein. Bei

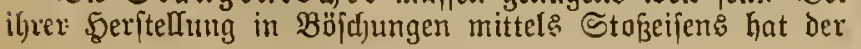

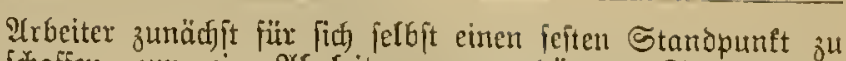

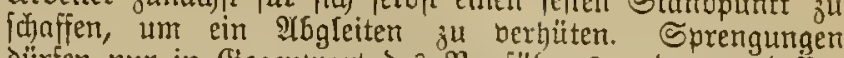
Dürfen mur in (Siegenwart des Baujührers uno unter Deffent periönlidjer \&eitung vorgenommen werder. Bei Sprengungen

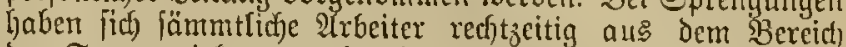
ber Sprengroirtuta zil begeben oder fidj bolitändig gedect aufujteller. Bortibergehende \$erjonen oier die Jïlyer

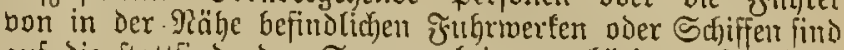
auf bie ftattfindenden Sprengarbeiten geförig aufmerffan zu machen. Etwa zll ben Sprengungen beitimmte: Tyna= mit ift niemals in 5̧äujern, fondern in anderer geficherter Weije nach näherer ?(nmeijung des bauleitenden Beamten

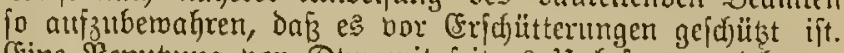
Fine Benutbung bon Dynamit jeitens llnbefugter zieht $g e=$ richtliche Bejtrajung nach jich.

Bei நerjtellung größzerer bz. tieierel Qöcjer oder Bräbet jür Doppelgeftänge, Doppelitänoer, Eroleitungen 2c. fino die Wände - bejonders bei locfercm ober fandigem Boden

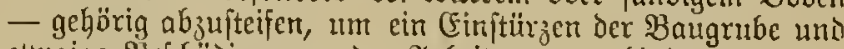
etmaige Befdjäbigungen Der 2lrbeiter $z^{u}$ verbindern.

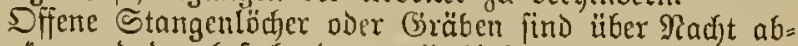
zudecten und den beitehenden polizeilichen Borjefriften ent= predhend 3u beleudften. $\mathfrak{B e i}$ Thibeiten längs ber $\mathfrak{B a h n}=$

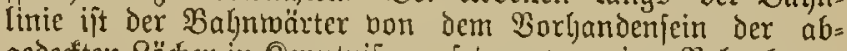

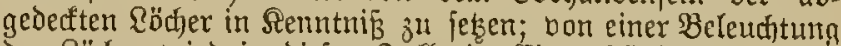

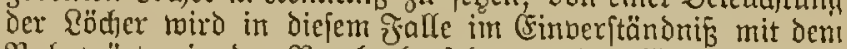

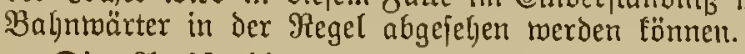

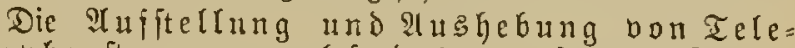
graphenftagen- bejonders bon ichmeren Doppel itändern, Doppelgeitängen òer Maften — Darf nur inter

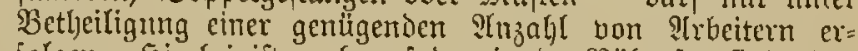

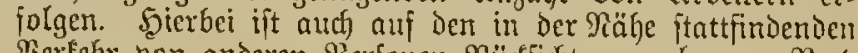

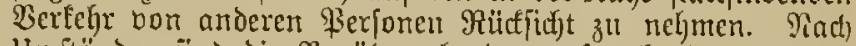

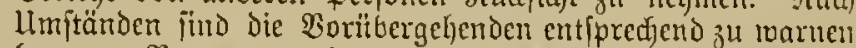
bj. jur Benubung eines nuberen 23 eges zu veranlaffen.

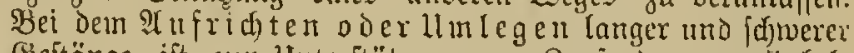

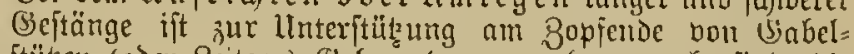
jtüksen (oder Reitern) (Sebraud) jll madfen, aud find dic Bicitänge am 3opjende anjucilen. Das ₹rußzende der Stangen ift geljörig feftzulegen, fo Daß̉ ein Slbgleiten oder Emporidnellen ausgefolofien ift. Das Jeftlegen des đus = endes Der Stange Dadurd) ju hewirken, daß̧ ein 2lrbeiter mit dem Jufe auf bie Stange tritt, ift unjtatthaft, meil hierbei leidht Dutethungen der :Hbeiter eintreten föment.

Bei der $\mathfrak{A} u \mathfrak{s}$ wedjelnng on $\subseteq$ tangen ijt, bebor die Söjung Der Bindeorähte und die Serabnalyme der Ecitungen ausgeiüfrt wird, zu priffen, ob die abgäugig ge wordene Stange mad) foviel 5 alt bietet, Daß̧ fie dem einfeitigen Dructe ber an fie anzulelynenden \&eiter und Des

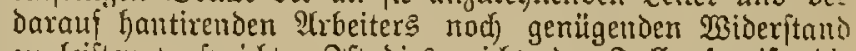

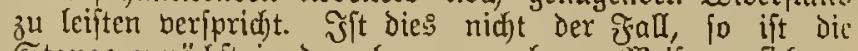
Stange zunächit in der oben angegebenen 13 eife ju fichern, bebor der Mrbeiter die Reiter exjteigt. Das Rufgrabell auşzumedffelnder Stangen hat erft nad) dem \&öfen fämut= licher Reitungsbindungen zu exfolgett.

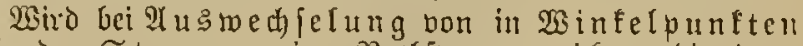

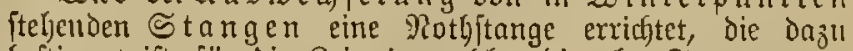
befitimmt ift, für Die Beit, in melcjer die alte Stange aus: gefoben und bie neue gejekst wird, dic Reitung gdrähte auf = zunegmen, fo fimo bei der wegen der ftarfen Spanumg ber Qeitunggorähte mit Befahr berfnilpften llebertragutg Der

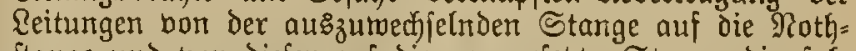
ftange und bon biefer auf bie neu gejelste Stange bie fol= genden $\mathfrak{B o r f i c h t 8 m a f 3 r e g e l n}$ z̆ beadjten. 
Die Reiter, twclifye der mit der Hebertragung: der Seitungen beauftragte $\mathfrak{3}$ (rbeiter ju befteigen hat, muß menn es irgend angeht, auf der dein Drahtzuge abgeférten Seite der auszumecfielnden Stange angelegt werien, damit Der $\mathfrak{A} r=$ beiter nicht bureh den abgehobenen und mit bedeutender Sraft zurülfidnellenden Drabt bon Der Reiter getworfen wird. Dem Zurüdfiffnellen des Drahte nach der Sothftange zu ift dadurch borzubeugen, dafi um ifn, Gebor ex bon dem Siolator gelölt ijt, eilt Seil gejeflungen wirb, reldhes über

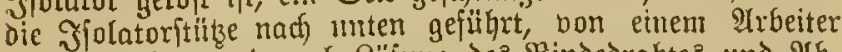
fraff gehalten und nach Qöjung des sindedrahtes und 2 Th= heben des Reitungsobrahtes langjam nadjgelajien wird, bis

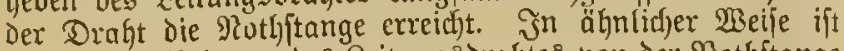

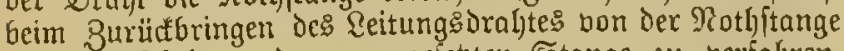
nuf Den siplator Der neu gejebten Stange zu berfalyen. (Seitatten Die örtlidjen Berbältuifife bie Sluffitelung der Seiter auf Der dem Drahtzuge entgegengejetsten Srite nidjt, und

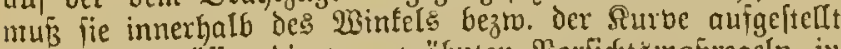
merden, fo mitffen bie borermähnten Borfidtesmaß̧regeln in

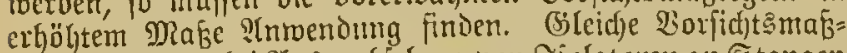

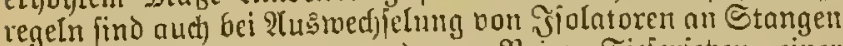
in Wintelpunten anjumenden. Beim Tiejerjetzen einer Stange it zur gröferen Sicheritellung der üher der faulen Stelle abzuiägenden Stange gegen llmfađen ein Seil um

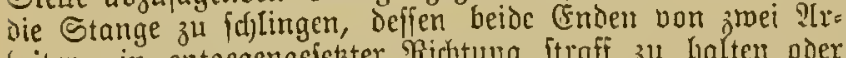

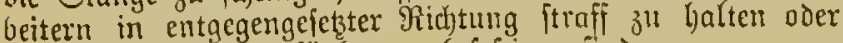
alt eingefajlagenen łfählen zu befelitigen find.

Beim Drehen bon Eroleitungs: und Anfericilen iit der Eifen= oder \$olzlnebel mit beiden Gänden jeitjuhalten, ım ein Burüffid)nellen ju berhüten.

umjulegende Stangen find nidjt bolfiändig aus

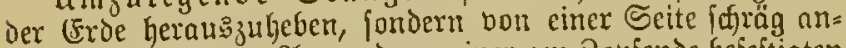
jugraben und unter $\mathfrak{Y n w e n d u n g ~ e i n e r ~ a m ~ Z o p f e n d e ~ b e f e j t i g t e n ~}$ Eeme tach und nad) umjulegen.

Beim Iragen vou Telegraphenftangen haben fid die Irbeiter nad) Der Folge ibrex Sd)ulterhöhe aufautellen; (tud) ift darauf zu adjtell, das die Stangen bon fämmtlidjen Wrbeitern auf der gleichen Schulter getragen werden. Beim Niederlegen fitid Die Stnngen nidht abjuwerfen, jondern zu=

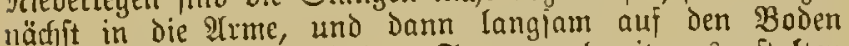
gleiten $j^{u}$ lafien. Thi Den Stnngen; find die unentrindeten Stangen in Der Regel mittel I Tage= hölzer fortzuberwegen.

Beim Berladen der geträntten Stangen auf bie $\mathfrak{W a g e n ,}$

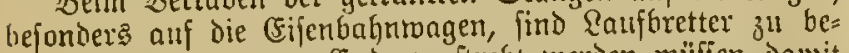
nutsen, die an unteren Ende berjtreft werden müfjen, Damit fie von den Wagen nidjt nGgleiten tönnen. Wenn bie wagent= rungen herausgentommen oder die $23 n g e n$ hod) Geladen merden müfick, io ift Da: Büüfrollen der Stangen bom Wagen

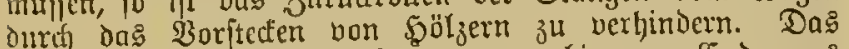
Stjieben der Wagen darf nur bam hinteren Ende aus erfolgen.

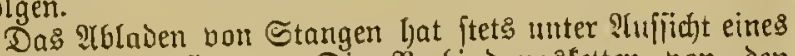
Beamten itattafinden. Die Berbimbungstetten pon den Wangenrungen dürjen exjt entjernt werden, went cin \$oerab: jallen dex Stangen vom Wagen nicht melji ju bejürd)ten ift. Die lleberanbe Der Stangen bon Der cinen Colonne alif

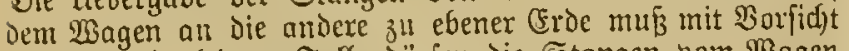
gefdjefen; in feinem Falle dürfen die Stangen bom $\mathfrak{B a g e n}$ abgemorfen oder über angelefinte Sölzer abgerollt werden.

5. Betreten des Bahnplanums.

$\mathfrak{B}$ or dem Beginn der $\mathfrak{A}$ rbeiten längs einer Bahnlinie

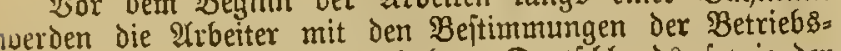
vronung für bie ఏaupteijenbahnen Deutjhlands forie der
Bahnoronung für bie Rebeneifentahnen Deutfulands, mit der Signaloronung und, fomeit a[s thunlich, mit dem (Bang ber Büge befannt gemant; bie erforberlichen luntermeijungen merden Durdh den vorgejestelt Baufühyer ftattfinden. Das Betreten der Bahngeleife ift auf das unungäliglud

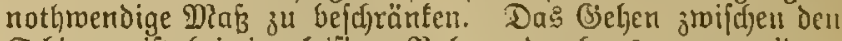
Sdjienen ift bei eingeleifigen Balynen durdjats zu bermeiden;

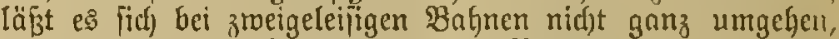
fo ift itets Dos linfe (Beleis in Der Ridtung des Behenden zu benutzen, da bie Büge bei zmeigeleifigen Bahnen in Det Regel das in der frabrtridjtung redfts gelegene Beleije be: nukzen, mithin beim (Seben in beren linfem Beleije das Бerannahen eines 8uges rechtzeitig bemerft werden faum. Beiondere $20 r j i c j t$ ift bei Biegungen der Strecfe oder itt Der গähe der Bafyngöfe anzumenden. Beim Serannahen eines 3uges find dic auf dcm Bahnplanum auşzufïhrenden

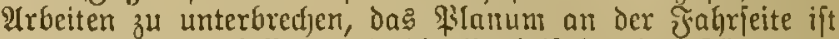
red)tzeitig zu berlafien und die Borbeifahrt ber Züge ent=

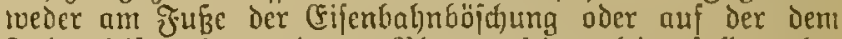

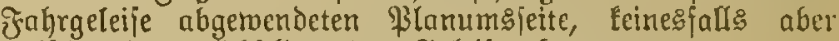
zwifhen dem nädjftliegenden Beleife abzuwarten.

Das Betreten bou Stellmerfen, Weichenftelferfuden voer

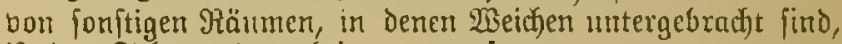
ift Den Telegraphenarbeitern unterjagt.

Die Reitungsmaterialien uno (Seräthe find toähreno Der

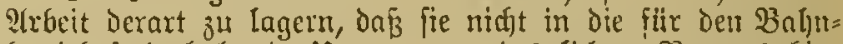
betrieb freizuhaltende llmgrenzung des licjten Raumes hin: eimagen. Die Transportfarren find nid)t anf Den $\mathfrak{B a h n =}$ törper, fondern feiträrts babon, wenn thunlich an $\mathfrak{W}$ ege $=$ übergängen aufzuftellen, meil fonjt nicjt ausgeichlofjen ift, Daf̧ Der Sarren Durd) Die (Erfähtterung Der voriberfahren= den 8üge in Berocgung geferst und vom Buge erfofit wird.

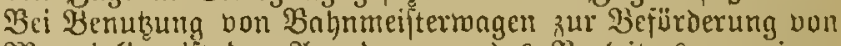
Materiafien ijt ben Itnoronungen de: Begleiters untoeiger= lich) Jolge zu Leiften.

Das Bimmern oon Doppelgeitn̈ngen, Doppel= ftändern und gefuppelten Stangeu, fowie Die शैus. rüftung bon Etangen mit Siolatoren jwifden Den Jahrgeleifen ift ftreng unterjagt. Qluch bei den fonftigen :Lbeiten an den Telegraphentinicn an (5ijen= bahnen ijt unter allen umftänden darauf Galten, dấ dic Umgrenzung Deš liditen Raumes frei gehalten mirb und Daß̧ diejenigen ?trbeitell, weld)e

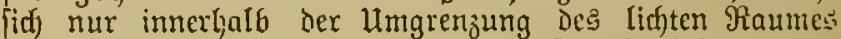
auşülyren lafien, wälyrend derjenigen Beit berwirt merden, in weld)er Büge auj Der Streffe nid)t gemeldet find.

Die ?tusfifgrung von Irbeiten in Tumels ift injofern mit gröBzeren Befahren verfnüpit, als megen der herrjaenden Duntelheit das Seramuahen der Büge leiffter überjejen werden fann; den jeitent der Tun= nelwärter gegebenen Signalen ift Daher erhöhte 2 (ufmerf = famfeit 3ujumenden. Tas Durdjidfeiten eines Tuntres:

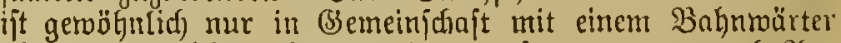
ohne einen jold)en aber nur bann gejtattet, wenn nad) S(11= gabe des Tunnelwärters Der $\mathfrak{T}$ uunel während der Dauer Des Durdjganges bon Bügen nidjt befahren virt. Dent Inoromungen bes zur Heberwacfung ber ?trbeiten eifenbahn=

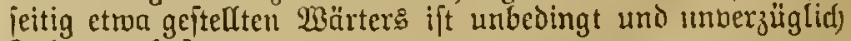
J̃olae zu leriten.

(EGerio ift aud] bei Itbeiten auf Brücten Biaduften uno fonjtigen gefälfroeten Stellen mit erhöhter Sorgfalt $z^{u}$ Werfe zu gehen.

Hebrigens ift zu allen Arbeiten an gefährlidjen Stellen die Zumeijung eines zuberläffigen Bahnarbeiters behuj\& Bes

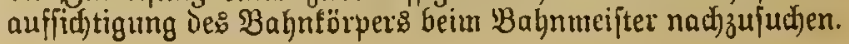


6. Sexfellung und $\mathfrak{A}$ ștwed felung dex Dragtleiturgen.

Bei Deritellung der Draftleitungen ift alf ben guten 8uftand und bie fichere Syanohafung ber Fl(ajd)enjüge uno Drahtminden nebjt 3 ubchör, jomie auf Die oronungsmä̈ige 5erjtellung ber \&öthftelen Gefonderer Werth ju legen, Damit der Draht beim $2(n j i c h e n$ in Den

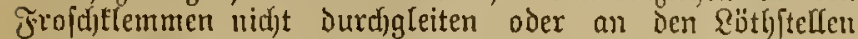
serreifen und beim Zurüeffdynelfen 9rbeciter ader it der Riäge befundlitfe andere Ferfonen berleben fann. Die für Dic QLesfiifrung Der श̂rbeiten jur Serftellung Der Draht leitungen feiten: De: bauleitenden Bcamten eingejübrten Signale find genau zu beadten. Soll eine Strabe mit einer Reitung überf(f)ritten merden, fo ift dort an jeber Seite Der Straß̄e ein Arbeiter aufauleflen, meldjer den Draht beftändig in ciner foldjen Rage zu halten hat, ba Der Verfelyr nicht befjindert wird mo giemand zu Sdjaden fommt. Jit bei Seréfellung einer \&eitung ein (Eifenbahn= geleife zu überfajreiten, fo barf bies nux zu einer 3eit ge= ihehen, in melder Büge auf der Strecfe wöhtend ber Dauer der $\mathfrak{A}$ rbeit nid)t verfehren.

Die Seerftellung bou Widfellöthftellen in Söhe ber Reitungen in Minfelpunften hat zur פoralşęung,

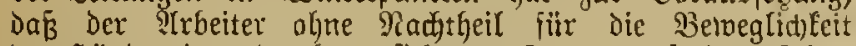
Der Şände cinen Durdjan fidjeren Etand auf Der Reiter voder auf Den Geftängen einnehmen fann, und daß̧ dabei

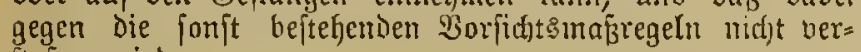
itoken wirb.

Bei Dex Şexftellung bon Seitungen über Dädjem fino die nachftelgeni unter 11 gegebenen $\mathfrak{B o r j d}$ riften genau zu beaditen.

\section{7. शुberfen bon Gegenftänden bon den Stangen.}

Es ift freng unterfagt, eutbelyrtiche Berätbe, afgej(hraubte Stitien u. F. w. von Den Etangenlerab= zurerfen; entreder find fie eineml unten jtehenien $\mathfrak{P} x=$ better bon 5and in 5and juzureict)en, oder Der 9 rbeiter hat zmects Siederlegung der (3egenitände am ₹̛̣e der Stange $b_{j}$. an dem dazu bejtimmten Srte bon ber Seiter herabujteigem. Der (siebraud) einer Seine jum Serablafien von (Segenjtänden bon ben Stangen ijt mit bejolloerer (Se= nefyntgung des bauleitenden Beamten zuläfifig. Beim Qöthen auf Der Stange u. F. m. ît es zur $\mathcal{B}$ erfintung von Verletzungen in Der giäl)e befindlidfer arbeiter ober bo: iibergefjender fierfonen fu vermeiden, Qöthmalfer zu ber: iprizen oder geid)molzenes Binn abtropfen zu laffen. Berden STrbeiten an Den Beftüngen oder Eeitungen bon Dur Reiter aus ausgeführt, fo haben Dic ïbrigen ?r.6eiter

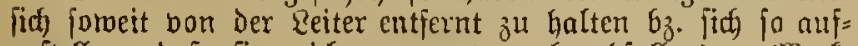

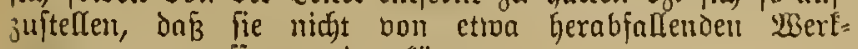
jeugen se. getroffen rerden fönnen.

\section{Derfahren Geim $\mathfrak{A}$ ఏäften.}

Beim $\mathfrak{A} u s a ̈ f t c \|$ von Bäumen ift bic Eeiter thun= lidffit an den Stamm felbit und nur ausnahmsimeife an itarfe ?(ejte anjulegen; Die Seiter zu berlaffen umD auf den

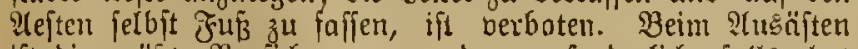
ift die gröbte $\mathfrak{B}_{0}$ orifid) anjumenden; erforderlid)enfalls bat (id) Der :(rbeiter eines Sid)erhcitsgurtes oder Der Eid)er= heitsleine zu Gedienell.

\section{Nieberlegen der Materialien und (seräthe.}

Dic Stangen unt fonftigen Materialien forvie die (Be= rätlye jind in teinem falle auf bie öffentlidjen $\mathfrak{T e g e , ~ f o n = ~}$ dern in bie Strafengräber u. [. to. To niederzulegen, dafs vorïbergehende \$erjonen nidjt Durd fie gefährdet werdell. Jü Dał शiederlegen von Materialien an Eifenbahnen gel= ten bie unter 5 aufgeführten befonderen Borfdy)iften. शRad Beendigung der Arbeiten ift die 2lrbeitsiftrecte jeoesmal ge= Görig roiedcr aufzuräumen; insbejondere find etwaige Draht= abfälle forgfältig zll fammeln b3. zu hefeitigen.

\section{Befteigen von Stangen mittels Steigeifen.}

Beim Befteigeu von Stangen mittels Steig= cifen lyat ficf) der Urbeiter unter allen llmftänden, und

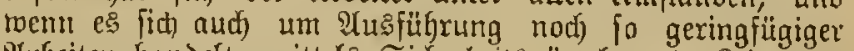
2(rbeiten handelt, mittels Sidjerbeitsgürtel tuid \&einc an Der Stange feftzubinden.

\section{Befteigen der Gerüfte bei den @tangen= oubereitungsanjtalten.}

Das Befteigen Der Stangengerüfte fomie Das Begehen der auf ifnen gelagerten Stangen ift in Der Regel zu ver: meiden. Die an ber Strectenlagerrinne und Dem mittleren Solmengeriffte ausjujülyrenden $\mathfrak{M}$ 'beiten find bon ebener Frde aus unter Benu(zung der jwifchen den einzelnen

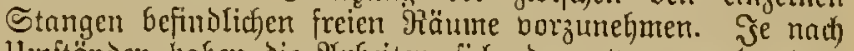

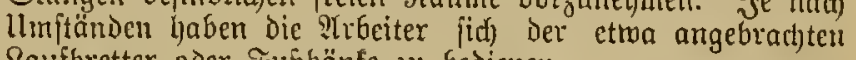

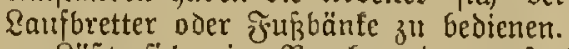

عäß̄t fich ein Begehen Der auf Berüftell gelagerteu Stangen ausnalymstocife nidft bermeiden, fo find bie $3 \mathrm{~L} b \mathrm{~b}=$ tretenden Stangen borher durd) Anbringung bon STöben oder in fonft gecigneter 3 cife bor Dcm Sin= und Serrolfen

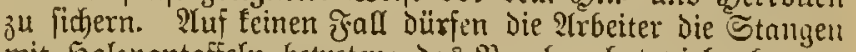
mit $50 l_{3}$ pantoffeln betreten; Da: 3 egehen hat vielmehr mur unter Bermendung ieftitzenden Sdjuhwerts ober mit ent=

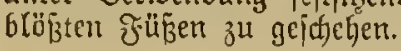

\section{Trbeiten a uf Däfern und an freien Siebelmänden.}

2or Beginn der ?Trbeiten auf Dächern find auf der Smaß̧e $u$. f. w. vor Den भrbeitsftellen Warnungstafeln auf= zuftelfen. Qtuf den Dädfern felbft fimd oberhalb Der Dad). rimuen ftarte Sdfutwoorridjtungen zum ?liffangen Gerabfallen= ber Begenftände auzubringen.

Die :Trbeiter haben fid Geim Bejteigen Der Dächer aus: nahmslos ber Stoff= oder Jil fidjuhe zu bedienen; aud milifen fie mit Sidferlyeitggürtel und \&eine berjehen fein; Iestere ift innerhalb Des Dadjes an cinem Dadjiparren ober fonftigen feiten Begenftande anjubinden; die Befejtigung au

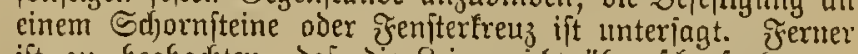
ift 34 beobadjten, daß Die Seine nidft liber idjarfe Santen berläuft, roeldfe fie bei ftarker 2Anfpannung jerjdyneiden tönuen.

Die Seitern müffen an ihrem oberen [ande fämmtlid] mit guten eifernen Şaten berfehen jein; Yeştere find vor ber

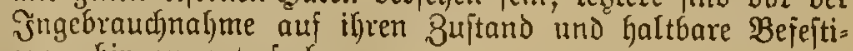
gung hin ôu interfudien.

Someit Die Dädyer mit Saufbrettern veriehen find, Dürfen nur Leß̧tere zum Begchen Der Dächer benukgt werden. Sann 
ein Bejteigen Der Dächer bei §roitwetter nicht vermieden werden, fo find die 2aufbretter 2 . vorlyer mit Samb ober פijag zu bejtreuen.

Shornfteine oder Daúfigefimfe find bon den Arbeiter" meder zu beiteigen, nod bei 9usfübrung der ?trbeiten nuf

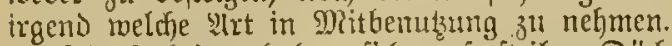

Die Mrbeiter haben fich auf fteilen Dädjern ftets in friechendem, niemals in aufred,tern (Bange fortzuberogen. Sdjieferdäther find nur unter İntwenoung von Dachdecfer: leitern 3 befteigen. Die auf Den meijten Edfeferdädjern zum (Einl)ängen Der Reitern angebradjten Safen find bor Dem Bejteigen bes Dactes auf iljre 5ुaltbarteit Durd) \$robe= belajtung (mittels Bichen an ber eingehangenen \&eiter 1t. f. w.)

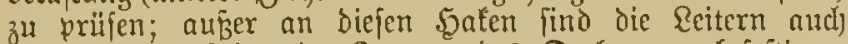
noct mittels Reine im Snnern des Dadjes ju befertigen. Cämuntlidje 2r.beitert find thunlicfft bon ben Eeitern aus aนริzulüfren.

Bejoniere $\mathfrak{B}$ orjid)t ift beim Betreten oer glatten Bint= bücjer und Der Dädjer mit Sberlidyt mährend ber Winter= monate geboten. Da Die Dähber bei Ĵrojt= und Ednee= wetter fehr glatt find, Deshalb igr Betreten bejonders ge iälyrlicf) ift, fo find fie borber mit Sand oher ?lfofe zu be= itrenen. Mit nicht minder grofjer ßorficht haben fich die Qrbeiter ober(jalb und unmeit Der Sidyt(d)adjte, deren jeniter= rahmen megen ifgrer leidjten Berbredflidifeit nidjt betreten merden dürfen, zน betoegen.

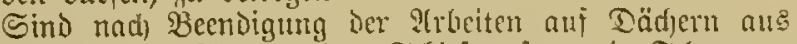
ben Dadfrimmen Biegel= oder Sdjiefertejte und Echutt $3^{\text {HI }}$ entfernen, fo hat bies nur unter ?tnmentumg bes Sidferheit: gurtes und der Sifferheitsleine, fowie in s!tnme fenteit cines zmeiten $\mathfrak{X}$ rbeiters, ju geidjchen, witcher Den mit her Rei= nigung Der Dad)rime beid)äftigten 2(rbeiter bon einem in

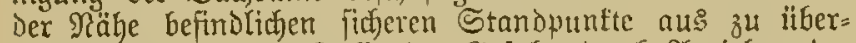

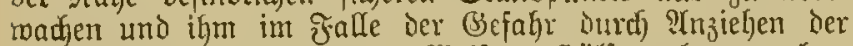
Qeine ober in jonjt geeigneter $23 e i f e$ zu şïlfe ju fommen hat.

Die Arbeiten an bereit $\mathfrak{g}$ vorhandenen (seftängen luat ier SIrbeiter bom Trittbrett aus wahrzunelymen und fith bierbei durch Tnlegen des Rarabinerlyafent an ben Rolhr= ftänder zu fidfern. Die Trittbretter fino jebod) exft dann ju betreten, menn jicf) Der ?lrbeiter bon Der Tragfäligkeit und der Feftigfeit berjelben überzengt hat. Die Trittbretter an cinfadhen (Sejtängen dïryen nie non zreci ?trbeitern $z^{u}$ gleid)er Zeit betreten werien.

Die Seräthe find in einer (Bexäthetafde anfube= walyen und thunlidfit feitzubinden, Damit cinem Entfalten wäbrend Der Sirbeit vorgebeugt wird. Drälte und Echnüre, meldje fidf an Dachziegeln 2e. verfangen haben, find nicht Durd) heftiges Reifen Loszumad)en, weil andemfalls (cid)t 3icgel= und Shieferjtïnfe losgeriffen uno herabgeidhleudert verven föntren.

Bum I Ifwinden oder 5eraufiehen von Materia= lien auf die Dädjer find ftets austeicfend frarte Reinen ju verwenden; aud haben fidf) bierbei bie oben und unten be=

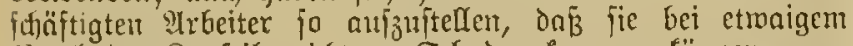
Bruch der Zugfeile nicht zu Schaden fommen fönnen.

Bor Der Benulang eines Fafrytuhle an Freiftelfenoen Gielelmänven hat oer Mrbeiter jedrsmal bie daju berwendeten Seile 2c. in $\mathfrak{B} \mathfrak{e}$ zug nuf Dauerljaftig= teit und die Prt und Weije dex Befeftigung der Seile zu priijen.
Bei Sexitellung oder Eo

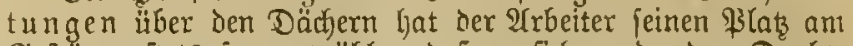
(Seftänge ftets io zu mählen, dafis er fidf an der dem Draht= 3nge abgefelyrten Seite befundet. Die 3ugborridytungen find

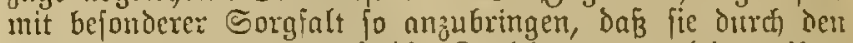
Reitunggovaht oder Durch die Bugleine mnter feinen $14 \mathrm{~m}=$ ftänden von ien Querträgern abgerifien tverden tönnen. 3ugborrichtungen, oie fich nidjt jicher befejtigen lafien, oilrfen itberbaupt nicht in Benutung genommen merien.

\section{Sicherheitsmaß̄regeln bei Benułzung De: Röthmaterials gegen ₹cuersgefahr ze.}

Beim Tragen des Grennenden \&öthofens, des gefdrmol=

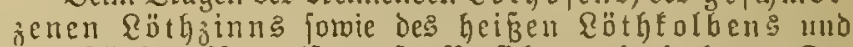
des Röthmaffers ift grof̧e Borficht zu beobarften. Der \&öthofen und Die Qötljpianne mit geifumolzenem Zinn fint ftets mit abgcitrecftem 2 rme thunlidffit entfernt nom Sibrper zu tragen; Die \&b̈thrajerflajdje ift gut verfichlofien 3 halten. Beei Pluffellung bes Röthofens ift mit befonderer ?lufnterf:

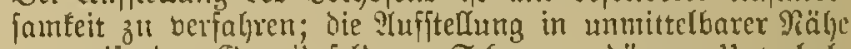
von reifenten (Setreidefeldern, Sdjemen, dürrem llnterhol u. f. ro. ijt nidjt geftattet; ein \&üthoien, ist melufjem fidl

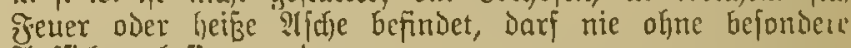
Uufficft gelafien werden.

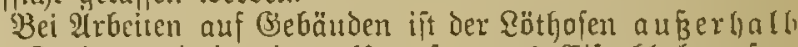
des Dadhes und in einem linterfais aus (Fijentled) auf 11 . itellen, aud) Dïrien nur fogenamnte Sidjerheitelöthoien be= nutbe merden. Solztoflen find ftets nur in ben für den augenblicf(ichen Berarf erforDerlichen Mengen und zmar in

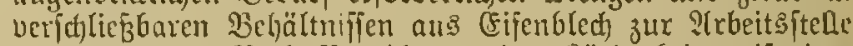
mitzunelymen. Padj Beendigung ber Qötrasbeiten it dos

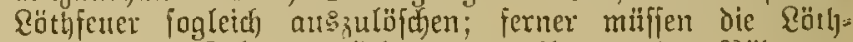
gern̈the und Roblentorräthe umbertbeilt bon den Büben ze. entiernt uno an cinem Drt niedergelegt werden, too fie z"l

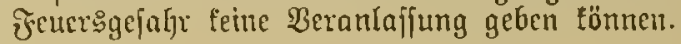

\section{Serwiter.}

Wäljrend der BSewitter find die Itrbeiten an den Teles graphen= und Jermprectleitungen zu unterbredjeu.

\section{Sonjtiges.}

Sat ein Strbeiter offene Wunden an den \$änden, fo bat er fie, mögent lie autf norf fo unbedeutend pein, bor dem

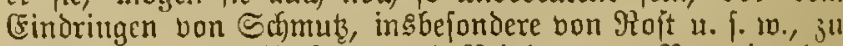
(c) itłen; mit Dem Umfetzen und Reinigen oon Batterien ljat ex fich unter biejeit llmptänden nicht ju befajien. YYuf den Stangenzubereitungsanftaltem muß der Rrbeiter in foldyem

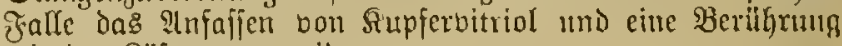
mit ber \&öjung vermetion.

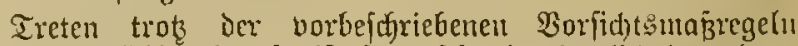
llnglitef şälle ein, fo ift fo rajd) als thunfid) Dent bau. lcitenden Seanten Mittheilung zu machen. Dem Berut= glücften ift unter Benubung der jeder Prbeiterfoloume über" wiejenen Berbandtafche bon Dem in Der erften Şülfeleiftung

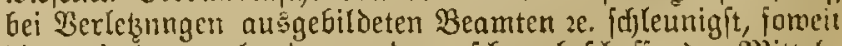

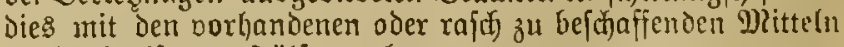
angängig ift, ju fiulfie zu fommen. 


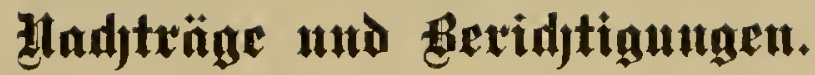

\section{A. Givillprozeckeromunt.}

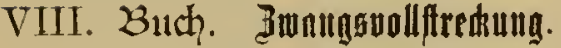

\author{
a) (Eeite 200, nad $\$ 744$ ).
}

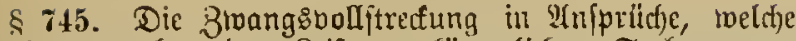
die Serausgabe oder Reiitung törperlicher Sachen zum (Segenitande Gaben, erfolgt nach) Den Borjatifiten Der $\$ \$ 730$ bi 744 unter Berübfiutigung ber nadfolgenten $\mathfrak{B} c=$ ftimmungen.

§ 746. (1) Bei Der F̧ändung eines 2 (njprudyes, weldyer cine betneglidje förperliche Sache betrifft, ift anzuorbnen, baß̧ die Sadje an einen vom Brläubiger zu beauftragenden (Serichtevoffzieher heraušzugeben ift.

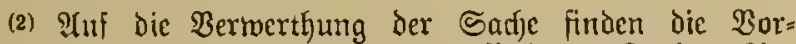
fdriften ïber bic Bermerthung gepfänieter Sodjen $\mathfrak{Q} \mathfrak{l}=$ menoung.

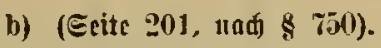

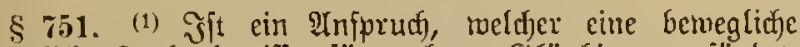
förperlidie Sarfje betrifft, für mehrere (SIäubiger gepfändet, fo ift der Drittiduldoner beredytigt und auf Derlangen eines (3läubigers, weld)em der Injpruef) übermiejen murde, ber= piliditet, Die Sache unter Înzeige der Sarblage und unter

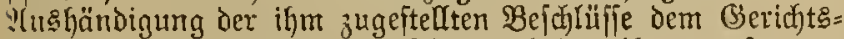
bollzicher herausjtigeben, welder nad) Dem ign zuerit zuge= itcllten Beidflufife zur Empfangnahme der Sachen beredjtigt ift. Soat ber (Bläubiger einen foldjen (Gerid)tsoollzicher

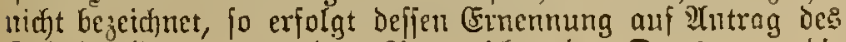
Drittiduldoners von Dem Amtgerid)te Des Drtes, wo die Sarthe heralls jugeben ift.

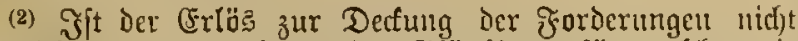
ausireidjend und berlangt ber Bläubiger, fïr welden die

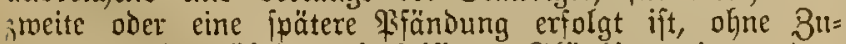
ftimmung Der übrigen betheiligten (3läubiger eine andere Bertheiluug aIš nad) Dex Reihenjolge Der ß̧fändumgen, fo hat Der Beridhtsoolzieher bie Sablage unter Sinterlegung

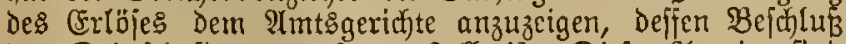
dem Drittidjuldner zuerit zugejtelt ijt. Dicjer $\mathfrak{U n}_{\text {zacige fino }}$ bie auf bas Berfabren fin bezieljenoen Edjriftitücte Geizu= fügen.
(3) Jn gleicher Weife ift zu verfahrea, wenn bie

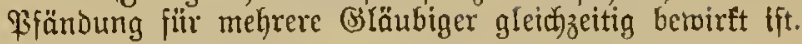

Iuj bicje $\$ \S$ (ebenfo auf bie $\Subset .199$ bezm. 201 abgebrudten

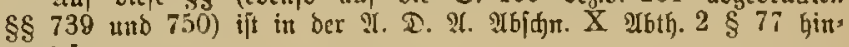
gemiejen.

\section{B. Hormumb[daftsoronmm}

(Exite 318).

$\S$ 25. (1) . . . .

(2) Эft der zum gejetstichen Dormund Berujene bevor, mundet oder handlunggunfähig oder nidht im Bejits der bitrgerlidien efhrenrect)te, fo tritt die gejetsliche Bormund= idjait nidid ein.

(3) ......

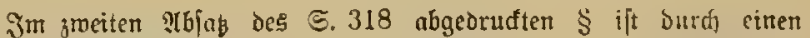
Drudfehler bas $\mathfrak{\text { Bort }}$ "tridjt" fortgelaflen.

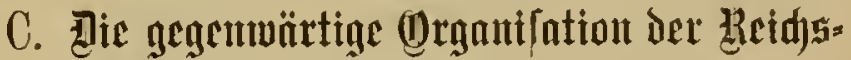

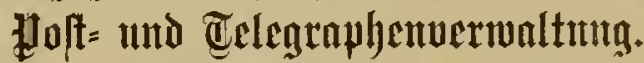

\section{A. Eentral-Bermalturtg (Eeite 3a1).}

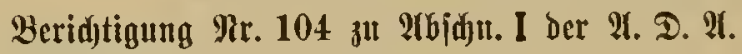

\section{Central = Vertoaltung.}

\$ 1. Das \$oft= und Telegraphenwejen des Deutjhen Reidjs mird durdf das dem Reidsfanzler unmittelhar unter. ftellte Reidfs= Bojtamt unter ber Seitung Des Staats. jefretärs des Reicts=\$3oftamts berwaltet. Dem Staats. fefretär ift ein Unterjtaatsjefretär nadjgcoronet, meld)er ben

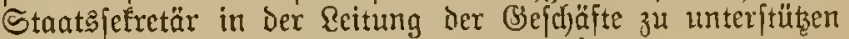
und in Befinderung

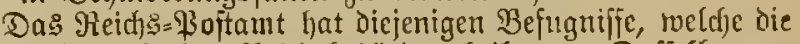

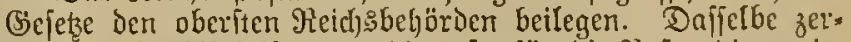
fält in vier 26theilungen: Die erjte für die \$oft=, die zmeite für die Telegraphen=, die britte filt die gemeinjamen $\mathfrak{B} e r=$ maltungsangelegenlfeiten, ausgenommen hiervon bas Perional=

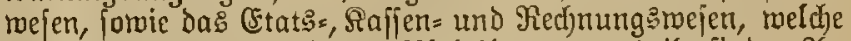
IIngelegenfyeiten ber vierten IIEtlycilung zugetheilt find. Ŝn Der Spitze einer ?(btheilung fteht Der unteritaatsijefretär, an Der Spize jeder ber übrigen YGtheilungen ein Direftor. 


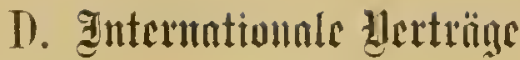

a) Weltpoit. Bertrng (Erite 361).

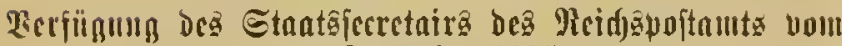
19. Defember 1875.

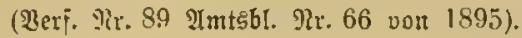

Berlin, 19. Dezemther 1895.

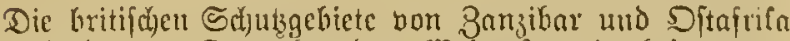
Fini mit Dem 1. Dezcmber bem Weltpoitberein beigetreten.

Der Briefuerfebr mit Diejen Bebieten unterliegt fortan allen Beitimmungen des Bereinsvertiages.

b. Eoultige internationale Poituerträgc (Seite 373/ $\mathrm{z}$ ).

Berîinแแ

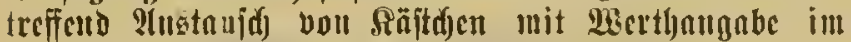
Berfehr mit dell Micocrlander.

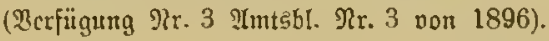

Berlin, 10. Эanuar 1898.

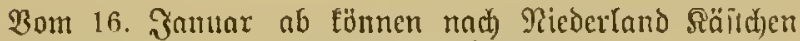
mit Berthaugabe unter Den Bedingungen des Wiener llebereinfommens boul 4. Suli 1891 abgejandt werden.

2c. $2 c$.

\section{E. Jaftorommm}

(Seite $577 / 78$ u. ff.)

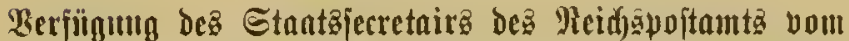

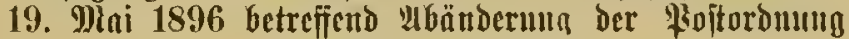
vom 11. Juni 1892.

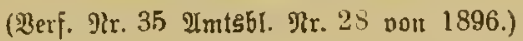

Berlin, 19. Mai 1896.

Die ßoftordunng bom 11. Funi 1896 hat folgende athänderungen erbalten:

1. $\Im m \S 2 t$ „\$oftnadjnahmejendungew" exhält der I b fat (1) 1) folgende veränderte Faffung:

(1) Softnadnahmen find bis zu vierhundert

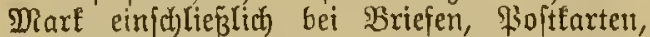
Dructiadfen umb Waareuproben, forwie bet Barfeten zulärifig.

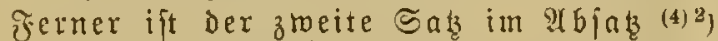
wic folgt, abzuändern:

wird die Senoung nidit innerlalb 7 Tagen nad) dem (Fingange eingelöit, fo wiro fie an Den ?lifgeber zurürfgeianot, fofern nicjt zu= uähit cine llubcftellbarfeits=:Meloung an bie

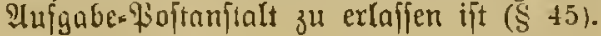

2. Der § 23 "Boftaufträge zu Büdjerfendungen" 3, mird allgeloben und ift zu freidien.

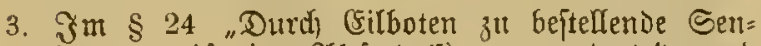
Dungen" ift" im S(b|ab (5) unter" $A$ a) ${ }^{4}$ ) unD b) ") itatt "Drtsocjtellbezirl Der \$3oftamitalten" bezm. "Eandheftellbezirf ier gopitanftalten" in feben:

"Drtabeftellbejitt oct Beftimmungs-\$3oft= anitniten" bejo.

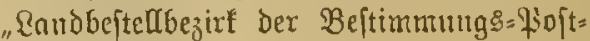
anftalten".

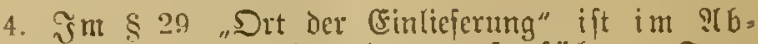
fats (3) ${ }^{5}$ ) unter den bort altfgefügrten Sen. dungen, welde ben Laubbriefträgeru anj igren Beftellgängen zur 刃ुblieferung an bie gioftanftalt iibergeben berden biirfen,

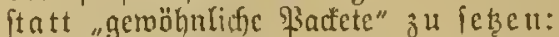

"gemöhnlid)e Fiacfete und (simfojreib= \$3acfete".

5. §m § 42 "Berec)tigutig des (5mpfängers jur

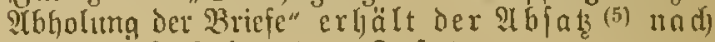
Fisult ${ }^{6}$ ) folgenden Bufabs:

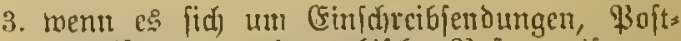
antweifungen, telegraphijd) fojojanmeifungen und Sendutugen mit $\mathfrak{B e r t h a n g a b e}$ hanoclt, veldite bom ?tbicnder nit dem Bermert "(Figenlyändig" verfegen fino;

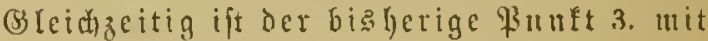
"4." zu bezeidfuen.

1) Є. 593 .

2) ร. 593 .

3) ร. 597.

4) G. 599 .

5) ङ. 602 .

6) ङ. 613 .

Borjtefende Acnderungen treien mit dem 1 Suni 1896 in Sraft.

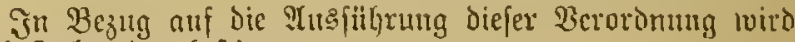
nocf) Folgendes bejtimmt:

\section{3u Mr. 1 ( 1 S. \$21).}

Das Meijtgemicht der Brieje, Druffacticn, Waaren= proben und Pacfete mit Radinahme ift gleid) Dem= jenigen ber gleidjartigen Sendungen ohne S(arfnahme.

Dem ielbftftändigen Befinden ber Dbers \$oit. direftionen bleibt eE ïberlaffen, ob exforderficfenfalls

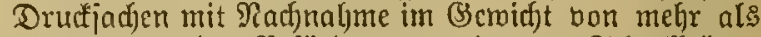
$250 \mathrm{~g}$ von ber Beförderung mit den Schtrllzügen auszujd\}liefzen find, und ob in 23 citeren je nadj Rage Der örtliç)en Berbältniffe die Beftcllung foldyer Drude fadjen den Briefträgern abzunehmen und ben Bacfet= beitellern zil iibertingen ift. Bejtellgeld fonmt it

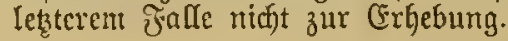

3แ Mr. 2 (1:0. § 23):

Die in ben eriten Tagen Des Monats Suni bei

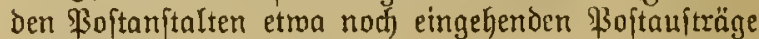
zu Büh)erpoftfendungen find in bisheriger Beife zut erledigen. 


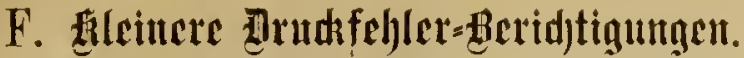

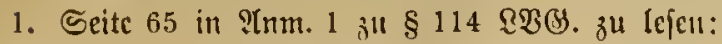
"unten 5. 99/100" (fintt 5. 107).

2. ङ. $105 / 106$ in Dem Bermerf zur Heberfatift des (अef. v. 27. 3. 1872 jiber DRR. zu Lejen: "im $\S 1$ bezeid)neten" (itatt int $\S 2$ ).

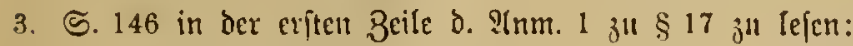
"oben @. 120" (irntt 121).

4. S. $213 / 214$ in der :Inus. jux lteberfdrift des Befesces v. 21. 6. 1869 zu le "oben S. 200" ([tatt 211).

5. S. $287 / 288$ Gefetz beroffentlid)t:

"RGQI. S. 346" (ftntt (3). S. 346 ).

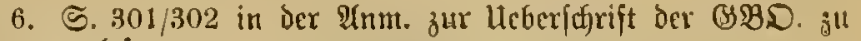
lejen:

"06cn S. 291" (fitatt 310 ).

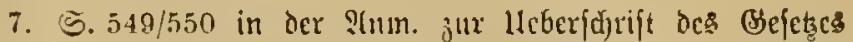
v. 22.6. 1888 zu Icjen: „oben S. 477" (ftntt 606).

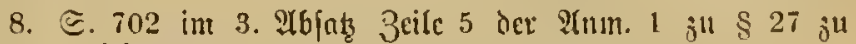
lejen:

"STrfarderungen" (ftutt ?(njordnungen).

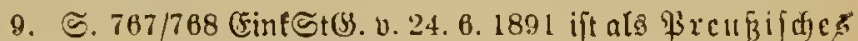
(Gefect veröffentlid)t:

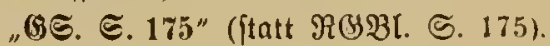

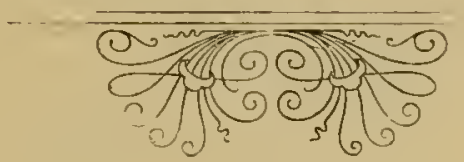




\section{So a d $\mathfrak{l} \mathfrak{e g} \mathfrak{i}$ it $\mathfrak{e}$ r.}

Die 3̆nhlm begeidnen bie Sciten.

21.

Xbönderung Des Reidjbenutengeiches, Befes über, v. 21. 4 1881. 685/6s6.

bes Reidsbcamtengcicbes, Gcies iiber, nom 25. 5. 1887. $687 / 688$.

bcs Bermolt. Ber.= Bejebcs, Bejeb über, ท. 26. 3. $189379 / 80$.

Ibfafiung oon Telegrammen (ID.) 636.

शbgeordnetenhaus, \$reufijdjes (\$r\$3.) 36.

\{lbjolung oon \$ofticndungen (PD) 612.

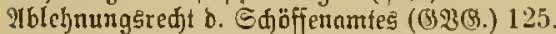

Iblehnung b. Gcjdinorentennutes (अ23.) 132.

- von (Sejdroorinen (St\$0) 258

- von Seridtsperionen (SIP0.) 225 .

- vou Geridtsperfonen (EßD) 149.

IIbjdrift non Telegrammen (TO.) 652.

Ybftimmung แno Bernthung ber Ridter 2 . (अशु(5.) 143.

- und Berathung ber Bejádmorenen (ङเRD.) 261.

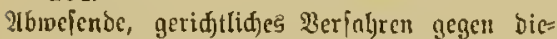
felben (St?D.) 262

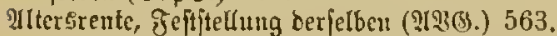

- Iuşahlung berf. burd) bie \$oft (III3) 566.

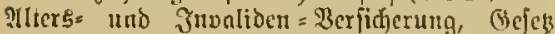
über, v. 22. 6. $1889549 / 55$ ?

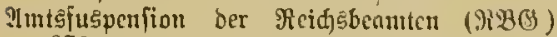
679.

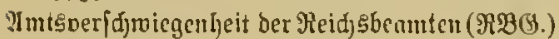
566.

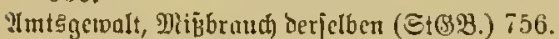

TImtEgeridjte (অ円(3) 121.

- Berfahren bei Deriellen (C\$O.) 177.

IInfertigung folider Po[t= und Telegr. STertl)= seiden (StSB.) 341.

Itrgaben, bẹpondere,bei Telegramuen(TO.) 637.

Ingellogter (Definition) (StßD.) 242

शn 1 bืbleiben Desjelben (StMD.) 249.

Ingejduldigter (Definition) (StPD.) 242

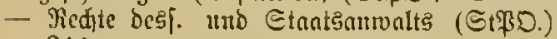
244.

Intfingcfdrift (ङt\$9D.) 245.

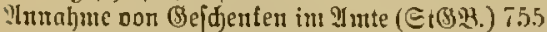

Intwort, bezablte, bei Telegrammen (IO.) $6+1$

IItroortformulare (TD.) 641 .

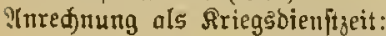

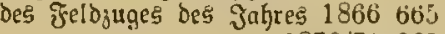
" " " J870/71665 Der militärifden Unternebmunge» is Ifrita 666 .

Der Sriegsgefangen/djaft «c. 667 .
Inid)uldigung, jaljde (ভt(જ) 75.5

Unitellungsbehörde 697 .

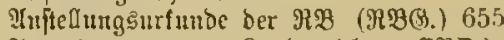

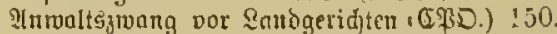

Irbeiter, Bertretung derielben bet Edicosge= riďten (II\$B.) 529.

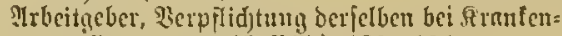
Derfid)erungen (

Үergtlið) Behandlung (

Bemeinderitri. 492.

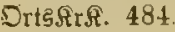

PoitfrR. 512.

शtrbeitg. unb Dienjtlohn, (Scję über Bcid)lag= nobme, v. 21,6. $1869213 / 214$.

Irmentedt (CPO.) 152.

Irrejt uno einftreilige Berfügungen ([9D.) 205.

Irrejtbeieh! (E\$D.) 206.

Aufgabe von Telegrammen (TD.) 638.

Iufgebotso erfahren (EßD.) 208.

Itufhebung birefter Etantsfteucr, Gcick über, o. 14. 7. $1893797 / 798$.

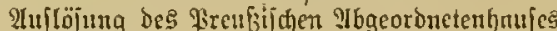
( $(\mathrm{rr} \cdot \mathrm{B}) 34$

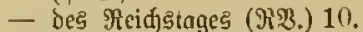

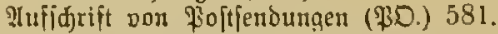

- von Telegrammen (TD.) 637

Iuffiditsredt bes Etantes über ßermaltung ber ftäbtiīgen Bemeindengelegenheiten (3แ10\%.) 81.

- bes Etantes über ßermaltung ber fïöbtijajen Rommunalbeitencrung ( $\Re \mathfrak{A}) 809$.

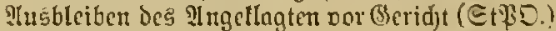
249.

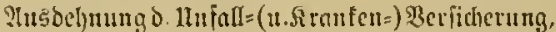
Gejeb über, v. 25. 5. $1885541 / 542$.

IIแร่hänotgutna vou Woft fenoungen (PD.) 609.

- - von Telegrnumen (TD.) 648 .

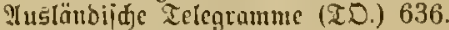

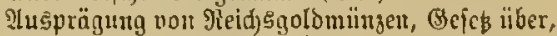
o. 4. 12. $1871333 / 334$.

গูแ 148.

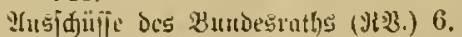

:Iusicbung bes (Seridtsverfobrens (C\$O.) l 60.

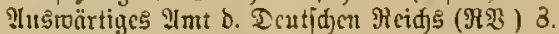

Iverfintirung oon Porto pp. Beträger, Ber= eirbarnng mit ber ßigl. \$reūi. Stants= regierung $409 / 410$.
Q.

Bat)hoisbrieic (BD.) 600

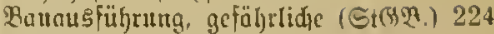

Buufraufenfaîen (Ærs30.) 503.

Batpolizei (3uftos.) 93.

Beamteneigenjdaft, Begriff besiclben it ftraf. redtlider Bejichumg (હt(32) 759.

Peaufïhtigung burd bas Reid) (Rश.) 4.

- ber Bormunóchaft (BO.) 324.

Pecibigung ber Edjöfen (ब23(\$.) 127.

- Der (Bcidjworenten (StDß.) 259.

- ber 3eugen (ERO.) 170.

- Der Zergen (SißBD.) 228.

Bcendigung der \$ormundfa)aft (פD.) 324

Bejähiaung jum ভわöffctant (\$2(3.) 124

Bcjugrifie bes अeridts (E\$D.) 154

Brglcitnbrefien ou Butcter (RD.) 580.

Begnabigungsted̆t des finifers (SıPD.) 284.

- " " (श9(9.) 678.

- " Rönigs (\$r\$2.) 28.

B̧chandung orbnungsmibrig befdaffener \$opt. jendungen (280.) 601.

- unbeftellb. Tofffenoungen ain Beftimmungs, orte (\$D.) 615 . am $\mathscr{R} u$ foubeort (FD.) 617

Telegramunc (TO) 650

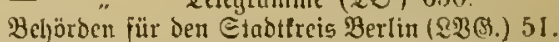
Belojtung non Brunditiefen, Bcieb ïber Fr. werb unb, o. 5. 5. 1878291.

Bclcibignng (EtPD.) 219, 755.

Berathung unb 2l[timmung ber Beridjte (अ23.) 143.

- unb פ6ftimmung ber Bejd)worener (St\$BD.) 26]

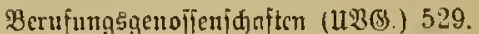

Berufung, gegen gerid)tlid)e Il:theil ((N).) 177.

-.

- " "Stcuervernnlngung (ङङt(.) 779 .

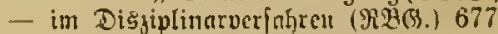

Berufungsgeridte (StฤD.) 267.

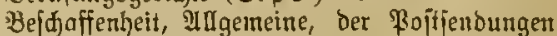
(PO.) 580.

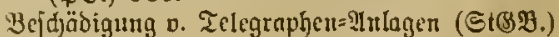
222.

Beldlaguahme on Mrbeits= ober Dienftlohn, (3cjes über, o. 21. 6. 1869 213/214.

non Drufidiriften (\$résgciç) 346.

- oon (Beldorberungen (C\$D.) 199.

- und Dutdjudung (SเTD.) 232.

Bejd)Infoerfahren (Rßa.) 65. 


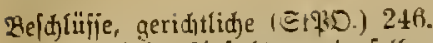

- geridttidje Unjedtuma derjelben (St\$DO.) 246.

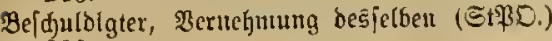
239.

Bejd)werde, geridtlidje ((ฐ\$D.) 181

- gerid)tlide (巨tPD.) 265.

- gegen Eteuerverunlagung (CEt(9) 780.

Bejondere Telegrnume (20.) 635.

- Telegraphenanlage (TS.) 651.

Beftellung von \$ojtienounget (\$20.) 607

- von Telegrammen (TD.) 648.

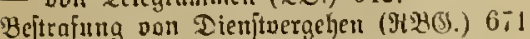

Betriebstranleutoffen (

Betrua (Et(\$B.) 221 .

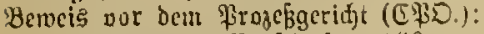

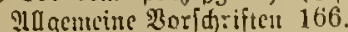

burd) 2(ugenid)ein 160.

Durch Cio $17 t$

burd) Eadjoerjtänoige 172

burd lltunden $17: 3$

ourd) Beugen 167.

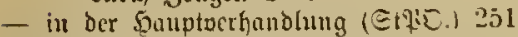

Beıerbungeı von Dilitäramnättern 697.

Bejirtsaus

Bejirłscijenbal)uräthe, (sejeb über, n. 1. 1. 1882 463.

Beztrtsregierung (Rง\}g.) 46 .

Brieje, gewöhnlide, 叉ejđuffentheit berjelben (BD.) 530

- cingejariebut (190.) 591

- mit Bujtellungsurlunde (98.) 601

mit 2Berthangabe 1920.$) 582$.

- unb säptchen mit sistrtgangabe (interu. Bertr.) 373.

Hruf) antlidger Eirgelung (こt(5), ) 754 .

Bundesgebiet ( $(\Re 3$.$) . 3$.

Bunbesrath ( $M$

\section{c.}

(Eioiltamuer, Вu[tündigfeit derjelben (SWDD.) 129.

Bivilpcogebordung o. $30.1,187 \% 145$

(Eivilverjorg̣ungsid)ein 693

\section{๖.}

Defelte von Beamten (MBS.) 681 .

Defraubationen von \$oft=8eträgen (\$3(3.) 334 .

Dientbriefe, portopflidjtige Befreiung berjelben. vom 3uidlacporto $397 / 398$.

Dienteis der Heidisbeanten (MB3.) 654.

- vor Weanten var (Sericht (こt(5B.) 754

Dienjtenthebung, norläufige (2unts̄|นspenfion) (MBß.) 679.

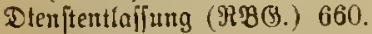

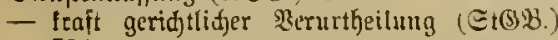
751 .

Dlenjtreijen ber Reidjbeamten Berjïgung des

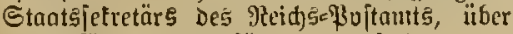

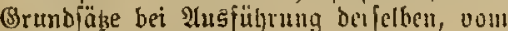
7. $11896 \quad 731 / 732$

besgl. o. $21.12 .1881733 / 734$.

Dienftunjähigleit und Deren Nadyeis 668.

Dienftoergeljen uno beren Beftrafung (RBBS.) 671.

Dien[tzeit, Berednuntg berjelhen 663.

Dinglide Belajung an (orunojitüđen :c., Bejes v. 5. 5. $1872291 / 292$.

- Mectite an (brunofitüden 293.

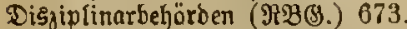

Disizinarhof (RßS.) 673/674.

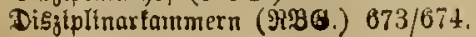

Dişiplinaroerfahren (

Dringende Radetienounaen ( $R O)$.

- Telegranme (To.) 641 .

Druffad)er (YSD.) 587.

- bebingt als folde zugelaifene Sdurifitüfe (PO.) 559 .

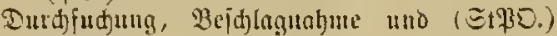
$2: 4: 2$

(5.

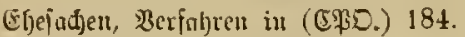

Ehrenred)te, bürgerlibhe, Betlujt beri. (St(SB.) 216.

Figenthumsenverb, Gejeb über, v. 5. 5. 1872 291/292.

Eigentfumsrente bes Reides, Bejeb̧ über, v. 25. 5. 1873357.

Eigentlümer, Eintragıng besfelben iu bas (Srundbud) (\$BD.) 307.

(Eilborenbeitellung von Boitjarten (PD.) 598.

- von Telegrammen (TD.) 646 .

cinführungsgejes jur Reidjnerfolimg vom 16. 4. 1871 1.

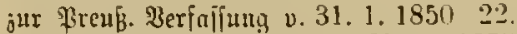

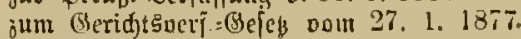
$143 / 144$.

jur @truprazeforonung vom 1. 2. 1877 $287 / 288$.

Eistheitlide Beitbejtinmung, Bejeb ïber, nout 12. 3. $1893: 347$

Eimfommeniteneryeicb v. 24. 6. 1894. i67/i68.

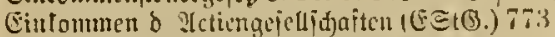

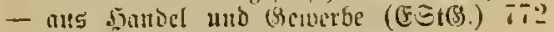

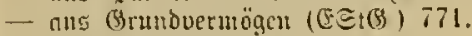

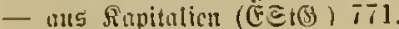

- jteuerpflid)tiges (E્t(9) 769.

- jteuerfreies (Eさt(3).) 768.

Eintiçerung von Bojtienoungen ( $\$ 30$.): Dr! Derfulber 602.

3eit 603.

Sd)eit 605 .

Einrid)tung un Befugniff ber Ober: = Red)nuys= fiammet, (5ejes itber, o. 27, 3. 1872. $105 / 106$

(Einjdrcibjendungen (180.) 591

Eintheifuna ber Iele gramume (TD) 634

-- ber ftrajbaren 5anblutuge (こt(B).) 215.

Eintragungen in bas (Srundbud), lltunden Darüber (GBD.) 311

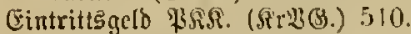

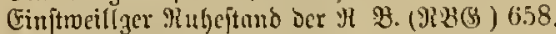

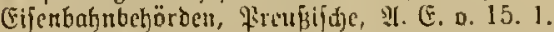
$189+45 \% / 458$

Cijenbahnen untergearoneter Bebutunt, Ber= pflidutugen fïr ben Poptsienfy $\$ 37433$

Fijertbalynojtgeies v. $12.12 .1875423 / 424$.

Eijenbahntelegraphenreglement $437 / 433$

Eilenbahnuejen bes Deutidnen Heides 13.

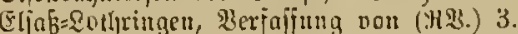

Empjangsangeige für Telcgramume (ID.) 64?.

Enteigmungsjad)en (Bujt(3.) 94 .

Entlaîlung van Dhilitärmuoärtern T02.

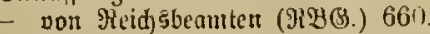

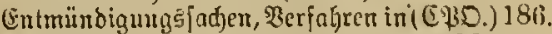

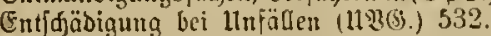

Entideidungen, yeridtidife (St\$20.) 226.

Erblidfeit Der 引renfichen frone (\$r:3.) 28.

Crgänzungsjteuer, (\$ejeß über, v. 14. 7. 1893 $789 / 790$

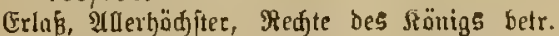
o. 4. 1. 188242 .

palizeilidjer Strafverïügungen, Bejes über, v. 23. 4. $1883289 / 290$.

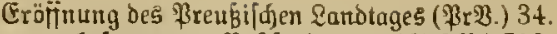

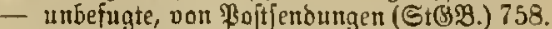

- unbejugte, oon relegrammen (ङt(B).) 758.

ช.

Fabriktrantentaijen (

Fahrt und llcberlagergebiil)ren ber Babupuit= beamten भ. \$3. D. 5. 7. 1875 729/730.

Jabrt und lleberlagergebülyreu ber 'Babnpojt= beantem Erl D. Heidj5t. v. 20. 10. 1875 $731 / 732$.

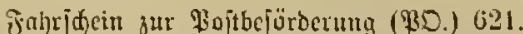

Fälidung von Telegrammen (હt(3).) 758

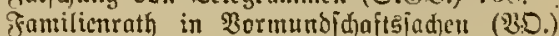
328

Feittalyme, varläufige, (StRD.) 235.

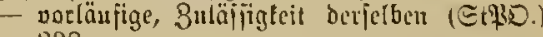
238.

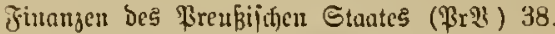

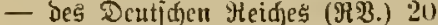

form und (Einrich)tung bes (Srundbudes ((SBD.) 301.

Farjtuerjorgungşdein 696.

Fragen ar Geidumorene (ভt\$o.) 259.

Jranlirungsoermerl bei Pojtfenoungeu (\$o. 605.

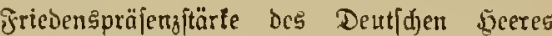
(अ习.) 17

Juhrloiten, Tagegelder sc. ber Reidsbeanteu: fejtjebung ber föhe berfelten burd Raijerlidje Beroronung im Einver= nehmen mit dem Bunbesratg(भBß.) 657.

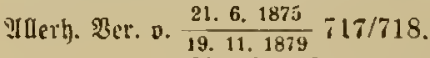
29. 6. 1877 (Dienft= reīen iu 2mts bुegirf) $721 / 722$.

$27.6 \quad 1894 \quad 723 / 724$

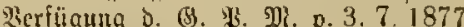
$721 / 724$

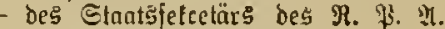
v. 3. 7. $1894725 / 726$.

Tafel über 5öhe derjelben $737 / 738$.

Jübrutg Der Bormunojdajt (30.) 319.

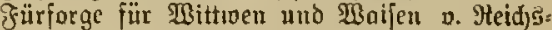
beamten, Bejes D. 20, 4. 1881737/738.

für Mittroen und 23 nijeu v. Reich gbeauten Be eleb v. 5. 3. $1888741 / 742$.

- bei Unґällen, ßejeb o. 7. 0. 1871 (\$aft pilidatneies) $743 / 744$.

- bci Ulnuällen, Befeb vom 15. 3. 1880 $747 / 78$.

\section{6.}

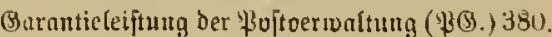
Bebühren fïr Telegranme (TD.) 640.

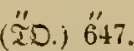

Eutrid)tung Derielbeu

Bebithrenfreiheit von Telegranmen, গ. 3. บ. 2. 6. $187 \overline{7}$, ̈̈ber. $417 / 418$.

(3) ltungsgebiet ber St 10.287.

(Segenourmund (BD.) 318.

Behaltszahlung an Beamte (P2)

Bcifteštranfe, Entmünbigung berjelben (E\$SD.) 186.

Belbitrafen Der Beamten (\$BB(s) 673 .

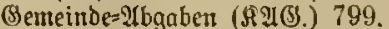

- Cinfommenftener (A20.) 805.

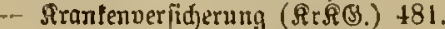

- Steuern, birecte (ग̃श).) 802.

" inbireste ( $\Omega \mathscr{Y}(\mathrm{S}) 802$. 


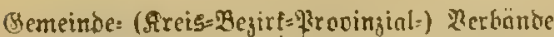
(अræB.) 38.

(Semeinde= Bertretung (Buits.) 82 .

(senerallommiffionen (\&93 ) 46 .

(Seridjtsbarleit (B2S) 120

(3erid)tsbeidliilfe (@t\$D ) 246.

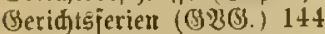

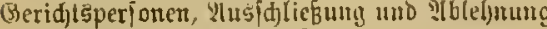
derlelben (1920.) 1 \$8

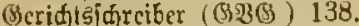

Geriftsiprade (B) $3(3)$.) 142 .

(Seridyts tano, allgenteiner (GPO.) 147.

- dinglidier (EPD.) 147

- ber (Erbjajaft (E\$O.) 148

- des Bermögens (eno.) 147

- bes Brortrages (EPO.) 148

- (ङ180) 223

(Seridtsver faten (CPO.) 153, 161

- (Stlio.) 242.

Geridgtruerfafungsgejes v. 2\%. 1. 137 . $119 / 120$.

(3)

- (E\$O) 192.

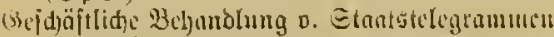
$421 / 422$.

(j)ejdente, Anuthme derjelben oult Reautcu (St?20.) 755

(3e)dyorenen ((5):3(5) ) 1.31

- Belebrung berielben (ङt\$D.) 260.

Zerathung berjelben (ङtMD.) 261.

- Sragen an dicjelben (ङt\$30.) 25!

(S)ijd)torenenbant, Dilbung Derjelben 257.

(Selverbepolizei (3ujt(5.) 91.

(3erö̈hrleiftung bei Iclegrammen (is) 651 .

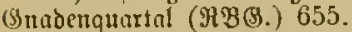

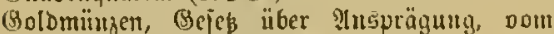
4. 12. $1871333 / 334$

(Srobiährige, Bormundfdalt über biejelben (\$O.) 330.

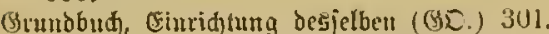

- Urindoen über vintrugung in basiclbe (BD.) 311

Grundbudoronutg ง. 5. 5. $1872 \quad 301 / 302$.

(Srunbbudjadjen, Berfahren in (GD.) 305.

(Brunblage Der Srganifation des Preubijacn Stautes (Pri.) 44.

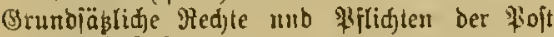
(\$B) 379 .

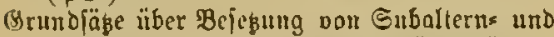
Ulnterbenmtenitellen mit Militärambärtern 693/694.

Brunbiकulden und Snpotheten (EEG.) 294.

Brundftüde, (Erroerb binglider Redte on (ECS). 293

(3utsbesufe, jelbftändige, Ingelegenlyeiten bers jelbelt (8uit(s.) 86.

\section{เ).}

\$ajt ( 5 PO.) 204

(St?30.) 235.

Dojtplidtgejes o. 7. 6. $1871 \quad 743 / 744$.

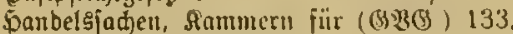

Dauptuerialjen (@tR5.) 245.

Sumptouthondung 247 .

- vor beu: $€$ dwargerid)t 25\%

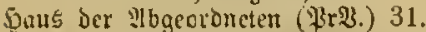

5ausfriebensbrud) (ङt(\$2).) 219, 754.

bilgoland, Cinfiibrung ber Reidsverfajiung (ヘที.) 3 .

Scranziehung der Stantsoliener zu Rommunal auflagen. ‥ ㄴ. ฉ. $23.9 .1867811 / 81$ ?.

Serrenhaus (\$r 31 . 31
Sinterbliebenc, Rewilligung an (भBด.) 670 . - " "(Liz) 749 .

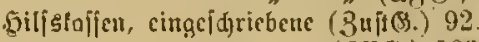
(R⿻彐丨() 503

Enpothelen und G̈rundjuldoen, Medjte ber = jelben (FES) 294.

- - Mुirfung Des Medtes berielben (E(5). 297.

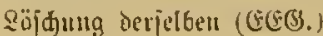

3.

Jahreslifte über Gđäffen ((BBS.) 126

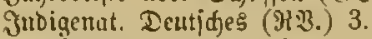

Эngcjahr jegung von (Eijenbohntronsporten (डt(S) 221 .

Ynlänbijđe Telegramme (ID.) 636.

Intrmationale Đoitoerträge $373 / 374$.

Jutermationaler Ielıgraphen 3ertrag $37.5 / 376$

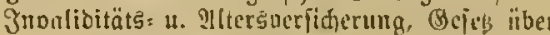
v. $22.6 \quad 1889 \quad 549 / 5.501$

\section{It.}

Saijer, Deutjuer (MVU.) T.

Saijer Willhelnt=こtifung $815 / 816$.

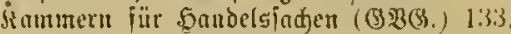

- Breufijde (Hril ) 31 .

Rutionen der Meidisbianten (beziv. Der Fojt und Telegraplien=B(amten):

Bejes, betr. S. o. $\frac{21.6 .1869}{16.1571} 705 / 706$.

Mllerb. Sicroromung betr. Söhe Dir, $\Omega$. v 18.4. $1883709 / 710$

_- ․ $28 \quad 12.1895 \quad 711 / 712$

Rerïigung o Stantsjetretärs des Meibs Mojtaints betr. \&. vou Boriteliern der *oitämter III nom 14.12 1895 $111 / 712$.

- - von Linterbeamten. v. 3. 3. 1895 713/714.

Taiel über Söle ber \$2. $713 / 714$

(5)ejeg betr. Etcllung ber $\mathfrak{r}$. butd) (Fintragung in bas ङ઼ulbbut) des Meides ober eines Hundesituates v. $22.3 .1893 \quad 713 / 714$.

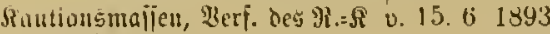
$715 / 716$.

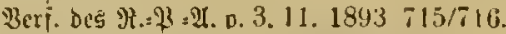

Flage, Erbebung Derjelben (C\$D.) 161.

- offentlide (डtPD.) 242

- private (ङt92) 275.

Rlafififation Der Reidsbcamlen (2B3(S) $689 / 690$

Rnaupid)aitstaije (Sir\$o ) 503

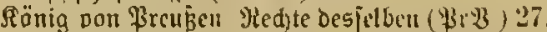

- vou Breuben, als foldher Bunnespräfioen

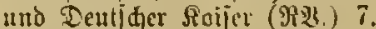

siörpernerlesungen (St(s) $2: 0$.

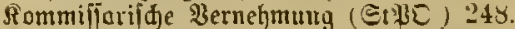

Romumumalnbgabengeies D. 14. $799 / 800$.

Kompctenstonflifle, Rag. Verorou, ïber, oum 1 8. $187997 / 98$.

Sionflifte bei geridtl. Berfolgung Dan $2 \mathrm{mts}$ unt Dienjtoergehen, Gejep v 13. 2. 1854 $99 / 100$.

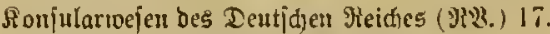

Ronzefïionen, geverblidje (3itits.) 91.

fiopten bes Disziplinarberfahrens ( $3 B(S) 679$.

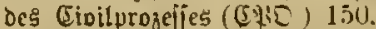

- Des Strajprozelies (Etßo.) 286

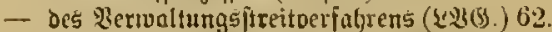

- her Elenerveranlagung uno Erhebung (ए巨シ) 706 .
Arautenţauspflege ( $\Re \Re \Re) ~ 514$

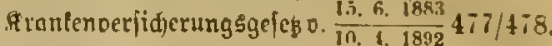
ftrib̧chürden (\&\$B) 49/50.

\section{te.}

Znbung, geriufllide, ber Barteien (5\$O.) 158 bes Mutgeflagten (હt\$D.) 247,263

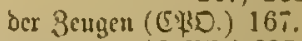
(ङเ\$0.) 227

Sonbeseijenbal)urath, "(Gejeb" über Crinjesuna v. I. $6.1882+63 / 464$.

Snnocsoetwaltung, affgemeine, (Bejeb iiber, v. $30.7 .1883+1 / 42$

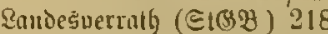

Vandgemctuben uno iclbittändige Butsbegirle, Dingelegenbeiten berielbcu (3njt(S) 86 .

Zanbgeridite (\$BOS.) 128.

- Berfaljren oor Denjelben (C\$E.) 161.

Qandrath (RBO.) 49

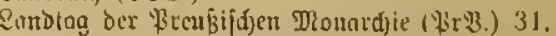

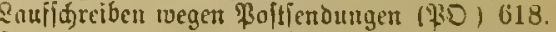

Eegislaturperiode des Deulideu Heidstagers (ग) 10 .

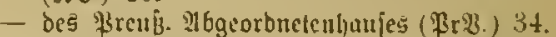

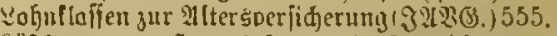

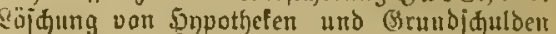
(EEB.) 300.

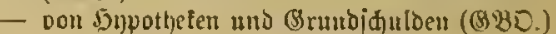
310.

D).

Dalume:fahren, geridtlid)es (CßO.) 158

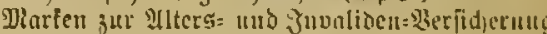
(32139.) 568.

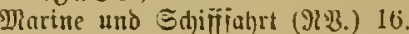

Meincib (ङt(5B.) 754.

Dititäraniörter, Denj. vorbehallenen Etcllen $693 / 694$.

Dimijter bes ßrenвijineu Etuates (ßr2?.) 29.

Difbraud Der IIntsgervalt (હt(3).) 75ti.

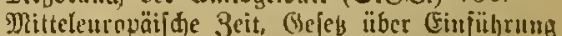
Dericlben, ข. 12. 3. $1893 \quad 347 / 348$.

Mlündelgeldcr, zinsbare alulegung serjelben (BOD.) 321

Snlubrednung über Deren Berwaltung (2) 327 .

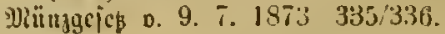

M.

Zind)ulnucienbungen 1950.) 593

PRáfiendury von \$ofitendungen (\$D.) 614 - dor Telearmmuten (20.) 643 .

Madträge und Heridtigungen $837 / 838$.

Tad)zablung v. Zelegramungebühren (20.) 65:.

Mebentelegrophen (テD.) 652.

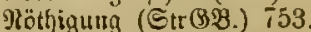

Jothwel)r (St(9B.) 217.

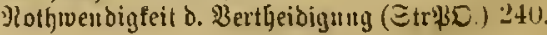

Oberbeiegl über Das Deutide fieer fïlyrt ber

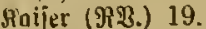

Dberlambesgerifte (अ230.) 133.

Dber=\$oitoireftionen, Besirf5:\$ojt= unt Zele: graphen:Bebörden 353.

- Berjonal derjelben 356.

- Stroperjabren bei \$ojt= :c. Defraubationen (RQS ) 385

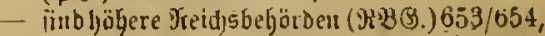
686. 
Obers\$räfibent 122\&\&.) $42,44$.

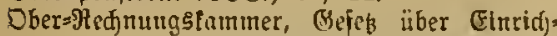
tung zc. bcri. D. 27. 3. $1872105 / 106$.

- Regulatio über (Befdäftsgang bei bericlben $111 / 112$.

Dber=2ermaltungagcridte (खタ) 77 .

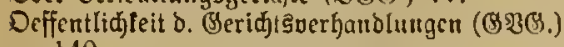
140.

Deffentlidje Sluge (StRD.) 242.

Obmann der Be[dworenen (ङt\$D.) 261.

Dffenbarungstid (EßD.) 195, 204.

Drbensverleihutg burd) ben fönig (ßrશ.) 28

Drcsung, offentliche, Birgchen :c. ongegcu (ङt@i).) 754 .

Oronung für bie Telegraphcu=?trbeiter v. 13. 7. $189+819 / 820$.

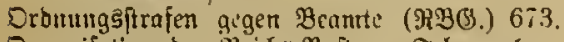

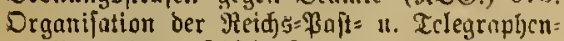
Bernaltung $349 / 3 ; 0$.

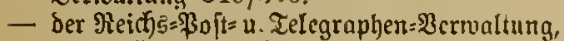
gegentürtige $351 / 352$.

- ber Preubiliden Ranbes=-2erwaltung, Befes v. 30 . T. $188341 / 42$.

- ber ßreub. Eifenbahn= Berwaltung 455/456.

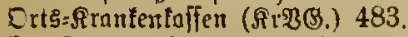

Sitsfituten betr. gemerblide Ingelegentheiten (3uits.) 92.

\section{P.}

ßadcte (\$D.) 580, 581.

- oringende ( $(30)$.

ßadetporto (円I\$S.) 391.

- (\$T:.) 391.

Parteies (EPO.) 149.

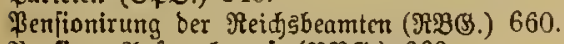

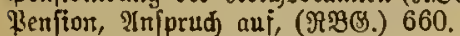

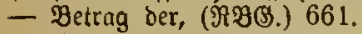

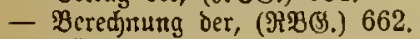

- Rürzung, Einjiehung u. शBiebergemährung

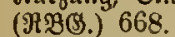

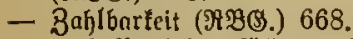

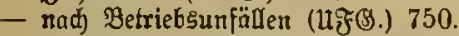

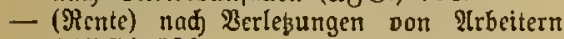
(แறBß.) 526.

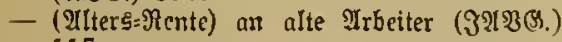
557.

- (Inoaliden-9tcnte) an invalioe Trbeiter (अभ习习.) 556.

ßerponenbefötberung mit ber ßo[t (\$D.) 620.

Pcrionengelo, Erhcbung (PD.) 621.

- Eritatung (\$DO.) 622 .

Berianal Der Dber. \$poitótreltian 356.

- Der Berlehrsanttalten 358.

ßerfanenftand unb Stanţnngehörigleit (Bujts.) 94.

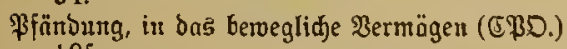
195.

- pon Belbforderungen (EßD.) 198.

- ir bas unberoglidje 囚ermögert (ERD.) 201.

ßrlegidaft (खD.) 330.

Pflidten, grunbfägliche Rechte unb - - ber \$oft (\$S.) 379.

ßläbe ber Reifenben (ફD.) 623.

Plaiboner (oor Beridt) (St\$D.) 260.

Bolizeilidje Strafoerfügungen regen Heber= tretuigen, Bepes betr. ErIn巨 Don - vom 23. $4.1883289 / 290$.

Bolizeineroromutgşredt (3uft(3.) 71.

Polizeiverwaltung, (Sefę über, D. 11. 3. 1850. $103 / 104$.

\$orto, 2Derfionirung, Bertrng mit ber \$reuß̄. Stantéregierung $409 / 410$.
Porto, Defraubationen( 384.

-- Defrnubationen (PG.), Strafaerjahren 385.

- Futridtung besfelben (PD.) 619.

- Fï $\mathfrak{B r i e f e}(\mathfrak{P T S}) 391$.

- für \$adete (\$T(\$).) 391

- für Padete (

\$ortofreiheiten, Gefeß über, v. 5. 6. 1869 $399 / 400$.

- bie fidj auf befonderen Berträgen beruben $407 / 408$.

- Oegulativ über 401/402.

\$ortopflichtige Dienttbriefe, Befreinng berielben onm Зu[Glngparto $397 / 398$.

\$artovergünjtigurgen für 2utgchörige o sूecres und ber Marine 395/396.

Boftänter utb Roftngenturen 357.

\$o|tantocifungen (\$D.) 591

- telegrapbifde (90.) 592.

(ว0.) 642

ßoftontecijungsbienft, internationaler 374.

Po|taufträge jur Eingięung van Bedobeträgen und Cinfolung pon 2 cebjelacrepten (\$D.) 594.

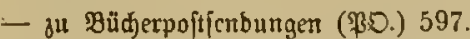

- - fro aufgehober (Nadirag) 823.

ßoptauftragstienft, isternationaler 375

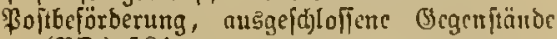
(\$D.) 584 .

- beblngt auqelaficue (Siegenitände (\$BD.) 585.

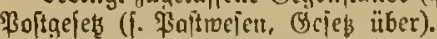

\$ojtforten ( $\$ 20) 586$.

Boftfranfenfafien (firgs.) 499.

- Sabungen berílben 507/508.

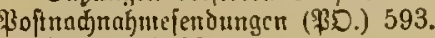

- (Nađ)trag) 823.

ßoptoronung, Jnhaltsangabe 389/390.

- oollitänoiger Iext $577 / 578$.

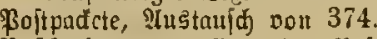

Poltjenbungen, allgemeite $\mathfrak{B c j}$ dinfferheit ber= felben ( $\$$ BD.) 580

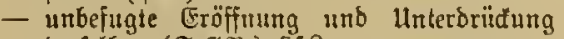
derfelben (ธt(52) 758.

Bopttarwefen, Befeb übcr, v. 28. 10. 1871 (\$ojttargefcs) 391/392.

- Sefess über, Aenberung o. 15. 5. 1873 (\$ofttarnouelle) 393/394.

Aenberung v. 3.11. 1874 $393 / 394$.

Pait = uno Telegraphen=\$erwaltung, Drganifa= tion berfelben $351 / 352$.

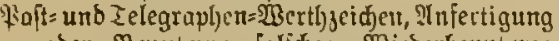
ader Benubung faljher, $\mathfrak{B}$ icberbenubung

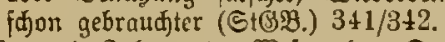

Poit= uno relegruphen=2Bejen bes Deutiden

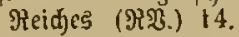

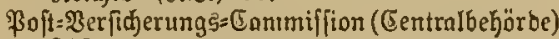
353.

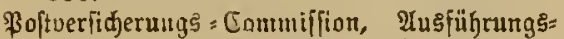

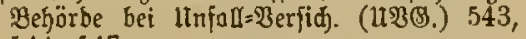
544,547 .

\$aftuerträge, internationole, Mुeltpoftoertrng 0 . 4. 7. 1891. 361/362.

- jonjtige $373 / 474$.

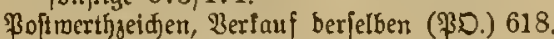

\$oftrofen, Bejeb über bns, o. 28. 10. 1871. (\$oft=-(Sejeb) $379 / 380$.

\$oftzollregulatio 367 .

Boftuftellungsurfunde, Briefe mit, (\$D.) 601.

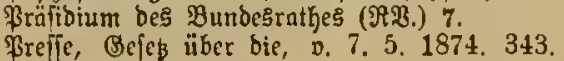

Brelle, Befeß
Brivattlage (St\$D.) 275.
Brioat=Telegranme, gewöhulidje (TO.) 635.

\$rianttslegrantme, bejonbere (ID.) 636.

ßravinzialbehörós (\&YG.) 44 .

- verbänbe (\$rश.. 38.

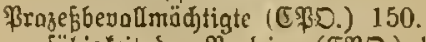

- fähigfeit ber \$artcien (ฮ\$D.) 149.

- lafter (巨\$D.) 150

Duittungelarten (ஒHIS.) 569.

\section{$\mathfrak{R}$.}

Rangarbnung ber auf bemfelben Srunbfüte laftendert Sypothefer urt Srunbjaulden (EGG.) 297.

Realíteucru (囚2S.) 803.

Rcd)tungshof bes Deutiden Reidjes 8, 105.

Red)mungslcgung über \$eribaltung oon Mïndel: gelbern (BD.) 325 .

Redjnungs[ndjer, vorbereitendes Berfabren in, (E\$D.) 166 .

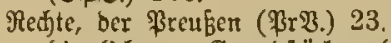

- Dinglidje nn Brunditüder (ESG.) 293.

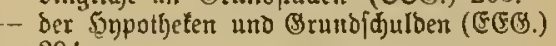
294.

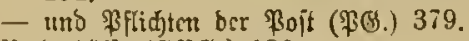

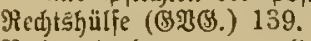

Bechtsmittel gegen palizeilidfe Berïïgungen (223.) 68

- im Civilprozcí (巨\$D.) 177.

- iim Strafprozes (ভเ\$P.) 264.

- geger Beranlagung zur Cinlommenteuer (ङ્ડા(.) 779 .

- geger Berariagung jur Ergänzangstener (ErgSt9.) 795.

- gegen Beranlagung ди Rommunalnbgaben (Rश(3.) 809 .

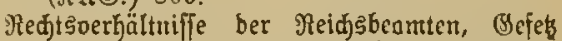
über, D. $31.3 .1873 .653 / 654$.

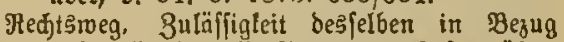
auf polizcilithe Serfügungen, Sefes über, v. 11. 5. 1842. 101/102.

Regierungsbezirte (2NOS.) 42.

Regierungspräfibent (\&ßS.) 46.

Regulativ, betreffeno 1 tnfa $\mathbb{Q}=\Re$ crjidjerung für

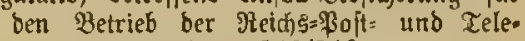
graphen=Bermaltung $545 / 546$.

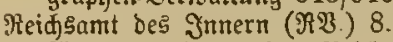

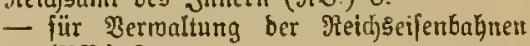

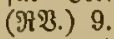

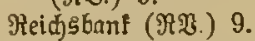

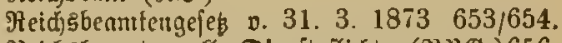

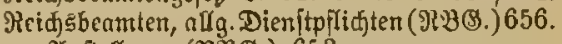

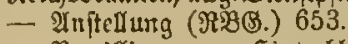

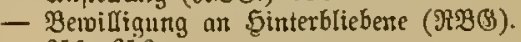
$655,656$.

- Pemilligung an ફinterbliebene bei ßen=

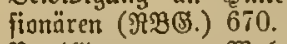

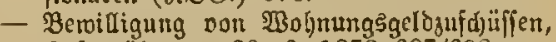
Seies über, o 30.6. $1873687 / 688$.

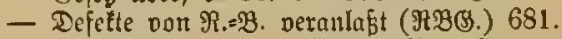

- Dienftentheburg, oorlüufige (AnISfuspen=

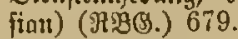

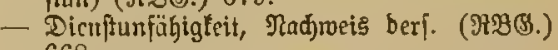
668.

- Dienfitzeit, Berednung berf. (RBB.) 663

- Entlafiurg ber auf \$robe angeftelten

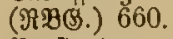

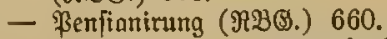

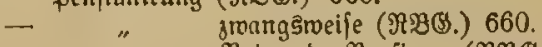
Betray der ßentionen( $\Re \mathfrak{B}$.) 661 . 
Reidjsbenmten, Henfioniaulg, Betrag ber ßen= fianen, Gejeb vom 21. 4. 1886685.

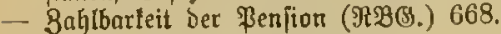

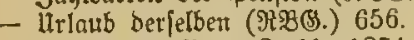

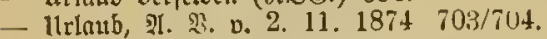

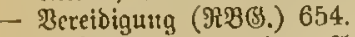

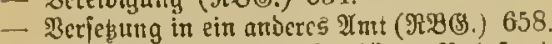

- Berfebung in ben eirjtwociligen Puheftato (भ30.) 658.

- Berjesung in ben banernben Ruljejtand (i. ßenfionirung) 660.

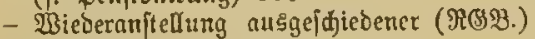
660.

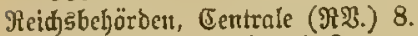

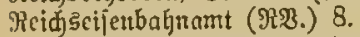

- Befes ïber Erriátung beşjelben v. 27.6. 1873455.

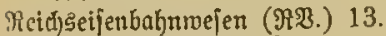

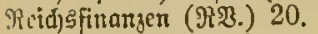

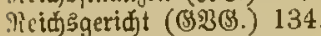

Irciagelesgebung ( $\Re$ ) 3 .

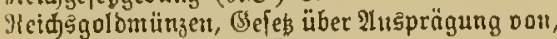
v. 4. 12. 1871333.

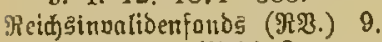

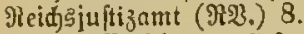

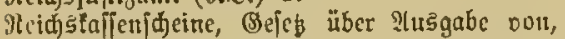
๖. 30.4 .1874339$.

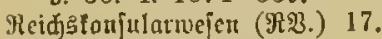

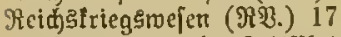

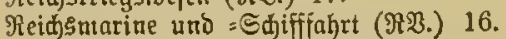

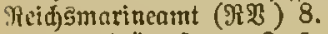

Mcid)รmilitärgc|es o. 2. 5. $1874 \quad 759 / 760$.

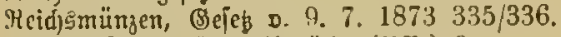

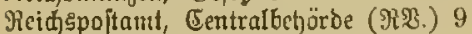

- Erridtung besjelben 352.

- Drganifation besielben 351.

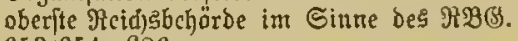
653654,686

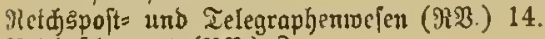

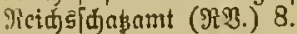

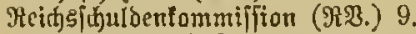

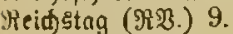

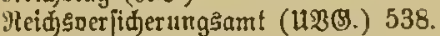

- (Эशฌ円.) 573.

Reijegcpäd (\$3.) 624.

Renten an Sinterbliebcre (11F(3) 749.

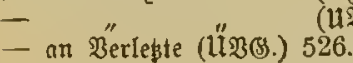

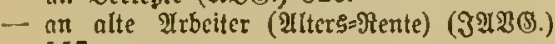
557.

- an tnvalibe शrbeiter (Jnoaliben- Rente)

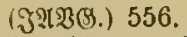

- Guvalioen= und altersor, Feftftellung beri. (З2ฑஒ(5.) 563.

Revifiton, cioilredtlide (ङ\$D.) 179.

- itrajrectlidje (ভt\$D.) 267.

Revifionşgeridt (ธt\$D.) 269.

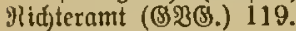

Ridjterlidie (Semalt im ßrenßiphen Staate (\$ræ.) 35

R̈̈djheit (\$D.) 605.

Rubeftand, eituftweiliger ber Neid5=\$eamten (3t23.) 658.

- bauernder der Sieid5= Beanten (MPB.) 660 .

Rubcn bes geriळtliden Berfahrens ((E\$O.) 160.

(5.

Sađjbejđäbrgung (ङt(アア.) 221.

Sachverftünoige, Beweis burd) (હ\$O.) 172.

Eabuttẹ en der ßoft=ßruntentaffe 507/508.
See=Tclegramme (XD.) $6 \pm 5$.

Săbenerjab bei unfälk (Syitpfl.=(9.) 745 .

(แ⿰B).) 526

Sdiedsgeridite" bei "Invalioent und Ilicrss

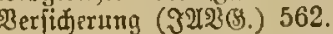

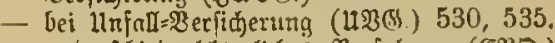

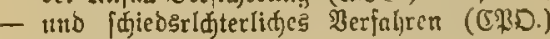
210.

S九iebsiprut (巨शD.) 212.

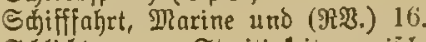

Sd)lidutung non Etreitigleiten grijitien Bunbes: itaater (R2.) 21 bei Sirantenfalfen

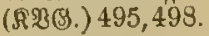
bei Baft- Fratten= taifen (Sabung) 523.

ber Эnoalibet $=u$. श1ter $3=$ शुerficierg. (รशำ ) 572 .

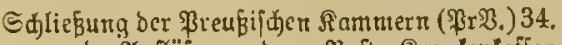

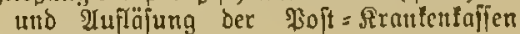
(ङaßsungen) 524 .

- uno Iluftölun ber Betriebs:Rrantentafien (న叉\$.) 502.

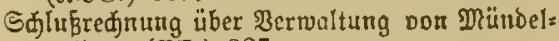
geldern (श0.) 327.

Sđjöffen, Int Derjelben (अ円ß.) 123.

- Beeibigung derfelben (BD(5.) 127.

- Befähigung bazu (Bஒ(B.) 124.

- Jahreslifte (BSBS.) 126.

Sdjoffengeridte (अ\$B.) 122.

- Berlahren vor denjelben (@เßD.) 247.

Sdmurgeridte (\$23(3.) 131.

- Samptverganolungen oor denjelben (EtßB.) 257.

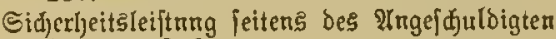
(St\$D.) 236 .

Signal=Dromug fïr die Eiferbabnen Deutid)= lanis $443 / 444$.

Sibungspolizei (\$ßS.) 141.

Eiturgsprototoll (ERD.) 154

Etaatsangehörtgfeit, ßerjomenitano nno (३uit= (b.) 94

Stnatsanroaltidajt (\$खG.) 136.

Slageerbebung uno Intlageidrift (StßD.) 244.

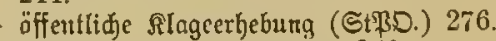

- Platboner ber - (Et\$0.) 260.

- Mechte ber - (St\$D.) 244.

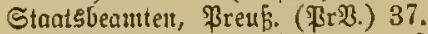

Staatieifenbabren=\$ehörben, ßreub. A. E. v. 15. 12. $1894 \quad 457 / 458$.

- Dermaltungsoronumg $459 / 460$.

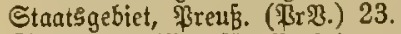

Staatstommifijar für Berfid̄erunģanjtalten

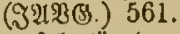

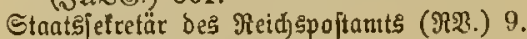

- Erridjung ber Stclie 352.

- Ehef des Reidjpoptants 351.

Staatitelegramme (TD.) 634.

- Beoorzugurg derjelbet (TO.) 635

- Beptimmung über gebührenfreie 417/418.

- Regulatio über gejめäftlide Bebandlung $421 / 422$.

Stadtaน:

Stabtgemeinden (3น.jt(3.) 81.

Stedbrief (ङtßD.) 239.

Stellenammärter (Dilitäraruärter) 698.

- Einberufung Derjelben 699.

Sterbegelo, von Drts=frantenfajien ( $\mathfrak{A r}(S$. $483,484$.

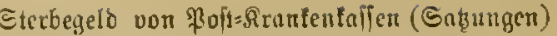
515.

- bet «nf̧ällen (1193.) 527.

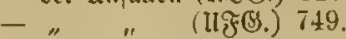

Steuererbebung Der Eintanmeniteuer (Eહt(.) 784.

- ber Ergänzungsโteuer (FrgSt(S.) 797.

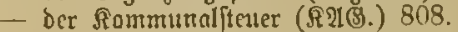

Stenterertlärung jur (Eintommenjtener (Eङ 775 .

ङteucrpfid̆t, sur Einfontuenfteuer, objeftive (ङSt63.) 768 .

Steucrpflidjt, zur Eintommenitcter, jubjcttioe (ङStB.) 767 .

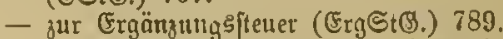

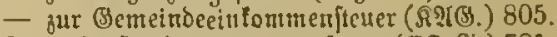

Stcuerjtrajen b. Einfammenjtener (ESt(3).) 785

- bei Ergäuzungs[teuer (Grg@tङ.) 797.

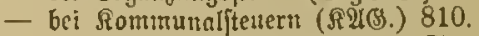

Steuertarif fur Einfomnteniteuer (ङSt(5.) 773. - Ermäpigung bes]elben 774.

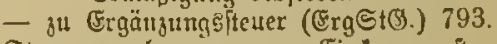

Stcucrveranlagung zur Finfonmenfteuer (ङङtङ.) 774 .

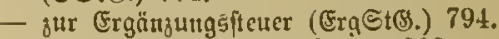

- zur Rommunalfterer (尺̌ig.) 808.

Strafantrag bci 2̉eleidigungen (StGM.) 75.5.

- bei Beamtenbeleidigungen (St(SB.) 755.

Strafbare Sanblungen, Fintbcilung berielben (ङt(B).) 215.

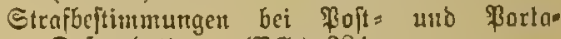
Defraubationen (\$B.) 384.

- bei शnjertigung uno Benubung falidje:

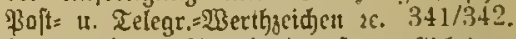

- bei unridjtiger IIngabe bes fteucrpitidutigen Einfommens (\&ङ!ß.) 786 .

- (

- - (R2S.) 810 .

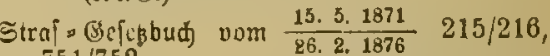
$751 / 752$

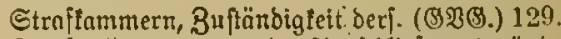

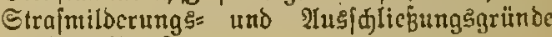
(ङt(38.) 216.

Strafproseboronung n. 1. 2. 1877. 223/224.

- Einfübrungsgejes v. 1. 2. 1877. 287/288.

Strafperfügungen, polizeilidie, (B)ejeß betreffetro, D. 23. 4. 1883. $289 / 290$.

Strafuolitređ

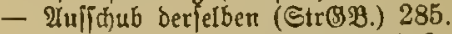

- Beriährung berjelben (St(3).) 218.

Strafocrfolgung, Berjährung berfelben (ङt(5タ.) 217.

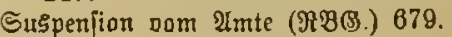

\section{T.}

Tafel über Sähe ber fiautionen 713/714.

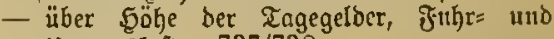
ปิmสน

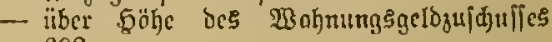
692.

Tagegelder, Fuhrtoiten 2c. Der Reidģeanten: थพ่. ․ 21. 6. 1875. $717 / 718$.

- ฤ. 19. 11. 1879. (2tbänderung ber \{พ. จ. 21. 6. 1875.) 721/722.

- v. 29.6.1877. (Dienftreifen im S.mtรbesirt.) $721 / 722$.

- v. 27. 6. 1894. (Dienftreijê tm शImtšberirt.) $723 / 724$.

- จ. 5. 7. 1875 . (Fahrt unto Hebct. lager=(B) ебйhr.) $729 / 730$. 


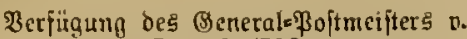
3. 7. $1877.721 / 722$.

- bes Stants:Satretärs bes Reiđj: Boit=\{int 3 v. 3. 7. 1894. 725/726.

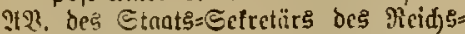
ßaît = ?mts o. 7. I. 1896. 731/732.

- bes Stnats.Setretärs des Reids= Bolt=21mts v.21. 12. 1881. 733/734.

Telegramme, allgemeine Erforberniffe berịtben (ID.) 636

- 2Iufabe berfelben (TD.) 638.

- Eintheilung berjelben (TD.) 634 .

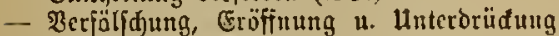
(ङt(3).) 758.

Iclegrammgebiifren (20.) 640

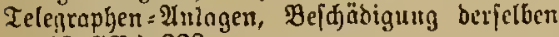
(डt(38.) 222.

- Behcimniß (TD.) 634.

- Gejes v. 6. 4. $1892.415 / 416$.

Dronung, Jnhnltsangabe $\$ 17 / 418$.

- Erdmung, vouftändiger Testt 631/632.

- Bertrag, internationaler boin $\frac{10}{23}$ 7. 1875. $375 / 376$.

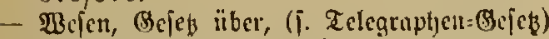

- Wejen, Boft uno, (ア゚.) 14.

Telegraphijife \$oftanweifungen (PD.) 592. (TD.) 642 .

\section{II.}

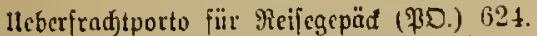

llebertretungen (Defintion) (StßY.) 215.

- Erlab polizeilidjer Strafoerjügungen gegen, अế v. 23. 4. 1883. 289/290.

llebermeifungs: relegrantme ju telegraphijden Baptanvei[unger (TD.) 643.

lleberzengungseio (EßD.) 175.

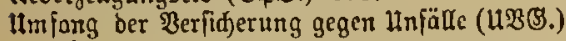
523.

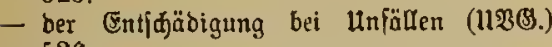
520.

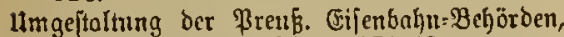
भE. D. 15. 12. 1894, $457 / 458$.

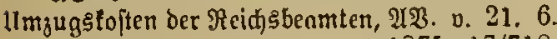
1875. $17 / 718$ \$öhe berlelben 719.

Tafel überøöhe beri. $737 / 738$

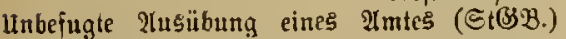
754 .

Hnbeftelbare \$ajtforbungen, Behanbluug ber, iclber am Befitinumingsort (\$OD.) $6 i 5$.

- Boftfenbungen, Behanolung bericlben am ในf gabearf (\$3D.) 617.

- Telegramme (TO.) 650 .

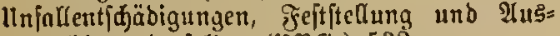
anhlung berjelber (UBB(s.) 532 .

- fïrjorge, Befes v. 15. 3. 1886. 747/748.

- Berhütumgs=9orforiften für Telegraphen= IIrbeiter $827 / 828$.

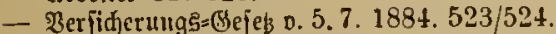

- (und Sranten=) Beritderung, (4eics ïber Iusoełnung ber, o. 28.5. 1885. $541 / 542$.

- Berfiderung, Regulatio betreffend, für Betrieb der Reids=\$olt= und Telegraphen= Berwaltung 545/546.

Unpfändbare f̧orderungen ((EßD.) 200.

- Snd)en (ङ\$D.) 196.

Unterbredung bes Cioilprozel[es (ङ\$D.) 160.

Unterbrüdung, unbefugte, oon \$oftienoungen (St(S).) 758 . lluterbrïdung, unbefugte, oon Telegranmen (St(BP.) 758.

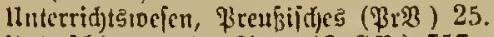

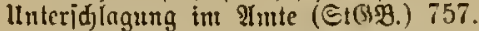

unter[udung shait (ङtPD.) 235/236.

- Inredinung berielben (StßD.) 284.

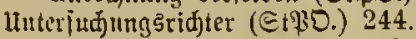

Itrfunden, offentlidie (C\&B.) 173.

- prinate (SPD.) 174 .

- über Eintragangen in bas Grunbbud) (BPO.) 311 .

- Berveis burd, (CBD.) 174.

llrfunbencib (GRD.) 174 .

Ittunbeuprojeß (EßD.) 183.

Itrlaub ber Reidsbcamten (

शํำ v. 2. 11.1874 $703 / 704$.

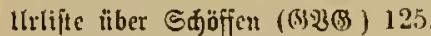

Itrtheil (CPD.) 163.

- (ভtßD.) 253

- Veurfunouna de, (C2D.) 164

- " (EIRD.) 256.

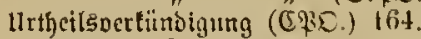

- (ङ+?D) 255 .

\section{3.}

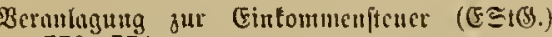
770,774

- zur Ergänzungsłtener (Ergહt(S.) 791, 794

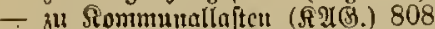

Beranlagungstommifín (EেSt(S) 778 .

- (ErgSi(s.) 794 .

Beränderung ber veranlagten Steuern (ESt(B.) 783.

- ber veranlngten Steuern (Ergङt(3.) 796.

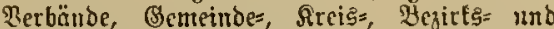
Broninginl= (\$rßB.) 38.

Berbredten, Definition (ङt(B).) 215.

- แnd Bergehen roiber bie öffentliafe Dro nung (SิtßB).) 219,754.

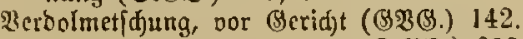

- (St:DD.) 253.

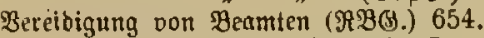
Beugen (ธPD.) 174.

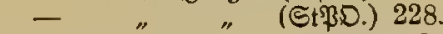

Berfahren, geridtidjes, im Civilproze巨 (EPD.) 15.3.

- geridttidjes, oor ben Sanbgeridyten in I. In" ftan (EPD.) 161.

geridttlides, vor ben Intsgeridjien in I 3nitan (ङ930.) 177 .

_ - in Eheindar (5\$0.) 184.

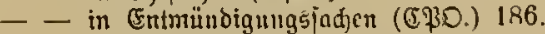

- - Wicberaufnahme besfetben (CPO.) 182.

- - im Strafprozeß, in I. 3njtang (ভtßD.) $2+2$

- - im Strafproze巨 oor bem Sdjöffergeridste (StPBD.) 247.

_ - im Strojprozés nor bem Sdjmurgeridjte (Stझס.) 257.

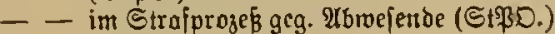
262.

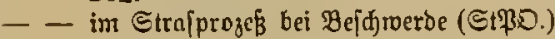
265.

- - im Strapprozeß oor bem Berufungs= geridift (ङt\$D) 267.

- - im Strofprozes oor dem Revifions= geridt (ভt?BO.) 270.

- - im Strajprozeई, Wiederaujnahme des (SIMD.) 271.

- - bet Mbnahme pon Eiben (ङ\$O.) 175.
Berfabren, geridftidies, bei 2lbnabute von Eiden (StßR.) 229.

- fifiebstichterlides (EPD.) 210.

- bei Dehöroen (\&3(S.) 53.

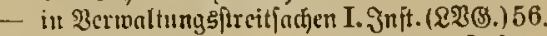
weiterer $\Im n f$ tanz (2ミ(\$).) 58.

Beriufing bes Deuiden Reides, Befe - on 16. $4.187 \mathrm{l} 1 / 2$.

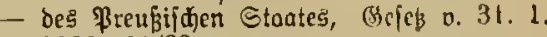
1850 21/22

- ber Bermaltungşgeriđ̆te, (Bejç v. $\frac{3.7 .1875}{\text { 2. 8. } 1880}$ $77 / 78$.

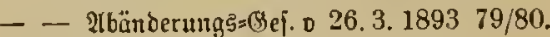

Bergekeu (Definiton (હt\$B.) 215.

Berglid)ene Telegramme (TD.) 642.

Berhaftung unb vorläufige ₹eitnahne bes \&n: acidulbigten (ङt\$D.) 253.

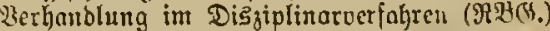
672 .

Berjährung v. Strajoerfolgungen (St(ㅉ.) 217

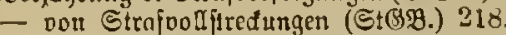

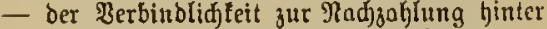
zogenter EirtSteuer (ESt(.) 785.

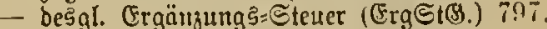

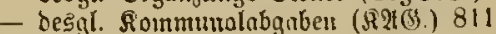

Bertanf von Boitmertbieid)en (BO.) 618

Berfeljugnnitalten 356

- Perional ber - 358 .

Bericitung vou lintergebenen (St@B.) 758.

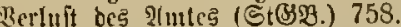

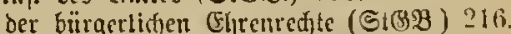
Bermögen, itetterbares (ErgSt@.) 790

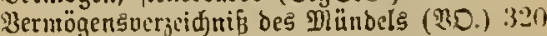

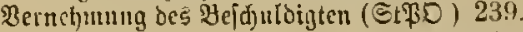
im Disziplinus: verfabr. (MB(ङ.) $674,676$.

ber Bengen im Diskiptinurberfaht.

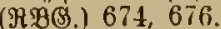

Cinilprozę ( (5QBD.) 170.

iin Etrafprozefi (StPD.) 228 .

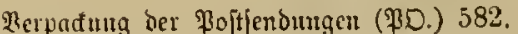

Berpfliditung ber Eijenbahnen untergeortueter Bcbeutung für ßoltz̧uede $437 / 438$.

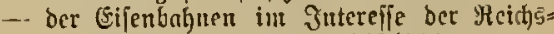
Telearaphent=?3erivaltung $443 / 444$.

- ber Strapenbauderwaltungen im Jntereifc ber Reids $=$ Telegrapl. = Berwaltung $475 / 476$.

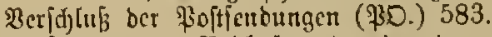

Berlesutg von Reidsbeanten in ein anberes

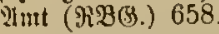

- oon Reidjbenmten in oen einftreilingen

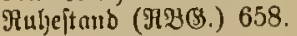

won Reidsbeamten it ben bauernben Ruhe:

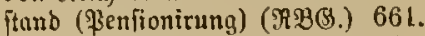

Berfidjerungs=2!njtaltet ber Invaliden, und

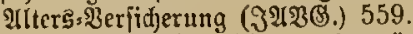

Berfiđherungs=(\$cbühr für Reijegepäd (ஐDD.) 624.

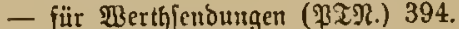

Beriiderungspflid)t gegen unfälle (น⿰ڤ) $523 / 524$.

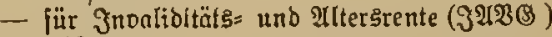
549.

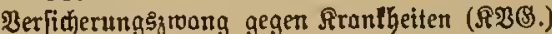
477.

ఇerjäนmn

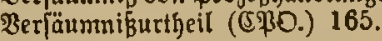


Berjarmenber, Entmündigung berielben (ND.) 187.

Berfteigerung gepfändoter Sadfen (ERD.) $19 \bar{T}$. Rertheidigung vor Beriht (SIBD.) 240, 241. Rertheilungs.\$erfahren, geridtlides (ERO.) 202.

Bertrag 0. $\frac{2.8}{8.9} 1877$ über ßerpflidjtungen ber söniglichen Stnatsbahnen gegenüber ber

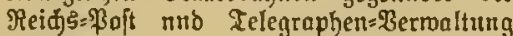
$451 / 452$.

Beroielfältigung oon Telegrammen (TD.) 614. Berwaltungsbehörben, \$reubijde (\&23(3.) 44.

Berroltungsoronuna für dic (Breus.) Stnats= (Eijenbabnen $459 / 460$.

Bermaltungsgeriojte uno Bermaltungsftreit= nerfohren, Gejekg oont $\frac{3.7 .1875}{2.8 .1880} 77 / 78$.

- unb Bermaltungsftreitotriahren, शtbänber= ungsgefes D. 26. 3. 1893. 79/80.

Berwaltungsftreitoerfahren (R囚S.) 56.

Rerzeidnis ber ben $\mathfrak{P}$ ilitär $=$ İnwärterı im Heidsbienjt norbehaltencu Stellen 703/704.

Bolftredungsbejehl, geriøtl. ((S\$D.) 190

- benmie (BפS.) 138.

- Haujel geridtl. (CPD.) 192.

- Seridt (E\$D.) 194.

Borelnjめäbungs = Eommifjionten fur Etenter= peranlagung (EStG.) 776.

Barführung eines Ergriffenen oor (Heridt (StPID.) 239.

Barmundjøaft ïber Dhinberiährige (BD.) 313,315 .

- \#̈ber Orobjährige (BD) $313,330$.

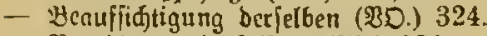

- Beendigusg berjelben (शO.) 326.

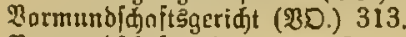

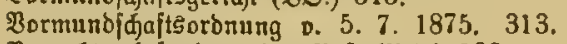
Borredte, bejonbere, ber ßajt (BS.) 382.

Boritano der Rrantenfafien (

- Der $\mathfrak{B}_{0} \mathrm{t}=$ Rrautentafien (Snbungen) 519.

Borunterjuओung, geriøtl. (ङเฉD.) 244.

I3.

Banrenpraben (PD.) 590.

TBahl zum Prcubifiden Tlbgeorbnctentyauje (શrश.) 33, 34.

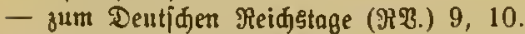

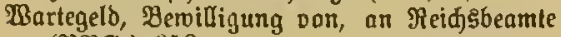

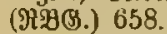

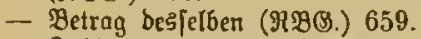

- 3ohlung desjelben (RBS. 659

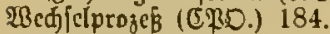

Wegepalizei (3ujts) 87.

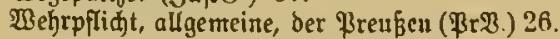

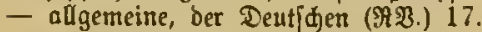

- Bejes betreffeno Penberungen ber, Dont 11. 2. 1888. $759 / 760$.
2Beiterbeförberung ber Telegramme (TD.) 645. Weltpoftoertrag v. 4. 7. 1891. 361/362.

Merthangnbe bei Roptjenbungen (PD.) 582.

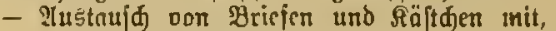
internationales Hehereirtommen v. 4. $\overline{7}$. 1891. 373.

Berthjenbungen, bejonbere 2tmporberumgen in (ఇD.) 583.

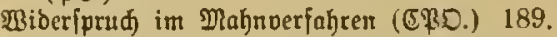

Widerftand gegen bie Stantsggemalt (St(B) ) $218,753$.

Mieberanjtellung ausgejఝicbener Meidjşbcanten

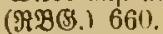

Wiederaufullute eines gejळloffenten geriळtl. Berfahrents (CPD.) 182.

- eires gejđloffenen geriđtliden ßerfagrens (ङเฆD.) 271 .

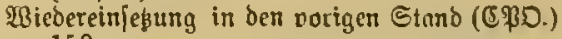
159.

शBieberherftellung zerftörter Grund = Büder (BSD.) 313 .

Mieberoerioendung gebrauditer \$ojt= unb Iele

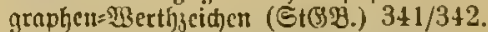

IZnohlfahrtsanjtalten (Raifer=2Bilhelm=Stiftung) $815 / 816$.

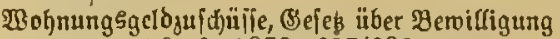
van, v. 30. 6. 1873. 687/688.

- Tarif zum Geleb̨ v. 30.6. 1873. 690.

-- Rlaffification ber Reids $=$ Peamten fum Tarif $689 / 690$.

- Tajel über Đöhe derjelber für Bofts uno Telegraphen=\$Beanten 692.

Wortzählung ber Telegramme (TD.) 638.

\section{3.}

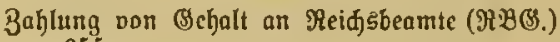
655.

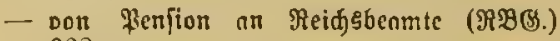
668.

- bon $\mathfrak{B a r t e g e l}$ an Reidjbeamte (RPS.) 659.

- ber (Fintommenjtcuer (GintStS.) 784.

- ber Ergänjungsftener (ErgSt\$.) 797.

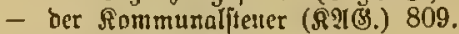

3ablungabejehl (ฮ\$D.) 188.

3eit ber Bejtellung oon ßoftenoungen (PD.) 609.

Beitungen und Beitjoriften, internationales llebereintommen o. 4. T. 1891, betreffeno Paftbezug oon, 375.

Beitungsvertrieb burd bie \$ajt (\$D.) 602. 3ritbeftimmung, einheitlide, Seleş betreffend, v. 12. 3. 1893 . $347 / 348$.

3eugen, \&aburg berjelben ([PD.) 167.

- " (ङ $\$$ " 227.

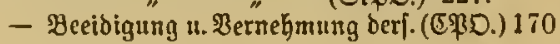

Beugen, Beeibigung unঠ शernefinung berf. (StBD.) 228.

- Bebiihrer berjelben (E\$D.) 171.

- " "EtæD.) 230.

Bengen im Dis̄łiplinaroerjahren gegen Beante

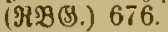

Brugenberdeis (CPD.) 167.

Berguif́ oon Benuten (C\$D.) 167.

(ธเß0.) 228

3eugnifoerweigerung (ฮףD.) 168;169.

- (STOD.) 227.

- Falgeu berjelben (cRo.) 170.

- "

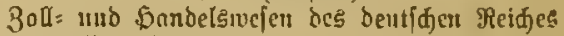
(9) 3 .) 1 t.

Bollregulatio, \$oft, $467 / 468$.

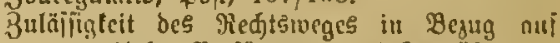
polizeilide Berfitgungen, Bejes iiber, 0 . 11. 5 1812. $101 / 102$.

- ber Berhaftung (ङt\$D.) 235.

- ber norläufigen Feitnahme (ভtญD.) 238.

3urüđgiehung oon ßaftienoungen (PD.) 606.

- van Telegramuen (TD.) 647.

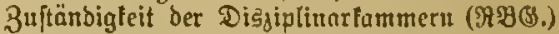
674.

- fadlide, ber Beridte (C\$D.) 147.

- Fadilife, ber (Beridjte, Bereinbarung nber (ङPD.) 148.

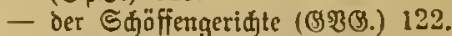

- ber Eidiltammern (\$श(\$) 129.

- ber Straftammern (BशB.) 129.

- ocs ReidSgeridtes (MßS.) 135.

- oor Sdiedsgeridjten (CPO.) 214.

- ber Berwaltungs= uno Bermalturgs=(\$) . Behörbe, Befes v. 1. 8. 1883. 81/82.

3uftellung von Telegrammen am Beftimmungs. orte (2D.) 648 .

3ultellungen, geridgtlide, burdi ben Geridgts= volfieher (ङ\$D.) 155.

- geridtlide, burd bie ßait (EßD.) 157.

- geridtliage, offentliche (EPD.) 157.

- geridtlide, bes urthetls (EMD.)

3uptellungs: und ßollitredungsbeamte, geridtl. (अखख). 138.

3uftellungsurfunbe, geridtlidje, (๔खి.) 156.

- poitalijhe, $\mathfrak{B}$ ejtellung ber Sdreiben mit, (\$D.) 612.

3rongsbefugniffe ber ßrenbilden Bebörde (2शS.) 70 .

3roangsoodftređung (ङ\$O.) 191, 203.

- meger Gelbforberungen (ङ\$D.) 195.

- in bas bemeglide \$ermöger (ङ\$2D.) 195.

- in bas unberveglidje ßermögen (C\$D.) 201.

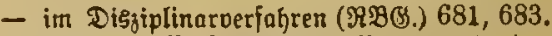

3mangsmeije Beriesung oon Beamten in ben

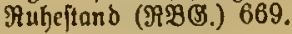




2016

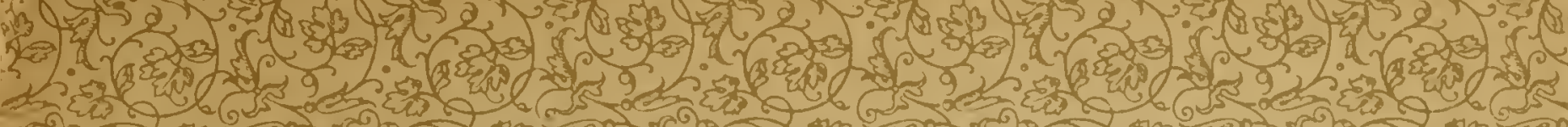

H. (2)

I.

W.

r.

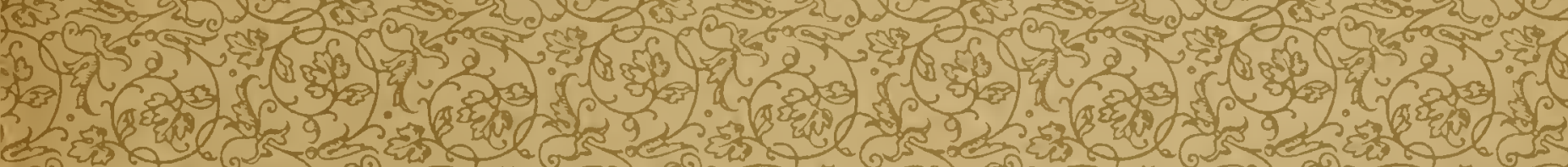

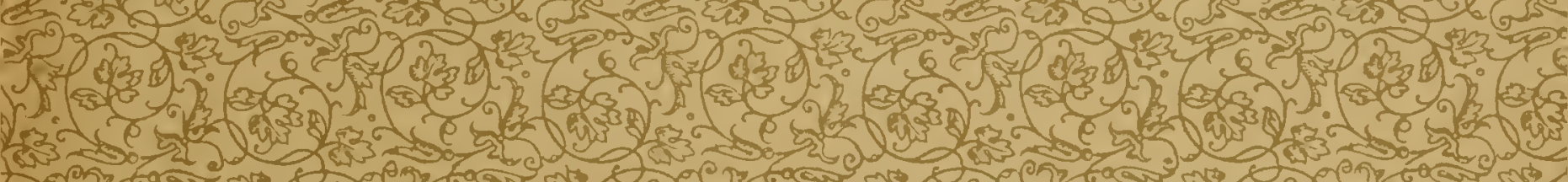

20 .

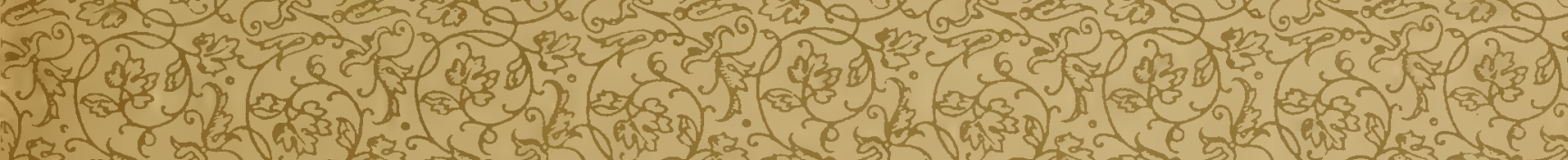

T.

3.

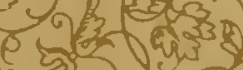

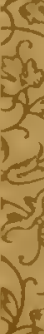

C.

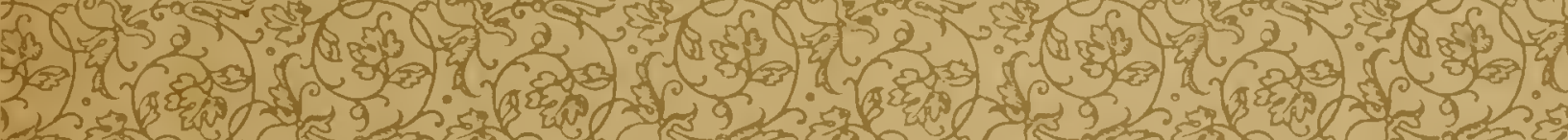

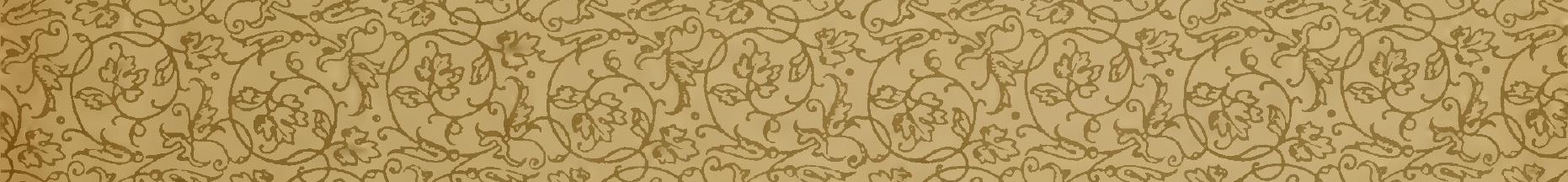

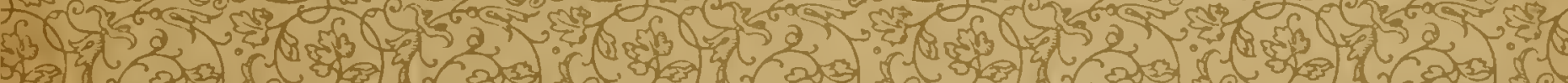
2 . Y. T. 1. . . ( 
SMITHSONIAN INSTITUTION LIBRARIES

$\begin{array}{llll}3 & 9088 & 00067 & 2931\end{array}$ 